\title{
LA-UR-17-20771
}

Approved for public release; distribution is unlimited.

Title: $\quad$ Stormwater Pollution Prevention Plan TA-60 Roads and Grounds Facility and Associated Sigma Mesa Staging Area

Author(s): $\quad$ Sandoval, Leonard Frank

Intended for: Regulatory Compliance Document

Environmental Programs

Issued:

2017-02-01 
Disclaimer:

Los Alamos National Laboratory, an affirmative action/equal opportunity employer, is operated by the Los Alamos National Security, LLC for the National Nuclear Security Administration of the U.S. Department of Energy under contract DE-AC52-06NA25396. By approving this article, the publisher recognizes that the U.S. Government retains nonexclusive, royalty-free license to publish or reproduce the published form of this contribution, or to allow others to do so, for U.S. Government purposes. Los Alamos National Laboratory requests that the publisher identify this article as work performed under the auspices of the U.S. Department of Energy. Los Alamos National Laboratory strongly supports academic freedom and a researcher's right to publish; as an institution, however, the Laboratory does not endorse the viewpoint of a publication or guarantee its technical correctness. 


\title{
STORM WATER POLLUTION PREVENTION PLAN
}

\section{TA-60 Roads and Grounds Facility and Associated Sigma Mesa Staging Area}

\section{Los Alamos National Laboratory}

\author{
A requirement of the \\ NPDES Multi-Sector General Permit \# NMR03195 \\ for Storm Water Discharges Associated with Industrial Activities \\ Prepared By: \\ Los Alamos National Security, LLC (LANS) \\ Environmental Protection Division \\ EPC-CP (Environmental Compliance Programs) \\ P. O. Box 1663 MS K490 \\ Los Alamos, New Mexico 87545
}

Revision 2: January 2017 
TA-60 Roads and Grounds Facility and Associated Sigma Mesa Staging Area STORM WATER POLLUTION PREVENTION PLAN

\section{TABLE OF CONTENTS}

Table of Contents.

List of Figures.

Preface.

SECTION 1: FACILITY DESCRIPTION AND CONTACT INFORMATION............................1

$1.1 \quad$ Facility Contact Information/Responsible Parties ...........................................

1.2 Stormwater Pollution Prevention Teams .......................................................

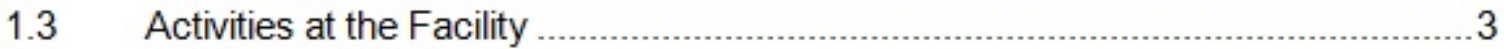

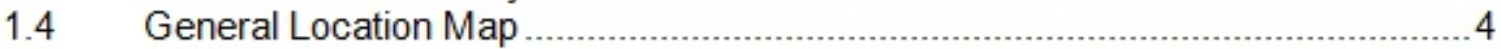

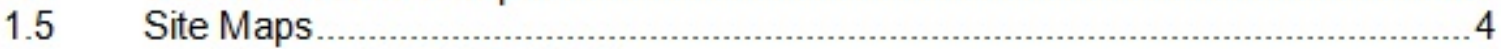

1.6 Site Maps with T \& E Habitat

SECTION 2: POTENTIAL POLLUTANT SOURCES............................................................

$2.1 \quad$ Industrial Activities and Associated Pollutant..................................... 8

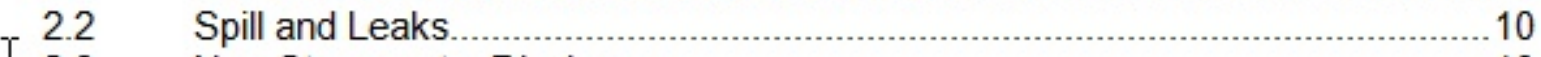

I 2.3 Non-Storm water Discharges............................................................ 10

2.4 Salt Storage

2.5 Sampling Data Summary ................................................................

SECTION 3: STORM WATER CONTROL MEASURES ......................................................12

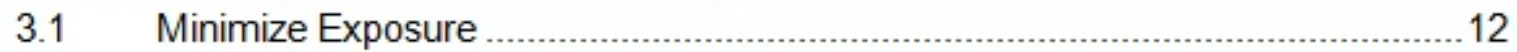

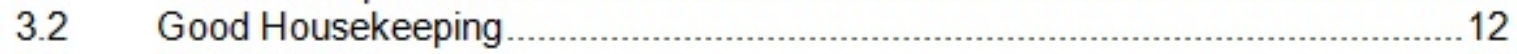

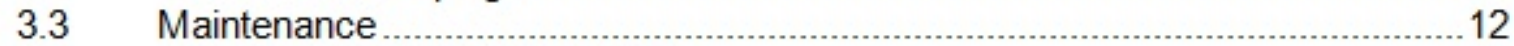

$3.4 \quad$ Spill Prevention and Response

3.5 Erosion and Sediment Controls ............................................................. 15

3.6 Management of Runoff.............................................................................. 16

3.7 Salt Storage Piles or Piles Containing Salt

3.8 MSGP Sector-Specific Non-Numeric Effluent Limits ......................................... 17

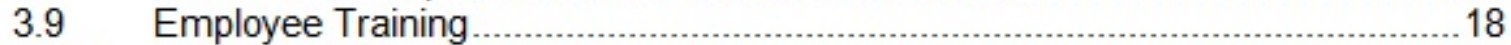

3.10 Non-storm Water Discharges ................................................................ 19

3.11 Waste Garbage and Floatable Debris .......................................................... 19

3.12 Dust Generation and Vehicle Tracking of Industrial Materials ...........................220

SECTION 4: SCHEDULES AND PROCEDURES FOR MONITORING ..............................20

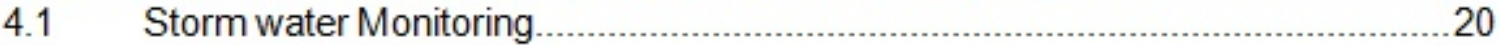

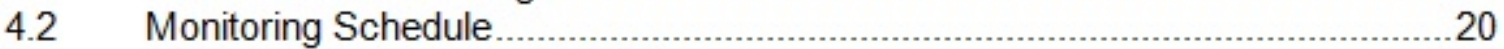

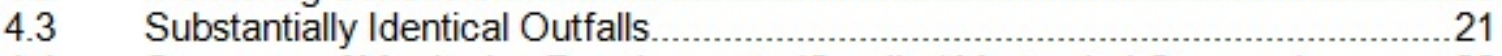

4.4 Summary of Monitoring Requirements (Sandia / Mortandad Canyons)..............22

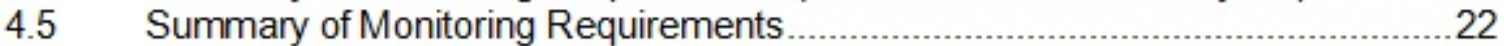

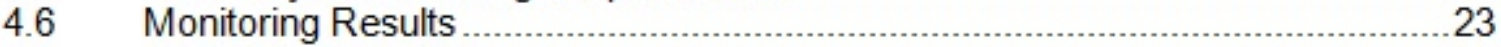

$4.7 \quad$ Recordkeeping

SECTION 5: INSPECTIONS AND CORRECTIVE ACTIONS PROCESS...........................24

$5.1 \quad$ Routine Facility Inspection Procedures ....................................................24

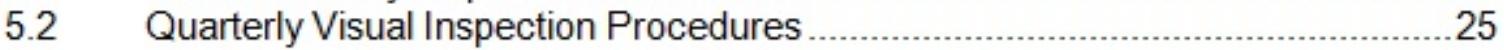




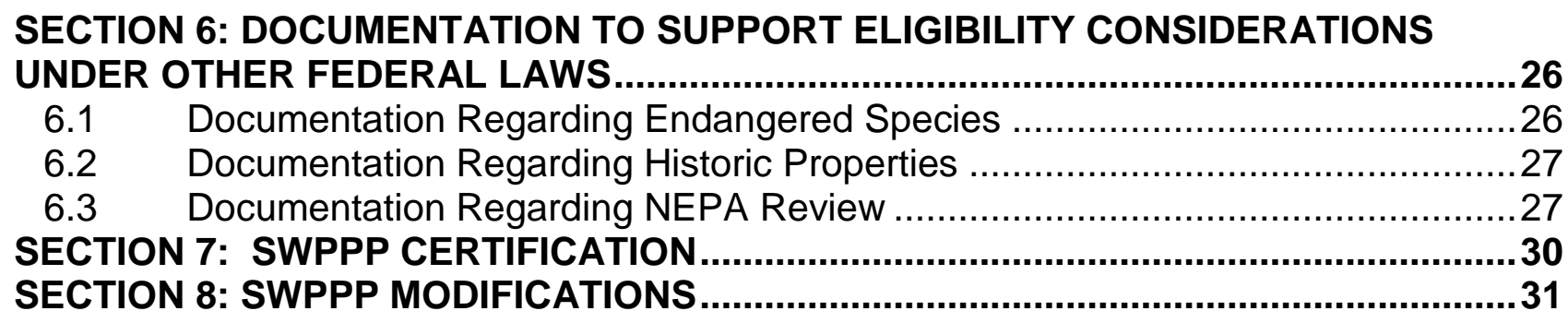

APPENDIX A: $\quad$ Pollution Prevention Team Members

APPENDIX B: Site Maps

\section{LIST OF FIGURES}

Figure 1 (Appendix B)

Figure 2 (Appendix B)

Figure 3 (Appendix B)
General Location Map

Site Maps 1 \& 2

Site Maps with T \& E Habitat 


\section{STORM WATER POLLUTION PREVENTION PLAN \\ FOR}

TA-60 Roads and Grounds Facility and Associated Sigma Mesa Staging Area

LOS ALAMOS NATIONAL LABORATORY

\section{PREFACE}

This Storm water Pollution Prevention Plan (SWPPP) was developed in accordance with the provisions of the Clean Water Act (33 U.S.C. §§1251 et seq., as amended), and the Multi-Sector General Permit for Storm water Discharges Associated with Industrial Activity (U.S. EPA, September 2008) issued by the U.S.

Environmental Protection Agency (EPA) for the National Pollutant Discharge Elimination System (NPDES) and using the industry specific permit requirements for Sector P- Land Transportation and Warehousing. The applicable storm water discharge permit is EPA General Permit Registration Number NMR05GB21 (Los Alamos National Security (LANS) (U.S. EPA, January 2009). Contents of the September 2008 Multi-Sector General Permit can be viewed at http://cfpub.epa.gov/npdes/stormwater/msgp.cfm

The current permit expires September 2020.

This SWPPP applies to discharges of storm water from the operational areas of TA-60 Roads and Grounds Facility and Sigma Mesa Staging Area at the Los Alamos National Laboratory (referred to as LANL or the "Laboratory"). The Laboratory is owned by the Department of Energy (DOE) and operated by LANS, LLC. Throughout this document, the term "Facility" refers to the TA-60 Roads and Grounds Facility and Sigma Mesa Staging Area.

A copy of the LANS NOI and Delegation of Authority Letter is located in this SWPPP. 


\title{
SECTION 1: FACILITY DESCRIPTION AND CONTACT INFORMATION
}

\subsection{Facility Contact Information/Responsible Parties}

\author{
Facility Operator(s) \\ Los Alamos National Security, LLC (LANS) \\ Environmental Protection Division \\ EPC-CP Environmental Compliance Programs \\ P. O. Box 1663 MS K90 \\ Los Alamos, N. M. 87545 \\ Facility Owner(s) \\ Andrew W. Erickson Utilities and Institutional Facilities, UI-DO \\ Los Alamos National Laboratory \\ P. O. Box 1663 MS K787 Los Alamos, N.M. 87545 \\ Office: (505) 665-0106 \\ Email address: erickson@lanl.gov \\ SWPPP Contact(s) \\ Holly Wheeler \\ EPC-CP (Environmental Compliance Programs) \\ Office: 505 667-1312 \\ Email address: hbenson@lanl.gov \\ Leonard F. Sandoval \\ Deployed Environmental Professional \\ Office: 505 667-3557 Cell: 505 231-1235 \\ Email address: lesandov@lanl.gov
}

Other applicable facility data and contact information is provided in the facility NOI. A copy of this SWPPP is maintained on-site with the Deployed Environmental Professional for the facility.

\subsection{Stormwater Pollution Prevention Teams}

This Stormwater Pollution Prevention Plan (SWPPP) is applicable to operations at the Technical Area -60 (TA-60) Roads and Grounds Facility and Associated Sigma Mesa Staging Area off Eniwetok Drive, in Los Alamos County, New Mexico. Utilities and Institutional Facilities (UI-DO) and Roads and Grounds Operations at Los Alamos National Laboratory (the Laboratory) has established a Pollution Prevention Team (PPT) whose members are responsible for assisting the facility manager in developing and revising the Facility's SWPPP as well as maintaining control measures and taking corrective actions where required. All PPT members will have access to either a hard copy or an electronic 
version of this SWPPP. A list of PPT members (along with contact information) is provided in Appendix A of this SWPPP.

\section{Designation of Pollution Prevention Teams}

The PPT for the TA-60 Roads and Grounds Facility and Sigma Mesa Staging Area consists of operations and management personnel from Roads and Grounds Operations for the facility, a representative from EPC-CP Stormwater Compliance and Permitting Team, and Deployed Environmental Professional assigned to the facility.

The EPC-CP representative is responsible for LANL's compliance with regards to the National Pollutant Discharge Elimination System (NPDES) 2015 MSGP permit. The team members are selected on the basis of their familiarity with the activities at the TA-60 Roads and Grounds Facility and Sigma Mesa Staging Area and the potential impacts of those activities on storm water runoff. The members of the team are identified in Appendix A.

The specific duties of individual team members of the PPT are listed below.

- EPC-CP Environmental Compliance Programs: Supports the facility and provides guidance associated with implementation of the compliance requirements identified in the 2015 MSGP. EPC-CP also acts as the institutional point of contact for all interactions with the regulatory authority (EPA) and supervises personnel implementing monitoring requirements for the facility.

- Deployed Environmental Professional: Responsible for conducting the routine facility inspections and entering corrective actions into the EPC-CP MSGP Corrective Action Report database. The DEP is also responsible for revising and updating the SWPPP and tracking and updating the status of corrective actions that cannot be implemented immediately. Updates to the SWPPP are required within 14 days of completing a corrective action.

- All members: All PPT members are responsible for being familiar with and implementing this SWPPP and for compliance with the 2015 MSGP. PPT members are also responsible for attending meetings that will be scheduled as needed to discuss revisions of the SWPPP, inspection findings, status of corrective actions and any other topics pertinent to management of the SWPPP.

\section{Appointment of New Team Members}

The PPT members from the appropriate organizations are appointed by the Facility Operations Director (FOD) responsible for the facility oversight of TA-60 Roads and Grounds Facility and Sigma Mesa Staging Area. Each representative will serve or be replaced by the FOD. The list of current team members is included in Appendix A of this SWPPP, and will be revised whenever a member is added or removed from the team, or when the SWPPP duties of an existing team member are changed. Revisions to the PPT alone shall not trigger recertification of this plan. The EPC-CP Team Leader appoints the MSGP Compliance Project Lead from EPC-CP. The ESH Deployed 
Services Division, UI \& MSS Group Leader shall provide Deployed Environmental Professional (DEP) personnel as requested by the FOD. The DEP or designated backup, acts as the Pollution Prevention Team Leader and the Environmental Inspector.

\subsection{Activities at the Facility}

The TA-60 Roads and Grounds Facility/Sigma Mesa Staging Area (RGF/SMSA) is located within the boundaries of LANL in Los Alamos County, New Mexico at Sigma Mesa. A general location map and site maps for the TA-60 RGF/SMSA facility are provided in Appendix B.

The RGF/SMSA falls under industrial Sector $\mathrm{P}$, Land Transportation and Warehousing, of the 2015 MSGP. The facility includes two locations; the main facility where operations personnel, trucks, equipment and materials used for deicing and maintaining roads and grounds are stored and the east location identified in the SWPPP as the TA-60 Sigma Mesa Staging Area, where trucks, equipment and construction materials (sand, gravel, rock and clean soil) are staged. The SMSA is located 0.9 miles east of the main Roads and Grounds facility. Most of the staging area is located north of Eniwetok Road with a smaller parking and storage area located south of Eniwetok Road. Some miscellaneous equipment parts (loading buckets, blades, etc) are stored on both sides of the staging area.

Activities at this facility include the following:

- Storage of equipment and supplies used to maintain roads and grounds at LANL,

- Storage of trucks and heavy equipment, used to transport/haul material or move debris,

- Storage of bulk potassium acetate and other liquids applied for deicing,

- Staging of clean soil prior to reuse,

- Potholing and Culvert Cleanout staging area,

- Staging of asphalt millings prior to reuse

- Sediment catchment in the basin,

- Salt retention in the lined retention pond, and

- Storage of sand, gravel, rock, landscaping materials and herbicides related to grounds keeping and road maintenance.

The TA-60 RGF main site covers approximately 8.4 acres including 65\% (about 5.35 acres) of impervious surfaces such as roofs and paved areas. The area immediately surrounding the main Roads and Grounds Building (TA-60-250) is paved with asphalt. The entire area within the fence of the pesticide storage shed is covered in asphalt and concrete. The areas immediately to the north and south of the salt shed are paved with asphalt. The entire heavy equipment storage yard is also covered in asphalt. The remainder of the facility with the exception of the storm water basins and drainage swales is covered in gravel and/or recycled asphalt millings. These areas include the employee 
parking area, truck parking areas, storage sheds and transportainers, sign storage area, and the access roadways.

The TA-60 Sigma Mesa Staging Area covers approximately 10.55 acres including less than $1 \%$ impervious asphalt (Eniwetok Road). The remainder is gravel, dirt surface and undisturbed land.

\subsection{General Location Map}

The general location map for the facility can be found in Appendix B as Figure 1. The map is a 2008 fly-over that provides a general overview of the facility boundary, structures and pervious and impervious areas.

\subsection{Site Maps}

Appendix B includes the facility site map. Map 1 is the main Roads \& Grounds Facility, and Map 2 is the Sigma Mesa Staging Area. Features located on these maps include the following:

- Direction of stormwater flow,

- Locations of structural control measures,

- Locations of non-TMDL impaired receiving waters (canyon bottoms),

- Locations of potential pollutant sources and locations where significant materials are exposed to precipitation,

- The location and extent of significant structures and impervious surfaces - main facility $=65 \%$ impervious, SMSA $=$ less than $1 \%$ impervious

- Spill locations (if any),

- Locations of industrial activities exposed to precipitation,

- Locations of outfalls,

- Locations of stormwater inlets and outfalls, with a unique identification code for each outfall, indicating if you are treating one or more outfalls as "substantially identical" - (see also Outfall section below and data table in Section 4.3 of this SWPPP

- Locations of all stormwater conveyances including ditches, pipes and swales,

- Locations of automated stormwater monitoring samplers,

- Loading and unloading areas,

- Location used for storage of waste,

- Locations of liquid product stored in tanks,

- The size of the property in acres, (main facility $=8.4$ and the SMSA $=10.55$ )

- Immediate access roads used or traveled by carriers or raw materials, manufactured products, waste material, or by-products used or created by the facility

- Transfer areas for substances in bulk

- Locations of significant run-on flows. 


\subsection{Site Maps with T \& E Habitat}

Found in Appendix B as Figure 3.

\section{Impaired Receiving Waters}

Mortandad Canyon, located south of the TA-60 RG/SMSA, is the primary receiving water body for site drainage. About $40 \%$ of the main site flows north to Sandia Canyon. The runoff from the Sigma Mesa Staging Area goes primarily to Sandia Canyon with a small percentage flowing south to Mortandad Canyon. Due to a berm recently installed at the clean soil staging area and another berm installed at the potholing staging area, it is highly unlikely that discharge will occur from these areas. However, the soil staging area does have three constructed weirs with rock run-downs towards the top of the berm to allow stormwater flow to discharge from the staging area if it reaches that high. The canyons have ephemeral or intermittent stream flow and eventually flow into the Rio Grande approximately 10 miles southeast of the TA-60 RGF/SMSA. This facility does not discharge to Tier 2, Tier 2.5, or Tier 3 waters.

Both Mortandad and Sandia Canyons are on the New Mexico Environmental Department's 303d list for non-attainment of their designated uses. EPA has not approved or established a Total Maximum Daily Load (TMDL) for either stream. Potential contaminants leading to the inclusion of Sandia Canyon on the 303d list are Aluminum, Copper, Adjusted Gross Alpha, Dissolved Thallium, and PCBs and for Mortandad Canyon are Aluminum, Copper, Adjusted Gross Alpha, and PCBs. These listings are based primarily on stormwater data. The TA-60 RG/SMSA operations do not involve the pollutants of concern.

\section{Outfalls \\ Roads and Grounds Main Facility (See Appendix B, Map 1)}

Outfall 60-RG-1 ID\# 031: Stormwater flows south of building TA-60-250, the employee parking area, and from the south truck parking area to the sedimentation basin (detention pond). This flow then drains west towards the outfall. Stormwater from the area south of the Salt Shed flows into the drainage channel south of the lined retention pond and then drains east toward the outfall. Drainage then travels through a culvert that runs south under Sigma Mesa road and discharges into Mortandad Canyon.

Outfall 60-RG-2 ID \# 030: Small amounts of stormwater from the Heavy Equipment Storage Yard driveway drains to the southeast corner of the yard where it enters the asphalt drainage swale along Sigma Mesa road, travels through a culvert under the road and discharges into Mortandad Canyon.

Outfall 60-RG-3 ID \# 032: Stormwater flows from the area north of the Salt Shed through the north Heavy Equipment Storage and parking area to a riprap lined channel that discharges via sampling station E123.4 (which is also known as Monitored Outfall \# 60RG-3 ID \# 032) and then to the north towards Sandia Canyon. 
Outfall 60-RG-4 ID \# 033: Stormwater flows north from the west side of the small Equipment Storage Area and through the north parking lot where it discharges at a point north of the facility and then drains towards Sandia Canyon.

Outfall 60-RG-5 ID \# 034: Stormwater flows north from the east side of the Small Equipment Storage Area, west side of Bldg. 250 (main Roads and Grounds Facility building) and north vehicle parking area located northwest of Bldg. 250 where it discharges at a point north of the facility and then drains towards Sandia Canyon.

Outfall 60-RG-6 ID \#035: Stormwater flows north from the east side of Bldg. 250, the north parking area behind the building, and from several transportainers on the northern site boundary. Stormwater discharges at a point on the northwest side of the transportainers and then flows north towards Sandia Canyon.

\section{Sigma Mesa Staging Area (See Appendix B, Map 2)}

Outfall 60-RG-7 ID \# 041: Stormwater flows southeast through a base course equipment staging area and discharges to a vegetated area that flows southeast towards Mortandad Canyon.

Monitored Outfall 60-RG-8 ID \# 042: Stormwater flows northeast from the north equipment staging and stockpile area to a pond. Water in the pond discharges to a riprap lined channel that flows northeast towards Sandia Canyon.

Outfall 60-RG-9 ID \# 040, outfall 60-RG-10 ID \# 039, outfall 60-RG-11 ID \# 038, 60 RG-12 ID\# 037 and 60-RG-13 ID \# 036: These outfalls are identical riprap lined weirs, which serve as discharge points for stormwater runoff that would accumulate along the berm that extends along the north end of the soil staging area. Stormwater, if discharged, would flow to the north, be collected in a swale located along the base of the berm and, if accumulated to an appropriate depth, would discharge through one of the weirs to Sandia Canyon.

Substantially Identical Outfalls The following outfalls at the Roads and Grounds Main Facility and Sigma Mesa Staging Area have been identified as substantially identical based on common potential pollutant sources, drainage areas, activities within the drainage areas and general site topography and characteristics. Information supporting this outfall determination for monitoring requirements is listed in Section 4.3 of this SWPPP and includes outfall locations, facility activities and associated potential pollutants, runoff coefficients and control measures.

Outfalls 60-RG-1 ID \# 031 and 60-RG-2 ID \# 030: Both of these areas receive stormwater runoff to the south of the main facility, discharge stormwater that may come in contact with 
heavy equipment or trucks, and both have the potential to discharge stormwater runoff to Mortandad Canyon.

Outfalls 60-RG-3 ID \# 032 , 60-RG-4 ID \# 033, 60-RG-5 ID \# 034, and 60-RG-6 ID \# 035: All of these outfalls receive stormwater runoff from the central portion of the main facility, discharge to Sandia Canyon, and discharge stormwater that may come in contact with vehicle or heavy equipment parking or storage. All outfalls at the facility are inclusive of monitoring performed at gage station E123.4 located at 60-RG-3 ID \# 032. This outfall receives runoff from all central areas of the main facility and is the outfall with the highest runoff coefficient. Therefore, monitoring at this outfall is representative of the remaining outfalls at the main facility discharging to Sandia Canyon.

Outfalls 60-RG-7 ID \# 041 and 60-RG-8 ID \# 042: These outfalls receive stormwater runoff from truck parking and equipment storage area and from construction material staging piles.

- Outfalls 60-RG-9 ID \# 040, 60-RG-10 ID \# 039, and 60-RG-11 ID \# 038: All of these outfalls may receive stormwater runoff from the east clean soil staging area. Each of these outfalls is a weir situated towards the top of an earthen berm with riprap to prevent erosion at the discharge point. These three outfalls are identified as substantially identical outfalls because all soil staged within the area is clean, with the potential pollutants being sediment, hydraulic fluids, or diesel fuel should the heavy equipment leak during loading and unloading operations.

All stormwater from these outfalls would discharge to Sandia Canyon.

- Outfalls 60-RG-12 ID \# 037 and 60-RG-13 ID \# 036: All of these outfalls may receive stormwater runoff from the west clean soil staging area. Each of these outfalls is a weir situated towards the top of an earthen berm with riprap to prevent erosion at the discharge point. These two outfalls are identified as substantially identical outfalls because all soil staged within the area is clean, with the potential pollutants being sediment, hydraulic fluids, or diesel fuel should the heavy equipment leak during loading and unloading operations. This yard is separated by a compacted earthen berm from the east Potholing and Culvert Clean-out staging areas. All stormwater from these outfalls would discharge to Sandia Canyon.

\section{SECTION 2: POTENTIAL POLLUTANT SOURCES}

The following is a description of site activities and materials that have been, are, or could be exposed to storm water. Controls used for each potential pollutant are described in Section 3.

\subsection{Industrial Activities and Associated Pollutants}

Industrial activities and associated pollutants for the TA-60-RG/SMSA are identified below. Storage of equipment and supplies used to maintain roads and grounds at LANL, 
The main Roads and Grounds facility has a yard to store 4-wheelers, lawn tractors, lawn mowers, snow blowers and miscellaneous small-engine equipment. There are approximately 100 pieces of equipment stored in the area although the inventory will vary depending upon how much equipment is deployed and/or in the shop for repairs or maintenance. Potential pollutants from this activity are fuel and oil from leaking equipment.

\section{Storage of trucks and heavy equipment, used to transport/haul material or move debris.}

Large trucks are parked at three locations in the parking lots around the main facility. Dump trucks, van trucks and flatbed trucks are parked outside the south and/or east corner of TA-60-0029 and to the north of the small equipment storage area. Road salt spreading trucks are parked to the north of the Salt Shed. Heavy equipment is stored in the heavy equipment yard identified on the map. This yard is west of the lined retention pond. Maintenance is performed off site at the Heavy Equipment shop. In addition, passenger cars are parked in the gravel lot north of the sediment pond. Potential pollutants for this activity include spills of salt from the salt spreading trucks, and leaks or spills of fuel, oil, fluids (transmission and hydraulic) and anti-freeze.

\section{Storage of bulk potassium acetate, GeoMelt ${ }^{\mathrm{TM}}$ and other liquids and road salt applied for deicing.}

Two 5000 gallon storage tanks with salt brine (potassium acetate) are located north of Bldg. TA-60-0178. Four 10,000 gallon storage tanks are located south of Bldg. TA-600178. They contain potassium acetate, calcium chloride, protein, super mix (anti-icing/prewetting solution) and CRYOTECH CF7- Potassium Acetate and Corrosion Inhibitors. The salt shed provides indoor storage for road salt and Ice Slicer ${ }^{\mathrm{TM}}$. The potential pollutant sources are leaks or spills during refilling or transfer of liquid or solid product including sodium chloride and Ice Slicer (which is naturally occurring complex chlorides including magnesium, calcium, sodium, and potassium.

\section{Staging of clean soil prior to reuse}

Soil pre-screened as originating from uncontaminated areas throughout LANL is transported by dump truck, or end-dumps to the east soil staging area located at the SMSA. One potential pollutant source would be sediment if it was transported with stormwater runoff from the site. The compacted earthen berm, weir and riprap prevent sediment migration from this location. A gravel surface is no longer effective at preventing sediment transport off site from the south central portion of the SMSA and therefore at the end of the day when loading and unloading operations cease the area affected by sediment transport is sweep with a vacuum truck. Other potential pollutants include leaks or spills of fuel, oil, fluids (transmission and hydraulic) and anti-freeze from heavy equipment performing work in the area.

\section{Asphalt Millings Staging Area}

Asphalt millings pre-screened as originating from uncontaminated areas throughout LANL is transported by dump truck, or end-dumps to the far east staging area located at the SMSA. Potential pollutants include leaks or spills of fuel, oil, fluids (transmission and hydraulic) and anti-freeze from heavy equipment performing work in the area. 


\section{Potholing and Culvert Cleanout Staging Areas}

Soil and mixture of water pre-screened as originating from uncontaminated areas throughout LANL is transported in a potholing machine to the far west staging area located at SMSA. One potential pollutant source would be sediment if it was transported with stormwater runoff from the site. A compacted earth berm and a vegetated buffer strip where water is allowed to evaporate from the mixture preventing sediment migration from this location. Other potential pollutants include leaks or spills of fuel, oil, fluids (transmission and hydraulic) and anti-freeze from heavy equipment performing work in the area.

\section{Sediment catchment in the detention basin}

Soil/sediment from the main facility could travel with stormwater runoff to the detention basin located south of the facility. However, it is unlikely that sediment would discharge from the pond.

\section{Salt retention in the lined retention pond}

Road salt and other deicing liquids could migrate to the lined retention pond. However, these pollutants will not migrate off-site since the retention pond was designed to fully contain a 100 year storm event.

\section{Storage of sand, gravel, rock, and other landscaping materials}

\section{Other potential pollutant sources \\ Pesticide Storage Shed (TA-60-29) Outfall 60-RG-4 ID \# 033}

\section{Other Sector P Specific Concerns}

- On-site waste storage or disposal.

- Parking areas for vehicle awaiting maintenance. None

- Illicit plumbing connections. No floor drains

- Fueling. None

\section{Solid Waste Management Units (SWMUs)}

There are two areas that are either within the boundary of the Roads and Grounds Facility, or that could be potentially affected by storm water runoff from the facility that have been designated as Solid Waste Management Units (SWMU's) in the Los Alamos National Laboratory (Operable Unit 1148) RCRA Facility Investigation (RFI) Work Plan for Environmental Restoration (May 1992).

- 60-001(d) - Bermed storage area next to the Pesticide Storage Shed. This SWMU was approved for No Further Action (NFA) status in 1994.

- 60-002 - This SWMU is actually comprised of several piles of asphalt, concrete and debris throughout Sigma Mesa. One of the piles was located within the current boundary of the Roads and Grounds Facility. The pile was removed and disposed prior to construction of the Roads and Grounds Facility and confirmation samples were collected from beneath the pile. The data will be included in the report for the 
Rev. 2: January 2017

final disposition of the entire SWMU once all of the piles comprising the SWMU have been remediated and/or sampled. In the interim, there is no exposure of this SWMU to storm water from the Roads and Grounds Facility since the portion included within the Roads and Grounds Facility Boundary has been removed.

\subsection{Spill and Leaks}

Areas of Site Where Potential Spills/Leaks Could Occur

\begin{tabular}{l|l}
\multicolumn{1}{c|}{ Location } & \multicolumn{1}{c}{ Outfalls } \\
\hline Heavy equipment Storage Yard & Outfall 60-RG ID \# 032 \\
\hline Heavy equipment Storage Yard & Outfalls 60-RG ID \# 032, 033 \\
\hline Small equipment Storage Yard & Outfalls 60-RG ID \# 032, 033, 034 \\
\hline Craft storage Buildings & Outfalls 60-RG ID \# 032, 033, 034, \\
\hline Vehicle storage at Sigma Mesa & 035 \\
\hline
\end{tabular}

See Spill Log for the list of past spills

\subsection{Non-Storm water Discharges}

Except for flows from fire hydrant activities, sources of non-storm water that are combined with storm water discharges associated with industrial activity must be identified in the SWPPP. Identified non-storm water discharges are summarized below.

Non-storm water discharges are also identified in the "Non-Storm water Discharge Assessment and Certification". This certification form certifies that all storm water outfalls have been evaluated for the presence of non-storm water discharges. This form will be updated whenever a change in possible non storm water discharges is determined.

- Discharges of water occur during testing of fire hydrants and preventive maintenance flushing of the fire suppression system. The hydrants are tested annually by the Los Alamos County Fire Department. Each test and flushing of a hydrant releases approximately 1,000 gallons of water. Preventive maintenance flushing occurs approximately every six months and releases an estimated 200 gallons of water. The runoff from flushing of fire hydrants and fire suppression system flows off the mesa top through areas in which no potential contaminants are stored or managed. The hydrants and fire suppression system are not tested or flushed during precipitation events.

- Discharges of water from a fire hydrant also occur from residual water left over in a backflow preventer from filling water trucks at the east end of TA-60 building 250 . Each release from the backflow preventer is less than 5 gallons of water. 


\section{$2.4 \quad$ Salt Storage}

Rev. 2: January 2017

Salt Shed, Super Mix Blending Station and Associated Storage Tanks (TA-60-178).

- Salt storage: The Salt Shed provides indoor storage for road salt and Ice Slicer. Bags of Ice Melt on wood pallets are also stored in a closed Transportainer (60-287) SE of TA-60 building 250. Potential Pollutants: Road salt is primarily sodium chloride and Ice Slicer is naturally occurring complex chlorides including magnesium, calcium, sodium, and potassium.

- Salt and brine loading area.

\subsection{Sampling Data Summary}

Analytical data from a storm event on 7/21/2016 at Outfall-RG-1 ID \# 031 exceeded the New Mexico water quality standard for total recoverable aluminum, dissolved Copper and Adjusted Gross Alpha.

Analytical data from a storm event on 8/3/2016 at Outfall-RG-8 ID \# 042 exceeded the New Mexico water quality standard for total recoverable aluminum and Adjusted Gross Alpha.

Outfalls 60-RG-1 ID \# 031 and 60-RG-2 ID \# 030 are Substantially Identical Outfalls (SIO). Both of these areas receive stormwater runoff to the south of the main facility, discharge stormwater that may come in contact with heavy equipment or trucks, and both have the potential to discharge stormwater runoff to Mortandad Canyon.

In 2016 Enviosoxx with MetalLoxx wattles were installed in the channel that discharges to Outfall 60-RG-2 ID \# 030 (SIO) and another one was also installed around the pile of river rock and vertical culvert to monitored Outfall 60-RG-1 ID \# 031 in an effort to address the exceeded New Mexico water quality standard for total recoverable aluminum and dissolved Copper. A Envirosoxx with MetalLoxx wattle was also installed where the sediment retention pond discharges to monitored Outfall-RG-8 ID \# 042 at the far east end of Sigma Mesa in an effort to address the exceeded New Mexico water quality standard for total recoverable aluminum. According to the manufacturing specifications the functional longevity for the Envirosoxx with MetalLoxx wattles is 6 months to a year and they will be replaced at the end of every March prior to the beginning of the new sampling season in April.

\section{SECTION 3: STORM WATER CONTROL MEASURES}

\subsection{Minimize Exposure}

Control measures at the facility are designed to minimize the potential for spills, releases, exposure of materials, or any other events that could adversely affect the quality of water and sediment that may be transported out of the area by stormwater runoff. 
The Salt Shed provides indoor storage for road salt and Ice Slicer that is protected from coming in contact with storm water by keeping three roll-up doors closed.

Small containers of fuel and oils are stored in a flammable cabinet located just inside the entrance to the small equipment storage area.

Pesticides are stored inside a building.

\subsection{Good Housekeeping}

Good housekeeping practices that are specifically applicable to the prevention of storm water contamination include:

- Individual mixing operations take place in closed vessels, so that the potential for exposure of storm water to materials is limited to loading and unloading activities. When possible, the road salt is stored inside the Salt Shed to prevent exposure to storm water. The use of a brine solution for deicing operations is also being transitioned in to reduce the use of road salt.

- All storage areas are kept clean and neat. Vehicles and other equipment are stored and maintained in specified areas and heavy equipment repair and maintenance is never performed at this site.

- Garbage and floatables are routinely picked up by facility personnel. All garbage containers are covered to prevent windblown debris.

\subsection{Maintenance}

Outdoor areas are inspected at least monthly as per Section 5.1 of the SWPPP to ensure that the grounds are kept in an orderly condition and those structures such as storm water control structures are properly maintained and free of debris or other obstructions. The inspection will also identify any leaks, spills, or non-storm water discharges in any of the areas. Deficient items identified during inspections are documented in the EPC-CP MSGP

Corrective Actions Tracking Database. If control measures are in need of routine maintenance, it must be conducted immediately in order to minimize pollutant discharges. If a control measure is found to need repair or replacement, all reasonable steps to prevent or minimize the discharge of pollutants must immediately occur until the final repair or replacement is implemented including cleaning up any contaminated surfaces so that the material will not be discharged during subsequent storm events. Final repairs/replacement of stormwater controls should be completed as soon as feasible but must be no later than the timeframe established in Part 4.3 of the 2015 MSGP for corrective actions, I.e., within 14 days or, if that is infeasible, within 45 days. If the completion of stormwater control repairs/replacement will exceed the 45 day timeframe, the site will take the minimum additional time necessary to complete the maintenance, provided that the EPA Regional Office is notified of the intention to exceed 45 days, and documentation of the rational is contained in this SWPPP. Note: "All reasonable steps" means that the permittee has undertaken initial actions to assess and address the condition causing the corrective action, including for example, cleaning up any exposed 
Rev. 2: January 2017

material that may be discharged in a storm event (e.g., through sweeping, vacuuming) or making arrangement (i.e., scheduling) for a new best management practice to be installed at a later date. If a control measure was never installed, was installed incorrectly or not in accordance with Part 2 and/or 8 of the 2015 MSGP, or is not being properly operated or maintained site personnel must conduct corrective action as specified in Part 4 of the 2015 MSGP. Temporary BMP's will be installed to serve as backup controls while a control measure is offline.

The Pollution Prevention Team Leader is responsible for ensuring that any maintenance or repairs associated with a deficiency or opportunity for improvement, including any regular or scheduled maintenance (such as the removal of debris) are promptly and adequately performed. Any necessary changes to operational procedures or structural features must be implemented in a timely manner.

\subsection{Spill Prevention and Response}

Operational controls are implemented to minimize the possibility of any accidents resulting in spills or releases. Regulatory environmental reporting requirements are described in LANL's Emergency Procedures and Protective Actions P1201-4 and Environmental Reporting Requirements for Releases or Events ENV-DO-QP-101.2. Spill Prevention practices at the facility include application of good housekeeping procedures, best management practices, and engineering and administrative controls. Examples of these measures include storing equipment with drip pans, and inspecting regularly for leaks.

One of the functions of the Roads and Grounds crew is to provide small spill and leak response and cleanup throughout the laboratory. Because of this, ample supplies of materials as well as trained and qualified response personnel are available at the facility to rapidly contain and clean up any spills or leaks. All unauthorized spills and leaks are entered in the EPC-CP MSGP Corrective Action Reporting database.

Operational controls are implemented to minimize the possibility of any accidents resulting in spills or releases off site. In general, the approach to spill clean-up of a known substance is to first contain the spill by securing the spill source and deploying spill containment materials. If secondary containment is being provided (e.g. secondary containment pallets for liquids) it will contain the spill. Small spills are responded to by the operator involved in the spill or by the operator located in the vicinity. For incidental releases, absorbents are used to pick-up free liquids and the contaminated absorbents are properly disposed. Standard procedures for spill containment and clean up include the use of spill control kits, sorbent pillows, socks, sheets, and granules. Clean-up residues are managed as appropriate and as determined by the facility waste management coordinator and EPC-CP personnel depending on the material spilled. Larger spills or spills of unknown substances require that EPC-CP personnel be contacted to respond to the spill, securing the spill area and contacting LANL's Emergency Management Division.

The Security and Emergency Operations (SEO), Emergency Response Group (SEO-1) has been appointed by the Laboratory Director as the organization responsible for 
emergency management at the Laboratory. The SEO and SEO-1 group will be notified if a spill cannot be easily controlled with the materials on hand, threatens to escape the facility or enter the environment, needs additional resources, involves an unidentified hazard, involves injuries to personnel, requires fire protection, is beyond the training and skill levels of operational or facility personnel regarding the use of spill control equipment, or personnel are not confident in their ability to carry out spill response activities. The SEO and SEO-1 group can be reached at 667-6211 during regular business hours as well as after hours. If a fire or explosion occurs, or if the potential for such exists, the situation must be reported by dialing 911 from a non-cellular phone or by activating a fire pull box. 911 should also be dialed in the event of an employee injury. In the event of a spill, the Emergency Management Office will notify the individuals or organizations responsible for the completion of spill reports or the fulfillment of regulatory reporting requirements.

At LANL, the completion of a spill report may be required in the event of a spill. This determination will be made by the Emergency Ops Office or EPC-CP in accordance with Laboratory and U.S. Department of Energy (DOE) policies, and federal and state regulatory reporting requirements. In addition to fulfilling reporting requirements, spill reports assist user Groups and Laboratory management in assessing the cause of a spill and in executing corrective action.

Two types of spill reporting are required at the Laboratory: internal spill record keeping and external agency notification. Copies of internal spill reports will be kept on file with ENV$\mathrm{CP}$, the responsible organization, and also in the Spill Records section of the SWPPP. External agency notification (as determined by EPC-CP personnel) may consist of verbal or written notification to the National Response Center, EPA Region VI, or the New Mexico Environment Department.

Copies of internal spill reports are maintained by EPC-CP. All spills occurring within the MSGP facility shall be entered in the EPC-CP Corrective Actions Reporting database and documented in the Spill Log.

\section{Pesticide Storage Shed (TA-60-29) Outfall 60-RG-4 ID \# 033}

- Product mixing area. Mixing is performed outside the building in a containment area located north of the shed. All containers with pesticides are labeled to encourage proper handling and facilitate rapid response in case of spills or leaks.

\section{Heavy Equipment Storage Yard Outfall 60-RG-3 ID \# 032}

- Storage of Heavy Equipment. Drip pans installed under leaking equipment and routine inspections look for drips. All heavy equipment vehicles have yellow spill kits. 


\section{Small Equipment Storage Yard Outfall 60-RG-5 ID \# 34}

- Fuel and oil are stored in a flammable cabinet located just inside the entrance to the small equipment storage area.

\section{Vehicle Parking Lots}

- Large trucks are parked at three locations in the parking lots around the facility. Dump trucks, van trucks and flatbed trucks are parked outside the southeast corner of TA-60-0029 and to the north of the small equipment storage area. Road salt spreading trucks are parked to the north of the Salt Shed. Drip pans installed under leaking equipment and routine inspections conducted to look for drips.

\section{Craft Storage Buildings}

- Materials are stored inside buildings. Potential for spills when loading and unloading. Absorbent is available at TA-60-250 to help address potential leaks and spills.

\subsection{Erosion and Sediment Controls}

Erosion and sediment are controlled at the Roads and Grounds Facilities by both preventing erosion through the use of pavement and compacted millings and stabilized ditches and by trapping sediment. Velocity dissipation devices are installed at each discharge point.

General structural controls include the following:

- Runoff from the north side of the facility is collected in a drainage swale/base course berm and released to the canyon through rock check dams.

- Sediment traps/check dams: A sediment traps/check dams is located at the northeast corner of SMSA to trap sediment from the stone stockpile area.

\section{Sigma Mesa Staging Area (SMSA)}

There are several control measures present at the SMSA. Compacted earthen berms are present on the north, east and west sides of the east and west soil staging areas. The northern berm of each of these staging areas has riprap lined weirs, which serve as discharge points for stormwater runoff that would accumulate along the berm. There is also a berm along the east central portion of the SMSA and on the north side in the same general area. A gravel surface is no longer effective at preventing sediment transport off site from the south central portion of the SMSA and therefore at the end of the day when loading and unloading operations cease the area affected by sediment transport is sweep with a vacuum truck. 
Rev. 2: January 2017

To retain stormwater runoff and to minimize the potential for offsite transport of material within the potholing and culvert clean-out staging areas, two primary control measures are implemented: a compacted earth berm and a vegetated buffer strip. The earth berm is approximately $430 \mathrm{ft}$. in length and extends across the entire length of the north side of the area. It is a minimum of two feet in height with approximately 2:1 side slopes and is 2 feet wide across the top. The berm was sized to retain stormwater runoff from a 25-yr, 2-hr storm event. The vegetated buffer strip, comprised of existing perennial vegetation and woodchips from on-site material, is 50 feet in width and located immediately upslope from the compacted earth berm (see the SMSA map in Appendix B).

North of Eniwetok Road at the far eastern portion of the SMSA, stormwater flows to a retention pond with a riprap lined discharge point located adjacent to the automated stormwater sampler (60-RG Outfall ID \# 42). Sediment is cleaned out of the retention pond when it's two thirds full.

The south central portion of the SMSA (south of Eniwetok Road) has a riprap lined area and a straw waddle leading to outfall 60-RG Outfall ID \# 041. In addition, there is a berm in the same area to control stormwater runoff velocity and direct stormwater prior to discharge at the outfall.

This area is located 0.9 miles east of the main facility. Most of the staging area is located north of Eniwetok Road with a smaller parking and storage area located south of Eniwetok Road. The area is mainly used as a Teamster vehicle parking area and materials (sand and gravel) storage area. Some miscellaneous equipment parts (loading buckets, blades, etc) are stored on both sides of the staging area.

- Gravel and Sand Piles: TSS

- Soil for use as clean fill and potholing staging area

- Vehicles and Various Miscellaneous Pieces of Equipment: Leaks are contained by drip pans, inspection and routine maintenance.

\subsection{Management of Runoff}

Runoff from the salt storage area goes to the lined retention pond where up to a 100 year storm is fully contained.

\subsection{Salt Storage Piles or Piles Containing Salt}

- Salt piles are primarily stored in the Salt Storage Shed and are not exposed to stormwater because three roll up doors on the shed are kept closed.

- Road Salt Runoff Control: Runoff from the area around the east, west and south sides of the Salt Storage Shed is directed into the lined retention pond to prevent salt discharge into the canyon. The pond is lined with an impervious plastic liner and will retain a 100 -year storm. 


\subsection{MSGP Sector-Specific Non-Numeric Effluent Limits}

- Vehicle and Equipment Storage Areas. See Section 3.4 for specific control measures to control spills and leaks.

Pesticide Storage Shed (TA-60-0029)

- Product mixing area: Mixing is performed outside the building in a containment area located north of the shed.

- Pesticide application equipment storage and maintenance: Spill prevention, containment and control and drip pans and good housekeeping.

- Storm water trapped in the secondary containment is usually allowed to evaporate. In order to release storm water from the secondary containment it must have a PH between 6.5 and 7 , no odor or visible oily sheen, and the release must be documented on a liquid discharge form and submitted to EPC-CP.

Heavy Equipment Storage Yard The equipment storage yard is located west of the Salt Shed.

- Storage of heavy equipment: Leaks are contained by drip pans and routine maintenance. Maintenance is performed off-site at the Heavy Equipment shop.

\section{Small Equipment Storage Yard}

- Small containers of fuel and oils are stored in a flammable cabinet located just inside the entrance to the small equipment storage area.

\section{Vehicle Parking Lots}

- Large trucks are parked at three locations in the parking lots around the facility. Dump trucks, van trucks and flatbed trucks are parked outside the southeast corner of TA-60-29 and to the north of the small equipment storage area. Road salt spreading trucks are parked to the north of the Salt Shed. Leaks are contained by drip pans and routine maintenance.

- Passenger cars are parked on asphalt north of the sediment pond. Leaks are contained by drip pans and routine maintenance.

\section{Clean Fill Yards}

- 2.8 acres clean fill yard is located in between the Potholing and Culvert Cleanout and Asphalt Millings staging areas. Equipment will be hauling fill into and out of these areas. There will also be equipment involved in 'working' the fill and soil. 


\section{Asphalt Millings Staging Yard}

- 0.3 acres asphalt millings staging yard is located east and adjacent to the clean fill yard. Equipment will be hauling asphalt millings into and out of this area. Equipment will also be used to load the asphalt millings.

\section{Potholing and Culvert Cleanout Staging Yard}

- 2.6 acres potholing and culvert cleanout staging yard are located west and adjacent to the clean fill yard. The staging area consists of three open pits: the first being 27 feet wide by 25 feet long, the second 14 feet wide by 45 long, and the third pit 15 feet wide by 35 feet long. The pits are between 4 to 8 feet deep. Equipment will be hauling potholing material into this area and will also be used to move the potholing material once it dries out.

- Fueling Areas. There are no fueling stations at Roads and Grounds.

- Material Storage Areas. Except as detailed under Small Equipment and Salt Storage there are no material storage areas.

- Vehicle and Equipment Maintenance Areas. No maintenance of equipment is done at this facility.

\section{$3.9 \quad$ Employee Training}

The primary object of the training program is to ensure employees who work in areas where industrial material or activities are exposed to stormwater or who are responsible for implementing activities necessary to meet the conditions of this permit, including all members of the stormwater pollution prevention team understand the requirements of the 2015 MSGP and their specific responsibilities with respect to those requirements.

Per section 2.1.2.8 of the 2015 MSGP, training relevant to the SWPPP is required for all operational workers at the facility who work in areas where industrial materials or activities are exposed to stormwater (MSGP sites); managers and supervisors who are responsible for implementing activities necessary to meet the conditions of this permit (e.g., inspectors, maintenance personnel); and all members of the PPT. Training provided and assigned to these personnel cover both the specific control measures used at the facility; along with monitoring, inspection, planning, reporting, and documentation requirements described in this SWPPP. Training is conducted at least annually.

The training incorporates at a minimum, the following topics:

- An overview of what is in the SWPPP;

- Spill response procedures, good housekeeping, maintenance requirements, and material management practices;

- The location of all controls on the site required by this permit, and how they are to 
be maintained;

Rev. 2: January 2017

- The proper procedures to follow with respect to the permit's pollution prevention requirements; and

- When and how to conduct inspections, record applicable findings, and take corrective actions (only applies to persons responsible for conducting inspections).

The EPC-CP sampling team is tasked with meeting monitoring requirements and train to the following procedures once a year:

- ENV-CP-QAPP-MSGP: Quality Assurance Project Plan for the Storm Water MultiSector General Permit for Industrial Activities Program,

- ENV-CP-QP-045: Installing, Setting up, and Operating ISCO Samplers for the MSGP,

- ENV-CP-QP-048: Processing MSGP Storm Water Samples,

- ENV-CP-QP-047: Inspecting Storm Water Runoff Samplers and Retrieving Samples for the MSGP, and

- ENV-CP-QP-064: Multi-Sector General Permit Storm Water Visual Inspections.

Training activities are documented in the SWPPP.

\subsection{Non-storm Water Discharges}

See section 2.3

\subsection{Waste Garbage and Floatable Debris}

The following control measures are used at the TA-60 RGF/SMSA facilities.

Good housekeeping practices that are specifically applicable to the prevention of storm water contamination include:

- Regular walk through inspections are conducted to ensure that no potential contaminants are present in exposed areas.

- Individual mixing operations take place in closed vessels, so that the potential for exposure of storm water to materials is limited to loading and unloading activities. The use of a brine solution for deicing operations is also being transitioned to reduce the use of road salt.

- All storage areas are kept clean and neat. Vehicles and other equipment are stored and maintained in specified areas and heavy equipment repair and maintenance is never performed at this site.

- Garbage and floatables are routinely picked up by facility personnel. All garbage containers are covered to prevent windblown debris. 


\subsection{Dust Generation and Vehicle Tracking of Industrial Materials}

Dust is controlled throughout the site by the use of pavement, compacted millings, gravel, speed limits, routine sweeping with a street sweeper, and watering for dust suppression when necessary.

\section{SECTION 4: SCHEDULES AND PROCEDURES FOR MONITORING}

\subsection{Storm water Monitoring}

Analytical monitoring comprised of quarterly benchmark and impaired waters monitoring is performed on stormwater discharges from the site. Monitoring events occur during storm events that result in as actual discharge from the site and that follow the preceding measurable storm event by at least 72 hours (3 days). From runoff from snowmelt, the monitoring is performed at a time when a measurable discharge from the site occurs.

Monitoring for substantially identical outfalls is conducted according to test procedures approved under 40 CFR Part 136. Runoff samples are collected by taking a minimum of one grab sample from a discharge, collected within the first 30 minutes of a measurable storm event. If it is not possible to collect the sample within the first 30 minutes of ameasurable storm event, the sample is collected as soon as practicable after the first 30 minutes and documentation is kept with the SWPPP explaining why it was not possible to take samples within the first 30 minutes. Any corrective actions required as a result of a quarterly visual assessment must be performed consistent with Part 4 of the 2015 MSGP.

\subsection{Monitoring Schedule}

Monitoring will begin in April 2016. Benchmark monitoring continues on a quarterly basis at least once in each of the following 2-month intervals:

- April 1 - May 31

- June 1 - July 31

- August 1 - September 30

- October 1 - November 30

Impaired waters monitoring is performed on an annual basis with a sample collected in the period between April 1 and November 30.

LANL is located in a high elevation, semi-arid climate where the majority of rainfall occurs during a period between July and September. Freezing conditions that would prevent runoff from occurring for extended periods may also occur during the winter months. For these conditions if benchmark monitoring cannot be performed on the quarterly schedule above, monitoring events will be distributed during seasons when precipitation occurs, or when snowmelt results in a measurable discharge from the site. If adverse weather conditions prevent the collection of samples according to the relevant monitoring schedule, a substitute sample will be collected during the next qualifying storm event or as soon as practical. 
Rev. 2: January 2017

\subsection{Substantially Identical Outfalls}

This facility utilizes substantially identical outfalls for monitoring events. The outfalls have been identified as substantially identical based on common potential pollutant sources, drainage areas, activities within the drainage areas, and general site topography and characteristics. Required information supporting this outfall determination is as follows:

\begin{tabular}{|c|c|c|c|c|}
\hline \multicolumn{5}{|c|}{ Roads \& Grounds Main Facility (See Appendix B - Fig. 2, Map 1) } \\
\hline $\begin{array}{l}\text { Outfall } \\
\text { ID }\end{array}$ & Outfall Location & $\begin{array}{l}\text { Activities/Potential } \\
\text { Pollutants }\end{array}$ & $\begin{array}{c}\text { Runoff } \\
\text { Coefficient }\end{array}$ & Control Measures \\
\hline $\begin{array}{l}\text { 60-RG-1 } \\
\text { ID \# } 031\end{array}$ & $\begin{array}{l}\text { Southern facility boundary, south } \\
\text { of sediment basin (Discharge to: } \\
\text { Mortandad Canyon) }\end{array}$ & $\begin{array}{l}\text { Vehicle parking - } \\
\text { oil/fuel/hydraulic fluids } \\
\text { Salt storage area - road salt }\end{array}$ & $65 \%$ & $\begin{array}{l}\text { Sediment basin (detention pond) } \\
\text { Vegetative buffer, check dams, culvert }\end{array}$ \\
\hline $\begin{array}{l}\text { 60-RG-2 } \\
\text { ID \# } 030\end{array}$ & $\begin{array}{l}\text { South facility boundary, south of } \\
\text { heavy equipment storage area } \\
\text { (Discharge to: Mortandad } \\
\text { Canyon) }\end{array}$ & $\begin{array}{l}\text { Heavy equipment storage } \\
\text { and parking - } \\
\text { oil/fuel/hydraulic fluids }\end{array}$ & $>65 \%$ & Asphalt drainage swale, riprap, culvert \\
\hline $\begin{array}{l}\text { 60-RG-3 } \\
\text { ID \# } 032\end{array}$ & $\begin{array}{l}\text { Northwest corner of facility } \\
\text { boundary (Discharge to: Sandia } \\
\text { Canyon }\end{array}$ & $\begin{array}{l}\text { Heavy equipment storage } \\
\text { and parking - } \\
\text { oil/fuel/hydraulic fluids }\end{array}$ & $>80 \%$ & $\begin{array}{l}\text { Riprap, asphalt berm, TRM (P-300), } \\
\text { Jersey barriers }\end{array}$ \\
\hline $\begin{array}{l}\text { 60-RG-4 } \\
\text { ID \# } 033\end{array}$ & $\begin{array}{l}\text { Northwest facility boundary } \\
\text { (Discharges to: Sandia Canyon) }\end{array}$ & $\begin{array}{l}\text { Heavy equipment storage } \\
\text { and parking - } \\
\text { oil/fuel/hydraulic fluids }\end{array}$ & $65 \%$ & $\begin{array}{l}\text { Riprap, asphalt berm, TRM (P-300), } \\
\text { Jersey barriers }\end{array}$ \\
\hline $\begin{array}{l}\text { 60-RG-5 } \\
\text { ID \# } 034\end{array}$ & $\begin{array}{l}\text { Northwest facility boundary } \\
\text { (Discharges to: Sandia Canyon) }\end{array}$ & $\begin{array}{l}\text { Small equipment storage and } \\
\text { parking - oil/fuel/hydraulic } \\
\text { fluids }\end{array}$ & $65 \%$ & $\begin{array}{l}\text { Riprap, asphalt berm, TRM (P-300), } \\
\text { Jersey barriers }\end{array}$ \\
\hline $\begin{array}{l}\text { 60-RG-6 } \\
\text { ID \# } 035\end{array}$ & $\begin{array}{l}\text { Northern facility boundary, north } \\
\text { of building } 60-0250 \text { (Discharges } \\
\text { to: Sandia Canyon }\end{array}$ & $\begin{array}{l}\text { Vehicle parking - } \\
\text { oil/fuel/hydraulic fluids }\end{array}$ & $65 \%$ & $\begin{array}{l}\text { Riprap, asphalt berm, TRM (P-300), } \\
\text { Jersey barriers }\end{array}$ \\
\hline
\end{tabular}

\begin{tabular}{|c|l|l|l|l|}
\hline \multicolumn{2}{|c|}{ Sigma Mesa Staging Area (See Appendix B - Fig. 2 Map 2) } \\
\hline $\begin{array}{c}\text { Outfall } \\
\text { ID }\end{array}$ & \multicolumn{1}{|c|}{ Outfall Location } & \multicolumn{1}{|c|}{$\begin{array}{c}\text { Activities/Potential } \\
\text { Pollutants }\end{array}$} & $\begin{array}{c}\text { Runoff } \\
\text { Coefficient }\end{array}$ & \multicolumn{1}{c|}{ Control Measures } \\
\hline $\begin{array}{l}\text { 60-RG-7 } \\
\text { ID \# 041 }\end{array}$ & $\begin{array}{l}\text { Southern facility boundary, } \\
\text { south of sediment basin } \\
\text { (Discharge to: Mortandad } \\
\text { Canyon) }\end{array}$ & $\begin{array}{l}\text { Equipment storage - } \\
\text { oil/fuel/hydraulic fluids }\end{array}$ & $45-60 \%$ & $\begin{array}{l}\text { Base course, riprap, vegetative } \\
\text { buffer }\end{array}$ \\
\hline $\begin{array}{l}\text { 60-RG-8 } \\
\text { ID \# 042 }\end{array}$ & $\begin{array}{l}\text { Northwest facility boundary } \\
\text { (Discharges to: Sandia } \\
\text { Canyon) }\end{array}$ & $\begin{array}{l}\text { equipment and stockpile } \\
\text { storage - oil/fuel/hydraulic } \\
\text { fluids }\end{array}$ & $45-60 \%$ & Riprap channel \\
\hline
\end{tabular}

Outfalls 60-RG-4 ID \# 033 thru 60-RG-60-6 ID \# 035: Monitoring performed at gage station E123.4, which is also known as Monitored Outfall 60-RG-3 ID \#032, receives runoff from all central areas of the main facility and is the outfall with the highest runoff coefficient. Therefore, monitoring at this outfall is representative of the site as a whole in regard to potential pollutant discharge stormwater runoff. 
TA-60 Roads and Grounds Facility and Associated Sigma Mesa Staging Area Storm Water Pollution Prevention Plan

Rev. 2: January 2017

\subsection{Summary of Monitoring Requirements (Sandia / Mortandad Canyons)}

\begin{tabular}{|c|c|c|c|c|c|c|}
\hline Monitoring & Location & \multicolumn{3}{|c|}{ Parameters } & Numeric & Schedule \\
\hline \multirow[t]{2}{*}{ Benchmark } & \multirow{2}{*}{$\begin{array}{l}\text { Refer to } \\
\text { SWPPP } \\
\text { Map }\end{array}$} & \multicolumn{3}{|c|}{ None } & \multirow[t]{2}{*}{ None } & \multirow[t]{2}{*}{ Quarterly } \\
\hline & & & Sandia & Mortandad & & \\
\hline \multirow{6}{*}{$\begin{array}{l}\text { Impaired } \\
\text { Waters }\end{array}$} & \multirow{6}{*}{$\begin{array}{l}\text { Refer to } \\
\text { SWPPP } \\
\text { Map }\end{array}$} & Aluminum & $530 \mathrm{mg} / \mathrm{L}$ & $1324 \mathrm{mg} / \mathrm{L}$ & \multirow[t]{6}{*}{ None } & \multirow[t]{6}{*}{ Annual } \\
\hline & & Copper & $5 \mathrm{mg} / \mathrm{L}$ & $7 \mathrm{mg} / \mathrm{L}$ & & \\
\hline & & $\begin{array}{l}\text { Gross } \\
\text { Alpha, } \\
\text { adjusted }\end{array}$ & $15 \mathrm{pCi} / \mathrm{L}$ & $15 \mathrm{pCi} / \mathrm{L}$ & & \\
\hline & & $\begin{array}{l}\text { Thallium, } \\
\text { dissolved } \\
\text { (Sandia } \\
\text { Canyon } \\
\text { only) }\end{array}$ & $0.47 \mathrm{mg} / \mathrm{L}$ & N/A & & \\
\hline & & $\begin{array}{l}\text { PCB in } \\
\text { Water } \\
\text { Column }\end{array}$ & $\begin{array}{l}0.014 \\
\mathrm{mg} / \mathrm{L}\end{array}$ & $0.014 \mathrm{mg} / \mathrm{L}$ & & \\
\hline & & $\begin{array}{l}\text { Total } \\
\text { Aroclors }\end{array}$ & $\begin{array}{c}0.00064 \\
\text { ug/L }\end{array}$ & $0.00064 \mathrm{ug} / \mathrm{L}$ & & \\
\hline
\end{tabular}

\section{Procedures:}

- ENV-CP-QP-045, Installing, Setting up, and Operating ISCO Samplers for the MSGP:

http://int.lanl.gov/training/env-courses/55962/env-cp-qp-045.pdf

- ENV-CP-QP-048, Processing MSGP Stormwater Samples:

http://int.lanl.gov/training/env-courses/56595/env-cp-qp-048.pdf

- ENV-RCRA-QP-047, Inspecting Stormwater Runoff Samplers and Retrieving Samples for the MSGP:

http://int.lanl.gov/training/env-courses/56594/env-rcra-qp-047.pdf

- ENV-CP-QAPP-MSGP, Quality Assurance Project Plan for the Stormwater MSGP: http://int.lanl.gov/training/env-courses/43337/env-cp-qapp-msgp.pdf

\subsection{Summary of Monitoring Requirements}

Pollutants under impaired waters monitoring and quarterly benchmark monitoring constituents are identified in the most recent version of the Quarterly Assurances Project Plan for the Storm Water Multi-Sector General Permit for Industrial Activities Program. All analyses and/or field parameters are identified in the most recent version of the MSGP Sampling and Analysis Plan. These plans were written and are updated by ENV-CP. Specific monitoring information contained in the Sampling Analysis Plan (SAP) includes the following: 
- Analytical constituent(s) per outfall

- Frequency of analysis (annual or quarterly)

- Matrix type (snow melt or rainfall)

- Sample type (grab)

- Preservation

- Container type

- Unfiltered

- Holding times

- Detection Limits

- Volume

- Analytical method

Numeric control values for comparison with analytical results are provided by EPC-CP stormwater compliance personnel. The results of these are documented in the MSGP Annual Reports.

\subsection{Monitoring Results}

If the average of the 4 monitoring values for any parameter exceeds the benchmark, or if prior to completion of 4 quarterly samples, an exceedance of the 4 quarter average is mathematically certain, the Pollution Prevention Team and EPC-CP personnel will:

- Review the selection, design, installation, and implementation of your control measures to determine if modifications are necessary to meet the effluent limits,

- Implement the necessary modifications, and

- Continue quarterly monitoring until 4 additional quarters of monitoring have been completed for which the average does not exceed the benchmark.

If the average of the 4 monitoring values for any parameter does not exceed the benchmark, monitoring for that particular parameter will no longer be performed.

\subsection{Recordkeeping}

For each monitoring event, except snowmelt monitoring, the following information is recorded and maintained through field data sheets, LANL database systems, and Discharge Monitoring Records:

- The date, exact place, and time of sampling or measurements;

- The date and duration (in hours) of the rainfall event;

- Rainfall total (in inches) for that rainfall event;

- Time (in days) since the previous measureable storm event;

- The individual (s) who performed the sampling or measurements; 
- The date (s) analyses were performed;

- The individual (s) who performed the analyses;

- The analytical techniques or methods used; and

- The results of such analyses.

For snowmelt monitoring, all information except rainfall event durations, totals, and time since previous event is included. Additionally, all records of monitoring information, including all calibration and maintenance records are maintained for a minimum period of at least three years from the date the permit expires.

\section{SECTION 5: INSPECTIONS AND CORRECTIVE ACTIONS PROCESS}

\subsection{Routine Facility Inspection Procedures}

Routine inspections are conducted and documented monthly. The third month of the quarter (March, June, September, December) will be considered as the quarterly routine inspection. The inspections are performed by a qualified member of the Stormwater PPT (Deployed Environmental Professional or EPC-CP Compliance Project Lead).

One routine inspection is conducted during an active stormwater discharge, if possible. Routine inspections evaluate the following, at a minimum:

- Areas where industrial material or activities are exposed to stormwater;

- Areas where potential pollutant sources are identified;

- Discharge points; and

- Examine and look for leaks or spills, offsite tracking, trash residue, or other industrial materials that may have or could come in contact with stormwater.

The Stormwater PPT member performing the inspection documents the inspection and notes potential stormwater pollution problems that were encountered on the routine facility inspection form. Any required corrective actions identified during the inspection are addressed in accordance with ENV-CP-QP-022, MSGP Stormwater Corrective Actions. All identified corrective actions found as a result of routine facility inspections must comply with Part 4 of the 2015 MSGP. Corrective actions are recorded and documented in the EPC-CP MSGP CAR database.

Facility personnel or the Deployed Environmental Professional may also perform daily, weekly, or other periodic facility surveys in between monthly routine inspections to further ensure compliance with the SWPPP.

When any of the following conditions occur or are detected during an inspection, monitoring or other means, the Pollution Prevention Team must review and revise the SWPPP, as appropriate.

- An unauthorized release or discharge (e.g., spill leak, or discharge of nonstormwater not authorized by the 2015 MSGP or another NPDES permit to a water of the U.S. occurs at your facility. 
Rev. 2: January 2017

- Your control measures are not stringent enough for the discharge to meet applicable water quality standards or the non-numeric effluent limits in the 2015 MSGP.

- A required control measure was never installed, was installed incorrectly, or not in accordance with Parts 2 and/or 8 of the 2015 MSGP or is not being properly operated or maintained.

- Whenever a visual assessment shows evidence of stormwater pollution (e.g., color, odor, floating solids, settled solids, suspended solids, and foam).

- Construction or a change in design, operation, or maintenance at the facility that significantly changes the nature of pollutants discharged into stormwater from the facility, or significantly increases the quantity of pollutants discharged.

Specific areas of the facility to be inspected include:

- Salt storage area and pond

- Pesticide storage area

- Heavy equipment parking/storage

- Small equipment storage

- Sediment basin and outfalls

- Vehicle parking back lot

- Craft's storage areas

- Sigma Mesa sediment trap

- Vehicle storage areas

- Stone storage piles

- Clean soil piles

- Potholing and Culvert Cleanout staging areas

- Asphalt millings staging area

- Outfalls

\subsection{Quarterly Visual Inspection Procedures}

The quarterly visual assessments are conducted at outfalls 60-RG-2 ID\# 030, 60-RG-4 ID\# 033 through 60-RG-7 ID\# 041, 60-RG-9 ID\# 040, 60-RG-11 ID\# 038, and 60-RG-12 ID\# 037 by a qualified member of the Storm water PPT (Deployed Environmental Professional or EPC-CP). Visual assessments will:

- use a clean clear glass or plastic sample container in a well lite area;

- sample collected as soon as practicable after the first 30 minutes of a discharge if not possible to collect within the first 30 minutes following a storm event;

- snowmelt samples must be collected during a period of measurable discharge from the site;

- be conducted at least 72 hours since the last storm event;

- 72 hour storm interval does apply if you document that less than a 72 hour interval is representative for local storm events during the sampling period;

- document rationale if a visual assessment is unable to be collected in a quarter (no precipitation event or adverse conditions); 
- perform an additional assessment during the next qualifying storm event if unable to perform in a particular quarter;

- Perform one quarterly assessment during snow melt discharge.

Collection of quarterly visual assessments occurs on the following schedule for each calendar year in accordance with ENV-RCRA QP-064, MSGP Storm Water Visual Inspections:

- April 1 - May 31

- June 1 - July 31

- August 1 - September 30

- October 1 - November 30

The visual assessment will inspect for the following water quality characteristics: color, odor, clarity, floating solids, settled solids, suspended solids foam, oil sheen, and other obvious indicators of stormwater pollution.

The Stormwater PPT member performing the visual assessment will document potential stormwater pollution problems that were observed during the assessment on the Quarterly Visual Assessment form.

\section{SECTION 6: DOCUMENTATION TO SUPPORT ELIGIBILITY CONSIDERATIONS UNDER OTHER FEDERAL LAWS}

\subsection{Documentation Regarding Endangered Species}

The Los Alamos National Laboratory (LANL) Threatened and Endangered Species Habitat Management Plan (HMP) was prepared to provide for the protection of federally listed threatened and endangered species and their habitats at LANL. The HMP was designed to be a comprehensive landscape-scale management plan that balances the current operations and future development needs of LANL with the habitat requirements of threatened and endangered species. It also facilitates DOE compliance with the Endangered Species Act and related federal regulations. The HMP received concurrence from the U.S. Fish and Wildlife Service (USFWS) and was first implemented in 1999. All changes to the HMP, such as adding new species or changing requirements, are assessed in a new consultation with the USFWS before being implemented. The HMP provides guidance by species for different types of activities allowed without further review by the USFWS.

Currently, the only federally-listed species that have habitat or occur at LANL are the Southwestern Willow Flycatcher (Empidonax trailii extimus), Jemez Mountains Salamander (Plethodon neomexicanus), and Mexican Spotted Owl (Strix occidentalis lucida). Suitable habitats for these species, along with a protective buffer area surrounding the habitats, have been designated as Areas of Environmental Interests (AEIs). An AEI consists of a core area that contains important breeding or wintering habitat for a specific species and a buffer area around the core area. The buffer protects the core area from disturbances that would degrade the value of the core area to the species. 
The HMP includes ecorisk analyses which account for any industrial facility's stormwater discharges, allowable non-stormwater discharges, and stormwater discharge-related Activities. In addition, the Site-wide Environmental Impact Statement (SWEIS) biological assessment (BA) covered the continuation of Laboratory operations and included outfalls.

As determined by earlier evaluations, stormwater discharges, allowable non-stormwater discharges, and stormwater discharge-related activities from LANL MSGP locations are not likely to adversely affect any species that is federally-listed as endangered or threatened under Criterion D Section iii, the ESA, and will not result in the adverse modification or destruction of habitat that is federally-designated as "critical habitat" under the ESA. New activities are evaluated to determine if they will have an impact to any species. If an activity can be completed within the guidelines of the HMP it can go forward as scheduled; however, if the activity can not comply with the guidelines, the HMP requires that a project-specific BA be prepared for the action and go through the consultation process with the USFWS.

\subsection{Documentation Regarding Historic Properties}

In August, 2015 and December 2008, the Cultural Resources Team (using GPS spatial data as well as conducting visual inspections), reviewed the Laboratory industrial sites (see list below) and their associated outfalls and monitoring stations subject to the 2015 Multi-Sector General Permit (Permit \#NMR03195) for effects on historic properties. All of these sites were found to be undertakings of no effect and in compliance with Section 106 of the National Historic Preservation Act (i.e., Criterion B).

- TA-3-22 Power and Steam Plant

- TA-3-38 Metals Fabrication Shop

- TA-3-38 Wood Shop

- TA-3-39 and 102 Metal Shop

- TA-3-66 Sigma Complex

- TA-60 Asphalt Batch Plant

- TA-60-1 Heavy Equipment Yard

- TA-60 Material Recycle Facility

- TA-60 Roads and Grounds

- TA-60-2 Warehouse

- TA-54 Area L

- TA-54 Area G

- TA-54 Maintenance Facility West

- TA-54 RANT

\subsection{Documentation Regarding NEPA Review}

The Final Site-Wide Environmental Impact Statement for the Operation of Los Alamos National Laboratory (DOE/EIS-0380) was issued in May 2008, and a Record of 
Decision in September 2008. Stormwater issues and associated pollution prevention requirements and activities at LANL are analyzed in Chapters 4 and 5 of the 2008 SiteWide EIS. These activities are integrated into environmental reviews on a projectspecific level through both the LANL excavation permit process and the LANL project requirements (PR-ID) process. Stormwater issues are identified and pollution prevention activities are implemented during the design and construction phases of all LANL projects, and as part of facility operations, including routine maintenance. LANL staff monitors stormwater pollution prevention compliance at the MSGP sites in accordance with Section 4.0 Monitoring of this plan. Corrective actions are taken as necessary as described in Section 3.3. 


\section{SECTION 7: SWPPP CERTIFICATION}

\section{TA-60 Roads and Grounds Facility and Sigma Mesa Staging Area \\ STORM WATER POLLUTION PREVENTION PLAN CERTIFICATION STATEMENT}

"I certify under penalty of law that this document and all attachments were prepared under my direction or supervision in accordance with a system designed to assure that qualified personnel properly gathered and evaluated the information submitted. Based on my inquiry of the person or persons who manage the system, or those persons directly responsible for gathering the information, the information submitted is, to the best of my knowledge and belief, true, accurate, and complete. I am aware that there are significant penalties for submitting false information, including the possibility of fine and imprisonment for knowing violations."

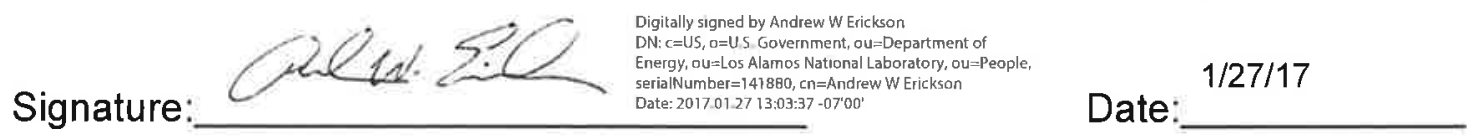
Andrew W. Erickson

Facility Operations Director Utilities and Institutional Facilities, UI-DO 


\section{SECTION 8: SWPPP MODIFICATIONS}

The SWPPP will be modified by the PPT and reviewed by the EPC-CP Technical Advisor(s) whenever necessary to address any of the triggering conditions for corrective actions listed in Section 3.3 of this SWPPP to ensure that they do not reoccur; or to reflect changes implemented when a review following the triggering conditions listed in Section 3.3 of this SWPPP indicates that changes to control measures are necessary to meet the effluent limits described in this SWPPP. Changes to this SWPPP document must be made in accordance with the corrective action deadlines defined in Section 5.4 and must be signed and dated in accordance with the signatory requirements listed in Appendix B Subsection 11 (Signatory Requirements) of the 2015 MSGP. SWPPP updates are required within 14 calendar days of completing corrective actions. 


\title{
APPENDIX A
}

\section{Pollution Prevention Team Members}

\section{POLLUTION PREVENTION TEAM MEMBERS}

\author{
Deployed Environmental Professional \\ Name: Leonard F. Sandoval \\ Title: $\quad$ Deployed Environmental Professional \\ Office: $505-667-3557$ \\ Cell: $\quad$ 505-231-1235 \\ Email: lesandov@lanl.gov \\ Duties: Provide technical guidance concerning SWPPP contents, adequacy, and implementation; assists \\ site representatives in performing and documenting the Site Compliance Evaluations; provides \\ guidance on BMPs, assists with revising and updating this SWPPP, documenting spills, and \\ conducts routine inspections.
}

\section{Site Operations}

Name: Larry Velasquez

Title: TA-60 Roads and Grounds Logistics Superintendent

Office: $505-667-6111$

Cell: $\quad$ 505-695-6949

Email: Ivelasquez@lanl.gov

Duties: Responsible for review of proposed work at the TA-60 RGF/SMSA to ensure compliance with the SWPPP; initiate and follows through with corrective measures to maintain BMPs.

\section{EPC-CP (Environmental Compliance Programs}

Name: Holly Wheeler

Title: $\quad$ EPC-CP Technical Advisor

Office: 505- 667-1312

Email: hbenson@lanl.gov

Duties: Provide technical guidance on SWPPP contents, adequacy, and implementation; aides in performing and documenting the Site Compliance Evaluations; provide guidance on BMPs; and assists with revising the SWPPP. 


\section{APPENDIX B}

\section{Site Maps}

Figure 1: General Location Map

Figure 2: Site Maps 1 \& 2

Figure 3: Site Maps with T \& E Habitat 


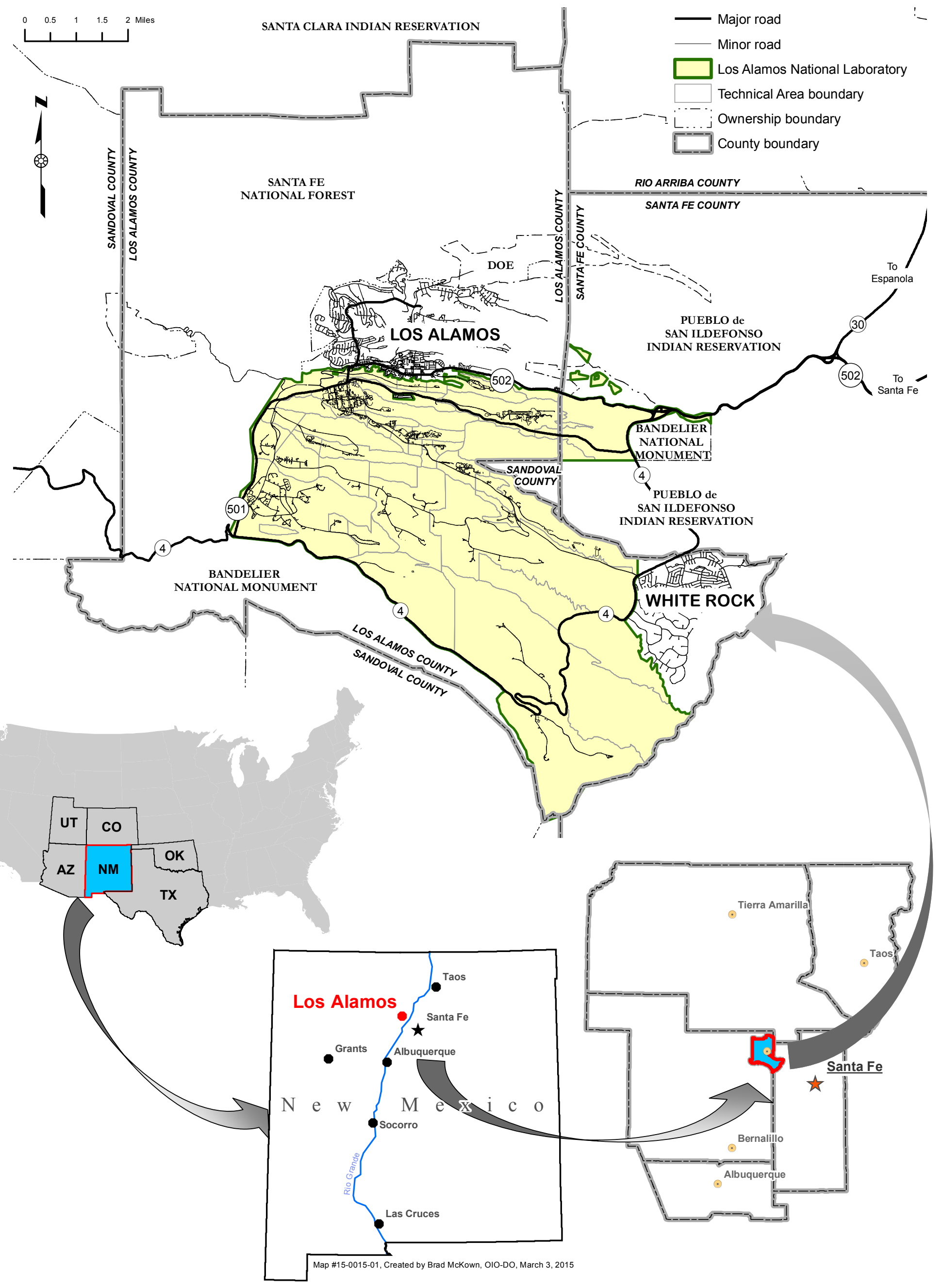




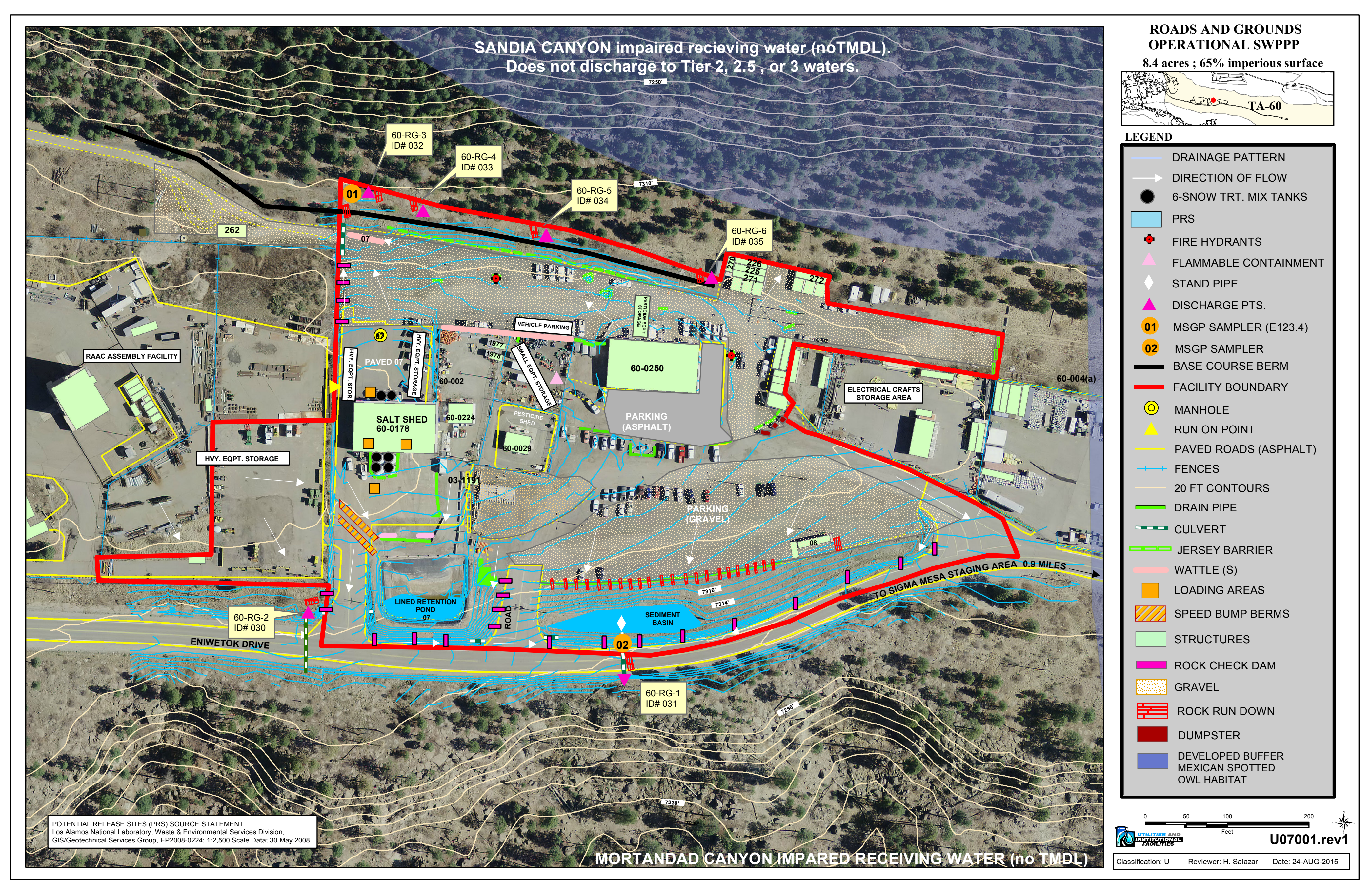




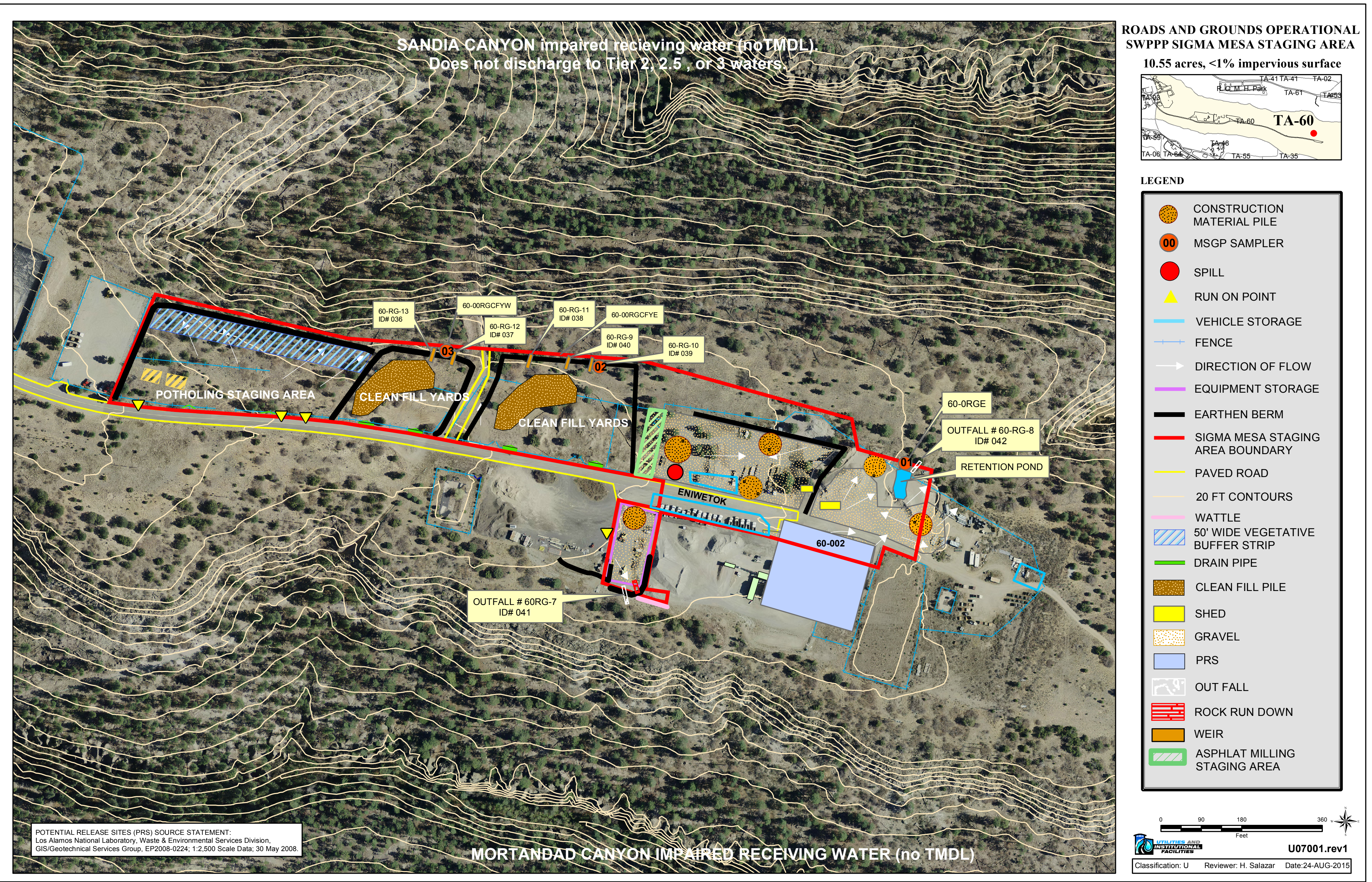




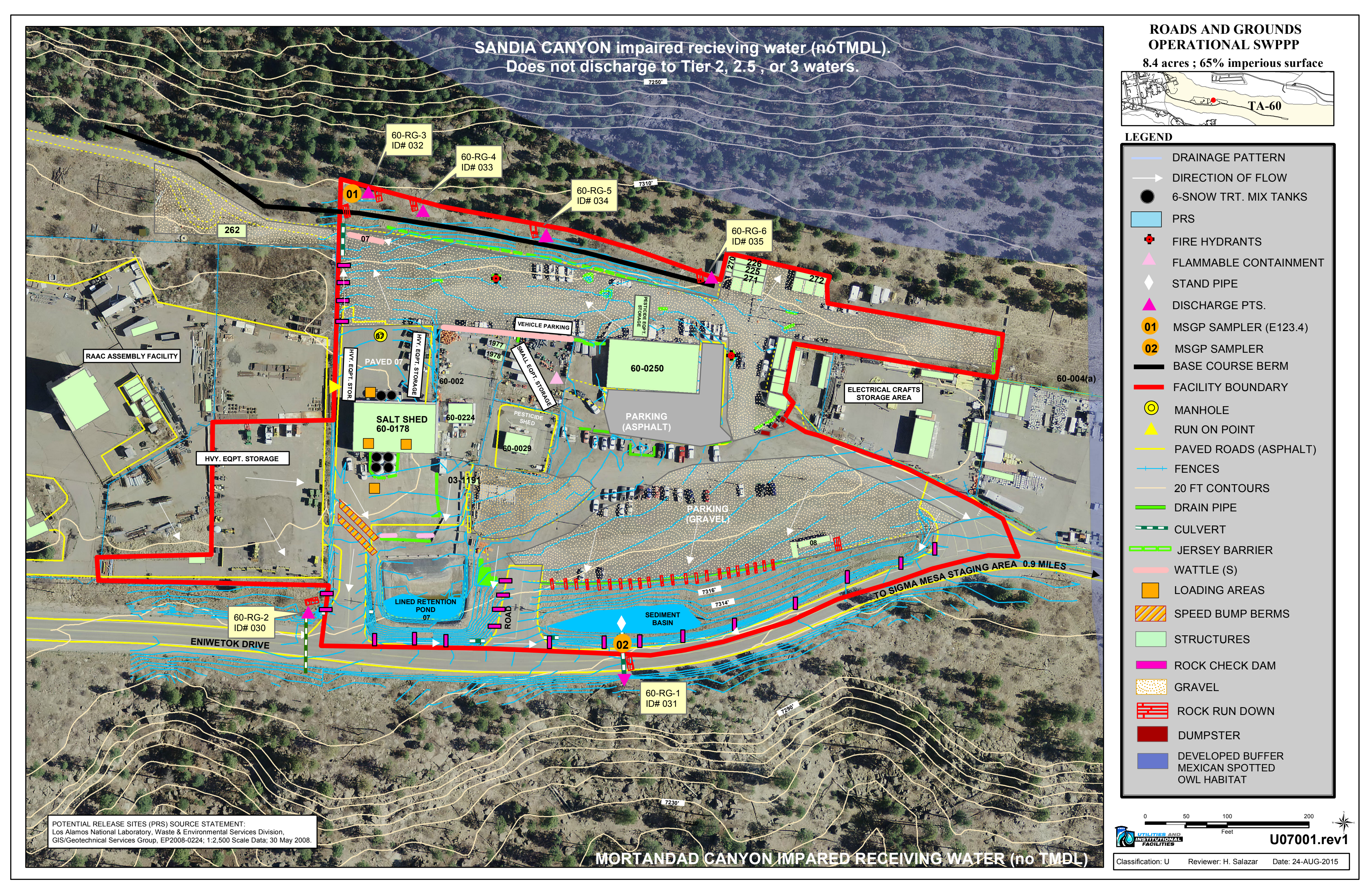




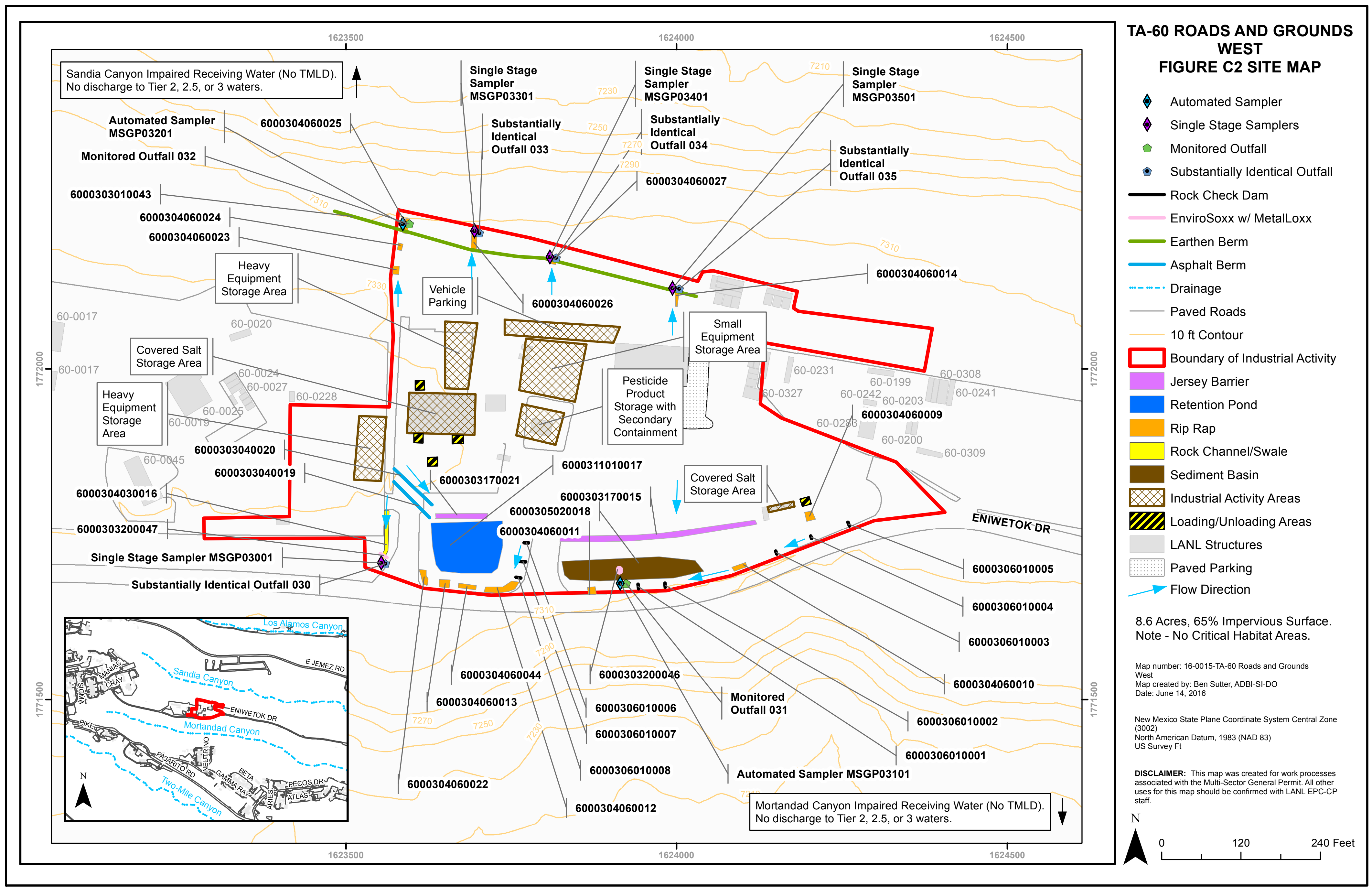




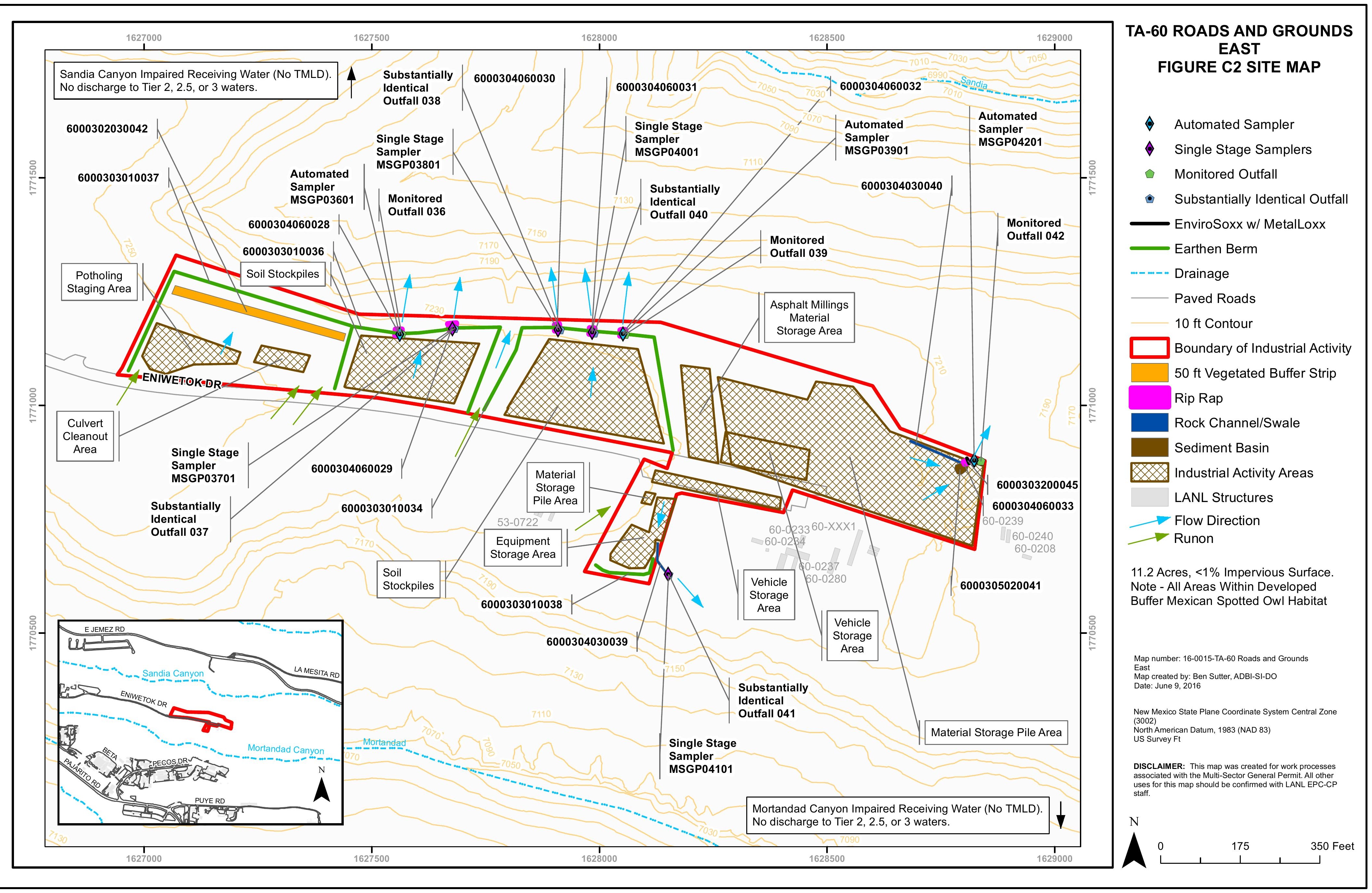




\section{Multi-Sector General Permit}




\section{UNTED STATTES ENVIRONMENTAL PROTECTION AGENCY (EPA) NATIONAL POWUTANTDISC HARGE EUMINATION SYSTEM (NPDES) MULTI-SECTOR GENERAL PERMITFOR STORMWATER DISCHARGES ASSOCIATED WTH INDUSTRIALACTIVITY (MSGP)}

In compliance with the provisions of the Clean Water Act (CWA), as amended ( 33 U.S.C. 1251 et seq.), operators of stormwater discharges a ssocia ted with industrial ac tivity located in an area identified in Appendix $C$ where EPA is the permitting authority are authorized to discharge to waters of the United States in accordance with the eligibility and Notice of Intent (NOI) requirements, effluent limita tions, inspection requirements, and other cond itions set forth in this permit. This permit is structured a sollows:

- General requirements that a pply to all facilities a re found in Parts 1 through 7;

- Industry sector-spec ific requirements are found in Part 8; and

- Specific requirements that a pply in individual states and Indian c ountry a re found in Part 9.

The Appendices ( $A$ through $\mathrm{P}$ ) conta in additional permit conditions that a pply to all operators covered under this pemit.

This permit becomes effective on J une 4, 2015.

This permit and the a uthorization to discharge shall expire at midnight, J une 4, 2020.

Signed and issued this $4^{\text {th }}$ day of J une, 2015

Ken Moraff

Director, Office of Ecosystem Protection,

EPA Region 1

Signed and issued this $4^{\text {th }}$ day of J une, 2015

José C. Font

Director, Caribbean Environmental Protection Division, EPA Region 2

Signed and issued this $4^{\text {th }}$ day of J une, 2015

Jon. M Capacasa

Water Protection Division, EPA Region 3

Signed and issued this $4^{\text {th }}$ day of J une, 2015

Tinka G. Hyde

Director, Water Division, EPA Region 5

Signed and issued this $4^{\text {th }}$ day of J une, 2015

William K. Honker

Director, Water Quality Protection Division, EPA Region 6
Signed and issued this $4^{\text {th }}$ day of J une, 2015

Karen Floumoy

Director, Water, Wetlands, and Pesticides Division, EPA Region 7

Signed and issued this $4^{\text {th }}$ day of J une, 2015

Darcy O'Connor

Acting Assistant Regional Administrator, EPA Region 8

Signed and issued this $4^{\text {th }}$ day of J une, 2015

Nancy Woo

Acting Director, Water Division, EPA Region 9

Signed and issued this $4^{\text {th }}$ day of J une, 2015

Daniel D. Opalski

Director, Office of Water and Watersheds, EPA Region 10 


\section{NPDES MULTI-SECTOR GENERAL PERMIT FOR STORMWATER DISCHARGES ASSOCIATED WITH INDUSTRIAL ACTIVITY}

\section{TABLE OF CONTENTS}

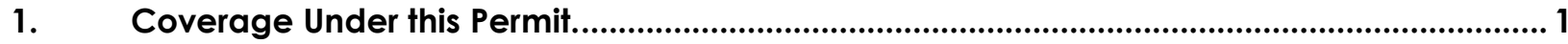

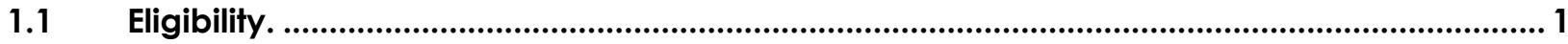

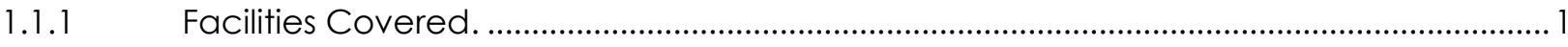

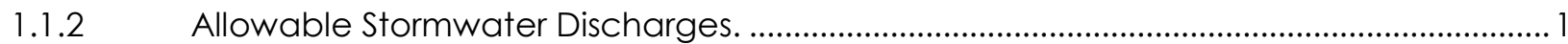

1.1.2.1 Stormwater discharges associated with industrial activity for any primary industrial activities and co-located industrial activities, as defined in Appendix

1.1.2.2 Discharges designated by EPA as needing a stormwater permit as provided in

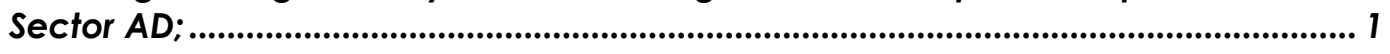

1.1.2.3 Discharges that are not otherwise required to obtain NPDES permit authorization but are mixed with discharges that are authorized under this permit; and. Stormwater discharges from facilities subject to any of the national

1.1.4.9 Eligibility for New Dischargers and New Sources to Waters with High Water Quality..................................................................................................................................... 8

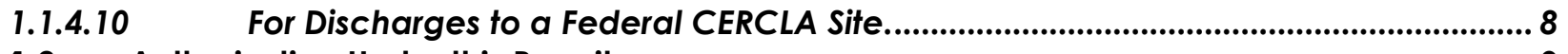

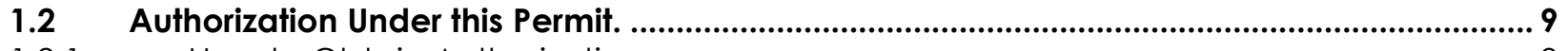

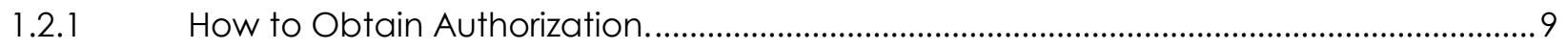

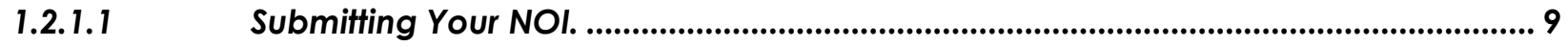

1.2.1.2 How to Submit Your NOI.......................................................................................................... 9

1.2.1.3 Deadlines for Submitting Your NOI and Your Official Date of Permit Coverage....... 9

1.2.2 Continuation of Coverage for Existing Permittees After the Permit Expires................... 11

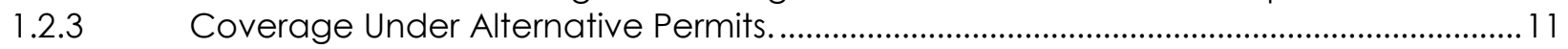

1.2.3.1 Denial of Coverage for New or Previously Unpermitted Facilities. ............................ 11

1.2.3.2 Loss of Authorization Under the 2015 MSGP for Existing Permitted Facilities. ........... 11

1.2.3.3 Operator Requesting Coverage Under an Alternative Permit. .................................... 12

1.3 Terminating Coverage. ........................................................................................................................ 12

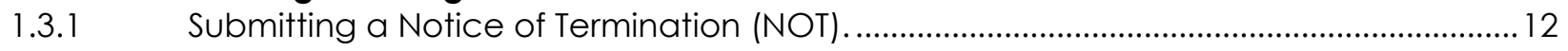

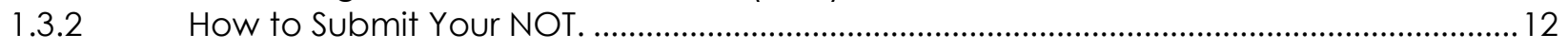




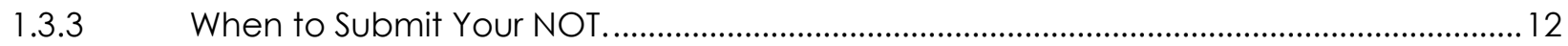

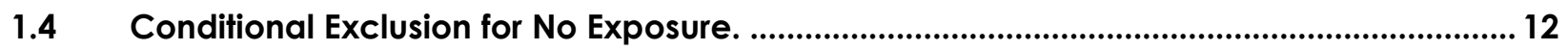

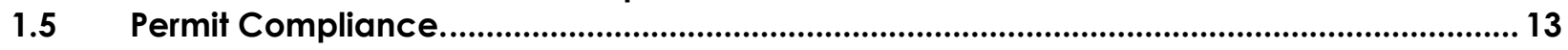

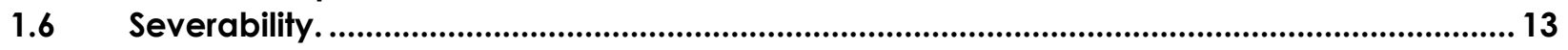

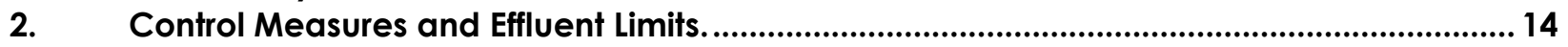

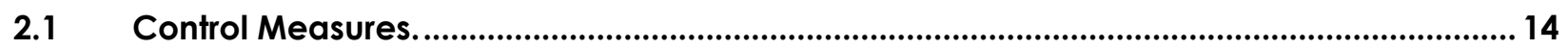

2.1.1 Control Measure Selection and Design Considerations.................................................. 14

2.1.2 Non-Numeric Technology-Based Effluent Limits (BPT/BAT/BCT) ...................................... 15

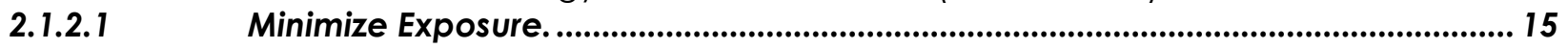

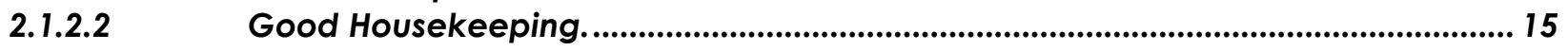

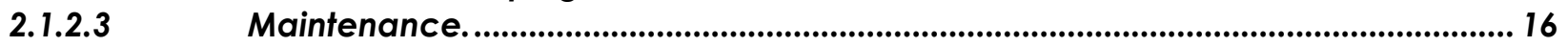

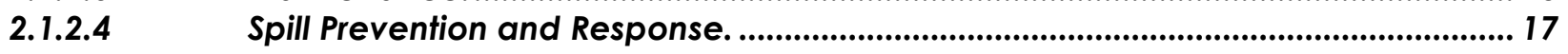

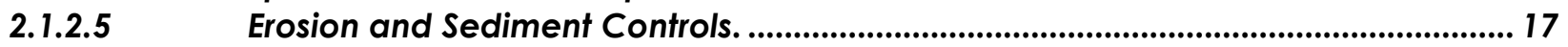

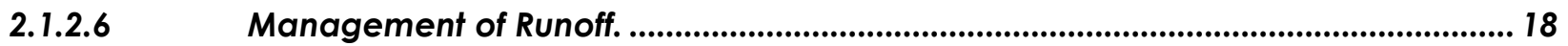

2.1.2.7 Salt Storage Piles or Piles Containing Salt. ..................................................................... 18

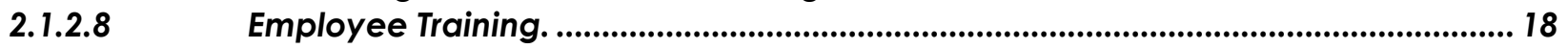

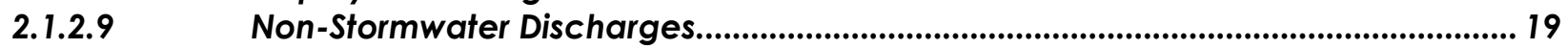

2.1.2.10 Dust Generation and Vehicle Tracking of Industrial Materials................................... 19

2.1.3 Numeric Effluent Limitations Based on Effluent Limitations Guidelines............................19

2.2 Water Quality-Based Effluent Limitations. .................................................................................. 20

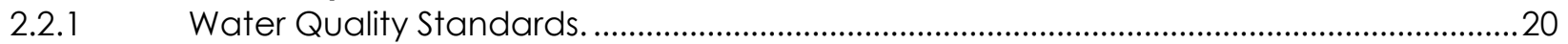

2.2.2 Discharges to Water Quality-Impaired Waters. ................................................................20

2.2.2.1 Existing Discharge to an Impaired Water with an EPA-Approved or Established

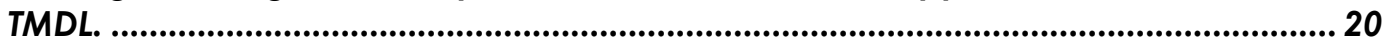

2.2.2.2 Existing Discharger to an Impaired Water without an EPA-Approved or

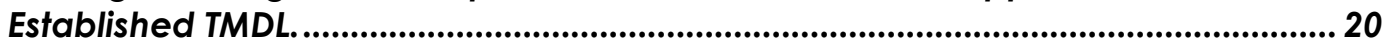

2.2.2.3 New Discharger or New Source to an Impaired Water.............................................. 21

2.2.3 Tier 2 Antidegradation Requirements for New Dischargers, New Sources, or Increased

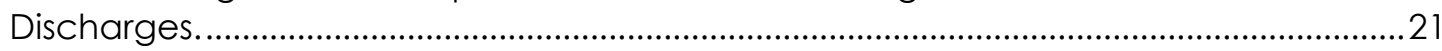

2.3 Requirements Relating to Endangered Species, Historic Properties, and Federal CERCLA

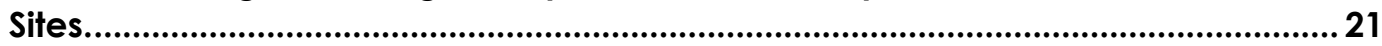

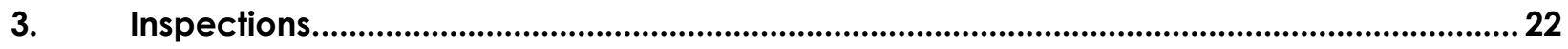

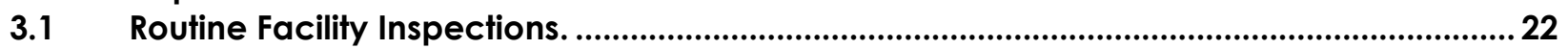

3.1.1 Exceptions to Routine Facility Inspections for Inactive and Unstaffed Sites....................22

3.1.2 Routine Facility Inspection Documentation. ..............................................................23

3.2 Quarterly Visual Assessment of Stormwater Discharges................................................... 24

3.2.1 Quarterly Visual Assessment Procedures............................................................................24

3.2.2 Quarterly Visual Assessment Documentation. ..................................................................24

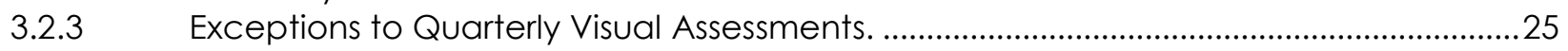

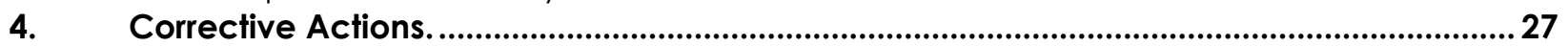

4.1 Conditions Requiring SWPPP Review and Revision to Ensure Effluent Limits are Met. .......... 27

4.2 Conditions Requiring SWPPP Review to Determine if Modifications Are Necessary............ 27

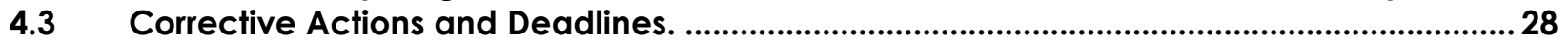

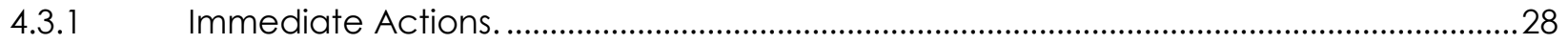

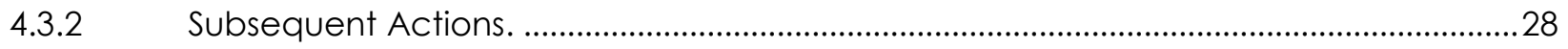

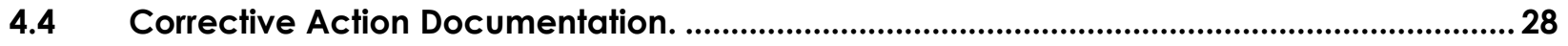

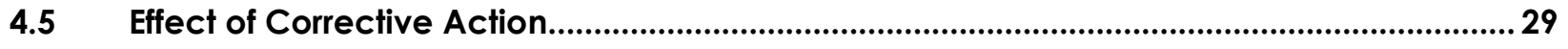

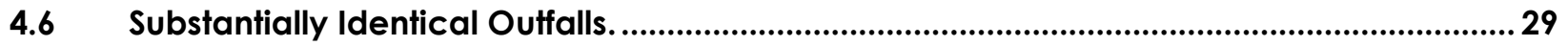

5. Stormwater Pollution Prevention Plan (SWPPP)......................................................................... 30

5.1 Person(s) Responsible for SWPPP Preparation. .......................................................................... 30

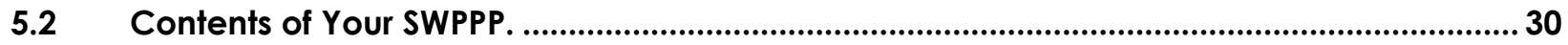

5.2.1 Stormwater Pollution Prevention Team .................................................................................31 
5.2 .2

5.2 .3

5.2.3.1

5.2.3.2

5.2.3.3

5.2.3.4

5.2.3.5

5.2.3.6

5.2 .4

5.2 .5

5.2.5.1

5.2.5.2

5.2.5.3

5.2 .6

5.2.6.1

5.2.6.2

5.2 .7

5.3

5.4

5.4 .1

5.4 .2

5.5

6.

6.1

6.1 .1

6.1 .2

6.1 .3

6.1 .4

6.1 .5

6.1 .6

6.1 .7

6.1 .8

6.1 .9

6.2

6.2.1

6.2.1.1

6.2.1.2

6.2.1.3

6.2.2

6.2.2.1

6.2.2.2

6.2.2.3

6.2.3

6.2.3.1

6.2.3.2

6.2.4

6.2.4.1

6.2.4.2

6.2 .5

7.

Site Description...... 31

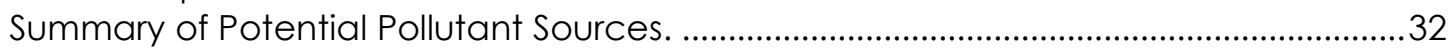

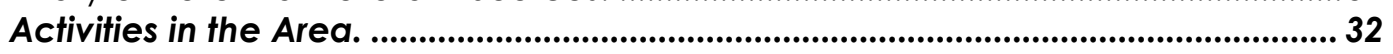

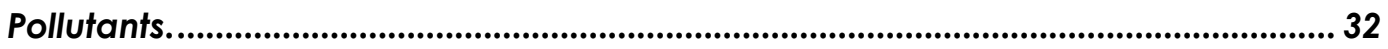

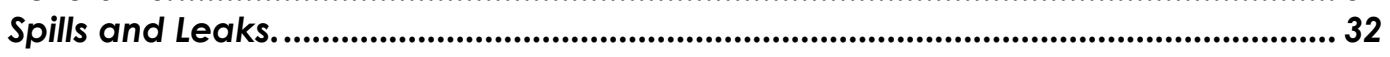

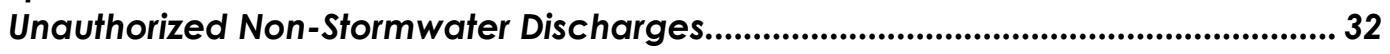

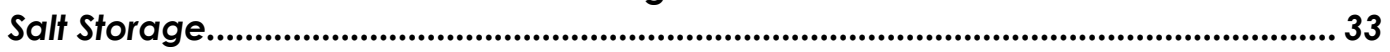

Sampling Data.................................................................................................................................. 33

Description of Control Measures to Meet Technology-Based and Water Quality-Based

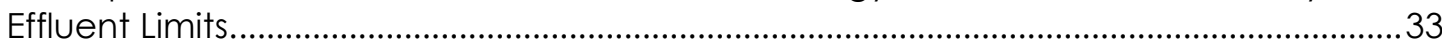

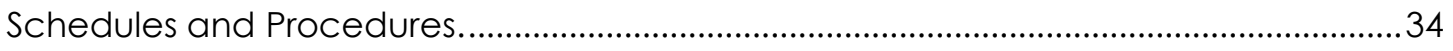

Pertaining to Control Measures Used to Comply with the Effluent Limits in Part 2. . 34

Pertaining to Inspections and Assessments..................................................................... 34

Pertaining to Monitoring.............................................................................................................. 35

Documentation to Support Eligibility Considerations Under Other Federal Laws...........36

Documentation Regarding Endangered and Threatened Species and Critical Habitat Protection........................................................................................................................ 36

Documentation Regarding Historic Properties. ................................................... 36

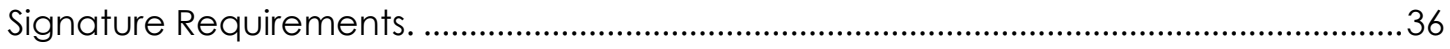

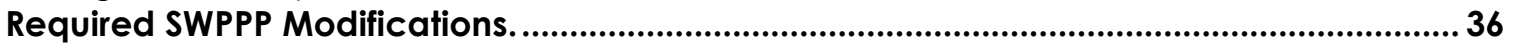

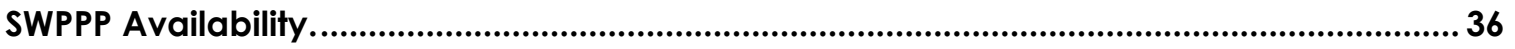

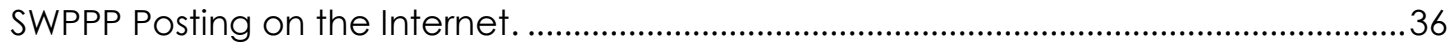

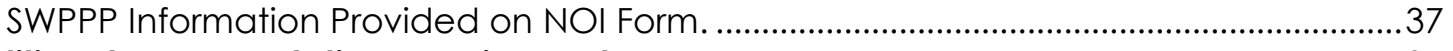

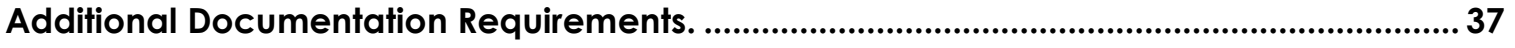

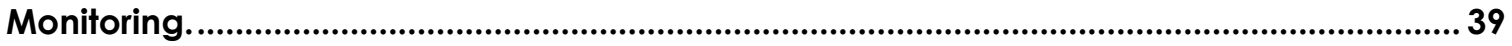

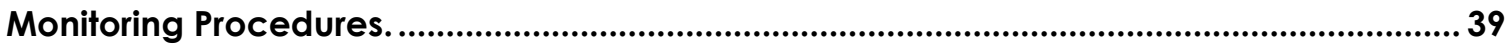

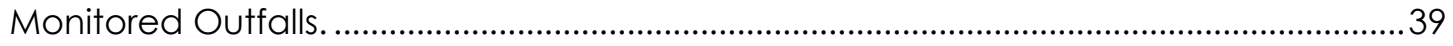

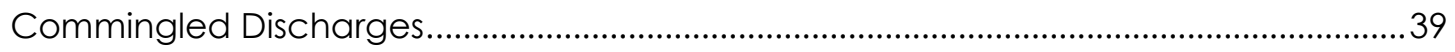

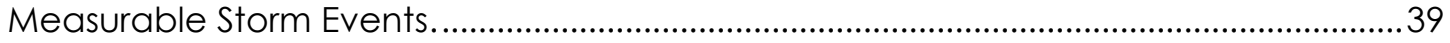

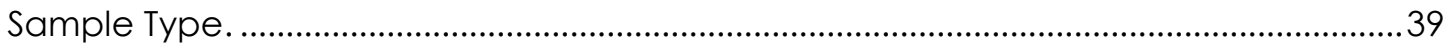

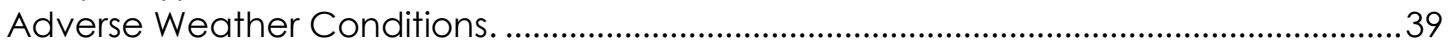

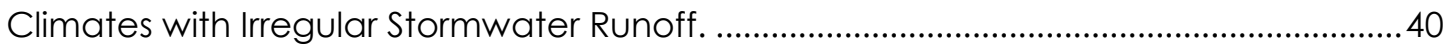

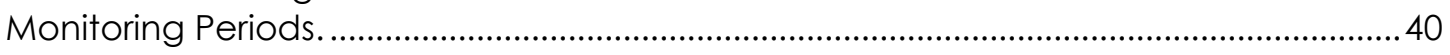

Monitoring for Allowable Non-Stormwater Discharges.................................................... 40

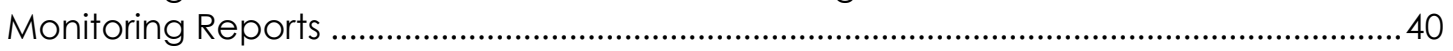

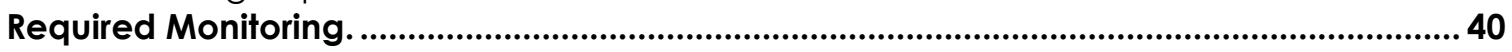

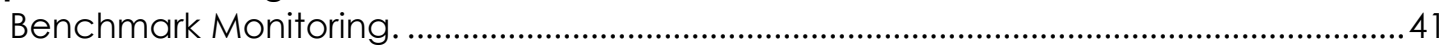

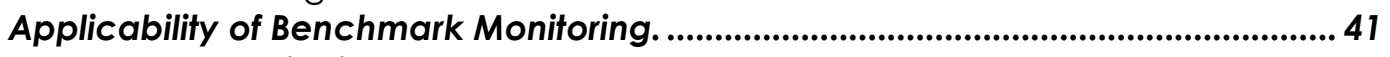

Benchmark Monitoring Schedule. ........................................................................................... 41

Exception for Inactive and Unstaffed Sites. .............................................................. 43

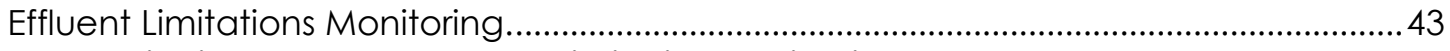

Monitoring Based on Effluent Limitations Guidelines.................................................. 43

Substantially Identical Outfalls................................................................................................ 44

Follow-up Actions if Discharge Exceeds Numeric Effluent Limitation. ....................... 44

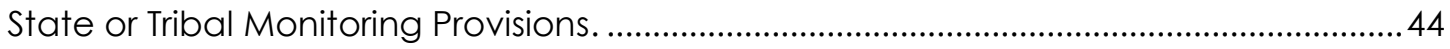

Sectors Required to Conduct State or Tribal Monitoring. ............................................... 44

State or Tribal Monitoring Schedule........................................................................................ 44

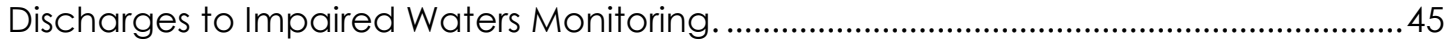

Permittees Required to Monitor Discharges to Impaired Waters. ............................... 45

Exception for Inactive and Unstaffed Sites. .................................................................... 46

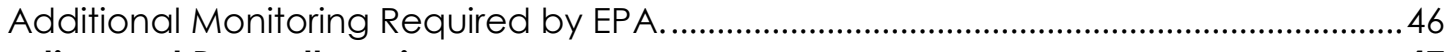

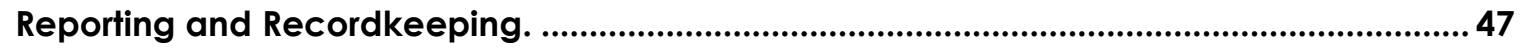




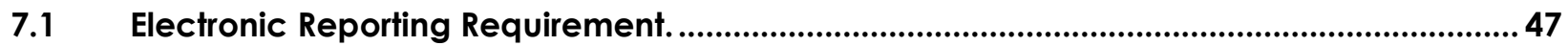

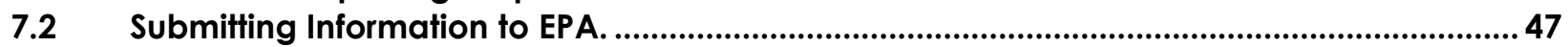

7.3 Additional SWPPP Information Required in Your NOI...................................................48

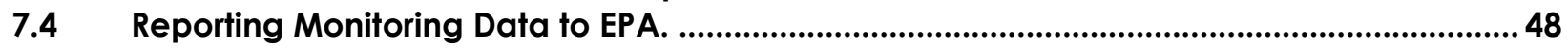

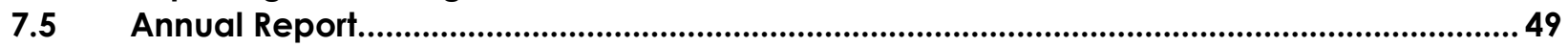

7.6 Exceedance Report for Numeric Effluent Limitations. .............................................................50

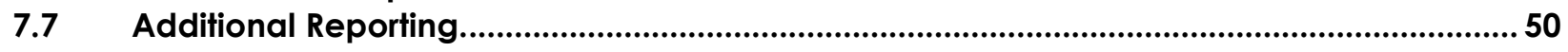

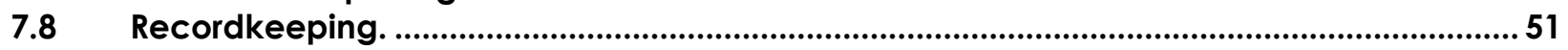

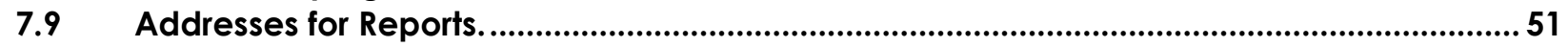

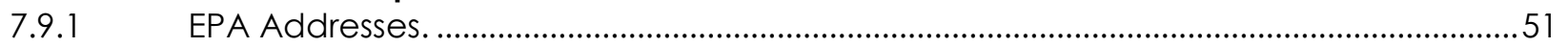

7.9.1.1 Region 1: Connecticut, Massachusetts, and New Hampshire, Rhode Island,

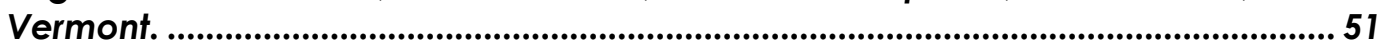

7.9.1.2 Region 2: New Jersey, New York, Puerto Rico, and Virgin Islands. ......................... 51

7.9.1.3 Region 3: Delaware, District of Columbia, Maryland, Pennsylvania, Virginia, West Virginia............................................................................................................................... 52

7.9.1.4 Region 4: Alabama, Florida, Georgia, Kentucky, Mississippi, North Carolina, South Carolina, Tennessee. ............................................................................................... 52

7.9.1.5 Region 5: Illinois, Indiana, Michigan, Minnesota, Ohio, Wisconsin............................. 52

7.9.1.6 Region 6: Arkansas, Lovisiana, Oklahoma, Texas, and New Mexico (except see Region 9 for Navajo lands, and see Region 8 for Ute Mountain Reservation

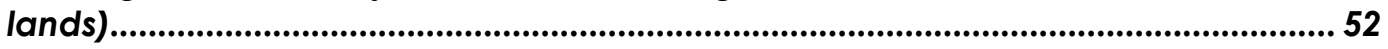

7.9.1.7 Region 7: lowa, Kansas, Missouri, Nebraska.............................................................. 52

7.9.1.8 Region 8: Colorado, Montana, North Dakota, South Dakota, Wyoming, Utah (except see Region 9 for Goshute Reservation and Navajo Reservation lands), the Ute Mountain Reservation in New Mexico, and the Pine Ridge Reservation in Nebraska.

7.9.1.9 Region 9: Arizona, California, Hawaii, Nevada, Guam, American Samoa, the Commonwealth of the Northern Mariana Islands, the Goshute Reservation in Utah and Nevada, the Navajo Reservation in Utah, New Mexico, and Arizona, the Duck Valley Reservation in Idaho, Fort McDermitt Reservation in Oregon....... 52

7.9.1.10 Region 10: Alaska, Idaho, Oregon (except see Region 9 for Fort McDermitt Reservation), Washington........................................................................................... 53

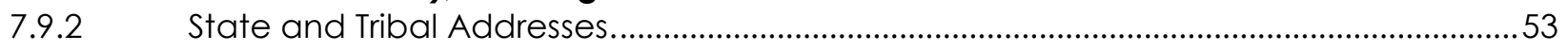

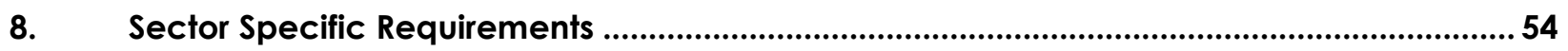

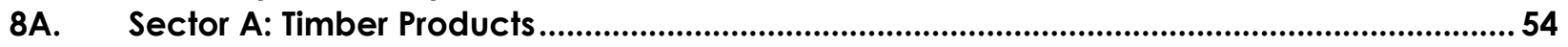

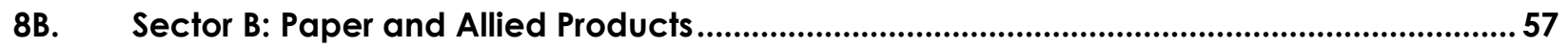

8C. Sector C: Chemicals and Allied Products Manufacturing .....................................................5

8D. Sector D: Asphalt Paving and Roofing Materials and Lubricant Manufacturing ...................6 61

8E. Sector E: Glass, Clay, Cement, Concrete, and Gypsum Products .......................................63 63

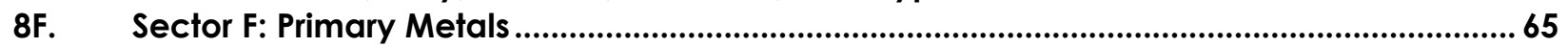

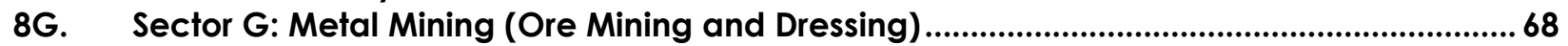

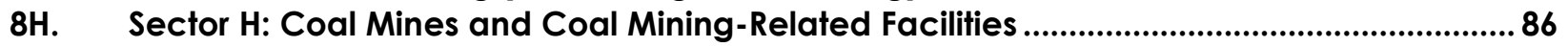

8I. Sector I: Oil and Gas Extraction and Refining ..................................................................... 99

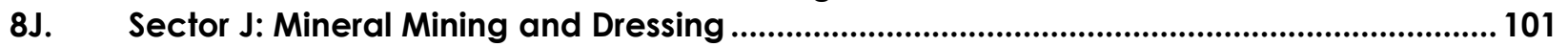

8K. Sector K: Hazardous Waste Treatment, Storage, or Disposal Facilities................................115

8L. Sector L: Landfills, Land Application Sites, and Open Dumps ........................................119

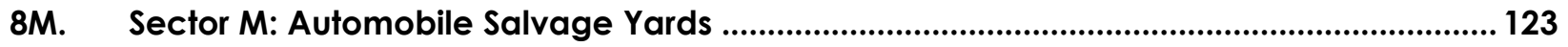

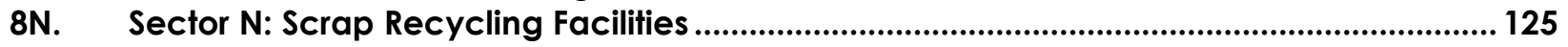

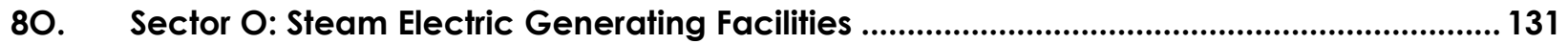

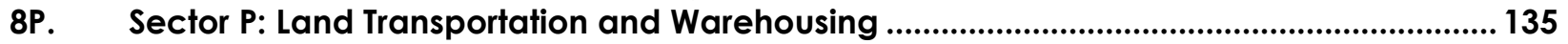

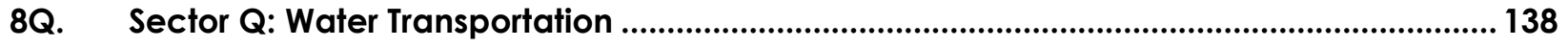

8R. Sector R: Ship and Boat Building and Repairing Yards...................................................... 141 


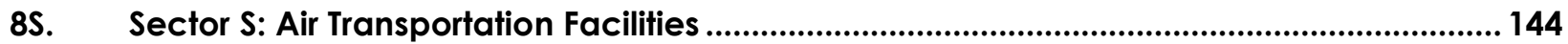

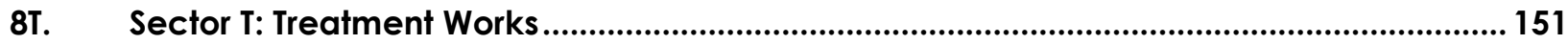

8U. Sector U: Food and Kindred Products................................................................................... 153

8V. Sector V: Textile Mills, Apparel, and Other Fabric Product Manufacturing; Leather and

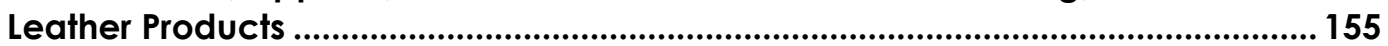

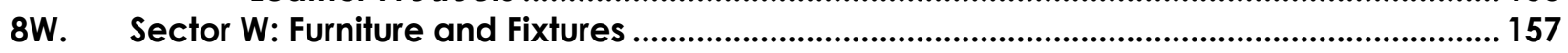

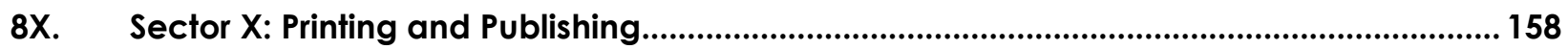

8Y. Sector Y: Rubber, Miscellaneous Plastic Products, and Miscellaneous Manufacturing

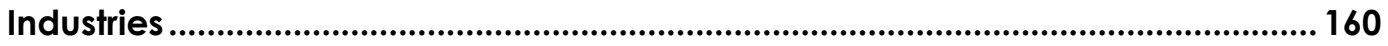

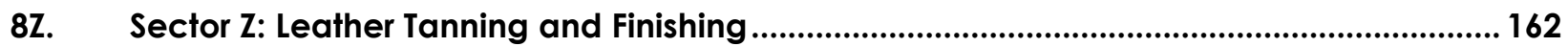

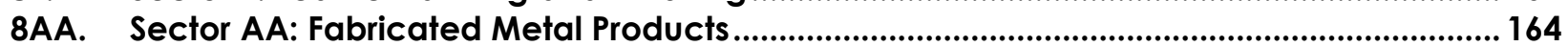

8AB. Sector AB: Transportation Equipment, Industrial or Commercial Machinery ...................... 167

8AC. Sector AC: Electronic, Electrical, Photographic, and Optical Goods ................................ 168

8AD. Sector AD: Non-Classified Facilities ..........................................................169

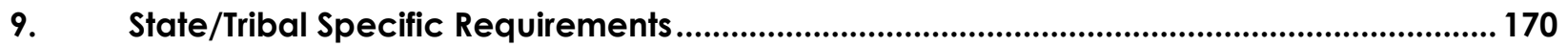

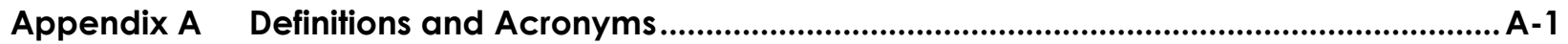

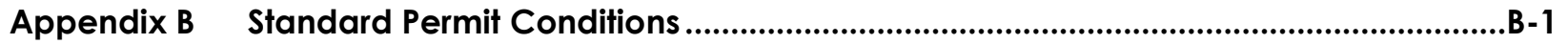

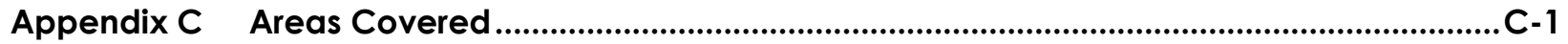

Appendix D Activities Covered …..........................................................................................................

Appendix E Procedures relating to Endangered Species..................................................................E-1

Appendix F National Historic Preservation Act Procedures....................................................F-1

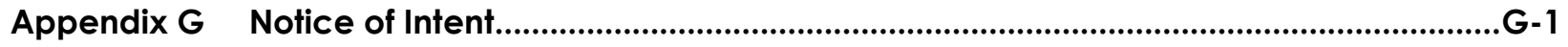

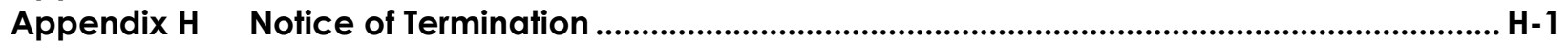

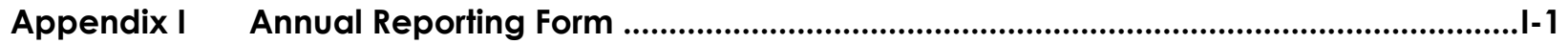

Appendix J Calculating Hardness in Receiving Waters for Hardness Dependent Metals.......... 1

Appendix $K \quad$ No Exposure Certification ...................................................................................................... K-1

Appendix $L \quad$ List of Tier 3, Tier 2, and Tier 2.5 Waters ........................................................................... L-1

Appendix M Discharge Monitoring Report (DMR) Form ................................................................... M-1

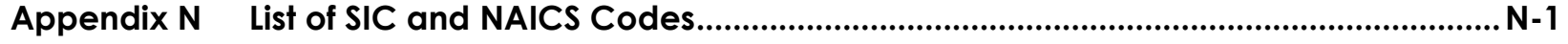

Appendix $O$ Summary of Permit Reports and Submittals ................................................................ O-1

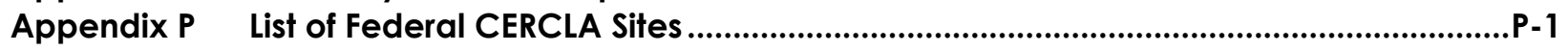


1. Coverage Under this Permit.

$1.1 \quad$ Eligibility.

1.1.1 Facilities Covered.

To be eligible to discharge under this permit, you must (1) have an allowable stormwater discharge or an allowable non-stormwater discharge associated with industrial activity from your primary industrial activity, as defined in Appendix A, provided your primary industrial activity is included in Appendix D, or (2) be notified by EPA that you are eligible for coverage under Sector AD of this permit. Your facility must also be located in an area where EPA is the permitting authority (see Appendix C).

\subsubsection{Allowable Stormwater Discharges.}

Unless otherwise made ineligible under Part 1.1.4, the following discharges are eligible for coverage under this permit:

1.1.2.1 Stormwater discharges associated with industrial activity for any primary industrial activities and co-located industrial activities, as defined in Appendix A, except for any stormwater discharges specifically prohibited in Part 8;

\subsubsection{Discharges designated by EPA as needing a stormwater permit as provided in} Sector AD;

\subsubsection{Discharges that are not otherwise required to obtain NPDES permit authorization but} are mixed with discharges that are authorized under this permit; and

\subsubsection{Stormwater discharges from facilities subject to any of the national stormwater-} specific effluent limitations guidelines listed in Table 1-1.

Table 1-1. Stormwater-Specific Effluent Limitations Guidelines

\begin{tabular}{|c|c|c|c|c|}
\hline Regulated Discharge & $\begin{array}{l}40 \text { CFR } \\
\text { Section }\end{array}$ & $\begin{array}{l}\text { MSGP } \\
\text { Sector }\end{array}$ & $\begin{array}{c}\text { New Source Performance } \\
\text { Standard (NSPS) }\end{array}$ & $\begin{array}{c}\text { New Source } \\
\text { Date }\end{array}$ \\
\hline $\begin{array}{l}\text { Discharges resulting from spray down or } \\
\text { intentional wetting of logs at wet deck storage } \\
\text { areas }\end{array}$ & $\begin{array}{l}\text { Part 429, } \\
\text { Subpart I }\end{array}$ & A & Yes & $1 / 26 / 81$ \\
\hline $\begin{array}{l}\text { Runoff from phosphate fertilizer } \\
\text { manufacturing facilities that comes into } \\
\text { contact with any raw materials, finished } \\
\text { product, by-products or waste products (SIC } \\
2874 \text { ) }\end{array}$ & $\begin{array}{l}\text { Part 418, } \\
\text { Subpart A }\end{array}$ & C & Yes & $4 / 8 / 74$ \\
\hline Runoff from asphalt emulsion facilities & $\begin{array}{l}\text { Part 443, } \\
\text { Subpart A }\end{array}$ & D & Yes & $7 / 28 / 75$ \\
\hline $\begin{array}{l}\text { Runoff from material storage piles at cement } \\
\text { manufacturing facilities }\end{array}$ & $\begin{array}{l}\text { Part 411, } \\
\text { Subpart C }\end{array}$ & $E$ & Yes & $2 / 20 / 74$ \\
\hline $\begin{array}{l}\text { Mine dewatering discharges at crushed } \\
\text { stone, construction sand and gravel, or } \\
\text { industrial sand mining facilities }\end{array}$ & $\begin{array}{l}\text { Part } 436, \\
\text { Subparts B, } \\
\text { C, and D }\end{array}$ & $\mathrm{J}$ & No & $\mathrm{N} / \mathrm{A}$ \\
\hline $\begin{array}{l}\text { Runoff from hazardous waste and non- } \\
\text { hazardous waste landfills }\end{array}$ & $\begin{array}{l}\text { Part } 445, \\
\text { Subparts A } \\
\text { and B }\end{array}$ & $\mathrm{K}, \mathrm{L}$ & Yes & $2 / 2 / 00$ \\
\hline $\begin{array}{l}\text { Runoff from coal storage piles at steam } \\
\text { electric generating facilities }\end{array}$ & Part 423 & O & Yes & $\begin{array}{l}11 / 19 / 82 \\
(10 / 8 / 74)^{1}\end{array}$ \\
\hline
\end{tabular}

1 NSPS promulgated in 1974 were not removed via the 1982 regulation; therefore wastewaters generated by Part 423applicable sources that were New Sources under the 1974 regulations are subject to the 1974 NSPS. 


\begin{tabular}{|l|l|l|l|l|}
\hline \multicolumn{1}{|c|}{ Regulated Discharge } & \multicolumn{1}{|c|}{$\begin{array}{l}\text { 40 CFR } \\
\text { Section }\end{array}$} & $\begin{array}{l}\text { MSGP } \\
\text { Sector }\end{array}$ & $\begin{array}{l}\text { New Source Performance } \\
\text { Standard (NSPS) }\end{array}$ & $\begin{array}{c}\text { New Source } \\
\text { Date }\end{array}$ \\
\hline $\begin{array}{l}\text { Runoff containing urea from airfield } \\
\text { pavement deicing at existing and new } \\
\text { primary airports with 1,000 or more annual } \\
\text { non-propeller aircraft departures }\end{array}$ & Part 449 & S & Yes & $6 / 15 / 12$ \\
\hline
\end{tabular}

\subsubsection{Allowable Non-Stormwater Discharges.}

Below in Part 1.1.3.1 are the only non-stormwater discharges authorized under this permit for all sectors provided that all discharges comply with the effluent limits set forth in Parts 2 and 8. In addition to the authorized non-stormwater discharges in Part 1.1.3.1 applicable to all sectors, for Sector $A$, there is an additional non-stormwater discharge in Part 1.1.3.2 below, and for the mining sectors (Sectors $G, H$, and J), there are additional authorized nonstormwater discharges in Part 1.1.3.3 below. The additional allowable non-stormwater discharges for Sectors $\mathrm{G}, \mathrm{H}$, and J apply only to discharges from earth-disturbing activities conducted prior to active mining activities as defined in Part 8.G.3.2, 8.H.3.2, and 8.J.3.2 provided that, with the exception of water used to control dust and to irrigate areas to be vegetatively stabilized, these discharges are not routed to areas of exposed soil and all discharges comply with the permit's effluent limits.

Also allowed for all sectors are discharges of stormwater listed above in Parts 1.1.2 or authorized non-stormwater discharges in Part 1.1.3, mixed with a discharge authorized by a different NPDES permit and/or a discharge that does not require NPDES permit authorization. All other non-stormwater discharges requiring NPDES permit coverage except those specifically listed in Part 1.1.3 are not authorized by this permit. If non-stormwater discharges requiring NPDES permit coverage other than those specifically authorized in Part 1.1.3, including sector-specific non-stormwater discharges that are listed in Part 8 as prohibited (a non-exclusive list provided to raise awareness of contaminants or sources of contaminants characteristic of certain sectors), will be discharged, such non-stormwater discharges are not authorized by this permit and must either be eliminated or covered under another NPDES permit.

\subsubsection{Allowable Non-Stormwater Discharges for all Sectors of Industrial Activity:}

- Discharges from emergency/unplanned fire-fighting activities;

- Fire hydrant flushings;

- Potable water, including water line flushings;

- Uncontaminated condensate from air conditioners, coolers/chillers, and other compressors and from the outside storage of refrigerated gases or liquids;

- Irrigation drainage;

- Landscape watering provided all pesticides, herbicides, and fertilizers have been applied in accordance with the approved labeling;

- Pavement wash waters where no detergents or hazardous cleaning products are used (e.g., bleach, hydrofluoric acid, muriatic acid, sodium hydroxide, nonylphenols), and the wash waters do not come into contact with oil and grease deposits, sources of pollutants associated with industrial activities (see Part 5.2.3), or any other toxic or hazardous materials, unless residues are first cleaned up using dry clean-up methods (e.g., applying absorbent materials and sweeping, using hydrophobic mops/rags) and you have implemented 
appropriate control measures to minimize discharges of mobilized solids and other pollutants (e.g., filtration, detention; settlement);

- Routine external building washdown / power wash water that does not use detergents or hazardous cleaning products (e.g., those containing bleach, hydrofluoric acid, muriatic acid, sodium hydroxide, nonylphenols);

- Uncontaminated ground water or spring water;

- Foundation or footing drains where flows are not contaminated with process materials; and

- Incidental windblown mist from cooling towers that collects on rooftops or adjacent portions of your facility, but not intentional discharges from the cooling tower (e.g., "piped" cooling tower blowdown; drains).

1.1.3.2 Additional Allowable Non-Stormwater Discharge for Sector A: Discharges from the spray down of lumber and wood product storage yards where no chemical additives are used in the spray-down waters and no chemicals are applied to the wood during storage (applicable only to Sector A facilities provided the nonstormwater component of the discharge is in compliance with the non-numeric effluent limits requirements in Part 2.1.2).

\subsubsection{Additional Allowable Non-Stormwater Discharges for Earth-Disturbing Activities} Conducted Prior to Active Mining Activities for Sectors $G, H$ and J:

- Water used to wash vehicles and equipment, provided that there is no discharge of soaps, solvents, or detergents used for such purposes;

- Water used to control dust; and

- Dewatering water that has been treated by an appropriate control under Parts 8.G.4.2.9, 8.H.4.2.9, or 8.J.4.2.9.

Note: These non-stormwater discharges are only authorized for earth-disturbing activities conducted prior to active mining activities, as defined in Part 8.G.3.2, 8.H.3.2, and 8.J.3.2. Once the earth-disturbing activities conducted prior to active mining activities have ceased, the only allowable non-stormwater discharges for Sectors $G, H$, and J are those listed in Part 1.1.3.1.

\subsubsection{Limitations on Coverage.}

Any discharges not expressly authorized in this permit cannot become authorized or shielded from liability under Clean Water Act (CWA) section 402(k) by disclosure to EPA, state, or local authorities after issuance of this permit via any means, including the Notice of Intent (NOI) to be covered by the permit, the Stormwater Pollution Prevention Plan (SWPPP), or during an inspection.

1.1.4.1 For Discharges Mixed with Non-Stormwater. Stormwater discharges that are mixed with non-stormwater discharges, other than those mixed with allowable nonstormwater discharges listed in Part 1.1.3 and/or those mixed with a discharge authorized by a different NPDES permit and/or a discharge that does not require NPDES authorization, are not eligible for coverage under this permit.

1.1.4.2 For Stormwater Discharges Associated with Construction Activity. Stormwater discharges associated with construction activity disturbing one acre or more, or that are part of a larger common plan of development or sale if the larger common plan will ultimately disturb one acre or more, are not eligible for coverage 
under this permit, unless in conjunction with mining activities or certain oil and gas extraction activities as specified in Sectors $G, H, I$, and $J$ of this permit.

1.1.4.3 For Discharges Currently or Previously Covered by Another Permit. Unless you have received written notification from EPA specifically allowing these discharges to be covered under this permit, you are not eligible for coverage under this permit for any of the following:

- Stormwater discharges associated with industrial activity that are currently covered under an individual NPDES permit or an alternative NPDES general permit;

- Discharges covered within five years prior to the effective date of this permit by an individual permit or alternative general permit where that permit established site-specific numeric water quality-based limitations developed for the stormwater component of the discharge; or

- Discharges from facilities where any NPDES permit has been or is in the process of being denied, terminated, or revoked by EPA (this does not apply to the routine reissuance of permits every five years).

1.1.4.4 For Stormwater Discharges Subject to Effluent Limitations Guidelines. For discharges from facilities subject to stormwater effluent limitation guidelines under 40 CFR, Subchapter N, only those stormwater discharges identified in Table 1-1 are eligible for coverage under this permit.

1.1.4.5 Endangered and Threatened Species and Critical Habitat Protection. Coverage under this permit is available only if your stormwater discharges, allowable nonstormwater discharges, and stormwater discharge-related activities were the subject of an Endangered Species Act (ESA) consultation or an ESA section 10 permit, or if your stormwater discharges, allowable non-stormwater discharges, and stormwater discharge-related activities are not likely to adversely affect any species that are federally listed as endangered or threatened ("listed") and are not likely to adversely affect habitat that is designated as "critical habitat" under the ESA. You must meet one of the criteria below, following the procedures in Appendix E:

Criterion A. No federally listed threatened or endangered species or their designated critical habitat(s) are likely to occur in the "action area" as defined in Appendix A. To certify your eligibility under this criterion, you must use the Criterion Selection Worksheet in Part E.4 of Appendix E. You must also provide a description of the basis for the criterion you selected on your $\mathrm{NOI}$ form and provide documentation supporting your eligibility determination in your SWPPP.

Criterion B. Your industrial activity's discharges and discharge-related activities were already addressed in another operator's valid certification of eligibility for your action area under this permit, and there is no reason to believe that federally listed species or designated critical habitat not considered in the prior certification may be present or located in the "action area" (e.g., due to a new species listing or critical habitat designation). To certify your eligibility under this criterion, you must use the Criterion Selection Worksheet in Part E.4 of Appendix E. There must be no lapse of NPDES permit coverage in the other operator's certification. You must also comply with any additional measures that formed the basis of the other operator's valid certification of eligibility to ensure that your discharges and discharge-related 
activities are protective of listed species and/or critical habitat. You must include in your NOI the NPDES ID (i.e., permit tracking number) assigned to the other operator's authorization under this permit, and a description of the basis for the criterion selected on your NOI form, including the eligibility criterion selected by the other operator's certification. You must also provide any documentation in your SWPPP that supports the other operator's eligibility determination, including any additional measures that formed the basis of the other operator's eligibility determination.

Criterion C. Federally listed threatened or endangered species or their designated critical habitat(s) are likely to occur in or near your facility's "action area," and your industrial activity's discharges and discharge-related activities are not likely to adversely affect listed threatened or endangered species or critical habitat. To certify your eligibility under this criterion, you must use the Criterion Selection Worksheet in Part E.4 of Appendix E, including completion of the Criterion C Eligibility Form, which you must submit to EPA at least 30 days prior to filing your $\mathrm{NOI}$ for permit coverage. After evaluation of your Criterion C Eligibility Form, EPA may require additional measures that you must implement to avoid or eliminate likely adverse effects on listed species and critical habitat from discharges and discharge-related activities. You may submit your $\mathrm{NOI}$ for permit coverage 30 days after submitting to EPA your completed Criterion $C$ worksheet. You must also provide a description of the basis for the criterion you selected on your $\mathrm{NOI}$ form and provide documentation supporting your eligibility determination in your SWPPP.

Criterion D. Consultation between a Federal Agency and the U.S. Fish and Wildlife Service and/or the National Marine Fisheries Service under section 7 of the ESA has been concluded. Consultations can be either formal or informal, and would have occurred only as a result of a separate federal action (e.g., during application for an individual wastewater discharge permit or the issuance of a wetlands dredge and fill permit), and consultation must have addressed the effects of the industrial activity's discharges and discharge-related activities on federally listed threatened or endangered species and designated critical habitat. The result of this consultation must be one of the following:

i. A biological opinion that concludes that the action in question (taking into account the effects of your facility's discharges and discharge-related activities) is not likely to jeopardize the continued existence of listed species, or result in the destruction or adverse modification of critical habitat;

ii. A biological opinion that concludes that the action is likely to jeopardize listed species or to result in the destruction or adverse modification of critical habitat, and any recommended reasonable and prudent alternatives or reasonable and prudent measures are being implemented; or

iii. Written concurrence from the applicable Service(s) with a finding that the facility's discharges and discharge-related activities are not likely to adversely affect listed species or critical habitat.

To certify your eligibility under this criterion, you must use the Criterion Selection Worksheet in Part E.4 of Appendix E. You must verify that the consultation does not warrant reinitiation under 50 CFR $\S 402.16$. If reinitiation of consultation is required, in order to be eligible under this Criterion you must ensure consultation is reinitiated and the result of the consultation must be consistent with (i), (ii), or (iii) above. 
If eligible, you must also provide supporting documentation for your determination in your NOI and SWPPP, including the Biological Opinion (or PCTS tracking number) or concurrence letter.

Criterion E. Your industrial activities are the subject of a permit under section 10 of the ESA, and this authorization addresses the effects of your facility's discharges and dischargerelated activities on federally listed species and designated critical habitat. To certify your eligibility under this criterion, you must use the Criterion Selection Worksheet. You must also provide supporting documentation for your determination in your $\mathrm{NOI}$ and SWPPP, including a copy of the permit from the Services.

You must comply with any measures that formed the basis of your eligibility determination in Part 1.1.4.5 to be in compliance with the permit. These measures become permit requirements per Part 2.3. Documentation of these measures must be kept as part of your SWPPP (see Part 5.2.6.1).

1.1.4.6 Historic Properties Preservation. Coverage under this permit is available only if your stormwater discharges, allowable non-stormwater discharges, and stormwater discharge-related activities meet one of the eligibility criteria below, following the procedures in Appendix F:

Criterion A. Your stormwater discharges and allowable non-stormwater discharges do not have the potential to have an effect on historic properties and you are not constructing or installing new stormwater control measures on your site that cause subsurface disturbance; or

Criterion B. Your discharge-related activities (i.e., construction and/or installation of stormwater control measures that involve subsurface disturbance) will not affect historic properties; or

Criterion C. Your stormwater discharges, allowable non-stormwater discharges, and dischargerelated activities have the potential to have an effect on historic properties, and you have consulted with the State Historic Preservation Officer (SHPO), Tribal Historic Preservation Officer (THPO), or other tribal representative regarding measures to mitigate or prevent any adverse effects on historic properties, and you have either (1) obtained and are in compliance with a written agreement that outlines all such measures, or (2) been unable to reach agreement on such measures; or

Criterion D. You have contacted the SHPO, THPO, or other tribal representative and EPA in writing informing them that you have the potential to have an effect on historic properties and you did not receive a response from the SHPO, THPO, or tribal representative within 30 days of receiving your letter.

If you have been unable to reach agreement with a SHPO, THPO, or other tribal representative regarding appropriate measures to mitigate or prevent adverse effects, EPA may notify you of additional measures you must implement to be eligible for coverage under this permit.

1.1.4.7 Eligibility for New Dischargers and New Sources: Based on Water Quality Standards. If you are a new discharger or a new source (as defined in Appendix A), you are ineligible for coverage under this permit if EPA determines prior to your authorization to discharge that your discharges will not meet an applicable water 
quality standard (i.e., your discharges will cause or contribute to an exceedance of a water quality standard). In such case, EPA may notify you that an individual permit application is necessary per Part 1.2.3, or, alternatively, EPA may authorize your coverage under this permit after you implement additional control measures so that your discharges will meet water quality standards.

1.1.4.8 Eligibility for New Dischargers and New Sources to Water-Quality Impaired Waters. If you are a new discharger or a new source (as defined in Appendix A), you are ineligible for coverage under this permit to discharge to an "impaired water" (as defined in Appendix A) unless you do one of the following:

a. Prevent all exposure to stormwater of the pollutant(s) for which the waterbody is impaired, and retain documentation of procedures taken to prevent exposure onsite with your SWPPP;

b. Prior to submitting your NOI, provide to the appropriate EPA Regional Office technical information or other documentation to support your claim that the pollutant(s) for which the waterbody is impaired is not present at your site, and retain such documentation with your SWPPP; or

c. Prior to submitting your $\mathrm{NOI}$, provide information to the appropriate EPA Regional Office, either data or other technical documentation, to support a conclusion that the discharge is expected to meet applicable water quality standards (i.e., that pollutants of concern will not be discharged at levels that will cause or contribute to an exceedance of a water quality standard), and retain such information with your SWPPP. The information to be submitted must be sufficient to demonstrate:

i. For discharges to waters without an EPA-approved or established total maximum daily load (TMDL), that the discharge of the pollutant for which the water is impaired will meet water quality standards at the point of discharge to the waterbody; or

ii. For discharges to waters with an applicable EPA-approved or established TMD), that there are, in accordance with 40 CFR 122.4(i), sufficient remaining wasteload allocations in the TMDL to allow your discharge and that existing dischargers to the waterbody are subject to compliance schedules designed to bring the waterbody into attainment with water quality standards (e.g., a reserve allocation for future growth).

You are eligible under Part 1.1.4.8.c if you receive a determination from the EPA Regional Office that your discharge will meet applicable water quality standards (i.e., will not cause or contribute to an exceedance of a water quality standard), and you document the Region's determination in your SWPPP. If the EPA Regional Office fails to respond to you within 30 days after submission of data, you are considered to be eligible for coverage.

Note: For the purposes of this permit, your project is considered to discharge to an impaired water if the first water of the U.S. to which you discharge is identified by a state, tribe, or EPA as not meeting an applicable water quality standard, and:

- Requires development of a TMDL (pursuant to section 303(d) of the CWA);

- Is addressed by an EPA-approved or established TMDL; or 
- Is not in either of the above categories but the waterbody is covered by pollution control requirements that meet the requirements of 40 CFR 130.7(b)(1).

For discharges that enter a separate storm sewer system² prior to discharge, the first water of the U.S. to which you discharge is the waterbody that receives the stormwater discharge from the storm sewer system.

1.1.4.9 Eligibility for New Dischargers and New Sources to Waters with High Water Quality. For new dischargers and new sources to Tier 2 or Tier 2.5 waters:

If you are a new discharger or a new source (as defined in Appendix A), you are eligible to discharge to a Tier 2 or Tier 2.5 water only if your discharge will not lower the water quality of the applicable water. See a list of Tier 2 and Tier 2.5 waters in Appendix L.

\section{For new dischargers and new sources to Tier 3 waters:}

If you are a new discharger or a new source (as defined in Appendix A), you are not eligible for coverage under this permit for discharges to waters designated by a state or tribe as Tier 3 (outstanding national resource waters) for antidegradation purposes under 40 CFR 131.13(a)(3). Instead, you must submit an application for an individual permit. See a list of Tier 3 waters in Appendix L.

Note: For the purposes of this permit, your project is considered to discharge to a Tier 2, Tier 2.5, or Tier 3 water if the first water of the U.S. to which you discharge is identified by a state, tribe, or EPA as a Tier 2, Tier 2.5, or Tier 3 water. For discharges that enter a separate storm sewer system ${ }^{2}$ prior to discharge, the first water of the U.S. to which you discharge is the waterbody that receives the storm water discharge from the storm sewer system.

1.1.4.10 For Discharges to a Federal CERCLA Site. If you discharge to a federal CERCLA Site listed in Appendix $P$, you are ineligible for coverage under this permit, unless you notify the EPA Regional Office in advance and the EPA Regional Office determines that you are eligible for permit coverage. In determining eligibility for coverage under this Part, the EPA Regional Office may evaluate whether you are implementing or plan to implement adequate controls and/or procedures to ensure that your discharge will not lead to recontamination of aquatic media at the CERCLA Site such that your discharge will cause or contribute to an exceedance of a water quality standard. If it is determined that your facility discharges to a CERCLA Site listed in Appendix $P$ after you have obtained coverage under this permit, you must contact the EPA Regional Office and ensure that you either have implemented or will implement adequate controls and/or procedures to ensure that your discharges will not lead to recontamination of aquatic media at the CERCLA Site such that it will to cause or contribute to an exceedance of a water quality standard.

For the purposes of this permit, a permittee discharges to a federal CERCLA Site if the discharge flows directly into the site through its own conveyance, or a through

2 Separate storm systems do not include combined sewer systems or sanitary sewer systems. Separate storm systems include both municipal storm sewer systems (MS4s) and non-municipal separate storm sewers. 
a conveyance owned by others, such as a municipal separate storm sewer system (MS4).

1.2 Authorization Under this Permit.

1.2.1 How to Obtain Authorization.

To obtain authorization under this permit, you must:

- Be an operator of a primary industrial activity in a sector covered by this permit (see Appendix D);

- Be located in a state, territory, or Indian country, or be a federal operator identified in Appendix C where EPA is the permitting authority;

- Meet the Part 1.1 eligibility requirements;

- Select, design, install, and implement control measures in accordance with Part 2.1 and Part 8 to meet numeric and non-numeric effluent limits;

- Develop a SWPPP per Part 5 of this permit or update your existing SWPPP consistent with Part 5 prior to submitting your $\mathrm{NOI}$ for coverage under this permit; and

- Submit a complete and accurate NOI in accordance with this Part.

1.2.1.1 Submitting Your NOI. To be covered under this permit, you must submit to EPA a complete and accurate NOI by the deadline applicable to your facility presented in Table 1-2. The NOI certifies to EPA that you are eligible for coverage according to Part 1.1, and provides information on your industrial activities and related discharges.

You must complete the development of a SWPPP or update your existing SWPPP consistent with Part 5 prior to submitting your $\mathrm{NOI}$ for coverage under this permit. If you choose to post your SWPPP on the Internet per Part 5.4.1, you must include the URL on your NOI form and this URL must directly link to the SWPPP (not just the corporate or facility homepage). If you do not post your SWPPP online, you must enter additional facility information from your SWPPP, per Part 5.4.2.

1.2.1.2 How to Submit Your NOI. You must submit your NOI electronically per Part 7.1, unless you have received a waiver from electronic reporting per Part 7.1, in which case you may use the paper NOI form in Appendix G.

1.2.1.3 Deadlines for Submitting Your NOI and Your Official Date of Permit Coverage. Table 1-2 provides the deadlines for submitting your $\mathrm{NOI}$ and your official start date of permit coverage. 
Table 1-2. NOI Submittal Deadlines and Discharge Authorization Dates

\begin{tabular}{|c|c|c|}
\hline Category & $\begin{array}{c}\text { NOI Submission } \\
\text { Deadline }\end{array}$ & Discharge Authorization Date ${ }^{1,2}$ \\
\hline $\begin{array}{l}\text { Operators of industrial activities that were } \\
\text { authorized for coverage under the } 2008 \\
\text { MSGP. }\end{array}$ & $\begin{array}{l}\text { No later than September } 2 \text {, } \\
2015 \text { unless EPA notifies } \\
\text { you that your deadline is } \\
\text { extended. }{ }^{3}\end{array}$ & $\begin{array}{l}30 \text { days after EPA notifies you that it has } \\
\text { received a complete NOI, unless EPA } \\
\text { notifies you that your authorization has } \\
\text { been denied or delayed. Note: You must } \\
\text { review and update your SWPPP to } \\
\text { ensure that this permit's requirements are } \\
\text { addressed prior to submitting your NOI. } \\
\text { Provided you submit your NOI in } \\
\text { accordance with the deadline, your } \\
\text { authorization under the } 2008 \text { MSGP is } \\
\text { automatically continued until you have } \\
\text { been granted coverage under this permit } \\
\text { or an alternative permit, or coverage is } \\
\text { otherwise terminated. }\end{array}$ \\
\hline $\begin{array}{l}\text { Operators of industrial activities that } \\
\text { commenced discharging between } \\
\text { September 30, } 2013 \text { and September 2, } 2015 \\
\text { and have been operating consistent with } \\
\text { EPA's no action assurance for the NPDES } \\
\text { Stormwater Multi-Sector General Permit for } \\
\text { Industrial Activities. }\end{array}$ & $\begin{array}{l}\text { As soon as possible, but } \\
\text { no later than September } 2 \text {, } \\
2015 \text {, unless EPA notifies } \\
\text { you that your deadline is } \\
\text { extended. }{ }^{3}\end{array}$ & $\begin{array}{l}30 \text { days after EPA notifies you that it has } \\
\text { received a complete NOI, unless EPA } \\
\text { notifies you that your authorization has } \\
\text { been denied or delayed. }\end{array}$ \\
\hline $\begin{array}{l}\text { Operators of industrial activities that } \\
\text { commence discharging after September } 2 \text {, } \\
2015 \text {, or operators seeking coverage for } \\
\text { discharges previously covered under an } \\
\text { individual permit or an alternative general } \\
\text { permit. }\end{array}$ & $\begin{array}{l}\text { A minimum of } 30 \text { days } \\
\text { prior to commencing } \\
\text { discharge in accordance } \\
\text { with the terms of the } 2015 \\
\text { MSGP. }{ }^{3}\end{array}$ & $\begin{array}{l}30 \text { days after EPA notifies you that it has } \\
\text { received a complete NOI, unless EPA } \\
\text { notifies you that your authorization has } \\
\text { been denied or delayed. }\end{array}$ \\
\hline $\begin{array}{l}\text { New operators of existing industrial activities } \\
\text { with discharges previously authorized under } \\
\text { the } 2015 \text { MSGP. }\end{array}$ & $\begin{array}{l}\text { A minimum of } 30 \text { days } \\
\text { prior to the date of transfer } \\
\text { of control to the new } \\
\text { operator. }\end{array}$ & $\begin{array}{l}30 \text { days after EPA notifies you that it has } \\
\text { received a complete NOI, unless EPA } \\
\text { notifies you that your authorization has } \\
\text { been denied or delayed. }\end{array}$ \\
\hline $\begin{array}{l}\text { Other eligible operators - Operators of } \\
\text { industrial activities that commenced } \\
\text { discharging prior to September 2, 2015, but } \\
\text { not covered under the } 2008 \text { MSGP or } \\
\text { another NPDES permit and not operating } \\
\text { consistent with EPA's no action assurance } \\
\text { for the NPDES Stormwater Multi-Sector } \\
\text { General Permit for Industrial Activities. }\end{array}$ & $\begin{array}{l}\text { Immediately, to minimize } \\
\text { the time discharges from } \\
\text { the facility will continue to } \\
\text { be unauthorized. }\end{array}$ & $\begin{array}{l}30 \text { days after EPA notifies you that it has } \\
\text { received a complete NOI, unless EPA } \\
\text { notifies you that your authorization has } \\
\text { been denied or delayed. }\end{array}$ \\
\hline
\end{tabular}

${ }^{1}$ If you have missed the deadline to submit your NOI, any and all discharges from your industrial activities will continue to be unauthorized under the CWA until they are covered by this or a different NPDES permit. EPA may take enforcement action for any unpermitted discharges that occur between the commencement of discharging and discharge authorization.

${ }^{2}$ Discharges are not authorized if your $\mathrm{NOI}$ is incomplete or inaccurate or if you are ineligible for permit coverage.

${ }^{3}$ Operators of industrial activities located in the State of Idaho (except Indian country), in the State of Washington (except Indian country) if operated by a federal operator, or on Spokane Tribe of Indians lands are not yet eligible for coverage under the MSGP because certifications required by section 401 of the CWA were not received in time. Once permit coverage is available in these areas, the following NOI deadlines will apply:

- For operators of industrial activities that were authorized for coverage under the 2008 MSGP: No later than 90 days after the date of permit issuance in these areas.

- For operators of industrial activities that commence discharging on or after September 30, 2013 and prior to 90 days after the date of permit issuance in these areas: As soon as possible, but no later than 90 days after permit issuance.

- For operators of industrial activities that commence discharging 90 days after permit issuance in these areas: A minimum of 30 days prior to commencing discharge in accordance with the terms of the 2015 MSGP. 


\subsubsection{Continuation of Coverage for Existing Permittees After the Permit Expires.}

If this permit is not reissued or replaced prior to the expiration date, it will be administratively continued in accordance with the Administrative Procedure Act and 40 CFR 122.6 and remain in force and effect for discharges that were covered prior to expiration. If you obtain authorization to discharge under this permit prior to the expiration date and this permit is administratively continued, any discharges authorized under this permit will automatically remain covered by this permit after its expiration date until the earliest of:

- Your authorization for coverage under a reissued permit or a replacement version of this permit following your timely submittal of a complete and accurate NOI for coverage under the new permit; or

Note: If you fail to submit a timely NOI for coverage under the reissued or replacement permit, your coverage will terminate on the date that the NOI was due.

- Your submittal of a Notice of Termination (NOT); or

- Issuance of an individual permit for the facility's discharges; or

- A formal permit decision by EPA not to reissue this general permit, at which time EPA will identify a reasonable time period for covered dischargers to seek coverage under an alternative general permit or an individual permit. Coverage under this permit will cease at the end of this time period.

EPA reserves the right to modify or revoke and reissue this permit under 40 CFR 122.62 and 63 , in which case you will be notified of any relevant changes or procedures to which you may be subject.

\subsubsection{Coverage Under Alternative Permits.}

EPA may require you to apply for and/or obtain authorization to discharge under an alternative permit, i.e., either an individual NPDES permit or an alternative NPDES general permit, in accordance with 40 CFR 122.64 and 124.5. If EPA requires you to apply for an alternative permit, the Agency will notify you in writing that a permit application or $\mathrm{NOI}$ is required. This notification will include a brief statement of the reasons for this decision and will contain alternative permit application or NOI requirements, including deadlines for completing your application or NOI.

1.2.3.1 Denial of Coverage for New or Previously Unpermitted Facilities. For new or previously unpermitted facilities, following the submittal of your $\mathrm{NOI}$, you may be denied coverage under the 2015 MSGP and must apply for and/or obtain authorization to discharge under an alternative permit, per Part 1.2.3.

1.2.3.2 Loss of Authorization Under the 2015 MSGP for Existing Permitted Facilities. If your stormwater discharges are covered under this permit, you may receive a written notification that you must either apply for coverage under an individual NPDES permit or submit an NOI for coverage under an alternative general NPDES permit, per Part 1.2.3. In addition to the reasons for the decision and alternative permit application or NOI deadlines, the notice will include a statement that on the effective date of your alternative permit coverage, your coverage under the 2015 MSGP will terminate. EPA may grant additional time to submit the application or $\mathrm{NOI}$ if you request it. If you fail to submit an alternative permit application or $\mathrm{NOI}$ as required by EPA, then your authorization to discharge under the 2015 MSGP is terminated at the end of the day EPA required you to submit your alternative 
permit application or NOI. EPA may take appropriate enforcement action for any unpermitted discharge.

1.2.3.3 Operator Requesting Coverage Under an Alternative Permit. You may request to be covered under an individual permit. In such a case, you must submit an individual permit application in accordance with the requirements of 40 CFR 122.28(b) (3) (iii), with reasons supporting the request, to the applicable EPA Regional Office listed in Part 7.9.1 of this permit. The request may be granted by issuance of an individual permit if your reasons are adequate to support the request. When you are authorized to discharge under an alternative permit, your authorization to discharge under the 2015 MSGP is terminated on the effective date of the alternative permit.

\section{$1.3 \quad$ Terminating Coverage.}

\subsubsection{Submitting a Notice of Termination (NOT).}

To terminate permit coverage, you must submit a complete and accurate NOT. Your authorization to discharge under this permit terminates at midnight of the day that you are notified that your complete NOT has been processed. If you submit a NOT without meeting one or more of the conditions identified in Part 1.3.3, then your NOT is not valid. You are responsible for meeting the terms of this permit until your authorization is terminated.

\subsubsection{How to Submit Your NOT.}

You must submit your NOT electronically per Part 7.2, unless you have received a waiver from electronic reporting per Part 7.1, in which case you may use the paper form in Appendix $\mathrm{H}$.

\subsubsection{When to Submit Your NOT.}

You must submit a NOT within 30 days after one or more of the following conditions have been met:

- A new owner or operator has taken over responsibility for the facility; or

- You have ceased operations at the facility, there are not or no longer will be discharges of stormwater associated with industrial activity from the facility, and you have already implemented necessary sediment and erosion controls per Part 2.1.2.5; or

- You are a Sector G, H, or J facility and you have met the applicable termination requirements; or

- You obtained coverage under an individual or alternative general permit for all discharges required to be covered by an NPDES permit.

\subsection{Conditional Exclusion for No Exposure.}

If you are covered by this permit, and become eligible for a "no exposure" exclusion from permitting under 40 CFR 122.26(g), you may file a No Exposure Certification. You are no longer required to have a permit upon submission of a complete and accurate No Exposure Certification to EPA. If you are no longer required to have permit coverage because of a no exposure exclusion and have submitted a No Exposure Certification form to EPA, you are not required to submit a NOT. You must submit a No Exposure Certification form to EPA once every five years. 
You must submit your No Exposure Certification electronically per Part 7.2, unless you have received a waiver from electronic reporting per Part 7.1, in which case you may use the paper form in Appendix K.

\section{$1.5 \quad$ Permit Compliance.}

Any noncompliance with any of the requirements of this permit constitutes a violation of this permit, and thus is a violation of the CWA. As detailed in Part 4 (Corrective Actions) of this permit, failure to take any required corrective actions constitutes an independent, additional violation of this permit, in addition to any original violation that triggered the need for corrective action. As such, any actions and time periods specified for remedying noncompliance do not absolve parties of the initial underlying noncompliance.

Where corrective action is triggered by an event that does not itself constitute permit noncompliance, such as an exceedance of an applicable benchmark, there is no permit violation provided you take the required corrective action within the relevant deadlines established in Part 4.3.

\subsection{Severability.}

Invalidation of a portion of this permit does not necessarily render the whole permit invalid. EPA's intent is that the permit is to remain in effect to the extent possible; in the event that any part of this permit is invalidated. EPA will advise the regulated community as to the effect of such invalidation. 


\section{2.}

Control Measures and Effluent Limits.

In the technology-based limits included in Parts 2.1 and 8, the term "minimize" means reduce and/or eliminate to the extent achievable using control measures (including best management practices) that are technologically available and economically practicable and achievable in light of best industry practice. The term "infeasible" means not technologically possible or not economically practicable and achievable in light of best industry practices. EPA notes that it does not intend for any permit requirement to conflict with state water rights law.

\subsection{Control Measures.}

You must select, design, install, and implement control measures (including best management practices) to minimize pollutant discharges that address the selection and design considerations in Part 2.1.1, meet the non-numeric effluent limits in Part 2.1.2, meet limits contained in applicable effluent limitations guidelines in Part 2.1.3, and meet the water qualitybased effluent limitations in Part 2.2. The selection, design, installation, and implementation of these control measures must be in accordance with good engineering practices and manufacturer's specifications. Note that you may deviate from such manufacturer's specifications where you provide justification for such deviation and include documentation of your rationale in the part of your SWPPP that describes your control measures, consistent with Part 5.2.4. If you find that your control measures are not achieving their intended effect of minimizing pollutant discharges to meet applicable water quality standards or any of the other non-numeric effluent limits in this permit, you must modify these control measures per the corrective action requirements in Part 4. Regulated stormwater discharges from your facility include stormwater run-on that commingles with stormwater discharges associated with industrial activity at your facility.

Effluent limit requirements in Part 2.1.2 that do not involve the site-specific selection of a control measure or are specific activity requirements (e.g., "Cleaning catch basins when the depth of debris reaches two-thirds (2/3) of the sump depth and keeping the debris surface at least six inches below the lowest outlet pipe") are marked with an asterisk (*). When documenting in your SWPPP, per Part 5, how you will comply with the requirements marked with an asterisk, you have the option of including additional information or you may just "cutand-paste" those effluent limits verbatim into your SWPPP without providing additional documentation (see Part 5.2.4).

\subsubsection{Control Measure Selection and Design Considerations.}

You must consider the following when selecting and designing control measures:

- Preventing stormwater from coming into contact with polluting materials is generally more effective, and less costly, than trying to remove pollutants from stormwater;

- Using control measures in combination may be more effective than using control measures in isolation for minimizing pollutants in your stormwater discharge;

- Assessing the type and quantity of pollutants, including their potential to impact receiving water quality, is critical to designing effective control measures that will achieve the limits in this permit;

- Minimizing impervious areas at your facility and infiltrating runoff onsite (including bioretention cells, green roofs, and pervious pavement, among other approaches) can reduce runoff and improve ground water recharge and 
stream base flows in local streams, although care must be taken to avoid ground water contamination;

- Attenuating flow using open vegetated swales and natural depressions can reduce in-stream impacts of erosive flows;

- Conserving and/or restoring riparian buffers will help protect streams from stormwater runoff and improve water quality; and

- Using treatment interceptors (e.g., swirl separators and sand filters) may be appropriate in some instances to minimize the discharge of pollutants.

\subsubsection{Non-Numeric Technology-Based Effluent Limits (BPT/BAT/BCT).}

You must comply with the following non-numeric effluent limits (except where otherwise specified in Part 8) as well as any sector-specific non-numeric effluent limits in Part 8:

2.1.2.1 Minimize Exposure. You must minimize the exposure of manufacturing, processing, and material storage areas (including loading and unloading, storage, disposal, cleaning, maintenance, and fueling operations) to rain, snow, snowmelt, and runoff in order to minimize pollutant discharges by either locating these industrial materials and activities inside or protecting them with storm resistant coverings. Unless infeasible, you must also:

- Use grading, berming or curbing to prevent runoff of contaminated flows and divert run-on away from these areas;

- Locate materials, equipment, and activities so that potential leaks and spills are contained or able to be contained or diverted before discharge;

- Clean up spills and leaks promptly using dry methods (e.g., absorbents) to prevent the discharge of pollutants;

- Store leaky vehicles and equipment indoors or, if stored outdoors, use drip pans and absorbents;

- Use spill/overflow protection equipment;

- Perform all vehicle and/or equipment cleaning operations indoors, under cover, or in bermed areas that prevent runoff and run-on and also that capture any overspray; and

- Drain fluids from equipment and vehicles that will be decommissioned, and, for any equipment and vehicles that will remain unused for extended periods of time, inspect at least monthly for leaks.

Note: Industrial materials do not need to be enclosed or covered if stormwater runoff from affected areas does not discharge pollutants to receiving waters or if discharges are authorized under another NPDES permit.

2.1.2.2 Good Housekeeping. You must keep clean all exposed areas that are potential sources of pollutants. You must perform good housekeeping measures in order to minimize pollutant discharges, including but not limited to, the following:

- Sweep or vacuum at regular intervals or, alternatively, wash down the area and collect and/or treat, and properly dispose of the washdown water;

- Store materials in appropriate containers; 
- Keep all dumpster lids closed when not in use. For dumpsters and roll off boxes that do not have lids and could leak, ensure that discharges have a control (e.g., secondary containment, treatment). Consistent with Part 1.1.3 above, this permit does not authorize dry weather discharges from dumpsters or roll off boxes:*

- Minimize the potential for waste, garbage and floatable debris to be discharged by keeping exposed areas free of such materials, or by intercepting them before they are discharged.

Plastic Materials Requirements: Facilities that handle pre-production plastic must implement best management practices to eliminate discharges of plastic in stormwater. Examples of plastic material required to be addressed as stormwater pollutants include plastic resin pellets, powders, flakes, additives, regrind, scrap, waste and recycling.

2.1.2.3 Maintenance. You must maintain all control measures that are used to achieve the effluent limits in this permit in effective operating condition, as well as all industrial equipment and systems, in order to minimize pollutant discharges. This includes:

- Performing inspections and preventive maintenance of stormwater drainage, source controls, treatment systems, and plant equipment and systems that could fail and result in contamination of stormwater.

- Diligently maintaining non-structural control measures (e.g., keep spill response supplies available, personnel appropriately trained).

- Inspecting and maintaining baghouses at least quarterly to prevent the escape of dust from the system and immediately removing any accumulated dust at the base of the exterior baghouse.*

- Cleaning catch basins when the depth of debris reaches two-thirds (2/3) of the sump depth and keeping the debris surface at least six inches below the lowest outlet pipe.*

If you find that your control measures are in need of routine maintenance, you must conduct the necessary maintenance immediately in order to minimize pollutant discharges. If you find that your control measures need to be repaired or replaced, you must immediately take all reasonable steps to prevent or minimize the discharge of pollutants until the final repair or replacement is implemented, including cleaning up any contaminated surfaces so that the material will not be discharged during subsequent storm events. Final repairs/replacement of stormwater controls should be completed as soon as feasible but must be no later than the timeframe established in Part 4.3 for corrective actions, i.e., within 14 days or, if that is infeasible, within 45 days. If the completion of stormwater control repairs/replacement will exceed the 45 day timeframe, you may take the minimum additional time necessary to complete the maintenance, provided that you notify the EPA Regional Office of your intention to exceed 45 days, and document in your SWPPP your rationale for your modified maintenance timeframe. If a control measure was never installed, was installed incorrectly or not in accordance with Parts 2 and/or 8, or is not being properly operated or maintained, you must conduct corrective action as specified in Part 4.

Note: In this context, the term "immediately" requires you to, on the same day you identify that a control measure needs to be maintained, take all reasonable steps 
to minimize or prevent the discharge of pollutants until a permanent solution is installed and made operational. However, if a problem is identified at a time in the work day when it is too late to take action, the initiation of action must begin no later than the following work day. "All reasonable steps" means that the permittee has undertaken initial actions to assess and address the condition causing the corrective action, including, for example, cleaning up any exposed materials that may be discharged in a storm event (e.g., through sweeping, vacuuming) or making arrangements (i.e., scheduling) for a new best management practice (BMP) to be installed at a later date. "All reasonable steps" for purposes of complying with Part 4.2 Conditions Requiring SWPPP Review to Determine if Modifications Are Necessary, when you conclude a corrective action is, in fact, not necessary, could include documenting why a corrective action is unnecessary.

2.1.2.4 Spill Prevention and Response. You must minimize the potential for leaks, spills and other releases that may be exposed to stormwater and develop plans for effective response to such spills if or when they occur in order to minimize pollutant discharges. You must conduct spill prevention and response measures, including but not limited to, the following:

- Plainly label containers (e.g., "Used Oil," "Spent Solvents," "Fertilizers and Pesticides") that could be susceptible to spillage or leakage to encourage proper handling and facilitate rapid response if spills or leaks occur;*

- Implement procedures for material storage and handling, including the use of secondary containment and barriers between material storage and traffic areas, or a similarly effective means designed to prevent the discharge of pollutants from these areas;

- Develop training on the procedures for expeditiously stopping, containing, and cleaning up leaks, spills, and other releases. As appropriate, execute such procedures as soon as possible;

- Keep spill kits on-site, located near areas where spills may occur or where a rapid response can be made; and

- Notify appropriate facility personnel when a leak, spill, or other release occurs.

Where a leak, spill or other release containing a hazardous substance or oil in an amount equal to or in excess of a reportable quantity established under either 40 CFR Part 110, 40 CFR Part 117, or 40 CFR Part 302, occurs during a 24-hour period, you must notify the National Response Center (NRC) at (800) 424-8802 or, in the Washington, DC, metropolitan area, call (202) 267-2675 in accordance with the requirements of 40 CFR Part 110, 40 CFR Part 117, and 40 CFR Part 302 as soon as you have knowledge of the discharge. State or local requirements may necessitate reporting spills or discharges to local emergency response, public health, or drinking water supply agencies. Contact information must be in locations that are readily accessible and available.

2.1.2.5 Erosion and Sediment Controls. You must minimize erosion by stabilizing exposed soils at your facility in order to minimize pollutant discharges and placing flow velocity dissipation devices at discharge locations to minimize channel and streambank erosion and scour in the immediate vicinity of discharge points. You must also use structural and non-structural control measures to minimize the discharge of sediment. If you use polymers and/or other chemical treatments as part of your controls, you must identify the polymers and/or chemicals used and 
the purpose in your SWPPP. There are many resources available to help you select appropriate BMPs for erosion and sediment control, including EPA's Stormwater Discharges from Construction Activities website at:

http://water.epa.gov/polwaste/npdes/stormwater/EPA-Construction-GeneralPermit.cfm.

2.1.2.6 Management of Runoff. You must divert, infiltrate, reuse, contain, or otherwise reduce stormwater runoff to minimize pollutants in your discharges. In selecting, designing, installing, and implementing appropriate control measures, you are encouraged to consult with EPA's Internet-based resources relating to runoff management, including the sector-specific Industrial Stormwater Fact Sheet Series, (http://water.epa.gov/polwaste/npdes/stormwater/EPA-Multi-Sector-GeneralPermit-MSGP.cfm), National Menu of Stormwater BMPs (http://water.epa.gov/polwaste/npdes/swbmp/index.cfm), and National Management Measures to Control Nonpoint Source Pollution from Urban Areas (http://water.epa.gov/polwaste/nps/urban/), and any similar state or tribal resources.

2.1.2.7 Salt Storage Piles or Piles Containing Salt. You must enclose or cover storage piles of salt, or piles containing salt, used for deicing or other commercial or industrial purposes, including maintenance of paved surfaces, in order to minimize pollutant discharges. You must implement appropriate measures (e.g., good housekeeping, diversions, containment) to minimize exposure resulting from adding to or removing materials from the pile. Piles do not need to be enclosed or covered pursuant to this permit if stormwater runoff from the piles is not discharged or if discharges from the piles are authorized under another NPDES permit.

2.1.2.8 Employee Training. You must train all employees who work in areas where industrial materials or activities are exposed to stormwater, or who are responsible for implementing activities necessary to meet the conditions of this permit (e.g., inspectors, maintenance personnel), including all members of your stormwater pollution prevention team. You must ensure the following personnel understand the requirements of this permit and their specific responsibilities with respect to those requirements:

- Personnel who are responsible for the design, installation, maintenance, and/or repair of controls (including pollution prevention measures);

- Personnel responsible for the storage and handling of chemicals and materials that could become contaminants in stormwater discharges;

- Personnel who are responsible for conducting and documenting monitoring and inspections as required in Parts 3 and 6; and

- Personnel who are responsible for taking and documenting corrective actions as required in Part 4.

Personnel must be trained in at least the following if related to the scope of their job duties (e.g., only personnel responsible for conducting inspections need to understand how to conduct inspections):

- An overview of what is in the SWPPP;

- Spill response procedures, good housekeeping, maintenance requirements, and material management practices; 
- The location of all controls on the site required by this permit, and how they are to be maintained;

- The proper procedures to follow with respect to the permit's pollution prevention requirements; and

- When and how to conduct inspections, record applicable findings, and take corrective actions.

2.1.2.9 Non-Stormwater Discharges. You must evaluate for the presence of non-stormwater discharges. Any non-stormwater discharges not explicitly authorized in Part 1.1.3 or covered by another NPDES permit must be eliminated. This includes vehicle and equipment/tank wash water (except for those authorized in Part 1.1.3.3 for Sectors $\mathrm{G}, \mathrm{H}$, and J). If not covered under a separate NPDES permit, wastewater, wash water and any other unauthorized non-stormwater must be discharged to a sanitary sewer in accordance with applicable industrial pretreatment requirements, or otherwise disposed of appropriately.

2.1.2.10 Dust Generation and Vehicle Tracking of Industrial Materials. You must minimize generation of dust and off-site tracking of raw, final, or waste materials in order to minimize pollutant discharges.

\subsubsection{Numeric Effluent Limitations Based on Effluent Limitations Guidelines.}

If you are in an industrial category subject to one of the effluent limitations guidelines identified in Table 6-1 (see Part 6.2.2.1), you must meet the effluent limits referenced in Table 2-1 below:

Table 2-1. Applicable Effluent Limitations Guidelines

\begin{tabular}{|c|c|c|}
\hline Regulated Activity & 40 CFR Part/Subpart & Effluent Limit \\
\hline $\begin{array}{l}\text { Discharges resulting from spray down or } \\
\text { intentional wetting of logs at wet deck storage } \\
\text { areas }\end{array}$ & Part 429, Subpart I & See Part 8.A.7 \\
\hline $\begin{array}{l}\text { Runoff from phosphate fertilizer manufacturing } \\
\text { facilities that comes into contact with any raw } \\
\text { materials, finished product, by-products or waste } \\
\text { products (SIC 2874) }\end{array}$ & Part 418, Subpart A & See Part 8.C.4 \\
\hline Runoff from asphalt emulsion facilities & Part 443, Subpart A & See Part 8.D.4 \\
\hline $\begin{array}{l}\text { Runoff from material storage piles at cement } \\
\text { manufacturing facilities }\end{array}$ & Part 411, Subpart C & See Part 8.E.5 \\
\hline $\begin{array}{l}\text { Mine dewatering discharges at crushed stone, } \\
\text { construction sand and gravel, or industrial sand } \\
\text { mining facilities }\end{array}$ & Part 436, Subparts B, C, or D & See Part 8.J.9 \\
\hline Runoff from hazardous waste landfills & Part 445, Subpart A & See Part 8.K.6 \\
\hline Runoff from non-hazardous waste landfills & Part 445, Subpart B & See Part 8. L.10 \\
\hline $\begin{array}{l}\text { Runoff from coal storage piles at steam electric } \\
\text { generating facilities }\end{array}$ & Part 423 & See Part 8.0.8 \\
\hline $\begin{array}{l}\text { Runoff containing urea from airfield pavement } \\
\text { deicing at existing and new primary airports with } \\
1,000 \text { or more annual non-propeller aircraft } \\
\text { departures }\end{array}$ & Part 449 & See Part 8.S.8 \\
\hline
\end{tabular}


Your discharge must be controlled as necessary to meet applicable water quality standards of all affected states (i.e., your discharge must not cause or contribute to an exceedance of applicable water quality standards in any affected state).

EPA expects that compliance with the conditions in this permit will control discharges as necessary to meet applicable water quality standards. If at any time you become aware, or EPA determines, that your discharge does not meet applicable water quality standards, you must take corrective action(s) as required in Part 4.1 and document the corrective actions as required in Part 4.4. You must also comply with any additional requirements that your state or tribe requires in Part 9.

EPA may also require that you undertake additional control measures (to meet the narrative water quality-based effluent limit above) on a site-specific basis, or require you to obtain coverage under an individual permit, if information in your NOl, required reports, or from other sources indicates that your discharges are not controlled as necessary to meet applicable water quality standards. You must implement all measures necessary to be consistent with an available wasteload allocation in an EPA-established or approved TMDL.

\subsubsection{Discharges to Water Quality-Impaired Waters.}

You are considered to discharge to an impaired water if the first water of the U.S. to which you discharge is identified by a state, tribe or EPA as not meeting an applicable water quality standard, and:

- Requires development of a TMDL (pursuant to section 303(d) of the CWA);

- Is addressed by an EPA-approved or established TMDL; or

- Is not in either of the above categories but the waterbody is covered by a pollution control program that meets the requirements of 40 CFR 130.7 (b) (1).

Note: For discharges that enter a separate storm sewer system ${ }^{3}$ prior to discharge, the first water of the U.S. to which you discharge is the waterbody that receives the water from the storm sewer system.

2.2.2.1 Existing Discharge to an Impaired Water with an EPA-Approved or Established TMDL. If you discharge to an impaired water with an EPA-approved or established TMDL, EPA will inform you whether any additional measures are necessary for your discharge to be consistent with the assumptions and requirements of the applicable TMDL and its wasteload allocation, or if coverage under an individual permit is necessary per Part 1.2.3.

\subsubsection{Existing Discharger to an Impaired Water without an EPA-Approved or Established}

TMDL. If you discharge to an impaired water without an EPA-approved or established TMDL, you are still required to comply with Part 2.2.1, and you must comply with the monitoring requirements of Part 6.2.4.1. Note that the impaired waters monitoring requirements of Part 6.2.4.1 also apply where EPA determines that your discharge is not controlled as necessary to meet applicable water quality

3 Separate storm systems do not include combined sewer systems or sanitary sewer systems. Separate storm systems include both municipal storm sewer systems (MS4s) and non-municipal separate storm sewers. 
standards in an impaired downstream water segment, even if your discharge is to a receiving water that is not identified as impaired according to Part 2.2.2.

2.2.2.3 New Discharger or New Source to an Impaired Water. If your authorization to discharge under this permit relied on Part 1.1.4.8 for a new discharger or a new source to an impaired water, you must implement and maintain any measures that enabled you to become eligible under Part 1.1.4.8, and modify such measures as necessary pursuant to any Part 4 corrective actions. You also must comply with Part 2.2.1 and the monitoring requirements of Parts 6.2.4.1.

\subsubsection{Tier 2 Antidegradation Requirements for New Dischargers, New Sources, or Increased Discharges.}

If you are a new discharger or a new source (as defined in Appendix A), or an existing discharger required to notify EPA of an increased discharge consistent with Part 7.7 (i.e., a "planned changes" report), and you discharge directly to waters designated by a state or tribe as Tier 2 or Tier 2.5 for antidegradation purposes under 40 CFR 131.12(a), EPA may require that you undertake additional control measures as necessary to ensure compliance with the applicable antidegradation requirements, or notify you that an individual permit application is necessary in accordance with Part 1.2.3. See list of Tier 2 and 2.5 waters in Appendix L.

\subsection{Requirements Relating to Endangered Species, Historic Properties, and Federal CERCLA Sites.}

If your eligibility under either Part 1.1.4.5, Part 1.1.4.6, and/or Part 1.1.4.10 was made possible through your, or another operator's, agreement to undertake additional measures, you must comply with all such measures to maintain eligibility under the MSGP.

Note that if at any time you become aware, or EPA determines, that your discharges and/or discharge-related activities have the potential to adversely affect listed species and/or critical habitat, EPA may inform you of the need to implement additional measures on a site-specific basis to meet the effluent limits in this permit, or require you to obtain coverage under an individual permit. 


\section{3.}

\section{Inspections.}

\section{1}

\section{Routine Facility Inspections.}

During normal facility operating hours you must conduct inspections of areas of the facility covered by the requirements in this permit, including, but not limited to, the following:

- Areas where industrial materials or activities are exposed to stormwater;

- Areas identified in the SWPPP and those that are potential pollutant sources (see Part 5.2.3);

- Areas where spills and leaks have occurred in the past three years;

- Discharge points; and

- Control measures used to comply with the effluent limits contained in this permit.

Inspections must be conducted at least quarterly (i.e., once each calendar quarter), or in some instances more frequently (e.g., monthly). Increased frequency may be appropriate for some types of equipment, processes and stormwater control measures, or areas of the facility with significant activities and materials exposed to stormwater. At least once each calendar year, the routine inspection must be conducted during a period when a stormwater discharge is occurring.

Inspections must be performed by qualified personnel (as defined in Appendix A) with at least one member of your stormwater pollution prevention team participating. Inspectors must consider the results of visual and analytical monitoring (if any) for the past year when planning and conducting inspections.

During the inspection you must examine or look out for the following:

- Industrial materials, residue or trash that may have or could come into contact with stormwater;

- Leaks or spills from industrial equipment, drums, tanks and other containers;

- Offsite tracking of industrial or waste materials, or sediment where vehicles enter or exit the site;

- Tracking or blowing of raw, final or waste materials from areas of no exposure to exposed areas;

- Control measures needing replacement, maintenance or repair.

During an inspection occurring during a stormwater event or discharge, control measures implemented to comply with effluent limits must be observed to ensure they are functioning correctly. Discharge points, as defined in Appendix A, must also be observed during this inspection. If such discharge locations are inaccessible, nearby downstream locations must be inspected.

\subsubsection{Exceptions to Routine Facility Inspections for Inactive and Unstaffed Sites.}

The requirement to conduct facility inspections on a routine basis does not apply at a facility that is inactive and unstaffed, as long as there are no industrial materials or activities exposed to stormwater. Such a facility is only required to conduct an annual site inspection in accordance with Part 3.1. To invoke this exception, you must indicate that your facility is inactive and unstaffed on your NOI. If you are already covered under the permit and your 
facility has changed from active to inactive and unstaffed, you must modify and re-certify your NOI. You must also include a statement in your SWPPP per Part 5.2.5.2 indicating that the site is inactive and unstaffed, and that there are no industrial materials or activities exposed to stormwater, in accordance with the substantive requirements in 40 CFR 122.26 (g) (4) (iii). The statement must be signed and certified in accordance with Appendix B, Subsection 11. If circumstances change and industrial materials or activities become exposed to stormwater or your facility becomes active and/or staffed, this exception no longer applies and you must immediately resume routine facility inspections. If you are not qualified for this exception at the time you become authorized under this permit, but during the permit term you become qualified because your facility becomes inactive and unstaffed, and there are no industrial materials or activities that are exposed to stormwater, you must include the same signed and certified statement as above and retain it with your records pursuant to Part 5.5.

Inactive and unstaffed facilities covered under Sectors G (Metal Mining), H (Coal Mines and Coal Mining-Related Facilities), and J (Non-Metallic Mineral Mining and Dressing) are not required to meet the "no industrial materials or activities exposed to stormwater" standard to be eligible for this exception from routine inspections, per Parts 8.G.8.4, 8.H.8.1, and 8.J.8.1.

\subsubsection{Routine Facility Inspection Documentation.}

You must document the findings of your facility inspections and maintain this report with your SWPPP as required in Part 5.5. Do not submit your routine facility inspection report to EPA, unless specifically requested to do so. However, you must summarize your findings in the annual report per Part 7.5. Document all findings, including but not limited to, the following information:

- The inspection date and time;

- The name(s) and signature(s) of the inspector(s);

- Weather information;

- All observations relating to the implementation of control measures at the facility, including:

- A description of any discharges occurring at the time of the inspection;

- Any previously unidentified discharges from and/or pollutants at the site;

- Any evidence of, or the potential for, pollutants entering the drainage system;

- Observations regarding the physical condition of and around all outfalls, including any flow dissipation devices, and evidence of pollutants in discharges and/or the receiving water;

- Any control measures needing maintenance, repairs, or replacement;

- Any additional control measures needed to comply with the permit requirements;

- Any incidents of noncompliance; and

- A statement, signed and certified in accordance with Appendix B, Subsection 11.

Any corrective action required as a result of a routine facility inspection must be performed consistent with Part 4 of this permit. 
If you performed a discharge visual assessment required in Part 3.2 during your facility inspection, you may include the results of the assessment with the report required in Part 3.1.2, as long as all components of both types of inspections are included in the report.

\subsection{Quarterly Visual Assessment of Stormwater Discharges.}

\subsubsection{Quarterly Visual Assessment Procedures.}

Once each quarter for the entire permit term, you must collect a stormwater sample from each outfall (except as noted in Part 3.2.3) and conduct a visual assessment of each of these samples. These samples are not required to be collected consistent with $40 \mathrm{CFR}$ Part 136 procedures but must be collected in such a manner that the samples are representative of the stormwater discharge. Guidance on monitoring is available at http://water.epa.gov/polwaste/npdes/stormwater/EPA-Multi-Sector-General-PermitMSGP.cfm.

The visual assessment must be made:

- Of a sample in a clean, colorless glass or plastic container, and examined in a well-lit area;

- On samples collected within the first 30 minutes of an actual discharge from a storm event. If it is not possible to collect the sample within the first 30 minutes of discharge, the sample must be collected as soon as practicable after the first 30 minutes and you must document why it was not possible to take the sample within the first 30 minutes. In the case of snowmelt, samples must be taken during a period with a measurable discharge from your site; and

- For storm events, on discharges that occur at least 72 hours (three days) from the previous discharge. The 72-hour (three-day) storm interval does not apply if you document that less than a 72-hour (three-day) interval is representative for local storm events during the sampling period.

You must visually inspect or observe the sample for the following water quality characteristics:

- Color;

- Odor;

- Clarity (diminished);

- Floating solids;

- Settled solids;

- Suspended solids;

- Foam;

- Oil sheen; and

- Other obvious indicators of stormwater pollution.

Whenever the visual assessment shows evidence of stormwater pollution, you must initiate the corrective action procedures in Part 4.

\subsubsection{Quarterly Visual Assessment Documentation.}

You must document the results of your visual assessments and maintain this documentation onsite with your SWPPP as required in Part 5.5. You are not required to submit 
your visual assessment findings to EPA, unless specifically requested to do so. However, you must summarize your findings in the annual report per Part 7.5. Your documentation of the visual assessment must include, but not be limited to:

- Sample location(s);

- Sample collection date and time, and visual assessment date and time for each sample;

- Personnel collecting the sample and performing visual assessment, and their signatures;

- Nature of the discharge (i.e., runoff or snowmelt);

- Results of observations of the stormwater discharge;

- Probable sources of any observed stormwater contamination;

- If applicable, why it was not possible to take samples within the first 30 minutes; and

- A statement, signed and certified in accordance with Appendix B, Subsection 11 .

Any corrective action required as a result of a quarterly visual assessment must be performed consistent with Part 4 of this permit.

\subsubsection{Exceptions to Quarterly Visual Assessments.}

Adverse Weather Conditions: When adverse weather conditions prevent the collection of samples during the quarter, you must take a substitute sample during the next qualifying storm event. Documentation of the rationale for no visual assessment for the quarter must be included with your SWPPP records as described in Part 5.5. Adverse conditions are those that are dangerous or create inaccessibility for personnel, such as local flooding, high winds, electrical storms, or situations that otherwise make sampling impractical, such as extended frozen conditions.

Climates with Irregular Stormwater Runoff: If your facility is located in an area where limited rainfall occurs during many parts of the year (e.g., arid or semi-arid climate) or in an area where freezing conditions exist that prevent runoff from occurring for extended periods, then your samples for the quarterly visual assessments may be distributed during seasons when precipitation runoff occurs.

Areas Subject to Snow: In areas subject to snow, at least one quarterly visual assessment must capture snowmelt discharge, as described in Part 6.1.3, taking into account the exception described above for climates with irregular stormwater runoff.

Inactive and Unstaffed Sites: The requirement for a quarterly visual assessment does not apply at a facility that is inactive and unstaffed, as long as there are no industrial materials or activities exposed to stormwater. To invoke this exception, you must maintain a statement in your SWPPP per Part 5.2.5.2 indicating that the site is inactive and unstaffed, and that there are no industrial materials or activities exposed to precipitation, in accordance with the substantive requirements in 40 CFR 122.26 (g) (4) (iii). The statement must be signed and certified in accordance with Appendix B, Subsection 11. If circumstances change and industrial materials or activities become exposed to stormwater or your facility becomes active and/or staffed, this exception no longer applies and you must immediately resume quarterly visual assessments. If you are not qualified for this exception at the time you are authorized under this 
permit, but during the permit term you become qualified because your facility becomes inactive and unstaffed, and there are no industrial materials or activities that are exposed to stormwater, then you must include the same signed and certified statement as above and retain it with your records pursuant to Part 5.5.

Inactive and unstaffed facilities covered under Sectors $G$ (Metal Mining), H (Coal Mines and Coal Mining-Related Facilities), and J (Non-Metallic Mineral Mining and Dressing), are not required to meet the "no industrial materials or activities exposed to stormwater" standard to be eligible for this exception from quarterly visual assessments, consistent with the requirements established in Parts 8.G.8.4, 8.H.8.1, and 8.J.8.1.

Substantially Identical Outfalls: If your facility has two or more outfalls that discharge substantially identical effluents, as documented in Part 5.2.5.3, you may conduct quarterly visual assessments of the discharge at just one of the outfalls and report that the results also apply to the substantially identical outfall(s) provided that you perform visual assessments on a rotating basis of each substantially identical outfall throughout the period of your coverage under this permit.

If stormwater contamination is identified through visual assessment performed at a substantially identical outfall, you must assess and modify your control measures as appropriate for each outfall represented by the monitored outfall. 


\section{4.}

Corrective Actions.

4.1

Conditions Requiring SWPPP Review and Revision to Ensure Effluent Limits are Met.

When any of the following conditions occur or are detected during an inspection, monitoring or other means, or EPA or the operator of the MS4 through which you discharge informs you that any of the following conditions have occurred, you must review and revise, as appropriate, your SWPPP (e.g., sources of pollution; spill and leak procedures; non-stormwater discharges; the selection, design, installation and implementation of your control measures) so that this permit's effluent limits are met and pollutant discharges are minimized:

- An unauthorized release or discharge (e.g., spill, leak, or discharge of nonstormwater not authorized by this or another NPDES permit to a water of the U.S.) occurs at your facility.

- A discharge violates a numeric effluent limit listed in Table 2-1 and in your Part 8 sector-specific requirements.

- Your control measures are not stringent enough for the discharge to meet applicable water quality standards or the non-numeric effluent limits in this permit.

- A required control measure was never installed, was installed incorrectly, or not in accordance with Parts 2 and/or 8 , or is not being properly operated or maintained.

- Whenever a visual assessment shows evidence of stormwater pollution (e.g., color, odor, floating solids, settled solids, suspended solids, foam).

\subsection{Conditions Requiring SWPPP Review to Determine if Modifications Are Necessary.}

If any of the following conditions occur, you must review your SWPPP (e.g., sources of pollution, spill and leak procedures, non-stormwater discharges, selection, design, installation and implementation of your control measures) to determine if modifications are necessary to meet the effluent limits in this permit:

- Construction or a change in design, operation, or maintenance at your facility that significantly changes the nature of pollutants discharged in stormwater from your facility, or significantly increases the quantity of pollutants discharged.

- The average of four quarterly sampling results exceeds an applicable benchmark (see Part 6.2.1.2). If less than four benchmark samples have been taken, but the results are such that an exceedance of the four quarter average is mathematically certain (i.e., if the sum of quarterly sample results to date is more than four times the benchmark level) this is considered a benchmark exceedance, triggering this review.

Note: A benchmark exceedance does not trigger a corrective action if you determine that the exceedance is solely attributable to natural background sources, or if you make a finding that no further pollutant reductions are technologically available and economically practicable and achievable in light of best industry practice (see Part 6.2. 1.2).

Note: When run-on to your facility causes a benchmark exceedance, in addition to reviewing and revising, as appropriate, your SWPPP, you should notify the other operators contributing run-on to your discharges to abate their pollutant contribution. Where the other operators fail to take action to address the stormwater run-on, you should contact your EPA Regional Office. 


\section{3}

\section{Corrective Actions and Deadlines.}

\subsubsection{Immediate Actions.}

If corrective action is needed, you must immediately take all reasonable steps necessary to minimize or prevent the discharge of pollutants until a permanent solution is installed and made operational, including cleaning up any contaminated surfaces so that the material will not discharge in subsequent storm events.

Note: In this context, the term "immediately" requires you to, on the same day a condition requiring corrective action is found, take all reasonable steps to minimize or prevent the discharge of pollutants until a permanent solution is installed and made operational. However, if a problem is identified at a time in the work day when it is too late to initiate corrective action, the initiation of corrective action must begin no later than the following work day. "All reasonable steps" means that the permittee has undertaken initial actions to assess and address the condition causing the corrective action, including, for example, cleaning up any exposed materials that may be discharged in a storm event (e.g., through sweeping, vacuuming) or making arrangements (i.e., scheduling) for a new BMP to be installed at a later date. "All reasonable steps" for purposes of complying with Part 4.2 Conditions Requiring SWPPP Review to Determine if Modifications Are Necessary, when you conclude a corrective action is, in fact, not necessary, could include documenting why a corrective action is unnecessary.

\subsubsection{Subsequent Actions.}

If you determine that additional actions are necessary beyond those implemented pursuant to Part 4.3.1, you must complete the corrective actions (e.g., install a new or modified control and make it operational, complete the repair) before the next storm event if possible, and within 14 calendar days from the time of discovery of the corrective action condition. If it is infeasible to complete the corrective action within 14 calendar days, you must document why it is infeasible to complete the corrective action within the 14-day timeframe. You must also identify your schedule for completing the work, which must be done as soon as practicable after the 14-day timeframe but no longer than 45 days after discovery. If the completion of corrective action will exceed the 45 day timeframe, you may take the minimum additional time necessary to complete the corrective action, provided that you notify the EPA Regional Office of your intention to exceed 45 days, your rationale for an extension, and a completion date, which you must also include in your corrective action documentation (see Part 4.4). Where your corrective actions result in changes to any of the controls or procedures documented in your SWPPP, you must modify your SWPPP accordingly within 14 calendar days of completing corrective action work.

These time intervals are not grace periods, but are schedules considered reasonable for documenting your findings and for making repairs and improvements. They are included in this permit to ensure that the conditions prompting the need for these repairs and improvements do not persist indefinitely.

\subsection{Corrective Action Documentation.}

You must document the existence of any of the conditions listed in Parts 4.1 or 4.2 within 24 hours of becoming aware of such condition. You are not required to submit your corrective action documentation to EPA, unless specifically requested to do so. However, you must summarize your findings in the annual report per Part 7.5. Include the following information in your documentation:

- Description of the condition triggering the need for corrective action review. For any spills or leaks, include the following information: a description of the 
incident including material, date/time, amount, location, and reason for spill, and any leaks, spills or other releases that resulted in discharges of pollutants to waters of U.S., through stormwater or otherwise;

- Date the condition was identified;

- Description of immediate actions taken pursuant to Part 4.3.1 to minimize or prevent the discharge of pollutants. For any spills or leaks, include response actions, the date/time clean-up completed, notifications made, and staff involved. Also include any measures taken to prevent the reoccurrence of such releases (see Part 2.1.2.4); and

- A statement, signed and certified in accordance with Appendix B, Subsection 11.

You must also document the corrective actions taken or to be taken as a result of the conditions listed in Part 4.1 or 4.2 (or, for triggering events in Part 4.2 where you determine that corrective action is not necessary, the basis for this determination) within 14 days from the time of discovery of any of those conditions. Provide the dates when each corrective action was initiated and completed (or is expected to be completed). If applicable, document why it is infeasible to complete the necessary installations or repairs within the 14-day timeframe and document your schedule for installing the controls and making them operational as soon as practicable after the 14-day timeframe. If you notified EPA regarding an extension of the 45 day timeframe, you must document your rationale for an extension.

\subsection{Effect of Corrective Action.}

If the event triggering the review is a permit violation (e.g., non-compliance with an effluent limit), correcting it does not remove the original violation. Additionally, failing to take corrective action in accordance with this section is an additional permit violation. EPA will consider the appropriateness and promptness of corrective action in determining enforcement responses to permit violations.

\subsection{Substantially Identical Outfalls.}

If the event triggering corrective action is associated with an outfall that had been identified as a "substantially identical outfall" (see Parts 3.2.3 and 6.1.1), your review must assess the need for corrective action for all related substantially identical outfalls. Any necessary changes to control measures that affect these other outfalls must also be made before the next storm event if possible, or as soon as practicable following that storm event. Any corrective actions must be conducted within the timeframes set forth in Part 4.3. 
5.

Stormwater Pollution Prevention Plan (SWPPP).

You must prepare a SWPPP for your facility before submitting your NOI for permit coverage. If you prepared a SWPPP for coverage under a previous version of this NPDES permit, you must review and update the SWPPP to implement all provisions of this permit prior to submitting your NOI. The SWPPP does not contain effluent limitations; such limitations are contained in Parts 2, 8, and 9 of the permit. The SWPPP is intended to document the selection, design, and installation of control measures to meet the permit's effluent limits. As distinct from the SWPPP, the additional documentation requirements (see Part 5.5) are intended to document the implementation (including inspection, maintenance, monitoring, and corrective action) of the permit requirements.

Note: Any discharges not expressly authorized in this permit cannot become authorized or shielded from liability under CWA section 402(k) by disclosure to EPA, state, or local authorities after issuance of this permit via any means, including the Notice of Intent (NOI) to be covered by the permit, the SWPPP, during an inspection, etc.

\subsection{Person(s) Responsible for SWPPP Preparation.}

The SWPPP shall be prepared in accordance with good engineering practices and to industry standards. The SWPPP may be developed by either a person on your staff or a third party you hire, but it must be developed by a "qualified person" and must be certified per the signature requirements in Part 5.2.7. If EPA concludes that the SWPPP is not in compliance with Part 5.2 of this permit, EPA may require the SWPPP to be reviewed, amended as necessary, and certified by a Professional Engineer, or for Sector G, H or J, by a Professional Geologist, with the education and experience necessary to prepare an adequate SWPPP.

Note: A "qualified person" is a person knowledgeable in the principles and practices of industrial stormwater controls and pollution prevention, and possesses the education and ability to assess conditions at the industrial facility that could impact stormwater quality, and the education and ability to assess the effectiveness of stormwater controls selected and installed to meet the requirements of the permit.

\subsection{Contents of Your SWPPP.}

For coverage under this permit, your SWPPP must contain all of the following elements:

- Stormwater pollution prevention team (see Part 5.2.1);

- $\quad$ Site description (see Part 5.2.2);

- Summary of potential pollutant sources (see Part 5.2.3);

- Description of control measures (see Part 5.2.4);

- Schedules and procedures (see Part 5.2.5);

- Documentation to support eligibility considerations under other federal laws (see Part 5.2.6); and

- $\quad$ Signature requirements (see Part 5.2.7).

Where your SWPPP refers to procedures in other facility documents, such as a Spill Prevention, Control and Countermeasure (SPCC) Plan or an Environmental Management System (EMS), copies of the relevant portions of those documents must be kept with your SWPPP. 


\subsubsection{Stormwater Pollution Prevention Team.}

You must identify the staff members (by name or title) that comprise the facility's stormwater pollution prevention team as well as their individual responsibilities. Your stormwater pollution prevention team is responsible for overseeing development of the SWPPP, any modifications to it, and for implementing and maintaining control measures and taking corrective actions when required. Each member of the stormwater pollution prevention team must have ready access to either an electronic or paper copy of applicable portions of this permit, the most updated copy of your SWPPP, and other relevant documents or information that must be kept with the SWPPP.

\subsubsection{Site Description.}

Your SWPPP must include the following:

- Activities at the Facility. Provide a description of the nature of the industrial activities at your facility.

- General location map. Provide a general location map (e.g., U.S. Geological Survey (USGS) quadrangle map) with enough detail to identify the location of your facility and all receiving waters for your stormwater discharges.

- Site map. Provide a map showing:

- Boundaries of the property and the size of the property in acres;

- Location and extent of significant structures and impervious surfaces;

- Directions of stormwater flow (use arrows);

- Locations of all stormwater control measures;

- Locations of all receiving waters, including wetlands, in the immediate vicinity of your facility. Indicate which waterbodies are listed as impaired and which are identified by your state, tribe, or EPA as Tier 2, Tier 2.5, or Tier 3 waters;

- Locations of all stormwater conveyances including ditches, pipes, and swales;

- Locations of potential pollutant sources identified under Part 5.2.3.2;

- Locations where significant spills or leaks identified under Part 5.2.3.3 have occurred;

- Locations of all stormwater monitoring points;

- Locations of stormwater inlets and outfalls, with a unique identification code for each outfall (e.g., Outfall 001, 002), indicating if you are treating one or more outfalls as "substantially identical" under Parts 3.2.3, 5.2.5.3, and 6.1.1, and an approximate outline of the areas draining to each outfall;

- If applicable, MS4s and where your stormwater discharges to them;

- Areas of designated critical habitat for endangered or threatened species, if applicable.

- Locations of the following activities where such activities are exposed to precipitation:

- fueling stations;

- vehicle and equipment maintenance and/or cleaning areas;

- loading/unloading areas;

- locations used for the treatment, storage, or disposal of wastes;

- liquid storage tanks; 
- processing and storage areas;

- immediate access roads and rail lines used or traveled by carriers of raw materials, manufactured products, waste material, or by-products used or created by the facility;

- transfer areas for substances in bulk;

- machinery;

- locations and sources of run-on to your site from adjacent property that contains significant quantities of pollutants.

\subsubsection{Summary of Potential Pollutant Sources.}

You must describe areas at your facility where industrial materials or activities are exposed to stormwater or from which allowable non-stormwater discharges originate. Industrial materials or activities include, but are not limited to: material handling equipment or activities; industrial machinery; raw materials; industrial production and processes; and intermediate products, by-products, final products, and waste products. Material handling activities include, but are not limited to: the storage, loading and unloading, transportation, disposal, or conveyance of any raw material, intermediate product, final product or waste product. For structures located in areas of industrial activity, you must be aware that the structures themselves are potential sources of pollutants. This could occur, for example, when metals such as aluminum or copper are leached from the structures as a result of acid rain.

For each area identified, the description must include:

5.2.3.1 Activities in the Area. A list of the industrial activities exposed to stormwater (e.g., material storage; equipment fueling, maintenance, and cleaning; cutting steel beams).

5.2.3.2 Pollutants. A list of the pollutant(s) or pollutant constituents (e.g., crankcase oil, zinc, sulfuric acid, cleaning solvents) associated with each identified activity, which could be exposed to rainfall or snowmelt and could be discharged from your facility. The pollutant list must include all significant materials that have been handled, treated, stored or disposed, and that have been exposed to stormwater in the three years prior to the date you prepare or amend your SWPPP.

5.2.3.3 Spills and Leaks. You must document where potential spills and leaks could occur that could contribute pollutants to stormwater discharges, and the corresponding outfall(s) that would be affected by such spills and leaks. You must document all significant spills and leaks of oil or toxic or hazardous substances that actually occurred at exposed areas, or that drained to a stormwater conveyance, in the three years prior to the date you prepare or amend your SWPPP.

Note: Significant spills and leaks include, but are not limited to, releases of oil or hazardous substances in excess of quantities that are reportable under CWA section 311 (see 40 CFR 110.6 and 40 CFR 117.21) or section 102 of the Comprehensive Environmental Response, Compensation and Liability Act (CERCLA), 42 USC \$9602. This permit does not relieve you of the reporting requirements of 40 CFR 110,40 CFR 117, and 40 CFR 302 relating to spills or other releases of oils or hazardous substances.

5.2.3.4 Unauthorized Non-Stormwater Discharges. You must document that you have evaluated for the presence of unauthorized non-stormwater discharges (see Part 
1.1.3 for the exclusive list of authorized non-stormwater discharges under this permit).

Documentation of your evaluation must include:

- The date of the evaluation;

- A description of the evaluation criteria used;

- A list of the outfalls or onsite drainage points that were directly observed during the evaluation; and

- The action(s) taken, such as a list of control measures used to eliminate unauthorized discharge(s), or documentation that a separate NPDES permit was obtained. For example, a floor drain was sealed, a sink drain was re-routed to sanitary, or an NPDES permit application was submitted for an unauthorized cooling water discharge.

5.2.3.5 Salt Storage. You must document the location of any storage piles containing salt used for deicing or other commercial or industrial purposes.

5.2.3.6 Sampling Data. Existing dischargers must summarize all stormwater discharge sampling data collected at the facility during the previous permit term. The summary shall include a narrative description (and may include data tables/figures) that adequately summarizes the collected sampling data to support identification of potential pollution sources at your facility. New dischargers and new sources must provide a summary of any available stormwater runoff data they may have.

\subsubsection{Description of Control Measures to Meet Technology-Based and Water Quality- Based Effluent Limits.}

You must document the location and type of control measures you have specifically chosen and/or designed to comply with:

- Non-numeric technology-based effluent limits in Part 2.1.2;

- Applicable numeric effluent limitations guidelines-based limits in Part 2.1.3 and Part 8;

- Water quality-based effluent limits in Part 2.2;

- Any additional measures that formed the basis of eligibility regarding threatened and endangered species, historic properties, and/or federal CERCLA Site requirements in Part 2.3;

- Applicable effluent limits in Parts 8 and 9.

- Regarding your control measures, you must also document, as appropriate:

- How you addressed the selection and design considerations in Part 2.1.1;

- How they address the pollutant sources identified in Part 5.2.3.

Effluent limit requirements in Part 2.1.2 that do not involve the site-specific selection of a control measure or are specific activity requirements (e.g., "cleaning catch basins when the depth of debris reaches two-thirds (2/3) of the sump depth and keeping the debris surface at least six inches below the lowest outlet pipe") are marked with an asterisk (*). For the requirements marked with an asterisk, you may include extra information, or you may just "cut- 
and-paste" these effluent limits verbatim into your SWPPP without providing additional documentation.

\subsubsection{Schedules and Procedures.}

5.2.5.1 Pertaining to Control Measures Used to Comply with the Effluent Limits in Part 2. The following must be documented in your SWPPP:

- Good Housekeeping (See Part 2.1.2.2) - A schedule or the convention used for determining when pickup and disposal of waste materials occurs. Also provide a schedule for routine inspections for leaks and conditions of drums, tanks and containers.

- Maintenance (See Part 2.1.2.3) - Preventative maintenance procedures, including regular inspections, testing, maintenance and repair of all control measures to avoid situations that may result in leaks, spills, and other releases, and any back-up practices in place should a runoff event occur while a control measure is off-line. The SWPPP shall include the schedule or frequency for maintaining all control measures used to comply with the effluent limits in Part 2;

- Spill Prevention and Response Procedures (See Part 2.1.2.4) - Procedures for preventing and responding to spills and leaks, including notification procedures. For preventing spills, include in your SWPPP the control measures for material handling and storage, and the procedures for preventing spills that can contaminate stormwater. Also specify cleanup equipment, procedures and spill logs, as appropriate, in the event of spills. You may reference the existence of other plans for Spill Prevention Control and Countermeasure (SPCC) developed for the facility under section 311 of the CWA or BMP programs otherwise required by an NPDES permit for the facility, provided that you keep a copy of that other plan onsite and make it available for review consistent with Part 5.4;

- Erosion and Sediment Controls (Part 2.1.2.5) - If you use polymers and/or other chemical treatments as part of your controls, you must identify the polymers and/or chemicals used and the purpose;

- Employee Training (Part 2.1.2.8) - The elements of your employee training plan shall include all, but not be limited to, the requirements set forth in Part 2.1.2.8, and also the following:

- The content of the training;

- The frequency/schedule of training for employees who work in areas where industrial materials or activities are exposed to stormwater, or who are responsible for implementing activities necessary to meet the conditions of this permit;

- A log of the dates on which specific employees received training.

5.2.5.2 Pertaining to Inspections and Assessments. You must document in your SWPPP your procedures for performing, as appropriate, the types of inspections specified by this permit, including:

- Routine facility inspections (see Part 3.1) and;

- Quarterly visual assessment of stormwater discharges (see Part 3.2).

For each type of inspection performed, your SWPPP must identify:

- Person(s) or positions of person(s) responsible for inspection; 
- Schedules for conducting inspections, including tentative schedule for facilities in climates with irregular stormwater runoff discharges (see Part 3.2.3);

- Specific items to be covered by the inspection, including schedules for specific outfalls.

If you are invoking the exception for inactive and unstaffed sites relating to routine facility inspections and quarterly visual assessments, you must include in your SWPPP the information to support this claim as required by Parts 3.1.1 and 3.2.3.

5.2.5.3 Pertaining to Monitoring. You must document in your SWPPP procedures for conducting the five types of analytical monitoring specified by this permit, where applicable to your facility, including:

- Benchmark monitoring (see Part 6.2.1);

- Effluent limitations guidelines monitoring (see Part 6.2.2);

- State- or tribal-specific monitoring (see Part 6.2.3);

- Impaired waters monitoring (see Part 6.2.4);

- Other monitoring as required by EPA (see Part 6.2.5).

For each type of monitoring, your SWPPP must document:

- Locations where samples are collected, including any determination that two or more outfalls are substantially identical;

- Parameters for sampling and the frequency of sampling for each parameter;

- Schedules for monitoring at your facility, including schedule for alternate monitoring periods for climates with irregular stormwater runoff (see Part 6.1.6);

- Any numeric control values (benchmarks, effluent limitations guidelines, TMDLrelated requirements, or other requirements) applicable to discharges from each outfall;

- Procedures (e.g., responsible staff, logistics, laboratory to be used) for gathering storm event data, as specified in Part 6.1.

If you are invoking the exception for inactive and unstaffed sites for benchmark monitoring or impaired waters monitoring, you must include in your SWPPP the information to support this claim as required by Part 6.2.1.3 and 6.2.4.2.

You must document the following in your SWPPP if you plan to use the substantially identical outfall exception for your quarterly visual assessment requirements in Part 3.2.3 or your benchmark or impaired waters monitoring requirements in Parts 6.2.1 and 6.2.4.1 (see also Part 6.1.1):

- Location of each of the substantially identical outfalls;

- Description of the general industrial activities conducted in the drainage area of each outfall;

- Description of the control measures implemented in the drainage area of each outfall; 
- Description of the exposed materials located in the drainage area of each outfall that are likely to be significant contributors of pollutants to stormwater discharges;

- An estimate of the runoff coefficient of the drainage areas (low = under 40\%; medium $=40$ to $65 \%$; high = above $65 \%$ );

- Why the outfalls are expected to discharge substantially identical effluents.

\subsubsection{Documentation to Support Eligibility Considerations Under Other Federal Laws.}

\subsubsection{Documentation Regarding Endangered and Threatened Species and Critical} Habitat Protection. You must keep with your SWPPP the documentation supporting your determination with regard to Part 1.1.4.5 (Endangered and Threatened Species and Critical Habitat Protection).

5.2.6.2 Documentation Regarding Historic Properties. You must keep with your SWPPP the documentation supporting your determination with regard to Part 1.1.4.6 (Historic Properties Preservation).

5.2.7 Signature Requirements. You must sign and date your SWPPP in accordance with Appendix B, Subsection 11.

\subsection{Required SWPPP Modifications.}

You must modify your SWPPP based on the corrective actions and deadlines required under Part 4.3 and that you documented under Part 4.4. SWPPP modifications must be signed and dated in accordance with Appendix B, Subsection 11.

\subsection{SWPPP Availability.}

You must retain a complete copy of your current SWPPP required by this permit at the facility in any accessible format. A complete SWPPP includes any documents incorporated by reference and all documentation supporting your permit eligibility pursuant to Part 1.1 of this permit, as well as your signed and dated certification page. Regardless of the format, the SWPPP must be immediately available to facility employees, EPA, a state or tribe, the operator of an MS4 into which you discharge, and representatives of the U.S. Fish and Wildlife Service (USFWS) or the National Marine Fisheries Service (NMFS) at the time of an onsite inspection. Your current SWPPP or certain information from your current SWPPP described below must also be made available to the public (except any confidential business information (CBI) or restricted information [as defined in Appendix A]), but you must clearly identify those portions of the SWPPP that are being withheld from public access; to do so, you must comply with one of the following two options:

\subsubsection{SWPPP Posting on the Internet.}

If you provide a URL in your NOI where your SWPPP can be found, and maintain your current SWPPP at this URL, you will have complied with the public availability requirements for the SWPPP. To remain current, you must post any SWPPP modifications, records and other reporting elements required for the previous year at the same URL as the main body of the SWPPP. The SWPPP update shall be no later than 45 days after conducting the final routine facility inspection for the year required in Part 3.1. If you did not provide a SWPPP URL in your $\mathrm{NOI}$, you may reopen your $\mathrm{NOI}$ at any time subsequent to your original $\mathrm{NOI}$ submittal to add a URL where your current SWPPP can be found. You are not required to post any CBI or restricted information (as defined in Appendix A) (such information may be redacted), but you must clearly identify those portions of the SWPPP that are being withheld from public access. CBI may not be withheld from those staff cleared for CBI review within EPA, USFWS or NMFS. 


\subsubsection{SWPPP Information Provided on NOI Form.}

If you did not provide a SWPPP URL in your NOI, your NOI must include the information required by Part 7.3. Irrespective of this requirement, EPA may provide access to portions of your SWPPP to a member of the public upon request (except any CBI or restricted information (as defined in Appendix A)). To remain current, you must report any modifications to the SWPPP information required by Part 7.3 through submittal of an "Change NOI" form. The SWPPP update shall be no later than 45 days after conducting the final routine facility inspection for the year required in Part 3.1.

\subsection{Additional Documentation Requirements.}

You are required to keep the following inspection, monitoring, and certification records with your SWPPP that together keep your records complete and up-to-date, and demonstrate your full compliance with the conditions of this permit:

- A copy of the NOI submitted to EPA along with any correspondence exchanged between you and EPA specific to coverage under this permit;

- A copy of the acknowledgment you receive from the EPA assigning your NPDES ID;

- A copy of this permit (an electronic copy easily available to SWPPP personnel is also acceptable);

- Documentation of maintenance and repairs of control measures, including the date(s) of regular maintenance, date(s) of discovery of areas in need of repair/replacement, and for repairs, date(s) that the control measure(s) returned to full function, and the justification for any extended maintenance/repair schedules (see Part 2.1.2.3);

- All inspection reports, including the Routine Facility Inspection Reports (see Part 3.1.2) and Quarterly Visual Assessment Reports (see Part 3.2.2);

- Description of any deviations from the schedule for visual assessments and/or monitoring, and the reason for the deviations (e.g., adverse weather or it was impracticable to collect samples within the first 30 minutes of a measurable storm event) (see Parts 3.2.3 and 6.1.5);

- Corrective action documentation required per Part 4.4;

- Documentation of any benchmark exceedances and the type of response to the exceedance you employed, including:

- the corrective action taken;

- a finding that the exceedance was due to natural background pollutant levels;

- a determination from EPA that benchmark monitoring can be discontinued because the exceedance was due to run-on; or

- a finding that no further pollutant reductions were technologically available and economically practicable and achievable in light of best industry practice consistent with Part 6.2.1.2.

- Documentation to support any determination that pollutants of concern are not expected to be present above natural background levels if you discharge directly to impaired waters, and that such pollutants were not detected in your discharge or were solely attributable to natural background sources (see Part 6.2.4.1); and 
- Documentation to support your claim that your facility has changed its status from active to inactive and unstaffed with respect to the requirements to conduct routine facility inspections (see Part 3.1.1), quarterly visual assessments (see Part 3.2.3), benchmark monitoring (see Part 6.2.1.3), and/or impaired waters monitoring (see Part 6.2.4.2). 
6.

Monitoring.

You must collect and analyze stormwater samples and document monitoring activities consistent with the procedures described in Part 6 and Appendix B, Subsections 10 12 , and any additional sector-specific or state/tribal-specific requirements in Parts 8 and 9 , respectively. Refer to Part 7 for reporting and recordkeeping requirements.

\subsection{Monitoring Procedures.}

\subsubsection{Monitored Outfalls.}

Applicable monitoring requirements apply to each outfall authorized by this permit, except as otherwise exempt from monitoring as a "substantially identical outfall." If your facility has two or more outfalls that you believe discharge substantially identical effluents, based on the similarities of the general industrial activities and control measures, exposed materials that may significantly contribute pollutants to stormwater, and runoff coefficients of their drainage areas, you may monitor the effluent of just one of the outfalls and report that the results also apply to the substantially identical outfall(s). As required in Part 5.2.5.3, your SWPPP must identify each outfall authorized by this permit and describe the rationale for any substantially identical outfall determinations. The allowance for monitoring only one of the substantially identical outfalls is not applicable to any outfalls with numeric effluent limitations. You are required to monitor each outfall covered by a numeric effluent limit as identified in Part 6.2.2.

\subsubsection{Commingled Discharges.}

If discharges authorized by this permit commingle with discharges not authorized under this permit, any required sampling of the authorized discharges must be performed at a point before they mix with other waste streams, to the extent practicable.

\subsubsection{Measurable Storm Events.}

All required monitoring must be performed on a storm event that results in an actual discharge from your site ("measurable storm event") that follows the preceding measurable storm event by at least 72 hours (three days). The 72-hour (3-day) storm interval does not apply if you are able to document that less than a 72-hour (3-day) interval is representative for local storm events during the sampling period. In the case of snowmelt, the monitoring must be performed at a time when a measurable discharge occurs at your site.

For each monitoring event, except snowmelt monitoring, you must identify the date and duration (in hours) of the rainfall event, rainfall total (in inches) for that rainfall event, and time (in days) since the previous measurable storm event. For snowmelt monitoring, you must identify the date of the sampling event.

\subsubsection{Sample Type.}

You must take a minimum of one grab sample from a discharge resulting from a measurable storm event as described in Part 6.1.3. Samples must be collected within the first 30 minutes of a discharge associated with a measurable storm event. If it is not possible to collect the sample within the first 30 minutes of a measurable storm event, the sample must be collected as soon as practicable after the first 30 minutes and documentation must be kept with the SWPPP explaining why it was not possible to take samples within the first 30 minutes. In the case of snowmelt, samples must be taken during a period with a measurable discharge.

\subsubsection{Adverse Weather Conditions.}

When adverse weather conditions as described in Part 3.2.3 prevent the collection of samples according to the relevant monitoring schedule, you must take a substitute sample 
during the next qualifying storm event. Adverse weather does not exempt you from having to file a benchmark monitoring report in accordance with your sampling schedule. As specified in Part 7.4, you must use NetDMR to report any failure to monitor using a "no data" or "NODI" code during the regular reporting period.

\subsubsection{Climates with Irregular Stormwater Runoff.}

If your facility is located in areas where limited rainfall occurs during parts of the year (e.g., arid or semi-arid climates) or in areas where freezing conditions exist that prevent runoff from occurring for extended periods, required monitoring events may be distributed during seasons when precipitation occurs, or when snowmelt results in a measurable discharge from your site. You must still collect the required number of samples. As specified in Part 7.4, you must also use NetDMR to report using a "no data" or "NODI" code for any of the regular reporting periods that there was no monitoring.

\subsubsection{Monitoring Periods.}

Monitoring requirements in this permit begin in the first full quarter following either September 2, 2015 or your date of discharge authorization, whichever date comes later. If your monitoring is required on a quarterly basis (e.g., benchmark monitoring), you must monitor at least once in each of the following 3-month intervals:

- January 1-March 31;

- April 1 - June 30;

- July 1 -September 30;

- October 1 - December 31.

For example, if you obtain permit coverage on July 2, 2015, then your first monitoring quarter is October 1 - December 31, 2015. This monitoring schedule may be modified in accordance with Part 6.1.6 if the revised schedule is documented with your SWPPP. However, using NetDMR you must report using a "no data" or "NODI" code for any 3month interval that you did not take a sample.

\subsubsection{Monitoring for Allowable Non-Stormwater Discharges.}

You are only required to monitor allowable non-stormwater discharges (as delineated in Part 1.1.3) when they are commingled with stormwater discharges associated with industrial activity.

\subsubsection{Monitoring Reports}

Monitoring data must be reported using EPA's electronic NetDMR tool at www.epa.gov/netdmr, as described in Part 7.4 (unless a waiver from electronic reporting has been granted from the EPA Regional Office, in which case you may submit a paper DMR form).

\subsection{Required Monitoring.}

This permit includes five types of required analytical monitoring, one or more of which may apply to your discharge:

- Quarterly benchmark monitoring (see Part 6.2.1);

- Annual effluent limitations guidelines monitoring (see Part 6.2.2);

- State- or tribal-specific monitoring (see Part 6.2.3); 
- Impaired waters monitoring (see Part 6.2.4); and

- Other monitoring as required by EPA (see Part 6.2.5).

When more than one type of monitoring for the same pollutant at the same outfall applies (e.g., total suspended solids once per year for an effluent limitation and once per quarter for benchmark monitoring at a given outfall), you may use a single sample to satisfy both monitoring requirements (i.e., one sample satisfying both the annual effluent limitation sample and one of the four quarterly benchmark monitoring samples). When the effluent limitation is lower than the benchmark concentration for the same pollutant, your corrective action trigger is based on an exceedance of the effluent limitation, which would subject you to the corrective action requirements of Part 4.1.

Note: Exceedance of an effluent limitation associated with the results of any analytical monitoring type required by this Part subjects you to the corrective action requirements of Part 4.1.

All required monitoring must be conducted in accordance with the procedures described in Appendix B, Subsection B.10.

\subsubsection{Benchmark Monitoring.}

This permit specifies pollutant benchmark concentrations that are applicable to certain sectors / subsectors. Benchmark monitoring data are primarily for your use to determine the overall effectiveness of your control measures and to assist you in determining when additional corrective action(s) may be necessary to comply with the effluent limitations in Part 2.

The benchmark concentrations are not effluent limitations; a benchmark exceedance, therefore, is not a permit violation. However, if corrective action is required as a result of a benchmark exceedance, failure to conduct required corrective action is a permit violation.

At your discretion, more than four samples may be taken during separate runoff events and used to determine the average benchmark parameter concentration for facility discharges.

6.2.1.1 Applicability of Benchmark Monitoring. You must monitor for any benchmark parameters specified for the industrial sector(s), both primary industrial activity and any co-located industrial activities, applicable to your discharge. Your industryspecific benchmark concentrations are listed in the sector-specific sections of Part 8. If your facility is in one of the industrial sectors subject to benchmark concentrations that are hardness-dependent, you are required to submit to EPA with your $\mathrm{NOI}$ a hardness value, established consistent with the procedures in Appendix $\mathrm{J}$, which is representative of your receiving water.

Samples must be analyzed consistent with 40 CFR Part 136 analytical methods and using test procedures with quantitation limits at or below benchmark values for all benchmark parameters for which you are required to sample.

6.2.1.2 Benchmark Monitoring Schedule. Benchmark monitoring must be conducted quarterly, as identified in Part 6.1.7, for your first four full quarters of permit coverage commencing no earlier than September 2, 2015. 
Facilities in climates with irregular stormwater runoff, as described in Part 6.1.6, may modify this quarterly schedule provided that this revised schedule is reported directly to EPA by the due date of the first benchmark sample (see EPA Regional contacts in Part 7.9.1), and that this revised schedule is kept with the facility's SWPPP as specified in Part 5.5. When conditions prevent you from obtaining four samples in four consecutive quarters, you must continue monitoring until you have the four samples required for calculating your benchmark monitoring average. As noted in Part 6.1.7, you must use NetDMR to report using a "no data" or "NODI" code for any 3-month interval that you did not take a sample.

Data not exceeding benchmarks: After collection of four quarterly samples, if the average of the four monitoring values for any parameter does not exceed the benchmark, you have fulfilled your monitoring requirements for that parameter for the permit term.

Data exceeding benchmarks: After collection of four quarterly samples, if the average of the four monitoring values for any parameter exceeds the benchmark, you must, in accordance with Part 4, review the selection, design, installation, and implementation of your control measures to determine if modifications are necessary to meet the effluent limits in this permit, and either:

- Make the necessary modifications and continue quarterly monitoring until you have completed four additional quarters of monitoring for which the average does not exceed the benchmark; or

- Make a determination that no further pollutant reductions are technologically available and economically practicable and achievable in light of best industry practice to meet the technology-based effluent limits or are necessary to meet the water-quality-based effluent limitations in Parts 2.1 and 2.2 of this permit, in which case you must continue monitoring once per year. You must also document your rationale for concluding that no further pollutant reductions are achievable, and retain all records related to this documentation with your SWPPP.

You must review your control measures and perform any required corrective action immediately (or document why no corrective action is required), per Part 4, without waiting for the full four quarters of monitoring data, when an exceedance of the four quarter average is mathematically certain. If after modifying your control measures and conducting four additional quarters of monitoring, your average still exceeds the benchmark (or if an exceedance of the benchmark by the four quarter average is mathematically certain prior to conducting the full four additional quarters of monitoring), you must again review your control measures and take one of the two actions above.

Natural background pollutant levels: Following the first four quarters of benchmark monitoring (or sooner if the exceedance is triggered by less than four quarters of data; see above), if the average concentration of a pollutant exceeds a benchmark value, and you determine that exceedance of the benchmark is attributable solely to the presence of that pollutant in the natural background, you are not required to perform corrective action or additional benchmark monitoring provided that:

- The average concentration of your benchmark monitoring results is less than or equal to the concentration of that pollutant in the natural background; and 
- You document and maintain with your SWPPP, as required in Part 5.5, your supporting rationale for concluding that benchmark exceedances are in fact attributable solely to natural background pollutant levels. You must include in your supporting rationale any data previously collected by you or others (including literature studies) that describe the levels of natural background pollutants in your stormwater discharge.

Natural background pollutants are those substances that are naturally occurring in soils or ground water. Natural background pollutants do not include legacy pollutants from earlier activity on your site, or pollutants in run-on from neighboring sources which are not naturally occurring, such as other industrial sites or roadways. However, the EPA Regional Office may determine that you are eligible to discontinue monitoring for pollutants that occur solely from run-on sources.

6.2.1.3 Exception for Inactive and Unstaffed Sites. The requirement for benchmark monitoring does not apply at a facility that is inactive and unstaffed, provided that there are no industrial materials or activities exposed to stormwater. To invoke this exception, you must do the following:

- Maintain a statement with your SWPPP stating that the site is inactive and unstaffed, and that there are no industrial materials or activities exposed to stormwater in accordance with the substantive requirements in 40 CFR $122.26(\mathrm{~g})$ and sign and certify the statement in accordance with Appendix B, Subsection 11.

- If circumstances change and industrial materials or activities become exposed to stormwater or your facility becomes active and/or staffed, this exception no longer applies and you must immediately begin complying with the applicable benchmark monitoring requirements under Part 6.2 as if you were in your first year of permit coverage. You must indicate in your NOI that your facility has materials or activities exposed to stormwater or has become active and/or staffed.

- If you are not qualified for this exception at the time you are authorized under this permit, but during the permit term you become qualified because your facility is inactive and unstaffed, and there are no industrial materials or activities that are exposed to stormwater, then you must notify EPA of this change on your NOl form. You may discontinue benchmark monitoring once you have notified EPA, and prepared and signed the certification statement described above concerning your facility's qualification for this special exception.

Note: This exception has different requirements for Sectors $G, H$, and J (see Part 8).

6.2.2 Effluent Limitations Monitoring.

6.2.2.1 Monitoring Based on Effluent Limitations Guidelines. Table 6-1 identifies the stormwater discharges subject to effluent limitation guidelines that are authorized for coverage under this permit. An exceedance of the effluent limitation is a permit violation. Beginning in the first full quarter following September 2, 2015 or your date of discharge authorization, whichever date comes later, you must monitor once per year at each outfall containing the discharges identified in Table 6-1 for the parameters specified in the sector-specific section of Part 8. 
Table 6-1. Required Monitoring for Effluent Limits Based on Effluent Limitations Guidelines

\begin{tabular}{|l|l|l|l|}
\hline \multicolumn{1}{|c|}{ Regulated Activity } & \multicolumn{1}{|c|}{ Effluent Limit } & $\begin{array}{c}\text { Monitoring } \\
\text { Frequency }\end{array}$ & \multicolumn{1}{|c|}{$\begin{array}{c}\text { Sample } \\
\text { Type }\end{array}$} \\
\hline $\begin{array}{l}\text { Discharges resulting from spray down or intentional wetting of } \\
\text { logs at wet deck storage areas }\end{array}$ & See Part 8.A.7 & $1 /$ year & Grab \\
\hline $\begin{array}{l}\text { Runoff from phosphate fertilizer manufacturing facilities that } \\
\text { comes into contact with any raw materials, finished product, by- } \\
\text { products or waste products (SIC 2874) }\end{array}$ & See Part 8.C.4 & $1 /$ year & Grab \\
\hline Runoff from asphalt emulsion facilities & See Part 8.D.4 & $1 /$ year & Grab \\
\hline $\begin{array}{l}\text { Runoff from material storage piles at cement manufacturing } \\
\text { facilities }\end{array}$ & See Part 8.E.5 & $1 /$ year & Grab \\
\hline $\begin{array}{l}\text { Mine dewatering discharges at crushed stone, construction sand } \\
\text { and gravel, or industrial sand mining facilities }\end{array}$ & See Part 8.J.9 & $1 /$ year & Grab \\
\hline Runoff from hazardous waste landfills & See Part 8.K.6 & $1 /$ year & Grab \\
\hline Runoff from non-hazardous waste landfills & See Part 8.L.10 & $1 /$ year & Grab \\
\hline $\begin{array}{l}\text { Runoff from coal storage piles at steam electric generating } \\
\text { facilities }\end{array}$ & See Part 8.0.8 & $1 /$ year & Grab \\
\hline $\begin{array}{l}\text { Runoff containing urea from airfield pavement deicing at existing } \\
\text { and new primary airports with 1,000 or more annual non- } \\
\text { propeller aircraft departures. }\end{array}$ & See Part 8.S.8 & $1 /$ year & Grab \\
\hline
\end{tabular}

6.2.2.2 Substantially Identical Outfalls. You must monitor each outfall discharging runoff from any regulated activity identified in Table 6-1. The substantially identical outfall monitoring provisions are not available for numeric effluent limits monitoring.

6.2.2.3 Follow-up Actions if Discharge Exceeds Numeric Effluent Limitation. If any monitoring value exceeds a numeric effluent limitation contained in this permit, you must indicate the exceedance on a "Change NOI" form in the NPDES eReporting Tool (NeT), and you must conduct follow-up monitoring within 30 calendar days (or during the next qualifying runoff event, should none occur within 30 days) of implementing corrective action(s) taken per Part 4. When your follow-up monitoring exceeds the applicable effluent limitation, you must:

- Submit an Exceedance Report: You must submit an Exceedance Report no later than 30 days after you have received your laboratory result consistent with Part 7.6; and

- Continue to Monitor: You must monitor, at least quarterly, until your discharge is in compliance with the effluent limit or until EPA waives the requirement for additional monitoring. Once your discharge is back in compliance with the effluent limitation you must indicate this on a "Change NOl" form per Part 7.4.

\subsubsection{State or Tribal Monitoring Provisions.}

6.2.3.1 Sectors Required to Conduct State or Tribal Monitoring. You must comply with any state or tribal monitoring requirements (see Part 9) applicable to your facility's location.

6.2.3.2 State or Tribal Monitoring Schedule. If a monitoring frequency is not specified for an applicable requirement in Part 9, you must monitor once per year for the entire permit term. 


\subsubsection{Discharges to Impaired Waters Monitoring.}

Note: For the purposes of this permit, your project is considered to discharge to an impaired water if the first water of the U.S. to which you discharge is identified by a state, tribe, or EPA pursuant to section 303(d) of the CWA as not meeting an applicable water quality standard, or has been removed from the 303(d) list either because the impairments are addressed by an EPA-approved or established TMDL or is covered by pollution control requirements that meet the requirements of 40 CFR 130.7(b)(1). For discharges that enter a separate storm sewer system ${ }^{4}$ prior to discharge, the first water of the U.S. to which you discharge is the waterbody that receives the stormwater discharge from the storm sewer system.

\subsubsection{Permittees Required to Monitor Discharges to Impaired Waters.} Discharges to impaired waters without an EPA-approved or established TMDL: Beginning in the first full quarter following September 2, 2015 or your date of discharge authorization, whichever date comes later, you must monitor all pollutants for which the waterbody is impaired and for which a standard analytical method exists (see 40 CFR Part 136) once per year at each outfall (except substantially identical outfalls) discharging stormwater to impaired waters without an EPA-approved or established TMDL.

If the pollutant of concern for the impaired waterbody is suspended solids, turbidity or sediment/sedimentation, you must monitor for Total Suspended Solids (TSS). If a pollutant of concern is expressed in the form of an indicator or surrogate pollutant, you must monitor for that indicator or surrogate pollutant. No monitoring is required when a waterbody's biological communities are impaired but no pollutant, including indicator or surrogate pollutants, is specified as causing the impairment, or when a waterbody's impairment is related to hydrologic modifications, impaired hydrology, or other non-pollutant. Permittees should consult the appropriate EPA Regional Office for any available guidance regarding required monitoring parameters under this part.

If the pollutant of concern is not detected and not expected to be present in your discharge, or it is detected but you have determined that its presence is caused solely by natural background sources, you may discontinue monitoring for that pollutant. To support a determination that the pollutant's presence is caused solely by natural background sources, you must document and maintain with your SWPPP, as required by Part 5.5:

- An explanation of why you believe that the presence of the pollutant of concern in your discharge is not related to the activities or materials at your facility; and

- Data and/or studies that tie the presence of the pollutant of concern in your discharge to natural background sources in the watershed.

Natural background pollutants include those that occur naturally as a result of native soils, and vegetation, wildlife, or ground water. Natural background pollutants do not include legacy pollutants from earlier activity on your site, or pollutants in run-on from neighboring sources that are not naturally occurring. However, you may be eligible to discontinue annual monitoring for pollutants that

4 Separate storm systems do not include combined sewer systems or sanitary sewer systems. Separate storm systems include both municipal storm sewer systems (MS4s) and non-municipal separate storm sewers. 
occur solely from these sources and should consult the appropriate EPA Regional Office for related guidance.

Discharges to impaired waters with an EPA-approved or established TMDL: For stormwater discharges to waters for which there is an EPA-approved or established TMDL, you are not required to monitor for the pollutant(s) for which the TMDL was written unless EPA informs you, upon examination of the applicable TMDL and its wasteload allocation, that you are subject to such a requirement consistent with the assumptions and requirements of the applicable TMDL and its wasteload allocation. EPA's notice will include specifications on monitoring parameters and frequency. Permittees must consult the appropriate EPA Regional Office for guidance regarding required monitoring under this Part.

6.2.4.2 Exception for Inactive and Unstaffed Sites. The requirement for impaired waters monitoring does not apply at a facility that is inactive and unstaffed, as long as there are no industrial materials or activities exposed to stormwater. To invoke this exception, you must do the following:

- Maintain a statement with your SWPPP stating that the site is inactive and unstaffed, and that there are no industrial materials or activities exposed to stormwater in accordance with the substantive requirements in 40 CFR $122.26(\mathrm{~g})$ and sign and certify the statement in accordance with Appendix B, Subsection 11.

- If circumstances change and industrial materials or activities become exposed to stormwater or your facility becomes active and/or staffed, this exception no longer applies and you must immediately begin complying with the applicable impaired waters monitoring requirements under Part 6.2 as if you were in your first year of permit coverage. You must indicate in a "Change NOl" form per Part 7.4 that your facility has materials or activities exposed to stormwater or has become active and/or staffed.

- If you are not qualified for this exception at the time you are authorized under this permit, but during the permit term you become qualified because your facility is inactive and unstaffed, and there are no industrial materials or activities that are exposed to stormwater, then you must notify EPA of this change on your NOl form. You may discontinue impaired waters monitoring once you have notified EPA, and prepared and signed the certification statement described above concerning your facility's qualification for this special exception.

Note: This exception has different requirements for Sectors $G, H$, and J (see Part 8).

\subsubsection{Additional Monitoring Required by EPA.}

EPA may notify you of additional discharge monitoring requirements that EPA determines are necessary to meet the permit's effluent limitations. Any such notice will briefly state the reasons for the monitoring, locations, and parameters to be monitored, frequency and period of monitoring, sample types, and reporting requirements. 


\section{Reporting and Recordkeeping.}

\subsection{Electronic Reporting Requirement.}

You must submit all NOls, NOTs, NOEs, Annual Reports, Discharge Monitoring Reports (DMRs), and other reporting information as appropriate electronically, unless you have received a waiver from your EPA Regional Office based on one of the following conditions:

- If your headquarters is physically located in a geographic area (i.e., zip code or census tract) that is identified as under-served for broadband Internet access in the most recent report from the Federal Communications Commission; or

- If you have limitations regarding available computer access or computer capability.

Waivers are only granted for a one-time use for a single information submittal, i.e., an initial waiver does not apply for the entire term of the permit. If you need to submit information on paper after your first waiver, you must apply for a new waiver. However, waivers may be extended on a case-by-case basis by the EPA Regional Office.

If you wish to obtain a waiver from submitting a report electronically, you must submit a request to your EPA Regional Office. EPA Regional Office contact information can be found in Part 7.9.1 of this permit. In that request you must document which exemption you meet, provide evidence supporting any claims, and a copy of your completed NOI form. A waiver may only be considered granted once you receive written confirmation from EPA or its authorized representative.

\subsection{Submitting Information to EPA.}

Most information required to be submitted by this permit shall be submitted via EPA's electronic NPDES eReporting tool (NeT), unless the permit states otherwise or unless a waiver has been granted per Part 7.1. NeT allows you to both prepare and submit required information using specific forms, found in the permit's appendices. To access NeT, go to http://water.epa.gov/polwaste/npdes/stormwater/Stormwater-eNOI-System-for-EPAsMultiSector-General-Permit.cfm.

Information required to be submitted to EPA via NeT:

- Notice of Intent (Part 1.2);

- No Exposure Certification (Part 1.4);

- Notice of Termination (Part 1.3); and

- Annual Report (Part 7.5).

Note: Discharge Monitoring Reports (see Part 7.4) are required to be submitted using EPA's NetDMR system, available at www.epa.gov/netdmr.

If you are given a waiver by the EPA Regional Office to submit information in paper form, you must utilize the required forms found in the Appendices.

Part 7.9.1:

Information required to be submitted to an EPA Regional Office at the address in

- New Dischargers and New Sources to Water Quality-Impaired Waters (Part 1.1.4.8); 
- Exceedance Report for Numeric Effluent Limitations (Part 7.6); and

- Additional Reporting (Part 7.7)

\subsection{Additional SWPPP Information Required in Your NOI.}

If you did not provide a SWPPP URL in your NOI per Part 5.4.1, your NOI must include the additional SWPPP information as follows:

- Onsite industrial activities exposed to stormwater, including potential spill and leak areas (see Parts 5.2.3.1, 5.2.3.3 and 5.2.3.5);

- Pollutants or pollutant constituents associated with each industrial activity exposed to stormwater that could be discharged in stormwater and/or any authorized non-stormwater discharges listed in Part 1.1.3 (see Part 5.2.3.2);

- Stormwater control measures you employ to comply with the non-numeric technology-based effluent limits required in Part 2.1.2 and Part 8, and any other measures taken to comply with the requirements in Part 2.2 Water Quality Based Effluent Limitations (see Part 5.2.4). If you use polymers and/or other chemical treatments as part of your controls, you must identify the polymers and/or chemicals used and the purpose; and

- Schedule for good housekeeping and maintenance (see Part 5.2.5.1) and schedule for all inspections required in Part 3 (see Part 5.2.5.2).

\subsection{Reporting Monitoring Data to EPA.}

All monitoring data collected pursuant to Part 6.2 must be submitted to EPA using EPA's NetDMR system (available at www.epa.gov/netdmr) (unless a waiver from electronic reporting has been granted, in which case you may submit a paper DMR form) no later than 30 days after you have received your complete laboratory results for all monitoring outfalls for the reporting period. Your monitoring requirements (i.e., parameters required to be monitored and sample frequency) will be prepopulated on your electronic Discharge Monitoring Report (DMR) form based on the information you reported on your NOI form (through the NDPES eReporting tool (NeT)). Accordingly, the following changes to your monitoring frequency must be reported to EPA through the submittal of a "Change NOI" form in NeT, which will trigger changes to your monitoring requirements in NetDMR:

- All benchmark monitoring requirements have been fulfilled for the permit term;

- All impaired waters monitoring requirements have been fulfilled for the permit term;

- Benchmark and/or impaired monitoring requirements no longer apply because your facility is inactive and unstaffed;

- Benchmark and/or impaired monitoring requirements now apply because your facility has changed from inactive and unstaffed to active and staffed;

- For Sector G2 only: Discharges from waste rock and overburden piles have exceeded benchmark values;

- A numeric effluent limitation guideline has been exceeded;

- A numeric effluent limitation guideline exceedance is back in compliance.

Once monitoring requirements have been completely fulfilled, you are no longer required to report monitoring results using NetDMR. If you have only partially fulfilled your benchmark monitoring and/or impaired waters monitoring requirements (e.g., your four 
quarterly average is below the benchmark for some, but not all, parameters; you did not detect some, but not all, impairment pollutants), you must continue to use NetDMR to report your results, but you must report a "no data" or "NODI" code for any monitoring parameters that have been fulfilled.

If you have received a waiver per Part 7.1, paper reporting forms must be submitted by the same deadline.

tribes.

See Part 9 for specific reporting requirements applicable to individual states or

For benchmark monitoring, note that you are required to submit sampling results to EPA no later than 30 days after receiving your complete laboratory results for all monitored outfalls for each quarter that you are required to collect benchmark samples, per Part 6.2.1.2. If you collect samples during multiple storm events in a single quarter (e.g., due to adverse weather conditions, climates with irregular stormwater runoff, or areas subject to snow), you are required to submit all sampling results for each storm event to EPA within 30 days of receiving all laboratory results for the event. Or, for any of your monitored outfalls that did not have a discharge within the reporting period, using NetDMR you must report using a "no data" or "NODI" code for that outfall no later than 30 days after the end of the reporting period.

\subsection{Annual Report.}

You must submit an Annual Report to EPA electronically, per Part 7.2, by January $30^{\text {th }}$ for each year of permit coverage containing information generated from the past calendar year. You must include the following information:

- A summary of your past year's routine facility inspection documentation required (Part 3.1.2). In addition, if you are an operator of an airport facility (Sector S) that is subject to the airport effluent limitations guidelines, and are complying with the Part 8.S.8.1 effluent limitation through the use of non-ureacontaining deicers, provide a statement certifying that you do not use pavement deicers containing urea. (Note: Operators of airport facilities that are complying with Part 8.S.8.1 by meeting the numeric effluent limitation for ammonia do not need to include this statement.)

- A summary of your past year's quarterly visual assessment documentation (see Part 3.2.2 of the permit);

- For any four-sample (minimum) average benchmark monitoring exceedance, if after reviewing the selection, design, installation, and implementation of your control measures and considering whether any modifications are necessary to meet the effluent limits in the permit, you determine that no further pollutant reductions are technologically available and economically practicable and achievable in light of best industry practice, your rationale for why you believe no further reductions are achievable (see Part 6.2.1.2 of the permit); and

- A summary of your past year's corrective action documentation (see Part 4.4). If corrective action is not yet completed at the time of submission of your annual report, you must describe the status of any outstanding corrective action(s). Also describe any incidents of noncompliance in the past year or currently ongoing, or if none, provide a statement that you are in compliance with the permit. 
Your Annual Report must also include a statement, signed and certified in accordance with Appendix B, Subsection 11.

\subsection{Exceedance Report for Numeric Effluent Limitations.}

If follow-up monitoring per Part 6.2.2.3 exceeds a numeric effluent limit, you must submit an Exceedance Report to EPA no later than 30 days after you have received your laboratory results. Your report must include the following:

- NPDES ID;

- Facility name, physical address and location;

- Name of receiving water;

- Monitoring data from this and the preceding monitoring event(s);

- An explanation of the situation, including what you have done and intend to do (should your corrective actions not yet be complete) to correct the violation;

- An appropriate contact name and phone number.

Send the Exceedance Report to the appropriate EPA Regional Office listed in Part 7.9.1, and report the monitoring data through NetDMR

\subsection{Additional Reporting.}

In addition to the reporting requirements stipulated in Part 7, you are also subject to the standard permit reporting provisions of Appendix B, Subsection 12.

You must submit the following reports to the appropriate EPA Regional Office listed in Part 7.9.1, as applicable. If you discharge through an MS4, you must also submit these reports to the MS4 operator (identified pursuant to Part 5.2.2).

- 24-hour reporting (see Appendix B, Subsection 12.F) - You must report any noncompliance which may endanger health or the environment. Any information must be provided orally within 24 hours from the time you become aware of the circumstances;

- 5-day follow-up reporting to the 24 hour reporting (see Appendix B, Subsection 12.F) - A written submission must also be provided within five days of the time you become aware of the circumstances;

- Reportable quantity spills (see Part 2.1.2.4) - You must provide notification, as required under Part 2.1.2.4, as soon as you have knowledge of a leak, spill, or other release containing a hazardous substance or oil in an amount equal to or in excess of a reportable quantity;

- Planned changes (see Appendix B, Subsection 12.A) - You must give notice to EPA promptly, no fewer than 30 days prior to making any planned physical alterations or additions to the permitted facility that qualify the facility as a new source or that could significantly change the nature or significantly increase the quantity of pollutants discharged;

- Anticipated noncompliance (see Appendix B, Subsection 12.B) - You must give advance notice to EPA of any planned changes in the permitted facility or activity which you anticipate will result in noncompliance with permit requirements; 
- Compliance schedules (see Appendix B, Subsection 12.F) - Reports of compliance or noncompliance with, or any progress reports on, interim and final requirements contained in any compliance schedule of this permit must be submitted no later than 14 days following each schedule date;

- Other noncompliance (see Appendix B, Subsection 12.G) - You must report all instances of noncompliance not reported in your annual report, compliance schedule report, or 24-hour report at the time monitoring reports are submitted; and

- Other information (see Appendix B, Subsection 12.H) - You must promptly submit facts or information if you become aware that you failed to submit relevant facts in your $\mathrm{NOI}$, or that you submitted incorrect information in your $\mathrm{NOI}$ or in any report.

\subsection{Recordkeeping.}

You must retain copies of your SWPPP (including any modifications made during the term of this permit), additional documentation requirements pursuant to Part 5.5 (including documentation related to corrective actions taken pursuant to Part 4), all reports and certifications required by this permit, monitoring data, and records of all data used to complete the NOI to be covered by this permit, for a period of at least three years from the date that your coverage under this permit expires or is terminated.

\subsection{Addresses for Reports.}

\subsubsection{EPA Addresses.}

\subsubsection{Region 1: Connecticut, Massachusetts, and New Hampshire, Rhode Island,} Vermont.

U.S. EPA Region 1

Office of Ecosystem Protection

Stormwater and Construction Permits Section

5 Post Office Square, Suite 100

(OEP 06-1)

Boston, MA 02109-3912

\subsubsection{Region 2: New Jersey, New York, Puerto Rico, and Virgin Islands.}

For Puerto Rico and the Virgin Islands

U.S. EPA Region 2

Caribbean Environmental Protection Division

NPDES Stormwater Program

City View Plaza II - Suite 7000

$48 \mathrm{Rd} .165 \mathrm{Km} 1.2$

Guaynabo, PR 00968-8069

For New Jersey and New York:

(Coverage not available under this permit.)

U.S. EPA Region 2

NPDES Stormwater Program

290 Broadway, 24th Floor

New York, NY 10007-1866 
7.9.1.3 Region 3: Delaware, District of Columbia, Maryland, Pennsylvania, Virginia, West Virginia.

U.S. EPA Region 3

Office of NPDES Permits and Enforcement

NPDES Permits Branch, Mailcode 3WP41

1650 Arch Street

Philadelphia, PA 19103

7.9.1.4 Region 4: Alabama, Florida, Georgia, Kentucky, Mississippi, North Carolina, South Carolina, Tennessee.

(Coverage not available under this permit.)

U.S. EPA Region 4

Water Protection Division

NPDES Stormwater Program

Atlanta Federal Center

61 Forsyth Street SW

Atlanta, GA 30303-3104

7.9.1.5 Region 5: Illinois, Indiana, Michigan, Minnesota, Ohio, Wisconsin.

U.S. EPA Region 5

NPDES Program Branch

77 W. Jackson Blvd.

Mail Code WN16J

Chicago, IL 60604-3507

7.9.1.6 Region 6: Arkansas, Lovisiana, Oklahoma, Texas, and New Mexico (except see

Region 9 for Navajo lands, and see Region 8 for Ute Mountain Reservation lands).

U.S. EPA Region 6

NPDES Stormwater Program (WQ-PP)

1445 Ross Avenue, Suite 1200

Dallas, TX 75202-2733

7.9.1.7 Region 7: lowa, Kansas, Missouri, Nebraska.

U.S. EPA Region 7

NPDES Stormwater Program

11201 Renner Blvd

Lenexa, KS 66219

7.9.1.8 Region 8: Colorado, Montana, North Dakota, South Dakota, Wyoming, Utah (except see Region 9 for Goshute Reservation and Navajo Reservation lands), the Ute Mountain Reservation in New Mexico, and the Pine Ridge Reservation in Nebraska.

EPA Region 8 Storm Water Program

Mailcode: 8P-W-WW

1595 Wynkoop Street

Denver, CO 80202-1129

7.9.1.9 Region 9: Arizona, California, Hawaii, Nevada, Guam, American Samoa, the Commonwealth of the Northern Mariana Islands, the Goshute Reservation in Utah 
and Nevada, the Navajo Reservation in Utah, New Mexico, and Arizona, the Duck Valley Reservation in Idaho, Fort McDermitt Reservation in Oregon.

U.S. EPA Region 9

Water Division

NPDES Stormwater Program (WTR-2-3)

75 Hawthorne Street

San Francisco, CA 94105-3901

7.9.1.10 Region 10: Alaska, Idaho, Oregon (except see Region 9 for Fort McDermitt Reservation), Washington.

U.S. EPA Region 10

NPDES Stormwater Program

1200 6th Avenue (OWW-191)

Seattle, WA $98101-3140$

\subsubsection{State and Tribal Addresses.}

See Part 9 (states and tribes) for the addresses of applicable states or tribes that require submission of information to their agencies. 


\section{Part 8 - Sector-Specific Requirements for Industrial Activity}

You must comply with the requirements applicable to your industrial sector(s) in this Part, in addition to the requirements applicable to all facilities in Parts 1 through 7 and the appendices to the permit.

\section{Subpart A - Sector A - Timber Products.}

You must comply with Part 8 sector-specific requirements associated with your primary industrial activity and any co-located industrial activities, as defined in Appendix A. The sectorspecific requirements apply to those areas of your facility where those sector-specific activities occur. These sector-specific requirements are in addition to any requirements specified elsewhere in this permit.

\section{A.1 Covered Stormwater Discharges.}

The requirements in Subpart A apply to stormwater discharges associated with industrial activity from Timber Products facilities as identified by the SIC Codes specified under Sector A in Table D-1 of Appendix D of the permit.

\section{A.2 Limitations on Coverage.}

8.A.2.1 Prohibition of Discharges. (See also Part 1.1.4) Not covered by this permit: stormwater discharges from areas where there may be contact with the chemical formulations sprayed to provide surface protection. These discharges must be covered by a separate NPDES permit.

8.A.2.2 Authorized Non-Stormwater Discharges. (See also Part 1.1.3) Also authorized by this permit, provided the non-stormwater component of the discharge is in compliance with the requirements in Part 2.1.2 (Non-Numeric Effluent Limits): discharges from the spray down of lumber and wood product storage yards where no chemical additives are used in the spray-down waters and no chemicals are applied to the wood during storage.

\section{A.3 Additional Technology-Based Effluent Limits.}

8.A.3.1 Good Housekeeping. (See also Part 2.1.2.2) In areas where storage, loading and unloading, and material handling occur, perform good housekeeping to minimize the discharge of wood debris, leachate generated from decaying wood materials, and the generation of dust.

\section{A.4 Additional SWPPP Requirements.}

8.A.4.1 Drainage Area Site Map. (See also Part 5.2.2) Document in your SWPPP where any of the following may be exposed to precipitation or surface runoff: processing areas, treatment chemical storage areas, treated wood and residue storage areas, wet decking areas, dry decking areas, untreated wood and residue storage areas, and treatment equipment storage areas.

8.A.4.2 Inventory of Exposed Materials. (See also Part 5.2.3.2) Where such information exists, if your facility has used chlorophenolic, creosote, or chromium-copper-arsenic formulations for wood surface protection or preserving, document in your SWPPP the following: areas where contaminated soils, treatment equipment, and stored materials still remain and the management practices employed to minimize the contact of these materials with stormwater runoff.

8.A.4.3 Description of Stormwater Management Controls. (See also Part 5.2.4) Document measures implemented to address the following activities and sources: log, lumber, and wood product storage areas; residue storage areas; loading and unloading areas; 
material handling areas; chemical storage areas; and equipment and vehicle maintenance, storage, and repair areas. If your facility performs wood surface protection and preservation activities, address the specific control measures, including any BMPs, for these activities.

\section{A.5 Additional Inspection Requirements. (See also Part 3.1)}

If your facility performs wood surface protection and preservation activities, inspect processing areas, transport areas, and treated wood storage areas monthly to assess the usefulness of practices to minimize the deposit of treatment chemicals on unprotected soils and in areas that will come in contact with stormwater discharges.

\section{A.6 Sector-Specific Benchmarks. (See also Part 6)}

Table 8.A-1 identifies benchmarks that apply to the specific subsectors of Sector A. These benchmarks apply to both your primary industrial activity and any co-located industrial activities.

\begin{tabular}{|c|c|c|}
\hline \multicolumn{3}{|c|}{ Table 8.A-1 } \\
\hline $\begin{array}{c}\text { Subsector } \\
\text { (You may be subject to requirements for more } \\
\text { than one sector/subsector) }\end{array}$ & Parameter & $\begin{array}{c}\text { Benchmark } \\
\text { Monitoring } \\
\text { Concentration } \\
\end{array}$ \\
\hline \multirow[t]{3}{*}{$\begin{array}{l}\text { Subsector A1. General Sawmills and Planing Mills } \\
\text { (SIC 2421) }\end{array}$} & $\begin{array}{l}\text { Chemical Oxygen } \\
\text { Demand (COD) }\end{array}$ & $120.0 \mathrm{mg} / \mathrm{L}$ \\
\hline & $\begin{array}{l}\text { Total Suspended } \\
\text { Solids (TSS) }\end{array}$ & $100 \mathrm{mg} / \mathrm{L}$ \\
\hline & $\begin{array}{c}\text { Total Zinc } \\
\text { (freshwater) }^{2} \\
\text { Total Zinc } \\
\text { (saltwater) }^{1} \\
\end{array}$ & $\begin{array}{c}\text { Hardness Dependent } \\
0.09 \mathrm{mg} / \mathrm{L}\end{array}$ \\
\hline \multirow[t]{2}{*}{ Subsector A2. Wood Preserving (SIC 2491) } & $\begin{array}{c}\text { Total Arsenic } \\
\text { (freshwater) } \\
\text { Total Arsenic } \\
\text { (saltwater) }^{1} \\
\end{array}$ & $\begin{array}{l}0.15 \mathrm{mg} / \mathrm{L} \\
0.069 \mathrm{mg} / \mathrm{L}\end{array}$ \\
\hline & $\begin{array}{l}\text { Total Copper } \\
\text { (freshwater) }^{2} \\
\text { Total Copper } \\
\text { (saltwater) }^{1} \\
\end{array}$ & $\begin{array}{c}\text { Hardness Dependent } \\
0.0048 \mathrm{mg} / \mathrm{L}\end{array}$ \\
\hline $\begin{array}{l}\text { Subsector A3. Log Storage and Handling } \\
\text { (SIC 2411) }\end{array}$ & $\begin{array}{l}\text { Total Suspended } \\
\text { Solids (TSS) } \\
\end{array}$ & $100 \mathrm{mg} / \mathrm{L}$ \\
\hline \multirow{2}{*}{$\begin{array}{l}\text { Subsector A4. Hardwood Dimension and Flooring } \\
\text { Mills; Special Products Sawmills, not elsewhere } \\
\text { classified; Millwork, Veneer, Plywood, and } \\
\text { Structural Wood; Wood Pallets and Skids; Wood } \\
\text { Containers, not elsewhere classified; Wood } \\
\text { Buildings and Mobile Homes; Reconstituted } \\
\text { Wood Products; and Wood Products Facilities } \\
\text { not elsewhere classified (SIC 2426, 2429, 2431- } \\
2439 \text { (except 2434), 2441, 2448, 2449, 2451, 2452, } \\
2493 \text {, and 2499) }\end{array}$} & $\begin{array}{l}\text { Chemical Oxygen } \\
\text { Demand (COD) }\end{array}$ & $120.0 \mathrm{mg} / \mathrm{L}$ \\
\hline & $\begin{array}{l}\text { Total Suspended } \\
\text { Solids (TSS) }\end{array}$ & $100.0 \mathrm{mg} / \mathrm{L}$ \\
\hline
\end{tabular}


ISaltwater benchmark values apply to stormwater discharges into saline waters where indicated.

2 The freshwater benchmark values of some metals are dependent on water hardness. For these parameters, permittees must determine the hardness of the receiving water (see Appendix J, "Calculating Hardness in Receiving Waters for Hardness Dependent Metals," for methodology), in accordance with Part 6.2.1.1, to identify the applicable 'hardness range' for determining their benchmark value applicable to their facility. Hardness Dependent Benchmarks follow in the table below:

\begin{tabular}{|l|l|l|}
\hline Freshwater Hardness Range & $\begin{array}{l}\text { Copper } \\
(\mathrm{mg} / \mathrm{L})\end{array}$ & $\begin{array}{l}\text { Zinc } \\
(\mathrm{mg} / \mathrm{L})\end{array}$ \\
\hline $0-24.99 \mathrm{mg} / \mathrm{L}$ & 0.0038 & 0.04 \\
\hline $25-49.99 \mathrm{mg} / \mathrm{L}$ & 0.0056 & 0.05 \\
\hline $50-74.99 \mathrm{mg} / \mathrm{L}$ & 0.0090 & 0.08 \\
\hline $75-99.99 \mathrm{mg} / \mathrm{L}$ & 0.0123 & 0.11 \\
\hline $100-124.99 \mathrm{mg} / \mathrm{L}$ & 0.0156 & 0.13 \\
\hline $125-149.99 \mathrm{mg} / \mathrm{L}$ & 0.0189 & 0.16 \\
\hline $150-174.99 \mathrm{mg} / \mathrm{L}$ & 0.0221 & 0.18 \\
\hline $175-199.99 \mathrm{mg} / \mathrm{L}$ & 0.0253 & 0.20 \\
\hline $200-224.99 \mathrm{mg} / \mathrm{L}$ & 0.0285 & 0.23 \\
\hline $225-249.99 \mathrm{mg} / \mathrm{L}$ & 0.0316 & 0.25 \\
\hline $250+\mathrm{mg} / \mathrm{L}$ & 0.0332 & 0.26 \\
\hline
\end{tabular}

8.A.7 Effluent Limitations Based on Effluent Limitations Guidelines. (See also Part 6.2.2) Table 8.A-2 identifies effluent limits that apply to the industrial activities described below. Compliance with these effluent limits is to be determined based on discharges from these industrial activities independent of commingling with any other waste streams that may be covered under this permit.

\begin{tabular}{|l|c|c|}
\hline \multicolumn{3}{|c|}{ Table 8.A-2 } \\
\hline \multicolumn{1}{|c|}{ Industrial Activity } & Parameter & Effluent Limitation \\
\hline $\begin{array}{l}\text { Discharges resulting from spray down or } \\
\text { intentional wetting of logs at wet deck } \\
\text { storage areas }\end{array}$ & $\begin{array}{c}\mathrm{pH} \\
\text { Debris (woody material } \\
\text { such as bark, twigs, } \\
\text { branches, heartwood, or } \\
\text { sapwood) }\end{array}$ & $\begin{array}{c}\text { No discharge of debris } \\
\text { that will not pass through } \\
\text { a 2.54-cm (1-in.) } \\
\text { diameter round opening }\end{array}$ \\
\hline
\end{tabular}

'Monitor annually.

8.A.7.1 Credit for Pollutants in Intake Water. For discharges that are comprised solely of water drawn from the same body of water into which the discharges flow and that exceed an applicable effluent limitation, you may be eligible for a credit to the extent necessary to meet the limitation. To obtain this credit, you must show that your discharge would meet the limitation in the absence of the pollutant(s) in the intake water by demonstrating that the control measures you use to meet the limitation would, if properly installed and operated, meet the limitations for the pollutant (i.e., the pollutant level in your discharge is in exceedance of the limitation due to the pollutant concentration in the source or intake water). You must consult the appropriate EPA Regional Office for guidance in seeking a pollutant credit under this Part. EPA will notify you whether you are eligible for the credit, and, if so, provide the scope of such credit. 


\section{Part 8 - Sector-Specific Requirements for Industrial Activity}

\section{Subpart B - Sector B - Paper and Allied Products.}

You must comply with Part 8 sector-specific requirements associated with your primary industrial activity and any co-located industrial activities, as defined in Appendix A. The sectorspecific requirements apply to those areas of your facility where those sector-specific activities occur. These sector-specific requirements are in addition to any requirements specified elsewhere in this permit.

\section{B.1 Covered Stormwater Discharges.}

The requirements in Subpart B apply to stormwater discharges associated with industrial activity from Paper and Allied Products Manufacturing facilities, as identified by the SIC Codes specified under Sector B in Table D-1 of Appendix D of the permit.

8.B.2 Sector-Specific Benchmarks. (See also Part 6)

Table 8.B-1 identifies benchmarks that apply to the specific subsectors of Sector B. These benchmarks apply to both your primary industrial activity and any co-located industrial activities.

Table 8.B-1.

\begin{tabular}{|l|c|c|}
\hline $\begin{array}{c}\text { Subsector } \\
\text { (You may be subject to requirements for more } \\
\text { than one sector/subsector) }\end{array}$ & Parameter & $\begin{array}{c}\text { Benchmark } \\
\text { Monitoring } \\
\text { Concentration }\end{array}$ \\
\hline $\begin{array}{l}\text { Subsector B1. Paperboard Mills } \\
\text { (SIC Code 2631) }\end{array}$ & $\begin{array}{c}\text { Chemical Oxygen } \\
\text { Demand (COD) }\end{array}$ & $120 \mathrm{mg} / \mathrm{L}$ \\
\hline
\end{tabular}




\section{Part 8 - Sector-Specific Requirements for Industrial Activity}

\section{Subpart C - Sector C - Chemical and Allied Products Manufacturing, and Refining.}

You must comply with Part 8 sector-specific requirements associated with your primary industrial activity and any co-located industrial activities, as defined in Appendix A. The sectorspecific requirements apply to those areas of your facility where those sector-specific activities occur. These sector-specific requirements are in addition to any requirements specified elsewhere in this permit.

\section{C.1 Covered Stormwater Discharges.}

The requirements in Subpart $C$ apply to stormwater discharges associated with industrial activity from Chemical and Allied Products Manufacturing, and Refining facilities, as identified by the SIC Codes specified under Sector C in Table D-1 of Appendix D of the permit.

\section{C.2 Limitations on Coverage.}

8.C.2.1 Prohibition of Non-Stormwater Discharges. (See also Part 1.1.4) The following are not covered by this permit: non-stormwater discharges containing inks, paints, or substances (hazardous, nonhazardous, etc.) resulting from an onsite spill, including materials collected in drip pans; wash water from material handling and processing areas; and wash water from drum, tank or container rinsing and cleaning. (EPA includes this prohibited non-stormwater discharge here solely as a helpful reminder to the operator that the only non-stormwater discharges authorized by this permit are at Part 1.1.3.)

8.C.3 Sector-Specific Benchmarks. (See also Part 6)

Table 8.C-1 identifies benchmarks that apply to the specific subsectors of Sector C. These benchmarks apply to both your primary industrial activity and any co-located industrial activities. 


\begin{tabular}{|c|c|c|}
\hline \multicolumn{3}{|c|}{ Table 8.C-1. } \\
\hline $\begin{array}{c}\text { Subsector } \\
\text { (You may be subject to requirements for } \\
\text { more than one sector/subsector) }\end{array}$ & Parameter & $\begin{array}{l}\text { Benchmark Monitoring } \\
\text { Concentration }\end{array}$ \\
\hline \multirow[t]{5}{*}{$\begin{array}{l}\text { Subsector C1. Agricultural Chemicals } \\
\text { (SIC 2873-2879) }\end{array}$} & $\begin{array}{c}\text { Nitrate plus Nitrite } \\
\text { Nitrogen }\end{array}$ & $0.68 \mathrm{mg} / \mathrm{L}$ \\
\hline & $\begin{array}{l}\text { Total Lead (freshwater) }{ }^{2} \\
\text { Total Lead (saltwater) }\end{array}$ & $\begin{array}{c}\text { Hardness Dependent } \\
0.21 \mathrm{mg} / \mathrm{L} \\
\end{array}$ \\
\hline & Total Iron & $1.0 \mathrm{mg} / \mathrm{L}$ \\
\hline & $\begin{array}{l}\text { Total Zinc (freshwater) } \\
\text { Total Zinc (saltwater) }\end{array}$ & $\begin{array}{l}\text { Hardness Dependent } \\
0.09 \mathrm{mg} / \mathrm{L}\end{array}$ \\
\hline & Phosphorus & $2.0 \mathrm{mg} / \mathrm{L}$ \\
\hline \multirow{3}{*}{$\begin{array}{l}\text { Subsector C2. Industrial Inorganic Chemicals } \\
\text { (SIC 2812-2819) }\end{array}$} & Total Aluminum & $0.75 \mathrm{mg} / \mathrm{L}$ \\
\hline & Total Iron & $1.0 \mathrm{mg} / \mathrm{L}$ \\
\hline & $\begin{array}{c}\text { Nitrate plus Nitrite } \\
\text { Nitrogen }\end{array}$ & $0.68 \mathrm{mg} / \mathrm{L}$ \\
\hline \multirow[t]{2}{*}{$\begin{array}{l}\text { Subsector C3. Soaps, Detergents, Cosmetics, } \\
\text { and Perfumes (SIC 2841-2844) }\end{array}$} & $\begin{array}{c}\text { Nitrate plus Nitrite } \\
\text { Nitrogen }\end{array}$ & $0.68 \mathrm{mg} / \mathrm{L}$ \\
\hline & $\begin{array}{l}\text { Total Zinc (freshwater) } \\
\text { Total Zinc (saltwater) }\end{array}$ & $\begin{array}{l}\text { Hardness Dependent } \\
0.09 \mathrm{mg} / \mathrm{L}\end{array}$ \\
\hline $\begin{array}{l}\text { Subsector C4. Plastics, Synthetics, and Resins } \\
\text { (SIC 2821-2824) }\end{array}$ & $\begin{array}{l}\text { Total Zinc (freshwater) } \\
\text { Total Zinc (saltwater) }\end{array}$ & $\begin{array}{l}\text { Hardness Dependent } \\
0.09 \mathrm{mg} / \mathrm{L}\end{array}$ \\
\hline
\end{tabular}

iSaltwater benchmark values apply to stormwater discharges into saline waters where indicated.

${ }^{2}$ The freshwater benchmark values of some metals are dependent on water hardness. For these parameters, permittees must determine the hardness of the receiving water (see Appendix J, "Calculating Hardness in Receiving Waters for Hardness Dependent Metals," for methodology), in accordance with Part 6.2.1.1, to identify the applicable "hardness range' for determining their benchmark value applicable to their facility. Hardness Dependent Benchmarks follow in the table below:

\begin{tabular}{|l|l|l|}
\hline $\begin{array}{l}\text { Freshwater Hardness } \\
\text { Range }\end{array}$ & $\begin{array}{l}\text { Lead } \\
\text { (mg/L) }\end{array}$ & $\begin{array}{l}\text { Zinc } \\
\text { (mg/L) }\end{array}$ \\
\hline $0-24.99 \mathrm{mg} / \mathrm{L}$ & 0.014 & 0.04 \\
\hline $25-49.99 \mathrm{mg} / \mathrm{L}$ & 0.023 & 0.05 \\
\hline $50-74.99 \mathrm{mg} / \mathrm{L}$ & 0.045 & 0.08 \\
\hline $75-99.99 \mathrm{mg} / \mathrm{L}$ & 0.069 & 0.11 \\
\hline $100-124.99 \mathrm{mg} / \mathrm{L}$ & 0.095 & 0.13 \\
\hline $125-149.99 \mathrm{mg} / \mathrm{L}$ & 0.122 & 0.16 \\
\hline $150-174.99 \mathrm{mg} / \mathrm{L}$ & 0.151 & 0.18 \\
\hline $175-199.99 \mathrm{mg} / \mathrm{L}$ & 0.182 & 0.20 \\
\hline $200-224.99 \mathrm{mg} / \mathrm{L}$ & 0.213 & 0.23 \\
\hline $225-249.99 \mathrm{mg} / \mathrm{L}$ & 0.246 & 0.25 \\
\hline $250+1 \mathrm{mg} / \mathrm{L}$ & 0.262 & 0.26 \\
\hline
\end{tabular}

\section{C.4 Effluent Limitations Based on Effluent Limitations Guidelines. (See also Part 6.2.2.1)}

Table 8.C-2 identifies effluent limits that apply to the industrial activities described below. Compliance with these effluent limits is to be determined based on discharges from these industrial activities independent of commingling with any other waste streams that may be covered under this permit. 


\begin{tabular}{|c|c|c|}
\hline \multicolumn{3}{|c|}{ Table 8.C-21 } \\
\hline Industrial Activity & Parameter & Effluent Limitation \\
\hline \multirow{4}{*}{$\begin{array}{l}\text { Runoff from phosphate fertilizer } \\
\text { manufacturing facilities that comes into } \\
\text { contact with any raw materials, finished } \\
\text { product, by-products or waste } \\
\text { products (SIC 2874) }\end{array}$} & \multirow[t]{2}{*}{ Total Phosphorus (as P) } & $105.0 \mathrm{mg} / \mathrm{L}$, daily maximum \\
\hline & & $\begin{array}{c}35 \mathrm{mg} / \mathrm{L} \\
30-\text { day avg. }\end{array}$ \\
\hline & \multirow[t]{2}{*}{ Fluoride } & $\begin{array}{c}75.0 \mathrm{mg} / \mathrm{L}, \\
\text { daily maximum }\end{array}$ \\
\hline & & $\begin{array}{c}25.0 \mathrm{mg} / \mathrm{L} \\
30-\text { day avg. }\end{array}$ \\
\hline
\end{tabular}

${ }^{1}$ Monitor annually. 
Part 8 - Sector-Specific Requirements for Industrial Activity

Subpart D - Sector D - Asphalt Paving and Roofing Materials and Lubricant Manufacturing.

You must comply with Part 8 sector-specific requirements associated with your primary industrial activity and any co-located industrial activities, as defined in Appendix A. The sectorspecific requirements apply to those areas of your facility where those sector-specific activities occur. These sector-specific requirements are in addition to any requirements specified elsewhere in this permit.

\section{D.1 Covered Stormwater Discharges.}

The requirements in Subpart D apply to stormwater discharges associated with industrial activity from Asphalt Paving and Roofing Materials and Lubricant Manufacturing facilities, as identified by the SIC Codes specified under Sector D in Table D-1 of Appendix D of the permit.

\section{D.2 Limitations on Coverage.}

The following stormwater discharges associated with industrial activity are not authorized by this permit (see also Part 1.1.4):

\section{D.2.1 Stormwater discharges from petroleum refining facilities, including those that manufacture asphalt or asphalt products, that are subject to nationally established effluent limitation guidelines found in 40 CFR Part 419 (Petroleum Refining).}

The following stormwater discharges associated with industrial activity are not authorized under Sector D:

8.D.2.2 Stormwater discharges from oil recycling facilities, which are covered under Sector $\mathbf{N}$ (see Part 8.N); and

8.D.2.3 Stormwater discharges associated with fats and oils rendering, which are covered under Sector U (see Part 8.U).

8.D.3 Sector-Specific Benchmarks. (See also Part 6)

Table 8.D-1 identifies benchmarks that apply to the specific subsectors of Sector D. These benchmarks apply to both your primary industrial activity and any co-located industrial activities.

\begin{tabular}{|l|c|c|}
\hline \multicolumn{3}{|c|}{ Table 8.D-1. } \\
\hline \multicolumn{1}{|c|}{ Subsector } & Parameter & $\begin{array}{c}\text { Benchmark Monitoring } \\
\text { Concentration }\end{array}$ \\
\hline $\begin{array}{l}\text { Subsector D1. Asphalt Paving and Roofing } \\
\text { Materials (SIC 2951, 2952) }\end{array}$ & $\begin{array}{c}\text { Total Suspended Solids } \\
\text { (TSS) }\end{array}$ & $100 \mathrm{mg} / \mathrm{L}$ \\
\hline
\end{tabular}

8.D.4 Effluent Limitations Based on Effluent Limitations Guidelines. (See also Part 6.2.2.1)

Table 8.D-2 identifies effluent limitations that apply to the industrial activities described below. Compliance with these effluent limitations is to be determined based on discharges from these industrial activities independent of commingling with any other waste streams that may be covered under this permit. 


\begin{tabular}{|c|c|c|}
\hline \multicolumn{3}{|c|}{ Table 8.D-21 } \\
\hline Industrial Activity & Parameter & Effluent Limitation \\
\hline \multirow[t]{4}{*}{ Discharges from asphalt emulsion facilities. } & $\begin{array}{l}\text { Total Suspended Solids } \\
\text { (TSS) }\end{array}$ & $\begin{array}{c}23.0 \mathrm{mg} / \mathrm{L} \\
\text { daily maximum } \\
15.0 \mathrm{mg} / \mathrm{L} \\
\text { 30-day avg. }\end{array}$ \\
\hline & $\mathrm{pH}$ & $6.0-9.0$ s.u. \\
\hline & \multirow[t]{2}{*}{ Oil and Grease } & $\begin{array}{c}15.0 \mathrm{mg} / \mathrm{L} \\
\text { daily maximum }\end{array}$ \\
\hline & & $\begin{array}{c}10 \mathrm{mg} / \mathrm{L} \\
\text { 30-day avg. }\end{array}$ \\
\hline
\end{tabular}

'Monitor annually. 


\section{Part 8 - Sector-Specific Requirements for Industrial Activity}

\section{Subpart E - Sector E - Glass, Clay, Cement, Concrete, and Gypsum Products.}

You must comply with Part 8 sector-specific requirements associated with your primary industrial activity and any co-located industrial activities, as defined in Appendix A. The sectorspecific requirements apply to those areas of your facility where those sector-specific activities occur. These sector-specific requirements are in addition to any requirements specified elsewhere in this permit.

\section{E.1 Covered Stormwater Discharges.}

The requirements in Subpart E apply to stormwater discharges associated with industrial activity from Glass, Clay, Cement, Concrete, and Gypsum Products facilities, as identified by the SIC Codes specified under Sector E in Table D-1 of Appendix D of the permit.

\section{E.2 Additional Technology-Based Effluent Limits.}

8.E.2.1 Good Housekeeping Measures. (See also Part 2.1.2.2) As part of your good housekeeping program, prevent or minimize the discharge of spilled cement, aggregate (including sand or gravel), kiln dust, fly ash, settled dust, or other significant material in stormwater from paved portions of the site that are exposed to stormwater. Sweep or vacuum paved surfaces of the site that are exposed to stormwater at regular intervals or use other equivalent measures (e.g., wash down the area and collect and/or treat and properly dispose of the washdown water) to minimize the potential discharge of these materials in stormwater. Indicate in your SWPPP the frequency of sweeping, vacuuming or other equivalent measures. Determine the frequency based on the amount of industrial activity occurring in the area and the frequency of precipitation, but it must be performed at least once a week in areas where cement, aggregate, kiln dust, fly ash or settled dust are being handled or processed and may be discharged in stormwater. You must also prevent the exposure of fine granular solids (e.g., cement, fly ash, kiln dust) to stormwater, where practicable, by storing these materials in enclosed silos, hoppers, buildings or under other covering.

\section{E.3 Additional SWPPP Requirements.}

8.E.3.1 Drainage Area Site Map. (See also Part 5.2.2) Document in the SWPPP the locations of the following, as applicable: bag house or other dust control device; recycle/ sedimentation pond, clarifier, or other device used for the treatment of process wastewater; and the areas that drain to the treatment device.

8.E.3.2 Discharge Testing. (See also Part 5.2.3.4) For facilities producing ready-mix concrete, concrete block, brick, or similar products, include in the non-stormwater discharge testing a description of measures that ensure that process wastewaters resulting from washing trucks, mixers, transport buckets, forms, or other equipment are discharged in accordance with NPDES wastewater permit requirements or are recycled.

\section{E.4 Sector-Specific Benchmarks. (See also Part 6)}

Table 8.E-1 identifies benchmarks that apply to the specific subsectors of Sector E. These benchmarks apply to both your primary industrial activity and any co-located industrial activities. 
Table 8.E-1.

\begin{tabular}{|l|c|c|}
\hline $\begin{array}{c}\text { Subsector } \\
\text { (You may be subject to requirements for } \\
\text { more than one sector/subsector) }\end{array}$ & Parameter & $\begin{array}{c}\text { Benchmark Monitoring } \\
\text { Concentration }\end{array}$ \\
\hline $\begin{array}{l}\text { Subsector E1. Clay Product Manufacturers } \\
\text { (SIC 3251-3259, 3261-3269) }\end{array}$ & Total Aluminum & $0.75 \mathrm{mg} / \mathrm{L}$ \\
\hline $\begin{array}{l}\text { Subsector E2. Concrete and Gypsum } \\
\text { Product Manufacturers (SIC 3271-3275) }\end{array}$ & $\begin{array}{c}\text { Total Suspended Solids } \\
\text { (TSS) }\end{array}$ & $100 \mathrm{mg} / \mathrm{L}$ \\
\cline { 2 - 3 } & Total Iron & $1.0 \mathrm{mg} / \mathrm{L}$ \\
\hline
\end{tabular}

8.E.5 Effluent Limitations Based on Effluent Limitations Guidelines. (See also Part 6.2.2.1)

Table 8.E-2 identifies effluent limits that apply to the industrial activities described below. Compliance with these limits is to be determined based on discharges from these industrial activities independent of commingling with any other waste streams that may be covered under this permit.

\begin{tabular}{|c|c|c|}
\hline \multicolumn{3}{|c|}{ Table $8 . E-2^{1}$} \\
\hline Industrial Activity & Parameter & Effluent Limitation \\
\hline \multirow[t]{2}{*}{$\begin{array}{l}\text { Discharges from material storage piles at } \\
\text { cement manufacturing facilities (SIC 3241) }\end{array}$} & $\begin{array}{l}\text { Total Suspended Solids } \\
\text { (TSS) }\end{array}$ & $\begin{array}{l}50 \mathrm{mg} / \mathrm{L} \text {, daily } \\
\text { maximum² }\end{array}$ \\
\hline & $\mathrm{pH}$ & $6.0-9.0$ s.U. ${ }^{2}$ \\
\hline
\end{tabular}

'Monitor annually.

${ }^{2}$ Any untreated overflow from facilities designed, constructed and operated to treat the volume of runoff from materials storage piles which is associated with a 10-year, 24-hour rainfall event shall not be subject to the pH and TSS limitations (40 CFR $411.32(\mathrm{~b})$ ). 


\section{Part 8 - Sector-Specific Requirements for Industrial Activity}

\section{Subpart F - Sector F - Primary Metals.}

You must comply with Part 8 sector-specific requirements associated with your primary industrial activity and any co-located industrial activities, as defined in Appendix A. The sectorspecific requirements apply to those areas of your facility where those sector-specific activities occur. These sector-specific requirements are in addition to any requirements specified elsewhere in this permit.

\section{F.1 Covered Stormwater Discharges.}

The requirements in Subpart $\mathrm{F}$ apply to stormwater discharges associated with industrial activity from Primary Metals facilities, as identified by the SIC Codes specified under Sector F in Table D-1 of Appendix D of the permit.

\section{F.2 Additional Technology-Based Effluent Limits.}

8.F.2.1 Good Housekeeping Measures. (See also Part 2.1.2.2) As part of your good housekeeping program, you must implement a cleaning and maintenance program for all impervious areas of the facility where particulate matter, dust or debris may accumulate to minimize the discharge of pollutants in stormwater. The cleaning and maintenance program must encompass, as appropriate, areas where material loading and unloading, storage, handling and processing occur.

Stabilize unpaved areas using vegetation or paving where there is vehicle traffic or where material loading and unloading, storage, handling and processing occurs, unless feasible.

For paved areas of the facility where particulate matter, dust or debris may accumulate, to minimize the discharge of pollutants in stormwater, implement control measures such as the following, where determined to be feasible (list not exclusive): sweeping or vacuuming at regular intervals; and washing down the area and collecting and/or treating and properly disposing of the washdown water. For unstabilized areas or for stabilized areas where sweeping, vacuuming, or washing down is not possible, to minimize the discharge of particulate matter, dust, or debris or other pollutants in stormwater, implement stormwater management devices such as the following, where determined to be feasible (list not exclusive): sediment traps, vegetative buffer strips, filter fabric fence, sediment filtering boom, gravel outlet protection, and other equivalent measures that effectively trap or remove sediment.

\section{F.3 Additional SWPPP Requirements.}

8.F.3.1 Drainage Area Site Map. (See also Part 5.2.2) Identify in the SWPPP where any of the following activities may be exposed to precipitation or surface runoff: storage or disposal of wastes such as spent solvents and baths, sand, slag and dross; liquid storage tanks and drums; processing areas including pollution control equipment (e.g., baghouses); and storage areas of raw material such as coal, coke, scrap, sand, fluxes, refractories or metal in any form. In addition, indicate where an accumulation of significant amounts of particulate matter could occur from such sources as furnace or oven emissions, losses from coal and coke handling operations, etc., and could result in a discharge of pollutants in stormwater.

8.F.3.2 Inventory of Exposed Material. (See also Part 5.2.3) Include in the inventory of materials handled at the site that potentially may be exposed to precipitation or runoff areas where there is the potential for deposition of particulate matter from process air emissions or losses during material-handling activities. 


\section{F.4 Additional Inspection Requirements. (See also Part 3.1)}

As part of conducting your routine facility inspections at least quarterly (Part 3.1), address all potential sources of pollutants, including (if applicable) air pollution control equipment (e.g., baghouses, electrostatic precipitators, scrubbers, cyclones), for any signs of degradation (e.g., leaks, corrosion, improper operation) that could limit their efficiency and lead to excessive emissions. Consider monitoring air flow at inlets and outlets (or use equivalent measures) to check for leaks (e.g., particulate deposition) or blockage in ducts. Also inspect all process and material handling equipment (e.g., conveyors, cranes and vehicles) for leaks, drips, or the potential loss of material; and material storage areas (e.g., piles, bins, or hoppers for storing coke, coal, scrap or slag, as well as chemicals stored in tanks and drums) for signs of material losses due to wind or stormwater runoff.

\section{F.5 Sector-Specific Benchmarks. (See also Part 6)}

Table 8.F-1 identifies benchmarks that apply to the specific subsectors of Sector F. These benchmarks apply to both your primary industrial activity and any co-located industrial activities.

\begin{tabular}{|c|c|c|}
\hline \multicolumn{3}{|c|}{ Table 8.F-1. } \\
\hline $\begin{array}{c}\text { Subsector } \\
\text { (You may be subject to requirements for } \\
\text { more than one sector/subsector) }\end{array}$ & Parameter & $\begin{array}{l}\text { Benchmark Monitoring } \\
\text { Concentration }\end{array}$ \\
\hline \multirow{2}{*}{$\begin{array}{l}\text { Subsector F1. Steel Works, Blast Furnaces, } \\
\text { and Rolling and Finishing Mills } \\
\text { (SIC 3312-3317) }\end{array}$} & Total Aluminum & $0.75 \mathrm{mg} / \mathrm{L}$ \\
\hline & $\begin{array}{l}\text { Total Zinc (freshwater) } \\
\text { Total Zinc (saltwater) }\end{array}$ & $\begin{array}{c}\text { Hardness Dependent } \\
0.09 \mathrm{mg} / \mathrm{L} \\
\end{array}$ \\
\hline \multirow{5}{*}{$\begin{array}{l}\text { Subsector F2. Iron and Steel Foundries } \\
\text { (SIC 3321-3325) }\end{array}$} & Total Aluminum & $0.75 \mathrm{mg} / \mathrm{L}$ \\
\hline & Total Suspended Solids (TSS) & $100 \mathrm{mg} / \mathrm{L}$ \\
\hline & $\begin{array}{c}\text { Total Copper (freshwater) } \\
\text { Total Copper (saltwater)' }\end{array}$ & $\begin{array}{l}\text { Hardness Dependent } \\
0.0048 \mathrm{mg} / \mathrm{L}\end{array}$ \\
\hline & Total Iron & $1.0 \mathrm{mg} / \mathrm{L}$ \\
\hline & $\begin{array}{l}\text { Total Zinc (freshwater) } \\
\text { Total Zinc (saltwater) } \\
\end{array}$ & $\begin{array}{c}\text { Hardness Dependent } \\
0.09 \mathrm{mg} / \mathrm{L} \\
\end{array}$ \\
\hline \multirow{2}{*}{$\begin{array}{l}\text { Subsector F3. Rolling, Drawing, and } \\
\text { Extruding of Nonferrous Metals } \\
\text { (SIC 3351-3357) }\end{array}$} & $\begin{array}{l}\text { Total Copper (freshwater) } \\
\text { Total Copper (saltwater) }\end{array}$ & $\begin{array}{c}\text { Hardness Dependent } \\
0.0048 \mathrm{mg} / \mathrm{L}\end{array}$ \\
\hline & $\begin{array}{l}\text { Total Zinc (freshwater) }{ }^{2} \\
\text { Total Zinc (saltwater) }\end{array}$ & $\begin{array}{c}\text { Hardness Dependent } \\
0.09 \mathrm{mg} / \mathrm{L} \\
\end{array}$ \\
\hline \multirow[t]{2}{*}{$\begin{array}{l}\text { Subsector F4. Nonferrous Foundries } \\
\text { (SIC 3363-3369) }\end{array}$} & $\begin{array}{l}\text { Total Copper (freshwater) } \\
\text { Total Copper (saltwater) } \\
\end{array}$ & $\begin{array}{c}\text { Hardness Dependent } \\
0.0048 \mathrm{mg} / \mathrm{L}\end{array}$ \\
\hline & $\begin{array}{l}\text { Total Zinc (freshwater) }{ }^{2} \\
\text { Total Zinc (saltwater) }\end{array}$ & $\begin{array}{c}\text { Hardness Dependent } \\
0.09 \mathrm{mg} / \mathrm{L}\end{array}$ \\
\hline \multicolumn{3}{|c|}{$\begin{array}{l}\text { Saltwater benchmark values apply to stormwater discharges into saline waters where indicated. } \\
2 \text { The freshwater benchmark values of some metals are dependent on water hardness. For these parameters, permittees } \\
\text { must determine the hardness of the receiving water (see Appendix J, "Calculating Hardness in Receiving Waters for } \\
\text { Hardness Dependent Metals," for methodology), in accordance with Part 6.2.1.1, to identify the applicable "hardness } \\
\text { range' for determining their benchmark value applicable to their facility. Hardness Dependent Benchmarks follow in the } \\
\text { table below: }\end{array}$} \\
\hline
\end{tabular}




\begin{tabular}{|l|l|l|}
\hline Freshwater Hardness Range & $\begin{array}{l}\text { Copper } \\
(\mathrm{mg} / \mathrm{L})\end{array}$ & $\begin{array}{l}\text { Zinc } \\
(\mathrm{mg} / \mathrm{L})\end{array}$ \\
\hline $0-24.99 \mathrm{mg} / \mathrm{L}$ & 0.0038 & 0.04 \\
\hline $25-49.99 \mathrm{mg} / \mathrm{L}$ & 0.0056 & 0.05 \\
\hline $50-74.99 \mathrm{mg} / \mathrm{L}$ & 0.0090 & 0.08 \\
\hline $75-99.99 \mathrm{mg} / \mathrm{L}$ & 0.0123 & 0.11 \\
\hline $100-124.99 \mathrm{mg} / \mathrm{L}$ & 0.0156 & 0.13 \\
\hline $125-149.99 \mathrm{mg} / \mathrm{L}$ & 0.0189 & 0.16 \\
\hline $150-174.99 \mathrm{mg} / \mathrm{L}$ & 0.0221 & 0.18 \\
\hline $175-199.99 \mathrm{mg} / \mathrm{L}$ & 0.0253 & 0.20 \\
\hline $200-224.99 \mathrm{mg} / \mathrm{L}$ & 0.0285 & 0.23 \\
\hline $225-249.99 \mathrm{mg} / \mathrm{L}$ & 0.0316 & 0.25 \\
\hline $250+\mathrm{mg} / \mathrm{L}$ & 0.0332 & 0.26 \\
\hline
\end{tabular}




\section{Part 8 - Sector-Specific Requirements for Industrial Activity}

\section{Subpart G - Sector G - Metal Mining.}

You must comply with Part 8 sector-specific requirements associated with your primary industrial activity and any co-located industrial activities, as defined in Appendix A. The sectorspecific requirements apply to those areas of your facility where those sector-specific activities occur. These sector-specific requirements are in addition to any requirements specified elsewhere in this permit.

Note: Where compliance with a requirement in a separate exploration permit, mining permit, reclamation plan, Surface Mining Control and Reclamation Act (SMCRA) requirements, etc. will result in you fully meeting any requirement in this Subpart, you are considered to have complied with the relevant requirement in this Subpart. You must include documentation in your SWPPP describing your rationale for concluding that any particular action on your part is sufficient to comply with the corresponding requirement in this Subpart.

\section{G.1 Covered Stormwater Discharges.}

The requirements in Subpart $G$ apply to stormwater discharges associated with industrial activity from Metal Mining facilities, including mines abandoned on Federal lands, as identified by the SIC Codes specified under Sector G in Table D-1 of Appendix D. Coverage is required for metal mining facilities that discharge stormwater contaminated by contact with, or that has come into contact with, any overburden, raw material, intermediate product, finished product, byproduct, or waste product located on the site of the operation.

8.G.1.1 Covered Discharges from Inactive Facilities. All stormwater discharges.

8.G.1.2 Covered Discharges from Active and Temporarily Inactive Facilities. Only the stormwater discharges from the following areas are covered:

- Waste rock and overburden piles if composed entirely of stormwater and not combined with mine drainage;

- Topsoil piles;

- Offsite haul and access roads;

- Onsite haul and access roads constructed of waste rock, overburden or spent ore if composed entirely of stormwater and not combining with mine drainage;

- Onsite haul and access roads not constructed of waste rock, overburden or spent ore except if mine drainage is used for dust control;

- Runoff from tailings dams or dikes when not constructed of waste rock or tailings and no process fluids are present;

- Runoff from tailings dams or dikes when constructed of waste rock or tailings and no process fluids are present, if composed entirely of stormwater and not combining with mine drainage;

- Concentration building if no contact with material piles;

- Mill site if no contact with material piles;

- Office or administrative building and housing if mixed with stormwater from industrial area;

- Chemical storage area;

- Docking facility if no excessive contact with waste product that would otherwise constitute mine drainage;

- Explosive storage;

- Fuel storage;

- Vehicle and equipment maintenance area and building;

- Parking areas (if necessary);

- Power plant; 
- Truck wash areas if no excessive contact with waste product that would otherwise constitute mine drainage;

- Unreclaimed, disturbed areas outside of active mining area;

- Reclaimed areas released from reclamation requirements prior to December 17, 1990;

- Partially or inadequately reclaimed areas or areas not released from reclamation requirements.

8.G.1.3 Covered Discharges from Earth-Disturbing Activities Conducted Prior to Active Mining Activities. All stormwater discharges.

8.G.1.4 Covered Discharges from Facilities Undergoing Reclamation. All stormwater discharges.

\section{G.2 Limitations on Coverage.}

8.G.2.1 Prohibition of Stormwater Discharges. Stormwater discharges not authorized by this permit: discharges from active metal mining facilities that are subject to effluent limitation guidelines for the Ore Mining and Dressing Point Source Category (40 CFR Part 440).

Note: Stormwater runoff from these sources are subject to 40 CFR Part 440 if they are mixed with other discharges subject to Part 440. In this case, they are not eligible for coverage under this permit. Discharges from overburden/waste rock and overburden/waste rock-related areas are not subject to 40 CFR Part 440 unless they: (1) drain naturally (or are intentionally diverted) to a point source; and (2) combine with "mine drainage" that is otherwise regulated under the Part 440 regulations. For such sources, coverage under this permit would be available if the discharge composed entirely of stormwater does not combine with other sources of mine drainage that are not subject to 40 CFR Part 440, and meets the other eligibility criteria contained in Part 1.1 of the permit. Operators bear the initial responsibility for determining if they are eligible for coverage under this permit, or must seek coverage under another NPDES permit. EPA recommends that operators contact the relevant NPDES permit issuance authority for assistance to determine the nature and scope of the "active mining area" on a mine-by-mine basis, as well as to determine the appropriate permitting mechanism for authorizing such discharges.

8.G.2.2 Prohibition of Non-Stormwater Discharges. Not authorized by this permit: adit drainage, and contaminated springs or seeps discharging from waste rock dumps that do not directly result from precipitation events (see also the standard Limitations on Coverage in Part 1.1.4). (EPA includes these prohibited non-stormwater discharges here solely as a helpful reminder to the operator that the only non-stormwater discharges authorized by this permit are at Part 1.1.3)

\section{G.3 Definitions.}

The following definitions are not intended to supersede the definitions of active and inactive mining facilities established by 40 CFR 122.26(b)(14)(iii).

8.G.3.1 Mining operations - For this permit, mining operations are grouped into two distinct categories, with distinct effluent limits and requirements applicable to each: a) earthdisturbing activities conducted prior to active mining activities); and b) active mining activities, which includes reclamation. "Mining operations" can occur at both inactive mining facilities and temporarily inactive mining facilities.

8.G.3.2 Earth-disturbing activities conducted prior to active mining activities - Consists of two classes of earth-disturbing (i.e., clearing, grading and excavation) activities: 
a. activities performed for purposes of mine site preparation, including: cutting new rights of way (except when related to access road construction); providing access to a mine site for vehicles and equipment (except when related to access road construction); other earth disturbances associated with site preparation activities on any areas where active mining activities have not yet commenced (e.g., for heap leach pads, waste rock facilities, tailings impoundments, wastewater treatment plants); and

b. construction of staging areas to prepare for erecting structures such as to house project personnel and equipment, mill buildings, etc., and construction of access roads. Earth-disturbing activities associated with the construction of staging areas and the construction of access roads conducted prior to active mining are considered to be "construction" and have additional effluent limits in Part 8.G.4.2.

8.G.3.3 Active mining activities - Activities related to the extraction, removal or recovery, and benefication of metal ore from the earth; removal of overburden and waste rock to expose mineable minerals; and site reclamation and closure activities. All such activities occur within the "active mining area." Reclamation involves activities undertaken, in compliance with applicable mined land reclamation requirements, to return the land to an appropriate post-mining contour and land use in order to meet applicable federal and state reclamation requirements. In addition, once earth-disturbing activities conducted prior to active mining activities have ceased and all related requirements in Part 8.G.4 have been met, and a well-delineated "active mining area" has been established, all activities (including any clearing, grading, and excavation) that occur within the active mining area are "active mining activities."

8.G.3.4 Active mining area - A place where work or other activity related to the extraction, removal or recovery of metal ore is being conducted, except, with respect to surface mines, any area of land on or in which grading has been completed to return the earth to desired contour and reclamation work has begun.

Note: Earth-disturbing activities described in the definition in Part 8.G.3.2 that occur on areas outside the active mining area (e.g., for expansion of the mine into undeveloped territory) are considered "earth-disturbing conducted prior to active mining activities", and must comply with the requirements in Part 8.G.4.

8.G.3.5 Inactive metal mining facility - A site or portion of a site where metal mining and/or milling occurred in the past but there are no active mining activities occurring as defined above, and where the inactive portion is not covered by an active mining permit issued by the applicable state or federal agency. An inactive metal mining facility has an identifiable owner / operator. Sites where mining claims are being maintained prior to disturbances associated with the extraction, beneficiation, or processing of mined materials and sites where minimal activities are undertaken for the sole purpose of maintaining a mining claim are not considered either active or inactive mining facilities and do not require an NPDES industrial stormwater permit.

8.G.3.6 Temporarily inactive metal mining facility - A site or portion of a site where metal mining and/or milling occurred in the past but currently are not being actively undertaken, and the facility is covered by an active mining permit issued by the applicable state or federal agency.

\section{G.4 Requirements Applicable to Earth-Disturbing Activities Conducted Prior to Active Mining Activities.}

Stormwater discharges from earth-disturbing activities conducted prior to active mining activities (defined in Part 8.G.3.2) are covered under this permit. For such earth-disturbing 
activities, you must comply with all applicable requirements in Parts 1-9 of the MSGP except for the technology-based effluent limits in Part 8.G.5 and Part 2.1.2, the inspection requirements in Part 8.G.7 and Part 3, and the monitoring requirements in Part 8.G.8 and Part 6.

Authorized discharges from areas where earth-disturbing activities have ceased and stabilization as specified in Part 8.G.4.1.9 or 8.G.4.2.11, where appropriate, has been completed (stabilization is not required for areas where active mining activities will occur), are no longer subject to the Part 8.G.4 requirements. At such time, authorized discharges become subject to all other applicable requirements in the MSGP, including the effluent limits in Parts 2.1.2 and 8.G.5, the inspection requirements in Parts 3 and 8.G.7, and the monitoring requirements in Parts 6 and 8.G.8.

\section{G.4.1 Technology-Based Effluent Limits Applicable to All Earth-Disturbing Activities Conducted Prior to Active Mining Activities. The following technology-based effluent limits apply to authorized discharges from all earth-disturbing activities conducted prior to active mining activities defined in Part 8.G.3.2(a) and 8.G.3.2(b). These limits supersede the technology-based limits listed in Part 2.1.2 and Part 8.G.5 of the MSGP.}

\section{G.4.1.1 Erosion and sediment control installation requirements.}

- By the time construction activities commence, install and make operational downgradient sediment controls, unless this timeframe is infeasible. If infeasible you must install and make such controls operational as soon as practicable or as soon as site conditions permit.

- All other stormwater controls described in the SWPPP must be installed and made operational as soon as conditions on each portion of the site allows.

8.G.4.1.2 Erosion and sediment control maintenance requirements. You must:

- Ensure that all erosion and sediment controls remain in effective operating condition.

- Wherever you determine that a stormwater control needs maintenance to continue operating effectively, initiate efforts to fix the problem immediately after its discovery, and complete such work by the end of the next work day.

- When a stormwater control must be replaced or significantly repaired, complete the work within 7 days, unless infeasible. If 7 days is infeasible, you must complete the installation or repair as soon practicable.

8.G.4.1.3 Perimeter controls. You must:

- Install sediment controls along those perimeter areas of your disturbed area that will receive stormwater, except where site conditions prevent the use of such controls (in which case, maximize their installation to the extent practicable).

- Remove sediment before it accumulates to one-half of the above-ground height of any perimeter control.

8.G.4.1.4 Sediment track-out. For construction vehicles and equipment exiting the site directly onto paved roads, you must:

- Use appropriate stabilization techniques to minimize sediment track-out from vehicles and equipment prior to exit;

- Use additional controls to remove sediment from vehicle and equipment tires prior to exit, where necessary;

- Remove sediment that is tracked out onto paved roads by end of the work day. 
Note: EPA recognizes that some fine grains may remain visible on the surfaces of off-site streets, other paved areas, and sidewalks even after you have implemented sediment removal practices. Such "staining" is not a violation of Part 8.G.4.1.4.

8.G.4.1.5 Soil or sediment stockpiles. You must:

- Minimize erosion of stockpiles from stormwater and wind via temporary cover, if feasible.

- Prevent up-slope stormwater flows from causing erosion of stockpiles (e.g., by diverting flows around the stockpile).

- Minimize sediment from stormwater that runs off of stockpiles, using sediment controls (e.g., a sediment barrier or downslope sediment control).

8.G.4.1.6 Sediment basins. If you intend to install a sediment basin to treat stormwater from your earth-disturbing activities, you must:

- Provide storage for either (1) the 2-year, 24-hour storm, or (2) 3,600 cubic feet per acre drained.

- Prevent erosion of (1) basin embankments using stabilization controls (e.g., erosion control blankets), and (2) the inlet and outlet points of the basin using erosion controls and velocity dissipation devices.

8.G.4.1.7 Minimize dust. You must minimize the generation of dust through the appropriate application of water or other dust suppression techniques that minimize pollutants being discharged into surface waters.

8.G.4.1.8 Restrictions on use of treatment chemicals. If you intend to use sediment treatment chemicals at your site, you are subject to the following minimum requirements:

- Use conventional erosion and sediment controls prior to and after application of chemicals;

- Select chemicals suited to soil type, and expected turbidity, $\mathrm{pH}$, flow rate;

- Minimize the discharge risk from stored chemicals;

- Comply with state/local requirements;

- Use chemicals in accordance with good engineering practices and specifications of chemical supplier;

- Ensure proper training;

- Provide proper SWPPP documentation.

If you plan to use cationic treatment chemicals (as defined in Appendix A), you are ineligible for coverage under this permit, unless you notify your applicable EPA Regional Office in advance and the EPA Regional Office authorizes coverage under this permit after you have included appropriate controls and implementation procedures designed to ensure that your use of cationic treatment chemicals will not lead to a violation of water quality standards.

8.G.4.1.9 Site stabilization requirements for earth-disturbing activities performed for purposes of mine site preparation as defined in 8.G.3.2(a) (i.e., not applicable to construction of staging areas for structures and access roads as defined in 8.G.3.2(b)). You must comply with the following stabilization requirements except where the intended function of the site accounts for such disturbed earth (e.g., the earth disturbances will become actively mined, or the controls implemented at the active mining area effectively control the disturbance) 
(although you are encouraged to do so within the active mining area, where appropriate):

- Temporary stabilization of disturbed areas. Stabilization measures must be initiated immediately in portions of the site where earth-disturbing activities performed for purposes of mine site preparation (as defined in 8.G.3.2(a)) have temporarily ceased, but in no case more than 14 days after such activities have temporarily ceased. In arid, semi-arid, and drought-stricken areas, or in areas subject to snow or freezing conditions, where initiating perennial vegetative stabilization measures is not possible within 14 days after earth-disturbing activities performed for purposes of mine site preparation has temporarily ceased, temporary vegetative stabilization measures must be initiated as soon as practicable. Until temporary vegetative stabilization is achieved, interim measures such as erosion control blankets with an appropriate seed base and tackifiers must be employed. In areas of the site where earth-disturbing activities performed for purposes of mine site preparation have permanently ceased prior to active mining, temporary stabilization measures must be implemented to minimize mobilization of sediment or other pollutants until active mining activities commence.

- Final stabilization of disturbed areas. Stabilization measures must be initiated immediately where earth-disturbing activities performed for purposes of mine site preparation (as defined in 8.G.3.2(a)) have permanently ceased, but in no case more than 14 days after the earthdisturbing activities have permanently ceased. In arid, semi-arid, and drought-stricken areas, or in areas subject to snow or freezing conditions, where initiating perennial vegetative stabilization measures is not possible within 14 days after earth-disturbing activities have permanently ceased, final vegetative stabilization measures must be initiated as soon as possible. Until final stabilization is achieved, temporary stabilization measures, such as erosion control blankets with an appropriate seed base and tackifiers, must be used.

\section{G.4.2 Additional Technology-Based Effluent Limits Applicable Only to the Construction of} Staging Areas for Structures and Access Roads. The following technology-based effluent limits apply to authorized discharges from earth-disturbing activities associated with the construction of staging areas and the construction of access roads, as defined in Part 8.G.3.2(b). These limits supersede the technology-based limits listed in Part 2.1.2 and Part 8.G.5 of the MSGP. These limits do not apply to earth-disturbing activities performed for purposes of mine site preparation (as defined in 8.G.3.2(a)).

8.G.4.2.1 Area of disturbance. You must minimize the amount of soil exposed during construction activities.

8.G.4.2.2 Erosion and sediment control design requirements. You must:

- Design, install and maintain effective erosion and sediment controls to minimize the discharge of pollutants from construction activities. Account for the following factors in designing your erosion and sediment controls:

- The expected amount, frequency, intensity and duration of precipitation;

- The nature of stormwater runoff and run-on at the site, including factors such as impervious surfaces, slopes and site drainage features;

- The range of soil particle sizes expected to be present on the site. 
- Direct discharges from your stormwater controls to vegetated areas of your site to increase sediment removal and maximize stormwater infiltration, including any natural buffers, unless infeasible. Use velocity dissipation devices if necessary to prevent erosion when directing stormwater to vegetated areas.

- If any stormwater flow becomes or will be channelized at your site, you must design erosion and sediment controls to control both peak flowrates and total stormwater volume to minimize channel and streambank erosion and scour in the immediate vicinity of discharge points.

- If you install stormwater conveyance channels, they must be designed to avoid unstabilized areas on the site and to reduce erosion, unless infeasible. In addition, you must minimize erosion of channels and their embankments, outlets, adjacent streambanks, slopes, and downstream waters during discharge conditions through the use of erosion controls and velocity dissipation devices within and along the length of any constructed stormwater conveyance channel, and at any outlet to provide a non-erosive flow velocity.

8.G.4.2.3 Natural Buffers. For any stormwater discharges from construction activities within 50 feet of a water of the U.S., you must comply with one of the following compliance alternatives:

1. Provide a 50-foot undisturbed natural buffer between construction activities and the water of the U.S.; or

2. Provide an undisturbed natural buffer that is less than 50 feet supplemented by additional erosion and sediment controls, which in combination, achieve a sediment load reduction that is equivalent to a 50-foot undisturbed natural buffer; or

3. If it is infeasible to provide an undisturbed natural buffer of any size, implement erosion and sediment controls that achieve a sediment load reduction that is equivalent to a 50 -foot undisturbed natural buffer.

There are exceptions when buffer requirements do not apply:

- There is no stormwater discharge from construction disturbances to a water of the U.S;

- The natural buffer has already been eliminated by preexisting development disturbances;

- The disturbance is for the construction of a water-dependent structure or construction approved under a CWA section 404 permit;

- For linear construction projects, you are not required to comply with the requirements if there are site constraints provided that, to the extent feasible, you limit disturbances within 50 feet of a water of the U.S. and/or you provide supplemental erosion and sediment controls to treat stormwater discharges from any disturbances within 50 feet of a water of the U.S.

See

http://water.epa.gov/polwaste/npdes/stormwater/upload/cgp2012_append ixg.pdf for guidance on complying with these alternatives. 
8.G.4.2.4 Soil or sediment stockpiles. In addition to the requirements in Part 8.G.4.1.5, you must locate any piles outside of any natural buffers established under Part 8.G.4.2.3.

8.G.4.2.5 Sediment basins. In addition to the requirements in Part 8.G.4.1.6, you must locate sediment basins outside of any surface waters and any natural buffers established under Part 8.G.4.2.3, and you must utilize outlet structures that withdraw water from the surface, unless infeasible.

8.G.4.2.6 Native topsoil preservation. You must preserve native topsoil removed during clearing, grading, or excavation, unless infeasible. Store topsoil in a manner that will maximize its use in reclamation or final vegetative stabilization (e.g., by keeping the topsoil stabilized with seed or similar measures). This requirement does not apply if the intended function of the disturbed area dictates that topsoil be disturbed or removed.

8.G.4.2.7 Steep slopes. You must minimize the disturbance of steep slopes. The permit does not prevent or prohibit disturbance on steep slopes.

Depending on site conditions and needs, disturbance on steep slopes may be necessary (e.g., a road cut in mountainous terrain; for grading steep slopes prior to erecting the mine office). Where steep slope disturbances are necessary, you can minimize the disturbances to steep slopes through the implementation of a number of standard erosion and sediment control practices, such as by phasing disturbances in these areas and using stabilization practices specifically for steep grades.

8.G.4.2.8 Soil compaction. Where final vegetative stabilization will occur or where infiltration practices will be installed, you must either restrict vehicle/ equipment use in these areas to avoid soil compaction or use soil conditioning techniques to support vegetative growth. Minimizing soil compaction is not required where compacted soil is integral to the functionality of the site.

8.G.4.2.9 Dewatering Practices. You are prohibited from discharging ground water or accumulated stormwater that is removed from excavations, trenches, foundations, vaults or other similar points of accumulation, unless such waters are first effectively managed by appropriate controls (e.g., sediment basins or sediment traps, sediment socks, dewatering tanks, tube settlers, weir tanks, or filtration systems). Uncontaminated, non-turbid dewatering water can be discharged without being routed to a control.

You must also meet the following requirements for dewatering activities:

- Discharge requirements:

- No discharging visible floating solids or foam;

- Remove oil, grease and other pollutants from dewatering water via an oil-water separator or suitable filtration device (such as a cartridge filter);

- Utilize vegetated upland areas of the site, to the extent feasible, to infiltrate dewatering water before discharge. In no case shall waters of the U.S. be considered part of the treatment area;

- Implement velocity dissipation devices at all points where dewatering water is discharged;

- Haul backwash water away for disposal or return it to the beginning of the treatment process; and 
- Clean or replace the filter media used in dewatering devices when the pressure differential equals or exceeds the manufacturer's specifications.

- Treatment chemical restrictions: If you use polymers, flocculants or other chemicals to treat dewatering water, you must comply with the requirements in Parts 8.G.4.1.8.

\section{G.4.2.10 Pollution prevention requirements.}

- Prohibited discharges (this non-exhaustive list of prohibited nonstormwater discharges is included here as a reminder that only the only allowable non-stormwater discharges are those enumerated in Part 1.1.3):

- Wastewater from washout of concrete;

- Wastewater from washout and cleanout of stucco, paint, form release oils, curing compounds, and other construction materials;

- Fuels, oils, or other pollutants used for operation and maintenance of vehicles or equipment;

- Soaps, solvents, or detergents used in vehicle or equipment washing;

- Toxic or hazardous substances from a spill or other release.

- Design and location requirements: Minimize the discharge of pollutants from pollutant sources by:

- Minimizing exposure;

- Using secondary containment, spill kits, or other equivalent measures;

- Locating pollution sources away from surface waters, storm sewer inlets, and drainageways;

- Cleaning up spills immediately (do not clean by hosing area down).

- Pollution prevention requirements for wash waters: Minimize the discharge of pollutants from equipment and vehicle washing, wheel wash water, and other wash waters. Wash waters must be treated in a sediment basin or alternative control that provides equivalent or better treatment prior to discharge;

- Pollution prevention requirements for the storage, handling, and disposal of construction products, materials, and wastes: Minimize the exposure of building materials, building products, construction wastes, trash, landscape materials, fertilizers, pesticides, herbicides, detergents, sanitary waste, and other materials present on the site to stormwater. Minimization of exposure is not required in cases where the exposure to stormwater will not result in a discharge of pollutants, or where exposure of a specific material or product poses little risk of stormwater contamination (such as final products and materials intended for outdoor use).

\section{G.4.2.11 Site Stabilization requirements for the construction of staging areas for} structures and access roads as defined in 8.G.3.2(b) (i.e., not applicable to earth-disturbing activities performed for purposes of mine site preparation as defined in 8.G.3.2(a)). You must comply with the following stabilization requirements, except where the intended function of the site accounts for such disturbed earth (e.g., the area of construction will become actively mined, or the controls implemented at the active mining area effectively control the disturbance):

- $\quad$ By no later than the end of the next work day after construction work in an area has stopped permanently or temporarily ("temporarily" means the land will be idle for a period of 14 days or more but earth-disturbing activities will resume in the future), immediately initiate stabilization measures; 
- If using vegetative measures, by no later than 14 days after initiating stabilization:

- Seed or plant the area, and provide temporary cover to protect the planted area;

- Once established, vegetation must be uniform, perennial (if final stabilization), and cover at least $70 \%$ of stabilized area based on density of native vegetation.

- If using non-vegetative stabilization, by no later than 14 days after initiating stabilization:

- Install or apply all non-vegetative measures;

- Cover all areas of exposed soil.

Note: For the purposes of this permit, EPA will consider any of the following types of activities to constitute the initiation of stabilization: 1. Prepping the soil for vegetative or non-vegetative stabilization; 2 . Applying mulch or other non-vegetative product to the exposed area; 3 . Seeding or planting the exposed area; 4. Starting any of the activities in \# $1-3$ on a portion of the area to be stabilized, but not on the entire area; and 5. Finalizing arrangements to have stabilization product fully installed in compliance with the applicable deadline for completing stabilization.

Exceptions:

- Arid, semi-arid (if construction occurs during seasonally dry period), or drought-stricken areas:

- Within 14 days of stopping construction work in an area, install any necessary non-vegetative stabilization measures;

- Initiate vegetative stabilization as soon as conditions on the site allow;

- Document the schedule that will be followed for initiating and completing vegetative stabilization;

- Plant the area so that within 3 years the $70 \%$ cover requirement is met.

- Sites affected by severe storm events or other unforeseen circumstances:

- Initiate vegetative stabilization as soon conditions on the site allow;

- Document the schedule that will be followed for initiating and completing vegetative stabilization;

- Plant the area so that so that within 3 years the $70 \%$ cover requirement is met.

\section{G.4.3 Water Quality-Based Requirements Applicable to Earth-Disturbing Activities Conducted Prior to Active Mining Activities.}

The following water quality-based limits apply to earth-disturbing activities conducted prior to active mining activities defined in Part 8.G.3.2(a) and 8.G.3.2(b), in addition to the water quality-based limits in Part 2.2 of the MSGP.

Stricter requirements apply if your site will discharge to an impaired water or a water that is identified by your state, tribe, or EPA as a Tier 2 or Tier 2.5 for antidegradation purposes:

- More rapid stabilization of exposed areas: Complete initial stabilization activities within 7 days of stopping earth-disturbing work.

- More frequent site inspections: Once every 7 days and within 24 hours of a storm event of 0.25 inches or greater. 


\section{G.4.4 Inspection Requirements Applicable to Earth-Disturbing Activities Conducted Prior to Active Mining Activities.}

The following requirements supersede the inspection requirements in Part 3 and 8.G.7 of the MSGP for earth-disturbing activities conducted prior to active mining activities defined in Part 8.G.3.2(a) and 8.G.3.2(b).

\section{G.4.4.1 Inspection frequency}

- At least once every 7 calendar days, or

- Once every 14 calendar days and within 24 hours of a storm event of 0.25 inches or greater.

Note:

- Inspections only required during working hours;

- Inspections not required during unsafe conditions; and

- If you choose to inspect once every 14 days, you must have a method for measuring rainfall amount on site (either rain gauge or representative weather station)

Note: To determine if a storm event of 0.25 inches or greater has occurred on your site, you must either keep a properly maintained rain gauge on your site, or obtain the storm event information from a weather station that is representative of your location. For any day of rainfall during normal business hours that measures 0.25 inches or greater, you must record the total rainfall measured for that day.

Note: You are required to specify in your SWPPP which schedule you will be following.

Note: "Within 24 hours of the occurrence of a storm event" means that you are required to conduct an inspection within 24 hours once a storm event has produced 0.25 inches, even if the storm event is still continuing. Thus, if you have elected to inspect bi-weekly and there is a storm event at your site that continues for multiple days, and each day of the storm produces 0.25 inches or more of rain, you are required to conduct an inspection within 24 hours of the first day of the storm and within 24 hours after the end of the storm.

\section{G.4.4.2 Reductions in inspection frequency.}

- Stabilized areas: You may reduce the frequency of inspections to once per month in any area of your site where stabilization has occurred pursuant to Part 8.G.4.1.9 or 8.G.4.2.11.

- Arid, semi-arid, and drought stricken areas: If earth-disturbing activities are occurring during the seasonally dry period or during a period in which drought is predicted to occur, you may reduce inspections to once per month and within 24 hours of a 0.25 inch storm event.

- Frozen conditions: You may temporarily suspend or reduce inspections to once per month until thawing conditions occur if frozen conditions are continuous and disturbed areas have been stabilized. For extreme conditions in remote areas, e.g., where transit to the site is perilous/restricted or temperatures are routinely below freezing, you may suspend inspections until the conditions are conducive to safe access, and more frequent inspections can resume.

8.G.4.4.3 Areas to be inspected. You must at a minimum inspect the all of the following areas:

- Disturbed areas;

- Stormwater controls and pollution prevention measures;

- Locations where stabilization measures have been implemented;

- Material, waste, borrow, or equipment storage and maintenance areas; 
- Areas where stormwater flows;

- Points of discharge.

8.G.4.4.4 What to check for during inspections. At a minimum you must check:

- Whether all stormwater controls are installed, operational and working as intended;

- Whether any new or modified stormwater controls are needed;

- For conditions that could lead to a spill or leak;

- For visual signs of erosion/sedimentation at points of discharge.

If a discharge is occurring, check:

- The quality and characteristics of the discharge;

- Whether controls are operating effectively.

8.G.4.4.5 Inspection report. Within 24 hours of an inspection, complete a report that includes:

- Inspection date;

- Name and title of inspector(s);

- Summary of inspection findings;

- Rainfall amount that triggered the inspection (if applicable);

- If it was unsafe to inspect a portion of the site, include documentation of the reason and the location(s);

- Each inspection report must be signed;

- Keep a current copy of all reports at the site or at an easily accessible location.

\section{G.5 Technology-Based Effluent Limits for Active Mining Activities.}

Note: These requirements do not apply for any discharges from earth-disturbing activities conducted prior to active mining as defined in 8.G.3.2(a) or 8.G.3.2(b).

8.G.5.1 Employee training. (See also Part 2.1.2.8) Conduct employee training at least annually at active and temporarily inactive facilities.

8.G.5.2 Stormwater controls. Apart from the control measures you implement to meet your Part 2 technology-based effluent limits, where necessary to minimize pollutant discharges in stormwater, implement the following control measures at your site. The potential pollutants identified in Part 8.G.6.3 shall determine the priority and appropriateness of the control measures selected. For mines subject to dust control requirements under state or county air quality permits, provided the requirements are equivalent, compliance with such air permit dust requirements shall constitute compliance with the dust control effluent limit in Part 2.1.2.10.

Stormwater diversions: Divert stormwater away from potential pollutant sources through implementation of control measures such as the following, where determined to be feasible (list not exclusive): interceptor or diversion controls (e.g., dikes, swales, curbs, berms); pipe slope drains; subsurface drains; conveyance systems (e.g., channels or gutters, open-top box culverts, and waterbars; rolling dips and road sloping; roadway surface water deflector and culverts); or their equivalents.

Capping: When capping is necessary to minimize pollutant discharges in stormwater, identify the source being capped and the material used to construct the cap.

Treatment: If treatment of stormwater (e.g., chemical or physical systems, oil - water separators, artificial wetlands) is necessary to protect water quality, describe the type and location of treatment used. Passive and/or active treatment of stormwater runoff is encouraged, where feasible. Treated runoff may be discharged as a stormwater 
source regulated under this permit provided the discharge is not combined with discharges subject to effluent limitation guidelines for the Ore Mining and Dressing Point Source Category (40 CFR Part 440).

8.G.5.3 Discharge testing. (See also Part 5.2.3.4) Test or evaluate all outfalls covered under this permit for the presence of specific mining-related but unauthorized non-stormwater discharges such as seeps or adit discharges, or discharges subject to effluent limitations guidelines (e.g., 40 CFR Part 440), such as mine drainage or process water. Alternatively (if applicable), you may keep a certification with your SWPPP consistent with Part 8.G.6.6.

\section{G.6 Additional SWPPP Requirements for Mining Operations.}

Note: The requirements in Part 8.G.6 are not applicable to inactive metal mining facilities.

8.G.6.1 Nature of industrial activities. (See also Part 5.2.2) Briefly document in your SWPPP the mining and associated activities that can potentially affect the stormwater discharges covered by this permit, including a general description of the location of the site relative to major transportation routes and communities.

8.G.6.2 Site map. (See also Part 5.2.2) Document in your SWPPP the locations of the following (as appropriate): mining or milling site boundaries; access and haul roads; outline of the drainage areas of each stormwater outfall within the facility with indications of the types of discharges from the drainage areas; location(s) of all permitted discharges covered under an individual NPDES permit; outdoor equipment storage, fueling, and maintenance areas; materials handling areas; outdoor manufacturing, outdoor storage, and material disposal areas; outdoor chemicals and explosives storage areas; overburden, materials, soils, or waste storage areas; location of mine drainage (where water leaves mine) or other process water; tailings piles and ponds (including proposed ones); heap leach pads; off-site points of discharge for mine drainage and process water; surface waters; boundary of tributary areas that are subject to effluent limitations guidelines; and location(s) of reclaimed areas.

8.G.6.3 Potential pollutant sources. (See also Part 5.2.3) For each area of the mine or mill site where stormwater discharges associated with industrial activities occur, identify the types of pollutants (e.g., heavy metals, sediment) likely to be present in significant amounts. Consider these factors: the mineralogy of the ore and waste rock (e.g., acid forming); toxicity and quantity of chemicals used, produced, or discharged; the likelihood of contact with stormwater; vegetation of site (if any); and history of significant leaks or spills of toxic or hazardous pollutants. Also include a summary of any existing ore or waste rock or overburden characterization data and test results for potential generation of acid rock. If any new data is acquired due to changes in ore type being mined, update your SWPPP with this information.

8.G.6.4 Documentation of control measures. Document all control measures that you implement consistent with Part 8.G.5.2. If control measures are implemented or planned but are not listed in Part 8.G.5.2 (e.g., substituting a less toxic chemical for a more toxic one), include descriptions of them in your SWPPP. If you are in compliance with dust control requirements under state or county air quality permits, you must include (or summarize, as necessary) what the state or county air quality permit dust control requirements are and how you've achieved compliance with them.

8.G.6.5 Employee training. All employee training(s) must be documented in the SWPPP. 
8.G.6.6 Certification of permit coverage for commingled non-stormwater discharges. If you are able, consistent with Part 8.G.5.3 above, to certify that a particular discharge composed of commingled stormwater and non-stormwater is covered under a separate NPDES permit, and that permit subjects the non-stormwater portion to effluent limitations prior to any commingling, retain such certification with your SWPPP. This certification must identify the non-stormwater discharges, the applicable NPDES permit(s), the effluent limitations placed on the non-stormwater discharge by the permit(s), and the points at which the limitations are applied.

\section{G.7 Additional Inspection Requirements. (See also Part 3.1)}

Except for earth-disturbing activities conducted prior to active mining activities as defined in Part 8.G.3.2(a) and 8.G.3.2(b), which are subject to Part 8.G.4.4, inspect sites at least quarterly unless adverse weather conditions make the site inaccessible. Sites which discharge to waters designated as Tier 2 or 2.5 or waters which are impaired for sediment or nitrogen must be inspected monthly. See Part 8.G.8.4 for inspection requirements for inactive and unstaffed sites.

8.G.8 Monitoring and Reporting Requirements. (See also Part 6)

Note: There are no Part 8.G.8 monitoring and reporting or impaired waters monitoring requirements for inactive and unstaffed sites.

\section{G.8.1 Benchmark Monitoring for Active Copper Ore Mining and Dressing Facilities.}

Table 8.G-1 identifies benchmarks that apply to active copper ore mining and dressing facilities. These benchmarks apply to both your primary industrial activity and any colocated industrial activities.

\begin{tabular}{|l|c|c|}
\hline \multicolumn{2}{|c|}{ Table 8.G-1 } \\
\hline \multicolumn{1}{|c|}{$\begin{array}{c}\text { Subsector } \\
\text { (You may be subject to requirements for } \\
\text { more than one sector/subsector) }\end{array}$} & Parameter & $\begin{array}{c}\text { Benchmark } \\
\text { Monitoring } \\
\text { Concentration }\end{array}$ \\
\hline $\begin{array}{l}\text { Subsector G1. Active Copper Ore Mining } \\
\text { and Dressing Facilities } \\
\text { (SIC 1021) }\end{array}$ & $\begin{array}{c}\text { Total Suspended Solids } \\
\text { (TSS) }\end{array}$ & $100 \mathrm{mg} / \mathrm{L}$ \\
\cline { 2 - 3 } & $\begin{array}{c}\text { Nitrate plus Nitrite } \\
\text { Nitrogen }\end{array}$ & $0.68 \mathrm{mg} / \mathrm{L}$ \\
\cline { 2 - 3 } & $\begin{array}{c}\text { Chemical Oxygen } \\
\text { Demand (COD) }\end{array}$ & $120 \mathrm{mg} / \mathrm{L}$ \\
\hline
\end{tabular}

8.G.8.2 Benchmark Monitoring Requirements for Discharges From Waste Rock and Overburden Piles at Active Metal Mining Facilities. For discharges from waste rock and overburden piles, perform benchmark monitoring once in the first year for the parameters listed in Table 8.G-2, and twice annually in all subsequent years of coverage under this permit for any parameters for which the benchmark has been exceeded. You are also required to conduct analytic monitoring for the parameters listed in Table 8.G-3 in accordance with the requirements in Part 8.G.8.3. The Director may also notify you that you must perform additional monitoring to accurately characterize the quality and quantity of pollutants discharged from your waste rock and overburden piles. 


\begin{tabular}{|c|c|c|}
\hline \multicolumn{3}{|c|}{ Table 8.G-2. } \\
\hline $\begin{array}{l}\text { Subsector } \\
\text { (Discharges may be subject to } \\
\text { requirements for more than one } \\
\text { sector/subsector) }\end{array}$ & Parameter & $\begin{array}{c}\text { Benchmark Monitoring } \\
\text { Concentration }\end{array}$ \\
\hline \multirow{16}{*}{$\begin{array}{l}\text { Subsector G2. Iron Ores; Copper Ores; } \\
\text { Lead and Zinc Ores; Gold and Silver } \\
\text { Ores; Ferroalloy Ores, Except } \\
\text { Vanadium; and Miscellaneous Metal } \\
\text { Ores (SIC Codes 1011, 1021, 1031, } \\
\text { 1041, 1044, 1061, 1081, 1094, 1099) } \\
\text { (Note: when analyzing hardness for a } \\
\text { suite of metals, it is more cost effective } \\
\text { to add analysis of calcium and } \\
\text { magnesium, and have hardness } \\
\text { calculated than to require hardness } \\
\text { analysis separately) }\end{array}$} & Total Suspended Solids (TSS) & $100 \mathrm{mg} / \mathrm{L}$ \\
\hline & Turbidity & $50 \mathrm{NTU}$ \\
\hline & $\mathrm{pH}$ & 6.0-9.0 s.u. \\
\hline & $\begin{array}{l}\text { Hardness (as } \mathrm{CaCO}_{3} ; \text { calc. } \\
\text { from } \mathrm{Ca}, \mathrm{Mg})^{2}\end{array}$ & no benchmark value \\
\hline & Total Antimony & $0.64 \mathrm{mg} / \mathrm{L}$ \\
\hline & $\begin{array}{c}\text { Total Arsenic (freshwater) } \\
\text { Total Arsenic } \\
\text { (saltwater) }^{1} \\
\end{array}$ & $\begin{array}{c}0.15 \mathrm{mg} / \mathrm{L} \\
0.069 \mathrm{mg} / \mathrm{L}\end{array}$ \\
\hline & Total Beryllium & $0.13 \mathrm{mg} / \mathrm{L}$ \\
\hline & $\begin{array}{c}\text { Total Cadmium (freshwater) }^{2} \\
\text { Total Cadmium (saltwater) }\end{array}$ & $\begin{array}{c}\text { Hardness Dependent } \\
0.04 \mathrm{mg} / \mathrm{L}\end{array}$ \\
\hline & $\begin{array}{c}\text { Total Copper (freshwater) } \\
\text { Total Copper (saltwater) }\end{array}$ & $\begin{array}{c}\text { Hardness Dependent } \\
0.0048 \mathrm{mg} / \mathrm{L} \\
\end{array}$ \\
\hline & Total Iron & $1.0 \mathrm{mg} / \mathrm{L}$ \\
\hline & $\begin{array}{l}\text { Total Lead (freshwater) } \\
\text { Total Lead (saltwater) } \\
\end{array}$ & $\begin{array}{c}\text { Hardness Dependent } \\
0.21 \mathrm{mg} / \mathrm{L} \\
\end{array}$ \\
\hline & $\begin{array}{l}\text { Total Mercury (freshwater) } \\
\text { Total Mercury (saltwater)' }\end{array}$ & $\begin{array}{l}0.0014 \mathrm{mg} / \mathrm{L} \\
0.0018 \mathrm{mg} / \mathrm{L}\end{array}$ \\
\hline & $\begin{array}{l}\text { Total Nickel (freshwater) } \\
\text { Total Nickel (saltwater) }\end{array}$ & $\begin{array}{c}\text { Hardness Dependent } \\
0.074 \mathrm{mg} / \mathrm{L} \\
\end{array}$ \\
\hline & $\begin{array}{l}\text { Total Selenium (freshwater) } \\
\text { Total Selenium (saltwater)' }\end{array}$ & $\begin{array}{c}0.005 \mathrm{mg} / \mathrm{L} \\
0.29 \mathrm{mg} / \mathrm{L} \\
\end{array}$ \\
\hline & $\begin{array}{l}\text { Total Silver (freshwater) } \\
\text { Total Silver (saltwater) } \\
\end{array}$ & $\begin{array}{c}\text { Hardness Dependent } \\
0.0019 \mathrm{mg} / \mathrm{L} \\
\end{array}$ \\
\hline & $\begin{array}{l}\text { Total Zinc (freshwater) } \\
\text { Total Zinc (saltwater) } \\
\end{array}$ & $\begin{array}{c}\text { Hardness Dependent } \\
0.09 \mathrm{mg} / \mathrm{L}\end{array}$ \\
\hline
\end{tabular}

'Saltwater benchmark values apply to stormwater discharges into saline waters where indicated.

2 The freshwater benchmark values of some metals are dependent on water hardness. For these parameters, permittees must determine the hardness of the receiving water (see Appendix J, "Calculating Hardness in Receiving Waters for Hardness Dependent Metals," for methodology), in accordance with Part 6.2.1.1, to identify the applicable 'hardness range' for determining their benchmark value applicable to their facility. Hardness Dependent Benchmarks follow in the table below:

\begin{tabular}{|l|l|l|l|l|l|l|}
\hline Freshwater Hardness Range & $\begin{array}{l}\text { Cadmium } \\
(\mathrm{mg} / \mathrm{L})\end{array}$ & $\begin{array}{l}\text { Copper } \\
(\mathrm{mg} / \mathrm{L})\end{array}$ & $\begin{array}{l}\text { Lead } \\
(\mathrm{mg} / \mathrm{L})\end{array}$ & $\begin{array}{l}\text { Nickel } \\
(\mathrm{mg} / \mathrm{L})\end{array}$ & $\begin{array}{l}\text { Silver } \\
(\mathrm{mg} / \mathrm{L})\end{array}$ & $\begin{array}{l}\text { Zinc } \\
\text { (mg/L) }\end{array}$ \\
\hline $0-24.99 \mathrm{mg} / \mathrm{L}$ & 0.0005 & 0.0038 & 0.014 & 0.15 & 0.0007 & 0.04 \\
\hline $25-49.99 \mathrm{mg} / \mathrm{L}$ & 0.0008 & 0.0056 & 0.023 & 0.20 & 0.0007 & 0.05 \\
\hline $50-74.99 \mathrm{mg} / \mathrm{L}$ & 0.0013 & 0.0090 & 0.045 & 0.32 & 0.0017 & 0.08 \\
\hline $75-99.99 \mathrm{mg} / \mathrm{L}$ & 0.0018 & 0.0123 & 0.069 & 0.42 & 0.0030 & 0.11 \\
\hline $100-124.99 \mathrm{mg} / \mathrm{L}$ & 0.0023 & 0.0156 & 0.095 & 0.52 & 0.0046 & 0.13 \\
\hline $125-149.99 \mathrm{mg} / \mathrm{L}$ & 0.0029 & 0.0189 & 0.122 & 0.61 & 0.0065 & 0.16 \\
\hline $150-174.99 \mathrm{mg} / \mathrm{L}$ & 0.0034 & 0.0221 & 0.151 & 0.71 & 0.0087 & 0.18 \\
\hline $175-199.99 \mathrm{mg} / \mathrm{L}$ & 0.0039 & 0.0253 & 0.182 & 0.80 & 0.0112 & 0.20 \\
\hline $200-224.99 \mathrm{mg} / \mathrm{L}$ & 0.0045 & 0.0285 & 0.213 & 0.89 & 0.0138 & 0.23 \\
\hline $225-249.99 \mathrm{mg} / \mathrm{L}$ & 0.0050 & 0.0316 & 0.246 & 0.98 & 0.0168 & 0.25 \\
\hline $250+\mathrm{mg} / \mathrm{L}$ & 0.0053 & 0.0332 & 0.262 & 1.02 & 0.0183 & 0.26 \\
\hline
\end{tabular}


8.G.8.3 Additional Analytic Monitoring Requirements for Discharges From Waste Rock and Overburden Piles at Active Metal Mining Facilities. In addition to the monitoring required in Part 8.G.8.2 for discharges from waste rock and overburden piles, you must also conduct monitoring for additional parameters based on the type of ore you mine at your site. Where a parameter in Table 8.G-3 is the same as a pollutant you are required to monitor for in Table 8.G-2 (i.e., for all of the metals), you must use the corresponding benchmark in Table 8.G-2 and you may use any monitoring results conducted for Part 8.G.8.2 to satisfy the monitoring requirement for that parameter for Part 8.G.8.3. For radium and uranium, which do not have corresponding benchmarks in Table 8.G-2, there are no applicable benchmarks. The frequency and schedule for monitoring for these additional parameters is the same as that specified in Part 6.2.1.2.

\begin{tabular}{|c|c|c|c|}
\hline \multicolumn{4}{|c|}{$\begin{array}{c}\text { Table 8.G-3. Additional Monitoring Requirements for Discl } \\
\text { Overburden Piles }\end{array}$} \\
\hline \multicolumn{4}{|c|}{ Supplemental Requirements } \\
\hline \multirow[b]{2}{*}{ Type of Ore Mined } & \multicolumn{3}{|c|}{ Pollutants of Concern } \\
\hline & $\begin{array}{l}\text { Total Suspended } \\
\text { Solids (TSS) }\end{array}$ & $\mathrm{pH}$ & Metals, Total \\
\hline Tungsten Ore & $\mathrm{X}$ & $\mathrm{X}$ & $\begin{array}{c}\text { Arsenic, Cadmium (H), Copper } \\
(H) \text {, Lead }(H) \text {, Zinc }(H) \\
\end{array}$ \\
\hline Nickel Ore & $\mathrm{X}$ & $X$ & $\begin{array}{c}\text { Arsenic, Cadmium (H), Copper } \\
(H) \text {, Lead }(H) \text {, Zinc }(H) \\
\end{array}$ \\
\hline Aluminum Ore & $\mathrm{X}$ & $\mathrm{X}$ & Iron \\
\hline Mercury Ore & $\mathrm{X}$ & $\mathrm{X}$ & Nickel $(\mathrm{H})$ \\
\hline Iron Ore & $\mathrm{X}$ & $\mathrm{X}$ & Iron (Dissolved) \\
\hline Platinum Ore & & & $\begin{array}{l}\text { Cadmium }(\mathrm{H}) \text {, Copper }(\mathrm{H}) \text {, } \\
\text { Mercury, Lead }(\mathrm{H}) \text {, Zinc }(\mathrm{H})\end{array}$ \\
\hline Titanium Ore & $\mathrm{X}$ & $\mathrm{X}$ & Iron, Nickel $(\mathrm{H})$, Zinc $(\mathrm{H})$ \\
\hline Vanadium Ore & $\mathrm{X}$ & $\mathrm{X}$ & $\begin{array}{c}\text { Arsenic, Cadmium (H), Copper } \\
(H) \text {, Lead }(H) \text {, Zinc }(H)\end{array}$ \\
\hline Molybdenum & $\mathrm{X}$ & $x$ & $\begin{array}{l}\text { Arsenic, Cadmium (H), Copper } \\
(H) \text {, Lead }(H) \text {, Mercury, Zinc }(H)\end{array}$ \\
\hline $\begin{array}{l}\text { Uranium, Radium, and } \\
\text { Vanadium Ore }\end{array}$ & $X$ & $x$ & $\begin{array}{l}\text { Chemical Oxygen Demand, } \\
\text { Arsenic, Radium (Dissolved and } \\
\text { Total), Uranium, Zinc (H) }\end{array}$ \\
\hline
\end{tabular}

Note: An " $\mathrm{X}$ " indicated for TSS and/or pH means that you are required to monitor for those parameters. (H) indicates that hardness must also be measured when this pollutant is measured.

8.G.8.4 Inactive and Unstaffed Sites - Conditional Exemption from No Exposure Requirements for Quarterly Visual Assessments and Routine Facility Inspections. As a Sector $G$ facility, if you are seeking to exercise a waiver from the quarterly visual assessment and routine facility inspection requirements for inactive and unstaffed sites (including temporarily inactive sites), you are conditionally exempt from the requirement to certify that "there are no industrial materials or activities exposed to stormwater" in Parts 3.1.1 and 3.2.3. This exemption is conditioned on the following:

- If circumstances change and your facility becomes active and/or staffed, this exception no longer applies and you must immediately begin complying with the quarterly visual assessment requirements; and

- EPA retains the authority to revoke this exemption and/or the monitoring waiver where it is determined that the discharge causes, has a reasonable potential to 
cause, or contributes to an instream excursion above an applicable water quality standard, including designated uses.

Subject to the two conditions above, if your facility is inactive and unstaffed, you are waived from the requirement to conduct quarterly visual assessments and routine facility inspections. You must still do an annual site inspection in accordance with Part 3.1. You are encouraged to inspect your site more frequently where you have reason to believe that severe weather or natural disasters may have damaged control measures or increased discharges.

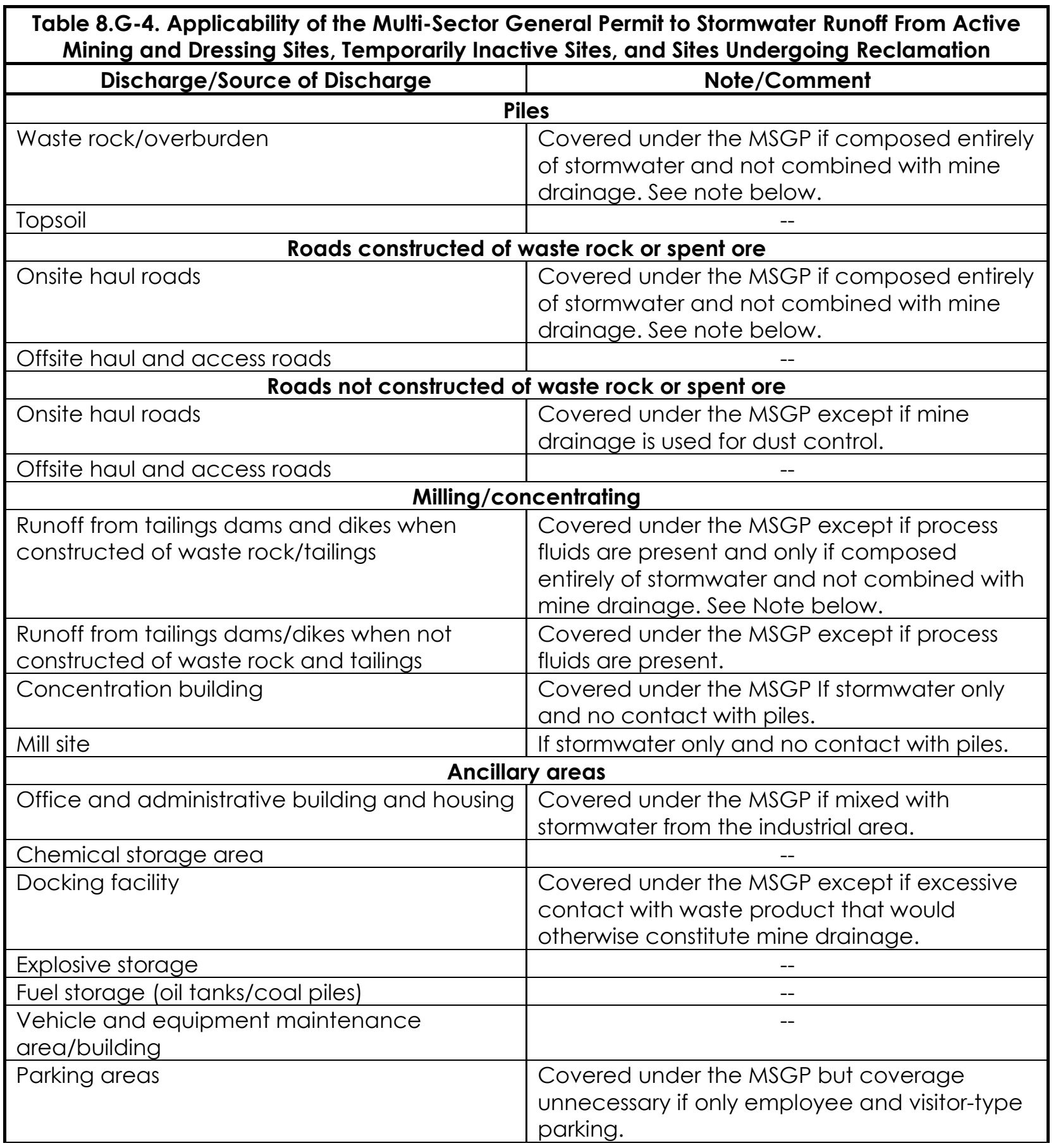




\begin{tabular}{|c|c|}
\hline $\begin{array}{l}\text { Table 8.G-4. Applicability of the Multi-Sector } \\
\text { Mining and Dressing Sites, Temporarily In }\end{array}$ & $\begin{array}{l}\text { neral Permit to Stormwater Runoff From Active } \\
\text { re Sites, and Sites Undergoing Reclamation }\end{array}$ \\
\hline Discharge/Source of Discharge & Note/Comment \\
\hline Pol & plant \\
\hline Truck wash area & $\begin{array}{l}\text { Covered under the MSGP except when } \\
\text { excessive contact with waste product that } \\
\text { would otherwise constitute mine drainage. }\end{array}$ \\
\hline Reclamatic & related areas \\
\hline Any disturbed area (unreclaimed) & $\begin{array}{l}\text { Covered under the MSGP only if not in active } \\
\text { mining area. }\end{array}$ \\
\hline $\begin{array}{l}\text { Reclaimed areas released from reclamation } \\
\text { requirements prior to Dec. } 17,1990\end{array}$ & -- \\
\hline $\begin{array}{l}\text { Partially/inadequately reclaimed areas or } \\
\text { areas not released from reclamation } \\
\text { requirements }\end{array}$ & $-\overline{-}$ \\
\hline
\end{tabular}

Note: Stormwater runoff from these sources are subject to the NPDES program for stormwater unless mixed with discharges subject to 40 CFR Part 440 that are regulated by another permit prior to mixing. Non-stormwater discharges from these sources are subject to NPDES permitting and may be subject to the effluent limitation guidelines under 40 CFR Part 440. Discharges from overburden/waste rock and overburden/waste rock-related areas are not subject to 40 CFR Part 440 unless: (1) it drains naturally (or is intentionally diverted) to a point source; and (2) combines with "mine drainage" that is otherwise regulated under the Part 440 regulations. For such sources, coverage under this permit would be available if the discharge composed entirely of stormwater does not combine with other sources of mine drainage that are not subject to 40 CFR Part 440, as well as meeting other eligibility criteria contained in Part 1.1 of the permit. Operators bear the initial responsibility for determining the applicable technology-based standard for such discharges. EPA recommends that operators contact the relevant NPDES permit issuance authority for assistance to determine the nature and scope of the "active mining area" on a mine-by-mine basis, as well as to determine the appropriate permitting mechanism for authorizing such discharges.

\section{G.9. Termination of Permit Coverage}

8.G.9.1 Termination of Permit Coverage for Sites Reclaimed After December 17, 1990. A site or a portion of a site that has been released from applicable state or federal reclamation requirements after December 17, 1990, is no longer required to maintain coverage under this permit. If the site or portion of a site reclaimed after December 17, 1990, was not subject to reclamation requirements, the site or portion of the site is no longer required to maintain coverage under this permit if the site or portion of the site has been reclaimed as defined in Part 8.G.3.3.

8.G.9.2 Termination of Permit Coverage for Sites Reclaimed Before December 17, 1990. A site or portion of a site that was released from applicable state or federal reclamation requirements before December 17, 1990, or that was otherwise reclaimed before December 17, 1990, is no longer required to maintain coverage under this permit if the site or portion of the site has been reclaimed. A site or portion of a site is considered to have been reclaimed if: (1) stormwater runoff that comes into contact with raw materials, intermediate byproducts, finished products, and waste products does not have the potential to cause or contribute to violations of state water quality standards, (2) soil disturbing activities related to mining at the sites or portion of the site have been completed, (3) the site or portion of the site has been stabilized to minimize soil erosion, and (4) as appropriate depending on location, size, and the potential to contribute pollutants to stormwater discharges, the site or portion of the site has been revegetated, will be amenable to natural revegetation, or will be left in a condition consistent with the post-mining land use. 


\section{Part 8 - Sector-Specific Requirements for Industrial Activity}

\section{Subpart H - Sector H - Coal Mines and Coal Mining-Related Facilities.}

You must comply with Part 8 sector-specific requirements associated with your primary industrial activity and any co-located industrial activities, as defined in Appendix A. The sectorspecific requirements apply to those areas of your facility where those sector-specific activities occur. These sector-specific requirements are in addition to any requirements specified elsewhere in this permit.

Note: Where compliance with a requirement in a separate exploration permit, mining permit, reclamation plan, Surface Mining Control and Reclamation Act (SMCRA) requirements, etc. will result in you fully meeting any requirement in this Subpart, you are considered to have complied with the relevant requirement in this Subpart. You must include documentation in your SWPPP describing your rationale for concluding that any particular action on your part is sufficient to comply with the corresponding requirement in this Subpart.

\section{H.1 Covered Stormwater Discharges.}

The requirements in Subpart $\mathrm{H}$ apply to stormwater discharges associated with industrial activity from Coal Mines and Coal Mining-Related facilities as identified by the SIC Codes specified under Sector H in Table D-1 of Appendix D.

\section{H.2 Limitations on Coverage.}

8.H.2.1 Prohibition of Non-Stormwater Discharges. (See also Part 1.1.4) Not covered by this permit: discharges from pollutant seeps or underground drainage from inactive coal mines and refuse disposal areas that do not result from precipitation events, and discharges from floor drains in maintenance buildings and other similar drains in mining and preparation plant areas. (EPA includes these prohibited non-stormwater discharges here solely as a helpful reminder to the operator that the only nonstormwater discharges authorized by this permit are at Part 1.1.3).

8.H.2.2 Discharges Subject to Stormwater Effluent Guidelines. (See also Part 1.1.2.4) Not authorized by this permit: stormwater discharges subject to an existing effluent limitation guideline at 40 CFR Part 434.

\section{H.3 Definitions}

The following definitions are not intended to supersede the definitions of active and inactive mining facilities established by 40 CFR 122.26 (b) (14)(iii).

8.H.3.1 Mining operations - For this permit, mining operations are grouped into two distinct categories, with distinct effluent limits and requirements applicable to each: a) earthdisturbing activities conducted prior to active mining activities); and b) active mining activities, which includes reclamation. "Mining operations" can occur at both inactive mining facilities and temporarily inactive mining facilities.

8.H.3.2 Earth-disturbing activities conducted prior to active mining activities - Consists of two classes of earth-disturbing (i.e., clearing, grading and excavation) activities:

a. activities performed for purposes of mine site preparation, including: cutting new rights of way (except when related to access road construction); providing access to a mine site for vehicles and equipment (except when related to access road construction); other earth disturbances associated with site preparation activities on any areas where active mining activities have not yet commenced (e.g., for heap leach pads, waste rock facilities, tailings impoundments, wastewater treatment plants); and 
b. construction of staging areas to prepare for erecting structures such as to house project personnel and equipment, mill buildings, etc., and construction of access roads. Earth-disturbing activities associated with the construction of staging areas and the construction of access roads conducted prior to active mining are considered to be "construction" and have additional effluent limits in Part 8.H.4.2.

8.H.3.3 Active mining activities - Activities related to the extraction, removal or recovery, and preparation of coal; removal of overburden and waste rock to expose mineable minerals; and site reclamation and closure activities. All such activities occur within the "active mining area." Reclamation involves activities undertaken, in compliance with applicable mined land reclamation requirements, to return the land to an appropriate post-mining contour and land use in order to meet applicable federal and state reclamation requirements. In addition, once earth-disturbing activities conducted prior to active mining activities have ceased and all related requirements in Part 8.H.4 have been met, and a well-delineated "active mining area" has been established, all activities (including any clearing, grading, and excavation) that occur within the active mining area are "active mining activities."

8.H.3.4 Active mining area - A place where work or other activity related to the extraction, removal or recovery of coal is being conducted, except, with respect to surface mines, any area of land on or in which grading has been completed to return the earth to desired contour and reclamation work has begun.

Note: Earth-disturbing activities described in the definition in Part 8.H.3.2 that occur on areas outside the active mining area (e.g., for expansion of the mine into undeveloped territory) are considered "earth-disturbing conducted prior to active mining activities", and must comply with the requirements in Part 8.H.4.

8.H.3.5 Inactive coal mining facility - A site or portion of a site where coal mining and/or milling occurred in the past but there are no active mining operations occurring as defined above, and where the inactive portion is not covered by an active mining permit issued by the applicable state or federal agency. An inactive coal mining facility has an identifiable owner / operator. Sites where mining claims are being maintained prior to disturbances associated with the extraction, beneficiation, or processing of mined materials and sites where minimal activities are undertaken for the sole purpose of maintaining a mining claim are not considered either active or inactive mining facilities and do not require an NPDES industrial stormwater permit.

8.H.3.6 Temporarily inactive coal mining facility - A site or portion of a site where coal mining and/or milling occurred in the past but currently are not being actively undertaken, and the facility is covered by an active mining permit issued by the applicable state or federal agency.

\section{H.4 Requirements Applicable to Earth-Disturbing Activities Conducted Prior to Active Mining Activities.}

Stormwater discharges from earth-disturbing activities conducted prior to active mining activities (defined in Part 8.H.3.2) are covered under this permit. For such earth-disturbing activities, you must comply with all applicable requirements in Parts 1-9 of the MSGP except for the technology-based effluent limits in Part 8.H.5 and Part 2.1.2, the inspection requirements in Part 8.H.7 and Part 3, and the monitoring requirements in Part 8.H.8 and Part 6.

Authorized discharges from areas where earth-disturbing activities have ceased and stabilization as specified in Part 8.H.4.19 or 8.H.4.2.11, where appropriate, has been completed (stabilization is not required for areas where active mining activities will occur), are no longer subject to the Part 8.H.4 requirements. At such time, authorized discharges become subject to all 
other applicable requirements in the MSGP, including the effluent limits in Parts 2.1.2 and 8.H.5, the inspection requirements in Parts 3 and 8.H.7, and the monitoring requirements in Parts 6 and 8.H.8.

8.H.4.1 Technology-Based Effluent Limits Applicable to All Earth-Disturbing Activities Conducted Prior to Active Mining Activities. The following technology-based effluent limits apply to authorized discharges from all earth-disturbing activities conducted prior to active mining activities defined in Part 8.H.3.2(a) and 8.H.3.2(b). These limits supersede the technology-based limits listed in Part 2.1.2 and Part 8.H.5 of the MSGP.

\section{H.4.1.1 Erosion and sediment control installation requirements.}

- By the time construction activities commence, install and make operational downgradient sediment controls, unless this timeframe is infeasible. If infeasible you must install and make such controls operational as soon as practicable or as soon as site conditions permit.

- All other stormwater controls described in the SWPPP must be installed and made operational as soon as conditions on each portion of the site allows.

8.H.4.1.2 Erosion and sediment control maintenance requirements. You must:

- Ensure that all erosion and sediment controls remain in effective operating condition.

- Wherever you determine that a stormwater control needs maintenance to continue operating effectively, initiate efforts to fix the problem immediately after its discovery, and complete such work by the end of the next work day.

- When a stormwater control must be replaced or significantly repaired, complete the work within 7 days, unless infeasible. If 7 days is infeasible, you must complete the installation or repair as soon practicable.

8.H.4.1.3 Perimeter controls. You must:

- Install sediment controls along those perimeter areas of your disturbed area that will receive stormwater, except where site conditions prevent the use of such controls (in which case, maximize their installation to the extent practicable).

- Remove sediment before it accumulates to one-half of the above-ground height of any perimeter control.

8.H.4.1.4 Sediment track-out. For construction vehicles and equipment exiting the site directly onto paved roads, you must:

- Use appropriate stabilization techniques to minimize sediment track-out from vehicles and equipment prior to exit;

- Use additional controls to remove sediment from vehicle and equipment tires prior to exit, where necessary;

- Remove sediment that is tracked out onto paved roads by end of the work day.

Note: EPA recognizes that some fine grains may remain visible on the surfaces of off-site streets, other paved areas, and sidewalks even after you have implemented sediment removal practices. Such "staining" is not a violation of Part 8.H.4.1.4.

8.H.4.1.5 Soil or sediment stockpiles. You must:

- Minimize erosion of stockpiles from stormwater and wind via temporary cover, if feasible. 
- Prevent up-slope stormwater flows from causing erosion of stockpiles (e.g., by diverting flows around the stockpile).

- Minimize sediment from stormwater that runs off of stockpiles, using sediment controls (e.g., a sediment barrier or downslope sediment control).

8.H.4.1.6 Sediment basins. If you intend to install a sediment basin to treat stormwater from your earth-disturbing activities, you must:

- Provide storage for either (1) the 2-year, 24-hour storm, or (2) 3,600 cubic feet per acre drained.

- Prevent erosion of (1) basin embankments using stabilization controls (e.g., erosion control blankets), and (2) the inlet and outlet points of the basin using erosion controls and velocity dissipation devices.

8.H.4.1.7 Minimize dust. You must minimize the generation of dust through the appropriate application of water or other dust suppression techniques that minimize pollutants being discharged into surface waters.

8.H.4.1.8 Restrictions on use of treatment chemicals. If you intend to use sediment treatment chemicals at your site, you are subject to the following minimum requirements:

- Use conventional erosion and sediment controls prior to and after application of chemicals;

- Select chemicals suited to soil type, and expected turbidity, $\mathrm{pH}$, flow rate;

- Minimize the discharge risk from stored chemicals;

- Comply with state/local requirements;

- Use chemicals in accordance with good engineering practices and specifications of chemical supplier;

- Ensure proper training;

- Provide proper SWPPP documentation.

If you plan to use cationic treatment chemicals (as defined in Appendix A), you are ineligible for coverage under this permit, unless you notify your applicable EPA Regional Office in advance and the EPA Regional Office authorizes coverage under this permit after you have included appropriate controls and implementation procedures designed to ensure that your use of cationic treatment chemicals will not lead to a violation of water quality standards.

\section{H.4.1.9 Site stabilization requirements for earth-disturbing activities performed for} purposes of mine site preparation as defined in 8.H.3.2(a) (i.e., not applicable to construction of staging areas for structures and access roads as defined in 8.H.3.2(b)). You must comply with the following stabilization requirements except where the intended function of the site accounts for such disturbed earth (e.g., the earth disturbances will become actively mined, or the controls implemented at the active mining area effectively control the disturbance):

- Temporary stabilization of disturbed areas. Stabilization measures must be initiated immediately in portions of the site where earth-disturbing activities performed for purposes of mine site preparation (as defined in 8.H.3.2(a)) have temporarily ceased, but in no case more than 14 days after such activities have temporarily ceased. In arid, semi-arid, and drought-stricken areas, or in areas subject to snow or freezing conditions, where initiating perennial vegetative stabilization measures is not possible within 14 days after earth-disturbing activities performed for purposes of mine site preparation has temporarily ceased, temporary vegetative 
stabilization measures must be initiated as soon as practicable. Until temporary vegetative stabilization is achieved, interim measures such as erosion control blankets with an appropriate seed base and tackifiers must be employed. In areas of the site where earth-disturbing activities performed for purposes of mine site preparation have permanently ceased prior to active mining, temporary stabilization measures must be implemented to minimize mobilization of sediment or other pollutants until active mining activities commence.

- Final stabilization of disturbed areas. Stabilization measures must be initiated immediately where earth-disturbing activities performed for purposes of mine site preparation (as defined in 8.H.3.2(a)) have permanently ceased, but in no case more than 14 days after the earthdisturbing activities have permanently ceased. In arid, semi-arid, and drought-stricken areas, or in areas subject to snow or freezing conditions, where initiating perennial vegetative stabilization measures is not possible within 14 days after earth-disturbing activities have permanently ceased, final vegetative stabilization measures must be initiated as soon as possible. Until final stabilization is achieved, temporary stabilization measures, such as erosion control blankets with an appropriate seed base and tackifiers, must be used.

8.H.4.2 Additional Technology-Based Effluent Limits Applicable Only to the Construction of Staging Areas for Structures and Access Roads. The following technology-based effluent limits apply to authorized discharges from earth-disturbing activities associated with the construction of staging areas and the construction of access roads, as defined in Part 8.H.3.2(b). These limits supersede the technology-based limits listed in Part 2.1.2 and Part 8.H.5 of the MSGP. These limits do not apply to earth-disturbing activities performed for purposes of mine site preparation (as defined in 8.H.3.2(a)).

8.H.4.2.1 Area of disturbance. You must minimize the amount of soil exposed during construction activities.

8.H.4.2.2 Erosion and sediment control design requirements. You must:

- Design, install and maintain effective erosion and sediment controls to minimize the discharge of pollutants from construction activities. Account for the following factors in designing your erosion and sediment controls:

- The expected amount, frequency, intensity and duration of precipitation;

- The nature of stormwater runoff and run-on at the site, including factors such as impervious surfaces, slopes and site drainage features;

- The range of soil particle sizes expected to be present on the site.

- Direct discharges from your stormwater controls to vegetated areas of your site to increase sediment removal and maximize stormwater infiltration, including any natural buffers, unless infeasible. Use velocity dissipation devices if necessary to prevent erosion when directing stormwater to vegetated areas.

- If any stormwater flow becomes or will be channelized at your site, you must design erosion and sediment controls to control both peak flowrates and total stormwater volume to minimize channel and streambank erosion and scour in the immediate vicinity of discharge points.

- If you install stormwater conveyance channels, they must be designed to avoid unstabilized areas on the site and to reduce erosion, unless infeasible. In addition, you must minimize erosion of channels and their embankments, outlets, adjacent streambanks, slopes, and downstream 
waters during discharge conditions through the use of erosion controls and velocity dissipation devices within and along the length of any constructed stormwater conveyance channel, and at any outlet to provide a non-erosive flow velocity.

8.H.4.2.3 Natural Buffers. For any stormwater discharges from construction activities within 50 feet of a water of the U.S., you must comply with one of the following compliance alternatives:

1. Provide a 50-foot undisturbed natural buffer between construction activities and the water of the U.S.; or

2. Provide an undisturbed natural buffer that is less than 50 feet supplemented by additional erosion and sediment controls, which in combination, achieve a sediment load reduction that is equivalent to a 50-foot undisturbed natural buffer; or

3. If it is infeasible to provide an undisturbed natural buffer of any size, implement erosion and sediment controls that achieve a sediment load reduction that is equivalent to a 50 -foot undisturbed natural buffer.

There are exceptions when buffer requirements do not apply:

- There is no stormwater discharge from construction disturbances to a water of the U.S;

- The natural buffer has already been eliminated by preexisting development disturbances;

- The disturbance is for the construction of a water-dependent structure or construction approved under a CWA section 404 permit;

- For linear construction projects, you are not required to comply with the requirements if there are site constraints provided that, to the extent feasible, you limit disturbances within 50 feet of a water of the U.S. and/or you provide supplemental erosion and sediment controls to treat stormwater discharges from any disturbances within 50 feet of a water of the U.S.

See

http://water.epa.gov/polwaste/npdes/stormwater/upload/cgp2012_append ixg.pdf for guidance on complying with these alternatives.

8.H.4.2.4 Soil or sediment stockpiles. In addition to the requirements in Part 8.H.4.1.5, you must locate any piles outside of any natural buffers established under Part 8.H.4.2.3.

8.H.4.2.5 Sediment basins. In addition to the requirements in Part 8.H.4.1.6, you must locate sediment basins outside of any surface waters and any natural buffers established under Part 8.H.4.2.3, and you must utilize outlet structures that withdraw water from the surface, unless infeasible.

8.H.4.2.6 Native topsoil preservation. You must preserve native topsoil removed during clearing, grading, or excavation, unless infeasible. Store topsoil in a manner that will maximize its use in reclamation or final vegetative stabilization (e.g., by keeping the topsoil stabilized with seed or similar measures). This requirement does not apply if the intended function of the disturbed area dictates that topsoil be disturbed or removed. 
8.H.4.2.7 Steep slopes. You must minimize the disturbance of steep slopes. The permit does not prevent or prohibit disturbance on steep slopes.

Depending on site conditions and needs, disturbance on steep slopes may be necessary (e.g., a road cut in mountainous terrain; for grading steep slopes prior to erecting the mine office). Where steep slope disturbances are necessary, you can minimize the disturbances to steep slopes through the implementation of a number of standard erosion and sediment control practices, such as by phasing disturbances in these areas and using stabilization practices specifically for steep grades.

8.H.4.2.8 Soil compaction. Where final vegetative stabilization will occur or where infiltration practices will be installed, you must either restrict vehicle/ equipment use in these areas to avoid soil compaction or use soil conditioning techniques to support vegetative growth. Minimizing soil compaction is not required where compacted soil is integral to the functionality of the site.

8.H.4.2.9 Dewatering Practices. You are prohibited from discharging ground water or accumulated stormwater that is removed from excavations, trenches, foundations, vaults or other similar points of accumulation, unless such waters are first effectively managed by appropriate controls (e.g., sediment basins or sediment traps, sediment socks, dewatering tanks, tube settlers, weir tanks, or filtration systems). Uncontaminated, non-turbid dewatering water can be discharged without being routed to a control.

You must also meet the following requirements for dewatering activities:

- Discharge requirements:

- No discharging visible floating solids or foam;

- Remove oil, grease and other pollutants from dewatering water via an oil-water separator or suitable filtration device (such as a cartridge filter);

- Utilize vegetated upland areas of the site, to the extent feasible, to infiltrate dewatering water before discharge. In no case shall waters of the U.S. be considered part of the treatment area;

- Implement velocity dissipation devices at all points where dewatering water is discharged;

- Haul backwash water away for disposal or return it to the beginning of the treatment process; and

- Clean or replace the filter media used in dewatering devices when the pressure differential equals or exceeds the manufacturer's specifications.

- Treatment chemical restrictions: If you use polymers, flocculants or other chemicals to treat dewatering water, you must comply with the requirements in Parts 8.H.4.1.8.

\section{H.4.2.10 Pollution prevention requirements.}

- Prohibited discharges (this non-exhaustive list of prohibited nonstormwater discharges is included here as a reminder that only the only allowable non-stormwater discharges are those enumerated in Part 1.1.3):

- Wastewater from washout of concrete;

- Wastewater from washout and cleanout of stucco, paint, form release oils, curing compounds, and other construction materials;

- Fuels, oils, or other pollutants used for operation and maintenance of vehicles or equipment; 
- Soaps, solvents, or detergents used in vehicle or equipment washing;

- Toxic or hazardous substances from a spill or other release.

- Design and location requirements: Minimize the discharge of pollutants from pollutant sources by:

- Minimizing exposure;

- Using secondary containment, spill kits, or other equivalent measures;

- Locating pollution sources away from surface waters, storm sewer inlets, and drainageways;

- Cleaning up spills immediately (do not clean by hosing area down).

- Pollution prevention requirements for wash waters: Minimize the discharge of pollutants from equipment and vehicle washing, wheel wash water, and other wash waters. Wash waters must be treated in a sediment basin or alternative control that provides equivalent or better treatment prior to discharge;

- Pollution prevention requirements for the storage, handling, and disposal of construction products, materials, and wastes: Minimize the exposure of building materials, building products, construction wastes, trash, landscape materials, fertilizers, pesticides, herbicides, detergents, sanitary waste, and other materials present on the site to stormwater. Minimization of exposure is not required in cases where the exposure to stormwater will not result in a discharge of pollutants, or where exposure of a specific material or product poses little risk of stormwater contamination (such as final products and materials intended for outdoor use).

\section{H.4.2.11 Site Stabilization requirements for the construction of staging areas for} structures and access roads as defined in 8.H.3.2(b) (i.e., not applicable to earth-disturbing activities performed for purposes of mine site preparation as defined in 8.H.3.2(a)). You must comply with the following stabilization requirements, except where the intended function of the site accounts for such disturbed earth (e.g., the area of construction will become actively mined, or the controls implemented at the active mining area effectively control the disturbance):

- By no later than the end of the next work day after construction work in an area has stopped permanently or temporarily ("temporarily" means the land will be idle for a period of 14 days or more but earth-disturbing activities will resume in the future), immediately initiate stabilization measures;

- If using vegetative measures, by no later than 14 days after initiating stabilization:

- Seed or plant the area, and provide temporary cover to protect the planted area;

- Once established, vegetation must be uniform, perennial (if final stabilization), and cover at least $70 \%$ of stabilized area based on density of native vegetation.

- If using non-vegetative stabilization, by no later than 14 days after initiating stabilization:

- Install or apply all non-vegetative measures;

- Cover all areas of exposed soil.

Note: For the purposes of this permit, EPA will consider any of the following types of activities to constitute the initiation of stabilization: 1. Prepping the soil for vegetative or non-vegetative stabilization; 2 . Applying mulch or other non-vegetative product to the exposed area; 3 . Seeding or planting 
the exposed area; 4 . Starting any of the activities in \# 1 - 3 on a portion of the area to be stabilized, but not on the entire area; and 5. Finalizing arrangements to have stabilization product fully installed in compliance with the applicable deadline for completing stabilization.

Exceptions:

- Arid, semi-arid (if construction occurs during seasonally dry period), or drought-stricken areas:

- Within 14 days of stopping construction work in an area, install any necessary non-vegetative stabilization measures;

- Initiate vegetative stabilization as soon as conditions on the site allow;

- Document the schedule that will be followed for initiating and completing vegetative stabilization;

- Plant the area so that within 3 years the $70 \%$ cover requirement is met.

- Sites affected by severe storm events or other unforeseen circumstances:

- Initiate vegetative stabilization as soon conditions on the site allow;

- Document the schedule that will be followed for initiating and completing vegetative stabilization;

- Plant the area so that so that within 3 years the $70 \%$ cover requirement is met.

8.H.4.3 Water Quality-Based Requirements Applicable to Earth-Disturbing Activities Conducted Prior to Active Mining Activities.

The following water quality-based limits apply to earth-disturbing activities conducted prior to active mining activities defined in Part 8.H.3.2(a) and 8.H.3.2(b), in addition to the water quality-based limits in Part 2.2 of the MSGP.

Stricter requirements apply if your site will discharge to an impaired water or a water that is identified by your state, tribe, or EPA as a Tier 2 or Tier 2.5 for antidegradation purposes:

- More rapid stabilization of exposed areas: Complete initial stabilization activities within 7 days of stopping earth-disturbing work.

- More frequent site inspections: Once every 7 days and within 24 hours of a storm event of 0.25 inches or greater.

8.H.4.4 Inspection Requirements Applicable to Earth-Disturbing Activities Conducted Prior to Active Mining Activities.

The following requirements supersede the inspections requirements in Part 3 and 8.H.7 of the MSGP for earth-disturbing activities conducted prior to active mining activities defined in Part 8.H.3.2(a) and 8.H.3.2(b).

\section{H.4.4.1 Inspection Frequency}

- At least once every 7 calendar days, or

- Once every 14 calendar days and within 24 hours of a storm event of 0.25 inches or greater. Note:

- Inspections only required during working hours;

- Inspections not required during unsafe conditions; and

- If you choose to inspect once every 14 days, you must have a method for measuring rainfall amount on site (either rain gauge or representative weather station)

Note: To determine if a storm event of 0.25 inches or greater has occurred on your site, you must either keep a properly maintained rain gauge on your site, or obtain the storm event information from a weather station that is representative of your location. For any 
day of rainfall during normal business hours that measures 0.25 inches or greater, you must record the total rainfall measured for that.

Note: You are required to specify in your SWPPP which schedule you will be following.

Note: "Within 24 hours of the occurrence of a storm event" means that you are required to conduct an inspection within 24 hours once a storm event has produced 0.25 inches, even if the storm event is still continuing. Thus, if you have elected to inspect bi-weekly in and there is a storm event at your site that continues for multiple days, and each day of the storm produces 0.25 inches or more of rain, you are required to conduct an inspection within 24 hours of the first day of the storm and within 24 hours after the end of the storm.

\section{H.4.4.2 Reductions in Inspection Frequency}

- Stabilized areas: You may reduce the frequency of inspections to once per month in any area of your site where stabilization has occurred pursuant to Part 8.H.4.1.9 or 8.H.4.2.11.

- Arid, semi-arid, and drought stricken areas: If earth-disturbing activities are occurring during the seasonally dry period or during a period in which drought is predicted to occur, you may reduce inspections to once per month and within 24 hours of a 0.25 inch storm event.

- Frozen conditions: You may temporarily suspend or reduce inspections to once per month until thawing conditions occur if frozen conditions are continuous and disturbed areas have been stabilized. For extreme conditions in remote areas, e.g., where transit to the site is perilous/restricted or temperatures are routinely below freezing, you may suspend inspections until the conditions are conducive to safe access, and more frequent inspections can resume.

8.H.4.4.3 Areas to be Inspected. You must at a minimum inspect the following areas:

- Disturbed areas;

- Stormwater controls and pollution prevention measures;

- Locations where stabilization measures have been implemented;

- Material, waste, borrow, or equipment storage and maintenance areas;

- Areas where stormwater flows;

- Points of discharge.

8.H.4.4.4 What to Check for During Inspections. At a minimum you must check:

- Whether all stormwater controls are installed, operational, and working as intended;

- Whether any new or modified stormwater controls are needed;

- For conditions that could lead to a spill or leak;

- For visual signs of erosion/sedimentation at points of discharge.

If a discharge is occurring:

- The quality and characteristics of the discharge;

- Whether controls are operating effectively.

8.H.4.4.5 Inspection Report. Within 24 hours of an inspection, complete a report that includes:

- Inspection date;

- Name and title of inspector(s);

- Summary of inspection findings;

- Rainfall amount that triggered the inspection (if applicable);

- If it was unsafe to inspect a portion of the site, include documentation of the reason and the location(s); 
- Each inspection report must be signed;

- Keep a current copy of all reports at the site or at an easily accessible location.

8.H.4.5 Cessation of Requirements Applicable to Earth-Disturbing Activities Conducted Prior to Active Mining Activities. The requirements in 8.H.4 no longer apply for any earthdisturbing activities conducted prior to active mining activities as defined in 8.H.3.2(a) or 8.H.3.2(b) where:

1. Earth-disturbing activities have ceased; and

2. Stabilization has been met consistent with Part 8.H.4.1.9 or 8.H.4.2.1 1 (not required for areas where active mining activities will occur).

\section{H.5 Technology-Based Effluent Limits for Active Mining Activities.}

Note: These requirements do not apply for any discharges from earth-disturbing activities conducted prior to active mining as defined in 8.H.3.2(a) or 8.H.3.2(b).

8.H.5.1 Good Housekeeping Measures. (See also Part 2.1.2.2) As part of your good housekeeping program, in order to minimize discharges of pollutants in stormwater, implement control measures such as the following, where determined to be feasible (list not inclusive): using sweepers and covered storage; watering haul roads to minimize dust generation; and conserving vegetation to minimize erosion. For mines subject to dust control requirements under state or county air quality permits, provided the requirements are equivalent, compliance with such air permit dust requirements shall constitute compliance with the dust control effluent limit in Part 2.1.2.10.

8.H.5.2 Preventive Maintenance. (See also Part 2.1.2.3) Perform inspections or other equivalent measures of storage tanks and pressure lines of fuels, lubricants, hydraulic fluid, and slurry to prevent leaks due to deterioration or faulty connections.

\section{H.6 Additional SWPPP Requirements for Mining Operations.}

Note: The requirements in Part 8.H.6 are not applicable to inactive coal mining facilities.

8.H.6.1 Other Applicable Regulations. Most active coal mining-related areas (SIC Codes 12211241) are subject to sediment and erosion control regulations of the U.S. Office of Surface Mining (OSM) that enforces the Surface Mining Control and Reclamation Act (SMCRA). OSM has granted authority to most coal-producing states to implement SMCRA through State SMCRA regulations. All SMCRA requirements regarding control of stormwater-related pollutant discharges must be addressed and then documented with the SWPPP (directly or by reference).

8.H.6.2 Site Map. (See also Part 5.2.2) Document in your SWPPP where any of the following may be exposed to precipitation or surface runoff: haul and access roads; railroad spurs, sliding, and internal hauling lines; conveyor belts, chutes, and aerial tramways; equipment storage and maintenance yards; coal handling buildings and structures; inactive mines and related areas; acidic spoil, refuse, or unreclaimed disturbed areas; and liquid storage tanks containing pollutants such as caustics, hydraulic fluids, and lubricants.

8.H.6.3 Potential Pollutant Sources. (See also Part 5.2.3) Document in your SWPPP the following sources and activities that have potential pollutants associated with them: truck traffic on haul roads and resulting generation of sediment subject to runoff and dust generation; fuel or other liquid storage; pressure lines containing slurry, hydraulic fluid, or other potential harmful liquids; and loading or temporary storage of acidic refuse or spoil. 
8.H.6.4 If you are in compliance with dust control requirements under state or county air quality permits, you must include (or summarize, as necessary) what the state or county air quality permit dust control requirements are and how you've achieved compliance with them.

8.H.7 Additional Inspection Requirements. (See also Part 3.1)

8.H.7.1 Inspections of Active Mining-Related Areas. (See also Part 3) Except for earth-disturbing activities conducted prior to active mining activities as defined in Part 8.H.3.2(a) and 8.H.3.2(b), which are subject to Part 8.H.4.4, perform routine inspections of active mining areas covered by this permit, corresponding with the inspections as performed by SMCRA inspectors, of all mining-related areas required by SMCRA. Also maintain the records of the SMCRA authority representative. See Part 8.H.8.1 for inspection requirements for inactive and unstaffed sties.

8.H.7.2 Sediment and Erosion Control. (See also Part 2.1.2.5) As indicated in Part 8.H.6.1, SMCRA requirements regarding sediment and erosion control measures must be complied with for those areas subject to SMCRA authority, including inspection requirements.

8.H.7.3 Routine Site Inspections. (See also Part 3.1) Your inspection program must include inspections for pollutants entering the drainage system from activities located on or near coal mining-related areas. Among the areas to be inspected are haul and access roads; railroad spurs, sliding, and internal hauling lines; conveyor belts, chutes, and aerial tramways; equipment storage and maintenance yards; coal handling buildings and structures; and inactive mines and related areas.

8.H.8 Sector-Specific Benchmarks. (See also Part 6)

Table 8.H-1 identifies benchmarks that apply to the specific subsectors of Sector $\mathrm{H}$. These benchmarks apply to both your primary industrial activity and any co-located industrial activities. Note: There are no Part 8.H. 8 monitoring and reporting or impaired waters monitoring requirements for inactive and unstaffed sites.

\begin{tabular}{|l|c|c|}
\hline \multicolumn{2}{|c|}{ Table 8.H-1. } \\
\hline \multicolumn{1}{|c|}{$\begin{array}{c}\text { Subsector } \\
\text { (You may be subject to requirements for } \\
\text { more than one sector/subsector) }\end{array}$} & Parameter & $\begin{array}{c}\text { Benchmark } \\
\text { Monitoring } \\
\text { Concentration }\end{array}$ \\
\hline $\begin{array}{l}\text { Subsector H1. Coal Mines and Related } \\
\text { Areas } \\
\text { (SIC 1221-1241) }\end{array}$ & Total Aluminum & $0.75 \mathrm{mg} / \mathrm{L}$ \\
\cline { 2 - 3 } & Total Iron & $1.0 \mathrm{mg} / \mathrm{L}$ \\
\cline { 2 - 3 } & Total Suspended Solids (TSS) & $100 \mathrm{mg} / \mathrm{L}$ \\
\hline
\end{tabular}

8.H.8.1 Inactive and Unstaffed Sites - Conditional Exemption from No Exposure Requirement for Routine Inspections, Quarterly Visual Assessments, and Benchmark and Impaired Waters Monitoring. As a Sector $\mathrm{H}$ facility, if you are seeking to exercise a waiver from either the quarterly visual assessment or the benchmark and/or impaired waters monitoring requirements for inactive and unstaffed sites (including temporarily inactive sites), you are conditionally exempt from the requirement to certify that "there are no industrial materials or activities exposed to stormwater" in Parts 3.2.3, 6.2.1.3, and 6.2.4.2. Additionally, if you are seeking to reduce your required routine inspection frequency, as is allowed under Part 3.1.1, you are also conditionally exempt from the requirement to certify that "there are no industrial materials or activities exposed to stormwater." These conditional exemptions are based on the following requirements: 
- If circumstances change and your facility becomes active and/or staffed, this exception no longer applies and you must immediately begin complying with the applicable benchmark monitoring requirements as if you were in your first year of permit coverage, and the quarterly visual assessment requirements; and

- EPA retains the authority to revoke this exemption and/or the monitoring waiver where it is determined that the discharge causes, has a reasonable potential to cause or contribute to an instream excursion above an applicable water quality standard, including designated uses.

Subject to the two conditions above, if your facility is inactive and unstaffed, you are waived from the requirement to conduct routine facility inspections, quarterly visual assessments, and benchmark and impaired waters monitoring. You must still conduct an annual site inspection in accordance with Part 3.1. You are encouraged to inspect your site more frequently where you have reason to believe that severe weather or natural disasters may have damaged control measures or increased discharges.

\section{H.9 Termination of Permit Coverage}

8.H.9.1 Termination of Permit Coverage for Sites Reclaimed After December 17, 1990. A site or a portion of a site that has been released from applicable state or federal reclamation requirements after December 17, 1990, is no longer required to maintain coverage under this permit. If the site or portion of a site reclaimed after December 17, 1990, was not subject to reclamation requirements, the site or portion of the site is no longer required to maintain coverage under this permit if the site or portion of the site has been reclaimed as defined in Part 8.H.3.5.

8.H.9.2 Termination of Permit Coverage for Sites Reclaimed Before December 17, 1990. A site or portion of a site that was released from applicable state or federal reclamation requirements before December 17, 1990, or that was otherwise reclaimed before December 17, 1990, is no longer required to maintain coverage under this permit if the site or portion of the site has been reclaimed. A site or portion of a site is considered to have been reclaimed if: (1) stormwater runoff that comes into contact with raw materials, intermediate byproducts, finished products, and waste products does not have the potential to cause or contribute to violations of state water quality standards, (2) soil disturbing activities related to mining at the sites or portion of the site have been completed, (3) the site or portion of the site has been stabilized to minimize soil erosion, and (4) as appropriate depending on location, size, and the potential to contribute pollutants to stormwater discharges, the site or portion of the site has been revegetated, will be amenable to natural revegetation, or will be left in a condition consistent with the post-mining land use. 


\section{Part 8 - Sector-Specific Requirements for Industrial Activity}

\section{Subpart I - Sector I - Oil and Gas Extraction.}

You must comply with Part 8 sector-specific requirements associated with your primary industrial activity and any co-located industrial activities, as defined in Appendix A. The sectorspecific requirements apply to those areas of your facility where those sector-specific activities occur. These sector-specific requirements are in addition to any requirements specified elsewhere in this permit.

\section{I.1 Covered Stormwater Discharges.}

The requirements in Subpart I apply to stormwater discharges associated with industrial activity from Oil and Gas Extraction facilities as identified by the SIC Codes specified under Sector I in Table D-1 of Appendix D of the permit.

\section{I.1.1 Discharges of stormwater runoff from field activities or operations associated with oil and gas exploration, production, processing, or treatment operations or transmission facilities are exempt from NPDES permit coverage unless, in accordance with 40 CFR 122.26(c)(1)(iii), the facility:}

- Has had a discharge of stormwater resulting in the discharge of a reportable quantity for which notification is or was required pursuant to 40 CFR 117.21 or 40 CFR 302.6 at any time since November 16, 1987; or

- Has had a discharge of stormwater resulting in the discharge of a reportable quantity for which notification is or was required pursuant to 40 CFR 110.6 at any time since November 16, 1987; or

- Contributes to a violation of a water quality standard.

Any stormwater discharges that require permit coverage as a result of meeting one of the conditions of 122.26(c)(1)(iii) may be covered under this permit unless otherwise required to obtain coverage under an alternative NPDES general permit or an individual NPDES permit as specified in Part 1.6.1.

\section{I.2 Limitations on Coverage.}

8.I.2.1 Stormwater Discharges Subject to Effluent Limitation Guidelines. (See also Part 1.1.4.5) This permit does not authorize stormwater discharges from petroleum drilling operations that are subject to nationally established effluent limitation guidelines found at 40 CFR Part 435, respectively.

8.I.2.2 Non-Stormwater Discharges. Discharges of vehicle and equipment wash water, including tank cleaning operations, are not authorized by this permit. Alternatively, wash water discharges must be authorized under a separate NPDES permit, or be discharged to a sanitary sewer in accordance with applicable industrial pretreatment requirements. (EPA includes this prohibited non-stormwater discharge here solely as a helpful reminder to the operator that the only non-stormwater discharges authorized by this permit are at Part 1.1.3).

\subsubsection{Additional Technology-Based Effluent Limits.}

8.I.3.1 Vegetative Controls. Implement vegetative practices designed to preserve existing vegetation, where attainable, and revegetate open areas as soon as practicable after grade drilling. Implement appropriate vegetative practices, such as the following (list not exclusive): temporary or permanent seeding, mulching, sod stabilization, vegetative buffer strips, and tree protection practices. Begin implementing appropriate vegetative practices on all disturbed areas within 14 days following the last activity in that area. 


\section{I.4 Additional SWPPP Requirements.}

8.I.4.1 Drainage Area Site Map. (See also Part 5.2.2) Document in your SWPPP where any of the following may be exposed to precipitation or surface runoff: Reportable Quantity $(R Q)$ releases; locations used for the treatment, storage, or disposal of wastes; processing areas and storage areas; chemical mixing areas; construction and drilling areas; all areas subject to the effluent guidelines requirements for "No Discharge" in accordance with 40 CFR 435.32; and the structural controls to achieve compliance with the "No Discharge" requirements.

8.I.4.2 Potential Pollutant Sources. (See also Part 5.2.3) Also document in your SWPPP the following sources and activities that have potential pollutants associated with them: chemical, cement, mud, or gel mixing activities; drilling or mining activities; and equipment cleaning and rehabilitation activities. In addition, include information about the reportable quantity $(R Q)$ release that triggered the permit application requirements: the nature of the release (e.g., spill of oil from a drum storage area), amount of oil or hazardous substance released, amount of substance recovered, date of the release, cause of the release (e.g., poor handling techniques and lack of containment in the area), areas affected by the release (i.e., land and water), procedures to clean up release, actions or procedures implemented to prevent or improve response to a release, and remaining potential contamination of stormwater from release (taking into account human health risks, the control of drinking water intakes, and the designated uses of the receiving water).

8.I.4.3 Erosion and Sediment Controls. (See also Part 2.1.2.5) Unless covered by EPA's Construction General Permit (CGP), the additional documentation requirements for sediment and erosion controls for well drillings and sand/shale mining areas include the following:

8.I.4.3.1 Site Description. Also include a description in your SWPPP of the nature of the exploration activity, estimates of the total area of site and area disturbed due to exploration activity, an estimate of runoff coefficient of the site, a site drainage map, including approximate slopes, and the names of all receiving waters.

8.I.4.3.2 Vegetative Controls. Document vegetative practices used consistent with Part 8.I.3.1 in the SWPPP.

\section{I.5 Additional Inspection Requirements.}

All erosion and sediment controls must be inspected either: 1) every 7 days; or 2) once every 14 calendar days and within 24 hours of a storm event of 0.25 inches or greater. 


\section{Part 8 - Sector-Specific Requirements for Industrial Activity}

\section{Subpart J - Sector J - Non-Metallic Mineral Mining and Dressing.}

You must comply with Part 8 sector-specific requirements associated with your primary industrial activity and any co-located industrial activities, as defined in Appendix A. The sectorspecific requirements apply to those areas of your facility where those sector-specific activities occur. These sector-specific requirements are in addition to any requirements specified elsewhere in this permit.

Note: Where compliance with a requirement in a separate exploration permit, mining permit, reclamation plan, Surface Mining Control and Reclamation Act (SMCRA) requirements, etc. will result in you fully meeting any requirement in this Subpart, you are considered to have complied with the relevant requirement in this Subpart. You must include documentation in your SWPPP describing your rationale for concluding that any particular action on your part is sufficient to comply with the corresponding requirement in this Subpart.

\section{J.1 Covered Stormwater Discharges.}

The requirements in Subpart $\mathrm{J}$ apply to stormwater discharges associated with industrial activity from Active and Inactive Non-Metallic Mineral Mining and Dressing facilities as identified by the SIC Codes specified under Sector J in Table D-1 of Appendix D of the permit.

\section{J.1.1 Covered Discharges from Inactive Facilities. All stormwater discharges.}

8.J.1.2 Covered Discharges from Active and Temporarily Inactive Facilities. All stormwater discharges, except for most stormwater discharges subject to the existing effluent limitation guideline at 40 CFR Part 436. Mine dewatering discharges composed entirely of stormwater or uncontaminated ground water seepage from: construction sand and gravel, industrial sand, and crushed stone mining facilities.

\section{J.1.3 Covered Discharges from Earth-Disturbing Activities Conducted Prior to Active Mining Activities. All stormwater discharges.}

8.J.1.4 Covered Discharges from Sites Undergoing Reclamation. All stormwater discharges.

\section{J.2 Limitations on Coverage.}

Most stormwater discharges subject to an existing effluent limitation guideline at $40 \mathrm{CFR}$ Part 436 are not authorized by this permit. The exceptions to this limitation, which are covered by this permit, are mine dewatering discharges composed entirely of stormwater or uncontaminated ground water seepage from construction sand and gravel, industrial sand, and crushed stone mining facilities.

\section{J.3 Definitions.}

The following definitions are not intended to supersede the definitions of active and inactive mining facilities established by 40 CFR 122.26 (b)(14)(iii).

8.J.3.1 Mining operations - For this permit, mining operations are grouped into two distinct categories, with distinct effluent limits and requirements applicable to each: a) earthdisturbing activities conducted prior to active mining activities); and b) active mining activities, which includes reclamation. "Mining operations" can occur at both inactive mining facilities and temporarily inactive mining facilities.

8.J.3.2 Earth-disturbing activities conducted prior to active mining activities - Consists of two classes of earth-disturbing (i.e., clearing, grading and excavation) activities:

a. activities performed for purposes of mine site preparation, including: cutting new rights of way (except when related to access road construction); providing access to a 
mine site for vehicles and equipment (except when related to access road construction); other earth disturbances associated with site preparation activities on any areas where active mining activities have not yet commenced (e.g., for heap leach pads, waste rock facilities, tailings impoundments, wastewater treatment plants); and

b. construction of staging areas to prepare for erecting structures such as to house project personnel and equipment, mill buildings, etc., and construction of access roads. Earth-disturbing activities associated with the construction of staging areas and the construction of access roads conducted prior to active mining are considered to be "construction" and have additional effluent limits in Part 8.J .4.2.

8.J.3.3 Active mining activities - Activities related to the extraction, removal or recovery, and benefication of non-metallic minerals from the earth; removal of overburden and waste rock to expose mineable minerals; and site reclamation and closure activities. All such activities occur within the "active mining area." Reclamation involves activities undertaken, in compliance with applicable mined land reclamation requirements, to return the land to an appropriate post-mining contour and land use in order to meet applicable federal and state reclamation requirements. In addition, once earthdisturbing activities conducted prior to active mining activities have ceased and all related requirements in Part 8.J.4 have been met, and a well-delineated "active mining area" has been established, all activities (including any clearing, grading, and excavation) that occur within the active mining area are "active mining activities

8.J.3.4 Active mining area - A place where work or other activity related to the extraction, removal or recovery of non-metallic minerals is being conducted, except, with respect to surface mines, any area of land on or in which grading has been completed to return the earth to desired contour and reclamation work has begun.

Note: Earth-disturbing activities described in the definition in Part 8.J.3.2 that occur on areas outside the active mining area (e.g., for expansion of the mine into undeveloped territory) are considered "earth-disturbing conducted prior to active mining activities", and must comply with the requirements in Part 8.J.4.

8.J.3.5 Inactive mineral mining facility - A site or portion of a site where mineral mining and/or milling occurred in the past but there are no active mining activities occurring as defined above, and where the inactive portion is not covered by an active mining permit issued by the applicable state or federal agency. An inactive mineral mining facility has an identifiable owner / operator. Sites where mining claims are being maintained prior to disturbances associated with the extraction, beneficiation, or processing of mined materials, and sites where minimal activities are undertaken for the sole purpose of maintaining a mining claim are not considered either active or inactive mining facilities and do not require an NPDES industrial stormwater permit.

8.J.3.6 Temporarily inactive mineral mining facility - A site or portion of a site where nonmetallic mineral mining and/or milling occurred in the past but currently are not being actively undertaken, and the facility is covered by an active mining permit issued by the applicable state or federal agency.

\section{J.4 Requirements Applicable to Earth-Disturbing Activities Conducted Prior to Active Mining Activities.}

Stormwater discharges from earth-disturbing activities conducted prior to active mining activities (defined in Part 8.J.3.2) are covered under this permit. For such earth-disturbing activities, you must comply with all applicable requirements in Parts 1-9 of the MSGP except for 
the technology-based effluent limits in Part 8.J.5 and Part 2.1.2, the inspection requirements in Part 8.J.7 and Part 3, and the monitoring requirements in Part 8.J.8 and Part 6.

Authorized discharges from areas where earth-disturbing activities have ceased and stabilization as specified in Part 8.J.4.19 or 8.J.4.2.11, where appropriate, has been completed (stabilization is not required for areas where active mining activities will occur), are no longer subject to the Part 8.J.4 requirements. At such time, authorized discharges become subject to all other applicable requirements in the MSGP, including the effluent limits in Parts 2.1.2 and 8.J.5, the inspection requirements in Parts 3 and 8.J.7, and the monitoring requirements in Parts 6 and 8.J.8.

8.J.4.1 Technology-Based Effluent Limits Applicable to All Earth-Disturbing Activities Conducted Prior to Active mining Activities. The following technology-based effluent limits apply to authorized discharges from all earth-disturbing activities conducted prior to active mining activities defined in Part 8.J.3.2(a) and 8.J.3.2(b). These limits supersede the technology-based limits listed in Part 2.1.2 and Part 8.J.5 of the MSGP.

\section{J.4.1.1 Erosion and sediment control installation requirements.}

- By the time construction activities commence, install and make operational downgradient sediment controls, unless this timeframe is infeasible. If infeasible you must install and make such controls operational as soon as practicable or as soon as site conditions permit.

- All other stormwater controls described in the SWPPP must be installed and made operational as soon as conditions on each portion of the site allows.

8.J.4.1.2 Erosion and sediment control maintenance requirements. You must:

- Ensure that all erosion and sediment controls remain in effective operating condition.

- Wherever you determine that a stormwater control needs maintenance to continue operating effectively, initiate efforts to fix the problem immediately after its discovery, and complete such work by the end of the next work day.

- When a stormwater control must be replaced or significantly repaired, complete the work within 7 days, unless infeasible. If 7 days is infeasible, you must complete the installation or repair as soon practicable.

8.J.4.1.3 Perimeter controls. You must:

- Install sediment controls along those perimeter areas of your disturbed area that will receive stormwater, except where site conditions prevent the use of such controls (in which case, maximize their installation to the extent practicable).

- Remove sediment before it accumulates to one-half of the above-ground height of any perimeter control.

8.J.4.1.4 Sediment track-out. For construction vehicles and equipment exiting the site directly onto paved roads, you must:

- Use appropriate stabilization techniques to minimize sediment track-out from vehicles and equipment prior to exit;

- Use additional controls to remove sediment from vehicle and equipment tires prior to exit, where necessary;

- Remove sediment that is tracked out onto paved roads by end of the work day.

Note: EPA recognizes that some fine grains may remain visible on the surfaces of off-site streets, other paved areas, and sidewalks even after you have 
implemented sediment removal practices. Such "staining" is not a violation of Part 8.J.4.1.4.

8.J.4.1.5 Soil or sediment stockpiles. You must:

- Minimize erosion of stockpiles from stormwater and wind via temporary cover, if feasible.

- Prevent up-slope stormwater flows from causing erosion of stockpiles (e.g., by diverting flows around the stockpile).

- Minimize sediment from stormwater that runs off of stockpiles, using sediment controls (e.g., a sediment barrier or downslope sediment control).

8.J.4.1.6 Sediment basins. If you intend to install a sediment basin to treat stormwater from your earth-disturbing activities, you must:

- Provide storage for either (1) the 2-year, 24-hour storm, or (2) 3,600 cubic feet per acre drained.

- Prevent erosion of (1) basin embankments using stabilization controls (e.g., erosion control blankets), and (2) the inlet and outlet points of the basin using erosion controls and velocity dissipation devices.

8.J.4.1.7 Minimize dust. You must minimize the generation of dust through the appropriate application of water or other dust suppression techniques that minimize pollutants being discharged into surface waters.

8.J.4.1.8 Restrictions on use of treatment chemicals. If you intend to use sediment treatment chemicals at your site, you are subject to the following minimum requirements:

- Use conventional erosion and sediment controls prior to and after application of chemicals;

- Select chemicals suited to soil type, and expected turbidity, $\mathrm{pH}$, flow rate;

- Minimize the discharge risk from stored chemicals;

- Comply with state/local requirements;

- Use chemicals in accordance with good engineering practices and specifications of chemical supplier;

- Ensure proper training;

- Provide proper SWPPP documentation.

If you plan to use cationic treatment chemicals (as defined in Appendix A), you are ineligible for coverage under this permit, unless you notify your applicable EPA Regional Office in advance and the EPA Regional Office authorizes coverage under this permit after you have included appropriate controls and implementation procedures designed to ensure that your use of cationic treatment chemicals will not lead to a violation of water quality standards.

\section{J.4.1.9 Site stabilization requirements for earth-disturbing activities performed for} purposes of mine site preparation as defined in 8.J.3.2(a) (i.e., not applicable to construction of staging areas for structures and access roads as defined in 8.J.3.2(b)). You must comply with the following stabilization requirements except where the intended function of the site accounts for such disturbed earth (e.g., the earth disturbances will become actively mined, or the controls implemented at the active mining area effectively control the disturbance):

- Temporary stabilization of disturbed areas. Stabilization measures must be initiated immediately in portions of the site where earth-disturbing activities performed for purposes of mine site preparation (as defined in 
8.J.3.2(a)) have temporarily ceased, but in no case more than 14 days after such activities have temporarily ceased. In arid, semi-arid, and drought-stricken areas, or in areas subject to snow or freezing conditions, where initiating perennial vegetative stabilization measures is not possible within 14 days after earth-disturbing activities performed for purposes of mine site preparation has temporarily ceased, temporary vegetative stabilization measures must be initiated as soon as practicable. Until temporary vegetative stabilization is achieved, interim measures such as erosion control blankets with an appropriate seed base and tackifiers must be employed. In areas of the site where earth-disturbing activities performed for purposes of mine site preparation have permanently ceased prior to active mining, temporary stabilization measures must be implemented to minimize mobilization of sediment or other pollutants until active mining activities commence.

- Final stabilization of disturbed areas. Stabilization measures must be initiated immediately where earth-disturbing activities performed for purposes of mine site preparation (as defined in 8.J.3.2(a)) have permanently ceased, but in no case more than 14 days after the earthdisturbing activities have permanently ceased. In arid, semi-arid, and drought-stricken areas, or in areas subject to snow or freezing conditions, where initiating perennial vegetative stabilization measures is not possible within 14 days after earth-disturbing activities have permanently ceased, final vegetative stabilization measures must be initiated as soon as possible. Until final stabilization is achieved, temporary stabilization measures, such as erosion control blankets with an appropriate seed base and tackifiers, must be used.

\section{J.4.2 Additional Technology-Based Effluent Limits Applicable Only to the Construction of Staging Areas for Structures and Access Roads. The following technology-based} effluent limits apply to authorized discharges from earth-disturbing activities associated with the construction of staging areas and the construction of access roads, as defined in Part 8.J.3.2(b). These limits supersede the technology-based limits listed in Part 2.1.2 and Part 8.J.5 of the MSGP. These limits do not apply to earth-disturbing activities performed for purposes of mine site preparation (as defined in 8.J.3.2(a)).

8.J.4.2.1 Area of disturbance. You must minimize the amount of soil exposed during construction activities.

\section{J.4.2.2 Erosion and sediment control design requirements. You must:}

- Design, install and maintain effective erosion and sediment controls to minimize the discharge of pollutants from construction activities. Account for the following factors in designing your erosion and sediment controls:

- The expected amount, frequency, intensity and duration of precipitation;

- The nature of stormwater runoff and run-on at the site, including factors such as impervious surfaces, slopes and site drainage features;

- The range of soil particle sizes expected to be present on the site.

- Direct discharges from your stormwater controls to vegetated areas of your site to increase sediment removal and maximize stormwater infiltration, including any natural buffers, unless infeasible. Use velocity dissipation devices if necessary to prevent erosion when directing stormwater to vegetated areas. 
- If any stormwater flow becomes or will be channelized at your site, you must design erosion and sediment controls to control both peak flowrates and total stormwater volume to minimize channel and streambank erosion and scour in the immediate vicinity of discharge points.

- If you install stormwater conveyance channels, they must be designed to avoid unstabilized areas on the site and to reduce erosion, unless infeasible. In addition, you must minimize erosion of channels and their embankments, outlets, adjacent streambanks, slopes, and downstream waters during discharge conditions through the use of erosion controls and velocity dissipation devices within and along the length of any constructed stormwater conveyance channel, and at any outlet to provide a non-erosive flow velocity.

8.J.4.2.3 Natural Buffers. For any stormwater discharges from construction activities within 50 feet of a water of the U.S., you must comply with one of the following compliance alternatives:

1. Provide a 50-foot undisturbed natural buffer between construction activities and the water of the U.S.; or

2. Provide an undisturbed natural buffer that is less than 50 feet supplemented by additional erosion and sediment controls, which in combination, achieve a sediment load reduction that is equivalent to a 50-foot undisturbed natural buffer; or

3. If it is infeasible to provide an undisturbed natural buffer of any size, implement erosion and sediment controls that achieve a sediment load reduction that is equivalent to a 50 -foot undisturbed natural buffer.

There are exceptions when buffer requirements do not apply:

- There is no stormwater discharge from construction disturbances to a water of the U.S;

- The natural buffer has already been eliminated by preexisting development disturbances;

- The disturbance is for the construction of a water-dependent structure or construction approved under a CWA section 404 permit;

- For linear construction projects, you are not required to comply with the requirements if there are site constraints provided that, to the extent feasible, you limit disturbances within 50 feet of a water of the U.S. and/or you provide supplemental erosion and sediment controls to treat stormwater discharges from any disturbances within 50 feet of a water of the U.S.

See

http://water.epa.gov/polwaste/npdes/stormwater/upload/cgp2012_append ixg.pdf for guidance on complying with these alternatives.

8.J.4.2.4 Soil or sediment stockpiles. In addition to the requirements in Part 8.J.4.1.5, you must locate any piles outside of any natural buffers established under Part 8.J.4.2.3.

8.J.4.2.5 Sediment basins. In addition to the requirements in Part 8.J.4.1.6, you must locate sediment basins outside of any surface waters and any natural buffers established under Part 8.J.4.2.3, and you must utilize outlet structures that withdraw water from the surface, unless infeasible. 
8.J.4.2.6 Native topsoil preservation. You must preserve native topsoil removed during clearing, grading, or excavation, unless infeasible. Store topsoil in a manner that will maximize its use in reclamation or final vegetative stabilization (e.g., by keeping the topsoil stabilized with seed or similar measures). This requirement does not apply if the intended function of the disturbed area dictates that topsoil be disturbed or removed.

8.J.4.2.7 Steep slopes. You must minimize the disturbance of steep slopes. The permit does not prevent or prohibit disturbance on steep slopes.

Depending on site conditions and needs, disturbance on steep slopes may be necessary (e.g., a road cut in mountainous terrain; for grading steep slopes prior to erecting the mine office). Where steep slope disturbances are necessary, you can minimize the disturbances to steep slopes through the implementation of a number of standard erosion and sediment control practices, such as by phasing disturbances in these areas and using stabilization practices specifically for steep grades.

8.J.4.2.8 Soil compaction. Where final vegetative stabilization will occur or where infiltration practices will be installed, you must either restrict vehicle/ equipment use in these areas to avoid soil compaction or use soil conditioning techniques to support vegetative growth. Minimizing soil compaction is not required where compacted soil is integral to the functionality of the site.

8.J.4.2.9 Dewatering Practices. You are prohibited from discharging ground water or accumulated stormwater that is removed from excavations, trenches, foundations, vaults or other similar points of accumulation, unless such waters are first effectively managed by appropriate controls (e.g., sediment basins or sediment traps, sediment socks, dewatering tanks, tube settlers, weir tanks, or filtration systems). Uncontaminated, non-turbid dewatering water can be discharged without being routed to a control.

You must also meet the following requirements for dewatering activities:

- Discharge requirements:

- No discharging visible floating solids or foam;

- Remove oil, grease and other pollutants from dewatering water via an oil-water separator or suitable filtration device (such as a cartridge filter);

- Utilize vegetated upland areas of the site, to the extent feasible, to infiltrate dewatering water before discharge. In no case shall waters of the U.S. be considered part of the treatment area;

- Implement velocity dissipation devices at all points where dewatering water is discharged;

- Haul backwash water away for disposal or return it to the beginning of the treatment process; and

- Clean or replace the filter media used in dewatering devices when the pressure differential equals or exceeds the manufacturer's specifications.

- Treatment chemical restrictions: If you use polymers, flocculants or other chemicals to treat dewatering water, you must comply with the requirements in Parts 8.J.4.1.8. 


\section{J.4.2.10 Pollution prevention requirements.}

- Prohibited discharges (this non-exhaustive list of prohibited non-

stormwater discharges is included here as a reminder that only the only

allowable non-stormwater discharges are those enumerated in Part 1.1.3):

- Wastewater from washout of concrete;

- Wastewater from washout and cleanout of stucco, paint, form release oils, curing compounds, and other construction materials;

- Fuels, oils, or other pollutants used for operation and maintenance of vehicles or equipment;

- Soaps, solvents, or detergents used in vehicle or equipment washing;

- Toxic or hazardous substances from a spill or other release.

- Design and location requirements: Minimize the discharge of pollutants from pollutant sources by:

- Minimizing exposure;

- Using secondary containment, spill kits, or other equivalent measures;

- Locating pollution sources away from surface waters, storm sewer inlets, and drainageways;

- Cleaning up spills immediately (do not clean by hosing area down).

- Pollution prevention requirements for wash waters: Minimize the discharge of pollutants from equipment and vehicle washing, wheel wash water, and other wash waters. Wash waters must be treated in a sediment basin or alternative control that provides equivalent or better treatment prior to discharge;

- Pollution prevention requirements for the storage, handling, and disposal of construction products, materials, and wastes: Minimize the exposure of building materials, building products, construction wastes, trash, landscape materials, fertilizers, pesticides, herbicides, detergents, sanitary waste, and other materials present on the site to stormwater. Minimization of exposure is not required in cases where the exposure to stormwater will not result in a discharge of pollutants, or where exposure of a specific material or product poses little risk of stormwater contamination (such as final products and materials intended for outdoor use).

\section{J.4.2.11 Site Stabilization requirements for the construction of staging areas for} structures and access roads as defined in 8.J.3.2(b) (i.e., not applicable to earth-disturbing activities performed for purposes of mine site preparation as defined in 8.J.3.2(a)). You must comply with the following stabilization requirements, except where the intended function of the site accounts for such disturbed earth (e.g., the area of construction will become actively mined, or the controls implemented at the active mining area effectively control the disturbance):

- By no later than the end of the next work day after construction work in an area has stopped permanently or temporarily ("temporarily" means the land will be idle for a period of 14 days or more but earth-disturbing activities will resume in the future), immediately initiate stabilization measures;

- If using vegetative measures, by no later than 14 days after initiating stabilization:

- Seed or plant the area, and provide temporary cover to protect the planted area;

- Once established, vegetation must be uniform, perennial (if final stabilization), and cover at least $70 \%$ of stabilized area based on density of native vegetation. 
- If using non-vegetative stabilization, by no later than 14 days after initiating stabilization:

- Install or apply all non-vegetative measures;

- Cover all areas of exposed soil.

Note: For the purposes of this permit, EPA will consider any of the following types of activities to constitute the initiation of stabilization: 1. Prepping the soil for vegetative or non-vegetative stabilization; 2. Applying mulch or other nonvegetative product to the exposed area; 3 . Seeding or planting the exposed area; 4 . Starting any of the activities in \# $1-3$ on a portion of the area to be stabilized, but not on the entire area; and 5. Finalizing arrangements to have stabilization product fully installed in compliance with the applicable deadline for completing stabilization.

Exceptions:

- Arid, semi-arid (if construction occurs during seasonally dry period), or drought-stricken areas:

- Within 14 days of stopping construction work in an area, install any necessary non-vegetative stabilization measures;

- Initiate vegetative stabilization as soon as conditions on the site allow;

- Document the schedule that will be followed for initiating and completing vegetative stabilization;

- Plant the area so that within 3 years the $70 \%$ cover requirement is met.

- Sites affected by severe storm events or other unforeseen circumstances:

- Initiate vegetative stabilization as soon conditions on the site allow;

- Document the schedule that will be followed for initiating and completing vegetative stabilization;

- Plant the area so that so that within 3 years the $70 \%$ cover requirement is met.

\section{J.4.3 Water Quality-Based Requirements Applicable to Earth-Disturbing Activities Conducted Prior to Active Mining Activities.}

The following water quality-based limits apply to earth-disturbing activities conducted prior to active mining activities defined in Part 8.J.3.2(a) and 8.J.3.2(b), in addition to the water quality-based limits in Part 2.2 of the MSGP.

Stricter requirements apply if your site will discharge to an impaired water or a water that is identified by your state, tribe, or EPA as a Tier 2 or Tier 2.5 for antidegradation purposes:

- More rapid stabilization of exposed areas: Complete initial stabilization activities within 7 days of stopping construction work.

- More frequent site inspections: Once every 7 days and within 24 hours of a storm event of 0.25 inches or greater.

\section{J.4.4 Inspection Requirements Applicable to Earth-Disturbing Activities Conducted Prior to Active Mining Activities.}

The following requirements supersede the inspections requirements in Part 3 and 8.J.7 of the MSGP for earth-disturbing activities conducted prior to active mining activities defined in Part 8.J.3.2(a) and 8.J.3.2(b).

\section{J.4.4.1 Inspection Frequency}

- At least once every 7 calendar days, or

- Once every 14 calendar days and within 24 hours of a storm event of 0.25 inches or greater. 
Note:

- Inspections only required during working hours;

- Inspections not required during unsafe conditions; and

- If you choose to inspect once every 14 days, you must have a method for measuring rainfall amount on site (either rain gauge or representative weather station)

Note: To determine if a storm event of 0.25 inches or greater has occurred on your site, you must either keep a properly maintained rain gauge on your site, or obtain the storm event information from a weather station that is representative of your location. For any day of rainfall during normal business hours that measures 0.25 inches or greater, you must record the total rainfall measured for that day.

Note: You are required to specify in your SWPPP which schedule you will be following.

Note: "Within 24 hours of the occurrence of a storm event" means that you are required to conduct an inspection within 24 hours once a storm event has produced 0.25 inches, even if the storm event is still continuing. Thus, if you have elected to inspect bi- and there is a storm event at your site that continues for multiple days, and each day of the storm produces 0.25 inches or more of rain, you are required to conduct an inspection within 24 hours of the first day of the storm and within 24 hours after the end of the storm.

\section{J.4.4.2 Reductions in Inspection Frequency}

- Stabilized areas: You may reduce the frequency of inspections to once per month in any area of your site where stabilization has occurred pursuant to Part 8.J.4.1.9 or 8.J.4.2.11.

- Arid, semi-arid, and drought stricken areas: If earth-disturbing activities are occurring during the seasonally dry period or during a period in which drought is predicted to occur, you may reduce inspections to once per month and within 24 hours of a 0.25 inch storm event.

- Frozen conditions: You may temporarily suspend or reduce inspections to once per month until thawing conditions occur if frozen conditions are continuous and disturbed areas have been stabilized. For extreme conditions in remote areas, e.g., where transit to the site is perilous/restricted or temperatures are routinely below freezing, you may suspend inspections until the conditions are conducive to safe access, and more frequent inspections can resume.

\section{J.4.4.3 Areas to be Inspected. You must at a minimum inspect the all of the following} areas:

- Disturbed areas;

- Stormwater controls and pollution prevention measures;

- Locations where stabilization measures have been implemented;

- Material, waste, borrow, or equipment storage and maintenance areas;

- Areas where stormwater flows;

- Points of discharge.

8.J.4.4.4 What to Check for During Inspections. At a minimum you must check:

- Whether all stormwater controls are installed, operational and working as intended;

- Whether any new or modified stormwater controls are needed;

- For conditions that could lead to a spill or leak; 
- For visual signs of erosion/sedimentation at points of discharge.

If a discharge is occurring:

- The quality and characteristics of the discharge;

- Whether controls are operating effectively.

8.J.4.4.5 Inspection Report. Within 24 hours of an inspection, complete a report that includes:

- Inspection date;

- Name and title of inspector(s);

- Summary of inspection findings;

- Rainfall amount that triggered the inspection (if applicable);

- If it was unsafe to inspect a portion of the site, include documentation of the reason and the location(s);

- Each inspection report must be signed;

- Keep a current copy of all reports at the site or at an easily accessible location.

8.J.4.5 Cessation of Requirements Applicable to Earth-Disturbing Activities Conducted Prior to

Active Mining Activities. The requirements in 8.J.4 no longer apply for any earthdisturbing activities conducted prior to active mining activities as defined in 8.J.3.2(a) or 8.J.3.2(b) where:

1. Earth-disturbing activities have ceased; and

2. Stabilization has been met consistent with Part 8.J.4.1.9 or 8.J.4.2.11 (not required for areas where active mining activities will occur).

\section{J.5 Technology-Based Effluent Limits for Active Mining Activities.}

Note: These requirements do not apply for any discharges from earth-disturbing activities conducted prior to active-mining as defined in 8.J.3.2(a) or 8.J.3.2(b).

8.J.5.1 Employee Training. Conduct employee training at least annually at active and temporarily inactive sites. (See also Part 2.1.2.8).

8.J.5.2 Stormwater Controls. Apart from the control measures you implement to meet your Part 2 effluent limits, where necessary to minimize pollutant discharges in stormwater, implement the following control measures at your site. The potential pollutants identified in Part 8.J.6.3 shall determine the priority and appropriateness of the control measures selected.

Stormwater Diversions: Divert stormwater away from potential pollutant sources through implementation of control measures such as the following, where determined to be feasible (list not exclusive): interceptor or diversion controls (e.g., dikes, swales, curbs, berms); pipe slope drains; subsurface drains; conveyance systems (e.g., channels or gutters, open-top box culverts, and waterbars; rolling dips and road sloping; roadway surface water deflector and culverts); or their equivalents. For mines subject to dust control requirements under state or county air quality permits, provided the requirements are equivalent, compliance with such air permit dust requirements shall constitute compliance with the dust control effluent limit in Part 2.1.2.10.

Capping: When capping is necessary to minimize pollutant discharges in stormwater, identify the source being capped and the material used to construct the cap.

Treatment: If treatment of stormwater (e.g., chemical or physical systems, oil and water separators, artificial wetlands) is necessary to protect water quality, describe the type and location of treatment used. Passive and/or active treatment of stormwater runoff is encouraged. Treated runoff may be discharged as a stormwater source regulated 
under this permit provided the discharge is not combined with discharges subject to effluent limitation guidelines for the Mineral Mining and Processing Point Source Category (40 CFR Part 436).

8.J.5.3 Discharge Testing. (See also Part 5.2.3.4) Test or evaluate all outfalls covered under this permit for the presence of specific mining-related but unauthorized non-stormwater discharges such as discharges subject to effluent limitations guidelines (e.g., 40 CFR Part 436). Alternatively (if applicable), you may keep a certification with your SWPPP, per Part 8.J.6.6.

\section{J.6 Additional SWPPP Requirements for Mining Operations.} facilities.

Note: The requirements in Part 8.J.6 are not applicable to inactive mineral mining

8.J.6.1 Nature of Industrial Activities. (See also Part 5.2.2) Document in your SWPPP the mining and associated activities that can potentially affect the stormwater discharges covered by this permit, including a general description of the location of the site relative to major transportation routes and communities.

8.J.6.2 Site Map. (See also Part 5.2.2) Document in your SWPPP the locations of the following (as appropriate): mining or milling site boundaries; access and haul roads; outline of the drainage areas of each stormwater outfall within the facility with indications of the types of discharges from the drainage areas; location(s) of all permitted discharges covered under an individual NPDES permit; outdoor equipment storage, fueling, and maintenance areas; materials handling areas; outdoor manufacturing, outdoor storage, and material disposal areas; outdoor chemicals and explosives storage areas; overburden, materials, soils, or waste storage areas; location of mine drainage dewatering or other process water; heap leach pads; off-site points of discharge for mine dewatering and process water; surface waters; boundary of tributary areas that are subject to effluent limitations guidelines; and location(s) of reclaimed areas.

8.J.6.3 Potential Pollutant Sources. (See also Part 5.2.3) For each area of the mine or mill site where stormwater discharges associated with industrial activities occur, document in your SWPPP the types of pollutants (e.g., heavy metals, sediment) likely to be present in significant amounts. For example, phosphate mining facilities will likely need to document pollutants such as selenium, which can be present in significant amounts in their discharges. Consider these factors: the mineralogy of the waste rock (e.g., acid forming); toxicity and quantity of chemicals used, produced, or discharged; the likelihood of contact with stormwater; vegetation of site (if any); and history of significant leaks or spills of toxic or hazardous pollutants. Also include a summary of any existing waste rock or overburden characterization data and test results for potential generation of acid rock drainage.

8.J.6.4 Documentation of Control Measures. To the extent that you use any of the control measures in Part 8.J.5.2, document them in your SWPPP per Part 5.2.4. If control measures are implemented or planned but are not listed here (e.g., substituting a less toxic chemical for a more toxic one), include descriptions of them in your SWPPP. If you are in compliance with dust control requirements under state or county air quality permits, you must state (or summarize, as necessary) what the state or county air quality permit dust control requirements are and how you've achieved compliance with them.

8.J.6.5 Employee Training. All employee training(s) conducted in accordance with Part 8.J.5.1 must be documented with the SWPPP.

8.J.6.6 Certification of Permit Coverage for Commingled Non-Stormwater Discharges. If you determine that you are able to certify, consistent with Part 8.J.5.3, that a particular 
discharge composed of commingled stormwater and non-stormwater is covered under a separate NPDES permit, and that permit subjects the non-stormwater portion to effluent limitations prior to any commingling, you must retain such certification with your SWPPP. This certification must identify the non-stormwater discharges, the applicable NPDES permit(s), the effluent limitations placed on the non-stormwater discharge by the permit(s), and the points at which the limitations are applied.

\section{J.7 Additional Inspection Requirements. (See also Part 3.1)}

Except for earth-disturbing activities conducted prior to active mining activities as defined in Part 8.J.3.2(a) and 8.J.3.2(b), which are subject to Part 8.J.4.4, perform inspections at least quarterly unless adverse weather conditions make the site inaccessible. Sites which discharge to waters which are designated as Tier 2 or 2.5 or waters which are impaired for sediment or nitrogen must be inspected monthly. See Part 8.J.8.1 for inspection requirements for inactive and unstaffed sites.

\section{J.8 Sector-Specific Benchmarks. (See also Part 6)}

Table 8.J-1 identifies benchmarks that apply to the specific subsectors of Sector J. These benchmarks apply to both your primary industrial activity and any co-located industrial activities. Note: There are no Part 8.J.8 monitoring and reporting or impaired waters monitoring requirements for inactive and unstaffed sites.

\begin{tabular}{|l|l|c|}
\hline \multicolumn{3}{|c|}{ Table 8.J-1. } \\
\hline \multicolumn{1}{|c|}{$\begin{array}{c}\text { Subsector } \\
\text { (You may be subject to requirements for } \\
\text { more than one sector/subsector) }\end{array}$} & \multicolumn{1}{|c|}{ Parameter } & $\begin{array}{c}\text { Benchmark } \\
\text { Monitoring } \\
\text { Concentration }\end{array}$ \\
\hline $\begin{array}{l}\text { Subsector J1. Sand and Gravel Mining (SIC } \\
\text { 1442, 1446) }\end{array}$ & Nitrate plus Nitrite Nitrogen & $0.68 \mathrm{mg} / \mathrm{L}$ \\
\cline { 2 - 3 } $\begin{array}{l}\text { Subsector J2. Dimension and Crushed Stone } \\
\text { and Nonmetallic Minerals (except fuels) (SIC } \\
1411,1422-1429,1481,1499)\end{array}$ & Total Suspended Solids (TSS) & $100 \mathrm{mg} / \mathrm{L}$ \\
\hline
\end{tabular}

8.J.8.1 Inactive and Unstaffed Sites - Conditional Exemption from No Exposure Requirement for Routine Inspections, Quarterly Visual Assessments, and Benchmark and Impaired Waters Monitoring. As a Sector J facility, if you are seeking to exercise a waiver from either the routine inspection, quarterly visual assessment or the benchmark and/or impaired monitoring requirements for inactive and unstaffed sites (including temporarily inactive sites), you are conditionally exempt from the requirement to certify that "there are no industrial materials or activities exposed to stormwater" in Parts 3.1.1, 3.2.3, 6.2.1.3, and 6.2.4.3. This exemption is conditioned on the following:

- If circumstances change and your facility becomes active and/or staffed, this exception no longer applies and you must immediately begin complying with the applicable benchmark monitoring requirements as if you were in your first year of permit coverage, and the quarterly visual assessment requirements; and

- EPA retains the authority to revoke this exemption and/or the monitoring waiver where it is determined that the discharge causes, has a reasonable potential to cause, or contributes to an instream excursion above an applicable water quality standard, including designated uses.

Subject to the two conditions above, if your facility is inactive and unstaffed, you are waived from the requirement to conduct routine facility inspections, quarterly visual assessments, and benchmark and impaired waters monitoring. You must still conduct an annual site inspection in 
accordance with Part 3.1. You are encouraged to inspect your site more frequently where you have reason to believe that severe weather or natural disasters may have damaged control measures or increased discharges.

8.J.9 Effluent Limitations Based on Effluent Limitations Guidelines. (See also Part 6.2.2.1).

Table 8.J-2 identifies effluent limits that apply to the industrial activities described below. Compliance with these effluent limits is to be determined based on discharges from these industrial activities independent of commingling with any other waste streams that may be covered under this permit.

\begin{tabular}{|c|c|c|}
\hline \multicolumn{3}{|c|}{ Table 8.J-2 } \\
\hline Industrial Activity & Parameter & Effluent Limitation 1 \\
\hline $\begin{array}{l}\text { Mine dewatering discharges at crushed stone } \\
\text { mining facilities (SIC } 1422-1429 \text { ) }\end{array}$ & $\overline{\mathrm{pH}}$ & $6.0-9.0$ \\
\hline $\begin{array}{l}\text { Mine dewatering discharges at construction } \\
\text { sand and gravel mining facilities (SIC 1442) }\end{array}$ & $\mathrm{pH}$ & $6.0-9.0$ \\
\hline \multirow{3}{*}{$\begin{array}{l}\text { Mine dewatering discharges at industrial sand } \\
\text { mining facilities (SIC 1446) }\end{array}$} & \multirow{2}{*}{$\begin{array}{l}\text { Total Suspended } \\
\text { Solids (TSS) }\end{array}$} & $25 \mathrm{mg} / \mathrm{L}$, monthly avg. \\
\hline & & $\begin{array}{l}45 \mathrm{mg} / \mathrm{L} \text {, daily } \\
\text { maximum }\end{array}$ \\
\hline & $\mathrm{pH}$ & $6.0-9.0$ \\
\hline
\end{tabular}

'Monitor annually.

\section{J.10 Termination of Permit Coverage.}

8.J.10.1 Termination of Permit Coverage for Sites Reclaimed After December 17, 1990. A site or a portion of a site that has been released from applicable state or federal reclamation requirements after December 17, 1990, is no longer required to maintain coverage under this permit. If the site or portion of a site reclaimed after December 17, 1990, was not subject to reclamation requirements, the site or portion of the site is no longer required to maintain coverage under this permit if the site or portion of the site has been reclaimed as defined in Part 8.J.3.5.

8.J.10.2 Termination of Permit Coverage for Sites Reclaimed Before December 17, 1990. A site or portion of a site that was released from applicable state or federal reclamation requirements before December 17, 1990, or that was otherwise reclaimed before December 17, 1990, is no longer required to maintain coverage under this permit if the site or portion of the site has been reclaimed. A site or portion of a site is considered to have been reclaimed if: (1) stormwater runoff that comes into contact with raw materials, intermediate byproducts, finished products, and waste products does not have the potential to cause or contribute to violations of state water quality standards, (2) soil disturbing activities related to mining at the sites or portion of the site have been completed, (3) the site or portion of the site has been stabilized to minimize soil erosion, and (4) as appropriate depending on location, size, and the potential to contribute pollutants to stormwater discharges, the site or portion of the site has been revegetated, will be amenable to natural revegetation, or will be left in a condition consistent with the post-mining land use. 


\section{Part 8 - Sector-Specific Requirements for Industrial Activity}

\section{Subpart K - Sector K - Hazardous Waste Treatment, Storage, or Disposal Facilities.}

You must comply with Part 8 sector-specific requirements associated with your primary industrial activity and any co-located industrial activities, as defined in Appendix A. The sectorspecific requirements apply to those areas of your facility where those sector-specific activities occur. These sector-specific requirements are in addition to any requirements specified elsewhere in this permit.

\section{K.1 Covered Stormwater Discharges.}

The requirements in Subpart $\mathrm{K}$ apply to stormwater discharges associated with industrial activity from Hazardous Waste Treatment, Storage, or Disposal facilities (TSDFs) as identified by the Activity Code specified under Sector K in Table D-1 of Appendix D of the permit.

\section{K.2 Industrial Activities Covered by Sector K.}

This permit authorizes stormwater discharges associated with industrial activity from facilities that treat, store, or dispose of hazardous wastes and that are operating under interim status or a permit under subtitle C of RCRA.

Disposal facilities that have been properly closed and capped, and have no significant materials exposed to stormwater, are considered inactive and do not require permits.

\section{K.3 Limitations on Coverage.}

8.K.3.1 Prohibition of Non-Stormwater Discharges. (See also Part 1.1.4) The following are not authorized by this permit: leachate, gas collection condensate, drained free liquids, contaminated ground water, laboratory-derived wastewater, and contact wash water from washing truck and railcar exteriors and surface areas that have come in direct contact with solid waste at the landfill facility. (EPA includes these prohibited nonstormwater discharges here solely as a helpful reminder to the operator that the only non-stormwater discharges authorized by this permit are at Part 1.1.3.)

8.K.3.2 Limitations on Coverage for Facilities Providing Commercial TSDF Services. For facilities located in Region 6 (see Appendix C) coverage is limited to hazardous waste TSDFs that are self-generating (including occasionally accepting wastes from community household hazardous waste collection events as public service), handle only residential wastes, and/or only store hazardous wastes and do not treat or dispose of them. Coverage under this permit is not available to commercial waste disposal and treatment facilities located in Region 6 that dispose and treat on a commercial basis any produced hazardous wastes (i.e., not their own) as a service to commercial or industrial generators.

\section{K.4 Definitions.}

8.K.4.1 Contaminated stormwater - stormwater that comes into direct contact with landfill wastes, the waste handling and treatment areas, or landfill wastewater as defined in Part 8.K.4.4. Some specific areas of a landfill that may produce contaminated stormwater include (but are not limited to) the open face of an active landfill with exposed waste (no cover added); the areas around wastewater treatment operations; trucks, equipment, or machinery that has been in direct contact with the waste; and waste dumping areas.

8.K.4.2 Drained free liquids - aqueous wastes drained from waste containers (e.g., drums) prior to landfilling.

8.K.4.3 Landfill - an area of land or an excavation in which wastes are placed for permanent disposal, but that is not a land application or land treatment unit, surface 
impoundment, underground injection well, waste pile, salt dome formation, salt bed formation, underground mine, or cave as these terms are defined in 40 CFR 257.2, 258.2, and 260.10.

8.K.4.4 Landfill wastewater - as defined in 40 CFR Part 445 (Landfills Point Source Category), all wastewater associated with, or produced by, landfilling activities except for sanitary wastewater, non-contaminated stormwater, contaminated ground water, and wastewater from recovery pumping wells. Landfill wastewater includes, but is not limited to, leachate, gas collection condensate, drained free liquids, laboratory derived wastewater, contaminated stormwater, and contact wash water from washing truck, equipment, and railcar exteriors and surface areas that have come in direct contact with solid waste at the landfill facility.

8.K.4.5 Leachate - liquid that has passed through or emerged from solid waste and contains soluble, suspended, or miscible materials removed from such waste.

8.K.4.6 Non-contaminated stormwater - stormwater that does not come into direct contact with landfill wastes, the waste handling and treatment areas, or landfill wastewater as defined in Part 8.K.4.4. Non-contaminated stormwater includes stormwater that flows off the cap, cover, intermediate cover, daily cover, and/or final cover of the landfill.

8.K.5 Sector-Specific Benchmarks. (See also Part 6)

Table 8.K-1 identifies benchmarks that apply to the specific subsectors of Sector K. These benchmarks apply to both your primary industrial activity and any co-located industrial activities.

\begin{tabular}{|c|c|c|}
\hline \multicolumn{3}{|c|}{ Table 8.K-1. } \\
\hline $\begin{array}{c}\text { Subsector } \\
\text { (You may be subject to requirements for more } \\
\text { than one sector/subsector) }\end{array}$ & Parameter & $\begin{array}{c}\text { Benchmark } \\
\text { Monitoring } \\
\text { Concentration } \\
\end{array}$ \\
\hline \multirow{10}{*}{$\begin{array}{l}\text { Subsector K1. ALL - Industrial Activity Code "HZ" } \\
\text { (Note: permit coverage limited in some states). } \\
\text { Benchmarks only applicable to discharges not } \\
\text { subject to effluent limitations in } 40 \text { CFR Part } 445 \\
\text { Subpart A (see below). }\end{array}$} & Ammonia & $2.14 \mathrm{mg} / \mathrm{L}$ \\
\hline & Total Magnesium & $0.064 \mathrm{mg} / \mathrm{L}$ \\
\hline & $\begin{array}{c}\text { Chemical Oxygen Demand } \\
\text { (COD) }\end{array}$ & $120 \mathrm{mg} / \mathrm{L}$ \\
\hline & $\begin{array}{c}\text { Total Arsenic (freshwater) } \\
\text { Total Arsenic } \\
\text { (saltwater) }^{1} \\
\end{array}$ & $\begin{array}{c}0.15 \mathrm{mg} / \mathrm{L} \\
0.069 \mathrm{mg} / \mathrm{L}\end{array}$ \\
\hline & $\begin{array}{l}\text { Total Cadmium (freshwater)² } \\
\text { Total Cadmium (saltwater) }^{1}\end{array}$ & $\begin{array}{c}\text { Hardness } \\
\text { Dependent } \\
0.04 \mathrm{mg} / \mathrm{L} \\
\end{array}$ \\
\hline & $\begin{array}{l}\text { Total Cyanide (freshwater) } \\
\text { Total Cyanide (saltwater) }\end{array}$ & $\begin{array}{l}0.022 \mathrm{mg} / \mathrm{L} \\
0.001 \mathrm{mg} / \mathrm{L}\end{array}$ \\
\hline & $\begin{array}{l}\text { Total Lead (freshwater)² } \\
\text { Total Lead (saltwater) }^{1} \\
\end{array}$ & $\begin{array}{l}\text { Hardness } \\
\text { Dependent } \\
0.21 \mathrm{mg} / \mathrm{L} \\
\end{array}$ \\
\hline & $\begin{array}{l}\text { Total Mercury (freshwater) } \\
\text { Total Mercury (saltwater) }\end{array}$ & $\begin{array}{l}0.0014 \mathrm{mg} / \mathrm{L} \\
0.0018 \mathrm{mg} / \mathrm{L}\end{array}$ \\
\hline & $\begin{array}{l}\text { Total Selenium (freshwater) } \\
\text { Total Selenium (saltwater)' }\end{array}$ & $\begin{array}{c}0.005 \mathrm{mg} / \mathrm{L} \\
0.29 \mathrm{mg} / \mathrm{L}\end{array}$ \\
\hline & $\begin{array}{l}\text { Total Silver (freshwater)² } \\
\text { Total Silver (saltwater)' }\end{array}$ & $\begin{array}{l}\text { Hardness } \\
\text { Dependent } \\
0.0019 \mathrm{mg} / \mathrm{L}\end{array}$ \\
\hline
\end{tabular}


ISaltwater benchmark values apply to stormwater discharges into saline waters where indicated.

2 The freshwater benchmark values of some metals are dependent on water hardness. For these parameters, permittees must determine the hardness of the receiving water (see Appendix J, "Calculating Hardness in Receiving Waters for Hardness Dependent Metals," for methodology), in accordance with Part 6.2.1.1, to identify the applicable "hardness range' for determining their benchmark value applicable to their facility. Hardness Dependent Benchmarks follow in the table below:

\begin{tabular}{|l|l|l|l|}
\hline Freshwater Hardness Range & $\begin{array}{l}\text { Cadmium } \\
(\mathrm{mg} / \mathrm{L})\end{array}$ & $\begin{array}{l}\text { Lead } \\
(\mathrm{mg} / \mathrm{L})\end{array}$ & $\begin{array}{l}\text { Silver } \\
(\mathrm{mg} / \mathrm{L})\end{array}$ \\
\hline $0-24.99 \mathrm{mg} / \mathrm{L}$ & 0.0005 & 0.014 & 0.0007 \\
\hline $25-49.99 \mathrm{mg} / \mathrm{L}$ & 0.0008 & 0.023 & 0.0007 \\
\hline $50-74.99 \mathrm{mg} / \mathrm{L}$ & 0.0013 & 0.045 & 0.0017 \\
\hline $75-99.99 \mathrm{mg} / \mathrm{L}$ & 0.0018 & 0.069 & 0.0030 \\
\hline $100-124.99 \mathrm{mg} / \mathrm{L}$ & 0.0023 & 0.095 & 0.0046 \\
\hline $125-149.99 \mathrm{mg} / \mathrm{L}$ & 0.0029 & 0.122 & 0.0065 \\
\hline $150-174.99 \mathrm{mg} / \mathrm{L}$ & 0.0034 & 0.151 & 0.0087 \\
\hline $175-199.99 \mathrm{mg} / \mathrm{L}$ & 0.0039 & 0.182 & 0.0112 \\
\hline $200-224.99 \mathrm{mg} / \mathrm{L}$ & 0.0045 & 0.213 & 0.0138 \\
\hline $225-249.99 \mathrm{mg} / \mathrm{L}$ & 0.0050 & 0.246 & 0.0168 \\
\hline $250+\mathrm{mg} / \mathrm{L}$ & 0.0053 & 0.262 & 0.0183 \\
\hline
\end{tabular}

\section{K.6 Effluent Limitations Based on Effluent Limitations Guidelines. (See also Part 6.2.2.1)}

Table 8.K-2 identifies effluent limitations that apply to the industrial activities described below. Compliance with these effluent limitations is to be determined based on discharges from these industrial activities independent of commingling with any other waste streams that may be covered under this permit. 
Table 8.K-21

\begin{tabular}{|c|c|c|}
\hline Industrial Activity & Parameter & Effluent Limitation \\
\hline \multirow{27}{*}{$\begin{array}{l}\text { Discharges from } \\
\text { hazardous waste landfills } \\
\text { subject to effluent } \\
\text { limitations in } 40 \text { CFR Part } \\
445 \text { Subpart A (see } \\
\text { footnote). }\end{array}$} & \multirow{2}{*}{$\begin{array}{l}\text { Biochemical Oxygen } \\
\text { Demand (BOD5) }\end{array}$} & 220 mg/L, daily maximum \\
\hline & & $56 \mathrm{mg} / \mathrm{L}$, monthly avg. maximum \\
\hline & \multirow{2}{*}{$\begin{array}{l}\text { Total Suspended } \\
\text { Solids (TSS) } \\
\end{array}$} & $88 \mathrm{mg} / \mathrm{L}$, daily maximum \\
\hline & & $27 \mathrm{mg} / \mathrm{L}, \mathrm{monthly}$ avg. maximum \\
\hline & \multirow[t]{2}{*}{ Ammonia } & $10 \mathrm{mg} / \mathrm{L}$, daily maximum \\
\hline & & $4.9 \mathrm{mg} / \mathrm{L}, \mathrm{monthly}$ avg. maximum \\
\hline & \multirow[t]{2}{*}{ Alpha Terpineol } & $0.042 \mathrm{mg} / \mathrm{L}$, daily maximum \\
\hline & & 0.019 mg/L, monthly avg. maximum \\
\hline & \multirow[t]{2}{*}{ Aniline } & $0.024 \mathrm{mg} / \mathrm{L}$, daily maximum \\
\hline & & $0.015 \mathrm{mg} / \mathrm{L}$, monthly avg. maximum \\
\hline & \multirow[t]{2}{*}{ Benzoic Acid } & $0.119 \mathrm{mg} / \mathrm{L}$, daily maximum \\
\hline & & $0.073 \mathrm{mg} / \mathrm{L}, \mathrm{monthly}$ avg. maximum \\
\hline & \multirow[t]{2}{*}{ Naphthalene } & $0.059 \mathrm{mg} / \mathrm{L}$, daily maximum \\
\hline & & 0.022 mg/L, monthly avg. maximum \\
\hline & \multirow[t]{2}{*}{ p-Cresol } & $0.024 \mathrm{mg} / \mathrm{L}$, daily maximum \\
\hline & & 0.015 mg/L, monthly avg. maximum \\
\hline & \multirow[t]{2}{*}{ Phenol } & $0.048 \mathrm{mg} / \mathrm{L}$, daily maximum \\
\hline & & 0.029 mg/L, monthly avg. maximum \\
\hline & \multirow[t]{2}{*}{ Pyridine } & $0.072 \mathrm{mg} / \mathrm{L}$, daily maximum \\
\hline & & 0.025 mg/L, monthly avg. maximum \\
\hline & \multirow[t]{2}{*}{ Total Arsenic } & $1.1 \mathrm{mg} / \mathrm{L}$, daily maximum \\
\hline & & $0.54 \mathrm{mg} / \mathrm{L}$, monthly avg. maximum \\
\hline & \multirow[t]{2}{*}{ Total Chromium } & $1.1 \mathrm{mg} / \mathrm{L}$, daily maximum \\
\hline & & $0.46 \mathrm{mg} / \mathrm{L}$, monthly avg. maximum \\
\hline & \multirow[t]{2}{*}{ Total Zinc } & $0.535 \mathrm{mg} / \mathrm{L}$, daily maximum \\
\hline & & $0.296 \mathrm{mg} / \mathrm{L}, \mathrm{monthly}$ avg. maximum \\
\hline & $\mathrm{pH}$ & $\begin{array}{c}\text { Within the range of 6-9 standard } \mathrm{pH} \text { units } \\
\text { (s.U.) }\end{array}$ \\
\hline
\end{tabular}

${ }^{1}$ Monitor annually. As set forth at 40 CFR Part 445 Subpart A, these numeric limitations apply to contaminated stormwater discharges from hazardous waste landfills subject to the provisions of RCRA Subtitle C at 40 CFR Parts 264 (Subpart N) and 265 (Subpart N) except for any of the following facilities:

(a) landfills operated in conjunction with other industrial or commercial operations when the landfill receives only wastes generated by the industrial or commercial operation directly associated with the landfill;

(b) landfills operated in conjunction with other industrial or commercial operations when the landfill receives wastes generated by the industrial or commercial operation directly associated with the landfill and also receives other wastes, provided that the other wastes received for disposal are generated by a facility that is subject to the same provisions in 40 CFR Subchapter $\mathrm{N}$ as the industrial or commercial operation or that the other wastes received are of similar nature to the wastes generated by the industrial or commercial operation;

(c) landfills operated in conjunction with Centralized Waste Treatment (CWT) facilities subject to 40 CFR Part 437, so long as the CWT facility commingles the landfill wastewater with other non-landfill wastewater for discharge. A landfill directly associated with a CWT facility is subject to this part if the CWT facility discharges landfill wastewater separately from other CWT wastewater or commingles the wastewater from its landfill only with wastewater from other landfills; or

(d) landfills operated in conjunction with other industrial or commercial operations when the landfill receives wastes from public service activities, so long as the company owning the landfill does not receive a fee or other remuneration for the disposal service. 


\section{Part 8 - Sector-Specific Requirements for Industrial Activity}

\section{Subpart L - Sector L - Landfills, Land Application Sites, and Open Dumps.}

You must comply with Part 8 sector-specific requirements associated with your primary industrial activity and any co-located industrial activities, as defined in Appendix A. The sectorspecific requirements apply to those areas of your facility where those sector-specific activities occur. These sector-specific requirements are in addition to any requirements specified elsewhere in this permit.

\section{L.1 Covered Stormwater Discharges.}

The requirements in Subpart $L$ apply to stormwater discharges associated with industrial activity from Landfills and Land Application Sites as identified by the Activity Code specified under Sector $L$ in Table D-1 of Appendix D of the permit.

\section{L.2 Industrial Activities Covered by Sector L.}

This permit may authorize stormwater discharges for Sector $L$ facilities associated with waste disposal at landfills, land application sites that receive or have received industrial waste, including sites subject to regulation under Subtitle D of RCRA. This permit does not cover discharges from landfills that receive only municipal wastes.

\section{L.3 Limitations on Coverage.}

8.L.3.1 Prohibition of Non-Stormwater Discharges. (See also Part 1.1.4) The following discharges are not authorized by this permit: leachate, gas collection condensate, drained free liquids, contaminated ground water, laboratory wastewater, and contact wash water from washing truck and railcar exteriors and surface areas that have come in direct contact with solid waste at the landfill facility. (EPA includes these prohibited nonstormwater discharges here solely as a helpful reminder to the operator that the only non-stormwater discharges authorized by this permit are at Part 1.1.3.)

8.L.3.2 Prohibition Stormwater Discharges from Open Dumps. Discharges from open dumps as defined under RCRA are also not authorized under this permit.

\section{L.4 Definitions.}

8.L.4.1 Contaminated stormwater - stormwater that comes into direct contact with landfill wastes, the waste handling and treatment areas, or landfill wastewater. Some areas of a landfill that may produce contaminated stormwater include (but are not limited to) the open face of an active landfill with exposed waste (no cover added); the areas around wastewater treatment operations; trucks, equipment, or machinery that has been in direct contact with the waste; and waste dumping areas.

8.L.4.2 Drained free liquids - aqueous wastes drained from waste containers (e.g., drums) prior to landfilling.

8.L.4.3 Landfill wastewater - as defined in 40 CFR Part 445 (Landfills Point Source Category) all wastewater associated with, or produced by, landfilling activities except for sanitary wastewater, non-contaminated stormwater, contaminated ground water, and wastewater from recovery pumping wells. Landfill process wastewater includes, but is not limited to, leachate; gas collection condensate; drained free liquids; laboratoryderived wastewater; contaminated stormwater; and contact wash water from washing truck, equipment, and railcar exteriors and surface areas that have come in direct contact with solid waste at the landfill facility.

8.L.4.4 Leachate - liquid that has passed through or emerged from solid waste and contains soluble, suspended, or miscible materials removed from such waste. 
8.L.4.5 Non-contaminated stormwater - stormwater that does not come into direct contact with landfill wastes, the waste handling and treatment areas, or landfill wastewater. Non-contaminated stormwater includes stormwater that flows off the cap, cover, intermediate cover, daily cover, and/or final cover of the landfill.

\section{L.5 Additional Technology-Based Effluent Limits.}

8.L.5.1 Preventive Maintenance Program. (See also Part 2.1.2.3) As part of your preventive maintenance program, maintain the following: all elements of leachate collection and treatment systems, to prevent commingling of leachate with stormwater; the integrity and effectiveness of any intermediate or final cover (including repairing the cover as necessary), to minimize the effects of settlement, sinking, and erosion.

8.L.5.2 Erosion and Sedimentation Control. (See also Part 2.1.2.5) Provide temporary stabilization (e.g., temporary seeding, mulching, and placing geotextiles on the inactive portions of stockpiles) for the following in order to minimize discharges of pollutants in stormwater: materials stockpiled for daily, intermediate, and final cover; inactive areas of the landfill or open dump; landfills or open dump areas that have gotten final covers but where vegetation has yet to establish itself; and land application sites where waste application has been completed but final vegetation has not yet been established.

\section{L.6 Additional SWPPP Requirements.}

8.L.5.1 Drainage Area Site Map. (See also Part 5.2.2) Document in your SWPPP where any of the following may be exposed to precipitation or surface runoff: active and closed landfill cells or trenches, active and closed land application areas, locations where open dumping is occurring or has occurred, locations of any known leachate springs or other areas where uncontrolled leachate may commingle with runoff, and leachate collection and handling systems.

8.L.5.2 Summary of Potential Pollutant Sources. (See also Part 5.2.3) Document in your SWPPP the following sources and activities that have potential pollutants associated with them: fertilizer, herbicide, and pesticide application; earth and soil moving; waste hauling and loading or unloading; outdoor storage of significant materials, including daily, interim, and final cover material stockpiles as well as temporary waste storage areas; exposure of active and inactive landfill and land application areas; uncontrolled leachate flows; and failure or leaks from leachate collection and treatment systems.

8.L.7 Additional Inspection Requirements. (See also Part 3)

8.L.7.1 Inspections of Active Sites. Except in arid and semi-arid climates, inspect operating landfills, open dumps, and land application sites at least once every 7 days. Focus on areas of landfills that have not yet been finally stabilized; active land application areas, areas used for storage of material and wastes that are exposed to precipitation, stabilization, and structural control measures; leachate collection and treatment systems; and locations where equipment and waste trucks enter and exit the site. Ensure that sediment and erosion control measures are operating properly. For stabilized sites and areas where land application has been completed, or where the climate is arid or semi-arid, conduct inspections at least once every month.

8.L.7.2 Inspections of Inactive Sites. Inspect inactive landfills, open dumps, and land application sites at least quarterly. Qualified personnel must inspect landfill (or open dump) stabilization and structural erosion control measures, leachate collection and treatment systems, and all closed land application areas. 


\section{L.8 Additional Post-Authorization Documentation Requirements.}

8.L.8.1 Recordkeeping and Internal Reporting. Keep records with your SWPPP of the types of wastes disposed of in each cell or trench of a landfill or open dump. For land application sites, track the types and quantities of wastes applied in specific areas.

\section{L.9 Sector-Specific Benchmarks. (See also Part 6)}

Table 8.L-1 identifies benchmarks that apply to the specific subsectors of Sector L. These benchmarks apply to both your primary industrial activity and any co-located industrial activities.

Table 8.L-1.

\begin{tabular}{|l|c|c|}
\hline \multicolumn{1}{|c|}{$\begin{array}{c}\text { Subsector } \\
\text { (You may be subject to requirements for more than one } \\
\text { sector/subsector) }\end{array}$} & Parameter & $\begin{array}{c}\text { Benchmark } \\
\text { Monitoring } \\
\text { Concentration' }\end{array}$ \\
\hline $\begin{array}{l}\text { Subsector L1. All Landfill, Land Application Sites and Open } \\
\text { Dumps (Industrial Activity Code "LF") }\end{array}$ & $\begin{array}{c}\text { Total } \\
\text { Suspended } \\
\text { Solids (TSS) }\end{array}$ & $100 \mathrm{mg} / \mathrm{L}$ \\
\hline $\begin{array}{l}\text { Subsector L2. All Landfill, Land Application Sites and Open } \\
\text { Dumps, except Municipal Solid Waste Landfill (MSWLF) Areas } \\
\text { Closed in Accordance with 40 CFR 258.60 (Industrial Activity } \\
\text { Code "LF") }\end{array}$ & Total Iron & $1.0 \mathrm{mg} / \mathrm{L}$ \\
\hline
\end{tabular}

'Benchmark monitoring required only for discharges not subject to effluent limitations in 40 CFR Part 445 Subpart B (see Table L-2 below).

8.L.10. Effluent Limitations Based on Effluent Limitations Guidelines. (See also Part 6.2.2.1)

Table 8.L-2 identifies effluent limitations that apply to the industrial activities described below. Compliance with these effluent limitations is to be determined based on discharges from these industrial activities independent of commingling with any other waste streams that may be covered under this permit.

\begin{tabular}{|c|c|c|}
\hline \multicolumn{3}{|c|}{ Table 8.L-21 } \\
\hline Industrial Activity & Parameter & Effluent Limitation \\
\hline \multirow{12}{*}{$\begin{array}{l}\text { Discharges from non- } \\
\text { hazardous waste landfills } \\
\text { subject to effluent } \\
\text { limitations in } 40 \text { CFR Part } \\
445 \text { Subpart B. }\end{array}$} & \multirow{2}{*}{$\begin{array}{c}\text { Biochemical Oxygen Demand } \\
(\text { (BOD } 5)^{-}\end{array}$} & 140 mg/L, daily maximum \\
\hline & & 37 mg/L, monthly avg. maximum \\
\hline & \multirow[t]{2}{*}{ Total Suspended Solids (TSS) } & $88 \mathrm{mg} / \mathrm{L}$, daily maximum \\
\hline & & $27 \mathrm{mg} / \mathrm{L}$, monthly avg. maximum \\
\hline & \multirow[t]{2}{*}{ Ammonia } & $10 \mathrm{mg} / \mathrm{L}$, daily maximum \\
\hline & & $4.9 \mathrm{mg} / \mathrm{L}$, monthly avg. maximum \\
\hline & \multirow[t]{2}{*}{ Alpha Terpineol } & $0.033 \mathrm{mg} / \mathrm{L}$, daily maximum \\
\hline & & $0.016 \mathrm{mg} / \mathrm{L}$ monthly avg. maximum \\
\hline & \multirow[t]{2}{*}{ Benzoic Acid } & $0.12 \mathrm{mg} / \mathrm{L}$, daily maximum \\
\hline & & $\begin{array}{c}0.071 \mathrm{mg} / \mathrm{L}, \text { monthly avg. } \\
\text { maximum }\end{array}$ \\
\hline & \multirow[t]{2}{*}{ p-Cresol } & $0.025 \mathrm{mg} / \mathrm{L}$, daily maximum \\
\hline & & $\begin{array}{c}0.014 \mathrm{mg} / \mathrm{L}, \text { monthly avg. } \\
\text { maximum }\end{array}$ \\
\hline
\end{tabular}




\begin{tabular}{|c|c|c|}
\hline \multicolumn{3}{|c|}{ Table 8.L-21 } \\
\hline Industrial Activity & Parameter & Effluent Limitation \\
\hline & \multirow[t]{2}{*}{ Phenol } & $0.026 \mathrm{mg} / \mathrm{L}$, daily maximum \\
\hline & & $\begin{array}{c}0.015 \mathrm{mg} / \mathrm{L} \text {, monthly avg. } \\
\text { maximum }\end{array}$ \\
\hline & \multirow[t]{2}{*}{ Total Zinc } & $0.20 \mathrm{mg} / \mathrm{L}$, daily maximum \\
\hline & & $0.11 \mathrm{mg} / \mathrm{L}$, monthly avg. maximum \\
\hline & $\mathrm{pH}$ & $\begin{array}{l}\text { Within the range of 6-9 standard } \\
\text { pH units (s.U.) }\end{array}$ \\
\hline
\end{tabular}

${ }^{1}$ Monitor annually. As set forth at 40 CFR Part 445 Subpart B, these numeric limitations apply to contaminated stormwater discharges from MSWLFs that have not been closed in accordance with 40 CFR 258.60, and to contaminated stormwater discharges from those landfills that are subject to the provisions of 40 CFR Part 257 except for discharges from any of the following facilities:

(a) landfills operated in conjunction with other industrial or commercial operations, when the landfill receives only wastes generated by the industrial or commercial operation directly associated with the landfill;

(b) landfills operated in conjunction with other industrial or commercial operations, when the landfill receives wastes generated by the industrial or commercial operation directly associated with the landfill and also receives other wastes, provided that the other wastes received for disposal are generated by a facility that is subject to the same provisions in 40 CFR Subchapter $\mathrm{N}$ as the industrial or commercial operation, or that the other wastes received are of similar nature to the wastes generated by the industrial or commercial operation;

(c) landfills operated in conjunction with CWT facilities subject to 40 CFR Part 437, so long as the CWT facility commingles the landfill wastewater with other non-landfill wastewater for discharge. A landfill directly associated with a CWT facility is subject to this part if the CWT facility discharges landfill wastewater separately from other CWT wastewater or commingles the wastewater from its landfill only with wastewater from other landfills; or

(d) landfills operated in conjunction with other industrial or commercial operations when the landfill receives wastes from public service activities, so long as the company owning the landfill does not receive a fee or other remuneration for the disposal service. 


\section{Part 8 - Sector-Specific Requirements for Industrial Activity}

\section{Subpart $M$ - Sector $M$ - Automobile Salvage Yards.}

You must comply with Part 8 sector-specific requirements associated with your primary industrial activity and any co-located industrial activities, as defined in Appendix A. The sectorspecific requirements apply to those areas of your facility where those sector-specific activities occur. These sector-specific requirements are in addition to any requirements specified elsewhere in this permit.

\section{M.1 Covered Stormwater Discharges.}

The requirements in Subpart $M$ apply to stormwater discharges associated with industrial activity from Automobile Salvage Yards as identified by the SIC Code specified under Sector M in Table D-1 of Appendix D of this permit.

\section{M.2 Additional Technology-Based Effluent Limits.}

8.M.2.1 Spill and Leak Prevention Procedures. (See also Part 2.1.2.4) Drain vehicles intended to be dismantled of all fluids upon arrival at the site (or as soon thereafter as practicable), or employ some other equivalent means to prevent spills and leaks.

8.M.2.2 Employee Training. (See also Part 2.1.2.8) If applicable to your facility, address the following areas (at a minimum) in your employee training program: proper handling (collection, storage, and disposal) of oil, used mineral spirits, anti-freeze, mercury switches, and solvents.

8.M.2.3 Management of Runoff. (See also Part 2.1.2.6) Implement control measures to minimize discharges of pollutants in runoff such as the following, where determined to be feasible (list not exclusive): berms or drainage ditches on the property line (to help prevent run-on from neighboring properties); berms for uncovered outdoor storage of oily parts, engine blocks, and above-ground liquid storage; installation of detention ponds; and installation of filtering devices and oil and water separators.

\section{M.3 Additional SWPPP Requirements.}

8.M.3.1 Drainage Area Site Map. (See also Part 5.2.2) Identify locations used for dismantling, storing, and maintaining used motor vehicle parts. Also identify where any of the following may be exposed to precipitation or surface runoff: dismantling areas, parts (e.g., engine blocks, tires, hub caps, batteries, hoods, mufflers) storage areas, and liquid storage tanks and drums for fuel and other fluids.

8.M.3.2 Potential Pollutant Sources. (See also Part 5.2.3) Assess the potential for the following to contribute pollutants to stormwater discharges: vehicle storage areas, dismantling areas, parts storage areas (e.g., engine blocks, tires, hub caps, batteries, hoods, mufflers), and fueling stations.

8.M.4 Additional Inspection Requirements. (See also Part 3.1)

Immediately (or as soon thereafter as practicable) inspect vehicles arriving at the site for leaks. Inspect quarterly for signs of leakage all equipment containing oily parts, hydraulic fluids, any other types of fluids, or mercury switches. Also, inspect quarterly for signs of leakage all vessels and areas where hazardous materials and general automotive fluids are stored, including, but not limited to, mercury switches, brake fluid, transmission fluid, radiator water, and antifreeze.

\section{M.5 Sector-Specific Benchmarks. (See also Part 6)}

Table 8.M-1 identifies benchmarks that apply to Sector M. These benchmarks apply to both your primary industrial activity and any co-located industrial activities. 
Table 8.M-1.

\begin{tabular}{|l|c|c|}
$\begin{array}{l}\text { Subsector } \\
\text { (You may be subject to requirements } \\
\text { for more than one sector/subsector) }\end{array}$ & Parameter & $\begin{array}{c}\text { Benchmark } \\
\text { Monitoring } \\
\text { Concentration }\end{array}$ \\
\hline $\begin{array}{l}\text { Subsector M1. Automobile Salvage } \\
\text { Yards (SIC 5015) }\end{array}$ & Total Suspended Solids (TSS) & $100 \mathrm{mg} / \mathrm{L}$ \\
\cline { 2 - 3 } & Total Aluminum & $0.75 \mathrm{mg} / \mathrm{L}$ \\
\cline { 2 - 3 } & Total Iron & $1.0 \mathrm{mg} / \mathrm{L}$ \\
\cline { 2 - 3 } & $\begin{array}{c}\text { Total Lead (freshwater) }{ }^{2} \\
\text { Total Lead (saltwater) }\end{array}$ & $\begin{array}{c}\text { Hardness Dependent } \\
0.21 \mathrm{mg} / \mathrm{L}\end{array}$ \\
\hline
\end{tabular}

'Saltwater benchmark values apply to stormwater discharges into saline waters where indicated.

2 The freshwater benchmark values of some metals are dependent on water hardness. For these parameters, permittees must determine the hardness of the receiving water (see Appendix J, "Calculating Hardness in Receiving Waters for Hardness Dependent Metals," for methodology), in accordance with Part 6.2.1.1, to identify the applicable "hardness range' for determining their benchmark value applicable to their facility. Hardness Dependent Benchmarks follow in the table below:

\begin{tabular}{|l|l|}
\hline Freshwater Hardness Range & $\begin{array}{l}\text { Lead } \\
\text { (mg/L) }\end{array}$ \\
\hline $0-24.99 \mathrm{mg} / \mathrm{L}$ & 0.014 \\
\hline $25-49.99 \mathrm{mg} / \mathrm{L}$ & 0.023 \\
\hline $50-74.99 \mathrm{mg} / \mathrm{L}$ & 0.045 \\
\hline $75-99.99 \mathrm{mg} / \mathrm{L}$ & 0.069 \\
\hline $100-124.99 \mathrm{mg} / \mathrm{L}$ & 0.095 \\
\hline $125-149.99 \mathrm{mg} / \mathrm{L}$ & 0.122 \\
\hline $150-174.99 \mathrm{mg} / \mathrm{L}$ & 0.151 \\
\hline $175-199.99 \mathrm{mg} / \mathrm{L}$ & 0.182 \\
\hline $200-224.99 \mathrm{mg} / \mathrm{L}$ & 0.213 \\
\hline $225-249.99 \mathrm{mg} / \mathrm{L}$ & 0.246 \\
\hline $250+\mathrm{mg} / \mathrm{L}$ & 0.262 \\
\hline
\end{tabular}




\section{Part 8 - Sector-Specific Requirements for Industrial Activity}

\section{Subpart N - Sector N - Scrap Recycling and Waste Recycling Facilities.}

You must comply with Part 8 sector-specific requirements associated with your primary industrial activity and any co-located industrial activities, as defined in Appendix A. The sectorspecific requirements apply to those areas of your facility where those sector-specific activities occur. These sector-specific requirements are in addition to any requirements specified elsewhere in this permit.

\section{N.1 Covered Stormwater Discharges.}

The requirements in Subpart $\mathrm{N}$ apply to stormwater discharges associated with industrial activity from Scrap Recycling and Waste Recycling facilities as identified by the SIC Code specified under Sector $N$ in Table D-1 of Appendix D of the permit.

\section{N.2 Limitation on Coverage.}

Separate permit requirements have been established for recycling facilities that receive, process, and do wholesale distribution of only source-separated recyclable materials primarily from non-industrial and residential sources (i.e., common consumer products including paper, newspaper, glass, cardboard, plastic containers, and aluminum and tin cans). This includes recycling facilities commonly referred to as material recovery facilities (MRF). See Part 8.N.3.3.

8.N.2.1 Prohibition of Non-Stormwater Discharges. (See also Part 1.1.4) Non-stormwater discharges from turnings containment areas are not covered by this permit (see also Part 8.N.3.1.3). Discharges from containment areas in the absence of a storm event are prohibited unless covered by a separate NPDES permit. (EPA includes these prohibited non-stormwater discharges here solely as a helpful reminder to the operator that the only non-stormwater discharges authorized by this permit are at Part 1.1.3.)

\section{N.3 Additional Technology-Based Effluent Limits.}

8.N.3.1 Scrap and Waste Recycling Facilities (Non-Source Separated, Nonliquid Recyclable Materials). The following requirements are for facilities that receive, process, and do wholesale distribution of non-source separated, nonliquid recyclable wastes (e.g., ferrous and nonferrous metals, plastics, glass, cardboard, and paper). These facilities may receive both nonrecyclable and recyclable materials. This section is not intended for those facilities that accept recyclables only from primarily non-industrial and residential sources.

8.N.3.1.1 Inbound Recyclable and Waste Material Control Program. Minimize the chance of accepting materials that could be significant sources of pollutants by conducting inspections of inbound recyclables and waste materials and through implementation of control measures such as the following, where determined to be feasible (list not exclusive): providing information and education to suppliers of scrap and recyclable waste materials on draining and properly disposing of residual fluids (e.g., from vehicles and equipment engines, radiators and transmissions, oil filled transformers, and individual containers or drums) and removal of mercury switches from vehicles before delivery to your facility; establishing procedures to minimize the potential of any residual fluids from coming into contact with precipitation or runoff; establishing procedures for accepting scrap lead-acid batteries (additional requirements for the handling, storage, and disposal or recycling of batteries are contained in the scrap lead-acid battery program provisions in Part 8.N.3.1.6); providing training targeted for those personnel engaged in the inspection and acceptance of inbound recyclable materials; and 
establishing procedures to ensure that liquid wastes, including used oil, are stored in materially compatible and non-leaking containers and are disposed of or recycled in accordance with the Resource Conservation and Recovery Act (RCRA).

8.N.3.1.2 Scrap and Waste Material Stockpiles and Storage (Outdoor). Minimize contact of stormwater runoff with stockpiled materials, processed materials, and nonrecyclable wastes through implementation of control measures such as the following, where determined to be feasible (list not exclusive): permanent or semi-permanent covers; sediment traps, vegetated swales and strips, catch basin filters, and sand filters to facilitate settling or filtering of pollutants; dikes, berms, containment trenches, culverts, and surface grading to divert runoff from storage areas; silt fencing; and oil and water separators, sumps, and dry absorbents for areas where potential sources of residual fluids are stockpiled (e.g., automobile engine storage areas).

8.N.3.1.3 Stockpiling of Turnings Exposed to Cutting Fluids (Outdoor Storage). Minimize contact of surface runoff with residual cutting fluids by storing all turnings exposed to cutting fluids under some form of permanent or semi-permanent cover, or establishing dedicated containment areas for all turnings that have been exposed to cutting fluids. Any containment areas must be constructed of concrete, asphalt, or other equivalent types of impermeable material and include a barrier (e.g., berms, curbing, elevated pads) to prevent contact with stormwater run-on. Stormwater runoff from these areas can be discharged, provided that any runoff is first collected and treated by an oil and water separator or its equivalent. You must regularly maintain the oil and water separator (or its equivalent) and properly dispose of or recycle collected residual fluids.

\section{N.3.1.4 Scrap and Waste Material Stockpiles and Storage (Covered or Indoor}

Storage). Minimize contact of residual liquids and particulate matter from materials stored indoors or under cover with surface runoff through implementation of control measures such as the following, where determined to be feasible (list not exclusive): good housekeeping measures, including the use of dry absorbents or wet vacuuming to contain, dispose of, or recycle residual liquids originating from recyclable containers, and mercury spill kits for spills from storage of mercury switches; not allowing wash water from tipping floors or other processing areas to discharge to the storm sewer system; and disconnecting or sealing off all floor drains connected to the storm sewer system.

8.N.3.1.5 Scrap and Recyclable Waste Processing Areas. Minimize surface runoff from coming in contact with scrap processing equipment. Pay attention to operations that generate visible amounts of particulate residue (e.g., shredding) to minimize the contact of accumulated particulate matter and residual fluids with runoff (i.e., through good housekeeping, preventive maintenance). To minimize discharges of pollutants in stormwater from scrap and recyclable waste processing areas, implement control measures such as the following, where determined to be feasible (list not exclusive): at least once per month inspecting equipment for spills or leaks and malfunctioning, worn, or corroded parts or equipment; establishing a preventive maintenance program for processing equipment; using dry-absorbents or other cleanup practices to collect and dispose of or recycle spilled or leaking fluids or use mercury spill kits for spills from storage of mercury switches; on unattended 
hydraulic reservoirs over 150 gallons in capacity, installing protection devices such as low-level alarms or equivalent devices, or secondary containment that can hold the entire volume of the reservoir; implementing containment or diversion structures such as dikes, berms, culverts, trenches, elevated concrete pads, and grading to minimize contact of stormwater runoff with outdoor processing equipment or stored materials; using oil and water separators or sumps; installing permanent or semi-permanent covers in processing areas where there are residual fluids and grease; and using retention or detention ponds or basins, sediment traps, vegetated swales or strips, and/or catch basin filters or sand filters for pollutant settling and filtration.

8.N.3.1.6 Scrap Lead-Acid Battery Program. To minimize the discharge of pollutants in stormwater from lead-acid batteries, properly handle, store, and dispose of scrap lead-acid batteries, and implement control measures such as the following, where determined to be feasible (list not exclusive): segregating scrap lead-acid batteries from other scrap materials; properly handling, storing, and disposing of cracked or broken batteries; collecting and disposing of leaking lead-acid battery fluid; minimizing or eliminating (if possible) exposure of scrap lead-acid batteries to precipitation or runoff; and providing employee training for the management of scrap batteries.

8.N.3.1.7 Spill Prevention and Response Procedures. (See also Part 2.1.2.4) Install alarms and/or pump shutoff systems on outdoor equipment with hydraulic reservoirs exceeding 150 gallons in the event of a line break. Alternatively, a secondary containment system capable of holding the entire contents of the reservoir plus room for precipitation can be used. Use a mercury spill kit for any release of mercury from switches, anti-lock brake systems, and switch storage areas.

8.N.3.1.8 Supplier Notification Program. As appropriate, notify major suppliers which scrap materials will not be accepted at the facility or will be accepted only under certain conditions.

8.N.3.2 Waste Recycling Facilities (Liquid Recyclable Materials).

8.N.3.2.1 Waste Material Storage (Indoor). Minimize or eliminate contact between residual liquids from waste materials stored indoors and from surface runoff. The plan may refer to applicable portions of other existing plans, such as Spill Prevention, Control, and Countermeasure (SPCC) plans required under 40 CFR Part 112. To minimize discharges of pollutants in stormwater from indoor waste material storage areas, implement control measures such as the following, where determined to be feasible (list not exclusive): implementing procedures for material handling (including labeling and marking); cleaning up spills and leaks with dry absorbent materials and/or a wet vacuum system; installing appropriate containment structures (e.g., trenching, curbing, gutters, etc.); and installing a drainage system, including appurtenances (e.g., pumps or ejectors, manually operated valves), to handle discharges from diked or bermed areas. Drainage should be discharged to an appropriate treatment facility or sanitary sewer system, or otherwise disposed of properly. These discharges may require coverage under a separate NPDES wastewater permit or industrial user permit under the pretreatment program.

8.N.3.2.2 Waste Material Storage (Outdoor). Minimize contact between stored residual liquids and precipitation or runoff. The plan may refer to applicable portions of other existing plans, such as SPCC plans required under 40 CFR Part 112. 
Discharges of stormwater from containment areas containing used oil must also be in accordance with applicable sections of 40 CFR Part 112. To minimize discharges of pollutants in stormwater from outdoor waste material storage areas, implement control measures such as the following, where determined to be feasible (list not exclusive): appropriate containment structures (e.g., dikes, berms, curbing, pits) to store the volume of the largest tank, with sufficient extra capacity for precipitation; drainage control and other diversionary structures; corrosion protection and/or leak detection systems for storage tanks; and dry-absorbent materials or a wet vacuum system to collect spills.

8.N.3.2.3 Trucks and Rail Car Waste Transfer Areas. Minimize pollutants in stormwater discharges from truck and rail car loading and unloading areas. Include measures to clean up minor spills and leaks resulting from the transfer of liquid wastes. To minimize discharges of pollutants in stormwater from truck and rail car waste transfer areas, implement control measures such as the following, where determined to be feasible (list not exclusive): containment and diversionary structures to minimize contact with precipitation or runoff; and dry clean-up methods, wet vacuuming, roof coverings, and/or runoff controls.

8.N.3.3 Recycling Facilities (Source-Separated Materials). The following requirements are for facilities that receive only source-separated recyclables, primarily from non-industrial and residential sources.

8.N.3.3.1 Inbound Recyclable Material Control. Minimize the chance of accepting nonrecyclables (e.g., hazardous materials) that could be a significant source of pollutants by conducting inspections of inbound materials and through the implementation of control measures such as the following, where determined to be feasible (list not exclusive): providing information and education measures to inform suppliers of recyclables about acceptable and nonacceptable materials; training drivers responsible for pickup of recycled material; clearly marking public drop-off containers regarding which materials can be accepted; rejecting nonrecyclable wastes or household hazardous wastes at the source; and establishing procedures for handling and disposal of nonrecyclable material.

8.N.3.3.2 Outdoor Storage. Minimize exposure of recyclables to precipitation and runoff by using good housekeeping measures to prevent accumulation of particulate matter and fluids, particularly in high traffic areas and through implementation of control measure such as the following, where determined to be feasible (list not exclusive): providing totally enclosed drop-off containers for the public; installing a sump and pump with each container pit and treat or discharge collected fluids to a sanitary sewer system; providing dikes and curbs for secondary containment (e.g., around bales of recyclable waste paper); diverting surface water runoff away from outside material storage areas; providing covers over containment bins, dumpsters, and roll-off boxes; and storing the equivalent of one day's volume of recyclable material indoors.

8.N.3.3.3 Indoor Storage and Material Processing. Minimize the release of pollutants from indoor storage and processing areas through implementation of control measures such as the following, where determined to be feasible (list not exclusive): scheduling routine good housekeeping measures for all storage and processing areas; prohibiting tipping floor wash water from draining to 
the storm sewer system; and providing employee training on pollution prevention practices.

8.N.3.3.4 Vehicle and Equipment Maintenance. Minimize the discharge of pollutants in stormwater from areas where vehicle and equipment maintenance occur outdoors through implementation of control measures such as the following, where determined to be feasible (list not exclusive): minimizing or eliminating outdoor maintenance areas; establishing spill prevention and clean-up procedures in fueling areas; avoiding topping off fuel tanks; diverting runoff from fueling areas; storing lubricants and hydraulic fluids indoors; and providing employee training on proper handling and storage of hydraulic fluids and lubricants.

\section{N.4 Additional SWPPP Requirements.}

8.N.4.1 Drainage Area Site Map. (See also Part 5.2.2) Document in your SWPPP the locations of any of the following activities or sources that may be exposed to precipitation or surface runoff: scrap and waste material storage; outdoor scrap and waste processing equipment; and containment areas for turnings exposed to cutting fluids.

8.N.4.2 Maintenance Schedules/Procedures for Collection, Handling, and Disposal or Recycling of Residual Fluids at Scrap and Waste Recycling Facilities. If you are subject to Part 8.N.3.1.3, your SWPPP must identify any applicable maintenance schedule and the procedures to collect, handle, and dispose of or recycle residual fluids.

\section{N.5 Additional Inspection Requirements.}

8.N.5.1 Inspections for Waste Recycling Facilities. The inspections must be performed quarterly, per Part 3.1, and include, at a minimum, all areas where waste is generated, received, stored, treated, or disposed of and that are exposed to either precipitation or stormwater runoff.

8.N.6 Sector-Specific Benchmarks. (See also Part 6)

Table 8.N-1 identifies benchmarks that apply to Sector N. These benchmarks apply to both your primary industrial activity and any co-located industrial activities.

\begin{tabular}{|c|c|c|}
\hline \multicolumn{3}{|c|}{ Table 8.N-1. } \\
\hline $\begin{array}{c}\text { Subsector } \\
\text { (You may be subject to requirements for more } \\
\text { than one sector/subsector) }\end{array}$ & Parameter & $\begin{array}{l}\text { Benchmark } \\
\text { Monitoring } \\
\text { Concentration }\end{array}$ \\
\hline \multirow{7}{*}{$\begin{array}{l}\text { Subsector N1. Scrap Recycling and Waste } \\
\text { Recycling Facilities except those only } \\
\text { receiving source-separate recyclable } \\
\text { materials primarily from non-industrial and } \\
\text { residential sources (SIC 5093) }\end{array}$} & $\begin{array}{c}\text { Chemical Oxygen Demand } \\
\text { (COD) }\end{array}$ & $120 \mathrm{mg} / \mathrm{L}$ \\
\hline & Total Suspended Solids (TSS) & $100 \mathrm{mg} / \mathrm{L}$ \\
\hline & Aluminum Total Recoverable & $0.75 \mathrm{mg} / \mathrm{L}$ \\
\hline & $\begin{array}{l}\text { Total Copper (freshwater)² } \\
\text { Total Copper (saltwater)' }\end{array}$ & $\begin{array}{c}\text { Hardness } \\
\text { Dependent } \\
0.0048 \mathrm{mg} / \mathrm{L} \\
\end{array}$ \\
\hline & Total Recoverable Iron & $1.0 \mathrm{mg} / \mathrm{L}$ \\
\hline & $\begin{array}{l}\text { Total Lead (freshwater)² } \\
\text { Total Lead (saltwater) }^{1}\end{array}$ & $\begin{array}{c}\text { Hardness } \\
\text { Dependent } \\
0.21 \mathrm{mg} / \mathrm{L} \\
\end{array}$ \\
\hline & $\begin{array}{l}\text { Total Zinc (freshwater)² } \\
\text { Total Zinc (saltwater) }\end{array}$ & $\begin{array}{l}\text { Hardness } \\
\text { Dependent } \\
0.09 \mathrm{mg} / \mathrm{L}\end{array}$ \\
\hline
\end{tabular}


ISaltwater benchmark values apply to stormwater discharges into saline waters where indicated.

2 The freshwater benchmark values of some metals are dependent on water hardness. For these parameters, permittees must determine the hardness of the receiving water (see Appendix J, "Calculating Hardness in Receiving Waters for Hardness Dependent Metals," for methodology), in accordance with Part 6.2.1.1, to identify the applicable "hardness range' for determining their benchmark value applicable to their facility. Hardness Dependent Benchmarks follow in the table below:

\begin{tabular}{|l|l|l|l|}
\hline Freshwater Hardness Range & $\begin{array}{l}\text { Copper } \\
(\mathrm{mg} / \mathrm{L})\end{array}$ & $\begin{array}{l}\text { Lead } \\
(\mathrm{mg} / \mathrm{L})\end{array}$ & $\begin{array}{l}\text { Zinc } \\
\text { (mg/L) }\end{array}$ \\
\hline $0-24.99 \mathrm{mg} / \mathrm{L}$ & 0.0038 & 0.014 & 0.04 \\
\hline $25-49.99 \mathrm{mg} / \mathrm{L}$ & 0.0056 & 0.023 & 0.05 \\
\hline $50-74.99 \mathrm{mg} / \mathrm{L}$ & 0.0090 & 0.045 & 0.08 \\
\hline $75-99.99 \mathrm{mg} / \mathrm{L}$ & 0.0123 & 0.069 & 0.11 \\
\hline $100-124.99 \mathrm{mg} / \mathrm{L}$ & 0.0156 & 0.095 & 0.13 \\
\hline $125-149.99 \mathrm{mg} / \mathrm{L}$ & 0.0189 & 0.122 & 0.16 \\
\hline $150-174.99 \mathrm{mg} / \mathrm{L}$ & 0.0221 & 0.151 & 0.18 \\
\hline $175-199.99 \mathrm{mg} / \mathrm{L}$ & 0.0253 & 0.182 & 0.20 \\
\hline $200-224.99 \mathrm{mg} / \mathrm{L}$ & 0.0285 & 0.213 & 0.23 \\
\hline $225-249.99 \mathrm{mg} / \mathrm{L}$ & 0.0316 & 0.246 & 0.25 \\
\hline $250+\mathrm{mg} / \mathrm{L}$ & 0.0332 & 0.262 & 0.26 \\
\hline
\end{tabular}


Part 8 - Sector-Specific Requirements for Industrial Activity

Subpart O - Sector O - Steam Electric Generating Facilities.

You must comply with Part 8 sector-specific requirements associated with your primary industrial activity and any co-located industrial activities, as defined in Appendix A. The sectorspecific requirements apply to those areas of your facility where those sector-specific activities occur. These sector-specific requirements are in addition to any requirements specified elsewhere in this permit.

\subsubsection{Covered Stormwater Discharges.}

The requirements in Subpart $O$ apply to stormwater discharges associated with industrial activity from Steam Electric Power Generating Facilities as identified by the Activity Code specified under Sector $O$ in Table D-1 of Appendix D.

\subsubsection{Industrial Activities Covered by Sector $O$.}

This permit authorizes stormwater discharges from the following industrial activities at Sector $O$ facilities:

8.0.2.1 Steam electric power generation using coal, natural gas, oil, nuclear energy, etc., to produce a steam source, including coal handling areas (does not include geothermal power);

8.0.2.2 Coal pile runoff, including effluent limitations established by 40 CFR Part 423;

8.0.2.3 Dual fuel facilities that could employ a steam boiler.

\subsubsection{Limitations on Coverage.}

8.O.3.1 Prohibition of Non-Stormwater Discharges. Non-stormwater discharges subject to effluent limitations guidelines are not covered by this permit. (EPA includes these prohibited non-stormwater discharges here solely as a helpful reminder to the operator that the only non-stormwater discharges authorized by this permit are at Part 1.1.3.)

8.0.3.2 Prohibition of Stormwater Discharges. Stormwater discharges from the following are not covered by this permit:

8.0.3.2.1 Ancillary facilities (e.g., fleet centers and substations) that are not contiguous to a steam electric power generating facility;

8.0.3.2.2 Gas turbine facilities (provided the facility is not a dual-fuel facility that includes a steam boiler), and combined-cycle facilities where no supplemental fuel oil is burned (and the facility is not a dual-fuel facility that includes a steam boiler);

8.0.3.2.3 Cogeneration (combined heat and power) facilities utilizing a gas turbine.

8.0.4 Additional Technology-Based Effluent Limits. The following good housekeeping measures are required in addition to Part 2.1.2.2:

8.0.4.1 Fugitive Dust Emissions. Minimize fugitive dust emissions from coal handling areas to minimize the tracking of coal dust offsite that could be discharged in stormwater through implementation of control measures such as the following, where determined to be feasible, (list not exclusive): installing specially designed tires; and washing vehicles in a designated area before they leave the site and controlling the wash water. 
Multi-Sector General Permit (MSGP)

8.0.4.2 Delivery Vehicles. Minimize contamination of stormwater runoff from delivery vehicles arriving at the plant site. Implement procedures to inspect delivery vehicles arriving at the plant site as necessary to minimize discharges of pollutants in stormwater. Ensure the overall integrity of the body or container of the delivery vehicle and implement procedures to deal with leakage or spillage from delivery vehicles.

8.0.4.3 Fuel Oil Unloading Areas. Minimize contamination of precipitation or surface runoff from fuel oil unloading areas. Use containment curbs in unloading areas where feasible. In addition, ensure personnel familiar with spill prevention and response procedures are available to respond expeditiously in the event of a leak or spill during deliveries. Ensure that any leaks or spills are immediately contained and cleaned up, and use spill and overflow protection devices (e.g., drip pans, drip diapers, or other containment devices placed beneath fuel oil connectors to contain potential spillage during deliveries or from leaks at the connectors).

8.0.4.4 Chemical Loading and Unloading. Minimize contamination of precipitation or surface runoff from chemical loading and unloading areas. Use containment curbs at chemical loading and unloading areas to contain spills, where practicable. In addition, ensure personnel familiar with spill prevention and response procedures are available to respond expeditiously in the event of a leak or spill during deliveries. Ensure leaks and spills are immediately contained and cleaned up and, where practicable, load and unload in covered areas and store chemicals indoors.

8.0.4.5 Miscellaneous Loading and Unloading Areas. Minimize contamination of precipitation or surface runoff from loading and unloading areas through implementation of control measures such as the following, where determined to be feasible (list not exclusive): covering the loading area; grading, curbing, or berming around the loading area to divert run-on; locating the loading and unloading equipment and vehicles so that leaks are contained in existing containment and flow diversion systems; or equivalent procedures.

8.0.4.6 Liquid Storage Tanks. Minimize contamination of surface runoff from above-ground liquid storage tanks through implementation of control measures such as the following, where determined to be feasible, the following (list not exclusive): using protective guards around tanks; using containment curbs; installing spill and overflow protection; using dry cleanup methods; or equivalent measures.

8.0.4.7 Large Bulk Fuel Storage Tanks. Minimize contamination of surface runoff from large bulk fuel storage tanks. Use containment berms (or their equivalent). You must also comply with applicable state and federal laws, including Spill Prevention, Control and Countermeasure (SPCC) Plan requirements.

8.0.4.8 Spill Reduction Measures. Minimize the potential for an oil or chemical spill, or reference the appropriate part of your SPCC plan. Visually inspect as part of your routine facility inspection the structural integrity of all above-ground tanks, pipelines, pumps, and related equipment that may be exposed to stormwater, and make any necessary repairs immediately.

8.0.4.9 Oil-Bearing Equipment in Switchyards. Minimize contamination of surface runoff from oilbearing equipment in switchyard areas. Use level grades and gravel surfaces to retard flows and limit the spread of spills, or collect runoff in perimeter ditches.

8.0.4.10 Residue-Hauling Vehicles. Inspect all residue-hauling vehicles for proper covering over the load, adequate gate sealing, and overall integrity of the container body. Repair vehicles without load covering or adequate gate sealing, or with leaking containers or beds. 
8.0.4.11 Ash Loading Areas. Reduce or control the tracking of ash and residue from ash loading areas. Clear the ash building floor and immediately adjacent roadways of spillage, debris, and excess water as necessary to minimize discharges of pollutants in stormwater.

8.0.4.12 Areas Adjacent to Disposal Ponds or Landfills. Minimize contamination of surface runoff from areas adjacent to disposal ponds or landfills. Reduce ash residue that may be tracked on to access roads traveled by residue handling vehicles, and reduce ash residue on exit roads leading into and out of residue handling areas.

8.0.4.13 Landfills, Scrap Yards, Surface Impoundments, Open Dumps, General Refuse Sites. Minimize the potential for contamination of runoff from these areas.

\subsubsection{Additional SWPPP Requirements.}

8.0.5.1 Drainage Area Site Map. (See also Part 5.2.2) Document in your SWPPP the locations of any of the following activities or sources that may be exposed to precipitation or surface runoff: storage tanks, scrap yards, and general refuse areas; short- and longterm storage of general materials (including but not limited to supplies, construction materials, paint equipment, oils, fuels, used and unused solvents, cleaning materials, paint, water treatment chemicals, fertilizer, and pesticides); landfills and construction sites; and stock pile areas (e.g., coal or limestone piles).

8.0.5.2 Documentation of Good Housekeeping Measures. You must document in your SWPPP the good housekeeping measures implemented to meet the effluent limits in Part 8.O.4.

\subsubsection{Additional Inspection Requirements.}

As part of your inspection, inspect the following areas monthly: coal handling areas, loading or unloading areas, switchyards, fueling areas, bulk storage areas, ash handling areas, areas adjacent to disposal ponds and landfills, maintenance areas, liquid storage tanks, and long term and short term material storage areas.

8.0.7 Sector-Specific Benchmarks. (See also Part 6)

Table 8.O-1 identifies benchmarks that apply to Sector O. These benchmarks apply to both your primary industrial activity and any co-located industrial activities.

\begin{tabular}{|c|c|c|}
\hline \multicolumn{2}{|c|}{ Table 8.0-1. } \\
\hline $\begin{array}{c}\text { Subsector } \\
\text { (You may be subject to requirements for more than one } \\
\text { sector/subsector) }\end{array}$ & Parameter & $\begin{array}{c}\text { Benchmark } \\
\text { Monitoring } \\
\text { Concentration }\end{array}$ \\
\hline $\begin{array}{l}\text { Subsector O1. Steam Electric Generating Facilities } \\
\text { (Industrial Activity Code "SE") }\end{array}$ & Total Iron & $1.0 \mathrm{mg} / \mathrm{L}$ \\
\hline
\end{tabular}

8.O.8 Effluent Limitations Based on Effluent Limitations Guidelines. (See also Part 6.2.2.1)

Table 8.0-2 identifies effluent limits that apply to the industrial activities described below. Compliance with these effluent limits is to be determined based on discharges from these industrial activities independent of commingling with any other waste streams that may be covered under this permit. 


\begin{tabular}{|l|c|c|}
\hline \multicolumn{2}{|c|}{ Table 8.0-21 } \\
\hline \multicolumn{1}{|c|}{ Industrial Activity } & Parameter & Effluent Limitation \\
\hline $\begin{array}{l}\text { Discharges from coal storage piles at Steam } \\
\text { Electric Generating Facilities }\end{array}$ & TSS & $50 \mathrm{mg} / \mathrm{I}^{2}$ \\
\cline { 2 - 3 } & $\mathrm{pH}$ & $6.0 \mathrm{~min}-9.0 \mathrm{max}$ \\
\hline $\begin{array}{l}\text { 1Monitor annually. } \\
\text { 2 If your facility is designed, constructed, and operated to treat the volume of coal pile runoff that is associated with a } \\
\text { 10-year, 24-hour rainfall event, any untreated overflow of coal pile runoff from the treatment unit is not subject to the } 50 \\
\text { mg/L limitation for total suspended solids. }\end{array}$ \\
\hline
\end{tabular}




\section{Part 8 - Sector-Specific Requirements for Industrial Activity}

Subpart $\mathbf{P}$ - Sector $\mathbf{P}$ - Land Transportation and Warehousing.

You must comply with Part 8 sector-specific requirements associated with your primary industrial activity and any co-located industrial activities, as defined in Appendix A. The sectorspecific requirements apply to those areas of your facility where those sector-specific activities occur. These sector-specific requirements are in addition to any requirements specified elsewhere in this permit.

\section{P.1 Covered Stormwater Discharges.}

The requirements in Subpart $P$ apply to stormwater discharges associated with industrial activity from Land Transportation and Warehousing facilities as identified by the SIC Codes specified under Sector P in Table D-1 of Appendix D of the permit.

\section{P.2 Limitation on Coverage.}

8.P.2.1 Prohibited Discharges (see also Parts 1.1.4 and 8.P.3.1.4) This permit does not authorize the discharge of vehicle/equipment/surface wash water, including tank cleaning operations. Such discharges must be authorized under a separate NPDES permit, discharged to a sanitary sewer in accordance with applicable industrial pretreatment requirements, or recycled on-site.

\section{P.3 Additional Technology-Based Effluent Limits.}

8.P.3.1 Good Housekeeping Measures. (See also Part 2.1.2.2) In addition to the Good Housekeeping requirements in Part 2.1.2.2, you must do the following.

8.P.3.1.1 Vehicle and Equipment Storage Areas. Minimize the potential for stormwater exposure to leaky or leak-prone vehicles/equipment awaiting maintenance through implementation of control measures such as the following, where determined to be feasible (list not exclusive): using of drip pans under vehicles/equipment; storing vehicles and equipment indoors; installing berms or dikes; using of absorbents; roofing or covering storage areas; and cleaning pavement surfaces to remove oil and grease.

8.P.3.1.2 Fueling Areas. Minimize contamination of stormwater runoff from fueling areas through implementation of control measures such as the following, where determined to be feasible: covering the fueling area; using spill/overflow protection and cleanup equipment; minimizing stormwater run-on/runoff to the fueling area; using dry cleanup methods; and treating and/or recycling collected stormwater runoff.

8.P.3.1.3 Material Storage Areas. Maintain all material storage vessels (e.g., for used oil/oil filters, spent solvents, paint wastes, hydraulic fluids) to prevent contamination of stormwater and plainly label them (e.g., "Used Oil," "Spent Solvents"). To minimize discharges of pollutants in stormwater from material storage areas, implement control measures such as the following, where determined to be feasible (list not exclusive): storing the materials indoors; installing berms/dikes around the areas; minimizing runoff of stormwater to the areas; using dry cleanup methods; and treating and/or recycling collected stormwater runoff.

8.P.3.1.4 Vehicle and Equipment Cleaning Areas. Minimize contamination of stormwater runoff from all areas used for vehicle/equipment cleaning through implementation of control measures such as the following, where determined to be feasible (list not exclusive): performing all cleaning operations indoors; 
covering the cleaning operation, ensuring that all wash water drains to a proper collection system (i.e., not the stormwater drainage system); treating and/or recycling collected wash water; or other equivalent measures. Discharges of vehicle and equipment wash water, including tank cleaning operations, are not authorized by this permit for this sector.

8.P.3.1.5 Vehicle and Equipment Maintenance Areas. Minimize contamination of stormwater runoff from all areas used for vehicle/equipment maintenance through implementation of control measures such as the following, where determined to be feasible (list not exclusive): performing maintenance activities indoors; using drip pans; keeping an organized inventory of materials used in the shop; draining all parts of fluid prior to disposal; prohibiting wet clean up practices if these practices would result in the discharge of pollutants to stormwater drainage systems; using dry cleanup methods; treating and/or recycling collected stormwater runoff; and minimizing run on/runoff of stormwater to maintenance areas.

8.P.3.1.6 Locomotive Sanding (Loading Sand for Traction) Areas. Minimize discharges of pollutants in stormwater from locomotive sanding areas through implementation of control measures such as the following, where determined to be feasible (list not exclusive): covering sanding areas; minimizing stormwater run on/runoff; or appropriate sediment removal practices to minimize the offsite transport of sanding material by stormwater.

8.P.3.2 Employee Training. (See also Part 2.1.2.8) Train personnel at least once a year and address the following activities, as applicable: used oil and spent solvent management; fueling procedures; general good housekeeping practices; proper painting procedures; and used battery management.

\section{P.4 Additional SWPPP Requirements.}

8.P.4.1 Drainage Area Site Map. (See also Part 5.2.2) Identify in the SWPPP the following areas of the facility and indicate whether activities occurring there may be exposed to precipitation/surface runoff: fueling stations; vehicle/equipment maintenance or cleaning areas; storage areas for vehicle/equipment with actual or potential fluid leaks; loading/unloading areas; areas where treatment, storage or disposal of wastes occur; liquid storage tanks; processing areas; and storage areas.

8.P.4.2 Potential Pollutant Sources. (See also Part 5.2.3) Assess the potential for the following activities and facility areas to contribute pollutants to stormwater discharges: onsite waste storage or disposal; dirt/gravel parking areas for vehicles awaiting maintenance; illicit plumbing connections between shop floor drains and the stormwater conveyance system(s); and fueling areas. Describe these activities in the SWPPP.

8.P.4.3 Description of Good Housekeeping Measures. You must document in your SWPPP the good housekeeping measures you implement consistent with Part 8.P.3.

8.P.4.4 Vehicle and Equipment Wash Water Requirements. If wash water is handled in a manner that does not involve separate NPDES permitting (e.g., hauled offsite), describe the disposal method and include all pertinent information (e.g., frequency, volume, destination, etc.) in your SWPPP. Discharges of vehicle and equipment wash water, including tank cleaning operations, are not authorized by this permit for this sector. 
8.P.5 Additional Inspection Requirements. (See also Part 3.1)

Inspect all the following areas/activities: storage areas for vehicles/equipment awaiting maintenance, fueling areas, indoor and outdoor vehicle/equipment maintenance areas, material storage areas, vehicle/equipment cleaning areas and loading/unloading areas. 


\section{Part 8 - Sector-Specific Requirements for Industrial Activity}

\section{Subpart Q - Sector Q - Water Transportation.}

You must comply with Part 8 sector-specific requirements associated with your primary industrial activity and any co-located industrial activities, as defined in Appendix A. The sectorspecific requirements apply to those areas of your facility where those sector-specific activities occur. These sector-specific requirements are in addition to any requirements specified elsewhere in this permit.

\section{Q.1 Covered Stormwater Discharges.}

The requirements in Subpart $Q$ apply to stormwater discharges associated with industrial activity from Water Transportation facilities as identified by the SIC Codes specified under Sector $Q$ in Table D-1 of Appendix D of the permit.

\section{Q.2 Limitations on Coverage.}

8.Q.2.1 Prohibition of Non-Stormwater Discharges. (See also Part 1.1.4) Not covered by this permit: discharges from vessels including bilge and ballast water, sanitary wastes, pressure wash water, and cooling water. Any discharge of pollutants from a point source to a water of the U.S. requires coverage under an NPDES permit. (EPA includes these prohibited non-stormwater discharges here solely as a helpful reminder to the operator that the only non-stormwater discharges authorized by this permit are at Part 1.1.3.)

\section{Q.3 Additional Technology-Based Effluent Limits.}

8.Q.3.1 Good Housekeeping Measures. You must implement the following good housekeeping measures in addition to the requirements of Part 2.1.2.2:

8.Q.3.1.1 Pressure Washing Area. If pressure washing is used to remove marine growth from vessels, the discharge water must be permitted by a separate NPDES permit. Collect or contain the discharges from the pressure washing area so that they are not commingled with stormwater discharges authorized by this permit.

8.Q.3.1.2 Blasting and Painting Area. Minimize the potential for spent abrasives, paint chips, and overspray to be discharged into receiving waters or the storm sewer system. Contain all blasting and painting activities, or use other measures, to minimize the discharge of contaminants (e.g., hanging plastic barriers or tarpaulins during blasting or painting operations to contain debris). At least once per month, you must clean stormwater conveyances of deposits of abrasive blasting debris and paint chips.

8.Q.3.1.3 Material Storage Areas. Store and plainly label all containerized materials (e.g., fuels, paints, solvents, waste oil, antifreeze, batteries) in a protected, secure location away from drains. Minimize the contamination of precipitation or surface runoff from the storage areas. Specify which materials are stored indoors, and contain or enclose or use other measures for those stored outdoors. If abrasive blasting is performed, discuss the storage and disposal of spent abrasive materials generated at the facility. Implement an inventory control plan to limit the presence of potentially hazardous materials onsite.

8.Q.3.1.4 Engine Maintenance and Repair Areas. Minimize the contamination of precipitation or surface runoff from all areas used for engine maintenance and repair through implementation of control measures such as the following, 
where determined to be feasible (list not exclusive): performing all maintenance activities indoors; maintaining an organized inventory of materials used in the shop; draining all parts of fluid prior to disposal; prohibiting the practice of hosing down the shop floor; using dry cleanup methods; and treating and/or recycling stormwater runoff collected from the maintenance area.

8.Q.3.1.5 Material Handling Area. Minimize the contamination of precipitation or surface runoff from material handling operations and areas (e.g., fueling, paint and solvent mixing, disposal of process wastewater streams from vessels) through implementation of control measures such as the following, where determined to be feasible (list not exclusive): covering fueling areas; using spill and overflow protection; mixing paints and solvents in a designated area (preferably indoors or under a shed); and minimizing runoff of stormwater to material handling areas.

8.Q.3.1.6 Drydock Activities. Routinely maintain and clean the drydock to minimize dischrges of pollutants in stormwater. Address the cleaning of accessible areas of the drydock prior to flooding, and final cleanup following removal of the vessel and raising the dock. Include procedures for cleaning up oil, grease, and fuel spills occurring on the drydock. To minimize discharges of pollutants in stormwater from drydock activities, implement control measures such as the following, where determined to be feasible (list not exclusive): sweeping rather than hosing off debris and spent blasting material from accessible areas of the drydock prior to flooding; and making absorbent materials and oil containment booms readily available to clean up or contain any spills.

8.Q.3.2 Employee Training. (See also Part 2.1.2.8) As part of your employee training program, address, at a minimum, the following activities (as applicable): used oil management; spent solvent management; disposal of spent abrasives; disposal of vessel wastewaters; spill prevention and control; fueling procedures; general good housekeeping practices; painting and blasting procedures; and used battery management.

8.Q.3.3 Preventive Maintenance. (See also Part 2.1.2.3) As part of your preventive maintenance program, perform timely inspection and maintenance of stormwater management devices (e.g., cleaning oil and water separators and sediment traps to ensure that spent abrasives, paint chips, and solids will be intercepted and retained prior to entering the storm drainage system), as well as inspecting and testing facility equipment and systems to uncover conditions that could cause breakdowns or failures resulting in discharges of pollutants to surface waters.

\section{Q.4 Additional SWPPP Requirements.}

8.Q.4.1 Drainage Area Site Map. (See also Part 5.2.2) Document in your SWPPP where any of the following may be exposed to precipitation or surface runoff: fueling; engine maintenance and repair; vessel maintenance and repair; pressure washing; painting; sanding; blasting; welding; metal fabrication; loading and unloading areas; locations used for the treatment, storage, or disposal of wastes; liquid storage tanks; liquid storage areas (e.g., paint, solvents, resins); and material storage areas (e.g., blasting media, aluminum, steel, scrap iron).

8.Q.4.2 Summary of Potential Pollutant Sources. (See also Part 5.2.3) Document in the SWPPP the following additional sources and activities that have potential pollutants associated with them: outdoor manufacturing or processing activities (e.g., welding, metal 
fabricating) and significant dust or particulate generating processes (e.g., abrasive blasting, sanding, and painting).

\section{Q.5 Additional Inspection Requirements. (See also Part 3.1)}

Include the following in all quarterly routine facility inspections: pressure washing areas; blasting, sanding, and painting areas; material storage areas; engine maintenance and repair areas; material handling areas; drydock area; and general yard area.

\section{Q.6 Sector-Specific Benchmarks. (See also Part 6)}

Table 8.Q-1 identifies benchmarks that apply to Sector Q. These benchmarks apply to both your primary industrial activity and any co-located industrial activities.

\begin{tabular}{|c|c|c|}
\hline \multicolumn{3}{|c|}{ Table 8.Q-1. } \\
\hline $\begin{array}{c}\text { Subsector } \\
\text { (You may be subject to requirements for } \\
\text { more than one sector/subsector) }\end{array}$ & Parameter & $\begin{array}{l}\text { Benchmark Monitoring } \\
\text { Concentration }\end{array}$ \\
\hline \multirow{4}{*}{$\begin{array}{l}\text { Subsector Q1. Water Transportation } \\
\text { Facilities } \\
\text { (SIC 4412-4499) }\end{array}$} & Total Aluminum & $0.75 \mathrm{mg} / \mathrm{L}$ \\
\hline & Total Iron & $1.0 \mathrm{mg} / \mathrm{L}$ \\
\hline & $\begin{array}{l}\text { Total Lead } \\
\text { (freshwater) }^{2} \\
\text { Total Lead } \\
\text { (saltwater) } 1 \\
\end{array}$ & $\begin{array}{l}\text { Hardness Dependent } \\
0.21 \mathrm{mg} / \mathrm{L}\end{array}$ \\
\hline & $\begin{array}{c}\text { Total Zinc } \\
\text { (freshwater) }^{2} \\
\text { Total Zinc (saltwater)1 }\end{array}$ & $\begin{array}{l}\text { Hardness Dependent } \\
\qquad .09 \mathrm{mg} / \mathrm{L}\end{array}$ \\
\hline
\end{tabular}

iSaltwater benchmark values apply to stormwater discharges into saline waters where indicated.

2 The freshwater benchmark values of some metals are dependent on water hardness. For these parameters, permittees must determine the hardness of the receiving water (see Appendix J, "Calculating Hardness in Receiving Waters for Hardness Dependent Metals," for methodology), in accordance with Part 6.2.1.1, to identify the applicable "hardness range' for determining their benchmark value applicable to their facility. Hardness Dependent Benchmarks follow in the table below:

\begin{tabular}{|l|l|l|}
\hline Freshwater Hardness Range & $\begin{array}{l}\text { Lead } \\
\text { (mg/L) }\end{array}$ & $\begin{array}{l}\text { Zinc } \\
\text { (mg/L) }\end{array}$ \\
\hline $0-24.99 \mathrm{mg} / \mathrm{L}$ & 0.014 & 0.04 \\
\hline $25-49.99 \mathrm{mg} / \mathrm{L}$ & 0.023 & 0.05 \\
\hline $50-74.99 \mathrm{mg} / \mathrm{L}$ & 0.045 & 0.08 \\
\hline $75-99.99 \mathrm{mg} / \mathrm{L}$ & 0.069 & 0.11 \\
\hline $100-124.99 \mathrm{mg} / \mathrm{L}$ & 0.095 & 0.13 \\
\hline $125-149.99 \mathrm{mg} / \mathrm{L}$ & 0.122 & 0.16 \\
\hline $150-174.99 \mathrm{mg} / \mathrm{L}$ & 0.151 & 0.18 \\
\hline $175-199.99 \mathrm{mg} / \mathrm{L}$ & 0.182 & 0.20 \\
\hline $200-224.99 \mathrm{mg} / \mathrm{L}$ & 0.213 & 0.23 \\
\hline $225-249.99 \mathrm{mg} / \mathrm{L}$ & 0.246 & 0.25 \\
\hline $250+\mathrm{mg} / \mathrm{L}$ & 0.262 & 0.26 \\
\hline
\end{tabular}




\section{Part 8 - Sector-Specific Requirements for Industrial Activity}

\section{Subpart R - Sector R - Ship and Boat Building and Repair Yards.}

You must comply with Part 8 sector-specific requirements associated with your primary industrial activity and any co-located industrial activities, as defined in Appendix A. The sectorspecific requirements apply to those areas of your facility where those sector-specific activities occur. These sector-specific requirements are in addition to any requirements specified elsewhere in this permit.

\section{R.1 Covered Stormwater Discharges.}

The requirements in Subpart $R$ apply to stormwater discharges associated with industrial activity from Ship and Boat Building and Repair Yards as identified by the SIC Codes specified under Sector $R$ in Table D-1 of Appendix D of the permit.

\section{R.2 Limitations on Coverage.}

8.R.2.1 Prohibition of Non-Stormwater Discharges. (See also Part 1.1.4) Not covered by this permit: discharges from vessels including bilge and ballast water, sanitary wastes, pressure wash water, and cooling water. (EPA includes these prohibited nonstormwater discharges here solely as a helpful reminder to the operator that the only non-stormwater discharges authorized by this permit are at Part 1.1.3.)

\section{R.3 Additional Technology-Based Effluent Limits.}

8.R.3.1 Good Housekeeping Measures. (See also Part 2.1.2.2)

8.R.3.1.1 Pressure Washing Area. If pressure washing is used to remove marine growth from vessels, the discharged water must be permitted as a process wastewater by a separate NPDES permit.

8.R.3.1.2 Blasting and Painting Area. Minimize the potential for spent abrasives, paint chips, and overspray to be discharged into receiving waters or the storm sewer system. Contain all blasting and painting activities, or use other measures, to prevent the discharge of the contaminants (e.g., hanging plastic barriers or tarpaulins during blasting or painting operations to contain debris). When necessary, regularly clean stormwater conveyances of deposits of abrasive blasting debris and paint chips.

8.R.3.1.3 Material Storage Areas. Store and plainly label all containerized materials (e.g., fuels, paints, solvents, waste oil, antifreeze, batteries) in a protected, secure location away from drains. Minimize the contamination of precipitation or surface runoff from the storage areas. If abrasive blasting is performed, discuss the storage and disposal of spent abrasive materials generated at the facility. Implement an inventory control plan to limit the presence of potentially hazardous materials onsite.

8.R.3.1.4 Engine Maintenance and Repair Areas. Minimize the contamination of precipitation or surface runoff from all areas used for engine maintenance and repair through implementation of control measures such as the following, where determined to be feasible (list not exclusive): performing all maintenance activities indoors; maintaining an organized inventory of materials used in the shop; draining all parts of fluid prior to disposal; prohibiting the practice of hosing down the shop floor; using dry cleanup methods; and treating and/or recycling stormwater runoff collected from the maintenance area. 
8.R.3.1.5 Material Handling Area. Minimize the discharge of pollutants in stormwater from material handling operations and areas (e.g., fueling, paint and solvent mixing, disposal of process wastewater streams from vessels) through implementation of control measures such as the following, where determined to be feasible (list not exclusive): covering fueling areas, using spill and overflow protection, mixing paints and solvents in a designated area (preferably indoors or under a shed), and minimizing stormwater run-on to material handling areas.

8.R.3.1.6 Drydock Activities. Routinely maintain and clean the drydock to minimize pollutants in stormwater runoff. Clean accessible areas of the drydock prior to flooding and final cleanup following removal of the vessel and raising the dock. Include procedures for cleaning up oil, grease, or fuel spills occurring on the drydock. To minimize discharges of pollutants in stormwater from drydock activities, implement control measures such as the following, where determined to be feasible (list not exclusive): sweeping rather than hosing off debris and spent blasting material from accessible areas of the drydock prior to flooding; and having absorbent materials and oil containment booms readily available to clean up and contain any spills.

8.R.3.2 Employee Training. (See also Part 2.1.2.8) As part of your employee training program, address, at a minimum, the following activities (as applicable): used oil management, spent solvent management, disposal of spent abrasives, disposal of vessel wastewaters, spill prevention and control, fueling procedures, general good housekeeping practices, painting and blasting procedures, and used battery management.

8.R.3.4 Preventive Maintenance. (See also Part 2.1.2.3) As part of your preventive maintenance program, perform timely inspection and maintenance of stormwater management devices (e.g., cleaning oil and water separators and sediment traps to ensure that spent abrasives, paint chips, and solids will be intercepted and retained prior to entering the storm drainage system), as well as inspecting and testing facility equipment and systems to uncover conditions that could cause breakdowns or failures resulting in discharges of pollutants to surface waters.

\section{R.4 Additional SWPPP Requirements.}

8.R.4.1 Drainage Area Site Map. (See also Part 5.2.2) Document in your SWPPP where any of the following may be exposed to precipitation or surface runoff: fueling; engine maintenance or repair; vessel maintenance or repair; pressure washing; painting; sanding; blasting; welding; metal fabrication; loading and unloading areas; treatment, storage, and waste disposal areas; liquid storage tanks; liquid storage areas (e.g., paint, solvents, resins); and material storage areas (e.g., blasting media, aluminum, steel, scrap iron).

8.R.4.2 Potential Pollutant Sources. (See also Part 5.2.3) Document in your SWPPP the following additional sources and activities that have potential pollutants associated with them (if applicable): outdoor manufacturing or processing activities (e.g., welding, metal fabricating) and significant dust or particulate generating processes (e.g., abrasive blasting, sanding, and painting).

8.R.4.3 Documentation of Good Housekeeping Measures. Document in your SWPPP any good housekeeping measures implemented to meet the effluent limits in Part 8.R.3. 
8.R.4.3.1 Blasting and Painting Areas. Document in the SWPPP any standard operating practices relating to blasting and painting (e.g., prohibiting uncontained blasting and painting over open water or prohibiting blasting and painting during windy conditions, which can render containment ineffective).

8.R.4.3.2 Storage Areas. Specify in your SWPPP which materials are stored indoors, and contain or enclose or use other measures for those stored outdoors.

\section{R.5 Additional Inspection Requirements. (See also Part 3.1)}

Include the following in all quarterly routine facility inspections: pressure washing areas; blasting, sanding, and painting areas; material storage areas; engine maintenance and repair areas; material handling areas; drydock area; and general yard area. 


\section{Part 8 - Sector-Specific Requirements for Industrial Activity}

\section{Subpart S - Sector S - Air Transportation.}

You must comply with Part 8 sector-specific requirements associated with your primary industrial activity and any co-located industrial activities, as defined in Appendix A. The sectorspecific requirements apply to those areas of your facility where those sector-specific activities occur. These sector-specific requirements are in addition to any requirements specified elsewhere in this permit.

\section{S.1 Covered Stormwater Discharges.}

The requirements in Subpart $S$ apply to stormwater discharges associated with industrial activity from Air Transportation facilities identified by the SIC Codes specified under Sector S in Table D-1 of Appendix D of the permit.

\section{S.2 Limitation on Coverage.}

8.S.2.1 Limitations on Coverage. This permit authorizes stormwater discharges from only those portions of the air transportation facility that are involved in vehicle maintenance (including vehicle rehabilitation, mechanical repairs, painting, fueling and lubrication), equipment cleaning operations or deicing operations.

Note: the term "deicing" in this permit will generally be used to mean both deicing (removing frost, snow or ice) and anti-icing (preventing accumulation of frost, snow or ice) activities, unless specific mention is made otherwise.

8.S.2.2 Prohibition of Non-Stormwater Discharges. (See also Part 1.1.4 and Part 8.S.5.3) This permit does not authorize the discharge of aircraft, ground vehicle, runway and equipment wash waters; nor the dry weather discharge of deicing chemicals. Such discharges must be covered by separate NPDES permit(s). Note that a discharge resulting from snowmelt is not a dry weather discharge. (EPA includes these prohibited non-stormwater discharges here solely as a helpful reminder to the operator that the only non-stormwater discharges authorized by this permit are at Part 1.1.3.)

\section{S.3 Multiple Operators at Air Transportation Facilities.}

Air transportation facilities often have more than one operator who could discharge stormwater associated with industrial activity. Operators include the airport authority and airport tenants, including air passenger or cargo companies, fixed based operators, and other parties who routinely perform industrial activities on airport property.

8.S.3.1 Permit Coverage/Submittal of NOls. Where an airport transportation facility has multiple industrial operators that discharge stormwater, each individual operator must obtain coverage under an NPDES stormwater permit. To obtain coverage under the MSGP, all such operators must meet the eligibility requirements in Part 1 and must submit an NOI, per Part 1.2.1.1 (or, if appropriate, a no exposure certification per Part 1.4).

8.S.3.2 MSGP Implementation Responsibilities for Airport Authority and Tenants. The airport authority, in collaboration with its tenants, may choose to implement certain MSGP requirements on behalf of its tenants in order to increase efficiency and eliminate redundancy or duplication of effort. Options available to the airport authority and its tenants for implementation of MSGP requirements include:

- The airport authority performs certain activities on behalf of itself and its tenants and reports on its activities;

- Tenants provide the airport authority with relevant inputs about tenants' activities, including deicing chemical usage*, and the airport authority compiles and reports on tenants' and its own activities; 
- Tenants independently perform, document and submit required information on their activities.

*Tenants who report their deicing chemical usage to the airport authority and rely on the airport authority to perform monitoring should not check the glycol and urea use box on their NOl forms.

8.S.3.3 SWPPP Requirements. A single comprehensive SWPPP must be developed for all stormwater discharges associated with industrial activity at the airport before submittal of any NOls. The comprehensive SWPPP should be developed collaboratively by the airport authority and tenants. If any operator develops a SWPPP for discharges from its own areas of the airport, that SWPPP must be coordinated and integrated with the comprehensive SWPPP. All operators and their separate SWPPP contributions and compliance responsibilities must be clearly identified in the comprehensive SWPPP, which all operators must sign and certify per Part 5.2.7. As applicable, the SWPPP must clearly specify the MSGP requirements to be complied with by:

- The airport authority for itself;

- The airport authority on behalf of its tenants;

- Tenants for themselves.

For each activity that an operator (e.g., the airport authority) conducts on behalf of another operator (e.g., a tenant), the SWPPP must describe a process for reporting results to the latter operator and for ensuring appropriate follow-up, if necessary, by all affected operators. This is to ensure all actions are taken to correct any potential deficiencies or permit violations. For example, where the airport authority is conducting monitoring for itself and its tenants, the SWPPP must identify how the airport authority will share the monitoring results with its tenants, and then follow-up with its tenants where there are any exceedances of benchmarks, effluent limits, or water quality standards. In turn, the SWPPP must describe how the tenants will also follow-up to ensure permit compliance.

8.S.3.4 Duty to Comply. All individual operators are responsible for implementing their assigned portion of the comprehensive SWPPP, and operators must ensure that their individual activities do not render another operator's stormwater controls ineffective. In addition, the standard permit conditions found in Appendix B apply to each individual operator, including B.1 Duty to Comply (which states, in part, "You [each individual operator] must comply with all conditions of this permit."). For multiple operators at an airport this means that each individual operator remains responsible for ensuring all requirements of its own MSGP coverage are met regardless of whether the comprehensive SWPPP allocates the actual implementation of any of those responsibilities to another entity. That is, the failure of the entity allocated responsibility in the SWPPP to implement an MSGP requirement on behalf of other operators does not negate the other operators' ultimate liability.

\section{S.4 Additional Technology-Based Effluent Limits.}

8.S.4.1 Good Housekeeping Measures. (See also Part 2.1.2.2)

8.S.4.1.1 Aircraft, Ground Vehicle and Equipment Maintenance Areas. Minimize the contamination of stormwater runoff from all areas used for aircraft, ground vehicle and equipment maintenance (including the maintenance conducted on the terminal apron and in dedicated hangers) through implementation of control measures such as the following, where determined to be feasible and that accommodate considerations of safety, space, operational constraints, and flight considerations (list not exclusive): 
performing maintenance activities indoors; maintaining an organized inventory of material used in the maintenance areas; draining all parts of fluids prior to disposal; prohibiting the practice of hosing down the apron or hanger floor; using dry cleanup methods; and collecting the stormwater runoff from the maintenance area and providing treatment or recycling.

8.S.4.1.2 Aircraft, Ground Vehicle and Equipment Cleaning Areas. (See also Part 8.S.4.6) Clearly demarcate these areas on the ground using signage or other appropriate means. Minimize the contamination of stormwater runoff from cleaning areas.

8.S.4.1.3 Aircraft, Ground Vehicle and Equipment Storage Areas. Store all aircraft, ground vehicles and equipment awaiting maintenance in designated areas only and implement control measures to minimize the discharge of pollutants in stormwater from these storage areas such as the following, where determined to be feasible and that accommodate considerations of safety, space, operational constraints, and flight considerations (list not exclusive): storing aircraft and ground vehicles indoors; using drip pans for the collection of fluid leaks; and perimeter drains, dikes or berms surrounding the storage areas.

8.S.4.1.4 Material Storage Areas. Maintain the vessels of stored materials (e.g., used oils, hydraulic fluids, spent solvents, and waste aircraft fuel) in good condition to prevent or minimize contamination of stormwater. Also plainly label the vessels (e.g., "used oil," "Contaminated Jet A"). To minimize contamination of precipitation/runoff from these areas, implement control measures such as the following, where determined to be feasible and that accommodate considerations of safety, space, operational constraints, and flight considerations (list not exclusive): storing materials indoors; storing waste materials in a centralized location; and installing berms/dikes around storage areas.

8.S.4.1.5 Airport Fuel System and Fueling Areas. Minimize the discharge of pollutants in stormwater from airport fuel system and fueling areas through implementation of control measures such as the following, where determined to be feasible and that accommodate considerations of safety, space, operational constraints, and flight considerations (list not exclusive): implementing spill and overflow practices (e.g., placing absorptive materials beneath aircraft during fueling operations); using only dry cleanup methods; and collecting stormwater runoff. If you have implemented a SPCC plan developed in accordance with the 2006 amendments to the SPCC rule, you may cite the relevant aspects from your SPCC plan that comply with the requirements of this section in your SWPPP.

8.S.4.1.6 Source Reduction. Consistent with safety considerations, minimize the use of urea and glycol-based deicing chemicals to reduce the aggregate amount of deicing chemicals used that could add pollutants to stormwater discharges. Chemical options to replace pavement deicers (urea or glycol) include (list not exclusive): potassium acetate; magnesium acetate; calcium acetate; and anhydrous sodium acetate.

8.S.4.1.6.1 Runway Deicing Operations. To minimize the discharge of pollutants in stormwater from runway deicing operations, implement source reduction control measures such as the following, where determined to be feasible and that 
accommodate considerations of safety, space, operational constraints, and flight considerations (list not exclusive): metered application of chemicals; pre-wetting dry chemical constituents prior to application; installing a runway ice detection system; implementing anti-icing operations as a preventive measure against ice buildup; heating sand; and product substitution.

8.S.4.1.6.2 Aircraft Deicing Operations. Minimize the discharge of pollutants in stormwater from aircraft deicing operations. Determine whether excessive application of deicing chemicals occurs and adjust as necessary, consistent with considerations of flight safety. Determine whether alternatives to glycol and whether containment measures for applied chemicals are feasible. Implement control measures for reducing deicing fluid such as the following, where determined to be feasible and that accommodate considerations of safety, space, operational constraints, and flight considerations (list not exclusive): forced-air deicing systems, computer-controlled fixed-gantry systems, infrared technology, hot water, varying glycol content to air temperature, enclosed-basket deicing trucks, mechanical methods, solar radiation, hangar storage, aircraft covers, and thermal blankets for MD-80s and DC-9s. Consider using icedetection systems and airport traffic flow strategies and departure slot allocation systems where feasible and that accommodate considerations of safety, space, operational constraints, and flight considerations. The evaluations and determinations required by this Part should be carried out by the personnel most familiar with the particular aircraft and flight operations and related systems in question (versus an outside entity such as the airport authority).

8.S.4.1.7 Management of Runoff. (See also Part 2.1.2.6) Minimize the discharge of pollutants in stormwater from deicing chemicals in runoff. To minimize discharges of pollutants in stormwater from aircraft deicing, implement runoff management control measures such as the following, where determined to be feasible and that accommodate considerations of safety, space, operational constraints, and flight considerations (list not exclusive): installing a centralized deicing pad to recover deicing fluid following application; plugand-pump (PnP); using vacuum/collection trucks (glycol recovery vehicles); storing contaminated stormwater/deicing fluids in tanks; recycling collected deicing fluid where feasible; releasing controlled amounts to a publicly owned treatment works; separation of contaminated snow; conveying contaminated runoff into a stormwater impoundment for biochemical decomposition (be aware of attracting wildlife that may prove hazardous to flight operations); and directing runoff into vegetative swales or other infiltration measures. To minimize discharges of pollutants in stormwater from runway deicing, implement runoff management control measures such as the following, where determined to be feasible and that accommodate considerations of safety, space, operational constraints, and flight considerations (list not exclusive): mechanical systems (snow plows, brushes); conveying contaminated runoff into swales and/or a stormwater impoundment; and pollution prevention practices such as ice detection systems, and airfield prewetting. 
When applying deicing fluids during non-precipitation events (also referred to as "clear ice deicing"), implement control measures to prevent unauthorized discharge of pollutants (dry-weather discharges of pollutants would need coverage under an NPDES wastewater permit), or to minimize the discharge of pollutants from deicing fluids in later stormwater discharges, implement control measures such as the following, where determined to be feasible and that accommodate considerations safety, space, operational constraints, and flight considerations (list not exclusive): recovering deicing fluids; preventing the fluids from entering storm sewers or other stormwater discharge conveyances (e.g., covering storm sewer inlets, using booms, installing absorptive interceptors in the drains); releasing controlled amounts to a publicly owned treatment works Used deicing fluid should be recycled whenever practicable.

8.S.4.2 Deicing Season. You must determine the seasonal timeframe (e.g., DecemberFebruary, October - March) during which deicing activities typically occur at the facility. Implementation of control measures, including any BMPs, facility inspections and monitoring must be conducted with particular emphasis throughout the defined deicing season. If you meet the deicing chemical usage thresholds of 100,000 gallons glycol and/or 100 tons of urea, the deicing season you identified is the timeframe during which you must obtain the four required benchmark monitoring event results for deicing-related parameters, i.e., BOD, COD, ammonia and pH. See also Part 8.S.7.

\section{S.5 Additional SWPPP Requirements.}

8.S.5.1 Drainage Area Site Map. (See also Part 5.2.2) Document in the SWPPP the following areas of the facility and indicate whether activities occurring there may be exposed to precipitation/surface runoff: aircraft and runway deicing operations; fueling stations; aircraft, ground vehicle and equipment maintenance/cleaning areas; and storage areas for aircraft, ground vehicles and equipment awaiting maintenance.

8.S.5.2 Potential Pollutant Sources. (See also Part 5.2.3) In the inventory of exposed materials, describe in the SWPPP the potential for the following activities and facility areas to contribute pollutants to stormwater discharges: aircraft, runway, ground vehicle and equipment maintenance and cleaning; and aircraft and runway deicing operations (including apron and centralized aircraft deicing stations, runways, taxiways and ramps). If deicing chemicals are used, a record of the types (including the Safety Data Sheets [SDS]) used and the monthly quantities, either as measured or, in the absence of metering, using best estimates, must be maintained. This includes all deicing chemicals, not just glycols and urea (e.g., potassium acetate), because large quantities of these other chemicals can still have an adverse impact on receiving waters. Deicing operators must provide the above information to the airport authority for inclusion with any comprehensive airport SWPPPS.

8.S.5.3 Vehicle and Equipment Wash Water Requirements. If wash water is handled in a manner that does not involve separate NPDES permitting or local pretreatment requirements (e.g., hauled offsite, retained onsite), describe the disposal method and include all pertinent information (e.g., frequency, volume, destination) in your SWPPP. Discharges of vehicle and equipment wash water are not authorized by this permit for this sector.

8.S.5.4 Documentation of Control Measures Used for Management of Runoff. Document in your SWPPP the control measures used for collecting or containing contaminated melt water from collection areas used for disposal of contaminated snow. 


\section{S.6 Additional Inspection Requirements.}

At a minimum conduct facility inspections at least monthly during the deicing season (e.g., October through April for most mid-latitude airports). If your facility needs to deice before or after this period, expand the monthly inspections to include all months during which deicing chemicals may be used. The Director may specifically require you to increase inspection frequencies.

\section{S.7 Sector-Specific Benchmarks. (See also Part 6)}

Table 8.S-1 identifies benchmarks that apply to Sector S. These benchmarks apply to both your primary industrial activity and any co-located industrial activities.

\begin{tabular}{|c|c|c|}
\hline \multicolumn{3}{|c|}{ Table 8.S-1. } \\
\hline $\begin{array}{c}\text { Subsector } \\
\text { (You may be subject to requirements for } \\
\text { more than one sector/subsector) }\end{array}$ & Parameter & $\begin{array}{l}\text { Benchmark } \\
\text { Monitoring } \\
\text { Concentration }\end{array}$ \\
\hline \multirow{4}{*}{$\begin{array}{l}\text { For airports where a single permittee, or a } \\
\text { combination of permitted facilities use more } \\
\text { than } 100,000 \text { gallons of pure glycol in glycol- } \\
\text { based deicing fluids and/or } 100 \text { tons or more } \\
\text { of urea on an average annual basis, monitor } \\
\text { the first four parameters in ONLY those } \\
\text { outfalls that collect runoff from areas where } \\
\text { deicing activities occur (SIC 4512-4581). }\end{array}$} & $\begin{array}{l}\text { Biochemical Oxygen } \\
\text { Demand }\left(\mathrm{BOD}_{5}\right)^{1} \\
\end{array}$ & $30 \mathrm{mg} / \mathrm{L}$ \\
\hline & $\begin{array}{l}\text { Chemical Oxygen Demand } \\
(\text { COD })^{1}\end{array}$ & $120 \mathrm{mg} / \mathrm{L}$ \\
\hline & Ammonia $^{1}$ & $2.14 \mathrm{mg} / \mathrm{L}$ \\
\hline & $\mathrm{pH}^{1}$ & 6.0 - 9.0 s.u. \\
\hline
\end{tabular}

1 These are deicing-related parameters. Collect the four benchmark samples, and any required follow-up benchmark samples, during the timeframe defined in Part 8.S.4.2 when deicing activities are occurring.

\section{S.8 Effluent Limitations Based on Effluent Limitations Guidelines and New Source Performance Standards. (See also Part 6.2.2.1)}

8.S.8.1 Airfield Pavement Deicing. For both existing and new "primary airports" (as defined at 40 CFR 449.2) with 1,000 or more annual non-propeller aircraft departures that discharge stormwater from airfield pavement deicing activities, there shall be no discharge of airfield pavement deicers containing urea. To comply with this limitation, such airports must do one of the following: (1) certify annually on the annual report that you do not use pavement deicers containing urea, or (2) meet the effluent limitation in Table 8.S-2.

8.S.8.2 Aircraft Deicing. Airports that are both "primary airports" (as defined at 40 CFR 449.2) and new sources ("new airports") with 1,000 or more annual non-propeller aircraft departures must meet the applicable requirements for aircraft deicing at 40 CFR 449.11 (a). Discharges of the collected aircraft deicing fluid directly to waters of the U.S. are not eligible for coverage under this permit.

8.S.8.3 Monitoring, Reporting and Recordkeeping. For new and existing airports subject to the effluent limitations in Part 8.S.8.1 or 8.S.8.2 of this permit, you must comply with the applicable monitoring, reporting and recordkeeping requirements outlined in 40 CFR 449.20. 
Table 8.5-2

\begin{tabular}{|l|c|c|}
\hline \multicolumn{1}{|c|}{ Industrial Activity } & Parameter & Effluent Limitation \\
\hline $\begin{array}{l}\text { Runoff containing urea from airfield } \\
\text { pavement deicing at existing and new } \\
\text { primary airports with 1,000 or more } \\
\text { annual non-propeller aircraft departures }\end{array}$ & Ammonia as Nitrogen & $\begin{array}{c}14.7 \mathrm{mg} / \mathrm{L} \text {, daily } \\
\text { maximum }\end{array}$ \\
\hline
\end{tabular}


Part 8 - Sector-Specific Requirements for Industrial Activity

Subpart T - Sector T - Treatment Works.

You must comply with Part 8 sector-specific requirements associated with your primary industrial activity and any co-located industrial activities, as defined in Appendix A. The sectorspecific requirements apply to those areas of your facility where those sector-specific activities occur. These sector-specific requirements are in addition to any requirements specified elsewhere in this permit.

\section{T.1 Covered Stormwater Discharges.}

The requirements in Subpart T apply to stormwater discharges associated with industrial activity from Treatment Works as identified by the Activity Code specified under Sector T in Table D-1 of Appendix D of the permit.

\section{T.2 Industrial Activities Covered by Sector T.}

The requirements listed under this part apply to all existing point source stormwater discharges associated with the following activities:

8.T.2.1 Treatment works treating domestic sewage, or any other sewage sludge or wastewater treatment device or system used in the storage, treatment, recycling, and reclamation of municipal or domestic sewage, including land dedicated to the disposal of sewage sludge; that are located within the confines of a facility with a design flow of 1.0 million gallons per day (MGD) or more; or are required to have an approved pretreatment program under 40 CFR Part 403.

8.T.2.2 The following are not required to have permit coverage: farm lands, domestic gardens or lands used for sludge management where sludge is beneficially reused and which are not physically located within the facility, or areas that are in compliance with Section 405 of the CWA.

8.T.3 Limitations on Coverage.

8.T.3.1 Prohibition of Non-Stormwater Discharges. (See also Part 1.1.4) Sanitary and industrial wastewater and equipment and vehicle wash water are not authorized by this permit. (EPA includes these prohibited non-stormwater discharges here solely as a helpful reminder to the operator that the only non-stormwater discharges authorized by this permit are at Part 1.1.3.)

\section{T.4 Additional Technology-Based Effluent Limits.}

8.T.4.1 Control Measures. (See also Part 2.1.2) To minimize the discharge of pollutants in stormwater, implement control measures such as the following, where determined to be feasible (list not exclusive): routing stormwater to the treatment works; or covering exposed materials (i.e., from the following areas: grit, screenings and other solids handling, storage or disposal areas; sludge drying beds; dried sludge piles; compost piles; and septage or hauled waste receiving station).

8.T.4.2 Employee Training. (See also Part 2.1.2.8) At a minimum, training must address the following areas when applicable to a facility: petroleum product management; process chemical management; spill prevention and controls; fueling procedures; general good housekeeping practices; and proper procedures for using fertilizer, herbicides, and pesticides. 


\section{T.5 Additional SWPPP Requirements.}

8.T.5.1 Site Map. (See also Part 5.2.2) Document in your SWPPP where any of the following may be exposed to precipitation or surface runoff: grit, screenings, and other solids handling, storage, or disposal areas; sludge drying beds; dried sludge piles; compost piles; septage or hauled waste receiving station; and storage areas for process chemicals, petroleum products, solvents, fertilizers, herbicides, and pesticides.

8.T.5.2 Potential Pollutant Sources. (See also Part 5.2.3) Document in your SWPPP the following additional sources and activities that have potential pollutants associated with them, as applicable: grit, screenings, and other solids handling, storage, or disposal areas; sludge drying beds; dried sludge piles; compost piles; septage or hauled waste receiving station; and access roads and rail lines.

8.T.5.3 Wastewater and Wash Water Requirements. If wastewater and/or vehicle and equipment wash water is not covered by another NPDES permit but is handled in another manner (e.g., hauled offsite, retained onsite), the disposal method must be described and all pertinent information (e.g., frequency, volume, destination) must be included in your SWPPP. Discharges of vehicle and equipment wash water, including tank cleaning operations, are not authorized by this permit for this sector.

\section{T.6 Additional Inspection Requirements. (See also Part 3.1)}

Include the following areas in all inspections: access roads and rail lines; grit, screenings, and other solids handling, storage, or disposal areas; sludge drying beds; dried sludge piles; compost piles; and septage or hauled waste receiving station. 


\section{Part 8 - Sector-Specific Requirements for Industrial Activity}

Subpart U - Sector U - Food and Kindred Products.

You must comply with Part 8 sector-specific requirements associated with your primary industrial activity and any co-located industrial activities, as defined in Appendix A. The sectorspecific requirements apply to those areas of your facility where those sector-specific activities occur. These sector-specific requirements are in addition to any requirements specified elsewhere in this permit.

\section{U.1 Covered Stormwater Discharges.}

The requirements in Subpart $U$ apply to stormwater discharges associated with industrial activity from Food and Kindred Products facilities as identified by the SIC Codes specified in Table D-1 of Appendix D of the permit.

\section{U.2 Limitations on Coverage.}

8.U.2.1 Prohibition of Non-Stormwater Discharges. (See also Part 1.1.4) The following discharges are not authorized by this permit: discharges containing boiler blowdown, cooling tower overflow and blowdown, ammonia refrigeration purging, and vehicle washing and clean-out operations. (EPA includes these prohibited non-stormwater discharges here solely as a helpful reminder to the operator that the only non-stormwater discharges authorized by this permit are at Part 1.1.3.)

\section{U.3 Additional Technology-Based Limitations.}

8.U.3.1 Employee Training. (See also Part 2.1.2.8) Address pest control in your employee training program.

\section{U.4 Additional SWPPP Requirements.}

8.U.4.1 Drainage Area Site Map. (See also Part 5.2.2) Document in your SWPPP the locations of the following activities if they are exposed to precipitation or runoff: vents and stacks from cooking, drying, and similar operations; dry product vacuum transfer lines; animal holding pens; spoiled product; and broken product container storage areas.

8.U.4.2 Potential Pollutant Sources. (See also Part 5.2.3) Document in your SWPPP, in addition to food and kindred products processing-related industrial activities, application and storage of pest control chemicals (e.g., rodenticides, insecticides, fungicides) used on plant grounds.

\section{U.5 Additional Inspection Requirements. (See also Part 3.1)}

Inspect on a quarterly basis, at a minimum, the following areas where the potential for exposure to stormwater exists: loading and unloading areas for all significant materials; storage areas, including associated containment areas; waste management units; vents and stacks emanating from industrial activities; spoiled product and broken product container holding areas; animal holding pens; staging areas; and air pollution control equipment.

\section{U.6 Sector-Specific Benchmarks. (See also Part 6)}

Table 8.U-1 identifies benchmarks that apply to the specific subsectors of Sector U. These benchmarks apply to both your primary industrial activity and any co-located industrial activities. 


\begin{tabular}{|c|c|c|}
\hline \multicolumn{3}{|c|}{ Table 8.U-1. } \\
\hline $\begin{array}{c}\text { Subsector } \\
\text { (You may be subject to requirements } \\
\text { for more than one Sector / } \\
\text { Subsector) }\end{array}$ & Parameter & $\begin{array}{l}\text { Benchmark } \\
\text { Monitoring } \\
\text { Concentration }\end{array}$ \\
\hline $\begin{array}{l}\text { Subsector U1. Grain Mill Products (SIC } \\
\text { 2041-2048) }\end{array}$ & Total Suspended Solids (TSS) & $100 \mathrm{mg} / \mathrm{L}$ \\
\hline \multirow[t]{4}{*}{$\begin{array}{l}\text { Subsector U2. Fats and Oils Products } \\
\text { (SIC 2074-2079) }\end{array}$} & $\begin{array}{c}\text { Biochemical Oxygen Demand } \\
\text { (BOD5) }\end{array}$ & $30 \mathrm{mg} / \mathrm{L}$ \\
\hline & $\begin{array}{c}\text { Chemical Oxygen Demand } \\
\text { (COD) }\end{array}$ & $120 \mathrm{mg} / \mathrm{L}$ \\
\hline & Nitrate plus Nitrite Nitrogen & $0.68 \mathrm{mg} / \mathrm{L}$ \\
\hline & Total Suspended Solids (TSS) & $100 \mathrm{mg} / \mathrm{L}$ \\
\hline
\end{tabular}




\section{Part 8 - Sector-Specific Requirements for Industrial Activity}

\section{Subpart V - Sector V - Textile Mills, Apparel, and Other Fabric Products.}

You must comply with Part 8 sector-specific requirements associated with your primary industrial activity and any co-located industrial activities, as defined in Appendix A. The sectorspecific requirements apply to those areas of your facility where those sector-specific activities occur. These sector-specific requirements are in addition to any requirements specified elsewhere in this permit.

\section{V.1 Covered Stormwater Discharges.}

The requirements in Subpart $\vee$ apply to stormwater discharges associated with industrial activity from Textile Mills, Apparel, and Other Fabric Product manufacturing as identified by the SIC Codes specified under Sector V in Table D-1 of Appendix D of the permit.

\section{V.2 Limitations on Coverage.}

8.V.2.1 Prohibition of Non-Stormwater Discharges. (See also Part 1.1.4) The following are not authorized by this permit: discharges of wastewater (e.g., wastewater resulting from wet processing or from any processes relating to the production process), reused or recycled water, and waters used in cooling towers. If you have these types of discharges from your facility, you must cover them under a separate NPDES permit. (EPA includes these prohibited non-stormwater discharges here solely as a helpful reminder to the operator that the only non-stormwater discharges authorized by this permit are at Part 1.1.3.)

\section{V.3 Additional Technology-Based Limitations.}

8.V.3.1 Good Housekeeping Measures. (See also Part 2.1.2.2)

8.V.3.1.1 Material Storage Areas. Plainly label and store all containerized materials (e.g., fuels, petroleum products, solvents, and dyes) in a protected area, away from drains. Minimize contamination of the stormwater runoff from such storage areas. Also consider an inventory control plan to prevent excessive purchasing of potentially hazardous substances. For storing empty chemical drums or containers, ensure that the drums and containers are clean (consider triple-rinsing) and that there is no contact of residuals with precipitation or runoff. Collect and dispose of wash water from these cleanings properly.

8.V.3.1.2 Material Handling Areas. Minimize contamination of stormwater runoff from material handling operations and areas through implementation of control measures such as the following, where determined to be feasible: using spill and overflow protection; covering fueling areas; and covering or enclosing areas where the transfer of material may occur. When applicable, address the replacement or repair of leaking connections, valves, transfer lines and pipes that may carry chemicals, dyes or wastewater.

8.V.3.1.3 Fueling Areas. Minimize contamination of stormwater runoff from fueling areas through implementation of control measures such as the following, where determined to be feasible: covering the fueling area; using spill and overflow protection; minimizing run-on of stormwater to the fueling areas; using dry cleanup methods; and treating and/or recycling stormwater runoff collected from the fueling area. 
8.V.3.1.4 Above-Ground Storage Tank Area. Minimize contamination of stormwater runoff from above-ground storage tank areas, including the associated piping and valves, through implementation of control measures such as the following, where determined to be feasible (list not exclusive): regular cleanup of these areas; including measures for tanks, piping and valves explicitly in your SPCC program; minimizing runoff of stormwater from adjacent areas; restricting access to the area; inserting filters in adjacent catch basins; providing absorbent booms in unbermed fueling areas; using dry cleanup methods; and permanently sealing drains within critical areas that may discharge to a storm drain.

8.V.3.2 Employee Training. (See also Part 2.1.2.8) As part of your employee training program, address, at a minimum, the following activities (as applicable): use of reused and recycled waters, solvents management, proper disposal of dyes, proper disposal of petroleum products and spent lubricants, spill prevention and control, fueling procedures, and general good housekeeping practices.

\section{V.4 Additional SWPPP Requirements.}

8.V.4.1 Potential Pollutant Sources. (See also Part 5.2.3) Document in your SWPPP the following additional sources and activities that have potential pollutants associated with them: industry-specific significant materials and industrial activities (e.g., backwinding, beaming, bleaching, backing bonding, carbonizing, carding, cut and sew operations, desizing, drawing, dyeing locking, fulling, knitting, mercerizing, opening, packing, plying, scouring, slashing, spinning, synthetic-felt processing, textile waste processing, tufting, turning, weaving, web forming, winging, yarn spinning, and yarn texturing).

8.V.4.2 Description of Good Housekeeping Measures for Material Storage Areas. Document in the SWPPP your containment area or enclosure for materials stored outdoors in connection with Part 8.V.3.1.1 above.

\section{V.5 Additional Inspection Requirements.}

Inspect, at least monthly, the following activities and areas (at a minimum): transfer and transmission lines, spill prevention, good housekeeping practices, management of process waste products, and all structural and nonstructural management practices. 


\section{Part 8 - Sector-Specific Requirements for Industrial Activity}

\section{Subpart W - Sector W - Furniture and Fixtures.}

You must comply with Part 8 sector-specific requirements associated with your primary industrial activity and any co-located industrial activities, as defined in Appendix A. The sectorspecific requirements apply to those areas of your facility where those sector-specific activities occur. These sector-specific requirements are in addition to any requirements specified elsewhere in this permit.

\section{W.1 Covered Stormwater Discharges.}

The requirements in Subpart $W$ apply to stormwater discharges associated with industrial activity from Furniture and Fixtures facilities as identified by the SIC Codes specified under Sector $W$ in Table D-1 of Appendix D of the permit.

\section{W.2 Additional SWPPP Requirements.}

8.W.2.1 Drainage Area Site Map. (See also Part 5.2.2) Document in your SWPPP where any of the following may be exposed to precipitation or surface runoff: material storage (including tanks or other vessels used for liquid or waste storage) areas; outdoor material processing areas; areas where wastes are treated, stored, or disposed of; access roads; and rail spurs. 


\section{Part 8 - Sector-Specific Requirements for Industrial Activity}

\section{Subpart $X$ - Sector $X$ - Printing and Publishing.}

You must comply with Part 8 sector-specific requirements associated with your primary industrial activity and any co-located industrial activities, as defined in Appendix A. The sectorspecific requirements apply to those areas of your facility where those sector-specific activities occur. These sector-specific requirements are in addition to any requirements specified elsewhere in this permit.

\section{X.1 Covered Stormwater Discharges.}

The requirements in Subpart $X$ apply to stormwater discharges associated with industrial activity from Printing and Publishing facilities as identified by the SIC Codes specified under Sector $X$ in Table D-1 of Appendix D of the permit.

\section{X.2 Additional Technology-Based Effluent Limits.}

8.X.2.1 Good Housekeeping Measures. (See also Part 2.1.2.2)

8.X.2.1.1 Material Storage Areas. Plainly label and store all containerized materials (e.g., skids, pallets, solvents, bulk inks, hazardous waste, empty drums, portable and mobile containers of plant debris, wood crates, steel racks, and fuel oil) in a protected area, away from drains. Minimize contamination of the stormwater runoff from such storage areas. Also consider an inventory control plan to prevent excessive purchasing of potentially hazardous substances.

8.X.2.1.2 Material Handling Area. Minimize contamination of stormwater runoff from material handling operations and areas (e.g., blanket wash, mixing solvents, loading and unloading materials) through implementation of control measures such as the following, where determined to be feasible (list not exclusive): using spill and overflow protection; covering fueling areas; and covering or enclosing areas where the transfer of materials may occur. When applicable, address the replacement or repair of leaking connections, valves, transfer lines, and pipes that may carry chemicals or wastewater.

8.X.2.1.3 Fueling Areas. Minimize contamination of stormwater runoff from fueling areas through implementation of control measures such as the following, where determined to be feasible (list not exclusive): covering the fueling area; using spill and overflow protection; minimizing runoff of stormwater to the fueling areas; using dry cleanup methods; and treating and/or recycling stormwater runoff collected from the fueling area.

8.X.2.1.4 Above Ground Storage Tank Area. Minimize contamination of the stormwater runoff from above-ground storage tank areas, including the associated piping and valves, through implementation of control measures such as the following, where determined to be feasible (list not exclusive): regularly cleaning these areas; explicitly addressing tanks; piping and valves in the SPCC program; minimizing stormwater runoff from adjacent areas; restricting access to the area; inserting filters in adjacent catch basins; providing absorbent booms in unbermed fueling areas; using dry cleanup methods; and permanently sealing drains within critical areas that may discharge to a storm drain. 
8.X.2.2 Employee Training. (See also Part 2.1.2.8) As part of your employee training program, address, at a minimum, the following activities (as applicable): spent solvent management, spill prevention and control, used oil management, fueling procedures, and general good housekeeping practices.

\section{X.3 Additional SWPPP Requirements.}

8.X.3.1 Description of Good Housekeeping Measures for Material Storage Areas. In connection with Part 8.X.2.1.1, describe in the SWPPP the containment area or enclosure for materials stored outdoors. 


\section{Part 8 - Sector-Specific Requirements for Industrial Activity}

\section{Subpart Y - Sector Y - Rubber, Miscellaneous Plastic Products, and Miscellaneous Manufacturing} Industries.

You must comply with Part 8 sector-specific requirements associated with your primary industrial activity and any co-located industrial activities, as defined in Appendix A. The sectorspecific requirements apply to those areas of your facility where those sector-specific activities occur. These sector-specific requirements are in addition to any requirements specified elsewhere in this permit.

\section{Y.1 Covered Stormwater Discharges.}

The requirements in Subpart $Y$ apply to stormwater discharges associated with industrial activity from Rubber, Miscellaneous Plastic Products, and Miscellaneous Manufacturing Industries facilities as identified by the SIC Codes specified under Sector Y in Table D-1 of Appendix D of the permit.

\section{Y.2 Additional Technology-Based Effluent Limits.}

8.Y.2.1 Controls for Rubber Manufacturers. (See also Part 2.1.2) Minimize the discharge of zinc in your stormwater discharges. Parts 8.Y.2.1.1 to 8.Y.2.1.5 give possible sources of zinc to be reviewed and list control measures to be implemented where determined to be feasible. Implement additional control measures such as the following, where determined to be feasible (list not exclusive): using chemicals purchased in preweighed, sealed polyethylene bags; storing in-use materials in sealable containers, ensuring an airspace between the container and the cover to minimize "puffing" losses when the container is opened; and using automatic dispensing and weighing equipment.

8.Y.2.1.1 Zinc Bags. Ensure proper handling and storage of zinc bags at your facility through implementation of control measures such as the following, where determined to be feasible (list not exclusive): employee training on the handling and storage of zinc bags; indoor storage of zinc bags; cleanup of zinc spills without washing the zinc into the storm drain; and the use of 2,500pound sacks of zinc rather than 50- to 100-pound sacks.

8.Y.2.1.2 Dumpsters. Minimize discharges of zinc from dumpsters through implementation of control measures such as the following, where determined to be feasible (list not exclusive): covering the dumpster; moving the dumpster indoors; and providing a lining for the dumpster.

8.Y.2.1.3 Dust Collectors and Baghouses. Minimize contributions of zinc to stormwater from dust collectors and baghouses. Replace or repair, as appropriate, improperly operating dust collectors and baghouses.

8.Y.2.1.4 Grinding Operations. Minimize contamination of stormwater as a result of dust generation from rubber grinding operations. Where determined to be feasible, install a dust collection system.

8.Y.2.1.5 Zinc Stearate Coating Operations. Minimize the potential for stormwater contamination from drips and spills of zinc stearate slurry that may be released to the storm drain. Where determined to be feasible, use alternative compounds to zinc stearate. 
8.Y.2.2 Controls for Plastic Products Manufacturers. Minimize the discharge of plastic resin pellets in your stormwater discharges through implementation of control measures such as the following, where determined to be feasible (list not exclusive): minimizing spills; cleaning up of spills promptly and thoroughly; sweeping thoroughly; pellet capturing; employee education; and disposal precautions.

\section{Y.3 Additional SWPPP Requirements.}

8.Y.3.1 Potential Pollutant Sources for Rubber Manufacturers. (See also Part 5.2.3) Document in your SWPPP the use of zinc at your facility and the possible pathways through which zinc may be discharged in stormwater runoff.

8.Y.4 Sector-Specific Benchmarks. (See also Part 6)

Table 8.Y-1 identifies benchmarks that apply to Sector Y. These benchmarks apply to both your primary industrial activity and any co-located industrial activities.

\begin{tabular}{|c|c|c|}
\hline \multicolumn{2}{|c|}{ Table 8.Y-1. } \\
\hline $\begin{array}{c}\text { Subsector } \\
\text { (You may be subject to requirements for more } \\
\text { than one sector/subsector) }\end{array}$ & Parameter & $\begin{array}{c}\text { Benchmark Monitoring } \\
\text { Concentration }\end{array}$ \\
\hline $\begin{array}{l}\text { Subsector Y1. Rubber Products Manufacturing } \\
\text { (SIC 3011, 3021, 3052, 3053, 3061, 3069) }\end{array}$ & $\begin{array}{c}\text { Total Zinc } \\
\text { (freshwater) } \\
\text { Total Zinc } \\
\text { (saltwater) }\end{array}$ & Hardness Dependent \\
\hline
\end{tabular}

'Saltwater benchmark values apply to stormwater discharges into saline waters where indicated.

2 The freshwater benchmark values of some metals are dependent on water hardness. For these parameters, permittees must determine the hardness of the receiving water (see Appendix J, "Calculating Hardness in Receiving Waters for Hardness Dependent Metals," for methodology), in accordance with Part 6.2.1.1, to identify the applicable 'hardness range' for determining their benchmark value applicable to their facility. Hardness Dependent Benchmarks follow in the table below:

\begin{tabular}{|l|l|}
\hline Freshwater Hardness Range & $\begin{array}{l}\text { Zinc } \\
(\mathrm{mg} / \mathrm{L})\end{array}$ \\
\hline $0-24.99 \mathrm{mg} / \mathrm{L}$ & 0.04 \\
\hline $25-49.99 \mathrm{mg} / \mathrm{L}$ & 0.05 \\
\hline $50-74.99 \mathrm{mg} / \mathrm{L}$ & 0.08 \\
\hline $75-99.99 \mathrm{mg} / \mathrm{L}$ & 0.11 \\
\hline $100-124.99 \mathrm{mg} / \mathrm{L}$ & 0.13 \\
\hline $125-149.99 \mathrm{mg} / \mathrm{L}$ & 0.16 \\
\hline $150-174.99 \mathrm{mg} / \mathrm{L}$ & 0.18 \\
\hline $175-199.99 \mathrm{mg} / \mathrm{L}$ & 0.20 \\
\hline $200-224.99 \mathrm{mg} / \mathrm{L}$ & 0.23 \\
\hline $225-249.99 \mathrm{mg} / \mathrm{L}$ & 0.25 \\
\hline $250+\mathrm{mg} / \mathrm{L}$ & 0.26 \\
\hline
\end{tabular}




\section{Part 8 - Sector-Specific Requirements for Industrial Activity}

\section{Subpart $Z$ - Sector $Z$ - Leather Tanning and Finishing.}

You must comply with Part 8 sector-specific requirements associated with your primary industrial activity and any co-located industrial activities, as defined in Appendix A. The sectorspecific requirements apply to those areas of your facility where those sector-specific activities occur. These sector-specific requirements are in addition to any requirements specified elsewhere in this permit.

\section{Z.1 Covered Stormwater Discharges.}

The requirements in Subpart $Z$ apply to stormwater discharges associated with industrial activity from Leather Tanning and Finishing facilities as identified by the SIC Code specified under Sector Z in Table D-1 of Appendix D of the permit.

\section{Z.2 Additional Technology-Based Effluent Limits.}

8.Z.2.3 Good Housekeeping Measures. (See also Part 2.1.2.2)

8.2.2.3.1 Storage Areas for Raw, Semiprocessed, or Finished Tannery By-products. Minimize contamination of stormwater runoff from pallets and bales of raw, semiprocessed, or finished tannery by-products (e.g., splits, trimmings, shavings). Store or protect indoors with polyethylene wrapping, tarpaulins, roofed storage, etc. where practicable. Place materials on an impermeable surface and enclose or put berms (or equivalent measures) around the area to prevent stormwater run-on and runoff where practicable.

8.2.2.3.2 Material Storage Areas. Label storage containers of all materials (e.g., specific chemicals, hazardous materials, spent solvents, waste materials) and minimize contact of such materials with stormwater.

8.2.2.3.3 Buffing and Shaving Areas. Minimize contamination of stormwater runoff with leather dust from buffing and shaving areas through implementation of control measures such as the following, where determined to be feasible (list not exclusive): implementing dust collection enclosures; implementing preventive inspection and maintenance programs; or other appropriate preventive measures.

8.2.2.3.4 Receiving, Unloading, and Storage Areas. Minimize contamination of stormwater runoff from receiving, unloading, and storage areas. If these areas are exposed, implement control measures such as the following, where determined to be feasible (list not exclusive): covering all hides and chemical supplies; diverting drainage to the process sewer; or grade berming or curbing the area to prevent stormwater runoff.

8.2.2.3.5 Outdoor Storage of Contaminated Equipment. Minimize contact of stormwater with contaminated equipment through implementation of control measures such as the following, where determined to be feasible (list not exclusive): covering equipment, diverting drainage to the process sewer, and cleaning thoroughly prior to storage.

8.Z.2.3.6 Waste Management. Minimize contamination of stormwater runoff from waste storage areas through implementation of control measures such as the following, where determined to be feasible (list not exclusive): covering dumpsters; moving waste management activities indoors; covering waste piles with temporary covering material such as tarpaulins or polyethylene; and 
minimizing stormwater runoff by enclosing the area or building berms around the area.

\section{Z.3 Additional SWPPP Requirements.}

8.Z.3.1 Drainage Area Site Map. (See also Part 5.2.2) Identify in your SWPPP where any of the following may be exposed to precipitation or surface runoff: processing and storage areas of the beamhouse, tanyard, and re-tan wet finishing and dry finishing operations.

8.Z.3.2 Potential Pollutant Sources. (See also Part 5.2.3) Document in your SWPPP the following sources and activities that have potential pollutants associated with them (as appropriate): temporary or permanent storage of fresh and brine-cured hides; extraneous hide substances and hair; leather dust, scraps, trimmings, and shavings. 


\section{Part 8 - Sector-Specific Requirements for Industrial Activity}

\section{Subpart AA - Sector AA - Fabricated Metal Products}

You must comply with Part 8 sector-specific requirements associated with your primary industrial activity and any co-located industrial activities, as defined in Appendix A. The sectorspecific requirements apply to those areas of your facility where those sector-specific activities occur. These sector-specific requirements are in addition to any requirements specified elsewhere in this permit.

\section{AA.1 Covered Stormwater Discharges.}

The requirements in Subpart AA apply to stormwater discharges associated with industrial activity from Fabricated Metal Products facilities as identified by the SIC Codes specified under Sector AA in Table D-1 of Appendix D of the permit.

\section{AA.2 Additional Technology-Based Effluent Limits.}

8.AA.2.1 Good Housekeeping Measures. (See also Part 2.1.2.2)

8.AA.2.1.1 Raw Steel Handling Storage. Minimize the generation of and/or recover and properly manage scrap metals, fines, and iron dust. Include measures for containing materials within storage handling areas.

8.AA.2.1.2 Paints and Painting Equipment. Minimize exposure of paint and painting equipment to stormwater.

8.AA.2.2 Spill Prevention and Response Procedures. (See also Part 2.1.2.4) Ensure that the necessary equipment to implement a cleanup is available to personnel. The following areas should be addressed:

8.AA.2.2.1 Metal Fabricating Areas. Maintain clean, dry, orderly conditions in these areas. Use dry clean-up techniques where practicable.

8.AA.2.2.2 Storage Areas for Raw Metal. Keep these areas free of conditions that could cause, or impede appropriate and timely response to, spills or leakage of materials through implementation of control measures such as the following, where determined to be feasible (list not exclusive): maintaining storage areas so that there is easy access in the event of a spill, and labeling stored materials to aid in identifying spill contents.

8.AA.2.2.3 Metal Working Fluid Storage Areas. Minimize the potential for stormwater contamination from storage areas for metal working fluids.

8.AA.2.2.4 Cleaners and Rinse Water. Control and clean up spills of solvents and other liquid cleaners, control sand buildup and disbursement from sand-blasting operations, and prevent exposure of recyclable wastes. Substitute environmentally benign cleaners when possible.

8.AA.2.2.5 Lubricating Oil and Hydraulic Fluid Operations. Minimize the potential for stormwater contamination from lubricating oil and hydraulic fluid operations. Use monitoring equipment or other devices to detect and control leaks and overflows where feasible. Install perimeter controls such as dikes, curbs, grass filter strips, or equivalent measures where feasible.

8.AA.2.2.6 Chemical Storage Areas. Minimize stormwater contamination and accidental spillage in chemical storage areas. Include a program to inspect containers and identify proper disposal methods. 
8.AA.2.3 Spills and Leaks. (See also Part 5.2.3.3) In your spill prevention and response procedures, required by Part 2.1.2.4, pay attention to the following materials (at a minimum): chromium, tolvene, pickle liquor, sulfuric acid, zinc and other water priority chemicals, and hazardous chemicals and wastes.

\section{AA.3 Additional SWPPP Requirements.}

8.AA.3.1 Drainage Area Site Map. (See also Part 5.2.2) Document in your SWPPP where any of the following may be exposed to precipitation or surface runoff: raw metal storage areas; finished metal storage areas; scrap disposal collection sites; equipment storage areas; retention and detention basins; temporary and permanent diversion dikes or berms; right-of-way or perimeter diversion devices; sediment traps and barriers; processing areas, including outside painting areas; wood preparation; recycling; and raw material storage.

8.AA.3.2 Potential Pollutant Sources. (See also Part 5.2.3) Document in your SWPPP the following additional sources and activities that have potential pollutants associated with them: loading and unloading operations for paints, chemicals, and raw materials; outdoor storage activities for raw materials, paints, empty containers, corn cobs, chemicals, and scrap metals; outdoor manufacturing or processing activities such as grinding, cutting, degreasing, buffing, and brazing; onsite waste disposal practices for spent solvents, sludge, pickling baths, shavings, ingot pieces, and refuse and waste piles.

\section{AA.4 Additional Inspection Requirements.}

8.AA.4.1 Inspections. (See also Part 3.1) At a minimum, include the following areas in all inspections: raw metal storage areas, finished product storage areas, material and chemical storage areas, spent solvents and chemical storage areas, recycling areas, loading and unloading areas, equipment storage areas, paint areas, drainage from roof and vehicle fueling and maintenance areas. Potential pollutants include chromium, zinc, lubricating oil, solvents, aluminum, oil and grease, methyl ethyl ketone, steel, and related materials.

\section{AA.5 Sector-Specific Benchmarks. (See also Part 6)}

Table 8.AA-1 identifies benchmarks that apply to the specific subsectors of Sector AA. These benchmarks apply to both your primary industrial activity and any co-located industrial activities.

\begin{tabular}{|c|c|c|}
\hline \multicolumn{3}{|c|}{ Table 8.AA-1 } \\
\hline $\begin{array}{c}\text { Subsector } \\
\text { (You may be subject to requirements } \\
\text { for more than one sector/subsector) }\end{array}$ & Parameter & $\begin{array}{l}\text { Benchmark Monitoring } \\
\text { Concentration }\end{array}$ \\
\hline \multirow{4}{*}{$\begin{array}{l}\text { Subsector AA1. Fabricated Metal } \\
\text { Products, except Coating (SIC 3411- } \\
3499 ; 3911-3915)\end{array}$} & Total Aluminum & $0.75 \mathrm{mg} / \mathrm{L}$ \\
\hline & Total Iron & $1.0 \mathrm{mg} / \mathrm{L}$ \\
\hline & $\begin{array}{l}\text { Total Zinc (freshwater) } \\
\text { Total Zinc (saltwater) }\end{array}$ & $\begin{array}{c}\text { Hardness Dependent } \\
0.09 \mathrm{mg} / \mathrm{L}\end{array}$ \\
\hline & Nitrate plus Nitrite Nitrogen & $0.68 \mathrm{mg} / \mathrm{L}$ \\
\hline \multirow[t]{2}{*}{$\begin{array}{l}\text { Subsector AA2. Fabricated Metal } \\
\text { Coating and Engraving (SIC 3479) }\end{array}$} & $\begin{array}{l}\text { Total Zinc (freshwater) } \\
\text { Total Zinc (saltwater) } \\
\end{array}$ & $\begin{array}{c}\text { Hardness Dependent } \\
0.09 \mathrm{mg} / \mathrm{L}\end{array}$ \\
\hline & Nitrate plus Nitrite Nitrogen & $0.68 \mathrm{mg} / \mathrm{L}$ \\
\hline
\end{tabular}


'Saltwater benchmark values apply to stormwater discharges into saline waters where indicated.

2 The freshwater benchmark values of some metals are dependent on water hardness. For these parameters, permittees must determine the hardness of the receiving water (see Appendix J, "Calculating Hardness in Receiving Waters for Hardness Dependent Metals," for methodology), in accordance with Part 6.2.1.1, to identify the applicable "hardness range' for determining their benchmark value applicable to their facility. Hardness Dependent Benchmarks follow in the table below:

\begin{tabular}{|l|l|}
\hline Freshwater Hardness Range & Zinc $(\mathrm{mg} / \mathrm{L})$ \\
\hline $0-24.99 \mathrm{mg} / \mathrm{L}$ & 0.04 \\
\hline $25-49.99 \mathrm{mg} / \mathrm{L}$ & 0.05 \\
\hline $50-74.99 \mathrm{mg} / \mathrm{L}$ & 0.08 \\
\hline $75-99.99 \mathrm{mg} / \mathrm{L}$ & 0.11 \\
\hline $100-124.99 \mathrm{mg} / \mathrm{L}$ & 0.13 \\
\hline $125-149.99 \mathrm{mg} / \mathrm{L}$ & 0.16 \\
\hline $150-174.99 \mathrm{mg} / \mathrm{L}$ & 0.18 \\
\hline $175-199.99 \mathrm{mg} / \mathrm{L}$ & 0.20 \\
\hline $200-224.99 \mathrm{mg} / \mathrm{L}$ & 0.23 \\
\hline $225-249.99 \mathrm{mg} / \mathrm{L}$ & 0.25 \\
\hline $250+\mathrm{mg} / \mathrm{L}$ & 0.26 \\
\hline
\end{tabular}




\section{Part 8 - Sector-Specific Requirements for Industrial Activity}

\section{Subpart AB - Sector AB - Transportation Equipment, Industrial or Commercial Machinery} Facilities.

You must comply with Part 8 sector-specific requirements associated with your primary industrial activity and any co-located industrial activities, as defined in Appendix A. The sectorspecific requirements apply to those areas of your facility where those sector-specific activities occur. These sector-specific requirements are in addition to any requirements specified elsewhere in this permit.

\section{AB.1 Covered Stormwater Discharges.}

The requirements in Subpart $A B$ apply to stormwater discharges associated with industrial activity from Transportation Equipment, Industrial or Commercial Machinery facilities as identified by the SIC Codes specified under Sector AB in Table D-1 of Appendix D of the permit.

\section{AB.2 Additional SWPPP Requirements.}

8.AB.2.1 Drainage Area Site Map. (See also Part 5.2.2) Identify in your SWPPP where any of the following may be exposed to precipitation or surface runoff: vents and stacks from metal processing and similar operations. 


\section{Part 8 - Sector-Specific Requirements for Industrial Activity}

\section{Subpart AC-Sector AC - Electronic and Electrical Equipment and Components, Photographic} and Optical Goods.

You must comply with Part 8 sector-specific requirements associated with your primary industrial activity and any co-located industrial activities, as defined in Appendix A. The sectorspecific requirements apply to those areas of your facility where those sector-specific activities occur. These sector-specific requirements are in addition to any requirements specified elsewhere in this permit.

\section{AC.1 Covered Stormwater Discharges.}

The requirements in Subpart AC apply to stormwater discharges associated with industrial activity from facilities that manufacture Electronic and Electrical Equipment and Components, Photographic and Optical goods as identified by the SIC Codes specified in Table D-1 of Appendix D of the permit.

\section{AC.2 Additional Requirements.}

No additional sector-specific requirements apply. 


\section{Part 8 - Sector-Specific Requirements for Industrial Activity}

\section{Subpart AD - Sector AD - Stormwater Discharges Designated by the Director as Requiring} Permits.

You must comply with Part 8 sector-specific requirements associated with your primary industrial activity and any co-located industrial activities, as defined in Appendix A. The sectorspecific requirements apply to those areas of your facility where those sector-specific activities occur. These sector-specific requirements are in addition to any requirements specified elsewhere in this permit.

\section{AD.1 Covered Stormwater Discharges.}

Sector AD is used to provide permit coverage for facilities designated by the Director as needing a stormwater permit, and any discharges of stormwater associated with industrial activity that do not meet the description of an industrial activity covered by Sectors A-AC.

8.AD.1.1 Eligibility for Permit Coverage. Because this sector is primarily intended for use by discharges designated by the Director as needing a stormwater permit (which is an atypical circumstance), and your facility may or may not normally be discharging stormwater associated with industrial activity, you must obtain the Director's written permission to use this permit prior to submitting an NOI. If you are authorized to use this permit, you will still be required to ensure that your discharges meet the basic eligibility provisions of this permit at Part 1.1.

\section{AD.2 Sector-Specific Benchmarks and Effluent Limits. (See also Part 6)}

The Director will establish any additional monitoring and reporting requirements for your facility prior to authorizing you to be covered by this permit. Additional monitoring requirements would be based on the nature of activities at your facility and your stormwater discharges. 
9. Permit Conditions Applicable to Specific States, Indian Country Lands, or Territories

9.1 EPA Region 1: Connecticut, Massachusetts, Maine, New Hampshire, Rhode Island, Vermont.

9.1.1 CTR051000: Indian Country within the State of Connecticut

No additional requirements.

9.1.2 MAR050000: Commonwealth of Massachusetts, except Indian country

Permittees in the Commonwealth of Massachusetts must meet the following conditions:

9.1.2.1 Additional conditions required by the Commonwealth of Massachusetts. Discharges covered by the general permit must comply with the provisions of 314 CMR 3.00; 314 CMR 4.00; 314 CMR 9.00; and 314 CMR 10.00 and any other related policies adopted under the authority of the Massachusetts Clean Waters Act, MGL C.21, ss. 26-53 and Wetlands Protection Act, MGL s. 40.

New facilities or redevelopment of existing facilities subject to this permit must comply with applicable stormwater performance standards prescribed by state regulation or policy. A permit under 314 CMR 3.04 is not required for existing facilities which meet state stormwater performance standards. An application for a permit under 314 CMR 3.00 is required only when required under 314 CMR 3.04(2) (b) \{designation of a discharge on a case-by-case basis\} or is otherwise identified in 314 CMR 3.00 or any Massachusetts Department of Environmental Protection policy as a discharge requiring a permit application. Department regulations and policies may be obtained through the State House Bookstore or online at www.mass.gov/dep.

9.1.2.2 SWPPP Availability. The Department may request a copy of the Stormwater Pollution Prevention Plan (SWPPP) and the permittee is required to submit the SWPPP to the Department within 14 days of such a request.

9.1.2.3 Authorization to Inspect. The Department may conduct an inspection of any facility covered by this permit to ensure compliance with state law requirements, including state water quality standards. The Department may enforce its certification conditions.

9.1.2.4 Submission of Monitoring Data. The results of any monitoring [four samples required in the first year of the permit] required by this permit must be sent to the appropriate Regional Office of the Department [attention: Bureau of Waste Prevention] where the monitoring identifies violations of any effluent limits or benchmarks for any parameter for which monitoring is required under this permit. In addition, any follow-up monitoring and a description of the corrective actions required and undertaken to meet the effluent limits or benchmarks must be sent to the appropriate Department Regional Office.

9.1.2.5 Sector-Specific Requirements. The Massachusetts Coastal Zone Management Program submitted the following conditions to be added to the permit in order to meet the Programs' Consistency Review and which are included in the requirements of this Water Quality Certification: 
- In Sector Q [Water Transportation] add copper to the required monitoring parameters with a benchmark monitoring concentration as included in the MSGP 2015 Fact Sheet Part X.B.1, and Appendix J.

- In Sector R [Ship and Boat Building and Repair Yards] add aluminum, iron, lead and copper to the list of required monitoring parameters with a benchmark monitoring concentration as included in the MSGP 2015 Fact Sheet Part X.B.1 and Appendix J.

- Modify the monitoring requirements [Part 6.2.1.2] for Sectors $Q$ and R such that all four of the quarterly monitoring samples must meet the benchmarks rather than the average of the four before no further monitoring is required.

\subsubsection{MAR051000: Indian country within the Commonwealth of Massachusetts}

No additional requirements.

\subsubsection{NHR050000: State of New Hampshire}

Permittees in New Hampshire must also meet the following conditions:

9.1.4.1 Consider Opportunities for on-site infiltration of stormwater. In Part 2.1.1 Control Measure Selection and Design Considerations, you are required to consider opportunities for infiltrating runoff onsite. This is encouraged, but it should only be done if consistent with the statutes and rules of the Department of Environmental Services written to protect groundwater, including Env-Wq 1507.04(e). Infiltration best management practices are not recommended at industrial sites except in areas where industrial activities do not occur, such as at office buildings and their associated parking facilities, or in drainage areas at the facility where a certification of no exposure will always be possible [see 40 CFR 122.26(g)].

9.1.4.2 Maintenance of Infiltration Best Management Practices. In Part 2.1.2.3 you are required to maintain control measures. In Parts 5.2.2, 5.2.5.1, and 5.5 you are required to document the location of control measures, perform inspections and maintenance, and keep records. Accordingly, the SWPPP must contain the following:

- A description of and the location of each on-site infiltration BMP installed;

- The maintenance procedures that will be followed to ensure proper operation, including the removal of sediment from pretreatment devices;

- The inspection produces that will be followed at least annually. These should include the produces for ensuring that the stormwater being infiltrated is not exposed to industrial pollutants and the procedures for ensuring proper drainage to prevent mosquito breeding;

- $\quad$ The employee name (or title of the position) who is a member of the stormwater pollution prevention team (see Part 5.2.1) who will be responsible for the maintenance required in this section, the inspection required in this section, and any necessary corrective action required in Part 4; and

- Records for all maintenance performed, inspections conducted, and corrective actions taken.

9.1.4.3 Discontinue, Permit or Register On-site Infiltration BMP if Necessary. If at any time a certification of no exposure can no longer be made for any of the stormwater to be infiltrated, then the infiltration BMP must cease for that portion of the runoff or 
the discharge must be permitted or registered as appropriate. The following may be required:

- Infiltration BMP that meets the definition of a Class $\vee$ well or that infiltrates stormwater via a subsurface structure (i.e. concrete chambers, dry well, leach field, etc.) will need an underground injection control (UIC) registration from NHDES; and

- Permitting as a groundwater discharge as required in Env-Wq 402, if the stormwater will or may contain regulated contaminants.

The SWPPP must be modified immediately if new infiltration BMPs are proposed or if existing infiltration BMPs will cease.

\subsubsection{Required NHDES notification.}

- Notify the NHDES Groundwater Discharge Permit Coordinator immediately if you believe that any infiltration BMP may need to be permitted or registered (See Part 9.1.4.3) during the permit term.

- Notify the NHDES Wastewater Engineering Bureau immediately of any plans to discharge any new non-stormwater discharges during the permit term. This does not include the allowable non-stormwater discharges listed in Part 1.1.3.

9.1.4.5 Information That May Be Requested by NHDES. To ensure compliance with RSA 485C, RSA 485-A, RSA 485-A:13, I(a), Env-Wq 400 and Env-Wq 401 the following information may be requested by NHDES. This information must be kept on site unless you receive a written request from NHDES that it be sent to the address shown in Part 9.1.4.6.

- The site map required in Part 5.2.2, showing the type and location of all on-site infiltration BMP utilized at the facility or the reason(s) why none were installed.

- A list of all non-stormwater discharges that occur at the facility, including their source locations and the control measures being used (See Sections 1.1.3 and 5.2.3.4).

- A copy of the Annual Reports required in Part 7.5

9.1.4.6 Where to Submit Information. Information submitted to NHDES must be sent to the following address:

$\mathrm{NH}$ Department of Environmental Services

Wastewater Engineering Bureau, Permits \& Compliance Section

P.O. Box 95

Concord, NH 03302-0095

9.1.4.7 Modification of Clean Water Act Section 401 Water Quality Certification. When NHDES determines that additional water quality certification requirements are necessary to protect water quality, it may require individual dischargers to meet additional conditions to obtain or continue coverage under the MSGP. Any such conditions shall be supplied to the permittee in writing. Any required pollutant loading analyses and any designs for structural best management practices necessary to protect water quality must be prepared by a civil or sanitary engineer registered in New Hampshire. 
9.1.5 RIR051000: Indian country within the State of Rhode Island

No additional requirements.

9.1.6 VTR05F000: Areas in the State of Vermont subject to industrial activity by a Federal Operator

No additional requirements.

9.2 EPA Region 2: New Jersey, New York, Puerto Rico, Virgin Islands.

9.2.1 PRR050000: Commonwealth of Puerto Rico

No additional requirements.

9.3 EPA Region 3: Delaware, District of Columbia, Maryland, Pennsylvania, Virginia, West Virginia.

9.3.1 DCR050000: District of Columbia

Permittees in the District of Columbia must also meet the following conditions:

9.3.1.1 Compliance with District of Columbia Laws and Regulations. Discharges covered by the MSGP must comply with the District of Columbia Water Pollution Control Act of 1984, as amended, D.C. Official Code § 8-103.01 et seq.; and its implementing regulations in Title 21, Chapters 11 and 19 of the District of Columbia Municipal Regulations. Nothing in this permit will be construed to preclude the institution of any legal action or relieve the permittee from any responsibilities, liabilities, or penalties established pursuant to District of Columbia laws and regulations.

9.3.1.2 Submission of SWPPP. The Stormwater Pollution Prevention Plan (SWPPP) shall be submitted to the District Department of the Environment (DDOE) at the same time the Notice of Intent (NOI) is submitted to EPA.

9.3.1.3 Submission of No Exposure Certification and NOT. Copies of the No Exposure Certification and Notice of Termination (NOT) shall be submitted to DDOE at the same time they are submitted to EPA.

9.3.1.4 Authorization to Inspect. The permittee shall allow DDOE to inspect any facility, equipment, practices, or operations regulated or required under this permit and to access records maintained under the conditions of this permit.

9.3.1.5 Submission of Reports. Signed copies of all reports required under this permit including the reporting requirements of Appendix B.12 shall be submitted to DDOE at the same time they are submitted to EPA.

9.3.1.6 Where to Submit Information. All required or requested documents shall be sent to the:

Attention: Associate Director

Water Quality Division, Natural Resources Administration

District Department of the Environment

1200 First Street, NE, 5th Floor

Washington, D.C. 20002 
9.3.2 DER05F000: Areas in the State of Delaware subject to industrial activity by a Federal Operator

No additional requirements.

9.4 EPA Region 4: Alabama, Florida, Georgia, Kentucky, Mississippi, North Carolina, South Carolina, Tennessee

Coverage not available under this permit.

9.5 EPA Region 5: Illinois, Indiana, Michigan, Minnesota, Ohio, Wisconsin.

9.5.1 MIR051000: Indian country within the State of Michigan

No additional requirements.

9.5.2 MNR051000: Indian country within the State of Minnesota

9.5.2.1 Fond du Lac Reservation

The following conditions apply only to discharges on the Fond du Lac Reservation.

9.5.2.1.1 Submission of SWPPP. A copy of the Stormwater Pollution Plan (SWPPP) must be submitted to the Office of Water Protection at least thirty (30) days in advance of sending the Notice of Intent to EPA. MSGP applicants are encouraged to work with the Fond du Lac Office of Water Protection in the identification of all proposed receiving waters.

9.5.2.1.2 Submission of NOI and NOT. Copies of the Notice of Intent (NOI) and Notice of Termination (NOT) must be sent to the Fond du Lac Office of Water Protection at the same time they are submitted to EPA.

9.5.2.1.3 Benchmark Monitoring for Turbidity. The Benchmark Monitoring Concentration (BMC) for Turbidity shall NOT exceed $10 \%$ of natural background as determined by Office of Water Protection staff as measured in NTU.

9.5.2.1.4 Effluent Limitations. The Effluent Limitations for ALL sectors shall NOT exceed more than two times (2x) Fond du Lac's ambient concentrations (based upon 15 years of monitoring data) for the following:
a) Ammonia
Ambient $=<0.3 \mathrm{mg} / \mathrm{l}$
b) Arsenic
Ambient $=<3.0 \mu \mathrm{g} / \mathrm{l}$
c) Chromium
Ambient $=<0.8 \mu \mathrm{g} / \mathrm{l}$
d) Total Phosphorus
Ambient $=<0.09 \mathrm{mg} / \mathrm{l}$
e) Total Suspended Solids
Ambient $=<16.0 \mathrm{mg} / \mathrm{l}$
f) Zinc
Ambient $=<24.0 \mathrm{mg} / \mathrm{l}$

9.5.2.1.5 Outstanding Reservation Resource Waters (ORRW). This Certification does not pertain to any new discharge to Outstanding Reservation Resource Waters (ORRW) as described in $\S 105$ b.3. of the Fond du Lac Water Quality Standards (Ordinance \# 12/98). Although additional waters may be designated in the future, currently Perch Lake, Rice Portage Lake, Miller Lake, Deadfish Lake, and Jaskari Lake are designated as ORRWs. New dischargers wishing to discharge to an ORRW must obtain an individual permit for storm water discharges. 
9.5.2.1.6 Water Quality Criteria. All industrial activities shall be carried out in such a manner as will prevent violations of water quality criteria as stated in the Water Quality Standards of the Fond du Lac Reservation, Ordinance 12/98, as amended. This includes, but is not limited to, the prevention of any discharge that causes a condition in which visible solids, bottom deposits, or turbidity impairs the usefulness of water of the Fond du Lac Reservation for any of the uses designated in the Water Quality Standards of the Fond du Lac Reservation. These uses include wildlife, aquatic life, warm and cold water fisheries, subsistence farming (netting), primary contact recreation, cultural, wild rice areas, aesthetic waters, agriculture, navigation, and commercial.

9.5.2.1.7 Impacts to cultural sites. This certification does not authorize impacts to cultural, historical, or archeological features or sites, or properties that may be eligible for such listing.

9.5.2.1.8 Where to Submit Information. All required or requested documents shall be sent to the:

Fond du Lac Reservation

Office of Water Protection

1720 Big Lake Road

Cloquet, Minnesota 55720

\subsubsection{Grand Portage Band of the Minnesota Chippewa Tribe}

The following conditions apply to industrial storm water discharges into Waters of the Grand Portage Reservation:

9.5.2.2.1 Definitions. The definitions set forth in the Grand Portage Water Resources Ordinance, as amended, ("Water Resources Ordinance") govern these certification conditions.

9.5.2.2.2 Water Quality Standards. All industrial storm water discharges authorized by this permit must comply with the Grand Portage Water Quality Standards, Applicable Federal Standards, and the Water Resources Ordinance.

9.5.2.2.3 Additional Monitoring. Grand Portage reserves the right to require monitoring of storm water discharges as determined on a case-by-case basis. If the Grand Portage Environmental Resources Board ("Board") determines that a monitoring plan is necessary, the monitoring plan must be prepared and incorporated into the Storm Water Pollution Prevention Plan ("SWPPP") before the SWPPP is submitted to the U.S. EPA. Accordingly, the Board must be contacted, at the address listed below, at the onset of writing the SWPPP.

9.5.2.2.4 Submission of SWPPP, NOI, and NOT. In addition, a copy of the SWPPP, Notice of Intent ("NOI"), and Notice of Termination (NOT) (collectively the "application") must be submitted to the Board at least 30 days before submitting the NOI to the U.S. EPA. Applications should be sent to the address below.

9.5.2.2.5 Additional information. Upon receipt of the application, the Board shall order the Grand Portage Environmental Department (Department) to conduct a technical review of the application materials. If necessary, Department staff will send a 
request for additional information to the applicant within 30 days of receipt of the application.

9.5.2.2.6 Preliminary coverage determination. After considering the application and such other information and data as the Department staff deems relevant, the Department Director will evaluate whether there is a reasonable probability that the proposed activity will violate the Grand Portage Water Quality Standards or any Applicable Federal Standards and recommend one of the following preliminary determinations:

- Unconditionally grant coverage under the MSGP;

- Grant coverage under the MSGP subject to certain conditions; or

- Deny coverage under the MSGP.

9.5.2.2.7 Final coverage determination. Within 30 days of the Department Director's recommendation, the Board will provide public notice of the application for coverage under the MSGP and the Department Director's recommendations. Upon request, the Department will schedule a hearing as provided in 40 CFR Part 25. If, after considering the evidence provided at the hearing and the entire record, the Board determines by a preponderance of the evidence that the proposed activity will violate the Grand Portage Water Quality Standards or any Applicable Federal Standards, the Board shall deny eligibility for coverage under the MSGP, unless there is a reasonable certainty that compliance can be achieved by the applicant's adherence to reasonable conditions. If the Board finds insufficient evidence to show that the proposed activity will violate the Grand Portage Water Quality Standards or any Applicable Federal Standards, it shall approve coverage under the MSGP.

9.5.2.2.8 Appeals. Appeals related to water quality certification decisions or permits will be heard by the Grand Portage Tribal Court.

9.5.2.2.9 Prohibition of Discharge. The applicant is prohibited from discharging into the Waters of the Reservation pursuant to the MSGP unless the Board has granted coverage under the MSGP, or until the applicant has adhered to conditions required by the Board's conditional grant of coverage.

9.5.2.2.10 Compliance. The Board retains full authority provided by the Water Resources Ordinance to ensure compliance with and enforce the provisions of the Water Resource Ordinance, the Grand Portage Water Quality Standards, Applicable Federal Standards, and these certification conditions.

9.5.2.2.11 Where to Submit Information. All required or requested information mentioned above shall be sent to:

Grand Portage Environmental Resources Board

P.O. Box 428

Grand Portage, MN 55605

9.5.3 WIR051000: Indian country within the State of Wisconsin, except those on Bad River Band of Lake Superior Tribe of Chippewa Indians lands and on Sokaogon Chippewa Community lands

No additional requirements. 
Note: Facilities in the Bad River Band of Lake Superior Tribe of Chippewa Indians land Sokaogon Chippewa Community lands and are not eligible for stormwater discharge coverage under this permit. Contact the EPA Region 5 office for an individual permit application.

9.6 EPA Region 6: Arkansas, Louisiana, Oklahoma, Texas, and New Mexico (except see Region 9 for Navajo lands, and see Region 8 for Ute Mountain Reservation lands).

9.6.1 LAR051000: Indian country within the State of Louisiana

No additional requirements.

9.6.2 NMR050000: The State of New Mexico, except Indian country

Permittees in New Mexico must also meet the following conditions:

9.6.2.1 Benchmark Monitoring Concentrations. The benchmark values for the indicated pollutants in the table below must be modified to reflect New Mexico water quality standards for the facilities in New Mexico, based on benchmark values from the Standards for Interstate and Intrastate Surface Waters (as approved on June. 5, 2013), 20.6.4.900 NMAC).

\begin{tabular}{|c|c|c|c|}
\hline Pollutant & $\begin{array}{c}\text { MSGP } \\
\text { Benchmark }\end{array}$ & $\begin{array}{c}\text { Lowest New Mexico } \\
\text { Water Quality Standard }\end{array}$ & $\begin{array}{l}\text { Hardness dependent } \\
\text { value (if appropriate) }\end{array}$ \\
\hline Ammonia* & $2.14 \mathrm{mg} / \mathrm{L}$ & No Standard & \\
\hline $\begin{array}{l}\text { Biochemical Oxygen Demand } \\
\text { (BOD } 5 \text { day) }\end{array}$ & $30 \mathrm{mg} / \mathrm{L}$ & No Standard & \\
\hline $\begin{array}{l}\text { Chemical Oxygen Demand } \\
\text { (COD) }\end{array}$ & $120 \mathrm{mg} / \mathrm{L}$ & No Standard & \\
\hline Total Suspended Solids & $100 \mathrm{mg} / \mathrm{L}$ & Segment specific & \\
\hline Turbidity & 50 NTU & Segment specific & \\
\hline Nitrate + Nitrite Nitrogen & $0.68 \mathrm{mg} / \mathrm{L}$ & $132 \mathrm{mg} / \mathrm{L}$ & \\
\hline Total Phosphorus & $2.0 \mathrm{mg} / \mathrm{L}$ & Segment specific & \\
\hline $\mathrm{pH}$ & $6.0-9.0 \mathrm{SU}$ & Segment specific & \\
\hline Aluminum $(\mathrm{T})(\mathrm{pH} 6.5-9)^{*}$ & $0.75 \mathrm{mg} / \mathrm{L}$ & -- & $\begin{array}{l}3.4 \mathrm{mg} / \mathrm{L} \text { (acute) } \\
1.37 \mathrm{mg} / \mathrm{L} \text { (chronic) }\end{array}$ \\
\hline Antimony $(\mathrm{T})$ & $0.64 \mathrm{mg} / \mathrm{L}$ & $0.006 \mathrm{mg} / \mathrm{L}$ & \\
\hline Arsenic $(\mathrm{T})(\text { Freshwater })^{*}$ & $0.15 \mathrm{mg} / \mathrm{L}$ & $0.01 \mathrm{mg} / \mathrm{L}$ & \\
\hline Beryllium $(T)$ & $0.13 \mathrm{mg} / \mathrm{L}$ & $0.004 \mathrm{mg} / \mathrm{L}$ & \\
\hline Cadmium (T) (Freshwater) $)^{\star}$ & $0.0021 \mathrm{mg} / \mathrm{L}$ & -- & $\begin{array}{l}0.00165 \mathrm{mg} / \mathrm{L} \text { (acute) } \\
0.00045 \mathrm{mg} / \mathrm{L} \text { (chronic) }\end{array}$ \\
\hline $\begin{array}{l}\text { Copper }(\mathrm{T}) \\
\text { (Freshwater) }^{*}\end{array}$ & $0.014 \mathrm{mg} / \mathrm{L}$ & -- & $\begin{array}{l}0.013 \mathrm{mg} / \mathrm{L} \text { (acute) } \\
0.009 \mathrm{mg} / \mathrm{L} \text { (chronic) }\end{array}$ \\
\hline Cyanide (Freshwater) ${ }^{\star}$ & $0.022 \mathrm{mg} / \mathrm{L}$ & $0.0052(\mathrm{WH})$ & \\
\hline Iron $(T)$ & $1.0 \mathrm{mg} / \mathrm{L}$ & No standard & \\
\hline Lead (Freshwater)* & $0.082 \mathrm{mg} / \mathrm{L}$ & & $\begin{array}{l}0.065 \mathrm{mg} / \mathrm{L} \text { (acute) } \\
0.003 \mathrm{mg} / \mathrm{L} \text { (chronic) }\end{array}$ \\
\hline Magnesium $(\mathrm{T})$ & $0.064 \mathrm{mg} / \mathrm{L}$ & No standard & \\
\hline Mercury (Freshwater) ${ }^{*}$ & $0.0014 \mathrm{mg} / \mathrm{L}$ & $0.00077 \mathrm{mg} / \mathrm{L}$ & \\
\hline Nickel $(T)\left(\right.$ Freshwater) ${ }^{*}$ & $0.47 \mathrm{mg} / \mathrm{L}$ & & $\begin{array}{l}0.47 \mathrm{mg} / \mathrm{L} \text { (acute) } \\
0.052 \mathrm{mg} / \mathrm{L} \text { (chronic) }\end{array}$ \\
\hline 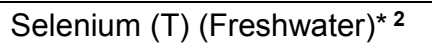 & $0.005 \mathrm{mg} / \mathrm{L}$ & $0.005 \mathrm{mg} / \mathrm{L}(\mathrm{WH})$ & \\
\hline
\end{tabular}




\begin{tabular}{|l|l|l|l|}
\hline \multicolumn{1}{|c|}{ Pollutant } & $\begin{array}{c}\text { MSGP } \\
\text { Benchmark }\end{array}$ & $\begin{array}{c}\text { Lowest New Mexico } \\
\text { Water Quality Standard }\end{array}$ & $\begin{array}{c}\text { Hardness dependent } \\
\text { value (if appropriate) }\end{array}$ \\
\hline Silver (Freshwater) & & & $0.0032 \mathrm{mg} / \mathrm{L}$ (acute) \\
\hline Zinc (T) (Freshwater) & $0.0038 \mathrm{mg} / \mathrm{L}$ & & $0.16 \mathrm{mg} / \mathrm{L}$ (acute) \\
& $0.12 \mathrm{mg} / \mathrm{L}$ & & $0.121 \mathrm{mg} / \mathrm{L}$ (chronic) \\
\hline
\end{tabular}

* EPA's Criteria are based on receiving water hardness of $100 \mathrm{mg} / \mathrm{L}$. The facility will need to test their receiving water these hardness values and use Table 1 in Appendix $\mathrm{J}$ of this permit to determine their applicable limit.

${ }^{1}$ New Mexico Environment Department's criteria are listed at a hardness value of $100 \mathrm{mg} / \mathrm{L}$ as $\mathrm{CaCO}_{3}$ for comparison to EPA's benchmark standard.

${ }^{2} \mathrm{SO}_{4}$ dependent

EPA defines saline/salt waters as having salinity concentrations greater than or equal to 10 parts per thousand 95 percent or more of the time (as discussed on Page 55 of the permit's proposed fact sheet). Saltwater values may apply to certain areas of New Mexico, such as the Pecos Basin below Santa Rosa and the Rio Grande below Elephant Butte. These values may also apply to waters that are part of the Colorado River Basin.

New Mexico water quality hardness-based values in the table below replace values listed in Appendix $\mathrm{J}$ and are the applicable benchmark values for $\mathrm{New}$ Mexico in this permit.

\begin{tabular}{|c|c|c|c|c|c|c|c|c|}
\hline \multirow{2}{*}{$\begin{array}{l}\text { All Units } \\
\text { mg/L }\end{array}$} & \multirow[b]{2}{*}{ * } & \multicolumn{7}{|c|}{ (mg/L, dissolved) } \\
\hline & & Aluminum & Cadmium & Copper & Lead & Nickel & Silver & Zinc \\
\hline \multirow[b]{2}{*}{25} & Acute & 0.512 & 0.00051 & 0.004 & 0.014 & 0.140 & 0.0003 & 0.045 \\
\hline & Chronic & 0.205 & 0.00017 & 0.003 & 0.001 & 0.016 & & 0.034 \\
\hline \multirow[b]{2}{*}{30} & Acute & 0.658 & 0.00059 & 0.004 & 0.017 & 0.170 & 0.0004 & 0.054 \\
\hline & Chronic & 0.263 & 0.00019 & 0.003 & 0.001 & 0.019 & & 0.041 \\
\hline \multirow[b]{2}{*}{40} & Acute & 0.975 & 0.00076 & 0.006 & 0.024 & 0.220 & 0.0007 & 0.070 \\
\hline & Chronic & 0.391 & 0.00023 & 0.004 & 0.001 & 0.024 & & 0.053 \\
\hline \multirow[b]{2}{*}{50} & Acute & 1.324 & 0.00091 & 0.007 & 0.03 & 0.260 & 0.0010 & 0.085 \\
\hline & Chronic & 0.530 & 0.00028 & 0.005 & 0.001 & 0.029 & & 0.065 \\
\hline \multirow[b]{2}{*}{60} & Acute & 1.699 & 0.00107 & 0.008 & 0.037 & 0.300 & 0.0013 & 0.101 \\
\hline & Chronic & 0.681 & 0.00031 & 0.006 & 0.001 & 0.034 & & 0.076 \\
\hline \multirow[b]{2}{*}{70} & Acute & 2.099 & 0.00122 & 0.010 & 0.044 & 0.350 & 0.0017 & 0.116 \\
\hline & Chronic & 0.841 & 0.00035 & 0.007 & 0.002 & 0.038 & & 0.088 \\
\hline \multirow[b]{2}{*}{80} & Acute & 2.520 & 0.00137 & 0.011 & 0.051 & 0.390 & 0.0022 & 0.131 \\
\hline & Chronic & 1.010 & 0.00039 & 0.007 & 0.002 & 0.043 & & 0.099 \\
\hline \multirow[b]{2}{*}{90} & Acute & 2.961 & 0.00151 & 0.012 & 0.058 & 0.430 & 0.0027 & 0.145 \\
\hline & Chronic & 1.186 & 0.00042 & 0.008 & 0.002 & 0.048 & & 0.110 \\
\hline \multirow[b]{2}{*}{100} & Acute & 3.421 & 0.00165 & 0.013 & 0.065 & 0.470 & 0.0032 & 0.160 \\
\hline & Chronic & 1.370 & 0.00045 & 0.009 & 0.003 & 0.052 & & 0.121 \\
\hline \multirow[b]{2}{*}{200} & Acute & 8.838 & 0.00298 & 0.026 & 0.14 & 0.840 & 0.011 & 0.301 \\
\hline & Chronic & 3.541 & 0.00075 & 0.016 & 0.005 & 0.09 & & 0.228 \\
\hline \multirow[b]{2}{*}{220} & Acute & 10.071 & & & & & & \\
\hline & Chronic & 4.035 & & & & & & \\
\hline \multirow[b]{2}{*}{300} & Acute & 10.071 & 0.00421 & 0.038 & 0.210 & 1.190 & 0.021 & 0.435 \\
\hline & Chronic & 4.035 & 0.00100 & 0.023 & 0.008 & 0.130 & & 0.329 \\
\hline \multirow[b]{2}{*}{$400+$} & Acute & 10.071 & 0.00538 & 0.050 & 0.280 & 1.510 & 0.035 & 0.564 \\
\hline & Chronic & 4.035 & 122 & 0.029 & 0.011 & 0.170 & & 428 \\
\hline
\end{tabular}


*Acute vs. Chronic applicability: Acute numeric standards shall be attained at the "point of discharge" (end-of-pipe) for any discharge to surface water with a designated aquatic life use. TSS values will be important for any criteria differences between total and dissolved measurements.

9.6.2.2 Notice of Termination. Requirements in Part 8 of the this permit, in sectors $G$ (Metal Mining), $\mathrm{H}$ (Coal Mines and Coal Mining-Related Facilities), I (Oil and Gas Extraction), and J (Non-Metallic Mineral Mining and Dressing), at the Requirements Applicable to Earth-Disturbing Activities Conducted Prior to Active Mining Activities" section were made more stringent as to inspection frequencies and timing of inspections and corrective actions required as a result of a rain event. These certification requirements will apply to these sectors mentioned in this condition, as follows:

Permittees can only use the option to "plant the area so that within 3 years the $70 \%$ cover requirement is met" as stated in Part 8.G.4.2.11, Part 8.H.4.2.11, and Part 8.J.4.2.11 of this Permit, in New Mexico as a method for final vegetative stabilization for purposes of filing a Notice of Termination (NOT) under the following conditions:

If this option is selected, you must notify New Mexico Environment Department (NMED) at the address listed below at the time the NOT is submitted to EPA. The information to be submitted includes:

- A copy of the NOT;

- Contact information, including individual name or title, address, and phone number for the party responsible for implementing the final stabilization measures; and

- The date that the permanent vegetative stabilization practice was implemented and the projected timeframe that the $70 \%$ native vegetative cover requirements are expected to be met. (Note that if more than three years is required to establish 70 percent of the natural vegetative cover, this technique cannot be used or cited for fulfillment of the final stabilization requirement- you remain responsible for establishment of final stabilization.)

NMED also requires that operators periodically (minimum once/year) inspect and properly maintain the area until the criteria for final stabilization, as specified in Part 2.2 of the Construction General Permit (CGP), have been met. Operators must prepare an inspection report documenting the findings of these inspections and signed in accordance with Appendix B.11. This inspection record must be retained along with the SWPPP for three years after the NOT is submitted for the site and additionally submitted to NMED at the address listed below. The inspections must at a minimum include the following:

- Observations of all areas of the site disturbed by construction activity;

- Best Management Practices (BMPs)/post-construction storm water controls must be observed to ensure they are effective;

- An assessment of the status of vegetative re-establishment; and

- Corrective actions required to ensure vegetative success within three years, and control of pollutants in storm water runoff from the site, including implementation dates.

9.6.2.3 Where to Submit Information. All required or requested information mentioned above shall be sent to: 
Program Manager

Point Source Regulation Section

NMED Surface Water Quality Bureau

PO Box 5469

Santa Fe, NM 87502

9.6.3 NMR051000: Indian country within the State of New Mexico, except Ute Mountain Reservation lands that are covered under Colorado permit COR05I000 and Navajo Reservation lands that are covered under Arizona permit AZR05I000

\subsubsection{Pueblo of Sandia}

The following conditions apply only to discharges on the Pueblo of Sandia:

9.6.3.1.1 Submission of NOI. Copies of all Notices of Intent (NOI) submitted to the EPA must also be sent concurrently to the Pueblo of Sandia Environment Department. Discharges are not authorized by this permit unless an accurate and complete NOI has been submitted to the Pueblo of Sandia.

9.6.3.1.2 SWPPP Availability. The Stormwater Pollution Prevention Plan (SWPPP) must be available to the Pueblo of Sandia Environment Department either electronically or hard copy upon request for review. Failure to provide a SWPPP to the Pueblo of Sandia Environment Department may result in denial of the water quality certification.

9.6.3.1.3 SWPPP Amendments. Any Stormwater Pollution Prevention Plan (SWPPP) modification, update or amendment shall be submitted to the Pueblo of Sandia Environment Department either electronically or hard copy within seven (7) calendar days of its finalization. Failure to provide a SWPPP to the Pueblo of Sandia Environment Department may result in denial of the water quality certification.

9.6.3.1.4 Submission of Monitoring Data. All monitoring and analytical data (e.g., Discharge Monitoring Reports (DMRs), follow-up monitoring reports, Exceedance Reports for Numeric Effluent Limits, etc.) submitted to the EPA must also be sent concurrently to the Pueblo of Sandia Environment Department.

9.6.3.1.5 Submission of Annual Reports. Copies of all Annual Reports submitted to the EPA must also be sent concurrently to the Pueblo of Sandia Environment Department. Discharges are not authorized by this permit unless an accurate and complete Annual Report has been submitted to the Pueblo of Sandia.

9.6.3.1.6 Submission of Quarterly Visual Assessments. Copies of all "Quarterly Visual Assessments" (Part 3.2) must be submitted either electronically or hard copy to the Pueblo of Sandia Environment Department within seven (7) calendar days.

9.6.3.1.7 Submission of Corrective Action Documentation. Copies of all "Corrective Action Documentation" (Part 4.4) must be submitted electronically or hard copy to the Pueblo of Sandia Environment Department within seven (7) calendar days.

9.6.3.1.8 Additional Reporting. Any notice of release of oils or hazardous substances shall be submitted to the Pueblo of Sandia Environment Department within twenty-four (24) hours of becoming aware of the situation or circumstance, followed by the reporting requirements of 40 CFR 110,40 CFR 300, and 40 CFR 302 relating to spills or other releases of oil or hazardous substances. The permittee must also telephone 
the Pueblo of Sandia Environment Department at (505) 867-4533 of any nonemergency spills or unauthorized discharges that may affect drinking water supplies, ceremonial and recreational surface waters, elicit fish kills, harm wildlife or endangered and threatened species, or endanger human health or the environment within eight (8) hours of becoming aware of the situation or circumstance, followed by the written report when it is sent to the EPA.

9.6.3.1.9 Authorization to Inspect. If requested by the Pueblo of Sandia Environment Department, the permittee must allow the Pueblo of Sandia to perform its own routine or compliance inspection to ensure the permittee is in compliance and any discharge is not contributing to a violation of the permit and the Pueblo of Sandia's Water Quality Standards.

9.6.3.1.10 Water Quality Standards. If requested by the Pueblo of Sandia Environment Department, the permittee shall provide additional information necessary for a "case by case" eligibility determination to assure compliance with the Pueblo of Sandia's Water Quality Standards. *Note: Upon receipt of a determination by the Pueblo of Sandia that discharges from a permittee under this general permit have reasonable potential to be causing or contributing to a violation of the Pueblo of Sandia's Water Quality Standards, EPA Region 6 would be notified. EPA Region 6 would then notify the permittee to either improve their Stormwater Pollution Prevention Plan (SWPPP) to achieve compliance with the Pueblo of Sandia's Water Quality Standards or have the permittee apply for and obtain an individual NPDES permit for these discharges per CFR 122.28(B)(3).

9.6.3.1.11 Alternative Permit. Any industry discharging to waters of the United States that has been designated by the EPA or the Pueblo of Sandia as impaired or degraded water shall not be covered under this general permit but will be required to obtain an individual permit.

9.6.3.1.12 Submission of NOT. Before submitting a Notice of Termination (NOT), permittees must clearly demonstrate to the Pueblo of Sandia Environment Department through a site visit or documentation that requirements for site stabilization have been met and any degradation has been mitigated. A short letter stating the stabilization requirements have been met will be sent to the permittee. Upon receipt the permittee may apply for an NOT to the EPA. Copies of the NOT submitted to the EPA must also be sent concurrently to the Pueblo of Sandia Environment Department.

9.6.3.1.13 Where to Submit Information. All required or requested information mentioned above shall be sent to:

- Regular U.S. Delivery Mail:

Pueblo of Sandia Environment Department

Attention: Scott Bulgrin, Water Quality Manager

481 Sandia Loop

Bernalillo, New Mexico 87004

- Or Electronically to: sbulgrin@sandiapueblo.nsn.us

\subsubsection{Pueblo of Santa Clara.}

The following condition applies only to discharges on the Santa Clara Indian Pueblo: 
9.6.3.2.1 Submission of NOI and NOT. The Notice of Intent (NOI) and Notice of Termination (NOT) must be provided to the Santa Clara Pueblo Governor's Office at the same time it is provided to EPA.

9.6.3.2.2 SWPPP Availability. A copy of the Stormwater Pollution Prevention Plan must be made available to the Pueblo of Santa Clara staff upon request.

9.6.3.2.3 Where to Submit Information. All required or requested documents shall be sent to the:

Santa Clara Pueblo

Governor's Office

P.O. Box 580

Espanola, NM 87532

9.6.4 OKR051000: Indian country within the State of Oklahoma

9.6.4.1 Certification Requirements. In accordance with Oklahoma's Water Quality Standards (OAC 785:45-5-25) certification is denied for any new or proposed discharges located within the watershed of any part of the Oklahoma Scenic Rivers system, including the Illinois River, Flint Creek, Barren Fork Creek, Upper Mountain Fork Creek, Little Lee Creek, Big Lee Creek or to any water designated as an Outstanding Resource Water (ORW). Existing discharges of stormwater in these watersheds may be permitted under this permit only from point sources existing as of June 25,1992 , whether or not such stormwater discharges were permitted as point sources prior to June 25,1992 . For any such existing discharge, increased load of any pollutant above levels of June 25, 1992 is prohibited.

Note: Operators of facilities within the watershed of any part of the Oklahoma Scenic Rivers system must contact the EPA Region 6 office for an individual permit application.

9.6.5 OKR05F000: Facilities in the State of Oklahoma not under the jurisdiction of the Oklahoma Department of Environmental Quality or the Oklahoma Department of Agriculture, Food and Forestry, except those on Indian Country. EPA jurisdiction facilities include SIC Codes 1311, 1381, 1382, 1389, and 5171

9.6.5.1 Certification Requirements. In accordance with Oklahoma's Water Quality Standards (OAC 785:45-5-25), Certification is denied for any new or proposed discharges located within the watershed or any part of the Oklahoma Scenic Rivers system, including the Illinois River, Flint Creek, Barren Fork Creek, Upper Mountain Fork River, Little Lee Creek, Big Lee Creek or to any water designated as an Outstanding Resource Water (ORW). Existing discharges of stormwater in these watersheds may be permitted under this permit only from point sources existing as of June 25, 1992, whether or not such stormwater discharges were permitted as point sources prior to June 25, 1992. For any such existing discharge, increased load of any pollutant above levels of June 25, 1992 is prohibited.

Note: Operators of facilities within the watershed of any part of the Oklahoma Scenic Rivers system must contact the EPA Region 6 office for an individual permit application.

9.6.6 TXR05F000: Facilities in the State of Texas not under the jurisdiction of the Texas Commission on Environmental Quality, except those on Indian Country. EPA- 
jurisdiction facilities include SIC Codes 1311, 1321, 1381, 1382, and 1389 (other than oil field service company "home base" facilities)

No additional requirements.

9.6.7 TXR051000: Indian country within the State of Texas

No additional requirements.

9.7 EPA Region 7: lowa, Kansas, Missouri, Nebraska (except see Region 8 for Pine Ridge Reservation Lands).

9.7.1 IAR051000: Indian country within the State of lowa

No additional requirements.

9.7.2 KSR051000: Indian country within the State of Kansas

No additional requirements.

9.7.3 NER051000: Indian country within the State of Nebraska, except Pine Ridge Reservation lands (see Region 8)

No additional requirements.

9.8 EPA Region 8: Colorado, Montana, North Dakota, South Dakota, Wyoming, Utah (except see Region 9 for Goshute Reservation and Navajo Reservation Lands), the Ute Mountain Reservation in NM, and the Pine Ridge Reservation in NE.

9.8.1 COR05F000: Areas in the State of Colorado, except those located on Indian country, subject to industrial activity by a Federal Operator

No additional requirements.

9.8.2 COR051000: Indian country within the State of Colorado, as well as the portion of the Ute Mountain Reservation located in New Mexico

No additional requirements

9.8.3 MTR051000: Indian country within the State of Montana

No additional requirements.

9.8.4 NDR051000: Indian country within the State of North Dakota, as well as that portion of the Standing Rock Reservation located in South Dakota (except for the portion of the lands within the former boundaries of the Lake Traverse Reservation which is covered under South Dakota permit SDR051000 listed below)

No additional requirements.

9.8.5 SDR051000: Indian country within the State of South Dakota, as well as the portion of the Pine Ridge Reservation located in Nebraska and the portion of the lands within the former boundaries of the Lake Traverse Reservation located in North Dakota (except for the Standing Rock Reservation which is covered under North Dakota permit NDR05I000 listed above)

No additional requirements.

9.8.6 UTR051000: Indian country within the State of Utah, except Goshute and Navajo Reservation lands (see Region 9)

No additional requirements. 
9.8.7 WYR051000: Indian country within the State of Wyoming

No additional requirements.

9.9 EPA Region 9: California, Hawaii, Nevada, Guam, American Samoa, the Commonwealth of the Northern Mariana Islands, the Confederated Tribes of the Goshute Reservation in Utah and Nevada, Indian Country within the State of Arizona including the Navajo Reservation in Utah and New Mexico and Arizona, the Duck Valley Reservation in Idaho, and the Fort McDermitt Reservation in Oregon.

9.9.1 ASR050000: American Samoa

No additional requirements.

9.9.2 AZR051000: Indian country within the State of Arizona, including Navajo Reservation lands in New Mexico and Utah

9.9.2.1 Hualapai Tribe

The following condition applies only to discharges on the Hualapai Tribe:

9.9.2.1.1 Submission of NOI and SWPPP. All Notices of Intent (NOI) for proposed stormwater discharges under this permit and all Stormwater Pollution Plans (SWPPPs) for stormwater discharges on Hualapai Tribal lands shall be submitted to the Water Resource Program through the Tribal Chairwoman for review and approval.

9.9.2.1.2 Where to Submit Information. All required or requested documents shall be sent to:

Water Resource Program through the Tribal Chairwoman

P.O. Box 179

Peach Springs, AZ 86434

\subsubsection{Navajo Nation}

The following conditions apply only to discharges on the Navajo Nation:

9.9.2.2.1 Submission of NOI and SWPPP. Courtesy copies of Notices of Intent (NOI) and Stormwater Water Pollution Plans (SWPPPs) shall be made available to Navajo EPA for facilities located on Navajo lands.

9.9.2.2.2 Submission of Monitoring Data. Copies of all monitoring reports must be provided to Navajo EPA for facilities located on Navajo lands.

9.9.2.2.3 Authorization to Inspect. Facilities located on Navajo lands and covered under this permit will be subject to compliance inspections by Navajo EPA staff with active Federal Inspector Credentials under authority of the Clean Water Act.

\subsubsection{White Mountain Apache Tribe}

The following condition applies only to discharges on the White Mountain Apache Tribe:

9.9.2.3.1 Submission of SWPPP. The Storm Water Pollution Prevention Plan (SWPPP) must be available to the White Mountain Apache Water Resources Programs either electronically or hard copy upon request for review before a Notice of Intent (NOI) for comments from the White Mountain Apache Water Resources Programs. Failure 
to provide a SWPPP to the White Mountain Apache Water Resources Programs may result in denial of the water quality certification.

9.9.2.3.2 Submission of NOI. Copies of all Notices of Intent (NOI)) submitted to the EPA must also be sent concurrently to the White Mountain Apache Water Resources Programs. Discharges are not authorized by this permit unless an accurate and complete $\mathrm{NOI}$ has been submitted to the White Mountain Apache Tribe.

9.9.2.3.3 SWPPP Modification. Any Storm Water Pollution Prevention Plan (SWPPP) modification, update or amendment shall be submitted to the White Mountain Apache Water Resources Programs either electronically or hard copy within seven (7) calendar days of its finalization. Failure to provide a SWPPP to the White Mountain Apache Water Resources Programs may result in denial of the water quality certification.

9.9.2.3.4 Submission of Monitoring Data. All monitoring and analytical data (e.g. Discharge Monitoring Reports (DMRs), follow-up monitoring reports, Exceedance Reports for Numerical Effluent Limits, etc.) submitted to EPA must also be sent concurrently to the White Mountain Apache Water Resources Programs.

9.9.2.3.5 Submission of Annual Reports. Copies of all Annual Reports submitted to the EPA must also be sent concurrently to the White Mountain Apache Water Resources Programs. Discharges are not authorized by this permit unless an accurate and complete Annual Report has been submitted to the White Mountain Apache Tribe.

9.9.2.3.6 Submission of Quarterly Visual Assessments. Copies of all "Quarterly Visual Assessments" (Part 3.2) must be submitted either electronically or hard copy to the White Mountain Apache Water Resources Programs within seven (7) calendar days.

9.9.2.3.7 Submission of Corrective Action Documentation. Copies of all "Corrective Action Documentation" (Part 4.4) must be submitted either electronically or hard copy to the White Mountain Apache Water Resources Programs within seven (7) calendar days.

9.9.2.3.8 Additional Reporting. Any notice of release of oils or hazardous substances shall be submitted to the White Mountain Apache Water Resources Programs within twentyfour (24) hours of becoming aware of the situation or circumstance, followed by the reporting requirements of 40 CFR 110, 40 CFR 300, and 40 CFR 302 relating to spills or other releases of oils or hazardous substances. The permittee must also telephone the White Mountain Apache Water Resources Programs at (928) 3384267 of any non-emergency spills or unauthorized discharge that may affect drinking water, supplies, ceremonial and recreational surface waters, elicit fish kills, harm wildlife or endangered and threaten species, or endanger human health or the environment within eight (8) hours of becoming aware of the situation or circumstance, followed by a written report when it is sent to the EPA.

9.9.2.3.9 Authorization to Inspect. If requested by the White Mountain Apache Water Resources Programs, the permittee must allow the White Mountain Apache Tribe to perform its own routine or compliance inspection to ensure the permittee is in compliance and any discharge is not contributing to a violation of the permit and the White Mountain Apache Tribe's Water Quality Standards. 
9.9.2.3.10 Water Quality Standards. If requested by the White Mountain Apache Water Resources Programs, the permittee shall provide additional information necessary for a "case by case" eligibility determination to assure compliance with the White Mountain Apache Tribe's Water Quality Standards. *Note: Upon receipt of a determination by the White Mountain Apache Tribe that discharges from a permittee under this general permit have reasonable potential to be causing or contributing to a violation of the White Mountain Apache Tribe's Water Quality Standards, EPA Region 9 would be notified. EPA Region 9 would then notify the permittee to either improve their Stormwater Pollution Prevention Plan (SWPPP) to achieve compliance with the White Mountain Apache Tribe's Water Quality Standards or have the permittee apply for and obtain an individual NPDES permit for those discharges per CFR 122.28 (B) (3).

9.9.2.3.11 Alternative Permit. Any industry discharging into waters of the United States that has been designated by the EPA or the White Mountain Apache Tribe as impaired or degraded water shall not be covered under this general permit but will be required to obtain an individual permit.

9.9.2.3.12 Submission of NOT. Before submitting a Notice of Termination (NOT), permittees must clearly demonstrate to the White Mountain Apache Water Resources Programs through a site visit or documentation that requirements for site stabilization have been met and any degradation has been mitigated. A short letter stating the stabilization requirements have been met will be sent to the permittee. Upon receipt the permittee may apply for an NOT to the EPA. Copies of the NOT submitted to the EPA must also be sent concurrently to the White Mountain Apache Water Resources Programs.

9.9.2.3.13 Where to Submit Information. All required or requested information mentioned above shall be sent to:

- Regular U.S. Delivery Mail:

White Mountain Apache Tribe Water Resources Programs

Attention: Tara Chief, Water Quality Officer

P.O. Box 816

Fort Apache, AZ 85926

- Or Electronically to: tarachief@wmat.us

9.9.3 CAR051000: Indian country within the State of California

\subsubsection{Hoopa Valley Tribe}

The following conditions apply only to discharges on the Hoopa Valley Tribe:

9.9.3.1.1 Submission of NOI. All Notices of Intent (NOI) submitted for stormwater discharges under the general permits in Hoopa Valley Indian Reservation (HVIR) shall be submitted to the Tribal Environmental Protection Agency (TEPA).

9.9.3.1.2 Submission of SWPPP. All Stormwater Pollution Plans (SWPPPs) for stormwater discharge in HVIR shall be submitted to TEPA for review and approval.

9.9.3.2 Twenty-Nine Palms Band of Mission Indians

The following conditions apply only to discharges on the Twenty-Nine Palms Band of Mission Indians: 
9.9.3.2.1 Submission of Monitoring Data. The Twenty-Nine Palms Tribal Water Quality Standards require that routine monitoring be performed quarterly at each sampling site. Additional special monitoring requirements include: a) Sampling following a significant storm event; and b) Sampling in the event of an accidental spill. Monitoring results for discharges into Twenty-Nine Palms Tribal waters must be reported to Twenty-Nine Palms Tribal EPA.

9.9.3.2.2 Certification. Certification does not relieve the applicant of the responsibility to comply with applicable local, state, or federal regulations or statutes, including regulations affecting any discharge into waters of the U.S. Copies of this certification shall be kept on the job site and readily available for reference by tribal members and tribal representatives. If the project is operated in a manner not consistent with the MSGPs, the permittee will be in violation of this certification.

9.9.3.2.3 Pollution Prevention. All practicable measures and precautions must be taken to prevent pollution affecting public health, fish, shellfish, wildlife, and recreation due to turbidity, $\mathrm{pH}$, temperature, nutrients, suspended solids, floating debris, visible oil and grease, or other pollutants entering tribal waters, including wetlands.

9.9.3.2.4 Spills or Leaks. All equipment operated within any tribal waters must be cleaned away from the tribal waters and maintained to prevent fuel and oil leaks. These methods include, but are not limited to: offsite/ upland fuel and oil storage and refueling areas, on-site spill containment equipment, a spill contingency plan, and spill prevention/contaminant training for on-site personnel. Should a spill of petroleum products or chemicals occur, immediately call the National Response Center at (800) 424-8802 and the Tribal Environmental Protection Agency at (760) 398-6767.

9.9.3.2.5 Ground Disturbance. Ground disturbance shall not exceed the minimum necessary.

9.9.3.2.6 Minimizing Adverse Impacts. All projects using the MSGP must avoid discharges to the maximum extent practicable, and utilize the best available and practicable means of minimizing the adverse impact of discharges that cannot be avoided.

9.9.4 GUR050000: Island of Guam

No additional requirements.

9.9.5 JAR050000: Johnston Atoll

No additional requirements.

9.9.6 MWR050000: Midway Island and Wake Island

No additional requirements.

9.9.7 MPR050000: Commonwealth of the Northern Mariana Islands

No additional requirements.

9.9.8 NVR051000: Indian country within the State of Nevada, including the Duck Valley Reservation in Idaho, the Fort McDermitt Reservation in Oregon and the Confederated Tribes of the Goshute Reservation in Utah

No additional requirements. 
9.10 Region 10: Alaska, Idaho (except see Region 9 for Duck Valley Reservation lands), Oregon (except see Region 9 for Fort McDermitt Reservation), Washington.

9.10.1 AKR05F000: Areas in the Denali National Park and Preserve subject to industrial activity by a Federal Operator

No additional requirements.

9.10.2 AKR051000: Indian country lands within the State of Alaska

No additional requirements.

9.10.3 IDR050000: The State of Idaho, except Indian country lands

Permit coverage not available until Clean Water Act (CWA) 401 certification is received.

9.10.4 IDR051000: Indian country lands within the State of Idaho, except Duck Valley Reservation lands, which are covered under Nevada permit NVR051000

9.10.4.1 Shoshone-Bannock Tribes

The following conditions apply only to discharges to waters of the ShoshoneBannock Tribes:

9.10.4.1.1 Submission of NOI, Monitoring Data, and Reports. Copies of the Notices of Intent (NOI), Monitoring data collected pursuant to section 6.2 of this permit, and Exceedance Reports must be sent to the Shoshone-Bannock Tribes Water Resources Department (SBT-WRD). The monitoring data and exceedance reports must be sent to the SBT-WRD within thirty (30) days of receipt of analytical results.

9.10.4.1.2 Submission of SWPPP. If requested by the SBT-WRD, the permittee must submit a copy of the SWPPP to SBT-WRD within fourteen (14) days of the request.

9.10.4.1.3 Where to Submit Information. All required or requested documents shall be sent to:

Shoshone-Bannock Tribes Water Resources Department

P.O. Box 306 Pima Drive

Fort Hall, ID 83203

Phone: (208) 239-4582

Fax: (208) 239-4592

9.10.5 ORR051000: Indian country lands within the State of Oregon, except Fort McDermitt Reservation lands, which are covered under Nevada permit NVR051000

9.10.5.1 Confederated Tribes of the Umatilla Indian Reservation

Projects located within the exterior boundaries of the Umatilla Indian Reservation must meet the following conditions:

9.10.5.1.1 Water Quality Standards. The operator shall be responsible for achieving compliance with Confederated Tribes of the Umatilla Indian Reservation's (CTUIR) Water Quality Standards.

9.10.5.1.2 Submission of NOI. The operator shall submit a copy of the Notice of Intent (NOI to be covered by this permit to the CTUIR Water Resources Program at the address below, at the same time it is submitted to EPA. 
9.10.5.1.3 Submission of SWPPP. The operator shall be responsible for submitting all Stormwater Pollution Prevention Plans (SWPPPs) required under this general permit to the CTUIR Water Resources Program for review and determination that the SWPPP is sufficient to meet Tribal Water Quality Standards, prior to the beginning of any discharge activities taking place.

9.10.5.1.4 Additional Reporting. The operator shall be responsible for reporting an exceedance to Tribal Water Quality Standards to the CTUIR Water Resources Program at the same time it is reported to EPA.

9.10.5.1.5 Additional Requirements for Historic Properties Preservation. The applicant shall submit copies of each NOI to the CTUIR Tribal Historic Preservation Office (THPO). The NOI shall define the undertaking's area of potential effect (APE). This information will be used to determine whether or not the undertaking has the potential to affect historic properties. To be in compliance with the NHPA and be eligible for coverage under this permit, the operator must meet the following criteria:

- The THPO will be provided 30 days to comment on the APE as defined in the permit application.

- If the project is an undertaking, a cultural resource investigation must occur. All fieldwork must be conducted by qualified personnel (as outlined by the Secretary of Interior's Standards and Guidelines) and documented using Oregon Reporting Standards. The resulting report must be submitted to the THPO and the THPO must concur with the findings and recommendations before any ground disturbing work can occur. The THPO requires 30 days to review all reports.

- The operator must obtain THPO concurrence in writing. If historic properties are present, this written concurrence will outline measures to be taken to prevent or mitigate effects to historic properties.

9.10.5.1.6 Where to Submit Information. The NOI, SWPPP, and reports must be sent to:

Confederated Tribes of the Umatilla Indian Reservation

Water Resources Program

46411 Timine Way

Pendleton, OR 97801

(541) 966-2420

All required Historic Properties Preservation information must be sent to:

Confederated Tribes of the Umatilla Indian Reservation

Cultural Resources Protection Program

Tribal Historic Preservation Office

46411 Timine Way

Pendleton, OR 97801

(541) 429-7234

\subsubsection{Confederated Tribes of the Warm Springs Indian Reservation}

The following conditions apply for projects within the exterior boundaries of the Warm Springs Indian Reservation: 
9.10.5.2.1 Water Quality Standards. The operator shall be responsible for achieving compliance with the Confederated Tribes of the Warm Springs Indian Reservation's Water Quality Standards. (Tribal Ordinance 80).

9.10.5.2.2 Submission of NOI. The operator shall submit a copy of the Notice of Intent (NOI) to be covered by this permit to the Tribes' Environmental Office at the address below, at the same time it is submitted to EPA.

9.10.5.2.3 Submission of SWPPP. The operator shall be responsible for filing all Stormwater Pollution Prevention Plans (SWPPP) required under this permit to the Tribes' Environmental Office for review and determination that the SWPPP is sufficient to meet Tribal Water Quality Standards, prior to the beginning of any discharge activities taking place.

9.10.5.2.4 Additional Reporting. The operator shall be responsible for reporting an exceedance to Tribal Water Quality Standards to the Tribes' Environmental Office at the same time it is reported to EPA.

9.10.5.2.5 Tribal Cultural Resources. The applicant shall submit copies of each NOI to the Tribal Historic Preservation Office (THPO). The NOI shall define the undertaking's area of potential effect (APE). This information will be used to determine whether or not the undertaking has the potential to affect historic properties. To be in compliance with the NHPA and be eligible for coverage under this permit, the operator must meet the following criteria:

- The THPO will be provided 30 days to comment on the APE as defined in the permit application.

- If the project is an undertaking, a cultural resource investigation must occur. All fieldwork must be conducted by qualified personnel (as outlined by the Secretary of Interior's Standards and Guidelines). The resulting report must be submitted to the THPO and the THPO must concur with the findings and recommendations before any ground disturbing work can occur. The THPO requires 30 days to review all reports.

- The operator must obtain THPO concurrence in writing. If historic properties are present, this written concurrence will outline measures to be taken to prevent or resolve effects to historic properties.

9.10.5.2.6 Where to Submit Information. All required or requested documents shall be sent to:

Confederated Tribes of Warm Springs

Branch of Natural Resources

Tribal Environmental Office

P.O. Box C

Warm Springs

Oregon, 97761

541-553-2002

9.10.6 WAR051000: Indian country lands within the State of Washington

9.10.6.1 Confederated Tribes of the Colville Reservation

No Additional Requirements.

\subsubsection{Lummi Nation}

The following conditions apply only to discharges within the Lummi Nation: 
9.10.6.2.1 Certification. This certification does not exempt and is provisional upon compliance with other applicable statutes and codes administered by federal and Lummi tribal agencies. Pursuant to Lummi Code of Laws (LCL) 17.05.020(a), the operator must also obtain a land use permit from the Lummi Planning Department as provided in Title 15 of the Lummi Code of Laws and regulations adopted thereunder.

9.10.6.2.2 Submission of SWPPP. Pursuant to LCL 17.05.020, each operator shall develop and submit a Storm Water Pollution Prevention Plan to the Lummi Water Resources Division for review and approval by the Water Resources Manager prior to beginning any discharge activities.

9.10.6.2.3 Water Quality Standards. Pursuant to LCL Title 17, each operator shall be responsible for achieving compliance with the Water Quality Standards for Surface Waters of the Lummi Indian Reservation (Lummi Administrative Regulations [LAR] 17 LAR 07.010 through 17 LAR 07.210).

9.10.6.2.4 Submission of NOI, Monitoring Data, Reports and NOT. Each operator shall submit a copy of the Notice of Intent (NOI), analytical monitoring results, any Exceedance Reports, Annual Reports, and Notice of Termination (NOT) to the Lummi Water Resources Division at the same time it is submitted to the Environmental Protection Agency (EPA).

9.10.6.2.5 Where to Submit Information. All required or requested documents shall be sent to:

Lummi Natural Resources Department

ATTN: Water Resources Manager

2665 Kwina Road

Bellingham, WA 98226

Please see the Lummi Nation website (www.lummi-nsn.gov) to review a copy of Title 17 of the Lummi Code of Laws and the references upon which the conditions identified above are based.

\subsubsection{Puyallup Tribe of Indians}

The following conditions apply only to discharges to waters of the Puyallup Tribe of Indians:

9.10.6.3.1 Submission of NOI, NOT and No Exposure. Copies of the Notice of Intent (NOI), Notice of Termination (NOT), and No Exposure Certification shall be submitted to the Tribe's Natural Resources Department.

9.10.6.3.2 Submission of SWPPP. A copy of the Stormwater Pollution Plan (SWPPP) shall be submitted to the Tribe's Natural Resources Department at least thirty (30) days in advance of submitting the NOI to EPA.

9.10.6.3.3 Compliance with Tribe's Water Quality Standards. Each permittee shall be responsible for achieving compliance with the Tribe's Water Quality Standards, including anti-degradation provisions.

9.10.6.3.4 Submission and Approval of Sampling Plan. A sampling plan shall be submitted to the Tribe's Natural Resources Department and approved by the Tribe prior to initiation of monitoring required under Part 6 of this permit. 
9.10.6.3.5 Submission of Monitoring Data and Reports. The results of any monitoring required by this permit and reports must be sent to the Tribe's Natural Resources Department, including a description of the corrective actions required and undertaken to meet effluent limits or benchmarks (as applicable).

9.10.6.3.6 Authorization to Inspect. The Natural Resources Department may conduct an inspection of any facility covered by this permit to ensure compliance with tribal water quality standards. The Department may enforce its certification conditions.

9.10.6.3.7 Tribal Endangered Species Act Consultation. Consultation with the Tribe that addresses the effects of your facility's stormwater discharges, allowable nonstormwater discharges, and stormwater discharge-related activities on federallylisted threatened or endangered species and designated critical habitat. Information required as part of the consultation shall include:

- Basis of the determination that your stormwater discharges, allowable nonstormwater discharges, and stormwater discharge-related activities will not adversely affect federally-listed as endangered or threatened ("listed") under the Endangered Species Act (ESA) and will not result in the adverse modification or destruction of designated critical habitat including appropriate measures to be undertaken to avoid or eliminate the likelihood of adverse effects (under Criterion $C$ in Section 1.1.4.5); and

- Notice of Intent form complete with extent of action area, list of federally-listed threatened or endangered species or designated critical habitat likely to occur in action area, list of potential pollutants (if you are a new discharger) or list of pollutants for which you have ever exceeded an applicable benchmark of effluent limitation guideline, or for which your discharge has ever been found to cause or contribute to an exceedance of an applicable water quality standard (if you are an existing discharger).

9.10.6.3.8 Discharges to CERCLA Sites. This permit does not authorize direct stormwater discharges to certain sites undergoing remedial cleanup actions pursuant to the Comprehensive Environmental Response, Compensation and Liability Act (CERCLA) unless first approved by the appropriate EPA Regional office. In the case of the Commencement Bay, Near Shore/Tide Flats (WAD980726368), the Puyallup Tribe also requests notification by the facility and consultation with EPA prior to discharge. Contaminants at this site include but are not limited to: dioxins, furans, arsenic, copper, lead, zinc, 4-methly-phenol, Hex-CB, HPAHs, PCBs, PCE, cadmium, mercury, and LPAHs.

9.10.6.3.9 Discharge-related Activities that have Potential to Cause an Adverse Effect on Historic Properties. Installation of stormwater controls that involve subsurface disturbances may potentially have an adverse impact on historic properties. Procedures detailed in Appendix F of the permit shall be completed. Brandon Reynon, the Puyallup Tribe's Cultural Regulatory Specialist, shall be contacted prior to initiating discharge-related activities that may have an impact on historic properties. His contact information is (253) 573-7986 and Brandon.reynon@puyalluptribe.com

9.10.6.3.10 Where to Submit Information. All required or requested documents shall be sent to the: 
Puyallup Tribe of Indians

Department of Natural Resources c/o Bill Sullivan and Char Naylor

3009 E. Portland Avenue

Tacoma, Washington 98404

\subsubsection{Spokane Tribe of Indians}

Permit coverage not available until Clean Water Act (CWA) 401 certification is received.

\subsubsection{Swinomish Indian Tribal Community}

The following conditions apply only to discharges to waters of the Swinomish Indian Tribal Community:

9.10.6.5.1 Certification. This certification does not exempt and is provisional upon compliance with other applicable statutes and codes administered by federal and Swinomish Indian Tribal Community (SITC) agencies. Operator must obtain any applicable SITC permits.

9.10.6.5.2 Submission of SWPPP. Each operator shall develop a Storm Water Pollution Prevention Plan (SWPPP) and submit it to the Swinomish Department of Environmental Protection (SDEP) for review and approval by the Director prior to beginning any discharge activities under the permit.

9.10.6.5.3 Water Quality Standards. Each operator shall be responsible for achieving compliance with applicable Water Quality Standards for Surface Waters of the Swinomish Indian Reservation.

9.10.6.5.4 Submission of NOI, Monitoring Data, Reports and NOT. Each operator shall submit a copy of the Notice of Intent (NOI), analytical monitoring results and Exceedance Reports if any, Annual Reports, and Notice of Termination (NOT) to the Swinomish DEP at the same time it is submitted to EPA.

9.10.6.5.5 Alternative Permit. The permit does not allow discharge of any pollutant on EPA's Persistent Bioaccumulative and Toxic pollutant list. Operator must eliminate such discharge or apply for an Individual permit.

9.10.6.5.6 Historic Properties Preservation. If any archeological/cultural resources or human remains are uncovered during the course of operations, all work will cease and operator must contact the Swinomish Tribal Historic Preservation Officer at 466-7352 or (cell) 840-4127.

9.10.6.5.7 Where to Submit Information. All submittals and correspondence required by this certification including but not limited to Storm Water Pollution Prevention Plans (SWPPP), monitoring results, reports of exceedances, and other notices are to be directed to the Environmental Director, Swinomish Department of Environmental Protection, 11430 Moorage Way, LaConner, WA 98257, phone (360) 466-7201, fax (360) 466-1615, and shall reference 401 Certification \# 2014-01 and NPDES MSGP WAR-5I000.

\subsubsection{Tulalip Tribes}

The following conditions apply only to discharges on waters of the Tulalip Tribes: 
9.10.6.6.1 Submission of NOI, NOT, and No Exposure. Copies of the Notice of Intent (NOI), Notice of Termination (NOT), and No Exposure Certification shall be submitted to the Tribe's Natural Resources Department.

9.10.6.6.2 Submission of SWPPP. A copy of the Stormwater Pollution Prevention Plan (SWPPP) shall be submitted to the Tribe's Natural Resources Department at least thirty (30) days in advance of submitting the NOI to EPA.

9.10.6.6.3 Compliance with Tribe's Water Quality Standards. Each permittee shall be responsible for achieving compliance with the Tribe's Water Quality Standards.

9.10.6.6.4 Submission and approval of Sampling Plans. A sampling plan shall be submitted to the Tribe's Natural Resources Department and approved by the Tribe prior to initiation of monitoring required under Part 6 of this permit.

9.10.6.6.5 Submission of Monitoring Data and Reports. The results of any monitoring required by this permit and reports must be sent to the Tribe's Natural Resources Department, including a description of the corrective actions required and undertaken to meet effluent limits or benchmarks (as applicable).

9.10.6.6.6 Authorization to Inspect. The Natural Resources Department may conduct an inspection of any facility covered by this permit to ensure compliance with tribal water quality standards. The Department may enforce its certification conditions.

9.10.6.6.7 Incorporation by reference. This certification does not exempt the applicant from compliance with other statues and codes administered by the tribes, county, state and federal agencies.

9.10.6.6.8 Invalidation. This certification will cease to be valid if the project is constructed and/or operated in a manner not consistent with the project description contained in the permit. This certification will also cease to be valid and the applicant must reapply with an updated application if information contained in the permit is voided by subsequent submittals.

9.10.6.6.9 Modification. Nothing in this certification waives the Tulalip Tribes of Washington's authority to issue modifications to this certification if additional impacts due to operational changes are identified, or if additional conditions are necessary to protect water quality or further protect the Tribal Communities interest.

9.10.6.6.10 Permits on-site. A copy of the permit shall be kept on the job site and readily available for reference by the construction supervisor, construction managers and foreman, and Tribal inspectors.

9.10.6.6.11 Project Management. The applicant shall ensure that project managers, construction managers and foreman, and other responsible parties have read and understand conditions of the permit, this certification, and other relevant documents, to avoid violations or noncompliance with this certification.

9.10.6.6.12 Emergencies/Contingency Measures. In the event the operator is unable to comply with the permit terms and conditions due to any cause, the contractor shall immediately take action to stop the violation and correct the problem, and immediately report spill events to EPA's 24-hour Spill Response Team at (206) 5531263 and the Tulalip Tribes Police Department (425) 508-1565. Compliance with this 
condition does not relieve the applicant from responsibility to maintain continuous compliance with the terms and conditions of this certification or the resulting liability from failure to comply.

9.10.6.6.13 Tribal Endangered Species Act Consultation. Consultation with the Tribes that addresses the effects of a facility's stormwater discharges, allowable nonstormwater discharges, and stormwater discharge-related activities on federallylisted threatened or endangered species and designated critical habitat. Information required as part of the consultation shall include:

- Basis of the determination that your stormwater discharges, allowable nonstormwater discharges, and stormwater discharge-related activities will not adversely affect federally-listed as endangered or threatened ("listed") under the Endangered Species Act (ESA) and will not result in the adverse modification or destruction of designated critical habitat including appropriate measures to be undertaken to avoid or eliminate the likelihood of adverse effects (under Criterion $C$ in Section 1.1.4.5); and

- Notice of Intent form complete with extent of action area, list of federally-listed threatened or endangered species or designated critical habitat likely to occur in action area, list of potential pollutants (if you are a new discharger) or list of pollutants for which you have ever exceeded an applicable benchmark or effluent limitations guideline, or for which your discharge has ever been found to cause or contribute to an exceedance of an applicable water quality standard (if you are an existing discharger).

9.10.6.6.14 Discharges to CERCLA Sites. This permit does not authorize direct stormwater discharges to certain sites undergoing remedial cleanup actions pursuant to the Comprehensive Environmental Response, Compensation and Liability Act (CERCLA) unless first approved by the appropriate EPA Regional office. In the case of the Tulalip Landfill site (WAD980639256), the Tulalip Tribes also requests notification by the facility and consultation with EPA prior to discharge. Contaminants at this site may include but are not limited to: dioxins, furans, arsenic, copper, lead, zinc, 4-methyl-phenol, Hex-CB, HPAHs, PCBs, PCE, cadmium, mercury, and LPAHs.

\subsection{Discharge-related Activities that have Potential to Cause an Adverse Effect on} Historic Properties. Installation of stormwater controls that involve subsurface disturbances may potentially have an adverse impact on historic properties. Procedures detailed in Appendix $\mathrm{F}$ of the permit shall be completed. Richard Young, of the Tulalip Tribe's Cultural Resources Department shall be contacted prior to initiating discharge-related activities that may have an impact on historic properties. His contact information is (360) 716-2652 and ryoung@tulaliptribesnsn.gov.

9.10.6.6.16 Where to Submit Information: All required or requested documents shall be sent to the:

Tulalip Tribes Natural Resources Environmental Division c/o Kurt Nelson and Valerie Streeter 6704 Marine Drive, Tulalip, Washington 98271 
9.10.7 WAR05F000: Areas in the State of Washington, except those located on Indian Country lands, subject to industrial activity by a Federal Operator

Permit coverage not available until Clean Water Act (CWA) 401 certification is received. 


\section{Appendix A - Definitions, Abbreviations, and Acronyms (for the purposes of this permit).}

\section{A.1. DEFINITIONS}

Action Area - all areas to be affected directly or indirectly by the federal action and not merely the immediate area involved in the action. See 50 CFR 402. For the purposes of this permit and for application of Endangered Species Act requirements, the following areas are included in the definition of action area:

- The areas where stormwater discharges originate and flow from the industrial facility to the point of discharge into receiving waters. (Example: Where stormwater flows into a ditch, swale, or gully that leads to receiving waters and where listed species (such as listed amphibians) are found in the ditch, swale, or gully.)

- The areas where stormwater from industrial activities discharge into receiving waters and the areas in the immediate vicinity of the point of discharge. (Example: Where stormwater from industrial activities discharges into a stream segment that is known to harbor listed aquatic species.)

- The areas where stormwater controls will be constructed and operated, including any areas where stormwater flows to and from the stormwater controls. (Example: Where a stormwater retention pond would be built.)

- The areas upstream and/or downstream from the stormwater discharge into a stream segment that may be affected by these discharges. (Example: Where sediment discharged to a receiving stream settles downstream and impacts a breeding area of a listed aquatic species.)

Antidegradation Policy or Antidegradation Requirements - the water quality standards regulation that requires States and Tribes to establish a three-tiered antidegradation program:

1. Tier 1 maintains and protects existing uses and water quality conditions necessary to support such uses. An existing use can be established by demonstrating that fishing, swimming, or other uses have actually occurred since November 28, 1975, or that the water quality is suitable to allow such uses to occur. Where an existing use is established, it must be protected even if it is not listed in the water quality standards as a designated use. Tier 1 requirements are applicable to all surface waters.

2. Tier 2 maintains and protects "high quality" waters -- water bodies where existing conditions are better than necessary to support CWA § 101 (a) (2) "fishable/swimmable" uses. Water quality can be lowered in such waters. However, state and tribal Tier 2 programs identify procedures that must be followed and questions that must be answered before a reduction in water quality can be allowed. In no case may water quality be lowered to a level which would interfere with existing or designated uses.

3. Tier 3 maintains and protects water quality in outstanding national resource waters (ONRWs). Except for certain temporary changes, water quality cannot be lowered in such waters. ONRWs generally include the highest quality waters of the United States. However, the ONRW classification also offers special protection for waters of exceptional ecological significance, i.e., those which are important, unique, or sensitive ecologically. Decisions regarding which water bodies qualify to be ONRWs are made by States and authorized Indian Tribes. 
Arid Areas - areas where annual rainfall averages from 0 to 10 inches.

Bypass - the intentional diversion of waste streams from any portion of a treatment facility. See 40 CFR $122.41(\mathrm{~m})(1)(\mathrm{i})$.

CERCLA Site (i.e., Superfund Site) - for the purposes of this permit, a site as defined in Section 101 (9) of the Comprehensive Environmental Response, Compensation and Liability Act (CERCLA), 42 U.S.C. $§ 9601$ (9), that is undergoing a remedial investigation and feasibility study, or for which a Record of Decision for remedial action has been issued in accordance with the National Contingency Plan, 40 CFR Part 300.

Co-located Industrial Activities - any industrial activities, excluding your primary industrial activity(ies), located on-site that are defined by the stormwater regulations at 122.26(b)(14)(i)(ix) and (xi). An activity at a facility is not considered co-located if the activity, when considered separately, does not meet the description of a category of industrial activity covered by the stormwater regulations or identified by the SIC code list in Appendix D.

Confidential Business Information (CBI) - see 40 CFR Part 2 for relevant definitions of CBI: http://www.gpo.gov/fdsys/pkg/CFR-2013-title40-vol1/pdf/CFR-2013-title40-vol1-part2subpartB.pdf.

Control Measures - refers to any stormwater control or other method (including narrative effluent limitations) used to prevent or reduce the discharge of pollutants to waters of the United States.

Corrective Action - for the purposes of the permit, any action taken, or required to be taken, to (1) repair, modify, or replace any stormwater control used at the site; (2) clean up and dispose of spills, releases, or other deposits found on the site; and (3) remedy a permit violation.

Critical Habitat - as defined in the Endangered Species Act at 16 U.S.C. 1531 for a threatened or endangered species, (i) the specific areas within the geographical area occupied by the species, at the time it is listed in accordance with the provisions of section 4 of the Endangered Species Act, on which are found those physical or biological features essential to the conservation of the species and which may require special management considerations or protection; and (ii) specific areas outside the geographical area occupied by the species at the time it is listed in accordance with the provisions of section 4 of the Endangered Species Act, upon a determination by the Secretary that such areas are essential for the conservation of the species.

Director - a Regional Administrator of the Environmental Protection Agency or an authorized representative. See 40 CFR 122.2.

Discharge - when used without qualification, means the "discharge of a pollutant." See 40 CFR 122.2.

Discharge of a Pollutant - any addition of any "pollutant" or combination of pollutants to "waters of the United States" from any "point source," or any addition of any pollutant or combination of pollutants to the waters of the "contiguous zone" or the ocean from any point source other than a vessel or other floating craft which is being used as a means of transportation. This includes additions of pollutants into waters of the United States from: surface runoff which is collected or channeled by man; discharges through pipes, sewers, or other conveyances, leading into privately owned treatment works. See 40 CFR 122.2. 
Discharge Point - for the purposes of this permit, the location where collected and concentrated stormwater flows are discharged from the facility such that the first receiving waterbody into which the discharge flows, either directly or through a separate storm sewer system, is a water of the U.S.

Discharge-Related Activity - activities that cause, contribute to, or result in stormwater and allowable non-stormwater point source discharges, and measures such as the siting, construction and operation of stormwater controls to control, reduce, or prevent pollution in the discharges.

Discharge to an Impaired Water - for the purposes of this permit, a discharge to an impaired water occurs if the first water of the U.S. to which you discharge is identified by a state, tribe, or EPA as not meeting an applicable water quality standard, and requires development of a total maximum daily load (TMDL) (pursuant to Section 303(d) of the Clean Water Act), or is addressed by an EPA-approved or established TMDL, or is not in either of the above categories but the waterbody is covered by pollution control requirements that meet the requirements of $40 \mathrm{CFR}$ 130.7 (b) (1). For discharges that enter a separate storm sewer system prior to discharge, the water of the U.S. to which you discharge is the waterbody that receives the stormwater discharge from the storm sewer system.

Drought-Stricken Area - for the purposes of this permit, an area in which the National Oceanic and Atomospheric Administration's U.S. Seasonal Drought Outlook indicates for the period that any of the following conditions are likely: (1) "Drought to persist or intensify", (2) "Drought ongoing, some improvement", (3) "Drought likely to improve, impacts ease", or (4) "Drought development likely". See http://www.cpc.ncep.noad.gov/products/expert assessment/season drought.gif.

Effective Operating Condition - for the purposes of this permit, a stormwater control is kept in effective operating condition if it has been implemented and maintained in such a manner that it is working as designed to minimize pollutant discharges.

Effluent Limitations - for the purposes of this permit, any of the Part 2 or Part 3 requirements.

Effluent Limitations Guideline (ELG) - defined in 40 CFR $\S 122.2$ as a regulation published by the Administrator under section 304 (b) of CWA to adopt or revise effluent limitations.

Eligible - for the purposes of this permit, refers to stormwater and allowable non-stormwater discharges that are authorized for coverage under this general permit.

Endangered Species - defined in the Endangered Species Act at 16 U.S.C. 1531 as any species which is in danger of extinction throughout all or a significant portion of its range other than a species of the Class Insecta determined by the Secretary to constitute a pest whose protection under the provisions of this Act would present an overwhelming and overriding risk to man.

Existing Discharger - an operator applying for coverage under this permit for discharges authorized previously under an NPDES general or individual permit.

Facility or Activity - any NPDES "point source" (including land or appurtenances thereto) that is subject to regulation under the NPDES program. See 40 CFR 122.2.

Feasible - for the purposes of this permit, feasible means technologically possible and economically practicable and achievable in light of best industry practices. EPA notes that it does not intend for any permit requirement to conlict with state water rights law. 
Federal Operator - an entity that meets the definition of "Operator" in this permit and is either any department, agency or instrumentality of the executive, legislative, and judicial branches of the Federal government of the United States, or another entity, such as a private contractor, operating for any such department, agency, or instrumentality.

Hazardous Materials or Hazardous Substances or Toxic Materials - for the purposes of this permit, any liquid, solid, or contained gas that contain properties that are dangerous or potentially harmful to human health or the environment. See also 40 CFR §261.2.

Historic Property - as defined in the National Historic Preservation Act regulations means any prehistoric or historic district, site, building, structure, or object included in, or eligible for inclusion in, the National Register of Historic Places maintained by the Secretary of the Interior. This term includes artifacts, records, and remains that are related to and located within such properties. The term includes properties of traditional religious and cultural importance to an Indian tribe or Native Hawaiian organization and that meet the National Register criteria.

Impaired Water (or "Water Quality Impaired Water" or "Water Quality Limited Segment") - for the purposes of this permit, waters identified by a state, tribe, or EPA as not meeting an applicable water quality standard, and require development of a total maximum daily load (TMDL) (pursuant to Section 303(d) of the CWA), or are addressed by an EPA-approved or established TMDL, or are covered by pollution controls requirements that meet the requirements of 40 FR 130.7 (b)(1). For discharges that enter a separate storm sewer system prior to discharge, the first water of the U.S. to which you discharge is the waterbody that receives the stormwater discharge from the storm sewer system.

Indian Country or Indian Country Lands - defined at 40 CFR 122.2 as:

a). All land within the limits of any Indian reservation under the jurisdiction of the United States Government, notwithstanding the issuance of any patent, and including rights-ofway running through the reservation;

b). All dependent Indian communities within the borders of the United States, whether within the original or subsequently acquired territory thereof, and whether within or without the limits of a State: and

c). All Indian allotments, the Indian titles to which have not been extinguished, including rights-of-way running through the same. This definition includes all land held in trust for an Indian tribe. (18 U.S.C. 1151)

Infeasible - for the purposes of this permit, infeasible means not technologically possible or not economically practicable and achievable in light of best industry practices. EPA notes that it does not intend for any permit requirement to conflict with state water rights law.

Industrial Activity - the 10 categories of industrial activities included in the definition of "stormwater discharges associated with industrial activity" as defined in 40 CFR 122.26(b)(14)(i)(ix) and (xi).

Industrial Stormwater - stormwater runoff from industrial activity.

Measurable Storm Event - a precipitation event that results in a measurable amount of precipitation (i.e., a storm event that results in an actual discharge) and that follows the preceding storm event by at least 72 hours (3-days). The 72-hour storm interval does not apply if you document that less than a 72-hour interval is representative for local storm events. 
Minimize - for the purposes of this permit, minimize means to reduce and/or eliminate to the extent achievable using control measures that are technologically available and economically practicable and achievable in light of best industry practices.

Municipal Separate Storm Sewer (MS4) - defined at 40 CFR §122.26(b) (8) as a conveyance or system of conveyances (including roads with drainage systems, municipal streets, catch basins, curbs, gutters, ditches, manmade channels, or storm drains):

1. Owned or operated by a state, city, town, borough, county, parish, district, association, or other public body (created by or pursuant to State law) having jurisdiction over disposal of sewage, industrial wastes, stormwater, or other wastes, including special districts under state law such as a sewer district, flood control district or drainage district, or similar entity, or an Indian tribe or an authorized Indian tribal organization, or a designated and approved management agency under section 208 of the CWA that discharges to waters of the United States;

2. Designed or used for collecting or conveying stormwater;

3. Which is not a combined sewer; and

4. Which is not part of a Publicly Owned Treatment Works (POTW) as defined at 40 CFR 122.2. See 40 CFR 122.26(b)(4) and (b) (7).

National Pollutant Discharge Elimination System (NPDES) - defined at 40 CFR $§ 122.2$ as the national program for issuing, modifying, revoking and reissuing, terminating, monitoring and enforcing permits, and imposing and enforcing pretreatment requirements, under sections 307 , 402,318 , and 405 of CWA. The term includes an 'approved program.'

New Discharger - a facility from which there is or may be a discharge, that did not commence the discharge of pollutants at a particular site prior to August 13, 1979, which is not a new source, and which has never received a finally effective NPDES permit for discharges at that site. See 40 CFR 122.2 .

New Source - any building, structure, facility, or installation from which there is or may be a "discharge of pollutants," the construction of which commenced:

- after promulgation of standards of performance under section 306 of the CWA which are applicable to such source, or

- after proposal of standards of performance in accordance with section 306 of the CWA which are applicable to such source, but only if the standards are promulgated in accordance with section 306 within 120 days of their proposal. See 40 CFR 122.2.

New Source Performance Standards (NSPS) - technology-based standards for facilities that qualify as new sources under 40 CFR 122.2 and 40 CFR 122.29.

No Exposure - all industrial materials or activities protected by a storm-resistant shelter to prevent exposure to rain, snow, snowmelt, and/or runoff. See 40 CFR 122.26(g).

Non-Stormwater Discharges - discharges that do not originate from storm events. They can include, but are not limited to, discharges of process water, air conditioner condensate, noncontact cooling water, pavement wash water, external building washdown, irrigation water, or uncontaminated ground water or spring water. 
Notice of Intent (NOI) - the form (electronic or paper) required for authorization of coverage under the Multi-Sector General Permit.

Notice of Termination (NOT) - the form (electronic or paper) required for terminating coverage under the Multi-Sector General Permit.

Operator - any entity with a stormwater discharge associated with industrial activity that meets either of the following two criteria:

1. The entity has operational control over industrial activities, including the ability to make modifications to those activities; or

2. The entity has day-to-day operational control of activities at a facility necessary to ensure compliance with the permit (e.g., the entity is authorized to direct workers at a facility to carry out activities required by the permit).

Outfall - see "Discharge Point."

Permitting Authority - for the purposes of this permit, EPA, a Regional Administrator of EPA, or an authorized representative.

Person - an individual, association, partnership, corporation, municipality, State or Federal agency, or an agent or employee thereof. See 40 CFR 122.2.

Point Source - any discernible, confined, and discrete conveyance, including but not limited to any pipe, ditch, channel, tunnel, conduit, well, discrete fissure, container, rolling stock, concentrated animal feeding operation, landfill leachate collection system, vessel, or other floating craft from which pollutants are or may be discharged. This term does not include return flows from irrigated agriculture or agricultural stormwater runoff. See 40 CFR 122.2.

Pollutant - defined at 40 CFR § 122.2. A partial listing from this definition includes: dredged spoil, solid waste, incinerator residue, filter backwash, sewage, garbage, sewage sludge, munitions, chemical wastes, biological materials, heat, wrecked or discarded equipment, rock, sand, cellar dirt, and industrial, municipal and agricultural waste discharged into water. See 40 CFR 122.2.

Pollutant of Concern - a pollutant which causes or contributes to a violation of a water quality standard, including a pollutant which is identified as causing an impairment in a state's 303(d) list.

Primary Industrial Activity - includes any activities performed on-site which are (1) identified by the facility's primary SIC code and included in the descriptions of 122.26 (b) (14) (ii), (iii), (vi), or (viii); or (2) included in the narrative descriptions of 122.26(b)(14) (i), (iv), (v), (vii), or (ix). [For colocated activities covered by multiple SIC codes, it is recommended that the primary industrial determination be based on the value of receipts or revenues or, if such information is not available for a particular facility, the number of employees or production rate for each process may be compared. The operation that generates the most revenue or employs the most personnel is the operation in which the facility is primarily engaged. In situations where the vast majority of on-site activity falls within one SIC code, that activity may be the primary industrial activity.] Narrative descriptions in 40 CFR 122.26(b)(14) identified above include: (i) activities subject to stormwater effluent limitations guidelines, new source performance standards, or toxic pollutant effluent standards; (iv) hazardous waste treatment storage, or disposal facilities including those that are operating under interim status or a permit under subtitle $C$ of the Resource Conservation and Recovery Act (RCRA); ( $v$ ) landfills, land application sites and open 
dumps that receive or have received industrial wastes; (vii) steam electric power generating facilities; and (ix) sewage treatment works with a design flow of $1.0 \mathrm{mgd}$ or more.

Qualified Personnel - qualified personnel are those who are knowledgeable in the principles and practices of industrial stormwater controls and pollution prevention, and who possess the education and ability to assess conditions at the industrial facility that could impact stormwater quality, and the education and ability to assess the effectiveness of stormwater controls selected and installed to meet the requirements of the permit.

Reportable Quantity Release - a release of a hazardous substance at or above the established legal threshold that requires emergency notification. Refer to 40 CFR Parts 110, 117, and 302 for complete definitions and reportable quantities for which notification is required.

Restricted Information - for the purposes of this permit, information that is privileged or that is otherwise protected from disclosure pursuant to applicable statutes, Executive Orders, or regulations. Such information includes, but is not limited to: classified national security information, protected critical infrastructure information, sensitive security information, and proprietary business information.

Runoff Coefficient - the fraction of total rainfall that will appear at the conveyance as runoff. See 40 CFR 122.26(b)(11).

Run-On - sources of stormwater that drain from land located upslope or upstream from the regulated facily in question.

Saline Water or Saltwater - for the purposes of this permit, a waterbody with salinity that is equal to or exceeds 10 parts per thousand 95 percent or more of the time, unless otherwise defined as a coastal or marine water by the applicable state or tribal surface water quality standards.

Semi-Arid Areas - areas where annual rainfall averages from 10 to 20 inches.

Significant Materials - includes, but is not limited to: raw materials; fuels; materials such as solvents, detergents, and plastic pellets; finished materials such as metallic products; raw materials used in food processing or production; hazardous substances designated under section 101(14) of CERCLA; any chemical the facility is required to report pursuant to section 313 of Title III of SARA; fertilizers; pesticides; and waste products such as ashes, slag and sludge that have the potential to be released with stormwater discharges. See 40 CFR 122.26(b)(12).

Special Aquatic Sites - sites identified in 40 CFR 230 Subpart E. These are geographic areas, large or small, possessing special ecological characteristics of productivity, habitat, wildlife protection, or other important and easily disrupted ecological values. These areas are generally recognized as significantly influencing or positively contributing to the general overall environmental health or vitality of the entire ecosystem of a region.

Spill - for the purpose of this permit, the release of a hazardous or toxic substance from its container or containment.

Stormwater - stormwater runoff, snow melt runoff, and surface runoff and drainage. See 40 CFR 122.26 (b) (13).

Stormwater Controls - see "Control Measures." 
Stormwater Discharges Associated with Construction Activity - as used in this permit, a discharge of pollutants in stormwater runoff from areas where land-disturbing activities (e.g., clearing, grading, or excavating) occur, or where construction materials or equipment storage or maintenance (e.g., fill piles, borrow areas, concrete truck washout, fueling), or other industrial stormwater directly related to the construction process (e.g., concrete or asphalt batch plants) are located. See 40 CFR 122.26(b)(14)(x) and 40 CFR 122.26(b)(15).

Stormwater Discharges Associated with Industrial Activity - the discharge from any conveyance that is used for collecting and conveying stormwater and that is directly related to manufacturing, processing or raw materials storage areas at an industrial plant. The term does not include discharges from facilities or activities excluded from the NPDES program under Part 122. For the categories of industries identified in this section, the term includes, but is not limited to, stormwater discharges from industrial plant yards; immediate access roads and rail lines used or traveled by carriers of raw materials, manufactured products, waste material, or by-products used or created by the facility; material handling sites; refuse sites; sites used for the application or disposal of process waste waters (as defined at part 401 of this chapter); sites used for the storage and maintenance of material handling equipment; sites used for residual treatment, storage, or disposal; shipping and receiving areas; manufacturing buildings; storage areas (including tank farms) for raw materials, and intermediate and final products; and areas where industrial activity has taken place in the past and significant materials remain and are exposed to stormwater. For the purposes of this paragraph, material handling activities include storage, loading and unloading, transportation, or conveyance of any raw material, intermediate product, final product, by-product or waste product. The term excludes areas located on plant lands separate from the plant's industrial activities, such as office buildings and accompanying parking lots as long as the drainage from the excluded areas is not mixed with stormwater drained from the above described areas. Industrial facilities include those that are federally, state, or municipally owned or operated that meet the description of the facilities listed in 40 CFR $122.26(\mathrm{~b})(14)$. The term also includes those facilities designated under the provisions of $40 \mathrm{CFR}$ 122.26(a)(1)(v). See 40 CFR 122.26(b)(14).

Stormwater Team - the group of individuals responsible for oversight of the development and modifications of the SWPPP, and oversight of compliance with the permit requirements. The individuals on the "Stormwater Team" must be identified in the SWPPP.

Storm Event - a precipitation event that results in a measurable amount of precipitation.

Threatened Species - defined in the Endangered Species Act at 16 U.S.C. 1531 as any species which is likely to become an endangered species within the foreseeable future throughout all or a significant portion of its range.

Tier 2 Waters - For antidegradation purposes, pursuant to 40 CFR 131.12(a)(2), Tier 2 waters are characterized as having water quality that exceeds the levels necessary to support propagation of fish, shellfish, and wildlife and recreation in and on the water.

Tier 2.5 Waters - For antidegradation purposes, Tier 2.5 waters are those waters designated by States or Tribes as requiring a level of protection equal to and above that given to Tier 2 waters, but less than that given Tier 3 waters.States have special requirements for these waters.

Tier 3 Waters - For antidegradation purposes, pursuant to 40 CFR 131.12(a)(3), Tier 3 waters are identified by states as having high quality waters constituting an Outstanding National Resource Water (ONRW), such as waters of National Parks and State Parks, wildlife refuges, and waters of exceptional recreational or ecological significance. 
Total Maximum Daily Loads (TMDLs) - The sum of the individual wasteload allocations (WLAs) for point sources and load allocations (LAs) for nonpoint sources and natural background. If receiving water has only one point source discharger, the TMDL is the sum of that point source WLA plus the LAs for any nonpoint sources of pollution and natural background sources, tributaries, or adjacent segments. TMDLs can be expressed in terms of either mass per time, toxicity, or other appropriate measure. (See section 303(d) of the Clean Water Act and 40 CFR 130.2 and 130.7).

Toxic Waste - see "Hazardous Materials."

Uncontaminated Discharge - a discharge that does not cause or contribute to an exceedance of applicable water quality standards.

Upset - Upset means an exceptional incident in which there is unintentional and temporary noncompliance with technology based permit effluent limitations because of factors beyond your reasonable control. An upset does not include noncompliance to the extent caused by operational error, improperly designed treatment facilities, inadequate treatment facilities, lack of preventive maintenance, or careless or improper operation. See 40 CFR 122.41 (n)(1).

Water Quality Impaired - See "Impaired Water."

Water Quality Standards - defined in 40 CFR $\S 131.3$, and are provisions of State or Federal law which consist of a designated use or uses for the waters of the United States, water quality criteria for such waters based upon such uses, and an antidegradation policy to protect highquality waters. Water quality standards protect the public health or welfare, enhance the quality of water and serve the purposes of the Act.

Waters of the United States - See definition at at 40 CFR § 122.2.

\section{A.2. ABBREVIATIONS AND ACRONYMS}

BAT - Best Available Technology Economically Achievable

BOD5 - Biochemical Oxygen Demand (5-day test)

BMP - Best Management Practice

BPJ - Best Professional Judgment

BPT - Best Practicable Control Technology Currently Available

CERCLA - Comprehensive Environmental Response, Compensation and Liability Act

CGP - Construction General Permit

CFR - Code of Federal Regulations

COD - Chemical Oxygen Demand

CWA - Clean Water Act (or the Federal Water Pollution Control Act, 33 U.S.C. §1251 et seq)

CWT - Centralized Waste Treatment 
DMR - Discharge Monitoring Report

ELG - Effluent Limitations Guideline

EPA - U. S. Environmental Protection Agency

ESA - Endangered Species Act

FWS - U. S. Fish and Wildlife Service

LA - Load Allocations

MGD - Million Gallons per Day

MOS - Margin of Safety

MS4 - Municipal Separate Storm Sewer System

MSGP - Multi-Sector General Permit

NAICS - North American Industry Classification System

NEPA - National Environmental Policy Act

NET - NPDES eReporting Tool

NHPA - National Historic Preservation Act

NMFS - U. S. National Marine Fisheries Service

$\mathrm{NOI}$ - Notice of Intent

NOE - No Exposure

NOT - Notice of Termination

NPDES - National Pollutant Discharge Elimination System

NRC - National Response Center

NRHP - National Register of Historic Places

NSPS - New Source Performance Standard

NTU - Nephelometric Turbidity Unit

OMB - U.S. Office of Management and Budget

ORW - Outstanding Resource Water

OSM - U.S. Office of Surface Mining

POTW - Publicly Owned Treatment Works 
RCRA - Resource Conservation and Recovery Act

$R Q$ - Reportable Quantity

SARA - Superfund Amendments and Reauthorization Act

SDS - Safety Data Sheet

SHPO - State Historic Preservation Officer

SIC - Standard Industrial Classification

SMCRA - Surface Mining Control and Reclamation Act

SPCC - Spill Prevention, Control, and Countermeasures

SWPPP - Stormwater Pollution Prevention Plan

THPO - Tribal Historic Preservation Officer

TMDL - Total Maximum Daily Load

TSDF - Treatment, Storage, or Disposal Facility

TSS - Total Suspended Solids

USGS - United States Geological Survey

WLA - Wasteload Allocation

WQS - Water Quality Standard 


\section{Appendix B - Standard Permit Conditions.}

Standard permit conditions in Appendix B are consistent with the general permit provisions required under 40 CFR 122.41.

\section{B.1 Duty To Comply.}

You must comply with all conditions of this permit. Any permit noncompliance constitutes a violation of the Clean Water Act and is grounds for enforcement action; for permit termination, revocation and reissuance, or modification; or for denial of a permit renewal application.

A. You must comply with effluent standards or prohibitions established under section 307(a) of the Clean Water Act for toxic pollutants within the time provided in the regulations that establish these standards, even if the permit has not yet been modified to incorporate the requirement.

B. Penalties for Violations of Permit Conditions: The Director will adjust the civil and administrative penalties listed below in accordance with the Civil Monetary Penalty Inflation Adjustment Rule (61 FR 252, December 31, 1996, pp. 69359-69366, as corrected in 62 FR 54, March 20, 1997, pp.13514-13517) as mandated by the Debt Collection Improvement Act of 1996 for inflation on a periodic basis. This rule allows EPA's penalties to keep pace with inflation. The Agency is required to review its penalties at least once every 4 years thereafter and to adjust them as necessary for inflation according to a specified formula. The civil and administrative penalties following were adjusted for inflation starting in 1996.

1. Criminal Penalties.

1.1 Negligent Violations. The CWA provides that any person who negligently violates permit conditions implementing Sections 301, 302, 306, 307, 308, 318, or 405 of the Act is subject to criminal penalties of not less than $\$ 2,500$ nor more than $\$ 25,000$ per day of violation, or imprisonment of not more than one year, or both. In the case of a second or subsequent conviction for a negligent violation, a person shall be subject to criminal penalties of not more than $\$ 50,000$ per day of violation or by imprisonment of not more than two years, or both.

1.2. Knowing Violations. The CWA provides that any person who knowingly violates permit conditions implementing Sections 301, 302, 306, 307, 308, 318 , or 405 of the Act is subject to a fine of not less than $\$ 5,000$ nor more than $\$ 50,000$ per day of violation, or by imprisonment for not more than 3 years, or both. In the case of a second or subsequent conviction for a knowing violation, a person shall be subject to criminal penalties of not more than $\$ 100,000$ per day of violation, or imprisonment of not more than 6 years, or both.

1.3. Knowing Endangerment. The CWA provides that any person who knowingly violates permit conditions implementing Sections 301, 302, 306, 307, 308, 318, or 405 of the Act and who knows at that time that he or she is placing another person in imminent danger of death or serious bodily injury shall upon conviction be subject to a fine of not more than $\$ 250,000$ or by imprisonment of not more than 15 years, or both. In the case of a second or subsequent conviction for a knowing endangerment violation, a person 
shall be subject to a fine of not more than $\$ 500,000$ or by imprisonment of not more than 30 years, or both. An organization, as defined in section 309 (c) (3) (B) (iii) of the Act, shall, upon conviction of violating the imminent danger provision be subject to a fine of not more than $\$ 1,000,000$ and can fined up to $\$ 2,000,000$ for second or subsequent convictions.

1.4. False Statement. The CWA provides that any person who falsifies, tampers with, or knowingly renders inaccurate any monitoring device or method required to be maintained under this permit shall, upon conviction, be punished by a fine of not more than $\$ 10,000$, or by imprisonment for not more than 2 years, or both. If a conviction of a person is for a violation committed after a first conviction of such person under this paragraph, punishment is a fine of not more than $\$ 20,000$ per day of violation, or by imprisonment of not more than 4 years, or both. The Act further provides that any person who knowingly makes any false statement, representation, or certification in any record or other document submitted or required to be maintained under this permit, including monitoring reports or reports of compliance or non-compliance shall, upon conviction, be punished by a fine of not more than $\$ 10,000$ per violation, or by imprisonment for not more than 6 months per violation, or by both.

2. Civil Penalties. The CWA provides that any person who violates a permit condition implementing Sections $301,302,306,307,308,318$, or 405 of the Act is subject to a civil penalty not to exceed the maximum amounts authorized by Section 309 (d) of the Act and the Federal Civil Penalties Inflation Adjustment Act (28 U.S.C. § 2461 note) as amended by the Debt Collection Improvement Act (31 U.S.C. § 3701 note) (currently $\$ 37,500$ per day for each violation).

3. Administrative Penalties. The CWA provides that any person who violates a permit condition implementing Sections 301, 302, 306, 307, 308, 318, or 405 of the Act is subject to an administrative penalty, as follows

3.1. Class I Penalty. Not to exceed the maximum amounts authorized by Section 309 (g) (2) (A) of the Act and the Federal Civil Penalties Inflation Adjustment Act (28 U.S.C. $\S 2461$ note) as amended by the Debt Collection Improvement Act (31 U.S.C. § 3701 note) (currently \$16,000 per violation, with the maximum amount of any Class I penalty assessed not to exceed $\$ 37,500)$.

3.2. Class II Penalty. Not to exceed the maximum amounts authorized by Section 309 (g) (2) (B) of the Act and the Federal Civil Penalties Inflation Adjustment Act (28 U.S.C. $\S 2461$ note) as amended by the Debt Collection Improvement Act (31 U.S.C. § 3701 note) (currently $\$ 11,000$ per day for each day during which the violation continues, with the maximum amount of any Class II penalty not to exceed $\$ 177,500$ ).

\section{B.2 Duty to Reapply.}

If you wish to continue an activity regulated by this permit after the expiration date of this permit, you must apply for and obtain authorization as required by the new permit once EPA issues it. 


\section{B.3 Need to Halt or Reduce Activity Not a Defense.}

It shall not be a defense for you in an enforcement action that it would have been necessary to halt or reduce the permitted activity in order to maintain compliance with the conditions of this permit.

\section{B.4 Duty to Mitigate.}

You must take all reasonable steps to minimize or prevent any discharge in violation of this permit which has a reasonable likelihood of adversely affecting human health or the environment.

\section{B.5 Proper Operation and Maintenance.}

You must at all times properly operate and maintain all facilities and systems of treatment and control (and related appurtenances) which are installed or used by you to achieve compliance with the conditions of this permit. Proper operation and maintenance also includes adequate laboratory controls and appropriate quality assurance procedures. This provision requires the operation of backup or auxiliary facilities or similar systems which are installed by you only when the operation is necessary to achieve compliance with the conditions of this permit.

\section{B.6 Permit Actions.}

This permit may be modified, revoked and reissued, or terminated for cause. Your filing of a request for a permit modification, revocation and reissuance, or termination, or a notification of planned changes or anticipated noncompliance does not stay any permit condition.

\section{B.7 Property Rights.}

This permit does not convey any property rights of any sort, or any exclusive privileges.

\section{B.8 Duty to Provide Information.}

You must furnish to EPA or an authorized representative (including an authorized contractor acting as a representative of EPA), within a reasonable time, any information which EPA may request to determine whether cause exists for modifying, revoking and reissuing, or terminating this permit or to determine compliance with this permit. You must also furnish to EPA or an authorized representative upon request, copies of records required to be kept by this permit.

\section{B.9 Inspection and Entry.}

You must allow EPA or an authorized representative (including an authorized contractor acting as a representative of EPA), upon presentation of credentials and other documents as may be required by law, to:

A. Enter upon your premises where a regulated facility or activity is located or conducted, or where records must be kept under the conditions of this permit;

B. Have access to and copy, at reasonable times, any records that must be kept under the conditions of this permit;

C. Inspect at reasonable times any facilities, equipment (including monitoring and control equipment), practices, or operations regulated or required under this permit; and 
D. Sample or monitor at reasonable times, for the purposes of assuring permit compliance or as otherwise authorized by the Clean Water Act, any substances or parameters at any location.

\section{B.10 Monitoring and Records.}

A. Samples and measurements taken for the purpose of monitoring must be representative of the volume and nature of the monitored activity.

B. You must retain records of all monitoring information, including all calibration and maintenance records and all original strip chart recordings for continuous monitoring instrumentation, copies of all reports required by this permit, and records of all data used to complete the application for this permit, for a period of at least three years from the date the permit expires or the date the permittee's authorization is terminated. This period may be extended by request of EPA at any time.

C. Records of monitoring information must include:

1. The date, exact place, and time of sampling or measurements;

2. The individual(s) who performed the sampling or measurements;

3. The date(s) analyses were performed

4. The individual(s) who performed the analyses;

5. The analytical techniques or methods used; and

6. The results of such analyses.

D. Monitoring must be conducted according to test procedures approved under 40 CFR Part 136, unless other test procedures have been specified in the permit.

E. The Clean Water Act provides that any person who falsifies, tampers with, or knowingly renders inaccurate any monitoring device or method required to be maintained under this permit shall, upon conviction, be punished by a fine of not more than $\$ 10,000$, or by imprisonment for not more than 2 years, or both. If a conviction of a person is for a violation committed after a first conviction of such person under this paragraph, punishment is a fine of not more than $\$ 20,000$ per day of violation, or by imprisonment of not more than 4 years, or both.

\section{B.11 Signatory Requirements.}

A. NOIs, NOTs, and NOEs must be signed as follows:

1. For a corporation: By a responsible corporate officer. For the purpose of this subsection, a responsible corporate officer means: (i) a president, secretary, treasurer, or vice-president of the corporation in charge of a principal business function, or any other person who performs similar policy- or decision-making functions for the corporation, or (ii) the manager of one or more manufacturing, production, or operating facilities, provided, the manager is authorized to make management decisions which govern the operation of the regulated facility including having the explicit or implicit duty of making major capital investment 
recommendations, and initiating and directing other comprehensive measures to assure long term environmental compliance with environmental laws and regulations; the manager can ensure that the necessary systems are established or actions taken to gather complete and accurate information for permit application requirements; and where authority to sign documents has been assigned or delegated to the manager in accordance with corporate procedures.

2. For a partnership or sole proprietorship: By a general partner or the proprietor, respectively; or

3. For a municipality, state, federal, or other public agency: By either a principal executive officer or ranking elected official. For purposes of this subsection, a principal executive officer of a federal agency includes (i) the chief executive officer of the agency, or (ii) a senior executive officer having responsibility for the overall operations of a principal geographic unit of the agency (e.g., Regional Administrator of EPA).

B. Your SWPPP, including changes to your SWPPP to document any corrective actions taken as required by Part 3.1, and any other compliance documentation required under this permit, including the Annual Report, DMRs, inspection reports, and corrective action reports, must be signed by a person described in Appendix B, Subsection 11.A above or by a duly authorized representative of that person. A person is a duly authorized representative only if:

1. The authorization is made in writing by a person described in Appendix B, Subsection 11.A;

2. The authorization specifies either an individual or a position having responsibility for the overall operation of the regulated facility or activity such as the position of plant manager, operator of a well or a well field, superintendent, position of equivalent responsibility, or an individual or position having overall responsibility for environmental matters for the company. (A duly authorized representative may thus be either a named individual or any individual occupying a named position); and

3. The signed and dated written authorization is included in the SWPPP. A copy must be submitted to EPA, if requested.

C. All other changes to your SWPPP, and other compliance documentation required under Part 5.4, must be signed and dated by the person preparing the change or documentation.

D. Changes to Authorization. If an authorization under Part 1.3.1.3 is no longer accurate because the industrial facility has been purchased by a different entity, a new NOI satisfying the requirements of Part 1.3 must be submitted to EPA. See Table 1-2 in Part 1.3.1.1 of the permit. However, if the only change that is occurring is a change in contact information or a change in the facility's address, the operator need only make a modification to the existing NOI submitted for authorization.

E. Any person signing documents in accordance with Appendix B, Subsections 11.A or 11.B above must include the following certification:

"I certify under penalty of law that this document and all attachments were prepared under my direction or supervision in accordance with a system designed to assure that qualified personnel properly gathered and evaluated the 
information contained therein. Based on my inquiry of the person or persons who manage the system, or those persons directly responsible for gathering the information, the information contained is, to the best of my knowledge and belief, true, accurate, and complete. I am aware that there are significant penalties for submitting false information, including the possibility of fine and imprisonment for knowing violations."

F. For persons signing documents electronically, in addition to meeting other applicable requirements in Appendix I, Subsection B.1 1, such signatures must be legally dependable with no less evidentiary value than their paper equivalent.

G. The CWA provides that any person who knowingly makes any false statement, representation, or certification in any record or other document submitted or required to be maintained under this permit, including monitoring reports or reports of compliance or noncompliance shall, upon conviction, be punished by a fine of not more than $\$ 10,000$ per violation, or by imprisonment for not more than 6 months per violation, or by both.

\section{B.12 Reporting Requirements.}

A. Planned changes. You must give notice to EPA as soon as possible, but no fewer than 30 days, of any planned physical alterations or additions to the permitted facility. Notice is required only when:

1. The alteration or addition to a permitted facility may meet one of the criteria for determining whether a facility is a new source in 40 CFR 122.29 (b); or

2. The alteration or addition could significantly change the nature or increase the quantity of pollutants discharged. This notification applies to pollutants which are subject neither to effluent limitations in the permit, nor to notification requirements under 40 CFR 122.42(a)(1).

B. Anticipated noncompliance. You must give advance notice to EPA of any planned changes in the permitted facility or activity which may result in noncompliance with permit requirements.

C. Transfers. This permit is not transferable to any person except after notice to EPA. Where a facility wants to change the name of the permittee, the original permittee (the first owner or operators) must submit a Notice of Termination pursuant to Part 1.4. The new owner or operator must submit a Notice of Intent in accordance with Part 1.3.1 and Table 1-2. See also requirements in Appendix B, Subsections 11.B and 11.D.

D. Monitoring reports. Monitoring results must be reported at the intervals specified elsewhere in this permit.

1. Pursuant to Part 7.1, all monitoring data collected pursuant to Part 6 must be submitted to EPA using EPA's online DMR system (http://www.epa.gov/netdmr/).

2. If you monitor any pollutant more frequently than required by the permit using test procedures approved under 40 CFR Part 136 or as specified in the permit, the results of this monitoring must be included in the calculation and reporting of the data submitted in the DMR. 
3. Calculations for all limitations which require averaging of measurements must use an arithmetic mean. For averaging purposes, use a value of zero for any individual sample parameter, which is determined to be less than the method detection limit. For sample values that fall between the method detection level and the quantitation limit (i.e., a confirmed detection but below the level that can be reliably quantified), use a value halfway between zero and the quantitation limit.

E. Compliance schedules. Reports of compliance or noncompliance with, or any progress reports on, interim and final requirements contained in any compliance schedule of this permit must be submitted no later than 14 days following each schedule date.

F. Twenty-four hour reporting.

1. You must report any noncompliance which may endanger health or the environment. Any information must be provided orally within 24 hours from the time you become aware of the circumstances. A written submission must also be provided within five days of the time you become aware of the circumstances. The written submission must contain a description of the noncompliance and its cause; the period of noncompliance, including exact dates and times, and if the noncompliance has not been corrected, the anticipated time it is expected to continue; and steps taken or planned to reduce, eliminate, and prevent reoccurrence of the noncompliance.

2. The following shall be included as information which must be reported within 24 hours under this paragraph.

a. Any unanticipated bypass which exceeds any effluent limitation in the permit. (See 40 CFR 122.41 (m)(3)(ii))

b. Any upset which exceeds any effluent limitation in the permit

c. Violation of a maximum daily discharge limit for any numeric effluent limitation. (See 40 CFR 122.44(g).)

3. EPA may waive the written report on a case-by-case basis for reports under Appendix B, Subsection 12.F.2 if the oral report has been received within 24 hours.

G. Other noncompliance. You must report all instances of noncompliance not reported under Appendix B, Subsections 12.D, 12.E, and 12.F, at the time monitoring reports are submitted. The reports must contain the information listed in Appendix B, Subsection 12.F.

H. Other information. Where you become aware that you failed to submit any relevant facts in your NOI, or submitted incorrect information in your $\mathrm{NOI}$ or in any report to the Permitting Authority, you must promptly submit such facts or information.

\section{B.13 Bypass.}

A. Definitions.

1. Bypass means the intentional diversion of waste streams from any portion of a treatment facility See 40 CFR 122.41 (m) (1)(i). 
2. Severe property damage means substantial physical damage to property, damage to the treatment facilities which causes them to become inoperable, or substantial and permanent loss of natural resources which can reasonably be expected to occur in the absence of a bypass. Severe property damage does not mean economic loss caused by delays in production. See 40 CFR 122.41 (m)(1)(ii).

B. Bypass not exceeding limitations. You may allow any bypass to occur which does not cause effluent limitations to be exceeded, but only if it also is for essential maintenance to assure efficient operation. These bypasses are not subject to the provisions of Appendix B, Subsections 13.C and 13.D. See 40 CFR $122.41(\mathrm{~m})(2)$.

C. Notice.

1. Anticipated bypass. If you know in advance of the need for a bypass, you must submit prior notice, if possible at least ten days before the date of the bypass. See 40 CFR $122.41(\mathrm{~m})(3)(\mathrm{i})$.

2. Unanticipated bypass. You must submit notice of an unanticipated bypass as required in Appendix B, Subsection 12.F (24-hour notice). See 40 CFR 122.41 (m) (3) (ii).

D. Prohibition of bypass. See 40 CFR $122.41(\mathrm{~m})(4)$.

1. Bypass is prohibited, and EPA may take enforcement action against you for bypass, unless:

a. Bypass was unavoidable to prevent loss of life, personal injury, or severe property damage;

b. There were no feasible alternatives to the bypass, such as the use of auxiliary treatment facilities, retention of untreated wastes, or maintenance during normal periods of equipment downtime. This condition is not satisfied if adequate back-up equipment should have been installed in the exercise of reasonable engineering judgment to prevent a bypass which occurred during normal periods of equipment downtime or preventive maintenance; and

c. You submitted notices as required under Appendix B, Subsection 13.C.

2. EPA may approve an anticipated bypass, after considering its adverse effects, if EPA determines that it will meet the three conditions listed above in Appendix B,

Subsection 13.D.1.

\section{B.14 Upset.}

A. Definition. Upset means an exceptional incident in which there is unintentional and temporary noncompliance with technology based permit effluent limitations because of factors beyond your reasonable control. An upset does not include noncompliance to the extent caused by operational error, improperly designed treatment facilities, inadequate treatment facilities, lack of preventive maintenance, or careless or improper operation. See 40 CFR 122.41 (n)(1).

B. Effect of an upset. An upset constitutes an affirmative defense to an action brought for noncompliance with such technology based permit effluent limitations if the requirements 
of Appendix B, Subsection 14.C are met. No determination made during administrative review of claims that noncompliance was caused by upset, and before an action for noncompliance, is final administrative action subject to judicial review. See 40 CFR $122.41(n)(2)$.

C. Conditions necessary for a demonstration of upset. See 40 CFR $122.41(n)(3)$. A permittee who wishes to establish the affirmative defense of upset must demonstrate, through properly signed, contemporaneous operating logs, or other relevant evidence that:

1. An upset occurred and that you can identify the cause(s) of the upset;

2. The permitted facility was at the time being properly operated; and

3. You submitted notice of the upset as required in Appendix B, Subsection 12.F.2.b (24 hour notice).

4. You complied with any remedial measures required under Appendix B, Subsection 4.

D. Burden of proof. In any enforcement proceeding, you, as the one seeking to establish the occurrence of an upset, have the burden of proof. See 40 CFR 122.41 (n) (4).

\section{B.15 Retention of Records.}

Copies of the SWPPP and all documentation required by this permit, including records of all data used to complete the NOI to be covered by this permit, must be retained for at least three years from the date that permit coverage expires or is terminated. This period may be extended by request of EPA at any time.

\section{B.16 Reopener Clause.}

A. Procedures for modification or revocation. Permit modification or revocation will be conducted according to 40 CFR §122.62, §122.63, §122.64 and §124.5.

B. Water quality protection. If there is evidence indicating that the stormwater discharges authorized by this permit cause, have the reasonable potential to cause or contribute to an excursion above any applicable water quality standard, you may be required to obtain an individual permit in accordance with Part 1.3.3 of this permit, or the permit may be modified to include different limitations and/or requirements.

C. Timing of permit modification. EPA may elect to modify the permit prior to its expiration (rather than waiting for the new permit cycle) to comply with any new statutory or regulatory requirements, such as for effluent limitation guidelines that may be promulgated in the course of the current permit cycle. 


\section{Appendix C - Permit Areas Eligible for Coverage.}

EPA can only provide permit coverage in these areas and for classes of discharges that are outside the scope of a state's NPDES program authorization.

\section{C.1 EPA Region 1: Connecticut, Massachusetts, Maine, New Hampshire, Rhode Island, Vermont.}

This permit offers NPDES permit coverage for stormwater discharges associated with industrial activity from the following areas in EPA Region 1:

\begin{tabular}{|l|l|}
\hline $\begin{array}{c}\text { Master Permit } \\
\text { Number }\end{array}$ & \multicolumn{1}{c|}{ Areas of Coverage/Where EPA Is Permitting Authority } \\
\hline CTR05I000 & Indian Country within the State of Connecticut \\
\hline MAR050000 & Commonwealth of Massachusetts, except Indian country \\
\hline MAR05I000 & Indian country within the Commonwealth of Massachusetts \\
\hline NHR050000 & State of New Hampshire \\
\hline RIR05I000 & Indian country within the State of Rhode Island \\
\hline VTR05F000 & $\begin{array}{l}\text { Areas in the State of Vermont subject to industrial activity by a Federal } \\
\text { Operator }\end{array}$ \\
\hline
\end{tabular}

For stormwater discharges in EPA Region 1 outside the areas of coverage identified above, please contact your state NPDES permitting authority to obtain coverage under a state-issued NPDES permit.

\section{C.2 EPA Region 2: New Jersey, New York, Puerto Rico, Virgin Islands.}

This permit offers NPDES permit coverage for stormwater discharges associated with industrial activity from the following areas in EPA Region 2:

\begin{tabular}{|c|c|}
\hline $\begin{array}{c}\text { Master Permit } \\
\text { Number }\end{array}$ & Areas of Coverage/Where EPA Is Permitting Authority \\
\hline PRR050000 & Commonwealth of Puerto Rico \\
\hline
\end{tabular}

For stormwater discharges in EPA Region 2 outside the areas of coverage identified above, please contact your state NPDES permitting authority to obtain coverage under a state-issued NPDES permit.

\section{C.3 EPA Region 3: Delaware, District of Columbia, Maryland, Pennsylvania, Virginia, West Virginia.}

This permit offers NPDES permit coverage for stormwater discharges associated with industrial activity from the following areas in EPA Region 3:

\begin{tabular}{|l|l|}
\hline $\begin{array}{c}\text { Master Permit } \\
\text { Number }\end{array}$ & \multicolumn{1}{c|}{ Areas of Coverage/Where EPA Is Permitting Authority } \\
\hline DCR050000 & District of Columbia \\
\hline DER05F000 & $\begin{array}{l}\text { Areas in the State of Delaware subject to industrial activity by a Federal } \\
\text { Operator }\end{array}$ \\
\hline
\end{tabular}


For stormwater discharges in EPA Region 3 outside the areas of coverage identified above, please contact your state NPDES permitting authority to obtain coverage under a state-issued NPDES permit.

\section{C.4 EPA Region 4: Alabama, Florida, Georgia, Kentucky, Mississippi, North Carolina, South Carolina, Tennessee (Coverage not available under this permit).}

For stormwater discharges in EPA Region 4, please contact your state NPDES permitting authority to obtain coverage under a state-issued NPDES permit.

\section{C.5 EPA Region 5: Illinois, Indiana, Michigan, Minnesota, Ohio, Wisconsin.}

This permit offers NPDES permit coverage for stormwater discharges associated with industrial activity from the following areas in EPA Region 5:

\begin{tabular}{|l|l|}
\hline $\begin{array}{c}\text { Master Permit } \\
\text { Number }\end{array}$ & \multicolumn{1}{c|}{ Areas of Coverage/Where EPA Is Permitting Authority } \\
\hline MIR05I000 & Indian country within the State of Michigan \\
\hline MNR05I000 & Indian country within the State of Minnesota \\
\hline WIR05I000 & $\begin{array}{l}\text { Indian country within the State of Wisconsin (except for facilities on } \\
\text { Sokaogon Chippewa Community lands and Bad River Band of Lake } \\
\text { Superior Tribe of Chippewa Indians lands, see EPA Region 5 for an } \\
\text { individual permit application). }\end{array}$ \\
\hline
\end{tabular}

For stormwater discharges in EPA Region 5 outside the areas of coverage identified above, please contact your state NPDES permitting authority to obtain coverage under a state-issued NPDES permit.

\section{C.6 EPA Region 6: Arkansas, Louisiana, Oklahoma, Texas, and New Mexico (except see Region 9 for Navajo lands, and see Region 8 for Ute Mountain Reservation lands).}

This permit offers NPDES permit coverage for stormwater discharges associated with industrial activity from the following areas in EPA Region 6:

\begin{tabular}{|c|c|}
\hline $\begin{array}{c}\text { Master Permit } \\
\text { Number }\end{array}$ & Areas of Coverage/Where EPA Is Permitting Authority \\
\hline LAR05I000 & Indian country within the State of Louisiana \\
\hline NMR050000 & The State of New Mexico, except Indian country \\
\hline NMR05I000 & $\begin{array}{l}\text { Indian country within the State of New Mexico, except Ute Mountain } \\
\text { Reservation lands that are covered under Colorado permit CORO5I000 and } \\
\text { Navajo Reservation lands that are covered under Arizona permit AZR05I000 }\end{array}$ \\
\hline OKR05I000 & Indian country within the State of Oklahoma \\
\hline OKR05F000 & $\begin{array}{l}\text { Facilities in the State of Oklahoma not under the jurisdiction of the } \\
\text { Oklahoma Department of Environmental Quality or the Oklahoma } \\
\text { Department of Agriculture, Food and Forestry, except those on Indian } \\
\text { Country. EPA jurisdiction facilities include SIC Codes } 1311,1381,1382,1389 \text {, } \\
\text { and } 5171 .\end{array}$ \\
\hline
\end{tabular}




\begin{tabular}{|l|l|}
\hline $\begin{array}{c}\text { Master Permit } \\
\text { Number }\end{array}$ & \multicolumn{1}{c|}{ Areas of Coverage/Where EPA Is Permitting Authority } \\
\hline TXR05F000 & $\begin{array}{l}\text { Facilities in the State of Texas not under the jurisdiction of the Texas } \\
\text { Commission on Environmental Quality, except those on Indian Country. EPA- } \\
\text { jurisdiction facilities include SIC Codes 1311, 1321, 1381, 1382, 1389, and } \\
5171 \text { (other than oil field service company "home base" facilities). }\end{array}$ \\
\hline TXR05I000 & Indian country within the State of Texas \\
\hline
\end{tabular}

For stormwater discharges in EPA Region 6 outside the areas of coverage identified above, please contact your state NPDES permitting authority to obtain coverage under a state-issued NPDES permit.

\section{C.7 EPA Region 7: lowa, Kansas, Missouri, Nebraska (except see Region 8 for Pine Ridge Reservation Lands).}

This permit offer NPDES permit coverage for stormwater discharges associated with industrial activity from the following areas in EPA Region 7:

\begin{tabular}{|l|l|}
\hline \multicolumn{1}{|c|}{$\begin{array}{c}\text { Master Permit } \\
\text { Number }\end{array}$} & \multicolumn{1}{c|}{ Areas of Coverage/Where EPA Is Permitting Authority } \\
\hline IAR05I000 & Indian country within the State of Iowa \\
\hline KSR05I000 & Indian country within the State of Kansas \\
\hline NER05I000 & $\begin{array}{l}\text { Indian country within the State of Nebraska, except Pine Ridge Reservation } \\
\text { lands (see Region 8) }\end{array}$ \\
\hline
\end{tabular}

For stormwater discharges in EPA Region 7 outside the areas of coverage identified above, please contact your state NPDES permitting authority to obtain coverage under a state-issued NPDES permit.

\section{C.8 EPA Region 8: Colorado, Montana, North Dakota, South Dakota, Wyoming, Utah (except see Region 9 for Goshute Reservation and Navajo Reservation Lands), the Ute Mountain Reservation in NM, and the Pine Ridge Reservation in NE.}

This permit offers NPDES permit coverage for stormwater discharges associated with industrial activity from the following areas in EPA Region 8:

\begin{tabular}{|l|l|}
\hline $\begin{array}{c}\text { Master Permit } \\
\text { Number }\end{array}$ & \multicolumn{1}{c|}{ Areas of Coverage/Where EPA Is Permitting Authority } \\
\hline COR05F000 & $\begin{array}{l}\text { Areas in the State of Colorado, except those located on Indian country, } \\
\text { subject to industrial activity by a Federal Operator }\end{array}$ \\
\hline COR05I000 & $\begin{array}{l}\text { Indian country within the State of Colorado, as well as the portion of the } \\
\text { Ute Mountain Reservation located in New Mexico }\end{array}$ \\
\hline MTR05I000 & Indian country within the State of Montana \\
\hline NDR05I000 & $\begin{array}{l}\text { Indian country within the State of North Dakota, as well as that portion of } \\
\text { the Standing Rock Reservation located in South Dakota (except for } \\
\text { the portion of the lands within the former boundaries of the Lake Traverse } \\
\text { Reservation, which is covered under South Dakota permit SDR05I000 listed } \\
\text { below) }\end{array}$ \\
\hline
\end{tabular}




\begin{tabular}{|l|l|}
\hline $\begin{array}{c}\text { Master Permit } \\
\text { Number }\end{array}$ & \multicolumn{1}{c|}{ Areas of Coverage/Where EPA Is Permitting Authority } \\
\hline SDR05I000 & $\begin{array}{l}\text { Indian country within the State of South Dakota, as well as the portion of } \\
\text { the Pine Ridge Reservation located in Nebraska and the portion of the } \\
\text { lands within the former boundaries of the Lake Traverse Reservation } \\
\text { located in North Dakota (except for the Standing Rock Reservation, which } \\
\text { is covered under North Dakota permit NDR05I000 listed above) }\end{array}$ \\
\hline UTR05I000 & $\begin{array}{l}\text { Indian country within the State of Utah, except Goshute and Navajo } \\
\text { Reservation lands (see Region 9) }\end{array}$ \\
\hline WYR05I000 & Indian country within the State of Wyoming \\
\hline
\end{tabular}

For stormwater discharges in EPA Region 8 outside the areas of coverage identified above, please contact your state NPDES permitting authority to obtain coverage under a state-issued NPDES permit.

C.9 EPA Region 9: California, Hawaii, Nevada, Guam, American Samoa, the Commonwealth of the Northern Mariana Islands, the Confederated Tribes of the Goshute Reservation in Utah and Nevada, Indian Country within the State of Arizona including the Navajo Reservation in Utah and New Mexico and Arizona, the Duck Valley Reservation in Idaho, and the Fort McDermitt Reservation in Oregon.

This permit offers NPDES permit coverage for stormwater discharges associated with industrial activity from the following areas in EPA Region 9:

\begin{tabular}{|l|l|}
\hline \multicolumn{1}{|c|}{$\begin{array}{c}\text { Master Permit } \\
\text { Number }\end{array}$} & \multicolumn{1}{c|}{ Areas of Coverage/Where EPA Is Permitting Authority } \\
\hline ASR050000 & American Samoa \\
\hline AZR05I000 & $\begin{array}{l}\text { Indian country within the State of Arizona, including Navajo Reservation } \\
\text { lands in New Mexico and Utah }\end{array}$ \\
\hline CAR05I000 & Indian country within the State of California \\
\hline GUR050000 & Island of Guam \\
\hline JAR050000 & Johnston Atoll \\
\hline MWR050000 & Midway Island and Wake Island \\
\hline MPR050000 & Commonwealth of the Northern Mariana Islands \\
\hline NVR05I000 & $\begin{array}{l}\text { Indian country within the State of Nevada, including the Duck Valley } \\
\text { Reservation in Idaho, the Fort McDermitt Reservation in Oregon and the } \\
\text { Confederated Tribes of the Goshute Reservation in Utah }\end{array}$ \\
\hline
\end{tabular}

For stormwater discharges in EPA Region 9 outside the areas of coverage identified above, please contact your state NPDES permitting authority to obtain coverage under a state-issued NPDES permit. 


\section{C.10 Region 10: Alaska, Idaho (except see Region 9 for Duck Valley Reservation lands), Oregon} (except see Region 9 for Fort McDermitt Reservation), Washington.

This permit offers NPDES permit coverage for stormwater discharges associated with industrial activity from the following areas in EPA Region 10:

\begin{tabular}{|c|c|}
\hline $\begin{array}{l}\text { Master Permit } \\
\text { Number }\end{array}$ & Areas of Coverage/Where EPA Is Permitting Authority \\
\hline AKR05F000 & Denali National Park and Preserve \\
\hline AKR05I000 & Indian country lands as defined in 18 U.S.C. 1151 within the State of Alaska \\
\hline IDR050000 & $\begin{array}{l}\text { The State of Idaho, except Indian country lands [PERMIT COVERAGE NOT } \\
\text { AVAILABLE UNTIL CWA } 401 \text { CERTIFICATION IS RECEIVED] }\end{array}$ \\
\hline IDR05I000 & $\begin{array}{l}\text { Indian country lands within the State of Idaho, except Duck Valley } \\
\text { Reservation lands, which are covered under Nevada permit NVR05I000 }\end{array}$ \\
\hline ORR05I000 & $\begin{array}{l}\text { Indian country lands within the State of Oregon, except Fort McDermitt } \\
\text { Reservation lands, which are covered under Nevada permit NVR05I000 }\end{array}$ \\
\hline WAR05I000 & $\begin{array}{l}\text { Indian country lands within the State of Washington [EXCEPT FOR } \\
\text { FACILITIES LOCATED ON SPOKANE TRIBE OF INDIANS LANDS (PERMIT } \\
\text { COVERAGE NOT AVAILABLE UNTIL CWA } 401 \text { CERTIFICATION IS RECEIVED)] }\end{array}$ \\
\hline WAR05F000 & $\begin{array}{l}\text { Areas in the State of Washington, except those located on Indian country } \\
\text { lands, subject to industrial activity by a Federal Operator } \\
\text { [PERMIT COVERAGE NOT AVAILABLE UNTIL CWA } 401 \text { CERTIFICATION IS } \\
\text { RECEIVED] }\end{array}$ \\
\hline
\end{tabular}

For stormwater discharges in EPA Region 10 outside the areas of coverage identified above, please contact your state NPDES permitting authority to obtain coverage under a state-issued NPDES permit. 


\section{Appendix D - Facilities and Activities Covered}

Your permit eligibility is limited to discharges from facilities in the "sectors" of industrial activity summarized in Table D-1. These sector descriptions are based on Standard Industrial Classification (SIC) Codes and Industrial Activity Codes. References to "sectors" in this permit (e.g., sector-specific monitoring requirements) refer to these groupings.

\begin{tabular}{|c|c|c|}
\hline \multicolumn{3}{|c|}{ Table D-1. Sectors of Industrial Activity Covered by This Permit } \\
\hline $\begin{array}{c}\text { Subsector } \\
\text { (May be subject } \\
\text { to more than one } \\
\text { sector/subsector) }\end{array}$ & $\begin{array}{l}\text { SIC Code or } \\
\text { Activity Code }\end{array}$ & Activity Represented \\
\hline \multicolumn{3}{|r|}{ SECTOR A: TIMBER PRODUCTS } \\
\hline Al & 2421 & General Sawmills and Planing Mills \\
\hline A2 & 2491 & Wood Preserving \\
\hline A3 & 2411 & Log Storage and Handling \\
\hline \multirow{9}{*}{ A4 } & 2426 & Hardwood Dimension and Flooring Mills \\
\hline & 2429 & Special Product Sawmills, Not Elsewhere Classified \\
\hline & $\begin{array}{c}2431-2439 \\
\text { (except 2434) }\end{array}$ & $\begin{array}{l}\text { Millwork, Veneer, Plywood, and Structural Wood (see Sector } \\
\text { W) }\end{array}$ \\
\hline & 2448 & Wood Pallets and Skids \\
\hline & 2449 & Wood Containers, Not Elsewhere Classified \\
\hline & 2451,2452 & Wood Buildings and Mobile Homes \\
\hline & 2493 & Reconstituted Wood Products \\
\hline & 2499 & Wood Products, Not Elsewhere Classified \\
\hline & 2441 & Nailed and Lock Corner Wood Boxes and Shook \\
\hline \multicolumn{3}{|c|}{ SECTOR B: PAPER AND ALLIED PRODUCTS } \\
\hline B1 & 2631 & Paperboard Mills \\
\hline \multirow{4}{*}{ B2 } & 2611 & Pulp Mills \\
\hline & 2621 & Paper Mills \\
\hline & $2652-2657$ & Paperboard Containers and Boxes \\
\hline & $2671-2679$ & $\begin{array}{l}\text { Converted Paper and Paperboard Products, Except } \\
\text { Containers and Boxes }\end{array}$ \\
\hline \multicolumn{3}{|c|}{ SECTOR C: CHEMICALS AND ALLIED PRODUCTS } \\
\hline $\mathrm{Cl}$ & $2873-2879$ & Agricultural Chemicals \\
\hline $\mathrm{C} 2$ & $2812-2819$ & Industrial Inorganic Chemicals \\
\hline C3 & $2841-2844$ & $\begin{array}{l}\text { Soaps, Detergents, and Cleaning Preparations; Perfumes, } \\
\text { Cosmetics, and Other Toilet Preparations }\end{array}$ \\
\hline $\mathrm{C} 4$ & $2821-2824$ & $\begin{array}{l}\text { Plastics Materials and Synthetic Resins, Synthetic Rubber, } \\
\text { Cellulosic and Other Manmade Fibers Except Glass }\end{array}$ \\
\hline
\end{tabular}




\begin{tabular}{|c|c|c|}
\hline \multicolumn{3}{|c|}{ Table D-1. Sectors of Industrial Activity Covered by This Permit } \\
\hline $\begin{array}{l}\text { Subsector } \\
\text { (May be subject } \\
\text { to more than one } \\
\text { sector/subsector) }\end{array}$ & $\begin{array}{l}\text { SIC Code or } \\
\text { Activity Code }\end{array}$ & Activity Represented \\
\hline \multirow{6}{*}{ C5 } & 2833-2836 & $\begin{array}{l}\text { Medicinal Chemicals and Botanical Products; } \\
\text { Pharmaceutical Preparations; in vitro and in vivo Diagnostic } \\
\text { Substances; and Biological Products, Except Diagnostic } \\
\text { Substances }\end{array}$ \\
\hline & 2851 & Paints, Varnishes, Lacquers, Enamels, and Allied Products \\
\hline & $2861-2869$ & Industrial Organic Chemicals \\
\hline & $2891-2899$ & Miscellaneous Chemical Products \\
\hline & $\begin{array}{l}3952 \\
\text { (limited to list of } \\
\text { inks and paints) }\end{array}$ & $\begin{array}{l}\text { Inks and Paints, Including China Painting Enamels, India Ink, } \\
\text { Drawing Ink, Platinum Paints for Burnt Wood or Leather Work, } \\
\text { Paints for China Painting, Artist's Paints and Artist's } \\
\text { Watercolors }\end{array}$ \\
\hline & 2911 & Petroleum Refining \\
\hline \multicolumn{3}{|c|}{ SECTOR D: ASPHALT PAVING AND ROOFING MATERIALS AND LUBRICANTS } \\
\hline Dl & 2951,2952 & Asphalt Paving and Roofing Materials \\
\hline D2 & 2992,2999 & Miscellaneous Products of Petroleum and Coal \\
\hline \multicolumn{3}{|c|}{ SECTOR E: GLASS, CLAY, CEMENT, CONCRETE, AND GYPSUM PRODUCTS } \\
\hline \multirow{2}{*}{ El } & 3251-3259 & Structural Clay Products \\
\hline & $3261-3269$ & Pottery and Related Products \\
\hline E2 & $3271-3275$ & Concrete, Gypsum, and Plaster Products \\
\hline \multirow{6}{*}{ E3 } & 3211 & Flat Glass \\
\hline & 3221,3229 & Glass and Glassware, Pressed or Blown \\
\hline & 3231 & Glass Products Made of Purchased Glass \\
\hline & 3241 & Hydraulic Cement \\
\hline & 3281 & Cut Stone and Stone Products \\
\hline & $3291-3299$ & $\begin{array}{l}\text { Abrasive, Asbestos, and Miscellaneous Nonmetallic Mineral } \\
\text { Products }\end{array}$ \\
\hline \multicolumn{3}{|r|}{ SECTOR F: PRIMARY METALS } \\
\hline $\mathrm{Fl}$ & $3312-3317$ & Steel Works, Blast Furnaces, and Rolling and Finishing Mills \\
\hline F2 & $3321-3325$ & Iron and Steel Foundries \\
\hline F3 & $3351-3357$ & Rolling, Drawing, and Extruding of Nonferrous Metals \\
\hline F4 & 3363-3369 & Nonferrous Foundries (Castings) \\
\hline \multirow{3}{*}{ F5 } & $3331-3339$ & Primary Smelting and Refining of Nonferrous Metals \\
\hline & 3341 & Secondary Smelting and Refining of Nonferrous Metals \\
\hline & 3398,3399 & Miscellaneous Primary Metal Products \\
\hline
\end{tabular}




\begin{tabular}{|c|c|c|}
\hline \multicolumn{3}{|c|}{ Table D-1. Sectors of Industrial Activity Covered by This Permit } \\
\hline $\begin{array}{l}\text { Subsector } \\
\text { (May be subject } \\
\text { to more than one } \\
\text { sector/subsector) }\end{array}$ & $\begin{array}{l}\text { SIC Code or } \\
\text { Activity Code }\end{array}$ & Activity Represented \\
\hline \multicolumn{3}{|c|}{ SECTOR G: METAL MINING (ORE MINING AND DRESSING) } \\
\hline G1 & 1021 & Copper Ore and Mining Dressing Facilities \\
\hline \multirow{7}{*}{ G2 } & 1011 & Iron Ores \\
\hline & 1021 & Copper Ores \\
\hline & 1031 & Lead and Zinc Ores \\
\hline & 1041,1044 & Gold and Silver Ores \\
\hline & 1061 & Ferroalloy Ores, Except Vanadium \\
\hline & 1081 & Metal Mining Services \\
\hline & 1094,1099 & Miscellaneous Metal Ores \\
\hline \multicolumn{3}{|c|}{ SECTOR H: COAL MINES AND COAL MINING-RELATED FACILITIES } \\
\hline $\mathrm{Hl}$ & $1221-1241$ & Coal Mines and Coal Mining-Related Facilities \\
\hline \multicolumn{3}{|c|}{ SECTOR I: OIL AND GAS EXTRACTION } \\
\hline \multirow{3}{*}{11} & 1311 & Crude Petroleum and Natural Gas \\
\hline & 1321 & Natural Gas Liquids \\
\hline & $1381-1389$ & Oil and Gas Field Services \\
\hline \multicolumn{3}{|c|}{ SECTOR J: MINERAL MINING AND DRESSING } \\
\hline \multirow{2}{*}{$\mathrm{J} 1$} & 1442 & Construction Sand and Gravel \\
\hline & 1446 & Industrial Sand \\
\hline \multirow{4}{*}{$\mathrm{J} 2$} & 1411 & Dimension Stone \\
\hline & $1422-1429$ & Crushed and Broken Stone, Including Rip Rap \\
\hline & 1481 & Nonmetallic Minerals Services, Except Fuels \\
\hline & 1499 & Miscellaneous Nonmetallic Minerals, Except Fuels \\
\hline \multirow{2}{*}{$\mathrm{J} 3$} & 1455,1459 & Clay, Ceramic, and Refractory Materials \\
\hline & $1474-1479$ & Chemical and Fertilizer Mineral Mining \\
\hline \multicolumn{3}{|c|}{ SECTOR K: HAZARDOUS WASTE TREATMENT, STORAGE, OR DISPOSAL FACILITIES } \\
\hline $\mathrm{K} 1$ & $\mathrm{HZ}$ & $\begin{array}{l}\text { Hazardous Waste Treatment, Storage, or Disposal Facilities, } \\
\text { including those that are operating under interim status or a } \\
\text { permit under subtitle C of RCRA }\end{array}$ \\
\hline \multicolumn{3}{|c|}{ SECTOR L: LANDFILLS, LAND APPLICATION SITES, AND OPEN DUMPS } \\
\hline L1 & LF & All Landfill, Land Application Sites and Open Dumps \\
\hline L2 & LF & $\begin{array}{l}\text { All Landfill, Land Application Sites and Open Dumps, except } \\
\text { Municipal Solid Waste Landfill (MSWLF) Areas Closed in } \\
\text { Accordance with } 40 \text { CFR } 258.60\end{array}$ \\
\hline \multicolumn{3}{|c|}{ SECTOR M: AUTOMOBILE SALVAGE YARDS } \\
\hline M1 & 5015 & Automobile Salvage Yards \\
\hline
\end{tabular}




\begin{tabular}{|c|c|c|}
\hline \multicolumn{3}{|c|}{ Table D-1. Sectors of Industrial Activity Covered by This Permit } \\
\hline $\begin{array}{c}\text { Subsector } \\
\text { (May be subject } \\
\text { to more than one } \\
\text { sector/subsector) }\end{array}$ & $\begin{array}{l}\text { SIC Code or } \\
\text { Activity Code }\end{array}$ & Activity Represented \\
\hline \multicolumn{3}{|c|}{ SECTOR N: SCRAP RECYCLING FACILITIES } \\
\hline N1 & 5093 & $\begin{array}{l}\text { Scrap Recycling and Waste Recycling Facilities except } \\
\text { Source-Separated Recycling }\end{array}$ \\
\hline N2 & 5093 & Source-separated Recycling Facility \\
\hline \multicolumn{3}{|c|}{ SECTOR O: STEAM ELECTRIC GENERATING FACILITIES } \\
\hline 01 & SE & $\begin{array}{l}\text { Steam Electric Generating Facilities, including coal handling } \\
\text { sites }\end{array}$ \\
\hline \multicolumn{3}{|c|}{ SECTOR P: LAND TRANSPORTATION AND WAREHOUSING } \\
\hline \multirow{5}{*}{$\mathrm{Pl}$} & 4011,4013 & Railroad Transportation \\
\hline & $4111-4173$ & Local and Highway Passenger Transportation \\
\hline & $4212-4231$ & Motor Freight Transportation and Warehousing \\
\hline & 4311 & United States Postal Service \\
\hline & 5171 & Petroleum Bulk Stations and Terminals \\
\hline \multicolumn{3}{|c|}{ SECTOR Q: WATER TRANSPORTATION } \\
\hline Q1 & $4412-4499$ & Water Transportation Facilities \\
\hline \multicolumn{3}{|c|}{ SECTOR R: SHIP AND BOAT BUILDING AND REPAIRING YARDS } \\
\hline R1 & 3731,3732 & Ship and Boat Building or Repairing Yards \\
\hline \multicolumn{3}{|c|}{ SECTOR S: AIR TRANSPORTATION FACILITIES } \\
\hline S1 & $4512-4581$ & Air Transportation Facilities \\
\hline \multicolumn{3}{|r|}{ SECTOR T: TREATMENT WORKS } \\
\hline $\mathrm{T} 1$ & TW & $\begin{array}{l}\text { Treatment Works treating domestic sewage or any other } \\
\text { sewage sludge or wastewater treatment device or system, } \\
\text { used in the storage, treatment, recycling, and reclamation of } \\
\text { municipal or domestic sewage, including land dedicated to } \\
\text { the disposal of sewage sludge that are located within the } \\
\text { confines of the facility, with a design flow of } 1.0 \text { mgd or more, } \\
\text { or required to have an approved pretreatment program } \\
\text { under } 40 \text { CFR Part } 403 \text {. Not included are farm lands, } \\
\text { domestic gardens or lands used for sludge management } \\
\text { where sludge is beneficially reused and which are not } \\
\text { physically located in the confines of the facility, or areas that } \\
\text { are in compliance with section } 405 \text { of the CWA }\end{array}$ \\
\hline \multicolumn{3}{|c|}{ SECTOR U: FOOD AND KINDRED PRODUCTS } \\
\hline U1 & $2041-2048$ & Grain Mill Products \\
\hline $\mathrm{U} 2$ & 2074-2079 & Fats and Oils Products \\
\hline \multirow{2}{*}{ U3 } & $2011-2015$ & Meat Products \\
\hline & $2021-2026$ & Dairy Products \\
\hline
\end{tabular}




\begin{tabular}{|c|c|c|}
\hline \multicolumn{3}{|c|}{ Table D-1. Sectors of Industrial Activity Covered by This Permit } \\
\hline $\begin{array}{c}\text { Subsector } \\
\text { (May be subject } \\
\text { to more than one }\end{array}$ & $\begin{array}{l}\text { SIC Code or } \\
\text { Activity Code }\end{array}$ & Activity Represented \\
\hline & $2032-2038$ & $\begin{array}{l}\text { Canned, Frozen, and Preserved Fruits, Vegetables, and Food } \\
\text { Specialties }\end{array}$ \\
\hline & $2051-2053$ & Bakery Products \\
\hline & $2061-2068$ & Sugar and Confectionery Products \\
\hline & $2082-2087$ & Beverages \\
\hline & 2091-2099 & Miscellaneous Food Preparations and Kindred Products \\
\hline & $2111-2141$ & Tobacco Products \\
\hline \multicolumn{3}{|c|}{$\begin{array}{l}\text { SECTOR V: TEXTILE MILLS, APPAREL, AND OTHER FABRIC PRODUCT MANUFACTURING; LEATHER AND } \\
\text { LEATHER PRODUCTS }\end{array}$} \\
\hline \multirow{3}{*}{$\mathrm{V} 1$} & $2211-2299$ & Textile Mill Products \\
\hline & $2311-2399$ & $\begin{array}{l}\text { Apparel and Other Finished Products Made from Fabrics and } \\
\text { Similar Materials }\end{array}$ \\
\hline & $3131-3199$ & $\begin{array}{l}\text { Leather and Leather Products (note: see Sector Z1 for } \\
\text { Leather Tanning and Finishing) }\end{array}$ \\
\hline \multicolumn{3}{|c|}{ SECTOR W: FURNITURE AND FIXTURES } \\
\hline \multirow{2}{*}{ W1 } & 2434 & Wood Kitchen Cabinets \\
\hline & $2511-2599$ & Furniture and Fixtures \\
\hline \multicolumn{3}{|c|}{ SECTOR X: PRINTING AND PUBLISHING } \\
\hline $\mathrm{X} 1$ & $2711-2796$ & Printing, Publishing, and Allied Industries \\
\hline \multicolumn{3}{|c|}{$\begin{array}{l}\text { SECTOR Y: RUBBER, MISCELLANEOUS PLASTIC PRODUCTS, AND MISCELLANEOUS MANUFACTURING } \\
\text { INDUSTRIES }\end{array}$} \\
\hline \multirow{4}{*}{ Y1 } & 3011 & Tires and Inner Tubes \\
\hline & 3021 & Rubber and Plastics Footwear \\
\hline & 3052,3053 & $\begin{array}{l}\text { Gaskets, Packing and Sealing Devices, and Rubber and } \\
\text { Plastic Hoses and Belting }\end{array}$ \\
\hline & 3061,3069 & Fabricated Rubber Products, Not Elsewhere Classified \\
\hline \multirow{6}{*}{ Y2 } & $3081-3089$ & Miscellaneous Plastics Products \\
\hline & 3931 & Musical Instruments \\
\hline & 3942-3949 & Dolls, Toys, Games, and Sporting and Athletic Goods \\
\hline & $\begin{array}{c}3951-3955 \\
\text { (except } 3952- \\
\text { see Sector C) }\end{array}$ & Pens, Pencils, and Other Artists' Materials \\
\hline & 3961,3965 & $\begin{array}{l}\text { Costume Jewelry, Costume Novelties, Buttons, and } \\
\text { Miscellaneous Notions, Except Precious Metal }\end{array}$ \\
\hline & 3991-3999 & Miscellaneous Manufacturing Industries \\
\hline \multicolumn{3}{|c|}{ SECTOR Z: LEATHER TANNING AND FINISHING } \\
\hline Z1 & 3111 & Leather Tanning and Finishing \\
\hline
\end{tabular}




\begin{tabular}{|c|c|c|}
\hline $\begin{array}{l}\text { Subsector } \\
\text { (May be subject } \\
\text { to more than one } \\
\text { sector/subsector) }\end{array}$ & $\begin{array}{l}\text { SIC Code or } \\
\text { Activity Code }\end{array}$ & Activity Represented \\
\hline \multicolumn{3}{|c|}{ SECTOR AA: FABRICATED METAL PRODUCTS } \\
\hline \multirow[t]{2}{*}{ AAl } & $\begin{array}{c}3411-3499 \\
(\text { except } 3479)\end{array}$ & $\begin{array}{l}\text { Fabricated Metal Products, Except Machinery and } \\
\text { Transportation Equipment, and Coating, Engraving, and } \\
\text { Allied Services. }\end{array}$ \\
\hline & $3911-3915$ & Jewelry, Silverware, and Plated Ware \\
\hline AA2 & 3479 & Fabricated Metal Coating and Engraving \\
\hline \multicolumn{3}{|c|}{ SECTOR AB: TRANSPORTATION EQUIPMENT, INDUSTRIAL OR COMMERCIAL MACHINERY } \\
\hline \multirow{2}{*}{$A B 1$} & $\begin{array}{c}3511-3599 \\
\text { (except 3571- } \\
3579)\end{array}$ & $\begin{array}{l}\text { Industrial and Commercial Machinery, Except Computer and } \\
\text { Office Equipment (see Sector AC) }\end{array}$ \\
\hline & $\begin{array}{c}3711-3799 \\
\text { (except } 3731 \\
3732) \\
\end{array}$ & $\begin{array}{l}\text { Transportation Equipment Except Ship and Boat Building and } \\
\text { Repairing (see Sector R) }\end{array}$ \\
\hline \multicolumn{3}{|c|}{ SECTOR AC: ELECTRONIC, ELECTRICAL, PHOTOGRAPHIC, AND OPTICAL GOODS } \\
\hline \multirow{3}{*}{$\mathrm{ACl}$} & $3571-3579$ & Computer and Office Equipment \\
\hline & $3812-3873$ & $\begin{array}{l}\text { Measuring, Analyzing, and Controlling Instruments; } \\
\text { Photographic and Optical Goods, Watches, and Clocks }\end{array}$ \\
\hline & $3612-3699$ & $\begin{array}{l}\text { Electronic and Electrical Equipment and Components, } \\
\text { Except Computer Equipment }\end{array}$ \\
\hline \multicolumn{3}{|c|}{ SECTOR AD: NON-CLASSIFIED FACILITIES } \\
\hline AD1 & \multicolumn{2}{|c|}{$\begin{array}{l}\text { Other stormwater discharges designated by the Director as needing a permit } \\
\text { (see } 40 \text { CFR } 122.26 \text { (a) (9) (i) (C) \& (D)) or any facility discharging stormwater } \\
\text { associated with industrial activity not described by any of Sectors A-AC. NOTE: } \\
\text { Facilities may not elect to be covered under Sector AD. Only the Director may } \\
\text { assign a facility to Sector AD. }\end{array}$} \\
\hline
\end{tabular}

${ }^{1}$ A complete list of SIC Codes (and conversions from the newer North American Industry Classification System" (NAICS)) can be obtained from the Internet at www.census.gov/epcd/www/naics.html or in paper form from various locations in the document titled Handbook of Standard Industrial Classifications, Office of Management and Budget, 1987. 


\section{Appendix E - Procedures Relating to Endangered Species Protection}

\section{E.1 Assessing the Effects of Your Discharges and Discharge-Related Activities}

You must follow the procedures in this appendix to determine which of the eligibility criteria in Part 1.1.4.5 (i.e., criterion A - E), if any, you qualify under, by assessing the potential effects of applicable stormwater discharges, discharge-related activities, and allowable nonstormwater discharges on listed threatened and endangered species and their designated critical habitat. In accordance with Part 5.2.6.1 of this permit, you must keep any documentation that supports your eligibilty determination, including the completed Criterion Selection Worksheet in Part E.4 of this appendix, with your Stormwater Pollution Prevention Plan (SWPPP). You must complete your eligibility determination prior to submitting your Notice of Intent (NOI) for coverage under the MSGP, and must provide all information as required on your NOI form that supports the Part 1.1.4.5 eligibility criterion you qualify under. Note that if you have determined that you may be eligible under criterion $C$, you must submit a completed Criterion $C$ Eligibility Form to EPA a minimum of $\mathbf{3 0}$ days prior to submitting your NOI for permit coverage.

When evaluating the potential effects of your activities, you must consider effects to listed species or critical habitats within the "action area" of your industrial activity. Action area is defined in Appendix A of the MSGP as all areas to be affected directly or indirectly by the federal action and not merely the immediate area involved in the action. This includes areas beyond the footprint of the facility that are likely to be affected by stormwater discharges, discharge-related activities, and allowable non-stormwater discharges. For example, discharges of pollutants into downstream areas can increase the "action area" beyond the footprint of the facility.

\section{E.2 Eligibility Criterion}

As required by Part 1.1.4.5, you must meet one or more of the following five criteria (A - E) to be eligible for coverage under the permit:

Criterion A. No federally listed threatened or endangered species or their designated critical habitat(s) are likely to occur in the "action area" as defined in Appendix A. To certify your eligibility under this criterion, you must use the Criterion Selection Worksheet in Part E.4 of Appendix E. You must also provide a description of the basis for the criterion you selected on your NOI form and provide documentation supporting your eligibility determination in your SWPPP.

Criterion B. Your industrial activity's discharges and discharge-related activities were already addressed in another operator's valid certification of eligibility for your action area under this permit and there is no reason to believe that federally listed species or designated critical habitat not considered in the prior certification may be present or located in the "action area" (e.g., due to a new species listing or critical habitat designation). To certify your eligibility under this criterion, you must use the Criterion Selection Worksheet in Part E.4 of Appendix E. There must be no lapse of NPDES permit coverage in the other operator's certification. You must also comply with any additional measures that formed the basis of the other operator's valid certification of eligibility to ensure that your discharges and discharge-related activities are protective of listed species and/or critical habitat. You must include in your NOI the NPDES ID (i.e., permit tracking number) assigned to the other operator's authorization under this permit, and a description of the basis for the criterion selected on your NOI form, including the eligibility criterion selected by the 
other operator's certification. You must also provide any documentation in your SWPPP that supports the other operator's eligibility determination, including any additional measures that formed the basis of the other operator's eligibility determination.

Criterion C. Federally listed threatened or endangered species or their designated critical habitat(s) are likely to occur in or near your facility's "action area," and your industrial activity's discharges and discharge-related activities are not likely to adversely affect listed threatened or endangered species or critical habitat. To certify your eligibility under this criterion, you must use the Criterion Selection Worksheet in Part E.4 of Appendix E, including completion of the Criterion C Eligibility Form, which you must submit to EPA at least 30 days prior to filing your $\mathrm{NOI}$ for permit coverage. After evaluation of your Criterion C Eligibility Form, EPA may require additional measures that you must implement to avoid or eliminate likely adverse effects on listed species and critical habitat from discharges and discharge-related activities. You may submit your NOI for permit coverage 30 days after submitting to EPA your completed Criterion C Eligibility Form. You must also provide a description of the basis for the criterion you selected on your $\mathrm{NOI}$ form and provide documentation supporting your eligibility determination in your SWPPP.

Criterion D. Consultation between a Federal Agency and the U.S. Fish and Wildlife Service and/or the National Marine Fisheries Service under section 7 of the Endangered Species Act (ESA) has been concluded. Consultations can be either formal or informal, and would have occurred only as a result of a separate federal action (e.g., during application for an individual wastewater discharge permit or the issuance of a wetlands dredge and fill permit), and consultation must have addressed the effects of the industrial activity's discharges and discharge-related activities on all federally listed threatened or endangered species and federally designated critical habitat. The result of this consultation must be one of the following:

i. A biological opinion that concludes that the action in question (taking into account the effects of your facility's discharges and discharge-related activities) is not likely to jeopardize the continued existence of listed species, or result in the destruction or adverse modification of critical habitat;

ii. A biological opinion that concludes that the action is likely to jeopardize listed species or to result in the destruction or adverse modification of critical habitat, and any recommended reasonable and prudent alternatives or reasonable and prudent measures are being implemented; or

iii. Written concurrence from the applicable Service(s) with a finding that your facility's discharges and discharge-related activities are not likely to adversely affect listed species or critical habitat.

To certify your eligibility under this criterion, you must use the Criterion Selection Worksheet in Part E.4 of Appendix E. You must verify that the consultation does not warrant reinitiation under 50 CFR $\S 402.16$. If reinitiation of consultation is required, in order to be eligible under this criterion you must ensure consultation is reinitiated and the result of the consultation must be consistent with (i), (ii), or (iii) above.

If eligible, you must also provide supporting documentation for your determination in your NOI and SWPPP, including the Biological Opinion (or PCTS tracking number) or concurrence letter. 
Criterion E. Your industrial activities are the subject of a permit under section 10 of the ESA, and this authorization addresses the effects of your facility's discharges and dischargerelated activities on federally listed species and designated critical habitat. To certify your eligibility under this criterion, you must use the Criterion Selection Worksheet in Part E.4 of Appendix E. You must also provide supporting documentation for your determination in your NOI and SWPPP, including a copy of the permit from the Services.

\section{E.3 Eligibility Compliance}

You must comply with any measures that formed the basis of your eligibility determination in Part 1.1.4.5 for the duration of your coverage under the MSGP in order to maintain your eligibility for coverage under the permit. These measures become permit requirements per Part 2.3.

Documentation of these measures must be kept as part of your SWPPP (see Part 5.2.6.1).

\section{E.4 Criterion Selection Worksheet}

\section{Instructions:}

You must follow the step-by-step instructions in this worksheet in order to determine your eligibility under the Part 1.1.4.5 criteria. Alternatively, if you prefer to use a Biological Evaluation (or its equivalent) in making a determination of your eligibility, you should ensure all of the information requested below for the criterion you are selecting is fully addressed in such a document. You must attach this completed document or Biological Evaluation (or equivalent) to your SWPPP to support your Part 1.1.4.5 eligibility determination.

\section{You may need the following information in order to determine your eligibility:}

1) Your facility's draft Stormwater Pollution Prevention Plan (SWPPP), including information on receiving waters.

2) Any additional site-specific information related to your facility's discharges and discharge-related activities.

3) The list(s) of endangered and threatened species and any designated critical habitat in your action area, as acquired from the Fish and Wildlife Service and/or the National Marine Fisheries Services. Directions on how to acquire species lists is described in a subsequent section below.

Note that much of the information needed to complete this worksheet is also needed in order to prepare your $\mathrm{NOI}$ for permit coverage, and is also information that you must develop as part of your SWPPP. You may copy and paste any information that is already required and completed in your SWPPP into this worksheet. (You may also decide to make minor changes or additions to your SWPPP while filling out the worksheet for clarification purposes or to address any concerns that are identified below.)

\section{STEP 1: DETERMINE IF THE ELIGIBILITY REQUIREMENTS OF CRITERION B, D, OR E CAN BE MET.}

A. You should first determine whether you are eligible under criterion B (because another operator has accounted for your action area in their valid certification of eligibility under the 2015 MSGP), criterion D (because of a previously completed ESA section 7 consultation), or criterion $\mathrm{E}$ (because of a previously issued ESA section 10 permit). 
B. If your facility is likely to be eligible under criterion B, D or E, you may skip ahead to the applicable criterion's requirements to determine if you are eligible. If after completing the relevant section you find that your facility does not in fact meet criteria B, D, or E (e.g., due to difference in action area described, lack of analysis of appropriate effects, new listings or designation of critical habitat), proceed to Step 2 below.

C. If your facility is not likely to be eligible under criterion B, D or E, you may proceed directly to Step 2.

\section{Criterion B Eligibility Requirements}

If your industrial activities were already addressed in another operator's valid certification of eligibility under the current 2015 MSGP, you may be eligible for coverage under criterion B. In order to be eligible for coverage under criterion $B$, you must confirm that all the following are true:

You have confirmed that the other operator's certification of eligibility accounted for your action area and that the eligibility determination was valid.

$\square$ There has been no lapse of NPDES permit coverage in the other operator's certification.

You will comply with all measures that formed the basis of the other operator's valid certification of eligibility. List any measures here (or enter "N/A" if none exist):

- If all of the above are true, you may select criterion B on your NOI. You must include in your NOI the NPDES ID assigned to the other operator's authorization under this permit, and a description of the basis for the criterion selected on your NOI form, including the eligibility criterion selected by the other operator's certification. You must include this completed worksheet in your SWPPP.

- If any of the above are not true, you may not select criterion B and must proceed to Step 2. For example, if there are any listed species in your action area that were not addressed in the other operator's certification, you are not eligible under criterion B.

\section{Criterion D Eligibility Requirements}

If consultation under section 7 of the ESA has been concluded, you may be eligible for coverage under criterion D. In order to be eligible or coverage under criterion D, you must confirm that all the following are true:

A consultation between a federal agency and the U.S. Fish and Wildlife Service and/or the National Marine Fisheries Service under section 7 of the ESA has been concluded. Consultations can be either formal or informal, and would have occurred only as a result of a separate federal action (e.g., during application for an individual wastewater discharge permit or the issuance of a wetlands dredge and fill permit), and the consultation must have addressed the effects of your industrial activity's discharges and discharge-related activities on all federally listed threatened or endangered species and all designated critical habitat in your action area. The result of this consultation must be either: 
i. A biological opinion that concludes that the action in question (taking into account the effects of your facility's discharges and discharge-related activities) is not likely to jeopardize the continued existence of listed species, or result in the destruction or adverse modification of critical habitat. The biological opinion must have included the effects of your facility's dischargesa and discharge-related activities on all the listed species and designated critical habitat in your action area;

ii. A biological opinion that concludes that the action is likely to jeopardize listed species or to result in the destruction or adverse modification of critical habitat, and any recommended reasonable and prudent alternatives or reasonable and prudent measures are being implemented; or

iii. Written concurrence (e.g., letter of concurrence) from the applicable Service(s) with a finding that concludes that your facility's discharges and discharge-related activities are not likely to adversely affect listed species or designated critical habitat. The concurrence letter must have included the effects of your facility's discharges and discharge-related activities on all the listed species and designated critical habitat on your species list(s) acquired from the Service(s) as part of this worksheet.

The consultation does not warrant reinitiation under 50 CFR $\S 402.16$; or, if reinitiation of consultation is required (e.g., due to a new species listing or critical habitat designation; new information), you have reinitiated the cosultation and the result of the consultation is consistent with the statements above. Attach a copy of any reinitiation documentation from the Services or other consulting federal agency.

- If all of the above are true, you may select criterion D on your NOI. You must also provide a description of the basis for the criterion selected on your NOI form and you must include this completed worksheet in your SWPPP. In both your SWPPP and NOI you must also provide the Biological Opinion (or PCTS tracking number) or concurrence letter and any other documentation supporting your eligibility determination.

- If any of the above are not true, you may not select criterion D and must proceed to Step 2. For example, if the biological opinion or written concurrence did not include the effects of the discharge or discharge-related activities as described above (e.g., the previous consultation covered some but not all of the species or critical habitat in your action area as shown on your species list), or if the consultation is no longer valid (e.g., due to new species listings), you are not eligible under criterion $D$.

\section{Criterion E Eligibility Requirements}

If your industrial activities are the subject of a permit under section 10 of the ESA, and this authorization addresses the effects of your facility's discharges and discharge-related activities on federally listed species and designated critical habitat in your action area, you may be eligible for coverage under criterion $\mathrm{E}$. In order to be eligible or coverage under criterion $\mathrm{E}$, you must confirm that the following is true:

A permit has been issued under section 10 of the ESA. The permit authorization specifically addresses the effects of your facility's discharges and discharge-related activities (if applicable) on all federally-listed species and designated critical habitat in your action area.

\footnotetext{
a Effects of discharge includes, but is not limited to, the analysis of the hydrological, chemical, and biological effects of the discharge on listed species, their prey, and their habitat, as well as critical habitat, where designated. For example, the effects analysis would have evaluated whether the various pollutants in the discharge (e.g., TSS, metals) would adversely affect listed species through exposure to the pollutants, or to their prey or habitat. Effects that look only at short-term effects unrelated to the stormwater discharge effects to listed species are not sufficient for these purposes.
} 
- If the above is true, you may select criterion E on your NOI. You must also provide a description of the basis for the criterion selected on your NOI form and must include this completed worksheet in your SWPPP. In both your SWPPP and your NOI you must provide a copy of the section 10 permit issued by the Services.

- If the above is not true, you may not select criterion $\mathrm{E}$ and must proceed to Step 2. For example, if a permit has been issued under section 10 of the ESA, but the permit authorization did not address the effects of your facility's discharges and/or discharge-related activities on all federally-listed species and designated critical habitat in your action area, you are not eligible under criterion E, but you should attach a copy of the permit to the SWPPP for reference.

\section{STEP 2: DETERMINE THE EXTENT OF YOUR ACTION AREA}

You must determine whether species listed as either threatened or endangered, or their critical habitat(s) (see definitions of these terms in Appendix A), are located in your facility's action area (i.e., all areas to be affected directly or indirectly by the federal action and not merely the immediate area involved in the action, including areas beyond the footprint of the facility that are likely to be affected by stormwater discharges, discharge-related activities, and allowable nonstormwater discharges). Consider the following in determining the action area for your facility:

- Discharges of pollutants into downstream areas can expand the action area well beyond the footprint of your facility and the discharge point(s). Take into account the controls you will be implementing to minimize pollutants and the receiving waterbody characteristics (e.g., perennial, intermittent, ephemeral) in determining the extent of physical, chemical, and/or biotic effects of the discharges. All receiving waterbodies that could receive pollutants from your facility must be included in your action area.

- Discharge-related activities must also be accounted for in determining your action area. Discharge-related activities are any activities that cause, contribute to, or result in stormwater and allowable non-stormwater point source discharges, and measures such as the siting, construction, and operation of stormwater controls to control, reduce, or prevent pollutants from being discharged. For example, any new or modified stormwater controls that will have noise or other similar effects, and any disturbances associated with construction of controls, are part of your action area.

If you have any questions about determining the extent of your action area, you may contact EPA or the Services for assistance.

You must include a map and a written description of the action area of your facility in Attachment 1 of this appendix. You may choose to include the map that is generated from the FWS' on-line mapping tool IPaC (the Information, Planning, and Consultation System) located at http://ecos.fws.gov/ipac/ (see Step 3 for information about using this tool).

You must proceed to step 3 below.

\section{STEP 3: DETERMINE IF LISTED THREATENED OR ENDANGERED SPECIES AND/OR CRITICAL HABITAT ARE PRESENT IN YOUR ACTION AREA.}

You must determine whether species listed as either threatened or endangered under the Endangered Species Act (ESA), and/or their designated critical habitat(s)b, are located in your facility's action area. Federally listed species and designated critical habitat are under the purview of the National Marine Fisheries Service (NMFS) and the U.S. Fish and Wildlife Service (FWS) (together, "Services"), and in many cases, species and critical habitat lists will need to be acquired from both Services.

\footnotetext{
b See definitions of these terms in Appendix A of the MSGP.
} 
- For NMFS species and critical habitat information, use the following webpages, which provide up-to-date information on listed species

(http://www.nmfs.noaa.gov/pr/species/esa/) and critical habitat (http://www.nmfs.noaa.gov/pr/species/criticalhabitat.htm). To determine the field office that corresponds to your facility, go to http://www.nmfs.noaa.gov/ (under the left tab for "Regions"). For NMFS species in the Greater Atlantic Region, go to http://www.greateratlantic.fisheries.noaa.gov/protected/section7/guidence/maps/index.html.

- For FWS species information, use the on-line mapping tool IPaC (the Information, Planning, and Consultation System) located at http://ecos.fws.gov/ipac/, and follow these steps:

- Select Get Started.

- Select Enter Project Location

- Use an address, city name or other location to zoom into your project area

- Use the zoom feature to see the entire extent of your action area on the screen.

- Use one of the mapping features (e.g., Polygon or line feature) to draw your action.

- For the aquatic portion of your action area, trace the waterbody(ies) with the tool to characterize your action area.

- If your proposal will include any upland activities (i.e., discharge-related activities), or if there is some aspect of your discharge that would potentially result in effects to terrestrial species, include the corresponding upland areas within your action area.

- When you are done, press Continue.

- Select Request an Official Species List

- Complete the fields on the Official Species List Request page, and include "(MSGP)" at the end of the project description.

- For Classification, select "Water Quality Modification".

- Select the appropriate requesting agency/organization type (for most applicants, this should be "Other").

- Submit the request to acquire an Official Species List, which should show both listed species as well as any designated critical habitat that are present in the action area in the previous step.

- Note: If a link to an Official Species List is not available on the page, follow the web link of the office(s) indicated, or contact the office directly by mail or phone if a web link is not shown.

The principle authority for critical habitat designations and associated requirementsis found at 50 CFR Parts 17 and 226. See http://www.access.gpo.gov.

Attach a copy of the species and critical habitat list(s) from the Service(s) to Attachment 2 of this appendix and use the list(s) to complete the rest of this worksheet. For FWS species, include the full printout from your IPaC query/Official Species List in Attachment 2. You can include the map from your IPaC query in Attachment 1.

If after following the steps you have determined that there are no listed species and/or designated critical habitat in your action area, you may be eligible for coverage under criterion $A$.

If you have determined that there are or may be listed species and/or designated critical habitat in your action area, you are not eligible under criterion A and must proceed to Step 4 below. 


\section{Criterion A Eligibility Requirements}

In order to be eligible for coverage under criterion A, you must confirm that the following is true:

I have confirmed there to be no listed species and no critical habitat in my action area.

- If the above is true, you may select criterion A on your NOI

form. You must also provide a description of the basis for the criterion selected on your NOI form. You must include this completed worksheet in your SWPPP. Note: If your Official Species List from the USFWS indicated no species or critical habitat were present in your action area, include the full consultation tracking code at the top of your Official Species List in your NOI submittal in the question "Provide a brief summary of the basis for the criterion selected in Appendix E." If an Official Species List was not available on IPaC, list the contact date and name of the Service staff with whom you corresponded to verify no USFWS species or critical habitat were present in your action area.

- If the above is not true, you may not select criterion A and must proceed to Step 4 to determine if you can become eligible under criterion $C$.

\section{STEP 4: DETERMINE IF YOUR INDUSTRIAL FACILITY'S DISCHARGES OR DISCHARGE-RELATED ACTIVITIES ARE LIKELY TO ADVERSELY AFFECT LISTED THREATENED OR ENDANGERED SPECIES OR DESIGNATED CRITICAL HABITAT AND ANY MEASURES THAT MUST BE IMPLEMENTED TO AVOID ADVERSE EFFECTS}

If in Step 3 you determined that listed species and/or designated critical habitat could exist in your action area, you must next assess whether your discharges and discharge-related activities are likely to adversely affect listed threatened or endangered species or designated critical habitat, and whether any additional measures are necessary to ensure no likely adverse effects. In order to make a determination of your facility's likelihood of adverse effects, you must complete the attached Criterion C Eligibility Form and must submit this form to EPA a minimum of 30 days prior to filing your $\mathrm{NOI}$ for permit coverage. After you submit your Criterion C Eligibility Form, you may be contacted by EPA with additional measures that you must implement in order to ensure your eligibililty under criterion C. 


\section{Criterion C Eligibility Form}

\section{Instructions:}

In order to be eligible for coverage under criterion $C$, you must complete the following form and you must submit it to EPA following the instructions in Section VII a minimum of $\mathbf{3 0}$ days prior to filing your NOI for permit coverage. After you submit your form, you may be contacted by EPA with additional measures (e.g., additional stormwater controls or modifications to your dischargerelated activities) that you must implement in order to ensure your eligibility under criterion $\mathrm{C}$.

If after completing this worksheet you cannot make a determination that your discharges and discharge-related activities are not likely to adversely affect listed threatened or endangered species or designated critical habitat, you must submit this completed worksheet to EPA, and you may not file your NOI for permit coverage until you receive a determination from EPA that your discharges and/or discharge-related activities are not likely to adversely affect listed species and critical habitat.

Note: Much of the information needed for this form can be obtained from your draft SWPPP which will be needed when you file your NOI.

\section{SECTION I. OPERATOR, FACILITY, AND SITE LOCATION INFORMATION.}

\section{1) Operator Information}

a) Operator Name:

b) Point of Contact

First Name: Last Name:

Phone Number:

E-mail:

\section{2) Facility Information}

a) Facility Name:

b) Check which of the following applies:

I am seeking coverage under the MSGP as a new discharger or as a new source

I am seeking coverage under the MSGP as an existing discharger and my facility has modifications to its discharge characteristics (e.g., changes in discharge flow or area drained, different pollutants) and/or discharge-related activities (e.g., stormwater controls)

Indicate the number of years the facility has been in operation: years

Provide your NPDES ID (i.e., permit tracking number) from your previous MSGP coverage:

I am seeking coverage under the MSGP as an existing discharger and there are no modifications to my facility.

Indicate the number of year the facility has been in operation: years

Provide your NPDES ID (i.e., permit tracking number) from your previous MSGP coverage: 
c) Facility Address:

Address 1:

Address 2:

City:

State:

Zip Code:

d) Identify the primary industrial sector to be covered under the 2015 MSGP:

SIC Code or Primary Activity Code

Sector and Subsector

e) Identify the sectors of any co-located activities to be covered under the 201r MSGP:

$\begin{array}{ll}\text { Sector } & \text { Subsector } \\ \text { Sector } & \text { Subsector } \\ \text { Sector _ } & \text { Subsector } \\ \text { Sector } & \text { Subsector } \\ \text { Sector } & \text { Subsector } \\ \text { Sector } & \text { Subsector }\end{array}$

f) Estimated area of industrial activity exposed to stormwater: acres

g) Provide a general description of the industrial activities that are taking place at this facility:

3) Receiving Waters Information

\begin{tabular}{|l|l|l|l|l|l|}
\hline \multicolumn{2}{|l|}{ List all the stormwater outfalls from your facility. } & \multicolumn{2}{l|}{$\begin{array}{l}\text { For each outfall, provide the following receiving } \\
\text { water information: }\end{array}$} \\
\hline Outfall ID & $\begin{array}{l}\text { Design } \\
\text { Capacity } \\
\text { (if known) }\end{array}$ & $\begin{array}{l}\text { Latitude } \\
\text { (decimal } \\
\text { degrees) }\end{array}$ & $\begin{array}{l}\text { Longitude } \\
\text { (decimal } \\
\text { degrees) }\end{array}$ & $\begin{array}{l}\text { Name of the receiving water } \\
\text { that receives stormwater } \\
\text { from the outfall and/or from } \\
\text { the MS4 that the outfall } \\
\text { discharges to }\end{array}$ & $\begin{array}{l}\text { Type of Waterbody } \\
\text { (e.g., lake, pond, } \\
\text { river/stream/creek, } \\
\text { estuarine/marine } \\
\text { water) }\end{array}$ \\
\hline & & $---\cdot----$ & $---\cdot----$ & & \\
\hline & $---\cdot----$ & $---\cdot----$ & & \\
\hline & & $---\cdot----$ & $---\cdot----$ & & \\
\hline & & $---\cdot----$ & $---\cdot----$ & & \\
\hline
\end{tabular}




\section{SECTION II. ACTION AREA}

Ensure that your action area is described in Attachment 1, as required in $\underline{\text { Step } 2 .}$

\section{SECTION III. LISTED SPECIES AND CRITICAL HABITAT LIST}

Ensure that the listed species and critical habitat list is included in Attachment 2, as required in Step 3.

Review your species list in Attachment 2, choose one of the following three statements, and follow the corresponding instructions:

$\square$ The species list includes only terrestrial species and/or their designated critical habitat. No aquatic or aquaticdependent species or their critical habitat are present in the action area. You may skip to Section IV of this form.

You are not required to fill out Section V.

The species list includes only aquatic and/or aquatic-

Note: For the purposes of this permit, "terrestrial species" would not include animal or plant species that 1) spends any portion of its life cycle in a waterbody or wetland, or 2) if an animal, depends on prey or habitat that occurs in a waterbody or wetland. For example, shorebirds, wading birds, amphibians, and certain reptiles would not be considered terrestrial species under this definition. Please also be aware that some terrestrial animals (e.g., certain insects, amphibians) may have an aquatic egg or larval/juvenile phase.

dependent species and/or their designated critical habitat. No terrestrial species or their critical habitat are present in the action area. You may skip to Section $\mathbf{V}$ of this form and are not required to fill out Section IV.

The species list includes both terrestrial and aquatic or aquatic-dependent species and/or their designated critical habitat. You must fill out both Sections $\underline{I V}$ and $\underline{\mathbf{V}}$ of this form.

\section{SECTION IV. EVALUATION OF DISCHARGE-RELATED ACTIVITIES EFFECTS}

Note: You are only required to fill out this section if your facility's action area contains terrestrial species and/or their designated critical habitat. If your action area only contains aquatic and/or aquatic-dependent species and/or their designated critical habitat, you can skip directly to Section $\mathrm{V}$.

Most of the potential effects related to coverage under the MSGP are assumed to occur to aquatic and/or aquatic-dependent species. However, in some cases, potential effects to terrestrial species and/or their critical habitat should be considered as well from any discharge-related activities that occur during coverage under the MSGP. Examples of discharge-related activities that could have potential effects on listed terrestrial species or their critical habitat include the storage of materials and land disturbances associated with stormwater management-related activities (e.g., the installation or placement of stormwater control measures).

\section{A. Select the applicable statement(s) below and follow the corresponding instructions:}

There are no discharge-related activities that are planned to occur during my coverage under the MSGP. You can conclude that your discharge-related activities will have no likely adverse effects, and:

- If there are any aquatic or aquatic-dependent species and/or their critical habitat in your action area, you must skip to Section V , Evaluation of Discharge Effects, below.

- If there are no aquatic or aquatic-dependent species you may skip to Section VI and verify that your activities will have no likely adverse effects. You must submit this form to EPA as specified in Section VII of this form. You may select criterion C on your NOI form and may submit your NOI for permit coverage 30 days after you have submitted this Criterion C Eligibility Form. You must also provide a description of the basis for the criterion you selected on your NOI form, including the species and critical habitat list(s) in your action area, as well as any other documentation supporting your eligibility. You must also include this completed Criterion C Eligiblity Form in your SWPPP. 
There are discharge-related activities planned as part of the proposal. Describe your dischargerelated activities in the following box and continue to (b) below.

Describe discharge-related activities:

B. In order to ensure any discharge-related activities will have no likely adverse effects on listed species and/or their designated critical habitat, you must certify that all the following are true:

$\square$ Discharge-related activities will occur:

- on previously cleared/developed areas of the site where maintenance and operation of the facility are currently occurring or where existing conditions of the area(s) in which the discharge-related activities will occur precludes its use by listed species (e.g., work on existing impervious surfaces, work occurring inside buildings, area is not used by species), and

- if discharge-related activities will include the establishment of structures (including, but not limited to, infiltration ponds and other controls) or any related disturbances, these structures and/or disturbances will be sited in areas that will not result in isolation or degradation of nesting, breeding, or foraging habitat or other habitat functions for listed animal species (or their designated critical habitat), and will avoid the destruction of native vegetation (including listed plant species).

If vegetation removal (e.g., brush clearing) or other similar activities will occur, no terrestrial listed species that use these areas for habitat would be expected to be present during vegetation removal.

If all the above are true, you can conclude that your discharge-related activities will have no likely adverse effects, and:

- If there are any aquatic or aquatic-dependent species and/or critical habitat in your action area, you must skip to Section V. Evaluation of Discharge Effects, below.

- If there are no aquatic or aquatic-dependent species you may skip to Section VI and verify that your activities will have no likely adverse effects. You must submit this form to EPA as specified in Section VII of this form. You may select criterion $\mathrm{C}$ on your NOI and may submit your NOI for permit coverage 30 days after you have submitted this completed form. You must also provide a description of the basis for the criterion you selected on your NOI form, including the species and critical habitat list(s), and any other documentation supporting your eligibility. You must also include this completed Criterion C Eligibility Form in your SWPPP.

- If any of the above are not true, you cannot conclude that your discharge-related activities will have no likely adverse effects. You must complete the rest of this form (if applicable), and must submit the form to EPA for assistance in determining your eligibility for coverage. 


\section{SECTION V. EVALUATION OF DISCHARGE EFFECTS}

Note: You are only required to fill out this section if your facility's action area includes aquatic and/or aquatic-dependent species and/or their critical habitat.

In this section, you will evaluate the likelihood of adverse effects from your facility's discharges. The scope of effects to consider will vary with each facility and species/critical habitat characteristics. The following are examples of discharge effects you should consider:

- Hydrological Effects. Stormwater discharges may adversely affect receiving waters from pollutant parameters such as turbidity, temperature, salinity, or $\mathrm{pH}$. These effects will vary with the amount of stormwater discharged and the volume and condition of the receiving water. Where a stormwater discharge constitutes a minute portion of the total volume of the receiving water, adverse hydrological effects are less likely.

- Toxicity of Pollutants. Pollutants in stormwater may have toxic effects on listed species and may adversely affect critical habitat. Exceedances of benchmarks, effluent limitation guidelines, or state or tribal water quality requirements may be indicative of potential adverse effects on listed species or critical habitat. However, some listed species may be adversely affected at pollutant concentrations below benchmarks, effluent limitation guidelines, and state or tribal water quality standards. In addition, stormwater pollutants identified in Part 5.2.3.2 of your SWPPP, but not monitored as benchmarks or effluent limitation guidelines, may also adversely affect listed species and critical habitat.

As these effects are difficult to analyze for listed species, their prey, habitat, and designated critical habitat, this form helps you to analyze your discharges and make a determination of whether your discharges will have likely adverse effects and whether there are any additional controls you can implement to ensure no likely adverse effects.

A. Evaluation of Pollutants and Controls to Avoid Adverse Effects. In this section, you must document all of your pollutant sources and pollutants expected to be discharged in stormwater. You must also document the controls you will implement to avoid adverse effects on listed aquatic and aquatic-dependent species. You must include specific details about the expected effectiveness of the controls in avoiding adverse effects to the listed aquatic-and aquatic-dependent species. Attach additional pages if needed.

\begin{tabular}{|c|c|c|}
\hline Potential Pollutant Source & Potential Pollutants & $\begin{array}{l}\text { Controls to Avoid Adverse Effects on Listed Aquatic and } \\
\text { Aquatic-Dependent Species. Include information supporting } \\
\text { why the control(s) will ensure no adverse effects, including any } \\
\text { data you have about the effectiveness of the control(s) in } \\
\text { reducing pollutant concentrations. You may also attach photos } \\
\text { of your controls to this form. }\end{array}$ \\
\hline $\begin{array}{l}\text { e.g., vehicle and } \\
\text { equipment fueling }\end{array}$ & $\begin{array}{l}\text { e.g., } \\
\text { - Oil \& grease } \\
\text { - Diesel } \\
\text { - Gasoline } \\
\text { - TSS } \\
\text { - Antifreeze }\end{array}$ & $\begin{array}{l}\text { e.g., } \\
\text { - Fueling operators (including the transfer of fuel from } \\
\text { tank trucks) will be conducted on an impervious or } \\
\text { contained pad or under cover } \\
\text { - Drip pans will be used where leaks or spills of fuel } \\
\text { can occur and where making and breaking hose } \\
\text { connections } \\
\text { - Spill kit will be kept on-site in close proximity to } \\
\text { potential spill areas } \\
\text { - Any spills will be cleaned-up immediately using dry } \\
\text { clean up methods } \\
\text { - Stormwater runoff will be diverted around fueling } \\
\text { areas using diversion dikes and curbing }\end{array}$ \\
\hline
\end{tabular}




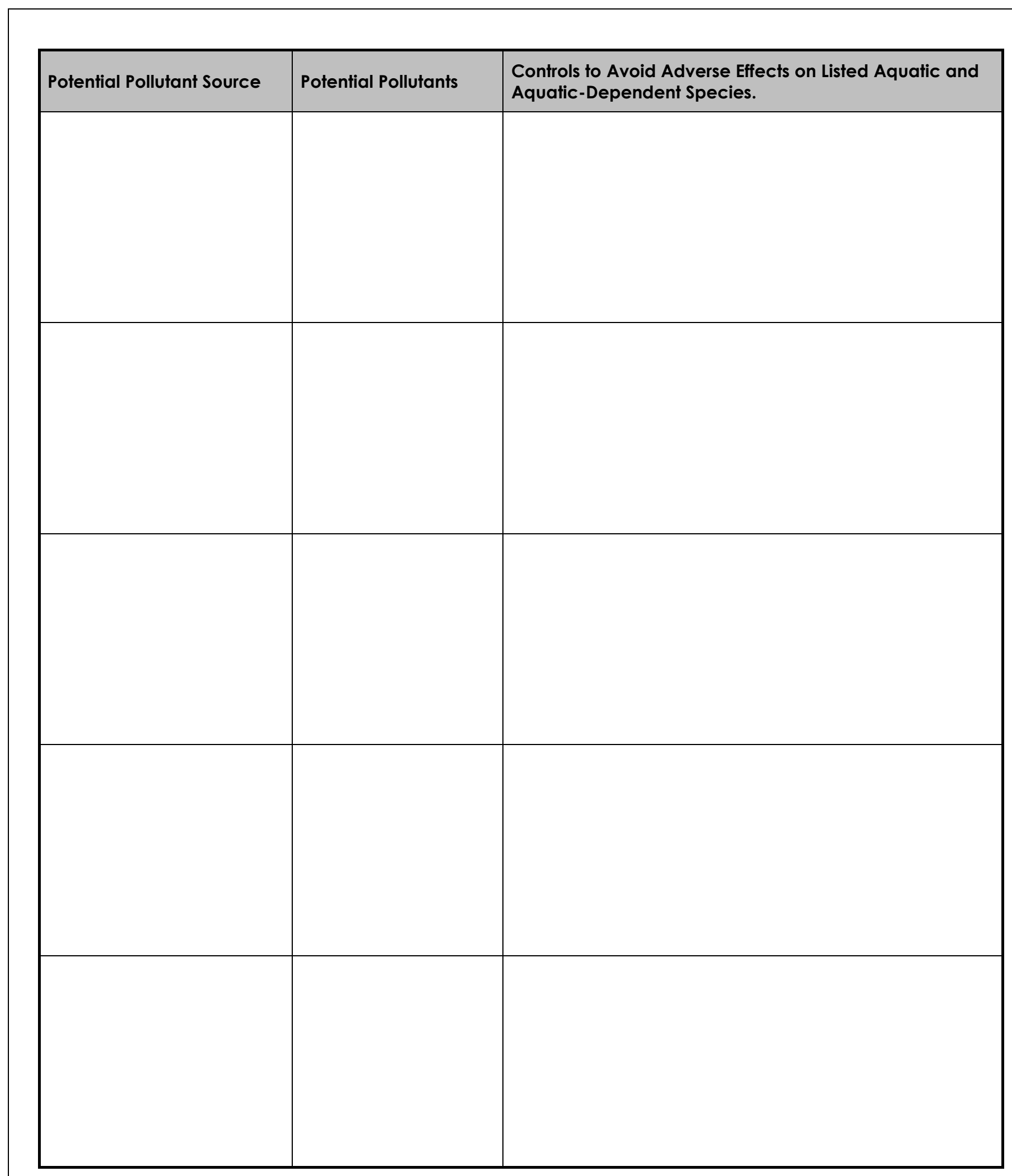




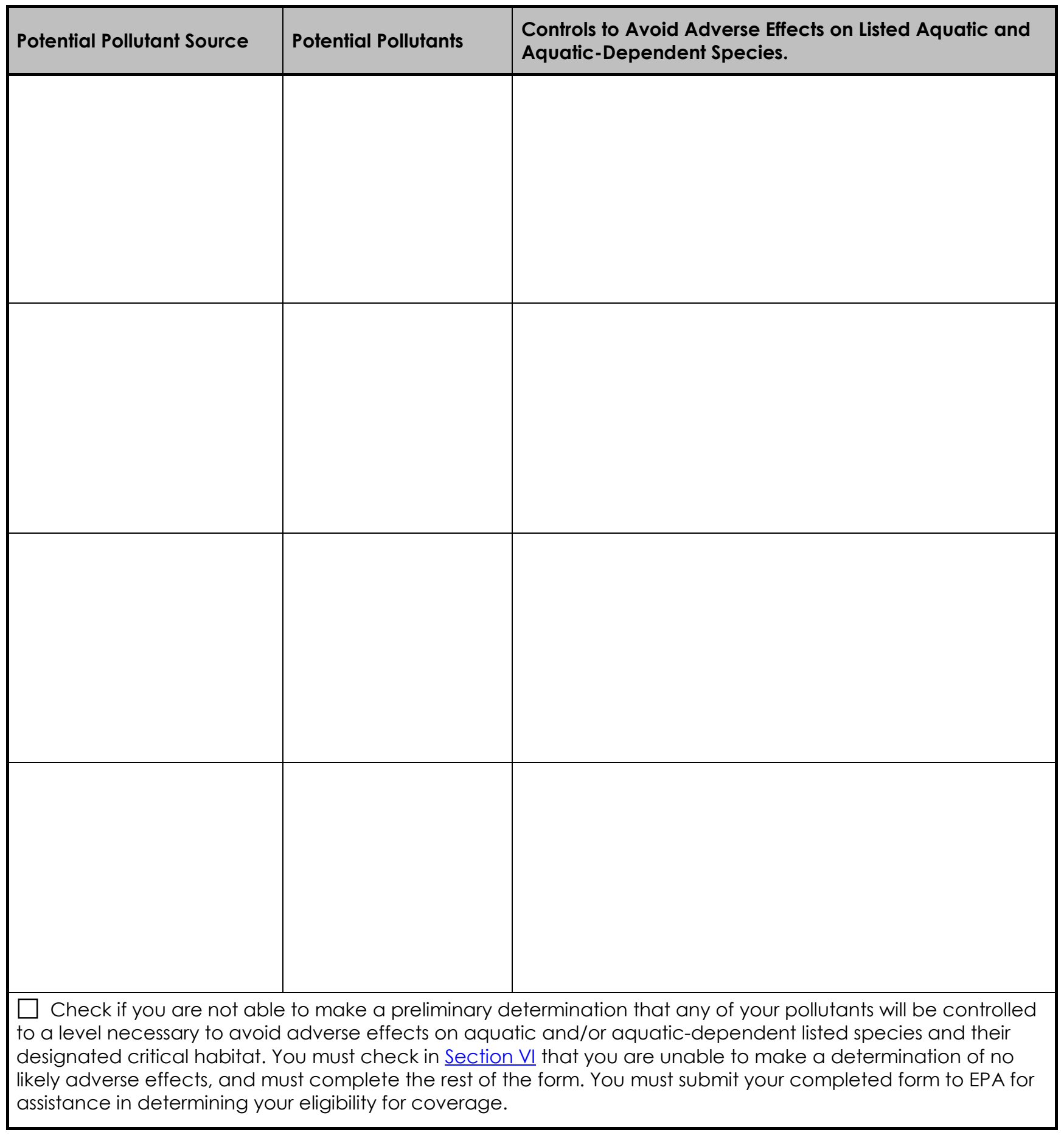


B. Analysis of Effects Based on Past Monitoring Data. Select which of the following applies to your facility:

I have no previous monitoring data for my facility because there are no applicable monitoring requirements for my facility's sector(s).

I have no previous monitoring data for my facility because I am a new discharger or a new source, but I am subject to monitoring under the 2015 MSGP. You must provide information to support a conclusion that your facility's discharges are not expected to result in benchmark or numeric effluent limit exceedances that will adversely affect listed species or their critical habitat:

My facility has not had any exceedances under the 2008 MSGP of any required benchmark(s) or numeric effluent limits.

My facility has had exceedances of one or more benchmark(s) or numeric effluent limits under the 2008 MSGP, but I have addressed them during my coverage under the 2008 MSGP, or in my evaluation of controls to avoid adverse effects in (A) above. Describe all actions (including specific controls) that you will implement to ensure that the pollutants in your discharge(s) will not result in likely adverse effects from future exceedances.

Check if your facility has had exceedances of one or more benchmarks or numeric effluent limits under the 2008 MSGP and you have not been able to address them to avoid adverse effects from future exceedances, or if you are a new discharger or a new source but you are not sure if you can avoid adverse effects from possible exceedances. You must check in Section VI that you are unable to make a determination of no likely adverse effects. You must submit your completed form to EPA for assistance in determining your eligibility for coverage. You may not file your NOI for permit coverage until you are able to make a determination that your discharges will avoid adverse effects on listed species and designated critical habitat.

\section{SECTION VI VERIFICATION OF PRELIMINARY EFFECTS DETERMINATION}

Based on Steps I - V of this form, you must verify your preliminary determination of effects on listed species and designated critical habitat from your discharges and/or discharge-related activities :

Following the applicable Steps in I - $V$ above, I have made a preliminary determination that my discharges and/or discharge-related activities are not likely to adversely affect listed species and designated critical habitats.

Following the applicable Steps in I - V above, I am not able to make a preliminary determination that my discharges and/or discharge-related activities are not likely to adversely affect listed species and designated critical habitats.

\section{Certification Information}

I certify under penalty of law that this document and all attachments were prepared under my direction or supervision in accordance with a system designed to assure that qualified personnel properly gathered and evaluated the information submitted. Based on my inquiry of the person or persons who manage the system, or those persons directly responsible for gathering the information, the information submitted is, to the best of my knowledge and belief, true, accurate, and complete. 
I am aware that there are significant penalties for submitting false information, including the possibility of fine and imprisonment for knowing violations.

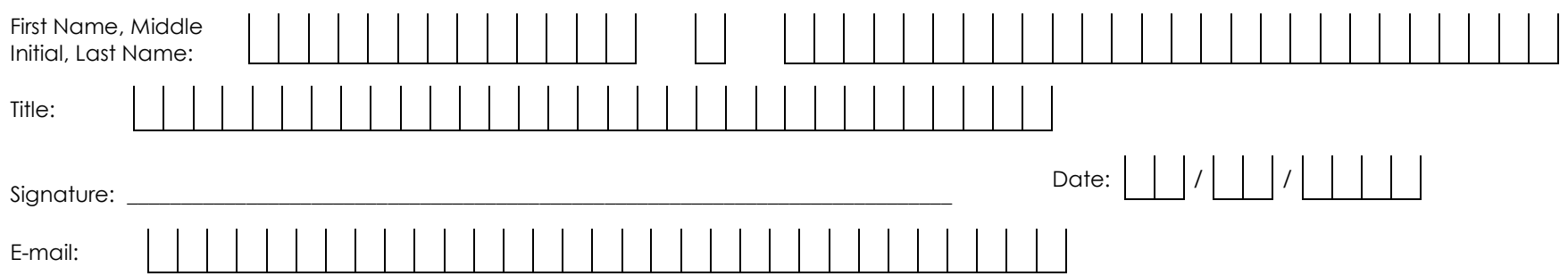

\section{SECTION VII CRITERION C ELIGIBILITY FORM SUBMISSION INSTRUCTIONS}

You must submit this completed form to EPA at msgpesa@epa.gov, including any attachments and any additional information that demonstrates how you will avoid or eliminate adverse effects to listed species or critical habitat (e.g., specific controls you will implement to avoid or eliminate adverse effects). Any missing or incomplete information may result in a delay of your coverage under the permit.

If you have made a preliminary determination that your discharges and/or discharge-related activities are not likely to adversely affect listed species and critical habitat, this form must be submitted a minimum of 30 days prior to submitting your NOI for permit coverage under criterion $\mathrm{C}$. Please note that during either the 30-day Criterion C Eligibility Form review period prior to your NOI submission, or within 30 days after your $\mathrm{NOI}$ submission and before you have been authorized for permit coverage, EPA may advise you that additional information is needed, or that there are additional measures you must implement to avoid likely adverse effects.

If you are unable to make a preliminary determination that your discharges and/or dischargerelated activities are not likely to adversely affect listed species and critical habitat, this worksheet must be submitted to EPA, but you may not file your NOI for permit coverage until you have received a determination from EPA that your discharges and/or discharge-related activities are not likely to adversely affect listed species and critical habitat. 


\section{Attachment 1}

Include a map and a written description of the action area of your facility, as required in Step 2. You may choose to include the map that is generated from the FWS' on-line mapping tool IPaC (the Information, Planning, and Consultation System) located at http://ecos.fws.gov/ipac/.

The written description of your action area that accompanies your action area map must explain your rationale for the extant of the action area drawn on your map. For example, your action area written description may look something like this:

The action area for the (name of your facility)'s stormwater discharges extends downstream from the outfall(s) in (name of receiving waterbody) (\# of meters/feet/kilometers/miles). The downstream limit of the action area reflects the approximate distance at which the discharge waters and any pollutants would be expected to cause potential adverse effects to listed species and/or critical habitat because (insert rationale). The action area does/does not extend to the (name of receiving waterbody)'s confluence with (name of confluence waterbody) because (insert rationale).

Note that you action area written description will be highly site-specific, depending on the expected effects of your facility's dishcarges and discharge-related activities, receiving waterbody characteristics, etc. 


\section{Attachment 2}

List or attach the listed species and critical habitat in your action area on this sheet, as required in Step 3. You must include a list for applicable listed NMFS and FWS species and critical habitat. If there are listed species and/or critical habitat for only one Service, you must include a statement confirming there are no listed species and/or critical habitat for the other Service. For FWS species, include the full printout from your IPaC query. Note: If your Official Species List from the USFWS indicated no species or critical habitat were present in your action area, include the full consultation tracking code at the top of your Official Species List in your NOI submittal in the question "Provide a brief summary of the basis for the criterion selected in Appendix E." If an Official Species List was not available on IPaC, list the contact date and name of the Service staff with whom you corresponded to identify the existence of any USFWS species or critical habitat present in your action area. 


\section{Appendix F - Procedures Relating to Historic Properties Preservation}

\section{F.1 Background}

Section 106 of the National Historic Preservation Act (NHPA) requires Federal agencies to take into account the effects of Federal "undertakings", such as the issuance of this permit, on historic properties that are either listed or eligible for listing on the National Register of Historic Places. To address any issues relating to historic properties in connection with the issuance of this permit, EPA has developed the screening process in this appendix that enables facility operators to appropriately consider the potential impacts, if any, from the installation of stormwater controls that involve subsurface disturbance, on historic properties and to determine whether actions can be taken, if applicable, to mitigate any such impacts. Although the coverage of individual industrial facilities under this permit does not constitute separate Federal undertakings, the screening process in this appendix provides an appropriate site-specific means of addressing historic property issues in connection with EPA's issuance of the permit.

Before an operator is eligible for coverage under the 2015 MSGP (unless otherwise noted, all references to "eligible" or "eligibility" refer only to coverage under the 2015 MSGP), the operator must meet one of the certification criteria related to historic properties included in the permit. In the event an operator cannot meet any of the certification criteria included in the permit relating to historic properties, the operator must apply for an individual permit.

\begin{abstract}
Key Terms
Historic Property - Prehistoric or historic districts, sites, buildings, structures, or objects that are included in or eligible for inclusion in the National Register of Historic Places, including artifacts, records, and remains that are related to and located within such properties.
\end{abstract}

ACHP - Advisory Council on Historic Preservation; an independent Federal agency.

SHPO - The State Historic Preservation Officer for a particular state.

THPO or Authorized Tribal Representative - The Tribal Historic Preservation Officer for a particular Tribe, or if there is no THPO, the representative designated by such Tribe for NHPA purposes. Historic properties could have significance to more than one Indian tribe; therefore, all Indian tribes that attach religious and cultural significance to a historic property must be identified and included in the historic properties screening process.

Area of Potential Effects (APE) - The geographic area or areas within which an undertaking may directly or indirectly cause changes in the character or use of historic properties, if any such properties exist. The area of potential effects is influenced by the scale and nature of an undertaking and may be different for different kinds of effects caused by the undertaking.

You must meet one or more of the four criteria (A-D), which are also included in Part 1.1.4.6, to be eligible for coverage under this permit.

\section{Activities with No Potential to Have an Effect on Historic Properties}

A determination that a Federal undertaking has no potential to have an effect on historic properties fulfills an agency's obligations under the NHPA. EPA has reason to believe that the vast majority of activities authorized under the MSGP have no potential to have effects on historic properties. The purpose of this permit is to control pollutants that may be transported in stormwater runoff from industrial facilities. EPA does not anticipate effects on historic properties from the pollutants in the stormwater and allowable non-stormwater discharges from these industrial facilities. Thus, to the extent EPA's issuance of this general permit authorizes discharges of such constituents, confined to existing stormwater channels or natural drainage areas; the permitting action does not have the potential to cause effects on historic properties.

In addition, the overwhelming majority of sources covered under this permit will be facilities that are seeking renewal of previous permit coverage. These existing dischargers should have already addressed NHPA issues in the 2008 MSGP as they were required to certify that they 
were either not affecting historic properties or they had obtained written agreement from the applicable State Historic Preservation Officer (SHPO) or Tribal Historic Preservation Officer (THPO) regarding methods of mitigating potential impacts. Both existing and new dischargers must follow the historic property screening procedures to determine their eligibility. EPA is not aware of any impacts on historic properties from activities covered under the 2008 MSGP, or, for that matter, any need for a written agreement. Therefore, to the extent this permit authorizes renewal of prior coverage without relevant changes in operations, it has no potential to have an effect on historic properties.

\section{Activities with Potential to Have an Effect on Historic Properties}

EPA believes this permit may have some potential to have an effect on historic properties where permittees construct and/or install stormwater control measures that involve subsurface disturbance and impact less than one (1) acre of land to comply with this permit. (Ground disturbances of one (1) acre or more require coverage under a different permit, the Construction General Permit.) Where you have to disturb the land through the construction and/or installation of control measures, there is a possibility that artifacts, records, or remains associated with historic properties could be impacted. Therefore, if you are establishing new or altering existing control measures to manage your stormwater that will involve subsurface ground disturbance of less than one (1) acre, you will need to ensure (1) that historic properties will not be impacted by your activities or (2) that you have consulted with the appropriate SHPO, THPO, or other tribal representative regarding measures that would mitigate or prevent any adverse effects on historic properties.

\section{Examples of Control Measures Which Involve Subsurface Disturbance}

EPA reviewed typical control measures currently employed to determine which practices involve some level of earth disturbance. The types of control measures that are presumptively expected to cause subsurface ground disturbance include:

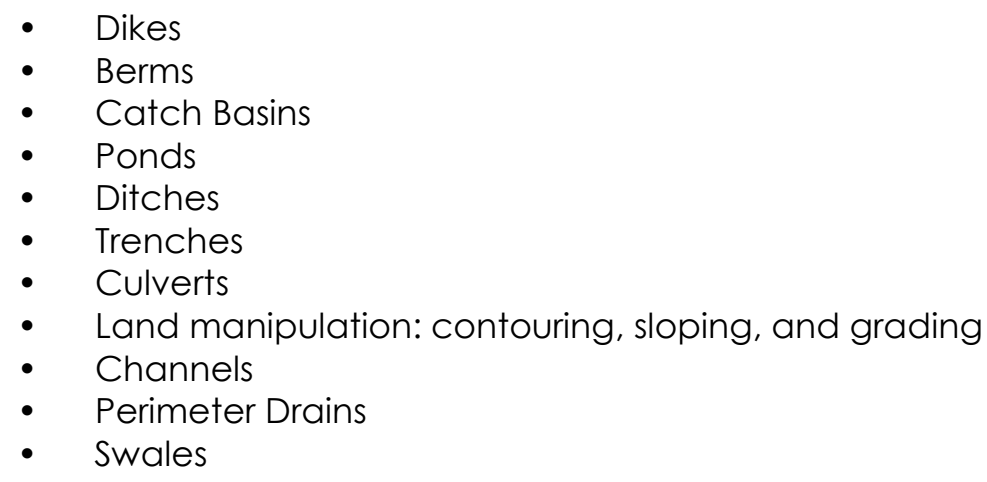

EPA cautions dischargers that this list is non-inclusive. Other control measures that involve earth disturbing activities that are not on this list must also be examined for the potential to affect historic properties.

\section{Historic Property Screening Process}

You should follow the following screening process in order to certify your compliance with historic property eligibility requirements under this permit (see Part 1.1.4.6). The following four steps describe how applicants can meet the permit eligibility criteria for protection of historic properties under this permit: 
Step One: Are you an existing facility that is reapplying for certification under the 2015 MSGP?

If you are an existing facility you should have already addressed NHPA issues. To gain coverage under the 2008 MSGP you were required to certify that you were either not affecting historic properties or had obtained written agreement from the relevant SHPO or THPO regarding methods of mitigating potential impacts. As long as you are not constructing or installing any new stormwater control measures then you have met eligibility Criterion A of the MSGP. After you submit your NOI, there is a 30-day waiting period during which the SHPO, THPO, or other tribal representative may review your NOI. The SHPO, THPO, or other tribal representative may request that EPA hold up authorization based on concerns about potential adverse impacts to historic properties. EPA will evaluate any such request and notify you if any additional measures to address adverse impacts to historic properties are necessary.

If you are an existing facility and will construct or install stormwater control measures that require subsurface disturbance of less than one (1) acre then you should proceed to Step Three. (Note: Construction activities disturbing one (1) acre or more are not eligible for coverage under this permit.)

If you are a new facility then you should proceed to Step Two.

\section{Step Two: Are you constructing or installing any stormwater control measures that require subsurface disturbance of less than one (1) acre?}

If, as part of your coverage under this permit, you are not building or installing control measures on your site that cause less than one (1) acre of subsurface disturbance, then your discharge-related activities do not have the potential to have an effect on historic properties. You have no further obligations relating to historic properties. You have met eligibility Criterion A of the MSGP. After you submit your NOI, there is a 30-day waiting period during which the SHPO, THPO, or other tribal representative may review your NOI. The SHPO, THPO, or other tribal representative may request that EPA hold up authorization based on concerns about potential adverse impacts to historic properties. EPA will evaluate any such request and notify you if any additional measures to address adverse impacts to historic properties are necessary.

If the answer to the Step Two question is yes, then you should proceed to Step Three.

\section{Step Three: Have prior earth disturbances determined that historic properties do not exist, or have prior disturbances precluded the existence of historic properties?}

If previous construction either revealed the absence of historic properties or prior disturbances preclude the existence of historic properties, then you have no further obligations relating to historic properties. You have met eligibility Criterion B of the MSGP. After you submit your NOI, there is a 30-day waiting period during which the SHPO, THPO, or other tribal representative may review your NOI. The SHPO, THPO, or other tribal representative may request that EPA hold up authorization based on concerns about potential adverse impacts to historic properties. EPA will evaluate any such request and notify you if any additional measures to address adverse impacts to historic properties are necessary.

If the answer to the Step Three question is no, then you should proceed to Step Four.

\section{Step Four: Contact the appropriate historic preservation authorities}

Where you are building and/or installing control measures affecting less than one (1) acre of land to control stormwater or allowable non-stormwater discharges associated with this 
permit, and the answer to Step Three is no, then you should contact the relevant SHPO, THPO, or other tribal representative to determine the likelihood that artifacts, records, or remains are potentially present on your site. This may involve examining local records to determine if historic artifacts have been found in nearby areas, as well as limited surface and subsurface examination carried out by qualified professionals.

If through this process it is determined that such historic properties potentially exist and may be impacted by your construction or installation of control measures, you should contact the relevant SHPO, THPO, or tribal representative in writing and request to discuss mitigation or prevention of any adverse effects. The letter should describe your facility, the nature and location of subsurface disturbance activities that are contemplated, any known or suspected historic properties in the area, and any anticipated effects on such properties. The letter should state that if the SHPO, THPO, or tribal representative does not respond within 30 days of receiving your letter, you may submit your NOI without further consultation. EPA encourages applicants to contact the appropriate authorities as soon as possible in the event of a potential adverse effect to an historic property.

If the SHPO, THPO, or tribal representative sent you a response within 30 days of receiving your letter and you enter into, and comply with, a written agreement with the SHPO, THPO, or other tribal representative regarding how to address any adverse impacts on historic properties, you have met eligibility Criterion $C$. In this case, you should retain a copy of the written agreement consistent with Part 5.1.6.2 of the MSGP. After you submit your NOI, there is a 30-day waiting period during which the SHPO, THPO, or other tribal representative may review your NOI. The SHPO, THPO, or other tribal representative may request that EPA delay authorization based on concerns about potential adverse impacts to historic properties. However, EPA would generally accept any written agreement as fully addressing such concerns unless new information was brought to the Agency's attention that was not considered in your previous discussions with the SHPO, THPO or other tribal representative.

If you receive a response within 30 days after the SHPO, THPO, or tribal representative received your letter and you consult with the SHPO, THPO or tribal representative regarding adverse impacts to historic properties and measures to mitigate them but an agreement cannot be reached between you and the SHPO, THPO, or other tribal representative, you have still met the eligibility for Criterion C. In this case you should include in your SWPPP a brief description of potential effects to historic properties, the consultation process, any measures you will adopt to address the potential adverse impacts, and any significant remaining disagreements between you and the SHPO, THPO or other tribal representative. After you submit your NOI, there is a $30-$ day waiting period during which the SHPO, THPO, or other tribal representative may review your NOI. The SHPO, THPO, or other tribal representative may request that EPA delay authorization based on concerns about potential adverse impacts to historic properties. EPA will evaluate any such request and notify you if any additional measures to address adverse impacts to historic properties are necessary.

If you have contacted the SHPO, THPO, or tribal representative in writing regarding your potential to have an effect on historic properties and the SHPO, THPO, or tribal representative did not respond within 30 days of receiving your letter, you have met eligibility Criterion D. You are advised to get a receipt from the post office or other carrier confirming the date on which your letter was received. In this case, you should submit a copy of your letter notifying the SHPO, THPO or tribal representative of potential impacts with your NOI. After you submit your NOI, there is a 30-day waiting period during which the SHPO, THPO, or other tribal representative may review your NOI. The SHPO, THPO, or other tribal representative may request that EPA hold up authorization based on concerns about potential adverse impacts to historic properties. EPA will 
evaluate any such request and notify you if any additional measures to address adverse impacts to historic properties are necessary.

Addresses for State Historic Preservation Officers and Tribal Historic Preservation Officers may be found on the Advisory Council on Historic Preservation's website (www.achp.gov/programs.html). In instances where a Tribe does not have a Tribal Historic Preservation Officer, you should contact the appropriate Tribal government office when responding to this permit eligibility condition. 


\section{Appendix G - Notice of Intent (NOI) Form}

Part 7.1 requires you to use the NPDES eReporting Tool, or "NeT", to prepare and submit your NOI. However, if you are given a waiver by the EPA Regional Office to use a paper NOI form, and you elect to use it, you must complete and submit the following form. 


\begin{tabular}{|c|c|c|}
\hline $\begin{array}{l}\text { NPDES } \\
\text { FORM } \\
3510-6\end{array}$ & $\begin{array}{c}\text { UNITED STATES ENVIRONMENTAL PROTECTION AgENCY } \\
\text { WASHINGTON, DC } 20460 \\
\text { NOTICE OF INTENT (NOI) FOR StORMWATER DISCHARGES ASSOCIATED WITH } \\
\text { INDUSTRIAL ACTIVITY UNDER THE NPDES MULTI-SECTOR GENERAL PERMIT }\end{array}$ & $\begin{array}{l}\text { Form Approved. } \\
\text { OMB No. 2040-0004 }\end{array}$ \\
\hline
\end{tabular}

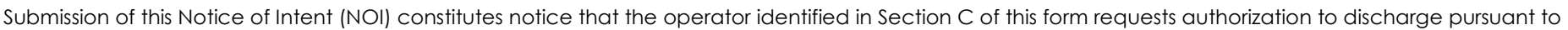

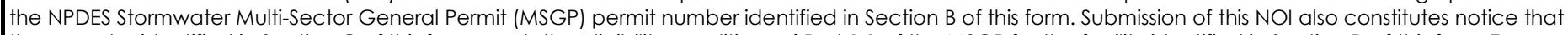
the operator identified in Section C of this form meets the eligibility conditions of Part 1.1 of the MSGP for the facility identified in Section D of this form. To

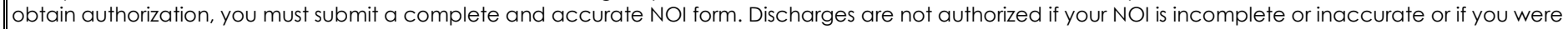
never eligible for permit coverage. Refer to the instructions at the end of this form to complete your NOI.

\section{A. Approval to Use Paper NOI Form}

1. Have you been granted a waiver from electronic reporting from the EPA Regional Office*? $\square$ YES $\square$ NO

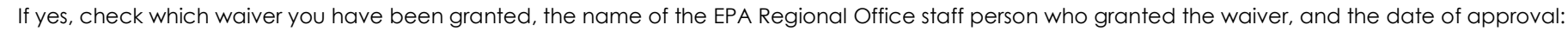

Waiver granted: $\quad \square$ The owner/operator's headquarters is physically located in a geographic area (i.e., ZIP code or census tract) that is identified as under-served for broadband Internet access in the most recent report from the Federal Communications Commission.

$\square \quad$ The owner/operator has issues regarding available computer access or computer capability.

Name of EPA staff person that granted the waiver:

Date approval obtained:

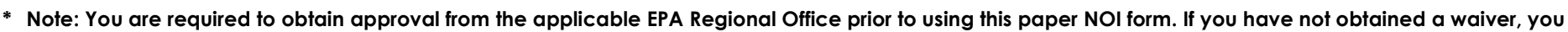

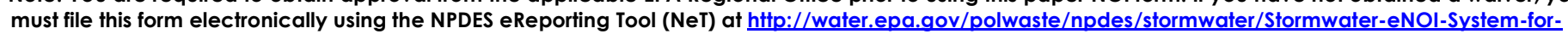
EPAs-MultiSector-General-Permit.cfm

\begin{tabular}{|c|c|}
\hline B. Permit Information & NPDES ID (EPA Use Only): \\
\hline
\end{tabular}

1. Master Permit Number: $\mid$ L

2. Are you a new discharger or a new source as defined in Appendix A? $\square$ YES $\square$ NO (If yes, skip to Part C of this form).

3. If you are not a new discharger or a new source, have stormwater discharges from your facility been covered previously under an NPDES permit?

$\square$ YES $\square$ NO

If yes, provide the NPDES ID if you had coverage under EPA's 2008 MSGP or the NPDES ID if you had coverage under an EPA individual permit:

\section{Facility Operator Information}

1. Operator Information:

Operator Name:

Mailing Address:

Street:

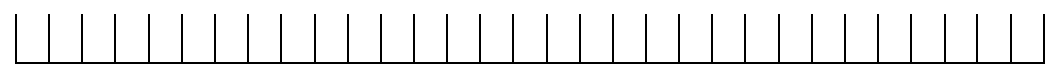

City:

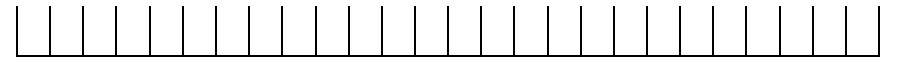

State:

ZIP Code:

County or Similar Government Subdivision:

Phone:

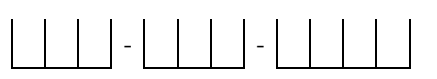

Ext.

E-mail:

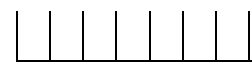

2. Operator Point of Contact Information:

First Name, Middle Initial, Last Name:

Title:

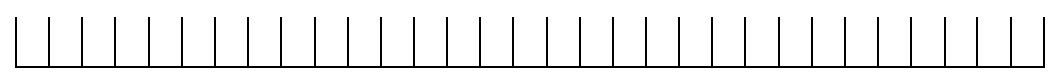

3. NOI Preparer Information (Complete if NOI was prepared by someone other than the certifier):

First Name, Middle Initial, Last Name:

Organization:

Phone:

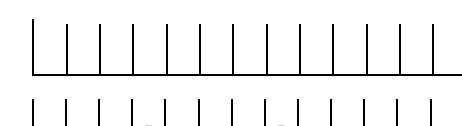

E-mail:

Ext.

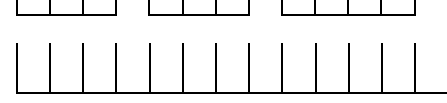

Ext. 


\section{Facility Information}

1. Facility Name:

2. Facility Address:

Street/Location:

City:

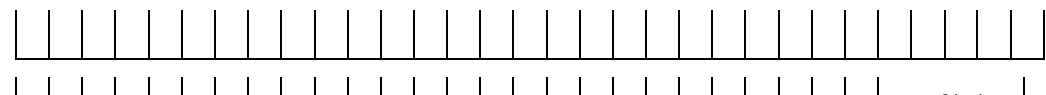

County or Similar Government Subdivision:

3. Latitude/Longitude for the facility:

Latitude:

${ }^{\circ} \mathrm{N}$ (decimal degrees)

Longitude:

State:

ZIP Code:
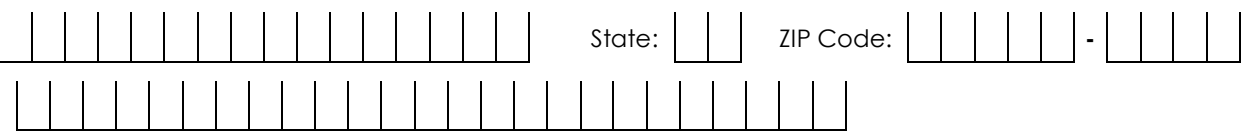

Latitude/Longitude Data Source: $\square$ Map

$\square$ GPS

${ }^{\circ} \mathrm{W}$ (decimal degrees)

If you used a USGS topographic map, what was the scale?

Horizontal Reference Datum: $\square$ NAD $27 \quad \square$ NAD 83 $\square$ WGS 84

4. Is your facility located on Indian Country lands? $\square$ YES $\square$ NO

If yes, provide the name of the Indian tribe associated with the area of Indian country (including name of Indian reservation, if applicable):

5. Are you requesting coverage under this $\mathrm{NOI}$ as a "federal operator" as defined in Appendix A? $\square$ YES $\square$ NO

6. What is the ownership type of the facility?

$\square$ Corporation

$\square$ Federal Facility (U.S. Government)

$\square$ Privately Owned Facility

$\square$ Municipality

$\square$ County Government

$\square$ District

$\square$ State Government

$\square$ Mixed Ownership (e.g.

Public/Private)

7. Estimated area of industrial activity at your facility exposed to stormwater:

8. Sector-Specific Information

Identify the 4-digit Standard Industrial Classification $(\mathrm{SIC})$ code or 2-letter Activity Code that best represents the products produced or services rendered for which your facility is primarily engaged, as defined in the MSGP, and the applicable sector and subsector of your primary industrial activity (See Appendix D):

Primary SIC Code:

Sector:<smiles>C1CC1</smiles>

\section{Subsector:}

OR Primary Activity Code:

$\square$ Tribal Government

$\square$ Municipal or Water

District

Identify the applicable sector(s) and subsector(s) of any co-located industrial activity for which you are requesting permit coverage:

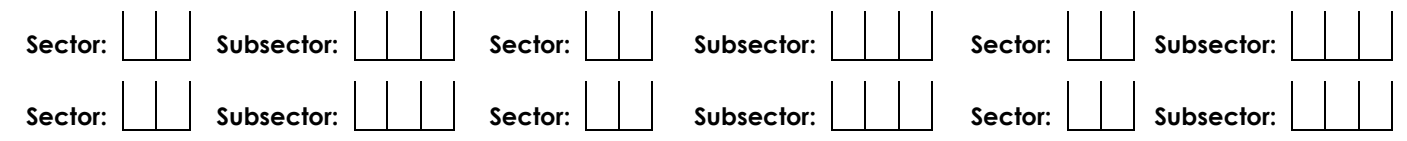

If you are a Sector S (Air Transportation) facility, do you anticipate using more than 100,000 gallons of pure glycol in glycol-based deicing fluids and/or 100 tons or more of urea on an average annual basis? $\square$ YES $\square$ NO

If you are a Sector $G$ (Metal Mining) facility, do you have discharges from waste rock and overburden piles? $\square$ YES $\square$ NO
Check the type of ore you mine at your facility:
$\square$ Tungsten Ore
$\square$ Nickel Ore
$\square$ Aluminum Ore
$\square$ Mercury Ore
$\square$ Iron Ore
$\square$ Platinum Ore
$\square$ Titanium Ore
$\square$ Vanadium Ore
$\square$ Molybdenum
$\square$ Uranium, Radium, and/or Vanadium Ore

9. Is your facility presently inactive and unstaffed?* $\square$ YES $\square$ NO

* Note that if your facility becomes inactive and unstaffed during the permit term, you must submit an NOI modification to reflect the change.

\section{E. Discharge Information}

1. By indicating "Yes" below, I confirm that I understand that the MSGP only authorizes the allowable stormwater discharges in Part 1.1.2 and the allowable non-stormwater discharges listed in Part 1.1.3. Any discharges not expressly authorized in this permit cannot become authorized or shielded from liability under CWA section $402(\mathrm{k})$ by disclosure to EPA, state, or local authorities after issuance of this permit via any means, including the Notice of Intent (NOI) to be covered by the permit, the Stormwater Pollution Prevention Plan (SWPPP), during an inspection, etc. If any discharges requiring NPDES permit coverage other than the allowable stormwater and non-stormwater discharges listed in Parts 1.1.2 and 1.1.3 will be discharged, they must be covered under another NPDES permit. $\square$ YES

2. Federal Effluent Limitation Guidelines

Are you requesting permit coverage for any stormwater discharges subject to effluent limitation guidelines? $\quad \square$ YES $\square$ NO 
If yes, which effluent limitation guidelines apply to your stormwater discharges?

\begin{tabular}{|c|c|c|c|c|}
\hline 40 CFR Part/Subpart & Eligible Discharges & Affected MSGP Sector & New Source Date & Check if Applicable \\
\hline Part 411, Subpart C & $\begin{array}{l}\text { Runoff from material storage piles at cement } \\
\text { manufacturing facilities }\end{array}$ & $\mathrm{E}$ & $2 / 20 / 1974$ & $\square$ \\
\hline Part 418 Subpart A & $\begin{array}{l}\text { Runoff from phosphate fertilizer manufacturing facilities } \\
\text { that comes into contact with any raw materials, finished } \\
\text { product, by-products or waste products (SIC 2874) }\end{array}$ & C & $4 / 8 / 1974$ & $\square$ \\
\hline Part 423 & Coal pile runoff at steam electric generating facilities & $\mathrm{O}$ & $\begin{array}{l}11 / 19 / 1982 \\
10 / 8 / 19741\end{array}$ & L \\
\hline Part 429, Subpart I & $\begin{array}{l}\text { Discharges resulting from spray down or intentional wetting } \\
\text { of logs at wet deck storage areas }\end{array}$ & A & $1 / 26 / 1981$ & [ \\
\hline $\begin{array}{l}\text { Part 436, Subpart B, C, or } \\
\text { D }\end{array}$ & $\begin{array}{l}\text { Mine dewatering discharges at crushed stone mines, } \\
\text { construction sand and gravel mines, or industrial sand } \\
\text { mines }\end{array}$ & $\mathrm{J}$ & N/A & $\square$ \\
\hline Part 443, Subpart A & Runoff from asphalt emulsion facilities & D & $7 / 28 / 1975$ & $\square$ \\
\hline Part 445, Subparts A \& B & $\begin{array}{l}\text { Runoff from hazardous waste and non-hazardous waste } \\
\text { landfills }\end{array}$ & $\mathrm{K}, \mathrm{L}$ & $2 / 2 / 2000$ & $\square$ \\
\hline Part 449 & $\begin{array}{l}\text { Runoff containing urea from airfield pavement deicing at } \\
\text { existing and new primary airports with 1,000 or more annual } \\
\text { non-propeller aircraft departures }\end{array}$ & $S$ & $6 / 15 / 2012$ & $\square$ \\
\hline
\end{tabular}

'NSPS promulgated in 1974 were not removed via the 1982 regulation; therefore wastewaters generated by Part 423 -applicable sources that were New

Sources under the 1974 regulations are subject to the 1974 NSPS.

3. Receiving Waters Information: (Attach a separate list if necessary)

\begin{tabular}{l|l}
\hline List all of the stormwater outfalls & For each outfall, provide the following receiving water information:
\end{tabular} from your facility. Each outfall must be identified by a unique 3-digit ID (e.g., 001, 002). Also provide the latitude and longitude in degrees decimal for each outfall.
Provide the name of the first water of the U.S. that receives stormwater directly from the outfall and/or from the MS4 that the outfall discharges to:
If the receiving water is impaired (on the CWA 303(d) list), list the pollutants that are causing the impairment:
If a TMDL been completed for this receiving waterbody, providing the following information:

TMDL Name and ID:

Pollutant(s) for which there is a TMDL:

TMDL Name and ID:

Pollutant(s) for which there is a TMDL: 


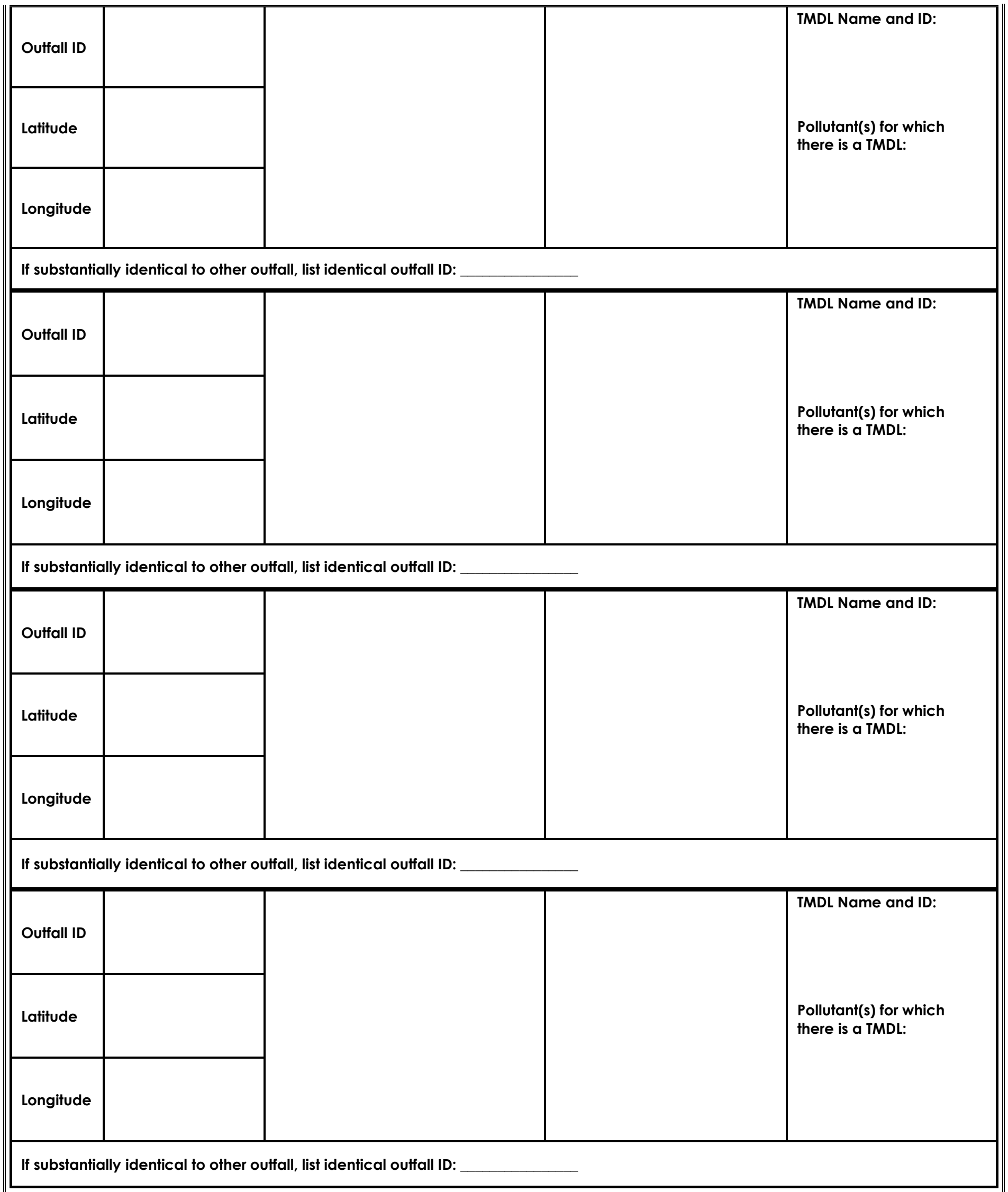


4. Provide the following Information about your outfall latitude longitude:

Latitude/Longitude Data Source: $\square$ Map $\square$ GPS $\square$ Other

If you used a USGS topographic map, what was the scale?

Horizontal Reference Datum: $\square$ NAD 27 $\square$ NAD 83 $\square$ WGS 84

5. Does your facility discharge into a Muncipal Separate Storm Sewer System (MS4)? $\square$ YES $\square$ NO

If yes, provide the name of the MS4 operator:

6. Check if you discharge to any of the waters of the U.S. that are designated by the state or tribal authority under its antidegradation policy as a Tier 2 (or Tier 2.5) water (water quality exceeds levels necessary to support propagation of fish, shellfish, and wildlife and recreation in and on the water) or as a Tier 3 water (Outstanding National Resource Water)? (See Appendix L).

$\square$ Tier 2/2.5. Provide the name(s) of receiving water(s):

$\square$ Tier 3 (Outstanding National Resource Waters)*

* Note: You are ineligible for coverage if you are a new discharger or new source to waters designated as Tier 3 (outstanding national resource waters) for antidegradation purposes under 40 CFR 131.13(a)(3).

7. If you are subject to benchmark monitoring requirements for a hardness-dependent metal, what is the hardness of your receiving water(s) (see Appendix J)? (mg/L)

8. If you are subject to benchmark monitoring requirements for a hardness-dependent metal, does your facility discharge into any saltwater receiving waters? $\square$ YES $\square$ NO

9. Does your facility discharge to a federal CERCLA site listed in Appendix P? $\square$ YES $\square$ NO

If yes, did you notify the EPA Regional Office in advance of filing your NOI, and did the EPA Regional Office determine that you are eligible for permit coverage pursuant to Part 1.1.4.10*? $\square$ YES $\square$ NO

* Note: If you discharge to a federal CERCLA site listed in Appendix $P$, you are ineligible for coverage under this permit unless you notify the EPA Regional Office in advance and the EPA Regional Office determines you are eligible coverage under this permit. In determining your eligibility for coverage under this Part, the EPA Regional Office may evaluate whether you have included adequate controls and/or procedures to ensure that your discharges will not lead to recontamination of aquatic media at the CERCLA Site such that it will to cause or contribute to an exceedance of a water quality standard.

\section{F. Stormwater Pollution Prevention Plan (SWPPP) Information}

1. Has the SWPPP been prepared in advance of filing this NOI, as required? $\square$ YES $\square$ NO

2. SWPPP Contact Information:

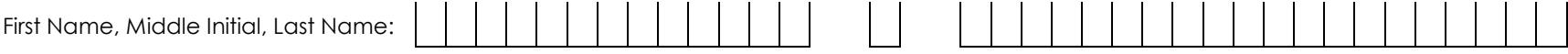

Professional Title:

Phone:

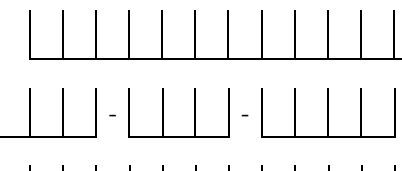

Ext.

E-mail:

3. SWPPP Availability:

Your current SWPPP or certain information from your SWPPP must be made available through one of the following two options. Select one of the options and provide the required information*:

* Note: You are not required to post any confidential business information (CBI) or restricted information (as defined in Appendix A) (such information may be redacted), but you must clearly identify those portions of the SWPPP that are being withheld from public access.

$\square$ Option 1: Maintain a current copy of your SWPPP on an Internet page (Universal Resource Locator or URL).

Provide the web address URL:

Option 2: Provide the following information from your SWPPP:

A. Describe your onsite industrial activities exposed to stormwater (e.g., material storage; equipment fueling, maintenance, and cleaning; cutting steel beams), and potential spill and leak areas: 


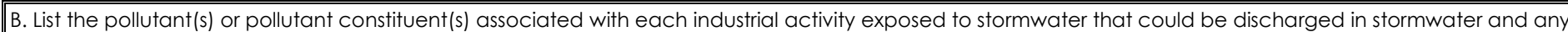
authorized non-stormwater discharges listed in Part 1.1.3:

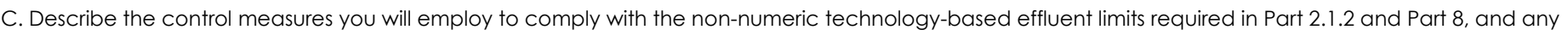
other measures taken to comply with the requirements in Part 2.2 Water Quality-Based Effluent Limitations (see Part 5.2.4):

D. Provide a schedule for good housekeeping and maintenance (see Part 5.2.5.1) and a schedule for all inspections required in Part 4 (see Part 5.2.5.2):

\section{G. Endangered Species Protection}

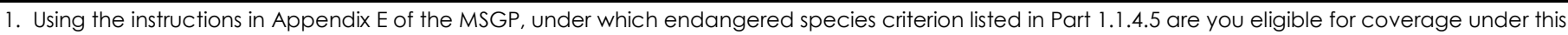
permit (only check 1 box)?*
$\square \mathrm{A}$
$\square \mathrm{B}$
$\square \mathrm{C}$
$\square \mathrm{D} \square \mathrm{E}$

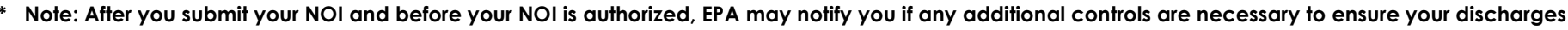
have no likely adverse affects on listed species and critical habitat.

2. Provide a brief summary of the basis for the criterion selected in Appendix E (e.g., communication with U.S. Fish and Wildlife Service or National Marine Fisheries Service to determine no species in action area; implementation of controls approved by EPA and the Services):

3. If you select criterion B, provide the NPDES ID from the other operator's NOI authorized under this permit:

4. If you select criterion $\mathrm{C}$, you must answer the following questions:

a. What federally-listed species or designated critical habitat are located in your "action area":

b. Using the Appendix E worksheet, check which of the following is applicable to your facility and answer any corresponding questions:

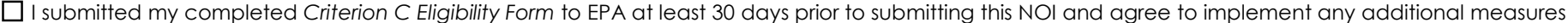
that were determined by EPA to be necessary to ensure that my discharges and/or discharge-related activities will not have likely adverse affects on listed species and critical habitat.

Date your Criterion C Eligibilty Form was sent to EPA:

Describe any EPA-approved measures you will implement to ensure no likely adverse affects on listed species and critical habitat:

I submitted my completed Criterion C Eligibility Form to EPA at least 30 days prior to submitting this NOI and have not been notified of any additional measures necessary to ensure no likely adverse affects on listed species and critical habitat.

Date your Criterion C Eligibility Form was sent to EPA:

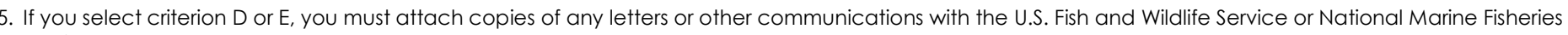
Service. 


\section{H. Historic Preservation}

1. If your facility is not located on Indian country lands, is your facility located on a property of religious or cultural significance to an Indian tribe? $\square$ YES $\square$ NO

If yes, provide the name of the Indian tribe associated with the property:

2. Using the instructions in Appendix F of the MSGP, under which historic properties preservation criterion listed in Part 1.1.4.6 are you eligible for coverage under this permit (only check 1 box)?

$\square$ A $\quad \square$ B $\quad \square$ C $\quad \square$ D

\section{Certification Information}

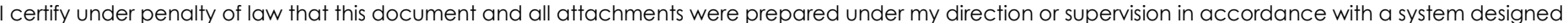

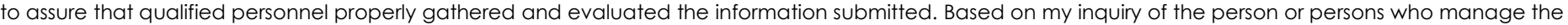

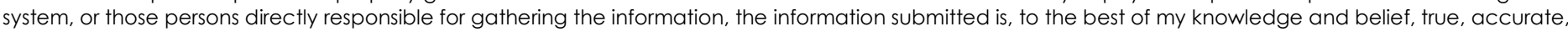

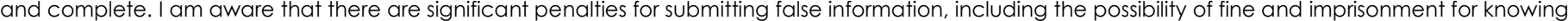
violations.

First Name, Middle Initial, Last Name:

: Title:

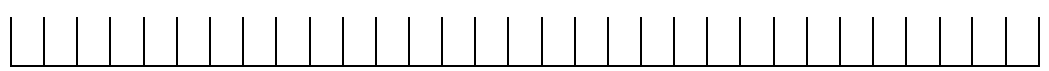

Signature:

E-mail:

Date:

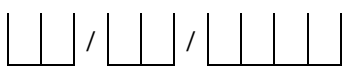




\section{Notice of Intent (NOI) for Stormwater Discharges \\ Associated with Industrial Activity Under the NPDES Multi-Sector General Permit}

NPDES Form Date (06/15) This Form Replaces From 3510-6 (09/08) Form Approved OMB No. 2040-0004

\section{Who Must File an NOI Form}

Under section 402(p) of the Clean Water Act (CWA) and regulations at 40 CFR Part 122, stormwater discharges associated with industrial activity are prohibited to waters of the United States unless authorized under a National Pollutant Discharge Elimination System (NPDES) permit. You can obtain coverage under the MSGP by submitting a completed Notice of Intent (NOI) if you are an operator a facility:

- that is located in a jurisdiction where EPA is the permitting authority, listed in Appendix C of the MSGP,

- that discharges stormwater associated with industrial activities, identified in Appendix D of the MSGP,

- that meets the eligibility requirements in Part 1.1 of the permit,

- that has developed a stormwater pollution prevention plan (SWPPP) in accordance with Part 5 of the MSGP; and

- that installs and implements control measures in accordance with Part 2 and Part 8 to meet numeric and non-numeric effluent limits.

\section{Completing the Form}

Obtain and read a copy of the 2015 MSGP, viewable at http://water.epa.gov/polwaste/npdes/stormwater/EPA-Multi-

Sector-General-Permit-MSGP.cfm. To complete this form, type or print, using uppercase letters, in the appropriate areas only. Please place each character between the marks. Abbreviate if necessary to stay within the number of characters allowed for each item. Use only one space for breaks between words, but not for punctuation marks unless they are needed to clarify your response. Please submit original document with signature in ink - do not send a photocopied signature.

\section{Section A. Approval to Use Paper NOI Form}

You must indicate whether you have been granted a waiver from electronic reporting from the EPA Regional Office. Note that you are not authorized to use this paper NOI form unless the EPA Regional Office has approved its use. Where you have obtained approval to use this form, indicate the waiver that you have been granted, the name of the EPA staff person who granted the waiver, and the date that approval was provided.

See http://water.epa.gov/polwaste/npdes/stormwater/StormwaterContacts.cfm for a list of EPA Regional Office contacts.

\section{Section B. Permit Information}

Provide the master permit number of the permit under which you are applying for coverage (see Appendix $C$ of the general permit for the list of eligible master permit numbers).

You must indicate whether you are a new discharger or a new source (see Appendix A for the definitions). If you are not a new discharger or a new source, you must indicate whether stormwater discharges from your facility have been previously covered under another NPDES permit. If yes, you must provide the unique NPDES ID (i.e., permit tracking number) for the previous permit your facility was covered under.

\section{Section C. Facility Operator Information}

Provide the legal name of the person, firm, public organization, or any other entity that operates the facility described in this NOI. An operator of a facility is the legal entity that controls the operation of the facility. Refer to Appendix A of the permit for the definition of "operator". Provide the operator's mailing address, phone number, and e-mail. Correspondence for the NOI will be sent to this address. Also provide the name and title for the operator point of contact (note that the point of contact name may be the same as the operator name).

If the NOl was prepared by someone other than the certifier (for example, if the NOI was prepared by the facility SWPPP contact or a consultant for the certifier's signature), include the full name, organization, phone number, and email address of the NOI preparer.

\section{Section D. Facility Information}

Enter the official or legal name and complete address, including city, state, ZIP code, and county or similar government subdivision of the facility. If the facility lacks a street address, indicate the general location of the facility (e.g., Intersection of State Highways 61 and 34). Complete facility information must be provided for permit coverage to be granted.

Provide the latitude and longitude of your facility in decimal degrees format. The latitude and longitude of your facility can be determined in several different ways, including through the use of global positioning system (GPS) receivers, U.S. Geological Survey (U.S.G.S.) topographic or quadrangle maps. Refer to http://transition.fcc.gov/mb/audio/bickel/DDDMMSSdecimal.html/ for assistance in providing the proper latitude/longitude format. For consistency, EPA requests that measurements be taken from the approximate center of the facility. Specify which method you used to determine latitude and longitude. If a U.S.G.S. topographic map is used, specify the scale of the map used. Enter the horizontal reference datum for your latitude and longitude. The horizontal reference datum used on USGS topographic maps is shown on the bottom left corner of USGS topographic maps; it is also available for GPS receivers.

Indicate whether the facility is on Indian country lands, and if so, provide the name of the Indian tribe associated with the area of Indian country (including name of Indian reservation, if applicable).

Indicate whether you are seeking coverage under this permit as a "federal operator" as defined in Appendix A. Also check the ownership type for the facility (e.g., Federal Facility, Privately Owned Facility, Municipality, County Government, Corporation, State Government, Tribal Government, School District, District, Mixed Ownership [e.g., public/private], Municipal or Water District).

Enter the estimated area of industrial activity at your facility exposed to stormwaterto the nearest quarter acre.

List the four-digit Standard Industrial Classification (SIC) code or two character activity code that best describes the primary industrial activities performed by your facility under which you are required to obtain permit coverage. Your primary industrial activity includes any activities performed on-site which are (1) identified by the facility's primary SIC code and included in the descriptions of 40 CFR 122.26(b)(14)(ii), (iii), (vi), or (viii); or (2) included in the narrative descriptions of 40 CFR 122.26(b)(14)(i), (iv), (v), (vii), or (ix). See Appendix $D$ of the MSGP for a complete list of SIC codes and activities codes covered under the MSGP. Also provide the applicable sector and subsector associated with the SIC code or activity code for your primary industrial activities. For a complete list of sector and subsector codes, see Appendix D of the MSGP.

If your facility has co-located industrial activities that are not identified as your primary industrial activity, identify the sector and subsector codes that describe these other industrial activities. 


\section{Notice of Intent (NOI) for Stormwater Discharges \\ Associated with Industrial Activity Under the NPDES Multi-Sector General Permit}

NPDES Form Date (06/15) This Form Replaces From 3510-6 (09/08) Form Approved OMB No. 2040-0004

For Sector $S$ facilities (Air Transportation), indicate whether you anticipate that the entire airport facility will use more than 100,000 gallons of pure glycol in glycol-based deicing fluids and/or 100 tons or more of urea on an average annual basis. If so, additional effluent limits and monitoring conditions apply to your discharge (see Part 8.S of the permit).

For Sector G facilities (Metal Mining), check the type of ore(s) mined at the facility.

Indicate whether your facility is currently inactive and unstaffed. Note that if your facility becomes inactive and unstaffed during the permit term, you must submit an $\mathrm{NOI}$ modification to reflect the change.

\section{Section E. Discharge Information}

You must confirm that you understand that the MSGP only authorizes the allowable stormwater discharges listed in Part 1.1.2 and the allowable non-stormwater discharges listed in Part 1.1.3. Any discharges not expressly authorized under the MSGP are not covered by the MSGP or the permit shield provision of the CWA Section 402(k) and they cannot become authorized or shielded by disclosure to EPA, state, or local authorities via the NOI to be covered by the permit or by any other means (e.g., in the SWPPP or during an inspection). If any discharges requiring NPDES permit coverage other than the allowable stormwater and non-stormwater discharges listed in Parts 1.1.2 and 1.1.3 will be discharged, they must either be eliminated or covered under another NPDES permit.

Depending on your industrial activities, your facility may be subject to federal effluent limitation guidelines which include additional effluent limits and monitoring requirements for your facility. Please review these requirements, described in Part 2.1.3 of the MSGP, and check any appropriate boxes on the $\mathrm{NOI}$ form.

You must identify all the outfalls from your facility that discharge stormwater. Each outfall must be assigned a unique 3-digit ID (e.g., 001, 002,003 ). You must also provide the latitude and longitude for each outfall from your facility. Indicate whether any outfalls are substantially identical to an outfall already listed, and identify the outfall it is identical to. For each unique outfall you list, you must specify the name of the first water of the U.S. that receives stormwater directly from the outfall and/or from the MS4 that the outfall discharges to. You must specify whether any receiving waters that you discharge to are listed as "impaired" as defined in Appendix A, and the pollutants for which the water is impaired. You must also check identify any Total Maximum Daily Loads (TMDL) that have been completed for any of the waters of the U.S. that you discharge to. You must also provide information about the outfall latitude/longitude, including data source, the scale (if applicable), and the horizontal reference datum. See the instructions in Section D for more information about determining the latitude and longitude.

Identify whether your facility discharges into a Municipal Separate Storm Sewer System (MS4). If yes, provide the name of the MS4 operator. If you are uncertain of the MS4 operator, contact your local government for that information.

Indicate whether discharges from the facility will enter into a water of the U.S that is designated as a Tier 2, Tier 2.5, or Tier 3 water. A list of Tier 2, 2.5, and 3 waters is provided as Appendix L. If the answer is "yes", name all waters designated as Tier 2, Tier 2.5, or Tier 3 to which the facility will discharge. Note that you are ineligible for coverage if you are a new discharger or a new source to waters designated as Tier 3 (outstanding national resource waters) for antidegradation purposes under 40 CFR 131.13(a)(3).
If you are subject to any benchmark monitoring requirements for metals (see the requirements applicable to your Sector(s) in Part 8 of the permit), indicate the hardness for your receiving water(s). See Appendix $\mathrm{J}$ of the permit for information about determining waterbody hardness.

If you are subject to benchmark monitoring requirements for hardnessdependent metals you must also answer whether your facility discharges into any saltwater receiving waters.

Indicate whether your facility will discharge to a federal CERCLA site listed in Appendix P. Note that if your facility will discharge into a federal CERCLA site listed in Appendix $P$, you are not eligible for coverage under this permit unless you notify the EPA Regional Office in advance and the EPA Regional Office authorizes overage under this permit after you have included adequate controls and/or procedures designed to ensure that discharges will not lead to recontamination of aquatic media at the CERCLA site such that your discharge will cause or contribute to an exceedance of a water quality standard.

\section{Section F. Stormwater Pollution Prevention Plan (SWPPP) Information}

All facilities eligible for coverage under this permit are required to prepare a SWPPP in advance of filing the NOI, in accordance with Part 5. Indicate whether the SWPPP has been prepared in advance of filing the NOI.

Indicate the contact information (name, phone, and email) for the person who developed the SWPPP for this facility.

You identify how your SWPPP information will be made available, consistent with Part 5.4 and 7.3 of the permit. If you are making your SWPPP publicly available on a web site, check Option 1 and provide the appropriate Internet URL address. If you are not providing a URL, check Option 2 and provide the selected SWPPP information on this NOI form. You may copy and paste this information directly from your SWPPP.

\section{Section G. Endangered Species Protection}

Using the instructions in Appendix $E$, indicate the Part 1.1.4.5 criterion (i.e., A, B, C, D, or E) you are eligible under with regard to the protection of federally listed endangered and threatened species and designated critical habitat. A description of the basis for the criterion selected must also be provided.

If criterion B is selected, provide the NPDES ID (i.e., permit tracking number) for the other operator who has certified their eligibility under this permit. The NPDES ID was assigned when the operator received coverage under this permit.

If criterion $C$ is selected, you must specify the federally-listed species or designated critical habitat that are located in the "action area" of the facility. You must also indicate under which scenario you determined you were eligible to submit your NOI under criterion $\mathrm{C}$ using Appendix $\mathrm{E}$, and answer any corresponding questions.

If criterion $D$ or $E$ is selected, attach copies of any communications between you and the U.S. Fish and Wildlife Service and National Marine Fisheries Service to this NOI.

\section{Section H. Historic Preservation}

If the project is not located in Indian country lands, indicate whether the project is located on a property of religious or cultural significance to an Indian tribe, and if so, provide the name of the Indian tribe associated with the property. Use the instructions in Appendix $F$ to complete the questions on the NOI form regarding historic preservation. 


\section{Notice of Intent (NOI) for Stormwater Discharges \\ Associated with Industrial Activity Under the NPDES Multi-Sector General Permit}

NPDES Form Date (06/15) This Form Replaces From 3510-6 (09/08) Form Approved OMB No. 2040-0004

(i) a president, secretary, treasurer, or vice-president of the corporation in charge of a principal business function, or any other person who performs similar policy- or decision-making functions for the corporation, or (ii) the manager of one or more manufacturing, production, or operating facilities, provided, the manager is authorized to make management decisions which govern the operation of the regulated facility including having the explicit or implicit duty of making major capital investment recommendations, and initiating and directing other comprehensive measures to assure long-term environmental compliance with environmental laws and regulations; the manager can ensure that the necessary systems are established or actions taken to gather complete and accurate information for permit application requirements; and where authority to sign documents has been assigned or delegated to the manager in accordance with corporate procedures.

For a partnership or sole proprietorship: By a general partner or the proprietor, respectively; or

For a municipality, state, federal, or other public agency: By either a principal executive officer or ranking elected official. For purposes of this Part, a principal executive officer of a federal agency includes (i) the chief executive officer of the agency, or (ii) a senior executive officer having responsibility for the overall operations of a principal geographic unit of the agency (e.g., Regional Administrator of EPA). Include the name and title of the person signing the form and the date of signing.

An unsigned or undated $\mathrm{NOI}$ form will not be considered eligible for permit coverage.

\section{Modifying Your NOI}

If you have been granted a waiver from your Regional Office from electronic reporting, and if after submitting your NOI you need to correct or update any fields on this $\mathrm{NOI}$ form, you may do so by indicating changes on this same form.

\section{Paperwork Reduction Act Notice}

Public reporting burden for this $\mathrm{NO}$ is estimated to average 3.7 hours, plus an additional 2 hours for certain respondents required to gather hardness data. This estimate includes time for reviewing instructions, searching existing data sources, gathering and maintaining the data needed, and completing and reviewing the collection of information. An agency may not conduct or sponsor, and a person is not required to respond to, a collection of information unless it displays a currently valid OMB control number. Send comments regarding the burden estimate, any other aspect of the collection of information, or suggestions for improving this form, including any suggestions which may increase or reduce this burden to: Director, Collection Strategies Division, U.S. Environmental Protection Agency (2822T), 1200 Pennsylvania Ave., NW, Washington, D.C. 20460. Include the OMB control number on any correspondence. Do not send the completed form to this address.

\section{Submitting Your Form}

If you have been granted a waiver from your Regional Office to submit a paper $\mathrm{NOI}$ form, you must send your $\mathrm{NOI}$ by mail to one of the following addresses:

For Regular U.S. Mail Delivery:

Stormwater Notice Processing Center

Mail Code 4203M, ATTN: 2015 MSGP Reports

U.S. EPA

1200 Pennsylvania Avenue, NW

Washington, DC 20460

For Overnight/Express Mail Delivery:

Stormwater Notice Processing Center

William Jefferson Clinton East Building - Room 7420

ATTN: 2015 MSGP Reports

U.S. EPA

1201 Constitution Avenue, NW

Washington, DC 20004

Visit this website for instructions on how to submit electronically: http://water.epa.gov/polwaste/npdes/stormwater/Stormwater-eNOISystem-for-EPAs-MultiSector-General-Permit.cfm 


\section{Appendix H - Notice of Termination (NOT) Form}

Part 7.1 requires you to use the NPDES eReporting Tool, or "NeT", to prepare and submit your Notice of Termination (NOT). However, if you are given a waiver by the EPA Regional Office to use a paper NOT form, and you elect to use it, you must complete and submit the following form. 


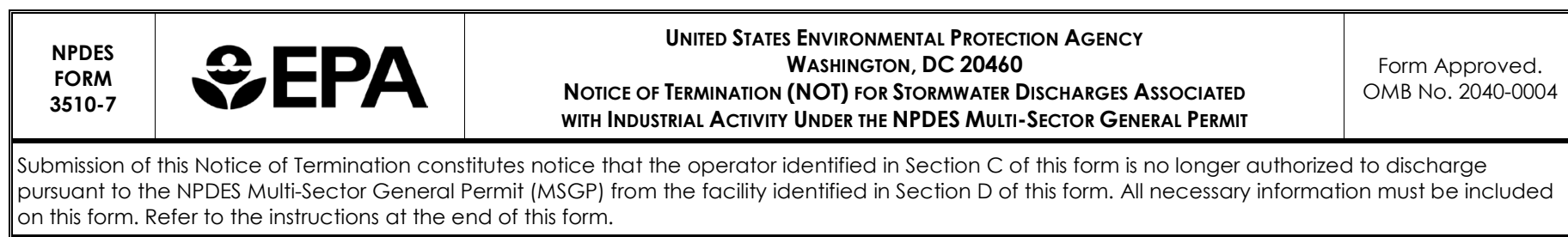

\section{A. Approval to use Paper NOT Form}

1. Have you been granted a waiver from electronic reporting from the Regional Office*? $\square$ YES $\square$ NO

If yes, check which waiver you have been granted, the name of the EPA Regional Office staff person who granted the waiver, and the date of approval:

Waiver granted:

$\square$ The owner/operator's headquarters is physically located in a geographic area (i.e., ZIP code or census tract) that is identified as under-served for broadband Internet access in the most recent report from the Federal Communications Commission.

$\square$ The owner/operator has issues regarding available computer access or computer capability.

Name of EPA staff person that granted the waiver:

Date approval obtained:

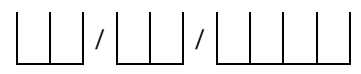

* Note: You are required to obtain approval from the applicable Regional Office prior to using this paper NOT form. If you have not obtained a waiver, you

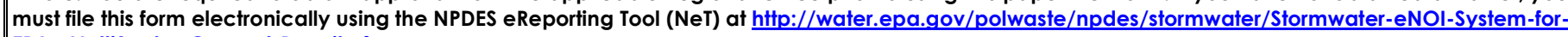
EPAs-MultiSector-General-Permit.cfm

\section{B. Permit Information}

1. NPDES ID:

2. Reason for Termination (check one only):

$\square \quad$ A new owner or operator has taken over responsibility for the facility.

$\square$ You have ceased operations at the facility, there are not or no longer will be discharges of stormwater associated with industrial activity from the facility, and you have already implemented necessary sediment and erosion controls as required by Part 2.1.2.5.

$\square$ You are a Sector $G, H$, or J facility and you have met the applicable termination requirements.

$\square$ You obtained coverage under an individual or alternative general permit for all discharges required to be covered by an NPDES permit.

\section{Facility Operator Information}

1. Operator Name:

2. Mailing Address:

Street:

City:
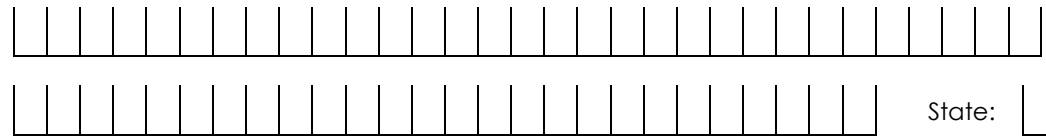

State:

ZIP Code:

3. Phone:

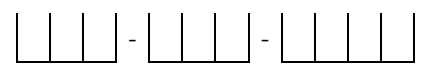

Ext.

4. E-mail:

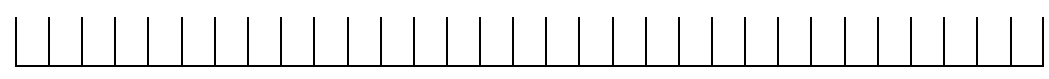

\section{Facility Information}

1. Facility Name:

2. Facility Address:

Street:

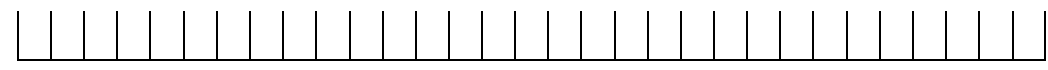

City:

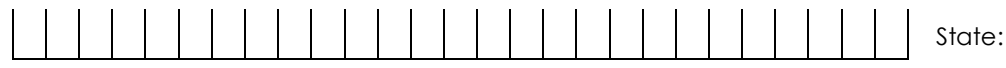
State:

ZIP Code:

County or similar government subdivision: 


\section{E. Certification Information}

I certify under penalty of law that this document and all attachments were prepared under my direction or supervision in accordance with a system

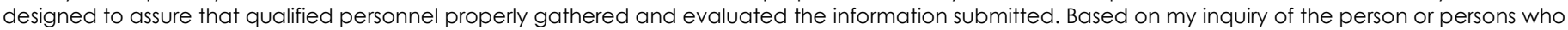
manage the system, or those persons directly responsible for gathering the information, the information submitted is, to the best of my knowledge and belief, true, accurate, and complete. I am aware that there are significant penalties for submitting false information, including the possibility of fine and imprisonment for knowing violations.

First Name, Middle

Initial, Last Name:

Title:

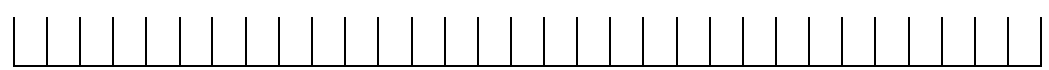

Signature:

Date:

E-mail: 


\title{
Notice of Termination for Stormwater Discharges Associated with Industrial Activity Under the NPDES Multi-Sector General Permit
}

\author{
NPDES Form Date (06/15) This Form Replaces From 3510-7 (09/08) ～Form Approved OMB No. 2040-0004
}

\section{Who May File Notice of Termination (NOT) Form}

Permittees currently covered by EPA's NPDES Stormwater MultiSector General must submit a Notice of Termination (NOT) within 30 days after one or more of the following conditions have been met:

- A new owner or operator has assumed responsibility for the facility;

- You have ceased operations at the facility and there are not or no longer will be discharges of stormwater associated with industrial activity from the facility and you have already implemented necessary sediment and erosion controls per Part 2.1.2.5;

- You are a Sector G, H, or J facility and you have met the applicable termination requirements; or

- You obtained coverage under an individual or alternative general permit for all discharges required to be covered by an NPDES permit.

See the MSGP Part 1.3.3 for more information.

\section{Completing the Form}

To complete this form, type or print, using uppercase letters, in the appropriate areas only. Please place each character between the marks. Abbreviate if necessary to stay within the number of characters allowed for each item. Use only one space for breaks between words, but not for punctuation marks unless they are needed to clarify your response. Please submit original document with signature in ink - do not send a photocopied signature.

\section{Section A. Approval to Use Paper NOT Form}

You must indicate whether you have been granted a waiver from electronic reporting from the EPA Regional Office. Note that you are not authorized to use this paper NOT form unless the EPA Regional Office has approved its use. Where you have obtained approval to use this form, indicate the waiver that you have been granted, the name of the EPA Regional Office staff person who granted the waiver, and the date that approval was provided. See

http://water.epa.gov/polwaste/npdes/stormwater/StormwaterContacts.cfm for a list of EPA Regional Office contacts.

\section{Section B. Permit Information}

Enter the existing NPDES ID (i.e., NOI tracking number) assigned to your permit authorization.

Indicate your reason for submitting this Notice of Termination by checking the appropriate box. Check only one box (see MSGP Part 1.3.3 for more information).

\section{Section C. Facility Operator Information}

Provide the legal name of the person, firm, public organization, or any other entity that operates the facility described in this NOT. An operator of a facility is the legal entity that controls the operation of the facility. Refer to Appendix A of the permit for the definition of "operator". Provide the operator's mailing address, phone number, and e-mail.

\section{Section D. Facility Information}

Enter the official or legal name and complete street address, including city, state, ZIP code, and county or similar government subdivision of the facility. If the facility lacks a street address, indicate the general location of the facility (e.g., Intersection of State Highways 61 and 34). Complete facility information must be provided for termination of permit coverage to be valid.

\section{Section E. Certification Information}

All NOTs must be signed as follows:

For a corporation: By a responsible corporate officer. For the purpose of this Section, a responsible corporate officer means: (i)a president, secretary, treasurer, or vice-president of the corporation in charge of a principal business function, or any other person who performs similar policy- or decision-making functions for the corporation, or (ii) the manager of one or more manufacturing, production, or operating facilities, provided, the manager is authorized to make management decisions which govern the operation of the regulated facility including having the explicit or implicit duty of making major capital investment recommendations, and initiating and directing other comprehensive measures to assure long-term environmental compliance with environmental laws and regulations; the manager can ensure that the necessary systems are established or actions taken to gather complete and accurate information for permit application requirements; and where authority to sign documents has been assigned or delegated to the manager in accordance with corporate procedures.

For a partnership or sole proprietorship: By a general partner or the proprietor, respectively; or

For a municipality, state, federal, or other public agency: By either a principal executive officer or ranking elected official. For purposes of this Part, a principal executive officer of a federal agency includes (i) the chief executive officer of the agency, or (ii) a senior executive officer having responsibility for the overall operations of a principal geographic unit of the agency (e.g., Regional Administrator of EPA). Include the name and title of the person signing the form and the date of signing.

Include the name, title, and email address of the person signing the form and the date of signing. An unsigned or undated NOT form will not be considered valid termination of permit coverage.

\section{Paperwork Reduction Act Notice}

Public reporting burden for this Notice of Termination is estimated to average 0.5 hours, including time for reviewing instructions, searching existing data sources, gathering and maintaining the data needed, and completing and reviewing the collection of information. Send comments regarding the burden estimate, any other aspect of the collection of information, or suggestions for improving this form, including any suggestions which may increase or reduce this burden to: Director, Collection Strategies Division, U.S. Environmental Protection Agency (2822T), 1200 Pennsylvania Ave., NW, Washington, D.C. 20460. Include the OMB control number of this form on any correspondence. Do not send the completed NOT form to this address. 
Instructions for Completing EPA Form 3510-7

Notice of Termination for Stormwater Discharges

\section{Associated with Industrial Activity Under the NPDES Multi-Sector General Permit}

NPDES Form Date (06/15) This Form Replaces From 3510-7 (09/08)

Form Approved OMB No. 2040-0004

Submitting Your Form

If you have been granted a waiver from your Regional Office to submit a paper NOT form, you must send your NOT by mail to one of the following addresses:

\section{For Regular U.S. Mail Delivery:}

Stormwater Notice Processing Center

Mail Code 4203M, ATTN: 2015 MSGP Reports

U.S. EPA

1200 Pennsylvania Avenue, NW

Washington, DC 20460
For Overnight/Express Mail Delivery:

Stormwater Notice Processing Center

William Jefferson Clinton East Building - Room 7420

ATTN: 2015 MSGP Reports

U.S. EPA

1201 Constitution Avenue, NW

Washington, DC 20004

Visit this website for instructions on how to submit electronically: http://water.epa.gov/polwaste/npdes/stormwater/StormwatereNOI-System-for-EPAs-MultiSector-General-Permit.cfm 


\section{Appendix I - Annual Report Form}

Part 7.1 requires you to use the NPDES eReporting Tool, or "NeT", to prepare and submit your Annual Report. However, if you are given a waiver by the EPA Regional Office to use a paper annual report form, and you elect to use it, you must complete and submit the following form. 


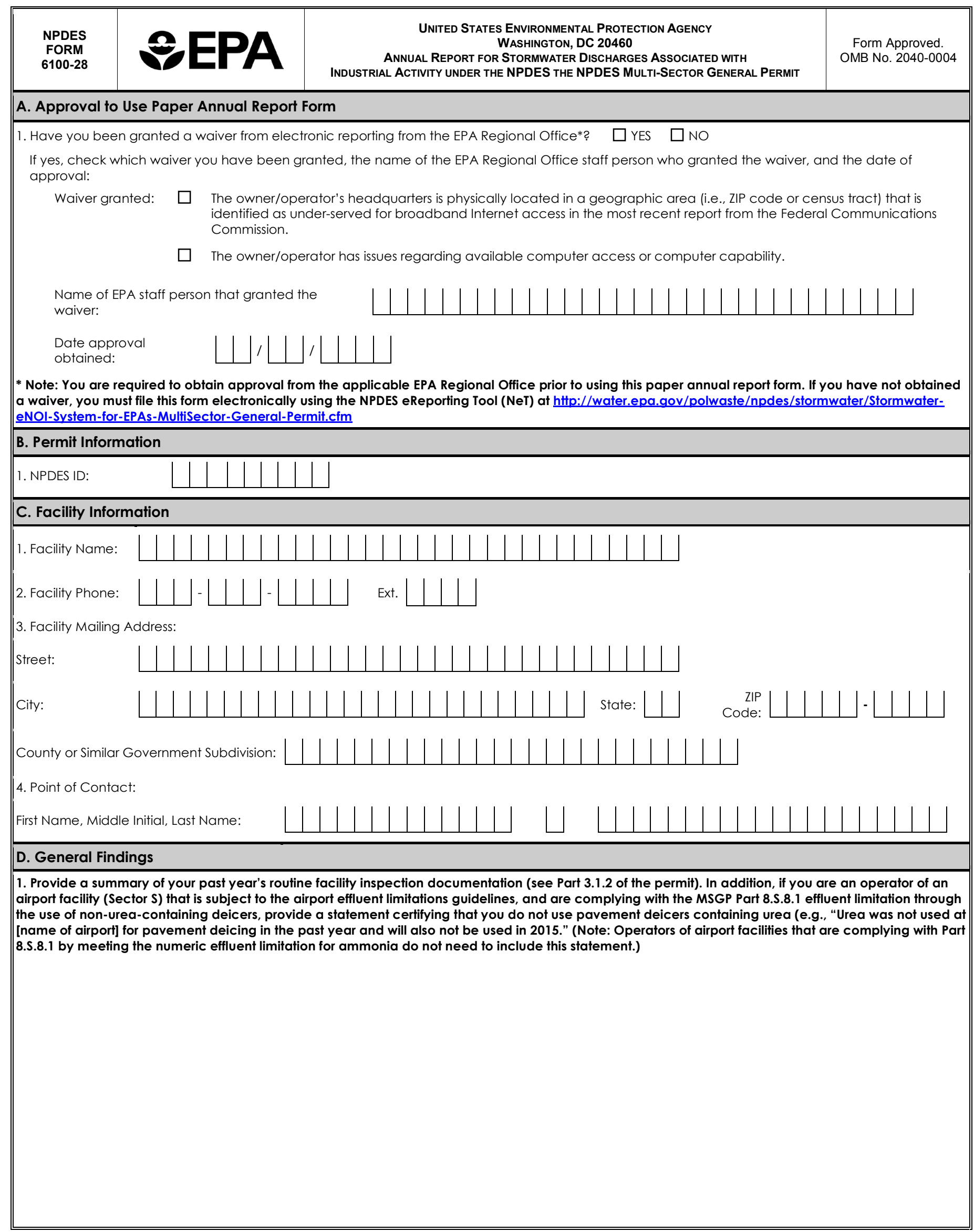


2. Provide a summary of your past year's quarterly visual assessment documentation (see Part 3.2.2 of the permit).

3. For any four-sample (minimum) average benchmark monitoring exceedance, if after reviewing the selection, design, installation, and implementation of your control measures and considering whether any modifications are necessary to meet the effluent limits in the permit, you determine that no further pollutant reductions are technologically available and economically practicable and achievable in light of best industry practice, provide your rationale for why you believe no further reductions are achievable (see Part 6.2.1.2 of the permit). Enter "NA" if not applicable.

4. Provide a summary of your past year's corrective action documentation (See Part 4.4 of the permit). (Note: If corrective action is not yet completed at the time of submission of this annual report, you must describe the status of any outstanding corrective action(s).) Also describe any incidents of noncompliance in the past year or currently ongoing, or if none, provide a statement that you are in compliance with the permit. 


\section{E. Certification Information}

I certify under penalty of law that this document and all attachments were prepared under my direction or supervision in accordance with a system designed to assure that qualified personnel properly gathered and evaluated the information submitted. Based on my inquiry of the person or persons who manage the system, or those persons directly responsible for gathering the information, the information submitted is, to the best of my knowledge and belief, true, accurate, and complete. I am aware that there are significant penalties for submitting false information, including the possibility of fine and imprisonment for knowing violations.

First Name, Middle Initial, Last Name:
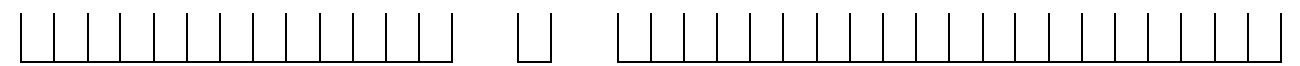

Title:

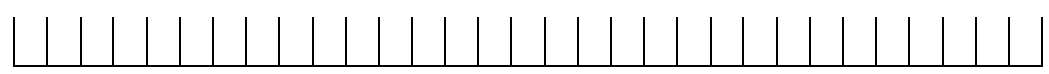

Signature:

Date:

E-mail:

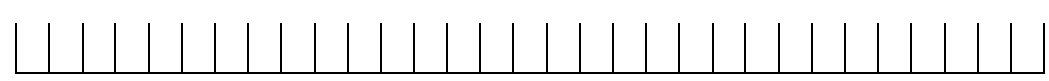


Annual Report for Stormwater Discharges Associated with Industrial Activity Under an NPDES General Permit

\section{Who Must File an Annual Report}

Operators must submit an Annual Report to EPA electronically, per Part 7.5, by January $30^{\text {th }}$ for each year of permit coverage containing information generated from the past calendar year.

\section{Completing the Form}

To complete this form, type or print, using uppercase letters, in the appropriate areas only. Please place each character between the marks. Abbreviate if necessary to stay within the number of characters allowed for each item. Use only one space for breaks between words, but not for punctuation marks unless they are needed to clarify your response. Please submit original document with signature in ink - do not send a photocopied signature.

\section{Section A. Approval to Use Paper Annual Report Form}

You must indicate whether you have been granted a waiver from electronic reporting from the EPA Regional Office. Note that you are not authorized to use this paper form unless the EPA Regional Office has approved its use. Where you have obtained approval to use this form, indicate the waiver that you have been granted, the name of the EPA staff person who granted the waiver, and the date that approval was provided. See http://water.epa.gov/polwaste/npdes/stormwater/StormwaterContacts.cfm for a list of EPA Regional Office contacts.

\section{Section B. Permit Information}

Provide the NPDES ID (i.e., NOI tracking number) assigned to your facility.

\section{Section C. Facility Information}

Enter the official or legal name, phone number, and complete street address, including city, state, ZIP code, and county or similar government subdivision, for the facility that is covered by the NPDES ID identified in Section B. If the facility lacks a street address, indicate the general location of the facility (e.g., Intersection of State Highways 61 and 34). Also provide a point of contact name for the facility.

\section{Section D. General Findings}

To complete this section you must provide the following information in your annual report:

1. A summary of your past year's routine facility inspection documentation required by Part 3.1.2 of the permit.

2. A summary of your past year's quarterly visual assessment documentation required by Part 3.2.2 of the permit.

3. If, after finding the average of your four monitoring values for any pollutant exceeds the benchmark, you decide no further pollutant reductions are technologically available and economically practicable and achievable in light of best industry practice, your rationale for why you believe no further reductions are achievable.

4. Information copied or summarized from the corrective action documentation required per Part 4.4 (if applicable). If corrective action is not yet completed at the time of submission of this Annual Report, you must describe the status of any outstanding corrective action(s). You must also describe any incidents of noncompliance in the past year or currently ongoing, or if none, provide a statement that you are in compliance with the permit.

\section{Section E. Certification Information}

The Annual Report must be signed by a person described below, or by a duly authorized representative of that person.

For a corporation: By a responsible corporate officer. For the purpose of this Section, a responsible corporate officer means:

(i) a president, secretary, treasurer, or vice-president of the corporation in charge of a principal business function, or any other person who performs similar policy- or decision-making functions for the corporation, or (ii) the manager of one or more manufacturing production, or operating facilities, provided, the manager is authorized to make management decisions which govern the operation of the regulated facility including having the explicit or implicit duty of making major capital investment recommendations, and initiating and directing other comprehensive measures to assure long-term environmental compliance with environmental laws and regulations; the manager can ensure that the necessary systems are established or actions taken to gather complete and accurate information for permit application requirements; and where authority to sign documents has been assigned or delegated to the manager in accordance with corporate procedures.

For a partnership or sole proprietorship: By a general partner or the proprietor, respectively; or

For a municipality, state, federal, or other public agency: By either a principal executive officer or ranking elected official. For purposes of this Part, a principal executive officer of a federal agency includes (i) the chief executive officer of the agency, or (ii) a senior executive officer having responsibility for the overall operations of a principal geographic unit of the agency (e.g., Regional Administrator of EPA). Include the name and title of the person signing the form and the date of signing.

A person is a duly authorized representative only if:

1. The authorization is made in writing by a person described above

2. The authorization specifies either an individual or a position having responsibility for the overall operation of the regulated facility or activity such as the position of plant manager, operator of a well or a well field, superintendent, position of equivalent responsibility, or an individual or position having overall responsibility for environmental matters for the company, (A duly authorized representative may thus be either a named individual or any individual occupying a named position.) and

\section{The written authorization is submitted to the Director.}

An unsigned or undated Annual Report form be considered incomplete.

\section{Paperwork Reduction Act Notice}

Public reporting burden for this form is estimated to average 2.5 hours per response, including time for reviewing instructions, searching existing data sources, gathering and maintaining the data needed, and completing and reviewing the collection of information. An agency may not conduct or sponsor, and a person is not required to respond to, a collection of information unless it displays a currently valid OMB control number. Send comments regarding the burden estimate, any other aspect of the collection of information, or suggestions for improving this form, including any suggestions which may increase or reduce this burden to: Director, Collection Strategies Division, U.S. Environmental Protection Agency (2822T), 1200 Pennsylvania Ave., NW, Washington, D.C. 20460. Include the OMB control number of this form on any correspondence. Do not send the completed Annual Report form to this address. 
Instructions for Completing the Annual Report Form

\section{Annual Report for Stormwater Discharges}

Associated with Industrial Activity Under an NPDES General Permit

\section{Submitting Your Form}

If you have been granted a waiver from your Regional Office to submit a paper Annual Report form, you must send your Annual Report form by mail to one of the following addresses:

For Regular U.S. Mail Delivery:

Stormwater Notice Processing Center

Mail Code 4203M, ATTN: 2015 MSGP Reports

U.S. EPA

1200 Pennsylvania Avenue, NW

Washington, DC 20460
For Overnight/Express Mail Delivery:

Stormwater Notice Processing Center

William Jefferson Clinton East Building - Room 7420

ATTN: 2015 MSGP Reports

U.S. EPA

1201 Constitution Avenue, NW

Washington, DC 20004

Visit this website for instructions on how to submit electronically: http://water.epa.gov/polwaste/npdes/stormwater/StormwatereNOI-System-for-EPAs-MultiSector-General-Permit.cfm 


\section{Appendix J - Calculating Hardness in Freshwater Receiving Waters for Hardness Dependent Metals}

\section{Overview}

For any sectors required to conduct benchmark samples for a hardness-dependent metal, EPA includes 'hardness ranges' from which benchmark values are determined. To determine which hardness range to use, you must collect data on the hardness of your receiving water(s). Once the site-specific hardness data have been collected, the corresponding benchmark value for each metal is determined by comparing where the hardness data fall within hardness ranges, as shown in Table 1. You only need to determine hardness for your discharges into freshwater as the benchmark values for metals do not vary for discharges to saline waters.

Table 1. Hardness Ranges to Be Used to Determine Benchmark Values for Cadmium, Copper, Lead, Nickel, Silver, and Zinc.

\begin{tabular}{|c|c|c|c|c|c|c|}
\hline \multirow{2}{*}{ All Units mg/L } & \multicolumn{7}{|c|}{ Benchmark Values (mg/L, total) } \\
\cline { 2 - 7 } & Cadmium & Copper & Lead & Nickel & Silver & Zinc \\
\hline $0-24.99 \mathrm{mg} / \mathrm{L}$ & 0.0005 & 0.0038 & 0.014 & 0.15 & 0.0007 & 0.04 \\
\hline $25-49.99 \mathrm{mg} / \mathrm{L}$ & 0.0008 & 0.0056 & 0.023 & 0.20 & 0.0007 & 0.05 \\
\hline $50-74.99 \mathrm{mg} / \mathrm{L}$ & 0.0013 & 0.0090 & 0.045 & 0.32 & 0.0017 & 0.08 \\
\hline $75-99.99 \mathrm{mg} / \mathrm{L}$ & 0.0018 & 0.0123 & 0.069 & 0.42 & 0.0030 & 0.11 \\
\hline $100-124.99 \mathrm{mg} / \mathrm{L}$ & 0.0023 & 0.0156 & 0.095 & 0.52 & 0.0046 & 0.13 \\
\hline $125-149.99 \mathrm{mg} / \mathrm{L}$ & 0.0029 & 0.0189 & 0.122 & 0.61 & 0.0065 & 0.16 \\
\hline $150-174.99 \mathrm{mg} / \mathrm{L}$ & 0.0034 & 0.0221 & 0.151 & 0.71 & 0.0087 & 0.18 \\
\hline $175-199.99 \mathrm{mg} / \mathrm{L}$ & 0.0039 & 0.0253 & 0.182 & 0.80 & 0.0112 & 0.20 \\
\hline $200-224.99 \mathrm{mg} / \mathrm{L}$ & 0.0045 & 0.0285 & 0.213 & 0.89 & 0.0138 & 0.23 \\
\hline $225-249.99 \mathrm{mg} / \mathrm{L}$ & 0.0050 & 0.0316 & 0.246 & 0.98 & 0.0168 & 0.25 \\
\hline $250+\mathrm{mg} / \mathrm{L}$ & 0.0053 & 0.0332 & 0.262 & 1.02 & 0.0183 & 0.26 \\
\hline
\end{tabular}

\section{How to Determine Hardness for Hardness-Dependent Parameters in Freshwater.}

You may select one of three methods to determine hardness, including: individual grab sampling, grab sampling by a group of operators which discharge to the same receiving water, or using third-party data. Regardless of the method used, you are responsible for documenting the procedures used for determining hardness values. The hardness value is required to be submitted to EPA with your Notice of Intent (NOI) so that your electronic Discharge Monitoring Report (DMR) which you will submit through NetDMR will include the appropriate limits. You must retain all report and monitoring data in accordance with Part 7.5 of the permit. The three method options for determining hardness are detailed in the following sections.

\section{(1) Permittee Samples for Receiving Stream Hardness}

This method involves collecting samples in the receiving water and submitting these to a laboratory for analysis. If you elect to sample your receiving water(s) and submit samples for analysis, hardness must be determined from the closest intermittent or perennial stream downstream of your point of discharge. The sample can be collected during either dry or wet weather. Collection of the sample during wet weather is more representative of conditions 
during stormwater discharges; however, collection of in-stream samples during wet weather events may be impracticable or present safety issues.

Hardness must be sampled and analyzed using approved methods as described in 40 CFR Part 136 (Guidelines Establishing Test Procedures for the Analysis of Pollutants).

(2) Group Monitoring for Receiving Stream Hardness

You can be part of a group of permittees discharging to the same receiving waters and collect samples that are representative of the hardness values for all members of the group. In this scenario, hardness of the receiving water must be determined using 40 CFR Part 136 procedures and the results shared by group members. To use the same results, hardness measurements must be taken on a stream reach within a reasonable distance of the discharge points of each of the group members.

\section{(3) Collection of Third-Party Hardness Data}

You can submit receiving stream hardness data collected by a third party provided the results are collected consistent with the approved 40 CFR Part 136 methods. These data may come from a local water utility, previously conducted stream reports, TMDLs, peer reviewed literature, other government publications, or data previously collected by the permittee. Data should be less than 10 years old.

Water quality data for many of the nation's surface waters are available on-line or by contacting EPA or a state environmental agency. EPA's data system STORET, short for STOrage and RETrieval, is a repository for receiving water quality, biological, and physical data and is used by state environmental agencies, EPA and other federal agencies, universities, private citizens, and many others. Similarly, state environmental agencies and the U.S. Geological Service (USGS) also have water quality data available that, in some instances, can be accessed online. "Legacy STORET" codes for hardness include: 259 hardness, carbonate; 260 hardness, noncarbonated; and 261 calcium + magnesium, while more recent, "Modern STORET" data codes include: 00900 hardness, 00901 carbonate hardness, and 00902 noncarbonate hardness; or the discrete measurements of calcium (00915) and magnesium (00925) can be used to calculate hardness. Hardness data historically has been reported as "carbonate,"

"noncarbonate," or "Ca + Mg." If these are unavailable, then individual results for calcium (Ca) and magnesium (Mg) may be used to calculate hardness using the following equation:

$$
\mathrm{mg} / \mathrm{L} \mathrm{CaCO}=2.497(\mathrm{Ca} \mathrm{mg} / \mathrm{L})+4.118(\mathrm{Mg} \mathrm{mg} / \mathrm{L})
$$

When interpreting the data for carbonate and non-carbonate hardness, note that total hardness is equivalent to the sum of carbonate and noncarbonate hardness if both forms are reported. If only carbonate hardness is reported, it is more than likely that noncarbonate hardness is absent and the total hardness is equivalent to the available carbonate hardness. 


\section{Appendix K - No Exposure Certification Form}

Part 7.1 requires you to use the NPDES eReporting Tool, or "NeT", to prepare and submit your No Exposure Certification (NOE) form. However, if you are given a waiver by the EPA Regional Office to use a paper NOE form, and you elect to use it, you must complete and submit the following form. 


\begin{tabular}{|c|c|c|}
\hline $\begin{array}{c}\text { NPDES } \\
\text { FORM } \\
3510-11\end{array}$ & 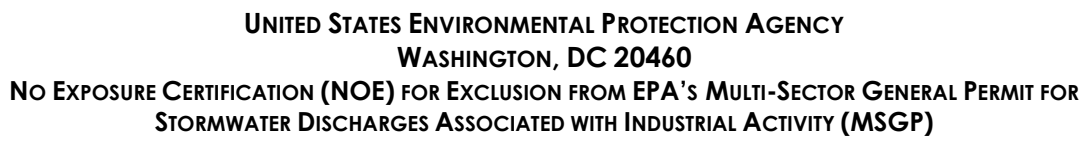 & $\begin{array}{c}\text { Form Approved } \\
\text { OMB No. 2040-0004 }\end{array}$ \\
\hline
\end{tabular}

Submission of this No Exposure Certification constitutes notice that the operator identified in Section C does not require permit authorization under EPA's Stormwater Multi Sector General Permit for its stormwater discharges associated with industrial activity from the facility identified in Section D of this form due to the existence of a condition of no exposure.

A condition of no exposure exists at an industrial facility when all industrial materials and activities are protected by a storm resistant shelter to prevent exposure to rain, snow, snowmelt, and/or runoff. Industrial materials or activities include, but are not limited to, material handling equipment or activities, industrial machinery, raw materials, intermediate products, by-products, final products, or waste products. Material handling activities include the storage, loading and unloading, transportation, or conveyance of any raw material, intermediate product, final product or waste product. A storm resistant shelter is not required for the following industrial materials and activities:

- drums, barrels, tanks, and similar containers that are tightly sealed, provided those containers are not deteriorated and do not leak. "Sealed" means banded or otherwise secured and without operational taps or valves;

- adequately maintained vehicles used in material handling; and

- final products, other than products that would be mobilized in stormwater discharges (e.g., rock salt).

A No Exposure Certification must be provided for each facility qualifying for the no exposure exclusion. In addition, the exclusion from NPDES permitting is available on a facility-wide basis only, not for individual outfalls. If any industrial activities or materials are or will be exposed to precipitation, the facility is not eligible for the no exposure exclusion.

By signing and submitting this No Exposure Certification form, the operator in Section C is certifying that a condition of no exposure exists at its facility or site, and is obligated to comply with the terms and conditions of 40 CFR $122.26(\mathrm{~g})$.

\section{A. Approval to Use Paper NOE Form}

1. Have you been granted a waiver from electronic reporting from the EPA Regional Office*? $\square$ YES $\square$ NO

If yes, check which waiver you have been granted, the name of the EPA Regional Office staff person who granted the waiver, and the date of approval:

Waiver granted: $\square$ The owner/operator's headquarters is physically located in a geographic area (i.e., zIP code or census tract) that is identified as under-served for broadband Internet access in the most recent report from the Federal Communications Commission.

$\square \quad$ The owner/operator has issues regarding available computer access or computer capability.

Name of EPA staff person that granted the waiver:

Date approval obtained:

* Note: You are required to obtain approval from the applicable EPA Regional Office prior to using this paper NOE form. If you have not obtained a waiver, you must file this form electronically using the NPDES eReporting Tool (NeT) at http://water.epa.gov/polwaste/npdes/stormwater/Stormwater-eNOI-Systemfor-EPAs-MultiSector-General-Permit.cfm

\section{B. Reason for Submission}

Select the purpose for filling out this form (check only 1).

$\square$ To obtain a new No Exposure Certification. Fill in Sections C, D, E and F.

$\square$ To discontinue an existing No Exposure Certification. Select this option if you would like to discontinue an existing No Exposure Certification because your facility is no longer subject to regulation under 40 CFR 122.26 (e.g., the facility has ceased the industrial activity that necessitated the No Exposure Certification)*. Provide the following information and fill out Section $G$.

Provide the existing NPDES ID for the No Exposure Certification that

you would like to discontinue:

* Note that if your facility no longer qualifies for the No Exposure Certification because permit coverage is required for exposed industrial materials or activities, you should not check this box, and must instead file for coverage under the Multi-Sector General Permit or an individual permit. Your No Exposure Certification will be automatically discontinued after you obtain coverage under the MSGP or an individual permit.

\section{Facility Operator Information}

1. Operator Name:

2. Mailing Address

Street:

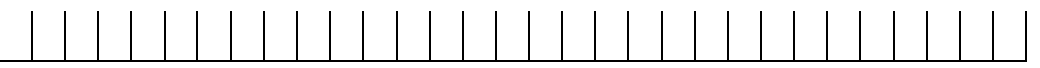

City:

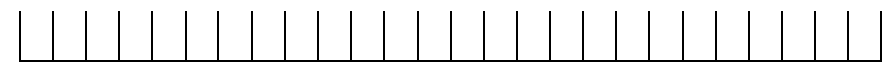

State:

Ext.

3. Phone:

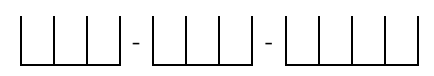

4. E-mail:

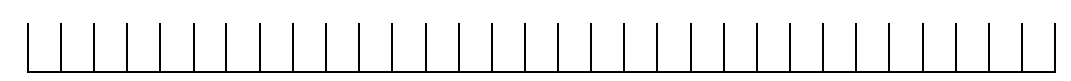


5. Operator Point of Contact Information:

First Name, Middle Initial, Last Name:

Title:

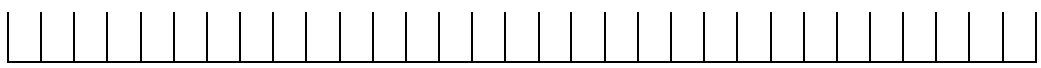

\section{Facility Information}

1. Facility Name:

2. Facility Address:

Street/Location:

City:

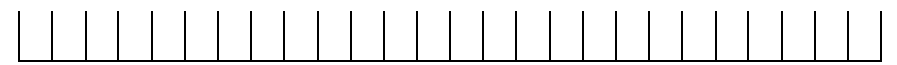

State:

ZIP Code:

County or Similar Government Subdivision:

3. Latitude/Longitude for the facility:

Latitude:

$\ldots \ldots \ldots \ldots \ldots$ _ $~ \ldots \ldots$ (decimal degrees)

Longitude:

${ }^{\circ} \mathrm{W}$ (decimal degrees)

Latitude/Longitude Data Source: $\square$ Map $\square$ GPS $\square$ Other:

If you used a USGS topographic map, what was the scale?

Horizontal Reference Datum: $\square$ NAD $27 \quad \square$ NAD $83 \square$ WGS 84

4. Is your project/site located on Indian country lands? $\quad \square$ YES $\quad \square$ NO

If yes, provide the name of the Indian tribe associated with the area of Indian country (including name of Indian reservation, if applicable):

5. Are you a "federal operator" as defined in Appendix A? $\quad \square$ YES $\square$ NO

6. What is the ownership type of the facility? $\square$ Federal Facility (U.S. Government) $\square$ Privately Owned Facility $\square$ Municipality

$\square$ County Government $\square$ Corporation $\square$ State Government $\square$ Tribal Government $\square$ School District

$\square$ District $\square$ Mixed Ownership (e.g. Public/Private) $\square$ Municipal or Water District

7. Have stormwater discharges from your facility been covered previously under an NPDES permit? $\quad \square$ YES $\square$ NO

If yes, provide the NPDES ID if you had coverage under EPA's MSGP or the NPDES

permit number if you had coverage under an EPA individual permit:

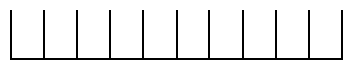

8. Has your facility previously been covered by a No Exposure exclusion? $\square$ YES $\square$ NO

If yes, provide the NPDES ID for your previous No Exposure exclusion:

9. Identify the 4-digit Standard Industrial Classification (SIC) code or 2-letter Activity Code that best represents the products produced or services rendered for which your facility is primarily engaged, as defined in MSGP:

\section{Primary SIC Code:}

OR

\section{Primary Activity Code}

10. Total size of site associated with industrial activity: (to the nearest quarter acre)

11. Have you paved or roofed over a formerly exposed, pervious area in order to qualify for the no exposure exclusion? $\square$ YES $\square$ NO

If yes, please indicate approximately how much area was paved or roofed over. Completing this question does not disqualify you for the no exposure exclusion. However, your permitting authority may use this information in considering whether stormwater discharges from your site are likely to have an adverse impact on water quality, in which case you could be required to obtain permit coverage.

$\square$ Less than one (1) acre $\square$ One (1) to five (5) acres $\square$ More than five (5) acres 


\section{E. Exposure Checklist}

Are any of the following materials or activities exposed to precipitation, now or in the foreseeable future?

(Please check either "Yes" or "No" in the appropriate box.) If you answer "Yes" to any of these questions, you are not eligible for the no exposure exclusion.

\begin{tabular}{|c|c|c|}
\hline & Yes & $\mathrm{No}$ \\
\hline $\begin{array}{l}\text { Using, storing or cleaning industrial machinery or equipment, and areas where residuals from using, storing or cleaning industrial } \\
\text { machinery or equipment remain and are exposed to stormwater }\end{array}$ & $\square$ & $\square$ \\
\hline Materials or residuals on the ground or in stormwater inlets from spills/leaks & $\square$ & $\square$ \\
\hline Materials or products from past industrial activity & $\square$ & $\square$ \\
\hline Material handling equipment (except adequately maintained vehicles) & $\square$ & $\square$ \\
\hline Materials or products during loading/unloading or transporting activities & $\square$ & $\square$ \\
\hline $\begin{array}{l}\text { Materials or products stored outdoors (except final products intended for outside use [e.g., new cars] where } \\
\text { exposure to stormwater does not result in the discharge of pollutants) }\end{array}$ & $\square$ & $\square$ \\
\hline Materials contained in open, deteriorated or leaking storage drums, barrels, tanks, and similar containers & $\square$ & $\square$ \\
\hline Materials or products handled/stored on roads or railways owned or maintained by the discharger & $\square$ & $\square$ \\
\hline Waste material (except waste in covered, non-leaking containers [e.g., dumpsters]) & $\square$ & $\square$ \\
\hline Application or disposal of process wastewater (unless otherwise permitted) & $\square$ & $\square$ \\
\hline $\begin{array}{l}\text { Particulate matter or visible deposits of residuals from roof stacks and/or vents not otherwise regulated (i.e., under an air quality } \\
\text { control permit) and evident in the stormwater outflow }\end{array}$ & $\square$ & $\square$ \\
\hline
\end{tabular}

\section{F. Certification Information}

I certify under penalty of law that I have read and understand the eligibility requirements for claiming a condition of "no exposure" and obtaining an exclusion from NPDES stormwater permitting.

I certify under penalty of law that there are no discharges of stormwater contaminated by exposure to industrial activities or materials from the industrial facility or site identified in this document (except as allowed under 40 CFR 122.26(g)(2)).

I understand that I am obligated to submit a no exposure certification form once every five years to the NPDES permitting authority and, if requested, to

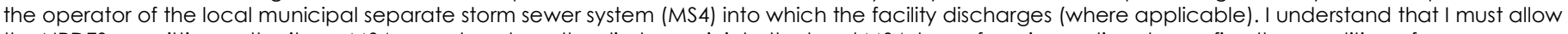
the NPDES permitting authority, or MS4 operator where the discharge is into the local MS4, to perform inspections to confirm the condition of no exposure and to make such inspection reports publicly available upon request. I understand that I must obtain coverage under an NPDES permit prior to any point source discharge of stormwater from the facility.

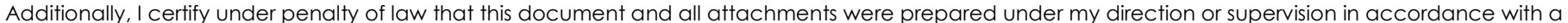
system designed to assure that qualified personnel properly gathered and evaluated the information submitted. Based on my inquiry of the person or persons who manage the system, or those persons directly responsible for gathering the information, the information submitted is to the best of my

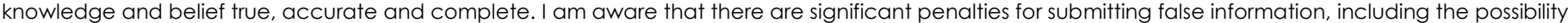
of fine and imprisonment for knowing violations.

First Name, Middle Initial, Last Name:
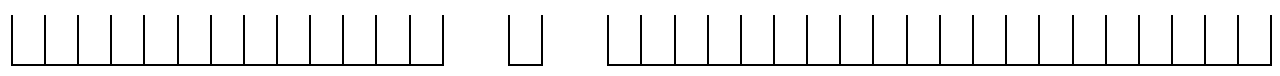

Title:

Signature:

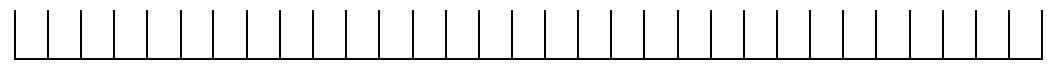

E-mail:
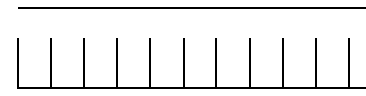

Date:

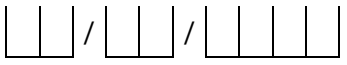

\section{G. Discontinuation of No Exposure Certification Information}

I certify under penalty of law that this document and all attachments were prepared under my direction or supervision in accordance with a system designed to assure that qualified personnel properly gathered and evaluated the information submitted. Based on my inquiry of the person or persons who manage the system, or those persons directly responsible for gathering the information, the information submitted is to the best of my knowledge and belief true, accurate and complete. I am aware that there are significant penalties for submitting false information, including the possibility of fine and imprisonment for knowing violations.

First Name, Middle Initial, Last Name:

Title:
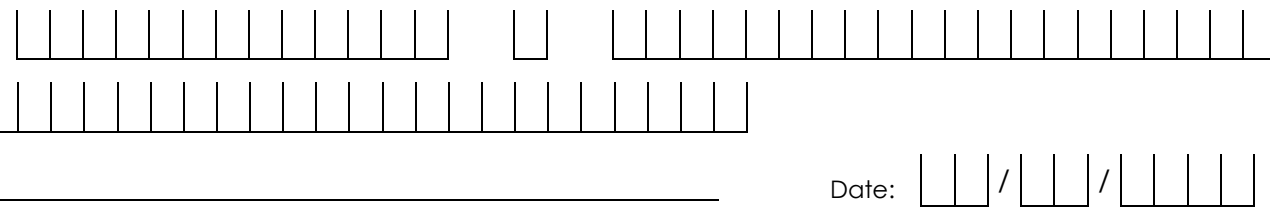

E-mail: 


\section{No Exposure Certification (NOE) for Exclusion from Stormwater Discharges Associated with Industrial Activity Under an NPDES General Permit}

NPDES Form Date (06/15) This Form Replaces From 3510-11 (09/08) Form Approved OMB No. 2040-0004

\section{Who May File a No Exposure Certification}

Federal law at 40 CFR Part 122.26 prohibits point source discharges of stormwater associated with industrial activity to waters of the U.S. without a National Pollutant Discharge Elimination System (NPDES) permit. However, NPDES permit coverage is not required for discharges of stormwater associated with industrial activities identified at 40 CFR 122.26(b)(14)(i)-(ix) and (xi) if the discharger can certify that a condition of "no exposure" exists at the industrial facility or site.

Stormwater discharges from construction activities identified in 40 CFR 122.26(b)(14)(x) and (b)(15) are not eligible for the no exposure exclusion.

\section{Obtaining and Maintaining the No Exposure Exclusion}

This form is used to certify that a condition of no exposure exists at the industrial facility or site described herein. This certification is only applicable in jurisdictions where EPA is the NPDES permitting authority and must be re-submitted at least once every five years.

The industrial facility operator must maintain a condition of no exposure at its facility or site in order for the no exposure exclusion to remain applicable. If conditions change resulting in the exposure of materials and activities to stormwater, the facility operator must obtain coverage under an NPDES stormwater permit immediately.

\section{Completing the Form}

You must type or print, using uppercase letters, in appropriate areas only. Enter only one character per space (i.e., between the marks). Abbreviate if necessary to stay within the number of characters allowed for each item. Use one space for breaks between words. One form must be completed for each facility or site for which you are seeking to certify a condition of no exposure. Please make sure you have addressed all applicable questions and have made a photocopy for your records before sending the completed form to the above address.

\section{Section A. Approval to Use Paper NOE Form}

You must indicate whether you have been granted a waiver from electronic reporting from the EPA Regional Office. Note that you are not authorized to use this paper No Exposure Certification (NOE) form unless the EPA Regional Office has approved its use. Where you have obtained approval to use this form, indicate the waiver that you have been granted, the name of the EPA Regional Office staff person who granted the waiver, and the date that approval was provided. See http://water.epa.gov/polwaste/npdes/stormwater/StormwaterContacts.cfm for a list of EPA Regional Office contacts.

\section{Section B. Reason for Submission}

You must check your reason for submitting this form. You may submit this form for obtaining a new No Exposure Certification, for renewing a previous No Exposure Certification, or for discontinuing an existing No Exposure Certification (for facilities that no longer need the exclusion from permit coverage for industrial stormwater discharges).

\section{Section C. Facility Operator Information}

Provide the legal name of the person, firm, public organization, or any other entity that operates the facility described in this certification form. An operator of a facility is the legal entity that controls the operation of the facility. Refer to Appendix A of the
MSGP for the definition of "operator". Provide the operator's mailing address, phone number, and e-mail. Correspondence for the NOE will be sent to this address. Also provide the name and title for the operator point of contact (note that the point of contact name may be the same as the operator name).

\section{Section D. Facility Information}

Enter the official or legal name and complete street address, including city, state, ZIP code, and county or similar government subdivision of the facility. If the facility lacks a street address, indicate the general location of the facility (e.g., Intersection of State Highways 61 and 34). Complete facility information must be provided for permit coverage to be granted.

Provide the latitude and longitude of your facility in decimal degrees format. The latitude and longitude of your facility can be determined in several different ways, including through the use of global positioning system (GPS) receivers and U.S. Geological Survey (U.S.G.S.) topographic or quadrangle maps. Refer to $\mathrm{http}$ ://transition.fcc.gov/mb/audio/bickel/DDDMMSSdecimal.html/ for assistance in providing the proper latitude/longitude format. For consistency, EPA requests that measurements be taken form the approximate center of the facility. Specify which method you used to determine latitude and longitude. If a U.S.G.S. topographic map is used, specify the scale of the map used. Enter the horizontal reference datum for your latitude and longitude. The horizontal reference datum used on USGS topographic maps is shown on the bottom left corner of USGS topographic maps; it is also available for GPS receivers.

Indicate whether the facility is on Indian country lands, and if so, provide the name of the Indian tribe associated with the area of Indian country (including name of Indian reservation, if applicable).

Indicate whether you are a "federal operator" as defined in Appendix A of the MSGP. Also check the facility's ownership type.

Indicate whether the facility was previously covered under an NPDES stormwater permit. If so, include the NPDES ID (i.e., NOI tracking number).

List the four-digit Standard Industrial Classification (SIC) code or two character activity code that best describes the primary industrial activities performed by your facility.

Enter the total size of the site associated with industrial activity in acres.

Check "Yes" or "No" as appropriate to indicate whether you have paved or roofed over a formerly exposed, pervious area (i.e., lawn, meadow, dirt or gravel road/parking lot) in order to qualify for no exposure. If yes, also indicate approximately how much area was paved or roofed over and is now impervious area. 


\section{No Exposure Certification (NOE) for Exclusion from Stormwater Discharges Associated with Industrial Activity Under an NPDES General Permit}

NPDES Form Date (06/15) This Form Replaces From 3510-11 (09/08) Form Approved OMB No. 2040-0004

\section{Section E. Exposure Checklist}

Check "Yes" or "No" as appropriate to describe the exposure condition at your facility. If you answer "Yes" to ANY of the questions in this section, a potential for exposure exists at your site and you cannot certify to a condition of no exposure. You must obtain (or already have) coverage under an NPDES stormwater permit. After obtaining permit coverage, you can institute modifications to eliminate the potential for a discharge of stormwater exposed to industrial activity, and then certify to a condition of no exposure.

\section{Section $\mathbf{F}$ and $\mathbf{G}$. Certification Information}

The NOE form must be signed as follows:

For a corporation: By a responsible corporate officer. For the purpose of this Section, a responsible corporate officer means:

(i) a president, secretary, treasurer, or vice-president of the corporation in charge of a principal business function, or any other person who performs similar policy- or decision-making functions for the corporation, or (ii) the manager of one or more manufacturing, production, or operating facilities, provided, the manager is authorized to make management decisions which govern the operation of the regulated facility including having the explicit or implicit duty of making major capital investment recommendations, and initiating and directing other comprehensive measures to assure long-term environmental compliance with environmental laws and regulations; the manager can ensure that the necessary systems are established or actions taken to gather complete and accurate information for permit application requirements; and where authority to sign documents has been assigned or delegated to the manager in accordance with corporate procedures.

For a partnership or sole proprietorship: By a general partner or the proprietor, respectively; or

For a municipality, state, federal, or other public agency: By either a principal executive officer or ranking elected official. For purposes of this Part, a principal executive officer of a federal agency includes (i) the chief executive officer of the agency, or (ii) a senior executive officer having responsibility for the overall operations of a principal geographic unit of the agency (e.g., Regional Administrator of EPA). Include the name and title of the person signing the form and the date of signing.

Include the name, title, and email address of the person signing the form and the date of signing.

An unsigned or undated NOE certification will not be considered valid.

\section{Paperwork Reduction Act Notice}

Public reporting burden for this certification is estimated to average 1.0 hour per certification, including time for reviewing instructions, searching existing data sources, gathering and maintaining the data needed, and completing and reviewing the collection of information. Burden means the total time, effort, or financial resources expended by persons to generate, maintain, retain, or disclose to provide information to or for a Federal agency. This includes the time needed to review instructions; develop, acquire, install, and utilize technology and systems for the purposes of collecting, validating, and verifying information, processing and maintaining information, and disclosing and providing information; adjust the existing ways to comply with any previously applicable instructions and requirements; train personnel to be able to respond to a collection of information; search data sources; complete and review the collection of information; and transmit or otherwise disclose the information.

An agency may not conduct or sponsor, and a person is not required to respond to, a collection of information unless it displays a currently valid OMB control number.

Send comments regarding the burden estimate, any other aspect of the collection of information, or suggestions for improving this form, including any suggestions which may increase or reduce this burden to: Director, Collection Strategies Division, U.S. Environmental Protection Agency (2822T), 1200 Pennsylvania Ave., NW, Washington, D.C. 20460. Include the $O M B$ control number of this form on any correspondence. Do not send the completed No Exposure Certification form to this address.

\section{Submitting Your Form}

If you have been granted a waiver from your Regional Office to submit a paper No Exposure Certification form, you must send your No Exposure Certification form by mail to one of the following addresses:

\section{For Regular U.S. Mail Delivery:}

Stormwater Notice Processing Center Mail Code 4203M, ATTN: MSGP No Exposure U.S. EPA

1200 Pennsylvania Avenue, NW

Washington, DC 20460

\section{For Overnight/Express Mail Delivery:}

Stormwater Notice Processing Center William Jefferson Clinton East Building - Room 7420 ATTN: MSGP No Exposure

U.S. EPA

1201 Constitution Avenue, NW

Washington, DC 20004

Visit this website for instructions on how to submit electronically: http://water.epa.gov/polwaste/npdes/stormwater/Stormwater -eNOI-System-for-EPAs-MultiSector-General-Permit.cfm 


\section{Appendix L - List of Tier 3, Tier 2, and Tier 2.5 Waters}

EPA'S MSGP has special requirements for discharges to waters designated by a state or tribe as Tier $2 / 2.5$ or Tier 3 for antidegradation purposes under 40 CFR 131.12(a). See Parts 1.1.4.8 and 1.1.4.10

The list below is provided as a resource for operators who must determine whether they discharge to a Tier $2 / 2.5$ or Tier 3 water. Only Tier $2 / 2.5$ or Tier 3 waters specifically identified by a water quality standard authority (e.g., a state, territory, or tribe) are identified in the table below. Many authorities evaluate the existing and protected quality of the receiving water on a pollutant-by-pollutant basis and determine whether water quality is better than the applicable criteria that would be affected by a new discharger or a new source or an increase in an existing discharge of the pollutant. In instances where water quality is better, the authority may choose to allow lower water quality, where lower water quality is determined to be necessary to support important social and economic development. Permittees are not required to identify those waters which are evaluated on an individual basis.

\begin{tabular}{|c|c|c|}
\hline $\begin{array}{l}\text { Permit } \\
\text { Number }\end{array}$ & & Areas of Coverage/Where EPA Is Permitting Authority \\
\hline \multirow[t]{5}{*}{ MAR050000 } & \multicolumn{2}{|c|}{ Commonwealth of Massachusetts, except Indian Country lands } \\
\hline & \multicolumn{2}{|c|}{$\begin{array}{l}\text { Tier 2, Tier 2.5, and } 3 \text { waters are identified and listed in the Massachusetts Water } \\
\text { Quality Standards } 314 \text { CMR 4.00. Surface water qualifiers that correspond with Tier } \\
\text { classifications are defined at } 314 \text { CMR } 4.06(1)(\mathrm{d}) \mathrm{m} \text { and listed in tables and figures } \\
\text { at the end of } 314 \text { CMR } 4.06 \text {. See MassDEP's web page at } \\
\text { http://www.mass.gov/eea/agencies/massdep/water/regulations/314-cmr-4-00- } \\
\text { mass-surface-water-quality-standards.html. }\end{array}$} \\
\hline & Tier 2 & $\begin{array}{l}\text { Listed as "High Quality Waters", and all wetlands that are not } \\
\text { designated as an Outstanding Resource Water }\end{array}$ \\
\hline & Tier 2.5 & $\begin{array}{l}\text { Listed as "Outstanding Resource Water", "Public Water Supply", } \\
\text { "Tributary to Public Water Supply", all wetlands bordering Outstanding } \\
\text { Resource Waters, and vernal pools }\end{array}$ \\
\hline & Tier 3 & $\begin{array}{l}\text { Defined as "Special Resource Water". Note: No waters have been } \\
\text { defined as a Special Resource Water as of the issuance of this permit. }\end{array}$ \\
\hline \multirow[t]{3}{*}{ NHR050000 } & \multicolumn{2}{|c|}{ State of New Hampshire } \\
\hline & Tier $2 / 2.5$ & $\begin{array}{l}\text { There is no list of Tier } 2 / \text { Tier } 2.5 \text { waters. New dischargers and new } \\
\text { sources should contact Thelma Murphy (EPA Region 1's stormwater } \\
\text { coordinator) at murphy.thelma@epa.gov. }\end{array}$ \\
\hline & Tier 3 & $\begin{array}{l}\text { Env-Ws } 1708.05 \text { (a) Surface waters of national forests and surface } \\
\text { waters designated as "natural" under RSA 483:7-a, I shall be } \\
\text { considered outstanding resource waters (ORW). "Natural waters" are } \\
\text { listed at http://www.gencourt.state.nh.us/rsa/html/L/483/483-15.htm. } \\
\text { Surface waters of national forests are not included in an official list. For } \\
\text { further questions, new dischargers and new sources should contact } \\
\text { Thelma Murphy (EPA Region 1's stormwater coordinator) at } \\
\text { murphy.thelma@epa.gov. }\end{array}$ \\
\hline
\end{tabular}




\begin{tabular}{|c|c|c|}
\hline $\begin{array}{l}\text { Permit } \\
\text { Number }\end{array}$ & & Areas of Coverage/Where EPA Is Permitting Authority \\
\hline \multirow[t]{2}{*}{ PRR050000 } & \multicolumn{2}{|c|}{ Commonwealth of Puerto Rico } \\
\hline & Tier 3 & $\begin{array}{l}\text { Tier III waters are those which are classified as either Class SA or Class } \\
\text { SE. Class SA waters are defined as "Coastal waters and estuarine } \\
\text { waters of high quality and/or exceptional ecological or recreational } \\
\text { value whose existing characteristics shall not be altered, except by } \\
\text { natural causes, in order to preserve the existing natural phenomena." } \\
\text { Class SA waters include bioluminescent lagoons and bays such as La } \\
\text { Parguera and Monsio José on the Southern Coast, Bahía de Mosquito } \\
\text { in Vieques, and any other coastal or estuarine waters of exceptional } \\
\text { quality of high ecological value or recreational which may be } \\
\text { designated by Puerto Rico, through Resolution, as requiring this } \\
\text { classification for protection of the waters. Class SE waters are defined } \\
\text { as "Surface waters and wetlands of exceptional ecological value, } \\
\text { whose existing characteristics should not be altered in order to } \\
\text { preserve the existing natural phenomena." Class SE waters include } \\
\text { Laguna Tortuguero, Laguna Cartagena and any other surface water } \\
\text { bodies of exceptional ecological value as may be designated by } \\
\text { Puerto Rico through Resolution. }\end{array}$ \\
\hline \multirow[t]{2}{*}{ DCR050000 } & \multicolumn{2}{|c|}{ District of Columbia } \\
\hline & $\begin{array}{l}\text { Tier } \\
2 / 2.5\end{array}$ & $\begin{array}{l}\text { RUle 1 102.4 SPECIAL WATERS OF THE DISTRICT OF COLUMBIA } \\
\text { (SWDC): Any segment or segments of the surface waters of the } \\
\text { District that are of water quality better than needed for the current } \\
\text { Use or have scenic or aesthetic importance shall be designated as } \\
\text { Special Waters of the District of Columbia (SWDC). } \\
\text { Rock Creek and its tributaries and Battery Kemble Creek and its } \\
\text { tributaries are considered Special Waters of the District of Columbia } \\
\text { (SWDC) under its antidegradation program. }\end{array}$ \\
\hline \multirow[t]{5}{*}{ MNR05000I } & \multicolumn{2}{|c|}{ Fond du Lac Band of MN Chippewa } \\
\hline & Tier 3 & $\begin{array}{l}\text { Six lakes are presently identified as Tier 3: (1) Dead Fish, (2) Jaskari, (3) } \\
\text { Miller (Mud), (4) Perch, (5) Rice Portage, (6) Wild Rice. }\end{array}$ \\
\hline & \multicolumn{2}{|c|}{ Grand Portage Band of MN Chippewa } \\
\hline & $\begin{array}{l}\text { Tier } \\
2 / 2.5\end{array}$ & $\begin{array}{l}\text { All waters, not already classified as Tier 3, are high quality Tier } 2 \text { waters. } \\
\text { (see Grand Portage Reservation Water Quality Standards, Section VI \& } \\
\text { VII, Pages 14-16). }\end{array}$ \\
\hline & Tier 3 & $\begin{array}{l}\text { "The portion of Lake Superior north of latitude } 47 \text { degrees, } 57 \text { minutes, } \\
13 \text { seconds, east of Hat Point, south of the Minnesota-Ontario } \\
\text { boundary, and west of the Minnesota-Michigan boundary." (see } \\
\text { Section VII, Page 16). }\end{array}$ \\
\hline \multirow[t]{3}{*}{ WIR05000I } & \multicolumn{2}{|c|}{ Lac du Flambeau Band of the Lake Superior Chippewa } \\
\hline & Tier 2 & $\begin{array}{l}\text { All named waters, including wetlands, not specified under an } \\
\text { antidegradation classification. }\end{array}$ \\
\hline & Tier 2.5 & $\begin{array}{l}\text { Bills Lake, Birch Lake, Bobidosh Lake, Bog Lake (SE SE Sec. 31, } \\
\text { T40NR6E), Bolton Lake, Broken Bow Lake, Chewalah Lake, Clear Lake } \\
\text { (Sec. 2, T39NR4E), Corn Great, Great, Corn Lake, Little "Least/Lesser", } \\
\text { Crawling Stone Lake, Big, Crawling Stone Lake, Little, Crescent Lake, } \\
\text { Crooked Lake, Big, David Lake, Ellerson Lake, Middle, Ellerson Lake, } \\
\text { West, Elsie Lake "Boundary Lake", Fat Lake, Fence Lake, Gresham }\end{array}$ \\
\hline
\end{tabular}




\begin{tabular}{|c|c|c|}
\hline $\begin{array}{l}\text { Permit } \\
\text { Number }\end{array}$ & \multicolumn{2}{|r|}{ Areas of Coverage/Where EPA Is Permitting Authority } \\
\hline & & $\begin{array}{l}\text { Creek, Green Lake (NW NW Sec. 19, T41R6E), Grey Lake, Gunlock } \\
\text { Lake, Haskell Lake, Headflyer Lake (Sec. 19, T41NR5E), Highway Lake } \\
\text { (NW NW Sec. 19, T41NR5E), Horsehead Lake (SE SW Sec. 9, T40NR5E), } \\
\text { Hutton's Creek, Ike Walton Lake, Lily Lake (SE SW Sec. 35, T40NR5E), } \\
\text { Little Ten Lake, Lodge Lake "L. Rice" (NW NW Sec. 8, T41NR6E), Lucy } \\
\text { Lake, Mindys Lake (Sec. 8, T40NR5E), Minette Lake, Mitten Lake, Monk's } \\
\text { Lake (Sec. 13, T40NR5E), Moving Cloud Lake, Mud Creek, Muskesin } \\
\text { Lake, Patterson Lake, Placid Twin Lake (North), Placid Twin Lake } \\
\text { (South), Plummer Lake, Poupart Lake, Prairie Lake (NE SW Sec. 13, } \\
\text { T40NR4E), Raven Lake, Ross Allen Lake, Sand Lake, Little, Scott Lake } \\
\text { (Sec. 22, T40N, R4E), Shishebogama Lake, Signal Lake, Snort Lake (Sec. } \\
\text { 5, T41N, R6E), Spring Lake "Jerms", Squirrel Lake, Statenaker Lake } \\
\text { "Hollow", Stearns Lake "Hourglass", Sugarbush "Hidden Lake" (NW NW } \\
\text { Sec. 17, T41NR5E), Sugarbush Creek, Sugarbush Lake, Little, Sugarbush } \\
\text { Lake, Lower, Sugarbush Lake, Middle, Sugarbush Lake, Upper, Sunfish } \\
\text { Lake, Tippecanoe Lake, Tomahawk River, To-To Tom Lake, Toulish } \\
\text { Lake, Trout River, Warrior Lake, White Sand Lake, Whitefish Lake } \\
\text { "Cattail Lake" (Sec. 34, T40N5R), Wishow Lake, Wyandock Lake }\end{array}$ \\
\hline & Tier 3 & $\begin{array}{l}\text { Bear River (1st bridge to Reservation boundary), Big Springs (Sec. 25, } \\
\text { T40NR4E), Black Lake, Cranberry Lake, Doud Lake, Eagle Lake, Gene } \\
\text { Lake, Johnson Springs, Little Trout Lake, Lost Lake (Sect. 1, T41NR4E), } \\
\text { Mishonagon Creek, Munnomin (Jesse, Duck) Lake, Negani (Hegani) } \\
\text { Lake, Reservation Line Lake, Spring Creek, Tank Lake, Thomas Lake, } \\
\text { Wild Rice Lake, Zee Lake }\end{array}$ \\
\hline & \multicolumn{2}{|c|}{$\begin{array}{l}\text { Mole Lake Band of the Lake Superior Tribe of the Chippewa Indians, Sokaogon } \\
\text { Chippewa Community }\end{array}$} \\
\hline & Tier 2.9 & $\begin{array}{l}\text { One Tribal Water, Wetland 22, is classified as Exceptional High Quality } \\
\text { Water (EHQW). It is a high-quality water body of significant cultural, } \\
\text { religious, social, ecological and recreational attributes. }\end{array}$ \\
\hline & Tier 3 & $\begin{array}{l}\text { All waters in the Sokaogon Chippewa Community (WI) as classified as } \\
\text { Tier 3, with one exception (Wetland 22). }\end{array}$ \\
\hline \multirow[t]{3}{*}{ COR0500I } & \multicolumn{2}{|c|}{ State of Colorado } \\
\hline & \multicolumn{2}{|c|}{ Ute Mountain Ute Tribe } \\
\hline & Tier 3 & $\begin{array}{l}\text { (2010 Proposed) Designations: } \\
\text { 1. Ute Spring and unnamed creek from Ute Spring downstream within } \\
\text { Section } \\
\text { 12, TWP35N R18W (Colorado). } \\
\text { 2. Allen Canyon Creek, Sections 17, 20, 29, 30, 31, TWP 35S, R21E (Utah) } \\
\text { 3. "Lopez" Spring and unnamed creek tributary to and downstream } \\
\text { from the } \\
\text { spring, within Section 35, TWP 34N, R18W }\end{array}$ \\
\hline \multirow[t]{2}{*}{ NMR050000 } & \multicolumn{2}{|c|}{ State of New Mexico } \\
\hline & Tier 3 & $\begin{array}{l}\text { (1) Rio Santa Barbara, including the west, middle and east forks from } \\
\text { their headwaters downstream to the boundary of the Pecos } \\
\text { Wilderness; and } \\
\text { (2) the waters within the United States forest service Valle Vidal special } \\
\text { management unit including: }\end{array}$ \\
\hline
\end{tabular}




\begin{tabular}{|c|c|}
\hline $\begin{array}{l}\text { Permit } \\
\text { Number }\end{array}$ & Areas of Coverage/Where EPA Is Permitting Authority \\
\hline & 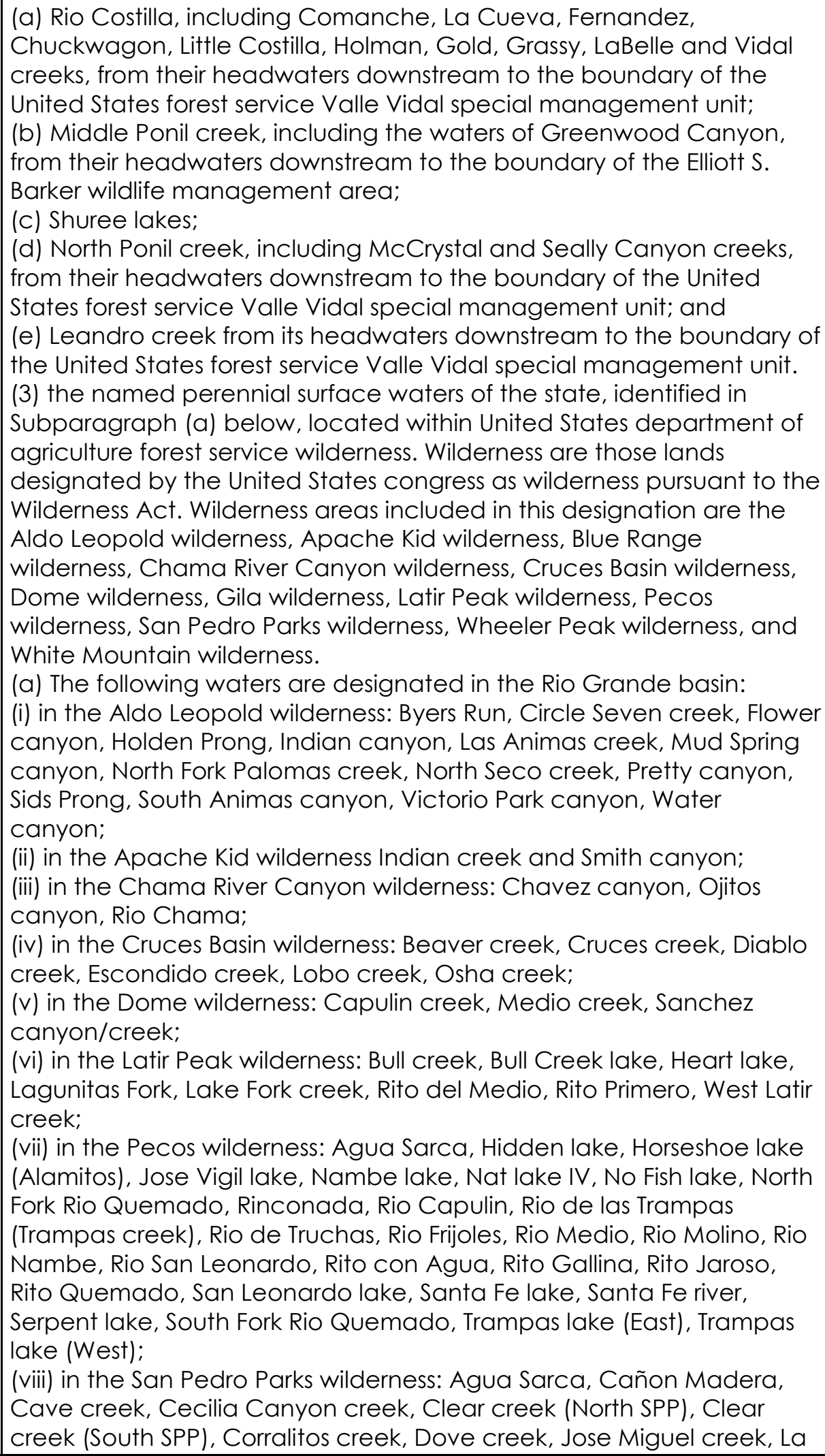 \\
\hline
\end{tabular}




\begin{tabular}{|c|c|}
\hline $\begin{array}{l}\text { Permit } \\
\text { Number }\end{array}$ & Areas of Coverage/Where EPA Is Permitting Authority \\
\hline & 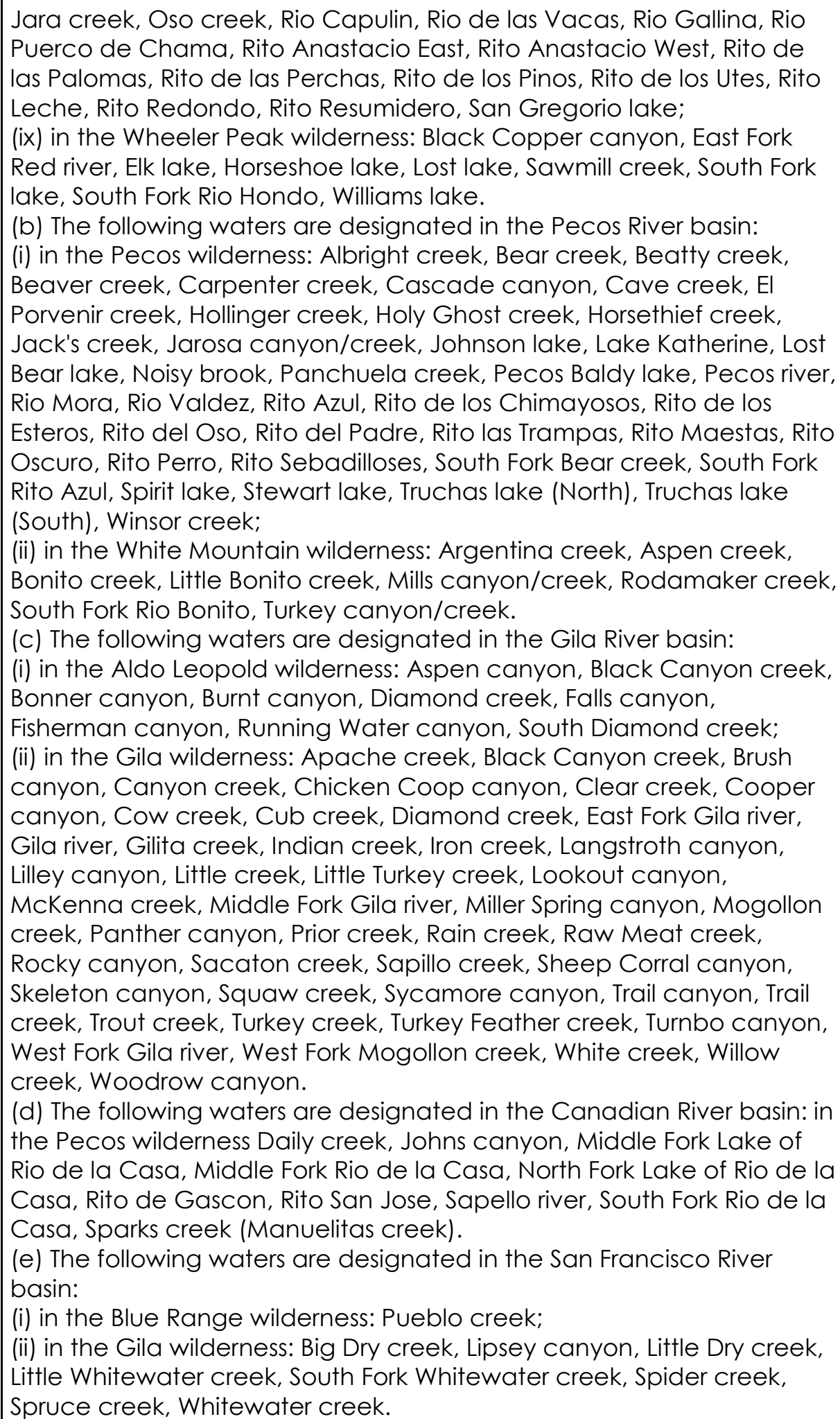 \\
\hline
\end{tabular}




\begin{tabular}{|c|c|c|}
\hline \multirow[t]{2}{*}{$\begin{array}{c}\text { Permit } \\
\text { Number }\end{array}$} & \multicolumn{2}{|r|}{ Areas of Coverage/Where EPA Is Permitting Authority } \\
\hline & & $\begin{array}{l}\text { (f) The following waters are designated in the Mimbres Closed basin: in } \\
\text { the Aldo Leopold wilderness Corral canyon, Mimbres river, North Fork } \\
\text { Mimbres river, South Fork Mimbres river. } \\
\text { (g) The following waters are designated in the Tularosa Closed basin: in } \\
\text { the White Mountain wilderness Indian creek, Nogal Arroyo, Three } \\
\text { Rivers. } \\
\text { (h) The wetlands designated are identified on the maps and list of } \\
\text { wetlands within United States forest service wilderness areas } \\
\text { designated as outstanding national resource waters published at the } \\
\text { New Mexico state library and available on the department's website. }\end{array}$ \\
\hline \multirow[t]{5}{*}{ CAR05000I } & \multicolumn{2}{|c|}{ Hualapai Tribe } \\
\hline & Tier 3 & $\begin{array}{l}\text { Spencer, Meriwhitica, Willow Spring, Upper Milkweed Spring, Bridge } \\
\text { Canyon, Travertine Spring, Travertine Falls, Diamond Creek, Diamond } \\
\text { Creek Spring, Blue Mountain, Metuck, Peach Springs Spring, } \\
\text { Westwater, Clay Tank, Hockey Puck, Pocamote Spring, Mohawk } \\
\text { Spring, Granite Spring, Three Spring, Warm Spring, Honga Spring, } \\
\text { National Canyon Spring, National Canyon, Moss Spring }\end{array}$ \\
\hline & \multicolumn{2}{|c|}{ White Mountain Apache Tripe of the Fort Apache Indian Reservation } \\
\hline & Tier $2 / 2.5$ & $\begin{array}{l}\text { East Fork White River, above R52 Road, East Fork White River below R52 } \\
\text { Road, above Rock Cr., Paradise Creek, above Wohlenberg, Ord } \\
\text { Creek, Smith Cienega, Bull Cienega, Smith Creek, Big Bonito, Tonto } \\
\text { Creek, below Y47 Crossing, Crooked Creek, Boggy Creek, Lofer } \\
\text { Cienego Creek, Little Bonito Creek, above Y55 Crossing, Flash Creek, } \\
\text { Squaw Creek, Hurricane Lake, Hurricane Creek, Hughey Creek, Bonito } \\
\text { Cienega, West Fork Black River, Hall Cienega, Purcell Cienega, } \\
\text { Thompson Creek, Carrizo Creek below Corduroy, Carrizo Creek above } \\
\text { Corduroy, Cedar Creek, Big Canyon (E. Cedar Creek), Middle Cedar } \\
\text { Creek, West Cedar Creek, Cibecue Creek in Box Canyon to Salt river, } \\
\text { Cibecue Creek, Box CallYon up to confluence with Salt Creek, Spring } \\
\text { Creek, Salt Creek, Cibecue Creek, from confluence w/Salt Cr, to Big } \\
\text { Springs, Cibecue Creek, above Big Springs, Rock Springs Creek, Salt } \\
\text { Draw, Canyon Creek S. of Chediski Farms, Willow Creek (Lower } \\
\text { Canyon Cr), Oak Creek, Canyon Creek. N. of Chedlski Fanns, }\end{array}$ \\
\hline & Tier 3 & East Fork While River, in Wilderness Area, Pumpkin Lake \\
\hline \multirow[t]{2}{*}{ IDR050000 } & \multicolumn{2}{|c|}{ State of Idaho } \\
\hline & \multicolumn{2}{|c|}{ 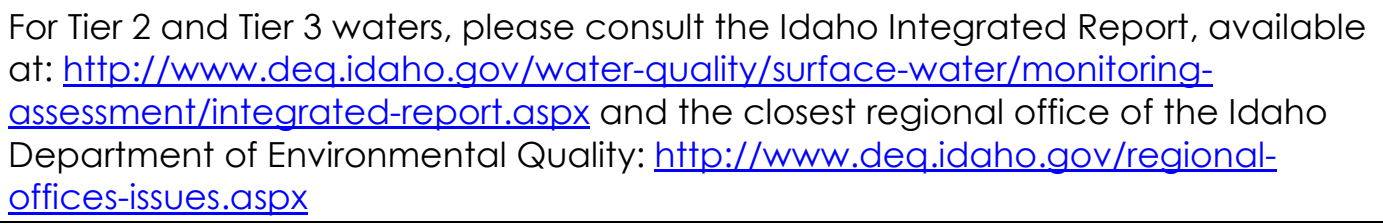 } \\
\hline
\end{tabular}




\section{Appendix M - Discharge Monitoring Report (DMR) Form}

Part 7.1 requires you to use the electronic NetDMR system to prepare and submit your Discharge Monitoring Report (DMR) form. However, if you are given approval by the EPA Regional Office to use a paper DMR form, and you elect to use it, you must complete and submit the following form. 


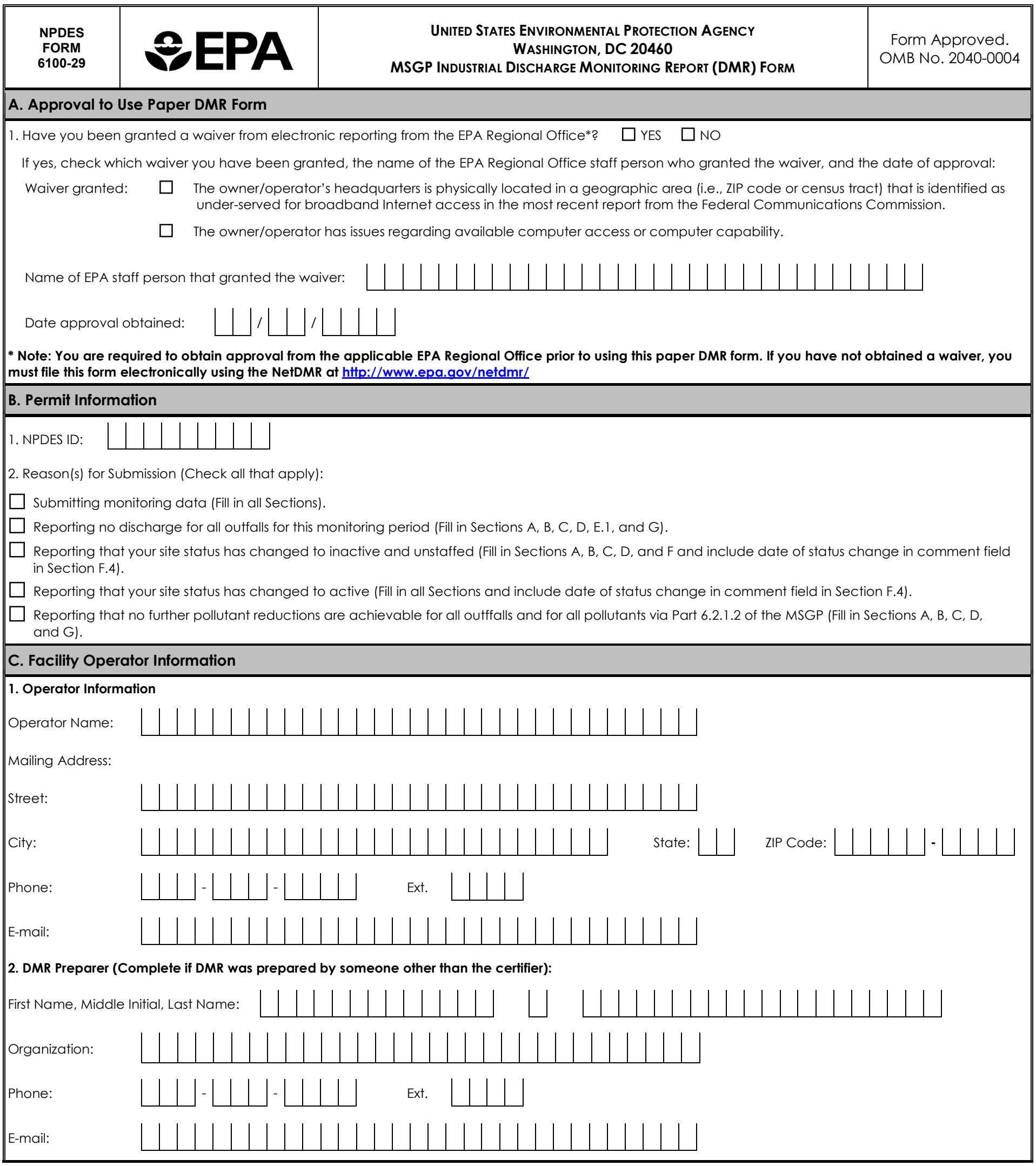




\section{Facility Information}

1. Facility Name:

2. Facility Address:

Street/Location:

City:

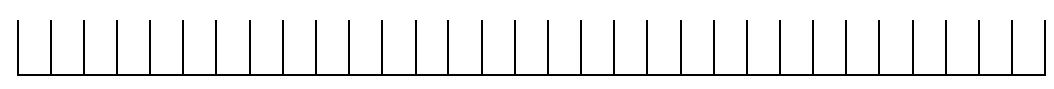

County or Similar Government Subdivision:

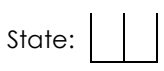

ZIP Code:

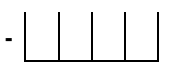

\section{E. Discharge Information}

1. Identify monitoring period:

$\square$ Quarter 1 (January 1-March 31)

$\square$ Quarter 2 (April 1 - June 30)

$\square$ Quarter 3 (July 1 - September 30)

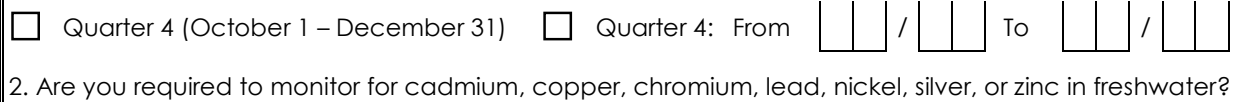

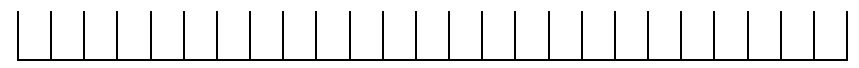

\section{(1)}

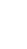

Check here if proposing alternative monitoring periods due to irregular stormwater runoff. Identify alternative
monitoring schedule and indicate for which alternative monitoring period you are reporting monitoring data:

3. What is the hardness level of the receiving water? ${ }^{\prime}|l| l(\mathrm{mg} / \mathrm{L})$

4. Does your facility discharge into any saltwater receiving waters? $\square$ Yes $\square$ No 


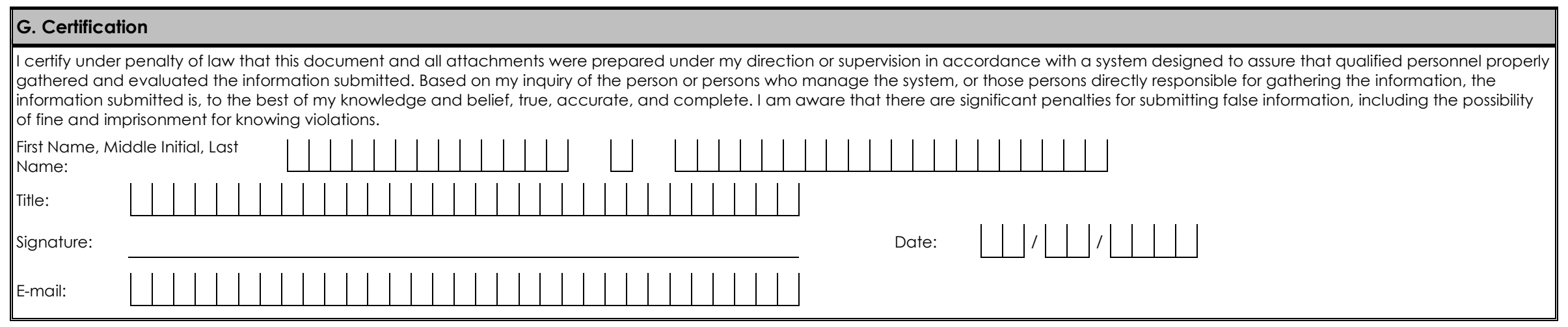




\begin{tabular}{|c|c|}
\hline \multicolumn{2}{|c|}{ Instructions for Completing EPA Form 6100-29 } \\
\hline NPDES Form Date $(06 / 15)$ & Form Approved OMB No. 2040-0004 \\
\hline 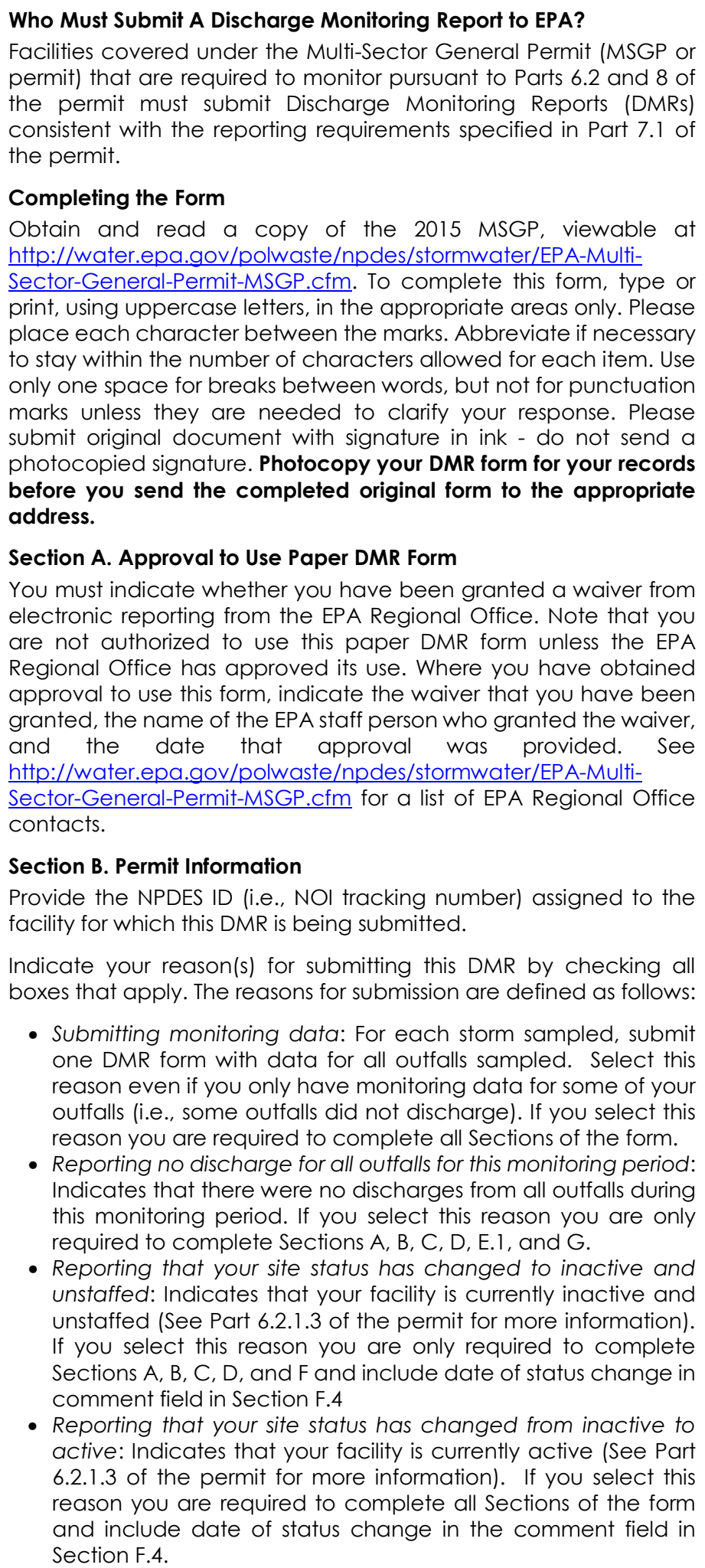 & $\begin{array}{l}\text { - Reporting that no further reductions are achievable for all } \\
\text { outfalls and for all pollutants via Part 6.2.1.2 of the permit: } \\
\text { Indicates that you have determined that no further pollutant } \\
\text { reductions are technologically and economically practicable } \\
\text { in light of best industry practice to meet the technology-based } \\
\text { effluent limits or are necessary to meet the water-quality-based } \\
\text { effluent limitations in Parts } 2 \text { of the permit (See Part } 6.2 .1 .2 \text { of the } \\
\text { permit for more information). If you select this reason you are } \\
\text { required to complete Sections A, B, C, D and G. However, if you } \\
\text { can make this finding for some outfalls and pollutants, but not } \\
\text { for others, you cannot select this reason; you will instead be } \\
\text { able to identify which outfalls and which pollutants you can } \\
\text { make this finding for in Section F. } \\
\text { Section C. Facility Operator Information. } \\
\text { Provide the legal name of the person, firm, public organization, or } \\
\text { any other entity that operates the facility for which this DMR is being } \\
\text { submitted. An operator of a facility is the legal entity that controls } \\
\text { the operation of the facility. Refer to Appendix A of the permit for } \\
\text { the definition of "operator". Provide the operator's mailing address, } \\
\text { phone number, and e-mail. The operator information in this Section } \\
\text { should match the operator information provided on your NOl form. } \\
\text { Provide the name, organization, phone number, an email address } \\
\text { for the person who prepared this DMR form. } \\
\text { Section D. Facility Information } \\
\text { Enter the official or legal name and complete street address, } \\
\text { including city, state, ZIP code, and county or similar government } \\
\text { subdivision of the facility. If the facility lacks a street address, } \\
\text { indicate the general location of the facility (e.g., Intersection of } \\
\text { State Highways } 61 \text { and } 34 \text { ). Complete facility information must be } \\
\text { provided for permit coverage to be granted. The facility } \\
\text { information in this Section should match the facility information } \\
\text { provided on your NOI form. } \\
\text { Section E. Discharge Information. } \\
\text { hacility is required to collect benchmark samples for one or more } \\
\text { hardness level of the receiving water (in mg/L)). If you select "no" } \\
\text { to this question, you must identify if your facility discharges into any } \\
\text { saltwater receiving waters. }\end{array}$ \\
\hline
\end{tabular}




\begin{tabular}{|c|c|}
\hline \multicolumn{2}{|c|}{ Instructions for Completing EPA Form 6100-29 } \\
\hline NPDES Form Date (06/15) & Form Approved OMB No. 2040-0004 \\
\hline 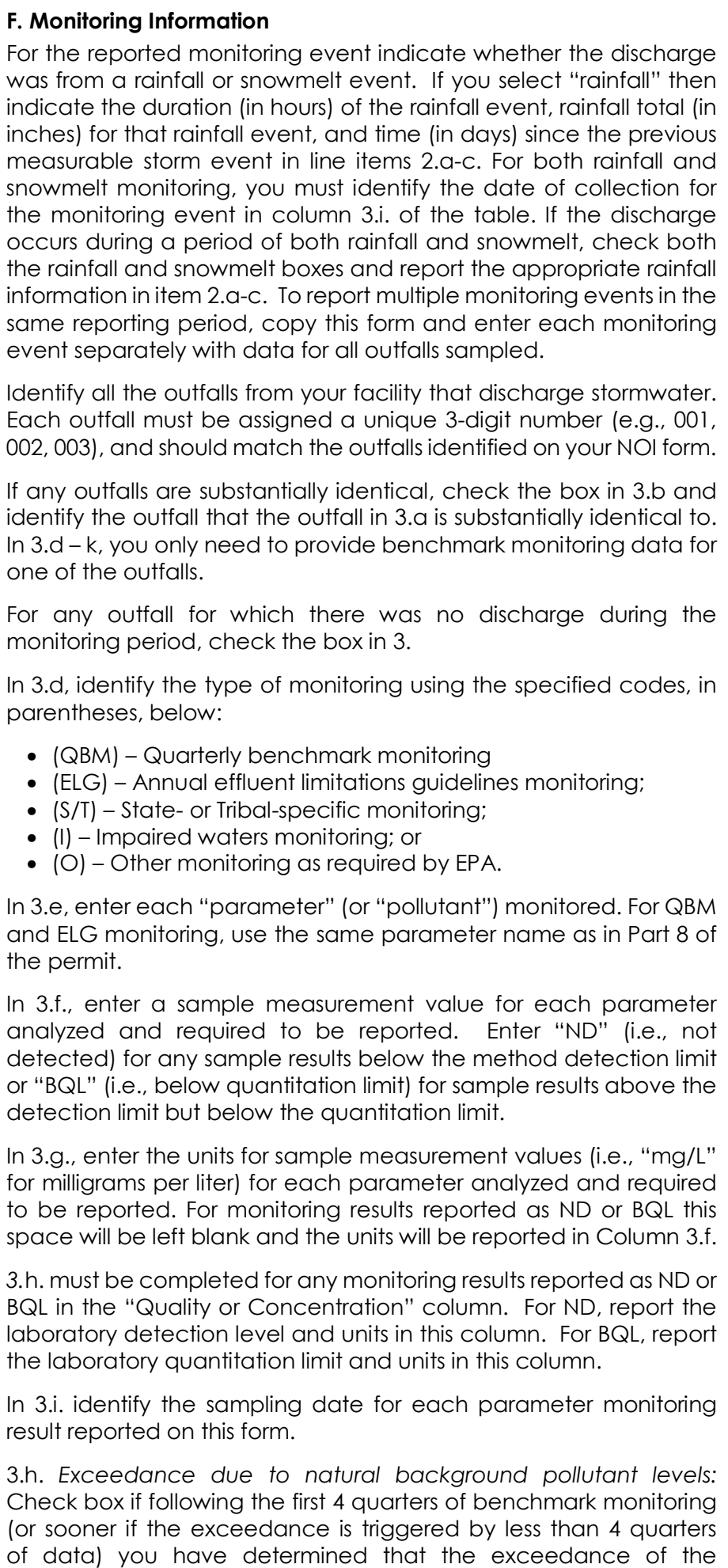 & 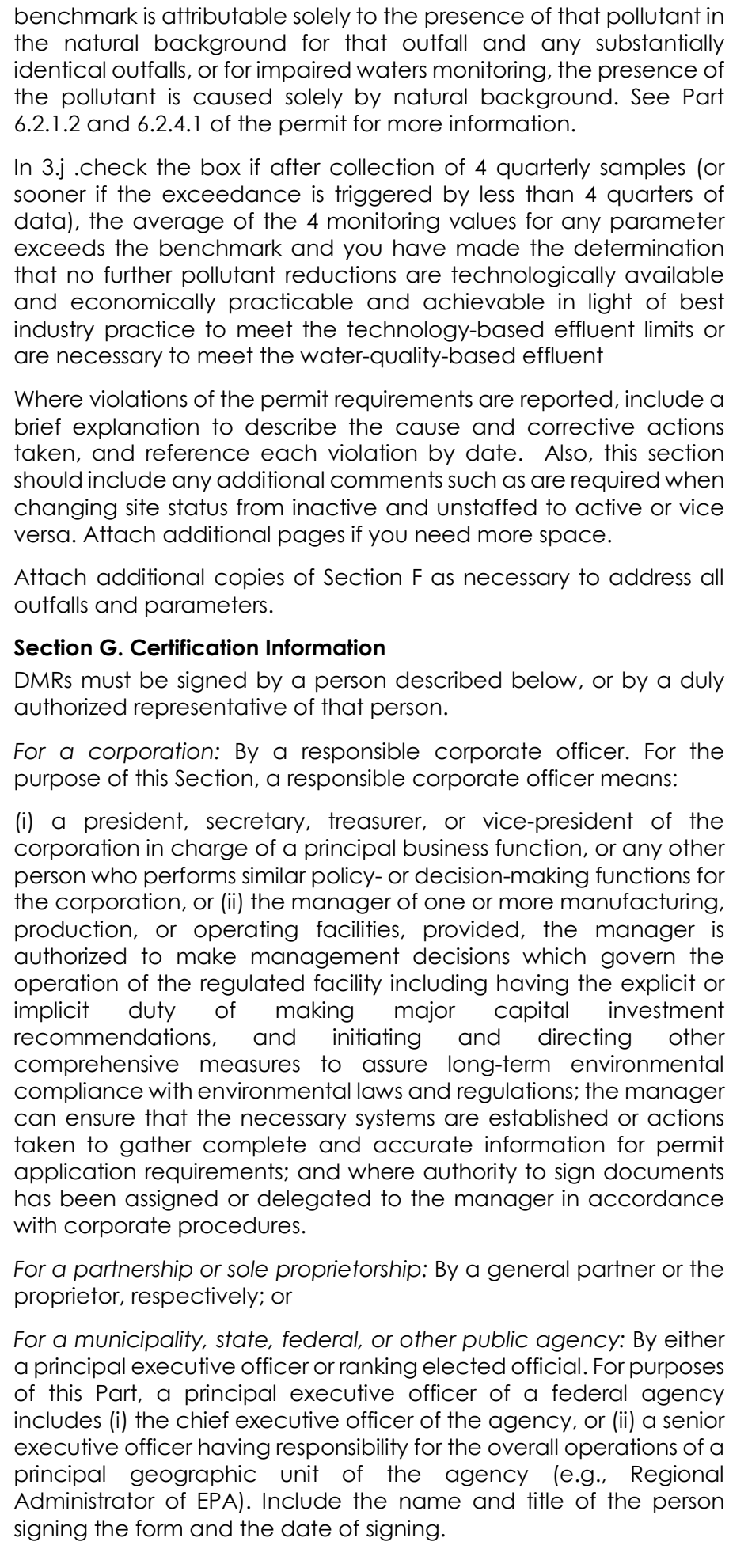 \\
\hline
\end{tabular}


Instructions for Completing EPA Form 6100-29

\section{Discharge Monitoring Report (DMR) for Stormwater Discharges Associated with Industrial Activity Under the NPDES Multi-Sector General Permit}

NPDES Form Date (06/15)

A person is a duly authorized representative only if:

1. The authorization is made in writing by a person described above;

2. The authorization specifies either an individual or a position having responsibility for the overall operation of the regulated facility or activity such as the position of plant manager, operator of a well or a well field, superintendent, position of equivalent responsibility, or an individual or position having overall responsibility for environmental matters for the company, (A duly authorized representative may thus be either a named individual or any individual occupying a named position.) and

3. The written authorization is submitted to the Director.

An unsigned or undated DMR form be considered incomplete.

\section{Paperwork Reduction Act Notice}

Public reporting burden for this form is estimated to average 7.25 hours per response, including time for reviewing instructions, searching existing data sources, gathering and maintaining the data needed, and completing and reviewing the collection of information. An agency may not conduct or sponsor, and a person is not required to respond to, a collection of information unless it displays a currently valid OMB control number. Send comments regarding the burden estimate, any other aspect of the collection of information, or suggestions for improving this form, including any suggestions which may increase or reduce this burden to: Director, Collection Strategies Division, U.S. Environmental Protection Agency (2822T), 1200 Pennsylvania Ave., NW, Washington, D.C. 20460. Include the $O M B$ control number of this form on any correspondence. Do not send the completed DMR form to this address.

\section{Submitting Your Form}

If you have been granted a waiver from your Regional Office to submit a paper DMR form, you must send your DMR form by mail to one of the following addresses:

\section{Region 1}

MSGP Discharge Monitoring Reports (OES4-SMR)

EPA New England, Region 1

5 Post Office Square - Suite 100

Boston, MA 02109-3912

\section{Region 2}

MSGP Discharge Monitoring Reports

290 Broadway

DECA/CAPBS/DMT

21st Floor

New York, NY, 10007-1866

\section{Region 3}

Nancy Ford

U.S. EPA Region 3

1650 Arch Street

Mail Code \#3WP60

Philadelphia, PA 19103
Form Approved OMB No. 2040-0004

\section{Region 5}

U.S. Environmental Protection Agency Region 5

77 West Jackson Boulevard (WN-16J)

Chicago, Illinois 60604

Attn: Brian Bell - Storm Water Coordinator

\section{Region 6}

U.S. EPA, Region 6 MSGP DMRs

Water Enforcement Branch (6EN-WC)

1445 Ross Avenue

Dallas, TX 75202

Region 7

Neal Gilbert

U.S. Environmental Protection Agency, Region 7

Enforcement Coordination Office

11201 Renner Blvd

Lenexa, KS 66219

Region 8

U.S. EPA, Region 8 (ENF-PJ)

Attention: DMR Coordinator

1595 Wynkoop Street

Denver, CO 80202-1129

Region 9

Sandra Chew

U.S. EPA Region 9

Information Management Section, ENF-4-1

75 Hawthorne Street

San Francisco, CA 94105

Region 10

U.S. EPA Region 10

Attn: NPDES Data Manager, OCE-101

1200 Sixth Avenue, Suite 900

Seattle, WA 98101

Visit this website for instructions on how to submit electronically: http://water.epa.gov/polwaste/npdes/stormwater/StormwatereNOI-System-for-EPAs-MultiSector-General-Permit.cfm 


\begin{tabular}{|c|c|c|c|c|c|}
\hline \multicolumn{6}{|c|}{ Appendix N - List of SIC and NAICS Codes } \\
\hline \multicolumn{6}{|c|}{ Sector A. Timber Products } \\
\hline $\begin{array}{l}\text { Sub- } \\
\text { sector }\end{array}$ & & SIC Codes & & NAICS Codes & Notes \\
\hline A3 & 2411 & $\begin{array}{r}\text { Logging } \\
\text { (log storage and handling activities } \\
\text { only; wet deck storage areas only } \\
\text { authorized if no chemical additives } \\
\text { are used in the spray water or applied } \\
\text { to the logs.) } \\
\end{array}$ & 113310 & Logging & \\
\hline \multirow[t]{5}{*}{$\overline{\mathrm{A1}}$} & \multirow[t]{5}{*}{2421} & $\begin{array}{l}\text { General Sawmills and Planing Mills } \\
\text { (sawmills) }\end{array}$ & 321113 & Sawmills & \\
\hline & & $\begin{array}{r}\text { (lumber manufacturing from } \\
\text { purchased lumber, softwood cut } \\
\text { stock, wood lath, fence pickets, and } \\
\text { planing mill products) }\end{array}$ & 321912 & Cut Stock, Resawing Lumber, and Planing & \\
\hline & & (softwood flooring) & 321918 & Other Millwork (including Flooring) & \\
\hline & & $\begin{array}{r}\text { (box lumber made from purchased } \\
\text { lumber) }\end{array}$ & 321920 & Wood Container and Pallet Manufacturing & \\
\hline & & (kiln drying) & 321999 & $\begin{array}{l}\text { All Other Miscellaneous Wood Product } \\
\text { Manufacturing }\end{array}$ & \\
\hline \multirow[t]{8}{*}{ A4 } & \multirow[t]{4}{*}{2426} & $\begin{array}{l}\text { Hardwood Dimension and Flooring } \\
\text { Mills } \\
\text { (hardwood dimension lumber made } \\
\text { from logs or bolts) }\end{array}$ & 321113 & Sawmills & \\
\hline & & $\begin{array}{r}\text { (hardwood cut stock, resawing } \\
\text { hardwood lumber, and planing } \\
\text { purchased hardwood lumber except } \\
\text { flooring }\end{array}$ & 321912 & Cut Stock, Resawing Lumber, and Planing & \\
\hline & & (hardwood flooring) & 321918 & Other Millwork (including Flooring) & \\
\hline & & $\begin{array}{r}\text { (wood furniture frames and finished } \\
\text { furniture parts) }\end{array}$ & 337215 & $\begin{array}{l}\text { Showcase, Partition, Shelving, and Locker } \\
\text { Manufacturing }\end{array}$ & \\
\hline & \multirow[t]{4}{*}{2429} & $\begin{array}{l}\begin{array}{l}\text { Special Product Sawmills, Not } \\
\text { Elsewhere Classified } \\
\text { (shingle mills, shakes) }\end{array}\end{array}$ & 321113 & ( & \\
\hline & & $\begin{array}{r}\text { (stave manufacturing from purchased } \\
\text { lumber) }\end{array}$ & 321912 & Cut Stock, Resawing Lumber, and Planing & \\
\hline & & (cooperage stock) & 321920 & Wood Container and Pallet Manufacturing & \\
\hline & & (excelsior) & 321999 & $\begin{array}{l}\text { All Other Miscellaneous Wood Product } \\
\text { Manufacturing }\end{array}$ & \\
\hline
\end{tabular}




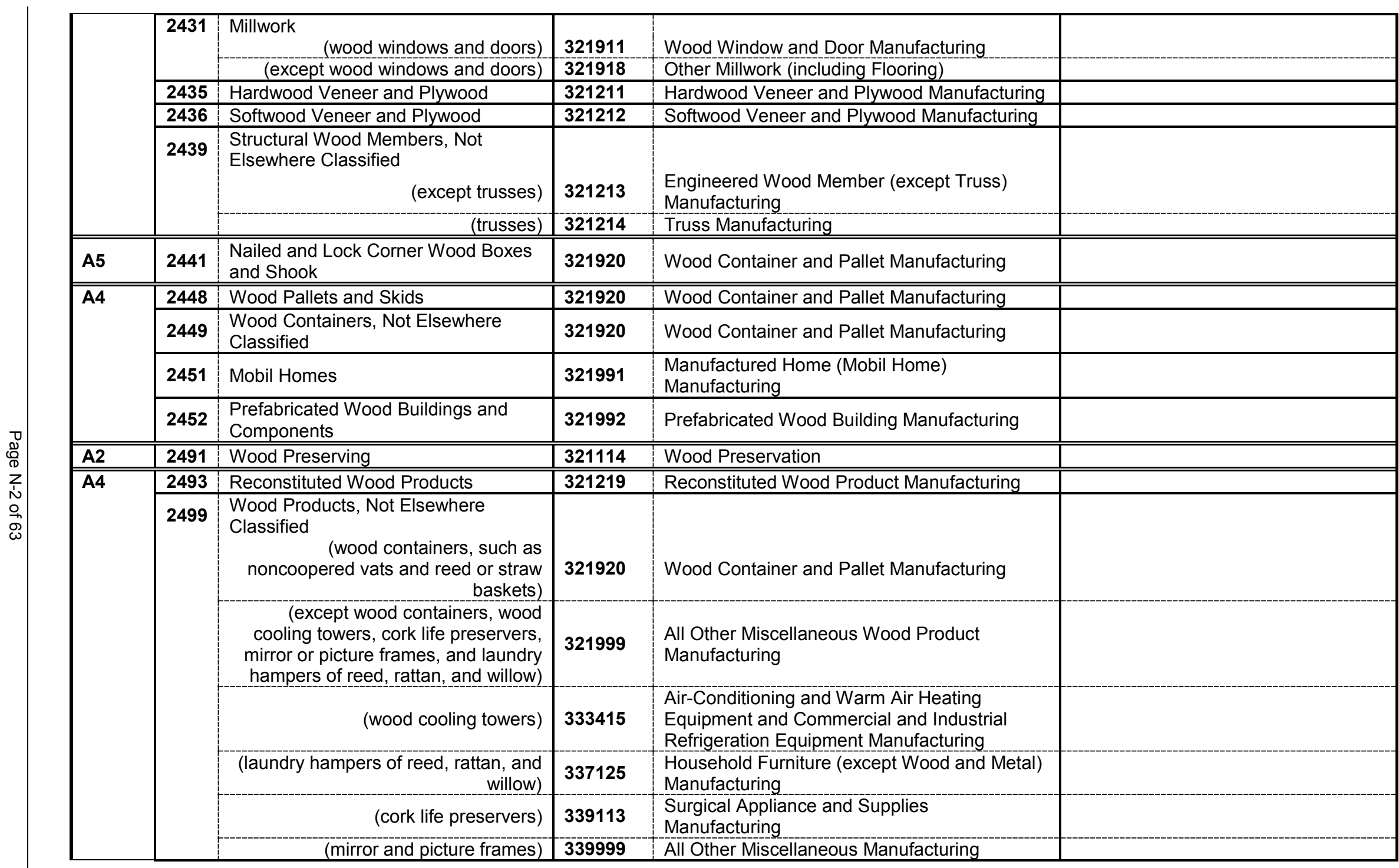




\begin{tabular}{|c|c|c|c|c|c|}
\hline \multicolumn{6}{|c|}{ Sector B. Paper and Allied Products Manufacturing } \\
\hline $\begin{array}{l}\text { Sub- } \\
\text { sector }\end{array}$ & \multicolumn{2}{|r|}{ SIC Codes } & \multicolumn{2}{|r|}{ NAICS Codes } & \multirow[t]{2}{*}{ Notes } \\
\hline \multirow[t]{6}{*}{ B2 } & 2611 & Pulp Mills $\quad$ (pulp producing mills only) & 322110 & Pulp Mills & \\
\hline & & (producing paper except newsprint) & 322121 & Paper (except Newsprint) Mills & \\
\hline & & (producing newsprint) & 322122 & Newsprint Mills & \\
\hline & & (producing paperboard) & 322130 & Paperboard Mills & \\
\hline & 2621 & Paper Mills (except newsprint mills) & 322121 & Paper (except Newsprint) Mills & \\
\hline & & (newsprint mills) & 322122 & Newsprint Mills & \\
\hline$\overline{\mathrm{B1}}$ & 2631 & Paperboard Mills & 322130 & Paperboard Mills & \\
\hline \multirow[t]{8}{*}{ B2 } & 2652 & Setup Paperboard Boxes & 322213 & Setup Paperboard Box Manufacturing & \\
\hline & 2653 & Corrugated and Solid Fiber Boxes & 322211 & $\begin{array}{l}\text { Corrugated and Solid Fiber Boxes } \\
\text { Manufacturing }\end{array}$ & \\
\hline & 2655 & $\begin{array}{l}\text { Fiber Cans, Tubes, Drums, and } \\
\text { Similar Products }\end{array}$ & 322214 & $\begin{array}{l}\text { Fiber Can, Tube, Drum, and Similar Products } \\
\text { Manufacturing }\end{array}$ & \\
\hline & $\begin{array}{l}2656 \\
2657\end{array}$ & $\begin{array}{l}\text { Sanitary Food Containers, Except } \\
\text { Folding } \\
\text { Folding Paperwork Boxes }\end{array}$ & $\begin{array}{l}322215 \\
322212\end{array}$ & $\begin{array}{l}\text { Nonfolding Sanitary Food Container } \\
\text { Manufacturing } \\
\text { Folding Paperboard Box Manufacturing }\end{array}$ & \\
\hline & 2671 & $\begin{array}{l}\text { Packaging Paper and Plastics Film, } \\
\text { Coated and Laminated }\end{array}$ & & & \\
\hline & & $\begin{array}{l}\text { (except single-web and multi-web } \\
\text { plastics packaging film and sheets) }\end{array}$ & 322221 & $\begin{array}{l}\text { Coated and Laminated Packaging Paper and } \\
\text { Plastics Film Manufacturing }\end{array}$ & \\
\hline & & $\begin{array}{r}\text { (single-web and multi-web plastics } \\
\text { packaging film and sheets) }\end{array}$ & 326112 & $\begin{array}{l}\text { Plastics Packaging Film and Sheet (including } \\
\text { Laminated) Manufacturing }\end{array}$ & $\begin{array}{l}\text { Any facility whose primary activity is } \\
\text { manufacturing single-web and multi- } \\
\text { web plastics packaging film and } \\
\text { sheets (SIC } 2671 \text { / NAICS } 326112 \text { ) } \\
\text { should be regulated under Sector Y, } \\
\text { but may continue to be regulated } \\
\text { under Sector B, or alternatively, under } \\
\text { Sector AD. Sectors Y, B, and AD do } \\
\text { not have specific requirements for } \\
\text { facilities manufacturing single-web } \\
\text { and multi-web plastics packaging film } \\
\text { and sheets. However, under Sector } \\
\text { AD EPA could establish additional } \\
\text { facility-specific monitoring and } \\
\text { reporting requirements. } \\
\text { Regulatory burden would not differ } \\
\text { between Sectors B and Y. }\end{array}$ \\
\hline & 2672 & Coated and Laminated Paper, NEC & 322222 & Coated and Laminated Paper Manufacturing & \\
\hline
\end{tabular}




\begin{tabular}{|c|c|c|c|c|}
\hline \multirow[t]{2}{*}{2673} & $\begin{array}{r}\text { Plastics, Foil, and Coated Paper Bags } \\
\text { (except single-web or multi-web } \\
\text { plastics bags) }\end{array}$ & 322223 & $\begin{array}{l}\text { Plastics, Foil, and Coated Paper Bags } \\
\text { Manufacturing }\end{array}$ & \\
\hline & $\begin{array}{r}\text { (single-web and multi-web plastics } \\
\text { bags) }\end{array}$ & 326111 & Plastics Bag Manufacturing & $\begin{array}{l}\text { Any facility whose primary activity is } \\
\text { manufacturing single-web and multi- } \\
\text { web plastics bags (SIC } 2673 \text { / NAICS } \\
326111 \text { ) should be regulated under } \\
\text { Sector Y, but may continue to be } \\
\text { regulated under Sector B, or } \\
\text { alternatively, under Sector AD. } \\
\text { Sectors Y, B, and AD do not have } \\
\text { specific requirements for facilities } \\
\text { manufacturing single-web and multi- } \\
\text { web plastics bags. However, under } \\
\text { Sector AD EPA could establish } \\
\text { additional facility-specific monitoring } \\
\text { and reporting requirements. } \\
\text { Regulatory burden would not differ } \\
\text { between Sectors B and } Y \text {. }\end{array}$ \\
\hline 2674 & Uncoated Paper and Multiwall Bags & 322224 & $\begin{array}{l}\text { Uncoated Paper and Multiwall Bags } \\
\text { Manufacturing }\end{array}$ & \\
\hline \multirow[t]{3}{*}{2675} & $\begin{array}{l}\text { Die Cut Paper and Paperboard and } \\
\text { Cardboard } \\
\text { (pasted, lined, laminated, or surface- } \\
\text { coated paperboard) }\end{array}$ & 322226 & Surface-Coated Paperboard Manufacturing & \\
\hline & $\begin{array}{r}\text { (die cut paper and paperboard office } \\
\text { supplies, such as file folders, } \\
\text { tabulating cards, and report covers) }\end{array}$ & 322231 & $\begin{array}{l}\text { Die Cut Paper and Paperboard Office Supplies } \\
\text { Manufacturing }\end{array}$ & \\
\hline & $\begin{array}{r}\text { (except pasted, lined, laminated, or } \\
\text { surface-coated paperboard and die- } \\
\text { cut paper and paperboard office } \\
\text { supplies) }\end{array}$ & 322299 & $\begin{array}{l}\text { All Other Converted Paper Product } \\
\text { Manufacturing }\end{array}$ & \\
\hline 2676 & Sanitary Paper Products & 322291 & Sanitary Paper Product Manufacturing & \\
\hline 2677 & Envelopes & 322232 & Envelope Manufacturing & \\
\hline 2678 & $\begin{array}{l}\text { Stationery, Tablets, and Related } \\
\text { Products }\end{array}$ & 322233 & $\begin{array}{l}\text { Stationery, Tablets, and Related Product } \\
\text { Manufacturing }\end{array}$ & \\
\hline \multirow[t]{3}{*}{2679} & $\begin{array}{l}\text { Converted Paper and Paperboard } \\
\text { Products, NEC } \\
\end{array}$ & 322211 & Corrugated and Solid Fiber Box Manufacturing & \\
\hline & (wallpaper and gift wrap paper) & 322222 & Coated and Laminated Paper Manufacturing & \\
\hline & $\begin{array}{r}\text { (paper supplies for business } \\
\text { machines, such as adding machine } \\
\text { tape, and other paper office supplies) }\end{array}$ & 322231 & $\begin{array}{l}\text { Die Cut Paper and Paperboard Office Supplies } \\
\text { Manufacturing }\end{array}$ & \\
\hline
\end{tabular}




\begin{tabular}{|c|c|c|c|c|c|}
\hline & & $\begin{array}{r}\text { (except corrugated paper, wall paper, } \\
\text { gift wrap paper, paper supplies for } \\
\text { business machines, and other paper } \\
\text { office supplies) }\end{array}$ & 322299 & $\begin{array}{l}\text { All Other Converted Paper Product } \\
\text { Manufacturing }\end{array}$ & \\
\hline \multicolumn{6}{|c|}{ Sector C. Chemical and Allied Products Manufacturing } \\
\hline $\begin{array}{l}\text { Sub- } \\
\text { sector }\end{array}$ & & SIC Codes & & NAICS Codes & Notes \\
\hline \multirow[t]{9}{*}{$\mathbf{C 2}$} & 2812 & Alkalies and Chlorine & 325181 & Alkalies and Chlorine Manufacturing & \\
\hline & 2813 & Industrial Gases & 325120 & Industrial Gas Manufacturing & \\
\hline & 2816 & $\begin{array}{l}\text { Inorganic Pigments } \\
\text { (except bone and lamp black) }\end{array}$ & 325131 & Inorganic Dye and Pigment Manufacturing & \\
\hline & & (bone and lamp black) & 325182 & Carbon Black Manufacturing & \\
\hline & 2819 & $\begin{array}{l}\text { Industrial Inorganic Chemicals, Not } \\
\text { Elsewhere Classified } \\
\quad \text { (recovering sulfur from natural gas) }\end{array}$ & 211112 & Natural Gas Liquid Extraction & \\
\hline & & (inorganic dyes) & 325131 & Inorganic Dye and Pigment Manufacturing & \\
\hline & & (other) & 325131 & $\begin{array}{l}\text { All Other Basic Inorganic Chemical } \\
\text { Manufacturing }\end{array}$ & \\
\hline & & (activated carbon and charcoal) & 325998 & $\begin{array}{l}\text { All Other Miscellaneous Chemical Product and } \\
\text { Preparation Manufacturing }\end{array}$ & \\
\hline & & (alumina) & 331311 & Alumina Refining & $\begin{array}{l}\text { Any facility whose primary activity is } \\
\text { alumina refining (NAICS } 331311 \text { ) } \\
\text { should be regulated under Sector } F \text {, } \\
\text { but may continue to be regulated } \\
\text { under Sector C. Sector } \mathrm{C} \text { requires } \\
\text { sector/subsector specific benchmark } \\
\text { monitoring for total aluminum, total } \\
\text { iron, and nitrate plus nitrite nitrogen. } \\
\text { Sector } \mathrm{F} \text { applies additional } \\
\text { technology-based effluent limits } \\
\text { comprised of good housekeeping } \\
\text { measures; additional SWPPP } \\
\text { requirements; and additional } \\
\text { inspection requirements. } \\
\text { Regulatory burdens differ between } \\
\text { Sectors } \mathrm{C} \text { and } \mathrm{F} \text { but determining } \\
\text { which sector would be more } \\
\text { burdensome would depend on the } \\
\text { regulated facility. }\end{array}$ \\
\hline \multirow[t]{2}{*}{ C4 } & 2821 & $\begin{array}{l}\text { Plastics Materials, Synthetic Resins, } \\
\text { and Nonvulcanizable Elastomers }\end{array}$ & 325211 & Plastics Material and Resin Manufacturing & \\
\hline & 2822 & Synthetic Rubber & 325212 & Synthetic Rubber Manufacturing & \\
\hline
\end{tabular}




\begin{tabular}{|c|c|c|c|c|c|}
\hline & 2823 & Cellulosic Manmade Fibers & 325221 & Cellulosic Organic Fiber Manufacturing & \\
\hline & 2824 & $\begin{array}{l}\text { Manmade Organic Fibers, Except } \\
\text { Cellulosic }\end{array}$ & 325222 & Noncellulosic Organic Fiber Manufacturing & \\
\hline \multirow[t]{5}{*}{ C5 } & 2833 & $\begin{array}{l}\text { Medicinal Chemicals and Botanical } \\
\text { Products }\end{array}$ & 325411 & Medicinal and Botanical Manufacturing & \\
\hline & 2834 & Pharmaceutical Preparations & 325412 & Pharmaceutical Preparation Manufacturing & \\
\hline & 2835 & $\begin{array}{l}\text { In Vitro and In Vivo Diagnostic } \\
\text { Substances } \\
\qquad \text { (except in vitro diagnostic) }\end{array}$ & 325412 & Pharmaceutical Preparation Manufacturing & \\
\hline & & (in vitro diagnostic substances) & 325413 & In Vitro Diagnostic Substance Manufacturing & \\
\hline & 2836 & $\begin{array}{l}\text { Biological Products, Except } \\
\text { Diagnostic Substances }\end{array}$ & 325414 & $\begin{array}{l}\text { Biological Product (except Diagnostic) } \\
\text { Manufacturing }\end{array}$ & \\
\hline \multirow[t]{5}{*}{ C3 } & 2841 & $\begin{array}{l}\text { Soaps and Other Detergents, Except } \\
\text { Specialty Cleaners }\end{array}$ & 325611 & Soap and Other Detergent Manufacturing & \\
\hline & 2842 & $\begin{array}{l}\text { Specialty Cleaning, Polishing, and } \\
\text { Sanitation Preparations }\end{array}$ & 325612 & $\begin{array}{l}\text { Polish and Other Sanitation Good } \\
\text { Manufacturing }\end{array}$ & \\
\hline & 2843 & $\begin{array}{l}\text { Surface Active Agents, Finishing } \\
\text { Agents, Sulfonated Oils, and } \\
\text { Assistants }\end{array}$ & 325613 & Surface Active Agent Manufacturing & \\
\hline & 2844 & $\begin{array}{l}\text { Perfumes, Cosmetics, and Other } \\
\text { Toilet Preparations } \\
\text { (toothpaste, gel and dentifrice } \\
\text { powders) }\end{array}$ & 325611 & Soap and Other Detergent Manufacturing & \\
\hline & & $\begin{array}{r}\text { (except toothpaste, gel and dentifrice } \\
\text { powders) }\end{array}$ & 325620 & Toilet Preparation Manufacturing & \\
\hline \multirow[t]{8}{*}{ C5 } & 2851 & $\begin{array}{l}\text { Paints, Varnishes, Lacquers, } \\
\text { Enamels, and Allied Products }\end{array}$ & 325510 & Paint and Coating Manufacturing & \\
\hline & 2861 & Gum and Wood Chemicals & 325191 & Gum and Wood Chemical Manufacturing & \\
\hline & 2865 & $\begin{array}{l}\text { Cyclic Organic Crudes and } \\
\text { Intermediates, and Organic Dyes and } \\
\text { Pigments }\end{array}$ & 325110 & Petrochemical Manufacturing & \\
\hline & & (organic dyes and pigments) & 325132 & $\begin{array}{l}\text { Synthetic Organic Dye and Pigment } \\
\text { Manufacturing }\end{array}$ & \\
\hline & & $\begin{array}{r}\text { (except aromatics and organic dyes } \\
\text { and pigments) }\end{array}$ & 325192 & Cyclic Crude and Intermediate Manufacturing & \\
\hline & 2869 & $\begin{array}{l}\text { Industrial Organic Chemicals, Not } \\
\text { Elsewhere Classified }\end{array}$ & 325110 & Petrochemical Manufacturing & \\
\hline & & (fluorocarbon gases) & 325120 & Industrial Gas Manufacturing & \\
\hline & & (carbon bisulfide) & 325188 & $\begin{array}{l}\text { All Other Basic Inorganic Chemical } \\
\text { Manufacturing }\end{array}$ & \\
\hline
\end{tabular}




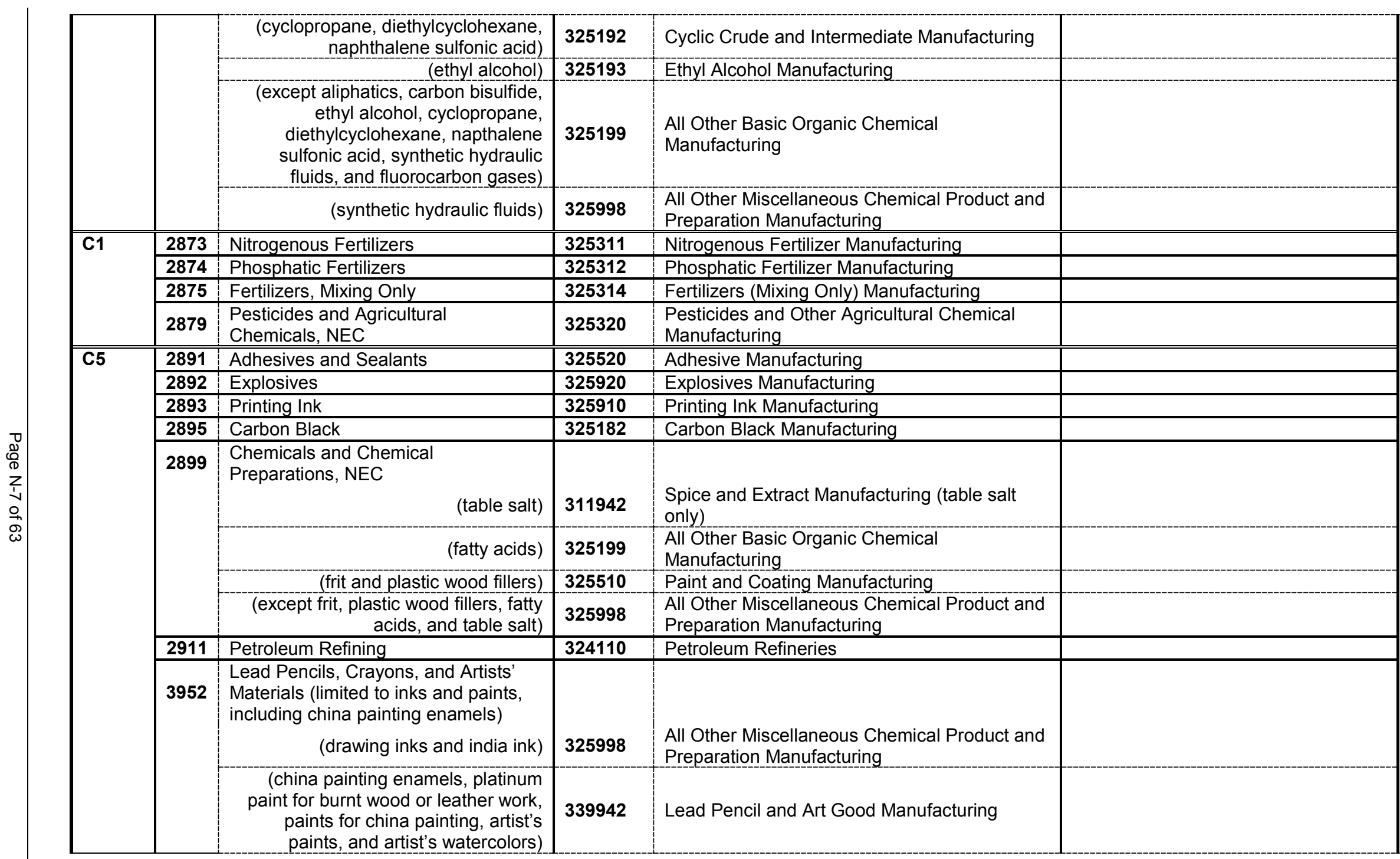




\begin{tabular}{|c|c|c|c|c|c|}
\hline \multicolumn{6}{|c|}{ Sector D. Asphalt Paving and Roofing Materials Manufacturers and Lubricant Manufacturers } \\
\hline $\begin{array}{l}\text { Sub- } \\
\text { sector }\end{array}$ & \multicolumn{2}{|r|}{ SIC Codes } & \multicolumn{2}{|c|}{ NAICS Codes } & Notes \\
\hline \multirow[t]{2}{*}{ D1 } & 2951 & Asphalt Paving Mixtures and Blocks & 324121 & $\begin{array}{l}\text { Asphalt Paving Mixture and Block } \\
\text { Manufacturing }\end{array}$ & \\
\hline & 2952 & Asphalt Felt and Coatings & 324122 & $\begin{array}{l}\text { Asphalt Shingle and Coating Materials } \\
\text { Manufacturing }\end{array}$ & \\
\hline \multirow[t]{2}{*}{ D2 } & 2992 & Lubricating Oils and Greases & 324191 & $\begin{array}{l}\text { Petroleum Lubricating Oil and Grease } \\
\text { Manufacturing }\end{array}$ & \\
\hline & 2999 & $\begin{array}{l}\text { Products of Petroleum and Coal, Not } \\
\text { Elsewhere Classified }\end{array}$ & 324199 & $\begin{array}{l}\text { All Other Petroleum and Coal Products } \\
\text { Manufacturing }\end{array}$ & \\
\hline \multicolumn{6}{|c|}{ Sector E. Glass, Clay, Cement, Concrete, and Gypsum Product Manufacturing } \\
\hline $\begin{array}{l}\text { Sub- } \\
\text { sector }\end{array}$ & \multicolumn{2}{|r|}{ SIC Codes } & \multicolumn{2}{|r|}{ NAICS Codes } & Notes \\
\hline \multirow[t]{5}{*}{ E3 } & 3211 & Flat Glass & 327211 & Flat Glass Manufacturing & \\
\hline & 3221 & Glass Containers & 327213 & Glass Container Manufacturing & \\
\hline & 3229 & $\begin{array}{l}\text { Pressed and Blown Glass and } \\
\text { Glassware, Not Elsewhere Classified }\end{array}$ & 327212 & $\begin{array}{l}\text { Other Pressed and Blown Glass and } \\
\text { Glassware Manufacturing }\end{array}$ & \\
\hline & 3231 & $\begin{array}{l}\text { Glass Product Manufacturing Made of } \\
\text { Purchased Glass }\end{array}$ & 327215 & $\begin{array}{l}\text { Glass Product Manufacturing Made of } \\
\text { Purchased Glass }\end{array}$ & \\
\hline & 3241 & Hydraulic Cement & 327310 & Cement Manufacturing & \\
\hline \multirow[t]{10}{*}{$\overline{E 1}$} & 3251 & $\begin{array}{l}\text { Brick and Structural Clay Tile } \\
\text { (except slumped brick) }\end{array}$ & 327121 & Brick and Structural Clay Tile Manufacturing & \\
\hline & & (slumped brick) & 327331 & Concrete Block and Brick Manufacturing & \\
\hline & 3253 & Ceramic Wall and Floor Tile & 327122 & Ceramic Wall and Floor Tile Manufacturing & \\
\hline & 3255 & Clay Refractories & 327124 & Clay Refractory Manufacturing & \\
\hline & 3259 & $\begin{array}{l}\text { Structural Clay Products, Not } \\
\text { Elsewhere Classified }\end{array}$ & 327123 & Other Structural Clay Product Manufacturing & \\
\hline & 3261 & $\begin{array}{l}\text { Vitreous China Plumbing Fixtures and } \\
\text { China and Earthenware Fittings and } \\
\text { Bathroom Accessories }\end{array}$ & 327111 & $\begin{array}{l}\text { Vitreous China Plumbing Fixture and China } \\
\text { and Earthenware Bathroom Accessories } \\
\text { Manufacturing }\end{array}$ & \\
\hline & 3262 & $\begin{array}{l}\text { Vitreous China Table and Kitchen } \\
\text { Articles }\end{array}$ & 327112 & $\begin{array}{l}\text { Vitreous China, Fine Earthenware, and Other } \\
\text { Pottery Product Manufacturing }\end{array}$ & \\
\hline & 3263 & $\begin{array}{l}\text { Fine Earthenware (Whiteware) Table } \\
\text { and Kitchen Articles }\end{array}$ & 327112 & $\begin{array}{l}\text { Vitreous China, Fine Earthenware, and Other } \\
\text { Pottery Product Manufacturing }\end{array}$ & \\
\hline & 3264 & Porcelain Electrical Supplies & 327113 & Porcelain Electrical Supply Manufacturing & \\
\hline & 3269 & $\begin{array}{l}\text { Pottery Products, Not Elsewhere } \\
\text { Classified }\end{array}$ & 327112 & $\begin{array}{l}\text { Vitreous China, Fine Earthenware, and Other } \\
\text { Pottery Product Manufacturing }\end{array}$ & \\
\hline
\end{tabular}




\begin{tabular}{|c|c|c|c|c|c|}
\hline \multirow[t]{13}{*}{$\overline{E 2}$} & 3271 & Concrete Block and Brick & 327331 & Concrete Block and Brick Manufacturing & \\
\hline & \multirow[t]{3}{*}{3272} & $\begin{array}{l}\text { Concrete Products, Except Block and } \\
\text { Brick } \\
\text { (concrete pipe) }\end{array}$ & 327332 & Concrete Pipe Manufacturing & \\
\hline & & $\begin{array}{r}\text { (concrete products, except dry mix } \\
\text { concrete and pipe) }\end{array}$ & 327390 & Other Concrete Product Manufacturing & \\
\hline & & (dry mixture concrete) & 327999 & $\begin{array}{l}\text { All Other Miscellaneous Nonmetallic Mineral } \\
\text { Product Manufacturing }\end{array}$ & \\
\hline & 3273 & Ready-Mixed Concrete & 327320 & Ready-Mix Concrete Manufacturing & \\
\hline & \multirow[t]{7}{*}{3274} & $\begin{array}{l}\text { Lime Manufacturing } \\
\text { Calcium hydroxide (i.e., hydrated } \\
\text { lime) manufacturing }\end{array}$ & 327410 & Lime Manufacturing & \\
\hline & & $\begin{array}{r}\text { Calcium oxide (i.e., quicklime) } \\
\text { manufacturing }\end{array}$ & 327410 & Lime Manufacturing & \\
\hline & & $\begin{array}{r}\text { Dolomite, dead-burned, } \\
\text { manufacturing }\end{array}$ & 327410 & Lime Manufacturing & \\
\hline & & $\begin{array}{l}\text { Hydrated lime (i.e., calcium } \\
\text { hydroxide) manufacturing }\end{array}$ & 327410 & Lime Manufacturing & \\
\hline & & $\begin{array}{r}\text { Quicklime (i.e., calcium oxide) } \\
\text { manufacturing }\end{array}$ & 327410 & Lime Manufacturing & \\
\hline & & Agricultural lime manufacturing & 327410 & Lime Manufacturing & \\
\hline & & Dolomitic lime manufacturing & 327410 & Lime Manufacturing & \\
\hline & 3275 & Gypsum Products & 327420 & Gypsum Product Manufacturing & \\
\hline \multirow[t]{3}{*}{ E3 } & 3281 & Cut Stone and Stone Products & 327991 & Cut Stone and Stone Product Manufacturing & \\
\hline & \multirow[t]{2}{*}{3291} & $\begin{array}{l}\text { Abrasive Products } \\
\text { (except steel wool manufacturing) }\end{array}$ & 327910 & Abrasive Product Manufacturing & \\
\hline & & (steel wool manufacturing) & 332999 & $\begin{array}{l}\text { All Other Miscellaneous Fabricated Metal } \\
\text { Product Manufacturing }\end{array}$ & $\begin{array}{l}\text { Any facility whose primary activity is } \\
\text { steel wool manufacturing (NAICS } \\
332999 \text { ) should be regulated under } \\
\text { Sector AA, but may continue to be } \\
\text { regulated under Sector E. Sector AA } \\
\text { applies additional technology-based } \\
\text { effluent limits comprised of good } \\
\text { housekeeping measures, spill } \\
\text { prevention and response procedures, } \\
\text { and spills and leaks; additional } \\
\text { SWPPP requirements; and additional } \\
\text { inspection requirements. Sector E } \\
\text { applies additional technology-based } \\
\text { effluent limits comprised of good } \\
\text { housekeeping measures, and } \\
\text { additional SWPPP requirements. }\end{array}$ \\
\hline
\end{tabular}




\begin{tabular}{|c|c|c|c|c|c|}
\hline & & & & & $\begin{array}{l}\text { Regulatory burden would likely be } \\
\text { greater under Sector AA. }\end{array}$ \\
\hline & \multirow[t]{3}{*}{3292} & $\begin{array}{l}\text { Asbestos Products } \\
\quad \text { (except brake pads and linings) }\end{array}$ & 327999 & $\begin{array}{l}\text { All Other Miscellaneous Nonmetallic Mineral } \\
\text { Product Manufacturing }\end{array}$ & \\
\hline & & (asbestos brake linings and pads) & 336340 & Motor Vehicle Brake System Manufacturing & \\
\hline & & $\begin{array}{r}\text { (asbestos clutch facings, motor } \\
\text { vehicle) }\end{array}$ & 336350 & $\begin{array}{l}\text { Motor Vehicle Transmission and Power Train } \\
\text { Parts Manufacturing }\end{array}$ & \\
\hline & \multirow[t]{5}{*}{3295} & $\begin{array}{l}\text { Minerals and Earths, Ground or } \\
\text { Otherwise Treated } \\
\text { (grinding, washing, separating, etc. of } \\
\text { kaolin and ball clay) }\end{array}$ & 212324 & Kaolin and Ball Clay Mining & \\
\hline & & $\begin{array}{l}\text { (grinding, washing, separating, etc. of } \\
\text { clay, ceramic, and refractory minerals } \\
\text { not elsewhere classified) }\end{array}$ & 212325 & $\begin{array}{l}\text { Clay and Ceramic and Refractory Minerals } \\
\text { Mining }\end{array}$ & \\
\hline & & $\begin{array}{r}\text { (grinding, washing, separating, etc. of } \\
\text { chemical and fertilizer minerals, not } \\
\text { elsewhere classified) }\end{array}$ & 212393 & Other Chemical and Fertilizer Mineral Mining & \\
\hline & & $\begin{array}{r}\text { (grinding, washing, separating, etc. of } \\
\text { nonmetallic minerals, not elsewhere } \\
\text { classified) }\end{array}$ & 212399 & All Other Nonmetallic Mineral Mining & \\
\hline & & $\begin{array}{l}\text { (except grinding, washing, separating, } \\
\text { etc. of nonmetallic minerals) }\end{array}$ & 327992 & $\begin{array}{l}\text { Ground or Treated Mineral and Earth } \\
\text { Manufacturing }\end{array}$ & \\
\hline & 3296 & Mineral Wool & 327993 & Mineral Wool Manufacturing & \\
\hline & 3297 & Nonclay Refractories & 327125 & Nonclay Refractory Manufacturing & \\
\hline & \multirow[t]{4}{*}{3299} & $\begin{array}{l}\text { Nonmetallic Mineral Products, Not } \\
\text { Elsewhere Classified }\end{array}$ & & & \\
\hline & & (clay statuary) & 327112 & $\begin{array}{l}\text { Vitreous China, Fine Earthenware, and Other } \\
\text { Pottery Product Manufacturing }\end{array}$ & \\
\hline & & $\begin{array}{r}\text { (moldings, ornamental and } \\
\text { architectural plaster work, and } \\
\text { gypsum statuary) }\end{array}$ & 327420 & Gypsum Product Manufacturing & \\
\hline & & $\begin{array}{l}\text { (except moldings, ornamental and } \\
\text { architectural plaster work, clay } \\
\text { statuary, and gypsum statuary) }\end{array}$ & 327999 & $\begin{array}{l}\text { All Other Miscellaneous Nonmetallic Mineral } \\
\text { Product Manufacturing }\end{array}$ & \\
\hline \multicolumn{6}{|c|}{ Sector F. Primary Metals } \\
\hline $\begin{array}{l}\text { Sub- } \\
\text { sector }\end{array}$ & \multicolumn{2}{|r|}{ SIC Codes } & \multicolumn{2}{|r|}{ NAICS Codes } & Notes \\
\hline F1 & 3312 & $\begin{array}{l}\text { Steel Works, Blast Furnaces } \\
\text { (Including Coke Ovens), and Rolling } \\
\text { Mills }\end{array}$ & & & \\
\hline
\end{tabular}




\begin{tabular}{|c|c|c|c|c|c|}
\hline & & $\begin{array}{r}\text { (coke oven products [e.g., coke, } \\
\text { gases, tars] made in coke oven } \\
\text { establishments) }\end{array}$ & 324199 & $\begin{array}{l}\text { All Other Petroleum and Coal Products } \\
\text { Manufacturing }\end{array}$ & $\begin{array}{l}\text { Any facility whose primary activity is } \\
\text { manufacturing coke oven products } \\
\text { (e.g., coke, gases, tars) made in coke } \\
\text { oven establishments should be } \\
\text { regulated under Sector } D \text {, but may } \\
\text { continue to be regulated under Sector } \\
\text { F. Sector F requires sector-specific } \\
\text { benchmark monitoring requirements } \\
\text { for total aluminum and total zinc, } \\
\text { Sector D does not require benchmark } \\
\text { monitoring from these facilities. } \\
\text { Regulatory burden would be greater } \\
\text { under Sector F. }\end{array}$ \\
\hline & & $\begin{array}{r}\text { (except coke ovens not integrated } \\
\text { with steel mills and hot-rolling } \\
\text { purchased steel) }\end{array}$ & 331111 & Iron and Steel Mills & \\
\hline & & (hot-rolling purchased steel) & 331221 & Rolled Steel Shape Manufacturing & \\
\hline & 3313 & $\begin{array}{l}\text { Electrometallurigcal Products, Except } \\
\text { Steel }\end{array}$ & 331112 & $\begin{array}{l}\text { Electrometallurigcal Ferroalloy Product } \\
\text { Manufacturing }\end{array}$ & \\
\hline & 3315 & $\begin{array}{l}\begin{array}{l}\text { Steel Wiredrawing and Steel Nails } \\
\text { and Spikes } \\
\\
\text { (steel wire drawing) }\end{array}\end{array}$ & 331222 & Steel Wire Drawing & \\
\hline & 3316 & $\begin{array}{l}\text { Cold-Rolled Steel Sheet, Strip, and } \\
\text { Bars }\end{array}$ & 331221 & Rolled Steel Shape Manufacturing & \\
\hline & 3317 & Steel Pipe and Tubes & 331210 & $\begin{array}{l}\text { Iron and Steel Pipe and Tube Manufacturing } \\
\text { from Purchased Steel }\end{array}$ & \\
\hline F2 & 3321 & Gray and Ductile Iron Foundries & 331511 & Iron Foundries & \\
\hline & 3322 & Malleable Iron Foundries & 331511 & Iron Foundries & \\
\hline & 3324 & Steel Investment Foundries & 331512 & Steel Investment Foundries & \\
\hline & 3325 & Steel Foundries, NEC & 331513 & Steel Foundries (except Investment) & \\
\hline F5 & 3331 & $\begin{array}{l}\text { Primary Smelting and Refining of } \\
\text { Copper }\end{array}$ & 331411 & Primary Smelting and Refining of Copper & \\
\hline & 3334 & Primary Production of Aluminum & 331312 & Primary Aluminum Production & \\
\hline & 3339 & $\begin{array}{l}\text { Primary Smelting and Refining of } \\
\text { Nonferrous Metals, Except Copper } \\
\text { and Aluminum }\end{array}$ & 331419 & $\begin{array}{l}\text { Primary Smelting and Refining of Nonferrous } \\
\text { Metal (except Copper and Aluminum) }\end{array}$ & \\
\hline & 3341 & $\begin{array}{l}\text { Secondary Smelting and Refining of } \\
\text { Nonferrous Metals } \\
\text { (aluminum) }\end{array}$ & 331314 & Secondary Smelting and Alloying of Aluminum & \\
\hline & & (copper) & 331423 & $\begin{array}{l}\text { Secondary Smelting, Refining and Alloying of } \\
\text { Copper }\end{array}$ & \\
\hline
\end{tabular}




\begin{tabular}{|c|c|c|c|c|c|}
\hline & & (except copper and aluminum) & 331492 & $\begin{array}{l}\text { Secondary Smelting, Refining and Alloying of } \\
\text { Nonferrous Metal (except Copper and } \\
\text { Aluminum) }\end{array}$ & \\
\hline \multirow[t]{10}{*}{ F3 } & 3351 & $\begin{array}{l}\text { Rolling, Drawing, and Extruding of } \\
\text { Copper }\end{array}$ & 331421 & Copper Rolling, Drawing, and Extruding & \\
\hline & 3353 & Aluminum Sheet, Plate, and Foil & 331315 & Aluminum Sheet, Plate, and Foil Manufacturing & \\
\hline & 3354 & Aluminum Extruded Products & 331316 & Aluminum Extruded Product Manufacturing & \\
\hline & 3355 & $\begin{array}{l}\text { Aluminum Rolling and Drawing, Not } \\
\text { Elsewhere Classified }\end{array}$ & 331319 & Other Aluminum Rolling and Drawing & \\
\hline & 3356 & $\begin{array}{l}\text { Rolling, Drawing, and Extruding of } \\
\text { Nonferrous Metals, Except Copper } \\
\text { and Aluminum }\end{array}$ & 331491 & $\begin{array}{l}\text { Nonferrous Metal (Except Copper and } \\
\text { Aluminum) Rolling, Drawing, and Extruding }\end{array}$ & \\
\hline & \multirow[t]{5}{*}{3357} & $\begin{array}{l}\text { Drawing and Insulating of Nonferrous } \\
\text { Wire } \quad \text { (aluminum wire drawing) }\end{array}$ & 331319 & Other Aluminum Rolling and Drawing & \\
\hline & & (copper wire drawing) & 331422 & Copper Wire (except Mechanical) Drawing & \\
\hline & & $\begin{array}{r}\text { (wire drawing except copper or } \\
\text { aluminum) }\end{array}$ & 331491 & $\begin{array}{l}\text { Nonferrous Metal (except Copper and } \\
\text { Aluminum) Rolling, Drawing, and Extruding }\end{array}$ & \\
\hline & & (fiber optic cable-insulating only) & 335921 & Fiber Optic Cable Manufacturing & \\
\hline & & $\begin{array}{l}\text { (communication and energy wire, } \\
\text { except fiber optic-insulating only) }\end{array}$ & 335929 & $\begin{array}{l}\text { Other Communication and Energy Wire } \\
\text { Manufacturing }\end{array}$ & \\
\hline \multirow[t]{5}{*}{$\overline{\text { F4 }}$} & 3363 & Aluminum Die Castings & 331521 & Aluminum Die Casting Foundries & \\
\hline & 3364 & $\begin{array}{l}\text { Nonferrous Die Castings, Except } \\
\text { Aluminum }\end{array}$ & 331522 & $\begin{array}{l}\text { Nonferrous (Except Aluminum) Die Casting } \\
\text { Foundries }\end{array}$ & \\
\hline & 3365 & Aluminum Foundries & 331524 & Aluminum Foundries (Except Die-Casting) & \\
\hline & 3366 & Copper Foundries & 331525 & Copper Foundries (Except Die-Casting) & \\
\hline & 3369 & $\begin{array}{l}\text { Nonferrous Foundries, Except Copper } \\
\text { and Aluminum }\end{array}$ & 331528 & $\begin{array}{l}\text { Other Nonferrous Foundries (Except Die- } \\
\text { Casting) }\end{array}$ & \\
\hline \multirow[t]{7}{*}{ F5 } & 3398 & Metal Heat Treating & 332811 & Metal Heat Treating & \\
\hline & \multirow[t]{6}{*}{3399} & $\begin{array}{l}\text { Primary Metal Products, Not } \\
\text { Elsewhere Classified } \\
\quad \text { (iron ore recovery from open hearth } \\
\text { slag) }\end{array}$ & 331111 & Iron and Steel Mills & \\
\hline & & (ferrous powder, paste, flakes, etc.) & 331221 & Rolled Steel Shape Manufacturing & \\
\hline & & (aluminum powder, paste, flakes, etc.) & 331314 & Secondary Smelting and Alloying of Aluminum & \\
\hline & & (copper powder, paste, flakes, etc.) & 331423 & $\begin{array}{l}\text { Secondary Smelting, Refining, and Alloying of } \\
\text { Copper }\end{array}$ & \\
\hline & & $\begin{array}{l}\text { (nonferrous powder, paste, flakes, } \\
\text { etc. except copper and aluminum) }\end{array}$ & 331492 & $\begin{array}{l}\text { Secondary Smelting, Refining, and Alloying of } \\
\text { Nonferrous Metal (except Copper and } \\
\text { Aluminum) }\end{array}$ & \\
\hline & & $\begin{array}{r}\text { (nonferrous nails, brads, staples, } \\
\text { tacks, etc. made from purchased } \\
\text { nonferrous wire) }\end{array}$ & 332618 & Other Fabricated Wire Product Manufacturing & \\
\hline
\end{tabular}




\begin{tabular}{|c|c|c|c|c|c|}
\hline \multicolumn{6}{|c|}{ Sector G. Metal Mining (Ore Mining and Dressing) } \\
\hline $\begin{array}{l}\text { Sub- } \\
\text { sector }\end{array}$ & \multicolumn{2}{|r|}{ SIC Codes } & \multicolumn{2}{|r|}{ NAICS Codes } & \multirow[t]{2}{*}{ Notes } \\
\hline G1 & 1021 & Copper Ores & 212234 & Copper Ore and Nickel Ore Mining & \\
\hline \multirow[t]{11}{*}{ G2 } & 1011 & Iron Ores & 212210 & Iron Ore Mining & \\
\hline & 1021 & Copper Ores & 212234 & Copper Ore and Nickel Ore Mining & \\
\hline & 1031 & Lead and Zinc Ores & 212231 & Lead Ore and Zinc Ore Mining & \\
\hline & 1041 & Gold Ores & 212221 & Gold Ore Mining & \\
\hline & 1044 & Silver Ores & 212222 & Silver Ore Mining & \\
\hline & \multirow[t]{2}{*}{1061} & 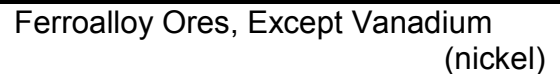 & 212234 & Copper Ore and Nickel Ore Mining & \\
\hline & & (other ferroalloys except nickel) & 212299 & All Other Metal Ore Mining & \\
\hline & \multirow[t]{2}{*}{1081} & $\begin{array}{r}\text { Metal Mining Services } \\
\text { (except site preparation and related } \\
\text { activities performed on a contract or } \\
\text { fee basis and geophysical surveying } \\
\text { and mapping) }\end{array}$ & 213114 & Support Activities for Metal Mining & \\
\hline & & $\begin{array}{r}\text { (site preparation and related } \\
\text { construction activities on a contract } \\
\text { basis) }\end{array}$ & 238910 & Site Preparation Contractors & \\
\hline & 1094 & Uranium-Radium-Vanadium Ores & 212291 & Uranium-Radium-Vanadium Ore Mining & \\
\hline & 1099 & $\begin{array}{l}\text { Miscellaneous Metal Ores, Not } \\
\text { Elsewhere Classified }\end{array}$ & 212299 & All Other Metal Ore Mining & \\
\hline \multicolumn{6}{|c|}{ Sector H. Coal Mines and Coal Mining-Related Facilities } \\
\hline $\begin{array}{l}\text { Sub- } \\
\text { sector }\end{array}$ & \multicolumn{2}{|r|}{ SIC Codes } & \multicolumn{2}{|c|}{$\begin{array}{l}\text { NAICS Codes } \\
\end{array}$} & Notes \\
\hline \multirow[t]{5}{*}{ H1 } & 1221 & $\begin{array}{l}\text { Bituminous Coal and Lignite Surface } \\
\text { Mining }\end{array}$ & 212111 & Bituminous Coal and Lignite Surface Mining & \\
\hline & 1222 & Bituminous Coal Underground Mining & 212112 & Bituminous Coal Underground Mining & \\
\hline & 1231 & Anthracite Mining & 212113 & Anthracite Mining & \\
\hline & \multirow[t]{2}{*}{1241} & $\begin{array}{l}\text { Coal Mining Services } \\
\text { (except site preparation and related } \\
\text { construction activities on a contract } \\
\text { basis) }\end{array}$ & 213113 & Support Activities for Coal Mining & \\
\hline & & $\begin{array}{r}\text { (site preparation and related } \\
\text { construction activities on a contract } \\
\text { basis) }\end{array}$ & 238910 & Site Preparation Contractors & \\
\hline
\end{tabular}




\begin{tabular}{|c|c|c|c|c|c|}
\hline \multicolumn{6}{|c|}{ Sector I. Oil and Gas Extraction } \\
\hline $\begin{array}{l}\text { Sub- } \\
\text { sector }\end{array}$ & & SIC Codes & & NAICS Codes & Notes \\
\hline \multirow[t]{7}{*}{11} & 1311 & Crude Petroleum and Natural Gas & 211111 & Crude Petroleum and Natural Gas Extraction & \\
\hline & 1321 & Natural Gas Liquids & 211112 & Natural Gas Liquid Extraction & \\
\hline & 1381 & Drilling Oil and Gas Wells & 213111 & Drilling Oil and Gas Wells & \\
\hline & 1382 & $\begin{array}{l}\text { Oil and Gas Field Exploration } \\
\text { Services }\end{array}$ & 213112 & Support Activities for Oil and Gas Operations & \\
\hline & 1389 & $\begin{array}{l}\text { Oil and Gas Field Services, Not } \\
\text { Elsewhere Classified } \\
\text { (except construction of field gathering } \\
\text { lines, site preparation and related } \\
\text { construction activities performed on a } \\
\text { contract or fee basis) }\end{array}$ & 213112 & Support Activities for Oil and Gas Operations & \\
\hline & & $\begin{array}{l}\text { (construction of field gathering lines } \\
\text { on a contract or fee basis) }\end{array}$ & 237120 & $\begin{array}{l}\text { Oil and Gas Pipeline and Related Structures } \\
\text { Construction }\end{array}$ & \\
\hline & & $\begin{array}{r}\text { (site preparation and related } \\
\text { construction activities on a contract } \\
\text { basis) }\end{array}$ & 238910 & Site Preparation Contractors & \\
\hline \multicolumn{6}{|c|}{ Sector J. Mineral Mining and Dressing } \\
\hline $\begin{array}{l}\text { Sub- } \\
\text { sector }\end{array}$ & & SIC Codes & & NAICS Codes & Notes \\
\hline \multirow[t]{4}{*}{ J2 } & 1411 & Dimension Stone & 212311 & Dimension Stone Mining and Quarrying & \\
\hline & 1422 & Crushed and Broken Limestone & 212312 & $\begin{array}{l}\text { Crushed and Broken Limestone Mining and } \\
\text { Quarrying }\end{array}$ & \\
\hline & 1423 & Crushed and Broken Granite & 212313 & $\begin{array}{l}\text { Crushed and Broken Granite Mining and } \\
\text { Quarrying }\end{array}$ & \\
\hline & 1429 & $\begin{array}{l}\text { Crushed and Broken Stone, Not } \\
\text { Elsewhere Classified }\end{array}$ & 212319 & $\begin{array}{l}\text { Other Crushed and Broken Stone Mining and } \\
\text { Quarrying }\end{array}$ & \\
\hline \multirow[t]{2}{*}{ J1 } & 1442 & Construction Sand and Gravel & 212321 & Construction Sand and Gravel Mining & \\
\hline & 1446 & Industrial Sand & 212322 & Industrial Sand Mining & \\
\hline \multirow[t]{5}{*}{ J3 } & 1455 & Kaolin and Ball Clay & 212324 & Kaolin and Ball Clay Mining & \\
\hline & 1459 & $\begin{array}{l}\text { Clay, Ceramic, and Refractory } \\
\text { Minerals, Not Elsewhere Classified }\end{array}$ & 212325 & Clay, Ceramic, and Refractory Minerals Mining & \\
\hline & 1474 & Potash, Soda, and Borate Minerals & 212391 & Potash, Soda, and Borate Mineral Mining & \\
\hline & 1475 & Phosphate Rock & 212392 & Phosphate Rock Mining & \\
\hline & 1479 & $\begin{array}{l}\text { Chemical and Fertilizer Mineral } \\
\text { Mining, Not Elsewhere Classified }\end{array}$ & 212393 & Other Chemical and Fertilizer Mineral Mining & \\
\hline J2 & 1481 & $\begin{array}{l}\text { Nonmetallic Minerals Services, } \\
\text { Except Fuels }\end{array}$ & & & \\
\hline
\end{tabular}




\begin{tabular}{|c|c|c|c|c|c|c|}
\hline & & $\begin{array}{l}\text { (except geophysical surveying and } \\
\text { mapping and site preparation and } \\
\text { related construction activities } \\
\text { performed on a contract or fee basis) }\end{array}$ & 213115 & \multicolumn{2}{|c|}{$\begin{array}{l}\text { Support Activities for Nonmetallic Minerals } \\
\text { (except Fuels) }\end{array}$} & \\
\hline & & $\begin{array}{l}\text { (site preparation and related } \\
\text { construction activities on a contract } \\
\text { basis) }\end{array}$ & \multirow[t]{2}{*}{238910} & \multicolumn{2}{|c|}{ Site Preparation Contractors } & \\
\hline & \multirow[t]{2}{*}{1499} & $\begin{array}{l}\text { Miscellaneous Nonmetallic Minerals, } \\
\text { Except Fuels }\end{array}$ & & & & \\
\hline & & $\begin{array}{r}\text { (except bituminous limestone and } \\
\text { bituminous sandstone) }\end{array}$ & 212399 & \multicolumn{2}{|c|}{ All Other Nonmetallic Mineral Mining } & \\
\hline \multicolumn{7}{|c|}{ Sector K. Hazardous Waste Treatment, Storage or Disposal Facilities } \\
\hline $\begin{array}{c}\text { Sub- } \\
\text { Sector }\end{array}$ & $\begin{array}{c}\text { Activity } \\
\text { Code }\end{array}$ & \multicolumn{3}{|c|}{ Narrative Description } & \multicolumn{2}{|r|}{ Notes } \\
\hline K1 & $\mathrm{HZ}$ & $\begin{array}{ll}\text { - } & \text { Hazardous waste treatment } \\
\text { - } & \text { Hazardous waste storage } \\
\text { - } & \text { Hazardous waste disposal } \\
\text { - } & \text { Hazardous waste facilities of } \\
& \text { Subtitle C of RCRA }\end{array}$ & $\begin{array}{l}\text { perating un } \\
\text { perating un }\end{array}$ & $\begin{array}{l}\text { er interim status } \\
\text { er a permit under }\end{array}$ & $\begin{array}{l}\mathrm{HZ} \text { is the Activity C } \\
\text { for this Sector. It } \mathrm{p} \\
\mathrm{SIC} / \text { NAICS Code } \\
\text { hazardous waste: } \\
\text { - SIC } 4953 \mathrm{R} \\
\text { and disposa } \\
\text { - NAICS } 5622 \\
\text { Disposal; } \\
\text { - NAICS } 5621 \\
\text { waste transf } \\
\end{array}$ & $\begin{array}{l}\text { ie., non-SIC / non-NAICS designation) } \\
\text { ally applies to any facility regardless of } \\
\text { dition to these specifically related to } \\
\text { Systems (hazardous waste treatment } \\
\text { azardous Waste Treatment and } \\
\text { azardous Waste Collection (hazardous } \\
\text { tions). }\end{array}$ \\
\hline & & Sector L. & Landf & and Land $\mathrm{A}$ & plication Sit & \\
\hline $\begin{array}{l}\text { Sub- } \\
\text { Sector }\end{array}$ & $\begin{array}{c}\text { Activity } \\
\text { Code }\end{array}$ & Narrative D & escriptic & & & Notes \\
\hline $\mathrm{L} 1$ & LF & - $\quad$ All Landfill, Land Application & Sites and & pen Dumps & LF is the Activity $C$ & non-SIC and non-NAICS \\
\hline L2 & LF & $\begin{array}{l}\text { All Landfill, Land Application Sites an } \\
\text { Solid Waste Landfill (MSWLI } \\
\text { with } 40 \text { CFR } 258 .\end{array}$ & $\begin{array}{l}\text { d Open Du } \\
\text { F) Areas C }\end{array}$ & $\begin{array}{l}\text { ps, except Municipal } \\
\text { sed in Accordance }\end{array}$ & $\begin{array}{l}\text { designation) tor thi } \\
\text { Code / NAICS Cod } \\
\text { landfills and landfill } \\
\text { - SIC } 4953 \mathrm{R} \\
\text { - NAICS } 5622 \\
\text { Industrial waste is } \\
\text { the MSGP (also de }\end{array}$ & $\begin{array}{l}\text { tor. It may apply to any facllity / SIC } \\
\text { addition to these specifically related to } \\
\text { cation sites: } \\
\text { Systems (solid waste landfills); } \\
\text { olid Waste Landfill. } \\
\text { from any of the facilities covered by } \\
\text { ed in } 40 \text { CFR } 122.26(\text { b)(14)). }\end{array}$ \\
\hline & & Secto & $\mathbf{r}$ M. & tomobile S & ige Yards & \\
\hline $\begin{array}{l}\text { Sub- } \\
\text { sector }\end{array}$ & & SIC Codes & & NAICS Co & & Notes \\
\hline M1 & 5015 & $\begin{array}{l}\text { Motor Vehicle Parts, Used } \\
\text { (merchant wholesalers except those } \\
\text { selling via retail method) }\end{array}$ & 423140 & $\begin{array}{l}\text { Motor Vehicle Parts } \\
\text { Wholesalers }\end{array}$ & sed) Merchant & \\
\hline
\end{tabular}




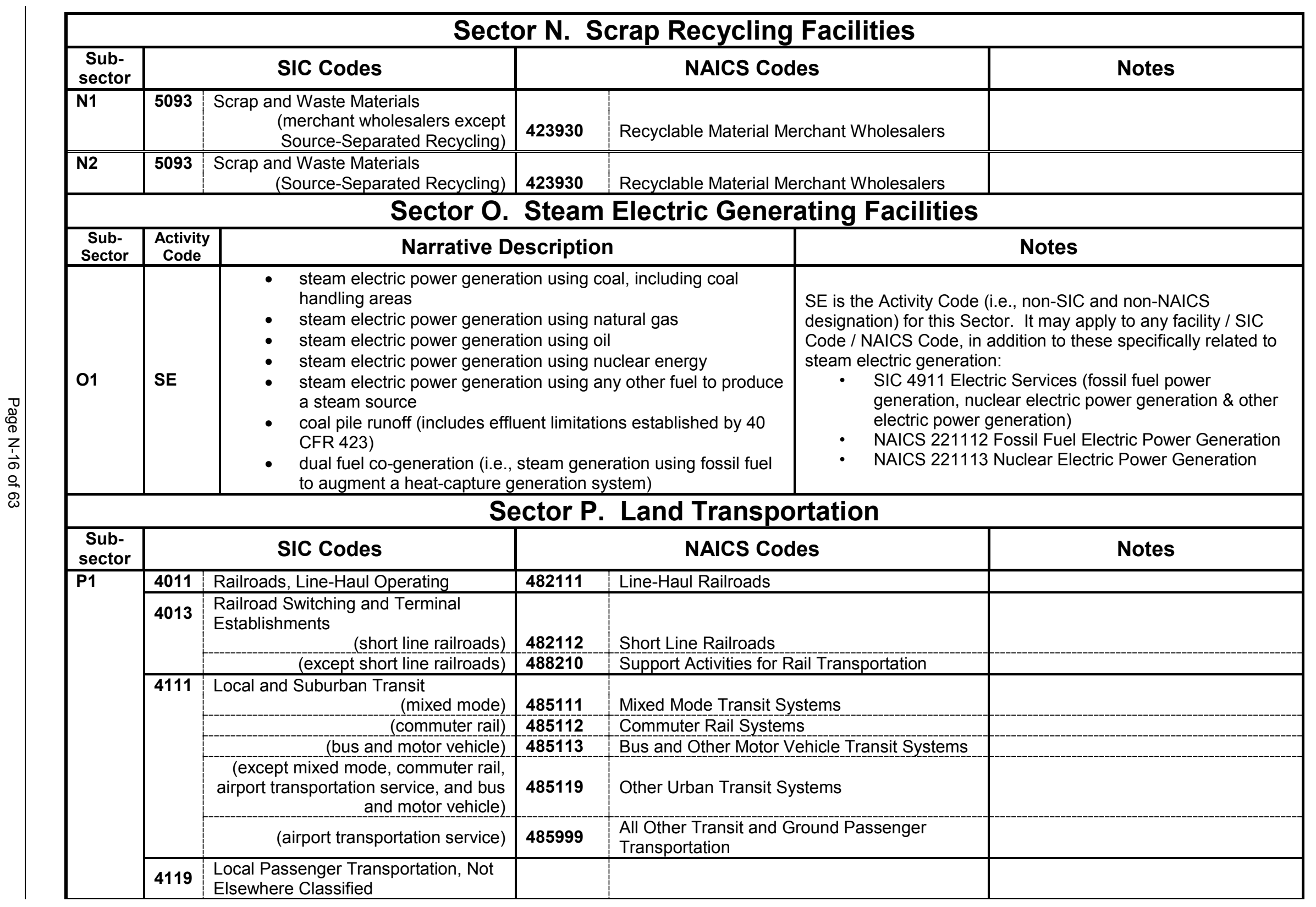




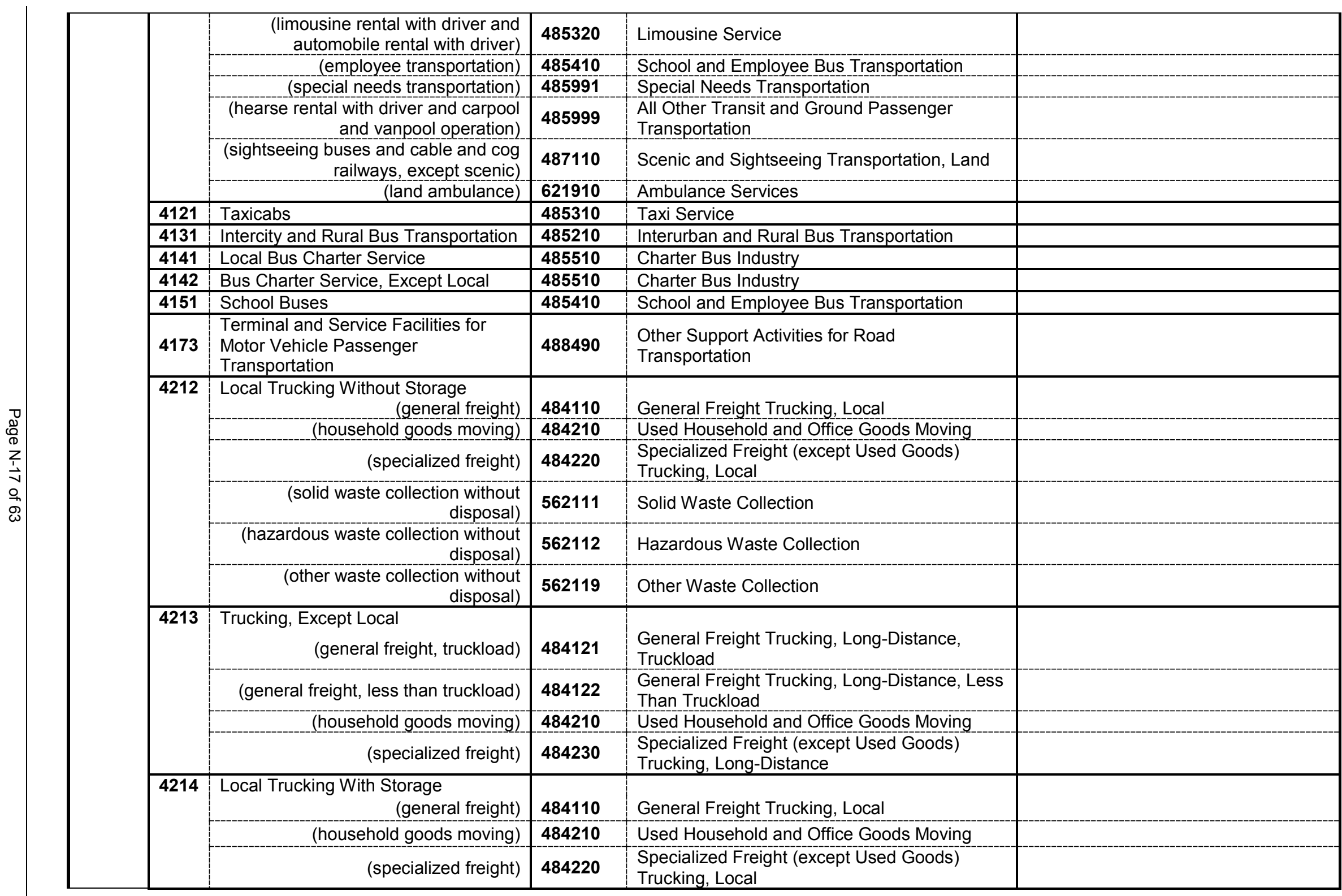




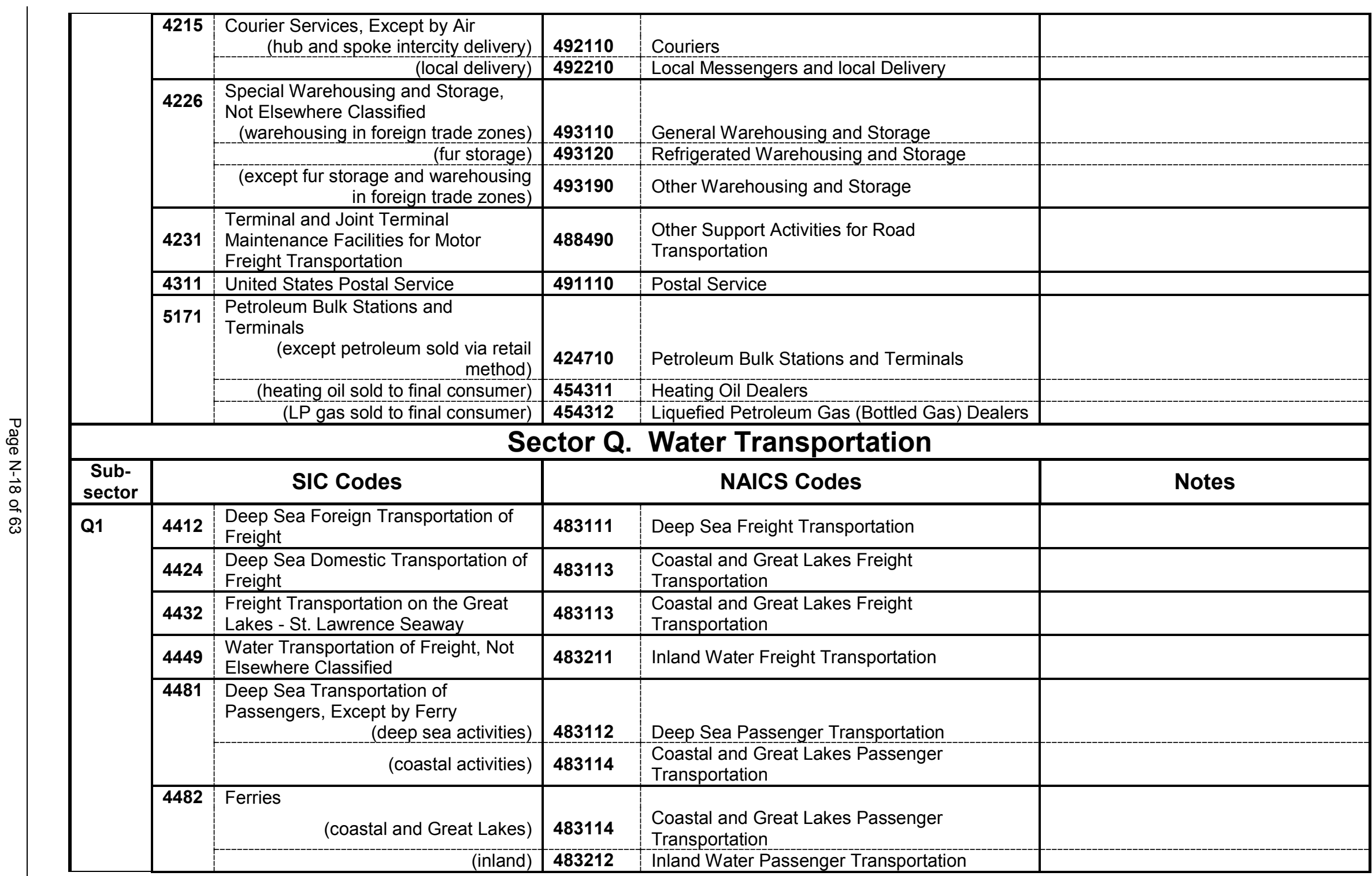




\begin{tabular}{|c|c|c|c|c|c|}
\hline & 4489 & $\begin{array}{l}\text { Water Transportation of Passengers, } \\
\text { Not Elsewhere Classified } \\
\end{array}$ & 483212 & Inland Water Passenger Transportation & \\
\hline & & $\begin{array}{r}\text { (airboats, excursion boats, and } \\
\text { sightseeing boats) }\end{array}$ & 487210 & Scenic and Sightseeing Transportation, Water & \\
\hline & 4491 & $\begin{array}{l}\text { Marine Cargo Handling } \\
\text { (dock and pier operations) }\end{array}$ & 488310 & Port and Harbor Operations & \\
\hline & & (all but dock and pier operations) & 488320 & Marine Cargo Handling & \\
\hline & 4492 & Towing and Tugboat Services & 488330 & Navigational Services to Shipping & \\
\hline & 4493 & Marinas & 713930 & Marinas & \\
\hline & 4499 & $\begin{array}{l}\begin{array}{l}\text { Water Transportation Services, Not } \\
\text { Elsewhere Classified }\end{array} \\
\end{array}$ & 483211 & Inland Water Freight Transportation & \\
\hline & & (lighthouse and canal operations) & 488310 & Port and Harbor Operations & \\
\hline & & $\begin{array}{l}\text { (piloting vessels in and out of harbors } \\
\text { and marine salvage) }\end{array}$ & 488330 & Navigational Services to Shipping & \\
\hline & & $\begin{array}{l}\text { (aill but lighthouse operations, piloting } \\
\text { vessels in and out of harbors, boat } \\
\text { and ship rental, marine salvage, } \\
\text { lighterage, marine surveyor services, } \\
\text { and canal operations) }\end{array}$ & 488390 & $\begin{array}{l}\text { Other Support Activities for Water } \\
\text { Transportation }\end{array}$ & \\
\hline & & (boat and ship rental, commercial) & 532411 & $\begin{array}{l}\text { Commercial Air, Rail, and Water } \\
\text { Transportation Equipment Rental and Leasing }\end{array}$ & \\
\hline & & Sector R. SI & ip a & 3oat Building and Repair Yar & \\
\hline $\begin{array}{c}\text { Sub- } \\
\text { sector }\end{array}$ & & SIC Codes & & NAICS Codes & Notes \\
\hline$\overline{\mathrm{R} 1}$ & 3731 & $\begin{array}{l}\text { Ship Building and Repairing } \\
\text { (except repairs in floating drydocks) }\end{array}$ & 336611 & Ship Building and Repairing & \\
\hline & & $\begin{array}{r}\text { (repair services provided by floating } \\
\text { drydocks) }\end{array}$ & 488390 & $\begin{array}{l}\text { Other Support Activities for Water } \\
\text { Transportation (includes ship scaling facilities) }\end{array}$ & \\
\hline & 3732 & $\begin{array}{l}\text { Boat Building and Repairing } \\
\text { (boat building) }\end{array}$ & 336612 & Boat Building & \\
\hline & & $\begin{array}{r}\text { (pleasure boat repair and } \\
\text { maintenance services without retailing } \\
\text { new boats) }\end{array}$ & 811490 & $\begin{array}{l}\text { Other Personal and Household Goods Repair } \\
\text { and Maintenance }\end{array}$ & \\
\hline & & (ship scaling) & 488390 & $\begin{array}{l}\text { Other Support Activities for Water } \\
\text { Transportation (drydocks, floating [i.e., routine } \\
\text { repair and maintenance of ships]; other } \\
\text { support activities for water transportation; ship } \\
\text { dismantling at floating drydock; ship scaling } \\
\text { services not done at a shipyard) }\end{array}$ & \\
\hline & & $\begin{array}{l}\text { (motorboat [i.e., inboard and } \\
\text { outboard] repair and maintenance }\end{array}$ & 811490 & $\begin{array}{l}\text { Other Personal and Household Goods Repair } \\
\text { and Maintenance }\end{array}$ & \\
\hline
\end{tabular}




\begin{tabular}{|c|c|c|c|c|c|}
\hline & & $\begin{array}{r}\text { services; outboard motor repair } \\
\text { shops) }\end{array}$ & & & \\
\hline \multicolumn{6}{|c|}{ Sector S. Air Transportation Facilities } \\
\hline $\begin{array}{c}\text { Sub- } \\
\text { sector }\end{array}$ & \multicolumn{2}{|r|}{ SIC Codes } & \multicolumn{2}{|r|}{ NAICS Codes } & Notes \\
\hline \multirow[t]{10}{*}{ s1 } & \multirow[t]{2}{*}{4512} & $\begin{array}{l}\text { Air Transportation, Scheduled } \\
\qquad \text { (passenger) }\end{array}$ & 481111 & Scheduled Passenger Air Transportation & \\
\hline & & (freight) & 481112 & Scheduled Freight Air Transportation & \\
\hline & 4513 & Air Courier Services & 492110 & Couriers & \\
\hline & \multirow[t]{5}{*}{4522} & $\begin{array}{l}\text { Air Transportation, Nonscheduled } \\
\qquad \text { (passenger) }\end{array}$ & 481211 & $\begin{array}{l}\text { Nonscheduled Chartered Passenger Air } \\
\text { Transportation }\end{array}$ & \\
\hline & & (freight) & 481212 & $\begin{array}{l}\text { Nonscheduled Chartered Freight Air } \\
\text { Transportation }\end{array}$ & \\
\hline & & $\begin{array}{r}\text { (using general purpose aircraft for a } \\
\text { variety of passenger, freight, courier, } \\
\text { and other uses) }\end{array}$ & 481219 & Other Nonscheduled Air Transportation & \\
\hline & & (sightseeing planes) & 487990 & Scenic and Sightseeing Transportation, Other & \\
\hline & & (air ambulance) & 621910 & Ambulance Services & \\
\hline & \multirow[t]{2}{*}{4581} & $\begin{array}{l}\text { Airports, Flying Fields, and Airport } \\
\text { Terminal Services } \\
\text { (air freight handling at airports, hangar } \\
\text { operations, airport terminal services, } \\
\text { aircraft storage, airports, and flying } \\
\text { fields) }\end{array}$ & 488119 & Other Airport Operations & \\
\hline & & (aircraft servicing and repairing) & 488190 & Other Support Activities for Air Transportation & \\
\hline
\end{tabular}




\begin{tabular}{|c|c|c|c|c|c|c|}
\hline \multicolumn{7}{|c|}{ Sector T. Treatment Works } \\
\hline $\begin{array}{l}\text { Sub- } \\
\text { sector }\end{array}$ & $\begin{array}{c}\text { Activity } \\
\text { Code }\end{array}$ & \multicolumn{3}{|c|}{ Narrative Description } & \multicolumn{2}{|r|}{ Notes } \\
\hline T1 & TW & \multicolumn{3}{|c|}{$\begin{array}{l}\text { treatment works with a design flow of 1.0 MGD or more treating } \\
\text { domestic sewage or any other sewage sludge; } \\
\text { wastewater treatment devices or system used by the treatment } \\
\text { works for the storage, treatment, recycling and reclamation of } \\
\text { municipal or domestic sewage; } \\
\text { land located within the confines of the treatment works that is } \\
\text { dedicated to the disposal of sewage sludge; } \\
\text { treatment works required to have an approved pretreatment } \\
\text { program under } 40 \text { CFR Part } 403\end{array}$} & \multicolumn{2}{|c|}{$\begin{array}{l}\text { TW is the Activity Code (i.e., non-SIC and non-NAICS } \\
\text { designation) for this Sector. It may apply to any facility / SIC } \\
\text { Code / NAICS Code, in addition to these specifically related to } \\
\text { treatment works: } \\
\text { - SIC } 4952 \text { Sewerage Systems } \\
\text { NAICS } 221320 \text { Sewage Treatment Facilities }\end{array}$} \\
\hline \multicolumn{7}{|c|}{ Sector U. Food and Kindred Products } \\
\hline $\begin{array}{l}\text { Sub- } \\
\text { sector }\end{array}$ & \multicolumn{2}{|r|}{ SIC Codes } & \multicolumn{3}{|c|}{ NAICS Codes } & Notes \\
\hline \multirow[t]{15}{*}{ U3 } & 2011 & Meat Packing Plants & 311611 & Animal (except Poultr) & Slaughtering & \\
\hline & 2013 & $\begin{array}{l}\text { Sausages and Other Prepared Meat } \\
\text { Products } \\
\text { (except lard made from purchased } \\
\text { materials) }\end{array}$ & 311612 & \multicolumn{2}{|c|}{ Meat Processed from Carcasses } & \\
\hline & & (lard made from purchased materials) & 311613 & \multicolumn{2}{|c|}{ Rendering and Meat Byproduct Processing } & \\
\hline & 2015 & $\begin{array}{l}\text { Poultry Slaughtering and Processing } \\
\text { (poultry slaughtering and processing) }\end{array}$ & 311615 & \multicolumn{2}{|c|}{ Poultry Processing } & \\
\hline & & (egg processing) & 311999 & \multicolumn{2}{|c|}{ All Other Miscellaneous Food Manufacturing } & \\
\hline & 2021 & Creamery Butter & 311512 & \multicolumn{2}{|c|}{ Creamery Butter Manufacturing } & \\
\hline & 2022 & $\begin{array}{l}\text { Natural, Processed, and Imitation } \\
\text { Cheese }\end{array}$ & 311513 & \multicolumn{2}{|c|}{ Cheese Manufacturing } & \\
\hline & 2023 & $\begin{array}{l}\text { Dry, Condensed and Evaporated } \\
\text { Dairy Products } \\
\quad \text { (liquid non-dairy creamer) }\end{array}$ & 311511 & \multicolumn{2}{|l|}{ Fluid Milk Manufacturing } & \\
\hline & & (except liquid non-dairy creamer) & 311514 & \multicolumn{2}{|c|}{$\begin{array}{l}\text { Dry, Condensed, and Evaporated Dairy } \\
\text { Product Manufacturing }\end{array}$} & \\
\hline & 2024 & Ice Cream and Frozen Deserts & 311520 & \multicolumn{2}{|c|}{ Ice Cream and Frozen Desert Manufacturing } & \\
\hline & 2026 & $\begin{array}{l}\text { Fluid Milk } \\
\quad \text { (except ultra-high temperature) }\end{array}$ & 311511 & \multicolumn{2}{|c|}{ Fluid Milk Manufacturing } & \\
\hline & & (ultra-high temperature) & 311514 & \multicolumn{2}{|c|}{$\begin{array}{l}\text { Dry, Condensed, and Evaporated Dairy } \\
\text { Product Manufacturing }\end{array}$} & \\
\hline & 2032 & $\begin{array}{l}\text { Canned Specialties } \\
\quad \text { (except canned puddings) }\end{array}$ & 311422 & \multicolumn{2}{|l|}{ Specialty Canning } & \\
\hline & & (canned puddings) & 311999 & \multicolumn{2}{|c|}{ All Other Miscellaneous Food Manufacturing } & \\
\hline & 2033 & $\begin{array}{l}\text { Canned Fruits, Vegetables, } \\
\text { Preserves, Jams, and Jellies }\end{array}$ & 311421 & \multicolumn{2}{|c|}{ Fruit and Vegetable Canning } & \\
\hline
\end{tabular}




\begin{tabular}{|c|c|c|c|c|c|}
\hline & \multirow[t]{3}{*}{2034} & $\begin{array}{l}\text { Dried and Dehydrated Fruits, } \\
\text { Vegetables and Soup Mixes } \\
\text { (vegetable flour) }\end{array}$ & 311211 & Flour Milling & \\
\hline & & $\begin{array}{l}\text { (except vegetable flour and soup } \\
\text { mixes made from purchased dried } \\
\text { and dehydrated ingredients) }\end{array}$ & 311423 & Dried and Dehydrated Food Manufacturing & \\
\hline & & $\begin{array}{r}\text { (soup mixes made from purchased } \\
\text { dehydrated ingredients) }\end{array}$ & 311999 & All Other Miscellaneous Food Manufacturing & \\
\hline & \multirow[t]{2}{*}{2035} & $\begin{array}{l}\text { Pickled Fruits and Vegetables, } \\
\text { Vegetable Sauces and Seasonings, } \\
\text { and Salad Dressings } \\
\text { (pickled fruits and vegetables) }\end{array}$ & 311421 & Fruit and Vegetable Canning & \\
\hline & & (sauces and salad dressings) & 311941 & $\begin{array}{l}\text { Mayonnaise, Dressing, and Other Prepared } \\
\text { Sauce Manufacturing }\end{array}$ & \\
\hline & 2037 & $\begin{array}{l}\text { Frozen Fruits, Fruit Juices, and } \\
\text { Vegetables }\end{array}$ & 311411 & $\begin{array}{l}\text { Frozen Fruit, Juice, and Vegetable } \\
\text { Manufacturing }\end{array}$ & \\
\hline & 2038 & $\begin{array}{l}\text { Frozen Specialties, Not Elsewhere } \\
\text { Classified }\end{array}$ & 311412 & Frozen Specialty Food Manufacturing & \\
\hline \multirow[t]{10}{*}{ U1 } & 2041 & Flour and Other Grain Mill Products & 311211 & Flour Milling & \\
\hline & \multirow[t]{2}{*}{2043} & $\begin{array}{r}\text { Cereal Breakfast Foods } \\
\text { (cereal breakfast foods and related } \\
\text { preparations except grain based } \\
\text { coffee substitutes) }\end{array}$ & 311230 & Breakfast Cereal Manufacturing & \\
\hline & & (grain based coffee substitutes) & 311920 & Coffee and Tea Manufacturing & \\
\hline & 2044 & Rice Milling & 311212 & Rice Milling & \\
\hline & 2045 & Prepared Flour Mixes and Doughs & 311822 & $\begin{array}{l}\text { Flour Mixes and Dough Manufacturing from } \\
\text { Purchased Flour }\end{array}$ & \\
\hline & \multirow[t]{2}{*}{2046} & $\begin{array}{l}\text { Wet Corn Milling } \\
\text { (except refining purchased corn oil) }\end{array}$ & 311221 & Wet Corn Milling & \\
\hline & & (refining purchased corn oil) & 311225 & Fats and Oils Refining and Blending & \\
\hline & 2047 & Dog and Cat Food & 311111 & Dog and Cat Food Manufacturing & \\
\hline & \multirow[t]{2}{*}{2048} & $\begin{array}{l}\text { Prepared Feeds and Feed Ingredients } \\
\text { for Animals and Fowls, Except Dogs } \\
\text { and Cats } \\
\text { (except slaughtering animals for pet } \\
\text { food) }\end{array}$ & 311119 & Other Animal Food Manufacturing & \\
\hline & & (slaughtering animals for pet food) & 311611 & Animal (except Poultry) Slaughtering & \\
\hline \multirow[t]{3}{*}{ U3 } & 2051 & $\begin{array}{l}\text { Bread and Other Bakery Products, } \\
\text { Except Cookies and Crackers }\end{array}$ & 311812 & Commercial Bakeries & \\
\hline & \multirow[t]{2}{*}{2052} & $\begin{array}{l}\text { Cookies and Crackers } \\
\text { (unleavened bread and soft pretzels) }\end{array}$ & 311812 & Commercial Bakeries & \\
\hline & & $\begin{array}{r}\text { (except unleavened bread and } \\
\text { pretzels) }\end{array}$ & 311821 & Cookie and Cracker Manufacturing & \\
\hline
\end{tabular}




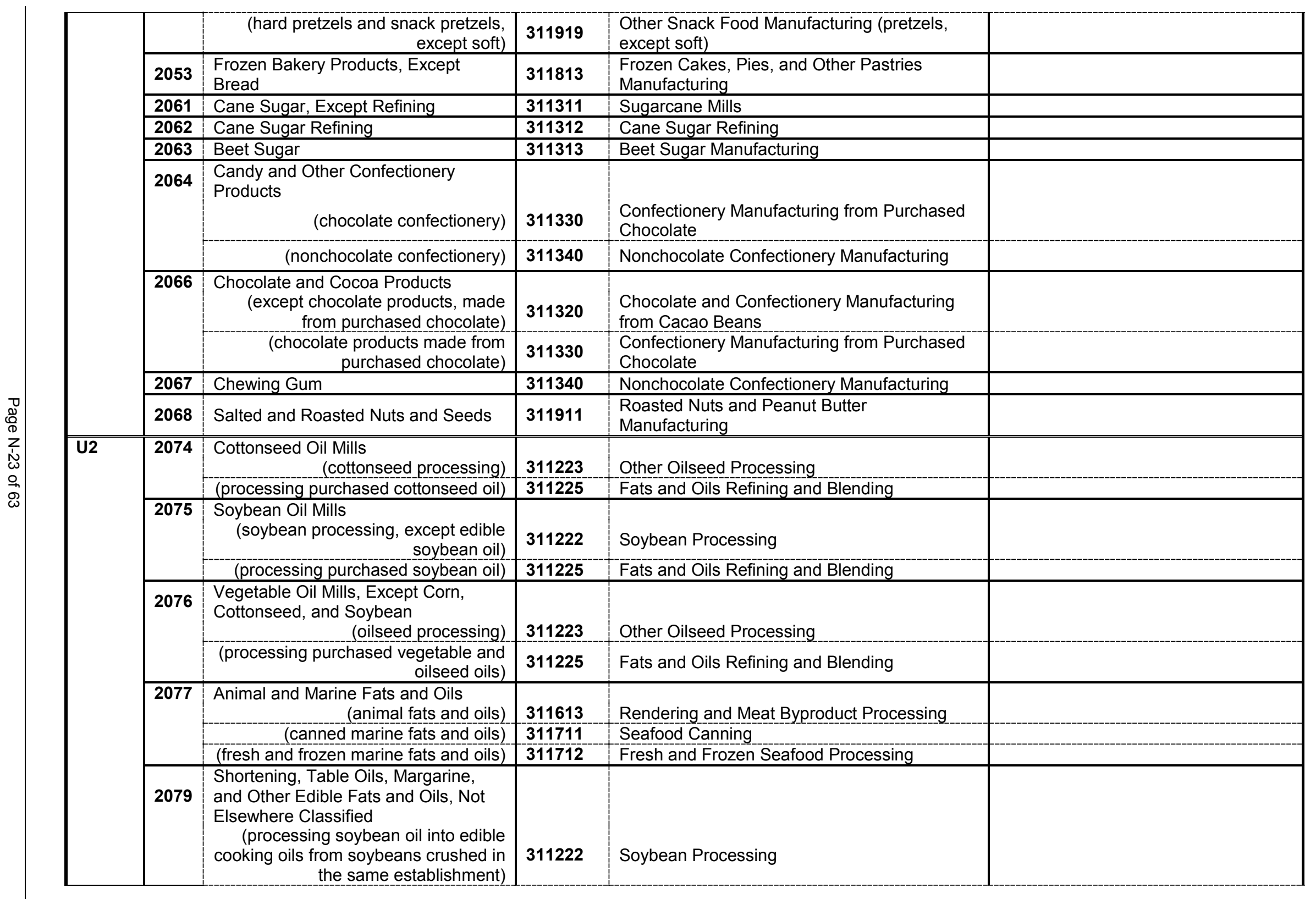




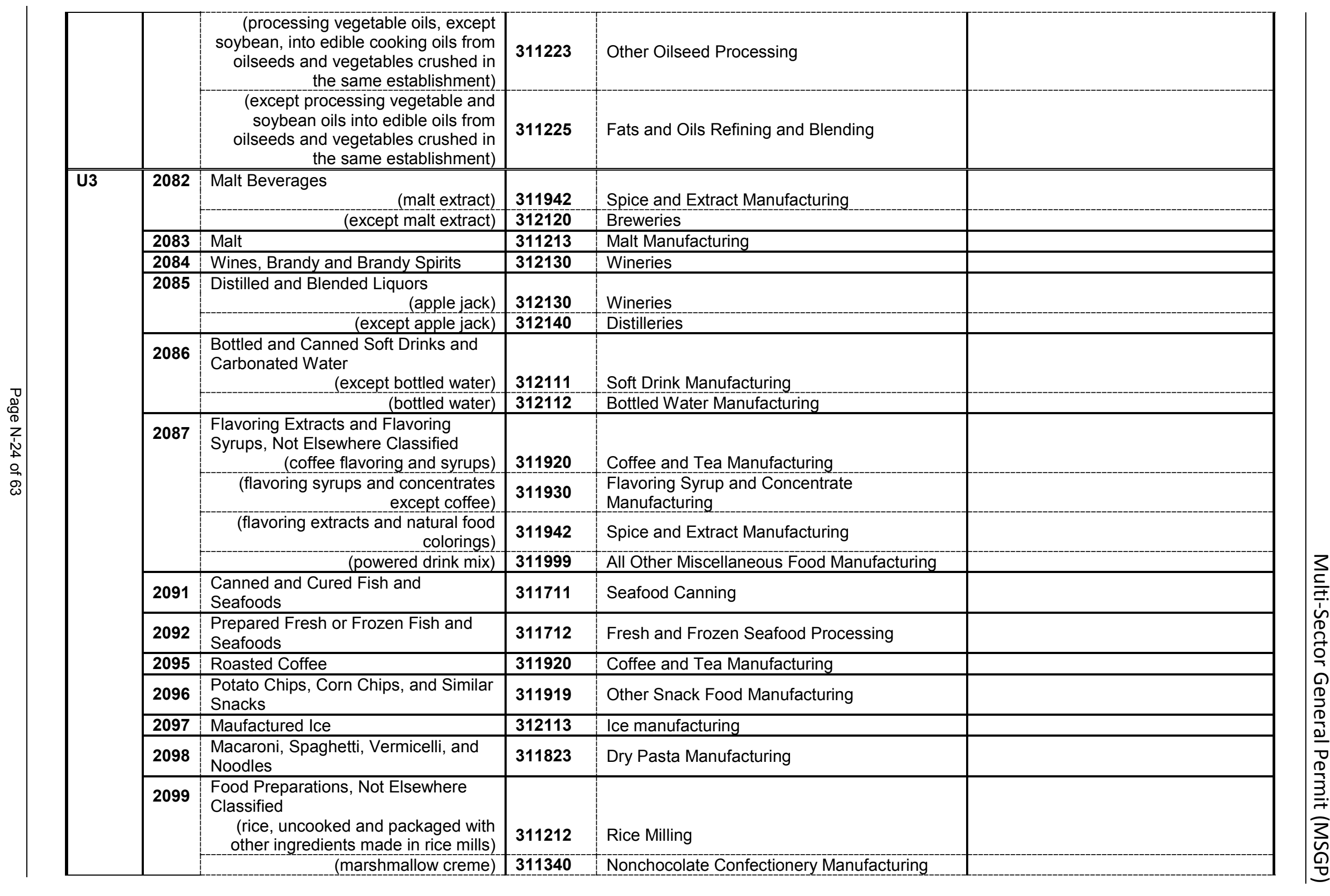




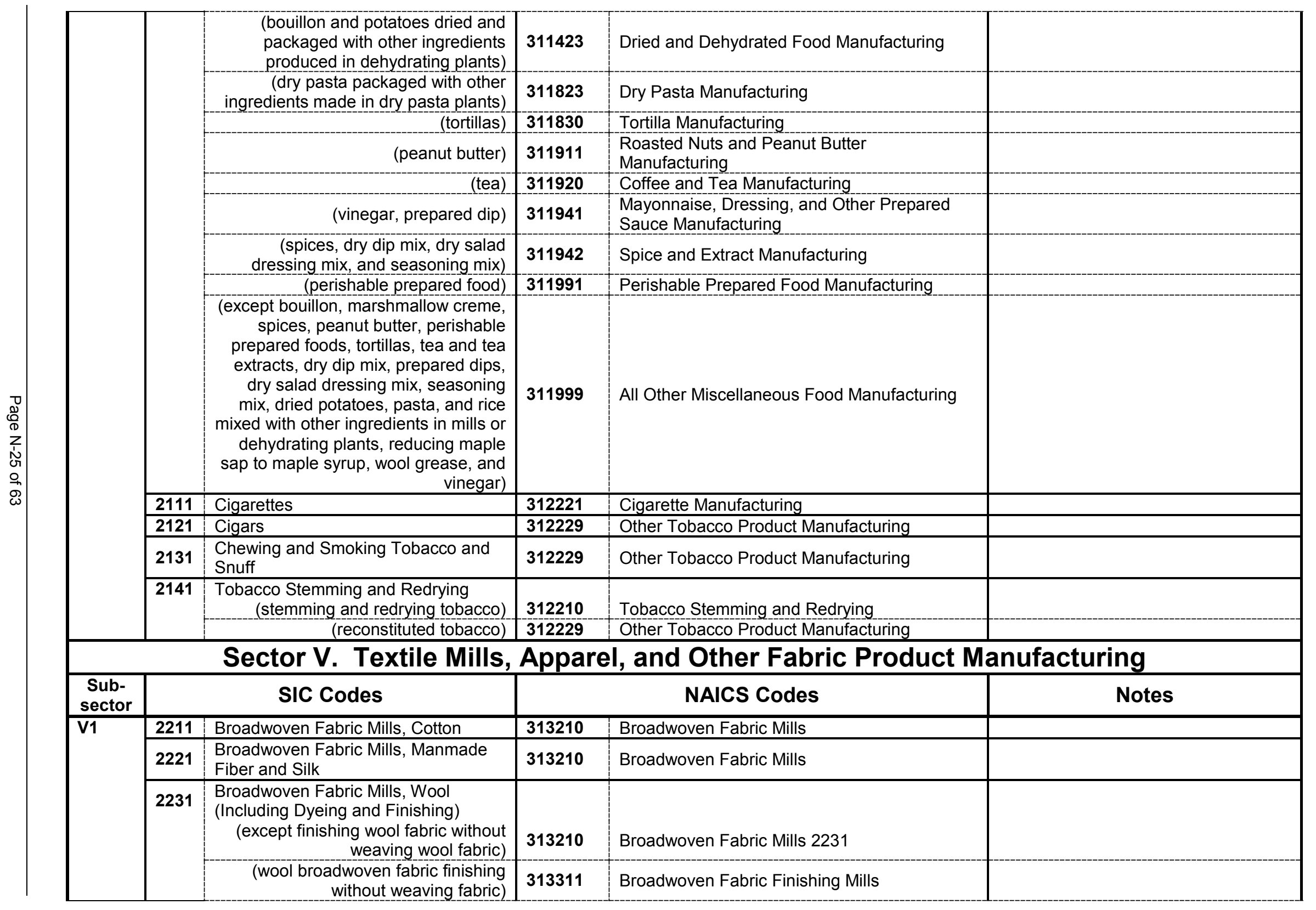




\begin{tabular}{|c|c|c|c|c|}
\hline & $\begin{array}{l}\text { (wool fabric, except broadwoven, } \\
\text { finishing without weaving fabric) }\end{array}$ & 313312 & $\begin{array}{l}\text { Textile and Fabric Finishing (except } \\
\text { Broadwoven Fabric) Mills }\end{array}$ & \\
\hline 2241 & $\begin{array}{l}\text { Narrow Fabric and Other Smallwares } \\
\text { Mills: Cotton, Wool, Silk and } \\
\text { Manmade Fiber }\end{array}$ & 313221 & Narrow Fabric Mills & \\
\hline \multirow[t]{2}{*}{2251} & $\begin{array}{l}\text { Women's Full-Length and Knee- } \\
\text { Length Hosiery, Except Socks } \\
\text { (dyeing and finishing sheer hosiery } \\
\text { without knitting sheer hosiery) }\end{array}$ & 313312 & $\begin{array}{l}\text { Textile and Fabric Finishing (except } \\
\text { Broadwoven Fabric) Mills }\end{array}$ & \\
\hline & $\begin{array}{l}\text { (except dyeing and finishing sheer } \\
\text { hosiery without knitting sheer hosiery) }\end{array}$ & 315111 & Sheer Hosiery Mills & \\
\hline \multirow[t]{3}{*}{2252} & $\begin{array}{l}\text { Hosiery, Not Elsewhere Classified } \\
\text { (dyeing and finishing hosiery, except } \\
\text { sheer, without knitting hosiery) }\end{array}$ & 313312 & $\begin{array}{l}\text { Textile and Fabric Finishing (except } \\
\text { Broadwoven Fabric) Mills }\end{array}$ & \\
\hline & $\begin{array}{r}\text { (girls full length and knee length } \\
\text { sheer hosiery) }\end{array}$ & 315111 & Sheer Hosiery Mills & \\
\hline & $\begin{array}{r}\text { (except girls' full-length and knee- } \\
\text { length sheer hosiery and dyeing and } \\
\text { finishing hosiery without knitting } \\
\text { hosiery) }\end{array}$ & 315119 & Other Hosiery and Sock Mills & \\
\hline \multirow[t]{3}{*}{2253} & $\begin{array}{l}\text { Knit Outerwear Mills } \\
\text { (dyeing and finishing knit outerwear } \\
\text { without knitting outerwear) }\end{array}$ & 313312 & $\begin{array}{l}\text { Textile and Fabric Finishing (except } \\
\text { Broadwoven Fabric) Mills }\end{array}$ & \\
\hline & $\begin{array}{r}\text { (except bath and lounging robes and } \\
\text { dying and finish without knitting } \\
\text { garments) }\end{array}$ & 315191 & Outerwear Knitting Mills & \\
\hline & (knitting bath or lounging robes) & 315192 & Underwear and Nightwear Knitting Mills & \\
\hline \multirow[t]{2}{*}{2254} & $\begin{array}{l}\text { Knit Underwear and Nightwear Mills } \\
\text { (dyeing and finishing underwear and } \\
\text { nightwear without knitting garments) }\end{array}$ & 313312 & $\begin{array}{l}\text { Textile and Fabric Finishing (except } \\
\text { Broadwoven Fabric) Mills }\end{array}$ & \\
\hline & $\begin{array}{r}\text { (except dyeing and finishing } \\
\text { underwear and nightwear without } \\
\text { knitting garments) }\end{array}$ & 315192 & Underwear and Nightwear Knitting Mills & \\
\hline \multirow[t]{2}{*}{2257} & $\begin{array}{l}\text { Weft Knit Fabric Mills } \\
\text { (except finishing without knitting weft } \\
\text { fabric) }\end{array}$ & 313241 & Weft Knit Fabric Mills & \\
\hline & $\begin{array}{r}\text { (finishing weft fabric without knitting } \\
\text { weft fabric) }\end{array}$ & 313312 & $\begin{array}{l}\text { Textile and Fabric Finishing (except } \\
\text { Broadwoven Fabric) Mills }\end{array}$ & \\
\hline \multirow[t]{2}{*}{2258} & $\begin{array}{l}\text { Weft Knit Fabric Mills } \\
\text { (except finishing without knitting weft } \\
\text { fabric) }\end{array}$ & 313241 & Weft Knit Fabric Mills & \\
\hline & $\begin{array}{r}\text { (finishing weft fabric without knitting } \\
\text { weft fabric) }\end{array}$ & 313312 & $\begin{array}{l}\text { Textile and Fabric Finishing (except } \\
\text { Broadwoven Fabric) Mills }\end{array}$ & \\
\hline
\end{tabular}




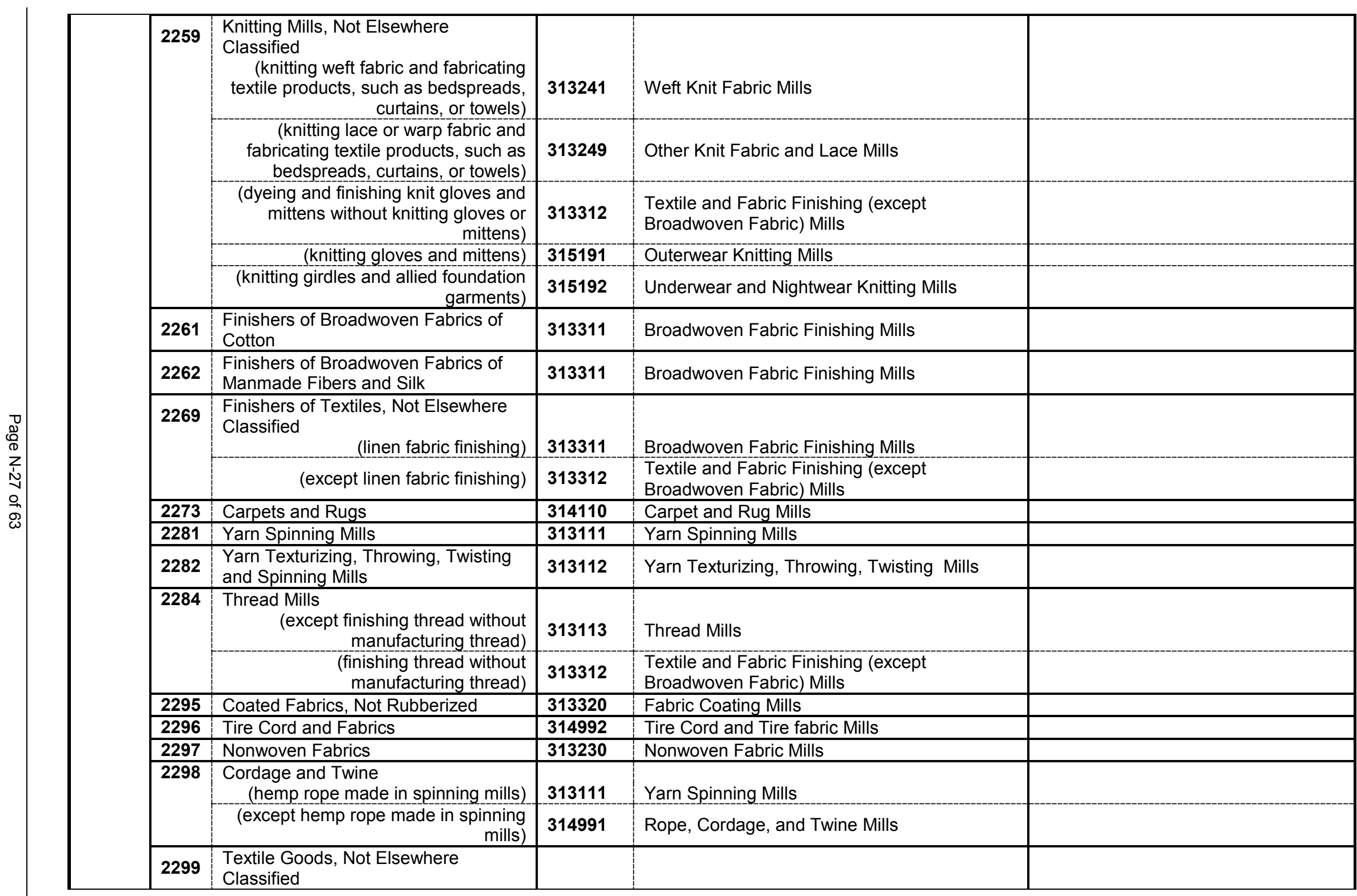




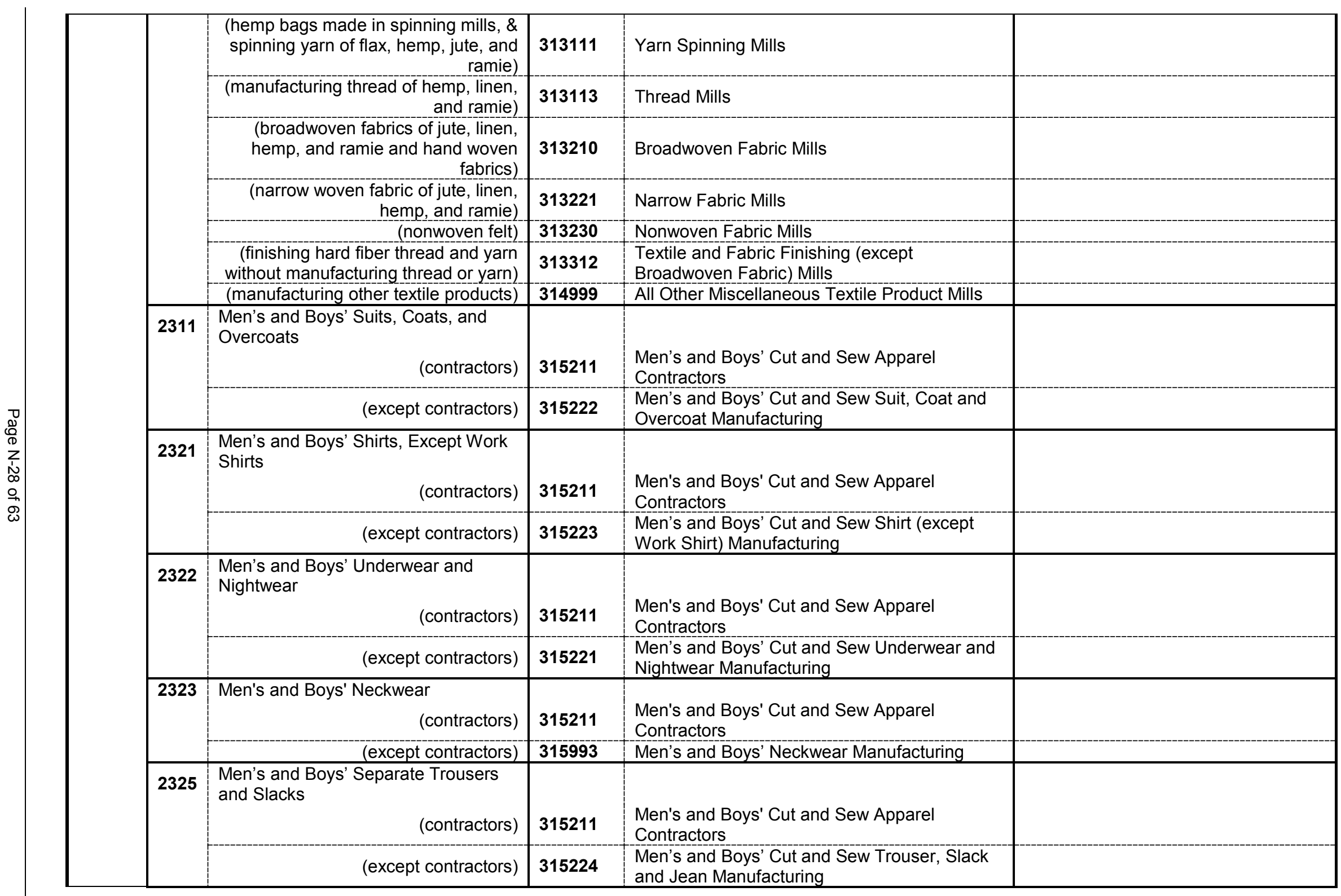




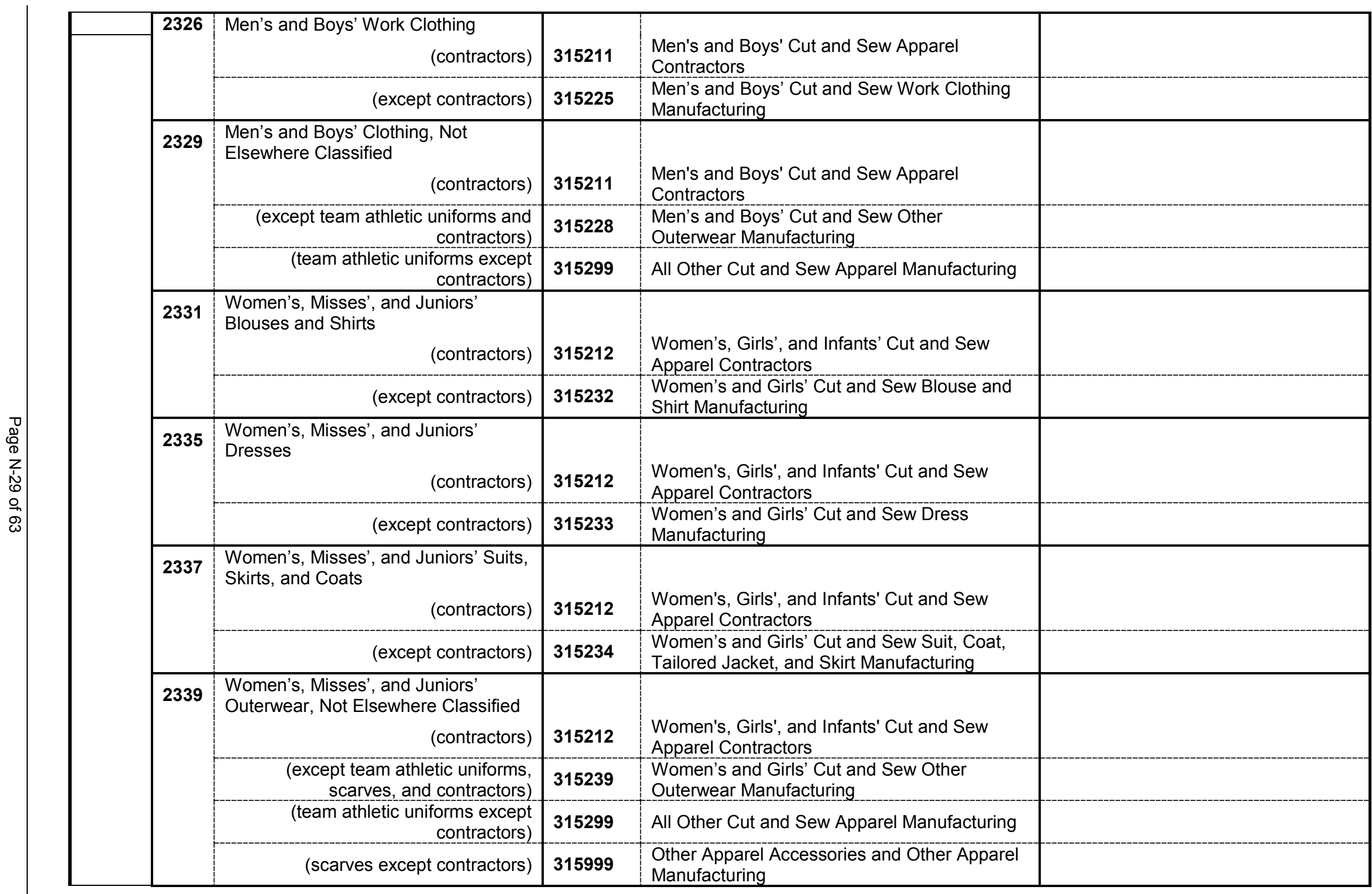




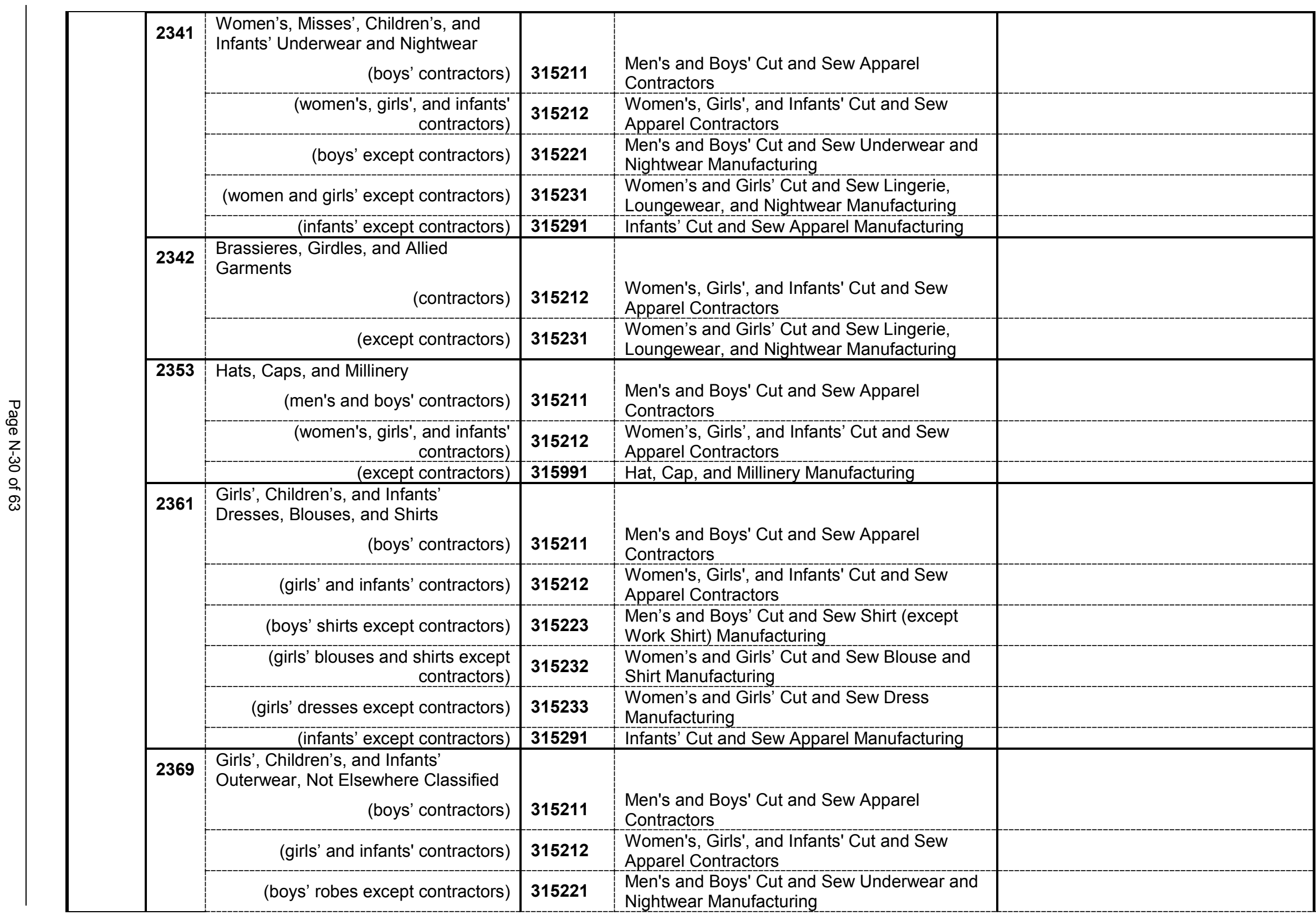




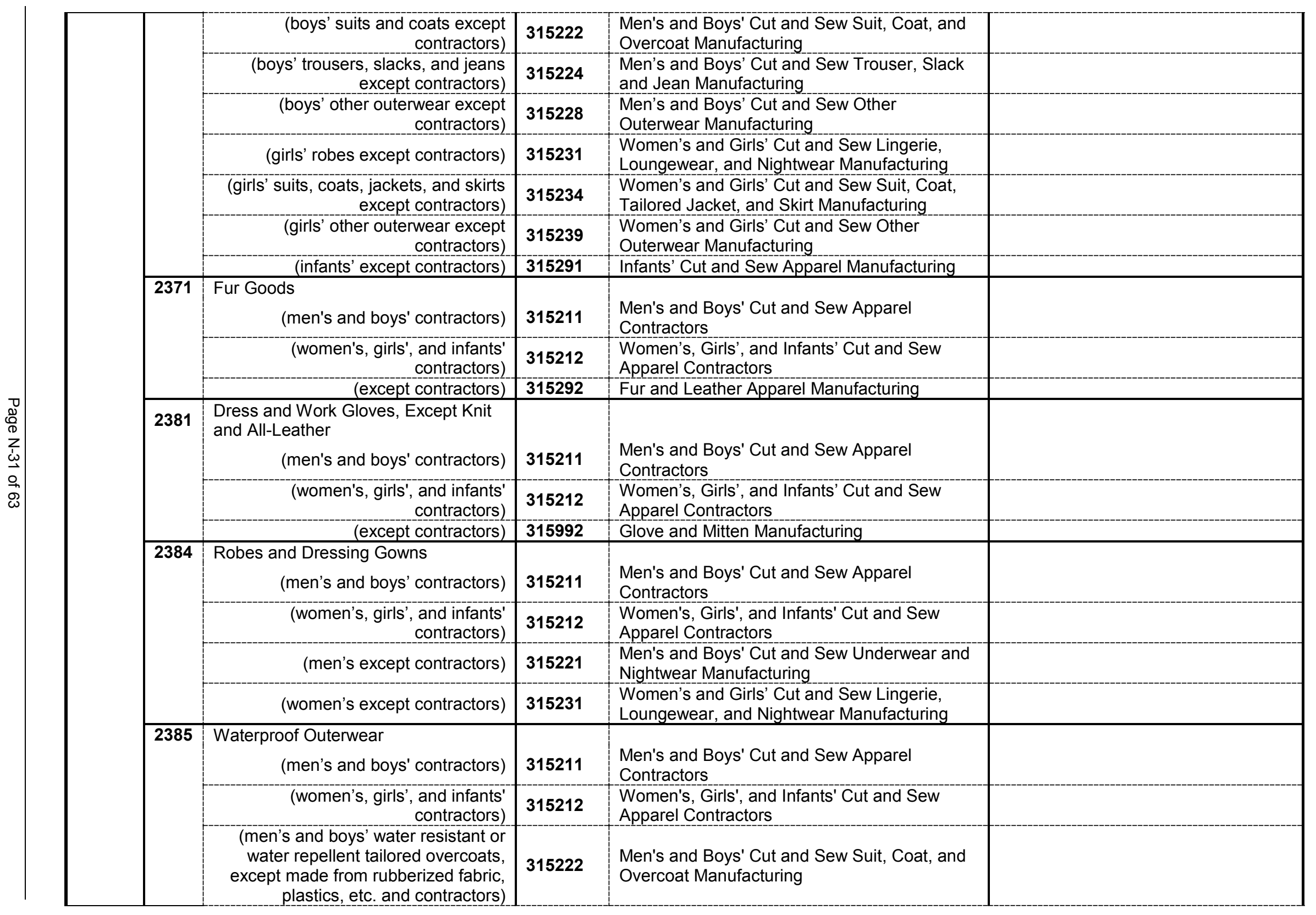




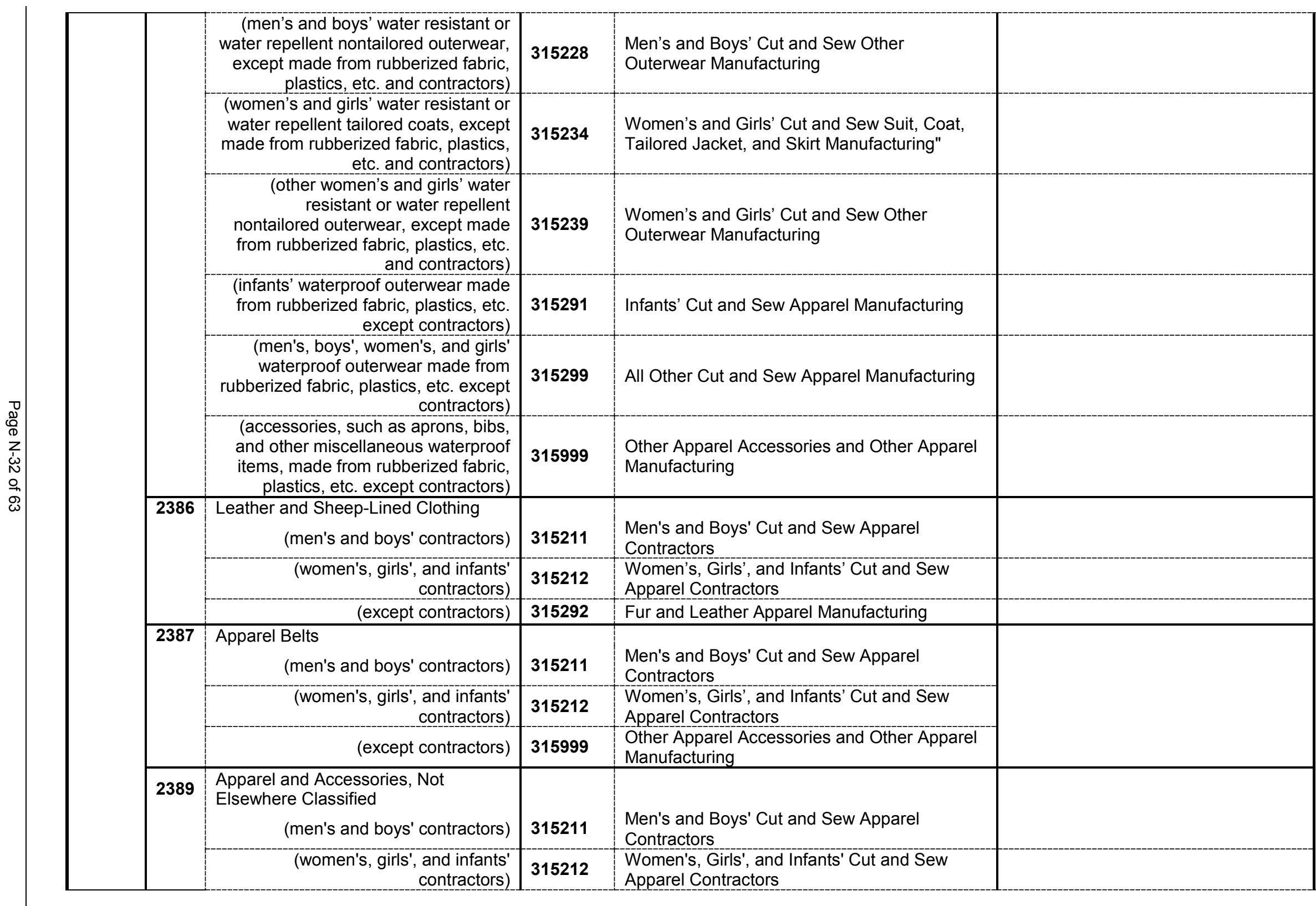




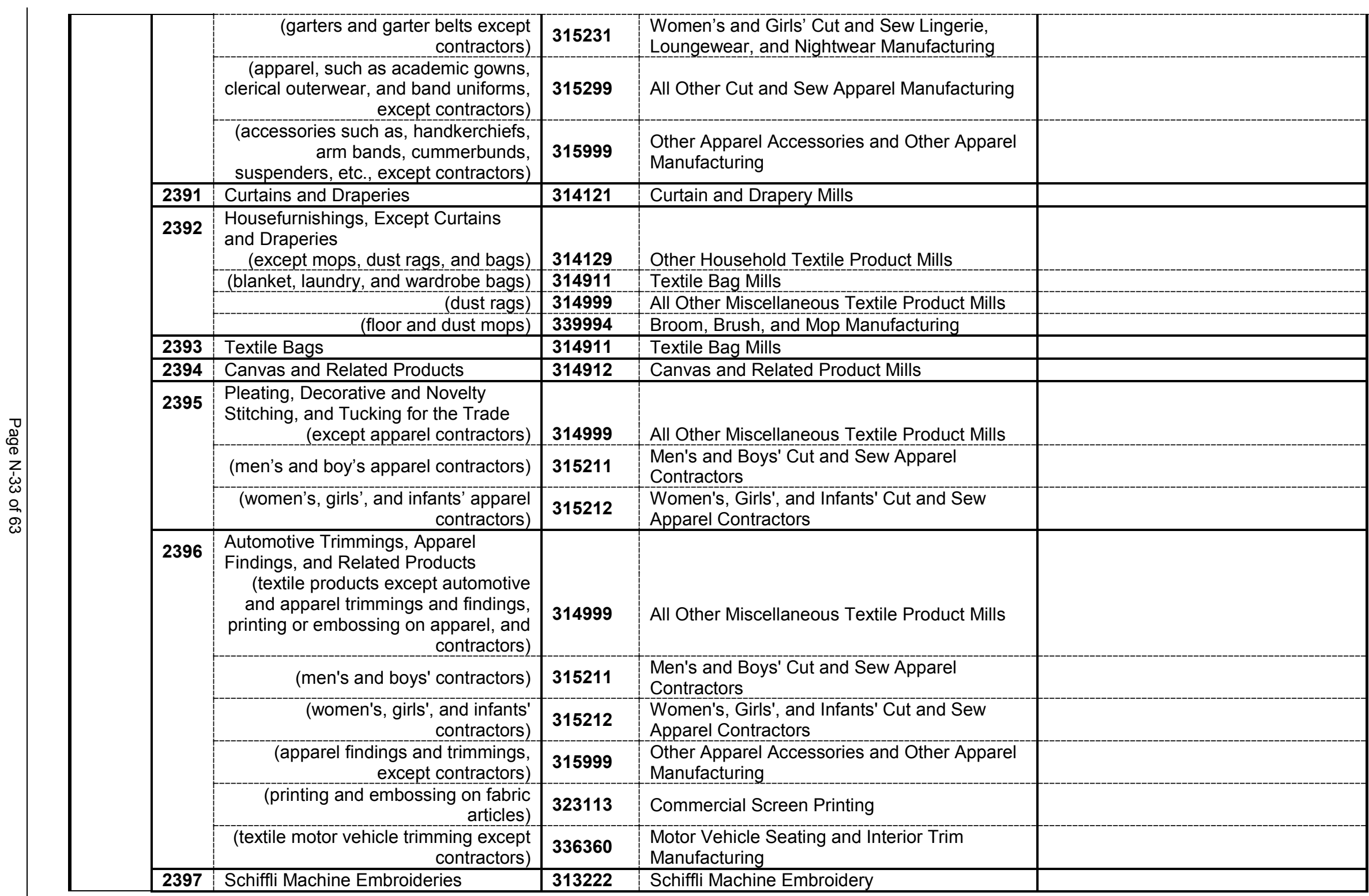




\begin{tabular}{|c|c|c|c|c|}
\hline 2399 & $\begin{array}{l}\text { Fabricated Textile Products, Not } \\
\text { Elsewhere Classified } \\
\text { (except apparel and accessories, } \\
\text { automotive seat belts, seat and tire } \\
\text { covers, and contractors) }\end{array}$ & 314999 & All Other Miscellaneous Textile Product Mills & \\
\hline & (men's and boys' contractors) & 315211 & $\begin{array}{l}\text { Men's and Boys' Cut and Sew Apparel } \\
\text { Contractors }\end{array}$ & \\
\hline & $\begin{array}{r}\text { (women's, girls', and infants' } \\
\text { contractors) }\end{array}$ & 315212 & $\begin{array}{l}\text { Women's, Girls', and Infants' Cut and Sew } \\
\text { Apparel Contractors }\end{array}$ & \\
\hline & $\begin{array}{r}\text { (apparel and apparel accessories, } \\
\text { except contractors) }\end{array}$ & 315999 & $\begin{array}{l}\text { Other Apparel Accessories and Other Apparel } \\
\text { Manufacturing }\end{array}$ & \\
\hline & (seat belts, and seat and tire covers) & 336360 & $\begin{array}{l}\text { Motor Vehicle Seating and Interior Trim } \\
\text { Manufacturing }\end{array}$ & \\
\hline 3131 & $\begin{array}{l}\text { Boot and Shoe Cut Stock and } \\
\text { Findings } \\
\text { (except wood heels and metal } \\
\text { buckles) }\end{array}$ & 316999 & All Other Leather Good Manufacturing & \\
\hline & $\begin{array}{r}\text { (heels, boot and shoe, finished wood, } \\
\text { manufacturing) }\end{array}$ & 321999 & $\begin{array}{l}\text { All Other Miscellaneous Wood Product } \\
\text { Manufacturing }\end{array}$ & $\begin{array}{l}\text { A facility with the primary activity of } \\
\text { NAICS } 321999 \text { "heels, boot and shoe, } \\
\text { finished wood, manufacturing" can be } \\
\text { regulated under Sector A or Sector V. } \\
\text { Sector A requires additional } \\
\text { technology-based effluent limits } \\
\text { comprising good housekeeping; } \\
\text { additional SWPPP requirements; } \\
\text { additional inspection requirements; } \\
\text { and benchmark monitoring for COD } \\
\text { and TSS. Sector V requires additional } \\
\text { technology-based effluent limits } \\
\text { comprised of good housekeeping } \\
\text { measures and employee training; } \\
\text { additional SWPPP requirements; and } \\
\text { additional inspection requirements. } \\
\text { Regulatory burden would likely be } \\
\text { greater under Sector A. }\end{array}$ \\
\hline & (metal buckles) & 339993 & $\begin{array}{l}\text { Fastener, Button, Needle, and Pin } \\
\text { Manufacturing }\end{array}$ & $\begin{array}{l}\text { Any facility whose primary activity is } \\
\text { manufacturing metal buckles (SIC } \\
3131 \text { / NAICS 339993) should be } \\
\text { regulated under Sector Y, but may } \\
\text { continue to be regulated under Sector } \\
\text { V, or alternatively, under Sector AD. } \\
\text { Sector Y does not apply additional } \\
\text { sector-specific requirements to metal }\end{array}$ \\
\hline
\end{tabular}




\begin{tabular}{|c|c|c|c|c|}
\hline & & & & $\begin{array}{l}\text { buckle manufacturers. Sector V } \\
\text { applies additional technology-based } \\
\text { limitations comprised of good } \\
\text { housekeeping measures for material } \\
\text { storage areas and employee training. } \\
\text { Under Sector AD EPA could establish } \\
\text { additional facility-specific monitoring } \\
\text { and reporting requirements. } \\
\text { Regulatory burden would likely be } \\
\text { greater under Sector V. }\end{array}$ \\
\hline 3142 & House Slippers & 316212 & House Slipper Manufacturing & \\
\hline 3143 & Men's Footwear, Except Athletic & 316213 & $\begin{array}{l}\text { Men's Footwear (except Athletic) } \\
\text { Manufacturing }\end{array}$ & \\
\hline 3144 & Women's Footwear, Except Athletic & 316214 & $\begin{array}{l}\text { Women's Footwear (except Athletic) } \\
\text { Manufacturing }\end{array}$ & \\
\hline 3149 & $\begin{array}{l}\text { Footwear, Except Rubber, Not } \\
\text { Elsewhere Classified }\end{array}$ & 316219 & Other Footwear Manufacturing & \\
\hline 3151 & $\begin{array}{l}\text { Leather Gloves and Mittens } \\
\text { (men's and boys' contractors) }\end{array}$ & 315211 & $\begin{array}{l}\text { Men's and Boys' Cut and Sew Apparel } \\
\text { Contractors }\end{array}$ & \\
\hline & $\begin{array}{r}\text { (women's, girls', and infants' } \\
\text { contractors) }\end{array}$ & 315212 & $\begin{array}{l}\text { Women's, Girls', and Infants' Cut and Sew } \\
\text { Apparel Contractors }\end{array}$ & \\
\hline & (except contractors) & 315992 & Glove and Mitten Manufacturing & \\
\hline 3161 & Luggage & 316991 & Luggage Manufacturing & \\
\hline 3171 & Women's Handbags and Purses & 316992 & Women's Handbag and Purse Manufacturing & \\
\hline 3172 & $\begin{array}{l}\text { Personal Leather Goods, Except } \\
\text { Women's Handbags and Purses } \\
\text { (except nonprecious metal personal } \\
\text { goods, such as card cases, cigar } \\
\text { cases, and comb cases) }\end{array}$ & 316993 & $\begin{array}{l}\text { Personal Leather Good (except Women's } \\
\text { Handbag and Purse) Manufacturing }\end{array}$ & \\
\hline & $\begin{array}{r}\text { (nonprecious metal personal goods, } \\
\text { such as card cases, cigar cases, and } \\
\text { comb cases) }\end{array}$ & 339914 & Costume Jewelry and Novelty Manufacturing & $\begin{array}{l}\text { Any facility whose primary activity is } \\
\text { manufacturing nonprecious metal } \\
\text { personal goods, such as card cases, } \\
\text { cigar cases, and comb cases (SIC } \\
3172 \text { / NAICS 339914) should be } \\
\text { regulated under Sector Y, but may } \\
\text { continue to be regulated under Sector } \\
\text { V, or alternatively, under Sector AD. } \\
\text { Sector Y does not apply additional } \\
\text { sector-specific requirements to metal } \\
\text { buckle manufacturers. Sector V } \\
\text { applies additional technology-based } \\
\text { limitations comprised of good }\end{array}$ \\
\hline
\end{tabular}




\begin{tabular}{|c|c|c|c|c|c|}
\hline & & & & & $\begin{array}{l}\text { housekeeping measures for material } \\
\text { storage areas and employee training. } \\
\text { Under Sector AD EPA could establish } \\
\text { additional facility-specific monitoring } \\
\text { and reporting requirements. } \\
\text { Regulatory burden would likely be } \\
\text { greater under Sector V. }\end{array}$ \\
\hline & 3199 & $\begin{array}{l}\text { Leather Goods, Not Elsewhere } \\
\text { Classified }\end{array}$ & 316999 & All Other Leather Good Manufacturing & \\
\hline \multicolumn{6}{|c|}{ Sector W. Furniture and Fixtures } \\
\hline $\begin{array}{l}\text { Sub- } \\
\text { sector }\end{array}$ & & SIC Codes & & NAICS Codes & Notes \\
\hline \multirow[t]{13}{*}{ W1 } & 2434 & Wood Kitchen Cabinets & 337110 & $\begin{array}{l}\text { Wood Kitchen Cabinet and Countertop } \\
\text { Manufacturing }\end{array}$ & \\
\hline & 2511 & $\begin{array}{l}\text { Wood Household Furniture, Except } \\
\text { Upholstered } \\
\qquad \text { (except wood box spring frames) }\end{array}$ & 337122 & $\begin{array}{l}\text { Nonupholstered Wood Household Furniture } \\
\text { Manufacturing }\end{array}$ & \\
\hline & & (wood box spring frames (parts)) & 337215 & $\begin{array}{l}\text { Showcase, Partition, Shelving, and Locker } \\
\text { Manufacturing }\end{array}$ & \\
\hline & 2512 & $\begin{array}{l}\text { Wood Household Furniture, } \\
\text { Upholstered }\end{array}$ & 337121 & $\begin{array}{l}\text { Upholstered Household Furniture } \\
\text { Manufacturing }\end{array}$ & \\
\hline & 2514 & $\begin{array}{l}\text { Metal Household Furniture } \\
\qquad \text { (upholstered) }\end{array}$ & 337121 & $\begin{array}{l}\text { Upholstered Household Furniture } \\
\text { Manufacturing }\end{array}$ & \\
\hline & & $\begin{array}{l}\text { (except upholstered metal furniture } \\
\text { and metal box spring frames) }\end{array}$ & 337124 & Metal Household Furniture Manufacturing & \\
\hline & & (metal box spring frames) & 337215 & $\begin{array}{l}\text { Showcase, Partition, Shelving, and Locker } \\
\text { Manufacturing }\end{array}$ & \\
\hline & 2515 & $\begin{array}{l}\text { Mattresses, Foundations, and } \\
\text { Convertible Beds } \\
\qquad \text { (convertible beds) }\end{array}$ & 337121 & $\begin{array}{l}\text { Upholstered Household Furniture } \\
\text { Manufacturing }\end{array}$ & \\
\hline & & (mattresses and foundations) & 337910 & Mattress Manufacturing & \\
\hline & 2517 & $\begin{array}{l}\text { Wood, Television, Radio, } \\
\text { Phonograph, and Sewing Machine } \\
\text { Cabinets }\end{array}$ & 337129 & $\begin{array}{l}\text { Wood, Television, Radio, Phonograph, and } \\
\text { Sewing Machine Cabinet Manufacturing }\end{array}$ & \\
\hline & 2519 & $\begin{array}{l}\text { Household Furniture, Not Elsewhere } \\
\text { Classified }\end{array}$ & 337125 & $\begin{array}{l}\text { Household Furniture (except Wood and Metal) } \\
\text { Manufacturing }\end{array}$ & \\
\hline & 2521 & Wood Office Furniture & 337211 & Wood Office Furniture Manufacturing & \\
\hline & 2522 & Office Furniture, Except Wood & 337214 & Office Furniture (Except Wood) Manufacturing & \\
\hline
\end{tabular}




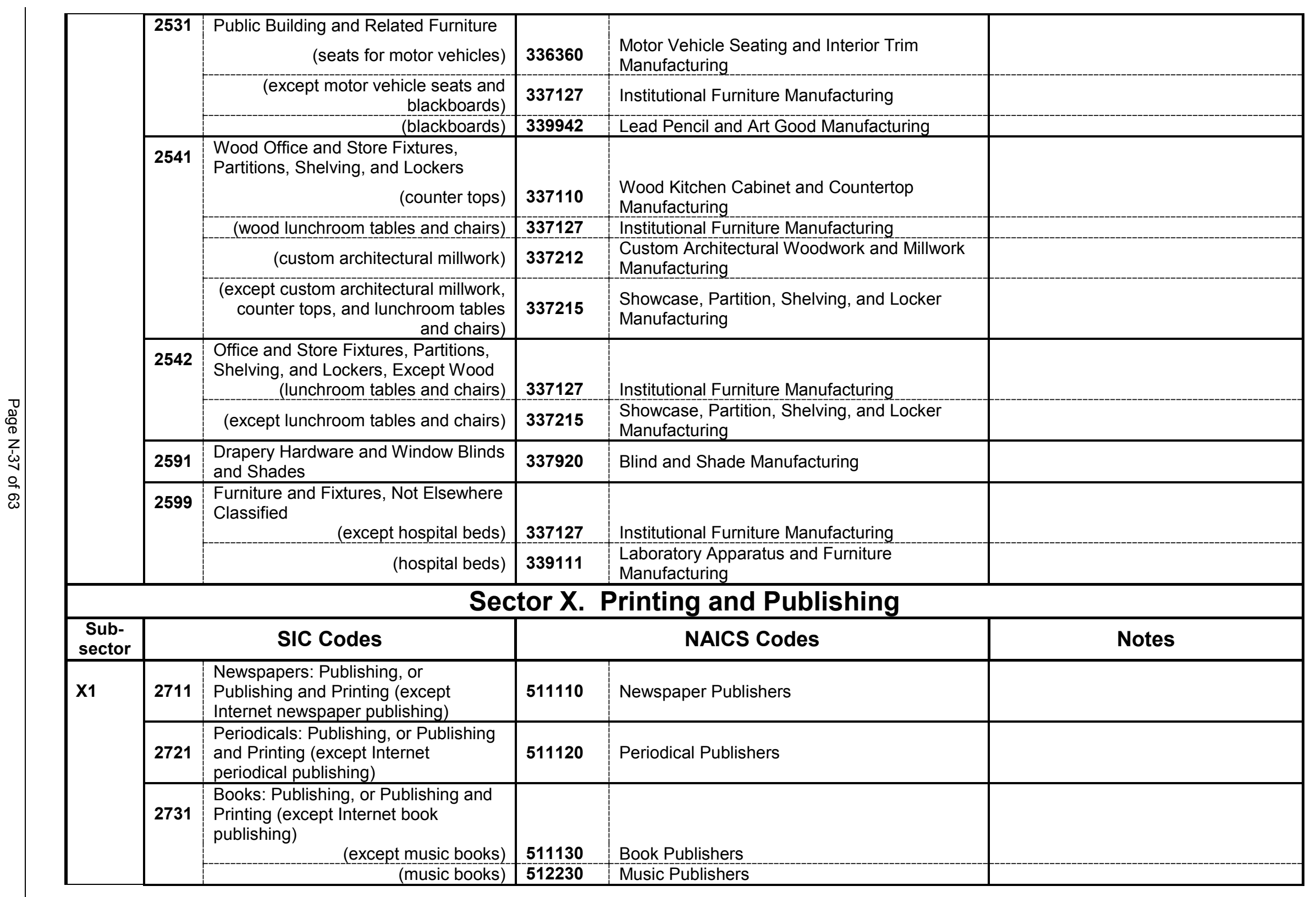




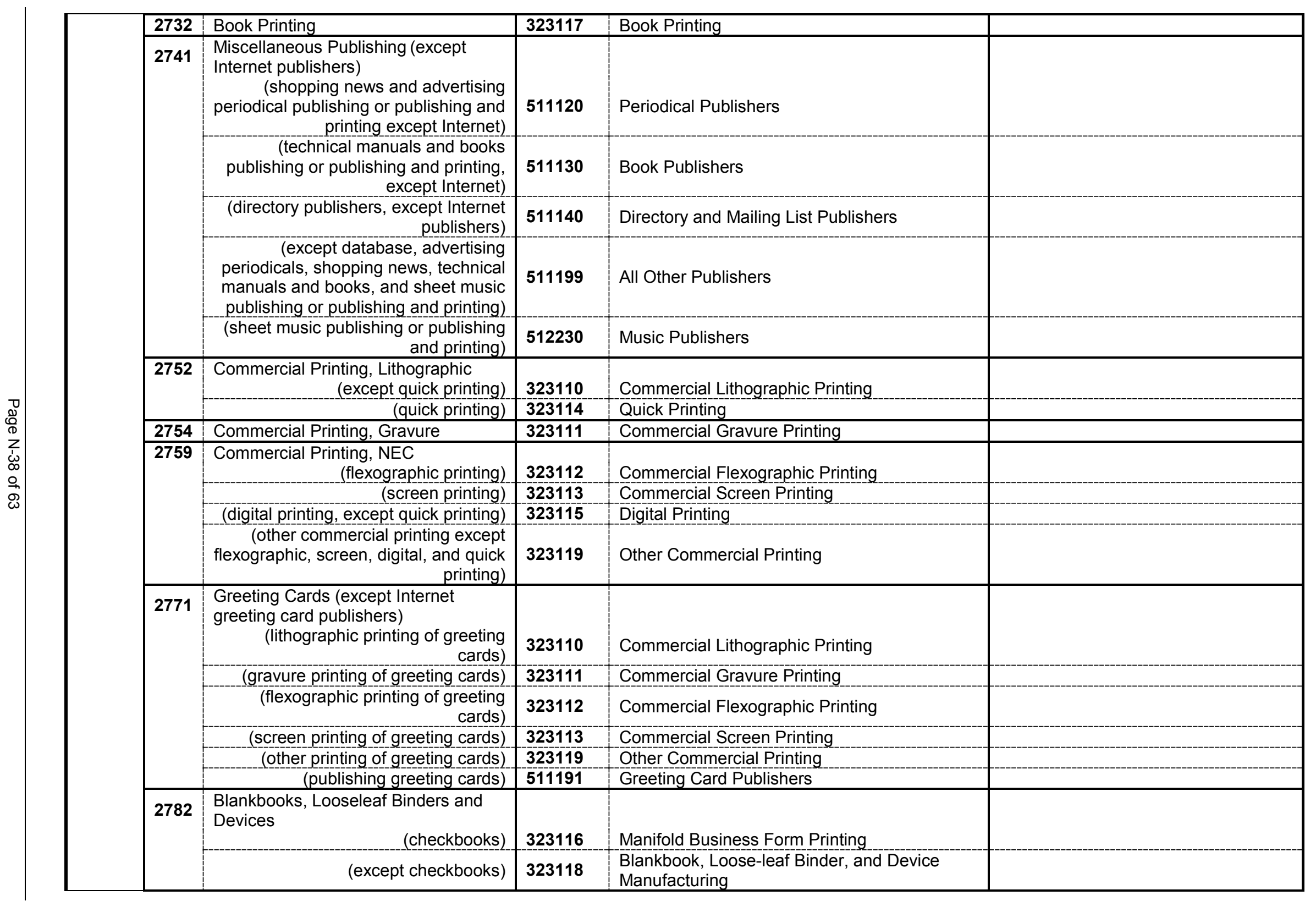




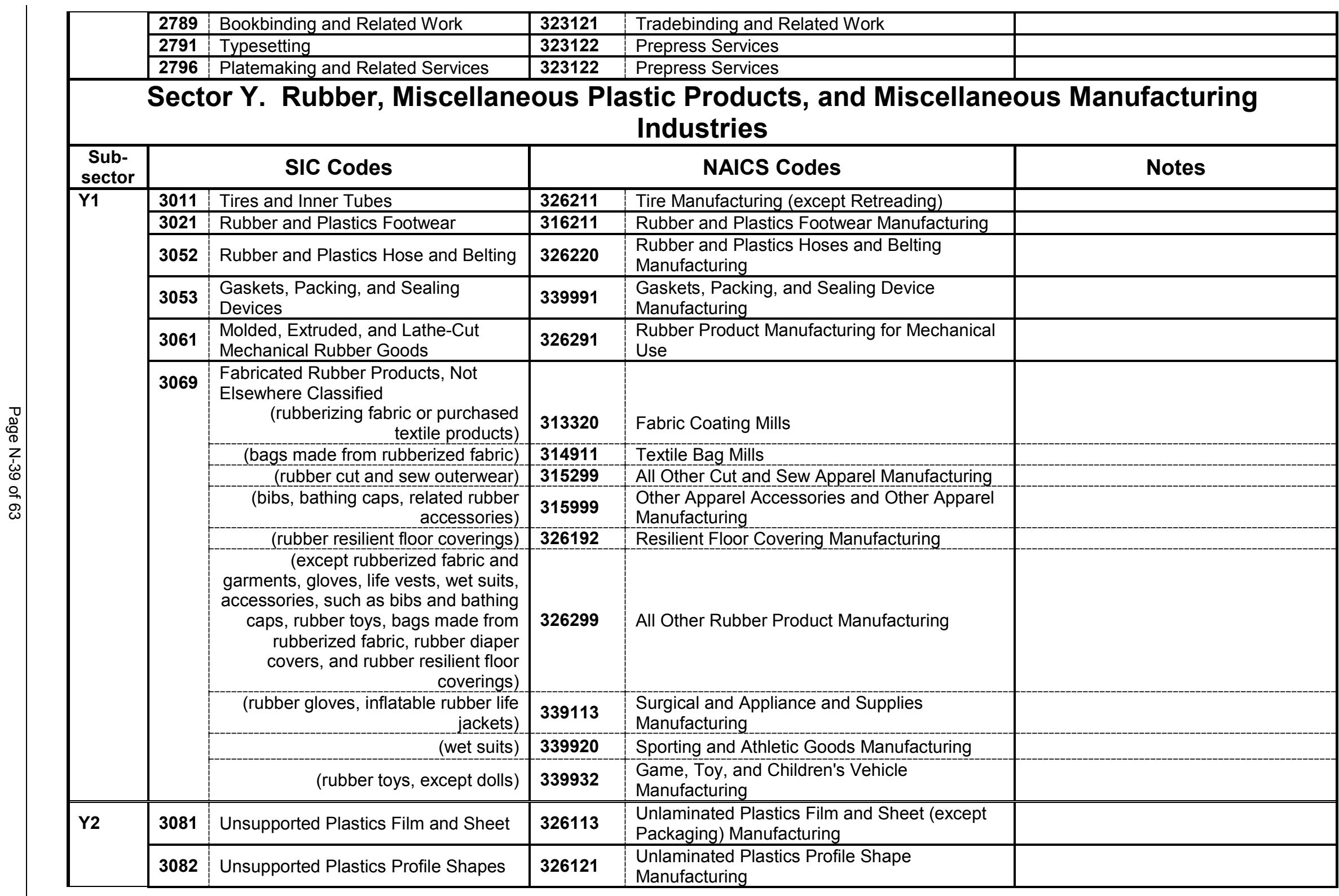




\begin{tabular}{|c|c|c|c|c|}
\hline 3083 & $\begin{array}{l}\text { Laminated Plastics Plate, Sheet, and } \\
\text { Profile Shapes }\end{array}$ & 326130 & $\begin{array}{l}\text { Laminated Plastics Plate, Sheet (except } \\
\text { Packaging), and Shape Manufacturing }\end{array}$ & \\
\hline 3084 & Plastics Pipe & 326122 & Plastics Pipe and Pipe Fitting Manufacturing & \\
\hline 3085 & Plastics Bottles & 326160 & Plastics Bottle Manufacturing & \\
\hline \multirow[t]{2}{*}{3086} & $\begin{array}{l}\text { Plastics Foam Products } \\
\text { (polystyrene foam products) }\end{array}$ & 326140 & Polystyrene Foam Product Manufacturing & \\
\hline & (except polystyrene foam products) & 326150 & $\begin{array}{l}\text { Urethane and Other Foam Product (except } \\
\text { Polystyrene) Manufacturing }\end{array}$ & \\
\hline 3087 & $\begin{array}{l}\text { Custom Compounding of Purchased } \\
\text { Plastics Resins }\end{array}$ & 325991 & Custom Compounding of Purchased Resins & \\
\hline 3088 & Plastics Plumbing Fixtures & 326191 & Plastics Plumbing Fixture Manufacturing & \\
\hline \multirow[t]{5}{*}{3089} & $\begin{array}{l}\text { Plastics Products, Not Elsewhere } \\
\text { Classified } \\
\text { (plastics sausage casings) }\end{array}$ & 326121 & $\begin{array}{l}\text { Unlaminated Plastics Profile Shape } \\
\text { Manufacturing }\end{array}$ & \\
\hline & (pipe fittings) & 326122 & Plastics Pipe and Pipe Fitting Manufacturing & \\
\hline & $\begin{array}{l}\text { (except plastics pipe fittings, inflatable } \\
\text { plastics life jackets, plastics furniture } \\
\text { parts, and plastics sausage casings) }\end{array}$ & 326199 & All Other Plastics Product Manufacturing & \\
\hline & (finished plastic furniture parts) & 337215 & $\begin{array}{l}\text { Showcase, Partition, Shelving, and Locker } \\
\text { Manufacturing }\end{array}$ & \\
\hline & (inflatable plastic life jackets) & 339113 & $\begin{array}{l}\text { Surgical Appliance and Supplies } \\
\text { Manufacturing }\end{array}$ & \\
\hline 3931 & Musical Instruments & 339992 & Musical Instrument Manufacturing & \\
\hline 3942 & Dolls and Stuffed Toys & 339931 & Doll and Stuffed Toy Manufacturing & \\
\hline 3944 & $\begin{array}{l}\text { Games, Toys, and Children's } \\
\text { Vehicles, Except Dolls and Bicycles } \\
\text { (metal tricycles) }\end{array}$ & 336991 & Motorcycle, Bicycle, and Parts Manufacturing & $\begin{array}{l}\text { Any facility whose primary activity is } \\
\text { manufacturing metal tricycles (SIC } \\
3944 \text { / NAICS } 336991 \text { ) should be } \\
\text { regulated under Sector AB, but may } \\
\text { continue to be regulated under Sector } \\
\text { Y, or alternatively, under Sector AD. } \\
\text { Sector AB applies additional SWPPP } \\
\text { requirements. Sector Y does not apply } \\
\text { additional sector-specific requirements } \\
\text { to metal tricycle manufacturers and } \\
\text { under Sector AD EPA could establish } \\
\text { additional facility-specific monitoring } \\
\text { and reporting requirements. } \\
\text { Regulatory burden would be greater } \\
\text { under Sector AB. }\end{array}$ \\
\hline
\end{tabular}




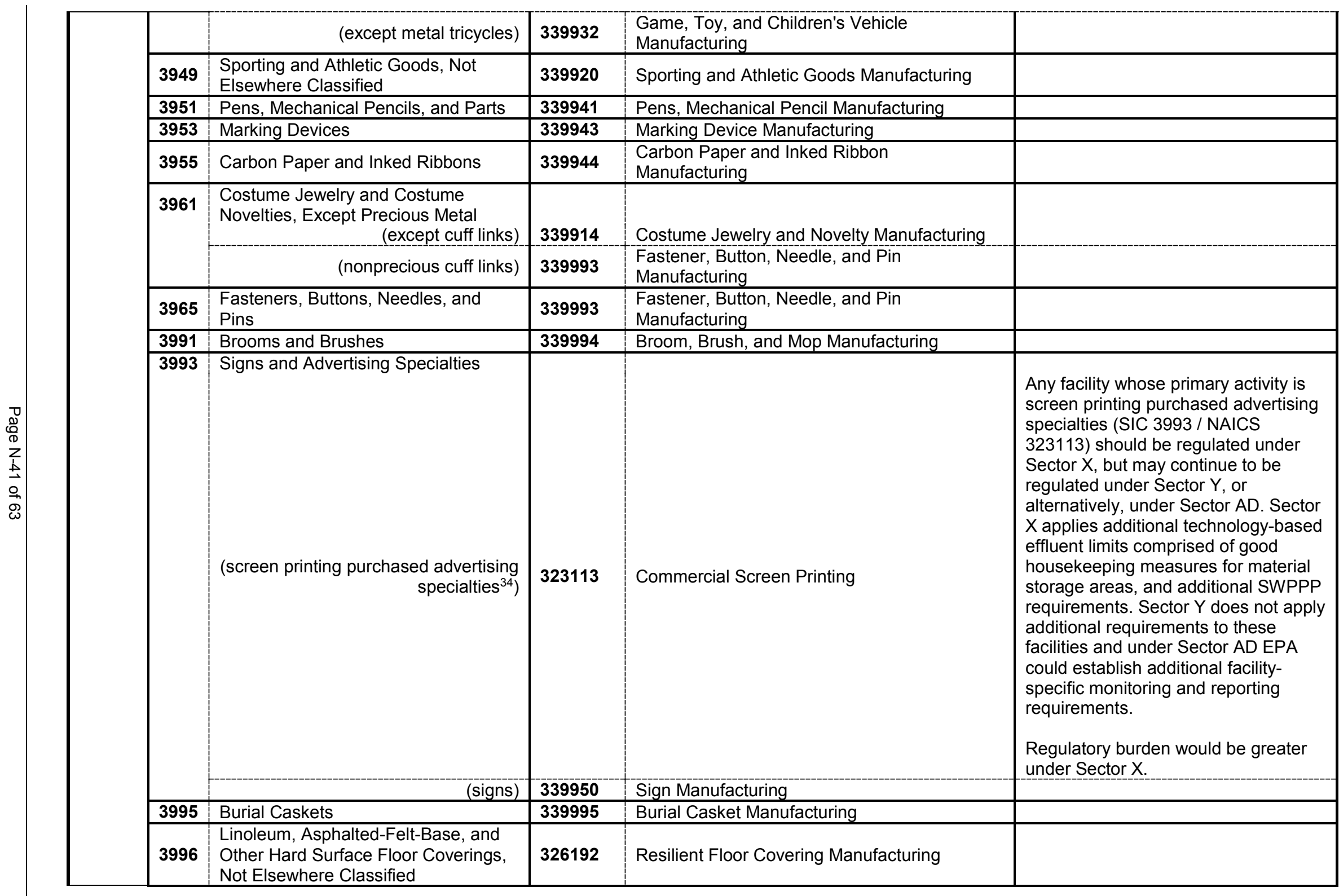




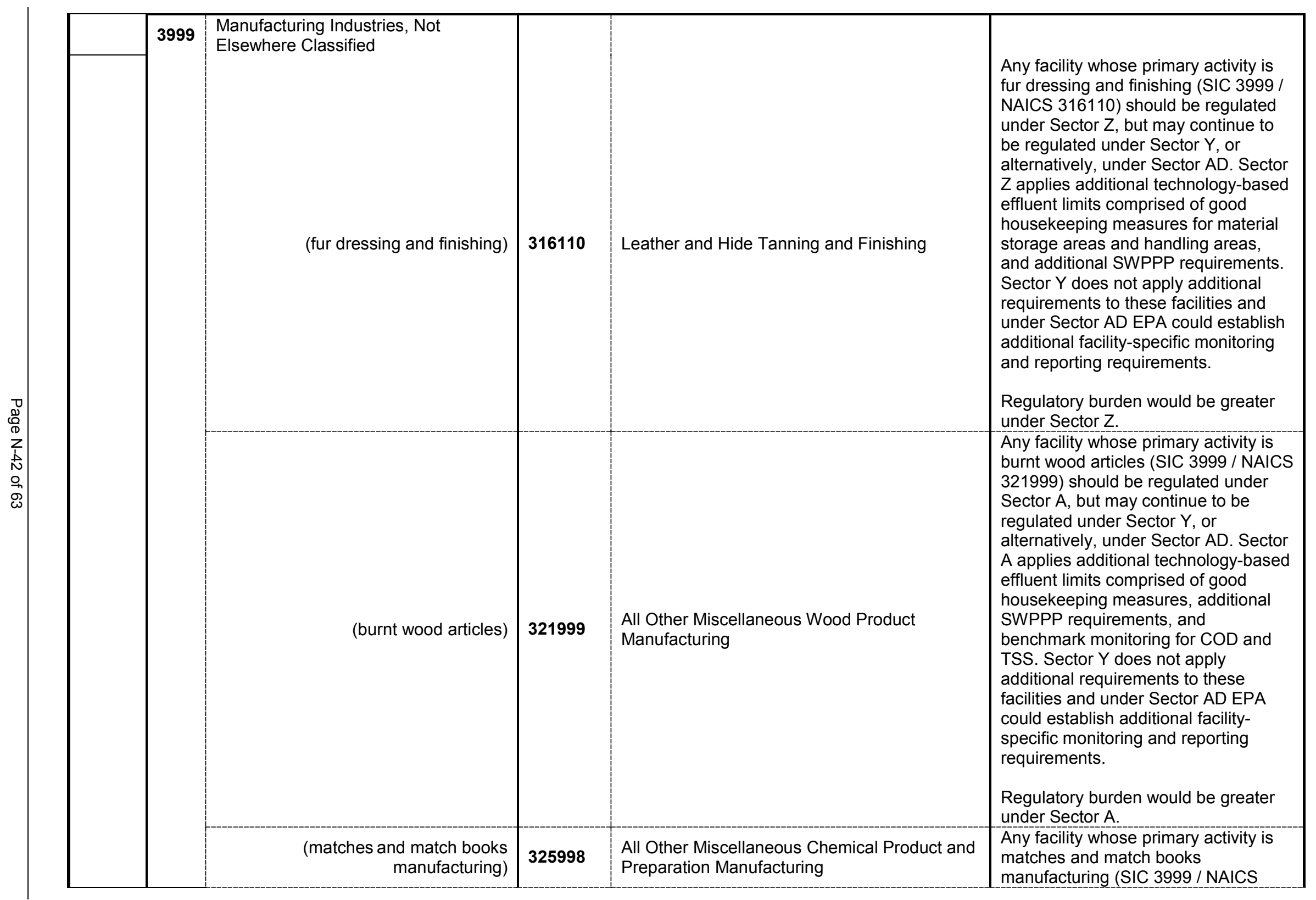




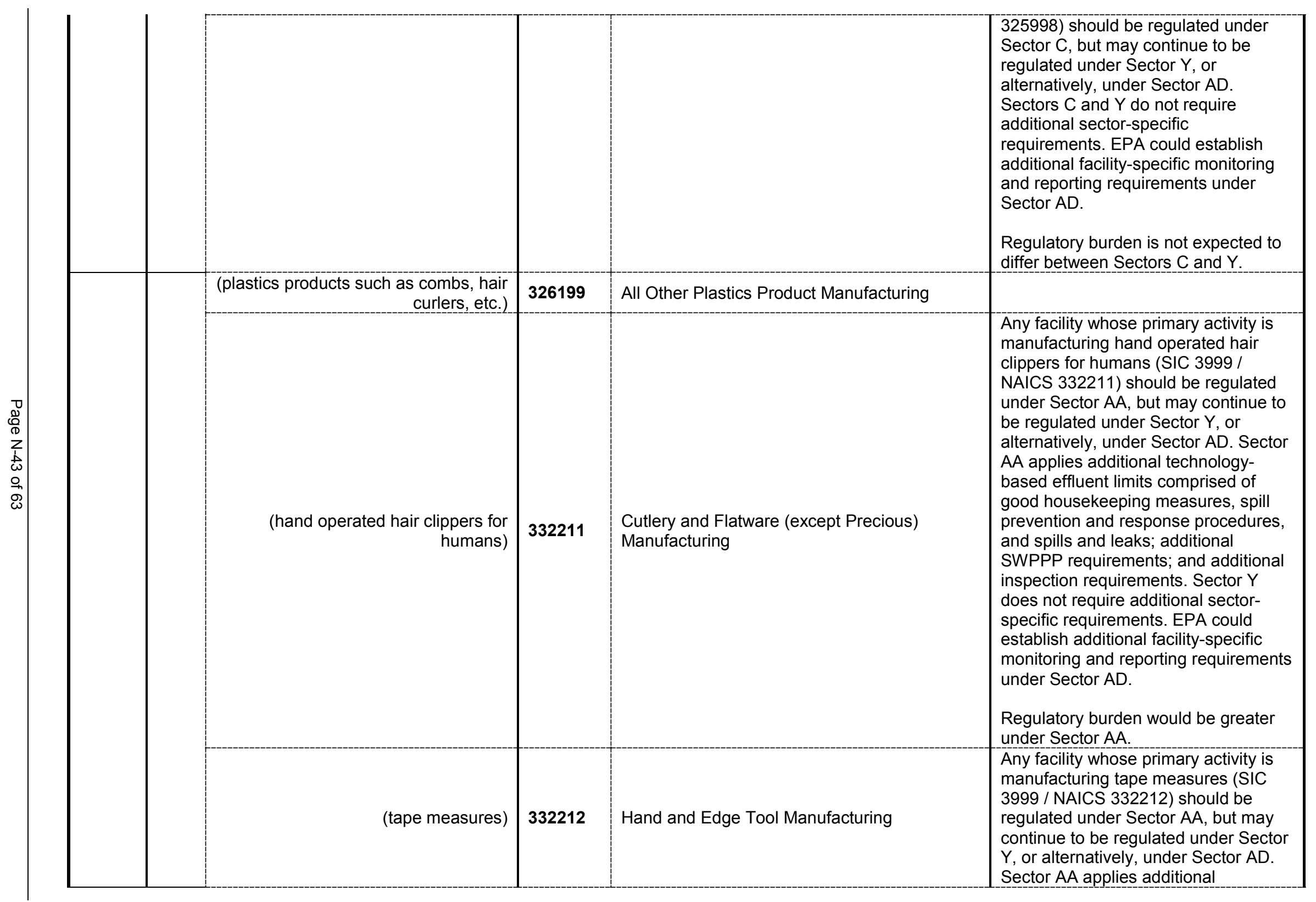




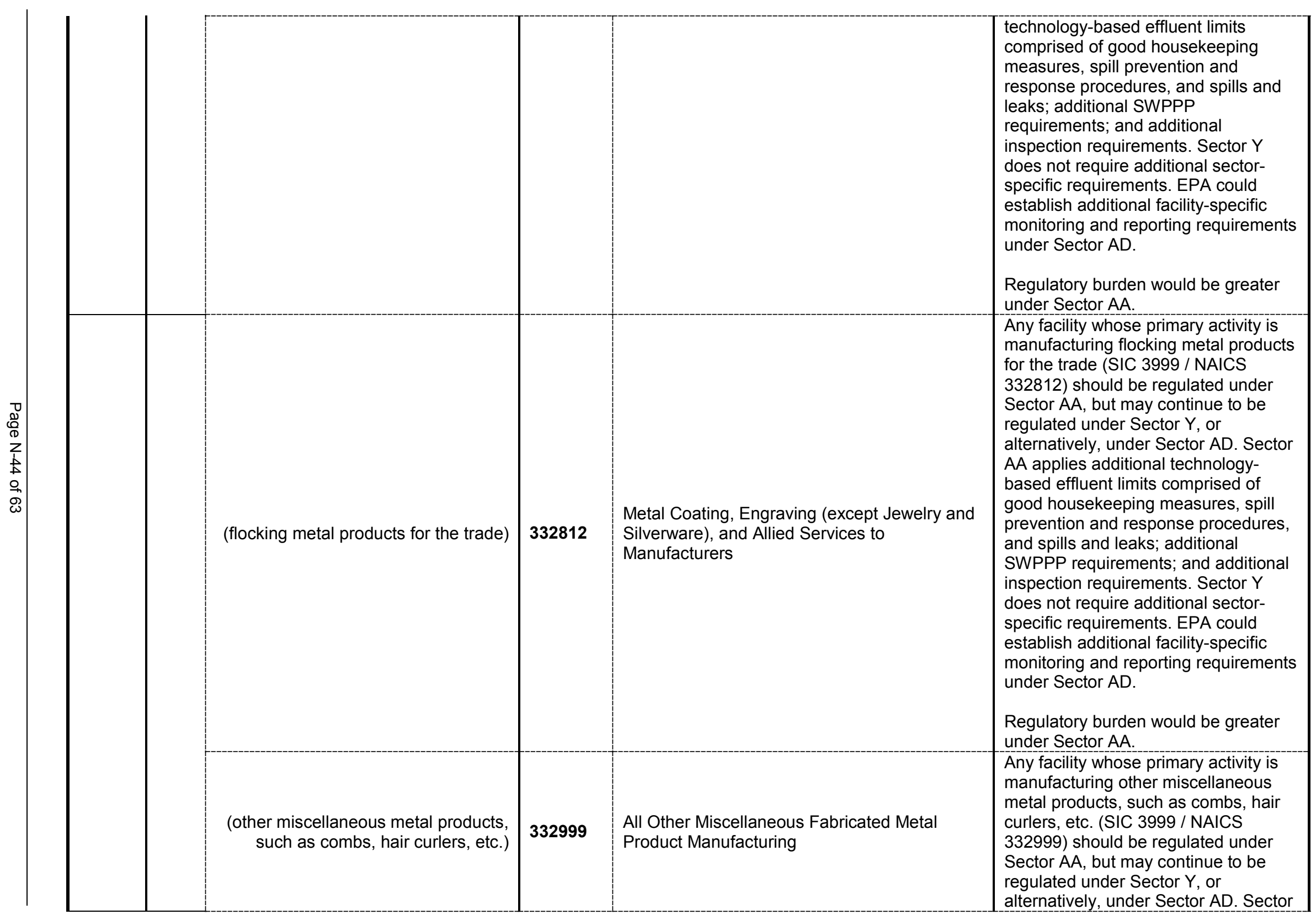




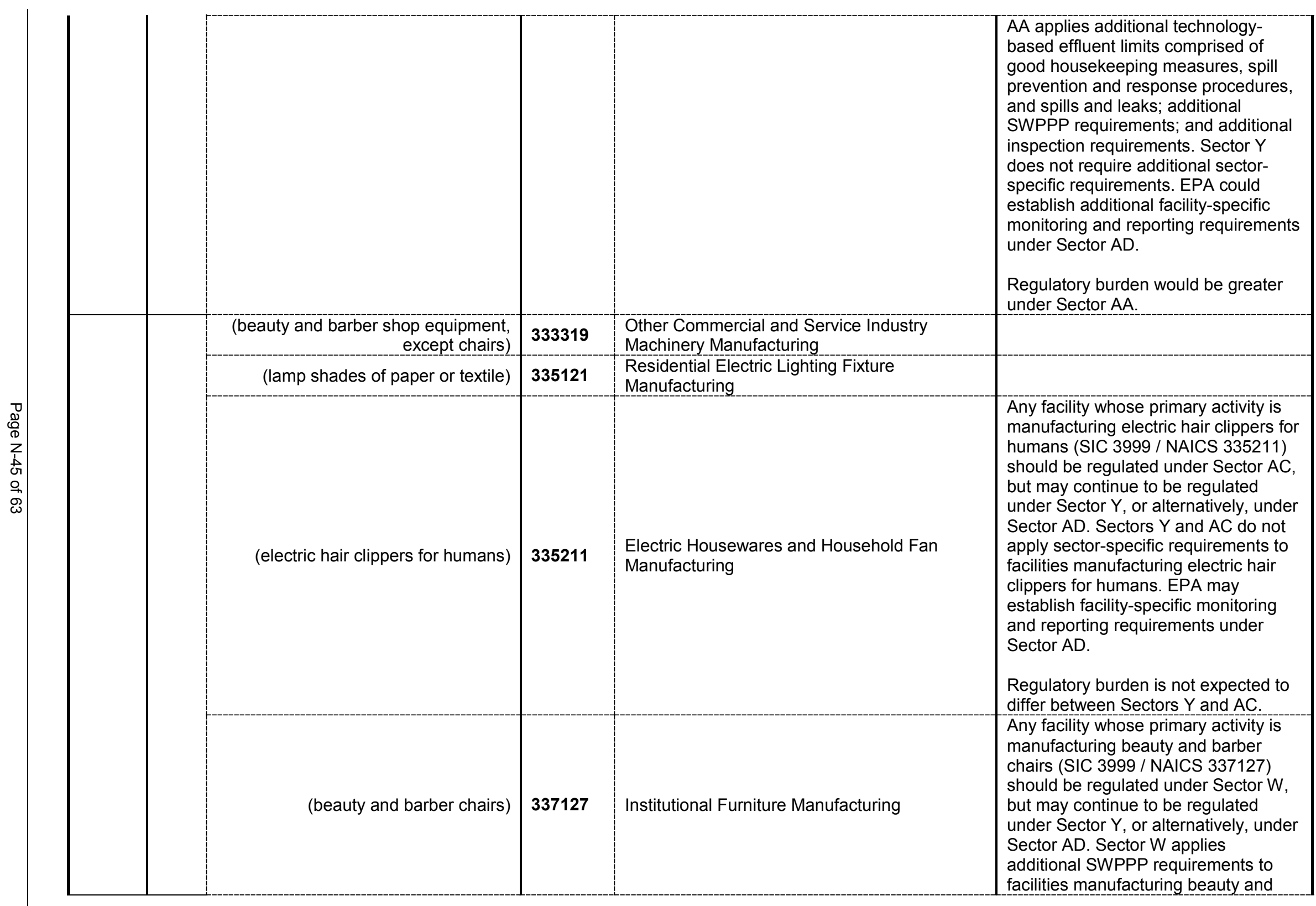




\begin{tabular}{|c|c|c|c|c|c|}
\hline & & & & & $\begin{array}{l}\text { barber chairs. Sector } Y \text { applies no } \\
\text { additional requirements and under } \\
\text { Sector AD EPA could establish } \\
\text { additional facility-specific monitoring } \\
\text { and reporting requirements. } \\
\text { Regulatory burden would be greater } \\
\text { under Sector } W \text {. }\end{array}$ \\
\hline & & (embroidery kits) & 339932 & $\begin{array}{l}\text { Game, Toy, and Children's Vehicle } \\
\text { Manufacturing }\end{array}$ & \\
\hline & & $\begin{array}{l}\text { (other miscellaneous products not } \\
\text { specially provided for previously) }\end{array}$ & 339999 & All Other Miscellaneous Manufacturing & \\
\hline \multicolumn{6}{|c|}{ Sector Z. Leather Tanning and Finishing } \\
\hline $\begin{array}{c}\text { Sub- } \\
\text { sector }\end{array}$ & & SIC Codes & & NAICS Codes & Notes \\
\hline $\mathrm{Z1}$ & 3111 & Leather Tanning and Finishing & 316110 & Leather and Hide Tanning and Finishing & \\
\hline \multicolumn{6}{|c|}{ Sector AA. Fabricated Metal Products } \\
\hline $\begin{array}{l}\text { Sub- } \\
\text { sector }\end{array}$ & & SIC Codes & & NAICS Codes & Notes \\
\hline \multirow[t]{8}{*}{$\overline{\text { AA1 }}$} & 3411 & Metal Cans & 332431 & Metal Can Manufacturing & \\
\hline & 3412 & $\begin{array}{l}\text { Metal Shipping Barrels, Drums, Kegs, } \\
\text { and Pails }\end{array}$ & 332439 & Other Metal Container Manufacturing & \\
\hline & 3421 & $\begin{array}{l}\text { Cutlery } \\
\text { (except hedge shears and trimmers, } \\
\text { tinners' snips, and similar nonelectric } \\
\text { hand tools) }\end{array}$ & 332211 & $\begin{array}{l}\text { Cutlery and Flatware (except Precious) } \\
\text { Manufacturing }\end{array}$ & \\
\hline & & $\begin{array}{r}\text { (hedge shears and trimmers, tinners } \\
\text { snips, and similar nonelectric hand } \\
\text { tools) }\end{array}$ & 332212 & Hand and Edge Tool Manufacturing & \\
\hline & 3423 & $\begin{array}{l}\text { Hand and Edge Tools, Except } \\
\text { Machine Tools and Handsaws }\end{array}$ & 332212 & Hand and Edge Tool Manufacturing & \\
\hline & 3425 & Saw Blades and Handsaws & 332213 & Saw Blade and Handsaw Manufacturing & \\
\hline & 3429 & $\begin{array}{l}\text { Hardware, Not Elsewhere Classified } \\
\text { (vacuum and insulated bottles, jugs, } \\
\text { and chests) }\end{array}$ & 332439 & Other Metal Container Manufacturing & \\
\hline & & $\begin{array}{r}\text { (except fire hose nozzles, hose } \\
\text { couplings, vacuum and insulated } \\
\text { bottles, jugs and chests, fireplace } \\
\text { fixtures, time locks, turnbuckles, } \\
\text { pulleys, tackle blocks, luggage and } \\
\text { utility racks, sleep sofa mechanisms } \\
\text { and chair glides, traps, handcuffs and }\end{array}$ & 332510 & Hardware Manufacturing & \\
\hline
\end{tabular}




\begin{tabular}{|c|c|c|c|c|}
\hline & $\begin{array}{r}\text { leg irons, ladder jacks, and other like } \\
\text { metal products) }\end{array}$ & & & \\
\hline & (turnbuckles and hose clamps) & 332722 & $\begin{array}{l}\text { Bolt, Nut, Screw, Rivet, and Washer } \\
\text { Manufacturing }\end{array}$ & \\
\hline & $\begin{array}{r}\text { (fire hose nozzles and hose } \\
\text { couplings) }\end{array}$ & 332919 & $\begin{array}{l}\text { Other Metal Valve and Pipe Fitting } \\
\text { Manufacturing }\end{array}$ & \\
\hline & $\begin{array}{r}\text { (fireplace fixtures, traps, handcuffs } \\
\text { and leg irons, ladder jacks, and other } \\
\text { like metal products) }\end{array}$ & 332999 & $\begin{array}{l}\text { All Other Miscellaneous Fabricated Metal } \\
\text { Product Manufacturing }\end{array}$ & \\
\hline & $\begin{array}{r}\text { (pulleys, tackle blocks, block and } \\
\text { tackle assemblies) }\end{array}$ & 333923 & $\begin{array}{l}\text { Overhead Traveling Crane, Hoist, and } \\
\text { Monorail System Manufacturing }\end{array}$ & \\
\hline & (time locks) & 334518 & Watch, Clock, and Part Manufacturing & \\
\hline & (luggage and utility racks) & 336399 & All Other Motor Vehicle Parts Manufacturing & \\
\hline & $\begin{array}{r}\text { (sleep sofa mechanisms and chair } \\
\text { glides) }\end{array}$ & 337215 & $\begin{array}{l}\text { Showcase, Partition, Shelving, and Locker } \\
\text { Manufacturing }\end{array}$ & \\
\hline 3431 & $\begin{array}{l}\text { Enameled Iron and Metal Sanitary } \\
\text { Ware }\end{array}$ & 332998 & $\begin{array}{l}\text { Enameled Iron and Metal Sanitary Ware } \\
\text { Manufacturing }\end{array}$ & \\
\hline 3432 & $\begin{array}{r}\text { Plumbing Fixture Fittings and Trim } \\
\text { (except shower rods, lawn hose } \\
\text { nozzles, and lawn sprinklers) }\end{array}$ & 332913 & $\begin{array}{l}\text { Plumbing Fixture Fitting and Trim } \\
\text { Manufacturing }\end{array}$ & \\
\hline & $\begin{array}{r}\text { (lawn hose nozzles and lawn } \\
\text { sprinklers) }\end{array}$ & 332919 & $\begin{array}{l}\text { Other Metal Valve and Pipe Fitting } \\
\text { Manufacturing }\end{array}$ & \\
\hline & (metal shower rods) & 332999 & $\begin{array}{l}\text { All Other Miscellaneous Fabricated Metal } \\
\text { Product Manufacturing }\end{array}$ & \\
\hline 3443 & $\begin{array}{r}\begin{array}{r}\text { Fabricated Plate Work (Boiler Shops) } \\
\text { (fabricated plate work and metal } \\
\text { weldments) }\end{array} \\
\end{array}$ & 332313 & Plate Work Manufacturing & \\
\hline & (power boilers and heat exchangers) & 332410 & $\begin{array}{l}\text { Power Boiler and Heat Exchanger } \\
\text { Manufacturing }\end{array}$ & \\
\hline & (heavy gauge tanks) & 332420 & Metal Tank (Heavy Gauge) Manufacturing & \\
\hline & (metal cooling towers) & 333415 & $\begin{array}{l}\text { Air-Conditioning and Warm Air Heating } \\
\text { Equipment and Commercial and Industrial } \\
\text { Refrigeration Equipment Manufacturing (metal } \\
\text { cooling towers) }\end{array}$ & \\
\hline 3444 & $\begin{array}{l}\text { Sheet Metal Work } \\
\text { (stamped metal skylights) }\end{array}$ & 332321 & Metal Window and Door Manufacturing & \\
\hline & $\begin{array}{r}\text { (except sheet metal bins and vats, } \\
\text { skylights, and sheet metal cooling } \\
\text { towers) }\end{array}$ & 332322 & Sheet Metal Work Manufacturing & \\
\hline & (metal bins and vats) & 332439 & Other Metal Container Manufacturing & \\
\hline & (cooling towers, sheet metal) & 333415 & $\begin{array}{l}\text { Air-Conditioning and Warm Air Heating } \\
\text { Equipment and Commercial and Industrial } \\
\text { Refrigeration Equipment Manufacturing }\end{array}$ & \\
\hline
\end{tabular}




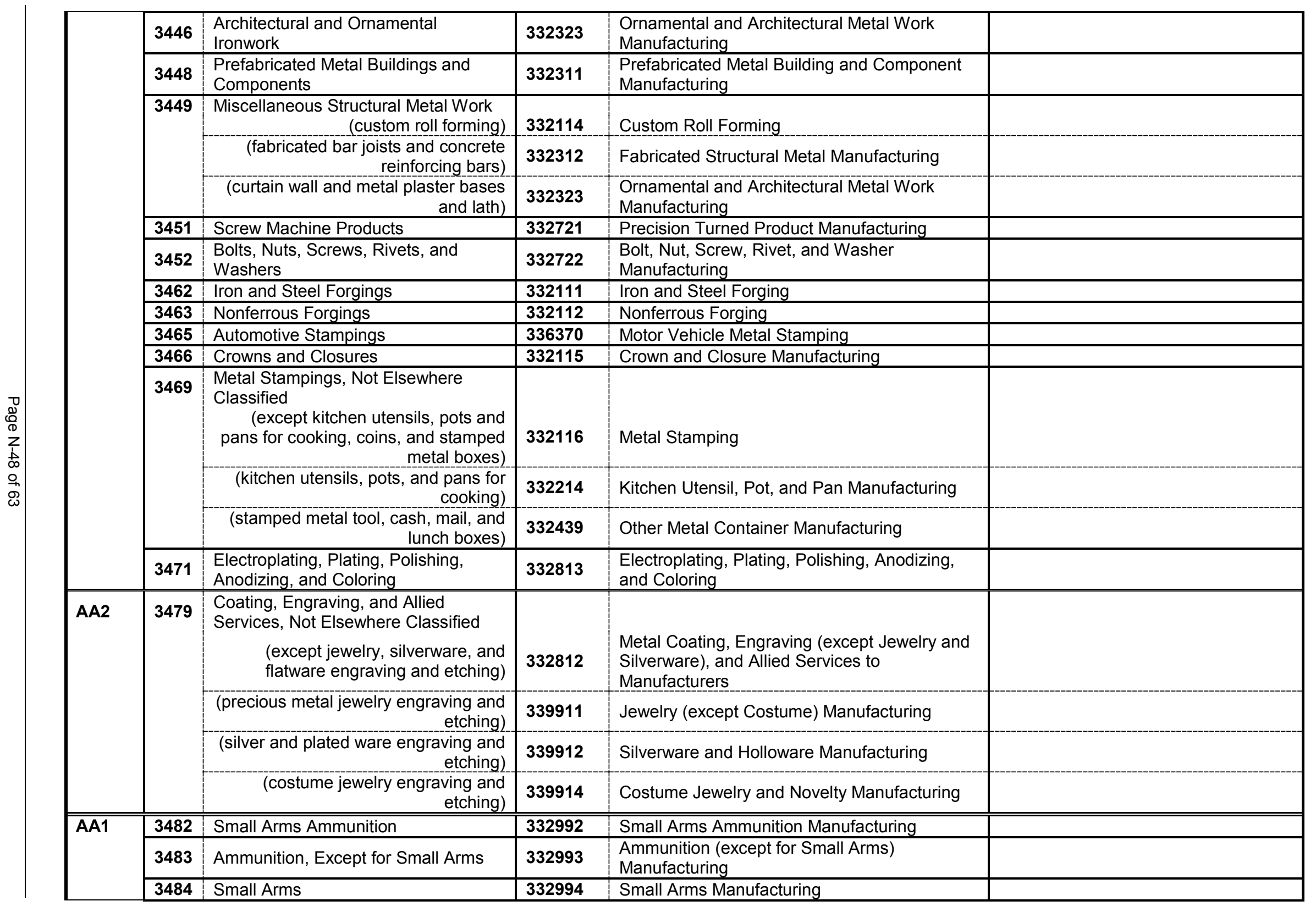




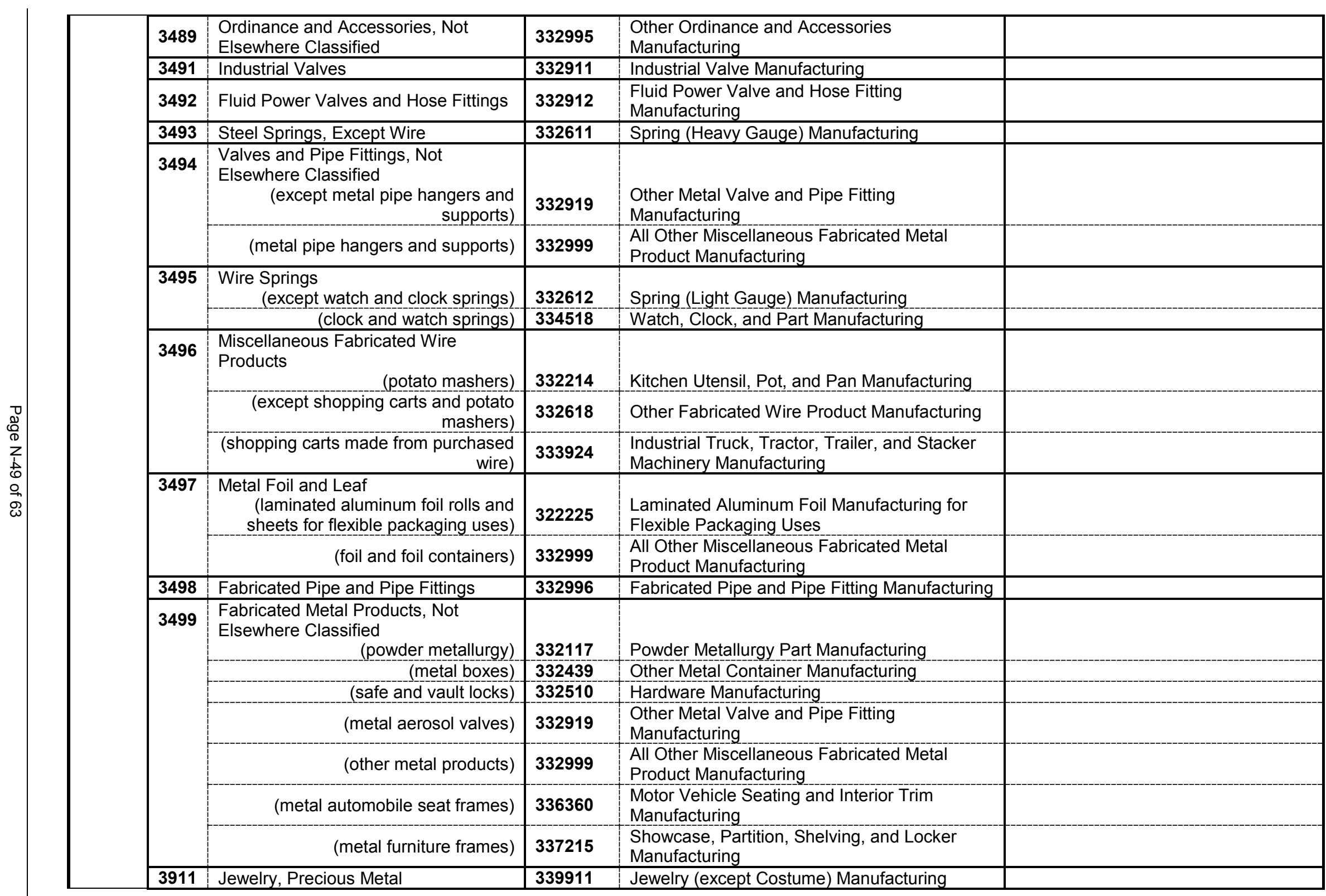




\begin{tabular}{|c|c|c|c|c|c|}
\hline & \multirow[t]{3}{*}{3914} & $\begin{array}{l}\text { Silverware, Plated Ware, and } \\
\text { Stainless Steel Ware } \\
\text { (cutlery and flatware, nonprecious and } \\
\text { precious plated) }\end{array}$ & 332211 & $\begin{array}{l}\text { Cutlery and Flatware (except Precious) } \\
\text { Manufacturing }\end{array}$ & \\
\hline & & (precious metal plated hollowware) & 332999 & $\begin{array}{l}\text { All Other Miscellaneous Fabricated Metal } \\
\text { Product Manufacturing }\end{array}$ & \\
\hline & & $\begin{array}{r}\text { (except nonprecious and precious } \\
\text { plated metal cutlery, flatware, and } \\
\text { hollowware) }\end{array}$ & 339912 & Silverware and Holloware Manufacturing & \\
\hline & 3915 & 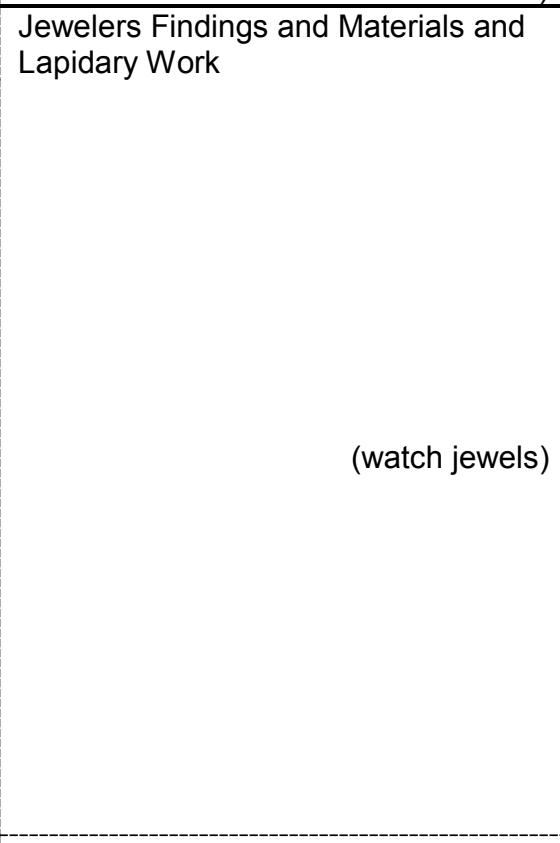 & 334518 & Watch, Clock, and Part Manufacturing & $\begin{array}{l}\text { Any facility whose primary activity is } \\
\text { manufacturing watch jewels (SIC } 3915 \\
\text { / NAICS } 334518 \text { ) should be regulated } \\
\text { under Sector AC, but may continue to } \\
\text { be regulated under Sector AA, or } \\
\text { alternatively, under Sector AD. Sector } \\
\text { AA applies additional technology- } \\
\text { based effluent limits comprising good } \\
\text { housekeeping measures, spill } \\
\text { prevention and response, and spills } \\
\text { and leaks; additional SWPPP } \\
\text { requirements; and additional } \\
\text { inspection requirements. Sector AC } \\
\text { does not apply additional sector- } \\
\text { specific requirements and EPA may } \\
\text { establish facility-specific monitoring } \\
\text { and reporting requirements under } \\
\text { Sector AD. } \\
\text { Regulatory burden would be greater } \\
\text { under Sector AA. }\end{array}$ \\
\hline & & (except watch jewels) & 339913 & $\begin{array}{l}\text { Jewelers' Material and Lapidary Work } \\
\text { Manufacturing }\end{array}$ & \\
\hline & & Sect & n Eq & pment, Industrial or Comr & al Machinery \\
\hline $\begin{array}{c}\text { Sub- } \\
\text { sector }\end{array}$ & & SIC Codes & & NAICS Codes & Notes \\
\hline AB1 & 3511 & $\begin{array}{l}\text { Steam, Gas, and Hydraulic Turbines, } \\
\text { and Turbine Generator Set Units }\end{array}$ & 333611 & $\begin{array}{l}\text { Turbine and Turbine Generator Set Units } \\
\text { Manufacturing }\end{array}$ & \\
\hline & 3519 & $\begin{array}{l}\text { Internal Combustion Engines, Not } \\
\text { Elsewhere Classified } \\
\text { (except stationary engine radiators) }\end{array}$ & 333618 & Other Engine Equipment Manufacturing & \\
\hline & & (stationary engine radiators) & 336399 & All Other Motor Vehicle Parts Manufacturing & \\
\hline
\end{tabular}




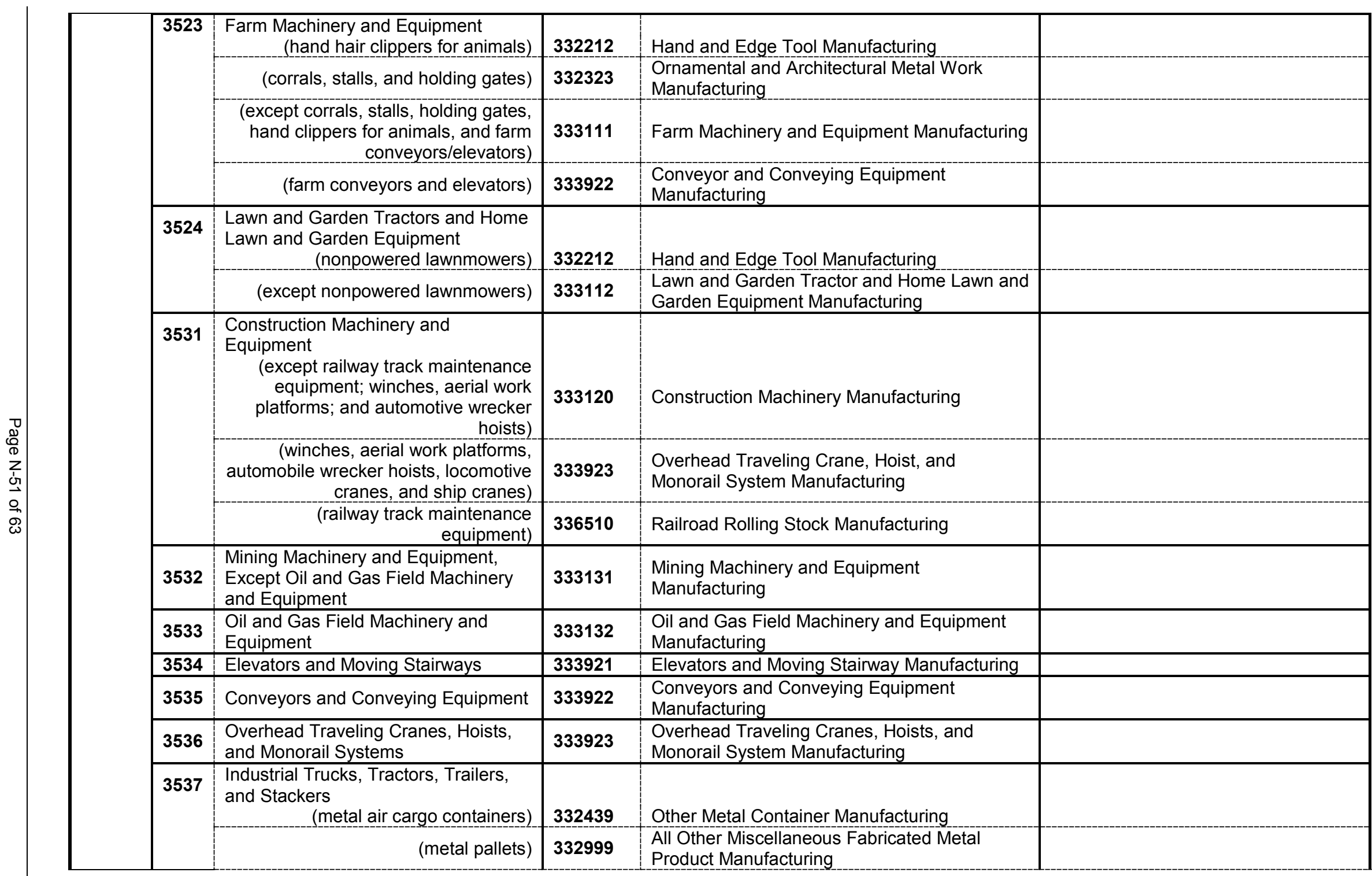




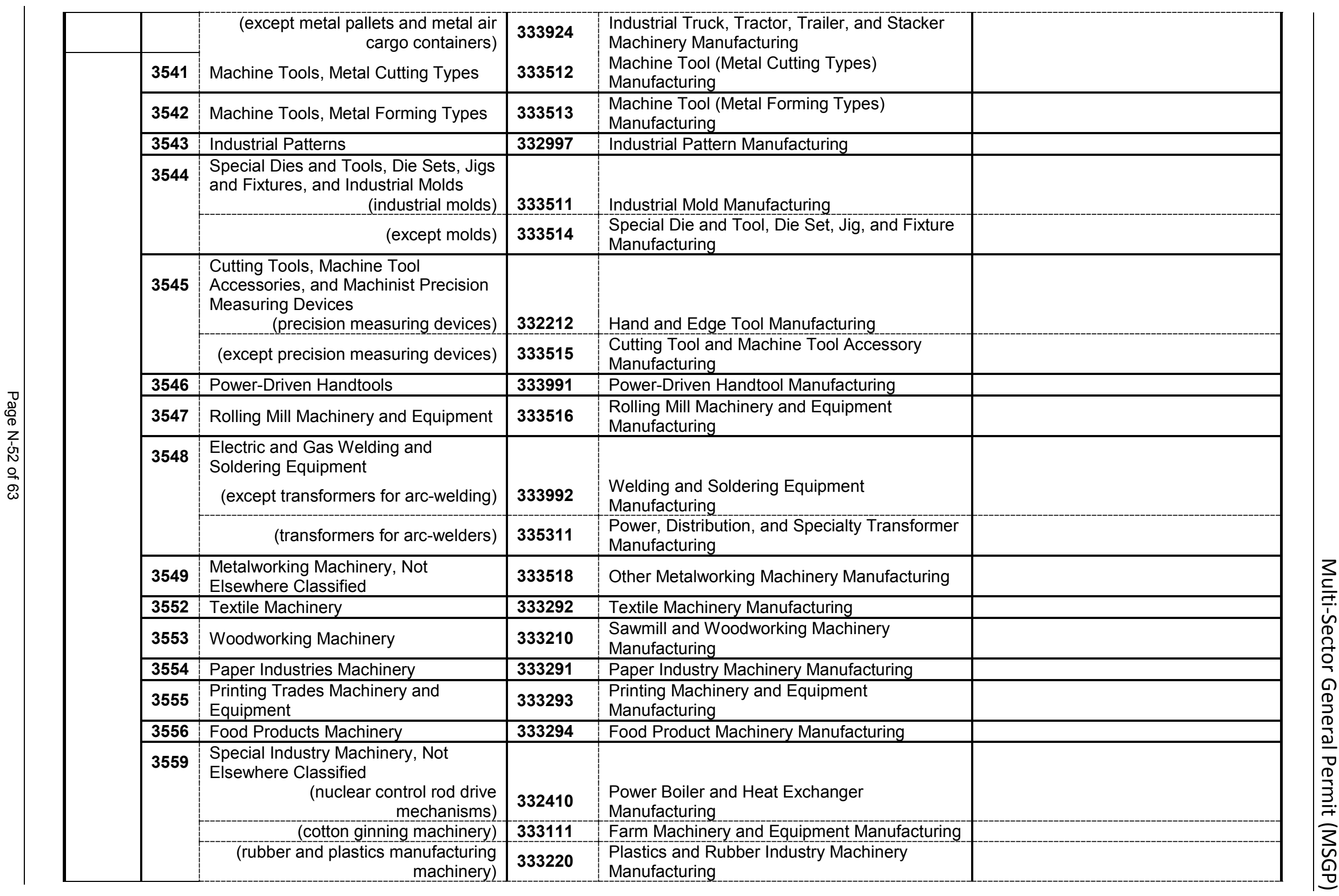




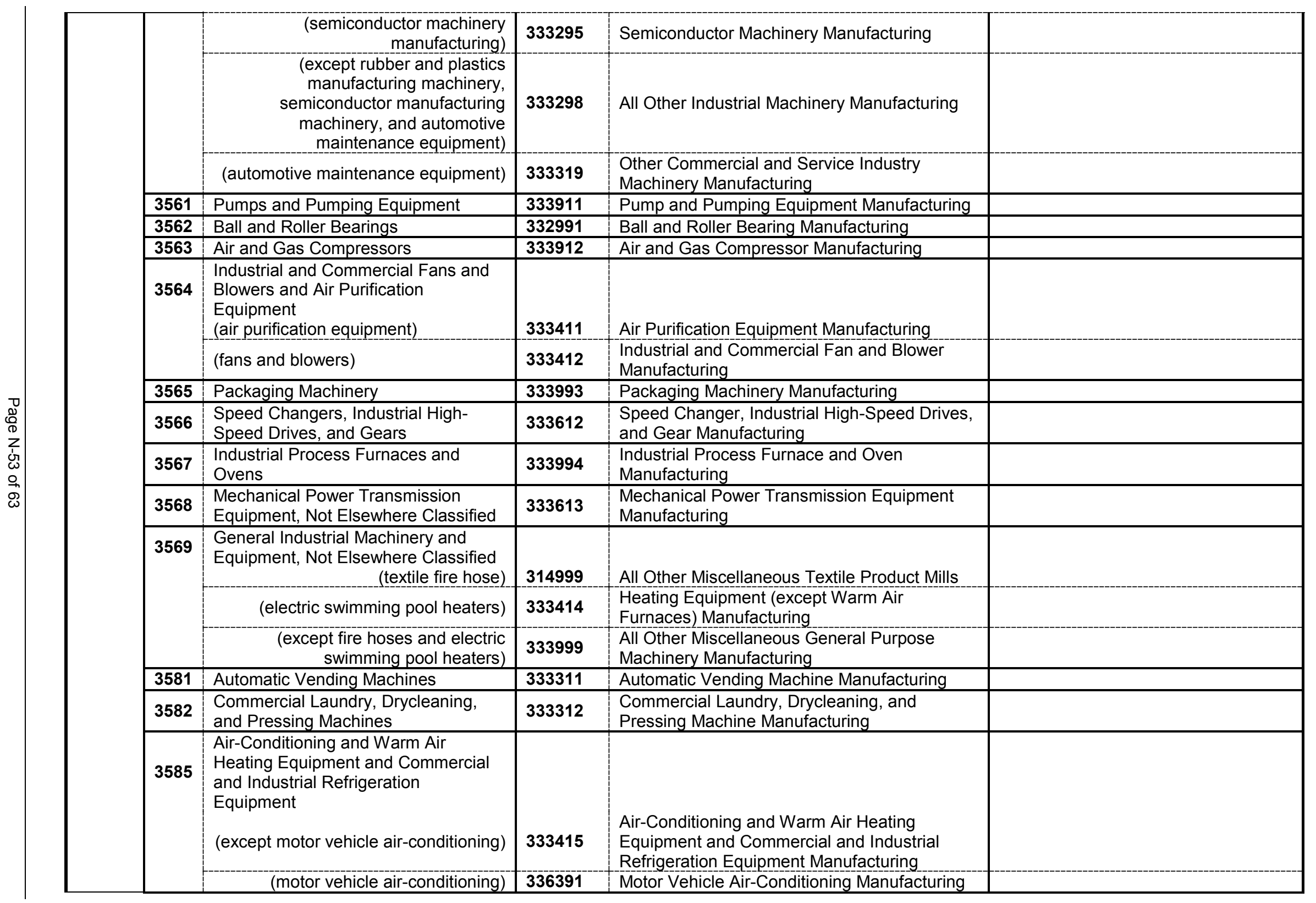




\begin{tabular}{|c|c|c|c|c|}
\hline 3586 & Measuring and Dispensing Pumps & 333913 & $\begin{array}{l}\text { Measuring and Dispensing Pump } \\
\text { Manufacturing }\end{array}$ & \\
\hline 3589 & $\begin{array}{l}\text { Service Industry Machinery, Not } \\
\text { Elsewhere Classified }\end{array}$ & 333319 & $\begin{array}{l}\text { Other Commercial and Service Industry } \\
\text { Machinery Manufacturing }\end{array}$ & \\
\hline 3592 & $\begin{array}{l}\text { Carburetors, Pistons, Piston Rings, } \\
\text { and Valves }\end{array}$ & 336311 & $\begin{array}{l}\text { Carburetor, Piston, Piston Ring, and Valve } \\
\text { Manufacturing }\end{array}$ & \\
\hline 3593 & Fluid Power Cylinders and Actuators & 333995 & $\begin{array}{l}\text { Fluid Power Cylinder and Actuator } \\
\text { Manufacturing }\end{array}$ & \\
\hline 3594 & Fluid Power Pumps and Motors & 333996 & Fluid Power Pumps and Motors Manufacturing & \\
\hline 3596 & $\begin{array}{l}\text { Scales and Balances, Except } \\
\text { Laboratory }\end{array}$ & 333997 & $\begin{array}{l}\text { Scale and Balance (except Laboratory) } \\
\text { Manufacturing }\end{array}$ & \\
\hline \multirow[t]{7}{*}{3599} & $\begin{array}{l}\text { Industrial and Commercial Machinery } \\
\text { and Equipment, Not Elsewhere } \\
\text { Classified } \\
\text { (machine shops) }\end{array}$ & 332710 & Machine Shops & \\
\hline & (grinding castings for the trade) & 332813 & $\begin{array}{l}\text { Electroplating, Plating, Polishing, Anodizing } \\
\text { and Coloring }\end{array}$ & \\
\hline & (flexible metal hose) & 332999 & $\begin{array}{l}\text { All Other Miscellaneous Fabricated Metal } \\
\text { Product Manufacturing }\end{array}$ & \\
\hline & (carnival amusement park equipment) & 333319 & $\begin{array}{l}\text { Other Commercial and Service Industry } \\
\text { Machinery Manufacturing }\end{array}$ & \\
\hline & $\begin{array}{r}\text { (other industrial and commercial } \\
\text { machinery and equipment) }\end{array}$ & 333999 & $\begin{array}{l}\text { All Other Miscellaneous General Purpose } \\
\text { Machinery Manufacturing }\end{array}$ & \\
\hline & (water leak detectors) & 334519 & $\begin{array}{l}\text { Other Measuring and Controlling Device } \\
\text { Manufacturing }\end{array}$ & \\
\hline & $\begin{array}{r}\text { (gasoline, oil, and intake filters for } \\
\text { internal combustion engines, except } \\
\text { for motor vehicles) }\end{array}$ & 336399 & All Other Motor Vehicle Parts Manufacturing & \\
\hline \multirow[t]{5}{*}{3711} & $\begin{array}{l}\text { Motor Vehicles and Passenger Car } \\
\text { Bodies }\end{array}$ & 336111 & Automobile Manufacturing & \\
\hline & (light trucks and utility vehicles) & 336112 & Light Truck and Utility Vehicle Manufacturing & \\
\hline & (heavy duty trucks) & 336120 & Heavy Duty Truck Manufacturing & \\
\hline & $\begin{array}{r}\text { (kit car and other passenger car } \\
\text { bodies) }\end{array}$ & 336211 & Motor Vehicle Body Manufacturing & \\
\hline & (military armored vehicles) & 336992 & $\begin{array}{l}\text { Military Armored Vehicle, Tank, and Tank } \\
\text { Component Manufacturing }\end{array}$ & \\
\hline 3713 & Truck and Bus Bodies & 336211 & Motor Vehicle Body Manufacturing & \\
\hline \multirow[t]{2}{*}{3714} & $\begin{array}{r}\text { Motor Vehicle Parts and Accessories } \\
\text { (dump truck lifting mechanisms and } \\
\text { fifth wheels) }\end{array}$ & 336211 & Motor Vehicle Body Manufacturing & \\
\hline & $\begin{array}{r}\text { (gasoline engines and engine parts } \\
\text { including rebuilt) }\end{array}$ & 336312 & $\begin{array}{l}\text { Gasoline Engine and Engine Parts } \\
\text { Manufacturing }\end{array}$ & \\
\hline
\end{tabular}




\begin{tabular}{|c|c|c|c|c|}
\hline & $\begin{array}{r}\text { (wiring harness sets, other than } \\
\text { ignition; block heaters and battery } \\
\text { heaters; instrument board assemblies; } \\
\text { permanent defrosters; windshield } \\
\text { washer-wiper mechanisms; cruise } \\
\text { control mechanisms; and other } \\
\text { electrical equipment for internal } \\
\text { combustion engines) }\end{array}$ & 336322 & $\begin{array}{l}\text { Other Motor Vehicle Electrical and Electronic } \\
\text { Equipment Manufacturing }\end{array}$ & \\
\hline & (steering and suspension parts) & 336330 & $\begin{array}{l}\text { Motor Vehicle Steering and Suspension } \\
\text { Components (except Spring) Manufacturing }\end{array}$ & \\
\hline & $\begin{array}{r}\text { (brake and brake systems, including } \\
\text { assemblies) }\end{array}$ & 336340 & Motor Vehicle Brake System Manufacturing & \\
\hline & $\begin{array}{r}\text { (transmissions and power train parts, } \\
\text { including rebuilding) }\end{array}$ & 336350 & $\begin{array}{l}\text { Motor Vehicle Transmission and Power Train } \\
\text { Parts Manufacturing }\end{array}$ & \\
\hline & $\begin{array}{r}\text { (except truck and bus bodies, trailers, } \\
\text { engine and engine parts, motor } \\
\text { vehicle electrical and electronic } \\
\text { equipment, motor vehicle steering and } \\
\text { suspension components, motor } \\
\text { vehicle brake systems, and motor } \\
\text { vehicle transmission and power train } \\
\text { parts) }\end{array}$ & 336399 & All Other Motor Vehicle Parts Manufacturing & \\
\hline 3715 & Truck Trailers & 336212 & Truck Trailer Manufacturing & \\
\hline 3716 & Motor Homes & 336213 & Motor Home Manufacturing & \\
\hline 3721 & $\begin{array}{l}\text { Aircraft } \\
\text { (except research and development } \\
\quad \text { not producing prototypes) }\end{array}$ & 336411 & Aircraft Manufacturing & \\
\hline 3724 & $\begin{array}{r}\text { Aircraft Engines and Engine Parts } \\
\text { (except research and development } \\
\text { not producing prototypes) }\end{array}$ & 336412 & $\begin{array}{l}\text { Aircraft Engine and Engine Parts } \\
\text { Manufacturing }\end{array}$ & \\
\hline 3728 & $\begin{array}{l}\text { Aircraft Parts and Auxiliary } \\
\text { Equipment, Not Elsewhere Classified } \\
\text { (fluid power aircraft subassemblies) }\end{array}$ & 332912 & $\begin{array}{l}\text { Fluid Power Valve and Hose Fitting } \\
\text { Manufacturing }\end{array}$ & \\
\hline & (target drones) & 336411 & Aircraft Manufacturing & \\
\hline & $\begin{array}{r}\text { (except fluid power aircraft } \\
\text { subassemblies, target drones, and } \\
\text { research and development not } \\
\text { producing prototypes) }\end{array}$ & 336413 & $\begin{array}{l}\text { Other Aircraft Part and Auxiliary Equipment } \\
\text { Manufacturing }\end{array}$ & \\
\hline 3743 & $\begin{array}{r}\text { Railroad Equipment } \\
\text { (locomotive fuel lubricating or cooling } \\
\text { medium pumps) }\end{array}$ & 333911 & Pump and Pumping Equipment Manufacturing & \\
\hline & $\begin{array}{r}\text { (except locomotive fuel lubricating or } \\
\text { cooling medium pumps) }\end{array}$ & 336510 & Railroad Rolling Stock Manufacturing & \\
\hline
\end{tabular}




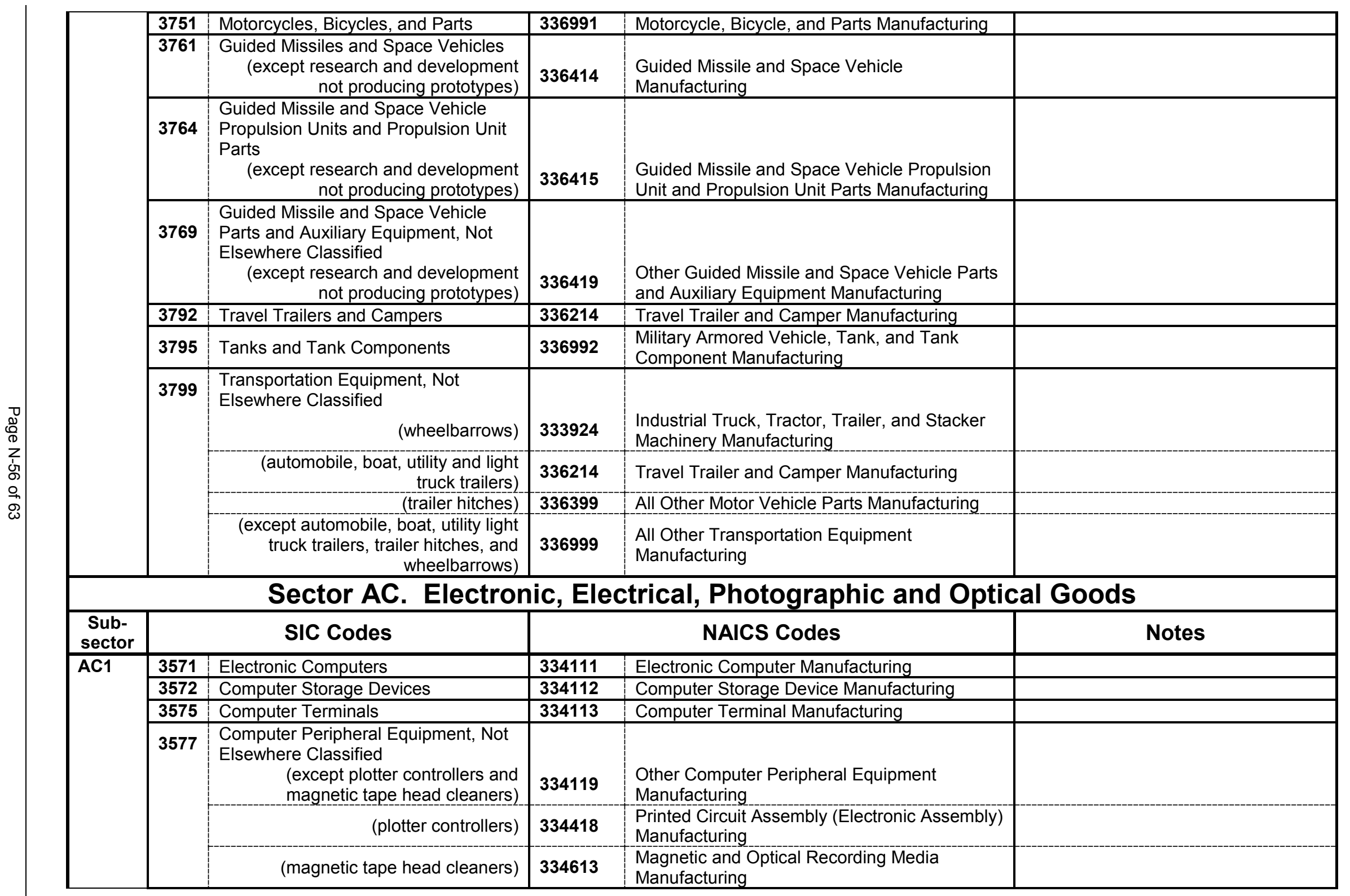




\begin{tabular}{|c|c|c|c|c|}
\hline \multirow[t]{3}{*}{3578} & $\begin{array}{l}\text { Calculating and Accounting } \\
\text { Machinery, Except Electronic } \\
\text { Computers } \\
\text { (change making machines) }\end{array}$ & 333311 & Automatic Vending Machine Manufacturing & \\
\hline & $\begin{array}{r}\text { (except point of sales terminals, } \\
\text { change making machines and funds } \\
\text { transfer devices) }\end{array}$ & 333313 & Office Machinery Manufacturing & \\
\hline & $\begin{array}{r}\text { (point of sale terminals and fund } \\
\text { transfer devices) } \\
\end{array}$ & 334119 & $\begin{array}{l}\text { Other Computer Peripheral Equipment } \\
\text { Manufacturing }\end{array}$ & \\
\hline \multirow[t]{3}{*}{3579} & $\begin{array}{l}\text { Office Machines, Not Elsewhere } \\
\text { Classified } \\
\text { (except timeclocks, time stamps, } \\
\text { pencil sharpeners, stapling machines, } \\
\text { etc.) }\end{array}$ & 333313 & Office Machinery Manufacturing & \\
\hline & $\begin{array}{r}\text { (time clocks and other time recording } \\
\text { devices) }\end{array}$ & 334518 & Watch, Clock, and Part Manufacturing & \\
\hline & $\begin{array}{r}\text { (pencil sharpeners, staplers and other } \\
\text { office equipment) }\end{array}$ & 339942 & Lead Pencil and Art Good Manufacturing & \\
\hline 3612 & $\begin{array}{l}\text { Power, Distribution, and Specialty } \\
\text { Transformers }\end{array}$ & 335311 & $\begin{array}{l}\text { Power, Distribution, and Specialty Transformer } \\
\text { Manufacturing }\end{array}$ & \\
\hline 3613 & $\begin{array}{l}\text { Switchgear and Switchboard } \\
\text { Apparatus }\end{array}$ & 335313 & $\begin{array}{l}\text { Switchgear and Switchboard Apparatus } \\
\text { Manufacturing }\end{array}$ & \\
\hline 3621 & Motors and Generators & 335312 & Motors and Generator Manufacturing & \\
\hline 3624 & Carbon and Graphite Products & 335991 & Carbon and Graphite Product Manufacturing & \\
\hline 3625 & Relays and Industrial Controls & 335314 & Relay and Industrial Control Manufacturing & \\
\hline 3629 & $\begin{array}{l}\text { Electrical Industrial Apparatus, Not } \\
\text { Elsewhere Classified }\end{array}$ & 335999 & $\begin{array}{l}\text { All Other Miscellaneous Electrical Equipment } \\
\text { and Component Manufacturing }\end{array}$ & \\
\hline 3631 & Household Cooking Equipment & 335221 & Household Cooking Appliance Manufacturing & \\
\hline 3632 & $\begin{array}{l}\text { Household Refrigerators and Home } \\
\text { and Farm Freezers }\end{array}$ & 335222 & $\begin{array}{l}\text { Household Refrigerator and Home Freezer } \\
\text { Manufacturing }\end{array}$ & \\
\hline 3633 & Household Laundry Equipment & 335224 & Household Laundry Equipment Manufacturing & \\
\hline \multirow[t]{3}{*}{3634} & $\begin{array}{l}\text { Electric Housewares and Fans } \\
\text { (wall and baseboard heating units for } \\
\text { permanent installation) }\end{array}$ & 333414 & $\begin{array}{l}\text { Heating Equipment (except Warm Air } \\
\text { Furnaces) Manufacturing }\end{array}$ & \\
\hline & $\begin{array}{l}\text { (except wall and baseboard heating } \\
\text { units for permanent installation, } \\
\text { electronic cigarette lighters, and wall } \\
\text { mount restroom hand dryers) }\end{array}$ & 335211 & $\begin{array}{l}\text { Electric Housewares and Household Fan } \\
\text { Manufacturing }\end{array}$ & \\
\hline & (electronic cigarette lighters) & 339999 & All Other Miscellaneous Manufacturing & \\
\hline 3635 & Household Vacuum Cleaners & 335212 & Household Vacuum Cleaner Manufacturing & \\
\hline 3639 & $\begin{array}{l}\text { Household Appliances, Not } \\
\text { Elsewhere Classified } \\
\text { (household sewing machines) }\end{array}$ & 333298 & All Other Industrial Machinery Manufacturing & \\
\hline
\end{tabular}




\begin{tabular}{|c|c|c|c|c|}
\hline & $\begin{array}{r}\text { (floor waxing and floor polishing } \\
\text { machines) }\end{array}$ & 335212 & Household Vacuum Cleaner Manufacturing & \\
\hline 3643 & Current-Carrying Wiring Devices & 335931 & Current-Carrying Wiring Device Manufacturing & \\
\hline 3644 & $\begin{array}{l}\text { Noncurrent-Carrying Wiring Devices } \\
\text { (fish wire, electrical wiring tool) }\end{array}$ & 332212 & Hand and Edge Tool Manufacturing & $\begin{array}{l}\text { Any facility whose primary activity is } \\
\text { manufacturing fish wire, electrical } \\
\text { wiring tool (SIC } 3644 \text { / NAICS } \\
332212 \text { ) should be regulated under } \\
\text { Sector AA, but may continue to be } \\
\text { regulated under Sector AC, or } \\
\text { alternatively, under Sector AD. Sector } \\
\text { AA applies additional technology- } \\
\text { based effluent limits comprising good } \\
\text { housekeeping measures, spill } \\
\text { prevention and response, and spills } \\
\text { and leaks; additional SWPPP } \\
\text { requirements; and additional } \\
\text { inspection requirements. Sector AC } \\
\text { does not apply additional sector- } \\
\text { specific requirements and EPA may } \\
\text { establish facility-specific monitoring } \\
\text { and reporting requirements under } \\
\text { Sector AD. } \\
\text { Regulatory burden would be greater } \\
\text { under Sector AA. }\end{array}$ \\
\hline & (except fishwire, electrical wiring tool) & 335932 & $\begin{array}{l}\text { Noncurrent-Carrying Wiring Device } \\
\text { Manufacturing }\end{array}$ & \\
\hline 3645 & Residential Electric Lighting Fixtures & 335121 & $\begin{array}{l}\text { Residential Electric Lighting Fixture } \\
\text { Manufacturing }\end{array}$ & \\
\hline 3646 & $\begin{array}{l}\text { Commercial, Industrial, and } \\
\text { Institutional Electric Lighting Fixtures }\end{array}$ & 335122 & $\begin{array}{l}\text { Commercial, Industrial, and Institutional } \\
\text { Electric Lighting Fixture Manufacturing }\end{array}$ & \\
\hline 3647 & Vehicular Lighting Equipment & 336321 & Vehicular Lighting Equipment Manufacturing & \\
\hline 3648 & $\begin{array}{l}\text { Lighting Equipment, Not Elsewhere } \\
\text { Classified }\end{array}$ & 335129 & Other Lighting Equipment Manufacturing & \\
\hline 3651 & $\begin{array}{l}\text { Household Audio and Video } \\
\text { Equipment }\end{array}$ & 334310 & Audio and Video Equipment Manufacturing & \\
\hline
\end{tabular}




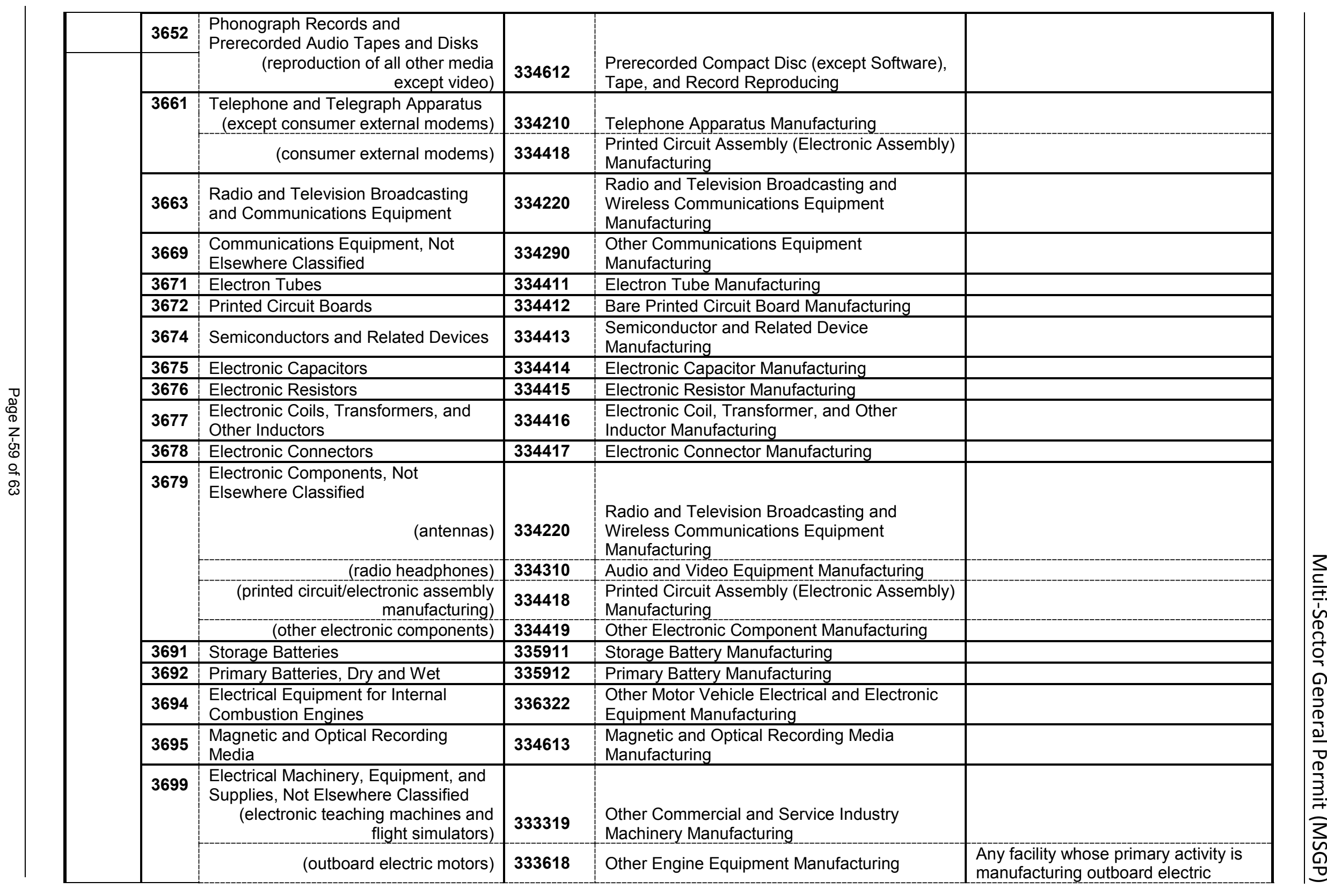




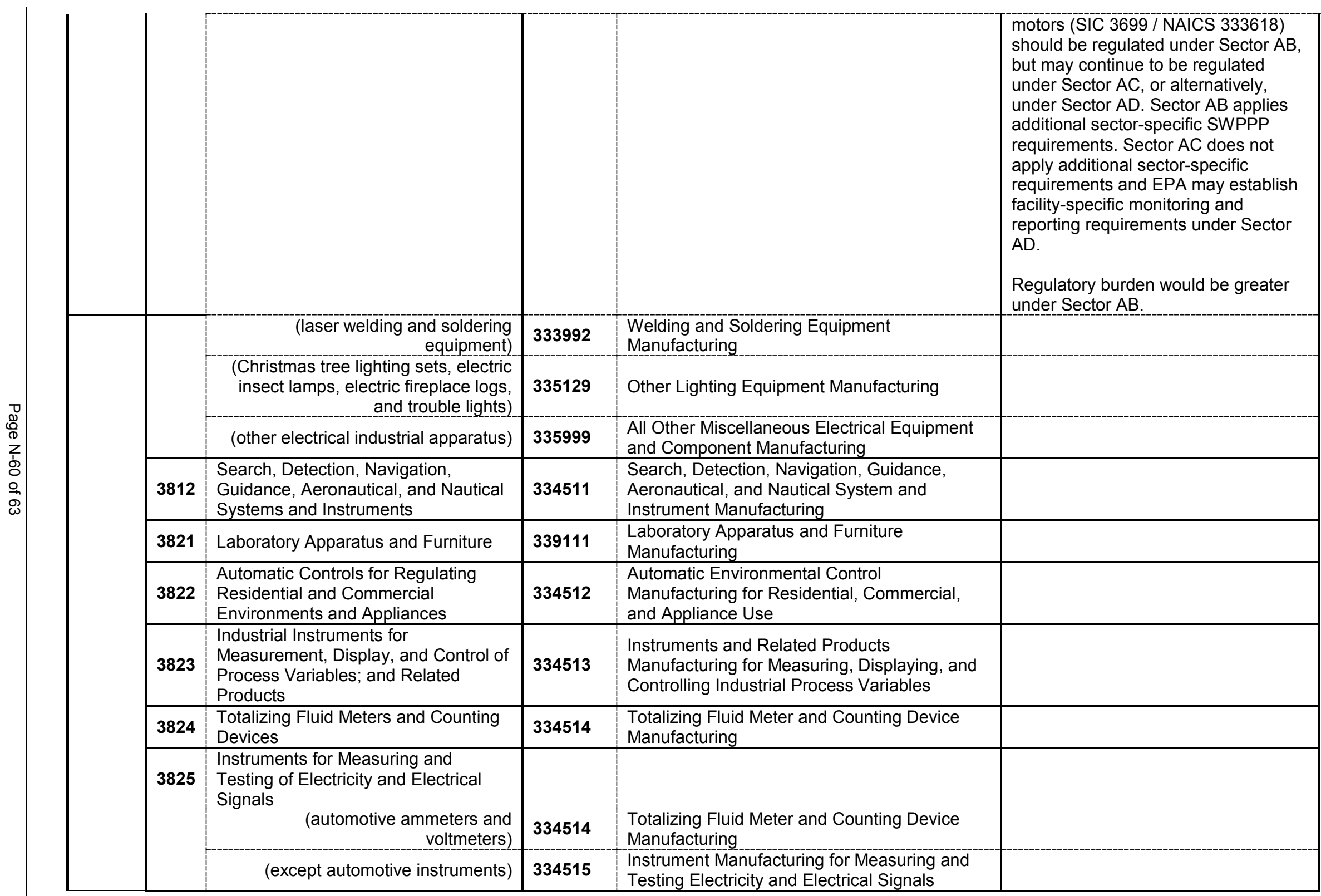




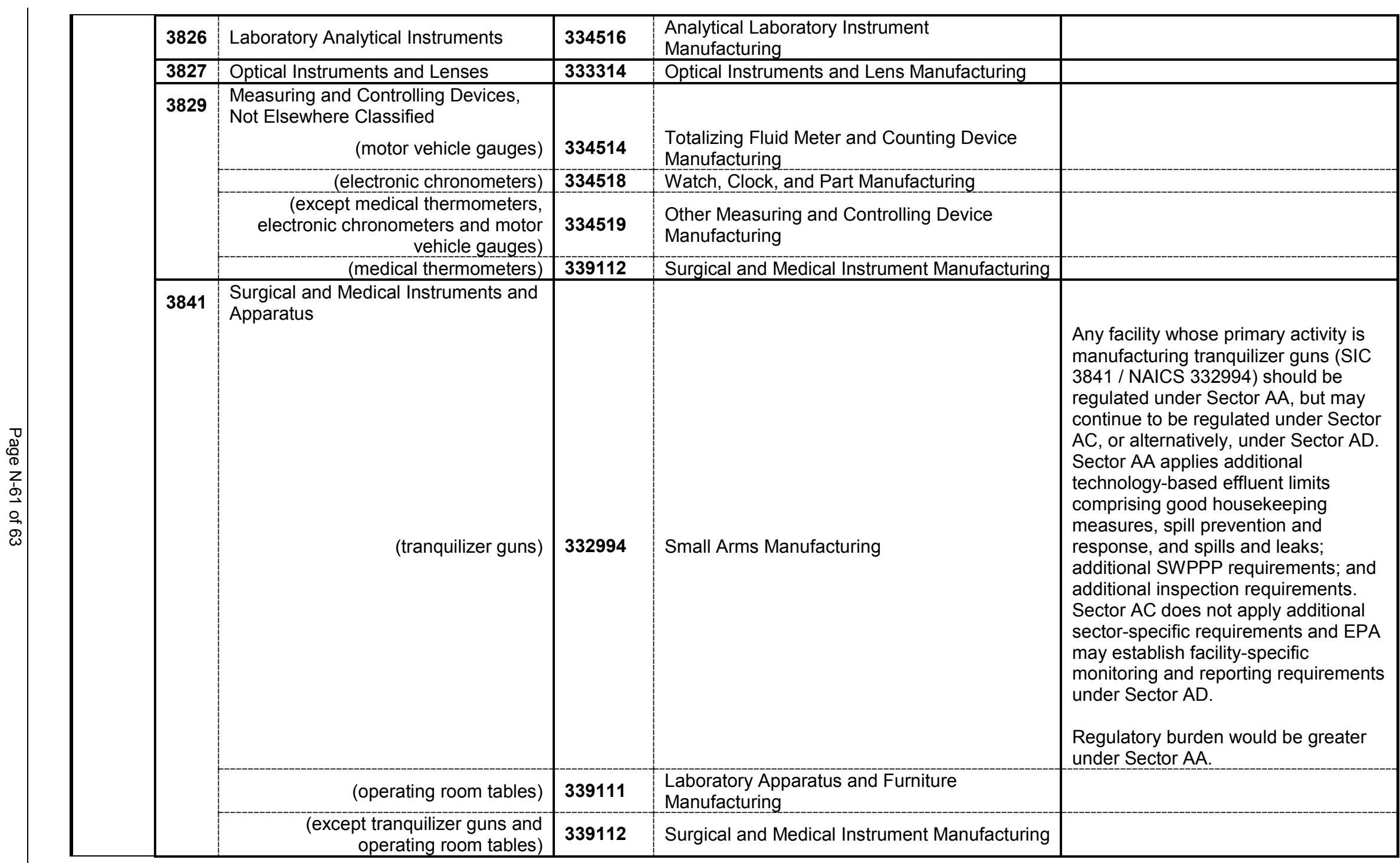




\begin{tabular}{|c|c|c|c|c|}
\hline 3842 & $\begin{array}{l}\text { Orthopedic, Prosthetic, and Surgical } \\
\text { Appliances and Supplies } \\
\text { (incontinent pads and bed pads) }\end{array}$ & 322291 & Sanitary Paper Product Manufacturing & $\begin{array}{l}\text { Any facility whose primary activity is } \\
\text { manufacturing incontinent pads and } \\
\text { bed pads (SIC } 3842 \text { / NAICS } 322291 \text { ) } \\
\text { should be regulated under Sector B, } \\
\text { but may continue to be regulated } \\
\text { under Sector AC, or alternatively, } \\
\text { under Sector AD. Sectors B and AC } \\
\text { do not apply additional sector-specific } \\
\text { requirements. EPA may require } \\
\text { additional facility-specific monitoring } \\
\text { and reporting requirement under } \\
\text { Sector AD. } \\
\text { Regulatory burden is not expected to } \\
\text { differ between Sectors B and AC. }\end{array}$ \\
\hline & (electronic hearing aids) & 334510 & $\begin{array}{l}\text { Electromedical and Electrotherapeutic } \\
\text { Apparatus Manufacturing }\end{array}$ & \\
\hline & $\begin{array}{r}\text { (except electronic hearing aids, } \\
\text { incontinent pads, anatomical models, } \\
\text { and bed pads) }\end{array}$ & 339113 & $\begin{array}{l}\text { Surgical Appliance and Supplies } \\
\text { Manufacturing }\end{array}$ & \\
\hline & (anatomical models) & 339999 & All Other Miscellaneous Manufacturing & \\
\hline 3843 & Dental Equipment and Supplies & 339114 & Dental Equipment and Supplies Manufacturing & \\
\hline 3844 & $\begin{array}{l}\text { X-Ray Apparatus and Tubes and } \\
\text { Related Irradiation Apparatus }\end{array}$ & 334517 & Irradiation Apparatus Manufacturing & \\
\hline 3845 & $\begin{array}{l}\text { Electromedical and Electrotherapeutic } \\
\text { Apparatus } \\
\text { (except CT and CAT scanners) }\end{array}$ & 334510 & $\begin{array}{l}\text { Electromedical and Electrotherapeutic } \\
\text { Apparatus Manufacturing }\end{array}$ & \\
\hline & (CT and CAT Scanners) & 334517 & Irradiation Apparatus Manufacturing & \\
\hline 3851 & $\begin{array}{l}\text { Ophthalmic Goods } \\
\quad \text { (intraoccular lenses, i.e., surgical } \\
\text { implants) }\end{array}$ & 339113 & $\begin{array}{l}\text { Surgical Appliance and Supplies } \\
\text { Manufacturing }\end{array}$ & \\
\hline & (except intraocular lenses) & 339115 & Ophthalmic Goods Manufacturing & \\
\hline 3861 & $\begin{array}{l}\text { Photographic Equipment and } \\
\text { Supplies } \\
\text { (photographic films, paper, plates and } \\
\text { chemicals) }\end{array}$ & 325992 & $\begin{array}{l}\text { Photographic Film, Paper, Plate, and Chemical } \\
\text { Manufacturing }\end{array}$ & \\
\hline & $\begin{array}{l}\text { (except photographic film, paper, } \\
\text { plates, and chemicals) }\end{array}$ & 333315 & $\begin{array}{l}\text { Photographic and Photocopying Equipment } \\
\text { Manufacturing }\end{array}$ & \\
\hline 3873 & $\begin{array}{l}\text { Watches, Clocks, Clockwork } \\
\text { Operated Devices, and Parts }\end{array}$ & 334518 & Watch, Clock, and Part Manufacturing & \\
\hline
\end{tabular}




\begin{tabular}{|c|c|c|}
\hline \multicolumn{3}{|c|}{ Sector AD. Non-Classified Facilities } \\
\hline $\begin{array}{l}\text { Sub- } \\
\text { Sector }\end{array}$ & Narrative Description & Notes \\
\hline AD1 & $\begin{array}{l}\text { Other stormwater discharges designated by the Director } \\
\text { as needing a permit (see } 40 \text { CFR } 122.26(a)(9)(\mathrm{i})(\mathrm{C}) \text { \& (D)) } \\
\text { or any facility discharging stormwater associated with } \\
\text { industrial activity not described by any of Sectors A-AC. } \\
\text { NOTE: Facilities may not elect to be covered under Sector } \\
\text { AD. Only the Director may assign a facility to Sector AD. }\end{array}$ & \\
\hline
\end{tabular}




\section{Appendix O - Summary of Reports Permit Submittals}

\begin{tabular}{|c|c|c|c|c|}
\hline $\begin{array}{l}\text { Permit } \\
\text { Section }\end{array}$ & Report/Submittal & Frequency & Due Date(s) & Where to Submit \\
\hline $\begin{array}{l}\text { Part } \\
1.1 .4 .5\end{array}$ & $\begin{array}{l}\text { Endangered and } \\
\text { Threatened } \\
\text { Species Appendix } \\
\text { E Criterion C } \\
\text { Eligibility Form } \\
\text { (Applicable only } \\
\text { for operators } \\
\text { seeking coverage } \\
\text { under Part } 1.1 .4 .5 \\
\text { eligibility criterion } \\
\text { C). }\end{array}$ & Once, if applicable & $\begin{array}{l}\text { At least } 30 \text { days } \\
\text { prior to submitting } \\
\text { the NOI for permit } \\
\text { coverage }\end{array}$ & $\begin{array}{l}\text { Email to } \\
\text { msgpesa@epa.gov }\end{array}$ \\
\hline Part 1.2 & $\begin{array}{l}\text { New Discharger: } \\
\text { Submittal of } \\
\text { Notice of Intent } \\
\text { (NOI) for Permit } \\
\text { Coverage }\end{array}$ & Once per permit term & $\begin{array}{l}\text { A minimum of } 30 \\
\text { days prior to } \\
\text { commencing } \\
\text { discharge }\end{array}$ & $\begin{array}{l}\text { Electronically using } \\
\text { the NPDES } \\
\text { eReporting Tool } \\
\text { (NeT) for MSGP }\end{array}$ \\
\hline Part 1.2 & $\begin{array}{l}\text { Existing } \\
\text { Discharger: } \\
\text { Submittal of } \\
\text { Notice of Intent } \\
\text { (NOI) for Permit } \\
\text { Coverage }\end{array}$ & Once per permit term & $\begin{array}{l}\text { No later than } \\
\text { Septemer 2, } 2015 . \\
\text { However, if you } \\
\text { have not previously } \\
\text { obtained coverage } \\
\text { under an NPDES } \\
\text { permit, you must } \\
\text { submit your NOI } \\
\text { immediately. } \\
\end{array}$ & $\begin{array}{l}\text { Electronically using } \\
\text { the NPDES } \\
\text { eReporting Tool } \\
\text { (NeT) for MSGP }\end{array}$ \\
\hline Part 1.3 & $\begin{array}{l}\text { Notice of } \\
\text { Termination }\end{array}$ & Once, if applicable & $\begin{array}{l}\text { Within } 30 \text { days } \\
\text { after: } \\
\text { - a new operator } \\
\text { takes over } \\
\text { responsibility for } \\
\text { the facility; or } \\
\text { - operations and } \\
\text { stormwater } \\
\text { discharges have } \\
\text { ceased; or } \\
\text { - for Sector G, H, } \\
\text { or J facilities, the } \\
\text { applicable } \\
\text { termination } \\
\text { requirements } \\
\text { have been met; } \\
\text { or } \\
\text { alternative } \\
\text { permit } \\
\text { coverage has } \\
\text { been obtained }\end{array}$ & $\begin{array}{l}\text { Electronically using } \\
\text { the NPDES } \\
\text { eReporting Tool } \\
\text { (NeT) for MSGP }\end{array}$ \\
\hline Part 1.4 & $\begin{array}{l}\text { Conditional "No } \\
\text { Exposure" } \\
\text { Certification Form }\end{array}$ & If eligible, once every 5 years & As necessary & $\begin{array}{l}\text { Electronically using } \\
\text { the NPDES } \\
\text { eReporting Tool } \\
\text { (NeT) for MSGP }\end{array}$ \\
\hline
\end{tabular}




\begin{tabular}{|c|c|c|c|c|}
\hline $\begin{array}{l}\text { Permit } \\
\text { Section }\end{array}$ & Report/Submittal & Frequency & Due Date(s) & Where to Submit \\
\hline Part 3.1.2 & $\begin{array}{l}\text { Routine Inspection } \\
\text { Documentation }\end{array}$ & At least quarterly & $\begin{array}{l}\text { By the end of the } \\
\text { quarter. }\end{array}$ & $\begin{array}{l}\text { Reports are kept } \\
\text { with SWPPP }\end{array}$ \\
\hline Part 3.2.2 & $\begin{array}{l}\text { Quarterly Visual } \\
\text { Assessment } \\
\text { Documentation }\end{array}$ & At least quarterly & $\begin{array}{l}\text { By the end of the } \\
\text { quarter. }\end{array}$ & $\begin{array}{l}\text { Reports are kept } \\
\text { with SWPPP }\end{array}$ \\
\hline Part 4.4 & $\begin{array}{l}\text { Corrective Action } \\
\text { Documentation }\end{array}$ & $\begin{array}{l}\text { Document existence of } \\
\text { corrective action } \\
\text { condition within } 24 \text { hours } \\
\text { of becoming aware of } \\
\text { the condition } \\
\text { Document corrective } \\
\text { actions taken or to be } \\
\text { taken within } 14 \text { days } \\
\text { from the time of } \\
\text { discovery of the } \\
\text { condition }\end{array}$ & As necessary & $\begin{array}{l}\text { Reports are kept } \\
\text { with SWPPP }\end{array}$ \\
\hline $\begin{array}{l}\text { Part } 5 \\
\text { Part } 7.3\end{array}$ & $\begin{array}{l}\text { Stormwater } \\
\text { Pollution } \\
\text { Prevention Plan } \\
\text { (SWPPP) }\end{array}$ & $\begin{array}{l}\text { - Provide URL for SWPPP or } \\
\text { provide SWPPP } \\
\text { information directly on } \\
\text { the NOI form. } \\
\text { - Update the on-site } \\
\text { SWPPP as site conditions } \\
\text { indicate. At minimum, } \\
\text { the SWPPP must be } \\
\text { modified based on } \\
\text { corrective actions and } \\
\text { deadlines required under } \\
\text { Part 4.2. }\end{array}$ & $\begin{array}{l}\text { Develop initial } \\
\text { SWPPP prior to the } \\
\text { submittal of NOI } \\
\text { form. } \\
\text { Update the SWPPP } \\
\text { information } \\
\text { included on URL or } \\
\text { on NOI form, at a } \\
\text { minimum, no later } \\
\text { than } 45 \text { days after } \\
\text { conducting the } \\
\text { final routine facility } \\
\text { inspection for the } \\
\text { year. }\end{array}$ & $\begin{array}{l}\text { Electronically using } \\
\text { the NPDES } \\
\text { eReporting Tool } \\
\text { (NeT) for MSGP }\end{array}$ \\
\hline $\begin{array}{l}\text { Part } 6 \\
\text { Part } 7.4\end{array}$ & $\begin{array}{l}\text { Discharge } \\
\text { Monitoring Reports } \\
\text { (DMRs) }\end{array}$ & $\begin{array}{ll}\text { - } & \text { 1/quarter for benchmark } \\
\text { monitoring } \\
\text { - } 1 / \text { year for numeric } \\
\text { effluent limitation } \\
\text { monitoring } \\
\text { - } 1 / \text { year for impaired } \\
\text { waters monitoring } \\
\end{array}$ & $\begin{array}{l}\text { Within } 30 \text { days of } \\
\text { receiving your full } \\
\text { laboratory results } \\
\text { for all monitored } \\
\text { outfalls during the } \\
\text { reporting period. }\end{array}$ & $\begin{array}{l}\text { Electronically using } \\
\text { NetDMR }\end{array}$ \\
\hline Part 7.5 & Annual Report & 1/year & By January 30th & $\begin{array}{l}\text { Electronically using } \\
\text { the NPDES } \\
\text { eReporting Tool } \\
\text { (NeT) for MSGP }\end{array}$ \\
\hline Part 7.6 & $\begin{array}{l}\text { Exceedance } \\
\text { Report for Numeric } \\
\text { Effluent Limitations }\end{array}$ & If applicable & $\begin{array}{l}30 \text { days after lab } \\
\text { results if } 30-d a y \\
\text { follow-up } \\
\text { monitoirng } \\
\text { indicates } \\
\text { exceedance }\end{array}$ & $\begin{array}{l}\text { Follow-up } \\
\text { monitoring } \\
\text { submitted } \\
\text { Electronically using } \\
\text { NetDMR } \\
\text { Exceedance eports } \\
\text { submitted directly } \\
\text { to the EPA Regional } \\
\text { Office listed in Part } \\
\text { 7.9.1 of the permit }\end{array}$ \\
\hline
\end{tabular}


Multi-Sector General Permit (MSGP)

\begin{tabular}{|c|l|l|l|l|}
\hline $\begin{array}{c}\text { Permit } \\
\text { Section }\end{array}$ & Report/Submittal & Frequency & Due Date(s) & Where to Submit \\
\hline Part 7.7 & $\begin{array}{l}\text { Additional } \\
\text { Reporting } \\
\text { (Noncompliance } \\
\text { endangering } \\
\text { health, reportable } \\
\text { quantity spills, } \\
\text { etc.) }\end{array}$ & As necessary & Varies - see Part 7.7 & \\
\hline
\end{tabular}




\section{Appendix P - List of Federal CERCLA Sites}

Part 1.1.4.10 of the MSGP has special requirements for discharges to a federal CERCLA site. ${ }^{3}$

If your facility discharges to one of the federal CERCLA sites listed below, you are ineligible for coverage under this permit, unless you notify the EPA Regional Office in advance and the EPA Regional Office determines that you are eligible for permit coverage. In determining eligibility for coverage under Part 1.1.4.10, the EPA Regional Office may evaluate whether you have included appropriate controls and implementation procedures designed to ensure your discharge will not lead to recontamination of aquatic media at the CERCLA Site, such that it would cause or contribute to a water quality standard exceedance. If it is determined that your facility discharges to a CERCLA Site listed below after you have obtained coverage under this permit, you must contact your applicable EPA Regional Office to develop appropriate controls and/or implementation procedures, as necessary, to ensure that your discharges will not lead to recontamination of aquatic media at the CERCLA Site such that they would cause or contribute to a water quality standard exceedance.

\section{EPA Region 10}

The CERCLA Sites and the receiving waters associated with these sites to which the requirements of Part 1.1.4.10 apply are listed in the table below. The areas where the permit applies are enumerated in Appendix C of the permit. For maps of CERCLA sites in Region 10 identified within this table, please check the Region 10 Superfund list viewable at

http://yosemite.epa.gov/R10/cleanup.nsf/sites/cleanuplist.

Operators who discharge / intend to discharge into the receiving waters listed below must first contact the EPA Regional Office before submitting an NOI. Contact information is viewable at: http://yosemite.epa.gov/r10/water.nsf/Stormwater/industrial/.

Similarly, if you have received notice from EPA that the facility to be covered under the MSGP is considered a potential source to a clean up site, you must first contact the Regional EPA office before submitting an NOI.

\begin{tabular}{|l|l|l|}
\hline & $\begin{array}{l}\text { Waterbody } \\
\text { (HUC code/Watershed) }\end{array}$ & $\begin{array}{l}\text { Superfund Sites } \\
\text { CERCLIS ID } \\
\text { Latitude / Longitude } \\
\text { Major Contaminants }\end{array}$ \\
\hline ID & $\begin{array}{l}\text { St. Joe River; Coeur } \\
\text { d'Alene Lake Basin }\end{array}$ & $\begin{array}{l}\text { St. Maries Creosote } \\
\text { IDSFN1002095 } \\
47.191697 /-116.343000 \text { LPAHS, HPAHs }\end{array}$ \\
\hline
\end{tabular}

3 "CERCLA site" means a facility as defined in Section 101 (9) of the Comprehensive Environmental Response, Compensation and Liability ACt (CERCLA), 42 U.S.C. § 9601 (9), that is undergoing a remedial investigation and feasibility study, or for which a Record of Decision for remedial action has been issued in accordance with the National Contingency Plan, 40 C.F.R. Part 300. 


\begin{tabular}{|c|c|c|}
\hline WA & $\begin{array}{l}\text { Commencement Bay, } \\
\text { Puget Sound }\end{array}$ & $\begin{array}{l}\text { Commencement Bay, Near Shore/Tide Flats } \\
\text { WAD980726368 } \\
\text { 47.155998 / - } 122.245998 \text { Dioxins, furans, arsenic, copper, lead, zinc, 4-methyl-phenol, Hex-CB, HPAHs, } \\
\text { PCBs, PCE, cadmium, mercury, LPAHs }\end{array}$ \\
\hline WA & $\begin{array}{l}\text { Duwamish Waterway; } \\
\text { Elliott Bay; Puget Sound }\end{array}$ & $\begin{array}{l}\text { Harbor Island (Lead) } \\
\text { WAD980722839 } \\
\text { 47.344584 / -122.210792Lead, arsenic, copper, HPAHs, LPAHs, mercury,PCBs, zinc, TBT }\end{array}$ \\
\hline WA & Clam Bay; Puget Sound & $\begin{array}{l}\text { Old Navy Dump/ Manchester Lab } \\
\text { WA8680030931 } \\
\text { 47.342798 / -122.325298 } \\
\text { PCBs, copper, lead, zinc, silver, 2,4-dimethyl-phenol, PCBs }\end{array}$ \\
\hline WA & Elliott Bay; Puget Sound & $\begin{array}{l}\text { Pacific Sound Resources } \\
\text { WAD009248287 } \\
\text { 47.345639/-122.215998LMWPAHs, HMWPAHs, PCBs }\end{array}$ \\
\hline WA & Columbia River & $\begin{array}{l}\text { Upper Columbia River (T2) } \\
\text { WASFN1002171 } \\
47.5722 /-118.5846 \\
\end{array}$ \\
\hline WA & Puget Sound & $\begin{array}{l}\text { Puget Sound Naval Shipyard } \\
\text { WA2170023418 } \\
47.333298 /-122.384999 \text { PCBs, mercury } \\
\end{array}$ \\
\hline WA & Puget Sound & $\begin{array}{l}\text { Wycoff / Eagle Harbor } \\
\text { WAD009248295 } \\
47.371798 /-122.310012 \text { Mercury, LPAHs, HPAHs, } \\
\end{array}$ \\
\hline WA & $\begin{array}{l}\text { Duwamish Waterway; } \\
\text { Elliott Bay; Puget Sound }\end{array}$ & $\begin{array}{l}\text { Lower Duwamish Waterway (T2) } \\
\text { WA0002329803 } \\
47.321608 /-122.194040 \text { PCBs, PAHs, phthalates, inorganics, mercury, semi-VOCs }\end{array}$ \\
\hline
\end{tabular}


Notice of Intent 


\section{Environmental Protection Division}

Environmental Compliance Programs (ENV-CP)

PO Box 1663, K490

Los Alamos, New Mexico 87545

(505) 667-0666

Date: OCT 292015

Symbol: ENV-DO-15-0309

LA-UR: 15-28383

Locates Action No.: $\quad$ N/A

Mr. Brent Larsen

Water Quality Protection Division (6WQ)

U.S. Environmental Protection Agency, Region 6

1445 Ross Avenue, Suite 1200

Dallas, TX 75202-2733

Dear Mr. Larsen:

Subject: National Pollutant Discharge Elimination System (NPDES) Permit Tracking No. NMR053195, Multi-Sector General Permit (MSGP) Notice of Intent (NOI) Reporting Pursuant to Part B.12.H.

In submitting a NOI for coverage under the new NPDES Multi-Sector General Permit, Los Alamos National Security (LANS) experienced significant problems with EPA's NeT NPDES eReporting Tool which resulted in certification of the NOI on September 3 and initial submission of a NOI with incomplete outfall attribute data and incorrect information. During this time LANS staff contacted EPA's NOI Processing Center for support and was given the recommendation to contact Region 6 personnel for further guidance. Per this direction, on September 1, 2015, Terrill Lemke left you a voicemail summarizing the issues and potential impacts of the difficulties experienced with the new electronic reporting system. For additional clarification, the following is a summary of the timeline of events associated with the NOI submission.

- Monday, August 31, 2015

- Initiated NOI submission using the NeT NPDES eReporting Tool. 
- As data was entered into each data field on the NOI form, the Tool was very slow in processing the data and allowing entry into the next field. This created a significant waiting time.

- Upon reaching the fields on the NOI form where outfall attribute data was entered the Tool began to randomly crash, repeatedly deleting all unsaved data.

- Tuesday, September 1, 2015

- Tool continued to be very slow and randomly crash, repeatedly deleting all unsaved data.

- For each outfall, when listing the constituents associated with impaired waters, the Tool's auto population feature initially displayed incorrect data which required additional editing and then eventually stopped functioning and caused the Tool to crash.

- Much of the outfall attribute data had to be reentered multiple times before it was possible to successfully save it to the system.

- After each save or Tool crash the eReporting Tool would close the NOI form. The time required for the Tool to repeatedly reopen the form made data entry very time consuming.

- LANS staff contacted the EPA NOI Processing Center on the afternoon of Sept 1 for technical support:

- NOI Processing Center staff stated that they had been "flooded" with calls over the past week on Tool problems.

- LANS staff expressed their concern about the length of time being required to enter data and the potential inability to complete the NOI form by the Sept 2 deadline. No solution was available.

- LANS staff explained the difficulty with entering outfall information for 73 outfalls and NOI Processing Center staff stated that they had received numerous calls on problems with entering outfall data and that some permittees couldn't even enter 20 outfalls.

- NOI Processing Center staff recommended contacting Regional personnel to notify them of the situation and to seek additional guidance.

- The eReporting Tool went down at approximately 3:30 pm MDT and remained down until after $9 \mathrm{pm}$ MDT. This eliminated the opportunity to input data during normal business hours.

- Wednesday, September 2, 2015

- Continued decrease in the performance of the eReporting Tool.

- Increase in the time for the Tool to process information after entry of each item of data.

- Increased frequency in the Tool crashing.

- For each outfall, when listing the constituents associated with impaired waters, the form had to be saved after entry of each individual constituent. Entry of more than one constituent without saving would cause the Tool to crash. 
- With the decreased performance of the eReporting Tool LANS staff contacted the EPA NOI Processing Center for direction and Processing Center staff stated the following:

- They were aware of the problems with the Tool but could provide no solutions or technical direction.

- They had been reporting daily to EPA on the problems and EPA was definitely aware of the issues.

- When asked about taking the Tool down at 3:30 MDT on Sept. 1, staff stated that they thought the programmers may have taken the system down to assess the problems.

- Stated again that they had received many calls about technical issues with the Tool.

- The more data that was entered the slower the Tool would get.

- When asked again about the possibility that LANS may not be able to get all information into the NOI, staff stated that LANS would be able to access the submitted NOI to modify/add data after the 30 day waiting period.

- eReporting Tool went down again at 3:30 pm MDT and did not come back up until after 10 pm MDT, again eliminating the opportunity to input data during normal business hours.

- The LANS NOI with all information except some remaining outfall attribute data was submitted by the Preparer at 10:50 pm MDT.

- The LANS NOI certification signatory was prepared to certify the NOI at this time but didn't get notification that the NOI was ready for certification until 9:37 am MDT on Sept. 3, almost 11 hours later.

- The NOI was certified on Sept 3, 2015.

Additionally, the NeT NPDES eReporting Tool did not provide dissolved Thallium as a constituent option, but only allowed the selection of total Thallium as an impaired water pollutant under a "Cause Group" when "Metals (other than Mercury)" was selected from the drop down menu. This resulted in LANS having to enter total Thallium as an impaired water pollutant in error for the following outfalls: 002, 005, $006,007,008,009,010,011,012,016,017,018,019$, and 020 . LANS appreciates any assistance you may have relative to the total Thallium vs. dissolved Thallium issue. During a subsequent quality assurance evaluation, LANS staff also determined that total Copper was erroneously entered as an impaired water pollutant for outfall 051 and needs to be deleted from the NOI.

LANS is committed to maintaining compliance with the MSGP requirements. Per Section B.12.H of the MSGP, the LANS NOI will be modified to include the remaining outfall attribute data that could not be included on the initial submission and to delete Copper as an impaired water pollutant for outfall 051. LANS coverage under the 2015 MSGP became effective on October 3, 2015, and with the NOI now accessible, actions to update the NOI have been initiated. 
Any additional direction or guidance you may have would be appreciated. Please contact Terrill W. Lemke at (505) 665-2397 of the Environmental Compliance Programs (ENV-CP) if you have any questions.

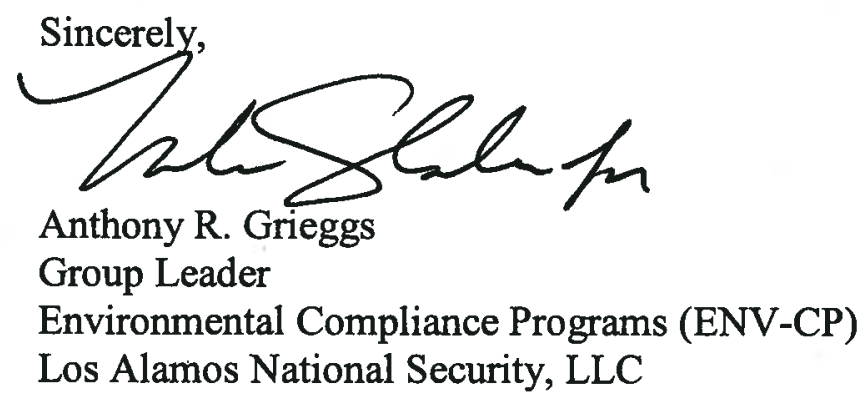

\section{ARG:MTS:TWL:HLW/lm}

Cy: Nasim Jahan, USEPA/Region 6, Dallas, TX, (E-File)

Bruce Yurdin, NMED/SWQB, Santa Fe, NM, (E-File)

Gene E. Turner, LASO-NS-LP, (E-File)

Jordan Amswald, LASO-NS-PI, (E-File)

Kirsten Laskey, EM-LA, (E-File)

Craig Leasure, PADOPS, (E-File)

Amy E. De Palma, PADOPS, (E-File)

Michael T. Brandt, ADESH, (E-File)

Raeanna Sharp-Geiger, ADESH, (E-File)

Alison M. Dorries, ENV-DO, (E-File)

Michael T. Saladen, ENV-CP, (E-File)

Terrill W. Lemke, ENV-CP, (E-File)

Holly L. Wheeler, ENV-CP, (E-File)

Timothy A. Dolan, LC-ESH, (E-File)

lasomailbox@nnsa.doe.gov,(E-File)

locatesteam@lanl.gov, (E-File)

env-correspondence@lanl.gov 


$\begin{array}{ll}\text { From: } & \text { Lemke, Terrill W } \\ \text { To: } & \text { Wheeler, Holly Lynn; Grieggs, Tony } \\ \text { Subject: } & \text { FW: EPA Multi-Sector General Permit (MSGP) Authorization is Active - Los Alamos National Laboratory, NPDES } \\ & \text { ID: NMR053195, NeT Submission ID: MSGP-3095 } \\ \text { Date: } & \text { Monday, October 05, 2015 8:22:15 AM } \\ \text { Attachments: } & \text { AcceptedNewNOI Receipt. pdf }\end{array}$

Terrill Lemke, PE, CPESC, CISEC

Environmental Compliance Programs

Los Alamos National Laboratory

Los Alamos, NM

Office: $505-665-2397$

Cell: $505-699-0725$

From: NeT@epa.gov [mailto: NeT@epa.gov]

Sent: Saturday, October 03, 2015 5:48 PM

To: Dorries, Alison Marie

Cc: Lemke, Terrill W; lee.won@epa.gov; lescure.nasrin@epa.gov; emily@avanticorporation.com; farris.erika@epa.gov; Christiane@avanticorporation.com; bius.catherine@epa.gov

Subject: EPA Multi-Sector General Permit (MSGP) Authorization is Active - Los Alamos National Laboratory, NPDES ID: NMR053195, NeT Submission ID: MSGP-3095

2015-10-03

Your Notice of Intent (NOI) requesting coverage for Los Alamos National Laboratory, PO Box 1663 MS K490 Los Alamos NM 87545 under EPA's Multi-Sector General Permit (MSGP) has been accepted and authorization to discharge under the MSGP became effective at the conclusion of your 30-day waiting period, on 2015-10-03.

For tracking purposes, the following NPDES ID has been assigned to your NOI: NMR053195. Attached to this email, you will find a copy of your completed NOI form. To access your NOI in NeT, please visit: https://cdx.epa.gov/epa home.asp.

As you know, the MSGP requires you to have developed a Stormwater Pollution Prevention Plan (SWPPP) prior to submitting your NOI. The MSGP also includes specific requirements for implementing control measures (e.g., minimize exposure, good housekeeping, maintenance, spill prevention and response), conducting self-inspections and visual assessments of your discharges, taking corrective actions, and conducting staff training. You must comply with any specific requirements applicable to your industrial sector(s) in Part 8 and any state/tribal-specific requirements in Part 9 (see http://water.epa.gov/polwaste/npdes/stormwater/EPA-Multi-Sector-General-PermitMSGP.cfm). You are also required to submit an Annual Report in accordance with Part 7.5 of the MSGP that will contain the results from your past year's routine facility inspections, quarterly visual assessments, and corrective actions. Annual Reports must be submitted to EPA through NeT.

The MSGP includes five types of required analytical monitoring, one or more of which may apply to your discharge: 
- Quarterly benchmark monitoring (see Part 6.2.1 and Part 8);

- Annual effluent limitations guidelines monitoring (see Part 6.2.2 and Part 8);

- State- or tribal-specific monitoring (see Part 6.2.3 and Part 9);

- Impaired waters monitoring (see Part 6.2.4); and

- Other monitoring as required by EPA (see Part 6.2.5).

Monitoring requirements in the MSGP (i.e., parameters required to be monitored and sample frequency) will be prepopulated on your electronic Discharge Monitoring Report (DMR) in EPA's NetDMR system, which is accessed at http://www.epa.gov/netdmr/. Where you have determined that no monitoring requirements apply to your discharge, there is no need to access the NetDMR system. In order to obtain access to this system, you must complete the electronic signature process. Please refer to the following guidance for information about submitting monitoring reports through NetDMR:

http://water.epa.gov/polwaste/npdes/stormwater/Stormwater-eNOI-System-for-EPAsMultiSector-General-Permit.cfm.

Please note that this email does not represent a determination by EPA regarding the validity of the information you provided in your NOI. Your eligibility for coverage under this permit is based on the validity of the certification you provided. Your electronic signature on the NOI form certifies that you have read, understood, and are implementing all of the applicable requirements. An important aspect of this certification requires that you have correctly determined whether you are eligible for coverage under this permit.

The 2014 MSGP and additional guidance are available at: http://water.epa.gov/polwaste/npdes/stormwater/EPA-Multi-Sector-General-PermitMSGP.cfm. Please contact your EPA Regional permitting authority at lee.won@epa.gov; lescure.nasrin@epa.gov; emily@avanticorporation.com; farris.erika@epa.gov; Christiane@avanticorporation.com; bius.catherine@epa.gov for more information.

This is an automated response; please do not reply to this email. 
Note: This is a "smart form"; as you fill out the form, additional questions willl appear that you will need to answer.

Permit Information

1. What action would you like to take?*

File a New Notice of Intent Form

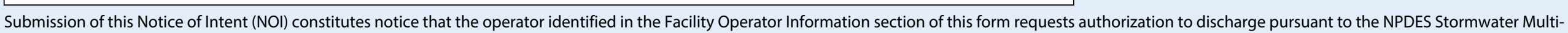

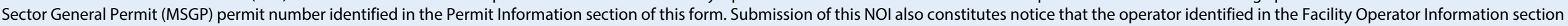

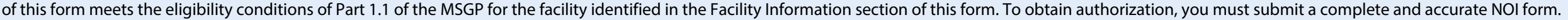
Discharges are not authorized if your NOI is incomplete or inaccurate or if you were never eligible for permit coverage.

Operator Name (Organization Name) *

LOS ALAMOS NATIONAL LABORATORY

Operator Name as Noted by the NOI Preparer

Los Alamos National Security, LLC

2. Select the state/territory where your facility is located * NM

4. Are you requesting coverage as a "federal operator" as defined in Appendix A?*
3. Is your facility located on Indian Country lands? *

- No 
5aa. Provide your most current NPDES ID (i.e., permit tracking number) if you had coverage under EPA's MSGP 2008 or the NPDES permit number if you had coverage under an EPA individual permit*

\section{NMR05GB21}

6. Do you directly discharge to any of the waters of the U.S. that are designated by the state or tribal authority under its antidegradation policy as a Tier 3 water (Outstanding Natural Resource Water) (See Appendix L)? Your project will be considered to discharge to a Tier 3 water if the first water of the US to which you discharge is identified by a state, tribe, or EPA as a Tier 3 water. For $\bigcirc$ Yes discharges that enter a storm sewer system prior to discharge, the first water of the US to which you discharge is the waterbody that receives the stormwater discharge from the storm sewer system. *

7. Does your facility directly discharge to a Federal CERCLA site listed in Appendix P? For the purposes of this permit, a permittee discharges to a Federal CERCLA site if the discharge flows directly into the site through its own conveyance, or through a conveyance owned by others, such as a municipal separate storm sewer system. *

8. Has the Stormwater Pollution Prevention Plan (SWPPP) been prepared in advance of filing this NOI, as required?*

9. By indicating "Yes", I confirm that I understand that the MSGP only authorizes the allowable stormwater discharges in Part 1.1.2 and the allowable non-stormwater discharges in Part 1.1.3. Any discharges not expressly authorized under the MSGP are not covered by the MSGP and they cannot become authorized by disclosure to EPA and/or a state via this Notice of Intent to be covered by the permit or by any other means (e.g., in the Stormwater Pollution Prevention Plan or during an inspection). If any discharges requiring NPDES permit coverage other than the allowable stormwater and non-stormwater discharges listed in Parts 1.1.2 and 1.1.3 will be discharged, they must be covered under another NPDES permit. *

10. Master Permit Number

\section{NMR050000}

\section{A: Facility Operator Information}

1. Operator Name (Organization Name)*

\section{LOS ALAMOS NATIONAL LABORATORY}

\section{Street*}

\section{PO Box 1663}

3. Supplemental Address

MS K490

4. City*

Los Alamos

5. State *

NM

6. Zip Code *

9. Extension

8. Phone (10-digits, No dashes) *

5056671312

Operator point of contact information

11. First Name *

Holly
12. Middle Initial

10. E-Mail*

hbenson@lanl.gov
7. Facility County or Similar Govt. Subdivision*

Los Alamos

B: Facility Information

14. Professional Title *

Environmental Professional 
1. Facility Name*

Los Alamos National Laboratory

$\bigotimes$ Facility address same as facility operator address

\begin{tabular}{|c|c|}
\hline \multicolumn{2}{|c|}{ PO Box 1663} \\
\hline \multicolumn{2}{|c|}{ 3. Supplemental Address } \\
\hline \multicolumn{2}{|c|}{ MS K490 } \\
\hline \multicolumn{2}{|c|}{ 4. City* } \\
\hline \multicolumn{2}{|c|}{ Los Alamos } \\
\hline \multicolumn{2}{|c|}{ Latitude/Longitude for the facility: } \\
\hline & 8. Latitude (Decimal Degrees) * \\
\hline+ & 35.872777 \\
\hline
\end{tabular}

12. What is the ownership type of the facility*

\section{Federal Facility (U.S. Government)}

\begin{tabular}{l} 
5. State $*$ \\
NM \\
\hline
\end{tabular}

6. Zip Code *

87545

7. Facility County or Similar Govt. Subdivision*

Los Alamos

Los Alamos

MSGP, and the 4-digit Standard Industrial Classification (SIC) code or 2-letter Activity Code:

15. Sector*

SECTOR AA: FABRICATED METAL PRODUCTS

9. Longitude (Decimal Degrees) *

10. Latitude/Longitude Data Source*

11. Horizontal Reference Datum

106.321127

Other

WGS84

13. Estimated area of industrial activity at your facility exposed to stormwater (to the nearest quarter acre) *

17. Subsector

AA1: Fabricated Metal Products, Except Machinery and Transportation Equipment, and Coating, Engraving, and Allied Services.

16. Primary SIC Code *

3449: Miscellaneous Metal Work 
18. Identify the applicable sectors(s) of any co-located industrial activity for which you are requesting permit coverage.

\begin{tabular}{l} 
Sector \\
SECTOR P: LAND TRANSPORTATION AND WAREHOUSING \\
Sector \\
\hline SECTOR K: HAZARDOUS WASTE TREATMENT, STORAGE, OR DISPOSAL FACILITIES \\
Sector \\
\hline SECTOR A: TIMBER PRODUCTS \\
Sector \\
\hline SECTOR D: ASPHALT PAVING AND ROOFING MATERIALS AND LUBRICANTS \\
Sector \\
\hline SECTOR O: STEAM ELECTRIC GENERATING FACILITIES \\
Sector \\
\hline SECTOR F: PRIMARY METALS \\
Sector \\
\hline SECTOR N: SCRAP RECYCLING FACILITIES \\
\hline
\end{tabular}

Subsector*

P1: Motor Freight Transportation and Warehousing

Delete Sector

Subsector*

K1: Hazardous Waste Treatment, Storage, or Disposal Facilities, including those that are operati

Delete Sector Subsector*

A4: Wood Products, Not Elsewhere Classified

Delete Sector

Subsector*

D1: Asphalt Paving and Roofing Materials

Delete Sector

Subsector*

O1: Steam Electric Generating Facilities, including coal handling sites

Subsector*

F4: Nonferrous Foundries (Castings)

Delete Sector

Subsector*

N2: Source-separated Recycling Facility

Delete Sector

\section{Add Sector}

22. Is your facility presently inactive and unstaffed? *

$\bigcirc$ Yes No

\section{C: Discharge Information}

1. Does your facility discharge into any saltwater receiving waters? *

2. What is the hardness of your receiving water(s) (see Appendix J) *

Yes

- No

$50-74.99 \mathrm{mg} / \mathrm{L}$

3. Identify if the following Effluent Limitation Guideline(s) apply to any of your discharges

\begin{tabular}{|c|c|c|c|c|}
\hline 40 CFR Part/Subpart: Part 423 & $\begin{array}{l}\text { Eligible Discharges: Coal pile runoff at steam electric } \\
\text { generating facilities }\end{array}$ & Affected MSGP Sector: $O$ & $\begin{array}{l}\text { New Source Date: 11/19/1982, } \\
\text { 10/8/1974 }\end{array}$ & $\begin{array}{l}\text { Does your facility have any } \\
\text { discharges subject to this effluent } \\
\text { limitation guideline? } *\end{array}$ \\
\hline & & & & Yyes \\
\hline \multirow[t]{2}{*}{40 CFR Part/Subpart: Part 429, Subpart I } & \multirow[t]{2}{*}{$\begin{array}{l}\text { Eligible Discharges: Discharges resulting from spray down } \\
\text { or intentional wetting of logs at wet deck storage areas }\end{array}$} & \multirow[t]{2}{*}{ Affected MSGP Sector: A } & \multirow[t]{2}{*}{ New Source Date: 1/26/1981 } & $\begin{array}{l}\text { Does your facility have any } \\
\text { discharges subject to this effluent } \\
\text { limitation guideline? * }\end{array}$ \\
\hline & & & & OYes @No \\
\hline \multirow[t]{2}{*}{40 CFR Part/Subpart: Part 443, Subpart A } & \multirow[t]{2}{*}{ Eligible Discharges: Runoff from asphalt emulsion facilities } & \multirow[t]{2}{*}{ Affected MSGP Sector: D } & \multirow[t]{2}{*}{ New Source Date: 7/28/1975 } & $\begin{array}{l}\text { Does your facility have any } \\
\text { discharges subject to this effluent } \\
\text { limitation guideline? } *\end{array}$ \\
\hline & & & & Yes \\
\hline
\end{tabular}


4. List all of the stormwater outfalls from your facility. Each outfall must be identified by a unique 3-digit ID (e.g., 001, 002) or a 4-digit ID. Also provide the latitude and longitude in decimal degrees for each outfall.

A. Outfall ID*

B. Latitude (Decimal Degrees)*

002

35.875801

C. Longitude (Decimal Degrees) *

106.327538

\section{Lookup Receiving Waters Information}

Delete Outfal (This button will prepopulate the receiving water information

associated with your outfall on your form. You may edit the information that is returned if you believe it is incorrect)

If for any reason the Lookup Receiving Water Information button does not prepopulate your form with receiving waters information, you must manually enter the information on your form.

Outfall Section

1. Provide the name of the first water of the U.S that receives stormwater directly from the outfall and/or from the MS4 that the outfall discharges to.

(You may edit the name of the water of the U.S. that was returned if incorrect.) *

SANDIA CANYON (SIGMA CANYON TO NPDES OUTFALL 001)

2. Is the receiving water listed as impaired on the 303(d) list and in need of a TMDL?*

Yes

No

4. List the pollutants that are causing the impairment:

Pollutant

Aluminum, total [as Al]

Delete Pollutant

Pollutant

Copper, total [as Cu]

Delete Pollutant

Pollutant

Alpha, total

Delete Pollutant

Pollutant

PCB IN WATER COLUMN

Delete Pollutant

Please select the cause group and pollutant for which the waterbody is impaired:

Cause Group *

Pollutant*

METALS (OTHER THAN MERCURY) 
3. Has a TMDL been completed for this receiving waterbody? *

Yes

- No

Outfalls

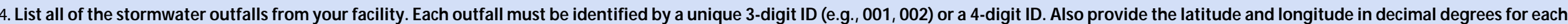
outfall.

A. Outfall ID *

003

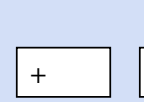

B. Latitude (Decimal Degrees) *

35.876369

D. Substantially Identical to Any Outfalls Listed Above?*

(-) Yes

No

E. Substantially identical to outfall ID *

C. Longitude (Decimal Degrees) *

106.326492

002
Lookup Receiving Waters Information

(This button will prepopulate the receiving water information associated with your outfall on your form. You may edit the information that is returned if you believe it is incorrect)

If for any reason the Lookup Receiving Water Information button does not prepopulate your form with receiving waters information, you must manually enter the information on your form.

5. Multiple Receiving Waters were returned for your outfall. Please select the receiving water that is associated with your outfall from this list: *

LOS ALAMOS CANYON (DP CANYON TO UPPER LANL BND)

Outfall Section

1. Provide the name of the first water of the U.S that receives stormwater directly from the outfall and/or from the MS4 that the outfall discharges to.

(You may edit the name of the water of the U.S. that was returned if incorrect.)*

LOS ALAMOS CANYON (DP CANYON TO UPPER LANL BND)

2. Is the receiving water listed as impaired on the 303(d) list and in need of a TMDL? *

- Yes $\bigcirc$ No

4. List the pollutants that are causing the impairment:

Pollutant

Aluminum, total [as Al]

\section{Delete Pollutant}

Pollutant

Alpha, total

Delete Pollutant

Pollutant

PCB IN WATER COLUMN 
Delete Pollutant

Please select the cause group and pollutant for which the waterbody is impaired:

Cause Group *

Pollutant*

MERCURY

Add Impairment Pollutant Associated with this Waterbody

3. Has a TMDL been completed for this receiving waterbody? *

Yes

- No

Outfalls

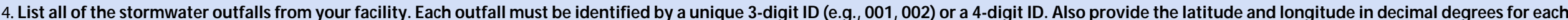
outfall.

A. Outfall ID*

Latitude (Decimal Degrees) *

005

35.873908

C. Longitude (Decimal Degrees) *

106.320709

Lookup Receiving Waters Information

Delete Outfal

D. Substantially Identical to Any Outfalls Listed Above?*

This button will prepopulate the receiving water information

ssociated with your outfall on your form. You may edit the

information that is returned if you believe it is incorrect)

Yes No

If for any reason the Lookup Receiving Water Information button does not prepopulate your form with receiving waters information, you must manually enter the information on your form.

Outfall Section

1. Provide the name of the first water of the U.S that receives stormwater directly from the outfall and/or from the MS4 that the outfall discharges to.

(You may edit the name of the water of the U.S. that was returned if incorrect.) *

SANDIA CANYON (SIGMA CANYON TO NPDES OUTFALL 001)

2. Is the receiving water listed as impaired on the 303(d) list and in need of a TMDL?*

- Yes

No

4. List the pollutants that are causing the impairment:

Pollutant

Aluminum, total [as Al]

Delete Pollutant

Pollutant

Copper, total [as $\mathrm{Cu}$ ]

Delete Pollutant 
Delete Pollutant

Pollutant

\section{PCB IN WATER COLUMN}

Delete Pollutant

Please select the cause group and pollutant for which the waterbody is impaired:

Cause Group *

Pollutant*

METALS (OTHER THAN MERCURY)

Add Impairment Pollutant Associated with this Waterbody

3. Has a TMDL been completed for this receiving waterbody?*

Yes

- No

Outfalls

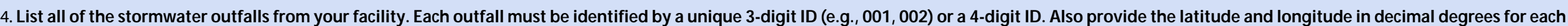
outfall.

A. Outfall ID*

B. Latitude (Decimal Degrees) *

35.874002

006

$+$

D. Substantially Identical to Any Outfalls Listed Above? *

E. Substantially identical to outfall ID *

C. Longitude (Decimal Degrees) *

106.319825

- Yes $\bigcirc$ No

005

If for any reason the Lookup Receiving Water Information button does not prepopulate your form with receiving waters information, you must manually enter the information on your form.

Outfall Section

1. Provide the name of the first water of the U.S that receives stormwater directly from the outfall and/or from the MS4 that the outfall discharges to.

(You may edit the name of the water of the U.S. that was returned if incorrect.) *

SANDIA CANYON (SIGMA CANYON TO NPDES OUTFALL 001)

2. Is the receiving water listed as impaired on the 303(d) list and in need of a TMDL? *

- Yes $\bigcirc$ No

4. List the pollutants that are causing the impairment:

Pollutant

Aluminum, total [as Al] 
Delete Pollutant

Pollutant

Copper, total [as $\mathrm{Cu}]$

Delete Pollutant

Pollutant

Alpha, total

Delete Pollutant

Pollutant

PCB IN WATER COLUMN

Delete Pollutant

Please select the cause group and pollutant for which the waterbody is impaired:

Cause Group *

METALS (OTHER THAN MERCURY)

Pollutant*

\begin{tabular}{|l|l|}
\hline Thallium, total [as TI] & Delete Pollutant \\
\hline
\end{tabular}

Add Impairment Pollutant Associated with this Waterbody

3. Has a TMDL been completed for this receiving waterbody?*

Yes

- No

\section{Outfalls}

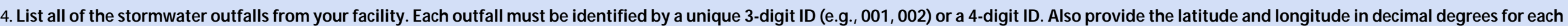
outfall.

A. Outfall ID*

009

B. Latitude (Decimal Degrees) *

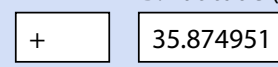

C. Longitude (Decimal Degrees) *

106.319263

\section{Lookup Receiving Waters Information}

(This button will prepopulate the receiving water information associated with your outfall on your form. You may edit the information that is returned if you believe it is incorrect)

D. Substantially Identical to Any Outfalls Listed Above?*

Yes

- No

If for any reason the Lookup Receiving Water Information button does not prepopulate your form with receiving waters information, you must manually enter the information on your form.

Outfall Section 
1. Provide the name of the first water of the U.S that receives stormwater directly from the outfall and/or from the MS4 that the outfall discharges to.

(You may edit the name of the water of the U.S. that was returned if incorrect.) *

SANDIA CANYON (SIGMA CANYON TO NPDES OUTFALL 001)

2. Is the receiving water listed as impaired on the $303(\mathrm{~d})$ list and in need of a TMDL? *

- Yes No

4. List the pollutants that are causing the impairment:

Pollutant

Aluminum, total [as Al]

Delete Pollutant

Pollutant

Copper, total [as $\mathrm{Cu}$ ]

Delete Pollutant

Pollutant

Alpha, total

Delete Pollutant

Pollutant

PCB IN WATER COLUMN

Delete Pollutant

Please select the cause group and pollutant for which the waterbody is impaired:

Cause Group*

Pollutant*

METALS (OTHER THAN MERCURY)

Add Impairment Pollutant Associated with this Waterbody

3. Has a TMDL been completed for this receiving waterbody? *

Yes No

Outfalls

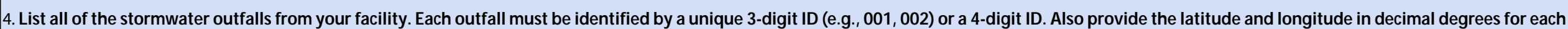
outfall.

A. Outfall ID *

007 


\section{B. Latitude (Decimal Degrees) *}

D. Substantially Identical to Any Outfalls Listed Above?*

- Yes

No
C. Longitude (Decimal Degrees)

106.319009

Lookup Receiving Waters Information

(This button will prepopulate the receiving water information

associated with your outfall on your form. You may edit the

information that is returned if you believe it is incorrect)

E. Substantially identical to outfall ID *

009

If for any reason the Lookup Receiving Water Information button does not prepopulate your form with receiving waters information, you must manually enter the information on your form.

Outfall Section

1. Provide the name of the first water of the U.S that receives stormwater directly from the outfall and/or from the MS4 that the outfall discharges to.

(You may edit the name of the water of the U.S. that was returned if incorrect.) *

SANDIA CANYON (SIGMA CANYON TO NPDES OUTFALL 001)

2. Is the receiving water listed as impaired on the 303(d) list and in need of a TMDL?*

Yes $\bigcirc$ No

4. List the pollutants that are causing the impairment:

Pollutant

Aluminum, total [as Al]

Delete Pollutant

Pollutant

Copper, total [as Cu]

Delete Pollutant

Pollutant

Alpha, total

Delete Pollutant

Pollutant

PCB IN WATER COLUMN

Delete Pollutant

Please select the cause group and pollutant for which the waterbody is impaired:

Cause Group *

METALS (OTHER THAN MERCURY)

Pollutant*

Thallium, total [as TI]

Delete Pollutant 


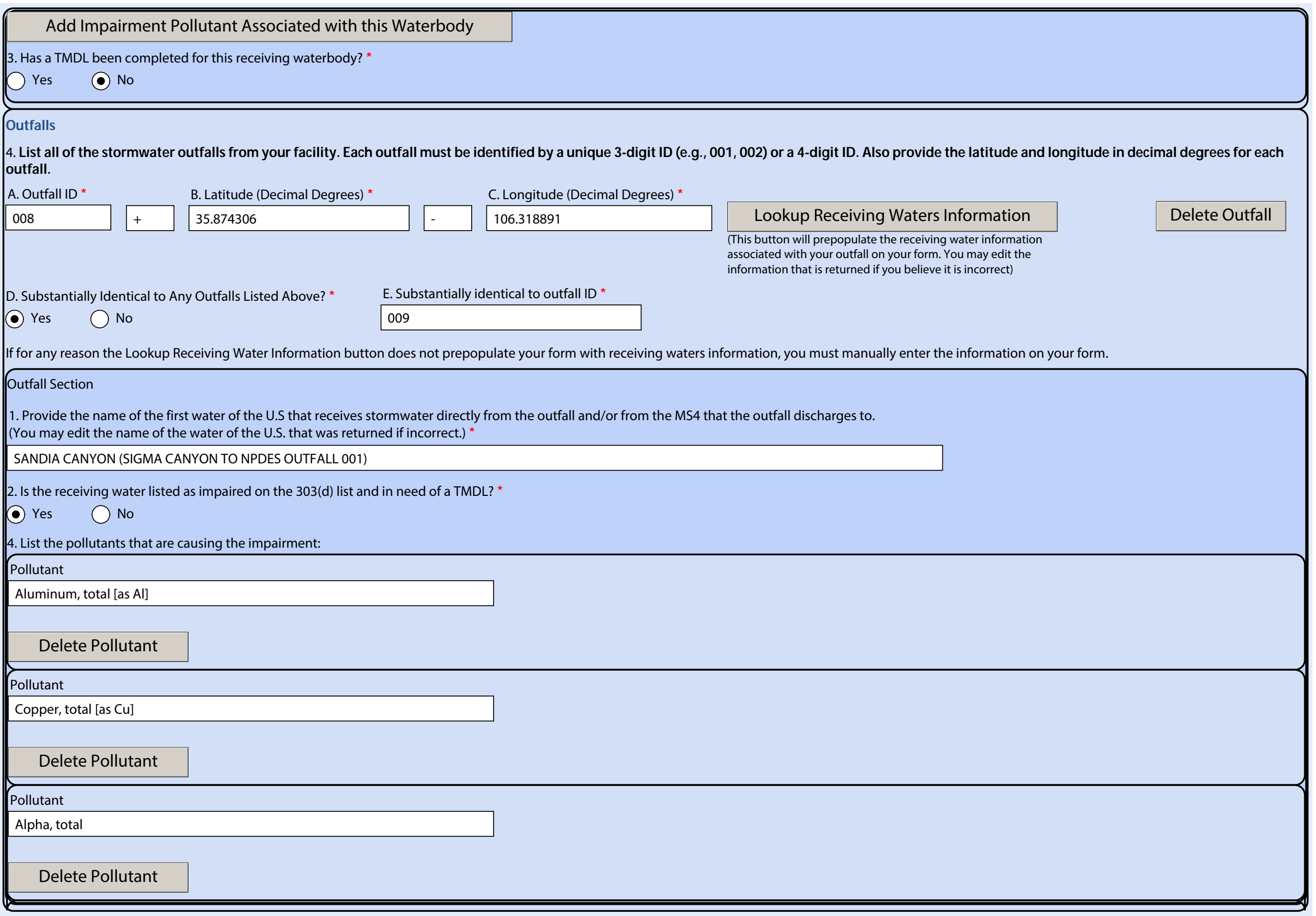




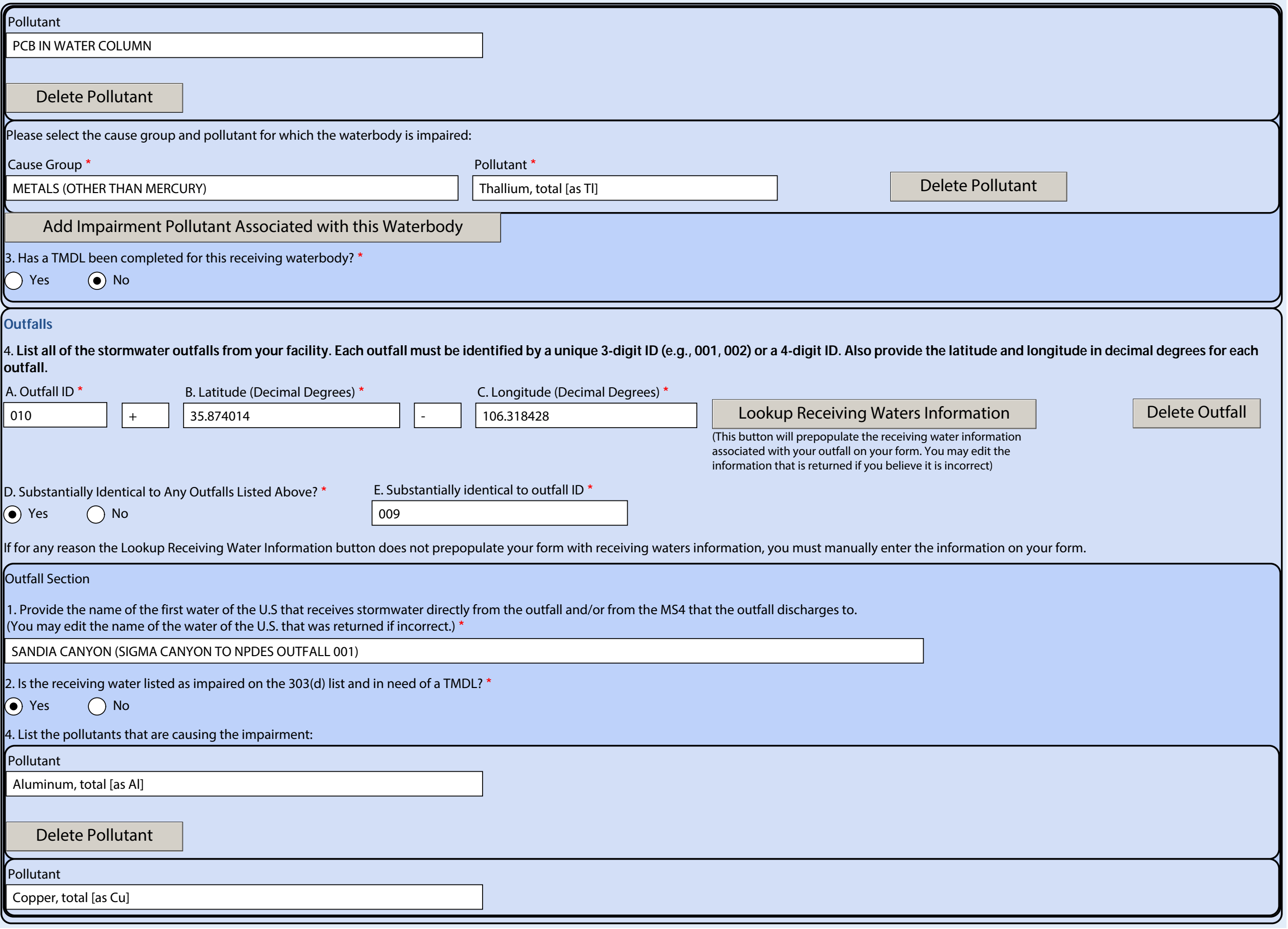


Delete Pollutant

Pollutant

Alpha, total

Delete Pollutant

Pollutant

PCB IN WATER COLUMN

Delete Pollutant

Please select the cause group and pollutant for which the waterbody is impaired:

Cause Group *

METALS (OTHER THAN MERCURY)

Pollutant*

\begin{tabular}{|l|l}
\hline Thallium, total [as TI] & Delete Pollutant \\
\hline
\end{tabular}

Add Impairment Pollutant Associated with this Waterbody

3. Has a TMDL been completed for this receiving waterbody?*

Yes

- No

Outfalls

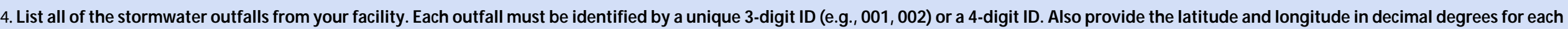
outfall.

A. Outfall ID * B. Latitude (Decimal Degrees) *

011

011

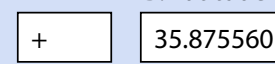

C. Longitude (Decimal Degrees) *

106.320764

\section{Lookup Receiving Waters Information}

(This button will prepopulate the receiving water information

associated with your outfall on your form. You may edit the

Delete Outfall

D. Substantially Identical to Any Outfalls Listed Above? *

E. Substantially identical to outfall ID * information that is returned if you believe it is incorrect)

- Yes No

012

If for any reason the Lookup Receiving Water Information button does not prepopulate your form with receiving waters information, you must manually enter the information on your form.

Outfall Section

1. Provide the name of the first water of the U.S that receives stormwater directly from the outfall and/or from the MS4 that the outfall discharges to.

(You may edit the name of the water of the U.S. that was returned if incorrect.) *

SANDIA CANYON (SIGMA CANYON TO NPDES OUTFALL 001)

2. Is the receiving water listed as impaired on the 303 (d) list and in need of a TMDL?*

- Yes No

4. List the pollutants that are causing the impairment: 


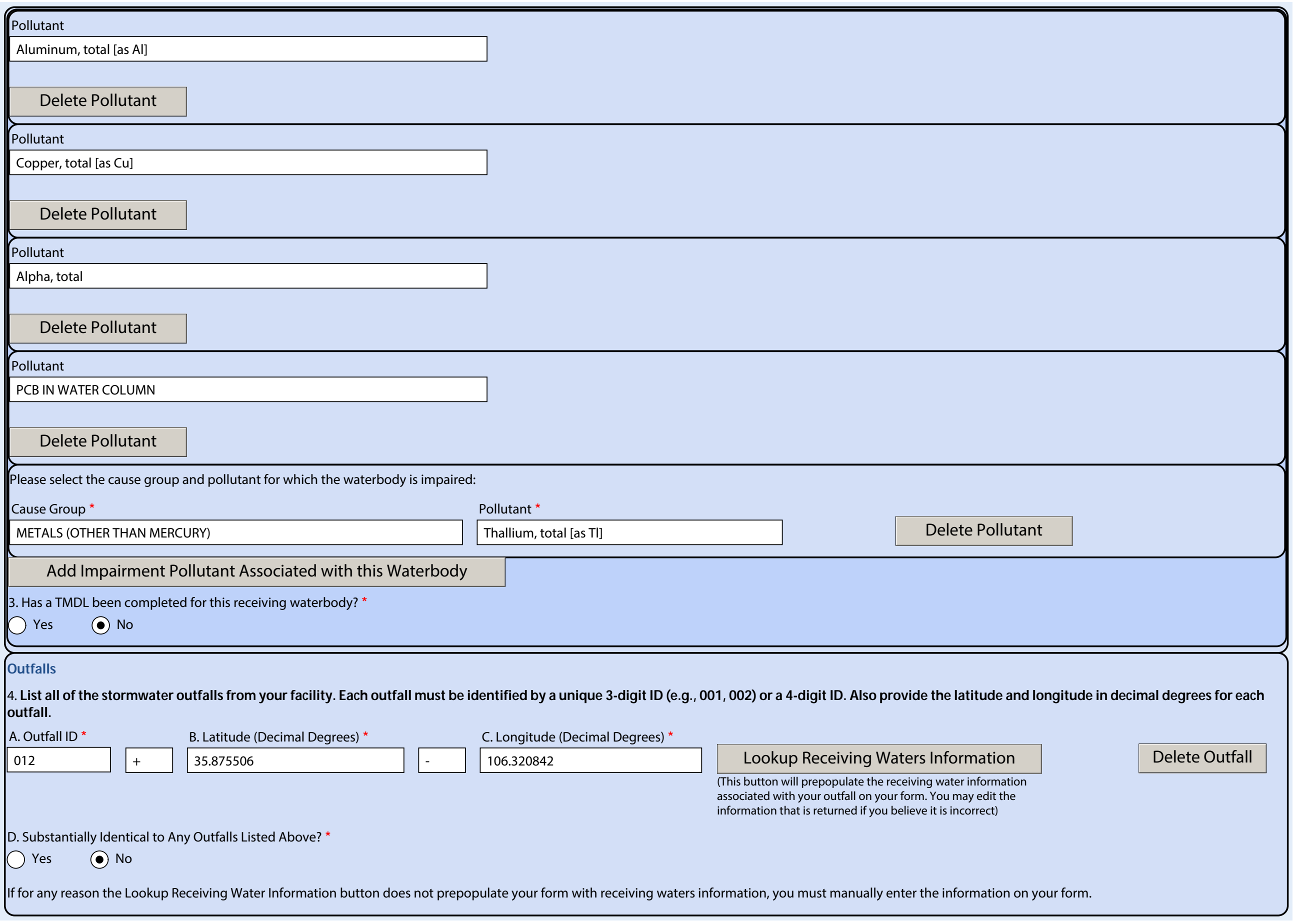




\section{utfall Section}

1. Provide the name of the first water of the U.S that receives stormwater directly from the outfall and/or from the MS4 that the outfall discharges to. (You may edit the name of the water of the U.S. that was returned if incorrect.) *

SANDIA CANYON (SIGMA CANYON TO NPDES OUTFALL 001)

2. Is the receiving water listed as impaired on the 303(d) list and in need of a TMDL?*

(-) Yes

No

4. List the pollutants that are causing the impairment:

Pollutant

Aluminum, total [as Al]

Delete Pollutant

Pollutant

Copper, total [as $\mathrm{Cu}$

Delete Pollutant

Pollutant

Alpha, total

Delete Pollutant

Pollutant

PCB IN WATER COLUMN

Delete Pollutant

Please select the cause group and pollutant for which the waterbody is impaired:

Cause Group *

Pollutant *

METALS (OTHER THAN MERCURY)

Add Impairment Pollutant Associated with this Waterbody

3. Has a TMDL been completed for this receiving waterbody? *

Yes

- No

Outfalls

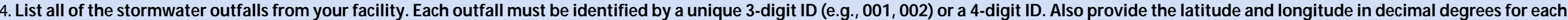
outfall. 


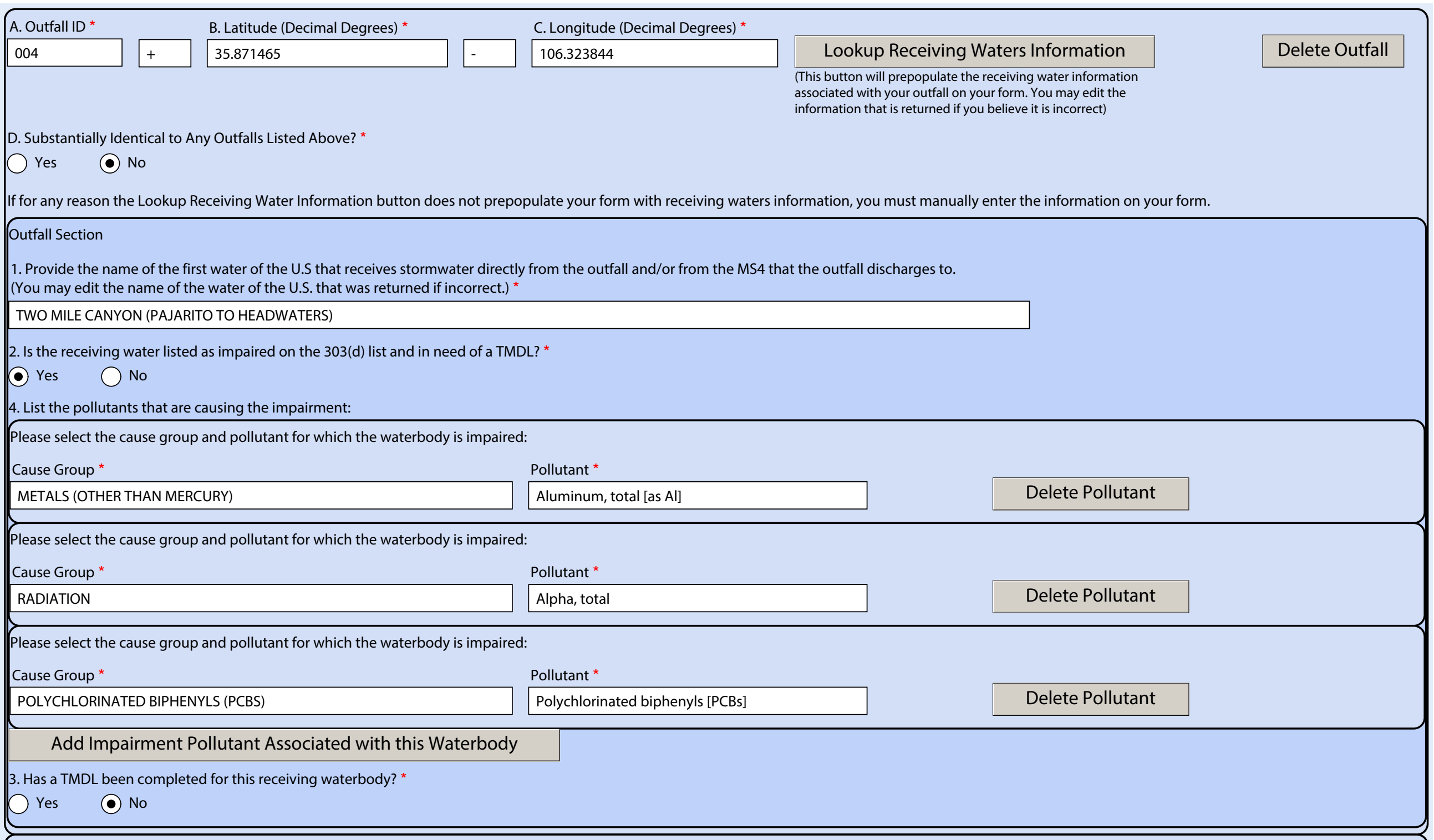

Outfalls

4. List all of the stormwater outfalls from your facility. Each outfall must be identified by a unique 3-digit ID (e.g., 001, 002) or a 4-digit ID. Also provide the latitude and longitude in decimal degrees for each outfall.

A. Outfall ID*

018
B. Latitude (Decimal Degrees)*

35.87278
C. Longitude (Decimal Degrees) *

106.317616

\section{Lookup Receiving Waters Information}

(This button will prepopulate the receiving water information associated with your outfall on your form. You may edit the information that is returned if you believe it is incorrect)
Delete Outfall 
D. Substantially Identical to Any Outfalls Listed Above? *

Yes

- No

If for any reason the Lookup Receiving Water Information button does not prepopulate your form with receiving waters information, you must manually enter the information on your form.

Outfall Section

1. Provide the name of the first water of the U.S that receives stormwater directly from the outfall and/or from the MS4 that the outfall discharges to.

(You may edit the name of the water of the U.S. that was returned if incorrect.)*

SANDIA CANYON (SIGMA CANYON TO NPDES OUTFALL 001)

2. Is the receiving water listed as impaired on the 303(d) list and in need of a TMDL? *

Yes $\bigcirc$ No

4. List the pollutants that are causing the impairment:

Pollutant

Aluminum, total [as Al]

\section{Delete Pollutant}

Pollutant

Copper, total [as $\mathrm{Cu}]$

Delete Pollutant

Pollutant

Alpha, total

Delete Pollutant

Pollutant

PCB IN WATER COLUMN

\section{Delete Pollutant}

Please select the cause group and pollutant for which the waterbody is impaired:

Cause Group *

METALS (OTHER THAN MERCURY)

Pollutant*

\begin{tabular}{|l|l|l|}
\hline Thallium, total [as $\mathrm{TI}]$ & Delete Pollutant
\end{tabular}

\section{Add Impairment Pollutant Associated with this Waterbody}

3. Has a TMDL been completed for this receiving waterbody? *

Yes

- No 
4. List all of the stormwater outfalls from your facility. Each outfall must be identified by a unique 3-digit ID (e.g., 001, 002) or a 4-digit ID. Also provide the latitude and longitude in decimal degrees for each outfall.

A. Outfall ID*

B. Latitude (Decimal Degrees)*

014

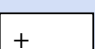

C. Longitude (Decimal Degrees)*

106.316865

\section{Lookup Receiving Waters Information} (This button will prepopulate the receiving water information associated with your outfall on your form. You may edit the information that is returned if you believe it is incorrect)

D. Substantially Identical to Any Outfalls Listed Above?*

E. Substantially identical to outfall ID*
- Yes
No

018

If for any reason the Lookup Receiving Water Information button does not prepopulate your form with receiving waters information, you must manually enter the information on your form.

Outfall Section

1. Provide the name of the first water of the U.S that receives stormwater directly from the outfall and/or from the MS4 that the outfall discharges to You may edit the name of the water of the U.S. that was returned if incorrect.) $*$

MORTANDAD CANYON (WITHIN LANL)

2. Is the receiving water listed as impaired on the 303(d) list and in need of a TMDL? *

- Yes

No

4. List the pollutants that are causing the impairment:

Please select the cause group and pollutant for which the waterbody is impaired:

Cause Group *

Pollutant*

METALS (OTHER THAN MERCURY)

Aluminum, total [as Al]

Delete Pollutant

Please select the cause group and pollutant for which the waterbody is impaired:

Cause Group *

METALS (OTHER THAN MERCURY)

Pollutant*

Copper, total [as $\mathrm{Cu}]$

Delete Pollutant

lease select the cause group and pollutant for which the waterbody is impaired:

Cause Group *

Pollutant*

POLYCHLORINATED BIPHENYLS (PCBS)

Polychlorinated biphenyls [PCBs]

Delete Pollutant

lease select the cause group and pollutant for which the waterbody is impaired:

Cause Group *

Pollutant*

RADIATION

Delete Pollutant

Add Impairment Pollutant Associated with this Waterbody

3. Has a TMDL been completed for this receiving waterbody? *

Yes

- No 
4. List all of the stormwater outfalls from your facility. Each outfall must be identified by a unique 3-digit ID (e.g., 001, 002) or a 4-digit ID. Also provide the latitude and longitude in decimal degrees for each outfall.

A. Outfall ID*

B. Latitude (Decimal Degrees)*

013

35.870783

C. Longitude (Decimal Degrees) *

106.317349

\section{Lookup Receiving Waters Information}

Delete Outfall

(This button will prepopulate the receiving water information

associated with your outfall on your form. You may edit the

information that is returned if you believe it is incorrect)

D. Substantially Identical to Any Outfalls Listed Above?*

E. Substantially identical to outfall ID*

- Yes $\bigcirc$ No

018

If for any reason the Lookup Receiving Water Information button does not prepopulate your form with receiving waters information, you must manually enter the information on your form.

Outfall Section

1. Provide the name of the first water of the U.S that receives stormwater directly from the outfall and/or from the MS4 that the outfall discharges to

(You may edit the name of the water of the U.S. that was returned if incorrect.)*

MORTANDAD CANYON (WITHIN LANL)

2. Is the receiving water listed as impaired on the 303(d) list and in need of a TMDL? *

- Yes No

4. List the pollutants that are causing the impairment:

Please select the cause group and pollutant for which the waterbody is impaired:

Cause Group *

Pollutant*

METALS (OTHER THAN MERCURY)

Aluminum, total [as Al]

Delete Pollutant

Please select the cause group and pollutant for which the waterbody is impaired:

Cause Group *

Pollutant*

METALS (OTHER THAN MERCURY)

Copper, total [as $\mathrm{Cu}]$

Delete Pollutant

Please select the cause group and pollutant for which the waterbody is impaired:

Cause Group *

Pollutant*

RADIATION

Alpha, total

Delete Pollutant

lease select the cause group and pollutant for which the waterbody is impaired:

Cause Group *

Pollutant*

POLYCHLORINATED BIPHENYLS (PCBS)

Polychlorinated biphenyls [PCBs]

Delete Pollutant

Add Impairment Pollutant Associated with this Waterbody

3. Has a TMDL been completed for this receiving waterbody? *

Yes

- No 
4. List all of the stormwater outfalls from your facility. Each outfall must be identified by a unique 3-digit ID (e.g., 001, 002) or a 4-digit ID. Also provide the latitude and longitude in decimal degrees for each outfall.

A. Outfall ID *

B. Latitude (Decimal Degrees)*

015

35.871403

C. Longitude (Decimal Degrees) *

106.316276

\section{Lookup Receiving Waters Information}

Delete Outfall (This button will prepopulate the receiving water information associated with your outfall on your form. You may edit the information that is returned if you believe it is incorrect)

D. Substantially Identical to Any Outfalls Listed Above?*

E. Substantially identical to outfall ID *

- Yes No 018

If for any reason the Lookup Receiving Water Information button does not prepopulate your form with receiving waters information, you must manually enter the information on your form.

Outfall Section

1. Provide the name of the first water of the U.S that receives stormwater directly from the outfall and/or from the MS4 that the outfall discharges to (You may edit the name of the water of the U.S. that was returned if incorrect.)*

MORTANDAD CANYON (WITHIN LANL)

2. Is the receiving water listed as impaired on the 303(d) list and in need of a TMDL? *

- Yes No

4. List the pollutants that are causing the impairment:

Please select the cause group and pollutant for which the waterbody is impaired:

Cause Group *

Pollutant*

METALS (OTHER THAN MERCURY)

Aluminum, total [as Al]

Delete Pollutant

Please select the cause group and pollutant for which the waterbody is impaired:

Cause Group *

METALS (OTHER THAN MERCURY)

Pollutant*

Copper, total [as $\mathrm{Cu}]$

Delete Pollutant

Please select the cause group and pollutant for which the waterbody is impaired:

Cause Group *

Pollutant*

RADIATION

Alpha, total

Delete Pollutant

lease select the cause group and pollutant for which the waterbody is impaired:

Cause Group *

Pollutant*

POLYCHLORINATED BIPHENYLS (PCBS)

Polychlorinated biphenyls [PCBs]

Delete Pollutant

Add Impairment Pollutant Associated with this Waterbody

3. Has a TMDL been completed for this receiving waterbody? *

Yes

- No 
4. List all of the stormwater outfalls from your facility. Each outfall must be identified by a unique 3-digit ID (e.g., 001, 002) or a 4-digit ID. Also provide the latitude and longitude in decimal degrees for each outfall.

A. Outfall ID*

016
B. Latitude (Decimal Degrees) *

$+35.872553$

C. Longitude (Decimal Degrees)*

106.316810

\section{Lookup Receiving Waters Information} (This button will prepopulate the receiving water information associated with your outfall on your form. You may edit the information that is returned if you believe it is incorrect)

D. Substantially Identical to Any Outfalls Listed Above?*

E. Substantially identical to outfall ID*
- Yes
No

018

If for any reason the Lookup Receiving Water Information button does not prepopulate your form with receiving waters information, you must manually enter the information on your form.

\section{Outfall Sectio}

1. Provide the name of the first water of the U.S that receives stormwater directly from the outfall and/or from the MS4 that the outfall discharges to (You may edit the name of the water of the U.S. that was returned if incorrect.) *

SANDIA CANYON (SIGMA CANYON TO NPDES OUTFALL 001)

2. Is the receiving water listed as impaired on the 303(d) list and in need of a TMDL? *

- Yes

No

4. List the pollutants that are causing the impairment:

Please select the cause group and pollutant for which the waterbody is impaired:

Cause Group *

Pollutant*

METALS (OTHER THAN MERCURY)

Aluminum, total [as Al]

Delete Pollutant

Please select the cause group and pollutant for which the waterbody is impaired:

Cause Group *

METALS (OTHER THAN MERCURY)

Pollutant*

Copper, total [as $\mathrm{Cu}$ ]

Delete Pollutant

Please select the cause group and pollutant for which the waterbody is impaired:

Cause Group *

Pollutant*

METALS (OTHER THAN MERCURY)

Thallium, total [as TI]

Delete Pollutant

lease select the cause group and pollutant for which the waterbody is impaired:

Cause Group *

Pollutant*

POLYCHLORINATED BIPHENYLS (PCBS)

Polychlorinated biphenyls [PCBs]

Delete Pollutant

Please select the cause group and pollutant for which the waterbody is impaired:

Cause Group *

Pollutant*

RADIATION

Alpha, tota

Delete Pollutant

RADIATION 


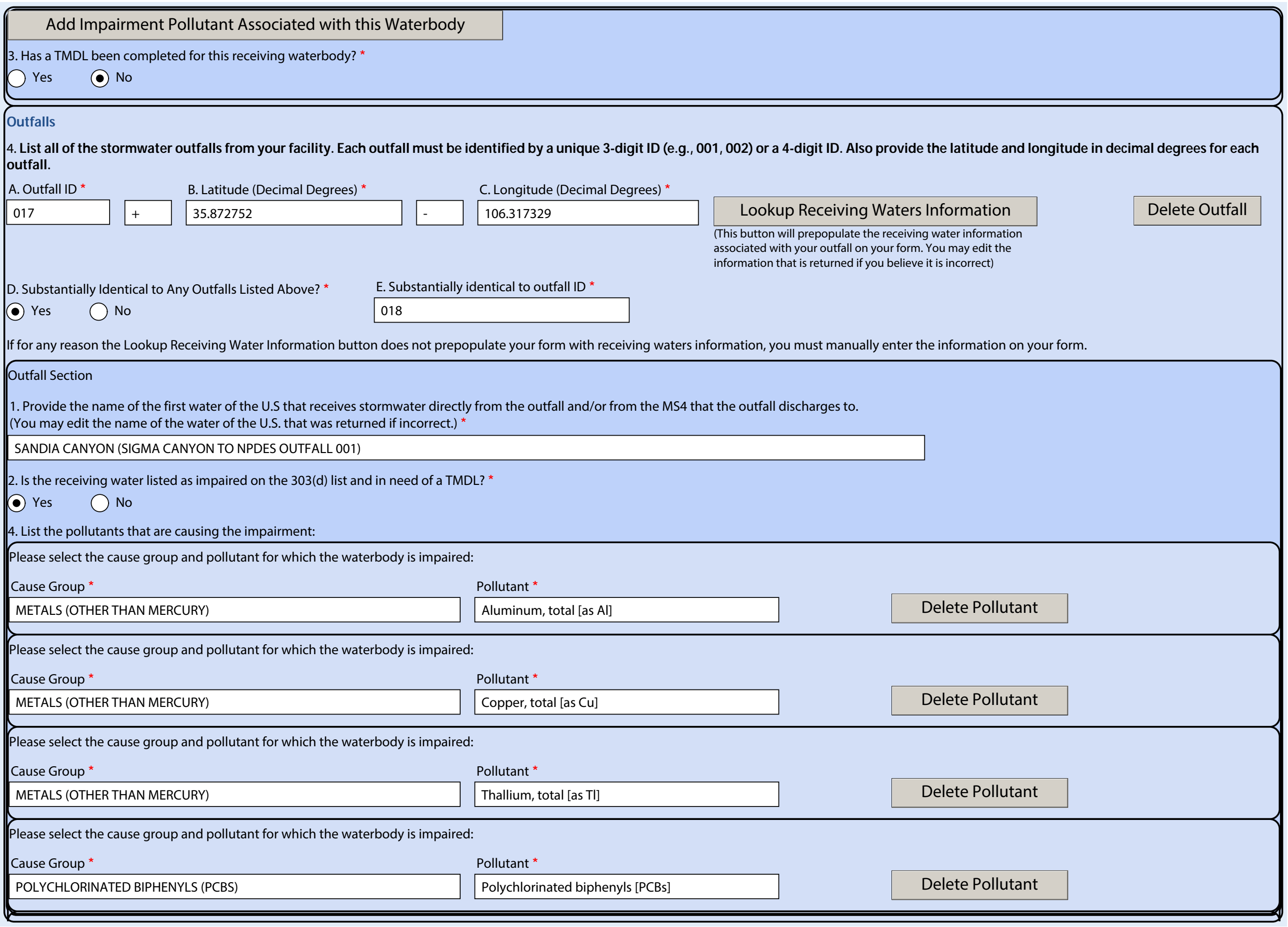


Please select the cause group and pollutant for which the waterbody is impaired:

Cause Group *

Pollutant*

RADIATION

Add Impairment Pollutant Associated with this Waterbody

3. Has a TMDL been completed for this receiving waterbody?*

Yes

- No

Outfalls

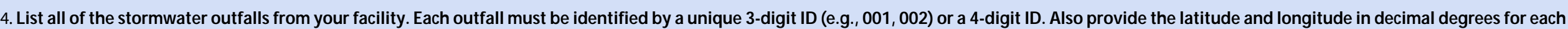
outfall.

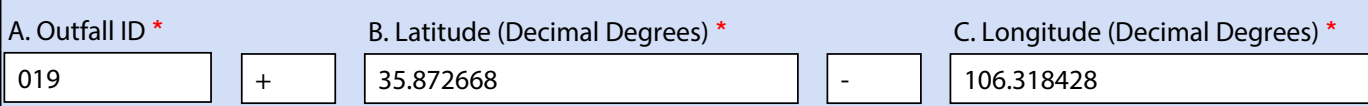

Lookup Receiving Waters Information

(This button will prepopulate the receiving water information associated with your outfall on your form. You may edit the information that is returned if you believe it is incorrect)

D. Substantially Identical to Any Outfalls Listed Above? * $\quad$ E. Substantially identical to outfall ID *

- Yes No

If for any reason the Lookup Receiving Water Information button does not prepopulate your form with receiving waters information, you must manually enter the information on your form.

Outfall Section

Provide the name of the first water of the U.S that receives stormwater directly from the outfall and/or from the MS4 that the outfall discharges to.

(You may edit the name of the water of the U.S. that was returned if incorrect.) *

SANDIA CANYON (SIGMA CANYON TO NPDES OUTFALL 001)

2. Is the receiving water listed as impaired on the 303(d) list and in need of a TMDL? *

- Yes No

4. List the pollutants that are causing the impairment

Please select the cause group and pollutant for which the waterbody is impaired:

Cause Group *

METALS (OTHER THAN MERCURY)

Pollutant*

\begin{tabular}{|l|l}
\hline Aluminum, total [as Al] & Delete Pollutant
\end{tabular}

Please select the cause group and pollutant for which the waterbody is impaired:

Cause Group *

Pollutant*

METALS (OTHER THAN MERCURY)

Copper, total [as Cu]

Delete Pollutant

lease select the cause group and pollutant for which the waterbody is impaired:

Cause Group *

Pollutant*

POLYCHLORINATED BIPHENYLS (PCBS)

Polychlorinated biphenyls [PCBs]

Delete Pollutant 
Please select the cause group and pollutant for which the waterbody is impaired:

Cause Group *

Pollutant*

METALS (OTHER THAN MERCURY)

Please select the cause group and pollutant for which the waterbody is impaired:

Cause Group *

Pollutant $*$

RADIATION

Add Impairment Pollutant Associated with this Waterbody

3. Has a TMDL been completed for this receiving waterbody? *

Yes

- No

Outfalls

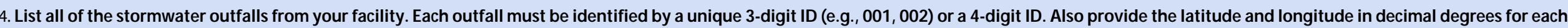
outfall.

A. Outfall ID *

051
B. Latitude (Decimal Degrees) *

\section{$+35.830145$}

C. Longitude (Decimal Degrees) *

106.242675
Lookup Receiving Waters Information

(This button will prepopulate the receiving water information associated with your outfall on your form. You may edit the information that is returned if you believe it is incorrect)

D. Substantially Identical to Any Outfalls Listed Above?*

$\bigcirc$ Yes No

If for any reason the Lookup Receiving Water Information button does not prepopulate your form with receiving waters information, you must manually enter the information on your form. Outfall Section

1. Provide the name of the first water of the U.S that receives stormwater directly from the outfall and/or from the MS4 that the outfall discharges to.

(You may edit the name of the water of the U.S. that was returned if incorrect.)*

PAJARITO CANYON (IN LANL BELOW ARROYO DE LA DELFE)

2. Is the receiving water listed as impaired on the 303(d) list and in need of a TMDL?*

Yes $\mathrm{No}$

4. List the pollutants that are causing the impairment:

Please select the cause group and pollutant for which the waterbody is impaired:

Cause Group *

Pollutant*

METALS (OTHER THAN MERCURY)

lease select the cause group and pollutant for which the waterbody is impaired:

Cause Group *

METALS (OTHER THAN MERCURY)
Pollutant*

Copper, total [as $\mathrm{Cu}$ ]
Delete Pollutant 
Please select the cause group and pollutant for which the waterbody is impaired:

Cause Group *

Pollutant*

POLYCHLORINATED BIPHENYLS (PCBS)

Add Impairment Pollutant Associated with this Waterbody

3. Has a TMDL been completed for this receiving waterbody? *

Yes

- No

Outfalls

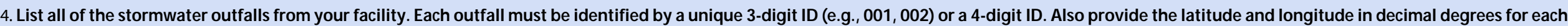
outfall.

\begin{tabular}{|l|l|l|l|l|}
\hline A. Outfall ID * & B. Latitude (Decimal Degrees) * \\
\hline 072 & -15.832885 & - & 106.239443 \\
\hline
\end{tabular}

\section{Lookup Receiving Waters Information}

Delete Outfall

(This button will prepopulate the receiving water information

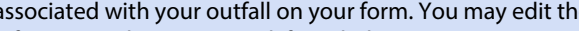

information that is returned if you believe it is incorrect)

D. Substantially Identical to Any Outfalls Listed Above?*

Yes No

If for any reason the Lookup Receiving Water Information button does not prepopulate your form with receiving waters information, you must manually enter the information on your form.

Outfall Section

1. Provide the name of the first water of the U.S that receives stormwater directly from the outfall and/or from the MS4 that the outfall discharges to.

(You may edit the name of the water of the U.S. that was returned if incorrect.) *

CANADA DEL BUEY (WITHIN LANL)

2. Is the receiving water listed as impaired on the 303(d) list and in need of a TMDL?*

- Yes No

4. List the pollutants that are causing the impairment

Please select the cause group and pollutant for which the waterbody is impaired:

Cause Group *

METALS (OTHER THAN MERCURY)

Pollutant *

Aluminum, total [as Al] $\quad$ Delete Pollutant

Please select the cause group and pollutant for which the waterbody is impaired:

Cause Group *

Pollutant*

POLYCHLORINATED BIPHENYLS (PCBS)

Polychlorinated biphenyls [PCBs]

Delete Pollutant

lease select the cause group and pollutant for which the waterbody is impaired:

Cause Group *

Pollutant*

RADIATION

Alpha, total

Delete Pollutant 


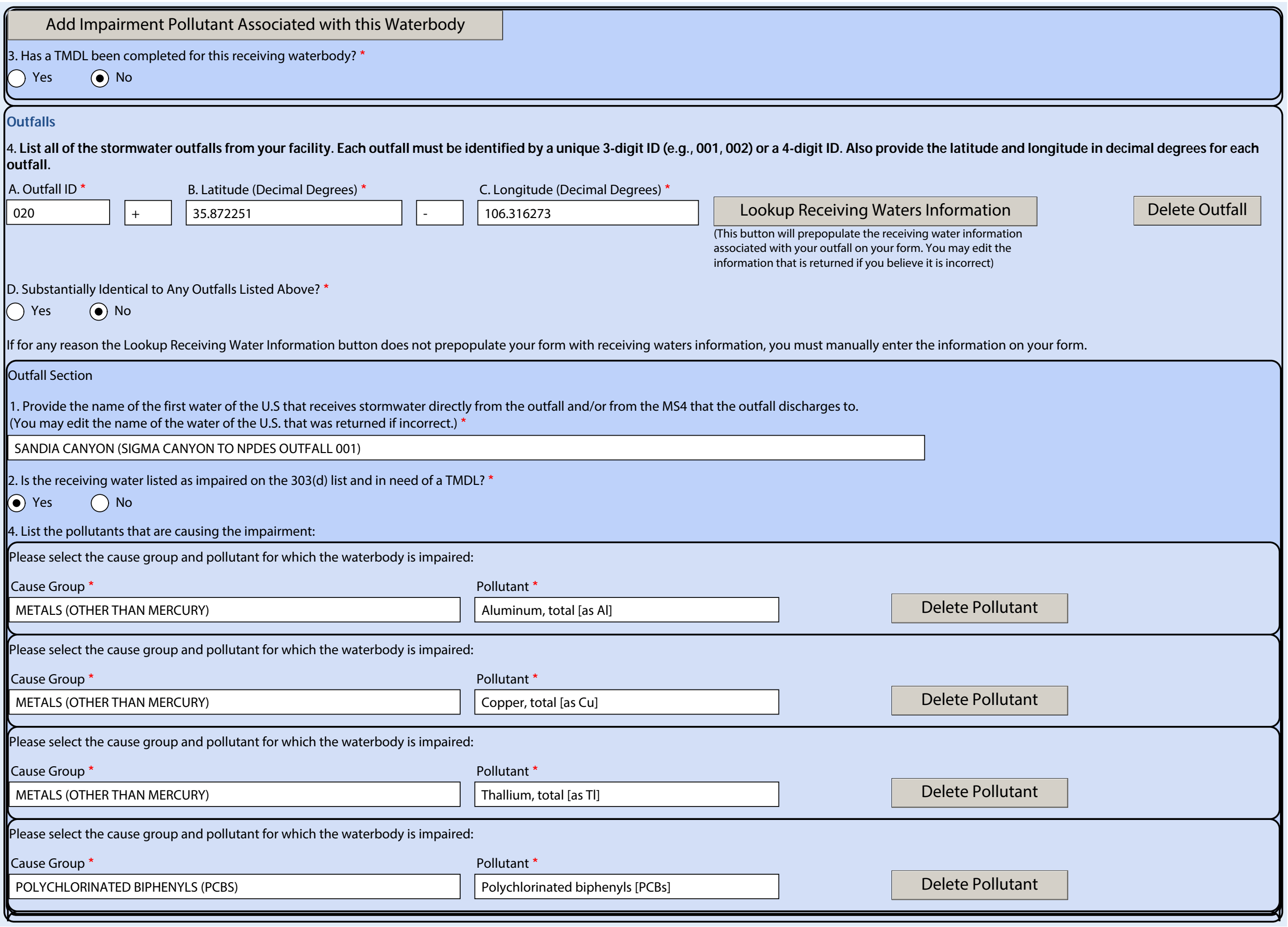




\begin{tabular}{||l|l|l|l|l|l|}
\hline Please select the cause group and pollutant for which the waterbody is impaired: \\
Cause Group* \\
\hline Add Impairment Pollutant Associated with this Waterbody \\
\hline 3. Has a TMDL been completed for this receiving waterbody?* \\
Yes $\quad$ No
\end{tabular}

\section{Add Another Outfall}

Provide the following information about your outfall latitude longitude.

5. Latitude/Longitude Data Source* $\quad$ 6. Horizontal Reference Datum

\begin{tabular}{|l|l|}
\hline GPS NAD83 \\
\hline
\end{tabular}

7. Does your facility discharge into a Municipal Separate Storm Sewer System (MS4)? *

$\bigcirc$ Yes No

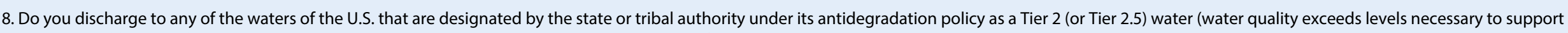
propagation of fish, shellfish, and wildlife and recreation in and on the water) (See Appendix L)? *
Yes
- No

\section{D: Stormwater Pollution Prevention Plan (SWPPP) Information}

SWPPP Contact Information

\begin{tabular}{|c|c|c|c|c|}
\hline \multirow{2}{*}{$\begin{array}{l}\text { 1. First Name } * \\
\text { Holly }\end{array}$} & \multicolumn{2}{|c|}{ 2. Middle Initial } & \multirow{2}{*}{$\begin{array}{l}\text { 3. Last Name * } \\
\text { Wheeler }\end{array}$} & \multirow{2}{*}{$\begin{array}{l}\text { 4. Professional Title }{ }^{*} \\
\text { Environmental Professional }\end{array}$} \\
\hline & & & & \\
\hline 5. Phone (10-digits, No dashes) * & 6. Extension & 7. E-Ma & & \\
\hline 5056671312 & & hbens & lanl.gov & \\
\hline
\end{tabular}

8. Your current SWPPP or certain information from your SWPPP must be made available through one of the following two options. Select one of the options and provide the required information. *

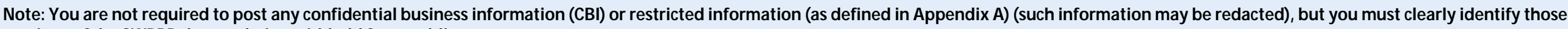
portions of the SWPPP that are being withheld from public access.

Option 1: Maintain a Current Copy of your SWPPP on an Internet page (Universal Resource Locator or URL).

Provide the web address URL *

eprr.lanl.gov

$\square$ Option 2: Provide the following information from your SWPPP. 
1. Using the instructions in Appendix E of the MSGP, under which endangered species criterion listed in Part 1.1.4.5 are you eligible for coverage under this permit? *

Criterion D - A separate ESA section 7 consultation has been completed

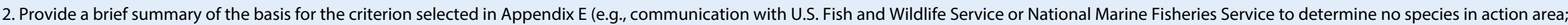
implementation of controls approved by EPA and the Services). *

Direct consultation with the U.S. Fish and Wildlife Service and corresponding development and implementation of a facility-specific Habitat Management Plan.

You must attach copies of any letters or other communications with the U.S. Fish and Wildlife Service or National Marine Fisheries Service on the attachments screen after you click "Submit Now"

\section{F: Historic Preservation}

1. If your facility is not located in Indian country lands, is your facility located on a property of religious or cultural significance to an Indian tribe? *
- Yes
No

1a. If yes, provide the name of the Indian tribe associated with the property*

San Ildefonso Pueblo

2. Using the instructions in Appendix F of the MSGP, under which historic properties preservation criterion listed in Part 1.1.4.7 are you eligible for coverage under this permit *

Criterion B - Subsurface stormwater controls will not affect historic properties

\section{Certification Information}

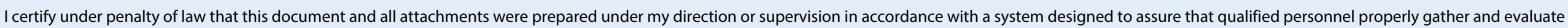

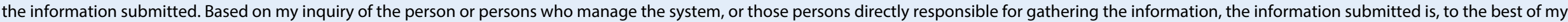

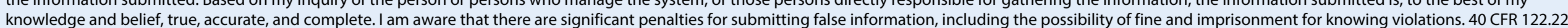
(d)

Certifier E-Mail *

Form Action *

ADORRIES@LANL.GOV

Approve


Environment Safety \& Health

PO Box 1663, MS K491

Los Alamos, New Mexico 87545

(505) 667-4218/Fax (505) 665-3811

\author{
Date: MAR 222016 \\ Symbol: ADESH-16-045 \\ LA-UR: 16-21721 \\ Locates Action No.: N/A
}

Stormwater Notice Processing Center

Mail Code 4203M, ATTN: 2015 MSGP Reports

U.S. EPA

1200 Pennsylvania Avenue, NW

Washington, DC 20460

To Whom It May Concern:

Subject: Transmittal of the National Pollutant Discharge Elimination System (NPDES) Notice of Intent (NOI) For Stormwater Discharges Associated with Industrial Activity under the Multi-Sector General Permit (MSGP) Tracking No. NMR053195

The purpose of this letter is to transmit a complete/correct NOI for stormwater discharges associated with industrial activity under the MSGP for Los Alamos National Laboratory (LANL) (Enclosure 1) on behalf of Los Alamos National Security LLC. LANS operates LANL for the Department of Energy. Per Section $G$ of the attached NOI, three concurrence letters from the United States Department of Interior, Fish and Wildlife Service are provided in Enclosure 2. While submitting a NOI for coverage under the new 2015 MSGP, LANS experienced significant problems with EPA's Net NPDES eReporting tool, which resulted in the initial submission of a NOI with incomplete outfall attribute data and incorrect information. The details of these issues were provided in a letter sent to Mr. Bret Larsen of EPA Region 6 on October 29, 2015 (ENV-DO-15-0309) (Enclosure 3).

The initial NOI was submitted in the Net eReporting tool on 9/02/2015, which resulted in a follow-up email on 9/03/2015 from NeT@epa.gov stating the NOI requesting coverage for Los Alamos National Laboratory under EPA's 2015 MSGP had been certified and submitted to EPA for review, and assigned NPDES ID NMR053195. Please note, this tracking number has been inserted in Section B of Enclosure 1 to prevent confusion or assignment of an additional tracking number. Authorization to discharge under the 2015 MSGP was sent to LANS on 10/03/2015.

Repeated attempts to update the NOI via the "Change NOI" form have resulted in the same system problems without successful submittal of all required information via NeT. As such, an e-mail request for waiver pursuant to Part 7.1 of the 2015 MSGP was sent to Ms. Nasim Jahan on 2/05/2016. On 2/09/2016 Ms. Jahan responded by indicating "LANL can submit their paper copy." 
LANL has 14 industrial sites covering eight (8) sectors, with 74 outfalls (26 monitored outfalls and 48 associated substantially identical outfalls) discharging to five (5) assessment units on the Clean Water Act 303(d) list (impaired waters without an EPA-approved or established TMDL pursuant to Part 6.2.4.1 of the 2015 MSGP). In addition, due to extended frozen conditions in the winter and the semi-arid climate, LANS implements an alternate monitoring period of four (4) two-month monitoring quarters for benchmark values as identified below, in accordance with Part 6.1.6 of the 2015 MSGP. This does not coincide with the four (4) three month monitoring quarters for benchmark values currently in the NetDMR.

April 1 through May 31

June 1 through July 31

August 1 through September 30

October 1 through November 30

To facilitate complete and accurate information in the NeT reporting system, LANS has provided an additional table (Enclosure 4) containing sector-specific information per MSGP site within the 36 square mile facility and listed each site's associated outfalls. The premise for providing this information is to determine whether the NeT tool can prepopulate the electronic Discharge Monitoring Report (DMR) form based on this information without causing inaccuracies or rejected data (non-fillable forms due to unresolvable hard errors). In addition, LANS is concerned that incomplete or incorrect NOI information will perpetuate a recurring prohibitive "domino effect" on subsequent electronic DMR filing and "Change NOI" forms.

LANS respectfully requests consideration of waivers for electronic submittal of MSGP DMRs using the NetDMR system until it is determined whether the attached NOI can be submitted by EPA's Subcontractor into the NeT tool. Once this occurs, LANS can determine how information is populating the NetDMR system and whether it will accept applicable data without causing prohibitive hard errors.

Any additional direction or guidance you may have would be appreciated. Please contact Terrill Lemke of Environmental Protection and Compliance, Compliance Programs (EPC-CP) at (505) 665-2397 if you have any questions regarding this NOI.

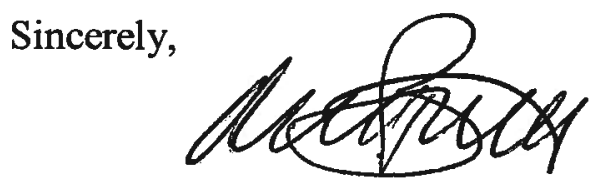

Michael T. Brandt, DrPH, CIH

Associate Director

Environment, Safety \& Health

Los Alamos National Security, LLC

Los Alamos National Laboratory

MTB:TWL:HLW//m

Enclosure: 1. Notice of Intent (NOI) For Stormwater Discharges Associated With Industrial Activity Under the NPDES Multi-Sector General Permit

2. Concurrence letters from United States Department of Interior, Fish and Wildlife Service 
3. Multi-Sector General Permit (MSGP) Notice of Intent (NOI) Reporting Pursuant to Part B.12.H

4. Industrial Sites and Outfalls by Sector

Cy: $\quad$ Nasim Jahan, USEPA/Region 6, Dallas, TX, (E-File)

Bruce Yurdin, NMED/SWQB, Santa Fe, NM, (E-File)

Jordan Arnswald, NA-LA, (E-File)

Craig S. Leasure, PADOPS, (E-File)

William Mairson, PADOPS, (E-File)

Michael T. Brandt, ADESH, (E-File)

Raeanna Sharp-Geiger, ADESH, (E-File)

John P. McCann, EPC-DO, (E-File)

Terrill W. Lemke, EPC-CP, (E-File)

Holly L. Wheeler, EPC-CP, (E-File)

Timothy A. Dolan, LC-ESH, (E-File)

lasomailbox@nnsa.doe.gov,(E-File)

locatesteam@lanl.gov,(E-File)

epc-correspondence@lanl.gov 


\title{
ENCLOSURE 1
}

\section{Notice of Intent (NOI) For Stormwater Discharges Associated With Industrial Activity Under the NPDES \\ Multi-Sector General Permit}

\author{
ADESH-16-045 \\ LA-UR-16-21721
}

Date: 


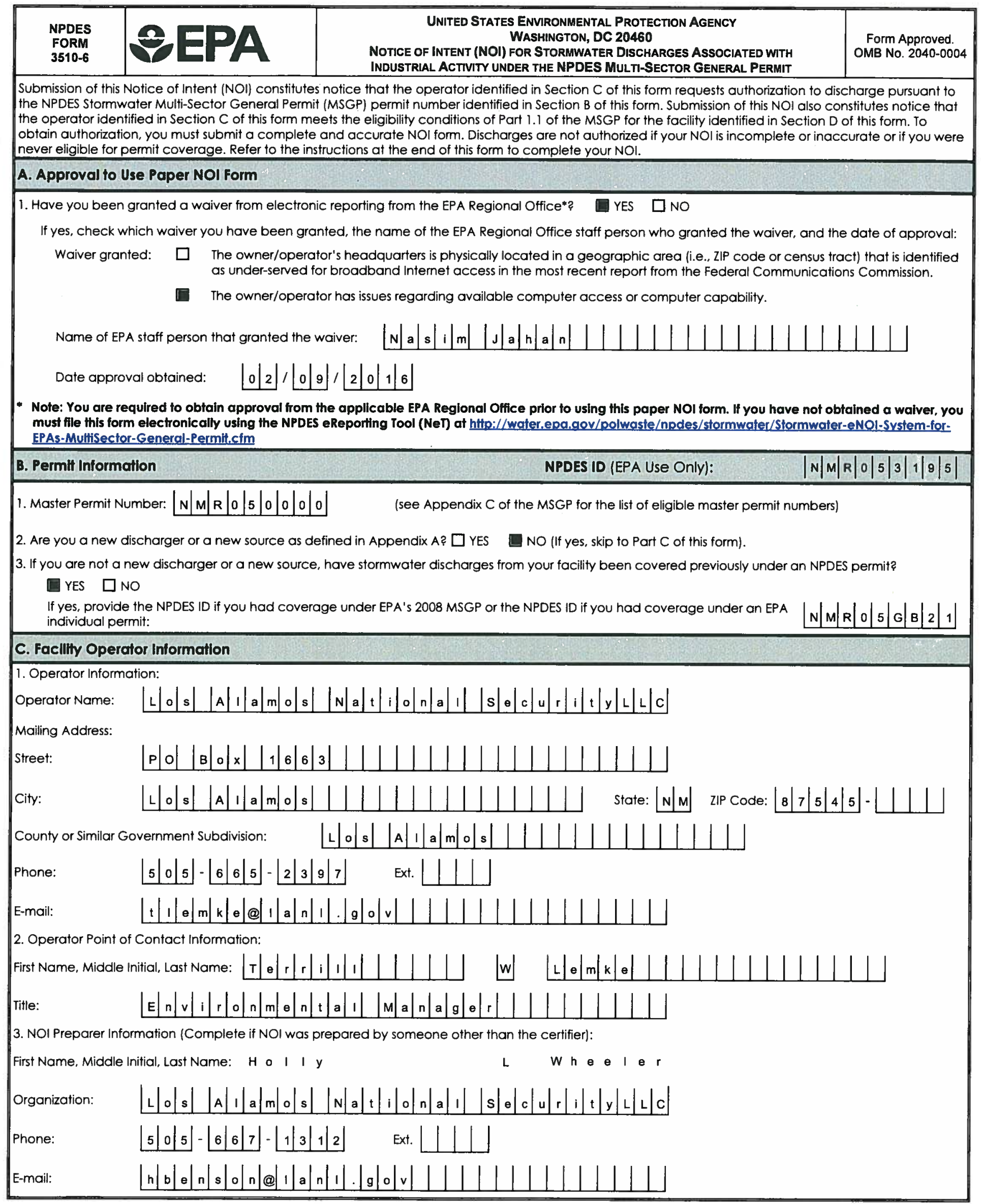




\section{Facillty Information}

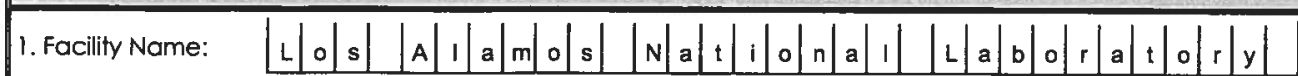

2. Facility Address:

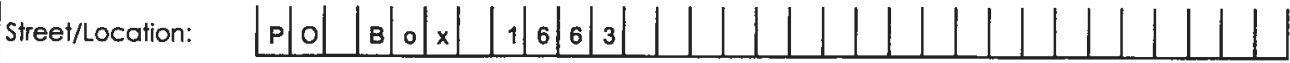

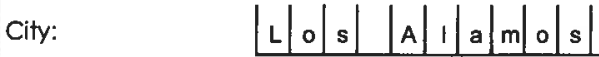

County or Similar Government Subdivision:

$\left\lfloor\mathrm{L}_{\mathrm{o}} \mathrm{s}|\mathrm{s}| \mathrm{l}|\mathrm{a}| \mathrm{m} / \mathrm{o} / \mathrm{s} \mid\right.$

3. Latitude/Longitude for the facility:

Latitude: $\quad$\begin{tabular}{l}
35 \\
\hline
\end{tabular}

Latitude/Longitude Data Source: $\square$ Map $\quad \square$ GPS

If you used a USGS topographic map, what was the scale?

Horizontal Reference Datum: $\square$ NAD $27 \square$ NAD 83 $\square$ WGS 84

4. Is your facility located on Indian Country lands? $\square$ YES $\square$ NO

If yes, provide the name of the Indian tribe associated with the area of Indian country (including name of Indian reservation, if applicable):

5. Are you requesting coverage under this NOI as a "federal operator" as defined in Appendix A? $\square$ YES $\square$ NO

6. What is the ownership type of the

facility?

Federal Facility (U.S. Government) $\square$ Privately Owned Facility $\square$ Municipality

County Government

$\square$ Corporation $\square$ State Government
$\square$ Mixed Ownership (e.g.
Public/Private)

$\square$ Tribal Government

School District

$\square$ District

$\square$ Municipal or Water District

7. Estimated.area of industrial activity at your facility exposed to stormwater: 131.36 (to the nearest quarter acre)

8. Sector-Specific Information

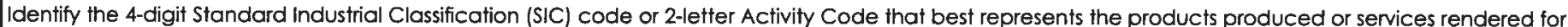

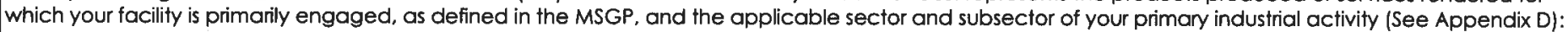

Primary SIC Code: \begin{tabular}{l|l|l|l|l|l|l|l|l|}
3 & 4 & 4 & 9 & OR Primary Activity Code:
\end{tabular}

Sector: $|A| A \mid$ Subsector: $|A| A|1|$

Identify the applicable sector(s) and subsector(s) of any co-located industrial activity for which you are requesting permit coverage:

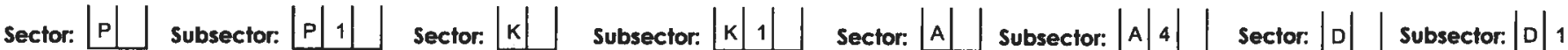

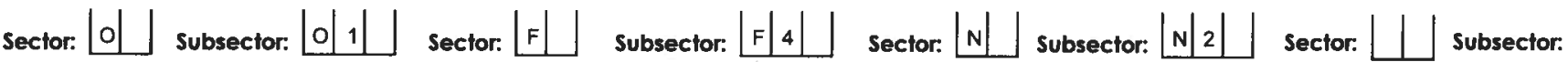

If you are a Sector S (Air Transportation) facility, do you anticipate using more than 100,000 gallons of pure glycol in glycol-based deicing fluids and/or 100 tons or more of urea on an average annual basis? $\square$ YES $\square$ NO

If you are a Sector $G$ (Metal Mining) facility, do you have discharges from waste rock and overburden piles? $\square$ YES $\square$ NO

Check the type of ore you mine at your facility: $\quad \square$ Tungsten Ore $\quad \square$ Nickel Ore $\quad \square$ Aluminum Ore

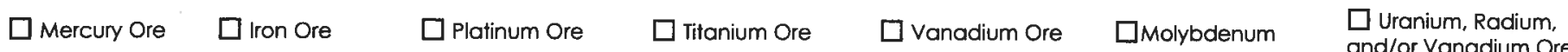

9. Is your facility presently inactive and unstaffed?* $\square$ YES $\square$ NO

* Note that if your facility becomes inactive and unstaffed during the permit term, you must submit an NOI modification to reflect the change.

\section{E. Discharge Information}

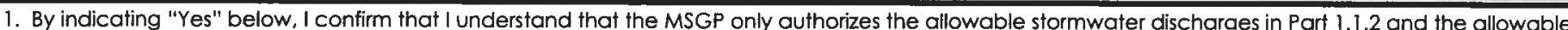
non-stormwater discharges listed in Part 1.1.3. Any discharges not expressly authorized in this permit cannot become authorized or shielded from liability

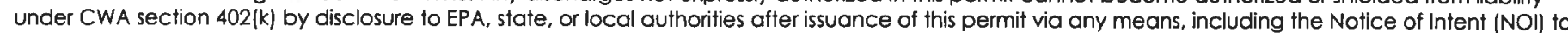

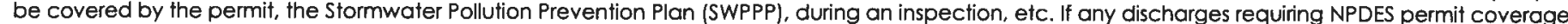

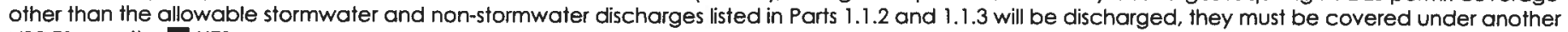
NPDES permit. $\square$ YES

2. Federal Effluent Limitation Guidelines

Are you requesting permit coverage for any stormwater discharges subject to effluent limitation guidelines? $\square$ YES $\square$ NO 


\begin{tabular}{|c|c|c|c|c|c|c|c|}
\hline \multicolumn{2}{|c|}{40 CFR Part/Subpart } & \multicolumn{2}{|c|}{$\begin{aligned} \text { Ellgible Discharges } \\
\end{aligned}$} & Affected MSGP Secior & \multicolumn{2}{|c|}{ New Source Date } & Check if Applicable \\
\hline \multicolumn{2}{|c|}{ Part 411, Subpart C } & \multicolumn{2}{|c|}{$\begin{array}{l}\text { Runoff from material storage piles at cement } \\
\text { manufacturing facilities }\end{array}$} & $\mathrm{E}$ & \multicolumn{2}{|c|}{$2 / 20 / 1974$} & $\square$ \\
\hline \multicolumn{2}{|c|}{ Part 418 Subpart A } & \multicolumn{2}{|c|}{$\begin{array}{l}\text { Runoff from phosphate fertilizer manufacturing facilities } \\
\text { that comes into contact with any raw materials, finished } \\
\text { product, by-products or waste products (SIC 2874) }\end{array}$} & c & \multicolumn{2}{|c|}{$4 / 8 / 1974$} & 口 \\
\hline \multicolumn{2}{|l|}{ Part 423} & \multicolumn{2}{|c|}{ Coal pile runoff at steam electric generating facilities } & o & \multicolumn{2}{|c|}{$\begin{array}{l}11 / 19 / 1982 \\
10 / 8 / 1974\end{array}$} & $\square$ \\
\hline \multicolumn{2}{|c|}{ Part 429, Subpart I } & \multicolumn{2}{|c|}{$\begin{array}{l}\text { Discharges resulting from spray down or intentional wetting } \\
\text { of logs at wet deck storage areas }\end{array}$} & 9 & \multicolumn{2}{|c|}{$1 / 26 / 1981$} & $\square$ \\
\hline \multicolumn{2}{|c|}{$\begin{array}{l}\text { Part 436, Subpart B, C, or } \\
\text { D }\end{array}$} & \multicolumn{2}{|c|}{$\begin{array}{l}\text { Mine dewatering discharges at crushed stone mines, } \\
\text { construction sand and gravel mines, or industrial sand } \\
\text { mines }\end{array}$} & J & \multicolumn{2}{|c|}{$N / A$} & $\square$ \\
\hline \multicolumn{2}{|c|}{ Part 443, Subpart A } & \multicolumn{2}{|c|}{ Runoff from asphalt emulsion facilities } & $\mathrm{D}$ & \multicolumn{2}{|c|}{$7 / 28 / 1975$} & 回 \\
\hline \multicolumn{2}{|c|}{ Part 445, Subparts A \& B } & \multicolumn{2}{|c|}{\begin{tabular}{|l|}
$\begin{array}{l}\text { Runoff from hazardous waste and non-hazardous waste } \\
\text { landfills }\end{array}$ \\
\end{tabular}} & $K, L$ & \multicolumn{2}{|c|}{$2 / 2 / 2000$} & $\square$ \\
\hline \multicolumn{2}{|l|}{ Part 449} & \multicolumn{2}{|c|}{$\begin{array}{l}\text { Runoff containing urea from airfield pavement deicing at } \\
\text { existing and new primary airports with } 1,000 \text { or more annual } \\
\text { non-propeller aircraft departures }\end{array}$} & al & \multicolumn{2}{|c|}{$6 / 15 / 2012$} & $\square$ \\
\hline \multicolumn{8}{|c|}{$\begin{array}{l}\text { 'NSPS promulgated in } 1974 \text { were not removed via the } 1982 \text { regulation; therefore wastewaters generated by Part 423-applicable sources that were New } \\
\text { Sources under the } 1974 \text { regulations are subject to the } 1974 \text { NSPS. } \\
\text { 3. Receiving Waters Information: (Attach a separate list if necessary) }\end{array}$} \\
\hline \multirow{2}{*}{\multicolumn{3}{|c|}{$\begin{array}{l}\text { Llst all of the stormwater outfalls } \\
\text { from your facilly. Each outfall } \\
\text { must be identified by a unique } \\
\text { 3-digit iD (e.g., 001, 002). Also } \\
\text { provide the latitude and } \\
\text { longitude in degrees decimal for } \\
\text { each outfall. }\end{array}$}} & \multicolumn{5}{|c|}{ For each outfall, provide the following receiving woter information: } \\
\hline & & & $\begin{array}{l}\text { Provide the name of the first water of } \\
\text { the U.S. that recelves stormwater } \\
\text { directly from the outfall and/or from } \\
\text { the MS4 that the outfall discharges } \\
\text { to: }\end{array}$ & \multicolumn{2}{|c|}{$\begin{array}{l}\text { If the receiving water is } \\
\text { impaired (on the CWA } 303 \text { (d) } \\
\text { list), list the pollutants that are } \\
\text { causing the impairment: }\end{array}$} & \multicolumn{2}{|c|}{$\begin{array}{l}\text { If a TMDL been completed } \\
\text { for this receiving } \\
\text { waterbody, providing the } \\
\text { following information: }\end{array}$} \\
\hline Outtall ID & 002 & & \multirow[t]{3}{*}{$\begin{array}{l}\text { Sandia Canyon (Sigma } \\
\text { Canyon to NPDES outfall } \\
\text { 001) }\end{array}$} & \multirow{3}{*}{\multicolumn{2}{|c|}{$\begin{array}{l}\text { Aluminum, total } \\
\text { Copper, dissolved } \\
\text { Gross Alpha, adjusted } \\
\text { Polychlorinated } \\
\text { Biphenyls (PCBs) } \\
\text { Thallium, dissolved }\end{array}$}} & \multicolumn{2}{|c|}{$\begin{array}{l}\text { TMDL Name and ID: } \\
\text { N/A }\end{array}$} \\
\hline Lattude & \multicolumn{2}{|c|}{35.875797} & & & & $\begin{array}{l}\text { Pollutan } \\
\text { there is }\end{array}$ & $\begin{array}{l}\text { (s) for which } \\
\text { TMDL: }\end{array}$ \\
\hline Longltude & -106.32 & 7580 & & & & N/A & \\
\hline Outfall ID & 004 & & $\begin{array}{l}\text { Two Mile Canyon (Pajarito } \\
\text { to headwaters) }\end{array}$ & $\begin{array}{l}\text { Aluminum, total } \\
\text { Gross Alpha, adju } \\
\text { PCBs }\end{array}$ & Isted & $\begin{array}{l}\text { TMDL No } \\
\text { N/A }\end{array}$ & me and ID: \\
\hline Latitude & 35.871 & 31 & & & & $\begin{array}{l}\text { Pollutan } \\
\text { there is }\end{array}$ & $\begin{array}{l}\text { (s) for which } \\
\text { TMDL: }\end{array}$ \\
\hline Longitude & -106.32 & 3832 & & & & $N / A$ & \\
\hline STC & . & ther & II, list identico & & & & \\
\hline
\end{tabular}




\begin{tabular}{|c|c|c|c|c|}
\hline Outfall ID & 005 & \multirow{3}{*}{$\begin{array}{l}\text { Sandia Canyon (Sigma } \\
\text { Canyon to NPDES outfall } \\
001 \text { ) }\end{array}$} & \multirow{3}{*}{$\begin{array}{l}\text { Aluminum, total } \\
\text { Copper, dissolved } \\
\text { Gross Alpha, adjusted } \\
\text { PCBs } \\
\text { Thallium, dissolved }\end{array}$} & \multirow{3}{*}{$\begin{array}{l}\text { TMDL Name and ID: } \\
\text { N/A } \\
\text { Pollutant(s) for which } \\
\text { there is o TMDL: } \\
\text { N/A }\end{array}$} \\
\hline Lotitude & 35.873919 & & & \\
\hline Longhtude & -106.320746 & & & \\
\hline \multicolumn{5}{|c|}{ If substantlally Identical to other outfall, Ilst Identical outfill ID: } \\
\hline Outtall ID & 006 & \multirow[t]{3}{*}{$\begin{array}{l}\text { Sandia Canyon (Sigma } \\
\text { Canyon to NPDES outfall } \\
001 \text { ) }\end{array}$} & \multirow{3}{*}{$\begin{array}{l}\text { Aluminum, total } \\
\text { Copper, dissolved } \\
\text { Gross Alpha, adjusted } \\
\text { PCBs } \\
\text { Thallium, dissolved }\end{array}$} & \multirow{3}{*}{$\begin{array}{l}\text { TMDL Name and ID: } \\
\text { N/A } \\
\text { Pollutant(s) for which } \\
\text { there is a TMDL: } \\
\text { N/A }\end{array}$} \\
\hline Lothude & 35.874011 & & & \\
\hline Longilude & -106.319858 & & & \\
\hline \multicolumn{5}{|c|}{ If substantially Identical to other outfall, Ist Identical outfill ID: 005} \\
\hline Outfall ID & 009 & \multirow[t]{3}{*}{$\begin{array}{l}\text { Sandia Canyon (Sigma } \\
\text { Canyon to NPDES outfall } \\
001 \text { ) }\end{array}$} & \multirow{3}{*}{$\begin{array}{l}\text { Aluminum, total } \\
\text { Copper, dissolved } \\
\text { Gross Alpha, adjusted } \\
\text { PCBs } \\
\text { Thallium, dissolved }\end{array}$} & \multirow{3}{*}{$\begin{array}{l}\text { TMDL Name and ID: } \\
\text { N/A } \\
\text { Pollutant(s) for which } \\
\text { there is a TMDL: } \\
\text { N/A }\end{array}$} \\
\hline Lottiude & 35.874843 & & & \\
\hline Longltude & -106.319412 & & & \\
\hline \multicolumn{5}{|c|}{ If substantlally Identical to other outfall, list Identical outfall ID: } \\
\hline Outfall ID & 007 & \multirow[t]{3}{*}{$\begin{array}{l}\text { Sandia Canyon (Sigma } \\
\text { Canyon to NPDES outfall } \\
001 \text { ) }\end{array}$} & \multirow{3}{*}{$\begin{array}{l}\text { Aluminum, total } \\
\text { Copper, dissolved } \\
\text { Gross Alpha, adjusted } \\
\text { PCBs } \\
\text { Thallium, dissolved }\end{array}$} & \multirow{3}{*}{$\begin{array}{l}\text { TMDL Name and ID: } \\
\text { N/A } \\
\text { Pollutant(s) for which } \\
\text { there is a TMDL: } \\
\text { N/A }\end{array}$} \\
\hline Lotifude & 35.874014 & & & \\
\hline Longltude & -106.319203 & & & \\
\hline \multicolumn{5}{|c|}{ If substantially identical to other outfall, Ist Identical outfall ID: $\underline{009}$} \\
\hline
\end{tabular}




\begin{tabular}{|c|c|c|c|c|}
\hline Outfall ID & 008 & \multirow{3}{*}{$\begin{array}{l}\text { Sandia Canyon (Sigma } \\
\text { Canyon to NPDES outfall } \\
\text { 001) }\end{array}$} & \multirow{3}{*}{$\begin{array}{l}\text { Aluminum, total } \\
\text { Copper, dissolved } \\
\text { Gross Alpha, adjusted } \\
\text { PCBs } \\
\text { Thallium, dissolved }\end{array}$} & \multirow{3}{*}{$\begin{array}{l}\text { TMDL Name and ID: } \\
\text { N/A } \\
\text { Pollutant(s) for which } \\
\text { there is a TMDL: } \\
\text { N/A }\end{array}$} \\
\hline Loflitude & 35.874617 & & & \\
\hline Longitude & -106.318925 & & & \\
\hline \multicolumn{5}{|c|}{ If substantially Identical to other outfall, Ilst Identical outfall ID: 009} \\
\hline Outfall ID & 010 & \multirow[t]{3}{*}{$\begin{array}{l}\text { Sandia Canyon (Sigma } \\
\text { Canyon to NPDES outfall } \\
\text { 001) }\end{array}$} & \multirow{3}{*}{$\begin{array}{l}\text { Aluminum, total } \\
\text { Copper, dissolved } \\
\text { Gross Alpha, adjusted } \\
\text { PCBs } \\
\text { Thallium, dissolved }\end{array}$} & \multirow{3}{*}{$\begin{array}{l}\text { TMDL Name and ID: } \\
\text { N/A } \\
\text { Pollutant(s) for which } \\
\text { there is a TMDL: } \\
\text { N/A }\end{array}$} \\
\hline Lotitude & 35.875402 & & & \\
\hline Longilude & -106.320301 & & & \\
\hline \multicolumn{5}{|c|}{ If substantially Identical to other outfall, list identical outfall ID: 009} \\
\hline Outfall ID & 012 & \multirow[t]{3}{*}{$\begin{array}{l}\text { Sandia Canyon (Sigma } \\
\text { Canyon to NPDES outfall } \\
001 \text { ) }\end{array}$} & \multirow{3}{*}{$\begin{array}{l}\text { Aluminum, total } \\
\text { Copper, dissolved } \\
\text { Gross Alpha, adjusted } \\
\text { PCBs } \\
\text { Thallium, dissolved }\end{array}$} & \multirow{3}{*}{$\begin{array}{l}\text { TMDL Name and ID: } \\
\text { N/A } \\
\text { Pollutant(s) for which } \\
\text { there is a TMDL: } \\
\text { N/A }\end{array}$} \\
\hline Latitude & 35.875532 & & & \\
\hline Longitude & -106.320884 & & & \\
\hline \multicolumn{5}{|c|}{ If substantially identical to other outfall, IIst Identical outfall ID: } \\
\hline Outfall ID & 011 & \multirow[t]{3}{*}{$\begin{array}{l}\text { Sandia Canyon (Sigma } \\
\text { Canyon to NPDES outfall } \\
001 \text { ) }\end{array}$} & \multirow{3}{*}{$\begin{array}{l}\text { Aluminum, total } \\
\text { Copper, dissolved } \\
\text { Gross Alpha, adjusted } \\
\text { PCBs } \\
\text { Thallium, dissolved }\end{array}$} & \multirow{3}{*}{$\begin{array}{l}\text { TMDL Name and ID: } \\
\text { N/A } \\
\text { Pollutant(s) for which } \\
\text { there is a TMDL: } \\
\text { N/A }\end{array}$} \\
\hline Loffiude & 35.875563 & & & \\
\hline Longilude & -106.320744 & & & \\
\hline \multicolumn{5}{|c|}{ If substantially Identical to other ouffall, list Identical ouffall ID: 012} \\
\hline
\end{tabular}




\begin{tabular}{|c|c|c|c|c|}
\hline Outfall ID & 018 & \multirow{3}{*}{$\begin{array}{l}\text { Sandia Canyon (Sigma } \\
\text { Canyon to NPDES outfall } \\
001 \text { ) }\end{array}$} & \multirow{3}{*}{$\begin{array}{l}\text { Aluminum, total } \\
\text { Copper, dissolved } \\
\text { Gross Alpha, adjusted } \\
\text { PCBs } \\
\text { Thallium, dissolved }\end{array}$} & \multirow{3}{*}{$\begin{array}{l}\text { TMDL Name and ID: } \\
\text { N/A } \\
\text { Pollutant(s) for which } \\
\text { there is a TMDL: } \\
\text { N/A }\end{array}$} \\
\hline Latifude & 35.872834 & & & \\
\hline Longltude & -106.317653 & & & \\
\hline \multicolumn{5}{|c|}{ If substantially identical to other outfall, Ilst Identical outfall ID: } \\
\hline Outfall ID & 013 & \multirow[t]{3}{*}{$\begin{array}{l}\text { Mortandad Canyon (Within } \\
\text { LANL) }\end{array}$} & \multirow{3}{*}{$\begin{array}{l}\text { Aluminum, total } \\
\text { Copper, dissolved } \\
\text { Gross Alpha, adjusted } \\
\text { PCBs }\end{array}$} & \multirow{3}{*}{$\begin{array}{l}\text { TMDL Name and ID: } \\
\text { N/A } \\
\text { Pollutant(s) for which } \\
\text { there is a TMDL: } \\
\text { N/A }\end{array}$} \\
\hline Lottlude & 35.870797 & & & \\
\hline Longilude & -106.317867 & & & \\
\hline \multicolumn{5}{|c|}{ If substantlally identical to other outfall, Iist Identical outfall ID: $\underline{018}$} \\
\hline Outfall ID & 014 & \multirow[t]{3}{*}{$\begin{array}{l}\text { Mortandad Canyon (Within } \\
\text { LANL) }\end{array}$} & \multirow{3}{*}{$\begin{array}{l}\text { Aluminum, total } \\
\text { Copper, dissolved } \\
\text { Gross Alpha, adjusted } \\
\text { PCBs }\end{array}$} & \multirow{3}{*}{$\begin{array}{l}\text { TMDL Name and ID: } \\
\text { N/A } \\
\text { Pollutant(s) for which } \\
\text { there is a TMDL: } \\
\text { N/A }\end{array}$} \\
\hline Latilude & 35.870890 & & & \\
\hline Longitude & -106.317393 & & & \\
\hline \multicolumn{5}{|c|}{ If substantially Identical to other outfall, list Identical ouffall ID: 018} \\
\hline Outfall ID & 015 & \multirow[t]{3}{*}{$\begin{array}{l}\text { Mortandad Canyon (Within } \\
\text { LANL) }\end{array}$} & \multirow{3}{*}{$\begin{array}{l}\text { Aluminum, total } \\
\text { Copper, dissolved } \\
\text { Gross Alpha, adjusted } \\
\text { PCBs }\end{array}$} & \multirow{3}{*}{$\begin{array}{l}\text { TMDL Name and ID: } \\
\text { N/A } \\
\text { Pollutant(s) for which } \\
\text { there is a TMDL: } \\
\text { N/A }\end{array}$} \\
\hline Lottiude & 35.871389 & & & \\
\hline Longitude & -106.316397 & & & \\
\hline \multicolumn{5}{|c|}{ If substantially Identical to other outfall, list Identical outfall ID: 018} \\
\hline
\end{tabular}




\begin{tabular}{|c|c|c|c|c|}
\hline Outtall ID & 016 & \multirow{3}{*}{$\begin{array}{l}\text { Sandia Canyon (Sigma } \\
\text { Canyon to NPDES outfall } \\
001 \text { ) }\end{array}$} & \multirow{3}{*}{$\begin{array}{l}\text { Aluminum, total } \\
\text { Copper, dissolved } \\
\text { Gross Alpha, adjusted } \\
\text { PCBs } \\
\text { Thallium, dissolved }\end{array}$} & \multirow{3}{*}{$\begin{array}{l}\text { TMDL Name and ID: } \\
\text { N/A } \\
\text { Pollutant(s) for which } \\
\text { there is a TMDL: } \\
\text { N/A }\end{array}$} \\
\hline Latflude & 35.872447 & & & \\
\hline Longltude & -106.316721 & & & \\
\hline \multicolumn{5}{|c|}{ If substantially Identical to other outfall, Ist Identical outfall ID: 018} \\
\hline Outfall ID & 017 & \multirow[t]{3}{*}{$\begin{array}{l}\text { Sandia Canyon (Sigma } \\
\text { Canyon to NPDES outfall } \\
\text { 001) }\end{array}$} & \multirow{3}{*}{$\begin{array}{l}\text { Aluminum, total } \\
\text { Copper, dissolved } \\
\text { Gross Alpha, adjusted } \\
\text { PCBs } \\
\text { Thallium, dissolved }\end{array}$} & \multirow{3}{*}{$\begin{array}{l}\text { TMDL Name and ID: } \\
\text { N/A } \\
\text { Pollutant(s) for which } \\
\text { there is a TMDL: } \\
\text { N/A }\end{array}$} \\
\hline Latilude & 35.872599 & & & \\
\hline Longilude & -106.317066 & & & \\
\hline \multicolumn{5}{|c|}{ If substantially Identical to other outtall, list Identical outfall ID: 018} \\
\hline Outfall ID & 019 & \multirow[t]{3}{*}{$\begin{array}{l}\text { Sandia Canyon (Sigma } \\
\text { Canyon to NPDES outfall } \\
001 \text { ) }\end{array}$} & \multirow{3}{*}{$\begin{array}{l}\text { Aluminum, total } \\
\text { Copper, dissolved } \\
\text { Gross Alpha, adjusted } \\
\text { PCBs } \\
\text { Thallium, dissolved }\end{array}$} & \multirow{3}{*}{$\begin{array}{l}\text { TMDL Name and ID: } \\
\text { N/A } \\
\text { Pollutant(s) for which } \\
\text { there is a TMDL: } \\
\text { N/A }\end{array}$} \\
\hline Latifude & 35.872682 & & & \\
\hline Longlitude & -106.318467 & & & \\
\hline \multicolumn{5}{|c|}{ If substantlally identical to other outfall, Iist identical ouffall ID: 018} \\
\hline Outfall ID & 020 & \multirow[t]{3}{*}{$\begin{array}{l}\text { Sandia Canyon (Sigma } \\
\text { Canyon to NPDES outfall } \\
001 \text { ) }\end{array}$} & \multirow{3}{*}{$\begin{array}{l}\text { Aluminum, total } \\
\text { Copper, dissolved } \\
\text { Gross Alpha, adjusted } \\
\text { PCBs } \\
\text { Thallium, dissolved }\end{array}$} & \multirow{3}{*}{$\begin{array}{l}\text { TMDL Name and ID: } \\
\text { N/A } \\
\text { Pollutant(s) for which } \\
\text { there is a TMDL: } \\
\text { N/A }\end{array}$} \\
\hline Latifude & 35.872240 & & & \\
\hline Longilude & -106.316340 & & & \\
\hline \multicolumn{5}{|c|}{ If substantially identical to other ouffall, list identical ouffall ID: } \\
\hline
\end{tabular}




\begin{tabular}{|c|c|c|c|c|}
\hline Outrall ID & 022 & \multirow{3}{*}{$\begin{array}{l}\text { Sandia Canyon (Sigma } \\
\text { Canyon to NPDES outfall } \\
001)\end{array}$} & \multirow{3}{*}{$\begin{array}{l}\text { Aluminum, total } \\
\text { Copper, dissolved } \\
\text { Gross Alpha, adjusted } \\
\text { PCBs } \\
\text { Thallium, dissolved }\end{array}$} & \multirow{3}{*}{$\begin{array}{l}\text { TMDL Name and ID: } \\
\text { N/A } \\
\text { Pollutant(s) for which } \\
\text { there is a TMDL: } \\
\text { N/A }\end{array}$} \\
\hline Lotfitude & 35.872661 & & & \\
\hline Longltude & -106.313691 & & & \\
\hline \multicolumn{5}{|c|}{ If substantially Identical to other outtall, Ist identical outfall ID: } \\
\hline Outfall ID & 021 & \multirow[t]{3}{*}{$\begin{array}{l}\text { Sandia Canyon (Sigma } \\
\text { Canyon to NPDES outfall } \\
\text { 001) }\end{array}$} & \multirow{3}{*}{$\begin{array}{l}\text { Aluminum, total } \\
\text { Copper, dissolved } \\
\text { Gross Alpha, adjusted } \\
\text { PCBs } \\
\text { Thallium, dissolved }\end{array}$} & \multirow{3}{*}{$\begin{array}{l}\text { TMDL Name and ID: } \\
\text { N/A } \\
\text { Pollutant(s) for which } \\
\text { there is a TMDL: } \\
\text { N/A }\end{array}$} \\
\hline Lottitude & 35.872514 & & & \\
\hline Longitude & -106.313562 & & & \\
\hline \multicolumn{5}{|c|}{ If substantially identical to other outfall, list Identical outfall ID: $\underline{022}$} \\
\hline Outfall ID & 023 & \multirow[t]{3}{*}{$\begin{array}{l}\text { Sandia Canyon (Sigma } \\
\text { Canyon to NPDES outfall } \\
001 \text { ) }\end{array}$} & \multirow{3}{*}{$\begin{array}{l}\text { Aluminum, total } \\
\text { Copper, dissolved } \\
\text { Gross Alpha, adjusted } \\
\text { PCBs } \\
\text { Thallium, dissolved }\end{array}$} & \multirow{3}{*}{$\begin{array}{l}\text { TMDL Name and ID: } \\
\text { N/A } \\
\text { Pollutant(s) for which } \\
\text { there is a TMDL: } \\
\text { N/A }\end{array}$} \\
\hline Lattiude & 35.873193 & & & \\
\hline Longitude & -106.313116 & & & \\
\hline \multicolumn{5}{|c|}{ If substantially identical to other outfall, Ilst identical outfall ID: 022} \\
\hline Outfall ID & 024 & \multirow[t]{3}{*}{$\begin{array}{l}\text { Sandia Canyon (Sigma } \\
\text { Canyon to NPDES outfall } \\
001 \text { ) }\end{array}$} & \multirow{3}{*}{$\begin{array}{l}\text { Aluminum, total } \\
\text { Copper, dissolved } \\
\text { Gross Alpha, adjusted } \\
\text { PCBs } \\
\text { Thallium, dissolved }\end{array}$} & \multirow{3}{*}{$\begin{array}{l}\text { TMDI Name and ID: } \\
\text { N/A } \\
\text { Pollutant(s) for which } \\
\text { there is a TMDL: } \\
\text { N/A }\end{array}$} \\
\hline Latifude & 35.873046 & & & \\
\hline Longitude & -106.315069 & & & \\
\hline \multicolumn{5}{|c|}{ If substantially Identical to other outfall, list Identical outfall ID: 022} \\
\hline
\end{tabular}




\begin{tabular}{|c|c|c|c|c|}
\hline Outfall ID & 025 & \multirow{3}{*}{$\begin{array}{l}\text { Sandia Canyon (Sigma } \\
\text { Canyon to NPDES outfall } \\
001 \text { ) }\end{array}$} & \multirow{3}{*}{$\begin{array}{l}\text { Aluminum, total } \\
\text { Copper, dissolved } \\
\text { Gross Alpha, adjusted } \\
\text { PCBs } \\
\text { Thallium, dissolved }\end{array}$} & \multirow{3}{*}{$\begin{array}{l}\text { TMDL Name and ID: } \\
\text { N/A } \\
\text { Pollutant(s) for which } \\
\text { there is a TMDL: } \\
\text { N/A }\end{array}$} \\
\hline Lattlude & 35.872928 & & & \\
\hline Longltude & -106.315400 & & & \\
\hline \multicolumn{5}{|c|}{ If substantlally Identical to other outtall, list Identical outfall ID: 022} \\
\hline Outfall ID & 026 & \multirow[t]{3}{*}{$\begin{array}{l}\text { Sandia Canyon (Sigma } \\
\text { Canyon to NPDES outfall } \\
\text { 001) }\end{array}$} & \multirow{3}{*}{$\begin{array}{l}\text { Aluminum, total } \\
\text { Copper, dissolved } \\
\text { Gross Alpha, adjusted } \\
\text { PCBs } \\
\text { Thallium, dissolved }\end{array}$} & \multirow{3}{*}{$\begin{array}{l}\text { TMDL Name and ID: } \\
\text { N/A } \\
\text { Pollutant(s) for which } \\
\text { there is a TMDL: } \\
\text { N/A }\end{array}$} \\
\hline Lotitude & 35.872114 & & & \\
\hline Longitude & -106.313105 & & & \\
\hline \multicolumn{5}{|c|}{ If substantlally identical to other outfall, list Identical outtall ID: } \\
\hline Ouffall ID & 027 & \multirow[t]{3}{*}{$\begin{array}{l}\text { Sandia Canyon (Sigma } \\
\text { Canyon to NPDES outfall } \\
001)\end{array}$} & \multirow{3}{*}{$\begin{array}{l}\text { Aluminum, total } \\
\text { Copper, dissolved } \\
\text { Gross Alpha, adjusted } \\
\text { PCBs } \\
\text { Thallium, dissolved }\end{array}$} & \multirow{3}{*}{$\begin{array}{l}\text { TMDL Name and ID: } \\
\text { N/A } \\
\text { Pollutant(s) for which } \\
\text { there is a TMDL: } \\
\text { N/A }\end{array}$} \\
\hline Latitude & 35.872401 & & & \\
\hline Longlitude & -106.313391 & & & \\
\hline \multicolumn{5}{|c|}{ If substantially identical to other outfall, list identical outfall ID: 026} \\
\hline Outfall ID & 028 & \multirow[t]{3}{*}{$\begin{array}{l}\text { Sandia Canyon (Sigma } \\
\text { Canyon to NPDES outfall } \\
001 \text { ) }\end{array}$} & \multirow{3}{*}{$\begin{array}{l}\text { Aluminum, total } \\
\text { Copper, dissolved } \\
\text { Gross Alpha, adjusted } \\
\text { PCBs } \\
\text { Thallium, dissolved }\end{array}$} & \multirow{3}{*}{$\begin{array}{l}\text { TMDL Name and ID: } \\
\text { N/A } \\
\text { Pollutant(s) for which } \\
\text { there is a TMDL: } \\
\text { N/A }\end{array}$} \\
\hline Lottlude & 35.872505 & & & \\
\hline Longltude & -106.313542 & & & \\
\hline \multicolumn{5}{|c|}{ If substantially identical to other outfall, list identical outfall ID: 026} \\
\hline
\end{tabular}




\begin{tabular}{|c|c|c|c|c|}
\hline Outfall ID & 029 & \multirow{3}{*}{$\begin{array}{l}\text { Sandia Canyon (Sigma } \\
\text { Canyon to NPDES outfall } \\
\text { 001) }\end{array}$} & \multirow{3}{*}{$\begin{array}{l}\text { Aluminum, total } \\
\text { Copper, dissolved } \\
\text { Gross Alpha, adjusted } \\
\text { PCBs } \\
\text { Thallium, dissolved }\end{array}$} & \multirow{3}{*}{$\begin{array}{l}\text { TMDL Name and ID: } \\
\text { N/A } \\
\text { Pollutant(s) for which } \\
\text { there is a TMDL: } \\
\text { N/A }\end{array}$} \\
\hline Latitude & 35.873969 & & & \\
\hline Longltude & -106.313281 & & & \\
\hline \multicolumn{5}{|c|}{ If substantially identical to other outfall, list Identical outfall ID: } \\
\hline Outfall ID & 031 & \multirow[t]{3}{*}{$\begin{array}{l}\text { Mortandad Canyon (within } \\
\text { LANL) }\end{array}$} & \multirow{3}{*}{\begin{tabular}{|l|} 
Aluminum, total \\
Copper, dissolved \\
Gross Alpha, adjusted \\
PCBs
\end{tabular}} & \multirow{3}{*}{$\begin{array}{l}\text { TMDL Name and ID: } \\
\text { N/A } \\
\text { Pollutant(s) for which } \\
\text { there is a TMDL: } \\
\text { N/A }\end{array}$} \\
\hline Latifude & 35.869227 & & & \\
\hline Longltude & -106.305685 & & & \\
\hline \multicolumn{5}{|c|}{ If substantially identical to other outfall, list Identical outfall ID: } \\
\hline Outfill ID & 030 & \multirow[t]{3}{*}{$\begin{array}{l}\text { Mortandad Canyon (within } \\
\text { LANL) }\end{array}$} & \multirow{3}{*}{$\begin{array}{l}\text { Aluminum, total } \\
\text { Copper, dissolved } \\
\text { Gross Alpha, adjusted } \\
\text { PCBs }\end{array}$} & \multirow{3}{*}{$\begin{array}{l}\text { TMDL Name and ID: } \\
\text { N/A } \\
\text { Pollutant(s) for which } \\
\text { there is a TMDL: } \\
\text { N/A }\end{array}$} \\
\hline Latitude & 35.869325 & & & \\
\hline Longitude & -106.306926 & & & \\
\hline \multicolumn{5}{|c|}{ If substantially identical to other outfall, list identical ouffall ID: 031} \\
\hline Outfall ID & 032 & \multirow[t]{3}{*}{$\begin{array}{l}\text { Sandia Canyon (Sigma } \\
\text { Canyon to NPDES outfall } \\
\text { 001) }\end{array}$} & \multirow{3}{*}{$\begin{array}{l}\text { Aluminum, total } \\
\text { Copper, dissolved } \\
\text { Gross Alpha, adjusted } \\
\text { PCBs } \\
\text { Thallium, dissolved }\end{array}$} & \multirow{3}{*}{$\begin{array}{l}\text { TMDL Name and ID: } \\
\text { N/A } \\
\text { Pollutant(s) for which } \\
\text { there is a IMDL: } \\
\text { N/A }\end{array}$} \\
\hline Lotflude & 35.870741 & & & \\
\hline Longltude & -106.306812 & & & \\
\hline If substantia & ally identical to other $c$ & fall, Ilst identical outfall ID: & & \\
\hline
\end{tabular}




\begin{tabular}{|c|c|c|c|c|}
\hline Outfall ID & 033 & \multirow{3}{*}{$\begin{array}{l}\text { Sandia Canyon (Sigma } \\
\text { Canyon to NPDES outfall } \\
001 \text { ) }\end{array}$} & \multirow{3}{*}{$\begin{array}{l}\text { Aluminum, total } \\
\text { Copper, dissolved } \\
\text { Gross Alpha, adjusted } \\
\text { PCBs } \\
\text { Thallium, dissolved }\end{array}$} & \multirow{3}{*}{$\begin{array}{l}\text { TMDL Name and ID: } \\
\text { N/A } \\
\text { Pollutant(s) for which } \\
\text { there is a TMDL: } \\
\text { N/A }\end{array}$} \\
\hline Lathude & 35.870712 & & & \\
\hline Longltude & -106.306443 & & & \\
\hline \multicolumn{5}{|c|}{ If substantially Identical to other outfall, list Identical outfall ID: 032} \\
\hline Outfall ID & 034 & \multirow[t]{3}{*}{$\begin{array}{l}\text { Sandia Canyon (Sigma } \\
\text { Canyon to NPDES outfall } \\
001 \text { ) }\end{array}$} & \multirow{3}{*}{$\begin{array}{l}\text { Aluminum, total } \\
\text { Copper, dissolved } \\
\text { Gross Alpha, adjusted } \\
\text { PCBs } \\
\text { Thallium, dissolved }\end{array}$} & \multirow{3}{*}{$\begin{array}{l}\text { TMDL Name and ID: } \\
\text { N/A } \\
\text { Pollutant(s) for which } \\
\text { there is a TMDL: } \\
\text { N/A }\end{array}$} \\
\hline Latitude & 35.870603 & & & \\
\hline Longltude & -106.306055 & & & \\
\hline \multicolumn{5}{|c|}{ If substantlally identical to other outfall, list Identical outfall ID: $\underline{032}$} \\
\hline Outfall ID & 035 & \multirow[t]{3}{*}{$\begin{array}{l}\text { Sandia Canyon (Sigma } \\
\text { Canyon to NPDES outfall } \\
\text { 001) }\end{array}$} & \multirow{3}{*}{$\begin{array}{l}\text { Aluminum, total } \\
\text { Copper, dissolved } \\
\text { Gross Alpha, adjusted } \\
\text { PCBs } \\
\text { Thallium, dissolved }\end{array}$} & \multirow{3}{*}{$\begin{array}{l}\text { TMDL Name and ID: } \\
\text { N/A } \\
\text { Pollutant(s) for which } \\
\text { there is a TMDL: } \\
\text { N/A }\end{array}$} \\
\hline Latifude & 35.870474 & & & \\
\hline Longitude & -106.305432 & & & \\
\hline \multicolumn{5}{|c|}{ If substantially identical to other outfall, list identical outfall ID: 032} \\
\hline Outfall ID & 036 & \multirow[t]{3}{*}{$\begin{array}{l}\text { Sandia Canyon (Sigma } \\
\text { Canyon to NPDES outfall } \\
\text { 001) }\end{array}$} & \multirow{3}{*}{$\begin{array}{l}\text { Aluminum, total } \\
\text { Copper, dissolved } \\
\text { Gross Alpha, adjusted } \\
\text { PCBs } \\
\text { Thallium, dissolved }\end{array}$} & \multirow{3}{*}{$\begin{array}{l}\text { TMDL Name and ID: } \\
\text { N/A } \\
\text { Pollutant(s) for which } \\
\text { there is a TMDL: } \\
\text { N/A }\end{array}$} \\
\hline Lathude & 35.867825 & & & \\
\hline Longitude & -106.293388 & & & \\
\hline \multicolumn{5}{|c|}{ If substantially Identical to other outfall, list identical ouffall ID: } \\
\hline
\end{tabular}




\begin{tabular}{|c|c|c|c|c|}
\hline Outtall ID & 037 & \multirow{3}{*}{$\begin{array}{l}\text { Sandia Canyon (Sigma } \\
\text { Canyon to NPDES outfall } \\
001 \text { ) }\end{array}$} & \multirow{3}{*}{$\begin{array}{l}\text { Aluminum, total } \\
\text { Copper, dissolved } \\
\text { Gross Alpha, adjusted } \\
\text { PCBs } \\
\text { Thallium, dissolved }\end{array}$} & \multirow{3}{*}{$\begin{array}{l}\text { TMDL Name and ID: } \\
\text { N/A } \\
\text { Pollutant(s) for which } \\
\text { there is a TMDL: } \\
\text { N/A }\end{array}$} \\
\hline Lotifude & 35.867859 & & & \\
\hline Longltude & -106.292992 & & & \\
\hline \multicolumn{5}{|c|}{ If substantially identical to other outfall, Ist Identical outfall ID: 036} \\
\hline Outfall ID & 039 & \multirow[t]{3}{*}{$\begin{array}{l}\text { Sandia Canyon (Sigma } \\
\text { Canyon to NPDES outfall } \\
\text { 001) }\end{array}$} & \multirow{3}{*}{$\begin{array}{l}\text { Aluminum, total } \\
\text { Copper, dissolved } \\
\text { Gross Alpha, adjusted } \\
\text { PCBs } \\
\text { Thallium, dissolved }\end{array}$} & \multirow{3}{*}{$\begin{array}{l}\text { TMDL Name and ID: } \\
\text { N/A } \\
\text { Pollutant(s) for which } \\
\text { there is a TMDL: } \\
\text { N/A }\end{array}$} \\
\hline Lotitude & 35.867826 & & & \\
\hline Longilude & -106.291726 & & & \\
\hline \multicolumn{5}{|c|}{ If substantially Identical to other outfall, list identical outfall ID: } \\
\hline Outfall ID & 038 & \multirow[t]{3}{*}{$\begin{array}{l}\text { Sandia Canyon (Sigma } \\
\text { Canyon to NPDES outfall } \\
001 \text { ) }\end{array}$} & \multirow{3}{*}{$\begin{array}{l}\text { Aluminum, total } \\
\text { Copper, dissolved } \\
\text { Gross Alpha, adjusted } \\
\text { PCBs } \\
\text { Thallium, dissolved }\end{array}$} & \multirow{3}{*}{$\begin{array}{l}\text { TMDL Name and ID: } \\
\text { N/A } \\
\text { Pollutant(s) for which } \\
\text { there is a TMDL: } \\
\text { N/A }\end{array}$} \\
\hline Latfiude & 35.867855 & & & \\
\hline Longitude & -106.292211 & & & \\
\hline \multicolumn{5}{|c|}{ If substantlally identical to other outfall, list Identical ouffall ID: 039} \\
\hline Outfall ID & 040 & \multirow[t]{3}{*}{$\begin{array}{l}\text { Sandia Canyon (Sigma } \\
\text { Canyon to NPDES outfall } \\
001 \text { ) }\end{array}$} & \multirow{3}{*}{$\begin{array}{l}\text { Aluminum, total } \\
\text { Copper, dissolved } \\
\text { Gross Alpha, adjusted } \\
\text { PCBs } \\
\text { Thallium, dissolved }\end{array}$} & \multirow{3}{*}{\begin{tabular}{|l} 
TMDL Name and ID: \\
N/A \\
Pollutant(s) for which \\
there is a TMDL: \\
N/A
\end{tabular}} \\
\hline Latifude & 35.867839 & & & \\
\hline Longitude & -106.291955 & & & \\
\hline \multicolumn{5}{|c|}{ If substantially Identical to other ouffall, list identical outfall ID: 039} \\
\hline
\end{tabular}




\begin{tabular}{|c|c|c|c|c|}
\hline Outfall ID & 042 & \multirow{3}{*}{$\begin{array}{l}\text { Sandia Canyon (Sigma } \\
\text { Canyon to NPDES outfall } \\
001 \text { ) }\end{array}$} & \multirow{3}{*}{$\begin{array}{l}\text { Aluminum, total } \\
\text { Copper, dissolved } \\
\text { Gross Alpha, adjusted } \\
\text { PCBs } \\
\text { Thallium, dissolved }\end{array}$} & \multirow{3}{*}{\begin{tabular}{|l} 
TMDL Name and ID: \\
N/A \\
Pollutant(s) for which \\
there is a TMDL: \\
N/A
\end{tabular}} \\
\hline Lotflude & 35.867047 & & & \\
\hline Longltude & -106.289163 & & & \\
\hline \multicolumn{5}{|c|}{ If substantially Identical to other outfall, list identical outfall ID: } \\
\hline Outfall ID & 041 & \multirow[t]{3}{*}{$\begin{array}{l}\text { Mortandad Canyon (within } \\
\text { LANL) }\end{array}$} & \multirow{3}{*}{$\begin{array}{l}\text { Aluminum, total } \\
\text { Copper, dissolved } \\
\text { Gross Alpha, adjusted } \\
\text { PCBs }\end{array}$} & \multirow{3}{*}{$\begin{array}{l}\text { TMDL Name and ID: } \\
\text { N/A } \\
\text { Pollutant(s) for which } \\
\text { there is a TMDL: } \\
\text { N/A }\end{array}$} \\
\hline Lottilude & 35.866377 & & & \\
\hline Longlitude & -106.291397 & & & \\
\hline \multicolumn{5}{|c|}{ If substantially identical to other outfall, list identical outfall ID: $\underline{042}$} \\
\hline Outfall ID & 043 & \multirow[t]{3}{*}{$\begin{array}{l}\text { Mortandad Canyon (within } \\
\text { LANL) }\end{array}$} & \multirow{3}{*}{$\begin{array}{l}\text { Aluminum, total } \\
\text { Copper, dissolved } \\
\text { Gross Alpha, adjusted } \\
\text { PCBs }\end{array}$} & \multirow{3}{*}{$\begin{array}{l}\text { TMDL Name and ID: } \\
\text { N/A } \\
\text { Pollutant(s) for which } \\
\text { there is a TMDL: } \\
\text { N/A }\end{array}$} \\
\hline Latifude & 35.866084 & & & \\
\hline Longlitude & -106.290165 & & & \\
\hline \multicolumn{5}{|c|}{ If substantialy Identical to other outfall, Ist Identical outfall ID: } \\
\hline Outiall ID & 047 & \multirow[t]{3}{*}{$\begin{array}{l}\text { Canada del Buey (within } \\
\text { LANL) }\end{array}$} & \multirow[t]{3}{*}{$\begin{array}{l}\text { Aluminum, total } \\
\text { Gross Alpha, adjusted } \\
\text { PCBs }\end{array}$} & \multirow{3}{*}{$\begin{array}{l}\text { TMDL Name and ID: } \\
\text { N/A } \\
\text { Pollutant(s) for whlch } \\
\text { there is a TMDL: } \\
\text { N/A }\end{array}$} \\
\hline Latifude & 35.844895 & & & \\
\hline Longltude & -106.264513 & & & \\
\hline \multicolumn{5}{|c|}{ If substantially identical to other outfoll, list identical outfall ID: } \\
\hline
\end{tabular}




\begin{tabular}{|c|c|c|c|c|}
\hline Outtall ID & 044 & \multirow[t]{3}{*}{$\begin{array}{l}\text { Canada del Buey (within } \\
\text { LANL) }\end{array}$} & \multirow{3}{*}{$\begin{array}{l}\text { Aluminum, total } \\
\text { Gross Alpha, adjusted } \\
\text { PCBs }\end{array}$} & \multirow{3}{*}{$\begin{array}{l}\text { TMDL Name and ID: } \\
\text { N/A } \\
\text { Pollutant(s) for which } \\
\text { there is a TMDL: } \\
\text { N/A }\end{array}$} \\
\hline Lotlfude & 35.845868 & & & \\
\hline Longltude & -106.265279 & & & \\
\hline \multicolumn{5}{|c|}{ If substantlally Identical to other outfall, list Identical outfall ID: $\underline{047}$} \\
\hline Outfall ID & 045 & \multirow[t]{3}{*}{$\begin{array}{l}\text { Canada del Buey (within } \\
\text { LANL) }\end{array}$} & \multirow[t]{3}{*}{$\begin{array}{l}\text { Aluminum, total } \\
\text { Gross Alpha, adjusted } \\
\text { PCBs }\end{array}$} & \multirow{3}{*}{$\begin{array}{l}\text { TMDL Name and ID: } \\
\text { N/A } \\
\text { Pollutant(s) for which } \\
\text { there is a TMDL: } \\
\text { N/A }\end{array}$} \\
\hline Lattlude & 35.845586 & & & \\
\hline Longltude & -106.265214 & & & \\
\hline \multicolumn{5}{|c|}{ If substanfially Identical to other outfall, list identical outfall ID: 047} \\
\hline Ouffall ID & 046 & \multirow[t]{3}{*}{$\begin{array}{l}\text { Canada del Buey (within } \\
\text { LANL) }\end{array}$} & \multirow[t]{3}{*}{$\begin{array}{l}\text { Aluminum, total } \\
\text { Gross Alpha, adjusted } \\
\text { PCBs }\end{array}$} & \multirow{3}{*}{$\begin{array}{l}\text { TMDL Name and ID: } \\
\text { N/A } \\
\text { Pollutant(s) for which } \\
\text { there is a TMDL: } \\
\text { N/A }\end{array}$} \\
\hline Latliude & 35.845200 & & & \\
\hline Longitude & -106.264844 & & & \\
\hline \multicolumn{5}{|c|}{ If substantlaly identical to other outfall, list identical outfall ID: 047} \\
\hline Outfall ID & 048 & \multirow[t]{3}{*}{$\begin{array}{l}\text { Canada del Buey (within } \\
\text { LANL) }\end{array}$} & \multirow[t]{3}{*}{$\begin{array}{l}\text { Aluminum, total } \\
\text { Gross Alpha, adjusted } \\
\text { PCBs }\end{array}$} & \multirow{3}{*}{$\begin{array}{l}\text { TMDL Name and ID: } \\
\text { N/A } \\
\text { Pollutant(s) for which } \\
\text { there is a TMDL: } \\
\text { N/A }\end{array}$} \\
\hline Lotitude & 35.844590 & & & \\
\hline Longitude & -106.265044 & & & \\
\hline \multicolumn{5}{|c|}{ If substantially identical to other outfall, list identical outfall ID: 047} \\
\hline
\end{tabular}




\begin{tabular}{|c|c|c|c|c|}
\hline Outtall ID & 049 & \multirow{3}{*}{$\begin{array}{l}\text { Pajarito Canyon (within } \\
\text { LANL below Arroyo de la } \\
\text { Delfe) }\end{array}$} & \multirow[t]{3}{*}{$\begin{array}{l}\text { Aluminum, total } \\
\text { PCBs }\end{array}$} & \multirow{3}{*}{$\begin{array}{l}\text { TMDL Name and ID: } \\
\text { N/A } \\
\text { Pollutant(s) for which } \\
\text { there is a TMDL: } \\
\text { N/A }\end{array}$} \\
\hline Latifude & 35.837228 & & & \\
\hline Longilude & -106.254840 & & & \\
\hline \multicolumn{5}{|c|}{ If substantially Identical to other outfall, list Identical outfall ID: } \\
\hline Outfall ID & 050 & \multirow[t]{3}{*}{$\begin{array}{l}\text { Canada del Buey (within } \\
\text { LANL) }\end{array}$} & \multirow[t]{3}{*}{$\begin{array}{l}\text { Aluminum, total } \\
\text { Gross Alpha, adjusted } \\
\text { PCBs }\end{array}$} & \multirow{3}{*}{$\begin{array}{l}\text { TMDL Name and ID: } \\
\text { N/A } \\
\text { Pollutant(s) for which } \\
\text { there is a TMDL: } \\
\text { N/A }\end{array}$} \\
\hline Lottlude & 35.835746 & & & \\
\hline Longltude & -106.250832 & & & \\
\hline \multicolumn{5}{|c|}{ If substantially identical to other outfall, list identical outfall ID: } \\
\hline Outfall ID & 051 & \multirow[t]{3}{*}{$\begin{array}{l}\text { Pajarito Canyon (within } \\
\text { LANL below Arroyo de la } \\
\text { Delfe) }\end{array}$} & \multirow[t]{3}{*}{$\begin{array}{l}\text { Aluminum, total } \\
\text { PCBs }\end{array}$} & \multirow{3}{*}{$\begin{array}{l}\text { TMDL Name and ID: } \\
\text { N/A } \\
\text { Pollutant(s) for which } \\
\text { there is a TMDL: } \\
\text { N/A }\end{array}$} \\
\hline Lotitude & 35.830143 & & & \\
\hline Longitude & -106.242662 & & & \\
\hline \multicolumn{5}{|c|}{ If substantially identical to other outfall, ilst identical outfall ID: } \\
\hline Outfall ID & 052 & \multirow[t]{3}{*}{$\begin{array}{l}\text { Pajarito Canyon (within } \\
\text { LANL below Arroyo de la } \\
\text { Delfe) }\end{array}$} & \multirow[t]{3}{*}{$\begin{array}{l}\text { Aluminum, total } \\
\text { PCBs }\end{array}$} & \multirow{3}{*}{$\begin{array}{l}\text { TMDL Name and ID: } \\
\text { N/A } \\
\text { Pollutant(s) for which } \\
\text { there is a IMDL: } \\
\text { N/A }\end{array}$} \\
\hline Lottlude & 35.831852 & & & \\
\hline Longitude & -106.242928 & & & \\
\hline \multicolumn{5}{|c|}{ If substantlally identical to other outfall, list identical ouffall ID: 051} \\
\hline
\end{tabular}




\begin{tabular}{|c|c|c|c|c|}
\hline Outfall ID & 053 & \multirow{3}{*}{$\begin{array}{l}\text { Pajarito Canyon (within } \\
\text { LANL below Arroyo de la } \\
\text { Delfe) }\end{array}$} & \multirow[t]{3}{*}{$\begin{array}{l}\text { Aluminum, total } \\
\text { PCBs }\end{array}$} & \multirow{3}{*}{$\begin{array}{l}\text { TMDL Name and ID: } \\
\text { N/A } \\
\text { Pollutant(s) for which } \\
\text { there is a TMDL: } \\
\text { N/A }\end{array}$} \\
\hline Latitude & 35.829232 & & & \\
\hline Longitude & -106.236793 & & & \\
\hline \multicolumn{5}{|c|}{ If substantlally Identical to other outfall, list Identical outfall ID: } \\
\hline Outfall ID & 065 & \multirow[t]{3}{*}{$\begin{array}{l}\text { Pajarito Canyon (within } \\
\text { LANL below Arroyo de la } \\
\text { Delfe) }\end{array}$} & \multirow[t]{3}{*}{$\begin{array}{l}\text { Aluminum, total } \\
\text { PCBs }\end{array}$} & \multirow{3}{*}{$\begin{array}{l}\text { TMDL Name and ID: } \\
\text { N/A } \\
\text { Pollutant(s) for which } \\
\text { there is a TMDL: } \\
\text { N/A }\end{array}$} \\
\hline Latitude & 35.829028 & & & \\
\hline Longitude & -106.236029 & & & \\
\hline \multicolumn{5}{|c|}{ If substantially Identical to other outfall, IIs Identical outfall ID: 053} \\
\hline Outfall ID & 066 & \multirow[t]{3}{*}{$\begin{array}{l}\text { Pajarito Canyon (within } \\
\text { LANL below Arroyo de la } \\
\text { Delfe) }\end{array}$} & \multirow[t]{3}{*}{$\begin{array}{l}\text { Aluminum, total } \\
\text { PCBs }\end{array}$} & \multirow{3}{*}{$\begin{array}{l}\text { TMDL Name and ID: } \\
\text { N/A } \\
\text { Pollutant(s) for which } \\
\text { there is a TMDL: } \\
\text { N/A }\end{array}$} \\
\hline Latilude & 35.830185 & & & \\
\hline Longlitude & -106.236107 & & & \\
\hline \multicolumn{5}{|c|}{ If substantially Identical to other outtall, list identical outtall ID: 053} \\
\hline Outfall ID & 069 & \multirow[t]{3}{*}{$\begin{array}{l}\text { Pajarito Canyon (within } \\
\text { LANL below Arroyo de la } \\
\text { Delfe) }\end{array}$} & \multirow[t]{3}{*}{$\begin{array}{l}\text { Aluminum, total } \\
\text { PCBs }\end{array}$} & \multirow{3}{*}{$\begin{array}{l}\text { TMDL Name and ID: } \\
\text { N/A } \\
\text { Pollutant(s) for which } \\
\text { there is a TMDL: } \\
\text { N/A }\end{array}$} \\
\hline Lattiude & 35.830285 & & & \\
\hline Longltude & -106.234518 & & & \\
\hline \multicolumn{5}{|c|}{ If substantially identical to other ouffall, list identical outfall ID: } \\
\hline
\end{tabular}




\begin{tabular}{|c|c|c|c|c|}
\hline Outfall ID & 054 & \multirow{3}{*}{$\begin{array}{l}\text { Pajarito Canyon (within } \\
\text { LANL below Arroyo de la } \\
\text { Delfe) }\end{array}$} & \multirow[t]{3}{*}{$\begin{array}{l}\text { Aluminum, total } \\
\text { PCBs }\end{array}$} & \multirow{3}{*}{$\begin{array}{l}\text { TMDL Name and ID: } \\
\text { N/A } \\
\text { Pollutant(s) for which } \\
\text { there is a TMDL: } \\
\text { N/A }\end{array}$} \\
\hline Latilude & 35.829036 & & & \\
\hline Longltude & -106.235125 & & & \\
\hline \multicolumn{5}{|c|}{ If substantially identical to other outfall, list Identical outfall ID: 069} \\
\hline Outfall ID & 055 & \multirow[t]{3}{*}{$\begin{array}{l}\text { Pajarito Canyon (within } \\
\text { LANL below Arroyo de la } \\
\text { Delfe) }\end{array}$} & \multirow[t]{3}{*}{$\begin{array}{l}\text { Aluminum, total } \\
\text { PCBs }\end{array}$} & \multirow{3}{*}{$\begin{array}{l}\text { TMDL Name and ID: } \\
\text { N/A } \\
\text { Pollutant(s) for which } \\
\text { there is a TMDL: } \\
\text { N/A }\end{array}$} \\
\hline Lottlude & 35.829173 & & & \\
\hline Longitude & -106.235121 & & & \\
\hline \multicolumn{5}{|c|}{ If substantially identical to other outfall, list identical outiall ID: 069} \\
\hline Outfall ID & 056 & \multirow[t]{3}{*}{$\begin{array}{l}\text { Pajarito Canyon (within } \\
\text { LANL below Arroyo de la } \\
\text { Delfe) }\end{array}$} & \multirow[t]{3}{*}{$\begin{array}{l}\text { Aluminum, total } \\
\text { PCBs }\end{array}$} & \multirow{3}{*}{$\begin{array}{l}\text { TMDL Name and ID: } \\
\text { N/A } \\
\text { Pollutant(s) for which } \\
\text { there is a TMDL: } \\
\text { N/A }\end{array}$} \\
\hline Latitude & 35.829310 & & & \\
\hline Longitude & -106.236107 & & & \\
\hline \multicolumn{5}{|c|}{ If substantially Identical to other ouffall, list identical ouffall ID: 069} \\
\hline Outfall ID & 057 & \multirow[t]{3}{*}{$\begin{array}{l}\text { Pajarito Canyon (within } \\
\text { LANL below Arroyo de la } \\
\text { Delfe) }\end{array}$} & \multirow[t]{3}{*}{$\begin{array}{l}\text { Aluminum, total } \\
\text { PCBs }\end{array}$} & \multirow{3}{*}{$\begin{array}{l}\text { TMDL Name and ID: } \\
\text { N/A } \\
\text { Pollutant(s) for which } \\
\text { there is a TMDL: } \\
\text { N/A }\end{array}$} \\
\hline Lattiude & 35.829440 & & & \\
\hline Longitude & -106.235117 & & & \\
\hline \multicolumn{5}{|c|}{ If substantially Identical to other outfall, Ilst identical outfall ID: 069} \\
\hline
\end{tabular}




\begin{tabular}{|c|c|c|c|c|}
\hline Outtall ID & 058 & \multirow{3}{*}{$\begin{array}{l}\text { Pajarito Canyon (within } \\
\text { LANL below Arroyo de la } \\
\text { Delfe) }\end{array}$} & \multirow[t]{3}{*}{$\begin{array}{l}\text { Aluminum, total } \\
\text { PCBs }\end{array}$} & \multirow{3}{*}{$\begin{array}{l}\text { TMDL Name and ID: } \\
\text { N/A } \\
\text { Pollutant(s) for which } \\
\text { there is a TMDL: } \\
\text { N/A }\end{array}$} \\
\hline Latifude & 35.829573 & & & \\
\hline Longlitude & -106.235112 & & & \\
\hline \multicolumn{5}{|c|}{ If substantially Identical to other outfall, Ist Identical outfall ID: 069} \\
\hline Outfall ID & 059 & \multirow[t]{3}{*}{$\begin{array}{l}\text { Pajarito Canyon (within } \\
\text { LANL below Arroyo de la } \\
\text { Delfe) }\end{array}$} & \multirow[t]{3}{*}{$\begin{array}{l}\text { Aluminum, total } \\
\text { PCBs }\end{array}$} & \multirow{3}{*}{$\begin{array}{l}\text { TMDL Name and ID: } \\
\text { N/A } \\
\text { Pollutant(s) for which } \\
\text { there is a TMDL: } \\
\text { N/A }\end{array}$} \\
\hline Latifude & 35.829711 & & & \\
\hline Longlitude & -106.235108 & & & \\
\hline \multicolumn{5}{|c|}{ If substantially Identical to other outfill, list identical outfall ID: $\underline{069}$} \\
\hline Outfall ID & 060 & \multirow[t]{3}{*}{$\begin{array}{l}\text { Pajarito Canyon (within } \\
\text { LANL below Arroyo de la } \\
\text { Delfe) }\end{array}$} & \multirow[t]{3}{*}{$\begin{array}{l}\text { Aluminum, total } \\
\text { PCBs }\end{array}$} & \multirow{3}{*}{$\begin{array}{l}\text { TMDL Name and ID: } \\
\text { N/A } \\
\text { Pollutant(s) for which } \\
\text { there is a TMDL: } \\
\text { N/A }\end{array}$} \\
\hline Latitude & 35.830340 & & & \\
\hline Longlitude & -106.234802 & & & \\
\hline \multicolumn{5}{|c|}{ If substantially identical to other outfall, Iist identical outfall ID: 069} \\
\hline Outfall ID & 061 & \multirow[t]{3}{*}{$\begin{array}{l}\text { Pajarito Canyon (within } \\
\text { LANL below Arroyo de la } \\
\text { Delfe) }\end{array}$} & \multirow[t]{3}{*}{$\begin{array}{l}\text { Aluminum, total } \\
\text { PCBs }\end{array}$} & \multirow{3}{*}{$\begin{array}{l}\text { TMDL Name and ID: } \\
\text { N/A } \\
\text { Pollutant(s) for which } \\
\text { there is a TMDL: } \\
\text { N/A }\end{array}$} \\
\hline Lattlude & 35.830343 & & & \\
\hline Longilude & -106.234766 & & & \\
\hline \multicolumn{5}{|c|}{ If substantially Identical to other outfall, Ilst Identical outfall ID: 069} \\
\hline
\end{tabular}




\begin{tabular}{|c|c|c|c|c|}
\hline Outfall ID & 062 & \multirow{3}{*}{$\begin{array}{l}\text { Pajarito Canyon (within } \\
\text { LANL below Arroyo de la } \\
\text { Delfe) }\end{array}$} & \multirow[t]{3}{*}{$\begin{array}{l}\text { Aluminum, total } \\
\text { PCBs }\end{array}$} & \multirow{3}{*}{$\begin{array}{l}\text { TMDL Name and ID: } \\
\text { N/A } \\
\text { Pollutant(s) for which } \\
\text { there is a TMDL: } \\
\text { N/A }\end{array}$} \\
\hline Lotitude & 35.830344 & & & \\
\hline Longlitude & -106.234725 & & & \\
\hline \multicolumn{5}{|c|}{ If substantlally identical to other outfall, Ilst Identical outfall ID: 069} \\
\hline Outfall ID & 063 & \multirow[t]{3}{*}{$\begin{array}{l}\text { Pajarito Canyon (within } \\
\text { LANL below Arroyo de la } \\
\text { Delfe) }\end{array}$} & \multirow[t]{3}{*}{$\begin{array}{l}\text { Aluminum, total } \\
\text { PCBs }\end{array}$} & \multirow{3}{*}{$\begin{array}{l}\text { TMDL Name and ID: } \\
\text { N/A } \\
\text { Pollutant(s) for which } \\
\text { there is a TMDL: } \\
\text { N/A }\end{array}$} \\
\hline Latitude & 35.830342 & & & \\
\hline Longltude & -106.234692 & & & \\
\hline \multicolumn{5}{|c|}{ If substanfially Identical to other outfall, list Identical outfall ID: 069} \\
\hline Outfall ID & 064 & \multirow[t]{3}{*}{$\begin{array}{l}\text { Pajarito Canyon (within } \\
\text { LANL below Arroyo de la } \\
\text { Delfe) }\end{array}$} & \multirow[t]{3}{*}{$\begin{array}{l}\text { Aluminum, total } \\
\text { PCBs }\end{array}$} & \multirow{3}{*}{$\begin{array}{l}\text { TMDL Name and ID: } \\
\text { N/A } \\
\text { Pollutant(s) for which } \\
\text { there is a TMDL: } \\
\text { N/A }\end{array}$} \\
\hline Lotitude & 35.830340 & & & \\
\hline Longltude & -106.234656 & & & \\
\hline \multicolumn{5}{|c|}{ If substantially Identical to other outfall, Ilst identical outfall ID: 069} \\
\hline Outfall ID & 067 & \multirow[t]{3}{*}{$\begin{array}{l}\text { Pajarito Canyon (within } \\
\text { LANL below Arroyo de la } \\
\text { Delfe) }\end{array}$} & \multirow[t]{3}{*}{$\begin{array}{l}\text { Aluminum, total } \\
\text { PCBs }\end{array}$} & \multirow{3}{*}{$\begin{array}{l}\text { TMDL Name and ID: } \\
\text { N/A } \\
\text { Pollutant(s) for which } \\
\text { there is a TMDL: } \\
\text { N/A }\end{array}$} \\
\hline Lotfiude & 35.829856 & & & \\
\hline Longlitude & -106.235110 & & & \\
\hline \multicolumn{5}{|c|}{ If substantially identical to other outfall, list Identical ouffall ID: 069} \\
\hline
\end{tabular}




\begin{tabular}{|c|c|c|c|c|}
\hline Outrall ID & 068 & \multirow{3}{*}{$\begin{array}{l}\text { Pajarito Canyon (within } \\
\text { LANL below Arroyo de la } \\
\text { Delfe) }\end{array}$} & \multirow[t]{3}{*}{$\begin{array}{l}\text { Aluminum, total } \\
\text { PCBs }\end{array}$} & \multirow{3}{*}{$\begin{array}{l}\text { TMDL Name and ID: } \\
\text { N/A } \\
\text { Pollutant(s) for which } \\
\text { there is a TMDL: } \\
\text { N/A }\end{array}$} \\
\hline Latitude & 35.830051 & & & \\
\hline Longltude & -106.235103 & & & \\
\hline \multicolumn{5}{|c|}{ If substantially Identical to other outfall, list identical outfall ID: 069} \\
\hline Ouffall ID & 072 & \multirow[t]{3}{*}{$\begin{array}{l}\text { Canada del Buey (within } \\
\text { LANL) }\end{array}$} & \multirow[t]{3}{*}{$\begin{array}{l}\text { Aluminum, total } \\
\text { Gross Alpha, adjusted } \\
\text { PCBs }\end{array}$} & \multirow{3}{*}{$\begin{array}{l}\text { TMDL Name and ID: } \\
\text { N/A } \\
\text { Pollutant(s) for which } \\
\text { there is a TMDL: } \\
\text { N/A }\end{array}$} \\
\hline Lattlude & 35.832885 & & & \\
\hline Longitude & -106.239444 & & & \\
\hline \multicolumn{5}{|c|}{ If substantially identical to other outfall, list identical ouffall ID: } \\
\hline Ouffall ID & 070 & \multirow[t]{3}{*}{$\begin{array}{l}\text { Canada del Buey (within } \\
\text { LANL). }\end{array}$} & \multirow[t]{3}{*}{$\begin{array}{l}\text { Aluminum, total } \\
\text { Gross Alpha, adjusted } \\
\text { PCBs }\end{array}$} & \multirow{3}{*}{$\begin{array}{l}\text { TMDL Name and ID: } \\
\text { N/A } \\
\text { Pollutant(s) for which } \\
\text { there is a TMDL: - } \\
\text { N/A }\end{array}$} \\
\hline Lotlitude & 35.832404 & & & \\
\hline Longlitude & -106.240510 & & & \\
\hline \multicolumn{5}{|c|}{ If substantially identical to other ouffall, list identical outfall ID: $\underline{072}$} \\
\hline Outfall ID & 071 & \multirow[t]{3}{*}{$\begin{array}{l}\text { Canada del Buey (within } \\
\text { LANL) }\end{array}$} & \multirow[t]{3}{*}{$\begin{array}{l}\text { Aluminum, total } \\
\text { Gross Alpha, adjusted } \\
\text { PCBs }\end{array}$} & \multirow{3}{*}{$\begin{array}{l}\text { TMDL Name and ID: } \\
\text { N/A } \\
\text { Pollutant(s) for which } \\
\text { there is a TMDL: } \\
\text { N/A }\end{array}$} \\
\hline Lathude & 35.832701 & & & \\
\hline Longitude & -106.240994 & & & \\
\hline \multicolumn{5}{|c|}{ If substantially Identical to other outfall, list identical outfall ID: $\underline{072}$} \\
\hline
\end{tabular}




\begin{tabular}{|c|c|c|c|c|}
\hline Outrall ID & 073 & \multirow{3}{*}{$\begin{array}{l}\text { Sandia Canyon (Sigma } \\
\text { Canyon to NPDES outfall } \\
\text { 001) }\end{array}$} & \multirow{3}{*}{$\begin{array}{l}\text { Aluminum, total } \\
\text { Copper, dissolved } \\
\text { Gross Alpha, adjusted } \\
\text { PCBs } \\
\text { Thallium, dissolved }\end{array}$} & \multirow{3}{*}{$\begin{array}{l}\text { TMDL Name and ID: } \\
\text { N/A } \\
\text { Pollutant(s) for which } \\
\text { there is a TMDL: } \\
\text { N/A }\end{array}$} \\
\hline Lattlude & 35.874819 & & & \\
\hline Longltude & -106.324283 & & & \\
\hline \multicolumn{5}{|c|}{ If substantially Identical to other outfall, Ilst Identical outfall ID: } \\
\hline Outfall ID & 074 & \multirow[t]{3}{*}{$\begin{array}{l}\text { Sandia Canyon (Sigma } \\
\text { Canyon to NPDES outfall } \\
001 \text { ) }\end{array}$} & \multirow{3}{*}{$\begin{array}{l}\text { Aluminum, total } \\
\text { Copper, dissolved } \\
\text { Gross Alpha, adjusted } \\
\text { PCBs } \\
\text { Thallium, dissolved }\end{array}$} & \multirow{3}{*}{$\begin{array}{l}\text { TMDL Name and ID: } \\
\text { N/A } \\
\text { Pollutant(s) for which } \\
\text { there is a TMDL: } \\
\text { N/A }\end{array}$} \\
\hline Latitude & 35.875034 & & & \\
\hline Longltude & -106.327328 & & & \\
\hline \multicolumn{5}{|c|}{ If substantlally identical to other outfall, list identical outfall ID: $\underline{073}$} \\
\hline Outfall ID & 075 & \multirow[t]{3}{*}{$\begin{array}{l}\text { Sandia Canyon (Sigma } \\
\text { Canyon to NPDES outfall } \\
001 \text { ) }\end{array}$} & \multirow{3}{*}{$\begin{array}{l}\text { Aluminum, total } \\
\text { Copper, dissolved } \\
\text { Gross Alpha, adjusted } \\
\text { PCBs } \\
\text { Thallium, dissolved }\end{array}$} & \multirow{3}{*}{$\begin{array}{l}\text { TMDL Name and ID: } \\
\text { N/A } \\
\text { Pollutant(s) for which } \\
\text { there is a TMDL: } \\
\text { N/A }\end{array}$} \\
\hline Loflitude & 35.871154 & & & \\
\hline Longitude & -106.312940 & & & \\
\hline \multicolumn{5}{|c|}{ If substantially identical to other outfall, list Identical outfall ID: } \\
\hline \multicolumn{2}{|l|}{ Outlall ID } & & & \multirow{3}{*}{$\begin{array}{l}\text { Pollutant(s) for which } \\
\text { there is a TMDL: }\end{array}$} \\
\hline Lathude & & & & \\
\hline Longlitude & & & & \\
\hline \multicolumn{5}{|c|}{ If substantially identical to other outfall, Ist Identical outfall ID: } \\
\hline
\end{tabular}


4. Provide the following Information about your outfall latitude longitude:

Latifude/Longitude Data Source: $\square$ Map $\square$ GPS $\square$ Other

If you used a USGS topographic map, what was the scale?

Horizontal Reference Datum: $\square$ NAD 27 $\square$ NAD 83 $\square$ WGS 84

5. Does your facility discharge into a Muncipal Separate Storm Sewer System (MS4)? $\square$ YES $\square$ NO

If yes, provide the name of the MS4 operator: N/A

6. Check if you discharge to any of the waters of the U.S. that are designated by the state or tribal authority under its antidegradation policy as a Tier 2 (or Tier 2.5) water (water quality exceeds levels necessary to support propagation of fish, shellfish, and wildlife and recreation in and on the water) or as a Tier 3 water (Outstanding National Resource Water)? (See Appendix L).

$\square$ Tier $2 / 2.5$. Provide the name(s) of receiving water(s):

$\square$ Tier 3 (Outstanding National Resource Waters)*

Nole: You are ineligible for coverage if you are a new discharger or new source to waters designated as Tier 3 (outstanding national resource waters) for antidegradation purposes under 40 CFR 131.13(a)(3).

7. If you are subject to benchmark monitoring requirements for a hardness-dependent metal, what is the hardness of your receiving water(s) (see Appendix J)? 57 (mg/L)

8. If you are subject to benchmark monitoring requirements for a hardness-dependent metal, does your facility discharge into any saltwater receiving waters? $\square$ YES $⿴$ NO

9. Does your facility discharge to a federal CERCLA site listed in Appendix P? $\square$ YES $\square$ NO

If yes, did you notify the EPA Regional Office in advance of filing your NOI, and did the EPA Regional Office determine that you are eligible for permit coverage pursuant to Part 1.1.4.10*? $\square$ YES $\square$ NO

- Note: If you discharge to a federal CERCLA site listed in Appendix P, you are ineligible for coverage under this permilt unless you notily the EPA Regional Office in advance and the EPA Regional Office determines you are eliglble coverage under this permilt. In determining your eligibilly for coverage under this Part, the EPA Regional Office may evaluate whether you have included adequate controls and/or procedures to ensure that your discharges will not lead to recontamination of aquatic media at the CERCLA Site such that it will to cause or contribute to an exceedance of a water quality standard.

F. Stormwater Pollution Prevention Plan (SWPPP) Information

1. Has the SWPPP been prepared in advance of filing this NOI, as required? $\square$ YES $\square$ NO

2. SWPPP Contact Information:

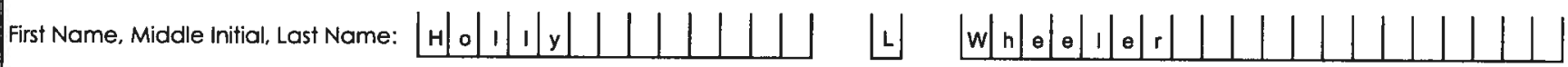

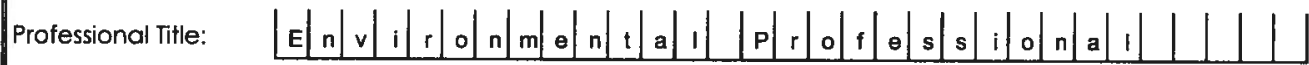

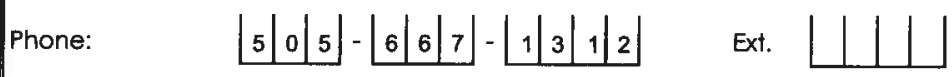

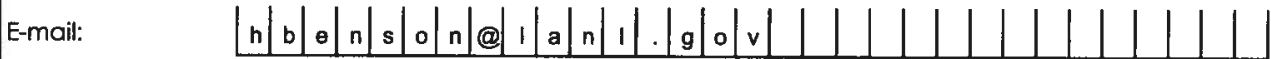

3. SWPPP Availability:

Your current SWPPP or certain information from your SWPPP must be made available through one of the following two options. Select one of the options and provide the required information*:

- Note: You are not required to post any confidential business information (CBI) or restricted information (as defined in Appendix A) (such information may be redacted), but you must clearly Identify those portions of the SWPPP that are being withheld trom public access.

Option 1: Maintain a current copy of your SWPPP on an Internet page (Universal Resource Locator or URL).

Provide the web address URL:eprr.lanl.gov

$\square$ Option 2: Provide the following information from your SWPPP:

A. Describe your onsite industrial activities exposed to stormwater (e.g., material storage; equipment fueling, maintenance, and cleaning; cutting steel beams), and potential spill and leak areas: 


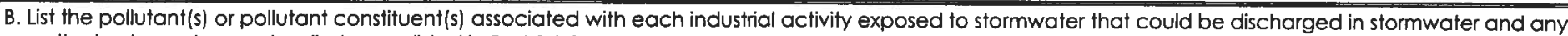
authorized non-stormwater discharges listed in Part 1.1.3:

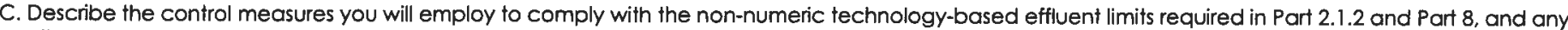
other measures taken to comply with the requirements in Part 2.2 Water Quality-Based Effluent Limitations (see Part 5.2.4):

D. Provide a schedule for good housekeeping and maintenance (see Part 5.2.5.1) and a schedule for all inspections required in Part 4 (see Part 5.2.5.2):

\section{G. Endangered Species Protection}

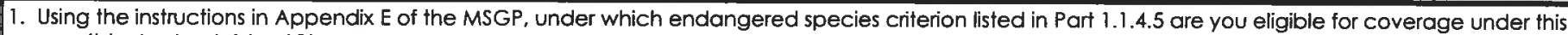
permif (only check 1 box)?*
$\square \mathrm{A}$
$\square \mathrm{B}$
$\square \mathrm{C}$
D
$\square \mathrm{E}$

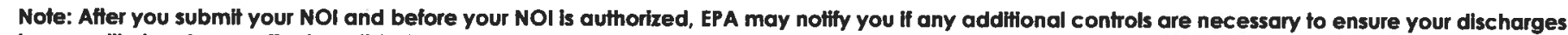
have no llkely adverse affects on listed species and crifical habitat.

2. Provide a brief summary of the basis for the criterion selected in Appendix E (e.g., communication with U.S. Fish and Wildlife Service or National Marine Fisheries Service to determine no species in action area: implementation of controls approved by EPA and the Services):

Direct consultation with the U.S. Fish and Wildlife Service and corresponding development and implementation of a facility-specific Habitat Management Plan.

3. If you select criterion B, provide the NPDES ID from the other operator's NOI authorized under this permit:

4. If you select criterion $C$, you must answer the following questions:

a. What federally-listed species or designated critical habitat are located in your "action area":

b. Using the Appendix E worksheet, check which of the following is applicable to your facility and answer any corresponding questions:

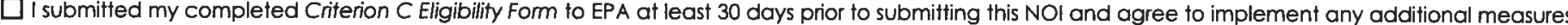
that were determined by EPA to be necessary to ensure that my discharges and/or discharge-related activities will not have likely adverse affects on listed species and critical habitat.

Date your Criterion C Eligibilty Form was sent to EPA

Describe any EPA-approved measures you will implement to ensure no likely adverse affects on listed species and critical habitat:

I submitted my completed Criterion C Eligibility Form to EPA at least 30 days prior to submitting this NOI and have not been notified of any additional measures necessary to ensure no likely adverse affects on listed species and critical habitat.

Date your Criterion C Eligibility Form was sent to EPA:

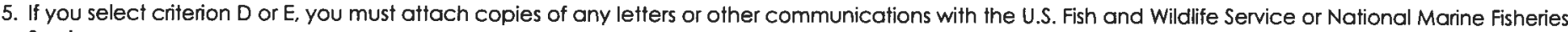
Service. 


\section{H. Historic Preservafion}

1. If your facility is not located on Indian country lands, is your facility located on a property of religious or cultural significance to an Indian tribe?

$\square$ YES $\square$ NO

If yes, provide the name of the Indian tribe associated with the property: San Ildefonso Pueblo

2. Using the instructions in Appendix F of the MSGP, under which historic properties preservation criterion listed in Part 1.1.4.6 are you eligible for coverage under this permit (only check 1 box)?

$\square$ A $\square$ B $\square C \quad \square D$

\section{Certilication Information}

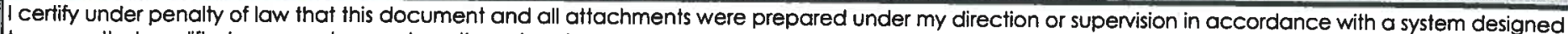

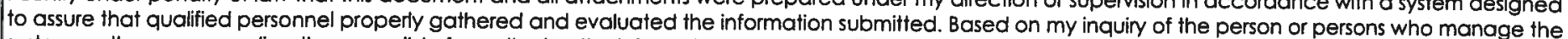

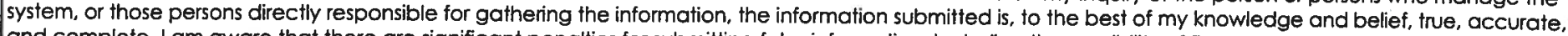

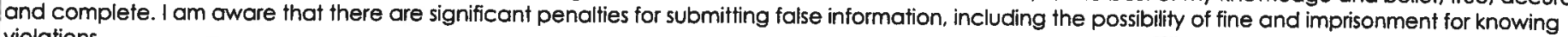
violations.

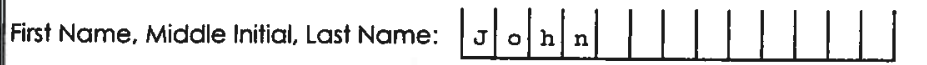

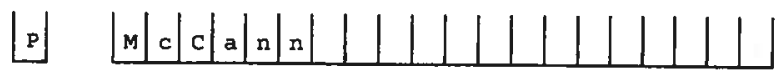

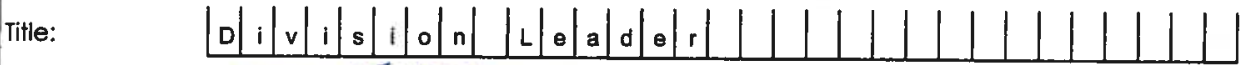

Signature:

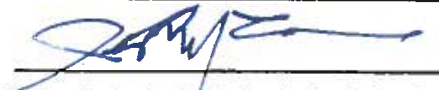

E-mail: 
Notice of Intent (NOI) for Stormwater Discharges

\section{Associated with Industrial Activity Under the NPDES Multi-Sector General Permit}

NPDES Form Date (06/15) This Form Replaces From 3510-6 (09/08) Form Approved OMB No. 2040-0004

\section{Who Must File an NOI Form}

Under section 402(p) of the Clean Water Act (CWA) and regulations at 40 CFR Part 122, stormwater discharges associated with industrial activity are prohibited to waters of the United States unless authorized under a National Pollutant Discharge Elimination System (NPDES) permit. You can obtain coverage under the MSGP by submitting a completed Notice of Intent (NOI) if you are an operator a facility:

- that is located in a jurisdiction where EPA is the permitting authority, listed in Appendix C of the MSGP,

- that discharges stormwater associated with industrial activities, identified in Appendix D of the MSGP,

- that meets the eligibility requirements in Part 1.1 of the permit,

- that has developed a stormwater pollution prevention plan (SWPPP) in accordance with Part 5 of the MSGP; and

- that installs and implements control measures in accordance with Part 2 and Part 8 to meet numeric and non-numeric effluent limits.

\section{Completing the Form}

Obtain and read a copy of the 2015 MSGP, viewable http://water.epa.gov/polwaste/nodes/stormwater/EPA-MultiSector-General-Permit-MSGP.cfm. To complete this form, type or print, using uppercase letters, in the appropriate areas only. Please place each character between the marks. Abbreviate if necessary to stay within the number of characters allowed for each item. Use only one space for breaks between words, but not for punctuation marks unless they are needed to clarify your response. Please submit original document with signature in ink - do not send a photocopied signature.

\section{Section A. Approval to Use Paper NOI Form}

You must indicate whether you have been granted a waiver from electronic reporting from the EPA Regional Office. Note that you are not authorized to use this paper NOI form unless the EPA Regiona Office has approved its use. Where you have obtained approval to use this form, indicate the waiver that you have been granted, the name of the EPA staff person who granted the waiver, and the date that approval was provided.

See http://water,epa.gov/polwaste/nodes/stormwater/StormwaterContacts.cfm for a list of EPA Regional Office contacts.

\section{Section B. Permit Information}

Provide the master permit number of the permit under which you are applying for coverage (see Appendix $\mathrm{C}$ of the general permit for the list of eligible master permit numbers).

You must indicate whether you are a new discharger or a new source (see Appendix $A$ for the definitions). If you are not a new discharger or a new source, you must indicate whether stormwater discharges from your facility have been previously covered under another NPDES permit. If yes, you must provide the unique NPDES ID (i.e., permit tracking number) for the previous permit your facility was covered under.

\section{Section C. Facility Operator Information}

Provide the legal name of the person, firm, public organization, or any other entity that operates the facility described in this NOI. An operator of a facility is the legal entity that controls the operation of the facility. Refer to Appendix $A$ of the permit for the definition of "operator". Provide the operator's mailing address, phone number, and e-mail. Correspondence for the NOI will be sent to this address. Also provide the name and title for the operator point of contact (note that the point of contact name may be the same as the operator name).

If the NOI was prepared by someone other than the certifier (for example, if the NOI was prepared by the facility SWPPP contact or a consultant for the certifier's signature), include the full name, organization, phone number, and email address of the NOI preparer.

\section{Section D. Facillity Information}

Enter the official or legal name and complete address, including city, state, ZIP code, and county or similar government subdivision of the facility. If the facility lacks a street address, indicate the general location of the facility (e.g., Intersection of State Highways 61 and 34). Complete facility information must be provided for permit coverage to be granted.

Provide the latitude and longitude of your facility in decimal degrees format. The latitude and longitude of your facility can be determined in several different ways, including through the use of global positioning system (GPS) receivers, U.S. Geological Survey (U.S.G.S.) topographic or quadrangle maps. Refer to http://transition.fcc.gov/mb/audio/bickel/DDDMMSSdecimal,html/ for assistance in providing the proper latitude/longitude format. For consistency, EPA requests that measurements be taken from the approximate center of the facility. Specify which method you used to determine latitude and longitude. If a U.S.G.S. topographic map is used, specity the scale of the map used. Enter the horizontal reference datum for your latitude and longitude. The horizontal reference datum used on USGS topographic maps is shown on the bottom left comer of USGS topographic maps; it is also available for GPS receivers.

Indicate whether the facility is on Indian country lands, and if so, provide the name of the Indian tribe associated with the area of Indian country (including name of Indian reservation, if applicable).

Indicate whether you are seeking coverage under this permit as a "federal operator" as defined in Appendix A. Also check the ownership type for the facility (e.g., Federal Facility, Privately Owned Facility, Municipality, County Government, Corporation, State Government, Tribal Government, School District, District, Mixed Ownership [e.g., public/private], Municipal or Water District).

Enter the estimated area of industrial activity at your facility exposed to stormwaterto the nearest quarter acre.

List the four-digit Standard Industrial Classification (SIC) code or two character activity code that best describes the primary industrial activities performed by your facility under which you are required to obtain permit coverage. Your primary industrial activity includes any activities performed on-site which are (1) identified by the facility's primary SIC code and included in the descriptions of 40 CFR 122.26(b)(14)(ii), (iii), (vi), or (viii); or (2) included in the narrative descriptions of 40 CFR 122.26 (b) (14) (i), (iv), (v). (vii), or (ix). See Appendix D of the MSGP for a complete list of SIC codes and activities codes covered under the MSGP. Also provide the applicable sector and subsector associated with the SIC code or activity code for your primary industrial activities. For a complete list of sector and subsector codes, see Appendix D of the MSGP.

If your facility has co-located industrial activities that are not identified as your primary industrial activity, identify the sector and subsector codes that describe these other industrial activities. 


\section{Notice of Intent (NOI) for Stormwater Discharges \\ Associated with Industrial Activity Under the NPDES Multi-Sector General Permit}

NPDES Form Date (06/15) This Form Replaces From 3510-6 (09/08) Form Approved OMB No. 2040-0004

For Sector $S$ facilities (Air Transportation), indicate whether you anticipate that the entire airport facility will use more than 100,000 gallons of pure glycol in glycol-based deicing fluids and/or 100 tons or more of urea on an average annual basis. If so, additional effluent limits and monitoring conditions apply to your discharge (see Part 8.5 of the permit).

For Sector $G$ facilities (Metal Mining), check the type of ore(s) mined at the facility.

Indicate whether your facility is currently inactive and unstaffed. Note that if your facility becomes inactive and unstaffed during the permit term, you must submit an NOI modification to reflect the change.

\section{Section E. Discharge Information}

You must confirm that you understand that the MSGP only authorizes the allowable stormwater discharges listed in Part 1.1.2 and the allowable non-stormwater discharges listed in Part 1.1.3. Any discharges not expressly authorized under the MSGP are not covered by the MSGP or the permit shield provision of the CWA Section $402(k)$ and they cannot become authorized or shielded by disclosure to EPA, state, or local authorities via the NOI to be covered by the permit or by any other means (e.g., in the SWPPP or during an inspection). If any discharges requiring NPDES permit coverage other than the allowable stormwater and non-stormwater discharges listed in Parts 1.1.2 and 1.1.3 will be discharged, they must either be eliminated or covered under another NPDES permit.

Depending on your industrial activities, your facility may be subject to federal effluent limitation guidelines which include additional effluent limits and monitoring requirements for your facility. Please review these requirements, described in Part 2.1.3 of the MSGP, and check any appropriate boxes on the NOl form.

You must identify all the outfalls from your facility that discharge stormwater. Each outfall must be assigned a unique 3-digit ID (e.g., 001, 002,003 ). You must also provide the latitude and longitude for each outfall from your facility. Indicate whether any outfalls are substantially identical to an outfall already listed, and identify the outfall it is identical to. For each unique outfall you list, you must specify the name of the first water of the U.S. that receives stormwater directly from the outfall and/or from the MS4 that the outfall discharges to. You must specify whether any receiving waters that you discharge to are listed as "impaired" as defined in Appendix A, and the pollutants for which the water is impaired. You must also check identify any Total Maximum Daily Loads (TMDL) that have been completed for any of the waters of the U.S. that you discharge to. You must also provide information about the outfall latitude/longitude, including data source, the scale (if applicable), and the horizontal reference datum. See the instructions in Section D for more information about determining the latitude and longitude.

Identify whether your facility discharges into a Municipal Separate Storm Sewer System (MS4). If yes, provide the name of the MS4 operator. If you are uncertain of the MS4 operator, contact your local government for that information.

Indicate whether discharges from the facility will enter into a water of the U.S that is designated as a Tier 2, Tier 2.5, or Tier 3 water. A list of Tier 2, 2.5, and 3 waters is provided as Appendix $L$. If the answer is "yes", name all waters designated as Tier 2, Tier 2.5, or Tier 3 to which the facility will discharge. Note that you are ineligible for coverage if you are a new discharger or a new source to waters designated as Tier 3 (outstanding national resource waters) for antidegradation purposes under 40 CFR 131.13(a)(3).
If you are subject to any benchmark monitoring requirements for metals (see the requirements applicable to your Sector(s) in Part 8 of the permit), indicate the hardness for your receiving water(s). See Appendix $\mathrm{J}$ of the permit for information about determining waterbody hardness.

If you are subject to benchmark monitoring requirements for hardnessdependent metals you must also answer whether your facility discharges into any saltwater receiving waters.

Indicate whether your facility will discharge to a federal CERCLA site listed in Appendix $P$. Note that if your facility will discharge into a federal CERCLA site listed in Appendix $P$, you are not eligible for coverage under this permit unless you notify the EPA Regional Office in advance and the EPA Regional Office authorizes overage under this permit after you have included adequate controls and/or procedures designed to ensure that discharges will not lead to recontamination of aquatic media at the CERCLA site such that your discharge will cause or contribute to an exceedance of a water quality standard.

\section{Section F. Stormwater Pollution Prevention Plan (SWPPP) Information}

All facilities eligible for coverage under this permit are required to prepare a SWPPP in advance of filing the NOI, in accordance with Part 5. Indicate whether the SWPPP has been prepared in advance of filing the NOI.

Indicate the contact information (name, phone, and email) for the person who developed the SWPPP for this facility.

You identify how your SWPPP information will be made available, consistent with Part 5.4 and 7.3 of the permit. If you are making your SWPPP publicly available on a web site, check Option 1 and provide the appropriate internet URL address. If you are not providing a URL, check Option 2 and provide the selected SWPPP information on this NOI form. You may copy and paste this information directly from your SWPPP.

\section{Section G. Endangered Species Protection}

Using the instructions in Appendix $E$, indicate the Part 1.1.4.5 criterion (i.e.. A, B, C, D. or E) you are eligible under with regard to the protection of federally listed endangered and threatened species and designated critical habitat. A description of the basis for the criterion selected must also be provided.

If criterion B is selected, provide the NPDES ID (i.e., permit tracking number] for the other operator who has certified their eligibility under this permit. The NPDES ID was assigned when the operator received coverage under this permit.

If criterion $C$ is selected, you must specify the federally-listed species or designated critical habitat that are located in the "action area" of the facility. You must also indicate under which scenario you determined you were eligible to submit your $\mathrm{NO}$ under criterion $\mathrm{C}$ using Appendix $E$, and answer any corresponding questions.

If criterion $D$ or $E$ is selected, attach copies of any communications between you and the U.S. Fish and Wildlife Service and National Marine Fisheries Service to this NOI.

\section{Section H. Historic Preservation}

If the project is not located in Indian country lands, indicate whether the project is located on a property of religious or cultural significance to an Indian tribe, and if so, provide the name of the Indian tribe associated with the property. Use the instructions in Appendix $F$ to complete the questions on the NOI form regarding historic preservation. 
Notice of Intent (NOI) for Stormwater Discharges

Associated with Industrial Activity Under the NPDES Multi-Sector General Permit

NPDES Form Date (06/15) This Form Replaces From 3510-6 (09/08)

Form Approved OMB No. 2040-0004

\section{Section I. Certification}

Certification statement and signature (see Section B.11 of Appendix $B$ of the MSGP for more information). Enter certifier's printed name, title and email address. Sign and date the form. (CAUTION: An unsigned or undated $\mathrm{NOI}$ form will prevent the granting of permit coverage.) Federal statutes provide for severe penalties for submitting false information on this application form. Federal regulations require this application to be signed as follows:

For a corporation: by a responsible corporate officer, which means: (i) a president, secretary, treasurer, or vice-president of the corporation in charge of a principal business function, or any other person who performs similar policy- or decision-making functions for the corporation, or (ii) the manager of one or more manufacturing, production, or operating facilities, provided, the manager is authorized to make management decisions which govern the operation of the regulated facility including having the explicit or implicit duty of making major capital investment recommendations, and initiating and directing other comprehensive measures to assure long-term environmental compliance with environmental laws and regulations; the manager can ensure that the necessary systems are established or actions taken to gather complete and accurate information for permit application requirements; and where authority to sign documents has been assigned or delegated to the manager in accordance with corporate procedures.

For a partnership or sole proprietorship: By a general partner or the proprietor, respectively; or

For a municipality, state, federal, or other public agency: By either a principal executive officer or ranking elected official. For purposes of this Part, a principal executive officer of a federal agency includes (i) the chief executive officer of the agency, or (ii) a senior executive officer having responsibility for the overall operations of a principal geographic unit of the agency (e.g.. Regional Administrator of EPA). Include the name and title of the person signing the form and the date of signing.

An unsigned or undated $\mathrm{NOI}$ form will not be considered eligible for permit coverage.

\section{Moditying Your NOI}

If you have been granted a waiver from your Regional Office from electronic reporting, and if after submitting your NOI you need to correct or update any fields on this NOI form, you may do so by indicating changes on this same form.

\section{Paperwork Reduction Acł Notice}

Public reporting burden for this NOI is estimated to average 3.7 hours, plus an additional 2 hours for certain respondents required to gather hardness data. This estimate includes time for reviewing instructions, searching existing data sources, gathering and maintaining the data needed, and completing and reviewing the collection of information. An agency may not conduct or sponsor, and a person is not required to respond to, a collection of information unless it displays a currently valid OMB control number. Send comments regarding the burden estimate, any other aspect of the collection of information, or suggestions for improving this form, including any suggestions which may increase or reduce this burden to: Director, Collection Strategies Division, U.S. Environmental Protection Agency (2822T), 1200 Pennsylvania Ave., NW. Washington, D.C. 20460. Include the OMB control number on any correspondence. Do not send the completed form to this address.

\section{Submitting Your Form}

If you have been granted a waiver from your Regional Office to submit a paper $\mathrm{NOl}$ form, you must send your NOl by mail to one of the following addresses:

For Regular U.S. Mail Delivery:

Stormwater Notice Processing Center

Mail Code 4203M, ATTN: 2015 MSGP Reports

U.S. EPA

1200 Pennsylvania Avenue, NW

Washington, DC 20460

For Overnight/Express Mail Delivery:

Stormwater Notice Processing Center

William Jefferson Clinton East Building - Room 7420

ATNN: 2015 MSGP Reports

U.S. EPA

1201 Constitution Avenue, NW

Washington, DC 20004

Visit this website for instructions on how to submit electronically: htto://water.epa.gov/polwaste/npdes/stormwater/Stormwater-eNOISystem-for-EPAs-MultiSector-General-Permit.cfm 


\section{ENCLOSURE 2}

Concurrence Letters From the United States Department of Interior, Fish and Wildlife Service

ADESH-16-045

LA-UR-16-21721

Date:

MAR 222016 


\title{
United States Department of the Interior
}

\author{
FISH AND WILDLIFE SERVICE \\ New Mexico Ecological Services Field Office \\ 2105 Osuna NE \\ Albuquerque, New Mexico 87113 \\ Phone: (505) 346-2525 Fax: (505) 346-2542
}

February 12, 1999

Cons. \#2-22-98-1-336

Cons. \#2-22-95-I-108

David A. Gurule, Acting Area Manager

Department of Energy

Albuquerque Operations Office

Los Alamos Area Office

Los Alamos, New Mexico 87545

Dear Mr. Gurule:

This responds to your letter dated August 6, 1998, requesting our review and concurrence with the Threatened and Endangered Species Habitat Management Plan (HMP) for Los Alamos National Laboratory (LANL). The HMP was prepared by the LANL Ecology Group for the Department of Energy (DOE) as part of the Dual-Axis Radiographic Hydrodynamics Test Facility (DAHRT) Mitigation Action Plan. The U.S. Fish and Wildlife Service (Service) has worked closely with LANL in the development of the HMP. As a result of discussions and meetings following the August 6, 1998, submittal, additional information/clarification was provided via letters, updated Biological Evaluations/HMPs, and e-mail messages, dated September 8, October 20, November 25, and December 9, 1998, and January 4, January 22, and January 29, 1999. The purpose of the HMP is to provide for the protection of threatened and endangered species and their habitats on LANL. The HMP consists of three components that must be used together to assure proper management of the threatened and endangered species: an Overview Document, Site Plans, and Monitoring Plans. It was determined that if all the restrictions and protective measures outlined in the HMP are strictly followed, the implementation of this HMP may affect, but is not likely to adversely affect the Mexican spotted owl (owl), peregrine falcon (falcon), bald eagle (eagle), and southwestern willow flycatcher (flycatcher). The Biological Evaluation (BE) also considered potential impacts on the black-footed ferret, arctic peregrine falcon, and whooping crane. It was determined that there would be no effect on these species because of a lack of habitat.

Property at LANL varies from remote isolation to heavily developed and/or industrialized. The Service agrees, as stated in the Overview document, that a number of activities at LANL have the potential to adversely impact threatened and endangered species. Many of the industrial processes used at LANL have involved hazardous and radioactive materials. These materials as well as remediation of potential release sites may disturb 
or reduce population viability of threatened and endangered species. In addition, other potential sources of disturbance or habitat alterations are possible as a result of the residential and commercial development in the LANL area. While the HMP identifies potential sources of adverse effects, this consultation does not necessarily cover all of those impacts. The Service does not anticipate that DOE will be able to plan all of its operations at LANL in accordance with this plan. The direct effects of most actions can be minimized through implementation of the HMP; however, a more thorough assessment is necessary to adequately evaluate the indirect and cumulative impacts of all actions that are funded, authorized, and permitted by DOE, as well as potential impacts from interrelated and interdependent actions. It was agreed (by Service, DOE, and LANL personnel) that consultation concerning ongoing LANL operations would be handled separately from the HMP, under the consultation on the Site-Wide EIS.

The Site Plans identify the particular areas of LANL where operations might impact known occupied or potential habitat for the flycatcher, eagle, falcon, and owl. Suitable habitat for these species, along with protective buffer areas surrounding their habitat, have been designated as Areas of Environmental Interest (AEIs). For the flycatcher, one AEl was established based on an observation of a migrant male flycatcher in 1997. The AEl is located in the Pajarito wetland area and includes the best available riparian habitat. For eagles, one AEI has been identified for wintering habitat that exists along the Rio Grande on the eastern edge of LANL. It is based on the locations of known and potential roost sites. For the falcon, four AEls have been identified. They consist of the habitat previously identified under the 1985 interagency agreement. These areas are centered on deep canyons on the eastern side of LANL or on adjacent lands. LANL has agreed to implement the recommended management guidelines, which utilize four management zones (A through D) to protect nesting peregrine falcons from disturbance. For the owl, six AEls have been identified, but only one of these sites is known to be occupied. These AEls are based on and located in canyons that have been defined as suitable nest/roost habitat.

The AEI management section of each Site Plan provides guidelines for LANL operations to reduce or eliminate threats to each species. The primary threats on LANL property are (1) impacts on habitat quality from LANL operations and (2) disturbance of nesting or roosting birds. The site plans provide information on their location and guidelines for their management. The AEI Site Plans consist of a species description, descriptions of the AEls for the species, descriptions of current impacts in the AEls, management plans that describe allowable activities within core and buffer areas under the guidelines of the sites plan and protective measures. Activities discussed in the site plans include day to day activities, such as access into an AEl, as well as long-term projects, such as levels of habitat alteration in the buffer area of an AEI. Restrictions will be implemented on activities that could cause disturbance (people, vehicles and machinery, aircraft, light production, and noise) within occupied AEls. The location of a potential disturbance activity within the AEl, the occupancy status of the AEI, and the type of activity all affect whether or not an activity is allowable. Habitat alterations are always restricted in core areas, but a limited amount of future development is allowed in currently undeveloped DOE-controlled buffer areas under the guidelines of this site plan as long 
as it does not alter habitat in the undeveloped AEI (including light and noise guidelines). The purpose of buffer areas is to protect core areas from undue disturbance or habitat alteration or habitat degradation. Each $A E I$ is specific to the situation or circumstances of the site it covers. According to the HMP, development beyond the cap established for each AEl, or greater than 2 hectares in size, including the developed-area border, requires independent review for ESA compliance.

Varying amounts of development and/or ongoing activities exist in the cores and buffers of each AEl. These developments may include residential, commercial, and light industrial areas, as well as roads and utility corridors. Existing/ongoing activities may include periodic scientific surveys, power line maintenance, recreational use, residential development, ER Program activities, and possible use of a firing site. Potential disturbance may be associated with automobile and truck traffic, construction activities, a live-fire range, explosives testing, and aircraft traffic at the County airport. Ongoing activities in developed areas constitute a baseline condition for the AEls and are not restricted. New activities including further development within already existing developed areas are not restricted unless they impact undeveloped portions of an AEI core. If a proposed action within a developed area does not meet site plan guidelines, it must be individually reviewed for ESA compliance.

Some activities such as utility corridor maintenance, fuels management, and a limited amount of development are allowed in each AEI (as described in the HMP). The potential impacts of these activities are considered to be insignificant or discountable because they will occur in habitat that has been previously disturbed or is of poor quality due to its size or proximity to already developed areas. It is our understanding (based on the January 22, 1999, e-mail response from Terry Foxx) that the fuels management activities within the owl AEls will only consist of ongoing and proposed fire protection activities around existing facilities (e.g. thinning around buildings) or those activities that are already covered under the Dome Fire Emergency BA. The other fire management activities mentioned in the HMP will go through the ESH-ID process and further consultation with the Service when a fire management plan is completed in the future.

In general, activities that detrimentally alter habitat in an AEI or would cause unacceptable disturbance to the species inhabiting the AEI are not allowed under the guidelines of a Site Plan. The Site Plans are designed to minimize impacts to threatened and endangered species and their habitat. The protective measures and restrictions outlined in the Site Plans were developed using the best available data, in cooperation with Service biologists.

The U.S. Fish and Wildlife Service concurs with DOE's determination that implementation of LANL's HMP mav affect, but is not likely to adversely affect the Mexican spotted owl, American peregrine falcon, bald eagle, and southwestern willow flycatcher based on the protective measures described in the BA and HMP. If all the restrictions and protective measures outlined in the HMP are strictly followed, potential impacts on owls, falcons, eagles, and flycatchers are expected to be insignificant or 
discountable for the following reasons: 1) appropriate seasonal restrictions will be implemented to avoid disturbance to potentially breeding flycatchers, peregrines, and owls and wintering eagles; 2) no nest or roost habitat for any listed species will be altered; 3) the total amount of potential foraging habitat that could be impacted within each species home ranges is expected to be insignificant compared to the amount of available foraging habitat throughout the area; 4) monitoring plans have been developed as an integral part of the HMP; and 5) a mechanism for incorporating necessary technical and regulatory changes and updating the HMP has been included (page 32 of the Overview Document).

In future communications regarding this project, please refer to Consultation \#2-22-981-336. If we can be of further assistance, please contact Carol Torrez of my staff at (505) 346-2525, ext. 115.

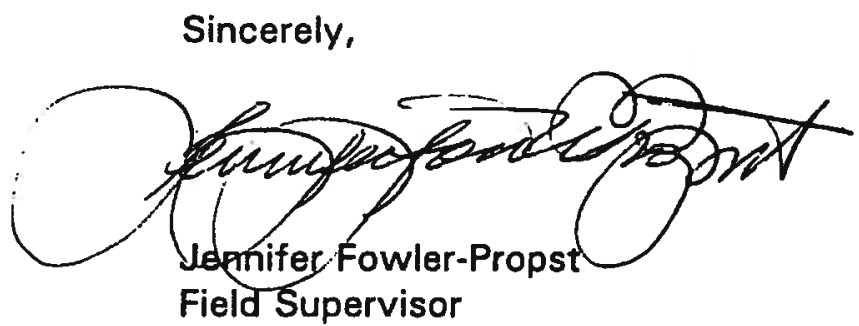

cc:

YTeralene Foxx, Project Manager, Ecology Group, Los Alamos National Laboratory, P.O. Box 1663, Mail Stop M887, Los Alamos, New Mexico 87545

Elizabeth Withers, U.S. Department of Energy., Los Alamos Area Office, $35^{\text {th }}$ Street, Los Alamos, New Mexico

Field Supervisor, Ecological Services, U.S. Fish and Wildlife Service, Phoenix, Arizona 


\title{
United States Department of the Interior
}

\author{
FISH AND WILDLIFE SERVICE \\ New Mexico Ecological Services Field Office \\ 2105 Osuna NE \\ Albuquerque, New Mexico 87113 \\ Phone: (505) 346-2525 Fax: (505) 346-2542
}

December 9, 2013

Cons. \#02ENNM00-2014-1-0014

Geoffrey L. Beausoleil, Acting Manager

National Nuclear Security Administration, Los Alamos Field Office

Department of Energy

Los Alamos, New Mexico 87544

Dear Mr. Beausoleil:

Thank you for your biological assessment entitled, "Biological Assessment of the Effects of Implementing the Jemez Mountains Salamander Site Plan on Federally Listed Threatened and Endangered Species at Los Alamos National Laboratory" (BA); the request for informal consultation and conferencing received on July 25, 2013 and supplemental information supplied in the "Jemez Mountains Salamander (Plethodon neomexicanus) Los Alamos National Laboratory (LANL) Site Plan" (Site Plan); and emails dated November 19 and December 3, 2013. The Department of Energy (DOE) requested concurrence with the determination of effects for the endangered Jemez Mountains salamander (Plethodon neomexicanus) (salamander) pursuant to Section 7(a)(2) of the Endangered Species Act of 1973 (ESA), as amended (16 U.S.C. § 1531 et seq.). Your proposed action consists of implementing the Site Plan, and includes of the incorporation of this Site Plan into LANL's Habitat Management Plan (HMP).

- The HMP was consulted upon in 1999 (Consultation \#2-22-981-336) as the primary mechanism to ensure compliance with the ESA at LANL. The actions described in the Site Plan and analyzed in the BA, and supplemental emails are hereby incorporated by reference. You determined that implementing the Site Plan "may affect, is not likely to adversely affect" the salamander, and includes placing restrictions on certain types of work in areas identified as core habitat for the salamander on LANL property with the purpose of ensuring that effects to the salamander from those actions identified in the Site Plan are insignificant and discountable.

The Site Plan does not include any areas within designated salamander critical habitat, indicating that no critical habitat will be affected. The Site Plan has modeled and field validated the model to identify the areas on LANL property with the highest potential to be occupied by salamanders based on habitat features for the salamander. Each area identified by the modeling is termed "Area of Environmental Interest" (AEI) and consists of a "core area" and a "buffer area". The core area habitat is defined as suitable habitat where the salamander occurs or may occur at LANL. The core area habitat consists of sections of north-facing slope that contain the required 
micro-habitat to support salamanders. The buffer area is 328 feet (100 meters) wide extending outward from the edge of the core area. Only the Los Alamos Canyon AEI is known to be occupied based on surveys. Surveys for the salamander are known to have a very low detection rate for occupied areas and DOE has assumed that all AEIs at LANL are occupied at all times by the salamander.

Within the Site Plan, DOE has assessed activities that could cause habitat alteration and includes any action that alters the soil structure, vegetative components necessary to the species, water quality, or hydrology in undeveloped areas of an AEI. If an activity were to take place outside of the AEI the activity will be assessed if it will have effects inside the AEI core. Within the core areas, only activities specified within the Site Plan and those that have no effect in the core areas (e.g. no habitat alterations or effects within the core areas) will be conducted without further consultation with the Service. Habitat alterations also include soil pits for soil samples deeper than 6 inches (15.2 centimeters) using either hand or mechanized augers. Within the Site Plan, DOE is proposing fuels management practices to reduce wildfire risk and maintenance of utility corridors within the AEIs. The likelihood that salamanders may be affected by the actions in the Site Plan is very low. To ensure that effects to the salamander are insignificant and discountable, the Site Plan incorporates the following conservation measures as restrictions to the identified work:

Fuels Management Practices to Reduce Wildfire Risk

a. Within undeveloped core areas, thinning trees to a level of $80 \%$ canopy cover or higher may occur; tree thinning below $80 \%$ canopy cover is not part of the action under this consultation.

b. Large logs on the ground will be left in place and not chipped.

c. Large trees that are felled will be left as large logs on the ground

d. When appropriate, smaller trees and understory shrubs that may be thinned will be dispersed and left on-site to aid in soil moisture retention.

e. In buffer areas, thinning of trees may occur to the current LANL-approved prescription level; clear-cutting will not occur.

f. Thinning activities will not occur during the rainy season when salamanders are surface active, between July 1 - October 31 . Thinning activities may occur earlier in October if freezing temperatures are present.

g. In the unlikely event that a salamander is observed surface active during thinning activities, all activities shall cease, and the Service will be notified.

Utility Corridors

a. Cutting trees that threaten power lines may occur within 26 feet (8 meters) of either side of an existing utility line at LANL

b. New utility lines and utility lines requiring clearance of a right-of-way greater than 52 feet (16 meters) total in core habitat is not part of the action under this consultation. 
Habitat alterations other than the fuels management practices and utility corridor maintenance described above will not occur in undeveloped core areas under the guidelines of the Site Plan or this consultation. The Service concurs with DOE's determination regarding the salamander for the following reasons:

Within the Site Plan, DOE has placed the above detailed restrictions to ensure that any effects to the salamander and its habitat remain insignificant and discountable. Canopy cover will remain at $80 \%$ or greater in undeveloped core areas and fire management actions will occur outside of the salamander surface activity period. Maintaining utility line corridors in areas with existing infrastructure (the utility lines) by removing individual hazard trees is not expected to have any measurable effect on salamanders or their potential habitat. Consequently, we concur that potential effects to the salamander from the proposed action will be insignificant and discountable.

This concludes section 7 consultation regarding the proposed action. If monitoring or other information results in modification or the inability to complete all aspects of the proposed action, consultation should be reinitiated. Please contact the Service if: 1) future surveys detect listed, proposed or candidate species in habitats where they have not been previously observed;2) the proposed action changes or new information reveals effects of the proposal to listed species that have not been considered in this analysis; or 3) a new species is listed or critical habitat designated that may be affected by the action.

Thank you for your concern for endangered and threatened species and New Mexico's wildlife habitats. In future correspondence regarding this project, please refer to consultation \#02ENNM00-2014-I-0014. If you have any questions, please contact Michelle Christman of my staff at (505) 761-4715.

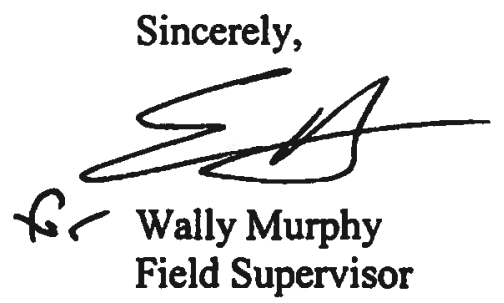

cc:

Wildlife Biologist, Cuba Ranger District, Cuba, NM (Attn: Ramon Borrego)

Director, New Mexico Department of Game and Fish, Santa Fe, New Mexico 


\title{
United States Department of the Interior
}

\author{
FISH AND WILDLIFE SERVICE \\ New Mexico Ecological Services Field Office \\ 2105 Osuna Road NE \\ Albuquerque, New Mexico 87113 \\ Telephone 505-346-2525 Fax 505-346-2542 \\ www.fws.gov/southwest/es/newmexico/
}

August 6, 2015

Cons. \# 02ENNM00-2015-I-0538

Kimberly Davis Lebak, Manager

Department of Energy

National Nuclear Security Administration

Los Alamos Field Office

Los Alamos, New Mexico 87544

Dear Ms. Lebak:

This responds to your July 9, 2015, cover letter and biological assessment (BA) requesting informal consultation for the addition of the Western distinct population segment of the yellowbilled cuckoo (Coccyzus americanus occidentalis) (cuckoo) and the New Mexico meadow jumping mouse (Zapus hudsonius luteus) (jumping mouse) to the Los Alamos National Laboratory Habitat Management Plan, Los Alamos, New Mexico. As documented in your BA, which is hereby incorporated by reference, we find that your proposed action will have insignificant and discountable effects to the cuckoo and the jumping mouse. Therefore, the Service concurs with your determination of "may affect, is not likely to adversely affect" for the cuckoo and the jumping mouse.

This concludes section 7 consultation regarding the proposed action. If monitoring or other information results in modification or the inability to complete all aspects of the proposed action, consultation should be reinitiated. Please contact the Service if: 1) future surveys detect listed, proposed or candidate species in habitats where they have not been previously observed; 2 ) the proposed action changes or new information reveals effects of the proposal to listed species that have not been considered in this analysis; or 3) a new species is listed or critical habitat designated that may be affected by the action. 
Thank you for your concern for endangered species and New Mexico's wildlife habitats. If you have any questions, please contact Eric Hein of my staff at the letterhead address or at (505) 7614735 .

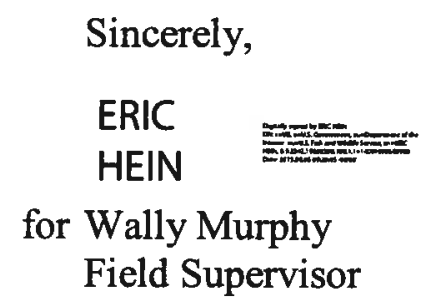

cc:

Director, New Mexico Department of Game and Fish, Santa Fe, New Mexico 


\title{
ENCLOSURE 3
}

\section{Multi-Sector General Permit (MSGP) Notice of Intent (NOI) Reporting Pursuant to Part B.12.H}

\author{
ADESH-16-045
}

LA-UR-16-21721

Date: 


\author{
Environmental Protection Division \\ Environmental Compliance Programs (ENV-CP) \\ PO Box 1663, K490 \\ Los Alamos, New Mexico 87545 \\ (505) 667-0666
}

\author{
Date: OCT 292015 \\ Symbol: ENV-DO-15-0309 \\ LA-UR: $\quad 15-28383$ \\ Locates Action No.: N/A
}

Mr. Brent Larsen

Water Quality Protection Division (6WQ)

U.S. Environmental Protection Agency, Region 6

1445 Ross Avenue, Suite 1200

Dallas, TX 75202-2733

Dear Mr. Larsen:

Subject: National Pollutant Discharge Elimination System (NPDES) Permit Tracking No. NMR053195, Multi-Sector General Permit (MSGP) Notice of Intent (NOI) Reporting Pursuant to Part B.12.H.

In submitting a NOI for coverage under the new NPDES Multi-Sector General Permit, Los Alamos National Security (LANS) experienced significant problems with EPA's NeT NPDES eReporting Tool which resulted in certification of the NOI on September 3 and initial submission of a NOI with incomplete outfall attribute data and incorrect information. During this time LANS staff contacted EPA's NOI Processing Center for support and was given the recommendation to contact Region 6 personnel for further guidance. Per this direction, on September 1, 2015, Terrill Lemke left you a voicemail summarizing the issues and potential impacts of the difficulties experienced with the new electronic reporting system. For additional clarification, the following is a summary of the timeline of events associated with the NOI submission.

- Monday, August 31, 2015

- Initiated NOI submission using the NeT NPDES eReporting Tool. 
- As data was entered into each data field on the NOI form, the Tool was very slow in processing the data and allowing entry into the next field. This created a significant waiting time.

- Upon reaching the fields on the NOI form where outfall attribute data was entered the Tool began to randomly crash, repeatedly deleting all unsaved data.

- Tuesday, September 1, 2015

- Tool continued to be very slow and randomly crash, repeatedly deleting all unsaved data.

- For each outfall, when listing the constituents associated with impaired waters, the Tool's auto population feature initially displayed incorrect data which required additional editing and then eventually stopped functioning and caused the Tool to crash.

- Much of the outfall attribute data had to be reentered multiple times before it was possible to successfully save it to the system.

- After each save or Tool crash the eReporting Tool would close the NOI form. The time required for the Tool to repeatedly reopen the form made data entry very time consuming.

- LANS staff contacted the EPA NOI Processing Center on the afternoon of Sept 1 for technical support:

- NOI Processing Center staff stated that they had been "flooded" with calls over the past week on Tool problems.

- LANS staff expressed their concern about the length of time being required to enter data and the potential inability to complete the NOI form by the Sept 2 deadline. No solution was available.

- LANS staff explained the difficulty with entering outfall information for 73 outfalls and NOI Processing Center staff stated that they had received numerous calls on problems with entering outfall data and that some permittees couldn't even enter 20 outfalls.

- NOI Processing Center staff recommended contacting Regional personnel to notify them of the situation and to seek additional guidance.

- The eReporting Tool went down at approximately 3:30 pm MDT and remained down until after $9 \mathrm{pm}$ MDT. This eliminated the opportunity to input data during normal business hours.

- Wednesday, September 2, 2015

- Continued decrease in the performance of the eReporting Tool.

- Increase in the time for the Tool to process information after entry of each item of data.

- Increased frequency in the Tool crashing.

- For each outfall, when listing the constituents associated with impaired waters, the form had to be saved after entry of each individual constituent. Entry of more than one constituent without saving would cause the Tool to crash. 
- With the decreased performance of the eReporting Tool LANS staff contacted the EPA NOI Processing Center for direction and Processing Center staff stated the following:

- They were aware of the problems with the Tool but could provide no solutions or technical direction.

- They had been reporting daily to EPA on the problems and EPA was definitely aware of the issues.

- When asked about taking the Tool down at 3:30 MDT on Sept. 1, staff stated that they thought the programmers may have taken the system down to assess the problems.

- Stated again that they had received many calls about technical issues with the Tool.

- The more data that was entered the slower the Tool would get.

- When asked again about the possibility that LANS may not be able to get all information into the NOI, staff stated that LANS would be able to access the submitted NOI to modify/add data after the 30 day waiting period.

- eReporting Tool went down again at 3:30 pm MDT and did not come back up until after 10 pm MDT, again eliminating the opportunity to input data during normal business hours.

- The LANS NOI with all information except some remaining outfall attribute data was submitted by the Preparer at 10:50 pm MDT.

- The LANS NOI certification signatory was prepared to certify the NOI at this time but didn't get notification that the NOI was ready for certification until 9:37 am MDT on Sept. 3, almost 11 hours later.

- The NOI was certified on Sept 3, 2015.

Additionally, the NeT NPDES eReporting Tool did not provide dissolved Thallium as a constituent option, but only allowed the selection of total Thallium as an impaired water pollutant under a "Cause Group" when "Metals (other than Mercury)" was selected from the drop down menu. This resulted in LANS having to enter total Thallium as an impaired water pollutant in error for the following outfalls: 002, 005, 006, 007, 008, 009, 010, 011, 012, 016, 017, 018, 019, and 020. LANS appreciates any assistance you may have relative to the total Thallium vs. dissolved Thallium issue. During a subsequent quality assurance evaluation, LANS staff also determined that total Copper was erroneously entered as an impaired water pollutant for outfall 051 and needs to be deleted from the NOI.

LANS is committed to maintaining compliance with the MSGP requirements. Per Section B.12.H of the MSGP, the LANS NOI will be modified to include the remaining outfall attribute data that could not be included on the initial submission and to delete Copper as an impaired water pollutant for outfall 051. LANS coverage under the 2015 MSGP became effective on October 3, 2015, and with the NOI now accessible, actions to update the NOI have been initiated. 
Any additional direction or guidance you may have would be appreciated. Please contact Terrill W. Lemke at (505) 665-2397 of the Environmental Compliance Programs (ENV-CP) if you have any questions.

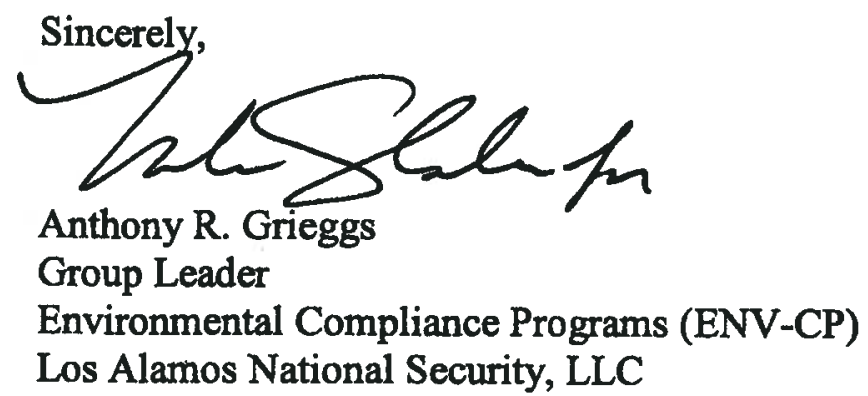

\section{ARG:MTS:TWL:HLW/lm}

Cy: Nasim Jahan, USEPA/Region 6, Dallas, TX, (E-File)

Bruce Yurdin, NMED/SWQB, Santa Fe, NM, (E-File)

Gene E. Turner, LASO-NS-LP, (E-File)

Jordan Amswald, LASO-NS-PI, (E-File)

Kirsten Laskey, EM-LA, (E-File)

Craig Leasure, PADOPS, (E-File)

Amy E. De Palma, PADOPS, (E-File)

Michael T. Brandt, ADESH, (E-File)

Raeanna Sharp-Geiger, ADESH, (E-File)

Alison M. Dorries, ENV-DO, (E-File)

Michael T. Saladen, ENV-CP, (E-File)

Terrill W. Lemke, ENV-CP, (E-File)

Holly L. Wheeler, ENV-CP, (E-File)

Timothy A. Dolan, LC-ESH, (E-File)

lasomailbox@nnsa.doe.gov, (E-File)

locatesteam@lanl.gov, (E-File)

env-correspondence@lanl.gov 


\title{
ENCLOSURE 4
}

\section{Industrial Sites and Outfalls by Sector}

\author{
ADESH-16-045
}

LA-UR-16-21721

Date: 
Industrial Sites and Outfalls by Sector

\begin{tabular}{|c|c|c|c|}
\hline Sector & Industrial Site & Monitored Outfalls & Substantially Identical Outfalls \\
\hline A & TA-3-38 Carpenter Shop & 073 & 074 \\
\hline AA & TA-3-38 Metals Fab Shop & 002 & N/A \\
\hline AA & TA-3-39 \& 102 Metal Shop & 004 & N/A \\
\hline$A A, F$ & TA-3-66 Sigma Complex & 018 & $\begin{array}{l}013 \\
014 \\
015 \\
016 \\
017 \\
019\end{array}$ \\
\hline$A A, F$ & TA-3-66 Sigma Complex & 020 & N/A \\
\hline D & TA-60 Asphalt Batch Plant & 043 & $N / A$ \\
\hline K & TA-54 Area G & 051 & 052 \\
\hline K & TA-54 Area G & 072 & $\begin{array}{l}070 \\
071\end{array}$ \\
\hline K & TA-54 Area G & 053 & $\begin{array}{l}065 \\
066\end{array}$ \\
\hline K & TA-54 Area G & 069 & $\begin{array}{l}059 \\
058 \\
057 \\
056 \\
055 \\
054 \\
067 \\
068 \\
060 \\
061 \\
062 \\
063 \\
064\end{array}$ \\
\hline K & TA-54 Area L & 050 & $N / A$ \\
\hline K & TA-54 RANT & 047 & $\begin{array}{l}048 \\
046 \\
045 \\
044\end{array}$ \\
\hline N & TA-60 MRF & 029 & N/A \\
\hline
\end{tabular}




\begin{tabular}{|c|c|c|c|}
\hline Sector & Industrial Site & Monitored Outfalls & Substantially Identical Outfalls \\
\hline 0 & TA-3-22 Power \& Steam Plant & 005 & 006 \\
\hline 0 & TA-3-22 Power \& Steam Plant & 009 & $\begin{array}{l}007 \\
008 \\
010\end{array}$ \\
\hline 0 & TA-3-22 Power \& Steam Plant & 012 & 011 \\
\hline $\mathbf{P}$ & TA-54 MFW & 049 & N/A \\
\hline $\mathbf{P}$ & TA-60 Roads and Grounds & 031 & 030 \\
\hline $\mathbf{P}$ & TA-60 Roads and Grounds & 039 & $\begin{array}{l}038 \\
040\end{array}$ \\
\hline$P$ & TA-60 Roads and Grounds & 036 & 037 \\
\hline $\mathbf{P}$ & TA-60 Roads and Grounds & 032 & $\begin{array}{l}033 \\
034 \\
035\end{array}$ \\
\hline $\mathbf{P}$ & TA-60 Roads and Grounds & 042 & 041 \\
\hline $\mathbf{P}$ & TA-60-1 Heavy Equipment Yard & 022 & $\begin{array}{l}021 \\
023 \\
024 \\
025\end{array}$ \\
\hline $\mathbf{P}$ & TA-60-2 Warehouse & 026 & $\begin{array}{l}027 \\
028\end{array}$ \\
\hline $\mathbf{P}$ & TA-60-2 Warehouse & 075 & N/A \\
\hline
\end{tabular}

$\mathrm{N} / \mathrm{A}=$ Not Applicable 


\section{Spill Log}




\section{Spill Log}

\section{Table for Tracking Past and Future Spills}

\begin{tabular}{|c|c|c|c|c|c|}
\hline Date & Spill Location & What Spilled & Quantity Spilled & $\begin{array}{l}\text { Corrective } \\
\text { Action Taken }\end{array}$ & $\begin{array}{l}\text { Plans to Prevent } \\
\text { Recurrence }\end{array}$ \\
\hline 2007 & $\begin{array}{l}\text { Yard at Roads } \\
\text { and Grounds }\end{array}$ & Hydraulic fluid & $\begin{array}{l}\text { Less than } 1 \\
\text { gallon }\end{array}$ & $\begin{array}{l}\text { Area was } \\
\text { immediately } \\
\text { cleaned up with } \\
\text { oil sponge } \\
\text { absorbent and } \\
\text { was collected as } \\
\text { New Mexico } \\
\text { Special Waste }\end{array}$ & $\begin{array}{l}\text { During the March } \\
\text { SWPPP inspection } \\
\text { staff checked all } \\
\text { vehicles for spills. } \\
\text { KSL-ENV informed } \\
\text { staff of various spill } \\
\text { prevention } \\
\text { methods. No } \\
\text { reportable leaks } \\
\text { were found during } \\
\text { this inspection. }\end{array}$ \\
\hline $1 / 3 / 2012$ & $\begin{array}{l}\text { South Vehicle } \\
\text { Storage }\end{array}$ & Diesel & 50 to70 gallons & $\begin{array}{l}\text { Area of spill } \\
\text { milled and } \\
\text { asphalt placed } \\
\text { in roll-off bins. } \\
\text { Soil sampled in } \\
\text { milled area. }\end{array}$ & $\begin{array}{l}\text { Added check of } \\
\text { bleeder valve to } \\
\text { PM. }\end{array}$ \\
\hline $1 / 7 / 2013$ & $\begin{array}{l}\text { TA-60 Building } \\
250\end{array}$ & Motor oil & $\begin{array}{l}\text { Less than } 1 \\
\text { gallon }\end{array}$ & $\begin{array}{l}\text { Stain on asphalt } \\
\text { was cleaned up } \\
\text { with absorbent } \\
\text { and affected } \\
\text { area was } \\
\text { sprayed with } \\
\text { micro-blaze. }\end{array}$ & $\begin{array}{l}\text { Equipment being } \\
\text { salvaged will be } \\
\text { checked for leaks } \\
\text { and have their } \\
\text { fluids removed. }\end{array}$ \\
\hline $2 / 7 / 2013$ & $\begin{array}{l}\text { Heavy } \\
\text { Equipment } \\
\text { Staging Area }\end{array}$ & Hydraulic Fluid & Less than a quart & $\begin{array}{l}\text { Affected area on } \\
\text { asphalt was } \\
\text { sprayed with } \\
\text { micro-blaze and } \\
\text { a drip pan was } \\
\text { place under the } \\
\text { leak. }\end{array}$ & $\begin{array}{l}\text { Hydraulic fluid leak } \\
\text { on frontend loader } \\
\text { was repaired. }\end{array}$ \\
\hline $4 / 12 / 2013$ & $\begin{array}{l}\text { North of the } \\
\text { Asphalt Batch } \\
\text { Plant }\end{array}$ & Diesel & 1 pint & $\begin{array}{l}\text { Affected area } \\
\text { was sprayed } \\
\text { with micro- } \\
\text { blaze. } \\
\text { Contaminated } \\
\text { soil collected as } \\
\text { N. M. Special } \\
\text { Waste. }\end{array}$ & $\begin{array}{l}\text { Check fuel filter for } \\
\text { leaks. }\end{array}$ \\
\hline
\end{tabular}




\begin{tabular}{|c|c|c|c|c|c|}
\hline $4 / 15 / 2013$ & $\begin{array}{l}\text { South of TA-60 } \\
\text { Building } 29\end{array}$ & Diesel & 1 pint & $\begin{array}{l}\text { Affected area } \\
\text { was sprayed } \\
\text { with micro- } \\
\text { blaze. } \\
\text { Contaminated } \\
\text { soil collected as } \\
\text { N. M. Special } \\
\text { Waste. }\end{array}$ & $\begin{array}{l}\text { Fuel filter port } \\
\text { checked for stipped } \\
\text { threads and fuel } \\
\text { filter replaced. }\end{array}$ \\
\hline $5 / 17 / 2013$ & $\begin{array}{l}\text { TA-60 Sigma } \\
\text { Mesa }\end{array}$ & Hydraulic Fluid & 5 gallons & $\begin{array}{l}\text { Absorbent was } \\
\text { used to clean up } \\
\text { the spill and the } \\
\text { affected area on } \\
\text { asphalt was } \\
\text { sprayed with } \\
\text { micro-blaze. } \\
\text { Absorbent was } \\
\text { collected as N. } \\
\text { M. Special } \\
\text { Waste. }\end{array}$ & $\begin{array}{l}\text { Daily inspection of } \\
\text { heavy equipment } \\
\text { for leaks and make } \\
\text { sure all heavy } \\
\text { equipment vehicles } \\
\text { have spill kits. }\end{array}$ \\
\hline $5 / 2 / 2014$ & $\begin{array}{l}\text { North of TA-60 } \\
\text { Asphalt Batch } \\
\text { Plant }\end{array}$ & Motor Oil & 1 quart & $\begin{array}{l}\text { Absorbent was } \\
\text { used to clean up } \\
\text { the spill and the } \\
\text { affected area on } \\
\text { asphalt was } \\
\text { sprayed with } \\
\text { micro-blaze. }\end{array}$ & $\begin{array}{l}\text { O-ring on the side } \\
\text { of the engine block } \\
\text { of frontend loader } \\
\text { leaking while } \\
\text { vehicle is running } \\
\text { and is scheduled to } \\
\text { be replaced. }\end{array}$ \\
\hline $5 / 30 / 2014$ & $\begin{array}{l}\text { Road way from } \\
\text { Clean fill yard } \\
\text { to Heavy } \\
\text { equipment } \\
\text { staging area }\end{array}$ & Motor oil & $\begin{array}{l}\text { Less than } 1 \\
\text { gallon }\end{array}$ & $\begin{array}{l}\text { Affected area on } \\
\text { asphalt was } \\
\text { sprayed with } \\
\text { micro-blaze. }\end{array}$ & $\begin{array}{l}\text { Oil leak on front } \\
\text { end loader has } \\
\text { been fixed. }\end{array}$ \\
\hline $11 / 12 / 2014$ & $\begin{array}{l}\text { South of Salt } \\
\text { Shed }\end{array}$ & $\begin{array}{l}\text { Brine (Beet } \\
\text { Liquid) }\end{array}$ & 5 gallons & $\begin{array}{l}\text { Water was used } \\
\text { to clean up the } \\
\text { staining on } \\
\text { asphalt. }\end{array}$ & $\begin{array}{l}400 \text { feet of hose } \\
\text { and valves were } \\
\text { replaced with new } \\
\text { ones. }\end{array}$ \\
\hline $2 / 18 / 2015$ & $\begin{array}{l}\text { Entrance to } \\
\text { Asphalt } \\
\text { Millings } \\
\text { Staging Area }\end{array}$ & Hydraulic Fluid & $\begin{array}{l}\text { Less than } 12 \\
\text { ounces }\end{array}$ & $\begin{array}{l}\text { Staining on } \\
\text { asphalt was } \\
\text { sprayed with } \\
\text { micro-blaze. }\end{array}$ & $\begin{array}{l}\text { Broken hydraulic } \\
\text { line on bulldozer } \\
\text { was replaced. }\end{array}$ \\
\hline $3 / 19 / 2015$ & $\begin{array}{l}\text { Heavy } \\
\text { Equipment } \\
\text { Staging Area }\end{array}$ & Hydraulic Fluid & $\begin{array}{l}\text { Less than } 6 \\
\text { ounces }\end{array}$ & $\begin{array}{l}\text { Absorbent was } \\
\text { used to clean up } \\
\text { the spill and the } \\
\text { affected area on } \\
\text { asphalt was } \\
\text { sprayed with } \\
\text { micro-blaze }\end{array}$ & $\begin{array}{l}\text { Leak on hydraulic } \\
\text { cylinder of tracked } \\
\text { vehicle was fixed. }\end{array}$ \\
\hline $4 / 20 / 2015$ & $\begin{array}{l}\text { Heavy } \\
\text { Equipment } \\
\text { Staging Area }\end{array}$ & Hydraulic Fluid & $\begin{array}{l}\text { Less than } 6 \\
\text { ounces }\end{array}$ & $\begin{array}{l}\text { Staining on } \\
\text { asphalt was } \\
\text { sprayed with } \\
\text { micro-blaze. }\end{array}$ & $\begin{array}{l}\text { Hydraulic hoses on } \\
\text { Grader were } \\
\text { replaced with new } \\
\text { ones. }\end{array}$ \\
\hline $1 / 25 / 2016$ & $\begin{array}{l}\text { Far East End } \\
\text { of TA-60 } \\
\text { Sigma Mesa }\end{array}$ & Hydraulic Fluid & $\begin{array}{l}\text { Less than } 1 \\
\text { ounce }\end{array}$ & $\begin{array}{l}\text { Shovel full of } \\
\text { gravel/soil } \\
\text { collected as } \\
\text { N.M. Special } \\
\text { Waste }\end{array}$ & $\begin{array}{l}\text { Liquid level gauge } \\
\text { on square tank of } \\
\text { G82-0535B water } \\
\text { truck was fixed. }\end{array}$ \\
\hline
\end{tabular}




\begin{tabular}{|c|c|c|c|c|c|}
\hline $2 / 22 / 2016$ & $\begin{array}{l}\text { TA-60 Sigma } \\
\text { Mesa heavy } \\
\text { equipment } \\
\text { yard }\end{array}$ & Hydraulic Fluid & $\begin{array}{l}\text { Less than } 3 \\
\text { ounces }\end{array}$ & $\begin{array}{l}\text { Hydraulic line on } \\
140 \text { G Grader } \\
\text { PN \# 30599 } \\
\text { repaired and } \\
\text { affected area on } \\
\text { asphalt sprayed } \\
\text { with micro- } \\
\text { blaze. }\end{array}$ & $\begin{array}{l}\text { Hydraulic line on } \\
\text { Grader repaired. }\end{array}$ \\
\hline $3 / 21 / 2016$ & $\begin{array}{l}\text { Northside of } \\
\text { TA-60 Building } \\
178\end{array}$ & Hydraulic Fluid & $\begin{array}{l}\text { Less than } 3 \\
\text { ounces }\end{array}$ & $\begin{array}{l}\text { Hydraulic line on } \\
\text { salt truck G82- } \\
\text { 0249F repaired } \\
\text { and affected } \\
\text { area on asphalt } \\
\text { sprayed with } \\
\text { micro-blaze. }\end{array}$ & $\begin{array}{l}\text { Hydraulic line on } \\
\text { salt truck repaired. }\end{array}$ \\
\hline $7 / 25 / 2016$ & $\begin{array}{l}\text { Heavy } \\
\text { Equipment } \\
\text { Staging Area }\end{array}$ & Hydraulic Fluid & $\begin{array}{l}\text { Less than } 5 \\
\text { ounces }\end{array}$ & $\begin{array}{l}\text { Residual fluid in } \\
\text { hydraulic lines } \\
\text { from front end } \\
\text { loader to tractor } \\
\text { attachment }\end{array}$ & $\begin{array}{l}\text { Hydraulic lines on } \\
\text { front end loader are } \\
\text { being capped when } \\
\text { removed from } \\
\text { tractor }\end{array}$ \\
\hline 11/10/2016 & $\begin{array}{l}\text { West of Sigma } \\
\text { Mesa Clean fill } \\
\text { yard }\end{array}$ & Hydraulic Fluid & 5 Gallons & $\begin{array}{l}\text { Failure of a } \\
\text { hydraulic hose } \\
\text { on a cylinder } \\
\text { hoist to dump } \\
\text { truck }\end{array}$ & $\begin{array}{l}\text { Hydraulic line } \\
\text { replaced on dump } \\
\text { truck and affected } \\
\text { area on soil } \\
\text { cleaned up and } \\
\text { sprayed with micro- } \\
\text { blaze }\end{array}$ \\
\hline
\end{tabular}




\section{Non-Stormwater Discharge Certification}




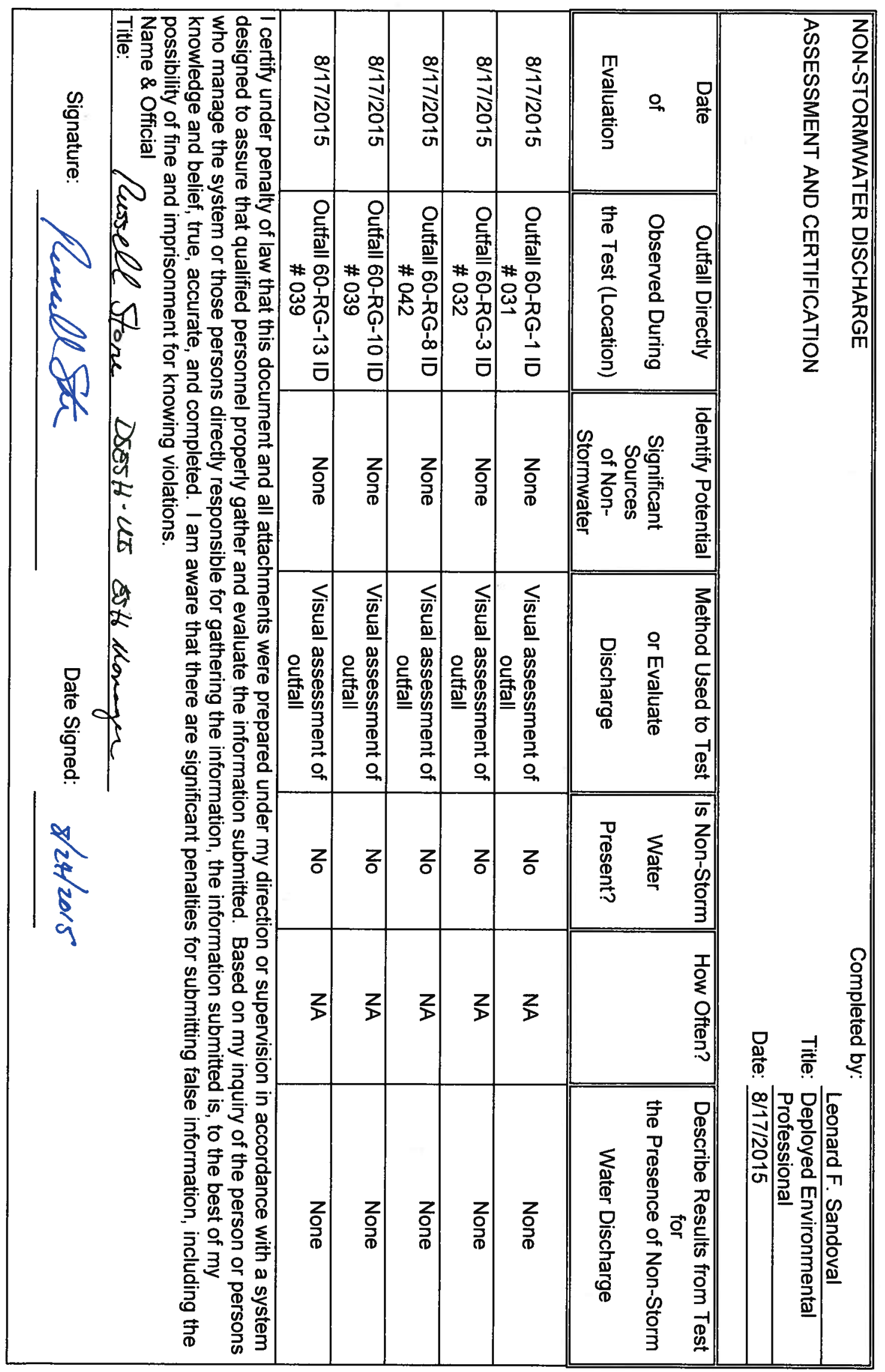




\section{Routine Facility Inspection Reports}




\section{Stormwater Industrial Routine Facility Inspection Report}

\begin{tabular}{|c|c|c|c|c|}
\hline \multicolumn{5}{|c|}{ General Information } \\
\hline Facility Name & \multicolumn{4}{|c|}{ Insert Name } \\
\hline NPDES Tracking No. & \multicolumn{4}{|c|}{ Insert Tracking No. } \\
\hline Date of Inspection & \multicolumn{2}{|c|}{ Insert Date } & Start/End Time & Insert Start/End Time \\
\hline Inspector's Name(s) & \multicolumn{4}{|c|}{ Insert Name } \\
\hline Inspector's Title(s) & \multicolumn{4}{|c|}{ Insert Title } \\
\hline Inspector's Contact Information & \multicolumn{4}{|c|}{ Insert Contact Info } \\
\hline Inspector's Qualifications & \multicolumn{4}{|c|}{ Insert qualifications or add reference to the SWPPP } \\
\hline \multicolumn{5}{|c|}{ Weather Information } \\
\hline \multicolumn{5}{|c|}{ 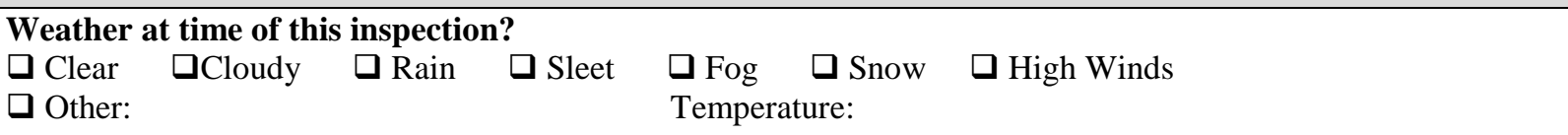 } \\
\hline \multicolumn{5}{|c|}{$\begin{array}{l}\text { Have any previously unidentified discharges of pollutants occurred since the last inspection? } \square \text { Yes } \square \text { No } \\
\text { If yes, describe: Describe }\end{array}$} \\
\hline \multicolumn{5}{|c|}{$\begin{array}{l}\text { Are there any discharges occurring at the time of inspection? } \square \text { Yes } \square \text { No } \\
\text { If yes, describe: Describe }\end{array}$} \\
\hline
\end{tabular}

\section{Control Measures}

- $\quad$ Number the structural stormwater control measures identified in your SWPPP on your site map and list them below (add as many control measures as are implemented on-site). Carry a copy of the numbered site map with you during your inspections. This list will ensure that you are inspecting all required control measures at your facility.

- Describe corrective actions initiated, date completed, and note the person that completed the work in the Corrective Action Log.

\begin{tabular}{|c|c|c|c|c|}
\hline & $\begin{array}{l}\text { Structural Control } \\
\text { Measure }\end{array}$ & $\begin{array}{l}\text { Control } \\
\text { Measure is } \\
\text { Operating } \\
\text { Effectively? }\end{array}$ & $\begin{array}{l}\text { If No, In Need of } \\
\text { Maintenance, } \\
\text { Repair, or } \\
\text { Replacement? }\end{array}$ & $\begin{array}{l}\text { Corrective Action Needed and Notes } \\
\text { (identify needed maintenance and repairs, or any } \\
\text { failed control measures that need replacement) }\end{array}$ \\
\hline 1 & $\begin{array}{l}\text { Insert Control Measure } \\
\text { Name }\end{array}$ & aYes aNo & $\begin{array}{l}\text { Maintenance } \\
\square \text { Repair } \\
\square \text { Replacement }\end{array}$ & Describe Corrective Actions \\
\hline 2 & $\begin{array}{l}\text { Insert Control Measure } \\
\text { Name }\end{array}$ & $\square$ Yes $\square$ No & $\begin{array}{l}\text { Maintenance } \\
\square \text { Repair } \\
\text { Replacement }\end{array}$ & Describe Corrective Actions \\
\hline 3 & $\begin{array}{l}\text { Insert Control Measure } \\
\text { Name }\end{array}$ & aYes $\square$ No & $\begin{array}{l}\text { Maintenance } \\
\square \text { Repair } \\
\square \text { Replacement }\end{array}$ & Describe Corrective Actions \\
\hline 4 & $\begin{array}{l}\text { Insert Control Measure } \\
\text { Name }\end{array}$ & aYes $\square$ No & $\begin{array}{l}\text { Maintenance } \\
\square \text { Repair } \\
\square \text { Replacement }\end{array}$ & Describe Corrective Actions \\
\hline 5 & $\begin{array}{l}\text { Insert Control Measure } \\
\text { Name }\end{array}$ & aYes $\square$ No & $\begin{array}{l}\text { Maintenance } \\
\square \text { Repair } \\
\square \text { Replacement }\end{array}$ & Describe Corrective Actions \\
\hline 6 & $\begin{array}{l}\text { Insert Control Measure } \\
\text { Name }\end{array}$ & aYes $\square$ No & $\begin{array}{l}\text { Maintenance } \\
\square \text { Repair } \\
\square \text { Replacement }\end{array}$ & Describe Corrective Actions \\
\hline 7 & Insert Control Measure & $\square$ Yes $\square$ No & $\begin{array}{l}\text { Maintenance } \\
\square \text { Repair }\end{array}$ & Describe Corrective Actions \\
\hline
\end{tabular}




\begin{tabular}{|c|c|c|c|c|}
\hline & $\begin{array}{l}\text { Structural Control } \\
\text { Measure }\end{array}$ & $\begin{array}{l}\text { Control } \\
\text { Measure is } \\
\text { Operating } \\
\text { Effectively? }\end{array}$ & $\begin{array}{l}\text { If No, In Need of } \\
\text { Maintenance, } \\
\text { Repair, or } \\
\text { Replacement? } \\
\end{array}$ & $\begin{array}{l}\text { Corrective Action Needed and Notes } \\
\text { (identify needed maintenance and repairs, or any } \\
\text { failed control measures that need replacement) }\end{array}$ \\
\hline & Name & & D Replacement & \\
\hline 8 & $\begin{array}{l}\text { Insert Control Measure } \\
\text { Name }\end{array}$ & DYes $\square$ No & $\begin{array}{l}\text { Maintenance } \\
\square \text { Repair } \\
\square \text { Replacement }\end{array}$ & Describe Corrective Actions \\
\hline 9 & $\begin{array}{l}\text { Insert Control Measure } \\
\text { Name }\end{array}$ & $\square$ Yes $\square$ No & $\begin{array}{l}\text { Maintenance } \\
\square \text { Repair } \\
\square \text { Replacement }\end{array}$ & Describe Corrective Actions \\
\hline 10 & $\begin{array}{l}\text { Insert Control Measure } \\
\text { Name }\end{array}$ & DYes aNo & $\begin{array}{l}\text { Maintenance } \\
\square \text { Repair } \\
\square \text { Replacement }\end{array}$ & Describe Corrective Actions \\
\hline
\end{tabular}

Areas of Industrial Materials or Activities exposed to stormwater

Below are some general areas that should be assessed during routine inspections. Customize this list as needed for the specific types of industrial materials or activities at your facility.

\begin{tabular}{|c|c|c|c|c|}
\hline & Area/Activity & Inspected? & $\begin{array}{l}\text { Controls } \\
\text { Adequate } \\
\text { (appropriate, } \\
\text { effective, and } \\
\text { operating)? }\end{array}$ & Corrective Action Needed and Notes \\
\hline 1 & $\begin{array}{l}\text { Material } \\
\text { loading/unloading and } \\
\text { storage areas }\end{array}$ & $\square$ Yes $\square$ No $\square$ N/A & $\square$ Yes $\square$ No & Describe Corrective Actions \\
\hline 2 & $\begin{array}{l}\text { Equipment operations } \\
\text { and maintenance areas }\end{array}$ & $\square$ Yes $\square$ No $\square$ N/A & aYes $\square$ No & Describe Corrective Actions \\
\hline 3 & Fueling areas & aYes $\square$ No $\square$ N/A & aYes aNo & Describe Corrective Actions \\
\hline 4 & $\begin{array}{l}\text { Outdoor vehicle and } \\
\text { equipment washing areas }\end{array}$ & $\square$ Yes $\square$ No $\square$ N/A & aYes $\square$ No & Describe Corrective Actions \\
\hline 5 & $\begin{array}{l}\text { Waste handling and } \\
\text { disposal areas }\end{array}$ & $\square$ Yes $\square$ No $\square$ N/A & aYes aNo & Describe Corrective Actions \\
\hline 6 & $\begin{array}{l}\text { Erodible } \\
\text { areas/construction }\end{array}$ & $\square$ Yes $\square$ No $\square$ N/A & $\square$ Yes $\square$ No & Describe Corrective Actions \\
\hline 7 & $\begin{array}{l}\text { Non-stormwater/ illicit } \\
\text { connections }\end{array}$ & $\square$ Yes $\square$ No $\square$ N/A & DYes aNo & Describe Corrective Actions \\
\hline 8 & $\begin{array}{l}\text { Salt storage piles or pile } \\
\text { containing salt }\end{array}$ & $\square$ Yes $\square$ No $\square$ N/A & aYes aNo & Describe Corrective Actions \\
\hline 9 & $\begin{array}{l}\text { Dust generation and } \\
\text { vehicle tracking }\end{array}$ & $\square$ Yes $\square$ No $\square$ N/A & aYes DNo & Describe Corrective Actions \\
\hline 10 & (Other) & aYes $\square$ No $\square$ N/A & aYes $\square$ No & Describe Corrective Actions \\
\hline 11 & (Other) & aYes $\square$ No $\square$ N/A & aYes DNo & Describe Corrective Actions \\
\hline
\end{tabular}




\begin{tabular}{|l|l|l|l|l|}
\hline & Area/Activity & Inspected? & $\begin{array}{l}\text { Controls } \\
\text { Adequate } \\
\text { (appropriate, } \\
\text { effective, and } \\
\text { operating)? }\end{array}$ & Corrective Action Needed and Notes \\
\hline & & & & \\
\hline 12 & (Other) & DYes DNo $\square$ N/A & DYes $\square$ No & Describe Corrective Actions \\
\hline
\end{tabular}

\section{Non-Compliance}

Describe any incidents of non-compliance observed and not described above:

Describe Non-compliance

Additional Control Measures

Describe any additional control measures needed to comply with the permit requirements:

Describe Additional Controls Needed 
Use this space for any additional notes or observations from the inspection:

Additional Notes

\section{CERTIFICATION STATEMENT}

"I certify under penalty of law that this document and all attachments were prepared under my direction or supervision in accordance with a system designed to assure that qualified personnel properly gathered and evaluated the information submitted. Based on my inquiry of the person or persons who manage the system, or those persons directly responsible for gathering the information, the information submitted is, to the best of my knowledge and belief, true, accurate, and complete. I am aware that there are significant penalties for submitting false information, including the possibility of fine and imprisonment for knowing violations.”

Print name and title:

Signature:

Date: 


\section{Stormwater Industrial Routine Facility Inspection Report}

\begin{tabular}{|c|c|c|c|}
\hline \multicolumn{4}{|c|}{ General Information } \\
\hline Facility Name & \multicolumn{3}{|c|}{ TA-60 Roads and Grounds } \\
\hline NPDES Tracking No. & \multicolumn{3}{|l|}{ NMR05000 } \\
\hline Date of Inspection & $10 / 26 / 2015$ & Start/End Time & 8:45 a.m. to 9:25 a.m. \\
\hline Inspector's Name(s) & \multicolumn{3}{|l|}{ Leonard F. Sandoval } \\
\hline Inspector's Title(s) & \multicolumn{3}{|c|}{ Deployed Environmental Professional } \\
\hline Inspector's Contact Information & \multicolumn{3}{|l|}{$667-3557$ or $231-1235$} \\
\hline Inspector's Qualifications & \multicolumn{3}{|l|}{ CISEC } \\
\hline \multicolumn{4}{|c|}{ Weather Information } \\
\hline \multirow{2}{*}{\multicolumn{4}{|c|}{ 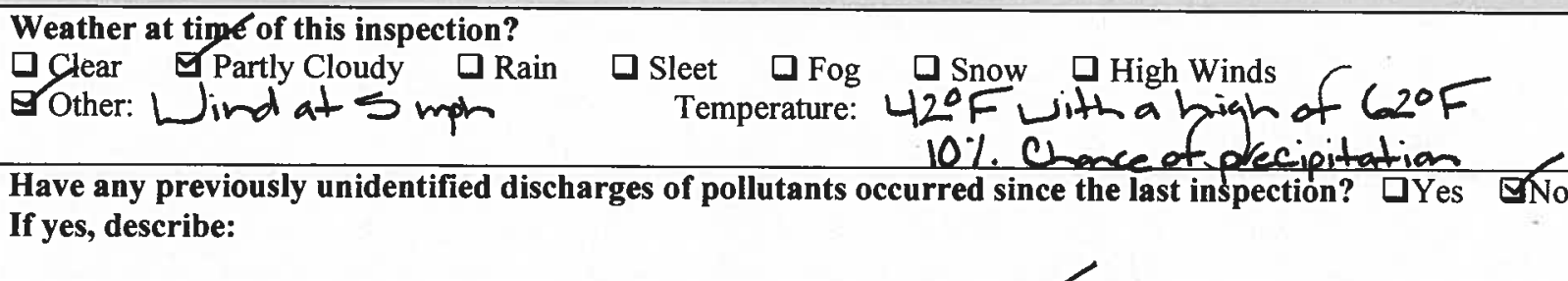 }} \\
\hline & & & \\
\hline \multicolumn{4}{|c|}{$\begin{array}{l}\text { Are there any discharges occurring at the time of inspection? } \square \text { Yes } \\
\text { If yes, describe: }\end{array}$} \\
\hline
\end{tabular}

\section{Control Measures}

- Number the structural stormwater control measures identified in your SWPPP on your site map and list them below (add as many control measures as are implemented on-site). Carry a copy of the numbered site map with you during your inspections. This list will ensure that you are inspecting all required control measures at your facility.

- Describe corrective actions initiated, date completed, and note the person that completed the work in the Corrective Action Log.

\begin{tabular}{|c|c|c|c|c|}
\hline & $\begin{array}{l}\text { Structural Control } \\
\text { Measure }\end{array}$ & $\begin{array}{l}\text { Control } \\
\text { Measure is } \\
\text { Operating } \\
\text { Effoctively? }\end{array}$ & $\begin{array}{l}\text { If No, In Need of } \\
\text { Maintenance, } \\
\text { Repair, or } \\
\text { Replacement? }\end{array}$ & $\begin{array}{l}\text { Corrective Action Needed and Notes } \\
\text { (identify needed maintenance and repairs, or any } \\
\text { failed control measures that need replacement) }\end{array}$ \\
\hline 1 & Straw Wattles & G Yes aNo & $\begin{array}{l}\square \text { Maintenance } \\
\square \text { Repair } \\
\square \text { Replacement }\end{array}$ & \\
\hline 2 & Rock Check Dams & EYes $\square$ No & $\begin{array}{l}\text { Q Maintenance } \\
\text { Repair } \\
\text { Replacement }\end{array}$ & \\
\hline 3 & $\begin{array}{l}\text { Lined Salt Retention } \\
\text { Pond }\end{array}$ & Wyes DNo & $\begin{array}{l}\text { Maintenance } \\
\square \text { Repair } \\
\square \text { Replacement }\end{array}$ & \\
\hline 4 & Sediment Basin & EYes DNo & $\begin{array}{l}\square \text { Maintenance } \\
\square \text { Repair } \\
\square \text { Replacement }\end{array}$ & \\
\hline 5 & Rip Rap/Jersey Barriers & Tyes $\square$ No & $\begin{array}{l}\text { Maintenance } \\
\square \text { Repair } \\
\square \text { Replacement }\end{array}$ & \\
\hline 6 & $\begin{array}{l}\text { Sediment Retention } \\
\text { Pond }\end{array}$ & VYes DNo & $\begin{array}{l}\text { Maintenance } \\
\text { Repair } \\
\text { Replacement }\end{array}$ & \\
\hline 7 & $\begin{array}{l}\text { Base Course/Earthen } \\
\text { Berms }\end{array}$ & 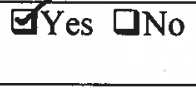 & $\begin{array}{l}\square \text { Maintenance } \\
\square \text { Repair }\end{array}$ & \\
\hline
\end{tabular}




\begin{tabular}{|c|c|c|c|c|}
\hline & $\begin{array}{l}\text { Structural Control } \\
\text { Measure }\end{array}$ & $\begin{array}{l}\text { Control } \\
\text { Measure is } \\
\text { Operating } \\
\text { Effectively? }\end{array}$ & $\begin{array}{l}\text { If No, In Need of } \\
\text { Maintenance, } \\
\text { Repair, or } \\
\text { Replacement? }\end{array}$ & $\begin{array}{l}\text { Corrective Action Needed and Notes } \\
\text { (identify needed maintenance and repairs, or any } \\
\text { failed control measures that need replacement) }\end{array}$ \\
\hline & & & Replacement & \\
\hline 8 & Rock Run Down & GYes $\square$ No & $\begin{array}{l}\text { Maintenance } \\
\text { Repair } \\
\text { Replacement }\end{array}$ & \\
\hline 9 & $\begin{array}{l}\text { Outfalls } 60 \text { RG-1ID \# } \\
31,60 \text { RG-2 ID \# 30, } 60 \\
\text { RG-3 ID \# 32, 60 RG-4 } \\
\text { ID \# 33, 60 RG-5 ID \# } \\
34, \& 60 \text { RG-6 ID \# } 35\end{array}$ & 四Yes & $\begin{array}{l}\text { Maintenance } \\
\text { Repair } \\
\text { Replacement }\end{array}$ & \\
\hline 10 & $\begin{array}{l}\text { Outfalls 60 RG-7 ID \# } \\
41 \& 60 \text { RG-8 ID \# } 42\end{array}$ & 面Yes $\square$ No & $\begin{array}{l}\text { Maintenance } \\
\square \text { Repair } \\
\square \text { Replacement }\end{array}$ & \\
\hline 11 & $\begin{array}{l}\text { Outfalls } 60 \text { RG-9 ID \# } \\
40,60 \text { RG-10 ID \# 39, } \\
60 \text { RG-11 ID \# } 38\end{array}$ & GYes DNo & $\begin{array}{l}\text { Maintenance } \\
\text { Repair } \\
\text { Replacement }\end{array}$ & \\
\hline 12 & $\begin{array}{l}\text { Outfalls } 60 \text { RG-12 ID \# } \\
37 \& 60 \text { RG-13 ID \# } 36\end{array}$ & 区Yes aNo & $\begin{array}{l}\text { Maintenance } \\
\square \text { Repair } \\
\square \text { Replacement }\end{array}$ & \\
\hline
\end{tabular}

Areas of Industrial Materials or Activities exposed to stormwater

Below are some general areas that should be assessed during routine inspections. Customize this list as needed for the specific types of industrial materials or activities at your facility.

\begin{tabular}{|c|c|c|c|c|}
\hline & Area/Activity & Inspected? & $\begin{array}{l}\text { Controls } \\
\text { Adequate } \\
\text { (appropriate, } \\
\text { effective, and } \\
\text { operating)? }\end{array}$ & Corrective Action Needed and Notes \\
\hline 1 & $\begin{array}{l}\text { Material } \\
\text { loading/unloading and } \\
\text { storage areas }\end{array}$ & 区Yes [No $\square$ N/A & DYes DNo & \\
\hline 2 & $\begin{array}{l}\text { Equipment operations } \\
\text { and maintenance areas }\end{array}$ & घ्र/Yes $\square$ No $\square$ N/A & $\square$ Yes $\square$ No & \\
\hline 3 & Fueling areas & $\square$ Yes $\square$ No $\bowtie N / A$ & aYes $\square$ No & \\
\hline 4 & $\begin{array}{l}\text { Outdoor vehicle and } \\
\text { equipment washing areas }\end{array}$ & $\square$ Yes $\square$ No $\otimes N / A$ & aYes aNo & \\
\hline 5 & $\begin{array}{l}\text { Waste handling and } \\
\text { disposal areas }\end{array}$ & 口Yes $\square$ No $\otimes N / A$ & DYes aNo & \\
\hline 6 & $\begin{array}{l}\text { Erodible } \\
\text { areas/construction }\end{array}$ & $\square$ Yes $\square$ No $\otimes N / A$ & DYes aNo & \\
\hline 7 & $\begin{array}{l}\text { Non-stormwater/illicit } \\
\text { connections }\end{array}$ & DYes $\square$ No $\otimes \mathrm{N} / \mathrm{A}$ & aYes DNo & \\
\hline 8 & $\begin{array}{l}\text { Salt storage piles or pile } \\
\text { containing salt }\end{array}$ & EYes DNo $\square$ N/A & DYes DNo & \\
\hline
\end{tabular}




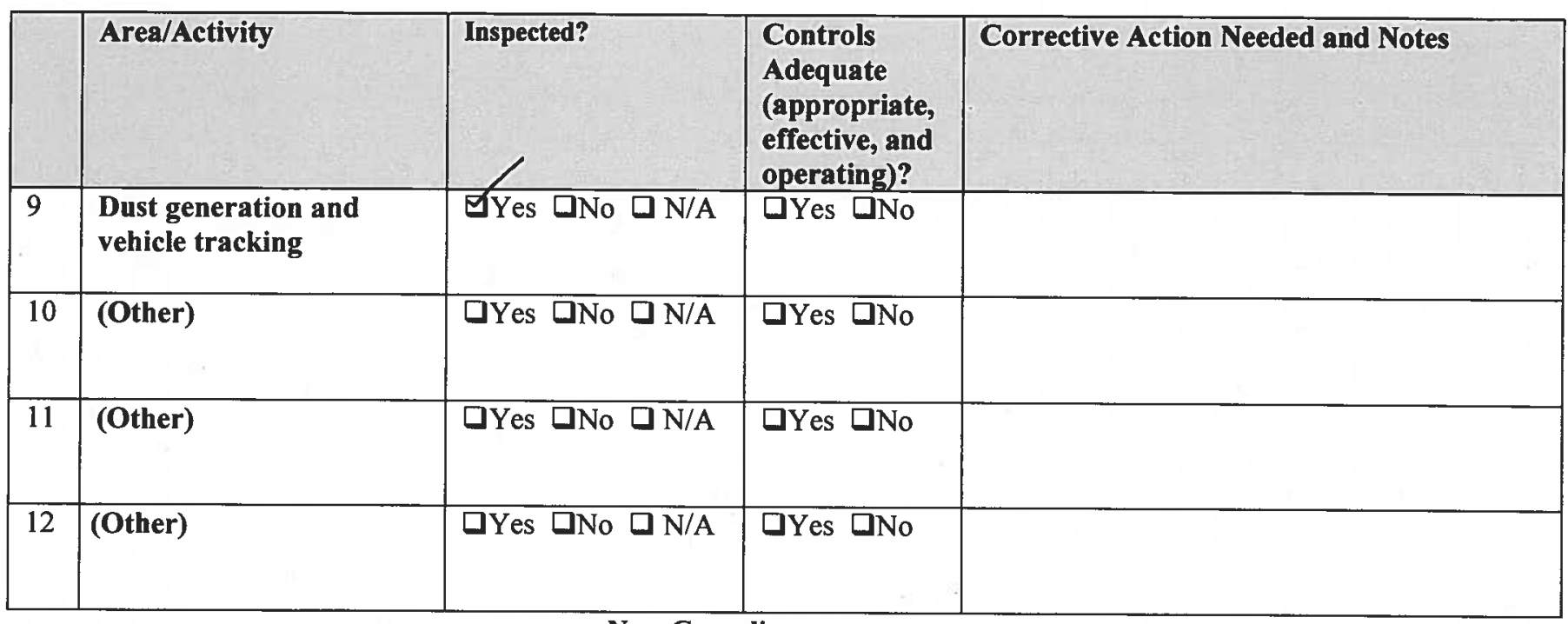

Non-Compliance

Describe any incidents of non-compliance observed and not described above: None

Additional Control Measures

Describe any additional control measures needed to comply with the permit requirements: None 
Notes

Use this space for any additional notes or observations from the inspection: Nane

\section{CERTIFICATION STATEMENT}

"I certify under penalty of law that this document and all attachments were prepared under my direction or supervision in accordance with a system designed to assure that qualified personnel properly gathered and evaluated the information submitted. Based on my inquiry of the person or persons who manage the system, or those persons directly responsible for gathering the information, the information submitted is, to the best of my knowledge and belief, true, accurate, and complete. I am aware that there are significant penalties for submitting false information, including the possibility of fine and imprisonment for knowing violations."

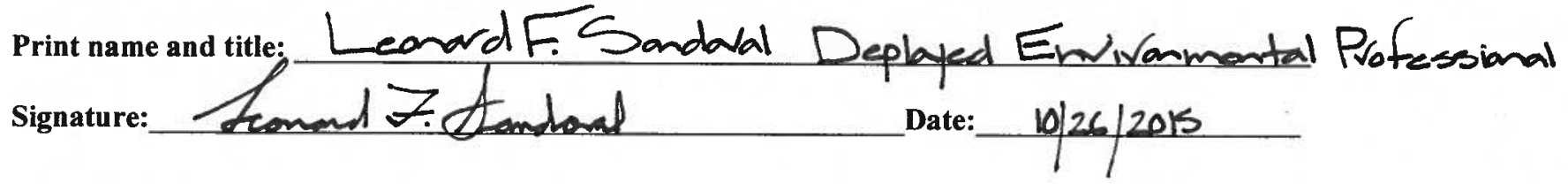




\section{Stormwater Industrial Routine Facility Inspection Report}

\begin{tabular}{|c|c|c|}
\hline \multicolumn{3}{|c|}{ General Information } \\
\hline Facility Name & \multicolumn{2}{|l|}{ TA-60 Roads and Grounds } \\
\hline NPDES Tracking No. & \multicolumn{2}{|l|}{ NMR05000 } \\
\hline Date of Inspection & Start/End Time & 8:33 a.m.to 9:10 a.m. \\
\hline Inspector's Name(s) & \multicolumn{2}{|l|}{ Leonard F. Sandoval } \\
\hline Inspector's Title(s) & \multicolumn{2}{|l|}{ Deployed Environmental Professional } \\
\hline Inspector's Contact Information & \multicolumn{2}{|l|}{$667-3557$ or $231-1235$} \\
\hline Inspector's Qualifications & \multicolumn{2}{|l|}{ CISEC } \\
\hline \multicolumn{3}{|c|}{ Weather Information } \\
\hline \multicolumn{3}{|c|}{ 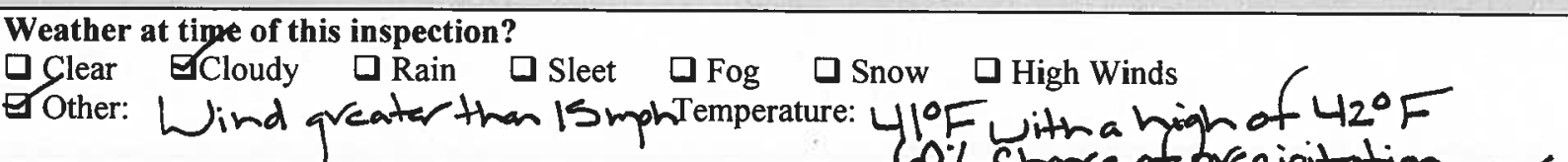 } \\
\hline \multicolumn{3}{|c|}{$\begin{array}{l}\text { Have any previously unidentified discharges of pollutants occurred since the last inspection? aYes } \\
\text { If yes, describe: }\end{array}$} \\
\hline \multicolumn{3}{|c|}{$\begin{array}{l}\text { Are there any discharges occurring at the time of inspection? DYes } \\
\text { If yes, describe: }\end{array}$} \\
\hline
\end{tabular}

\section{Control Measures}

- Number the structural stormwater control measures identified in your SWPPP on your site map and list them below (add as many control measures as are implemented on-site). Carry a copy of the numbered site map with you during your inspections. This list will ensure that you are inspecting all required control measures at your facility.

- Describe corrective actions initiated, date completed, and note the person that completed the work in the Corrective Action Log.

\begin{tabular}{|c|c|c|c|c|}
\hline & $\begin{array}{l}\text { Structural Control } \\
\text { Measure }\end{array}$ & $\begin{array}{l}\text { Control } \\
\text { Measure is } \\
\text { Operating } \\
\text { Effectively? }\end{array}$ & $\begin{array}{l}\text { If No, In Need of } \\
\text { Maintenance, } \\
\text { Repair, or } \\
\text { Replacement? }\end{array}$ & $\begin{array}{l}\text { Corrective Action Needed and Notes } \\
\text { (identify needed maintenance and repairs, or any } \\
\text { failed control measures that need replacement) }\end{array}$ \\
\hline 1 & Straw Wattles & Y Yeso & $\begin{array}{l}\text { Maintenance } \\
\square \text { Repair } \\
\square \text { Replacement }\end{array}$ & \\
\hline 2 & Rock Check Dams & YYes aNo & $\begin{array}{l}\text { Maintenance } \\
\square \text { Repair } \\
\square \text { Replacement }\end{array}$ & \\
\hline 3 & $\begin{array}{l}\text { Lined Salt Retention } \\
\text { Pond }\end{array}$ & 而Yes $\square$ No & $\begin{array}{l}\square \text { Maintenance } \\
\square \text { Repair } \\
\square \text { Replacement }\end{array}$ & \\
\hline 4 & Sediment Basin & EYes $\square$ No & $\begin{array}{l}\square \text { Maintenance } \\
\square \text { Repair } \\
\square \text { Replacement }\end{array}$ & \\
\hline 5 & Rip Rap/Jersey Barriers & 区 Y $\mathrm{U}$ No & $\begin{array}{l}\text { Maintenance } \\
\text { Repair } \\
\square \text { Replacement }\end{array}$ & \\
\hline 6 & $\begin{array}{l}\text { Sediment Retention } \\
\text { Pond }\end{array}$ & Gyes aNo & $\begin{array}{l}\text { Maintenance } \\
\square \text { Repair } \\
\square \text { Replacement }\end{array}$ & \\
\hline 7 & $\begin{array}{l}\text { Base Course/Earthen } \\
\text { Berms }\end{array}$ & EYes $\square$ No & $\begin{array}{l}\square \text { Maintenance } \\
\text { Repair }\end{array}$ & \\
\hline
\end{tabular}




\begin{tabular}{|c|c|c|c|c|}
\hline & $\begin{array}{l}\text { Structural Control } \\
\text { Measure }\end{array}$ & $\begin{array}{l}\text { Control } \\
\text { Measure is } \\
\text { Operating } \\
\text { Effectively? }\end{array}$ & $\begin{array}{l}\text { If No, In Need of } \\
\text { Maintenance, } \\
\text { Repair, or } \\
\text { Replacement? }\end{array}$ & $\begin{array}{l}\text { Corrective Action Needed and Notes } \\
\text { (identify needed maintenance and repairs, or any } \\
\text { failed control measures that need replacement) }\end{array}$ \\
\hline & & & Replacement & \\
\hline 8 & Rock Run Down & बיa & $\begin{array}{l}\text { Maintenance } \\
\square \text { Repair } \\
\square \text { Replacement }\end{array}$ & \\
\hline 9 & $\begin{array}{l}\text { Outfalls } 60 \text { RG-1ID \# } \\
31,60 \text { RG-2 ID \# 30, } 60 \\
\text { RG-3 ID \# 32, } 60 \text { RG-4 } \\
\text { ID \# 33, } 60 \text { RG-5 ID \# } \\
34, \& 60 \text { RG-6 ID \# } 35 \\
\end{array}$ & অ Yes $\square$ No & $\begin{array}{l}\text { Maintenance } \\
\text { Repair } \\
\text { Replacement }\end{array}$ & \\
\hline 10 & $\begin{array}{l}\text { Outfalls } 60 \text { RG-7 ID \# } \\
41 \& 60 \text { RG-8 ID \# } 42\end{array}$ & GYYes aNo & $\begin{array}{l}\square \text { Maintenance } \\
\square \text { Repair } \\
\square \text { Replacement }\end{array}$ & . \\
\hline 11 & $\begin{array}{l}\text { Outfalls } 60 \text { RG-9 ID \# } \\
40,60 \text { RG-10 ID \# 39, } \\
60 \text { RG-11 ID \# } 38\end{array}$ & चיano & $\begin{array}{l}\text { Maintenance } \\
\square \text { Repair } \\
\square \text { Replacement }\end{array}$ & \\
\hline 12 & $\begin{array}{l}\text { Outfalls } 60 \text { RG-12 ID \# } \\
37 \& 60 \text { RG-13 ID \# } 36\end{array}$ & EYes aNo & $\begin{array}{l}\text { Maintenance } \\
\text { Repair } \\
\square \text { Replacement }\end{array}$ & \\
\hline
\end{tabular}

Areas of Industrial Materials or Activities exposed to stormwater

Below are some general areas that should be assessed during routine inspections. Customize this list as needed for the specific types of industrial materials or activities at your facility.

\begin{tabular}{|c|c|c|c|c|}
\hline & Area/Activity & Inspected? & $\begin{array}{l}\text { Controls } \\
\text { Adequate } \\
\text { (appropriate, } \\
\text { effective, and } \\
\text { operating)? }\end{array}$ & Corrective Action Needed and Notes \\
\hline 1 & $\begin{array}{l}\text { Material } \\
\text { loading/unloading and } \\
\text { storage areas }\end{array}$ & YNos $\square$ N/A & DYes DNo & \\
\hline 2 & $\begin{array}{l}\text { Equipment operations } \\
\text { and maintenance areas }\end{array}$ & E్d Yes $\square$ No $/ A$ & ¿Yes $\square$ No & \\
\hline 3 & Fueling areas & GYes $\square$ No $\otimes N / A$ & GYes DNo & \\
\hline 4 & $\begin{array}{l}\text { Outdoor vehicle and } \\
\text { equipment washing areas }\end{array}$ & 口Yes $\square$ No $\otimes N / A$ & $\square$ Yes $\square$ No & \\
\hline$\overline{5}$ & $\begin{array}{l}\text { Waste handling and } \\
\text { disposal areas }\end{array}$ & QYes $\square$ No $\otimes N / A$ & aYes $\square$ No & \\
\hline 6 & $\begin{array}{l}\text { Erodible } \\
\text { areas/construction }\end{array}$ & aYes $\square$ No $\otimes N / A$ & QYes $\square$ No & \\
\hline 7 & $\begin{array}{l}\text { Non-stormwater/illicit } \\
\text { connections }\end{array}$ & 口Yes $\square$ No $\otimes N / A$ & aYes $\square$ No & \\
\hline 8 & $\begin{array}{l}\text { Salt storage piles or pile } \\
\text { containing salt }\end{array}$ & שY Yes $\square$ No $\square \mathrm{N} / \mathrm{A}$ & $\square$ Yes $\square$ No & \\
\hline
\end{tabular}




\begin{tabular}{|c|c|c|c|c|}
\hline & Area/Activity & Inspected? & $\begin{array}{l}\text { Controls } \\
\text { Adequate } \\
\text { (appropriate, } \\
\text { effective, and } \\
\text { operating)? }\end{array}$ & Corrective Action Needed and Notes \\
\hline 9 & $\begin{array}{l}\text { Dust generation and } \\
\text { vehicle tracking }\end{array}$ & GYes $\square$ No $\square \mathrm{N} / \mathrm{A}$ & DYes aNo & \\
\hline 10 & (Other) & $\square$ Yes $\square$ No $\square$ N/A & aYes $\square$ No & \\
\hline 11 & (Other) & aYes $\square$ No $\square \mathrm{N} / \mathrm{A}$ & aYes aNo & \\
\hline 12 & (Other) & $\square$ Yes $\square$ No $\square \mathrm{N} / \mathrm{A}$ & aYes aNo & \\
\hline
\end{tabular}

Non-Compliance

Describe any incidents of non-compliance observed and not described above: Nane

Additional Control Measures

Describe any additional control measures needed to comply with the permit requirements: 
Notes

Use this space for any additional notes or observations from the inspection: Duving the inspectim the
Sediment vetentien pond was full of watar with no visible oily
sheen.

\section{CERTIFICATION STATEMENT}

"I certify under penalty of law that this document and all attachments were prepared under my direction or supervision in accordance with a system designed to assure that qualified personnel properly gathered and evaluated the information submitted. Based on my inquiry of the person or persons who manage the system, or those persons directly responsible for gathering the information, the information submitted is, to the best of my knowledge and belief, true, accurate, and complete. I am aware that there are significant penalties for submitting false information, including the possibility of fine and imprisonment for knowing violations."

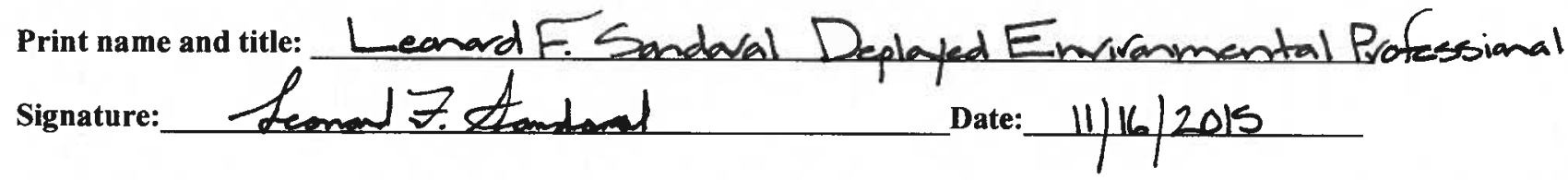


Stormwater Industrial Routine Facility Inspection Report

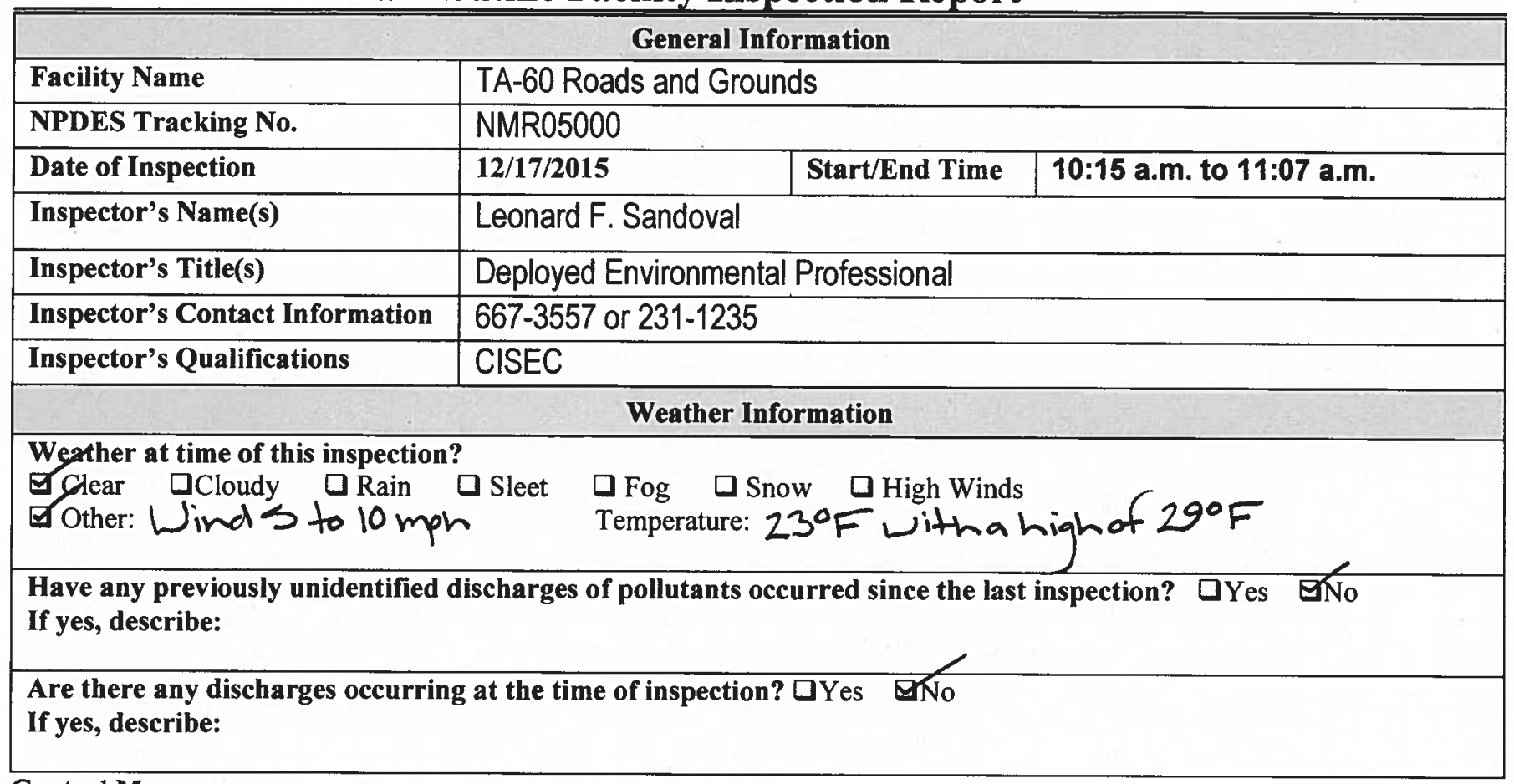

\section{Control Measures}

- Number the structural stormwater control measures identified in your SWPPP on your site map and list them below (add as many control measures as are implemented on-site). Carry a copy of the numbered site map with you during your inspections. This list will ensure that you are inspecting all required control measures at your facility.

- Describe corrective actions initiated, date completed, and note the person that completed the work in the Corrective Action Log.

\begin{tabular}{|c|c|c|c|c|}
\hline & $\begin{array}{l}\text { Structural Control } \\
\text { Measure }\end{array}$ & $\begin{array}{l}\text { Control } \\
\text { Measure is } \\
\text { Operating } \\
\text { Effoctively? }\end{array}$ & $\begin{array}{l}\text { If No, In Need of } \\
\text { Maintenance, } \\
\text { Repair, or } \\
\text { Replacement? }\end{array}$ & $\begin{array}{l}\text { Corrective Action Needed and Notes } \\
\text { (identify needed maintenance and repairs, or any } \\
\text { failed control measures that need replacement) }\end{array}$ \\
\hline 1 & Straw Wattles & VYes DNo & $\begin{array}{l}\text { Maintenance } \\
\text { Repair } \\
\text { Replacement }\end{array}$ & \\
\hline 2 & Rock Check Dams & 可Yes aNo & $\begin{array}{l}\text { Maintenance } \\
\text { Q Repair } \\
\text { Q Replacement }\end{array}$ & \\
\hline 3 & $\begin{array}{l}\text { Lined Salt Retention } \\
\text { Pond }\end{array}$ & GYes DNo & $\begin{array}{l}\text { Maintenance } \\
\text { Repair } \\
\text { Replacement }\end{array}$ & \\
\hline 4 & Sediment Basin & GYyes aNo & $\begin{array}{l}\text { Maintenance } \\
\text { Repair } \\
\text { Replacement }\end{array}$ & \\
\hline 5 & Rip Rap/Jersey Barriers & EYes aNo & $\begin{array}{l}\text { Maintenance } \\
\text { Repair } \\
\text { Replacement }\end{array}$ & \\
\hline 6 & $\begin{array}{l}\text { Sediment Retention } \\
\text { Pond }\end{array}$ & GYes aNo & $\begin{array}{l}\text { D Maintenance } \\
\text { Repair } \\
\text { Q Replacement }\end{array}$ & \\
\hline 7 & $\begin{array}{l}\text { Base Course/Earthen } \\
\text { Berms }\end{array}$ & EYes DNo & $\begin{array}{l}\text { Maintenance } \\
\text { Repair }\end{array}$ & \\
\hline
\end{tabular}




\begin{tabular}{|c|c|c|c|c|}
\hline & $\begin{array}{l}\text { Structural Control } \\
\text { Measure }\end{array}$ & $\begin{array}{l}\text { Control } \\
\text { Measure is } \\
\text { Operating } \\
\text { Effectively? }\end{array}$ & $\begin{array}{l}\text { If No, In Need of } \\
\text { Maintenance, } \\
\text { Repair, or } \\
\text { Replacement? }\end{array}$ & $\begin{array}{l}\text { Corrective Action Needed and Notes } \\
\text { (identify needed maintenance and repairs, or any } \\
\text { failed control measures that need replacement) }\end{array}$ \\
\hline & & & Deplacement & \\
\hline 8 & Rock Run Down & WYes DNo & $\begin{array}{l}\text { Maintenance } \\
\square \text { Repair } \\
\square \text { Replacement }\end{array}$ & \\
\hline 9 & $\begin{array}{l}\text { Outfalls } 60 \text { RG-IID \# } \\
31,60 \text { RG-2 ID \# 30, } 60 \\
\text { RG-3 ID \# 32, } 60 \text { RG-4 } \\
\text { ID \# 33, } 60 \text { RG-5 ID \# } \\
34, \& 60 \text { RG-6 ID \# } 35\end{array}$ & 区्रYes QNo & $\begin{array}{l}\text { Maintenance } \\
\text { Repair } \\
\text { Replacement }\end{array}$ & \\
\hline 10 & $\begin{array}{l}\text { Outfalls } 60 \text { RG-7 ID \# } \\
41 \& 60 \text { RG-8 ID \# } 42\end{array}$ & GYes DNo & $\begin{array}{l}\text { Maintenance } \\
\text { Repair } \\
\text { Q Replacement }\end{array}$ & \\
\hline 11 & $\begin{array}{l}\text { Outfalls } 60 \text { RG-9 ID \# } \\
40,60 \text { RG-10 ID \# 39, } \\
60 \text { RG-11 ID \# } 38\end{array}$ & E Y & $\begin{array}{l}\text { Daintenance } \\
\square \text { Repair } \\
\square \text { Replacement }\end{array}$ & \\
\hline 12 & $\begin{array}{l}\text { Outfalls } 60 \text { RG-12 ID \# } \\
37 \& 60 \text { RG-13 ID \# } 36\end{array}$ & Q & $\begin{array}{l}\text { Maintenance } \\
\square \text { Repair } \\
\square \text { Replacement }\end{array}$ & \\
\hline
\end{tabular}

Areas of Industrial Materials or Activities exposed to stormwater

Below are some general areas that should be assessed during routine inspections. Customize this list as needed for the specific types of industrial materials or activities at your facility.

\begin{tabular}{|c|c|c|c|c|}
\hline & Area/Activity & Inspected? & $\begin{array}{l}\text { Controls } \\
\text { Adequate } \\
\text { (appropriate, } \\
\text { effective, and } \\
\text { operating)? }\end{array}$ & Corrective Action Needed and Notes \\
\hline 1 & $\begin{array}{l}\text { Material } \\
\text { loading/unloading and } \\
\text { storage areas }\end{array}$ & EYyes aNo $\square \mathrm{N} / \mathrm{A}$ & DYes DNo & \\
\hline 2 & $\begin{array}{l}\text { Equipment operations } \\
\text { and maintenance areas }\end{array}$ & G.Yes aNo $\square \mathrm{N} / \mathrm{A}$ & aYes aNo & \\
\hline 3 & Fueling areas & aYes $\square$ No $\otimes N / A$ & aYes $\square$ No & \\
\hline 4 & $\begin{array}{l}\text { Outdoor vehicle and } \\
\text { equipment washing areas }\end{array}$ & aYes $\square$ No $\otimes \mathrm{N} / \mathrm{A}$ & DYes aNo & \\
\hline 5 & $\begin{array}{l}\text { Waste handling and } \\
\text { disposal areas }\end{array}$ & $\square$ Yes $\square$ No $\otimes N / A$ & aYes DNo & \\
\hline 6 & $\begin{array}{l}\text { Erodible } \\
\text { areas/construction }\end{array}$ & aYes $\square$ No $\otimes N / A$ & DYes aNo & \\
\hline 7 & $\begin{array}{l}\text { Non-stormwater/illicit } \\
\text { connections }\end{array}$ & QYes DNo $\otimes N / A$ & aYes aNo & \\
\hline 8 & $\begin{array}{l}\text { Salt storage piles or pile } \\
\text { containing salt }\end{array}$ & 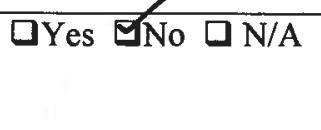 & aYes DNo & $\begin{array}{l}\text { Roll-up dar to salt shed stuck } \\
\text { oper. Entred as CAR } 486 \text { in th } \\
\text { Msce tracking }\end{array}$ \\
\hline
\end{tabular}




\begin{tabular}{|c|c|c|c|c|}
\hline & Area/Activity & Inspected? & $\begin{array}{l}\text { Controls } \\
\text { Adequate } \\
\text { (appropriate, } \\
\text { effective, and } \\
\text { operating)? }\end{array}$ & Corrective Action Needed and Notes \\
\hline 9 & $\begin{array}{l}\text { Dust generation and } \\
\text { vehicle tracking }\end{array}$ & 可 $\square$ Nos $\square \mathrm{N} / \mathrm{A}$ & DYes DNo & \\
\hline 10 & (Other) & aYes $\square$ No $\square \mathrm{N} / \mathrm{A}$ & aYes DNo & \\
\hline 11 & (Other) & aYes $\square$ No $\square \mathrm{N} / \mathrm{A}$ & QYes aNo & \\
\hline 12 & (Other) & aYes $\square$ No $\square \mathrm{N} / \mathrm{A}$ & DYes DNo & \\
\hline
\end{tabular}

\section{Non-Compliance}

Describe any incidents of non-compliance observed and not described above: On the North end of transpartainar 60-287 the are savaral pallets of ice melt that heed to be covared with taps. Thare ore also sovoral metal cabinets that Lak eithor fallen or been blown aver onto basls of ice melt and wood pallets, metal bending, an ovong bavel, 4 other trash that is a harbekeeping issue. This lus entoled into the MSGP tracking database as CAR \#85s. On the same dy of the inspection the pallets of fee melt ware cavered With taps, the metal cablucts ware stacked aut of the Way, 4 the material causing the hasekeeping issuk was picked up $\$$ put in a trash bin. CAR \# 8Ss wes closed in the MSGP tracking datababe on 12/17/2015.

\section{Additional Control Measures}

Describe any additional control measures needed to comply with the permit requirements: Nare 
Notes

Use this space for any additional notes or observations from the inspection: The lined solt vetation
pond $\frac{1}{4}$ Sediment vetention pond were both frozen ater.

\section{CERTIFICATION STATEMENT}

"I certify under penalty of law that this document and all attachments were prepared under my direction or supervision in accordance with a system designed to assure that qualified personnel properly gathered and evaluated the information submitted. Based on my inquiry of the person or persons who manage the system, or those persons directly responsible for gathering the information, the information submitted is, to the best of my knowledge and belief, true, accurate, and complete. I am aware that there are significant penalties for submitting false information, including the possibility of fine and imprisonment for knowing violations."

Print name and title: LeandF. Sondaval Deplayed Envivenmental Professional Signature: Leomand I. Aandonal Date: 12/7/2015 


\section{Stormwater Industrial Routine Facility Inspection Report}

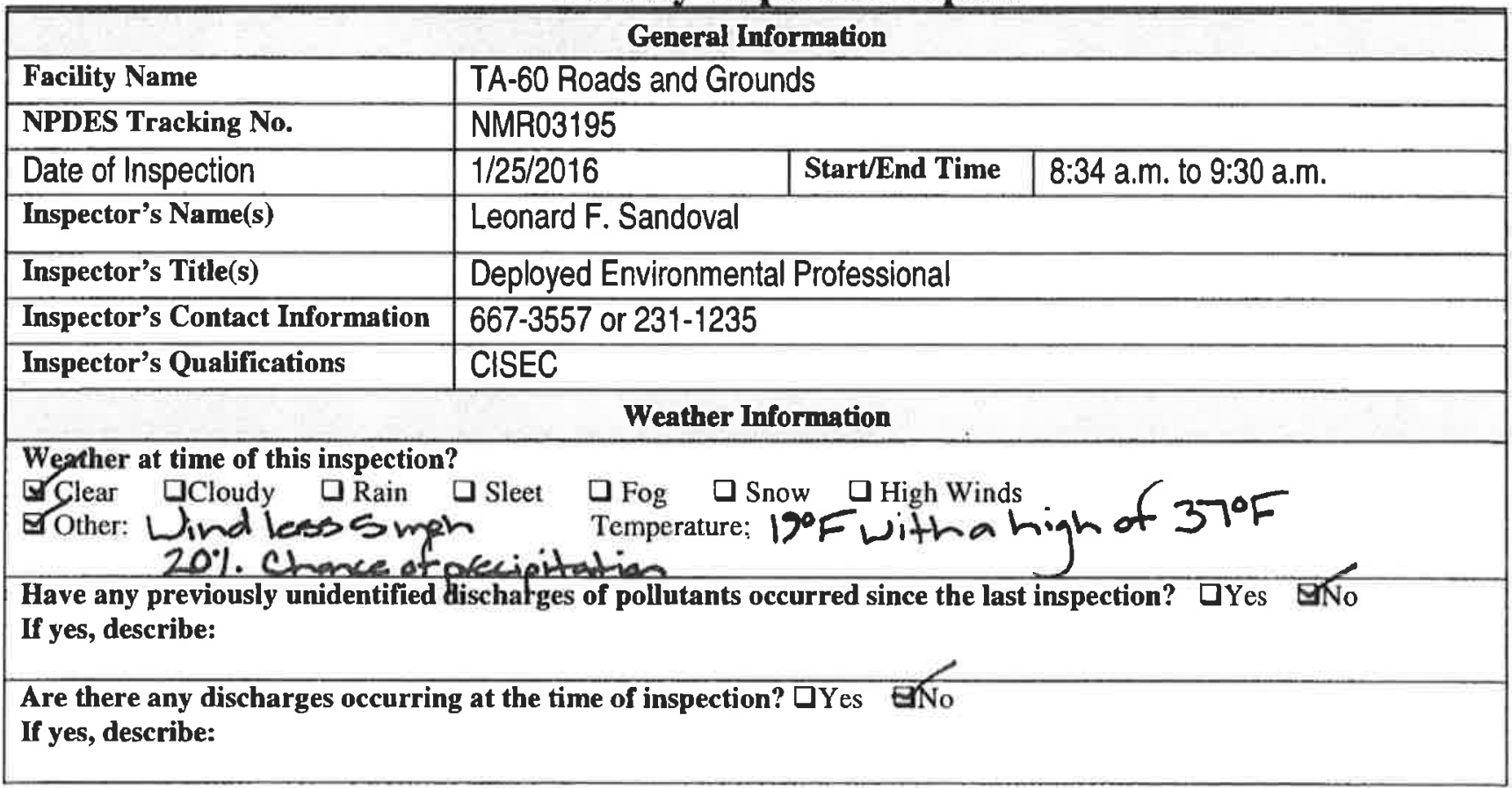

\section{Control Measures}

- Number the structural stormwater control measures identified in your SWPPP on your site map and list them below (add as many control measures as are implemented on-site). Carry a copy of the numbered site map with you during your inspections. This list will ensure that you are inspecting all required control measures at your facility.

- Describe corrective actions initiated, date completed, and note the person that completed the work in the Corrective Action Log.

\begin{tabular}{|c|c|c|c|c|}
\hline & $\begin{array}{l}\text { Structural Control } \\
\text { Measure }\end{array}$ & $\begin{array}{l}\text { Control } \\
\text { Measure is } \\
\text { Operating } \\
\text { Efictively? }\end{array}$ & $\begin{array}{l}\text { If No, In Need of } \\
\text { Maintenance, } \\
\text { Repair, or } \\
\text { Replacement? }\end{array}$ & $\begin{array}{l}\text { Corrective Action Needed and Notes } \\
\text { (identify needed maintenance and repairs, or any } \\
\text { failed control measures that need replacement) }\end{array}$ \\
\hline 1 & Straw Wattles & EYes DNo & $\begin{array}{l}\square \text { Maintenance } \\
\square \text { Repair } \\
\square \text { Replacement }\end{array}$ & \\
\hline 2 & Rock Check Dams & EYes $\square$ No & $\begin{array}{l}\square \text { Maintenance } \\
\square \text { Repair } \\
\square \text { Replacement }\end{array}$ & \\
\hline 3 & $\begin{array}{l}\text { Lined Salt Retention } \\
\text { Pond }\end{array}$ & g्uYes $\square$ No & $\begin{array}{l}\square \text { Maintenance } \\
\square \text { Repair } \\
\square \text { Replacement }\end{array}$ & \\
\hline 4 & Sediment Basin & EYes aNo & $\begin{array}{l}\square \text { Maintenance } \\
\square \text { Repair } \\
\square \text { Replacement }\end{array}$ & \\
\hline 5 & Rip Rap/Jersey Barriers & $\overline{-}$ Yes $\square$ No & $\begin{array}{l}\square \text { Maintenance } \\
\square \text { Repair } \\
\square \text { Replacement }\end{array}$ & \\
\hline 6 & $\begin{array}{l}\text { Sediment Retention } \\
\text { Pond }\end{array}$ & EYes DNo & $\begin{array}{l}\square \text { Maintenance } \\
\square \text { Repair } \\
\square \text { Replacement }\end{array}$ & \\
\hline 7 & $\begin{array}{l}\text { Base Course/Earthen } \\
\text { Berms }\end{array}$ & VYes $\square$ No & $\begin{array}{l}\square \text { Maintenance } \\
\square \text { Repair }\end{array}$ & \\
\hline
\end{tabular}




\begin{tabular}{|c|c|c|c|c|}
\hline & $\begin{array}{l}\text { Structural Control } \\
\text { Measure }\end{array}$ & $\begin{array}{l}\text { Control } \\
\text { Measure is } \\
\text { Operating } \\
\text { Effectively? }\end{array}$ & $\begin{array}{l}\text { If No, In Need of } \\
\text { Maintenance, } \\
\text { Repair, or } \\
\text { Replacement? } \\
\end{array}$ & $\begin{array}{l}\text { Corrective Action Needed and Notes } \\
\text { (identify needed maintenance and repairs, or any } \\
\text { failed control measures that need replacement) }\end{array}$ \\
\hline & & & R Replacement & \\
\hline 8 & Rock Run Down & 可Yes aNo & $\begin{array}{l}\text { Q Maintenance } \\
\text { Repair } \\
\text { Q Replacement }\end{array}$ & \\
\hline 9 & $\begin{array}{l}\text { Outfalls 60 RG-1ID \# } \\
31,60 \text { RG-2 ID \# 30, } 60 \\
\text { RG-3 ID \# 32,60 RG-4 } \\
\text { ID \# 33, 60 RG-5 ID \# } \\
34, \& 60 \text { RG-6 ID \# } 35\end{array}$ & EYes aNo & $\begin{array}{l}\text { Maintenance } \\
\text { Repair } \\
\text { Replacement }\end{array}$ & - \\
\hline 10 & $\begin{array}{l}\text { Outfalls 60 RG-7 ID \# } \\
41 \& 60 \text { RG-8 ID \# } 42\end{array}$ & GYNo & $\begin{array}{l}\text { Daintenance } \\
\text { Repair } \\
\text { Replacement }\end{array}$ & \\
\hline 11 & $\begin{array}{l}\text { Outfalls 60 RG-9 ID \# } \\
40,60 \text { RG-10 ID \# } 39, \\
60 \text { RG-11 ID \# } 38\end{array}$ & 可Yes DNo & $\begin{array}{l}\text { Maintenance } \\
\text { Q Repair } \\
\text { Replacement }\end{array}$ & \\
\hline 12 & $\begin{array}{l}\text { Outfalls 60 RG-12 ID \# } \\
37 \& 60 \text { RG-13 ID \# } 36\end{array}$ & 可Yes DNo & $\begin{array}{l}\text { Maintenance } \\
\text { Repair } \\
\text { Replacement }\end{array}$ & \\
\hline
\end{tabular}

Areas of Industrial Materials or Activities exposed to stormwater

Below are some general areas that should be assessed during routine inspections. Customize this list as needed for the specific types of industrial materials or activities at your facility.

\begin{tabular}{|c|c|c|c|c|}
\hline & Area/Activity & Inspected? & $\begin{array}{l}\text { Controls } \\
\text { Adequate } \\
\text { (appropriate, } \\
\text { effective, and } \\
\text { operating)? }\end{array}$ & Corrective Action Needed and Notes \\
\hline 1 & $\begin{array}{l}\text { Material } \\
\text { loading/unloading and } \\
\text { storage areas }\end{array}$ & E्रYes $\square \mathrm{No}-\mathrm{N} / \mathrm{A}$ & DYes DNo & \\
\hline 2 & $\begin{array}{l}\text { Equipment operations } \\
\text { and maintenance areas }\end{array}$ & EYes $\square$ No $\square$ N/A & DYes DNo & \\
\hline 3 & Fueling areas & GYes $\square$ No 四/A & QYes $\square$ No & \\
\hline 4 & $\begin{array}{l}\text { Outdoor vehicle and } \\
\text { equipment washing areas }\end{array}$ & DYes $\square$ No $\mathbf{X}$ N/A & QYes $\square$ No & \\
\hline 5 & $\begin{array}{l}\text { Waste handling and } \\
\text { disposal areas }\end{array}$ & 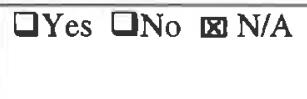 & QYes $\square$ No & \\
\hline 6 & $\begin{array}{l}\text { Erodible } \\
\text { areas/construction }\end{array}$ & DYes $\square$ No $\mathbf{B}$ N/A & DYes DNo & \\
\hline 7 & $\begin{array}{l}\text { Non-stormwater/illicit } \\
\text { connections }\end{array}$ & 口Yes $\square$ No ख N/A & DYes DNo & \\
\hline 8 & $\begin{array}{l}\text { Salt storage piles or pile } \\
\text { containing salt }\end{array}$ & GYes $\square$ No $\square$ N/A & aYes $\square$ No & \\
\hline
\end{tabular}




\begin{tabular}{|c|c|c|c|c|}
\hline & Area/Activity & Inspected? & $\begin{array}{l}\text { Controls } \\
\text { Adequate } \\
\text { (appropriate, } \\
\text { effective, and } \\
\text { operating)? }\end{array}$ & Corrective Action Needed and Notes \\
\hline 9 & $\begin{array}{l}\text { Dust generation and } \\
\text { vehicle tracking }\end{array}$ & E्uYes $\square$ No $\square \mathrm{N} / \mathrm{A}$ & DYes DNo & \\
\hline 10 & (Other) & QYes $\square$ No $\square$ N/A & aYes $\square_{\text {No }}$ & \\
\hline 11 & (Other) & GYes $\square$ No $\square$ N/A & DYes DNo & \\
\hline 12 & (Other) & $\square$ Yes $\square$ No $\square$ N/A & QYes $\square$ No & \\
\hline
\end{tabular}

Non-Compliance

Describe any incidents of non-compliance observed and not described above: None

Additional Control Measures

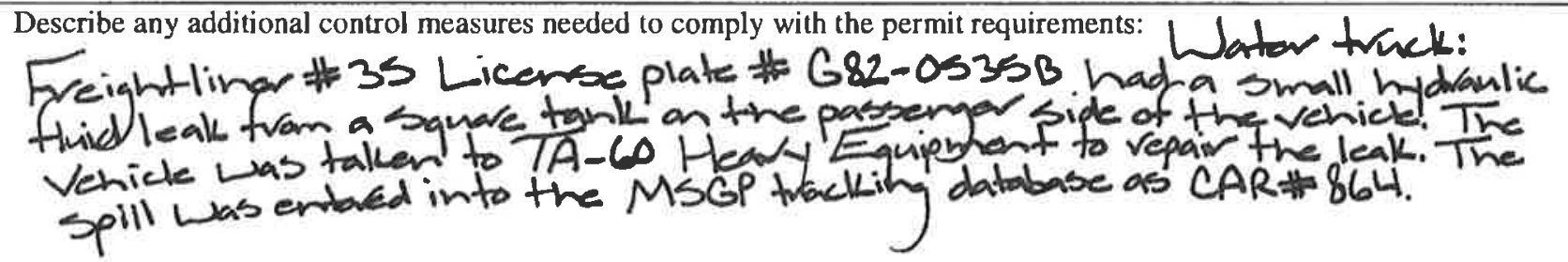


Notes

Use this space for any additional notes or observations from the inspection:

With frozen snow.

Majority of site cared

CERTIFICATION STATEMENT

"I certify under penalty of law that this document and all attachments were prepared under my direction or supervision in accordance with a system designed to assure that qualified personnel properly gathered and evaluated the information submitted. Based on my inquiry of the person or persons who manage the system, or those persons directly responsible for gathering the information, the information submitted is, to the best of my knowledge and belief, true, accurate, and complete. I am aware that there are significant penalties for submitting false information, including the possibility of fine and imprisonment for knowing violations."

Print name and title: Leaned F. Sandal al Deployed Envivamantal Professional Signature: Demand I. Sandal Date: $1 / 25 / 2016$ Russell Stone /DSostrut Group ene le Ranelshe.

2) $1 / 2016$ 


\section{Stormwater Industrial Routine Facility Inspection Report}

\begin{tabular}{|c|c|c|c|}
\hline \multicolumn{4}{|c|}{ General Information } \\
\hline Facility Name & \multicolumn{3}{|c|}{ TA-60 Roads and Grounds } \\
\hline NPDES Tracking No. & \multicolumn{3}{|l|}{ NMR03195 } \\
\hline Date of Inspection & $2 / 22 / 2016$ & Start/End Time & 9:15 a.m. to $10: 13$ a.m. \\
\hline Inspector's Name(s) & \multicolumn{3}{|c|}{ Leonard F. Sandoval } \\
\hline Inspector's Title(s) & \multicolumn{3}{|c|}{ Deployed Environmental Professional } \\
\hline Inspector's Contact Information & \multicolumn{3}{|c|}{$667-3557$ or $231-1235$} \\
\hline Inspector's Qualifications & \multicolumn{3}{|l|}{ CISEC } \\
\hline \multicolumn{4}{|c|}{ Weather Information } \\
\hline \multicolumn{4}{|c|}{$\begin{array}{l}\text { Weather at time of this inspection? } \\
\text { घGear aCloudy aRain a Sleet a Fog a Snow a High Winds } \\
\text { GOther: Wind less than Smph Temperature: } 30^{\circ} \mathrm{F} \text { ith a high of } 53^{\circ} \mathrm{F}\end{array}$} \\
\hline \multicolumn{4}{|c|}{$\begin{array}{l}\text { Have any previously unidentified discharges of pollutants occurred since the last inspection? DYes } \\
\text { If yes, describe: }\end{array}$} \\
\hline \multicolumn{4}{|c|}{$\begin{array}{l}\text { Are there any discharges occurring at the time of inspection? aYes } \\
\text { If yes, describe: }\end{array}$} \\
\hline
\end{tabular}

\section{Control Measures}

- Number the structural stormwater control measures identified in your SWPPP on your site map and list them below (add as many control measures as are implemented on-site). Carry a copy of the numbered site map with you during your inspections. This list will ensure that you are inspecting all required control measures at your facility.

- Describe corrective actions initiated, date completed, and note the person that completed the work in the Corrective Action Log.

\begin{tabular}{|c|c|c|c|c|}
\hline & $\begin{array}{l}\text { Structural Control } \\
\text { Measure }\end{array}$ & $\begin{array}{l}\text { Control } \\
\text { Measure is } \\
\text { Operating } \\
\text { Effectively? }\end{array}$ & $\begin{array}{l}\text { If No, In Need of } \\
\text { Maintenance, } \\
\text { Repair, or } \\
\text { Replacement? }\end{array}$ & $\begin{array}{l}\text { Corrective Action Needed and Notes } \\
\text { (identify needed maintenance and repairs, or any } \\
\text { failed control measures that need replacement) }\end{array}$ \\
\hline 1 & Straw Wattles & 区Yes 口No & $\begin{array}{l}\text { Maintenance } \\
\square \text { Repair } \\
\square \text { Replacement }\end{array}$ & \\
\hline 2 & Rock Check Dams & שYes DNo & $\begin{array}{l}\text { Maintenance } \\
\square \text { Repair } \\
\square \text { Replacement }\end{array}$ & . \\
\hline 3 & $\begin{array}{l}\text { Lined Salt Retention } \\
\text { Pond }\end{array}$ & Ees DNo & $\begin{array}{l}\text { Maintenance } \\
\square \text { Repair } \\
\square \text { Replacement }\end{array}$ & \\
\hline 4 & Sediment Basin & EYes $\square$ No & $\begin{array}{l}\text { Maintenance } \\
\square \text { Repair } \\
\square \text { Replacement }\end{array}$ & \\
\hline 5 & Rip Rap/Jersey Barriers & EYes QNo & $\begin{array}{l}\text { Maintenance } \\
\square \text { Repair } \\
\square \text { Replacement }\end{array}$ & \\
\hline 6 & $\begin{array}{l}\text { Sediment Retention } \\
\text { Pond }\end{array}$ & 可 Yes $\square$ No & $\begin{array}{l}\text { Maintenance } \\
\square \text { Repair } \\
\square \text { Replacement }\end{array}$ & \\
\hline 7 & $\begin{array}{l}\text { Base Course/Earthen } \\
\text { Berms }\end{array}$ & aYes ENo & $\begin{array}{l}\text { DJaintenance } \\
\text { VRepair }\end{array}$ & $\begin{array}{l}\text { Hole throyh earthen borm that } \\
\text { parallelis Eniwetol Drive. }\end{array}$ \\
\hline
\end{tabular}




\begin{tabular}{|c|c|c|c|c|}
\hline & $\begin{array}{l}\text { Structural Control } \\
\text { Measure }\end{array}$ & $\begin{array}{l}\text { Control } \\
\text { Measure is } \\
\text { Operating } \\
\text { Effectively? }\end{array}$ & $\begin{array}{l}\text { If No, In Need of } \\
\text { Maintenance, } \\
\text { Repair, or } \\
\text { Replacement? }\end{array}$ & $\begin{array}{l}\text { Corrective Action Needed and Notes } \\
\text { (identify needed maintenance and repairs, or any } \\
\text { failed control measures that need replacement) }\end{array}$ \\
\hline & & & $\square$ Replacement & \\
\hline 8 & Rock Run Down & GYes aNo & $\begin{array}{l}\text { Maintenance } \\
\square \text { Repair } \\
\text { Replacement }\end{array}$ & \\
\hline 9 & $\begin{array}{l}\text { Outfalls } 60 \text { RG-1ID \# } \\
31,60 \text { RG-2 ID \# 30, } 60 \\
\text { RG-3 ID \# 32, 60 RG-4 } \\
\text { ID \# 33, 60 RG-5 ID \# } \\
34, \& 60 \text { RG-6 ID \# } 35\end{array}$ & EYes aNo & $\begin{array}{l}\text { Maintenance } \\
\square \text { Repair } \\
\square \text { Replacement }\end{array}$ & \\
\hline 10 & $\begin{array}{l}\text { Outfalls 60 RG-7 ID \# } \\
41 \& 60 \text { RG-8 ID \# } 42\end{array}$ & 可 & $\begin{array}{l}\text { Maintenance } \\
\text { Repair } \\
\text { Replacement }\end{array}$ & $\mathrm{i}$ \\
\hline 11 & $\begin{array}{l}\text { Outfalls } 60 \text { RG-9 ID \# } \\
40,60 \text { RG-10 ID \# 39, } \\
60 \text { RG-11 ID \# } 38\end{array}$ & GYes [No & $\begin{array}{l}\text { Maintenance } \\
\text { Repair } \\
\text { Replacement }\end{array}$ & \\
\hline 12 & $\begin{array}{l}\text { Outfalls 60 RG-12 ID \# } \\
37 \& 60 \text { RG-13 ID \# } 36\end{array}$ & 区Yes aNo & $\begin{array}{l}\text { Maintenance } \\
\square \text { Repair } \\
\square \text { Replacement }\end{array}$ & \\
\hline
\end{tabular}

Areas of Industrial Materials or Activities exposed to stormwater

Below are some general areas that should be assessed during routine inspections. Customize this list as needed for the specific types of industrial materials or activities at your facility.

\begin{tabular}{|c|c|c|c|c|}
\hline & Area/Activity & Inspected? & $\begin{array}{l}\text { Controls } \\
\text { Adequate } \\
\text { (appropriate, } \\
\text { effective, and } \\
\text { operating)? }\end{array}$ & Corrective Action Needed and Notes \\
\hline 1 & $\begin{array}{l}\text { Material } \\
\text { loading/unloading and } \\
\text { storage areas }\end{array}$ & EYes aNo a & aYes DNo & \\
\hline 2 & $\begin{array}{l}\text { Equipment operations } \\
\text { and maintenance areas }\end{array}$ & EYes $\square$ No $\square$ N/A & aYes aNo & 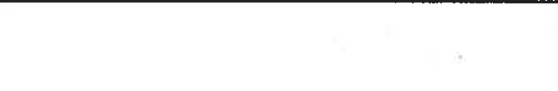 \\
\hline 3 & Fueling areas & 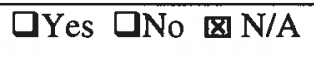 & aYes $\mathrm{DNo}$ & \\
\hline 4 & $\begin{array}{l}\text { Outdoor vehicle and } \\
\text { equipment washing areas }\end{array}$ & aYes $\square$ No $\mathbf{X} / \mathrm{A}$ & aYes DNo & \\
\hline 5 & $\begin{array}{l}\text { Waste handling and } \\
\text { disposal areas }\end{array}$ & DYes $\square$ No X N/A & DYes aNo & \\
\hline 6 & $\begin{array}{l}\text { Erodible } \\
\text { areas/construction }\end{array}$ & GYes DNo $⿴ 囗 \mathbf{N} / \mathrm{A}$ & aYes aNo & . \\
\hline 7 & $\begin{array}{l}\text { Non-stormwater/ illicit } \\
\text { connections }\end{array}$ & GYes DNo $\otimes N / A$ & DYes DNo & \\
\hline 8 & $\begin{array}{l}\text { Salt storage piles or pile } \\
\text { containing salt }\end{array}$ & GYes $\square$ No $\square$ N/A & QYes aNo & \\
\hline
\end{tabular}




\begin{tabular}{|c|c|c|c|c|}
\hline & Area/Activity & Inspected? & $\begin{array}{l}\text { Controls } \\
\text { Adequate } \\
\text { (appropriate, } \\
\text { effective, and } \\
\text { operating)? }\end{array}$ & Corrective Action Needed and Notes \\
\hline 9 & $\begin{array}{l}\text { Dust generation and } \\
\text { vehicle tracking }\end{array}$ & $\square$ Yes $\square$ No $\square$ N/A & QYes DNo & \\
\hline 10 & (Other) & $\square$ Yes $\square$ No $\square$ N/A & QYes aNo & \\
\hline 11 & (Other) & 口Yes 口No $\square \mathrm{N} / \mathrm{A}$ & QYes DNo & \\
\hline 12 & (Other) & $\square$ Yes $\square$ No $\square$ N/A & QYes DNo & \\
\hline
\end{tabular}

Non-Compliance

Describe any incidents of non-compliance observed and not described above: In peay equipment yad $140 G$ Grader PN\# 30599 has a small hydraulic fluid heal on vight side

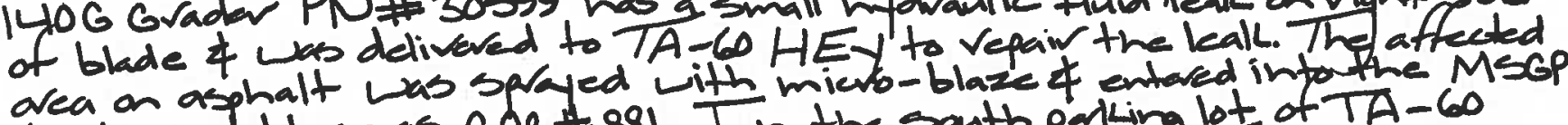
Wacluing datubese as CAR $\#$ 881. In the south palling lot of TA -60

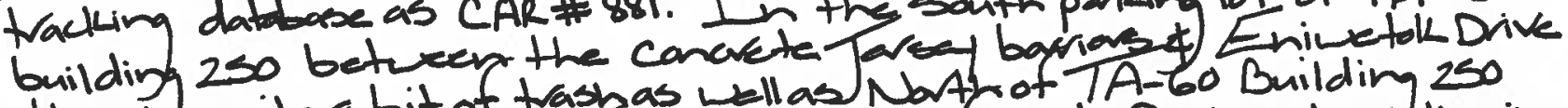
thare's quite a bit of trashas wallas Nart of TA-60 Building 250

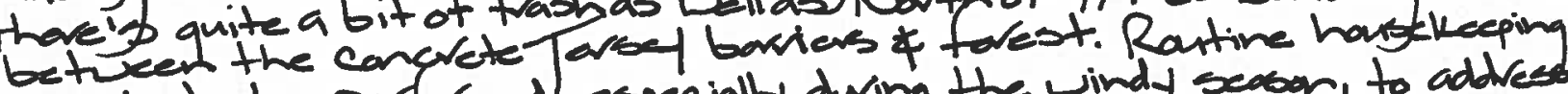
heeds to be pertatmed, especially during the windy seasen, to addreso this issue that was entered into the Ms6P trocklng database as
CAR $\$ 883$.

Additional Control Measures

Describe any additional control measures needed to comply with the permit requirements: 
Notes

Use this space for any additional notes or observations from the inspection:

CERTIFICATION STATEMENT

"I certify under penalty of law that this document and all attachments were prepared under my direction or supervision in accordance with a system designed to assure that qualified personnel properly gathered and evaluated the information submitted. Based on my inquiry of the person or persons who manage the system, or those persons directly responsible for gathering the information, the information submitted is, to the best of my knowledge and belief, true, accurate, and complete. I am aware that there are significant penalties for submitting false information, including the possibility of fine and imprisonment for knowing violations."

Print name and title: Russell Store oESt5-UIS Group Ladder

Signature:

Date: $2 / 22 / 20 / 6$ 


\section{Stormwater Industrial Routine Facility Inspection Report}

\begin{tabular}{|c|c|c|c|}
\hline \multicolumn{4}{|c|}{ General Information } \\
\hline Facility Name & \multicolumn{3}{|c|}{ TA-60 Roads and Grounds } \\
\hline NPDES Tracking No. & \multicolumn{3}{|l|}{ NMR03195 } \\
\hline Date of Inspection & $3 / 21 / 2016$ & Start/End Time & 8:38 a.m. to $10: 06$ a.m. \\
\hline Inspector's Name(s) & \multicolumn{3}{|l|}{ Leonard F. Sandoval } \\
\hline Inspector's Title(s) & \multicolumn{3}{|c|}{ Deployed Environmental Professional } \\
\hline Inspector's Contact Information & \multicolumn{3}{|l|}{$667-3557$ or $231-1235$} \\
\hline Inspector's Qualifications & \multicolumn{3}{|l|}{ CISEC } \\
\hline \multicolumn{4}{|c|}{ Weather Information } \\
\hline \multicolumn{4}{|c|}{$\begin{array}{l}\text { Weather at time of this inspection? } \\
\text { Ggear acloudy a Rain asleet a Fog a Snow a High Winds } \\
\text { gother: No Sind }\end{array}$} \\
\hline \multicolumn{4}{|c|}{$\begin{array}{l}\text { Have any previously unidentified discharges of pollutants occurred since the last inspection? DYes G G } \\
\text { If yes, describe: }\end{array}$} \\
\hline \multicolumn{4}{|c|}{$\begin{array}{l}\text { Are there any discharges occurring at the time of inspection? } \square \mathrm{Yes} \\
\text { If yes, describe: }\end{array}$} \\
\hline
\end{tabular}

\section{Control Measures}

- Number the structural stormwater control measures identified in your SWPPP on your site map and list them below (add as many control measures as are implemented on-site). Carry a copy of the numbered site map with you during your inspections. This list will ensure that you are inspecting all required control measures at your facility.

- Describe corrective actions initiated, date completed, and note the person that completed the work in the Corrective Action Log.

\begin{tabular}{|c|c|c|c|c|}
\hline & $\begin{array}{l}\text { Structural Control } \\
\text { Measure }\end{array}$ & $\begin{array}{l}\text { Control } \\
\text { Measure is } \\
\text { Operating } \\
\text { Effectively? }\end{array}$ & $\begin{array}{l}\text { If No, In Need of } \\
\text { Maintenance, } \\
\text { Repair, or } \\
\text { Replacement? }\end{array}$ & $\begin{array}{l}\text { Corrective Action Needed and Notes } \\
\text { (identify needed maintenance and repairs, or any } \\
\text { failed control measures that need replacement) }\end{array}$ \\
\hline 1 & Straw Wattles & GYes aNo & $\begin{array}{l}\text { Maintenance } \\
\square \text { Repair } \\
\square \text { Replacement }\end{array}$ & \\
\hline 2 & Rock Check Dams & EYes aNo & $\begin{array}{l}\text { Maintenance } \\
\square \text { Repair } \\
\square \text { Replacement }\end{array}$ & \\
\hline 3 & $\begin{array}{l}\text { Lined Salt Retention } \\
\text { Pond }\end{array}$ & GYes aNo & $\begin{array}{l}\text { Maintenance } \\
\square \text { Repair } \\
\square \text { Replacement }\end{array}$ & \\
\hline 4 & Sediment Basin & GYes aNo & $\begin{array}{l}\text { Maintenance } \\
\square \text { Repair } \\
\square \text { Replacement }\end{array}$ & \\
\hline 5 & Rip Rap/Jersey Barriers & aNo & $\begin{array}{l}\text { Maintenance } \\
\square \text { Repair } \\
\square \text { Replacement }\end{array}$ & \\
\hline 6 & $\begin{array}{l}\text { Sediment Retention } \\
\text { Pond }\end{array}$ & GYes $\square$ No & $\begin{array}{l}\text { Maintenance } \\
\text { Repair } \\
\square \text { Replacement }\end{array}$ & \\
\hline 7 & $\begin{array}{l}\text { Base Course/Earthen } \\
\text { Berms }\end{array}$ & VYes aNo & $\begin{array}{l}\text { Maintenance } \\
\text { Repair }\end{array}$ & \\
\hline
\end{tabular}




\begin{tabular}{|c|c|c|c|c|}
\hline & $\begin{array}{l}\text { Structural Control } \\
\text { Measure }\end{array}$ & $\begin{array}{l}\text { Control } \\
\text { Measure is } \\
\text { Operating } \\
\text { Effectively? }\end{array}$ & $\begin{array}{l}\text { If No, In Need of } \\
\text { Maintenance, } \\
\text { Repair, or } \\
\text { Replacement? }\end{array}$ & $\begin{array}{l}\text { Corrective Action Needed and Notes } \\
\text { (identify needed maintenance and repairs, or any } \\
\text { failed control measures that need replacement) }\end{array}$ \\
\hline & & & Replacement & \\
\hline 8 & Rock Run Down & GYes aNo & $\begin{array}{l}\text { Maintenance } \\
\text { Repair } \\
\text { Replacement }\end{array}$ & \\
\hline 9 & $\begin{array}{l}\text { Outfalls } 60 \text { RG-1ID \# } \\
31,60 \text { RG-2 ID \# 30, } 60 \\
\text { RG-3 ID \# 32, } 60 \text { RG-4 } \\
\text { ID \# 33, 60 RG-5 ID \# } \\
34, \& 60 \text { RG-6 ID \# } 35\end{array}$ & पYes DNo & $\begin{array}{l}\text { Maintenance } \\
\text { Repair } \\
\square \text { Replacement }\end{array}$ & \\
\hline 10 & $\begin{array}{l}\text { Outfalls } 60 \text { RG-7 ID \# } \\
41 \& 60 \text { RG-8 ID \# } 42\end{array}$ & व्रYes $\mathrm{DNo}$ & $\begin{array}{l}\text { Maintenance } \\
\square \text { Repair } \\
\square \text { Replacement }\end{array}$ & \\
\hline 11 & $\begin{array}{l}\text { Outfalls } 60 \text { RG-9 ID \# } \\
40,60 \text { RG-10 ID \# 39, } \\
60 \text { RG-11 ID \# } 38\end{array}$ & שYes DNo & $\begin{array}{l}\text { Maintenance } \\
\square \text { Repair } \\
\square \text { Replacement }\end{array}$ & \\
\hline 12 & $\begin{array}{l}\text { Outfalls } 60 \text { RG-12 ID \# } \\
37 \& 60 \text { RG-13 ID \# } 36\end{array}$ & 可Yes DNo & $\begin{array}{l}\text { Daintenance } \\
\square \text { Repair } \\
\square \text { Replacement }\end{array}$ & \\
\hline
\end{tabular}

Areas of Industrial Materials or Activities exposed to stormwater

Below are some general areas that should be assessed during routine inspections. Customize this list as needed for the specific types of industrial materials or activities at your facility.

\begin{tabular}{|c|c|c|c|c|}
\hline & Area/Activity & Inspected? & $\begin{array}{l}\text { Controls } \\
\text { Adequate } \\
\text { (appropriate, } \\
\text { effective, and } \\
\text { operating)? }\end{array}$ & Corrective Action Needed and Notes \\
\hline 1 & $\begin{array}{l}\text { Material } \\
\text { loading/unloading and } \\
\text { storage areas }\end{array}$ & व्रYes DNo DN/A & UYes QNo & $\therefore$ \\
\hline 2 & $\begin{array}{l}\text { Equipment operations } \\
\text { and maintenance areas }\end{array}$ & 可Yes $\square$ No $\square$ N/A & DYes DNo & \\
\hline 3 & Fueling areas & $\square$ Yes $\square$ No $\otimes N / A$ & QYes $\square$ No & \\
\hline 4 & $\begin{array}{l}\text { Outdoor vehicle and } \\
\text { equipment washing areas }\end{array}$ & aYes $\square$ No $₫ \mathrm{~N} / \mathrm{A}$ & DYes $\square$ No & \\
\hline 5 & $\begin{array}{l}\text { Waste handling and } \\
\text { disposal areas }\end{array}$ & $\square$ Yes $\square$ No $\otimes N / A$ & DYes DNo & \\
\hline 6 & $\begin{array}{l}\text { Erodible } \\
\text { areas/construction }\end{array}$ & $\square$ Yes $\square$ No $\otimes N / A$ & DYes aNo & \\
\hline 7 & $\begin{array}{l}\text { Non-stormwater/ illicit } \\
\text { connections }\end{array}$ & 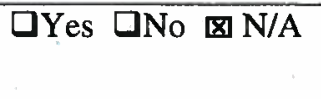 & DYes DNo & \\
\hline 8 & $\begin{array}{l}\text { Salt storage piles or pile } \\
\text { containing salt }\end{array}$ & 可Yes 口No $\square \mathrm{N} / \mathrm{A}$ & QYes DNo & \\
\hline
\end{tabular}




\begin{tabular}{|c|c|c|c|c|}
\hline & Area/Activity & Inspected? & $\begin{array}{l}\text { Controls } \\
\text { Adequate } \\
\text { (appropriate, } \\
\text { effective, and } \\
\text { operating)? }\end{array}$ & Corrective Action Needed and Notes \\
\hline 9 & $\begin{array}{l}\text { Dust generation and } \\
\text { vehicle tracking }\end{array}$ & Yes $\square$ No $\square$ N/A & DYes DNo & \\
\hline 10 & (Other) & $\square$ Yes $\square$ No $\square \mathrm{N} / \mathrm{A}$ & QYes $\square$ No & \\
\hline 11 & (Other) & aYes $\square$ No $\square$ N/A & QYes Q QNo & \\
\hline 12 & (Other) & DYes DNo $\square \mathrm{N} / \mathrm{A}$ & DYes DNo & \\
\hline
\end{tabular}

Non-Compliance

Describe any incidents of non-compliance observed and not described above: On the hathside of TA-6o-building 178 Salt tuck 682-0249 F had a small hydraulic leak from an aluminum box behind the passonger door that Las entared into the MSGP tracking database as CAR \# 891.

Additional Control Measures

Describe any additional control measures needed to comply with the permit requirements: 
Notes

Use this space for any additional notes or observations from the inspection: The sediment retention pond at the for cast end of Sigma Mesa had water in it with
wo visible oily sheen.

CERTIFICATION STATEMENT

"I certify under penalty of law that this document and all attachments were prepared under my direction or supervision in accordance with a system designed to assure that qualified personnel properly gathered and evaluated the information submitted. Based on my inquiry of the person or persons who manage the system, or those persons directly responsible for gathering the information, the information submitted is, to the best of my knowledge and belief, true, accurate, and complete. I am aware that there are significant penalties for submitting false information, including the possibility of fine and imprisonment for knowing violations."

Print name and title: Russell Stone Destis-uts GL

Signature:

Date: $3 / 22 / 2016$ 


\section{Stormwater Industrial Routine Facility Inspection Report}

\begin{tabular}{|c|c|c|c|}
\hline \multicolumn{4}{|c|}{ General Information } \\
\hline Facility Name & \multicolumn{3}{|c|}{ TA-60 Roads and Grounds } \\
\hline NPDES Tracking No. & \multicolumn{3}{|c|}{ NMR03195 } \\
\hline Date of Inspection & $4 / 26 / 2016$ & Start/End Time & 9:12 a.m. to $10: 09$ a.m. \\
\hline Inspector's Name(s) & \multicolumn{3}{|c|}{ Leonard F. Sandoval } \\
\hline Inspector's Title(s) & \multicolumn{3}{|c|}{ Deployed Environmental Professional } \\
\hline Inspector's Contact Information & \multicolumn{3}{|c|}{$667-3557$ or $231-1235$} \\
\hline Inspector's Qualifications & \multicolumn{3}{|l|}{ CISEC } \\
\hline \multicolumn{4}{|c|}{ Weather Information } \\
\hline \multicolumn{4}{|c|}{ 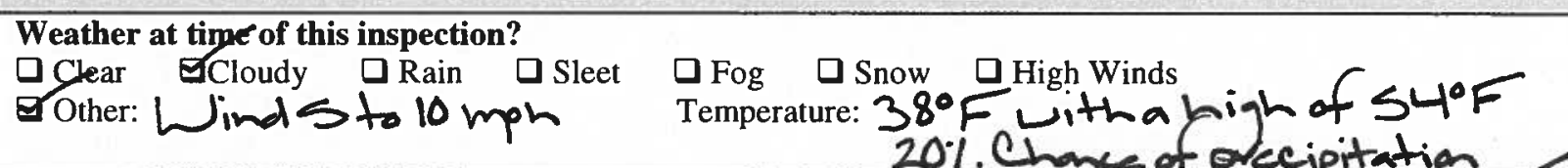 } \\
\hline \multicolumn{4}{|c|}{$\begin{array}{l}\text { Have any previously unidentified discharges of pollutants occurred since the last inspection? QYes प्रNo } \\
\text { If yes, describe: }\end{array}$} \\
\hline \multicolumn{4}{|c|}{$\begin{array}{l}\text { Are there any discharges occurring at the time of inspection? } \square \text { Yes } \\
\text { If yes, describe: }\end{array}$} \\
\hline
\end{tabular}

\section{Control Measures}

- Number the structural stormwater control measures identified in your SWPPP on your site map and list them below (add as many control measures as are implemented on-site). Carry a copy of the numbered site map with you during your inspections. This list will ensure that you are inspecting all required control measures at your facility.

- Describe corrective actions initiated, date completed, and note the person that completed the work in the Corrective Action Log.

\begin{tabular}{|c|c|c|c|c|}
\hline & $\begin{array}{l}\text { Structural Control } \\
\text { Measure }\end{array}$ & $\begin{array}{l}\text { Control } \\
\text { Measure is } \\
\text { Operating } \\
\text { Effoctively? }\end{array}$ & $\begin{array}{l}\text { If No, In Need of } \\
\text { Maintenance, } \\
\text { Repair, or } \\
\text { Replacement? }\end{array}$ & $\begin{array}{l}\text { Corrective Action Needed and Notes } \\
\text { (identify needed maintenance and repairs, or any } \\
\text { failed control measures that need replacement) }\end{array}$ \\
\hline 1 & Straw Wattles & EYes DNo & $\begin{array}{l}\text { Maintenance } \\
\square \text { Repair } \\
\text { Replacement }\end{array}$ & \\
\hline 2 & Rock Check Dams & Gyes $\square$ No & $\begin{array}{l}\text { Maintenance } \\
\square \text { Repair } \\
\square \text { Replacement }\end{array}$ & \\
\hline 3 & $\begin{array}{l}\text { Lined Salt Retention } \\
\text { Pond }\end{array}$ & E्रYes aNo & $\begin{array}{l}\text { Maintenance } \\
\square \text { Repair } \\
\square \text { Replacement }\end{array}$ & \\
\hline 4 & Sediment Basin & שY Yes $\square$ No & $\begin{array}{l}\square \text { Maintenance } \\
\square \text { Repair } \\
\square \text { Replacement }\end{array}$ & \\
\hline 5 & Rip Rap/Jersey Barriers & EYes aNo & $\begin{array}{l}\square \text { Maintenance } \\
\square \text { Repair } \\
\square \text { Replacement }\end{array}$ & \\
\hline 6 & $\begin{array}{l}\text { Sediment Retention } \\
\text { Pond }\end{array}$ & שY Yes aNo & $\begin{array}{l}\text { Maintenance } \\
\square \text { Repair } \\
\square \text { Replacement }\end{array}$ & \\
\hline 7 & $\begin{array}{l}\text { Base Course/Earthen } \\
\text { Berms }\end{array}$ & UYes $\square$ No & $\begin{array}{l}\text { Maintenance } \\
\text { Repair }\end{array}$ & \\
\hline
\end{tabular}




\begin{tabular}{|c|c|c|c|c|}
\hline & $\begin{array}{l}\text { Structural Control } \\
\text { Measure }\end{array}$ & $\begin{array}{l}\text { Control } \\
\text { Measure is } \\
\text { Operating } \\
\text { Effectively? }\end{array}$ & $\begin{array}{l}\text { If No, In Need of } \\
\text { Maintenance, } \\
\text { Repair, or } \\
\text { Replacement? }\end{array}$ & $\begin{array}{l}\text { Corrective Action Needed and Notes } \\
\text { (identify needed maintenance and repairs, or any } \\
\text { failed control measures that need replacement) }\end{array}$ \\
\hline & & & D Replacement & \\
\hline 8 & Rock Run Down & Efyes QNo & $\begin{array}{l}\text { Maintenance } \\
\square \text { Repair } \\
\square \text { Replacement }\end{array}$ & \\
\hline 9 & $\begin{array}{l}\text { Outfalls } 60 \text { RG-1ID \# } \\
31,60 \text { RG-2 ID \# 30, } 60 \\
\text { RG-3 ID \# 32, } 60 \text { RG-4 } \\
\text { ID \# 33, } 60 \text { RG-5 ID \# } \\
34, \& 60 \text { RG-6 ID \# } 35 \\
\end{array}$ & GYes DNo & $\begin{array}{l}\text { Maintenance } \\
\text { Repair } \\
\text { Replacement }\end{array}$ & \\
\hline 10 & $\begin{array}{l}\text { Outfalls } 60 \text { RG-7 ID \# } \\
41 \& 60 \text { RG-8 ID \# } 42\end{array}$ & EYes $\square$ No & $\begin{array}{l}\text { Maintenance } \\
\square \text { Repair } \\
\square \text { Replacement }\end{array}$ & \\
\hline 11 & $\begin{array}{l}\text { Outfalls } 60 \text { RG-9 ID \# } \\
40,60 \text { RG-10 ID \# 39, } \\
60 \text { RG-11 ID \# } 38\end{array}$ & YYes aNo & $\begin{array}{l}\text { Maintenance } \\
\square \text { Repair } \\
\square \text { Replacement }\end{array}$ & \\
\hline 12 & $\begin{array}{l}\text { Outfalls } 60 \text { RG-12 ID \# } \\
37 \& 60 \text { RG-13 ID \# } 36\end{array}$ & GYes DNo & $\begin{array}{l}\text { Maintenance } \\
\square \text { Repair } \\
\text { Q Replacement }\end{array}$ & \\
\hline
\end{tabular}

Areas of Industrial Materials or Activities exposed to stormwater

Below are some general areas that should be assessed during routine inspections. Customize this list as needed for the specific types of industrial materials or activities at your facility.

\begin{tabular}{|c|c|c|c|c|}
\hline & Area/Activity & Inspected? & $\begin{array}{l}\text { Controls } \\
\text { Adequate } \\
\text { (appropriate, } \\
\text { effective, and } \\
\text { operating)? }\end{array}$ & Corrective Action Needed and Notes \\
\hline 1 & $\begin{array}{l}\text { Material } \\
\text { loading/unloading and } \\
\text { storage areas }\end{array}$ & YYes $\square$ No $\square$ /A & DYes DNo & \\
\hline 2 & $\begin{array}{l}\text { Equipment operations } \\
\text { and maintenance areas }\end{array}$ & EYyes $\square$ No $\square$ N/A & DYes DNo & \\
\hline 3 & Fueling areas & $\square$ Yes aNo $\otimes N / A$ & DYes $\mathrm{DNo}$ & \\
\hline 4 & $\begin{array}{l}\text { Outdoor vehicle and } \\
\text { equipment washing areas }\end{array}$ & $\square$ Yes $\square$ No $\otimes N / A$ & DYes DNo & \\
\hline 5 & $\begin{array}{l}\text { Waste handling and } \\
\text { disposal areas }\end{array}$ & $\square$ Yes $\square$ No $\otimes$ N/A & ¿Yes DNo & \\
\hline 6 & $\begin{array}{l}\text { Erodible } \\
\text { areas/construction }\end{array}$ & DYes $\square$ No $\otimes$ N/A & DYes DNo & \\
\hline 7 & $\begin{array}{l}\text { Non-stormwater/ illicit } \\
\text { connections }\end{array}$ & 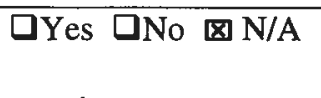 & DYes DNo & \\
\hline 8 & $\begin{array}{l}\text { Salt storage piles or pile } \\
\text { containing salt }\end{array}$ & $\square$ Yes $\square$ No $\square$ N/A & DYes DNo & \\
\hline
\end{tabular}




\begin{tabular}{|c|c|c|c|c|}
\hline & Area/Activity & Inspected? & $\begin{array}{l}\text { Controls } \\
\text { Adequate } \\
\text { (appropriate, } \\
\text { effective, and } \\
\text { operating)? }\end{array}$ & Corrective Action Needed and Notes \\
\hline 9 & $\begin{array}{l}\text { Dust generation and } \\
\text { vehicle tracking }\end{array}$ & EY Yes $\square$ No $\square$ N/A & DYes DNo & \\
\hline 10 & (Other) & $\square$ Yes $\square$ No $\square$ N/A & QYes $\square$ No & \\
\hline 11 & (Other) & $\square$ Yes $\square$ No $\square$ N/A & DYes DNo & \\
\hline 12 & (Other) & aYes $\square$ No $\square$ N/A & DYes QNo & \\
\hline
\end{tabular}

Non-Compliance

Describe any incidents of non-compliance observed and not described above: Hansckeeping to address trash thraighout Roads $\$$ Grayds was entered into tbe MS6p traking database as CAR $\#$ 500. Bays of ice melt on the hat th side of Hansportipar 60-287 to hold down a fojp aver a woden pallet that ate exposed to moisture \& three metal cabinets on the SW Cafrer of traspartaing 60-287 that either need to be put back into one of Hansportinens or crushed and have the metal reajcled ware abo entaled into the MSGP tracking database as CAR $\$ 901$.

Additional Control Measures

Describe any additional control measures needed to comply with the permit requirements: 
Notes

Use this space for any additional notes or observations from the inspection: The Sediment retention pond at the for east end of Sigma Mesa Was full of storm water
with no visible sheen.

CERTIFICATION STATEMENT

"I certify under penalty of law that this document and all attachments were prepared under my direction or supervision in accordance with a system designed to assure that qualified personnel properly gathered and evaluated the information submitted. Based on my inquiry of the person or persons who manage the system, or those persons directly responsible for gathering the information, the information submitted is, to the best of my knowledge and belief, true, accurate, and complete. I am aware that there are significant penalties for submitting false information, including the possibility of fine and imprisonment for knowing violations."

Print name and title: Russell Stone DESHS. UtS Group Leader signature:_usuelerer

Date: $4 / 27 / 2016$ 
Stormwater Industrial Routine Facility Inspection Report

\begin{tabular}{|c|c|c|c|}
\hline \multicolumn{4}{|c|}{ General Information } \\
\hline Facility Name & \multicolumn{3}{|c|}{ TA-60 Roads and Grounds } \\
\hline NPDES Tracking No. & \multicolumn{3}{|c|}{ NMR03195 } \\
\hline Date of Inspection & $5 / 25 / 2016$ & Start/End Time & 9:05 a.m. to $9: 52$ a.m. \\
\hline Inspector's Name(s) & \multicolumn{3}{|c|}{ Leonard F. Sandoval } \\
\hline Inspector's Title(s) & \multicolumn{3}{|c|}{ Deployed Environmental Professional } \\
\hline Inspector's Contact Information & \multicolumn{3}{|c|}{$667-3557$ or $231-1235$} \\
\hline Inspector's Qualifications & \multicolumn{3}{|c|}{ CISEC } \\
\hline \multicolumn{4}{|c|}{ Weather Information } \\
\hline \multicolumn{4}{|c|}{ 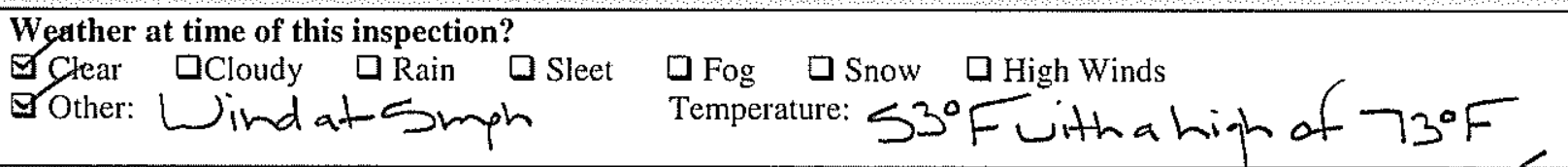 } \\
\hline \multicolumn{4}{|c|}{$\begin{array}{l}\text { Have any previously unidentified discharges of pollutants occurred since the last inspection? QYes ত্রNo } \\
\text { If yes, describe: }\end{array}$} \\
\hline \multicolumn{4}{|c|}{$\begin{array}{l}\text { Are there any discharges occurring at the time of inspection? } \square \text { Yes } \square_{\text {No }} \\
\text { If yes, describe: }\end{array}$} \\
\hline
\end{tabular}

\section{Control Measures}

- Number the structural stormwater control measures identified in your SWPPP on your site map and list them below (add as many control measures as are implemented on-site). Carry a copy of the numbered site map with you during your inspections. This list will ensure that you are inspecting all required control measures at your facility.

- Describe corrective actions initiated, date completed, and note the person that completed the work in the Corrective Action Log.

\begin{tabular}{|c|c|c|c|c|}
\hline & $\begin{array}{l}\text { Structural Control } \\
\text { Measure }\end{array}$ & $\begin{array}{l}\text { Control } \\
\text { Measure is } \\
\text { Operating } \\
\text { Effectively? }\end{array}$ & $\begin{array}{l}\text { If No, In Need of } \\
\text { Maintenance, } \\
\text { Repair, or } \\
\text { Replacement? }\end{array}$ & $\begin{array}{l}\text { Corrective Action Needed and Notes } \\
\text { (identify needed maintenance and repairs, or any } \\
\text { failed control measures that need replacement) }\end{array}$ \\
\hline 1 & Straw Wattles & $\square$ Yes $\square$ No & $\begin{array}{l}\square \text { Maintenance } \\
\square \text { Repair } \\
\square \text { Replacement }\end{array}$ & \\
\hline 2 & Rock Check Dams & 可Yes DNo & $\begin{array}{l}\square \text { Maintenance } \\
\square \text { Repair } \\
\square \text { Replacement }\end{array}$ & \\
\hline 3 & $\begin{array}{l}\text { Lined Salt Retention } \\
\text { Pond }\end{array}$ & 『Yes aNo & $\begin{array}{l}\square \text { Maintenance } \\
\square \text { Repair } \\
\square \text { Replacement }\end{array}$ & \\
\hline 4 & Sediment Basin & ⿶Yyes వNo & $\begin{array}{l}\square \text { Maintenance } \\
\square \text { Repair } \\
\square \text { Replacement }\end{array}$ & \\
\hline 5 & Rip Rap/Jersey Barriers & YYes & $\begin{array}{l}\square \text { Maintenance } \\
\square \text { Repair } \\
\square \text { Replacement }\end{array}$ & \\
\hline 6 & $\begin{array}{l}\text { Sediment Retention } \\
\text { Pond }\end{array}$ & 区Y GNos & $\begin{array}{l}\square \text { Maintenance } \\
\square \text { Repair } \\
\square \text { Replacement }\end{array}$ & \\
\hline 7 & $\begin{array}{l}\text { Base Course/Earthen } \\
\text { Berms }\end{array}$ & অYes DNo & $\begin{array}{l}\text { Maintenance } \\
\text { Repair }\end{array}$ & \\
\hline
\end{tabular}




\begin{tabular}{|c|c|c|c|c|}
\hline & $\begin{array}{l}\text { Structural Control } \\
\text { Measure }\end{array}$ & $\begin{array}{l}\text { Control } \\
\text { Measure is } \\
\text { Operating } \\
\text { Effectively? }\end{array}$ & $\begin{array}{l}\text { If No, In Need of } \\
\text { Maintenance, } \\
\text { Repair, or } \\
\text { Replacement? }\end{array}$ & $\begin{array}{l}\text { Corrective Action Needed and Notes } \\
\text { (identify needed maintenance and repairs, or any } \\
\text { failed control measures that need replacement) }\end{array}$ \\
\hline & & 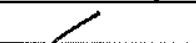 & Replacement & \\
\hline 8 & Rock Run Down & - $\mathrm{Y}$ YNo & $\begin{array}{l}\square \text { Maintenance } \\
\square \text { Repair } \\
\square \text { Replacement }\end{array}$ & \\
\hline 9 & $\begin{array}{l}\text { Outfalls 60 RG-1ID \# } \\
31,60 \text { RG-2 ID \# } 30,60 \\
\text { RG-3 ID \# 32,60 RG-4 } \\
\text { ID \# 33, 60 RG-5 ID \# } \\
34, \& 60 \text { RG-6 ID \# 35 }\end{array}$ & $\bar{G}$ Yes $\square$ No & $\begin{array}{l}\square \text { Maintenance } \\
\square \text { Repair } \\
\square \text { Replacement }\end{array}$ & \\
\hline 10 & $\begin{array}{l}\text { Outfalls 60 RG-7 ID \# } \\
41 \& 60 \text { RG-8 ID \# } 42\end{array}$ & 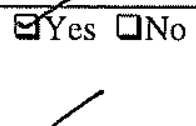 & $\begin{array}{l}\square \text { Maintenance } \\
\square \text { Repair } \\
\square \text { Replacement }\end{array}$ & \\
\hline 11 & $\begin{array}{l}\text { Outfalls } 60 \text { RG-9 ID \# } \\
40,60 \text { RG-10 ID \# } 39 \text {, } \\
60 \text { RG-11 ID \# } 38\end{array}$ & GYes aNo & $\begin{array}{l}\text { Maintenance } \\
\square \text { Repair } \\
\square \text { Replacement }\end{array}$ & \\
\hline 12 & $\begin{array}{l}\text { Outfalls } 60 \text { RG-12 ID \# } \\
37 \& 60 \text { RG-13 ID \# } 36\end{array}$ & Q & $\begin{array}{l}\text { Maintenance } \\
\square \text { Repair } \\
\square \text { Replacement }\end{array}$ & \\
\hline
\end{tabular}

Areas of Industrial Materials or Activities exposed to stormwater

Below are some general areas that should be assessed during routine inspections. Customize this list as needed for the specific types of industrial materials or activities at your facility.

\begin{tabular}{|c|c|c|c|c|}
\hline & Area/Activity & Inspected? & $\begin{array}{l}\text { Controls } \\
\text { Adequate } \\
\text { (appropriate, } \\
\text { effective, and } \\
\text { operating)? }\end{array}$ & Corrective Action Needed and Notes \\
\hline 1 & $\begin{array}{l}\text { Material } \\
\text { loading/unloading and } \\
\text { storage areas }\end{array}$ & GYes $\square$ No $\square$ N/A & DYes $\square$ No & \\
\hline 2 & $\begin{array}{l}\text { Equipment operations } \\
\text { and maintenance areas }\end{array}$ & gYes $\square$ No $\square$ N/A & $\square$ Yes $\square$ No & \\
\hline 3 & Fueling areas & aYes $\square$ No $\otimes N / A$ & QYes DNo & \\
\hline 4 & $\begin{array}{l}\text { Outdoor vehicle and } \\
\text { equipment washing areas }\end{array}$ & DYes $\square$ No $\otimes$ N/A & QYes $\square$ No & \\
\hline 5 & $\begin{array}{l}\text { Waste handling and } \\
\text { disposal areas }\end{array}$ & $\square$ Yes $\square$ No $\otimes$ N/A & QYes aNo & \\
\hline 6 & $\begin{array}{l}\text { Erodible } \\
\text { areas/construction }\end{array}$ & $\square Y e s \square$ No $\square \mathrm{N} / \mathrm{A}$ & aYes $\square$ No & \\
\hline 7 & $\begin{array}{l}\text { Non-stormwater/illicit } \\
\text { connections }\end{array}$ & $\square$ Yes $\square$ No $\otimes N / A$ & aYes aNo & \\
\hline 8 & $\begin{array}{l}\text { Salt storage piles or pile } \\
\text { containing salt }\end{array}$ & चיyes $\square$ No $\square \mathrm{N} / \mathrm{A}$ & aYes DNo & \\
\hline
\end{tabular}




\begin{tabular}{|c|c|c|c|c|}
\hline & Area/Activity & 4 & $\begin{array}{l}\text { Controls } \\
\text { Adequate } \\
\text { (appropriate, } \\
\text { effective, and } \\
\text { operating)? }\end{array}$ & Corrective Action Needed and Notes \\
\hline 9 & $\begin{array}{l}\text { Dust generation and } \\
\text { vehicle tracking }\end{array}$ & অYes $\square$ No $\square$ N/A & aYes aNo & \\
\hline 10 & (Other) & $\square$ Yes $\square$ No $\square$ N/A & $\square$ Yes $\square$ No & \\
\hline 11 & (Other) & $\square$ Yes $\square$ No $\square$ N/A & QYes $\square$ No & \\
\hline 12 & (Other) & $\square Y e s \square N_{0} \square$ N/A & DYes $\square$ No & \\
\hline
\end{tabular}

\section{Non-Compliance}

Describe any incidents of non-compliance observed and not described above:

Additional Control Measures

Describe any additional control measures needed to comply with the permit requirements: 
Notes

Use this space for any additional notes or observations from the inspection:

During the inspection I

met with Rick Velasquez of ENV-CP who boded access into the Cleon -fill yard \& help lifting the samplers out of the Greenlee boxes in order to turn theron for the Sampling season. The storm water in the sediment retention pard at the tor cast end of Sigma Mesa is going down as a result of evaporation, which is also happening with the water in the Salt pond by TA-60 bldg 250.

CERTIFICATION STATEMENT

"I certify under penalty of law that this document and all attachments were prepared under my direction or supervision in accordance with a system designed to assure that qualified personnel properly gathered and evaluated the information submitted. Based on my inquiry of the person or persons who manage the system, or those persons directly responsible for gathering the information, the information submitted is, to the best of my knowledge and belief, true, accurate, and complete. I am aware that there are significant penalties for submitting false information, including the possibility of fine and imprisonment for knowing violations."

Print name and title: Russell Stone QC DSESH-uTS

Signature:_Cucullete Date: $5 / 21 / 2016$ 


\section{Stormwater Industrial Routine Facility Inspection Report}

\begin{tabular}{|c|c|c|c|}
\hline \multicolumn{4}{|c|}{ General Information } \\
\hline Facility Name & \multicolumn{3}{|c|}{ TA-60 Roads and Grounds } \\
\hline NPDES Tracking No. & \multicolumn{3}{|c|}{ NMR03195 } \\
\hline Date of Inspection & $6 / 7 / 2016$ & Start/End Time & 8:29 a.m. to 9:30 a.m. \\
\hline Inspector's Name(s) & \multicolumn{3}{|c|}{ Leonard F. Sandoval } \\
\hline Inspector's Title(s) & \multicolumn{3}{|c|}{ Deployed Environmental Professional } \\
\hline Inspector's Contact Information & \multicolumn{3}{|c|}{$667-3557$ or $231-1235$} \\
\hline Inspector's Qualifications & \multicolumn{3}{|l|}{ CISEC } \\
\hline \multicolumn{4}{|c|}{ Weather Information } \\
\hline \multicolumn{4}{|c|}{ 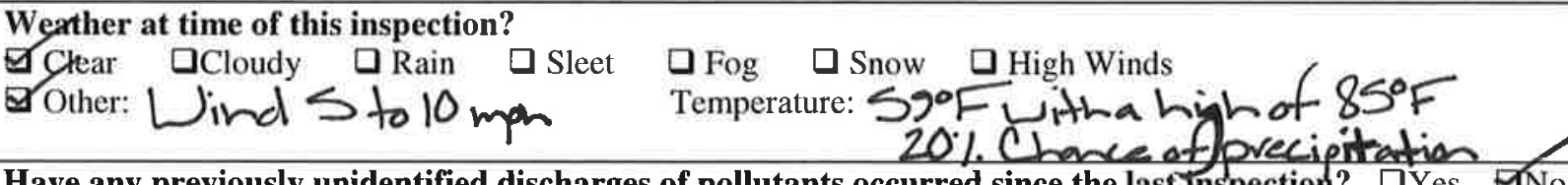 } \\
\hline \multicolumn{4}{|c|}{$\begin{array}{l}\text { Have any previously unidentified discharges of pollutants occurred since the last Tnspection? DYes yNo } \\
\text { If yes, describe: }\end{array}$} \\
\hline
\end{tabular}

\section{Control Measures}

- Number the structural stormwater control measures identified in your SWPPP on your site map and list them below (add as many control measures as are implemented on-site). Carry a copy of the numbered site map with you during your inspections. This list will ensure that you are inspecting all required control measures at your facility.

- Describe corrective actions initiated, date completed, and note the person that completed the work in the Corrective Action Log.

\begin{tabular}{|c|c|c|c|c|}
\hline & $\begin{array}{l}\text { Structural Control } \\
\text { Measure }\end{array}$ & $\begin{array}{l}\text { Control } \\
\text { Measure is } \\
\text { Operating } \\
\text { Effectively? }\end{array}$ & $\begin{array}{l}\text { If No, In Need of } \\
\text { Maintenance, } \\
\text { Repair, or } \\
\text { Replacement? }\end{array}$ & $\begin{array}{l}\text { Corrective Action Needed and Notes } \\
\text { (identify needed maintenance and repairs, or any } \\
\text { failed control measures that need replacement) }\end{array}$ \\
\hline 1 & Straw Wattles & GYes $\square$ No & $\begin{array}{l}\text { Maintenance } \\
\square \text { Repair } \\
\square \text { Replacement }\end{array}$ & \\
\hline 2 & Rock Check Dams & 可Yes aNo & $\begin{array}{l}\square \text { Maintenance } \\
\square \text { Repair } \\
\square \text { Replacement }\end{array}$ & \\
\hline 3 & $\begin{array}{l}\text { Lined Salt Retention } \\
\text { Pond }\end{array}$ & GYes DNo & $\begin{array}{l}\text { Maintenance } \\
\square \text { Repair } \\
\square \text { Replacement }\end{array}$ & \\
\hline 4 & Sediment Basin & चYes $\square$ No & $\begin{array}{l}\square \text { Maintenance } \\
\square \text { Repair } \\
\square \text { Replacement }\end{array}$ & \\
\hline 5 & Rip Rap/Jersey Barriers & GYes $\square$ No & $\begin{array}{l}\square \text { Maintenance } \\
\square \text { Repair } \\
\square \text { Replacement }\end{array}$ & \\
\hline 6 & $\begin{array}{l}\text { Sediment Retention } \\
\text { Pond }\end{array}$ & VYes DNo & $\begin{array}{l}\text { Maintenance } \\
\square \text { Repair } \\
\square \text { Replacement }\end{array}$ & \\
\hline 7 & $\begin{array}{l}\text { Base Course/Earthen } \\
\text { Berms }\end{array}$ & GYes DNo & $\begin{array}{l}\square \text { Maintenance } \\
\square \text { Repair }\end{array}$ & \\
\hline
\end{tabular}




\begin{tabular}{|c|c|c|c|c|}
\hline & $\begin{array}{l}\text { Structural Control } \\
\text { Measure }\end{array}$ & $\begin{array}{l}\text { Control } \\
\text { Measure is } \\
\text { Operating } \\
\text { Effectively? }\end{array}$ & $\begin{array}{l}\text { If No, In Need of } \\
\text { Maintenance, } \\
\text { Repair, or } \\
\text { Replacement? }\end{array}$ & $\begin{array}{l}\text { Corrective Action Needed and Notes } \\
\text { (identify needed maintenance and repairs, or any } \\
\text { failed control measures that need replacement) }\end{array}$ \\
\hline & & & $\square$ Replacement & \\
\hline 8 & Rock Run Down & $\exists$ Yes DNo & $\begin{array}{l}\square \text { Maintenance } \\
\square \text { Repair } \\
\square \text { Replacement }\end{array}$ & \\
\hline 9 & $\begin{array}{l}\text { Outfalls } 60 \text { RG-1ID \# } \\
31,60 \text { RG-2 ID \# 30, } 60 \\
\text { RG-3 ID \# 32, } 60 \text { RG-4 } \\
\text { ID \# 33, } 60 \text { RG-5 ID \# } \\
34, \& 60 \text { RG-6 ID \# } 35\end{array}$ & GYes $\square$ No & $\begin{array}{l}\square \text { Maintenance } \\
\square \text { Repair } \\
\square \text { Replacement }\end{array}$ & \\
\hline 10 & $\begin{array}{l}\text { Outfalls } 60 \text { RG-7 ID \# } \\
41 \text { \& } 60 \text { RG-8 ID \# } 42\end{array}$ & 可Yes DNo & $\begin{array}{l}\text { Maintenance } \\
\square \text { Repair } \\
\text { Replacement }\end{array}$ & \\
\hline 11 & $\begin{array}{l}\text { Outfalls } 60 \text { RG-9 ID \# } \\
40,60 \text { RG-10 ID \# 39, } \\
60 \text { RG-11 ID \# } 38 \\
\end{array}$ & GYes $\square$ No & $\begin{array}{l}\text { Maintenance } \\
\text { Repair } \\
\square \text { Replacement }\end{array}$ &. \\
\hline 12 & $\begin{array}{l}\text { Outfalls } 60 \text { RG-12 ID \# } \\
37 \& 60 \text { RG-13 ID \# } 36\end{array}$ & - & $\begin{array}{l}\square \text { Maintenance } \\
\square \text { Repair } \\
\square \text { Replacement }\end{array}$ & \\
\hline
\end{tabular}

Areas of Industrial Materials or Activities exposed to stormwater

Below are some general areas that should be assessed during routine inspections. Customize this list as needed for the specific types of industrial materials or activities at your facility.

\begin{tabular}{|c|c|c|c|c|}
\hline & Area/Activity & Inspected? & $\begin{array}{l}\text { Controls } \\
\text { Adequate } \\
\text { (appropriate, } \\
\text { effective, and } \\
\text { operating)? }\end{array}$ & Corrective Action Needed and Notes \\
\hline 1 & $\begin{array}{l}\text { Material } \\
\text { loading/unloading and } \\
\text { storage areas }\end{array}$ & EYes aNo $\square$ N/A & QYes $\square \mathrm{No}$ & \\
\hline 2 & $\begin{array}{l}\text { Equipment operations } \\
\text { and maintenance areas }\end{array}$ & $\square$ Yes $\square$ No $\square \mathrm{N} / \mathrm{A}$ & DYes $\square$ No & \\
\hline 3 & Fueling areas & DYes $\square$ No $\otimes N / A$ & aYes $\square$ No & . \\
\hline 4 & $\begin{array}{l}\text { Outdoor vehicle and } \\
\text { equipment washing areas }\end{array}$ & 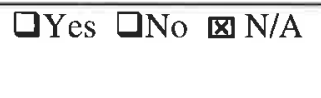 & DYes DNo & . \\
\hline 5 & $\begin{array}{l}\text { Waste handling and } \\
\text { disposal areas }\end{array}$ & aYes $\square$ No $\otimes \mathrm{N} / \mathrm{A}$ & DYes DNo & \\
\hline 6 & $\begin{array}{l}\text { Erodible } \\
\text { areas/construction }\end{array}$ & $\square$ Yes $\square$ No $\otimes \mathrm{N} / \mathrm{A}$ & DYes $\square$ No & \\
\hline 7 & $\begin{array}{l}\text { Non-stormwater/ illicit } \\
\text { connections }\end{array}$ & $\square$ Yes $\square$ No $\bowtie N / A$ & DYes $\square$ No & \\
\hline 8 & $\begin{array}{l}\text { Salt storage piles or pile } \\
\text { containing salt }\end{array}$ & VYes $\square$ No $\square$ N/A & DYes DNo & \\
\hline
\end{tabular}




\begin{tabular}{|c|c|c|c|c|}
\hline & Area/Activity & Inspected? & $\begin{array}{l}\text { Controls } \\
\text { Adequate } \\
\text { (appropriate, } \\
\text { effective, and } \\
\text { operating)? }\end{array}$ & Corrective Action Needed and Notes \\
\hline 9 & $\begin{array}{l}\text { Dust generation and } \\
\text { vehicle tracking }\end{array}$ & GYes $\square$ No $\square$ N/A & DYes $\square$ No & \\
\hline 10 & (Other) & $\square$ Yes $\square$ No $\square$ N/A & aYes aNo & \\
\hline 11 & (Other) & $\square$ Yes $\square$ No $\square \mathrm{N} / \mathrm{A}$ & QYes aNo & \\
\hline 12 & (Other) & $\square$ Yes $\square$ No $\square$ N/A & aYes $\square$ No & \\
\hline
\end{tabular}

Non-Compliance

Describe any incidents of non-compliance observed and not described above:

Additional Control Measures

Describe any additional control measures needed to comply with the permit requirements: 
Notes

Use this space for any additional notes or ob observations from the inspection: The Sediment \& Salt ponds both had additional stormuator in them from recent vain with ho visible oily sheen.

CERTIFICATION STATEMENT

"I certify under penalty of law that this document and all attachments were prepared under my direction or supervision in accordance with a system designed to assure that qualified personnel properly gathered and evaluated the information submitted. Based on my inquiry of the person or persons who manage the system, or those persons directly responsible for gathering the information, the information submitted is, to the best of my knowledge and belief, true, accurate, and complete. I am aware that there are significant penalties for submitting false information, including the possibility of fine and imprisonment for knowing violations."

Print name and title: Russell Stone GC DEstos-4TS

Signature:

Date: $6 / 1 / 2016$ 


\section{Stormwater Industrial Routine Facility Inspection Report}

\begin{tabular}{|c|c|c|c|}
\hline \multicolumn{4}{|c|}{ General Information } \\
\hline Facility Name & \multicolumn{3}{|c|}{ TA-60 Roads and Grounds } \\
\hline NPDES Tracking No. & \multicolumn{3}{|c|}{ NMR03195 } \\
\hline Date of Inspection & $7 / 25 / 2016$ & Start/End Time & 8:04 a.m. to $8: 55$ a.m. \\
\hline Inspector's Name(s) & \multicolumn{3}{|c|}{ Leonard F. Sandoval } \\
\hline Inspector's Title(s) & \multicolumn{3}{|c|}{ Deployed Environmental Professional } \\
\hline Inspector's Contact Information & \multicolumn{3}{|c|}{$667-3557$ or $231-1235$} \\
\hline Inspector's Qualifications & \multicolumn{3}{|l|}{ CISEC } \\
\hline \multicolumn{4}{|c|}{ Weather Information } \\
\hline \multicolumn{4}{|c|}{ 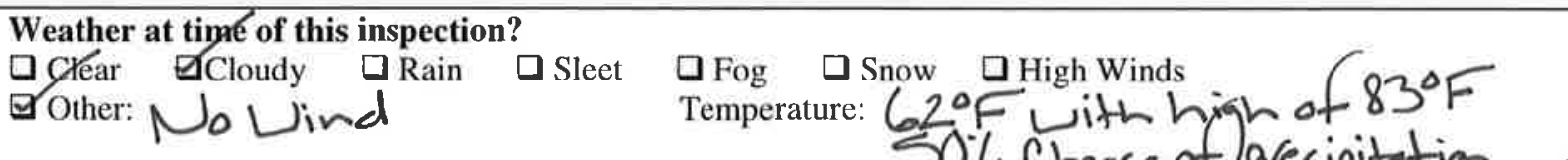 } \\
\hline \multicolumn{4}{|c|}{$\begin{array}{l}\text { Have any previously unidentified discharges of pollutants occurred since the last inspection? DYes aNo } \\
\text { If yes, describe: }\end{array}$} \\
\hline \multicolumn{4}{|c|}{$\begin{array}{l}\text { Are there any discharges occurring at the time of inspection? } \square \text { Yes } \text { № } \\
\text { If yes, describe: }\end{array}$} \\
\hline
\end{tabular}

\section{Control Measures}

- Number the structural stormwater control measures identified in your SWPPP on your site map and list them below (add as many control measures as are implemented on-site). Carry a copy of the numbered site map with you during your inspections. This list will ensure that you are inspecting all required control measures at your facility.

- Describe corrective actions initiated, date completed, and note the person that completed the work in the Corrective Action Log.

\begin{tabular}{|c|c|c|c|c|}
\hline & $\begin{array}{l}\text { Structural Control } \\
\text { Measure }\end{array}$ & $\begin{array}{l}\text { Control } \\
\text { Measure is } \\
\text { Operating } \\
\text { Effeetively? }\end{array}$ & $\begin{array}{l}\text { If No, In Need of } \\
\text { Maintenance, } \\
\text { Repair, or } \\
\text { Replacement? } \\
\end{array}$ & $\begin{array}{l}\text { Corrective Action Needed and Notes } \\
\text { (identify needed maintenance and repairs, or any } \\
\text { failed control measures that need replacement) }\end{array}$ \\
\hline 1 & Straw Wattles & EYes aNo & $\begin{array}{l}\square \text { Maintenance } \\
\square \text { Repair } \\
\square \text { Replacement }\end{array}$ & \\
\hline 2 & Rock Check Dams & GYes DNo & $\begin{array}{l}\square \text { Maintenance } \\
\square \text { Repair } \\
\square \text { Replacement }\end{array}$ & \\
\hline 3 & $\begin{array}{l}\text { Lined Salt Retention } \\
\text { Pond }\end{array}$ & VYes aNo & $\begin{array}{l}\text { Maintenance } \\
\square \text { Repair } \\
\square \text { Replacement }\end{array}$ & \\
\hline 4 & Sediment Basin & EYes $\square$ No & $\begin{array}{l}\square \text { Maintenance } \\
\square \text { Repair } \\
\square \text { Replacement }\end{array}$ & \\
\hline 5 & Rip Rap/Jersey Barriers & GYes $\square$ No & $\begin{array}{l}\square \text { Maintenance } \\
\square \text { Repair } \\
\square \text { Replacement }\end{array}$ & \\
\hline 6 & $\begin{array}{l}\text { Sediment Retention } \\
\text { Pond }\end{array}$ & YYes $\square$ No & $\begin{array}{l}\text { Maintenance } \\
\square \text { Repair } \\
\square \text { Replacement }\end{array}$ & \\
\hline 7 & $\begin{array}{l}\text { Base Course/Earthen } \\
\text { Berms }\end{array}$ & GYes $\square$ No & $\begin{array}{l}\text { Maintenance } \\
\square \text { Repair }\end{array}$ & \\
\hline
\end{tabular}




\begin{tabular}{|c|c|c|c|c|}
\hline & $\begin{array}{l}\text { Structural Control } \\
\text { Measure }\end{array}$ & $\begin{array}{l}\text { Control } \\
\text { Measure is } \\
\text { Operating } \\
\text { Effectively? }\end{array}$ & $\begin{array}{l}\text { If No, In Need of } \\
\text { Maintenance, } \\
\text { Repair, or } \\
\text { Replacement? } \\
\end{array}$ & $\begin{array}{l}\text { Corrective Action Needed and Notes } \\
\text { (identify needed maintenance and repairs, or any } \\
\text { failed control measures that need replacement) }\end{array}$ \\
\hline & & & $\square$ Replacement & \\
\hline 8 & Rock Run Down & VYes aNo & $\begin{array}{l}\text { Maintenance } \\
\square \text { Repair } \\
\square \text { Replacement }\end{array}$ & \\
\hline 9 & $\begin{array}{l}\text { Outfalls } 60 \text { RG-1ID \# } \\
31,60 \text { RG-2 ID \# 30, } 60 \\
\text { RG-3 ID \# 32, } 60 \text { RG-4 } \\
\text { ID \# 33, } 60 \text { RG-5 ID \# } \\
34, \& 60 \text { RG-6 ID \# } 35\end{array}$ & 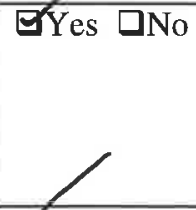 & $\begin{array}{l}\square \text { Maintenance } \\
\square \text { Repair } \\
\square \text { Replacement }\end{array}$ & \\
\hline 10 & $\begin{array}{l}\text { Outfalls } 60 \text { RG-7 ID \# } \\
41 \& 60 \text { RG-8 ID \# } 42\end{array}$ & GYes $\square$ No & $\begin{array}{l}\square \text { Maintenance } \\
\square \text { Repair } \\
\square \text { Replacement }\end{array}$ & \\
\hline 11 & $\begin{array}{l}\text { Outfalls } 60 \text { RG-9 ID \# } \\
40,60 \text { RG-10 ID \# } 39 \text {, } \\
60 \text { RG-11 ID \# } 38\end{array}$ & ØYes aNo & $\begin{array}{l}\text { Maintenance } \\
\square \text { Repair } \\
\square \text { Replacement }\end{array}$ & \\
\hline 12 & $\begin{array}{l}\text { Outfalls } 60 \text { RG-12 ID \# } \\
37 \& 60 \text { RG-13 ID \# } 36\end{array}$ & घyes $\square$ No & $\begin{array}{l}\square \text { Maintenance } \\
\square \text { Repair } \\
\square \text { Replacement }\end{array}$ & \\
\hline
\end{tabular}

Areas of Industrial Materials or Activities exposed to stormwater

Below are some general areas that should be assessed during routine inspections. Customize this list as needed for the specific types of industrial materials or activities at your facility.

\begin{tabular}{|c|c|c|c|c|}
\hline & Area/Activity & Inspected? & $\begin{array}{l}\text { Controls } \\
\text { Adequate } \\
\text { (appropriate, } \\
\text { effective, and } \\
\text { operating)? }\end{array}$ & Corrective Action Needed and Notes \\
\hline 1 & $\begin{array}{l}\text { Material } \\
\text { loading/unloading and } \\
\text { storage areas }\end{array}$ & YYes aNo $\square$ N/A & QYes DNo & \\
\hline 2 & $\begin{array}{l}\text { Equipment operations } \\
\text { and maintenance areas }\end{array}$ & $\square$ Yes $\square$ No $\square$ N/A & $\square$ Yes $\square$ No & \\
\hline 3 & Fueling areas & $\square$ Yes $\square$ No $\otimes \mathrm{N} / \mathrm{A}$ & $\square$ Yes $\square$ No & \\
\hline 4 & $\begin{array}{l}\text { Outdoor vehicle and } \\
\text { equipment washing areas }\end{array}$ & $\square$ Yes $\square$ No $\mathbf{X}$ N/A & DYes DNo & \\
\hline 5 & $\begin{array}{l}\text { Waste handling and } \\
\text { disposal areas }\end{array}$ & DYes $\square$ No $\otimes \mathrm{N} / \mathrm{A}$ & DYes DNo & \\
\hline 6 & $\begin{array}{l}\text { Erodible } \\
\text { areas/construction }\end{array}$ & पYes DNo $\triangle \mathrm{N} / \mathrm{A}$ & DYes $\square$ No & \\
\hline 7 & $\begin{array}{l}\text { Non-stormwater/illicit } \\
\text { connections }\end{array}$ & aYes $\square$ No $\bowtie \mathrm{N} / \mathrm{A}$ & DYes $\square$ No & \\
\hline 8 & $\begin{array}{l}\text { Salt storage piles or pile } \\
\text { containing salt }\end{array}$ & चYes $\square$ No $\square \mathrm{N} / \mathrm{A}$ & DYes $\square$ No & \\
\hline
\end{tabular}




\begin{tabular}{|c|c|c|c|c|}
\hline & Area/Activity & Inspected? & $\begin{array}{l}\text { Controls } \\
\text { Adequate } \\
\text { (appropriate, } \\
\text { effective, and } \\
\text { operating)? }\end{array}$ & Corrective Action Needed and Notes \\
\hline 9 & $\begin{array}{l}\text { Dust generation and } \\
\text { vehicle tracking }\end{array}$ & Yes $\square$ No $\square \mathrm{N} / \mathrm{A}$ & $\square Y e s \quad \square$ No & \\
\hline 10 & (Other) & $\square$ Yes $\square$ No $\square \mathrm{N} / \mathrm{A}$ & aYes $\square$ No & \\
\hline 11 & (Other) & $\square$ Yes $\square$ No $\square \mathrm{N} / \mathrm{A}$ & DYes $\square$ No & \\
\hline 12 & (Other) & $\square$ Yes $\square$ No $\square \mathrm{N} / \mathrm{A}$ & DYes DNo & \\
\hline
\end{tabular}

\section{Non-Compliance}

Describe any incidents of non-compliance observed and not described above: CAR \#941 tor frant end loader attachment to Jom Dene tactor that leaked vesidual hydrulic fluid on asphalt in the heary equipment. Staging olea. CAR \# 942 for the berm SW of trarspartainar 60-287 With goph holes that is allowing Sterm water through the berm. CAR \# 943 for hasselkeeping associated With Straw wattles abrg $N$ fenceline in the heary equipment staging avea of Wooden pallet with torn bags of asphalt milling along tanceline
$S$ of $60-283$.

\section{Additional Control Measures}

Describe any additional control measures needed to comply with the permit requirements: 
Notes

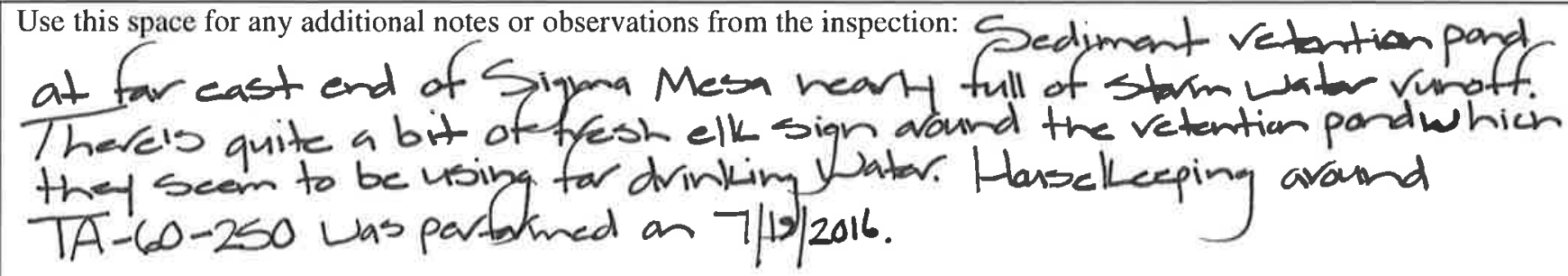

\section{CERTIFICATION STATEMENT}

"I certify under penalty of law that this document and all attachments were prepared under my direction or supervision in accordance with a system designed to assure that qualified personnel properly gathered and evaluated the information submitted. Based on my inquiry of the person or persons who manage the system, or those persons directly responsible for gathering the information, the information submitted is, to the best of my knowledge and belief, true, accurate, and complete. I am aware that there are significant penalties for submitting false information, including the possibility of fine and imprisonment for knowing violations."

Print name and title: Reessell Stome, GL DEStis-uIS

Signature:

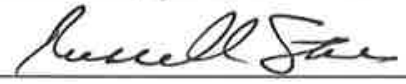

Date: $7 / 26 / 2016$ 
Stormwater Industrial Routine Facility Inspection Report

\begin{tabular}{|c|c|c|}
\hline \multicolumn{3}{|c|}{ General Information } \\
\hline Facility Name & \multicolumn{2}{|l|}{ TA-60 Roads and Grounds } \\
\hline NPDES Tracking No. & \multicolumn{2}{|l|}{ NMR03195 } \\
\hline Date of Inspection & Start/End Time & 8:00 a.m. to 9:07 a.m. \\
\hline Inspector's Name(s) & \multicolumn{2}{|l|}{ Leonard F. Sandoval } \\
\hline Inspector's Title(s) & \multicolumn{2}{|l|}{ Deployed Environmental Professional } \\
\hline Inspector's Contact Information & \multicolumn{2}{|l|}{$667-3557$ or $231-1235$} \\
\hline Inspector's Qualifications & \multicolumn{2}{|l|}{ CISEC } \\
\hline \multicolumn{3}{|c|}{ Weather Information } \\
\hline \multicolumn{3}{|c|}{ 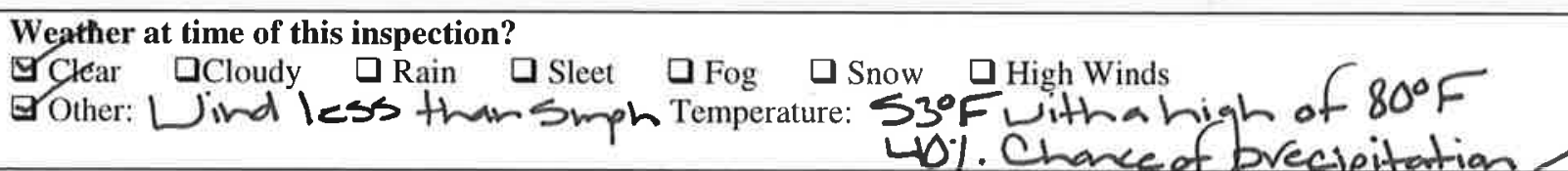 } \\
\hline \multicolumn{3}{|c|}{ 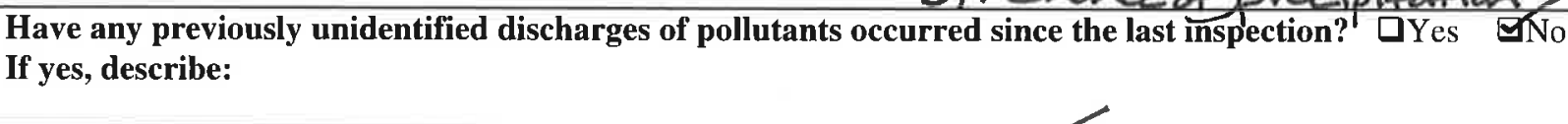 } \\
\hline \multicolumn{3}{|c|}{$\begin{array}{l}\text { Are there any discharges occurring at the time of inspection? } \square \text { Yes } \text { 四o } \\
\text { If yes, describe: }\end{array}$} \\
\hline
\end{tabular}

\section{Control Measures}

- Number the structural stormwater control measures identified in your SWPPP on your site map and list them below (add as many control measures as are implemented on-site). Carry a copy of the numbered site map with you during your inspections. This list will ensure that you are inspecting all required control measures at your facility.

- Describe corrective actions initiated, date completed, and note the person that completed the work in the Corrective Action Log.

\begin{tabular}{|c|c|c|c|c|}
\hline & $\begin{array}{l}\text { Structural Control } \\
\text { Measure }\end{array}$ & $\begin{array}{l}\text { Control } \\
\text { Measure is } \\
\text { Operating } \\
\text { Effoctively? }\end{array}$ & $\begin{array}{l}\text { If No, In Need of } \\
\text { Maintenance, } \\
\text { Repair, or } \\
\text { Replacement? }\end{array}$ & $\begin{array}{l}\text { Corrective Action Needed and Notes } \\
\text { (identify needed maintenance and repairs, or any } \\
\text { failed control measures that need replacement) }\end{array}$ \\
\hline 1 & Straw Wattles & 可Yes aNo & $\begin{array}{l}\text { Maintenance } \\
\square \text { Repair } \\
\square \text { Replacement }\end{array}$ & \\
\hline 2 & Rock Check Dams & 可Yes 口No & $\begin{array}{l}\text { Maintenance } \\
\square \text { Repair } \\
\square \text { Replacement }\end{array}$ & \\
\hline 3 & $\begin{array}{l}\text { Lined Salt Retention } \\
\text { Pond }\end{array}$ & DY Yes QNo & $\begin{array}{l}\square \text { Maintenance } \\
\square \text { Repair } \\
\square \text { Replacement }\end{array}$ & \\
\hline 4 & Sediment Basin & GYes $\square$ No & $\begin{array}{l}\text { Maintenance } \\
\square \text { Repair } \\
\square \text { Replacement }\end{array}$ & \\
\hline 5 & Rip Rap/Jersey Barriers & Q & $\begin{array}{l}\text { Maintenance } \\
\square \text { Repair } \\
\square \text { Replacement }\end{array}$ & \\
\hline 6 & $\begin{array}{l}\text { Sediment Retention } \\
\text { Pond }\end{array}$ & Z्रYes DNo & $\begin{array}{l}\text { Maintenance } \\
\text { Q Repair } \\
\square \text { Replacement }\end{array}$ & \\
\hline 7 & $\begin{array}{l}\text { Base Course/Earthen } \\
\text { Berms }\end{array}$ & GYes DNo & $\begin{array}{l}\square \text { Maintenance } \\
\square \text { Repair }\end{array}$ & \\
\hline
\end{tabular}




\begin{tabular}{|c|c|c|c|c|}
\hline & $\begin{array}{l}\text { Structural Control } \\
\text { Measure }\end{array}$ & $\begin{array}{l}\text { Control } \\
\text { Measure is } \\
\text { Operating } \\
\text { Effectively? }\end{array}$ & $\begin{array}{l}\text { If No, In Need of } \\
\text { Maintenance, } \\
\text { Repair, or } \\
\text { Replacement? }\end{array}$ & $\begin{array}{l}\text { Corrective Action Needed and Notes } \\
\text { (identify needed maintenance and repairs, or any } \\
\text { failed control measures that need replacement) }\end{array}$ \\
\hline & & & $\square$ Replacement & \\
\hline 8 & Rock Run Down & GYes & $\begin{array}{l}\square \text { Maintenance } \\
\square \text { Repair } \\
\square \text { Replacement }\end{array}$ & \\
\hline 9 & $\begin{array}{l}\text { Outfalls } 60 \text { RG-1ID \# } \\
31,60 \text { RG-2 ID \# 30, } 60 \\
\text { RG-3 ID \# 32, 60 RG-4 } \\
\text { ID \# 33, } 60 \text { RG-5 ID \# } \\
34, \& 60 \text { RG-6 ID \# } 35\end{array}$ & 可Yes DNo & $\begin{array}{l}\square \text { Maintenance } \\
\square \text { Repair } \\
\square \text { Replacement }\end{array}$ & \\
\hline 10 & $\begin{array}{l}\text { Outfalls } 60 \text { RG-7 ID \# } \\
41 \& 60 \text { RG-8 ID \# } 42\end{array}$ & bYes aNo & $\begin{array}{l}\square \text { Maintenance } \\
\square \text { Repair } \\
\square \text { Replacement }\end{array}$ & . \\
\hline 11 & $\begin{array}{l}\text { Outfalls } 60 \text { RG-9 ID \# } \\
40,60 \text { RG-10 ID \# 39, } \\
60 \text { RG-11 ID \# } 38\end{array}$ & 可Yes $\square$ No & $\begin{array}{l}\text { Maintenance } \\
\square \text { Repair } \\
\square \text { Replacement }\end{array}$ & \\
\hline 12 & $\begin{array}{l}\text { Outfalls } 60 \text { RG-12 ID \# } \\
37 \& 60 \text { RG-13 ID \# } 36\end{array}$ & 区Yyes aNo & $\begin{array}{l}\text { Maintenance } \\
\square \text { Repair } \\
\square \text { Replacement }\end{array}$ & . \\
\hline
\end{tabular}

Areas of Industrial Materials or Activities exposed to stormwater

Below are some general areas that should be assessed during routine inspections. Customize this list as needed for the specific types of industrial materials or activities at your facility.

\begin{tabular}{|c|c|c|c|c|}
\hline & Area/Activity & Inspected? & $\begin{array}{l}\text { Controls } \\
\text { Adequate } \\
\text { (appropriate, } \\
\text { effective, and } \\
\text { operating)? }\end{array}$ & Corrective Action Needed and Notes \\
\hline 1 & $\begin{array}{l}\text { Material } \\
\text { loading/unloading and } \\
\text { storage areas }\end{array}$ & 乙Yes $\square$ No $\square$ N/A & $\overline{D Y e s} \mathrm{DNo}$ & \\
\hline 2 & $\begin{array}{l}\text { Equipment operations } \\
\text { and maintenance areas }\end{array}$ & $\Xi$ Yes $\square$ No $\square$ N/A & DYes $\square$ No & \\
\hline 3 & Fueling areas & $\square$ Yes $\square$ No $\otimes N / A$ & $\square$ Yes $\square$ No & \\
\hline 4 & $\begin{array}{l}\text { Outdoor vehicle and } \\
\text { equipment washing areas }\end{array}$ & $\square$ Yes $\square$ No $\otimes N / A$ & $\square$ Yes $\square$ No & \\
\hline 5 & $\begin{array}{l}\text { Waste handling and } \\
\text { disposal areas }\end{array}$ & $\square$ Yes $\square$ No $\otimes N / A$ & $\square$ Yes $\square$ No & \\
\hline 6 & $\begin{array}{l}\text { Erodible } \\
\text { areas/construction }\end{array}$ & $\square$ Yes $\square$ No $\bowtie$ N/A & $\square$ Yes $\square$ No & \\
\hline 7 & $\begin{array}{l}\text { Non-stormwater/illicit } \\
\text { connections }\end{array}$ & aYes $\square$ No $\otimes N / A$ & aYes $\square$ No & \\
\hline 8 & $\begin{array}{l}\text { Salt storage piles or pile } \\
\text { containing salt }\end{array}$ & $\square$ Yes $\square$ No $\square \mathrm{N} / \mathrm{A}$ & DYes $\square$ No & \\
\hline
\end{tabular}




\begin{tabular}{|c|c|c|c|c|}
\hline & Area/Activity & Inspected? & $\begin{array}{l}\text { Controls } \\
\text { Adequate } \\
\text { (appropriate, } \\
\text { effective, and } \\
\text { operating)? }\end{array}$ & Corrective Action Needed and Notes \\
\hline 9 & $\begin{array}{l}\text { Dust generation and } \\
\text { vehicle tracking }\end{array}$ & YYes $\square$ No $\square \mathrm{N} / \mathrm{A}$ & DYes DNo & \\
\hline 10 & (Other) & $\square$ Yes $\square$ No $\square \mathrm{N} / \mathrm{A}$ & 口Yes 口No & \\
\hline 11 & (Other) & 口Yes $\square$ No $\square$ N/A & DYes $\square$ No & \\
\hline 12 & (Other) & $\square$ Yes $\square$ No $\square$ N/A & DYes DNo & \\
\hline
\end{tabular}

Non-Compliance

Describe any incidents of non-compliance observed and not described above:

\section{Additional Control Measures}

Describe any additional control measures needed to comply with the permit requirements: 
Notes

Use this space for any additional notes or observations from the inspection: The Sediment retention pond e For east and of Sigmeg-Mesa 3/4 full of water. Lined pond Saith of the salt shed $y_{2}$ full of water.

CERTIFICATION STATEMENT

"I certify under penalty of law that this document and all attachments were prepared under my direction or supervision in accordance with a system designed to assure that qualified personnel properly gathered and evaluated the information submitted. Based on my inquiry of the person or persons who manage the system, or those persons directly responsible for gathering the information, the information submitted is, to the best of my knowledge and belief, true, accurate, and complete. I am aware that there are significant penalties for submitting false information, including the possibility of fine and imprisonment for knowing violations."

Print name and title: Russell Stone GL Dests-uts

Signature:

Date: $8 / 15 / 2016$ 
Stormwater Industrial Routine Facility Inspection Report

\begin{tabular}{|c|c|c|c|}
\hline \multicolumn{4}{|c|}{ General Information } \\
\hline Facility Name & \multicolumn{3}{|c|}{ TA-60 Roads and Grounds } \\
\hline NPDES Tracking No. & \multicolumn{3}{|c|}{ NMR03195 } \\
\hline Date of Inspection & 9/6/2016 & Start/End Time & 9:05 a.m. to $10: 10$ a.m. \\
\hline Inspector's Name(s) & \multicolumn{3}{|c|}{ Leonard F. Sandoval } \\
\hline Inspector's Title(s) & \multicolumn{3}{|c|}{ Deployed Environmental Professional } \\
\hline Inspector's Contact Information & \multicolumn{3}{|c|}{$667-3557$ or $231-1235$} \\
\hline Inspector's Qualifications & \multicolumn{3}{|l|}{ CISEC } \\
\hline \multicolumn{4}{|c|}{ Weather Information } \\
\hline \multicolumn{4}{|c|}{ 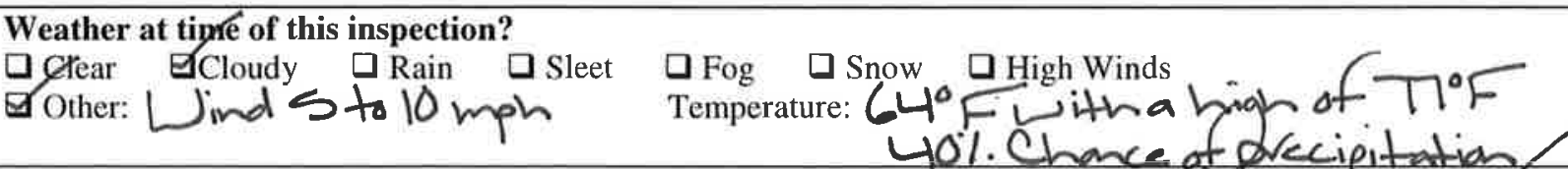 } \\
\hline \multicolumn{4}{|c|}{$\begin{array}{l}\text { Have any previously unidentified discharges of pollutants occurred since the last inspection? } \\
\text { If yes, describe: }\end{array}$} \\
\hline \multicolumn{4}{|c|}{$\begin{array}{l}\text { Are there any discharges occurring at the time of inspection? } \square \text { Yes } \square \text { No } \\
\text { If yes, describe: }\end{array}$} \\
\hline
\end{tabular}

Control Measures

- Number the structural stormwater control measures identified in your SWPPP on your site map and list them below (add as many control measures as are implemented on-site). Carry a copy of the numbered site map with you during your inspections. This list will ensure that you are inspecting all required control measures at your facility.

- Describe corrective actions initiated, date completed, and note the person that completed the work in the Corrective Action Log.

\begin{tabular}{|c|c|c|c|c|}
\hline & $\begin{array}{l}\text { Structural Control } \\
\text { Measure }\end{array}$ & $\begin{array}{l}\text { Control } \\
\text { Measure is } \\
\text { Operating } \\
\text { Effectively? }\end{array}$ & $\begin{array}{l}\text { If No, In Need of } \\
\text { Maintenance, } \\
\text { Repair, or } \\
\text { Replacement? }\end{array}$ & $\begin{array}{l}\text { Corrective Action Needed and Notes } \\
\text { (identify needed maintenance and repairs, or any } \\
\text { failed control measures that need replacement) }\end{array}$ \\
\hline 1 & Straw Wattles & VYeso & $\begin{array}{l}\square \text { Maintenance } \\
\square \text { Repair } \\
\square \text { Replacement }\end{array}$ & \\
\hline 2 & Rock Check Dams & GYeso & $\begin{array}{l}\text { Maintenance } \\
\text { Repair } \\
\text { Replacement }\end{array}$ & \\
\hline 3 & $\begin{array}{l}\text { Lined Salt Retention } \\
\text { Pond }\end{array}$ & EYes aNo & $\begin{array}{l}\text { Maintenance } \\
\square \text { Repair } \\
\square \text { Replacement }\end{array}$ & \\
\hline 4 & Sediment Basin & चYes aNo & $\begin{array}{l}\square \text { Maintenance } \\
\square \text { Repair } \\
\square \text { Replacement }\end{array}$ & \\
\hline 5 & Rip Rap/Jersey Barriers & GNo & $\begin{array}{l}\text { Maintenance } \\
\square \text { Repair } \\
\square \text { Replacement }\end{array}$ & \\
\hline 6 & $\begin{array}{l}\text { Sediment Retention } \\
\text { Pond }\end{array}$ & 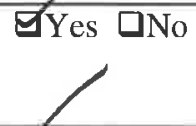 & $\begin{array}{l}\text { Maintenance } \\
\square \text { Repair } \\
\square \text { Replacement }\end{array}$ & . \\
\hline 7 & $\begin{array}{l}\text { Base Course/Earthen } \\
\text { Berms }\end{array}$ & 可Yes $\square N_{0}$ & $\begin{array}{l}\square \text { Maintenance } \\
\square \text { Repair }\end{array}$ & \\
\hline
\end{tabular}




\begin{tabular}{|c|c|c|c|c|}
\hline & $\begin{array}{l}\text { Structural Control } \\
\text { Measure }\end{array}$ & $\begin{array}{l}\text { Control } \\
\text { Measure is } \\
\text { Operating } \\
\text { Effectively? }\end{array}$ & $\begin{array}{l}\text { If No, In Need of } \\
\text { Maintenance, } \\
\text { Repair, or } \\
\text { Replacement? }\end{array}$ & $\begin{array}{l}\text { Corrective Action Needed and Notes } \\
\text { (identify needed maintenance and repairs, or any } \\
\text { failed control measures that need replacement) }\end{array}$ \\
\hline & & & $\square$ Replacement & \\
\hline 8 & Rock Run Down & 可Yes $\square$ No & $\begin{array}{l}\text { Maintenance } \\
\square \text { Repair } \\
\square \text { Replacement }\end{array}$ & \\
\hline 9 & $\begin{array}{l}\text { Outfalls } 60 \text { RG-1ID \# } \\
31,60 \text { RG-2 ID \# 30, } 60 \\
\text { RG-3 ID \# 32, } 60 \text { RG-4 } \\
\text { ID \# 33, } 60 \text { RG-5 ID \# } \\
34, \& 60 \text { RG-6 ID \# } 35\end{array}$ & EYes DNo & $\begin{array}{l}\text { Maintenance } \\
\text { Repair } \\
\text { Replacement }\end{array}$ & \\
\hline 10 & $\begin{array}{l}\text { Outfalls } 60 \text { RG-7 ID \# } \\
41 \& 60 \text { RG-8 ID \# } 42\end{array}$ & GYes $\square$ No & $\begin{array}{l}\text { Maintenance } \\
\square \text { Repair } \\
\square \text { Replacement }\end{array}$ & \\
\hline 11 & $\begin{array}{l}\text { Outfalls } 60 \text { RG-9 ID \# } \\
40,60 \text { RG-10 ID \# } 39 \text {, } \\
60 \text { RG-11 ID \# } 38\end{array}$ & GYes aNo & $\begin{array}{l}\text { Maintenance } \\
\square \text { Repair } \\
\square \text { Replacement }\end{array}$ & \\
\hline 12 & $\begin{array}{l}\text { Outfalls } 60 \text { RG-12 ID \# } \\
37 \& 60 \text { RG-13 ID \# } 36\end{array}$ & 口́ryes $\square$ No & $\begin{array}{l}\square \text { Maintenance } \\
\square \text { Repair } \\
\square \text { Replacement }\end{array}$ & \\
\hline
\end{tabular}

Areas of Industrial Materials or Activities exposed to stormwater

Below are some general areas that should be assessed during routine inspections. Customize this list as needed for the specific types of industrial materials or activities at your facility.

\begin{tabular}{|c|c|c|c|c|}
\hline & Area/Activity & Inspected? & $\begin{array}{l}\text { Controls } \\
\text { Adequate } \\
\text { (appropriate, } \\
\text { effective, and } \\
\text { operating)? }\end{array}$ & Corrective Action Needed and Notes \\
\hline 1 & $\begin{array}{l}\text { Material } \\
\text { loading/unloading and } \\
\text { storage areas }\end{array}$ & 四 & $\square$ Yes $\square$ No & \\
\hline 2 & $\begin{array}{l}\text { Equipment operations } \\
\text { and maintenance areas }\end{array}$ & שYes $\square$ No $\square \mathrm{N} / \mathrm{A}$ & $\square$ Yes $\square$ No & \\
\hline 3 & Fueling areas & $\square$ Yes $\square$ No $\bowtie N / A$ & QYes DNo & \\
\hline 4 & $\begin{array}{l}\text { Outdoor vehicle and } \\
\text { equipment washing areas }\end{array}$ & $\square$ Yes $\square$ No $\otimes N / A$ & DYes DNo & \\
\hline 5 & $\begin{array}{l}\text { Waste handling and } \\
\text { disposal areas }\end{array}$ & $\square$ Yes $\square$ No $\bowtie \mathrm{N} / \mathrm{A}$ & aYes $\square$ No & \\
\hline 6 & $\begin{array}{l}\text { Erodible } \\
\text { areas/construction }\end{array}$ & $\square$ Yes $\square$ No $\otimes \mathrm{N} / \mathrm{A}$ & $\square$ Yes $\square$ No & \\
\hline 7 & $\begin{array}{l}\text { Non-stormwater/illicit } \\
\text { connections }\end{array}$ & $\square$ Yes $\square$ No $\otimes \mathrm{N} / \mathrm{A}$ & DYes DNo & \\
\hline 8 & $\begin{array}{l}\text { Salt storage piles or pile } \\
\text { containing salt }\end{array}$ & $\square$ Yes $\square$ No $\square$ N/A & DYes DNo & \\
\hline
\end{tabular}




\begin{tabular}{|c|c|c|c|c|}
\hline & Area/Activity & Inspected? & $\begin{array}{l}\text { Controls } \\
\text { Adequate } \\
\text { (appropriate, } \\
\text { effective, and } \\
\text { operating)? }\end{array}$ & Corrective Action Needed and Notes \\
\hline 9 & $\begin{array}{l}\text { Dust generation and } \\
\text { vehicle tracking }\end{array}$ & घYes $\square$ No $\square$ N/A & DYes DNo & \\
\hline 10 & (Other) & $\square$ Yes $\square$ No $\square$ N/A & DYes DNo & \\
\hline 11 & (Other) & $\square$ Yes $\square$ No $\square$ N/A & $\square$ Yes $\square$ No & \\
\hline 12 & (Other) & $\square$ Yes $\square$ No $\square$ N/A & DYes aNo & \\
\hline
\end{tabular}

Non-Compliance

Describe any incidents of non-compliance observed and notescribed above: CAR \# 92 was entaved 4 closed in the MSGP Hacking for a hose at the fire hydvant East of 1A-60 building 250 that had a hole in it 4 the Clamp that attacheo to the water track had a Eorn O-ring that have been veplaced.

Additional Control Measures

Describe any additional control measures needed to comply with the permit requirements: CAR \#963 Jas entared into the MSGP tracking database for a berm with goph holes SW of transpartaina 60-287 that pavalleks Enivetok Drive that is still albuin storm vater to dischare throug the borm aftar the gopher holes ware plingged with gravel bags an 81112016 . 
Notes

Use this space for any additional notes or observations from the inspection: The sediment retention pond at the far East end of Sigmantepa is full of Storm water. The lined salt retention pond is atilt full.

CERTIFICATION STATEMENT

"I certify under penalty of law that this document and all attachments were prepared under my direction or supervision in accordance with a system designed to assure that qualified personnel properly gathered and evaluated the information submitted. Based on my inquiry of the person or persons who manage the system, or those persons directly responsible for gathering the information, the information submitted is, to the best of my knowledge and belief, true, accurate, and complete. I am aware that there are significant penalties for submitting false information, including the possibility of fine and imprisonment for knowing violations."

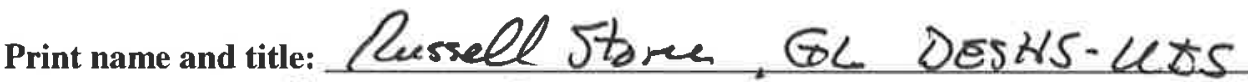

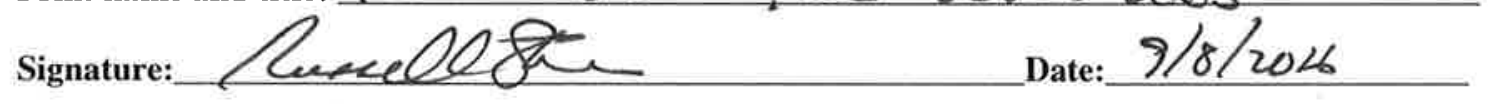




\section{Maintenance Details}

Requested By: Banar, Alethea on 9/19/2016 11:00:00 AM

Taken By:

Banar, Alethea

Procedure: MSGP Stormwater Industria! Routine Facilty Inspection (EPC-CP-Form1020.1)

Last PM: N/A

Project: Monthly Routine Inspections 9-6-16 (P-MSGP-RI-5119)
Target: $\quad 9 / 30 / 2016$

Priority/Type: / Routine

Department: Utilities and

Infrastructure
1 MSGP Program

뭄 RG200.5

4. TA-60 Roads and Grounds

Contact: Banar, Alethea

Phone: 699-5836

Reason: MSGP Routine Facility Inspection TA-60 Roads and Grounds

Weather at inspection:

Special Instructions: NMR053195

Tasks

\# Description

Weather Information

Describe the weather at time of inspection in the Weather lookup table. If "Other" is chosen, provide description in task comments of this line. Document

20 the temperature $\left(\mathrm{F}^{\circ}\right)$ in the "Reading" field of this

Within the Facility Boundary

Is the facility free of new discharges of pollutants that have occurred since the last inspection? If "Failed"

40 describe

If "Failed" has a CAR been previously initiated for

50 this new discharge? (Range: 0 - 0 )

Is the facility free of discharge of pollutants at the

60 time of inspection? If "Failed" describe: (Range: 0 -

$60 \quad 0)$

Is the facility free of evidence of, or the potential for pollutants entering the drainage system. If "Failed"

70 describe: (Range: 0 - 0 )
Rating Meas. Initials Failed N/A Complete

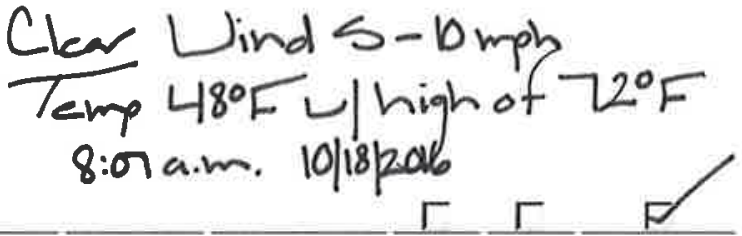

Outfall Inspection needed maintenance and repairs, failed control measures that need replacement, or a description of corrective actions in relevant task comment)

Monitored Outfall [031] DO: Free of Evidence of

$90 \quad$ Erosion? (Range: 0 - 0)

Monitored Outfall [031] DO: Flow Dissipation

100 Devices Operating Effectively? (Range: 0 - 0)

Monitored Outfall [031] DO: Free of Evidence of

Pollutants in Discharges and/or Receiving Water?

110 (Range: 0 - 0)

Monitored Outfall [032] Free of Evidence of

120 Erosion? (Range: 0 - 0)

Monitored Outfall [032] Flow Dissipation Devices

130 Operating Effectively? (Range: 0 - 0)

140

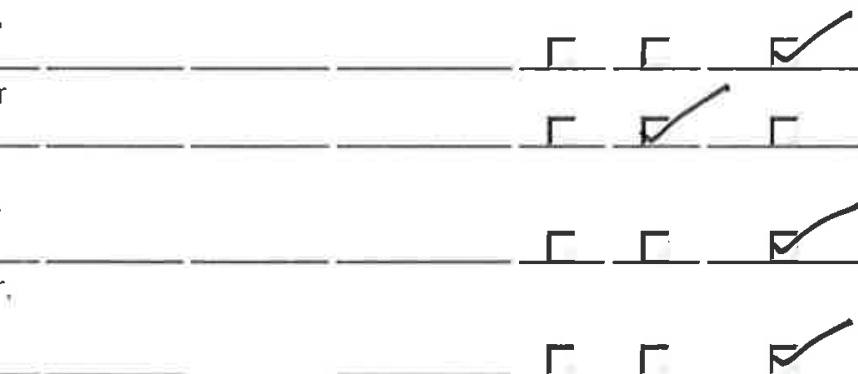


Monitored Outfall [032] Free of Evidence of

Pollutants in Discharges and/or Receiving Water?

(Range: 0 - 0)

Monitored Outfall [036] Free of Evidence of

150

Erosion? (Range: 0 - 0)

Monitored Outfall [036] Flow Dissipation Devices

160 Operating Effectively? (Range: 0 - 0)

Monitored Outfall [036] Free of Evidence of

Pollutants in Discharges and/or Receiving Water?

$170 \quad$ (Range: 0 - 0)

Monitored Outfall [039] Free of Evidence of

180 Erosion? (Range: 0 - 0)

Monitored Outfall [039] Flow Dissipation Devices

190 Operating Effectively? (Range: 0 - 0)

Monitored Outfall [039] Free of Evidence of

Pollutants in Discharges and/or Receiving Water?

$200 \quad$ (Range: 0 - O)

Monitored Outfall [042] Free of Evidence of

210 Erosion? (Range: 0 - 0)

Monitored Outfall [042] Flow Dissipation Devices

220 Operating Effectively? (Range: 0 - 0)

Monitored Outfall [042] Free of Evidence of

Pollutants in Discharges and/or Receiving Water?

230 (Range: 0 - 0 )

Substantially Identical Outfall [030] Free of

240 Evidence of Erosion? (Range: 0 - 0)

Substantially Identical Outfall [030] Flow

Dissipation Devices Operating Effectively? (Range: 0

$250-0)$

Substantially Identical Outfall [030] Free of

Evidence of Pollutants in Discharges and/or

260 Receiving Water? (Range: 0 - 0)

Substantially Identical Outfall [033] Free of

270 Evidence of Erosion? (Range: 0 - 0)

Substantially Identical Outfall [033] Flow

Dissipation Devices Operating Effectively? (Range: 0

$280-0)$

Substantially Identical Outfall [033] Free of

Evidence of Pollutants in Discharges and/or

290 Receiving Water? (Range: 0 - 0)

Substantially Identical Outfall [034] Free of

$300 \quad$ Evidence of Erosion? (Range: 0 - 0)

Substantially Identical Outfall [034] Flow

$\underline{310}-\underline{-0}$

Devices Operating Effectively? (Range: 0

Substantially Identical Outfall [034] Free of

Evidence of Pollutants in Discharges and/or

320 Receiving Water? (Range: 0 - 0)

Substantially Identical Outfall [035] Free of

330

Evidence of Erosion? (Range: 0 - 0)

Substantially Identical Outfall [035] Flow

Dissipation Devices Operating Effectively? (Range: 0

340

-0)

Substantially Identical Outfall [035] Free of

Evidence of Pollutants in Discharges and/or

350

Receiving Water? (Range: 0 - 0)

Substantially Identical Outfall [037] Free of

360 Evidence of Erosion? (Range: 0 - 0)

Substantially Identical Outfall [037] Flow

370

Dissipation Devices Operating Effectively? (Range: 0

- 0) 
Substantially Identical Outfall [037] Free of

Evidence of Pollutants in Discharges and/or

Receiving Water? (Range: 0 - 0)

390 Substantially Identical Outfall [038] Free of

Evidence of Erosion? (Range: 0 - 0)

Substantially Identical Outfall [038] Flow

Dissipation Devices Operating Effectively? (Range: 0

$400-0)$

Substantially Identical Outfall [038] Free of

Evidence of Pollutants in Discharges and/or

$410 \quad$ Receiving Water? (Range: 0 - 0)

Substantially Identical Outfall [040] Free of

$420 \quad$ Evidence of Erosion? (Range: 0 - 0)

Substantially Identical Outfall [040] Flow

Dissipation Devices Operating Effectively? (Range: 0

$430-0)$

Substantially Identical Outfall [040] Free of

Evidence of Pollutants in Discharges and/or

$440 \quad$ Receiving Water? (Range: 0 - 0)

Substantially Identical Outfall [041] Free of

450 Evidence of Erosion? (Range: 0 - 0)

Substantially Identical Outfall [041] Flow

Dissipation Devices Operating Effectively? (Range: 0

460

$-0)$

Substantially Identical Outfall [041] Free of

Evidence of Pollutants in Discharges and/or

$470 \quad$ Receiving Water? (Range: 0 - 0)

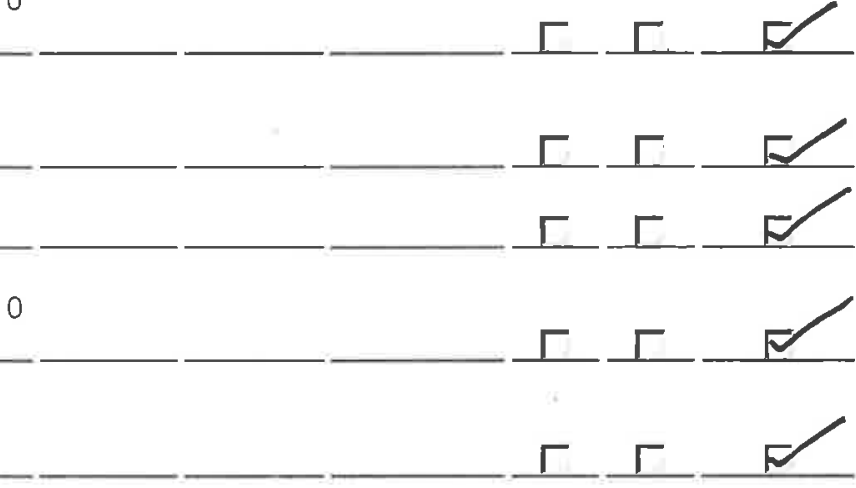

Control Measures (identify needed maintenance and repairs, failed control measures that need replacment, or a description of corrective actions in relevant task comments).

Asphalt Berm [6000303040019] Control Measure is

490 operating effectively? (Range: 0 - 0)

Asphalt Berm [6000303040019] If "Failed", is

control measure in need of maintenance, Repair, or

$\underline{500}$ Replacement?

Asphalt Berm [6000303040020] Control Measure is

510 operating effectively? (Range: 0 - 0)

Asphalt Berm [6000303040020] If "Failed", is

control measure in need of maintenance, Repair, or

520 Replacement?

Rock Channel/Swale [6000304030016] Control

530 Measure is operating effectively? (Range: 0 - 0)

Rock Channel/Swale [6000304030016] If "Failed"

is control measure in need of maintenance, Repair,

540 or Replacement?

Rock Channel/Swale [6000304030039] Control

550 Measure is operating effectively? (Range: 0 - 0)

Rock Channel/Swale [6000304030039] If "Failed"

is control measure in need of maintenance, Repair,

560 or Replacement?

Rock Channel/Swale [6000304030040] Control

$570 \quad$ Measure is operating effectively? (Range: 0 - 0 )

Rock Channel/Swale [6000304030040] If "Failed",

is control measure in need of maintenance Repair,

580 or Replacement?

Rock Channel/Swale [6000311010017] Control

590 Measure is operating effectively? (Range: 0 - 0 )

Rock Channel/Swale [6000311010017] If "Failed",

is control measure in need of maintenance, Repair,

600

or Replacement?

Rip Rap [6000304060009] Control Measure is

610 operating effectively? (Range: 0 - 0)

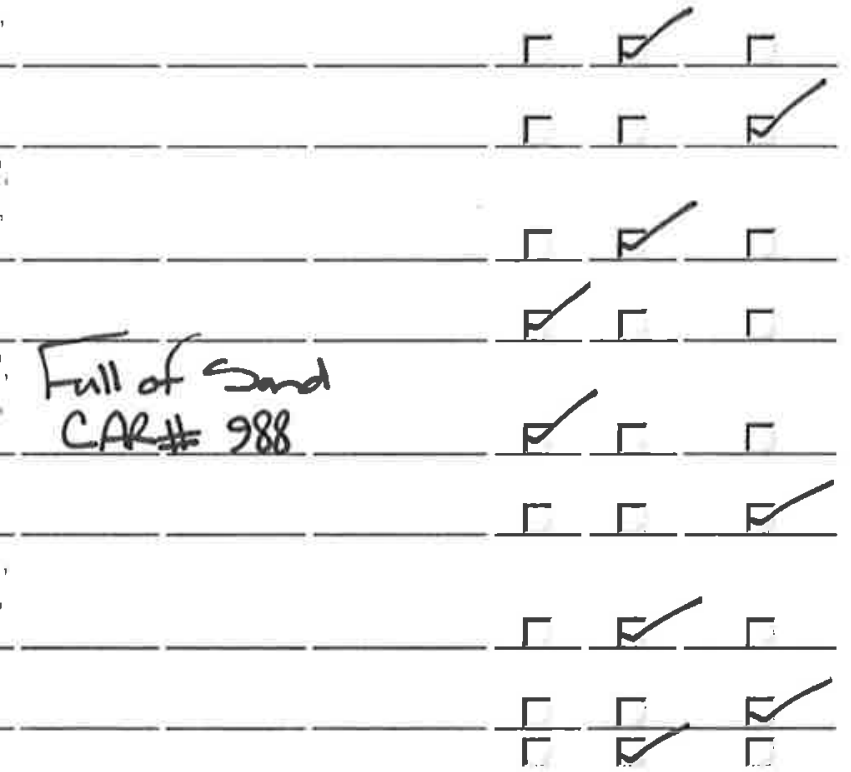


Rip Rap [6000304060009] If "Failed", is control measure in need of maintenance, Repair, or Replacement?

Rip Rap [6000304060010] Control Measure is 630 operating effectively? (Range: 0 - 0)

Rip Rap [6000304060010] If "Failed", is control

measure in need of maintenance, Repair, or

640 Replacement?

Rip Rap [6000304060011] Control Measure is

650 operating effectively? (Range: 0 - 0)

Rip Rap [6000304060011] If "Failed", is contro

measure in need of maintenance, Repair, or

660 Replacement?

Rip Rap [6000304060012] Control Measure is

670 operating effectively? (Range: 0 - 0)

Rip Rap [6000304060012] If "Failed", is contro

measure in need of maintenance, Repair, or

680 Replacement?

Rip Rap [6000304060013] Control Measure is

690 operating effectively? (Range: 0 - 0)

Rip Rap [6000304060013] If "Failed", is control

measure in need of maintenance, Repair, or

$700 \quad$ Replacement?

Rip Rap [6000304060014] Control Measure is

710 operating effectively? (Range: 0 - 0)

Rip Rap [6000304060014] If "Failed", is control

measure in need of maintenance, Repair, or

$720 \quad$ Replacement?

Rip Rap [6000304060022] Control Measure is

730 operating effectively? (Range: 0 - 0 )

Rip Rap [6000304060022] If "Failed", is control

measure in need of maintenance, Repair, or

$740 \quad$ Replacement?

Rip Rap [6000304060023] Control Measure is

750 operating effectively? (Range: 0 - 0)

Rip Rap [6000304060023] If "Failed", is control

measure in need of maintenance, Repair, or

760

Replacement?

Rip Rap [6000304060024] Control Measure is

770 operating effectively? (Range: 0 - 0)

Rip Rap [6000304060024] If "Failed", is control

measure in need of maintenance, Repair, or

$\underline{780}$

Replacement?

Rip Rap [6000304060025] Control Measure is

790 operating effectively? (Range: 0 - 0)

Rip Rap [6000304060025] If "Failed", is control

measure in need of maintenance, Repair, or

800

Replacement?

Rip Rap [6000304060026] Control Measure is

810 operating effectively? (Range: 0 - 0)

Rip Rap [6000304060026] If "Failed", is control

measure in need of maintenance, Repair, or

820

Replacement?

Rip Rap [6000304060027] Control Measure is

830 operating effectively? (Range: 0 - 0)

Rip Rap [6000304060027] If "Failed", is control

measure in need of maintenance, Repair, or

$840 \quad$ Replacement?

Rip Rap [6000304060028] Control Measure is

850

operating effectively? (Range: 0 - 0 )

860 
Rip Rap [6000304060028] If "Failed", is control

measure in need of maintenance, Repair, or

Replacement?

$870 \quad$ Rip Rap [6000304060029] Control Measure is operating effectively? (Range: 0 - 0)

Rip Rap [6000304060029] If "Failed", is control

measure in need of maintenance, Repair, or

$880 \quad$ Replacement?

Rip Rap [6000304060030] Control Measure is

890 operating effectively? (Range: 0 - 0)

Rip Rap [6000304060030] If "Failed", is control

measure in need of maintenance, Repair, or

$900 \quad$ Replacement?

Rip Rap [6000304060031] Control Measure js

910 operating effectively? (Range: 0 - 0)

Rip Rap [6000304060031] If "Failed", is control

measure in need of maintenance, Repair, or

$920 \quad$ Replacement?

Rip Rap [6000304060032] Control Measure is

930 operating effectively? (Range: 0 - 0 )

Rip Rap [6000304060032] If "Failed", is control

measure in need of maintenance, Repair, or

$940 \quad$ Replacement?

Rip Rap [6000304060033] Control Measure is

950 operating effectively? (Range: 0 - 0)

Rip Rap [6000304060033] If "Failed", is control

measure in need of maintenance, Repair, or

960 Replacement?

Earthen Berm [6000303010034] Control Measure is

$970 \quad$ operating effectively? (Range: 0 - 0)

Earthen Berm [6000303010034] If "Failed", is

control measure in need of maintenance, Repair, or

$\underline{980}$

Replacement?

Earthen Berm [6000303010035] Control Measure is 990 operating effectively? (Range: 0 - 0)

Earthen Berm [6000303010035] If "Failed", is

control measure in need of maintenance, Repair, or

1000 Replacement?

Earthen Berm [6000303010036] Control Measure is

1010 operating effectively? (Range: 0 - 0)

Earthen Berm [6000303010036] If "Failed", is

control measure in need of maintenance, Repair, or

1020 Replacement?

Earthen Berm [6000303010037] Control Measure is

1030 operating effectively? (Range: 0 - 0)

Earthen Berm [6000303010037] If "Failed", is

control measure in need of maintenance, Repair, or

1040 Replacement?

Earthen Berm [6000303010038] Control Measure is

1050 operating effectively? (Range: 0 - 0)

Earthen Berm [6000303010038] If "Failed", is

control measure in need of maintenance, Repair, or

1060 Replacement?

Sediment Basin [6000305020018] Control Measure

1070 is operating effectively? (Range: 0 - 0)

Sediment Basin [6000305020018] If "Failed", is

control measure in need of maintenance, Repair, or

1080

Replacement?

Sediment Basin [6000305020041] Control Measure

1090 is operating effectively? (Range: 0 - 0)

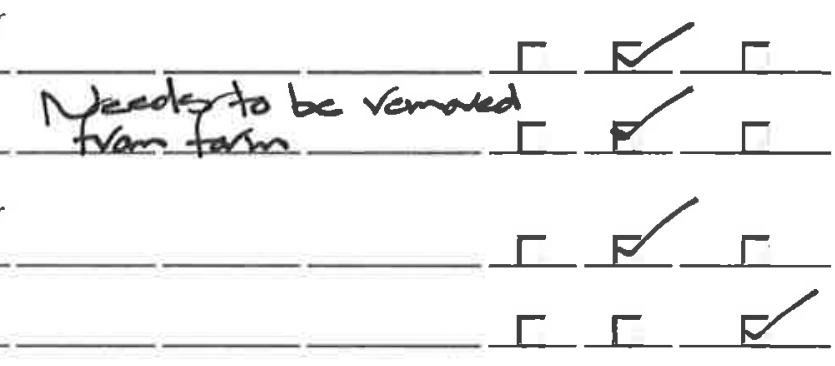

\section{政}

(1)

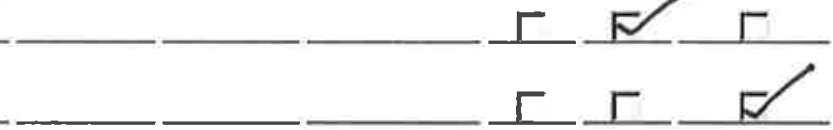

$+\cdots$

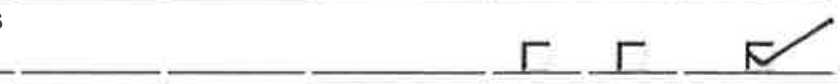

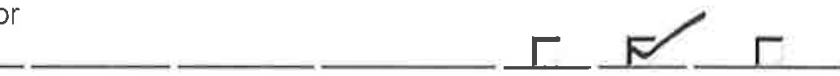


Sediment Basin [6000305020041] If "Failed", is

control measure in need of maintenance, Repair, or Replacement?

Rock Check Dam [6000306010001] Control

1110 Measure is operating effectively? (Range: 0 - 0 )

Rock Check Dam [6000306010001] If "Failed", is

control measure in need of maintenance, Repair, or

1120 Replacement?

Rock Check Dam [6000306010002] Control

1130 Measure is operating effectively? (Range: 0 - 0)

Rock Check Dam [6000306010002] If "Failed", is

control measure in need of maintenance, Repair, or

1140 Replacement?

Rock Check Dam [6000306010003] Control

1150 Measure is operating effectively? (Range: 0 - 0)

Rock Check Dam [6000306010003] If "Failed", is

control measure in need of maintenance, Repair, or

1160 Replacement?

Rock Check Dam [6000306010004] Control

1170 Measure is operating effectively? (Range: 0 - 0)

Rock Check Dam [6000306010004] If "Failed", is

control measure in need of maintenance, Repair, or

1180 Replacement?

Rock Check Dam [6000306010005] Control

1190 Measure is operating effectively? (Range: 0 - 0)

Rock Check Dam [6000306010005] If "Failed", is

control measure in need of maintenance, Repair, or

1200 Replacement?

Rock Check Dam [6000306010006] Control

1210 Measure is operating effectively? (Range: 0 - 0 )

Rock Check Dam [6000306010006] If "Failed", is

control measure in need of maintenance, Repair, or

1220 Replacement?

Rock Check Dam [6000306010007] Control

1230 Measure is operating effectively? (Range: 0 - 0)

Rock Check Dam [6000306010007] If "Failed", is

control measure in need of maintenance, Repair, or

1240 Replacement?

Rock Check Dam [6000306010008] Control

1250 Measure is operating effectively? (Range: 0 - 0)

Rock Check Dam [6000306010008] If "Failed", is

control measure in need of maintenance, Repair, or

1260

Replacement?

Jersey Barriers [6000303170015] Control Measure

1270 is operating effectively?

Jersey Barriers [6000303170015] If "Failed", is

control measure in need of maintenance, Repair, or

1280

Replacement?

Jersey Barriers [6000303170021] Control Measure

1290 is operating effectively?

Jersey Barriers [6000303170021] If "Failed", is

control measure in need of maintenance, Repair, or

1300 Replacement?

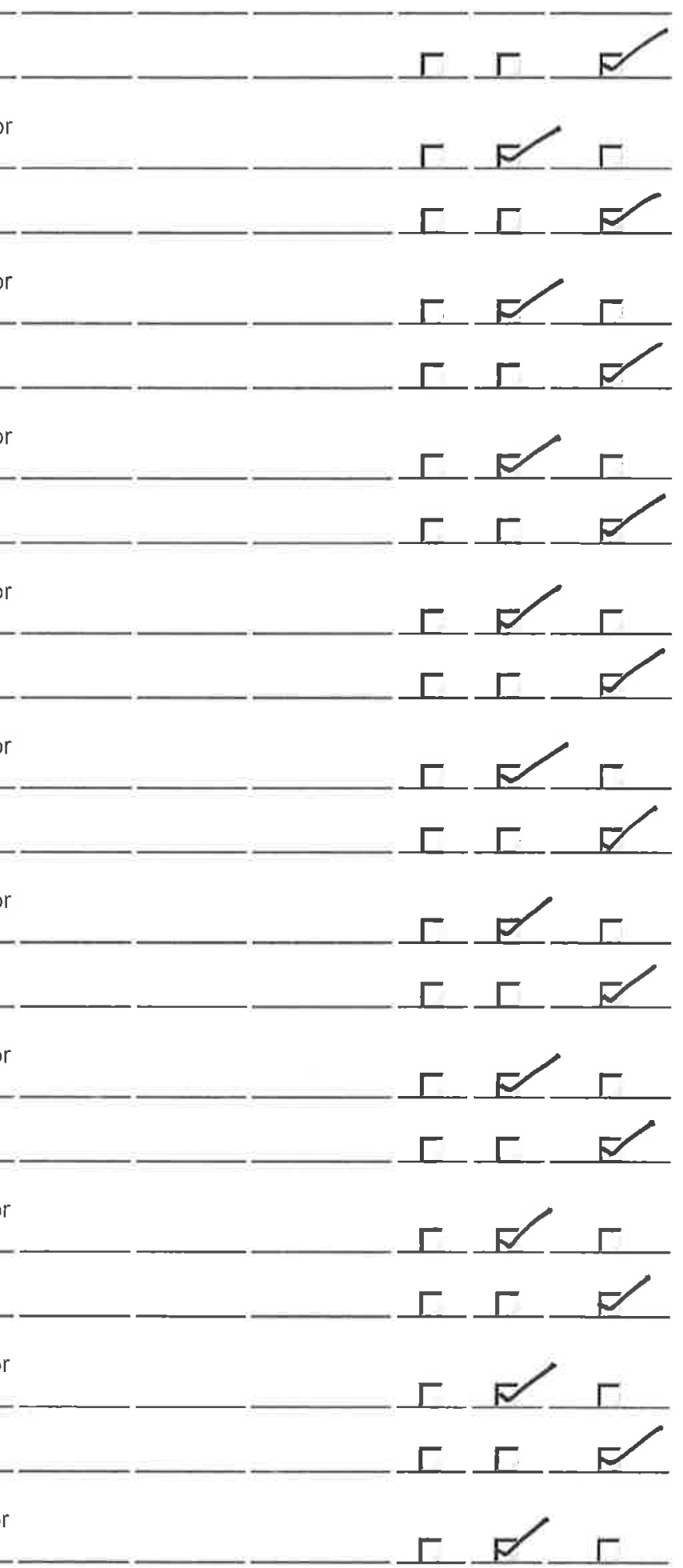

Area/Activity exposed to stormwater (identify needed mainteance or a description of corrective actions in relevant task comment).

Material loading/unloading and storage areas

1320 inspected?

Area/Activity controls adequate (appropriate,

1330 effective, and operating)? (Range: 0 - 0)

1340 Transfer areas for substances in bulk inspected?

1350

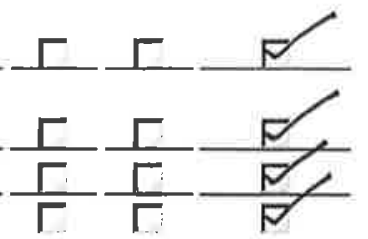


Area/Activity controls adequate (appropriate,

effective, and operating)? (Range: 0 - 0)

$1360 \quad \begin{aligned} & \text { Produce/chemical storage areas (raw material) } \\ & \text { inspected? }\end{aligned}$

Area/Activity controls adequate (appropriate,

1370 effective, and operating)? (Range: 0 - 0)

Liquid tank storage/secondary containment

1380 inspected?

Area/Activity controls adequate (appropriate,

1390 effective, and operating)? (Range: 0 - 0)

Industrial processing and finished product storage

1400 areas inspected?

Area/Activity controls adequate (appropriate,

1410 effective, and operating)? (Range: 0 - 0)

Equipment operation and maintenance areas

1420 inspected?

Area/Activity controls adequate (appropriate,

1430 effective, and operating)? (Range: 0 - 0)

1440 Fueling areas inspected?

Area/Activity controls adequate (appropriate,

1450 effective, and operating)? (Range: 0 - 0)

Outdoor vehicle and equipment washing areas

1460 inspected?

Area/Activity controls adequate (appropriate,

1470 effective, and operating)? (Range: 0 - 0)

1480 Machinery inspected?

Area/Activity controls adequate (appropriate,

1490 effective, and operating)? (Range: 0 - 0)

1500 Waste handling and disposal areas inspected?

Area/Activity controls adequate (appropriate,

1510 effective, and operating)? (Range: 0 - 0)

1520 Erodible areas/construction inspected?f

Area/Activity controls adequate (appropriate,

1530 effective, and operating)? (Range: 0 - 0)

Locations and sources of run-on to the site

1540 inspected?

Area/Activity controls adequate (appropriate,

1550 effective, and operating)? (Range: 0 - 0)

1560 Non-stormwater/illicit connections inspected?

Area/Activity controls adequate (appropriate,

1570 effective, and operating)? (Range: 0 - 0)

1580 Salt storage piles or pile containing salt inspected?

Area/Activity controls adequate (appropriate,

1590 effective, and operating)? (Range: 0 - 0)

1600 Dust generation and vehicle tracking inspected?

Area/Activity controls adequate (appropriate,

1610 effective, and operating)? (Range: 0 - 0)

Housekeeping (Industrial materials/residues/trash in

1620

contact with stormwater) inspected?

Area/Activity controls adequate (appropriate,

1630 effective, and operating)? (Range: 0 - 0)

1640 Leaks and spills inspected?

Area/Activity controls adequate (appropriate,

1650 effective, and operating)? (Range: 0 - 0)

Sector P [60003-] Vehicle storage/maintenance

1660 areas inspected?

Sector P [60003-] Area/Activity controls adequate

1670

(appropriate, effective, and operating)? (Range: 0 -

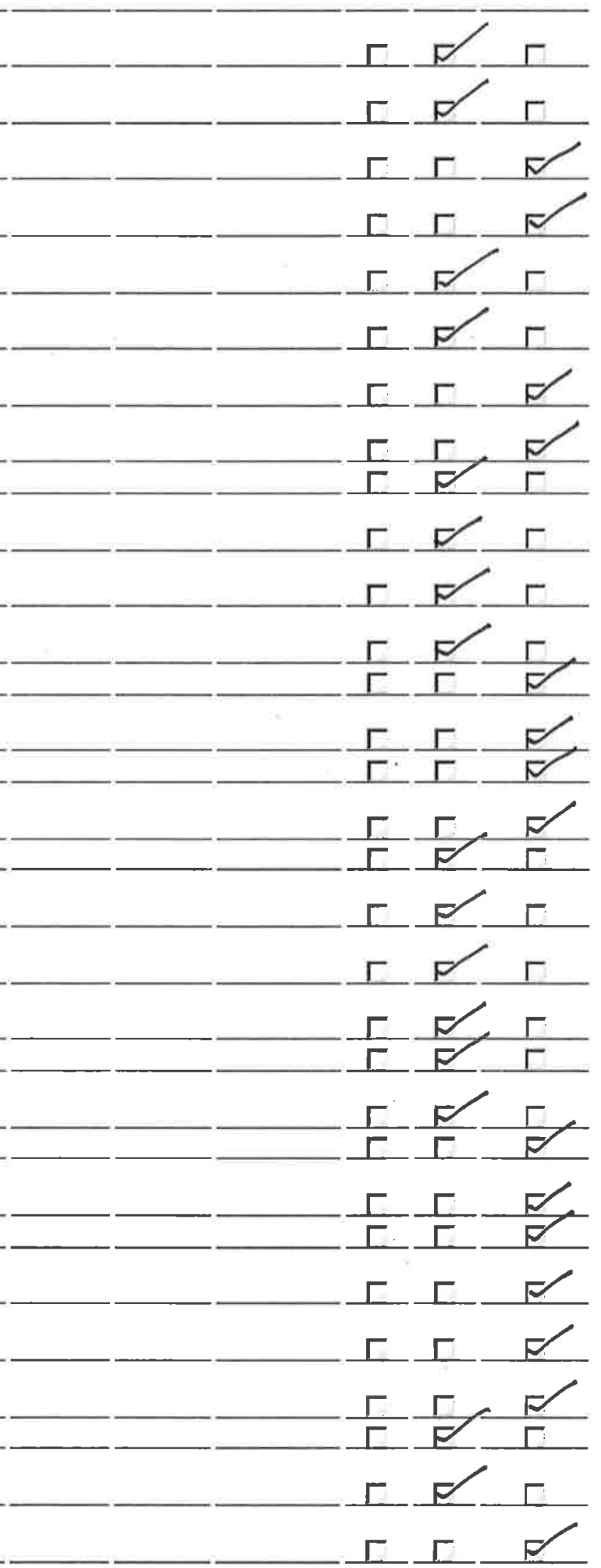
o) 


\section{Non-Compliance}

Free of incidents of observed non-compliance not 1690 associated with any of the above? (Range: 0 - 0 )

Additional Control Measures

Are permit requirements satisfied with existing control measure(s) not associated with any of the above?

1710 (Range: 0 - 0)

\section{Labor}

Labor

Leonard Sandoval

Assigned Work Date Reg Hrs OT Hrs Other Hrs

\section{Labor Report-}

Completed:

Failure:

Meter 1:

Meter 2:

Report: 
WO ID:

Page

of

Signature (lead inspector):

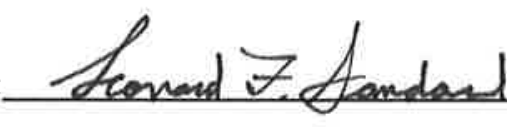

Date and Time: 1011812016 2:50 am.

CERTIFICATION STATEMENT

"I certify under penalty of law that this document and all attachments were prepared under my direction or supervision in accordance with a system designed to assure that qualified personnel properly gathered and evaluated the information submitted. Based on my inquiry of the person or persons who manage the system, or those persons directly responsible for gathering information, the information submitted is, to the best of my knowledge and belief, true, accurate, and complete. I am aware that there are significant penalties for submitting false information, including the possibility of fine and imprisonment for knowing violations".

(Signatory must meet definition in Section B.11.A, eg., FOD, Ops Mgr, DSESH Group Leader, EPC Group Leader)

Print name and title: Russell Stone GC DESHS-UtS

Signature:

Date:

$10 / 19 / 2016$ 


\section{Maintenance Details}

\author{
Requested: 11/1/2016 1:15:42 PM \\ Procedure: MSGP Stormwater \\ Industrial Routine Facilty \\ Inspection (EPC-CP-Form- \\ 1020.1)
}

Last PM: $\quad \mathrm{N} / \mathrm{A}$

Project: Routine Facility Inspections Nov 2016 (P-MSGP-5146)
Target: $\quad$ 11/30/2016

Priority/Type: Normal/Inspection

Department: Utilities and Infrastructure

\section{MSGP Program \\ 虽 RG200.5 \\ 4. TA-60 Roads and Grounds}

Contact:

Phone:

Reason: MSGP Stormwater Industrial Routine Facilty Inspection

Weather at inspection:

Special Instructions: NMR053195

\section{Tasks}

\# Description

Weather Information

Describe the weather at time of inspection in the Weather lookup table. If "Other" is chosen, provide description in task comments of this line. Document

20 the temperature $\left(\mathrm{F}^{\circ}\right)$ in the "Reading" field of this

Within the Facility Boundary

Is the facility free of new discharges of pollutants that have occurred since the last inspection? If "Failed",

40 describe:

If "Failed" has a CAR been previously initiated for

50 this new discharge? (Range: 0 - 0 )

Is the facility free of discharge of pollutants at the time of inspection? If "Failed" describe: (Range: 0 -

$\underline{60} \quad 0)$

Is the facility free of evidence of, or the potential for, pollutants entering the drainage system. If "Failed"

70 describe: (Range: 0 - 0)

-

Rating Meas. Initials Failed N/A Complete

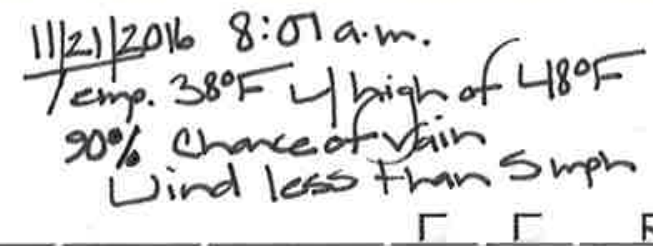

Outfall Inspection (needed maintenance and repairs, failed control measures that need replacement, or a description of corrective actions in relevant task comment)

Monitored Outfall [031] DO: Free of Evidence of

$90 \quad$ Erosion? (Range: 0 - 0)

Monitored Outfall [031] DO: Flow Dissipation

100 Devices Operating Effectively? (Range: 0 - 0)

Monitored Outfall [031] DO: Free of Evidence of

Pollutants in Discharges and/or Receiving Water?

110 (Range: 0 - 0)

Monitored Outfall [032] Free of Evidence of

120 Erosion? (Range: 0 - 0)

Monitored Outfall [032] Flow Dissipation Devices

130 Operating Effectively? (Range: 0 - 0)

Monitored Outfall [032] Free of Evidence of

Pollutants in Discharges and/or Receiving Water?

140 (Range: 0 - 0)

Monitored Outfall [036] Free of Evidence of

150 Erosion? (Range: 0 - 0)

r


Monitored Outfall [036] Flow Dissipation Devices

Operating Effectively? (Range: 0 - 0)

Monitored Outfall [036] Free of Evidence of

Pollutants in Discharges and/or Receiving Water?

170

(Range: 0 - 0)

Monitored Outfall [039] Free of Evidence of

$180 \quad$ Erosion? (Range: 0 - 0)

Monitored Outfall [039] Flow Dissipation Devices

190 Operating Effectively? (Range: 0 - 0)

Monitored Outfall [039] Free of Evidence of

Pollutants in Discharges and/or Receiving Water?

200 (Range: 0 - 0)

Monitored Outfall [042] Free of Evidence of

210 Erosion? (Range: 0 - 0)

Monitored Outfall [042] Flow Dissipation Devices

220 Operating Effectively? (Range: 0 - 0)

Monitored Outfall [042] Free of Evidence of

Pollutants in Discharges and/or Receiving Water?

230 (Range: 0 - 0)

Substantially Identical Outfall [030] Free of

240 Evidence of Erosion? (Range: 0 - 0)

Substantially Identical Outfall [030] Flow

Dissipation Devices Operating Effectively? (Range: 0

$\underline{250}-0$ )

Substantially Identical Outfall [030] Free of

Evidence of Pollutants in Discharges and/or

260 Receiving Water? (Range: 0 - 0)

Substantially Identical Outfall [033] Free of

270 Evidence of Erosion? (Range: 0 - 0)

Substantially Identical Outfall [033] Flow

Dissipation Devices Operating Effectively? (Range: 0

280 -

Substantially Identical Outfall [033] Free of

Evidence of Pollutants in Discharges and/or

290 Receiving Water? (Range: 0 - 0)

Substantially Identical Outfall [034] Free of

$300 \quad$ Evidence of Erosion? (Range: 0 - 0)

Substantially Identical Outfall [034] Flow

Dissipation Devices Operating Effectively? (Range: 0

$310-0)$

Substantially Identical Outfall [034] Free of

Evidence of Pollutants in Discharges and/or

320 Receiving Water? (Range: 0 - 0)

Substantially Identical Outfall [035] Free of

330 Evidence of Erosion? (Range: 0 - 0)

Substantially Identical Outfall [035] Flow

Dissipation Devices Operating Effectively? (Range: 0

340 -0)

Substantially Identical Outfall [035] Free of

Evidence of Pollutants in Discharges and/or

$350 \quad$ Receiving Water? (Range: 0 - 0)

Substantially Identical Outfall [037] Free of

360 Evidence of Erosion? (Range: 0 - 0)

Substantially Identical Outfall [037] Flow

Dissipation Devices Operating Effectively? (Range: 0

370

-0)

Substantially Identical Outfall [037] Free of

Evidence of Pollutants in Discharges and/or

$380 \quad$ Receiving Water? (Range: 0 - 0)

Substantially Identical Outfall [038] Free of

390 Evidence of Erosion? (Range: 0 - 0 )

Elosion? (Range. 0 -0)


Substantially Identical Outfall [038] Flow

Dissipation Devices Operating Effectively? (Range: 0

-0)

Substantially Identical Outfall [038] Free of

Evidence of Pollutants in Discharges and/or

410 Receiving Water? (Range: 0 - 0)

Substantially Identical Outfall [040] Free of

420 Evidence of Erosion? (Range: 0 - 0)

Substantially Identical Outfall [040] Flow

Dissipation Devices Operating Effectively? (Range: 0

$430-0)$

Substantially Identical Outfall [040] Free of

Evidence of Pollutants in Discharges and/or

$440 \quad$ Receiving Water? (Range: 0 - 0)

Substantially Identical Outfall [041] Free of

450 Evidence of Erosion? (Range: 0 - 0)

Substantially Identical Outfall [041] Flow

Dissipation Devices Operating Effectively? (Range: 0

460 -0)

Substantially Identical Outfall [041] Free of

Evidence of Pollutants in Discharges and/or

470 Receiving Water? (Range: 0 - 0)

Control Measures (identify needed maintenance and repairs, failed control measures that need replacment, or a description of corrective actions in relevant task comments).

Asphalt Berm [6000303040019] Control Measure is

490 operating effectively? (Range: 0 - 0)

Asphalt Berm [6000303040019] If "Failed", is

control measure in need of maintenance, Repair, or

500 Replacement?

Asphalt Berm [6000303040020] Control Measure is

510 operating effectively? (Range: 0 - 0)

Asphalt Berm [6000303040020] If "Failed", is

control measure in need of maintenance, Repair, or

$520 \quad$ Replacement?

Rock Channel/Swale [6000304030016] Control

530 Measure is operating effectively? (Range: 0 - 0)

Rock Channel/Swale [6000304030016] If "Failed",

is control measure in need of maintenance, Repair

540 or Replacement?

Rock Channel/Swale [6000304030039] Control

550 Measure is operating effectively? (Range: 0 - 0)

Rock Channel/Swale [6000304030039] If "Failed",

is control measure in need of maintenance, Repair

560

or Replacement?

Rock Channel/Swale [6000304030040] Control

570 Measure is operating effectively? (Range: 0 - 0)

Rock Channel/Swale [6000304030040] If "Failed",

is control measure in need of maintenance, Repair,

580

or Replacement?

Rock Channel/Swale [6000311010017] Control

590 Measure is operating effectively? (Range: 0 - 0)

Rock Channel/Swale [6000311010017] If "Failed",

is control measure in need of maintenance, Repair,

600

or Replacement?

Rip Rap [6000304060009] Control Measure is

610 operating effectively? (Range: 0 - 0)

Rip Rap [6000304060009] If "Failed", is control

measure in need of maintenance, Repair, or

620

Replacement?

Rip Rap [6000304060010] Control Measure is

630

operating effectively? (Range: 0 - 0 )

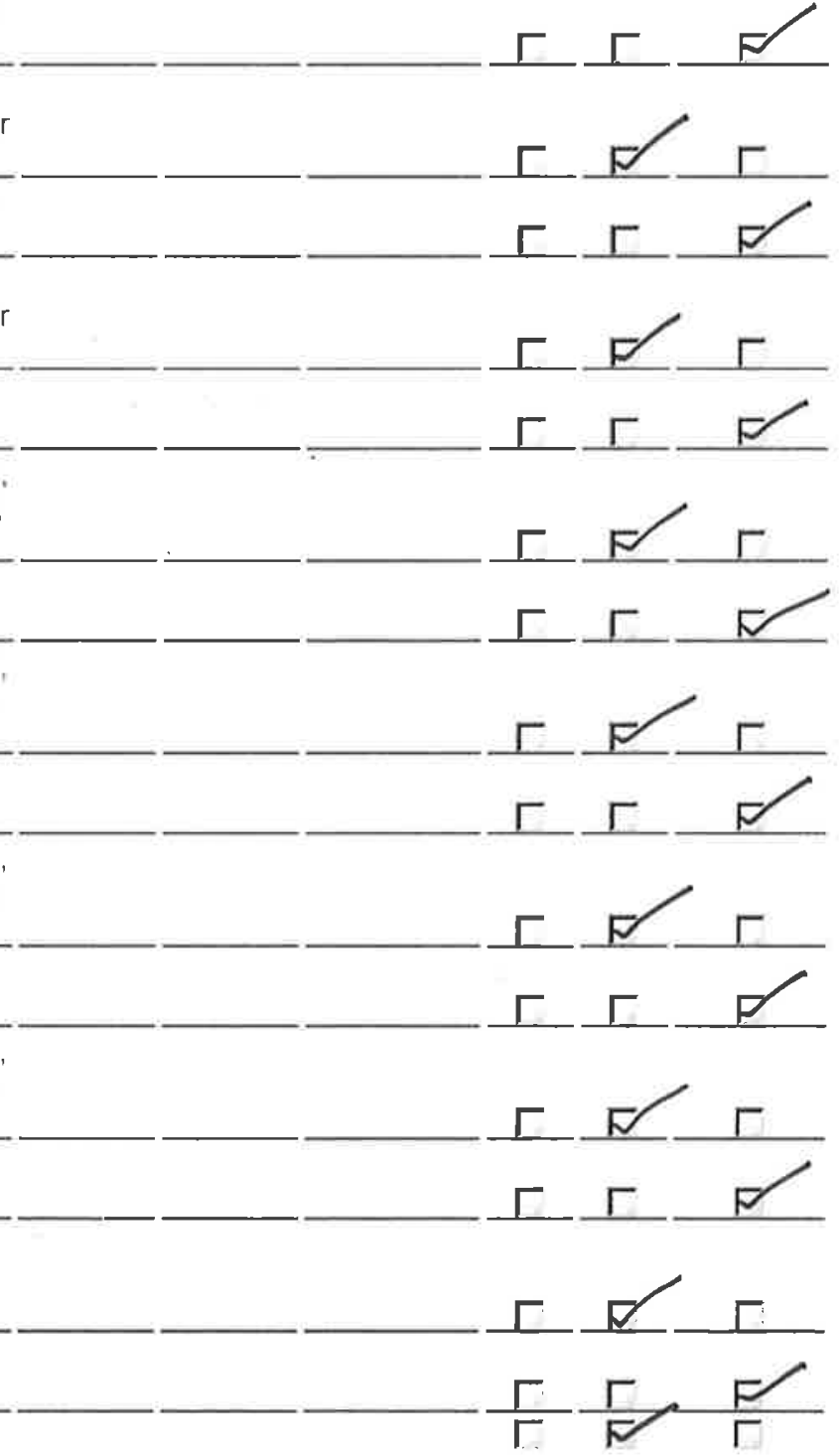


Rip Rap [6000304060010] If "Failed", is control measure in need of maintenance, Repair, or Replacement?

Rip Rap [6000304060011] Control Measure is

650 operating effectively? (Range: 0 - 0)

Rip Rap [6000304060011] If "Failed", is contro

measure in need of maintenance, Repair, or

660 Replacement?

Rip Rap [6000304060012] Control Measure is

670 operating effectively? (Range: 0 - 0)

Rip Rap [6000304060012] If "Failed", is control

measure in need of maintenance, Repair, or

680 Replacement?

Rip Rap [6000304060013] Control Measure is

690 operating effectively? (Range: 0 - 0)

Rip Rap [6000304060013] If "Failed", is control

measure in need of maintenance, Repair, or

$700 \quad$ Replacement?

Rip Rap [6000304060014] Control Measure is

710 operating effectively? (Range: 0 - 0)

Rip Rap [6000304060014] If "Failed", is control

measure in need of maintenance, Repair, or

$720 \quad$ Replacement?

Rip Rap [6000304060022] Control Measure is

730 operating effectively? (Range: 0 - 0)

Rip Rap [6000304060022] If "Failed", is control

measure in need of maintenance, Repair, or

$740 \quad$ Replacement?

Rip Rap [6000304060023] Control Measure is

750 operating effectively? (Range: 0 - 0)

Rip Rap [6000304060023] If "Failed", is control

measure in need of maintenance, Repair, or

760 Replacement?

Rip Rap [6000304060024] Control Measure is

770 __ operating effectively? (Range: 0 - 0)

Rip Rap [6000304060024] If "Failed", is contro

measure in need of maintenance, Repair, or

780

Replacement?

Rip Rap [6000304060025] Control Measure is

790 operating effectively? (Range: 0 - 0)

Rip Rap [6000304060025] If "Failed", is control

measure in need of maintenance, Repair, or

800

Replacement?

Rip Rap [6000304060026] Control Measure is

810 operating effectively? (Range: 0 - 0)

Rip Rap [6000304060026] If "Failed", is control

measure in need of maintenance, Repair, or

820

Replacement?

Rip Rap [6000304060027] Control Measure is

830 operating effectively? (Range: 0 - 0)

Rip Rap [6000304060027] If "Failed", is control

measure in need of maintenance, Repair, or

840

Replacement?

Rip Rap [6000304060028] Control Measure is

850 operating effectively? (Range: 0 - 0)

Rip Rap [6000304060028] If "Failed", is control

measure in need of maintenance, Repair, or

860 Replacement?

Rip Rap [6000304060029] Control Measure is

870 operating effectively? (Range: 0 - 0) 
Rip Rap [6000304060029] If "Failed", is control

measure in need of maintenance, Repair, or

Replacement?

Rip Rap [6000304060030] Control Measure is

890 operating effectively? (Range: 0 - 0)

Rip Rap [6000304060030] If "Failed", is control

measure in need of maintenance, Repair, or

900 Replacement?

Rip Rap [6000304060031] Control Measure is

910 operating effectively? (Range: 0 - 0)

Rip Rap [6000304060031] If "Failed", is control

measure in need of maintenance, Repair, or

920 Replacement?

Rip Rap [6000304060032] Control Measure is

930 operating effectively? (Range: 0 - 0)

Rip Rap [6000304060032] If "Failed", is control

measure in need of maintenance, Repair, or

940 Replacement?

Rip Rap [6000304060033] Control Measure is

950 operating effectively? (Range: 0 - 0)

Rip Rap [6000304060033] If "Failed", is control

measure in need of maintenance, Repair, or

960 Replacement?

Rip Rap [6000304060044] Control Measure is

970 operating effectively? (Range: 0 - 0)

Rip Rap [6000304060044] If "Failed", is control

measure in need of maintenance, Repair, or

980 Replacement?

Earthen Berm [6000303010034] Control Measure is

990 operating effectively? (Range: 0 - 0)

Earthen Berm [6000303010034] If "Failed", is

control measure in need of maintenance, Repair, or

1000 Repiacement?

Earthen Berm [6000303010036] Control Measure is

1010 operating effectively? (Range: 0 - 0)

Earthen Berm [6000303010036] If "Failed", is

control measure in need of maintenance, Repair, or

1020

Replacement?

Earthen Berm [6000303010037] Control Measure is

1030 operating effectively? (Range: 0 - 0)

Earthen Berm [6000303010037] If "Failed", is

control measure in need of maintenance, Repair, or

1040

Replacement?

Earthen Berm [6000303010038] Control Measure is

1050 operating effectively? (Range: 0 - 0)

Earthen Berm [6000303010038] If "Failed", is

control measure in need of maintenance, Repair, or

1060 Replacement?

Earthen Berm [6000303010043] Control Measure is

1070 operating effectively? (Range: 0 - 0)

Earthen Berm [6000303010043] If "Failed", is

control measure in need of maintenance, Repair, or

1080

Replacement?

Sediment Basin [6000305020018] Control Measure

1090 is operating effectively? (Range: 0 - 0)

Sediment Basin [6000305020018] If "Failed", is

control measure in need of maintenance, Repair, or

1100 Replacement?

Sediment Basin [6000305020041] Control Measure

1110

is operating effectively? (Range: 0 - 0)

.

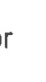


Sediment Basin [6000305020041] If "Failed", is control measure in need of maintenance, Repair, or Replacement?

Rock Check Dam [6000306010001] Control

1130 Measure is operating effectively? (Range: 0 - 0)

Rock Check Dam [6000306010001] If "Failed", is

control measure in need of maintenance, Repair, or

1140 Replacement?

Rock Check Dam [6000306010002] Control

1150 Measure is operating effectively? (Range: 0 - 0)

Rock Check Dam [6000306010002] If "Failed", is

control measure in need of maintenance, Repair, or

1160 Replacement?

Rock Check Dam [6000306010003] Control

1170 Measure is operating effectively? (Range: 0 - 0)

Rock Check Dam [6000306010003] If "Failed", is

control measure in need of maintenance, Repair, or

1180 Replacement?

Rock Check Dam [6000306010004] Control

1190 Measure is operating effectively? (Range: 0 - 0)

Rock Check Dam [6000306010004] If "Failed", is

control measure in need of maintenance, Repair, or

$1200 \quad$ Replacement?

Rock Check Dam [6000306010005] Control

1210 Measure is operating effectively? (Range: 0 - 0)

Rock Check Dam [6000306010005] If "Failed", is

control measure in need of maintenance, Repair, or

1220 Replacement?

Rock Check Dam [6000306010006] Control

1230 Measure is operating effectively? (Range: 0 - 0)

Rock Check Dam [6000306010006] If "Failed", is

control measure in need of maintenance, Repair, or

1240 Replacement?

Rock Check Dam [6000306010007] Control

1250 Measure is operating effectively? (Range: 0 - 0)

Rock Check Dam [6000306010007] If "Failed", is

control measure in need of maintenance, Repair, or

1260

Replacement?

Rock Check Dam [6000306010008] Control

1270 Measure is operating effectively? (Range: 0 - 0)

Rock Check Dam [6000306010008] If "Failed", is

control measure in need of maintenance, Repair, or

1280

Replacement?

Jersey Barriers [6000303170015] Control Measure

1290 is operating effectively?

Jersey Barriers [6000303170015] If "Failed", is

control measure in need of maintenance, Repair, or

1300

Replacement?

Jersey Barriers [6000303170021] Control Measure

1310 is operating effectively?

Jersey Barriers [6000303170021] If "Failed", is

control measure in need of maintenance, Repair, or

1320 Replacement?

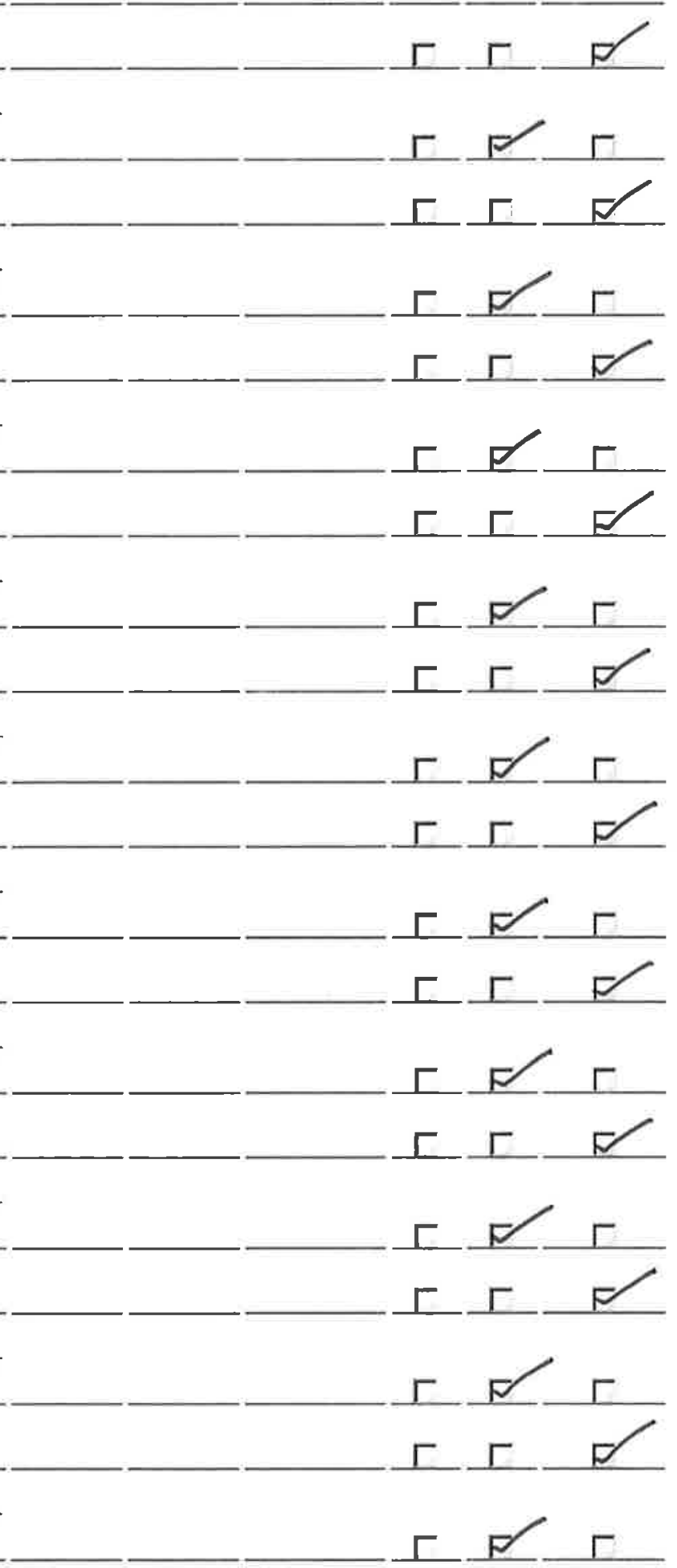

Area/Activity exposed to stormwater (identify needed mainteance or a description of corrective actions in relevant task comment).

Material loading/unloading and storage areas

1340 inspected?

Area/Activity controls adequate (appropriate,

1350 effective, and operating)? (Range: 0 - 0)

1360 Transfer areas for substances in bulk inspected?

1370

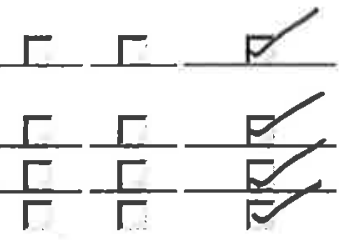


Area/Activity controls adequate (appropriate,

effective, and operating)? (Range: 0 - 0)

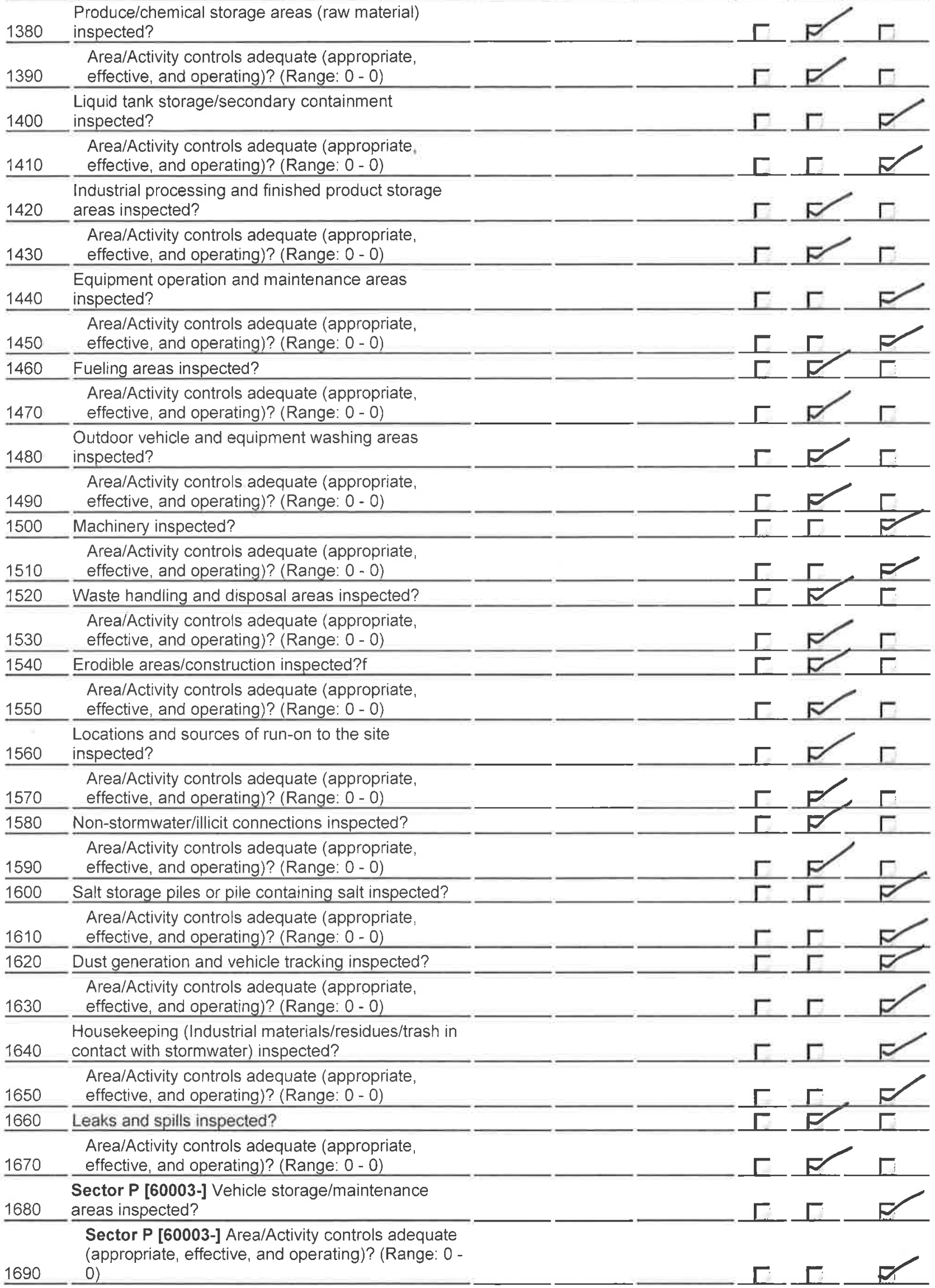


Non-Compliance

Free of incidents of observed non-compliance not

1710

associated with any of the above? (Range: 0 - 0 )

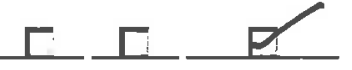

\section{Additional Control Measures}

Are permit requirements satisfied with existing control measure(s) not associated with any of the above? (Range: 0 - 0 )

\section{Labor}

Labor

Assigned

Work Date

Reg Hrs OT Hrs Other Hrs

Leonard Sandoval

$11 / 30 / 2016 /$

14

\section{Labor Report}

Completed: Failure:

Meter 1:

Meter 2:

Report:

Signature / Name

Date

Signature / Name

Date

Soft Vegetated Buffar Strip 6000302030042 - Inspected \& OK Envivo Soxx w Metalloxx 6000303200045 6000383200046 - Irspected \& OK 
WO ID:

Page

of

Signature (lead inspector):

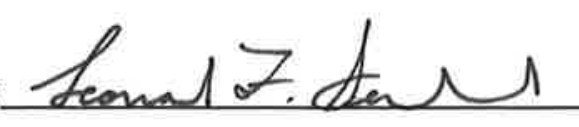

Date and Time:

$11 / 21 / 2016 \quad 2: 16$ arm.

"I confirm the information as recorded is true, accurate and complete."

CERTIFICATION STATEMENT

"I certify under penalty of law that this document and all attachments were prepared under my direction or supervision in accordance with a system designed to assure that qualified personnel properly gathered and evaluated the information submitted. Based on my inquiry of the person or persons who manage the system, or those persons directly responsible for gathering information, the information submitted is, to the best of my knowledge and belief, true, accurate, and complete. I am aware that there are significant penalties for submitting false information, including the possibility of fine and imprisonment for knowing violations".

(Signatory must meet definition in Section B.11.A, eg., FOD, Ops Mgr, DSESH Group Leader, EPC Group Leader)

Print name and title:

Signature:

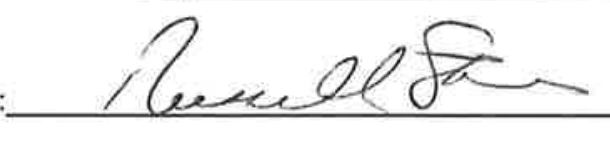
GL DOSHS-UTS

Date: $\quad 1 / 2 / 20 / 6$ 


\section{Maintenance Details}

Requested: 12/6/2016 3:51:00 PM

Procedure: MSGP Stormwater Industrial Routine Facility Inspection (EPC-CP-Form1020.1)

Last PM: $\quad 11 / 21 / 2016$

Project: Routine Facility Inspections Dec 2016 (P-MSGP-RI5158)
Target: $\quad$ 12/30/2016

Priority/Type: Normal/Inspection

Department: Utilities and Infrastructure

\section{MSGP Program \\ 몸 RG200.5 \\ 4) TA-60 Roads and Grounds}

Contact:

Phone:

Reason: MSGP Stormwater Industrial Routine Facility Inspection

Weather at inspection: W1

Special Instructions: NMR053195

\section{Tasks}

\# Description

Rating Meas. Initials Failed N/A Complete

Weather Information

Describe the weather at time of inspection in the

Weather lookup table. If "Other" is chosen, provide description in task comments of this line. Document the temperature $\left(\mathrm{F}^{\circ}\right)$ in the "Reading" field of this line.

20 Comments: Clear, no wind, 41F AKB $\Gamma-\Gamma+[$

\section{Within the Facility Boundary}

Is the facility free of new discharges of pollutants that have occurred since the last inspection? If "Failed",

40 describe

If "Failed" has a CAR been previously initiated for

50 this new discharge? (Range: 0 - 0 )

s the facility free of discharge of pollutants at the time of inspection? If "Failed" describe: (Range: 0 -

$\underline{60} \underline{0)}$

Is the facility free of evidence of, or the potential for pollutants entering the drainage system. If "Failed" describe: (Range: 0 - 0)

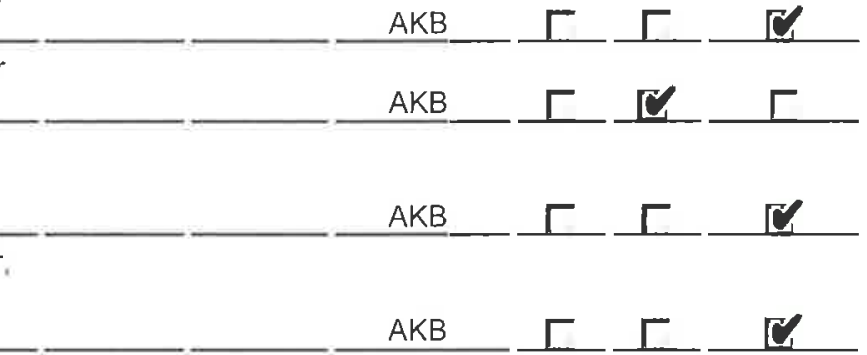

Outfall Inspection (needed maintenance and repairs, failed control measures that need replacement, or a description of corrective actions in relevant task comment)

Monitored Outfall [031] DO: Free of Evidence of

\begin{tabular}{|c|c|c|c|c|c|}
\hline 90 & Erosion? (Range: $0-0$ ) & AKB & $\Gamma$ & $\Gamma$ & {$[\mathbf{C}$} \\
\hline 100 & $\begin{array}{l}\text { Monitored Outfall [031] DO: Flow Dissipation } \\
\text { Devices Operating Effectively? (Range: } 0-0 \text { ) }\end{array}$ & AKB & $\Gamma$ & $\Gamma$ & C \\
\hline 110 & $\begin{array}{l}\text { Monitored Outfall [031] DO: Free of Evidence of } \\
\text { Pollutants in Discharges and/or Receiving Water? } \\
\text { (Range: } 0-0)\end{array}$ & AKB & $\Gamma$ & $\Gamma$ & $\mathbb{C}$ \\
\hline 120 & $\begin{array}{l}\text { Monitored Outfall [032] Free of Evidence of } \\
\text { Erosion? (Range: } 0 \text { - 0) }\end{array}$ & AKB & $\Gamma$ & $\Gamma$ & {[} \\
\hline 130 & $\begin{array}{l}\text { Monitored Outfall [032] Flow Dissipation Devices } \\
\text { Operating Effectively? (Range: } 0-0 \text { ) }\end{array}$ & AKB & $\Gamma$ & $\Gamma$ & $\mathrm{C}$ \\
\hline 140 & $\begin{array}{l}\text { Monitored Outfall [032] Free of Evidence of } \\
\text { Pollutants in Discharges and/or Receiving Water? } \\
\text { (Range: } 0-0 \text { ) }\end{array}$ & AKB & $\Gamma$ & $\Gamma$ & $\mathrm{C}$ \\
\hline 150 & & $\overrightarrow{A K B}$ & $\Gamma$ & $\Gamma$ & $\mathbf{C}$ \\
\hline
\end{tabular}


Monitored Outfall [036] Free of Evidence of Erosion? (Range: 0 - 0)

Monitored Outfall [036] Flow Dissipation Devices

160

Operating Effectively? (Range: 0 - 0) AKB $-\Gamma+\Gamma$

Monitored Outfall [036] Free of Evidence of

Pollutants in Discharges and/or Receiving Water?

170 (Range: 0 - 0)

Monitored Outfall [039] Free of Evidence of

180 Erosion? (Range: 0 - 0)

Monitored Outfall [039] Flow Dissipation Devices

190 Operating Effectively? (Range: 0 - 0)

Monitored Outfall [039] Free of Evidence of

Pollutants in Discharges and/or Receiving Water?

200 (Range: 0 - 0)

Monitored Outfall [042] Free of Evidence of

210 Erosion? (Range: 0 - 0)

Monitored Outfall [042] Flow Dissipation Devices

220 Operating Effectively? (Range: 0 - 0)

Monitored Outfall [042] Free of Evidence of

Pollutants in Discharges and/or Receiving Water?

230 (Range: 0 - 0)

Substantially Identical Outfall [030] Free of

240 Evidence of Erosion? (Range: 0 - 0)

Substantially Identical Outfall [030] Flow

Dissipation Devices Operating Effectively? (Range: 0

$250-0$ )

Substantially Identical Outfall [030] Free of

Evidence of Pollutants in Discharges and/or

260 Receiving Water? (Range: 0 - 0)

Substantially Identical Outfall [033] Free of

270 Evidence of Erosion? (Range: 0 - 0)

Substantially Identical Outfall [033] Flow

Dissipation Devices Operating Effectively? (Range: 0

$280-0)$

Substantially Identical Outfall [033] Free of

Evidence of Pollutants in Discharges and/or

290

Receiving Water? (Range: 0 -0)

Substantially Identical Outfall [034] Free of

300 Evidence of Erosion? (Range: 0 - 0)

Substantially Identical Outfall [034] Flow

Dissipation Devices Operating Effectively? (Range: 0 - 0)

Substantially Identical Outfall [034] Free of

Evidence of Pollutants in Discharges and/or

320 Receiving Water? (Range: 0 - 0)

Substantially Identical Outfall [035] Free of

330 Evidence of Erosion? (Range: 0 - 0)

Substantially Identical Outfall [035] Flow

Dissipation Devices Operating Effectively? (Range: 0

$340-0)$

Substantially Identical Outfall [035] Free of

Evidence of Pollutants in Discharges and/or

350 Receiving Water? (Range: 0 - 0)

Substantially Identical Outfall [037] Free of

360 Evidence of Erosion? (Range: 0 - 0)

Substantially Identical Outfall [037] Flow

Dissipation Devices Operating Effectively? (Range: 0

$\underline{370}-\underline{-0)}$

Substantially Identical Outfall [037] Free of

Evidence of Pollutants in Discharges and/or

$380 \quad$ Receiving Water? (Range: 0 - 0) AKB $\frac{\Gamma}{\Gamma} \frac{\Gamma}{\Gamma} \frac{\Gamma}{\complement}$ $\frac{\mathrm{AKB}}{\mathrm{AKB}} \frac{\Gamma}{\Gamma} \frac{\Gamma}{\Gamma} \frac{\Gamma / C}{\Gamma}$

$\frac{A K B}{A K B} \frac{\Gamma}{\Gamma} \frac{\Gamma}{A_{A K B}}-\frac{\Gamma}{\Gamma} \frac{\Gamma}{\Gamma}$

AKB $-\Gamma-\Gamma$

$\mathrm{AKB}-[-\Gamma$

$\mathrm{AKB}-\Gamma \Gamma-\mathrm{C}$

AKB $\Gamma \Gamma \Gamma$

$\mathrm{AKB}-\Gamma+\Gamma$

$\mathrm{AKB}-\Gamma+\Gamma$

AKB $-\Gamma-\Gamma$

AKB $\Gamma \Gamma$

$\mathrm{AKB}-\Gamma-\Gamma$ $\mathrm{AKB}-\Gamma+\Gamma$

$\mathrm{AKB}-\Gamma \Gamma$

AKB $-\Gamma \Gamma$
$\mathrm{AKB}-\Gamma+\Gamma$ $\mathrm{AKB}-\Gamma+\Gamma$ AKB $\Gamma+\Gamma$ $A K B+\Gamma+\Gamma$ AKB $\Gamma-\Gamma$ $\mathrm{AKB}-\Gamma-\Gamma$ 
Substantially Identical Outfall [038] Free of

Evidence of Erosion? (Range: 0 - 0)

Substantially Identical Outfall [038] Flow

Dissipation Devices Operating Effectively? (Range: 0

400 -0)

Substantially Identical Outfall [038] Free of

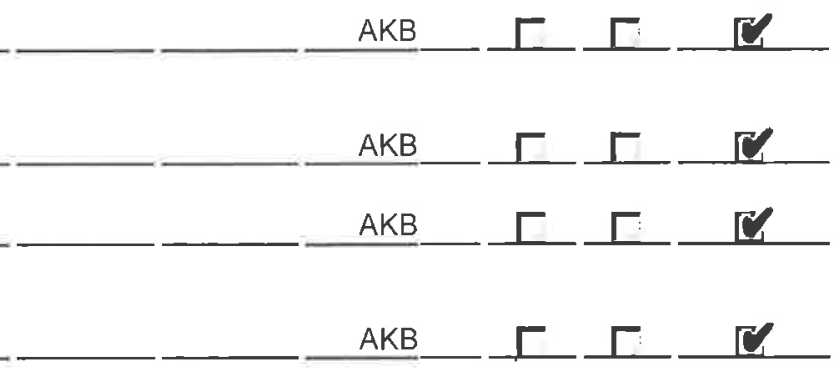

Evidence of Pollutants in Discharges and/or

410 Receiving Water? (Range: 0 - 0)

Substantially Identical Outfall [040] Free of

420 Evidence of Erosion? (Range: 0 - 0)

Substantially Identical Outfall [040] Flow

Dissipation Devices Operating Effectively? (Range: 0

$430-0)$

Substantially Identical Outfall [040] Free of

Evidence of Pollutants in Discharges and/or

$440 \quad$ Receiving Water? (Range: 0 - 0)

Substantially Identical Outfall [041] Free of

450 Evidence of Erosion? (Range: 0 - 0)

Substantially Identical Outfall [041] Flow

Dissipation Devices Operating Effectively? (Range: 0

460 - 0)

Substantially Identical Outfall [041] Free of

Evidence of Pollutants in Discharges and/or

$470 \quad$ Receiving Water? (Range: 0 - 0)

Control Measures (identify needed maintenance and repairs, failed control measures that need replacment, or a description of corrective actions in relevant task comments).

Asphalt Berm [6000303040019] Control Measure is

490 operating effectively? (Range: 0 - 0 ) $\mathrm{AKB}-\Gamma+\Gamma+\Gamma$

Asphalt Berm [6000303040019] If "Failed", is

control measure in need of maintenance, Repair, or

500 Replacement?

Asphalt Berm [6000303040020] Control Measure is

510 operating effectively? (Range: 0 - 0)

Asphalt Berm [6000303040020] If "Failed", is

control measure in need of maintenance, Repair, or

$\underline{520}$ Replacement?

Rock Channel/Swale [6000304030016] Control

530 Measure is operating effectively? (Range: $0-0$ )

Rock Channel/Swale [6000304030016] If "Failed",

is control measure in need of maintenance, Repair,

540 or Replacement?

Rock Channel/Swale [6000304030039] Control

550 Measure is operating effectively? (Range: 0 - 0)

Rock Channel/Swale [6000304030039] If "Failed"

is control measure in need of maintenance, Repair,

560 or Replacement?

Rock Channel/Swale [6000304030040] Control

570 Measure is operating effectively? (Range: 0 - 0)

Rock Channel/Swale [6000304030040] If "Failed"

is control measure in need of maintenance, Repair,

580

or Replacement?

Rock Channel/Swale [6000311010017] Control

590 Measure is operating effectively? (Range: 0 - 0)

Rock Channel/Swale [6000311010017] If "Failed",

is control measure in need of maintenance, Repair,

600

or Replacement?

Rip Rap [6000304060009] Control Measure is

610 operating effectively? (Range: 0 - 0)

Rip Rap [6000304060009] If "Failed", is control

measure in need of maintenance, Repair, or

620

Replacement?

$-\frac{A K B}{A K B}-\Gamma \frac{\Gamma}{\Gamma}-\Gamma$

$-\frac{A K B}{\Gamma-\Gamma} \frac{\Gamma}{\Gamma-\Gamma} \frac{\Gamma}{\Gamma}-\Gamma$

$-\frac{A K B}{C}-\frac{\Gamma}{A K B} \frac{\Gamma}{\Gamma-\Gamma}$

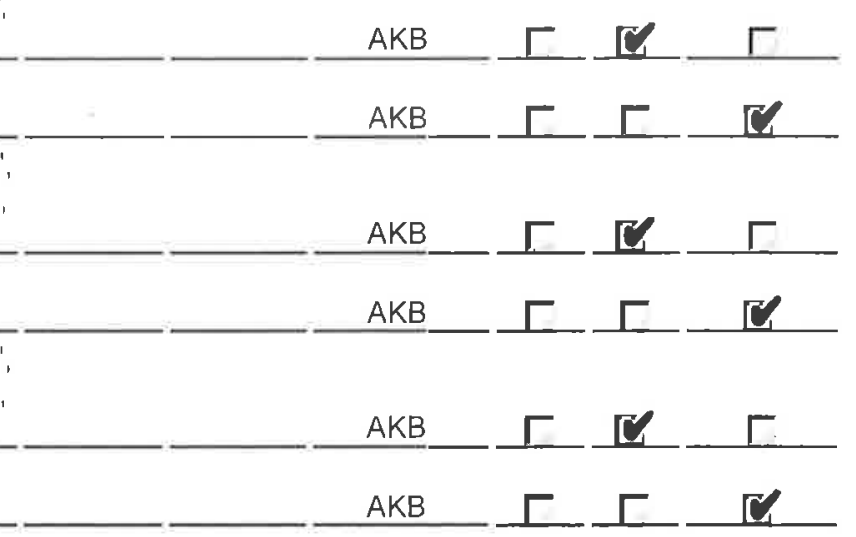

630

$\mathrm{AKB}$

$\mathrm{AKB}$

$-\frac{\Gamma}{\Gamma} \frac{\Gamma}{\Gamma} \frac{\Gamma}{\Gamma}$


Rip Rap [6000304060010] Control Measure is operating effectively? (Range: 0 - 0)

Rip Rap [6000304060010] If "Failed", is control

measure in need of maintenance, Repair, or

640

Replacement?

Rip Rap [6000304060011] Control Measure is

650 operating effectively? (Range: 0 - 0)

Rip Rap [6000304060011] If "Failed", is control

measure in need of maintenance, Repair, or

$660 \quad$ Replacement?

Rip Rap [6000304060012] Control Measure is

670 operating effectively? (Range: 0 - 0)

Rip Rap [6000304060012] If "Failed", is control

measure in need of maintenance, Repair, or

680

Replacement?

Rip Rap [6000304060013] Control Measure is

690 operating effectively? (Range: 0 - 0)

Rip Rap [6000304060013] If "Failed", is control

measure in need of maintenance, Repair, or

700 Replacement?

Rip Rap [6000304060014] Control Measure is

710 operating effectively? (Range: 0 - 0)

Rip Rap [6000304060014] If "Failed", is control

measure in need of maintenance, Repair, or

720 Replacement?

Rip Rap [6000304060022] Control Measure is

730 operating effectively? (Range: 0 - 0)

Rip Rap [6000304060022] If "Failed", is control

measure in need of maintenance, Repair, or

740 Replacement?

Rip Rap [6000304060023] Control Measure is

750 operating effectively? (Range: 0 - 0)

Rip Rap [6000304060023] If "Failed", is control

measure in need of maintenance, Repair, or

760

Replacement?

Rip Rap [6000304060024] Control Measure is

770 operating effectively? (Range: 0 - 0)

Rip Rap [6000304060024] If "Failed", is control

measure in need of maintenance, Repair, or

780

Replacement?

Rip Rap [6000304060025] Control Measure is

790 operating effectively? (Range: 0 - 0)

Rip Rap [6000304060025] If "Failed", is control

measure in need of maintenance, Repair, or

800

Replacement?

Rip Rap [6000304060026] Control Measure is

810 operating effectively? (Range: 0 - 0)

Rip Rap [6000304060026] If "Failed", is control

measure in need of maintenance, Repair, or

820

Replacement?

Rip Rap [6000304060027] Control Measure is

830 operating effectively? (Range: 0 - 0)

Rip Rap [6000304060027] If "Failed", is control

measure in need of maintenance, Repair, or

$840 \quad$ Replacement?

Rip Rap [6000304060028] Control Measure is

850 operating effectively? (Range: 0 - 0)

Rip Rap [6000304060028] If "Failed", is control

measure in need of maintenance, Repair, or

860

Replacement?

Rip Rap [6000304060029] Control Measure is

870

operating effectively? (Range: 0 - 0)

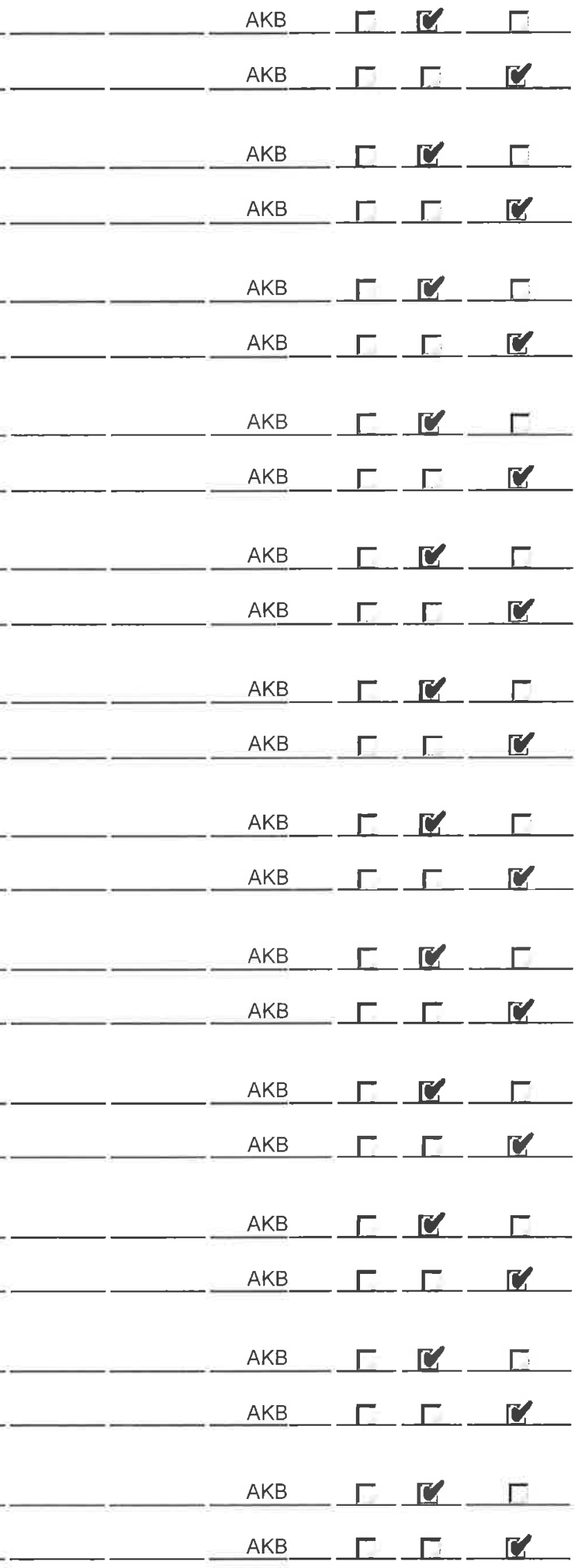


Rip Rap [6000304060030] Control Measure is

890 operating effectively? (Range: 0 - 0)

Rip Rap [6000304060030] If "Failed", is control

measure in need of maintenance, Repair, or

$900 \quad$ Replacement?

Rip Rap [6000304060031] Control Measure is

910 operating effectively? (Range: 0 - 0)

Rip Rap [6000304060031] If "Failed", is control

measure in need of maintenance, Repair, or

$920 \quad$ Replacement?

Rip Rap [6000304060032] Control Measure is

930 operating effectively? (Range: 0 - 0)

Rip Rap [6000304060032] If "Failed", is control

measure in need of maintenance, Repair, or

940 Replacement?

Rip Rap [6000304060033] Control Measure is

950 operating effectively? (Range: 0 - 0)

Rip Rap [6000304060033] If "Failed", is control

measure in need of maintenance, Repair, or

960

Replacement?

Rip Rap [6000304060044] Control Measure is

970 operating effectively? (Range: 0 - 0)

Rip Rap [6000304060044] If "Failed", is control

measure in need of maintenance, Repair, or

980 Replacement?

Earthen Berm [6000303010034] Control Measure is

990 operating effectively? (Range: 0 - 0)

Earthen Berm [6000303010034] If "Failed", is

control measure in need of maintenance, Repair, or

Earthen Berm [6000303010036] Control Measure is

operating effectively? (Range: 0 - 0) AKB $\Gamma+\Gamma$

$-1-1$

$\mathrm{AKB}-\Gamma+\mathrm{C}-\Gamma$

AKB $匚 \Gamma-[$

Earthen Berm [6000303010036] If "Failed", is

control measure in need of maintenance, Repair, or

1020 Replacement?

Earthen Berm [6000303010037] Control Measure is

1030 operating effectively? (Range: 0 - 0)

Earthen Berm [6000303010037] If "Failed", is

control measure in need of maintenance, Repair, or

1040 Replacement?

Earthen Berm [6000303010038] Control Measure is

1050 operating effectively? (Range: 0 - 0)

Earthen Berm [6000303010038] If "Failed", is

control measure in need of maintenance, Repair, or

1060 Replacement?

Earthen Berm [6000303010043] Control Measure is

1070 operating effectively? (Range: 0 - 0)

Earthen Berm [6000303010043] If "Failed", is

control measure in need of maintenance, Repair, or

1080 Replacement?

Sediment Basin [6000305020018] Control Measure

1090 is operating effectively? (Range: 0 - 0)

Sediment Basin [6000305020018] If "Failed", is

control measure in need of maintenance, Repair, or

1100 Replacement?

Sediment Basin [6000305020041] Control Measure

1110 is operating effectively? (Range: 0 - 0)

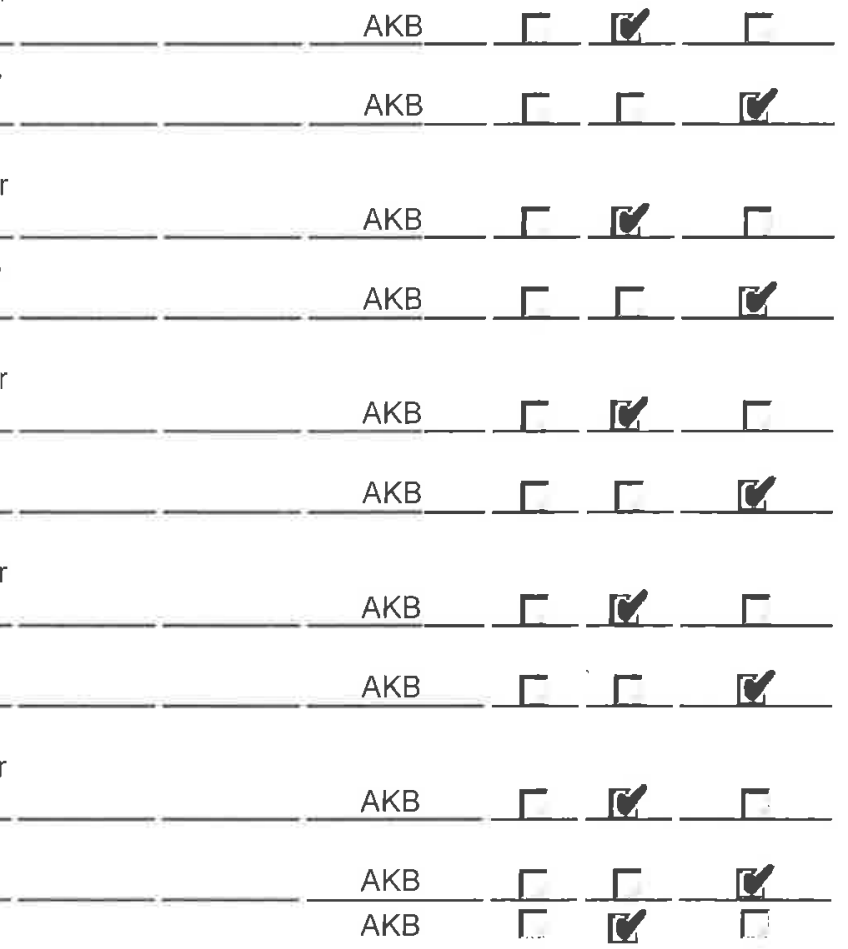


Sediment Basin [6000305020041] If "Failed", is control measure in need of maintenance, Repair, or Replacement?

\begin{tabular}{|c|c|c|c|c|c|}
\hline 1130 & $\begin{array}{l}\text { Rock Check Dam [6000306010001] Control } \\
\text { Measure is operating effectively? (Range: } 0-0 \text { ) }\end{array}$ & AKB & $\Gamma$ & $\Gamma$ & $\mathbf{C}$ \\
\hline 1140 & $\begin{array}{l}\text { Rock Check Dam [6000306010001] If "Failed", is } \\
\text { control measure in need of maintenance, Repair, or } \\
\text { Replacement? }\end{array}$ & $\mathrm{AKB}$ & $\Gamma$ & C & $\Gamma$ \\
\hline 1150 & $\begin{array}{l}\text { Rock Check Dam [6000306010002] Control } \\
\text { Measure is operating effectively? (Range: } 0-0 \text { ) }\end{array}$ & $\mathrm{AKB}$ & $\Gamma$ & $\Gamma$ & $\mathrm{C}$ \\
\hline 1160 & $\begin{array}{l}\text { Rock Check Dam [6000306010002] If "Failed", is } \\
\text { control measure in need of maintenance, Repair, or } \\
\text { Replacement? }\end{array}$ & AKB & $\Gamma$ & $\boldsymbol{C}$ & $\Gamma$ \\
\hline 1170 & $\begin{array}{l}\text { Rock Check Dam [6000306010003] Control } \\
\text { - Measure is operating effectively? (Range: } 0-0 \text { ) }\end{array}$ & AKB & $\Gamma$ & $\Gamma$ & $\boldsymbol{C}$ \\
\hline 1180 & $\begin{array}{l}\text { Rock Check Dam [6000306010003] If "Failed", is } \\
\text { control measure in need of maintenance, Repair, or } \\
\text { Replacement? }\end{array}$ & AKB & $\Gamma$ & {$[\mathbf{C}$} & $\Gamma$ \\
\hline 1190 & $\begin{array}{l}\text { Rock Check Dam [6000306010004] Control } \\
\text { Measure is operating effectively? (Range: } 0-0 \text { ) }\end{array}$ & AKB & $\Gamma$ & $\Gamma$ & C \\
\hline 1200 & $\begin{array}{l}\text { Rock Check Dam [6000306010004] If "Failed", is } \\
\text { control measure in need of maintenance, Repair, or } \\
\text { Replacement? }\end{array}$ & AKB & $ᄃ$ & $\boldsymbol{C}$ & $\Gamma$ \\
\hline 1210 & $\begin{array}{l}\text { Rock Check Dam [ } 6000306010005] \text { Control } \\
\text { Measure is operating effectively? (Range: } 0-0 \text { ) }\end{array}$ & AKB & $\Gamma$ & $\Gamma$ & C \\
\hline 1220 & $\begin{array}{l}\text { Rock Check Dam [6000306010005] If "Failed", is } \\
\text { control measure in need of maintenance, Repair, or } \\
\text { Replacement? }\end{array}$ & AKB & $\Gamma$ & 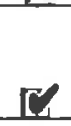 & $\Gamma$ \\
\hline 1230 & $\begin{array}{l}\text { Rock Check Dam [6000306010006] Control } \\
\text { Measure is operating effectively? (Range: } 0-0 \text { ) }\end{array}$ & AKB & $\Gamma$ & $\Gamma$ & C \\
\hline 1240 & $\begin{array}{l}\text { Rock Check Dam [6000306010006] If "Failed", is } \\
\text { control measure in need of maintenance, Repair, or } \\
\text { Replacement? }\end{array}$ & AKB & $\Gamma$ & $\Gamma$ & $\Gamma$ \\
\hline 1250 & $\begin{array}{l}\text { Rock Check Dam [6000306010007] Control } \\
\text { Measure is operating effectively? (Range: } 0-0 \text { ) }\end{array}$ & AKB & $\Gamma$ & $\Gamma$ & $\boldsymbol{C}$ \\
\hline 1260 & $\begin{array}{l}\text { Rock Check Dam [6000306010007] If "Failed", is } \\
\text { control measure in need of maintenance, Repair, or } \\
\text { Replacement? }\end{array}$ & AKB & $\Gamma$ & $\boldsymbol{C}$ & $\Gamma$ \\
\hline 1270 & $\begin{array}{l}\text { Rock Check Dam [ } 6000306010008] \text { Control } \\
\text { Measure is operating effectively? (Range: } 0-0 \text { ) }\end{array}$ & $\mathrm{AKB}$ & $\Gamma$ & $\Gamma$ & [C \\
\hline 1280 & $\begin{array}{l}\text { Rock Check Dam [6000306010008] If "Failed", is } \\
\text { control measure in need of maintenance, Repair, or } \\
\text { Replacement? }\end{array}$ & AKB & $\Gamma$ & $\boldsymbol{C}$ & $\Gamma$ \\
\hline 1290 & $\begin{array}{l}\text { Jersey Barriers [6000303170015] Control Measure } \\
\text { is operating effectively? }\end{array}$ & $\mathrm{AKB}$ & ᄃ & $\Gamma$ & C \\
\hline 1300 & $\begin{array}{l}\text { Jersey Barriers [6000303170015] If "Failed", is } \\
\text { control measure in need of maintenance, Repair, or } \\
\text { Replacement? }\end{array}$ & $A K B$ & $\Gamma$ & $\boldsymbol{C}$ & $\Gamma$ \\
\hline 1310 & $\begin{array}{l}\text { Jersey Barriers [6000303170021] Control Measure } \\
\text { is operating effectively? }\end{array}$ & AKB & $ᄃ$ & $\Gamma$ & $\boldsymbol{C}$ \\
\hline 1320 & $\begin{array}{l}\text { Jersey Barriers [ } 6000303170021] \text { If "Failed", is } \\
\text { control measure in need of maintenance, Repair, or } \\
\text { Replacement? }\end{array}$ & AKB & $\Gamma$ & ⿷ & $\Gamma$ \\
\hline 1330 & $\begin{array}{l}\text { EnviroSoxx w/ MetalLoxx [6000303200045] Control } \\
\text { Measure is operating effectively? }\end{array}$ & $A K B$ & $\Gamma$ & $\Gamma$ & $\mathbb{C}$ \\
\hline 1340 & $\begin{array}{l}\text { EnviroSoxx w/ MetalLoxx [6000303200045] If } \\
\text { "Failed", is control measure in need of } \\
\text { maintenance, Repair, or Replacement? }\end{array}$ & $\mathrm{AKB}$ & $\Gamma$ & [ & $\Gamma$ \\
\hline 1350 & $\begin{array}{l}\text { EnviroSoxx w/ MetalLoxx [6000303200046] Control } \\
\text { Measure is operating effectively? }\end{array}$ & AKB & $\Gamma$ & $\Gamma$ & [C \\
\hline 1360 & & $A K B$ & $\Gamma$ & $\widetilde{C}$ & $\Gamma$ \\
\hline
\end{tabular}


EnviroSoxx w/ MetalLoxx [6000303200046] If

"Failed", is control measure in need of

maintenance, Repair, or Replacement?

\begin{tabular}{|c|c|c|c|c|c|}
\hline 1370 & $\begin{array}{l}\text { EnviroSoxx w/ MetalLoxx [6000303200047] Control } \\
\text { Measure is operating effectively? }\end{array}$ & $A K B$ & $\Gamma$ & $\Gamma$ & $C$ \\
\hline 1380 & $\begin{array}{l}\text { EnviroSoxx w/ MetalLoxx [6000303200047] If } \\
\text { "Failed", is control measure in need of } \\
\text { maintenance, Repair, or Replacement? }\end{array}$ & AKB & $\Gamma$ & C & $\Gamma$ \\
\hline 1390 & $\begin{array}{l}\text { Permanent Vegetation Vegetative Buffer Strip } \\
\text { [6000302030042] Control Measure is operating } \\
\text { effectively? (Range: } 0-0 \text { ) }\end{array}$ & AKB & $\Gamma$ & $\Gamma$ & $\mathbf{C}$ \\
\hline 1400 & $\begin{array}{l}\text { Permanent Vegetation Vegetative Buffer Strip } \\
\text { [6000302030042] If "Failed", is control measure in } \\
\text { need of maintenance, Repair, or Replacement? }\end{array}$ & $\mathrm{AKB}$ & $\Gamma$ & $\mathrm{C}$ & $\Gamma$ \\
\hline
\end{tabular}

Area/Activity exposed to stormwater (identify needed mainteance or a description of corrective actions in relevant task comment).

Material loading/unloading and storage areas

1420 inspected?

Area/Activity controls adequate (appropriate

1430 effective, and operating)? (Range: 0 - 0)

1440 Transfer areas for substances in bulk inspected?

Area/Activity controls adequate (appropriate,

1450 effective, and operating)? (Range: 0 - 0)

Produce/chemical storage areas (raw material)

1460 inspected?

Area/Activity controls adequate (appropriate,

1470 effective, and operating)? (Range: 0 - 0 )

Liquid tank storage/secondary containment

1480 inspected?

Area/Activity controls adequate (appropriate,

1490 effective, and operating)? (Range: 0 - 0)

Industrial processing and finished product storage

1500 areas inspected?

Area/Activity controls adequate (appropriate,

1510 effective, and operating)? (Range: 0 - 0)

Equipment operation and maintenance areas

1520 inspected?

Area/Activity controls adequate (appropriate,

1530 effective, and operating)? (Range: 0 - 0)

1540 Fueling areas inspected?

Area/Activity controls adequate (appropriate,

1550 effective, and operating)? (Range: 0 - 0)

Outdoor vehicle and equipment washing areas

1560 inspected?

Area/Activity controls adequate (appropriate,

1570 effective, and operating)? (Range: 0 - 0)

1580 Machinery inspected?

Area/Activity controls adequate (appropriate, Entacd into MSGP

effective, and operating)? (Range: 0 - 0 )

effective, and operating)? (Range: 0 - 0 )
Comments: Small spots of oil drippings from tracking databose as CAR 1035
heavy equipment present in vehicle storage

area near structure 60-0233; heavy equipment

storage area south of SIO 033; heavy equipment

storage area southwest of covered salt storage

building; and under heavy equipment located

along south boundary fence east of structure

$1590 \quad 336$.

1600 Waste handling and disposal areas inspected?

$-\frac{A K B}{A K B} \frac{\Gamma}{\Gamma} \frac{\Gamma}{\Gamma} \frac{\Gamma}{\Gamma} \frac{\Gamma}{\frac{A K B}{C K B}} \frac{\Gamma}{\Gamma} \frac{\Gamma}{\Gamma} \frac{\Gamma}{\Gamma}$

1610

Area/Activity controls adequate (appropriate

1620 Erodible areas/construction inspected?f 
Comments: Small area of fire hydrant line work

south of SIO 034. Stormwater controls in place

around temporary dirt pile (eco-block and

gravel bags). Berm -0043 controls potential

runoff.

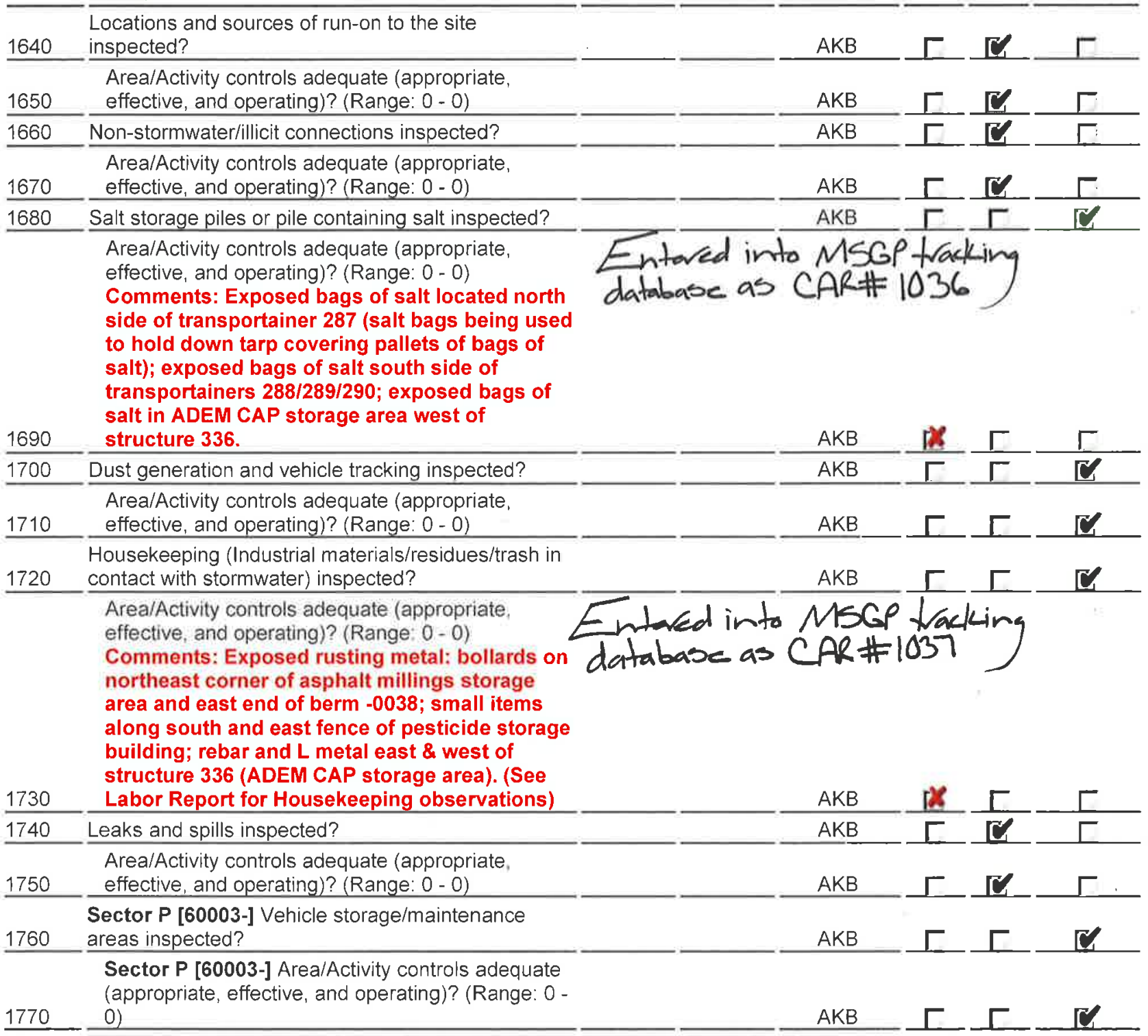

Non-Compliance

Free of incidents of observed non-compliance not

1790 associated with any of the above? (Range: 0 - 0)

$\mathrm{AKB}-\Gamma \Gamma$

\section{Additional Control Measures}

Are permit requirements satisfied with existing control

measure(s)? If "Failed" describe additional control

1810 measures needed. (Range: 0 - 0)

$\mathrm{AKB}-\Gamma \Gamma$

\section{Labor Report}

$12 / 21 / 2016$

Completed: 11:05:00 AM

Failure:
Meter(s): 2

Report: Housekeeping needed (e.g. trash pickup); along boundary north and east of asphalt milling storage area; in sediment basin -0041 , between transportainers $320 / 321$; \& area north of $60-0199$. Trash can west side of transportainer 293 needs lid; ADEM CAP storage area has trash, unsecured tarps, deteriorated bags of soil 
stabilizer (fiber) and plaster(?) exposing material to stormwater.

Exposed metal plates found at west end of rock channel -0040. These are believed earmarked for recycle pending authorization of work package. 
WO ID:

Page

of

Signature (lead inspector):

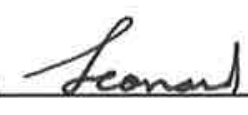

F. Amman

Date and Time: $12 / 21 / 2016 \quad 11: 00 \mathrm{arm}$.

"I confirm the information as recorded is true, accurate and complete."

CERTIFICATION STATEMENT

"I certify under penalty of law that this document and all attachments were prepared under my direction or supervision in accordance with a system designed to assure that qualified personnel properly gathered and evaluated the information submitted. Based on my inquiry of the person or persons who manage the system, or those persons directly responsible for gathering information, the information submitted is, to the best of my knowledge and belief, true, accurate, and complete. I am aware that there are significant penalties for submitting false information, including the possibility of fine and imprisonment for knowing violations".

(Signatory must meet definition in Section B.11.A, eg., FOD, Ops Mgr, DSESH Group Leader, EPC Group Leader)

Print name and title: Store GL destis-utas

Signature:

Date:

$1 / 5 / 2017$ 


\section{Maintenance Details}

\section{Requested: 1/23/2017 10:55:06 AM \\ Procedure: MSGP Stormwater Industrial Routine Facility Inspection (EPC-CP-Form- 1020.1)}

Last PM: $\quad$ 12/21/2016

Project: Routine Facility Inspections Jan 21017 (P-MSGP-RI5159)

Reason: 2017 January Inspections Weather at inspection:

Special Instructions: NMR053195
Target: $\quad 1 / 31 / 2017$

Priority/Type: Normal / Inspection

Department: Utilities and Infrastructure
1 MSGP Program 高 RG200.5

is TA-60 Roads and Grounds

Contact:

Phone:

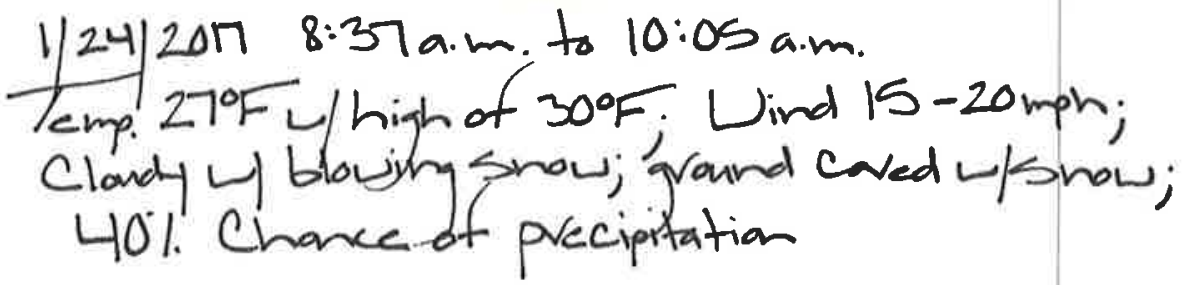

\section{-Tasks}

\# Description

Weather Information

Describe the weather at time of inspection in the Weather lookup table. If "Other" is chosen, provide description in task comments of this line. Document the temperature $\left(\mathrm{F}^{\circ}\right)$ in the "Reading" field of this $20 \quad$ line.

\section{Within the Facility Boundary}

Is the facility free of new discharges of pollutants that have occurred since the last inspection? If "Failed", 40 describe:

If "Failed" has a CAR been previously initiated for
this new discharge? (Range: 0 - 0 )
Is the facility free of discharge of pollutants at the
time of inspection? If "Failed" describe: (Range: 0 -
$00 \quad \frac{0 \text { ) }}{60}$ Is the facility free of evidence of, or the potential for,
pollutants entering the drainage system. If "Failed"
describe: (Range: 0 - 0 )

Outfall Inspection (needed maintenance and repairs, failed control measures that need replacement, or a description of corrective actions in relevant task comment)

Monitored Outfall [031] DO: Free of Evidence of

$90 \quad$ Erosion? (Range: 0 - 0)

Monitored Outfall [031] DO: Flow Dissipation

100 Devices Operating Effectively? (Range: 0 - 0)

Monitored Outfall [031] DO: Free of Evidence of

Pollutants in Discharges and/or Receiving Water?

110 (Range: 0 - 0)

Monitored Outfall [032] Free of Evidence of

120 Erosion? (Range: $0-0)$

Monitored Outfall [032] Flow Dissipation Devices

130 Operating Effectively? (Range: 0 - 0)

Monitored Outfall [032] Free of Evidence of

Pollutants in Discharges and/or Receiving Water?

140 (Range: 0 - 0)

Monitored Outfall [036] Free of Evidence of

150 Erosion? (Range: $0-0$ ) 
160 Monitored Outfall [036] Flow Dissipation Devices

$\Gamma \Gamma$

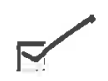

Operating Effectively? (Range: 0 - 0)

Monitored Outfall [036] Free of Evidence of

Pollutants in Discharges and/or Receiving Water?

170 (Range: 0 - 0)

Monitored Outfall [039] Free of Evidence of

180 Erosion? (Range: 0 - 0)

Monitored Outfall [039] Flow Dissipation Devices

190 Operating Effectively? (Range: 0 - 0)

Monitored Outfall [039] Free of Evidence of

Pollutants in Discharges and/or Receiving Water?

$200 \quad$ (Range: 0 - 0)

Monitored Outfall [042] Free of Evidence of

210 Erosion? (Range: 0 - 0)

Monitored Outfall [042] Flow Dissipation Devices

220 Operating Effectively? (Range: 0 - 0)

Monitored Outfall [042] Free of Evidence of

Pollutants in Discharges and/or Receiving Water?

230

(Range: 0 - 0)

Substantially Identical Outfall [030] Free of

240 Evidence of Erosion? (Range: 0 - 0)

Substantially Identical Outfall [030] Flow

Dissipation Devices Operating Effectively? (Range: 0

250

-0)

Substantially Identical Outfall [030] Free of

Evidence of Pollutants in Discharges and/or

260 Receiving Water? (Range: 0 - 0)

Substantially Identical Outfall [033] Free of

$270 \quad$ Evidence of Erosion? (Range: 0 - 0)

Substantially Identical Outfall [033] Flow

Dissipation Devices Operating Effectively? (Range: 0

280

- 0)

Substantially Identical Outfall [033] Free of

Evidence of Pollutants in Discharges and/or

$290 \quad$ Receiving Water? (Range: 0 - 0)

Substantially Identical Outfall [034] Free of

$300 \quad$ Evidence of Erosion? (Range: 0 - 0 )

Substantially Identical Outfall [034] Flow

Dissipation Devices Operating Effectively? (Range: 0

$310-0$ )

Substantially Identical Outfall [034] Free of

Evidence of Pollutants in Discharges and/or

320 Receiving Water? (Range: 0 - 0)

Substantially Identical Outfall [035] Free of

330 Evidence of Erosion? (Range: 0 - 0)

Substantially Identical Outfall [035] Flow

Dissipation Devices Operating Effectively? (Range: 0

340

- 0)

Substantially Identical Outfall [035] Free of

Evidence of Pollutants in Discharges and/or

350 Receiving Water? (Range: 0 - 0)

Substantially Identical Outfall [037] Free of

$360 \quad$ Evidence of Erosion? (Range: 0 - 0)

Substantially Identical Outfall [037] Flow

Dissipation Devices Operating Effectively? (Range: 0

$370-0)$

Substantially Identical Outfall [037] Free of

Evidence of Pollutants in Discharges and/or

380

Receiving Water? (Range: 0 - 0)

Substantially Identical Outfall [038] Free of

390 Evidence of Erosion? (Range: 0 - 0)

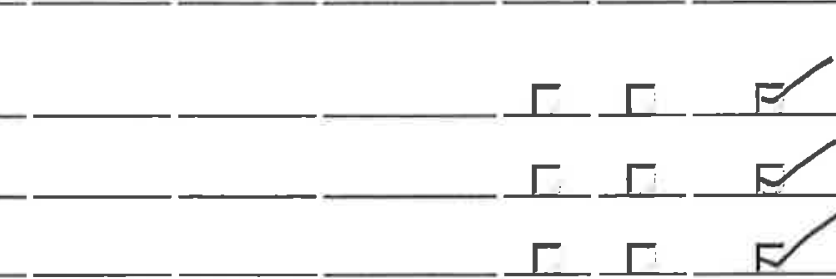

$-\cdots+\Gamma-\Gamma$

-


Substantially Identical Outfall [038] Flow

Dissipation Devices Operating Effectively? (Range: 0

$-0)$

Substantially Identical Outfall [038] Free of

Evidence of Pollutants in Discharges and/or

$410 \quad$ Receiving Water? (Range: 0 - 0)

Substantially Identical Outfall [040] Free of

420 Evidence of Erosion? (Range: 0 - 0)

Substantially Identical Outfall [040] Flow

Dissipation Devices Operating Effectively? (Range: 0

$430-0)$

Substantially Identical Outfall [040] Free of

Evidence of Pollutants in Discharges and/or

$440 \quad$ Receiving Water? (Range: 0 - 0)

Substantially Identical Outfall [041] Free of

450 Evidence of Erosion? (Range: 0 - 0)

Substantially Identical Outfall [041] Flow

Dissipation Devices Operating Effectively? (Range: 0

460

-0)

Substantially Identical Outfall [041] Free of

Evidence of Pollutants in Discharges and/or

$470 \quad$ Receiving Water? (Range: 0 - 0)

Control Measures (identify needed maintenance and repairs, failed control measures that need replacment, or a description of corrective actions in relevant task comments).

Asphalt Berm [6000303040019] Control Measure is

490 operating effectively? (Range: 0 - 0)

Asphalt Berm [6000303040019] If "Failed", is

control measure in need of maintenance, Repair, or

$500 \quad$ Replacement?

Asphalt Berm [6000303040020] Control Measure is

510 operating effectively? (Range: 0 - 0)

Asphalt Berm [6000303040020] If "Failed", is

control measure in need of maintenance, Repair, or

520 Replacement?

Rock Channel/Swale [6000304030016] Control

530 Measure is operating effectively? (Range: 0 - 0 )

Rock Channel/Swale [6000304030016] If "Failed",

is control measure in need of maintenance, Repair,

540 or Replacement?

Rock Channel/Swale [6000304030039] Control

550 Measure is operating effectively? (Range: 0 - 0)

Rock Channel/Swale [6000304030039] If "Failed",

is control measure in need of maintenance, Repair,

$\underline{560}$ or Replacement?

Rock Channel/Swale [6000304030040] Control

570 Measure is operating effectively? (Range: 0 - 0)

Rock Channel/Swale [6000304030040] If "Failed"

is control measure in need of maintenance, Repair

580

or Replacement?

Rock Channel/Swale [6000311010017] Control

590 Measure is operating effectively? (Range: 0 - 0)

Rock Channel/Swale [6000311010017] If "Failed"

is control measure in need of maintenance, Repair,

600

or Replacement?

Rip Rap [6000304060009] Control Measure is

610 operating effectively? (Range: 0 - 0)

Rip Rap [6000304060009] If "Failed", is control

measure in need of maintenance, Repair, or

620

Replacement?

630

Rip Rap [6000304060010] Control Measure is

640

operating effectively? (Range: 0 - 0)

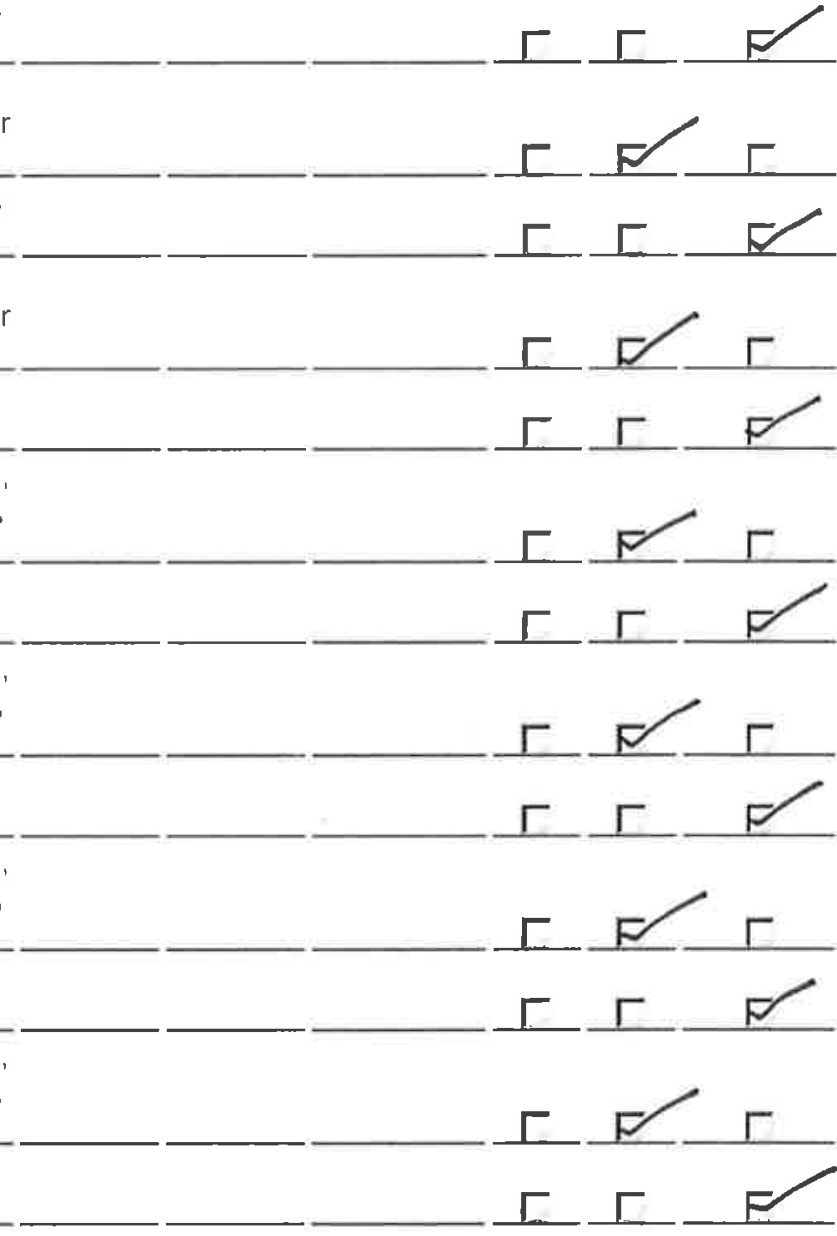


Rip Rap [6000304060010] If "Failed", is control measure in need of maintenance, Repair, or Replacement?

Rip Rap [6000304060011] Control Measure is

650 operating effectively? (Range: 0 - 0)

Rip Rap [6000304060011] If "Failed", is control

measure in need of maintenance, Repair, or

660

Replacement?

Rip Rap [6000304060012] Control Measure is

670 operating effectively? (Range: 0 - 0)

Rip Rap [6000304060012] If "Failed", is control

measure in need of maintenance, Repair, or

680

Replacement?

Rip Rap [6000304060013] Control Measure is

690 operating effectively? (Range: 0 - 0)

Rip Rap [6000304060013] If "Failed", is control

measure in need of maintenance, Repair, or

700

Replacement?

Rip Rap [6000304060014] Control Measure is

710 operating effectively? (Range: 0 - 0)

Rip Rap [6000304060014] If "Failed", is control

measure in need of maintenance, Repair, or

720 Replacement?

Rip Rap [6000304060022] Control Measure is

730 operating effectively? (Range: 0 - 0)

Rip Rap [6000304060022] If "Failed", is control

measure in need of maintenance, Repair, or

740 Replacement?

Rip Rap [6000304060023] Control Measure is

750 operating effectively? (Range: 0 - 0)

Rip Rap [6000304060023] If "Failed", is control

measure in need of maintenance, Repair, or

760 Replacement?

Rip Rap [6000304060024] Control Measure is

770 operating effectively? (Range: 0 - 0)

Rip Rap [6000304060024] If "Failed", is control

measure in need of maintenance, Repair, or

$780 \quad$ Replacement?

Rip Rap [6000304060025] Control Measure is

790 operating effectively? (Range: 0 - 0)

Rip Rap [6000304060025] If "Failed", is control

measure in need of maintenance, Repair, or

800

Replacement?

Rip Rap [6000304060026] Control Measure is

810 operating effectively? (Range: 0 - 0)

Rip Rap [6000304060026] If "Failed", is control

measure in need of maintenance, Repair, or

820

Replacement?

Rip Rap [6000304060027] Control Measure is

830 operating effectively? (Range: 0 - 0)

Rip Rap [6000304060027] If "Failed", is control

measure in need of maintenance, Repair, or

840 Replacement?

Rip Rap [6000304060028] Control Measure is

850 operating effectively? (Range: 0 - 0 )

Rip Rap [6000304060028] If "Failed", is control

measure in need of maintenance, Repair, or

860

Replacement?

Rip Rap [6000304060029] Control Measure is

$\underline{870}$

operating effectively? (Range: 0 - 0 )

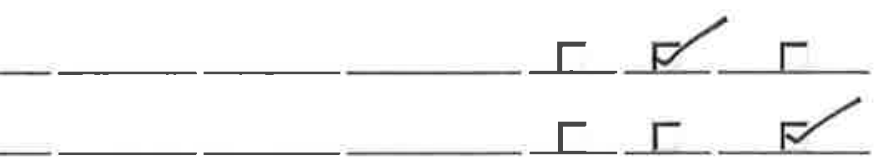

$-\longrightarrow \Gamma \Gamma$


Rip Rap [6000304060029] If "Failed", is control measure in need of maintenance, Repair, or Replacement?

Rip Rap [6000304060030] Control Measure is

890 operating effectively? (Range: 0 - 0)

Rip Rap [6000304060030] If "Failed", is control measure in need of maintenance, Repair, or

900 Replacement?

Rip Rap [6000304060031] Control Measure is

910 operating effectively? (Range: 0 - 0)

Rip Rap [6000304060031] If "Failed", is control measure in need of maintenance, Repair, or

920 Replacement?

Rip Rap [6000304060032] Control Measure is

930 operating effectively? (Range: 0 - 0)

Rip Rap [6000304060032] If "Failed", is control measure in need of maintenance, Repair, or

940 Replacement?

Rip Rap [6000304060033] Control Measure is

950 operating effectively? (Range: 0 - 0)

Rip Rap [6000304060033] If "Failed", is control

measure in need of maintenance, Repair, or

960 Replacement?

Rip Rap [6000304060044] Control Measure is

970 operating effectively? (Range: 0 - 0)

Rip Rap [6000304060044] If "Failed", is control

measure in need of maintenance, Repair, or

$980 \quad$ Replacement?

Earthen Berm [6000303010034] Control Measure is

990 operating effectively? (Range: 0 - 0)

Earthen Berm [6000303010034] If "Failed", is

control measure in need of maintenance, Repair, or

1000 Replacement?

Earthen Berm [6000303010036] Control Measure is

1010 operating effectively? (Range: 0 - 0)

Earthen Berm [6000303010036] If "Failed", is

control measure in need of maintenance, Repair, or

1020 Replacement?

Earthen Berm [6000303010037] Control Measure is

1030 operating effectively? (Range: 0 - 0)

Earthen Berm [6000303010037] If "Failed", is

control measure in need of maintenance, Repair, or

1040 Replacement?

Earthen Berm [6000303010038] Control Measure is

1050 operating effectively? (Range: 0 - 0)

Earthen Berm [6000303010038] If "Failed", is

control measure in need of maintenance, Repair, or

1060 Replacement?

Earthen Berm [6000303010043] Control Measure is

1070 operating effectively? (Range: 0 - 0)

Earthen Berm [6000303010043] If "Failed", is

control measure in need of maintenance, Repair, or

1080 Replacement?

Sediment Basin [6000305020018] Control Measure

1090 is operating effectively? (Range: 0 - 0)

Sediment Basin [6000305020018] If "Failed", is

control measure in need of maintenance, Repair, or

1100

Replacement?

Sediment Basin [6000305020041] Control Measure

1110 is operating effectively? (Range: 0 - 0)

$-\frac{\Gamma}{\Gamma} \frac{\Gamma}{\Gamma}$

$-\frac{\Gamma}{\Gamma}+\Gamma \frac{\Gamma}{\Gamma / \Gamma /}$

$-\frac{\Gamma}{\Gamma-\Gamma} \frac{\Gamma}{\Gamma-P}$

$+-\frac{\Gamma}{\Gamma-\frac{\Gamma}{\Gamma}}$

$-\frac{\Gamma}{\Gamma} \frac{\Gamma}{\Gamma}+\frac{\Gamma}{\Gamma}$


Sediment Basin [6000305020041] If "Failed", is control measure in need of maintenance, Repair, or Replacement?

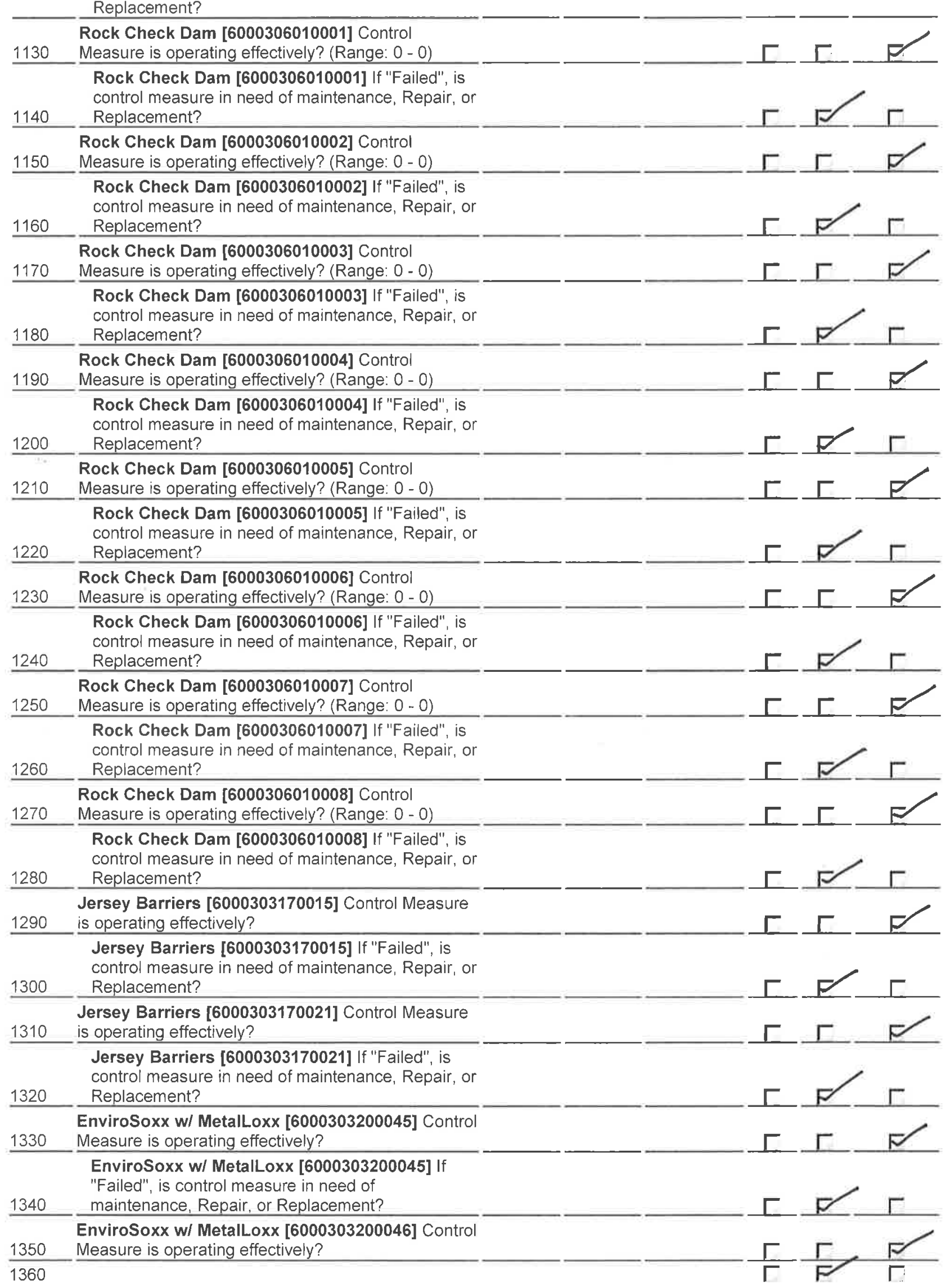


EnviroSoxx w/ MetalLoxx [6000303200046] If

"Failed", is control measure in need of

maintenance, Repair, or Replacement?

\begin{tabular}{|c|c|c|c|c|}
\hline 1370 & $\begin{array}{l}\text { EnviroSoxx w/ MetalLoxx [6000303200047] Control } \\
\text { Measure is operating effectively? }\end{array}$ & $\Gamma$ & $\Gamma$ & $\Gamma$ \\
\hline 1380 & $\begin{array}{l}\text { EnviroSoxx w/ MetalLoxx [ } 6000303200047] \text { If } \\
\text { "Failed", is control measure in need of } \\
\text { maintenance, Repair, or Replacement? }\end{array}$ & & $F$ & $\Gamma$ \\
\hline 1390 & $\begin{array}{l}\text { Permanent Vegetation Vegetative Buffer Strip } \\
\text { [6000302030042] Control Measure is operating } \\
\text { effectively? (Range: } 0-0 \text { ) }\end{array}$ & $\Gamma$ & $\Gamma$ & $\Gamma$ \\
\hline 1400 & $\begin{array}{l}\text { Permanent Vegetation Vegetative Buffer Strip } \\
\text { [6000302030042] If "Failed", is control measure in } \\
\text { need of maintenance, Repair, or Replacement? }\end{array}$ & & & $\Gamma$ \\
\hline
\end{tabular}

Area/Activity exposed to stormwater (identify needed mainteance or a description of corrective actions in relevant task comment).

Material loading/unloading and storage areas

1420 inspected?

Area/Activity controls adequate (appropriate.

1430 effective, and operating)? (Range: 0 - 0 )

1440 Transfer areas for substances in bulk inspected?

Area/Activity controls adequate (appropriate.

1450 effective, and operating)? (Range: 0 - 0)

Product/chemical storage areas (raw material)

1460 inspected?

Area/Activity controls adequate (appropriate

1470 effective, and operating)? (Range: 0 - 0)

Liquid tank storage/secondary containment

1480 inspected?

Area/Activity controls adequate (appropriate

1490 effective, and operating)? (Range: 0 - 0)

Industrial processing and finished product storage

1500 areas inspected?

Area/Activity controls adequate (appropriate.

1510 effective, and operating)? (Range: 0 - 0)

Equipment operation and maintenance areas

1520 inspected?

Area/Activity controls adequate (appropriate,

1530 effective, and operating)? (Range: 0 - 0)

1540 Fueling areas inspected?

Area/Activity controls adequate (appropriate,

1550 effective, and operating)? (Range: 0 - 0)

Outdoor vehicle and equipment washing areas

1560 inspected?

Area/Activity controls adequate (appropriate,

1570 effective, and operating)? (Range: 0 - 0)

1580 Machinery inspected?

Area/Activity controis adequate (appropriate,

1590 effective, and operating)? (Range: 0 - 0)

1600 Waste handling and disposal areas inspected?

Area/Activity controls adequate (appropriate,

1610 effective, and operating)? (Range: 0 - 0)

1620 Erodible areas/construction inspected?

Area/Activity controls adequate (appropriate,

1630 effective, and operating)? (Range: 0 - 0)

Locations and sources of run-on to the site

1640 inspected?

Area/Activity controls adequate (appropriate,

1650

effective, and operating)? (Range: 0 - 0)

1660 Non-stormwater/illicit connections inspected?

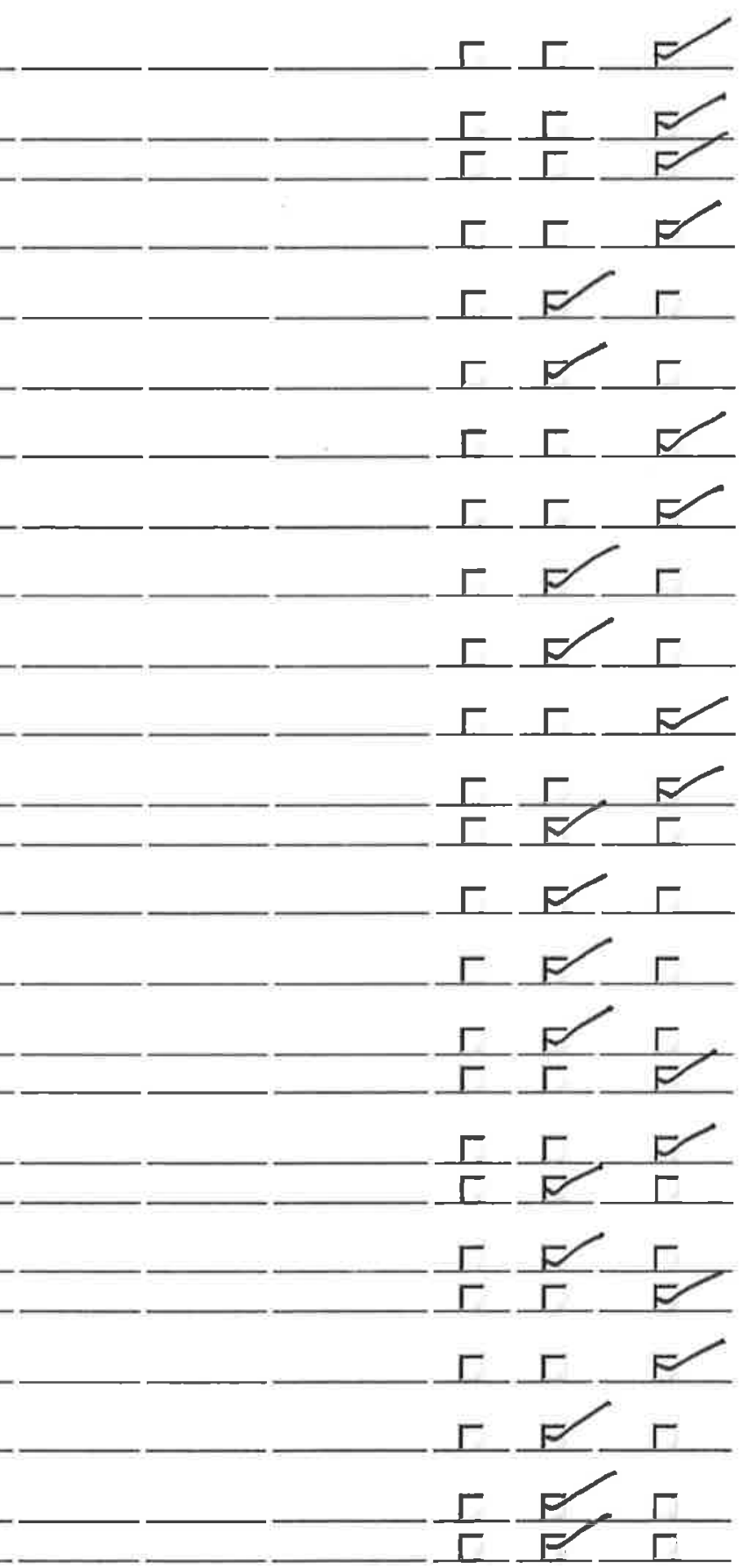


1670 Area/Activity controls adequate (appropriate, effective, and operating)? (Range $0-0$ )

1680 Salt storage piles or pile containing salt inspected? Area/Activity controls adequate (appropriate,

1690 effective, and operating)? (Range: 0 - 0)

1700 Dust generation and vehicle tracking inspected?

Area/Activity controls adequate (appropriate,

1710 effective, and operating)? (Range: 0 - 0)

Housekeeping (Industrial materials/residues/trash in

1720 contact with stormwater) inspected?

Area/Activity controls adequate (appropriate,

1730 effective, and operating)? (Range: 0 - 0)

1740 Leaks and spills inspected?

Area/Activity controls adequate (appropriate,

1750 effective, and operating)? (Range: 0 - 0)

Sector P [60003-] Vehicle storage/maintenance

1760 areas inspected?

Sector P [60003-] Area/Activity controls adequate

(appropriate, effective, and operating)? (Range: 0 -

1770 0)

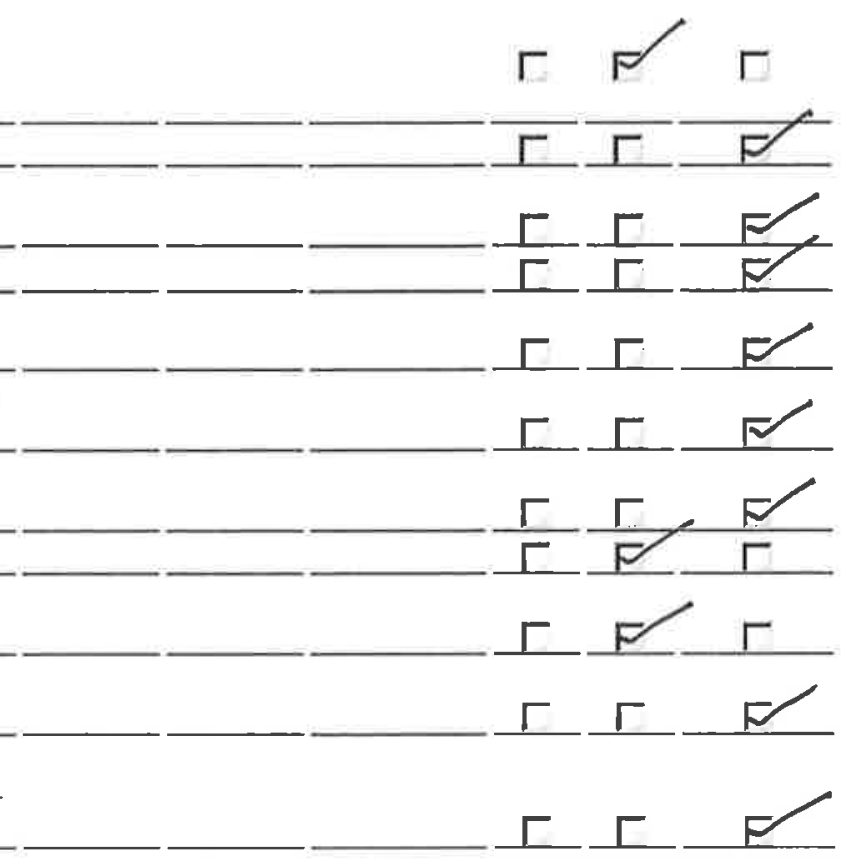

\section{Non-Compliance}

Free of incidents of observed non-compliance not

1790 associated with any of the above? (Range: 0 - 0 )

\section{Additional Control Measures}

Are permit requirements satisfied with existing control measure(s)? If "Failed" describe additional control

1810 measures needed. (Range: 0 - 0)

\section{Labor}

Labor

Assigned

Work Date $1 / 30 / 2017 / 14$

Leonard Sandoval

$1 / 30 / 2017 / 14$

\section{Labor Report}

Completed: Failure:

Meter 1

Meter 2:

Report:

The Sediment Vetention pand at manitored Outfall 042 was partially frozen 4 full of snawelt watar which was discharging dwing the inspection. The yorli to velocate a tive hydromt sauth of 034 from Decembar has been completed. 
WO ID:

Page

of

Signature (lead inspector):
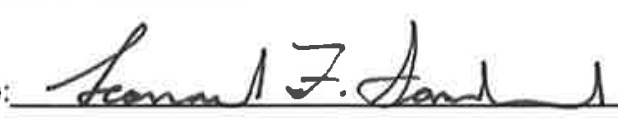

Date and Time:

2017 10:05a.m.

"I confirm the information as recorded is true, accurate and complete."

CERTIFICATION STATEMENT

"I certify under penalty of law that this document and all attachments were prepared under my direction or supervision in accordance with a system designed to assure that qualified personnel properly gathered and evaluated the information submitted. Based on my inquiry of the person or persons who manage the system, or those persons directly responsible for gathering information, the information submitted is, to the best of my knowledge and belief, true, accurate, and complete. I am aware that there are significant penalties for submitting false information, including the possibility of fine and imprisonment for knowing violations".

(Signatory must meet definition in Section B.11.A, eg., FOD, Ops Mgr, DSESH Group Leader, EPC Group Leader)

Print name and title: Teessell Stone GL DESAS- LES

Signature:

Date:

$24 / 2017$ 
2016 Annual Report 
Permit Information ${ }^{*}$ indicates form required data)

What action would you like to take?*

New Industrial Stormwater Annual Report

Please select the NPDES ID corresponding to the facility for which you would like to submit an Annual Report and click the Submit button.

NPDES ID*

NMR053195: LOS ALAMOS NATIONAL LABORATORY

\ Confirm NPDES ID: NMR053195: LOS ALAMOS NATIONAL LABORATORY*

Facility Information

Facility Name

Los Alamos National Laboratory

\section{Street}

PO Box 1663

Supplemental address

MS K490

City

Los Alamos

First Name

Holly

Middle Name

Last Name

Wheeler

Telephone Number

5056671312 


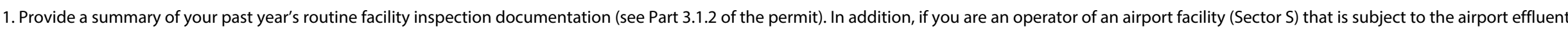

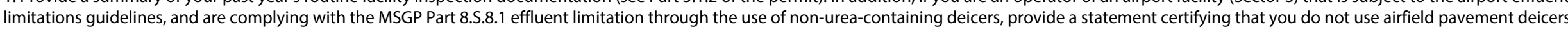

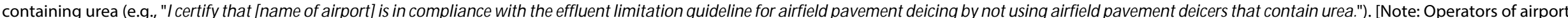
facilities that are complying with Part 8.S.8.1 by meeting the numeric effluent limitation for ammonia do not need to include this statement.] ${ }^{*}$

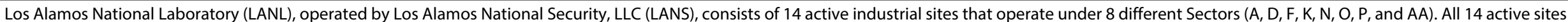

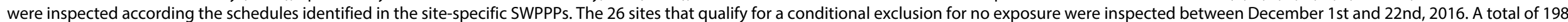
inspections and/or evaluations resulting in corrective actions were conducted at a total of 40 sites as follows:

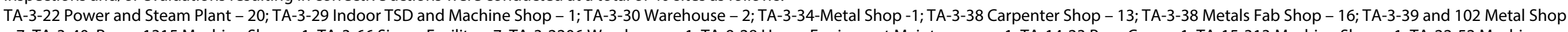

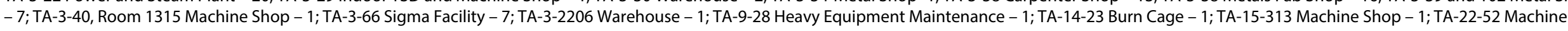

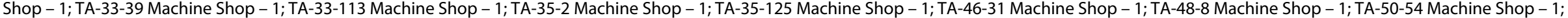

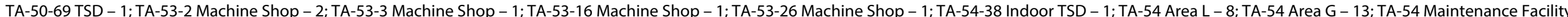

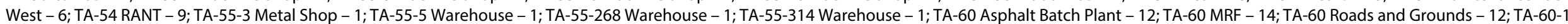
Heavy Equipment Yard - 19; and TA-60-2 Warehouse - 16

2. Provide a summary of your past year's quarterly visual assessment documentation (see Part 3.2.2 of the permit) *

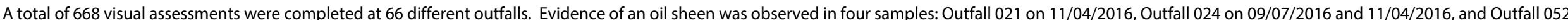
on $05 / 02 / 2016$. No other evidence of pollutants were observed.

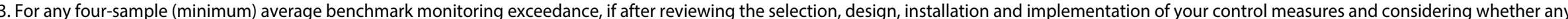

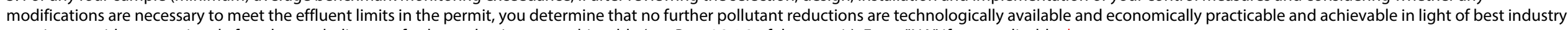
practice, provide your rationale for why you believe no further reductions are achievable (see Part 6.2.1.2 of the permit). Enter "NA" if not applicable. *

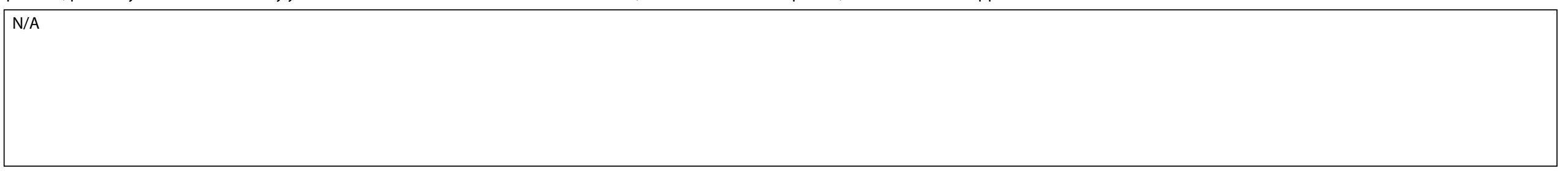

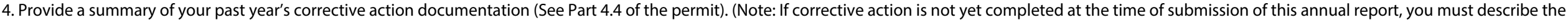

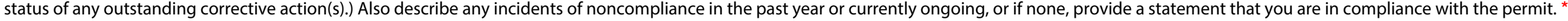

\footnotetext{
A total of 198 inspections and/or evaluations resulting in corrective actions were conducted at a total of 40 sites with the following total count of conditions observed:

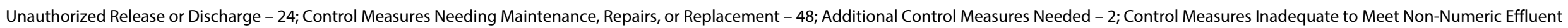

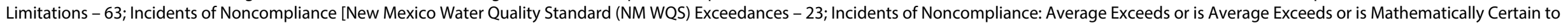
Exceed Benchmark Value - 6; Average Exceeds or is Mathematically Certain to Exceed Benchmark Value - 23.

At this time, there are only 2 outstanding corrective actions, both identified on December 19, 2016 and proposed for completion by February 2, 2017.

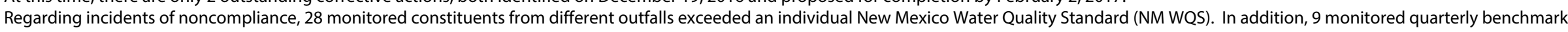
constituent value exceedances occurred where the benchmark value was modified to reflect a NM WQS per Section 9.6.2.1. Corrective actions to address these exceedances have been completed.

EPC-DO: 17-084; LA-UR-17-20556
} 


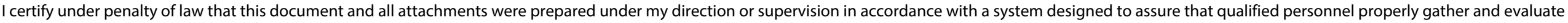

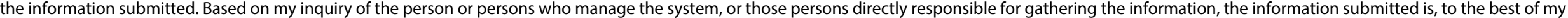

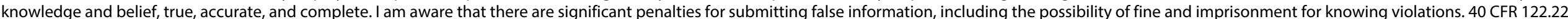




\section{Quarterly Visual Assessments}




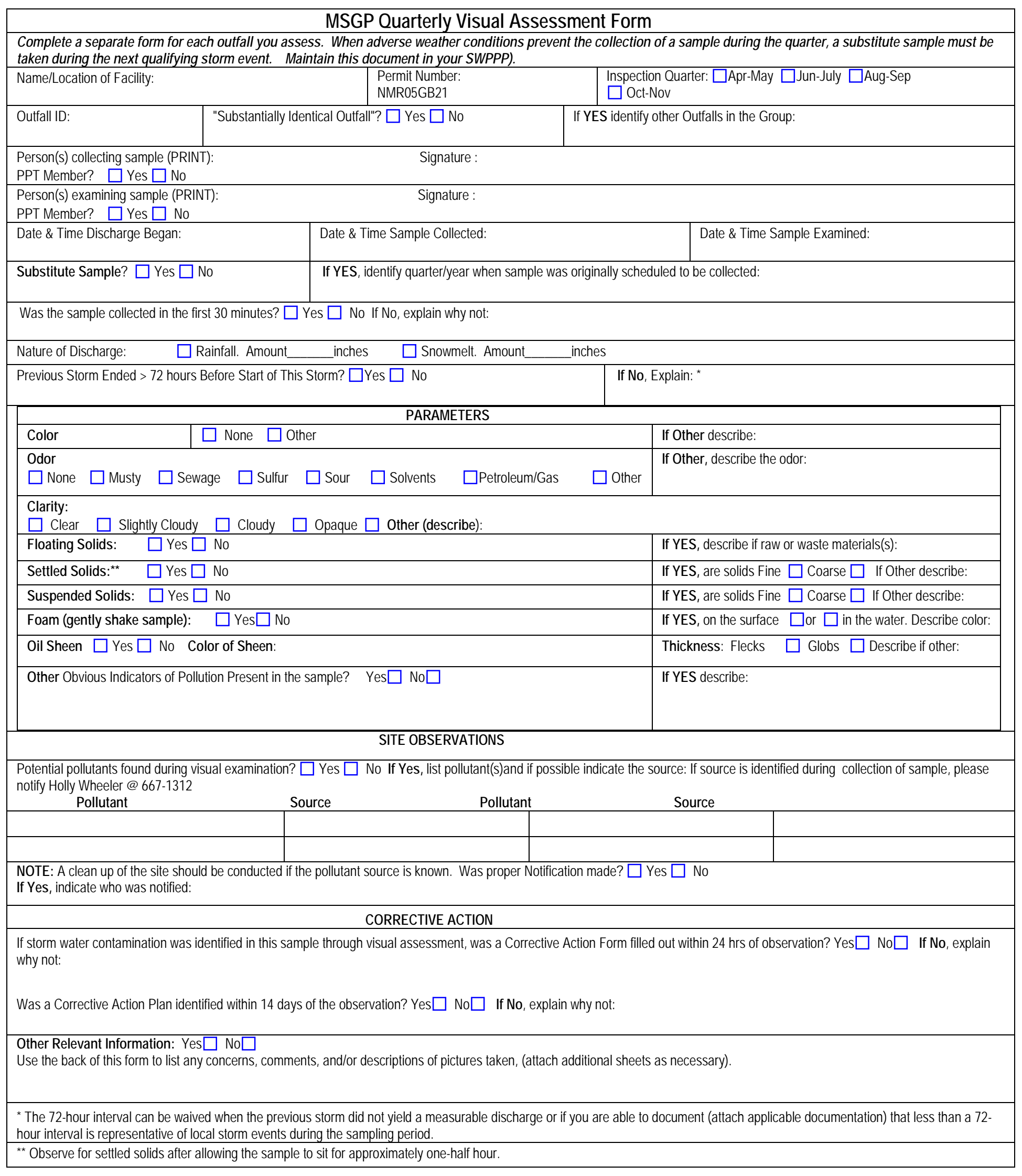




\section{memorandum}

Environmental Protection \& Compliance Division

Environmental Compliance Programs (EPC-CP)
To/MS: Leonard Sandoval, DESHS-UIS, P908

Thru/MS: Terrill Lemke, EPC-CP, (E-File) ze

From/MS: Holly Wheeler, EPC-CP, (E-File)Ych)

Phone/Fax: 667-1312

Symbol: EPC-DO: 17-027

Date: JAN 122017

\section{Subject: National Pollutant Discharge Elimination System (NPDES) Permit No. NMR053195, Multi-Sector General Permit (MSGP) Quarterly Visual Assessment (QVA) Forms for June and July of 2016 for TA-60 Roads and Grounds}

Please find attached completed MSGP QVA Forms documenting visual assessments performed during the second quarter of monitoring at TA-60 Roads and Grounds. Per Parts 3.2.2 and 5.5 of the 2015 MSGP, the QVA forms shall be incorporated into your MSGP Storm Water Pollution Prevention Plan (SWPPP).

Part 3.2.1 of the 2015 MSGP requires the visual assessment of storm water discharge samples collected from each outfall once each quarter for the entire permit term. Part 3.2.3 allows facilities that are located in an area with a semi-arid climate and/or in an area where freezing conditions exist for an extended period to distribute the quarterly visual assessments during seasons when precipitation runoff occurs. Accordingly, LANS has designated the following MSGP monitoring quarters.

Quarter 1: $\quad$ April - May

Quarter 3: $\quad$ August - September
Quarter 2: June-July

Quarter 4: October - November

The attached QVA forms document the following information as required by Part 3.2 .2 of the 2015 MSGP and were completed by Environment Compliance Programs (EPC-CP) personnel.

- Sample location;

- Sample collection date and time, and visual assessment date and time for each sample;

- Personnel collecting the sample and performing the visual assessment, and their signatures;

- Nature of the discharge (i.e., runoff or snowmelt);

- Results of observations of the stormwater discharge;

- Probable sources of any observed stormwater contamination (if applicable);

- If applicable, why it was not possible to take a sample within the first 30 minutes of the storm event.

Part 3.2.3 of the 2008 MSGP allows the facility to take a substitute sample during the next qualifying storm event when adverse weather conditions prevent the collection of samples during a specific quarter. Adverse weather conditions are those that are dangerous or create inaccessibility for personnel, or situations that otherwise make sampling impractical, such as drought or extended frozen 
conditions. Documentation of the rationale for no visual assessment for the quarter must be included in the facility-specific SWPPP.

Please contact Holly Wheeler at 667-1312 (hbenson@lanl.gov) if you have questions regarding the QVA documentation. Thank you for your assistance in meeting the requirements of the Laboratory's NPDES 2015 MSGP Permit.

TWL:HLW/am

Enclosure: 1. Quarterly Visual Assessment Forms, Second Quarter, 2016 Monitoring Year

\begin{tabular}{lll} 
Facility Name & Sampling Station & Work Order \# \\
\hline TA-60 Roads and Grounds & MSGP03101 & MSGP-53605 \\
TA-60 Roads and Grounds & MSGP03301 & MSGP-54214 \\
TA-60 Roads and Grounds & MSGP03401 & MSGP-54215 \\
TA-60 Roads and Grounds & MSGP03501 & MSGP-54216 \\
TA-60 Roads and Grounds & MSGP03001 & MSGP-54217 \\
TA-60 Roads and Grounds & MSGP04101 & MSGP-54218 \\
TA-60 Roads and Grounds & MSGP03701 & MSGP-54219 \\
TA-60 Roads and Grounds & MSGP04001 & MSGP-54220 \\
TA-60 Roads and Grounds & MSGP03801 & MSGP-54221 \\
TA-60 Roads and Grounds & MSGP03201 & MSGP-54681 \\
TA-60 Roads and Grounds & MSGP03301 & MSGP-54920 \\
TA-60 Roads and Grounds & MSGP03401 & MSGP-54921 \\
TA-60 Roads and Grounds & MSGP03001 & MSGP-54922 \\
TA-60 Roads and Grounds & MSGP04101 & MSGP-54923 \\
TA-60 Roads and Grounds & MSGP03301 & MSGP-56125 \\
TA-60 Roads and Grounds & MSGP03401 & MSGP-56126 \\
TA-60 Roads and Grounds & MSGP03001 & MSGP-56127 \\
TA-60 Roads and Grounds & MSGP03301 & MSGP-56616 \\
TA-60 Roads and Grounds & MSGP03401 & MSGP-56617 \\
TA-60 Roads and Grounds & MSGP03301 & MSGP-57141 \\
TA-60 Roads and Grounds & MSGP03401 & MSGP-57142
\end{tabular}

Copy: Russell Stone, DESHS-UIS, (E-File)

Adesh-records@lanl.gov, (E-File)

lasomailbox@nnsa.doe.gov, (E-File)

locatesteam@lanl.gov, (E-File)

epc-correspondence@lanl.gov, (E-File) 


\title{
ENCLOSURE 1
}

\author{
Quarterly Visual Assessment Forms \\ Second Quarter, 2016 Monitoring Year
}

\author{
EPC-DO-17-027
}

Date:

JAN 122017 


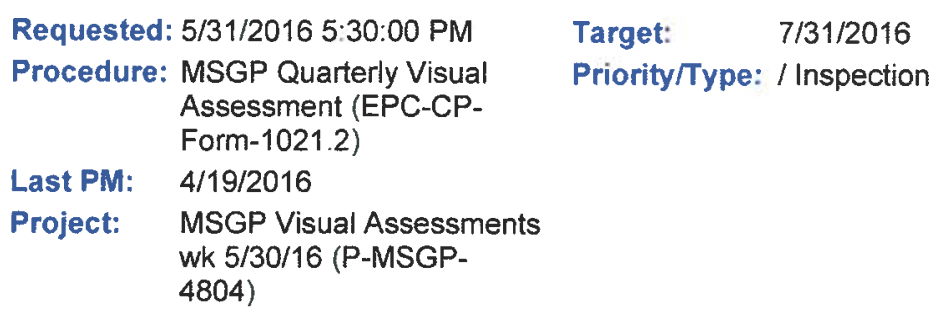

\section{Target: $\quad$ 7/31/2016}

Priority/Type: / Inspection

Reason: MSGP 2016 Quarterly Visual Assessment

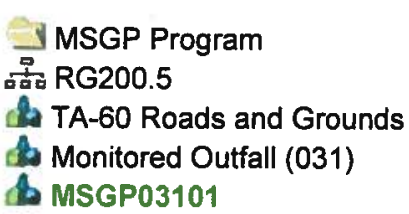

Contact:

Phone:

Special Instructions: NMR053195

\section{Tasks}

\# Description

Rating Meas. Initials Failed N/A Complete

The result of this VA applies to associated SIOs as defined in the SWPPP, where applicable.

\section{Sample information}

Document the monitoring Period by using the

$30 \quad$ Monitoring Period lookup table.

Is visual assessment performed on an unfiltered

35 sample? (Use filtered only if unfiltered unavailable.)

Document the Date/Time Discharge began in the

"Reading" field of this line (using mm/dd/yy hh:mm

40 format)

Document the Date/time sample collected in the

"Reading" field of this line (using mm/dd/yy hh:mm

50 format)

Document the Date/time sample visually assessed in

the "Reading" field of this line (using $\mathrm{mm} / \mathrm{dd} / \mathrm{yy}$

60 hh:mm format).

Document the nature of discharge using the

70

Precipitation Type lookup table. Document the amount (in) in the "Reading" field of this line.

Sample collected in first 30 minutes of discharge? If

"Failed" or unknown, provide reason in comments of

80 this line.

\section{Parameters}

110

Is sample colorless? If "Failed", describe.

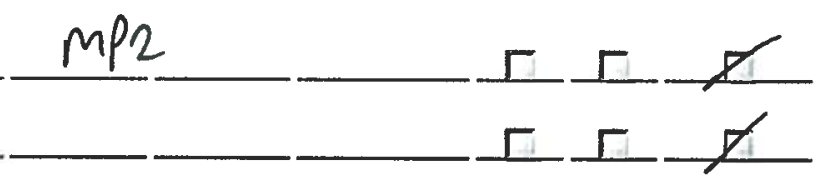

(1)
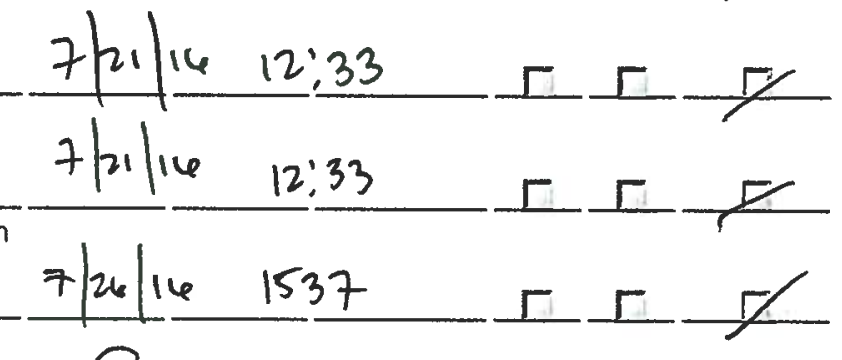

Is sample oderless? If "Failed", document
observation using the Odor lookup table. If "other" is
chosen from the lookup table, provide description in

120 comments of this line.

Is sample clear? If. "Failed", document observation using the Clarity lookup table. If "other" is chosen

from the lookup table, provide description in

$130 \quad$ comments of this line. Is sample free of floating solids? If "Failed", describe

Bown

$0.36 \mathrm{in}$. axes 7) 2716

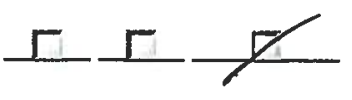
if raw or waste material(s) in the comments of this line.

Is sample free of settled solids? If "Failed", document observation using the Settled Solids lookup table. If "other" is chosen from the lookup table, provide description in comments of this line.
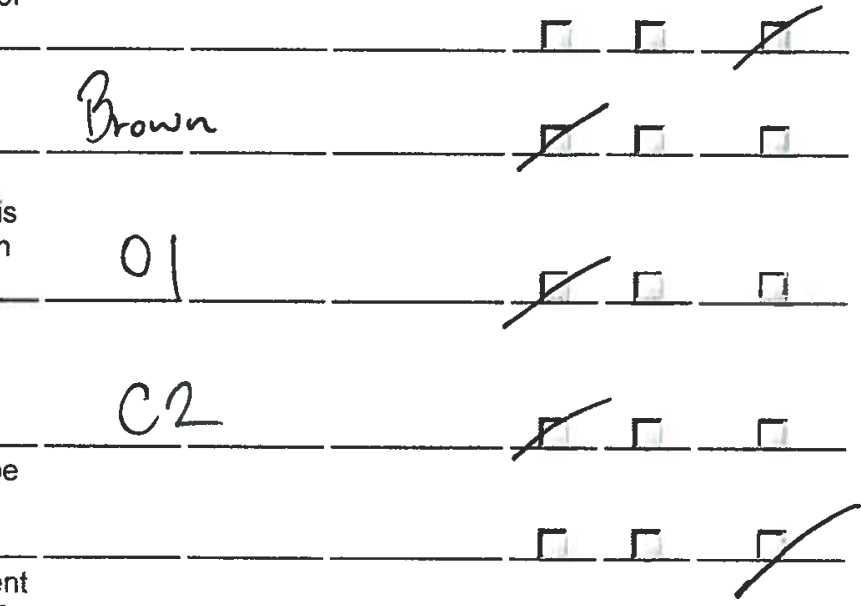

SETSOLI

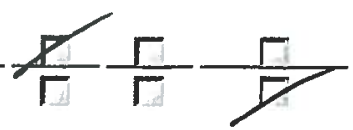


Is sample free of suspended solids? If "Failed",

document observation using the Suspended Solids

lookup table. If "other" is chosen from the lookup

table, provide description in comments of this line.

Is sample foamless after gently shaking? If "Failed" describe foam color and location ('on the surface' or

170 'in the sample') in the comments of this line.

Is sample devoid of an oil sheen? If "Failed", describe

color and thickness (e.g. flecks, globs) in the

180 comments of this line.

Is sample free of other obvious indicators of pollution? If "Failed", describe in the comments of this

190 line.

\section{Labor Report}

Completed:

Failure:

Meter 1:

Meter 2:

Report: 
WO ID: MSG P.53605

Page 3 of 3

Signature (collecting sample):

Hive.

Date and Time: $7 / 21 / 16 \quad 12: 33$

Signature (conducting visual assessment):

sine.

Date and Time: $7 / 26 / 16 \quad 1537$

CERTIFICATION STATEMENT

"I certify under penalty of law that this document and all attachments were prepared under my direction or supervision in accordance with a system designed to assure that qualified personnel properly gathered and evaluated the information submitted. Based on my inquiry of the person or persons who manage the system, or those persons directly responsible for gathering information, the information submitted is, to the best of my knowledge and belief, true, accurate, and complete. I am aware that there are significant penalties for submitting false information, including the possibility of fine and imprisonment for knowing violations".

(Signatory must meet definition in Section B.11.A, eg., FOD, Ops Mgr, DSESH Group Leader, EPC Group Leader)

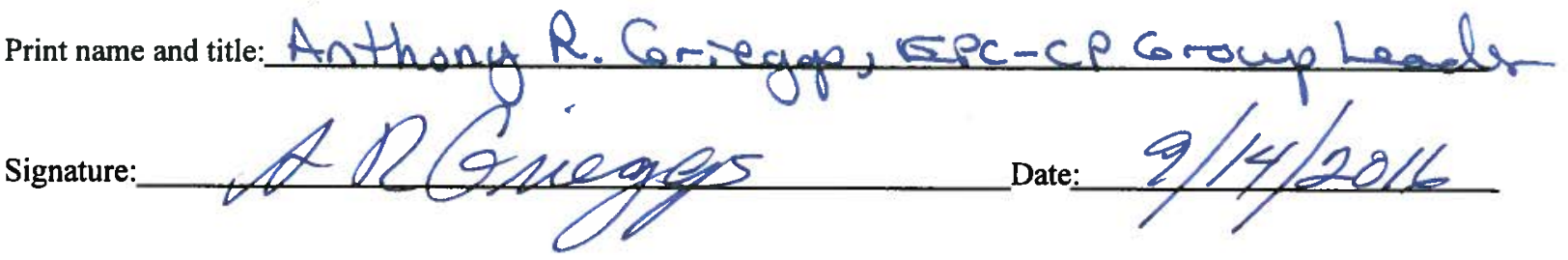




\title{
Maintenance Details
}

\author{
Requested: 5/16/2016 11:58:00 AM \\ Procedure: MSGP Quarterly Visual \\ Assessment (EPC-CP- \\ Form-1021.2) \\ Last PM: N/A \\ Project: SIO Visual Assessments \\ wk 5/30/16 (P-MSGP- \\ 4806)
}

Reason: MSGP Quarterly Visual Assessment

Target: $\quad 7 / 31 / 2016$

Priority/Type: Normal / Inspection

Department: Utilities and Infrastructure

\section{MSGP Program 禺 RG200.5}

c) TA-60 Roads and Grounds

honitored Outfall (032)

Q. Substantially Identical Outfall (033)

th MSGP03301

Contact:

Phone:

Special Instructions: NMR053195

\section{Tasks}

\# Description

Rating Meas. Initials Failed N/A Complete

The result of this VA applies to associated SIOs as defined in the SWPPP, where applicable.

\section{Sample information}

Document the monitoring Period by using the

30 Monitoring Period lookup table.

Q2

Is visual assessment performed on an unfiltered

35 sample? (Use filtered only if unfiltered unavailable.) Document the Date/Time Discharge began in the "Reading" field of this line (using mm/dd/yy hh:mm $40 \quad$ format).

Document the Date/time sample collected in the "Reading" field of this line (using $\mathrm{mm} / \mathrm{dd} / \mathrm{yy} \mathrm{hh}: \mathrm{mm}$ 50 format).

Document the Date/time sample visually assessed in the "Reading" field of this line (using $\mathrm{mm} / \mathrm{dd} / \mathrm{yy}$

$60 \quad$ hh:mm format).

Document the nature of discharge using the Precipitation Type lookup table. Document the

$70 \quad$ amount (in) in the "Reading" field of this line Sample collected in first 30 minutes of discharge? If "Failed" or unknown, provide reason in comments of 80 this line.

\section{Parameters}

110 Is sample colorless? If "Failed", describe. Is sample oderless? If "Failed", document observation using the Odor lookup table. If "other" is chosen from the lookup table, provide description in .

is sample clear? If "Failed", document observation using the Clarity lookup table. If "other" is chosen from the lookup table, provide description in comments of this line.

Is sample free of floating solids? If "Failed", describe if raw or waste material(s) in the comments of this Is sample free of settled solids? If "Failed", document observation using the Settled Solids lookup table. If "other" is chosen from the lookup table, provide description in comments of this line.
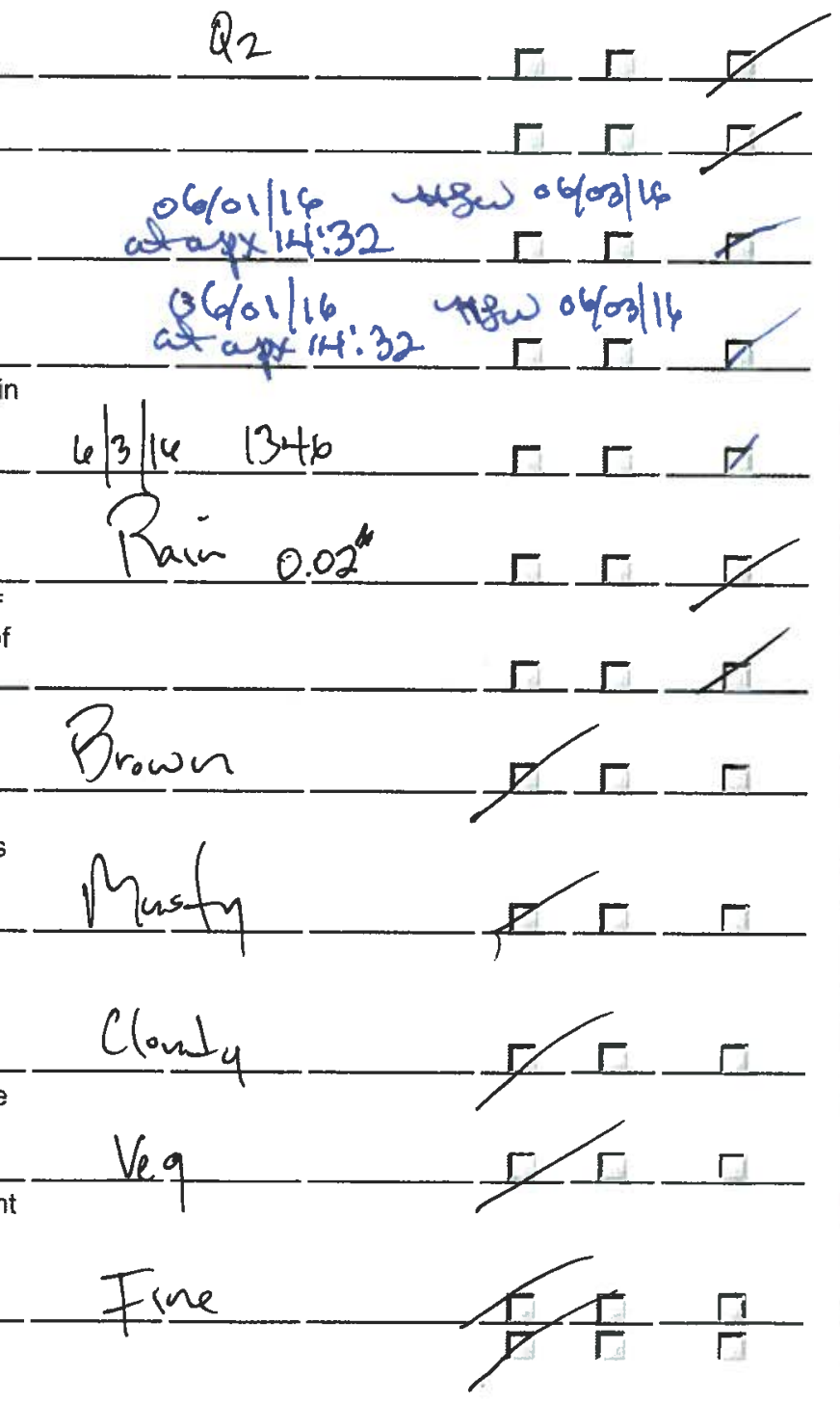
Is sample free of suspended solids? If "Failed" document observation using the Suspended Solids lookup table. If "other" is chosen from the lookup table, provide description in comments of this line.

Is sample foamless after gently shaking? If "Failed" describe foam color and location ('on the surface' or

170 'in the sample') in the comments of this line.

Is sample devoid of an oil sheen? If "Failed", describe

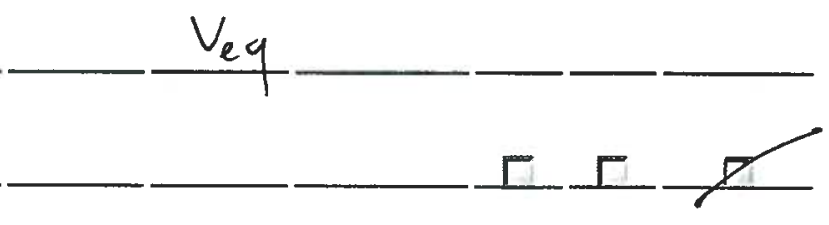

180 color and thickness (e.g. flecks, globs) in the comments of this line.

Is sample free of other obvious indicators of

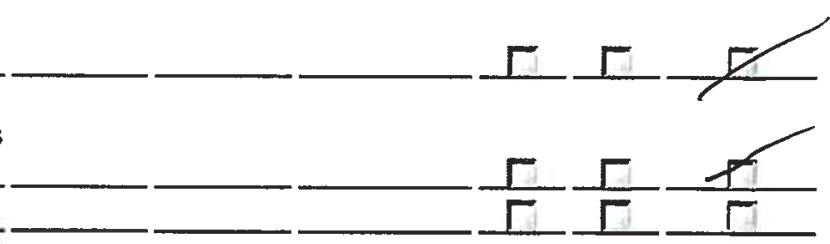

pollution? If "Failed", describe in the comments of this

190

line.

\section{Labor Report}

Completed:

Failure:

Report: 
WO ID:

54214

Page 3 of 3

Signature (collecting sample)

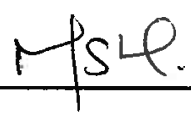

Mss
Date and Time: $6 / 1 / 16 \quad 1432$

Date and Time: $6 / 3 / 16 \quad 1346$

CERTIFICATION STATEMENT

"I certify under penalty of law that this document and all attachments were prepared under my direction or supervision in accordance with a system designed to assure that qualified personnel properly gathered and evaluated the information submitted. Based on my inquiry of the person or persons who manage the system, or those persons directly responsible for gathering information, the information submitted is, to the best of my knowledge and belief, true, accurate, and complete. I am aware that there are significant penalties for submitting false information, including the possibility of fine and imprisonment for knowing violations".

(Signatory must meet definition in Section B.11.A, eg., FOD, Ops Mgr, DSESH Group Leader, EPC Group Leader)

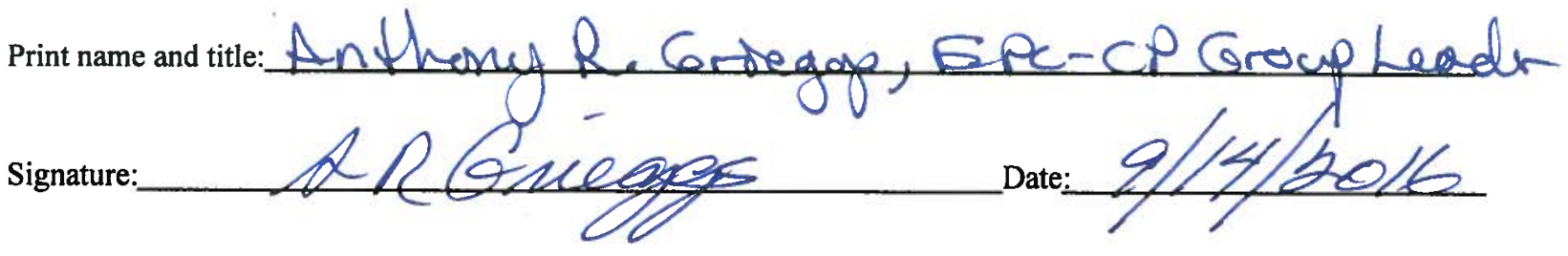


Maintenance Details

\begin{tabular}{|c|c|c|c|c|}
\hline Requested & :5/16/2016 11:58:00 AM & Target: & $7 / 31 / 2016$ & MSGP Program \\
\hline Procedure: & MSGP Quarterly Visual & Priority/Type: & Normal / Inspection & 告 RG200.5 \\
\hline & $\begin{array}{l}\text { Assessment (EPC-CP- } \\
\text { Form-1021.2) }\end{array}$ & Department: & $\begin{array}{l}\text { Utilities and } \\
\text { Infrastructure }\end{array}$ & $\begin{array}{l}\text { TA-60 Roads and Grounds } \\
\text { Monitored Outfall (032) }\end{array}$ \\
\hline Last PM: & $N / A$ & & & A Substantially Identical Outfall (034) \\
\hline Project: & $\begin{array}{l}\text { SIO Visual Assessments } \\
\text { Wk 5/30/16 (P-MSGP- } \\
4806 \text { ) }\end{array}$ & & & fo MSGP03401 \\
\hline Reason: & ISGP Quarterly Vis & ent & & $\begin{array}{l}\text { Contact: } \\
\text { Phone: }\end{array}$ \\
\hline
\end{tabular}

Special Instructions: NMR053195

\section{Tasks}

\# Description

Rating Meas. Initials Failed N/A Complete

The result of this VA applies to associated SIOs as defined in the SWPPP, where applicable.

Sample information

Document the monitoring Period by using the

$30 \quad$ Monitoring Period lookup table.

Is visual assessment performed on an unfiltered

35 sample? (Use filtered only if unfiltered unavailable.)

Document the DaterTime Discharge began in the

"Reading" field of this line (using $\mathrm{mm} / \mathrm{dd} / \mathrm{yy} \mathrm{hh}: \mathrm{mm}$

40 format)

Document the Date/time sample collected in the

"Reading" field of this line (using $\mathrm{mm} / \mathrm{dd} / \mathrm{yy} \mathrm{hh}: \mathrm{mm}$

$50 \quad$ format).

Document the Date/time sample visually assessed in the "Reading" field of this line (using $\mathrm{mm} / \mathrm{dd} / \mathrm{yy}$

60 hh:mm format).

Document the nature of discharge using the Precipitation Type lookup table. Document the

70 amount (in) in the "Reading" field of this line.

Sample collected in first 30 minutes of discharge? If

"Failed" or unknown, provide reason in comments of

80 this line.

Parameters

110 Is sample colorless? If "Failed", describe.

Is sample oderless? If "Failed", document

observation using the Odor lookup table. If "other" is chosen from the lookup table, provide description in

120 comments of this line.

is sample clear? If "Failed", document observation using the Clarity lookup table. If "other" is chosen from the lookup table, provide description in

130 comments of this line.

Is sample free of floating solids? If "Failed", describe if raw or waste material(s) in the comments of this

140 line.

Is sample free of settled solids? If "Failed", document observation using the Settled Solids lookup table. If "other" is chosen from the lookup table, provide description in comments of this line.
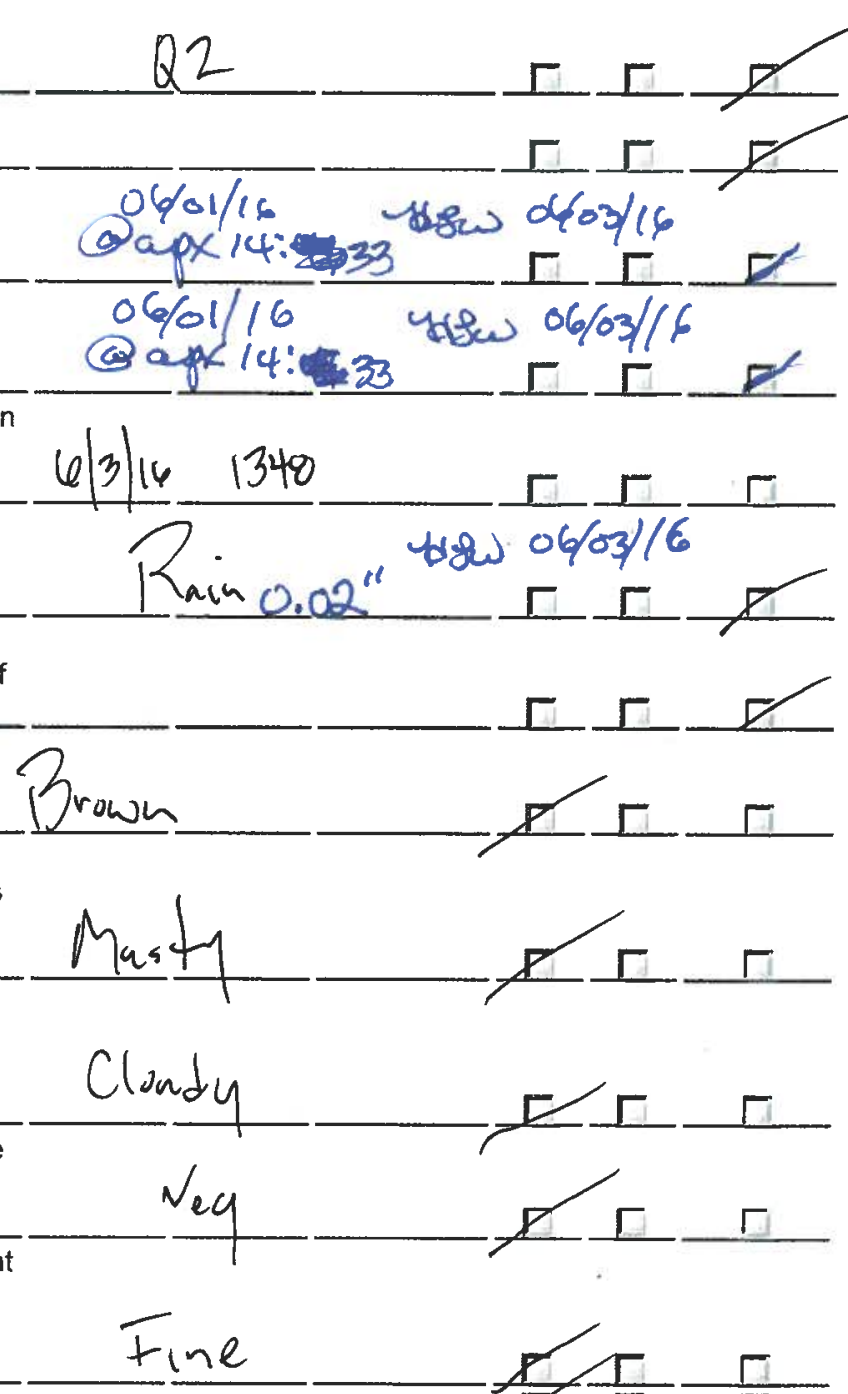
Is sample free of suspended solids? If "Failed", document observation using the Suspended Solids lookup table. If "other" is chosen from the lookup table, provide description in comments of this line.

Is sample foamless after gently shaking? If "Failed" describe foam color and location ('on the surface' or

170 'in the sample') in the comments of this line Is sample devoid of an oil sheen? If "Failed", describe

$-\frac{V \alpha g}{J}$
color and thickness (e.g. flecks, globs) in the comments of this line.

Is sample free of other obvious indicators of

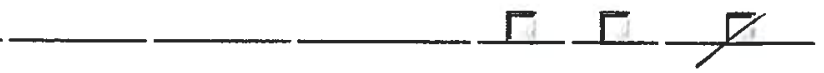
pollution? If "Failed", describe in the comments of this 190 line.

\section{Labor Report}

Completed: Failure:

Report: 
WO ID:

$542 / 5$

Page _3 of 3

Signature (collecting sample):

Signature (conducting visual assessment):
Mil

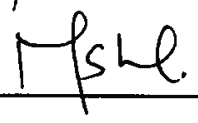

Date and Time:

Date and Time: $6 \sqrt{3} 16$

1348

CERTIFICATION STATEMENT

"I certify under penalty of law that this document and all attachments were prepared under my direction or supervision in accordance with a system designed to assure that qualified personnel properly gathered and evaluated the information submitted. Based on my inquiry of the person or persons who manage the system, or those persons directly responsible for gathering information, the information submitted is, to the best of my knowledge and belief, true, accurate, and complete. I am aware that there are significant penalties for submitting false information, including the possibility of fine and imprisonment for knowing violations".

(Signatory must meet definition in Section B.11.A, eg., FOD, Ops Mgr, DSESH Group Leader, EPC Group Leader)

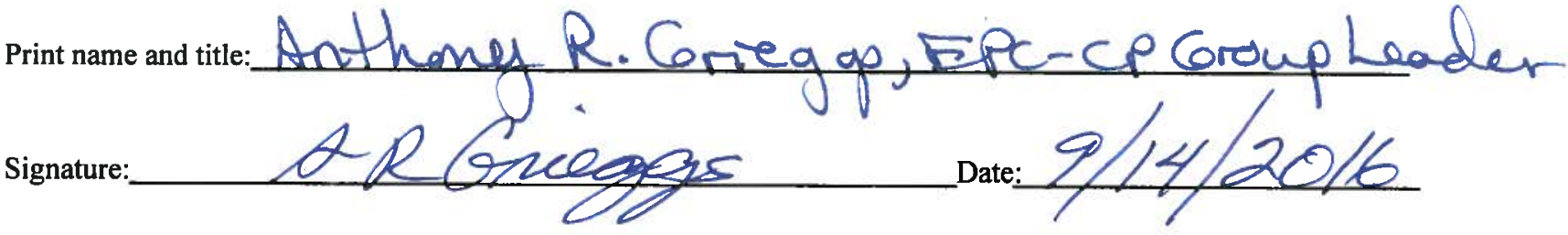


Maintenance Details

\begin{tabular}{|c|c|c|c|c|}
\hline & Target: & $7 / 31 / 2016$ & \multirow{5}{*}{$\begin{array}{l}\text { MSGP Program } \\
\text { 뭄 RG200.5 } \\
\text { TA-60 Roads and Grounds } \\
\text { Monitored Outfall (032) } \\
\text { Substantially Identical Outfall (035) } \\
\text { MSGP03501 }\end{array}$} \\
\hline \multirow{2}{*}{\multicolumn{2}{|c|}{$\begin{aligned} \text { Requested: } & \text { 5/16/2016 11:58:00 AM } \\
\text { Procedure: } & \text { MSGP Quarterly Visual } \\
& \text { Assessment (EPC-CP- } \\
& \text { Form-1021.2) }\end{aligned}$}} & Priority/Type: & Normal / Inspection & \\
\hline & & Department: & $\begin{array}{l}\text { Utilities and } \\
\text { Infrastructure }\end{array}$ & \\
\hline Last PM: & $N / A$ & & & \\
\hline Project: & $\begin{array}{l}\text { SIO Visual Assessments } \\
\text { wk 5/30/16 (P-MSGP- } \\
4806 \text { ) }\end{array}$ & & & \\
\hline Reason: & ISGP Quarterly Visual A & & & $\begin{array}{l}\text { Contact: } \\
\text { Phone: }\end{array}$ \\
\hline
\end{tabular}

Special Instructions: NMR053195

\section{Tasks}

\# Description

Rating Meas. Initials Failed N/A Complete

The result of this VA applies to associated SIOs as defined in the SWPPP, where applicable.

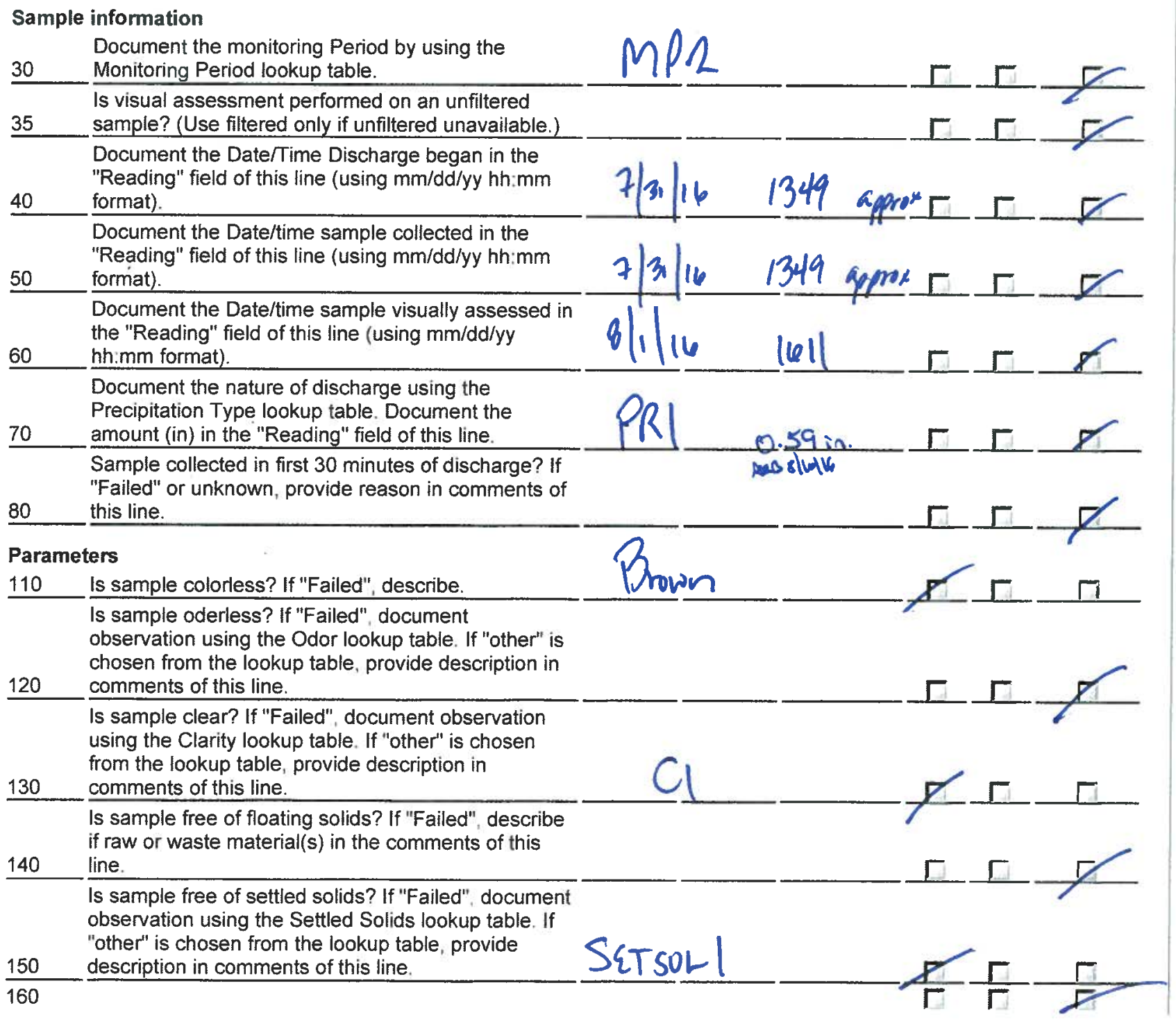


Is sample free of suspended solids? If "Failed", document observation using the Suspended Solids lookup table. If "other" is chosen from the lookup table, provide description in comments of this line. Is sample foamless after gently shaking? If "Failed" describe foam color and location ('on the surface' or

170 'in the sample') in the comments of this line. Is sample devoid of an oil sheen? If "Failed", describe

$+-\frac{\Gamma}{\Gamma-\frac{\Gamma}{\Gamma}} \frac{\Gamma}{\Gamma-\frac{\Gamma}{\Gamma}-\frac{\Gamma}{\Gamma}}$

\section{Labor Report}

Completed:

Failure:

Report: 
WO ID:

Signature (collecting sample):

Signature (conducting visual assessment):

\section{CERTIFICATION STATEMENT}

"I certify under penalty of law that this document and all attachments were prepared under my direction or supervision in accordance with a system designed to assure that qualified personnel properly gathered and evaluated the information submitted. Based on my inquiry of the person or persons who manage the system, or those persons directly responsible for gathering information, the information submitted is, to the best of my knowledge and belief, true, accurate, and complete. I am aware that there are significant penalties for submitting false information, including the possibility of fine and imprisonment for knowing violations".

(Signatory must meet definition in Section B.11.A, eg., FOD, Ops Mgr, DSESH Group Leader, EPC Group Leader)

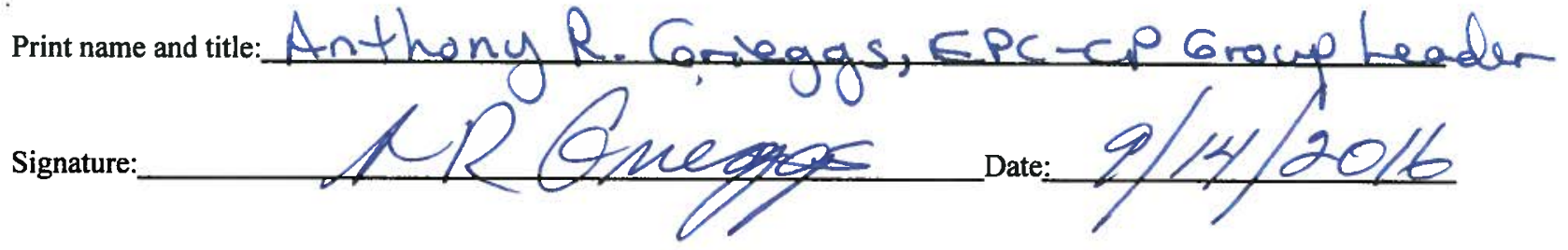


-Maintenance Details

\begin{tabular}{|c|c|c|c|c|}
\hline Requested: & : 5/16/2016 11:58:00 AM & Target: & $7 / 31 / 2016$ & MSGP Program \\
\hline Procedure: & MSGP Quarterly Visual & Priority/Type: & Normal / Inspection & 是 RG200.5 \\
\hline & $\begin{array}{l}\text { Assessment (EPC-CP- } \\
\text { Form-1021.2) }\end{array}$ & Department: & $\begin{array}{l}\text { Utilities and } \\
\text { Infrastructure }\end{array}$ & $\begin{array}{l}\text { TA-60 Roads and Grounds } \\
\text { Monitored Outfall (031) }\end{array}$ \\
\hline Last PM: & N/A & & & Q Substantially Identical Outfall $(030)$ \\
\hline Project: & $\begin{array}{l}\text { SIO Visual Assessments } \\
\text { wk 5/30/16 (P-MSGP- } \\
4806 \text { ) }\end{array}$ & & & AS MSP03001 \\
\hline Reason: N & ASGP Quarterly Visual As & ent & & $\begin{array}{l}\text { Contact: } \\
\text { Phone: }\end{array}$ \\
\hline
\end{tabular}

Special instructions: NMR053195

\section{Tasks}

\# Description

Rating Meas. Initials Failed N/A Complete

The result of this VA applies to associated SIOs as defined in the SWPPP, where applicable.

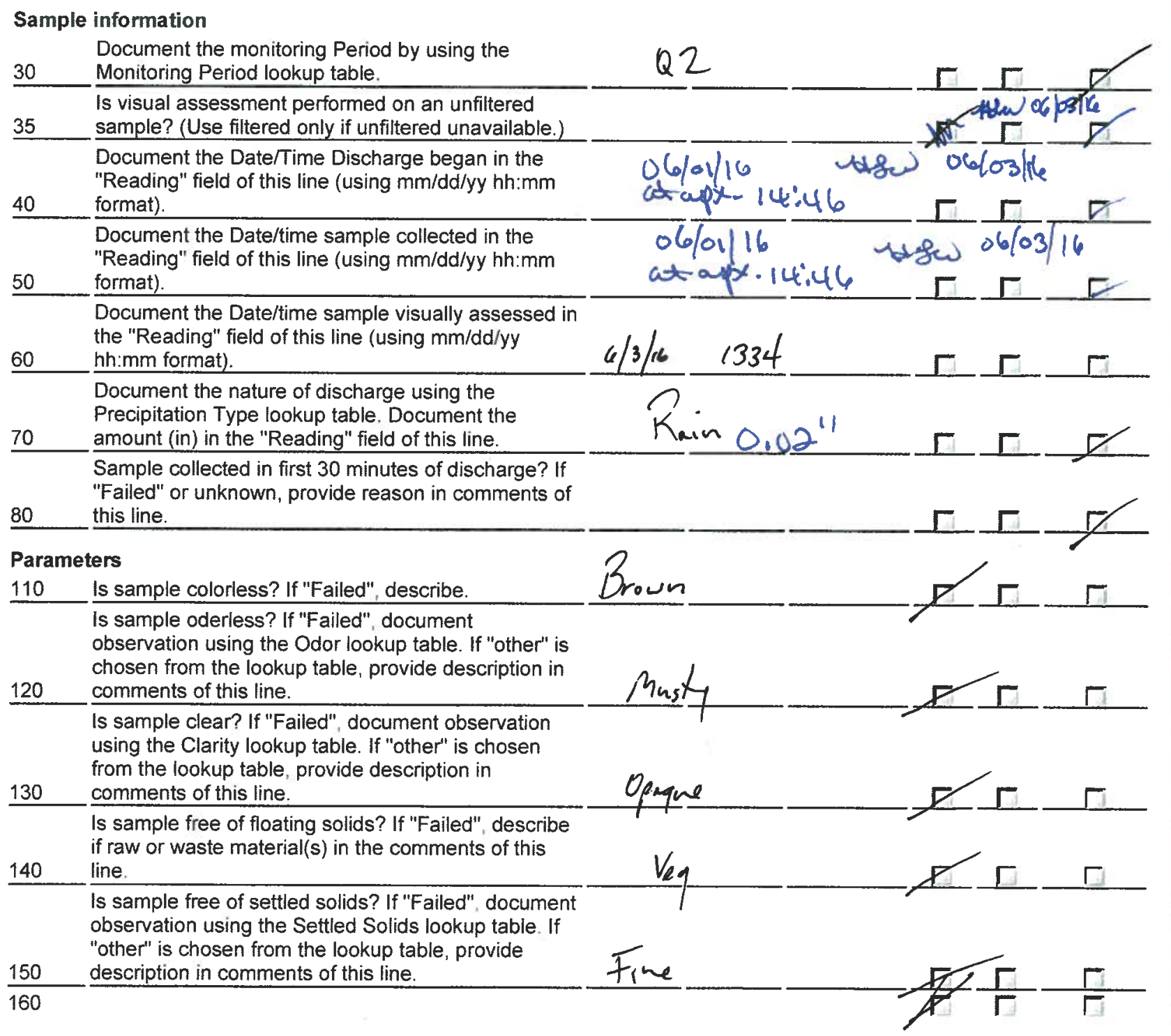


Is sample free of suspended solids? If "Failed", document observation using the Suspended Solids

lookup table. If "other" is chosen from the lookup table, provide description in comments of this line.

Veq

Is sample foamless after gently shaking? If "Failed" describe foam color and location ('on the surface' or

170 'in the sample') in the comments of this line.

Is sample devoid of an oil sheen? If "Failed", describe F color and thickness (e.g. flecks, globs) in the

180 comments of this line.

Is sample free of other obvious indicators of

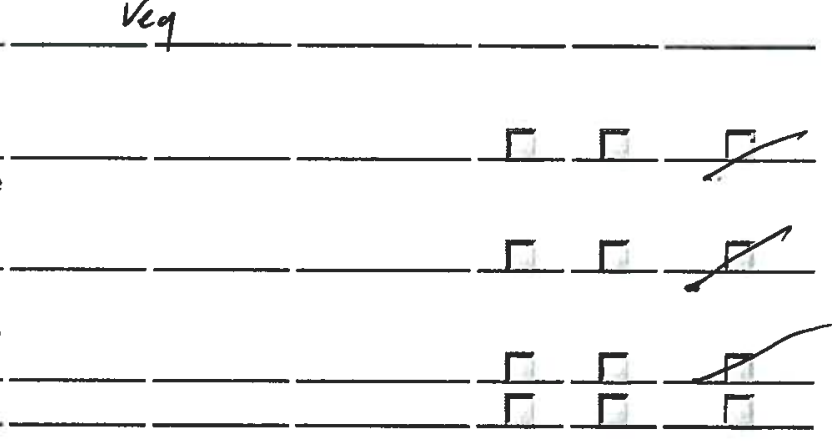
pollution? If "Failed", describe in the comments of this

190 ine.

\section{-Labor Report}

Completed: Failure:

Report: 
WO ID:

54217

Page $\frac{3}{2}$ of $\frac{3}{2}$

Signature (collecting sample):

Psid.

Date and Time:

$6 / 1 / 16 \quad 1446$

Signature (conducting visual assessment):

sse.

Date and Time: $6 / 3 / 16 \quad 1334$

CERTIFICATION STATEMENT

"I certify under penalty of law that this document and all attachments were prepared under my direction or supervision in accordance with a system designed to assure that qualified personnel properly gathered and evaluated the information submitted. Based on my inquiry of the person or persons who manage the system, or those persons directly responsible for gathering information, the information submitted is, to the best of my knowledge and belief, true, accurate, and complete. I am aware that there are significant penalties for submitting false information, including the possibility of fine and imprisonment for knowing violations".

(Signatory must meet definition in Section B.11.A, eg., FOD, Ops Mgr, DSESH Group Leader, EPC Group Leader)

Print name and title:

Signature:

Date:

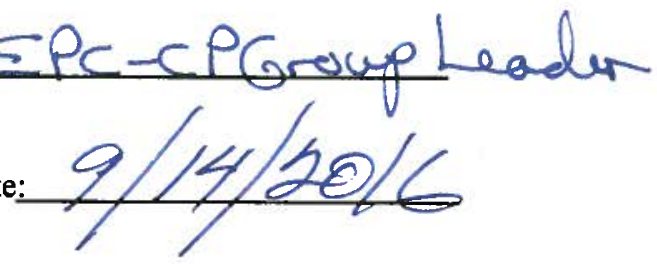


- Maintenance Details

\begin{tabular}{|c|c|c|c|c|}
\hline \multicolumn{2}{|c|}{ Requested: 5/16/2016 11:58:00 AM } & Target: & $7 / 31 / 2016$ & MSGP Program \\
\hline Procedure: & MSGP Quarterly Visuał & Priority/Type: & Normal / Inspection & 뭄 RG200.5 \\
\hline & $\begin{array}{l}\text { Assessment (EPC-CP- } \\
\text { Form-1021.2) }\end{array}$ & Department: & $\begin{array}{l}\text { Utilities and } \\
\text { Infrastructure }\end{array}$ & $\begin{array}{l}\text { TA-60 Roads and Grounds } \\
\text { Monitored Outfall (042) }\end{array}$ \\
\hline Last PM: & N/A & & & Q Substantially Identical Outfall (041) \\
\hline Project: & $\begin{array}{l}\text { SIO Visual Assessments } \\
\text { wk 5/30/16 (P-MSGP- } \\
4806 \text { ) }\end{array}$ & & & do MSGP04101 \\
\hline Reason: $N$ & ASGP Quarterly Visu & ent & & $\begin{array}{l}\text { Contact: } \\
\text { Phone: }\end{array}$ \\
\hline
\end{tabular}

Special Instructions: NMR053195

\section{Tasks}

\# Description

Rating Meas. Initials Failed N/A Complete

The result of this VA applies to associated SIOs as defined in the SWPPP, where applicable.

Sample information

Document the monitoring Period by using the

$30 \quad$ Monitoring Period lookup table.

Is visual assessment performed on an unfiltered

35 sample? (Use filtered only if unfiltered unavailable.)

Document the Date/Time Discharge began in the

"Reading" field of this line (using $\mathrm{mm} / \mathrm{dd} / \mathrm{yy} \mathrm{hh}: \mathrm{mm}$

40 format)

Document the Date/time sample collected in the

"Reading" field of this line (using mm/dd/yy hh:mm

50 format).

Document the Date/time sample visually assessed in

60 the "Reading" field of this line (using $\mathrm{mm} / \mathrm{dd} / \mathrm{yy}$

60 hh:mm format)

Document the nature of discharge using the

Precipitation Type lookup table. Document the

$70 \quad$ amount (in) in the "Reading" field of this line

Sample collected in first 30 minutes of discharge? If

"Failed" or unknown, provide reason in comments of

80 this line.

\section{Parameters}

110 Is sample colorless? If "Failed", describe.

Is sample oderless? If "Failed", document

observation using the Odor lookup table. If "other" is

chosen from the lookup table, provide description in

120 comments of this line.

Is sample clear? If "Failed", document observation

using the Clarity lookup table. If "other" is chosen

from the lookup table, provide description in

130 comments of this line.

Is sample free of floating solids? If "Failed", describe

if raw or waste material(s) in the comments of this

$140 \quad$ line

Is sample free of settled solids? If "Failed", document

observation using the Settled Solids lookup table. If

"other" is chosen from the lookup table, provide

150 description in comments of this line. 
Is sample free of suspended solids? If "Failed",

document observation using the Suspended Solids

lookup table. If "other" is chosen from the lookup

table, provide description in comments of this line.

Is sample foamless after gently shaking? If "Failed"

describe foam color and location ('on the surface' or

170 'in the sample') in the comments of this line.

Is sample devoid of an oil sheen? If "Failed", describe

color and thickness (e.g. flecks, globs) in the

180 comments of this line.

Is sample free of other obvious indicators of

190

pollution? If "Failed", describe in the comments of this

line.

Labor Report

Completed:

Failure:

Report:

No flow. No sample. No visud assessment candurtel 
wo 10:MS6P-54218

Page 3 of 3

Signature (collecting sample):

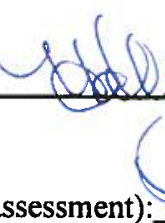

Signature (conducting visual assessment):

Date and Time :06/03/2016 15:59

Date and Time: $=0$ e/ $/ 3 / 201615159$

CERTIFICATION STATEMENT

"I certify under penalty of law that this document and all attachments were prepared under my direction or supervision in accordance with a system designed to assure that qualified personnel properly gathered and evaluated the information submitted. Based on my inquiry of the person or persons who manage the system, or those persons directly responsible for gathering information, the information submitted is, to the best of my knowledge and belief, true, accurate, and complete. I am aware that there are significant penalties for submitting false information, including the possibility of fine and imprisonment for knowing violations".

(Signatory must meet definition in Section B.11.A, eg., FOD, Ops Mgr, DSESH Group Leader, EPC Group Leader)

Print name and title:

Signature:

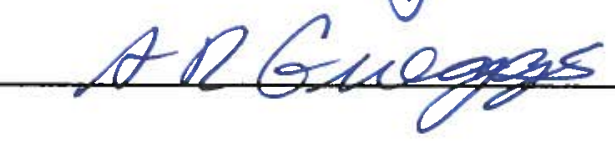

Date:

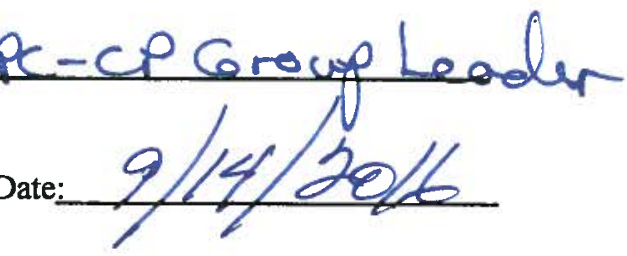




\section{Maintenance Details}

Requested: 5/16/2016 11:58:00 AM

Procedure: MSGP Quarterly Visual Assessment (EPC-CP. Form-1021.2)

Last PM: N/A

Project: $\quad$ SIO Visual Assessments wk 5/30/16 (P-MSGP4806)

Reason: MSGP Quarterly Visual Assessment

Special Instructions: NMR053195
Target: $\quad 7 / 31 / 2016$

Priority/Type: Normal / Inspection

Department: Utilities and Infrastructure

\author{
1 MSGP Program \\ 뭄르 RG200.5 \\ 1. TA-60 Roads and Grounds \\ A Monitored Outfall (036) \\ Q Substantially Identical Outfall (037) \\ b MSGP03701
}

Contact:

Phone:

\section{Tasks}

\# Description

The result of this VA applies to associated SIOs as defined in the SWPPP, where applicable.

\section{Sample information}

Document the monitoring Period by using the

$30 \quad$ Monitoring Period lookup table.

is visual assessment performed on an unfiltered

35 sample? (Use filtered only if unfiltered unavailable.)

Document the Date/Time Discharge began in the

"Reading" field of this line (using $\mathrm{mm} / \mathrm{dd} / \mathrm{yy}$ hh:mm

40 format)

Document the Date/time sample collected in the

"Reading" field of this line (using $\mathrm{mm} / \mathrm{dd} / \mathrm{yy} \mathrm{hh}$ :mm

50 format).

Document the Date/time sample visually assessed in

the "Reading" fiek

Document the nature of discharge using the

Precipitation Type lookup table. Document the

$70 \quad$ amount (in) in the "Reading" field of this line

Sample collected in first 30 minutes of discharge? If

"Failed" or unknown, provide reason in comments of

80 this line.

Parameters

$110 \quad$ Is sample colorless? If "Failed", describe

Is sample oderless? If "Failed", document

observation using the Odor lookup table. If "other" is

chosen from the lookup table, provide description in

120 comments of this line.

Is sample clear? If "Failed", document observation

using the Clarity lookup table. If "other" is chosen

from the lookup table, provide description in

130

comments of this line.

Is sample free of floating solids? If "Failed", describe

if raw or waste material(s) in the comments of this

140 line.

Is sample free of settled solids? If "Failed" document

observation using the Settled Solids lookup table. If

"other" is chosen from the lookup table, provide

150 description in comments of this line 
Is sample free of suspended solids? If "Failed", document observation using the Suspended Solids lookup table. If "other" is chosen from the lookup table, provide description in comments of this line.

Is sample foamless after gently shaking? If "Failed" describe foam color and location ('on the surface' or

170 'in the sample') in the comments of this line.

Is sample devoid of an oil sheen? If "Failed", describe color and thickness (e.g. flecks, globs) in the

180 comments of this line.

Is sample free of other obvious indicators of 厂 pollution? If "Failed", describe in the comments of this

190 line.

\section{- Labor Report}

Completed: Failure:

Report:
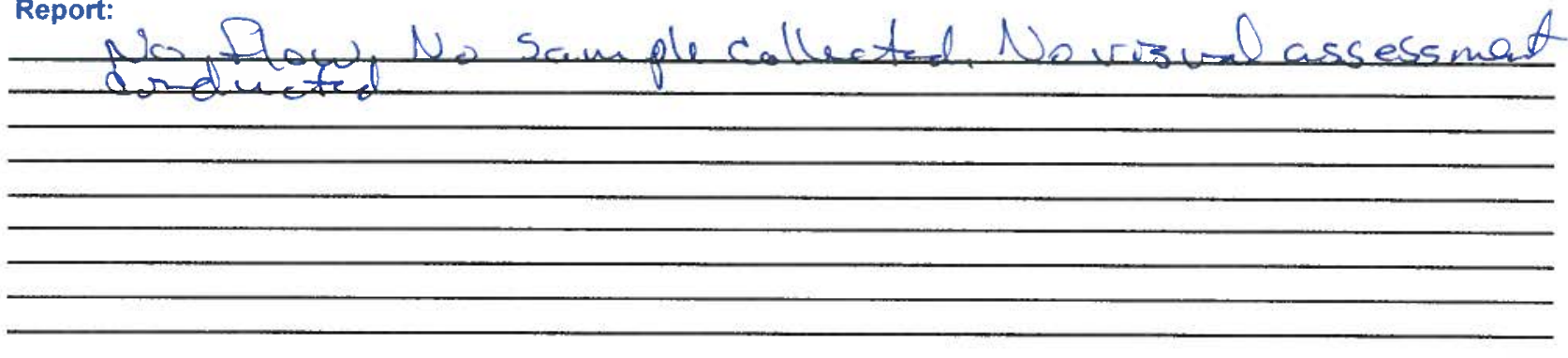
WO ID:

Page 2 of 2

Signature (collecting sample):

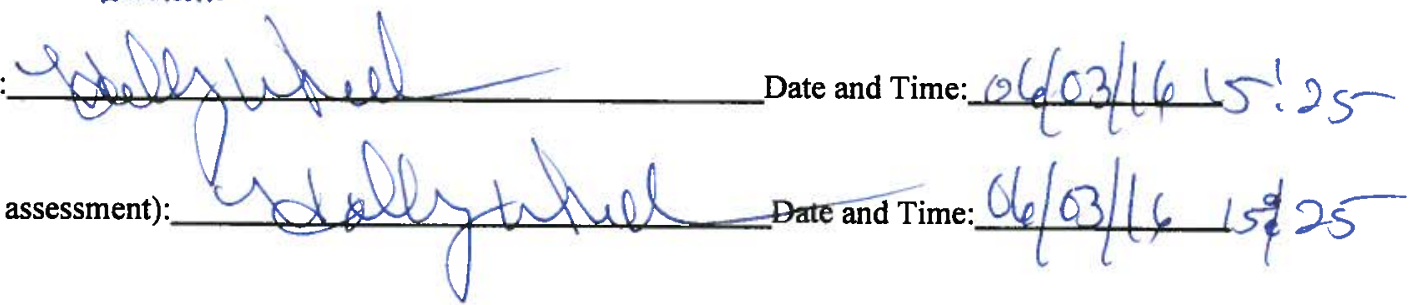

CERTIFICATION STATEMENT

"I certify under penalty of law that this document and all attachments were prepared under my direction or supervision in accordance with a system designed to assure that qualified personnel properly gathered and evaluated the information submitted. Based on my inquiry of the person or persons who manage the system, or those persons directly responsible for gathering information, the information submitted is, to the best of my knowledge and belief, true, accurate, and complete. I am aware that there are significant penalties for submitting false information, including the possibility of fine and imprisonment for knowing violations".

(Signatory must meet definition in Section B.11.A, eg., FOD, Ops Mgr, DSESH Group Leader, EPC Group Leader)

Print name and title:

Signature:

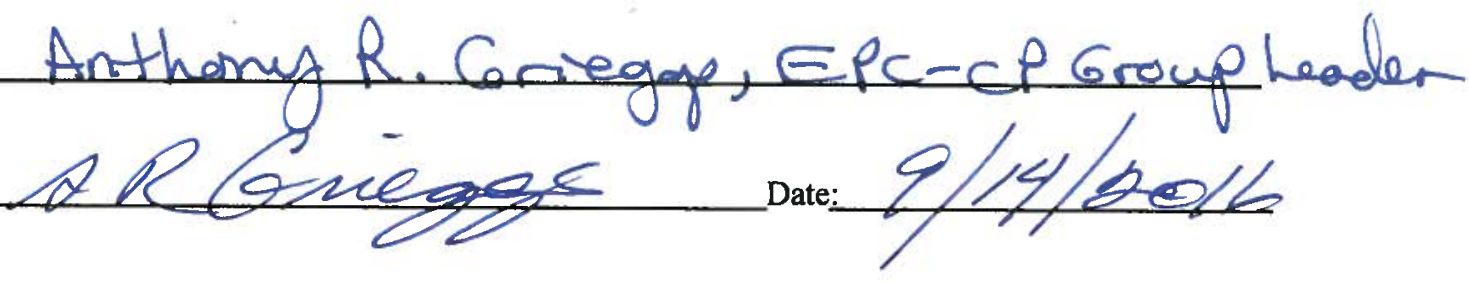




\section{Maintenance Details}

Requested: 5/16/2016 11:58:00 AM

Procedure: MSGP Quarterly Visual Assessment (EPC-CPForm-1021.2)

Last PM: N/A

Project: $\quad$ SIO Visual Assessments wk 5/30/16 (P-MSGP. 4806)

Reason: MSGP Quarterly Visual Assessment

Special Instructions: NMR053195

\section{Target: $\quad 7 / 31 / 2016$}

Priority/Type: Normal / Inspection

Department: Utilities and Infrastructure

\author{
MSGP Program \\ 亭 RG200.5 \\ 19 TA-60 Roads and Grounds \\ Aonitored Outfall (039) \\ Q. Substantially Identical Outfall (040) \\ to MSGP04001
}

Contact:

Phone:

\section{Tasks}

\# Description

Rating Meas. Initials Failed N/A Complete

The result of this VA applies to associated SIOs as defined in the SWPPP, where applicable.

\begin{tabular}{|c|c|c|c|c|}
\hline \multicolumn{5}{|c|}{ Sample information } \\
\hline 30 & $\begin{array}{l}\text { Document the monitoring Period by using the } \\
\text { Monitoring Period lookup table. }\end{array}$ & $\Gamma$ & Z & $\Gamma$ \\
\hline 35 & $\begin{array}{l}\text { Is visual assessment performed on an unfiltered } \\
\text { sample? (Use filtered only if unfiltered unavailable.) }\end{array}$ & $\Gamma$ & Z & $\Gamma$ \\
\hline 40 & $\begin{array}{l}\text { Document the Date/Time Discharge began in the } \\
\text { "Reading" field of this line (using } \mathrm{mm} / \mathrm{dd} / \mathrm{yy} \mathrm{hh}: \mathrm{mm} \\
\text { format). }\end{array}$ & $\Gamma$ & $K$ & $\Gamma$ \\
\hline 50 & $\begin{array}{l}\text { Document the Date/time sample collected in the } \\
\text { "Reading" field of this line (using mm/dd/yy hh:mm } \\
\text { format). }\end{array}$ & $\Gamma$ & $K$ & $\Gamma$ \\
\hline 60 & $\begin{array}{l}\text { Document the Date/time sample visually assessed in } \\
\text { the "Reading" field of this line (using mm/dd/yy } \\
\text { hh:mm format). }\end{array}$ & $\Gamma$ & X & $\Gamma$ \\
\hline 70 & $\begin{array}{l}\text { Document the nature of discharge using the } \\
\text { Precipitation Type lookup table. Document the } \\
\text { amount (in) in the "Reading" field of this line. }\end{array}$ & $\Gamma$ & $R$ & $\Gamma$ \\
\hline 80 & $\begin{array}{l}\text { Sample collected in first } 30 \text { minutes of discharge? If } \\
\text { "Failed" or unknown, provide reason in comments of } \\
\text { this line. }\end{array}$ & & K & $\Gamma$ \\
\hline
\end{tabular}

Parameters

110 Is sample colorless? If "Failed", describe

Is sample oderless? If "Failed", document observation using the Odor lookup table. If "other" is chosen from the lookup table, provide description in

120 comments of this line.

Is sample clear? If "Failed", document observation using the Clarity lookup table. If "other" is chosen from the lookup table, provide description in

130 comments of this line. Is sample free of floating solids? If "Failed", describe if raw or waste material(s) in the comments of this $140 \quad$ line.

Is sample free of settled solids? If "Failed", document observation using the Settled Solids lookup table. If "other" is chosen from the lookup table, provide 150 description in comments of this line 
Is sample free of suspended solids? If "Failed", document observation using the Suspended Solids

lookup table. If "other" is chosen from the lookup table, provide description in comments of this line.

Is sample foamless after gently shaking? If "Failed" describe foam color and location ('on the surface' or

170 'in the sample') in the comments of this line.

Is sample devoid of an oil sheen? If "Failed", describe color and thickness (e.g. flecks, globs) in the

180 comments of this line.

Is sample free of other obvious indicators of $\Gamma-\Gamma$ pollution? If "Failed", describe in the comments of this

190 line. $\frac{\Gamma}{\Gamma} \frac{\Gamma}{\Gamma}$

\section{Labor Report}

Completed: Failure:

Report:

Tar nets in positim do cateh flow.

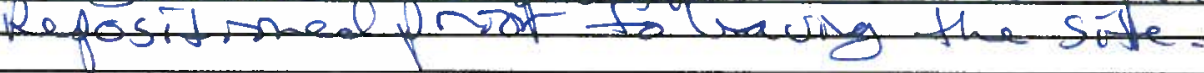




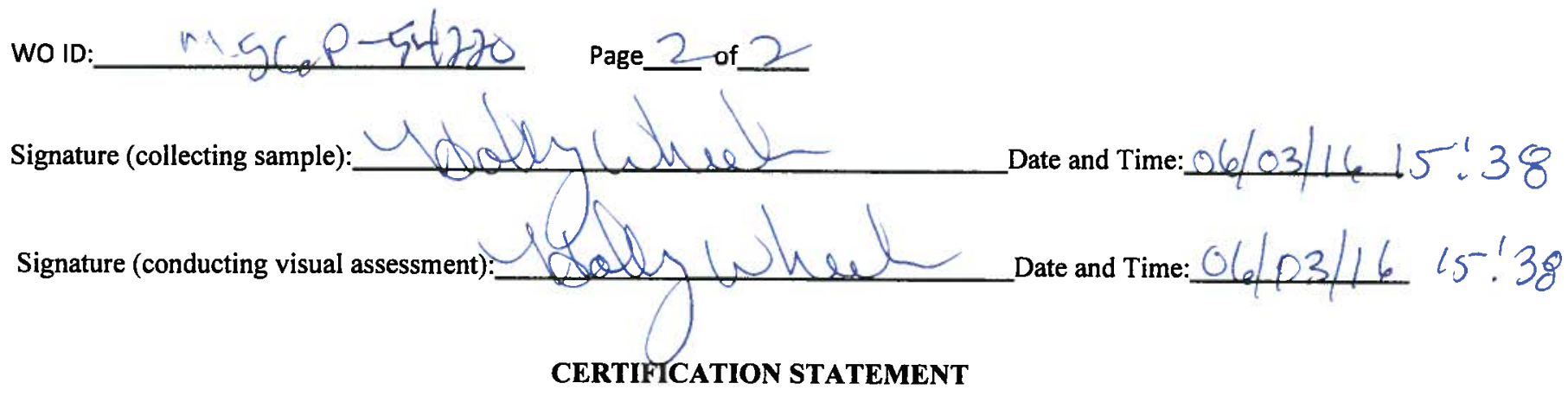

"I certify under penalty of law that this document and all attachments were prepared under my direction or supervision in accordance with a system designed to assure that qualified personnel properly gathered and evaluated the information submitted. Based on my inquiry of the person or persons who manage the system, or those persons directly responsible for gathering information, the information submitted is, to the best of my knowledge and belief, true, accurate, and complete. I am aware that there are significant penalties for submitting false information, including the possibility of fine and imprisonment for knowing violations".

\section{(Signatory must meet definition in Section B.11.A, eg., FOD, Ops Mgr, DSESH Group Leader, EPC Group Leader)}

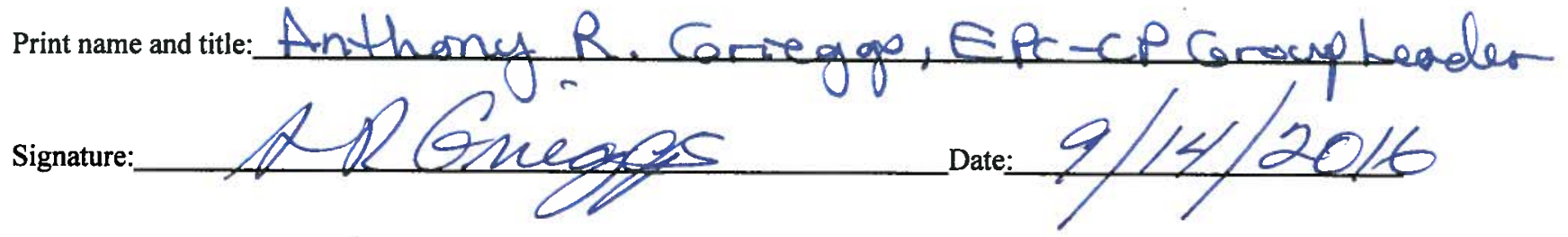


Maintenance Details

\begin{tabular}{|c|c|c|c|c|}
\hline Requested & : 5/16/2016 11:58:00 AM & Target: & $7 / 31 / 2016$ & MSGP Program \\
\hline Procedure: & MSGP Quarterly Visual & Priority/Type: & Normal / Inspection & 맘 RG200.5 \\
\hline & $\begin{array}{l}\text { Assessment (EPC-CP- } \\
\text { Form-1021.2) }\end{array}$ & Department: & $\begin{array}{l}\text { Utilities and } \\
\text { Infrastructure }\end{array}$ & $\begin{array}{l}\text { TA-60 Roads and Grounds } \\
\text { Monitored Outfall (039) }\end{array}$ \\
\hline Last PM: & N/A & & & Q Substantially Identical Outfall (038) \\
\hline Project: & $\begin{array}{l}\text { SIO Visual Assessments } \\
\text { wk 5/30/16 (P-MSGP- } \\
4806 \text { ) }\end{array}$ & & & A. MSGP03801 \\
\hline Reason: & ISGP Quarterly Visual & ient & & $\begin{array}{l}\text { Contact: } \\
\text { Phone: }\end{array}$ \\
\hline
\end{tabular}

Special Instructions: NMR053195

\section{Tasks}

\# Description Rating Meas. Initials Failed N/A Complete

The result of this VA applies to associated SIOs as defined in the SWPPP, where applicable.

\section{Sample information}

Document the monitoring Period by using the

30 Monitoring Period lookup table.

Is visual assessment performed on an unfiltered

35 sample? (Use filtered only if unfiltered unavailable.)

Document the Date/Time Discharge began in the

"Reading" field of this line (using mm/dd/yy hh:mm

40 format).

Document the Date/time sample collected in the

"Reading" field of this line (using $\mathrm{mm} / \mathrm{dd} / \mathrm{yy} \mathrm{hh}: \mathrm{mm}$

50 format).

Document the Date/time sample visually assessed in

60 the "Reading" field of this line (using $\mathrm{mm} / \mathrm{dd} / \mathrm{yy}$

60 hh:mm format)

Document the nature of discharge using the

Precipitation Type lookup table. Document the

$70 \quad$ amount (in) in the "Reading" field of this line.

Sample collected in first 30 minutes of discharge? If

"Failed" or unknown, provide reason in comments of

80 this line.

Parameters

$110 \quad$ Is sample colorless? If "Failed", describe.

Is sample oderless? If "Failed", document

observation using the Odor lookup table. If "other" is

chosen from the lookup table, provide description in

120 comments of this line.

Is sample clear? If "Failed", document observation

using the Clarity lookup table. If "other" is chosen

from the lookup table, provide description in

130 comments of this line.

is sample free of floating solids? If "Failed", describe

if raw or waste material(s) in the comments of this

140 line.

is sample free of settled solids? If "Failed", document

observation using the Settled Solids lookup table. If

"other" is chosen from the lookup table, provide

150 description in comments of this line. 
Is sample free of suspended solids? If "Failed",

document observation using the Suspended Solids

lookup table. If "other" is chosen from the lookup table, provide description in comments of this line.

Is sample foamless after gently shaking? If "Failed"

describe foam color and location ('on the surface' or

170 'in the sample') in the comments of this line.

Is sample devoid of an oil sheen? If "Failed", describe

color and thickness (e.g. flecks, globs) in the

180 comments of this line.

Is sample free of other obvious indicators of

pollution? If "Failed", describe in the comments of this

190

line.

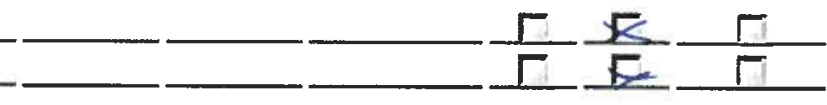

\section{Labor Report}

Completed:

Failure:

Report:

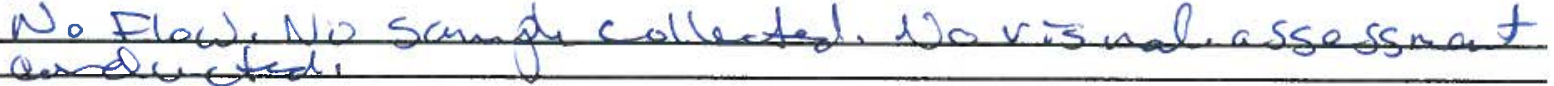




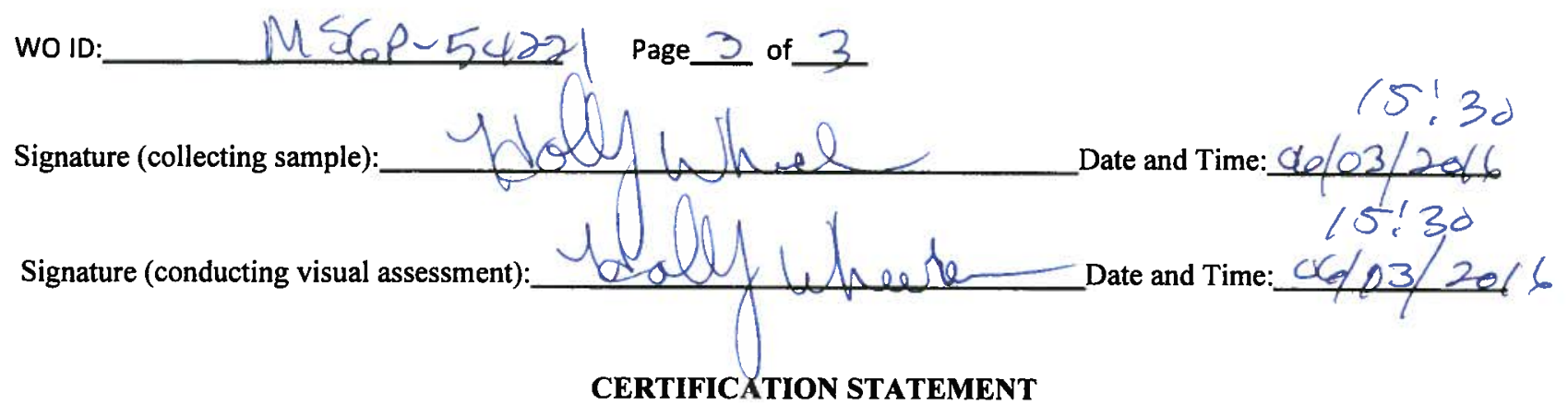

"I certify under penalty of law that this document and all attachments were prepared under my direction or supervision in accordance with a system designed to assure that qualified personnel properly gathered and evaluated the information submitted. Based on my inquiry of the person or persons who manage the system, or those persons directly responsible for gathering information, the information submitted is, to the best of my knowledge and belief, true, accurate, and complete. I am aware that there are significant penalties for submitting false information, including the possibility of fine and imprisonment for knowing violations".

\section{(Signatory must meet definition in Section B.11.A, eg., FOD, Ops Mgr, DSESH Group Leader, EPC Group Leader)}

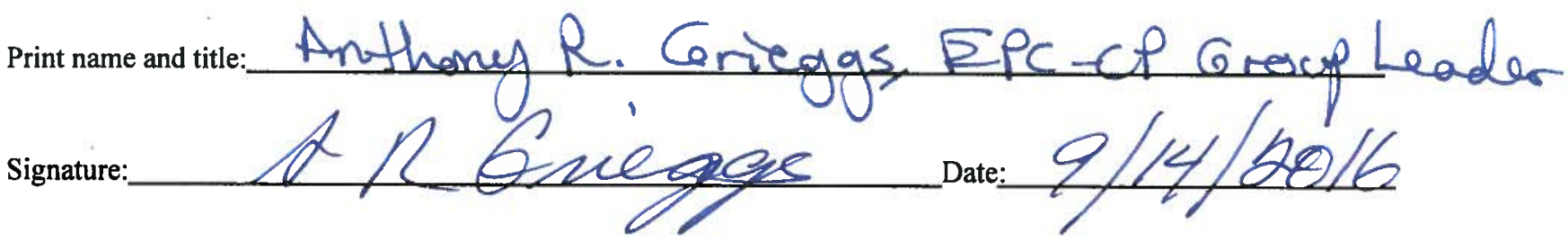




\section{Maintenance Details}

Requested: 5/31/2016 6:06:00 PM

Procedure: MSGP Quarterly Visual Assessment (EPC-CPForm-1021.2)

Last PM: $\quad$ 5/16/2016

Project: MSGP Visual Assessments wk 5/30/16 (P-MSGP. 4804)

Reason: MSGP 2016 Quarterly Visual Assessment

Target: $\quad 7 / 31 / 2016$

Priority/Type: Normal / Inspection

Department: Utilities and Infrastructure

Special Instructions: NMR053195

\section{Tasks}

\# Description

Rating Meas. Initials Failed N/A Complete

The result of this VA applies to associated SIOs as defined in the SWPPP, where applicable.

Sample information

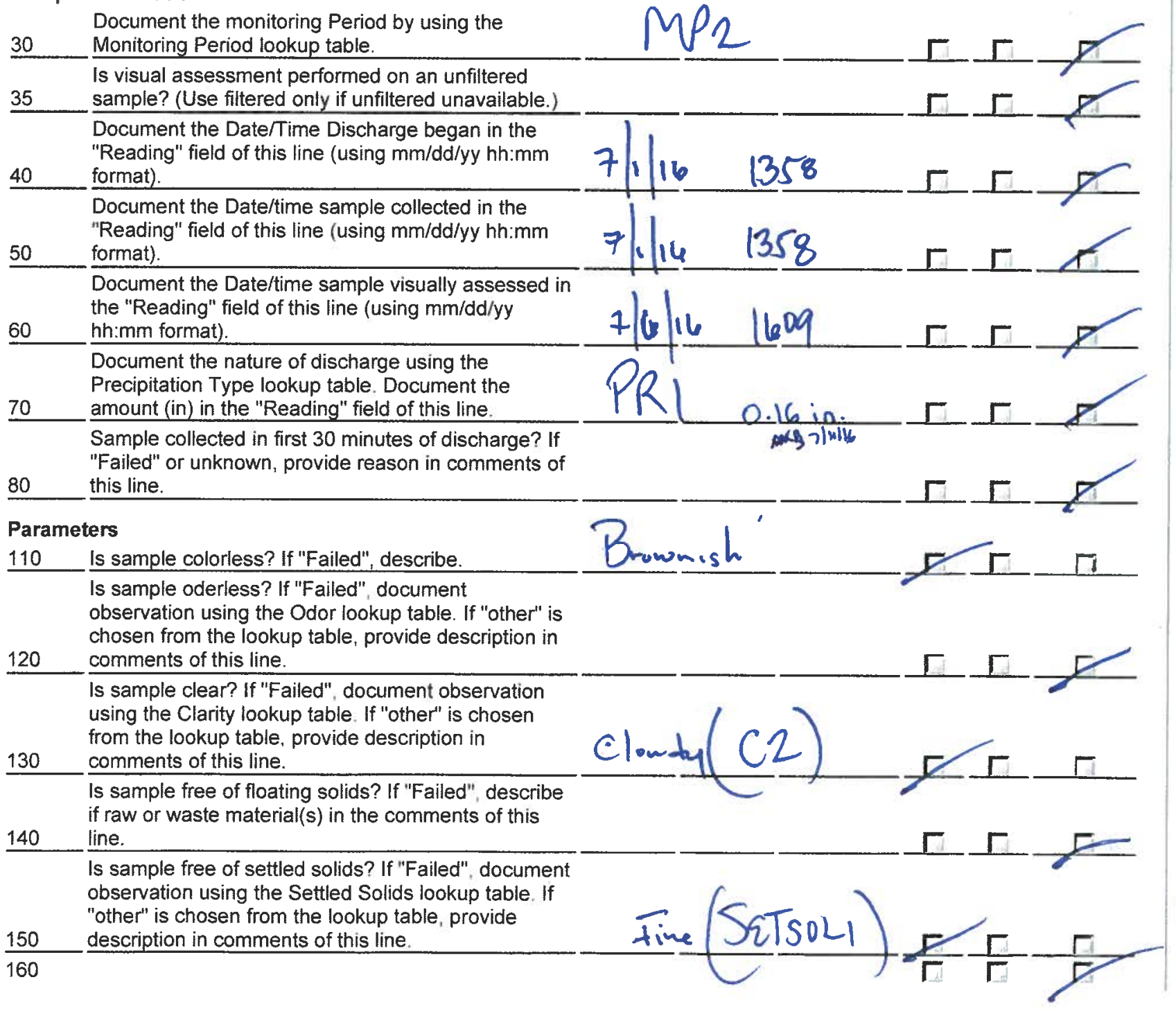


Is sample free of suspended solids? If "Failed", document observation using the Suspended Solids lookup table. If "other" is chosen from the lookup table, provide description in comments of this line. Is sample foamless after gently shaking? If "Failed" describe foam color and location ('on the surface' or

170 'in the sample') in the comments of this line.

Is sample devoid of an oil sheen? If "Failed", describe color and thickness (e.g. flecks, globs) in the

180 comments of this line.

Is sample free of other obvious indicators of

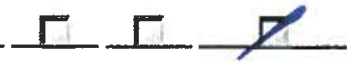

pollution? If "Failed", describe in the comments of this

190 line.

\section{Labor Report}

Completed:

Failure:

Meter 1:

Meter 2:

Report: 
wo ID: MSGP. 54681

Page 3 of 3

Signature (collecting sample):

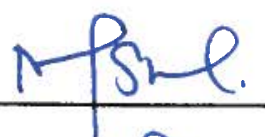

Date and Time: $7 / 1 / 16 \quad 1358$

Signature (conducting visual assessment):

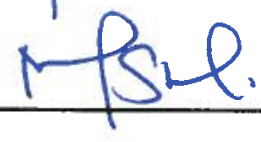

Date and Time: $7 / 4 / 16 \quad 1609$

CERTIFICATION STATEMENT

"I certify under penalty of law that this document and all attachments were prepared under my direction or supervision in accordance with a system designed to assure that qualified personnel properly gathered and evaluated the information submitted. Based on my inquiry of the person or persons who manage the system, or those persons directly responsible for gathering information, the information submitted is, to the best of my knowledge and belief, true, accurate, and complete. I am aware that there are significant penalties for submitting false information, including the possibility of fine and imprisonment for knowing violations".

(Signatory must meet definition in Section B.11.A, eg., FOD, Ops Mgr, DSESH Group Leader, EPC Group Leader)

Print name and title

Signature:

cg es

Date:

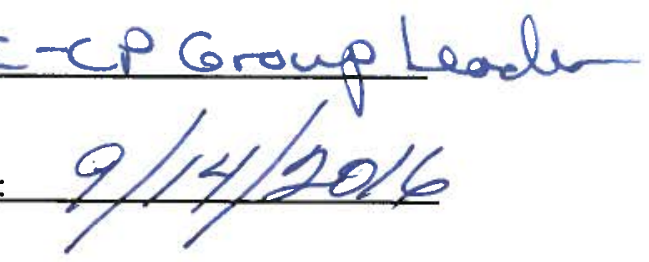




\section{Maintenance Details}

\section{Requested: 6/6/2016 1:02:33 PM \\ Procedure: MSGP Quarterly Visual Assessment (EPC-CP. Form-1021.2)}

Last PM: N/A

Project: SIO Visual Assessments wk 6/6/16 (P-MSGP-4823)

Reason: MSGP Quarterly Visual Assessment

\section{Target: $\quad 7 / 31 / 2016$}

Priority/Type: Normal / Inspection

Department: Utilities and Infrastructure

Special Instructions: NMR053195

\section{Tasks}

\# Description

Rating Meas. Initials

Failed N/A Complete

The result of this VA applies to associated SIOs as defined in the SWPPP, where applicable.

Sample information

Document the monitoring Period by using the

$30 \quad$ Monitoring Period lookup table.

Is visual assessment performed on an unfiltered

Contact:

Phone:

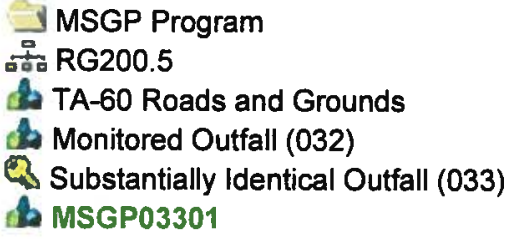

MSGP Program

200.5

A Monitored Outfall (032)

MSGP03301

35 sample? (Use filtered only if unfiltered unavailable.)

Document the Date/Time Discharge began in the

"Reading" field of this line (using $\mathrm{mm} / \mathrm{dd} / \mathrm{yy} \mathrm{hh}: \mathrm{mm}$

40 format)

Document the Date/time sample collected in the

"Reading" field of this line (using $\mathrm{mm} / \mathrm{dd} / \mathrm{yy}$ hh:mm

50 format)

Document the Date/time sample visually assessed in

the "Reading" field of this line (using $\mathrm{mm} / \mathrm{dd} / \mathrm{yy}$

$\underline{60}$ hh:mm format).

Document the nature of discharge using the

Precipitation Type lookup table. Document the

70 amount (in) in the "Reading" field of this line.

Sample collected in first 30 minutes of discharge? If

"Failed" or unknown, provide reason in comments of

80 this line.

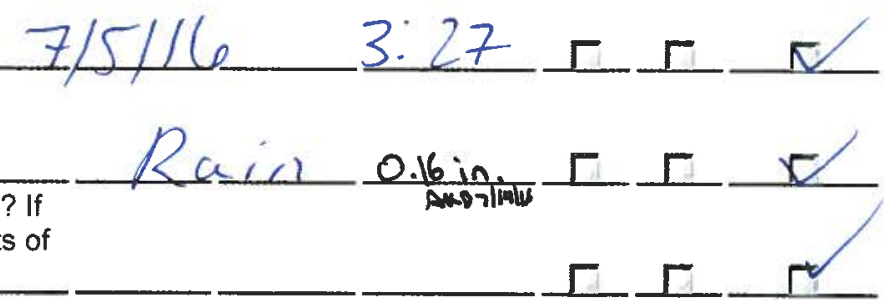

Parameters

110 Is sample colorless? If "Failed", describe.

Is sample oderless? If "Failed", document

observation using the Odor lookup table. If "other" is

chosen from the lookup table, provide description in

120 comments of this line.

Is sample clear? If "Failed", document observation

light tesn

$\Gamma$

$7 / 1 / 161345$

345 $\Gamma-\Gamma$ using the Clarity lookup table. If "other" is chosen from the lookup table, provide description in

130 comments of this line.

is sample free of floating solids? If "Failed", describe

if raw or waste material(s) in the comments of this

140 line.

Is sample free of settled solids? If "Failed", document

observation using the Settled Solids lookup table. If

"other" is chosen from the lookup table, provide

150 description in comments of this line.

160

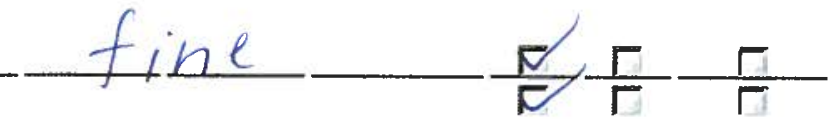


Is sample free of suspended solids? If "Failed",

document observation using the Suspended Solids

lookup table. If "other" is chosen from the lookup

table, provide description in comments of this line.

Is sample foamless after gently shaking? If "Failed" describe foam color and location ('on the surface' or

170 'in the sample') in the comments of this line.

is sample devoid of an oil sheen? If "Failed", describe

color and thickness (e.g. flecks, globs) in the

180 comments of this line.

Is sample free of other obvious indicators of pollution? If "Failed", describe in the comments of this

190 line.

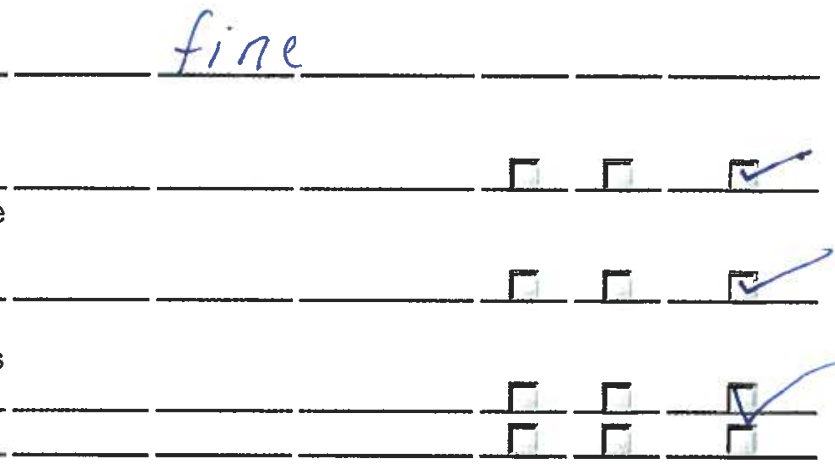

\section{Labor Report}

Completed: Failure:

Report: 
WO ID:

54920

Page 3 of 3

Signature (collecting sample)

Date and Time: $3: 27 \quad 7 / 5 / 16$

Signature (conducting visual assessment):

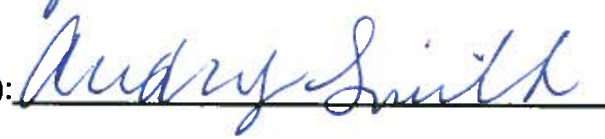

Date and Time: $3: 27 \quad 7 / 5 / 16$

CERTIFICATION STATEMENT

"I certify under penalty of law that this document and all attachments were prepared under my direction or supervision in accordance with a system designed to assure that qualified personnel properly gathered and evaluated the information submitted. Based on my inquiry of the person or persons who manage the system, or those persons directly responsible for gathering information, the information submitted is, to the best of my knowledge and belief, true, accurate, and complete. I am aware that there are significant penalties for submitting false information, including the possibility of fine and imprisonment for knowing violations".

(Signatory must meet definition in Section B.11.A, eg., FOD, Ops Mgr, DSESH Group Leader, EPC Group Leader)

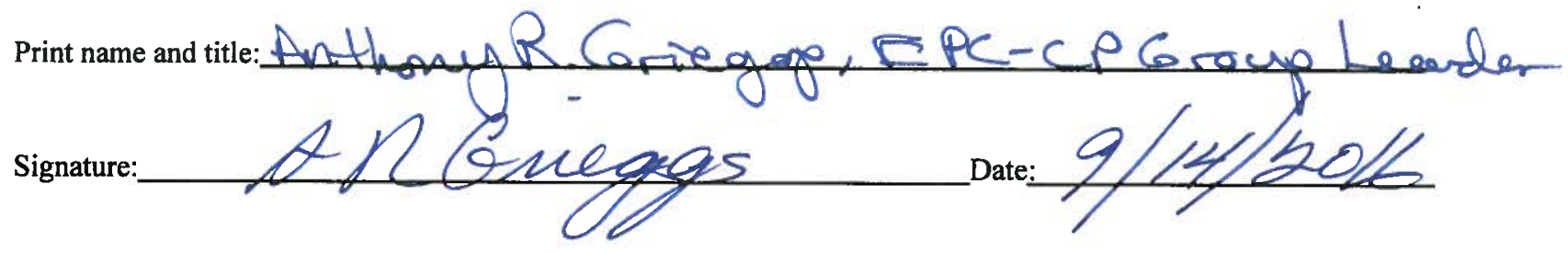




\section{-Maintenance Details}

\section{Requested: 6/6/2016 1:02:34 PM \\ Procedure: MSGP Quarterly Visual Assessment (EPC-CP- Form-1021.2)}

Last PM: N/A

Project: SIO Visual Assessments

wk 6/6/16 (P-MSGP-4823)

Reason: MSGP Quarterly Visual Assessment

\section{Target: $\quad 7 / 31 / 2016$}

Priority/Type: Normal / Inspection

Department: Utilities and Infrastructure

Special Instructions: NMR053195

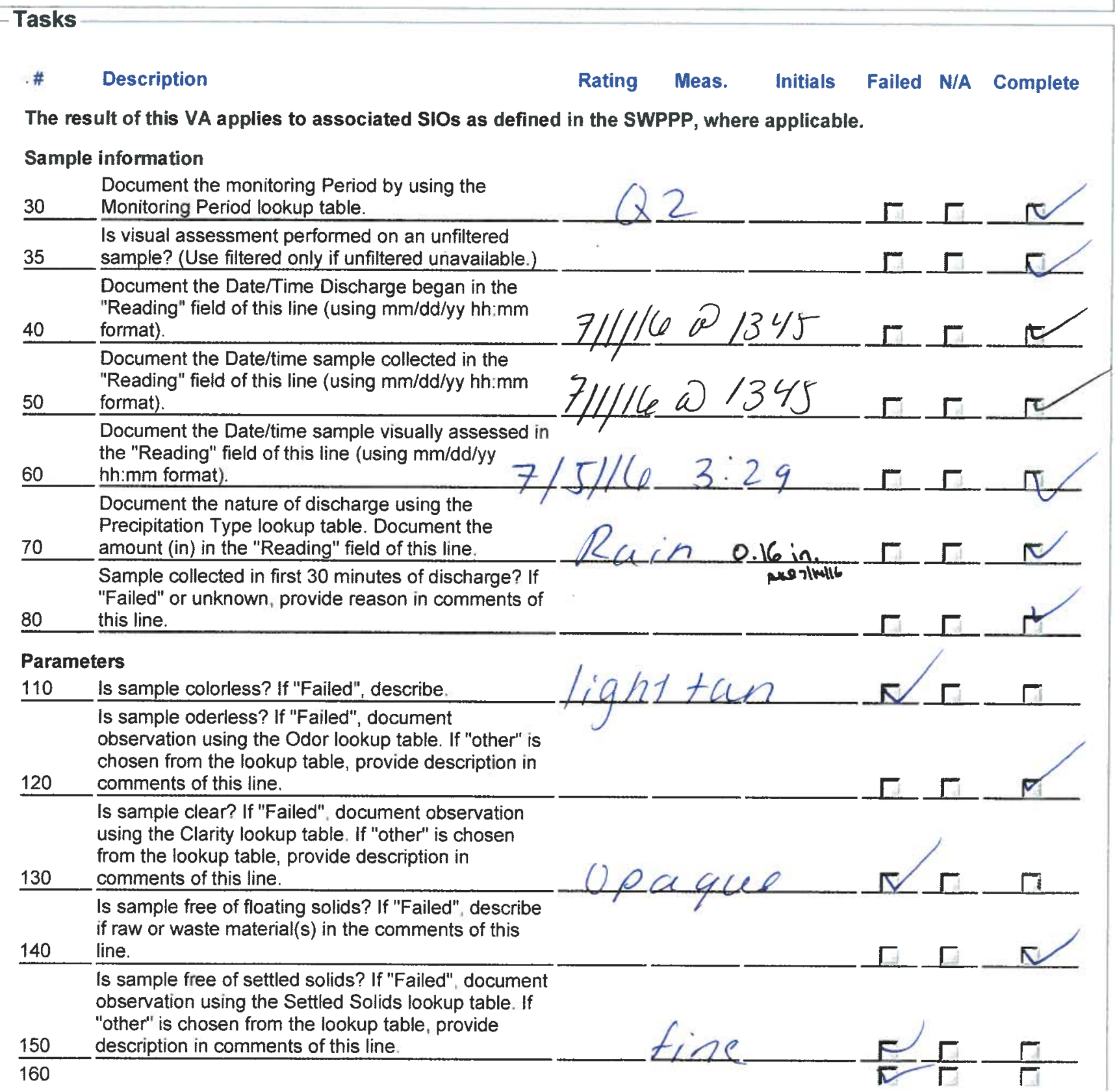


Is sample free of suspended solids? If "Failed",

document observation using the Suspended Solids

lookup table. If "other" is chosen from the lookup

table, provide description in comments of this line.

Is sample foamless after gently shaking? If "Failed"

describe foam color and location ('on the surface' or

170 'in the sample') in the comments of this line.

is sample devoid of an oil sheen? If "Failed", describe

color and thickness (e.g. flecks, globs) in the

180 comments of this line.

is sample free of other obvious indicators of

pollution? If "Failed", describe in the comments of this

190 line.

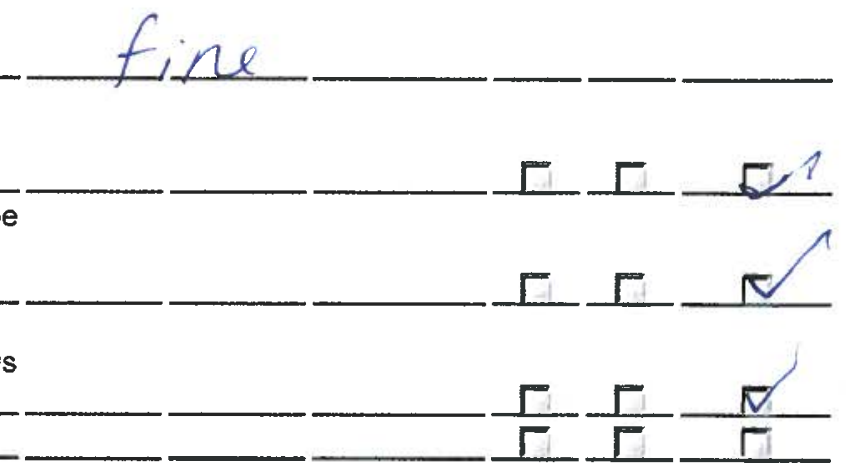

\section{Labor Report}

Completed: Failure:

Report: 
WO ID:

54921

Page 2 of 3

Signature (collecting sample):

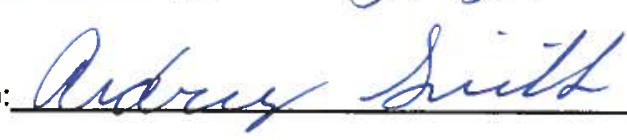

Date and Time: $7 / 57 / 6 \quad 3: 29$

Signature (conducting visual assessment):

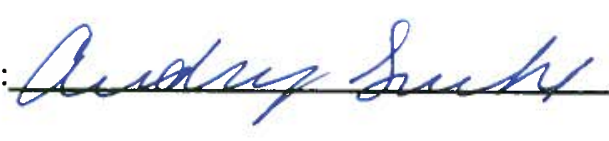

Date and Time:

$3: 297 / 5 / 16$

CERTIFICATION STATEMENT

"I certify under penalty of law that this document and all attachments were prepared under my direction or supervision in accordance with a system designed to assure that qualified personnel properly gathered and evaluated the information submitted. Based on my inquiry of the person or persons who manage the system, or those persons directly responsible for gathering information, the information submitted is, to the best of my knowledge and belief, true, accurate, and complete. I am aware that there are significant penalties for submitting false information, including the possibility of fine and imprisonment for knowing violations".

(Signatory must meet definition in Section B.11.A, eg., FOD, Ops Mgr, DSESH Group Leader, EPC Group Leader)

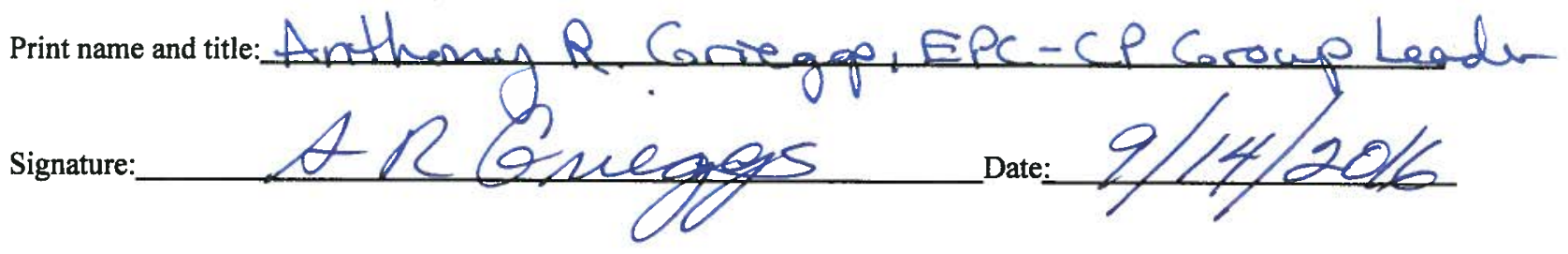


-Maintenance Details
Requested: 6/6/2016 1:02:35 PM
Procedure: MSGP Quarterly Visual Assessment (EPC-CP- Form-1021.2)
Target:
7/31/2016
Priority/Type: Normal / Inspection
Department: Utilities and Infrastructure

Last PM: N/A

Project: SIO Visual Assessments wk 6/6/16 (P-MSGP-4823)

Reason: MSGP Quarterly Visual Assessment

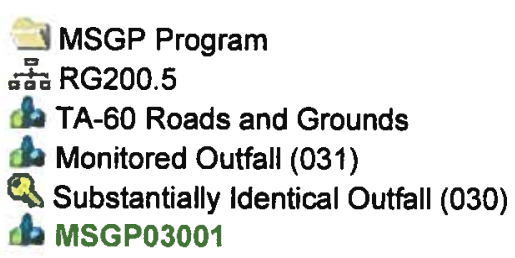

Contact:

Phone:

Special Instructions: NMR053195

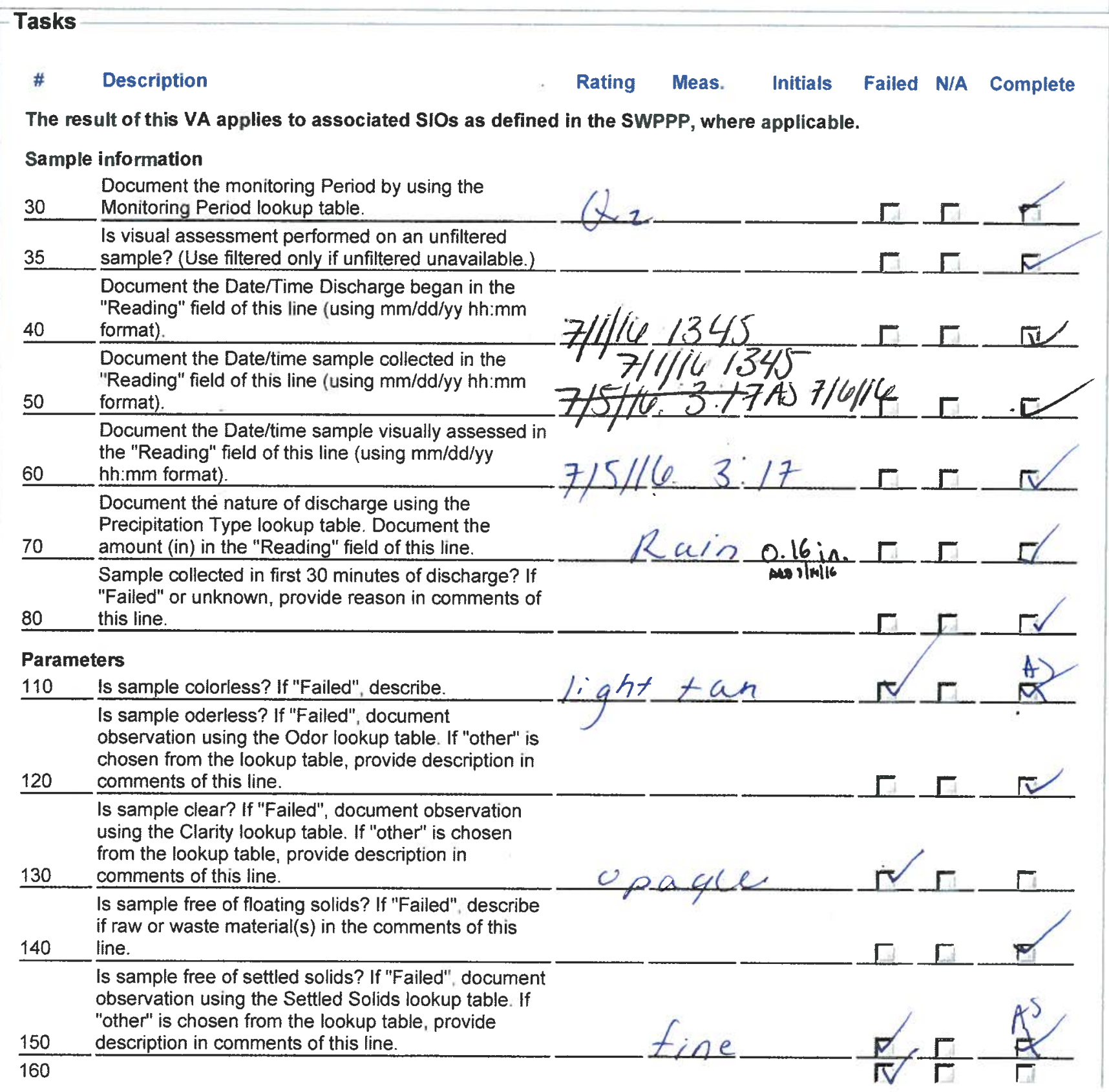


Is sample free of suspended solids? If "Failed",

document observation using the Suspended Solids

lookup table. If "other" is chosen from the lookup

table, provide description in comments of this line.

Is sample foamless after gently shaking? If "Failed"

describe foam color and location ('on the surface' or

170 'in the sample') in the comments of this line.

Is sample devoid of an oil sheen? If "Failed", describe

color and thickness (e.g. flecks, globs) in the

180 comments of this line.

Is sample free of other obvious indicators of

pollution? If "Failed", describe in the comments of this

190 line.

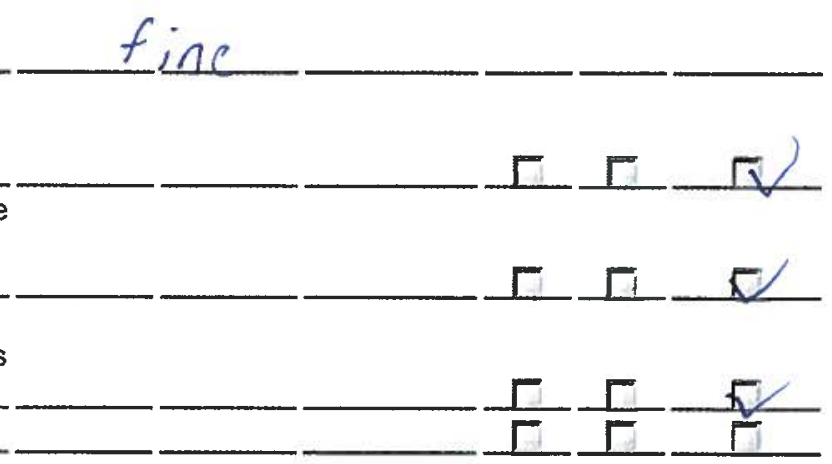

\section{- Labor Report}

Completed: Failure:

Report: 
wo 10: 54922

Page 3 of 3

Signature (collecting sample):

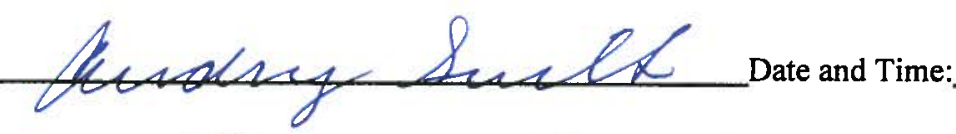

$7 / 5 / 163: 17$

Signature (conducting visual assessment):

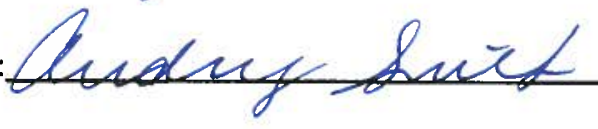

Date and Time: $7 / 5 / 16-3: 17$

CERTIFICATION STATEMENT

"I certify under penalty of law that this document and all attachments were prepared under my direction or supervision in accordance with a system designed to assure that qualified personnel properly gathered and evaluated the information submitted. Based on my inquiry of the person or persons who manage the system, or those persons directly responsible for gathering information, the information submitted is, to the best of my knowledge and belief, true, accurate, and complete. I am aware that there are significant penalties for submitting false information, including the possibility of fine and imprisonment for knowing violations".

(Signatory must meet definition in Section B.11.A, eg., FOD, Ops Mgr, DSESH Group Leader, EPC Group Leader)

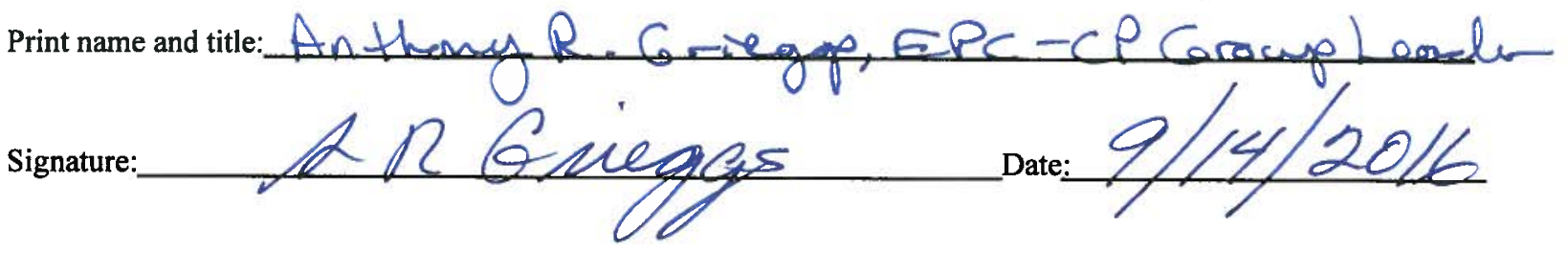




\section{Maintenance Details}

\section{Requested: 6/6/2016 1:02:35 PM \\ Procedure: MSGP Quarterly Visual Assessment (EPC-CP- Form-1021.2)}

Last PM: N/A

Project: SIO Visual Assessments wk 6/6/16 (P-MSGP-4823)

Reason: MSGP Quarterly Visual Assessment

\section{Target: $\quad$ 7/31/2016}

Priority/Type: Normal / Inspection

Department: Utilities and Infrastructure

Special Instructions: NMR053195

\section{Tasks}

\# Description

Rating Meas. Initials Failed N/A Complete

The result of this VA applies to associated SIOs as defined in the SWPPP, where applicable.

Sample information

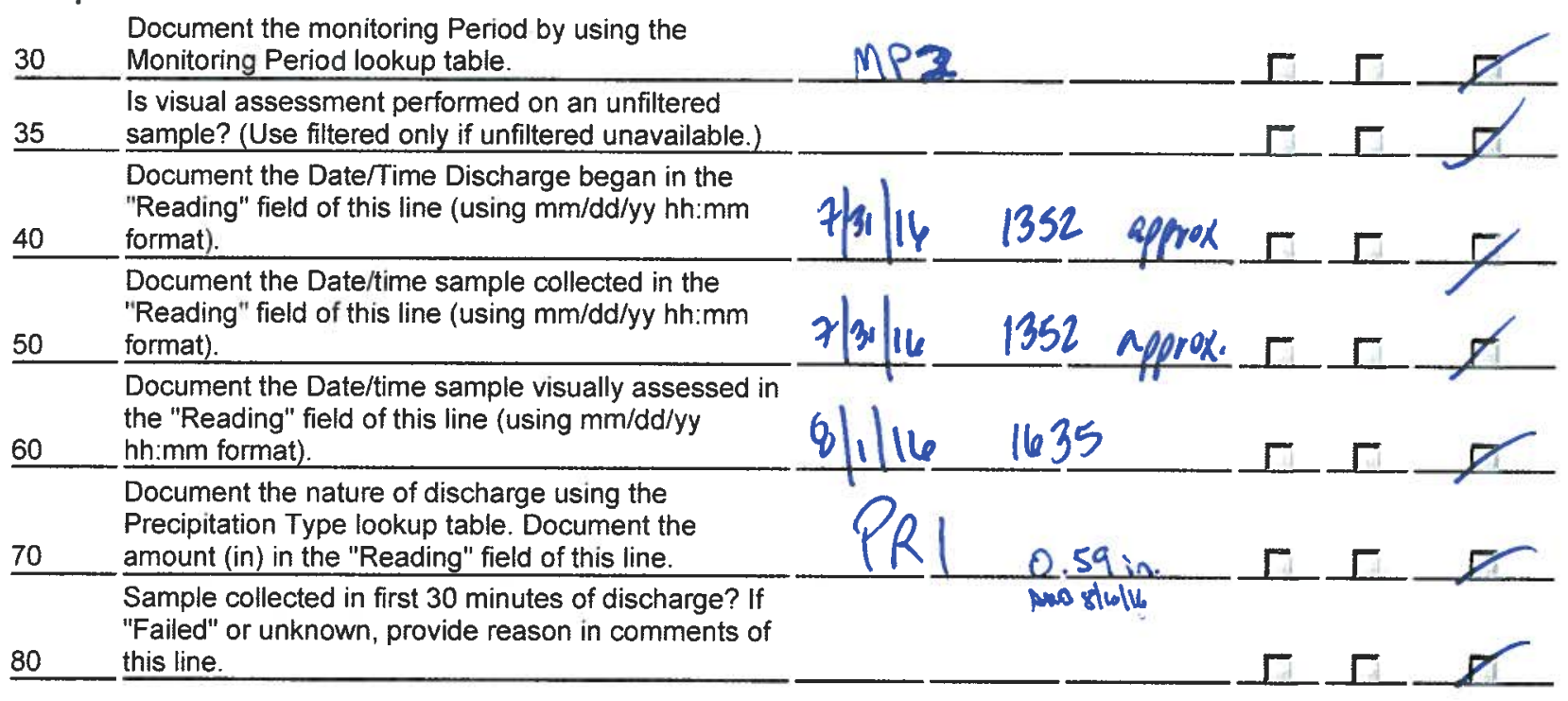

Parameters

110 Is sample colorless? If "Failed", describe.

Brown

Contact:

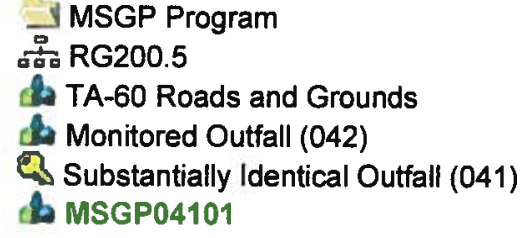

Phone:

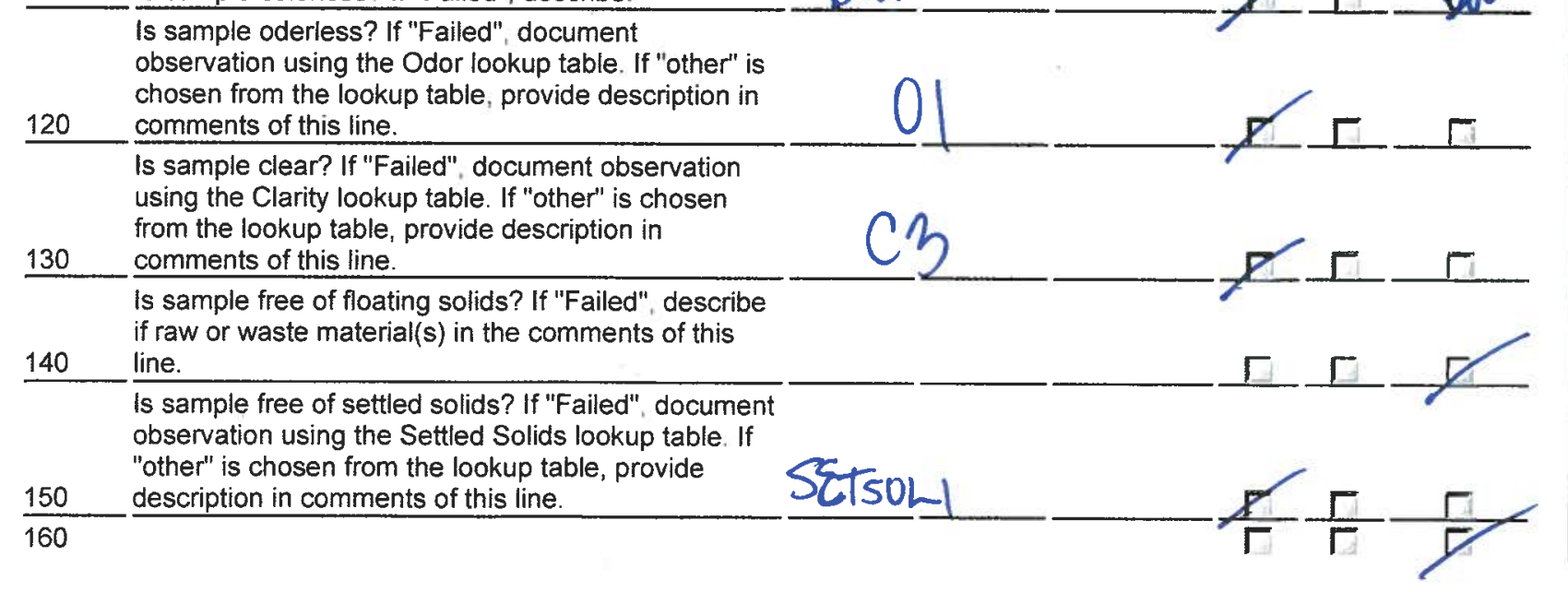


Is sample free of suspended solids? If "Failed", document observation using the Suspended Solids lookup table. If "other" is chosen from the lookup table, provide description in comments of this line.

Is sample foamless after gently shaking? If "Failed" describe foam color and location ('on the surface' or

170 'in the sample') in the comments of this line.

Is sample devoid of an oil sheen? If "Failed", describe color and thickness (e.g. flecks, globs) in the

180 comments of this line.

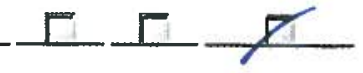

Is sample free of other obvious indicators of

pollution? If "Failed", describe in the comments of this

190 line.

\section{Labor Report}

Completed:

Failure:

Report: 
WO ID:

MSGP-54923

Page 3 of 3

Signature (collecting sample):

Signature (conducting visual assessment):
Mst.

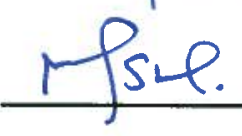

Date and Time: $3 / 31 / 16 \quad 1352$

Date and Time: $8 /, / 6 \quad 1635$

CERTIFICATION STATEMENT

"I certify under penalty of law that this document and all attachments were prepared under my direction or supervision in accordance with a system designed to assure that qualified personnel properly gathered and evaluated the information submitted. Based on my inquiry of the person or persons who manage the system, or those persons directly responsible for gathering information, the information submitted is, to the best of my knowledge and belief, true, accurate, and complete. I am aware that there are significant penalties for submitting false information, including the possibility of fine and imprisonment for knowing violations".

(Signatory must meet definition in Section B.11.A, eg., FOD, Ops Mgr, DSESH Group Leader, EPC Group Leader)

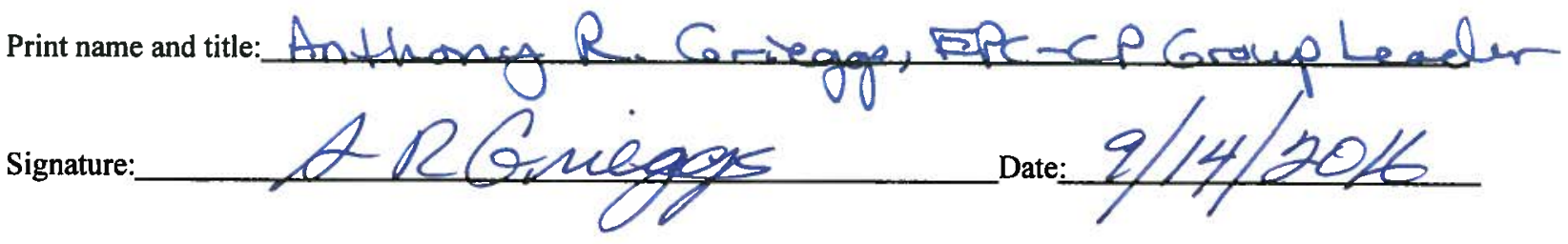




\section{Maintenance Details}

\section{Requested: 7/14/2016 5:55:59 PM \\ Procedure: MSGP Quarterly Visual Assessment (EPC-CP. Form-1021.2) \\ Last PM: $\quad 7 / 5 / 2016$ \\ Project: $\quad$ SIO Visual Assessments \\ 7-14-16 (P-MSGP-4944)}

$\begin{array}{ll}\text { Target: } & 7 / 31 / 2016 \\ \text { Priority/Type: } & \text { Normal / Inspection } \\ \text { Department: } & \text { Utilities and } \\ & \text { Infrastructure }\end{array}$

Target: $\quad$ 7/31/2016

Utilities and

\section{MSGP Program \\ 品 RG200.5 \\ d) TA-60 Roads and Grounds \\ th Monitored Outfall (032) \\ Substantially Identical Outfall (033) \\ ch MSGP03301}

Contact:

Phone:

Reason: MSGP Quarterly Visual Assessment

Special Instructions: NMR053195

\section{Tasks}

\# Description

Rating Meas. Initials Failed N/A Complete

The result of this VA applies to associated SIOs as defined in the SWPPP, where applicable.

\section{Sample information}

Document the monitoring Period by using the

$30 \quad$ Monitoring Period lookup table.

Is visual assessment performed on an unfiltered

35 sample? (Use filtered only if unfiltered unavailable.)

Document the Date/Time Discharge began in the

"Reading" field of this line (using mm/dd/yy hh:mm

40 format)

Document the Date/time sample collected in the

"Reading" field of this line (using mm/dd/yy hh:mm

50 format)

Document the Date/time sample visually assessed in the "Reading" field of this line (using $\mathrm{mm} / \mathrm{dd} / \mathrm{yy}$

60 hh:mm format).

Document the nature of discharge using the

Precipitation Type lookup table. Document the

$70 \quad$ amount (in) in the "Reading" field of this line

Sample collected in first 30 minutes of discharge? If

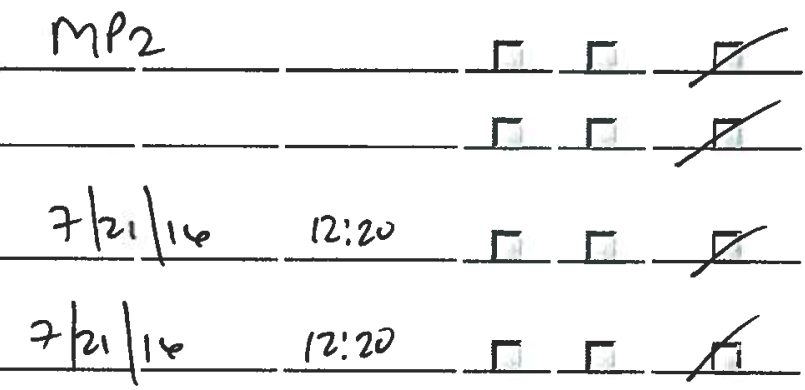

"Failed" or unknown, provide reason in comments of

80 this line.

\section{Parameters}

110 Is sample colorless? If "Failed", describe.

Is sample oderless? If "Failed", document

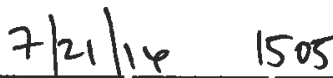

1505

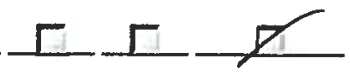
observation using the Odor lookup table. If "other" is
chosen from the lookup table, provide description in

20 comments of this line.

Is sample clear? If "Failed", document observation

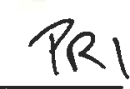

PRI

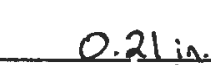
Axs $7(27)$
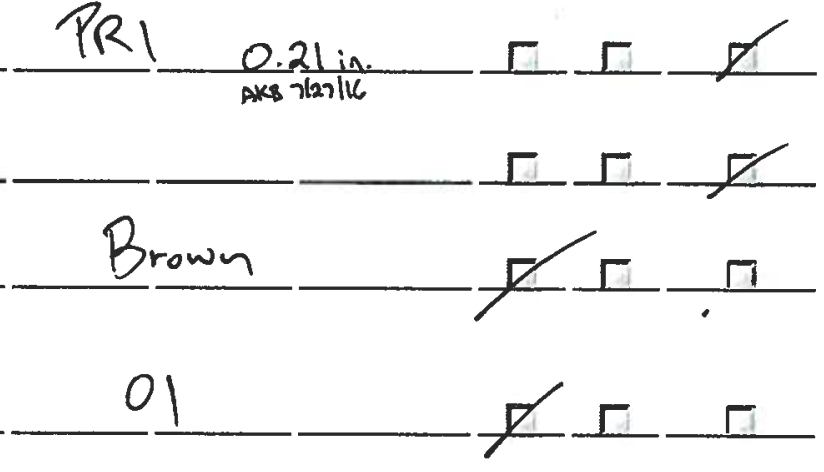

using the Clarity lookup table. If "other" is chosen

from the lookup table, provide description in

130 comments of this line.

is sample free of floating solids? If "Failed" describe

if raw or waste material(s) in the comments of this

140 line.

is sample free of settled solids? If "Failed", document observation using the Settled Solids lookup table. If "other" is chosen from the lookup table, provide description in comments of this line
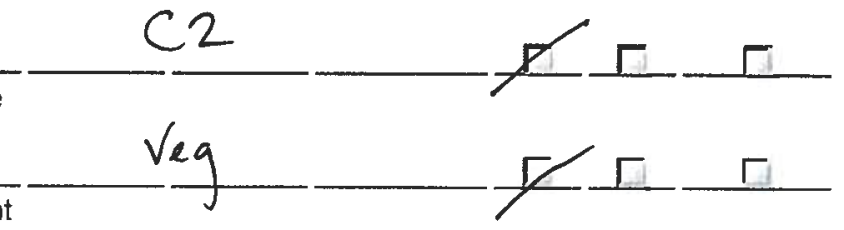

160
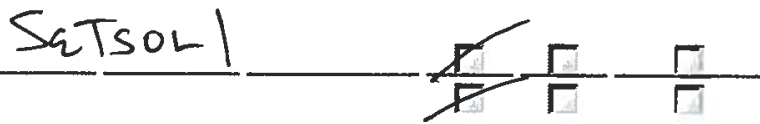
Is sample free of suspended solids? If "Failed", document observation using the Suspended Solids lookup table. If "other" is chosen from the lookup table, provide description in comments of this line.

\section{Susson 2}

Is sample foamless after gently shaking? If "Failed" describe foam color and location ('on the surface' or

170 'in the sample') in the comments of this line. (Range: $0-0)$

Is sample devoid of an oil sheen? If "Failed", describe color and thickness (e.g. flecks, globs) in the

180 comments of this line. (Range: 0 - 0)

Is sample free of other obvious indicators of pollution? If "Failed", describe in the comments of this

190 line. (Range: 0 - 0)

\section{Labor Report}

Completed: Failure:

Report: 
wo 1D: $56 / 25$

Page 3 of 3

Signature (collecting sample):

Psi.

Date and Time: $7|21| 16$

Signature (conducting visual assessment): Ps ul.

Date and Time: $7 / 21 \mid 16 \quad 1505$

CERTIFICATION STATEMENT

"I certify under penalty of law that this document and all attachments were prepared under my direction or supervision in accordance with a system designed to assure that qualified personnel properly gathered and evaluated the information submitted. Based on my inquiry of the person or persons who manage the system, or those persons directly responsible for gathering information, the information submitted is, to the best of my knowledge and belief, true, accurate, and complete. I am aware that there are significant penalties for submitting false information, including the possibility of fine and imprisonment for knowing violations".

(Signatory must meet definition in Section B.11.A, eg., FOD, Ops Mgr, DSESH Group Leader, EPC Group Leader)

Print name and title:

Signature:

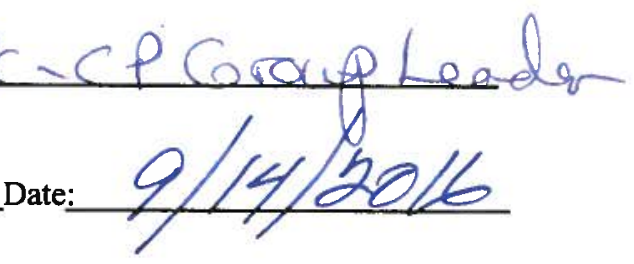


Maintenance Details

\begin{tabular}{|c|c|c|c|c|}
\hline & Target: & $7 / 31 / 2016$ & \multirow{5}{*}{$\begin{array}{l}\text { MSGP Program } \\
\text { T RG200.5 } \\
\text { TA-60 Roads and Grounds } \\
\text { Sonitored Outfall (032) } \\
\text { MSGPtantially Identical Outfall (034) }\end{array}$} \\
\hline \multirow{2}{*}{\multicolumn{2}{|c|}{$\begin{array}{c}\text { Requested: } 7 / 14 / 20165: 55: 59 \text { PM } \\
\text { Procedure: MSGP Quarterly Visual } \\
\text { Assessment (EPC-CP- } \\
\text { Form-1021.2) }\end{array}$}} & Priority/Type: & Normal / Inspection & \\
\hline & & Department: & $\begin{array}{l}\text { Utilities and } \\
\text { Infrastructure }\end{array}$ & \\
\hline Last PM: & $7 / 5 / 2016$ & & & \\
\hline Project: & $\begin{array}{l}\text { SIO Visual Assessments } \\
7-14-16 \text { (P-MSGP-4944) }\end{array}$ & & & \\
\hline
\end{tabular}

Reason: MSGP Quarterly Visual Assessment

Contact:

Special Instructions: NMR053195

Phone:

\section{Tasks}

\# Description

Rating Meas. Initials Failed N/A Complete

The result of this VA applies to associated SIOs as defined in the SWPPP, where applicable.

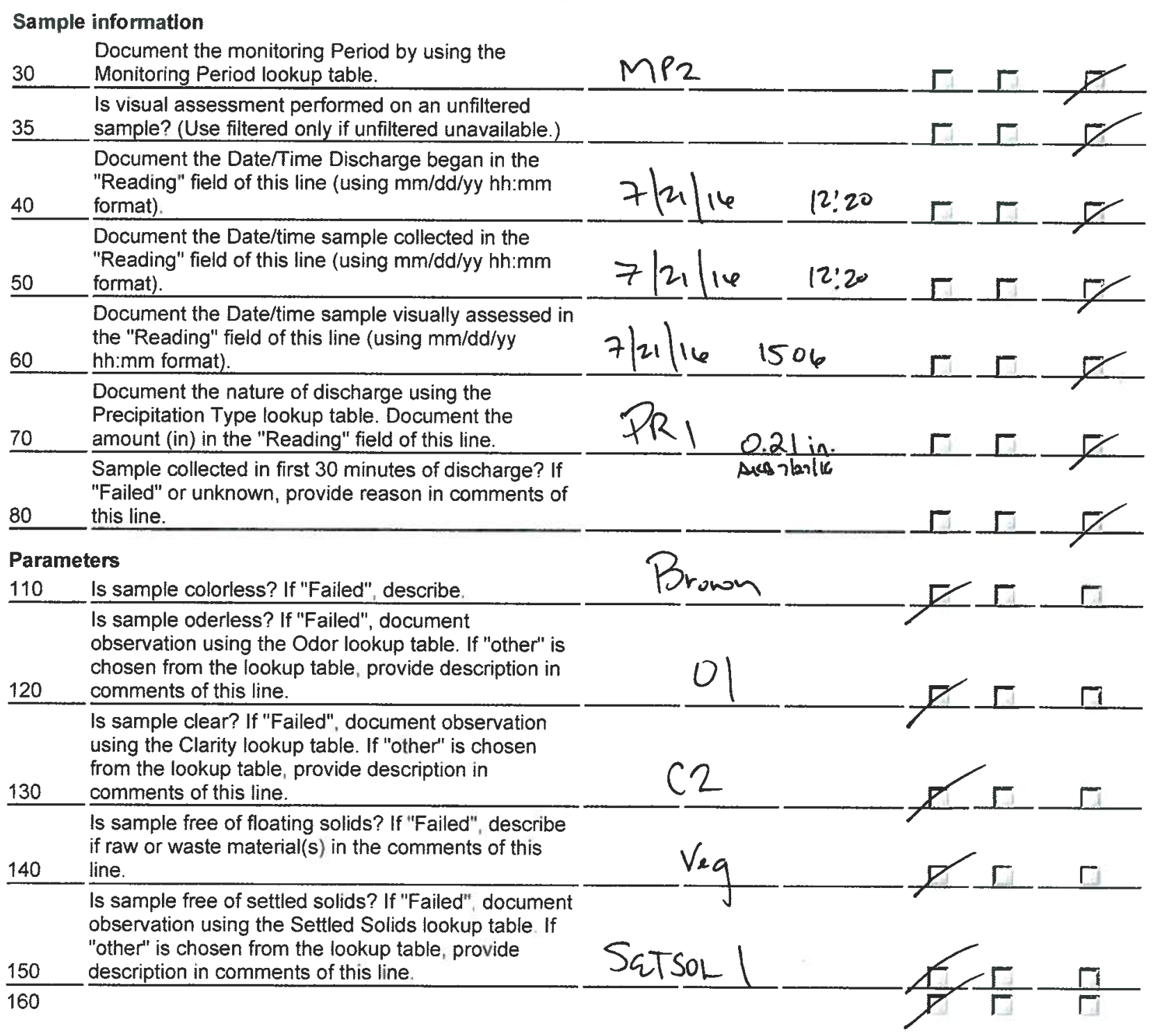


Is sample free of suspended solids? If "Failed", document observation using the Suspended Solids lookup table. If "other" is chosen from the lookup table, provide description in comments of this line.

\section{SuSSOL 2}

Is sample foamless after gently shaking? If "Failed" describe foam color and location ('on the surface' or

170 'in the sample') in the comments of this line. (Range: 0 - 0)

Is sample devoid of an oil sheen? If "Failed", describe color and thickness (e.g. flecks, globs) in the

180 comments of this line. (Range: 0 -0)

Is sample free of other obvious indicators of pollution? If "Failed", describe in the comments of this

190 line. (Range: $0-0$ )

\section{Labor Report}

Completed:

Failure:

Report: 
wo 10:56/26 Page. 3 of 3

Signature (collecting sample):

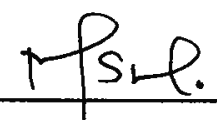

Date and Time: $7 / 21 / 16$

Signature (conducting visual assessment):

Psis.

Date and Time: $7|21| 16 \quad 1506$

CERTIFICATION STATEMENT

"I certify under penalty of law that this document and all attachments were prepared under my direction or supervision in accordance with a system designed to assure that qualified personnel properly gathered and evaluated the information submitted. Based on my inquiry of the person or persons who manage the system, or those persons directly responsible for gathering information, the information submitted is, to the best of my knowledge and belief, true, accurate, and complete. I am aware that there are significant penalties for submitting false information, including the possibility of fine and imprisonment for knowing violations".

(Signatory must meet definition in Section B.11.A, eg., FOD, Ops Mgr, DSESH Group Leader, EPC Group Leader)

Print name and title:

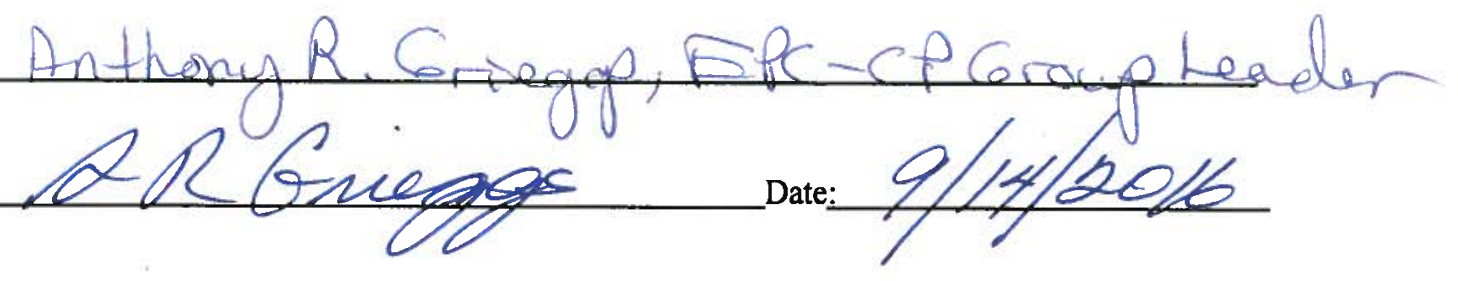


Maintenance Details

\begin{tabular}{|c|c|}
\hline \multicolumn{2}{|c|}{ Requested: 7/14/2016 5:56:00 PM } \\
\hline Procedure & $\begin{array}{l}\text { MSGP Quarterly Visual } \\
\text { Assessment (EPC-CP- } \\
\text { Form-1021.2) }\end{array}$ \\
\hline Last PM: & $7 / 5 / 2016$ \\
\hline Project: & $\begin{array}{l}\text { SIO Visual Assessments } \\
7-14-16 \text { (P-MSGP-4944) }\end{array}$ \\
\hline
\end{tabular}

Reason: MSGP Quarterly Visual Assessment

Target: $\quad 7 / 31 / 2016$

Priority/Type: Normal / Inspection

Department: Utilities and Infrastructure

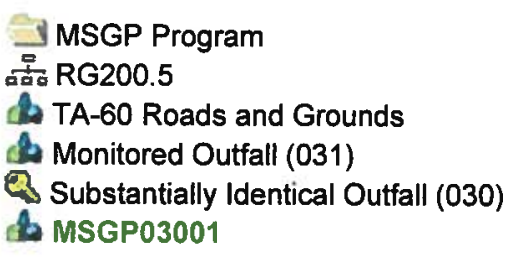

Contact:

Phone:

Special Instructions: NMR053195

\section{-Tasks}

\# Description

$$
\text { Rating Meas. Initials Failed N/A Complete }
$$

The result of this VA applies to associated SIOs as defined in the SWPPP, where applicable.

Sample information

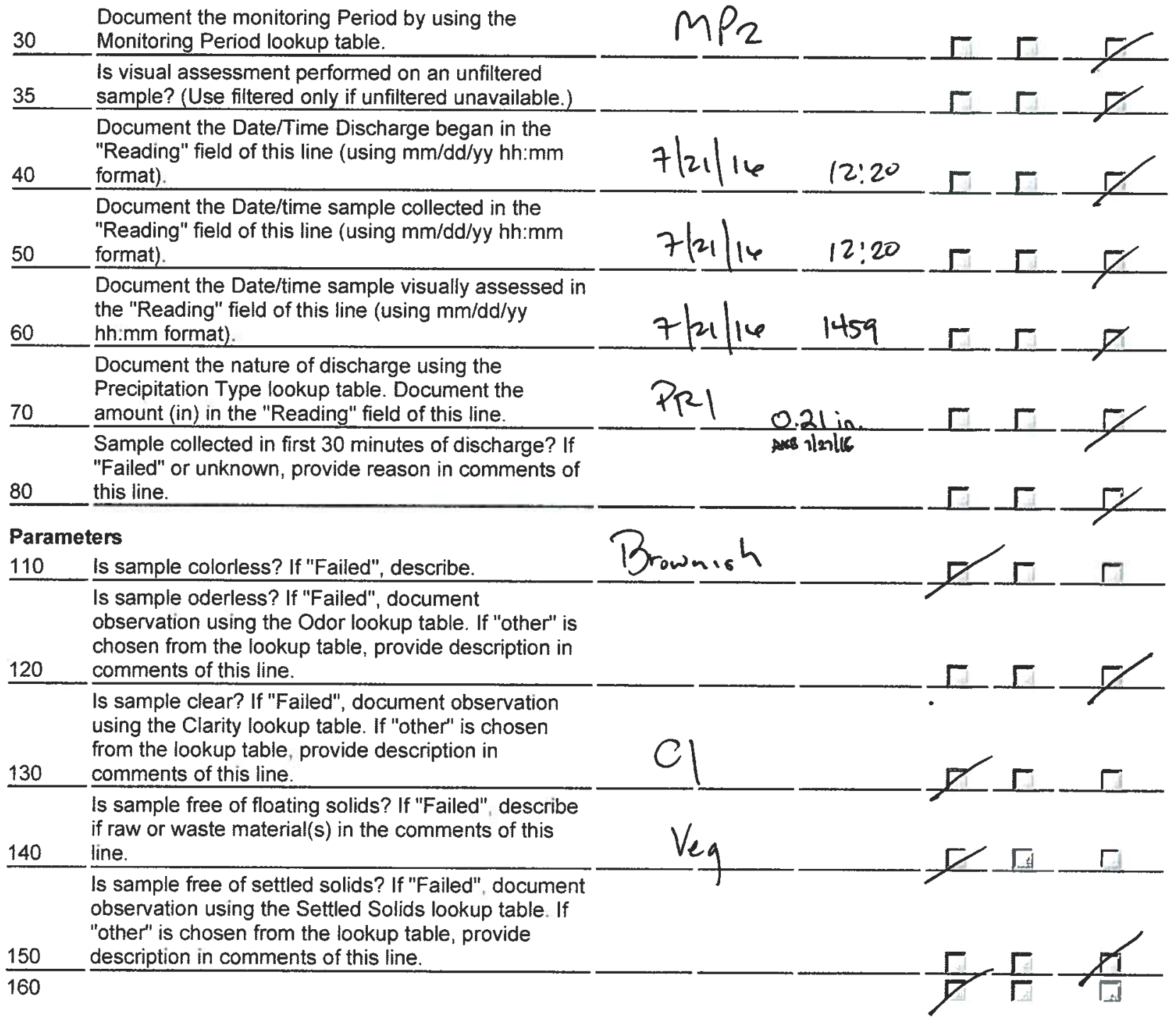


Is sample free of suspended solids? If "Failed",

document observation using the Suspended Solids

lookup table. If "other" is chosen from the lookup

table, provide description in comments of this line.

\section{SUSSOL 2}

Is sample foamless after gently shaking? If "Failed" describe foam color and location ('on the surface' or

170 'in the sample') in the comments of this line. (Range $0-0)$

Is sample devoid of an oil sheen? If "Failed", describe color and thickness (e.g. flecks, globs) in the

180 comments of this line. (Range: 0 - 0)

Is sample free of other obvious indicators of

pollution? If "Failed", describe in the comments of this

190 line. (Range: 0 - 0)

\section{Labor Report}

Completed:

Failure:

Report: 
WO ID:

$56 / 27$

Page 3 of 3

Signature (collecting sample):

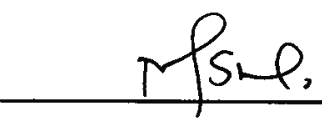

Date and Time: $7 / 21 / 16$

Signature (conducting visual assessment):

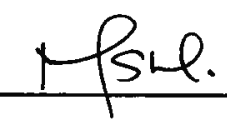

Date and Time: $7 / 21 / 16 \quad 1459$

CERTIFICATION STATEMENT

"I certify under penalty of law that this document and all attachments were prepared under my direction or supervision in accordance with a system designed to assure that qualified personnel properly gathered and evaluated the information submitted. Based on my inquiry of the person or persons who manage the system, or those persons directly responsible for gathering information, the information submitted is, to the best of my knowledge and belief, true, accurate, and complete. I am aware that there are significant penalties for submitting false information, including the possibility of fine and imprisonment for knowing violations".

(Signatory must meet definition in Section B.11.A, eg., FOD, Ops Mgr, DSESH Group Leader, EPC Group Leader)

Print name and title:

Signature:

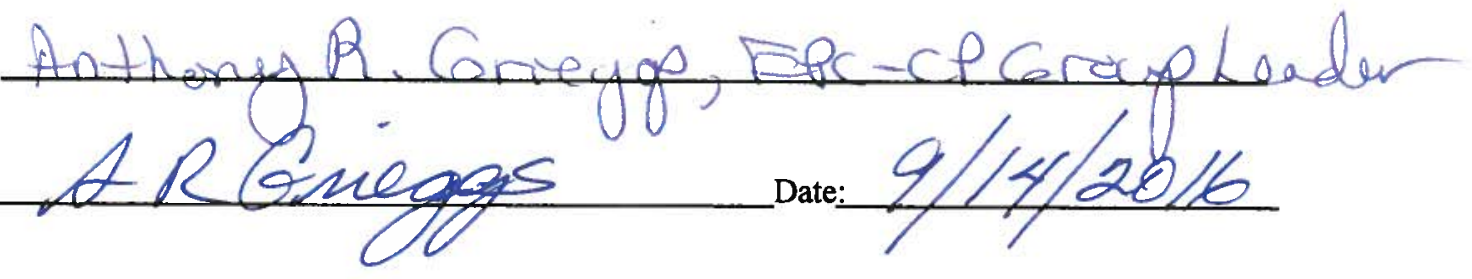




\section{Maintenance Details}

Requested: 7/26/2016 10:13:40 AM

Procedure: MSGP Quarterly Visual Assessment (EPC-CP. Form-1021.2)

Last PM: $\quad 7 / 20 / 2016$

Project: $\quad$ SIO Visual Assessments

7-25-16 (P-MSGP-4983)

Reason: MSGP Quarterly Visual Assessment

Target:

$7 / 31 / 2016$

Priority/Type: Normal/Inspection

Department: Utilities and Infrastructure

\section{MSGP Program 몸 RG200.5 \\ 1. TA-60 Roads and Grounds \\ t. Monitored Outfall (032) \\ Q Substantially Identical Outfall (033) \\ t) MSGP03301}

Contact:

Phone:

Special Instructions: NMR053195

\section{Tasks}

\# Description

Rating Meas.

Initials Failed N/A Complete

The result of this VA applies to associated SIOs as defined in the SWPPP, where applicable.

Sample information

Document the monitoring Period by using the

$30 \quad$ Monitoring Period lookup table.

Is visual assessment performed on an unfiltered

$M P_{\Omega}$ sample? (Use filtered only if unfiltered unavailable.)

Document the Date/Time Discharge began in the "Reading" field of this line (using $\mathrm{mm} / \mathrm{dd} / \mathrm{yy} \mathrm{hh} / \mathrm{mm}$

40 format)

Document the Date/time sample collected in the "Reading" field of this line (using mm/dd/yy hh:mm 50 format).

Document the Date/time sample visually assessed in the "Reading" field of this line (using $\mathrm{mm} / \mathrm{dd} / \mathrm{yy}$

60 hh:mm format).

Document the nature of discharge using the Precipitation Type lookup table. Document the

70 amount (in) in the "Reading" field of this line.

Sample collected in first 30 minutes of discharge? If

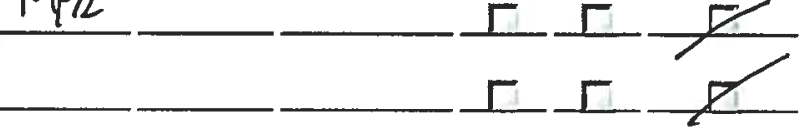

"Failed" or unknown, provide reason in comments of

80 this line.

\section{Parameters}

110 Is sample colorless? If "Failed", describe

Is sample oderless? If "Failed", document

observation using the Odor lookup table. If "other" is

chosen from the lookup table, provide description in

120 comments of this line.

Is sample clear? If "Failed", document observation using the Clarity lookup table. If "other" is chosen

from the lookup table, provide description in

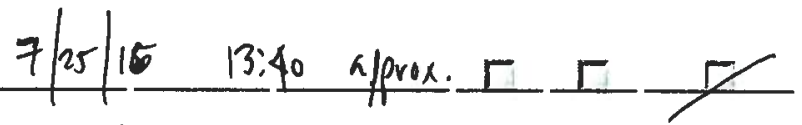

Is sample free of floating solids? If "Failed", describe if raw or waste material(s) in the comments of this

140 line.

Is sample free of settled solids? If "Failed", document observation using the Settled Solids lookup table. If "other" is chosen from the lookup table, provide description in comments of this line.

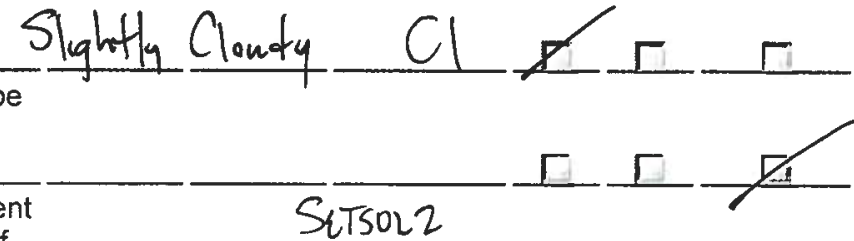


Is sample free of suspended solids? If "Failed", document observation using the Suspended Solids lookup table. If "other" is chosen from the lookup table, provide description in comments of this line.

Is sample foamless after gently shaking? If "Failed" describe foam color and location ('on the surface' or

170 'in the sample') in the comments of this line. (Range

is sample devoid of an oil sheen? If "Failed", describe $\Gamma+$ color and thickness (e.g. flecks, globs) in the

180 comments of this line. (Range: 0 - 0)

Is sample free of other obvious indicators of

pollution? If "Failed", describe in the comments of this 190 line. (Range: 0 - 0)

\section{$\longrightarrow$ \\ Labor Report}

Completed: Failure:

Report: 
wo ID: MSGP.5/6al _ Page 3 of 3

Signature (collecting sample):

Hole.

Date and Time: $7 / 25 / 16 \quad 13.40$

Signature (conducting visual assessment):

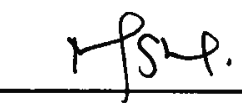

Date and Time: $7 / 2 k / 14$

1123

CERTIFICATION STATEMENT

"I certify under penalty of law that this document and all attachments were prepared under my direction or supervision in accordance with a system designed to assure that qualified personnel properly gathered and evaluated the information submitted. Based on my inquiry of the person or persons who manage the system, or those persons directly responsible for gathering information, the information submitted is, to the best of my knowledge and belief, true, accurate, and complete. I am aware that there are significant penalties for submitting false information, including the possibility of fine and imprisonment for knowing violations".

(Signatory must meet definition in Section B.11.A, eg., FOD, Ops Mgr, DSESH Group Leader, EPC Group Leader)

Print name and title:

Signature:

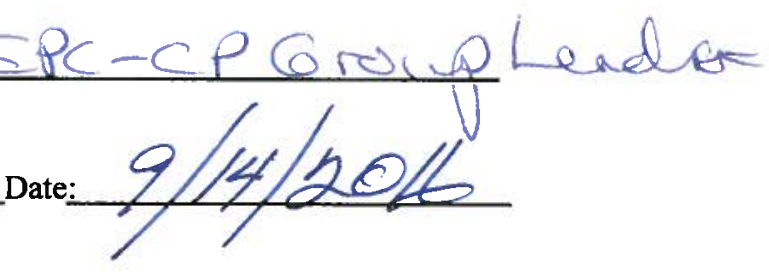




\section{Maintenance Details}
Requested: 7/26/2016 10:13:40 AM
Procedure: MSGP Quarterly Visual Assessment (EPC-CP- Form-1021.2)

\section{Target: $\quad 7 / 31 / 2016$ \\ Priority/Type: Normal / Inspection \\ Department: Utilities and Infrastructure}

Last PM: $\quad 7 / 20 / 2016$

Project: $\quad$ SIO Visual Assessments 7-25-16 (P-MSGP-4983)

Reason: MSGP Quarterly Visual Assessment

\section{$\checkmark$ MSGP Program 몸 RG200.5 \\ 4. TA-60 Roads and Grounds thonitored Outfall (032) \\ Q Substantially Identical Outfall (034) d. MSGP03401}

Contact:

Phone:

Special Instructions: NMR053195

Tasks

\# Description

Rating Meas. Initials Failed N/A Complete

The result of this VA applies to associated SIOs as defined in the SWPPP, where applicable.

Sample information

\begin{tabular}{|c|c|c|c|c|c|c|}
\hline 30 & $\begin{array}{l}\text { Document the monitoring Period by using the } \\
\text { Monitoring Period lookup table. }\end{array}$ & mpl & & $\Gamma$ & - & \\
\hline 35 & $\begin{array}{l}\text { Is visual assessment performed on an unfiltered } \\
\text { sample? (Use filtered only if unfiltered unavailable.) }\end{array}$ & & & + & $\Gamma$ & \\
\hline 40 & $\begin{array}{l}\text { Document the Date/Time Discharge began in the } \\
\text { "Reading" field of this line (using } \mathrm{mm} / \mathrm{dd} / \mathrm{yy} \mathrm{hh}: \mathrm{mm} \\
\text { format). }\end{array}$ & $7 / 25 \mid 16$ & $13: 40$ approx. & $\Gamma$ & $\Gamma$ & \\
\hline 50 & $\begin{array}{l}\text { Document the Date/time sample collected in the } \\
\text { "Reading" field of this line (using mm/dd/yy hh:mm } \\
\text { format). }\end{array}$ & $7 / 25 / 16$ & $13: 40$ approx. & $\Gamma$ & $\Gamma$ & \\
\hline 60 & $\begin{array}{l}\text { Document the Date/time sample visually assessed in } \\
\text { the "Reading" field of this line (using } \mathrm{mm} / \mathrm{dd} / \mathrm{yy} \\
\text { hh:mm format). }\end{array}$ & $7 / 2 k \mid 16$ & 1127 & $\Gamma$ & $\Gamma$ & \\
\hline 70 & $\begin{array}{l}\text { Document the nature of discharge using the } \\
\text { Precipitation Type lookup table. Document the } \\
\text { amount (in) in the "Reading" field of this line. }\end{array}$ & $a_{1}$ & & $\Gamma$ & $\Gamma$ & \\
\hline 80 & $\begin{array}{l}\text { Sample collected in first } 30 \text { minutes of discharge? If } \\
\text { "Failed" or unknown, provide reason in comments of } \\
\text { this line. }\end{array}$ & & & & $\Gamma$ & \\
\hline
\end{tabular}

Parameters

110 Is sample colorless? If "Failed", describe

Is sample oderless? If "Failed", document

observation using the Odor lookup table. If "other" is

chosen from the lookup table, provide description in

120 comments of this line.

Is sample clear? If "Failed", document observation using the Clarity lookup table. If "other" is chosen from the lookup table, provide description in comments of this line.

Is sample free of floating solids? If "Failed", describe if raw or waste material(s) in the comments of this

140 line

Is sample free of settled solids? If "Failed", document

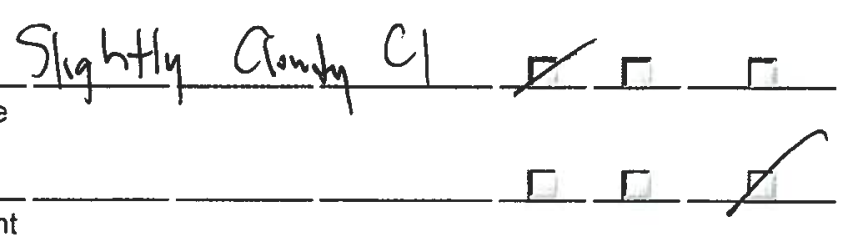
observation using the Settled Solids lookup table. If "other" is chosen from the lookup table, provide description in comments of this line

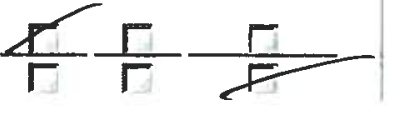


Is sample free of suspended solids? If "Failed", document observation using the Suspended Solids lookup table. If "other" is chosen from the lookup table, provide description in comments of this line.

is sample foamless after gently shaking? If "Failed" describe foam color and location ('on the surface' or 'in the sample') in the comments of this line. (Range

170 0 - 0)

Is sample devoid of an oil sheen? If "Failed", describe color and thickness (e.g. flecks, globs) in the

180 comments of this line. (Range: $0-0$ )

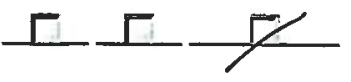

Is sample free of other obvious indicators of

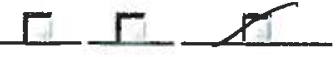

pollution? If "Failed", describe in the comments of this

190 line. (Range: 0 - 0)

\section{Labor Report}

Completed: Failure:

Report: 
wo ID: MS GP. 56617

Page 3 of 3

Signature (collecting sample):

Mst

Date and Time: $7 / 25 / 16 \quad 13.40$

Signature (conducting visual assessment):

Hit.

Date and Time: $7 / 26 / 16 \quad 1127$

CERTIFICATION STATEMENT

"I certify under penalty of law that this document and all attachments were prepared under my direction or supervision in accordance with a system designed to assure that qualified personnel properly gathered and evaluated the information submitted. Based on my inquiry of the person or persons who manage the system, or those persons directly responsible for gathering information, the information submitted is, to the best of my knowledge and belief, true, accurate, and complete. I am aware that there are significant penalties for submitting false information, including the possibility of fine and imprisonment for knowing violations".

(Signatory must meet definition in Section B.11.A, eg., FOD, Ops Mgr, DSESH Group Leader, EPC Group Leader)

Print name and title:

Signature:

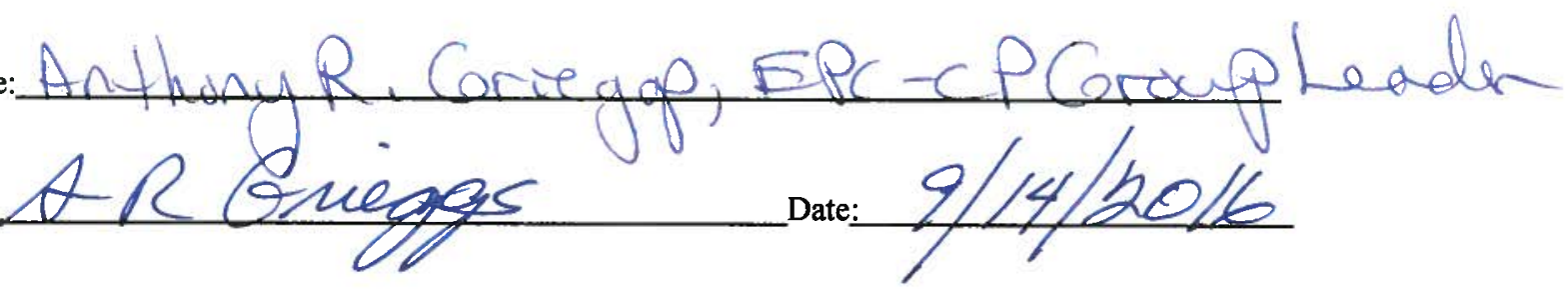




\section{Maintenance Details}

\section{Requested: 8/3/2016 9:44:00 AM \\ Procedure: MSGP Quarterly Visual Assessment (EPC-CP. Form-1021.2) \\ Last PM: $\quad 7 / 26 / 2016$ \\ Project: $\quad$ SIO Visual Assessments 8/1/16 (P-MSGP-5014)}

Reason: MSGP Quarterly Visual Assessment

Target: $\quad 7 / 31 / 2016$

Priority/Type: Normal/ Inspection

Department: Utilities and Infrastructure

Special Instructions: NMR053195

Tasks

\# . Description

Rating Meas. Initials Failed N/A Complete

The result of this VA applies to associated SIOs as defined in the SWPPP, where applicable.

Sample information

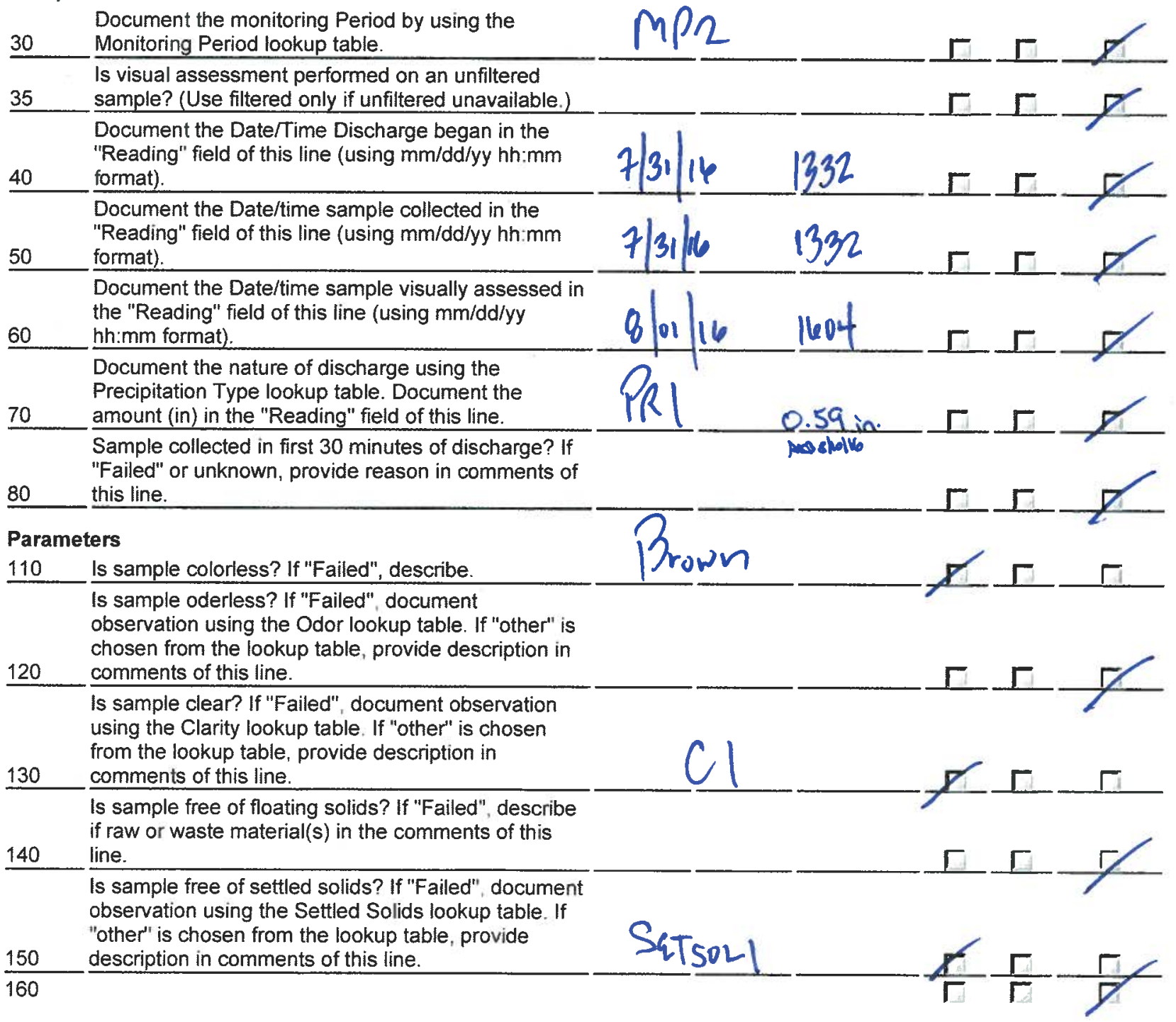


Is sample free of suspended solids? If "Failed", document observation using the Suspended Solids lookup table. If "other" is chosen from the lookup table, provide description in comments of this line.

is sample foamless after gently shaking? If "Failed" describe foam color and location ('on the surface' or

170 'in the sample') in the comments of this line. (Range: $0-0)$

Is sample devoid of an oil sheen? If "Failed", describe $\Gamma \Gamma$ color and thickness (e.g. flecks, globs) in the

180 comments of this line. (Range: $0-0$ )

Is sample free of other obvious indicators of pollution? If "Failed", describe in the comments of this

190 line. (Range: 0 - 0)

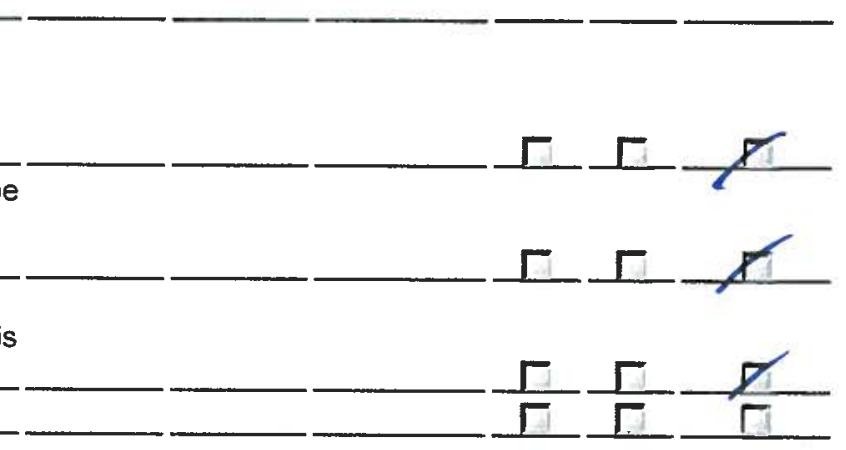

\section{Labor Report}

Completed:

Failure:

Report: 
WO ID: MSGP.57141 Page 3 of 3

Signature (conducting visual assessment): $\mathrm{HSH}$. Date and Time: $8 / 01 / 16 \quad 1604$
Date and Time: $1 / 31 / 16 \quad 1332$

\section{CERTIFICATION STATEMENT}

"I certify under penalty of law that this document and all attachments were prepared under my direction or supervision in accordance with a system designed to assure that qualified personnel properly gathered and evaluated the information submitted. Based on my inquiry of the person or persons who manage the system, or those persons directly responsible for gathering information, the information submitted is, to the best of my knowledge and belief, true, accurate, and complete. I am aware that there are significant penalties for submitting false information, including the possibility of fine and imprisonment for knowing violations".

(Signatory must meet definition in Section B.11.A, eg., FOD, Ops Mgr, DSESH Group Leader, EPC Group Leader)

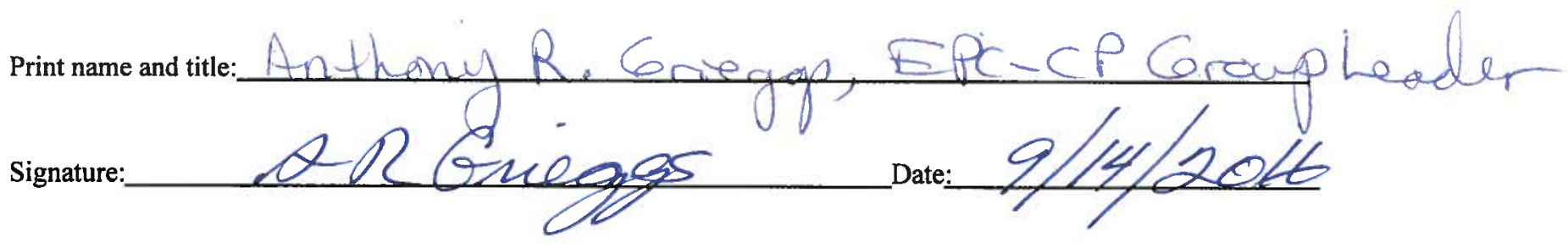




\begin{tabular}{|c|c|}
\hline Requested: & : 8/3/2016 9:44:01 AM \\
\hline Procedure: & $\begin{array}{l}\text { MSGP Quarterly Visual } \\
\text { Assessment (EPC-CP- } \\
\text { Form-1021.2) }\end{array}$ \\
\hline Last PM: & $7 / 26 / 2016$ \\
\hline Project: & $\begin{array}{l}\text { SIO Visual Assessments } \\
8 / 1 / 16 \text { (P-MSGP-5014) }\end{array}$ \\
\hline
\end{tabular}

Reason: MSGP Quarterly Visual Assessment

Special Instructions: NMR053195

\section{Target: $\quad 7 / 31 / 2016$}

Priority/Type: Normal/Inspection

Department: Utilities and

Infrastructure

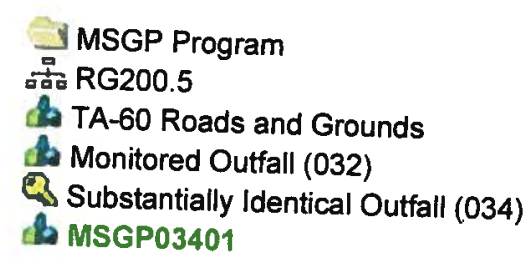

Contact:

Phone:

\section{Tasks}

\# Description The result of this VA applies to associated SIOs as defined in the SWPPP, where applicable.
Sample information

Rating Meas. Initials Failed N/A Complete

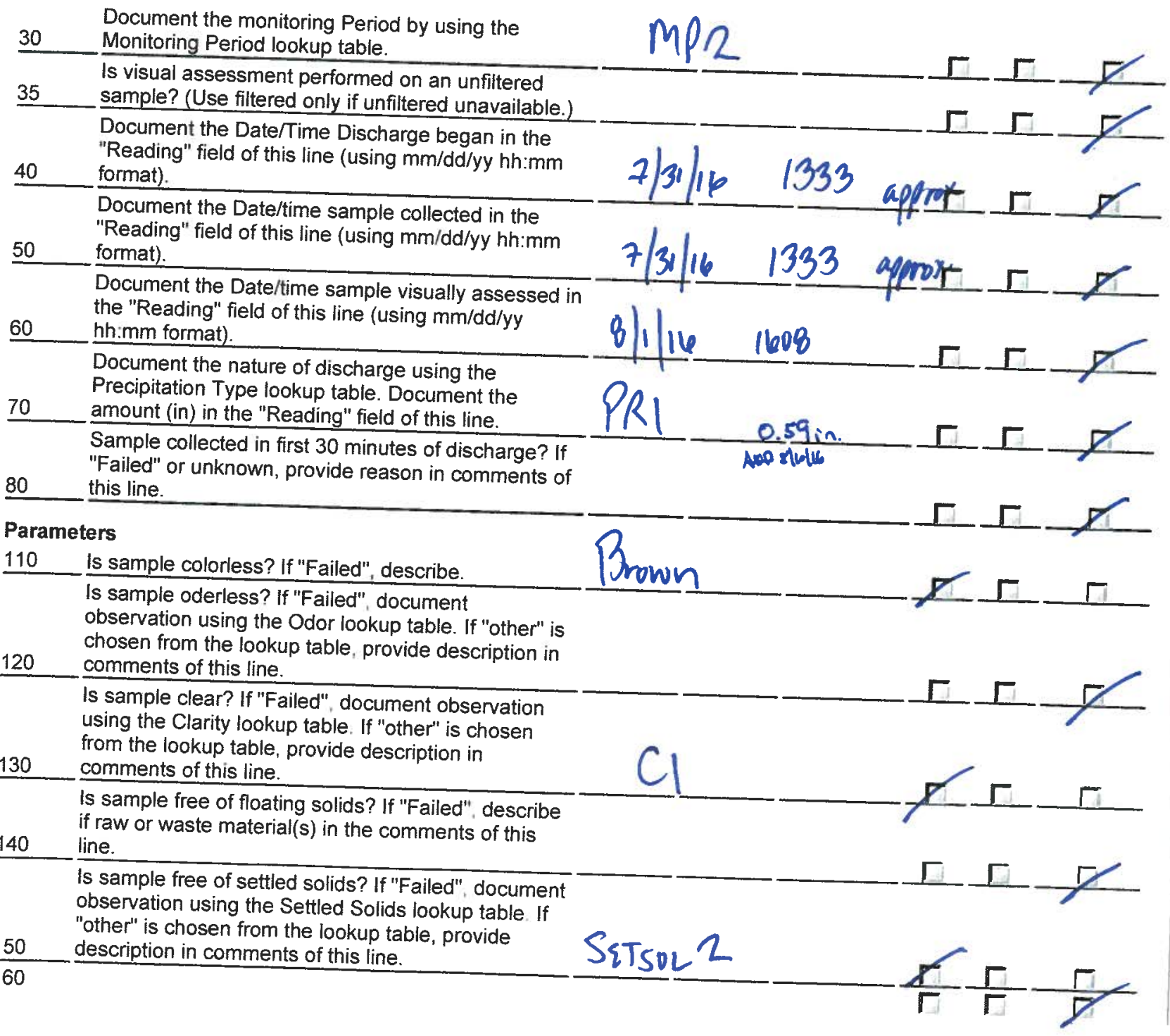


Is sample free of suspended solids? If "Failed", document observation using the Suspended Solids lookup table. If "other" is chosen from the lookup table, provide description in comments of this line.

Is sample foamless after gently shaking? If "Failed" describe foam color and location ('on the surface' or 'in the sample') in the comments of this line. (Range: $170 \quad 0-0)$

Is sample devoid of an oil sheen? If "Failed", describe

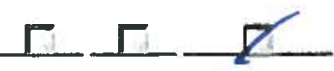
color and thickness (e.g. flecks, globs) in the

180 comments of this line. (Range: 0-0)

Is sample free of other obvious indicators of pollution? If "Failed", describe in the comments of this 190 line. (Range: 0 - 0)

\section{Labor Report}

Completed: Failure:

Report: 
wo ID: MSGP-57142

Page 3 of 3

Signature (collecting sample):

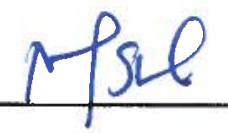

Date and Time:

$7 / 31 / 16 \quad 1333$

Signature (conducting visual assessment):

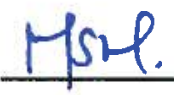

Date and Time:

$16 \quad 1609$

CERTIFICATION STATEMENT

"I certify under penalty of law that this document and all attachments were prepared under my direction or supervision in accordance with a system designed to assure that qualified personnel properly gathered and evaluated the information submitted. Based on my inquiry of the person or persons who manage the system, or those persons directly responsible for gathering information, the information submitted is, to the best of my knowledge and belief, true, accurate, and complete. I am aware that there are significant penalties for submitting false information, including the possibility of fine and imprisonment for knowing violations".

(Signatory must meet definition in Section B.11.A, eg., FOD, Ops Mgr, DSESH Group Leader, EPC Group Leader)

Print name and title:

Signature:

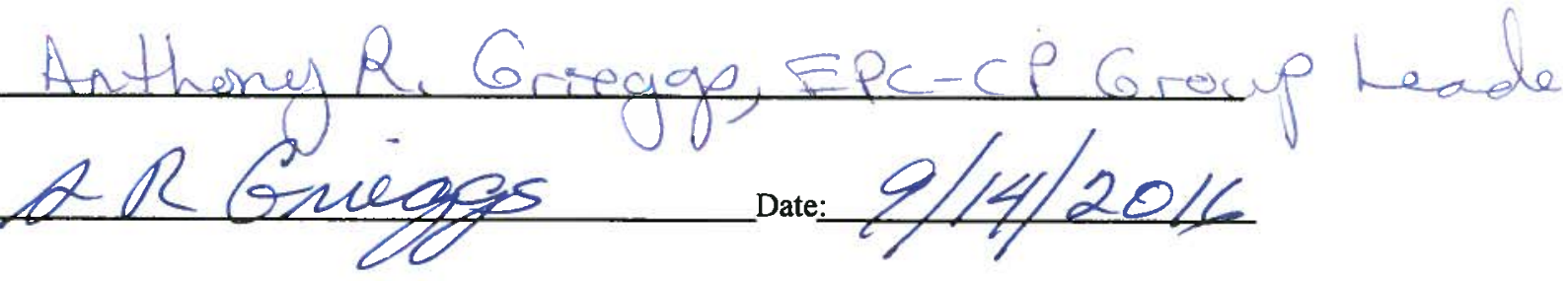




\section{memorandum}

Environmental Protection \& Compliance Division Environmental Compliance Programs (EPC-CP)
To/MS: Leonard Sandoval, DESHS-UIS, P908

Thru/MS: Terrill Lemke, EPC-CP, (E-File)

From/MS: Holly Wheeler, EPC-CP, (E-File) WdW

Phone/Fax: 667-1312

Symbol: EPC-DO: 17-041

Date:

\title{
JAN 172017
}

\begin{abstract}
Subject: $\quad$ National Pollutant Discharge Elimination System (NPDES) Permit No. NMR053195, Multi-Sector General Permit (MSGP) Quarterly Visual Assessment (QVA) Forms for August and September of 2016 for TA-60 Roads and Grounds
\end{abstract}

Please find attached completed MSGP QVA Forms documenting visual assessments performed during the third quarter of monitoring at TA-60 Roads and Grounds. Per Parts 3.2.2 and 5.5 of the 2015 MSGP, this memorandum along with all of the attached QVA forms shall be incorporated into your MSGP Storm Water Pollution Prevention Plan (SWPPP).

Part 3.2.1 of the 2015 MSGP requires the visual assessment of storm water discharge samples collected from each outfall once each quarter for the entire permit term. Part 3.2.3 allows facilities that are located in an area with a semi-arid climate and/or in an area where freezing conditions exist for an extended period to distribute the quarterly visual assessments during seasons when precipitation runoff occurs. Accordingly, Los Alamos National Security, LLC (LANS) has designated the following MSGP monitoring quarters.

Quarter 1: $\quad$ April - May

Quarter 3: $\quad$ August - September
Quarter 2: June - July

Quarter 4: $\quad$ October - November

The attached QVA forms document the following information as required by Part 3.2.2 of the 2015 MSGP and were completed by Deployed Environment, Safety, and Health Services (DESHS) and Environmental Compliance Programs (EPC-CP) personnel.

- Sample location;

- Sample collection date and time, and visual assessment date and time for each sample;

- Personnel collecting the sample and performing the visual assessment, and their signatures;

- Nature of the discharge (i.e., runoff or snowmelt);

- Results of observations of the stormwater discharge;

- Probable sources of any observed stormwater contamination (if applicable);

- If applicable, why it was not possible to take a sample within the first 30 minutes of the storm event.

The signed certification statement contained in this memorandum satisfies the duly authorized signatory requirement for the QVAs completed by EPC-CP representatives contained in Enclosure 1. 
I certify under penalty of law that this document and all attachments were prepared under my direction or supervision in accordance with a system designed to assure that qualified personnel properly gathered and evaluated the information contained therein. Based on my inquiry of the person or persons who manage the system, or those persons directly responsible for gathering the information, the information contained is, to the best of my knowledge and belief, true, accurate, and complete. I am aware that there are significant penalties for submitting false information, including the possibility of fine and imprisonment for knowing violations.

\section{Anthony R. Grieggs, EPC-CP Group Leader}

(Print name and title)

Los Alamos National Laboratory
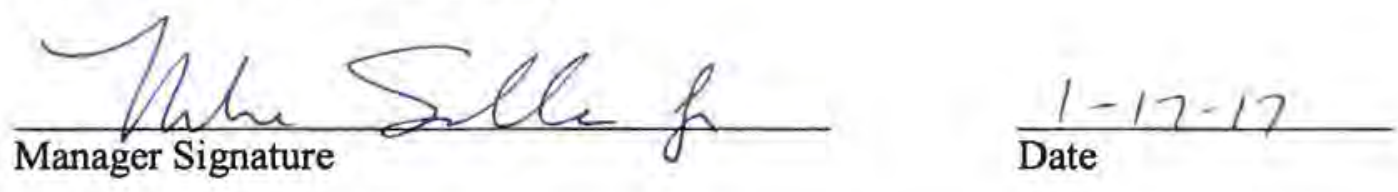

Part 3.2.3 of the 2015 MSGP allows the facility to take a substitute sample during the next qualifying storm event when adverse weather conditions prevent the collection of samples during a specific quarter. Adverse weather conditions are those that are dangerous or create inaccessibility for personnel, or situations that otherwise make sampling impractical, such as drought or extended frozen conditions. Documentation of the rationale for no visual assessment for the quarter must be included in the facility-specific SWPPP.

Please contact Holly Wheeler at 667-1312 (hbenson@lanl.gov) if you have questions regarding the QVA documentation. Thank you for your assistance in meeting the requirements of the Laboratory's NPDES 2015 MSGP Permit.

TWL:HLW/am 
Leonard Sandoval

Enclosure: 1. Quarterly Visual Assessment Forms Requiring a Certification Statement Signature, Third Quarter, 2016 Monitoring Year

\begin{tabular}{|c|c|c|}
\hline Facility Name & Sampling Station & Work Order \# \\
\hline TA-60 Roads and Grounds & MSGP04201 & MSGP-53600 \\
\hline TA-60 Roads and Grounds & MSGP03801 & MSGP-54926 \\
\hline TA-60 Roads and Grounds & MSGP03001 & MSGP-56618 \\
\hline TA-60 Roads and Grounds & MSGP03101 & MSGP-56956 \\
\hline TA-60 Roads and Grounds & MSGP03201 & MSGP-56958 \\
\hline TA-60 Roads and Grounds & MSGP03301 & MSGP-57549 \\
\hline TA-60 Roads and Grounds & MSGP03401 & MSGP-57550 \\
\hline TA-60 Roads and Grounds & MSGP03501 & MSGP-57551 \\
\hline TA-60 Roads and Grounds & MSGP03001 & MSGP-57552 \\
\hline TA-60 Roads and Grounds & MSGP04101 & MSGP-57553 \\
\hline TA-60 Roads and Grounds & MSGP03401 & MSGP-57566 \\
\hline TA-60 Roads and Grounds & MSGP04201 & MSGP-57868 \\
\hline TA-60 Roads and Grounds & MSGP04201 & MSGP-57869 \\
\hline TA-60 Roads and Grounds & MSGP03301 & MSGP-57994 \\
\hline TA-60 Roads and Grounds & MSGP03401 & MSGP-57995 \\
\hline TA-60 Roads and Grounds & MSGP03501 & MSGP-57996 \\
\hline TA-60 Roads and Grounds & MSGP03001 & MSGP-57997 \\
\hline TA-60 Roads and Grounds & MSGP04101 & MSGP-57998 \\
\hline TA-60 Roads and Grounds & MSGP03301 & MSGP-58327 \\
\hline TA-60 Roads and Grounds & MSGP03401 & MSGP-58328 \\
\hline TA-60 Roads and Grounds & MSGP03501 & MSGP-58329 \\
\hline TA-60 Roads and Grounds & MSGP03001 & MSGP-58330 \\
\hline TA-60 Roads and Grounds & MSGP04101 & MSGP-58331 \\
\hline TA-60 Roads and Grounds & MSGP03101 & MSGP-58332 \\
\hline TA-60 Roads and Grounds & MSGP03301 & MSGP-58417 \\
\hline TA-60 Roads and Grounds & MSGP03401 & MSGP-58418 \\
\hline TA-60 Roads and Grounds & MSGP03501 & MSGP-58419 \\
\hline TA-60 Roads and Grounds & MSGP03001 & MSGP-58420 \\
\hline TA-60 Roads and Grounds & MSGP03301 & MSGP-58505 \\
\hline TA-60 Roads and Grounds & MSGP03401 & MSGP-58506 \\
\hline TA-60 Roads and Grounds & MSGP03001 & MSGP-58507 \\
\hline TA-60 Roads and Grounds & MSGP04101 & MSGP-58508 \\
\hline TA-60 Roads and Grounds & MSGP03301 & MSGP-58516 \\
\hline TA-60 Roads and Grounds & MSGP03401 & MSGP-58517 \\
\hline TA-60 Roads and Grounds & MSGP03001 & MSGP-58518 \\
\hline TA-60 Roads and Grounds & MSGP03501 & MSGP-58537 \\
\hline
\end{tabular}


Leonard Sandoval

\begin{tabular}{|l|l|l|}
\hline TA-60 Roads and Grounds & MSGP04101 & MSGP-58538 \\
\hline TA-60 Roads and Grounds & MSGP03801 & MSGP-58539 \\
\hline TA-60 Roads and Grounds & MSGP03301 & MSGP-58552 \\
\hline TA-60 Roads and Grounds & MSGP03401 & MSGP-58553 \\
\hline TA-60 Roads and Grounds & MSGP03001 & MSGP-58554 \\
\hline
\end{tabular}

Copy: Russell Stone, DESHS-UIS, (E-File)

Adesh-records@lanl.gov, (E-File)

lasomailbox@nnsa.doe.gov, (E-File)

locatesteam@lanl.gov, (E-File)

epc-correspondence@lanl.gov, (E-File) 


\title{
ENCLOSURE 1
}

Quarterly Visual Assessment Forms Requiring a Certification Statement Signature Third Quarter, 2016 Monitoring Year

\author{
EPC-DO:17-041
}

Date: 


\section{Maintenance Details}

Requested: 5/31/2016 5:28:00 PM

Procedure: MSGP Quarterly Visual Assessment (EPC-CP. Form-1021 2)

Last PM: $\quad 4 / 20 / 2016$

Project: MSGP Visual Assessments wk 5/30/16 (P-MSGP. 4804)

Reason: MSGP 2016 Quarterly Visual Assessment

Special Instructions: NMR053195

$\begin{array}{ll} & 9 / 30 / 16 \\ \text { Target: } & 7 / 9+45016 / 516 \\ \text { Priority/Type: } / \text { Inspection } \\ \text { Department: } & \begin{array}{l}\text { Utilities and } \\ \text { Infrastructure }\end{array}\end{array}$

Infrastructure

\section{MSGP Program \\ 옴 RG200.5 \\ 1. TA-60 Roads and Grounds \\ bo Monitored Outfall (042) \\ d. MSGP04201}

Contact:

Phone:

\section{Tasks}

\# Description

Rating Meas, Initials

Failed N/A Complete

The result of this VA applies to associated SIOs as defined in the SWPPP, where applicable.

\section{Sample information}

Document the monitoring Period by using the

$30 \quad$ Monitoring Period lookup table.

Is visual assessment perfored on an unflered

35 sample? (Use filtered only if unfiltered unavailable.)

Document the Date/Time Discharge began in the "Reading" field of this line (using $\mathrm{mm} / \mathrm{dd} / \mathrm{yy} \mathrm{hh}: \mathrm{mm}$

40 format).

Document the Date/time sample collected in the

"Reading" field of this line (using mm/dd/yy hh:mm

50 format).

Document the Date/time sample visually assessed in the "Reading" field of this line (using $\mathrm{mm} / \mathrm{dd} / \mathrm{yy}$

60 hh:mm format).

Document the nature of discharge using the

Precipitation Type lookup table. Document the

$70 \quad$ amount (in) in the "Reading" field of this line.

Sample collected in first 30 minutes of discharge? If

"Failed" or unknown, provide reason in comments of

80 this line.

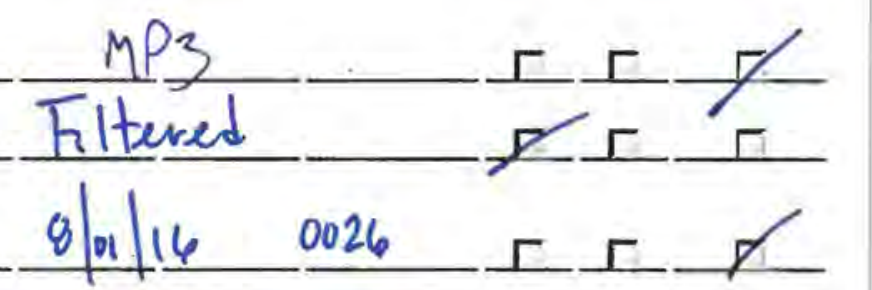

\section{Parameters}

110 Is sample colorless? If "Failed", describe.

Is sample oderless? If "Failed", document

observation using the Odor lookup table. If "other" is

chosen from the lookup table. provide description in

120 comments of this line.

Is sample clear? If "Failed", document observation

using the Clarity lookup table. If "other" is chosen

from the lookup table, provide description in

130 comments of this line.

Is sample free of floating solids? If "Failed" describe

if raw or waste material(s) in the comments of this

140

line.

Is sample free of settled solids? If "Failed". document

$010116 \quad 0026$
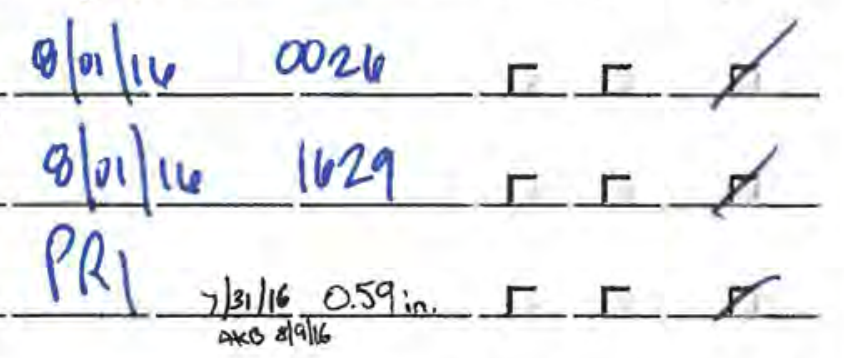
observation using the Settled Solids lookup table. If

"other" is chosen from the lookup table, provide

150 description in comments of this line.
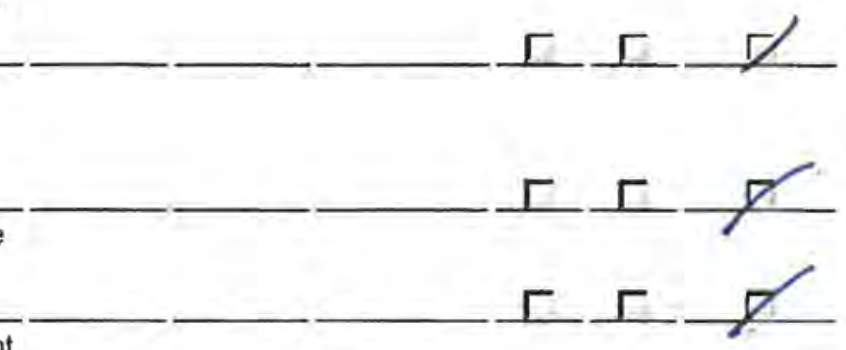
Is sample free of suspended solids? If "Failed", document observation using the Suspended Solids lookup table. If "other" is chosen from the lookup table, provide description in comments of this line.

Is sample foamless after gently shaking? If "Failed" describe foam color and location ('on the surface' or 'in the sample') in the comments of this line.

Is sample devoid of an oil sheen? If "Failed" describe color and thickness (e.g. flecks, globs) in the comments of this line.

Is sample free of other obvious indicators of

190 pollution? If "Failed", describe in the comments of this line.

\section{Labor Report}

Completed: Failure:

Meter 1:

Meter 2:

Report: 


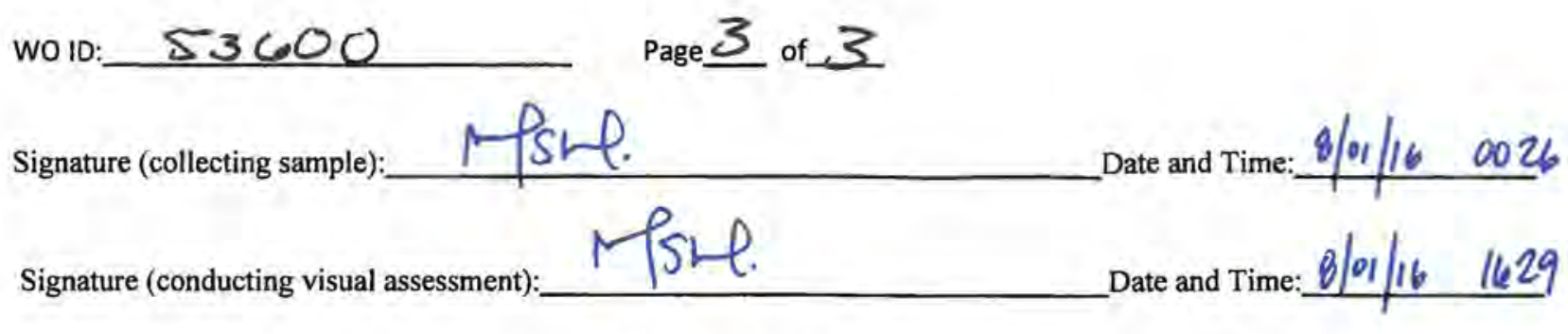

\section{CERTIFICATION STATEMENT}

"I certify under penalty of law that this document and all attachments were prepared under my direction or supervision in accordance with a system designed to assure that qualified personnel properly gathered and evaluated the information submitted. Based on my inquiry of the person or persons who manage the system, or those persons directly responsible for gathering information, the information submitted is, to the best of my knowledge and belief, true, accurate, and complete. I am aware that there are significant penalties for submitting false information, including the possibility of fine and imprisonment for knowing violations".

(Signatory must meet definition in Section B.11.A, eg., FOD, Ops Mgr, DSESH Group Leader, EPC Group Leader)

Print name and title: 
Maintenance Details

Requested: 6/6/2016 1:02:37 PM

Procedure: MSGP Quarterly Visual Assessment (EPC-CPForm-1021.2)

Last PM: N/A

Project: $\quad$ SIO Visual Assessments

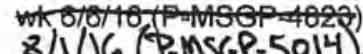

8/1/6 (P.NSGP-5014)

Reason: MSGP Quarterly Visual Assessment

\section{$\quad 9 / 30 / 2016$}

(Inspection

Department: Utilities and

Infrastructure

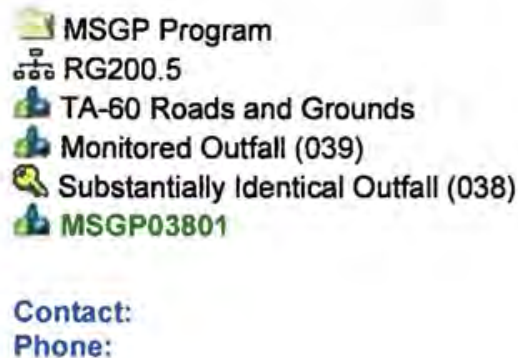

7 MSGP Program

웅 RG200.5

fo TA-60 Roads and Grounds

da Monitored Outfall (039)

Q. Substantially Identical Outfall (038)

Phone:

Special Instructions: NMR053195

\section{Tasks}

\# Description

Rating Meas. Initials Failed N/A Complete

The result of this VA applies to associated SIOs as defined in the SWPPP, where applicable.

Sample information

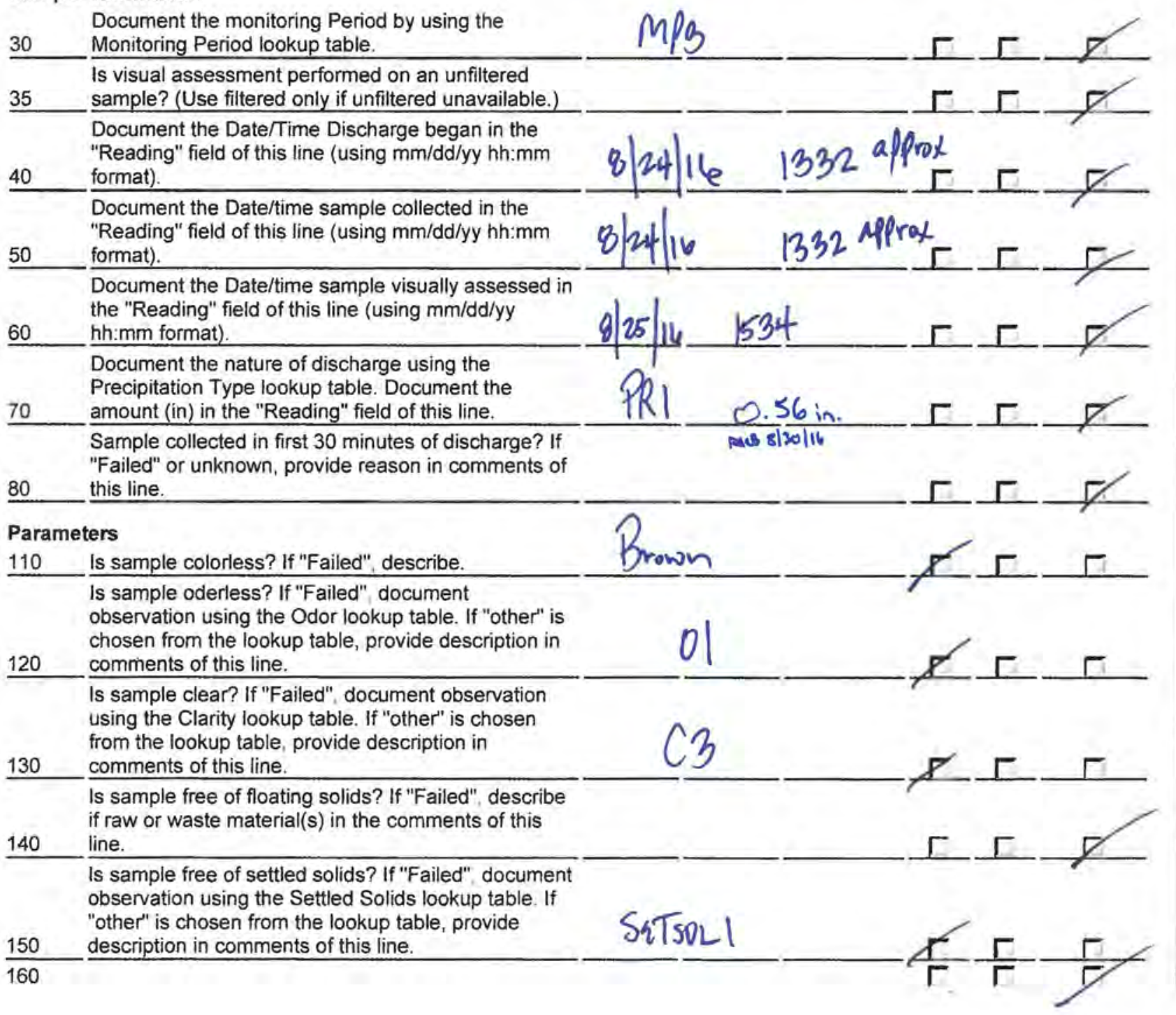


Is sample free of suspended solids? If "Failed",

document observation using the Suspended Solids

lookup table. If "other" is chosen from the lookup

table, provide description in comments of this line.

Is sample foamless after gently shaking? If "Failed"

describe foam color and location ('on the surface' or

170 'in the sample') in the comments of this line.

Is sample devoid of an oil sheen? If "Failed", describe

color and thickness (e.g. flecks, globs) in the

180 comments of this line.

is sample free of other obvious indicators of

190 pollution? If "Failed", describe in the comments of this line.

\section{Labor Report}

Completed: Failure:

Report: 


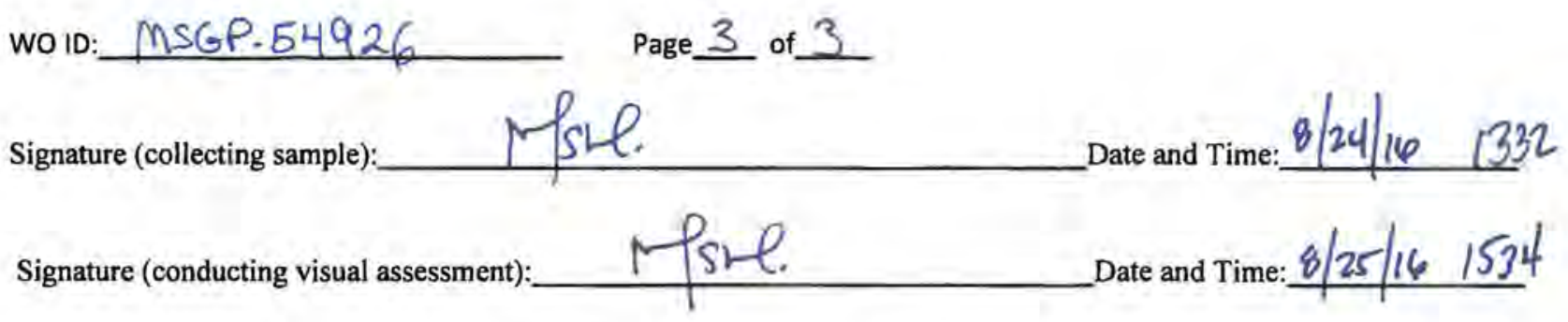

\section{CERTIFICATION STATEMENT}

"I certify under penalty of law that this document and all attachments were prepared under my direction or supervision in accordance with a system designed to assure that qualified personnel properly gathered and evaluated the information submitted. Based on my inquiry of the person or persons who manage the system, or those persons directly responsible for gathering information, the information submitted is, to the best of my knowledge and belief, true, accurate, and complete. I am aware that there are significant penalties for submitting false information, including the possibility of fine and imprisonment for knowing violations".

(Signatory must meet definition in Section B.11.A, eg., FOD, Ops Mgr, DSESH Group Leader, EPC Group Leader)

Print name and title:

Signature:

Date: 


\section{Maintenance Details}

\section{Requested: 7/26/2016 10:13:41 AM \\ Procedure: MSGP Quarterly Visual Assessment (EPC-CP- Form-1021.2) \\ Target: $\quad 7131 / 20160$ doll6 \\ Priority/Type: Normal/Inspection \\ Department: Utilities and Infrastructure}

Last PM: $\quad 7 / 20 / 2016$

Project: SIO Visual Assessments 7-25-16 (P-MSGP-4983)

Reason: MSGP Quarterly Visual Assessment

\section{MSGP Program \\ 뭉 RG200.5 \\ th TA-60 Roads and Grounds \\ B. Monitored Outfall (031) \\ Q Substantially Identical Outfall (030) to MSGP03001}

Contact:

Phone:

Special Instructions: NMR053195

\section{Tasks}

\# Description

Rating Meas. Initials Failed N/A Complete

The result of this VA applies to associated SIOs as defined in the SWPPP, where applicable.

\section{Sample information}

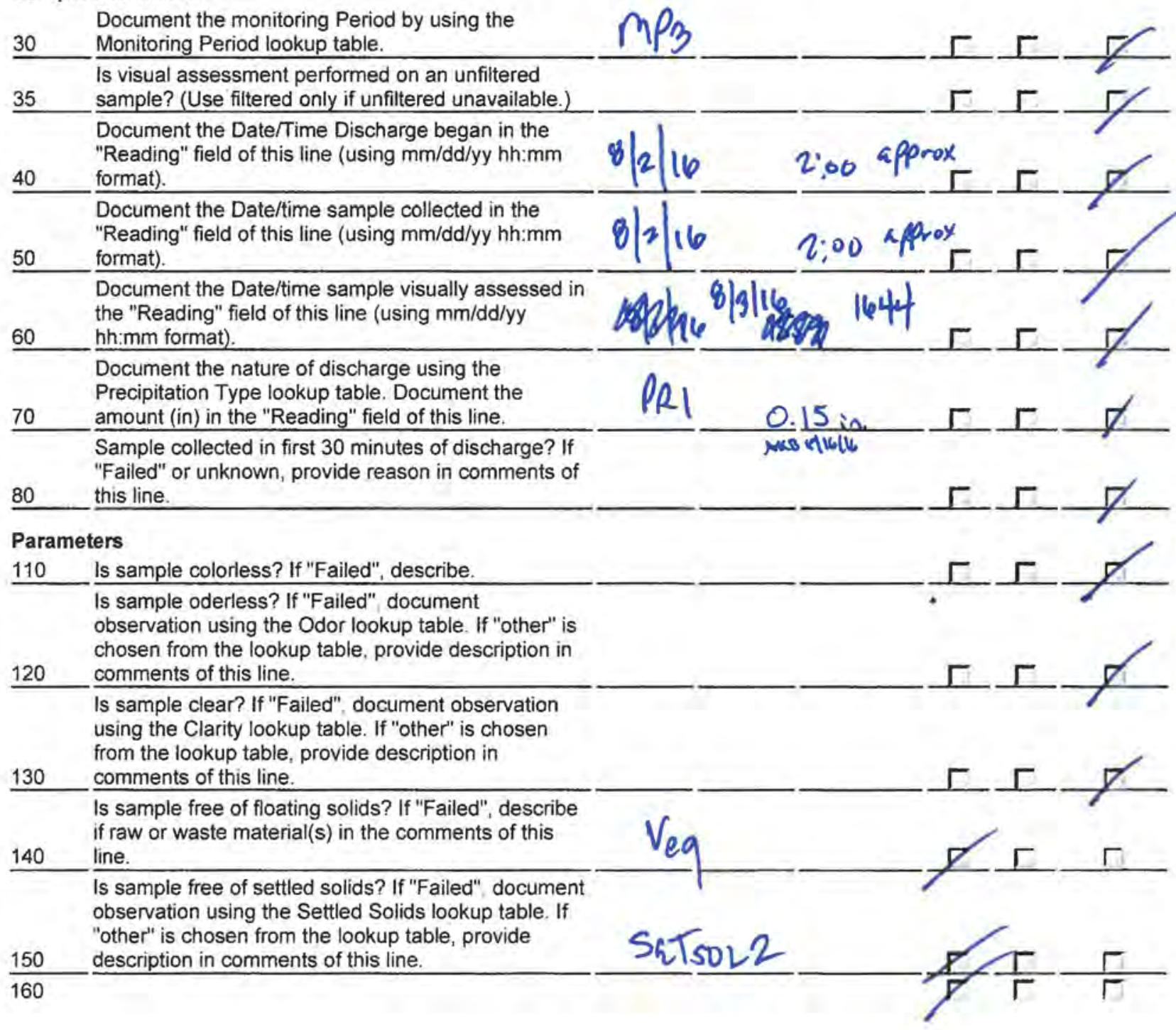


Is sample free of suspended solids? If "Failed", document observation using the Suspended Solids lookup table. If "other" is chosen from the lookup table, provide description in comments of this line. SussoL 2

Is sample foamless after gently shaking? If "Failed" describe foam color and location ('on the surface' or 'in the sample') in the comments of this line. (Range: 0 -0)

Is sample devoid of an oil sheen? If "Failed", describe

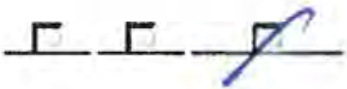
color and thickness (e.g. flecks, globs) in the

180 comments of this line. (Range: $0-0$ )

is sample free of other obvious indicators of pollution? If "Failed", describe in the comments of this 190 line. (Range: $0-0$ )

\section{Labor Report}

Completed: Failure:

Report: 
Signature (collecting sample)

Hsit

Signature (conducting visual assessment):

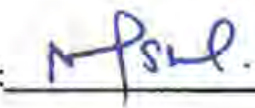

\section{CERTIFICATION STATEMENT}

"I certify under penalty of law that this document and all attachments were prepared under my direction or supervision in accordance with a system designed to assure that qualified personnel properly gathered and evaluated the information submitted. Based on my inquiry of the person or persons who manage the system, or those persons directly responsible for gathering information, the information submitted is, to the best of my knowledge and belief, true, accurate, and complete. I am aware that there are significant penalties for submitting false information, including the possibility of fine and imprisonment for knowing violations".

(Signatory must meet definition in Section B.11.A, eg., FOD, Ops Mgr, DSESH Group Leader, EPC Group Leader)
Date and Time: $8 / 2 / 16 \quad 2: 00$

Date and Time: $0 / 3 / 161644$

Print name and title: 


\section{Maintenance Details}

Requested: 8/1/2016 9:43:53 AM

Procedure: MSGP Quarterly Visual Assessment (EPC-CPForm-1021.2)

Last PM: $\quad 7 / 6 / 2016$

Project: Visual Assessments wk 8/1/16 (P-MSGP-5007)

Reason: MSGP Quarterly Visual Assessment

\section{Target: $\quad 9 / 30 / 2016$}

Priority/Type: Normal / Inspection

Department: Utilities and infrastructure

Special Instructions: NMR053195

\section{Tasks}

\# Description

Rating Meas. Initials

3 MSGP Program

몸 RG200.5

(6) TA-60 Roads and Grounds

(b) Monitored Outfall (032)

\& MSGP03201

Contact:

Phone:

The result of this VA applies to associated SIOs as defined in the SWPPP, where applicable.

Sample information

Document the monitoring Period by using the

30 Monitoring Period lookup table.

Is visual assessment performed on an unfiltered

35 sample? (Use filtered only if unfiltered unavailable.)

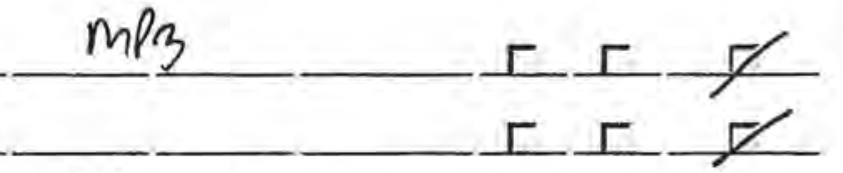

Document the Date/Time Discharge began in the "Reading" field of this line (using $\mathrm{mm} / \mathrm{dd} / \mathrm{yy} \mathrm{hh} / \mathrm{mm}$

$\underline{40}$ format)

Document the Date/time sample collected in the "Reading" field of this line (using $\mathrm{mm} / \mathrm{dd} / \mathrm{yy} \mathrm{hh}: \mathrm{mm}$

50 format).

Document the Date/time sample visually assessed in the "Reading" field of this line (using mm/dd/yy

60 hh:mm format).

Document the nature of discharge using the Precipitation Type lookup table. Document the $70 \quad$ amount (in) in the "Reading" field of this line. Sample collected in first 30 minutes of discharge? If "Failed" or unknown, provide reason in comments of 80 this line.

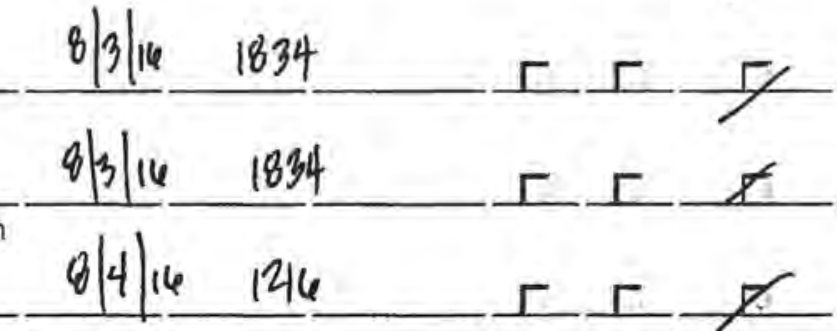

Parameters

110 Is sample colorless? If "Failed", describe. Is sample oderless? If "Failed" document observation using the Odor lookup table. If "other" is chosen from the lookup table, provide description in comments of this line.

Is sample clear? If "Failed", document observation using the Clarity lookup table. If "other" is chosen from the lookup table, provide description in comments of this line.

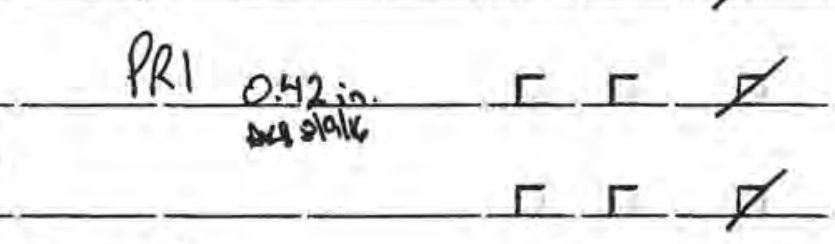

Is sample free of floating solids? If "Failed", describe

light Brown

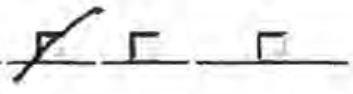
if raw or waste material(s) in the comments of this

140 line.

Is sample free of settled solids? If "Failed", document observation using the Settled Solids lookup table. If "other" is chosen from the lookup table, provide

150 description in comments of this line.

160 Is sample free of suspended solids? If "Failed" document observation using the Suspended Solids

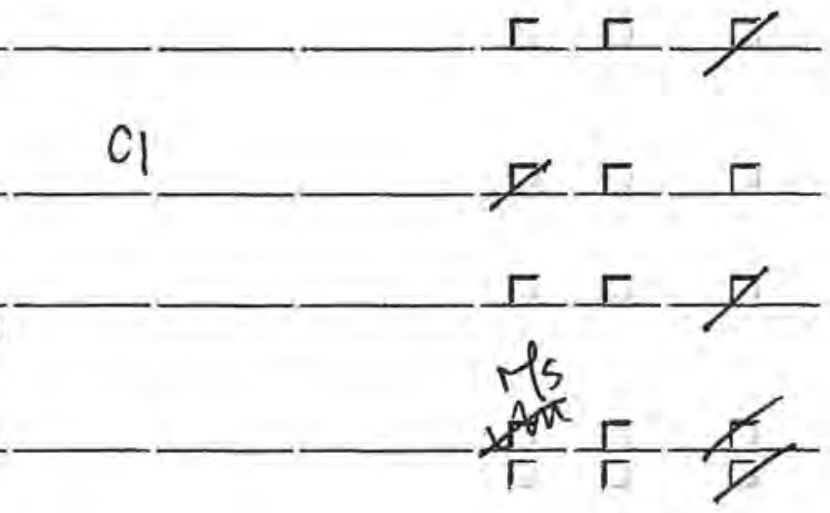


lookup table. If "other" is chosen from the lookup

table, provide description in comments of this line.

Is sample foamless after gently shaking? If "Failed" describe foam color and location ('on the surface' or

170 'in the sample') in the comments of this line. (Range

Is sample devoid of an oil sheen? If "Failed", describe color and thickness (e.g. flecks, globs) in the

180 comments of this line. (Range: $0-0$ )

Is sample free of other obvious indicators of pollution? If "Failed", describe in the comments of this

190 line. (Range: 0-0)

\section{Labor Report}

Completed: Failure:

Meter 1:

Meter 2:

Report: 


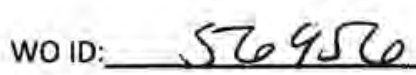

Page $\{$ of 3

Signature (collecting sample):

Psif.

Date and Time: $8 / 3 \mid 16 \quad 1834$

Signature (conducting visual assessment):

PSLl.

Date and Time: $8 / 416 \quad 1216$

\section{CERTIFICATION STATEMENT}

"I certify under penalty of law that this document and all attachments were prepared under my direction or supervision in accordance with a system designed to assure that qualified personnel properly gathered and evaluated the information submitted. Based on my inquiry of the person or persons who manage the system, or those persons directly responsible for gathering information, the information submitted is, to the best of my knowledge and belief, true, accurate, and complete. I am aware that there are significant penalties for submitting false information, including the possibility of fine and imprisonment for knowing violations".

(Signatory must meet definition in Section B.11.A, eg., FOD, Ops Mgr, DSESH Group Leader, EPC Group Leader)

Print name and title: 


\section{Maintenance Details}

\begin{tabular}{llll} 
Requested By: & Banar, Alethea on & Target: & \multicolumn{1}{c}{$9 / 30 / 16$} \\
& $7 / 27 / 20169: 44: 00 \mathrm{AM}$ & Priority/Type: I Inspection \\
Procedure: & MSGP Quarterly Visual & Department: & Utilities and \\
& Assessment (EPC-CP- & & \\
& Form-1021.2) & & \\
Last PM: & $7 / 26 / 2016$ & & \\
Project: & MSGP Visual & & \\
& Assessments 7/13/16 & \\
& (P-MSGP-4934) &
\end{tabular}

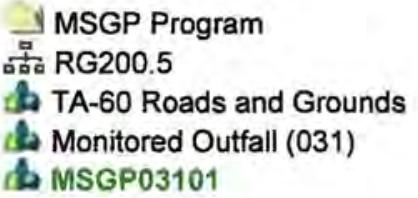

Contact: Banar, Alethea

Phone: 665-0454

Reason: MSGP Quarterly Visual Assessment

Special Instructions: NMR053195

\section{Tasks}

\# Description

Rating Meas. Initials Failed N/A Complete

The result of this VA applies to associated SIOs as defined in the SWPPP, where applicable.

Sample information

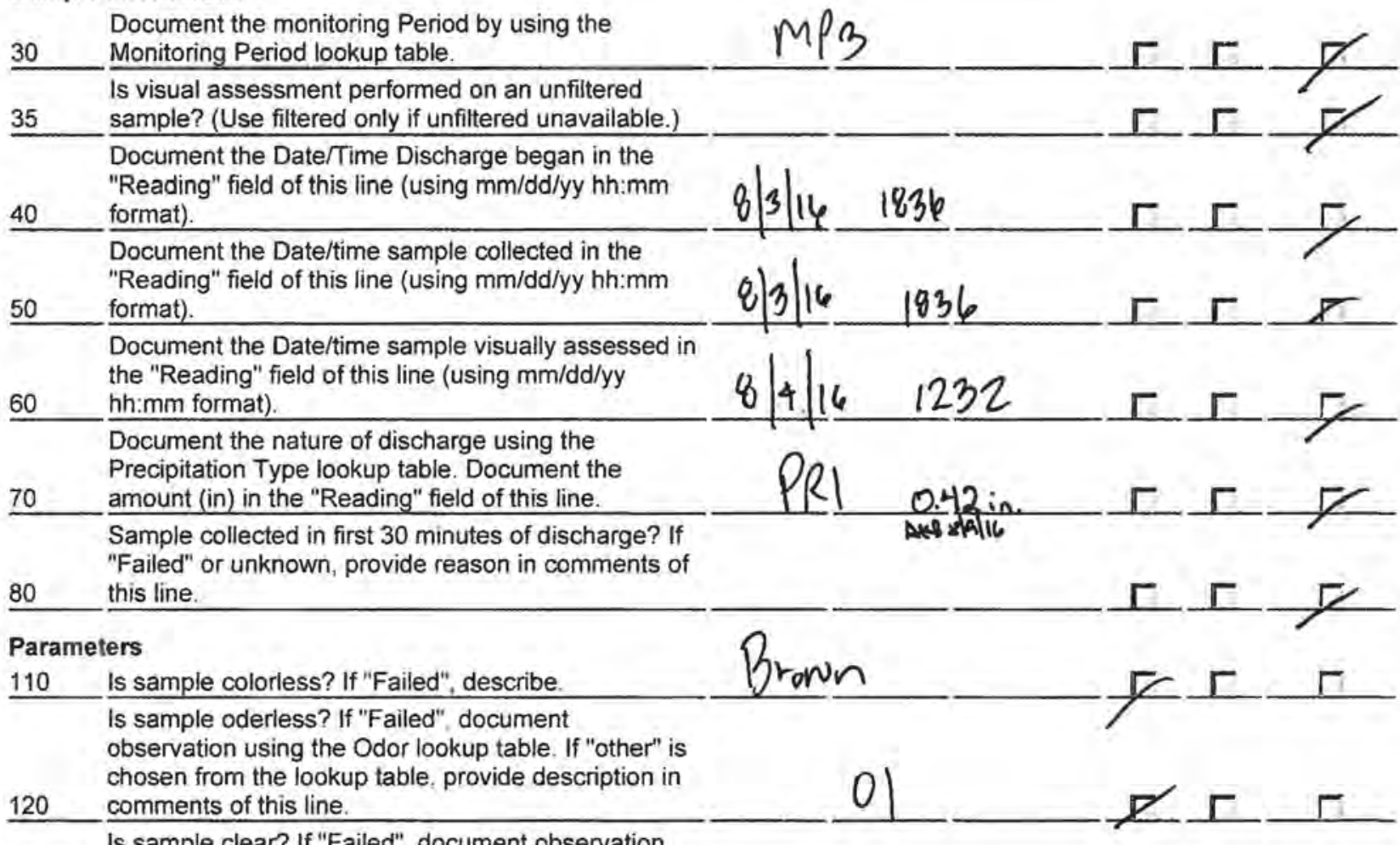

Is sample clear? If "Failed", document observation using the Clarity lookup table. If "other" is chosen from the lookup table, provide description in

130 comments of this line.

Is sample free of floating solids? If "Failed", describe if raw or waste material(s) in the comments of this 140 line.

150 is sample free of settled solids? If "Failed" document observation using the Settled Solids lookup table. If

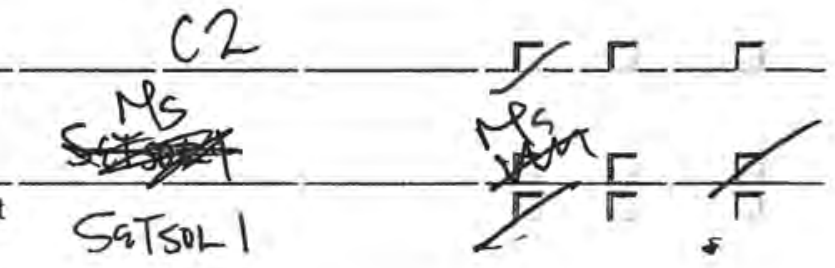


"other" is chosen from the lookup table, provide description in comments of this line.

Is sample free of suspended solids? If "Failed"

document observation using the Suspended Solids

lookup table. If "other" is chosen from the lookup

160 table, provide description in comments of this line.

Is sample foamless after gently shaking? If "Failed" describe foam color and location ('on the surface' or

$170 \quad 0-0)$ 'in the sample') in the comments of this line. (Range:

Is sample devoid of an oil sheen? If "Failed". describe color and thickness (e.g. flecks, globs) in the

180 comments of this line. (Range: $0-0$ )

Is sample free of other obvious indicators of pollution? If "Failed", describe in the comments of this 190 line. (Range: 0 - 0)

\section{Labor Report}

Completed: Failure:

Meter 1:

Meter 2:

Report: 
wo ID: 56658

Signature (collecting sample):_ Pfsl. Date and Time: $8 / 3 / 16 \quad 1636$

Signature (conducting visual assessment): MSHe Date and Time: $8 / 4 / 16 \quad 1232$

\section{CERTIFICATION STATEMENT}

"I certify under penalty of law that this document and all attachments were prepared under my direction or supervision in accordance with a system designed to assure that qualified personnel properly gathered and evaluated the information submitted. Based on my inquiry of the person or persons who manage the system, or those persons directly responsible for gathering information, the information submitted is, to the best of my knowledge and belief, true, accurate, and complete. I am aware that there are significant penalties for submitting false information, including the possibility of fine and imprisonment for knowing violations".

(Signatory must meet definition in Section B.11.A, eg., FOD, Ops Mgr, DSESH Group Leader, EPC Group Leader)

Print name and title:

Signature: Date: 


\section{Maintenance Details}

\section{Requested: 8/4/2016 7:06:05 PM \\ Procedure: MSGP Quarterly Visual Assessment (EPC-CP- Form-1021,2) \\ Last PM: $\quad 7 / 26 / 2016$ \\ Project: $\quad$ SIO Visual Assessments 8-4-16 (P-MSGP-5054)}

Target: $\quad$ 9/30/2016

Priority/Type: Normal / Inspection

Department: Utilities and Infrastructure

Reason: MSGP Quarterly Visual Assessment

Weather at inspection:

Finding Descprition:

Inspection Type:

Monitoring Period:

Precipitation Type:

Special Instructions: NMR053195

\section{Tasks}

\# Description

Rating Meas, Initials

Failed N/A Complete

The result of this VA applies to associated SIOs as defined in the SWPPP, where applicable.

\section{Sample information}

Document the monitoring Period by using the

30 Monitoring Period lookup table.

MP3

Is visual assessment performed on an unfiltered

35 sample? (Use filtered only if unfiltered unavailable.)

Document the Date/Time Discharge began in the

"Reading" field of this line (using mm/dd/yy hh:mm

40 format).

Document the Date/time sample collected in the

"Reading" field of this line (using mm/dd/yy hh:mm

50 format).

Document the Date/time sample visually assessed in the "Reading" field of this line (using $\mathrm{mm} / \mathrm{dd} / \mathrm{yy}$

60 hh:mm format).

Document the nature of discharge using the Precipitation Type lookup table. Document the

70 amount (in) in the "Reading" field of this line.

Sample collected in first 30 minutes of discharge? If

"Failed" or unknown, provide reason in comments of

80 this line.

\section{Parameters}

110 Is sample colorless? If "Failed", describe.

Is sample oderless? If "Failed", document

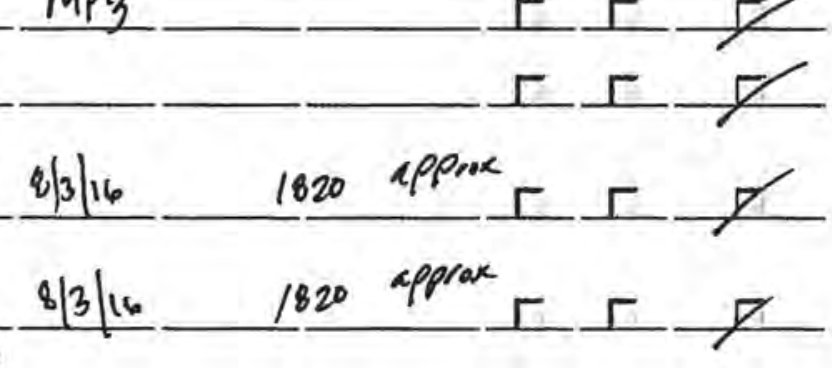

$1820 \mathrm{xpprax}$

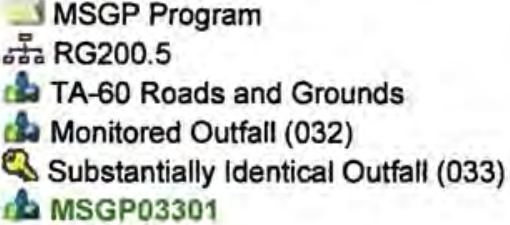

Contact:

Phone: 
Is sample free of settled solids? If "Failed", document observation using the Settled Solids lookup table. If "other" is chosen from the lookup table, provide description in comments of this line.

\section{SETSOLI}

Is sample free of suspended solids? If "Failed".

document observation using the Suspended Solids

lookup table. If "other" is chosen from the lookup

160 table, provide description in comments of this line.

Is sample foamless after gently shaking? If "Failed"

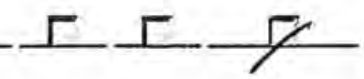

describe foam color and location ('on the surface' or

$170 \quad 0-0)$

'in the sample') in the comments of this line. (Range:

Is sample devoid of an oil sheen? If "Failed", describe

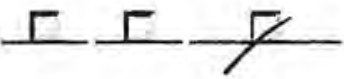

color and thickness (e.g. flecks, globs) in the

180 comments of this line. (Range: 0 - 0)

Is sample free of other obvious indicators of

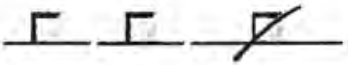

pollution? If "Failed", describe in the comments of this

190 line. (Range: 0-0)

\section{Labor Report}

Completed:

Failure:

Report: 
wo 10: MSGP. 57549

Signature (collecting sample): MSH . Date and Time: $8 / 3 / 16 \quad 1820$

Signature (conducting visual assessment): M $\mathrm{MLl}$ Date and Time: $8 / 4 / 16 \quad 12 / 8$

\section{CERTIFICATION STATEMENT}

"I certify under penalty of law that this document and all attachments were prepared under my direction or supervision in accordance with a system designed to assure that qualified personnel properly gathered and evaluated the information submitted. Based on my inquiry of the person or persons who manage the system, or those persons directly responsible for gathering information, the information submitted is, to the best of my knowledge and belief, true, accurate, and complete. I am aware that there are significant penalties for submitting false information, including the possibility of fine and imprisonment for knowing violations".

(Signatory must meet definition in Section B.11.A, eg., FOD, Ops Mgr, DSESH Group Leader, EPC Group Leader)

Print name and title:

Signature: Date: 


\section{Maintenance Details}

\section{Requested: 8/4/2016 7:06:06 PM \\ Procedure: MSGP Quarterly Visual Assessment (EPC-CP- Form-1021.2) \\ Last PM: 7/26/2016 \\ Project: $\quad$ SIO Visual Assessments 8-4-16 (P-MSGP-5054) \\ Target: $\quad$ 9/30/2016 \\ Priority/Type: Normal/Inspection \\ Department: Utilities and Infrastructure}

Reason: MSGP Quarterly Visual Assessment

Weather at inspection:

Finding Descprition:

Inspection Type:

Monitoring Period:

Precipitation Type:

Special instructions: NMR053195

\section{Tasks}

\# Description

Rating Meas. Initials Failed N/A Complete

The result of this VA applies to associated SIOs as defined in the SWPPP, where applicable.

Sample information

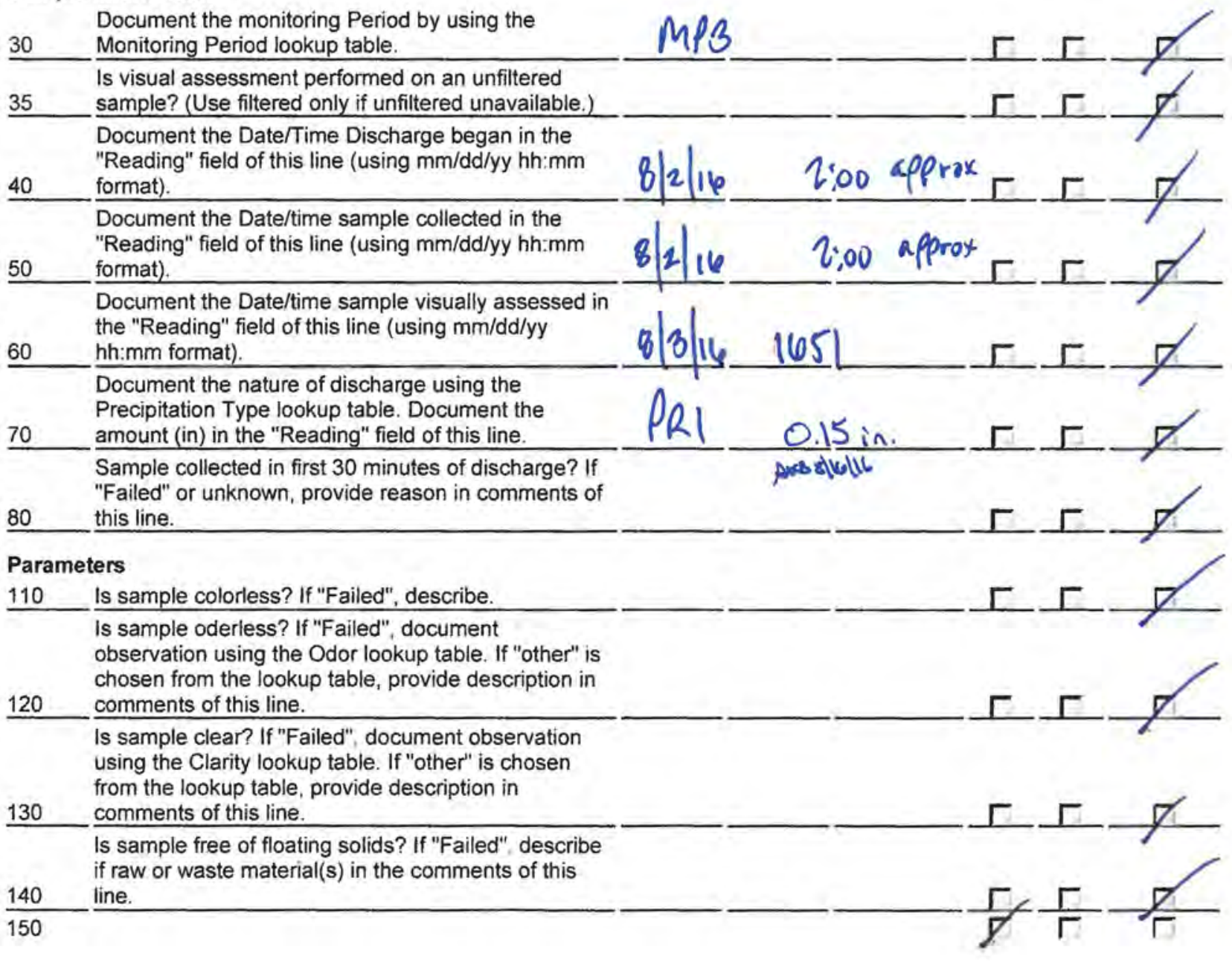


Is sample free of settled solids? If "Failed", document observation using the Settled Solids lookup table. If "other" is chosen from the lookup table, provide description in comments of this line.

Is sample free of suspended solids? If "Failed", document observation using the Suspended Solids lookup table. If "other" is chosen from the lookup table, provide description in comments of this line.

Is sample foamless after gently shaking? If "Failed" S幺TSOL 2 describe foam color and location ('on the surface' or

$170 \quad 0-0)$

'in the sample') in the comments of this line. (Range:

is sample devoid of an oil sheen? If "Failed", describe color and thickness (e.g. flecks, globs) in the

180 comments of this line. (Range: $0-0$ )

Is sample free of other obvious indicators of

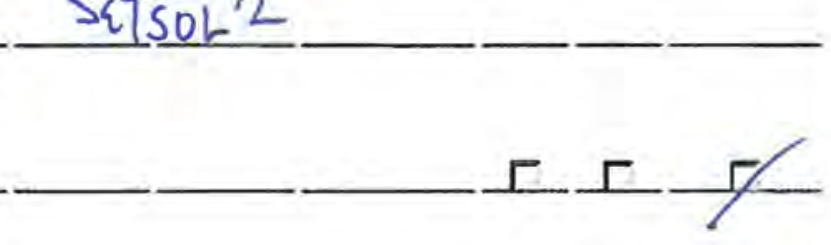
pollution? If "Failed", describe in the comments of this

190 line. (Range: $0-0$ )

\section{Labor Report}

Completed: Failure:

Report: 


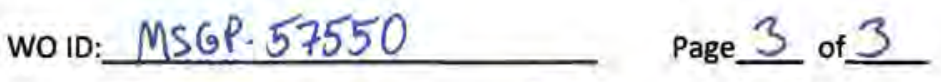

Signature (collecting sample):

\section{CERTIFICATION STATEMENT}

"I certify under penalty of law that this document and all attachments were prepared under my direction or supervision in accordance with a system designed to assure that qualified personnel properly gathered and evaluated the information submitted. Based on my inquiry of the person or persons who manage the system, or those persons directly responsible for gathering information, the information submitted is, to the best of my knowledge and belief, true, accurate, and complete. I am aware that there are significant penalties for submitting false information, including the possibility of fine and imprisonment for knowing violations".

(Signatory must meet definition in Section B.11.A, eg., FOD, Ops Mgr, DSESH Group Leader, EPC Group Leader)

Print name and title:

Signature: Date: 


\section{Maintenance Details}

Requested: 8/4/2016 7:06:06 PM

Procedure: MSGP Quarterly Visual Assessment (EPC-CP. Form-1021.2)

Last PM: $\quad 7 / 20 / 2016$

Project: SIO Visual Assessments 8-4-16 (P-MSGP-5054)
Target: $\quad$ 9/30/2016

Priority/Type: Normal / Inspection

Department: Utilities and Infrastructure

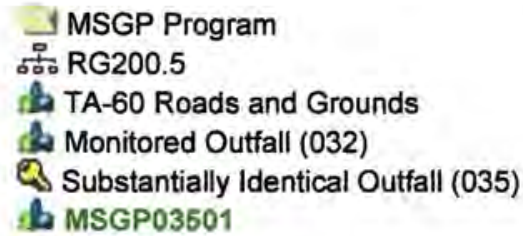

1 MSGP Program

옴 $\mathrm{RG} 200.5$

2 TA-60 Roads and Grounds

b MSGP03501

Contact:

Phone:

\section{Weather at inspection:}

Inspection Type:

Precipitation Type:

Special Instructions: NMR053195
Finding Descprition:

Monitoring Period:

\section{Tasks}

\# Description

Rating Meas. Initials Failed N/A Complete

The result of this VA applies to associated SIOs as defined in the SWPPP, where applicable.

\section{Sample information}

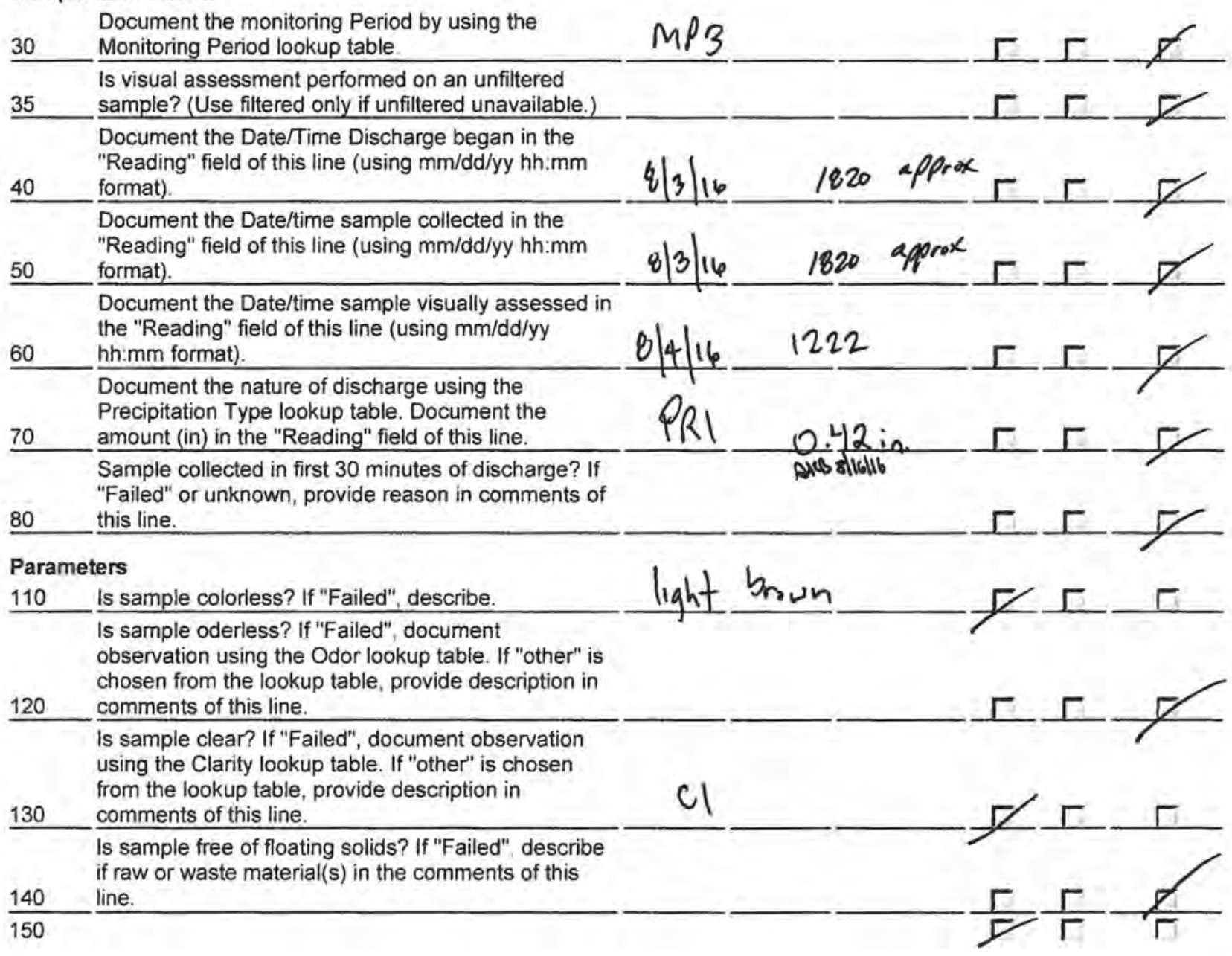


Is sample free of settled solids? If "Failed", document observation using the Settled Solids lookup table. If "other" is chosen from the lookup table, provide description in comments of this line.

\section{SLTSOL2}

Is sample free of suspended solids? If "Failed" document observation using the Suspended Solids lookup table. If "other" is chosen from the lookup

160 table, provide description in comments of this line.

Is sample foamless after gently shaking? If "Failed" describe foam color and location ('on the surface' or 'in the sample') in the comments of this line. (Range:

170 0 -0)

Is sample devoid of an oil sheen? If "Failed", describe color and thickness (e.g. flecks, globs) in the

180 comments of this line. (Range: $0-0$ )

Is sample free of other obvious indicators of pollution? If "Failed", describe in the comments of this 190 line. (Range: 0 - 0)

\section{Labor Report}

Completed: Failure:

Report: 
wo ID: MSGP. 57551

Signature (collecting sample):_ Psul. Date and Time: $8 / 3 / 16 \quad 1820$

Signature (conducting visual assessment): M S

\section{CERTIFICATION STATEMENT}

"I certify under penalty of law that this document and all attachments were prepared under my direction or supervision in accordance with a system designed to assure that qualified personnel properly gathered and evaluated the information submitted. Based on my inquiry of the person or persons who manage the system, or those persons directly responsible for gathering information, the information submitted is, to the best of my knowledge and belief, true, accurate, and complete. I am aware that there are significant penalties for submitting false information, including the possibility of fine and imprisonment for knowing violations".

(Signatory must meet definition in Section B.11.A, eg., FOD, Ops Mgr, DSESH Group Leader, EPC Group Leader)

Print name and title:

Signature:

Date: 


\section{Maintenance Details}

\begin{tabular}{|c|c|c|c|c|}
\hline \multicolumn{2}{|c|}{ Requested: 8/4/2016 7:06:07 PM } & Target: & $9 / 30 / 2016$ & \multirow{5}{*}{$\begin{array}{l}\text { MSGP Program } \\
\text { TA-60 Roads and Grounds } \\
\text { T. RG200.5 } \\
\text { Monitored Outfall (031) } \\
\text { Substantially Identical Outfall (030) } \\
\text { MSGP03001 }\end{array}$} \\
\hline \multirow{2}{*}{\multicolumn{2}{|c|}{ 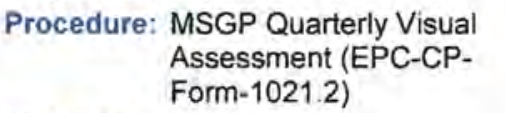 }} & Priority/Type: & Normal / Inspection & \\
\hline & & Department: & $\begin{array}{l}\text { Utilities and } \\
\text { Infrastructure }\end{array}$ & \\
\hline Last PM: & $7 / 26 / 2016$ & & & \\
\hline Project: & $\begin{array}{l}\text { SIO Visual Assessments } \\
\text { 8-4-16 (P-MSGP-5054) }\end{array}$ & & & \\
\hline \multicolumn{4}{|c|}{ Reason: MSGP Quarterly Visual Assessment } & Contact: \\
\hline \multirow{2}{*}{\multicolumn{2}{|c|}{ Weather at inspection: }} & \multicolumn{2}{|c|}{ Finding Descprition: } & Phon \\
\hline & & \multicolumn{2}{|c|}{ Monitoring Period: } & \\
\hline
\end{tabular}

Precipitation Type:

Special Instructions: NMR053195

\section{Tasks}

\# Description

Rating Meas. Initials Failed N/A Complete

The result of this VA applies to associated SIOs as defined in the SWPPP, where applicable.

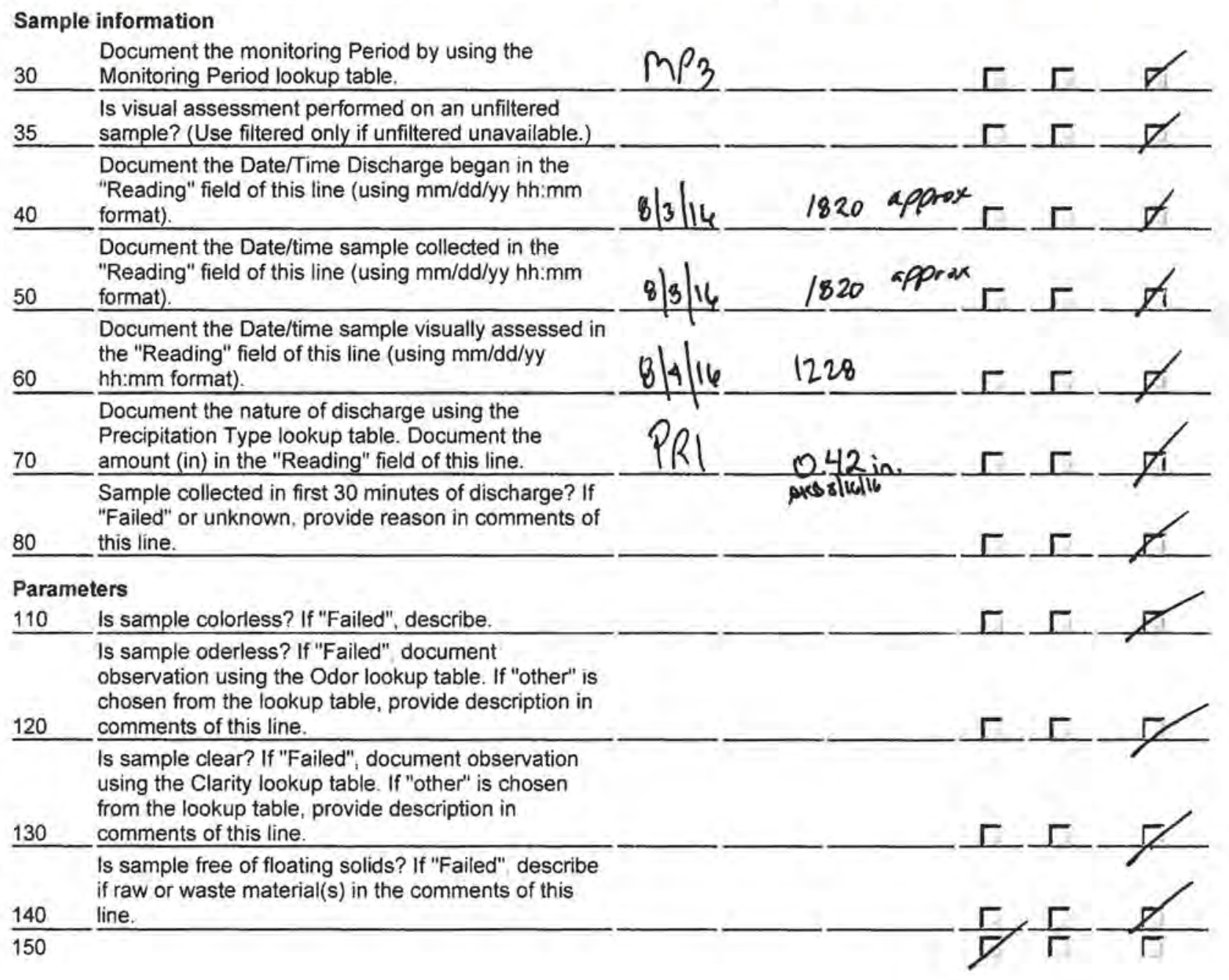


Is sample free of settled solids? If "Failed", document observation using the Settled Solids lookup table. If "other" is chosen from the lookup table, provide description in comments of this line.

SETSOLZ

Is sample free of suspended solids? If "Failed". document observation using the Suspended Solids lookup table. If "other" is chosen from the lookup

160 table, provide description in comments of this line.

Is sample foamless after gently shaking? If "Failed" describe foam color and location ('on the surface' or 'in the sample') in the comments of this line. (Range:

$170 \quad 0-0)$

Is sample devoid of an oil sheen? If "Failed", describe color and thickness (e.g. flecks, globs) in the

180 comments of this line. (Range: $0-0$ )

Is sample free of other obvious indicators of

pollution? If "Failed", describe in the comments of this

190 line. (Range: $0-0$ )

\section{Labor Report}

Completed: Failure:

Report: 


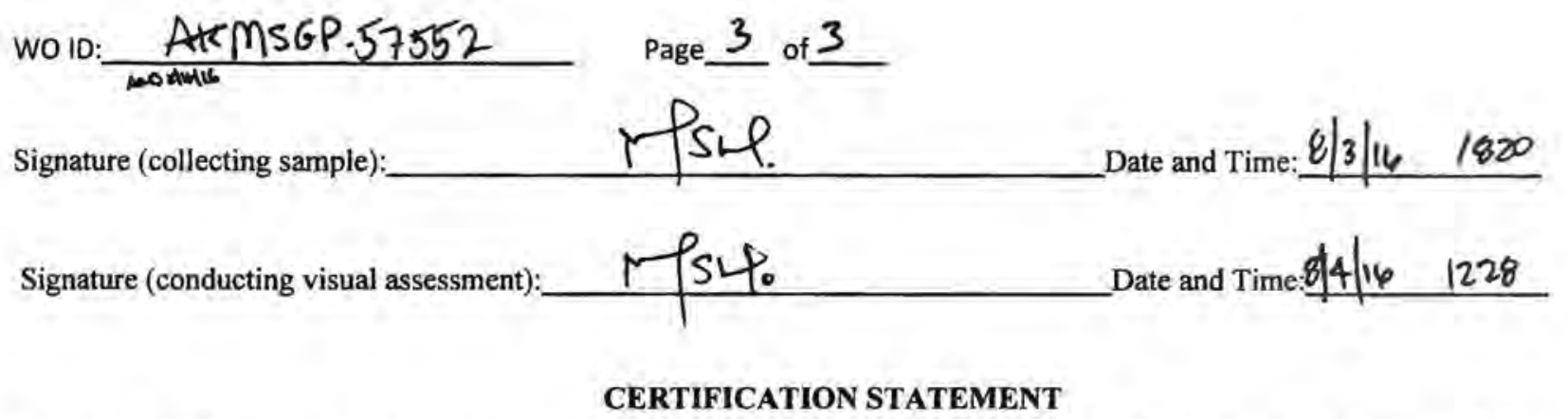

"I certify under penalty of law that this document and all attachments were prepared under my direction or supervision in accordance with a system designed to assure that qualified personnel properly gathered and evaluated the information submitted. Based on my inquiry of the person or persons who manage the system, or those persons directly responsible for gathering information, the information submitted is, to the best of my knowledge and belief, true, accurate, and complete. I am aware that there are significant penalties for submitting false information, including the possibility of fine and imprisonment for knowing violations",

\section{(Signatory must meet definition in Section B.11.A, eg., FOD, Ops Mgr, DSESH Group Leader, EPC Group Leader)}

Print name and title: 


\section{Maintenance Details}

\begin{tabular}{|c|c|c|c|c|}
\hline \multicolumn{2}{|c|}{ Requested: 8/4/2016 7:06:08 PM } & Target: & $9 / 30 / 2016$ & MSGP Program \\
\hline \multirow{2}{*}{\multicolumn{2}{|c|}{ 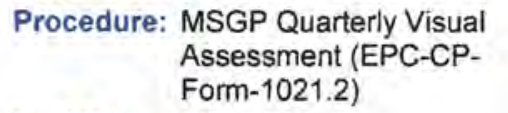 }} & Priority/Type: & Normal / inspection & \multirow{4}{*}{$\begin{array}{l}\text { D. RG200.5 } \\
\text { TA-60 Roads and Grounds } \\
\text { Monitored Outfall (042) } \\
\text { Substantially Identical Outfall (041) } \\
\text { MSGP04101 }\end{array}$} \\
\hline & & \multirow[t]{3}{*}{ Department: } & \multirow[t]{3}{*}{$\begin{array}{l}\text { Utilities and } \\
\text { Infrastructure }\end{array}$} & \\
\hline Last PM: & $7 / 21 / 2016$ & & & \\
\hline Project: & $\begin{array}{l}\text { SIO Visual Assessments } \\
\text { 8-4-16 (P-MSGP-5054) }\end{array}$ & & & \\
\hline \multicolumn{4}{|c|}{ Reason: MSGP Quarterly Visual Assessment } & \multirow{3}{*}{$\begin{array}{l}\text { Contact: } \\
\text { Phone: }\end{array}$} \\
\hline \multirow{2}{*}{\multicolumn{2}{|c|}{$\begin{array}{l}\text { Weather at inspection: } \\
\text { Inspection Type: }\end{array}$}} & \multicolumn{2}{|c|}{ Finding Descprition: } & \\
\hline & & \multicolumn{2}{|c|}{ Monitoring Period: } & \\
\hline
\end{tabular}

Precipitation Type:

Special Instructions: NMR053195

Tasks

\# Description Rating Meas. Initials Failed N/A Complete

The result of this VA applies to associated SIOs as defined in the SWPPP, where applicable.

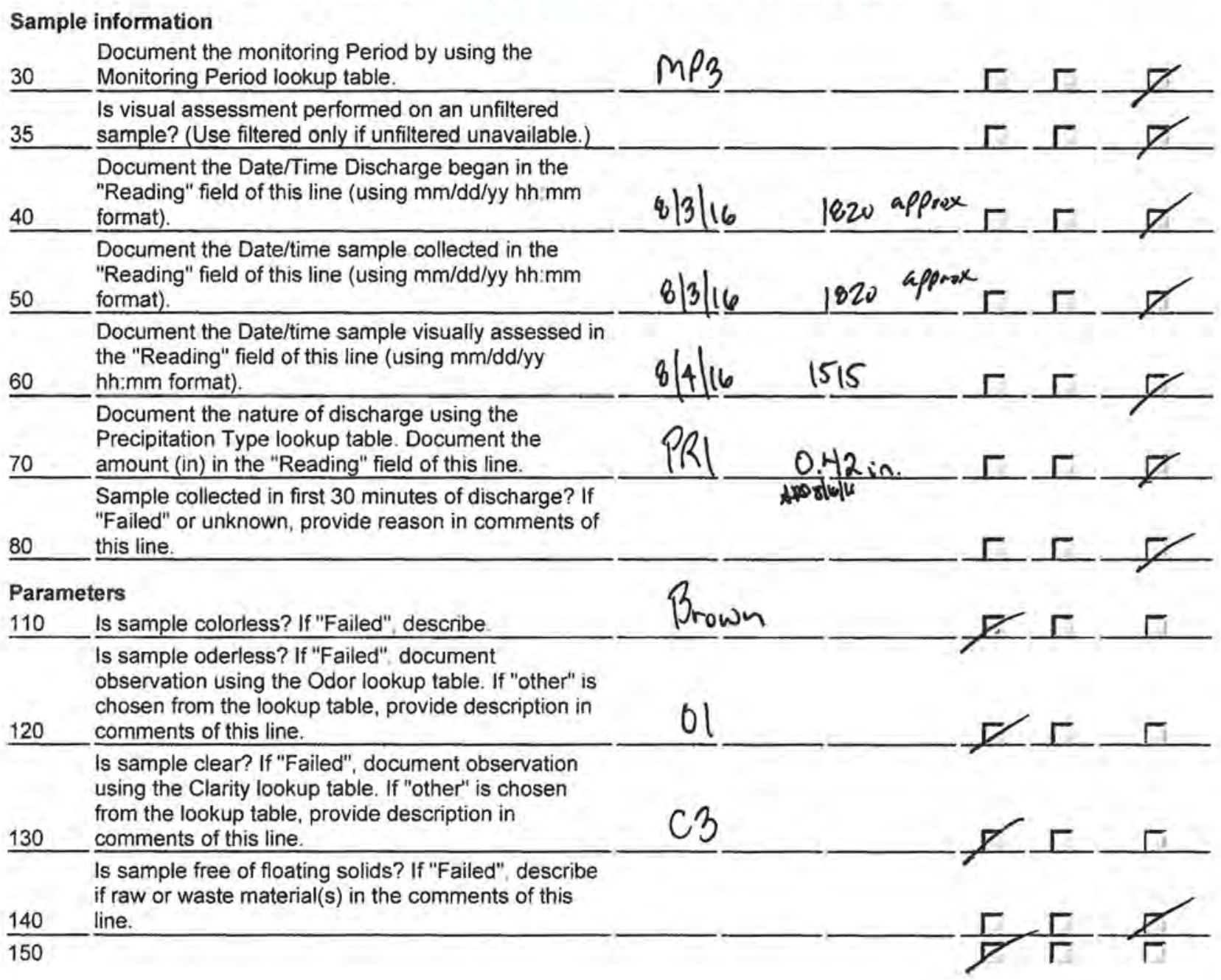


Is sample free of settled solids? If "Failed", document observation using the Settled Solids lookup table. If "other" is chosen from the lookup table, provide description in comments of this line.

SETSOLI

Is sample free of suspended solids? If "Failed", document observation using the Suspended Solids lookup table. If "other" is chosen from the lookup

160 table, provide description in comments of this line.

Is sample foamless after gently shaking? If "Failed" describe foam color and location ('on the surface' or 'in the sample') in the comments of this line. (Range:

170 0 - 0)

Is sample devoid of an oil sheen? If "Failed", describe color and thickness (e.g. flecks, globs) in the

180 comments of this line. (Range: 0 - 0)

Is sample free of other obvious indicators of

pollution? If "Failed". describe in the comments of this

190 line. (Range: 0 - 0 )

\section{Labor Report}

Completed: Failure;

Report: 
wo ID: MSGP. 57553

Page 3 of 3

Signature (collecting sample): $\quad$ Date and Time: $8 / 3 / 16 \quad 1820$

Signature (conducting visual assessment): $\quad$ Date and Time: $8 / 4 / 16 \quad 15 / 5$

\section{CERTIFICATION STATEMENT}

"I certify under penalty of law that this document and all attachments were prepared under my direction or supervision in accordance with a system designed to assure that qualified personnel properly gathered and evaluated the information submitted. Based on my inquiry of the person or persons who manage the system, or those persons directly responsible for gathering information, the information submitted is, to the best of my knowledge and belief, true, accurate, and complete. I am aware that there are significant penalties for submitting false information, including the possibility of fine and imprisonment for knowing violations".

(Signatory must meet definition in Section B.11.A, eg., FOD, Ops Mgr, DSESH Group Leader, EPC Group Leader)

Print name and title:

Signature:

Date: 
Maintenance Details

\begin{tabular}{|c|c|c|c|c|}
\hline \multicolumn{2}{|c|}{ Requested: 8/4/2016 7·11 $15 \mathrm{PM}$} & Target: & $9 / 30 / 2016$ & \multirow{5}{*}{$\begin{array}{l}\text { MSGP Program } \\
\text { 홈 RG200.5 } \\
\text { 1. TA-60 Roads and Grounds } \\
\text { 1. Monitored Outfall (032) } \\
\text { Substantially Identical Outfall (034) } \\
\text { A MSGP03401 }\end{array}$} \\
\hline \multirow{2}{*}{\multicolumn{2}{|c|}{$\begin{aligned} \text { Procedure: } & \text { MSGP Quarterly Visual } \\
& \text { Assessment (EPC-CP- } \\
& \text { Form-1021.2) }\end{aligned}$}} & Priority/Type: & Normal / Inspection & \\
\hline & & Department: & $\begin{array}{l}\text { Utilities and } \\
\text { Infrastructure }\end{array}$ & \\
\hline Last PM: & \multicolumn{3}{|l|}{$7 / 26 / 2016$} & \\
\hline Project: & \multicolumn{3}{|l|}{$\begin{array}{l}\text { SIO Visual Assessments } \\
\text { 8-4-16 (P-MSGP-5054) }\end{array}$} & \\
\hline \multicolumn{4}{|c|}{ Reason: MSGP Quarterly Visual Assessment } & \multirow{3}{*}{$\begin{array}{l}\text { Contact: } \\
\text { Phone: }\end{array}$} \\
\hline \multirow{2}{*}{\multicolumn{2}{|c|}{$\begin{array}{l}\text { Weather at inspection: } \\
\text { Inspection Type: }\end{array}$}} & \multicolumn{2}{|c|}{ Finding Descprition: } & \\
\hline & & \multicolumn{2}{|c|}{ Monitoring Period: } & \\
\hline
\end{tabular}

Precipitation Type:

Special Instructions: NMR053195

\section{Tasks}

\# Description

Rating Meas. Initials Failed N/A Complete

The result of this VA applies to associated SIOs as defined in the SWPPP, where applicable.

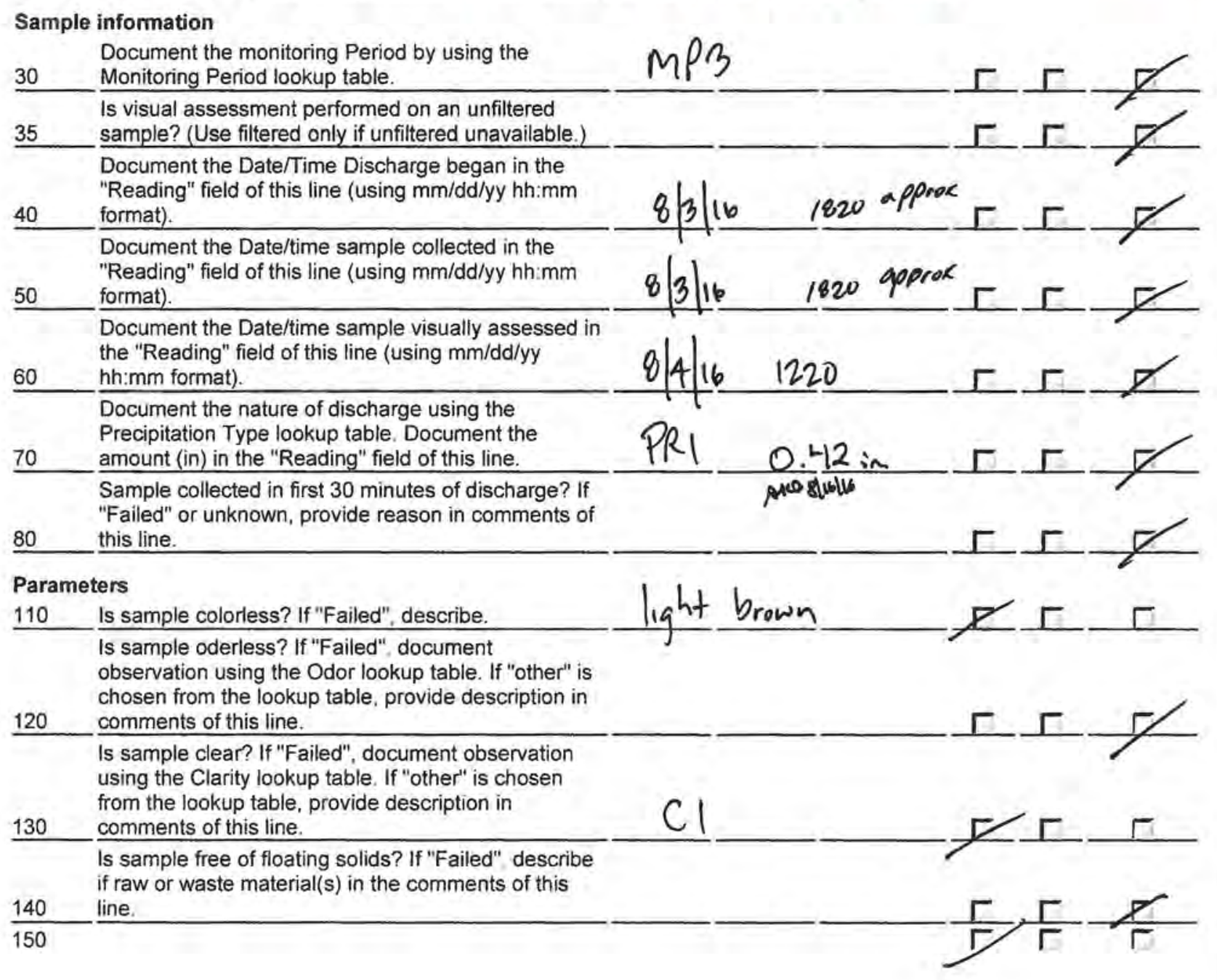


Is sample free of settled solids? If "Failed", document observation using the Settled Solids lookup table. If "other" is chosen from the lookup table, provide description in comments of this line.

Is sample free of suspended solids? If "Failed". document observation using the Suspended Solids lookup table. If "other" is chosen from the lookup

160 table, provide description in comments of this line

is sample foamless after gently shaking? If "Failed" describe foam color and location ('on the surface' or 'in the sample') in the comments of this line. (Range

$170 \quad 0-0)$

Is sample devoid of an oil sheen? If "Failed", describe color and thickness (e.g. flecks, globs) in the

180 comments of this line. (Range: 0 - 0)

Is sample free of other obvious indicators of pollution? If "Failed", describe in the comments of this 190 line. (Range: $0-0$ )

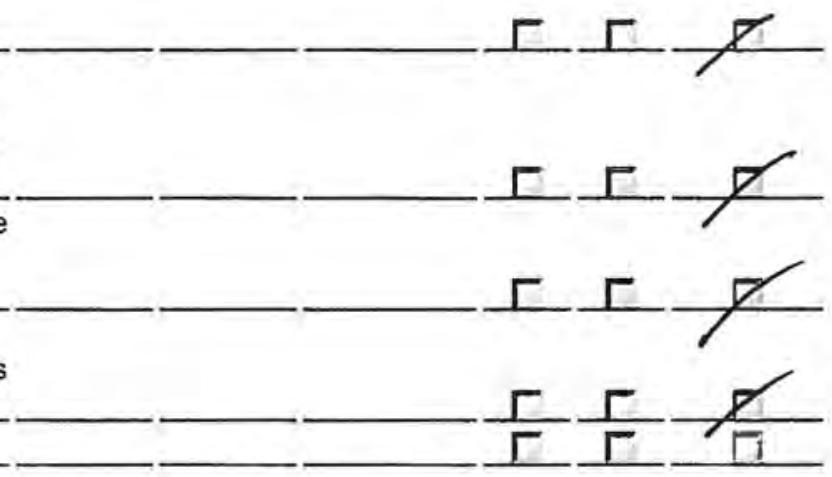

\section{Labor Report}

Completed: Failure:

Report: 
Wo ID: MSGP. 57566

Page 3 of 3

Signature (collecting sample):

Signature (conducting visual assessment):
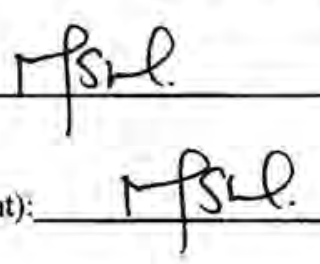

Date and Time:

8) $3 / 16 / 820$

Date and Time: $y / 4 / 16 \quad 1220$

CERTIFICATION STATEMENT

"I certify under penalty of law that this document and all attachments were prepared under my direction or supervision in accordance with a system designed to assure that qualified personnel properly gathered and evaluated the information submitted. Based on my inquiry of the person or persons who manage the system, or those persons directly responsible for gathering information, the information submitted is, to the best of my knowledge and belief, true, accurate, and complete. I am aware that there are significant penalties for submitting false information, including the possibility of fine and imprisonment for knowing violations".

(Signatory must meet definition in Section B.11.A, eg, FOD, Ops Mgr, DSESH Group Leader, EPC Group Leader)

Print name and title:

Signature:

Date: 
Maintenance Details

$\begin{array}{ll}\text { Requested By: } & \text { Banar, Alethea on } \\ & \text { 8/8/2016 4:54:00 PM } \\ \text { Taken By: } & \text { Banar, Alethea } \\ \text { Procedure: } & \text { MSGP Quarterly Visual } \\ & \text { Assessment (EPC-CP- } \\ & \text { Form-1021.2) } \\ \text { Last PM: } & 8 / 1 / 2016 \\ \text { Project: } & \text { Visual Assessments } \\ & \text { 8-8-16 (P-MSGP-5074) }\end{array}$

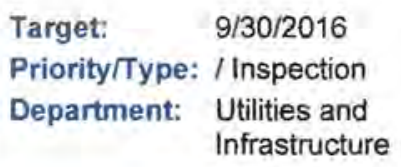

Reason: MSGP Quarterly Visual Assessment

Monitoring Period:

Clarity:

Suspended Solids:

Special instructions: NMR053195

Odor:

Settled Solids:

Tasks

\# Description

Rating Meas. Initials Failed N/A Complete

The result of this VA applies to associated SIOs as defined in the SWPPP, where applicable.

Sample information

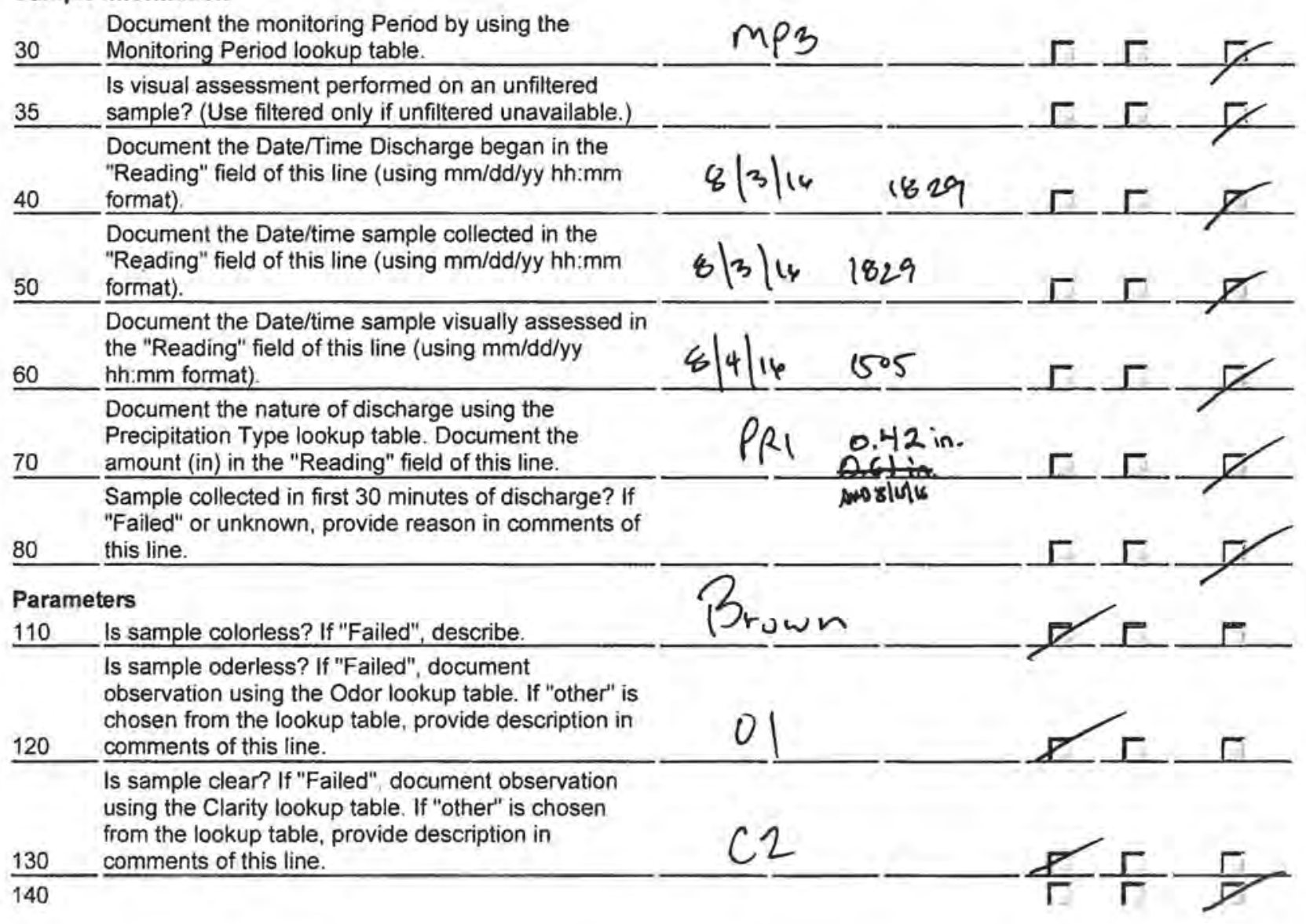


Is sample free of floating solids? If "Failed", describe

if raw or waste material(s) in the comments of this

line.

Is sample free of settled solids? If "Failed", document observation using the Settled Solids lookup table. If

"other" is chosen from the lookup table, provide

150 description in comments of this line.
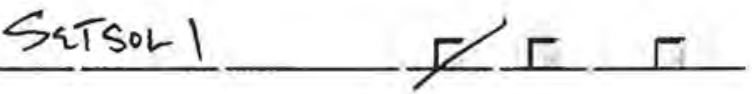

Is sample free of suspended solids? If "Failed", document observation using the Suspended Solids lookup table. If "other" is chosen from the lookup

160 table, provide description in comments of this line.

Is sample foamless after gently shaking? If "Failed" describe foam color and location ('on the surface' or 'in the sample') in the comments of this line. (Range:

$170 \quad 0-0)$

Is sample devoid of an oil sheen? If "Failed", describe color and thickness (e.g, flecks, globs) in the

180 comments of this line. (Range: $0-0$ )

Is sample free of other obvious indicators of pollution? If "Failed", describe in the comments of this

190 line. (Range: 0 - 0)

\section{Labor}

Labor

Work Date Reg Hrs OT Hrs Other Hrs

\section{Labor Report}

Completed: Failure:

Meter 1: Meter 2: 
Signature (collecting sample):__ MfSU Date and Time: $8 / 3 / 16 \quad 1829$

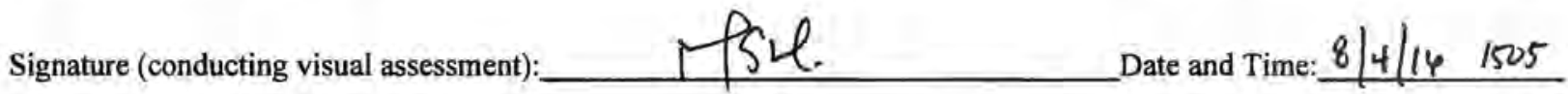

\section{CERTIFICATION STATEMENT}

"I certify under penalty of law that this document and all attachments were prepared under my direction or supervision in accordance with a system designed to assure that qualified personnel properly gathered and evaluated the information submitted. Based on my inquiry of the person or persons who manage the system, or those persons directly responsible for gathering information, the information submitted is, to the best of my knowledge and belief, true, accurate, and complete. I am aware that there are significant penalties for submitting false information, including the possibility of fine and imprisonment for knowing violations".

(Signatory must meet definition in Section B.11.A, eg., FOD, Ops Mgr, DSESH Group Leader, EPC Group Leader)

Print name and title:

Signature: Date: 


\section{Maintenance Details}

$\begin{array}{llll}\text { Requested By: } & \text { Banar. Alethea on } & \text { Target: } & 9 / 30 / 2016 \\ & 8 / 8 / 20164: 55: 00 \text { PM } & \text { Priority } / \text { Type: / Inspection } \\ \text { Taken By: } & \text { Banar, Alethea } & \text { Department: Utilities and } \\ \text { Procedure: } & \text { MSGP Quarterly Visual } & & \\ & \text { Assessment (EPC-CP- } & & \\ & \text { Form-1021.2) } & & \\ \text { Last PM: } & 8 / 1 / 2016 & \\ \text { Project: } & \text { Visual Assessments } & & \\ & \text { 8-8-16 (P-MSGP-5074) } & \end{array}$

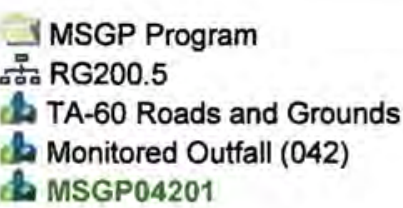

Contact: Banar, Alethea

Phone: 699-5836

Reason: MSGP Quarterly Visual Assessment

Monitoring Period:

Odor:

Clarity:

Settled Solids:

Suspended Solids:

Special Instructions: NMR053195

\section{Tasks}

\# Description

Rating Meas. Initials Failed N/A Complete

The result of this VA applies to associated SIOs as defined in the SWPPP, where applicable.

\section{Sample information}

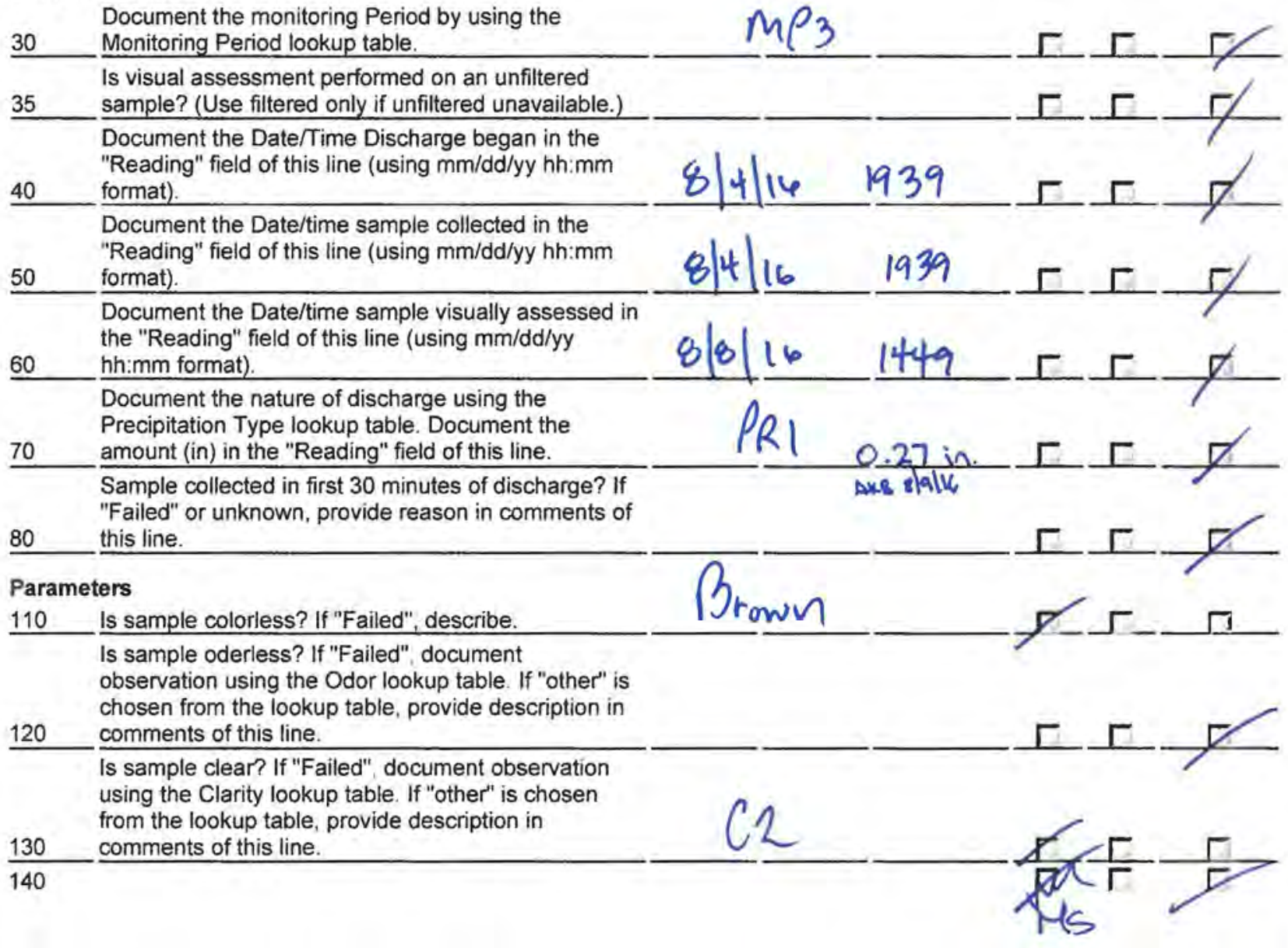


Is sample free of floating solids? If "Failed", describe if raw or waste material(s) in the comments of this line.

Is sample free of settled solids? If "Failed", document observation using the Settled Solids lookup table. If "other" is chosen from the lookup table, provide

150 description in comments of this line. Is sample free of suspended solids? If "Failed", document observation using the Suspended Solids lookup table. If "other" is chosen from the lookup

160 table, provide description in comments of this line.

Is sample foamless after gently shaking? If "Failed"

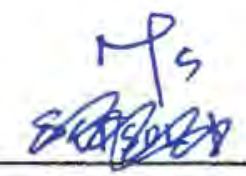

describe foam color and location ('on the surface' or 'in the sample') in the comments of this line. (Range:

170 0 -0)

Is sample devoid of an oil sheen? If "Failed", describe

\section{SATBOLI} $\Gamma$

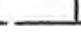
$\Gamma$ color and thickness (e.g. flecks, globs) in the

180 comments of this line. (Range: $0-0$ )

Is sample free of other obvious indicators of pollution? If "Failed", describe in the comments of this

190 line. (Range: $0-0$ )

\section{Labor}

Labor

Work Date Reg Hrs OT Hrs Other Hrs

\section{Labor Report}

Completed:

Failure:

Meter 1:

Meter 2:

Report: 
Signature (collecting sample):

Signature (conducting visual assessment):

\section{CERTIFICATION STATEMENT}

"I certify under penalty of law that this document and all attachments were prepared under my direction or supervision in accordance with a system designed to assure that qualified personnel properly gathered and evaluated the information submitted. Based on my inquiry of the person or persons who manage the system, or those persons directly responsible for gathering information, the information submitted is, to the best of my knowledge and belief, true, accurate, and complete. I am aware that there are significant penalties for submitting false information, including the possibility of fine and imprisonment for knowing violations".

(Signatory must meet definition in Section B.11.A, eg., FOD, Ops Mgr, DSESH Group Leader, EPC Group Leader)

Print name and title:

Signature: Date: 


\section{Maintenance Details}

\section{Requested: 8/10/2016 1:18:12 PM \\ Procedure: MSGP Quarterly Visual Assessment (EPC-CP- Form-1021.2) \\ Last PM: $\quad 8 / 1 / 2016$ \\ Project: SIO Visual Assessments 8/8/16 (P-MSGP-5073)}

Reason: MSGP Quarterly Visual Assessment

Monitoring Period:

Odor:

\section{Target: $\quad 9 / 30 / 2016$ \\ Priority/Type: Normal/Inspection \\ Department: Utilities and Infrastructure}

Clarity:

Settled Solids:

Suspended Solids:

Special Instructions: NMR053195

\section{Tasks}

* Description

Rating Meas. Initials Failed N/A Complete

The result of this VA applies to associated SIOs as defined in the SWPPP, where applicable.

\section{Sample information}

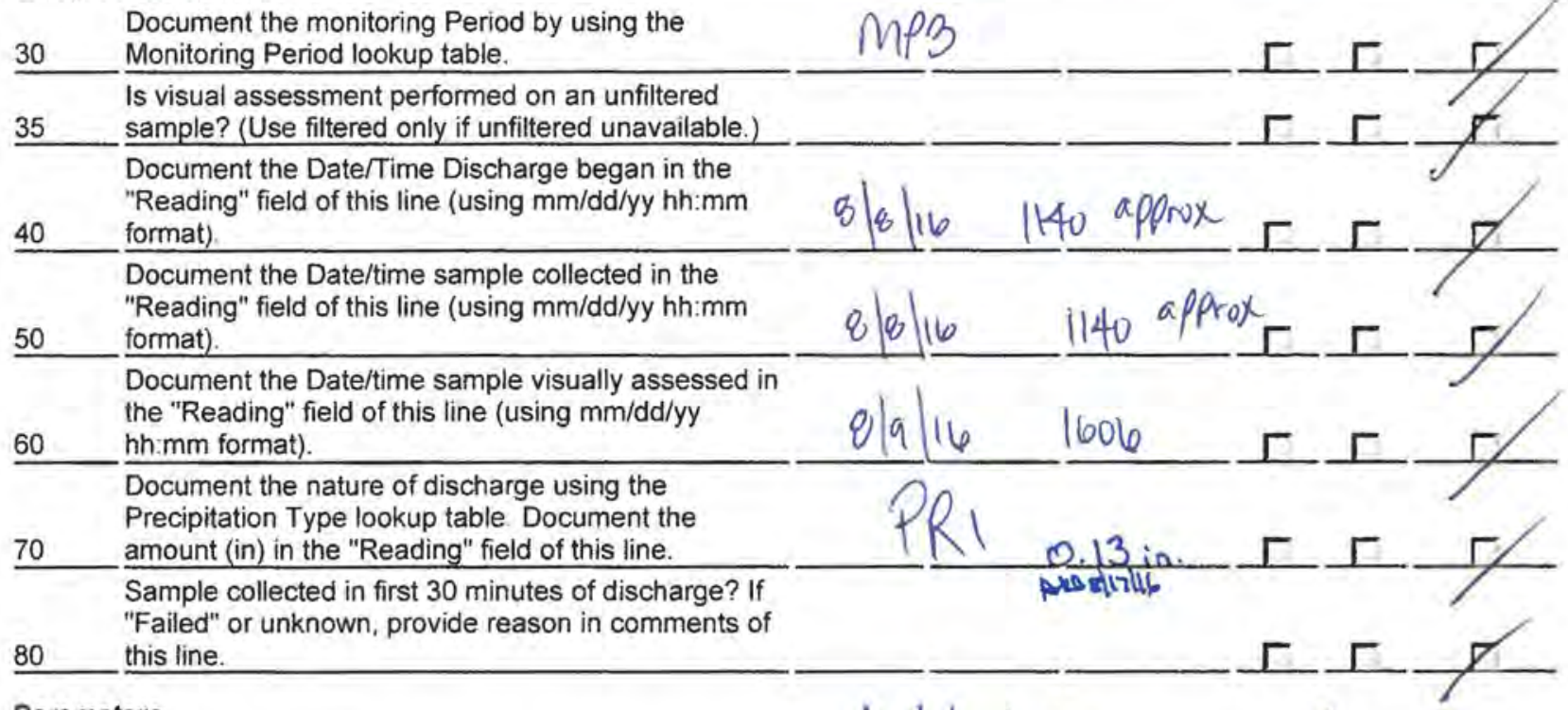

Parameters

110 Is sample colorless? If "Failed", describe.

Is sample oderless? If "Failed", document

observation using the Odor lookup table. If "other" is chosen from the lookup table, provide description in comments of this line.

Is sample clear? If "Failed", document observation using the Clarity lookup table. If "other" is chosen from the lookup table, provide description in

130 comments of this line.

Is sample free of floating solids? If "Failed", describe if raw or waste material(s) in the comments of this 140 line.

150

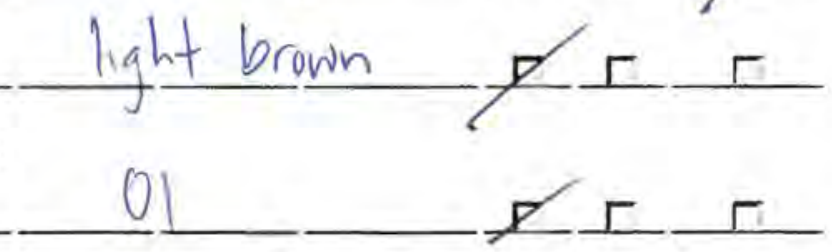

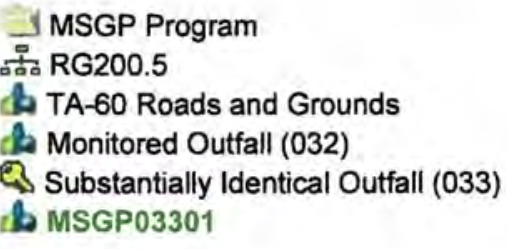

Contact:

Phone: 
Is sample free of settled solids? If "Failed", document observation using the Settled Solids lookup table. If

"other" is chosen from the lookup table, provide description in comments of this line.

SRTSOL 2

Is sample free of suspended solids? If "Failed", document observation using the Suspended Solids

160 lookup table. If "other" is chosen from the lookup table, provide description in comments of this line. Is sample foamless after gently shaking? If "Failed" describe foam color and location ('on the surface' or 'in the sample') in the comments of this line. (Range: $170 \quad 0-0)$ Is sample devoid of an oil sheen? If "Failed" describe color and thickness (e.g. flecks, globs) in the

180 comments of this line. (Range: $0-0$ )

Is sample free of other obvious indicators of pollution? If "Failed", describe in the comments of this

190 line. (Range: $0-0$ )

\section{Labor}

Labor

Work Date Reg Hrs OT Hrs Other Hrs

\section{Labor Report}

Completed: Failure:

Report: 


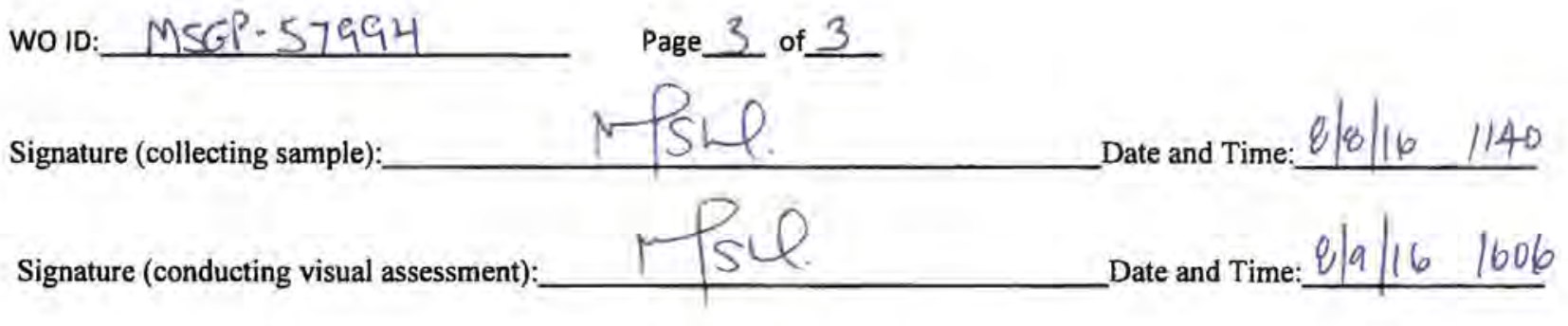

\section{CERTIFICATION STATEMENT}

"I certify under penalty of law that this document and all attachments were prepared under my direction or supervision in accordance with a system designed to assure that qualified personnel properly gathered and evaluated the information submitted. Based on my inquiry of the person or persons who manage the system, or those persons directly responsible for gathering information, the information submitted is, to the best of my knowledge and belief, true, accurate, and complete. I am aware that there are significant penalties for submitting false information, including the possibility of fine and imprisonment for knowing violations".

(Signatory must meet definition in Section B.11.A, eg., FOD, Ops Mgr, DSESH Group Leader, EPC Group Leader)

Print name and title:

Signature:

Date: 
Maintenance Details

\section{Requested: 8/10/2016 1:18:13 PM \\ Procedure: MSGP Quarterly Visual Assessment (EPC-CP- Form-1021.2) \\ Last PM: $\quad 8 / 1 / 2016$ \\ Project: $\quad$ SIO Visual Assessments 8/8/16 (P-MSGP-5073)}

Reason: MSGP Quarterly Visual Assessment

Monitoring Period:

Odor:

\section{Target: $\quad 9 / 30 / 2016$ \\ Priority/Type: Normal / Inspection \\ Department: Utilities and Infrastructure}

Clarity:

Settled Solids:

Suspended Solids:

Special Instructions: NMR053195

\section{Tasks}

\# Description Rating Meas. Initials Failed N/A Complete

The result of this VA applies to associated SIOs as defined in the SWPPP, where applicable.

\section{Sample information}

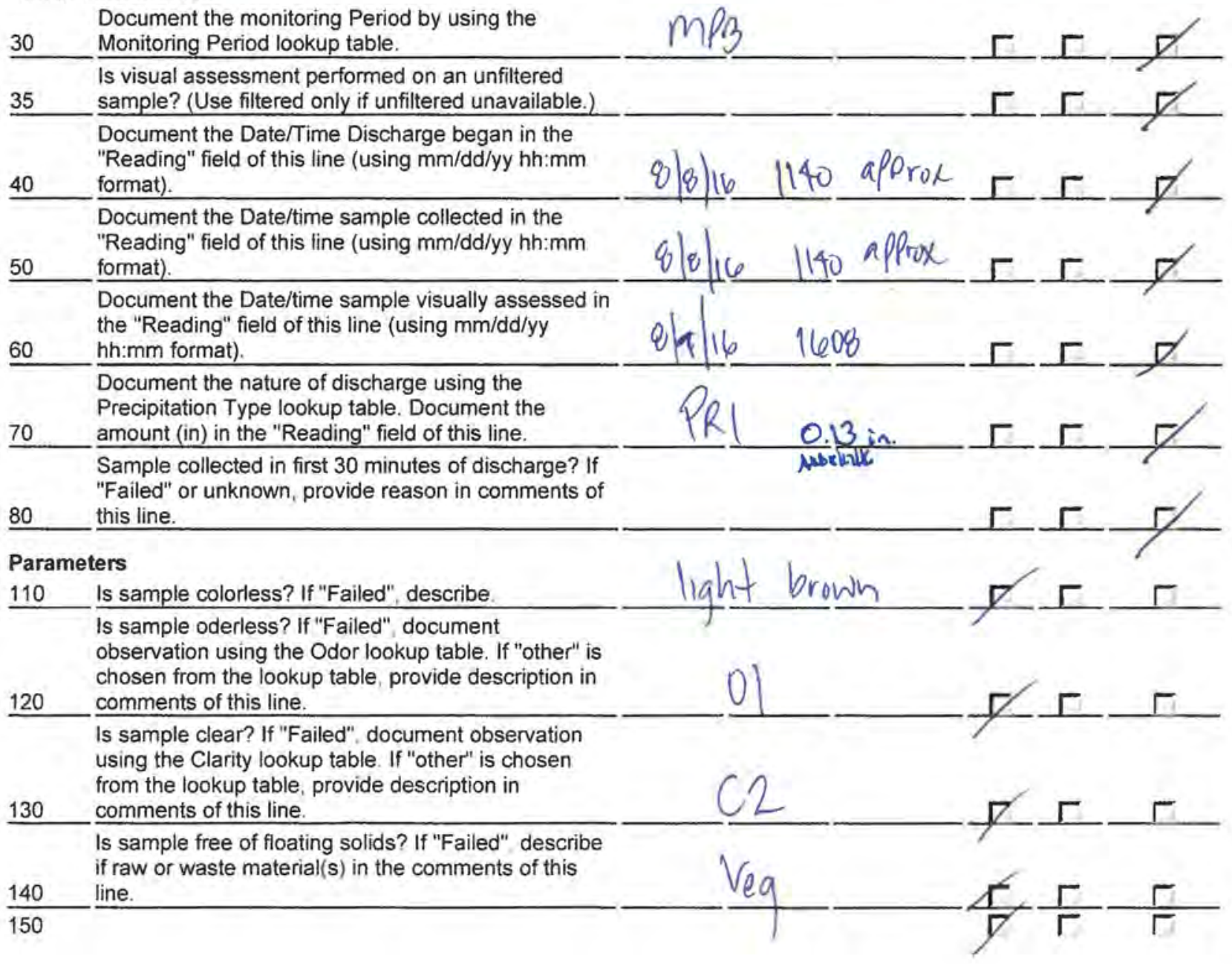


Is sample free of settled solids? If "Failed", document observation using the Settled Solids lookup table. If "other" is chosen from the lookup table, provide description in comments of this line.

SETSOL

Is sample free of suspended solids? If "Failed" document observation using the Suspended Solids lookup table. If "other" is chosen from the lookup

160 table, provide description in comments of this line. Is sample foamless after gently shaking? If "Failed"

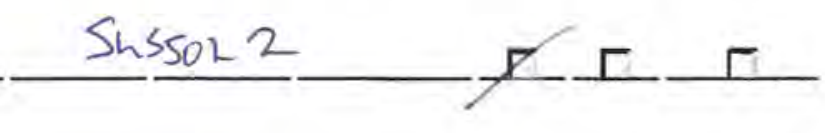
describe foam color and location ('on the surface' or

170 'in the sample') in the comments of this line. (Range: 0 - 0)

Is sample devoid of an oil sheen? If "Failed" describe color and thickness (e.g. flecks, globs) in the

180 comments of this line. (Range: $0-0$ )

Is sample free of other obvious indicators of

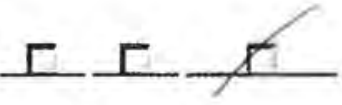
pollution? If "Failed", describe in the comments of this

190 line. (Range: 0 -0)

\section{Labor}

Labor

Work Date Reg Hrs OT Hrs Other Hrs

\section{Labor Report}

Completed: Failure:

Report: 
WO ID: MSGP-57995 Page 3 of 3

Signature (collecting sample):_ Date and Time: $8 / 6 / 16 \quad 1140$

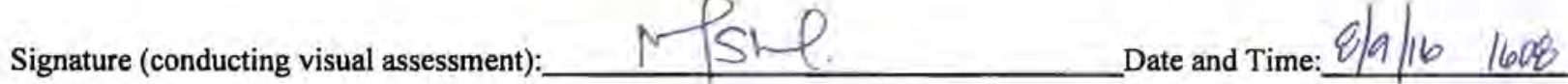

\section{CERTIFICATION STATEMENT}

"I certify under penalty of law that this document and all attachments were prepared under my direction or supervision in accordance with a system designed to assure that qualified personnel properly gathered and evaluated the information submitted. Based on my inquiry of the person or persons who manage the system, or those persons directly responsible for gathering information, the information submitted is, to the best of my knowledge and belief, true, accurate, and complete. I am aware that there are significant penalties for submitting false information, including the possibility of fine and imprisonment for knowing violations".

(Signatory must meet definition in Section B.11.A, eg., FOD, Ops Mgr, DSESH Group Leader, EPC Group Leader)

Print name and title: 
Maintenance Details

\section{Requested: 8/10/2016 1:18:14 PM \\ Procedure: MSGP Quarterly Visual Assessment (EPC-CP- Form-1021.2) \\ Last PM: $\quad 8 / 1 / 2016$ \\ Project: SIO Visual Assessments 8/8/16 (P-MSGP-5073)}

Reason: MSGP Quarterly Visual Assessment

Monitoring Period:

Odor:

\author{
MSGP Program \\ ธैं⿰ RG200.5 \\ 15 TA-60 Roads and Grounds \\ ch Monitored Outfall (032) \\ Substantially Identical Outfall (035) \\ ib MSGP03501
}

Contact:

Phone:

Clarity:

Settled Solids:

Suspended Solids:

Special instructions: NMR053195

\section{Tasks}

\# Description

Rating

Meas.

Initials

Failed N/A Complete

The result of this VA applies to associated SIOs as defined in the SWPPP, where applicable.

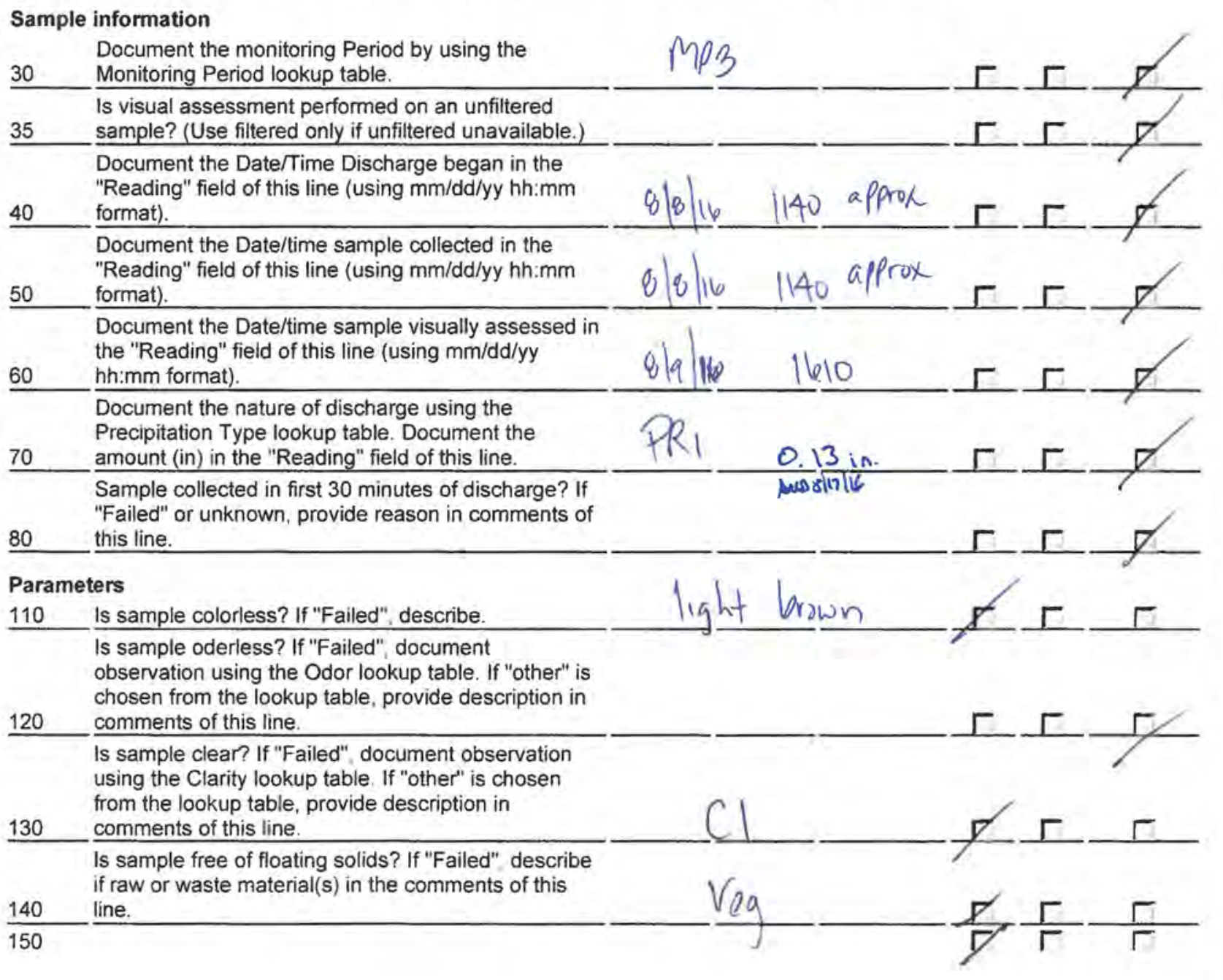


Is sample free of settled solids? If "Failed", document observation using the Settled Solids lookup table. If "other" is chosen from the lookup table, provide description in comments of this line.

Is sample free of suspended solids? If "Failed", document observation using the Suspended Solids lookup table. If "other" is chosen from the lookup table, provide description in comments of this line.

Is sample foamless after gently shaking? If "Failed"

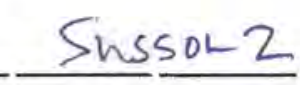
describe foam color and location ('on the surface' or 'in the sample') in the comments of this line. (Range: $170 \quad 0-0)$ Is sample devoid of an oil sheen? If "Failed", describe color and thickness (e.g. flecks, globs) in the

180 comments of this line. (Range: $0-0$ )

Is sample free of other obvious indicators of pollution? If "Failed", describe in the comments of this 190 line. (Range: $0-0$ )

\section{Labor}

Labor

Work Date Reg Hrs OT Hrs Other Hrs

\section{Labor Report}

Completed: Failure:

Report: 


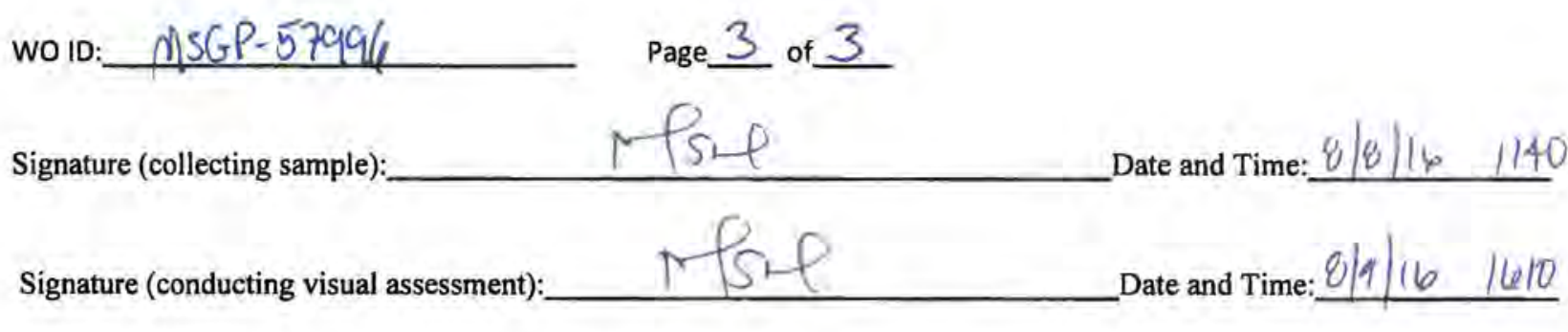

\section{CERTIFICATION STATEMENT}

"I certify under penalty of law that this document and all attachments were prepared under my direction or supervision in accordance with a system designed to assure that qualified personnel properly gathered and evaluated the information submitted. Based on my inquiry of the person or persons who manage the system, or those persons directly responsible for gathering information, the information submitted is, to the best of my knowledge and belief, true, accurate, and complete. I am aware that there are significant penalties for submitting false information, including the possibility of fine and imprisonment for knowing violations".

(Signatory must meet definition in Section B.11.A, eg., FOD, Ops Mgr, DSESH Group Leader, EPC Group Leader)

Print name and title: 


\section{Maintenance Details}

\begin{tabular}{|c|c|c|c|c|}
\hline \multicolumn{2}{|c|}{ Requested: 8/10/2016 1:18:14 PM } & Target: & $9 / 30 / 2016$ & \multirow{5}{*}{ 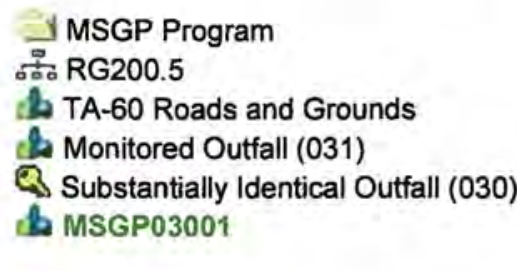 } \\
\hline \multirow{2}{*}{\multicolumn{2}{|c|}{$\begin{aligned} \text { Procedure: } & \text { MSGP Quarterly Visual } \\
& \text { Assessment (EPC-CP- } \\
& \text { Form-1021.2) }\end{aligned}$}} & Priority/Type: & Normal / Inspection & \\
\hline & & Department: & $\begin{array}{l}\text { Utilities and } \\
\text { Infrastructure }\end{array}$ & \\
\hline Last PM: & $8 / 1 / 2016$ & & & \\
\hline Project: & $\begin{array}{l}\text { SIO Visual Assessments } \\
\text { 8/8/16 (P-MSGP-5073) }\end{array}$ & & & \\
\hline Reason: & GP Quarterly Visual A & nent & & Con \\
\hline onitoring & Period: & Odor: & & \\
\hline
\end{tabular}

Clarity:

Settled Solids:

Suspended Solids:

Special Instructions: NMR053195

\section{Tasks}

\# Description

Rating Meas. Initials Failed N/A Complete

The result of this VA applies to associated SIOs as defined in the SWPPP, where applicable.

Sample information

Document the monitoring Period by using the
Monitoring Period lookup table.
$35 \quad$ Is visual assessment performed on an unfiltered
sample? (Use filtered only if unfiltered unavailable.)
Document the Date/Time Discharge began in the
"Reading" field of this line (using $\mathrm{mm} / \mathrm{dd} / \mathrm{yy} \mathrm{hh:mm}$
format).
Document the Date/time sample collected in the
"Reading" field of this line (using $\mathrm{mm} / \mathrm{dd} / \mathrm{yy} \mathrm{hh}: \mathrm{mm}$

Document the Date/time sample visually assessed in the "Reading" field of this line (using $\mathrm{mm} / \mathrm{dd} / \mathrm{yy}$

60 hh:mm format).

Document the nature of discharge using the Precipitation Type lookup table. Document the

$70 \quad$ amount (in) in the "Reading" field of this line.

Sample collected in first 30 minutes of discharge? If

"Failed" or unknown, provide reason in comments of 80 this line.

Parameters

110 Is sample colorless? If "Failed", describe.

Is sample oderless? If "Failed". document

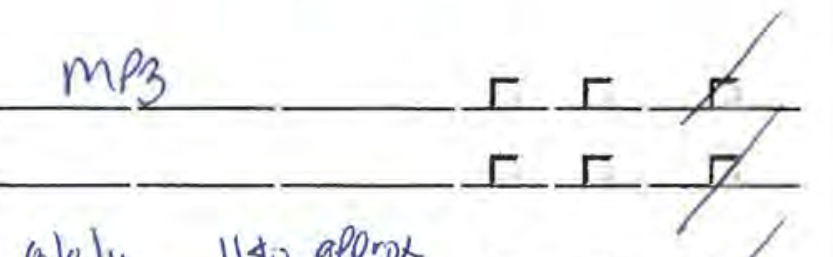
observation using the Odor lookup table. If "other" is

chosen from the lookup table, provide description in comments of this line.

Is sample clear? If "Failed", document observation using the Clarity lookup table. If "other" is chosen from the lookup table, provide description in comments of this line.

Is sample free of floating solids? If "Failed" describe if raw or waste material(s) in the comments of this 140 line. 
Is sample free of settled solids? If "Failed", document observation using the Settled Solids lookup table. If "other" is chosen from the lookup table, provide description in comments of this line.

SETSOL 2

is sample free of suspended solids? If "Failed", document observation using the Suspended Solids lookup table. If "other" is chosen from the lookup table, provide description in comments of this line.

Susso2 2

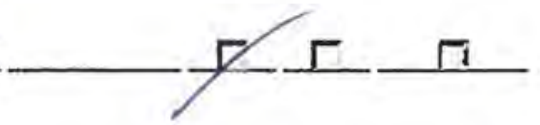
describe foam color and location ('on the surface' or

170 'in the sample') in the comments of this line (Range:

Is sample devoid of an oil sheen? If "Failed", describe color and thickness (e.g. flecks, globs) in the

180 comments of this line. (Range: $0-0$ )

Is sample free of other obvious indicators of pollution? If "Failed", describe in the comments of this

190 line. (Range: 0 - 0 )

\section{Labor}

Labor

Work Date Reg Hrs OT Hrs Other Hrs

\section{Labor Report}

Completed: Failure:

Report: 
wo 10:MSGP. 57997

Signature (collecting sample)

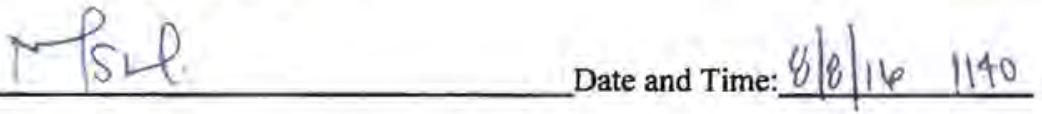

Signature (conducting visual assessment):

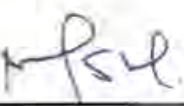

Date and Time: $8 / 9616 \quad 1603$

\section{CERTIFICATION STATEMENT}

"I certify under penalty of law that this document and all attachments were prepared under my direction or supervision in accordance with a system designed to assure that qualified personnel properly gathered and evaluated the information submitted. Based on my inquiry of the person or persons who manage the system, or those persons directly responsible for gathering information, the information submitted is, to the best of my knowledge and belief, true, accurate, and complete. I am aware that there are significant penalties for submitting false information, including the possibility of fine and imprisonment for knowing violations".

(Signatory must meet definition in Section B.11.A, eg., FOD, Ops Mgr, DSESH Group Leader, EPC Group Leader)

Print name and title: 


\section{Maintenance Details}

\begin{tabular}{|c|c|c|c|c|}
\hline \multicolumn{2}{|c|}{ Requested: $8 / 10 / 20161: 18: 15$ PM } & Target: & $9 / 30 / 2016$ & \multirow{5}{*}{$\begin{array}{l}\text { I MSGP Program } \\
\text { 뭄 RG200.5 } \\
\text { to TA-60 Roads and Grounds } \\
\text { o Monitored Outfall (042) } \\
\text { \& Substantially Identical Outfall (041) } \\
\text { is MSGP04101 }\end{array}$} \\
\hline \multirow{2}{*}{\multicolumn{2}{|c|}{$\begin{aligned} \text { Procedure: } & \text { MSGP Quarterly Visual } \\
& \text { Assessment (EPC-CP- } \\
& \text { Form-1021.2) }\end{aligned}$}} & Priority/Type: & Normal / Inspection & \\
\hline & & Department: & $\begin{array}{l}\text { Utilities and } \\
\text { Infrastructure }\end{array}$ & \\
\hline Last PM: & $8 / 1 / 2016$ & & & \\
\hline Project: & $\begin{array}{l}\text { SIO Visual Assessments } \\
8 / 8 / 16 \text { (P-MSGP-5073) }\end{array}$ & & & \\
\hline Reason: & GP Quarterly VisL & $\pi$ & & Cont \\
\hline Monitorin & eriod: & Odor: & & \\
\hline
\end{tabular}

Clarity:

Settled Solids:

Suspended Solids:

Special Instructions: NMR053195

\section{Tasks}

\# Description Rating Meas. Initials Failed N/A Complete

The result of this VA applies to associated SIOs as defined in the SWPPP, where applicable.

Sample information

Document the monitoring Period by using the

30 Monitoring Period lookup table.

Is visual assessment performed on an unfiltered

35 sample? (Use filtered only if unfiltered unavailable.)

Document the Date/Time Discharge began in the "Reading" field of this line (using $\mathrm{mm} / \mathrm{dd} / \mathrm{yy} \mathrm{hh}: \mathrm{mm}$ 40 format).

Document the Date/time sample collected in the "Reading" field of this line (using mm/dd/yy hh:mm 50 format)

Document the Date/time sample visually assessed in the "Reading" field of this line (using $\mathrm{mm} / \mathrm{dd} / \mathrm{yy}$

60 hh:mm format).

Document the nature of discharge using the Precipitation Type lookup table. Document the

$70 \quad$ amount (in) in the "Reading" field of this line. Sample collected in first 30 minutes of discharge? If "Failed" or unknown, provide reason in comments of 80 this line.

Parameters

110 Is sample colorless? If "Failed", describe

Is sample oderless? If "Failed" document

Phone:

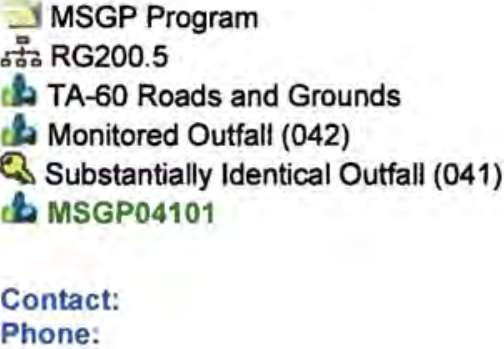


Is sample free of settled solids? If "Failed", document observation using the Settled Solids lookup table. If "other" is chosen from the lookup table, provide description in comments of this line.

\section{$S\{T$ SOLI}

Is sample free of suspended solids? If "Failed". document observation using the Suspended Solids lookup table. If "other" is chosen from the lookup

160 table, provide description in comments of this line. Is sample foamless after gently shaking? If "Failed" describe foam color and location ('on the surface' or

170 'in the sample') in the comments of this line. (Range: 0 -0)

Is sample devoid of an oil sheen? If "Failed", describe color and thickness (e.g. flecks, globs) in the

180 comments of this line. (Range: 0 - 0)

Is sample free of other obvious indicators of pollution? If "Failed", describe in the comments of this

190 line. (Range: $0-0$ )

\section{Labor}

Labor

Work Date Reg Hrs OT Hrs Other Hrs

\section{Labor Report}

Completed: Failure:

Report: 


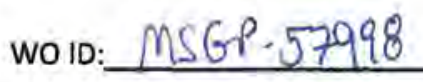

$$
\text { Page } 3 \text { of } 3
$$

Signature (collecting sample):

Signature (conducting visual assessment):

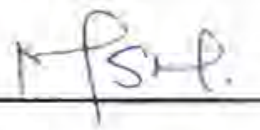

Date and Time: $8 / 9116 \quad 1620$

\section{CERTIFICATION STATEMENT}

"I certify under penalty of law that this document and all attachments were prepared under my direction or supervision in accordance with a system designed to assure that qualified personnel properly gathered and evaluated the information submitted. Based on my inquiry of the person or persons who manage the system, or those persons directly responsible for gathering information, the information submitted is, to the best of my knowledge and belief, true, accurate, and complete. I am aware that there are significant penalties for submitting false information, including the possibility of fine and imprisonment for knowing violations".

\section{(Signatory must meet definition in Section B.11.A, eg., FOD, Ops Mgr, DSESH Group Leader, EPC Group Leader)}

Print name and title: 


\section{Maintenance Details}

\begin{tabular}{|c|c|c|c|}
\hline Requested & $8 / 17 / 20162: 21: 03$ PM & Target: & $9 / 30 / 2016$ \\
\hline Procedure: & MSGP Quarterly Visual & Priority/Type: & Normal / Inspection \\
\hline & $\begin{array}{l}\text { Assessment (EPC-CP- } \\
\text { Form-1021.2) }\end{array}$ & Department: & $\begin{array}{l}\text { Utilities and } \\
\text { Infrastructure }\end{array}$ \\
\hline Last PM: & $8 / 9 / 2016$ & & \\
\hline Project: & $\begin{array}{l}\text { SIO Visuals 8-16-16 } \\
\text { (P-MSGP-5099) }\end{array}$ & & \\
\hline
\end{tabular}

Reason: MSGP Quarterly Visual Assessment

Monitoring Period:

Odor:

Clarity:

Settled Solids:

Suspended Solids:

Special Instructions: NMR053195

\section{Tasks}

* Description

Rating Meas. Initials Failed N/A Complete

The result of this VA applies to associated SIOs as defined in the SWPPP, where applicable.

\section{Sample information}

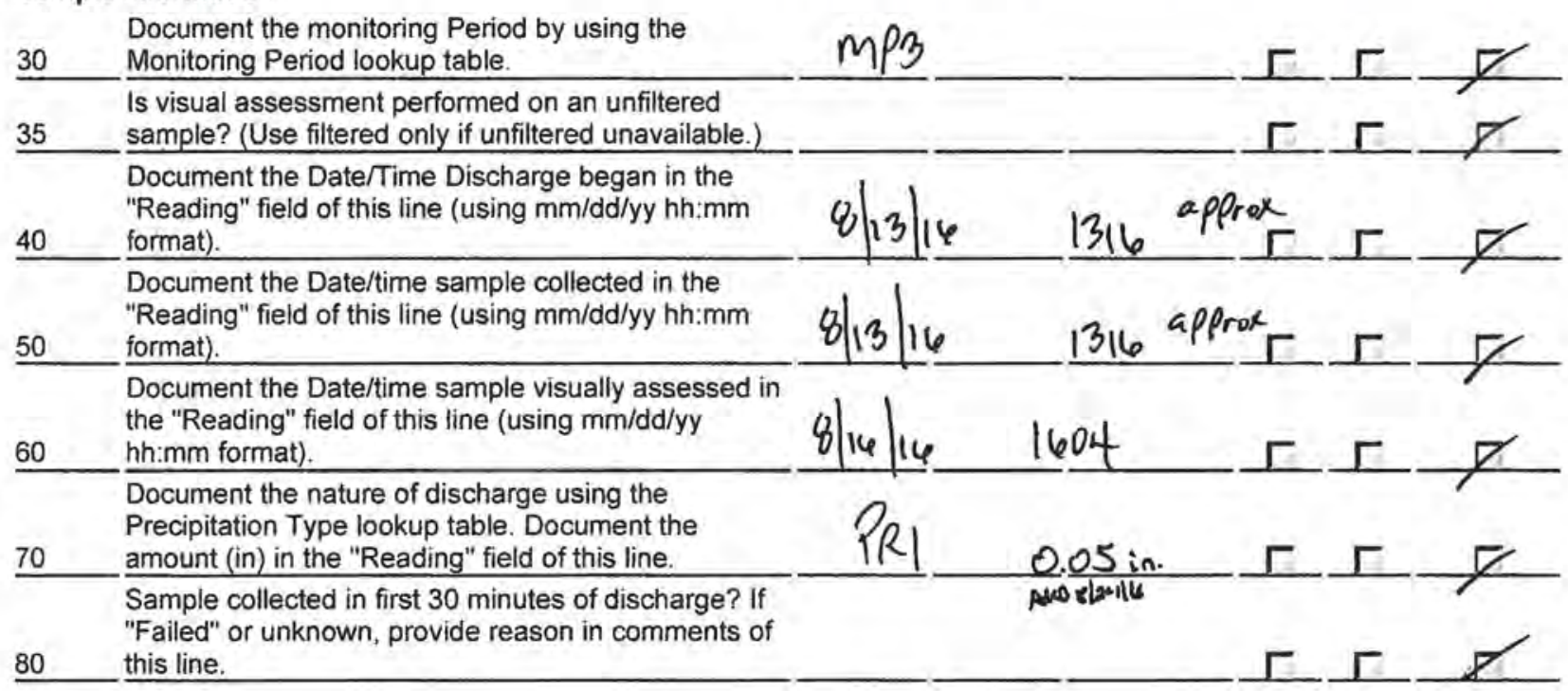

\section{Parameters}

110 Is sample colorless? If "Failed", describe.

Is sample oderless? If "Failed", document

Contact:

Phone:

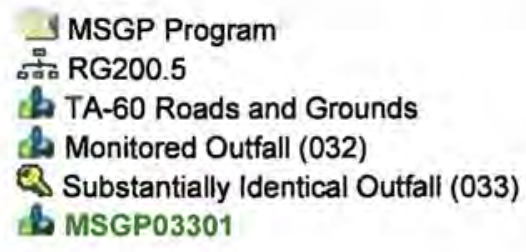 \\ 1 MSGP Program \\ TA-60 Roads and Grounds \\ MSGP03301}


Is sample free of settled solids? If "Failed", document observation using the Settled Solids lookup table. If

"other" is chosen from the lookup table, provide description in comments of this line.

SATSOL 2

Is sample free of suspended solids? If "Failed".

document observation using the Suspended Solids

lookup table. If "other" is chosen from the lookup

160

table, provide description in comments of this line.

Is sample foamless after gently shaking? If "Failed"

describe foam color and location ('on the surface' or

'in the sample') in the comments of this line. (Range.

$170 \quad 0-0)$

Is sample devoid of an oil sheen? If "Failed" describe color and thickness (e.g. flecks, globs) in the

180 comments of this line. (Range: $0-0$ )

Is sample free of other obvious indicators of

pollution? If "Failed" describe in the comments of this line. (Range: 0 - 0 )

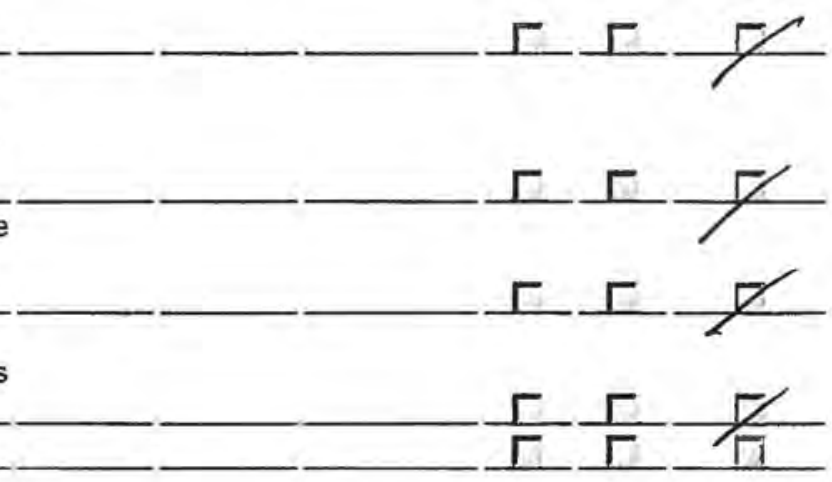

\section{Labor}

Labor

Work Date Reg Hrs OT Hrs Other Hrs

\section{Labor Report}

Completed: Failure:

Report: 


\section{wo ID: MSGP. 58327}

Signature (collecting sample)

Signature (conducting visual assessment):

$$
\text { Page } 3 \text { of } 3
$$

plsue.

Date and Time: $8 / 13 / 16 \quad 13 / 6$

Psil.

Date and Time: $8 / 16 / 16 \quad 1604$

\section{CERTIFICATION STATEMENT}

"I certify under penalty of law that this document and all attachments were prepared under my direction or supervision in accordance with a system designed to assure that qualified personnel properly gathered and evaluated the information submitted. Based on my inquiry of the person or persons who manage the system, or those persons directly responsible for gathering information, the information submitted is, to the best of my knowledge and belief, true, accurate, and complete. I am aware that there are significant penalties for submitting false information, including the possibility of fine and imprisonment for knowing violations".

(Signatory must meet definition in Section B.11.A, eg., FOD, Ops Mgr, DSESH Group Leader, EPC Group Leader)

Print name and title: 


\section{- Maintenance Details}

\section{Requested: 8/17/2016 2:21:05 PM \\ Procedure: MSGP Quarterly Visual Assessment (EPC-CP- Form-1021.2) \\ Last PM: $\quad$ 8/9/2016 \\ Project: $\quad$ SIO Visuals 8-16-16 (P-MSGP-5099)}

Reason: MSGP Quarterly Visual Assessment Monitoring Period:

Odor:

\section{Target: $\quad 9 / 30 / 2016$ \\ Priority/Type: Normal / Inspection \\ Department: Utilities and Infrastructure}

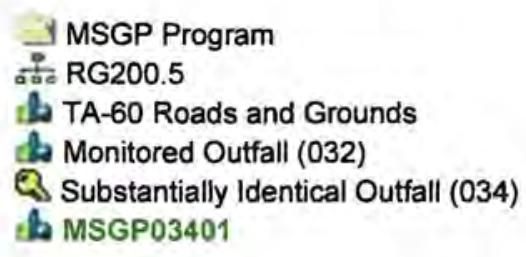

Contact:

Phone:

Clarity:

Settled Solids:

Suspended Solids:

Special Instructions: NMR053195

\section{Tasks}

\# Description

Rating Meas, Initials

Failed N/A Complete

The result of this VA applies to associated SIOs as defined in the SWPPP, where applicable.

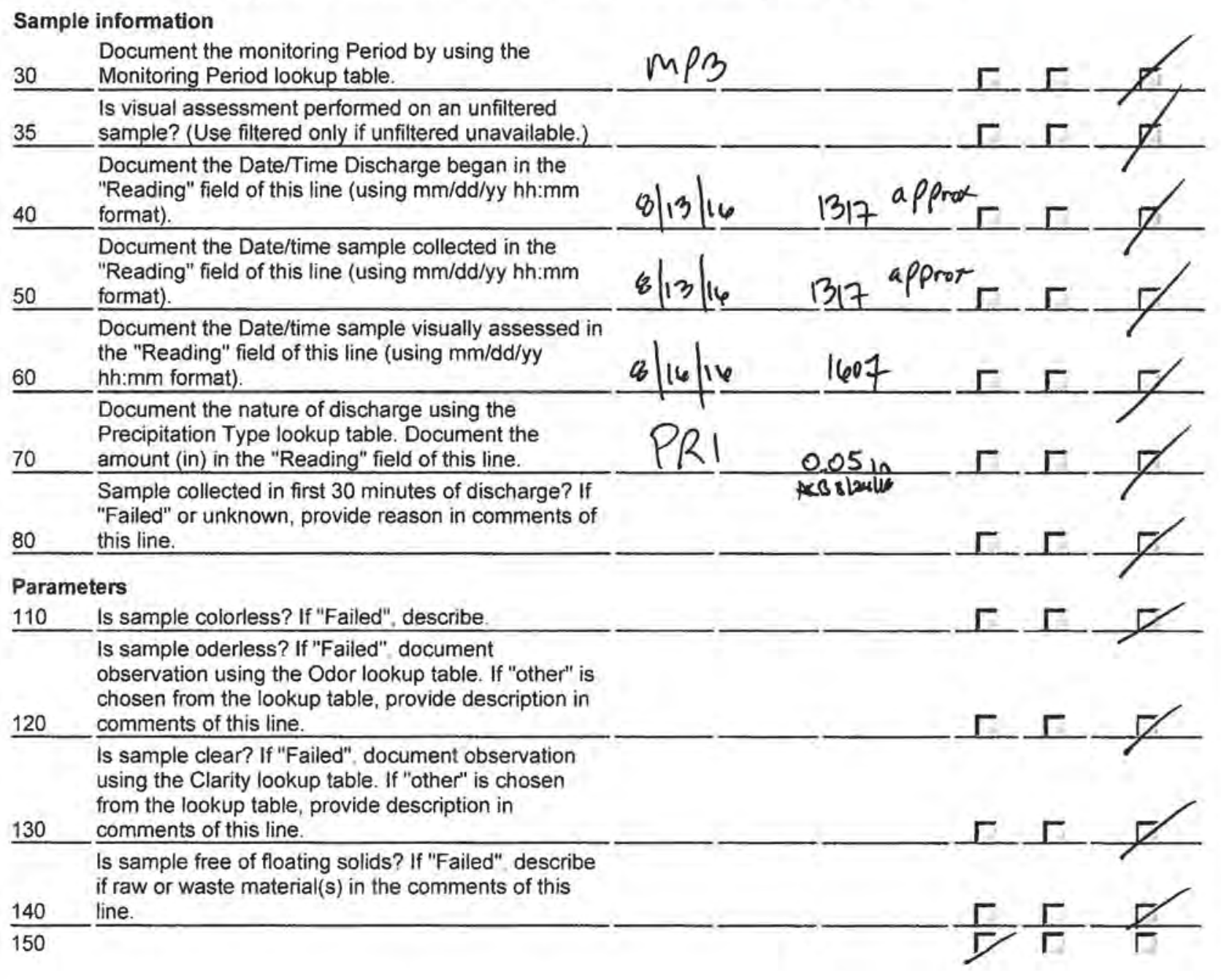


Is sample free of settled solids? If "Failed", document observation using the Settled Solids lookup table. If "other" is chosen from the lookup table, provide description in comments of this line.

SerTsor 2

Is sample free of suspended solids? If "Failed" document observation using the Suspended Solids

lookup table. If "other" is chosen from the lookup

160 table, provide description in comments of this line.

Is sample foamless after gently shaking? If "Failed" describe foam color and location ('on the surface' or 'in the sample') in the comments of this line. (Range: $170 \quad 0-0)$

Is sample devoid of an oil sheen? If "Failed", describe color and thickness (e.g. flecks, globs) in the

180 comments of this line. (Range: $0-0$ )

Is sample free of other obvious indicators of pollution? If "Failed", describe in the comments of this

190 line. (Range: 0 -0)

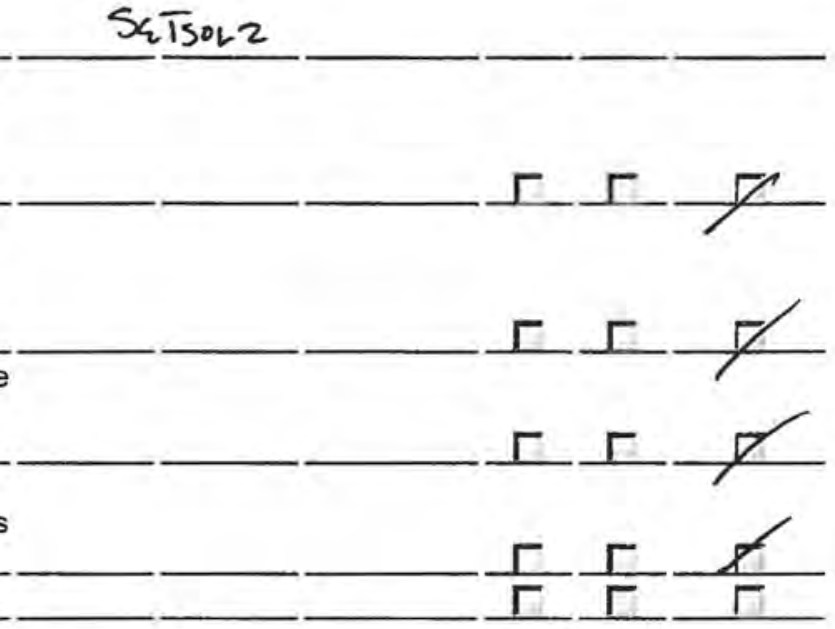

\section{Labor}

Labor

Work Date Reg Hrs OT Hrs Other Hrs

\section{Labor Report}

Completed: Failure:

Report: 
WO ID:

Signature (collecting sample):_ resu. Date and Time: $8 / 13 / 16 \quad 13 / 7$

Signature (conducting visual assessment):_ $\quad \mathrm{Ps}$ Date and Time: $8 / 16 / 16 \quad 1607$

\section{CERTIFICATION STATEMENT}

"I certify under penalty of law that this document and all attachments were prepared under my direction or supervision in accordance with a system designed to assure that qualified personnel properly gathered and evaluated the information submitted. Based on my inquiry of the person or persons who manage the system, or those persons directly responsible for gathering information, the information submitted is, to the best of my knowledge and belief, true, accurate, and complete. I am aware that there are significant penalties for submitting false information, including the possibility of fine and imprisonment for knowing violations".

(Signatory must meet definition in Section B.11.A, eg., FOD, Ops Mgr, DSESH Group Leader, EPC Group Leader)

Print name and title:

Signature;

Date: 
Maintenance Details

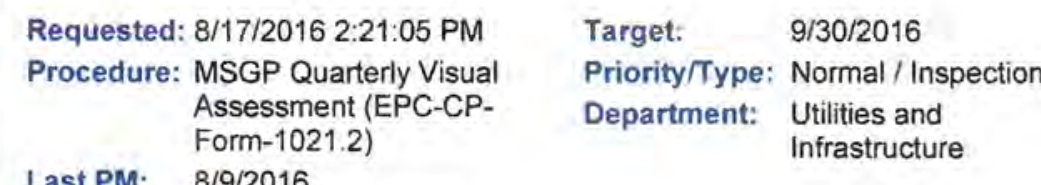

Last PM: $\quad 8 / 9 / 2016$

Project: SIO Visuals 8-16-16

(P-MSGP-5099)

Reason: MSGP Quarterly Visual Assessment

Monitoring Period:

Odor:

Settled Solids:

Clarity:

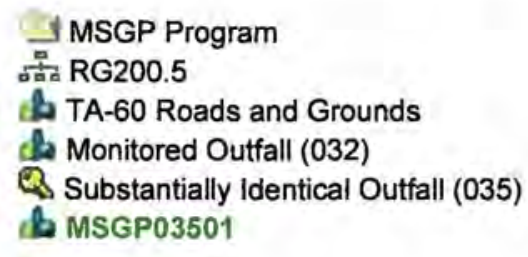

Contact:

Phone:

Suspended Solids:

Special Instructions: NMR053195

\section{Tasks}

\# Description

Rating

Meas.

Initials

Failed N/A Complete

The result of this VA applies to associated SIOs as defined in the SWPPP, where applicable.

\section{Sample information}

Document the monitoring Period by using the

$\underline{30}$ Monitoring Period lookup table.

Is visual assessment performed on an unfiltered

35 sample? (Use filtered only if unfiltered unavailable.)

Document the Date/Time Discharge began in the "Reading" field of this line (using $\mathrm{mm} / \mathrm{dd} / \mathrm{yy} \mathrm{hh}: \mathrm{mm}$

40 format).

Document the Date/time sample collected in the "Reading" field of this line (using mm/dd/yy hh:mm

50 format).

Document the Date/time sample visually assessed in

the "Reading" field of this line (using $\mathrm{mm} / \mathrm{dd} / \mathrm{yy}$

60 hh:mm format).

Document the nature of discharge using the

Precipitation Type lookup table. Document the

70 amount (in) in the "Reading" field of this line.

Sample collected in first 30 minutes of discharge? If

"Failed" or unknown, provide reason in comments of

80 this line.

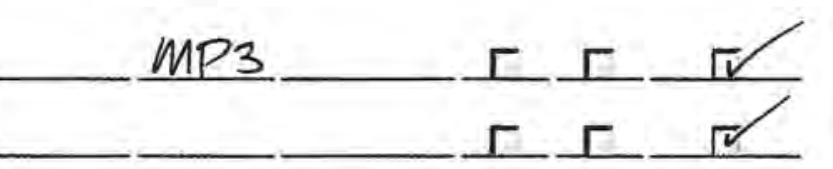

Parameters

110 Is sample colorless? If "Failed", describe.

Is sample oderless? If "Failed". document

observation using the Odor lookup table. If "other" is

chosen from the lookup table, provide description in

120 comments of this line.

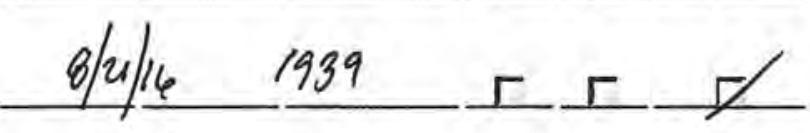

-

Is sample clear? If "Failed", document observation

using the Clarity lookup table. If "other" is chosen

from the lookup table, provide description in

130 comments of this line.

$8 / 4 / 16 \quad 1939$

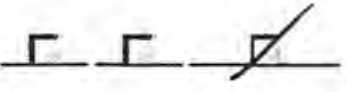

$8 / 22 / 16 \quad 11: 53$

$\Gamma \Gamma$

D

Is sample free of floating solids? If "Failed", describe

PR1 0.20 in

$\Gamma$
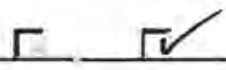

$\Gamma$

$\sqrt{2}$

if raw or waste material(s) in the comments of this

140 line.

150 
Is sample free of settled solids? If "Failed", document observation using the Settled Solids lookup table. If

"other" is chosen from the lookup table, provide description in comments of this line.

fine

Is sample free of suspended solids? If "Failed", document observation using the Suspended Solids lookup table. If "other" is chosen from the lookup table, provide description in comments of this line.

Is sample foamless after gently shaking? If "Failed" describe foam color and location ('on the surface' or 'in the sample') in the comments of this line. (Range: $170 \quad 0-0)$

Is sample devoid of an oil sheen? If "Failed", describe color and thickness (e.g. flecks, globs) in the

180 comments of this line. (Range: $0-0$ )

Is sample free of other obvious indicators of pollution? If "Failed", describe in the comments of this 190 line. (Range: $0-0$ )

Fine

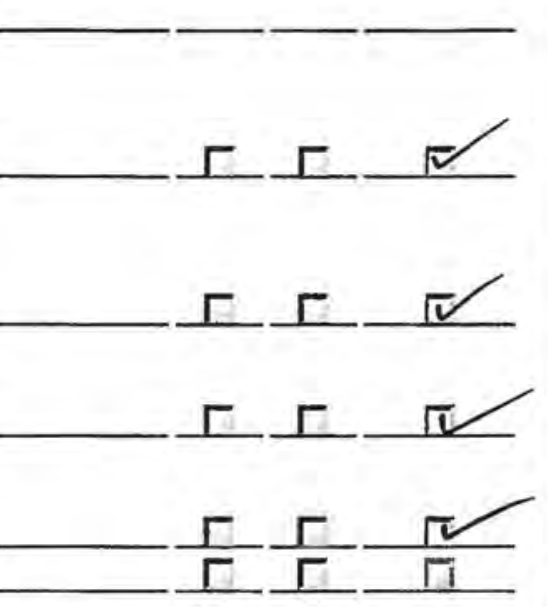

\section{Labor}

Labor

Work Date Reg Hrs OT Hrs Other Hrs

\section{Labor Report}

Completed: Failure:

Report: 


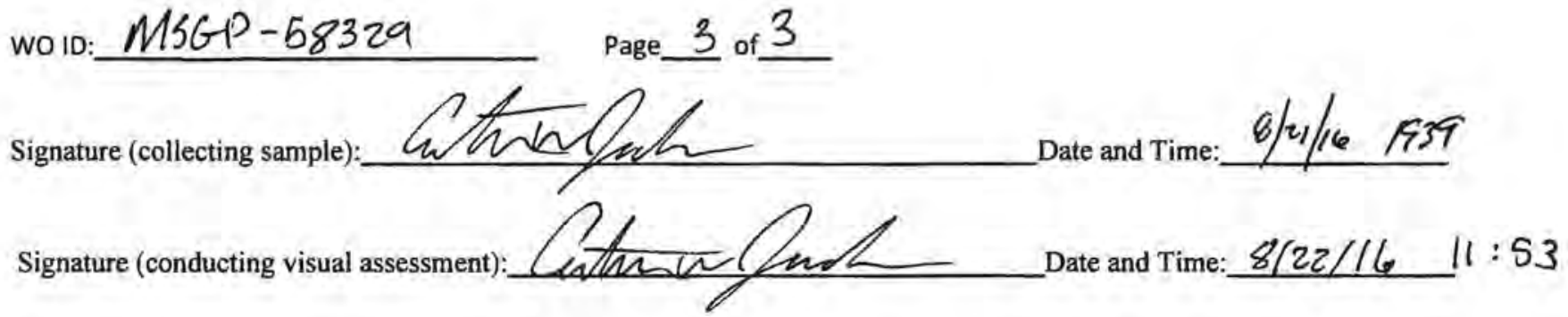

\section{CERTIFICATION STATEMENT}

"I certify under penalty of law that this document and all attachments were prepared under my direction or supervision in accordance with a system designed to assure that qualified personnel properly gathered and evaluated the information submitted. Based on my inquiry of the person or persons who manage the system, or those persons directly responsible for gathering information, the information submitted is, to the best of my knowledge and belief, true, accurate, and complete. I am aware that there are significant penalties for submitting false information, including the possibility of fine and imprisonment for knowing violations".

(Signatory must meet definition in Section B.11.A, eg., FOD, Ops Mgr, DSESH Group Leader, EPC Group Leader)

Print name and title:

Signature: Date: 


\section{Maintenance Details}

$\begin{array}{cll}\text { Requested: } 8 / 17 / 20162: 21: 06 \text { PM } & \text { Target: } & 9 / 30 / 2016 \\ \text { Procedure: } & \text { MSGP Quarterly Visual } & \text { Priority/Type: Normal/Inspection } \\ \text { Assessment (EPC-CP- } & \text { Department: Utilities and } \\ \text { Form-1021 2) } & & \text { Infrastructure }\end{array}$

Last PM: $\quad 8 / 9 / 2016$

Project: SIO Visuals 8-16-16

(P-MSGP-5099)

Reason: MSGP Quarterly Visual Assessment

Monitoring Period:

Odor:

Settled Solids:

Clarity:

\section{MSGP Program \\ 造 RG200.5 \\ th TA-60 Roads and Grounds \\ d. Monitored Outfall (031) \\ Q. Substantially Identical Outfall (030) \\ b MSGP03001}

Contact:

Phone:

Suspended Solids:

Special Instructions: NMR053195

\section{Tasks}

\# Description

Rating

Meas.

Initials

Failed N/A

Complete

The result of this VA applies to associated SIOs as defined in the SWPPP, where applicable.

Sample information

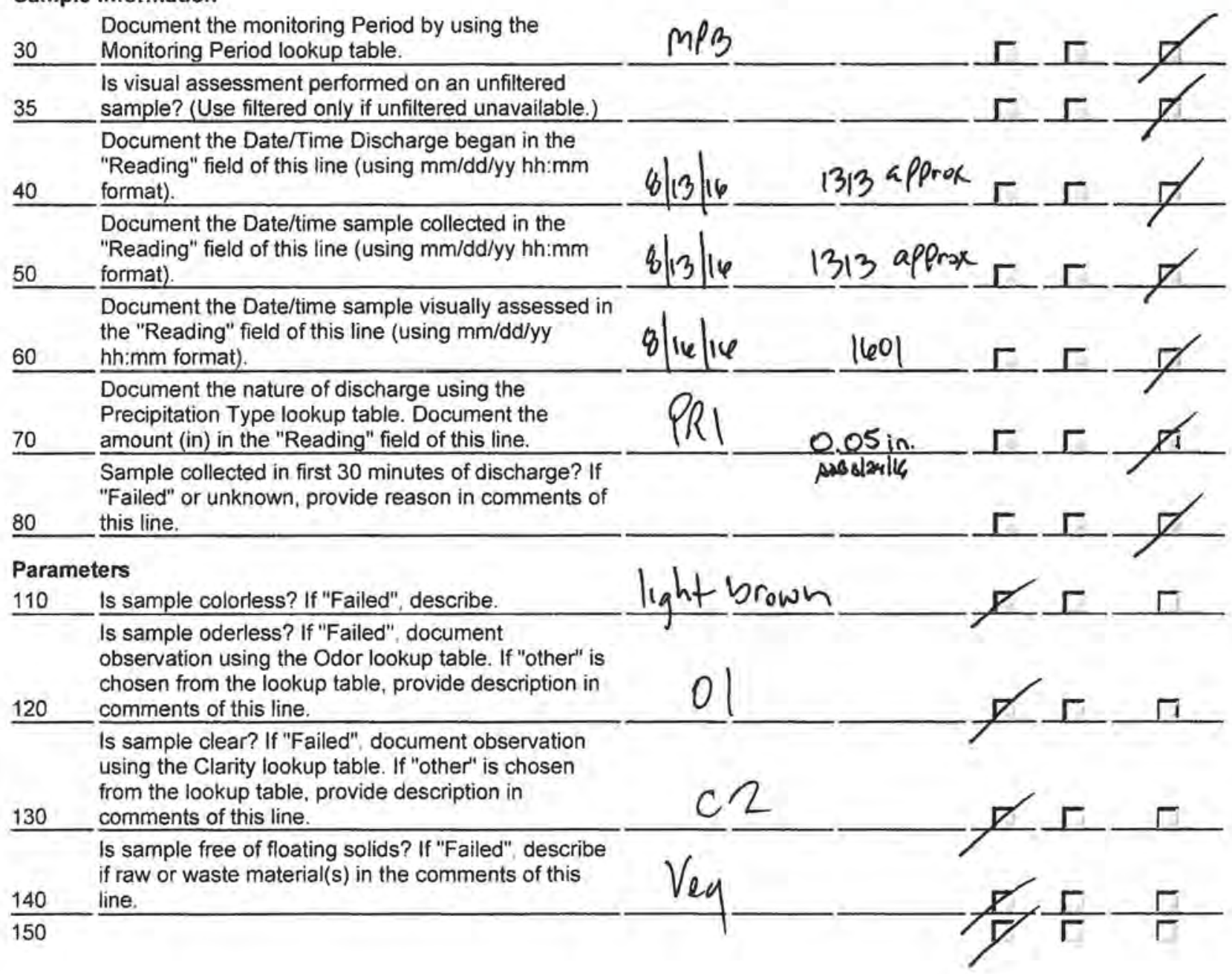


Is sample free of settled solids? If "Failed", document observation using the Settled Solids lookup table. If "other" is chosen from the lookup table, provide description in comments of this line.

\section{SETSOL2}

Is sample free of suspended solids? If "Failed" document observation using the Suspended Solids lookup table. If "other" is chosen from the lookup table, provide description in comments of this line.

Is sample foamless after gently shaking? If "Failed"

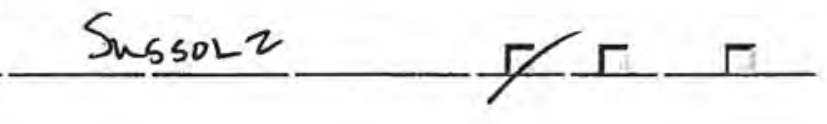
describe foam color and location ('on the surface' or 'in the sample') in the comments of this line. (Range: $170 \quad 0-0)$ Is sample devoid of an oil sheen? If "Failed", describe color and thickness (e.g. flecks, globs) in the

180 comments of this line. (Range: $0-0$ )

is sample free of other obvious indicators of pollution? If "Failed", describe in the comments of this

190 line. (Range: $0-0$ )

\section{Labor}

Labor

Work Date Reg Hrs OT Hrs Other Hrs

\section{Labor Report}

Completed: Failure:

Report: 
Wo ID: MSGP. 58330

Page 3 of 3

Signature (collecting sample)

nsul.

Date and Time: $8 / 13 / 16 \quad 1313$

Signature (conducting visual assessment):

Pst.

Date and Time: $8 / 16 \mid 16 \quad 1601$

\section{CERTIFICATION STATEMENT}

"I certify under penalty of law that this document and all attachments were prepared under my direction or supervision in accordance with a system designed to assure that qualified personnel properly gathered and evaluated the information submitted. Based on my inquiry of the person or persons who manage the system, or those persons directly responsible for gathering information, the information submitted is, to the best of my knowledge and belief, true, accurate, and complete. I am aware that there are significant penalties for submitting false information, including the possibility of fine and imprisonment for knowing violations".

(Signatory must meet definition in Section B.11.A, eg., FOD, Ops Mgr, DSESH Group Leader, EPC Group Leader)

Print name and title:

Signature: Date: 
Maintenance Details

\begin{tabular}{|c|c|c|}
\hline Requested: 8/17/2016 2:21:07 PM & Target: & $9 / 30 / 2016$ \\
\hline Procedure: MSGP Quarterly Visual & Priority/Type: & Normal / Inspectior \\
\hline $\begin{array}{l}\text { Assessment (EPC-CP- } \\
\text { Form-1021.2) }\end{array}$ & Department: & $\begin{array}{l}\text { Utilities and } \\
\text { Infrastructure }\end{array}$ \\
\hline
\end{tabular}

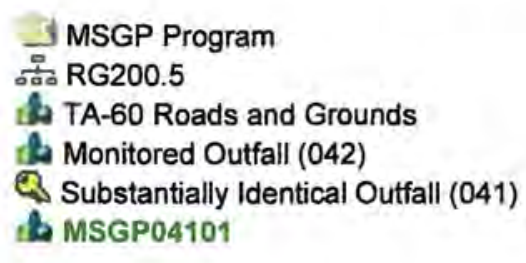

Project: SIO Visuals 8-16-16

(P-MSGP-5099)

Reason: MSGP Quarterly Visual Assessment

Monitoring Period:

Odor:

Contact:

Clarity:

Settled Solids:

Suspended Solids:

Special Instructions: NMR053195

\section{Tasks}

\# Description Rating Meas. Initials Failed N/A Complete

The result of this VA applies to associated SIOs as defined in the SWPPP, where applicable.

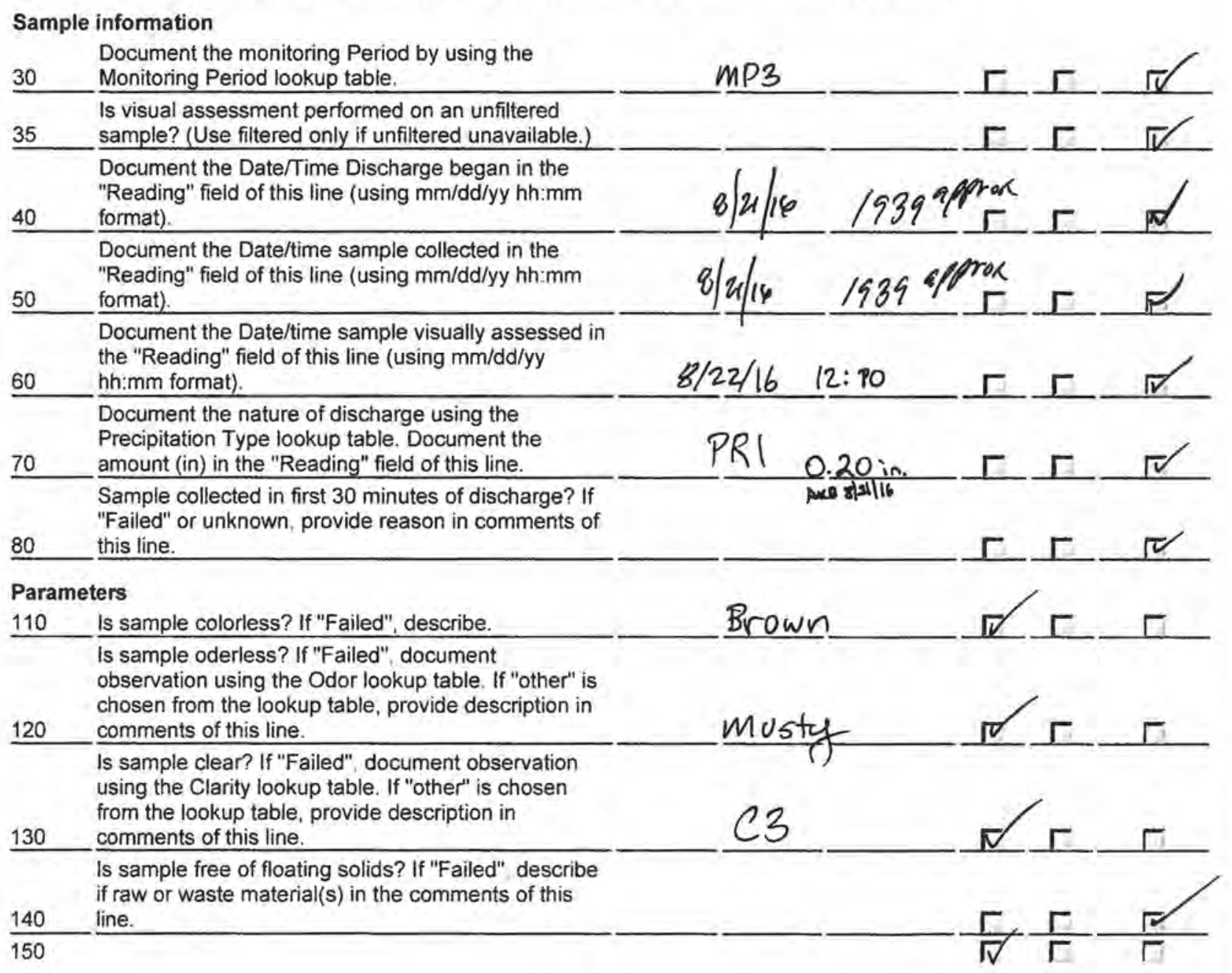


Is sample free of settled solids? If "Failed", document observation using the Settled Solids lookup table. If "other" is chosen from the lookup table, provide description in comments of this line.

\section{Fine}

Is sample free of suspended solids? If "Failed", document observation using the Suspended Solids lookup table. If "other" is chosen from the lookup

160 table, provide description in comments of this line.

Is sample foamless after gently shaking? If "Failed" describe foam color and location ('on the surface' or 'in the sample') in the comments of this line. (Range: $170 \quad 0-0)$ Is sample devoid of an oil sheen? If "Failed", describe color and thickness (e.g. flecks, globs) in the comments of this line. (Range: $0-0$ )

Is sample free of other obvious indicators of pollution? If "Failed", describe in the comments of this

190 line. (Range: 0 - 0)

\section{Labor}

Labor

Work Date Reg Hrs OT Hrs Other Hrs

\section{Labor Report}

Completed: Failure:

Report: 


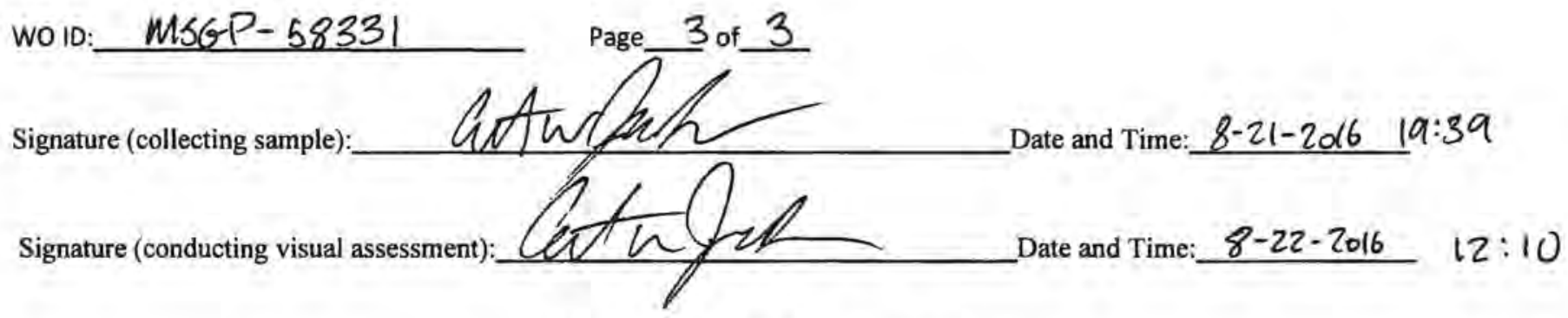

\section{CERTIFICATION STATEMENT}

"I certify under penalty of law that this document and all attachments were prepared under my direction or supervision in accordance with a system designed to assure that qualified personnel properly gathered and evaluated the information submitted. Based on my inquiry of the person or persons who manage the system, or those persons directly responsible for gathering information, the information submitted is, to the best of my knowledge and belief, true, accurate, and complete. I am aware that there are significant penalties for submitting false information, including the possibility of fine and imprisonment for knowing violations".

(Signatory must meet definition in Section B.11.A, eg., FOD, Ops Mgr, DSESH Group Leader, EPC Group Leader)

Print name and title: 
Maintenance Details

$\begin{array}{ll}\text { Requested By: } & \text { Banar, Alethea on } \\ & 8 / 17 / 20162: 23: 00 \text { PM } \\ \text { Taken By: } & \text { Banar, Alethea } \\ \text { Procedure: } & \text { MSGP Quarterly Visual } \\ & \text { Assessment (EPC-CP- } \\ & \text { Form-1021.2) } \\ \text { Last PM: } & 8 / 8 / 2016 \\ \text { Project: } & \text { Visual Assessments } \\ & \text { 8-8-16 (P-MSGP-5074) }\end{array}$

Target: $\quad$ 9/30/2016

Priority/Type: / Inspection

Department: Utilities and

Infrastructure

\section{MSGP Program \\ 옴 RG200.5 \\ 14 TA-60 Roads and Grounds \\ th Monitored Outfall (031) \\ is MSGP03101}

Contact: Banar, Alethea

Phone: 699-5836

Reason: MSGP Quarterly Visual Assessment

Monitoring Period:

Clarity:

Suspended Solids:

Special instructions: NMR053195
Odor:

Settled Solids:

\section{Tasks}

\# Description Rating Meas, Initials Failed N/A Complete

The result of this VA applies to associated SIOs as defined in the SWPPP, where applicable.

Sample information

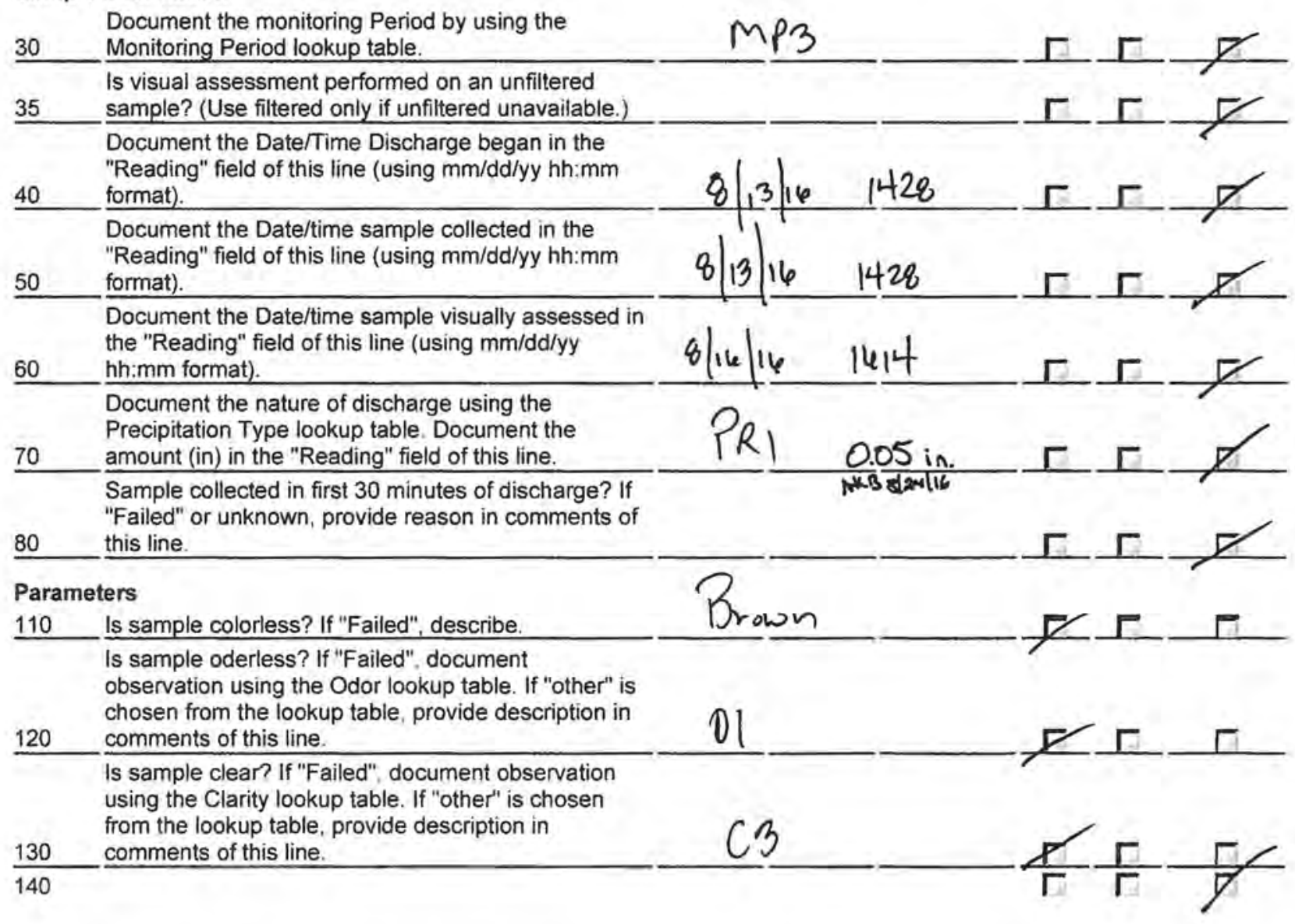


Is sample free of floating solids? If "Failed", describe if raw or waste material(s) in the comments of this line.

Is sample free of settled solids? If "Failed", document observation using the Settled Solids lookup table. If "other" is chosen from the lookup table, provide

150 description in comments of this line.

SETSOL 2

Is sample free of suspended solids? If "Failed", document observation using the Suspended Solids lookup table. If "other" is chosen from the lookup

160 table, provide description in comments of this line. Is sample foamless after gently shaking? If "Failed" describe foam color and location ('on the surface' or 'in the sample') in the comments of this line. (Range $170 \quad 0-0)$ Is sample devoid of an oil sheen? If "Failed", describe color and thickness (e.g. flecks, globs) in the comments of this line. (Range: $0-0$ )

Is sample free of other obvious indicators of pollution? If "Failed", describe in the comments of this 190 line. (Range: 0 - 0)

\section{Labor}

Labor

\section{Labor Report}

Completed: Failure:

Meter 1:

Meter 2:

Report: 
wo ID: MSGP.58332

Page 3 of 3

Signature (collecting sample):

CERTIFICATION STATEMENT

"I certify under penalty of law that this document and all attachments were prepared under my direction or supervision in accordance with a system designed to assure that qualified personnel properly gathered and evaluated the information submitted. Based on my inquiry of the person or persons who manage the system, or those persons directly responsible for gathering information, the information submitted is, to the best of my knowledge and belief, true, accurate, and complete. I am aware that there are significant penalties for submitting false information, including the possibility of fine and imprisonment for knowing violations".

(Signatory must meet definition in Section B.11.A, eg., FOD, Ops Mgr, DSESH Group Leader, EPC Group Leader)

Print name and title:

Signature:

Date; 


\section{Maintenance Details}

Requested: 8/23/2016 3:44:01 PM

Procedure: MSGP Quarterly Visual Assessment (EPC-CPForm-1021.2)

Last PM: $\quad 8 / 9 / 2016$

Project: $\quad$ SIO Visuals $8 / 23 / 16$

(P-MSGP-5107)

Reason: MSGP Quarterly Visual Assessment

Monitoring Period:

Odor:

Clarity:

Settled Solids:
9/30/2016

Priority/Type: Normal / Inspection

Department: Utilities and Infrastructure

Suspended Solids:

Special Instructions: NMR053195

\section{Tasks}

\# Description

Rating Meas. Initials Failed N/A Complete

The result of this VA applies to associated SIOs as defined in the SWPPP, where applicable.

Sample information

Document the monitoring Period by using the

$30 \quad$ Monitoring Period lookup table.

Is visual assessment performed on an unfiltered

35 sample? (Use filtered only if unfiltered unavailable.)

Document the Date/Time Discharge began in the

"Reading" field of this line (using $\mathrm{mm} / \mathrm{dd} / \mathrm{yy} \mathrm{hh}$ /mm

40 format).

Document the Date/time sample collected in the

"Reading" field of this line (using $\mathrm{mm} / \mathrm{dd} / \mathrm{yy} \mathrm{hh}: \mathrm{mm}$

50 format).

Document the Date/time sample visually assessed in

the "Reading" field of this line (using $\mathrm{mm} / \mathrm{dd} / \mathrm{yy}$

60 hh:mm format).

Document the nature of discharge using the

Precipitation Type lookup table. Document the

$70 \quad$ amount (in) in the "Reading" field of this line.

Sample collected in first 30 minutes of discharge? If

"Failed" or unknown, provide reason in comments of

80 this line.

Mp3

3 MSGP Program

몽 RG200.5

4 TA-60 Roads and Grounds

th Monitored Outfall (032)

Substantially Identical Outfall (033)

th MSGP03301

Contact:

Phone: 
Is sample free of settled solids? If "Failed", document observation using the Settled Solids lookup table. If

"other" is chosen from the lookup table, provide description in comments of this line.

Fine

Is sample free of suspended solids? If "Failed", document observation using the Suspended Solids lookup table. If "other" is chosen from the lookup

160 table, provide description in comments of this line.

Is sample foamless after gently shaking? If "Failed" describe foam color and location ('on the surface' or 'in the sample') in the comments of this line. (Range:

$170 \quad 0-0)$

Is sample devoid of an oil sheen? If "Failed", describe color and thickness (e.g. flecks, globs) in the

180 comments of this line. (Range: $0-0$ )

Is sample free of other obvious indicators of pollution? If "Failed", describe in the comments of this 190 line. (Range: 0 - 0)

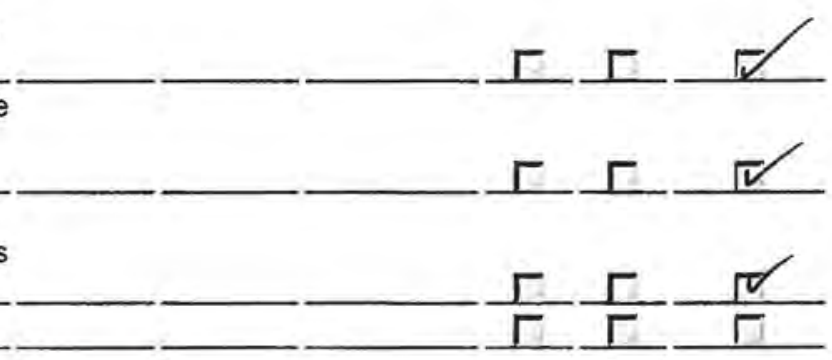

\section{Labor}

Labor

\section{Labor Report}

Completed: Failure:

Report: 


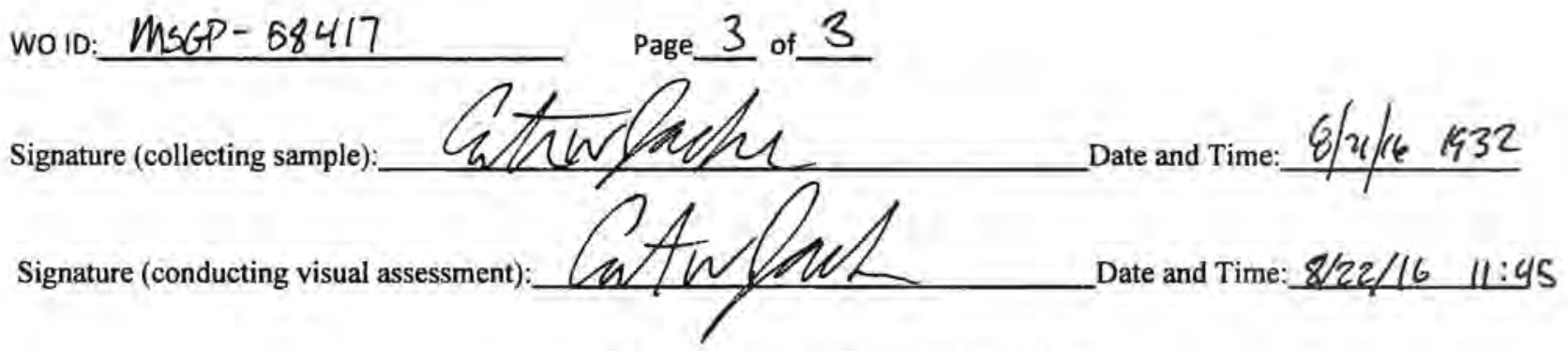

\section{CERTIFICATION STATEMENT}

"I certify under penalty of law that this document and all attachments were prepared under my direction or supervision in accordance with a system designed to assure that qualified personnel properly gathered and evaluated the information submitted. Based on my inquiry of the person or persons who manage the system, or those persons directly responsible for gathering information, the information submitted is, to the best of my knowledge and belief, true, accurate, and complete. I am aware that there are significant penalties for submitting false information, including the possibility of fine and imprisonment for knowing violations".

(Signatory must meet definition in Section B.11.A, eg., FOD, Ops Mgr, DSESH Group Leader, EPC Group Leader)

Print name and title:

Signature: Date: 


\section{Maintenance Details}

$\begin{array}{llll}\text { Requested: } & 8 / 23 / 20163: 44: 02 \text { PM } & \text { Target: } & 9 / 30 / 2016 \\ \text { Procedure: } & \text { MSGP Quarterly Visual } & \text { Priority/Type: Normal / Inspection } \\ & \text { Assessment (EPC-CP- } & \text { Department: } & \begin{array}{l}\text { Utilities and } \\ \text { Infrastructure }\end{array} \\ \text { Last PM: } & \text { 8/9/2016 } & & \\ \text { Project: } & \text { SIO Visuals 8/23/16 } & & \\ & \text { (P-MSGP-5107) } & & \end{array}$

Reason: MSGP Quarterly Visual Assessment

Monitoring Period:

Odor:

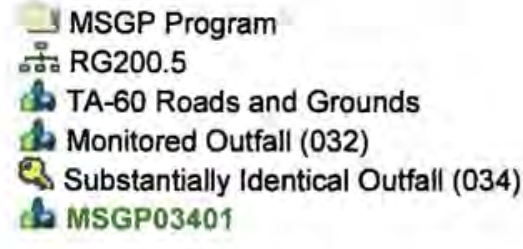

Contact:

Phone:

Clarity:

Settled Solids:

Suspended Solids:

Special Instructions: NMR053195

\section{Tasks}

\# Description

Rating Meas. Initials Failed N/A Complete

The result of this VA applies to associated SIOs as defined in the SWPPP, where applicable.

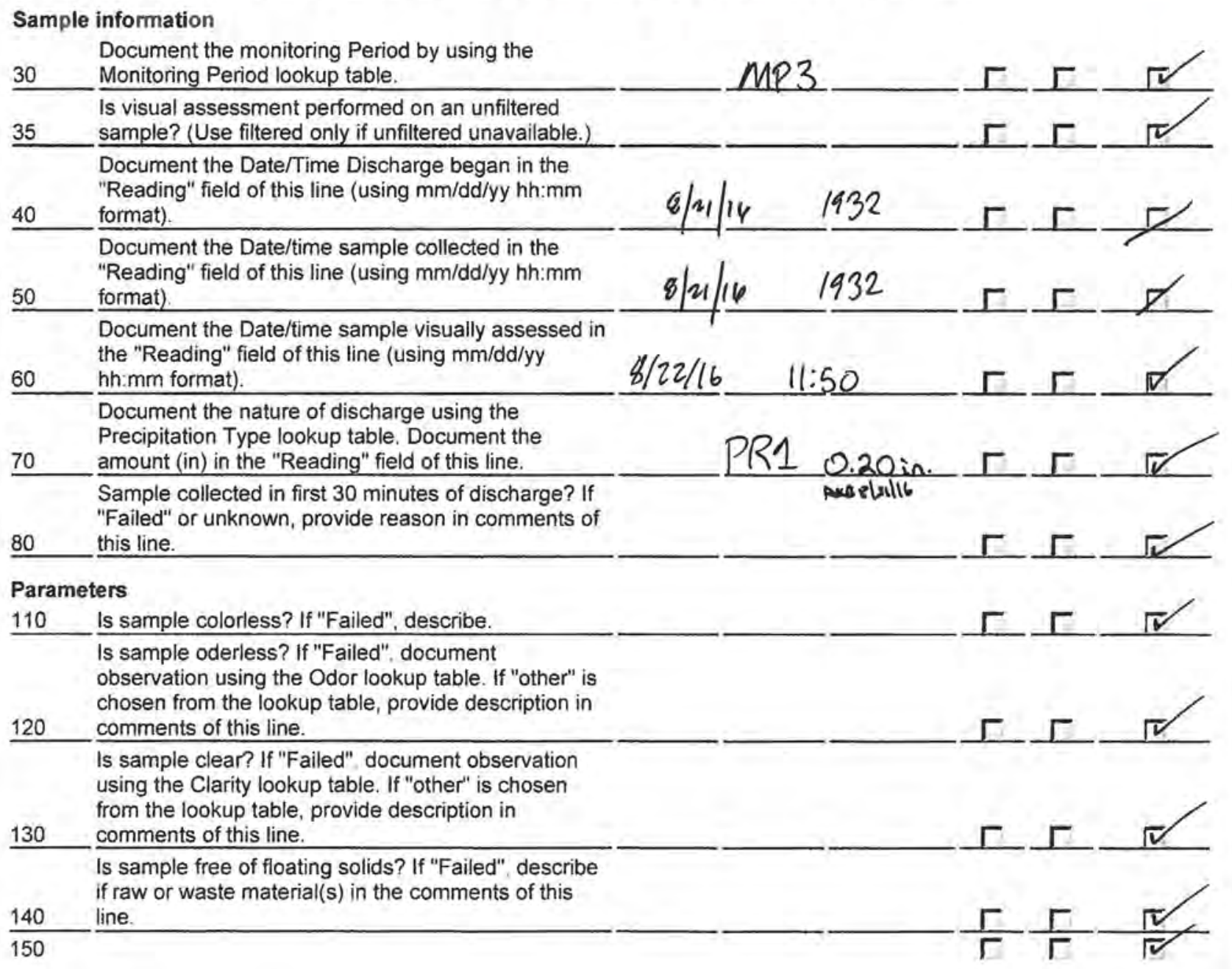


Is sample free of settled solids? If "Failed", document observation using the Settled Solids lookup table. If

"other" is chosen from the lookup table, provide description in comments of this line.

Is sample free of suspended solids? If "Failed" document observation using the Suspended Solids lookup table. If "other" is chosen from the lookup table, provide description in comments of this line.

Is sample foamless after gently shaking? If "Failed" describe foam color and location ('on the surface' or 'in the sample') in the comments of this line. (Range:

170 0 -0)

Is sample devoid of an oil sheen? If "Failed" describe color and thickness (e.g. flecks, globs) in the

180 comments of this line. (Range: $0-0$ )

is sample free of other obvious indicators of pollution? If "Failed", describe in the comments of this 190 line. (Range: 0 - 0)

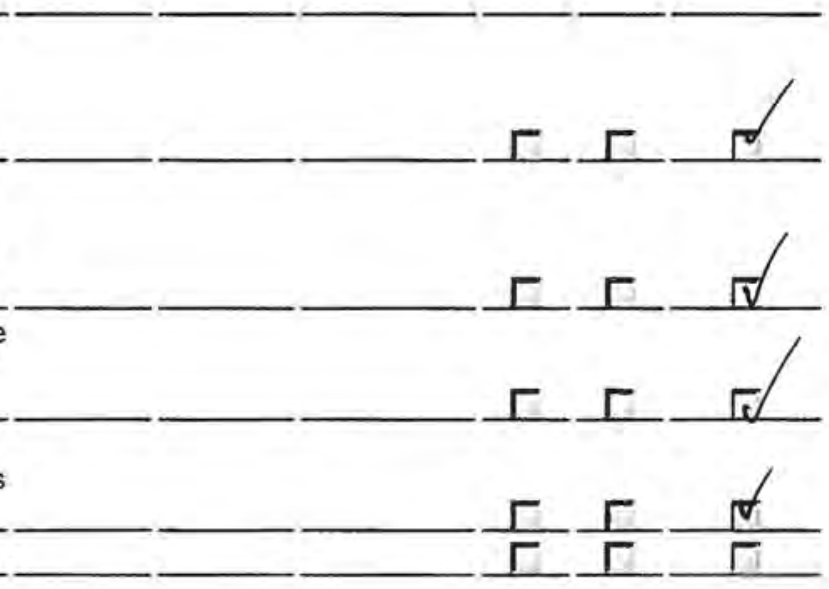

\section{Labor}

Labor

Shendo, Marwin

\section{Labor Report}

Completed: Failure:

Report: 


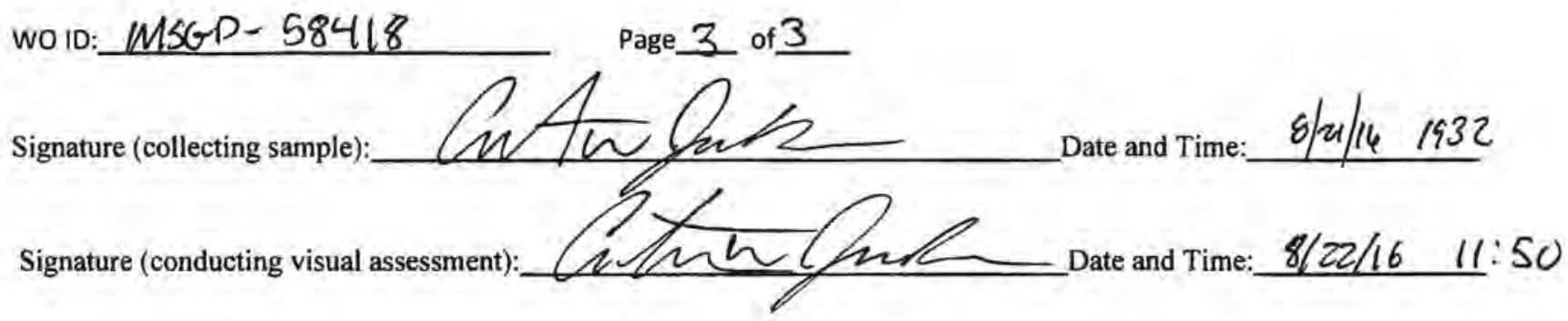

\section{CERTIFICATION STATEMENT}

"I certify under penalty of law that this document and all attachments were prepared under my direction or supervision in accordance with a system designed to assure that qualified personnel properly gathered and evaluated the information submitted. Based on my inquiry of the person or persons who manage the system, or those persons directly responsible for gathering information, the information submitted is, to the best of my knowledge and belief, true, accurate, and complete. I am aware that there are significant penalties for submitting false information, including the possibility of fine and imprisonment for knowing violations".

\section{(Signatory must meet definition in Section B.11.A, eg., FOD, Ops Mgr, DSESH Group Leader, EPC Group Leader)}

Print name and title: 


\section{Maintenance Details}

Requested: 8/23/2016 3:44:03 PM

Procedure: MSGP Quarterly Visual Assessment (EPC-CP. Form-1021.2)

Last PM: $\quad 8 / 9 / 2016$

Project: $\quad$ SIO Visuals $8 / 23 / 16$

(P-MSGP-5107)

Reason: MSGP Quarterly Visual Assessment

Monitoring Period:

Odor:

Clarity:

Settled Solids:
9/30/2016

Priority/Type: Normal / Inspection

Department: Utilities and Infrastructure

Suspended Solids:

Special Instructions: NMR053195

\section{Tasks}

\# Description

Rating Meas. Initials Failed N/A Complete

The result of this VA applies to associated SIOs as defined in the SWPPP, where applicable.

Sample information

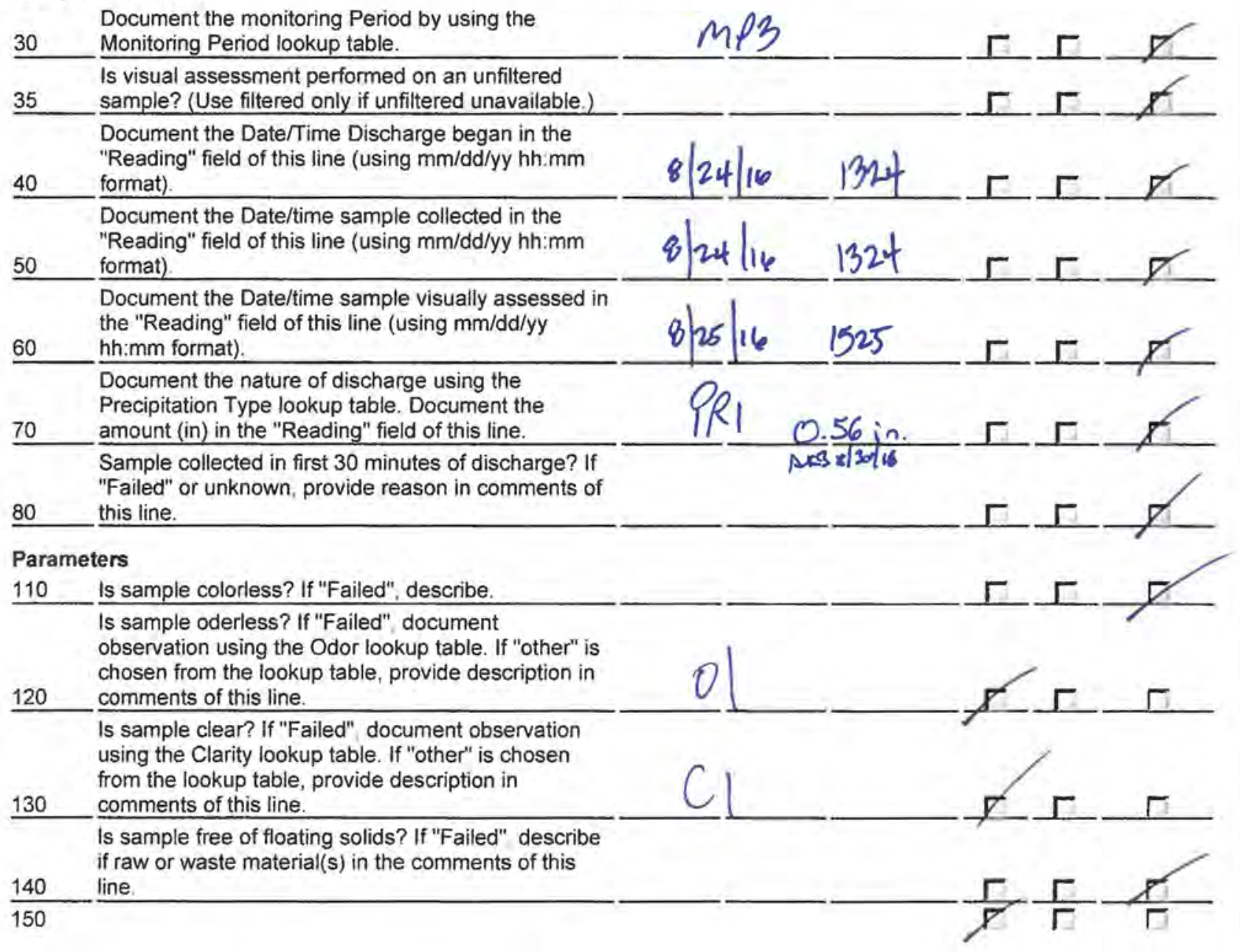


Is sample free of settled solids? If "Failed" document observation using the Settled Solids lookup table. If "other" is chosen from the lookup table, provide description in comments of this line.

\section{SETSOL 2}

Is sample free of suspended solids? If "Failed"

document observation using the Suspended Solids

lookup table. If "other" is chosen from the lookup

160

table, provide description in comments of this line.

Is sample foamless after gently shaking? If "Failed" describe foam color and location ('on the surface' or 'in the sample') in the comments of this line. (Range:

$170 \quad 0-0)$

Is sample devoid of an oil sheen? If "Failed", describe color and thickness (e.g. flecks, globs) in the

180 comments of this line. (Range: 0 - 0)

Is sample free of other obvious indicators of pollution? If "Failed" describe in the comments of this

190 line. (Range: 0 - 0)

\section{- Labor}

Labor

Assigned Work Date

Reg Hrs OT Hrs Other Hrs

Shendo, Marwin 9/30/2016/ 14

\section{Labor Report}

Completed: Failure:

Report: 


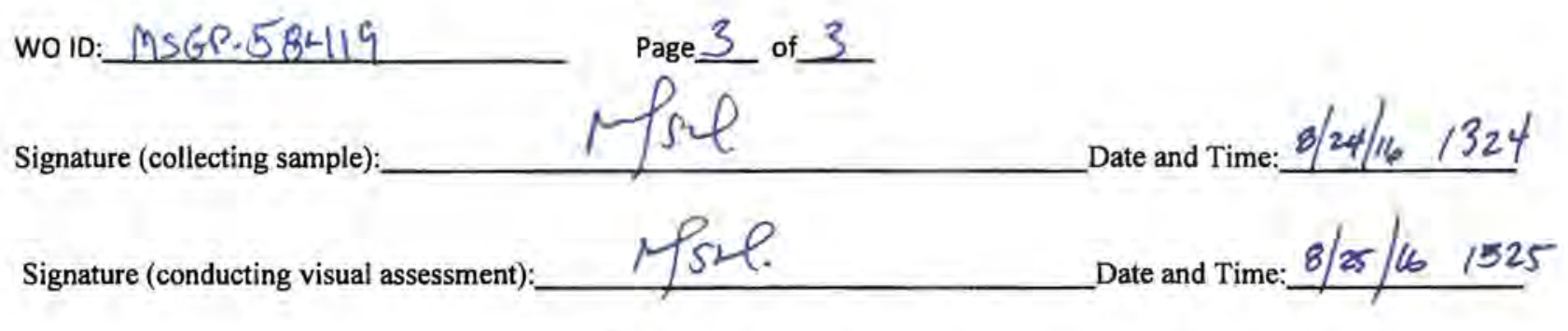

\section{CERTIFICATION STATEMENT}

"I certify under penalty of law that this document and all attachments were prepared under my direction or supervision in accordance with a system designed to assure that qualified personnel properly gathered and evaluated the information submitted. Based on my inquiry of the person or persons who manage the system, or those persons directly responsible for gathering information, the information submitted is, to the best of my knowledge and belief, true, accurate, and complete. I am aware that there are significant penalties for submitting false information, including the possibility of fine and imprisonment for knowing violations".

(Signatory must meet definition in Section B.11.A, eg., FOD, Ops Mgr, DSESH Group Leader, EPC Group Leader)

Print name and title:

Signature: Date: 


\section{Maintenance Details}

\section{Requested: 8/23/2016 3:44:03 PM \\ Procedure: MSGP Quarterly Visual Assessment (EPC-CP. Form-1021.2) \\ Last PM: $\quad 8 / 9 / 2016$ \\ Project: $\quad$ SIO Visuals $8 / 23 / 16$ \\ (P-MSGP-5107)}

Reason: MSGP Quarterly Visual Assessment

Monitoring Period:

Odor:

$\begin{array}{ll}\text { Target: } & 9 / 30 / 2016 \\ \text { Priority/Type: } & \text { Normal / Inspection } \\ \text { Department: } & \text { Utilities and } \\ & \text { Infrastructure }\end{array}$

Clarity:

Settled Solids:

\author{
MSGP Program \\ 뭄 RG200.5 \\ th TA-60 Roads and Grounds \\ ba Monitored Outfall (031) \\ Substantially Identical Outfall (030) \\ Ab MSGP03001
}

Contact:

Phone:

Suspended Solids:

Special Instructions: NMR053195

Tasks

\# Description

Rating Meas. Initials Failed N/A Complete

The result of this VA applies to associated SIOs as defined in the SWPPP, where applicable.

\section{Sample information}

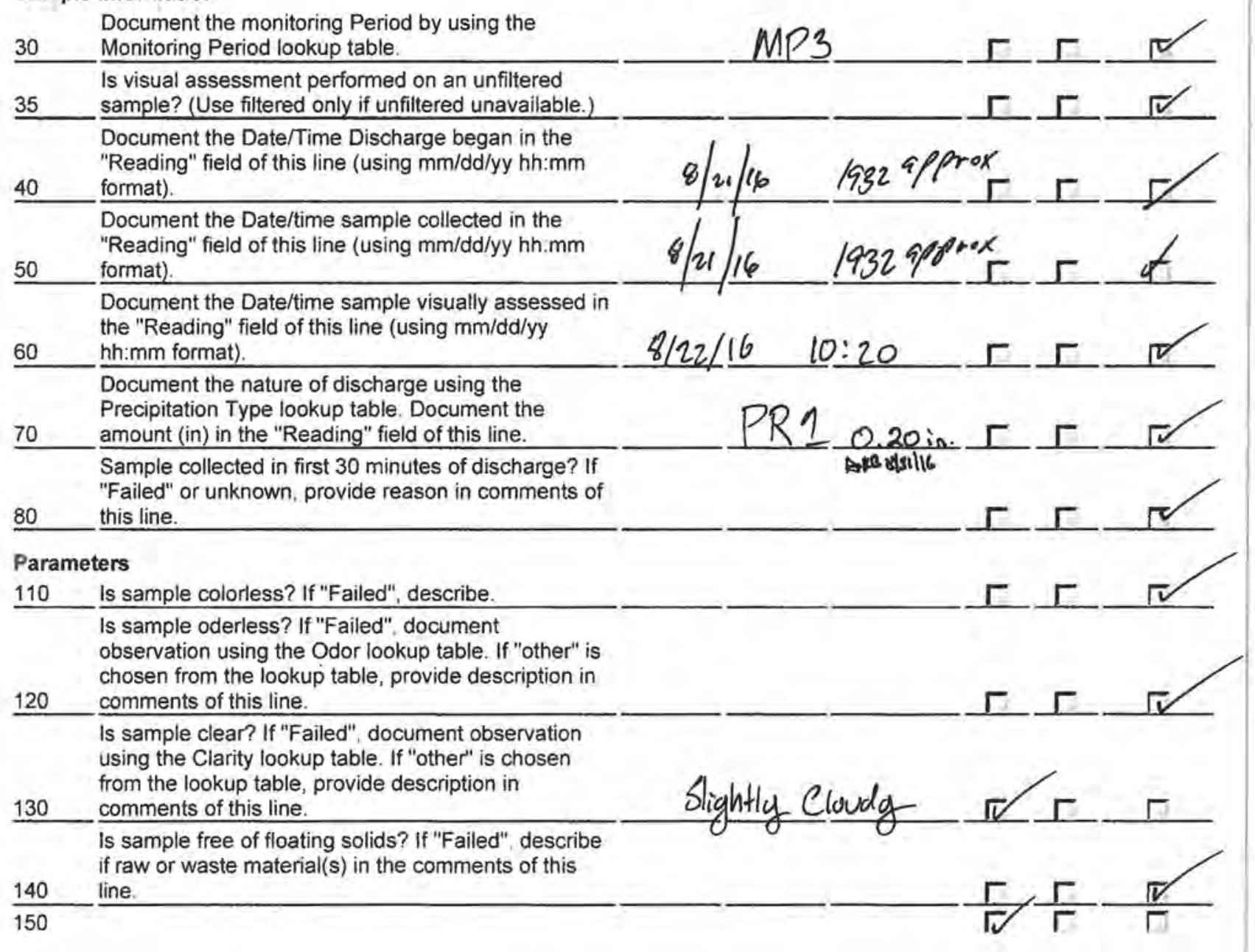


Is sample free of settled solids? If "Failed", document observation using the Settled Solids lookup table. If "other" is chosen from the lookup table, provide description in comments of this line.

Course

Is sample free of suspended solids? If "Failed" document observation using the Suspended Solids lookup table. If "other" is chosen from the lookup table, provide description in comments of this line.

Is sample foamless after gently shaking? If "Failed" describe foam color and location ('on the surface' or 'in the sample') in the comments of this line. (Range:

$170 \quad 0-0)$

Is sample devoid of an oil sheen? If "Failed", describe color and thickness (e.g. flecks, globs) in the

180 comments of this line. (Range: $0-0$ )

is sample free of other obvious indicators of pollution? If "Failed", describe in the comments of this 190 line. (Range: 0 - 0 )

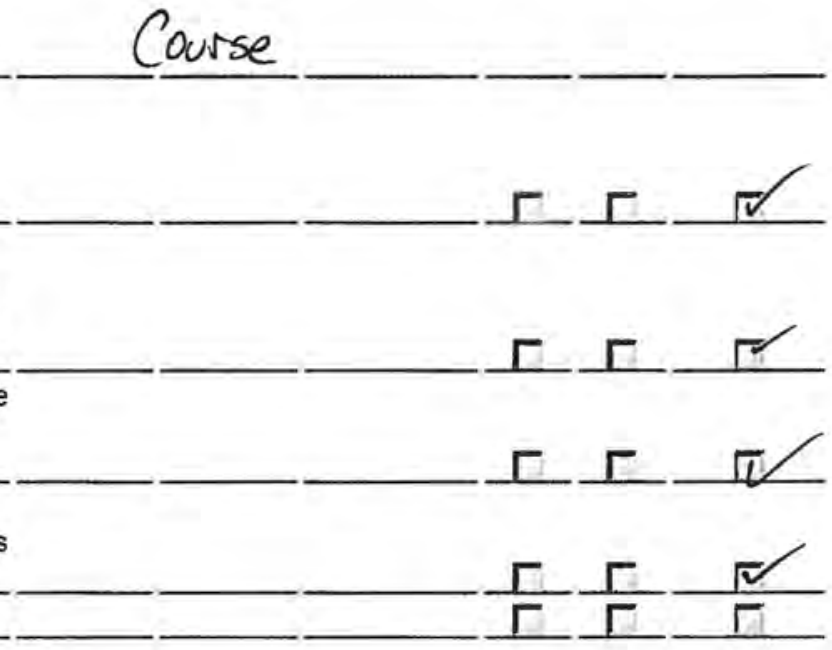

\section{Labor}

Labor

Shendo, Marwin

Assigned Work Date Reg Hrs OT Hrs Other Hrs $9 / 30 / 2016 / 14$

\section{Labor Report}

Completed: Failure:

Report: 


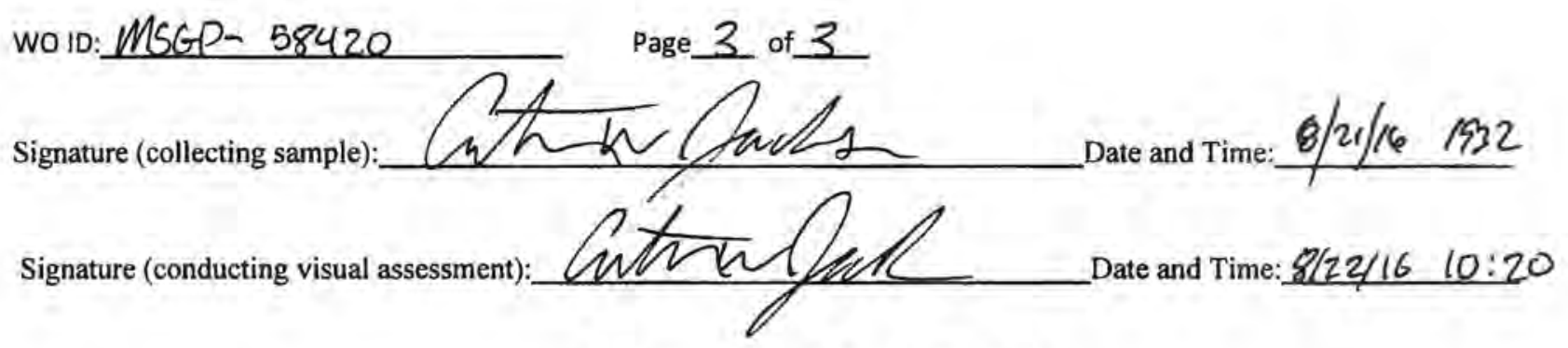

\section{CERTIFICATION STATEMENT}

"I certify under penalty of law that this document and all attachments were prepared under my direction or supervision in accordance with a system designed to assure that qualified personnel properly gathered and evaluated the information submitted. Based on my inquiry of the person or persons who manage the system, or those persons directly responsible for gathering information, the information submitted is, to the best of my knowledge and belief, true, accurate, and complete. I am aware that there are significant penalties for submitting false information, including the possibility of fine and imprisonment for knowing violations".

\section{(Signatory must meet definition in Section B.11.A, eg., FOD, Ops Mgr, DSESH Group Leader, EPC Group Leader)}

Print name and title: 


\section{Maintenance Details}

$\begin{array}{llll}\text { Requested: } & \text { 8/31/2016 2:36:03 PM } & \text { Target: } & 9 / 30 / 2016 \\ \text { Procedure: } & \text { MSGP Quarterly Visual } \\ & \text { Assessment (EPC-CP- } & \text { Priority/Type: Normal/Inspection } \\ & \text { Form-1021.2) } & \text { Department: Utilities and } \\ \text { Last PM: } & 8 / 22 / 2016 & & \text { Infrastructure } \\ \text { Project: } & \begin{array}{l}\text { SIO Visuals } 8 / 31 / 16 \\ \text { (P-MSGP-5113) }\end{array} & & \end{array}$

Reason: MSGP Quarterly Visual Assessment

Monitoring Period:

Odor:

\section{MSGP Program 몸 RG200.5 \\ 1. TA-60 Roads and Grounds 4. Monitored Outfall (032) \\ Q Substantially Identical Outfall (033) th MSGP03301}

Contact:

Phone:

Clarity:

Settled Solids:

Suspended Solids:

Special Instructions: NMR053195

Tasks

\# Description

Rating Meas.

Initials

Failed N/A Complete

The result of this VA applies to associated SIOs as defined in the SWPPP, where applicable.

\section{Sample information}

Document the monitoring Period by using the

30 Monitoring Period lookup table.

Is visual assessment performed on an unfiltered

35 sample? (Use filtered only if unfiltered unavailable.)

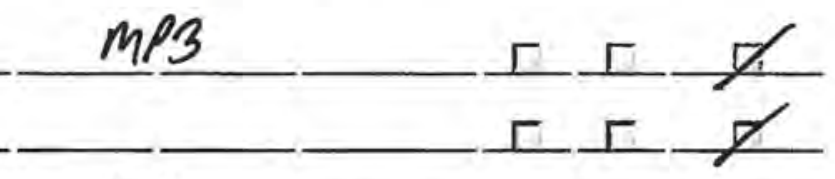

Document the Date/Time Discharge began in the

"Reading" field of this line (using mm/dd/yy hh:mm

40 format).

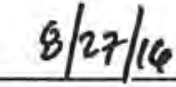

1147

Document the Date/time sample collected in the

"Reading" field of this line (using mm/dd/yy hh:mm

50 format).

Document the Date/time sample visually assessed in the "Reading" field of this line (using $\mathrm{mm} / \mathrm{dd} / \mathrm{yy}$

60 hh:mm format).

Document the nature of discharge using the

Precipitation Type lookup table. Document the

70 amount (in) in the "Reading" field of this line.

Sample collected in first 30 minutes of discharge? If

"Failed" or unknown, provide reason in comments of

80 this line.

Parameters

110 Is sample coloriess? If "Failed", describe.

Is sample oderless? If "Failed", document

$8 / 27 / 16$

1147 $\Gamma \Gamma \frac{7}{\Gamma}$ observation using the Odor lookup table. If "other" is chosen from the lookup table, provide description in comments of this line.

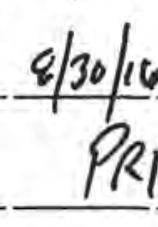

$16 \quad 1527$
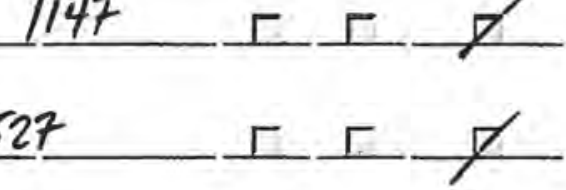

Is sample clear? If "Failed", document observation

$0.15 \mathrm{in}$

pase 91616

using the Clarity lookup table. If "other" is chosen

from the lookup table, provide description in

130 comments of this line.

Is sample free of floating solids? If "Failed", describe

light Brown

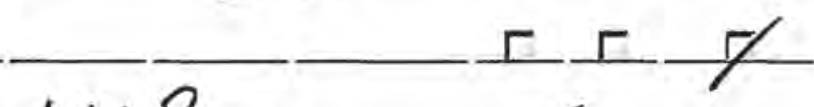

if raw or waste material(s) in the comments of this

140 line

150 


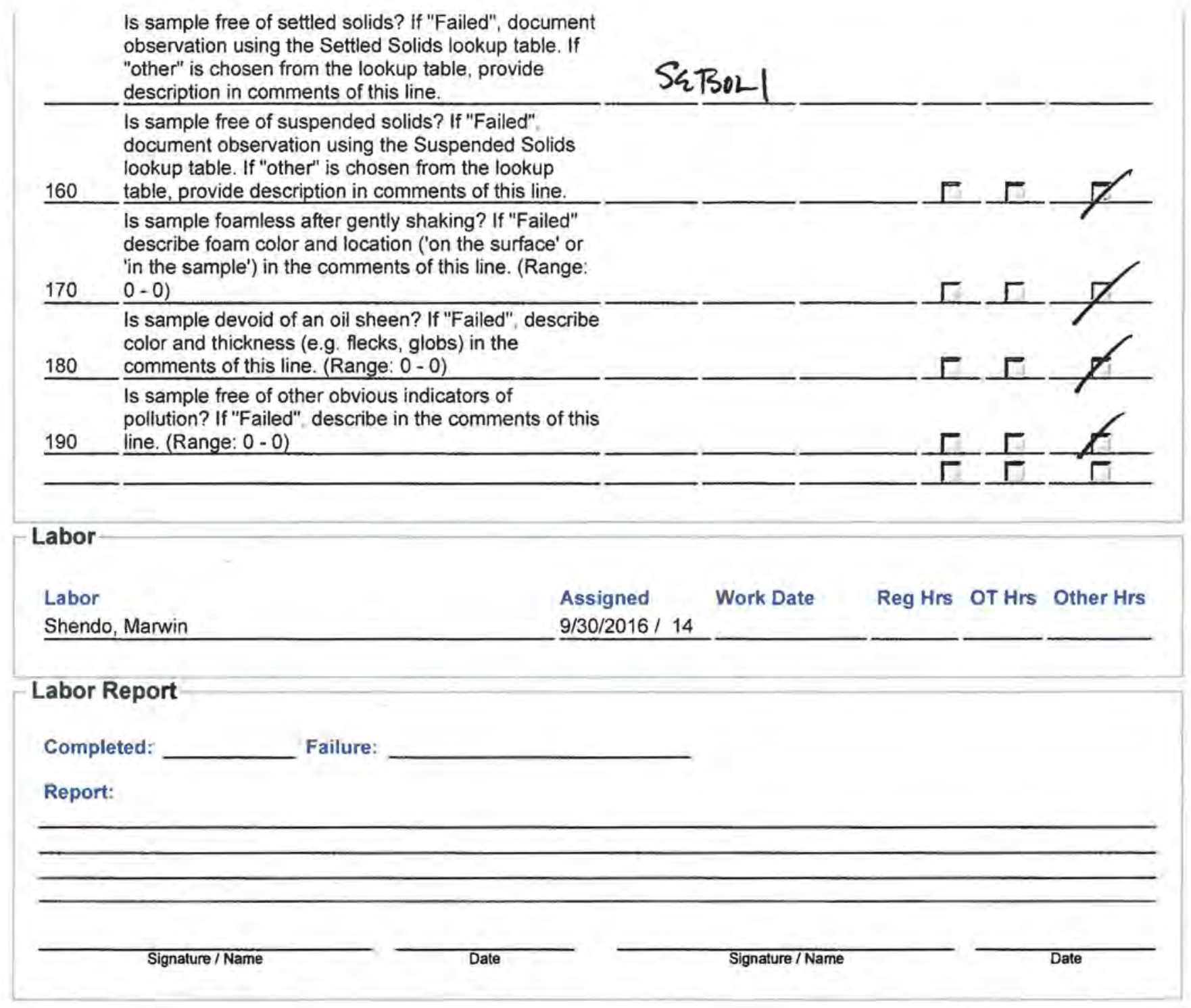


Wo 10: MSGP-58505 Page 3 of 3

Signature (collecting sample): $\quad$ S S L L P Date and Time: $8 / 27 / 16 \quad 1 / 47$

Signature (conducting visual assessment):

\section{CERTIFICATION STATEMENT}

"I certify under penalty of law that this document and all attachments were prepared under my direction or supervision in accordance with a system designed to assure that qualified personnel properly gathered and evaluated the information submitted. Based on my inquiry of the person or persons who manage the system, or those persons directly responsible for gathering information, the information submitted is, to the best of my knowledge and belief, true, accurate, and complete. I am aware that there are significant penalties for submitting false information, including the possibility of fine and imprisonment for knowing violations".

(Signatory must meet definition in Section B.11.A, eg., FOD, Ops Mgr, DSESH Group Leader, EPC Group Leader)

Print name and title:

Signature:

Date: 


\section{Maintenance Details}

\begin{tabular}{|c|c|c|c|c|}
\hline \multicolumn{2}{|c|}{ Requested: 8/31/2016 2:36:04 PM } & Target: & $9 / 30 / 2016$ & \multirow{5}{*}{$\begin{array}{l}\text { MSGP Program } \\
\text { of RG200.5 } \\
\text { of TA-60 Roads and Grounds } \\
\text { is Monitored Outfall (032) } \\
\text { \& Substantially Identical Outfall (034) } \\
\text { is MSGP03401 }\end{array}$} \\
\hline \multirow{2}{*}{\multicolumn{2}{|c|}{$\begin{aligned} \text { Procedure: } & \text { MSGP Quarterly Visual } \\
& \text { Assessment (EPC-CP- } \\
& \text { Form-1021.2) }\end{aligned}$}} & Priority/Type: & Normal / Inspection & \\
\hline & & Department: & $\begin{array}{l}\text { Utilities and } \\
\text { Infrastructure }\end{array}$ & \\
\hline Last PM: & \multicolumn{3}{|l|}{$8 / 22 / 2016$} & \\
\hline Project: & \multicolumn{3}{|l|}{$\begin{array}{l}\text { SIO Visuals 8/31/16 } \\
\text { (P-MSGP-5113) }\end{array}$} & \\
\hline \multicolumn{4}{|c|}{ Reason: MSGP Quarterly Visual Assessment } & \multirow{2}{*}{$\begin{array}{l}\text { Contact: } \\
\text { Phone: }\end{array}$} \\
\hline \multicolumn{2}{|c|}{ Monitoring Period: } & Odor: & & \\
\hline
\end{tabular}

Clarity:

Settled Solids:

Suspended Solids:

Special Instructions: NMR053195

Tasks

\# Description

Rating Meas, Initials Failed N/A Complete

The result of this VA applies to associated SIOs as defined in the SWPPP, where applicable.

Sample information

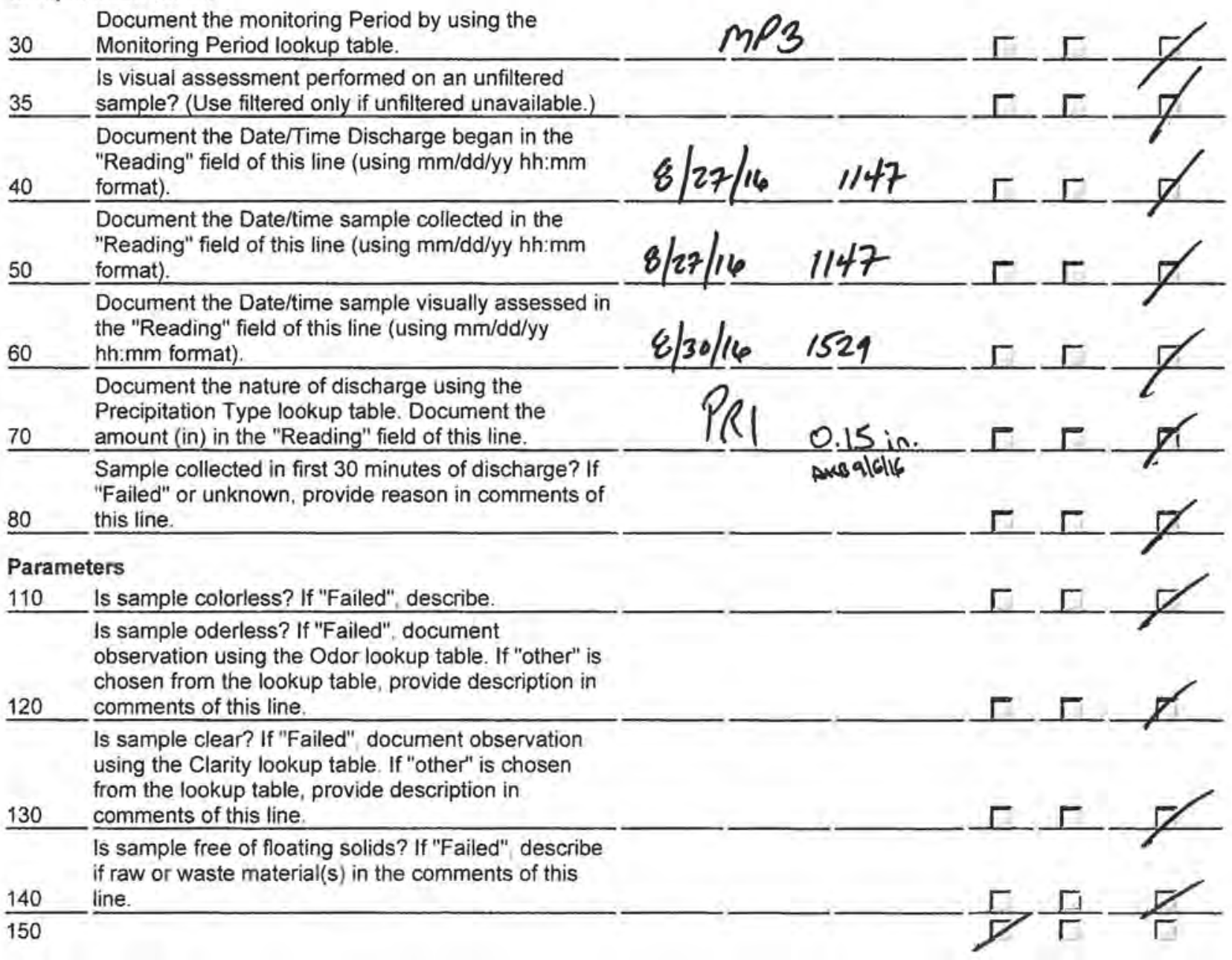




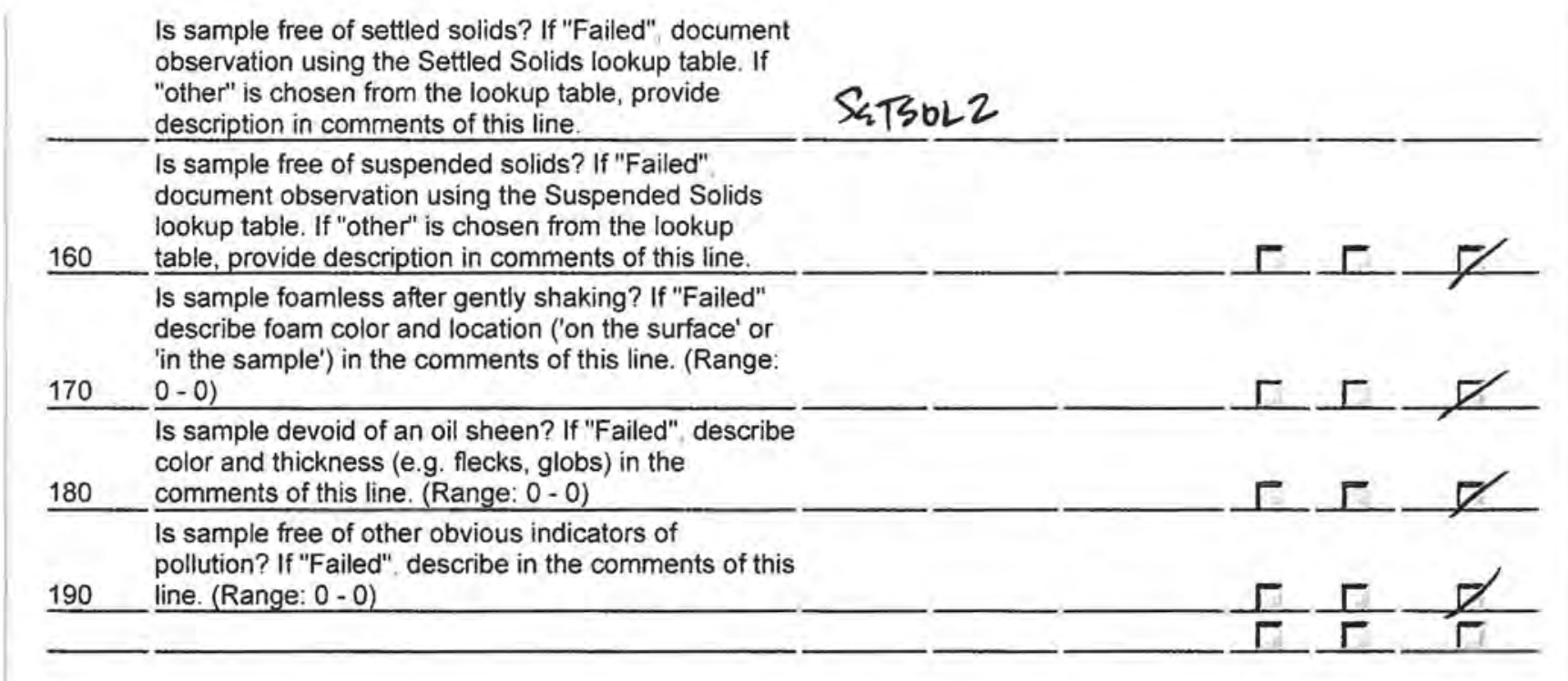

\section{- Labor}

Labor

Shendo, Marwin

Assigned Work Date Reg Hrs OT Hrs Other Hrs
$9 / 30 / 2016 / 14$

\section{Labor Report}

Completed:

Failure:

Report: 
Signature (collecting sample):

Signature (conducting visual assessment):

NPsul.

Date and Time: $8 / 30 / 16 \quad 1529$

\section{CERTIFICATION STATEMENT}

"I certify under penalty of law that this document and all attachments were prepared under my direction or supervision in accordance with a system designed to assure that qualified personnel properly gathered and evaluated the information submitted. Based on my inquiry of the person or persons who manage the system, or those persons directly responsible for gathering information, the information submitted is, to the best of my knowledge and belief, true, accurate, and complete. I am aware that there are significant penalties for submitting false information, including the possibility of fine and imprisonment for knowing violations".

(Signatory must meet definition in Section B.11.A, eg., FOD, Ops Mgr, DSESH Group Leader, EPC Group Leader)

Print name and title:

Signature:

Date: 


\section{Maintenance Details}

Requested: 8/31/2016 2:36:04 PM

Procedure: MSGP Quarterly Visual Assessment (EPC-CPForm-10212)

Last PM: $\quad 8 / 22 / 2016$

Project: SIO Visuals $8 / 31 / 16$

(P-MSGP-5113)

\section{Target: $\quad$ 9/30/2016}

Priority/Type: Normal / Inspection

Department: Utilities and Infrastructure

\section{MSGP Program 몸 RG200.5 \\ 16. TA-60 Roads and Grounds th Monitored Outfall (031) \\ Q Substantially Identical Outfall (030) is MSGP03001}

Reason: MSGP Quarterly Visual Assessment

Contact:

Monitoring Period:

Odor:

Phone:

Clarity:

Settled Solids:

Suspended Solids:

Special Instructions: NMR053195

Tasks

\# Description

Rating Meas. Initials Failed N/A Complete

The result of this VA applies to associated SIOs as defined in the SWPPP, where applicable.

Sample information

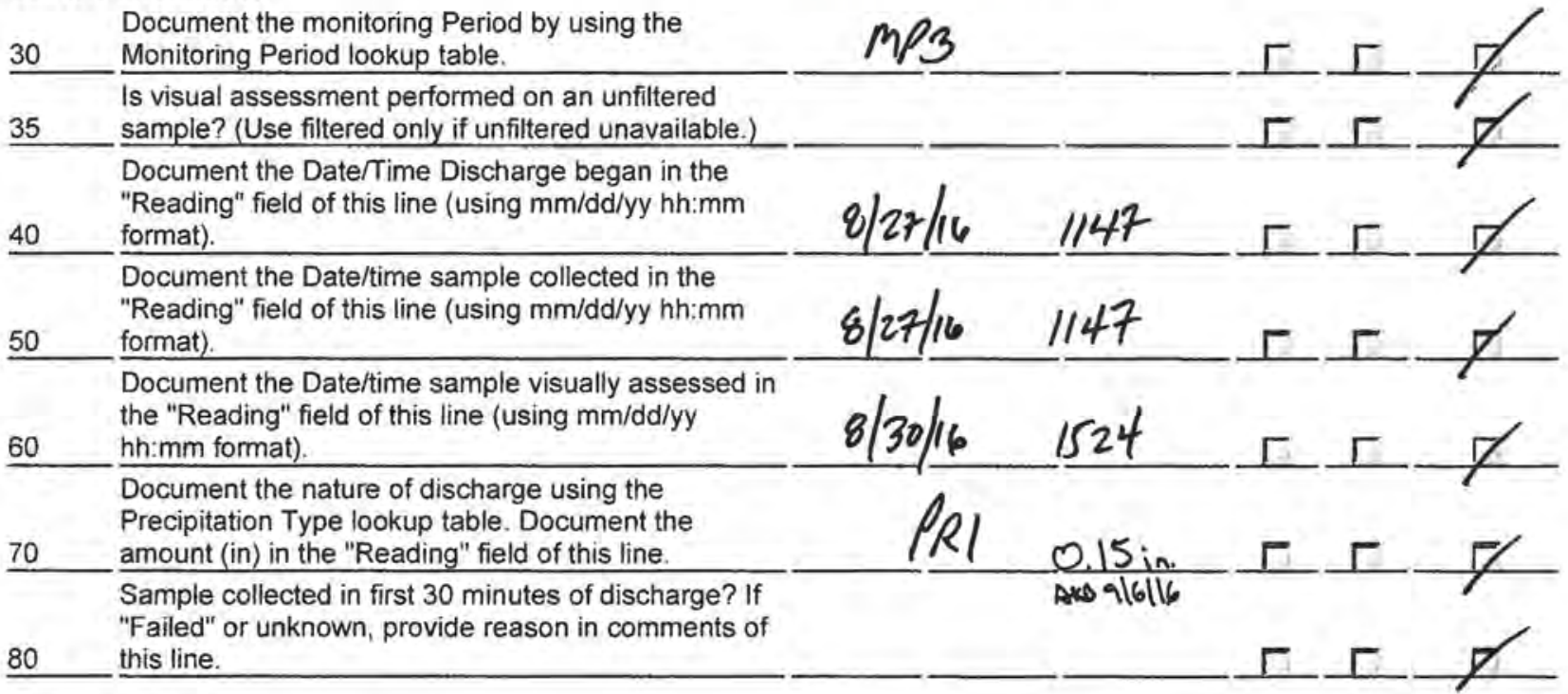

Parameters

110 Is sample colorless? If "Failed", describe. Is sample oderless? If "Failed", document observation using the Odor lookup table. If "other" is chosen from the lookup table, provide description in

$\underline{120}$ comments of this line.

Is sample clear? If "Failed", document observation using the Clarity lookup table. If "other" is chosen from the lookup table, provide description in

130 comments of this line.

Is sample free of floating solids? If "Failed", describe if raw or waste material(s) in the comments of this line.

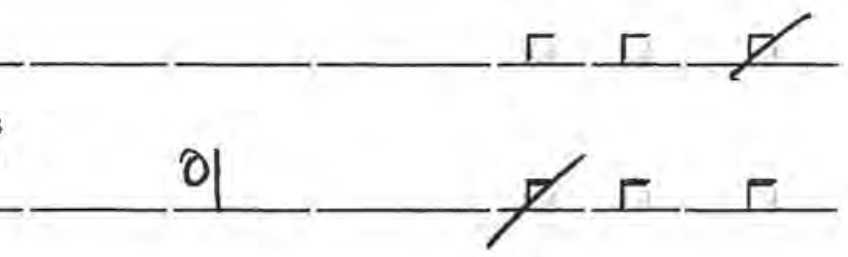


Is sample free of settled solids? If "Failed", document observation using the Settled Solids lookup table. If "other" is chosen from the lookup table, provide description in comments of this line.

\section{SATSOLI}

Is sample free of suspended solids? If "Failed"

document observation using the Suspended Solids

lookup table. If "other" is chosen from the lookup

160

table, provide description in comments of this line.

Is sample foamless after gently shaking? If "Failed" describe foam color and location ('on the surface' or 'in the sample') in the comments of this line. (Range:

$170 \quad 0-0)$

Is sample devoid of an oil sheen? If "Failed", describe color and thickness (e.g. flecks, globs) in the

180 comments of this line. (Range: $0-0$ )

Is sample free of other obvious indicators of pollution? If "Failed" describe in the comments of this 190 line. (Range: 0 - 0)

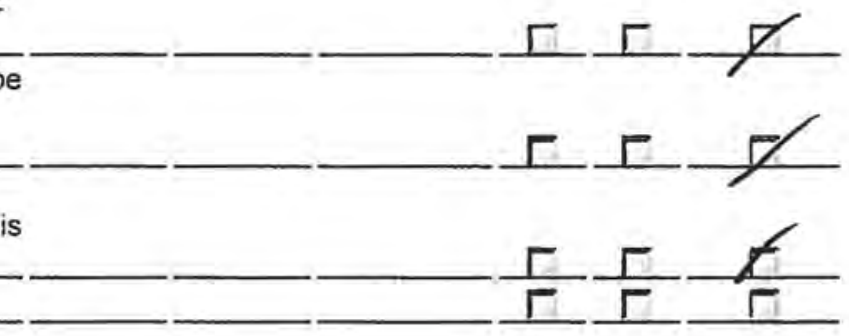

\section{Labor}

Labor

Assigned Work Date

Reg Hrs OT Hrs Other Hrs

Shendo, Marwin 9/30/2016/ 14

\section{Labor Report}

Completed: Failure:

Report: 


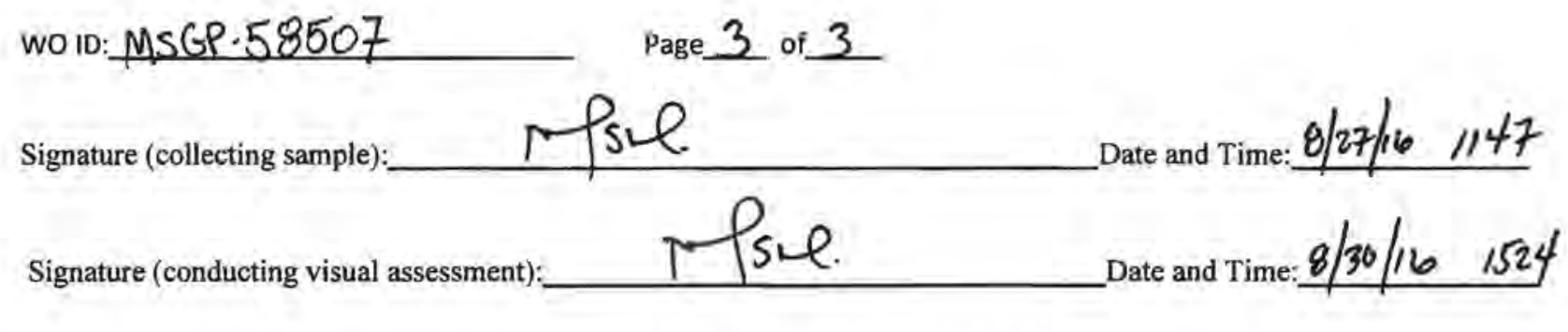

\section{CERTIFICATION STATEMENT}

"I certify under penalty of law that this document and all attachments were prepared under my direction or supervision in accordance with a system designed to assure that qualified personnel properly gathered and evaluated the information submitted. Based on my inquiry of the person or persons who manage the system, or those persons directly responsible for gathering information, the information submitted is, to the best of my knowledge and belief, true, accurate, and complete. I am aware that there are significant penalties for submitting false information, including the possibility of fine and imprisonment for knowing violations".

(Signatory must meet definition in Section B.11.A, eg., FOD, Ops Mgr, DSESH Group Leader, EPC Group Leader)

Print name and title:

Signature:

Date: 


\section{Maintenance Details}

\begin{tabular}{|c|c|c|c|}
\hline Requested & $8 / 31 / 20162: 36: 05$ PM & Target: & $9 / 30 / 2016$ \\
\hline Procedure: & MSGP Quarterly Visual & Priority/Type: & Normal / Inspection \\
\hline & $\begin{array}{l}\text { Assessment (EPC-CP- } \\
\text { Form-1021.2) }\end{array}$ & Department: & $\begin{array}{l}\text { Utilities and } \\
\text { Infrastructure }\end{array}$ \\
\hline Last PM: & $8 / 22 / 2016$ & & \\
\hline Project: & $\begin{array}{l}\text { SIO Visuals } 8 / 31 / 16 \\
\text { (P-MSGP-5113) }\end{array}$ & & \\
\hline
\end{tabular}

Reason: MSGP Quarterly Visual Assessment

Monitoring Period:

Odor:

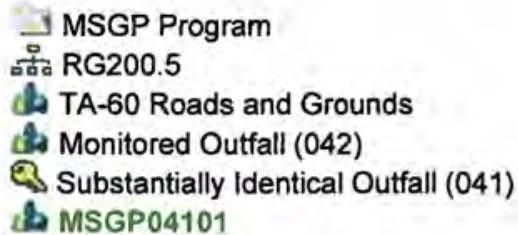

Contact:

Phone:

Clarity:

Settled Solids:

Suspended Solids:

Special Instructions: NMR053195

Tasks

\# Description

Rating Meas, Initials Failed N/A Complete

The result of this VA applies to associated SIOs as defined in the SWPPP, where applicable.

\section{Sample information}

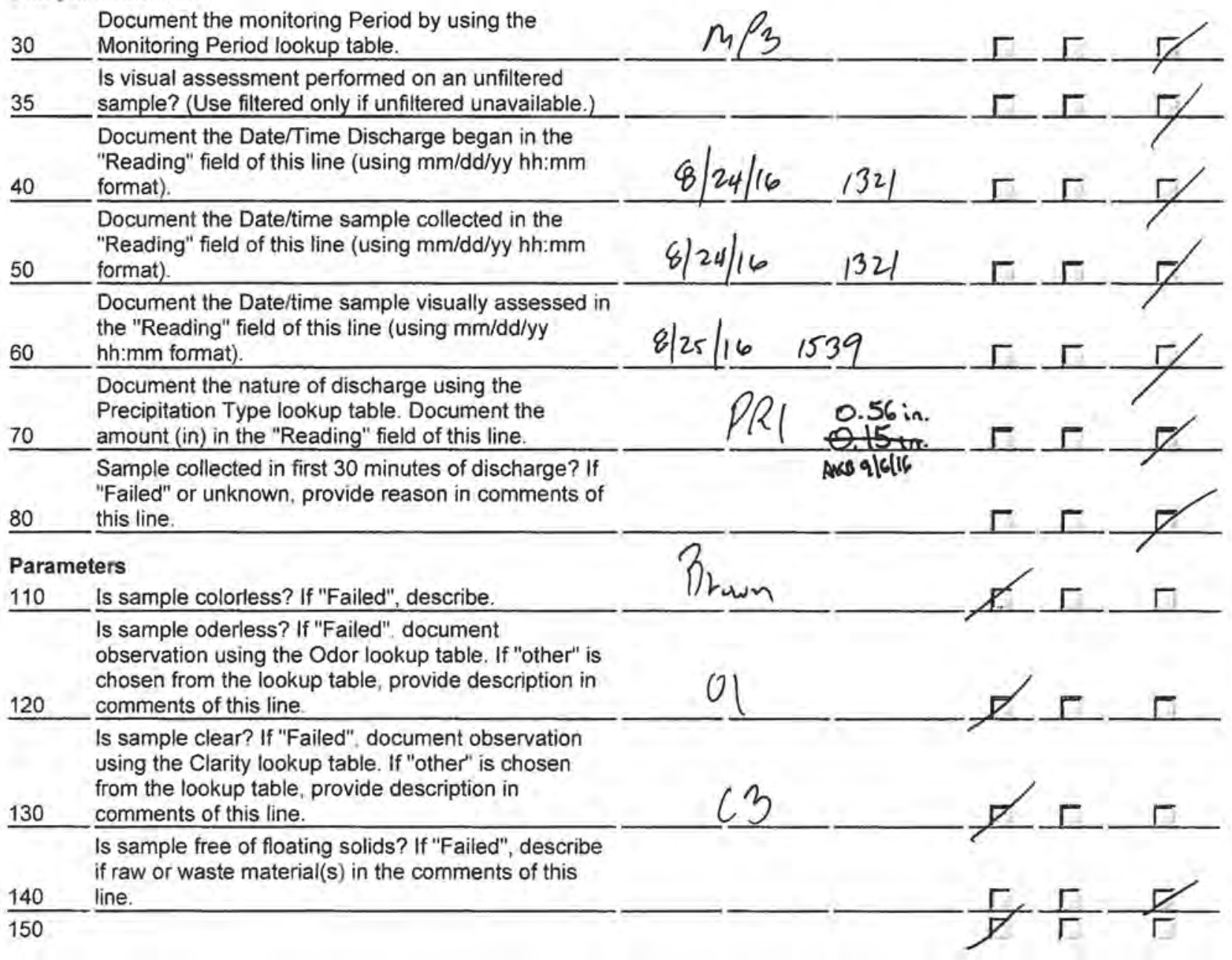


Is sample free of settled solids? If "Failed", document observation using the Settled Solids lookup table. If "other" is chosen from the lookup table, provide description in comments of this line.

\section{SETSOL)}

Is sample free of suspended solids? If "Failed". document observation using the Suspended Solids lookup table. If "other" is chosen from the lookup

160 table, provide description in comments of this line.

Is sample foamless after gently shaking? If "Failed" describe foam color and location ('on the surface' or

170 'in the sample') in the comments of this line. (Range:

Is sample devoid of an oil sheen? If "Failed", describe color and thickness (e.g. flecks, globs) in the

180 comments of this line. (Range: $0-0$ )

Is sample free of other obvious indicators of pollution? If "Failed". describe in the comments of this 190 line. (Range: $0-0$ )

\section{Labor}

Labor

\section{Labor Report}

Completed: Failure:

Report: 


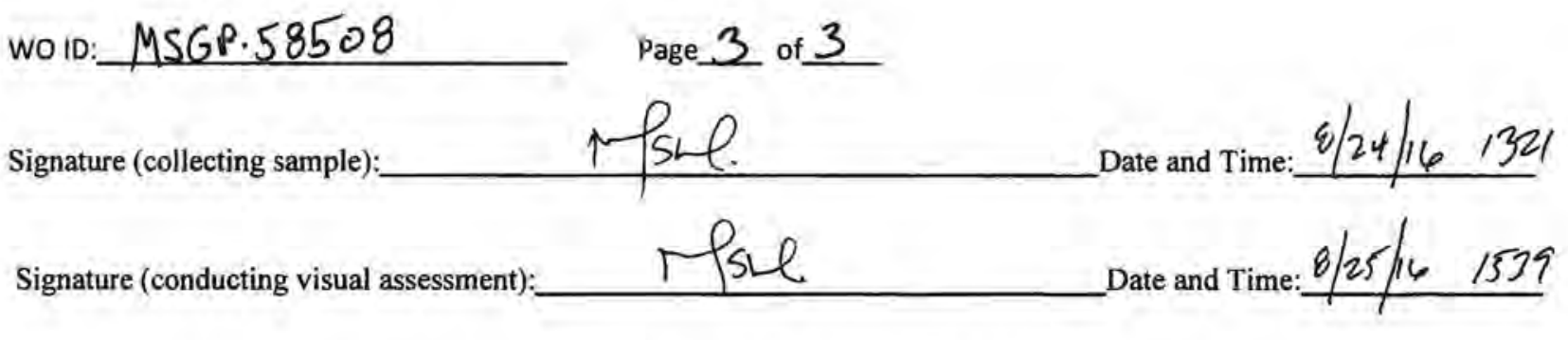

\section{CERTIFICATION STATEMENT}

"I certify under penalty of law that this document and all attachments were prepared under my direction or supervision in accordance with a system designed to assure that qualified personnel properly gathered and evaluated the information submitted. Based on my inquiry of the person or persons who manage the system, or those persons directly responsible for gathering information, the information submitted is, to the best of my knowledge and belief, true, accurate, and complete. I am aware that there are significant penalties for submitting false information, including the possibility of fine and imprisonment for knowing violations".

(Signatory must meet definition in Section B.11.A, eg., FOD, Ops Mgr, DSESH Group Leader, EPC Group Leader)

Print name and title:

Signature:

Date: 


\section{Maintenance Details}

\author{
Requested: 8/31/2016 2:57:52 PM \\ Procedure: MSGP Quarterly Visual \\ Assessment (EPC-CP- \\ Form-1021.2) \\ Last PM: $\quad 8 / 22 / 2016$ \\ Project: $\quad$ SIO Visuals 9/1/16 \\ (P-MSGP-5114)
}
Target:
9/30/2016
Priority/Type: Normal / Inspection
Department: Utilities and Infrastructure

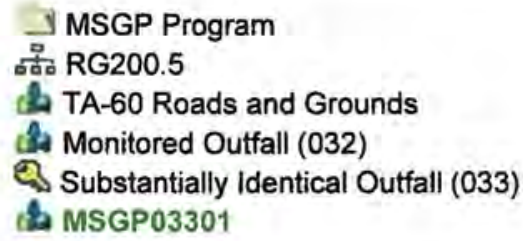

Reason: MSGP Quarterly Visual Assessment

Monitoring Period:

Odor:

Clarity:

Suspended Solids:

Special Instructions: NMR053195
Settled Solids:
Contact:

Phone:

\section{Tasks}

\# Description

Rating Meas. Initials Failed N/A Complete

The result of this VA applies to associated SIOS as defined in the SWPPP, where applicable.

\section{Sample information}

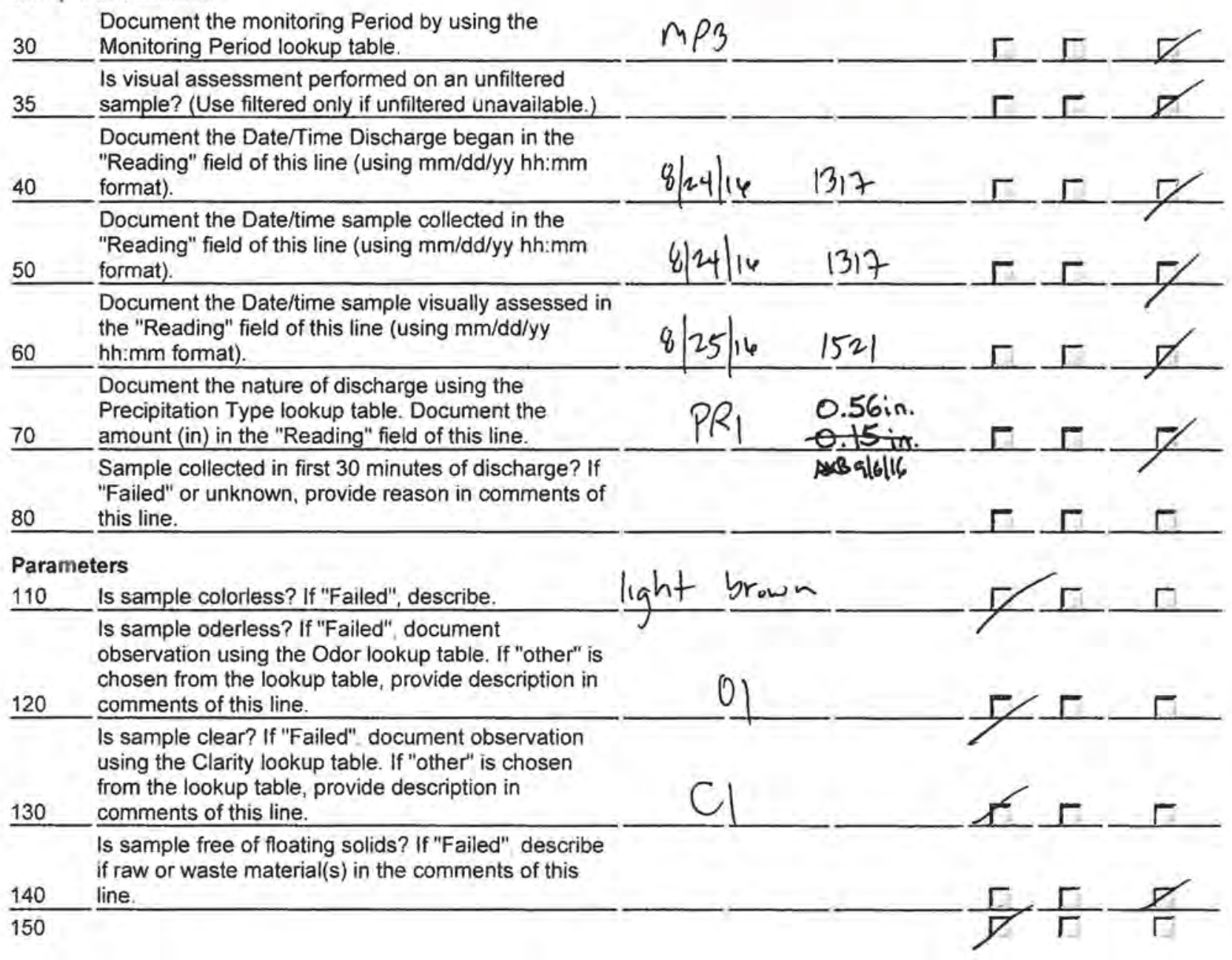


Is sample free of settled solids? If "Failed", document observation using the Settled Solids lookup table. If "other" is chosen from the lookup table, provide description in comments of this line.

Is sample free of suspended solids? If "Failed",

document observation using the Suspended Solids

lookup table. If "other" is chosen from the lookup

160 table, provide description in comments of this line.

Is sample foamless after gently shaking? If "Failed" describe foam color and location ('on the surface' or 'in the sample') in the comments of this line. (Range:

170 $0-0)$

Is sample devoid of an oil sheen? If "Failed", describe color and thickness (e.g. flecks, globs) in the

180 comments of this line. (Range: $0-0$ )

Is sample free of other obvious indicators of pollution? If "Failed" describe in the comments of this

190 line. (Range: $0-0$ )

\section{Labor}

Labor

Shendo, Marwin 9/30/2016/ 14

\section{Labor Report}

Completed Failure:

Report: 
wo 1D:MSGP.58516 Page 3 of 3

Signature (collecting sample):_ TSS L Date and Time: $6 / 24 / 16 \quad 1317$

Signature (conducting visual assessment):_ M S L . Date and Time: $8 / 25 / 10 \quad 1521$

\section{CERTIFICATION STATEMENT}

"I certify under penalty of law that this document and all attachments were prepared under my direction or supervision in accordance with a system designed to assure that qualified personnel properly gathered and evaluated the information submitted. Based on my inquiry of the person or persons who manage the system, or those persons directly responsible for gathering information, the information submitted is, to the best of my knowledge and belief, true, accurate, and complete. I am aware that there are significant penalties for submitting false information, including the possibility of fine and imprisonment for knowing violations".

\section{(Signatory must meet definition in Section B.11.A, eg., FOD, Ops Mgr, DSESH Group Leader, EPC Group Leader)}

Print name and title:

Signature:

Date: 


\section{Maintenance Details}

$\begin{array}{llll}\text { Requested: } & 8 / 31 / 20162: 57: 52 \text { PM } & \text { Target: } & 9 / 30 / 2016 \\ \text { Procedure: } & \text { MSGP Quarterly Visual } & \text { Priority/Type: Normal/Inspection } \\ & \text { Assessment (EPC-CP- } & \text { Form-1021.2) } & \text { Department: Utilies and } \\ \text { Last PM: } & 8 / 22 / 2016 & & \text { Infrastructure } \\ \text { Project: } & \begin{array}{l}\text { SIO Visuals 9/1/16 } \\ \text { (P-MSGP-5114) }\end{array} & & \\ & \text { (P-MS } & & \end{array}$

Reason: MSGP Quarterly Visual Assessment

Monitoring Period:

Clarity:

Odor:

Settled Solids:

\section{MSGP Program 몸 RG200.5 \\ 16 TA-60 Roads and Grounds \\ to Monitored Outfall (032) \\ S Substantially Identical Outfall (034) \\ is MSGP03401}

Contact:

Phone:

Suspended Solids:

Special Instructions: NMR053195

Tasks

* Description

Rating Meas. Initials Failed N/A Complete

The result of this VA applies to associated SIOs as defined in the SWPPP, where applicable.

Sample information

\begin{tabular}{|c|c|c|c|c|c|c|}
\hline 30 & $\begin{array}{l}\text { Document the monitoring Period by using the } \\
\text { Monitoring Period lookup table. }\end{array}$ & $\mathrm{MPz}$ & & $\Gamma$ & $\Gamma$ & \\
\hline 35 & $\begin{array}{l}\text { Is visual assessment performed on an unfiltered } \\
\text { sample? (Use filtered only if unfiltered unavailable.) }\end{array}$ & & & $\Gamma$ & $\Gamma$ & \\
\hline 40 & $\begin{array}{l}\text { Document the Date/Time Discharge began in the } \\
\text { "Reading" field of this line (using } \mathrm{mm} / \mathrm{dd} / \mathrm{yy} \mathrm{hh}: \mathrm{mm} \\
\text { format). }\end{array}$ & $8 \longdiv { 2 4 } 1 6$ & 1317 & $\Gamma$ & $\Gamma$ & \\
\hline 50 & $\begin{array}{l}\text { Document the Date/time sample collected in the } \\
\text { "Reading" field of this line (using mm/dd/yy hh:mm } \\
\text { format). }\end{array}$ & $8 / 24) 16$ & 1317 & & & \\
\hline 60 & $\begin{array}{l}\text { Document the Date/time sample visually assessed in } \\
\text { the "Reading" field of this line (using mm/dd/yy } \\
\text { hh:mm format). }\end{array}$ & $8 \mid 25) 16$ & 1523 & $\Gamma$ & $\Gamma$ & \\
\hline 70 & $\begin{array}{l}\text { Document the nature of discharge using the } \\
\text { Precipitation Type lookup table. Document the } \\
\text { amount (in) in the "Reading" field of this line. }\end{array}$ & $P R$ & $\begin{array}{r}0.56 \mathrm{in} . \\
-0.15 \mathrm{in} . \\
\end{array}$ & F & & \\
\hline 80 & $\begin{array}{l}\text { Sample collected in first } 30 \text { minutes of discharge? If } \\
\text { "Failed" or unknown, provide reason in comments of } \\
\text { this line. }\end{array}$ & & Aweal6I6 & & & \\
\hline
\end{tabular}

Parameters

110 Is sample colorless? If "Failed", describe. is sample oderless? If "Failed", document
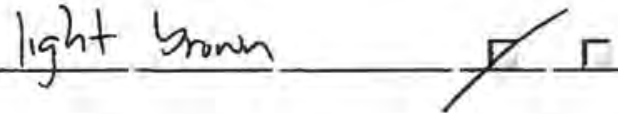
$\Gamma$ observation using the Odor lookup table. If "other" is chosen from the lookup table, provide description in comments of this line.

Is sample clear? If "Failed", document observation using the Clarity lookup table. If "other" is chosen from the lookup table, provide description in comments of this line.

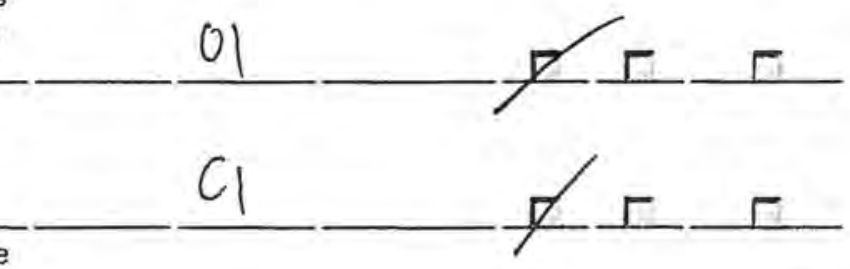

Is sample free of floating solids? If "Failed", describe if raw or waste material(s) in the comments of this 140 line.

150

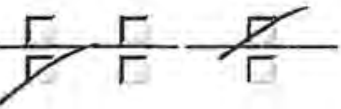




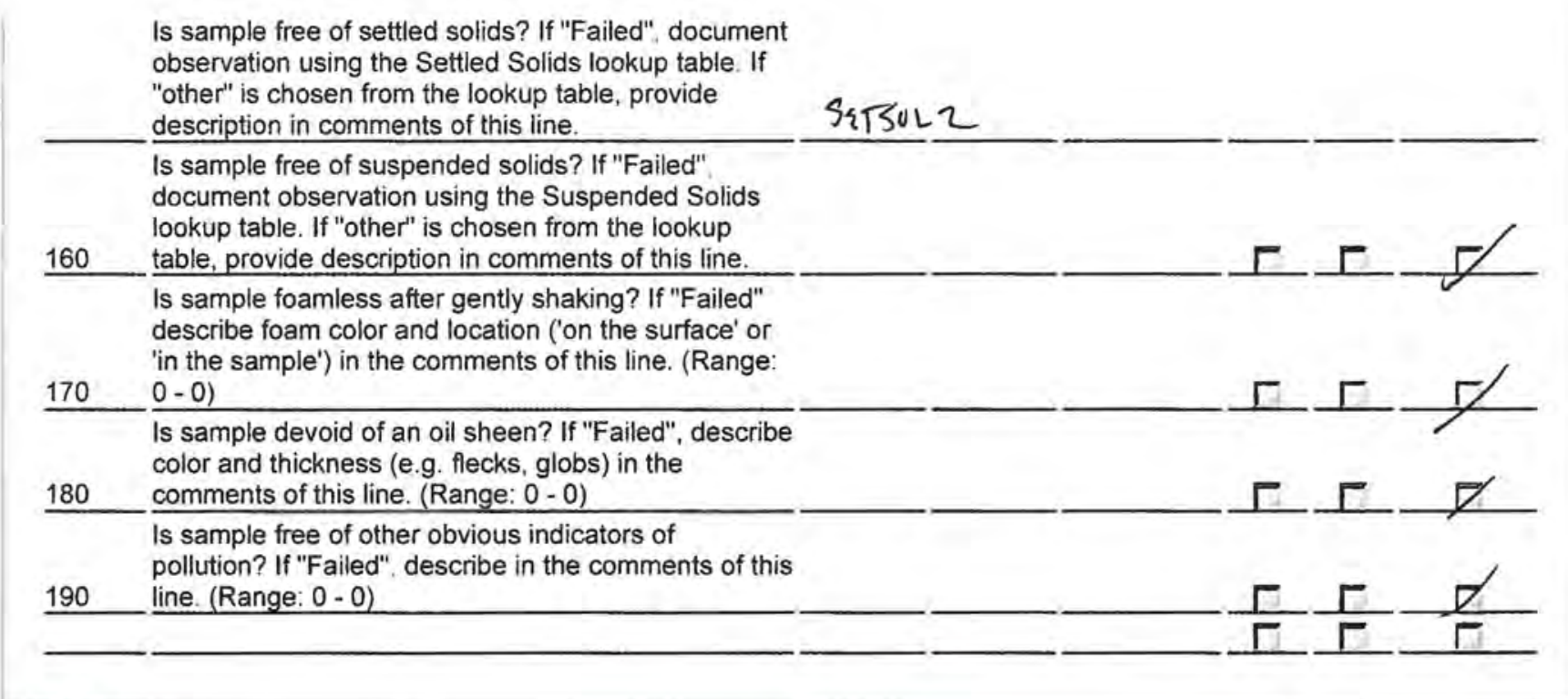

\section{Labor}

\begin{tabular}{llll} 
Labor & Assigned & Work Date & Reg Hrs OTHrs Other Hrs \\
Shendo, Marwin & $9 / 30 / 2016 / 14$ & \\
\hline
\end{tabular}

\section{Labor Report}

Completed:

Failure:

Report: 
wo ID: MSGP-58517 Page 3 of 3

Signature (collecting sample): Ms P L Date and Time: $8 / 24 / 16 \quad 13 / 7$

Signature (conducting visual assessment):_ Pate and Time: $8 / 25 / 16 \quad 1523$

\section{CERTIFICATION STATEMENT}

"I certify under penalty of law that this document and all attachments were prepared under my direction or supervision in accordance with a system designed to assure that qualified personnel properly gathered and evaluated the information submitted. Based on my inquiry of the person or persons who manage the system, or those persons directly responsible for gathering information, the information submitted is, to the best of my knowledge and belief, true, accurate, and complete. I am aware that there are significant penalties for submitting false information, including the possibility of fine and imprisonment for knowing violations".

(Signatory must meet definition in Section B.11.A, eg., FOD, Ops Mgr, DSESH Group Leader, EPC Group Leader)

Print name and title:

Signature:

Date: 


\section{Maintenance Details}

$\begin{array}{llll}\text { Requested: } & \text { 8/31/2016 2:57:53 PM } & \text { Target: } & 9 / 30 / 2016 \\ \text { Procedure: } & \text { MSGP Quarterly Visual } & \text { Priority/Type: Normal/ Inspection } \\ & \text { Assessment (EPC-CP- } & \text { Department: Utilies and } \\ & \text { Form-1021.2) } & & \begin{array}{l}\text { Infrastructure } \\ \text { Last PM: }\end{array} \\ \text { Project: } & \text { SIO Visuals 9/1/16 } & & \\ & \text { (P-MSGP-5114) } & & \end{array}$

Reason: MSGP Quarterly Visual Assessment

Monitoring Period:

Odor:

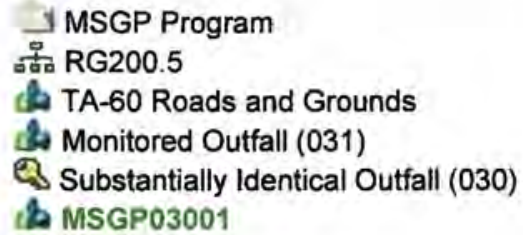

1 MSGP Program

옴 RG200.5

(4) TA-60 Roads and Grounds

Substantially Identical Outfall (030)

is MSGP03001

Contact:

Phone:

Clarity:

Settled Solids:

Suspended Solids:

Special Instructions: NMR053195

Tasks

\# Description

Rating Meas. Initials Failed N/A Complete

The result of this VA applies to associated SIOs as defined in the SWPPP, where applicable.

\section{Sample information}

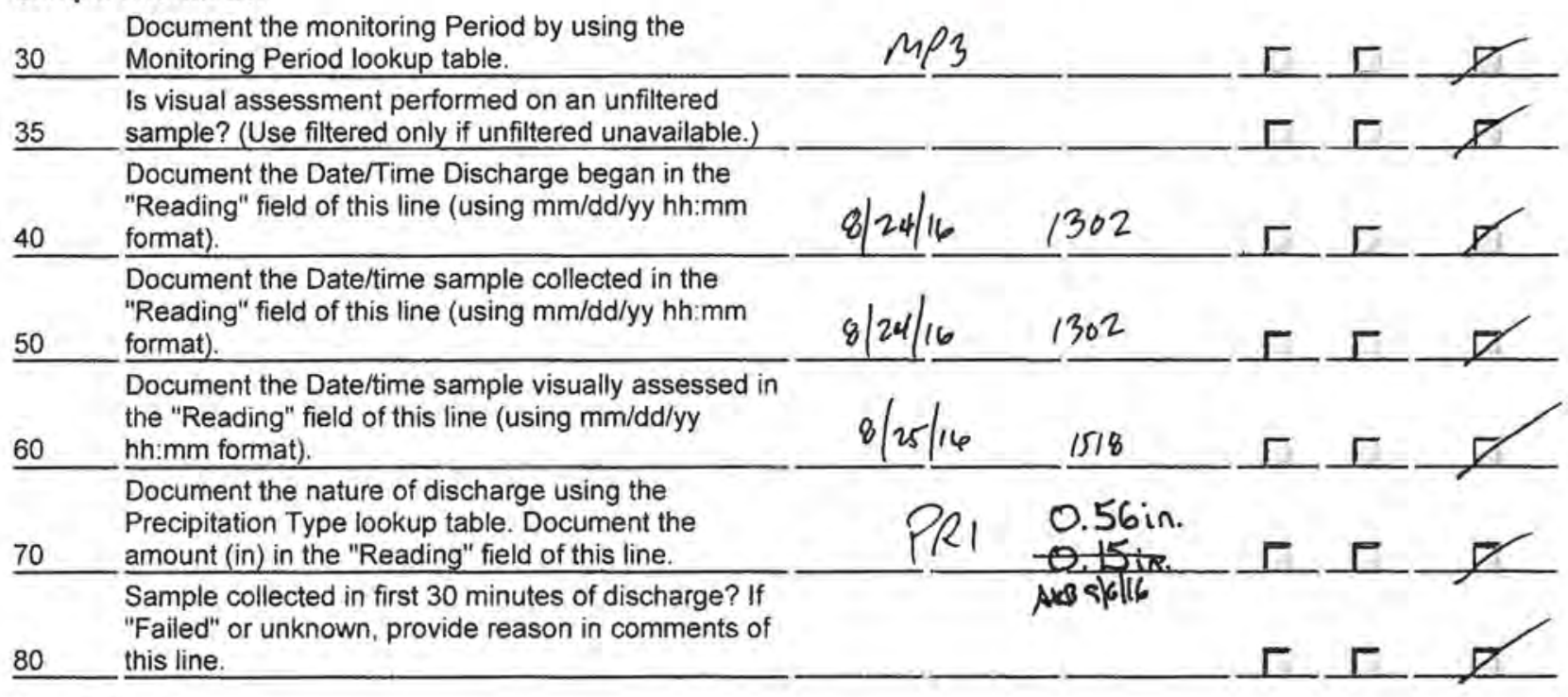

Parameters

110 Is sample colorless? If "Failed", describe. chosen from the lookup table, provide description in comments of this line.

Is sample clear? If "Failed" document observation
using the Clarity lookup table. If "other" is chosen

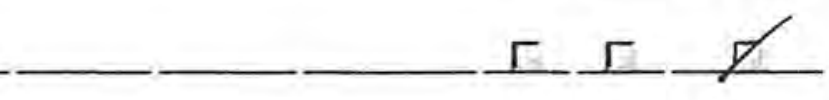

\section{Is sample oderless? If "Failed", document
observation using the Odor lookup table. If "other" is \\ Is sample oderless? If "Failed", document
observation using the Odor lookup table. If "other" is}

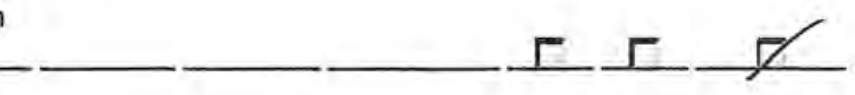

from the lookup table, provide description in

130 comments of this line.

Is sample free of floating solids? If "Failed", describe

if raw or waste material(s) in the comments of this

140 line.

150 
Is sample free of settled solids? If "Failed", document observation using the Settled Solids lookup table. If

"other" is chosen from the lookup table, provide

description in comments of this line.

is sample free of suspended solids? If "Failed"

document observation using the Suspended Solids

lookup table. If "other" is chosen from the lookup

160 table, provide description in comments of this line.

Is sample foamless after gently shaking? If "Failed"

describe foam color and location ('on the surface' or

'in the sample') in the comments of this line. (Range:

$170 \quad 0-0)$

Is sample devoid of an oil sheen? If "Failed", describe color and thickness (e.g. flecks, globs) in the

180 comments of this line. (Range: $0-0$ )

is sample free of other obvious indicators of

pollution? If "Failed", describe in the comments of this

190 line. (Range: 0 - 0)

\section{Labor}

Labor

\section{Labor Report}

Completed:

Failure:

Report: 
Wo ID: MSGP. 58518

Page 3 of 3

Signature (collecting sample): $\quad \mathrm{M} / \mathrm{SL}$ Date and Time: $8 / 24 / 16 \quad 1302$

Signature (conducting visual assessment):

risul

Date and Time: $8 / 25 / 16 \quad 1518$

\section{CERTIFICATION STATEMENT}

"I certify under penalty of law that this document and all attachments were prepared under my direction or supervision in accordance with a system designed to assure that qualified personnel properly gathered and evaluated the information submitted. Based on my inquiry of the person or persons who manage the system, or those persons directly responsible for gathering information, the information submitted is, to the best of my knowledge and belief, true, accurate, and complete. I am aware that there are significant penalties for submitting false information, including the possibility of fine and imprisonment for knowing violations".

(Signatory must meet definition in Section B.11.A, eg., FOD, Ops Mgr, DSESH Group Leader, EPC Group Leader)

Print name and title:

Signature:

Date: 


\section{Maintenance Details}
Requested: 9/8/2016 11:57:21 AM
Procedure: MSGP Quarterly Visual Assessment (EPC-CP- Form-1021.2)

\section{Target: $\quad 9 / 30 / 2016$ \\ Priority/Type: Normal / Inspection \\ Department: Utilities and Infrastructure}

Last PM: $\quad 8 / 25 / 2016$

Project: $\quad$ SIO Visuals $9 / 1 / 16$

(P-MSGP-5114)

\section{MSGP Program \\ 몸 RG200.5 \\ if TA-60 Roads and Grounds \\ ch Monitored Outfall (032) \\ Q. Substantially Identical Outfall (035) \\ th MSGP03501}

Contact:

Phone:

Reason: MSGP Quarterly Visual Assessment

Monitoring Period:

Odor:

Settled Solids:

Clarity:

Suspended Solids:

Special Instructions: NMR053195

\section{Tasks}

\# Description

Rating

Meas.

Initials

Failed N/A Complete

The result of this VA applies to associated SIOs as defined in the SWPPP, where applicable.

Sample information

Document the monitoring Period by using the

$30 \quad$ Monitoring Period lookup table.

Is visual assessment performed on an unfiltered

35 sample? (Use filtered only if unfiltered unavailable.)

Document the Date/Time Discharge began in the "Reading" field of this line (using $\mathrm{mm} / \mathrm{dd} / \mathrm{yy}$ hh:mm

40 format).

Document the Date/time sample collected in the "Reading" field of this line (using $\mathrm{mm} / \mathrm{dd} / \mathrm{yy} \mathrm{hh}: \mathrm{mm}$

$\underline{50}$ format).

Document the Date/time sample visually assessed in

the "Reading" field of this line (using mm/dd/yy

60 hh:mm format).

Document the nature of discharge using the Precipitation Type lookup table. Document the

$70 \quad$ amount (in) in the "Reading" field of this line. Sample collected in first 30 minutes of discharge? If "Failed" or unknown, provide reason in comments of 80 this line.

\section{Parameters}

110 Is sample colorless? If "Failed", describe.

Is sample oderless? If "Failed", document observation using the Odor lookup table. If "other" is chosen from the lookup table, provide description in

120 comments of this line.
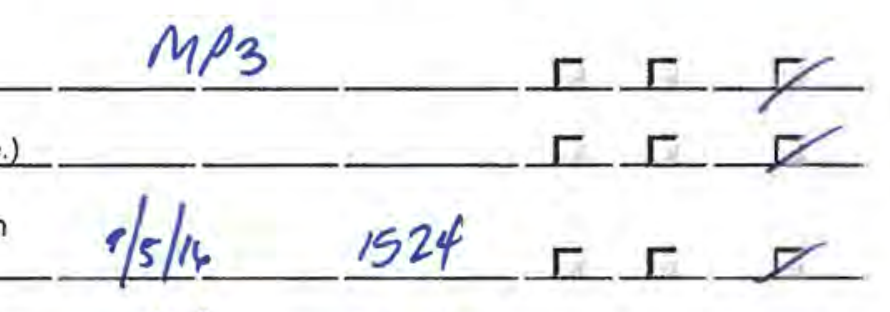
$-1 / 5 / 16$

in

$9 / 5 / 16$

1524

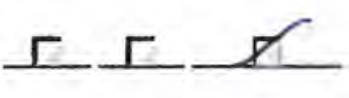

$9 / 7 / 16$

1500

$P R 1$

0.31 in ANB 918 (16

Is sample clear? If "Failed", document observation using the Clarity lookup table. If "other" is chosen from the lookup table, provide description in comments of this line.

Is sample free of floating solids? If "Failed", describe if raw or waste material(s) in the comments of this line.

150

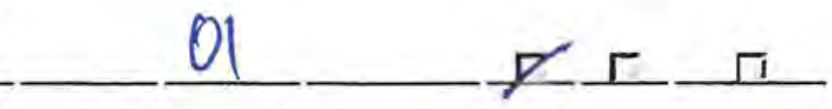


Is sample free of settled solids? If "Failed", document observation using the Settled Solids lookup table. If "other" is chosen from the lookup table, provide description in comments of this line.

\section{SETBOLI}

Is sample free of suspended solids? If "Failed", document observation using the Suspended Solids lookup table. If "other" is chosen from the lookup

160 table, provide description in comments of this line.

Is sample foamless after gently shaking? If "Failed"

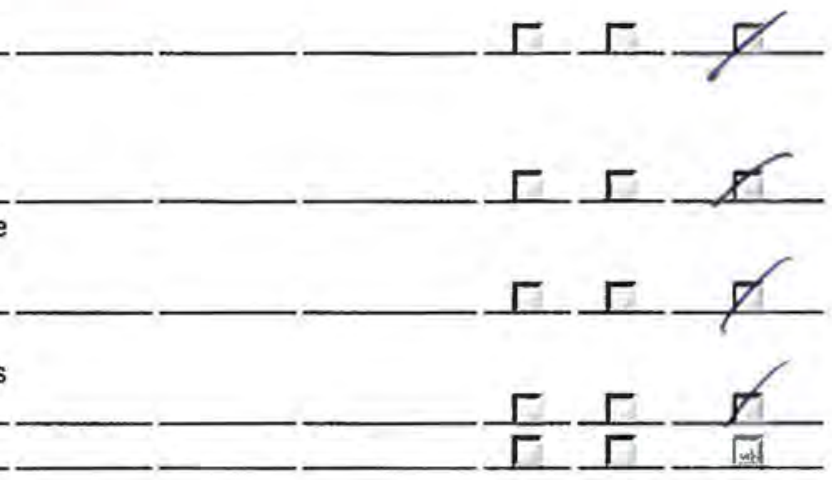

describe foam color and location ('on the surface' or

'in the sample') in the comments of this line. (Range:

170 $0-0$ )

Is sample devoid of an oil sheen? If "Failed", describe color and thickness (e.g. flecks, globs) in the

180 comments of this line. (Range: 0 -0)

Is sample free of other obvious indicators of pollution? If "Failed" describe in the comments of this

190 line. (Range: $0-0$ )

\section{Labor}

\begin{tabular}{lll} 
Labor & Assigned & Work Date \\
Shendo, Marwin & $9 / 30 / 2016 / 14$ \\
\hline
\end{tabular}

\section{Labor Report}

Completed: Failure:

Report: 
Signature (collecting sample):_Late and Time: $\frac{9 / 7 / 16}{1500}$

\section{CERTIFICATION STATEMENT}

"I certify under penalty of law that this document and all attachments were prepared under my direction or supervision in accordance with a system designed to assure that qualified personnel properly gathered and evaluated the information submitted. Based on my inquiry of the person or persons who manage the system, or those persons directly responsible for gathering information, the information submitted is, to the best of my knowledge and belief, true, accurate, and complete. I am aware that there are significant penalties for submitting false information, including the possibility of fine and imprisonment for knowing violations".

(Signatory must meet definition in Section B.11.A, eg., FOD, Ops Mgr, DSESH Group Leader, EPC Group Leader)

Print name and title: 


\section{Maintenance Details}

\begin{tabular}{|c|c|c|c|c|}
\hline \multicolumn{2}{|c|}{ Requested: 9/8/2016 11:57:26 AM } & Target: & $9 / 30 / 2016$ & \multirow{5}{*}{ 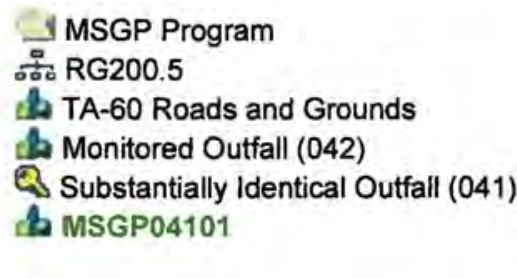 } \\
\hline \multirow{2}{*}{\multicolumn{2}{|c|}{$\begin{aligned} & \text { Procedure: } \text { MSGP Quarterly Visual } \\
& \text { Assessment (EPC-CP- } \\
& \text { Form-1021.2) }\end{aligned}$}} & Priority/Type: & Normal / Inspection & \\
\hline & & Department: & $\begin{array}{l}\text { Utilities and } \\
\text { Infrastructure }\end{array}$ & \\
\hline Last PM: & $8 / 25 / 2016$ & & & \\
\hline Project: & $\begin{array}{l}\text { SIO Visuals 9/1/16 } \\
\text { (P-MSGP-5114) }\end{array}$ & & & \\
\hline Reason: & ISGP Quarterly Visual & nt & & Contact: \\
\hline Monitoring & Period: & Odor: & & \\
\hline
\end{tabular}

Monitoring Period:

Odor:

Clarity:

Settled Solids:

Suspended Solids:

Special Instructions: NMR053195

\section{Tasks}

\# Description

Rating Meas. Initials Failed N/A Complete

The result of this VA applies to associated SIOs as defined in the SWPPP, where applicable.

Sample information

Document the monitoring Period by using the

30 Monitoring Period lookup table.

Is visual assessment performed on an unfiltered

35 sample? (Use filtered only if unfiltered unavailable.)

Document the Date/Time Discharge began in the "Reading" field of this line (using mm/dd/yy hh:mm 40 format).

Document the Date/time sample collected in the

50

"Reading" field of this line (using $\mathrm{mm} / \mathrm{dd} / \mathrm{yy} \mathrm{hh}: \mathrm{mm}$ format).

Document the Date/time sample visually assessed in the "Reading" field of this line (using $\mathrm{mm} / \mathrm{dd} / \mathrm{yy}$

60 hh:mm format)

Document the nature of discharge using the

Precipitation Type lookup table. Document the

70 amount (in) in the "Reading" field of this line.

Sample collected in first 30 minutes of discharge? If

"Failed" or unknown, provide reason in comments of 80 this line.

Parameters

110 Is sample colorless? If "Failed", describe.

Is sample oderless? If "Failed", document observation using the Odor lookup table. If "other" is chosen from the lookup table, provide description in comments of this line.

Is sample clear? If "Failed" document observation

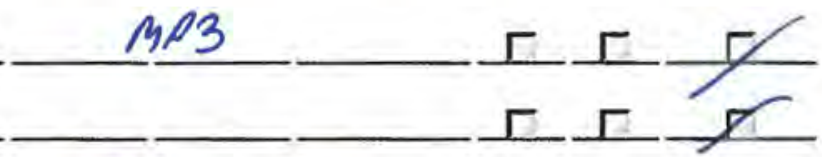
using the Clarity lookup table. If "other" is chosen from the lookup table, provide description in comments of this line.

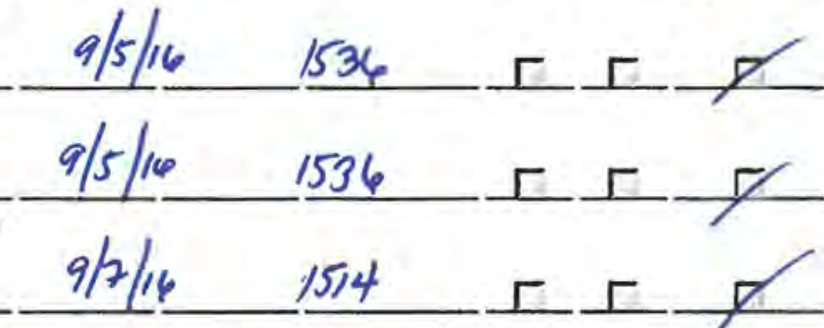

is sample free of floating solids? If "Failed", describe

if raw or waste material(s) in the comments of this

140 line.

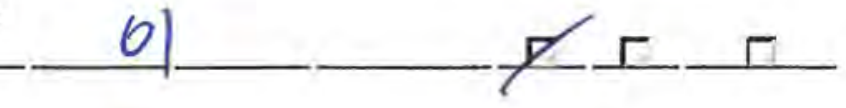

0.31 in $\operatorname{mag} 91816$
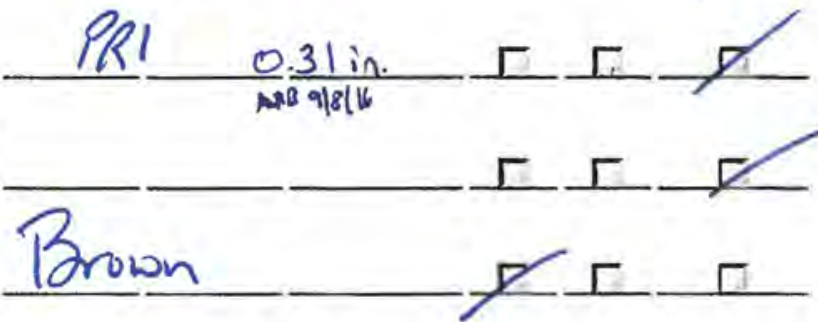
(1)

C3

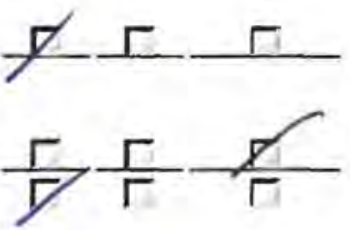


Is sample free of settled solids? If "Failed", document observation using the Settled Solids lookup table. If

"other" is chosen from the lookup table, provide description in comments of this line.

SqSTOLI

Is sample free of suspended solids? If "Failed". document observation using the Suspended Solids lookup table. If "other" is chosen from the lookup table, provide description in comments of this line. Is sample foamless after gently shaking? If "Failed" $\Gamma \Gamma-\Gamma$ describe foam color and location ('on the surface' or 'in the sample') in the comments of this line. (Range:

170 0 - 0)

Is sample devoid of an oil sheen? If "Failed" describe color and thickness (e.g. flecks, globs) in the

180 comments of this line. (Range: 0 - 0 )

Is sample free of other obvious indicators of pollution? If "Failed", describe in the comments of this

190 line. (Range: $0-0$ )

\section{- Labor}

Labor

Assigned

Work Date

Reg Hrs OTHrs Other Hrs

Shendo, Marwin $9 / 30 / 2016 / 14$

\section{Labor Report}

Completed: Failure:

Report: 
Signature (collecting sample):

Signature (conducting visual assessment)

\section{CERTIFICATION STATEMENT}

"I certify under penalty of law that this document and all attachments were prepared under my direction or supervision in accordance with a system designed to assure that qualified personnel properly gathered and evaluated the information submitted. Based on my inquiry of the person or persons who manage the system, or those persons directly responsible for gathering information, the information submitted is, to the best of my knowledge and belief, true, accurate, and complete. I am aware that there are significant penalties for submitting false information, including the possibility of fine and imprisonment for knowing violations".

(Signatory must meet definition in Section B.11.A, eg., FOD, Ops Mgr, DSESH Group Leader, EPC Group Leader)

Print name and title:

Signature: Date: 


\section{Maintenance Details}
Requested: 9/8/2016 11:57:26 AM
Procedure: MSGP Quarterly Visual Assessment (EPC-CP. Form-1021.2)
Target:
$9 / 30 / 2016$
Priority/Type: Normal / Inspection
Department: Utilities and Infrastructure

Last PM: $\quad 8 / 25 / 2016$

Project: $\quad$ SIO Visuals 9/1/16

(P-MSGP-5114)

\section{MSGP Program 함 RG200.5 \\ 14. TA-60 Roads and Grounds Monitored Outfall (039) \\ Substantially Identical Outfall (038) d. MSGP03801}

Reason: MSGP Quarterly Visual Assessment

Monitoring Period:

Odor:
Contact:

Phone:

Clarity:

Settled Solids:

Suspended Solids:

Special Instructions: NMR053195

\section{Tasks}

\# Description

Rating Meas. Initials Failed N/A Complete

The result of this VA applies to associated SIOs as defined in the SWPPP, where applicable.

\section{Sample information}

Document the monitoring Period by using the

30 Monitoring Period lookup table.

Is visual assessment performed on an unfiltered

$35 \quad$ sample? (Use filtered only if unfiltered unavailable.)

Document the Date/Time Discharge began in the "Reading" field of this line (using mm/dd/yy hh:mm 40 format)

Document the Date/time sample collected in the "Reading" field of this line (using mm/dd/yy hh:mm 50 format) Document the Date/time sample visually assessed in the "Reading" field of this line (using $\mathrm{mm} / \mathrm{dd} / \mathrm{yy}$

60 hh:mm format).

Document the nature of discharge using the Precipitation Type lookup table. Document the

70 amount (in) in the "Reading" field of this line.

Sample collected in first 30 minutes of discharge? If

"Failed" or unknown, provide reason in comments of

80 this line.

Parameters

110 Is sample colorless? If "Failed", describe.

Is sample oderless? If "Failed", document observation using the Odor lookup table. If "other" is chosen from the lookup table, provide description in comments of this line.

Is sample clear? If "Failed", document observation using the Clarity lookup table. If "other" is chosen from the lookup table, provide description in comments of this line.

Is sample free of floating solids? If "Failed" describe

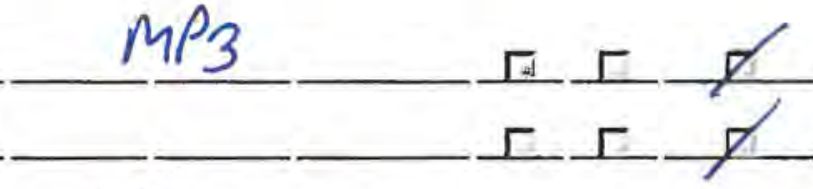

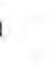

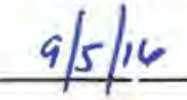

1517<smiles>CCC(C)CC1CC1</smiles>
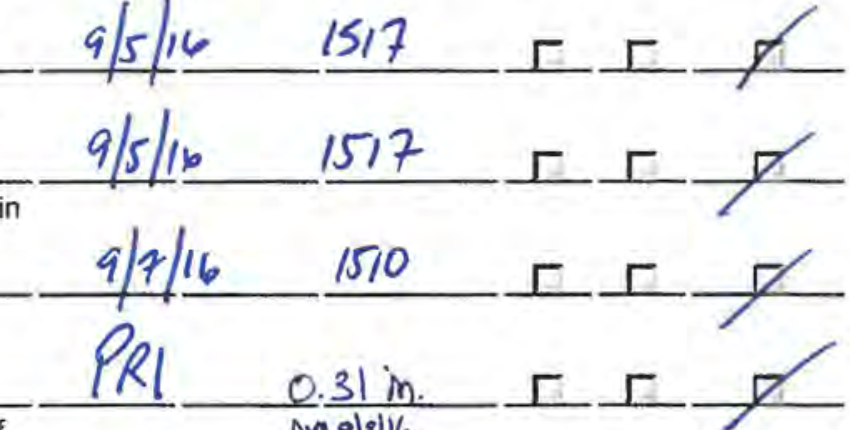
if raw or waste material(s) in the comments of this 140 line.
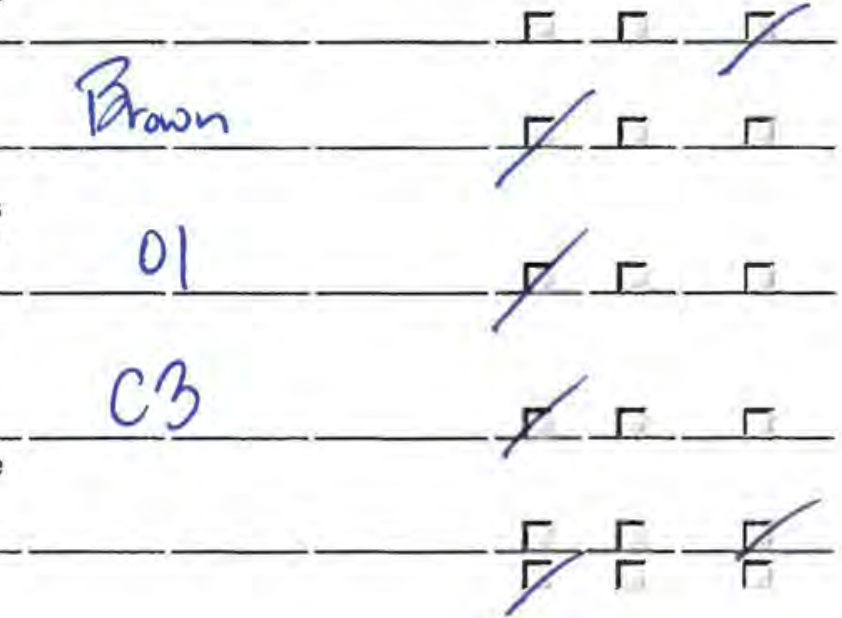
Is sample free of settled solids? If "Failed" document observation using the Settled Solids lookup table. If "other" is chosen from the lookup table. provide description in comments of this line.

\section{SETSOL}

Is sample free of suspended solids? If "Failed"

document observation using the Suspended Solids

lookup table. If "other" is chosen from the lookup

160

table, provide description in comments of this line.

Is sample foamless after gently shaking? If "Failed"

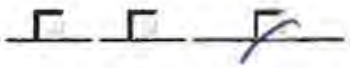

describe foam color and location ('on the surface' or

'in the sample') in the comments of this line. (Range.

$170 \quad 0-0)$

Is sample devoid of an oil sheen? If "Failed", describe

color and thickness (e.g. flecks, globs) in the

180 comments of this line. (Range: $0-0$ )

Is sample free of other obvious indicators of

pollution? If "Failed", describe in the comments of this

190 line. (Range: 0 - 0)

\section{Labor}

Labor

Assigned Work Date

Reg Hrs OT Hrs Other Hrs

Shendo, Marwin

9/30/2016/ 14

\section{Labor Report}

Completed: Failure:

Report: 
Signature (collecting sample):

Signature (conducting visual assessment):

\section{CERTIFICATION STATEMENT}

"I certify under penalty of law that this document and all attachments were prepared under my direction or supervision in accordance with a system designed to assure that qualified personnel properly gathered and evaluated the information submitted. Based on my inquiry of the person or persons who manage the system, or those persons directly responsible for gathering information, the information submitted is, to the best of my knowledge and belief, true, accurate, and complete. I am aware that there are significant penalties for submitting false information, including the possibility of fine and imprisonment for knowing violations".

(Signatory must meet definition in Section B.11.A, eg., FOD, Ops Mgr, DSESH Group Leader, EPC Group Leader)

Print name and title: 


\section{Maintenance Details}

Requested: 9/9/2016 10:12:26 AM

Procedure: MSGP Quarterly Visual Assessment (EPC-CPForm-1021.2)

Last PM: $\quad 8 / 25 / 2016$

Project: $\quad$ SIO Visual Assessments 9-8-16 (P-MSGP-5120)

\section{Target: $\quad$ 9/30/2016}

Priority/Type: Normal / Inspection

Department: Utilities and Infrastructure

Reason: MSGP Quarterly Visual Assessment

Monitoring Period:

Odor:

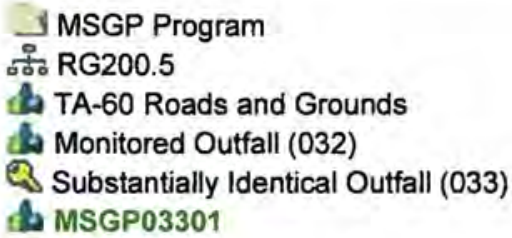

3 MSGP Program

옹 RG200.5

A MSGP03301

Contact:

Phone:

Clarity:

Settled Solids:

Suspended Solids:

Special Instructions: NMR053195

\section{Tasks}

\# Description

Rating Meas. Initials

Failed N/A Complete

The result of this VA applies to associated SIOs as defined in the SWPPP, where applicable.

Sample information

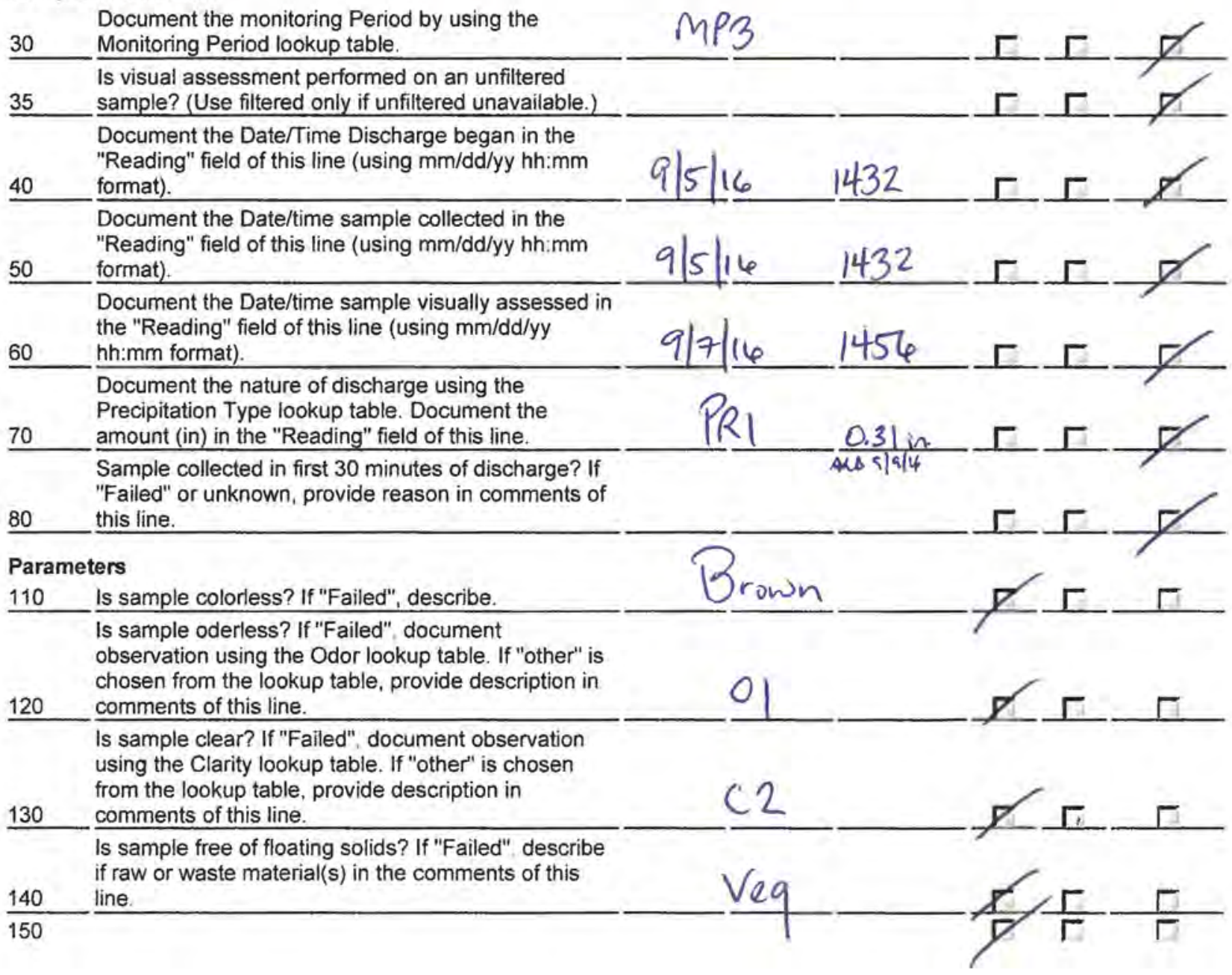


Is sample free of settled solids? If "Failed", document observation using the Settled Solids lookup table. If "other" is chosen from the lookup table, provide description in comments of this line.

SETSOL

Is sample free of suspended solids? If "Failed"

document observation using the Suspended Solids

lookup table. If "other" is chosen from the lookup

160 table, provide description in comments of this line.

Is sample foamless after gently shaking? If "Failed"

SnSSOL2

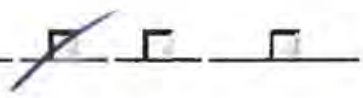
describe foam color and location ('on the surface' or

$170 \quad 0-0)$ 'in the sample') in the comments of this line. (Range:

is sample devoid of an oil sheen? If "Failed", describe color and thickness (e.g. flecks, globs) in the

180 comments of this line. (Range: $0-0$ )

Is sample free of other obvious indicators of pollution? If "Failed", describe in the comments of this

190 line. (Range: $0-0$ )

\section{- Labor}

Labor

Assigned Work Date

Reg Hrs OT Hrs Other Hrs

Shendo, Marwin

9/30/2016/ 14

\section{Labor Report}

Completed: Failure:

Report: 
WO ID: MSGP.58552 Page 3 of 3

Signature (collecting sample): $\quad R / 5 / \Omega . \quad$ Date and Time: $9 / 7 / 16 \quad 14 \Omega$

Signature (conducting visual assessment): $\quad$ Date and Time: $9 / 7 / 16 \quad 1456$

\section{CERTIFICATION STATEMENT}

"I certify under penalty of law that this document and all attachments were prepared under my direction or supervision in accordance with a system designed to assure that qualified personnel properly gathered and evaluated the information submitted. Based on my inquiry of the person or persons who manage the system, or those persons directly responsible for gathering information, the information submitted is, to the best of my knowledge and belief, true, accurate, and complete. I am aware that there are significant penalties for submitting false information, including the possibility of fine and imprisonment for knowing violations".

(Signatory must meet definition in Section B.11.A, eg., FOD, Ops Mgr, DSESH Group Leader, EPC Group Leader)

Print name and title:

Signature:

Date: 


\section{Maintenance Details}

$\begin{array}{cll}\text { Requested: } 9 / 9 / 2016 \text { 10:12:27 AM } & \text { Target: } & 9 / 30 / 2016 \\ \text { Procedure: MSGP Quarterly Visual } & \text { Priority/Type: Normal / Inspection } \\ \text { Assessment (EPC-CP. } & \text { Department: } & \text { Utilities and } \\ \text { Form-1021.2) } & & \text { Infrastructure }\end{array}$

Last PM: $\quad 8 / 25 / 2016$

Project: SIO Visual Assessments 9-8-16 (P-MSGP-5120)

Reason: MSGP Quarterly Visual Assessment

Monitoring Period:

Odor:

\section{MSGP Program 둠 RG200.5 \\ 16 TA-60 Roads and Grounds da Monitored Outfall (032) \\ Q. Substantially Identical Outfall (034) th MSGP03401}

Contact:

Phone:

Clarity:

Settled Solids:

Suspended Solids:

Special Instructions: NMR053195

\section{Tasks}

\# Description

Rating Meas. Initials Failed N/A Complete

The result of this VA applies to associated SIOs as defined in the SWPPP, where applicable.

Sample information

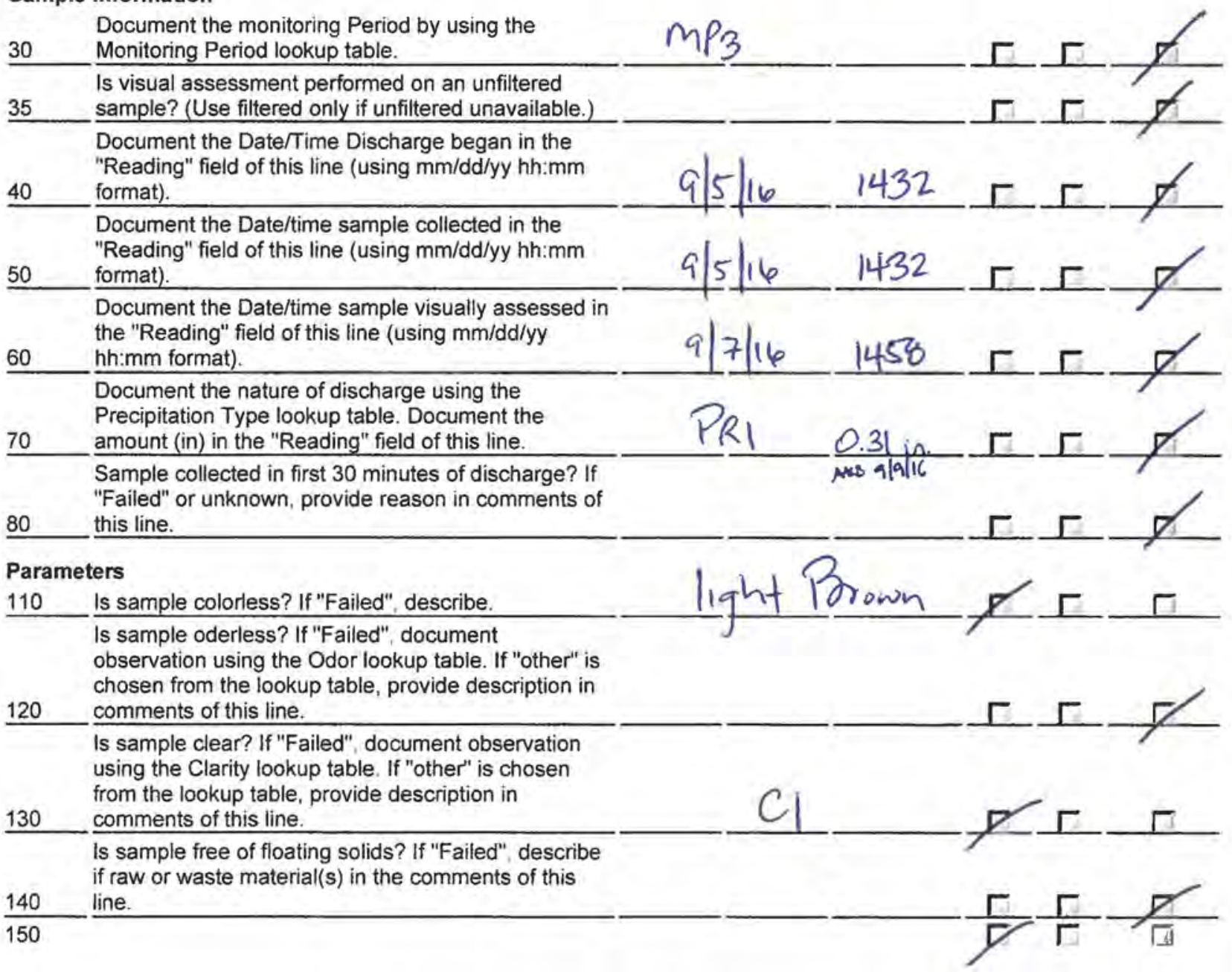


Is sample free of settled solids? If "Failed", document observation using the Settled Solids lookup table. If "other" is chosen from the lookup table, provide description in comments of this line.

SETSOL2

Is sample free of suspended solids? If "Failed", document observation using the Suspended Solids lookup table. If "other" is chosen from the lookup

160 table, provide description in comments of this line.

is sample foamless after gently shaking? If "Failed" describe foam color and location ('on the surface' or

$170 \quad 0-0)$

'in the sample') in the comments of this line. (Range:

Is sample devoid of an oil sheen? If "Failed", describe color and thickness (e.g. flecks, globs) in the

180 comments of this line. (Range: $0-0$ )

Is sample free of other obvious indicators of pollution? If "Failed", describe in the comments of this 190 line. (Range: $0-0$ )

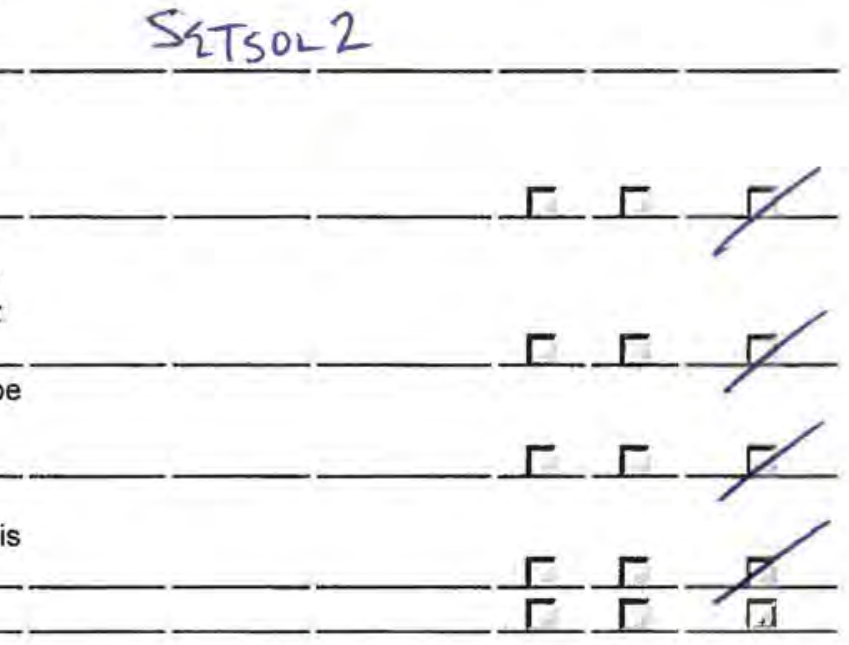

\section{Labor}

Labor

Assigned

Work Date

Reg Hrs OT Hrs Other Hrs

Shendo, Marwin 9/30/2016/14

\section{Labor Report}

Completed: Failure:

Report: 
WO ID: MSGP. $58553 \quad$ Page 3 of 3

Signature (collecting sample):

Psr

Date and Time: $917 / 16 \quad 1458$

Signature (conducting visual assessment):

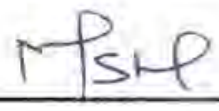

Date and Time: $9 / 7 / 16 \quad 1458$

\section{CERTIFICATION STATEMENT}

"I certify under penalty of law that this document and all attachments were prepared under my direction or supervision in accordance with a system designed to assure that qualified personnel properly gathered and evaluated the information submitted. Based on my inquiry of the person or persons who manage the system, or those persons directly responsible for gathering information, the information submitted is, to the best of my knowledge and belief, true, accurate, and complete. I am aware that there are significant penalties for submitting false information, including the possibility of fine and imprisonment for knowing violations".

(Signatory must meet definition in Section B.11.A, eg., FOD, Ops Mgr, DSESH Group Leader, EPC Group Leader)

Print name and title:

Signature: Date: 


\section{Maintenance Details}
Requested: 9/9/2016 10:12:28 AM
Procedure: MSGP Quarterly Visual Assessment (EPC-CP. Form-1021,2)
Target: $\quad 9 / 30 / 2016$
Priority/Type: Normal / Inspection
Department: Utilities and Infrastructure

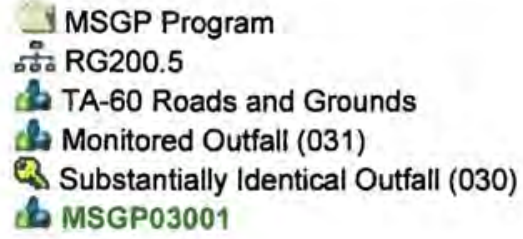

MSGP Program

范 RG200.5

6. TA-60 Roads and Grounds

Substantially Identical Outfall (030)

MSGP03001

Contact:

Phone:
Reason: MSGP Quarterly Visual Assessment

Monitoring Period:

Odor:

Clarity:

Suspended Solids:

Special Instructions: NMR053195
Settled Solids:

\section{Tasks}

\# Description

Rating Meas. Initials Failed N/A Complete

The result of this VA applies to associated SIOs as defined in the SWPPP, where applicable.

Sample information

Document the monitoring Period by using the

30 Monitoring Period lookup table.

Is visual assessment performed on an unfiltered

35 sample? (Use filtered only if unfiltered unavailable.)

Document the Date/Time Discharge began in the

"Reading" field of this line (using mm/dd/yy hh:mm

40 format).

Document the Date/time sample collected in the

"Reading" field of this line (using $\mathrm{mm} / \mathrm{dd} / \mathrm{yy} \mathrm{hh}: \mathrm{mm}$

50 format).

Document the Date/time sample visually assessed in the "Reading" field of this line (using $\mathrm{mm} / \mathrm{dd} / \mathrm{yy}$

60 hh:mm format).

Document the nature of discharge using the Precipitation Type lookup table. Document the

70 amount (in) in the "Reading" field of this line.

Sample collected in first 30 minutes of discharge? If

"Failed" or unknown, provide reason in comments of 80 this line.

\section{Parameters}

110 Is sample colorless? If "Failed", describe.

Is sample oderless? If "Failed", document observation using the Odor lookup table. If "other" is chosen from the lookup table, provide description in

120 comments of this line.

Is sample clear? If "Failed", document observation using the Clarity lookup table. If "other" is chosen

from the lookup table, provide description in comments of this line.

Is sample free of floating solids? If "Failed", describe

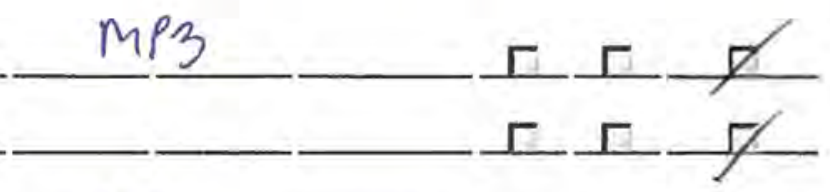

$9 / 516$

1432

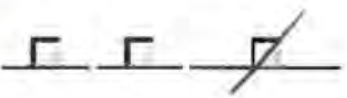

$9 / 5116$

1432
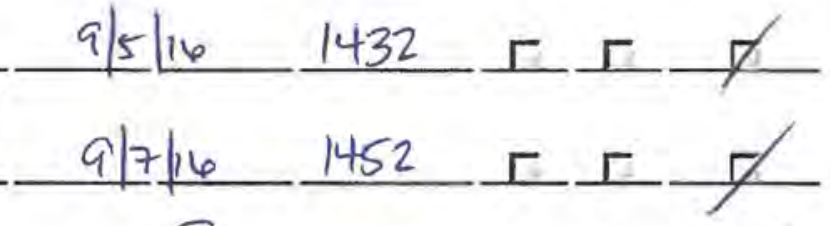

if raw or waste material(s) in the comments of this

140 line.

150
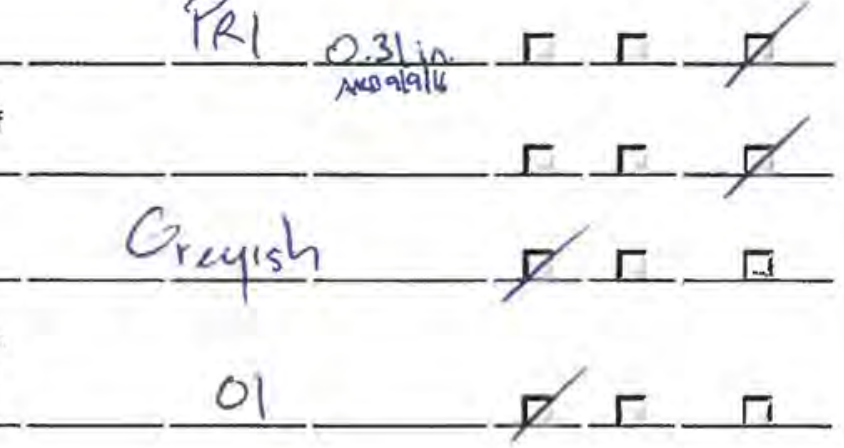

.

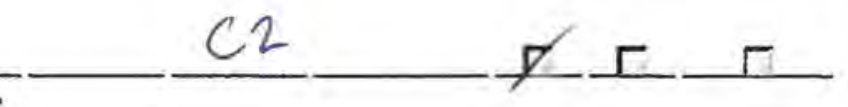


Is sample free of settled solids? If "Failed", document observation using the Settled Solids lookup table. If "other" is chosen from the lookup table, provide description in comments of this line.

SqTSOL

Is sample free of suspended solids? If "Failed",

document observation using the Suspended Solids

lookup table. If "other" is chosen from the lookup

160 table, provide description in comments of this line.

Is sample foamless after gently shaking? If "Failed" describe foam color and location ('on the surface' or 'in the sample') in the comments of this line. (Range:

$170 \quad 0-0)$

Is sample devoid of an oil sheen? If "Failed" describe color and thickness (e.g. flecks, globs) in the

180 comments of this line. (Range: $0-0$ )

is sample free of other obvious indicators of pollution? If "Failed", describe in the comments of this

190 line. (Range: 0 -0)

\section{Labor}

Labor

Shendo, Marwin 9/30/2016/ 14

\section{Labor Report}

Completed: Failure:

Report: 
Wo ID: MSGP.58554 Page 3 of 3

Signature (collecting sample): $\quad$ Date and Time: $9 / 7 / 16 \quad 1452$

Signature (conducting visual assessment): $\quad$ Date and Time: $9 / 7 / 16 \quad 1452$

\section{CERTIFICATION STATEMENT}

"I certify under penalty of law that this document and all attachments were prepared under my direction or supervision in accordance with a system designed to assure that qualified personnel properly gathered and evaluated the information submitted. Based on my inquiry of the person or persons who manage the system, or those persons directly responsible for gathering information, the information submitted is, to the best of my knowledge and belief, true, accurate, and complete. I am aware that there are significant penalties for submitting false information, including the possibility of fine and imprisonment for knowing violations".

(Signatory must meet definition in Section B.11.A, eg., FOD, Ops Mgr, DSESH Group Leader, EPC Group Leader)

Print name and title:

Signature: Date: 


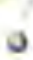

memorandum

Environmental Protection \& Compliance Division Compliance Programs (EPC-CP)
To/MS: Leonard Sandoval, DESHS-UIS, P908

Thru/MS: Terrill Lemke, EPC-CP, (E-File) שc

From/MS: Holly Wheeler, EPC-CP, (E-File) W( )

Phone/Fax: 667-1312

Symbol: EPC-DO:17-061

\section{Subject: National Pollutant Discharge Elimination System (NPDES) Permit No. NMR053195, Multi-Sector General Permit (MSGP) Quarterly Visual Assessment (QVA) Forms for October and November of 2016 for TA-60 Roads and Grounds}

Please find attached completed MSGP QVA Forms documenting visual assessments performed during the fourth quarter of monitoring at TA-60 Roads and Grounds. Pursuant to Parts 3.2.2 and 5.5 of the 2015 MSGP, this memorandum along with all of the attached QVA forms shall be incorporated into your MSGP Storm Water Pollution Prevention Plan (SWPPP).

Part 3.2.1 of the 2015 MSGP requires the visual assessment of storm water discharge samples collected from each outfall once each quarter for the entire permit term. Part 3.2.3 allows facilities that are located in an area with a semi-arid climate and/or in an area where freezing conditions exist for an extended period to distribute the quarterly visual assessments during seasons when precipitation runoff occurs. Accordingly, Los Alamos National Security, LLC (LANS) has designated the following MSGP monitoring quarters.
Quarter 1: $\quad$ April - May
Quarter 2: June - July
Quarter 3: $\quad$ August - September
Quarter 4: October - November

The attached QVA forms document the following information as required by Part 3.2 .2 of the 2015 MSGP.

- Sample location;

- Sample collection date and time, and visual assessment date and time for each sample;

- Personnel collecting the sample and performing the visual assessment, and their signatures;

- Nature of the discharge (i.e., runoff or snowmelt);

- Results of observations of the stormwater discharge;

- Probable sources of any observed stormwater contamination (if applicable);

- If applicable, why it was not possible to take a sample within the first 30 minutes of the storm event.

The signed certification statement contained in this memorandum satisfies the duly authorized signatory requirement for the QVAs completed by EPC-CP representatives contained in Enclosure 1. 
I certify under penalty of law that this document and all attachments were prepared under my direction or supervision in accordance with a system designed to assure that qualified personnel properly gathered and evaluated the information contained therein. Based on my inquiry of the person or persons who manage the system, or those persons directly responsible for gathering the information, the information contained is, to the best of my knowledge and belief, true, accurate, and complete. I am aware that there are significant penalties for submitting false information, including the possibility of fine and imprisonment for knowing violations.

\section{Anthony R. Grieggs, EPC-CP Group Leader}

(Print name and title)

Los Alamos National Laboratory
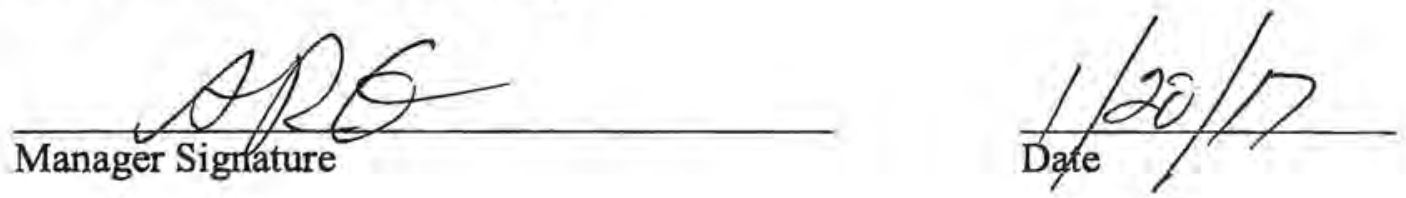

Part 3.2.3 of the 2015 MSGP allows the facility to take a substitute sample during the next qualifying storm event when adverse weather conditions prevent the collection of samples during a specific quarter. Adverse weather conditions are those that are dangerous or create inaccessibility for personnel, or situations that otherwise make sampling impractical, such as drought or extended frozen conditions. Documentation of the rationale for no visual assessment for the quarter must be included in the facility-specific SWPPP.

Please contact Holly Wheeler at 667-1312 (hbenson@lanl.gov) if you have questions regarding the QVA documentation. Thank you for your assistance in meeting the requirements of the Laboratory's NPDES 2015 MSGP Permit.

TWL:HLW/am 
Enclosure: 1. Quarterly Visual Assessment Forms Requiring a Certification Statement Signature, Fourth Quarter, 2016 Monitoring Year

\begin{tabular}{|l|l|l|}
\hline Facility Name & Sampling Station & Work Order \# \\
\hline TA-60 Roads and Grounds & MSGP03401 & MSGP-58624 \\
\hline TA-60 Roads and Grounds & MSGP03501 & MSGP-58625 \\
\hline TA-60 Roads and Grounds & MSGP03001 & MSGP-58626 \\
\hline TA-60 Roads and Grounds & MSGP04101 & MSGP-58627 \\
\hline TA-60 Roads and Grounds & MSGP03201 & MSGP-58867 \\
\hline TA-60 Roads and Grounds & MSGP04201 & MSGP-58869 \\
\hline TA-60 Roads and Grounds & MSGP03301 & MSGP-59011 \\
\hline TA-60 Roads and Grounds & MSGP03301 & MSGP-59364 \\
\hline TA-60 Roads and Grounds & MSGP03401 & MSGP-59365 \\
\hline TA-60 Roads and Grounds & MSGP03501 & MSGP-59366 \\
\hline TA-60 Roads and Grounds & MSGP03001 & MSGP-59367 \\
\hline TA-60 Roads and Grounds & MSGP04101 & MSGP-59368 \\
\hline
\end{tabular}

Copy: Russell Stone, DESHS-UIS, (E-File)

Adesh-records@lanl.gov, (E-File)

lasomailbox@nnsa.doe.gov, (E-File)

locatesteam@lanl.gov, (E-File)

epc-correspondence@lanl.gov, (E-File)

Holly Wheeler, EPC-CP, (E-File) 


\title{
ENCLOSURE 1
}

Quarterly Visual Assessment Forms Requiring a Certification Statement Signature Fourth Quarter, 2016 Monitoring Year

\author{
EPC-DO:17-061
}

JAN 202017

Date: 
Maintenance Details

$$
\begin{aligned}
\text { Requested: } & \text { 9/12/2016 11:52:00 AM } \\
\text { Procedure: } & \text { MSGP Quarterly Visual } \\
& \text { Assessment (EPC Sig) } \\
& \text { (EPC-CP-Form-1021.2 A) }
\end{aligned}
$$

Last PM: 9/22/2016

Project: SIO Visual Assess. OctNov 2016 (P-MSGP-5138)

Reason: MSGP Quarterly Visual Assessment

Precipitation Type: PR1

Clarity: NA

Odor: NA

\section{Target: \\ $11 / 30 / 2016$}

Priority/Type: Normal / Inspection

Department: Utilities and Infrastructure
Suspended Solids: NA

Special Instructions: NMR053195

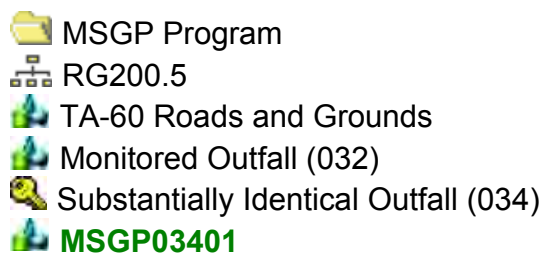

Contact:

Phone:

\section{Tasks}

\# Description

Rating Meas. Initials Failed N/A Complete

The result of this VA applies to associated SIOs as defined in the SWPPP, where applicable.

\section{Sample information}

Document the monitoring Period by using the

30 Monitoring Period lookup table.

Is visual assessment performed on an unfiltered

35 sample? (Use filtered only if unfiltered unavailable.)

Document the Date/Time Discharge began in the

"Reading" field of this line (using mm/dd/yy hh:mm

40 format).

Document the Date/time sample collected in the

$\underline{50}$

"Reading" field of this line (using mm/dd/yy hh:mm format).

Document the Date/time sample visually assessed in

60 format).

the "Reading" field of this line (using mm/dd/yy hh:mm

Document the nature of discharge using the

Precipitation Type lookup table. Document the amount

$70 \quad$ (in) in the "Reading" field of this line.

\begin{tabular}{|c|c|c|c|c|}
\hline & MS & $\Gamma$ & $\Gamma$ & {$[\mathrm{C}$} \\
\hline & MS & $\Gamma$ & $\Gamma$ & {$[/$} \\
\hline $\begin{array}{r}11 / 4 / 16 \\
\text { at } 15: 09\end{array}$ & MS & $\Gamma$ & $\Gamma$ & {$[/$} \\
\hline $\begin{array}{r}11 / 4 / 16 \\
\text { at } 15: 09 \\
\end{array}$ & MS & $\Gamma$ & $\Gamma$ & {[} \\
\hline $\begin{array}{r}11 / 8 / 16 \\
\text { at } 14: 32\end{array}$ & MS & $\Gamma$ & $\Gamma$ & {[} \\
\hline $\begin{array}{c}.67 \\
\text { inches } \\
\end{array}$ & MS & Г & Г & {$[\mathrm{C}$} \\
\hline & MS & $\Gamma$ & $\Gamma$ & {$[C$} \\
\hline
\end{tabular}

Sample collected in first 30 minutes of discharge? If

"Failed" or unknown, provide reason in comments of

80 this line.

Parameters

110 Is sample colorless? If "Failed", describe.

MS

Is sample oderless? If "Failed", document observation using the Odor lookup table. If "other" is chosen from the lookup table, provide description in comments of

120 this line.

Is sample clear? If "Failed", document observation using the Clarity lookup table. If "other" is chosen from the lookup table, provide description in comments of

130 this line.

Is sample free of floating solids? If "Failed", describe if

140 raw or waste material(s) in the comments of this line.

150 Is sample free of settled solids? If "Failed", document observation using the Settled Solids lookup table. If

$-$

MS

MS 
"other" is chosen from the lookup table, provide description in comments of this line.

Is sample free of suspended solids? If "Failed", document observation using the Suspended Solids lookup table. If "other" is chosen from the lookup

160 table, provide description in comments of this line. Is sample foamless after gently shaking? If "Failed" describe foam color and location ('on the surface' or 'in the sample') in the comments of this line. (Range: 0

170 $-0)$

Is sample devoid of an oil sheen? If "Failed", describe color and thickness (e.g. flecks, globs) in the

180 comments of this line. (Range: 0 - 0)

Is sample free of other obvious indicators of pollution? If "Failed", describe in the comments of this line. (Range: 0 - 0)

MS

MS MS

MS

\section{-Labor Report}

Completed: 11/8/2016 2:32:00 PM Failure:

Report:

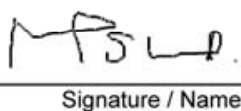

$11 / 14 / 2016$

Date

Signature / Name 
WO ID

Page of

Date: Time:

Name/Z\#:

Signature (collecting sample \& conducting visual assessment):

"I confirm the information as recorded is true, accurate and complete."

\section{CERTIFICATION STATEMENT}

"I certify under penalty of law that this document and all attachments were prepared under my direction or supervision in accordance with a system designed to assure that qualified personnel properly gathered and evaluated the information submitted. Based on my inquiry of the person or persons who manage the system, or those persons directly responsible for gathering information, the information submitted is, to the best of my knowledge and belief, true, accurate, and complete. I am aware that there are significant penalties for submitting false information, including the possibility of fine and imprisonment for knowing violations".

(Signatory must meet definition in Section B.11.A, eg., FOD, Ops Mgr, DSESH Group Leader, EPC Group Leader)

Print name and title: Anthony R. Grieggs, EPC-CP Group Leader

Signature:__ (See signature on file) Date: 
-Maintenance Details

\author{
Requested: 9/12/2016 11:52:00 AM \\ Procedure: MSGP Quarterly Visual \\ Assessment (EPC Sig) \\ (EPC-CP-Form-1021.2 A) \\ Last PM: $\quad$ 9/22/2016
}

Project: $\quad$ SIO Visual Assess. OctNov 2016 (P-MSGP-5138)
Target:
$11 / 30 / 2016$
Priority/Type: Normal / Inspection
Department: Utilities and Infrastructure

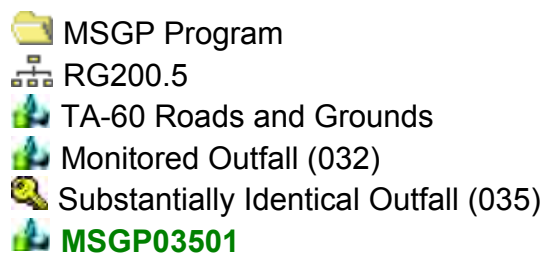

Reason: MSGP Quarterly Visual Assessment

Precipitation Type: PR1

Odor: 01

Contact:

Phone:

Clarity: C1

Settled Solids: SETSOL2

Suspended Solids: SUSSOL2

Special Instructions: NMR053195

\section{Tasks}

\# Description

Rating Meas.

Initials

Failed N/A Complete

The result of this VA applies to associated SIOs as defined in the SWPPP, where applicable.

Sample information

Document the monitoring Period by using the

$30 \quad$ Monitoring Period lookup table.

Is visual assessment performed on an unfiltered

MS sample? (Use filtered only if unfiltered

35 unavailable.)

Document the Date/Time Discharge began in the "Reading" field of this line (using $\mathrm{mm} / \mathrm{dd} / \mathrm{yy}$

40 hh:mm format).

Document the Date/time sample collected in the

"Reading" field of this line (using mm/dd/yy

50 hh:mm format).

Document the Date/time sample visually assessed in the "Reading" field of this line (using

60 $\mathrm{mm} / \mathrm{dd} / \mathrm{yy} \mathrm{hh:mm} \mathrm{format).}$

Document the nature of discharge using the

Precipitation Type lookup table. Document the

$70 \quad$ amount (in) in the "Reading" field of this line.

Sample collected in first 30 minutes of discharge?

If "Failed" or unknown, provide reason in

80 comments of this line.

\begin{tabular}{|c|c|c|c|c|}
\hline & MS & $\Gamma$ & $\Gamma$ & $C$ \\
\hline & MS & $\Gamma$ & $\Gamma$ & $\Gamma$ \\
\hline $\begin{array}{c}11 / 4 / 16 \text { at } \\
15: 40 \text { rain } \\
\text { data }\end{array}$ & MS & $\Gamma$ & $\Gamma$ & 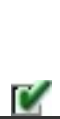 \\
\hline $\begin{array}{c}\text { 11/4/16 at } \\
\text { 15:40 rain } \\
\text { data }\end{array}$ & MS & $\Gamma$ & $\Gamma$ & 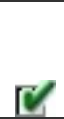 \\
\hline $\begin{array}{c}11 / 8 / 16 \text { at } \\
14: 34\end{array}$ & MS & $\Gamma$ & Г & $\Gamma$ \\
\hline .67 inches & MS & $\Gamma$ & Г & $\Gamma$ \\
\hline & MS & $\Gamma$ & $\Gamma$ & $\Gamma$ \\
\hline
\end{tabular}

Parameters

110 Is sample colorless? If "Failed", describe.

brown

MS

[?

Is sample oderless? If "Failed", document observation using the Odor lookup table. If "other"

is chosen from the lookup table, provide

120 description in comments of this line.

MS

Is sample clear? If "Failed", document

observation using the Clarity lookup table. If

"other" is chosen from the lookup table, provide

130 description in comments of this line.

MS

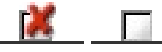

Is sample free of floating solids? If "Failed",

describe if raw or waste material(s) in the 
150 Is sample free of settled solids? If "Failed",

MS

document observation using the Settled Solids lookup table. If "other" is chosen from the lookup table, provide description in comments of this line.

Is sample free of suspended solids? If "Failed", document observation using the Suspended Solids lookup table. If "other" is chosen from the lookup table, provide description in comments of this line.

Is sample foamless after gently shaking? If

"Failed" describe foam color and location ('on the surface' or 'in the sample') in the comments of

170 this line. (Range: 0 - 0)

Is sample devoid of an oil sheen? If "Failed", describe color and thickness (e.g. flecks, globs) in

180 the comments of this line. (Range: 0 - 0 )

Is sample free of other obvious indicators of pollution? If "Failed", describe in the comments of this line. (Range: 0 - 0)

MS

[K

MS

MS

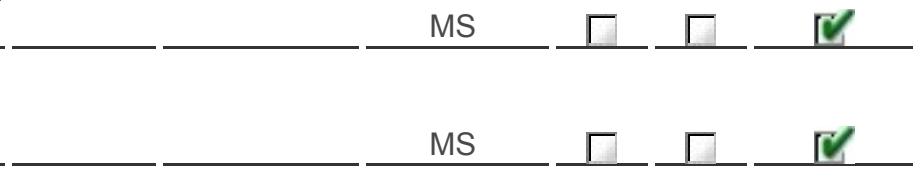

\section{Labor Report}

Completed: 11/8/2016 2:34:00 PM Failure:

Report:

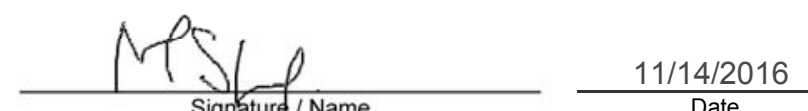


WO ID

Page of

Date: Time:

Name/Z\#:

Signature (collecting sample \& conducting visual assessment):

"I confirm the information as recorded is true, accurate and complete."

\section{CERTIFICATION STATEMENT}

"I certify under penalty of law that this document and all attachments were prepared under my direction or supervision in accordance with a system designed to assure that qualified personnel properly gathered and evaluated the information submitted. Based on my inquiry of the person or persons who manage the system, or those persons directly responsible for gathering information, the information submitted is, to the best of my knowledge and belief, true, accurate, and complete. I am aware that there are significant penalties for submitting false information, including the possibility of fine and imprisonment for knowing violations".

(Signatory must meet definition in Section B.11.A, eg., FOD, Ops Mgr, DSESH Group Leader, EPC Group Leader)

Print name and title: Anthony R. Grieggs, EPC-CP Group Leader

Signature:__ (See signature on file) Date: 
Maintenance Details

\author{
Requested: 9/12/2016 11:52:00 AM \\ Procedure: MSGP Quarterly Visual \\ Assessment (EPC Sig) \\ (EPC-CP-Form-1021.2 A) \\ Last PM: 9/22/2016
}

Project: $\quad$ SIO Visual Assess. OctNov 2016 (P-MSGP-5138)

Reason: MSGP Quarterly Visual Assessment

Precipitation Type: PR1

Clarity: C2

Odor: 01

\section{Target: \\ $11 / 30 / 2016$}

Priority/Type: Normal / Inspection

Department: Utilities and Infrastructure
Suspended Solids: SUSSOL2

Special Instructions: NMR053195

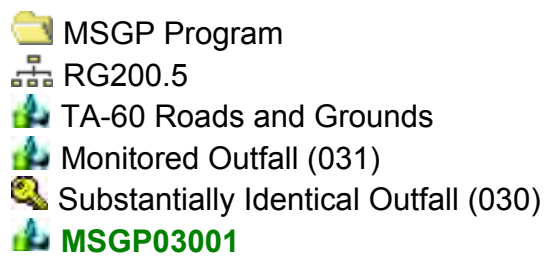

Contact:

Phone:

\section{Tasks}

\# Description

Rating Meas.

Initials

Failed N/A Complete

The result of this VA applies to associated SIOs as defined in the SWPPP, where applicable.

Sample information

Document the monitoring Period by using the

$30 \quad$ Monitoring Period lookup table.

Is visual assessment performed on an unfiltered

MS sample? (Use filtered only if unfiltered

35 unavailable.)

Document the Date/Time Discharge began in the

"Reading" field of this line (using mm/dd/yy hh:mm

40 format).

Document the Date/time sample collected in the

"Reading" field of this line (using mm/dd/yy hh:mm

50 format).

$-\frac{M S}{-}-\Gamma \frac{\Gamma}{\square}$

Document the Date/time sample visually assessed in the "Reading" field of this line (using $\mathrm{mm} / \mathrm{dd} / \mathrm{yy}$

60 hh:mm format).

Document the nature of discharge using the

Precipitation Type lookup table. Document the

70 amount (in) in the "Reading" field of this line.

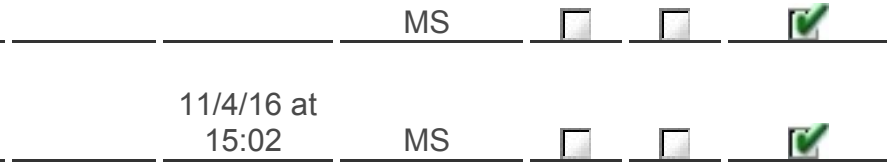

Sample collected in first 30 minutes of discharge? If

$11 / 4 / 16$ at 15:02

MS

$11 / 8 / 16$ at

$14: 19$

MS

MS

$\Gamma \Gamma-\Gamma$

"Failed" or unknown, provide reason in comments

80 of this line. .67 inches MS

$\Gamma \frac{\Gamma}{\Gamma} \frac{\Gamma}{\Gamma}$
$\Gamma-\Gamma$

Parameters

110 Is sample colorless? If "Failed", describe.

Is sample oderless? If "Failed", document observation using the Odor lookup table. If "other"

is chosen from the lookup table, provide description

120 in comments of this line.

MS

Is sample clear? If "Failed", document observation using the Clarity lookup table. If "other" is chosen from the lookup table, provide description in comments of this line. 
150 Is sample free of settled solids? If "Failed",

lookup table. If "other" is chosen from the lookup

table, provide description in comments of this line.

Is sample free of suspended solids? If "Failed", document observation using the Suspended Solids lookup table. If "other" is chosen from the lookup table, provide description in comments of this line.

Is sample foamless after gently shaking? If "Failed" describe foam color and location ('on the surface' or 'in the sample') in the comments of this line.

170 (Range: 0 - 0)

Is sample devoid of an oil sheen? If "Failed", describe color and thickness (e.g. flecks, globs) in

180 the comments of this line. (Range: 0 - 0)

Is sample free of other obvious indicators of pollution? If "Failed", describe in the comments of this line. (Range: 0 - 0)

MS

[6. MS $\Gamma+\Gamma$ MS $[\mathrm{C}$

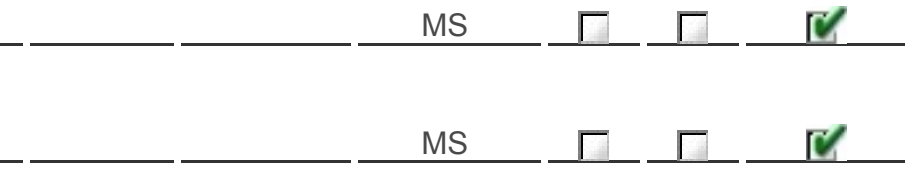

\section{Labor Report}

Completed: 11/8/2016 2:19:00 PM Failure:

Report:

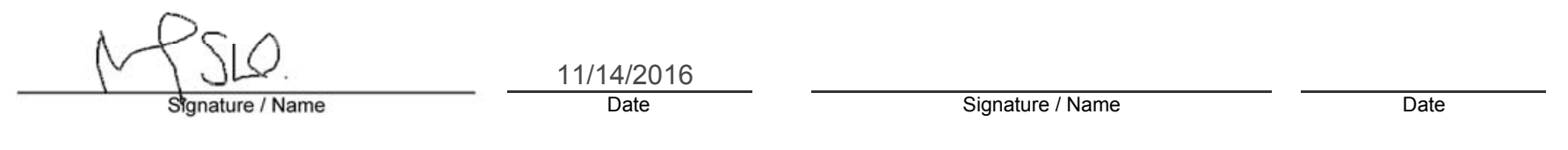


WO ID

Page of

Date: Time:

Name/Z\#:

Signature (collecting sample \& conducting visual assessment):

"I confirm the information as recorded is true, accurate and complete."

\section{CERTIFICATION STATEMENT}

"I certify under penalty of law that this document and all attachments were prepared under my direction or supervision in accordance with a system designed to assure that qualified personnel properly gathered and evaluated the information submitted. Based on my inquiry of the person or persons who manage the system, or those persons directly responsible for gathering information, the information submitted is, to the best of my knowledge and belief, true, accurate, and complete. I am aware that there are significant penalties for submitting false information, including the possibility of fine and imprisonment for knowing violations".

(Signatory must meet definition in Section B.11.A, eg., FOD, Ops Mgr, DSESH Group Leader, EPC Group Leader)

Print name and title: Anthony R. Grieggs, EPC-CP Group Leader

Signature:__ (See signature on file) Date: 
Maintenance Details

\author{
Requested: 9/12/2016 11:52:00 AM \\ Procedure: MSGP Quarterly Visual \\ Assessment (EPC Sig) \\ (EPC-CP-Form-1021.2 A) \\ Last PM: 9/22/2016
}

Project: $\quad$ SIO Visual Assess. OctNov 2016 (P-MSGP-5138)

Reason: MSGP Quarterly Visual Assessment

Precipitation Type: PR1

Clarity: C3

Odor: 01
Target: $\quad$ 11/30/2016

Priority/Type: Normal / Inspection

Department: Utilities and Infrastructure
Suspended Solids: NA

Special Instructions: NMR053195

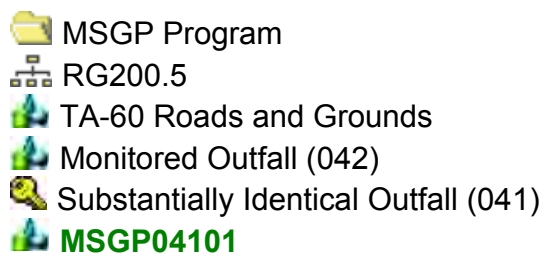

MSGP Program

高 RG200.5

t. TA-60 Roads and Grounds

Monitored Outfall (042)

A. MSGP04101

Contact:

Phone:

\section{Tasks}

\# Description

Rating Meas. Initials Failed N/A Complete

The result of this VA applies to associated SIOs as defined in the SWPPP, where applicable.

\section{Sample information}

Document the monitoring Period by using the

30

Monitoring Period lookup table.

Is visual assessment performed on an unfiltered sample? (Use filtered only if unfiltered unavailable.)

Document the Date/Time Discharge began in the

"Reading" field of this line (using $\mathrm{mm} / \mathrm{dd} / \mathrm{yy} \mathrm{hh}: \mathrm{mm}$

40 format).

Document the Date/time sample collected in the

"Reading" field of this line (using $\mathrm{mm} / \mathrm{dd} / \mathrm{yy} \mathrm{hh}: \mathrm{mm}$

50 format).

Document the Date/time sample visually assessed in

60 the "Reading" field of this line (using $\mathrm{mm} / \mathrm{dd} / \mathrm{yy} \mathrm{hh}: \mathrm{mm}$ format).

Document the nature of discharge using the

Precipitation Type lookup table. Document the amount

70 (in) in the "Reading" field of this line.

Sample collected in first 30 minutes of discharge? If

"Failed" or unknown, provide reason in comments of

80 this line.

\begin{tabular}{|c|c|c|c|c|}
\hline & MS & $\Gamma$ & $\Gamma$ & {$[\mathrm{C}$} \\
\hline & MS & $\Gamma$ & $\Gamma$ & {$[/$} \\
\hline $\begin{array}{r}11 / 5 / 16 \\
\text { at } 21: 36\end{array}$ & MS & $\Gamma$ & $\Gamma$ & {$[/$} \\
\hline $\begin{array}{r}11 / 5 / 16 \\
\text { at } 21: 36 \\
\end{array}$ & MS & $\Gamma$ & $\Gamma$ & {[} \\
\hline $\begin{array}{r}11 / 8 / 16 \\
\text { at } 14: 55 \\
\end{array}$ & MS & $\Gamma$ & $\Gamma$ & {[} \\
\hline $\begin{array}{c}.61 \\
\text { inches } \\
\end{array}$ & MS & Г & $\Gamma$ & {[} \\
\hline & MS & $\Gamma$ & $\Gamma$ & {$[\mathrm{C}$} \\
\hline
\end{tabular}

\section{Parameters}

110 Is sample colorless? If "Failed", describe.

Is sample oderless? If "Failed", document observation using the Odor lookup table. If "other" is chosen from the lookup table, provide description in comments of

120 this line.

Is sample clear? If "Failed", document observation using the Clarity lookup table. If "other" is chosen from the lookup table, provide description in comments of 130 this line.

Is sample free of floating solids? If "Failed", describe if

140 raw or waste material(s) in the comments of this line.

150 Is sample free of settled solids? If "Failed", document observation using the Settled Solids lookup table. If

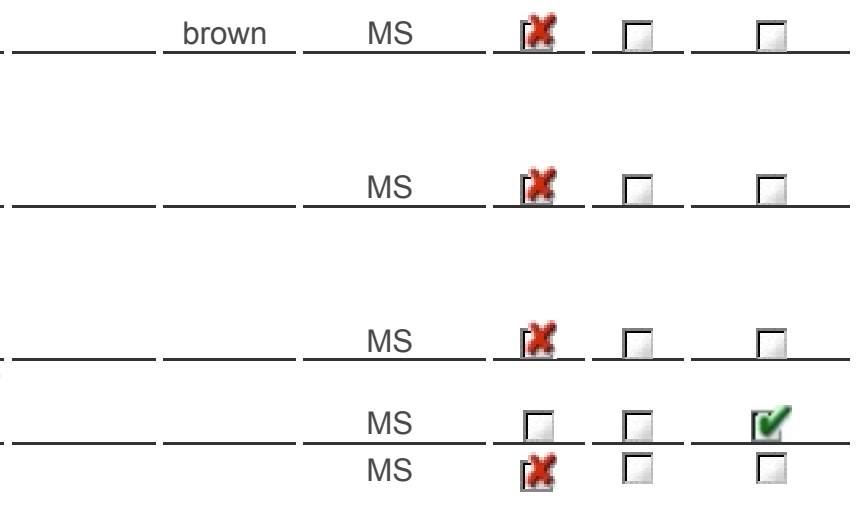


"other" is chosen from the lookup table, provide description in comments of this line.

Is sample free of suspended solids? If "Failed", document observation using the Suspended Solids lookup table. If "other" is chosen from the lookup

160 table, provide description in comments of this line. Is sample foamless after gently shaking? If "Failed" describe foam color and location ('on the surface' or 'in the sample') in the comments of this line. (Range: 0

170 $-0)$

Is sample devoid of an oil sheen? If "Failed", describe color and thickness (e.g. flecks, globs) in the

180 comments of this line. (Range: 0 - 0)

Is sample free of other obvious indicators of pollution? If "Failed", describe in the comments of this line. (Range: 0 - 0)

MS

MS MS

MS

\section{-Labor Report}

Completed: 11/8/2016 2:55:00 PM Failure:

Report:

Mesio

Signature / Name

$11 / 14 / 2016$

Date Signature / Name 
WO ID

Page of

Date: Time:

Name/Z\#:

Signature (collecting sample \& conducting visual assessment):

"I confirm the information as recorded is true, accurate and complete."

\section{CERTIFICATION STATEMENT}

"I certify under penalty of law that this document and all attachments were prepared under my direction or supervision in accordance with a system designed to assure that qualified personnel properly gathered and evaluated the information submitted. Based on my inquiry of the person or persons who manage the system, or those persons directly responsible for gathering information, the information submitted is, to the best of my knowledge and belief, true, accurate, and complete. I am aware that there are significant penalties for submitting false information, including the possibility of fine and imprisonment for knowing violations".

(Signatory must meet definition in Section B.11.A, eg., FOD, Ops Mgr, DSESH Group Leader, EPC Group Leader)

Print name and title: Anthony R. Grieggs, EPC-CP Group Leader

Signature:__ (See signature on file) Date: 
Maintenance Details

\author{
Requested: 10/6/2016 4:53:00 PM \\ Procedure: MSGP Quarterly Visual \\ Assessment (EPC Sig) \\ (EPC-CP-Form-1021.2 A) \\ Last PM: 10/6/2016 \\ Project: ISCO Visual Assess. Oct- \\ Nov 2016 (P-MSGP-5135)
}

Reason: MSGP Quarterly Visual Assessment

\section{Target: \\ $11 / 30 / 2016$}

Priority/Type: Normal / Inspection

Department: Utilities and Infrastructure
Precipitation Type: PR1

Odor: 01

Clarity: C2

Settled Solids: NA

Suspended Solids: NA

Special Instructions: NMR053195

\section{Tasks}

\# Description

Rating Meas. Initials Failed N/A Complete

The result of this VA applies to associated SIOs as defined in the SWPPP, where applicable.

\section{Sample information}

Document the monitoring Period by using the

$30 \quad$ Monitoring Period lookup table.

Is visual assessment performed on an unfiltered

35 sample? (Use filtered only if unfiltered unavailable.)

Document the Date/Time Discharge began in the

"Reading" field of this line (using mm/dd/yy hh:mm

40 format).

Document the Date/time sample collected in the

"Reading" field of this line (using $\mathrm{mm} / \mathrm{dd} / \mathrm{yy} \mathrm{hh}: \mathrm{mm}$

50 format)

Document the Date/time sample visually assessed in the "Reading" field of this line (using mm/dd/yy hh:mm

60 format).

Document the nature of discharge using the

Precipitation Type lookup table. Document the amount

$70 \quad$ (in) in the "Reading" field of this line.

Sample collected in first 30 minutes of discharge? If

"Failed" or unknown, provide reason in comments of

$\underline{80}$ this line.

\begin{tabular}{|c|c|c|c|c|}
\hline & MS & $\Gamma$ & $\Gamma$ & {[} \\
\hline & MS & $\Gamma$ & Г & {$[\bar{C}$} \\
\hline $\begin{array}{r}11 / 4 / 16 \\
\text { at } 15: 52 \\
\end{array}$ & MS & $\Gamma$ & $\Gamma$ & {$[\bar{C}$} \\
\hline $\begin{array}{r}11 / 4 / 16 \\
\text { at } 15: 52 \\
\end{array}$ & MS & $\Gamma$ & $\Gamma$ & $\Gamma$ \\
\hline $\begin{array}{r}11 / 8 / 16 \\
\text { at } 14: 22 \\
\end{array}$ & MS & $\Gamma$ & $\Gamma$ & $\mathbb{C}$ \\
\hline $\begin{array}{c}.67 \\
\text { inches }\end{array}$ & MS & $\Gamma$ & $\Gamma$ & $\Gamma$ \\
\hline & MS & $\Gamma$ & Г & $\Gamma$ \\
\hline
\end{tabular}

Parameters

110 Is sample colorless? If "Failed", describe.

light

Is sample oderless? If "Failed", document observation

brown

Contact:

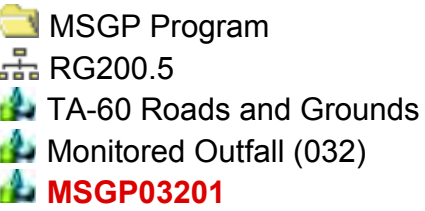

Phone: 
Is sample free of settled solids? If "Failed", document observation using the Settled Solids lookup table. If "other" is chosen from the lookup table, provide description in comments of this line.

Is sample free of suspended solids? If "Failed", document observation using the Suspended Solids lookup table. If "other" is chosen from the lookup

$\underline{160}$ table, provide description in comments of this line.

MS

Is sample foamless after gently shaking? If "Failed" describe foam color and location ('on the surface' or

170 'in the sample') in the comments of this line. (Range: 0

-
-0)

Is sample devoid of an oil sheen? If "Failed", describe color and thickness (e.g. flecks, globs) in the

180 comments of this line. (Range: 0 - 0)

Is sample free of other obvious indicators of pollution?

If "Failed", describe in the comments of this line.

190 (Range: 0 - 0)

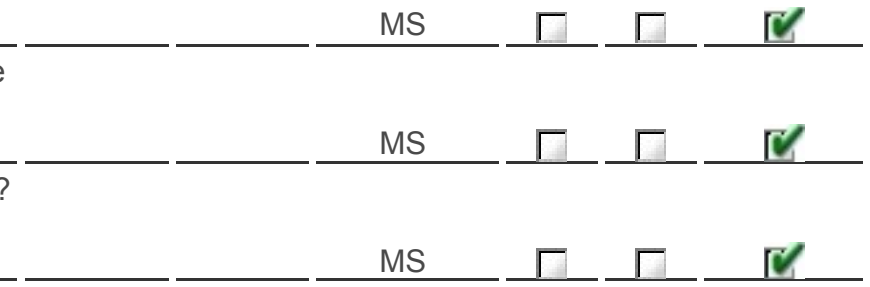

\section{Labor Report}

11/8/2016

Completed: 2:22:00 PM
$\operatorname{Meter(s):~} 2$

Report:

MSLl

Signature / Name
11/9/2016

Date 
WO ID

Page of

Date: Time:

Name/Z\#:

Signature (collecting sample \& conducting visual assessment):

"I confirm the information as recorded is true, accurate and complete."

\section{CERTIFICATION STATEMENT}

"I certify under penalty of law that this document and all attachments were prepared under my direction or supervision in accordance with a system designed to assure that qualified personnel properly gathered and evaluated the information submitted. Based on my inquiry of the person or persons who manage the system, or those persons directly responsible for gathering information, the information submitted is, to the best of my knowledge and belief, true, accurate, and complete. I am aware that there are significant penalties for submitting false information, including the possibility of fine and imprisonment for knowing violations".

(Signatory must meet definition in Section B.11.A, eg., FOD, Ops Mgr, DSESH Group Leader, EPC Group Leader)

Print name and title: Anthony R. Grieggs, EPC-CP Group Leader

Signature:__ (See signature on file) Date: 
Maintenance Details

\author{
Requested: 10/6/2016 4:54:00 PM \\ Procedure: MSGP Quarterly Visual \\ Assessment (EPC Sig) \\ (EPC-CP-Form-1021.2 A) \\ Last PM: 10/5/2016 \\ Project: ISCO Visual Assess. Oct- \\ Nov 2016 (P-MSGP-5135)
}

Reason: MSGP Quarterly Visual Assessment

\section{Target: \\ $11 / 30 / 2016$}

Priority/Type: Normal / Inspection

Department: Utilities and Infrastructure

Precipitation Type: PR1

Odor: 01

Clarity: C2

Settled Solids: NA

Suspended Solids: NA

Special Instructions: NMR053195

\title{
Tasks
}

\# Description

Rating Meas. Initials Failed N/A Complete

The result of this VA applies to associated SIOs as defined in the SWPPP, where applicable.

\section{Sample information}

Document the monitoring Period by using the

30

Monitoring Period lookup table.

Is visual assessment performed on an unfiltered sample? (Use filtered only if unfiltered unavailable.)

Document the Date/Time Discharge began in the

"Reading" field of this line (using $\mathrm{mm} / \mathrm{dd} / \mathrm{yy} \mathrm{hh}: \mathrm{mm}$

40 format).

Document the Date/time sample collected in the

"Reading" field of this line (using mm/dd/yy hh:mm

50 format).

Document the Date/time sample visually assessed in

the "Reading" field of this line (using $\mathrm{mm} / \mathrm{dd} / \mathrm{yy}$

60 hh:mm format).

Document the nature of discharge using the Precipitation Type lookup table. Document the

$70 \quad$ amount (in) in the "Reading" field of this line.

Sample collected in first 30 minutes of discharge? If

"Failed" or unknown, provide reason in comments of

80 this line.

\begin{tabular}{|c|c|c|c|c|}
\hline & MS & $\Gamma$ & $\Gamma$ & {[} \\
\hline & MS & $\Gamma$ & $\Gamma$ & {$[\bar{C}$} \\
\hline $\begin{array}{l}11 / 5 / 16 \text { at } \\
4: 13 \mathrm{am}\end{array}$ & MS & $\Gamma$ & Г & {$[\bar{C}$} \\
\hline $\begin{array}{l}11 / 5 / 16 \text { at } \\
4: 13 \mathrm{am}\end{array}$ & MS & $\Gamma$ & $\Gamma$ & $\Gamma$ \\
\hline $\begin{array}{c}11 / 8 / 16 \text { at } \\
14: 47 \\
\end{array}$ & MS & $\Gamma$ & $\Gamma$ & {[} \\
\hline $\begin{array}{c}.61 \\
\text { inches }\end{array}$ & MS & $\Gamma$ & $\Gamma$ & $\Gamma$ \\
\hline & MS & $\Gamma$ & $\Gamma$ & $\Gamma$ \\
\hline
\end{tabular}

Parameters

110 Is sample colorless? If "Failed", describe.

light

Is sample oderless? If "Failed", document observation

brown

Contact:

Phone:

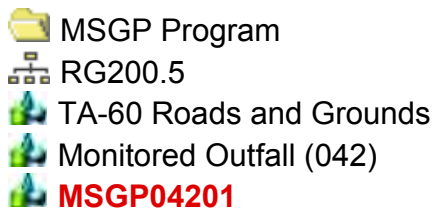



observation using the Settled Solids lookup table. If "other" is chosen from the lookup table, provide description in comments of this line.

Is sample free of suspended solids? If "Failed", document observation using the Suspended Solids lookup table. If "other" is chosen from the lookup

160 table, provide description in comments of this line.

Is sample foamless after gently shaking? If "Failed" describe foam color and location ('on the surface' or 'in the sample') in the comments of this line. (Range:

170 0 - 0)

Is sample devoid of an oil sheen? If "Failed", describe

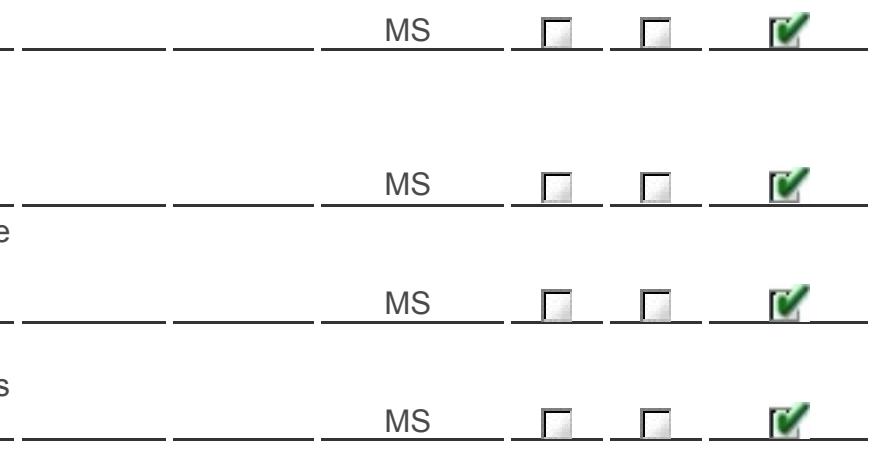
color and thickness (e.g. flecks, globs) in the

180 comments of this line. (Range: 0 - 0)

Is sample free of other obvious indicators of pollution? If "Failed", describe in the comments of this 190 line. (Range: 0 - 0)

MS

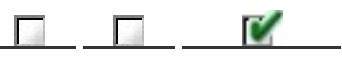

\section{Labor Report}

$11 / 8 / 2016$

Completed: 2:47:00 PM

Failure:

Report:

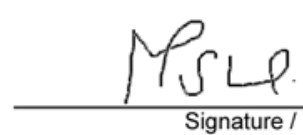


WO ID

Page of

Date: Time:

Name/Z\#:

Signature (collecting sample \& conducting visual assessment):

"I confirm the information as recorded is true, accurate and complete."

\section{CERTIFICATION STATEMENT}

"I certify under penalty of law that this document and all attachments were prepared under my direction or supervision in accordance with a system designed to assure that qualified personnel properly gathered and evaluated the information submitted. Based on my inquiry of the person or persons who manage the system, or those persons directly responsible for gathering information, the information submitted is, to the best of my knowledge and belief, true, accurate, and complete. I am aware that there are significant penalties for submitting false information, including the possibility of fine and imprisonment for knowing violations".

(Signatory must meet definition in Section B.11.A, eg., FOD, Ops Mgr, DSESH Group Leader, EPC Group Leader)

Print name and title: Anthony R. Grieggs, EPC-CP Group Leader

Signature:__ (See signature on file) Date: 
Maintenance Details

$$
\begin{aligned}
& \text { Requested By: } \text { Banar, Alethea on } \\
& \text { 10/20/2016 1:20:00 } \\
& \text { PM }
\end{aligned}
$$

Taken By:

Banar, Alethea

Procedure:

MSGP Quarterly Visual

Assessment (EPC Sig)

(EPC-CP-Form-1021.2

A)

Last PM: $\quad$ 10/21/2016

Project: $\quad$ SIO Visual Assess.

Oct-Nov 2016

(P-MSGP-5138)

\section{Target: \\ $11 / 30 / 2016$}

Priority/Type: Normal / Inspection

Department: Utilities and Infrastructure

Reason: MSGP Quarterly Visual Assessment

Precipitation Type: PR1

Clarity: NA

Suspended Solids: SUSSOL2

Special Instructions: NMR053195
Odor: 01

Settled Solids: NA

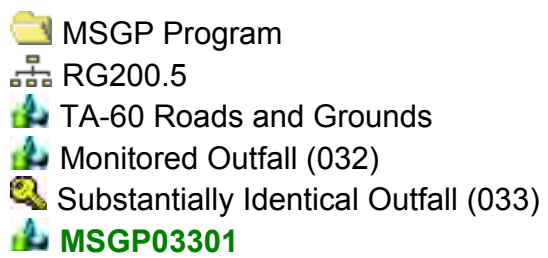

Contact: Banar, Alethea

Phone: 699-5836

\section{Tasks}

\# Description

Rating

Meas.

Initials

Failed N/A Complete

The result of this VA applies to associated SIOs as defined in the SWPPP, where applicable.

\section{Sample information}

Document the monitoring Period by using the

30 Monitoring Period lookup table.

MS $\Gamma \Gamma$

Is visual assessment performed on an unfiltered

sample? (Use filtered only if unfiltered

35 unavailable.)

Document the Date/Time Discharge began in the

"Reading" field of this line (using mm/dd/yy hh:mm

\begin{tabular}{|c|c|c|c|c|}
\hline & MS & $\Gamma$ & $\Gamma$ & {$[\mathrm{C}$} \\
\hline & MS & $\Gamma$ & $\Gamma$ & {$[\mathrm{C}$} \\
\hline $\begin{array}{c}11 / 4 / 16 \text { at } \\
15: 00\end{array}$ & MS & $\Gamma$ & $\Gamma$ & {$[/$} \\
\hline $\begin{array}{c}11 / 4 / 16 \text { at } \\
15: 00\end{array}$ & MS & $\Gamma$ & $\Gamma$ & {$[\mathrm{C}$} \\
\hline $\begin{array}{c}11 / 8 / 16 \text { at } \\
14: 29\end{array}$ & MS & $\Gamma$ & $\Gamma$ & {[} \\
\hline .67 inches & MS & Г & $\Gamma$ & {$[\mathrm{C}$} \\
\hline & MS & Г & $\Gamma$ & {$[\mathrm{C}$} \\
\hline
\end{tabular}

40 format).

Document the Date/time sample collected in the

"Reading" field of this line (using mm/dd/yy hh:mm

$\underline{50}$ format).

Document the Date/time sample visually assessed

in the "Reading" field of this line (using mm/dd/yy

60 hh:mm format).

Document the nature of discharge using the

Precipitation Type lookup table. Document the

$70 \quad$ amount (in) in the "Reading" field of this line.

Sample collected in first 30 minutes of discharge? If

"Failed" or unknown, provide reason in comments

80 of this line.

MS
110 Is sample colorless? If "Failed", describe.
Is sample oderless? If "Failed", document observation using the Odor lookup table. If "other" is chosen from the lookup table, provide description
120 in comments of this line.
130 Is sample clear? If "Failed", document observation

$-\frac{M S}{M S} \frac{\Gamma}{\Gamma} \frac{\Gamma}{\Gamma} \frac{\Gamma}{\Gamma}$


from the lookup table, provide description in comments of this line.

Is sample free of floating solids? If "Failed", describe if raw or waste material(s) in the

140 comments of this line. vegetation

MS [K $\Gamma$ Is sample free of settled solids? If "Failed", document observation using the Settled Solids lookup table. If "other" is chosen from the lookup

150 table, provide description in comments of this line. MS $\Gamma \Gamma$ Is sample free of suspended solids? If "Failed", document observation using the Suspended Solids lookup table. If "other" is chosen from the lookup

160 table, provide description in comments of this line. Is sample foamless after gently shaking? If "Failed" describe foam color and location ('on the surface' or 'in the sample') in the comments of this line.

$170 \quad$ (Range: 0 - 0)

Is sample devoid of an oil sheen? If "Failed", describe color and thickness (e.g. flecks, globs) in

180 the comments of this line. (Range: 0 - 0)

Is sample free of other obvious indicators of pollution? If "Failed", describe in the comments of this line. (Range: 0 - 0)

MS $\stackrel{\boldsymbol{K}}{\Gamma} \longrightarrow$

\section{Labor Report}

Completed: 11/8/2016 2:29:00 PM Failure:

Report:

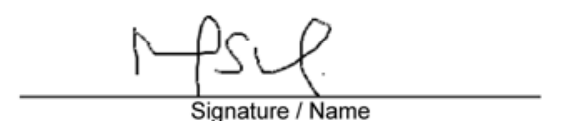


WO ID

Page of

Date: Time:

Name/Z\#:

Signature (collecting sample \& conducting visual assessment):

"I confirm the information as recorded is true, accurate and complete."

\section{CERTIFICATION STATEMENT}

"I certify under penalty of law that this document and all attachments were prepared under my direction or supervision in accordance with a system designed to assure that qualified personnel properly gathered and evaluated the information submitted. Based on my inquiry of the person or persons who manage the system, or those persons directly responsible for gathering information, the information submitted is, to the best of my knowledge and belief, true, accurate, and complete. I am aware that there are significant penalties for submitting false information, including the possibility of fine and imprisonment for knowing violations".

(Signatory must meet definition in Section B.11.A, eg., FOD, Ops Mgr, DSESH Group Leader, EPC Group Leader)

Print name and title: Anthony R. Grieggs, EPC-CP Group Leader

Signature:__ (See signature on file) Date: 
Maintenance Details

$$
\begin{aligned}
\text { Requested: } & 11 / 22 / 2016 \text { 4:44:00 PM } \\
\text { Procedure: } & \text { MSGP Quarterly Visual } \\
& \text { Assessment (EPC Sig) } \\
& \text { (EPC-CP-Form-1021.2 A) }
\end{aligned}
$$

Last PM: $\quad 11 / 22 / 2016$

Project: SIO Visual Assess. OctNov 2016 (P-MSGP-5138)

\section{Target: \\ $11 / 30 / 2016$}

Priority/Type: Normal / Inspection

Department: Utilities and Infrastructure
Reason: MSGP Quarterly Visual Assessment (EPC Sig)

Precipitation Type: PR1

Odor: NA

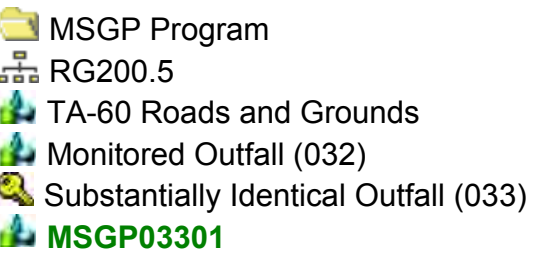

Clarity: NA

Settled Solids: NA

Suspended Solids: SUSSOL2

Special Instructions: NMR053195

\section{Tasks}

\# Description

Rating Meas.

Contact:

Phone:

The result of this VA applies to associated SIOs as defined in the SWPPP, where applicable.

Sample information

Document the monitoring Period by using the

$30 \quad$ Monitoring Period lookup table.

Is visual assessment performed on an unfiltered

MS sample? (Use filtered only if unfiltered

35 unavailable.)

Document the Date/Time Discharge began in the "Reading" field of this line (using $\mathrm{mm} / \mathrm{dd} / \mathrm{yy} \mathrm{hh}: \mathrm{mm}$

40 format)

Document the Date/time sample collected in the "Reading" field of this line (using $\mathrm{mm} / \mathrm{dd} / \mathrm{yy} \mathrm{hh}: \mathrm{mm}$

50 format).

Document the Date/time sample visually assessed in the "Reading" field of this line (using $\mathrm{mm} / \mathrm{dd} / \mathrm{yy}$

60 hh:mm format).

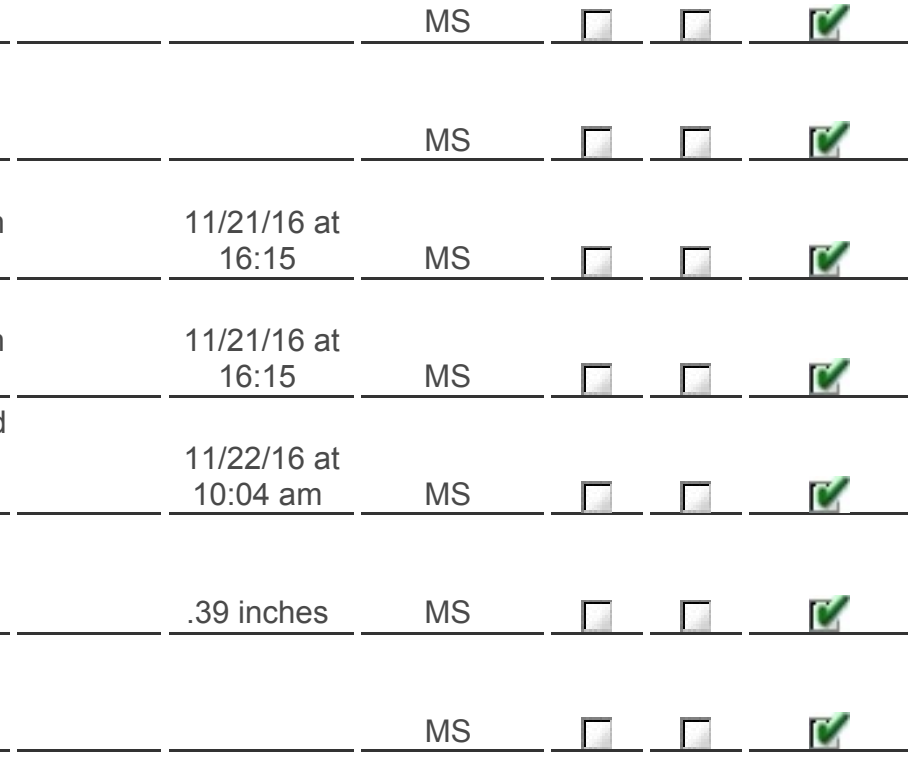

Parameters

110 Is sample colorless? If "Failed", describe.

MS

Is sample oderless? If "Failed", document observation using the Odor lookup table. If "other" is chosen from the lookup table, provide

120 description in comments of this line.

Is sample clear? If "Failed", document observation

MS using the Clarity lookup table. If "other" is chosen from the lookup table, provide description in comments of this line.

MS

Is sample free of floating solids? If "Failed", describe if raw or waste material(s) in the 
150 Is sample free of settled solids? If "Failed",

lookup table. If "other" is chosen from the lookup

table, provide description in comments of this line.

Is sample free of suspended solids? If "Failed",

document observation using the Suspended

Solids lookup table. If "other" is chosen from the lookup table, provide description in comments of

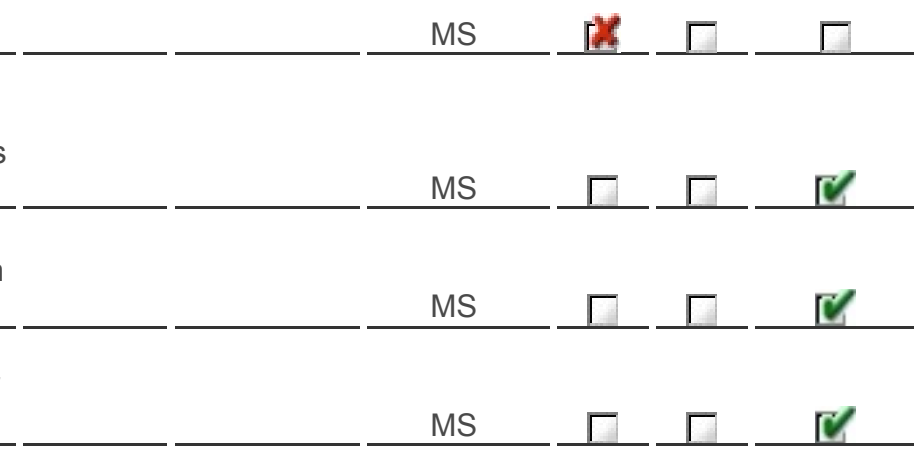

Is sample foamless after gently shaking? If

"Failed" describe foam color and location ('on the surface' or 'in the sample') in the comments of this

170 line. (Range: 0 - 0)

Is sample devoid of an oil sheen? If "Failed", describe color and thickness (e.g. flecks, globs) in the comments of this line. (Range: 0 - 0)

Is sample free of other obvious indicators of pollution? If "Failed", describe in the comments of this line. (Range: 0 - 0)

\section{-Labor Report}

Completed: AM

11/22/2016 10:04:00

Report:

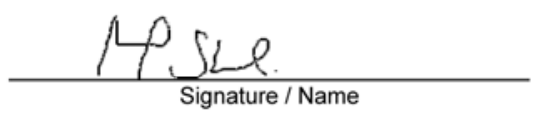

Failure: 
WO ID

Page of

Date: Time:

Name/Z\#:

Signature (collecting sample \& conducting visual assessment):

"I confirm the information as recorded is true, accurate and complete."

\section{CERTIFICATION STATEMENT}

"I certify under penalty of law that this document and all attachments were prepared under my direction or supervision in accordance with a system designed to assure that qualified personnel properly gathered and evaluated the information submitted. Based on my inquiry of the person or persons who manage the system, or those persons directly responsible for gathering information, the information submitted is, to the best of my knowledge and belief, true, accurate, and complete. I am aware that there are significant penalties for submitting false information, including the possibility of fine and imprisonment for knowing violations".

(Signatory must meet definition in Section B.11.A, eg., FOD, Ops Mgr, DSESH Group Leader, EPC Group Leader)

Print name and title: Anthony R. Grieggs, EPC-CP Group Leader

Signature:__ (See signature on file) Date: 
Maintenance Details

$$
\begin{aligned}
\text { Requested: } & 11 / 22 / 2016 \text { 4:44:00 PM } \\
\text { Procedure: } & \text { MSGP Quarterly Visual } \\
& \text { Assessment (EPC Sig) } \\
& \text { (EPC-CP-Form-1021.2 A) }
\end{aligned}
$$

Last PM: $\quad$ 11/22/2016

Project: SIO Visual Assess. OctNov 2016 (P-MSGP-5138)

Reason: MSGP Quarterly Visual Assessment (EPC Sig)

Precipitation Type: PR1

Clarity: NA

Odor: NA

$11 / 30 / 2016$

Priority/Type: Normal / Inspection

Department: Utilities and Infrastructure

Settled Solids: NA

Suspended Solids: NA

Special Instructions: NMR053195

\section{Tasks}

\# Description

Rating

Meas.

Initials

Failed N/A Complete

The result of this VA applies to associated SIOs as defined in the SWPPP, where applicable.

\section{Sample information}

Document the monitoring Period by using the

$30 \quad$ Monitoring Period lookup table.

Is visual assessment performed on an unfiltered

35 sample? (Use filtered only if unfiltered unavailable.)

Document the Date/Time Discharge began in the

"Reading" field of this line (using mm/dd/yy hh:mm

40 format).

Document the Date/time sample collected in the

$\underline{50}$

"Reading" field of this line (using mm/dd/yy hh:mm

50 format).

Document the Date/time sample visually assessed

60 hh:mm format).

in the "Reading" field of this line (using mm/dd/yy

Document the nature of discharge using the

Precipitation Type lookup table. Document the

$70 \quad$ amount (in) in the "Reading" field of this line.

Sample collected in first 30 minutes of discharge? If

\begin{tabular}{|c|c|c|c|c|}
\hline & MS & $\Gamma$ & $\Gamma$ & {[} \\
\hline & MS & Г & $\Gamma$ & {$[\bar{C}$} \\
\hline $\begin{array}{c}11 / 21 / 16 \text { at } \\
16: 09 \\
\end{array}$ & MS & $\Gamma$ & $\Gamma$ & {[} \\
\hline $\begin{array}{c}11 / 21 / 16 \text { at } \\
16: 09 \\
\end{array}$ & MS & $\Gamma$ & $\Gamma$ & {[} \\
\hline $\begin{array}{c}11 / 22 / 16 \text { at } \\
10: 02 \mathrm{am} \\
\end{array}$ & MS & $\Gamma$ & $\Gamma$ & $C$ \\
\hline .39 inches & MS & Г & $\Gamma$ & {$[\mathrm{C}$} \\
\hline & MS & $\Gamma$ & Г & $\Gamma$ \\
\hline
\end{tabular}

"Failed" or unknown, provide reason in comments of

80 this line.

\section{Parameters}

110 Is sample colorless? If "Failed", describe.

MS

Is sample oderless? If "Failed", document

observation using the Odor lookup table. If "other" is chosen from the lookup table, provide description in

120 comments of this line.

Contact:

Phone:

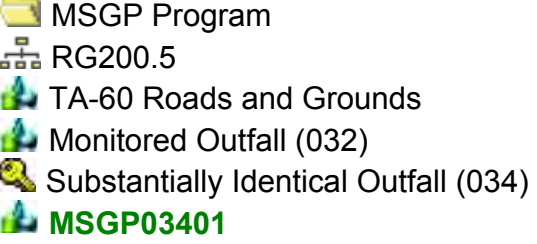


Is sample free of settled solids? If "Failed",

document observation using the Settled Solids

lookup table. If "other" is chosen from the lookup

table, provide description in comments of this line.

Is sample free of suspended solids? If "Failed", document observation using the Suspended Solids lookup table. If "other" is chosen from the lookup

160 table, provide description in comments of this line.

Is sample foamless after gently shaking? If "Failed" describe foam color and location ('on the surface' or 'in the sample') in the comments of this line. (Range:

170 0 - 0)

Is sample devoid of an oil sheen? If "Failed", describe color and thickness (e.g. flecks, globs) in

180 the comments of this line. (Range: 0 - 0)

Is sample free of other obvious indicators of pollution? If "Failed", describe in the comments of this line. (Range: 0 - 0)

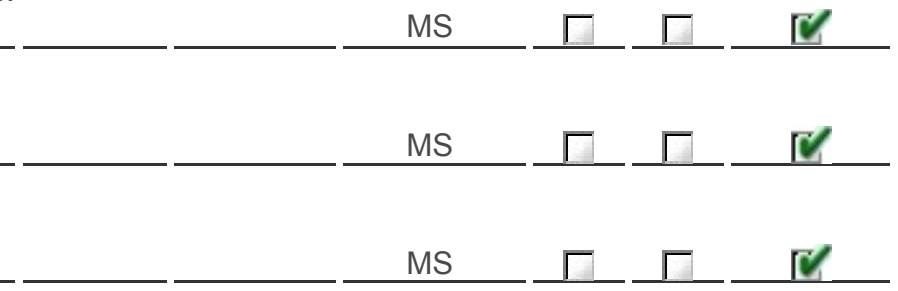

\section{Labor Report}

Completed: AM

$11 / 22 / 2016$ 10:02:00

Failure:

Report:

MStP $11 / 29 / 2016$ 
WO ID

Page of

Date: Time:

Name/Z\#:

Signature (collecting sample \& conducting visual assessment):

"I confirm the information as recorded is true, accurate and complete."

\section{CERTIFICATION STATEMENT}

"I certify under penalty of law that this document and all attachments were prepared under my direction or supervision in accordance with a system designed to assure that qualified personnel properly gathered and evaluated the information submitted. Based on my inquiry of the person or persons who manage the system, or those persons directly responsible for gathering information, the information submitted is, to the best of my knowledge and belief, true, accurate, and complete. I am aware that there are significant penalties for submitting false information, including the possibility of fine and imprisonment for knowing violations".

(Signatory must meet definition in Section B.11.A, eg., FOD, Ops Mgr, DSESH Group Leader, EPC Group Leader)

Print name and title: Anthony R. Grieggs, EPC-CP Group Leader

Signature:__ (See signature on file) Date: 
Maintenance Details

\author{
Requested: 11/22/2016 4:44:00 PM \\ Procedure: MSGP Quarterly Visual \\ Assessment (EPC Sig) \\ (EPC-CP-Form-1021.2 A) \\ Last PM: $\quad 11 / 22 / 2016$
}

Project: SIO Visual Assess. OctNov 2016 (P-MSGP-5138)
Target:
$11 / 30 / 2016$
Priority/Type: Normal / Inspection
Department: Utilities and Infrastructure

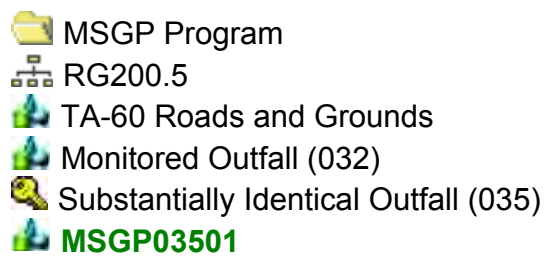

Reason: MSGP Quarterly Visual Assessment (EPC Sig)

Contact:

Precipitation Type: PR1

Odor: NA

Phone:

Clarity: NA

Settled Solids: SETSOL1

Suspended Solids: NA

Special Instructions: NMR053195

\section{Tasks}

\# Description

Meas.

Initials

Failed N/A Complete

The result of this VA applies to associated SIOs as defined in the SWPPP, where applicable.

\section{Sample information}

Document the monitoring Period by using the

$30 \quad$ Monitoring Period lookup table.

Is visual assessment performed on an unfiltered

35 sample? (Use filtered only if unfiltered unavailable.)

Document the Date/Time Discharge began in the

"Reading" field of this line (using mm/dd/yy hh:mm

40 format).

Document the Date/time sample collected in the

$\underline{50}$

"Reading" field of this line (using mm/dd/yy hh:mm

50 format).

Document the Date/time sample visually assessed

60

in the "Reading" field of this line (using mm/dd/yy hh:mm format).

Document the nature of discharge using the

Precipitation Type lookup table. Document the

$70 \quad$ amount (in) in the "Reading" field of this line.

Sample collected in first 30 minutes of discharge? If

"Failed" or unknown, provide reason in comments of

80 this line.

\begin{tabular}{|c|c|c|c|c|}
\hline & MS & $\Gamma$ & $\Gamma$ & {[} \\
\hline & MS & Г & $\Gamma$ & {$[\bar{C}$} \\
\hline $\begin{array}{c}11 / 21 / 16 \text { at } \\
16: 00 \\
\end{array}$ & MS & $\Gamma$ & $\Gamma$ & {[} \\
\hline $\begin{array}{c}11 / 21 / 16 \text { at } \\
16: 00 \\
\end{array}$ & MS & $\Gamma$ & $\Gamma$ & {[} \\
\hline $\begin{array}{c}11 / 22 / 16 \text { at } \\
10: 00 \mathrm{am} \\
\end{array}$ & MS & $\Gamma$ & $\Gamma$ & $C$ \\
\hline .39 inches & MS & Г & $\Gamma$ & {$[\mathrm{C}$} \\
\hline & MS & $\Gamma$ & Г & $\Gamma$ \\
\hline
\end{tabular}

Parameters

110 Is sample colorless? If "Failed", describe. MS Is sample oderless? If "Failed", document observation using the Odor lookup table. If "other" is chosen from the lookup table, provide description in

120 comments of this line.

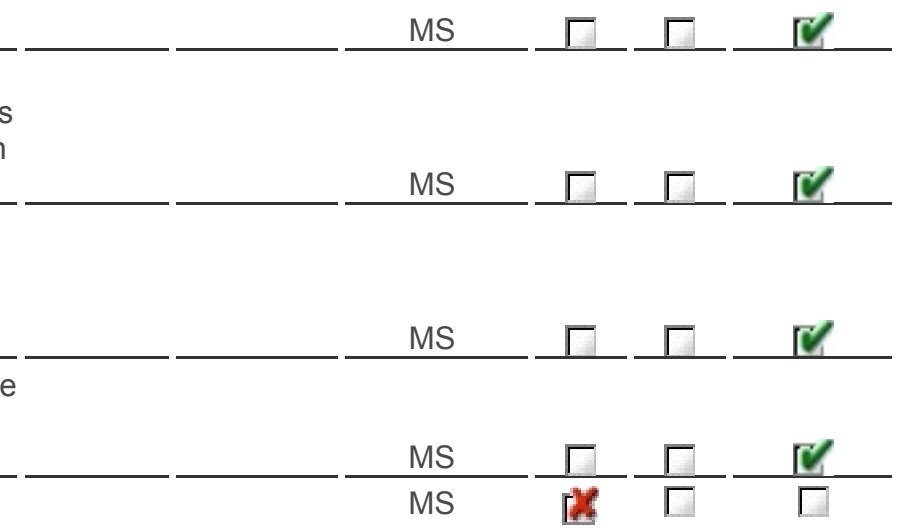

s sample clear? If "Failed", document observation using the Clarity lookup table. If "other" is chosen from the lookup table, provide description in

130 comments of this line.

Is sample free of floating solids? If "Failed", describe if raw or waste material(s) in the comments of this

140 line. 
Is sample free of settled solids? If "Failed",

document observation using the Settled Solids

lookup table. If "other" is chosen from the lookup

table, provide description in comments of this line.

Is sample free of suspended solids? If "Failed", document observation using the Suspended Solids lookup table. If "other" is chosen from the lookup

160 table, provide description in comments of this line.

Is sample foamless after gently shaking? If "Failed" describe foam color and location ('on the surface' or 'in the sample') in the comments of this line. (Range:

170 0 - 0)

Is sample devoid of an oil sheen? If "Failed", describe color and thickness (e.g. flecks, globs) in

180 the comments of this line. (Range: 0 - 0)

Is sample free of other obvious indicators of pollution? If "Failed", describe in the comments of this line. (Range: 0 - 0)

MS

MS

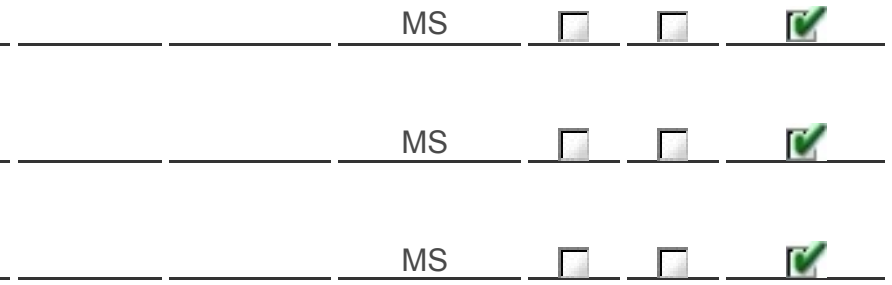

\section{Labor Report}

Completed: AM

$11 / 22 / 201610: 00: 00$

Failure:

Report:

Nisup

$11 / 28 / 2016$

Signature / Name

Date

Signature / Name

Date 
WO ID

Page of

Date: Time:

Name/Z\#:

Signature (collecting sample \& conducting visual assessment):

"I confirm the information as recorded is true, accurate and complete."

\section{CERTIFICATION STATEMENT}

"I certify under penalty of law that this document and all attachments were prepared under my direction or supervision in accordance with a system designed to assure that qualified personnel properly gathered and evaluated the information submitted. Based on my inquiry of the person or persons who manage the system, or those persons directly responsible for gathering information, the information submitted is, to the best of my knowledge and belief, true, accurate, and complete. I am aware that there are significant penalties for submitting false information, including the possibility of fine and imprisonment for knowing violations".

(Signatory must meet definition in Section B.11.A, eg., FOD, Ops Mgr, DSESH Group Leader, EPC Group Leader)

Print name and title: Anthony R. Grieggs, EPC-CP Group Leader

Signature:__ (See signature on file) Date: 
Maintenance Details

$$
\begin{aligned}
\text { Requested: } & 11 / 22 / 2016 \text { 4:44:00 PM } \\
\text { Procedure: } & \text { MSGP Quarterly Visual } \\
& \text { Assessment (EPC Sig) } \\
& \text { (EPC-CP-Form-1021.2 A) }
\end{aligned}
$$

Last PM: $\quad 11 / 22 / 2016$

Project: SIO Visual Assess. OctNov 2016 (P-MSGP-5138)

Reason: MSGP Quarterly Visual Assessment (EPC Sig)

Precipitation Type: PR1

Clarity: NA

Odor: NA

Target: $\quad$ 11/30/2016

Priority/Type: Normal / Inspection

Department: Utilities and Infrastructure

Settled Solids: NA

Suspended Solids: SUSSOL2

Special Instructions: NMR053195

Tasks

\# Description

Rating Meas.

Initials

Failed N/A Complete

The result of this VA applies to associated SIOs as defined in the SWPPP, where applicable.

Sample information

Document the monitoring Period by using the

$30 \quad$ Monitoring Period lookup table.

Is visual assessment performed on an unfiltered

MS sample? (Use filtered only if unfiltered

35 unavailable.)

Document the Date/Time Discharge began in the "Reading" field of this line (using $\mathrm{mm} / \mathrm{dd} / \mathrm{yy} \mathrm{hh}: \mathrm{mm}$

40 format).

Document the Date/time sample collected in the

"Reading" field of this line (using $\mathrm{mm} / \mathrm{dd} / \mathrm{yy} \mathrm{hh}: \mathrm{mm}$

50 format).

$-\frac{M S}{-}-\Gamma \frac{\Gamma}{\Gamma}$

Document the Date/time sample visually assessed in the "Reading" field of this line (using $\mathrm{mm} / \mathrm{dd} / \mathrm{yy}$

60 hh:mm format).

$\frac{M S}{11 / 21 / 16 \text { at }}-\Gamma \frac{\Gamma}{16: 17}$

Document the nature of discharge using the

Precipitation Type lookup table. Document the

$70 \quad$ amount (in) in the "Reading" field of this line.

Sample collected in first 30 minutes of discharge?

16:17

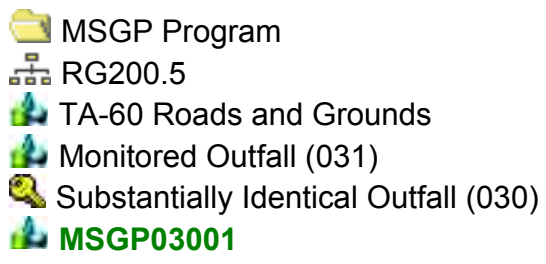

Contact:

Phone: 
150

Is sample free of settled solids? If "Failed", document observation using the Settled Solids lookup table. If "other" is chosen from the lookup table, provide description in comments of this line.

Is sample free of suspended solids? If "Failed", document observation using the Suspended

Solids lookup table. If "other" is chosen from the lookup table, provide description in comments of

160 this line.

Is sample formless after gently shaking? If

"Failed" describe foam color and location ('on the surface' or 'in the sample') in the comments of this

170 line. (Range: 0 - 0)

MS Is sample devoid of an oil sheen? If "Failed", describe color and thickness (e.g. flecks, globs) in the comments of this line. (Range: 0 - 0)

Is sample free of other obvious indicators of pollution? If "Failed", describe in the comments of this line. (Range: 0 - 0)

MS

Ba

MS

MS

MS

190

Failure:

Report:

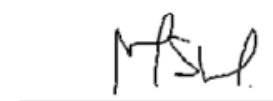

Signature / Name
11/29/2016

Date

Signature / Name

Date 
WO ID

Page of

Date: Time:

Name/Z\#:

Signature (collecting sample \& conducting visual assessment):

"I confirm the information as recorded is true, accurate and complete."

\section{CERTIFICATION STATEMENT}

"I certify under penalty of law that this document and all attachments were prepared under my direction or supervision in accordance with a system designed to assure that qualified personnel properly gathered and evaluated the information submitted. Based on my inquiry of the person or persons who manage the system, or those persons directly responsible for gathering information, the information submitted is, to the best of my knowledge and belief, true, accurate, and complete. I am aware that there are significant penalties for submitting false information, including the possibility of fine and imprisonment for knowing violations".

(Signatory must meet definition in Section B.11.A, eg., FOD, Ops Mgr, DSESH Group Leader, EPC Group Leader)

Print name and title: Anthony R. Grieggs, EPC-CP Group Leader

Signature:__ (See signature on file) Date: 
Maintenance Details

$$
\begin{aligned}
\text { Requested: } & 11 / 22 / 2016 \text { 4:45:00 PM } \\
\text { Procedure: } & \text { MSGP Quarterly Visual } \\
& \text { Assessment (EPC Sig) } \\
& \text { (EPC-CP-Form-1021.2 A) }
\end{aligned}
$$

Last PM: $\quad$ 11/22/2016

Project: SIO Visual Assess. OctNov 2016 (P-MSGP-5138)

Reason: MSGP Quarterly Visual Assessment (EPC Sig)

Precipitation Type: PR1

Clarity: C2

Odor: 01

\section{Target: \\ $11 / 30 / 2016$}

Priority/Type: Normal / Inspection

Department: Utilities and Infrastructure
Suspended Solids: NA

Special Instructions: NMR053195

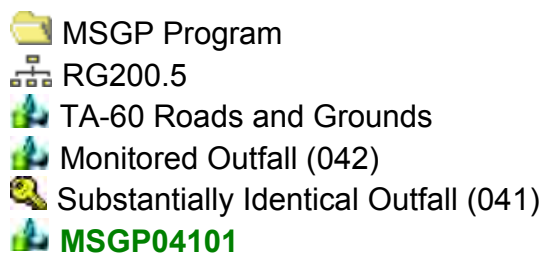

Contact:

Phone:

\section{Tasks}

\# Description

Meas.

Initials

Failed N/A Complete

The result of this VA applies to associated SIOs as defined in the SWPPP, where applicable.

\section{Sample information}

Document the monitoring Period by using the

$30 \quad$ Monitoring Period lookup table.

Is visual assessment performed on an unfiltered

35 sample? (Use filtered only if unfiltered unavailable.)

Document the Date/Time Discharge began in the

"Reading" field of this line (using $\mathrm{mm} / \mathrm{dd} / \mathrm{yy} \mathrm{hh}: \mathrm{mm}$

40 format).

Document the Date/time sample collected in the

$\underline{50}$

"Reading" field of this line (using $\mathrm{mm} / \mathrm{dd} / \mathrm{yy}$ hh:mm

50 format).

Document the Date/time sample visually assessed

60

in the "Reading" field of this line (using mm/dd/yy hh:mm format).

Document the nature of discharge using the

Precipitation Type lookup table. Document the

$70 \quad$ amount (in) in the "Reading" field of this line.

Sample collected in first 30 minutes of discharge? If

\begin{tabular}{|c|c|c|c|c|}
\hline & MS & $\Gamma$ & $\Gamma$ & {[} \\
\hline & MS & $\Gamma$ & $\Gamma$ & {[} \\
\hline $\begin{array}{c}11 / 21 / 16 \text { at } \\
16: 04\end{array}$ & MS & $\Gamma$ & $\Gamma$ & {$[C$} \\
\hline $\begin{array}{c}11 / 21 / 16 \text { at } \\
16: 04\end{array}$ & MS & $\Gamma$ & $\Gamma$ & {$[\bar{C}$} \\
\hline $\begin{array}{l}11 / 22 / 16 \text { at } \\
09: 40 \mathrm{am} \\
\end{array}$ & MS & $\Gamma$ & $\Gamma$ & $C$ \\
\hline .39 inches & MS & Г & $\Gamma$ & {$[\mathrm{C}$} \\
\hline & MS & Г & $\Gamma$ & {$[/$} \\
\hline
\end{tabular}

"Failed" or unknown, provide reason in comments of

80 this line.

Parameters

110 Is sample colorless? If "Failed", describe.

Is sample oderless? If "Failed", document

observation using the Odor lookup table. If "other" is chosen from the lookup table, provide description in

120 comments of this line.

Is sample clear? If "Failed", document observation using the Clarity lookup table. If "other" is chosen from the lookup table, provide description in

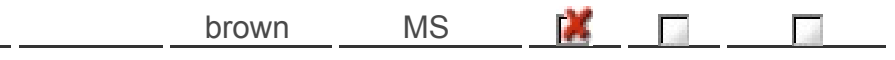

Is sample free of floating solids? If "Failed", describe if raw or waste material(s) in the comments of this 140 line.

$-$ MS MS

MS $\frac{\Gamma}{\Gamma} \frac{\Gamma}{\Gamma} \frac{\Gamma}{\Gamma}$


Is sample free of settled solids? If "Failed",

document observation using the Settled Solids

lookup table. If "other" is chosen from the lookup

table, provide description in comments of this line.

Is sample free of suspended solids? If "Failed", document observation using the Suspended Solids lookup table. If "other" is chosen from the lookup

160 table, provide description in comments of this line.

Is sample foamless after gently shaking? If "Failed" describe foam color and location ('on the surface' or 'in the sample') in the comments of this line. (Range:

170 0 - 0)

Is sample devoid of an oil sheen? If "Failed", describe color and thickness (e.g. flecks, globs) in

180 the comments of this line. (Range: 0 - 0)

Is sample free of other obvious indicators of pollution? If "Failed", describe in the comments of this line. (Range: 0 - 0)

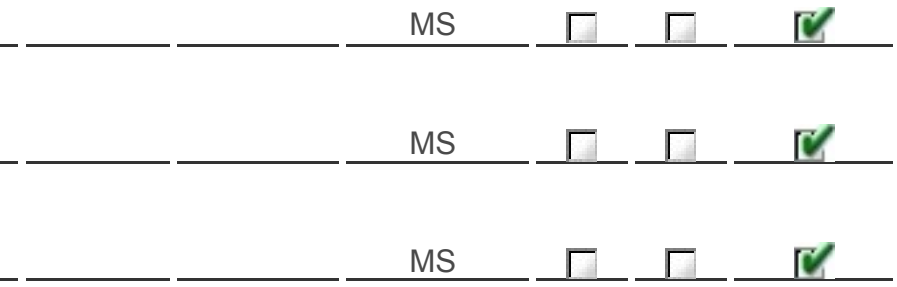

\section{Labor Report}

Completed: $\mathrm{AM}$

11/22/2016 9:40:00

Failure:

Report:

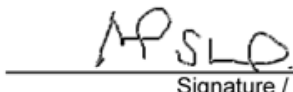

Signature / Name

$11 / 28 / 2016$

Date

Signature / Name

Date 
WO ID

Page of

Date: Time:

Name/Z\#:

Signature (collecting sample \& conducting visual assessment):

"I confirm the information as recorded is true, accurate and complete."

\section{CERTIFICATION STATEMENT}

"I certify under penalty of law that this document and all attachments were prepared under my direction or supervision in accordance with a system designed to assure that qualified personnel properly gathered and evaluated the information submitted. Based on my inquiry of the person or persons who manage the system, or those persons directly responsible for gathering information, the information submitted is, to the best of my knowledge and belief, true, accurate, and complete. I am aware that there are significant penalties for submitting false information, including the possibility of fine and imprisonment for knowing violations".

(Signatory must meet definition in Section B.11.A, eg., FOD, Ops Mgr, DSESH Group Leader, EPC Group Leader)

Print name and title: Anthony R. Grieggs, EPC-CP Group Leader

Signature:__ (See signature on file) Date: 


\section{Monthly Discharge Monitoring Reports}


Environmental Protection \& Compliance Division (EPC-DO)

Environmental Compliance Programs (EPC-CP)

PO Box 1663, K490

Los Alamos, New Mexico 87545

(505) 667-0666

\author{
Date: JUL 012016 \\ Symbol: EPC-DO-16-180 \\ LA-UR: $\quad 16-24542$ \\ Locates Action No.: $\quad$ N/A
}

U.S. EPA Region 6

NPDES Stormwater Program (WQ-PP)

1445 Ross Avenue, Suite 1200

Dallas, TX 75202-2733

To whom it may concern:

Subject: National Pollutant Discharge Elimination System (NPDES) Permit Tracking No. NMR053195, Multi-Sector General Permit (MSGP) Industrial Discharge Monitoring Reports (MDMRs) For April 15, 18 and 19, 2016 and a "No Discharge" Report For April 1 through May 31, 2016

Enclosed are Los Alamos National Laboratory's MDMRs (Enclosure 1) for April 15, 18 and 19, 2016, and a "no discharge" MDMR for the end of the first quarter of monitoring (April 1, 2016 through May 31, 2016) as required under MSGP Permit Tracking No. NMR053195, submitted on behalf of Los Alamos National Security LLC. These MDMRs contain analytical results for impaired water and quarterly benchmark monitoring at outfalls $018,026,029,004,032,002$, and 009.

Please contact Holly Wheeler at (505) 667-1312 or Terrill Lemke at (505) 665-2397 if you have questions regarding these MDMRs.

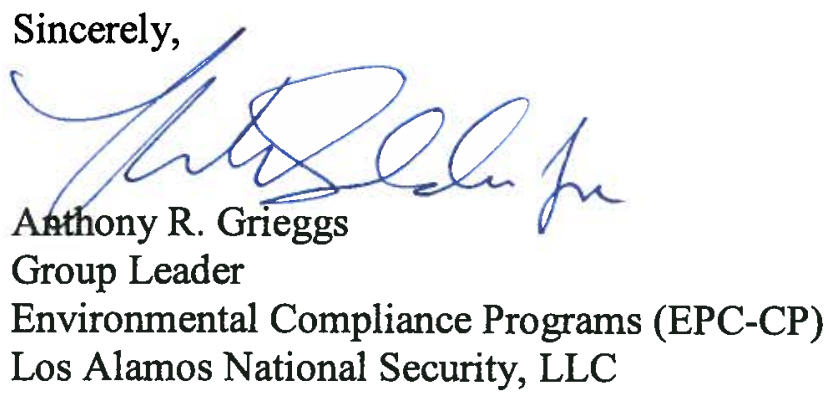




\section{ARG:TWL:HLW/ms}

Enclosure: 1. NPDES Permit Tracking No. NMR053195, MDMRs for April 15, 18 and 19, 2016 and a "No Discharge" Report for April 1 through May 31, 2016

Cy: $\quad$ Everett Spencer, EPA Region 6, Dallas TX (E-File)

Helen Nguyen, EPA Region 6, Dallas TX (E-File)

Craig S. Leasure, PADOPS, (E-File)

William R. Mairson, PADOPS, (E-File)

Michael T. Brandt, ADESH, (E-File)

Raeanna Sharp-Geiger, ADESH, (E-File)

John P. McCann, EPC-DO, (E-File)

Anthony R. Grieggs, EPC-CP, (E-File)

Terrill W. Lemke, EPC-CP, (E-File)

Holly L. Wheeler, EPC-CP, (E-File)

lasomailbox@nnsa.doe.gov, (E-File)

locatesteam@lanl.gov, (E-File)

epc-correspondence@lanl.gov 


\title{
ENCLOSURE 1
}

NPDES Permit Tracking No. NMR053195, MDMRs for April 15, 18 and 19, 2016 and a "No Discharge" Report for April 1 through May 31, 2016

\author{
EPC-DO-16-180 \\ LA-UR-16-24542
}

Date: 


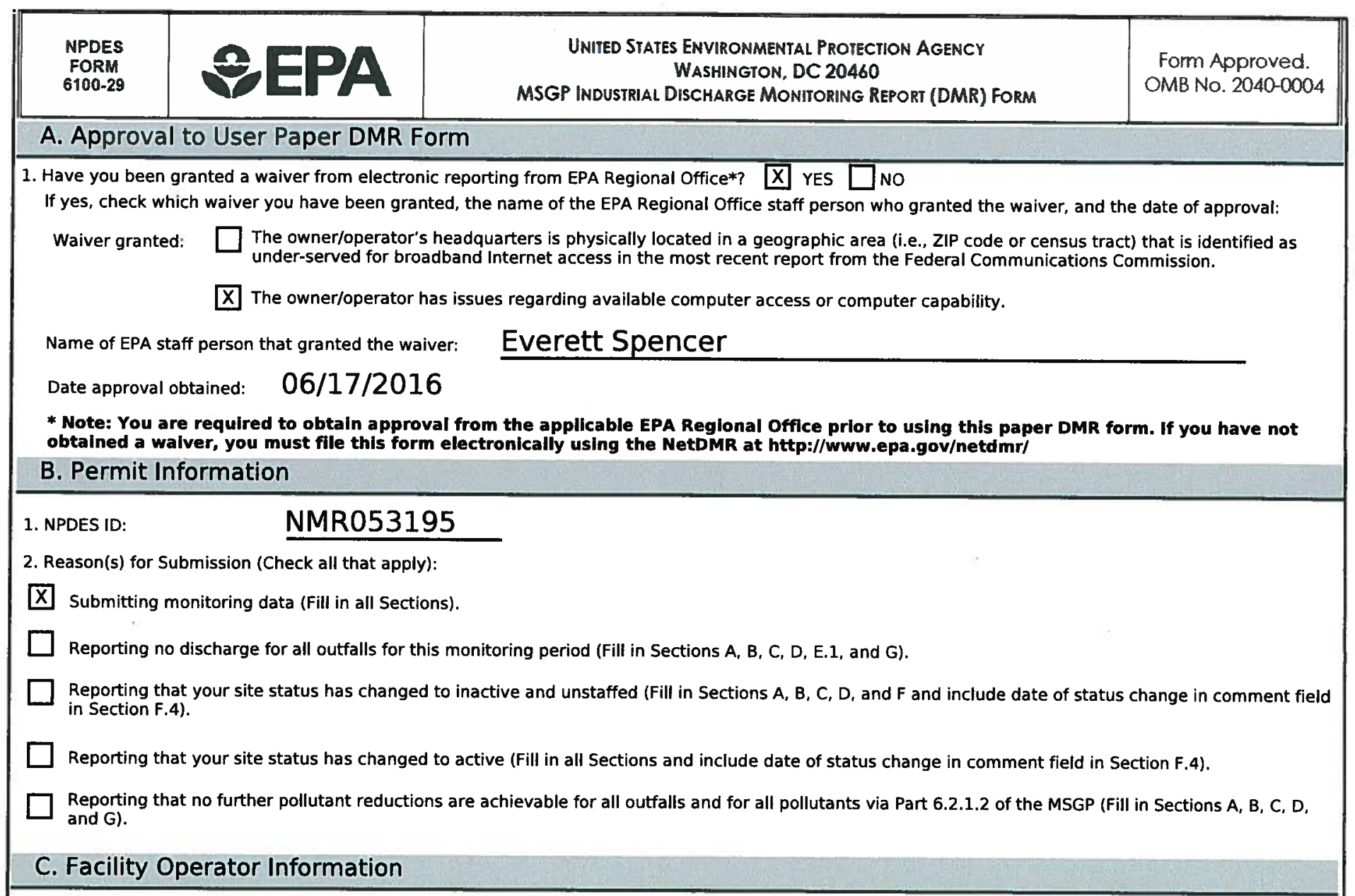

1. Operator Information

Operator Name: $\quad$ Los Alamos National Security, LLC

Mailing Address:

Street: $\quad$ P.O. Box 1663, MS K490

$\begin{array}{llll}\text { City: } & \text { Los Alamos } & \text { State: } \quad \text { NM } & \text { ZIP Code: } 87545- \\ \text { Phone: } & 5056670666 & \end{array}$

E-mail: $\quad$ grieggst@lanl.gov

2. DMR Preparer (Complete if DMR was prepared by someone other than the certifier):

First Name, Middle Initial, Last Name: Holly L. Wheeler

Organization: $\quad$ EPC-CP

Phone: $\quad \underline{5056671312}$ Ext.

E-mail: hbenson@lanl.gov 


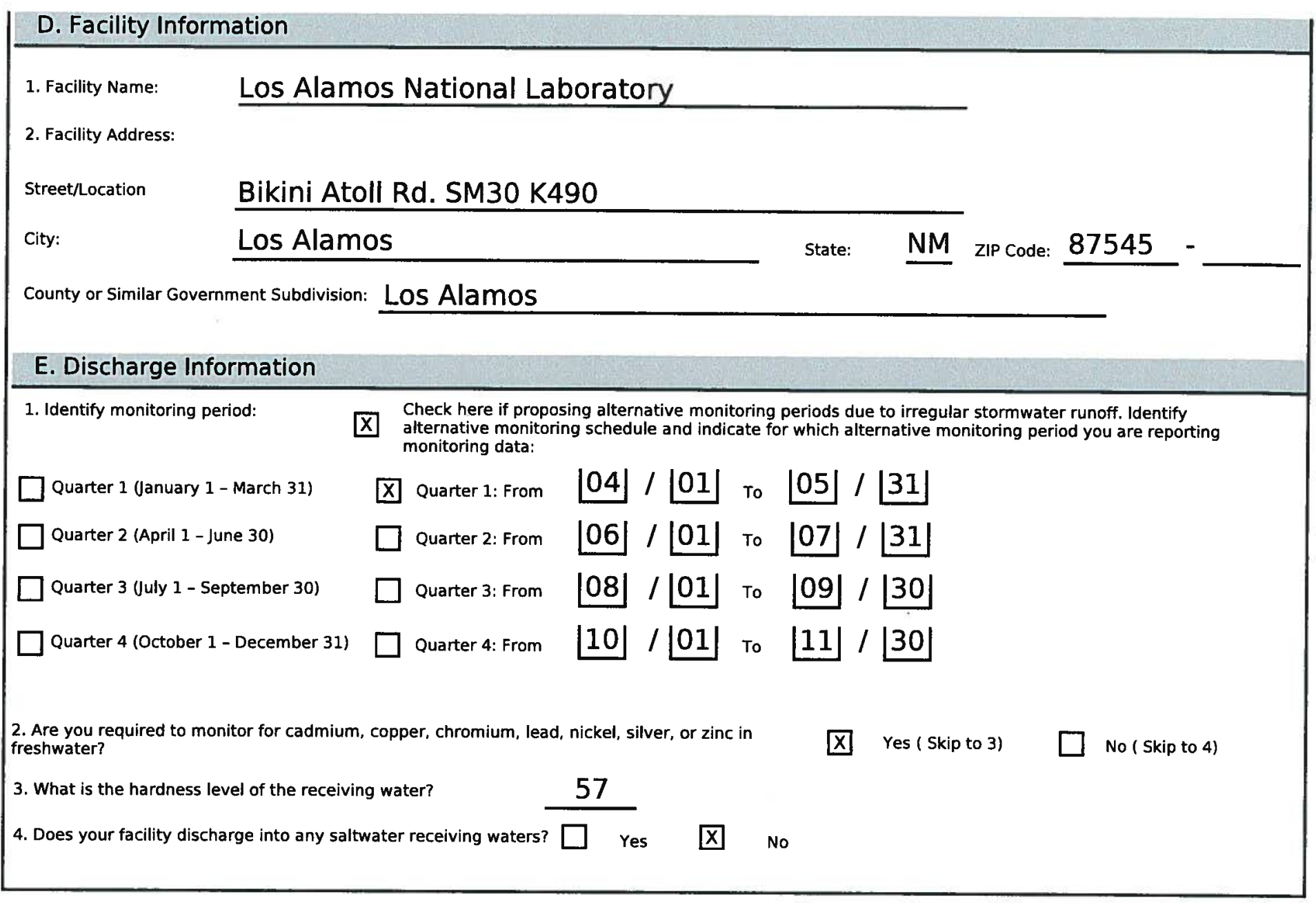




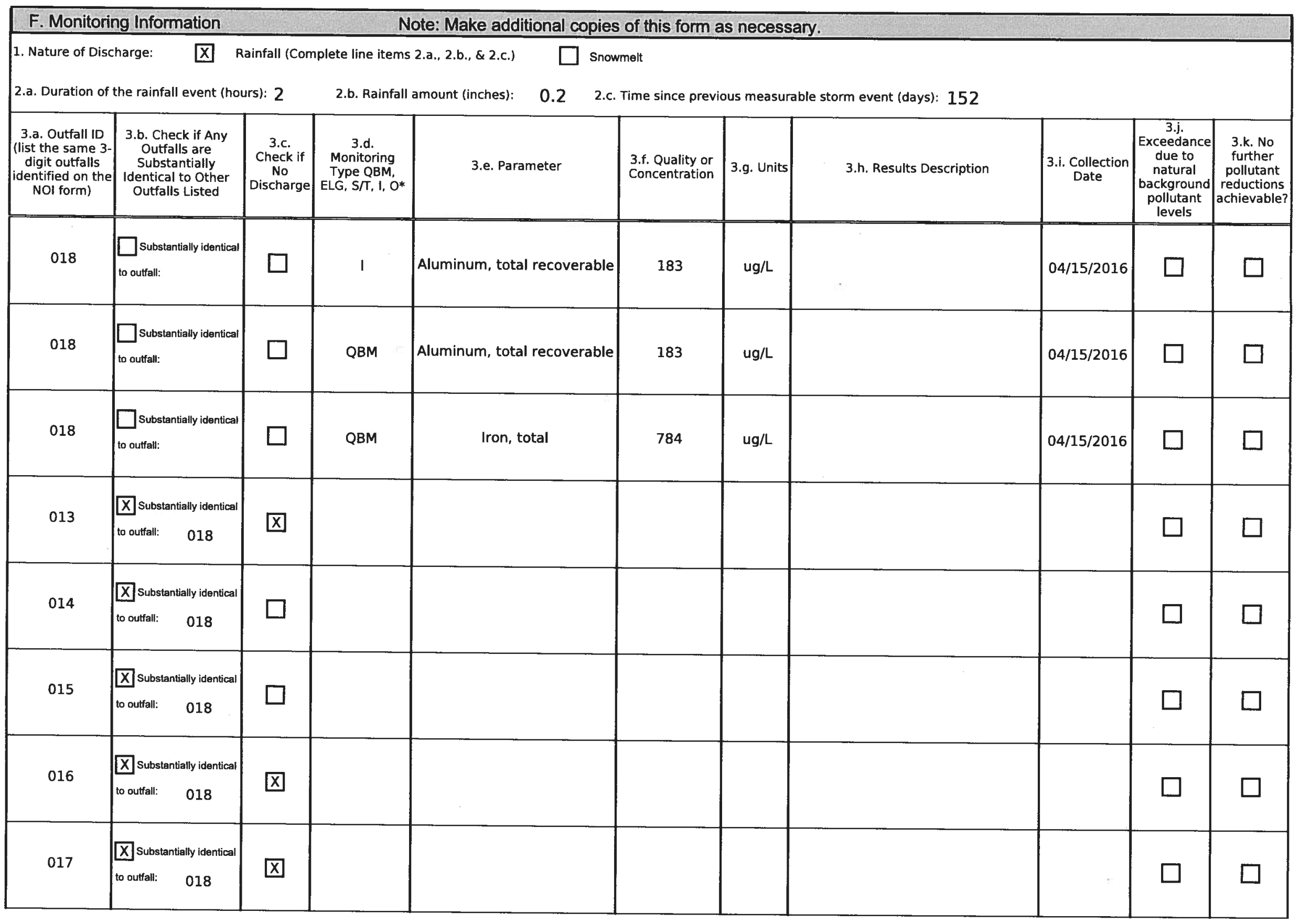

\section{EPA FORM 6100-29}

Page 3 of 7 


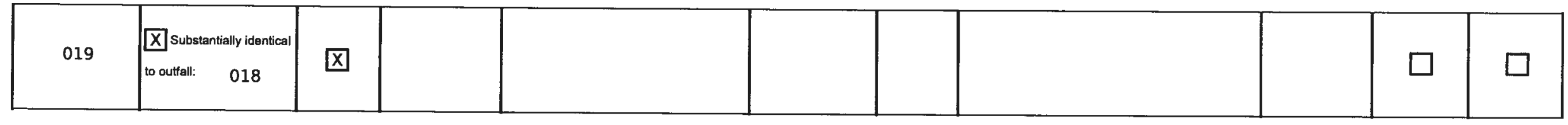

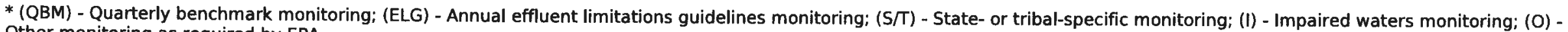
Other monitoring as required by EPA

4. Comment and/or Explanation of Any Violations (Reference all attachments here)

Rainfall duration $=1.58$ hours. Rainfall amount $=0.24$ inches. 


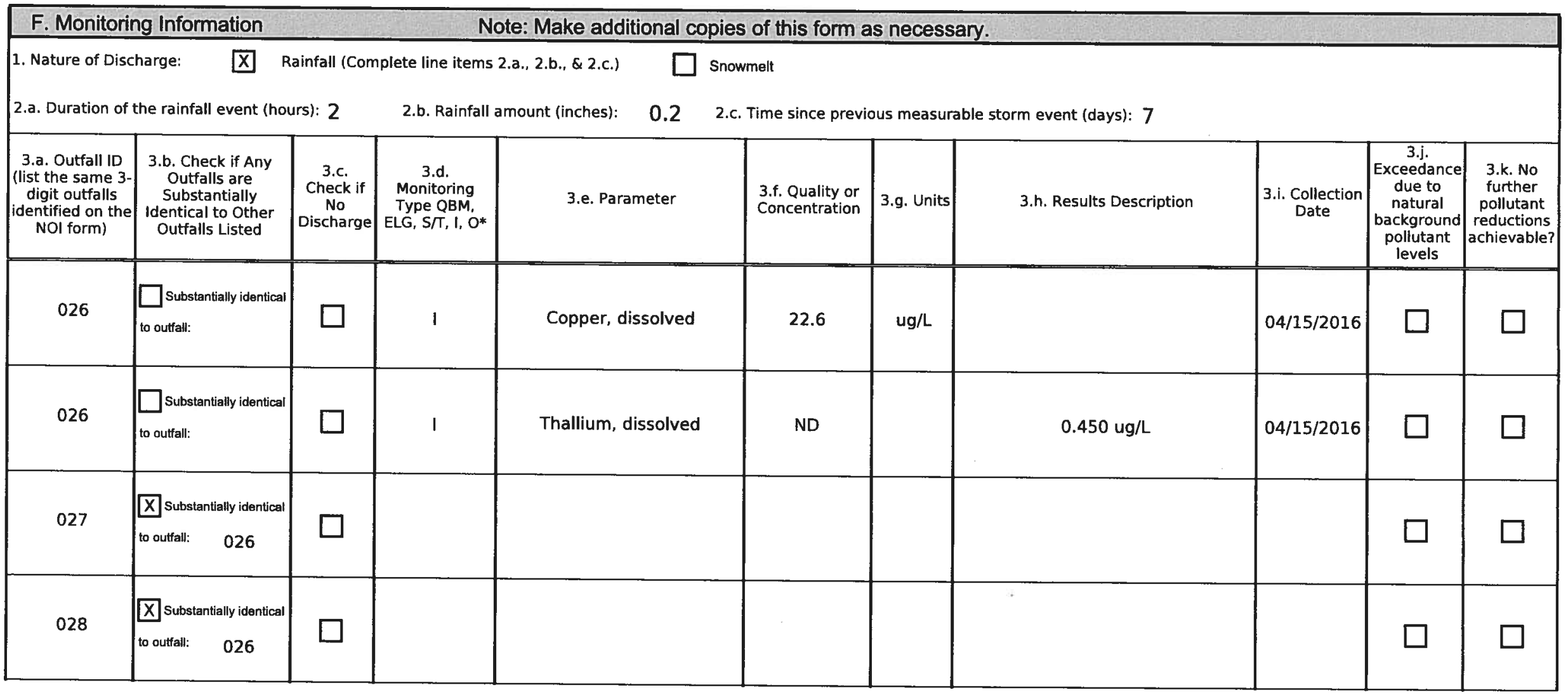

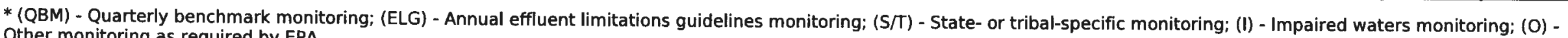
Other monitoring as required by EPA

4. Comment and/or Explanation of Any Violations (Reference all attachments here) Rainfall duration $=1.58$ hours. Rainfall amount $=0.24$ inches.

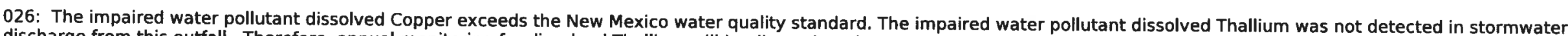
discharge from this outfall. Therefore, annual monitoring for dissolved Thallium will be discontinued per Part 6.2.4.1. 


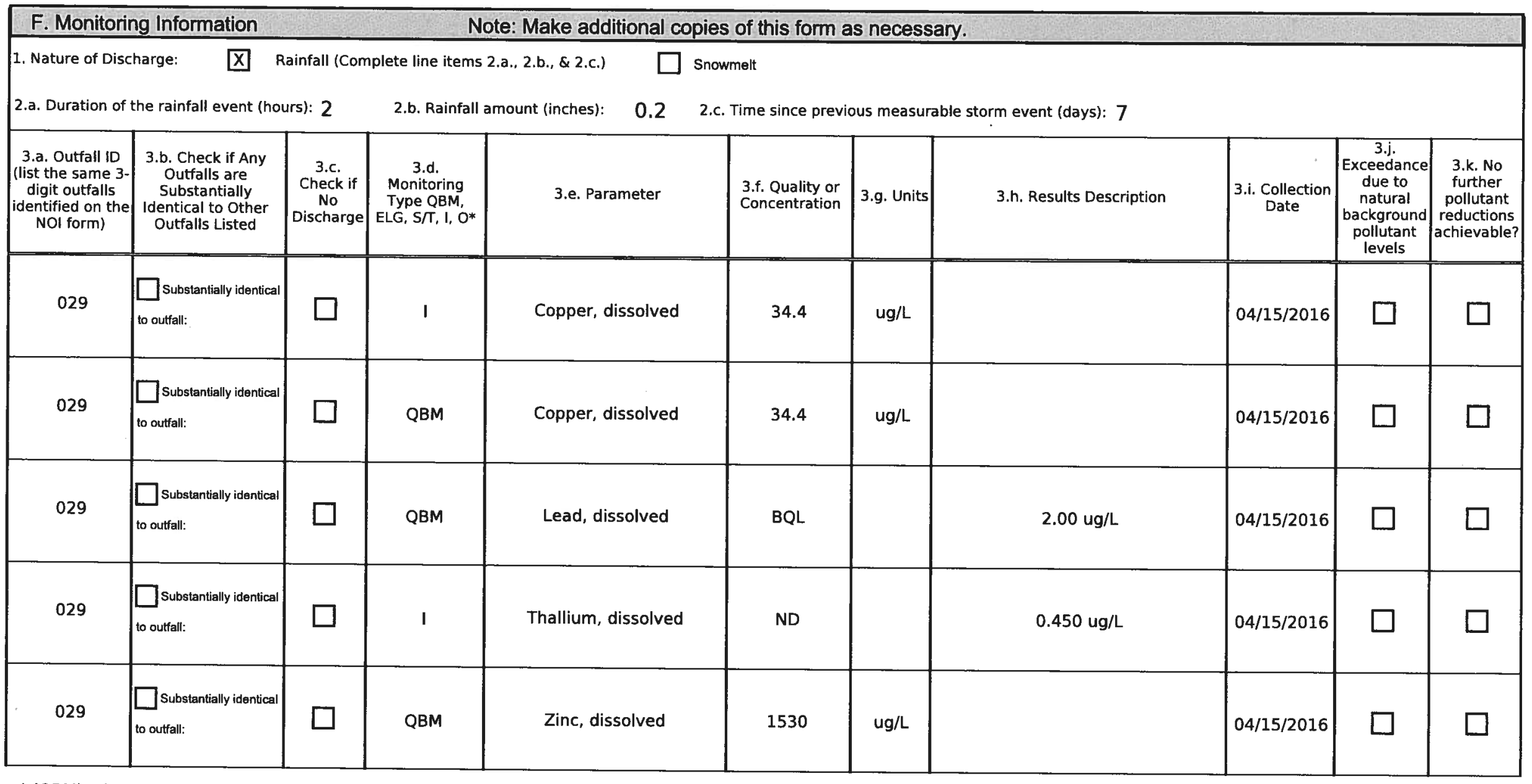

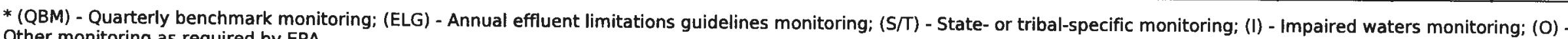
Other monitoring as required by EPA

4. Comment and/or Explanation of Any Violations (Reference all attachments here)

Rainfall duration $=1.58$ hours. Rainfall amount $=0.24$ inches

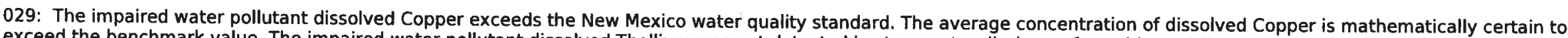

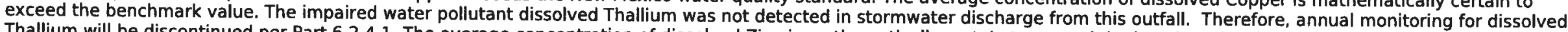
Thallium will be discontinued per Part 6.2.4.1. The average concentration of dissolved Zinc is mathematically certain to exceed the benchmark value. 


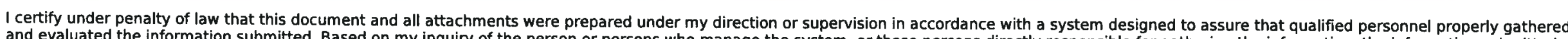

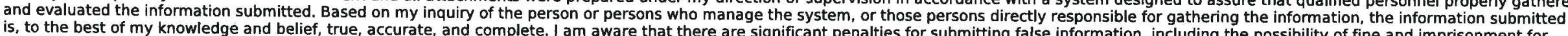
knowing violations.

First Name, Middle Initial, Last Name: Anthony

Title:

Signature:

E-mail:

EPC-CP Group Leader

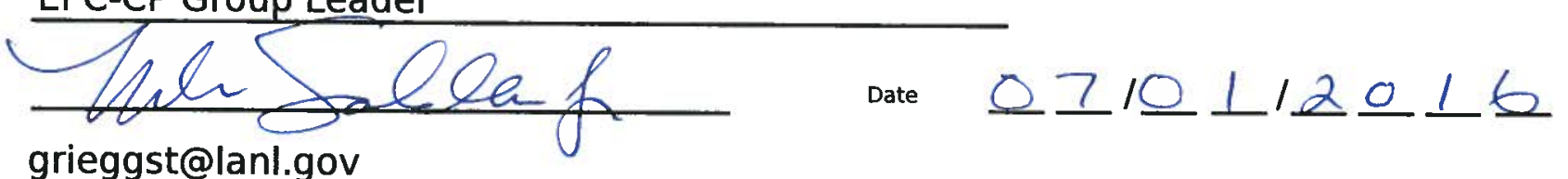

R Grieggs

-




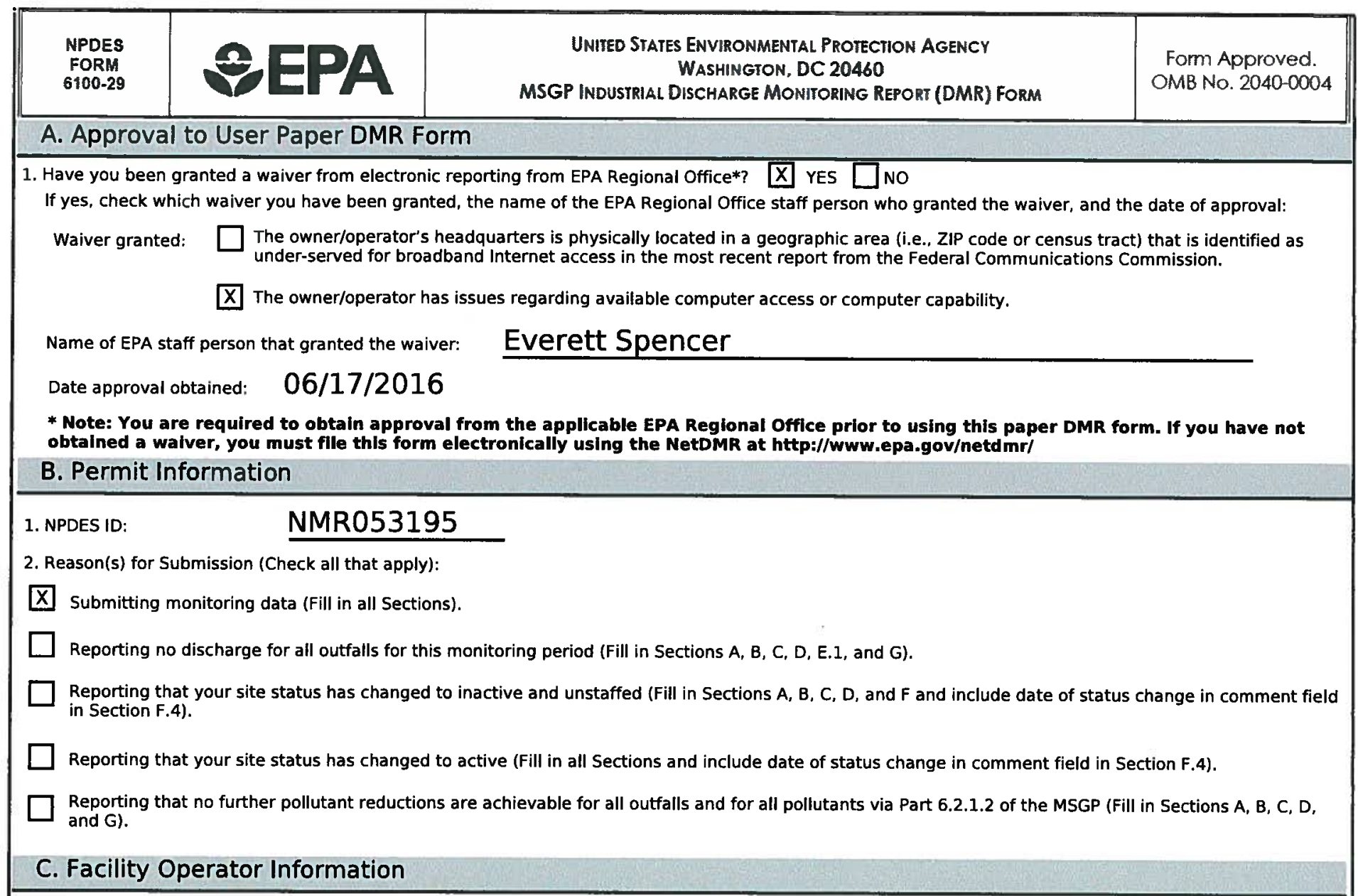

\section{Operator Information}

Operator Name:

Los Alamos National Security, LLC

Mailing Address:

Street:

P.O. Box 1663, MS K490

City:

\begin{tabular}{lll}
\hline Los Alamos & state: $\quad$ NM \\
\hline 5056670666 & \\
\hline grieggst@lanl.gov & \\
\hline
\end{tabular}

2. DMR Preparer (Complete if DMR was prepared by someone other than the certifier):

First Name, Middle Initial, Last Name: Holly L. Wheeler

Organization:

EPC-CP

Phone:

5056671312

Ext.

E-mail:

hbenson@lanl.gov 


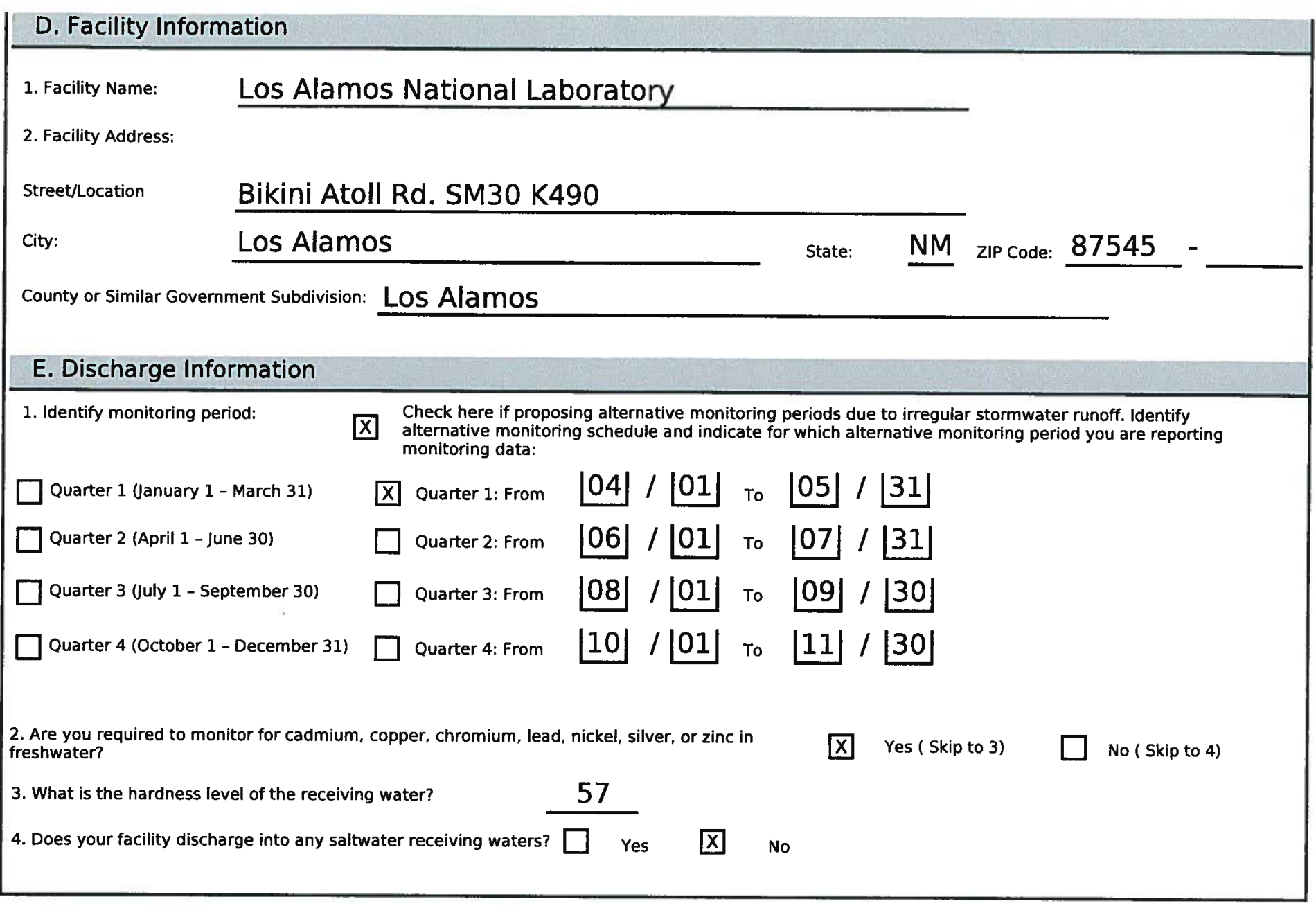




\begin{tabular}{|c|c|c|c|c|c|c|c|c|c|c|}
\hline \multicolumn{2}{|c|}{ F. Monitoring Information } & \multicolumn{6}{|c|}{ Note: Make additional copies of this form as necessary. } & & & \\
\hline \multirow{2}{*}{\multicolumn{11}{|c|}{$\begin{array}{l}\text { 1. Nature of Discharge: } \square \text { Rainfall (Complete line items 2.a., 2.b., \& 2.c.) } \quad \text { Xnowmelt } \\
\begin{array}{lll}\text { 2.a. Duration of the rainfall event (hours): } & \text { 2.b. Rainfall amount (inches): } & \text { 2.c. Time since previous measurable storm event (days): }\end{array}\end{array}$}} \\
\hline & & & & & & & & & & \\
\hline $\begin{array}{l}\text { 3.a. Outfall ID } \\
\text { (list the same } 3- \\
\text { digit outfalls } \\
\text { identified on the } \\
\text { NOI form) }\end{array}$ & $\begin{array}{l}\text { 3.b. Check if Any } \\
\text { Outfalls are } \\
\text { Substantially } \\
\text { Identical to Other } \\
\text { Outfalls Listed }\end{array}$ & \begin{tabular}{c|} 
3.c. \\
Check if \\
No \\
Discharge
\end{tabular} & $\begin{array}{l}\text { 3.d. } \\
\text { Monitoring } \\
\text { Type QBM, } \\
\text { ELG, S/T, I, O* }\end{array}$ & 3.e. Parameter & $\begin{array}{l}\text { 3.f. Quality or } \\
\text { Concentration }\end{array}$ & 3.g. Units & 3.h. Results Description & $\begin{array}{l}\text { 3.i. Collection } \\
\text { Date }\end{array}$ & \begin{tabular}{|c|} 
3.j. \\
Exceedance \\
due to \\
natural \\
background \\
pollutant \\
levels \\
\end{tabular} & $\begin{array}{c}\text { 3.k. No } \\
\text { further } \\
\text { pollutant } \\
\text { reductions } \\
\text { achievable? }\end{array}$ \\
\hline 004 & $\begin{array}{l}\square \text { Substantially identical } \\
\text { to outfall: }\end{array}$ & & I & Adjusted Gross Alpha & 3.19 & $\mathrm{pCi} / \mathrm{L}$ & & \multicolumn{2}{|l|}{$04 / 18 / 2016$} & \\
\hline 004 & $\begin{array}{l}\text { L Substantially identical } \\
\text { to outfall: }\end{array}$ & & 1 & Aluminum, total recoverable & 9060 & $u g / L$ & & \multicolumn{2}{|l|}{$04 / 18 / 2016$} & \\
\hline 004 & $\begin{array}{l}\square \text { Substantially identical } \\
\text { to outfall: }\end{array}$ & & QBM & Aluminum, total recoverable & 9060 & $u g / L$ & & \multicolumn{2}{|l|}{$04 / 18 / 2016$} & \\
\hline 004 & $\begin{array}{l}\text { L Substantially identical } \\
\text { to outfall: }\end{array}$ & & 1 & Aroclor, total & BQL & & $0.103 \mathrm{ug} / \mathrm{L}$ & \multicolumn{2}{|l|}{$04 / 18 / 2016$} & \\
\hline 004 & $\begin{array}{l}\mid L] \text { Substantially identical } \\
\text { to outfall: }\end{array}$ & & QBM & Iron, total & 1590 & $u g / L$ & & \multicolumn{2}{|l|}{$04 / 18 / 2016$} & \\
\hline 004 & $\begin{array}{l}\square \text { Substantially identical } \\
\text { to outfall: }\end{array}$ & & QBM & Nitrate plus Nitrite Nitrogen & 0.163 & $\mathrm{mg} / \mathrm{L}$ & & $04 / 18 / 2016$ & & \\
\hline
\end{tabular}

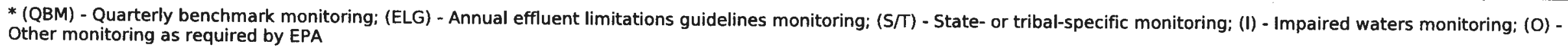

4. Comment and/or Explanation of Any Violations (Reference all attachments here) 
004: The impaired water pollutant total recoverable Aluminum exceeds the New Mexico water quality standard. The average concentration of total recoverable Aluminum is mathematically certain to exceed the benchmark value. 


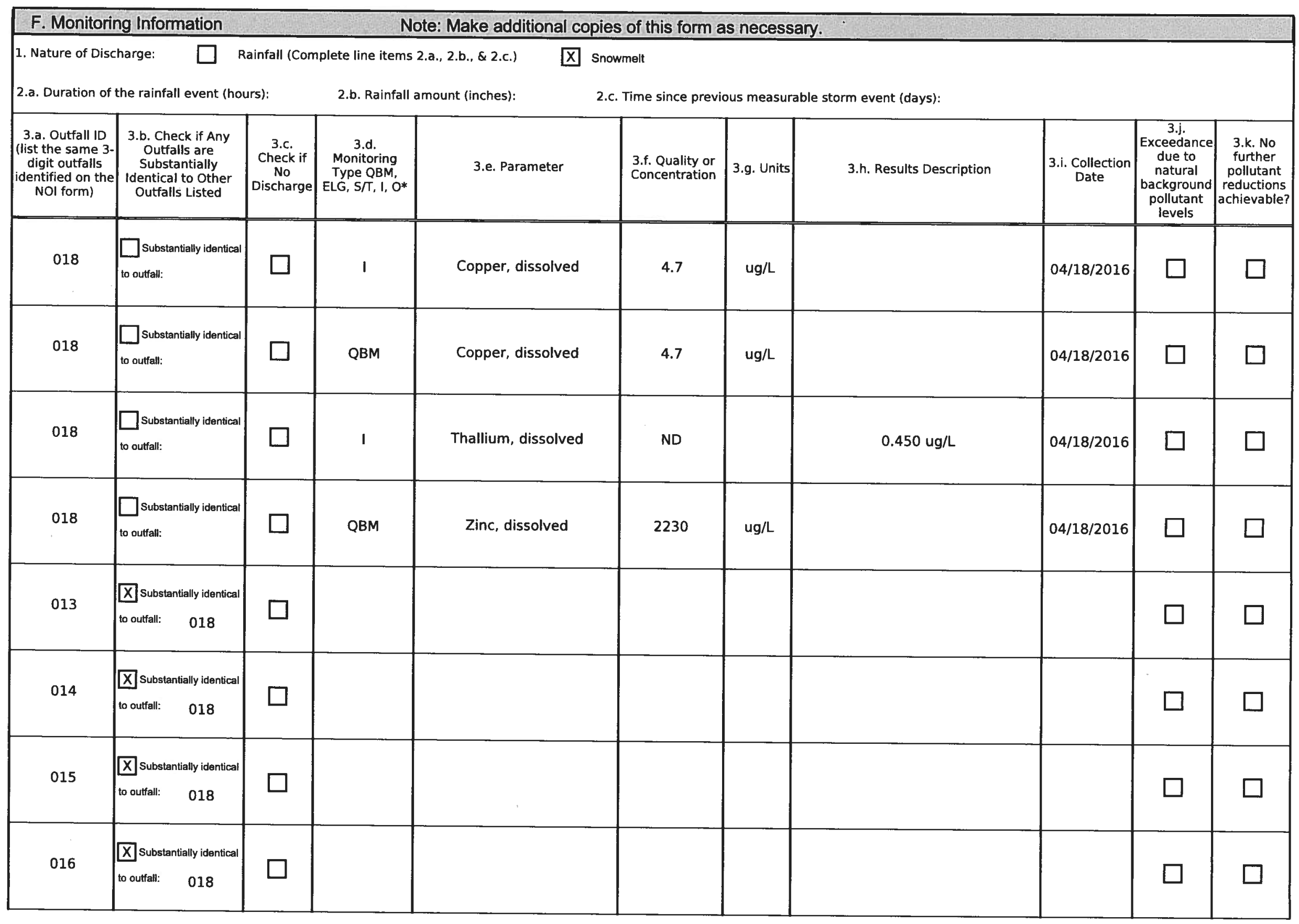

\section{EPA FORM 6100-29}




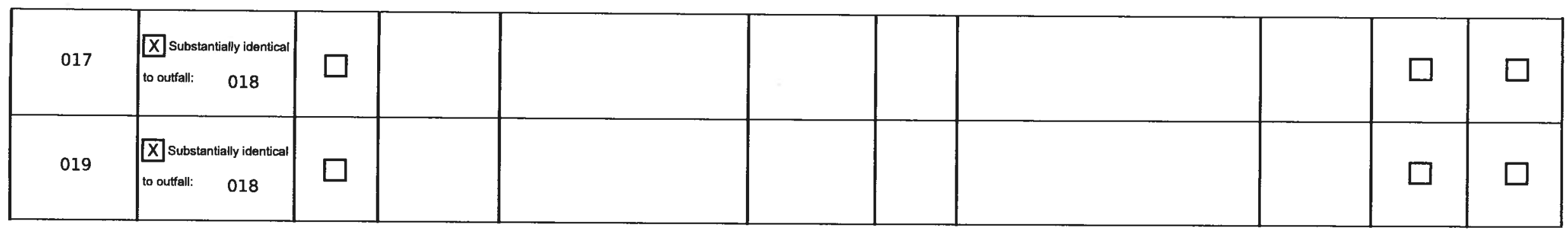

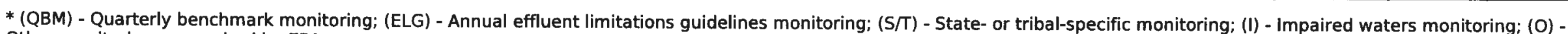
Other monitoring as required by EPA

4. Comment and/or Explanation of Any Violations (Reference all attachments here)

018: The impaired water pollutant dissolved Thallium was not detected in stormwater discharge from this outfall. Therefore, annual monitoring for dissolved Thallium will be discontinued per Part 6.2.4.1. The average concentration of dissolved Zinc is mathematically certain to exceed the benchmark value. 


\begin{tabular}{|c|c|c|c|c|c|c|c|c|c|c|}
\hline \multicolumn{2}{|c|}{ F. Monitoring Information } & \multicolumn{6}{|c|}{ Note: Make additional copies of this form as necessary. } & & & \\
\hline \multirow{2}{*}{\multicolumn{11}{|c|}{$\begin{array}{l}\text { 1. Nature of Discharge: } \square \text { Rainfall (Complete line items 2.a., 2.b., \& 2.c.) } \\
\begin{array}{ll}\text { 2.a. Duration of the rainfall event (hours): } & \text { 2.b. Rainfall amount (inches): }\end{array}\end{array}$}} \\
\hline & & & & & & & & & & \\
\hline $\begin{array}{c}\text { 3.a. Outfall ID } \\
\text { (list the same } 3- \\
\text { digit outfalls } \\
\text { identified on the } \\
\text { NOl form) }\end{array}$ & $\begin{array}{l}\text { 3.b. Check if Any } \\
\text { Outfalls are } \\
\text { Substantially } \\
\text { Identical to Other } \\
\text { Outfalls Listed }\end{array}$ & $\begin{array}{c}\text { 3.c. } \\
\text { Check if } \\
\text { No } \\
\text { Discharge }\end{array}$ & $\begin{array}{l}\text { 3.d. } \\
\text { Monitoring } \\
\text { Type QBM, } \\
\text { ELG, S/T, I, O* }\end{array}$ & 3.e. Parameter & $\begin{array}{l}\text { 3.f. Quality or } \\
\text { Concentration }\end{array}$ & 3.g. Units & 3.h. Results Description & $\begin{array}{l}\text { 3.i. Collection } \\
\text { Date }\end{array}$ & $\begin{array}{c}\text { 3.j. } \\
\text { Exceedance } \\
\text { due to } \\
\text { natural } \\
\text { background } \\
\text { pollutant } \\
\text { levels } \\
\end{array}$ & $\begin{array}{l}\text { 3.k. No } \\
\text { further } \\
\text { pollutant } \\
\text { reductions } \\
\text { achievable? }\end{array}$ \\
\hline 032 & $\begin{array}{l}\square \text { substantially identical } \\
\text { to outtall: }\end{array}$ & $\square$ & 1 & Copper, dissolved & 3.72 & $u g / L$ & & $04 / 18 / 2016$ & $\square$ & $\square$ \\
\hline 032 & $\begin{array}{l}\square \text { substantially identical } \\
\text { to ouffall: }\end{array}$ & $\square$ & $\mathbf{I}$ & Thallium, dissolved & ND & & $0.450 \mathrm{ug} / \mathrm{L}$ & $04 / 18 / 2016$ & $\square$ & $\square$ \\
\hline \multirow{2}{*}{033} & Х Substantially identical & \multirow{2}{*}{$\square$} & & & & & & & \multirow{2}{*}{$\square$} & \multirow{2}{*}{$\square$} \\
\hline & to ouffall: $\quad 032$ & & & & & & & & & \\
\hline \multirow{2}{*}{034} & $\mathrm{X}$ Substantially Identical & \multirow{2}{*}{$\square$} & & & & & & & \multirow{2}{*}{$\square$} & \multirow{2}{*}{$\square$} \\
\hline & to outfall: & & & & & & & & & \\
\hline \multirow{2}{*}{035} & Х Substantially identical & 1 & & & & & & & \multirow[b]{2}{*}{$\square$} & \multirow{2}{*}{$\square$} \\
\hline & | to outfall: & 口 & & & & & & & & \\
\hline
\end{tabular}

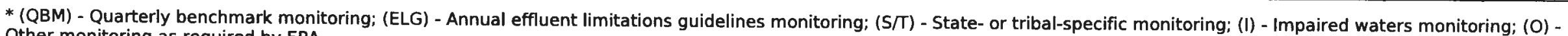
Other monitoring as required by EPA

4. Comment and/or Explanation of Any Violations (Reference all attachments here) 032: The impaired water pollutant dissolved Thallium was not detected in stormwater discharge from this outfall. Therefore, annual monitoring for dissolved Thallium will be
discontinued per Part 6.2.4.1. 


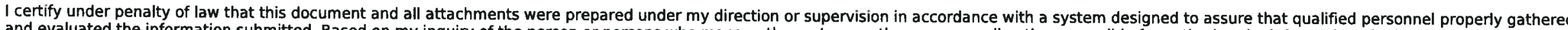

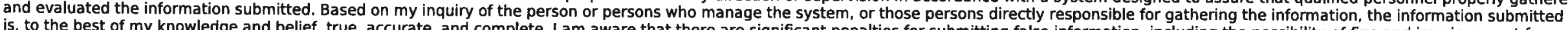

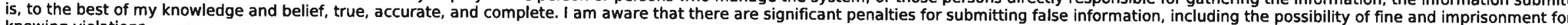
knowing violations.

First Name, Middle Initial, Last Name: Anthony

Title:

Signature:

E-mail:

\section{EPC-CP Group Leader}

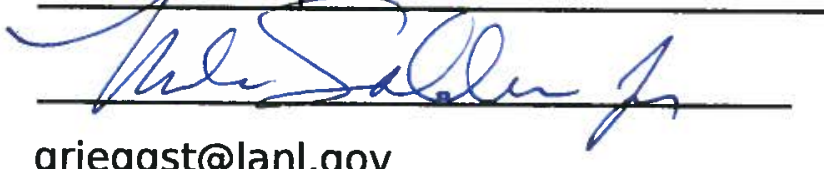

grieggst@lanl.gov
$\underline{\mathrm{R}}$ Grieggs

Date

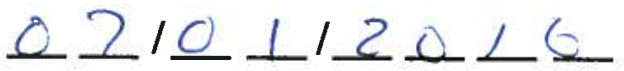




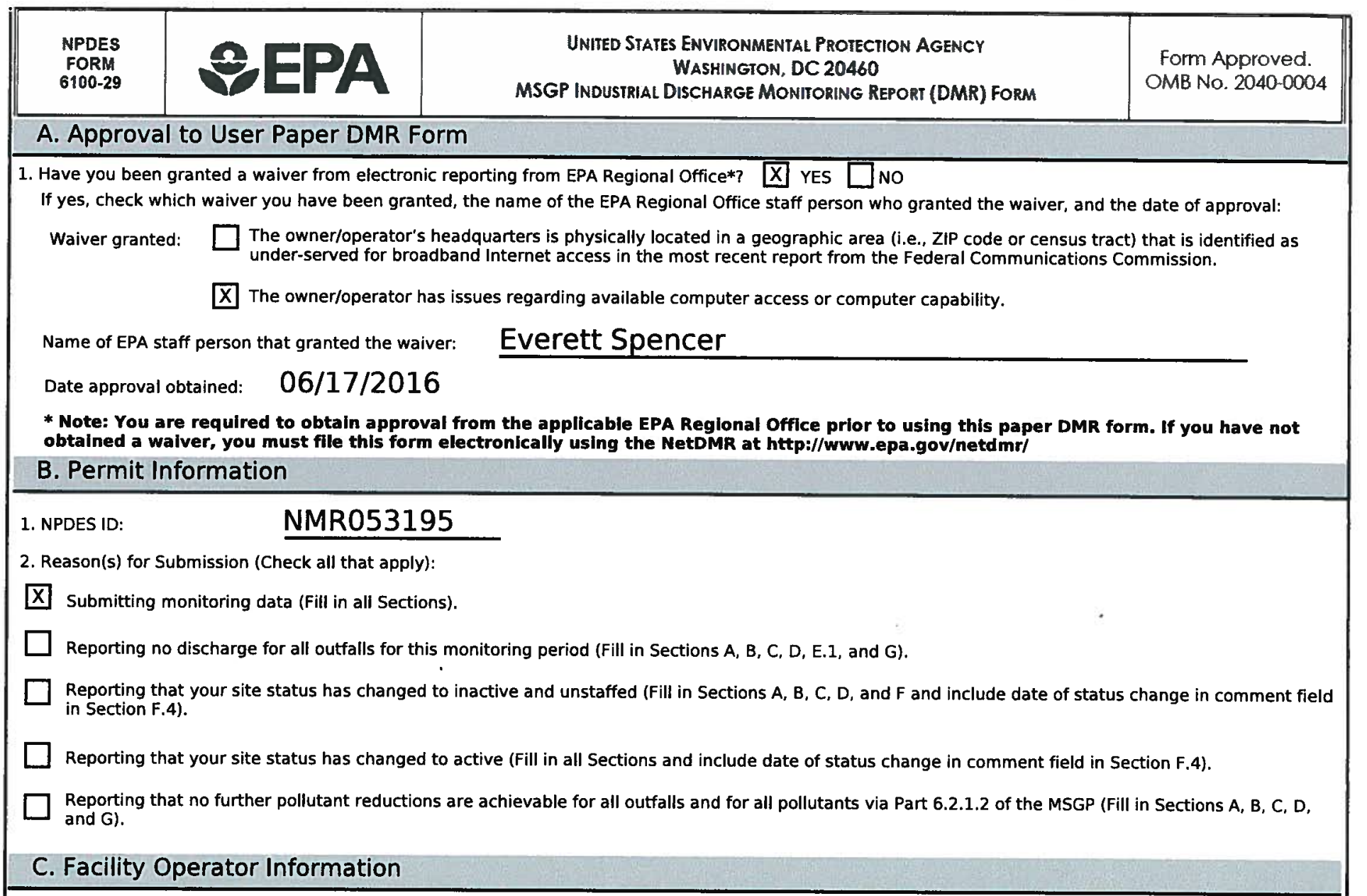

1. Operator Information

Operator Name: $\quad$ Los Alamos National Security, LLC

Mailing Address:

Street: $\quad$ P.O. Box 1663, MS K490

$\begin{array}{lll}\text { City: } & \frac{\text { Los Alamos }}{5056670666} \text { State: } & \text { NM ZIP Code: } 87545- \\ \text { Phone: } & \text { grieggst@lanl.gov } & \end{array}$

2. DMR Preparer (Complete if DMR was prepared by someone other than the certifier):

First Name, Middle Initial, Last Name: Holly L. Wheeler

Organization: $\quad$ EPC-CP

Phone:

5056671312

Ext.

E-mail: hbenson@lanl.gov 


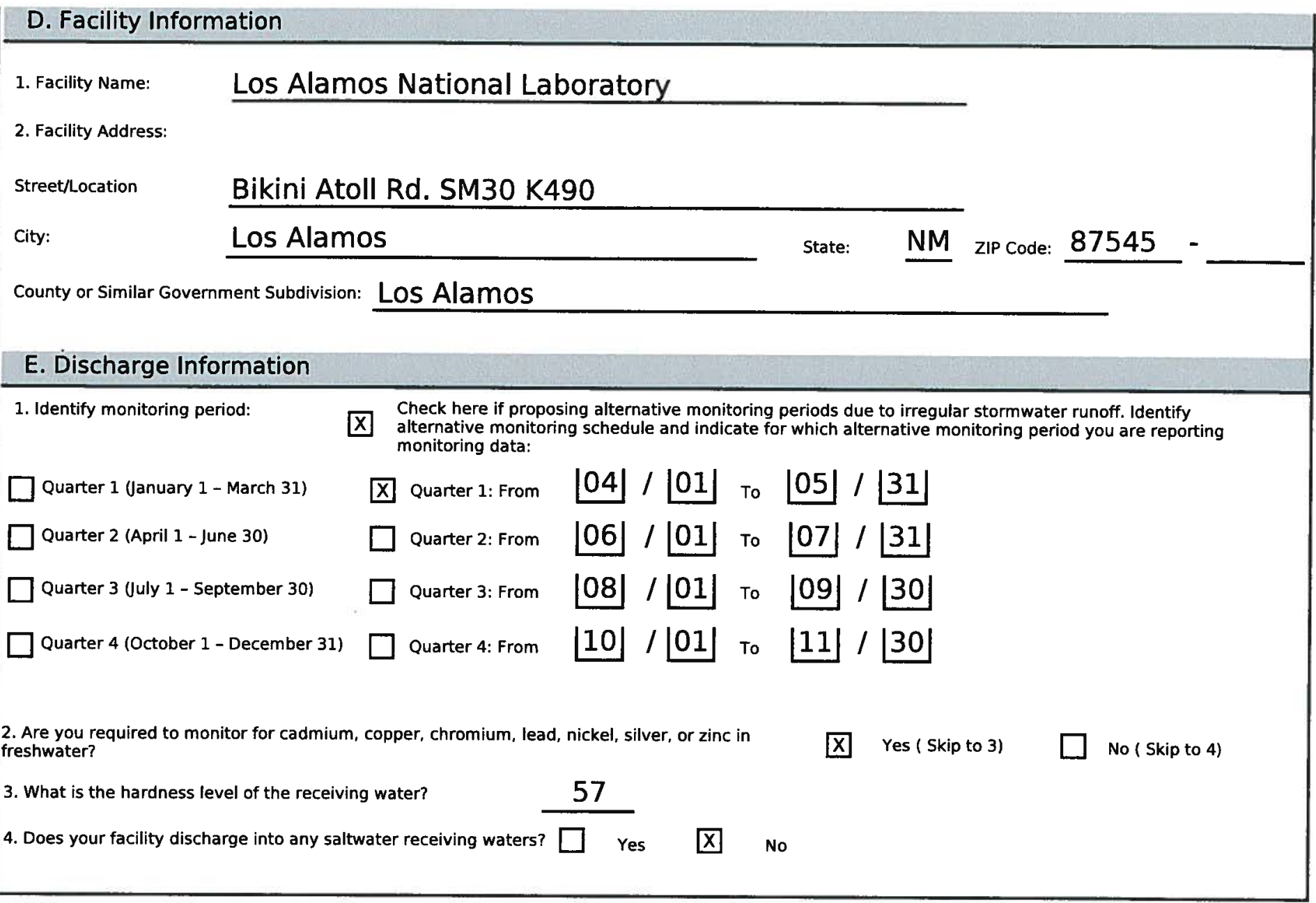




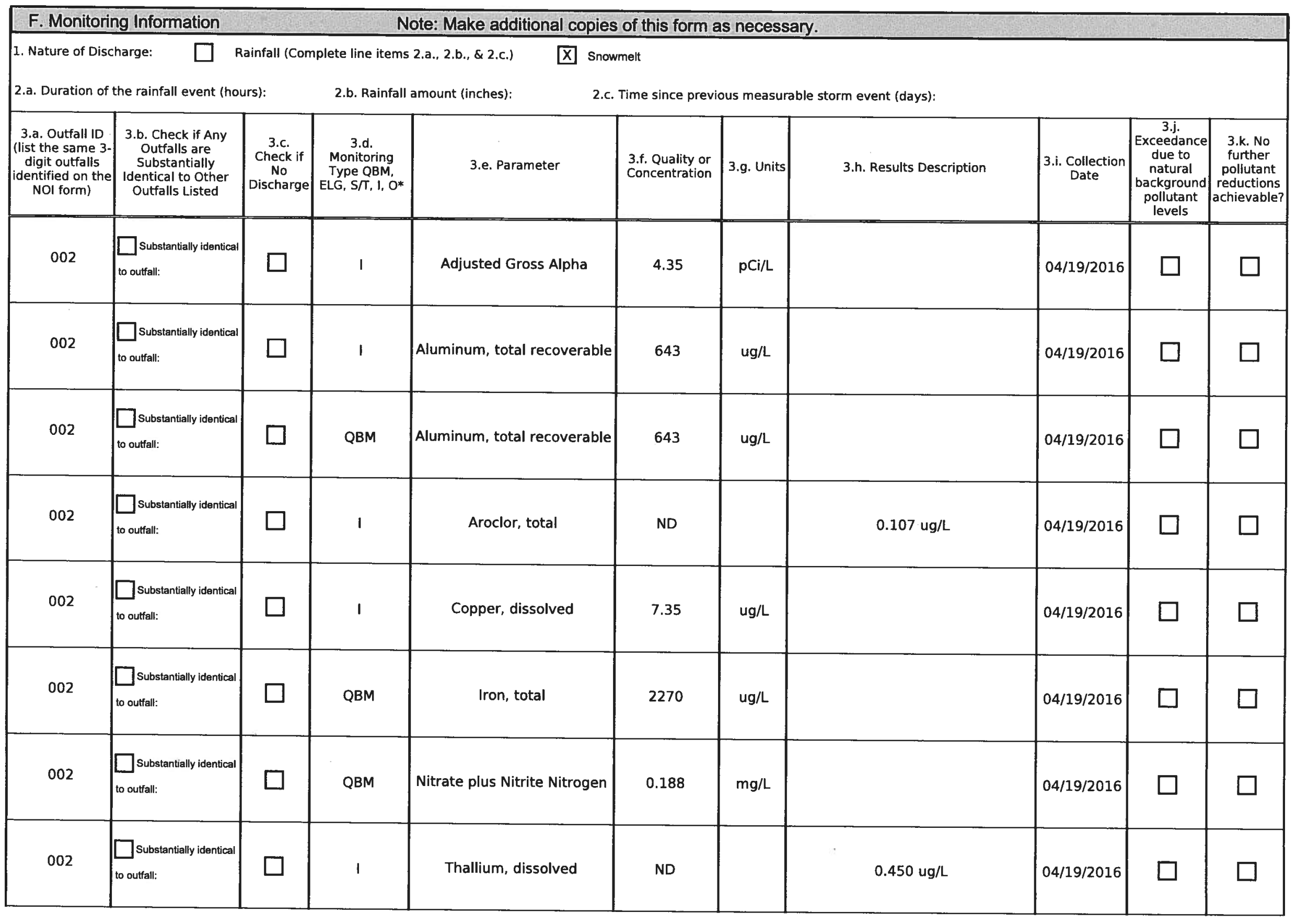

\section{EPA FORM 6100-29}




\begin{tabular}{|l|l|l|l|l|l|l|l|l|l|}
\hline 002 & $\begin{array}{l}\square \text { substantially identical } \\
\text { to outtall: }\end{array}$ & $\square$ & QBM & Zinc, dissolved & 32 & ug/L & & $04 / 19 / 2016$ & $\square$ \\
\hline
\end{tabular}

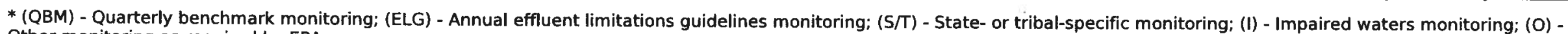
Other monitoring as required by EPA

4. Comment and/or Explanation of Any Violations (Reference all attachments here)

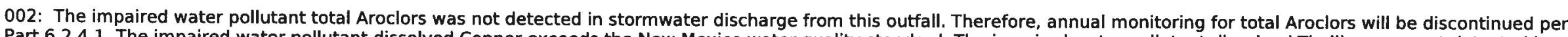

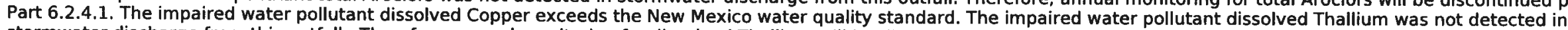
stormwater discharge from this outfall. Therefore, annual monitoring for dissolved Thallium will be discontinued per Part 6.2.4.1. 


\begin{tabular}{|c|c|c|c|c|c|c|c|c|c|c|}
\hline \multicolumn{4}{|c|}{ F. Monitoring Information } & \multicolumn{7}{|c|}{ Note: Make additional copies of this form as necessary. } \\
\hline 1. Nature of Disc & charge: $\square$ & tainfall (Con & plete line item & 2.b., \& 2,c.) & & & & & & \\
\hline \multicolumn{5}{|c|}{ 2.a. Duration of the rainfall event (hours): } & Time since previ & ous measur & orm event (days): & & & \\
\hline $\begin{array}{l}\text { 3.a. Outfall ID } \\
\text { (list the same } 3- \\
\text { digit outfalls } \\
\text { identified on the } \\
\text { NOl form) }\end{array}$ & $\begin{array}{l}\text { 3.b. Check if Any } \\
\text { Outfalls are } \\
\text { Substantially } \\
\text { Identical to Other } \\
\text { Outfalls Listed }\end{array}$ & \begin{tabular}{|c|} 
\\
3.c. \\
Check if \\
No \\
Discharge
\end{tabular} & $\begin{array}{c}\text { 3.d. } \\
\text { Monitoring } \\
\text { Type QBM, } \\
\text { ELG, ST, L, O* }\end{array}$ & 3.e. Parameter & $\begin{array}{l}\text { 3.f. Quality or } \\
\text { Concentration }\end{array}$ & 3.g. Units & 3.h. Results Description & $\begin{array}{l}\text { 3.i. Collection } \\
\text { Date }\end{array}$ & \begin{tabular}{|c|}
$3 . j$. \\
Exceedance \\
due to \\
natural \\
background \\
pollutant \\
levels \\
\end{tabular} & $\begin{array}{c}\text { 3.k. No } \\
\text { further } \\
\text { pollutant } \\
\text { reductions } \\
\text { achievable? }\end{array}$ \\
\hline 009 & $\begin{array}{l}\square \text { substantially identical } \\
\text { to outfall: }\end{array}$ & $\square$ & 1 & Copper, dissolved & 9.01 & $u g / L$ & & $04 / 19 / 2016$ & $\square$ & $\square$ \\
\hline 009 & $\begin{array}{l}\square \text { substantially identical } \\
\text { to outfall: }\end{array}$ & $\square$ & 1 & Thallium, dissolved & BQL & & $2.00 \mathrm{ug} / \mathrm{L}$ & $04 / 19 / 2016$ & $\square$ & $\square$ \\
\hline \multirow[t]{2}{*}{007} & Х Substantially identical & \multirow{2}{*}{$\square$} & & & & & & & \multirow{2}{*}{$\square$} & \multirow{2}{*}{$\square$} \\
\hline & | to outfall: & & & & & & & & & \\
\hline \multirow{2}{*}{008} & Q Substantially identical & \multirow{2}{*}{$\mathrm{X}$} & & & & & & & \multirow{2}{*}{$\square$} & \multirow{2}{*}{$\square$} \\
\hline & to outfall: & & & & & & & & & \\
\hline \multirow[t]{2}{*}{010} & Х Substantially identical & \multirow{2}{*}{$\square$} & & & & & & & \multirow{2}{*}{$\square$} & \multirow{2}{*}{$\square$} \\
\hline & to outfall: $\quad 009$ & & & & & & & & & \\
\hline
\end{tabular}

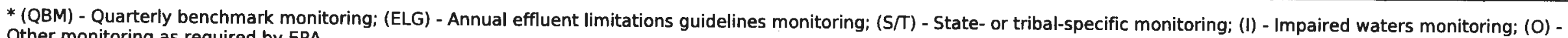
Other monitoring as required by EPA

4. Comment and/or Explanation of Any Violations (Reference all attachments here)

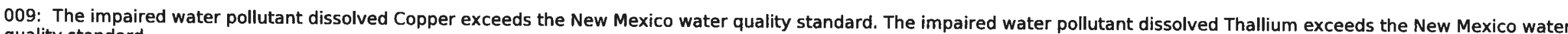
quality standard. 


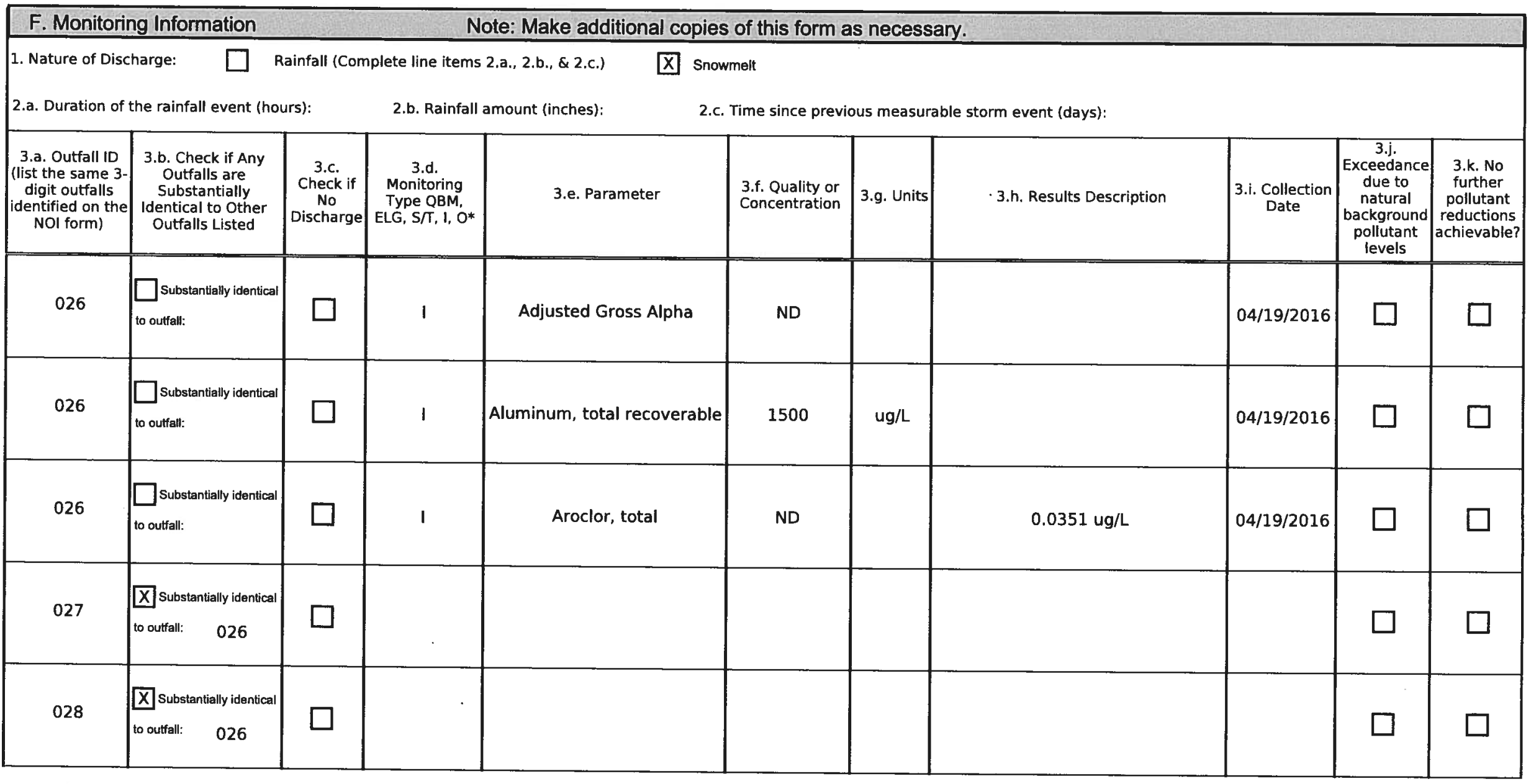

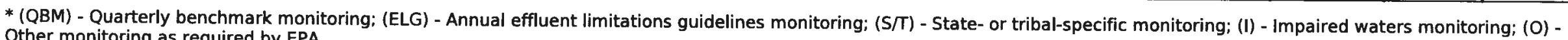
Other monitoring as required by EPA

4. Comment and/or Explanation of Any Violations (Reference all attachments here)

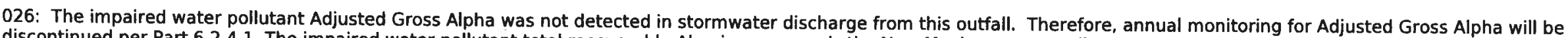

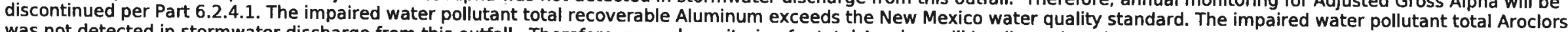
was not detected in stormwater discharge from this outfall. Therefore, annual monitoring for total Aroclors will be discontinued per Part 6.2.4.1. 


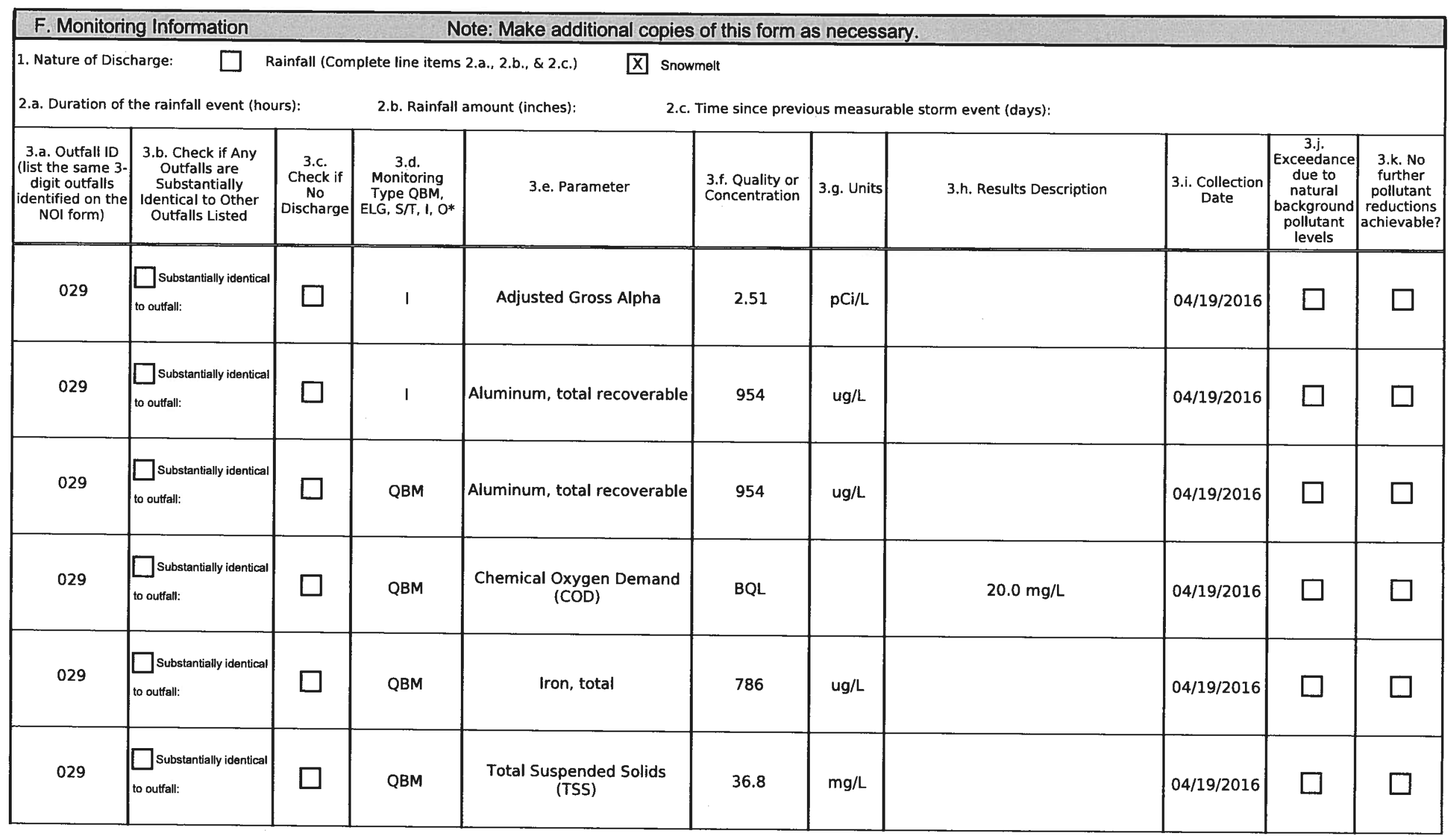

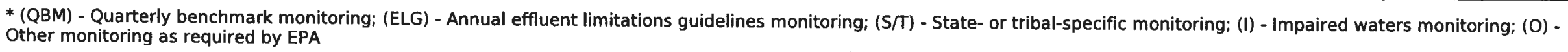

4. Comment and/or Explanation of Any Violations (Reference all attachments here) 
029: The impaired water pollutant total recoverable Aluminum exceeds the New Mexico water quality standard 


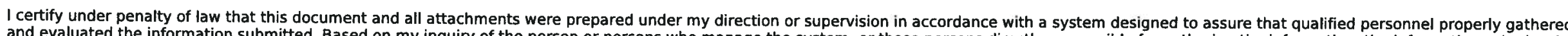

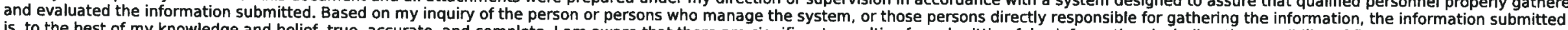

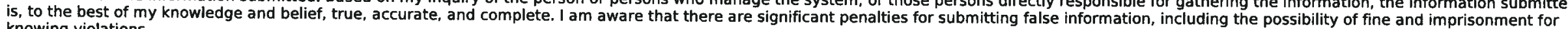
knowing violations.

First Name, Middle Initial, Last Name: Anthony

Title:

Signature:

E-mail:

\section{EPC-CP Group Leader}

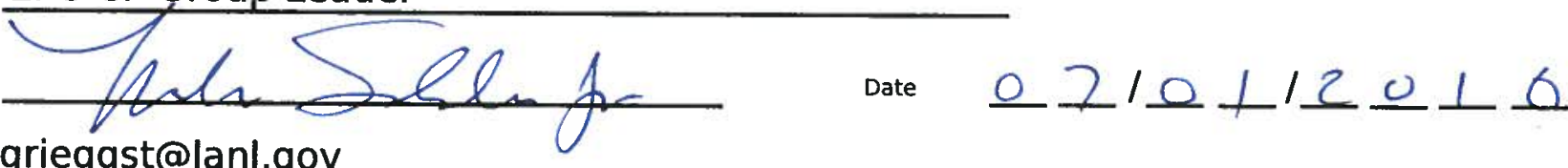

R Grieggs

\section{grieggst@lanl.gov}




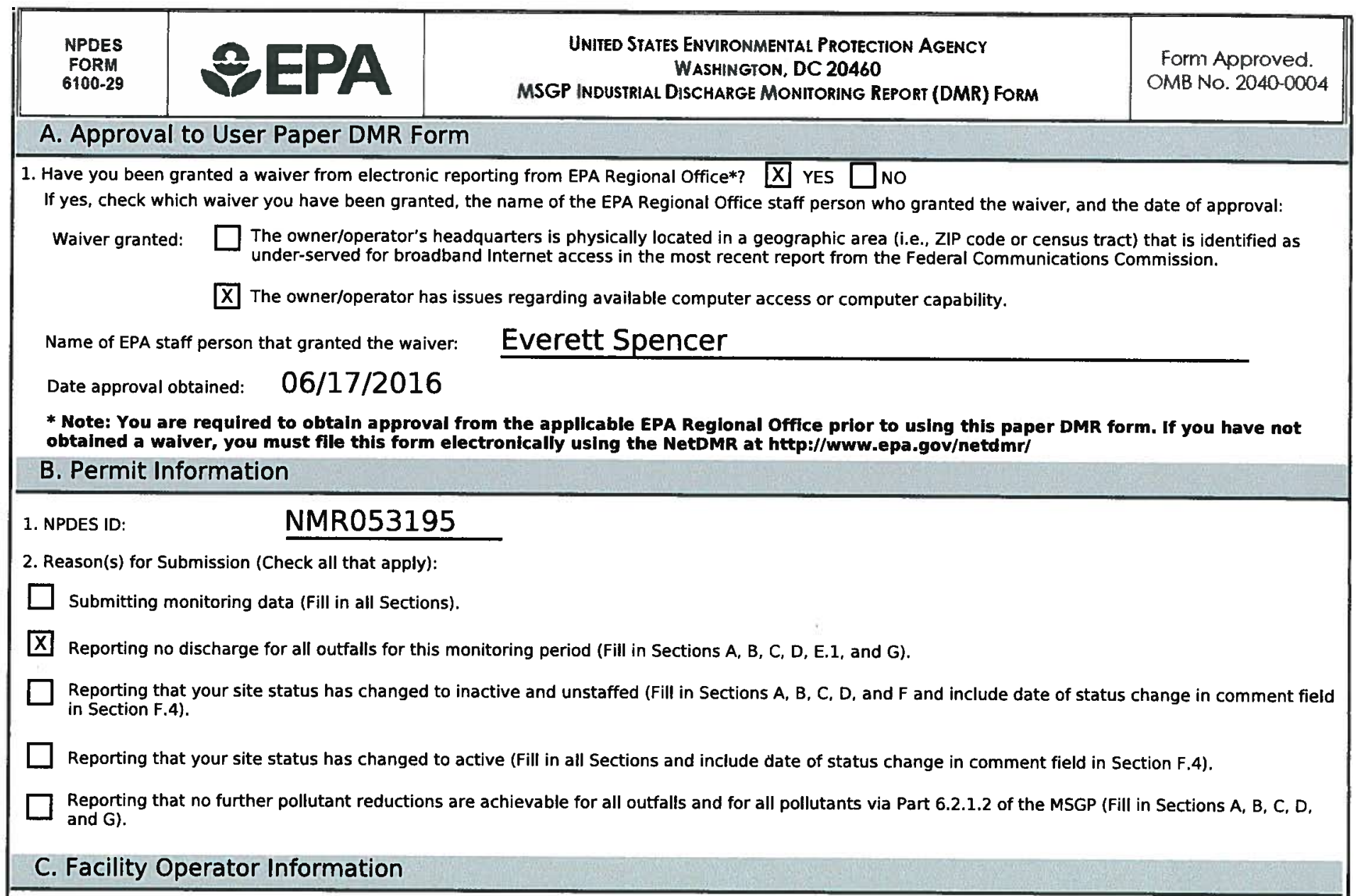

\section{Operator Information}

Operator Name: $\quad$ Los Alamos National Security, LLC

Mailing Address:

Street:

P.O. Box 1663, MS K490

City:

\begin{tabular}{lll}
\hline Los Alamos & state: $\quad$ NM \\
\hline 5056670666 & \\
\hline grieggst@lanl.gov & \\
\hline
\end{tabular}

2. DMR Preparer (Complete if DMR was prepared by someone other than the certifier):

First Name, Middle Initial, Last Name: Holly L. Wheeler

Organization:

EPC-CP

Phone:

5056671312

Ext.

E-mail:

hbenson@lanl.gov 


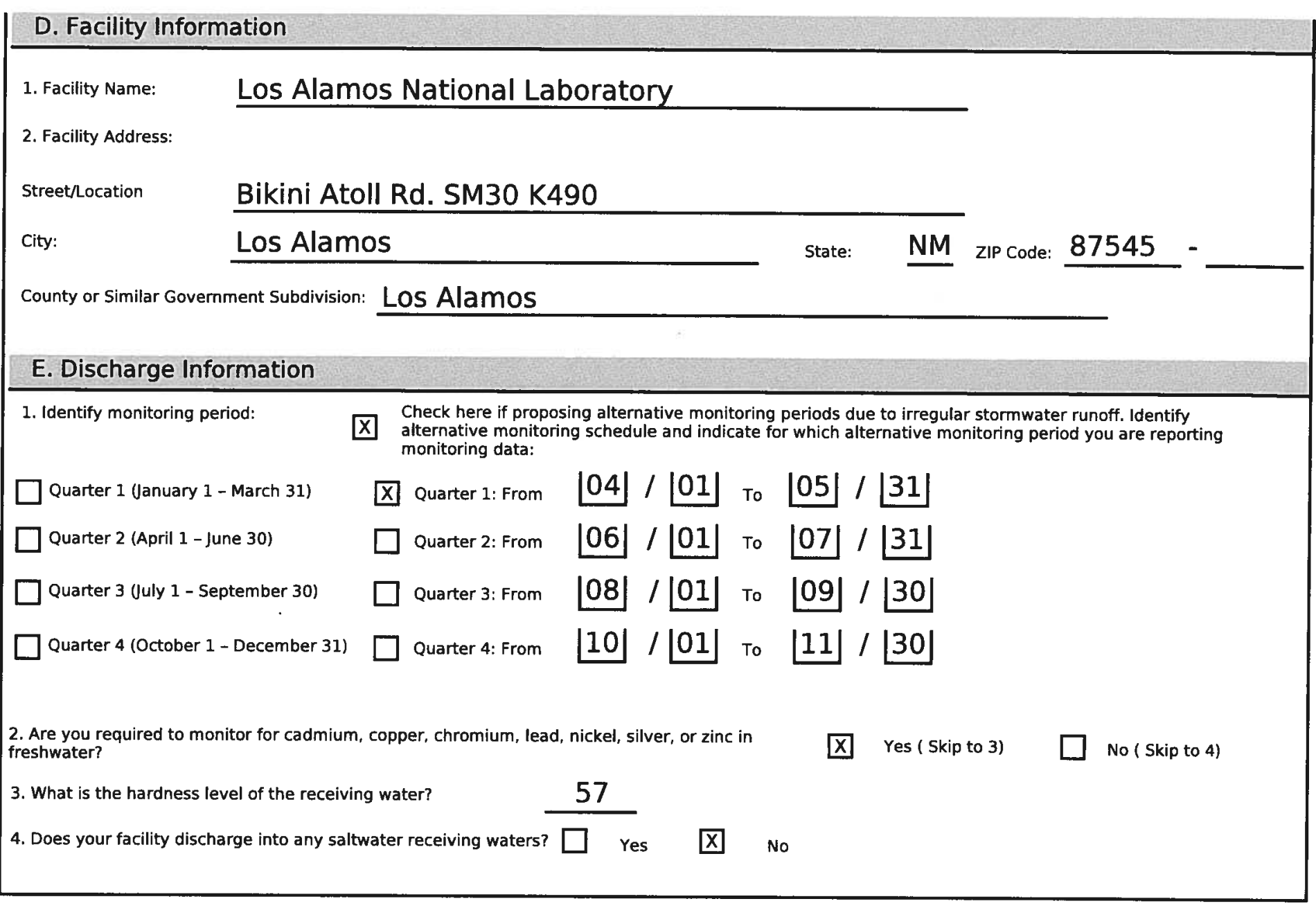




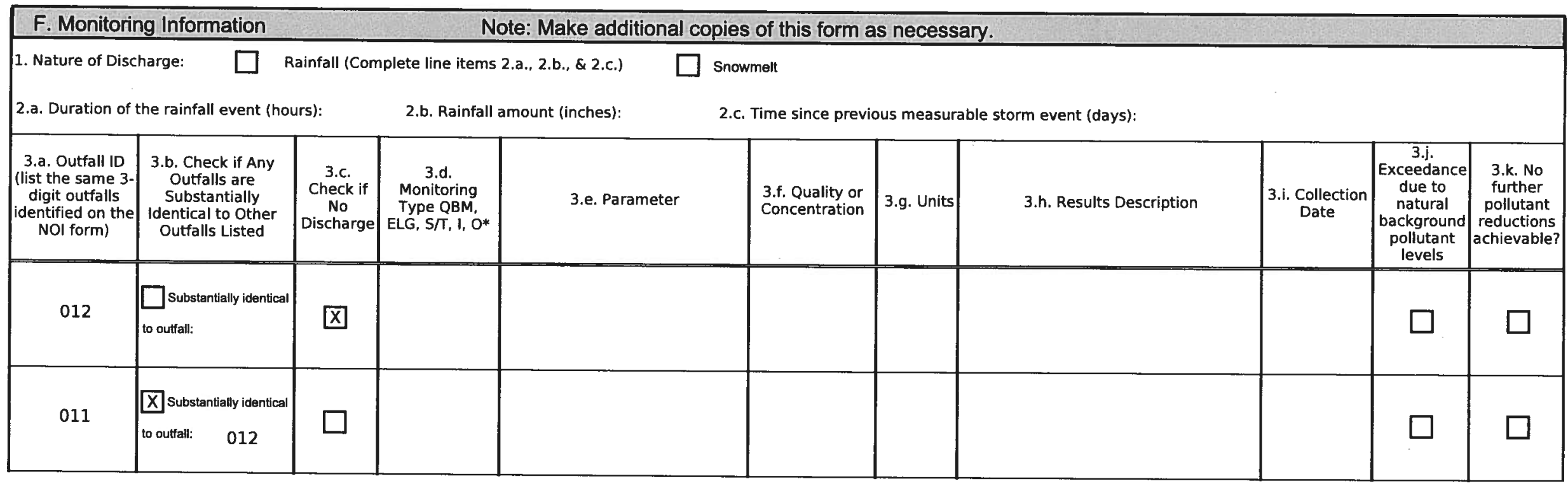

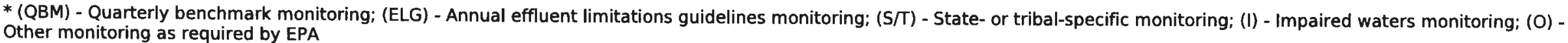

4. Comment and/or Explanation of Any Violations (Reference all attachments here)

012: NODI: C 


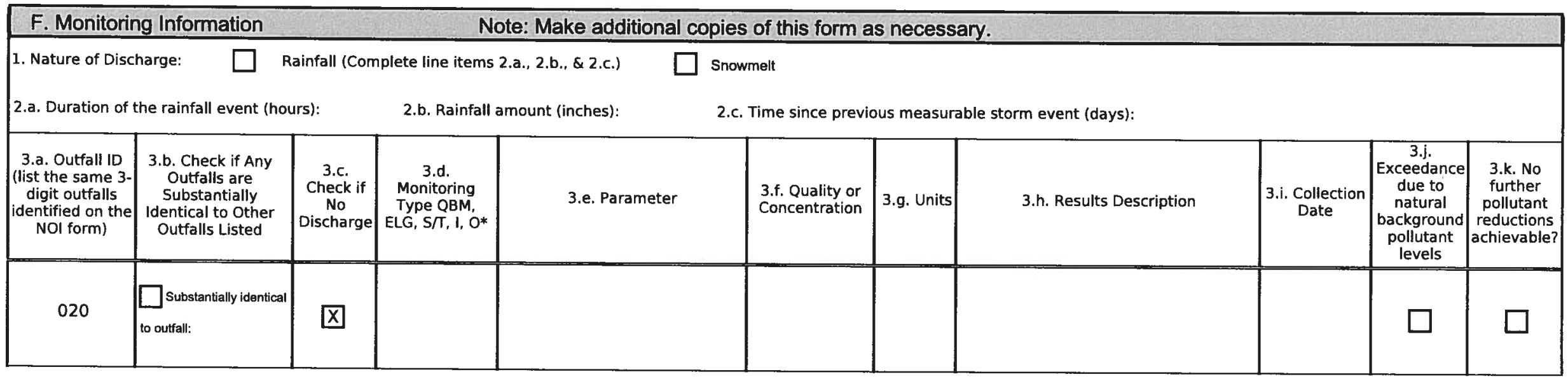

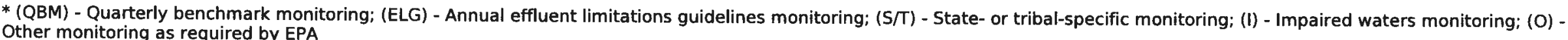

4. Comment and/or Explanation of Any Violations (Reference all attachments here)

020: NODI: C 


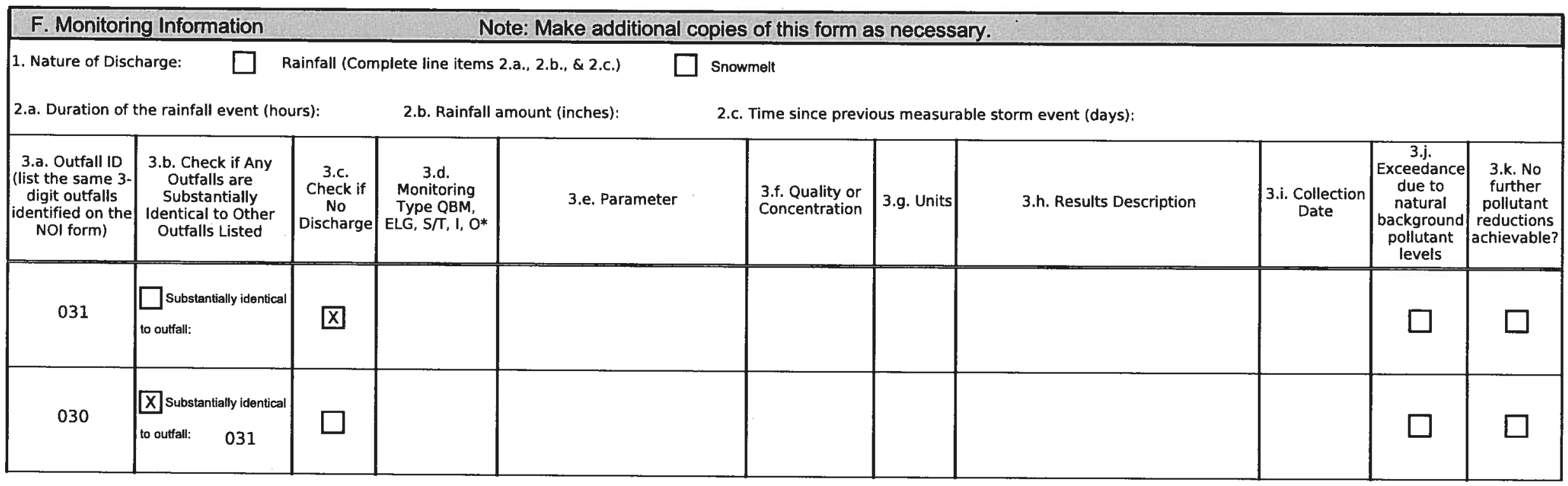

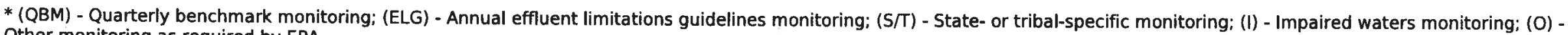
Other monitoring as required by EPA

4. Comment and/or Explanation of Any Violations (Reference all attachments here)

031: NODI: C 


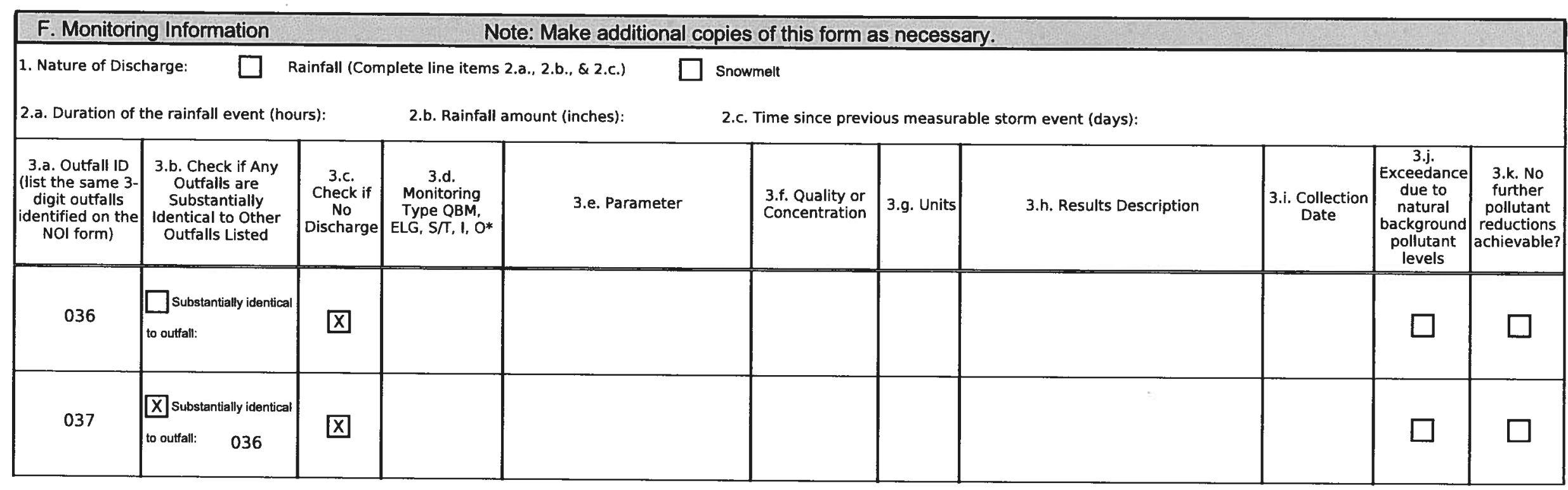

* (QBM) - Quarterly benchmark monitoring; (ELG) - Annual effluent limitations guidelines monitoring; (S/T) - State- or tribal-specific monitoring; (I) - Impaired waters monitoring; (O) Other monitoring as required by EPA

4. Comment and/or Explanation of Any Violations (Reference all attachments here)

036: NODI: C 


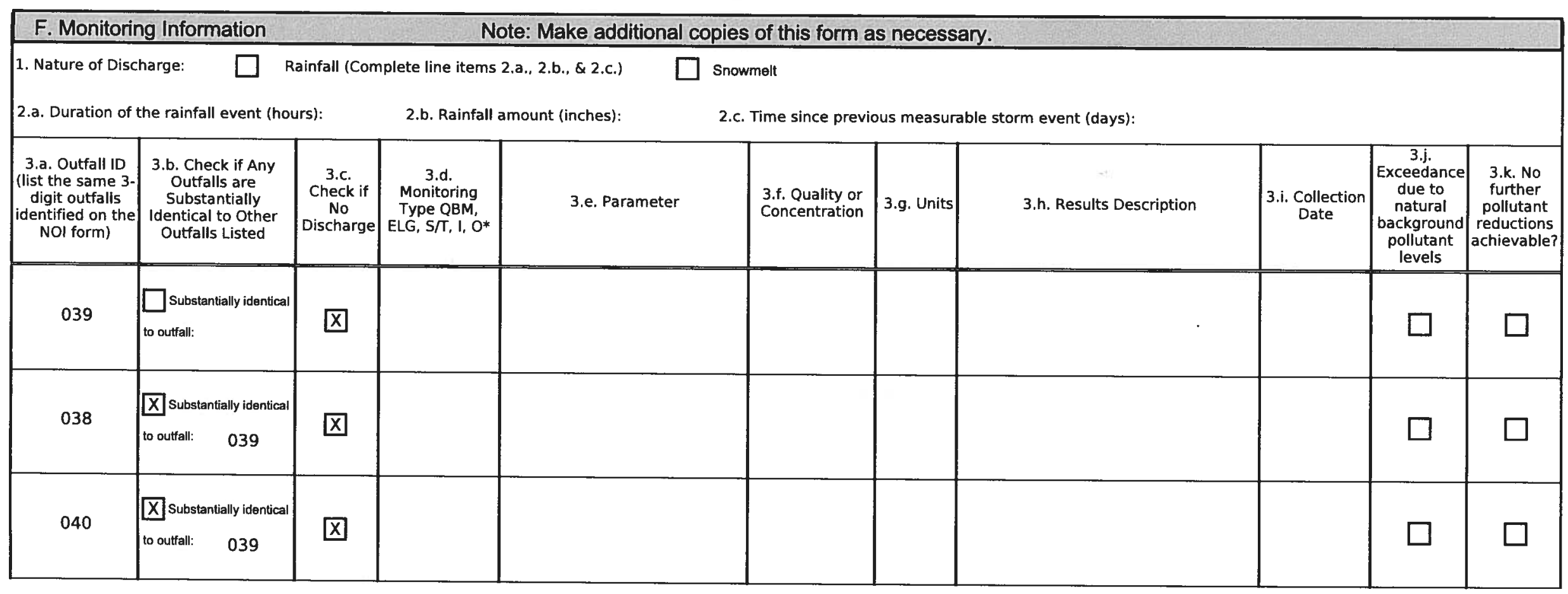

* (QBM) - Quarterly benchmark monitoring; (ELG) - Annual effluent limitations guidelines monitoring; (S/T) - State- or tribal-specific monitoring; (I) - Impaired waters monitoring; (O) Other monitoring as required by EPA

4. Comment and/or Explanation of Any Violations (Reference all attachments here)

039: NODI: C 


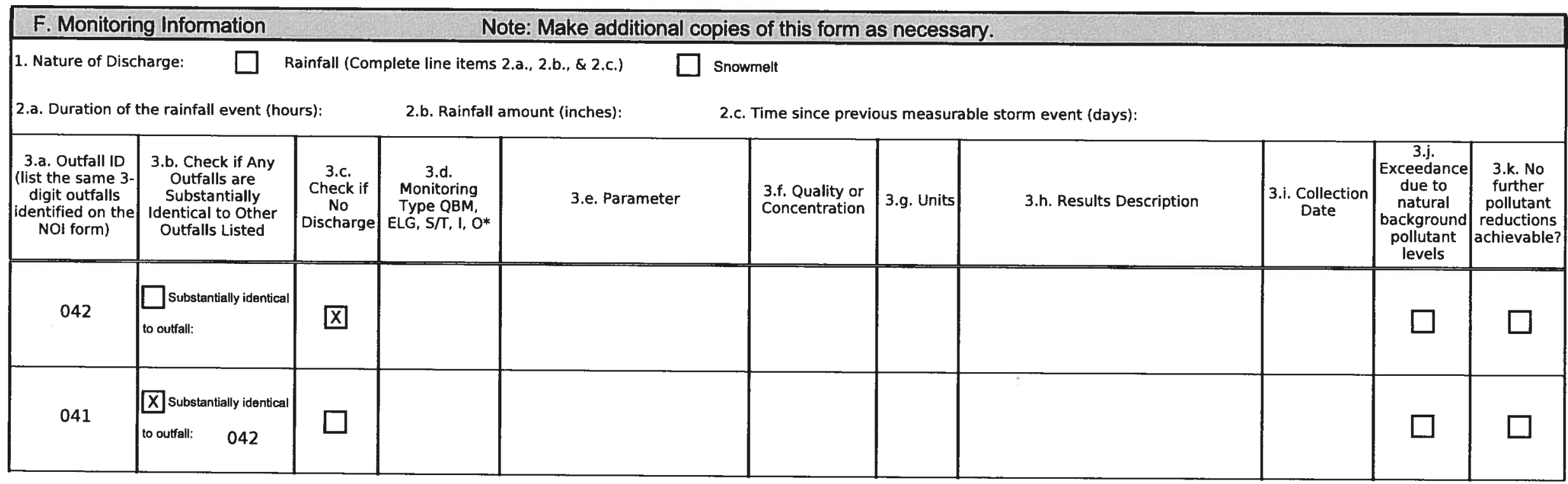

*(QBM) - Quarterly benchmark monitoring; (ELG) - Annual effluent limitations guidelines monitoring; (S/T) - State- or tribal-specific monitoring; (I) - Impaired waters monitoring; (O) Other monitoring as required by EPA

4. Comment and/or Explanation of Any Violations (Reference all attachments here)

042: NODI: C 


\begin{tabular}{|c|c|c|c|c|c|c|c|c|c|c|}
\hline \multicolumn{2}{|c|}{ F. Monitoring Information } & \multicolumn{6}{|c|}{ Note: Make additional copies of this form as necessary. } & & & \\
\hline \multicolumn{5}{|c|}{ 1. Nature of Discharge: } & & & & & & \\
\hline \multicolumn{3}{|c|}{ 2.a. Duration of the rainfall event (hours): } & \multicolumn{2}{|c|}{ 2.b. Rainfall amount (inches): } & \multicolumn{3}{|c|}{ 2.c. Time since previous measurable storm event (days): } & & & \\
\hline $\begin{array}{l}\text { 3.a. Outfall ID } \\
\text { (list the same } 3- \\
\text { digit outfalls } \\
\text { identified on the } \\
\text { NOI form) }\end{array}$ & $\begin{array}{l}\text { 3.b. Check if Any } \\
\text { Outfalls are } \\
\text { Substantially } \\
\text { Identical to Other } \\
\text { Outfalls Listed }\end{array}$ & $\begin{array}{c}\text { 3.c. } \\
\text { Check if } \\
\text { No } \\
\text { Discharge }\end{array}$ & $\begin{array}{c}\text { 3.d. } \\
\text { Monitoring } \\
\text { Type QBM, } \\
\text { ELG, S/T, I, O* }\end{array}$ & 3.e. Parameter & $\begin{array}{l}\text { 3.f. Quality or } \\
\text { Concentration }\end{array}$ & 3.g. Units & 3.h. Results Description & $\begin{array}{c}\text { 3.i. Collection } \\
\text { Date }\end{array}$ & \begin{tabular}{|c|}
$3 . j$. \\
Exceedance \\
due to \\
natural \\
background \\
pollutant \\
levels
\end{tabular} & $\begin{array}{l}\text { 3.k. No } \\
\text { further } \\
\text { pollutant } \\
\text { reductions } \\
\text { achievable? }\end{array}$ \\
\hline 043 & $\begin{array}{l}\square \text { Substantially identical } \\
\text { to outfall: }\end{array}$ & $\mathrm{X}$ & & & & & & & & \\
\hline
\end{tabular}

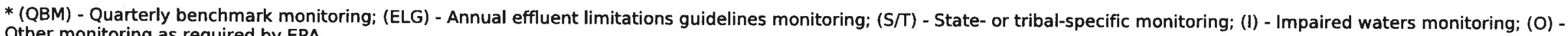
Other monitoring as required by EPA

4. Comment and/or Explanation of Any Violations (Reference all attachments here)

043: NODI: C 


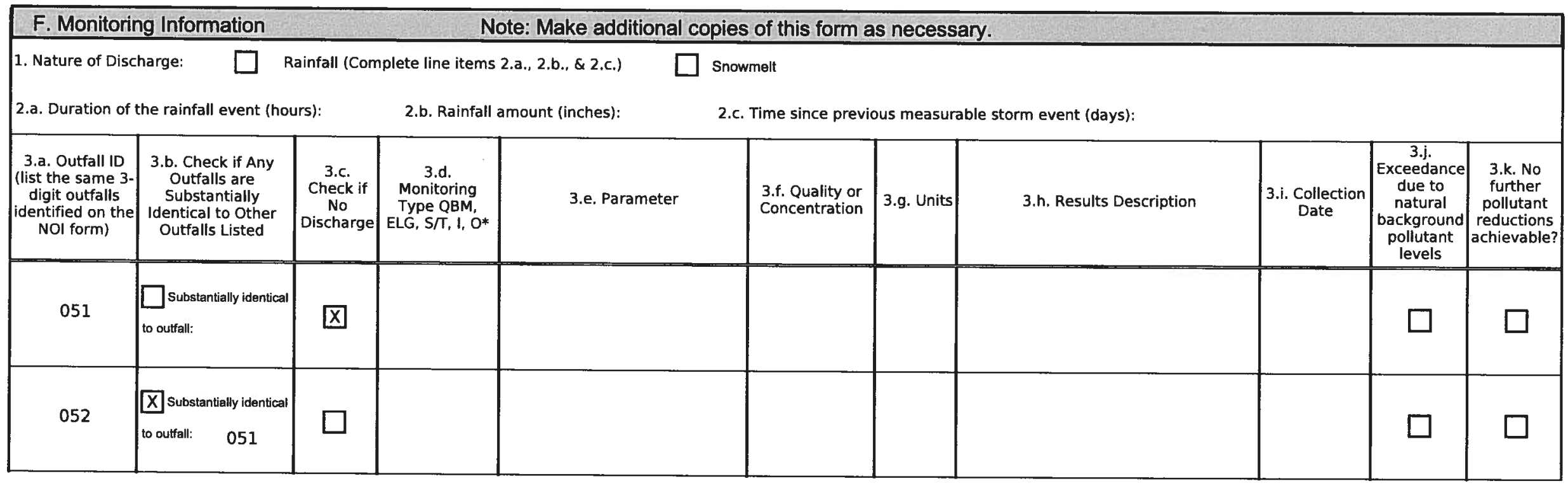

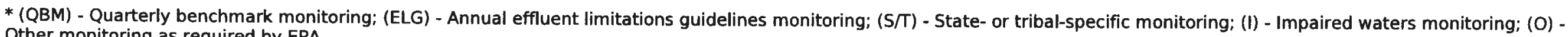
Other monitoring as required by EPA

4. Comment and/or Explanation of Any Violations (Reference all attachments here)

051: NODI: C 


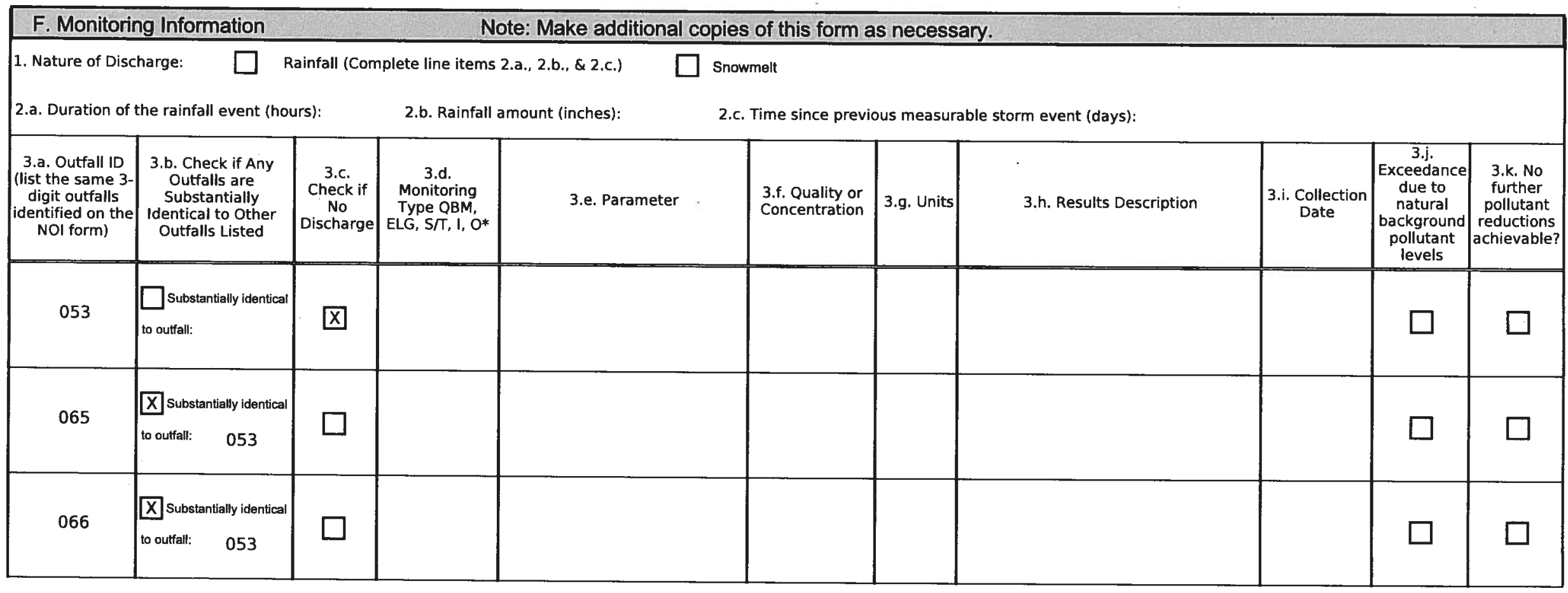

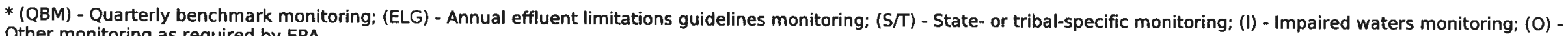
Other monitoring as required by EPA

4. Comment and/or Explanation of Any Violations (Reference all attachments here)

053: NODI: C 


\begin{tabular}{|c|c|c|c|c|c|c|c|c|c|c|}
\hline \multicolumn{4}{|c|}{ F. Monitoring Information } & \multicolumn{7}{|c|}{ Note: Make additional copies of this form as necessary. } \\
\hline \multirow{2}{*}{\multicolumn{11}{|c|}{$\begin{array}{l}\text { 1. Nature of Discharge: } \square \text { Rainfall (Complete line items 2.a., 2.b., \& 2.c.) } \\
\begin{array}{ll}\text { 2.a. Duration of the rainfall event (hours): } & \text { 2.b. Rainfall amount (inches): }\end{array}\end{array}$}} \\
\hline & & \multicolumn{3}{|c|}{ 2.a. Duration of the rainfall event (hours): } & \multicolumn{6}{|c|}{ 2.c. Time since previous measurable storm event (days): } \\
\hline $\begin{array}{l}\text { 3.a. Outfall ID } \\
\text { (list the same 3- } \\
\text { digit outfalls } \\
\text { identified on the } \\
\text { NOI form) }\end{array}$ & $\begin{array}{l}\text { 3.b. Check if Any } \\
\text { Outfalls are } \\
\text { Substantially } \\
\text { Identical to Other } \\
\text { Outfalls Listed }\end{array}$ & $\begin{array}{c}\text { 3.c. } \\
\text { Check if } \\
\text { No } \\
\text { Discharge }\end{array}$ & $\begin{array}{l}\text { 3.d. } \\
\text { Monitoring } \\
\text { Type QBM, } \\
\text { ELG, S IT, I, O* }\end{array}$ & 3.e. Parameter & $\begin{array}{l}\text { 3.f. Quality or } \\
\text { Concentration }\end{array}$ & 3.g. Units & 3.h. Results Description & $\begin{array}{l}\text { 3.i. Collection } \\
\text { Date }\end{array}$ & \begin{tabular}{|c|}
$3 . j$. \\
Exceedance \\
due to \\
natural \\
background \\
pollutant \\
levels \\
\end{tabular} & $\begin{array}{c}\text { 3.k. No } \\
\text { further } \\
\text { pollutant } \\
\text { reductions } \\
\text { achievable? }\end{array}$ \\
\hline 072 & $\begin{array}{l}\square \text { substantially identical } \\
\text { to outfall: }\end{array}$ & 冈 & & & & & & & $\square$ & $\square$ \\
\hline 070 & \Substantially identical & 1 & & & & & & & 口 & \\
\hline & to outfall: $\quad 072$ & ப & & & & & & & $\square$ & $\square$ \\
\hline 071 & X Substantially identical & 7 & & & & & & & & \\
\hline & to outfall: $\quad 072$ & $\square$ & & & & & & & $\square$ & $\square$ \\
\hline
\end{tabular}

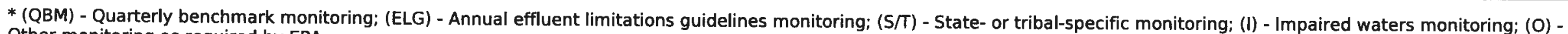
Other monitoring as required by EPA

4. Comment and/or Explanation of Any Violations (Reference all attachments here)

072: NODI: C 


\begin{tabular}{|c|c|c|c|c|c|c|c|c|c|c|}
\hline \multicolumn{11}{|c|}{ Note: Make additional copies of this form as necessary. } \\
\hline \multirow{2}{*}{\multicolumn{11}{|c|}{$\begin{array}{l}\text { 1. Nature of Discharge: } \square \text { Rainfall (Complete line items 2.a., 2.b., \& 2.c.) } \\
\begin{array}{l}\text { 2.a. Duration of the rainfall event (hours): } \\
\text { 2.b. Rainfall amount (inches): }\end{array}\end{array}$}} \\
\hline & & & & & & & & & & \\
\hline $\begin{array}{l}\text { 3.a. Outfall ID } \\
\text { (list the same } 3 \text { - } \\
\text { digit outfalls } \\
\text { identified on the } \\
\text { NOI form) }\end{array}$ & $\begin{array}{l}\text { 3.b. Check if Any } \\
\text { Outfalls are } \\
\text { Substantially } \\
\text { Identical to Other } \\
\text { Outfalls Listed }\end{array}$ & $\begin{array}{c}\text { 3.c. } \\
\text { Check if } \\
\text { No } \\
\text { Discharge }\end{array}$ & $\begin{array}{c}\text { 3.d. } \\
\text { Monitoring } \\
\text { Type QBM, } \\
\text { ELG, ST, I, O* }\end{array}$ & 3.e. Parameter & $\begin{array}{l}\text { 3.f. Quality or } \\
\text { Concentration }\end{array}$ & 3.g. Units & 3.h. Results Description & $\begin{array}{l}\text { 3.i. Collection } \\
\text { Date }\end{array}$ & \begin{tabular}{|c|}
$3 . j$ \\
Exceedance \\
due to \\
natural \\
background \\
pollutant \\
levels \\
\end{tabular} & $\begin{array}{l}\text { 3.k. No } \\
\text { further } \\
\text { pollutant } \\
\text { reductions } \\
\text { achievable? }\end{array}$ \\
\hline 075 & \begin{tabular}{|l}
$\square$ substantially identical \\
to outfall:
\end{tabular} & 区 & & & & & & & $\square$ & $\square$ \\
\hline
\end{tabular}

*(QBM) - Quarterly benchmark monitoring; (ELG) - Annual effluent limitations guidelines monitoring; (S/T) - State- or tribal-specific monitoring; (I) - Impaired waters monitoring; (O) Other monitoring as required by EPA

4. Comment and/or Explanation of Any Violations (Reference all attachments here)

075: NODI: C 


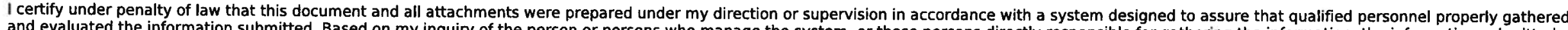

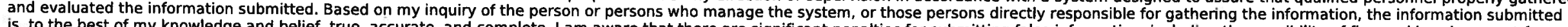

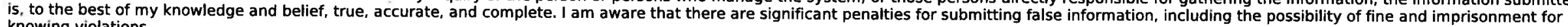
knowing violations.

First Name, Middle Initial, Last Name: Anthony

Title:

Signature:

E-mail:

\section{EPC-CP Group Leader}

EPC-CP GroupLeader grieggst@lanl.gov

\section{R Grieggs}

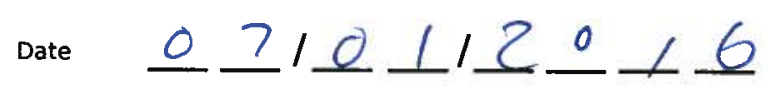


Environmental Protection \& Compliance Division (EPC-DO)

Environmental Compliance Programs (EPC-CP)

PO Box 1663, K490

Los Alamos, New Mexico 87545

(505) 667-0666

\author{
Date: JUL 132016 \\ Symbol: EPC-DO-16-200 \\ LA-UR: $\quad 16-24915$ \\ Locates Action No.: N/A
}

\author{
U.S. EPA Region 6 \\ NPDES Stormwater Program (WQ-PP) \\ 1445 Ross Avenue, Suite 1200 \\ Dallas, TX 75202-2733
}

To whom it may concern:

Subject: $\quad$ National Pollutant Discharge Elimination System (NPDES) Permit Tracking No. NMR053195, Multi-Sector General Permit (MSGP) Industrial Discharge Monitoring Reports (MDMRs) For April 29 and May 06, 2016

Enclosed are Los Alamos National Laboratory's MDMRs (Enclosure 1) for April 29 and May 06, 2016, as required under MSGP Permit Tracking No. NMR053195, submitted on behalf of Los Alamos National Security LLC. These MDMRs contain analytical results for impaired water and quarterly benchmark monitoring at outfalls $005,029,032$, and 050.

Relative to the duration of the rainfall event and rainfall amount being zero, no rain was measured at LANS' Meteorological Network. However, the sample was collected early in the morning (04:09) and no releases were reported. Our Meteorologist evaluated regional radar and found that there was a storm cell overhead during that time. In addition, facility personnel reported the site was wet when they arrived for work that morning; therefore, the sample was analyzed as a monitoring sample. 
Please contact Holly Wheeler at (505) 667-1312 or Terrill Lemke at (505) 665-2397 if you have questions regarding these MDMRs.

Sincerely,

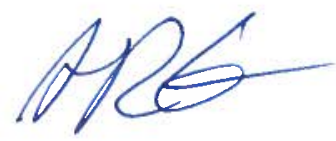

Anthony R. Grieggs

Group Leader

Environmental Compliance Programs (EPC-CP)

Los Alamos National Security, LLC

ARG:TWL:HLW/lm

Enclosure: $\quad$ 1. NPDES Permit Tracking No. NMR053195, MDMRs for April 29 and May 06, 2016

Cy: $\quad$ Everett Spencer, USEPA/Region 6, Dallas TX, (E-File)

Helen Nguyen, USEPA/Region 6, Dallas TX, (E-File)

Craig S. Leasure, PADOPS, (E-File)

William R. Mairson, PADOPS, (E-File)

Michael T. Brandt, ADESH, (E-File)

Raeanna Sharp-Geiger, ADESH, (E-File)

John P. McCann, EPC-DO, (E-File)

Terrill W. Lemke, EPC-CP, (E-File)

Holly L. Wheeler, EPC-CP, (E-File)

lasomailbox@nnsa.doe.gov, (E-File)

locatesteam@lanl.gov,(E-File)

epc-correspondence@lanl.gov 


\title{
ENCLOSURE 1
}

NPDES Permit Tracking No NMR053195,

MDMRs for April 29 and May 06, 2016

\author{
EPC-DO-16-200 \\ LA-UR-16-24915
}

Date:

JUL 132016 


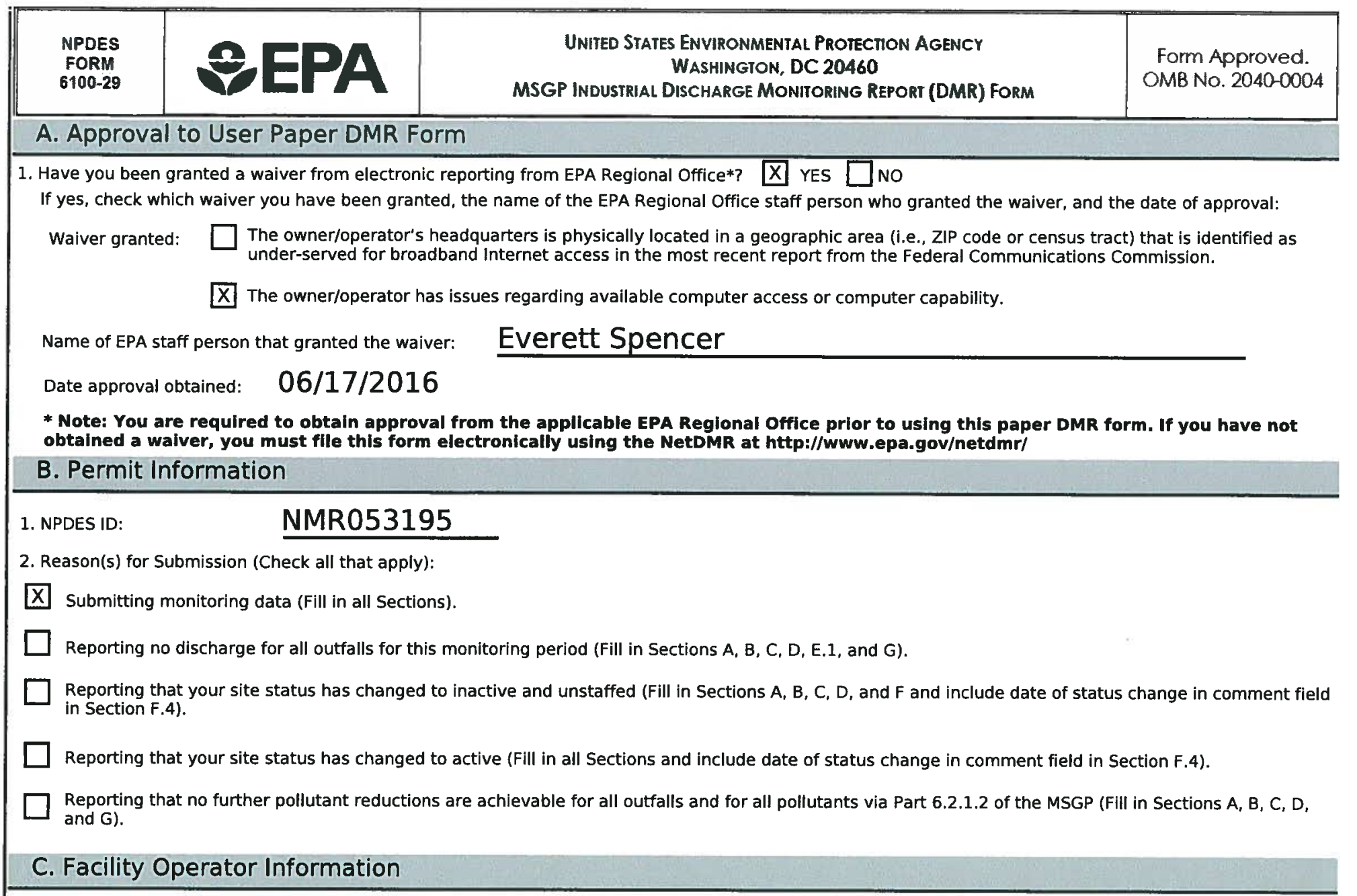

1. Operator Information

Operator Name: $\quad$ Los Alamos National Security, LLC

Mailing Address:

Street:

P.O. Box 1663, MS K490

City: Los Alamos State:

NM ZIP Code:

87545 5056670666

E-mail: grieggst@lanl.gov

2. DMR Preparer (Complete if DMR was prepared by someone other than the certifier):

First Name, Middle Initial, Last Name: Holly L. Wheeler

Organization:

EPC-CP

Phone:

5056671312

Ext.

E-mail:

hbenson@lanl.gov 


\section{Facility Information}

1. Facility Name: $\quad$ Los Alamos National Laboratory

2. Facility Address:

Street/Location

Bikini Atoll Rd. SM30 K490

City:

Los Alamos

State: NM ZIP Code: 87545 -

County or Similar Government Subdivision: LoS Alamos

\section{E. Discharge Information}

1. Identify monitoring period:

Check here if proposing alternative monitoring periods due to irregular stormwater runoff. Identify
alternative monitoring schedule and indicate for which alternative monitoring period you are reporting monitoring data:

$\square$ Quarter 1 (January 1 - March 31)

X Quarter 1: From

[04 / 011 To 05 / 31

$\square$ Quarter 2 (April 1 - June 30)

$\square$ Quarter 2: From

[06] / 01 то

[07] / $31 \mid$

Quarter 3 (July 1 - September 30)

$\square$ Quarter 3: From

108] /01] to

09] $/ 30$

Quarter 4 (October 1 - December 31)

Quarter 4: From

(10) / 01 to $11 / 30$

2. Are you required to monitor for cadmium, copper, chromium, lead, nickel, silver, or zinc in freshwater?

X Yes ( Skip to 3)

No (Skip to 4)

3. What is the hardness level of the receiving water?

57

4. Does your facility discharge into any saltwater receiving waters? 


1. Nature of Discharge: $\square$ Rainfall (Complete line items 2.a., 2.b., \& 2.c.) $\square$ Snowmelt

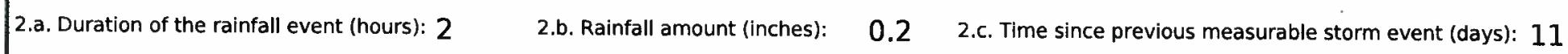

\begin{tabular}{|c|c|c|c|c|c|c|c|c|c|c|}
\hline $\begin{array}{l}\text { 3.a. Outfall ID } \\
\text { (list the same } 3 \text { - } \\
\text { digit outfalls } \\
\text { identified on the } \\
\text { NOl form) }\end{array}$ & $\begin{array}{l}\text { 3.b. Check if Any } \\
\text { Outfalls are } \\
\text { Substantially } \\
\text { Identical to Other } \\
\text { Outfalls Listed }\end{array}$ & $\begin{array}{c}\text { 3.c. } \\
\text { Check if } \\
\text { No } \\
\text { Discharge }\end{array}$ & $\begin{array}{c}\text { 3.d. } \\
\text { Monitoring } \\
\text { Type QBM, } \\
\text { ELG, S/T, I, O* }\end{array}$ & 3.e. Parameter & $\begin{array}{l}\text { 3.f. Quality or } \\
\text { Concentration }\end{array}$ & 3.g. Units & 3.h. Results Description & $\begin{array}{l}\text { 3.i. Collection } \\
\text { Date }\end{array}$ & \begin{tabular}{|c|}
$3 . j$ \\
Exceedance \\
due to \\
natural \\
background \\
pollutant \\
levels \\
\end{tabular} & $\begin{array}{l}\text { 3.k. No } \\
\text { further } \\
\text { pollutant } \\
\text { reductions } \\
\text { achievable? }\end{array}$ \\
\hline 005 & $\begin{array}{l}\square \text { Substantially identical } \\
\text { to outfall: }\end{array}$ & & I & Copper, dissolved & 11.8 & $\mathrm{ug} / \mathrm{L}$ & & $04 / 29 / 2016$ & & \\
\hline 005 & $\begin{array}{l}\square \text { Substantially identical } \\
\text { to outfall: }\end{array}$ & & I & Thallium, dissolved & ND & & $0.450 \mathrm{ug} / \mathrm{L}$ & $04 / 29 / 2016$ & & \\
\hline 006 & $\mathrm{X}$ Substantially identical & & & & & & & & & \\
\hline & to outfall: $\quad 005$ & & & & & & & & & \\
\hline
\end{tabular}

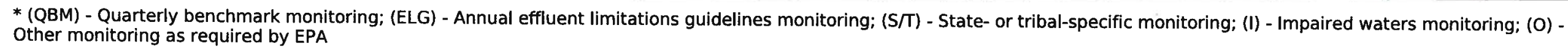

4. Comment and/or Explanation of Any Violations (Reference all attachments here)

Rainfall duration $=1.67$ hours. Rainfall amount $=0.24$ inches.

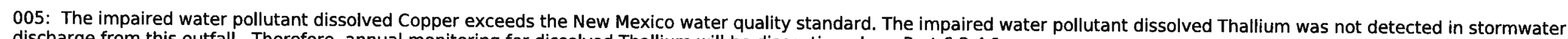
discharge from this outfall. Therefore, annual monitoring for dissolved Thallium will be discontinued per Part 6.2.4.1. 


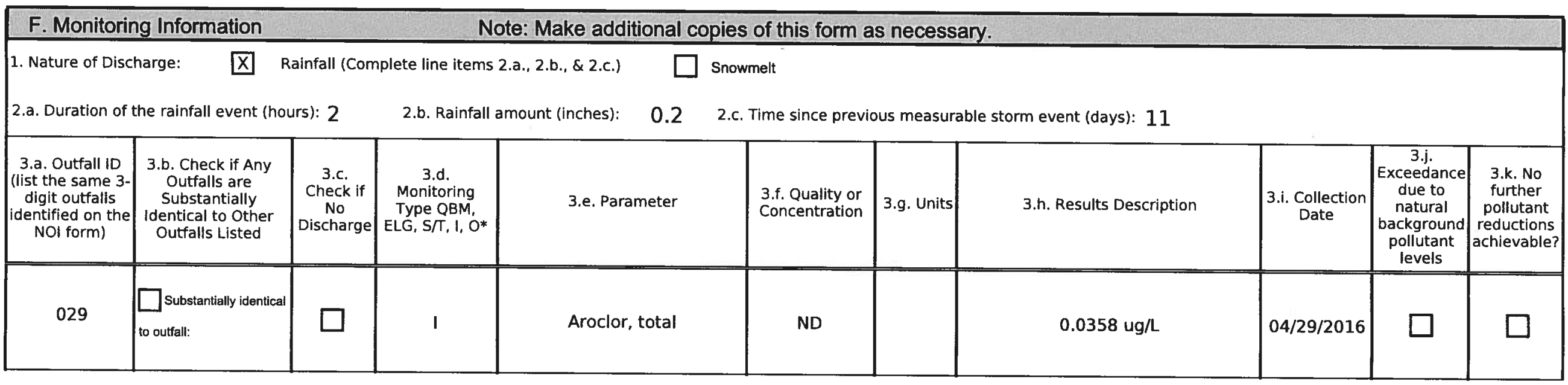

* (QBM) - Quarterly benchmark monitoring; (ELG) - Annual effluent limitations guidelines monitoring; (S/T) - State- or tribal-specific monitoring; (I) - Impaired waters monitoring; (O) Other monitoring as required by EPA

4. Comment and/or Explanation of Any Violations (Reference all attachments here) Rainfall duration $=1.67$ hours. Rainfall amount $=0.24$ inches.

029: The impaired water pollutant total Aroclors was not detected in stormwater discharge from this outfall. Therefore, annual monitoring for total Aroclors will be discontinued per Part 6.2.4.1. 


1. Nature of Discharge: $\quad \mathrm{X}$ Rainfall (Complete line items 2.a., 2.b., \& 2.c.) $\square$ Snowmelt

\section{$\begin{array}{llll}\text { 2.a. Duration of the rainfall event (hours): } 1 & \text { 2.b. Rainfall amount (inches): } 0.2 & \text { 2.c. Time since previous measurable storm event (days): } 11\end{array}$}

\begin{tabular}{|c|c|c|c|c|c|c|c|c|c|c|}
\hline $\begin{array}{l}\text { 3.a. Outfall ID } \\
\text { (list the same } 3- \\
\text { digit outfalls } \\
\text { identified on the } \\
\text { NOI form) }\end{array}$ & $\begin{array}{l}\text { 3.b. Check if Any } \\
\text { Outfalls are } \\
\text { Substantially } \\
\text { Identical to Other } \\
\text { Outfalls Listed }\end{array}$ & $\begin{array}{c}\text { 3.c. } \\
\text { Check if } \\
\text { No } \\
\text { Discharge }\end{array}$ & $\begin{array}{c}\text { 3.d. } \\
\text { Monitoring } \\
\text { Type QBM, } \\
\text { ELG, S/T, I, O* }\end{array}$ & 3.e. Parameter & $\begin{array}{l}\text { 3.f. Quality or } \\
\text { Concentration }\end{array}$ & 3.g. Units & 3.h. Results Description & $\begin{array}{l}\text { 3.i. Collection } \\
\text { Date }\end{array}$ & \begin{tabular}{|c|}
$3 . j$. \\
Exceedance \\
due to \\
natural \\
background \\
pollutant \\
levels
\end{tabular} & $\begin{array}{c}\text { 3.k. No } \\
\text { further } \\
\text { pollutant } \\
\text { reductions } \\
\text { achievable? }\end{array}$ \\
\hline 032 & $\begin{array}{l}\text { Substantially identical } \\
\text { to outfall: }\end{array}$ & & I & Adjusted Gross Alpha & 2.17 & $\mathrm{pCi} / \mathrm{L}$ & & $04 / 29 / 2016$ & & \\
\hline 032 & $\begin{array}{l}\square \text { Substantially identical } \\
\text { to outfall: }\end{array}$ & & I & Aluminum, total recoverable & 897 & $\mathrm{ug} / \mathrm{L}$ & & $04 / 29 / 2016$ & & \\
\hline 032 & $\begin{array}{l}\square \text { Substantially identical } \\
\text { to outfall: }\end{array}$ & & I & Aroclor, total & ND & & $0.0366 \mathrm{ug} / \mathrm{L}$ & $04 / 29 / 2016$ & & \\
\hline 033 & $\begin{array}{l}\text { X] Substantially identical } \\
\text { to outfall: } \quad 032\end{array}$ & & & & & & & & & \\
\hline 034 & $\begin{array}{l}\text { X Substantially identical } \\
\text { to outfall: } \quad 032\end{array}$ & & & & & & & & & \\
\hline 035 & $\begin{array}{l}\mathrm{X} \text { Substantially identical } \\
\text { to outfall: } \quad 032\end{array}$ & & & & & & & & & \\
\hline
\end{tabular}

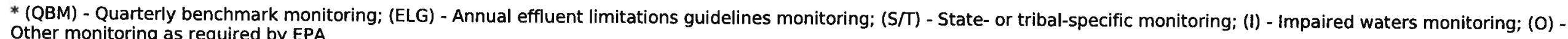
Other monitoring as required by EPA

4. Comment and/or Explanation of Any Violations (Reference all attachments here) 
Rainfall duration $=1.17$ hours. Rainfall amount $=0.17$ inches.

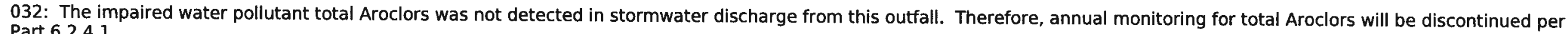
Part 6.2.4.1. 


\section{G. Certification}

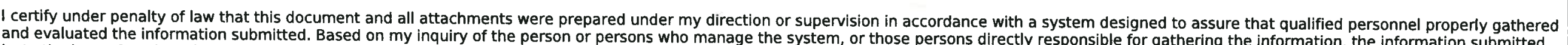

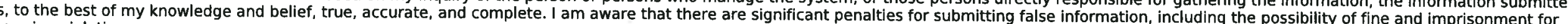
knowing violations.

First Name, Middle Initial, Last Name: Anthony

Title

Signature:

E-mail:

\section{EPC-CP Group Leader}

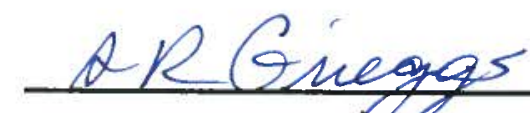

grieggst@lanl.gov

\section{R Grieggs}

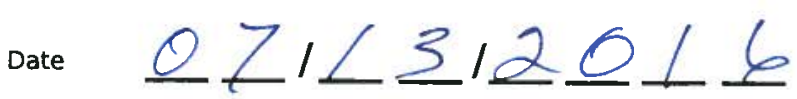




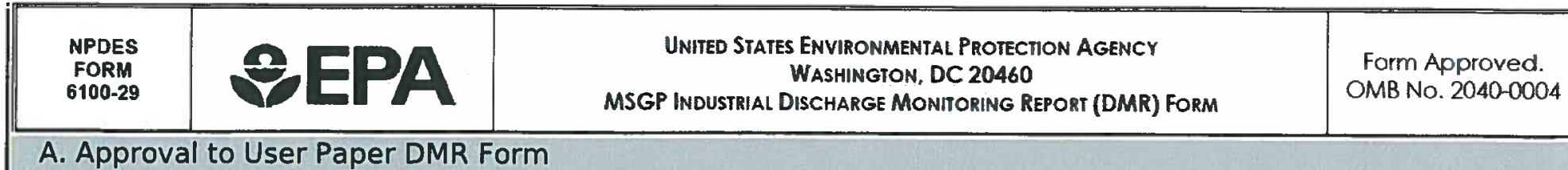

1. Have you been granted a waiver from electronic reporting from EPA Regional Office*? $\bar{X}$ YES $\square$ NO

If yes, check which waiver you have been granted, the name of the EPA Regional Office staff person who granted the waiver, and the date of approval:

Waiver granted: $\square$ The owner/operator's headquarters is physically located in a geographic area (i.e., ZIP code or census tract) that is identified as under-served for broadband Internet access in the most recent report from the Federal Communications Commission.

X The owner/operator has issues regarding available computer access or computer capability.

Name of EPA staff person that granted the waiver: Everett Spencer

Date approval obtained: $\quad 06 / 17 / 2016$

* Note: You are required to obtain approval from the applicable EPA Regional Office prior to using this paper DMR form. If you have not obtained a waiver, you must file this form electronically using the NetDMR at http://www.epa.gov/netdmr/

B. Permit Information

1. NPDES ID

NMR053195

2. Reason(s) for Submission (Check all that apply):

$\mathrm{X}$ Submitting monitoring data (Fill in all Sections).

Reporting no discharge for all outfalls for this monitoring period (Fill in Sections A, B, C, D, E.1, and G).

Reporting that your site status has changed to inactive and unstaffed (Fill in Sections A, B, C, D, and F and include date of status change in comment field in Section F.4).

Reporting that your site status has changed to active (Fill in all Sections and include date of status change in comment field in Section F.4).

Reporting that no further pollutant reductions are achievable for all outfalls and for all pollutants via Part 6.2.1.2 of the MSGP (Fill in Sections A, B, C, D, and $G$ ).

\section{Facility Operator Information}

1. Operator Information

Operator Name:

Los Alamos National Security, LLC

Mailing Address:

Street:

P.O. Box 1663, MS K490

City: Los Alamos

State:

NM

ZIP Code:

87545

Phone: 5056670666

E-mail: grieggst@lanl.gov

2. DMR Preparer (Complete if DMR was prepared by someone other than the certifier):

First Name, Middle Initial, Last Name: Holly L. Wheeler

Organization:

EPC-CP

Phone:

5056671312

Ext.

E-mail:

hbenson@lanl.gov 
1. Facility Name:

Los Alamos National Laboratory

2. Facility Address:

Street/Location

Bikini Atoll Rd. SM30 K490

City:

\section{Los Alamos}

State:

NM ZIP Code:

87545

County or Similar Government Subdivision: LOS AlamoS

\section{E. Discharge Information}

1. Identify monitoring period:

$\mathrm{X}$ Check here if proposing alternative monitoring periods due to irregular stormwater runoff. Identify alternative monitoring schedule and indicate for which alternative monitoring period you are reporting monitoring data:

$\square$ Quarter I (January 1 - March 31)

X Quarter 1: From

[04 / 01 To 05 / 131

Quarter 2 (April 1 - June 30)

Quarter 2: From

106 / 01 To $07 /$ / 31

Quarter 3 (July 1 - September 30)

Quarter 3: From

|08

$/ 01$ To

$09 /[30 \mid$

$\square$ Quarter 4 (October 1 - December 31)

Quarter 4: From

[10] / 01 To 11$] / 30$

2. Are you required to monitor for cadmium, copper, chromium, lead, nickel, silver, or zinc in freshwater?

X Yes ( Skip to 3)

No ( Skip to 4)

3. What is the hardness level of the receiving water?

57

4. Does your facility discharge into any saltwater receiving waters?

Yes

X

No 
1. Nature of Discharge: $\square$ Rainfall (Complete line items 2.a., 2.b., \& 2.c.) $\square$ Snowmelt

$\begin{array}{llll}\text { 2.a. Duration of the rainfall event (hours): } 0 & \text { 2.b. Rainfall amount (inches): } 0.0 & \text { 2.c. Time since previous measurable storm event (days): } 5\end{array}$

\begin{tabular}{|c|c|c|c|c|c|c|c|c|c|c|}
\hline $\begin{array}{l}\text { 3.a. Outfall ID } \\
\text { (llst the same 3- } \\
\text { digit outfalls } \\
\text { identified on the } \\
\text { NOI form) }\end{array}$ & $\begin{array}{l}\text { 3.b. Check if Any } \\
\text { Outfalls are } \\
\text { Substantially } \\
\text { Identical to Other } \\
\text { Outfalls Listed }\end{array}$ & $\begin{array}{c}\text { 3.c. } \\
\text { Check if } \\
\text { No } \\
\text { Discharge }\end{array}$ & $\begin{array}{c}\text { 3.d. } \\
\text { Monitoring } \\
\text { Type QBM, } \\
\text { ELG, S/T, I, O* }\end{array}$ & 3.e. Parameter & $\begin{array}{l}\text { 3.f. Quality or } \\
\text { Concentration }\end{array}$ & 3.g. Units & 3.h. Results Description & $\begin{array}{l}\text { 3.i. Collection } \\
\text { Date }\end{array}$ & \begin{tabular}{|c|} 
3.j. \\
Exceedance \\
due to \\
natural \\
background \\
pollutant \\
levels \\
\end{tabular} & $\begin{array}{l}\text { 3.k. No } \\
\text { further } \\
\text { pollutant } \\
\text { reductions } \\
\text { achievable? }\end{array}$ \\
\hline 050 & $\begin{array}{l}\square \text { substantially identical } \\
\text { to outfall: }\end{array}$ & $\square$ & 1 & Aluminum, total recoverable & 373 & $u g / L$ & & $05 / 06 / 2016$ & $\square$ & $\square$ \\
\hline 050 & \begin{tabular}{|l}
$\square$ substantially identical \\
to outfall:
\end{tabular} & $\square$ & QBM & Ammonia, total & 1.17 & $\mathrm{mg} / \mathrm{L}$ & & $05 / 06 / 2016$ & L & $\square$ \\
\hline 050 & \begin{tabular}{|l|}
$\square$ substantially identical \\
to outfall:
\end{tabular} & $\square$ & QBM & $\begin{array}{l}\text { Chemical Oxygen Demand } \\
\text { (COD) }\end{array}$ & 129 & $\mathrm{mg} / \mathrm{L}$ & & $05 / 06 / 2016$ & 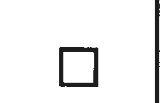 & L \\
\hline 050 & \begin{tabular}{|l|}
$\square$ substantially identical \\
to outfall:
\end{tabular} & $\square$ & QBM & Cyanide, total & BQL & & $0.005 \mathrm{mg} / \mathrm{L}$ & $05 / 06 / 2016$ & $\square$ & L \\
\hline 050 & $\begin{array}{l}\square \text { substantially identical } \\
\text { to outfall: }\end{array}$ & $\square$ & QBM & Magnesium, total & 1.4 & $\mathrm{mg} / \mathrm{L}$ & & 05/06/2016 & $\square$ & $\square$ \\
\hline 050 & $\begin{array}{l}\square \text { substantially identical } \\
\text { to outfall: }\end{array}$ & $\square$ & QBM & Mercury, total & ND & & $0.067 \mathrm{ug} / \mathrm{L}$ & $05 / 06 / 2016$ & $\square$ & $\square$ \\
\hline 050 & \begin{tabular}{|l|}
$\square$ substantially identical \\
to outfall:
\end{tabular} & $\square$ & QBM & Selenium, total & ND & & $1.50 \mathrm{ug} / \mathrm{L}$ & $05 / 06 / 2016$ & $\square$ & \\
\hline
\end{tabular}

* (QBM) - Quarterly benchmark monitoring; (ELG) - Annual effluent limitations guidelines monitoring; (S/T) - State- or tribal-specific monitoring; (I) - Impaired waters monitoring; (O) Other monitoring as required by EPA

4. Comment and/or Explanation of Any Violations (Reference all attachments here) 
Rainfall duration $=0.00$ hours. Rainfall amount $=0.00$ inches.

050: The average concentration of Magnesium is mathematically certain to exceed the benchmark value. 


\section{G. Certification}

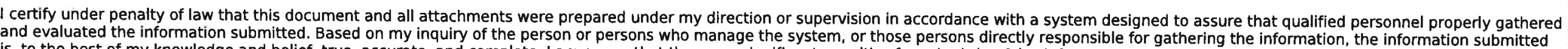

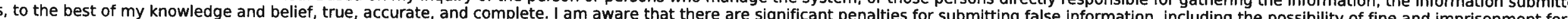
knowing violations.

First Name, Middle Initial, Last Name: Anthony

Title: $\quad$ EPC-CP Group Leader

Signature:

E-mail:

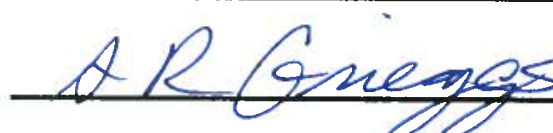

grieggst@lanl.gov

\section{R Grieggs}

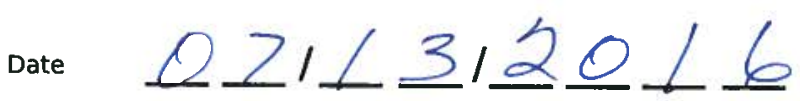


Environmental Protection \& Compliance Division (EPC-DO)

Environmental Compliance Programs (EPC-CP)

PO Box 1663, K490

Los Alamos, New Mexico 87545

(505) 667-0666

\author{
Date: OCT 062016 \\ Symbol: EPC-DO-16-291 \\ LA-UR: $\quad 16-27686$ \\ Locates Action No.: N/A
}

\title{
U.S. EPA Region 6
}

NPDES Stormwater Program (WQ-PP)

1445 Ross Avenue, Suite 1200

Dallas, TX 75202-2733

To whom it may concern:

Subject: National Pollutant Discharge Elimination System (NPDES) Permit Tracking No. NMR053195, Multi-Sector General Permit (MSGP) Industrial Discharge Monitoring Reports (MDMRs) for July 31, August 1, 2, 3, 4, and 8, 2016

Enclosed are Los Alamos National Laboratory's MDMRs (Enclosure 1) for July 31, August 1, 2, 3, 4 and 8, 2016, as required under MSGP Permit Tracking No. NMR053195. These reports are being submitted on behalf of Los Alamos National Security LLC and contain analytical results for impaired waters and quarterly benchmark monitoring at outfalls $042,075,029,047,050,069,072,004,020,051,002,005$, 009, 012, and 018.

Please contact Holly Wheeler at (505) 667-1312 or Terrill Lemke at (505) 665-2397 if you have questions regarding these MDMRs.

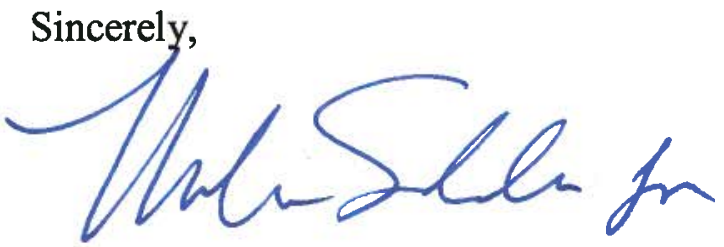

Anthony R. Grieggs

Group Leader

Environmental Compliance Programs (EPC-CP)

Los Alamos National Security, LLC 


\section{ARG:TWL:HLW/lm}

Enclosure: 1. NPDES Permit Tracking No. NMR053195, MDMRs for July 31, August 1, 2, 3, 4 and 8,2016

Cy: $\quad$ Everett Spencer, USEPA/Region 6, Dallas, TX, (E-File)

Helen Nguyen, USEPA/Region 6, Dallas, TX, (E-File)

Michelle Hunter, NMED/GWQB, Santa Fe, NM, (E-File)

Shelly Lemon, NMED/SWQB, Santa Fe, NM, (E-File)

Craig S. Leasure, PADOPS, (E-File)

William R. Mairson, PADOPS, (E-File)

Michael T. Brandt, ADESH, (E-File)

Raeanna Sharp-Geiger, ADESH, (E-File)

Karen E. Armijo, NA-LA, (E-File)

Terrill W. Lemke, EPC-CP, (E-File)

Holly L. Wheeler, EPC-CP, (E-File)

Leslie J. Dale, EPC-CP, (E-File)

Ellena I. Martinez, EPC-DP, (E-File)

Saundra Martinez, ADEM-PO, (E-File)

lasomailbox@nnsa.doe.gov, (E-File)

locatesteam@lanl.gov, (E-File)

epc-correspondence@lanl.gov 


\section{ENCLOSURE 1}

NPDES Permit Tracking No. NMR053195, MDMRs

for July 31, August 1, 2, 3, 4 and 8, 2016

EPC-DO-16-291

LA-UR-16-27686

Date: $\quad$ OCT 062016 


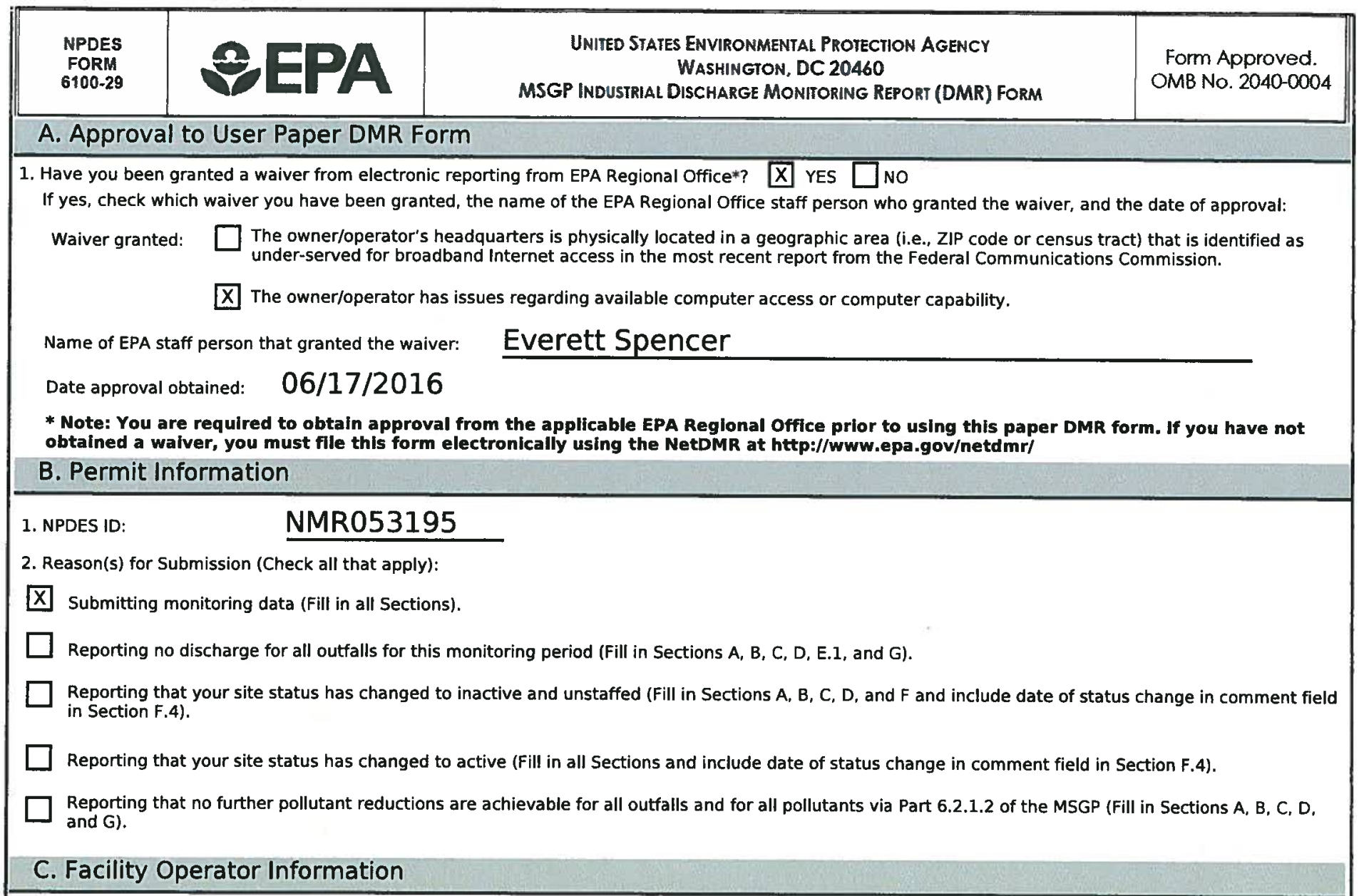

1. Operator Information

Operator Name:

Los Alamos National Security, LLC

Mailing Address:

Street:

P.O. Box 1663, MS K490

City:

\begin{tabular}{lll}
\hline Los Alamos & state: $\quad$ NM \\
\hline 5056670666 & \\
\hline grieggst@lanl.gov & \\
\hline
\end{tabular}

2. DMR Preparer (Complete if DMR was prepared by someone other than the certifier):

First Name, Middle Initial, Last Name: Holly L. Wheeler

Organization:

EPC-CP

Phone:

5056671312

Ext.

E-mail:

hbenson@lanl.gov 


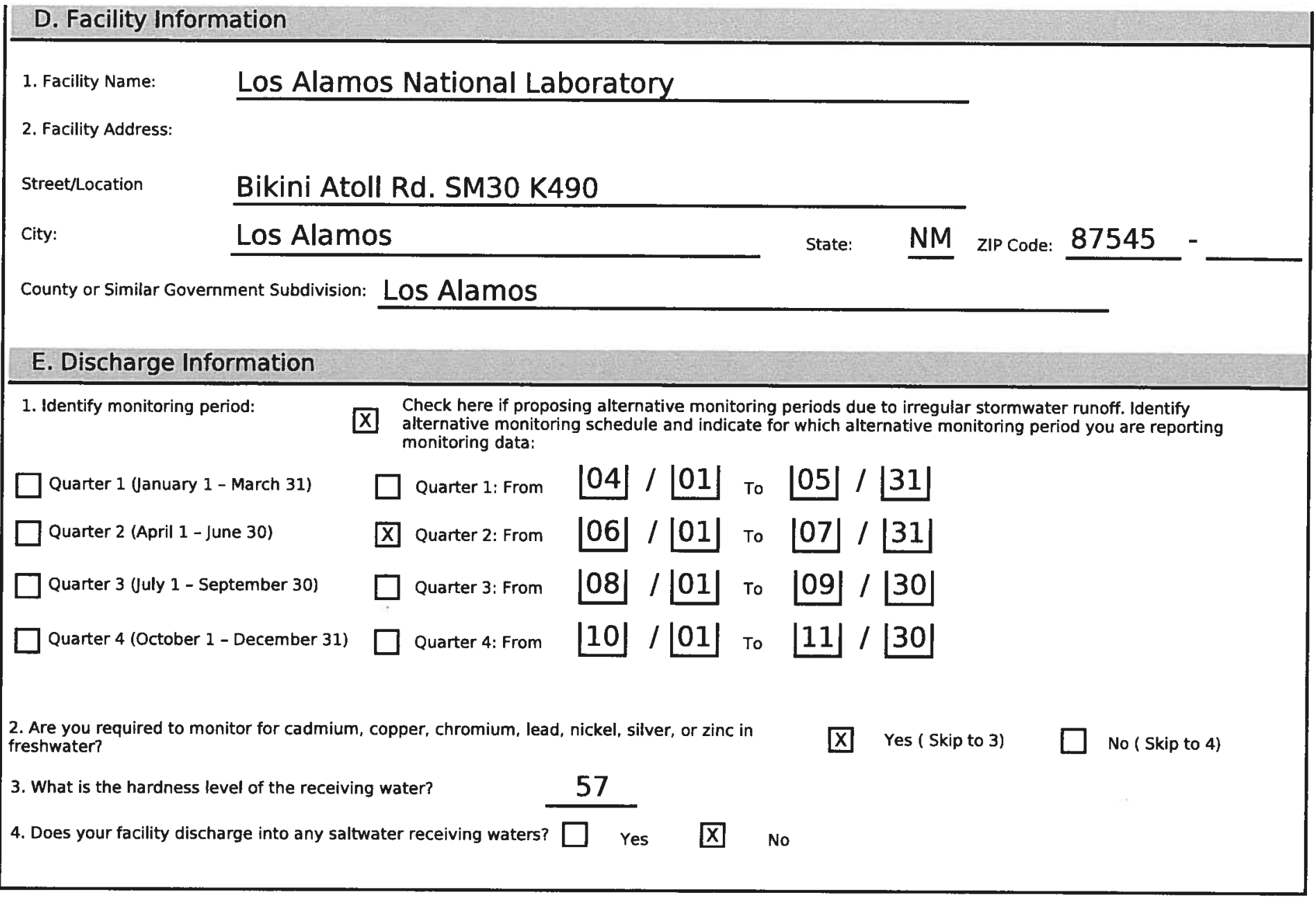




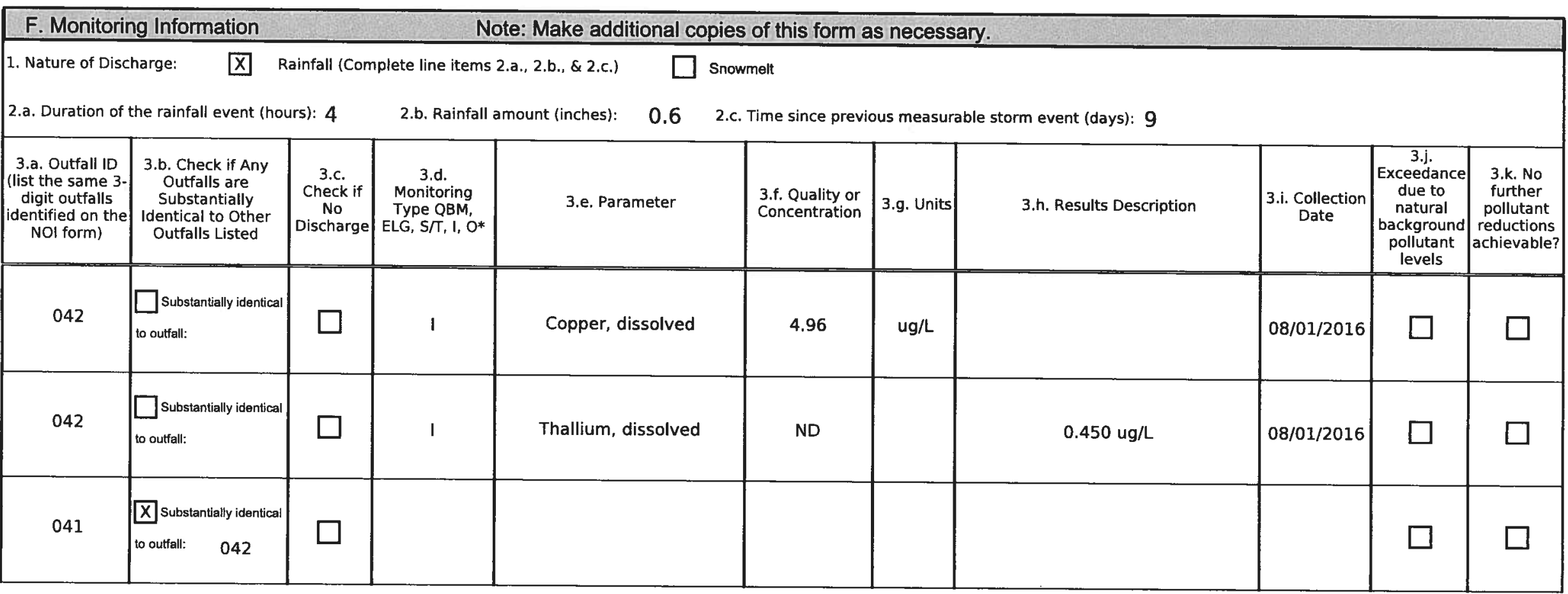

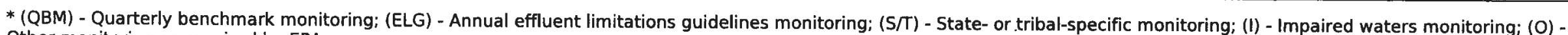
Other monitoring as required by EPA

4. Comment and/or Explanation of Any Violations (Reference all attachments here)

Rainfall duration $=3.58$ hours. Rainfall amount $=0.59$ inches.

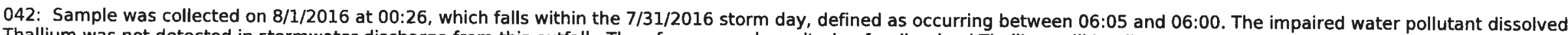
Thallium was not detected in stormwater discharge from this outfall. Therefore, annual monitoring for dissolved Thallium will be discontinued per Part 6.2 .4 .1$. 


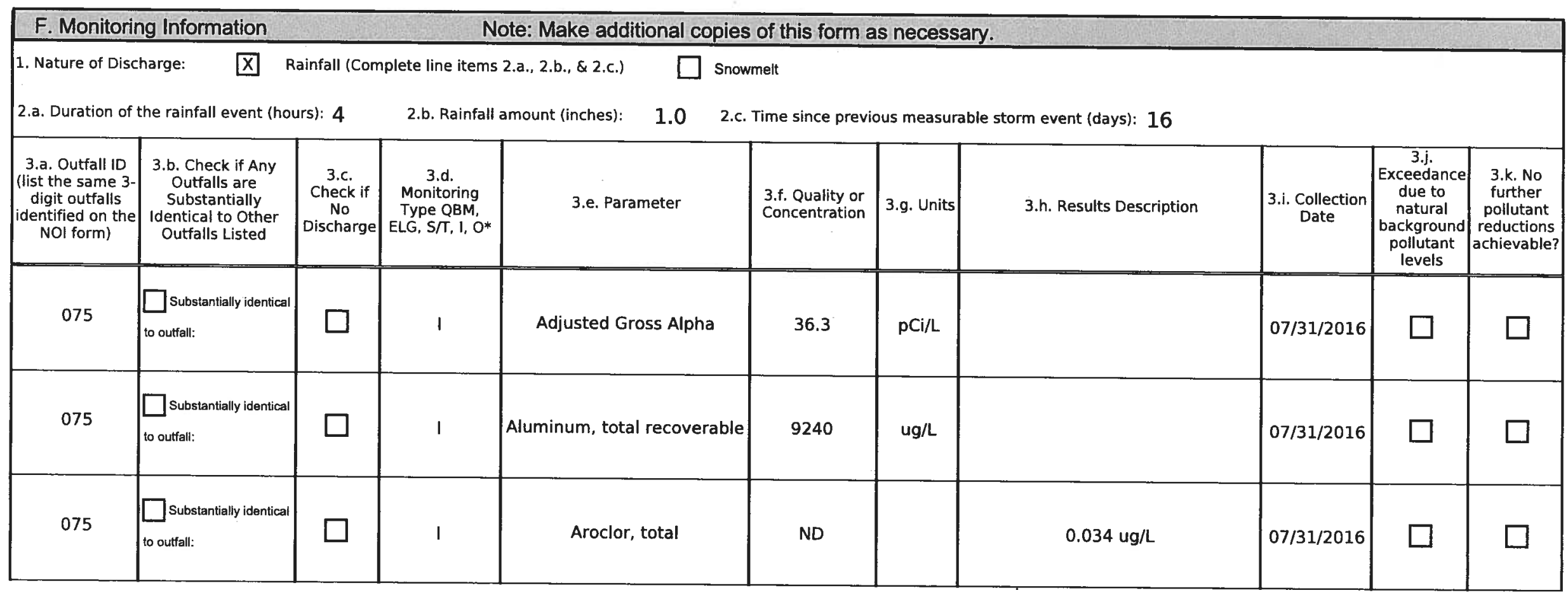
* (QBM) - Quarterly benchmark monitoring; (ELG) - Annual effluent limitations guidelines monitoring; (S/T) - State- or tribal-specific monitoring; (I) - Impaired waters monitoring; (O) -
Other monitoring as required by EPA

4. Comment and/or Explanation of Any Violations (Reference all attachments here)

Rainfall duration $=3.92$ hours. Rainfall amount $=1.00$ inches.

075: The impaired water pollutant Adjusted Gross Alpha exceeds the New Mexico water quality standard. The impaired water pollutant total recoverable Aluminum exceeds the New Mexico water quality standard. The impaired water pollutant total Aroclor was not detected in stormwater discharge from this outfall. Therefore, annual monitoring for total Aroclor will be discontinued per Part 6.2.4.1. Copper, dissolved (I) - NODI 9. Thallium, dissolved (I) - NODI B. 


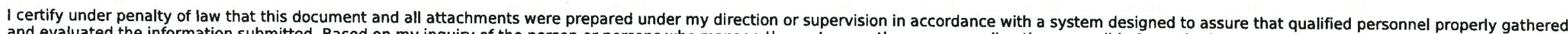

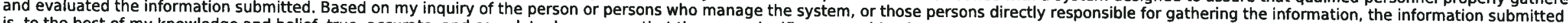
belief, true, accurate, and compte. I am aware that there are significant penalties for submitting false information, including the possibility of fine and imprisonment for

knowing violations.

First Name, Middie Initial, Last Name:

Anthony

Title:

Signature:

E-mail:
EPC-CP Group Leader

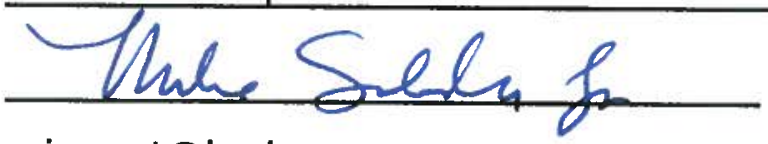

grieggst@lanl.gov
R Grieggs

Date $10106 / 2016$ 


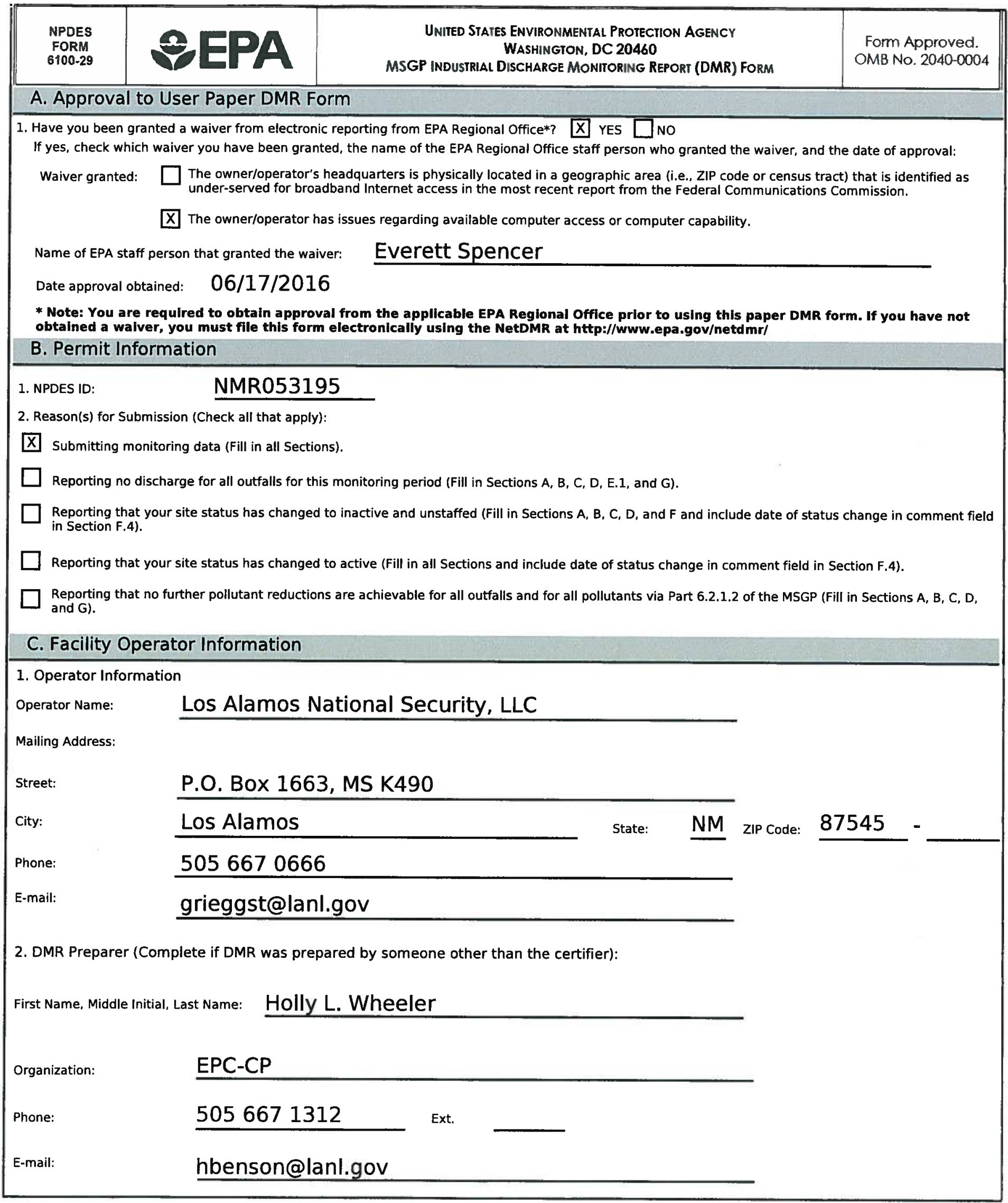




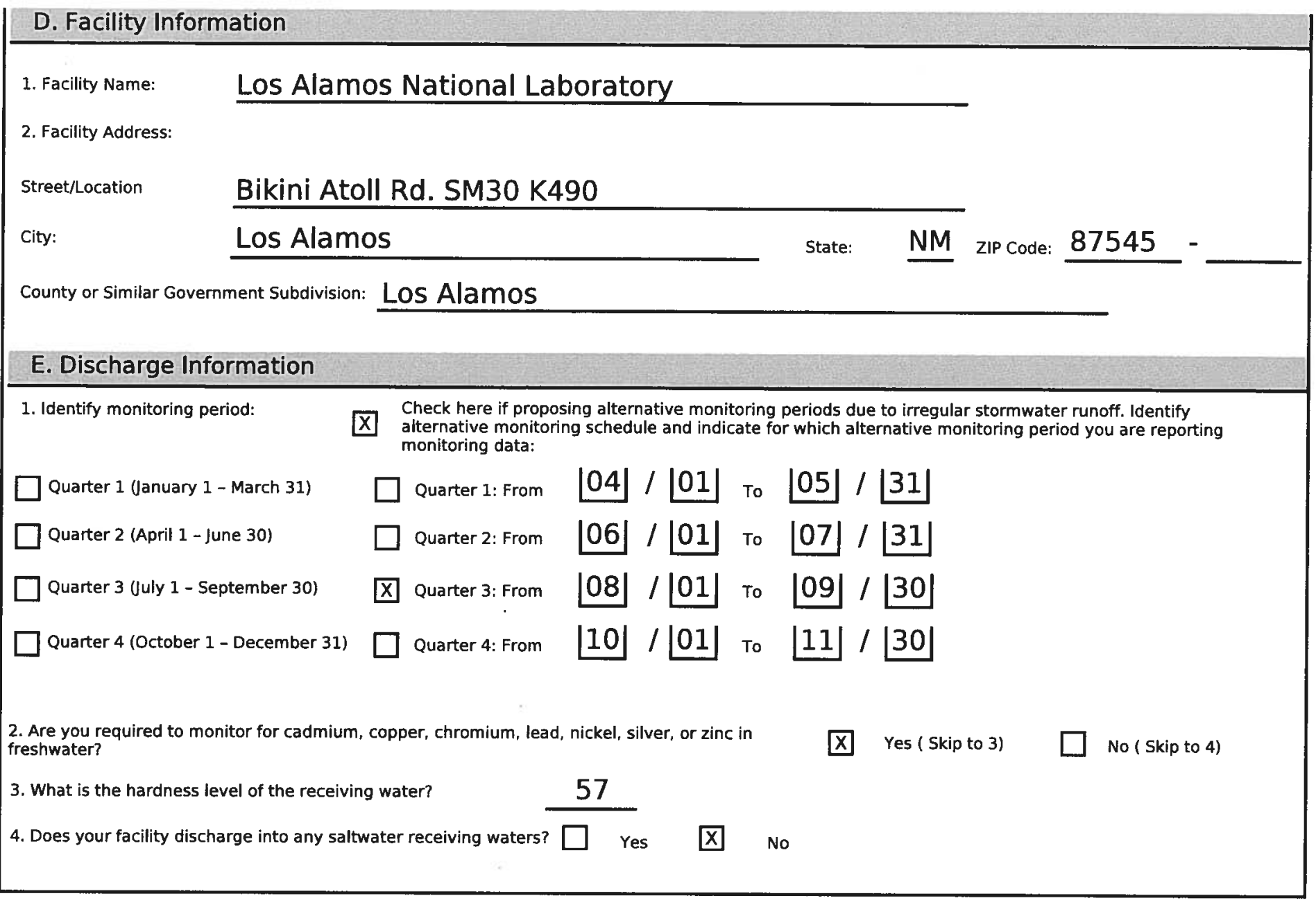




\begin{tabular}{|c|c|c|c|c|c|c|c|c|c|c|c|}
\hline \multicolumn{2}{|c|}{ F. Monitoring Information } & \multicolumn{7}{|c|}{ Note: Make additional copies of this form as necessary. } & & & \\
\hline \multicolumn{12}{|c|}{ 1. Nature of Discharge: $\searrow$ Rainfall (Complete line items 2.a., 2.b., \& 2.c.) } \\
\hline \multicolumn{3}{|c|}{ 2.a. Duration of the rainfall event (hours): 0} & \multicolumn{2}{|c|}{ 2.b. Rainfall amount (inches): } & \multirow{2}{*}{$\begin{array}{r}0.0 \\
\text { ieter }\end{array}$} & \multicolumn{6}{|c|}{ 2.c. Time since previous measurable storm event (days): 1} \\
\hline $\begin{array}{l}\text { 3.a. Outfalt ID } \\
\text { (list the same 3- } \\
\text { digit outfalls } \\
\text { identified on the } \\
\text { NOI form) }\end{array}$ & $\begin{array}{l}\text { 3.b. Check if Any } \\
\text { Outfalls are } \\
\text { Substantially } \\
\text { Identical to Other } \\
\text { Outfalls Listed }\end{array}$ & $\begin{array}{c}\text { 3.c. } \\
\text { Check if } \\
\text { No } \\
\text { Discharge }\end{array}$ & $\begin{array}{c}\text { 3.d. } \\
\text { Monitoring } \\
\text { Type QBM, } \\
\text { ELG, S/T, I, O* }\end{array}$ & 3.e. Pare & & $\begin{array}{l}\text { 3.f. Quality or } \\
\text { Concentration }\end{array}$ & 3.g. Units & 3.h. Results Description & $\begin{array}{l}\text { 3.i. Collection } \\
\text { Date }\end{array}$ & \begin{tabular}{|c|}
$3 . j$. \\
Exceedance \\
due to \\
natural \\
background \\
pollutant \\
levels \\
\end{tabular} & $\begin{array}{c}\text { 3.k. No } \\
\text { further } \\
\text { pollutant } \\
\text { reductions } \\
\text { achievable? }\end{array}$ \\
\hline 029 & \begin{tabular}{|l}
$\square$ Substantially identical \\
to outfall:
\end{tabular} & & QBM & Copper, d & ssolved & 17.7 & $\mathrm{ug} / \mathrm{L}$ & & $08 / 01 / 2016$ & & \\
\hline 029 & $\begin{array}{l}\square \text { Substantially identical } \\
\text { to outfall: }\end{array}$ & & QBM & Lead, dis & solved & ND & & $0.500 \mathrm{ug} / \mathrm{L}$ & $08 / 01 / 2016$ & & \\
\hline 029 & $\begin{array}{l}\square \text { Substantially identical } \\
\text { to outfall: }\end{array}$ & & QBM & Zinc, dis & olved & 35 & $\mathrm{ug} / \mathrm{L}$ & & $08 / 01 / 2016$ & & \\
\hline
\end{tabular}

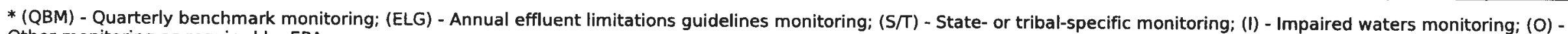
Other monitoring as required by EPA

4. Comment and/or Explanation of Any Violations (Reference all attachments here)

Rainfall duration $=0.08$ hours. Rainfall amount $=0.01$ inches.

029: Adjusted Gross Alpha (I) - NODI 9. Aluminum, total recoverable (I) - NODI 9. Aroclor, total (I) - NODI B. Thallium, dissolved (I) - NODI B. Copper, dissolved (I) - NODI 9. 


\section{G. Certification}

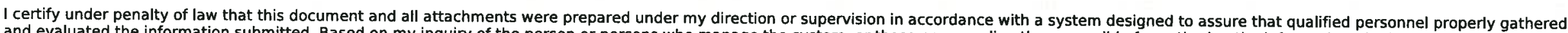

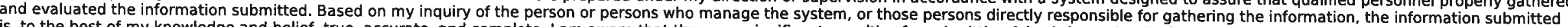
belie, true, accurate, and complete. I am aware that there are significant penalties for submitting false information, including the possibility of fine and imprisonment for

(1)

First Name, Middle Initial, Last Name

Anthony

Title:

Signature:

E-mail:

\section{EPC-CP Group Leader}

The Solnge Date 1010612016

R Grieggs

\section{grieggst@lanl.gov}




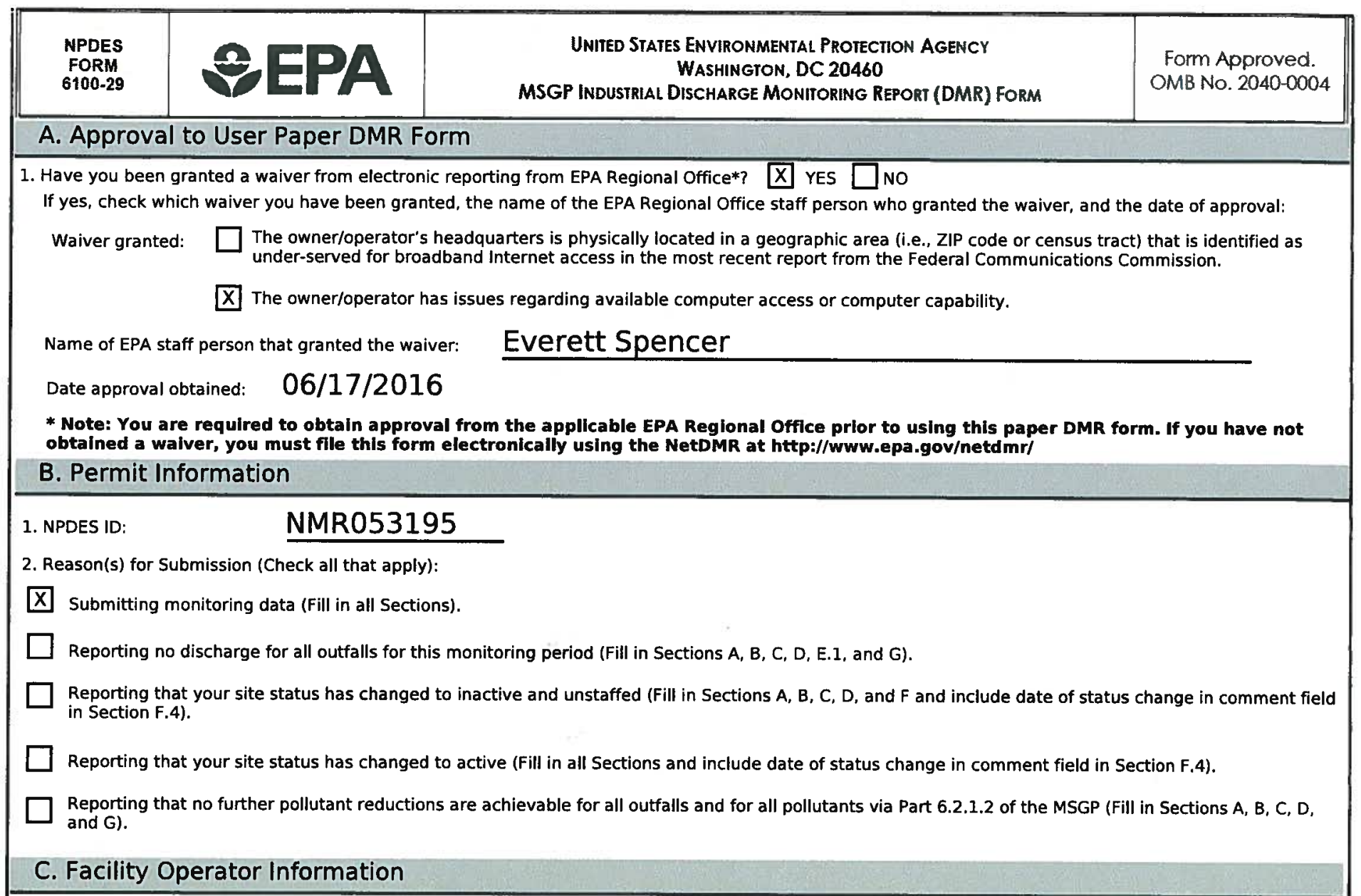

1. Operator Information

Operator Name: $\quad$ Los Alamos National Security, LLC

Mailing Address:

Street:

P.O. Box 1663, MS K490

City: Los Alamos State:

NM ZIP Code: $\underline{87545}-$

Phone: 5056670666

E-mail: grieggst@lanl.gov

2. DMR Preparer (Complete if DMR was prepared by someone other than the certifier):

First Name, Middle Initial, Last Name: Holly L. Wheeler

Organization: $\quad$ EPC-CP

Phone:

5056671312

Ext.

E-mail: hbenson@lanl.gov 


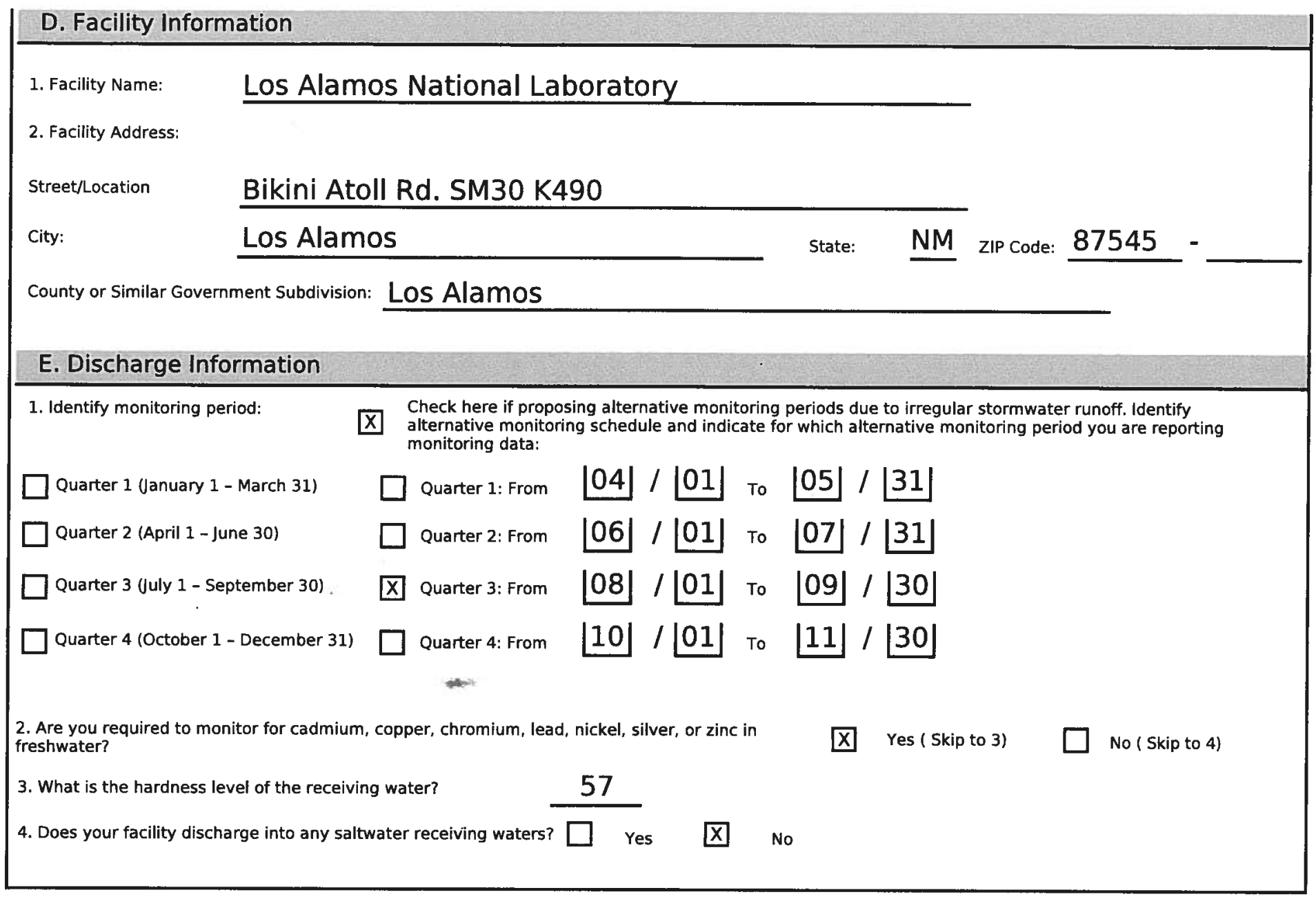




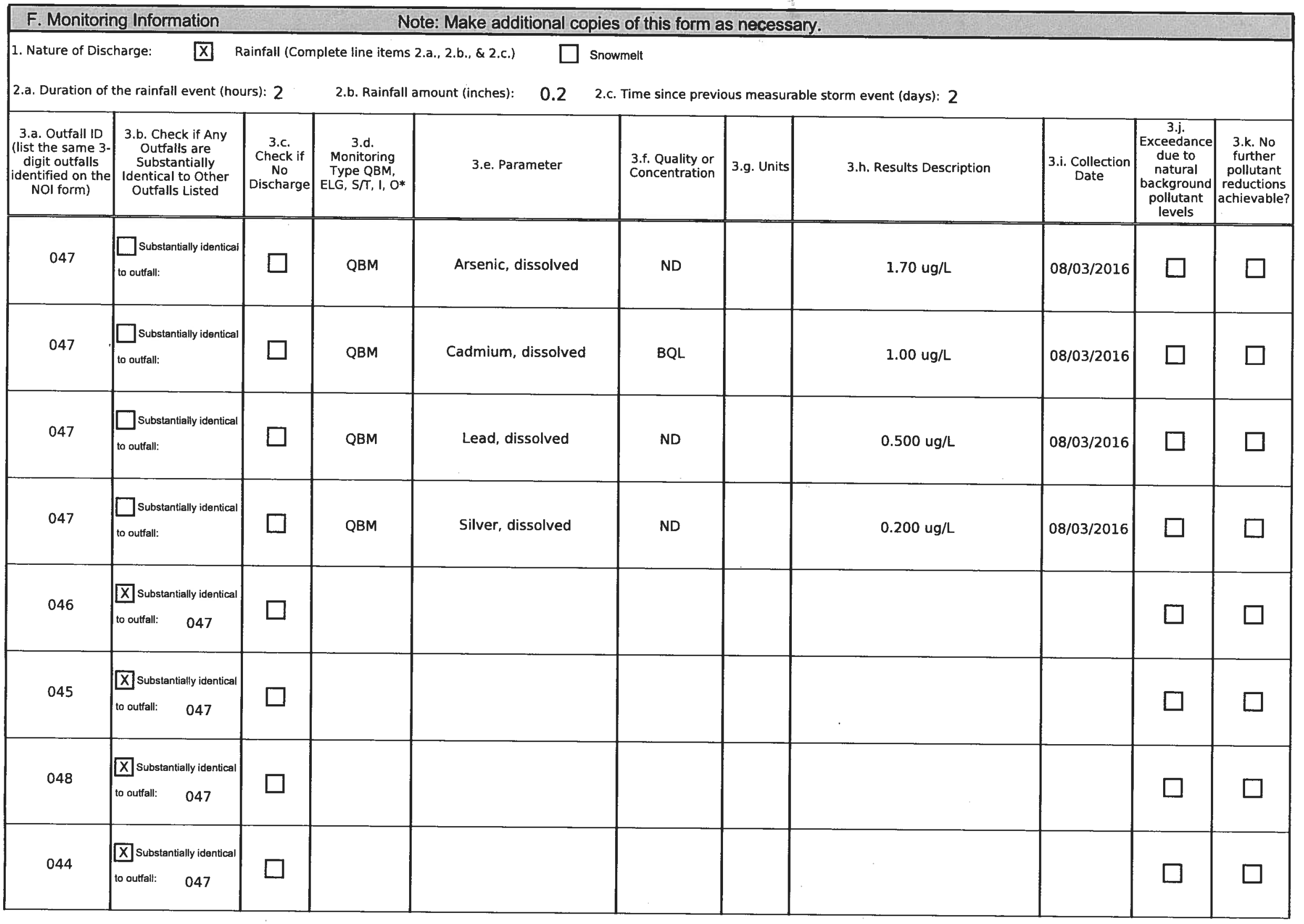




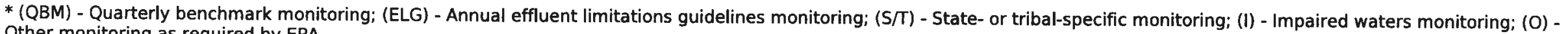
Other monitoring as required by EPA

4. Comment and/or Explanation of Any Violations (Reference all attachments here)

Rainfall duration $=1.75$ hours. Rainfall amount $=0.22$ inches

047: Sample was collected on 8/3/2016 at 00:56, which falls within the 8/2/2016 storm day, defined as occurring between 06:05 and 06:00. Adjusted Gross Alpha (I) - NODI 9. Aluminum, total recoverable (I) - NODI 9. Aroclor, total (I) - NODI B. 


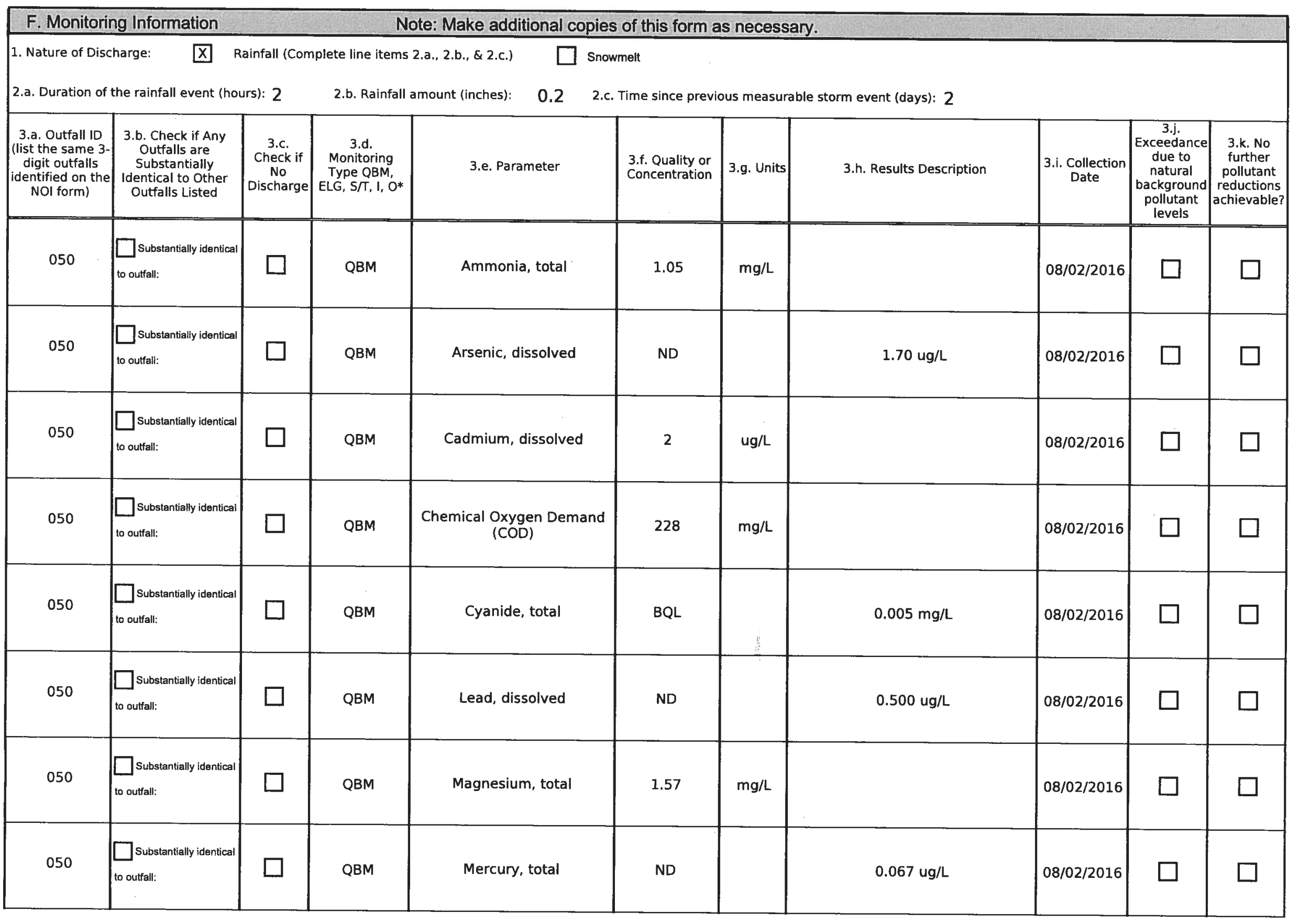




\begin{tabular}{|c|c|c|c|c|c|c|c|c|c|}
\hline 050 & \begin{tabular}{|l}
$\square$ substantially identical \\
to outfall:
\end{tabular} & $\square$ & QBM & Selenium, total & ND & $1.50 \mathrm{ug} / \mathrm{L}$ & $08 / 02 / 2016$ & $\square$ & $\square$ \\
\hline 050 & \begin{tabular}{|l|}
$\square$ substantially identical \\
to outfall:
\end{tabular} & $\square$ & QBM & Silver, dissolved & ND & $0.200 \mathrm{ug} / \mathrm{L}$ & $08 / 02 / 2016$ & $\square$ & $\square$ \\
\hline
\end{tabular}

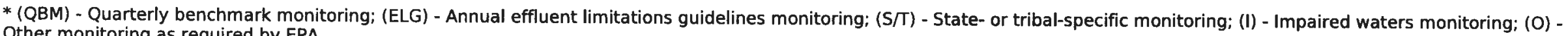
Other monitoring as required by EPA

4. Comment and/or Explanation of Any Violations (Reference all attachments here)

Rainfall duration $=1.75$ hours. Rainfall amount $=0.22$ inches.

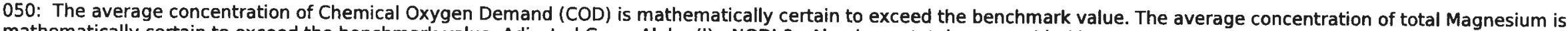
mathematically certain to exceed the benchmark value. Adjusted Gross Alpha (I) - NODI 9. Aluminum, total recoverable (I) - NODI 9. Aroclor, total (I) - NODI B. 


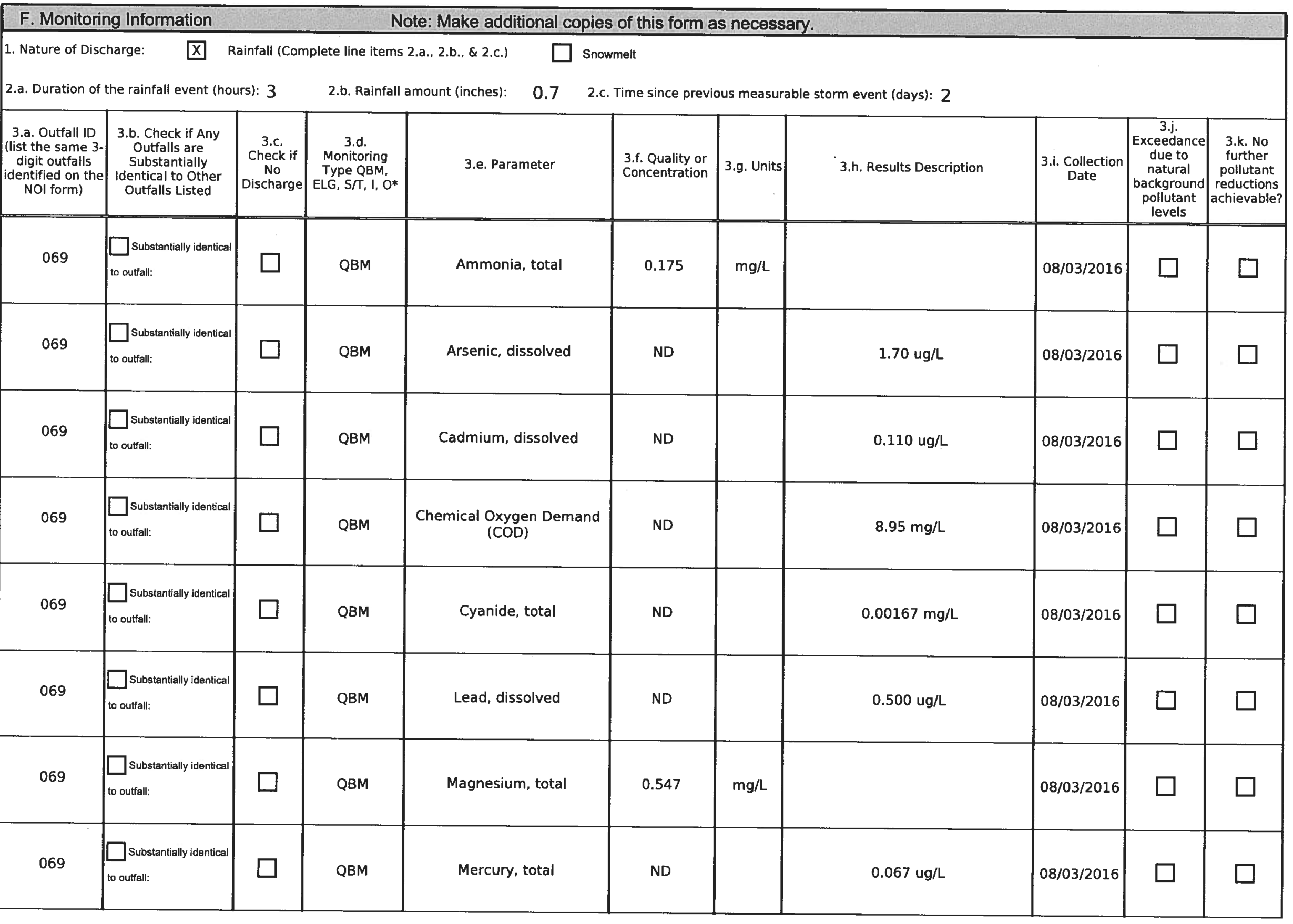




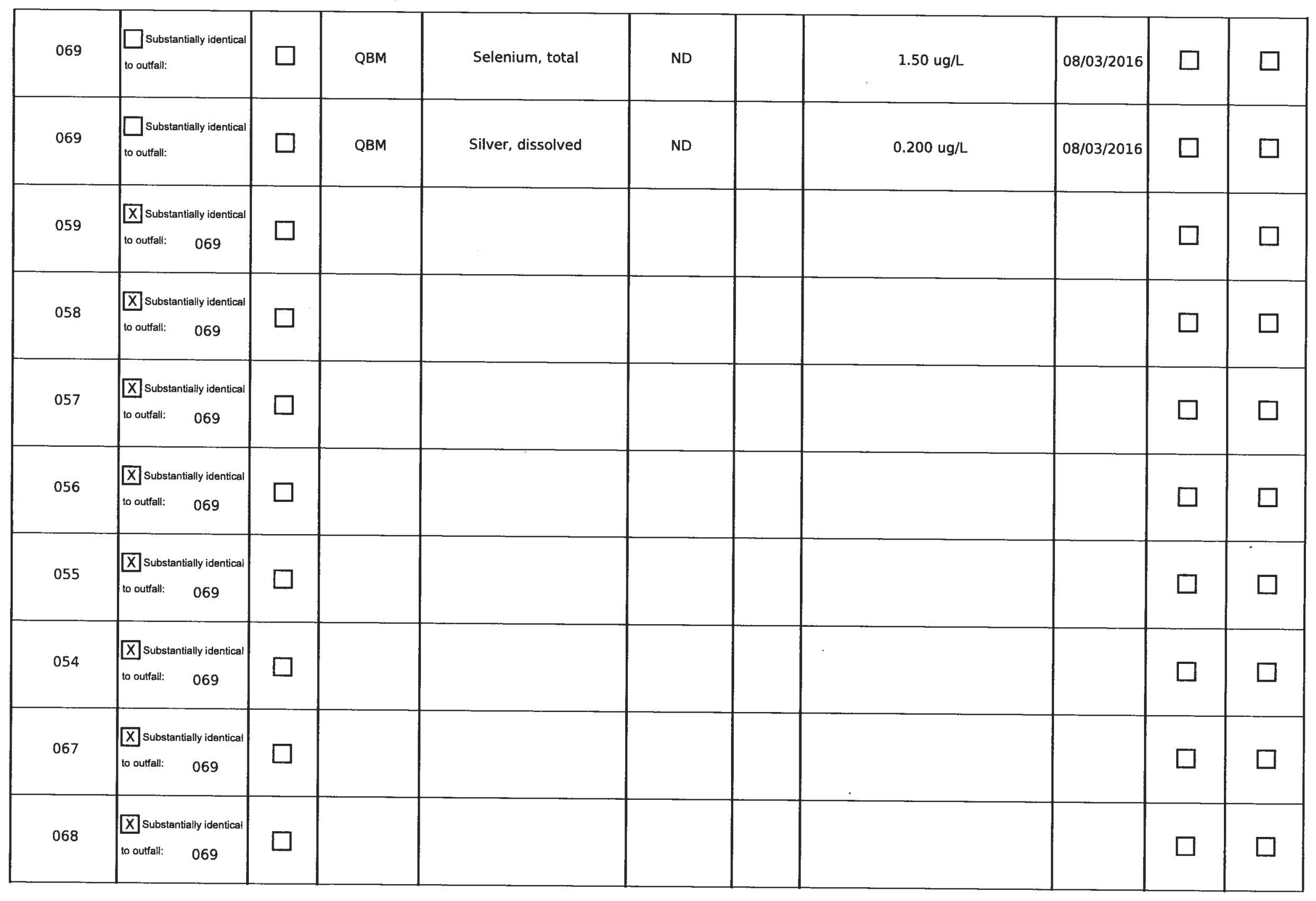




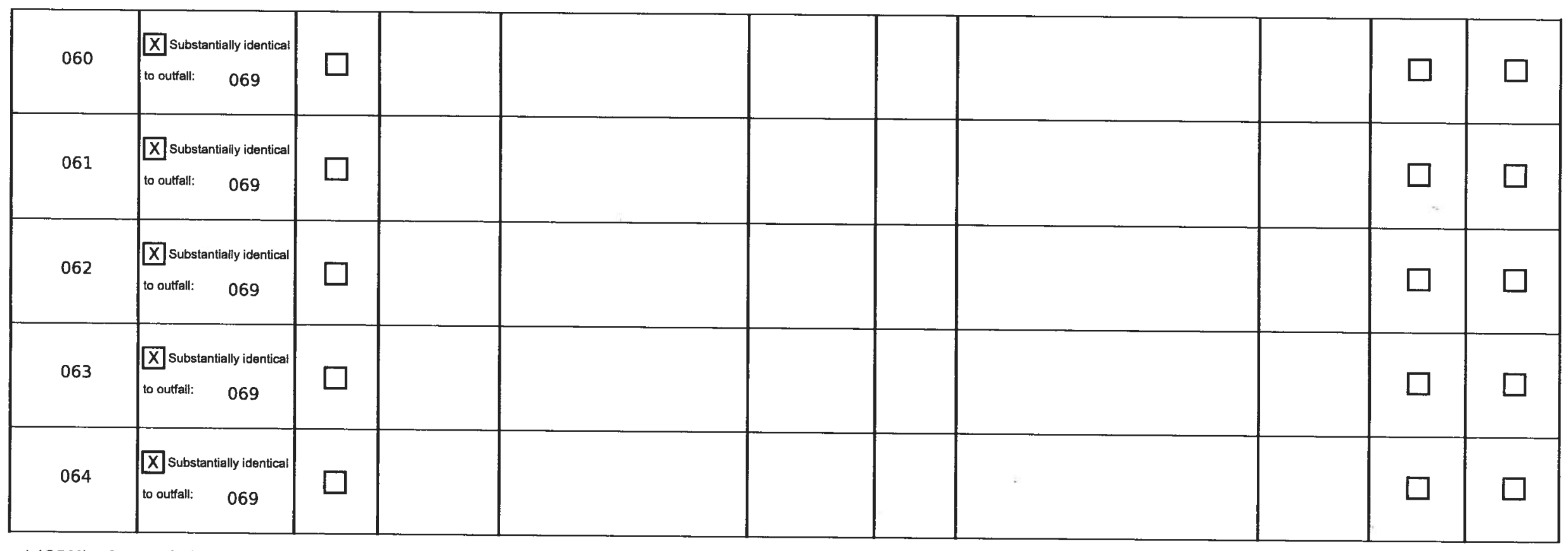

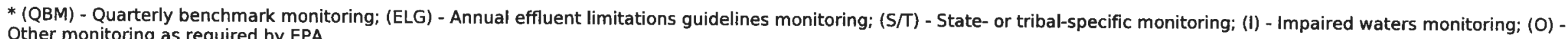
Other monitoring as required by EPA

4. Comment and/or Explanation of Any Violations (Reference all attachments here)

Rainfall duration $=2.75$ hours. Rainfall amount $=0.68$ inches.

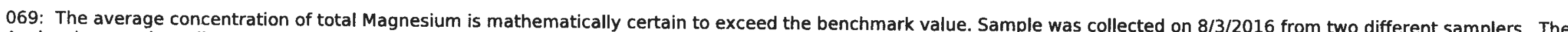
Avalanche sampler collected at $03: 35$ and the 3700 collected at $03: 33$, both of which fall within the 8/2/2016 storm day defined as 0 ccurring total recoverable (I) - NODI 9. Aroclor, total (I) - NODI B. 


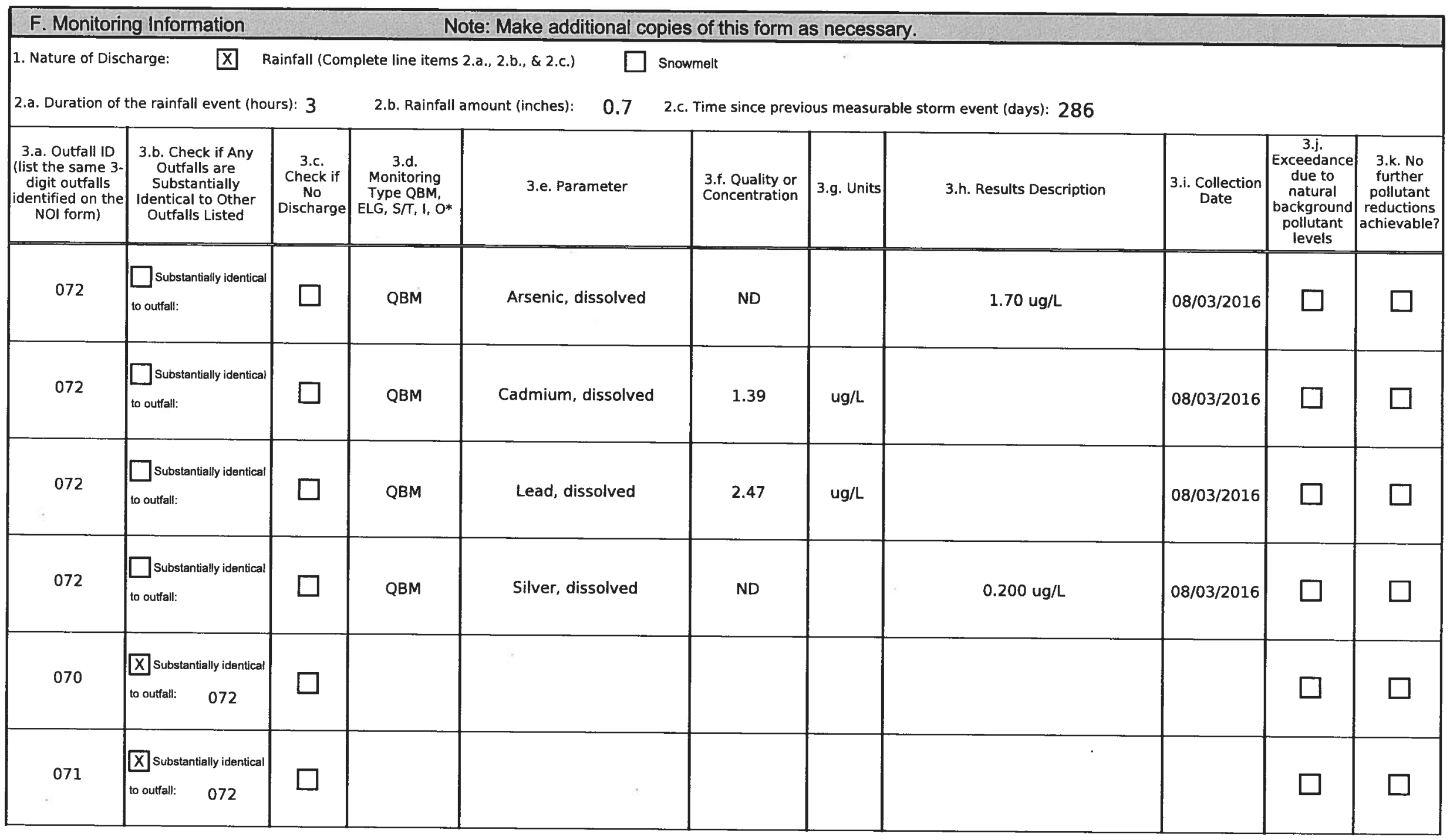

* (QBM) - Quarterly benchmark monitoring; (ELG) - Annual effluent limitations guidelines monitoring; (S/T) - State- or tribal-specific monitoring; (I) - Impaired waters monitoring; (O) Other monitoring as required by EPA

4. Comment and/or Explanation of Any Violations (Reference all attachments here) 
Rainfall duration $=2.75$ hours. Rainfall amount $=0.68$ inches.

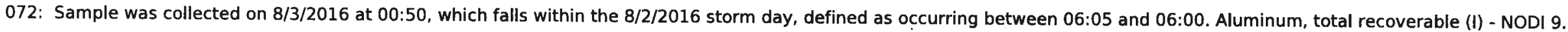




\section{G. Certification}

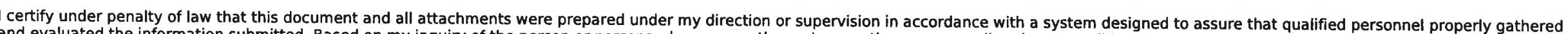

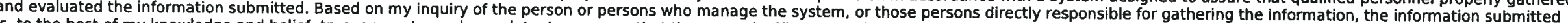

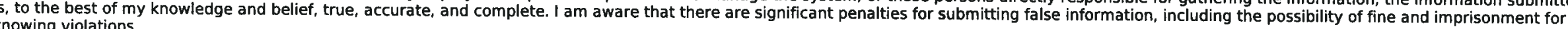

First Name, Middle Initial, Last Name:

Anthony

Title:

Signature

E-mail:

\section{EPC-CP Group Leader}

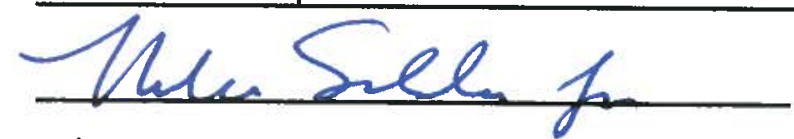
grieggst@lanl.gov $\underline{\text { R Grieggs }}$ 


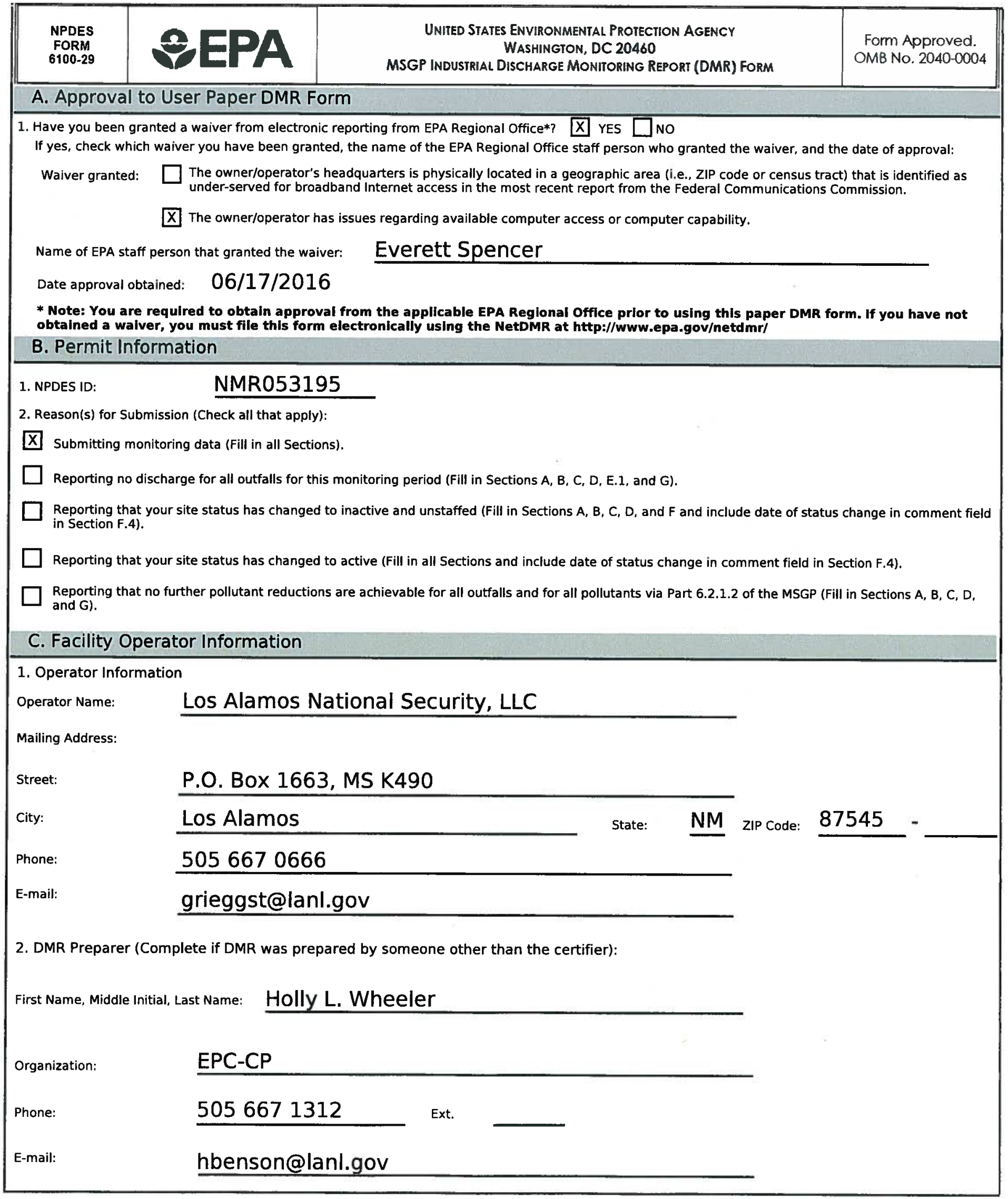




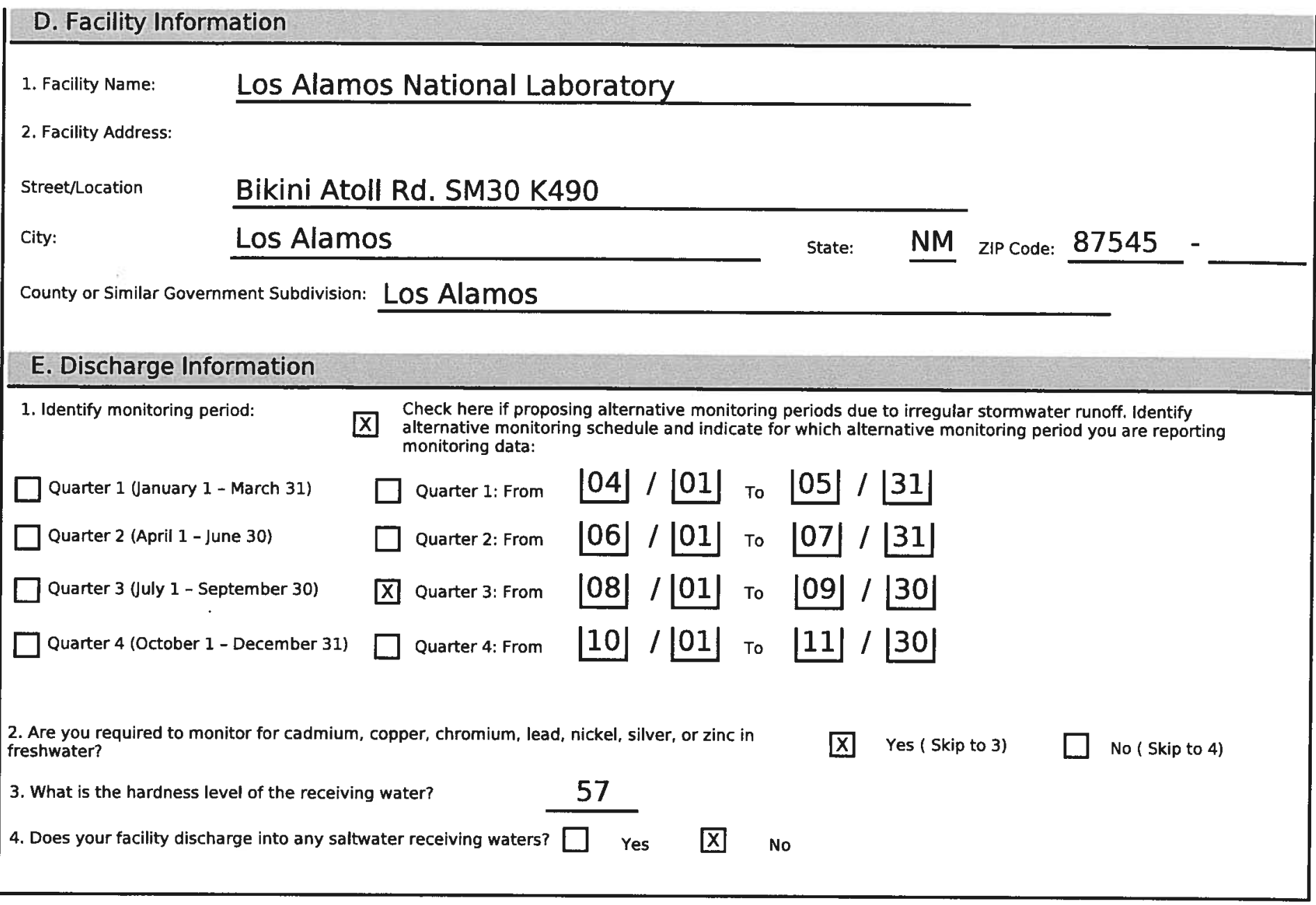




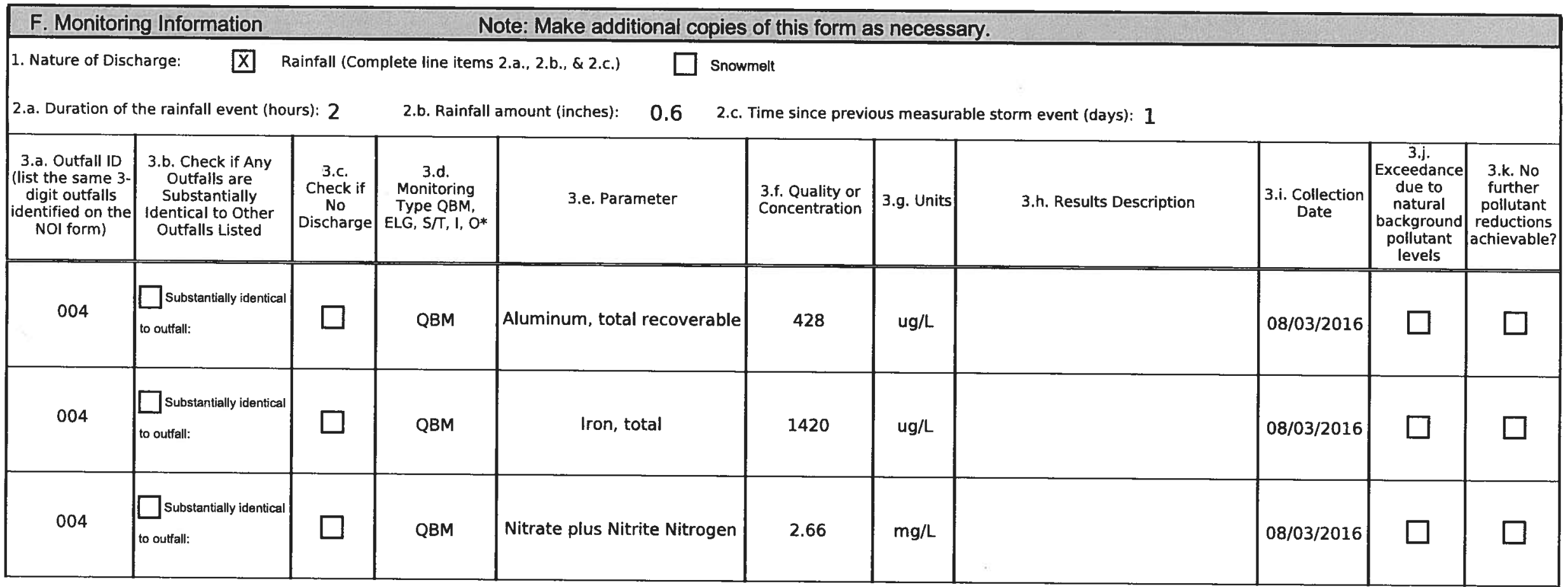

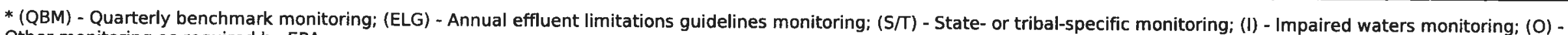
Other monitoring as required by EPA

4. Comment and/or Explanation of Any Violations (Reference all attachments here)

Rainfall duration $=2.00$ hours. Rainfall amount $=0.61$ inches.

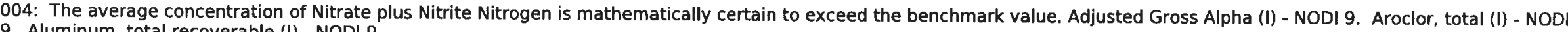
9. Aluminum, total recoverable (I) - NODI 9. 


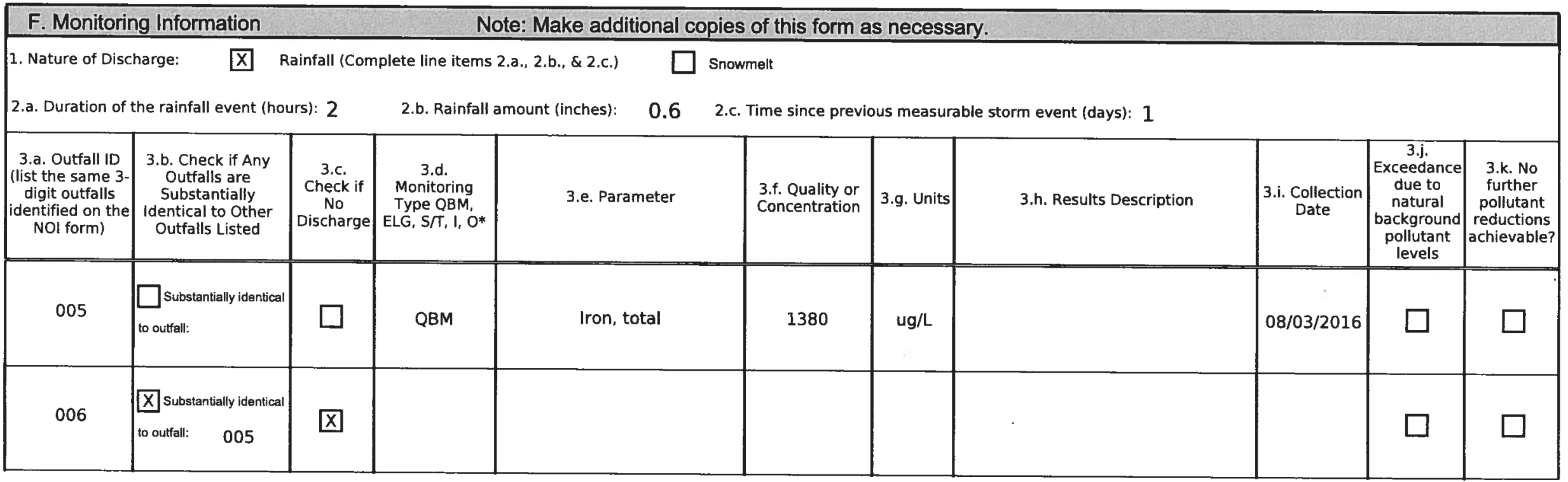

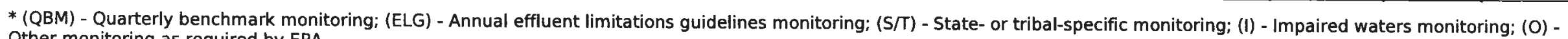
Other monitoring as required by EPA

4. Comment and/or Explanation of Any Violations (Reference all attachments here)

Rainfall duration $=2.00$ hours. Rainfall amount $=0.61$ inches.

005: Adjusted Gross Alpha (I) - NODI 9. Aluminum, total recoverable (I) - NODI 9. Aroclor, total (I) - NODI B. Copper, dissolved (I) - NODI 9. Thallium, dissolved (I) - NODI B. 


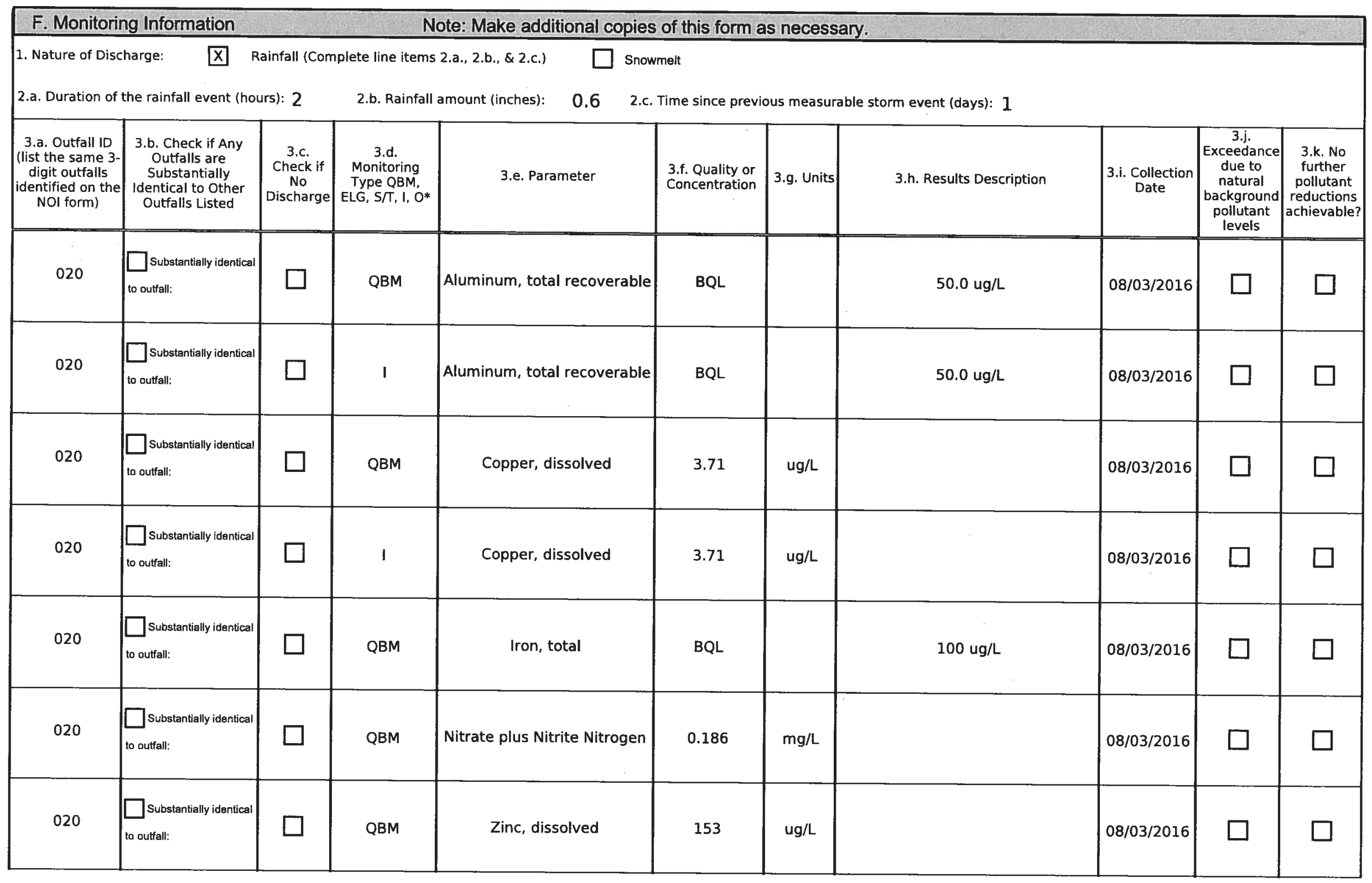

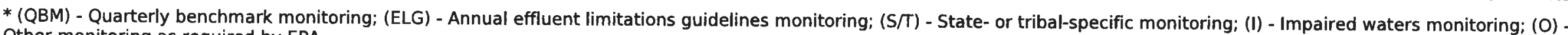
Other monitoring as required by EPA

4. Comment and/or Explanation of Any Violations (Reference all attachments here) 
Rainfall duration $=2.00$ hours. Rainfall amount $=0.61$ inches.

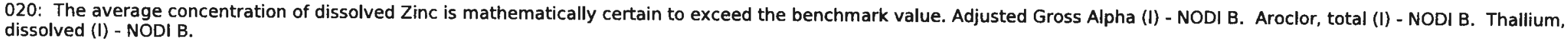




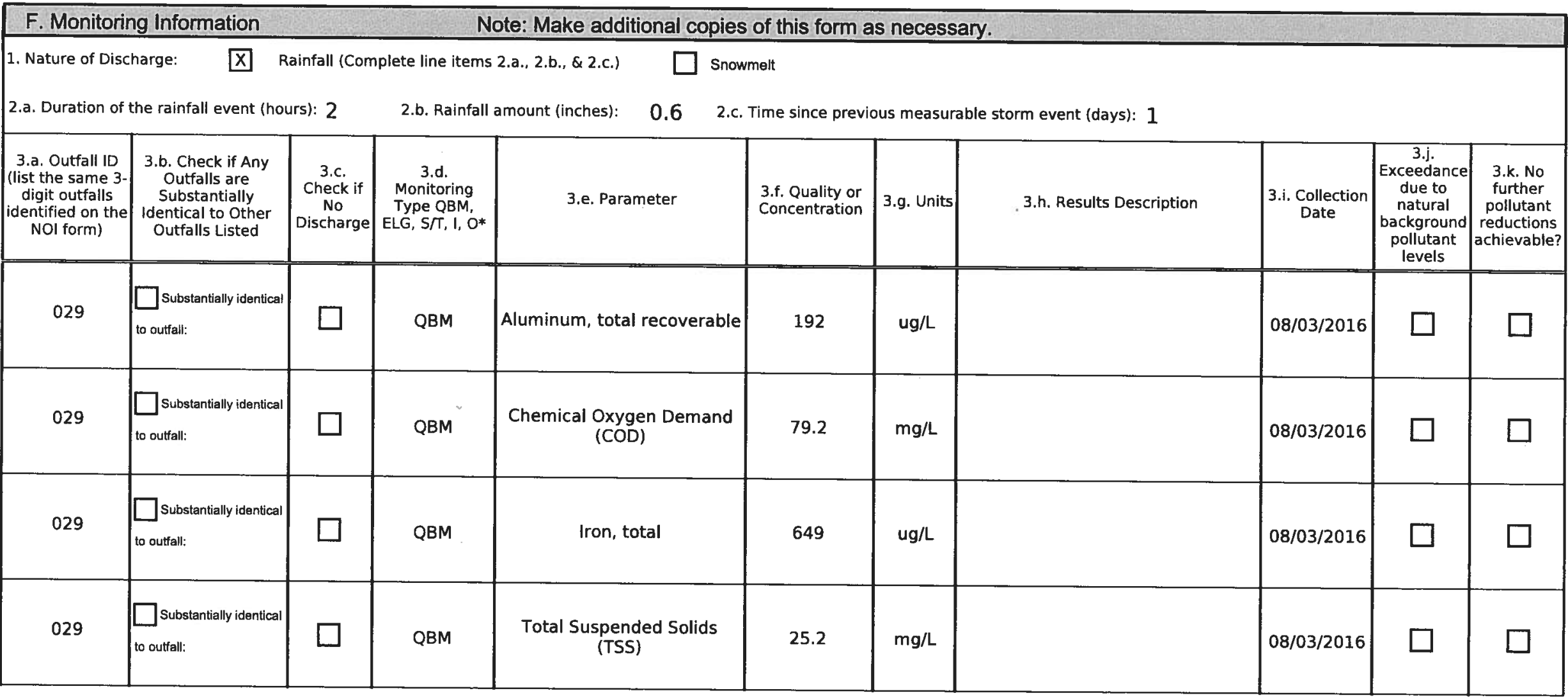
* (QBM) - Quarterly benchmark monitoring; (ELG) - Annual effluent limitations guidelines monitoring; (S/T) - State- or tribal-specific monitoring; (I) - Impaired waters monitoring; (O) -
Other monitoring as required by EPA

4. Comment and/or Explanation of Any Violations (Reference all attachments here)

Rainfall duration $=2.00$ hours. Rainfall amount $=0.61$ inches.

029: Adjusted Gross Alpha (I) - NODI 9. Aroclor, total (I) - NODI B. Copper, dissolved (I) - NODI 9. Thallium, dissolved (I) - NODI B. Aluminum, total recoverable (I) - NODI 9. 


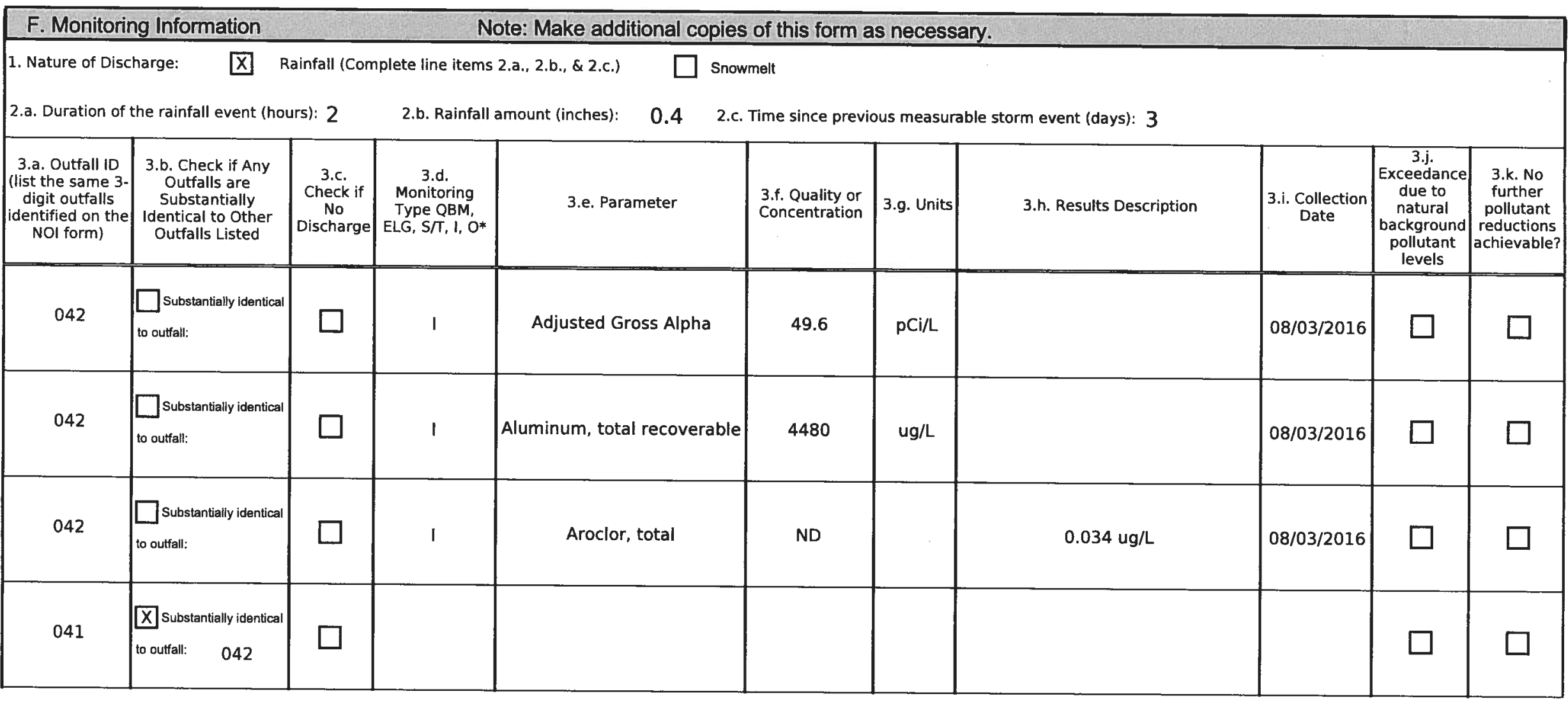

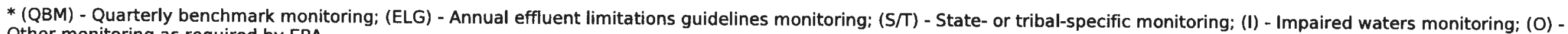
Other monitoring as required by EPA

4. Comment and/or Explanation of Any Violations (Reference all attachments here)

Rainfall duration $=2.42$ hours. Rainfall amount $=0.42$ inches.

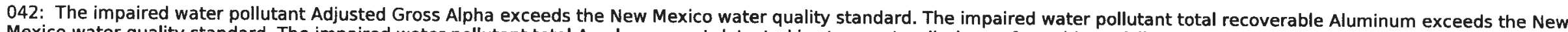

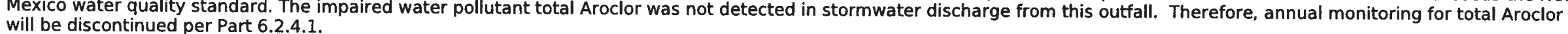




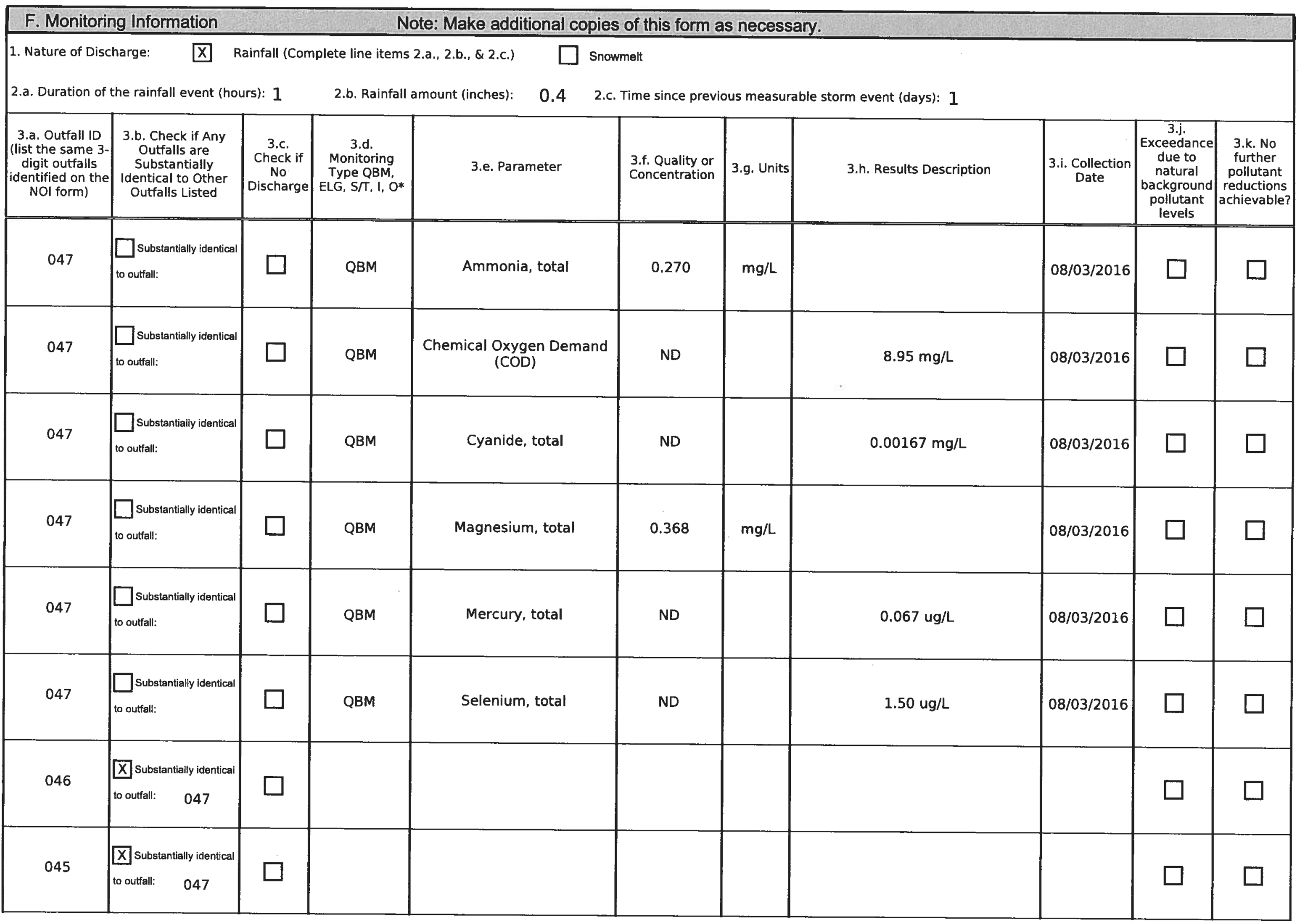




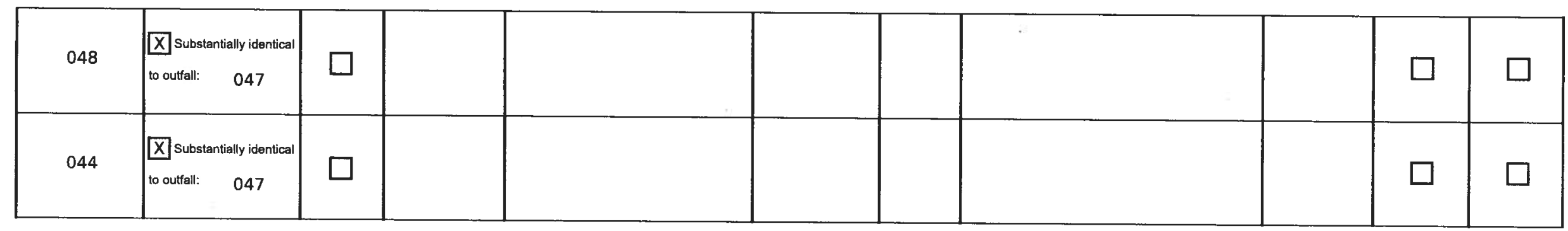

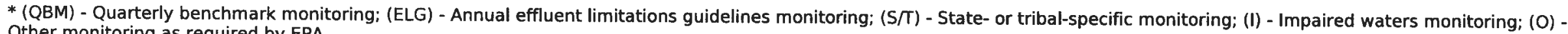
Other monitoring as required by EPA

4. Comment and/or Explanation of Any Violations (Reference all attachments here)

Rainfall duration $=1.50$ hours. Rainfall amount $=0.37$ inches.

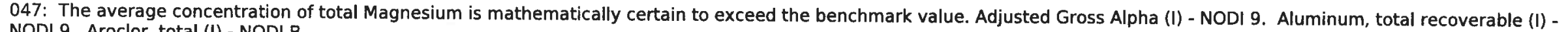
NODI 9. Aroclor, total (I) - NODI B. 


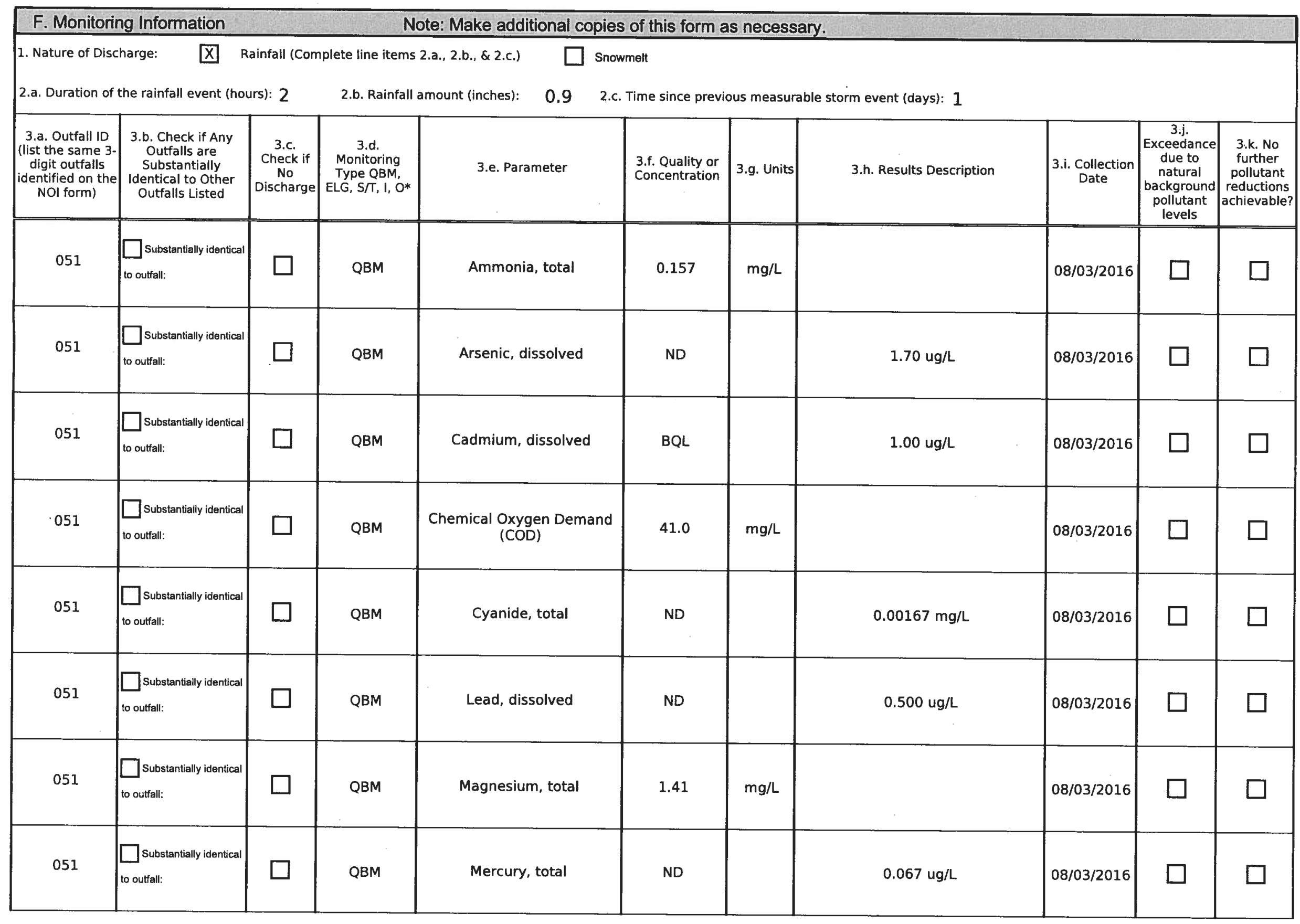




\begin{tabular}{|c|c|c|c|c|c|c|c|c|c|}
\hline 051 & $\begin{array}{l}\square \text { substantially identical } \\
\text { to outfall: }\end{array}$ & $\square$ & QBM & Selenium, total & ND & $1.50 \mathrm{ug} / \mathrm{L}$ & $08 / 03 / 2016$ & $\square$ & $\square$ \\
\hline 051 & $\begin{array}{l}\square \text { substantially identical } \\
\text { to ouffall: }\end{array}$ & $\square$ & QBM & Silver, dissolved & ND & $0.200 \mathrm{ug} / \mathrm{L}$ & $08 / 03 / 2016$ & $\square$ & $\square$ \\
\hline 052 & $\begin{array}{l}\text { 冈 Substantially identical } \\
\text { to outfall: } \quad 051\end{array}$ & $\square$ & & & & & & $\square$ & $\square$ \\
\hline
\end{tabular}

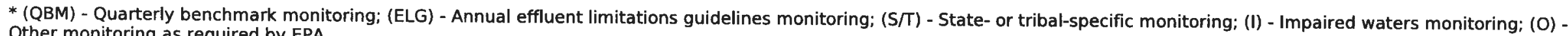
Other monitoring as required by EPA

4. Comment and/or Explanation of Any Violations (Reference all attachments here)

Rainfall duration $=2.00$ hours. Rainfall amount $=0.91$ inches.

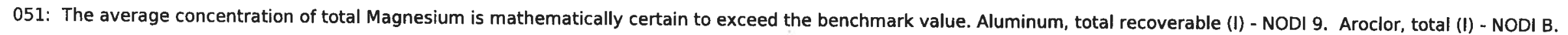




\section{G. Certification}

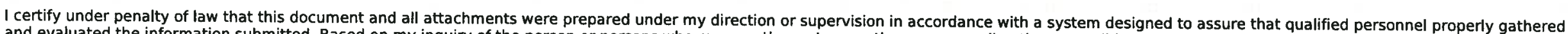

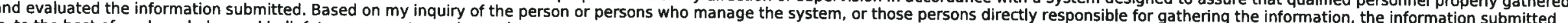

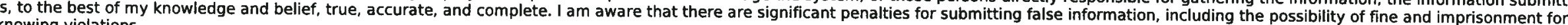

knowing violations.

First Name, Middle Initial, Last Name:

Anthony

Title:

Signature:

E-mail:
EPC-CP Group Leader

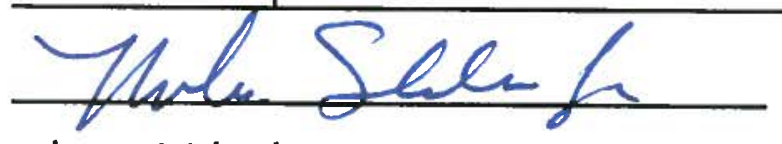

grieggst@lanl.gov
$\underline{R}$ Grieggs
1010612016 


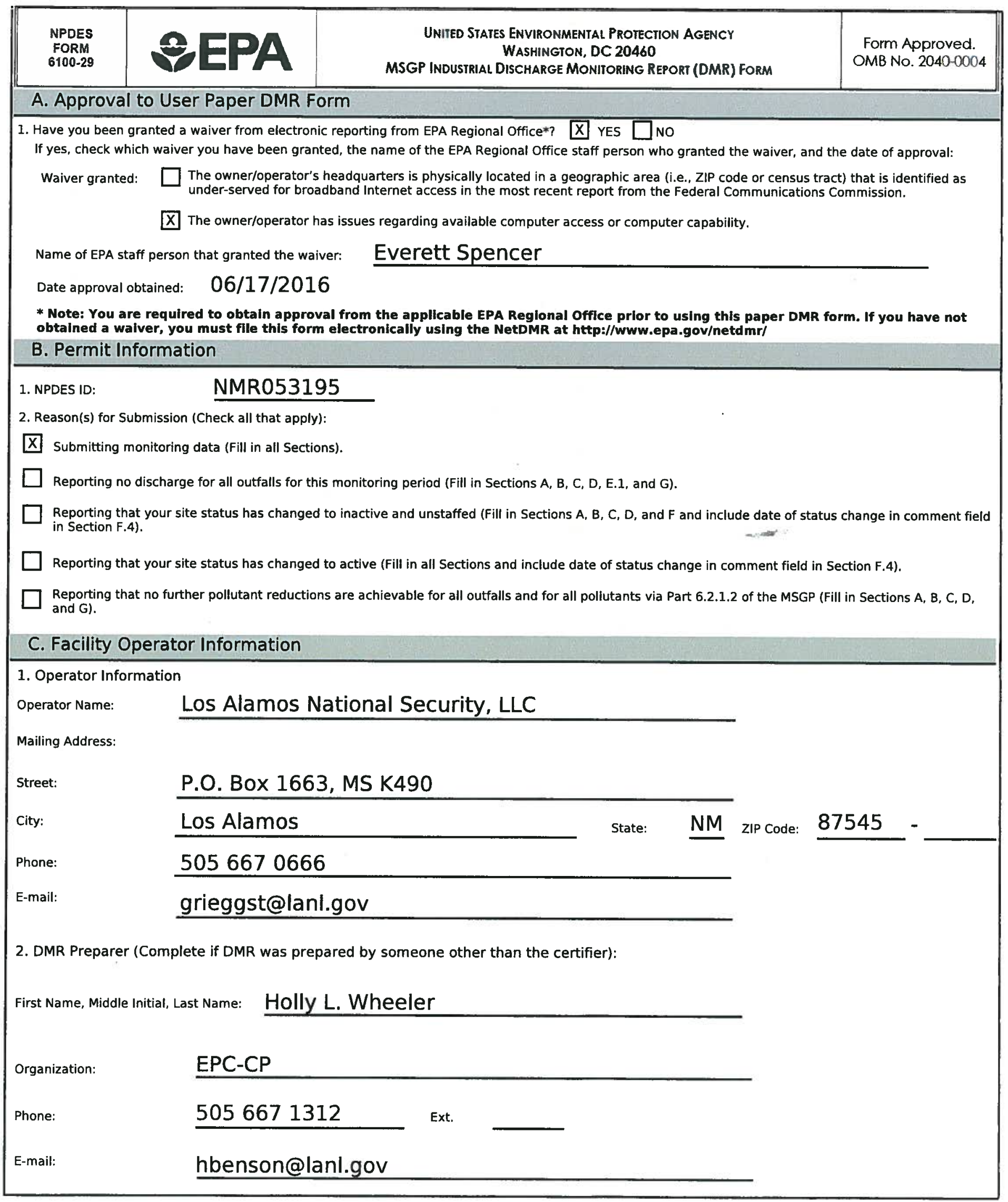




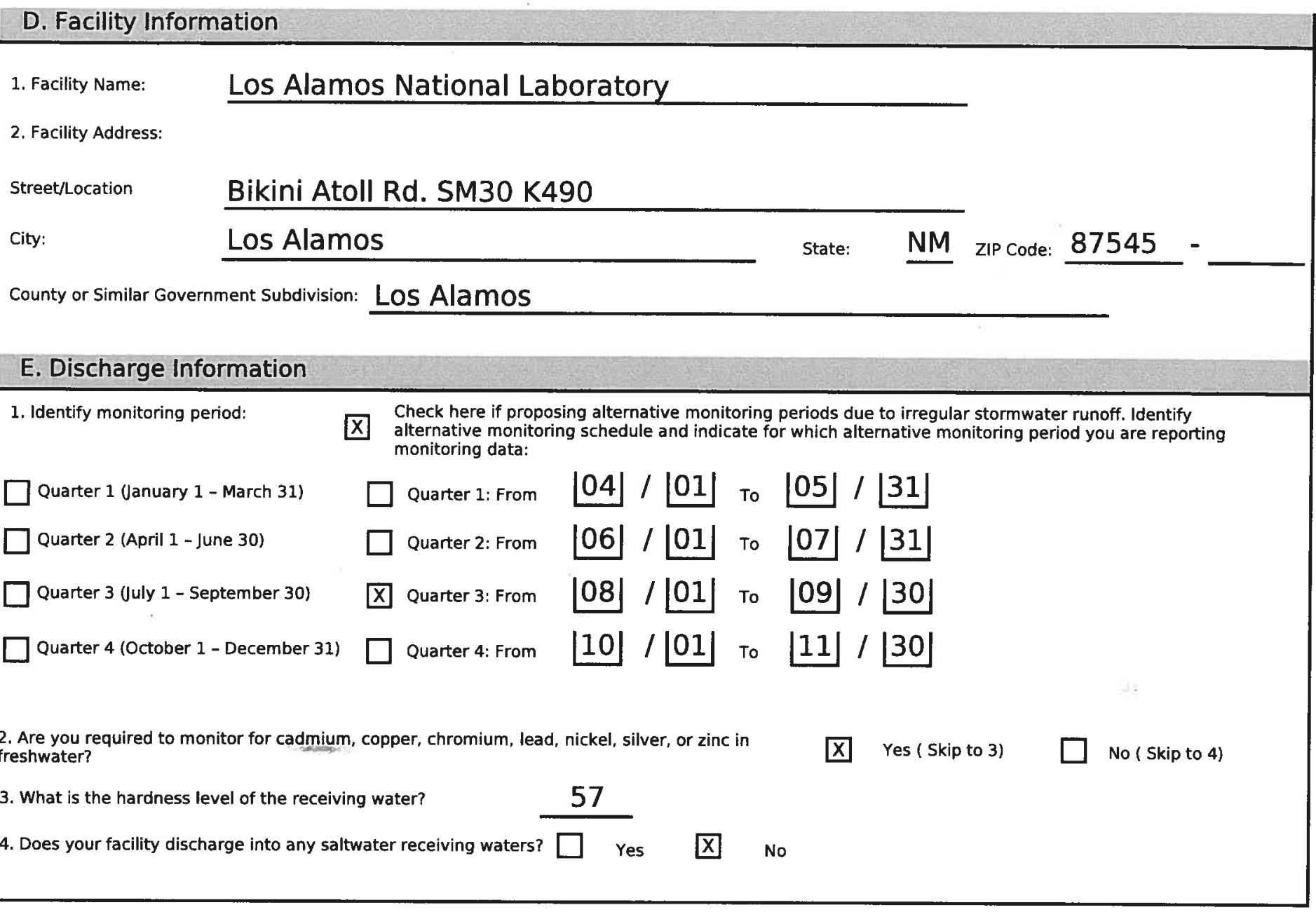




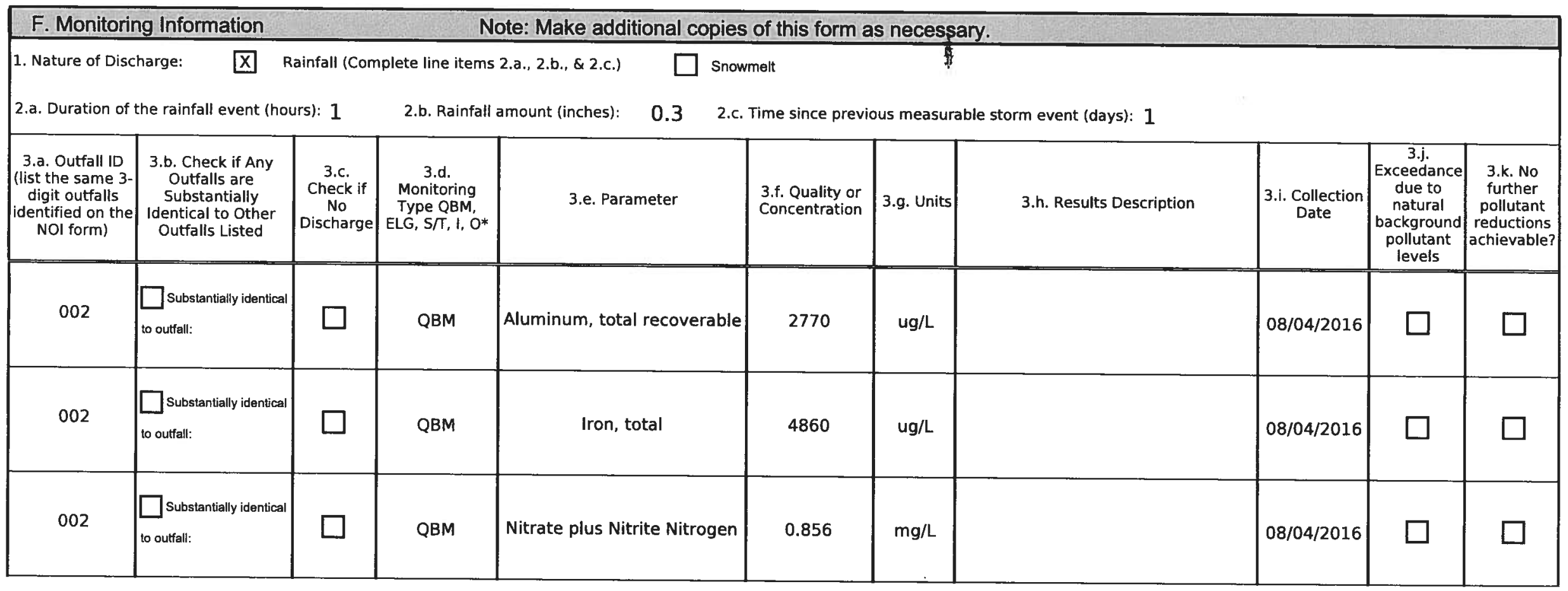

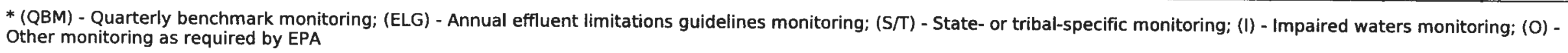

4. Comment and/or Explanation of Any Violations (Reference all attachments here)

Rainfall duration $=1.42$ hours. Rainfall amount $=0.28$ inches.

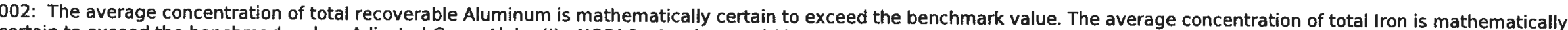

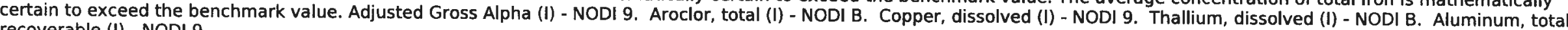
recoverable (I) - NODI 9. 


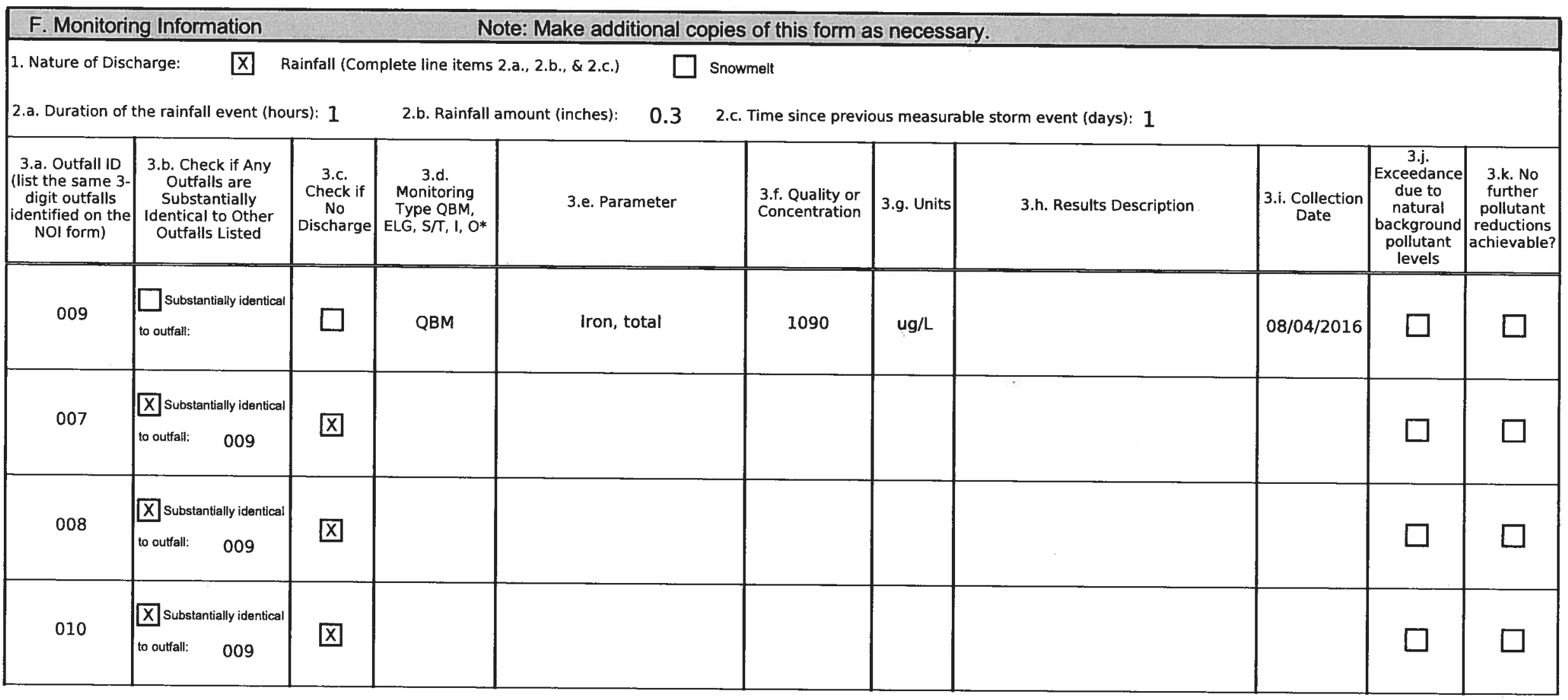

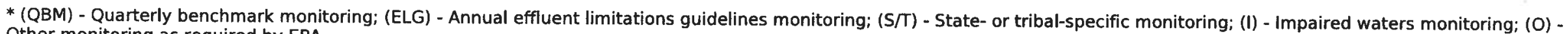
Other monitoring as required by EPA

4. Comment and/or Explanation of Any Violations (Reference all attachments here)

Rainfall duration $=1.42$ hours. Rainfall amount $=0.28$ inches.

009: Adjusted Gross Alpha (I) - NODI 9. Aluminum, total recoverable (I) - NODI 9. Aroclor, total (I) - NODI B. Copper, dissolved (I) - NODI 9. Thallium, dissolved (I) - NODI 9. 


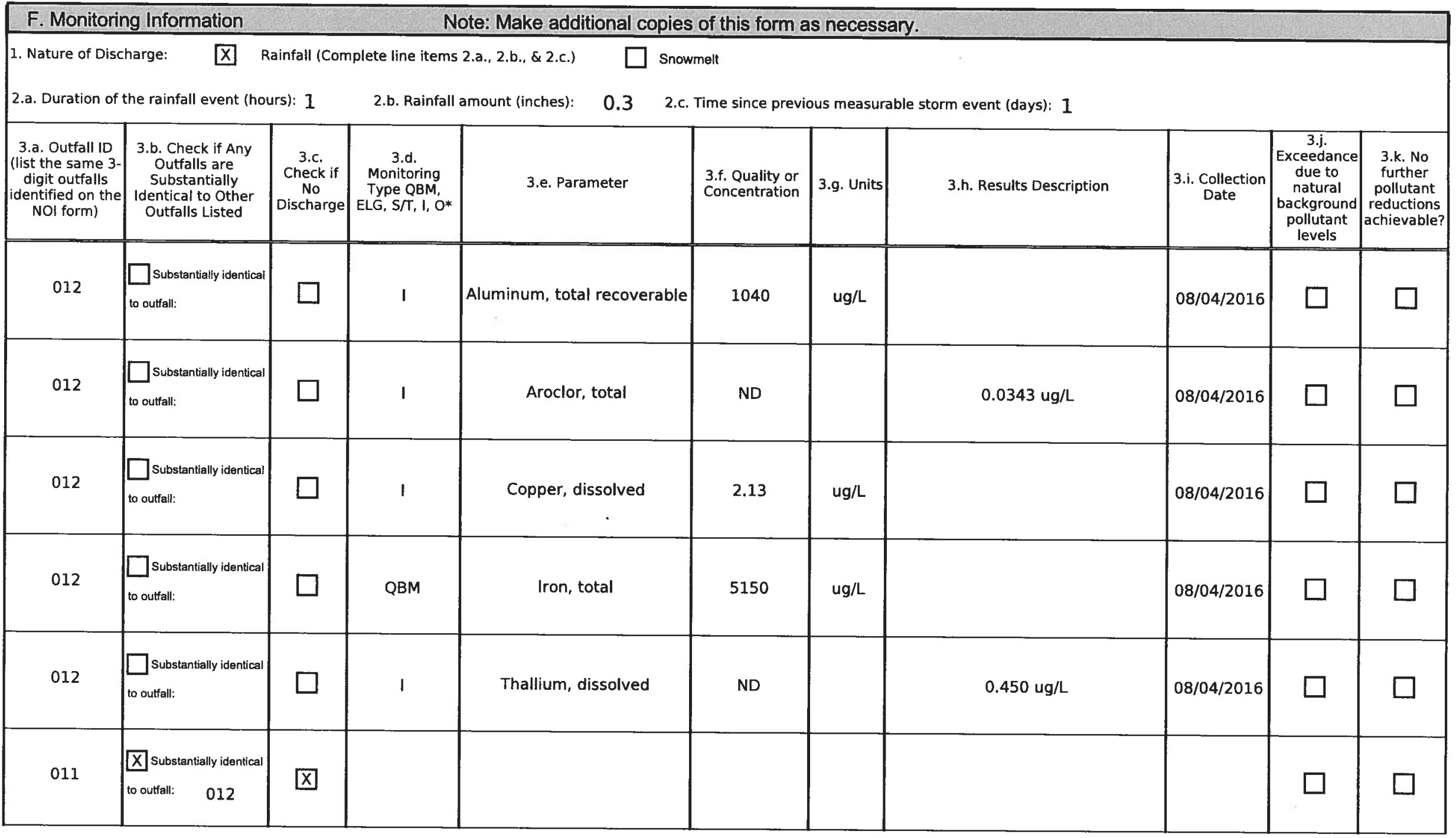

* (QBM) - Quarterly benchmark monitoring; (ELG) - Annual effluent limitations guidelines monitoring; (S/T) - State- or tribal-specific monitoring; (I) - Impaired waters monitoring; (O) Other monitoring as required by EPA

4. Comment and/or Explanation of Any Violations (Reference all attachments here) 
012: The impaired water pollutant total recoverable Aluminum exceeds the New Mexico water quality standard. The impaired water pollutant total Aroclor was not detected in

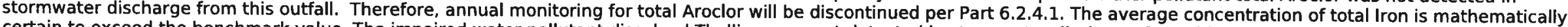

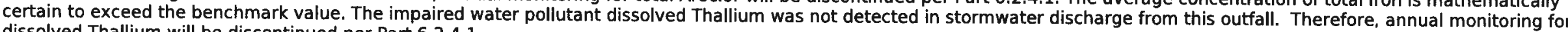
dissolved Thallium will be discontinued per Part 6.2.4.1. 


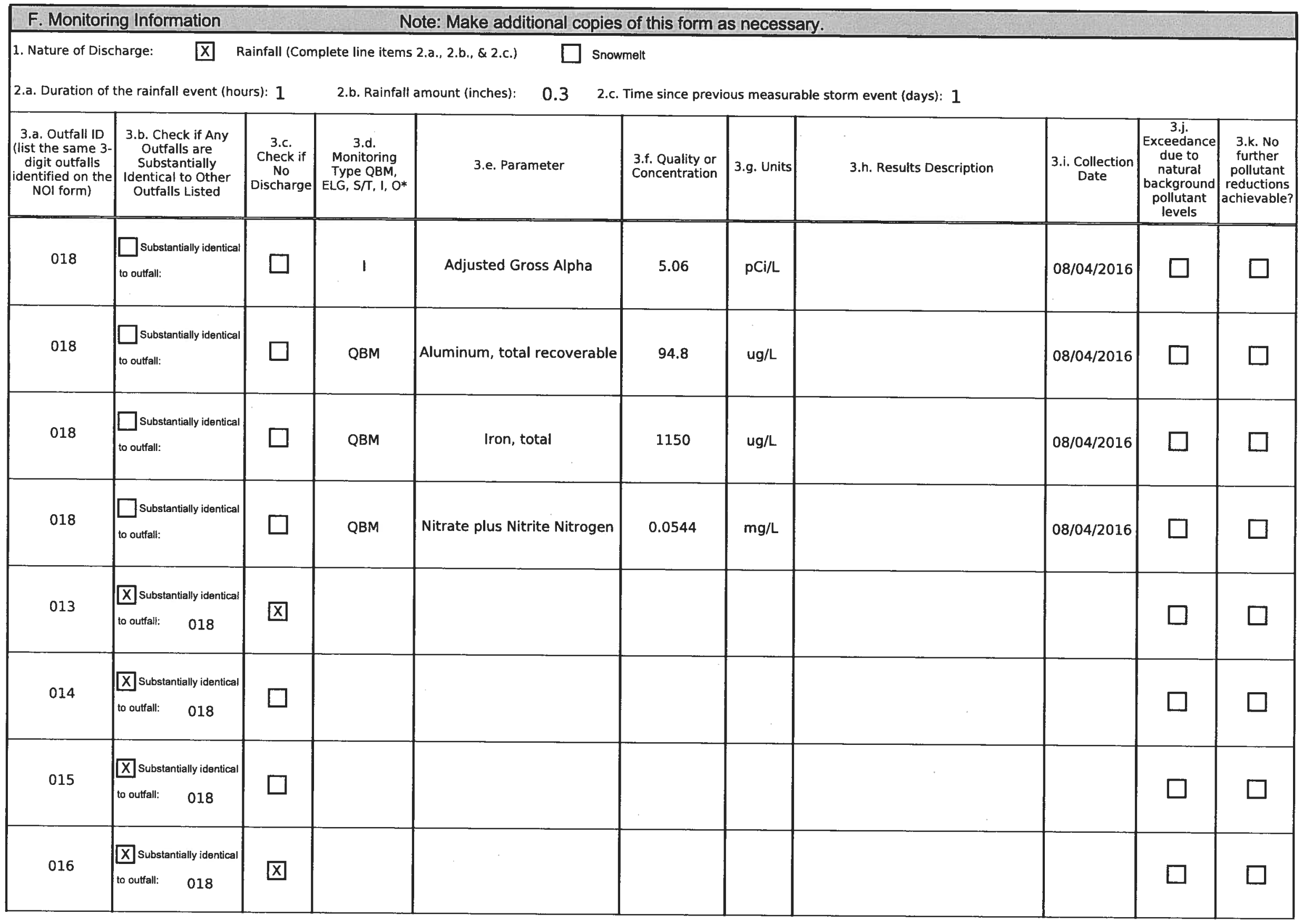




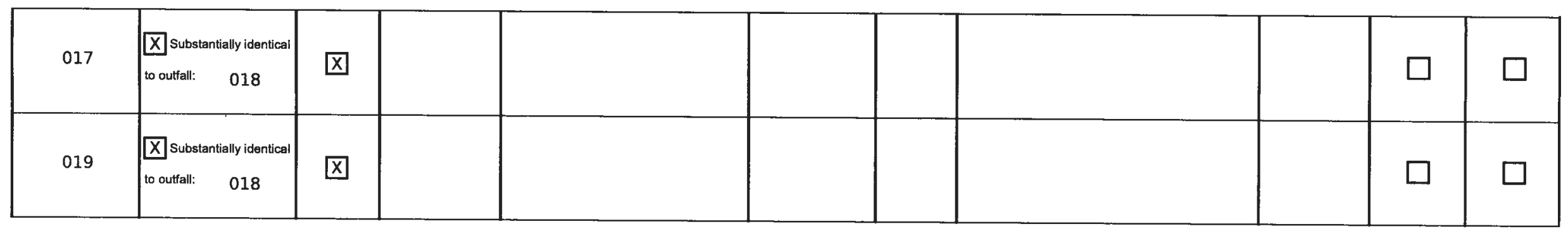

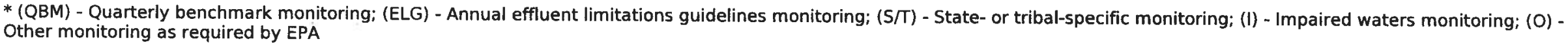

4. Comment and/or Explanation of Any Violations (Reference all attachments here)

Rainfall duration $=1.42$ hours. Rainfall amount $=0.28$ inches.

018: Copper, dissolved (I) - NODI 9. Thallium, dissolved (I) - NODI B. Aluminum, total recoverable (I) - NODI 9. 


\section{G. Certification}

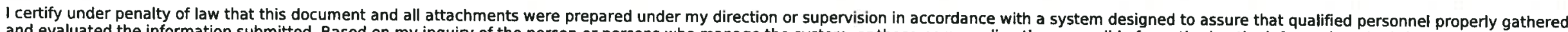

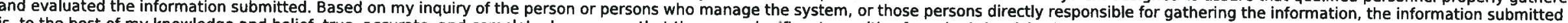
am aware that there are significant penalties for submitting false information. including the possibility of fine and imprisonment for

First Name, Middle Initial, Last Name

Anthony

EPC-CP Group Leader

E-mail:

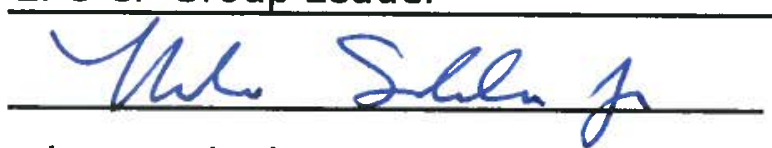

grieggst@lanl.gov
$\underline{R} \quad$ Grieggs 


\begin{tabular}{|c|c|c|c|}
\hline $\begin{array}{l}\text { NPDES } \\
\text { FORM } \\
6100-29\end{array}$ & & 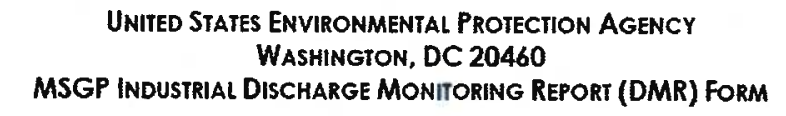 & $\begin{array}{l}\text { Form Approved. } \\
\text { OMB No. } 2040-0004\end{array}$ \\
\hline \multicolumn{4}{|c|}{ A. Approval to User Paper DMR Form } \\
\hline \multicolumn{4}{|c|}{$\begin{array}{l}\text { 1. Have you been granted a waiver from electronic reporting from EPA Regional Office*? } \mathrm{X} \text { YES } \square \text { NO } \\
\text { If yes, check which waiver you have been granted, the name of the EPA Regional Office staff person who granted the waiver, and the date of approval: }\end{array}$} \\
\hline \multicolumn{4}{|c|}{ Waiver granted: } \\
\hline \multicolumn{4}{|c|}{ Name of EPA staff person that granted the waiver: Everett Spencer } \\
\hline \multicolumn{4}{|c|}{ Date approval obtained: $\quad 06 / 17 / 2016$} \\
\hline \multicolumn{4}{|c|}{$\begin{array}{l}\text { * Note: You are required to obtain approval from the applicable EPA Reglonal Office prior to using this paper DMR form. If you have not } \\
\text { obtained a waiver, you must flie this form electronically using the NetDMR at http://www.epa.gov/netdmr/ }\end{array}$} \\
\hline \multicolumn{4}{|c|}{ B. Permit Information } \\
\hline \multirow{3}{*}{\multicolumn{4}{|c|}{$\begin{array}{l}\text { 1. NPDES ID: NMR053195 } \\
\text { 2. Reason(s) for Submission (Check all that apply): } \\
X \text { Submitting monitoring data (Fill in all Sections). }\end{array}$}} \\
\hline & & & \\
\hline & & & \\
\hline \multicolumn{4}{|c|}{ Reporting no discharge for all outfalls for this monitoring period (Fill in Sections A, B, C, D, E.1, and G). } \\
\hline \multirow{2}{*}{\multicolumn{4}{|c|}{$\begin{array}{l}\text { Reporting that your site status has changed to inactive and unstaffed (Fill in Sections A, B, C, D, and F and include date of status change in comment field } \\
\text { in Section F.4). }\end{array}$}} \\
\hline & & & \\
\hline \multicolumn{4}{|c|}{ Reporting that your site status has changed to active (Fill in all Sections and include date of status change in comment field in Section. F.4). } \\
\hline \multicolumn{4}{|c|}{$\begin{array}{l}\text { Reporting that no further pollutant reductions are achievable for all outfalls and for all pollutants via Part } 6.2 .1 .2 \text { of the MSGP (Fill in Sections A, B, C, D, } \\
\text { and G). }\end{array}$} \\
\hline \multicolumn{4}{|c|}{ C. Facility Operator Information } \\
\hline
\end{tabular}

1. Operator Information

Operator Name:

Los Alamos National Security, LLC

Mailing Address:

Street:

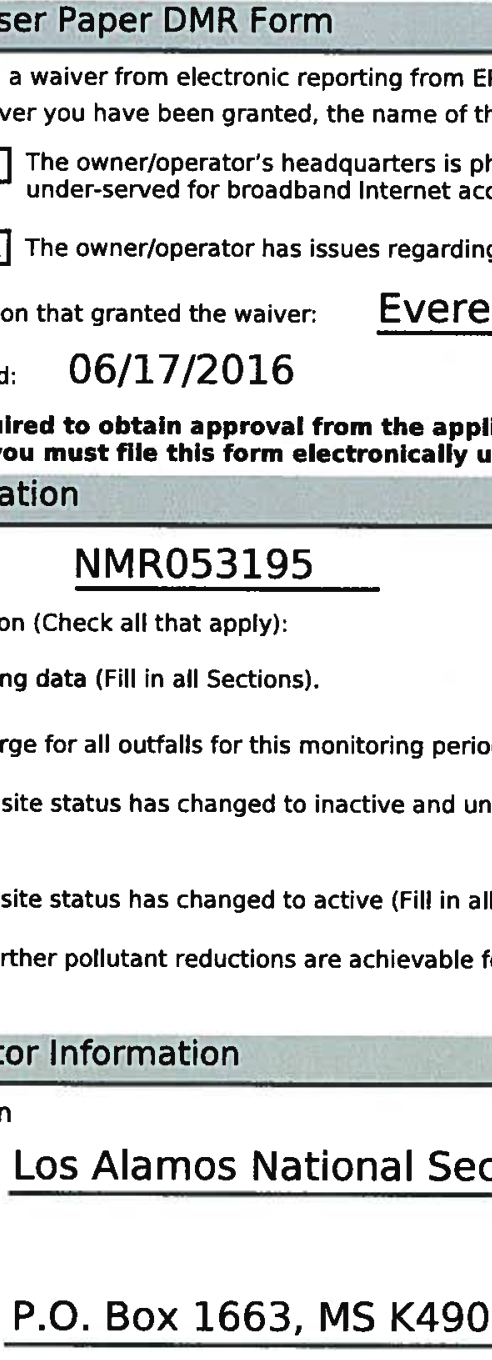

City:

Los Alamos

State:

NM

5056670666

Phone:

grieggst@lanl.gov

2. DMR Preparer (Complete if DMR was prepared by someone other than the certifier):

First Name, Middle Initial, Last Name: Holly L. Wheeler

Organization:

EPC-CP

Phone:

5056671312

Ext.

E-mail:

hbenson@lanl.gov 


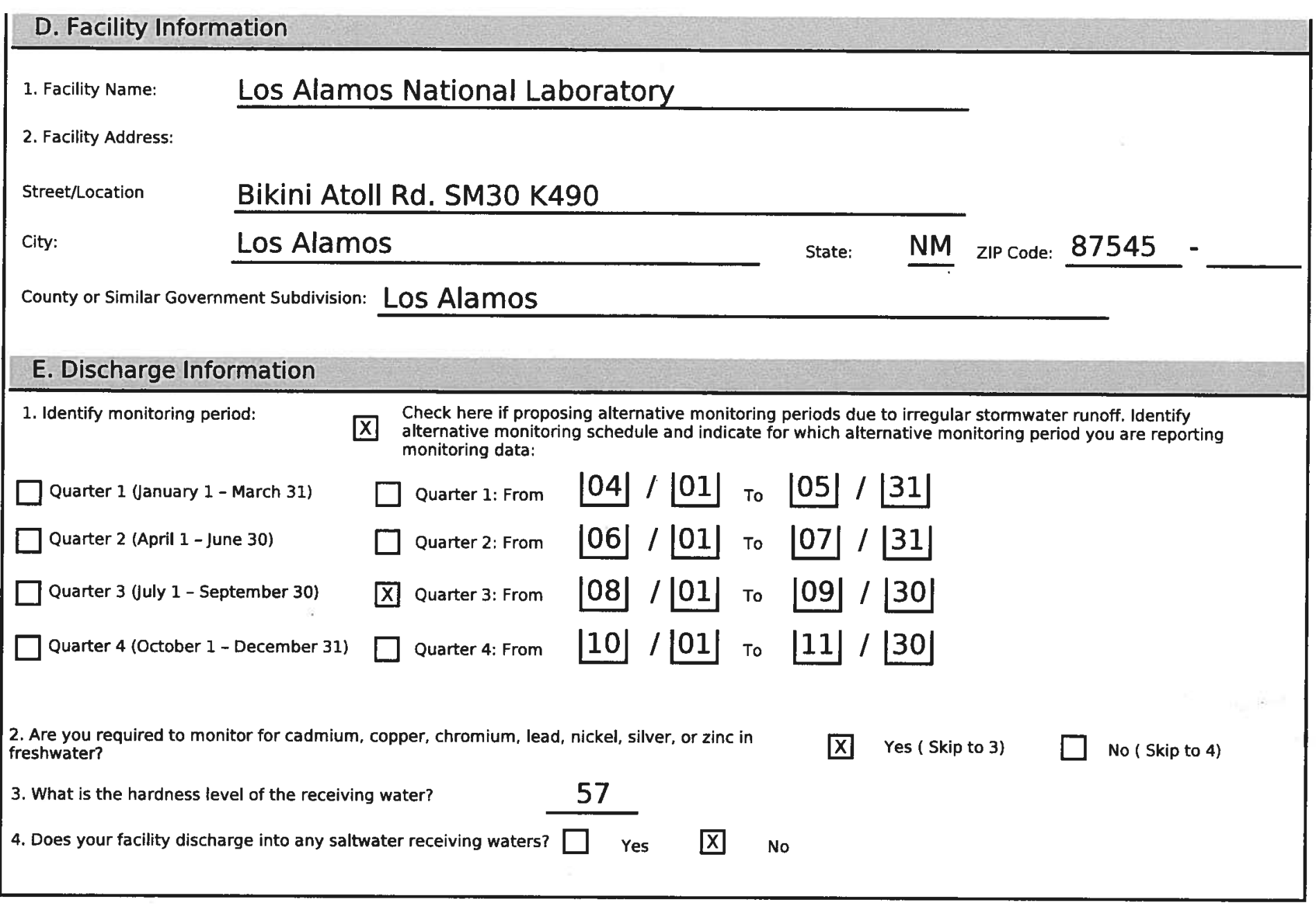


2.b. Rainfall amount (inches):

0.4

2.c. Time since previous measurable storm event (days): 1

\begin{tabular}{|c|c|c|c|c|c|c|c|c|c|c|}
\hline $\begin{array}{l}\text { 3.a. Outfall ID } \\
\text { (list the same 3- } \\
\text { digit outfalls } \\
\text { identified on the } \\
\text { NOI form) }\end{array}$ & $\begin{array}{l}\text { 3.b. Check if Any } \\
\text { Outfalls are } \\
\text { Substantially } \\
\text { Identical to Other } \\
\text { Outfalls Listed }\end{array}$ & $\begin{array}{c}\text { 3.c. } \\
\text { Check if } \\
\text { No } \\
\text { Discharge }\end{array}$ & $\begin{array}{c}\text { 3.d. } \\
\text { Monitoring } \\
\text { Type QBM, } \\
\text { ELG, S/T, I, O* }\end{array}$ & 3.e. Parameter & $\begin{array}{l}\text { 3.f. Quality or } \\
\text { Concentration }\end{array}$ & 3.g. Units & 3.h. Results Description & $\begin{array}{c}\text { 3.i. Collection } \\
\text { Date }\end{array}$ & $\begin{array}{c}\text { 3.j. } \\
\text { Exceedance } \\
\text { due to } \\
\text { natural } \\
\text { background } \\
\text { pollutant } \\
\text { levels }\end{array}$ & $\begin{array}{c}\text { 3.k. No } \\
\text { further } \\
\text { pollutant } \\
\text { reductions } \\
\text { achievable? }\end{array}$ \\
\hline 002 & $\begin{array}{l}\square \text { Substantially identical } \\
\text { to outfall: }\end{array}$ & & QBM & Zinc, dissolved & 54.3 & ug/L & & 08/08/2016 & & \\
\hline
\end{tabular}

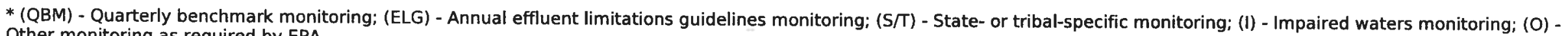
Other monitoring as required by EPA

4. Comment and/or Explanation of Any Violations (Reference all attachments here)

Rainfall duration $=0.83$ hours. Rainfall amount $=0.37$ inches.

002: Adjusted Gross Alpha (I) - NODI 9. Aluminum, total recoverable (I) - NODI 9. Aroclor, total (I) - NODI B. Copper, dissolved (I) - NODI 9. Thallium, dissolved (I) - NODI B. 


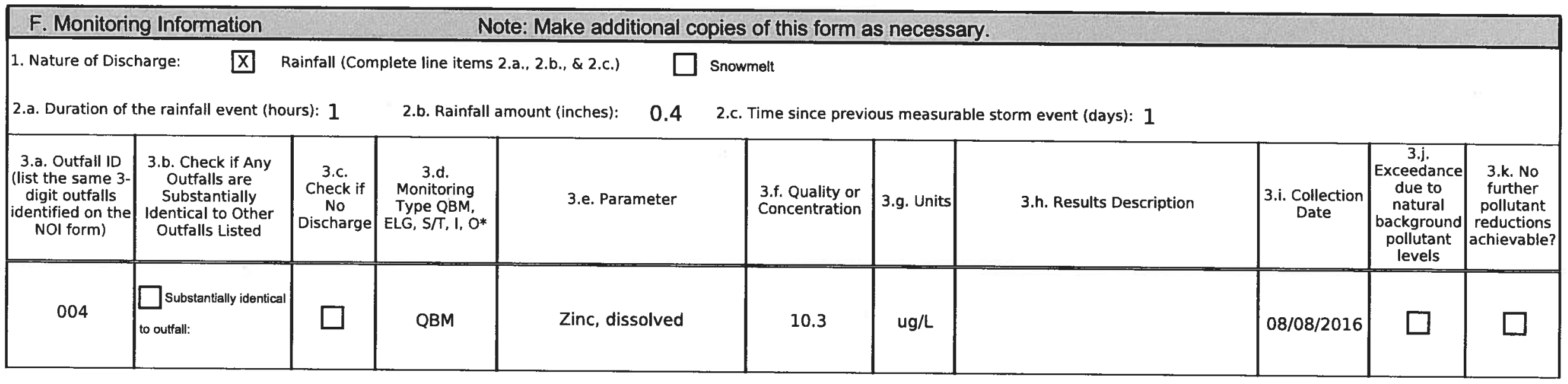

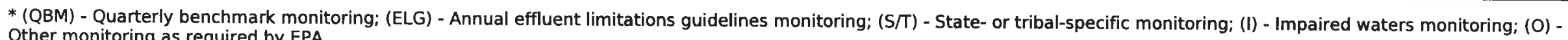
Other monitoring as required by EPA

4. Comment and/or Explanation of Any Violations (Reference all attachments here)

Rainfall duration $=0.83$ hours. Rainfall amount $=0.37$ inches.

004: Adjusted Gross Alpha (I) - NODI 9. Aluminum, total recoverable (I) - NODI 9. Aroclor, total (I) - NODI 9. 


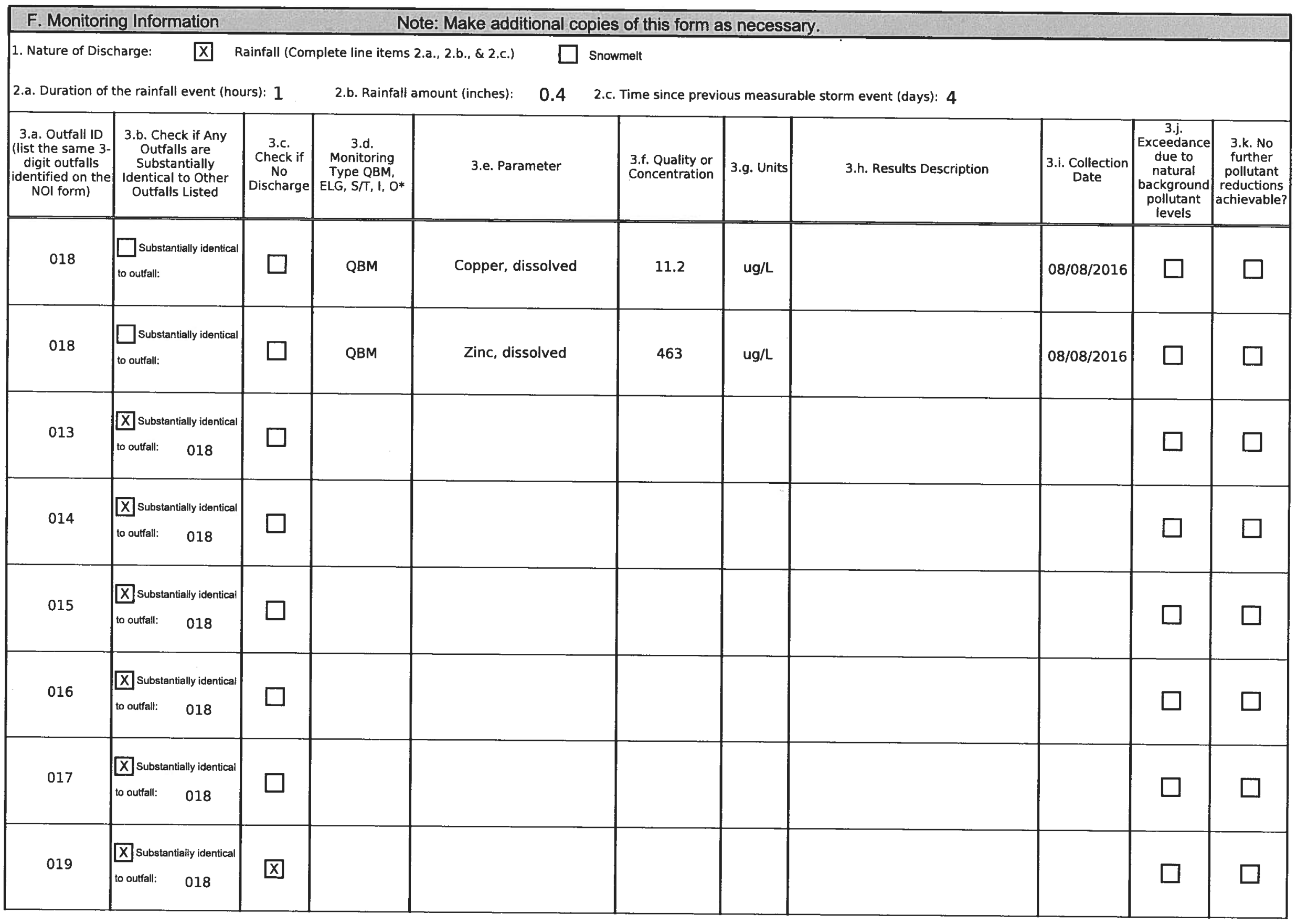




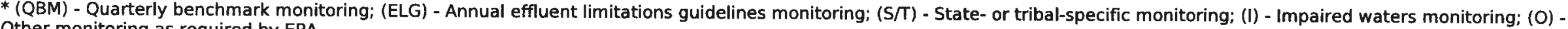
Other monitoring as required by EPA

4. Comment and/or Explanation of Any Violations (Reference all attachments here)

Rainfall duration $=0.83$ hours. Rainfall amount $=0.37$ inches.

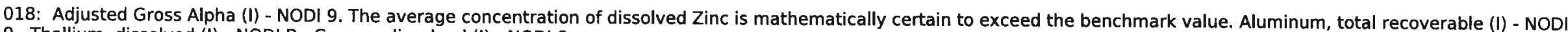
9. Thallium, dissolved (I) - NODI B. Copper, dissolved (I) - NODI 9. 


\section{G. Certification}

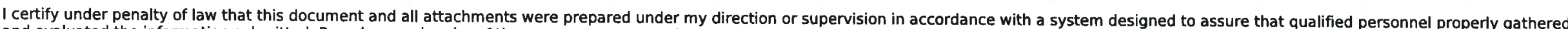

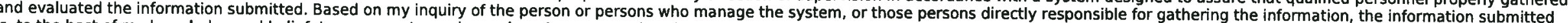

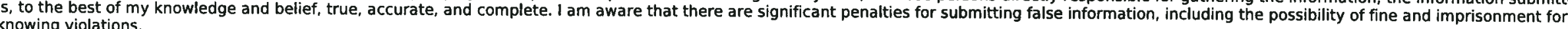

First Name, Middle Initial, Last Name: Anthony

Title

Signature:

E-mail:
EPC-CP Group Leader

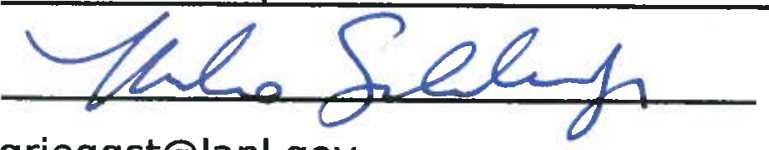

grieggst@lanl.gov
R Grieggs

Date 
Training 


\title{
2015 MSGP Corrective Actions
}

\author{
Presented by \\ Terrill Lemke and Holly Wheeler \\ Environmental Protection Division \\ Compliance Programs (ENV-CP)
}

December 01, 2015 


\section{Agenda}

- Definition of Corrective Action

- What triggers a corrective action

- Examples of issues requiring corrective actions

- Timeframes to address corrective actions

- 45 Day Extension

- Corrective action process

- Results of initial inspection

- Suggestions

- Expectations and questions

- Request for other topics 


\section{Corrective Action}

Definition: "Any action taken, or required to be taken, to

(1) repair, modify, or replace any stormwater control used at the site;

(2) clean up and dispose of spills, releases, or other deposits found on the site;

(3) remedy a permit violation. 


\section{What Triggers A Corrective Action?}

- Unauthorized release or discharge

- Discharge that violated a numeric effluent limit

- Control measures that are not stringent enough to ensure stormwater discharges meet Water Quality Standards.

- These are the threshold values in your SWPPPS

- Visual assessment that shows evidence of stormwater pollution (e.g., color, odor, floating solids, settled solids, suspended solids, foam)

- Failure to meet any permit condition or those specified in the site specific SWPPP 


\section{Examples of Issues Requiring Corrective Action}

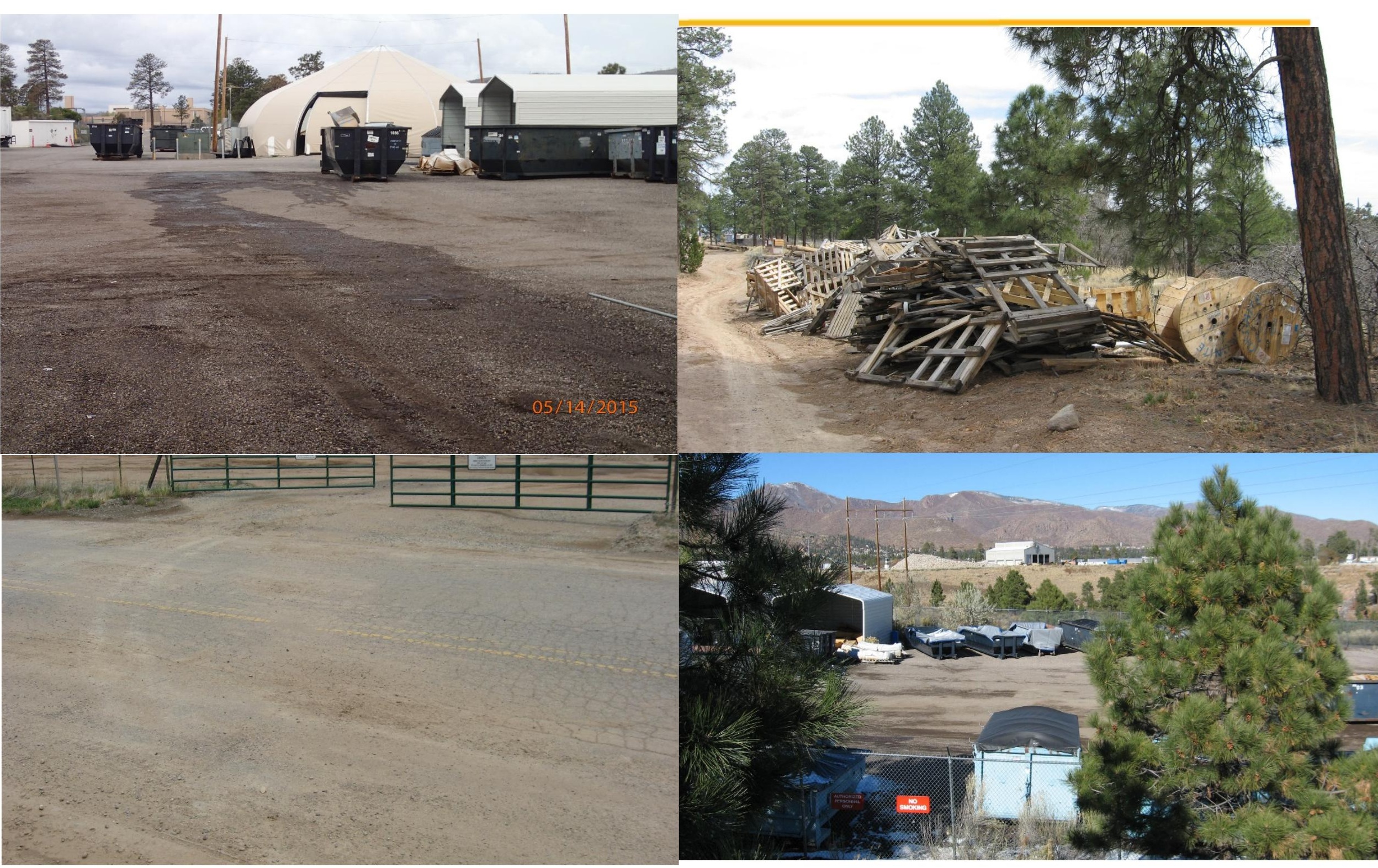




\section{Examples of Issues Requiring Corrective Action (continued)}

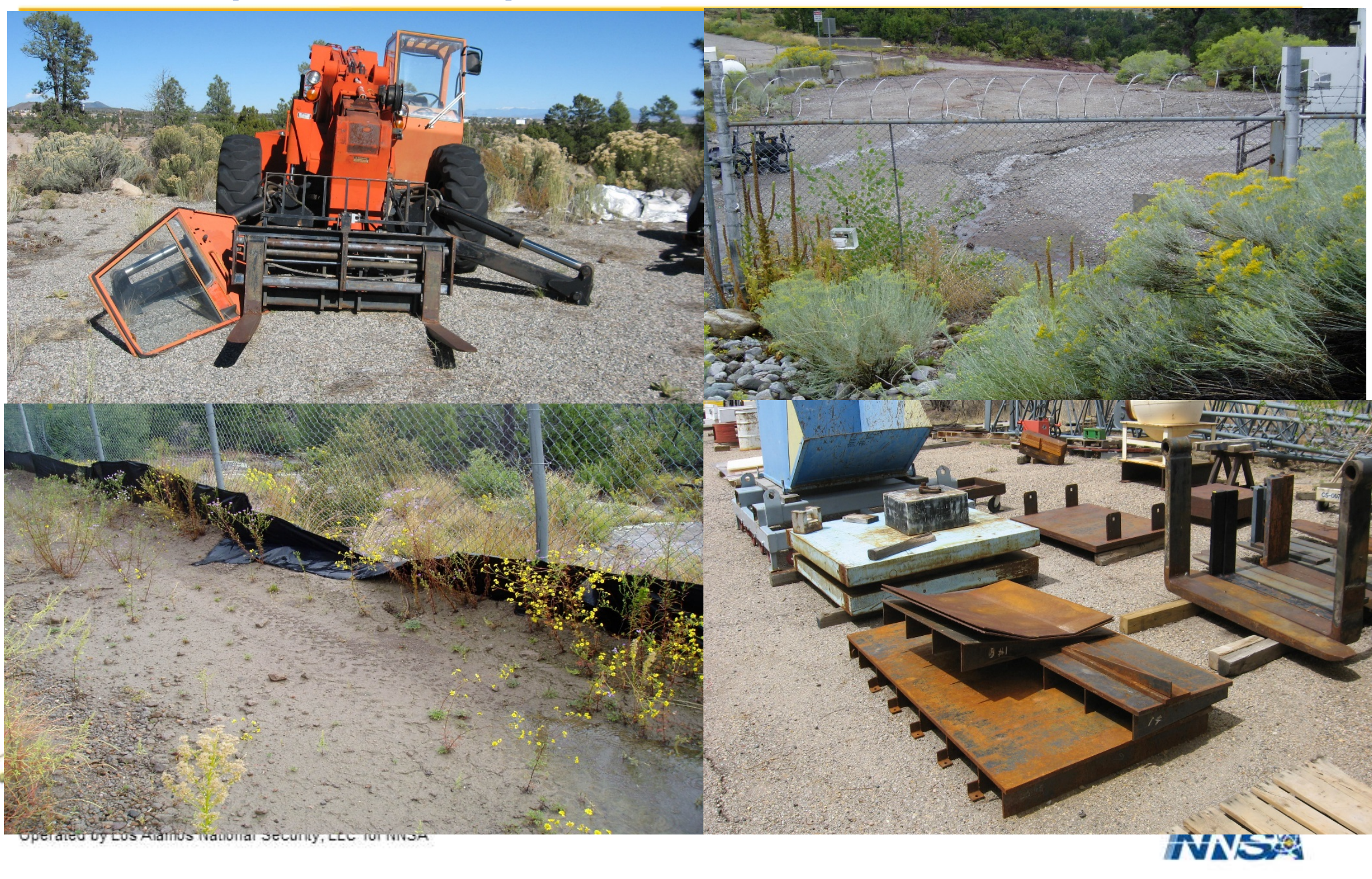




\section{Timeframes to address new corrective actions}

- Shall $\underline{I m m e d i a t e l y}$ take action upon identification of an issue

- Immediately is the same day a condition is found

- If found after 3:00 pm, action must be taken the next work day

- If follow-up action is needed - before the next storm event or within 14 calendar days

- If finalization of CA is not feasible within 14 days the following is required

- Documentation of why it is not feasible to close the CA within this timeframe

- A formal schedule for completion of the action A.S.A.P. but no longer than 45 days after discovery 


\section{Day Extension}

- If a CA is expected to exceed the 45 day timeframe (as identified above) the DEP shall provide ENV-CP the following information

- Rationale for an extension (e.g., a defensible position that does not put LANS at risk)

- Provide a realistic completion date

- Take the minimum additional time necessary to complete the corrective action.

- Where a corrective action results in a change to any control measure or procedure the SWPPP must be modified within 14 calendar days of the day the CA was closed. 


\section{Corrective Action Process}

- Identification of an issue either during routine operations or during an inspection

- Notify the Deployed Environmental Professional

- Take immediate action

- Record the issue and corrective action

- Enter the issue into the MSGP Corrective Action Report (CAR) Database

- Propose a completion date

- System notifies FOD, DSESH Manager, and ENV-CP of new CA

- Follow-up and completion of corrective action

- Perform work and record completed activities and date of completion in the database

- Database automatically sends e-mail notifications to key personnel every 30 days until corrective actions are closed (process may change/compress in the future) 


\section{Corrective Action Process (continued)}

- Follow-up and completion of corrective action (continued)

- If CA is expected to exceed 14 days, enter a schedule for completion in the database

- At about day 30, ENV-CP will be contacting the DEP for the following information:

- Rationale for a 45 day extension

- Realistic completion date taking the minimum amount of time necessary

- Letter will be sent to Region 6 EPA prior to the $45^{\text {th }}$ day.

- ENV-CP will track progress according to the schedule provided in the 45 day extension letter

- If timeframes in the letter are exceeded, it is a permit non-compliance. 


\section{Results of initial inspection}

- Started with 40 corrective actions with potential to exceed 45 day timeframe

- Corrective action initiated well into the 45-day period (not started immediately)

- Three CA's reported to Region 6 EPA with rationale and completion dates.

- Took numerous phone calls and discussions up the management chain to the AD level to accomplish this

- Not efficient use of resources

- Must strive for proactivity, not reactivity

- One was closed within identified timeframe

- One has exceeded the completion date reported to EPA

- One must be addressed by this Friday

- EPA will consider the appropriateness and promptness of corrective action in determining enforcement response to permit violations 


\section{Suggestions for Improvements?}

- How does the institution speed up the corrective action process?

- Improve the FSR system?

- Flag compliance driven work

- Allow compliance driven work to move through system without cost code or automatically be assigned a specific cost code

- Use Maintenance Connection to push out work order to DEPs with deadline and notification to managers

- What are the barriers you face in taking immediate action and/or completing work within 14 days?

- How do we improve this? Ideas? 


\section{Expectations}

- Be timely and diligent in implementing 2015 MSGP requirements at your facilities

- Plan ahead for budget \& resources

- Look for opportunities to streamline and improve processes

- Ask for help

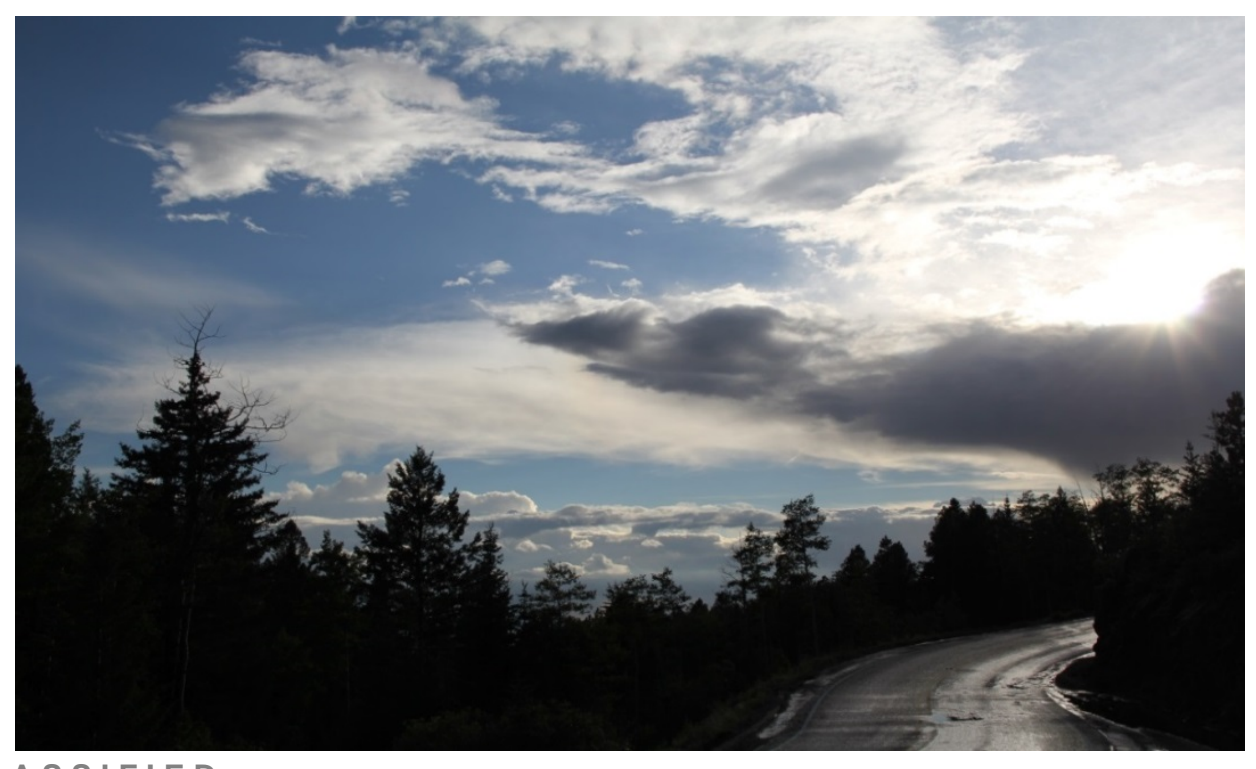




\section{Questions?}




\section{Requests for Other Topics?}




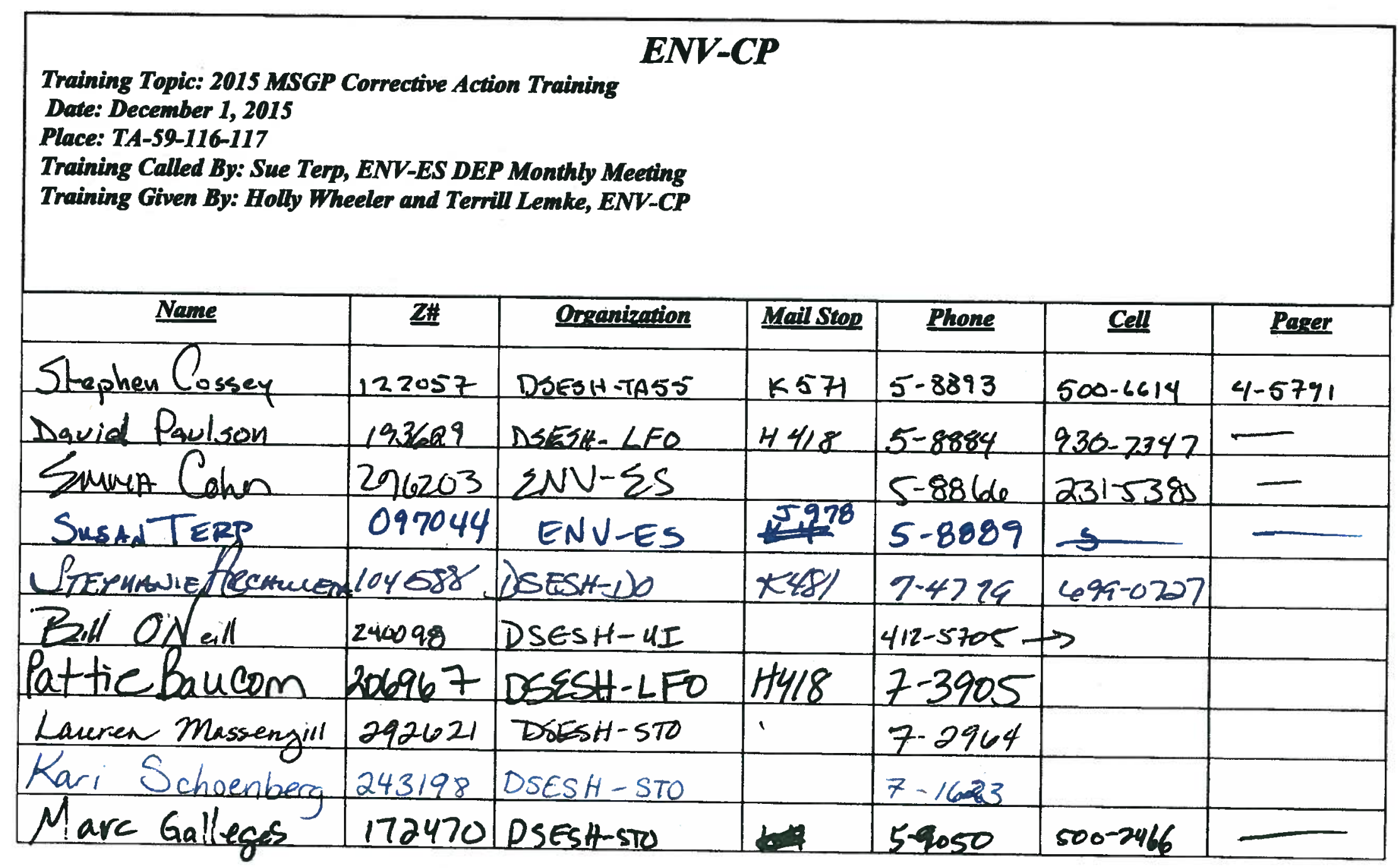




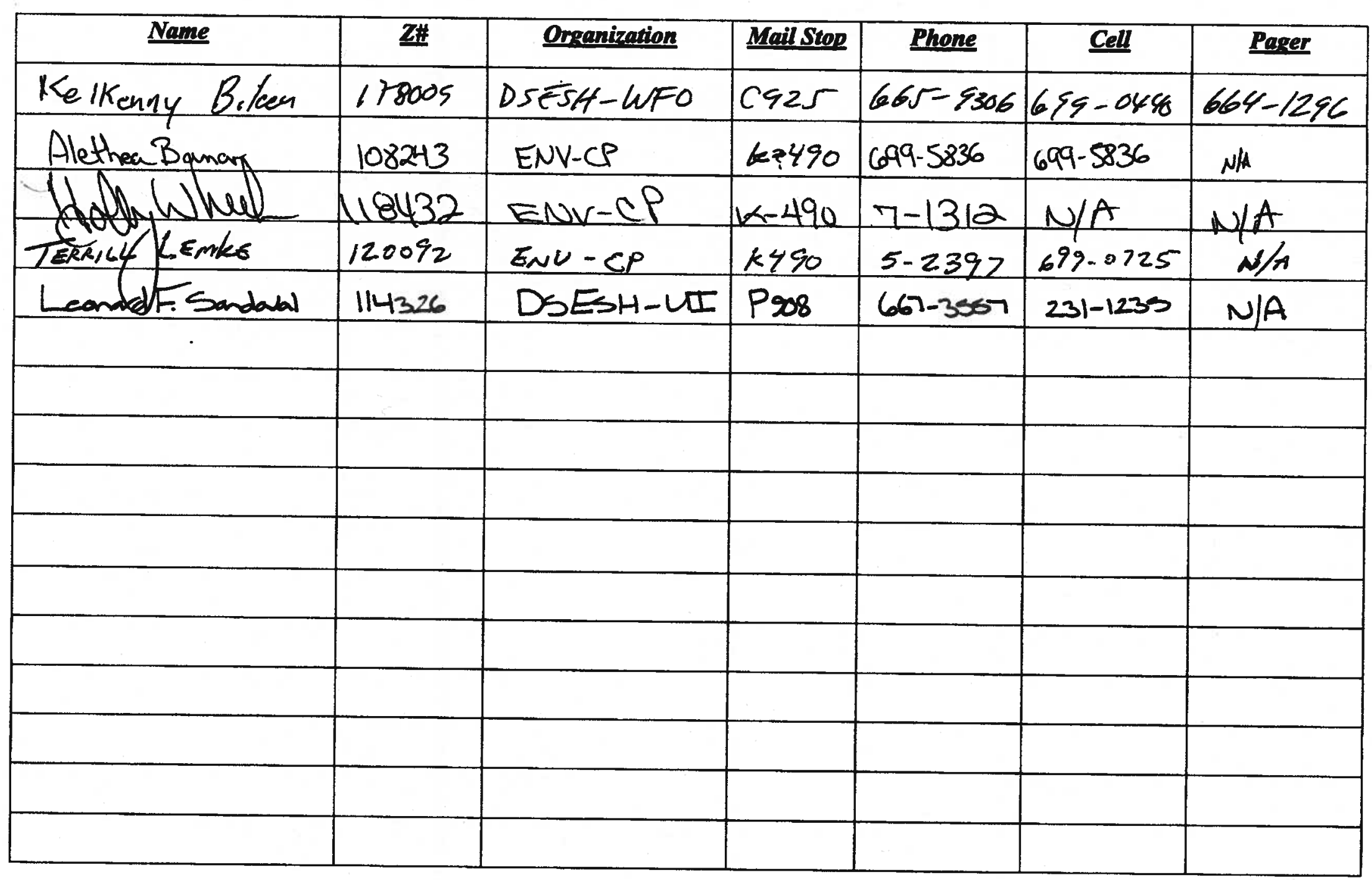



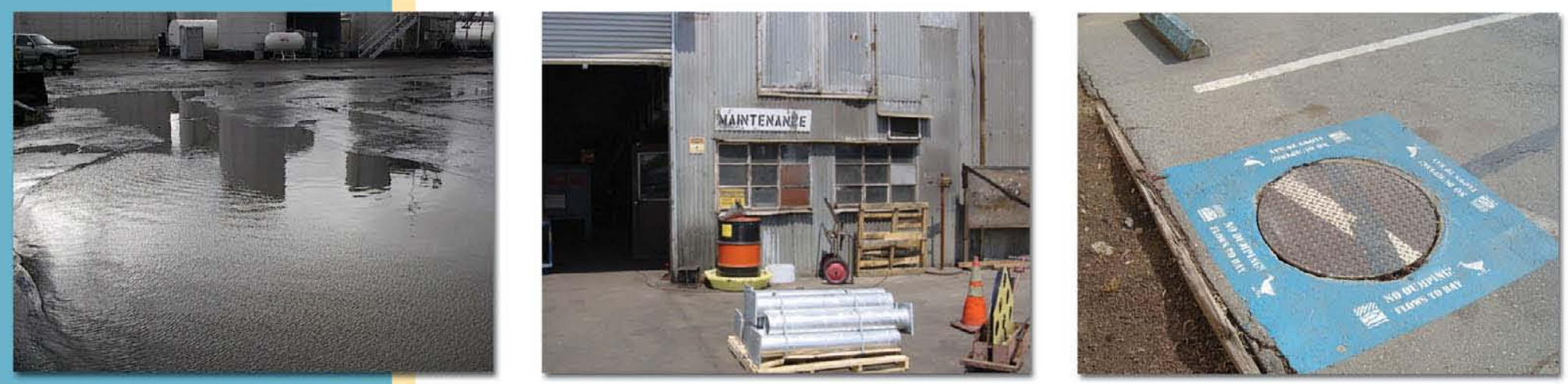

EPA 833-B-09-002

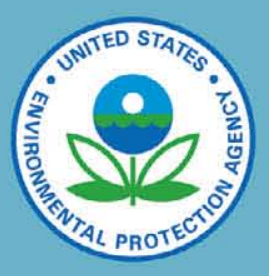

Developing Your Stormwater Pollution Prevention Plan A Guide for Industrial Operators

February 2009

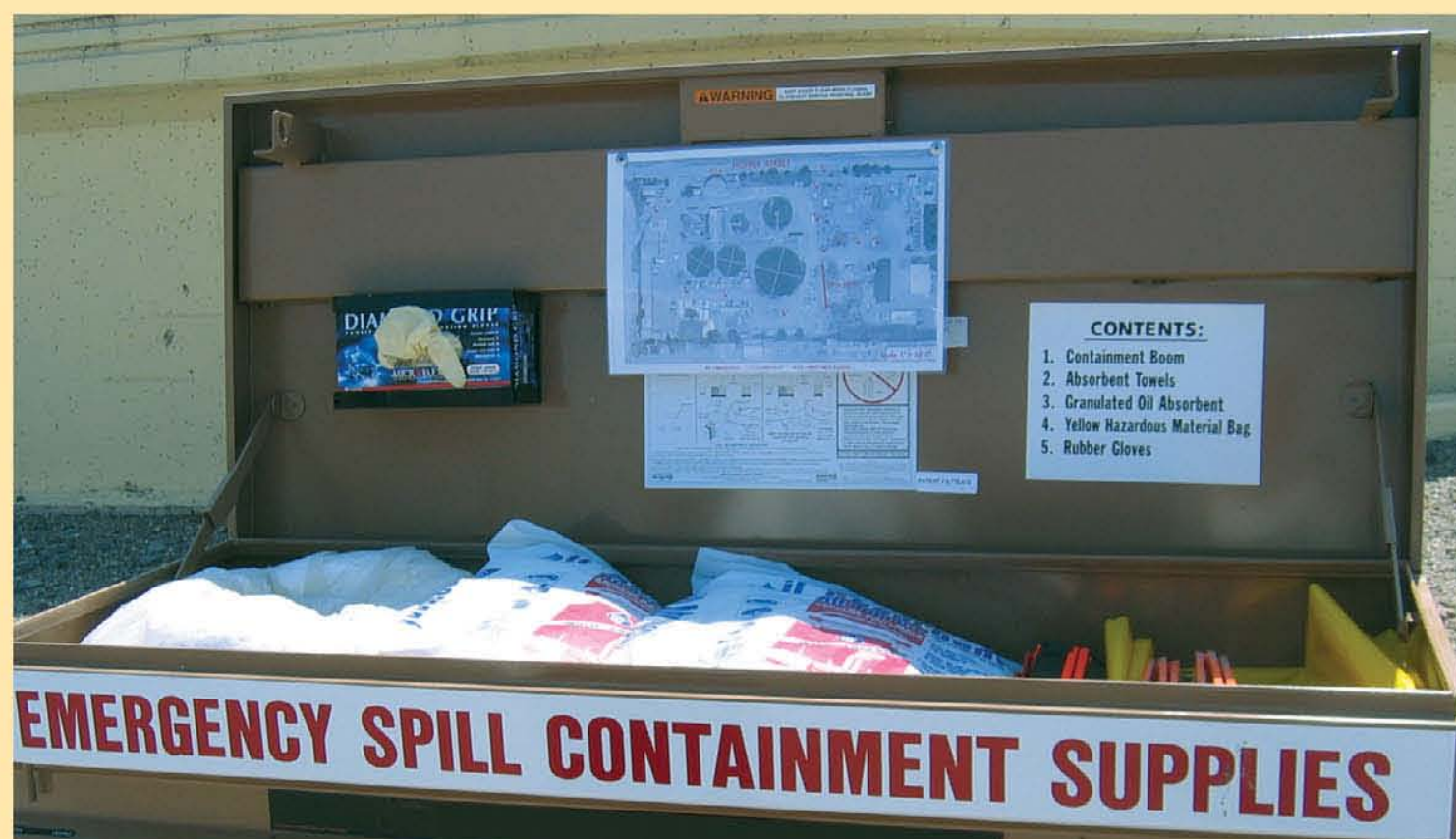




\section{Contents}

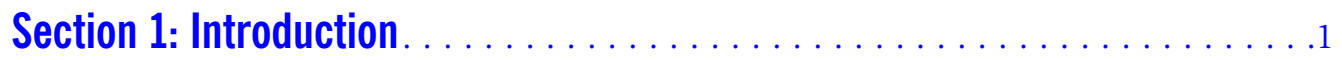

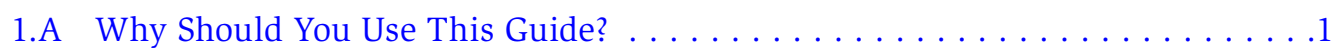

1.B What Is Stormwater Runoff and What Are Its Impacts? . . . . . . . . . . .

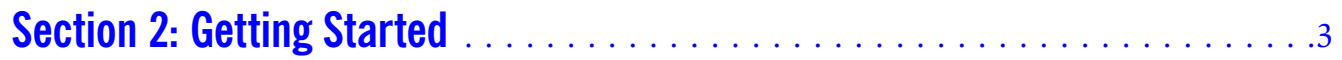

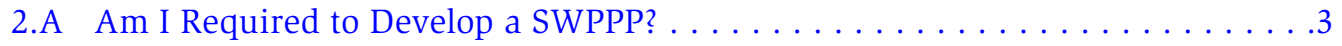

2.B What Are the Basic Elements Required in a SWPPP? . . . . . . . . . . . . .4

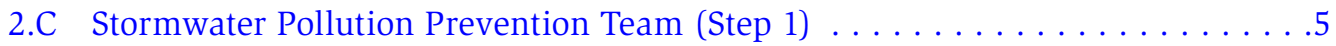

2.D What Do I Need to Do to Complete My SWPPP? . . . . . . . . . . . . . .6

Section 3: Site Assessment and Planning (Step 2) . . . . . . . . . . .

3.A Conduct an Assessment of the Activities Performed at Your Facility . . . . . . . .7

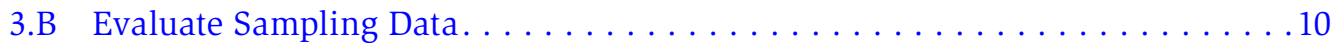

3.C Develop General Location and Site Maps . . . . . . . . . . . . . . . . . 11

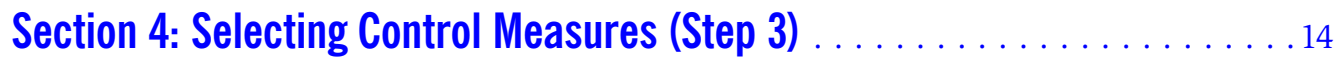

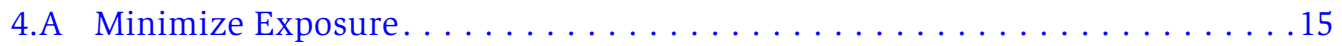

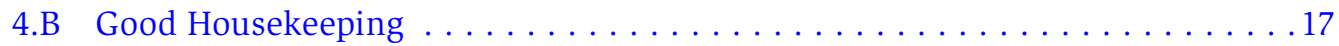

4.C Maintenance..................................18

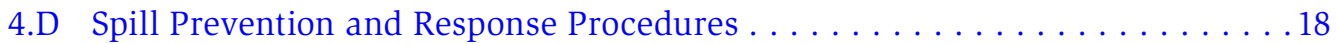

4.E Erosion and Sediment Controls . . . . . . . . . . . . . . . . . . . . . . . 19

4.F Management of Runoff . . . . . . . . . . . . . . . . . . . . . . . . 20

4.G Salt Storage Piles or Piles Containing Salt. . . . . . . . . . . . . . . . 20

4.H Sector-Specific Requirements . . . . . . . . . . . . . . . . . . . . . . . . 21

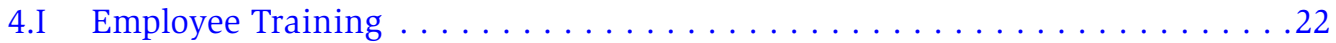

4.J Non-Stormwater Discharges. . . . . . . . . . . . . . . . . . . . . 23

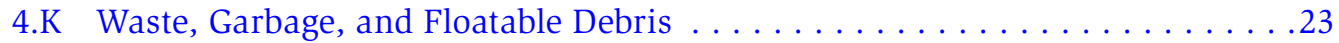

4.L Dust Generation and Vehicle Tracking of Industrial Materials . . . . . . . . . . .24

4.M Numeric Effluent Limitations Based on Effluent Limit Guidelines . . . . . . . . . 24

4.N Additional Controls to Address Impaired Waters . . . . . . . . . . . . . . . 25

Section 5: Procedures for Inspections and Monitoring (Step 4) $\ldots \ldots \ldots 26$

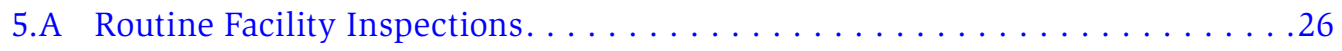

5.B Visual Assessments . . . . . . . . . . . . . . . . . . . . . . . . . . . . . . . 29

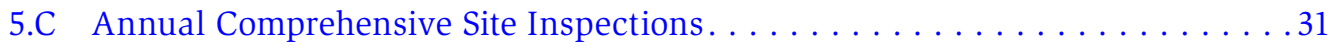

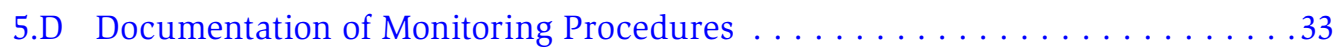




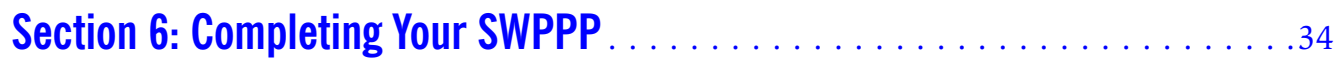

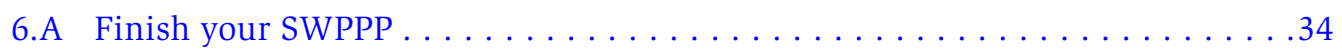

6.B Obtain NPDES Permit Coverage ............................... 34

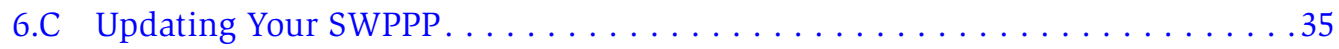

Section 7: Keeping Records of Your Implementation Activities . . . . . . . 36

Section 8: Common Compliance Problems at Industrial Facilities ........37

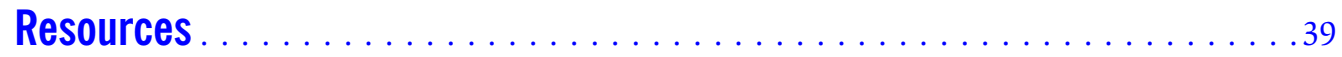

\section{Appendices}

Appendix A: MSGP SWPPP Template .........................40

Appendix B: Additional MSGP Documentation Template. ................41

Appendix C: Example Site Map . . . . . . . . . . . . . . . . . . . . . 42 


\section{Section 1: Introduction}

This guide includes suggestions on how to develop a stormwater pollution prevention plan (SWPPP). This guide does not impose any new legally binding requirements on EPA, States, or the regulated community, and does not confer legal rights or impose legal obligations upon any member of the public. In the event of a conflict between the discussion in this document and any statute, regulation, or permit, this document would not be controlling.

Interested parties are free to raise questions and objections about the substance of this guide and the appropriateness of the application of this guide to a particular situation. EPA and other decision makers retain the discretion to adopt approaches on a case-by-case basis that differ from those described in this guide where appropriate.

\section{A Why Should You Use This Guide?}

You should use this guide if you are an operator of an industrial facility required to develop a stormwater pollution prevention plan (SWPPP) that complies with a National Pollutant Discharge Elimination System (NPDES) industrial stormwater permit issued by your State or the U.S. Environmental Protection Agency (EPA). You may also find this guide to be useful if you are a State or EPA inspector who reviews SWPPPs, or you operate a commercial facility that is not required to obtain an NPDES permit but you are nevertheless interested in ways to minimize stormwater-related pollution at your facility.

Because each State permit can be slightly different, this guide is written more generically in an attempt to make it applicable to as many industrial general permits as possible. Owners and operators of industrial facilities should carefully read their respective industrial stormwater general permit to understand where using this guide may conflict with a State SWPPP requirement, and make adjustments to their SWPPPs as needed. EPA includes additional text describing how to address SWPPP requirements that are specifically included in the Agency's own 2008 Multi-Sector General Permit (MSGP), the "2008 MSGP”.

In addition to helping you develop a SWPPP, this guide also includes sections that will assist you in keeping your implementation records and in avoiding common compliance problems, after you are authorized under the EPA 2008 MSGP or your State's general permit. See Section 7 for a discussion of how to keep implementation records. See Section 8 for a discussion of common compliance problems.

\section{SWPPP TIP!}

Owners and operators of industrial facilities, which are subject to a State or EPA industrial stormwater general permit typically must develop a SWPPP as a basic requirement. If your facility is subject to such a requirement, failing to develop a SWPPP can result in enforcement action against your facility by EPA or a State! For example, EPA has targeted enforcement actions against some industrial sectors for failing to have developed SWPPPS for their facilities.

\section{B What Is Stormwater Runoff and What Are Its Impacts?}

Stormwater runoff is water from rain or snowmelt that does not immediately infiltrate into the ground and flows over or through natural or man-made storage or conveyance systems. When undeveloped areas are converted to land uses with impervious surfaces such as buildings, parking lots, and roads, the natural hydrology of the land is altered and can result in increased surface runoff rates, volumes, and pollutant loads. Stormwater runoff picks up industrial pollutants and typically discharges them directly into nearby waterbodies or indirectly via storm sewer systems. Runoff from areas where industrial activities occur can contain toxic pollutants (e.g., heavy 


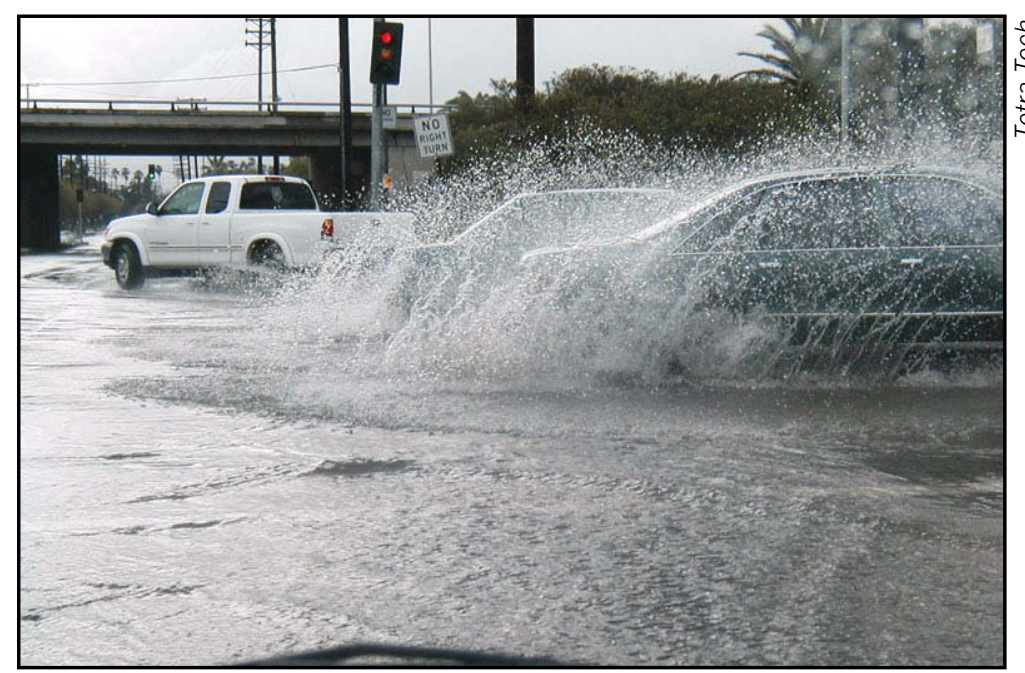

Figure 1. Stormwater runoff can carry pollutants from impervious surfaces to receiving waters. equipment. Material spills or losses in these areas can accumulate and be washed away during a storm.

\section{- Outdoor Storage}

Outdoor storage activities include storage of fuels, raw materials, by-products, intermediate products, final products, and process residuals. Materials may be stored in containers, on platforms or pads, in bins, boxes or silos, or as piles. Storage areas that are exposed to rainfall and/or runoff can contribute pollutants to stormwater when solid materials wash off or materials dissolve into solution.

\section{- Outdoor Process Activities}

Although many manufacturing activities are performed indoors, some activities, such as timber processing, rock crushing, and concrete mixing, occur outdoors. Outdoor processing activities can result in liquid spillage and losses of material solids, which makes associated pollutants available for discharge in runoff. waterbodies, degrade biological habitats, pollute drinking water sources, and cause flooding and hydrologic changes to the receiving water, such as channel erosion.

Industrial facilities typically perform a portion of their activities in outdoor areas exposed to the elements. This may include activities such as material storage and handling, vehicle fueling and maintenance, shipping and receiving, and salt storage, all of which can result in pollutants being exposed to precipitation and capable of being carried off in stormwater runoff. Also, facilities may have performed industrial activities outdoors in the past and materials from those activities still remain exposed to precipitation. In addition, accidental spills and leaks, improper waste disposal, and illicit connections to storm sewers may also lead to exposure of pollutants to stormwater.

EPA has identified six types of activities at industrial facilities that have the potential to be major sources of pollutants in stormwater:

\section{- Loading and Unloading Operations}

Loading and unloading operations can include pumping of liquids or gases from tankers to storage facilities, pneumatic transfer of dry chemicals, transfer by mechanical conveyor systems, or transfer of bags, boxes, drums or other containers by forklift or other material handling

\section{- Dust or Particulate Generating Processes}

Dust or particulate generating processes include industrial activities with stack emissions or process dusts that settle on surfaces. Some industries, such as mines, cement manufacturing, and refractories, also generate significant levels of dust that can be mobilized in stormwater runoff.

\section{- Illicit Connections and Non-Stormwater Discharges}

Illicit connections of process wastes or other pollutants to stormwater collection systems, instead of to sanitary sewers, can be a significant source of stormwater pollution. Non-stormwater discharges include any discharge from the facility that is not generated by rainfall runoff (for example, wash water from industrial processes). With few exceptions, these non-stormwater discharges are prohibited. Refer to your permit for a list of authorized non-stormwater discharges.

\section{- Waste Management}

Waste management practices include everything from landfills to waste piles to trash containment. All industrial facilities conduct some type of waste management at their site, much of it outdoors, which must be controlled to prevent pollutant discharges in stormwater. 


\section{Section 2: Getting Started}

\section{A Am I Required to Develop a SWPPP?}

The Clean Water Act (Section 402(p)) requires that operators of "discharges associated with industrial activity" obtain a National Pollutant Discharge Elimination System (NPDES) permit. EPA regulations (40 CFR 122.26) define the categories of industrial activity required to obtain NPDES permits, and specify the application requirements for these permits. To regulate stormwater discharges from these industrial activities, EPA and authorized States issue NPDES general permits.

Most industrial stormwater discharges are covered under general permits, as opposed to individual permits, although States and EPA can and do issue individual permits to some facilities based on site-specific or industry-specific concerns. General permits are used primarily because they avoid the need to issue multiple permits, and instead only require a single permit to cover a large number of industrial facilities performing similar types of activities. To be covered under a general permit, an eligible operator of an industry must read the general permit, typically develop a SWPPP, comply with any special eligibility provisions, and submit a notice of intent (NOI) or permit application to the permitting authority.

Federal regulations require NPDES permit coverage for stormwater discharges from the following categories of industrial activity:

- Category One (i): Facilities subject to federal stormwater effluent discharge standards in 40 CFR Parts 405-471

- Category Two (ii): Heavy manufacturing (for example, paper mills, chemical plants, petroleum refineries, and steel mills and foundries)

- Category Three (iii): Coal and mineral mining and oil and gas exploration and processing

- Category Four (iv): Hazardous waste treatment, storage, or disposal facilities

- Category Five (v): Landfills, land application sites, and open dumps with industrial wastes

- Category Six (vi): Metal scrapyards, salvage yards, automobile junkyards, and battery reclaimers

- Category Seven (vii): Steam electric power generating plants

- Category Eight (viii): Transportation facilities that have vehicle maintenance, equipment cleaning, or airport deicing operations

- Category Nine (ix): Treatment works treating domestic sewage with a design flow of 1 million gallons a day or more

- Category Eleven (xi): Light manufacturing (For example, food processing, printing and publishing, electronic and other electrical equipment manufacturing, and public warehousing and

\section{SWPPP TTP!}

EPA's 2008 Multi-Sector General Permit (2008 MSGP) Applies to a Limited Geographic Area The 2008 MSGP applies in five States (Alaska, Idaho, New Mexico, Massachusetts, and New Hampshire), Indian Country lands, most territories, and some federal facilities. Alaska will be taking over administration of stormwater permits beginning in 2009. Information on where the 2008 MSGP is available is included as Appendix C of the 2008 MSGP, which can be found at www.epa.gov/npdes/stormwater/msgp. 


\section{Where Do I Get a Copy of the Industrial Stormwater General Permit in My State?}

To determine who issues the industrial stormwater permit in your State, you can visit EPA's stormwater website at www.epa.gov/ npdes/stormwater/authorizationstatus or the Industrial Stormwater Resource Locator at www.envcap.org/iswrl.

\section{Who Is an Operator?}

EPA defines the operator of an industrial facility as:

- The entity that has operational control over industrial activities, including the ability to modify those activities, or

- The entity that has day-to-day operational control of activities at a facility necessary to ensure compliance with the permit (e.g., the entity that is authorized to direct workers at a facility to carry out activities required by the permit). See definition in Appendix A of the 2008 MSGP.

In many cases, the owner and operator are one in the same person. In a few instances, there may be more than one operator at a site (with the owner being an operator based on the definition provided above). Where there is both an owner (without operational control) and an operator, it is the operator's responsibility to obtain permit coverage and comply with the permit provisions.

\section{SWPPP Tip!}

What is a SWPPP?

A SWPPP is a site-specific, written document that:

- Identifies potential sources of stormwater pollution at the industrial facility;

- Describes stormwater control measures that are used to reduce or eliminate pollutants in stormwater discharges from the industrial facility; and

- Identifies procedures the operator will use to comply with the terms and conditions of the 2008 MSGP or a State general industrial stormwater permit.

You are required to develop your SWPPP to address the specific conditions at your site and keep it up-to-date to reflect changes at your site both for your use and for review by the regulatory agencies responsible for overseeing your permit compliance.

\section{B What Are the Basic Elements Required in a SWPPP?}

A SWPPP is a written document that identifies the industrial activities conducted at the site, including any structural control practices, which the industrial facility operator will implement to prevent pollutants from making their way into stormwater runoff. The SWPPP also must include descriptions of other relevant information, such as the physical features of the facility, and procedures for spill prevention, conducting inspections, and training of employees. The SWPPP is intended to be a "living" document, updated as necessary, such that when industrial activities or stormwater control practices are modified or replaced, the SWPPP is similarly revised to reflect these changes.

The process of developing a SWPPP involves the following four steps:

- Step 1: Formation of a pollution prevention team of qualified personnel who will be responsible for preparing the plan and assisting the plant manager in implementing practices to comply with the permit;

- Step 2: Assessment of potential stormwater pollution sources;

- Step 3: Selection of appropriate control measures that minimize the discharge of pollutants during storm events for each of these sources; and

- Step 4: Development of procedures for conducting required inspection/monitoring activities, as well as regular maintenance of control measures.

This guide will assist you with these four steps. The selection of a pollution prevention team is discussed in the next section (Section 2.C). Site assessment is addressed in Section 3, the selection of control measures is discussed in Section 4, and inspection/monitoring procedures are addressed in Section 5. The remaining sections of the guide address implementation of practices to comply with the permit and periodic evaluation of your SWPPP.

\section{SWPPP TTि!}

Prepare your SWPPP before submitting an NOI or permit application for coverage! 
A typical SWPPP includes the following elements:

- Stormwater pollution prevention team;

- Site description;

- Summary of potential pollutant sources;

- Description of control measures;

- Schedules and procedures;

- Documentation to support eligibility considerations under other federal laws; and

- Certification of the SWPPP.

EPA has developed a model Industrial SWPPP Template, which can be found in Appendix A, and on EPA's website at www.epa.gov/npdes/ stormwater/msgp. This template, developed for permit holders subject to the 2008 MSGP, is available in Microsoft Word and can be customized to address SWPPP requirements in different State NPDES permits.

Where your facility has other written procedures in place, such as a Spill Prevention, Control and Countermeasure (SPCC) Plan or an Environmental Management System (EMS) developed for a National Environmental Performance Track facility, your SWPPP can reference the portions of those documents in lieu of duplicating that information in your SWPPP. In these instances, you should keep copies of the relevant portions of those documents with your SWPPP.

\section{SWPPP Tip!}

EPA's 2008 MSGP includes the requirements for a SWPPP in Part 5 of the permit.

\section{Additional SWPPP Documentation}

After you become authorized under the permit, you will need to keep records on any implementation activities required under your permit, including records related to inspections, maintenance, monitoring results, and corrective actions. This additional documentation, although separate from the actual SWPPP, should be kept with the SWPPP so that all of your NPDES stormwater records are filed in one central location (see Section 7).
To assist permittees in their recordkeeping, EPA has developed an Additional MSGP

Documentation template, which is available at www.epa.gov/npdes/stormwater/msgp. This template, developed for permit holders subject to the 2008 MSGP, is available in Microsoft Word and can be modified as necessary to address State-specific permit requirements.

\section{C Stormwater Pollution Prevention Team (Step 1)}

The first step in developing the SWPPP is to identify the stormwater pollution prevention team. The stormwater pollution prevention team is responsible for assisting the facility manager in developing the facility's SWPPP as well as implementing and maintaining stormwater control measures, taking corrective action where necessary to address permit violations or to improve the performance of control measures, and modifying the SWPPP to reflect changes made to the control measures. Since industrial facilities differ in size and complexity, the number of team members will also vary. The stormwater pollution prevention team should consist of those people on-site who are most familiar with the facility and its operations and responsible for ensuring that necessary controls are in place to eliminate or minimize the impacts of stormwater from the facility.

A key member of the stormwater pollution prevention team (for some facilities, this may be the only member) is the person with primary responsibility for developing and overseeing facility activities necessary to comply with the permit. This should be someone who will be on-site on a daily basis and who is familiar with the facility and its operations. This person will also likely have primary responsibility for ensuring that inspections and monitoring activities are conducted. If an EPA or State inspector visits the facility, this person will be the main point of contact for the SWPPP.

\footnotetext{
What to Include in Your SWPPP

In your SWPPP, identify the staff members (by name or title) that comprise the facility's stormwater pollution prevention team as well as their individual responsibilities. Make sure you keep this information up-to-date as staff members change.
} 


\section{SWPPP Tip!}

Consider adding a stormwater management component to employee job descriptions and annual reviews, as appropriate to specific jobs. Often these requirements compliment existing tasks such as maintaining a clean work area; promptly cleaning up spills and leaks; performing regularly scheduled equipment maintenance; and properly storing all chemicals, oils, and other liquid pollutants.

Each member of the stormwater pollution prevention team should have ready access to either an electronic or paper copy of applicable portions of the industrial stormwater general permit and the SWPPP.

\section{SWPPP Tip!}

Qualified Personnel - Members of your stormwater pollution prevention team and those conducting inspections and monitoring activities should be "qualified personnel." EPA defines qualified personnel as "those who posses the knowledge and skills to assess conditions and activities that could impact stormwater quality at your facility, and who can also evaluate the effectiveness of control measures."

\section{D What Do I Need to Do to Complete My SWPPP?}

After identifying your pollution prevention team, you are ready to complete the next three steps in the development of your SWPPP:

- Step 2: Assessing your site and activities (Section 3);

- Step 3: Selecting control measures (Section 4); and

- Step 4: Developing procedures for inspections and monitoring (Section 5).

Section 6 describes final steps necessary to complete your SWPPP and to obtain permit coverage. Section 7 suggests how records relating to permit compliance should be kept. 


\section{Section 3: Site Assessment and Planning (Step 2)}

This section describes how to collect the information needed for your SWPPP. This information includes:

- An assessment of the activities performed at your facility - this assessment will help identify potential pollutant sources.

- An evaluation of existing sampling data - a review of sampling data will show where past problems have occurred.

- Preparing maps of your facility - site maps will identify the location of industrial activities, pollutant sources, control measures, and the direction of stormwater flow.

\section{A Conduct an Assessment of the Activities Performed at Your Facility}

The first step in developing a SWPPP is to gain a thorough understanding of the activities conducted and equipment located at your facility to be able to identify potential pollutant discharge concerns. To complete this step, you will need to conduct a detailed walk-through of your facility to identify industrial materials or material handling activities exposed to stormwater (see text box below), any stormwater controls already in place at your facility, the direction of stormwater flow through and from your facility, and the location of all stormwater outfalls. If possible, you should conduct your walk-through durWhat to Include in Your SWPPP

Develop a list of industrial activities at your site exposed to stormwater. Identify these activities on your site map.

How Does EPA Define Industrial Materials and Material Handling Activities?

Industrial materials or activities include, but are not limited to: material handling equipment or activities; industrial machinery; raw materials; industrial production and processes; and intermediate products, by-products, final products, and waste products. Material handling activities include, but are not limited to: the storage, loading and unloading, transportation, disposal, or conveyance of any raw material, intermediate product, final product or waste product. See 40 CFR 122.26(g). 
The facility assessment will reveal locations where industrial materials or material handling activities may be contributing stormwater contaminants, and help you identify the most important pollutant sources. The following approach is suggested for completing your facility assessment:

\section{Identification of Activities Exposed to} Stormwater. As you conduct your facility assessment, make a list of the industrial activities exposed to stormwater (e.g., material storage; equipment fueling, maintenance, and cleaning; cutting steel beams). Note their location so they can be identified on the site map.

Inventory of Materials and Pollutants. Make a list of the materials and pollutants (e.g., crankcase oil, zinc, sulfuric acid, and cleaning solvents) associated with each identified activity, including pollutants associated with these materials, based on how they are stored, handled, disposed, etc. Note whether these materials are exposed to stormwater, or have the potential to be exposed to stormwater. How materials are stored and handled has a bearing on the potential for stormwater pollution.

\section{What to Include in Your SWPPP}

For each of the activities identified above, create an inventory of the materials associated with each activity (this may be easiest to do in a table). Identify whether these materials are or have the potential to be exposed to stormwater. Also, identify any pollutants associated with these materials based on how they are stored, handled, disposed, etc.

Areas with Spill or Leak Potential. Document where potential spills and leaks may occur, and specify the outfall(s) that could be affected by such spills and leaks. Document all significant spills and leaks that actually occurred at exposed areas, or that drained to a stormwater conveyance, in the three years prior to the date you prepare or amend your SWPPP. You should consider spillage and leakage of all types of materials when preparing for and documenting such releases.

\section{What to Include in Your SWPPP}

Identify locations of potential spills and leaks that could contribute pollutants to stormwater discharges, and the corresponding outfalls that would be affected. Review past records of all significant spills and leaks that occurred in areas exposed to stormwater or that drained to a stormwater conveyance over the past three years, and provide a summary or copy of such records in your SWPPP.

Presence of Non-Stormwater Discharges. A nonstormwater discharge is any discharge from your facility this is not composed entirely of rainfall or snowmelt runoff. Non-stormwater discharges often come from potable water sources or process wastewater discharges. With few exceptions, the discharge of nonstormwater as runoff from your facility is prohibited unless it is specifically allowed under an NPDES permit.

You must evaluate for the presence of nonstormwater discharges and be able to demonstrate that all unauthorized non-stormwater discharges have been eliminated prior to obtaining coverage under a stormwater permit (or that any other discharges are otherwise covered under a different NPDES permit). Conduct your evaluation during a period of dry weather (no rain for at least the previous three days). Walk your site and evaluate each outfall to identify any locations with flowing or stagnant water or discharging liquid; the presence of such water or liquid that would be indicative of a non-stormwater discharge. You should try to identify the source of the water or liquid, and determine if it is one of the allowable non-stormwater discharges identified below or otherwise in need of further action to eliminate the source. You should also identify any indicators of past or intermittent non-stormwater discharges (such as evidence of stains at the outfall). 


\section{SWPPP Tip!}

\section{Allowable Non-Stormwater Discharges}

Most industrial stormwater general permits include a list of non-stormwater discharges that are "allowable" and do not need to be eliminated. As used in EPA's 2008 MSGP, "allowable non-stormwater discharges" are those that while not stormwater discharges, are covered under the terms and conditions of the stormwater permit. These are often discharges that if not covered under a stormwater permit would require coverage under some other NPDES permit. The list of allowable non-stormwater discharges from the 2008 MSGP (Part 1.1.3) includes:

- Discharges from fire-fighting activities;

- Fire hydrant flushings;

- Potable water, including water line flushings;

- Uncontaminated condensate from air conditioners, coolers, and other compressors and from the outside storage of refrigerated gases or liquids;

- Irrigation drainage;

- Landscape watering provided all pesticides, herbicides, and fertilizer have been applied in accordance with the approved labeling;

- Pavement wash waters where no detergents are used and no spills or leaks of toxic or hazardous materials have occurred (unless all spilled material has been removed);

- Routine external building washdown that does not use detergents;

- Uncontaminated ground water or spring water;

- Foundation or footing drains where flows are not contaminated with process materials; and

- Incidental windblown mist from cooling towers that collects on rooftops or adjacent portions of your facility, but not intentional discharges from the cooling tower (e.g., "piped" cooling tower blowdown or drains).

If any non-stormwater discharges are identified during the evaluation, you should take steps to eliminate any that are prohibited under your permit. For example, plug a floor drain, re-route a sink drain to the sanitary sewer, or submit an NPDES permit application for an unauthorized cooling water discharge.

\section{What to Include in Your SWPPP}

Documentation of your evaluation for nonstormwater discharges. Typically, this documentation should include:

- The date of any evaluation;

- A description of the evaluation criteria used;

- A list of the outfalls or onsite drainage points that were directly observed during the evaluation;

- The different types of non-stormwater discharge(s) and source locations; and

- The action(s) taken, such as a list of control measures used to eliminate unauthorized discharge(s), if any were identified.
Location of Salt Storage. Document the location of any storage piles containing salt used for deicing or that are used for other commercial or industrial purposes. Salt and deicing materials should be stored inside and not exposed to stormwater runoff, if possible.

\section{What to Include in Your SWPPP}

If your facility has storage piles containing salt, document the type of material, amount, and its location. 


\section{B Evaluate Sampling Data}

You should evaluate any stormwater sampling data you, or others, collected, from the previous permit term or any time in the past 5 years, which are associated with stormwater discharges from the facility. This includes any analytic sampling data, such as benchmark monitoring or effluent limitation guideline data. The purpose of evaluating your past sampling data is to identify or pinpoint any pollutants of concern, hotspots, or control measures that are not functioning correctly. This information will be useful as you identify and select control measures (described in Section 4).

\section{What to Include in Your SWPPP}

A summary of all stormwater discharge sampling data collected at your facility during the previous permit term. You should summarize the data by pollutant, and indicate whether the pollutant parameter exceeded any applicable benchmark or effluent limit.

Include in your SWPPP your evaluation of the data, particularly where pollutants exceeded the 2008 MSGP benchmark values (see SWPPP Tip below). Attempt to identify why that pollutant existed in elevated concentrations, what are the potential sources of that pollutant at your facility, and what potential measures you could use to reduce that pollutant.

\section{SWPPP Tip!}

Compare your sampling results to EPA's 2008 MSGP Benchmark values below.

\begin{tabular}{|c|c|}
\hline Pollutant & $\begin{array}{l}2008 \text { MSGP } \\
\text { Benchmark }\end{array}$ \\
\hline Ammonia* & $2.14 \mathrm{mg} / \mathrm{L}$ \\
\hline $\begin{array}{l}\text { Biochemical Oxygen } \\
\text { Demand ( } 5 \text { day) }\end{array}$ & $30 \mathrm{mg} / \mathrm{L}$ \\
\hline Chemical Oxygen Demand & $120 \mathrm{mg} / \mathrm{L}$ \\
\hline Total Suspended Solids & $100 \mathrm{mg} / \mathrm{L}$ \\
\hline Turbidity & $50 \mathrm{NTU}$ \\
\hline Nitrate + Nitrite Nitrogen & $0.68 \mathrm{mg} / \mathrm{L}$ \\
\hline Total Phosphorus & $2.0 \mathrm{mg} / \mathrm{L}$ \\
\hline $\mathrm{pH}$ & $6.0-9.0$ s.u. \\
\hline Aluminum (T) (pH $6.5-9)$ & $0.75 \mathrm{mg} / \mathrm{L}$ \\
\hline Antimony $(\mathrm{T})$ & $0.64 \mathrm{mg} / \mathrm{L}$ \\
\hline Arsenic $(T)$ & $0.15 \mathrm{mg} / \mathrm{L}$ \\
\hline Beryllium (T) & $0.13 \mathrm{mg} / \mathrm{L}$ \\
\hline Cadmium $(\mathrm{T}) \dagger$ & $0.0021 \mathrm{mg} / \mathrm{L}$ \\
\hline Copper $(\mathrm{T})^{*} \dagger$ & $0.014 \mathrm{mg} / \mathrm{L}$ \\
\hline Cyanide & $0.022 \mathrm{mg} / \mathrm{L}$ \\
\hline Iron $(\mathrm{T})$ & $1.0 \mathrm{mg} / \mathrm{L}$ \\
\hline Lead $(T)^{*} \dagger$ & $0.082 \mathrm{mg} / \mathrm{L}$ \\
\hline Magnesium (T) & $0.064 \mathrm{mg} / \mathrm{L}$ \\
\hline Mercury $(T)$ & $0.0014 \mathrm{mg} / \mathrm{L}$ \\
\hline Nickel $(\mathrm{T}) \dagger$ & $0.47 \mathrm{mg} / \mathrm{L}$ \\
\hline Selenium $(T)^{*}$ & $0.005 \mathrm{mg} / \mathrm{L}$ \\
\hline Silver $(T)^{*} \dagger$ & $0.0038 \mathrm{mg} / \mathrm{L}$ \\
\hline $\operatorname{Zinc}(\mathrm{T}) \dagger$ & $0.12 \mathrm{mg} / \mathrm{L}$ \\
\hline \multicolumn{2}{|l|}{ (T) Total recoverable } \\
\hline \multicolumn{2}{|c|}{$\begin{array}{l}\text { * New criteria are currently under development, but } \\
\text { values are based on existing criteria. }\end{array}$} \\
\hline \multicolumn{2}{|c|}{$\begin{array}{l}\dagger \quad \text { These pollutants are dependent on water } \\
\text { hardness. The benchmark value listed is based } \\
\text { on a hardness of } 100 \mathrm{mg} / \mathrm{L} \text {. The } 2008 \mathrm{MSGP} \\
\text { requires industrial facility to analyze receiving } \\
\text { water samples for hardness, and use the hardness } \\
\text { tables provided in the } 2008 \text { MSGP to determine } \\
\text { the applicable benchmark value for that facility. }\end{array}$} \\
\hline
\end{tabular}




\section{C Develop General Location and Site Maps}

The final step in the site assessment process is to document the results of your site assessment on a detailed site map. If you have already developed a site map for an earlier permit, you should modify the map as necessary to reflect changes at your facility, including changes to any of your control measures or industrial activities.

Your SWPPP must include both a general location map and a detailed site map. The following is a discussion of what is required for each type.

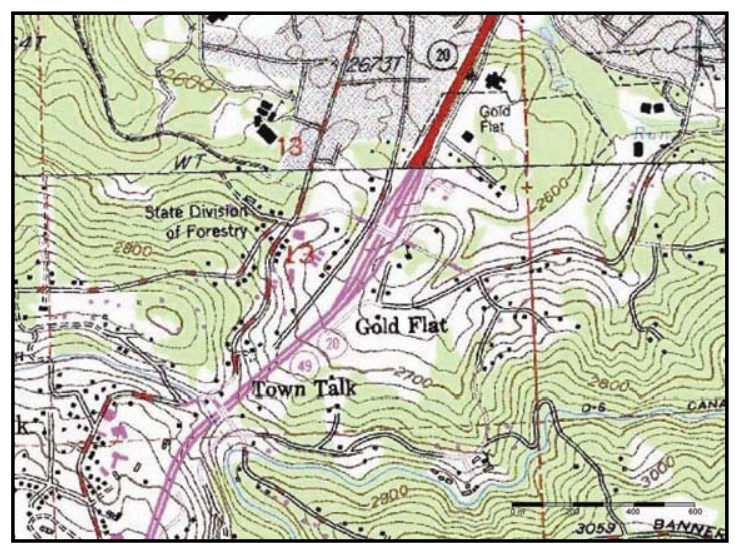

Figure 2. Example general location map.

\section{General Location Map}

A general location map is helpful to identify nearby, but not necessarily adjacent, waterbodies around your facility. Include in your SWPPP a general location map (e.g., U.S. Geological Survey (USGS) quadrangle map, or other large scale area map) with enough detail to identify the location of your facility and all nearby receiving waters that may receive your stormwater discharges. Create a USGS map for your area by using the USGS National Map Viewer (http://nmviewogc. cr.usgs.gov/viewer.htm). Maps can be printed or saved as PDF documents and inserted into your SWPPP.

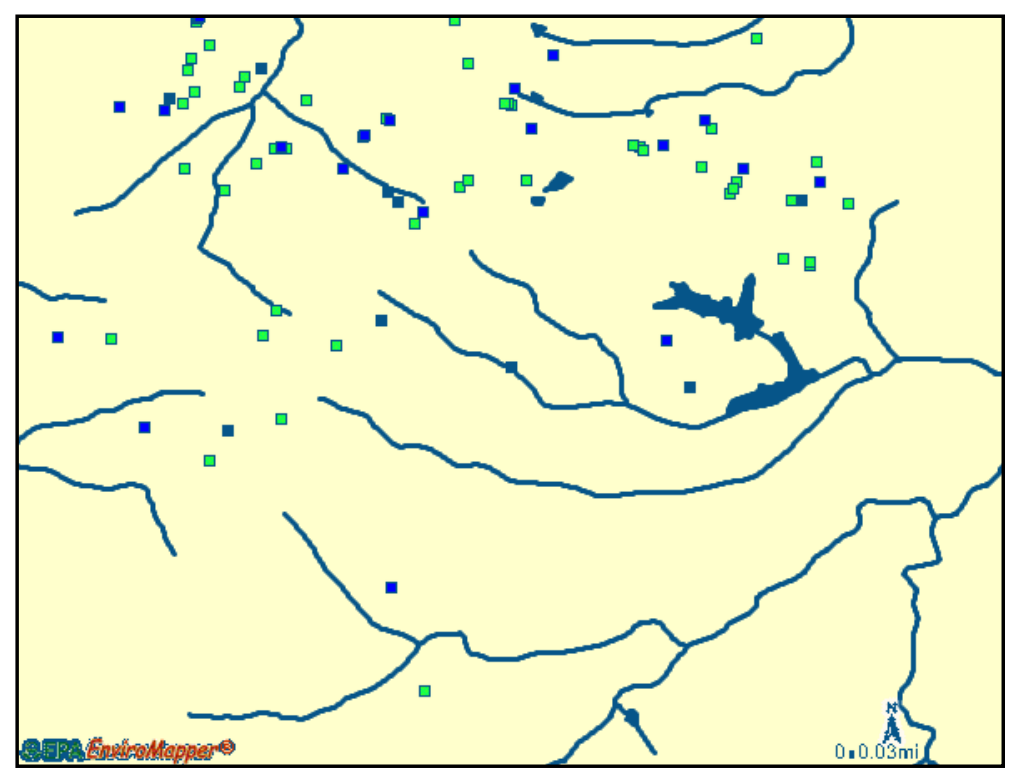

Figure 3. Example general location map.

One free web-based mapping service is EPA's Water Locator Tool, which is available at www.epa.gov/npdes/stormwater/ msgp. To use the tool, enter your facility address in Step 1, then click on "Window to My Environment" in Step 2 (make sure your pop-up blocker is turned off). You will be able to zoom and reposition the map. When you get the map to the appropriate scale and location, you can copy and paste it into your SWPPP. Use a graphics program or a pen to mark the location of your facility on the map. An example general location map is included in Figure 3.

\section{What to Include in Your SWPPP}

Develop a general location map of your facility that shows:

- the location of your facility

- receiving waters to which your facility discharges

It may also be helpful to include roads or political boundaries to better locate your facility. 


\section{Site Map}

Develop a map of your site that includes, among other things, the footprint of all buildings, structures, paved areas, and parking lots. The site map is intended to show the direction of stormwater flow throughout your facility and the potential pollutant sources that may come into contact with your stormwater runoff.

EPA recommends that you develop a first draft of the site map based on the information collected during your assessment. After you select appropriate control measures (Section 4) and monitoring locations (Section 5), you should revise your site map to reflect this information and any additional changes identified as you develop your SWPPP. If you are unable to fit all the information on one map, use multiple maps to provide a full characterization of the information described above. Also, if activities and conditions change at your site during the term of the NPDES permit, you should update the map as described in Section 6.C of this guide. An example of a site map is included (see Figure 4) and in Appendix C.

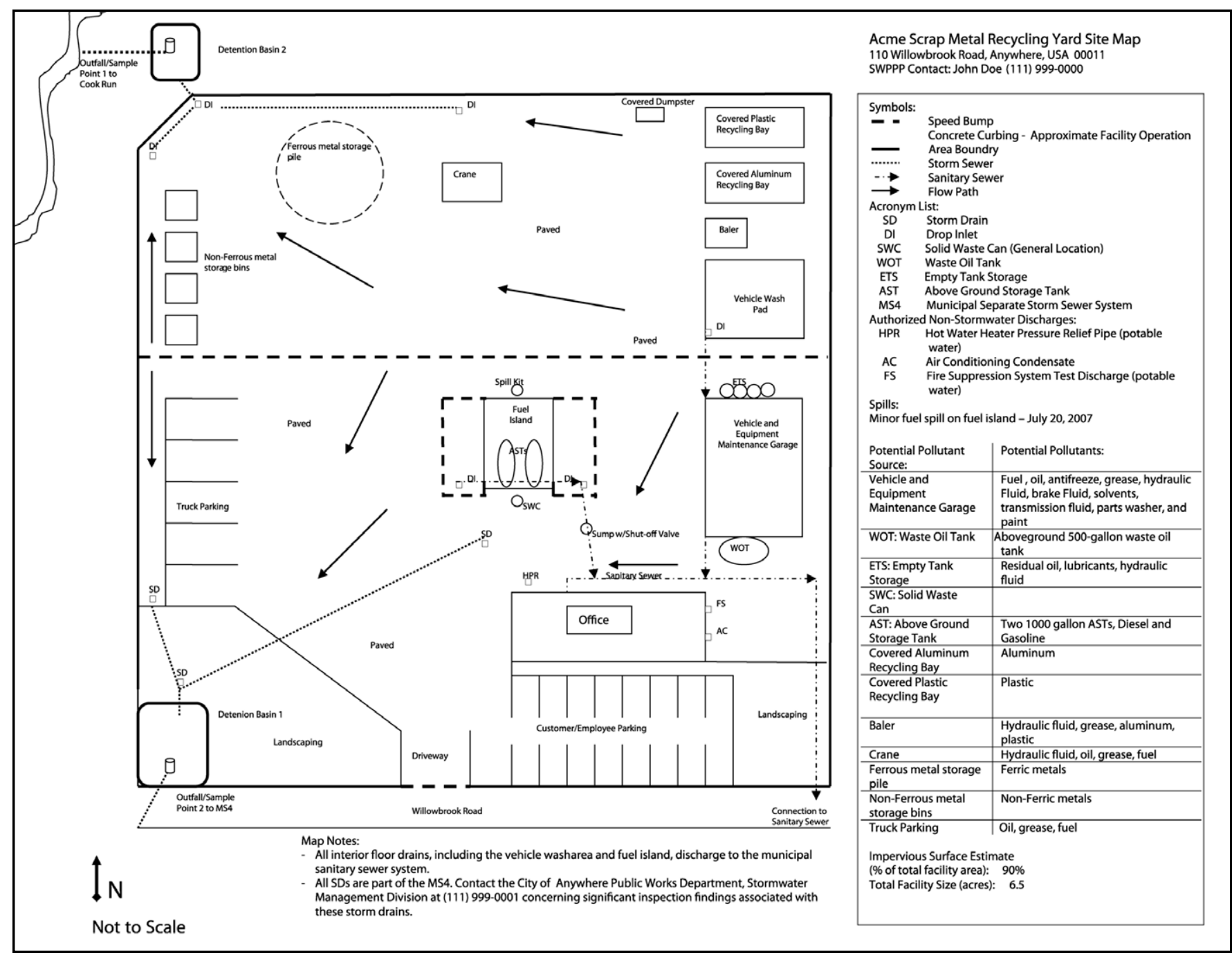

Figure 4. Example site map. 


\section{What to Include in Your SWPPP}

Include a site map of your facility which includes the items below:

- The size of the property in acres;

- The location and extent of significant structures and impervious surfaces;

- Directions of stormwater flow (use arrows);

- Locations of all existing structural control measures;

- Locations of all receiving waters in the immediate vicinity of your facility, indicating if any of the waters are impaired and, if so, whether the waters have TMDLs established for them;

- Locations of all stormwater conveyances including ditches, pipes, and swales;

- Locations of potential pollutant sources identified (see Section 3.B);

- Locations where significant spills or leaks have occurred;

- Locations of all stormwater monitoring points;

- Locations of stormwater inlets and outfalls, with a unique identification code for each outfall (e.g., Outfall No. 1 , No. 2, etc), indicating if you are treating one or more outfalls as "substantially identical", and an approximate outline of the areas draining to each outfall;

- Municipal separate storm sewer systems, where your stormwater discharges to them;

- Locations and descriptions of all non-stormwater discharges;

- Locations of the following activities where such activities are exposed to precipitation:

- Fueling stations;

- Vehicle and equipment maintenance and/or cleaning areas;

- Loading/unloading areas;

- Locations used for the treatment, storage, or disposal of wastes;

- Liquid storage tanks;

- Processing and storage areas;

- Immediate access roads and rail lines used or traveled by carriers of raw materials, manufactured products, waste material, or by-products used or created by the facility;

- Transfer areas for substances in bulk; and

- Machinery; and

- Locations and sources of run-on to your site from adjacent property that contains significant quantities of pollutants. 


\section{Section 4: Selecting Control Measures (Step 3)}

Control measures are the best management practices (BMPs) or other structural or non-structural practices that are used to prevent or reduce the discharge of pollutants in stormwater. Structural control measures, as the name implies, focus on installation of hard structures to control discharges. Structural controls include practices such as vegetative swales, collection and reuse of stormwater, inlet controls, snow management, infiltration devices, and wet retention measures. Non-structural control measures are intended to prevent or reduce the generation of pollutants in stormwater and/or the volume of stormwater runoff using practices that focus on facility operations and procedures. Examples of non-structural control measures include procedural practices such as employee trainings and the posting of signs that raise staff awareness to the BMPs and procedures in place to control stormwater pollutants.

\section{SWPPP Tip!}

Effluent limits $=$ stormwater control requirements. In the 2008 MSGP, as with most state industrial stormwater general permits, stormwater control measures are those structural or non-structural practices that are used to achieve the permit's effluent limits.

A combination of preventive and active treatment control measures usually results in the most effective stormwater management for minimizing the offsite discharge of pollutants in stormwater runoff. Most control measures require regular maintenance to function as intended. Some control measures have simple maintenance requirements, while others may require more extensive upkeep in order to maximize their performance. Note that identifying weaknesses in current facility practices will help permittees determine appropriate control measures for use at the site.

\section{General Stormwater Management Principles}

In most industrial stormwater permits, including the 2008 MSGP, the site operator is given the flexibility to select the type of control measures, including specific technologies, which he/she believes are best suited to the facility and that will meet the permit's requirements. This flexibility is necessary given the variability of each industrial operation, the differences in the topography from site to site, and the dissimilarities in the activities and materials exposed to stormwater. However, there are certain general principles of stormwater management that are common to all sites, and that can be used by operators in their selection and design of control measures. These general principles, listed below, should be considered as a way to maximize the performance of control measures at your site.

\section{What does "minimize" mean?}

The technology-based limits included in EPA's 2008 MSGP require that you minimize (i.e., defined as reduce and/or eliminate) stormwater exposure to pollutants using control measures that are technologically available, economically practicable, and achievable in light of best industry practice.

- Pollution prevention - The best way to prevent stormwater pollution is to minimize the use of water contaminants in your industrial activities. When selecting control measures for the facility, you should focus on controls that are geared toward reducing pollutants at the source to prevent stormwater pollution. Source control practices include maintaining equipment, picking up trash and debris, training site staff on appropriate spill procedures, and proper materials management and storage. 
- Minimizing exposure - Another effective way to minimize stormwater pollution is to eliminate opportunities for stormwater to come into contact with industrial activities and polluting materials. You should look for opportunities to relocate industrial activities/materials to covered or contained areas and to properly store and transport any accumulated scrap or waste material.

- Combining controls - Combined control measures are often more effective than control measures in isolation. For example, good housekeeping will often go a long way to minimize stormwater pollution but is more effective when combined with minimizing the exposure of significant materials or activities and a structural control, such as inlet protection.

- Examining your site's pollutant sources Understand the type and quantity of pollutants that could contaminate stormwater leaving your facility. Use your knowledge of the potential pollutants to drive your selection and design of effective control measures.

- Maximizing infiltration - Onsite infiltration reduces overland runoff, improves groundwater recharge, and augments base flow in local streams. You should look for opportunities to minimize impervious area and increase areas where stormwater can infiltrate on-site. Keep in mind, however, that the use of onsite infiltration typically must be combined with other control measures to avoid ground water contamination.

- Using existing vegetated areas - Open vegetated swales and natural depressions can be used to dissipate energy in overland flow and reduce erosion. Vegetated swales and natural depressions can increase infiltration and, in some cases, promote uptake of metals and nutrients by plants.

- Buffering on-site or adjacent waterbodies or drainage systems - Maintain or restore vegetated buffer zones between your facility's impervious areas and adjacent surface waters.
- Using structural practices (as applicable) When non-structural control measures are not effective in preventing stormwater contamination, structural control measures (e.g., swirl separators, sand filters, retention basins, etc.) may be needed to treat stormwater before it leaves your facility.

\section{EPA's Technology-Based Discharge Requirements}

The following sections describe the 12 categories of discharge requirements (or "effluent limits") required by the 2008 MSGP. Although the wording of these requirements may be unique to the EPA permit, many State permits include requirements that are similar to the 2008 MSGP.

\section{A Minimize Exposure}

The first step in an effective stormwater control program is minimizing exposure of manufacturing, processing, material storage areas, loading and unloading areas, dumpsters and other disposal areas, maintenance activities, and fueling operations to rain, snow, snowmelt, and runoff by both locating industrial materials and activities inside or protecting them with storm resistant coverings.

\section{SWPPP Tip!}

\section{No Exposure Exemption}

EPA's regulations recognize the effectiveness of minimizing exposure by allowing facilities to opt out of the permit by submitting a "No Exposure Certification" when all industrial activities are protected from contact with stormwater. The "No Exposure Certification" is included as Appendix K of the 2008 MSGP. Note that industrial materials do not need to be enclosed or covered if stormwater runoff from affected areas will not be discharged to receiving waters or if discharges are authorized under another NPDES permit. Check your State permit for specific requirements for incorporating minimizing exposure into your SWPPP. 


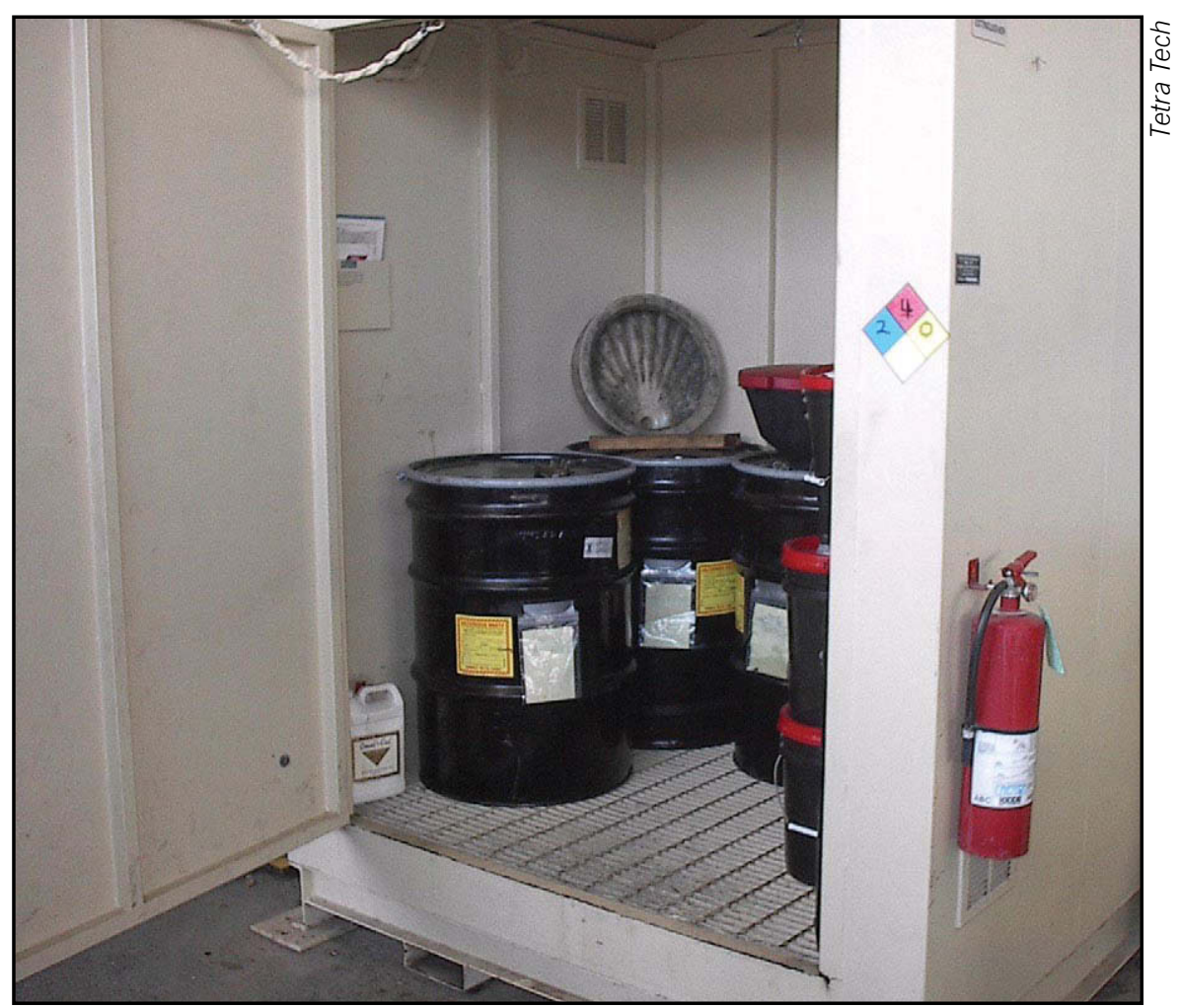

Figure 5. Minimize exposure by providing cover for potential contaminants.

\section{What to Include in Your SWPPP}

Describe all structural controls or practices used to minimize the exposure of industrial activities to rain, snow, snowmelt, and runoff. The SWPPP must describe where the controls or practices are being implemented at your site. The location must also be identified on the SWPPP site map. Examples of exposure-minimizing control measures that could be used at your facility and described in the SWPPP include:

- The location and extent of grading, berms, or curbs used to contain contaminated stormwater or divert stormwater around areas of industrial activity;

- A description of the types of materials and equipment that are stored within secondary containment and the location of contained storage areas;

- The location of spill cleanup kits and a description and schedule for employee spill abatement and cleanup training;

- Proper procedures for leaky vehicles and equipment, such as drip pans; parking in a contained area, or parking indoors;

- The use and location of spill/overflow protection equipment;

- Procedures for long-term storage or disposal of equipment and vehicles, such as draining all fluids;

- The location of covered and/or contained equipment cleaning areas; and

- The disposal method for all wash water, such as an on-site sump (if a sump is used, specify the pumping frequency) or sanitary sewer. 


\section{B Good Housekeeping}

Good housekeeping practices offer a practical and cost-effective way to maintain a clean and orderly facility to prevent potential pollution sources from coming into contact with stormwater. Good housekeeping practices also help to enhance safety and improve the overall work environment. To effectively document in your SWPPP that you are including good housekeeping procedures at your site, you should establish protocols to reduce the possibility of mishandling materials or equipment and train employees in good housekeeping techniques. An effective good housekeeping program not only benefits stormwater quality but makes the facility a clean, safe place for employees and clients.

\section{SWPPP Tip!}

Labeling Storm Drains - A good stormwater awareness practice is to label all storm drains on your industrial facility with a "No Dumping Drains to Stream" or similar message. If select drains at your facility discharge to the sanitary sewer system or to a sump (for example, at a wash rack), you should label those with a "Drains to Sanitary Sewer" or similar message.

Common areas where good housekeeping practices should be followed include areas where trash containers are kept and adjacent areas, material storage areas, vehicle and equipment maintenance areas, and loading docks. Involving employees in routine monitoring of housekeeping practices has proven to be an effective means of ensuring the continued implementation of this control measure.

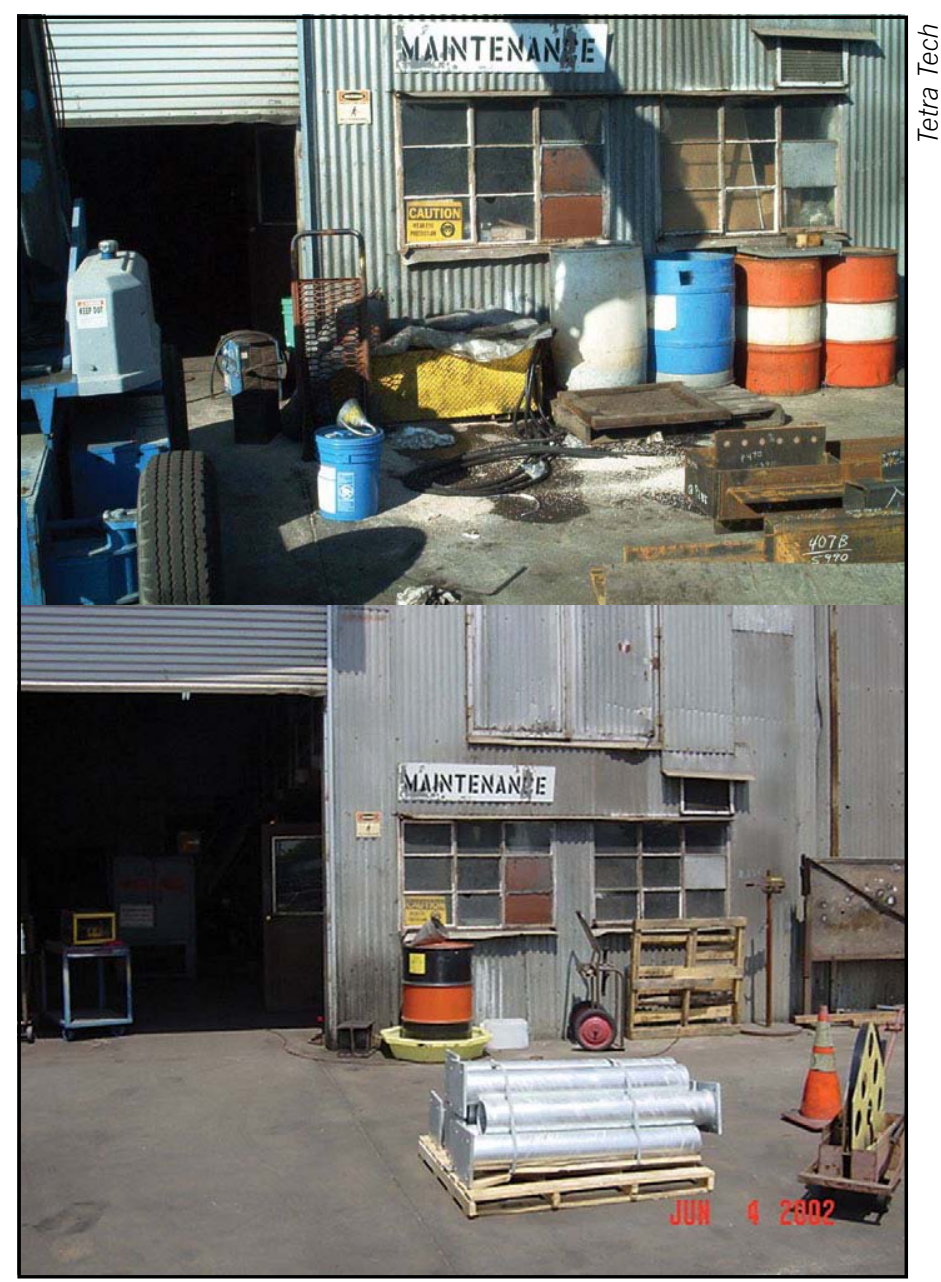

Figure 6 . Two photos showing an industrial facility before and after it followed good housekeeping practices.

\section{What to Include in Your SWPPP}

Describe any practices you are implementing to keep exposed areas of your site clean. Describe where each practice is being implemented at your site. Include here your schedule or approach for:

- Regular pickup and disposal of waste materials and scrap equipment;

- Maintenance of clean work spaces;

- Routine inspections for leaks and of the condition of drums, tanks, and containers;

- Routine inspections to make sure that industrial materials are properly stored and labeled;

- A schedule for sweeping paved areas and floors, including who will perform the sweeping (employee or contractor);

- The individual or position responsible for emptying drip pans placed beneath leaking equipment, valves, and fill lines. 


\section{C Maintenance}

A good maintenance program requires regular inspections, testing, and the preventive maintenance and repair of industrial equipment (stationary and mobile) and industrial systems. Maintenance programs are intended to ensure that structural control measures and industrial equipment are kept in good operating condition and to prevent or minimize leaks and other releases of pollutants (see Section 4.D for more specific information). If you notice a deficiency or otherwise find that your control measures or industrial equipment need to be replaced or repaired to ensure proper functioning, and to avoid leaks or other releases, you must make the necessary repairs or modifications, typically prior to the next wet weather event and as expeditiously as practicable.

Facilities with good maintenance programs will keep a maintenance log that tracks the regular maintenance of industrial equipment and stormwater control measures. The log provides a maintenance history for each piece of equipment and demonstrates to regulatory authorities that you have implemented the maintenance program outlined in your SWPPP.

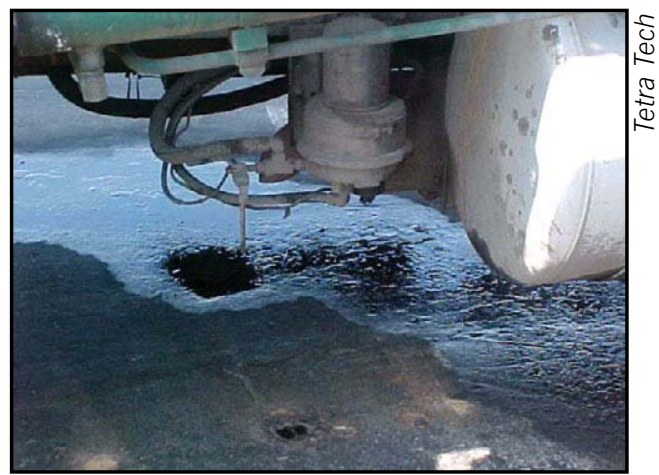

Figure 7. Equipment should receive routine preventative maintenance to prevent drips and leaks.

\section{What to Include in Your SWPPP}

Describe procedures to:

- Maintain industrial equipment so that leaks and other releases are avoided, and

- Maintain any of your site's control measures in effective operating condition.

Include the schedule you will follow for such maintenance activities. Describe where each applicable procedure is being implemented at the site.

\section{D Spill Prevention and Response Procedures}

Spills and leaks, together, are the largest source of industrial stormwater pollution. For this reason, your SWPPP must identify control measures that are used at your site to minimize the potential for spills, leaks, and other releases that may come into contact with stormwater. Among the practices that should be in place at your site are plans for effective response to spills if or when they occur. If your facility has more than 1,320 gallons of oil storage capacity in aboveground tanks you may also be required to develop a Spill Prevention, Control and Countermeasure (SPCC) plan consistent with 40 CFR 112.1.

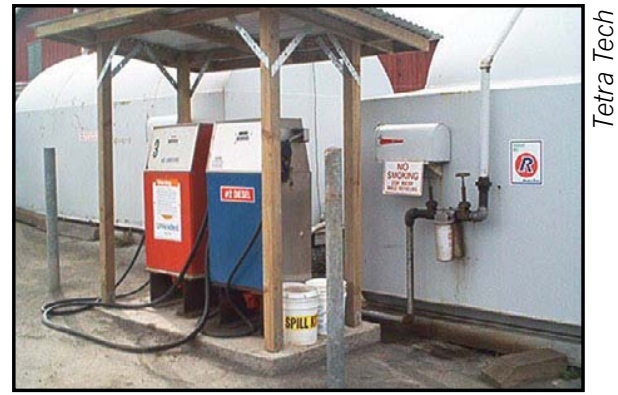

Figure 8. Spill kits should be maintained in areas with spill potential, such as fueling stations.

\section{SWPPP TIP!}

Employees must be aware of notification procedures in the event of a spill or leak, including when to contact appropriate facility personnel, emergency response agencies, and regulatory agencies. State or local requirements may necessitate reporting of spills or other prohibited discharges to local emergency response, public health, or drinking water supply agencies. Contact information must be posted in locations that are readily accessible and available to employees. Where a leak, spill, or other release containing a hazardous substance or oil in an amount equal to or in excess of a reportable quantity established under either 40 CFR Part 110, 40 CFR Part 117, or 40 CFR Part 302, occurs during a 24-hour period, you must notify the National Response Center (NRC) at (800) 424-8802 or, in the Washington, DC, metropolitan area, call (202) 267-2675 in accordance with the requirements of 40 CFR Part 110, 40 CFR Part 117, and 40 CFR Part 302 as soon as you have knowledge of the discharge. 


\section{What to Include in Your SWPPP}

Describe any structural controls or procedures you are putting in place to minimize the potential for leaks, spills, and other releases. At a minimum, your SWPPP should include:

- The location(s) of spill response plans for significant materials;

- A schedule for training employees in spill response procedures;

- Procedures for plainly labeling containers (e.g., "Used Oil," "Spent Solvents," "Fertilizers and Pesticides," etc.) that could be susceptible to spillage or leakage to encourage proper handling and facilitate rapid response if spills or leaks occur;

- Preventative measures such as barriers between material storage and traffic areas, secondary containment provisions, and procedures for material storage and handling;

- The individual or position responsible for making sure the spill kits are complete and ready for use;

- Procedures for expeditiously stopping, containing, and cleaning up leaks, spills, and other releases; and

- Procedures for notification of appropriate facility personnel, emergency response agencies, and regulatory agencies.

Describe where each control is to be located or where applicable procedures will be implemented.

\section{E Erosion and Sediment Controls}

Permits typically require control measures to be selected and implemented to limit erosion on areas of the site that, due to topography, land disturbing activities, soils, cover, materials, or other factors, are likely to experience erosion. In general, erosion control measures, which prevent soil or sediment from becoming mobilized, should be used as the primary line of defense, while sediment control measures, which trap, infiltrate, or settle out mobilized sediments, should be used to back-up the erosion control measures. For instance, erosion control measures, include grading, seeding, mulching, and sodding, that prevent soil from becoming dislodged, should be considered first. Where sediment may be dislodged and potentially mobilized in stormwater runoff, sediment control measures that trap eroded sediment include silt fences, sediment ponds, and stabilized entrances should be considered.

When selecting, designing, installing, and implementing appropriate erosion and sediment control measures, you should consult with your Tribal, State, and local authorities to

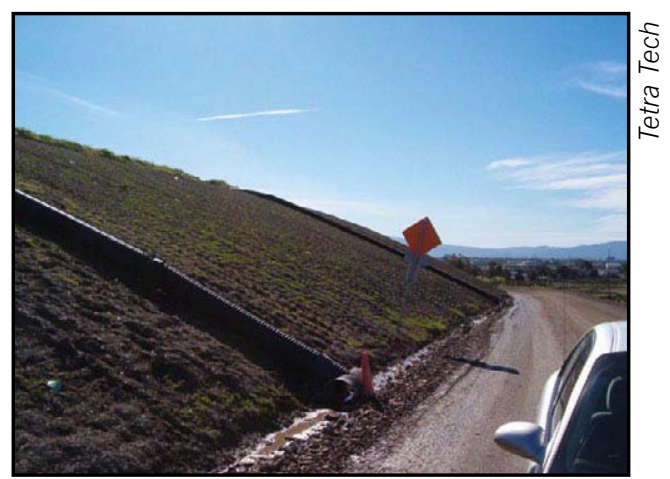

Figure 9. Slope drains to protect a hillside from erosion.

\section{SWPPP TIिए!}

Projects that disturb 1 acre or more of land generally require coverage under an NPDES construction general permit (CGP). Information on EPA's 2008 CGP requirements, including links to construction SWPPP resources, is available at www.epa.gov/npdes/stormwater/cgp.

ensure that you consider the appropriate control measures. EPA's internet-based resources relating to controlling erosion and sedimentation include the sector-specific Industrial Stormwater Fact Sheet Series, (www.epa.gov/ npdes/stormwater/msgp), National Menu of Stormwater BMPs (www.epa.gov/npdes/ stormwater/menuofbmps), and National Management Measures to Control Nonpoint Source Pollution from Urban Areas (www.epa.gov/owow/nps/urbanmm/ index.html).

\section{What to Include in Your SWPPP}

Include the following:

- A narrative description of areas of your site that are susceptible to erosion (note: the site map will also identify these areas);

- A description of erosion and sediment control measures used at your site to stabilize exposed areas and contain runoff to minimize onsite erosion and potential offsite discharges of sediment.

Note: Permits often require flow velocity dissipation devices at discharge locations and within outfall channels where necessary to reduce erosion and/or settle out pollutants. Describe in your SWPPP the location of each control implemented at your site. 


\section{F Management of Runoff}

Similar to erosion and sediment controls, the management of stormwater runoff that flows through your site is an effective way to reduce the pollutants that are discharged from your site. Where you employ structures or practices that are intended to divert, infiltrate, reuse, or otherwise reduce stormwater runoff so as to reduce the discharge of pollutants, your SWPPP must include a description of those controls. Appropriate measures are highly site-specific, but may include vegetative swales, berms, collection and reuse of stormwater, inlet controls, snow management, infiltration devices, and wet retention measures.

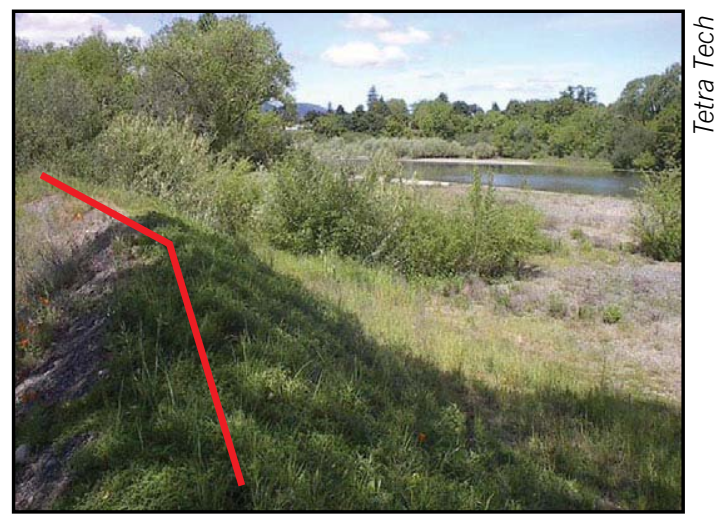

Figure 10. Vegetated berm used to prevent facility inundation when the river is at flood stage.

As mentioned previously, a combination of preventive and treatment control measures usually results in the most effective approach to stormwater management for minimizing the offsite discharge of pollutants in stormwater runoff.

\section{SWPPP Tip!}

When selecting control measures, be careful not to violate local building or fire codes and other ordinances. An example would be constructing a shed for storage of chemicals and then finding out from the fire department that you are in violation for locating the shed too close to the main building, not equipping the shed with sprinklers or other fire control device, and not properly labeling containers.

\section{What to Include in Your SWPPP}

Include the following:

- A description of controls used at your site to divert, infiltrate, reuse, contain, or otherwise reduce stormwater runoff.

- A description of locations at your site where each control will be implemented.

\section{G Salt Storage Piles or Piles Containing Salt}

Salt is commonly used for deicing and other commercial or industrial purposes, including maintenance of paved surfaces. Salt piles or piles that are predominantly composed of other materials that contain some salt typically must be covered or enclosed and otherwise isolated from coming into contact with stormwater (e.g., good housekeeping, diversions, containment). Piles do not need to be enclosed or covered if stormwater runoff from the piles is not discharged or if discharges from the piles are authorized under another NPDES permit.

To effectively document in your SWPPP that you are minimizing exposure of these piles to stormwater, you should consider creating a checklist to verify that salt loading and offloading operations occur within contained areas with appropriate measures in place to prevent the track out of salt from the contained areas.

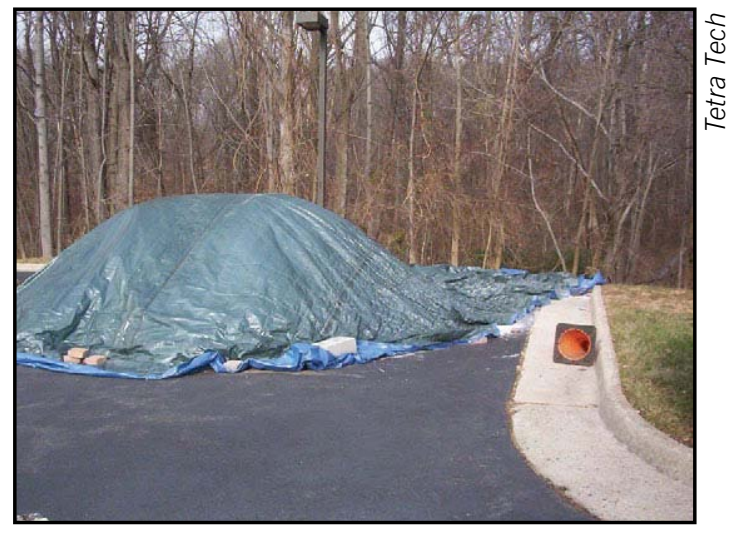

Figure 11. Salt pile covered with a tarp. 


\section{What to Include in Your SWPPP}

Include the following:

- The identification of salt storage piles or piles containing salt, and a description of structures at your site covering or enclosing such piles, or that prevent the discharge of stormwater from such piles.

- If tarps are used to cover piles, the SWPPP should describe procedures for when tarps will be placed over the piles.

- A description of any controls or procedures used to minimize exposure resulting from adding to or removing materials from the pile.

- The locations at your site where each control and/or procedure are implemented. Note that these locations must be identified on the SWPPP site map as well.

\section{H Sector-Specific Requirements}

Most industrial stormwater general permits regulate discharges of stormwater from a number of different industrial sectors. For instance, EPA's 2008 MSGP regulates discharges from 29 different industrial sectors. These "sectors" consist of similar facilities categorized by the nature of their industrial activity, type of materials handled, and material management practices employed. The sectors are structured to a large extent on the definition of "stormwater discharge associated with industrial activity" found at $40 \mathrm{CFR}$ 122.26 (b) (14)(i)-(ix), (xi), under which many sectors are identified based on their standard industrial classification (SIC) code.

Review your industrial stormwater general permit to determine if there are additional sector-specific discharge requirements (or "effluent limits") for which your type of industrial activity are subject. If so, you will need to specifically document how you will comply with those requirements in your SWPPP. Not all sectors will necessarily have additional sector-specific discharge requirements. For example, Sector N of EPA's 2008 MSGP includes specific requirements for scrap recycling and waste recycling facilities as defined by SIC Major Group Code 50 (5093). One of the specific Sector N discharge requirements is to "minimize surface runoff from coming in contact with scrap processing equipment.” Alternatively, the Chemical and Allied Products Manufacturing, and Refining sector (Sector C) does not have any sectorspecific discharge requirements in the 2008 MSGP.
Note that, if covered by the 2008 MSGP, you are responsible for complying with sectorspecific requirements associated with your primary industrial activity and all co-located industrial activities. Co-located industrial activities are industrial activities, excluding your primary industrial activity, located on-site that are also required to be covered by the 2008 MSGP or a State general permit. Statewide general permits may have different requirements for specific industrial sectors.

\section{SWPPP Tip!}

Sector-specific requirements for the 2008 MSGP - All sector-specific requirements can be found in Part 8 of the 2008 MSGP.

Sector-specific fact sheets - EPA has developed fact sheets specific to the industrial activities, pollutants and control measures used at each of the 29 sectors covered by the 2008 MSGP. These sector fact sheets can be found at http://cfpub.epa.gov/npdes/stormwater/ swsectors.cfm.

\section{What to Include in Your SWPPP}

Include the following:

- The industrial sector, or sectors, applicable to the permitted site.

- A discussion of the control measures implemented to address sector-specific requirements, if applicable, consistent with Part 8 of the 2008 MSGP.

- The location of each control and/or procedure used to comply with the sector-specific requirements. 


\section{I Employee Training}

Stormwater training is required for all employees who work in areas where industrial activities or material handling activities are exposed to stormwater, or who are responsible for implementing activities necessary to meet the conditions of this permit. These employees include inspectors, maintenance personnel, and all members of your Pollution Prevention Team. The training session or sessions are expected to cover the contents of the facility SWPPP, control measures implemented to achieve compliance with applicable discharge requirements, spill containment and cleanup procedures, maintenance, monitoring, inspection, planning, reporting, and documentation requirements.

EPA recommends that training be conducted for any applicable employees at least annually and whenever a new employee starts who meets the description above. You should have a sign-in/sign-out sheet at each training class to document that employees have participated. Keep the sign-in/sign-out sheet with your SWPPP.

\section{What to Include in Your SWPPP}

Include the following:

- Person(s) responsible for conducting the training (a member of the Pollution Prevention Team, contractor, or other?)

- The employees or positions that will receive stormwater training.

- The frequency of stormwater training sessions (annually, upon hire, or other). EPA recommends at least once per year. For example, the SWPPP might state that stormwater training will be conducted annually in September so employees are ready for the upcoming wet weather season.

- The stormwater topics covered during the training session or sessions.

- The sign-in/sign-out sheets from the training session.

\section{SWPPP TTि!}

Customize the employee training to the issues at your facility, and ensure that employees are trained on the control measures they are expected to implement. Among the topics you cover in your training should be some of the basic principles of stormwater management. For example, you should convey that:

- Stormwater pollution occurs when rainfall runoff picks up pollutants from the ground or areas exposed to rainfall.

- Polluted stormwater can cause significant water quality problems, such as fish kills and drinking water contamination. Stormwater runoff is typically discharged directly to receiving waters, and is not treated somewhere else, like at a wastewater treatment plant.

- Potential stormwater pollutants should be kept inside or under cover whenever possible.

- The best way to prevent stormwater problems is through general good housekeeping practices. A clean and organized facility will usually have very few stormwater problems.

- If anyone sees any potential stormwater problems, they should report it to the facility operator or a member of the stormwater pollution prevention team.

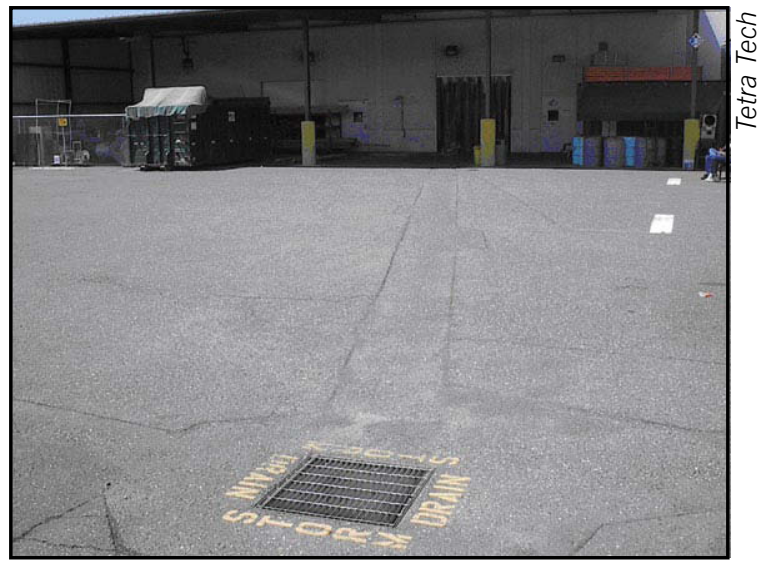

Figure 12. In addition to employee training, labeling storm drains is a good measure to educate employees. 


\section{J Non-Stormwater Discharges}

In Section 3.A, this guide discussed the assessment of allowable and prohibited nonstormwater discharges at your site. As stated in that section, unauthorized non-stormwater discharges cannot be discharged from your facility unless specifically authorized by a separate, individual NPDES permit. Your SWPPP should describe the assessment you conducted under Section 3.A, how you eliminated any unauthorized non-stormwater discharges, and your plans to prevent unauthorized non-stormwater discharges at your facility.

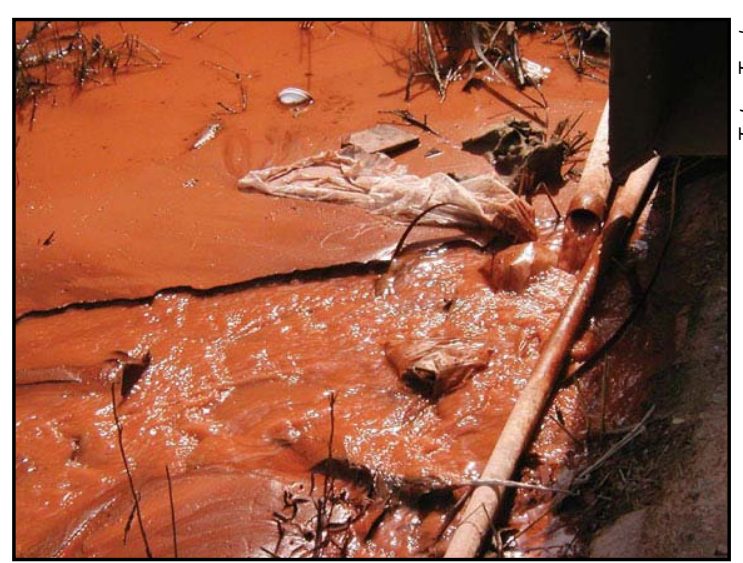

Figure 13. Unauthorized non-stormwater discharge from an industrial facility.

\section{What to Include in Your SWPPP}

Include the following:

- A list of allowable non-stormwater discharges that occur at your facility.

- A description of unauthorized non-stormwater discharges found at your site and how they were eliminated.

- Steps taken to ensure that other unauthorized non-stormwater discharges do not occur in the future.

Note: If this section is already addressed by your documentation of non-stormwater discharges (see Section 3.A), you can simply include a crossreference to that section of your SWPPP.

\section{K Waste, Garbage, and Floatable Debris}

You are responsible for making sure that stormwater runoff does not carry waste, garbage, and floatable debris to receiving waters. To verify compliance with this requirement, you should identify and implement control measures (e.g., good housekeeping, sweeping, keeping lids closed on dumpsters) to keep exposed areas free of such materials. Alternatively, your SWPPP should identify how you will intercept and properly dispose of these materials before they leave your facility.

\section{What to Include in Your SWPPP \\ Include the following: \\ - A description of controls and procedures that will be used to minimize discharges of waste, garbage, and floatable debris. \\ - Descriptions of the location of these control measures and procedures at your site.}

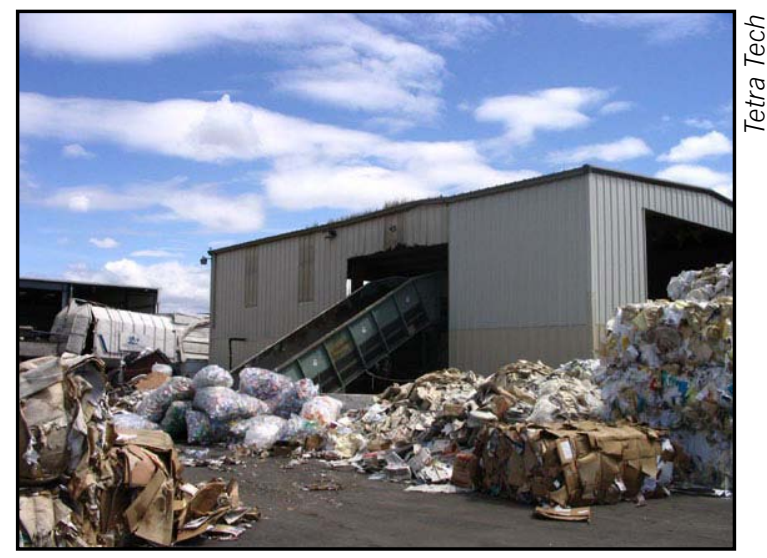

Figure 14. Poor management of waste and garbage at a facility. 


\section{L Dust Generation and Vehicle Tracking of Industrial Materials}

As an operator, you are responsible for minimizing generation of dust and off-site tracking of raw, final or waste materials. Dust control practices can reduce the activities and air movement that cause dust to be generated from disturbed soil surfaces. Airborne particles pose a dual threat to the environment and human health. Dust can be carried offsite, thereby increasing soil loss from disturbed areas and increasing the likelihood of sedimentation and water pollution. Control measures to minimize the generation of dust include:

- Sprinkling/Irrigation. Moistening the ground surface with water is an effective dust control method for haul roads and other traffic routes.

- Vegetative Cover. By establishing a vegetative cover on areas that will not see vehicle traffic, exposed soil is stabilized and wind velocity at ground level can be reduced, thus reducing the potential for dust to become airborne.

- Mulch. Mulch is a quick and effective, but not permanent, means of dust control for newly disturbed areas.

- Wind Breaks. Wind breaks can be trees or shrubs left in place during site clearing or constructed barriers such as a wind fence, snow fence, tarp curtain, hay bale, crate wall or sediment wall. The break reduces wind velocity, minimizing airborne transfer of soil off site.

- Tillage. Deep tillage in large open areas brings soil clods to the surface where they rest on top of dust, preventing it from becoming airborne.

- Stone. Stone can be an effective dust deterrent for construction roads and entrances or as a mulch in areas where vegetation cannot be established.

- Spray-on Chemical Soil Treatments (Palliatives). Examples of chemical adhesives include anionic asphalt emulsion, latex emulsion, resin-water emulsions and calcium chloride. Chemical palliatives should be used only on mineral soils. When considering chemical application to suppress dust, determine whether the chemical is biodegradable or water-soluble and what effect its application could have on the surrounding environment, including waterbodies and wildlife.

To reduce vehicle tracking of materials and sediment, the operator should keep stored or spilled materials away from all roads within the site. Specific measures such as setting up a wash site or separate pad to clean vehicles prior to their leaving the site may be effective as well.

\section{What to Include in Your SWPPP \\ Include the following: \\ - A description of controls and procedures used at your site to minimize the generation of dust. \\ - Descriptions of procedures and controls used to minimize off-site tracking of raw, final, or waste materials. \\ - Describe the location where each control and/ or procedure will be implemented and include on the SWPPP site map.}

\section{M Numeric Effluent Limitations Based on Effluent Limit Guidelines}

Some industrial activities identified in industrial stormwater permits also have Federal numeric effluent limits (called effluent limitation guidelines) that must be achieved in stormwater discharges. The effluent limits are maximum concentrations or levels of specific pollutants that can be discharged in facility stormwater. If your facility includes one of the industrial categories listed below, refer to your industrial stormwater general permit (Parts 6.2.2.1 and 2.1.3 of EPA's 2008 MSGP) regarding numeric effluent limits and monitoring requirements to which you are subject:

- Discharges resulting from spray down or intentional wetting of logs at wet deck storage areas

- Runoff from phosphate fertilizer manufacturing facilities that comes into contact with any raw materials, finished product, by-products or waste products

- Runoff from asphalt emulsion facilities

- Runoff from material storage piles at cement manufacturing facilities

- Mine dewatering discharges at crushed stone, construction sand and gravel, or industrial sand mining facilities

- Runoff from hazardous waste landfills 
- Runoff from non-hazardous waste landfills

- Runoff from coal storage piles at steam electric generating facilities

An example of a numeric effluent limit is the requirement for facilities that discharge stormwater from asphalt emulsion facilities to meet specific, numeric concentration limits for TSS, $\mathrm{pH}$, and oil and grease (i.e., based on the limits in 40 CFR Part 443, Subpart A).

If your facility is subject to numeric effluent limits, you must document the location and type of control measures installed at your site to meet those limits.

\section{What to Include in Your SWPPP}

Include the following:

- All numeric effluent limits the facility is required to meet based on effluent limit guidelines.

- A description of the control measures used to meet the numeric effluent limits.

- The location of each control measure at your site.

\section{N Additional Controls to Address Impaired Waters}

Many general permits have additional requirements for discharges to impaired waters.

"Impaired waters" have been identified by a Tribe, State, or EPA as not meeting applicable State water quality standards pursuant to Section 303(d) of the Clean Water Act. This may include both waters with approved or established Total Maximum Daily Loads (TMDLs), and those for which a TMDL has not yet been approved or established.

\section{SWPPP Tip!}

Impaired waters are streams, rivers, and lakes that do not currently meet designated uses and water quality standards. States, territories, and authorized tribes are required under the Clean Water Act to compile lists of known impaired waters, called 303(d) lists. Stormwater discharges to impaired waters may trigger additional control measures and monitoring requirements. For facilities subject to EPA's 2008 MSGP, see Part 2.2 for a more detailed discussion of water quality-based effluent limitations and conditions for discharging to impaired waters.
A TMDL determines the greatest amount of a given pollutant, such as sediment, that a water body can receive without violating water quality standards and designated uses. The TMDL then establishes pollution reduction goals to bring the water body into compliance with water quality standards. Facilities that are subject to NPDES permits (i.e., "point sources"), such as facilities subject to EPA's 2008 MSGP, which discharge the pollutant causing the water body impairment, receive "waste load allocations" or "WLAs". The WLA estimates the daily amount of the impairment pollutant that can be discharged from particular sources or categories of sources so that the waterbody can be restored to meeting its applicable water quality standards.

Should your facility discharge stormwater to a water body subject to a TMDL, EPA or a State permit authority may require additional effluent limits, monitoring requirements, or other restrictions consistent with an applicable WLA, or you may be required to apply for an individual NPDES permit. Where you have been informed either in the permit or directly by EPA or a State permit authority that you are subject to any "water qualitybased" discharge requirement consistent with an applicable WLA, you are required to document in your SWPPP the control measures used to meet that requirement and to describe the location of such control measures.

\section{SWPPP Tip!}

Find impaired waters near your facility - Use EPA's Water Locator Tool (available at www.epa.gov/npdes/stormwater/msgp) or other tool to map impaired waters within 10 miles of your facility. Enter your facility address in Step 1, then click on "Retrieve List of Impaired Waterbodies" under step 3 to see the list.

\section{What to Include in Your SWPPP}

Include the following:

- A description of the control measures used to meet the water quality-based effluent limits.

- The location of each control measure at your site. 


\section{Section 5: Procedures for Inspections and Monitoring (Step 4)}

The next step in developing your SWPPP is to set out the procedures you will follow for inspecting your site and monitoring your stormwater discharge. The procedures you develop in your SWPPP for inspection and monitoring will help you understand whether your control measures are working and, if not, provide you with ways you may improve your stormwater control.

Industrial stormwater permits typically require three types of inspections:

1. Routine facility inspections (see Section 5.A)

2. Visual assessments (see Section 5.B)

3. Annual comprehensive site inspections (see Section 5.C)

EPA's 2008 MSGP requires three types of facility inspections.

1. Routine facility inspections (2008 MSGP, Part 4.1)

2. Quarterly visual assessment of stormwater discharges (2008 MSGP, Part 4.2)

Some States also require you to take samples of your stormwater discharge for laboratory analysis. Check the applicable section of your industrial stormwater permit to determine if you are required to collect water quality monitoring samples. See Section 5.D for guidance on how to address your monitoring procedures in the SWPPP.

The following sections describe the type of information you should document in your SWPPP and the associated decisions you will have to make when planning for and conducting each of the three types of inspections.

3. Comprehensive site inspections (2008 MSGP, Part 4.3)

The 2008 MSGP also includes the requirements for the following types of monitoring:

1. Benchmark monitoring (2008 MSGP, Part 6.2.1)

2. Effluent guidelines limitation monitoring (2008 MSGP, Part 6.2.2)

3. State or Tribal monitoring (2008 MSGP, Part 6.2.3)

4. Impaired waters monitoring (2008 MSGP, Part 6.2.4)

Monitoring procedures are described in Part 6.1 of the 2008 MSGP.

\section{A Routine Facility Inspections}

Your industrial stormwater permit will likely specify a minimum frequency for conducting routine facility inspections. The minimum frequency typically ranges from once per month to once per quarter; however, EPA recommends that you develop a routine inspection schedule customized for your facility and specific site conditions, which in many instances will require that you inspect more frequently than the minimum requirement. EPA also suggests conducting routine inspections when measurable precipitation falls during normal business hours. Observing site conditions during storms provides you with real-time feedback on control measures that are working and those that are not working effectively. 
EPA's 2008 MSGP requires quarterly routine facility inspections of all areas where industrial materials or activities are exposed to stormwater, and of all stormwater control measures used to comply with the effluent limits contained in the permit. Inspections must be conducted by qualified personnel, including at least one member of your pollution prevention team, during regular business hours. You must specify the relevant inspection schedules in your SWPPP document as required in Part 5.1.5.

The 2008 MSGP requires that at least one of the four quarterly inspections each year be conducted when a stormwater discharge is occurring.

\section{SWPPP Tip!}

You should check your industrial stormwater general permit to determine if it establishes exceptions to the inspection requirements for certain types of sites. For example, 2008 MSGP Part 4.1.3 identifies exceptions to routine visual inspections for inactive or unstaffed sites.

\section{Recommended Routine Facility Inspection Sequence}

Although you are given the discretion to determine how best to conduct your inspection, EPA recommends that your inspection follow a sequence that corresponds to how raw materials arrive at your site and are stored or processed in areas exposed to stormwater, and to how intermediate or finished products are stored, processed, or transported from your facility. Accordingly, the following recommended inspection sequence will help ensure that you conduct a thorough routine inspection at your facility. Whichever process you determine is appropriate for your facility, you are required to describe that approach in your SWPPP.

\section{SWPPP Tip!}

Invest in an inexpensive digital camera to photo-document your inspections. Maintaining a photo history of inspections and control measures can help you to recognize if conditions changed or your control measures are degrading. Photographs can also help provide documentation to EPA or state inspectors that control measures are being maintained and replaced as needed.
1. Plan your inspection: Develop a consistent process to ensure that you inspect all areas. One method to ensure that your inspections are consistent and thorough is to create a checklist (or make notes on a copy of your SWPPP) of areas to inspect. Use as a resource your updated site map identifying the locations of industrial activities exposed to stormwater, stormwater conveyances and discharge points, and any BMPs.

2. Evaluate the area where raw materials are delivered. Are these areas contained or is there potential for stormwater to carry spills or pollutants away from the drop area? If so, can these pollutants leave your site to an adjoining facility, storm drain, or surface water? If so, additional control measures should be implemented.

3. Are raw materials stored in a contained area with overhead cover, berms, or other secondary containment? If not, do the raw materials have the potential to contribute to stormwater pollution?

Note: Single-wall chemical containers need to be located within secondary containment structures, behind berms, or covered to prevent stormwater contamination from an accidental release of containerized chemicals. Similarly, solid materials with the potential to contain pollutants (i.e., scrap material or wrecked vehicles) should include secondary containment.

4. Is equipment maintenance and fueling conducted in appropriately contained areas? Are spill kits present and full in areas where a liquid spill could be expected?

5. Do the industrial processes occur in covered and contained areas?

6. Where do you store waste material?

Note: If the waste material has the potential to contaminate stormwater it must be stored in a contained area or otherwise controlled. Be sure to evaluate the facility "bone-yard" and scrap all equipment that is out-of-date and not intended to be reused. 
7. Is the finished product appropriately contained for potential pollutant sources?

8. Following the internal evaluation, walk the perimeter of your site and look for evidence of stormwater discharges-particularly stains from oil and grease or chemicals. Should you observe these, look at the discharge area and consider additional control measures. You should specifically observe all stormwater outfalls where stormwater leaves your facility.

9. Following each inspection, you will need to make note of control measures that require maintenance, or that need to be replaced, and make sure that the SWPPP and site map are current regarding industrial activities and potential pollutants.

10. Finally, where appropriate, repair or replace worn or ineffective control measures as soon as possible but certainly before the next forecasted precipitation event.

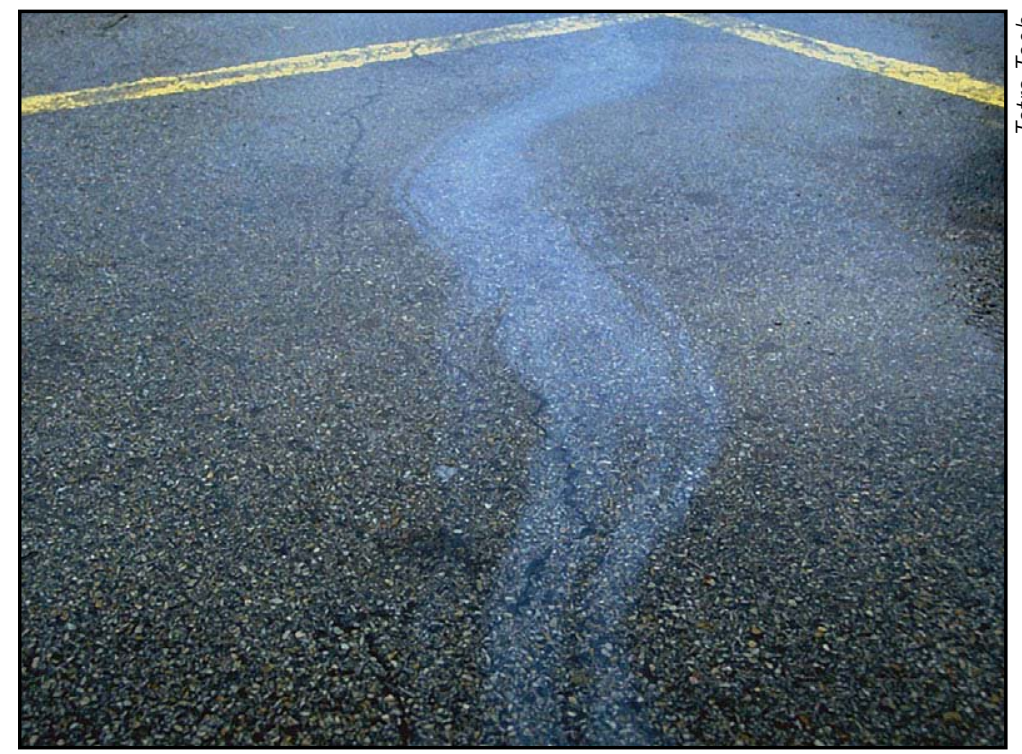

Figure 15. Example of a sheen indicating the presence of oil or other hydro carbons.

\section{SWPPP TTि!}

As you conduct your routine facility inspections, keep in mind these visual indicators of poor control measures or missing control measures:

1. Rainbow colored sheen on the surface of stormwater indicates the presence of oil or other hydrocarbons;

2. Brown or other dark colored streaks in flowing stormwater indicates soil erosion or uncontained sediment;

3. Stormwater flowing through straw waddles or other stormwater containment barriers;

4. Foam;

5. Trash and other debris being carried off-site by stormwater; and

6. Overflowing storm drains or detention ponds could be indicative of a clog or poor inlet design.

\section{Routine Facility Inspection Reports}

Your routine facility inspections will need to be recorded and documented. Generally, a standard inspection report is taken into the field and completed for each inspection. You should include in your SWPPP a copy of the standard inspection form you will use. An example routine facility inspection form can be found in the "Additional MSGP Documentation Template" on EPA's website at www.epa.gov/npdes/pubs/ msgp2008_recordkeepingtemplate.doc.

\section{SWPPP Tip!}

Remember to update your SWPPP if you add, remove, or modify control measures following a routine visual, or other, inspection. Should you get inspected, EPA or the State agency will expect that all control measures identified in your SWPPP to be current and to be effectively implemented at your facility. 


\section{What to Include in Your SWPPP}

Your SWPPP should describe the routine facility inspection process in enough detail that a member of your staff could complete an inspection by following the description in the SWPPP. The SWPPP description should include:

1. Person(s) or positions of person(s) responsible for conducting the routine facility inspections

At least one member of your stormwater pollution prevention team should be involved in the routine facility inspections. Consider involving employees who regularly work in areas where stormwater may come into contact with industrial activity or materials.

2. Schedules for conducting the routine facility inspections

Identify the minimum inspection frequency (e.g., monthly, quarterly) in your SWPPP. Consider scheduling the inspections for a set day every month or quarter, yet allow sufficient flexibility to be able to take advantage of a storm event, since many permits require that at least one inspection be conducted during a rain event.

3. Routine facility inspection procedures

Describe how the routine facility inspection will be conducted, including which control measures or areas will be inspected and what the inspector will be looking for. Examples of things the inspector should be looking for include the condition of stormwater outfalls (trash accumulation, staining, evidence of unauthorized non-stormwater discharges, etc.); overall good housekeeping; and the condition of installed control measures (do any need to be maintained or replaced?).

Among other procedures to describe, provide a description of the sequence you will follow during each inspection. One option is to use the recommended inspection sequence above or customize it to better suit your facility's layout.

\section{Reporting procedures}

Describe your reporting procedures and include a blank copy of the inspection form that will be used during the routine inspections. Most industrial stormwater general permits require that inspection reports include the following:

- The inspection date and time.

- The name(s), title(s), and signature(s) of the inspector(s).

- Weather information for the day of the inspection and, if appropriate, days or weeks prior to the inspection.

- A description of any discharges observed.

- A description of the visual quality of discharges (sheen, turbid, etc.).

- Control measures in need of maintenance or repairs.

- Control measures that need to be replaced.

- Any incidents of noncompliance observed.

- Additional control measures needed to comply with the permit requirements.

Inspection reports also need to be signed by the inspector. Your inspection form should include a signature line for this

\section{B Visual Assessments}

The second component of an effective stormwater inspection program is periodic visual assessments of the stormwater discharging from your facility. Visual assessments are conducted on samples taken during a storm event, and require that you make observations of the stormwater sample in order to qualitatively assess the nature of your discharge based on several visual parameters. This requires that you collect a stormwater sample in a clean, clear jar and look at the sample in a well lit area. Generally, a sample must be collected from each stormwater discharge location associated with industrial activity. The purpose of conducting visual assessments is to make sure that stormwater discharges are free from objectionable characteristics (i.e., pollutants you can see). Should you observe objectionable characteristics, you should backtrack upstream from the sample collection location to identify potential sources of the pollutants.
Some pollutants may be present in stormwater but cannot be seen; for this reason EPA or your State may require benchmark or effluent limit monitoring depending on the facility SIC code or industrial sector. See Section 5.D for more information on monitoring.

Most industrial stormwater permits do not require visual assessment samples to be collected consistent with 40 CFR Part 136 procedures (the Clean Water Act guidelines for

\section{SWPPP Tip!}

Check your industrial stormwater permit to determine if you are required to submit your visual assessment samples to a laboratory for analysis. The 2008 MSGP does not require samples to be submitted to a laboratory. However, if your permit does require you to submit samples for laboratory analysis, the samples must be collected and documented in accordance with 40 CFR Part 136 guidelines. 
establishing test procedures for the analysis of pollutants); however, visual assessment samples should be collected in such a manner that the samples are representative of the stormwater discharge.

EPA's 2008 MSGP includes specific requirements for when and how to collect the visual assessment sample. You should look in your permit to determine what requirements apply to your facility's visual assessments. However, EPA believes its permit's requirements offer a clear and consistent way to conduct these assessments. They are summarized as follows:

- Collect stormwater samples within the first 30 minutes of an actual discharge from a storm event. If it is not possible to collect the sample within the first 30 minutes of discharge, collect the sample as soon as possible after the first 30 minutes. In this case, be sure to document in your records (kept with your SWPPP) why it was not possible to take samples within the first 30 minutes. In the case of snowmelt, samples must only be taken during a period with a measurable discharge from your site.

- Collect the sample in a clean, clear glass, or plastic container.

- Examine the sample in a well-lit area or, if necessary, illuminate with a strong flashlight.

- Collect the samples from discharges that happen at least 72 hours ( 3 days) from the previous discharge event.

\section{What to Include in Your SWPPP}

Include in your SWPPP a description of your visual assessment process:

1. Person(s) or positions of person(s) responsible for visual assessments.

Note: The visual assessment should be conducted by a member of your stormwater pollution prevention team.

2. Schedules for conducting the visual assessments.

Note: Identify the minimum inspection frequency (typically quarterly) in your SWPPP. You should also describe procedures for determining when to conduct the visual assessments (e.g., within 30 minutes of an actual discharge, at least 3 days from previous discharge, etc.).

3. Specific items to be covered by the assessment (e.g., the 2008 MSGP requires permittees to visually inspect the sample in a well-lit area to assess the following water quality characteristics:

- Color

- Odor

- Clarity

- Floating solids

- Settled solids
- Suspended solids

- Foam

- Oil sheen

- Other obvious indicators of stormwater pollution)

4. The number and locations of outfalls scheduled for visual assessments. List the outfalls where visual assessments will take place, and make sure these locations are identified on your site map.

5. A description of safety considerations, requirements, and equipment for collecting samples during wet weather events. Note: Sample must be collected in a clean, clear glass (required for oil and grease samples) or plastic container. Describe any other equipment necessary to collect the samples (such as sampling poles for hard to reach outfalls, rain gear, etc.). Describe any necessary safety considerations for staff while collecting the samples (for example, if they are sampling at an outfall discharging into receiving water with high flows, or sampling in a manhole).

6. Reporting procedures: Describe your reporting procedures and include a blank copy of the assessment form that will be used during the visual assessments. Most industrial stormwater general permits require that visual assessment reports include the following:

- Sample location(s)

- Sample collection date and time, and visual assessment date and time for each sample

- The names of individuals, and titles or job positions, collecting the sample and performing visual assessment, and their signatures

- Nature of the discharge (i.e., runoff or snowmelt)

- Results of observations of the stormwater discharge

- Probable sources of any observed stormwater contamination

- If applicable, why it was not possible to collect samples within the first 30 minutes of discharge.

The SWPPP should also contain a checklist or list of the water quality parameters that must be observed and documented. 


\section{Visual Assessment Documentation}

Similar to the inspection reports for the routine facility inspections, you must document the results of your visual assessments in a written report. You should include a blank copy of your visual assessment report form that you will use in your SWPPP. An example of a visual assessment report can be found in the "Additional MSGP Documentation Template" on EPA's website at www.epa.gov/npdes/pubs/msgp2008_ recordkeepingtemplate.doc.

Digital photos of the samples are recommended, but not required, to document the condition of the sample and future reference.

\section{C Annual Comprehensive Site Inspections}

Most industrial stormwater general permits require an annual comprehensive site inspection. The annual comprehensive site inspection is a more in-depth version of the routine facility inspection. The annual comprehensive site inspection evaluates the condition of control measures, taking into account trends observed in analytic and visual stormwater samples taken during the year, and found during routine inspections.

Check your general permit to determine if the comprehensive site inspection needs to be conducted at a certain time (e.g., by the end of the fiscal year). Some permits require you to submit your comprehensive site inspection findings to the State permit authority as part of your annual report, typically due shortly after the end of the fiscal year. EPA's 2008 MSGP requires that the annual report be submitted and postmarked within 45 days of completing the annual comprehensive site inspection.

The comprehensive site inspection must cover all areas of the facility affected by the requirements of your industrial stormwater general permit, including all potential stormwater pollutant sources identified in the SWPPP, areas where control measures are used to comply with applicable effluent limits, and areas where spills and leaks have been documented in the three years prior to the annual comprehensive site inspection. In addition, the annual inspection must, as appropriate, include a review of visual stormwater monitoring data collected each quarter of the previous year and the results of the routine site inspections.

\section{SWPPP Tip!}

EPA's 2008 MSGP requires you to conduct annual comprehensive site inspections once during each of the following inspection periods:

Year 1: September 29, 2008 - September 29, 2009

Year 2: September 29, 2009 - September 29, 2010

Year 3: September 29, 2010 - September 29, 2011

Year 4: September 29, 2011 - September 29, 2012

Year 5: September 29, 2012 - September 29, 2013

Comprehensive site inspections must be conducted by qualified personnel with at least one member of your stormwater pollution prevention team participating in the comprehensive site inspections.

The annual inspection should be preceded by evaluation of the year's visual stormwater sample observations, analytic monitoring data, and your routine site inspection findings. The overall review of the previous year's visual and analytic monitoring results will provide you with areas of focus for the annual inspection; however, the annual inspection must include all control measures included in the SWPPP, regardless of the results from the past visual assessments and site inspections. Inspecting all stormwater control measures is meant to ensure that they are functioning correctly, and, if not, to correct any deficiency or malfunction. Accordingly, at the end of the annual comprehensive inspection you, and your stormwater pollution prevention team, should be able to answer the following questions.

- Are the control measures in place, maintained, and operating effectively?

- Is the routine site inspection protocol effective and conducted at the appropriate frequency?

- If your previous visual samples been were indicated the presence of pollutants in your stormwater, and your analytic samples been found to have high levels of any benchmark pollutants or other pollutants of concern, do you suspect that any particular areas of your site are contributing to these monitoring results? Do you suspect that the improper functioning of any stormwater control measures is contributing to these monitoring results?

- Is the SWPPP up-to-date regarding all of the stated control measures and monitoring schedules? 
Based on the answers to these questions, you may need to modify your stormwater management program and to update your SWPPP to address problems found during your inspection.

\section{Comprehensive Site Inspection Documentation}

The results, and documentation, of your annual site inspection must be maintained on-site and, depending on the requirements in your stormwater permit, submitted with your annual report. An example of a comprehensive site inspection report can be found in the "Additional MSGP Documentation Template" on EPA's website at www.epa.gov/npdes/pubs/msgp2008_ recordkeepingtemplate.doc.

\section{What to Include in Your SWPPP}

Include in your SWPPP a description of the annual comprehensive site inspection process:

1. Person(s) or positions of person(s) responsible for inspection

Note: Include at least one member of the stormwater pollution prevention team.

2. Schedules for conducting the inspections

Note: Describe when during the year the annual inspection will take place.

3. Describe the list of documents to be reviewed prior to the annual site inspection. This list will typically include:

- The current SWPPP

- All routine inspection reports for the past year

- All visual assessment reports for the past year

- Other documentation that may relate to how your facility complies with stormwater permit requirements, such as maintenance records, spill records, etc. for the past year.

\section{A copy of the current SWPPP site map}

Note: A current copy of the site map can be used during the comprehensive site inspection to make sure the inspector is covering all required areas.

5. Procedures for how the annual inspection will be conducted. Describe how the annual inspection will be conducted, including which control measures or areas will be inspected and what the inspector will be looking for. Specific items to be covered by the inspection include:

- Industrial materials, residue, or trash that may have or could come into contact with stormwater;

- Leaks or spills from industrial equipment, drums, tanks, and other containers;

- Offsite tracking of industrial or waste materials, or sediment where vehicles enter or exit the site;

- Tracking or blowing of raw, final, or waste materials from areas of no exposure to exposed areas; and

- Control measures needing replacement, maintenance, or repair.

6. A copy of the annual site inspection form you will use.

Note: EPA's 2008 MSGP has a comprehensive site inspection form in Appendix I of EPA's 2008 MSGP. Your annual site inspection form should contain:

- The date of the inspection;

- The name(s) and title(s) of the personnel making the inspection;

- Findings from the areas of your facility that were examined;

- All observations relating to the implementation of your control measures including:

- Previously unidentified discharges from the site,

- Previously unidentified pollutants in existing discharges,

- Evidence of, or the potential for, pollutants entering the drainage system;

- Evidence of pollutants discharging to receiving waters at all facility outfall(s), and the condition of and around the outfall, including flow dissipation measures to prevent scouring, and

- Additional control measures needed to address any conditions requiring corrective action identified during the inspection.

- Any required revisions to the SWPPP resulting from the inspection;

- Any incidents of noncompliance observed or a certification stating the facility is in compliance with this permit (if there is no noncompliance); and

- A statement, signed and certified in accordance with Appendix B, Subsection 11 of EPA's 2008 MSGP.

7. A schedule for completing and submitting (if required) the annual site inspection form/report in a timely manner. 


\section{D Documentation of Monitoring Procedures}

Your industrial stormwater general permit may include requirements to conduct stormwater discharge monitoring. The type of monitoring you are required to conduct will likely be based on your type of industrial activity. Not all types of industrial activity will be required to collect stormwater discharge samples, however, if your facility is required to conduct monitoring (such as benchmark monitoring or effluent limitation guideline monitoring), you must describe the procedures you will use to carry out this monitoring in your SWPPP.

EPA has prepared an Industrial Stormwater Monitoring and Sampling Guide (available at www.epa.gov/npdes/stormwater/msgp) that will support this guide. The Industrial Stormwater Monitoring and Sampling Guide provides a more detailed description of monitoring approaches and procedures that are recommended than is included in this guide.

As a general matter, your stormwater discharge samples will be taken at your facility's stormwater outfall locations, not at locations within your facility. Some stormwater general permits allow you to sample at only one outfall when multiple outfalls at your facility have similar industrial activities, control measures, exposed materials, and runoff coefficients. Outfalls that have these similar characteristics are called "substantially identical outfalls" or "representative outfalls." See your industrial stormwater general permit for more information.

\section{What to Include in Your SWPPP}

Include in your SWPPP, a description of the following monitoring requirements:

1. What you need to monitor

Make sure your SWPPP clearly identifies the parameters you need to monitor, and any applicable benchmark concentrations or effluent limits associated with each parameter.

2. Where you need to monitor

Your site map should identify the outfalls at your facility. In your SWPPP, identify at which outfalls you will be required to monitor. If you are allowed to sample one of the outfalls that are "substantially identical", and you plan on using a representative outfall, include the following documentation in your SWPPP:

- Location of each substantially identical outfall;

- Description of the general industrial activities conducted in the drainage area of each substantially identical outfall;

- Description of the control measures implemented in the drainage area of each substantially identical outfall;

- Description of the exposed materials located in the drainage area of each substantially identical outfall that are likely to be significant contributors of pollutants to stormwater discharges;

- An estimate of the runoff coefficient of the drainage areas (low = under $40 \%$; medium $=40$ to $65 \%$; high $=$ above $65 \%$ ); and

- Why the outfalls are expected to discharge substantially identical effluents.

3. When you need to monitor

If you are required to monitor, your industrial stormwater general permit will specify a monitoring frequency (typically quarterly or annually). For each of the parameters you identified above, include in your SWPPP the monitoring frequency. Some permits also specify exemptions or alternative monitoring periods, which should also be addressed in your SWPPP.

Your SWPPP should also describe the type of storm event that should be monitored. In the 2008 MSGP, EPA requires monitoring during a storm event those results in an actual discharge from your site ("measurable storm event") that follows the preceding measurable storm event by at least 72 hours (3 days).

4. How you will conduct the monitoring

Describe in your SWPPP how you will conduct the monitoring, including who will collect the samples. Typically, monitoring is conducted by taking one grab sample from a discharge resulting from a measurable storm event and collected within the first 30 minutes of a measurable storm event, during normal business hours, when stormwater is discharging from your facility.

Also describe any sample documentation and preservation procedures you plan to use. Some samples may need to be analyzed within a short time, or may need to be preserved with blue ice before being analyzed.

5. Where you will send the sample for analysis

Finally, in your SWPPP, include information about the laboratory where you will send the samples for analysis. Include information such as lab name and address, any sampling procedures required by the lab, and who will take the samples to the lab. 


\section{Section 6: Completing Your SWPPP}

Now that you have conducted a site assessment of your facility, developed maps, selected control measures, and developed procedures for inspections and monitoring. You are almost done with your SWPPP! The last step is to make sure all this information is organized into a single document (your SWPPP) and to obtain NPDES permit coverage.

\section{A Finish your SWPPP}

The information you put together as part of Sections 3 through 5 make up the contents of your SWPPP. There are only two more steps for you to finish before your SWPPP is complete:

- Conduct a final review of your SWPPP; and

- Sign and certify your SWPPP

\section{Review Your Draft SWPPP}

You should review the SWPPP requirements in your industrial stormwater general permit to ensure that your SWPPP includes all required elements. For example, in the 2008 MSGP, the SWPPP requirements are in Part 5. Check off all the SWPPP permit requirements as you verify that they have been met. Also, develop a final copy of your site map and make sure that all required elements are addressed.

EPA recommends that you have both your stormwater pollution prevention team, and someone who was not involved in developing the SWPPP, review your draft SWPPP.

\section{Sign and Certify Your SWPPP}

The last step in completing your SWPPP is to have a facility executive or duly authorized representative of that executive sign and certify that the SWPPP meets all the requirements in the general permit. This signature demonstrates that the SWPPP was reviewed by someone who has operational control over the facility (i.e., can commit resources to implementing the SWPPP and ensuring compliance with the permit). You should check your general permit to determine which person is required to sign and certify the SWPPP. Note that the signatory requirements for the 2008 MSGP are found in Appendix B, Subsection 11 of EPA's 2008 MSGP.

\section{B Obtain NPDES Permit Coverage}

Important! Before obtaining permit coverage, you should read the appropriate industrial stormwater permit and develop your SWPPP.

Most permits require that you develop your SWPPP before you can obtain NPDES permit coverage for your industrial stormwater discharges. However, in some instances, the permit may provide you with additional time to complete or update a SWPPP after permit coverage is obtained. Nevertheless, it is recommended that your SWPPP be completed at least in draft form prior to applying for permit coverage, even in those States where additional time is granted.

\section{Obtaining Coverage Under a General Permit}

To obtain coverage under a State industrial stormwater general permit, you will typically need to fill out and submit an application form, often called a Notice of Intent or 
NOI. Submitting an NOI form to the permitting authority indicates your certification that you have met the eligibility requirements for coverage under the permit, and your agreement to abide by the terms and conditions of the general permit. Depending on the permit, you may be authorized to discharge immediately or at some later time. In some cases, you are not authorized to discharge until the State has notified you accordingly. EPA's 2008 MSGP (see Part 1.3.1) uses a 30 to 60-day waiting period following the receipt of a facility's complete NOI. The waiting period expires when the permit's status changes from "waiting" to "active" on the Agency's eNOI website.

Read the application requirements in your general permit for information on the procedures and the specific form you will need to complete before becoming authorized. Some States charge an administrative fee to apply for permit coverage. Before submitting your application, you must also make sure that you meet all eligibility requirements in the permit. For example, if your facility discharges to one of several highly protected waters (e.g., a Tier 3 or "Outstanding Natural Resource Water"), you may not be eligible for coverage under a general permit and instead may have to file an application for individual permit coverage.

\section{SWPPP TIP!}

Documentation to Support Eligibility Considerations Under Other Federal Laws

The 2008 MSGP requires that you keep with your SWPPP the documentation supporting your eligibility pertaining to endangered species requirements, historic properties requirements, and NEPA review requirements described in the permit (see Part 5.1.6 of the permit). State industrial stormwater permits may have other documentation requirements.

\section{C Updating Your SWPPP}

Your SWPPP is a document that will need to be reviewed and updated on a regular basis. Whenever you find the need to change a procedure that is described in your SWPPP or to modify a control measure described therein, you must update the SWPPP to reflect those changes as quickly as practicable. Should the SWPPP require modification to document corrective actions, a new certification statement must be signed and dated upon completion of the revision.
Below are some examples of events that, if they result in a change in control measures or procedures, will require prompt revision of the SWPPP to reflect the new facility conditions.

- A change in the composition of the stormwater pollution prevention team or new responsible official.

- An unauthorized release or discharge (e.g., spill, leak, or discharge of non-stormwater not authorized by this or another NPDES permit) occurs at your facility.

- A discharge violates a numeric effluent limit.

- You become aware, or EPA determines, that your control measures are not stringent enough for the discharge to meet applicable water quality standards;

- An inspection or evaluation of your facility by an EPA official, or local, State, or Tribal entity, determines that modifications to the control measures are necessary to meet the non-numeric effluent limits in this permit.

- Construction or a change in design, operation, or maintenance at your facility significantly changes the nature of pollutants discharged in stormwater from your facility, or significantly increases the quantity of pollutants discharged.

- The average of four quarterly sampling results exceeds an applicable benchmark. If less than four benchmark samples have been taken, but the results are such that an exceedance of the 4 quarter average is mathematically certain (i.e., if the sum of quarterly sample results to date is more than 4 times the benchmark level) this is considered a benchmark exceedance, triggering a review of control measures and possible SWPPP modification.

Remember, revisions to the SWPPP to document corrective actions requires a new signed and dated certification statement by the responsible official. All other changes must be signed and dated by the person preparing the change.

\section{SWPPP Tip!}

In the interim between the annual inspection and completed SWPPP revision, keep a copy of the original SWPPP with your handwritten notes for SWPPP modifications at the facility. Should you be inspected before the revised SWPPP is complete, the copy with your notes can be used to demonstrate the changes that will be in the revised document. 


\section{Section 7: Keeping Records of Your Implementation Activities}

Completing your SWPPP and obtaining NPDES permit coverage is an important step towards complying with your State or EPA Clean Water Act requirements. Having completed these steps, you are now ready to begin documenting your compliance with the requirements of your permit. EPA's 2008 MSGP and many State permits require you to keep records of any activities at your site that are related to your compliance, such as conducting inspections, visual assessments, stormwater discharge monitoring, and corrective actions.

As you conduct inspections, monitoring, corrective actions, and other permit implementation activities, you will generate additional records, such as inspection reports and monitoring results. Keep this additional documentation on-site with your SWPPP, and ensure these records are accessible, complete, and up-to-date so that they demonstrate your full compliance with the conditions of your permit.

Some examples of this additional documentation include:

- Permit records - copies of the NOI or permit application submitted, any letters received from the permitting authority, and a copy of your general permit.

- Spill records - dates of any incidences of significant spills, leaks, or other releases that resulted in a discharge of pollutants, the circumstances leading to the release, actions taken in response to the release, and measures taken to prevent the recurrence of a release.

- Employee training records - keep copies of all employee training records, including dates, who was trained, and the training topics.

- Maintenance records - retain copies of all maintenance and repairs of control measures, including dates of regular maintenance, dates when maintenance needs were discovered, and dates when control measures were returned to full function.

- Inspection records - keep copies of all routine facility inspection reports, quarterly visual assessment reports, and annual comprehensive site inspection reports.

- Monitoring records - retain records of all sampling results including data collection forms, lab results, and discharge monitoring reports (DMRs).

- Corrective action records - keep records of any corrective actions and follow-up activities conducted to demonstrate compliance with the permit.

\section{SWPPP TTp!}

For 2008 MSGP permit holders, the list of additional documentation requirements can be found in Part 5.4 of the permit. Also, EPA has developed an "Additional MSGP Documentation Template" with sample forms that you can download from www.epa.gov/npdes/stormwater/ msgp to help you organize this information. 


\section{Section 8: Common Compliance Problems at Industrial Facilities}

The following are common problems found during inspections of industrial sites conducted by EPA. These are provided to assist you in developing and maintaining an effective SWPPP. As a general matter, it is not enough to simply have a completed SWPPP at your site. To establish compliance with your permit's limits and conditions, you must also implement the procedures, and install and maintain the control measures, described in your SWPPP, and make modifications as necessary to improve your performance.

You should review these common compliance problems and consider how your SWPPP, or how your implementation of the procedures described in your SWPPP, can be modified to ensure you are not making the same mistakes.

1. No SWPPP developed. Some facilities do not realize that they need to develop a SWPPP, or they may copy a generic SWPPP or a SWPPP for another facility. A SWPPP is a site-specific plan and should address only your facility.

2. Control measures described in SWPPP not used. The SWPPP identifies stormwater control measures that are not actually being used at the site. The stormwater regulations hold you responsible for effectively implementing all control measures identified in your SWPPP. If your SWPPP has identified control measures not being used at your site, you need to edit your SWPPP accordingly to accurately reflect those measures you are in fact using.

3. No SWPPP on-site. A copy of the SWPPP is not available on-site for review when a permitting authority or other regulatory agency inspects your site. You are responsible for maintaining a copy on-site at all times. If your SWPPP is being updated off-site, keep

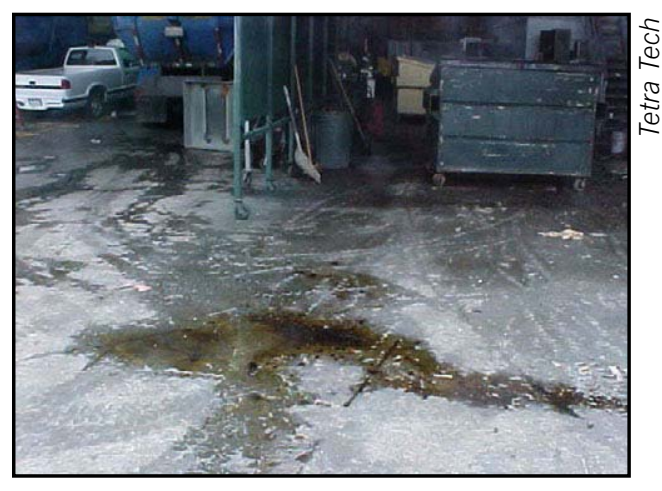

Figure 16. Good housekeeping is probably the most common BMP in SWPPPs. Poor sweeping practices can contribute significant pollutants in stormwater runoff. a marked-up copy on-site or an electronic copy until the revised SWPPP arrives.

4. SWPPP not signed. The responsible facility representative did not sign and authorize the current version of the SWPPP.

5. Stormwater pollution prevention team not up-to-date. The stormwater pollution prevention team identified in the SWPPP is not current. This is particularly a problem at facilities with high turnover. Remember, you can identify team members by title rather than by name if high turnover makes it difficult to keep a current list of names.

6. On-site staff not familiar with SWPPP. Upon arrival of an inspector, no one familiar with the stormwater program is available. A common permit requirement is that at least one employee per shift is familiar with the stormwater program and has access to the relevant files. 


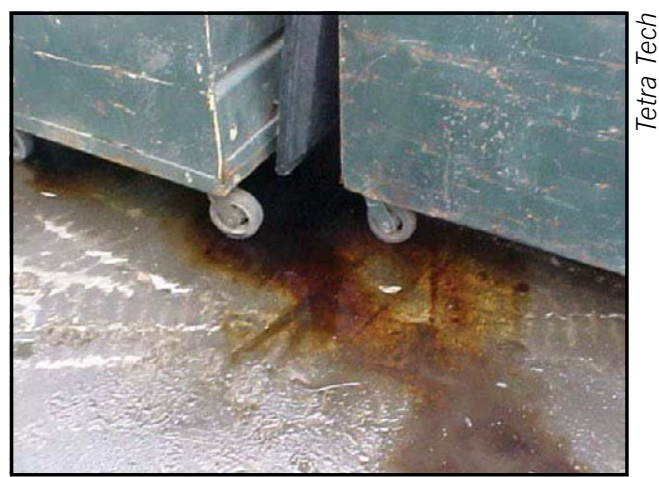

Figure 17. Leaking dumpsters can introduce pollutants into stormwater runoff.

7. Improper collection of visual assessment samples. Visual stormwater samples are collected from pooled areas on site. Pooled areas tend to concentrate pollutants and are not representative, unless the contents of the pooled areas flow off of the facility (this is to your disadvantage).

8. Uncovered dumpsters. Dumpsters that receive metal waste are not covered or contained. Dumpsters from contract waste collection agencies are often not appropriately sealed and can leak oils or other contaminants.

\section{SWPPP Tip!}

SWPPP Availability - Keep a copy of the current, signed and certified SWPPP at your facility, and make it available to EPA, State, local agency or other regulatory agency staff at the time of an onsite inspection or upon request. The SWPPP should also be made easily available to facility staff, and should be readily referred to during regular facility operations to ensure that all activities are implemented as described in the SWPPP.

9. Poor employee/contract staff training. Employees or contract staff are not familiar with your stormwater management program. You are responsible for educating employees and contractors because if they release pollutants at your facility, you are responsible. If you use contractors, they should be referred to in your SWPPP and required to be trained as a part of the contract.

10. Inspection or monitoring records are not kept with the SWPPP. Records of routine site inspections, visual assessments, or monitoring results are not available with the SWPPP for review. All records on implementation of practices required in the permit must be kept with the SWPPP (see Section 6.C for more information). 


\section{Resources}

EPA, 2008 Multi-Sector General Permit, issued September 29, 2008

(available at www.epa.gov/npdes/stormwater/msgp).

EPA's Stormwater Website - www.epa.gov/npdes/stormwater

Industrial Stormwater Resource Locator - www.envcap.org/iswrl/

EPA's Industrial Stormwater Website - www.epa.gov/npdes/stormwater/indust

EPA's 2008 MSGP Website - www.epa.gov/npdes/stormwater/msgp

The Industrial Stormwater and MSGP Websites have a number of resources and tools to aid MSGP permittees, which include:

- Annual Reporting Form - Permittees can use this form to report their annual comprehensive site inspection and corrective actions to EPA.

- Conditional "No Exposure" Exclusion - Industrial facilities can use this form to certify that their industrial materials and operations are not exposed to stormwater.

- Developing your Stormwater Pollution Prevention Plan: A Guide for Industrial Operators Provides guidance on how to develop a SWPPP that meets the requirements of the 2008 MSGP.

- Electronic Notice of Intent (eNOI) System - Allows permittees to quickly apply for permit coverage under EPA's 2008 MSGP.

- Industrial Stormwater Monitoring and Sampling Guide - Provides guidance on how to meet the monitoring and sampling requirements in the 2008 MSGP.

- Industrial Sector Fact Sheets - These fact sheets summarize the types of facilities included that sector, the pollutants associated with this sector, and the types of stormwater control measures generally used.

- List of Tier 2 and Tier 3 Waters - Lists of waters currently designated by states as Tier 2 or Tier 3 for antidegradation purposes to help you complete your NOI.

- MSGP Discharge Monitoring Report (MDMR) - Permittees can use this paper copy form to submit monitoring data to EPA.

- Reporting MSGP Monitoring Data - Allows permittees to electronically file all benchmark, effluent limitation guidelines, and impaired waters monitoring data through the eNOI system.

- Sample MSGP SWPPP Template - Industrial facilities can use the "Industrial SWPPP Template" to create their own SWPPPs.

- Sample Recordkeeping Templates - Use the sample templates and forms to keep records of your monitoring, inspection, maintenance, visual evaluation, and corrective action activities.

- Search, Sort, and View Industrial NOIs - Searchable database of stormwater notices of intent (NOIs) for industrial facilities seeking coverage under EPA's MSGP.

- Water Locator Tool - Helps industrial facilities pinpoint their site's latitude and longitude, receiving water, and impairment status of the water, applicable total maximum daily loads (TMDLs), and potential pollutants of concern.

EPA's NPDES Authorization Status Website - www.epa.gov/npdes/stormwater/authorizationstatus

EPA's Menu of National Stormwater BMPs - www.epa.gov/npdes/stormwater/menuofbmps

Industrial Stormwater Permit Guide - www.pneac.org/stormwater/ 


\section{Appendix A: MSGP SWPPP Template}

EPA has created a template to assist operators in developing an industrial SWPPP that addresses the requirements in the 2008 MSGP. The template includes instructions and space to help operators document activities specific to their facility, such as:

- Facility Description and Contact Information

- Potential Pollutant Sources

- Stormwater Control Measures

- Schedules and Procedures for Monitoring

- Inspections

- Documentation to Support Eligibility Considerations under Other Federal Laws

- SWPPP Certification

- SWPPP Modifications

- SWPPP Attachments

A customizable Microsoft Word version of the MSGP SWPPP Template is available for download from www.epa.gov/npdes/stormwater/msgp. 


\section{Appendix B: Additional MSGP Documentation Template}

EPA has created a template to assist 2008 MSGP permit holders in collecting the additional documentation required during implementation of the permit. The Additional MSGP Documentation Template includes example forms and tables to help permittees document activities related to:

- Significant spills, leaks or other releases

- Employee training

- Maintenance

- Routine Facility Inspection Reports

- Quarterly Visual Assessment Reports

- Comprehensive Site Inspection Reports

- Monitoring results

- Deviations from assessment or monitoring schedule

- Benchmark Exceedances

- Impaired Waters Monitoring: Documentation of Natural Background Sources or Non-Presence of Impairment Pollutant

- Active/Inactive status change

- SWPPP Amendment Log

The Additional MSGP Documentation template can be downloaded in Microsoft Word format at www.epa.gov/npdes/stormwater/msgp. 


\section{Appendix C: Example Site Map}

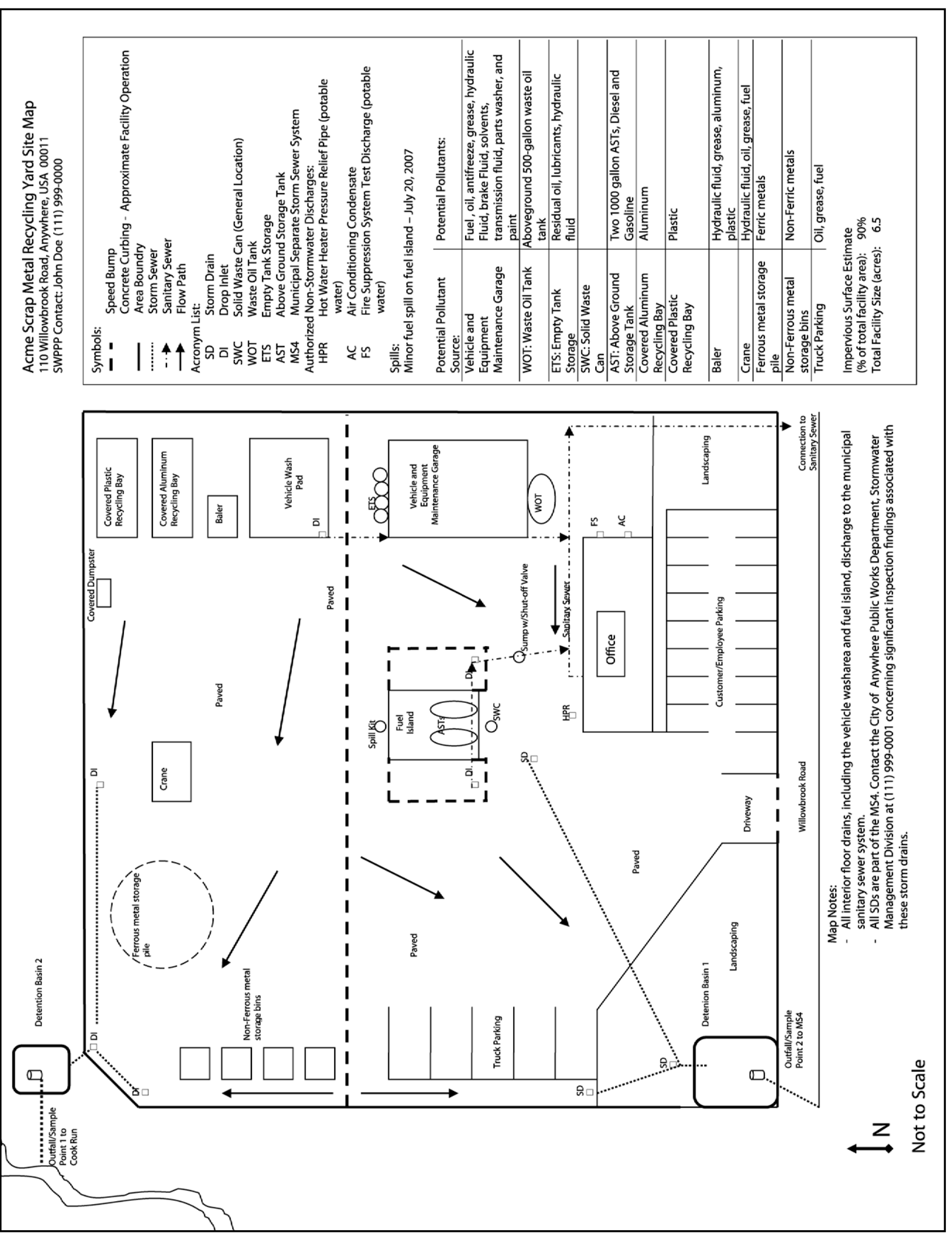




\title{
Certificate of Completion
}

\author{
This certifies that
}

\section{Leonard Frank Sandoval}

Has successfully completed

EPA - Developing Your Stormwater

Pollution Prevention Plan

Completed On 11/3/2016 12:51 PM MT 
Endangered Species Documentation 


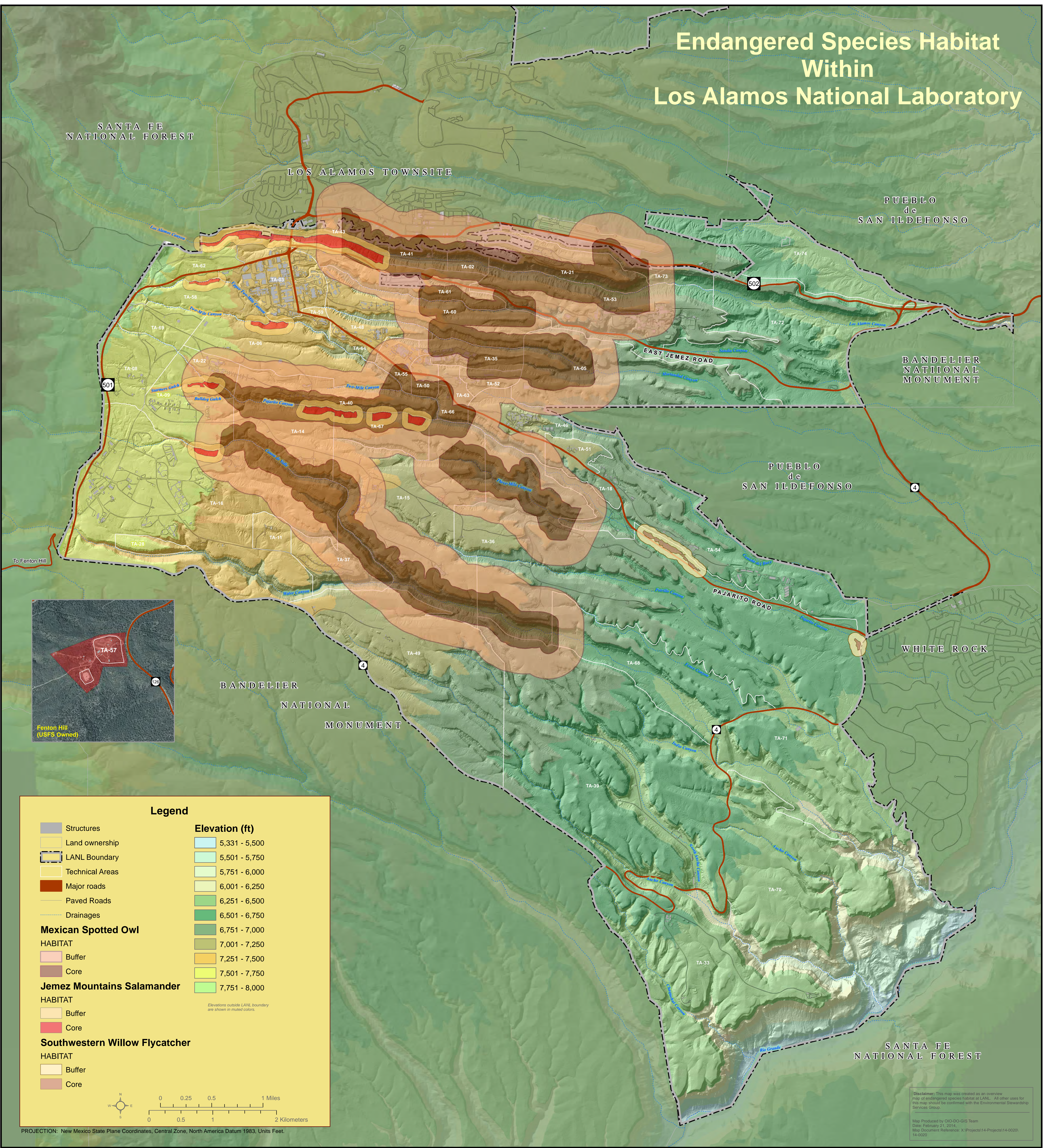




\title{
United States Department of the Interior
}

\author{
FISH AND WILDLIFE SERVICE \\ New Mexico Ecological Services Field Office \\ 2105 Osuna NE \\ Albuquerque, New Mexico 87113 \\ Phone: (505) 346-2525 Fax: (505) 346-2542
}

December 9, 2013

Cons. \#02ENNM00-2014-I-0014

Geoffrey L. Beausoleil, Acting Manager

National Nuclear Security Administration, Los Alamos Field Office

Department of Energy

Los Alamos, New Mexico 87544

Dear Mr. Beausoleil:

Thank you for your biological assessment entitled, "Biological Assessment of the Effects of Implementing the Jemez Mountains Salamander Site Plan on Federally Listed Threatened and Endangered Species at Los Alamos National Laboratory" (BA); the request for informal consultation and conferencing received on July 25, 2013 and supplemental information supplied in the "Jemez Mountains Salamander (Plethodon neomexicanus) Los Alamos National Laboratory (LANL) Site Plan" (Site Plan); and emails dated November 19 and December 3, 2013. The Department of Energy (DOE) requested concurrence with the determination of effects for the endangered Jemez Mountains salamander (Plethodon neomexicanus) (salamander) pursuant to Section 7(a)(2) of the Endangered Species Act of 1973 (ESA), as amended (16 U.S.C. $\S 1531$ et seq.). Your proposed action consists of implementing the Site Plan, and includes of the incorporation of this Site Plan into LANL's Habitat Management Plan (HMP).

- The HMP was consulted upon in 1999 (Consultation \#2-22-981-336) as the primary mechanism to ensure compliance with the ESA at LANL. The actions described in the Site Plan and analyzed in the BA, and supplemental emails are hereby incorporated by reference. You determined that implementing the Site Plan "may affect, is not likely to adversely affect" the salamander, and includes placing restrictions on certain types of work in areas identified as core habitat for the salamander on LANL property with the purpose of ensuring that effects to the salamander from those actions identified in the Site Plan are insignificant and discountable.

The Site Plan does not include any areas within designated salamander critical habitat, indicating that no critical habitat will be affected. The Site Plan has modeled and field validated the model to identify the areas on LANL property with the highest potential to be occupied by salamanders based on habitat features for the salamander. Each area identified by the modeling is termed "Area of Environmental Interest" (AEI) and consists of a "core area" and a "buffer area". The core area habitat is defined as suitable habitat where the salamander occurs or may occur at LANL. The core area habitat consists of sections of north-facing slope that contain the required 
micro-habitat to support salamanders. The buffer area is 328 feet (100 meters) wide extending outward from the edge of the core area. Only the Los Alamos Canyon AEI is known to be occupied based on surveys. Surveys for the salamander are known to have a very low detection rate for occupied areas and DOE has assumed that all AEIs at LANL are occupied at all times by the salamander.

Within the Site Plan, DOE has assessed activities that could cause habitat alteration and includes any action that alters the soil structure, vegetative components necessary to the species, water quality, or hydrology in undeveloped areas of an AEI. If an activity were to take place outside of the AEI the activity will be assessed if it will have effects inside the AEI core. Within the core areas, only activities specified within the Site Plan and those that have no effect in the core areas (e.g. no habitat alterations or effects within the core areas) will be conducted without further consultation with the Service. Habitat alterations also include soil pits for soil samples deeper than 6 inches (15.2 centimeters) using either hand or mechanized augers. Within the Site Plan, DOE is proposing fuels management practices to reduce wildfire risk and maintenance of utility corridors within the AEIs. The likelihood that salamanders may be affected by the actions in the Site Plan is very low. To ensure that effects to the salamander are insignificant and discountable, the Site Plan incorporates the following conservation measures as restrictions to the identified work:

Fuels Management Practices to Reduce Wildfire Risk

a. Within undeveloped core areas, thinning trees to a level of $80 \%$ canopy cover or higher may occur; tree thinning below $80 \%$ canopy cover is not part of the action under this consultation.

b. Large logs on the ground will be left in place and not chipped.

c. Large trees that are felled will be left as large logs on the ground

d. When appropriate, smaller trees and understory shrubs that may be thinned will be dispersed and left on-site to aid in soil moisture retention.

e. In buffer areas, thinning of trees may occur to the current LANL-approved prescription level; clear-cutting will not occur.

f. Thinning activities will not occur during the rainy season when salamanders are surface active, between July 1 - October 31 . Thinning activities may occur earlier in October if freezing temperatures are present.

g. In the unlikely event that a salamander is observed surface active during thinning activities, all activities shall cease, and the Service will be notified.

\section{Utility Corridors}

a. Cutting trees that threaten power lines may occur within 26 feet ( 8 meters) of either side of an existing utility line at LANL

b. New utility lines and utility lines requiring clearance of a right-of-way greater than 52 feet (16 meters) total in core habitat is not part of the action under this consultation. 
Habitat alterations other than the fuels management practices and utility corridor maintenance described above will not occur in undeveloped core areas under the guidelines of the Site Plan or this consultation. The Service concurs with DOE's determination regarding the salamander for the following reasons:

Within the Site Plan, DOE has placed the above detailed restrictions to ensure that any effects to the salamander and its habitat remain insignificant and discountable. Canopy cover will remain at $80 \%$ or greater in undeveloped core areas and fire management actions will occur outside of the salamander surface activity period. Maintaining utility line corridors in areas with existing infrastructure (the utility lines) by removing individual hazard trees is not expected to have any measurable effect on salamanders or their potential habitat. Consequently, we concur that potential effects to the salamander from the proposed action will be insignificant and discountable.

This concludes section 7 consultation regarding the proposed action. If monitoring or other information results in modification or the inability to complete all aspects of the proposed action, consultation should be reinitiated. Please contact the Service if: 1) future surveys detect listed, proposed or candidate species in habitats where they have not been previously observed; 2) the proposed action changes or new information reveals effects of the proposal to listed species that have not been considered in this analysis; or 3) a new species is listed or critical habitat designated that may be affected by the action.

Thank you for your concern for endangered and threatened species and New Mexico's wildlife habitats. In future correspondence regarding this project, please refer to consultation \#02ENNM00-2014-I-0014. If you have any questions, please contact Michelle Christman of my staff at (505) 761-4715.

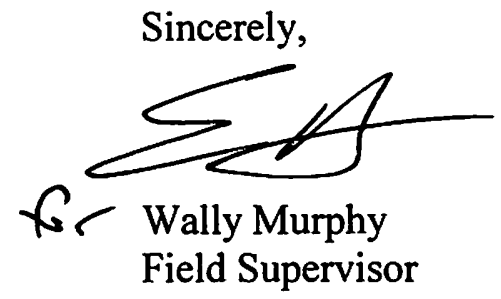

cc:

Wildlife Biologist, Cuba Ranger District, Cuba, NM (Attn: Ramon Borrego) Director, New Mexico Department of Game and Fish, Santa Fe, New Mexico 


\section{U.S. Fish \& Wildlife Service}

\section{MSGP}

\section{IPaC Trust Resource Report}

Generated July 27, 2015 07:29 PM MDT

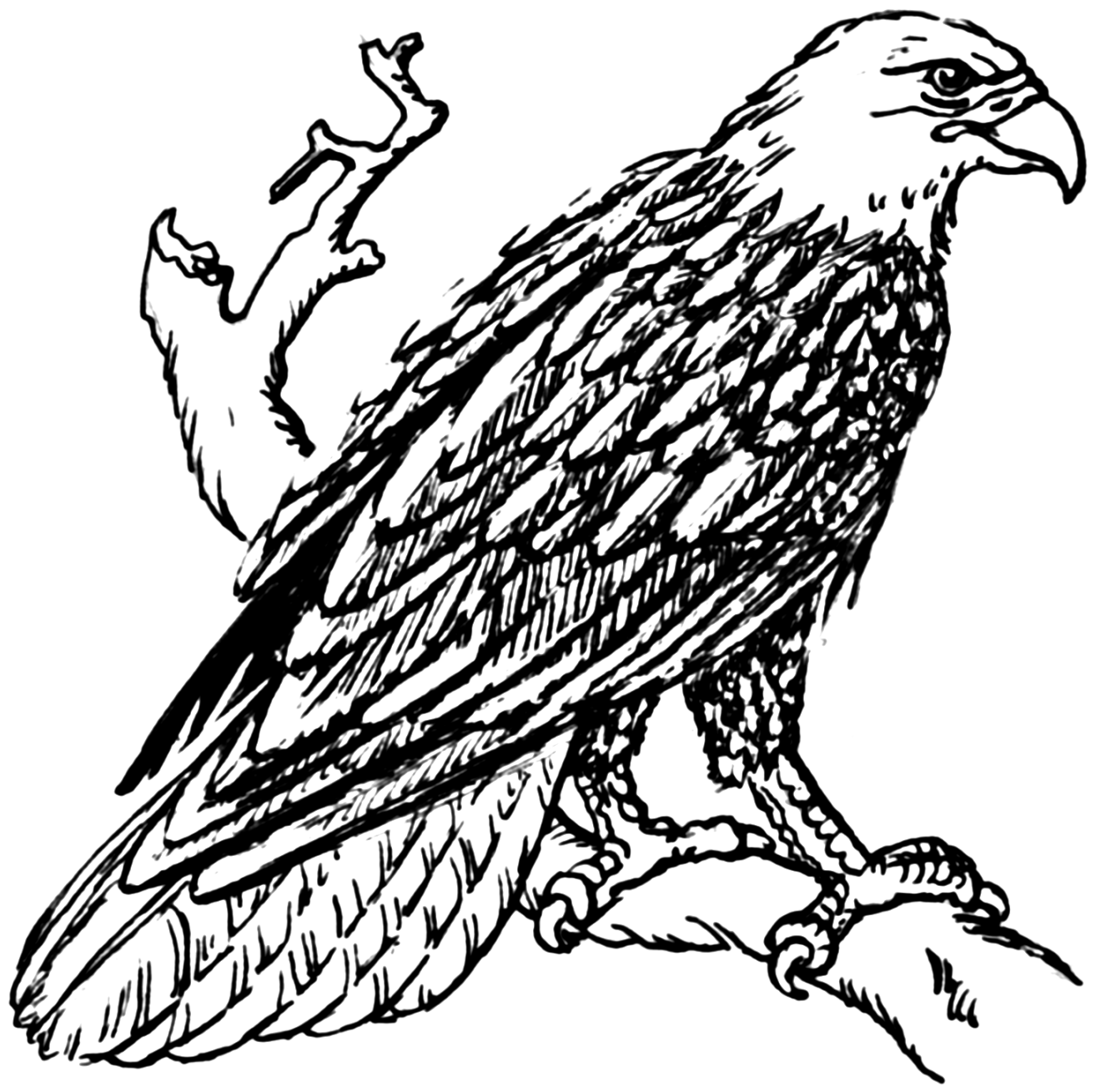


US Fish \& Wildlife Service

\section{IPaC Trust Resource Report}

\section{Project Description}

NAME

MSGP

PROJECT CODE

LXATM-TI5EJ-BAJEQ-3NC5E-SOGYTE

LOCATION

Los Alamos County, New Mexico

DESCRIPTION

Facilities that discharge to Sandia

Canyon within TA-3 and TA-60.

Industrial facilities subject to the MSGP. July, 2015.

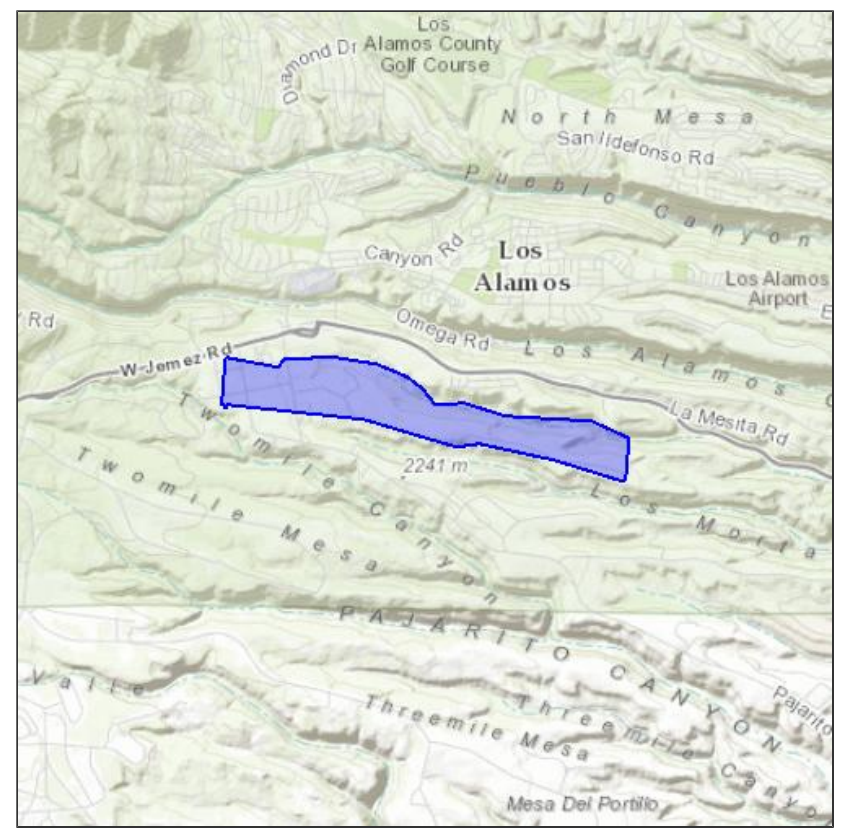

\section{U.S. Fish \& Wildlife Contact Information}

Species in this report are managed by:

New Mexico Ecological Services Field Office

2105 Osuna Road Ne

Albuquerque, NM 87113-1001

(505) 346-2525 


\section{Endangered Species}

Proposed, candidate, threatened, and endangered species that are managed by the Endangered Species Program and should be considered as part of an effect analysis for this project.

This unofficial species list is for informational purposes only and does not fulfill the requirements under Section 7 of the Endangered Species Act, which states that Federal agencies are required to "request of the Secretary of Interior information whether any species which is listed or proposed to be listed may be present in the area of a proposed action." This requirement applies to projects which are conducted, permitted or licensed by any Federal agency.

A letter from the local office and a species list which fulfills this requirement can be obtained by returning to this project on the IPaC website and requesting an Official Species List from the regulatory documents section.

\section{Amphibians}

Jemez Mountains Salamander Plethodon neomexicanus

Endangered

CRITICAL HABITAT

There is final critical habitat designated for this species.

https://ecos.fws.gov/speciesProfile/profile/speciesProfile.action?spcode=D019

\section{Birds}

Mexican Spotted Owl Strix occidentalis lucida

Threatened

CRITICAL HABITAT

There is final critical habitat designated for this species.

https://ecos.fws.gov/speciesProfile/profile/speciesProfile.action?spcode=B074

Southwestern Willow Flycatcher Empidonax traillii extimus

Endangered

CRITICAL HABITAT

There is final critical habitat designated for this species.

https://ecos.fws.gov/speciesProfile/profile/speciesProfile.action?spcode=B094

Yellow-billed Cuckoo Coccyzus americanus

Threatened

CRITICAL HABITAT

There is proposed critical habitat designated for this species.

https://ecos.fws.gov/speciesProfile/profile/speciesProfile.action?spcode=B06R

\section{Mammals}

New Mexico Meadow Jumping Mouse Zapus hudsonius luteus

Endangered

CRITICAL HABITAT

There is proposed critical habitat designated for this species.

https://ecos.fws.gov/speciesProfile/profile/speciesProfile.action?spcode=A0BX 


\section{Critical Habitats}

Potential effects to critical habitat(s) within the project area must be analyzed along with the endangered species themselves.

There is no critical habitat within this project area 


\section{Migratory Birds}

Birds are protected by the Migratory Bird Treaty Act and the Bald and Golden Eagle Protection Act.

Any activity which results in the take of migratory birds or eagles is prohibited unless authorized by the U.S. Fish and Wildlife Service (1). There are no provisions for allowing the take of migratory birds that are unintentionally killed or injured.

You are responsible for complying with the appropriate regulations for the protection of birds as part of this project. This involves analyzing potential impacts and implementing appropriate conservation measures for all project activities.

Bald Eagle Haliaeetus leucocephalus

Season: Wintering

https://ecos.fws.gov/speciesProfile/profile/speciesProfile.action?spcode=B008

Bendire's Thrasher Toxostoma bendirei

Season: Breeding

Brewer's Sparrow Spizella breweri

Season: Migrating https://ecos.fws.gov/speciesProfile/profile/speciesProfile.action?spcode=BOHA

Brown-capped Rosy-finch Leucosticte australis Season: Wintering

Burrowing Owl Athene cunicularia Season: Breeding

Cassin's Finch Carpodacus cassinii Year-round

Flammulated Owl Otus flammeolus Season: Breeding https://ecos.fws.gov/speciesProfile/profile/speciesProfile.action?spcode=B0DK

Fox Sparrow Passerella iliaca Season: Wintering

Golden Eagle Aquila chrysaetos

Year-round https://ecos.fws.gov/speciesProfile/profile/speciesProfile.action?spcode=BODV

Grace's Warbler Dendroica graciae

Bird of conservation concern

Bird of conservation concern Season: Breeding

Juniper Titmouse Baeolophus ridgwayi Year-round

Lewis's Woodpecker Melanerpes lewis Year-round

Loggerhead Shrike Lanius ludovicianus Year-round https://ecos.fws.gov/speciesProfile/profile/speciesProfile.action?spcode=BOFY

Bird of conservation concern

Bird of conservation concern

Bird of conservation concern

Bird of conservation concern

Bird of conservation concern

Bird of conservation concern

Bird of conservation concern

Bird of conservation concern

Bird of conservation concern

Bird of conservation concern 
Mountain Plover Charadrius montanus

Bird of conservation concern

Season: Breeding

https://ecos.fws.gov/speciesProfile/profile/speciesProfile.action?spcode=B078

Olive-sided Flycatcher Contopus cooperi

Season: Breeding

https://ecos.fws.gov/speciesProfile/profile/speciesProfile.action?spcode=B0AN

Peregrine Falcon Falco peregrinus

Bird of conservation concern

Season: Breeding

https://ecos.fws.gov/speciesProfile/profile/speciesProfile.action?spcode=B0FU

Pinyon Jay Gymnorhinus cyanocephalus

Year-round

Prairie Falcon Falco mexicanus

Bird of conservation concern

Year-round

https://ecos.fws.gov/speciesProfile/profile/speciesProfile.action?spcode=B0ER

Swainson's Hawk Buteo swainsoni

Bird of conservation concern

Season: Breeding

https://ecos.fws.gov/speciesProfile/profile/speciesProfile.action?spcode =B070

Williamson's Sapsucker Sphyrapicus thyroideus

Bird of conservation concern

Bird of conservation concern

Season: Breeding

https://ecos.fws.gov/speciesProfile/profile/speciesProfile.action?spcode=B0FX

Willow Flycatcher Empidonax traillii

Bird of conservation concern

Season: Breeding

https://ecos.fws.gov/speciesProfile/profile/speciesProfile.action?spcode=B0F6

Bird of conservation concern 


\section{Refuges}

Any activity proposed on National Wildlife Refuge lands must undergo a 'Compatibility Determination' conducted by the Refuge. If your project overlaps or otherwise impacts a Refuge, please contact that Refuge to discuss the authorization process.

There are no refuges within this project area 


\section{Wetlands}

Impacts to NWI wetlands and other aquatic habitats from your project may be subject to regulation under Section 404 of the Clean Water Act, or other State/Federal Statutes.

Project proponents should discuss the relationship of these requirements to their project with the Regulatory Program of the appropriate U.S. Army Corps of Engineers District.

\section{DATA LIMITATIONS}

The Service's objective of mapping wetlands and deepwater habitats is to produce reconnaissance level information on the location, type and size of these resources. The maps are prepared from the analysis of high altitude imagery. Wetlands are identified based on vegetation, visible hydrology and geography. A margin of error is inherent in the use of imagery; thus, detailed on-the-ground inspection of any particular site may result in revision of the wetland boundaries or classification established through image analysis.

The accuracy of image interpretation depends on the quality of the imagery, the experience of the image analysts, the amount and quality of the collateral data and the amount of ground truth verification work conducted. Metadata should be consulted to determine the date of the source imagery used and any mapping problems.

Wetlands or other mapped features may have changed since the date of the imagery or field work. There may be occasional differences in polygon boundaries or classifications between the information depicted on the map and the actual conditions on site.

\section{DATA EXCLUSIONS}

Certain wetland habitats are excluded from the National mapping program because of the limitations of aerial imagery as the primary data source used to detect wetlands. These habitats include seagrasses or submerged aquatic vegetation that are found in the intertidal and subtidal zones of estuaries and nearshore coastal waters. Some deepwater reef communities (coral or tuberficid worm reefs) have also been excluded from the inventory. These habitats, because of their depth, go undetected by aerial imagery.

\section{DATA PRECAUTIONS}

Federal, state, and local regulatory agencies with jurisdiction over wetlands may define and describe wetlands in a different manner than that used in this inventory. There is no attempt, in either the design or products of this inventory, to define the limits of proprietary jurisdiction of any Federal, state, or local government or to establish the geographical scope of the regulatory programs of government agencies. Persons intending to engage in activities involving modifications within or adjacent to wetland areas should seek the advice of appropriate federal, state, or local agencies concerning specified agency regulatory programs and proprietary jurisdictions that may affect such activities.

There are no wetlands identified in this project area 
LA-UR-14-21863

Approved for public release;

distribution is unlimited.

\title{
Title: $\quad$ Threatened and Endangered Species Habitat Management Plan for Los Alamos National Laboratory
}

\author{
Author(s): $\quad$ Environmental Protection Division \\ Resources Management Team
}

Intended for:

Reference purposes

Date: $\quad$ March 2014

Los Alamos National Laboratory, an affirmative action/equal opportunity employer, is operated by the Los Alamos National Security, LLC for the National Nuclear Security Administration of the U.S. Department of Energy under contract DE-AC52-06NA25396. By acceptance of this article, the publisher recognizes that the U.S. Government retains a nonexclusive, royalty-free license to publish or reproduce the published form of this contribution, or to allow others to do so, for U.S. Government purposes. Los Alamos National Laboratory requests that the publisher identify this article as work performed under the auspices of the U.S. Department of Energy. Los Alamos National Laboratory strongly supports academic freedom and a researcher's right to publish; as an institution, however, the Laboratory does not endorse the viewpoint of a publication or guarantee its technical correctness. 



\section{Contents}

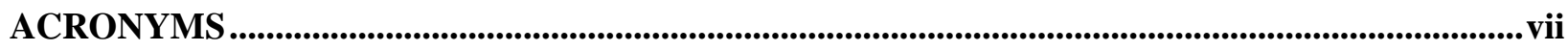

I. THREATENED AND ENDANGERED SPECIES HABITAT MANAGEMENT PLAN GENERAL OVERVIEW ................................................................................................................. 1

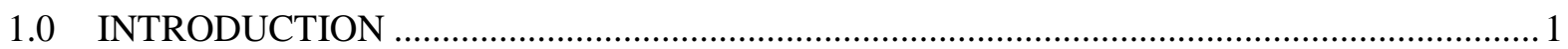

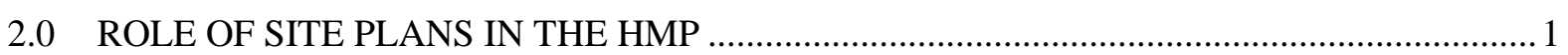

3.0 DESCRIPTION OF AREAS OF ENVIRONMENTAL INTEREST …..................................... 1

3.1 Definition and Role of Developed Areas in AEI Management ............................................ 1

3.2 General Description of Buffer Areas and Allowable Buffer Area Development .....................2

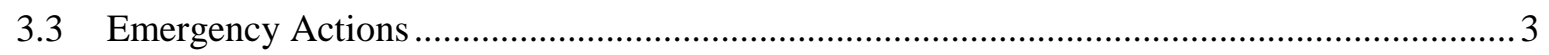

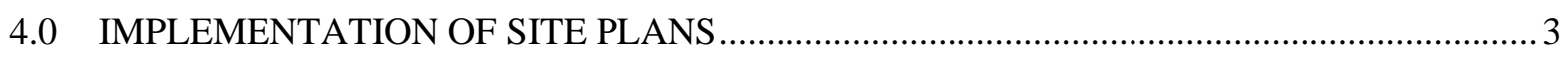

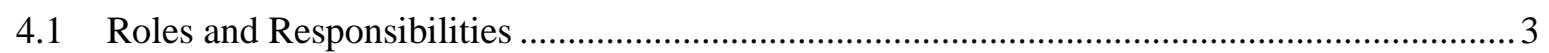

4.2 If an Activity Does Not Meet Site Plan Guidelines ........................................................... 4

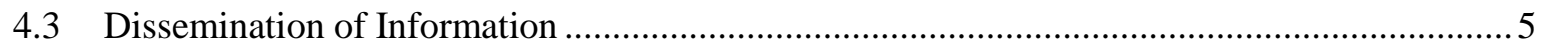

5.0 CHANGES IN THE HMP SINCE IMPLEMENTION ......................................................... 5

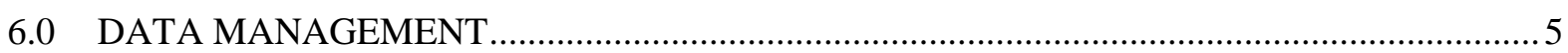

II. AREA OF ENVIRONMENTAL INTEREST SITE PLAN FOR THE MEXICAN SPOTTED

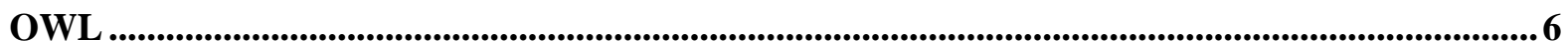

1.0 SPECIES DESCRIPTION—MEXICAN SPOTTED OWL _................................................... 6

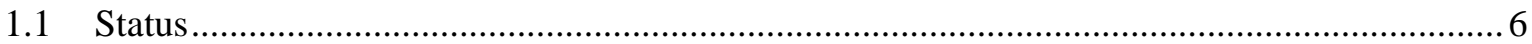

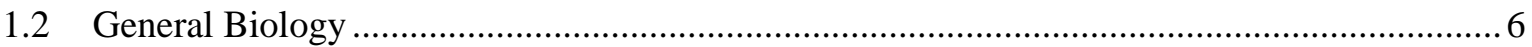

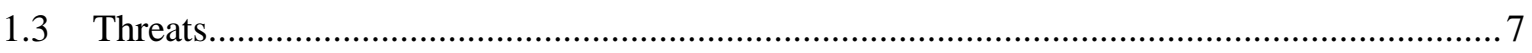

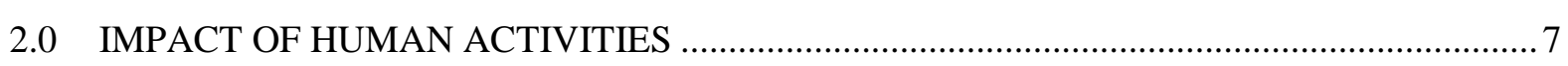

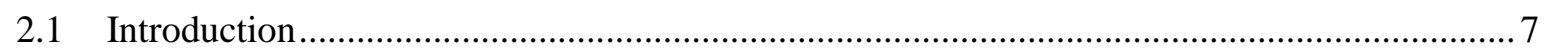

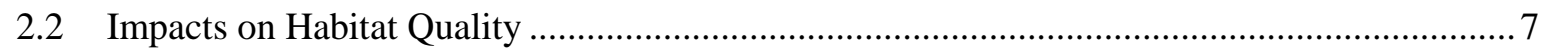

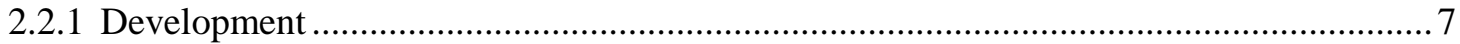

2.2.2 Ecological Risk ......................................................................................... 7

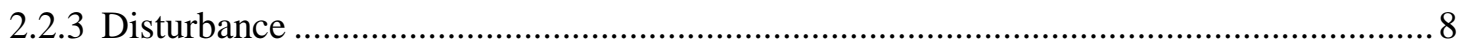

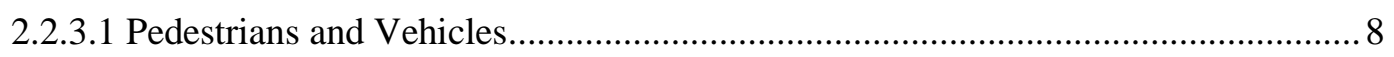

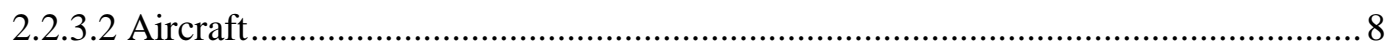

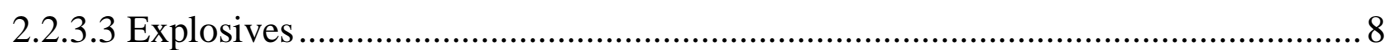

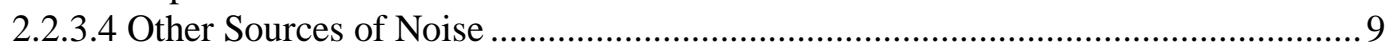

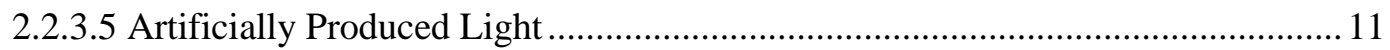

3.0 AEI GENERAL DESCRIPTION FOR MEXICAN SPOTTED OWL ….................................. 11

3.1 Method for Identifying a Mexican Spotted Owl AEI ........................................................... 12

3.2 Location and Number of Mexican Spotted Owl AEIs ........................................................ 12

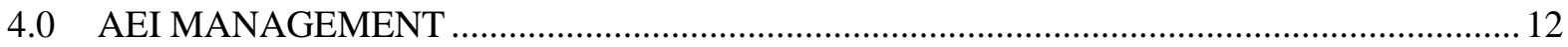

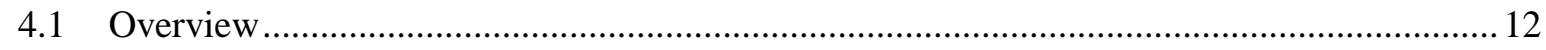

4.2 Definition and Role of Occupancy in AEI Management .................................................... 13 


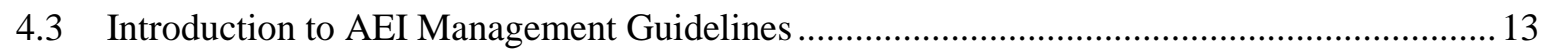

4.4 Definition of and Restrictions on Habitat Alterations............................................................ 14

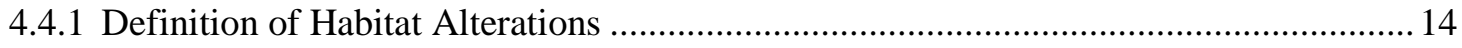

4.4.2 Fuels Management Practices to Reduce Wildfire Risk ................................................... 14

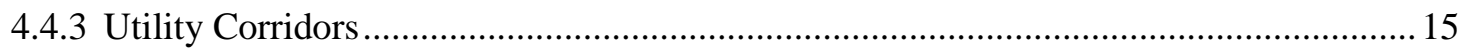

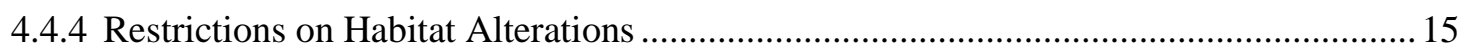

4.5 Definition of and Restrictions on Disturbance Activities ................................................... 15

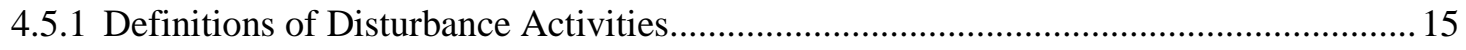

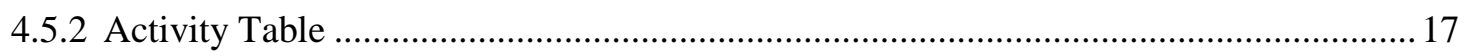

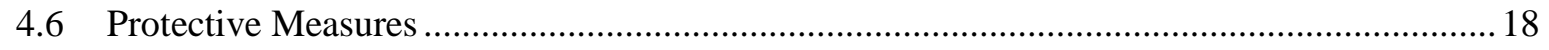

5.0 LEVELS OF DEVELOPMENT IN AEI CORE AND BUFFERS ........................................ 19

5.1 Allowable Habitat Alteration in the Buffer Areas .............................................................. 19

\section{AREA OF ENVIRONMENTAL INTEREST SITE PLAN FOR THE SOUTHWESTERN}

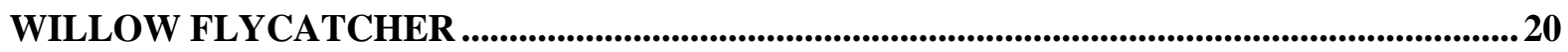

1.0 SPECIES DESCRIPTION—SOUTHWESTERN WILLOW FLYCATCHER ........................20

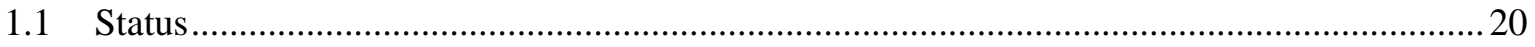

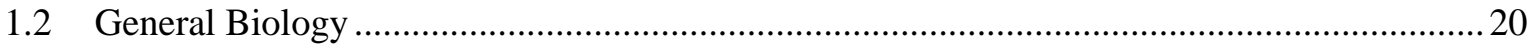

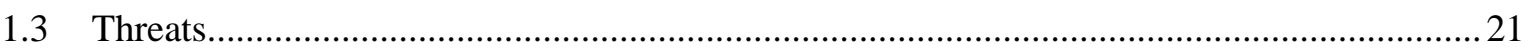

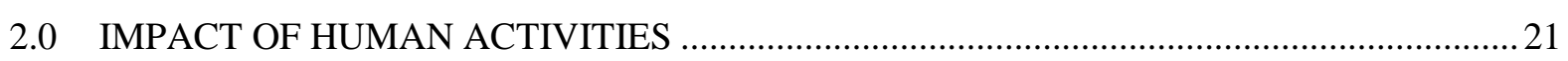

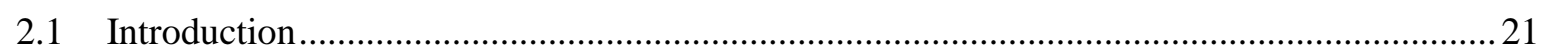

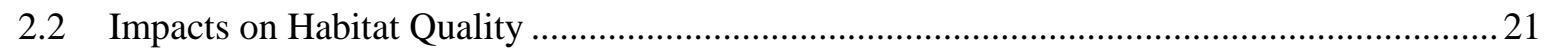

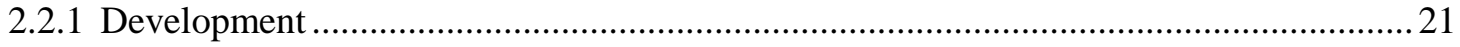

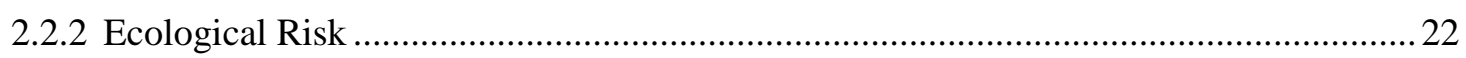

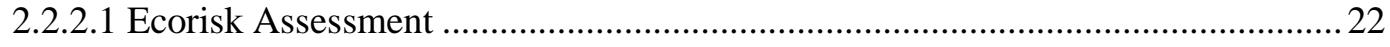

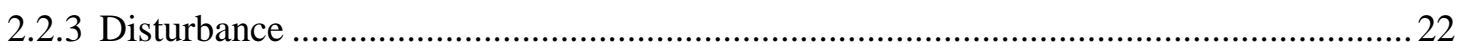

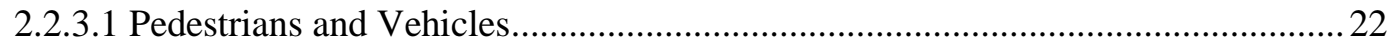

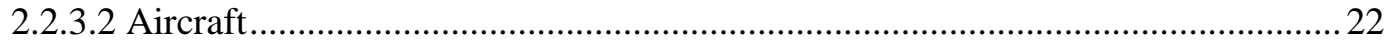

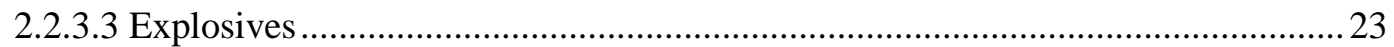

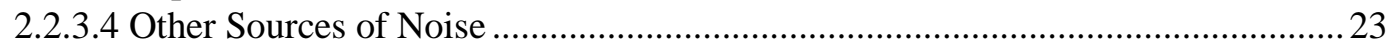

2.2.3.5 Artificially Produced Light ................................................................................ 23

3.0 AEI GENERAL DESCRIPTION FOR SOUTHWESTERN WILLOW FLYCATCHER ..........23

3.1 Method for Identifying the Southwestern Willow Flycatcher AEI........................................23

3.2 Location of the Southwestern Willow Flycatcher AEI .......................................................23

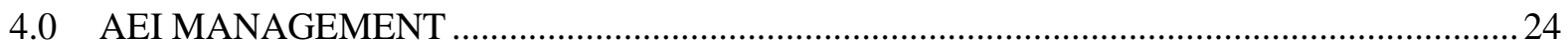

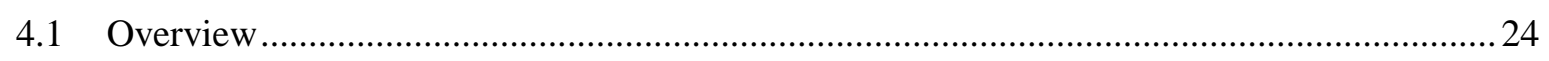

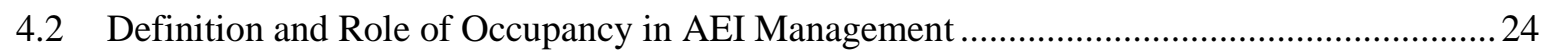

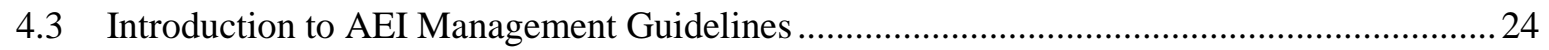

4.4 Definition of and Restrictions on Habitat Alterations ..........................................................2

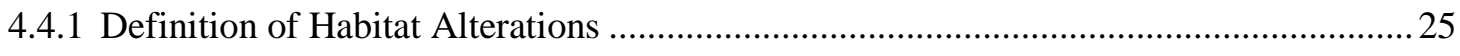

4.4.2 Fuels Management Practices to Reduce Wildfire Risk ...............................................25 


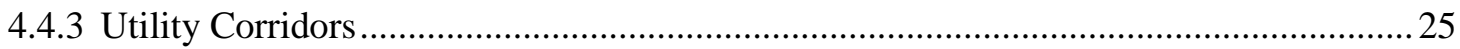

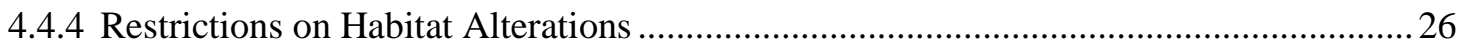

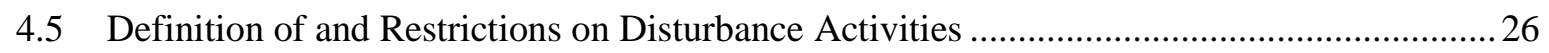

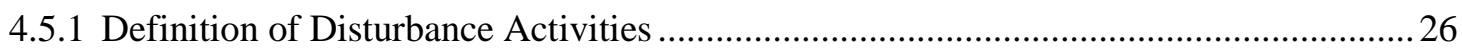

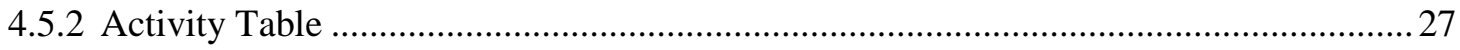

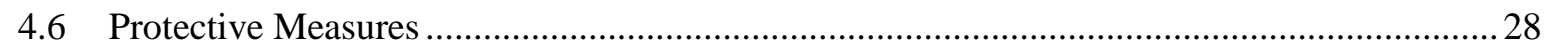

5.0 SOUTHWESTERN WILLOW FLYCATCHER AEI DESCRIPTION …..............................29

5.1 Pajarito Canyon Southwestern Willow Flycatcher AEI.....................................................29

5.1.1 Allowable Habitat Alteration in the Buffer Area ........................................................29

IV. AREA OF ENVIRONMENTAL INTEREST SITE PLAN FOR THE JEMEZ MOUNTAINS

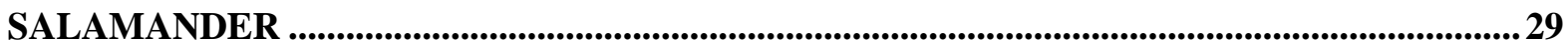

1.0 SPECIES DESCRIPTION_JEMEZ MOUNTAINS SALAMANDER …............................29

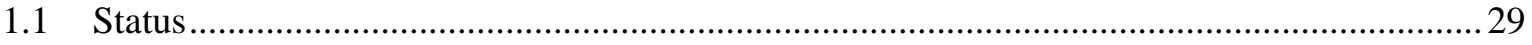

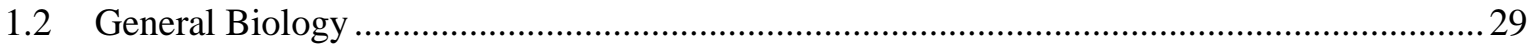

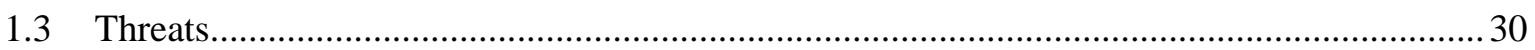

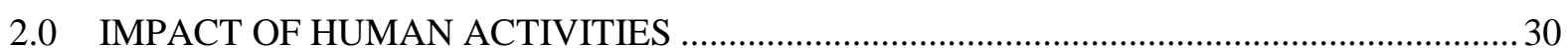

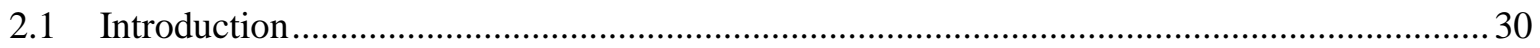

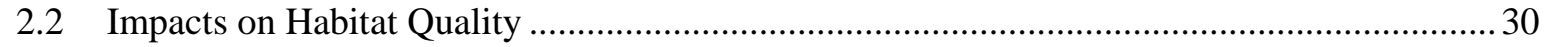

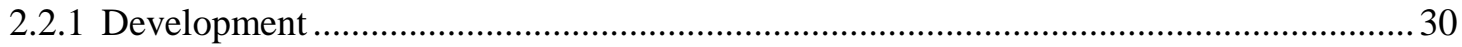

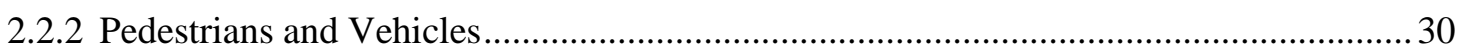

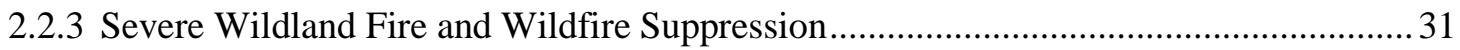

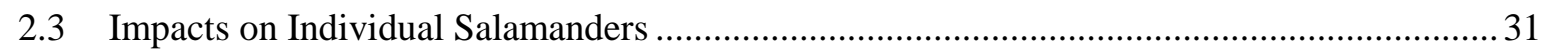

2.3.1 Disease 31

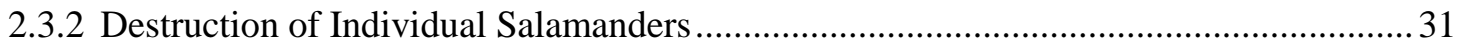

3.0 AEI GENERAL DESCRIPTION FOR JEMEZ MOUNTAINS SALAMANDER.....................31

3.1 Method for Identifying a Jemez Mountains Salamander AEI................................................ 32

3.2 Location and Number of Jemez Mountains Salamander AEIs ............................................. 33

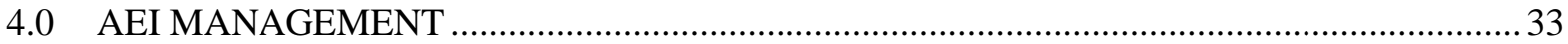

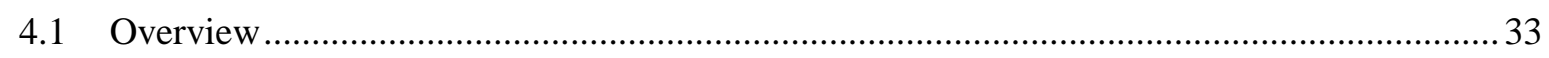

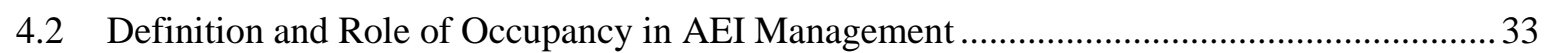

4.3 Definition and Role of Developed Areas in AEI Management …......................................... 34

4.4 General Description of Core and Buffer Areas and Allowable Area Development ............... 34

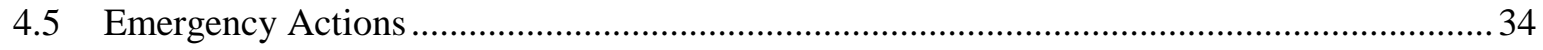

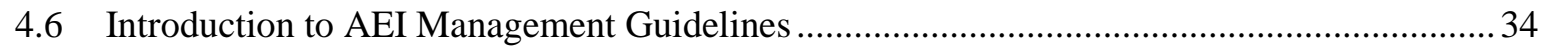

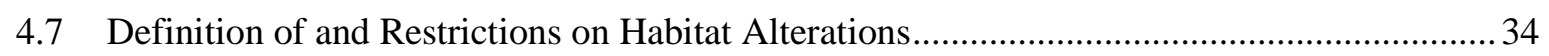

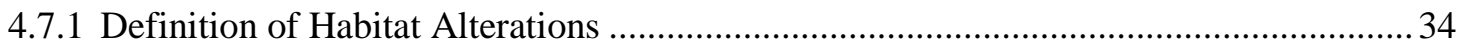

4.7.2 Fuels Management Practices to Reduce Wildfire Risk ……….......................................... 35

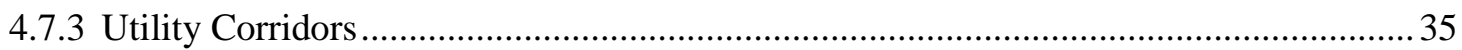

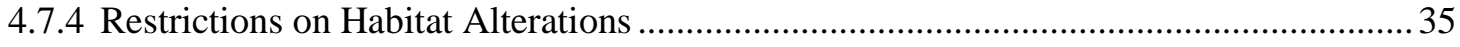




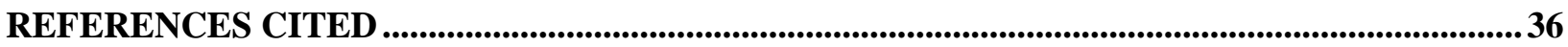

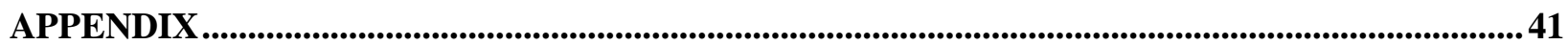

\section{Figure}

Figure 1. Process flowchart for determining site plan requirements.

\section{Tables}

Table 1. Restrictions on Activities in Undeveloped Occupied Mexican Spotted Owl AEIs... 18

Table 2. Restrictions on Activities in Undeveloped Occupied Southwestern Willow

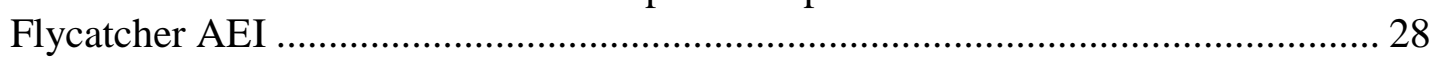

Table A-1. The percentage of each food type found in Mexican Spotted Owl food remains

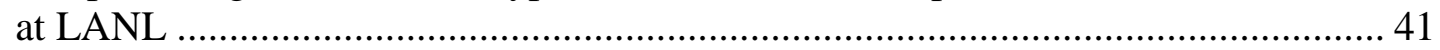

Table A-2. Preliminary light measurements in ftc for Mexican Spotted Owl site plan.............. 41 


\section{ACRONYMS}

AEI Area of Environmental Interest

BA biological assessment

Bd Batrachochytrium dendrobatidis

BSL-3 Biosafety Level 3

COPCs chemicals of potential concern

DARHT Dual-Axis Radiographic Hydrodynamic Test (Facility)

dB Decibel

DDT (dichloro-diphenyl-trichloroethane)

DOE U.S. Department of Energy

EPA Environmental Protection Agency

ESA Endangered Species Act of 1973

fc foot candles

FR Federal Register

GIS geographic information system

HMP Threatened and Endangered Species Habitat Management Plan

HVAC heating, ventilation, and air conditioning

LANL Los Alamos National Laboratory

NEPA National Environmental Policy Act

NMED New Mexico Environment Department

NPDES National Pollutant Discharge Eliminations System

PCBs polychlorinated biphenyls

PR-ID Permits and Requirements Identification

SME subject matter expert

USFWS U.S. Fish and Wildlife Service 


\section{THREATENED AND ENDANGERED SPECIES HABITAT MANAGEMENT PLAN GENERAL OVERVIEW}

\subsection{INTRODUCTION}

Los Alamos National Laboratory's (LANL) Threatened and Endangered Species Habitat Management Plan (HMP) was prepared to fulfill a commitment made in the U.S. Department of Energy's (DOE) "Final Environmental Impact Statement for the Dual-Axis Radiographic Hydrodynamic Test Facility Mitigation Action Plan" (DOE 1996). The HMP received concurrence from the U.S. Fish and Wildlife Service (USFWS) in 1999 (USFWS consultation numbers 2-22-98-I-336 and 2-22-95-I-108). In this 2014 update, we retained the management guidelines from the 1999 HMP for listed species, updated some descriptive information, and added the Jemez Mountains salamander (Plethodon neomexicanus), which was federally listed in September 2013 (USFWS consultation number 02ENNM00-2014-I-0014).

\subsection{ROLE OF SITE PLANS IN THE HMP}

The purpose of the HMP is to provide a management strategy for the protection of threatened and endangered species and their habitats on LANL property. The HMP consists of site plans for federally listed threatened or endangered species with a moderate or high probability of occurring at LANL. The following federally listed threatened or endangered species currently have site plans at LANL: Mexican Spotted Owl (Strix occidentalis lucida), Southwestern Willow Flycatcher (Empidonax trailii extimus), and the Jemez Mountains salamander. Site plans provide guidance to ensure that LANL operations do not adversely affect threatened or endangered species or their habitats.

\subsection{DESCRIPTION OF AREAS OF ENVIRONMENTAL INTEREST}

Suitable habitats for federally listed threatened and endangered species have been designated as Areas of Environmental Interest (AEIs). AEIs are geographical units at LANL that are managed for the protection of federally listed species and consist of core habitat areas and buffer areas. The purpose of the core habitat is to protect areas essential for the existence of the specific threatened or endangered species. This includes the appropriate habitat type for breeding, prey availability, and micro-climate conditions. The purpose of buffer areas is to protect core areas from undue disturbance and habitat degradation.

Site plans identify restrictions on activities within the AEIs. Allowable activities are activities that the USFWS has reviewed and provided concurrence that these activities are not likely to adversely affect federally listed species. Activities discussed in site plans include day-to-day activities causing disturbance (hereafter referred to as "disturbance activities"), such as access into an AEI, and long-term impacts, such as habitat alteration.

\subsection{Definition and Role of Developed Areas in AEI Management}

Summary: Habitat alteration is not restricted in developed areas unless it impacts undeveloped core areas of an AEI (e.g., noise and light impacts on a core area). Current ongoing disturbance activities are not restricted in developed areas. Disturbance activities not currently ongoing are 
restricted when impacts occur to undeveloped core areas of an AEI that are occupied by a threatened or endangered species.

Developed areas include all building structures, paved roads, improved gravel roads, paved and unpaved parking lots, and firing sites. The extent of developed areas in each AEI was determined using two methods. First, LANL geographic information system (GIS) analysts placed a $15 \mathrm{~m}$ (49 ft) border around all buildings and parking lots. For paved and improved gravel roads, the developed area was defined as the area to a roadside fence, if one exists within $9 \mathrm{~m}(30 \mathrm{ft})$ of the road, or $5 \mathrm{~m}(15 \mathrm{ft})$ on each side of the road, if there is no fence within $9 \mathrm{~m}(30 \mathrm{ft})$. If an area of highly fragmented habitat was enclosed by roads, a security fence, or connected buildings, that area was also classified as developed. Developed areas at firing sites were defined as a circle with a 91-m (300-ft) radius from the most centrally located firing pad. Second, LANL GIS analysts overlaid scanned orthophotos onto a map of the Los Alamos area and digitized all areas that appeared developed. These two information sources were overlaid and combined, so that areas classified as developed by either method were considered developed in final maps and analyses. Some areas were confirmed by ground surveys, such as the firing sites. Developed areas are contained in the HMP GIS database.

Developed areas are located in the core and/or buffer of some AEIs. However, developed areas do not constitute suitable habitat for federally listed species. Current ongoing activities in developed areas constitute a baseline condition for the AEIs and are not restricted. New activities including further development within already existing developed areas are not restricted unless they impact undeveloped portions of an AEI core. For example, if light or noise from a new office building in a developed area were to raise levels in an undeveloped core area, those light and noise levels would be subject to the guidelines on habitat alterations. If a proposed action within a developed area does not meet site plan guidelines, it must be individually reviewed for compliance with the Endangered Species Act of 1973 (ESA).

Building a new structure or clearing land within a previously designated developed area in an AEI core does not add to the size of the developed area. New structures in core areas will not be given any developed-area border unless they are individually reviewed for ESA compliance.

Development occurring in the developed area in an AEI buffer can be given a $15 \mathrm{~m}(49 \mathrm{ft})$ developed-area border at the discretion of the project leader or facility manager. To expand the size of a developed area in a buffer based on new developments, please contact a LANL biological resources subject matter expert (SME) (http://int.lanl.gov/environment/bio/controls/index.shtml).

\subsection{General Description of Buffer Areas and Allowable Buffer Area Development}

Summary: Limited future development is allowed in the currently undeveloped DOE-controlled buffer area under the guidelines of this HMP as long as it does not alter habitat in the undeveloped AEI core (including light and noise guidelines). Development beyond the cap established for each AEI, or greater than 2 ha ( $5 \mathrm{ac}$ ) in size including the developed-area border, requires independent review for ESA compliance.

The purpose of buffer areas is to protect core areas from undue disturbance or habitat degradation. The current levels of development in buffer and core areas represent baseline conditions for this 
HMP. No further development is allowed in the core area under the guidelines of this HMP. A limited amount of development is allowed in buffer areas. Under the guidelines of this HMP, individual development projects are limited to $2 \mathrm{ha}(5 \mathrm{ac})$ in size, including a $15 \mathrm{~m}(49 \mathrm{ft})$ developed-area border around structures and a $5 \mathrm{~m}(15 \mathrm{ft})$ developed-area border around paved and improved gravel roads. Projects greater than 2 ha $(5 \mathrm{ac})$ in area require individual review for ESA compliance (see exceptions for fuels management activities and utility corridor maintenance). New development projects in AEI buffer areas must be reported to LANL biological resources SMEs for tracking (http://int.lanl.gov/environment/bio/controls/index.shtml). Descriptions of each of the AEIs give the total area in each buffer area available for development.

\subsection{Emergency Actions}

Summary: Contact DOE and LANL biological resources SMEs as soon as possible.

If safety and/or property is immediately threatened by something occurring within an AEI (for example, wildfire, water line breakage, etc.) managers may activate emergency actions. Contact a LANL biological resources SME (http://int.lanl.gov/environment/bio/controls/index.shtml), the Environmental Stewardship Group (1-505-665-8855), or the DOE Los Alamos Field Office (Field Office; 1-505-667-6819) as soon as possible. If the emergency occurs outside of regular business hours, contact the Emergency Management Office (1-505-667-6211). This office will then communicate with the appropriate LANL and DOE Field Office personnel.

\subsection{IMPLEMENTATION OF SITE PLANS}

\subsection{Roles and Responsibilities}

Summary: LANL's facility managers and operational staff are responsible for ensuring that activities are reviewed for compliance with all applicable site plans. Figure 1 illustrates the process for utilizing site plans. If activities follow approved guidance, there is no requirement for additional ESA regulatory compliance. However, additional National Environmental Policy Act (NEPA), cultural resources, wetlands, or other regulatory compliance actions may be required.

If an activity or project occurs outside of all LANL AEIs and will not impact habitat within an AEI, it does not have to be reviewed for ESA compliance, unless it is a large project. Projects that are larger than 2 ha $(5 \mathrm{ac})$ or cost more than $\$ 5$ million require an individual ESA compliance review, even if they are not located within an AEI.

LANL's facility managers are responsible for determining if operations within their geographic and/or programmatic area of responsibility comply with the guidelines in these site plans. Submission of a Permits and Requirements Identification (PR-ID) for a new or modified project is required under Program Description 400 (LANL 2013) and allows managers to identify the requirements within their project area. Deployed environmental professionals and core LANL biological resources SMEs are available to support facility managers. If activities follow site plan guidelines, they do not require any additional ESA regulatory compliance action. However, NEPA, cultural resources, wetlands, or other regulatory compliance actions are not addressed in site plans and additional compliance actions may be required. It is the responsibility of the project leader or facility management staff to ensure that all requirements are satisfied. If you have 
questions, contact biological, cultural, NEPA, or other environmental SMEs. Contacts can be found at http://int.lanl.gov/environment/compliance/ier/index.shtml.

A single facility may have one or more AEIs within its boundary and the AEIs may be for different species. Some AEIs overlap. In areas where overlap occurs, project managers must follow the guidelines for AEIs of all involved species.

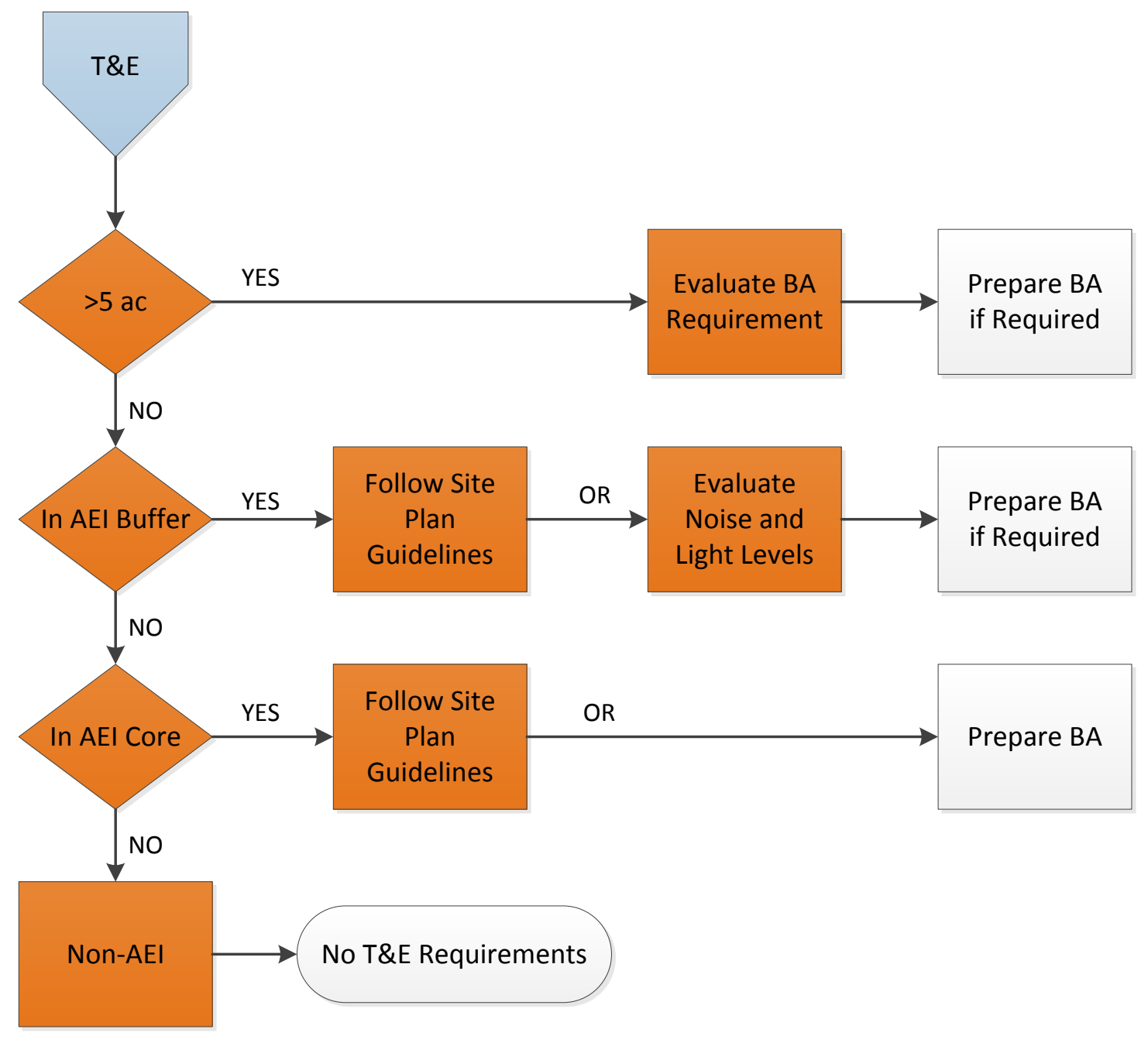

Figure 1. Process flowchart for determining site plan requirements.

\subsection{If an Activity Does Not Meet Site Plan Guidelines}

Summary: Activities or projects that do not meet all applicable site plan guidelines must be evaluated individually for compliance with the ESA.

If a project reviewer determines that an activity or project cannot meet the guidelines in applicable site plans, LANL biological resources SMEs evaluate that activity individually for compliance with the ESA. Results of the evaluation of potential impacts allow LANL biological resources SMEs to make recommendations to the DOE Field Office Biological Resources Program Manager 
regarding the need for USFWS consultation. An evaluation may result in 1) a DOE Field Office determination that there is no possibility of adverse effects and the activity can proceed, 2) a DOE Field Office suggestion for modifications of the action to avoid adverse effects so that it can proceed, or 3) a DOE Field Office decision to prepare a biological assessment (BA) for the activity and submit it to the USFWS for concurrence. Fieldwork and preparation of a BA can take a few months with an additional 2 to 12 months for DOE Field Office review and then final USFWS concurrence.

\subsection{Dissemination of Information}

Although information about threatened and endangered species is not classified, it is considered sensitive information. It is in the best interest of threatened and endangered species to restrict specific knowledge about their locations. Habitat locations of threatened and endangered species are not considered sensitive.

\subsection{CHANGES IN THE HMP SINCE IMPLEMENTION}

The HMP received concurrence from USFWS and was first implemented in 1999. Since that time, both the Peregrine Falcon (Falco peregrinus) and the Bald Eagle (Haliaeetus leucocephalus) have been delisted. Site plans for those species have been removed from LANL's HMP. Both species are protected at LANL under the Migratory Bird Treaty Act, and the Bald Eagle is also protected under the Bald and Golden Eagle Protection Act.

The black-footed ferret (Mustela nigripes) is federally listed as endangered. However, no sightings of black-footed ferrets have been reported in Los Alamos County for more than 50 years. In addition, no large prairie dog towns, which are prime habitat for black-footed ferrets, have been observed on DOE property around LANL. Therefore, there is no site plan for this species.

In 2005, the USFWS concurred with DOE's proposal for new Mexican Spotted Owl habitat boundaries based on a revised analysis of Mexican Spotted Owl habitat quality within DOE property around LANL (USFWS consultation number22420-2006-I-0010).

In 2012, the USFWS concurred with DOE's proposal to modify the habitat boundaries for the Los Alamos Canyon Mexican Spotted Owl AEI due to changes from the fire response activities after the Las Conchas wildfire (USFWS consultation number 02ENNM00-2012-IE-0088).

In 2013, the USFWS concurred with the DOE's new site plan for the Jemez Mountains salamander and its addition to LANL's HMP (USFWS consultation number 02ENNM00-2014-I-0014).

\subsection{DATA MANAGEMENT}

The data used in the implementation of the HMP is stored in a GIS database at LANL. 


\section{AREA OF ENVIRONMENTAL INTEREST SITE PLAN FOR THE MEXICAN SPOTTED OWL}

\subsection{SPECIES DESCRIPTION-MEXICAN SPOTTED OWL}

\subsection{Status}

In 1993, the USFWS determined the Mexican Spotted Owl to be a threatened species under the authority of the ESA, as amended (58 Federal Register [FR] 14248). In 1995, the USFWS released its final recovery plan for the owl (USFWS 1995), which was revised in 2012 (USFWS 2012). The USFWS most recently designated critical habitat for Mexican Spotted Owl in 2004 (69 FR 53181).

\subsection{General Biology}

The Mexican Spotted Owl is found in northern Arizona, southeastern Utah, and southwestern Colorado south through New Mexico, west Texas, and into Mexico. It is the only subspecies of Spotted Owl recognized in New Mexico (USFWS 1995).

The Mexican Spotted Owl generally inhabits mixed conifer and ponderosa pine (Pinus ponderosa; Lawson \& C. Lawson) - Gambel oak (Quercus gambelli; Nutt.) forests in mountains and canyons. High canopy closure, high stand diversity, multilayered canopy resulting from an uneven-aged stand, large, mature trees, downed logs, snags, and stand decadence as indicated by the presence of mistletoe are characteristic of Mexican Spotted Owl habitat. Some owls have been found in second-growth forests (i.e., younger forests that have been logged); however, these areas were found to contain characteristics typical of old-growth forests. Mexican Spotted Owls in the Jemez Mountains seem to prefer cliff faces in canyons for their nest sites (Johnson and Johnson 1985). The recovery plan for the Mexican Spotted Owl recommends that mixed conifer and pine-oak woodland types on slopes greater than 40 percent be protected for the conservation of this owl.

A mated pair of adult Spotted Owls may use the same home range and general nesting areas throughout their lives. A pair of owls requires approximately 800 ha $(1,976 \mathrm{ac})$ of suitable nesting and foraging habitat to ensure reproductive success. Incubation is carried out by the female. The incubation period is approximately 30 days, and most eggs hatch by the end of May. Most owlets fledge in June, 34 to 36 days after hatching (USFWS 1995). The owlets are "semi-independent" by late August or early September, although juvenile begging calls have been heard as late as September 30. Young are fully independent by early October. The non-breeding season runs from September 1 through February 28. Although seasonal movements vary among owls, most adults remain within their summer home ranges throughout the year.

The diet of Mexican Spotted Owls nesting in canyons consists primarily of woodrats (Neotoma spp.) and mice (Peromyscus spp.) with lesser amounts of rabbits, birds, reptiles, and arthropods (Willey 2013). The relative abundance of prey types in Mexican Spotted Owl pellets collected at LANL are listed in Table A-1 in the Appendix. Ganey and Balda (1994) found core areas of individuals (i.e., where owls spent 60 percent of their time) averaged 134 ha (331 ac), and core areas for pairs averaged $160 \mathrm{ha}(395 \mathrm{ac})$. 


\subsection{Threats}

The Mexican Spotted Owl was listed as threatened because of destruction and modification of habitat caused by timber harvest and fires, increased predation on owls associated with habitat fragmentation, and a lack of adequate protective regulations.

\subsection{IMPACT OF HUMAN ACTIVITIES}

\subsection{Introduction}

The primary threats to Mexican Spotted Owls on DOE property around LANL property are 1) impacts to habitat quality from LANL operations and 2) disturbance of nesting owls. This section provides a review and summary of scientific knowledge of the effects of various types of human activities on the Mexican Spotted Owl and provides an overview of the current levels of activities at LANL.

\subsection{Impacts on Habitat Quality}

\subsubsection{Development}

The type of habitat used by Mexican Spotted Owls, late seral stage forests with large trees, are usually not found in large quantities near developed areas or near areas that have had recent agricultural or forest product extraction land uses. Therefore, Mexican Spotted Owls are generally not found near developments. Whether it is the development itself or a lack of suitable habitat that discourages colonization of these areas by Mexican Spotted Owls is unknown.

Areas of LANL vary from remote undeveloped areas to heavily developed and/or industrialized facilities. Most LANL facilities are situated atop mesas, primarily in the northern and western portion of the DOE property. LANL is bounded by developed residential, industrial, and retail areas along its northern boundary (the town of Los Alamos) and by residential and retail development along a portion of its eastern boundary (the town of White Rock). Three major paved roads traverse LANL from northeast to southwest. Sandia, Pajarito, and Los Alamos canyons have paved roads within AEIs, and several AEIs have dirt roads along at least a portion of the canyon bottom. AEIs containing paved or dirt roads in the canyon bottoms have not been occupied at LANL (Hathcock et al. 2010).

\subsubsection{Ecological Risk}

There is no specific information on the impact of chemicals on the Mexican Spotted Owl, although experience with other raptor species suggests that exposure to polychlorinated biphenyls (PCBs), dichloro-diphenyl-trichloroethane (DDT) and its derivatives, and other organophosphate or organochlorine pesticides would probably be harmful. Exposure to other chemicals could also be harmful (Cain 1988).

LANL completed three ecological risk assessments that included the Mexican Spotted Owl between 1997 and 2009. The ecological risk assessment process involves using computer modeling to assess potential effects to animals from chemicals of potential concern (COPCs) that have been detected in the environment. All of the following ecological risk assessments concluded that, on average, no appreciable impact is expected to Mexican Spotted Owls from COPCs (Gallegos et al. 1997; Gonzales et al. 2004; Gonzales et al. 2009). 


\subsubsection{Disturbance}

\subsubsection{Pedestrians and Vehicles}

Based on work with other raptors, LANL biological resources SMEs assume that Mexican Spotted Owls would likely be disturbed by the approach of either pedestrians or vehicles. At an equal distance, pedestrians are frequently more disturbing to raptors than vehicles (Grubb and King 1991). Brown and Stevens (1997) reported that during surveys in Grand Canyon National Park, 22 times more Bald Eagles were found in canyon reaches with low human recreational use compared

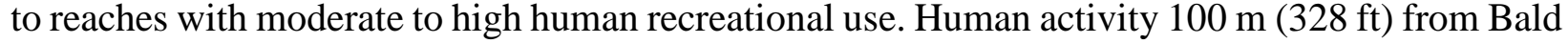
Eagle nests in Alaska caused clear and consistent changes in behavior of breeding eagles (Steidl and Anthony 2000).

Swarthout and Steidl (2001) found that both juvenile and adult roosting Mexican Spotted Owls were unlikely to alter their behavior in the presence of a single hiker at distances greater than $55 \mathrm{~m}$ $(180 \mathrm{ft})$. Swarthout and Steidl (2003) concluded that cumulative effects of high levels of short-duration recreational hiking near Mexican Spotted Owl nests may be detrimental.

Many canyon bottoms and mesa tops at LANL have dirt roads traversing them. Most of these roads are gated. However, these roads are accessible to LANL employees and some of them are accessible to the public on foot or by bike. LANL biological resources SMEs have found that AEIs are occupied less often if there is recreational access into a canyon (Hathcock et al. 2010).

\subsubsection{Aircraft}

Ground-based disturbances appear to impact raptor reproductive success more than aerial disturbances (Grubb and King 1991). Grubb and Bowerman (1997) concluded that an exclusion of aircraft within $600 \mathrm{~m}$ (1,968 ft) of Bald Eagle nest sites would limit Bald Eagle response frequency to 19 percent.

Delaney et al. (1999) found for Mexican Spotted Owls that chainsaws consistently elicited higher response rates than helicopters at similar distances. Owl flush rates did not differ between nesting and non-nesting seasons. No owls flushed when noise stimuli (helicopter or chainsaws) were at distances greater than $105 \mathrm{~m}(344 \mathrm{ft})$. Distance was generally a better predictor of owl response to helicopter overflights than sound level.

LANL is restricted airspace, and planes infrequently fly less than $609 \mathrm{~m}$ (2,000 ft) above ground level. The County of Los Alamos operates an airport along the northern edge of LANL. The airport is located on the southern rim of Pueblo Canyon. Most flights approach and depart to the east of the airport, over the Rio Grande.

\subsubsection{Explosives}

There is no specific information on the reaction of Mexican Spotted Owls to explosives detonation currently available. Explosive blasts set off 120 to $140 \mathrm{~m} \mathrm{(393} \mathrm{to} 459 \mathrm{ft}$ ) from active Prairie Falcon (Falco mexicanus) nests caused perched Prairie Falcons to flush from perches 79 percent of the time, and, in 26 percent of the cases, caused incubating Prairie Falcons to flush from nests. Measured sound levels at aerie entrances during blasts ranged from 129 to 141 decibel (dB) (Holthuijzen et al. 1990). Explosives blasting for dam construction 560 to 1,000 $\mathrm{m}(1,837$ to 3,280 ft) from active Prairie Falcon nests caused a change in behavior 26 percent of the time, and 
birds flushed in 17 percent of all cases. No incubating birds flushed (Holthuijzen et al. 1990). Brown et al. (1999) found little activity change in roosting or nesting Bald Eagles and no population-level impacts from weapons detonations at the Aberdeen Proving Ground. Holthuijzen et al. (1990) found that a 167-g (5.89-oz) charge of Kinestik produced noise levels between

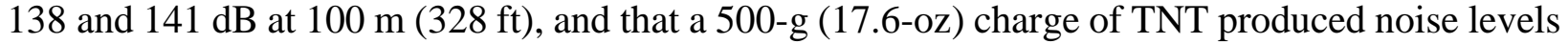
between 144 and $146 \mathrm{~dB}$ at $100 \mathrm{~m}(328 \mathrm{ft})$. A 20-kg (44-lb) charge of TNT produced noise levels that measured $163 \mathrm{~dB}$ at $100 \mathrm{~m}$ (328 ft) (Paakkonen 1991).

Measurements of noise levels during explosives testing were conducted at three locations at LANL using quantities of high explosives ranging from 4.5 to $67.5 \mathrm{~kg}$ (10 to $148 \mathrm{lb})$ of TNT during six shots. Noise levels increased during the test from a background level of $31 \mathrm{~dB}(\mathrm{~A})^{1}$ to a range between 64 and $71 \mathrm{~dB}(\mathrm{~A})$ during shots at a distance of $1.8 \mathrm{~km}(1.1 \mathrm{mi})$. At a distance of $4.3 \mathrm{~km}$ (2.67 mi), noise levels rose from a background range of 35 to $64 \mathrm{~dB}(\mathrm{~A})$ to a range of 60 to 63 $\mathrm{dB}(\mathrm{A})$ (Vigil 1995). At a distance of $6.7 \mathrm{~km}$ (4.16 mi), noise levels rose from a background range of 38 to $51 \mathrm{~dB}(\mathrm{~A})$ to a range of 60 to $71 \mathrm{~dB}(\mathrm{~A})$ (Burns 1995). LANL biological resources SMEs estimated that the noise from a shot at the Dual-Axis Radiographic Hydrodynamic Test (DARHT) Facility would be $150 \mathrm{~dB}(\mathrm{~A})$ at the source and $80 \mathrm{~dB}(\mathrm{~A})$ at $400 \mathrm{~m}(1,312 \mathrm{ft})$ (Keller and Risberg 1995). LANL biological resources SMEs found that Mexican Spotted Owl AEIs located within the explosives testing buffer area were occupied more frequently than AEIs in other locations (Hathcock et al. 2010). This is likely due to the strict access control in explosives areas which limit human activity and development in the canyon bottoms.

\subsubsection{Other Sources of Noise}

Major noise-producing activities at LANL include automobile and truck traffic and noise associated with office buildings, construction activities, a live-fire range, and explosives testing. Also, there is noise associated with aircraft traffic at the Los Alamos County airport. Construction and maintenance activities involved with operations at LANL are fairly common. In addition, implementation of the 2005 Compliance Order on Consent (NMED 2005) issued by the New Mexico Environmental Department (NMED) has resulted in an increased frequency of drilling groundwater monitoring wells in protected habitat at LANL. Also, forest fuels management operations use chainsaws, chippers, and other noise-generating equipment. The 2010 National Pollutant Discharge Elimination System (NPDES) Individual Permit (EPA 2010) issued by the Environmental Protection Agency (EPA) requires sediment control features such as berms and small rock check dams to be installed at various sites with stormwater runoff; these are sometimes installed in protected habitat. LANL biological resources SMEs conducted a study of noise levels in canyons and found that the primary sources of noise exceeding $55 \mathrm{~dB}(\mathrm{~A})$ were cars and trucks. Readings taken near flowing water were up to $11 \mathrm{~dB}(\mathrm{~A})$ higher than readings taken elsewhere. The average $\mathrm{dB}(\mathrm{A})$ in canyons near paved roads ranged from 41 to 62 , with maximum values ranging from 62 to 74 . Away from paved roads $1.6 \mathrm{~km}(1 \mathrm{mi})$ or more, average $\mathrm{dB}(\mathrm{A})$ in canyons ranged from 37 to 50, with all but one average below 45. Maximum $\mathrm{dB}(\mathrm{A})$ away from paved roads ranged from 38 to 76 [76 dB(A) was measured during a thunder clap] (Huchton et al. 1997).

\footnotetext{
${ }^{1}$ Sound can be measured as decibels $(\mathrm{dB})$, C-weighted $\mathrm{dB}[\mathrm{dB}(\mathrm{C})]$, or A-weighted $\mathrm{dB}[\mathrm{dB}(\mathrm{A})]$. The $\mathrm{dB}(\mathrm{A})$ measurement best resembles the response of the human ear by filtering out lower and higher frequency sound not normally heard by the human ear.
} 
Noise measurements were conducted by LANL biological resources SMEs at the Los Alamos County airport and in Bayo and Pueblo canyons, including the Los Alamos County Sewage Treatment Facility, in December 1997. Sound levels near the airport runway during the maximum use time (6:30 to 7:30 am) had background values averaging $54 \mathrm{~dB}(\mathrm{~A})$. Noise during plane arrivals ranged from 47 to $63 \mathrm{~dB}(\mathrm{~A})$. No measurements were collected during plane take-off. Sound measurements conducted in the bottoms of Pueblo and Bayo canyons ranged from 37 to $40 \mathrm{~dB}(\mathrm{~A})$ in most areas of the canyon. At the sewage treatment facility parking lot during a working day, the average $\mathrm{dB}(\mathrm{A})$ during a three-minute period was 46 (range 45 to 49). At the intersection of the road going into Pueblo Canyon with State Road 502, the average $\mathrm{dB}(\mathrm{A})$ during a three-minute period was 60 (range 41 to 70 ).

LANL biological resources SMEs conducted sound measurements at successive distances from an industrial area near a canyon rim, into the canyon, and to the opposite rim, using a C-weighted decibel scale (Keller and Foxx 1997). Measurements of noise levels using the C-weighted decibel scale are greater than if measured using A-weighted decibels. The average background noise on the mesa was $65.8 \mathrm{~dB}(\mathrm{C})$ [with a range of $43-81 \mathrm{~dB}(\mathrm{C})$ ]. The average background noise in the canyon bottom was $62.3 \mathrm{~dB}(\mathrm{C})$ [with a range of $54-78 \mathrm{~dB}(\mathrm{C})$ ]. The average background noise at the bottom of the north-facing slope was $53.8 \mathrm{~dB}(\mathrm{C})$ [with a range of $48-64 \mathrm{~dB}(\mathrm{C})$ ]. Measurements were taken mid-day.

LANL biological resources SMEs measured sound levels from various pieces of construction equipment used at project sites at LANL over 5-minute intervals at distances of 6 to $31 \mathrm{~m}$ (20 to $100 \mathrm{ft}$ ) (Knight and Vrooman 1999). Average values ranged from $58.5 \mathrm{~dB}(\mathrm{~A})$ to $80.9 \mathrm{~dB}(\mathrm{~A})$. Peak values ranged from 75.7 to $155.4 \mathrm{~dB}(\mathrm{~A})$. Additional data were collected by other LANL operators on specific pieces of construction equipment and on the Security Computer Complex construction site fence perimeter at Technical Area 3 before and during construction (Knight and Vrooman 1999). The average noise levels before construction began was $56.6 \mathrm{~dB}(\mathrm{~A})$, and the average during construction was $82.1 \mathrm{~dB}(\mathrm{~A})$.

LANL biological resources SMEs conducted a series of sound measurements at LANL to investigate background noise levels around AEIs (Vrooman et al. 2000). Background noise levels were significantly higher in daytime than in nighttime. AEIs with greater than 10 percent developed area in their buffers had significantly higher levels of background noise than undeveloped AEIs. Mean background sound levels were $51.3 \mathrm{~dB}(\mathrm{~A})$ in developed AEIs and $39.6 \mathrm{~dB}(\mathrm{~A})$ in undeveloped AEIs. The LANL biological resources project review process uses the individual AEI background measurements from Vrooman et al. (2000) to screen project activities for increases more than $6 \mathrm{~dB}(\mathrm{~A})$ above background.

LANL biological resources SMEs took sound level measurements of heavy equipment use associated with concrete recycling on Sigma Mesa at LANL in 2004 (Hansen 2004). At this location, background noise levels at two different locations were 55.2 and $58.8 \mathrm{~dB}(\mathrm{~A})$. Operation of a dump truck hauling and dumping concrete increased noise levels above background by a mean of $22.7 \mathrm{~dB}(\mathrm{~A})$ at $30 \mathrm{~m}(98 \mathrm{ft})$ and $2.4 \mathrm{~dB}(\mathrm{~A})$ at $80 \mathrm{~m} \mathrm{(262} \mathrm{ft).} \mathrm{Additional} \mathrm{sound} \mathrm{level} \mathrm{measurements}$ were taken in the same general area on Sigma Mesa in 2005 as part of a BA for the operation of an asphalt batch plant (Hansen 2005). Measurements were taken on the north rim of Mortandad Canyon (south of the asphalt batch plant at distances of approximately 30 to $122 \mathrm{~m}$ (100 to $400 \mathrm{ft}$ ), at the bottom of Mortandad Canyon, approximately 183 to $244 \mathrm{~m} \mathrm{(600} \mathrm{to} 800 \mathrm{ft}$ ) from the asphalt 
batch plant, and on the south rim of Mortandad Canyon approximately $305 \mathrm{~m}(1,000 \mathrm{ft})$ from the asphalt batch plant. Background noise levels at the various locations ranged from 41.1 to 48.7 $\mathrm{dB}(\mathrm{A})$. The only locations with increases greater than $3 \mathrm{~dB}(\mathrm{~A})$ during operation of the asphalt batch plant were the locations on the north rim of Mortandad Canyon, within $122 \mathrm{~m}$ (400 ft) of the asphalt batch plant. Noise from the operation of the asphalt batch plant was not detected in the bottom of Mortandad Canyon or on the south rim.

LANL biological resources SMEs took sound level measurements around the LANL Biosafety Level 3 (BSL-3) Laboratory with the heating, ventilation, and air conditioning (HVAC) system on and with it off (Hansen 2009). The area to the north of the BSL-3 is developed, the area to the south is not. Background noise levels north of the facility ranged from 53.6 to $57.6 \mathrm{~dB}(\mathrm{~A})$. Background noise levels south of the facility ranged from 41.6 to $49.7 \mathrm{~dB}(\mathrm{~A})$. Noise from the HVAC system was detected at $25 \mathrm{~m}(82 \mathrm{ft})$ from the facility on both sides, but was not detected at $81 \mathrm{~m}(266 \mathrm{ft})$ on

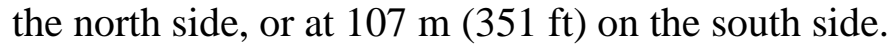

Overall, these studies appear to show that areas adjacent to or within developed areas or paved roads are likely to have daytime average background noise levels between 45 and $63 \mathrm{~dB}(\mathrm{~A})$. Less disturbed areas are likely to have average background noise levels between 37 and $50 \mathrm{~dB}(\mathrm{~A})$.

\subsubsection{Artificially Produced Light}

There is no information available on the effects of artificially produced light on Mexican Spotted Owls. Under the Los Alamos County Code, commercial site development plans are reviewed to ensure that lighting serves the intended use of the site while minimizing adverse impacts to adjacent residential property (Section 16-276). Section 16-276 of the County Code includes light source measurement limitations by zoning district. The code allows off-site light to be 0.5 foot candles (fc) in residential areas. By comparison, full moonlight measures $0.1 \mathrm{fc}$, and a crescent moon was measured at $0.01 \mathrm{fc}$. Table A-2 in the Appendix presents preliminary light measurements in fc.

Preliminary surveys were conducted for light levels within Los Alamos Canyon at the Omega Reactor (Keller and Foxx 1997). The Omega Reactor was brightly lit for purposes of security; therefore, total light intensity was greater than the average street lighting. Measurements were conducted at a light pole with an open parking lot at the reactor as the source. Trees did not obscure the area. Using the relationship of light intensity reducing as a square of the distance, calculations using the field data indicated that at $30 \mathrm{~m}(98 \mathrm{ft})$ from the source the light levels would be equivalent or nearly equivalent to full moonlight.

\subsection{AEI GENERAL DESCRIPTION FOR MEXICAN SPOTTED OWL}

An AEI consists of two areas - a core and a buffer. The core of the habitat is defined as suitable

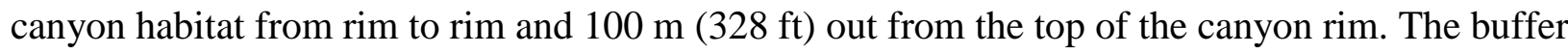
area is $400 \mathrm{~m}(1,312 \mathrm{ft})$ wide extending outward from the edge of the core area. Although adult Mexican Spotted Owls may be found within their home range anytime throughout the year, the primary threat from disturbance to the owls is during the breeding season when owl pairs are tied to their nest sites. Therefore, management of disturbance in Mexican Spotted Owl AEIs is concentrated on the breeding season. 


\subsection{Method for Identifying a Mexican Spotted Owl AEI}

The original location of each Mexican Spotted Owl AEI was identified using a habitat model developed by Johnson (1998) that classified nesting and roosting habitat for Mexican Spotted Owls using topographic characteristics and vegetative diversity. LANL biological resources SMEs compared the results from the Johnson (1998) model to a different model identifying slopes $>40$ percent in mixed conifer and ponderosa pine cover types at LANL. Areas identified from the Johnson (1998) model application to LANL that were over five contiguous $30 \times 30 \mathrm{~m}(97 \times 98 \mathrm{ft})$ pixels in size, were above $1,980 \mathrm{~m}(6,496 \mathrm{ft})$ in elevation, and that had mixed conifer or ponderosa pine forest cover, were considered suitable Mexican Spotted Owl habitat. Where suitable habitat was identified, AEI core area boundaries were established to include the canyons and $100 \mathrm{~m}$ (328ft) outward from the canyon rims.

A new Mexican Spotted Owl habitat model was developed and refined for application on LANL following the Cerro Grande wildfire (Hathcock and Haarmann 2008). This model incorporated finer-scale vegetation characteristics into the Mexican Spotted Owl habitat quality assessment. This model was used to redelineate the boundaries of the Mexican Spotted Owl AEIs at LANL in 2005 following wildfire, drought, and a regional bark beetle outbreak (USFWS consultation number 22420-2006-I-0010).

The new core boundaries were delineated with an area approximately $0.4 \mathrm{~km}(0.25 \mathrm{mi})$ from the edge of the nearest suitable habitat, up and down canyon. Core boundaries were established along readily recognizable geologic features or anthropogenic features in the terrain wherever possible to facilitate the ease of identification of core boundaries when in the field.

\subsection{Location and Number of Mexican Spotted Owl AEls}

There are currently five Mexican Spotted Owl AEIs on LANL, each encompassing one or more canyons. In general, the AEI cores are centered in canyons on the western side of LANL. The canyons with AEIs are Cañon de Valle, Water, Pajarito, Los Alamos, Sandia, Mortandad, and Three-Mile. AEI boundaries are maintained in the LANL biological resources program GIS database.

\subsection{AEI MANAGEMENT}

\subsection{Overview}

This AEI management section provides guidelines for LANL operations to reduce or eliminate the threats to Mexican Spotted Owls from 1) habitat alterations that reduce habitat quality and 2) disturbance of breeding or potentially breeding owls. Habitat alterations are considered for all AEIs and for both core and buffer areas. Disturbance activities to owls are considered only for occupied AEIs and only for impacts on core areas. Developed areas (see Part I, Section 3.1) that have ongoing baseline levels of activities and are not suitable habitat for Mexican Spotted Owls have different restrictions than undeveloped core or buffer areas. Therefore, the location of the disturbance activity within the AEI, the occupancy status of the AEI, and the type of activity all affect whether or not the activity is allowable. AEIs for different species may overlap, and an activity must meet the guidelines of all applicable site plans to be allowable. 


\subsection{Definition and Role of Occupancy in AEI Management}

Summary: The occupancy status of an AEI affects what disturbance activities are allowable in different areas (core, buffer, developed) of the AEI. All Mexican Spotted Owl AEIs are considered occupied during March 1 through August 31 or until surveys show the AEI to be unoccupied. See the Activity Table (Table 1, Section 4.5.2) for restrictions on occupied undeveloped core and buffer areas, and Part I, Section 3.1 for restrictions on developed areas.

Occupancy simply refers to whether or not an AEI is occupied during a species' period of sensitivity. For Mexican Spotted Owls, LANL is primarily concerned with protecting the owls from disturbance during the breeding season. Because individuals may colonize suitable habitat, all Mexican Spotted Owl AEIs are treated as though they are occupied from March 1 through August 31 or until surveys show an AEI to be unoccupied. Mexican Spotted Owl surveys are conducted from late March through June. In general, surveys in areas with ongoing or proposed projects are completed by May 15. If a nest is located during surveys, then the AEI can be treated as unoccupied except for the area within a $400 \mathrm{~m}(1,312 \mathrm{ft})$ radius of the nest site. Because owls are not as sensitive to disturbance during the non-breeding season, Mexican Spotted Owl AEIs are treated as unoccupied from September 1 to February 28.

The occupancy status of an AEI affects what activities are allowable in the AEI. Although activities causing habitat alterations are restricted in all AEIs, disturbance activities are restricted only in occupied AEIs. The Activity Table (Table 1, Section 4.5.2) provides dates and levels of allowable disturbance activities within occupied Mexican Spotted Owl AEIs under the guidelines of this site plan. Contact a LANL biological resources SME to find out the current occupancy status of an AEI (http://int.lanl.gov/environment/bio/controls/index.shtml).

\subsection{Introduction to AEI Management Guidelines}

Summary: The habitat alterations section and the activities section give the guidelines for habitat alteration and disturbance activities, respectively, for Mexican Spotted Owl AEIs. The flow chart (see Figure 1) provides a quick reference to determine what, if any, guidelines need to be consulted for a specific activity. Protective measures give management practices that should be applied when working or considering work in AEIs. LANL biological resources SMEs are available to answer questions and provide advice (http://int.lanl.gov/environment/bio/controls/index.shtml).

Sections 4.4 and 4.5 provide the guidelines for habitat alterations and allowable activities in AEI core and buffer areas. Section 4.4 describes what and where habitat alterations are allowed under the guidelines of this site plan. Section 4.5 describes what, when, and where disturbance activities are allowed in occupied AEIs under the guidelines of this site plan. If an activity does not meet the restrictions given in the guidelines, the activity must be individually reviewed for ESA compliance. This site plan only provides guidelines for Mexican Spotted Owl AEIs. If an activity is desired in an area with overlapping AEIs, all applicable site plans must be consulted. AEI maps show the location of all AEIs in an area. Section 4.6 describes management practices that should be applied when working or considering work in an AEI. LANL biological resources SMEs are available to answer questions and provide advice (http://int.lanl.gov/environment/bio/controls/index.shtml). 


\subsection{Definition of and Restrictions on Habitat Alterations}

\subsubsection{Definition of Habitat Alterations}

Habitat alteration includes any action that alters the soil structure, vegetative components necessary to the species, prey quality and quantity, water quality, hydrology, or noise or light levels in undeveloped areas of an AEI. Long-term means the alteration lasts for more than one year. For physical disturbances, in general, any activity that can be accomplished by one person with a hand tool is generally not considered habitat alteration; any activity that requires mechanized equipment on a landscape is habitat alteration. An actual activity may take place outside of the AEI and will be considered habitat alteration if consequences of the activity have effects inside the AEI core.

The habitat components most important to Mexican Spotted Owls include vegetative structure, food quality and quantity, and disturbance levels, including noise and light. The forest structure within a canyon designated as a Mexican Spotted Owl AEI is important because it provides roost sites and a suitable habitat for nesting and foraging. Trees along the canyon rim are used for foraging and territorial calling, and they shelter the canyon interior from light and noise disturbances.

A long-term change in light or noise levels within the undeveloped core of an AEI is considered to be a habitat alteration if it increases average noise levels by $\geq 6 \mathrm{~dB}(\mathrm{~A})$ during any portion of the 24-hour day, or it increases average light levels by $\geq 0.05 \mathrm{fc}$ at night. Changes in noise and light levels are measured at the core area boundary if the source is outside the core area, or at $10 \mathrm{~m}$ (33 ft) from the source if the source is inside the undeveloped core area. Impacts of changes in developed areas on undeveloped cores are measured at the developed area boundary if it is within the core, or at the core area boundary if the developed area is outside of the core.

\subsubsection{Fuels Management Practices to Reduce Wildfire Risk}

The recovery plan for the Mexican Spotted Owl lists stand-replacing wildfires as a primary threat to their habitat and encourages land managers to reduce fuel levels and abate fire risks in ways compatible with owl presence on the landscape (USFWS 1995). Within undeveloped core areas, on slopes $>40$ percent, in the bottoms of steep canyons, and within $30 \mathrm{~m}(100 \mathrm{ft})$ of a canyon rim, thinning of trees $<22 \mathrm{~cm}$ (9 in) diameter at breast height, treatment of fuels, and prescribed and natural prescribed fires are allowed. Exceptions allowing trees $>22 \mathrm{~cm}(9$ in) to be thinned within $30 \mathrm{~m}$ (100 ft) of buildings are granted to protect facilities. Large logs (>30 cm [11.8 in] midpoint diameter) and snags should be retained. Thinning within core areas not meeting the characteristics

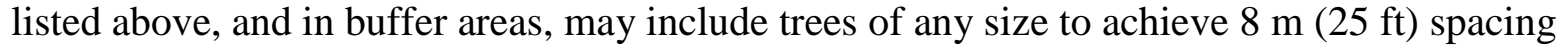
between tree crowns. However, clear cutting is not allowed in undeveloped core areas.

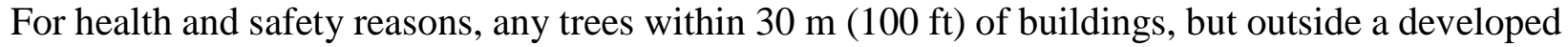
area, may be thinned to achieve $8 \mathrm{~m}(25 \mathrm{ft})$ spacing between crowns. Habitat alterations including thinning are not restricted in developed areas. However, LANL biological resources SMEs encourage the retention of trees and snags along canyon rims if the rim is in a developed area. Because of the extreme fire danger associated with firing sites and the potential impact of a fire on Mexican Spotted Owl habitat, firing sites and burn areas are treated separately for the purposes of fuels management. Trees within $380 \mathrm{~m}(1,246 \mathrm{ft})$ of firing sites and burn areas in both core and 
buffer areas may be thinned to a $15 \mathrm{~m}$ (49 ft) spacing between trees everywhere except on slopes $>40$ percent or in the bottoms of steep canyons. Any tree over $22 \mathrm{~cm}$ (9 in) diameter at breast height within $380 \mathrm{~m}(1,246 \mathrm{ft})$ of a firing site may be delimbed to a height of $2 \mathrm{~m}(6 \mathrm{ft})$ to help prevent crown fires.

In historically occupied core areas, fuels treatment may not exceed 10 percent of the undeveloped core area and is not allowed within $400 \mathrm{~m}(1,312 \mathrm{ft})$ of nesting areas. In occupied core areas, forest management activities must take place during the nonbreeding season (September 1 to February 28) (USFWS 1995). Fuels management activities that are allowable in core areas have to be reported to LANL biological resources SMEs for tracking.

\subsubsection{Utility Corridors}

Habitat alterations such as cutting down trees that threaten power lines are allowed within $8 \mathrm{~m}$ $(26 \mathrm{ft})$ of either side of an existing utility line in all areas of an AEI (Trujillo and Racinez 1995). New utility lines and utility lines requiring clearance of a right-of-way greater than $16 \mathrm{~m} \mathrm{(52 \textrm {ft } )}$ total must be individually reviewed for ESA compliance. Disturbance activities must follow the guidelines given in the Activities Table (Table 1, Section 4.5.2) for occupied AEIs.

\subsubsection{Restrictions on Habitat Alterations}

Summary: Habitat alterations other than fuels management practices and utility corridor maintenance are not allowed in undeveloped core areas. Habitat alterations in buffer areas are restricted to 2 ha $(5 \mathrm{ac})$ per project, with a maximum cap on development in the buffer for each AEI. Habitat alterations other than fuels management and utility corridor maintenance must be reported to LANL biological resources SMEs for tracking (http://int.lanl.gov/environment/bio/controls/index.shtml).

Habitat alterations other than the fuels management practices and utility corridor maintenance described above are not allowed in undeveloped core areas under the guidelines of this site plan. If a project or activity is planned that would alter habitat in an undeveloped core area, it must be individually evaluated for ESA compliance. Habitat alterations in undeveloped buffer areas other than the fuels management activities and utility corridor maintenance described above are restricted to 2 ha (5 ac) in area per project and are subject to other restrictions including light and noise effects in the core (see Section 2.2.3). Projects in the buffer over 2 ha (5 ac) in size will require individual ESA compliance review.

Habitat alterations in a buffer area other than the fuels management and utility corridor maintenance described above must be reported to LANL's biological resources SMEs for tracking (http://int.lanl.gov/environment/bio/controls/index.shtml). There is a cumulative maximum area that can be developed in each AEI's buffer. Once that cumulative area is reached, all habitat alterations in a buffer will require individual ESA reviews for compliance.

\subsection{Definition of and Restrictions on Disturbance Activities}

\subsubsection{Definitions of Disturbance Activities}

LANL biological resources SMEs considered six categories of activities that might cause disturbance in an AEI. Most of the categories were first identified in the document "Peregrine 
Falcon Habitat Management in the National Forests of New Mexico," prepared for the United States Forest Service (Johnson 1994). LANL biological resources SMEs added explosives detonation, other light production, and other noise production to provide the most comprehensive list of activities possible, thereby reducing the need for individual review of activities for ESA compliance. The categories of activities are people, vehicles, aircraft, other light production, other noise production, and explosives detonation. LANL biological resources SMEs have defined low, medium, and high levels of impact for these activities except for explosives detonation. Activity levels for explosives detonation have been designed to follow the guidelines agreed upon by LANL, DOE, and USFWS in the DARHT BA (Keller and Risberg 1995). Restrictions on explosives detonation are described in the definition of the activity, but are not included in the Activity Table (Table 1, Section 4.5.2). These six categories of activities are restricted only in AEIs that are classified as occupied.

People - includes any entry of people into an AEI on foot.

- Low impact is the presence of three or fewer people per project and duration of one day or less during a breeding season.

- Medium impact is the exceedance of either the number of people or the duration criteria.

- High impact is the exceedance of both the number of people and the duration criteria.

Vehicles - includes the entry of any two-axle highway vehicle, all-terrain vehicle, or motorized machinery into an AEI by any route other than a paved road or an improved gravel road.

- Low impact is the presence of two or fewer vehicles per project and duration of one day or less during a breeding season.

- Medium impact is the exceedance of either the number of vehicles or the duration criteria.

- High impact is the exceedance of both the number of vehicles and the duration criteria.

Aircraft - includes the operation of any aircraft below an elevation of $600 \mathrm{~m}(2,000 \mathrm{ft})$ above the highest ground level in the local vicinity.

- Low impact is the presence of one single-engine airplane and the duration of one day or less during a breeding season.

- Medium impact is the exceedance of either the number of aircraft or the duration criteria.

- High impact is the exceedance of both the number of aircraft and the duration criteria.

Any use of helicopters, jet airplanes, and propeller airplanes with two or more engines is classified as medium impact or above, depending on duration.

Other Light Production - includes any activity not previously listed that causes additional light to occur in an AEI core area. For example, plans for construction of a new building at the edge of a developed area may call for lighting at night to facilitate nighttime work that impacts an undeveloped core area. 
- Low impact is the increase of light intensity by $\leq 0.05 \mathrm{fc}$ and a duration of one night or less per project per breeding season.

- Medium impact is the exceedance of either the intensity or duration criteria.

- High impact is the exceedance of both the intensity and duration criteria.

Measurements for increases in light are taken at the AEI core area boundary closest to the light

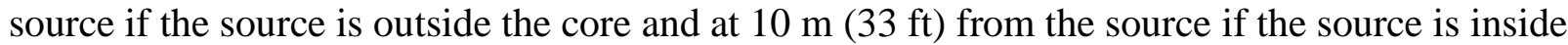
the core. Light measurements for developed areas are taken at the edge of the developed area if the developed area is within an AEI core or at the closest core boundary if the developed area is outside of an AEI core.

Other Noise Production - includes any activity not previously listed except for explosives detonation that causes additional noise to occur in an AEI. For example, operation of machinery creates noise.

- Low impact is increasing noise levels in an AEI core by $6 \mathrm{~dB}(\mathrm{~A})$ or less for one day or less per project per breeding season.

- Medium impact is the exceedance of either the level or the duration criteria.

- High impact is the exceedance of both the level and the duration criteria.

Measurements for increases in noise are taken at the AEI core boundary closest to the noise

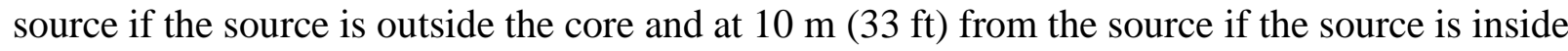
the core. Noise measurements for developed areas are taken at the edge of the developed area if the developed area is within an AEI core or at the closest core boundary if the developed area is outside of an AEI core.

Explosives Detonation - includes the use of high explosives for any purpose. LANL biological resources SMEs did not define low, medium, and high levels of this activity because of the difficulty of determining levels for a shot before actually doing the shot. For the purpose of explosives detonation near Mexican Spotted Owl AEIs, occupied habitat is defined as the area within $400 \mathrm{~m}(1,312 \mathrm{ft})$ of the current year's nest/roost sites or the previous year's nest site if a current site has not been identified. No explosives detonation will take place within $400 \mathrm{~m}$ $(1,312 \mathrm{ft})$ of nest/roost sites in occupied habitat between March 1 and August 31. Explosives detonation at night at sites within 400 to $800 \mathrm{~m}(1,312$ to $2,624 \mathrm{ft})$ of a nest site in occupied habitat is restricted to once a month from March 1 and August 31.There are no restrictions on daytime explosives testing between 400 and $800 \mathrm{~m}(1,312$ to 2,624 ft). There are no restrictions between September 1 and February 28 or in unoccupied habitat. Explosives detonation adjacent to AEIs that have not previously been recorded by LANL as occupied will have no restrictions unless surveys detect Mexican Spotted Owls. Explosives tests not allowed under the guidelines of this site plan must be individually reviewed for ESA compliance.

\subsubsection{Activity Table}

The dates shown in the Activity Table (Table 1) are the dates between which the activity in the row is restricted under the guidelines of this site plan. All AEIs are considered occupied from March 1 to August 31 or until surveys show an AEI to be unoccupied. If owls are detected, AEIs 
are considered occupied until August 31 within $400 \mathrm{~m}(1,312 \mathrm{ft})$ of the nest site. Consult with LANL biological resources SMEs to find out occupancy status of AEIs and what locations are within $400 \mathrm{~m}$ (1,312 ft) of nest sites (http://int.lanl.gov/environment/bio/controls/index.shtml).

Table 1. Restrictions on Activities in Undeveloped Occupied Mexican Spotted Owl AEIs

\begin{tabular}{|c|c|c|}
\hline & Core & Buffer \\
\hline \multicolumn{3}{|l|}{ People } \\
\hline Low & No Restrictions* & No Restrictions \\
\hline Medium & March 1 to August 31 & No Restrictions \\
\hline High & March 1 to August 31 & No Restrictions \\
\hline \multicolumn{3}{|l|}{ Vehicles } \\
\hline Low & No Restrictions & No Restrictions \\
\hline Medium & March 1 to August 31 & No Restrictions \\
\hline High & March 1 to August 31 & No Restrictions \\
\hline \multicolumn{3}{|l|}{ Aircraft } \\
\hline Low & March 1 to August 31 & No Restrictions \\
\hline Medium & March 1 to August 31 & March 1 to May 15 \\
\hline High & March 1 to August 31 & March 1 to August 31 \\
\hline \multicolumn{3}{|l|}{ Other Light Production } \\
\hline Low & March 1 to August 31 & No Restrictions** \\
\hline Medium & March 1 to August 31 & No Restrictions** \\
\hline High & March 1 to August 31 & No Restrictions** \\
\hline \multicolumn{3}{|l|}{ Other Noise Production } \\
\hline Low & March 1 to August 31 & No Restrictions** \\
\hline Medium & March 1 to August 31 & No Restrictions** \\
\hline High & March 1 to August 31 & No Restrictions** \\
\hline
\end{tabular}

*Entry is restricted in core areas that are occupied within $400 \mathrm{~m}(1,312 \mathrm{ft})$ of the nest site from March 1 to August 31. If the current nest has not been located, entry is restricted within $400 \mathrm{~m}$ $(1,312 \mathrm{ft})$ of the previous year's nest site.

**Noise or light production in the buffer is restricted if the activity would violate core area restrictions on noise or light.

\subsection{Protective Measures}

Summary: This section provides a list of management practices to apply in Mexican Spotted Owl AEIs.

- Timing of projects must take into account that projects in core areas or projects that violate restrictions for occupied buffer areas must stop on February 28 each year until occupancy status of the AEI is determined.

- Every reasonable effort should be made to reduce the noise from explosives testing within $800 \mathrm{~m}(2,624 \mathrm{ft})$ of occupied habitat. Methods to reduce noise could include contained shots, noise shields in the direction of AEI cores, etc. For night shots, every reasonable effort should be made to limit the amount of light directed into AEI core areas. 
- Put signs on dirt roads and trails leading into AEIs labeling them as restricted access areas and providing a number to contact for access restrictions.

- Keep disturbance and noise to a minimum.

- Avoid unnecessary disturbance to vegetation (e.g., excessive parking areas or equipment storage areas, off-road travel, materials storage areas, crossing of streams or washes).

- Avoid removal of vegetation along drainage systems and stream channels.

- Avoid all vegetation removals not absolutely necessary.

- Appropriate erosion and runoff controls should be employed to reduce soil loss. The controls must be put in place and periodically checked throughout the life of projects.

- All exposed soils must be revegetated as soon as feasible after construction to minimize erosion.

- In the Los Alamos Canyon AEI, development should be focused away from undeveloped areas on the western end of the AEI.

\subsection{LEVELS OF DEVELOPMENT IN AEI CORE AND BUFFERS}

\subsection{Allowable Habitat Alteration in the Buffer Areas}

The following quantifications of development and guidance for allowable habitat alteration in buffer areas were published and consulted on in the 1999 version of the HMP. Most AEIs changed in dimensions during the 2005 redelination of the habitats, and many have experienced additional development. Development in buffer habitat was not addressed during the 2005 consultation. Many projects were reviewed and received USFWS concurrence between 1999 and 2014.

LANL biological resources SMEs have provided the current development status for each of the AEIs at the end of each paragraph. The percent developed numbers were derived with the original size of the AEIs.

Cañon de Valle - In 1999, 16.3 ha (40.3 ac, 2.9 percent) of the core was developed and 52.2 ha (129 ac, 6.8 percent) of the DOE-controlled buffer was developed. For this AEI, it was recommended that only an additional 25.30 ha $(62.5 \mathrm{ac})$ of the AEI buffer be developed. The 1999 HMP stated that once this cap is reached or a large-scale project is proposed, additional consultation with USFWS would be required. By 2011, 28 ha (69.2 ac) of the core and 84 ha (207.5 ac) of the buffer had been developed.

Pajarito-In 1999, there were 6.7 ha (16.5 ac, 5.5 percent) of the core developed and 75.1 ha (186.5 ac, 16.7percent) developed in the buffer. LANL biological resources SMEs recommended only an additional 35 ha $(86.4 \mathrm{ac})$ of the buffer be developed before additional USFWS consultations take place. The 1999 HMP stated that once the cap is reached or a single large-scale project is proposed, additional consultation would be required. By 2011, 27 ha (66.7 ac) of the core and 89 ha $(220 \mathrm{ac})$ of the buffer had been developed.

Los Alamos - In 1999, there were 77.16 ha (190 ac) of the core developed and 167.2 ha (413.1 ac) developed in the buffer. For this AEI, LANL biological resources SMEs recommended only an 
additional 28.6 ha (70.6 ac, 5.9 percent) of the DOE-owned buffer be developed before additional USFWS consultations take place.

Because this AEI is so heavily developed, additional development was restricted to a few selected areas within the buffer. Development outside of these areas requires individual review for ESA compliance. A large percentage of this AEI was removed in the 2005 and 2013 BAs. By 2011, 94 ha $(232.2 \mathrm{ac})$ of the core and 181 ha $(447.3 \mathrm{ac})$ of the buffer had been developed.

Sandia-Mortandad - In 1999, 98.4 ha (243.2 ac) of this AEI on DOE lands were developed, including 29 ha (71.7 ac, 10.7 percent) of the core and 75.1 ha (185.6 ac, 16.7 percent) of the buffer. For this AEI, LANL biological resources SMEs recommended only an additional 38.1 ha (94.1 ac) of the buffer be developed before additional USFWS consultations take place. Once this cap is reached or a single large-scale project is proposed, additional consultation will be required. By 2011, 45 ha (111.2 ac) of the core and 83 ha $(205.1 \mathrm{ac})$ of the buffer had been developed.

Three Mile - In 1999, 25.3 ha (62.5 ac) of this AEI on DOE lands were developed, including 3.8 ha (9.4 ac, 2.8percent) of the core and 21.5 ha (51.1 ac, 7.3 percent) of the buffer. For this AEI, LANL biological resources SMEs recommended only 64.3 ha (158.8 ac) additional area of buffer be developed before additional USFWS consultations take place. Once this cap is reached or a single large-scale project is proposed, additional consultation will be required. By 2011, 12 ha (29.6 ac) of the core and 37 ha (91.4 ac) of the buffer had been developed.

\section{AREA OF ENVIRONMENTAL INTEREST SITE PLAN FOR THE SOUTHWESTERN WILLOW FLYCATCHER}

\subsection{SPECIES DESCRIPTION-SOUTHWESTERN WILLOW FLYCATCHER}

\subsection{Status}

In 1995, the USFWS designated the Southwestern Willow Flycatcher as a federally endangered species (60 FR 10693). The USFWS most recently designated critical habitat for the Southwestern Willow Flycatcher in 2005 (70 FR 60885). The most recent recovery plan was published for Southwestern Willow Flycatcher in 2002 (USFWS 2002).

\subsection{General Biology}

The Southwestern Willow Flycatcher is one of four subspecies of the Willow Flycatcher. The historic range of the Southwestern Willow Flycatcher included Arizona, California, Colorado, New Mexico, Texas, Utah, and Mexico. Currently, this flycatcher breeds in riparian habitats from southern California to Arizona and New Mexico, plus southern Colorado, Utah, Nevada, and far western Texas. In winter it is found in southern Mexico, Central America, and northern South America (USFWS 2002).

Southwestern Willow Flycatchers are present in New Mexico from early May through mid-September and breed from late May through late July (Finch and Kelly 1999; USFWS 2002; Yong and Finch 1997). The flycatcher's nesting cycle is approximately 28 days. Three or four eggs are laid at one-day intervals, and incubation begins when the clutch is complete. The female incubates eggs for approximately 12 days, and the young fledge about 13 days after hatching. 
Southwestern Willow Flycatchers typically raise one brood per year (USFWS 2002). Because arrival dates vary, northbound migrant Willow Flycatchers (of all subspecies) pass through areas where Southwestern Willow Flycatchers have already begun nesting. Similarly, southbound migrants (of all subspecies) in late July and August may occur where Southwestern Willow Flycatchers are still breeding. Therefore, it is only during a short period of the breeding season (approximately June15 through July 20) that one can assume that a Willow Flycatcher seen within Southwestern Willow Flycatcher range is probably of that subspecies (USFWS 2002).

The Southwestern Willow Flycatcher only nests along rivers, streams, and other wetlands. It is found in close association with dense stands of willows (Salix spp.), arrowweed (Pluchea spp.), buttonbush (Cephalanthus spp.), tamarisk (Tamarix spp.), Russian olive (Eleagnus angustifolia L.), and other riparian vegetation, often with a scattered overstory of cottonwood (Populus spp.) (USFWS 2002). The size of vegetation patches or habitat mosaics used by Southwestern Willow Flycatchers varies considerably and ranges from as small as $0.8 \mathrm{ha}(1.9 \mathrm{ac})$ to several hundred hectares (Hatten and Paradzick 2003). The Southwestern Willow Flycatcher nests in thickets of trees and shrubs approximately 2 to $15 \mathrm{~m}$ (6 to $49 \mathrm{ft}$ ) tall, with a high percentage of canopy cover and dense foliage from 0 to $4 \mathrm{~m}(0$ to $13 \mathrm{ft})$ above ground. Regardless of the plant species composition or height, occupied sites always have dense vegetation in the patch interior (Allison et al. 2003; USFWS 2002).

The Southwestern Willow Flycatcher is an insectivore. It forages within and occasionally above dense riparian vegetation, taking insects on the wing and gleaning them from foliage. The flycatcher's prey includes flies, bees, wasps, ants, beetles, moths, butterflies, grasshoppers, crickets, dragonflies, damselflies, and spiders (Durst et al. 2008; Wiesenborn and Heydon 2007).

\subsection{Threats}

The current population of Southwestern Willow Flycatchers in the United States is estimated at 1,214 territories (Durst et al. 2006). The distribution of breeding groups is highly fragmented, with groups often separated by considerable distances. This subspecies has suffered declines attributed to extensive loss of its cottonwood-willow habitat and to poor productivity resulting from brood parasitism by Brown-headed Cowbirds (Molothrus ater) (USFWS 2002).

\subsection{IMPACT OF HUMAN ACTIVITIES}

\subsection{Introduction}

The primary threats to the Southwestern Willow Flycatcher on LANL property are 1) impacts on habitat quality from LANL operations and 2) disturbance of nesting flycatchers. This section includes a review and summary of the known effects of various types of human activities to the Southwestern Willow Flycatcher and an overview of the current levels of activities at LANL within species habitat.

\subsection{Impacts on Habitat Quality}

\subsubsection{Development}

Throughout the Southwest, riparian habitats are rare and tend to be small and separated by vast expanses of arid lands. The Southwestern Willow Flycatcher has experienced extensive loss and 
modification of its habitat resulting from urban and agricultural development, water diversion and impoundment, channelization of waterways, livestock grazing, off-road vehicle and other recreational uses, and hydrological changes resulting from these and other land uses (USFWS 2002). River and stream impoundments, groundwater pumping, and overuse of riparian areas have altered as much as 90 percent of the Southwestern Willow Flycatcher's habitat (USFWS 2002). Loss of cottonwood-willow riparian forests has had widespread impact on the distribution and abundance of bird species associated with that forest. Development itself may be tolerated if the habitat is left intact.

Because watercourses at LANL tend to be intermittent to ephemeral, riparian habitat is uncommon. There has been extensive degradation of the riparian zone along the Rio Grande caused by feral cattle grazing and flood control operations of Cochiti Lake. There are other riparian/wetland areas on LANL associated with canyon bottoms, the most significant one being Pajarito wetlands in the lower end of Pajarito Canyon. A major paved road traverses the wetlands area in Pajarito Canyon.

\subsubsection{Ecological Risk}

There is no specific information on the impact of chemicals on Southwestern Willow Flycatcher.

\subsubsection{Ecorisk Assessment}

LANL completed two ecological risk assessments that included the Southwestern Willow Flycatcher between 1997 and 2009. The ecological risk assessment process involves using computer modeling to assess potential effects to animals from COPCs that have been detected in the environment. The ecological risk assessments concluded that, in general, there is a small potential for effects to Southwestern Willow Flycatcher from COPCs (Gonzales et al. 1998; Gonzales et al. 2009).

An ecotoxicological risk assessment for the Southwestern Willow Flycatcher, centered on the Pajarito wetlands, found that between 7 and 16 percent of 100 hypothetical nest sites examined had hazard indices $>1.0$ and <10.0, depending on the foraging scenario (Gonzales et al. 1998). This indicates a small potential for impacts from chemicals. The primary chemicals driving the risk scenario were pentachlorophenol, aluminum, radium-226, calcium, and thorium-228. Aluminum, radium, and thorium are naturally occurring substances in northern New Mexico.

\subsubsection{Disturbance}

\subsubsection{Pedestrians and Vehicles}

There is no specific information on the reactions of Southwestern Willow Flycatchers to pedestrians and vehicles available. The recovery plan for the Southwestern Willow Flycatcher recommends providing protected areas, reducing unpredictable activities providing visual barriers, and reducing noise disturbance (USFWS 2002).

\subsubsection{Aircraft}

There is no specific information on the reaction of Southwestern Willow Flycatchers to aircraft available. 
LANL lies within restricted airspace and planes infrequently fly less than $609 \mathrm{~m}(2,000 \mathrm{ft})$ above ground level. The County of Los Alamos operates an airport along the northern edge of LANL. The airport is located on the southern rim of Pueblo Canyon. Most flights approach and depart to the east of the airport, over the Rio Grande.

\subsubsection{Explosives}

There is no specific information on the reaction of Southwestern Willow Flycatchers to explosives detonation available. The Southwestern Willow Flycatcher AEI is not located close to any explosives testing sites at LANL.

\subsubsection{Other Sources of Noise}

LANL biological resources SMEs do not have good information on the effects of noise, including machinery operation, on Southwestern Willow Flycatchers. However, Southwestern Willow Flycatchers are probably not as sensitive to disturbance as some other threatened or endangered species (USFWS 2002). For a description of noise levels at LANL, see Part I, Section 2.2.3.

\subsubsection{Artificially Produced Light}

There is no information on the effects of artificially produced light on Southwestern Willow Flycatchers available. Under the Los Alamos County Code, commercial site development plans are reviewed to ensure that lighting serves the intended use of the site while minimizing adverse impacts to adjacent residential property (Section 16-276). Section 16-276 of the County Code includes light source measurement limitations by zoning district. The code allows off-site light to be $0.5 \mathrm{fc}$ in residential areas. By comparison, full moonlight measures $0.1 \mathrm{fc}$, and a crescent moon was measured at $0.01 \mathrm{fc}$.

\subsection{AEI GENERAL DESCRIPTION FOR SOUTHWESTERN WILLOW FLYCATCHER}

The AEI consists of two types of areas - core and buffer. Core areas represent wetland areas with suitable vegetation for nesting, primarily dense willows. The buffer area is the area within $100 \mathrm{~m}$ (328 ft) of core areas. The Southwestern Willow Flycatcher AEI on LANL consists of two separate core areas. For purposes of this site plan, both core areas and associated buffers are considered one AEI unit.

\subsection{Method for Identifying the Southwestern Willow Flycatcher AEI}

The core areas were defined by the presence of riparian habitat and suitable wetland vegetation. These areas were identified in 1994 during a survey of wetlands at LANL and mapped using a global positioning system receiver. Wetlands without stands of dense willows at least $2 \mathrm{~m}(7 \mathrm{ft})$ tall and $30 \mathrm{~m}(98 \mathrm{ft})$ wide were not included in the AEI. The buffer area is the area within $100 \mathrm{~m}$ $(328 \mathrm{ft})$ of the core areas.

\subsection{Location of the Southwestern Willow Flycatcher AEI}

LANL has one AEI for Southwestern Willow Flycatcher. It is composed of two core areas with associated buffers. The AEI core areas are located in the bottom of Pajarito Canyon, on the eastern side of LANL adjacent to Pajarito Road and State Road 4. The boundaries of the Southwestern 
Willow Flycatcher AEI are maintained in the biological resources program GIS database at LANL.

\subsection{AEI MANAGEMENT}

\subsection{Overview}

This AEI management section provides guidelines for LANL operations to reduce or eliminate the threats to the Southwestern Willow Flycatcher from 1) habitat alterations that reduce habitat quality and 2) disturbance of breeding or potentially breeding flycatchers. Habitat alterations are considered for all AEIs and for both core and buffer areas. Disturbance activities to flycatchers are considered only for occupied AEIs and only for impacts on core areas. Developed areas (see Part I, Section 2.3) with ongoing baseline levels of activities and are not suitable habitat for Southwestern Willow Flycatchers have different restrictions than undeveloped core or buffer areas. Therefore, the location of the disturbance activity within the AEI, the occupancy status of the AEI, and the type of activity all affect whether or not the activity is allowable. AEIs for different species may overlap, and an activity must meet the guidelines of all applicable site plans to be allowable. Protective measures are described as management practices that should be followed when working in AEIs.

\subsection{Definition and Role of Occupancy in AEI Management}

Summary: The occupancy status of an AEI affects what disturbance activities are allowable in different areas (core, buffer, developed) of the AEI. The Southwestern Willow Flycatcher AEI is considered occupied during May 15 through September 15 or until the surveys show the AEI to be unoccupied. See the Activity Table (Table 2, Section 4.5.2) for restrictions on occupied undeveloped core and buffer areas, and Part I, Section 2.3 for restrictions on developed areas.

Occupancy simply refers to whether or not an AEI is occupied during a species' period of sensitivity. For Southwestern Willow Flycatchers, LANL biological resources SMEs are primarily concerned with protecting the birds from disturbance during the breeding season. Because individuals may colonize suitable habitat, the Southwestern Willow Flycatcher AEI is treated as though it is occupied from May 15 through September 15 or until surveys show an AEI to be unoccupied. Southwestern Willow Flycatcher surveys are conducted during May, June, and July. Because Southwestern Willow Flycatchers migrate south for the winter, the AEI is treated as unoccupied from September 16 to May 14.

The occupancy status of an AEI affects what activities are allowable in the AEI. Although activities causing habitat alterations are always restricted, disturbance activities are restricted only in occupied AEIs. Table 2 provides dates and levels of disturbance activities allowable in the occupied Southwestern Willow Flycatcher AEI under the guidelines of this site plan. The dates in Table 2 indicate the time period during which the activity is restricted. Contact a LANL biological resources SME to find out the current occupancy status of an AEI (http://int.lanl.gov/environment/bio/controls/index.shtml).

\subsection{Introduction to AEI Management Guidelines}

Summary: The habitat alterations section (Section 4.4) and the activities section (Section 4.5) gives the guidelines for habitat alteration and disturbance activities, respectively, for the 
Southwestern Willow Flycatcher AEI. The flow chart (see Figure 1) provides a quick reference to determine what, if any, guidelines need to be consulted for a specific activity. Protective measures give management practices that should be applied when working or considering work in AEIs. LANL biological resources SMEs are available to answer questions and provide advice (http://int.lanl.gov/environment/bio/controls/index.shtml).

Sections 4.4 and 4.5 provide the guidelines for habitat alterations and allowable activities in AEI core and buffer areas. The flow chart (see Figure 1) provides a quick reference that should be used to determine whether a project or activity will affect an AEI and what sections of the site plan need to be consulted. The section on habitat alterations (Section 4.4) describes what and where habitat alterations are allowed under the guidelines of this site plan. The section and table on allowable activities (Section 4.5 and Table 2) describe what, when, and where disturbance activities are allowed in occupied AEIs under the guidelines of this site plan. If an activity does not meet the restrictions given in the guidelines, the activity must be individually reviewed for ESA compliance. This site plan only provides guidelines for the Southwestern Willow Flycatcher AEI. If an activity is desired in an area with overlapping AEIs, all applicable site plans must be consulted. Section 4.6 describes management practices that should be applied when working or considering work in an AEI. LANL biological resources SMEs are available to help interpret site plans and answer questions (http://int.lanl.gov/environment/bio/controls/index.shtml).

\subsection{Definition of and Restrictions on Habitat Alterations}

\subsubsection{Definition of Habitat Alterations}

Habitat alteration includes any action that alters over the long-term the soil structure, vegetative components necessary to the species, prey quality and quantity, water quality, hydrology, or noise or light levels in undeveloped areas of an AEI. Long-term means the alteration lasts for more than one year. Habitat alteration includes any activity that removes vegetative components important to the Southwestern Willow Flycatcher (primarily trees and shrubs). An actual activity may take place outside of the AEI and will be considered habitat alteration if consequences of the activity have effects inside the AEI core.

The habitat components most important to flycatchers include vegetative structure, food quality and quantity, and disturbance levels, including noise and light. The thickets of certain trees and shrubs along wetlands are important because they provide roost sites and a suitable habitat for nesting and foraging.

\subsubsection{Fuels Management Practices to Reduce Wildfire Risk}

Thinning within undeveloped buffer areas may include trees of any size to achieve $7.6 \mathrm{~m} \mathrm{(25 \textrm {ft } )}$ spacing between tree crowns. However, clear cutting is not allowed in undeveloped buffer areas. No fuels management practices are allowed in core areas. Habitat alterations including thinning are not restricted in developed areas. All fuels management activities in developed and buffer areas must follow the guidelines in the Activity Table (Table 2, Section 4.5.2) if the AEI is occupied.

\subsubsection{Utility Corridors}

Habitat alterations such as cutting down trees that threaten power lines are allowed within $8 \mathrm{~m}$ (26 ft) of either side of an existing utility line in all areas of an AEI (Trujillo and Racinez 1995). 
New utility lines and utility lines requiring clearance of a right-of-way greater than $16 \mathrm{~m}(52 \mathrm{ft})$ total must be individually reviewed for ESA compliance. Disturbance activities must follow the guidelines given in the Activities Table for occupied AEIs.

\subsubsection{Restrictions on Habitat Alterations}

Summary: Habitat alterations other than the utility corridor maintenance described above are not allowed in undeveloped core areas under the guidelines of this site plan. Habitat alteration in buffers is limited. If a project or activity is planned that would alter habitat in an undeveloped core area, it must be individually evaluated for ESA compliance. Habitat alterations in a buffer area other than fuels management activities or utility corridor maintenance must be reported to a LANL biological resources SME for tracking (http://int.lanl.gov/environment/bio/controls/index.shtml).

\subsection{Definition of and Restrictions on Disturbance Activities}

\subsubsection{Definition of Disturbance Activities}

LANL biological resources SMEs considered five categories of activities that might cause disturbance in an AEI. Most of the categories were first identified in the document "Peregrine Falcon Habitat Management in the National Forests of New Mexico" prepared for the U.S. Forest Service (Johnson 1994). Other light production and other noise production were included to provide the most comprehensive list of activities possible, reducing the need for individual review of activities for ESA compliance. The categories of activities are people, vehicles, aircraft, other light production, and other noise production. The impact of explosives detonation on this species is not considered here because there are no explosives testing sites within $2 \mathrm{~km}$ (1.25 mi) of potential nesting habitat. Low, medium, and high levels of impact for these activities are considered here. The following categories of activities are restricted only in AEIs that are classified as occupied.

People - includes any entry of people into an AEI on foot.

- Low impact is the presence of three or fewer people per project and duration of one day or less during a breeding season.

- Medium impact is the exceedance of either the number of people or the duration criteria.

- High impact is the exceedance of both the number of people and the duration criteria.

Vehicles - includes the entry of any two-axle highway vehicle, all-terrain vehicle, or motorized machinery into an AEI by any route other than a paved road or an improved gravel road.

- Low impact is the presence of two or fewer vehicles per project and duration of one day or less during a breeding season.

- Medium impact is the exceedance of either the number of vehicles or the duration criteria.

- High impact is the exceedance of both the number of vehicles and the duration criteria.

Aircraft - includes the operation of any aircraft below an elevation of $600 \mathrm{~m}(2,000 \mathrm{ft})$ above the highest ground level in the local vicinity. 
- Low impact is the presence of one single-engine airplane and duration of one day or less during a breeding season.

- Medium impact is the exceedance of either the number of aircraft or the duration criteria.

- High impact is the exceedance of both the number of aircraft and the duration criteria.

Any use of helicopters, jet airplanes, and propeller airplanes with two or more engines is classified as medium impact or above, depending on duration.

Other Light Production - includes any activity not previously listed that causes additional light to occur in an AEI core area (e.g., plans for construction of a new building at the edge of a developed area may call for lighting at night to facilitate nighttime work that impacts an undeveloped core area).

- Low impact is the increase of light intensity by up to $0.05 \mathrm{fc}$ and a duration of one night or less per project per breeding season.

- Medium impact is the exceedance of either the intensity or duration criteria.

- High impact is the exceedance of both the intensity and duration criteria.

Measurements for increases in light are taken at the AEI core area boundary closest to the light

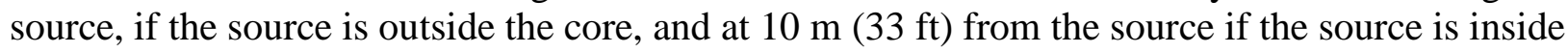
the core. Light measurements for developed areas are taken at the edge of the developed area if the developed area is within an AEI core, or at the closest core boundary, if the developed area is outside of an AEI core.

Other Noise Production - includes any activity not previously listed except for explosives detonation that causes additional noise to occur in an AEI. For example, operation of machinery causes noise.

- Low impact is increasing noise levels in an AEI core by $6 \mathrm{~dB}(\mathrm{~A})$ or less for one day or less per project per breeding season.

- Medium impact is the exceedance of either the level or the duration criteria.

- High impact is the exceedance of both the level and the duration criteria.

Measurements for increases in noise are taken at the AEI core boundary closest to the noise source

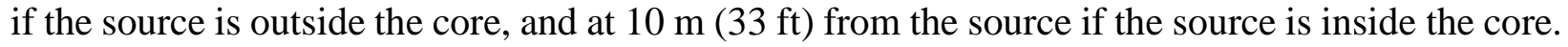
Noise measurements for developed areas are taken at the edge of the developed area if the developed area is within an AEI core, or at the closest core boundary if the developed area is outside of an AEI core.

\subsubsection{Activity Table}

Disturbance activities are of concern only when Southwestern Willow Flycatchers occupy an AEI. The AEI is always considered occupied between May 15 and September 15, or until surveys show the AEI to be unoccupied. The Southwestern Willow Flycatcher AEI is always considered unoccupied between September 16 and May 14, when flycatchers have migrated for the winter. 
For occupancy status of an AEI after completion of surveys, contact a LANL biological resources SME (http://int.lanl.gov/environment/bio/controls/index.shtml).

Table 2. Restrictions on Activities in Undeveloped Occupied Southwestern Willow Flycatcher AEI

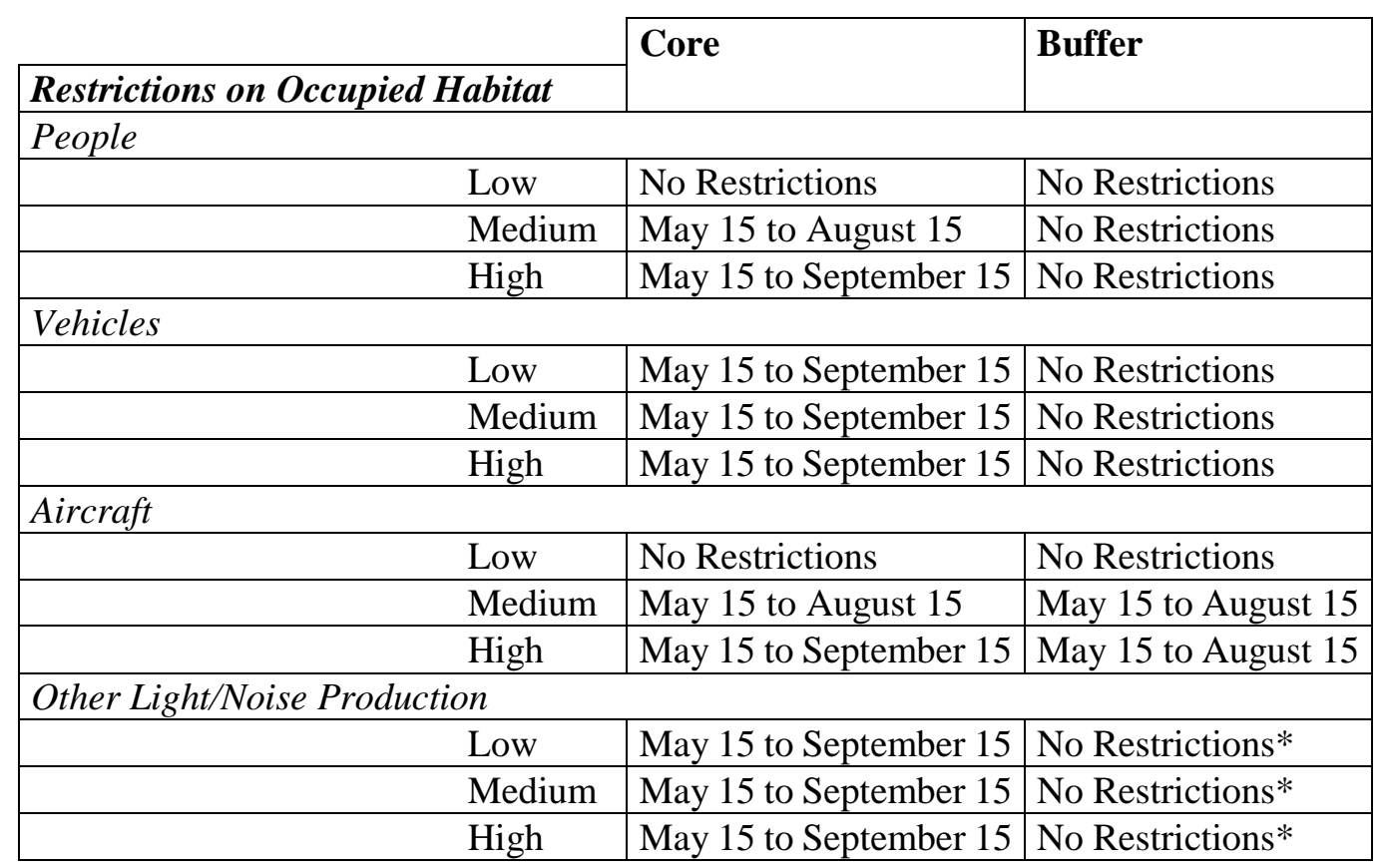

*Noise or light production in the buffer is restricted if the activity would violate core area restriction on noise or light.

\subsection{Protective Measures}

Summary: This section provides a list of management practices to apply in the AEI.

- No wetland vegetation will be removed outside of developed areas.

- Appropriate erosion and runoff controls should be employed to reduce soil loss.

- Avoid unnecessary disturbance to vegetation (e.g., excessive parking areas or equipment storage areas, off-road travel, materials storage areas, crossing of streams or washes).

- Avoid removal of vegetation along drainage systems and stream channels.

- Avoid all vegetation removals not absolutely necessary.

- Appropriate erosion controls must be put in place and periodically checked throughout the life of any projects.

- All exposed soils must be revegetated as soon as feasible after disturbance to minimize erosion. 


\subsection{SOUTHWESTERN WILLOW FLYCATCHER AEI DESCRIPTION}

\subsection{Pajarito Canyon Southwestern Willow Flycatcher AEI}

\subsubsection{Allowable Habitat Alteration in the Buffer Area}

Since the purpose of the buffer area is to help maintain the core area as suitable Southwestern Willow Flycatcher habitat, habitat alteration in the buffer area will be extremely limited. There are two areas in which restrictions on habitat alteration are relaxed.

1. The mesa top of Mesita del Buey. This mesa top can be developed as long as restrictions on impacts to the core area are met.

2. Pajarito Road within the AEI. Mowing of upland vegetation is allowed up to $5 \mathrm{~m}(15 \mathrm{ft})$ from Pajarito Road, or to the fence, if the fence is within $9 \mathrm{~m}(30 \mathrm{ft})$. Vegetation must cover the roadsides to prevent sediment runoff, so mowed plants should be at least $5 \mathrm{~cm}(2 \mathrm{in})$ high. LANL biological resources SMEs encourage the growth of willow throughout the AEI — even the area along Pajarito Road - to enhance habitat. If, within this area, it is absolutely necessary to remove new willow growth (i.e., to improve visibility for human safety), LANL biological resources SMEs recommend that only willows at or above the level of the roadway surface be mowed.

\section{AREA OF ENVIRONMENTAL INTEREST SITE PLAN FOR THE JEMEZ MOUNTAINS SALAMANDER}

\subsection{SPECIES DESCRIPTION-JEMEZ MOUNTAINS SALAMANDER}

\subsection{Status}

The Jemez Mountains Salamander (Plethodon neomexicanus) was listed in New Mexico as endangered under the Wildlife Conservation Act of New Mexico in 2006 (NMDGF 2006). In September 2012 the USFWS proposed the Jemez Mountains Salamander as endangered under the ESA (FR 2012) and the final listing as endangered was on 10 September 2013 (FR 2013a)

\subsection{General Biology}

The Jemez Mountains Salamander is endemic to the Jemez Mountains of north-central New Mexico and is found in Los Alamos, Rio Arriba, and Sandoval counties (Stebbins and Riemer 1950). It is one of two endemic plethodontid salamanders that occur in New Mexico. It occurs predominantly at elevations between 2,130 to $3,430 \mathrm{~m}(6,988$ to $11,254 \mathrm{ft})$ in mixed-conifer forest with greater than 50 percent canopy cover consisting mainly of Douglas fir (Pseudotsuga menziesii [Mirb.] Franco), blue spruce (Picea pungens Engelm.), Engelmann spruce (Picea engelmannii Parry ex Engelm.), white fir (Abies concolor [Gord. \& Glend.] Lindl. ex Hildebr.), limber pine (Pinus flexilis James), ponderosa pine, and quaking aspen (Populus tremuloides Michx.). The ground surface in forest areas has (a) moderate to high volumes of large fallen trees and other woody debris, especially coniferous $\operatorname{logs}$ at least $25 \mathrm{~cm}$ (10 in) in diameter, particularly Douglas fir, which are in contact with the soil in varying stages of decay from freshly fallen to nearly fully decomposed; or (b) structural features, such as rocks, bark, and moss mats that provide 
the species with food and cover. Underground habitat in forest or meadow areas contains interstitial spaces provided by (a) igneous rock with fractures or loose rocky soils, (b) rotted tree root channels, or (c) burrows of rodents or large invertebrates (Degenhardt et al. 1996; FR 2013b).

Plethodontid salamanders, which lack both lungs and gills, breathe through the mucous membranes in their mouth and throat and through their moist skin. The Jemez Mountains Salamander is completely terrestrial and does not use standing surface water for any life stage (FR 2012). Present in its habitat year-round, the Jemez Mountains Salamander spends most of its life underground, but can be found on the surface when conditions are warm and wet, approximately July through October. During this time, the Jemez Mountains Salamander can be found under rocks, bark, and moss mats and inside and under logs (Ramotnik 1986, Everett 2003). The Jemez Mountains Salamander eats invertebrates, including ants, mites, and beetles, and is thought to lay its eggs underground (FR 2013b).

\subsection{Threats}

Principal threats to habitat include historical fire exclusion and suppression and severe wildland fires; forest composition and structure conversions; post-fire rehabilitation; forest and fire management; roads, trails, and habitat fragmentation; recreation; and disease (FR 2012).

\subsection{IMPACT OF HUMAN ACTIVITIES}

\subsection{Introduction}

Primary threats to the Jemez Mountains Salamander on LANL property are impacts to habitat quality or destruction of individual salamanders caused by LANL or Los Alamos County operations. Forested LANL property is also subject to impacts from severe wildland fire and wildfire suppression.

\subsection{Impacts on Habitat Quality}

\subsubsection{Development}

Property at LANL varies from remote isolated land to heavily developed and/or industrialized. Most of the large developed areas at LANL are found on mesa tops, generally in the northern and western portion of LANL. The areas of Jemez Mountains Salamander habitat currently most impacted by development occur in Los Alamos Canyon. There is a secondary paved road (West Road) in the bottom of the canyon that exits the canyon on the north-facing slope through Jemez Mountains Salamander habitat. The canyon bottom also contains a recreational ice rink operated by Los Alamos County on an inholding owned by Los Alamos County. Development that reduces the occurrence of primary constituent elements of Jemez Mountains Salamander in core habitat would likely have a negative impact on the species.

\subsubsection{Pedestrians and Vehicles}

Many canyon bottoms and mesa tops at LANL have dirt roads traversing them. Most of these roads are gated; however, many of these roads are accessible to LANL employees and the public on foot or by bike. Some areas, such as Los Alamos Canyon, are frequently used by hikers and dog owners on active and historic trails which traverse the canyon, through Jemez Mountains 
Salamander habitat in places. Maintenance of roads and trails in the habitat may have a negative impact on the species.

\subsubsection{Severe Wildland Fire and Wildfire Suppression}

Stand-replacing wildfires significantly change forest composition and structure, and reduce canopy cover. Even ground wildfires may reduce the volume of fallen logs and large woody debris. Large areas of historic Jemez Mountains Salamander habitat have been impacted by stand-replacing wildfires associated with current forest stocking conditions, drought, and high temperatures (FR 2012). Forested habitats on LANL are also subject to severe wildland fires. To mitigate wildfire risks, some areas of LANL have been treated for fuels reduction and creation of fuel breaks both pre-emptively and during active wildfire suppression. Both wildfires and wildfire suppression activities can negatively impact the primary constituent elements of Jemez Mountains Salamander core habitat.

\subsection{Impacts on Individual Salamanders}

\subsubsection{Disease}

The amphibian pathogenic fungus Batrachochytrium dendrobatidis $(\mathrm{Bd})$ was found in a wild-caught Jemez Mountains Salamander in 2003 (Cummer et al. 2005) on the east side of the species' range and again in another Jemez Mountains Salamander in 2010 on the west side of the species' range (FR 2012). Bd causes the disease chytridiomycosis, whereby the Bd fungus attacks keratin in amphibians. In adult amphibians, keratin primarily occurs in the skin. The symptoms of chytridiomycosis can include sloughing of skin, lethargy, morbidity, and death. Chytridiomycosis has been linked with worldwide amphibian declines, die-offs, and extinctions, possibly in association with climate change (Pounds et al. 2006). Chytridiomycosis may be a threat to the Jemez Mountains Salamander because this disease is a threat to many other species of amphibians and the pathogen has been detected in the Jemez Mountains Salamander (FR 2012).

As part of a cooperative study with the New Mexico Department of Game and Fish between 2007 and 2013, various amphibian species including the canyon tree frog (Hyla arenicolor), western chorus frog (Pseudacris triseriata), Woodhouse's toad (Anaxyrus woodhousii), tiger salamander (Ambystoma tigrinum), and Jemez Mountains Salamander were tested for Bd infection at LANL. To date, all sampling has been negative for Bd infection (Fresquez et al. 2013).

\subsubsection{Destruction of Individual Salamanders}

During periods of the year when Jemez Mountains Salamander are on the soil surface, when conditions are warm and wet (generally July to October), they are vulnerable to injury and mortality from soil-disturbing activities, including operation of heavy equipment in core habitat. They also are at risk to be found and collected by people.

\subsection{AEI GENERAL DESCRIPTION FOR JEMEZ MOUNTAINS SALAMANDER}

The AEI consists of two areas, a core area and a buffer area. The core habitat is defined as suitable habitat where the Jemez Mountains Salamander occurs or may occur at LANL. The core habitat consists of sections of north-facing slope that contain the required micro-habitat to support Jemez 
Mountains Salamander. The buffer area is $100 \mathrm{~m}(328 \mathrm{ft})$ wide extending outward from the edge of the core area.

\subsection{Method for Identifying a Jemez Mountains Salamander AEI}

The first step in identifying potential Jemez Mountains Salamander at LANL was to use a GIS to model habitat. Early modeling efforts by Hathcock (2008) identified areas of potential habitat and that model was further refined. The following parameters were modeled in the GIS:

- Elevation: 7,000 ft $(2,150 \mathrm{~m})$ and above

- Slope: Greater than 20 degrees

- Aspect: north-facing +/- 20 degrees

- Land cover: Mixed conifer

- Land use: Undeveloped

- Modeled habitat is only selected if it is greater than five contiguous $30 \times 30 \mathrm{~m}(98 \times 98 \mathrm{ft})$ pixels in size

Once this habitat layer was developed, a second layer was modeled that examined the level of shade in the habitat, also known as an illumination index. Since the Jemez Mountains Salamander needs cool moist conditions, an illumination index model would further highlight areas where this habitat type may occur or further reinforce the areas selected by the GIS modeling. The illumination index describes the amount and extent of solar radiation reaching the Earth's surface at a given point. This takes into account the topography that may cast shadows. The illumination model was developed using the $5 \mathrm{~m}$ (16 ft) resolution digital elevation model hillshade and using the Surface toolbox in ArcToolbox (Environmental Science Research Institute, Redlands, California) using the highest height of the sun on June 21 at 1:00 pm, altitude of 74.4 and Azimuth of 178.4, when the sun would be at its maximum height. These procedures were based on work done by Reilly et al. (2009).

Once this modeling was complete, LANL biological resources SMEs performed field validation to verify the suitability of the modeled habitat. The goal was to verify that mixed conifer was still the dominant cover class in the selected area. The GIS analysis used data from a landcover map created by McKown et al. (2003). There have been changes in habitat since this landcover map was published from fire and extreme drought effects. Since LANL is on the extreme edge of Jemez Mountains Salamander lower elevational range, a key component in this part of its range is soil moisture content. During field validation, evidence of a moist mixed conifer habitat versus a dry mixed conifer habitat was noted. One of the key indicators used to delimit areas of moist versus dry mixed conifer during the field validation was the presence of white fir (Evans et al. 2011) combined with a high canopy cover.

Field validation of the model occurred in May 2013, or decisions were based on earlier field visits to the sites from other projects. Each field validation consisted of LANL biological resources SMEs walking down all of the modeled habitat polygons to look for the presence of indictor features. If a polygon of modeled habitat contained white fir, indicating a moist wet conifer type habitat, a high canopy closure, and other signs of high habitat quality such as dead logs, moss or 
other areas that could be used as cover by the Jemez Mountains Salamander, then the polygon was marked for retention in the final core habitat. Polygons that did not contain the necessary habitat requirements were omitted.

After the field validation was complete, the final core habitat boundaries that LANL would recognize were hand digitized using ArcGIS (Environmental Science Research Institute, Redlands, California) by LANL biological resources SMEs in and around the validated modeled polygon and areas between polygons if appropriate. The final identified core habitat at LANL occurs on the north-facing slopes of canyons. Toward the rim of the canyon the core boundaries end where the mixed conifer ends. In the canyon bottoms the core boundary extends to the edge of the stream channel. The upstream and downstream core boundaries end where the mixed conifer

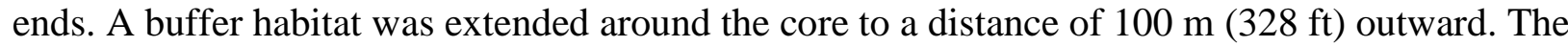
LANL Fenton Hill satellite facility in the Jemez Mountains off of New Mexico Highway 126 is on land leased to DOE by the Santa Fe National Forest. The entire footprint is considered to be developed core habitat for the Jemez Mountains Salamander, since proposed critical habitat is adjacent to the facility.

\subsection{Location and Number of Jemez Mountains Salamander AEls}

The identified Jemez Mountains Salamander core habitats were grouped by canyon system into AEIs, which contain contiguous and noncontiguous habitat areas. The largest contiguous section of habitat at LANL is in Los Alamos Canyon. There are two noncontiguous areas of habitat in Two-mile Canyon, four in Pajarito Canyon, one contiguous area in Cañon de Valle, and the entire Fenton Hill facility.

\subsection{AEI MANAGEMENT}

\subsection{Overview}

This AEI management section provides guidelines for LANL operations to reduce or eliminate the threats to the Jemez Mountains Salamander from habitat alterations that reduce habitat quality. Habitat alterations are considered for all AEIs and for both core and buffer areas. Developed areas that have ongoing baseline levels of activities and are not suitable habitat for Jemez Mountains Salamander have different restrictions than undeveloped core or buffer areas. AEIs for different species may overlap, and an activity must meet the guidelines of all applicable site plans to be allowable. Protective measures are described as management practices that should be followed when working in AEIs.

\subsection{Definition and Role of Occupancy in AEI Management}

Occupancy simply refers to whether or not an AEI is occupied by the Jemez Mountains Salamander. The Los Alamos Canyon AEI is known to be occupied based on past surveys. Surveys for the Jemez Mountains Salamander are known to have a very low detection rate for occupied areas, so at LANL all AEIs are assumed to be occupied at all times. If needed, site-specific surveys will be conducted by federally permitted LANL biological resources SMEs. 


\subsection{Definition and Role of Developed Areas in AEI Management}

Developed areas include all building structures, paved roads, improved gravel roads, and paved and unpaved parking lots. The majority of Jemez Mountains Salamander core habitat is in undeveloped areas, except for the satellite facility at Fenton Hill and a small amount of habitat in Los Alamos Canyon where West Road crosses the habitat. Generally, developed areas will not have restrictions; however, some of the undeveloped sections within the footprint of Fenton Hill may have restrictions because they may contain Jemez Mountains Salamanders when they move to the surface between July and October. Any project that occurs within developed core habitat will be evaluated by LANL biological resources SMEs for ESA compliance.

\subsection{General Description of Core and Buffer Areas and Allowable Area Development}

The purpose of buffer areas is to protect core areas from habitat degradation. The current levels of development in buffer and core areas represent baseline conditions for this site plan. No further development is allowed in the core area under the guidelines of this site plan. Any development in a buffer area will be reviewed by LANL biological resources SMEs to ensure that there are no impacts to the core habitat.

\subsection{Emergency Actions}

If safety and/or property are immediately threatened by something occurring within an AEI (for example, wildfire, water line breakage, etc.) please contact a LANL biological resources SME (1-505-665-3366) as soon as possible. If the emergency occurs outside of regular business hours, contact the Emergency Management Office (1-505-667-6211). This office will then communicate with the appropriate LANL personnel.

\subsection{Introduction to AEI Management Guidelines}

Section 4.7 provides the guidelines for habitat alterations and allowable activities in AEI core and buffer areas. It describes what and where habitat alterations are allowed under the guidelines of this site plan. If an activity does not meet the restrictions given in the guidelines, the activity must be individually reviewed for ESA compliance. This site plan only provides guidelines for the Jemez Mountains Salamander AEIs. If an activity is desired in an area with overlapping AEIs, all applicable site plans must be consulted. AEI maps show the location of all AEIs in an area. LANL biological resources SMEs are always available to help interpret site plans and answer questions (http://int.lanl.gov/environment/bio/controls/index.shtml).

\subsection{Definition of and Restrictions on Habitat Alterations}

\subsubsection{Definition of Habitat Alterations}

Habitat alteration includes any action that alters the soil structure, vegetative components necessary to the species, water quality, or hydrology in undeveloped areas of an AEI. An actual activity may take place outside of the AEI and will be considered habitat alteration if consequences of the activity have effects inside the AEI core. Habitat alterations would also include soil pits for soil samples deeper than $15 \mathrm{~cm}$ (6 in) using either hand or mechanized augers. Any activity that might disturb the soil will need to be reviewed by LANL biological resources SMEs. 
The habitat components most important to the Jemez Mountains Salamander include soil structure and vegetative structure. The forest structure within an area designated as a Jemez Mountains Salamander AEI is important because it provides the necessary moist, cool microclimate.

\subsubsection{Fuels Management Practices to Reduce Wildfire Risk}

One of the primary threats to the Jemez Mountains Salamander is wildfire (FR 2012), but they also require habitat with a high canopy cover which makes fuels reduction challenging. Within undeveloped core areas, thinning trees to a level of 80 percent canopy cover or higher is approved. Trees may not be thinned below 80 percent canopy cover without further ESA review by LANL biological resources SMEs. Large logs on the ground should be left in place and not chipped. Understory thinning that does not reduce total canopy cover below 80 percent is permitted. Large trees that are felled should be left as large logs on the ground. Smaller trees and understory shrubs that may be thinned should be dispersed and left on-site to aid in soil moisture retention. Thinning activities should not occur during the rainy season between July to October (or when freezing temperatures begin, whichever comes first) when the Jemez Mountains Salamander is found on the surface.

In buffer areas, thinning of trees can occur to the current LANL-approved prescription level (LAAO 2000). LANL biological resources SMEs are available to provide guidance and mark trees for thinning (http://int.lanl.gov/environment/bio/controls/index.shtml).

\subsubsection{Utility Corridors}

Habitat alterations such as cutting down trees that threaten power lines are allowed within $8 \mathrm{~m}$ (26 ft) of either side of an existing electrical utility line at LANL under existing guidelines and engineering controls (Hathcock 2013). This level is approved in all areas of an AEI. New utility lines and utility lines requiring clearance of a right-of-way greater than $16 \mathrm{~m}(52 \mathrm{ft})$ total in core habitat must be individually reviewed for ESA compliance.

\subsubsection{Restrictions on Habitat Alterations}

Habitat alterations other than the fuels management practices and utility corridor maintenance described above are not allowed in undeveloped core areas under the guidelines of this site plan. If a project or activity is planned that would alter habitat in an undeveloped core area, it must be individually evaluated for ESA compliance. Habitat alterations in buffer areas must be reviewed by LANL biological resources SMEs to ensure that there are no impacts to core habitat. 


\section{REFERENCES CITED}

Allison, L.J., C.E. Paradzick, J.W. Rourke, and T.D. McCarthey. 2003. A characterization of vegetation in nesting and non-nesting plots for southwestern willow flycatchers in central Arizona. In Ecology and Conservation of the Willow Flycatcher (eds) M.K. Sogge, B.E. Kus, S.J. Sferra \& M.J. Whitfield. Studies In Avian Biology: Cooper Ornithological Society.

Brown, B.T., G.S. Mills, C. Powels, W.A. Russell, G.D. Therres, and J.J. Pottie. 1999. The influence of weapons-testing noise on bald eagle behavior. Journal of Raptor Research $33: 227-32$.

Brown, B.T. and L.E. Stevens. 1997. Winter bald eagle distribution is inversely correlated with human activity along the Colorado River, Arizona. Journal of Raptor Research 31:7-10.

Burns, M.J. 1995. White Rock noise measurements during PHERMEX tests, 11 March 1995. Los Alamos National Laboratory Memorandum DX-DO:DARHT-95-31 and 35.

Cain, B.W. 1988. The impact of environmental contaminants on Southwestern USA raptors. Proceedings of the Southwest Raptor Management Symposium and Workshop (ed) by R.L. Glinski, B.G. Pendleton, M.B. Moss, M.N. LeFranc Jr., B.A. Millsap \& S.W. Hoffman, 348-54. Tucson, AZ, USA, May 21-24, 1986: National Wildlife Federation, Washington, D.C., USA.

Cummer, M. R., D. E. Green, and E. M. O’Neill. 2005. Aquatic chytrid pathogen detected in terrestrial plethodontid salamander. Herpetological Review 36(3):248-249.

Degenhardt, W.G., C.W. Painter, and A.H. Price. 1996. Amphibians and Reptiles of New Mexico. University of New Mexico Press, Albuquerque, New Mexico.

Delaney, D.K., T.G. Grubb, P. Beier, L.L. Pater, and M.H. Reiser. 1999. Effects of helicopter noise on Mexican spotted owls. Journal of Wildlife Management 63:60-76.

Department of Energy (DOE). 1996. Dual-Axis Radiographic Hydrodynamic Test Facility final environmental impact statement mitigation action plan. DOE/EIS-0228.

Durst, S.L., M.K. Sogge, H.C. English, S.O. Williams, B.E. Kus, and S.J. Sferra. 2006. Southwestern Willow Flycatcher breeding site and territory summary - 2005. USGS Southwest Biological Science Center report to the U.S. Bureau of Reclamation.

Durst, S.L., T.C. Theimer, E.H. Paxton, and M.K. Sogge. 2008. Age, habitat, and yearly variation in the diet of a generalist insectivore, the southwestern willow flycatcher. Condor 110:514-25.

Environmental Protection Agency (EPA). 2010. National Pollutant Discharge Elimination System Storm Water Individual Permit number NM0030759. 
Evans, A.M., R.G. Everett, S.L. Stephens, and J.A. Youtz. 2011. Comprehensive Fuels Treatment Practices Guide for Mixed Conifer Forests: California, Central and Southern Rockies, and the Southwest. Forest Guild 106pp.

Everett, E. 2003. Habitat Characterization and Environmental Influences of the Jemez Mountains Salamander (Plethodon neomexicanus). M.S. Thesis, New Mexico State University, Las Cruces, New Mexico, 55pp.

Federal Register. 2012. September 12, 2012. Endangered and Threatened Wildlife and Plants; Proposed Endangered Status for the Jemez Mountains Salamander and Proposed Designation of Critical Habitat. Proposed Rule 77(177):56482-56513.

Federal Register. 2013a. September 10, 2013. Endangered and Threatened Wildlife and Plants; Determination of Endangered Species Status for Jemez Mountains Salamander (Plethodon neomexicanus) Throughout Its Range. 78(175):55600-55627.

Federal Register. 2013b. February 12, 2013. Endangered and Threatened Wildlife and Plants; Endangered Status and Designation of Critical Habitat for the Jemez Mountains Salamander. Proposed rule; reopening of comment period 78(29):9876-9882.

Finch, D.M. and J.F. Kelly. 1999. Status and migration of the southwestern willow flycatcher in New Mexico. In Rio Grande Ecosystems: Linking Land, Water, and People: Toward a Sustainable Future for the Middle Rio Grande Basin (ed) D.M. Finch, J.C. Whitney, J.F. Kelly \& S.R. Loftin, 197-203, Albuquerque, New Mexico.

Fresquez, P.R., C. Hathcock, D. Keller, and J. Fair. 2013. "Foodstuffs and Biota Monitoring", in Environmental Report 2012. Los Alamos National Laboratory report LA-UR-13-27065.

Gallegos, A., G. Gonzales, K. Bennett, and L. Pratt. 1997. Preliminary Risk Assessment of the Mexican Spotted Owl under a Spatially-weighted Foraging Regime at the Los Alamos National Laboratory. LANL report LA-13259-MS.

Gonzales, G., R. Ryti, P. Newell, A. Gallegos, and S. Sherwood. 2004. Modeled Ecological Risk to the Deer Mouse, Mexican Spotted Owl, and Western Bluebird at the Los Alamos National Laboratory using ECORSK.7. LANL report LA-14118.

Gonzales, G., P. Gallegos, A. Gallegos, and K. Bennett. 2009. Site-wide Application of ECORSK.9 at the Los Alamos National Laboratory. LANL report LA-UR-09-02833.

Ganey, J.L. and R.P. Balda. 1994. Habitat selection by Mexican spotted owls in northern Arizona. Auk 111:162-69.

Gonzales, G.J., A.F. Gallegos, K.D. Bennett, M.A. Mullen, and T.S. Foxx. 1998. Preliminary Risk Assessment of the Southwestern Willow Flycatcher (Empidonax traillii extimus) at the Los Alamos National Laboratory. Los Alamos National Laboratory report LA-13508MS. 
Grubb, T.G. and W.W. Bowerman. 1997. Variations in breeding bald eagle responses to jets, light planes, and helicopters. Journal of Raptor Research 31:213-22.

Grubb, T.G. and R.M. King. 1991. Assessing human disturbance of breeding bald eagles with classification tree models. Journal of Wildlife Management 55:500-11.

Hansen, L.A. 2004. Sigma Mesa Construction Debris Recycling Project. Los Alamos National Laboratory Memorandum RRES/Ecol-04-0049.

Hansen, L.A. 2005. A Biological Assessment of the Potential Effects of the Operation of an Asphalt Batch Plant and a Rock Crusher at Sigma Mesa on Federally Listed Threatened and Endangered Species. Los Alamos National Laboratory report LA-CP-05-0293.

Hansen, L.A. 2009. Sound studies of the Biosafety Level 3 (BSL-3) Laboratory at TA-3, Building 1076. Los Alamos National Laboratory report LA-UR-09-05482.

Hathcock, C.D. and T.K. Haarmann. 2008. Development of a predictive model for habitat of the Mexican spotted owl in Northern New Mexico. Southwestern Naturalist 53:34-38.

Hathcock, C. D. 2008. The Status of the Jemez Mountains Salamander (Plethodon neomexicanus) at Los Alamos National Laboratory, 2008. Los Alamos National Laboratory Report LA-UR-08-0826.

Hathcock, C.D., L.A. Hansen, and D.C. Keller. 2010. Occupancy of habitats by Mexican spotted owl in relation to explosives noise and recreational access at Los Alamos National Laboratory. Western Birds 41:102-06.

Hathcock, C. D. 2013. Email from C. D. Hathcock to S. Martinez on June 20, 2013, Los Alamos National Laboratory communication.

Hatten, J.R. and C.E. Paradzick. 2003. A multiscaled model of southwestern willow flycatcher breeding habitat. Journal of Wildlife Management 67:774-88.

Holthuijzen, A.M.A., W.G. Eastland, A.R. Ansell, M.N. Kochert, R.D. Williams, and L.S. Young. 1990. Effects of blasting on behavior and productivity of nesting prairie falcons. Wildlife Society Bulletin 18:270-81.

Huchton, K., S.W. Koch, and R.J. Robinson. 1997. An analysis of background noise in selected canyons of Los Alamos County. Los Alamos National Laboratory report LA-13372-MS.

Johnson, J.A. and T.H. Johnson. 1985. Timber type model of spotted owl habitat in northern New Mexico. New Mexico Department of Game and Fish report, Santa Fe, New Mexico.

Johnson, T.H. 1994. Peregrine falcon habitat management in national forests of New Mexico. USDA Forest Service unpublished report. 
Johnson, T.H. 1998. Topographic-Landsat model of suitable spotted owl habitat around Los Alamos National Laboratory. Los Alamos National Laboratory unpublished report.

Keller, D.C. and T.S. Foxx. 1997. Biological assessment for threatened and endangered species at the DP Road Tract land transfer. Los Alamos National Laboratory unpublished report.

Keller, D.C. and D. Risberg. 1995. Biological and floodplain/wetland assessment for the Dual-Axis Radiographic Hydrodynamics Test Facility (DARHT). Los Alamos National Laboratory report LA-UR-95-647.

Knight, J.L. and S.S. Vrooman. 1999. A study of construction machinery noise levels at Los Alamos National Laboratory. Los Alamos National Laboratory report LA-UR-99-5740.

Department of Energy, Los Alamos Area Office (LAAO). 2000. Environmental Assessment for the Wildfire Hazard Reduction and Forest Health Improvement Program at Los Alamos National Laboratory, Los Alamos, New Mexico. DOE-EA-1329.

Los Alamos National Laboratory (LANL). 2013. Environmental Protection. Los Alamos National Laboratory Program Description 400, Revision 2.

McKown, B., S.W. Koch, R.G. Balice, and P. Neville. 2003. Land Cover Classification Map for the Eastern Jemez Region. Los Alamos National Laboratory report LA-14029.

New Mexico Department of Game and Fish (NMDGF), April 2006. Threatened and Endangered Species of New Mexico-2006 Draft Biennial Review and Recommendations. Authority: Wildlife Conservation Act (NMSA 17-2-37+B1 through 17-2-46, 1978).

New Mexico Environment Department (NMED). 2005. Compliance Order on Consent New Mexico Environment Department.

Paakkonen, R. 1991. Low-frequency noise impulses from explosions. Journal of Low Frequency Noise \& Vibration 10:78-82.

Pounds, J.A., M.R. Bustamante, L.A. Coloma, J.A. Consuegra, M.P.L. Fogden, P.N.Foter, E. La Marca, K.L. Masters, A. Merino-Viteri, R. Puschendorf, S.R. Ron, G.A. Sanchez-Azofeifa, C.J. Still, and B.E. Yound. 2006. Widespread amphibian extinctions from epidemic disease driven by global warming. Nature 439(7073):161-167.

Ramotnik, C.A. 1986. Status Report: Plethodon neomexicanus Jemez Mountains Salamander. U.S. Fish and Wildlife Service Report.

Reilly, E.C., D. Clayton, R.S. Nauman, D.H. Olson, H.H. Welsh Jr, B. Devlin. 2009. Spatial Model of Optimal Habitat for the Siskiyou Mountains Salamander (Plethodon stormi) North of the Siskyou Crest. Chapter 2. In: Olson, D.H., D. Clayton, R.S. Nauman, and H.H. Welsh Jr (Editors). 2009. Conservation of the Siskiyou Mountains Salamander (Plethodon stormi). Northwest Fauna 6:1-73. 
Stebbins, R.C., and W.J. Riemer. 1950. A New Species of Plethodontid Salamander from the Jemez Mountains of New Mexico. Copeia 1950(2):73-80.

Steidl, R.J. and R.G. Anthony. 2000. Experimental effects of human activity on breeding bald eagles. Ecological Applications 10:258-68.

Swarthout, E.C.H. and R.J. Steidl. 2001. Flush responses of Mexican spotted owls to recreationists. Journal of Wildlife Management 65:312-17.

Swarthout, E.C.H. and R.J. Steidl. 2003. Experimental effects of hiking on breeding Mexican spotted owls. Conservation Biology 17:307-15.

Trujillo, C.T. and E. Racinez. 1995. Meeting notes on the 13.8-kV transmission line tree trimming. Los Alamos National Laboratory Memorandum FSS-8-95-114.

U.S. Fish and Wildlife Service (USFWS). 1995. Recovery plan for the Mexican spotted owl. Albuquerque, New Mexico.

U.S. Fish and Wildlife Service (USFWS). 2012. Recovery plan for the Mexican Spotted Owl, First Revision. Albuquerque, New Mexico.

U.S. Fish and Wildlife Service (USFWS). 2002. Southwestern willow flycatcher recovery plan. Albuquerque, New Mexico.

Vigil, E.A. 1995. Noise measurements at State Road 4 and Bandelier turn-off at State Road 4 during PHERMEX test on March 11, 1995. Los Alamos National Laboratory Memorandum ESH-5:95-11825.

Vrooman, S.S., S.W. Koch, and J.L. Knight. 2000. Temporal and spatial variation in background noise levels at Los Alamos National Laboratory. Los Alamos National Laboratory report LA-13684-MS.

Wiesenborn, W.D. and S.L. Heydon. 2007. Diets of breeding southwestern willow flycatchers in different habitats. Wilson Journal of Ornithology 119:547-57.

Willey, D.W. 2013. Diet of Mexican Spotted Owls in Utah and Arizona. The Wilson Journal of Ornithology 125(4):775-781.

Yong, W. and D.M. Finch. 1997. Migration of the willow flycatcher along the middle Rio Grande. Wilson Bulletin 109:253-68. 


\section{APPENDIX}

Table A-1. The percentage of each food type found in Mexican Spotted Owl food remains at LANL

\begin{tabular}{|l|c|}
\hline Species & Relative Abundance \\
\hline Neotoma spp. & 26.22 \\
\hline Peromyscus spp. & 10.22 \\
\hline Microtus spp. & 4.44 \\
\hline Gophers & 4.89 \\
\hline Bats & 5.78 \\
\hline Chipmunks & 0.89 \\
\hline Rabbits & 12.89 \\
\hline Shrews & 1.33 \\
\hline Small Mammal & 1.33 \\
\hline Medium Mammal & 1.78 \\
\hline Medium Bird & 8.00 \\
\hline Small Bird & 4.89 \\
\hline Nocturnal Birds & 0.89 \\
\hline Reptiles & 4.89 \\
\hline Arthropods & 11.56 \\
\hline
\end{tabular}

Table A-2. Preliminary light measurements in ftc for Mexican Spotted Owl site plan

\begin{tabular}{|l|l|l|l|l|l|}
\cline { 3 - 6 } \multicolumn{4}{c|}{} & \multicolumn{4}{|c|}{ Distance from Source } \\
\cline { 2 - 6 } \multicolumn{1}{c|}{} & Source (street light) & $5 \mathrm{~m}$ & $10 \mathrm{~m}$ & $15 \mathrm{~m}$ & $20 \mathrm{~m}$ \\
\hline $\mathrm{ftc}$ & 3.70 & 2.28 & 1.20 & 0.62 & 0.32 \\
\hline
\end{tabular}




\section{Corrective Actions}




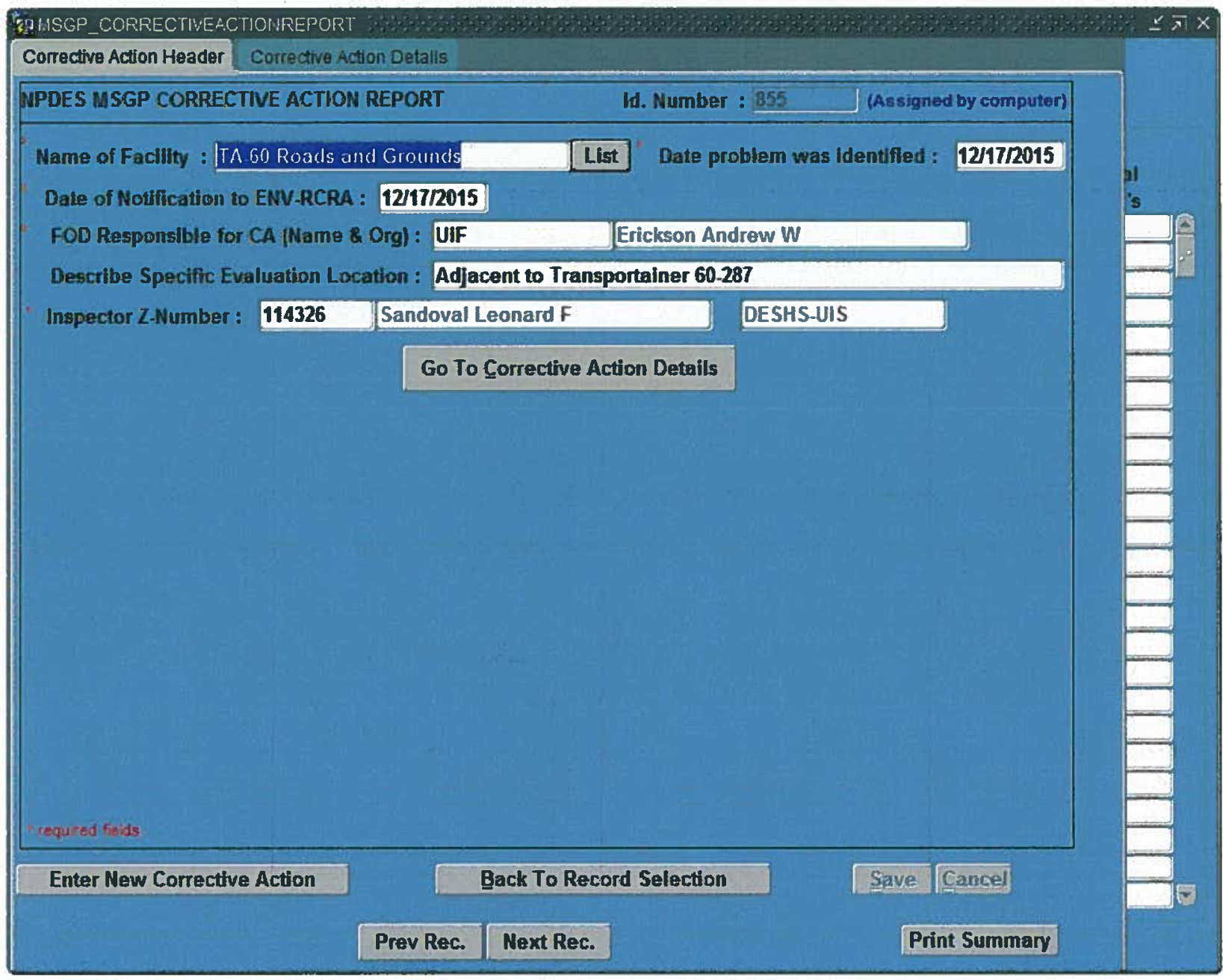




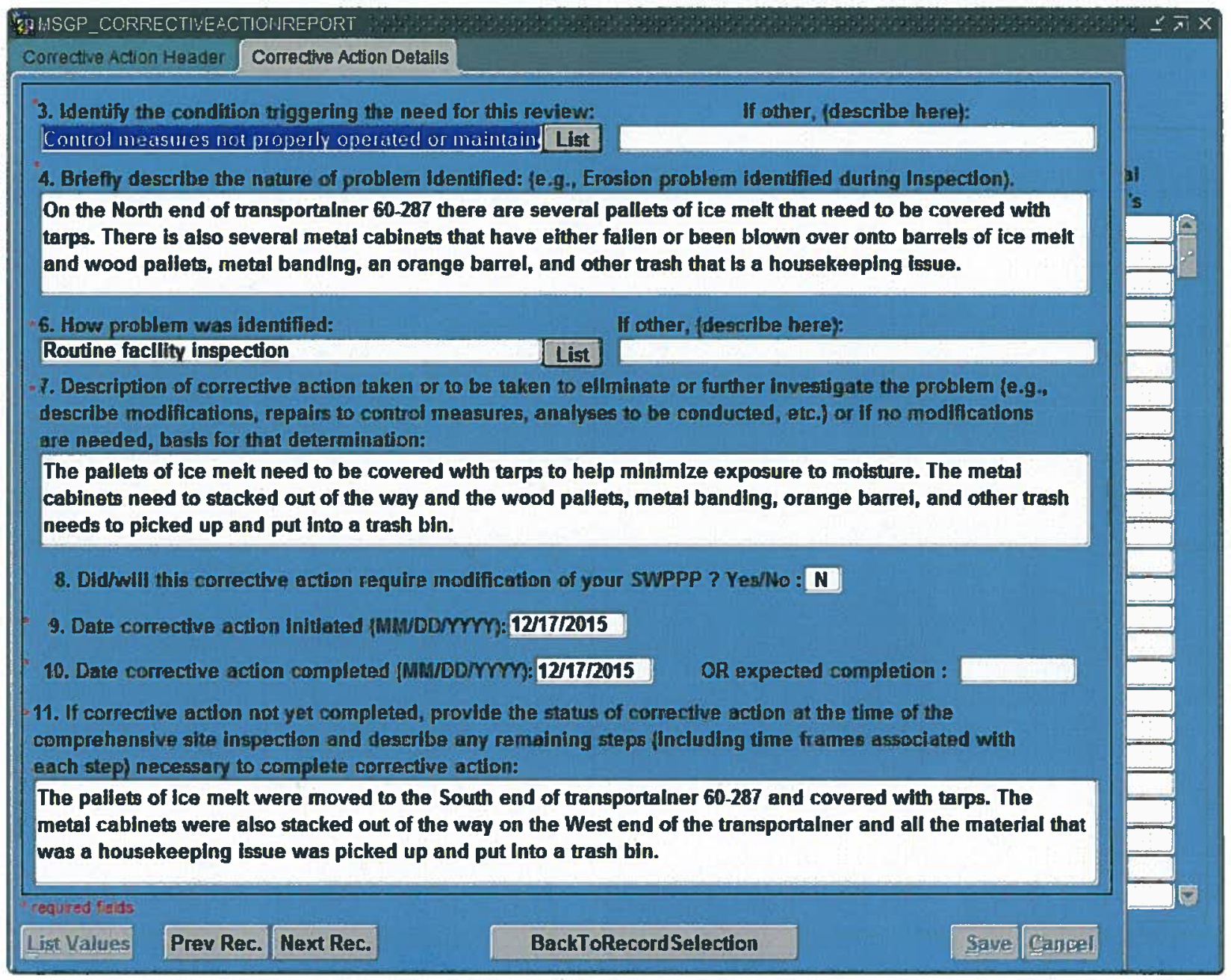




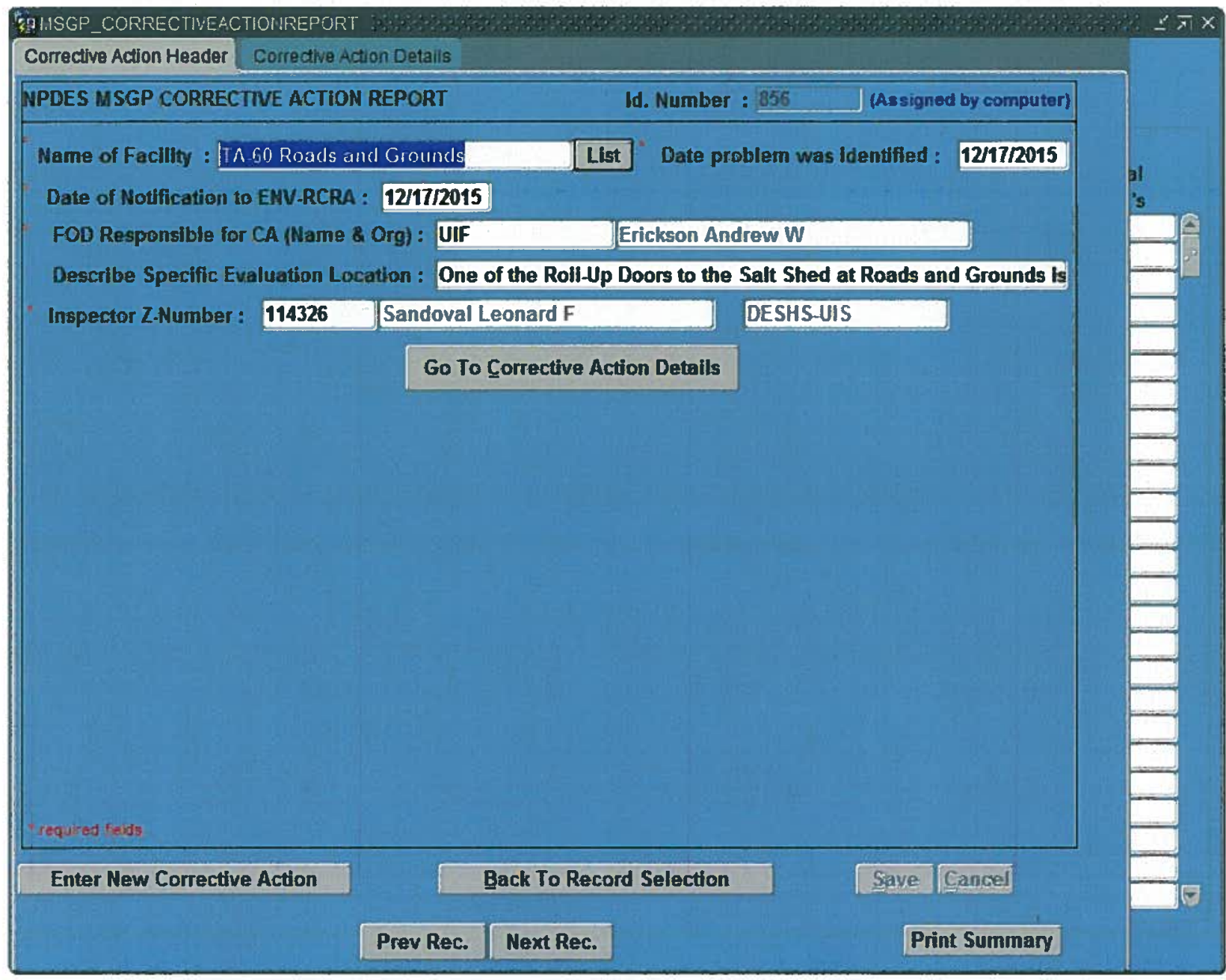




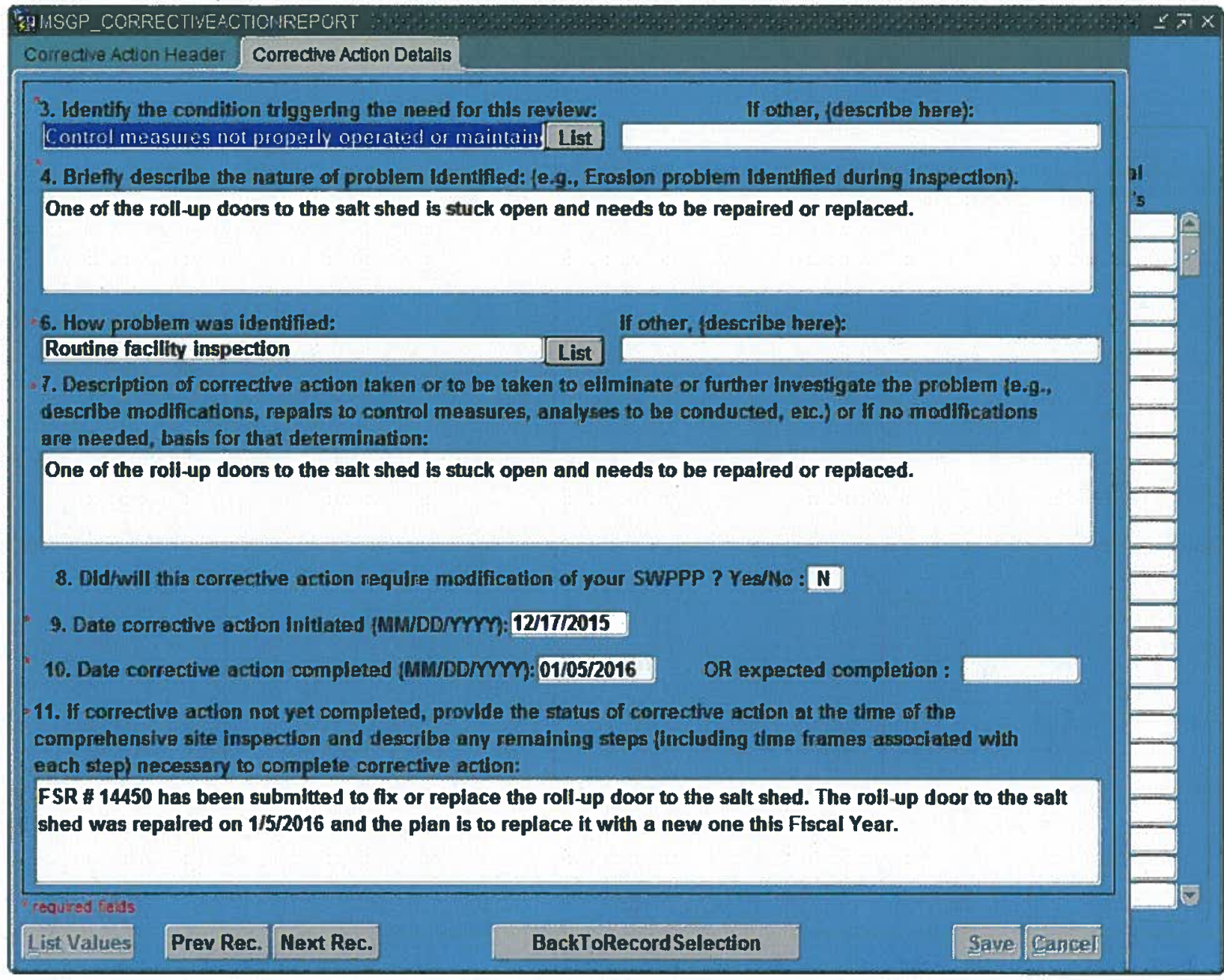




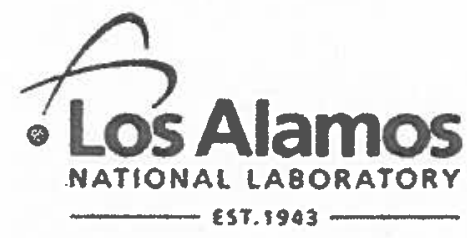

Environmental Protection Division

Environmental Compliance Programs (ENV-CP)

PO Box 1663, K490

Los Alamos, New Mexico 87545

(505) 667-0666

$\begin{aligned} \text { Date: } & \text { NOV } 172015 \\ \text { Symbol: } & \text { ENV-DO-15-0326 } \\ \text { LA-UR: } & 15-28966 \\ \text { Locates Action No.: } & \text { N/A }\end{aligned}$

Ms. Nasim Jahan

Water Quality Protection Division (6WQ)

U.S. Environmental Protection Agency, Region 6

1445 Ross Avenue, Suite 1200

Dallas, TX 75202-2733

Dear Ms. Jahan:

Subject: $\quad$ National Pollutant Discharge Elimination System (NPDES) Permit Tracking No. NMR053195, Multi-Sector General Permit (MSGP) 45 Day Extension Notification Pursuant to Part 4.3.2

In accordance with Part 4.3.2 of the 2015 NPDES Multi-Sector General Permit, the purpose of this letter is to notify EPA Region 6 personnel that completion of corrective actions for three items at Los Alamos National Laboratory (MSGP Tracking No. NMR053195) will exceed 45 days. For each of these items, the rationale for an extension and a proposed completion date are included in the Table 1 , below.

Table 1 - MSGP Corrective Action 45 Day Extensions

\begin{tabular}{|l|l|l|l|}
\hline $\begin{array}{l}\text { LANL } \\
\text { Tracking \# }\end{array}$ & $\begin{array}{l}\text { Condition Requiring } \\
\text { Corrective Action }\end{array}$ & Rationale for Extension & $\begin{array}{l}\text { Proposed } \\
\text { Completion Date }\end{array}$ \\
\hline 778 & $\begin{array}{l}\text { The channel on the south } \\
\text { end of the lower yard at the } \\
\text { TA-60 Heavy Equipment } \\
\text { Yard needs to be cleaned } \\
\text { out and re-established. } \\
\begin{array}{l}\text { There is one point in the } \\
\text { channel by a Chinese Elm } \\
\text { tree that the water is } \\
\text { bypassing the channel. }\end{array}\end{array}$ & $\begin{array}{l}\text { This corrective action is being addressed } \\
\text { through LANL's institutional computer- } \\
\text { based Facility Service Request (FSR) } \\
\text { system, which utilizes multiple inputs } \\
\text { for prioritizing work. However, the FSR } \\
\text { system is not currently designed to } \\
\text { recognize or accept MSGP corrective } \\
\text { action as an input for work } \\
\text { prioritization. This affects work } \\
\text { scheduling and execution. The inability }\end{array}$ & \\
\hline
\end{tabular}




\begin{tabular}{|c|c|c|c|}
\hline & & $\begin{array}{l}\text { of the LANL FSR system to prioritize } \\
\text { MSGP corrective actions is being } \\
\text { recognized at this time (management } \\
\text { system policy and procedures). This } \\
\text { corrective action is being scheduled for } \\
\text { completion. }\end{array}$ & \\
\hline 792 & $\begin{array}{l}\text { Water was discharging from } \\
\text { a leak in the steam } \\
\text { condensate line into a } \\
\text { drainage swale east of TA- } \\
\text { 3-66. }\end{array}$ & $\begin{array}{l}\text { This corrective action is being addressed } \\
\text { through LANL's institutional computer- } \\
\text { based FSR system. The LANL Utilities } \\
\text { Organization responsible for the work is } \\
\text { also currently addressing multiple steam } \\
\text { leaks across the LANL site. The FSR } \\
\text { system utilizes multiple inputs for } \\
\text { prioritizing work, however, it is not } \\
\text { currently designed to recognize or } \\
\text { accept MSGP corrective action as an } \\
\text { input for work prioritization. This } \\
\text { affects work scheduling and execution. } \\
\text { The responsiveness of the LANL work } \\
\text { control system to prioritize MSGP } \\
\text { corrective actions is being recognized at } \\
\text { this time (management system policy } \\
\text { and procedures). The Utilities } \\
\text { Organization is preparing a work } \\
\text { package and will schedule the work in } \\
\text { the near future. }\end{array}$ & $11 / 25 / 2015$ \\
\hline 845 & $\begin{array}{l}\text { At TA-60 Roads and } \\
\text { Grounds east, there is a pile } \\
\text { of soil, tuff, asphalt, and } \\
\text { concrete mixed with metal } \\
\text { bollards staged north of } \\
\text { Eniwetok Road. }\end{array}$ & $\begin{array}{l}\text { The work crew is still segregating the } \\
\text { material to identify content acceptable } \\
\text { for recycling and material requiring } \\
\text { disposal. This process requires } \\
\text { development and evaluation of an } \\
\text { internal waste profile, which is currently } \\
\text { in process. }\end{array}$ & $11 / 24 / 2015$ \\
\hline
\end{tabular}


If you have any questions or need additional information, please contact Terrill Lemke at (505) 665-2397.

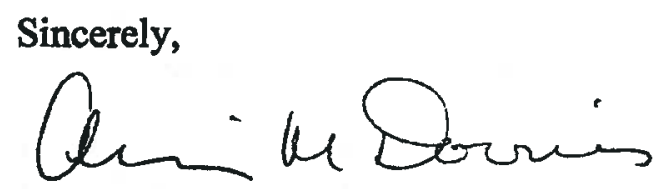

Alison M. Dorries

Division Leader

Environmental Protection Division

Los Alamos National Security, LLC

\section{AMD:TWL:HLW/lm}

Cy: Bruce Yurdin, NMED/SWQB, Santa Fe, NM, (E-File)

Gene E. Turner, LASO-NS-LP, (E-File)

Jorden Arnswald, LASO-NS-PI, (E-File)

Kirsten Lanskey, LASO-SUP, (E-File)

Craig Leasure, PADOPS, (E-File)

Amy E. De Palma, PADOPS, (E-File)

Michael T. Brandt, ADESH, (E-File)

Raeanna Sharp-Geiger, ADESH, (E-File)

Alison M. Dorries, ENV-DO, (E-File)

Michael T. Saladen, ENV-CP, (E-File)

Terrill W. Lemke, ENV-CP, (E-File)

Holly L. Wheeler, ENV-CP, (E-File)

lasomailbox@nnsa.doe.gov, (E-File)

locatesteam@lanl.gov, (E-File)

env-correspondence@lanl.gov 


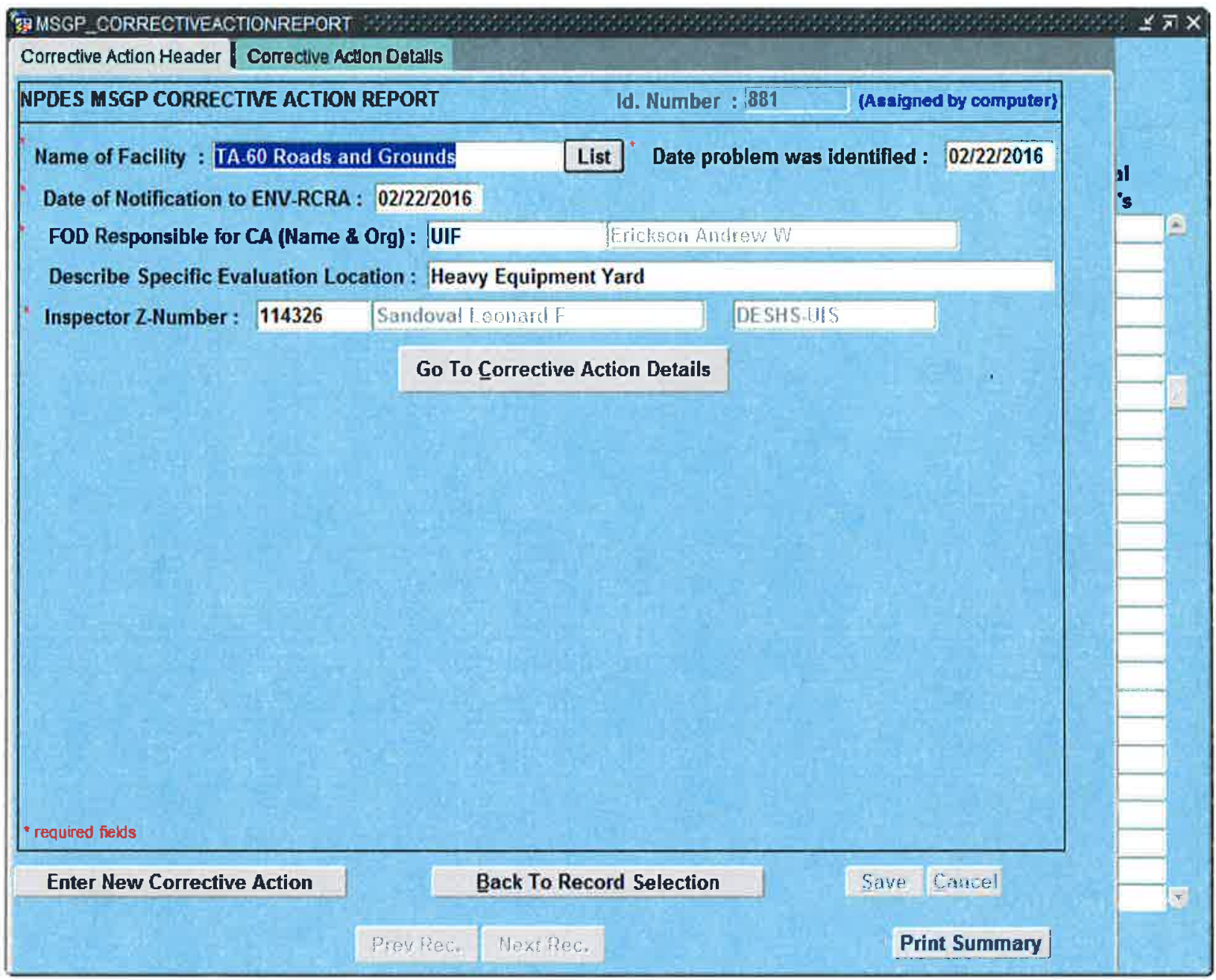




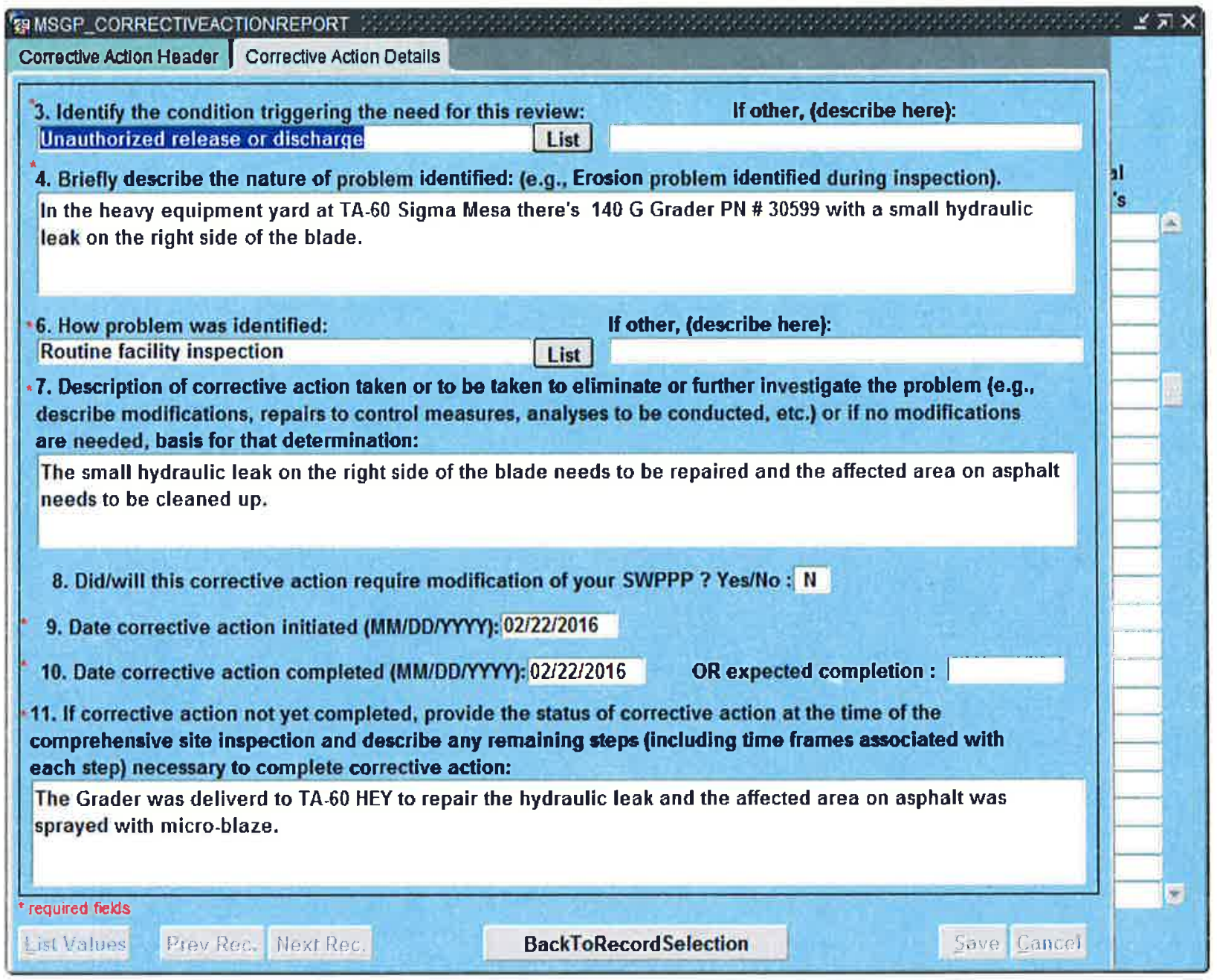




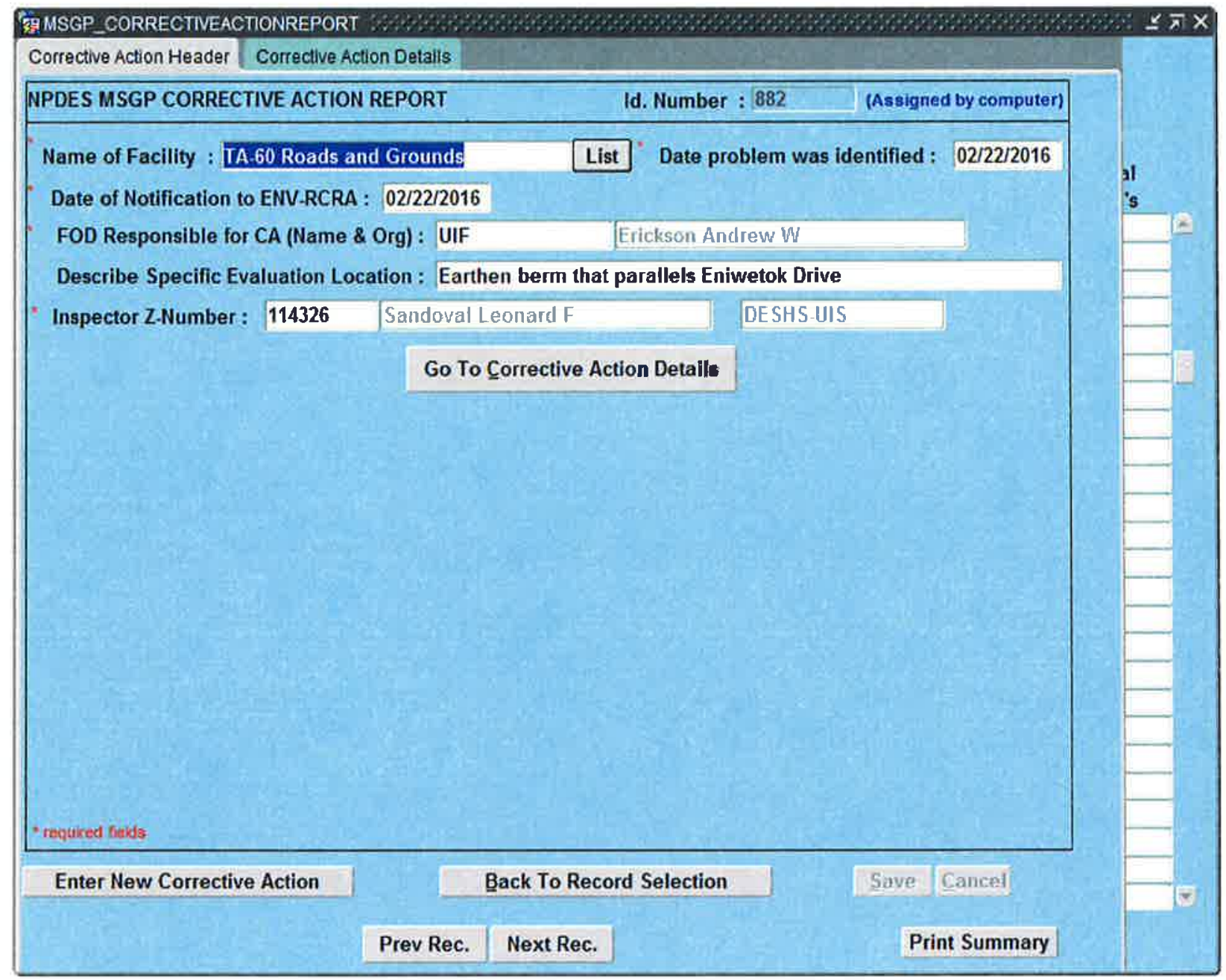




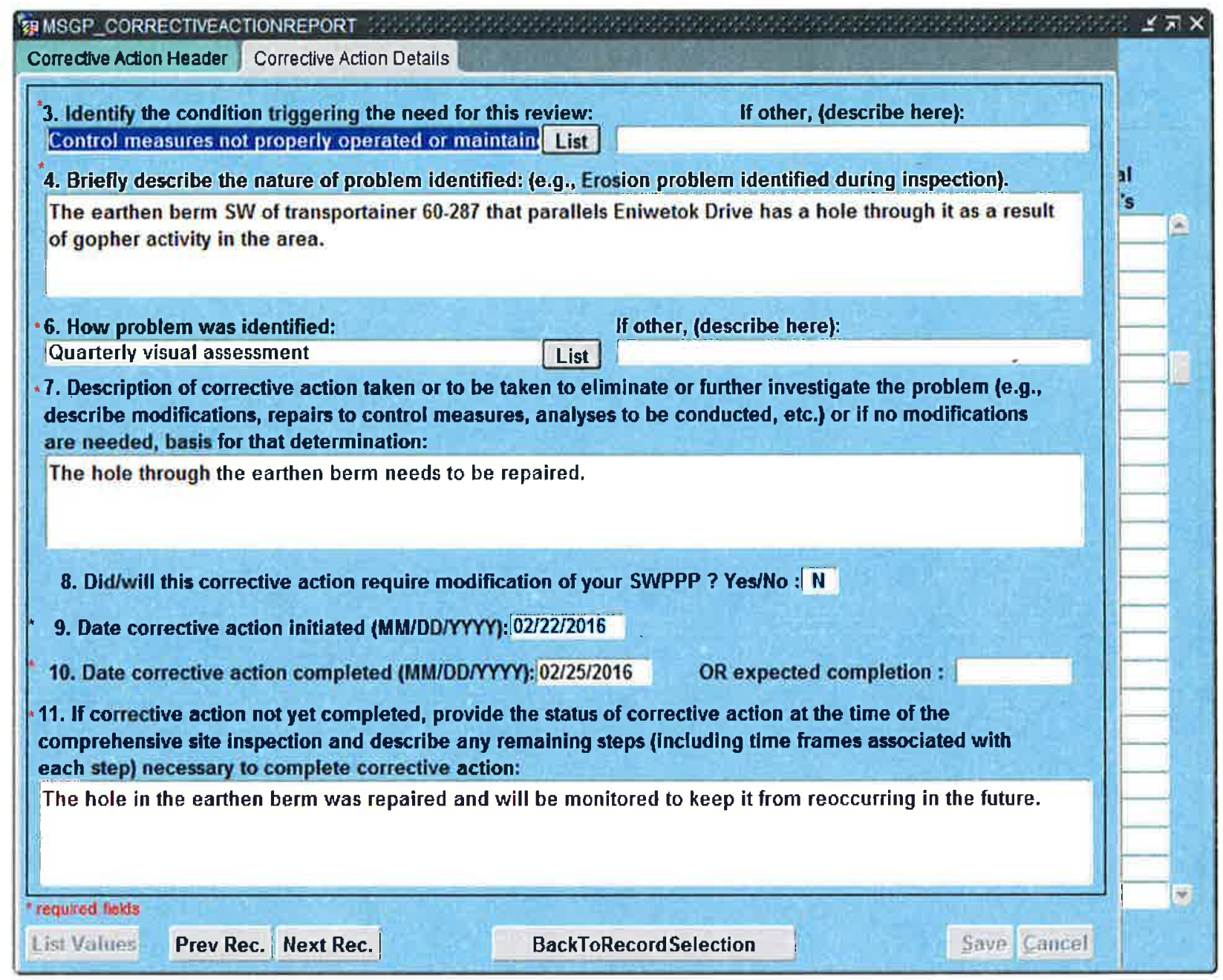




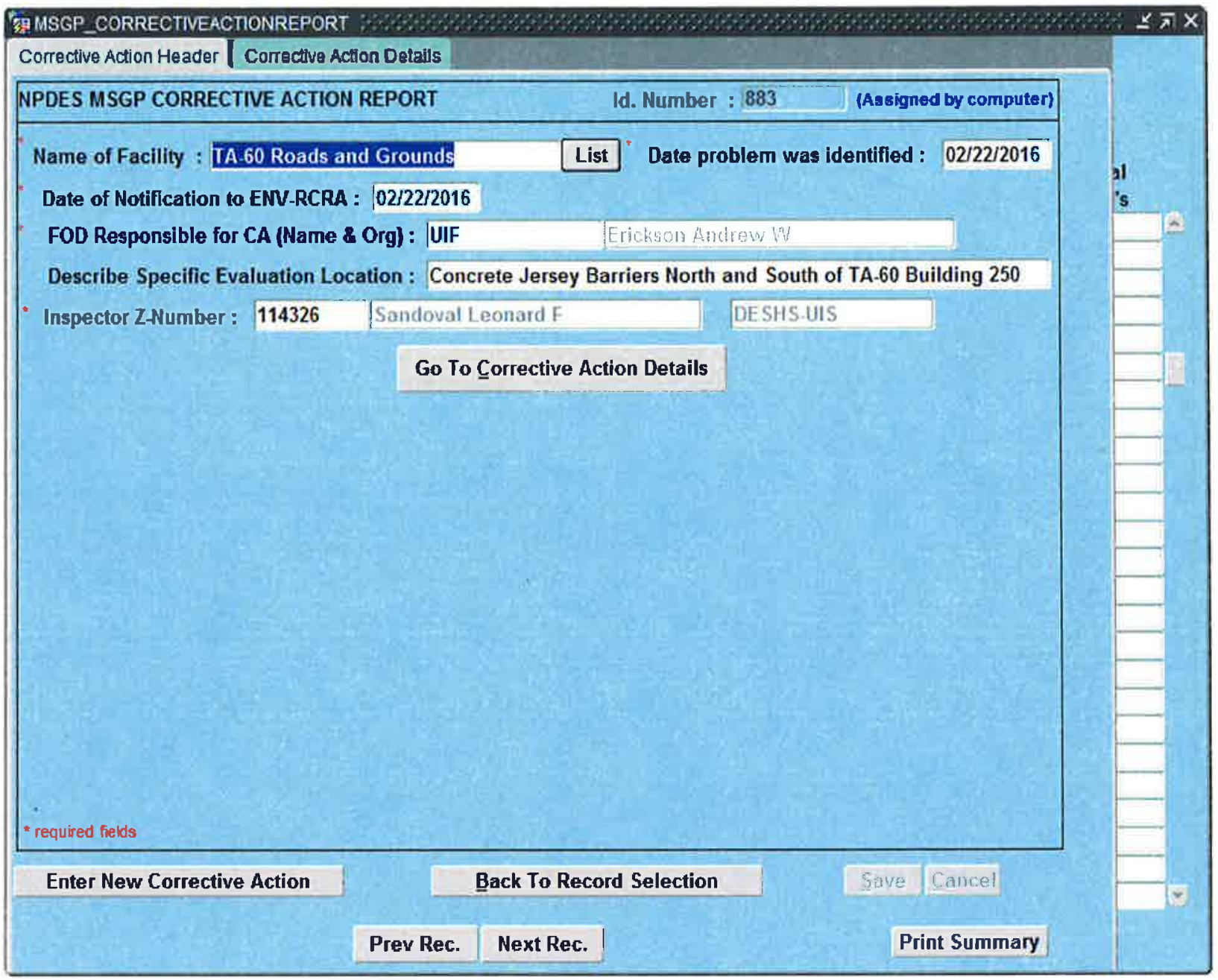




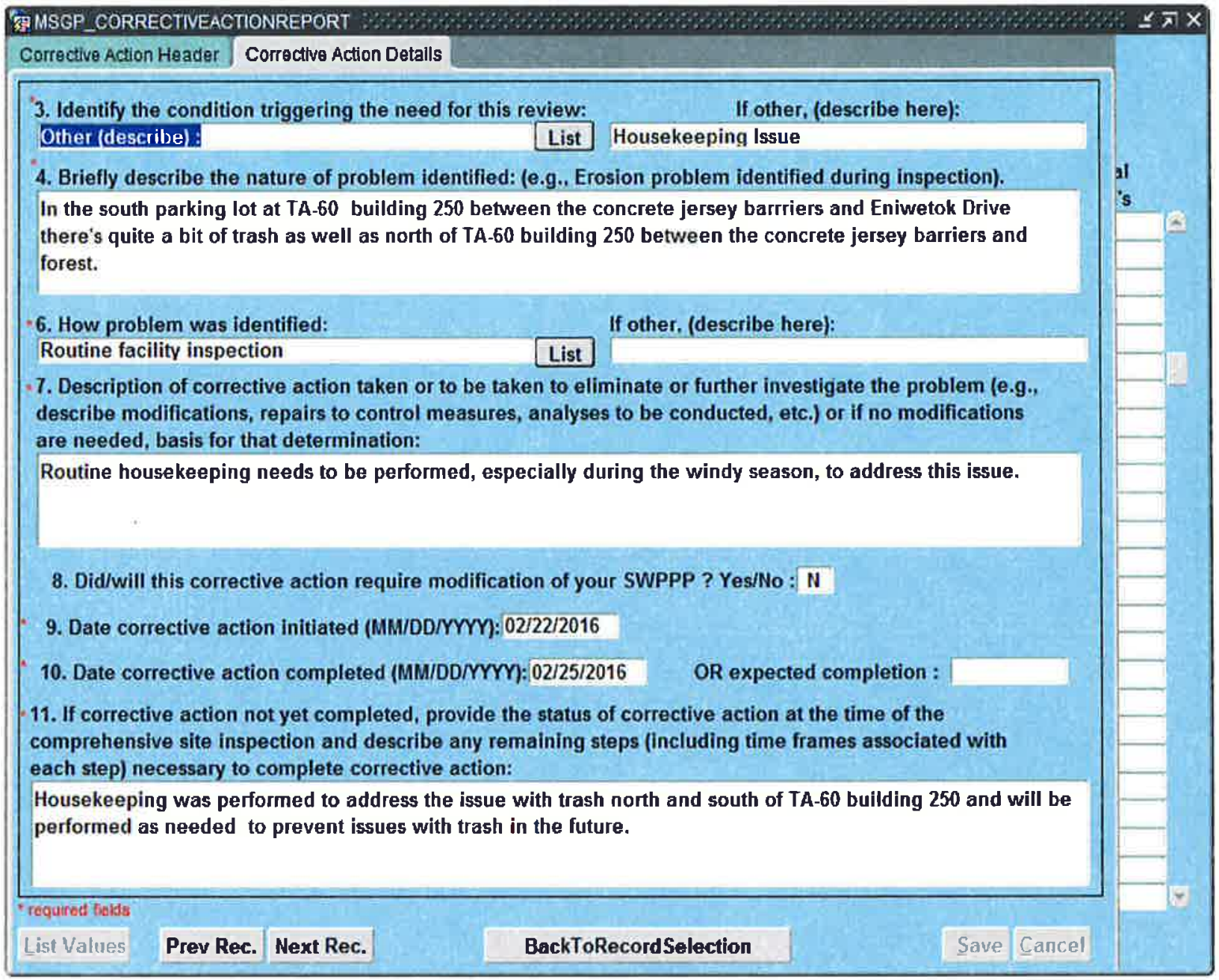




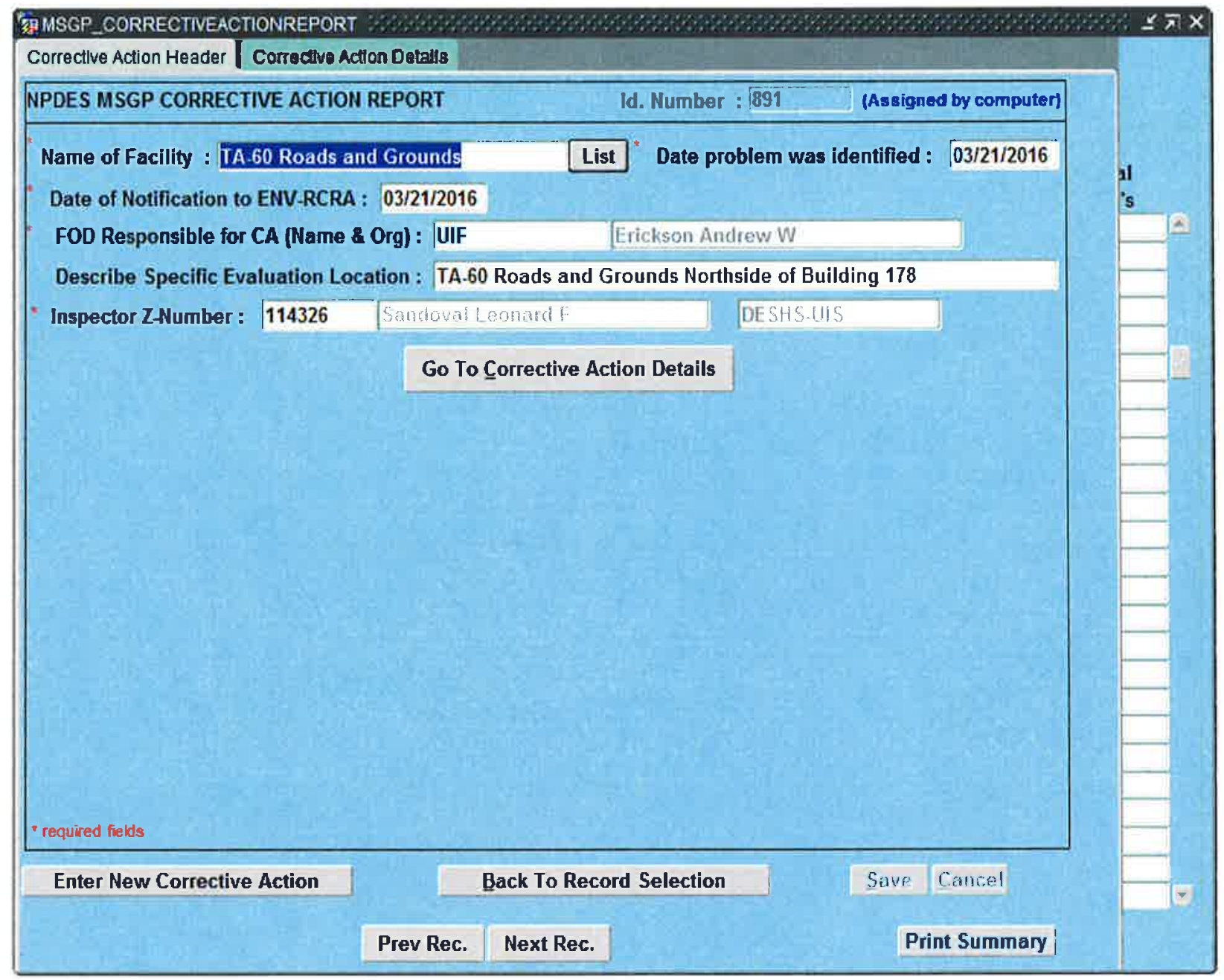




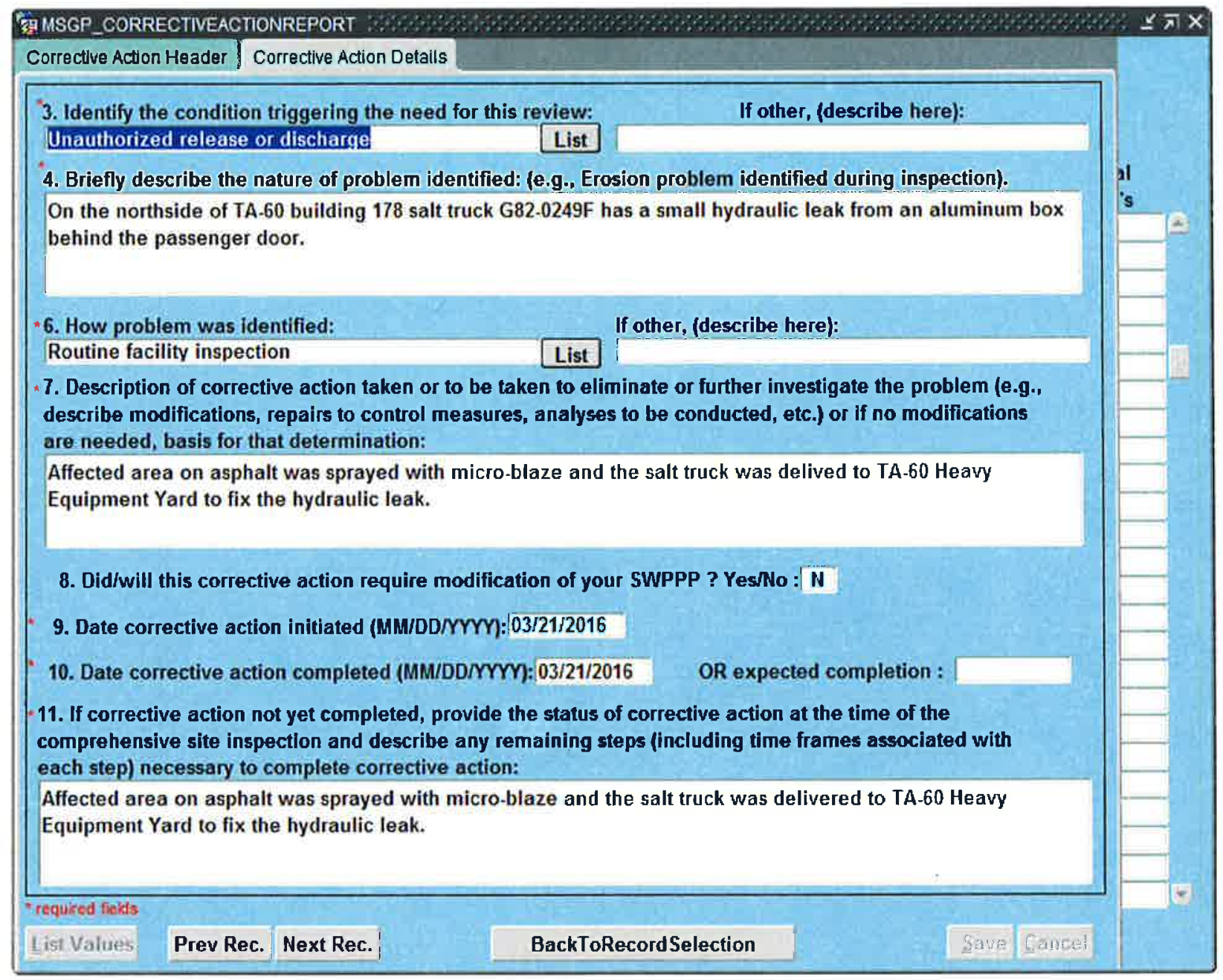




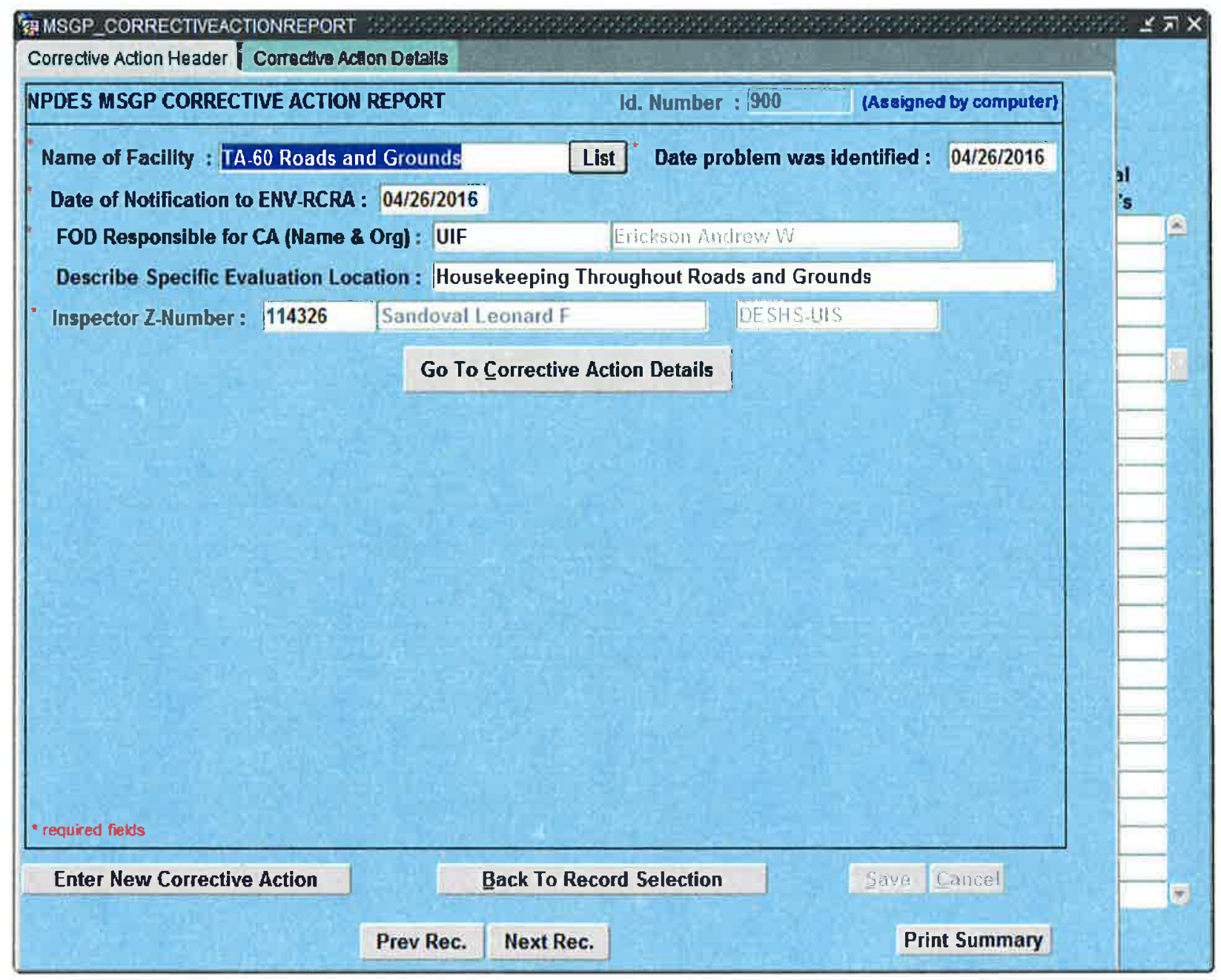




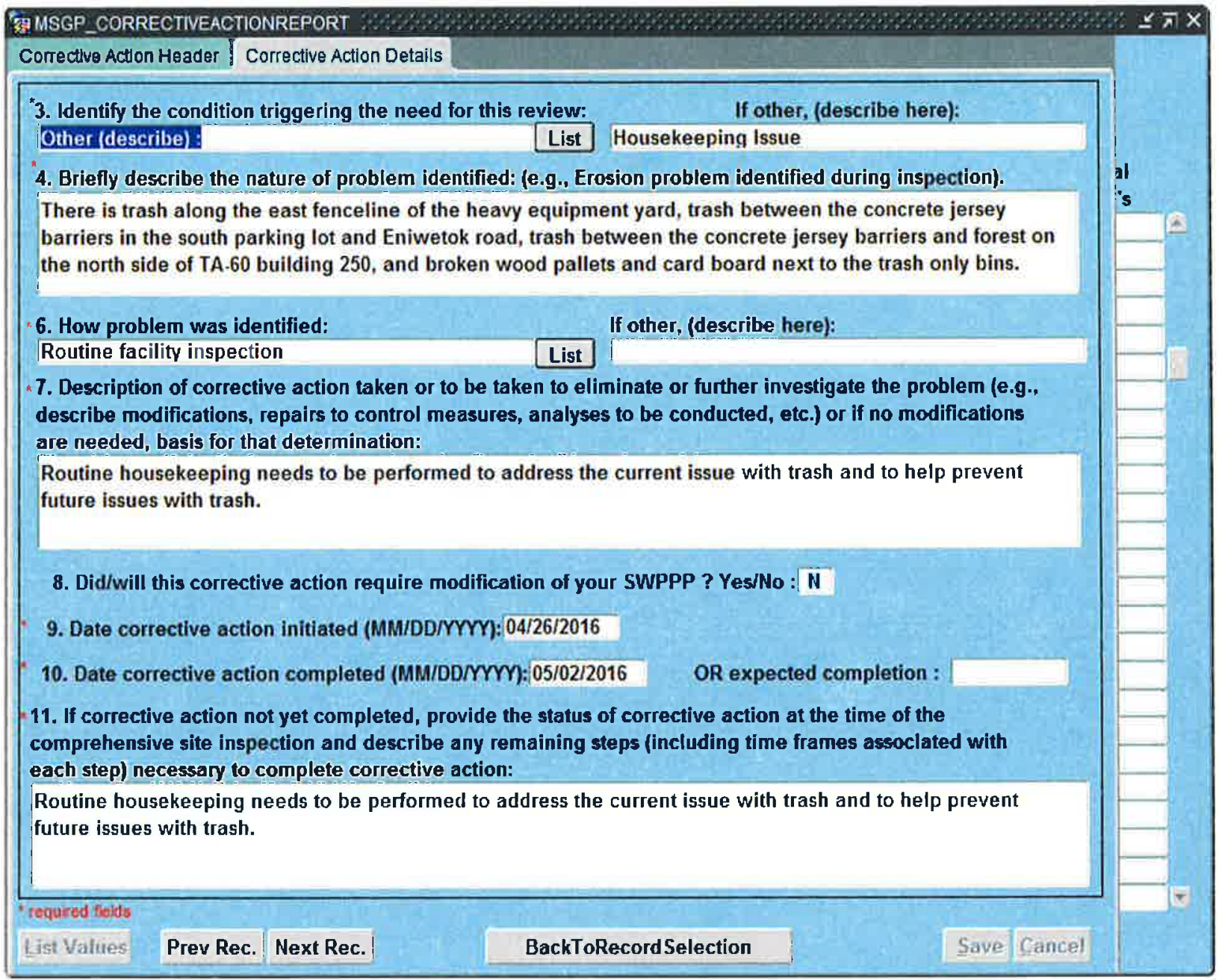




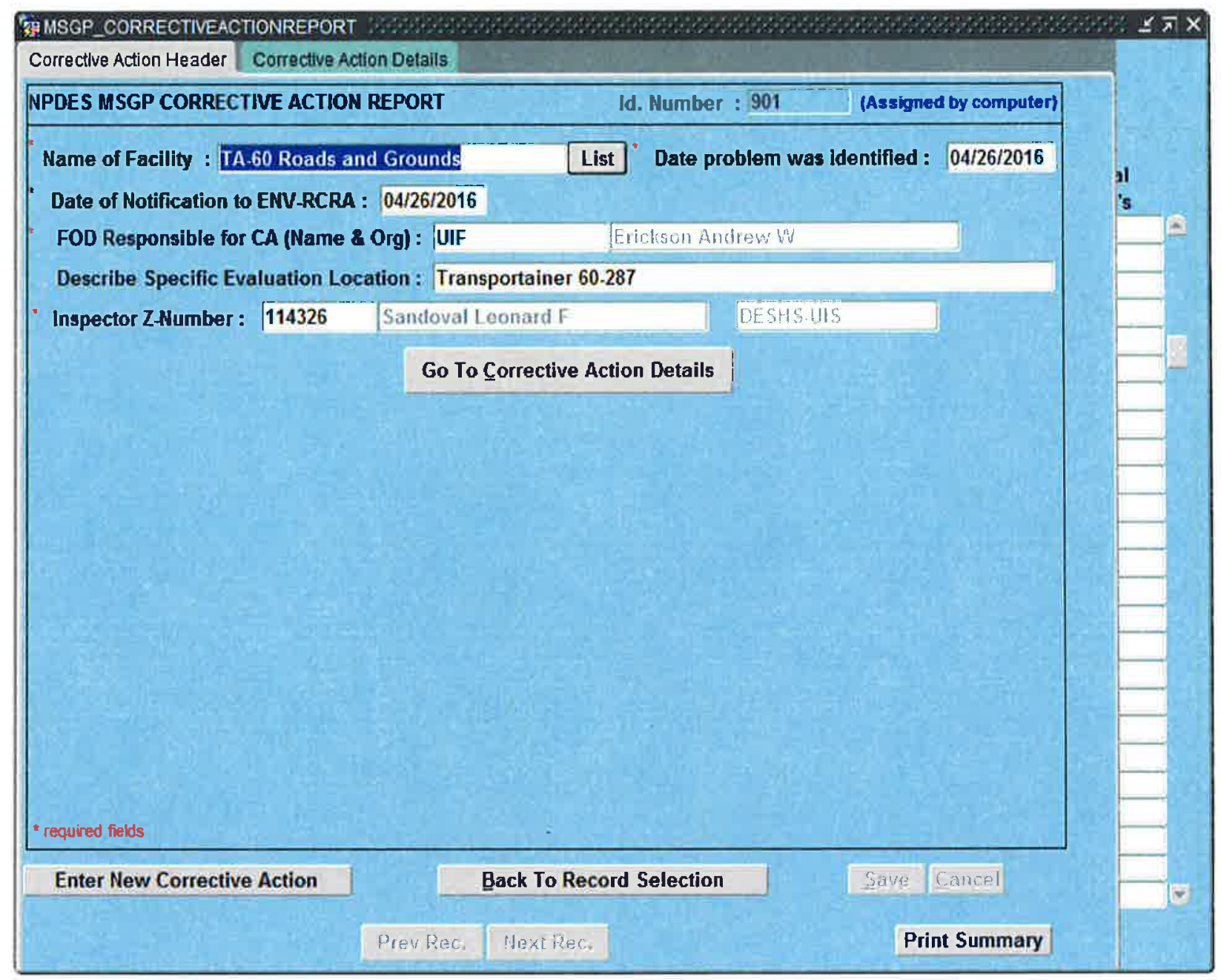




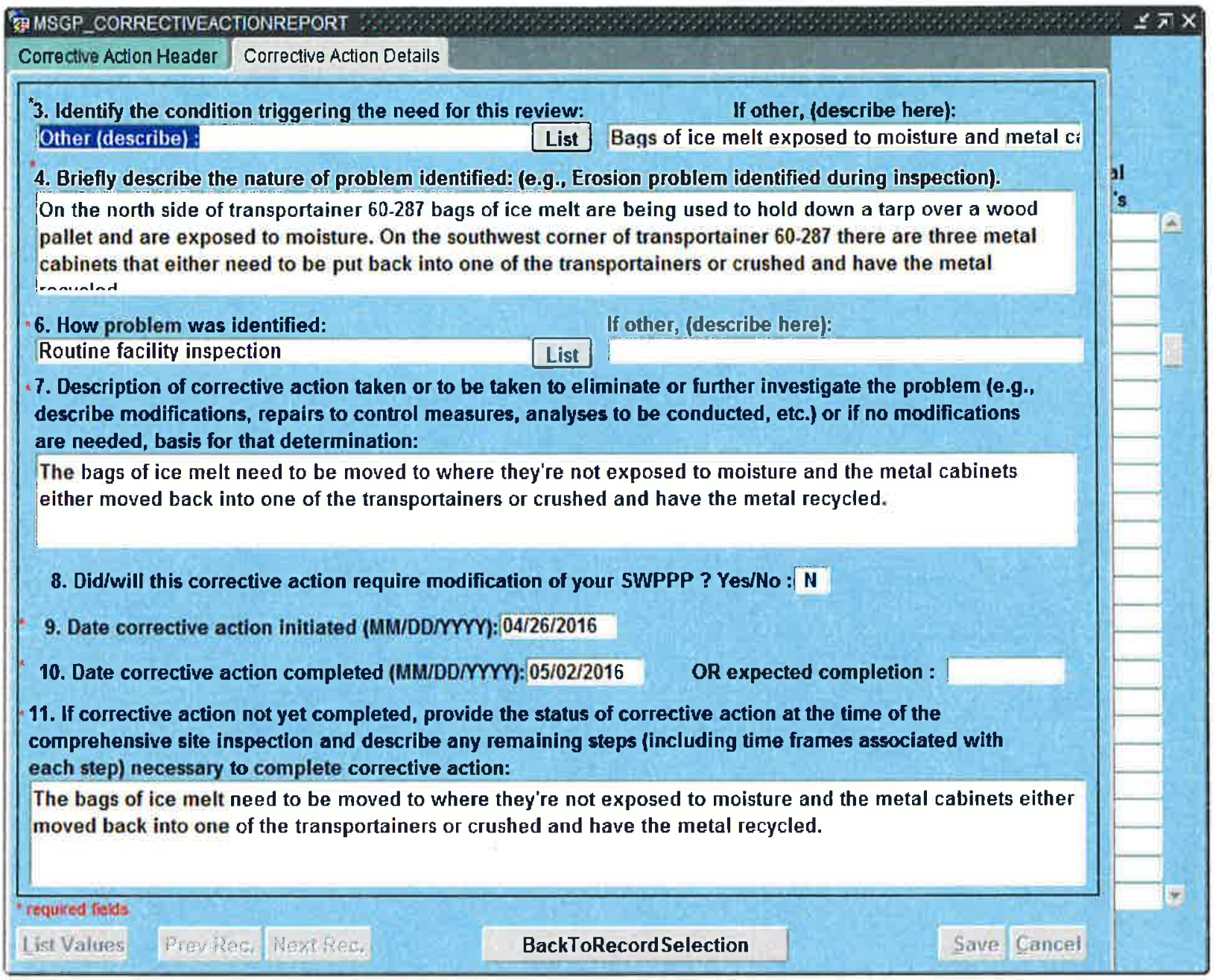




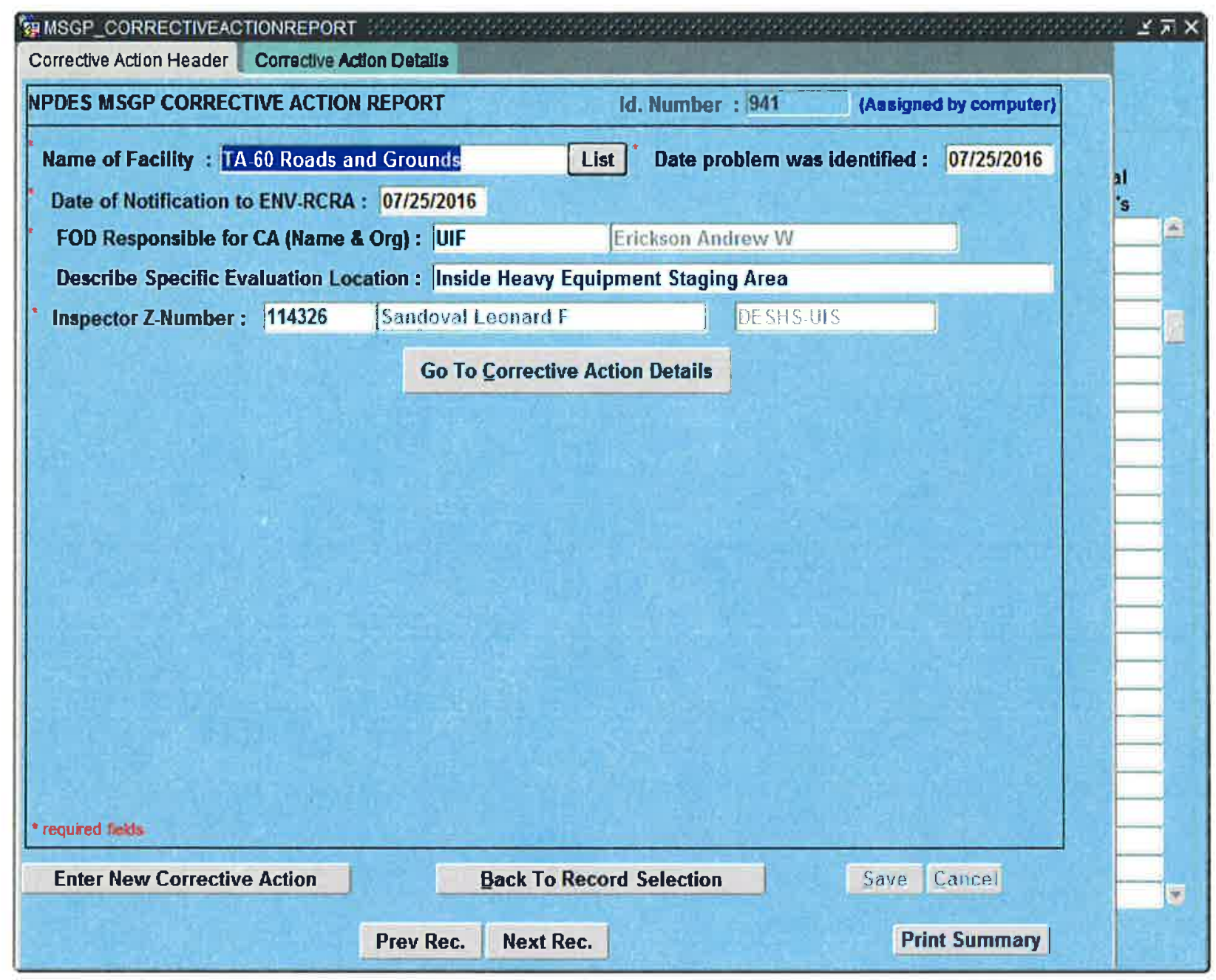




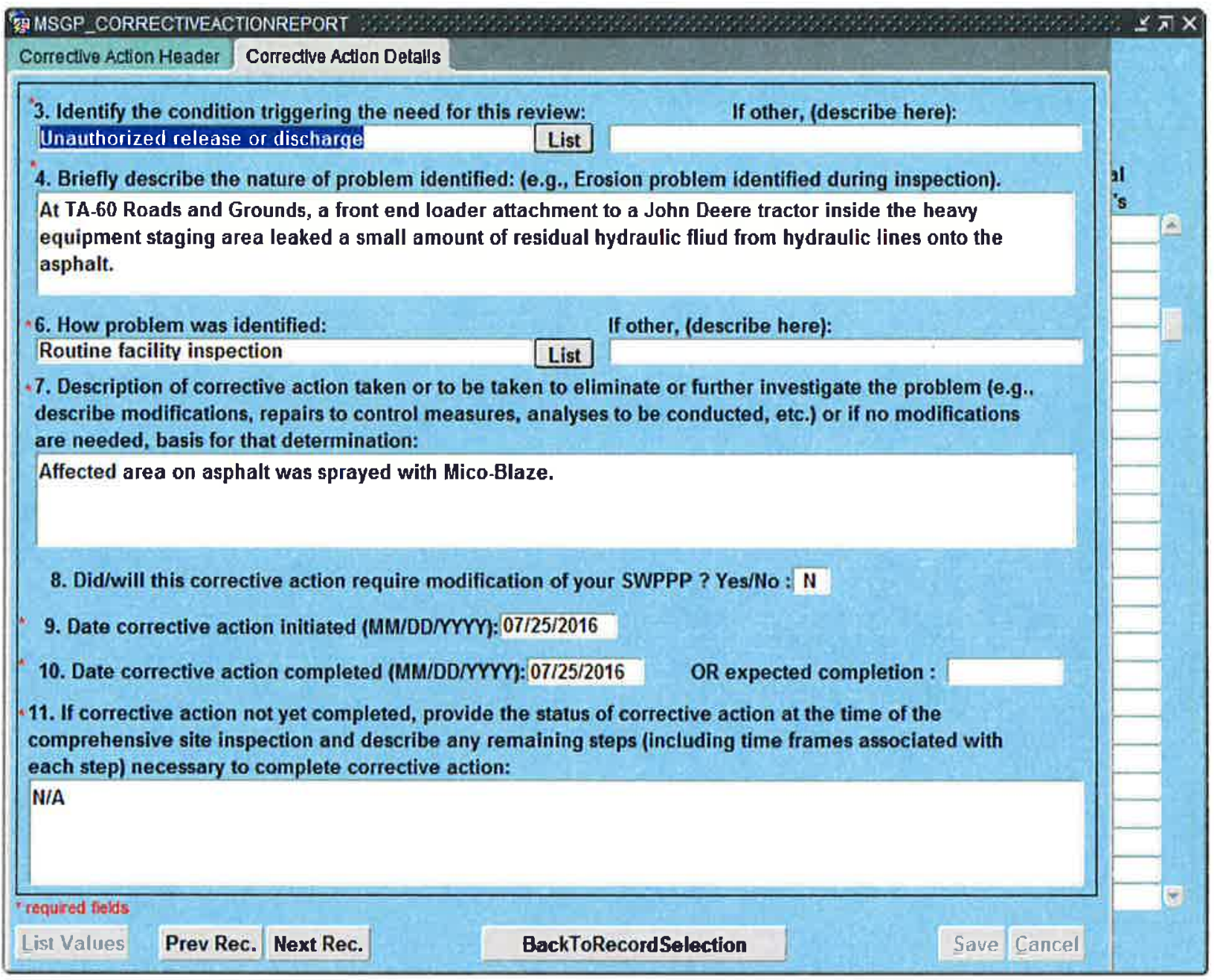




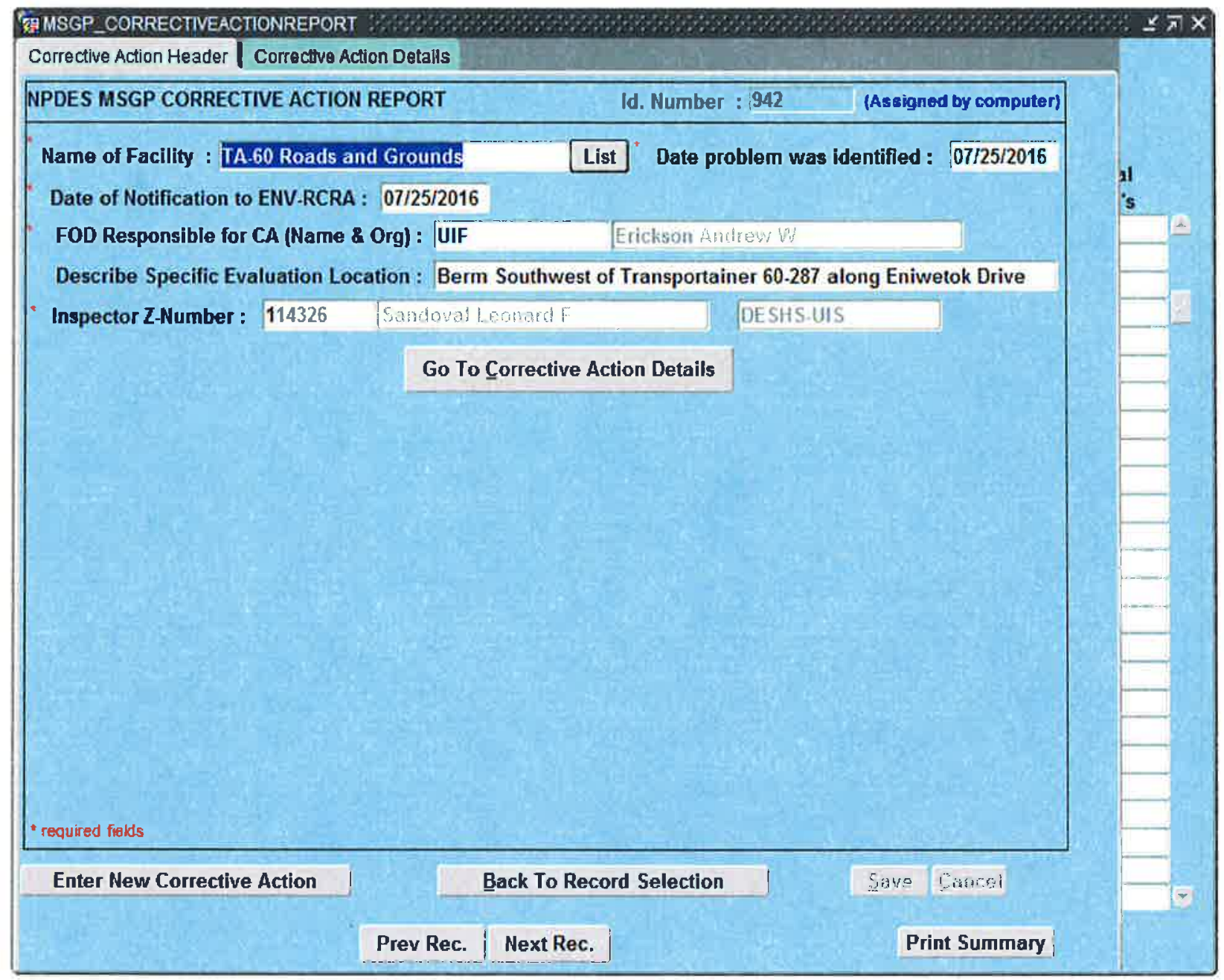




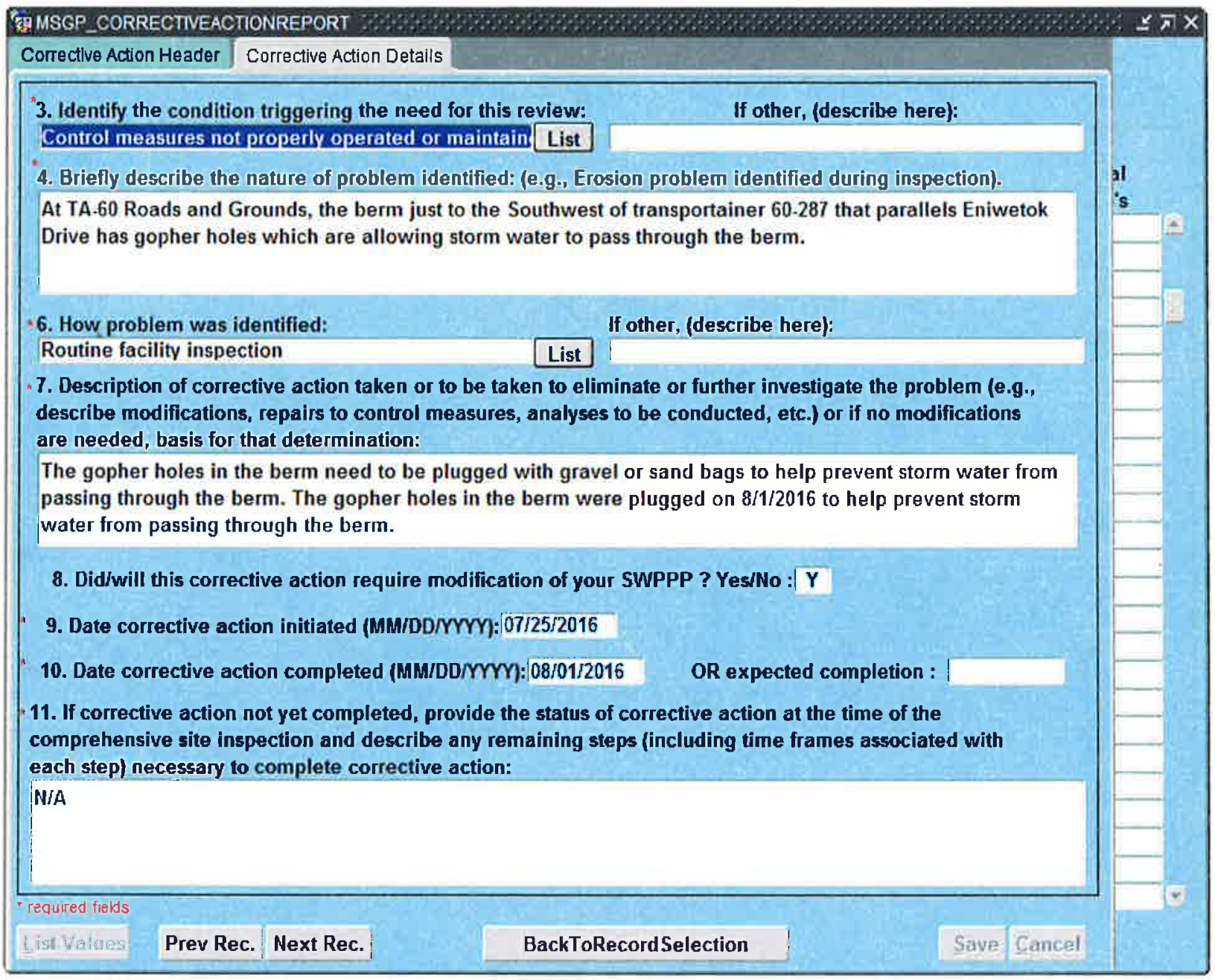




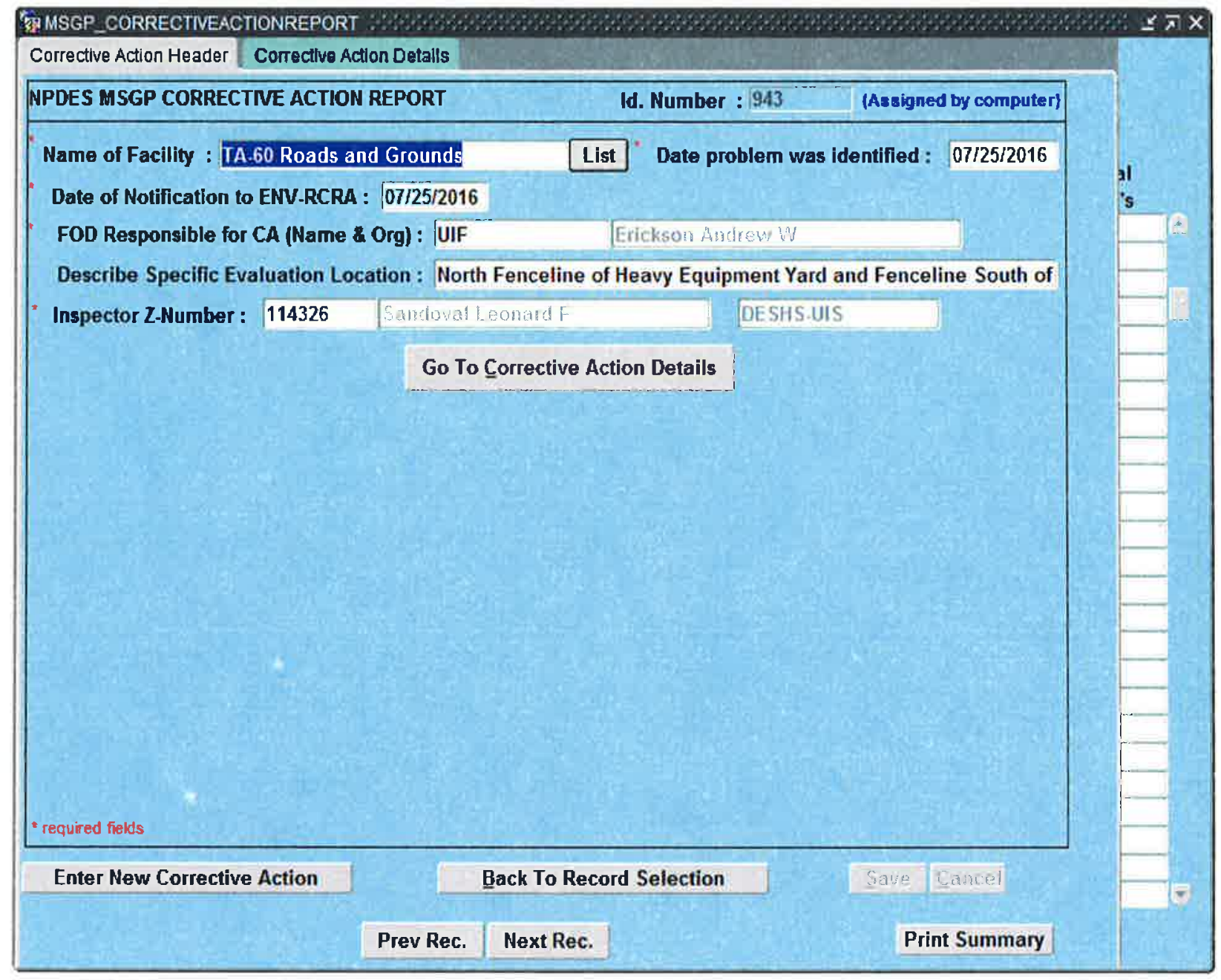




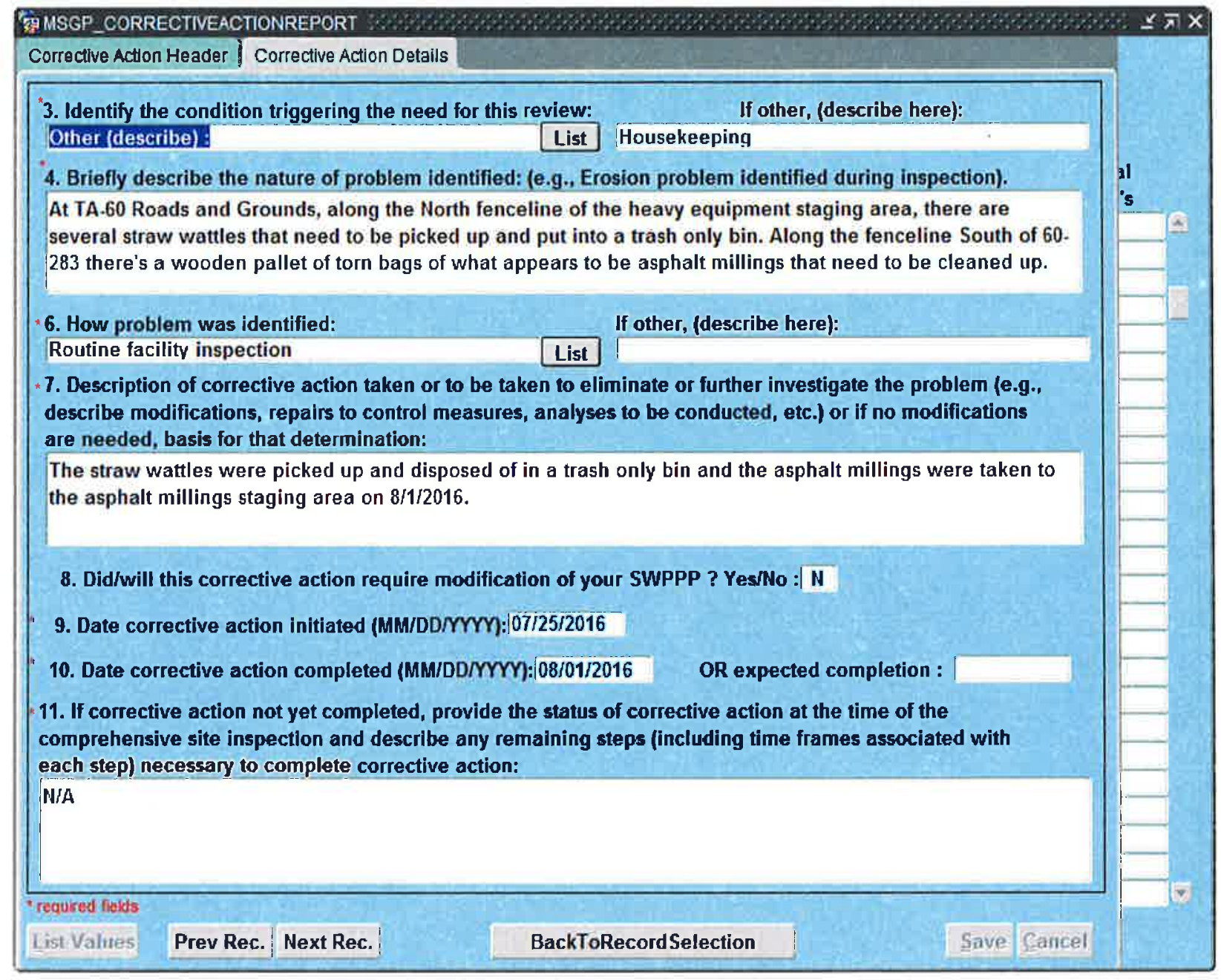




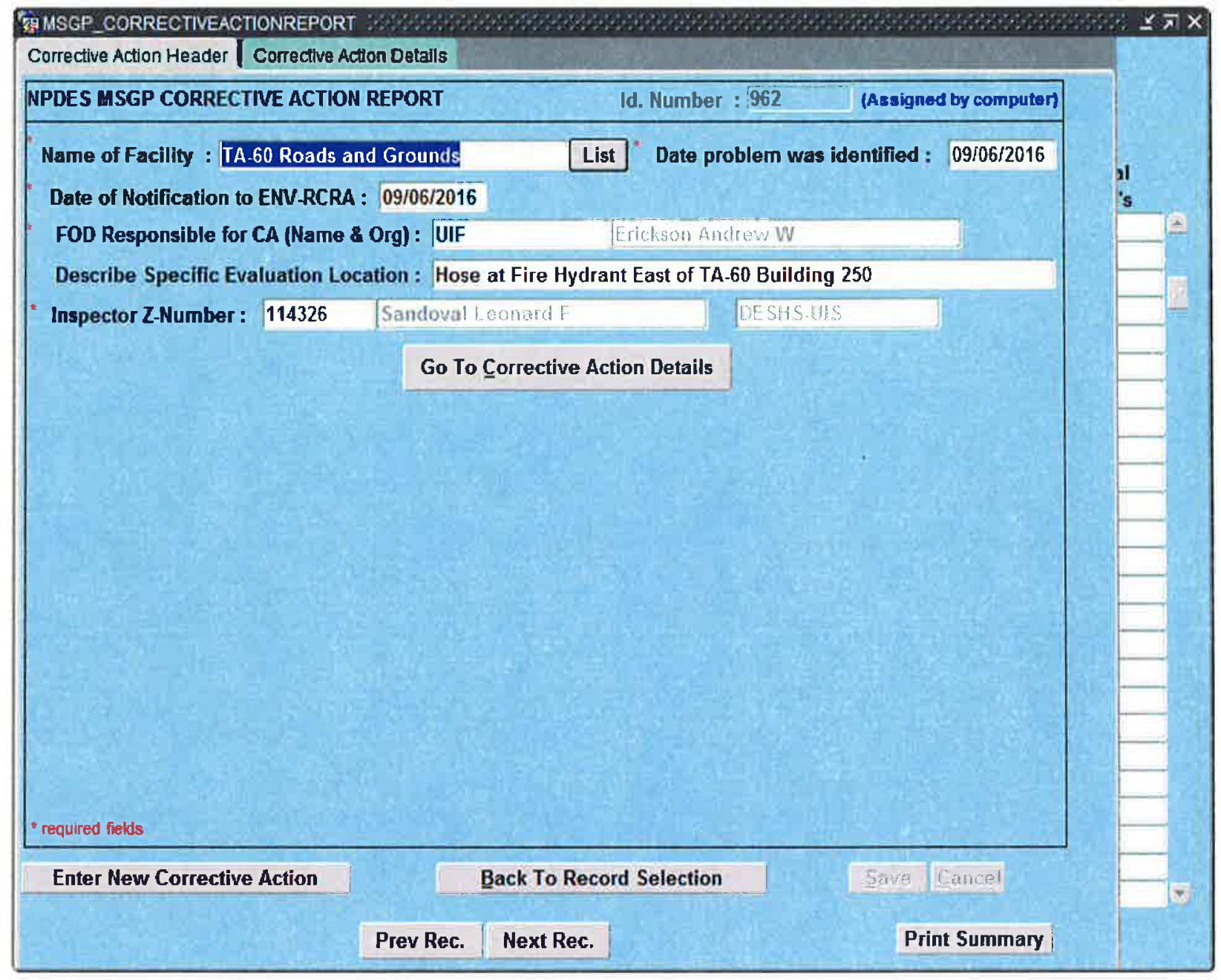




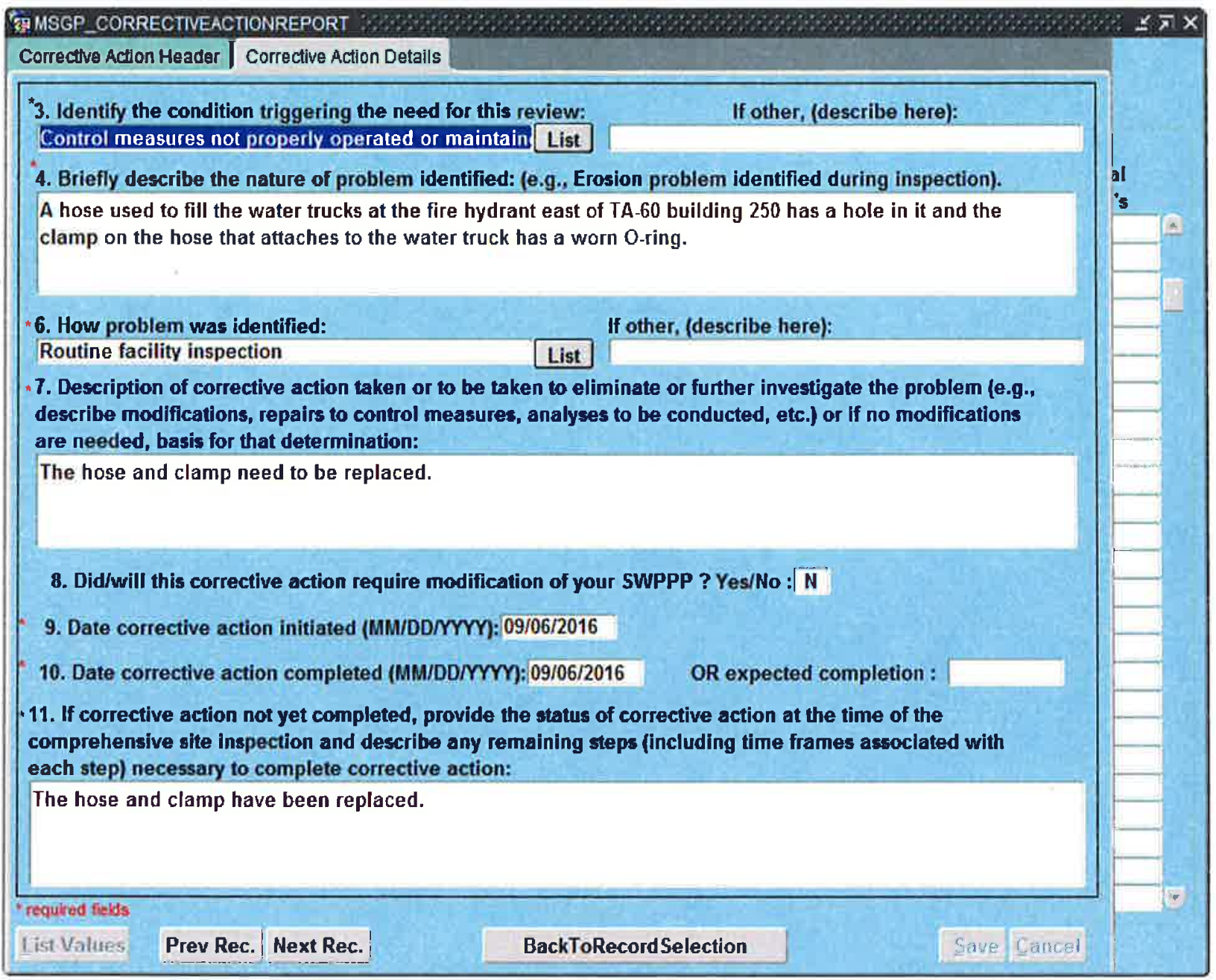




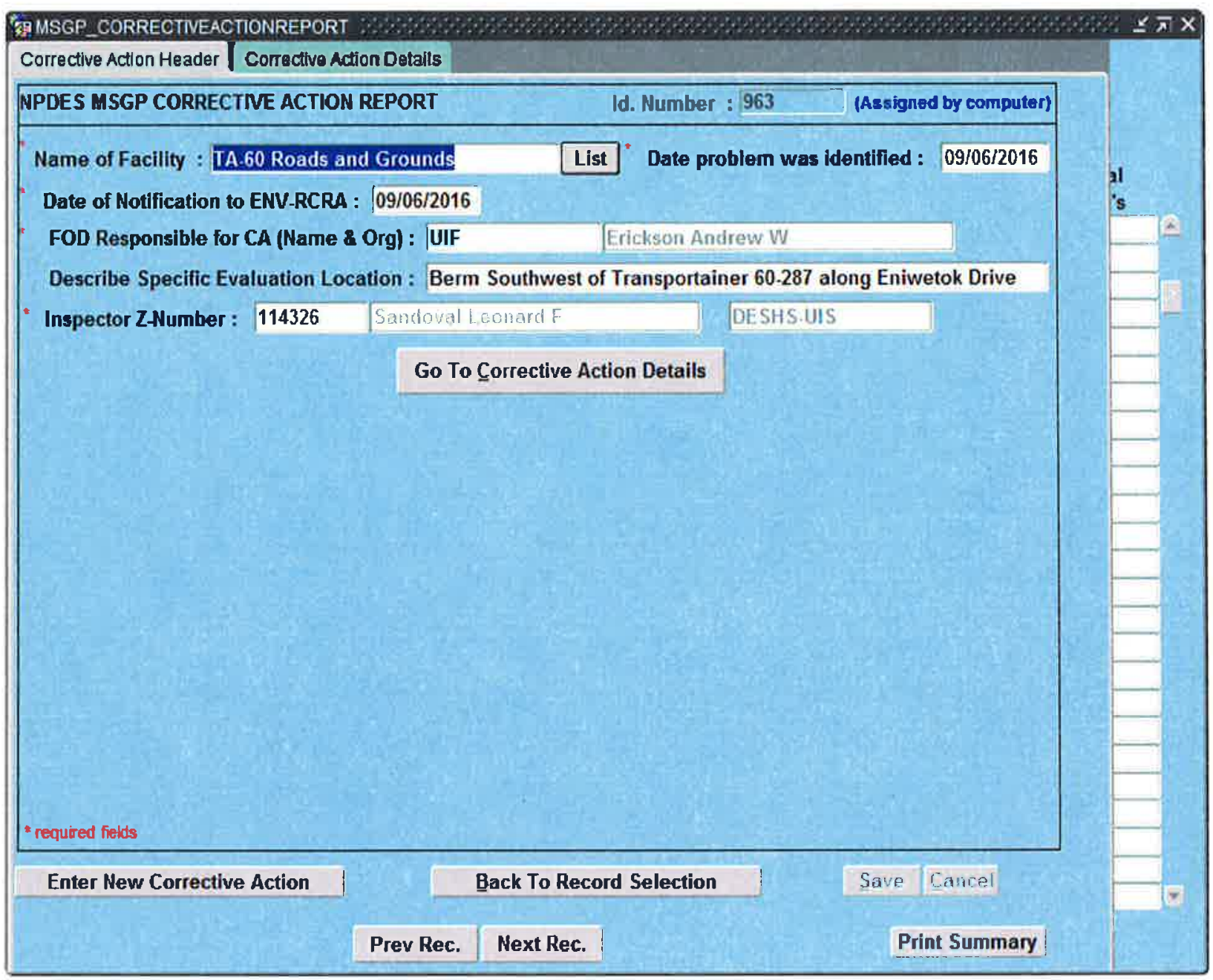




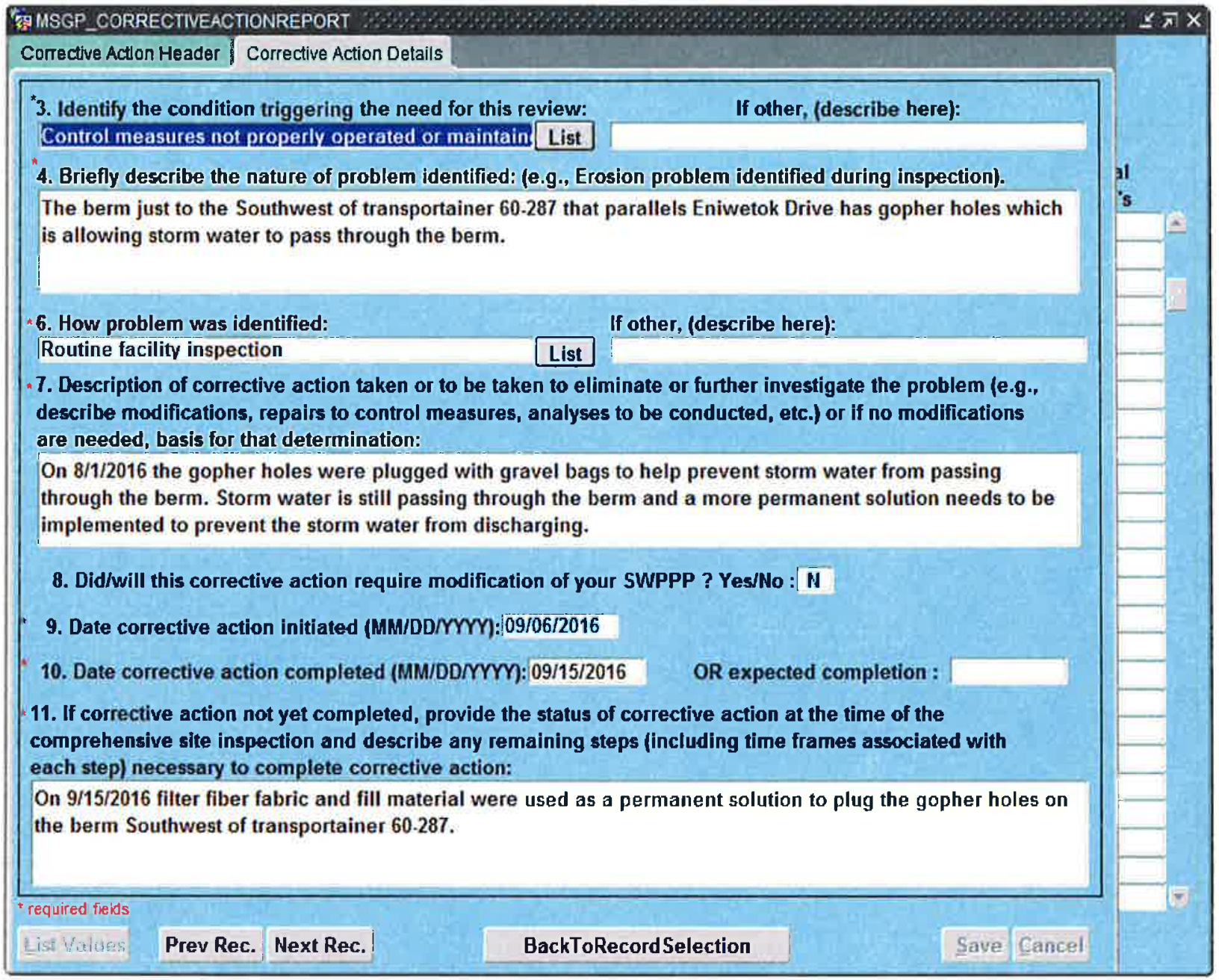




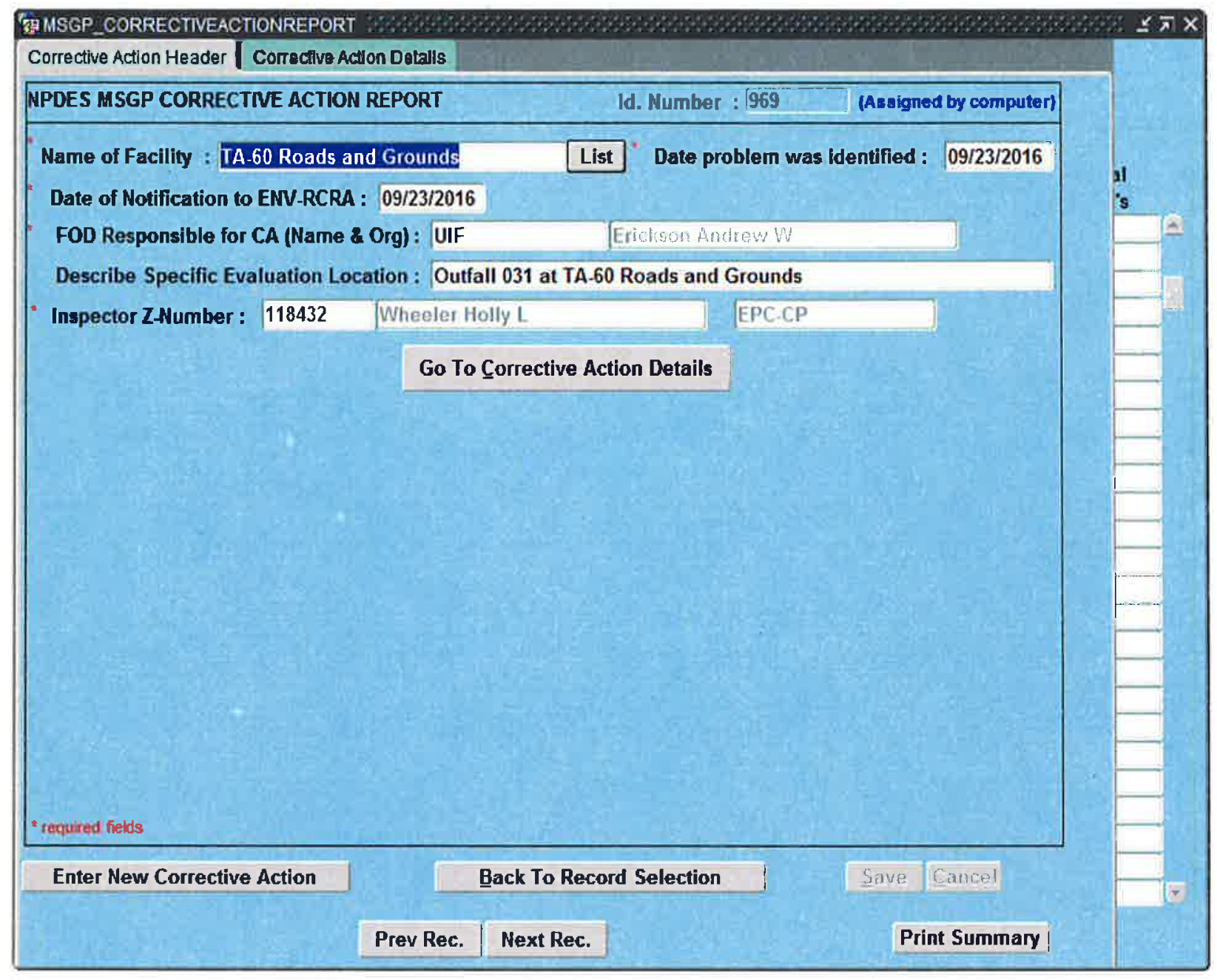




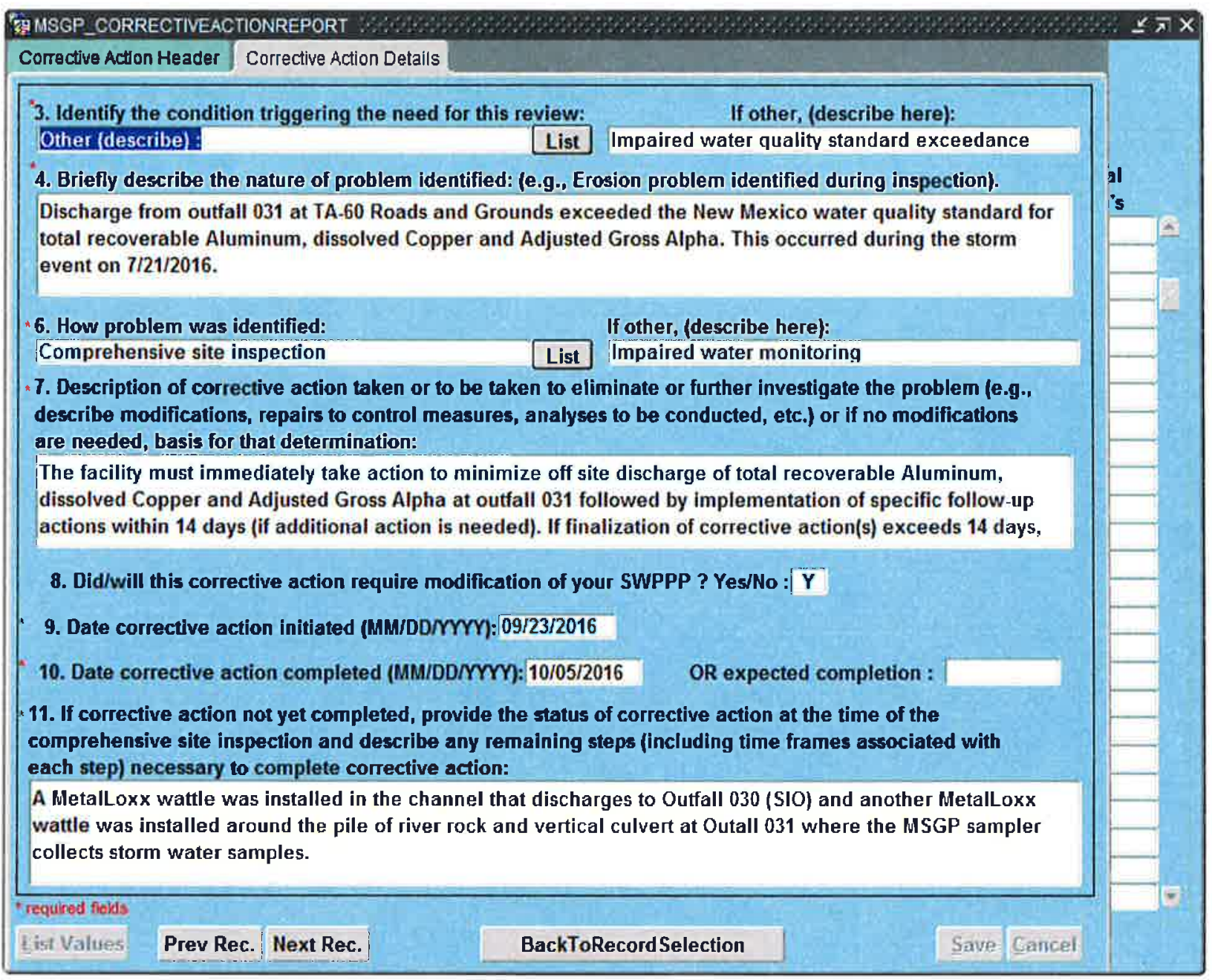




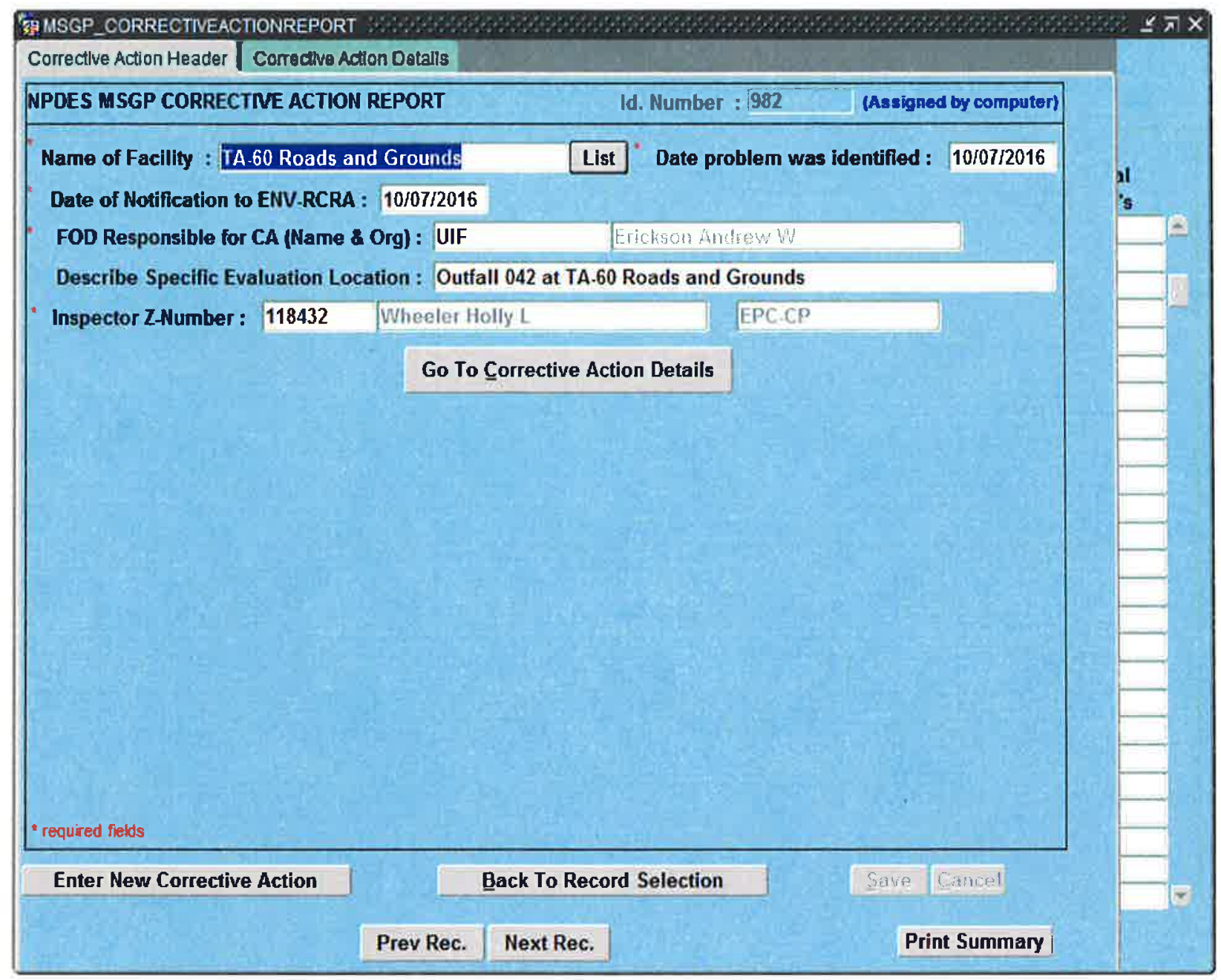




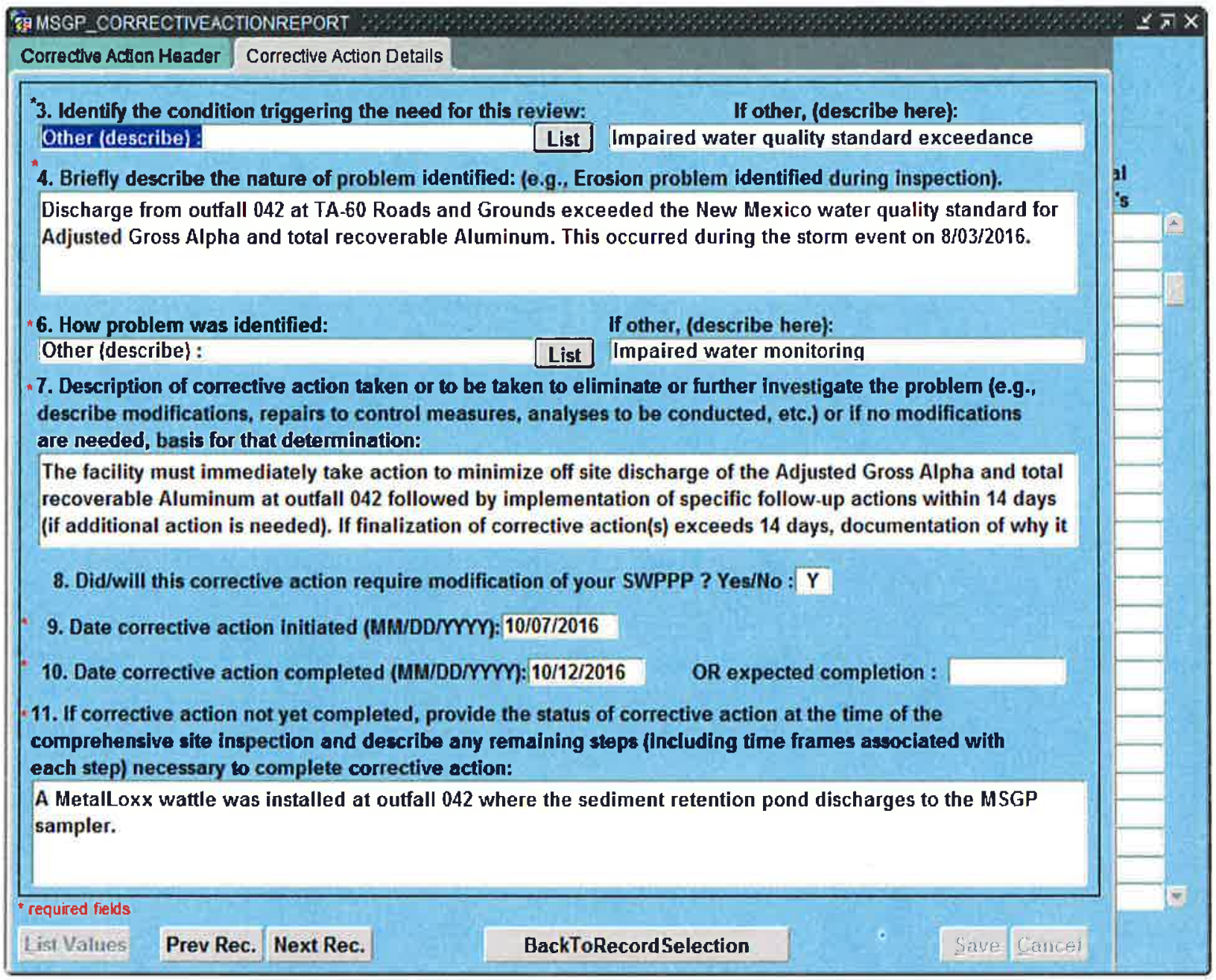




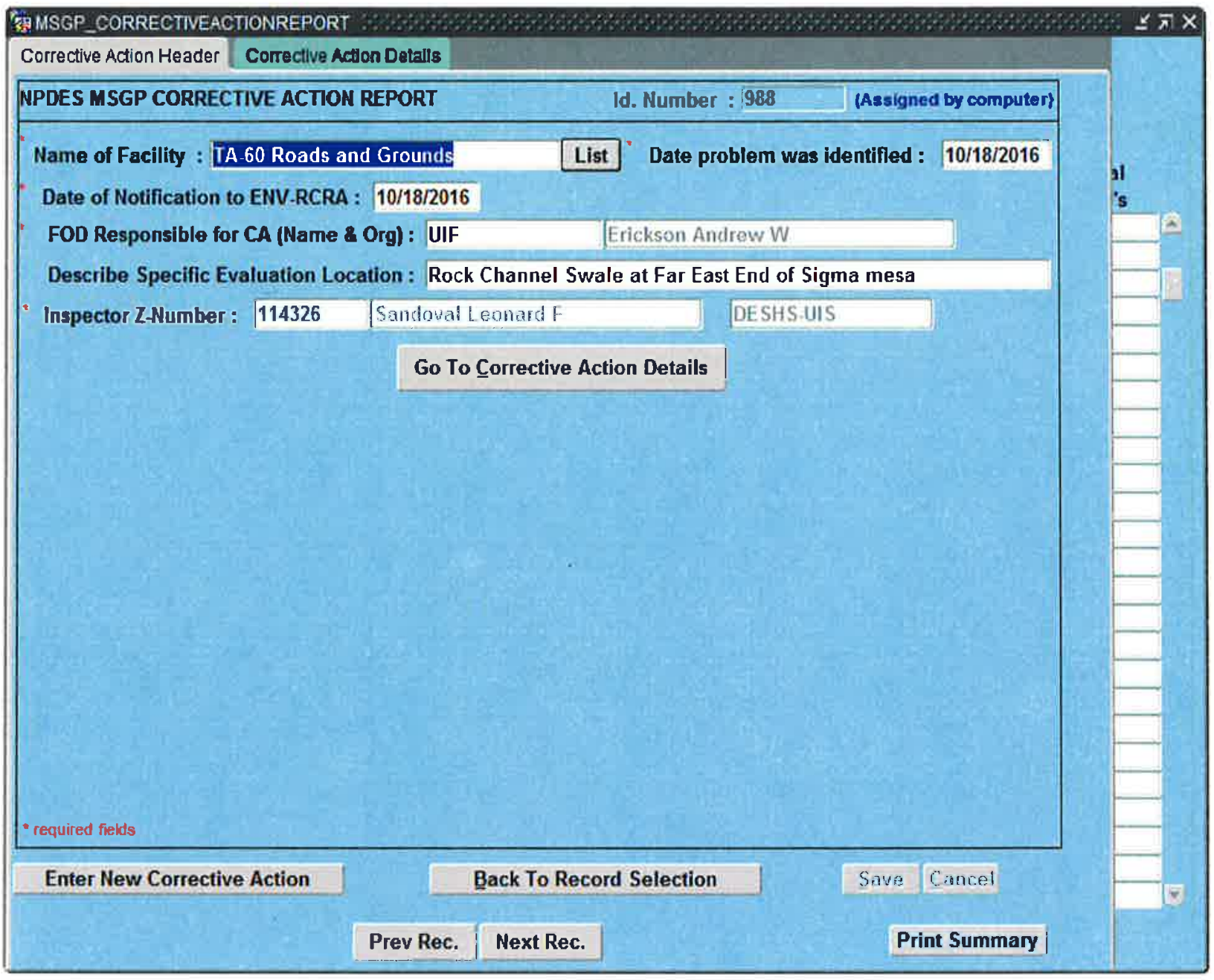




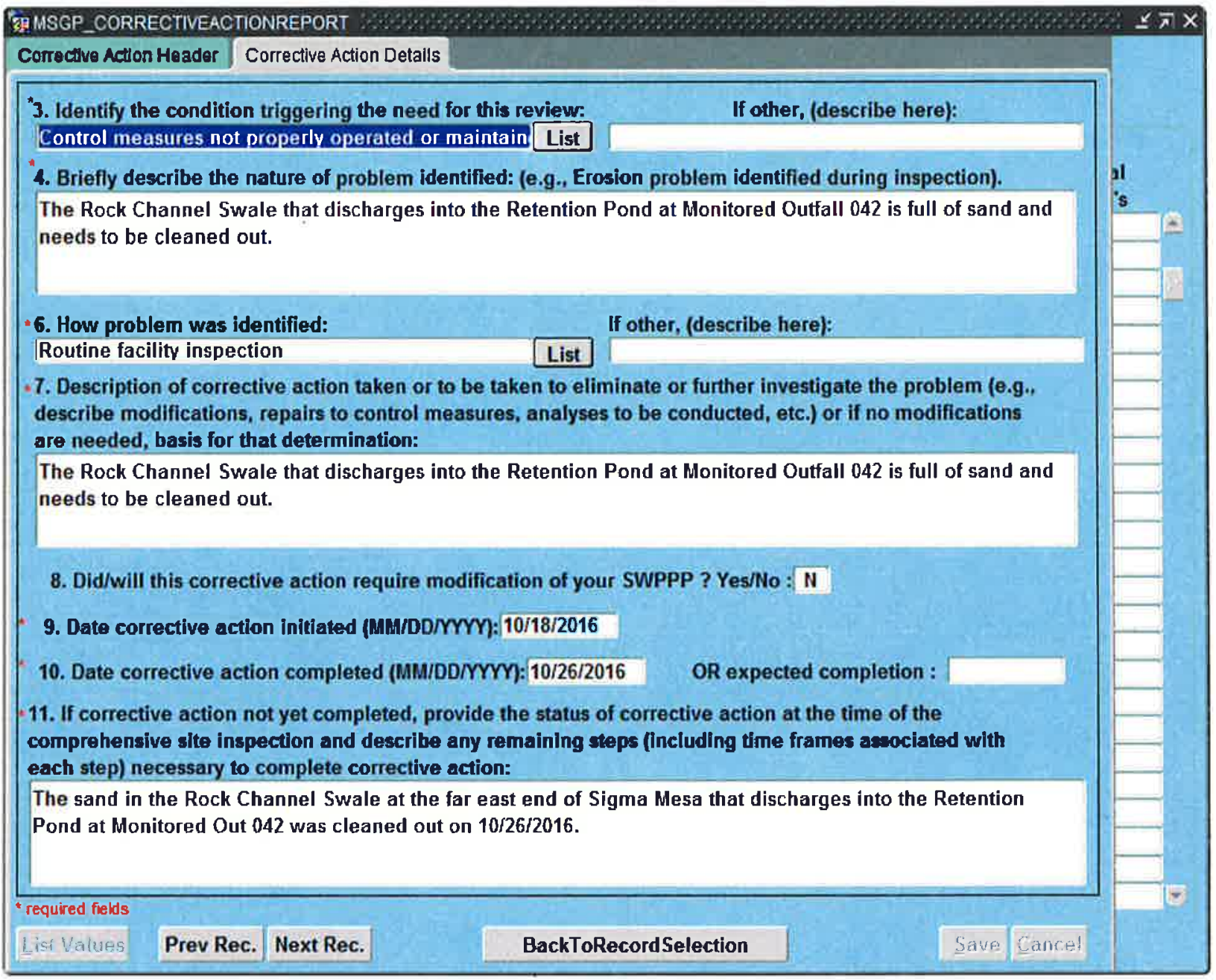




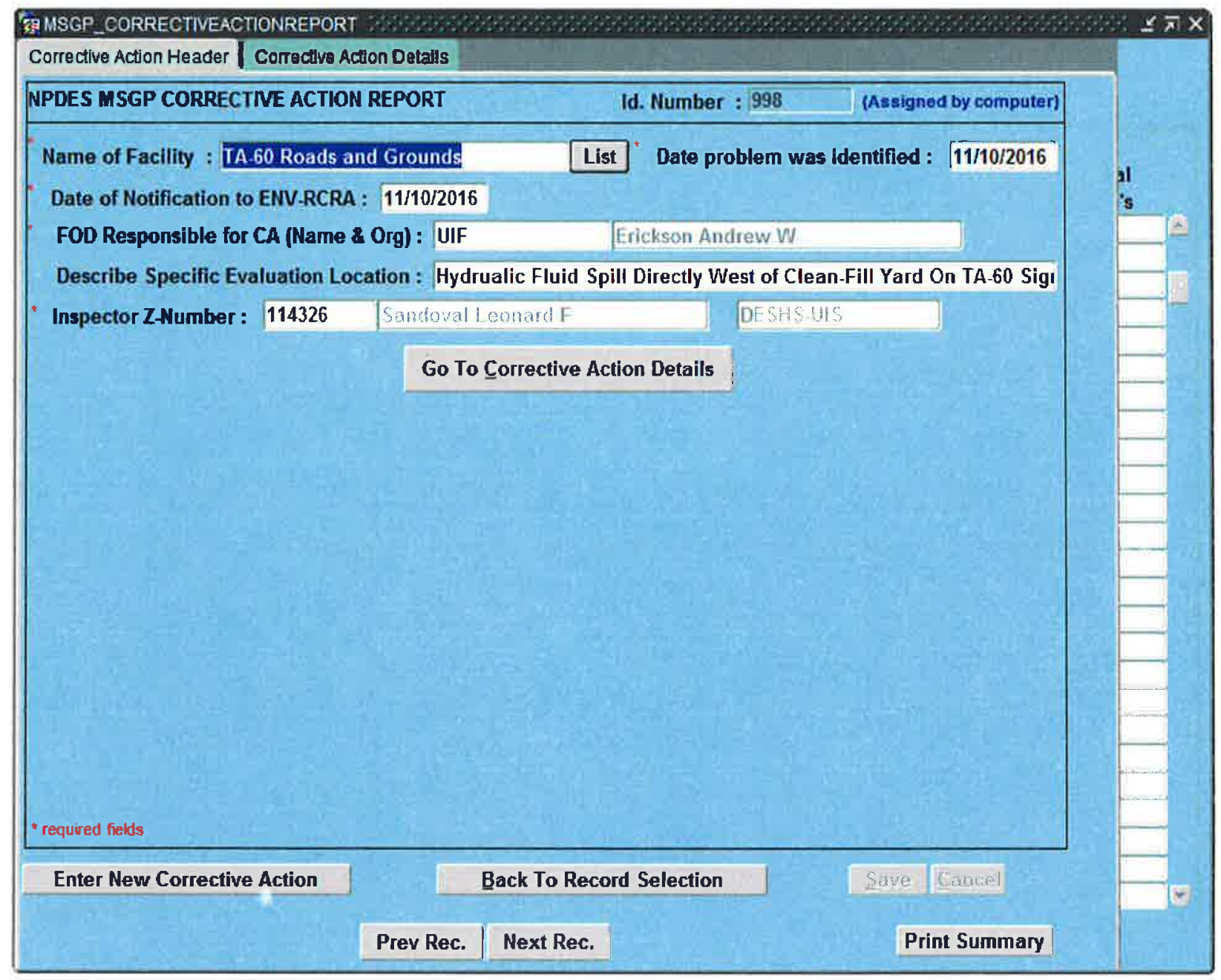




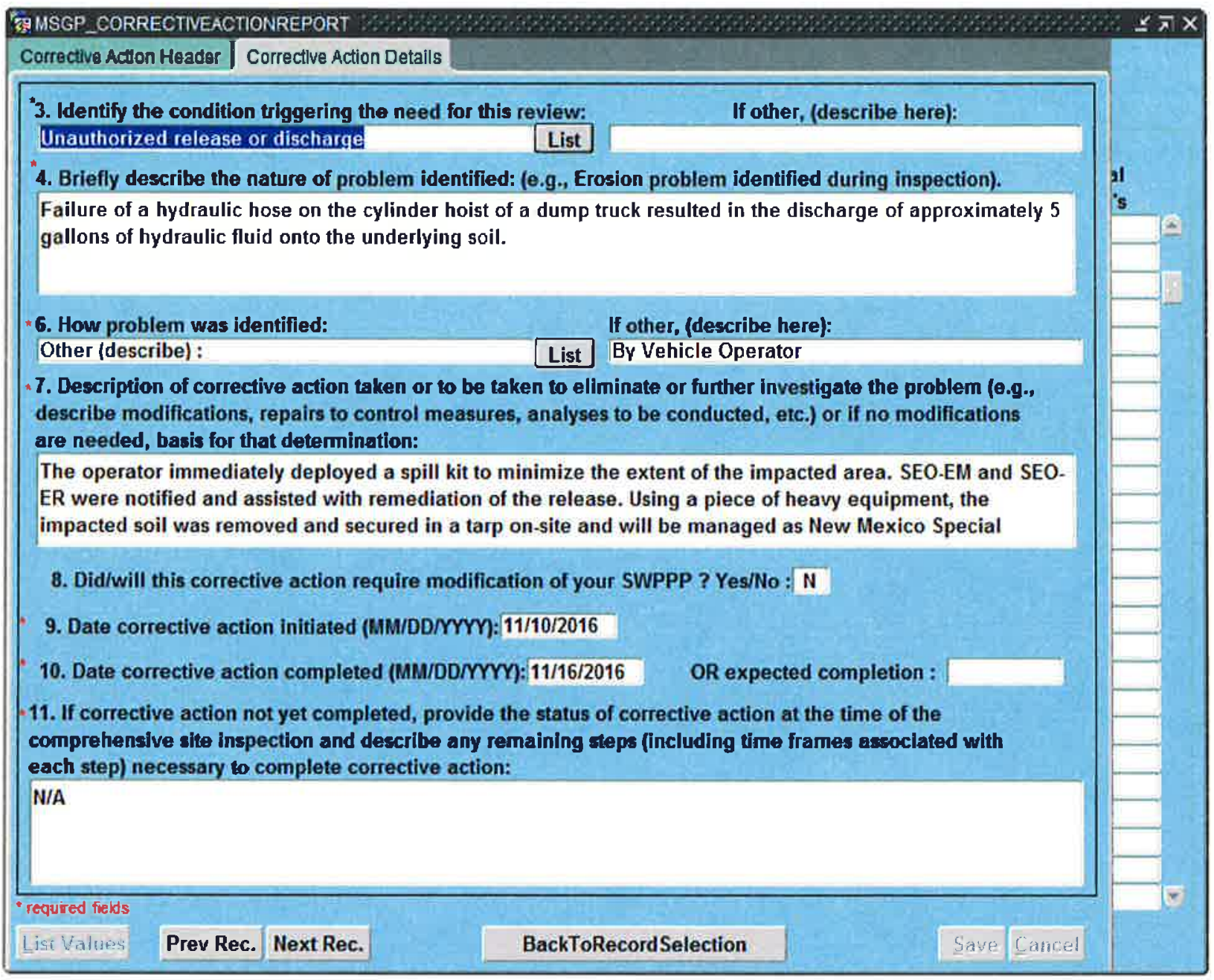




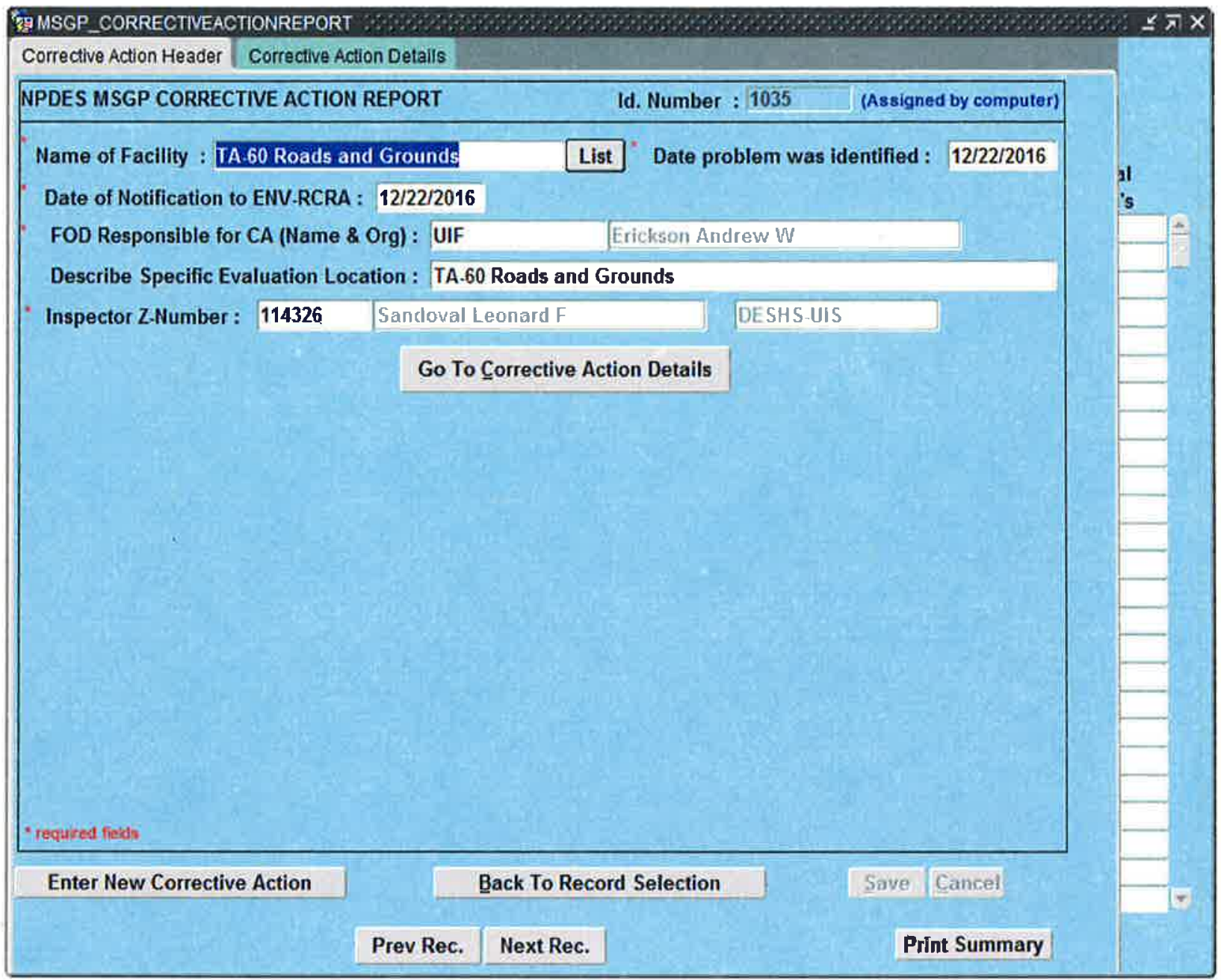




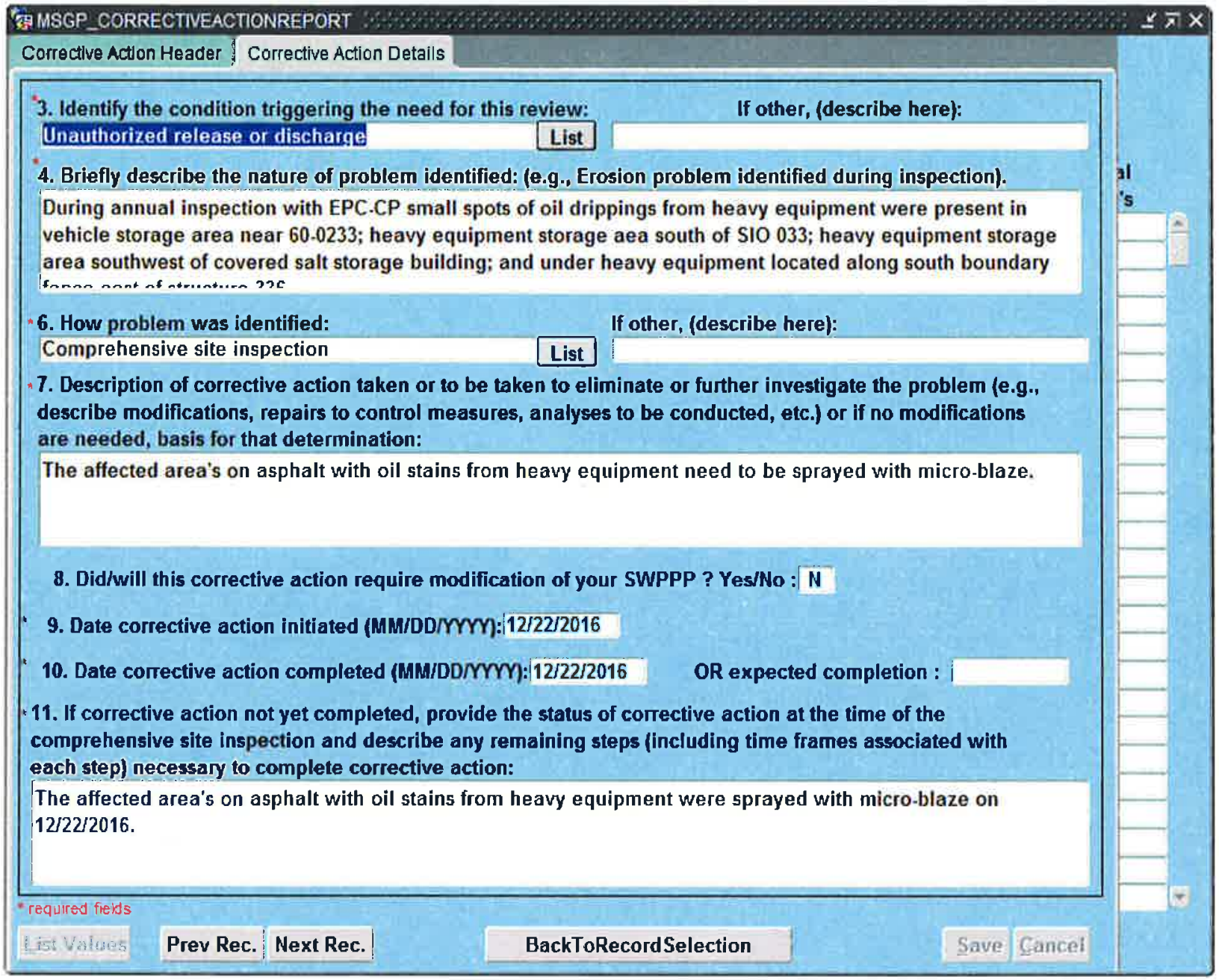




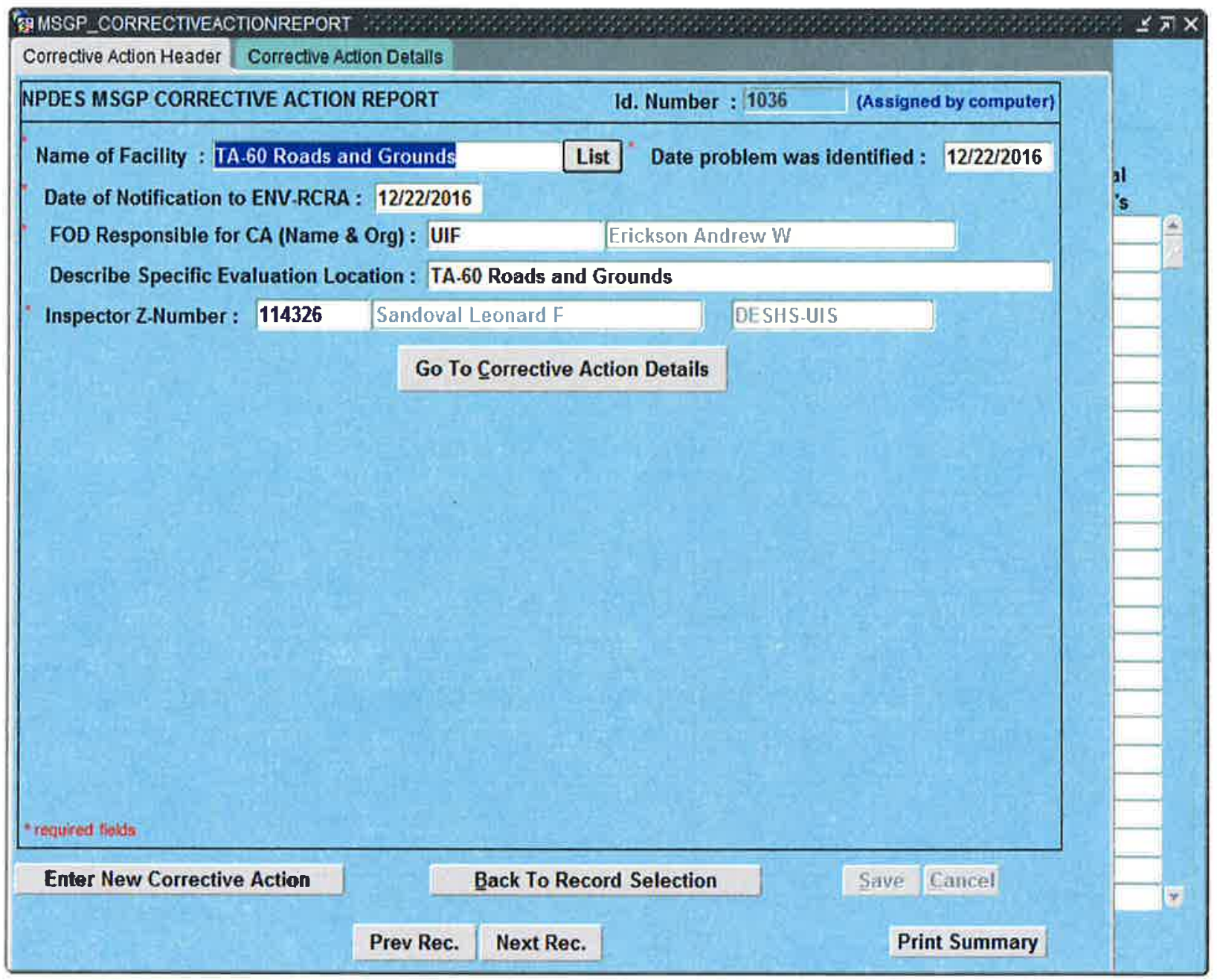




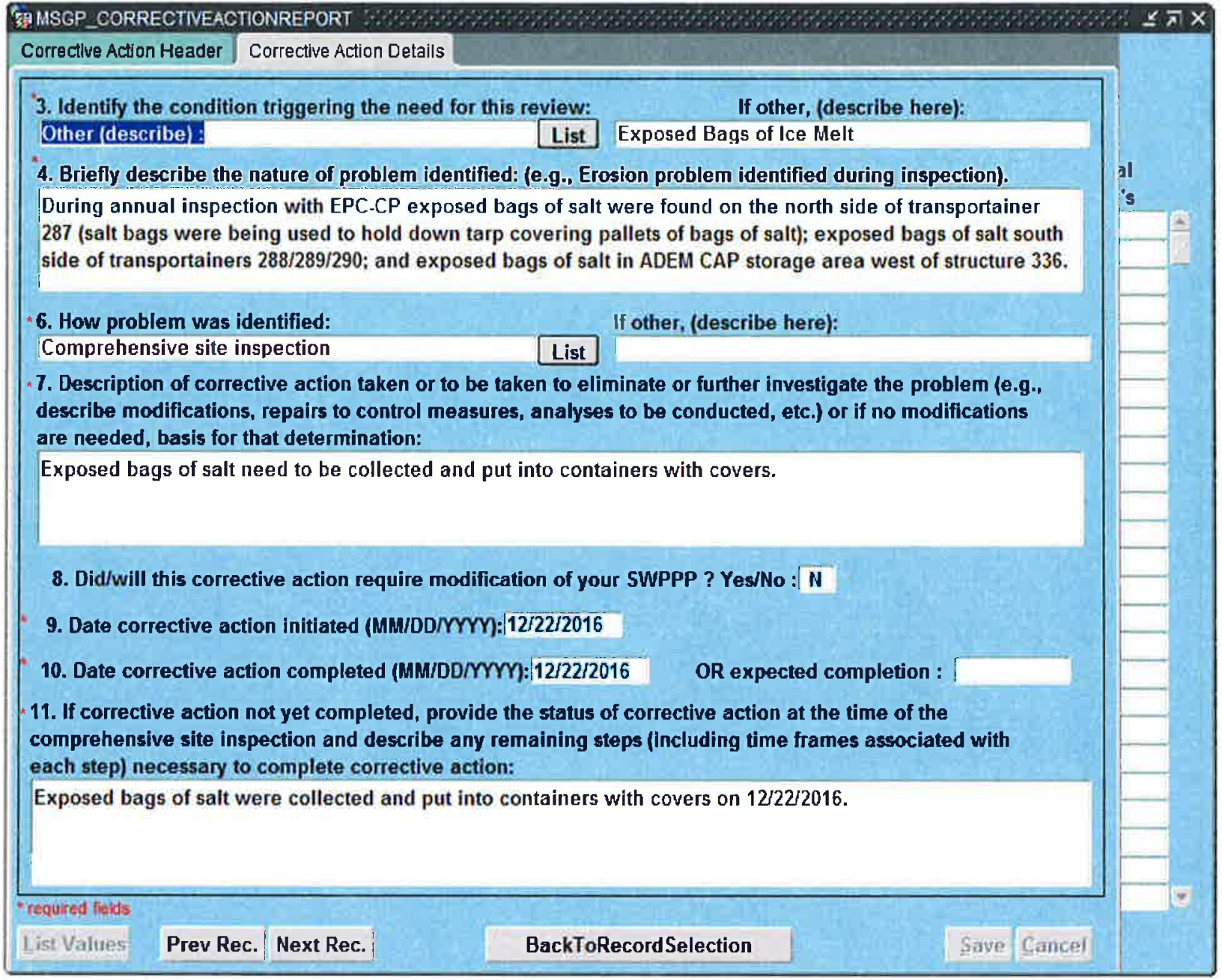




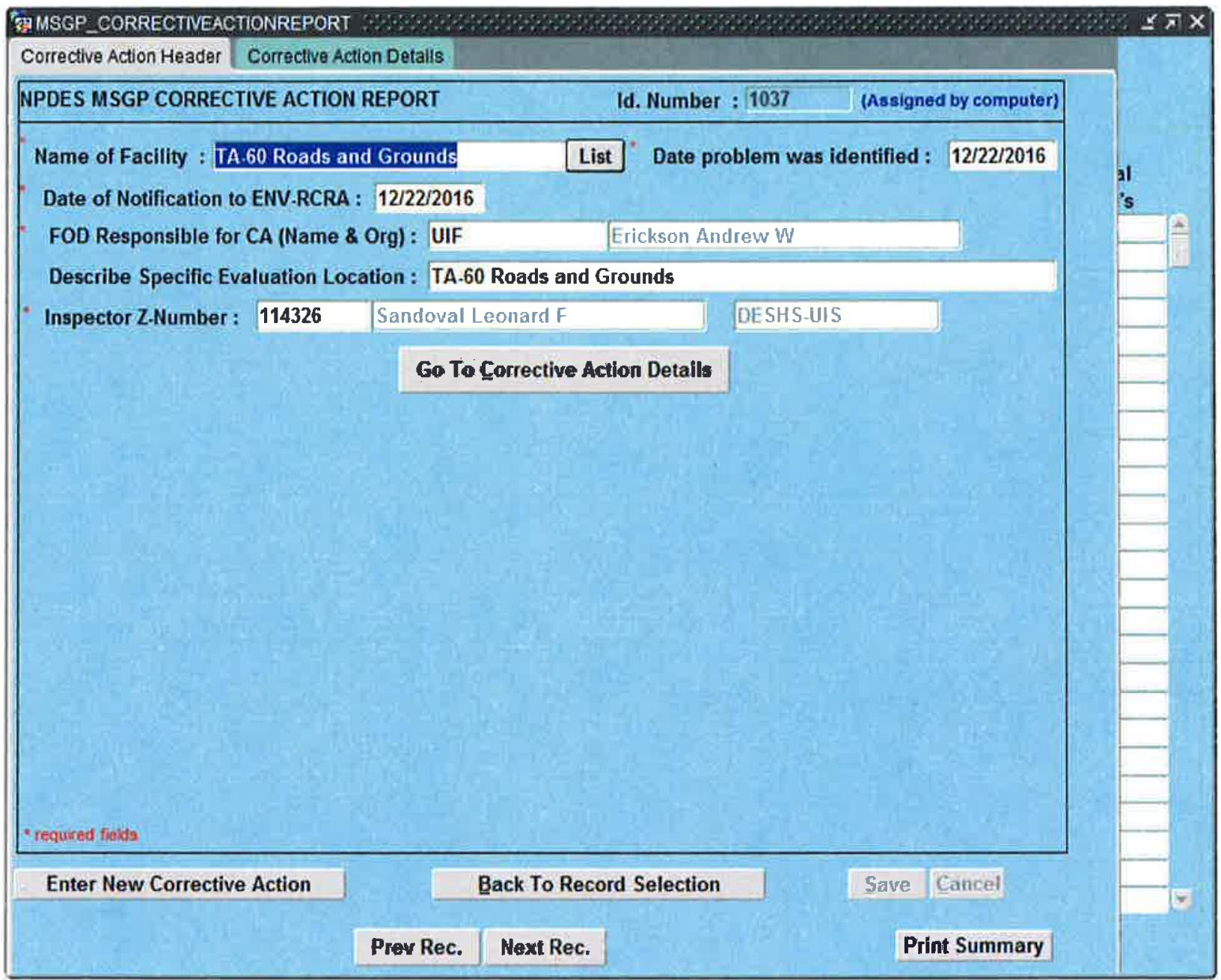




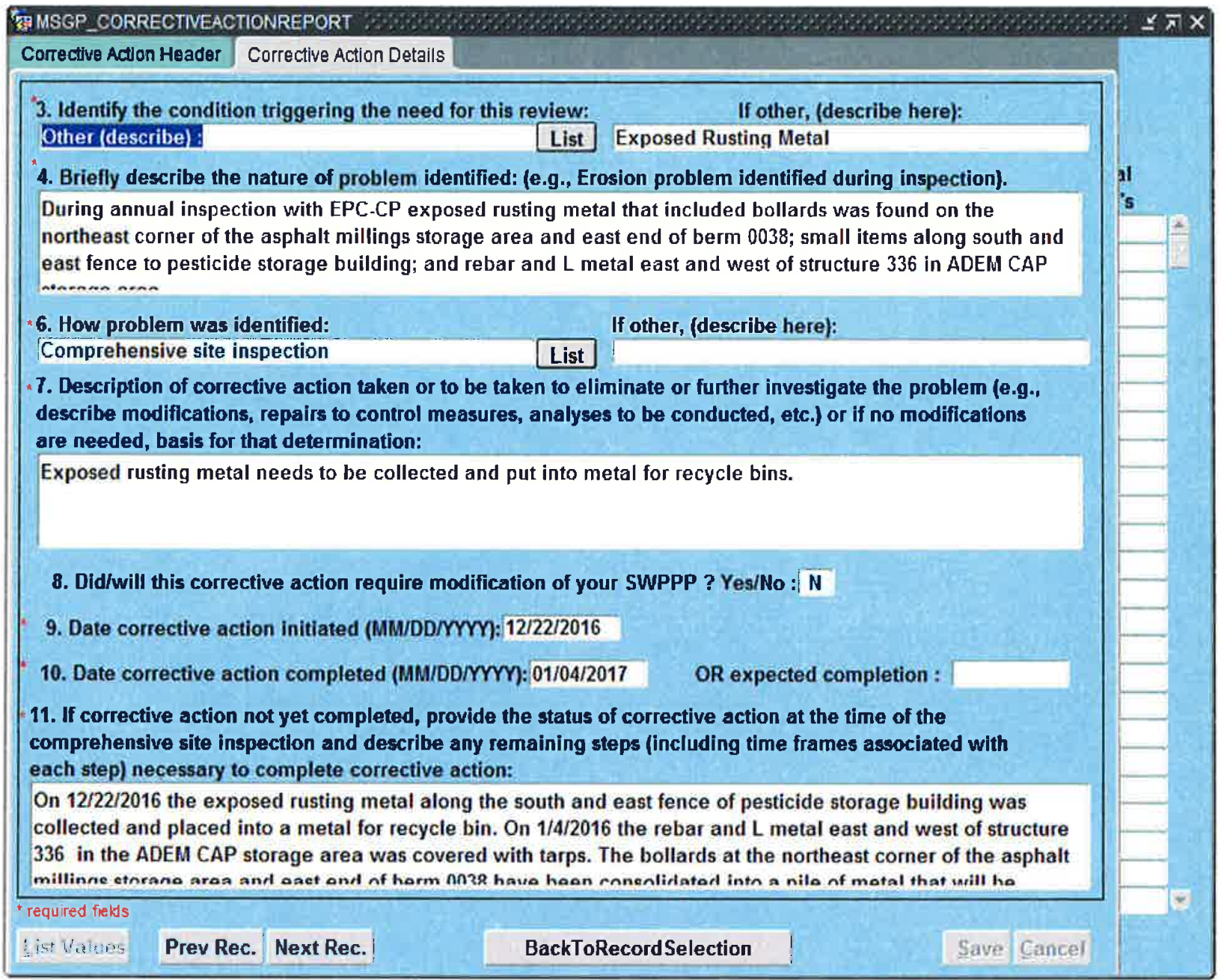




\section{Referenced Documents}


No: P1201-4

Revision: 3

Issued: $12 / 22 / 15$

Effective Date: 12/22/15

\section{LANL Emergency Procedures and Protective Actions}

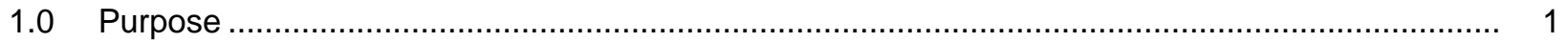

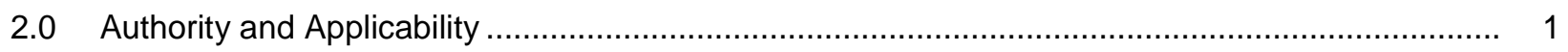

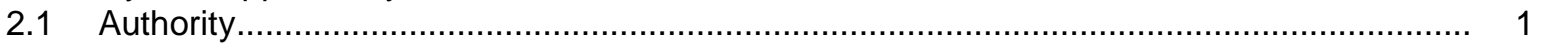

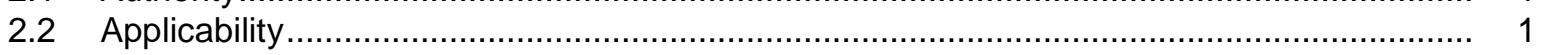

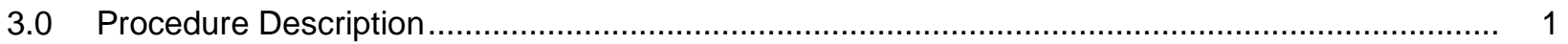

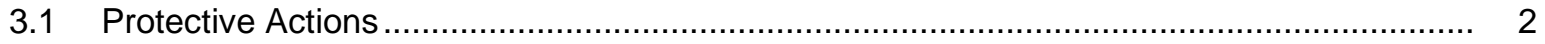

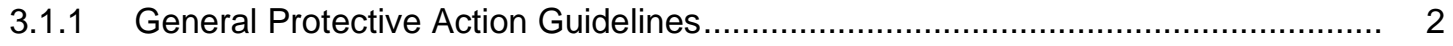

3.1.1.a Protective Action Decision Making ................................................... 2

3.1.1.b Protective Action Notifications................................................... 2

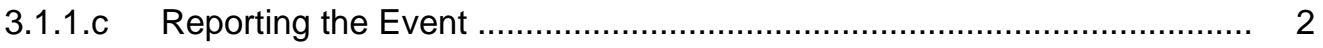

3.1.1.d Reporting the Event at LANL Leased Buildings with LANL

3.1.1.e Rescue and Medical Treatment .......................................................... 3

3.1.2 Building Evacuation ...................................................................................... 3

3.1.2.a Evacuation of Individuals with Special Needs.................................... 5

3.1.2.b Visitor Evacuation......................................................................... 5

3.1.3 Site-Wide Evacuation ............................................................................ 5

3.1.3.a LANL Evacuation Planning Sections .............................................. 6

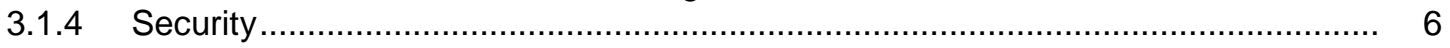

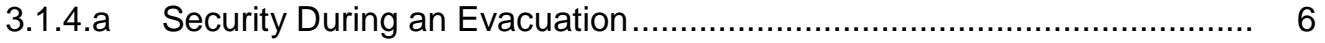

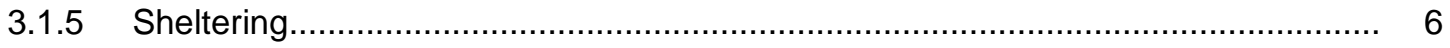

3.1.5.a Shelter in Place ............................................................................. 7

3.1.5.b Stay Put Sheltering..................................................................... 8

3.1.5.c Lock Down/Hide Out ................................................................. 9

3.2 Emergency Events Response Guidelines …............................................................ 9

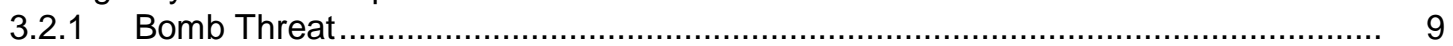

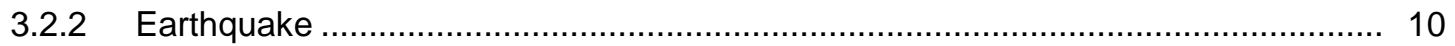

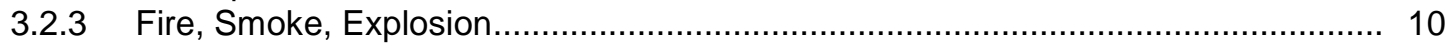

3.2.4 Hazardous Material (Chemical, Biological, or Radiological) Spill/Release ............. 10

3.2.4.a Chemical or Biological Spill/Release............................................... 10

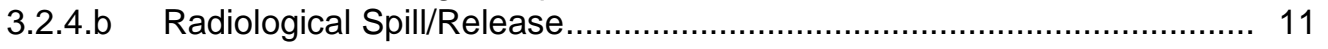

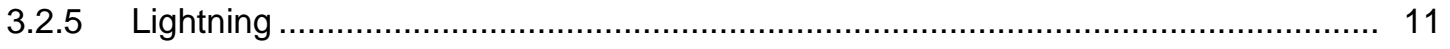

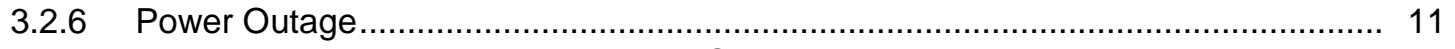

3.2.7 Unattended Package or Unexploded Ordnance ............................................. 11

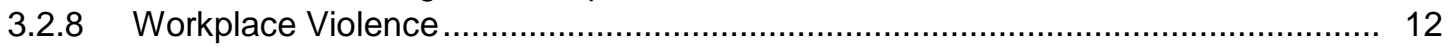

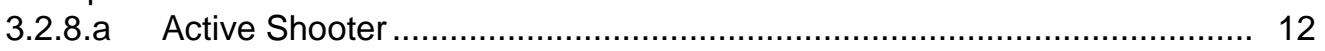

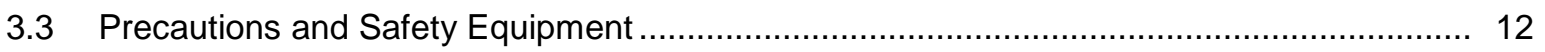

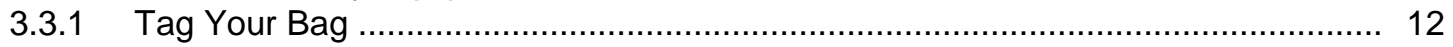

3.3.2 Automatic External Defibrillator (AED) Program ............................................... 13

3.3.3 Telephones and Emergency Calling .............................................................. 13

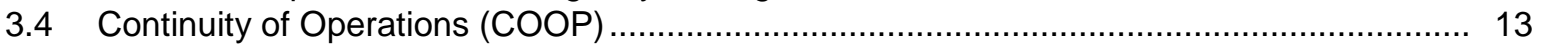

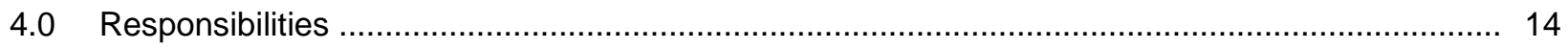

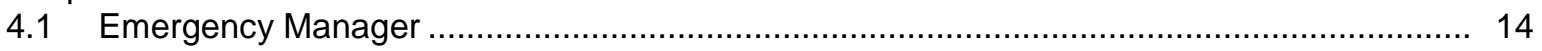

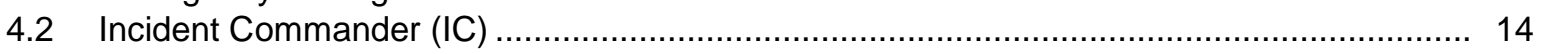

\section{LANL}


4.3 LANL First Responders (Hazardous Devices Team, HAZMAT Team, medically-trained facility response teams, etc.) and Emergency Management

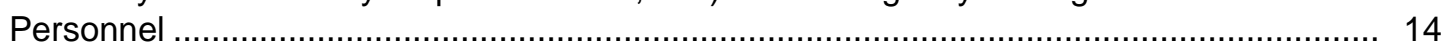

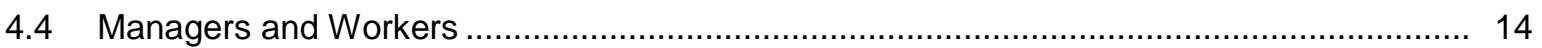

4.5 Assembly Area Leader (AAL) and Facility/Site Operations Center ................................... 15

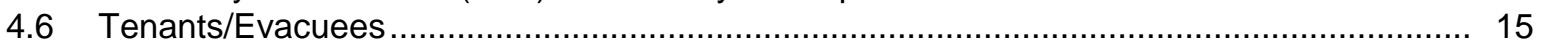

4.7 Runner (may be a facility Subject Matter Expert [SME]) …........................................ 16

4.8 Facility Operations Director (FOD) Emergency Preparedness Coordinator (EPC) ............. 16

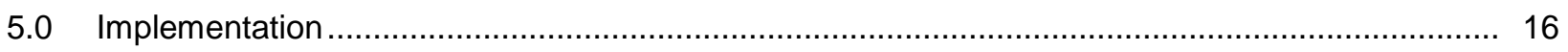

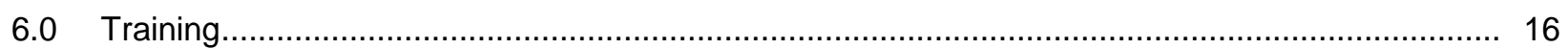

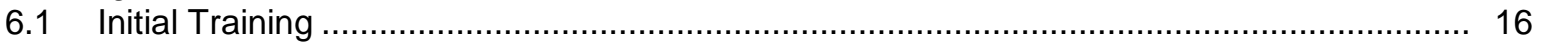

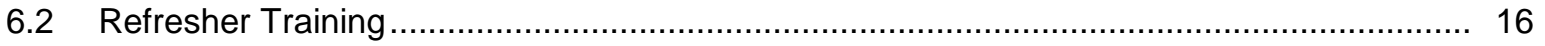

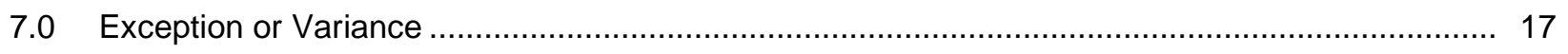

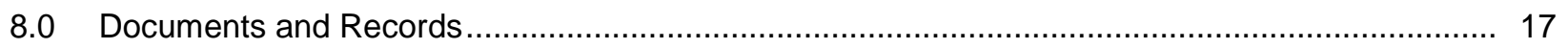

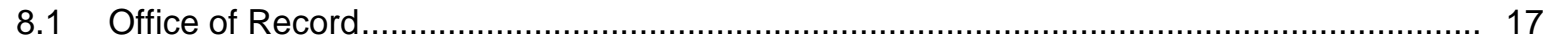

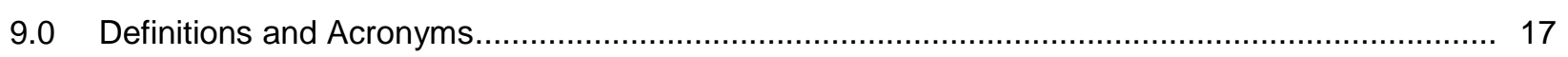

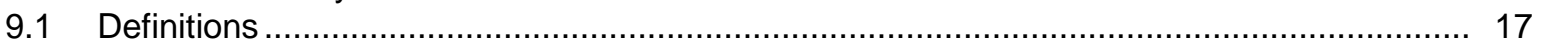

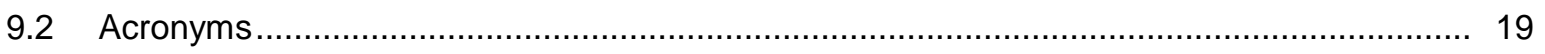

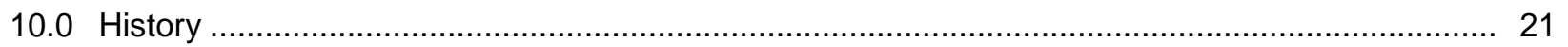

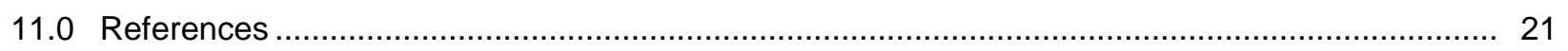

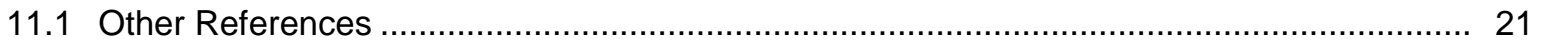

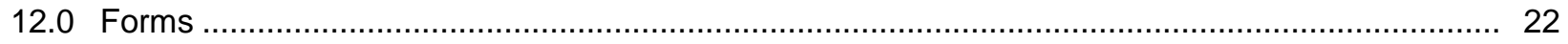

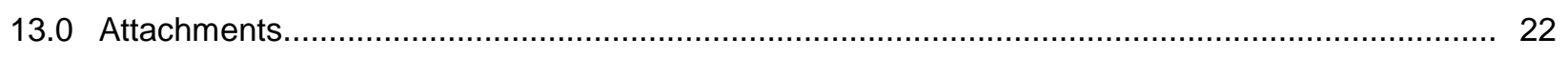

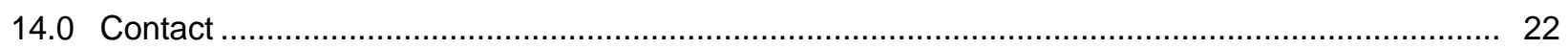

\section{LANL}

P1201-4, Rev. 3 


\section{LANL Emergency Procedures and Protective Actions}

\subsection{PURPOSE}

The purpose of this document is to provide requirements and guidance for Laboratory personnel and visitors in the event of an emergency event or situation. This document identifies the protective actions to be followed in the event of a hazardous material release, fire, or other emergency event.

Security and Emergency Operations Division (SEO) serves the Laboratory, Department of Energy (DOE)/National Nuclear Security Administration (NNSA), the nation and the community surrounding the Laboratory by providing the emergency planning, preparedness, mitigation, management, response, and recovery expertise for emergency events or situations. These services are provided by SEO to minimize the consequences of an emergency event; to maximize effective protection and safety of workers, the public, and the environment; and ensure the Laboratory's mission and national security are maintained.

This document provides standard emergency procedures. Building-specific emergency plans provide specific procedures for ensuring the safe and orderly sheltering or evacuation of building occupants (including individuals with special needs and visitors) that are unique to Laboratory and LANL leased buildings. Specific building emergency plans provide essential information for workers to remove themselves from danger within the facility or to respond to danger from outside. They are a required local training document that the Facility Operations Director (FOD) is responsible for implementing in accordance with P781-1, Conduct of Training, and the Conduct of Training Manual. In addition, emergency plans are considered emergency operating records and are subject to the requirements in $\underline{\mathrm{P} 1021}$, Vital Records Program.

\subsection{AUTHORITY AND APPLICABILITY}

\section{$2.1 \quad$ Authority}

This document is issued under the authority of the Laboratory Director to direct the management and operation of the Laboratory, as delegated to the Associate Director for Mission Assurance, Security, and Emergency Response (ADMASER), as provided in the Prime Contract. This document derives from the Laboratory Governing Policies, particularly the section on Emergency Management, and DOE Order (O) 151.1C, Comprehensive Emergency Management System.

- Issuing Authority (IA): Associate Director for Mission Assurance, Security, and Emergency Response (ADMASER)

- Responsible Manager (RM): Security and Emergency Operations (SEO) Division Leader

- Responsible Office (RO): Security and Emergency Operations Division (SEO)

\subsection{Applicability}

This document applies to all persons working at the Laboratory, including visitors.

\subsection{PROCEDURE DESCRIPTION}

The Laboratory is required to develop and maintain an emergency management program that, through mitigation, emergency planning, emergency preparedness and effective response capabilities, generates appropriate response to emergencies and mitigates the consequences of emergency events or situations. Effective emergency planning can greatly reduce the potential for loss of life and property damage, as well as increase the safety of all workers and provide protection to the environment.

\section{LANL}




\subsection{Protective Actions}

\subsubsection{General Protective Action Guidelines}

\subsection{1.a Protective Action Decision Making}

Initial protective actions, including sheltering and/or evacuation, may be issued by any worker who observes the initiating event in the immediate area; by Operations Centers; or by line management who is aware of the event. Thereafter, protective actions are determined, verified and issued by trained Incident Commanders (ICs) (Los Alamos County Fire Department [LAFD] or LANL Emergency Manager) based on currently available event information with consideration to all potentially affected personnel/populations and locations.

\subsection{1.b Protective Action Notifications}

Workers in facilities with operation centers or access control rooms may receive initial notifications as outlined in the facility Emergency Operating Procedures. Protective actions issued by the IC are usually sent from the Emergency Operations Center (EOC). The methods of communication are by voice to office and cell phones, text messages to cell phones and pagers, and e-mail messages. The Communications and Public Affairs-Communications Office (CPA-CO) may also send e-mail messages to all LANL workers.

\subsection{1.c Reporting the Event}

Initial emergency reporting must be made promptly, accurately, and effectively by any on-scene observer/worker who is knowledgeable of the event. The worker must call:

- 911 for life threatening events such as a person needing medical attention or a fire,

- 667-6211 (Security and Emergency Operations-Emergency Management Group [SEO-3], hereinafter referred to as Emergency Management),

- Workers should provide a description of the emergency, location, and protective actions taken (evacuation/sheltering).

- if applicable, response teams in the facility, and

- line/facility management and/or local Operations Center, where applicable.

\subsection{1.d Reporting the Event at LANL Leased Buildings with LANL Occupants and Visitors}

The worker must call:

- 911 for life threatening events such as a person needing medical attention or a fire

- Workers should provide a description of the emergency, location, and protective actions taken (evacuation/sheltering) to the 911 operators.

- 667-6211

- Workers should provide a description of the emergency, location, and protective actions taken (evacuation/sheltering). Note: Emergency Management will not respond to LANL leased buildings at the TA-00 sites. This is a notification only.

- Line and/or facility management.

\section{LANL}




\subsection{1.e Rescue and Medical Treatment}

Rescue and medical treatment for injured employees/visitors will be provided by:

- the responding fire department and Emergency Medical Services (EMS) unit;

- workers who, in accordance with LANL requirements, obtain and maintain a New Mexico EMS Bureau license as a First Responder and are designated members of a Laboratory Medical Response Team (MRT), or

- workers who are comfortable providing help up to their capabilities.

Note: It is recommended that workers providing help have current training in basic first aid, CPR and the use of Automatic External Defibrillators (AEDs). Subject to certain exceptions, the New Mexico "Good Samaritan" law provides protections from civil liability for persons who come to the aid or rescue of another person at or near the scene of an emergency.

\subsubsection{Building Evacuation}

The purpose of evacuating a building is to remove oneself from danger such as a chemical spill, fire, suspicious package, bomb threat, or other emergency event that is within the building. It is important that all LANL workers be familiar with the evacuation procedure and posted emergency evacuation diagrams for the building that is their primary place of employment as well as other areas that they frequent. See Section 9.1 for more information on emergency evacuation diagrams.

Once a worker has received a notification to take protective actions, under no circumstances should he or she return to a hazardous area or building to perform sweeps, make notifications, or collect belongings. Building-specific emergency/facility plans may provide additional information.

If it is unsafe to go outside (e.g., due to lightning), evacuees are expected to make safe, secure, and responsible decisions. The best course of action may be to evacuate to another building, or to personal vehicles in the parking lot.

Upon hearing the notification to evacuate, all occupants will evacuate the building immediately, if safe to do so, and perform the following with minimal delay:

1. Evacuate the building

- If accessible and safe to do so, take coats, hand bags/briefcases, and car keys in the event re-entry to the building is not allowed, or there is inclement weather.

- DO NOT carry food, drinks, or items that, if dropped, could inhibit safe egress and cause slips, trips, or falls.

- If the route is blocked by unsafe conditions, take the nearest safe path out of the building.

- DO NOT deviate from the exit route to sweep an area.

- DO NOT use the elevator.

2. Sweep while evacuating

\section{LANL}


Sweeping is the action of paying attention while evacuating. The steps for sweeping are the following:

- Conduct a visual sweep along the route between the work location and the building exit.

- Knock on office doors that are closed or locked, shout loudly to evacuate.

- If safe, open doors and shout "evacuate" in areas such as restrooms, locker rooms, conference rooms, etc., or anywhere a facility occupant could be unaware of an emergency condition.

- Pay attention to anything that may assist with the timely rescue of personnel or identify the source of the emergency event.

- Notify the AAL of any person needing assistance to evacuate.

3. Assemble at the designated Assembly Area (AA) for accountability.

Accounting for all persons after emergency evacuation is essential. When gathering at the AA, workers must:

- Be aware of and give the right-of-way to responding emergency vehicles and personnel.

- Provide the Assembly Area Leader (AAL), applicable local Operations Center, or IC with any information (e.g., smoke, pool of water, person-down, strange odor, hazardous conditions) obtained during the sweep.

- Provide information regarding any resident who is absent or missing from the AA to the AAL, applicable local Operations Center, or IC.

- Remain at the designated AA for further instructions or until the "All Clear" signal is given by the IC or designee.

- NOT re-enter the building until instructed to do so by the AAL or applicable local Operations Center (who will be instructed by the IC).

Note: Some emergency events may deteriorate rather than improve. If this is the case, the IC or building residents will determine the need to move a population from their initial AA to a relocation center, or move uphill or upwind of the event. The AAL or applicable local Operations Center will report accountability and status of personnel to the EOC at 667-6211 and/or the IC.

4. Report the event to the IC or EOC via the AAL, runner, radio, or phone call. The following should be conveyed in the report:

- Why evacuated, accountability, and changes in AA

- Observed hazards or unusual conditions

- Any known injuries

- Status of critical equipment/operations

5. Additional information from the IC will be relayed to the AAL such as all clear, etc.

6. Return to normal operations

Returning to normal operations is the point at which the IC turns the facility back over to the facility personnel (typically the FOD or designee). Facility personnel must participate in a

\section{LANL}


face-to-face briefing with the IC to determine if recovery tasks must be completed. The IC or the facility personnel will then direct workers to return to the building so operations may resume.

Workers must not return to the building until they have received the "All Clear" from the IC. The IC may provide the facility personnel/AAL the "All Clear" to provide to building residents.

\subsection{2.a Evacuation of Individuals with Special Needs}

Any worker having a permanent or temporary special need that may hinder his or her evacuation must notify his or her line manager. The line manager will assign a co-worker(s) to assist the worker during all emergency events including, but not limited to, drills and real events requiring evacuation or sheltering.

Workers assisting others should:

- Always ask someone with a disability how they can be of help before attempting any rescue technique or giving assistance.

- Assist special needs individuals out of the building using the nearest exit.

- If unable to exit the building, and if safe to do so, assist the individual to the nearest exit stairwell or safe area of refuge, and inform emergency personnel of the situation.

- Notify the AAL/IC.

\subsection{2.b Visitor Evacuation}

All guests, visitors, and outside personnel (including subcontract and crafts workers, maintenance workers, delivery personnel, or persons attending a meeting) conducting business in a building are responsible to ask for evacuation information or to follow a resident during an evacuation. If an emergency evacuation occurs, building residents should consider escorting visitors and ensuring visitors know they can follow the resident out of the building.

\subsubsection{Site-Wide Evacuation}

Depending on the nature and urgency of the emergency, a decision by the IC will be made whether to evacuate the entire site or specific zones, and whether to allow workers to exit at a normal pace or enforce immediate site-wide evacuation. Under conditions where a site-wide evacuation is not practical, an ad hoc evacuation will be implemented depending on the nature of the threat, affected areas, and time available to move workers. Emergency Management will give specific instructions to LANL managers and workers regarding evacuation routes and other emergency-related information. During site-wide evacuations, CPA-CO acts as a point of contact for community entities outside of LANL.

Managers and mentors of students should be able to communicate to their direct reports, workers, and students in the event of a site-wide evacuation or site closure at any time (during the work day or after hours/weekends). It is recommended that worker phone trees are maintained and available to managers and their administrative professionals in the event that contact with workers is requested by Laboratory leadership. In the event that a site-wide evacuation is ordered, managers should have on hand a prepared and tested safe-shut down plan for equipment and operations.

\section{LANL}


Evacuations may prevent personnel from using their normal egress routes. LANL workers should consider alternate routes and/or egress methods to address closed roadways, detours, or evacuation timing that may make it impossible to catch their regular buses or carpools.

Note: LANL workers working within the town site will proceed to their destination using their normal route or as otherwise directed by Los Alamos County.

\subsection{3.a LANL Evacuation Planning Sections}

During events or situations that allow sufficient planning and warning time for a large area to be evacuated, established LANL Evacuation Planning Sections will be used to identify affected populations and establish evacuation priorities and routes. See the Evacuation Route Maps, available on request from Emergency Management at 667-6211.

The IC or the EOC will notify LANL management and CPA-CO when evacuation plans are complete and provide evacuation details for distribution to LANL populations. CPA-CO will provide evacuation instructions for each section and an evacuation map when available via e-mail. The general evacuation sections at LANL are described below:

- Section A: Technical Areas (TAs) 06, 08, 09, 11, 14, 15, 16, 22, 28, 33, 36, 37, 39, 40, 49, and 69

- Section B: TA-03, 59, and 60

- Section C: TA-05, 18, 35, 46, 48, 50, 51, 52, 54, 55, 63, 64, and 66

- Section D: TA-53, 61, and 72

- Section E: TA-02, 21, 41, 43, and 73

\subsubsection{Security}

\subsection{4.a Security During an Evacuation}

When handling classified materials in an emergency, the health and safety of workers comes first. Workers must understand their security responsibilities before an emergency occurs. Workers must inform their management and the IC of any classified materials that are left unsecured during an evacuation.

Workers with questions regarding the handling of classified matter in an emergency should contact the Security Help Desk at 665-2002 or e-mail security@lanl.gov.

See P204-2, Classified Matter Protection and Control Handbook for details regarding handling classified matter in an emergency situation.

\subsubsection{Sheltering}

LANL uses three types of sheltering: Shelter in Place, Stay Put, and Lock Down/Hide Out. It is essential that LANL workers know how to appropriately carry out any of these sheltering protective actions.

The recommended sheltering protective action depends on the triggering event as follows:

- Shelter in Place (workers make a shelter out of the place where they are located) is triggered by a hazardous material release such as a chemical, biological, or radiological release. See Sections 3.1.5.a and 9.1.

\section{LANL}


- Stay Put (workers stay in their offices) is triggered by inclement weather, such as ice, snow, flooding, or lightning; or wild land fire. See Sections 3.1.5.b and 9.1.

- Lock Down/Hide Out (workers lock themselves in or hide a safe place) is triggered by an active shooter or other workplace violence. See Sections 3.1.5.c and 9.1.

\subsection{5.a Shelter in Place}

Shelter in place is the protective action used primarily during a hazardous material release. Sheltering in place in any building will provide some shelter, and is better than being outside and potentially receiving a greater exposure to the hazard.

Upon receiving the notification to shelter in place workers will do the following:

- stay calm,

- stay inside or move indoors,

- close windows and doors,

- notify building personnel and visitors of the need to shelter in place,

- in buildings that have simple thermostat-controlled heating and air conditioning units with an "off" setting, shut down the ventilation system. See Section 3.1.5.a[4]).

Note: Some buildings have Heating, Ventilating, and Air Conditioning [HVAC] systems that do not require shutting down ventilation systems). The FOD maintenance manager will have this information.

- go to the pre-determined shelter in place location (see Section 3.1.5.a[1]),

- check the LANL internal or external home pages for a news bulletin from CPA-CO,

- keep communication lines open for emergencies (land line telephones and cell phones), and

- take accountability and report it to the EOC at 667-6211,and/or report it to the applicable local Operations Center who will then report it to the EOC.

Note: Real events and drills must be documented. It is recommended that AALs collect a list of names and $Z$ numbers of the sheltered-in-place personnel and after the event, send the list to the applicable FOD Emergency Preparedness Coordinator (EPC). For further instructions or a list of FOD EPCs call 667-6211.

\subsection{5.a(1) Shelter in Place Location Guidelines}

The best shelter location will be an internal conference room or an internal hallway.

Room(s)/hallways should, if possible, have the following attributes:

- approximately 10 square feet of floor space per person to provide ample oxygen for a one to three hour period;

- minimal connections to the outside of a building (few or no exterior doors, windows, or vents);

- a telephone to allow contact with the outside;

- a computer to check for updates;

- restrooms close by; and

- a water source (i.e., water fountain or kitchen) close by.

\section{LANL}


Personnel in vehicles should roll up windows and close vents that draw in outside air (including heater and air-conditioning vents, if applicable) and proceed to a safe location.

\subsection{5.a(2) Shelter in Place Kit Guidance}

As specified in building emergency plans, some buildings need a shelter in place kit. A kit may be necessary for transportables (trailers) or other older buildings with leaky windows and doors. A kit may include the following items:

- wide painter's tape, to be used to cover external windows/vents and doors,

- flashlight with batteries,

- first aid kit,

- roll call sheet for accountability, or paper to document names and $Z$ numbers, and

- facility specific instructions that detail how to report accountability.

\subsection{5.a(3) Optional Personal Shelter in Place Kit}

The following items are suggestions for inclusion in a personal shelter in place kit:

- personal medications, such as insulin (enough for 2-3 hours maximum);

- coat, jacket, or sweater;

- snacks;

- cell phone, where permitted by building security requirements; and

- a change of clothes in case of potential contamination.

Note: If workers do not have a work pager or cell phone, their building/group may not be able to notify them that sheltering in place protective actions are taking place. Road blocks may be in place. Training and good judgment will dictate what to do to reach a shelter location.

\subsection{5.a(4) Shutting Down Ventilation}

Shutting down HVAC systems in some facilities can be complicated, and there may be some critical operations that require special considerations. In these cases, only those individuals who are trained, have the necessary Personal Protective Equipment (PPE), and are in facilities with approved ventilation shutdown procedures may shut down HVAC systems or set air to re-circulate only. If unsure about the ability to shut down ventilation in your building, ask for assistance from facility or maintenance personnel.

Note: Shelter in place is still effective even if the facility ventilation system cannot be shut down. Remember, sheltering is for a short duration. Once it is safe to move a population or allow them to go outside, the IC will provide this information.

\subsection{5.b Stay Put Sheltering}

Stay put sheltering is the protective action used primarily during hazardous weather events (snow, ice, floods, and lightning), or other events that put workers in harm's way outside. This protective action calls for personnel to move or remain indoors.

Upon hearing the notification to stay put shelter, all LANL workers will do the following:

- stay inside,

\section{LANL}


- check e-mail or the LANL home page for information from CPA-CO, and

- follow instructions provided by Emergency Management and the applicable local Operations Center.

\subsection{5.c Lock Down/Hide Out}

Lock Down/Hide Out is the protective action used primarily during workplace violence events, including active shooter situations. Workers must take responsibility and take care of themselves until law enforcement arrives by integrating security event responses into emergency

preparedness.

Upon hearing gunshots or other indicators of violence (screams, warning shouts, etc.) or receiving a notification to Lock Down/Hide Out, workers will do the following:

- Evacuate (RUN) if safe to do so.

- Lock themselves in a room (HIDE); turn lights off, keep communication equipment muted, stay in a location where they cannot be seen. If available, push furniture (desks, cabinets, etc.) against the door. Spread out in the room, and DO NOT huddle in a group.

- If all else fails and the worker is in immediate danger, FIGHT back with anything and everything at hand. Stay committed.

- Call 911 when it is safe to do so.

- When law enforcement arrives, comply with their instructions. Workers will show their hands and not carry or hold anything. Provide any information requested, (e.g., description of shooter[s], etc.).

\subsection{Emergency Events Response Guidelines}

All workers should call 911 and 667-6211, and, if applicable, the local Operations Center, for fire and life threatening emergencies. In addition, workers should call 667-6211 for potential hazards such as strange odors, suspicious packages, spills and releases, vehicle collisions, and other miscellaneous incidents.

The sections below identify the steps to take in response to certain events. In general, during an emergency event, workers should remain calm and follow instructions from the emergency responders. Facility specific and/or programmatic-specific instructions may apply to certain workers and will be incident dependent.

\subsubsection{Bomb Threat}

A person receiving a telephone bomb threat should remain calm and obtain as much information as possible from the caller by completing the Bomb Threat Checklist.

- DO NOT pull the fire alarm pull box.

- DO NOT open/close windows and doors, unless to exit.

- DO NOT touch light switches during a bomb threat evacuation.

- DO NOT use cell phones.

- Call Emergency Management (667-6211). At LANL leased facilities call 911 first with a follow up notification to Emergency Management.

- Follow emergency responders' instructions.

\section{LANL}




\subsubsection{Earthquake}

During an earthquake, fire alarms and sprinkler systems may activate even if there is no fire involved. Workers should follow these guidelines:

- Stay inside.

- Take cover underneath a table or against an inside wall, protecting their heads and necks.

- Stay away from windows (where glass can shatter) and from objects that could fall.

- Call 911 then Emergency Management (667-6211).

Note: Emergency Management and 911 will likely be experiencing heavy call traffic during an earthquake, so workers should keep trying to make contact,

After an earthquake, workers should follow these guidelines:

- Evacuate the building and report to designated AA or relocation shelter unless directed otherwise.

- DO NOT use elevators. Use the stairs if they are not damaged or blocked with debris.

- Move away from structural damage and watch for other hazards (downed power lines or dangerous overhead lines, pipeline breaks, spills and releases).

\subsubsection{Fire, Smoke, Explosion}

In the event of a fire, explosion, or if a worker sees smoke, in general, the worker should:

- Activate fire alarm or verbally direct employees to evacuate.

- Proceed to the AA for accountability.

- Follow evacuation, sweep, and accountability procedures.

- Call 911 then Emergency Management (667-6211),

- If applicable call the local Operations Center.

Note: If a worker is at risk in trying to get to a pull box or in calling 911, he or she should evacuate first and then find a safe location to call 911 and (if possible) pull the alarm.

In the event of a wild land fire, the order may be given by the IC to Stay Put rather than evacuate.

If a worker is familiar with or trained in the use of a portable fire extinguisher, he or she should first pull the fire alarm and call 911, then attempt to put out the fire if it is safe to do so.

\subsubsection{Hazardous Material (Chemical, Biological, or Radiological) Spill/Release}

In the event of a hazardous material incident workers should follow these steps, as applicable:

\subsection{4.a Chemical or Biological Spill/Release}

- Notify and evacuate personnel in the immediate area.

- Call the facility Industrial Hygienist (IH) for instructions.

- Notify Emergency Management at 667-6211.

- Follow IH instructions.

\section{LANL}


- Notify facility management and/or the applicable local Operations Center.

- Segregate potentially contaminated workers from other evacuees.

- Follow facility-specific procedures (if applicable).

\subsection{4.b Radiological Spill/Release}

- Notify and evacuate personnel in the immediate area.

- Call the Radiological Control Technician (RCT) for instructions.

- Follow RCT instructions.

- Notify Emergency Management at 667-6211.

- Notify facility management and/or the applicable local Operations Center.

- Segregate personnel in Radiological PPE and other potentially contaminated workers from other evacuees (i.e., do not co-mingle).

- Follow facility-specific procedures (if applicable).

- Follow facility-specific instructions from applicable local Operations Centers.

\subsubsection{Lightning}

If workers are outdoors during a thunderstorm, they should:

- Move to a safe location to minimize chance of injury or death.

- Avoid contact with trees and metal objects, including bicycles. Find a low spot, not prone to flooding, away from trees, fences, and poles. Crouch low, feet together, providing a single point of contact with the ground.

\subsubsection{Power Outage}

- Remain calm.

- If safe to do so, unplug all electrical equipment, including computers, and turn off light switches.

- DO NOT use elevators.

\subsubsection{Unattended Package or Unexploded Ordnance}

If a suspicious or unattended package or device is found:

- Remain calm.

- Isolate area immediately around package or device.

- DO NOT use a cell phone in the area.

- Immediately call 667-6211 and the applicable local Operations Center from a safe location, preferably from a landline phone. At LANL leased facilities call 911 first with a follow up notification to Emergency Management.

- DO NOT PULL FIRE ALARM PULL BOX FOR SUSPICIOUS PACKAGES.

- DO NOT move any suspicious object(s).

- Follow instructions from the Emergency Manager.

\section{LANL}




\subsubsection{Workplace Violence}

Workplace violence is violence or the threat of violence against workers. It can range from threats and verbal abuse to physical assaults and homicide. Violence in the workplace is an emergency.

LANL has a zero-tolerance policy toward workplace violence. If workers notice workplace violence, they must call 911. For more information see P724, Workplace Violence.

Workplace violence cannot be predicted, but workers can be prepared for emergencies by following these guidelines:

- be observant and aware of surroundings;

- report abnormalities;

- keep training current;

- practice emergency procedures; and

- talk with family and co-workers about preparing for this type of event and actions to take during this type of event.

\subsection{8.a Active Shooter}

In the case of an active shooter, workers should follow the steps below. Safety is the number one priority:

- Evacuate- (RUN) if safe to do so.

- Lock themselves in a room- (HIDE), lights off, communication equipment muted, in a location where they cannot be seen. Spread out and DO NOT huddle in a group.

- If all else fails and the worker is in immediate danger, FIGHT back with anything and everything at hand.

- Call 911 when it is safe to do so.

- Wait until law enforcement arrives and comply with their instructions. Provide any information requested, (e.g., description of shooter[s], etc.).

Note: All emergencies occur under a unique set of circumstances. As such, no emergency plan can cover all situations. Building occupants must be prepared for the unexpected in any emergency situation, and plan to act as if they are "first responders" until Emergency Management or LAFD arrives on the scene.

For all of the above types of events, real events as well as drills must be documented. The FOD EPC will fill out the appropriate internal forms to document shelter or evacuation events. The FOD EPC can be contacted by e-mailing epcs@lanl.gov.

\subsection{Precautions and Safety Equipment}

\subsubsection{Tag Your Bag}

The Laboratory requires that all personal items be properly tagged. Untagged bags abandoned in public places at the Laboratory are assumed to be hazardous devices by the Hazardous Devices Team. If the owner cannot be located the item(s) will be destroyed.

Workers should do their part to prevent expensive false alarms by taking the time to Tag Your Bag. The tag should identify the owner and list a number where the owner can be reached.

\section{LANL}


The badge office can make a tag from a worker's business card. Or workers may call Emergency Management at 667-6211 or e-mail bagtag@emo.lanl.gov to request a tag.

\subsubsection{Automatic External Defibrillator (AED) Program}

AEDs may be used during administration of help to someone who is not breathing and is in need of CPR. The point of contact for the AED program at the Laboratory is Occupational Medicine; call 667-0660 for information. More information can also be found at the Automatic External Defibrillator (AED) Program webpage.

- Workers should call 911 prior to AED use.

Note: It is recommended that workers providing help have current training in basic first aid, CPR and the use of AEDs. Subject to certain exceptions, the New Mexico "Good Samaritan" law provides protections from civil liability for persons who come to the aid or rescue of another person at or near the scene of an emergency.

\subsubsection{Telephones and Emergency Calling}

All LANL telephones have direct access to a local Public Safety Dispatch Center by dialing 911. Enhanced 911 services (E911) also identify the physical location of the caller. As telephone location records are the primary source for E911 first responders, these location records must be accurate.

Most telephones at LANL are Voice Over Internet Protocol (VoIP) telephones. Whenever a VolP telephone is relocated, a notification of that new location must be given to the LANL communications team by e-mailing tcateam@lanl.gov to update location records. This new location notification is the responsibility of the phone's listed owner, but anyone may make the notification.

Along with the advantages of VolP phones, there are some caveats the LANL worker must be aware of:

- The VolP phone may not function during an electrical power outage.

- The VolP service will not function if the network connection fails.

In the event of a failure in VoIP telephone service, personal cellular phones and LANL-issued mobile devices function as primary backup at LANL. In areas of poor cellular service, an alternative is often provided in buildings. An analog telephone (may be red) may be installed in hallways, near exits, and in other areas that are occupied but have poor/no cellular reception. These red analog telephones are available for emergency or general use and are not dependent on building power or data network support. They are in highly visible locations and designated by red signage.

When dialing 911 from a cell phone on LANL property, the caller must report a location to the dispatcher who may be in Santa Fe.

\subsection{Continuity of Operations (COOP)}

Continuity planning is an effort to document and ensure the capability to continue organization essential functions during a wide range of potential emergencies.

\section{LANL}


Workers can help ensure the continuity of LANL operations by making sure their organization knows how best to reach the worker in an emergency and by knowing their emergency responsibilities.

During an emergency event, routine processes may become more difficult, complicated and the consequences may have a higher impact. COOP implementation involves intentional, preplanned movement of selected personnel and critical resources to an alternate operating facility if applicable.

It is the worker's responsibility to be comfortable with their roles and responsibilities relative to emergency response, report their whereabouts to management as soon as possible, and ensure accurate and current contact information for notification. This will reduce the need to expend valuable resources verifying a worker's safety, ensure workers receive critical communications related to an emergency event, and provide leadership with personnel resource information impacting activities required as a result of the event.

For more information see DOE O 150.1, Continuity Programs and the EPP-COOP-006, LANL COOP [Continuity of Operations] Plan.

\subsection{RESPONSIBILITIES}

\subsection{Emergency Manager}

- Provides on-call, 24-hour coverage for emergency response.

- May become the IC.

- Is responsible for initial notification and communications, classification/categorization and providing protective actions for on-site entities and for providing protective action recommendations for off-site entities such as Los Alamos County and surrounding jurisdictions.

\subsection{Incident Commander (IC)}

- Has authority and responsibility for command and control at the event scene. Depending on the type of event, LANL Emergency Managers, a Fire Department Company or Chief Officer or police officer may be the IC. Specific training is required before any of these organization's personnel can legally be declared the IC.

\subsection{LANL First Responders (Hazardous Devices Team, HAZMAT Team, medically-trained facility response teams, etc.) and Emergency Management Personnel}

- Respond to emergency events at LANL and mitigate them as safely and quickly as possible.

- Together with the responding fire department and Emergency Medical Services units, provide rescue and medical treatment for injured employees at LANL, as appropriate.

\subsection{Managers and Workers}

- Be familiar with the emergency plans for their buildings, this document, and appropriate facility plans.

- Discuss emergency procedures with all workers, managers and co-workers.

- Invite the FOD EPC to explain the emergency protective action notifications and Sheltering actions.

- Know evacuation and sheltering procedures.

\section{LANL}




\subsection{Assembly Area Leader (AAL) and Facility/Site Operations Center}

Note: This role can be assumed by any worker on-site at the time an emergency event occurs. At some sites/facilities, facility management and/or the applicable local Operations Center fulfill the duties of the AAL. Building-specific emergency plans will identify these roles.

- Conducts and reports accountability during evacuation and/or sheltering events.

- Acts as the point of contact for the IC (the IC is normally a representative from the LAFD or Emergency Management).

- Announces oneself upon arrival to the AA.

- Assigns additional AAL(s), when necessary. If more than one AA is used during an evacuation, additional AALs are to collect accountability and sweep information from those present and report information gathered to the primary AAL or applicable local Operations Center.

- Contacts other AALs (if applicable) and/or the applicable local Operations Center, collects information on accountability and sweeps of the buildings, and submits results to IC.

- Ensures notifications are made to tenants who are located in buildings with no audible or visible alarms to evacuate (e.g., sends a runner).

- Questions all persons at the AA, gathering information such as the presence of pools of water, strange odors, smoke, person down or missing, etc.

- Gathers and disseminates pertinent information relative to evacuation/sheltering, i.e., existing or new hazards that may be created by the event.

- Notifies evacuees they can re-enter the building only upon receiving an "All Clear" signal from the IC.

- Selects an alternate AA if conditions/situation warrant (e.g., wind, weather, event location) and notifies the IC/Emergency Management immediately of AA location.

- Is in charge of the personnel at the AA until the arrival of the IC.

\subsection{Tenants/Evacuees}

- Assume the AAL role upon arrival at the AA if comfortable performing the AAL responsibilities.

- Communicate to the AAL concerns, information, missing personnel, status or hazards of facility work, and any observed hazardous conditions.

- Respond to emergencies in accordance with the facility-specific emergency plans.

- Obey all signs and postings.

- Follow the instructions of the ICs.

- Complete Laboratory-wide Emergency Preparedness and Protective Actions Training (part of General Employee Training [GET]) and other protective actions training as required.

- Familiarize themselves with the nearest emergency exits, fire alarm pull stations, fire extinguishers, automatic external defibrillator(s), and emergency contact numbers.

- Know the primary and alternate evacuation routes from their office areas.

- Know the designated Assembly Area.

- Participate in scheduled drills.

\section{LANL}


- Direct concerns or questions related to these activities to line managers.

\subsection{Runner (may be a facility Subject Matter Expert [SME])}

- Appointed by the AAL (or may be the AAL), to establish communications between the $A A$, the applicable local Operations Center, and the IC, other AAs, or other entities involved in the building emergency or responding to it.

- Establishes and maintains continuous communications with all entities involved in the emergency, especially the IC, until the "All clear" signal has been given.

- Assists the AAL in establishing accountability for the building, and reporting this and related information to the EOC, the applicable local Operations Center, or the IC.

- Assists the AAL in determining and delivering emergency first aid support and performing other duties in response to the emergency.

\subsection{Facility Operations Director (FOD) Emergency Preparedness Coordinator (EPC)}

- Briefs workers on the emergency protective action notifications and Sheltering actions recommended for their buildings.

- Completes the appropriate internal forms to document shelter or evacuation events or drills.

\subsection{IMPLEMENTATION}

The requirements in this document are effective on the issue date.

\subsection{TRAINING}

\subsection{Initial Training}

New workers at LANL will receive Emergency Preparedness and Protective Actions training as a part of GET. Workers will receive Facility Emergency Plan-specific training in emergency procedures and protective actions at their work locations.

\subsection{Refresher Training}

Refresher training will not be a repetition of initial training, and Facility Emergency Plan-specific training will not be a repetition of the Laboratory-wide Emergency Preparedness and Protective Actions Training.

Laboratory-wide Emergency Preparedness and Protective Actions Refresher Training (Course \#10922, LANL Emergency Procedures and Protective Actions Refresher Training) will be provided to all LANL workers whenever there is a change in the worker's responsibilities or in emergency procedures. This refresher training will be based on a training needs analysis, documenting the changes and the need for training. This refresher training will include, but is not limited to:

- changes required by applicable codes, regulations, standards, policies, and procedures,

- lessons learned and near-miss events based on the past year's performance from both LANL and across the DOE complex,

- LANL and industry operating experience,

- training on selected topics from initial training to correct identified inadequate performance by workers at LANL,

- training on seldom used, abnormal, and emergency procedures and contacts,

\section{LANL}


- training on fundamentals of seldom used knowledge and skills necessary to assure safety, and

- training on other topics directed by LANL or DOE management.

Facility Emergency Plan-specific refresher training is required whenever there are significant changes to the emergency plans or the worker's emergency responsibilities. This training will be based on a training needs analysis and will be approved by the FOD before implementing the refresher training requirement.

Facility Emergency Plan-specific training refresher training will include:

- changes in the Facility Emergency Plan, such as the relocation of AAs, shelter facilities, etc.,

- lessons learned and near-miss events based on the past year's performance in the building or at the facility,

- refresher training on selected topics from initial Facility Emergency Plan training to correct identified inadequate performance by workers in the building or facility,

- refresher training on seldom used abnormal and emergency procedures and contacts,

- refresher training on fundamentals of seldom used knowledge and skills necessary to assure safety, and

- refresher training on other limited topics directed by the Responsible Associate Director (RAD) or FOD.

Workers will participate in protective action drills and/or exercises when provided, to reinforce the emergency procedures and help ensure they are trained to respond to a real emergency event.

See P781-1, Conduct of Training, for requirements and procedures for the format, delivery, and content of Emergency Protective Actions and Facility Emergency Plan training.

\subsection{EXCEPTION OR VARIANCE}

To obtain an exception or variance to this document, see the following instructions:

- Managers may request an exception or variance from the IA through the RM.

- At the IA's request, the RM will provide a recommendation or supporting information.

- The IA or designee will provide the requester with a written response and copy the RM.

The requesting organization must maintain the official copy of record of the approved correspondence granting the exception or variance.

\subsection{DOCUMENTS AND RECORDS}

\subsection{Office of Record}

The Policy Office is the Laboratory Office of Record for this Institutional Document and maintains the administrative record.

\subsection{DEFINITIONS AND ACRONYMS}

\subsection{Definitions}

See LANL Definition of Terms.

\section{LANL}


Drill—A supervised, hands-on training intended to test, develop, and maintain a specific emergency response capability.

Emergency-A serious event that consists of any unwanted operational, civil, naturalphenomenon, or security occurrences that could endanger or adversely affect people, property, or the environment.

Emergency Evacuation Diagram-A diagram reflecting the actual floor arrangement and exit locations of a building. Development of emergency evacuation diagrams must be in accordance with the Emergency Operations/Building Emergency Plan Program and the LANL Engineering Standards Manual. Emergency evacuation diagrams must be developed for all new buildings at LANL and modified when existing buildings are altered.

Emergency Management-The development, coordination, and direction of planning, preparedness, and readiness assurance activities.

Emergency Operations Center (EOC)—A central facility from which management and support personnel carry out coordinated emergency response activities.

Emergency Operations Support Center (EOSC)—A LANL center staffed 24/7 with communications specialists and on-call emergency managers, who can be reached at (505) 667-6211 for assistance with or information about all non-life-threatening situations that involve abnormal or unusual circumstances or emergency events.

Emergency Plan-Documents the emergency management program and describes the provisions for response to an operational emergency. It contains a clear and concise description of the overall emergency organization, designation of responsibilities, and procedures, including notifications, involved in coping with any or all aspects of a potential credible operational emergency.

Emergency Preparedness Specialist/Coordinator-An individual assigned to a FOD/division to work with Security and Emergency Operations-Integrated Services (SEO-4), the Building Emergency Planning Program (BEPP), and EOC to fulfill responsibilities for emergency planning, preparedness, and response at the facility level.

Evacuation-A protective action that calls for the controlled relocation of personnel from a hazardous or potentially hazardous area.

Exercise-A scheduled and planned large-scale activity that tests the integrated capability and most aspects of the emergency management program associated with a particular DOE facility.

Facility-An area, physical structure, or combination of structures that form the envelope in which work is accomplished. At LANL, this is typically a building or complex of buildings within one Technical Area.

Facility or Site Operations Center-A LANL center that typically operates in support of medium- or high-hazard facilities and/or sites to provide access control during normal and emergency operations. Also provides notifications and communications to site personnel and emergency responders. May be staffed 24/7, only during normal work hours, or for unique operations.

\section{LANL}


Hazardous Material—Any solid, liquid, or gaseous material that is toxic, flammable, radioactive, corrosive, chemically reactive, or that may be unstable upon prolonged storage, in quantities that could pose a threat to life, property, or the environment and that is used in work.

Hide Out-The protective action of hiding, typically from an active shooter or other source of workplace violence.

Lock Down-The protective action of locking oneself in isolation or a restricted access area, typically in response to an active shooter or other source of workplace violence.

Response-Activities to address the immediate and short-term effects of an emergency or disaster. Response includes immediate actions to save lives, protect property, and meet basic human needs.

Safe Area of Refuge-A location in a building designed to hold occupants during a fire or other emergency, when evacuation may not be safe or possible. Occupants can wait there until rescued by firefighters. A safe area of refuge may be used by any person who cannot access a safe escape route, any person assisting another who is prevented from escaping, any sick person, and any person with a disability. FOD EPCs will work with LAFD personnel who can assist with defining specific safe areas of refuge.

Shelter In Place-The use of a structure and its indoor atmosphere to temporarily separate individuals from a hazardous outdoor atmosphere. Shelter In Place entails closing all doors, windows and vents and taking immediate shelter in a readily accessible location that puts as much indoor air and mass between the individual and the hazardous outside air, such as a basement or centrally located medium to small room, and trying to make it as airtight as possible by shutting off all ventilation/HVAC systems.

Site-LANL as a whole.

Stay Put-A protective action by a person to remain somewhere (such as in his/her office) without moving or being moved.

Workplace Violence-Violence that originates from employees or employers and threatens employers and/or other employees. This may include assaults, other violent acts or threats that occur in or are related to the workplace and entail a substantial risk of physical or emotional harm to individuals, or damage to government resources or capabilities. Types of perpetrators are:

- Outsider-Someone who has no legitimate relationship with the victim or workplace and usually enters the workplace to commit a robbery or other criminal act.

- Customer-Someone who is a recipient of a service provided by the affected workplace or victim.

- Employee-Someone who has an employment-related relationship with the workplace victim. This may include current or former employees.

- Employee-related outsider-A current or former spouse/lover, relative, acquaintance, or some other person who has a dispute involving an employee of the workplace.

\subsection{Acronyms}

See LANL Acronym Master List.
AA
Assembly Area

\section{LANL}




\begin{tabular}{|c|c|}
\hline AAL & Assembly Area Leader \\
\hline ADMASER & $\begin{array}{l}\text { Associate Director for Mission Assurance, Security, and Emergency } \\
\text { Response }\end{array}$ \\
\hline AED & Automatic External Defibrillator \\
\hline BEPP & Building Emergency Planning Program \\
\hline CPA-CO & Communications and Public Affairs-Communications Office \\
\hline COOP & Continuity of Operations \\
\hline CPR & Cardiopulmonary Resuscitation \\
\hline DOE & Department of Energy \\
\hline EMS & Emergency Medical Services \\
\hline EOC & Emergency Operations Center \\
\hline EOSC & Emergency Operations Support Center \\
\hline EPC & Emergency Preparedness Coordinator \\
\hline EPP & Emergency Planning and Preparedness \\
\hline FOD & Facility Operations Director \\
\hline GET & General Employee Training \\
\hline HAZMAT & Hazardous Material \\
\hline HVAC & Heating, Ventilating, and Air Conditioning \\
\hline IA & Issuing Authority \\
\hline IC & Incident Commander \\
\hline $\mathrm{IH}$ & Industrial Hygienist \\
\hline LAFD & Los Alamos County Fire Department \\
\hline LANL & Los Alamos National Laboratory \\
\hline MRT & Medical Response Team \\
\hline NNSA & National Nuclear Security Administration \\
\hline $\mathrm{O}$ & Order \\
\hline PPE & Personal Protective Equipment \\
\hline RAD & Responsible Associate Director \\
\hline RM & Responsible Manager \\
\hline RTC & Radiological Control Technician \\
\hline RO & Responsible Office \\
\hline SBP & Safety Basis Procedure \\
\hline SEO & Security and Emergency Operations \\
\hline SEO-3 & Security and Emergency Operations-Emergency Management \\
\hline SEO-4 & Security and Emergency Operations-Integrated Services \\
\hline SME & Subject Matter Expert \\
\hline TA & Technical Area \\
\hline USI & Unreviewed Safety Issue \\
\hline USQ & Unreviewed Safety Question \\
\hline VolP & Voice Over Internet Protocol \\
\hline
\end{tabular}

\section{LANL}




\subsection{HISTORY}

\begin{tabular}{|l|l|l|}
\hline Revision History & \multicolumn{2}{|c|}{} \\
\hline 05/26/10 & P1201-4, Rev. 0 & $\begin{array}{l}\text { Initial Issue. This document cancels P1201-2, Evacuation } \\
\text { Plan, and P1201-3, LANL Shelter-In-Place Standard. }\end{array}$ \\
\hline $12 / 16 / 10$ & P1201-4, Rev. 1 & $\begin{array}{l}\text { Added Section 3.10 to fulfill requirement from DOE O 150.1, } \\
\text { Continuity Programs, to provide "all workers with an } \\
\text { awareness briefing/training on continuity of operations." } \\
\text { Added new Section 3.11 to address workplace violence } \\
\text { issues and corresponding emergency procedures and } \\
\text { protective actions. } \\
\text { Updated Section 5.0 regarding the Unreviewed Safety } \\
\text { Question/Unreviewed Safety Issue (USQ)/(USI) process. }\end{array}$ \\
\hline 06/17/14 & P1201-4, Rev. 2 & $\begin{array}{l}\text { Reorganized content in Sections 3.0 and 4.0. Simplified roles, } \\
\text { responsibilities and protective action descriptions. Combined } \\
\text { related content. } \\
\text { Removed attachments and provided links instead. } \\
\text { Updated language in Section 5.0 to reflect USQ/USI process } \\
\text { and implementation dates for affected facilities. } \\
\text { Updated links, organization names, and acronyms. }\end{array}$ \\
\hline $12 / 22 / 15$ & P1201-4, Rev. 3 & $\begin{array}{l}\text { Throughout document, clarified requirements for LANL leased } \\
\text { buildings. } \\
\text { Section 4.6: Updated last bullet to read "Direct concerns or } \\
\text { questions related to these activities to line managers." } \\
\text { Updated links, titles, and acronyms. }\end{array}$ \\
\hline
\end{tabular}

\subsection{REFERENCES}

Prime Contract:

- DOE O 151.1C, Comprehensive Emergency Management System

- DOE O 150.1, Continuity Programs

\subsection{Other References}

- P781-1, Conduct of Training

- Conduct of Training Manual

- P1021, Vital Records Program

- P204-2, Classified Matter Protection and Control Handbook

- P724, Workplace Violence

- Bomb Threat Checklist

- Automatic External Defibrillator (AED) Program

- EPP-COOP-006, LANL COOP [Continuity of Operations] Plan

- Engineering Standards Manual

- $\underline{\mathrm{P} 313}$, Roles, Responsibilities, Authorities, and Accountability

\section{LANL}




\subsection{FORMS}

There are no forms associated with this document.

\subsection{ATTACHMENTS}

There are no attachments associated with this document.

\subsection{CONTACT}

Security and Emergency Operations (SEO) Division

Telephone: (505) 667-6211

Fax: (505) 665-7770

Location: TA-69, Bldg. 0033

E-mail: epc@lanl.gov

Website: http://int.lanl.gov/org/padops/admaser/index.shtml

\section{LANL}




\section{ENV-DO-QP-101.2}

Effective Date: June 12, 2012

Next Review Date: May 12, 2014

\section{Environment, Safety, Health Directorate}

\section{Environmental Protection - Division Office}

\section{Quality Procedure}

\section{Title: Environmental Reporting Requirements for Releases or Events}

Reviewers:

\begin{tabular}{|c|c|c|c|}
\hline $\begin{array}{l}\text { Name: } \\
\text { Melanie Lamb }\end{array}$ & $\begin{array}{l}\text { Organization: ENV- } \\
\text { QPMO, QA Specialist }\end{array}$ & $\begin{array}{l}\text { Signature: } \\
\text { Signature on file }\end{array}$ & $\begin{array}{l}\text { Date: } \\
6 / 1 / 12\end{array}$ \\
\hline \multicolumn{4}{|c|}{ Derivative Classifier: $\bigotimes$ Unclassified } \\
\hline $\begin{array}{l}\text { Name: } \\
\text { Anthony Grieggs }\end{array}$ & $\begin{array}{l}\text { Organization: } \\
\text { ENV-RCRA }\end{array}$ & $\begin{array}{l}\text { Signature: } \\
\text { Signature on file }\end{array}$ & $\begin{array}{l}\text { Date: } \\
6 / 7 / 12\end{array}$ \\
\hline
\end{tabular}

Approval Signatures:

\begin{tabular}{|c|c|c|c|}
\hline $\begin{array}{l}\text { Responsible Line Manager: } \\
\text { Anthony Grieggs }\end{array}$ & $\begin{array}{l}\text { Organization: } \\
\text { ENV-RCRA, Group Leader }\end{array}$ & $\begin{array}{l}\text { Signature: } \\
\text { Signature on file }\end{array}$ & $\begin{array}{l}\text { Date: } \\
6 / 7 / 12\end{array}$ \\
\hline $\begin{array}{l}\text { Responsible Line Manager: } \\
\text { Tina Marie Sandoval }\end{array}$ & $\begin{array}{l}\text { Organization: } \\
\text { ENV-QPMO, Office Leader }\end{array}$ & $\begin{array}{l}\text { Signature: } \\
\text { Signature on file }\end{array}$ & $\begin{array}{l}\text { Date: } \\
6 / 4 / 12\end{array}$ \\
\hline $\begin{array}{l}\text { Responsible Line Manager: } \\
\text { Alison M. Dorries }\end{array}$ & $\begin{array}{l}\text { Organization: } \\
\text { ENV-DO, Division Leader }\end{array}$ & $\begin{array}{l}\text { Signature: } \\
\text { Signature on file }\end{array}$ & $\begin{array}{l}\text { Date: } \\
6 / 12 / 12\end{array}$ \\
\hline
\end{tabular}

CONTROLLED DOCUMENT

This copy is uncontrolled. The controlled copy can be found on the ENV Division Webpage. Users are responsible for ensuring they work to the latest approved version. 


\section{History of Revisions}

\begin{tabular}{|c|c|l|}
\hline $\begin{array}{c}\text { Document Number } \\
\text { [Include revision number, } \\
\text { beginning with Revision 0] }\end{array}$ & $\begin{array}{c}\text { Effective Date } \\
\text { [Document Control Coordinator } \\
\text { inserts effective date] }\end{array}$ & $\begin{array}{c}\text { Description of Changes } \\
\text { [List specific changes made since the previous revision] }\end{array}$ \\
\hline 0 & $02 / 09$ & New document \\
\hline 1 & $4 / 10$ & Revision and update \\
\hline 2 & $6 / 12$ & $\begin{array}{l}\text { Biennial Review/Revision, new template } \\
\text { implemented. }\end{array}$ \\
\hline
\end{tabular}




\section{Table of Contents}

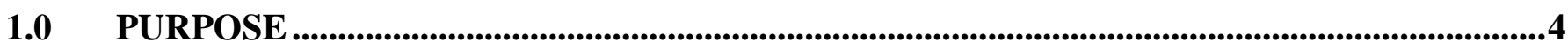

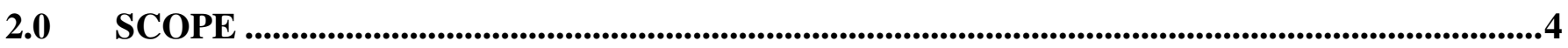

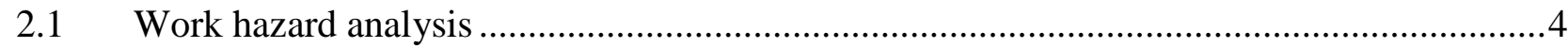

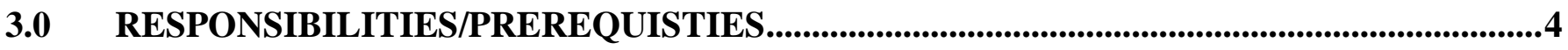

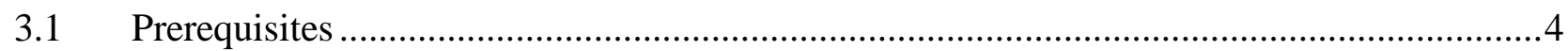

4.0 DOCUMENT CONTROL/RECORDS MANAGEMENT ................................................5

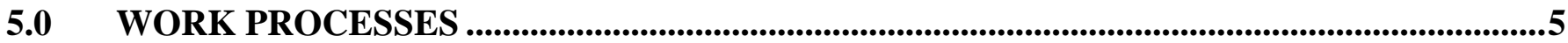

5.1 Responsibility of on-call representative...................................................................... 5

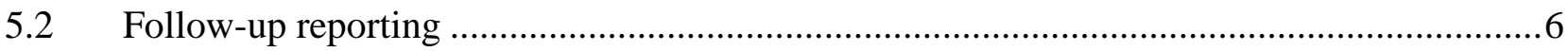

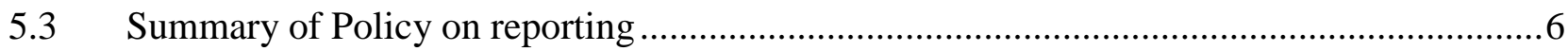

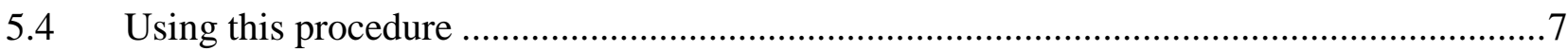

5.5 Determining if a release is reportable under RCRA .................................................... 7

5.6 Determining if a release is reportable under TSCA ...................................................

5.7 Determining if a release is reportable under CWA or NM Water Quality Act.....................9

5.8 Determining if a release is reportable under CERCLA or EPCRA ..................................11

5.9 Determining if a release is reportable under Biological or Cultural Requirements .............13

5.10 Reporting a Release or Event ..............................................................................14

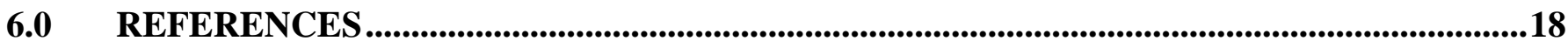

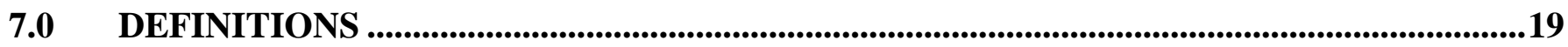

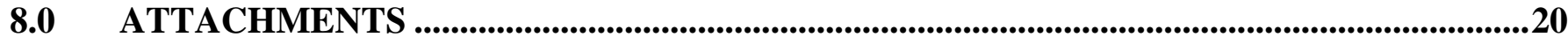

ATTACHMENT 1: Emergency Notification Requirements for RCRA.....................................21

ATTACHMENT 2: Summary of Emergency Release or Event Reporting Requirements.............23 


\subsection{PURPOSE}

This Environmental Protection Division (ENV-DO) procedure describes how to determine whether an unplanned release, spill, fire, or other event needs to be reported under environmental regulations and how to fulfill all immediate reporting requirements (within the first 24 hours). Emergency and abnormal event notification requirements for reporting to Laboratory and DOE management are specified in PD1200, Emergency Management, and P322-3, Performance Improvement from Abnormal Events. Environmental reporting requirements regarding releases or other events are included in this procedure.

\section{$2.0 \quad$ SCOPE}

This procedure applies to ENV-DO on-call representatives and subject matter experts (SMEs) who must respond to any release, spill, or event at the Laboratory that may require immediate notification to local, state or federal regulatory agencies or Pueblo Environmental Departments (refer to ENV-DO-QP-111, Reporting Environmental Releases To Pueblo Governments) and describes the actions that must be performed within the first 24 hours. This procedure does not cover the response procedures for "continuous releases" under CERCLA and EPCRA (see definitions) nor the follow-up notifications and reports.

\subsection{WORK HAZARD ANALYSIS}

The work described in this procedure consists of field work that does not require an Integrated Work Document (IWD) and is rated as having a LOW hazard level as documented by submittal of an ENV Low Hazard Verification form to the Quality Assurance Specialist.

\subsection{RESPONSIBILITIES/PREREQUISTIES}

The following personnel require training before implementing this procedure:

- ENV-DO managers and designated on-call representatives and SMEs who may be asked to fulfill reporting requirements during release-related exercises or during actual releases, or within 24 hours.

Annual retraining to this procedure is required. This procedure will be reviewed biennially by all affected personnel and updated as necessary.

Training to this procedure will be by "self-study" (reading) and is documented in accordance with the trainee's organization's procedure for training.

\subsection{PREREQUISITES}

- None

Note: Actions specified within this procedure, unless preceded with "should," or "may," are to be considered mandatory (i.e., "shall," "must," "will”). 


\subsection{DOCUMENT CONTROL/RECORDS MANAGEMENT}

The following records generated as a result of this procedure are to be submitted as records according to the responder's group's internal records management process:

- Field documentation of the release, including:

o Time and date of the release

o Time, date, and description of notifications

o Location and source of the release

o Type of material released

o Quantity of material released

o Impacted media

o Time release was stopped

o Any immediate mitigation actions taken to contain or control the release

o Documentation of any verbal notifications

o Samples taken

- Copies of any written notifications generated

- Documentation of any analytical results, and quality assurance of results

- Any other contingency plan or emergency plan documentation

- Documentation of any PCB notification

- Documentation of any RCRA permit non-compliance that threatens human health and environment

- Documentation of treatment of any RCRA unstable chemicals, leaking or compromised gas cylinders

\subsection{WORK PROCESSES}

Events covered by this procedure include detonation or burns of unstable material, leaking or compromised gas cylinders, puncturing of bulging containers, fires, explosions, chemical or radiological spills inside or outside of buildings, wastewater spills, potable water or fire fighting water as well as impacts to cultural and biological resources not adequately documented, and other releases to the environment.

On a semi-annual basis ENV-DO will prepare a list of individuals designated as on-call representatives and will designate the week each will be on-call. This list will be distributed to on-call representatives and Laboratory managers including PADOPS, ADES\&H, ADEP, Emergency Operations (ADSS-EO), ENVDO, ENV-RCRA, and ENV-ES. The on-call representative can be reached by pager at 664-7722.

\subsection{RESPONSIBILITY OF ON-CALL REPRESENTATIVE}

The ENV on-call representative is the party primarily responsible for:

- determining if the incident will require immediate notification to external agencies in accordance with LANL, State, and Federal regulatory reporting requirements

- notifying ENV Division management of immediate reporting requirements; and 
- if needed, coordinating with other on-call SMEs and the Emergency Operations Center (EOC) to ensure the required notifications for environmental reporting and abnormal events are being addressed for the Laboratory.

The ENV-DO on-call representative is not responsible for the following, EOC will make these determinations:

- determining if the RCRA Contingency Plan must be implemented, or

- if a shock-sensitive material or leaking or compromised gas cylinder constitutes an emergency.

However, in order to ensure that the appropriate expertise is available for the affected media, the ENV on-call representative may immediately confer with an SME of the ENV group that has programmatic responsibility. If an SME from the responsible group is able to respond to the event, the remaining steps in this procedure may be passed to that person.

A list of contact numbers for on-call representatives and SMEs for ENV groups (ES \& RCRA) is available in the ENV-RCRA group office. The ENV-DO and ADSS-EO may also be contacted to determine the on-call representative for each group.

\subsection{FOLLOW-UP REPORTING}

This procedure describes the initial external notifications (within the first 24 hours) to regulatory agencies and Pueblo Environmental Departments. After completion of the steps in this procedure, the ENV group specifically responsible for compliance with the relevant regulations (responsible group) will complete the required notifications and reports, as applicable under the appropriate regulations, according to established procedures.

\subsection{SUMARY OF POLICY ON REPORTING}

The ENV on-call representative and SMEs have the authority and responsibility for deciding when to report and for making the report to regulatory agencies within regulatory deadlines and to Pueblo Environmental Departments when potentially impacted.

LANL management and DOE LASO must be informed as soon as possible that a report was or will be made, but their approval is not required prior to the report being made to the regulatory agency or Pueblo. LANL management, with input from ENV SMEs, will determine if an ORPS (Occurrence Reporting Processing System) report or other type of Lessons Learned will be necessary.

NOTE: ADSS-EO maintains a current list of on-call LANL managers. 


\subsection{USING THIS PROCEDURE}

This procedure has four separate paths (and corresponding sections) to follow for determining if a release or event is reportable. Follow each of these paths to determine if one or more are applicable:

- RCRA

- TSCA

- CWA, NM WQA, and NM WQCC Regulations

- CERCLA and EPCRA.

- CAA

- Endangered Species Act (ESA), New Mexico Endangered Plant Species Act

- Bald Eagle Protection Act, Migratory Bird Treaty Act

- New Mexico Wildlife Conservation Act

- National Environmental Policy Act (NEPA)

- National Historic Preservation Act (NHPA)

- Native American Graves Protection and Repatriation Act (NAGPRA)

- Archaeological Resources Protection Act (ARPA)

Under CERCLA or EPCRA, a Reportable Quantity (RQ) is the action level that may trigger an appropriate response to a release under the provisions of these regulations. A release may not meet RQ reporting limits but still may be reportable under RCRA and CWA requirements.

NOTE: The 24-hour deadline (15 minutes in some cases) applies regardless of whether it occurs during business hours, non-business days or after business hours.

Additional information and guidance on how and when to report a release is available at this link: http://homer.ornl.gov/nuclearsafety/env/guidance/cercla/rqs-gen.pdf.

All potential ENV-DO on-call representatives or SMEs should follow the various links at this site and be familiar with the guidance before any release or event occurs.

\subsection{DETERMINING IF A RELEASE IS REPORTABLE UNDER RCRA}

Follow the flow charts in Attachment 1 to determine if an event is reportable under RCRA. The three groups of circumstances described below (also delineated in the flow charts in Attachment 1) are evaluated to determine if an event is reportable.

Under the RCRA permit requirements, the ADSS-EO manager determines if the "RCRA Contingency Plan” provisions should be implemented. The flow chart in Attachment 1 starts with this determination. The ENV on-call representative or an ENV-RCRA SME performs notifications that are necessary.

The ADSS-EO Manager will normally attempt to contact the ENV-RCRA SME for guidance in making this decision. If the ENV-RCRA SME is successfully contacted, the completion of the remainder of this procedure may be passed on to this individual. 
The ENV on-call representative makes the determination that one or more of these conditions occurred through consultation with ENV-RCRA and appropriate SMEs. 24-hour notification can be made by the on-call representative or by an SME of ENV-DO.

The EOC manager makes the determination that unstable chemicals, leaking or compromised gas cylinders represent an emergency situation and, typically with ENVRCRA, how best to respond. 24-hour notification can be made by the on-call representative or ENV-RCRA SME.

If a release/event is reportable under RCRA rules, determine if the release/event is reportable under other rules and proceed to the section Reporting a Release or Event.

\subsection{DETERMINING IF A RELEASE IS REPORTABLE UNDER TSCA}

In practice, only spills of Polychlorinated Biphenyls (PCBs) or PCB-suspect untested mineral oil to the environment (generally outdoors or with the potential to reach the outdoors) are reportable. Spills that are contained indoors are generally not reported.

A release of PCB's is reportable to the EPA under TSCA if it is over 10 pounds PCB's by weight or at concentrations of $50 \mathrm{ppm}$ or greater.

Follow the steps in Determining if a Release is Reportable under CERCLA, EPCRA, or Other Regulations to determine if the RQ (of 1 pound) for PCBs has been triggered. Additionally, reporting requirements are triggered if over 270 gallons of untested mineral oil suspected of containing PCBs has been spilled.

There are nine items containing PCBs that are in use at the CMR Building. In addition, there is one PCB contaminated transformer in use at TA-48. All other known PCB equipment at the Laboratory has been taken out of service and disposed of in accordance with TSCA regulations.

If a release (see definitions) is reportable under TSCA, continue through the next sections to determine if the release/event is reportable under other rules and proceed to Reporting $a$ Release or Event and determine if additional reporting is necessary (below).

\section{If the spill is ...}

over 10 pounds by weight of PCBs (TSCA)

\section{OR}

if PCBs are at concentrations $~ 50$ ppm that directly contaminate surface water sewers, drinking water supplies, grazing lands, or vegetable gardens
Then...

Report to EPA Region 6 (Office of Prevention, Pesticides and Toxic Substances Branch) through EPA's 24-hour spill response number 866-372-7745 as soon as possible after discovery but no later than 24 hours after discovery. 


\subsection{DETERMINING IF A RELEASE IS REPORTABLE UNDER CWA OR NM WATER QUALITY} ACT

The CWA and NM Water Quality Act (NMWQA) (equivalent to the national Clean Water Act) does not use RQs (as described in the next section). Instead the NM Water Quality Control Commission (NMWQCC) regulations state: "Any amount of any material in such quantity as may with reasonable probability injure or be detrimental to human health, animal or plant life, or property, or may unreasonably interfere with the public welfare or the use of property. This includes chemical, biohazardous, petroleum-product, and sewage spills and incidents. In addition to recent spills, the discovery of evidence of previous unauthorized discharges, such as contaminated soil or ground water, also must be reported."

The above rule requires the use of professional judgment to determine if reporting is required. No quantifiable metric is available to assist in making this determination, however. The ENV on-call representative or SME has the authority and responsibility to make this determination.

Spills of potable water or fire fighting water (e.g., water line breaks) require reporting if there is a release of over 5000 gallons or if the release impacts a Solid Waste Management Unit (SWMU). Contact the ADEP for the location of SWMUs and coordinate any necessary water quality notifications with ENV-RCRA.

For oil discharges (film/sheen/discoloration) to water in stream channels, additionally notify the National Response Center (24-hour verbal notification) and EPA Region 6.

\subsubsection{Additional Reporting Requirement for Petroleum Storage TanKs}

New Mexico Environment Department (NMED) regulations from June 2009 require verbal reporting within 24 hours of release of petroleum products from regulated tanks to the Petroleum Storage Tank (PST) Bureau when there is:

- evidence of release of regulated substances;

- unusual operational conditions (that would cause concern about a release); or

- monitoring results that show loss from the system.

Regulated tanks include those of 1320 gallons to 55,000 gallons and exclude all sizes of tanks used to fuel emergency generators.

This reporting requirement is in addition to the reporting under NMWQCC Regulations and CWA requirements for such releases. Call the PST Bureau at 476-4397 during business hours and 827-9329 after closing.

If there is more than one activity team member, the PIC conducts a readiness check during the tailgate briefing to note any local work conditions that could affect the work and reminds the team of the documented hazards and controls. At this time workers also verify that each other's PPE is adequate. 
If a release (see Definitions) is reportable under NMWQCC Regulations, continue through the next sections to determine if the release/event is reportable under other rules and proceed to the Section, Reporting a Release or Event.

\subsubsection{Additional Reporting Requirements Under NPDES Pesticide General PERMIT}

Adverse incidents, an unusual or unexpected incident that an Operator has observed upon inspection or of which the Operator otherwise becomes aware, requires reporting under the NPDES Pesticide General Permit (PGP).

The Operator should report any adverse incidents in which:

(1) There is evidence that a person or non-target organism has likely been exposed to a pesticide residue, and

(2) The person or non-target organism suffered a toxic or adverse effect. The phrase toxic or adverse effect includes effects that occur within Waters of the United States on nontarget plants, fish, or wildlife that are unusual or unexpected (e.g. effects are to organisms not otherwise described on the pesticide product label or otherwise not expected to be present) as a result of exposure to a pesticide residue, and may include:

- Distressed or dead juvenile and small fishes;

- Washed up or floating fish;

- Fish swimming abnormally or erratically;

- Fish lying lethargically at water surface or in shallow water;

- Fish that are listless or nonresponsive to disturbance;

- Stunting, wilting, or desiccation of non-target submerged or emergent aquatic plants; and/or

- Other dead or visibly distressed non-target aquatic organisms (amphibians, turtles, invertebrates, etc.)

The phrase toxic or adverse effects also includes any adverse effects to humans (e.g. skin rashes) or domesticated animals that occur either from direct contact with or as a secondary effect from a discharge (e.g. sickness from consumption of plants or animals containing pesticides) to Waters of the United States that are temporally and spatially related to exposure to a pesticide residue.

If an Operator observes or otherwise becomes aware of an adverse incident due to pesticide application, the Operator must immediately notify the appropriate EPA Incident Reporting contact within 24 hours of the incident of the Operator becoming aware of the adverse incident. EPA Incident Reporting Contacts are listed at www.epa.gov/npdes/pesticides. These reporting requirements are in addition to any required under Federal Insecticide, Fungicide, and Rodenticide Act (FIFRA). 


\subsection{DETERMINING IF A RELEASE IS REPORTABLE UNDER CERCLA OR EPCRA}

Under CERCLA or EPCRA, a Reportable Quantity is the action level that may trigger an appropriate response to a release under the provisions of these regulations. RQs are summarized in 40 CFR Part 302. An RQ is based on the quantity of chemical released within any 24-hour period. The RQs for extremely hazardous substances can be found in 40 CFR Part 355, Appendices A and B, in the column labeled "RQ". This table has two columns of RQs: the Statutory RQ and the Final RQ. Use the weight in the Final RQ column for determining if the release must be reported. The chemicals that have not been assigned RQs by EPA have been given statutory RQs of one pound by Congress.

Releases (see definitions) that occur within a closed space with no emissions to the ambient environment (see definitions) are exempt from this requirement.

The exceedance of an $\mathrm{RQ}$ requires immediate notification.

NOTE: Response procedures for "Continuous Releases” are not covered in this procedure.

\subsubsection{REGULATORY CLASSIFICATION OF THE RELEASED MATERIAL}

Determine the regulatory classification of the substance released with respect to the hazard classifications: Extremely Hazardous Substance (EHS) and/or Hazardous Substance (HS) (see definitions).

Often during the course of an emergency, complete information will not be available regarding type and amount of material released. In this case, best professional judgment must be used to establish the level of confidence associated with the estimates. If the uncertainty is high enough that future estimates may require reporting, it is best to err on the side of caution and follow the reporting requirements in the section Reporting a Release or Event.

- Identify the constituents in the material released using the Material Safety Data Sheet (MSDS), laboratory analysis, data sheet, manifest, or manufacturer information.

- A summary of the RQs can be found in 40 CFR Part 302 and 40 CFR Part 355, Appendices A and B. The RQ may also be determined using the on-line RQ Calculator (http://homer.ornl.gov/rq/)

- Calculate the amount of the listed chemical involved in the release (the weight of the material released multiplied by the percentage of the concentration of the listed chemical present in the material).

After determining the RQ of a released material, the ENV-DO on-call representative or SME will perform the following steps to determine if an RQ has been released. 


\begin{tabular}{|c|c|c|}
\hline Step & & Action \\
\hline 1 & \multicolumn{2}{|c|}{$\begin{array}{l}\text { Obtain an estimate of the quantity and type of material released (e.g. } 4 \text { pounds o } \\
\text { chlorine gas or } 150 \text { curies of tritium). }\end{array}$} \\
\hline 2 & \multicolumn{2}{|c|}{$\begin{array}{l}\text { Compare this quantity against the RQs provided in Appendix B to } 40 \text { CFR } 302 \\
\text { and } 40 \text { CFR 355, Appendices A and B. }\end{array}$} \\
\hline \multirow[t]{6}{*}{3} & \multicolumn{2}{|c|}{$\begin{array}{l}\text { If this is an airborne release of radioactive materials, it is reportable if the RQ is } \\
\text { exceeded AND if the release could cause an annual exposure to the nearest } \\
\text { downwind residence or business of } 10 \text { mrem ( } 40 \text { CFR } 61 \text {, Subpart H). }{ }^{1} \text { The } \\
\text { exposure estimate should be made by an environmental health physicist. }\end{array}$} \\
\hline & If the release... & Then... \\
\hline & $\begin{array}{l}\text { Is over the RQ AND could } \\
\text { cause the Laboratory to } \\
\text { exceed the } 10 \mathrm{mrem} / \mathrm{yr} \\
\text { standard to downwind } \\
\text { businesses or residences }\end{array}$ & $\begin{array}{l}\text { Proceed to section Reporting } \\
\text { a Release or Event. }\end{array}$ \\
\hline & Is less than the RQ AND & No reporting is required under \\
\hline & could NOT cause the & CERCLA or EPCRA. \\
\hline & $\begin{array}{l}\text { Laboratory to exceed the } 10 \\
\text { mrem/yr standard. }\end{array}$ & Proceed to Step 4. \\
\hline \multirow[t]{4}{*}{4} & \multicolumn{2}{|c|}{ If this is a release of non-rad material, it is reportable if the RQ is exceeded. } \\
\hline & If the amount released is.., & Then... \\
\hline & $\begin{array}{l}\text { Equal to or greater than the } \\
\text { RQ }\end{array}$ & $\begin{array}{l}\text { Proceed to Section Reporting } \\
\text { a Release or Event. }\end{array}$ \\
\hline & Less than the RQ & Proceed to Step 3 \\
\hline 5 & \multicolumn{2}{|c|}{$\begin{array}{l}\text { Continue to re-evaluate the release as new data becomes available. Perform } \\
\text { Steps } 1 \text { through } 3 \text { as necessary. }\end{array}$} \\
\hline
\end{tabular}

${ }^{1}$ It should be noted that "Area sources and other sources that are subject to regulations that limits their total annual emissions should generally report their releases at or above the RQ of hazardous substances (HSs) and extremely hazardous substances (EHSs) that are caused by accidents, malfunctions, unanticipated releases and other releases that are not part of the facility's normal operations.” Federal Register, Volume 67, No. 47, Notices FRL-7172-4, Guidance on the CERCLA Section 101(10)H, “Federally Permitted Release Definition for Certain Air Emissions”. 


\subsection{DETERMINING IF A RELEASE IS REPORTABLE UNDER BIOLOGICAL OR CULTURAL REQUIREMENTS}

There are a number of laws and regulations related to protection of biological and cultural resources which are applicable to the Laboratory. These laws and regulations include:

- National Environmental Policy Act

- Endangered Species Act

- Bald Eagle Protection Act

- Migratory Bird Treaty Act

- New Mexico Wildlife Conservation Act

- New Mexico Endangered Species Act

- National Historic Preservation Act

- Native American Graves Protection and Repatriation Act

- Archaeological Resources Protection Act

Reporting of impacts to biological resources under the preceding laws and associated regulations is not specifically defined. This is also the case for reporting of most cultural resources impacts under the National Historic Preservation Act. The use of professional judgment by the ENV-DO on-call representative and SME is required.

Reporting of impacts under the Native American Graves Protection and Repatriation Act is specifically governed by the following document "A Standard Operating Procedure for the Inadvertent Discovery of Native American Human Remains and Associated Funerary Objects, Sacred Objects, or Objects of Cultural Patrimony at Los Alamos National Laboratory” (LA-UR-06-6712) prepared for the Department of Energy Los Alamos Site Office (DOE LASO) by the LANL Cultural Resources Team and implemented on January 30, 2008.

Reporting of impacts under the Archaeological Resources Protection Act (ARPA) is governed in part by the Act and also by LANL Cultural Resources Team Procedure ES-415, Archaeological Resources Protection Act.

\subsubsection{REPORTS TO DOE LASO}

In general, any release or event that poses a significant impact to biological or cultural resources requires reporting to DOE LASO as soon as possible and may require reporting to LANL management and DOE HQ through the ORPS. Examples of significant impacts to biological resources include:

- Release of toxic substances into listed species habitat

- Damage to a wetland or listed species habitat by a landscapealtering event such as wildfire

- Other events that would likely result in death or injury of a threatened or endangered species 
- Examples of significant impacts to cultural resources include:

- Unauthorized excavation of an archaeological site

- Damage to an archaeological or historic site

- Removal of archaeological or historic artifacts

The ENV on-call representative or SME for biological or cultural resources should notify DOE LASO as soon as possible so that DOE LASO can complete the required notifications to the appropriate agencies (e.g., U.S. Fish and Wildlife Service, State Historic Preservation Office) within 24 hours.

\subsection{REPORTING A RELEASE OR EVENT}

If a release or event is reportable (as determined by one or more of the previous sections), the Laboratory is required to meet certain reporting requirements. The emergency notification requirements in this section must be followed upon determination that a release or event is reportable.

For informational purposes, a summary of emergency release/event reporting requirements is provided in Attachment 2. This document summarizes the primary statutes and the associated reporting requirements.

Maintain a notebook to record pertinent information about the release and to document the actions taken (see section Records Resulting from This Procedure).

If RCRA reporting requirements are triggered, see the flow chart in Attachment 1 , Emergency Notification Requirements for RCRA. 
Perform the following steps immediately after establishing that reporting will be performed:

\begin{tabular}{|c|c|}
\hline Step & Action \\
\hline 1 & $\begin{array}{l}\text { - } \quad \text { Number of persons injured and the nature of injuries (e.g., } \\
\text { - } \text { life-threatening or minor injury) } \\
\text { - } \quad \text { Name, address, and telephone number of the person to contact for } \\
\text { further information } \\
\text { - Whether the substance is an HS or EHS (see definitions) } \\
\text { - } \text { Associated health risks and medical attention necessary for exposed } \\
\text { individuals } \\
\text { - If available, information concerning the release of any hazardous } \\
\text { and/or mixed waste which may endanger public or private drinking } \\
\text { - } \text { water supplies } \\
\text { - } \text { Assessment of actual or potential hazards to human health or the } \\
\text { - If available, estimated quantity and disposition of recovered material } \\
\text { that resulted from the incident } \\
\text { Precautions to take due to the release/event, including, in the case of } \\
\text { fire, those associated with special hazards due to hazardous and/or } \\
\text { mixed waste } \\
\text { Any other information which may help emergency personnel } \\
\text { responding to the incident. }\end{array}$ \\
\hline 2 & $\begin{array}{l}\text { [For RCRA: skip this step; see flow chart (Attachment 1).] } \\
\text { For releases of substances that are classified as CERCLA hazardous } \\
\text { substances, contact the National Response Center at 800-424-8802. } \\
\text { Note: If it is an EHS but not a CERCLA hazardous substance, reporting is only } \\
\text { necessary to state and local authorities. } \\
\text { Exception: For reportable water releases, the NRC needs to be notified } \\
\text { ONLY if the release includes oil (such as a sheen on the water surface). }\end{array}$ \\
\hline
\end{tabular}




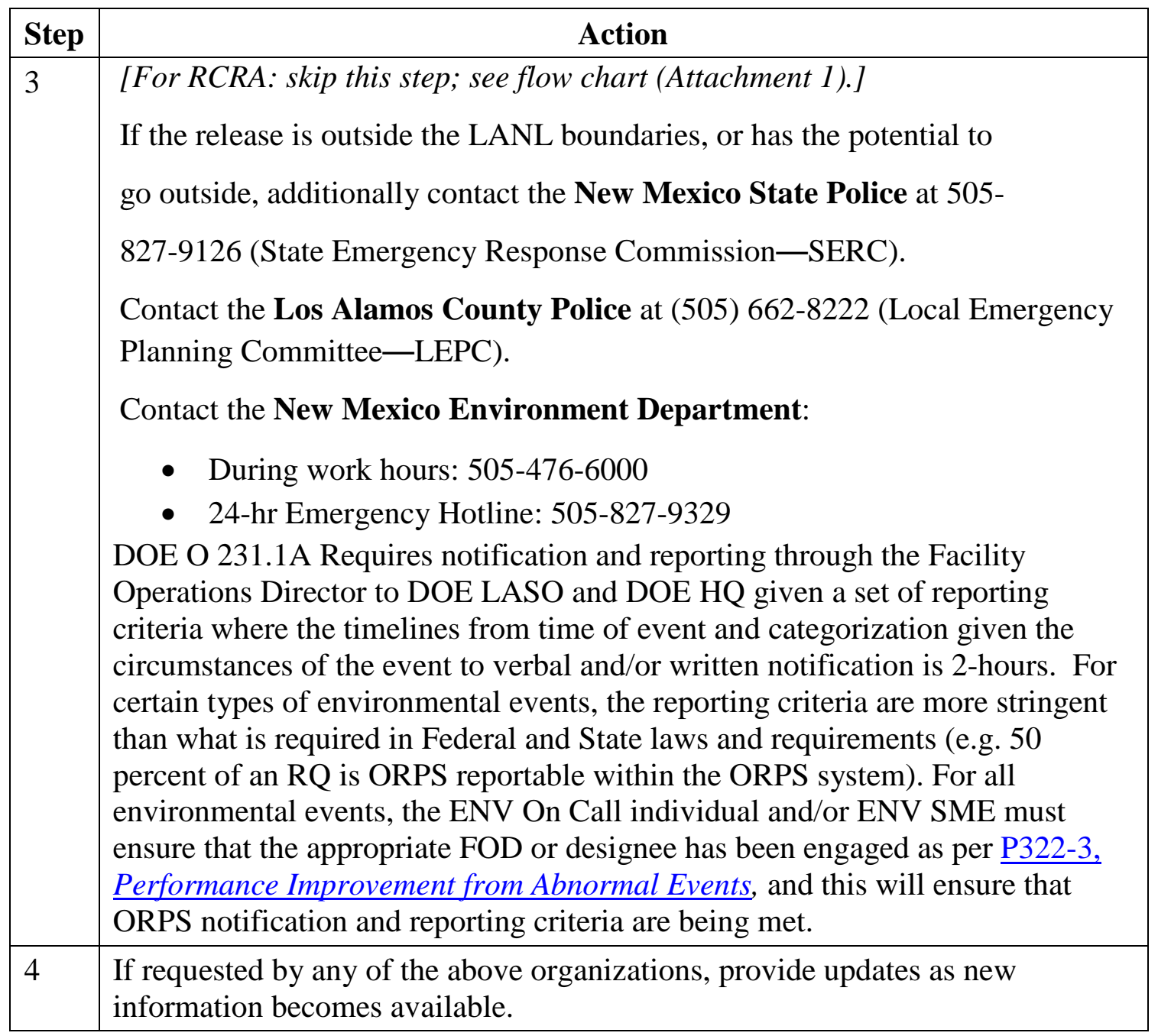

Any release to the environment that has been determined to be reportable by the ENV on-call representative or SME shall be reported through the LANL management chain in accordance with PD1200, Emergency Management and P322-3, Performance Improvement from Abnormal Events. LANL management shall be notified immediately that a release notification to state or federal regulatory agencies is required so that DOE notification and reporting requirements are met. LANL management approval is not required prior to environmental reports and notifications made to the regulatory agencies in order to assure that the deadline for reporting is not exceeded.

\subsubsection{STEPS TO NOTIFY LANL MANAGEMENT}

To notify LANL management and to complete the environmental reporting process to DOE, state and federal agencies, and Pueblo Environmental Departments, perform the following steps: 


\begin{tabular}{|c|c|c|}
\hline Who & Step & Action \\
\hline \multirow[t]{2}{*}{$\begin{array}{l}\text { ENV-DO } \\
\text { on-call } \\
\text { representativ } \\
\text { e or SME }\end{array}$} & 1 & $\begin{array}{l}\text { Determine that a release to the environment is reportable to } \\
\text { state, federal, or Pueblo entities and required under } \\
\text { regulations. } \\
\text { NOTE: ORPS reporting is a FOD and RAD responsibility } \\
\text { and will seek advisement from ENV SMEs. }\end{array}$ \\
\hline & 2 & $\begin{array}{l}\text { Contact the following individuals by phone. } \\
\text { - Team Leader/Direct Supervisor } \\
\text { - Group Leader/Deputy Group Leader } \\
\text { - } \text { ENV-DO Division Leader or Designee for } \\
\text { Reporting } \\
\text { If no direct contact can be made, leave messages by pages } \\
\text { or phone. }\end{array}$ \\
\hline \multirow[t]{3}{*}{$\begin{array}{l}\text { ENV-DO } \\
\text { Division } \\
\text { Leader or } \\
\text { Designee for } \\
\text { Reporting }\end{array}$} & 3 & $\begin{array}{l}\text { Notify the ADES\&H Directorate Office and assure that the } \\
\text { notification process continues through the LANL } \\
\text { management chain to the PADOPs Office as specified in } \\
\text { PD 1200-1 Emergency Management, and P322-3, } \\
\text { Performance Improvement from Abnormal Events. }\end{array}$ \\
\hline & 4 & $\begin{array}{l}\text { Notify the ADEP Directorate Office if the release } \\
\text { originated or impacted a Solid Waste Management Unit } \\
\text { (SWMU) or Potential Release Site (PRS). }\end{array}$ \\
\hline & & $\begin{array}{l}\text { As per PD1200, verbal and written notifications must be } \\
\text { made up the management chain by use of the PADOPS } \\
\text { report. Generally, this is the responsibility of the FOD or } \\
\text { the FOD designee. However, ENV on-call personnel may } \\
\text { be required to perform this function from time to time. } \\
\text { Therefore, on-call personnel must understand who will } \\
\text { perform this reporting function. }\end{array}$ \\
\hline \multirow{3}{*}{$\begin{array}{l}\text { ENV-DO } \\
\text { on-call } \\
\text { representativ } \\
\text { e or SME }\end{array}$} & 5 & Notify the DOE LASO program contact for the release. \\
\hline & 6 & $\begin{array}{l}\text { Complete the environmental reporting to state and federal } \\
\text { agencies prior to the regulatory deadline for reporting. }\end{array}$ \\
\hline & 7 & $\begin{array}{l}\text { Notify Pueblo Environmental Departments of the release } \\
\text { when potentially impacted. }\end{array}$ \\
\hline SME & 8 & $\begin{array}{l}\text { Complete 14-day and other follow-up reports to the state } \\
\text { and federal agencies. }\end{array}$ \\
\hline
\end{tabular}


If the release involved radioactive materials, the ENV on-call representative or SME will notify ENV-ES. ENV-ES will additionally notify:

EPA Region 6

(214) 665-8541

If there is a release of contaminants to a wetland or destruction of a wetland, OR if the event could result in the "take" of a threatened or endangered species (i.e., a wildfire), the ENV on-call representative or SME will notify DOE LASO Environmental Office as soon as possible. DOE LASO is required to notify U.S Fish and Wildlife Service within 24 hours.

After all the above notifications have been made, or when requested, the ENV oncall representative or SME will hand off responsibility for additional actions and follow-up to the affected environmental group. (Which group is responsible will depend on the type and location of the release and the governing regulations or statutes.) Provide all relevant records. See Section: Records Resulting from this Procedure.

In order to communicate events at LANL which may impact the public and or the environment, ENV staff will notify the New Mexico Environment Department of events that may not require formal regulatory notification. Examples of such events in the past have been small wild land fires.

\subsection{REFERENCES}

The following documents are referenced in this procedure:40 CFR 302, Designation, Reportable Quantities, and Notification

- 40 CFR 261, 264 Subpart D 270.30

- DOE guidance document PCB Spill Response and Notification Requirements (EH-231-059/1294), available on the ENV-RCRA web page

- DOE - Office of Environmental Guidance, CERCLA Information Brief, EH-231-001-0490 (April 1990)

- EPA Web Site: http://www.epa.gov/

- EPCRA Information Web Site: http://www.chemicalspill.org/EPCRA-facilities/spill.html

- Federal Register, Volume 67, No. 47, Notices FRL-7172-4, Guidance on the CERCLA Section 101(10)H, Federally Permitted Release Definition for Certain Air Emissions

- $\quad$ PD1200, Emergency Management

- $\quad$ P322-3, Performance Improvement from Abnormal Events

- LANL RCRA Permit No. NM0890010515-1

- $\quad$ LANL NPDES Permit No. NM00283 National Response Center (NRC) Web Site: http://www.nrc.uscg.mil/

- $\quad$ NMWQCC Regulations, 20.6.2 NMAC, dated December 1, 2001

- $\quad$ P407, Water Quality 
- QP-5.8, Identification, Documentation, and Reporting of Newly Discovered Potential Release Sites, ADEP Procedure.

- RQ Calculator Web Site: http://homer.ornl.gov/rq/

\subsection{DEFINITIONS}

ADES\&H: Associate Directorate for Environment, Safety, and Health

ADEP: Associate Directorate for Environmental Programs

CAA: Clean Air Act

CERCLA: Comprehensive Environmental Response, Compensation, and Liability Act

Continuous Release: A release is continuous if it "occurs without interruption or abatement or if it is routine, anticipated, intermittent, and incidental to normal operations or treatment processes." The release must also be "stable in quantity and rate," which means that it must be predictable and regular in the amount and rate of emission. The response procedures for continuous releases are not covered by this document. See guidance in Reporting Continuous Releases of Hazardous and Extremely Hazardous Substances under CERCLA and EPCRA. [DOE/EH-0441, guidance document, 372,099 bytes, 51 pp.], available at: http://homer.ornl.gov/sesa/environment/guidance/cercla/CONTIN.PDF.

CWA: Clean Water Act

ENV-DO: Environmental Protection Division

Environment: includes "water, air, land, and the interrelationship which exists among and between water, air, land, and all living things." (40 CFR 355.20)

EPCRA: Emergency Planning and Community Right-to-Know Act

ER-DO: Emergency Response Division

Extremely Hazardous Substance (EHS): EPCRA establishes emergency reporting requirements for extremely hazardous substances in 40 CFR 355, Appendix A. All of these substances are also CWA and CERCLA "hazardous" substances

FOD: Facility Operations Director

Hazardous Substance (HS): These substances are summarized in 40 CFR Part 302. As used in this context, refers to: (1) any elements, compounds, mixtures, solutions, or substances specially designated by EPA under Section 311 of the Clean Water Act (CWA) (40 CFR 116.4); (2) any toxic pollutants listed under Section 307(a) of the CWA; (3) any hazardous substances regulated under Section 311 (b)(2)(A) of the CWA; (4) any listed or characteristic RCRA hazardous waste (40 CFR 261), (5) any hazardous air pollutants listed under Section 112 of the Clean Air Act (CAA); or (6) any imminently hazardous chemical substances or mixtures regulated under Section 7 of the Toxic Substances Control Act (TSCA) LEPC: Local Emergency Planning Committee. Locally, the contact is through Los Alamos County Police and Fire Departments

NMWQA: New Mexico Water Quality Act 
NMWQCC: New Mexico Water Quality Control Commission

NPDES: National Pollutant Discharge Elimination System

NRC: National Response Center

OSC: On-Scene Commander

PADOPS: Principal Associate Director for Operations

PCBs: Polychlorinated Biphenyls

PST: Petroleum Storage Tank

RCRA: Resource Conservation and Recovery Act

Release: Any unpermitted spilling, leaking, pumping, pouring, emitting, emptying, discharging, injecting, escaping, leaching, dumping, or disposing of contaminants into the environment, excluding: (1) emissions from the engine exhaust of any vehicle, (2) certain releases of source, byproduct, or special nuclear material from a nuclear incident, or (3) normal application of fertilizer

RQ: Reportable quantity

SARA: Superfund Amendments and Reauthorization Act

SERC: State Emergency Response Commission. In NM, the contact is through the NM Department of Public Safety.

SME: Subject Matter Expert.

TSCA: Toxic Substances Control Act

\subsection{ATTACHMENTS}

Attachment 1: Emergency Notification Requirements for RCRA

Attachment 2: Summary of Emergency Release or Event Reporting Requirements

Click to

Acknowledge 


\section{ATTACHMENT 1: EMERGENCY NOTIFICATION REQUIREMENTS FOR RCRA}

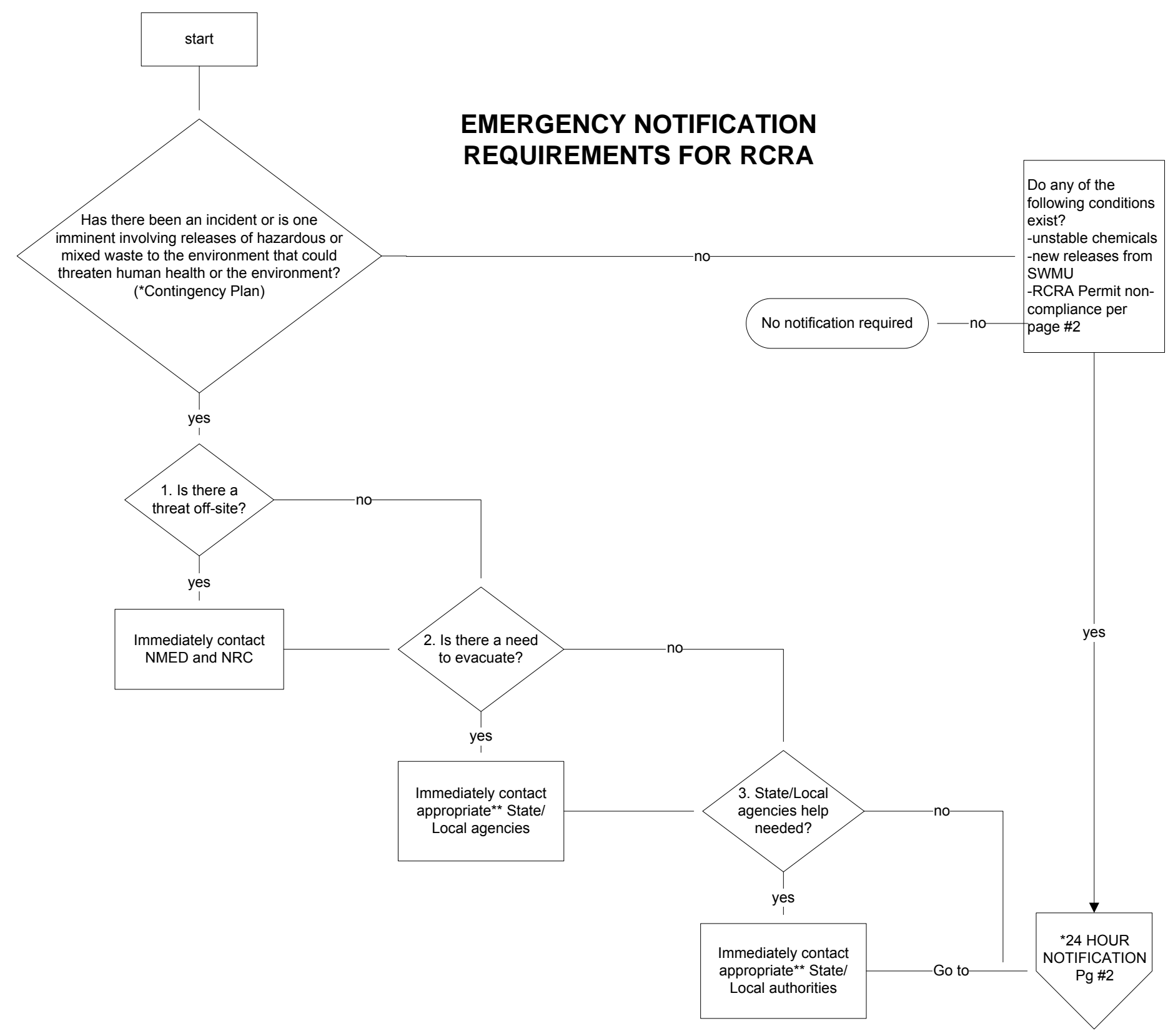


Title: Environmental Reporting Requirements for Releases or Events
ENV-DO-QP-101.2

Page 22 of 24

Effective Date: June 12, 2012

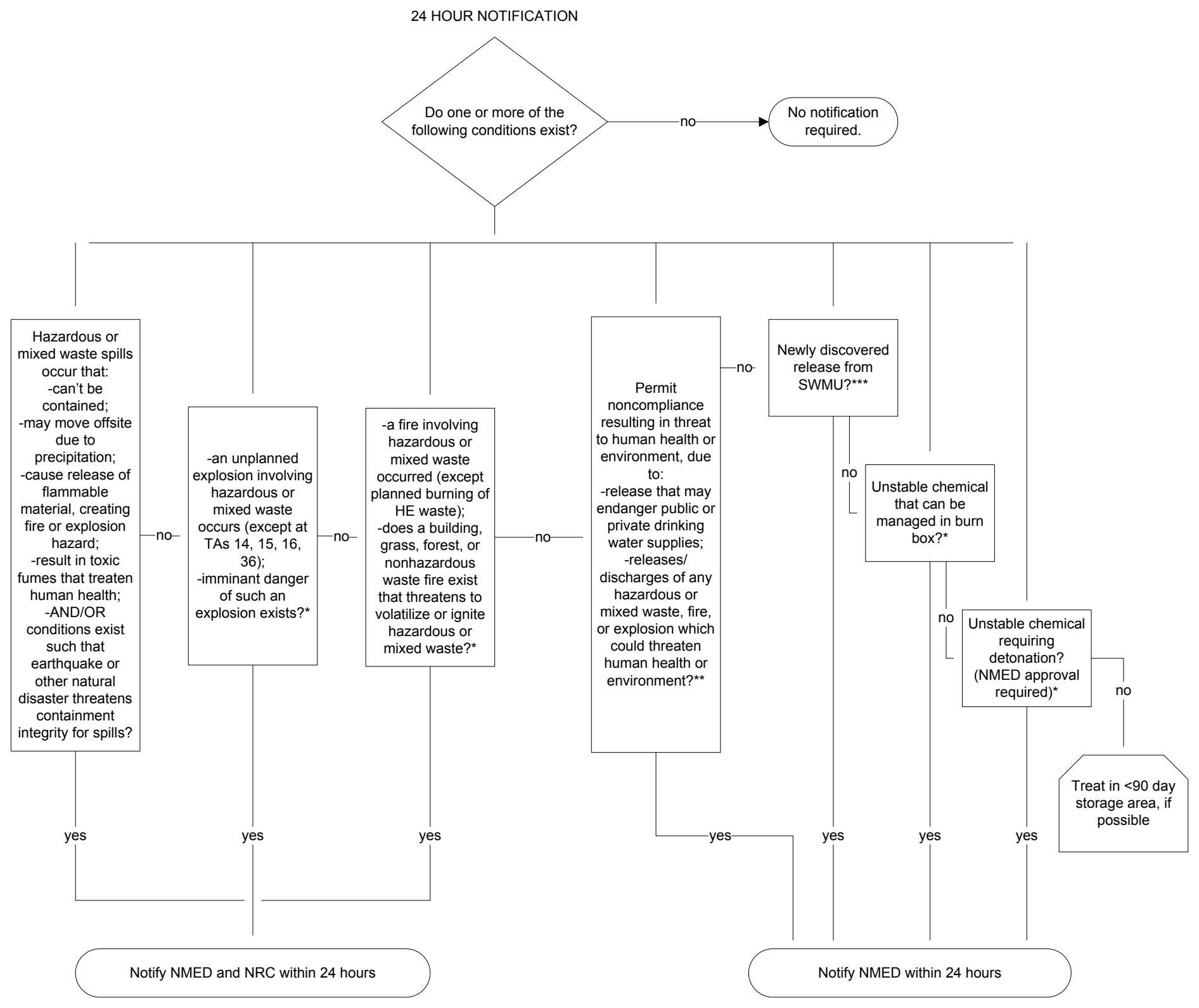

${ }^{*}$ Contingency Plan implementation, need for burn box use, or for detonation to be determined by EM\&R

**To be determined by ENV-RCRA

${ }^{* * *}$ To be determined by WES-WA and ENV-RCRA 


\section{ATTACHMENT 2: SUMMARY OF EMERGENCY RELEASE OR EVENT REPORTING REQUIREMENTS}

NOTE: This is only a guide and does not cover all federal, state, or permit reporting requirements. Refer to the Code of Federal Regulations and the RCRA Permit for more details regarding these regulations.

\begin{tabular}{|c|c|c|c|c|}
\hline STATUTE & REGULATIONS & INCIDENT & REPORT TO/BY & REPORTING \\
\hline $\begin{array}{l}\text { Clean Water } \\
\text { Act(CWA) }\end{array}$ & 40 CFR 110.6 & $\begin{array}{l}\text { Oil discharge } \\
\text { (film/sheen/discoloration) to water } \\
\text { surface or shoreline, or violation } \\
\text { of water quality standards. }\end{array}$ & $\begin{array}{l}\text { NRC. If not practical then } \\
\text { EPA by person in charge } \\
\text { of facility. }\end{array}$ & $\begin{array}{l}\text { Immediately, no later than } \\
24 \text { hours. } \\
\text { Follow-up not required. }\end{array}$ \\
\hline $\begin{array}{l}\text { Clean Water Act } \\
\text { (CWA) }\end{array}$ & 40 CFR 117.21 & $\begin{array}{l}\text { Discharge of hazardous } \\
\text { substance (equal to or above } \\
\text { RQ) }\end{array}$ & $\begin{array}{l}\text { Appropriate govt. } \\
\text { agencies by person in } \\
\text { charge of facility. }\end{array}$ & $\begin{array}{l}\text { Immediately } \\
\text { Follow-up not required. }\end{array}$ \\
\hline $\begin{array}{l}\text { Clean Water Act } \\
\text { (CWA) }\end{array}$ & 40 CFR 122.28 & $\begin{array}{l}\text { Adverse incident which includes } \\
\text { evidence that a person or non- } \\
\text { target organism has been exposed } \\
\text { to a pesticide residue or the person } \\
\text { or non-target organism suffered a } \\
\text { toxic or adverse effect. }\end{array}$ & $\begin{array}{l}\text { Report to EPA within } 24 \\
\text { hrs. }\end{array}$ & $\begin{array}{l}30 \text { Day Adverse Incident } \\
\text { Written Report for PGP } \\
\text { required. }\end{array}$ \\
\hline $\begin{array}{l}\text { New Mexico } \\
\text { Water Quality } \\
\text { Control } \\
\text { Commission } \\
\text { Regulations } \\
\text { (NMWQCC } \\
\text { Regulations) }\end{array}$ & 20.6.2.1203 NMAC & $\begin{array}{l}\text { Discharge from any facility } \\
\text { of oil or other water } \\
\text { contaminant, in such } \\
\text { quantity as may with } \\
\text { reasonable probability } \\
\text { injure or be detrimental to } \\
\text { human health, animal or } \\
\text { plant life, or property, or } \\
\text { unreasonably interfere with } \\
\text { the public welfare or use of } \\
\text { the property. }\end{array}$ & $\begin{array}{l}\text { New Mexico } \\
\text { Environment } \\
\text { Department by ENV- } \\
\text { RCRA. Copy to EPA. }\end{array}$ & $\begin{array}{l}\text { As soon as possible after } \\
\text { learning of such a } \\
\text { discharge, but in no event } \\
\text { more than } 24 \text { hours } \\
\text { thereafter (verbal } \\
\text { notification). } \\
7 \text { day written report } \\
\text { (Calendar Days) } \\
15 \text { day written Corrective } \\
\text { Action Plan. }\end{array}$ \\
\hline $\begin{array}{l}\text { Comprehensive } \\
\text { Environmental, } \\
\text { Response, } \\
\text { Compensation, } \\
\text { and Liability Act } \\
\text { (CERCLA) } \\
\end{array}$ & 40 CFR 302.6(a) & $\begin{array}{l}\text { Hazardous substance release } \\
\text { (Equal to or greater than } \\
\text { RQ). }\end{array}$ & $\begin{array}{l}\text { Report to NRC by ENV or } \\
\text { WES SME }\end{array}$ & $\begin{array}{l}\text { Within fifteen minutes } \\
\text { Follow-up not required }\end{array}$ \\
\hline $\begin{array}{l}\text { Emergency } \\
\text { Planning and } \\
\text { Community } \\
\text { Right- to-Know } \\
\text { Act (EPCRA) }\end{array}$ & 40 CFR 355.40 & $\begin{array}{l}\text { Release of SARA extremely } \\
\text { hazardous substance or } \\
\text { CERCLA hazardous substance } \\
\text { equal to or greater than RQ. }\end{array}$ & $\begin{array}{l}\text { LEPC, SERC, or local } \\
\text { emergency response } \\
\text { personnel (911 in case } \\
\text { of transportation } \\
\text { related release) by } \\
\text { owner/operator. }\end{array}$ & $\begin{array}{l}\text { Within fifteen minutes } \\
\text { Follow-up required within } \\
\text { seven calendar days. }\end{array}$ \\
\hline
\end{tabular}




\begin{tabular}{|c|c|c|c|c|}
\hline STATUTE & REGULATIONS & INCIDENT & REPORT TO/BY & REPORTING \\
\hline $\begin{array}{l}\text { Resource } \\
\text { Conservation and } \\
\text { Recovery Act } \\
\text { (RCRA) }\end{array}$ & $\begin{array}{l}40 \text { CFR 262.34, } \\
263.30, \\
264.51, \\
264.56 \& .196, \\
265.51, .56 \& .196, \\
270.14, \& .30, \\
273.17, .37 \& .54, \\
279.43 \& .53, \\
280.50, .52, .53, .60,\end{array}$ & $\begin{array}{l}\text { Release, fire, or facility explosion } \\
\text { that threatens human health or } \\
\text { environment. }\end{array}$ & $\begin{array}{l}\text { NRC/OS C/state/ local } \\
\text { /EPA Regional } \\
\text { Administrator by ENV-DO } \\
\text { or ENV-RCRA SME. }\end{array}$ & $\begin{array}{l}\text { Immediate and/or within } \\
24 \text { hours (see flow chart) } \\
\text { Follow-up: varies from } 5 \\
\text { to } 30 \text { days report to } \\
\text { OSC/NRC/EPA Regional } \\
\text { Administrator. }\end{array}$ \\
\hline $\begin{array}{l}\text { Toxic Substance } \\
\text { Control Act } \\
\text { (TSCA) }\end{array}$ & $\begin{array}{l}40 \text { CFR } 761.120 \text {, } \\
761.125\end{array}$ & $\begin{array}{l}\text { PCB spill (equal to or } \\
\text { greater than } 50 \mathrm{ppm} \text { ) with release } \\
\text { to surface water/drinking water } \\
\text { supplies/sewers/ grazing lands, } \\
\text { etc. } \\
\text { OR } \\
\text { PCB spill over } 10 \text { pounds }\end{array}$ & $\begin{array}{l}\text { NRC and EPA Region } \\
6 \text { Office of Pesticides } \\
\text { and Toxic Substances by } \\
\text { person in } \\
\text { charge. }\end{array}$ & $\begin{array}{l}\text { Within } 24 \text { hours } \\
\text { Follow-up: as required by } \\
\text { agency. }\end{array}$ \\
\hline $\begin{array}{l}\text { Operational } \\
\text { events to include } \\
\text { environmental } \\
\text { releases and } \\
\text { reporting }\end{array}$ & DOE Order 231.1A & $\begin{array}{l}\text { As per criteria within DOE Order } \\
\text { 231.1A. Examples include } 50 \\
\text { percent of an RQ }\end{array}$ & $\begin{array}{l}\text { DOE LASO and DOE HQ } \\
\text { by FOD through ESH-OFF }\end{array}$ & $\begin{array}{l}\text { Verbal notifications in } 2 \\
\text { hours after categorization } \\
\text { and written notifications } \\
\text { within from } 2 \text { hours to NLT } \\
2 \text { business days depending } \\
\text { on the severity and DOE } \\
\text { criteria }\end{array}$ \\
\hline N/A & $\mathrm{N} / \mathrm{A}$ & $\begin{array}{l}\text { Incidents which may be of } \\
\text { concern to the public, such as wild } \\
\text { land fires, activities which may } \\
\text { have a visual impact that concerns } \\
\text { the public, etc. }\end{array}$ & NMED & As soon as possible \\
\hline
\end{tabular}




\section{ENV-CP-QP-045.1}

Effective Date: September 5, 2013
Next Review Date: August 5, 2015

\section{Environment, Safety, Health Directorate}

\section{Environmental Protection - Compliance Programs Quality Procedure}

\section{Installing, Setting Up, and Operating ISCO Samplers for the MSGP}

Reviewers:

\begin{tabular}{|l|l|l|l|}
\hline $\begin{array}{l}\text { Name: } \\
\text { Melanie Lamb }\end{array}$ & $\begin{array}{l}\text { Organization: } \\
\text { ADESH-OIO, QA } \\
\text { Specialist }\end{array}$ & $\begin{array}{l}\text { Signature: } \\
\text { Signature on file }\end{array}$ & $\begin{array}{l}\text { Date: } \\
8 / 28 / 13\end{array}$ \\
\hline \begin{tabular}{|l|l|l|l|} 
Name: \\
Ellena Martinez
\end{tabular} \\
$\qquad \begin{array}{l}\text { Organization: } \\
\text { ADESH-OIO }\end{array}$ & $\begin{array}{l}\text { Signature: } \\
\text { Signature on file }\end{array}$ & $8 / 28 / 13$ \\
\hline
\end{tabular}

Approval Signatures:

\begin{tabular}{|c|c|c|c|}
\hline $\begin{array}{l}\text { Subject Matter Expert: } \\
\text { Holly Wheeler }\end{array}$ & $\begin{array}{l}\text { Organization: } \\
\text { ENV-CP }\end{array}$ & $\begin{array}{l}\text { Signature: } \\
\text { Signature on file }\end{array}$ & $\begin{array}{l}\text { Date: } \\
\text { 8/29/13 }\end{array}$ \\
\hline $\begin{array}{l}\text { Responsible Line Manager: } \\
\text { Michael Saladen }\end{array}$ & $\begin{array}{l}\text { Organization: } \\
\text { ENV-CP Team Lead }\end{array}$ & $\begin{array}{l}\text { Signature: } \\
\text { Signature on file }\end{array}$ & $\begin{array}{l}\text { Date: } \\
\text { 8/29/13 }\end{array}$ \\
\hline $\begin{array}{l}\text { Responsible Line Manager: } \\
\text { Anthony Grieggs }\end{array}$ & $\begin{array}{l}\text { Organization: } \\
\text { ENV-CP Group Leader }\end{array}$ & $\begin{array}{l}\text { Signature: } \\
\text { Signature on file }\end{array}$ & $\begin{array}{l}\text { Date: } \\
\text { 9/5/13 }\end{array}$ \\
\hline
\end{tabular}

CONTROLLED DOCUMENT

This copy is uncontrolled. The controlled copy can be found on the ENV Division Web page.

Users are responsible for ensuring they work to the latest approved version. 


\section{History of Revisions}

\begin{tabular}{|c|c|l|}
\hline $\begin{array}{c}\text { Document Number } \\
\text { [Include revision number, } \\
\text { beginning with Revision 0] }\end{array}$ & $\begin{array}{c}\text { Effective Date } \\
\text { [Document Control Coordinator } \\
\text { inserts effective date] }\end{array}$ & $\begin{array}{c}\text { Description of Changes } \\
\text { [List specific changes made since the previous revision] }\end{array}$ \\
\hline 0 & $03 / 11$ & New Document. \\
\hline 1 & $04 / 13$ & Biennial Review and Revision \\
\hline 2 & $09 / 13$ & Biennial Review and Revision \\
\hline
\end{tabular}




\section{Table of Contents}

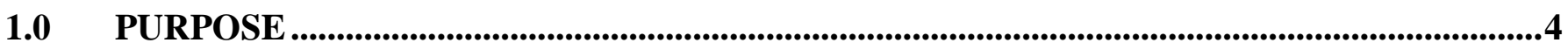

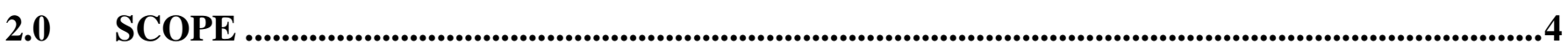

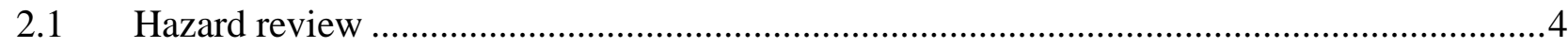

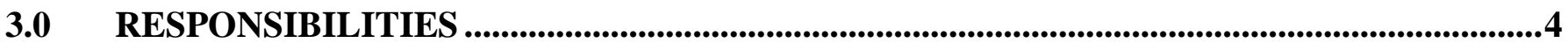

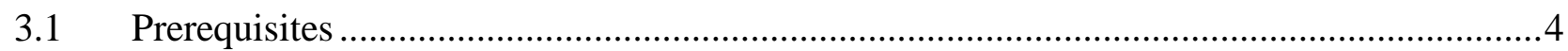

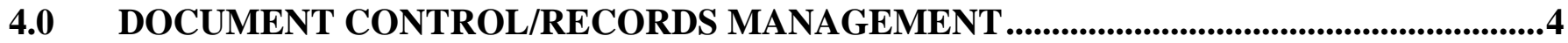

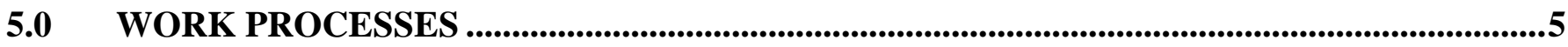

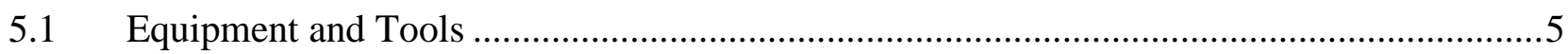

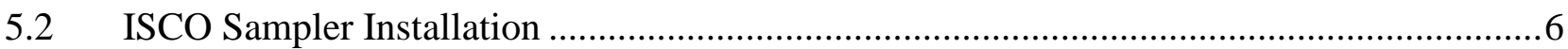

5.3 Configuring ISCO 3700 Samplers ........................................................................... 7

5.4 Programming ISCO 3700 Samplers........................................................................

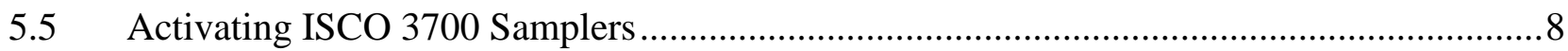

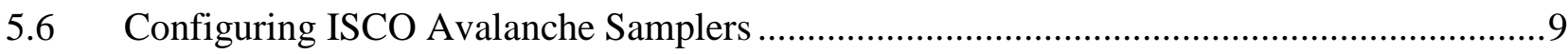

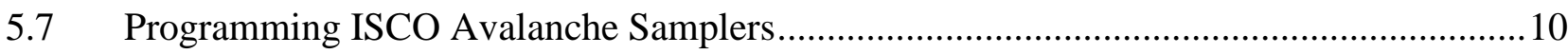

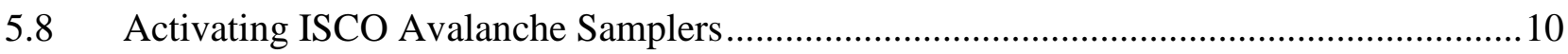

5.9 Standing Down or Winterizing Samplers ...................................................................... 11

5.10 Sampler Reset and Re-initialization After Sample Collection.........................................12

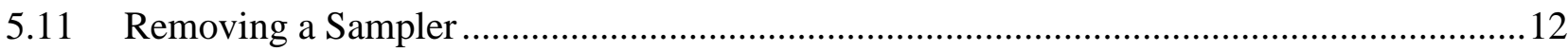

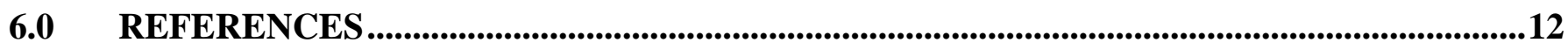

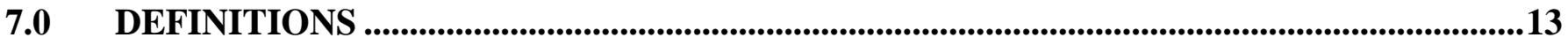

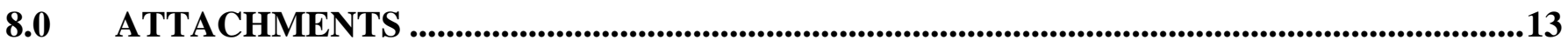

Attachment 1- LANL MSGP ISCO Sampler Installation Form 045-1......................................14

Attachment 2- Wiring Diagram for Avalanche Sampler .......................................................15

Attachment 3 - Battery Photovoltaic Connection Wiring ....................................................... 16

Attachment 4 - ISCO 3700 Configuration Settings .................................................................18

Attachment 5 - ISCO 3700 Program Sequence ...................................................................19

Attachment 6 - LANL MSGP ISCO Sampler Activation Form 045-3 ........................................22

Attachment 7 - ISCO Avalanche Configuration Settings........................................................23

Attachment 8 - ISCO Avalanche Program Sequence ..............................................................24

Attachment 9 - LANL MSGP ISCO Sampler Winter Shut-Down Form 045-5 ..........................25

Attachment 10 - LANL MSGP ISCO Sampler Decommission Form 045-6 ..............................26 


\subsection{PURPOSE}

This procedure describes the installation, setup, programming, and operation of Teledyne ISCO Avalanche and Model 3700 full-size portable automated samplers used to collect storm water runoff samples for the Multi-Sector General Permit (MSGP).

\subsection{SCOPE}

This procedure applies to all ENV-CP technical staff and contractor personnel conducting installation, operation, maintenance and sampling activities at single stage stations used for monitoring under the MSGP.

\subsection{HAZARD REVIEW}

Hazards in the work described in this procedure are controlled thorough site specific IWDs. The hazard level of the activities in this procedure is moderate.

\subsection{RESPONSIBILITIES}

The following personnel require training before implementing this procedure:

- This procedure applies to all ENV-CP MSGP storm water compliance personnel conducting installation, operation, maintenance and sampling activities at MSGP single stage monitoring stations.

The training method for this procedure is "self-study" (reading). For ENV-CP staff, this is documented in accordance with ENV-DO-QP-115, Personnel Training. Other participating groups may require training documentation pursuant to local procedures.

Actions specified within this procedure, unless proceeded with "should" or "may," are to be considered mandatory (i.e., "shall”, “will”, “must”).

\subsection{Prerequisites}

Personnel performing this procedure will be familiar with the most current versions of the following procedures and operation manuals:

- ENV-CP MSGP Sampling and Analysis Plan for the current monitoring year

- Manual for Teledyne ISCO Sampler Model 3700.

- Manual for Teledyne ISCO Avalanche refrigerated sampler

- Facility/FOD specific IWDs for the MSGP

\subsection{DOCUMENT CONTROL/RECORDS MANAGEMENT}

The following records are generated as a result of this procedure and are maintained in accordance with ENV-DO-QP-110, Records Management Program with the originals on file at ENV-CP offices:

Completed work orders for: 
- LANL MSGP ISCO Sampler Installation Form 045-1(Attachment 1)

- LANL MSGP ISCO Sampler Activation Form 045-3 (Attachment 6)

- LANL MSGP ISCO Sampler Winter Shutdown 045-5 (Attachment 9)

- LANL MSGP ISCO Sampler Decommission 045-6 (Attachment 10)

\subsection{WORK PROCESSES}

The discharge of storm water from industrial facilities at Los Alamos National Laboratory (LANL, the Laboratory) is regulated under the National Pollutant Discharge Elimination System (NPDES) MultiSector General Permit for Storm Water Discharges Associated with Industrial Activity (MSGP). The current MSGP became effective on September 29, 2008 pursuant to 73 FR 56572. The Laboratory's MSGP permit coverage (Permit Tracking No. NMR05GB21) requires storm water quality monitoring to evaluate the overall effectiveness of control measures. ISCO samplers coupled with Model 1640 sampler actuators are used at MSGP Program monitoring stations. Refrigerated (Avalanche) and/or nonrefrigerated (Model 3700) samplers may be deployed; and may be configured with multi-battery arrays, solar panels, and surge protectors.

\subsection{EQUIPMENT AND TOOLS}

Ensure the following equipment is available in the field vehicle:

- Copy of this procedure

- Copy of the appropriate Integrated Work Document(s) (IWDs)

- Charged spare battery(ies)

- Battery voltage tester

- Spare tubing (pump, suction, discharge types, sampler specific)

- Spare sample bottles

- Shovels

- Wooden stakes

- Plastic wire "zip" ties

- Cell phone (only government cell phones with the battery removed are allowed in secure areas)

- Appropriate tools (including insulated tools for electrical work) in tool box

- Issued Work Orders and associated forms

- Necessary access and station keys

- Ziploc ${ }^{\circledR}$ plastic storage bags

- Tape measure

- Sturdy hiking boots or steel toed shoes with soles that grip

The time on the ISCO sampler clock must be verified upon arrival at the site. The ISCO clocks must be set to Mountain Standard Time (MST) at all times, with no daylight saving time adjustment. Cellular phones can be used to verify the time. 


\subsection{ISCO SAMPLER INSTALLATION}

\begin{tabular}{|c|c|}
\hline Step & Action \\
\hline 1 & $\begin{array}{l}\text { Work Orders are issued for all field operations at individual MSGP monitored outfalls. Obtain the } \\
\text { Work Order with the LANL MSGP ISCO Sampler Installation Form 045-1 (Attachment 1). The } \\
\text { Work Order specifies the MSGP outfall and target date for the work to be performed. An outfall- } \\
\text { specific equipment list with specifications and configuration settings is provided on each Work } \\
\text { Order. }\end{array}$ \\
\hline 2 & $\begin{array}{l}\text { Deploy the ISCO sampler and charged battery on level ground above the flood plain. Often, large } \\
\text { tool/storage boxes (Greenlee }{ }^{\mathrm{TM}} \text { ) are used for equipment protection in the field. } \\
\text { NOTE: These boxes are locked. Therefore, a key should be obtained prior to accessing them. } \\
\text { The sampler should be as level as possible to allow effective sample collection. Verify/record the } \\
\text { ISCO sampler serial number and the battery tracking number(s) on the Work Order. }\end{array}$ \\
\hline 3 & $\begin{array}{l}\text { Install the separate protective battery box for the charged battery (follow manufacturer's } \\
\text { instructions). }\end{array}$ \\
\hline 4 & $\begin{array}{l}\text { Determine the bottle set configuration from the equipment list on the Work Order. } \\
\text { - If a Model } 3700 \text { sampler is indicated, install the correct distributor arm (has either "12” or } \\
\text { " } 24 \text { " embossed on bottom at outlet). } \\
\text { - For an Avalanche sampler, attach either the discharge tube guide (single bottle } \\
\text { configuration) or the distributor arm (multi-bottle configuration) and the appropriate bottle } \\
\text { adapter plate. If an adapter plate is not available, the inside of the sampler may need to be } \\
\text { configured by hand (i.e., add form) to prevent bottles from moving around during a } \\
\text { sampling event. } \\
\text { - Install required bottles and retaining devices in the sampler base. } \\
\text { - Check that the end of the discharge tubing does not extend below the bottom face of the } \\
\text { distributor arm (where it could snag the bottle tops and jam as the arm advances through the } \\
\text { bottle sequence). } \\
\text { - Remove and place the clean bottle caps in a new Ziploc }{ }^{\circledR} \text { plastic bag. }\end{array}$ \\
\hline 5 & $\begin{array}{l}\text { Attach a length (in whole foot increments) of 3/8-inch diameter Teflon suction line to the sampler } \\
\text { intake line and anchor as needed for the Outfall location. Measure and record (for later programming } \\
\text { steps) the tubing length used. Route the sample tubing downslope from the sampler to the intake } \\
\text { point so that there is a continuous slope with no valleys that could retain water between sample } \\
\text { intervals. }\end{array}$ \\
\hline 6 & $\begin{array}{l}\text { Install the actuator: } \\
\text { - Anchor a stake to the channel bottom in the main flow of the outfall discharge. } \\
\text { - } \quad \text { Attach the sampler intake tube and the } 1640 \text { liquid level detector (actuator) to the stake. } \\
\text { submerge the intake when the sampler is activated. } \\
\text { - Connect the actuator to the sampler using the cable connector provided by the manufacturer. } \\
\text { - If necessary, use a gravel bag to create a small pooling area for the actuator and sampler } \\
\text { intake to sit in. } \\
\text { The actuator height above the channel bottom is established using professional judgment. For } \\
\text { example, the intake may be positioned } 1 \text { inch or less above the bottom of low-flowing wide channels, } \\
\text { but higher than } 1 \text { inch in a high-flowing narrow channel. }\end{array}$ \\
\hline
\end{tabular}


NOTE: You must be a trained electrical worker and have completed all required courses in Training Plan \#2876 to conduct this step.

Connect the sampler to the power source, either a 12 Volt 110 A-h deep cycle lead acid battery or other power source such as a multi-battery array coupled with a solar panel, as appropriate. Record the battery tracking numbers in the equipment list section of the Work Order. (Refer to Attachments 2 and 3 for the wiring diagram for Avalanche sampler installation.)

\subsection{CONFIGURING ISCO 3700 SAMPLERS}

\begin{tabular}{|c|c|}
\hline Step & Action \\
\hline 1 & $\begin{array}{l}\text { When a new ISCO } 3700 \text { sampler is being installed, configure the sampler in accordance with the } \\
\text { steps contained in this section. Follow the project-specific configuration settings as indicated on the } \\
\text { Work Order and given in Attachment 4, ISCO } 3700 \text { Configuration Settings. }\end{array}$ \\
\hline 2 & Turn on the sampler by pressing the "On” button. \\
\hline 3 & Press the "Enter/Program” button. \\
\hline 4 & Select “Configuration”. \\
\hline 5 & $\begin{array}{l}\text { Set the configuration parameters in accordance with the guidance in Attachment 4, ISCO } 3700 \\
\text { Configuration Settings. After each selection is made, press the "Enter" button to allow the next } \\
\text { configuration parameter to be displayed on the screen. }\end{array}$ \\
\hline 6 & $\begin{array}{l}\text { After the programming is complete, select "Run diagnostics" and press "Enter" to run the system } \\
\text { diagnostic test. The diagnostic tests include the following: } \\
\text { - } \quad \text { RAM and ROM test } \\
\text { - LCD test } \\
\text { - Pump test ("OFF/ON" number should be between } 50 \text { and } 200 \text { for a successful test) } \\
\text { - Distributor test -- select "YES" to run test. Test will move the distributor to Position } 24 \text { and } \\
\text { then return it to Position } 1 .\end{array}$ \\
\hline 7 & $\begin{array}{l}\text { Following the diagnostic tests, "Reinitialize Controller” will be displayed. Select “No" and press } \\
\text { "Enter.” Do not select "Yes.” If "Yes” is selected, the sampler will reset a number of configuration } \\
\text { and program settings to the factory default values. }\end{array}$ \\
\hline 8 & $\begin{array}{l}\text { To leave the configuration sequence, use the "Exit configuration" and press "Yes" or press the } \\
\text { "Enter/Program" key. }\end{array}$ \\
\hline
\end{tabular}

\subsection{Programming ISCO 3700 SAMPLERS}

\begin{tabular}{|l|l|}
\hline Step & Action \\
\hline 1 & $\begin{array}{l}\text { Follow the steps in this process to program a new ISCO or to confirm the program settings are } \\
\text { correct for a specific location. Follow the project-specific program settings as indicated on the }\end{array}$ \\
\hline
\end{tabular}


Installing, Setting Up, and Operating ISCO Samplers for the MSGP
No. ENV-CP-QP-045.1

Page 8 of 26

Effective Date: September 5, 2013

\begin{tabular}{|c|c|}
\hline & work order and given in Attachment 5, ISCO 3700 Program Sequence. \\
\hline 2 & Turn on the sampler by pressing the "ON" button \\
\hline 3 & Press the "Enter/Program" button. \\
\hline 4 & Select "Program”. \\
\hline 5 & $\begin{array}{l}\text { Set the program parameters in accordance with the guidance on Attachment 5, ISCO } 3700 \text { Program } \\
\text { Sequence. After each selection is made, press the "Enter" button to allow the next configuration } \\
\text { parameter to be displayed on the screen. }\end{array}$ \\
\hline 6 & Set the switch on the actuator to "Latch." \\
\hline 7 & $\begin{array}{l}\text { NOTE: You must be a trained electrical worker and have completed all required courses in } \\
\text { Training Plan \#2876 to conduct this step. }\end{array}$ \\
\hline 8 & $\begin{array}{l}\text { Complete the responses for the sampler installation tasks listed on the Work Order. Sign and date } \\
\text { the Work Order and ensure all items contained within it have been completed. }\end{array}$ \\
\hline
\end{tabular}

\subsection{ACTIVATING ISCO 3700 SAMPLERS}

\begin{tabular}{|c|c|}
\hline Step & Action \\
\hline 1 & $\begin{array}{l}\text { Follow the steps in this section when a Work Order is received to activate a sampler (generally } \\
\text { at the beginning of a field season or at the beginning of the next quarter after the last quarterly } \\
\text { monitoring sample was obtained). } \\
\text { Note: The MSGP monitoring quarters are as follows } \\
\text { - April } 1 \text { through May } 31 \\
\text { - June } 1 \text { through July } 31 \\
\text { - August } 1 \text { through September } 30 \text {, and } \\
\text { - October } 1 \text {, through November } 30 \text {. }\end{array}$ \\
\hline 2 & $\begin{array}{l}\text { Obtain the Work Order with the LANL MSGP Sampler Activation Form 045-3 (Attachment } \\
\text { 6). The Work Order specifies the MSGP Outfall and target date for the work to be performed. } \\
\text { An Outfall-specific equipment list with specifications and configuration settings is provided on } \\
\text { each Work Order. } \\
\text { NOTE: You must be a trained electrical worker and have completed all required courses in } \\
\text { Training Plan \#2876 to conduct this step. } \\
\text { If not already installed, install and hook up the charged battery. } \\
\text { If a battery is already in place, use the voltage tester to check for minimum voltage of } 11.7 \\
\text { volts. If the voltage is lower, replace the battery with a charged battery. }\end{array}$ \\
\hline 3 & $\begin{array}{l}\text { Turn the sampler ON. "Program halted” will be displayed; press the Enter/Program button to } \\
\text { enter program/configure sequence. }\end{array}$ \\
\hline 4 & $\begin{array}{l}\text { Check the configuration and programming parameters to ensure they are still correct for the } \\
\text { specific installation (see Attachment } 4 \text { and } 5 \text { for the correct parameters). }\end{array}$ \\
\hline 5 & $\begin{array}{l}\text { Check integrity and condition of sampler tubing, actuator, wiring, etc., to ensure sampler will } \\
\text { properly collect a sample. }\end{array}$ \\
\hline
\end{tabular}


Installing, Setting Up, and Operating ISCO Samplers for the MSGP
No. ENV-CP-QP-045.1

Page 9 of 26

Effective Date: September 5, 2013

\begin{tabular}{|c|l|}
\hline $\mathbf{6}$ & $\begin{array}{l}\text { To test the integrity of the tubing, press "Pump forward” to turn on pump and test for suction at } \\
\text { the tubing intake. Press "Stop” to turn off pump. } \\
\text { If no suction is felt at the intake, check the integrity of the tubing and replace as necessary. }\end{array}$ \\
\hline 7 & To activate the sampler, press "Start sampling” and "Enter" twice. \\
\hline $\mathbf{8}$ & Ensure the sampler indicates "Sampler Inhibited". \\
\hline $\mathbf{9}$ & $\begin{array}{l}\text { Complete the responses for the sampler activation tasks listed on the Work Order. Sign and } \\
\text { date the Work Order and ensure all items contained within it have been completed. }\end{array}$ \\
\hline
\end{tabular}

\subsection{CONFIgURING ISCO AVALANCHE SAMPLERS}

\begin{tabular}{|c|c|}
\hline Step & Action \\
\hline 1 & $\begin{array}{l}\text { When a new ISCO Avalanche sampler is being installed, configure the sampler in } \\
\text { accordance with the steps contained in this section. Follow the project-specific configuration } \\
\text { settings as indicated on the work order and given in Attachment 8, ISCO Avalanche } \\
\text { Configuration Settings. }\end{array}$ \\
\hline 2 & Turn on the sampler by pressing the "Standby” key. \\
\hline 3 & $\begin{array}{l}\text { From the main menu, select Other Functions, to access the menus and select options given } \\
\text { in Attachment } 8 .\end{array}$ \\
\hline 4 & $\begin{array}{l}\text { Set the configuration parameters in accordance with the guidance on Attachment 8, ISCO } \\
\text { Avalanche Configuration Settings. }\end{array}$ \\
\hline 5 & $\begin{array}{l}\text { After the programming is complete, select "Run diagnostics" and press "Enter" to run the } \\
\text { system diagnostic test. These include the following: } \\
\text { - } \quad \text { RAM and ROM test } \\
\text { - Pump test ("ON/OFF" ratio should be between } 0.80 \text { and } 1.25 \text { for a successful test) } \\
\text { - Distributor test -- select "YES" to run test. Test will move the distributor to } \\
\text { Position } 14 \text { and then return it to Position } 1 .\end{array}$ \\
\hline 6 & $\begin{array}{l}\text { Following the diagnostic tests, "Reinitialize Controller" will be displayed. Select "No" and } \\
\text { press the "Enter" key. (If "Yes" is selected, the sampler will reset a number of configuration } \\
\text { and program settings to the factory default values). }\end{array}$ \\
\hline 7 & $\begin{array}{l}\text { If a } 700 \text { series module (e.g., } \mathrm{pH} \text { ) is to be installed, consult the equipment manufacturer's } \\
\text { manual for installation instructions. NOTE: The pH module is only required at the Asphalt } \\
\text { Batch Plant. }\end{array}$ \\
\hline 8 & $\begin{array}{l}\text { Complete the responses for the sampler installation tasks listed on the Work Order. Sign and } \\
\text { date the Work Order and ensure all items contained within it have been completed. }\end{array}$ \\
\hline
\end{tabular}




\subsection{Programming ISCO Avalanche Samplers}

\begin{tabular}{|c|c|}
\hline Step & Action \\
\hline 1 & $\begin{array}{l}\text { Follow the steps in this process to program a new ISCO or to confirm the program } \\
\text { settings are correct for a specific location and bottle configuration. Follow the project- } \\
\text { specific program settings as indicated on the work order and given in Attachment 8, ISCO } \\
\text { Avalanche Program Sequence. }\end{array}$ \\
\hline 2 & Turn on the sampler by pressing the "Standby" key. \\
\hline 3 & Press the "Program" button. \\
\hline 4 & $\begin{array}{l}\text { Select the current program to review settings, or choose "Select New Program" to create a } \\
\text { new program with different settings. }\end{array}$ \\
\hline 5 & $\begin{array}{l}\text { Select the current program to review settings, or choose "Select New Program" to create a } \\
\text { new program with different settings. }\end{array}$ \\
\hline 6 & $\begin{array}{l}\text { At the prompt "Programming complete, run this program now?", select "Yes" if sampler } \\
\text { is scheduled to be active, and "No" if sampler is in stand down. }\end{array}$ \\
\hline 7 & Set switch on actuator to "Latch." \\
\hline 8 & $\begin{array}{l}\text { Complete the responses for the sampler installation tasks listed on the Work Order. Sign } \\
\text { and date the Work Order and ensure all items within it have been completed. }\end{array}$ \\
\hline
\end{tabular}

\subsection{ACTIVATING ISCO AVALANCHE SAMPLERS}

\begin{tabular}{|c|c|}
\hline Step & Action \\
\hline 1 & $\begin{array}{l}\text { Follow the steps in this section when a Work Order is received to activate a sampler } \\
\text { (generally at the beginning of a field season or at the beginning of the next quarter after } \\
\text { the last quarterly monitoring sample was obtained). } \\
\text { Note: The MSGP monitoring quarters are as follows } \\
\text { - April } 1 \text { through May } 31 \\
\text { - June } 1 \text { through July } 31 \\
\text { - August } 1 \text { through September } 30 \text {, and } \\
\text { - October } 1 \text {, through November } 30 \text {. }\end{array}$ \\
\hline 2 & $\begin{array}{l}\text { NOTE: You must be a trained electrical worker and have completed all required courses } \\
\text { in Training Plan \#2876 to conduct this step. } \\
\text { If not already installed, install and hook up the charged battery(ies). } \\
\text { If a battery is already in place, use the voltage tester to check for minimum voltage of } 11.7 \\
\text { volts. If the voltage is lower, replace the battery with a charged battery. }\end{array}$ \\
\hline 3 & $\begin{array}{l}\text { Turn on sampler power. From the main menu, select "Program" and the "Enter" key to } \\
\text { enter programming sequence, and "Other Functions" to enter the configuration settings. }\end{array}$ \\
\hline 4 & $\begin{array}{l}\text { Check the programming/configuration parameters to ensure they are still correct for the } \\
\text { specific installation - follow the two preceding sections for the steps and see Attachment } \\
7 \text { and } 8 \text { for the correct parameters. }\end{array}$ \\
\hline 5 & Check integrity and condition of sampling tubes, actuator, wiring, etc., to ensure sampler \\
\hline
\end{tabular}




\begin{tabular}{|c|l|}
\hline & will properly collect a sample. \\
\hline 6 & $\begin{array}{l}\text { From the main menu, select "Other Functions" "Manual Functions" "Operate Pump" } \\
\text { to perform a manual suction test. To test the integrity of the tubing, press "Pump forward" } \\
\text { to turn on pump and test for suction at the tubing intake. Press "Stop" to turn off pump. } \\
\text { If no suction is felt at the intake, check the integrity of the tubing and replace as } \\
\text { necessary. }\end{array}$ \\
\hline 7 & $\begin{array}{l}\text { Reset the actuator by toggling the switch to "Reset" then back to "Latch." To activate the } \\
\text { sampler, ensure the correct program name is displayed on the main menu and select } \\
\text { "Run". }\end{array}$ \\
\hline 8 & $\begin{array}{l}\text { Ensure the sampler indicates "Program Disabled". } \\
\text { Note: The Avalanche refrigeration system is active any time the controller is powered. } \\
\text { this is true for all states (including OFF), except for the time between entering RUN and } \\
\text { Avalanche assumes that during this time there is no sample liquid to cool. }\end{array}$ \\
\hline 10 & \begin{tabular}{l} 
Ensure that all items on the Work Order have been completed. \\
\hline 9
\end{tabular} \\
\hline
\end{tabular}

\subsection{STANDING DOWN OR WINTERIZING SAMPLERS}

\begin{tabular}{|c|l|}
\hline Step & Action \\
\hline 1 & $\begin{array}{l}\text { Follow the steps in this section when a Work Order is received to turn off ("stand down") } \\
\text { a sampler (generally at the end of a field season, which is November 30, or to disable a } \\
\text { sampler for a certain time period after a sample was collected). Fill out the LANL MSGP } \\
\text { ISCO Sampler Winter Shut-Down Form in Attachment 9. }\end{array}$ \\
\hline 2 & $\begin{array}{l}\text { ISCO 3700: Turn off power. } \\
\text { ISCO Avalanche: The Avalanche refrigeration system is active any time the controller is } \\
\text { powered. This is true for all states (including OFF), except for the time between entering } \\
\text { RUN and the completion of the first sample, and when the pump is running. To conserve } \\
\text { power, the Avalanche assumes that during this time there is no sample liquid to cool. } \\
\text { NOTE: To ensure that the refrigeration system does not activate during an intended stand } \\
\text { down, disconnect the sampler from the power source. }\end{array}$ \\
\hline 3 & $\begin{array}{l}\text { Remove the battery and return it to the storage compound at TA-64 or other specified } \\
\text { location identified by ENV-CP MSGP stormwater compliance personnel. Store cables } \\
\text { inside the GreenleeTM box. If the actuator and tubing are not contained within conduit, } \\
\text { disconnect these and place them in the box. Close sampler. } \\
\text { Avalanche samplers must not be left in place for the winter, and are required to be } \\
\text { returned to ENV-CP's storage shed. }\end{array}$ \\
\hline 4 & \begin{tabular}{l} 
Ensure that all items on the Work Order have been completed. \\
\hline
\end{tabular}
\end{tabular}


Installing, Setting Up, and Operating ISCO Samplers for the MSGP
No. ENV-CP-QP-045.1

Page 12 of 26

Effective Date: September 5, 2013

\subsection{SAMPler Reset AND Re-INITIALIZATION AfTER SAMPle COLLECTION}

\begin{tabular}{|c|l|}
\hline Step & Action \\
\hline 1 & $\begin{array}{l}\text { Follow ENV-CP-QP-047, Inspecting Storm Water Runoff Samplers and Retrieving } \\
\text { Samples for the MSGP for collecting samples from an ISCO and installing new bottles so } \\
\text { it is ready to collect new samples. }\end{array}$ \\
\hline 2 & $\begin{array}{l}\text { After collecting samples and resetting the sampler, follow instructions on sample } \\
\text { collection Work Order, the updated sample tracking log or confer with the MSGP Project } \\
\text { Lead regarding whether the sampler should be disabled. } \\
\text { If sampler is to be deactivated, follow the steps specific to each sampler provided in the } \\
\text { preceding section. } \\
\text { If an ISCO 3700 sampler is to be left activated, reset the actuator by toggling the switch } \\
\text { to "Reset" then back to "Latch", and press “Start sampling” and "Enter” twice. Ensure } \\
\text { the sampler display indicates "Sampler Inhibited”: } \\
\text { If an ISCO Avalanche sampler is to be left activated, reset the actuator by toggling the } \\
\text { switch to "Reset” then back to "Latch.” From the main menu, verify the correct program } \\
\text { name is displayed and select "Run." Ensure the sampler display indicates "Program } \\
\text { Disabled.” }\end{array}$ \\
\hline
\end{tabular}

\subsection{REMOVING A SAMPLER}

\begin{tabular}{|c|l|}
\hline Step & Action \\
\hline 1 & $\begin{array}{l}\text { Follow the steps in this process when a Work Order is received to un-install or remove a } \\
\text { sampler. Fill out the LANL MSGP ISCO Sampler Decommission Form in Attachment } \\
10 .\end{array}$ \\
\hline 2 & $\begin{array}{l}\text { Disconnect all equipment and remove it from the site. Return the equipment to the ENV- } \\
\text { CP Storage Shed or other location specified by MSGP storm water compliance } \\
\text { personnel. }\end{array}$ \\
\hline 3 & $\begin{array}{l}\text { Dispose of all equipment components that contacted samples (tubing, bottles, etc.) as } \\
\text { waste according to applicable waste management procedure. For assistance, contact the } \\
\text { Waste Management Coordinator for TA-59. }\end{array}$ \\
\hline 4 & \begin{tabular}{l} 
Ensure that all items on the Work Order have been completed. \\
\hline
\end{tabular}
\end{tabular}

\subsection{REFERENCES}

ENV-DO-QP-110, Records Management Program

ENV-DO-QP-115, Personnel Training

ENV-CP-QP-047, Inspecting Storm Water Runoff Samplers and Retrieving Samples for the MSGP 
Installing, Setting Up, and Operating ISCO Samplers for the MSGP
No. ENV-CP-QP-045.1

Page 13 of 26

Effective Date: September 5, 2013

\subsection{DEFINITIONS}

ENV-CP: Environmental Protection Division, Compliance Programs Group

Grab Sample: A single sample collected at an NPDES outfall (using approved EPA methods) at a particular time that represents the composition of the storm water at that time and place.

IWD: Integrated Work Document

MSGP: Multi-Sector General Permit

MST: Mountain Standard Time

NPDES: National Pollutant Discharge Elimination System

\subsection{ATTACHMENTS}

Attachment 1- LANL MSGP ISCO Sampler Installation Form 045-1

Attachment 2- Wiring Diagram for Avalanche Sampler

Attachment 3 - Battery Photovoltaic Connection Wiring

Attachment 4 - ISCO 3700 Configuration Settings

Attachment 5 - ISCO 3700 Program Sequence

Attachment 6 - LANL MSGP ISCO Sampler Activation Form 045-3

Attachment 7 - ISCO Avalanche Configuration Settings

Attachment 8 - ISCO Avalanche Program Sequence

Attachment 9 - LANL MSGP ISCO Sampler Winter Shut-Down Form 045-5

Attachment 10 - LANL MSGP ISCO Sampler Decommission Form 045-6

By requesting credit for this required reading I acknowledge that I have read and understand the contents of this document and I will follow and meet the requirements in this document unless it is unsafe to do so.

Click to

Acknowledge 


\section{ATTACHMENT 1- LANL MSGP ISCO SAMPLER INSTALLATION FORM 045-1}

ENV-QP-045.0

Target Date: 4/1/2013

Project: MSGP 2013 Sampler Install

Reason: MSGP 2013 Sampler Installation
Outfall: 54-G-4 : 54-PAD10E
LANL Multi-Sector General Permit

ISCO Sampler Installation Form

Project ID: P-MSGP-2443
Form 045-1 (3/2011)

Work Order ID: MSGP-31193

Date:_- Time:___
Name/Z\#._
Name/Z\#._-
Lead Signature:-
"I confirm the information as recorded is true, accurate and complete."

Verify the equipment list below. Make corrections as required and fill in missing information (e.g., serial numbers).

\begin{tabular}{|c|c|c|c|c|c|c|}
\hline Equipment & Manufacturer & Model & Serial No. & \multicolumn{2}{|c|}{ Specification } & Configuration \\
\hline Actuator & ISCO & 1640 & \multicolumn{4}{|l|}{ 210J01660 } \\
\hline Charge Controller & Xantrex & C-12 & \multicolumn{4}{|l|}{ B20037667 } \\
\hline ISCO 3700 Sampler & Teledyne & 3700 & $198 \mathrm{H} 00978$ & \multicolumn{2}{|l|}{ Bottle Set } & 12c- $11 \mathrm{LL}$ Glass, 11 1L Poly \\
\hline ISCO 3700 Sampler & Teledyne & 3700 & $198 \mathrm{H} 00978$ & \multicolumn{2}{|l|}{ Program } & Time / Multiplex no delay \\
\hline ISCO Avalanche Sampler & Teledyne & Avalanche & 210J00066 & \multicolumn{2}{|l|}{ Bottle Set } & $14950 \mathrm{~mL}$ Poly \\
\hline ISCO Avalanche Sampler & Teledyne & Avalanche & 210J00066 & \multicolumn{2}{|l|}{ Program } & 1-Part, 14 Bottles, $950 \mathrm{~mL}$ \\
\hline Pb-Acid Battery & Universal & $110 \mathrm{~A}-\mathrm{h}$ & MSGP-110-0311-07 & \multicolumn{2}{|l|}{ Voltage } & $>11.7 \mathrm{~V}$ \\
\hline Pb-Acid Battery & Universal & $110 \mathrm{~A}-\mathrm{h}$ & MSGP-110-0311-08 & \multicolumn{2}{|l|}{ Voltage } & $>11.7 \mathrm{~V}$ \\
\hline $\mathrm{Pb}$-Acid Battery & Universal & $110 \mathrm{~A}-\mathrm{h}$ & MSGP-110-0311-09 & \multicolumn{2}{|l|}{ Voltage } & $>11.7 \mathrm{~V}$ \\
\hline Solar Panel & SunWize & SW-S85P & \multicolumn{4}{|l|}{11004467} \\
\hline \multicolumn{5}{|c|}{ ISCO Sampler Tasks } & \multicolumn{2}{|c|}{ Note: If "No" provide correct information or explanation. } \\
\hline \multicolumn{5}{|c|}{ Deploy battery(ies) if not listed in equipment list above. Record serial numbers of battery(ies) installed. } & QYes $\square$ & No \\
\hline \multicolumn{5}{|c|}{ Deploy Avalanche sampler matching serial number listed in equipment list above for installation. } & aYes ם & No \\
\hline \multicolumn{5}{|c|}{ Deploy and install pH and Temperature Probe listed in equipment list above and probe saturation reservior. } & aYes $\square$ & No \\
\hline \multicolumn{5}{|c|}{$\begin{array}{l}\text { Refer to the wiring diagram in ENV-QP-0 } 045.0 \text { for the solar panel, battery configuration, and type of sampler } \\
\text { being installed. Has wiring been completed according to instructions? }\end{array}$} & aYes ם & No \\
\hline \multicolumn{5}{|c|}{ Is the sampler installed according to steps in ENV-QP-045.0? } & aYes $\square$ & No \\
\hline \multicolumn{5}{|l|}{ Is a Greenlee box used? } & aYes ם & No \\
\hline \multicolumn{5}{|c|}{ Are electrical connections secure? } & aYes a & No \\
\hline \multicolumn{5}{|c|}{ Record battery voltage(s). Voltage(s) $>11.7 \mathrm{~V} ?$} & aYes a & No \\
\hline \multicolumn{5}{|c|}{$\begin{array}{l}\text { Is the sampler physically configured for the types and number of bottles specified above (i.e., correct carousel, } \\
\text { base, arm)? }\end{array}$} & aYes $\square$ & No \\
\hline \multicolumn{5}{|c|}{ Is the sampler programmed correctly per ENV-QP-045.0 for the program / bottle set specified above? } & aYes a & No \\
\hline \multicolumn{5}{|c|}{ Does sampler pass the ISCO diagnostics test? } & aYes $\square$ & No \\
\hline \multicolumn{5}{|c|}{ Does sample tubing pass suction test? } & aYes a & No \\
\hline \multicolumn{5}{|c|}{ Is sampler ON upon departure? } & aYes 口 & No \\
\hline \multicolumn{5}{|c|}{ Does ISCO display either "Sampler Inhibited" or "Program Disabled"? } & वYes 口 & iNo \\
\hline \multicolumn{5}{|c|}{ Has the actuator switch been reset to "Latch"? } & aYes 口 & ino \\
\hline \multicolumn{5}{|c|}{ If any maintenance completed, check YES and describe. } & aYes $\square$ & No \\
\hline \multicolumn{5}{|c|}{ If any follow-on maintenance is required, check YES and describe. } & aYes $\square$ & No \\
\hline & & LA & SONNEL USE O: & als and date & & \\
\hline Accepted & & & & & & NV-RCRA Review \\
\hline
\end{tabular}

Page 1 of 1 for MSGP-31193 


\section{ATtaChMENT 2- Wiring DiagRam for AVAlanche SAMPLER}

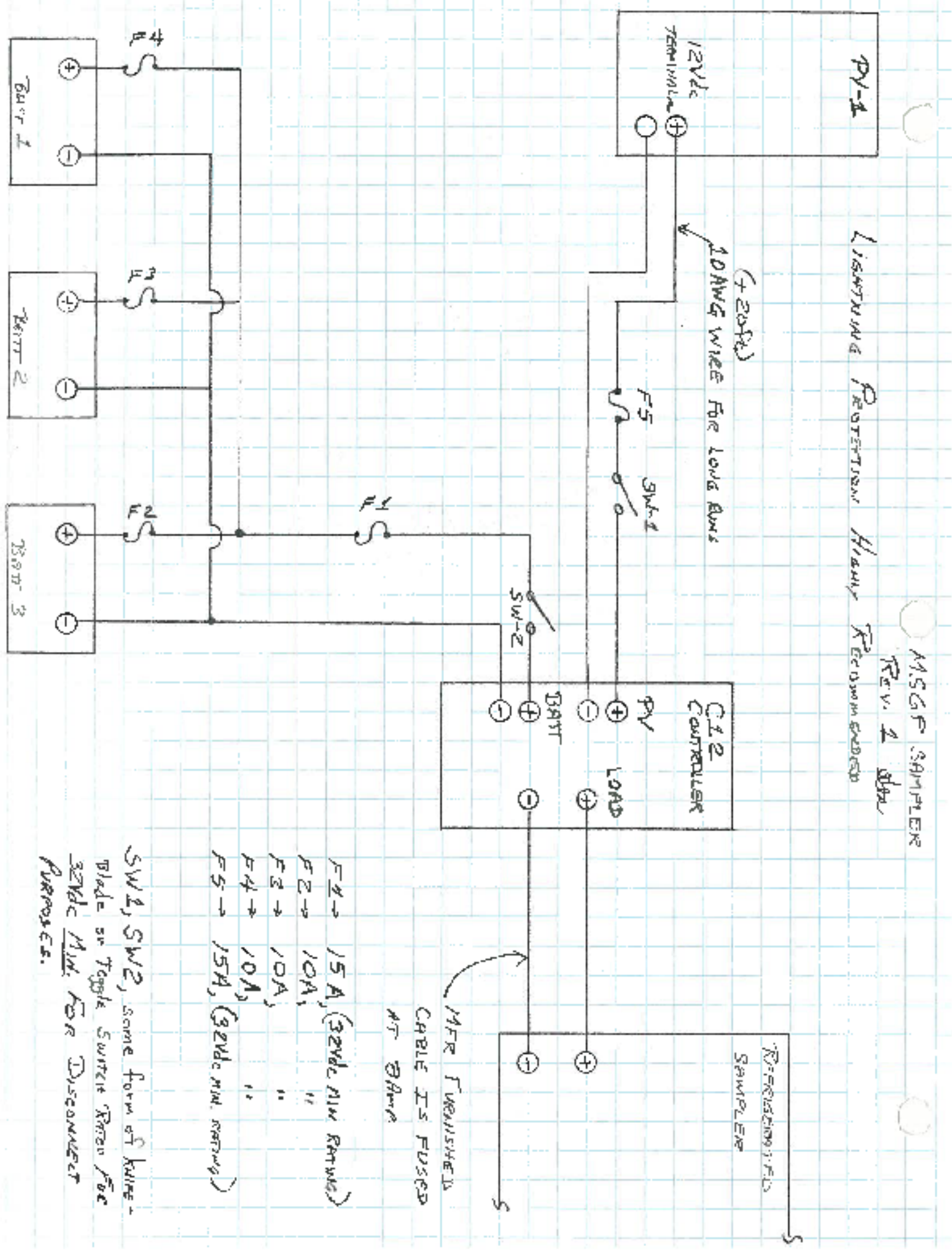


Attachment 3 - Battery Photovoltaic Connection Wiring
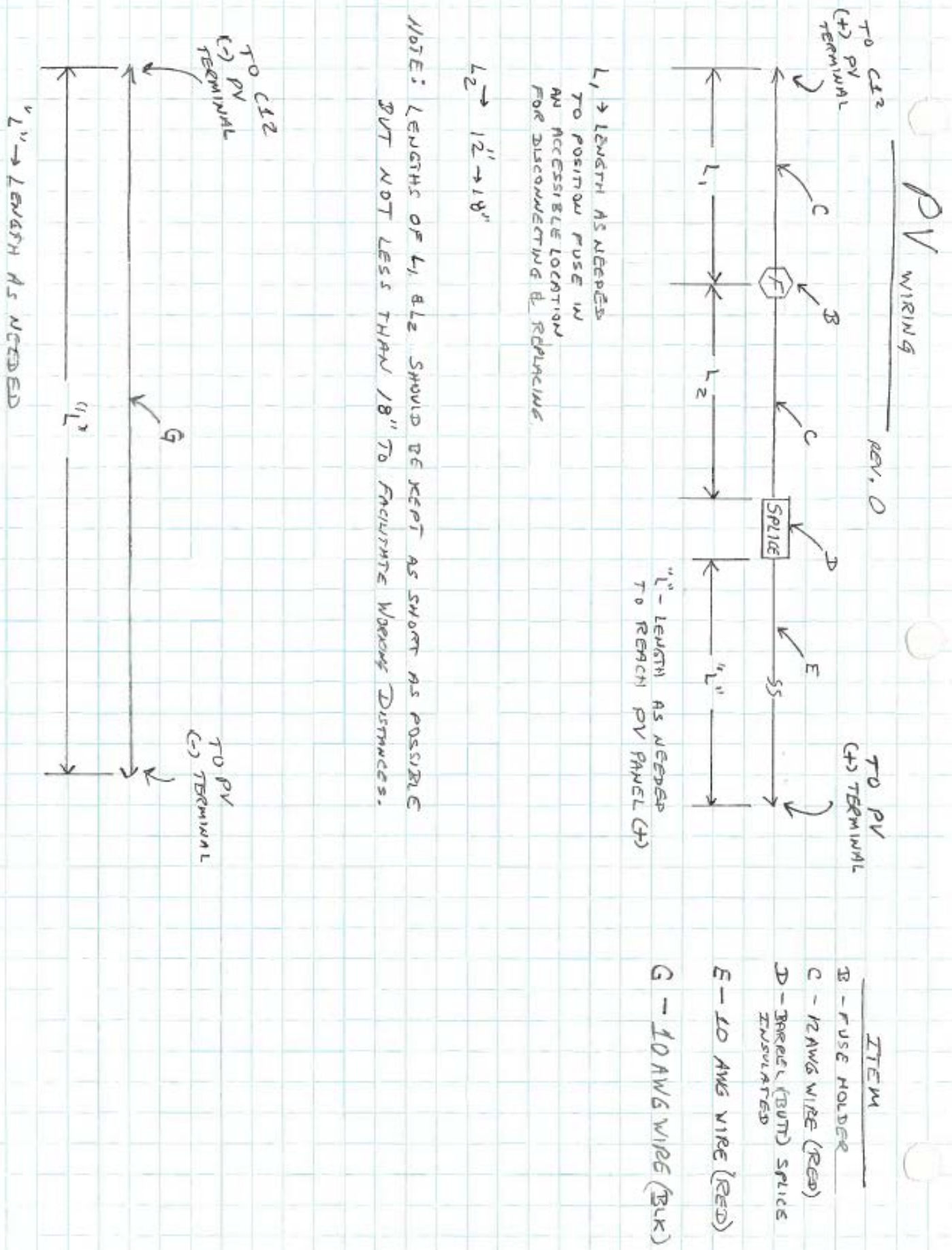


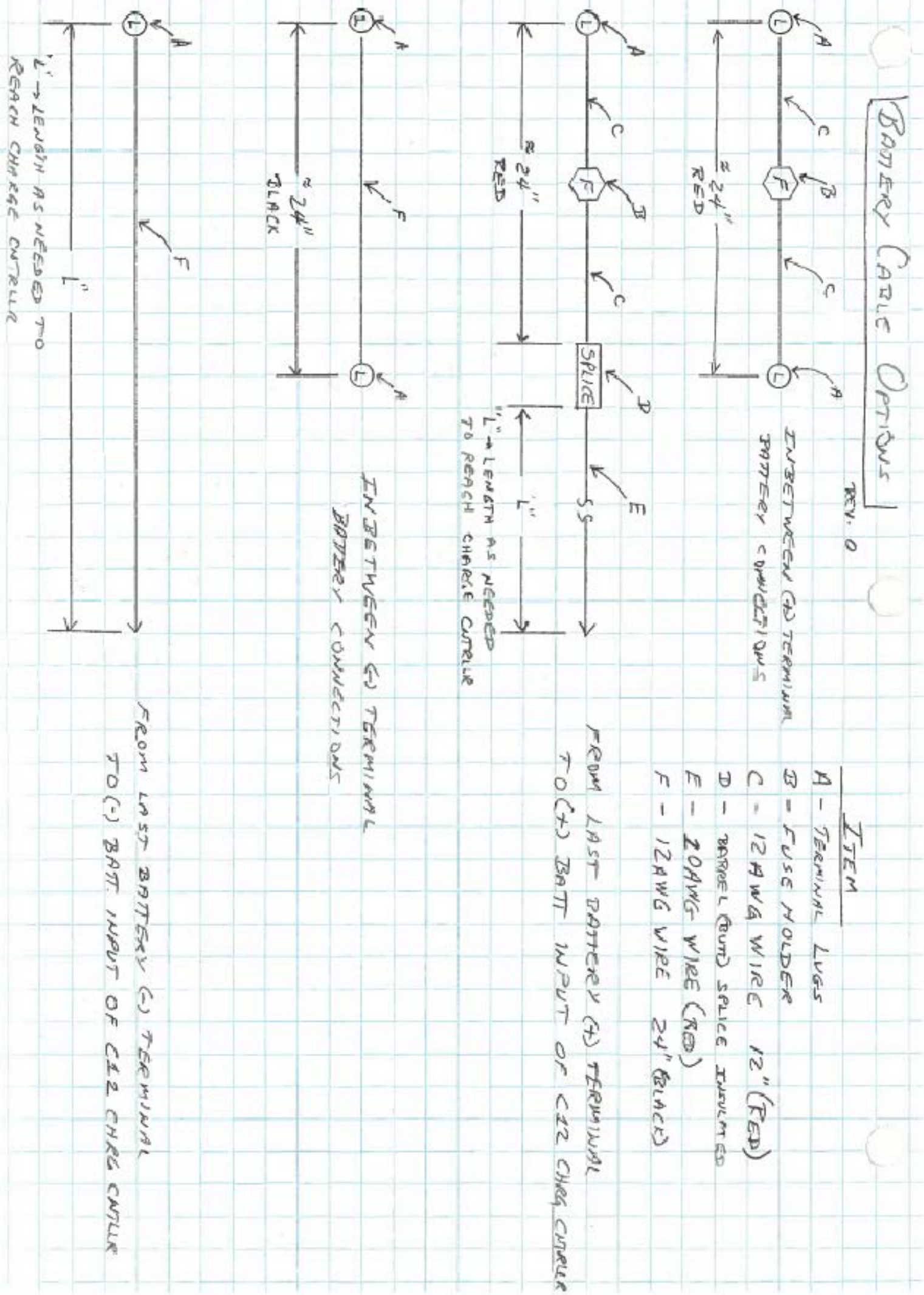




\section{ATTACHMENT 4 - ISCO 3700 CONFIGURATION SETTINGS}

\begin{tabular}{|c|c|c|c|}
\hline Parameter & $\begin{array}{c}\text { Storm sampling } \\
\text { with multiplex, } \\
\text { timed delay }\end{array}$ & $\begin{array}{c}\text { Time } \\
\text { sampling } \\
\text { with } \\
\text { multiplex }\end{array}$ & $\begin{array}{c}\text { Flow sampling with } \\
\text { multiplex }\end{array}$ \\
\hline Time/ Date & [Set to MST] & [Set to MST] & [Set to MST] \\
\hline Portable/ Refrig & Portable & Portable & Portable \\
\hline Bottles & 12 or 24 & 12 or 24 & 12 or 24 \\
\hline Bottle volume & $950 \mathrm{ml}$ & $1000 \mathrm{ml}$ & $1000 \mathrm{ml}$ \\
\hline Suction line diameter & $3 / 8$ inch & $3 / 8$ inch & $3 / 8$ inch \\
\hline Suction line type & Teflon & Teflon & Teflon \\
\hline Suction line length & $\mathrm{X}$ feet & $\mathrm{X}$ feet & $\mathrm{X}$ feet \\
\hline Liquid detector & Enable & Enable & Enable \\
\hline Rinse cycles & 0 & 1 & 1 \\
\hline Enter Head Manually & No & Yes & Yes \\
\hline Retry & 1 & 1 & 1 \\
\hline Program mode & Extended & Basic & Basic \\
\hline Load program & None & N/A & N/A \\
\hline Save program as & None & N/A & N/A \\
\hline Take sample at start time & No & N/A & N/A \\
\hline Take sample at time switch & No & N/A & N/A \\
\hline Enter intervals in minutes & 1 minute & N/A & N/A \\
\hline Calibrate sampler & Disable & Enable & Enable \\
\hline Sampling stop/resume & Disable & N/A & N/A \\
\hline Start time delay & 0 minutes & 0 minutes & 0 minutes \\
\hline Master slave & No & No & No \\
\hline Sample upon Disable & No & No & No \\
\hline Sample upon enable & No & Yes & Yes \\
\hline Reset sample interval & Yes & Yes & No \\
\hline Inhibit countdown & Yes & Yes & No \\
\hline Event marker & Pulse & Pulse & Pulse \\
\hline At the beginning of: & Purge & Purge & Purge \\
\hline Purge counts presample counts & 150 & 100 & 100 \\
\hline Post sample counts & 394 & 1000 & 1000 \\
\hline Pump counts & {$[500,000]$} & {$[500,000]$} & {$[500,000]$} \\
\hline Reset pump counter & No & No & No \\
\hline Pump counts to warning & 500,000 & 500,000 & 500,000 \\
\hline Program lock & Disable & Disable & Disable \\
\hline Sampler ID number is: & [leave blank] & [leave blank] & [leave blank] \\
\hline Run diagnostics & Yes & Yes & Yes \\
\hline Test distributor & Yes & Yes & Yes \\
\hline Re-initialize & No & No & No \\
\hline
\end{tabular}


ATtACHMENT 5 - ISCO 3700 Program SEQUENCE

\begin{tabular}{|l|c|}
\hline Parameter & $\begin{array}{l}\text { Storm sampling with } \\
\text { multiplex, timed delay }\end{array}$ \\
\hline $\begin{array}{l}\text { [Switch on } \\
\text { liquid actuator] }\end{array}$ & Set to “Latch” \\
\hline Paced sampling & Storm \\
\hline $\begin{array}{l}\text { Time Mode 1st } \\
\text { Bottle Group }\end{array}$ & X-minute delay \\
\hline $\begin{array}{l}\text { Timed Sample } \\
\text { Event }\end{array}$ & 1 \\
\hline $\begin{array}{l}\text { Bottle per } \\
\text { sample event }\end{array}$ & 11 or 23 \\
\hline \begin{tabular}{l} 
Sample volume \\
\hline $\begin{array}{l}\text { Bottles } \\
\text { available }\end{array}$
\end{tabular} \\
\hline $2^{\text {nd bottle group }}$ & T50 ml \\
\hline $\begin{array}{l}2^{\text {nd }} \text { group } \\
\text { samples }\end{array}$ & Time \\
\hline Sample interval & 1 minute delay \\
\hline $\begin{array}{l}\text { Bottles per } \\
\text { sampling event }\end{array}$ & 1 \\
\hline $\begin{array}{l}\text { Sample per } \\
\text { bottle }\end{array}$ & No \\
\hline Sample volume & 1 \\
\hline Enter start time \\
\hline $\begin{array}{l}\text { [Programming } \\
\text { complete] }\end{array}$
\end{tabular}

\begin{tabular}{|c|c|}
\hline Parameter & $\begin{array}{l}\text { Time sampling with } \\
\text { multiplex }\end{array}$ \\
\hline $\begin{array}{l}\text { [Switch on } \\
\text { liquid actuator] }\end{array}$ & Set to "Latch" \\
\hline Time/Flow & Time \\
\hline $\mathrm{Min} / \mathrm{Hr}$ & $1 \mathrm{~min}$ \\
\hline $\begin{array}{l}\text { Multiplex } \\
\text { samples }\end{array}$ & Yes \\
\hline $\begin{array}{l}\text { Bottles/sample } \\
\text { or } \\
\text { Samples/Bottle }\end{array}$ & Bottles/ sample \\
\hline $\begin{array}{l}\text { Number of } \\
\text { bottles }\end{array}$ & 12 or 24 \\
\hline Sample volume & $1000 \mathrm{ml}$ \\
\hline Suction head & $\mathrm{XX} \mathrm{Ft}$ \\
\hline $\begin{array}{l}\text { Calibrate sample } \\
\text { vol }\end{array}$ & No \\
\hline Enter start time & No \\
\hline
\end{tabular}


Installing, Setting Up, and Operating ISCO Samplers for the MSGP
No. ENV-CP-QP-045.1

Page 20 of 26

Effective Date: September 5, 2013

\section{Avalanche Program Sequence, cont.}

\begin{tabular}{|c|c|c|c|}
\hline Parameter & $\begin{array}{l}\text { Time sampling, } \\
\text { single bottle } \\
\text { composite sample }\end{array}$ & $\begin{array}{l}\text { Time sampling, } 1- \\
\text { part program }\end{array}$ & $\begin{array}{l}\text { Time sampling, } \\
\text { 2-part program }\end{array}$ \\
\hline \multicolumn{4}{|c|}{ Two-Part Program } \\
\hline Part A & N/A & N/A & Yes \\
\hline Assign bottle & N/A & N/A & $1-\mathrm{X}$ of 4 or 14 \\
\hline Pacing & N/A & N/A & Uniform time paced \\
\hline Time between samples & N/A & N/A & 1 minute \\
\hline Distribution & N/A & N/A & Sequential \\
\hline Bottles per event & N/A & N/A & 1 \\
\hline Switch bottles on & N/A & N/A & Number of samples \\
\hline Switch bottles every X samples & N/A & $\mathrm{N} /$ & 1 \\
\hline Run continuously & N/A & N/A & No \\
\hline Sample volumes dependent on flow? & N/A & N/A & No \\
\hline Sample volume & N/A & N/A & $\begin{array}{l}\text { Select between } 10 \mathrm{ml} \text { and full } \\
\text { container volume }\end{array}$ \\
\hline Enable programmed & N/A & N/A & None \\
\hline Once enabled, stay enabled & N/A & N/A & Yes \\
\hline Sample at enable & N/A & N/A & Yes \\
\hline Sample at disable & N/A & N/A & No \\
\hline Pauses and resumes & N/A & N/A & 0 \\
\hline Part B & N/A & N/A & Yes \\
\hline Pacing & N/A & & Uniform time paced \\
\hline Time between sample events & N/A & N/A & 1 minute \\
\hline Distribution & N/A & N/A & Sequential \\
\hline Bottles per event & N/A & N/A & 1 \\
\hline Switch bottles on & N/A & N/A & Number of samples \\
\hline Switch bottles every X samples & N/A & N/A & 1 \\
\hline Run continuously & N/A & N/A & No \\
\hline Sample volumes dependent on flow? & N/A & N/A & No \\
\hline Sample volume & $\mathrm{N} / \mathrm{A}$ & N/A & $\begin{array}{l}\text { Select between } 10 \mathrm{ml} \text { and full } \\
\text { container volume }\end{array}$ \\
\hline Enable programmed & N/A & N/A & No \\
\hline
\end{tabular}


Installing, Setting Up, and Operating ISCO Samplers for the MSGP
No. ENV-CP-QP-045.1

Page 21 of 26

Effective Date: September 5, 2013

\section{Avalanche Program Sequence, cont.}

\begin{tabular}{|c|c|c|c|}
\hline Parameter & $\begin{array}{l}\text { Time sampling, } \\
\text { single bottle } \\
\text { composite sample }\end{array}$ & $\begin{array}{l}\text { Time sampling, 1- } \\
\text { part program }\end{array}$ & $\begin{array}{l}\text { Time sampling, } \\
\text { 2-part program }\end{array}$ \\
\hline Once enabled, stay enabled & N/A & N/A & Yes \\
\hline Sample at disable & N/A & N/A & No \\
\hline Sample at enable & N/A & N/A & Yes \\
\hline Once enabled, stay enabled & N/A & N/A & Yes \\
\hline Pauses and resumes & N/A & N/A & 0 \\
\hline Delay to start & N/A & N/A & No \\
\hline \multicolumn{4}{|c|}{ Reset Sampler } \\
\hline Switch on liquid actuator & $\begin{array}{l}\text { Toggle to "Reset" } \\
\text { then back to "Latch" }\end{array}$ & $\begin{array}{l}\text { Toggle to "Reset" } \\
\text { then back to "Latch" }\end{array}$ & $\begin{array}{l}\text { Toggle to "Reset" } \\
\text { then back to } \\
\text { "Latch" }\end{array}$ \\
\hline Select Program name & Run & Run & Run \\
\hline
\end{tabular}



the MSGP

\section{ATTACHMENT 6 - LANL MSGP ISCO SAMPLER ACTIVATION FoRM 045-3}

ENV-QP-045.0

Target Date: 4/11/2011

Project: MSGP Sampler Activation Q1 2011

Reason: MSGP Sampler Activation 2011 Q1
LANL Multi-Sector General Permit ISCO Sampler Activation Form

Project ID: P-MSGP-830

Date:_ Tim

Name/Z\#

NamelZ\#:

Lead Signature:

"I confirm the information as recorded is true, accurate and complete."

\begin{tabular}{|llllll|}
\hline Equipment & Manufacturer & \multicolumn{1}{c}{ Model } & Serial No. & Specification & Configuration \\
\hline Actuator & ISCO & 1640 & & Actuator Height & \\
\hline ISCO Sampler 12C & Teledyne ISCO & ISCO 3700 & $198 \mathrm{H} 01553$ & Bottle Set & 12C-11L Poly \\
\hline ISCO Sampler 12C & Teledyne ISCO & ISCO 3700 & $198 \mathrm{H} 01553$ & Program & Time /Multiplex no delay \\
\hline Pb-Acid Battery & & & & Voltage & $>11.7 \mathrm{~V}$ \\
\hline
\end{tabular}

ISCO Sampler Tasks

Is the ISCO time delta $<1 \mathrm{~min}$ (MST)? If no, record adjustment.

Does sampler pass the ISCO diagnostics test?

Are electrical connections secure?

Record battery voltage(s). Is/are voltage(s) $>11.7 \mathrm{~V}$ ?

Does ISCO display either "Bottle 1 of $X$ afer 1 " or "Sampler Inhibited"?

Is bottle set described above installed?

Is recorded height of actuator above channel bottom correct?

If any maintenance completed, check Yes: Describe.

If any follow-on maintenance is required, check Yes: Describe.

Is sampler ON upon departure?

Note: If "No" provide correct information or explanation.

\section{$\square$ Yes $\square$ No}

$\square$ Yes $\square$ No

$\square$ Yes $\square$ No

$\square$ Yes $\square$ No

$\square$ Yes $\square$ No

$\square$ Yes $\square$ No

$\square$ Yes $\square$ No

$\square$ Yes $\square$ No

$\square$ Yes $\square$ No

$\square$ Yes aNo

Additional Notes: 
AtTaChMENT 7 - ISCO Avalanche Configuration SetTings

\section{ISCO Avalanche Configuration Settings}

\begin{tabular}{|l|c|}
\hline Parameter & All programs \\
\hline \multicolumn{2}{|c|}{ Maintenance } \\
\hline Set Clock & [Set to MST] \\
\hline Pump Tube Alarm & No \\
\hline Reset pump counter & Yes \\
\hline Run diagnostics & No \\
\hline Re-initialize & Liquid detect on \\
\hline \multicolumn{2}{|c|}{${ }^{\circ}$ Coftware } \\
\hline Liquid detector & Options minute \\
\hline Target temperature & Off \\
\hline Measurement interval & Yes \\
\hline Dual sampler mode & Every sample \\
\hline Bottle full detect & 3 second pulse at initial purge \\
\hline Event mark & 100 \\
\hline Duration & Dependent on head \\
\hline Presample purge counts & No \\
\hline Post sample counts & Alarm dial-outs only \\
\hline Periodic serial output & Disable \\
\hline Interrogator connector power & Manual option \\
\hline \multicolumn{2}{|c|}{ Manual Functions } \\
\hline Grab Sample & Manual option \\
\hline Calibrate volume & Manual option \\
\hline Operate pump & Manual option \\
\hline Move distributor & Other Settings/Misc \\
\hline Suction line diameter & \\
\hline Suction line type & \\
\hline Program lock & \\
\hline
\end{tabular}


Installing, Setting Up, and Operating ISCO Samplers for the MSGP
No. ENV-CP-QP-045.1

Page 24 of 26

Effective Date: September 5, 2013

\section{Attachment 8 - ISCo Avalanche Program Sequence}

\begin{tabular}{|c|c|c|c|}
\hline Parameter & $\begin{array}{l}\text { Time sampling, single } \\
\text { bottle composite } \\
\text { sample }\end{array}$ & $\begin{array}{l}\text { Time sampling, } 1 \text { - } \\
\text { part program }\end{array}$ & $\begin{array}{l}\text { Time sampling, } 2- \\
\text { part program }\end{array}$ \\
\hline \multicolumn{4}{|c|}{ Program } \\
\hline Program mode & Extended & Extended & Extended \\
\hline Program name & COMPOSITE & 1-PART (\# bottles) & 2-PART (\# bottles) \\
\hline Site description & Station number & Station number & Station number \\
\hline Units (length) & $\mathrm{ft}$ & $\mathrm{ft}$ & $\mathrm{ft}$ \\
\hline Units (temperature) & ${ }^{\circ} \mathrm{C}$ & ${ }^{\circ} \mathrm{C}$ & ${ }^{\circ} \mathrm{C}$ \\
\hline Data storage interval & 1 minute & 1 minute & 1 minute \\
\hline Number of bottles & 1 & 4 or 14 & 4 or 14 \\
\hline Bottle volume & $10000 \mathrm{ml}, 4000 \mathrm{ml}$ & $2000 \mathrm{ml}, 950 \mathrm{ml}$ & $2000 \mathrm{ml}, 950 \mathrm{ml}$ \\
\hline Suction line length & $\mathrm{X}$ feet & $\mathrm{X}$ feet & $\mathrm{X}$ feet \\
\hline Enter Head Manually & Yes & Yes & Yes \\
\hline Rinse cycles & 1 & 1 & 1 \\
\hline Retries & 1 & 1 & 1 \\
\hline \multicolumn{4}{|c|}{ One-Part Program } \\
\hline Pacing & Uniform time paced & Uniform time paced & $\mathrm{N} / \mathrm{A}$ \\
\hline Time between samples & Every one minute & Every one minute & N/A \\
\hline Composite & 1 sample & $\mathrm{N} / \mathrm{A}$ & N/A \\
\hline Run continuously & No & N/A & N/A \\
\hline Take X sample(s) & 1 & N/A & $\mathrm{N} / \mathrm{A}$ \\
\hline Distribution & N/A & Sequential & N/A \\
\hline Volume & $\begin{array}{l}\text { Select between } 10 \mathrm{ml} \\
\text { and full container } \\
\text { volume }\end{array}$ & $\begin{array}{l}\text { Select between } 10 \mathrm{ml} \\
\text { and full container } \\
\text { volume }\end{array}$ & $\mathrm{N} / \mathrm{A}$ \\
\hline $\begin{array}{l}\text { Sample volumes dependent on } \\
\text { flow }\end{array}$ & No & No & N/A \\
\hline Enable programmed & None & None & N/A \\
\hline Once enabled, stay enabled & Yes & Yes & N/A \\
\hline Sample at enable & Yes & Yes & N/A \\
\hline Sample at disable & No & No & N/A \\
\hline Pauses and resumes & 0 & 0 & N/A \\
\hline Delay to start & No & No & N/A \\
\hline
\end{tabular}




\section{ATTACHMENT 9 - LANL MSGP ISCO SAMPLER WINTER SHUT-DOWN FORM 045-5}

ENV-QP-045.0

Outfall: 3-PSP-5 : E121.9-ISCO 12

Target Date: 11/30/2011

Project: MSGP ISCO Sampler Winter Shutdown

Reason: MSGP Sampler Winter Shutdown 2011
LANL Multi-Sector General Permit ISCO Sampler Winter Shutdown Form

Project ID: P-MSGP-833

Date:
Name/Z\#:_
Name/Z\#:_ Time:
Lead Signature:
"I confirm the information as recorded is true, accurate and complete."

Verify the equipment list below. Make corrections as required and fill in missing information (e.g., serial numbers).

\begin{tabular}{|llllll|}
\hline Equipment & Manufacturer & Model & Serial No. & Specification & Configuration \\
\hline Actuator & ISCO & 1640 & & Actuator Height & \\
\hline ISCO Sampler 12C & Teledyne ISCO & ISCO 3700 & 198H01553 & Bottle Set & 12c-11L Poly \\
\hline ISCO Sampler 12C & Teledyne ISCO & ISCO 3700 & $198 \mathrm{H} 01553$ & Program & Time /Multiplex no delay \\
Pb-Acid Battery & & & Voltage & $>11.7 \mathrm{~V}$ \\
\hline
\end{tabular}

\begin{tabular}{|c|c|c|}
\hline ISCO Sampler Tasks & \multicolumn{2}{|c|}{ Note: If "No" provide correct information or explanation. } \\
\hline Turn ISCO unit "OFF." & $\square$ Yes $\square$ No & \\
\hline Place caps securely on bottles in the sample carousel. & $\square$ Yes $\square$ No & \\
\hline Verify equipment list above. & $\square$ Yes $\square$ No & \\
\hline \multicolumn{3}{|l|}{ ISC0 3700 Sampler Units } \\
\hline $\begin{array}{l}\text { Disconnect and remove battery. Transport battery to MSGP stockroom for } \\
\text { maintenance and storage. }\end{array}$ & $\square$ Yes $\square N_{0}$ & \\
\hline Place battery cables securely inside Greenlee box or ISCO casing. & $\square$ Yes $\square$ No & \\
\hline Pull up actuator and tubing and store in Greenlee box or ISCO casing. & $\square$ Yes $\square$ No & \\
\hline \multicolumn{3}{|l|}{ Avalanche ISCO Sampler Units: } \\
\hline $\begin{array}{l}\text { Disconnect and remove batteries. Transport batteries to MSGP stockroom for } \\
\text { maintenance and storage. }\end{array}$ & $\square$ Yes $\square$ No & \\
\hline Place battery cables securely inside Greenlee box or ISCO casing. & $\square$ Yes $\square$ No & \\
\hline Pull up actuator and tubing and store inside Greenlee box or ISCO casing. & $\square$ Yes $\square$ No & \\
\hline Transport Avalanche sampler to MSGP stockroom for maintenance and storage. & $\square$ Yes $\square$ No & \\
\hline
\end{tabular}

\begin{tabular}{lll}
\hline & \\
\hline & LANL PERSONNEL USE ONLY (Initials and dates) & ENV-RCRA Review \\
\hline Accepted & Tech QC & C \\
\hline
\end{tabular}



the MSGP

\section{ATTACHMENT 10 - LANL MSGP ISCO SAMPLER DECOMMISSION FORM 045-6}

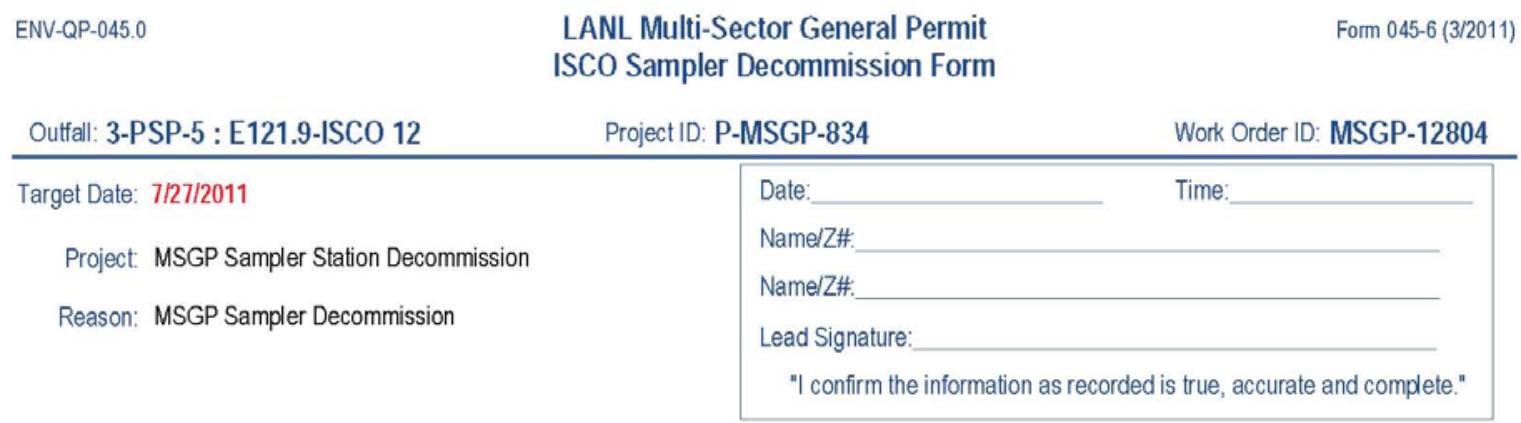

Verify the equipment list below. Make corrections as required and fill in missing information (e.g., serial numbers).

\begin{tabular}{|llllll|}
\hline Equipment & Manufacturer & Model & Serial No. & Specification & Configuration \\
\hline Actuator & ISCO & 1640 & & Actuator Height & \\
\hline ISCO Sampler 12C & Teledyne ISCO & ISCO 3700 & $198 \mathrm{H} 01553$ & Bottle Set & 12C-11L Poly \\
\hline ISCO Sampler 12C & Teledyne ISCO & ISCO 3700 & $198 \mathrm{H} 01553$ & Program & Time /Multiplex no delay \\
Pb-Acid Battery & & & & Voltage & $>11.7 \mathrm{~V}$ \\
\hline
\end{tabular}

\begin{tabular}{|c|c|c|}
\hline ISCO Sampler Tasks & Note: If "No" p & vide correct information or explanation. \\
\hline Is equipment list above complete and accurate? & aYes ano & \\
\hline Turn sampler "OFF." Remove bottles from carousel. & aYes ano & \\
\hline Disconnect and remove battery(ies), solar panel, and cables (as applicable). & $\square$ Yes $\square$ No & \\
\hline Pull up actuator and tubing. Disconnect from sampler unit. & $\square$ Yes $\square$ No & \\
\hline Uninstall Greenlee box, as applicable. & $\square$ Yes $\square$ No & \\
\hline $\begin{array}{l}\text { Transport all removed equipment to the MSGP stockroom for maintenance and } \\
\text { storage. }\end{array}$ & $\square$ Yes $\square$ No & \\
\hline
\end{tabular}

Additional Notes: 


\section{ENV-RCRA-QP-047.1}

Effective Date: May 14, 2013

Next Review Date: April 14, 2015

\section{Environment, Safety, Health Directorate}

\section{Environmental Protection - Water Quality and RCRA Quality Procedure}

\section{Inspecting Storm Water Runoff Samplers and Retrieving Samples for the MSGP}

Reviewers:

\begin{tabular}{|l|l|l|l|}
\hline Name: & $\begin{array}{l}\text { Organization: } \\
\text { ENV-QPMO QA } \\
\text { Specialist }\end{array}$ & $\begin{array}{l}\text { Signature: } \\
\text { Signature on file }\end{array}$ & $\begin{array}{l}\text { Date: } \\
3 / 7 / 13\end{array}$ \\
\hline
\end{tabular}

Derivative Classifier: $\triangle$ Unclassified $\square$ DUSA

\begin{tabular}{|l|l|l|l|}
\hline $\begin{array}{l}\text { Name: } \\
\text { Anthony Grieggs }\end{array}$ & $\begin{array}{l}\text { Organization: } \\
\text { ENV-RCRA }\end{array}$ & $\begin{array}{l}\text { Signature: } \\
\text { Signature on file }\end{array}$ & $\begin{array}{l}\text { Date: } \\
5 / 14 / 13\end{array}$ \\
\hline
\end{tabular}

Approval Signatures:

\begin{tabular}{|c|c|c|c|}
\hline $\begin{array}{l}\text { Subject Matter Expert: } \\
\text { Holly Wheeler }\end{array}$ & $\begin{array}{l}\text { Organization: } \\
\text { ENV-RCRA }\end{array}$ & $\begin{array}{l}\text { Signature: } \\
\text { Signature on file }\end{array}$ & $\begin{array}{l}\text { Date: } \\
\text { 3/20/13 }\end{array}$ \\
\hline $\begin{array}{l}\text { Responsible Line Manager: } \\
\text { Terrill Lemke }\end{array}$ & $\begin{array}{l}\text { Organization: } \\
\text { ENV-RCRA Team Lead }\end{array}$ & $\begin{array}{l}\text { Signature: } \\
\text { Signature on file }\end{array}$ & $\begin{array}{l}\text { Date: } \\
5 / 3 / 13\end{array}$ \\
\hline $\begin{array}{l}\text { Responsible Line Manager: } \\
\text { Anthony Grieggs }\end{array}$ & $\begin{array}{l}\text { Organization: } \\
\text { ENV-RCRA Group Leader }\end{array}$ & $\begin{array}{l}\text { Signature: } \\
\text { Signature on file }\end{array}$ & $\begin{array}{l}\text { Date: } \\
5 / 14 / 13\end{array}$ \\
\hline
\end{tabular}

CONTROLLED DOCUMENT

This copy is uncontrolled. The controlled copy can be found on the ENV Division Web page.

Users are responsible for ensuring they work to the latest approved version. 


\section{History of Revisions}

\begin{tabular}{|c|c|l|}
\hline $\begin{array}{c}\text { Document Number } \\
\text { [nclude revision number, } \\
\text { beginning with Revision 0] }\end{array}$ & $\begin{array}{c}\text { Effective Date } \\
\text { [Document Control Coordinator } \\
\text { inserts effective date] }\end{array}$ & $\begin{array}{c}\text { Description of Changes } \\
\text { [List specific changes made since the previous revision] }\end{array}$ \\
\hline 0 & $03 / 11$ & New Document. \\
\hline 1 & $02 / 13$ & Annual Review and Revision \\
\hline
\end{tabular}




\section{Table of Contents}

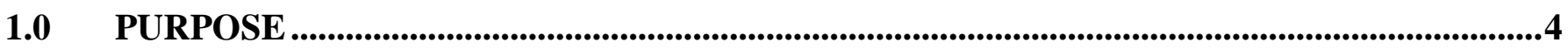

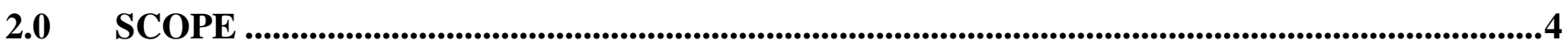

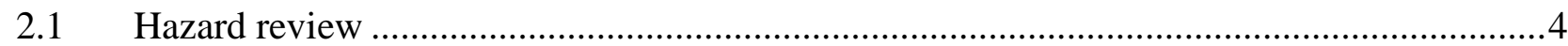

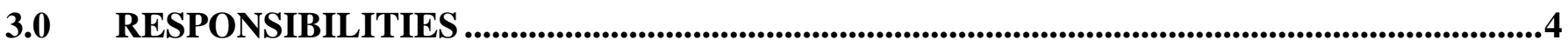

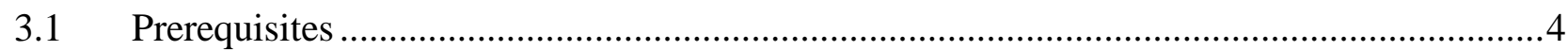

4.0 DOCUMENT CONTROL/RECORDS MANAGEMENT ........................................................4

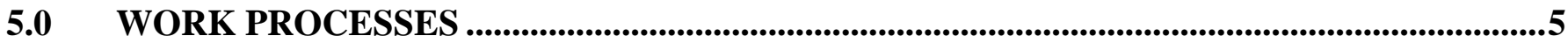

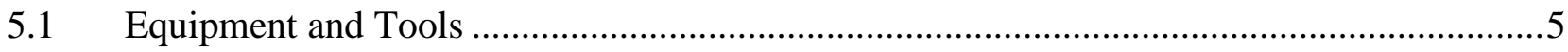

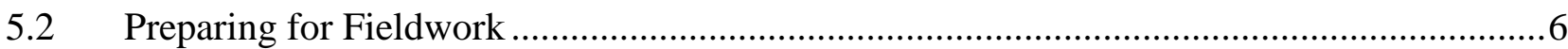

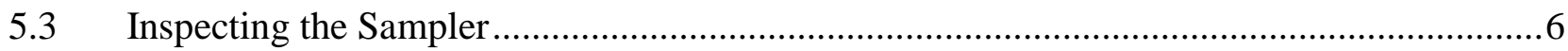

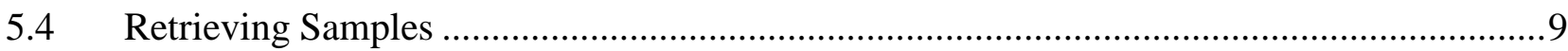

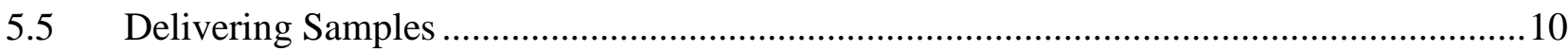

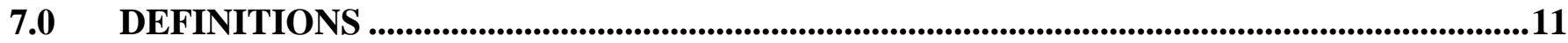

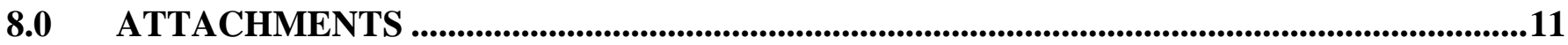

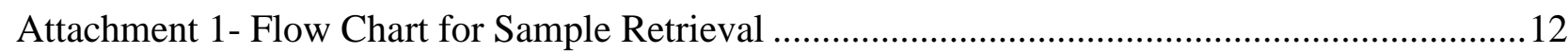

Attachment 2- ISCO Sampler Inspection and Sample Retrieval Form..........................................13 


\subsection{PURPOSE}

This procedure describes the process for inspecting ISCO storm water runoff samplers and retrieving storm water runoff samples from all locations where the Los Alamos National Laboratory (LANL) conducts storm water sampling activities for the Multi-Sector General Permit (MSGP).

\subsection{SCOPE}

This procedure applies to the ENV-RCRA technical staff and subcontractor personnel conducting activities at single stage stations used for monitoring under the MSGP.

\subsection{HAZARD REVIEW}

Hazards in the work described in this procedure are controlled thorough site specific IWDs. The hazard level of the activities in this procedure is moderate.

\subsection{RESPONSIBILITIES}

The following personnel require training before implementing this procedure:

- ENV-RCRA technical staff and subcontract or other personnel who inspect storm water samplers and retrieve storm water samples for the MSGP.

The training method for this procedure is "self-study" (reading). For ENV-RCRA staff, this is documented in accordance with ENV-DO-QP-115, Personnel Training. Other participating groups may require training documentation pursuant to local procedures.

Actions specified within this procedure, unless proceeded with "should” or "may," are to be considered mandatory (i.e., “shall”, “will”, “must”).

\subsection{PREREQUISITES}

Personnel performing this procedure will be familiar with the most current versions of the following procedures and operation manuals:

- ENV-RCRA MSGP Sampling and Analysis Plan for the current monitoring year.

- Manual for Teledyne ISCO Sampler model 3700.

- Manual for Teledyne ISCO Avalanche sampler

\subsection{DOCUMENT CONTROL/RECORDS MANAGEMENT}

The following records are generated as a result of this procedure and are maintained in accordance with ENV-DO-QP-110, Records Management Program with the originals on file at ENV-RCRA offices:

- Completed work order for ISCO Sampler Inspection and Sample Retrieval and Collection forms (example in Attachment 2). 


\subsection{WORK PROCESSES}

ISCO samplers are used to collect storm water runoff for Multi-Sector General Permit (MSGP) Program stations. ISCOs are designed to automatically collect water when the water surface is high enough to trigger the actuator and fill the sample bottles. Field personnel are required to inspect the sampling station while retrieving water samples and at other intervals determined by the project or as directed by work orders issued by project personnel.

A LANL Project Leader is the primary person with responsibility for the steps in this procedure. ENVRCRA personnel will be appointed with responsibility for a subset of sampling stations.

If subsequent rain events occur before all sampler locations have been visited after the first rain event, finish the route to collect the first-event samples (safety permitting).

Inspections may be discontinued during periods or conditions that make sites dangerous for worker safety or prevent personnel from safely accessing sites (e.g., weather-related events such as flash floods, flooding, lightning, wildfires, hail, icy roads, deep snow, and LANL operations such as shots or burns at the OBOD sites).

\subsection{EQUIPMENT AND TOOLS}

Ensure the following equipment is available in the field vehicle:

- Copy of this procedure

- Copy of the Integrated Work Documents (IWDs)

- Charged spare battery(ies)

- Battery voltage tester

- Spare tubing (pump, suction, discharge types, sampler specific)

- Spare/replacement sample bottles (glass and poly)

- Shovel

- Wooden stakes

- Plastic wire "zip" ties

- Cell phone (only government cell phones with batteries removed are allowed in secure areas)

- Appropriate tools in tool box

- Issued Work Orders and associated forms

- Necessary access and station keys

- Coolers with ice or Blue Ice®

- Expanded Site Field Maps

- Nitrile gloves

- Paper Towels

- Marker pen (permanent, waterproof)

- Ball point pen

- Zip lock bags

- Safety glasses with side shields

- Chain of custody seals

- Sturdy hiking boots or steel toed shoes with soles that grip 


\subsection{Preparing For FieldWORK}

Once the work orders have been approved, the following steps should be followed to prepare for fieldwork:

\begin{tabular}{|c|l|}
\hline Step & Action \\
\hline 1 & $\begin{array}{l}\text { Receipt of a work order indicates that sampler inspections have been approved by the LANL Project } \\
\text { Leader. Schedule work to be completed by the target date appearing on the work order(s). }\end{array}$ \\
\hline 2 & $\begin{array}{l}\text { Distribute work order(s) to field personnel. A sample Work Order form is provided in Attachment 1, } \\
\text { ISCO Sampler Inspection and Sample Retrieval Form. }\end{array}$ \\
\hline 3 & $\begin{array}{l}\text { Inform (e.g., by e-mail) the Field Operations designee, as specified in the IWD, of the schedule for } \\
\text { sampler inspection work and locations up to a week (preferred) before but no later than the day } \\
\text { before (for minor changes) to be added to the appropriate plan of the day. }\end{array}$ \\
\hline 4 & $\begin{array}{l}\text { For work at sites operated by Weapons Facility Operations or Nuclear Environmental Sites, notify } \\
\text { the appropriate access control before traveling to those sites. The IWD Part II (2101 Form) addresses } \\
\text { specific requirements and training for these sites. }\end{array}$ \\
\hline 5 & $\begin{array}{l}\text { Obtain any necessary additional paperwork before conducting this work, including IWD's, and } \\
\text { excavation permits (if necessary). }\end{array}$ \\
\hline 7 & $\begin{array}{l}\text { Gather the required equipment (see section above) for the work to be done. } \\
\text { Set watch(s) to the precise Mountain Standard (not daylight saving) Time. This can be done by } \\
\text { logging on to the time page at www.time.gov (or click on the clock icon on the lab's internal home } \\
\text { page). When at the site, the clock time on the ISCO sampler needs to be verified. Clocks must be set } \\
\text { to Mountain Standard Time at all times, with no daylight saving time adjustment. }\end{array}$ \\
\hline
\end{tabular}

\subsection{INSPECTING THE SAMPLER}

The following table details the inspection requirements for the sampler:

\begin{tabular}{|c|l|}
\hline Step & Action \\
\hline 1 & $\begin{array}{l}\text { If conditions prevent a sampler inspection, document the conditions on the work order and notify the } \\
\text { Project Lead or designee within 24 hours. Multiple attempts can be documented on the original } \\
\text { inspection work order up to the target date. After the target date, return work order to the ENV- } \\
\text { RCRA Storm Water Data Stewards Team for reissuance (if necessary). }\end{array}$ \\
\hline 2 & $\begin{array}{l}\text { Item 1: on work order (see example in attachment 2): Enter the date and time inspection and water } \\
\text { retrieval is performed and the name(s) and Z number(s) of the field personnel performing the work in } \\
\text { the upper right corner of the work order. }\end{array}$ \\
\hline 3 & $\begin{array}{l}\text { Item 2: Verify and document the sampler is ON and its condition upon arrival by checking the "Yes" } \\
\text { or "No" box. Explain any non-functional status in third column. }\end{array}$ \\
\hline 4 & $\begin{array}{l}\text { Item 3: Verify and document the ISCO programming displays by checking the "Yes" or "No" box in } \\
\text { second column. } \\
\text { For ISCO 3700 samplers = "Sampler Inhibited” }\end{array}$ \\
\hline
\end{tabular}




\begin{tabular}{|c|c|}
\hline & $\begin{array}{l}\text { OR } \\
\text { • For Avalanche samplers = "Program Disabled" } \\
\text { If No, repair or describe (e.g., "Done X samples", or "sampler off”, etc). If more space is needed, } \\
\text { continue notes in the “Additional Notes" section at the bottom of the page. }\end{array}$ \\
\hline 5 & Don nitrile gloves and safety glasses. \\
\hline 6 & Remove the lid from the sampler. \\
\hline 7 & $\begin{array}{l}\text { Item 4: If water was collected, check "Yes" and collect the water according to the steps in } \\
\text { "Retrieving Storm Water Runoff Samples" below. } \\
\text { Note: Complete the required MSGP Visual Assessment form to document the water appearance } \\
\text { (foam, sheen, etc.). Ensure this form is submitted to the appropriate MSGP project personnel (see } \\
\text { item 11). } \\
\text { If No, describe (e.g., "no water collected", "sampler off") in the third column; check "No" for Item } 4 .\end{array}$ \\
\hline 8 & $\begin{array}{l}\text { Item 5: Verify and document the sampler is set to the correct Mountain Standard Time +/- no more } \\
\text { than } 1 \text { minute by checking the "Yes" or "No" box in the second column. If the sampler is set } \\
\text { incorrectly, reprogram for the correct Mountain Standard Time. Describe the work performed and } \\
\text { correction applied (e.g., "ISCO clock was X minutes slow") in the third column. }\end{array}$ \\
\hline 9 & $\begin{array}{l}\text { Item 6: Review the Sampling Results report and document any error messages from the sampler } \\
\text { display by checking the "Yes" or "No" box. If a message is displayed, record the message in the } \\
\text { "Comments" section on page } 2 \text { next to the sample bottle being filled when the problem occurred. } \\
\text { If there is no indication of flow and the sampler triggered due to a non-flow event (e.g., animal, } \\
\text { tumbleweed), indicate this in the third column. }\end{array}$ \\
\hline 10 & $\begin{array}{l}\text { Item 7: For the Avalanche sampler equipped with an ISCO } 701 \mathrm{pH} \text { Module, record the } \mathrm{pH} \\
\text { measurement taken at the time of Bottle } 1 \text { from the Combined Results report. }\end{array}$ \\
\hline 11 & $\begin{array}{l}\text { Item 8: For Avalanche samplers only, and if water was collected, check "Yes" and record the } \\
\text { refrigerator temperature }\left({ }^{\circ} \mathrm{C}\right) \text { upon arrival. If no water was collected, or unable to review temperature, } \\
\text { check "No" and describe in column } 3 \text { (e.g., no sample, dead battery). }\end{array}$ \\
\hline 12 & $\begin{array}{l}\text { Item 9: Verify and document whether sample volumes were retrieved by checking the "Yes" or "No" } \\
\text { box. Refer to the volume retrieval instructions on page } 2 \text { of work order. } \\
\text { Record the volume retrieved in third column. }\end{array}$ \\
\hline 13 & $\begin{array}{l}\text { Item 10: If water was collected, perform a visual assessment of the water using the MSGP program } \\
\text { visual assessment form (not included in this procedure). Document whether a visual assessment was } \\
\text { performed by checking the "Yes" or "No" box. }\end{array}$ \\
\hline 14 & $\begin{array}{l}\text { Item 11: Verify and document sample station equipment, model, serial number, actuator height, } \\
\text { sampler program, and bottle configuration match the header on the work order page } 1 \text { by checking } \\
\text { the "Yes" or "No". If they do not match the data on the work order, ensure you are at the correct } \\
\text { location. If the location is verified, check "No" and update inaccurate information. }\end{array}$ \\
\hline 15 & $\begin{array}{l}\text { Item 12: Verify and document power supply function. Use the voltage tester to check the voltage of } \\
\text { the battery and record the voltage. Check "Yes" or "No" to indicate if battery voltage is acceptable } \\
\text { ( } \geq 11.7 \text { V for non-floating charged batteries at ISCO } 3700 \text { samplers and } \geq 11.0 \text { for floating-charged } \\
\text { batteries at Avalanche samplers as described in ENV-RCRA-QP-045). }\end{array}$ \\
\hline 16 & $\begin{array}{l}\text { Item 13: Verify and document the sampler passed the diagnostics test by checking the "Yes" or "No" } \\
\text { box. Directions for running the diagnostics test is provided in ENV-RCRA-QP-045) }\end{array}$ \\
\hline
\end{tabular}




\begin{tabular}{|c|c|}
\hline & $\begin{array}{l}\text { If maintenance is necessary and can be performed at the time of inspection, perform the work and } \\
\text { describe in third column. } \\
\text { If maintenance cannot be completed at the time of inspection, then describe the condition and work } \\
\text { needed in the third column. }\end{array}$ \\
\hline 17 & $\begin{array}{l}\text { Item 14: Verify and document the sample tubing passed a suction test by checking the "Yes" or "No" } \\
\text { box. } \\
\text { Check the condition of sample tubing and vent tubing. If maintenance (e.g., clearing the tube, } \\
\text { replacing the tube) is necessary and can be performed at the time of inspection, perform the work and } \\
\text { describe in third column. } \\
\text { If maintenance cannot be completed at the time of inspection, then describe the condition and work } \\
\text { needed in third column. }\end{array}$ \\
\hline 18 & $\begin{array}{l}\text { Item 15: Verify all cable and electrical connections are attached and secure by checking the "Yes" or } \\
\text { "No" box. } \\
\text { If maintenance (e.g., tightening connection, replacing cables) is necessary and can be performed at } \\
\text { the time of inspection, describe the work performed in the third column. If more space is needed, } \\
\text { continue notes in the "Additional Notes" section. } \\
\text { If maintenance cannot be completed at the time of inspection, then describe the condition and work } \\
\text { needed in the third column. }\end{array}$ \\
\hline 19 & $\begin{array}{l}\text { Item 16: Verify and document sampler is ON prior to departing the site by checking the "Yes" or } \\
\text { "No" box. If the sampler is not on, document the reason. }\end{array}$ \\
\hline 20 & $\begin{array}{l}\text { Item 17: If the sampler tripped and requires reset of the sampling program, reset the actuator by } \\
\text { toggling the switch to "Reset" then back to "Latch" } \\
\text { • Verify and document the ISCO programming displays the following by checking the "Yes" or } \\
\text { "No" box in column 2, page } 1 . \\
\text { - ISCO } 3700 \text { stand-alone samplers = "Sampler Inhibited" } \\
\text { OR } \\
\text { - Avalanche samplers = "Program Disabled" } \\
\text { If an error occurs, reconfigure the sampler (see ENV-RCRA-QP-045 for settings) }\end{array}$ \\
\hline 21 & $\begin{array}{l}\text { Item 18: Verify and document any maintenance completed while on site. Describe the work } \\
\text { performed or indicate "none completed” in third column. } \\
\text { Maintenance items may include (but are not limited to) battery replacement, tubing clearing or } \\
\text { replacement, site clearing, securing electrical connections, or sampler diagnostics or repair. }\end{array}$ \\
\hline 22 & $\begin{array}{l}\text { Item 19: Verify and document any follow-on maintenance needed that could not be completed while } \\
\text { on site. Describe the needed maintenance in the third column. If more space is needed, continue } \\
\text { notes in the "Additional Notes" section. A separate work order for the station maintenance will be } \\
\text { issued. } \\
\text { If no follow-on maintenance is required, indicate "none required” in third column. } \\
\text { Maintenance items may include (but are not limited to) battery replacement, tubing clearing or } \\
\text { replacement, site clearing, securing electrical connections, or sampler diagnostics or repair. }\end{array}$ \\
\hline 23 & $\begin{array}{l}\text { Item 20: If no storm water samples were collected by the sampler, draw a line through page } 2 \text { of the } \\
\text { work order, initial, and date. } \\
\text { If storm water samples were collected by the sampler, skip to "Retrieving storm water runoff }\end{array}$ \\
\hline
\end{tabular}




\begin{tabular}{|c|l|}
\hline & samples” section. \\
\hline 24 & Replace and secure the sampler lid and secure the sampler shelter (if sampler is in a shelter). \\
\hline 25 & $\begin{array}{l}\text { Review the completed work order(s) for accuracy and completeness and sign and date "Review by } \\
\text { Signature” line on page 2 of work order. }\end{array}$ \\
\hline 26 & $\begin{array}{l}\text { Item 21: Review the work order(s) for accuracy and certify that the information submitted is "true, } \\
\text { accurate, and complete” by signing and dating "Lead Signature" line on page 1. }\end{array}$ \\
\hline 27 & $\begin{array}{l}\text { Return completed original work orders to the Project Leader the same day following completion of } \\
\text { field work. If original work orders must remain with collected samples, return photocopies of } \\
\text { incomplete work orders to the Project Leader the same day field work is completed. Stamp or write } \\
\text { "Copy” on the work order returned. }\end{array}$ \\
\hline
\end{tabular}

\subsection{RETRIEVING SAMPLES}

The following steps should be followed when retrieving samples:

\begin{tabular}{|c|c|}
\hline Step & Action \\
\hline 1 & Don nitrile gloves and safety glasses. \\
\hline 2 & $\begin{array}{l}\text { See flow chart in Attachment } 1 . \\
\text { Item 5: Refer to the "Earliest Sample Collect Date” on work order. } \\
\text { If the "Earliest Sample Collect Date” field is empty OR the ISCO sample collection date is ON or } \\
\text { AFTER that date, samples may be retrieved per the volume requirements given on the work order. } \\
\text { Continue with next step below. } \\
\text { If the ISCO sample collection date is BEFORE the "Earliest Sample Collect Date": } \\
\text { - Indicate "non-qualifying storm event" in Item } 5 \text { third column. } \\
\text { - Discard the collected sample water on the ground. } \\
\text { - Skip to Step } 10 \text { below. }\end{array}$ \\
\hline 3 & Remove filled and partially-filled bottles from the carousel. \\
\hline 4 & $\begin{array}{l}\text { Add up the total volume of water collected and check that the collected volume of water in glass and } \\
\text { poly matches the required volume in the header of the work order page } 2 \text {. The volume of water } \\
\text { required to complete a sample set may vary. Retrieval of partial volume is allowed as long as the } \\
\text { minimum specified volume is met. } \\
\text { For "Partial Volume Retrieval Allowed, Minimum Volume NOT Met" samplers: } \\
\text { If sample volume was sufficient, continue with next step } 5 \text { below. } \\
\text { If sample volume was NOT sufficient: } \\
\text { - Record the date and time the ISCO collected water in each glass and poly bottle by the } \\
\text { position number in the carousel in Item } 21 \text {. } \\
\text { - Record total volume retrieved as "0" in Item } 22 \text {. } \\
\text { - Skip to step } 11 \text { below. } \\
\text { For "Partial Volume Retrieval Allowed, Minimum Volume Met" samplers: } \\
\text { - Record the date and time the ISCO collected water in each glass and poly bottle by the } \\
\text { position number in the carousel on Item } 21 \text { of page } 2\end{array}$ \\
\hline
\end{tabular}




\begin{tabular}{|c|c|}
\hline & $\begin{array}{l}\text { - Record the specific ISCO displayed message for each bottle, if present, in the "Comments" } \\
\text { column on Item } 21 . \\
\text { - Record total volume retrieved in Item } 22 . \\
\text { - Skip to step } 11 \text { below. }\end{array}$ \\
\hline 5 & For samples retrieved, place lids onto the sample bottles with storm water. \\
\hline 6 & $\begin{array}{l}\text { Write the date and time collected, Station Number, and the corresponding carousel number on each } \\
\text { retrieved sample bottle. Obtain the sample collection date and time from the ISCO sampler. }\end{array}$ \\
\hline 7 & $\begin{array}{l}\text { Item 21: Record the date and time the ISCO collected water in each glass and poly bottle by the } \\
\text { position number in the carousel. } \\
\text { Record the specific ISCO displayed message for each bottle, if present, in the "Comments" column. }\end{array}$ \\
\hline 8 & $\begin{array}{l}\text { Item 22: } \\
\text { For "Partial Volume Retrieval Allowed, Minimum Volume NOT Met” samplers, if sample volume } \\
\text { was NOT sufficient, record the total volume retrieved as “0” and discard sample water on ground. } \\
\text { For "Partial Volume Retrieval Allowed" samplers, record the total volume retrieved. }\end{array}$ \\
\hline 9 & Place retrieved sample bottles in a cooler with blue ice (or equivalent). \\
\hline 10 & Return any excess water or collected volume that exceeded the amount required to the ground. \\
\hline 11 & $\begin{array}{l}\text { Install new sample bottles in the carousel for the next sampling event. The number and type of bottles } \\
\text { may vary. Ensure bottles match the configuration specified on page } 1 \text { of the work order. }\end{array}$ \\
\hline 12 & Item 23: Document any additional notes or site information in the "Additional Notes" section. \\
\hline 13 & Return to steps in "Inspecting the Sampler" above. \\
\hline
\end{tabular}

\subsection{DeliVering SAMPLES}

The following steps should be followed when delivering samples:

\begin{tabular}{|c|l|}
\hline Step & \multicolumn{1}{c|}{ Action } \\
\hline 1 & $\begin{array}{l}\text { If samples were collected, deliver the samples, and completed, reviewed, and signed work order to } \\
\text { the Storm Water Program Laboratory. }\end{array}$ \\
\hline 2 & $\begin{array}{l}\text { Item 25: Relinquish samples to MSGP personnel by signing "Relinquished By" or if self processed, } \\
\text { refer to ENV-RCRA-QP-048, Processing MSGP Storm Water Samples. }\end{array}$ \\
\hline 3 & $\begin{array}{l}\text { Place samples in the refrigerators in the laboratory within the basement of TA-59-1 and lock the } \\
\text { refrigerator to prevent tampering. }\end{array}$ \\
\hline
\end{tabular}

\subsection{REFERENCES}

None 


\subsection{DEFINITIONS}

None

\subsection{ATTACHMENTS}

Attachment 1- Flow Chart for Sample Retrieval

Attachment 2- ISCO Sampler Inspection and Sample Retrieval Form

By requesting credit for this required reading I acknowledge that I have read and understand the contents of this document and I will follow and meet the requirements in this document unless it

Click to Acknowledge 


\section{ATtachment 1- Flow Chart fOR SAMPLe Retrieval}

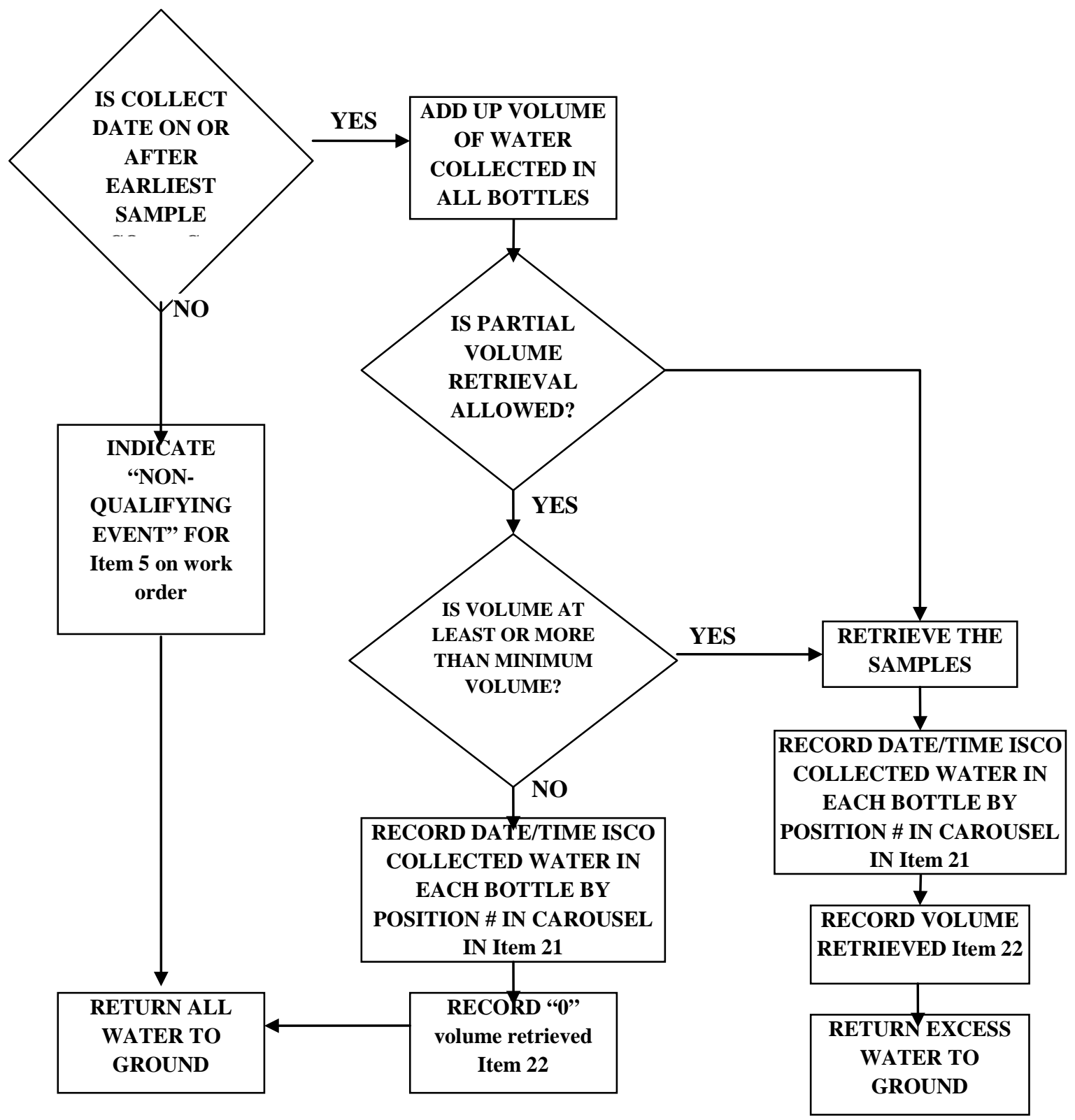




\section{ATTACHMENT 2- ISCO SAMPLER INSPECTION AND SAMPLE RETRIEVAL FORM}

ENV-QP-047.0

Outfall: 3-MFS-1 : 03-0038W

Target Date: 9/30/2012

Project: MSGP Q3 Sampler Inspection \& Retrieval

Reason: MSGP ISCO Sampler Inspection - Sample Retrieval

Earliest Sample Collect Date: 8/1/2012

\begin{tabular}{|c|c|c|c|c|}
\hline Manufacturer & Model & \multicolumn{2}{|l|}{ Serial No. } & Configuration \\
\hline Actuator & 1640 & \multicolumn{2}{|l|}{ 210J01655 } & 2" \\
\hline ISCO 3700 Sampler & 3700 & $209 \mathrm{H} 01284$ & Bottle Set & 12c- $11 \mathrm{~L}$ Glass, $111 \mathrm{~L}$ Poly \\
\hline ISCO 3700 Sampler & 3700 & $209 \mathrm{H} 01284$ & Program & Storm / Multiplex 10 min delay \\
\hline $\mathrm{Pb}$-Acid Battery & 110 A-h & MSGP-110-0310-06 & Voltage & $>11.7 \mathrm{~V}$ \\
\hline \multicolumn{3}{|c|}{ ISCO Sampler Inspection Tasks } & \multicolumn{2}{|c|}{ Note: If "No", provide explanation and/or correct information. } \\
\hline \multicolumn{3}{|l|}{ ON ARRIVAL } & & \\
\hline \multicolumn{3}{|c|}{ Is sampler $\mathrm{ON}$ and functioning properly upon arrival? } & $\square$ Yes $\square$ No & \\
\hline \multicolumn{3}{|c|}{ Does ISCO display either "Sampler Inhibited" or "Program Disabled"? } & $\square$ Yes aNo & \\
\hline \multicolumn{3}{|c|}{ Is ISCO time delta < $1 \mathrm{~min}$ (MST)? If NO, record adjustment. } & $\square$ Yes $\square$ No & \\
\hline \multicolumn{3}{|l|}{ Is any water collected? If YES, complete Page 2.} & $\square$ Yes $\square$ No & \\
\hline \multicolumn{3}{|c|}{$\begin{array}{l}\text { Does the Sampling Results report indicate any error messages(s)? If YES, record error } \\
\text { message(s) in the applicable Bottle Comment field on Page } 2 .\end{array}$} & $\square$ Yes $\square$ No & \\
\hline \multicolumn{3}{|c|}{ Is any water collected on or after the "Earliest Sample Collect Date"? } & $\square$ Yes $\square$ No & \\
\hline \multicolumn{3}{|l|}{ Was sample volume retrieved? } & $\square$ Yes $\square$ No & \\
\hline \multicolumn{3}{|c|}{$\begin{array}{l}\text { Was a Visual Assessment performed? If YES, complete the MSGP Visual Assessment } \\
\text { form (ENV-RCRA-QP-064.0 Att. 1). }\end{array}$} & $\square$ Yes $\square$ No & \\
\hline \multicolumn{5}{|l|}{ ON DEPARTURE } \\
\hline \multicolumn{3}{|c|}{ Is the equipment information listed above, including specifications, correct? } & $\square$ Yes a No & \\
\hline \multicolumn{3}{|l|}{ Are electrical connections secure? } & $\square$ Yes $\square$ No & \\
\hline \multicolumn{3}{|l|}{ Record battery voltage(s). Voltage(s) $>11.7 \mathrm{~V} ?$} & $\square$ Yes $\square$ No & \\
\hline \multicolumn{3}{|l|}{ Does the ISCO diagnostics test pass? } & $\square$ Yes $\square$ No & \\
\hline \multicolumn{3}{|l|}{ Does sample tubing pass suction test? } & $\square$ Yes $\square$ No & \\
\hline \multicolumn{3}{|l|}{ Is sampler ON upon departure? } & aYes aNo & \\
\hline \multicolumn{3}{|l|}{ Has the actuator swtich been reset to "Latch"? } & aYes aNo & \\
\hline \multicolumn{3}{|c|}{ Does ISCO display either "Sampler Inhibited" or "Program Disabled"? } & $\square$ Yes aNo & \\
\hline \multicolumn{3}{|c|}{ If any maintenance completed during inspection, check YES and describe. } & aYes a No & \\
\hline \multicolumn{3}{|c|}{ If any follow-on maintenance is required, check YES and describe. } & $\square$ Yes $\square$ No & \\
\hline
\end{tabular}

Work Order ID: MSGP-26090

Project ID: P-MSGP-2046

Time:

Name/Z\#:

Name/Z\#.

Lead Signature:

"I confirm the information as recorded is true, accurate and complete." ISCO Sampler Inspection and Sample Retrieval Form

Form 047-1 (3/2011)

Date: Time:


Inspecting Storm Water Runoff Samplers and Retrieving Samples for the MSGP
No. ENV-RCRA-QP-047.1

Page 14 of 14

Effective Date: May 14, 2013
ENV-QP-047.0
LANL Multi-Sector General Permit ISCO Sampler Inspection and Sample Retrieval Form

Project ID: P-MSGP-2046

Work Order ID: MSGP-26090

Complete if sample bottles contain water OR to to record ISCO message

\begin{tabular}{|lcl|}
\hline \multicolumn{3}{|c|}{ Sample Volume Requirements } \\
\hline Bottle Type: Poly or Gass bottles & Minimum Volume (L): 0.5 & Maximum Volume (L): 1 \\
\hline
\end{tabular}

\begin{tabular}{|c|cc|cc|c|c|}
\hline Botte \# & \multicolumn{2}{|c|}{ Botte Type } & \multicolumn{2}{|c|}{ Date: } & Time (MST): & Comments \\
\hline 1 & $\square P$ & $\square G$ & $/$ & 12012 & & \\
\hline 2 & $\square P$ & $\square G$ & $/$ & 12012 & & \\
\hline 3 & $\square P$ & $\square G$ & $/$ & 12012 & & \\
\hline 4 & $\square P$ & $\square G$ & $/$ & 12012 & & \\
\hline 5 & $\square P$ & $\square G$ & $/$ & 12012 & & \\
\hline 6 & $\square P$ & $\square G$ & $/$ & 12012 & & \\
\hline 7 & $\square P$ & $\square G$ & $/$ & 12012 & & \\
\hline 8 & $\square P$ & $\square G$ & $/$ & 12012 & & \\
\hline 9 & $\square P$ & $\square G$ & $/$ & 12012 & & \\
\hline 10 & $\square P$ & $\square G$ & $/$ & 12012 & & \\
\hline 11 & $\square P$ & $\square G$ & $/$ & 12012 & & \\
\hline 12 & $\square P$ & $\square G$ & $/$ & 12012 & & \\
\hline 13 & $\square P$ & $\square G$ & $/$ & 12012 & & \\
\hline 14 & $\square P$ & $\square G$ & $/$ & 12012 & & \\
\hline
\end{tabular}

Total Volume Retrieved (liters): $\quad$ Poly Glass

\begin{tabular}{|l|l|l|l|l|l|}
\hline Relinquished by Signature & Date: & Time: & Received by Signature & Date: & Time: \\
\hline & & & & & \\
\hline & & & & & \\
\hline & & & & & \\
\hline
\end{tabular}

Additional Notes: 


\section{ENV-CP-QP-048.1}

Effective Date: September 5, 2013
Next Review Date: August 5, 2015

\section{Environment, Safety, Health Directorate}

\section{Environmental Protection - Compliance Programs Quality Procedure}

\section{Processing MSGP Stormwater Samples}

Reviewers:

\begin{tabular}{|l|l|l|l|}
\hline Name: & $\begin{array}{l}\text { Organization: } \\
\text { Melanie Lamb }\end{array}$ & $\begin{array}{l}\text { Signature: } \\
\text { SpeSH-OIO, QA } \\
\text { Specialist }\end{array}$ & Signature on file \\
\hline
\end{tabular}

Derivative Classifier: $\square$ Unclassified $\triangle$ DUSA__ENVPRO

\begin{tabular}{|l|l|l|l|}
\hline $\begin{array}{l}\text { Name: } \\
\text { Ellena Martinez }\end{array}$ & $\begin{array}{l}\text { Organization: } \\
\text { ADESH-OIO }\end{array}$ & $\begin{array}{l}\text { Signature: } \\
\text { Signature on file }\end{array}$ & $\begin{array}{l}\text { Date: } \\
8 / 29 / 13\end{array}$ \\
\hline
\end{tabular}

Approval Signatures:

\begin{tabular}{|l|l|l|l|}
\hline $\begin{array}{l}\text { Subject Matter Expert: } \\
\text { Holly Wheeler }\end{array}$ & $\begin{array}{l}\text { Organization: } \\
\text { ENV-CP }\end{array}$ & $\begin{array}{l}\text { Signature: } \\
\text { Signature on file }\end{array}$ & $\begin{array}{l}\text { Date: } \\
8 / 29 / 13\end{array}$ \\
\hline $\begin{array}{l}\text { Responsible Line Manager: } \\
\text { Michael Saladen }\end{array}$ & $\begin{array}{l}\text { Organization: } \\
\text { ENV-CP Team Lead }\end{array}$ & $\begin{array}{l}\text { Signature: } \\
\text { Signature on file }\end{array}$ & $\begin{array}{l}\text { Date: } \\
8 / 29 / 13\end{array}$ \\
\hline $\begin{array}{l}\text { Responsible Line Manager: } \\
\text { Anthony Grieggs }\end{array}$ & $\begin{array}{l}\text { Organization: } \\
\text { ENV-CP Group Leader }\end{array}$ & $\begin{array}{l}\text { Signature: } \\
\text { Signature on file }\end{array}$ & $\begin{array}{l}\text { Date: } \\
9 / 5 / 13\end{array}$ \\
\hline
\end{tabular}

CONTROLLED DOCUMENT

This copy is uncontrolled. The controlled copy can be found on the ENV Division Web page. Users are responsible for ensuring they work to the latest approved version. 


\section{History of Revisions}

\begin{tabular}{|c|c|l|}
\hline $\begin{array}{c}\text { Document Number } \\
\text { [Include revision number, } \\
\text { beginning with Revision 0] }\end{array}$ & $\begin{array}{c}\text { Effective Date } \\
\text { [Document Control Coordinator } \\
\text { inserts effective date] }\end{array}$ & $\begin{array}{c}\text { Description of Changes } \\
\text { [List specific changes made since the previous revision] }\end{array}$ \\
\hline 0 & $07 / 11$ & New Document. \\
\hline 1 & $09 / 13$ & $\begin{array}{l}\text { Annual Review and Revision, new format, } \\
\text { process change, and new organization name. }\end{array}$ \\
\hline
\end{tabular}




\section{Table of Contents}

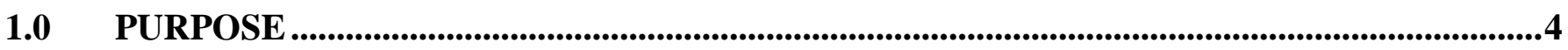

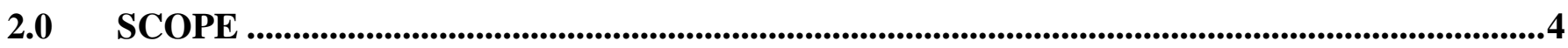

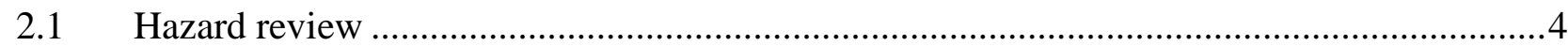

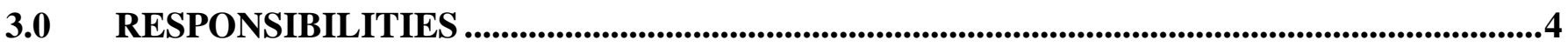

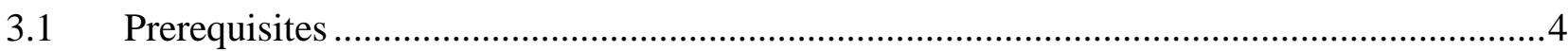

4.0 DOCUMENT CONTROL/RECORDS MANAGEMENT ........................................................4

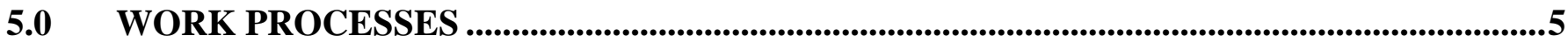

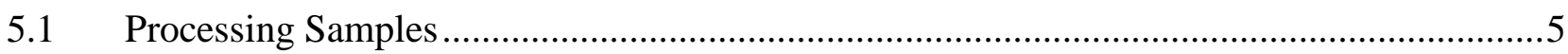

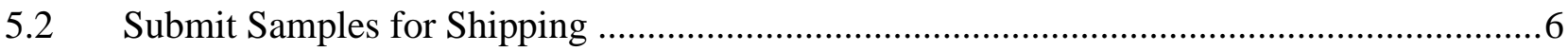

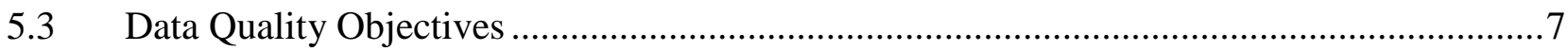

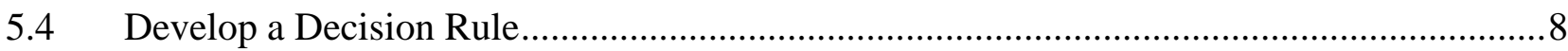

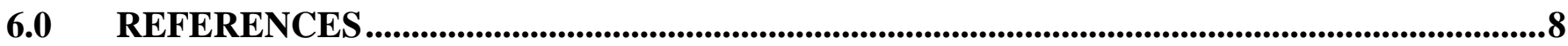

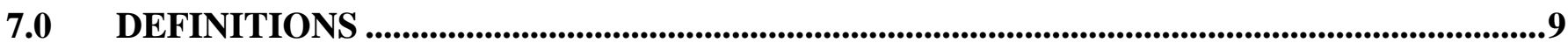

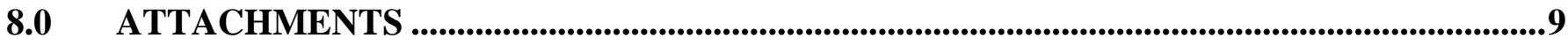

Attachment 1- Sample Collection Log/Field Chain of Custody Form ............................................10

Attachment 2- Sample Container Labels .......................................................................................11 


\subsection{PURPOSE}

This procedure describes the process for preserving stormwater samples for shipment to an offsite analytical laboratory.

\subsection{SCOPE}

This procedure applies to all LANL personnel and subcontractors who conduct chemical preservation of stormwater samples either in the stormwater Laboratory located in TA-59-1 or out in the field.

\subsection{HAZARD REVIEW}

The work specified in this procedure is conducted in accordance with the following integrated work documents: IWDs 007, 007a, 007b, 007c, 007d, 007e, 007f, 008, 010, 010b, and 010c. Each IWD is associated with a specific FOD depending on location of sample activity. The hazard level of this procedure is MODERATE.

\subsection{RESPONSIBILITIES}

The following personnel require training before implementing this procedure:

- ENV-CP staff and contract personnel who process Stormwater samples for the MSGP.

The training method for this procedure is "self-study" (reading). For ENV-CP staff, this is documented in accordance with ENV-DO-QP-115, Personnel Training. Other participating groups may require training documentation pursuant to local procedures.

Actions specified within this procedure, unless proceeded with "should” or "may," are to be considered mandatory (i.e., "shall”, “will”, “must”).

\subsection{Prerequisites}

In addition to training to this procedure, the following training and data systems access is also required prior to performing this procedure:

- Personnel performing this procedure will be familiar with the most recent version of the ENV-CP MSGP Sampling and Analysis Plan.

- WES-EDA-QP-219, Sample Control and Field Documentation

- ENV-RCRA-QP-022, MSGP Stormwater Corrective Action

\subsection{DOCUMENT CONTROL/RECORDS MANAGEMENT}

The following records are generated as a result of this procedure and are maintained in accordance with ENV-DO-QP-110, Records Management Program with the originals on file at ENV-CP records room:

- Copy of the Sample Collection Log/Field Chain of Custody Form 


\subsection{WORK PROCESSES}

The Environmental Protection Agency (EPA) issued the National Pollutant Discharge Elimination System (NPDES) Multi-Sector General Permit (MSGP) on September 29, 2008. The MSGP requires LANL to monitor stormwater runoff from industrial sites relative to potential pollutants.

Stormwater samples are collected in the field either from refrigerated Avalanche ${ }^{\mathrm{TM}}$ or ISCO $3700^{\mathrm{TM}}$ automated samplers. Chemical preservation is conducted in the Stormwater Laboratory (in TA-59-01) immediately following sample collection or in the field.

A LANL Project Leader is the primary person responsible for the steps in this procedure.

The following equipment and tools are required:

- Copy of this procedure

- Copy of Integrated Work Documents (IWDs)

- Copy of the ENV-CP MSGP Sampling and Analysis Plan

- Work Orders (if issued)

- Sample Collection Log/Field Chain of Custody Form (provided by the Sample Management Office (SMO)

- Sample containers

- Sample container labels

- Necessary keys

- Safety glasses with side shields

- Nitrile gloves

- Leather gloves or equivalent work gloves

- Glass and poly bottles appropriate for samples to be collected at the site (reference sampling plan)

- Preservative

- Lids for bottles

- Teflon tubing for intake

- Tygon tubing for exhaust

\subsection{Processing SAMPLeS}

\begin{tabular}{|c|l|}
\hline Step & \multicolumn{1}{c|}{ Action } \\
\hline 1 & $\begin{array}{l}\text { Obtain required Sample Collection Log/Field Chain of Custody Form(s) from the SMO. Collect } \\
\text { samples and deliver them to the Water Laboratory in coolers containing Blue Ice }{ }^{\circledR} .\end{array}$ \\
\hline 2 & $\begin{array}{l}\text { Double check to make sure the Location ID on the Sample Collection Log/Field Chain of Custody } \\
\text { Form matches the sample collection station number. If preservation beyond ice is indicated on } \\
\text { the form, obtain required preservative and sample containers for identified volume if different } \\
\text { from the amount of sample collected. } \\
\text { NOTE: Specific preservatives and required sample volumes are listed on the Sample Collection } \\
\text { Log/Field Chain of Custody Form. }\end{array}$ \\
\hline 3 & $\begin{array}{l}\text { Process only one sample set (i.e., samples from one site) at a time. } \\
\text { NOTE: Sample collection bottles are the bottles used to collect the sample in the field. Sample } \\
\text { containers are containers/bottles that the original sample is transferred to after processing. These }\end{array}$ \\
\hline
\end{tabular}




\begin{tabular}{|c|l|}
\hline & $\begin{array}{l}\text { containers are transferred to the Sample Management Office for shipment to the analytical } \\
\text { laboratory. }\end{array}$ \\
\hline 4 & Affix appropriate label to sample container. \\
\hline 5 & Split up samples into appropriate sample containers. \\
\hline 6 & $\begin{array}{l}\text { Verify that the sample ID number on the container label matches the sample ID number on the } \\
\text { Sample Collection Log/Filed Chain of Custody Form }\end{array}$ \\
\hline
\end{tabular}

The following steps should be followed when preserving samples:

\begin{tabular}{|c|c|}
\hline Step & Action \\
\hline 1 & $\begin{array}{l}\text { IMPORTANT: Preservation entails the addition of acid or base to a sample. Acids used include } \\
\text { hydrochloric acid }(\mathrm{HCl}) \text {, nitric acid }\left(\mathrm{HNO}_{3}\right) \text {, and sulfuric acid }\left(\mathrm{H}_{2} \mathrm{SO}_{4}\right) \text {. Bases used in } \\
\text { preservation include sodium hydroxide }(\mathrm{NaOH}) \text {. These are all strong acids and bases that can } \\
\text { cause severe burns. Extreme care should be taken when using these acids and bases. }\end{array}$ \\
\hline 2 & $\begin{array}{l}\text { Preserve (add acid or base) samples according to the requirements on the Sample Collection } \\
\text { Log/Field Chain of Custody Form. } \\
\text { NOTE: Make sure the pre-measured preservative labeled size matches the sample container size. } \\
\text { If you only have one size pre-measured preservative that does not match the sample container size } \\
\text { you may need to use more than one. For example, if you have a } 1 \text { liter sample container and } 500 \\
\text { ml pre-measured preservative vial, you would need to add two preservative vials to the sample } \\
\text { container. }\end{array}$ \\
\hline 3 & $\begin{array}{l}\text { Mark each container after preservative has been added to designate that the process has taken } \\
\text { place. }\end{array}$ \\
\hline 4 & $\begin{array}{l}\text { Securely affix lid to sample container. Clean and dry the exterior of sample container, ensure lid } \\
\text { is on securely, and check sample container for leakage and breakage. }\end{array}$ \\
\hline 5 & Apply chain-of-custody tape around the mouth and lid of the bottle. \\
\hline 6 & Carefully place sample containers in the cooler and package sample containers with Blue Ice ${ }^{\circledR}$. \\
\hline
\end{tabular}

\subsection{SUBMIT SAMPLES FOR SHIPPING}

Submit samples with original Sample Collection Log/Field Chain of Custody Form to SMO for shipping to an offsite analytical laboratory. The person delivering the sample to SMO relinquishes the sample by signing, dating and recording the time under "Relinquished By." The SMO accepts samples by signing, dating and recording the time under "Received By." Obtain a signed copy of the Sample Collection Log/Field Chain of Custody Form from the SMO. Make a copy of the Sample Collection Log/Field Chain of Custody Form and provide it to the MSGP Project Leader.

Every attempt will be made to minimize the amount of waste generated. Field personnel will diligently collect only the volumes identified as the minimum or maximum allowable identified on Form. If there is not enough liquid collected to meet these volumes, the Stormwater will be 
discharged at the sampler location. Extra Stormwater collected will also be discharged at the sampler location. If waste is generated, contact the Waste Management Coordinator for TA-59-1 or the MSGP Project Leader.

\subsection{Data Quality OBJECTIVES}

The 2008 MSGP permit requires quarterly and annual Stormwater monitoring to determine if pollutants from industrial activities are migrating into U.S. waters. The permit specifies benchmark parameters that are indicators of potential pollutant sources. In addition, certain impaired water quality standards must be met. Factors which must be considered in making the decision of whether pollutant sources are present or water quality standards have been exceeded are analytical data quality and whether the collected sample is representative of the permitted discharge.

To determine whether the Laboratory is in compliance with all relevant laws and regulations, sample collection and analytical data must be evaluated by the a representatives of ADESH, Operations and Integration Office (OIO) by requesting formal focused validation and/or by the MSGP Project Leader.

Sample collection and submission is conducted under the guidelines found in:

- NPDES Permit Tracking No. NMR05GB21

- 40 CFR Subpart 136 Guidelines establishing the test procedure for the analysis of pollutants.

Sample analysis must use EPA approved methods as set forth in the NPDES permit.

Benchmark levels are identified in the 2008 MSGP. Outfall and sampling locations are identified in the individual facility Stormwater Pollution Prevention Plans (SWPPP).

Monitoring frequencies and reporting requirements are specified in the 2008 MSGP.

Sampling location(s):

Annual, quarterly, and visual assessments shall be conducted in compliance with the monitoring requirements specified in the 2008 MSGP. As specified previously, specific sampling location(s) are identified in the facility specific SWPPP.

Grab Sample:

A minimum of one grab sample from a discharge resulting from a measurable storm event is required. Samples must be collected within the first 30 minutes of a measurable storm event. If that is not possible, the sample must be collected as soon as practicable after the first 30 minutes and documentation must be kept with the SWPPP explaining why it was not possible to take samples within the required time frame. In the case of snowmelt, samples must be taken during a period with a measurable discharge. 
NOTE: A grab sample is defined as a single sample collected at a NPDES outfall (using approved EPA methods) at a particular time that represents the composition of the stormwater at that time and place.

\section{Representative Sampling:}

Samples and measurements taken for the purpose of monitoring shall be representative of the monitored activity.

MSGP Discharge Monitoring Reports and Other Reports (MDMRS):

Monitoring results must be reported on an MDMR form (EPA Form No. 2040-0004) in accordance with the "Instructions for Completing the MSGP Industrial Discharge Monitoring Report" provided on the form. The permittee shall submit the original MDMR signed and certified to EPA as required by Part 7.1 of the MSGP.

Duty to Comply:

The permittee must comply with all conditions of the 2008 MSGP permit. Any permit noncompliance constitutes a violation of the Act and is grounds for enforcement action.

\subsection{DEVELOP A DECISION RULE}

If analytical results from monitoring activities are above benchmark and/or natural background levels, a corrective action is entered into the ENV-CP Corrective Action Report Database, in accordance with ENV-RCRA-QP-022, MSGP Stormwater Corrective Actions. An e-mail is automatically generated and sent to personnel responsible for evaluating and modifying controls to prevent further exceedances. Data validation is conducted under the guidelines of the DOE Statement of Work.

Acceptable analytical error is addressed in the DOE Statement of Work.

The current MSGP monitoring program is based on the 2008 MSGP. Activities that could affect the current or next MSGP permit include:

- Addition or removal of constituents into the 303(b) list,

- Discontinued monitoring based on no detection or constituent levels below benchmark or natural background,

- Specific changes identified by EPA within the next permit,

- DOE Statement of Work requirement for analytical laboratories.

\subsection{REFERENCES}

None 


\subsection{DEFINITIONS}

None

\subsection{ATTACHMENTS}

Attachment 1- Example Sample Collection Log/Field Chain of Custody Form

Attachment 2- Sample Container Labels

By requesting credit for this required reading I acknowledge that I have read and understand the contents of this document and I will follow and meet the requirements in this document unless it

Click to Acknowledge 


\section{AtTachment 1- Sample Collection Log/Field Chain of Custody Form}

Los Alamos National Laboratory

$\begin{array}{llll}\text { EVENT ID: } & 4179 & \text { EVENT NAME: } & \text { MSGP - } 2013 \\ \text { SAMPLE ID: } & \text { WTMSGP-13-29841 } & \text { WORK ORDER: } & \end{array}$

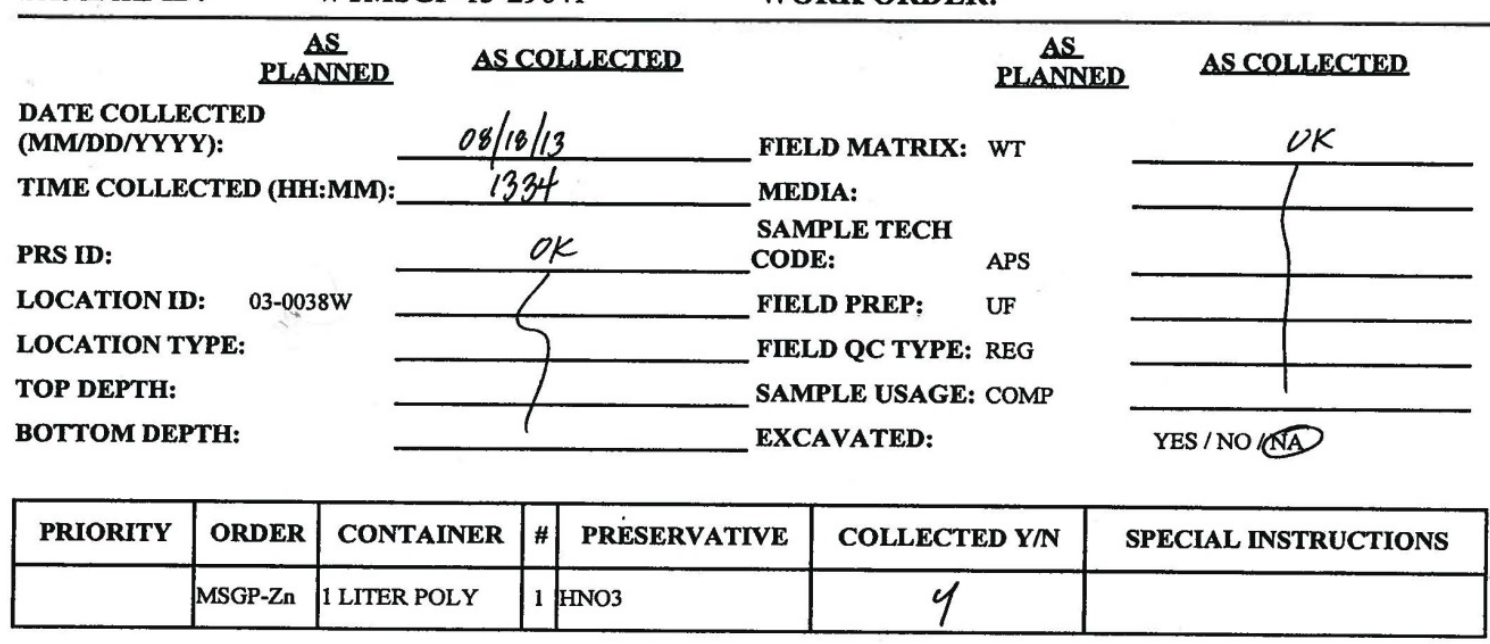

SAMPLE COMMENTS:

Q3

LOCATION COMMENTS:

FIELD PARAMETERS:

COLLECTED BY (PRINT) MARWIN SHENDO

\begin{tabular}{|c|c|c|c|}
\hline $\begin{array}{l}\text { RELINQUISHED BY } \\
\text { (Printed Name) Marwin Shendo } \\
\text { (Signature) }\end{array}$ & $\begin{array}{l}\text { Date/Time } \\
8 / 20 / 1: 45 \\
\end{array}$ & 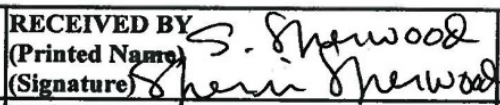 & $\begin{array}{c}8 \text { ate/Tinge } \\
81: 45 \\
\end{array}$ \\
\hline $\begin{array}{l}\text { RELINQUISHED BY } \\
\text { (Printed Name) } \\
\text { (Signature) } \\
\end{array}$ & Date/Time & $\begin{array}{l}\text { RECEIVED BY } \\
\text { (Printed Name) } \\
\text { (Signature) }\end{array}$ & Date/Time \\
\hline
\end{tabular}




\section{AtTACHMEnT 2- SAMPle Container LABElS}

шоэ'КАอле'MMM

\begin{tabular}{|l|l|}
\hline \multicolumn{2}{|c|}{ Los Alamos National Laboratory } \\
\hline Sample ID: WTMSGP-13-28856 \\
\hline Container: 1 LITER POLY & 1 of 1 \\
\hline Preservative: $\mathrm{HNO} 3$ & \\
\hline Analysis: $\mathrm{Ag}+\mathrm{As}+\mathrm{Cd}+\mathrm{Mg}+\mathrm{Pb}+\mathrm{Se}+\mathrm{Hg}$ \\
\hline Date: & Time: \\
\hline
\end{tabular}

\begin{tabular}{|l|l|}
\hline \multicolumn{2}{|c|}{ LoS Alamos National Laboratory } \\
\hline Sample ID: WTMSGP-13-29858 \\
\hline Container: 0.5 LITER POLY & 1 of 1 \\
\hline Preservative: H2SO4 \\
\hline Analysis: MSGP-COD & Time: \\
\hline Date: & \\
\hline
\end{tabular}

\begin{tabular}{|l|l|}
\hline \multicolumn{2}{|c|}{ Los Alamos National Laboratory } \\
\hline Sample ID: WTMSGP-13-29858 \\
\hline Container: 1 LITER POLY & 1 of 1 \\
\hline Preservative: HNO3 \\
\hline Analysis: MSGP-GrossA \\
\hline Date: & Time: \\
\hline
\end{tabular}

\begin{tabular}{|c|c|}
\hline \multicolumn{2}{|c|}{ Los Alamos National Laboratory } \\
\hline \multicolumn{2}{|c|}{ Sample ID: WTMSGP-13-29858 } \\
\hline Container: 1 LITER GLASS & 2 of 3 \\
\hline \multicolumn{2}{|l|}{ Preservative: ICE } \\
\hline \multicolumn{2}{|l|}{ Analysis: MSGP-PCB(Aroctor) } \\
\hline Date: & Time: \\
\hline
\end{tabular}

\begin{tabular}{|c|c|}
\hline \multicolumn{2}{|c|}{ Los Alamos National Laboratory } \\
\hline \multicolumn{2}{|c|}{ Sample ID: WTMSGP-13-29859 } \\
\hline Container: 1 LITER POLY & 1 of 1 \\
\hline \multicolumn{2}{|l|}{ Preservative: $\mathrm{HNO} 3$} \\
\hline \multicolumn{2}{|c|}{ Analysis: $\mathrm{Ag}+\mathrm{As}+\mathrm{Cd}+\mathrm{Mg}+\mathrm{Pb}+\mathrm{Se}+\mathrm{Hg}$} \\
\hline Date: & Time: \\
\hline
\end{tabular}

\begin{tabular}{|c|c|}
\hline \multicolumn{2}{|c|}{ Los Alamos National Laboratory } \\
\hline \multicolumn{2}{|c|}{ Sample ID: WTMSGP-13-29856 } \\
\hline Container: 0.5 LITER POLY & 1 of 1 \\
\hline \multicolumn{2}{|l|}{ Preservative: $\mathrm{NAOH}$} \\
\hline \multicolumn{2}{|l|}{ Analysls: MSGP-CN(TOTAL) } \\
\hline Date: & Time: \\
\hline
\end{tabular}

\begin{tabular}{|l|l|}
\hline \multicolumn{2}{|c|}{ Los Alamos National Laboratory } \\
\hline Sample ID: WTMSGP-13-29856 \\
\hline Container: 0.5 LITER POLY & 1 of 1 \\
\hline Preservative: H2SO4 \\
\hline Analysis: MSGP-NH3-N \\
\hline Date: & Time: \\
\hline
\end{tabular}

\begin{tabular}{|c|c|}
\hline \multicolumn{2}{|c|}{ Los Alamos National Laboratory } \\
\hline \multicolumn{2}{|c|}{ Sample ID: WTMSGP-13-29858 } \\
\hline Container: 1 LITER GLASS & 1 of 3 \\
\hline \multicolumn{2}{|l|}{ Preservative: ICE } \\
\hline \multicolumn{2}{|l|}{ Analysis: MSGP-PCB(Arocior) } \\
\hline Date: & Time: \\
\hline
\end{tabular}

\begin{tabular}{|c|c|}
\hline \multicolumn{2}{|c|}{ Los Alamos National Laboratory } \\
\hline \multicolumn{2}{|c|}{ Sample ID: WTMSGP-13-29858 } \\
\hline Container: 1 LITER GLASS & 3 of 3 \\
\hline \multicolumn{2}{|l|}{ Preservative: ICE } \\
\hline \multicolumn{2}{|l|}{ Analysis: MSGP-PCB(Arodor) } \\
\hline Date: & Time: \\
\hline
\end{tabular}

\begin{tabular}{|c|c|}
\hline \multicolumn{2}{|c|}{ Los Alamos National Laboratory } \\
\hline \multicolumn{2}{|l|}{ Sample ID: WTMSGP-13-29859 } \\
\hline Container: 0.5 LITER POLY & 1 of 1 \\
\hline \multicolumn{2}{|l|}{ Preservative: $\mathrm{NAOH}$} \\
\hline \multicolumn{2}{|l|}{ Analysis: MSGP-CN(TOTAL) } \\
\hline Date: & Time: \\
\hline
\end{tabular}

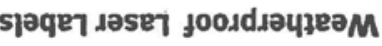




\section{MSGP STORM WATER VISUAL INSPECTIONS}

Purpose This procedure is written to provide requirements for conducting visual monitoring under the 2008 National Pollutant Discharge Elimination System (NPDES) Storm Water Multi-Sector General Permit (MSGP) for industrial facilities.

Scope $\quad$ Requirements set forth in this document apply to Los Alamos National Laboratory industrial facilities covered by the MSGP. These facilities include, a warehouse, several metal fabrication areas/shops, a heavy equipment yard, an asphalt batch plant, roads and grounds, a foundry, a power plant, a material recycling facility and several hazardous waste treatment, storage or disposal (TSD) facilities. Inspection waivers may be granted by ENV-RCRA for adverse weather conditions and unstaffed or inactive sites.

Hazard review The work described in this procedure is field work and consists solely of visual evaluations, and has been documented to have a LOW hazard rating by submittal of a completed ENV Low Hazard Verification form to the Quality Assurance Specialist.

\section{Signatures}

\begin{tabular}{|c|c|}
\hline $\begin{array}{l}\text { Prepared by: } \\
\qquad \text { Signature on File } \\
\text { Holly Wheeler, ENV-RCRA } \\
\end{array}$ & Date: \\
\hline Approved by: & Date: \\
\hline \multicolumn{2}{|l|}{ Melanie Lamb, ENV Quality Assurance Specialist } \\
\hline Authorized by: & Date: \\
\hline \multicolumn{2}{|l|}{ Terrill Lemke, ENV-RCRA Team Leader } \\
\hline Authorized by: & Date $^{\star *}:$ \\
\hline \multicolumn{2}{|l|}{ Anthony Grieggs, ENV-RCRA Group Leader } \\
\hline $\begin{array}{l}\text { Classification Review by } \\
\qquad \text { Signature on File }\end{array}$ & $\begin{array}{l}\text { Date: } \quad 03 / 06 / 12 \\
\text { Unclassified }\end{array}$ \\
\hline$\overline{\text { Anthony Grieggs, Derivative Classifier }}$ & \\
\hline
\end{tabular}




\section{General information about this procedure}

In this procedure

\begin{tabular}{|l|c|}
\hline \multicolumn{1}{|c|}{ Topic } & Page \\
\hline General information about this procedure & 2 \\
\hline Who requires training to this procedure? & 2 \\
\hline Roles and responsibilities & 5 \\
\hline Visual examinations & 5 \\
\hline Completing the MSGP storm water visual inspection form & 6 \\
\hline Guidance & 8 \\
\hline Records resulting from this procedure & 9 \\
\hline
\end{tabular}

Attachments

History of revision \& review

\begin{tabular}{|c|c|l|}
\hline Revision & Date & \multicolumn{1}{|c|}{ Description of Changes or Review } \\
\hline 0 & $7 / 09$ & New document. \\
\hline 1 & $3 / 10$ & Clarifications and added attachments. \\
\hline 2 & $2 / 12$ & Biennial review/revision. \\
\hline
\end{tabular}

Who requires training to

this procedure?
This procedure has the following attachments:

\begin{tabular}{|c|l|c|}
\hline Number & \multicolumn{1}{|c|}{ Attachment Title } & No. of pages \\
\hline 1 & MSGP Visual Inspection Form & 1 \\
\hline 2 & Example MSGP Visual Inspection Form & 1 \\
\hline 3 & $\begin{array}{l}\text { Facilities and Storm Water Stations Associated With } \\
\text { Industrial Activity }\end{array}$ & 1 \\
\hline
\end{tabular}

This table lists the revision history, reviews, and effective dates of this procedure:

The following personnel require training before implementing this procedure:

- Group and Project Leader

- MSGP Visual Assessors

- ENV-Deployed Environmental Professional (DEP)

- ENV-RCRA Sampling Team

\section{Training} method

Training to this procedure will be by "self-study" (reading) and will be documented in accordance with ENV-DO-QP-115 Personnel Training. 


\section{General information about this procedure, continued}

Prerequisites In addition to training to this procedure, the following training is also required prior to performing this procedure:

- $\quad$ ENV-RCRA-QAPP-MSGP Multi-Sector General Permit Quality Assurance Project Plan

Definitions Adverse weather conditions: Weather that prohibits collection of samples such as local specific to this flooding, high winds, hurricanes, tornadoes, electrical storms, etc. Could also include procedure drought, extended frozen conditions, etc.

Best Management Practices (BMPs): Schedules of activities, practices, prohibitions of practices, structures, vegetation, maintenance procedures, and other management practices to prevent or reduce pollution. BMPs can also include treatment requirements, operating procedures, and practices to control facility site runoff, spillage or leaks, sludge or waste disposal, or drainage from raw material storage.

Clarity: Clearness or cleanness of appearance. This includes the visual observation of suspended sediment.

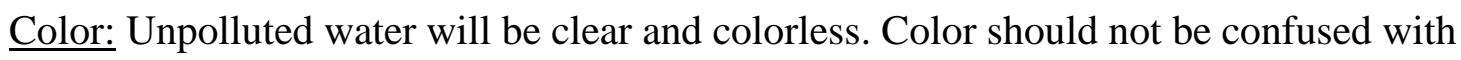
clarity.

Floating solids: Particulate material floating on the surface of the water. Examples include: leaves, pinecones, pine needles, dead grass, twigs, branches, and common trash.

Foam: An accumulation of fine frothy bubbles formed in or on the surface of water. A mass of bubbles of air in a matrix of liquid film.

Odor: The property or quality of waters that affects or stimulates the sense of smell. Examples of odors that may be present are burnt oil, sewage, diesel, sulfuric, or detergent odors.

Oil sheen: The presence of rainbow-like colors glistening on the surface of a liquid. The color of oil sheen will vary dependent on thickness and consistency.

Settled solids: Settled particulate material i.e. heavier than water. Examples include sand, gravel, metal turnings, and glass.

Suspended solids: Particulate materials that are floating between the bottom of the sample and the surface of the water.

Unstaffed and Inactive Sites: A facility maintaining certification with the SWPPP that it is inactive and unstaffed and visual examinations are not required. 


\section{General information about this procedure, continued}

References
- Federal Register: Final National Pollutant Discharge Elimination System (NPDES) General Permit for Storm Water Discharges from Industrial Activities. Federal Register: September 29, 2008, Volume 73, Number 189.

- P300, Integrated Work Management for Work Activities

- P315, Laboratory Institutional Operations Program

- PD103, Worker Safety and Health Policy

- SD100, Integrated Safety Management System Description

- P101-18, Procedure for Pause/Stop Work

- PD410, Los Alamos National Laboratory Environmental ALARA Program P121 Radiation Protection

- ENV-DO-QP-106, Document Control

- ENV-DO-QP-102, Office Safety and Security

- ENV-DO-QP-104, Work Safety Review

- ENV-DO-QP-115, Personnel Training

In addition to these documents, please read any site specific requirements before proceeding with work. 


\section{Roles and Responsibilities}

Deployed Deployed environmental professionals (DEPs) are responsible for collecting quarterly Environ- $\quad$ visual samples at substantially identical outfalls and completing required mental documentation, unless arrangements are made to use ENV-RCRA resources. DEPs

Professionals will be fully knowledgeable of the site specific SWPPP. Whenever practicable the same person should carry out the inspection and examination of the discharges throughout the life of the permit to ensure consistency in interpretation of results. Further, DEPs shall be familiar with facility operations so that potential pollution discharge sources can be determined.

ENV-RCRA MSGP storm water compliance personnel are responsible for filling out a visual MSGP storm assessment form if requested by work order for MSGP monitored outfalls. Storm water water compliance personnel compliance personnel are also responsible for evaluating the quality of completed visual assessments, retaining a record of QA'd forms on the server and distributing these forms to the DEPs for inclusion into the appropriate facility SWPPP.

\section{Visual Examinations}

Visual Visual examinations of storm water discharge shall be conducted quarterly for each examinations discharge point covered by the MSGP and the site specific SWPPP.

Grab samples A grab sample will be collected during daylight hours in a 1 liter wide mouth clear glass bottle or plastic container within 30 minutes of discharge from a storm event. If it is not possible to collect the sample within the first 30 minutes of discharge, the sample must be collected as soon as practicable after the first 30 minutes. The sampler will document the reason a sample could not be collected within 30 minutes.

If no samples are collected because the sampler was not triggered (or for some other reason), documentation shall be kept in the facility's SWPPP explaining why visual examinations were not conducted. 


\section{Completing the MSGP Storm Water Visual Inspection Form}

Location, date Complete the top section of form including location as indicated on site map, date and \& time, inspector, etc. and signature, and inspection quarter.

NOTE: See Attachment 2 for an example of a filled-out MSGP Visual Inspection form.

NOTE: See Attachment 3 for facility name, location, and station numbers.

Include the date and time the discharge began, sample collection date and time and visual assessment date and time for each sample. Identify the nature of the discharge (i.e., rainfall or snowmelt). Determine whether it has been greater than 72 hours from the last storm event. If "No", explain when the last storm event occurred.

\section{Sample}

Provide documentation if sample is not collected within 30 minutes of discharge. 


\section{Completing the MSGP Storm Water Visual Inspection Form, continued}

\section{Describe sample parameters}

Refer to section 3.0, Definitions. See attachment 2 for an example of a filled-out MSGP Visual Inspection form.

\begin{tabular}{|c|c|}
\hline Parameter & Description \\
\hline Color & Describe the color of the discharge. \\
\hline Odor & $\begin{array}{l}\text { Describe any odors that may be observed in the discharge. Caution: } \\
\text { any unusual odors should be documented. }\end{array}$ \\
\hline Clarity & $\begin{array}{l}\text { Clarity can be described as the depth in which you can look into or } \\
\text { through water. For example an individual can see through a clear glass } \\
\text { of clean water in daylight. Generally the clarity of the water is a good } \\
\text { visual indicator of the purity of water. If the water is poor in clarity } \\
\text { there is most likely suspended solids throughout the water. }\end{array}$ \\
\hline $\begin{array}{l}\text { Floating } \\
\text { Solids }\end{array}$ & $\begin{array}{l}\text { Note any floating solids in the sample. Careful examination should } \\
\text { determine whether the solids are raw or waste materials (i.e. } \\
\text { vegetative materials). }\end{array}$ \\
\hline $\begin{array}{l}\text { Settled } \\
\text { Solids }\end{array}$ & $\begin{array}{l}\text { Note any settled solids in the sample. Settled solids may be an } \\
\text { indicator of unstable ground cover combined with a high intensity } \\
\text { storm water runoff event. }\end{array}$ \\
\hline $\begin{array}{l}\text { Suspended } \\
\text { Solids }\end{array}$ & $\begin{array}{l}\text { Note any suspended solids in the sample. Most often suspended solids } \\
\text { include fine sediment. This may be an indication of an unstable } \\
\text { channel that may have eroding banks. Some water appears to be } \\
\text { colored because of relatively coarse particulate material in suspension } \\
\text { such as sediment. }\end{array}$ \\
\hline Foam & $\begin{array}{l}\text { Note an accumulation of fine frothy bubbles formed in or on the } \\
\text { surface of water. Describe the color of the foam. }\end{array}$ \\
\hline Oil Sheen & $\begin{array}{l}\text { Note if there is an oil sheen present, the thickness, and consistency. If } \\
\text { yes, contact the ENV-RCRA Project Leader for MSGP immediately. } \\
\text { Follow-up action is required within } 24 \text { hours. }\end{array}$ \\
\hline Other & $\begin{array}{l}\text { Describe any other indicators of storm water pollution in addition to } \\
\text { the descriptions mentioned above. }\end{array}$ \\
\hline
\end{tabular}




\section{Completing the MSGP Storm Water Visual Inspection Form, continued}

ENV
Deployed
Environ-
mental
Professional

Site

observations

Source of pollutants

\section{Guidance}

Clean up A clean up of the site should be conducted if the pollutant source is known and well defined. The FOD, ESH Manager, and MSGP representative of ENV-RCRA should also be contacted and made aware of the situation. A design change could also be incorporated into the storm water pollution prevention plan to eliminate or minimize the contaminant source from occurring in the future. Personnel should evaluate whether or not additional BMPs should be implemented in the pollution prevention plan to address the observed contaminant, and if BMPs have already been implemented, evaluate whether or not these are working correctly or need maintenance. Corrective actions must be taken if BMPs are not performing effectively. Actions should be taken as soon as practicable from the discovery of any pollutants.

NOTE: This time frame (and those listed below) is not a grace period. Rather, it is a schedule considered reasonable for documenting your findings and for making repairs and improvements. The time frame is to ensure that the conditions prompting the need for these repairs and improvements are not allowed to persist indefinitely. Failure to take prompt action can result in fines and penalties for non-compliance. 


\section{Guidance, continued}

Corrective If storm water contamination is identified through visual assessment, a corrective action action must be entered into the ENV-RCRA MSGP Corrective Action Report database within 24 hours of the observation. A corrective action plan must be identified within 14 days of the observation.

NOTE: If possible, the corrective action must be implemented before the next anticipated storm event.

Follow up A date for completion of implementation must be entered into the database to ensure that appropriate actions are taken in response to the examinations.

\section{Records resulting from this procedure}

Records

The following records generated as a result of this procedure are to be submitted to an MSGP representative of ENV-RCRA in accordance with ENV-DO-QP-110 Records Management.

- MSGP Quarterly Visual Assessment Form

\section{Click here to record "self-study" training to this procedure.}




\section{Water Quality \& RCRA Group \\ Los Alamos National Laboratory}

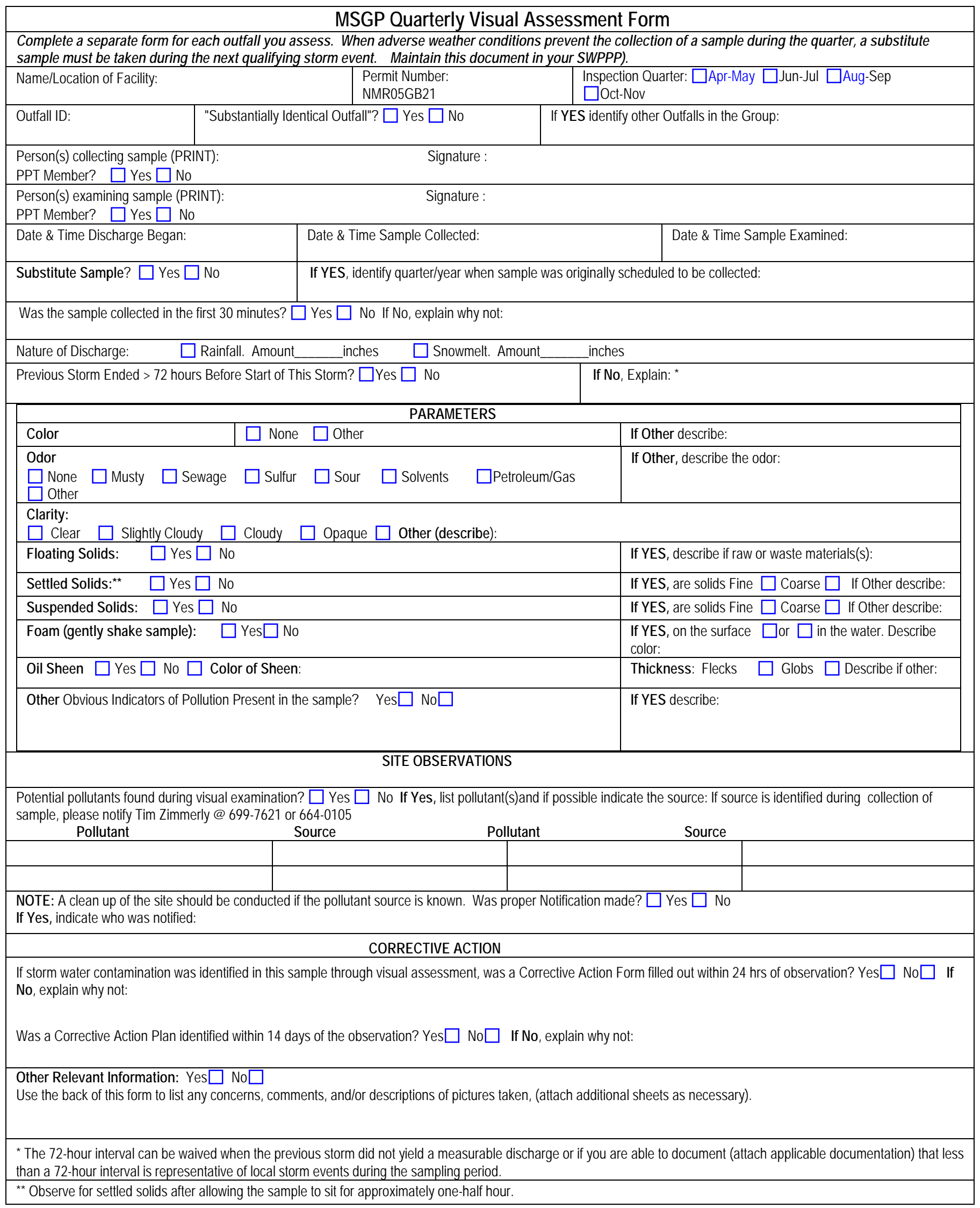




\section{Example of Filled-Out MSGP Quarterly Visual Assessment Form}

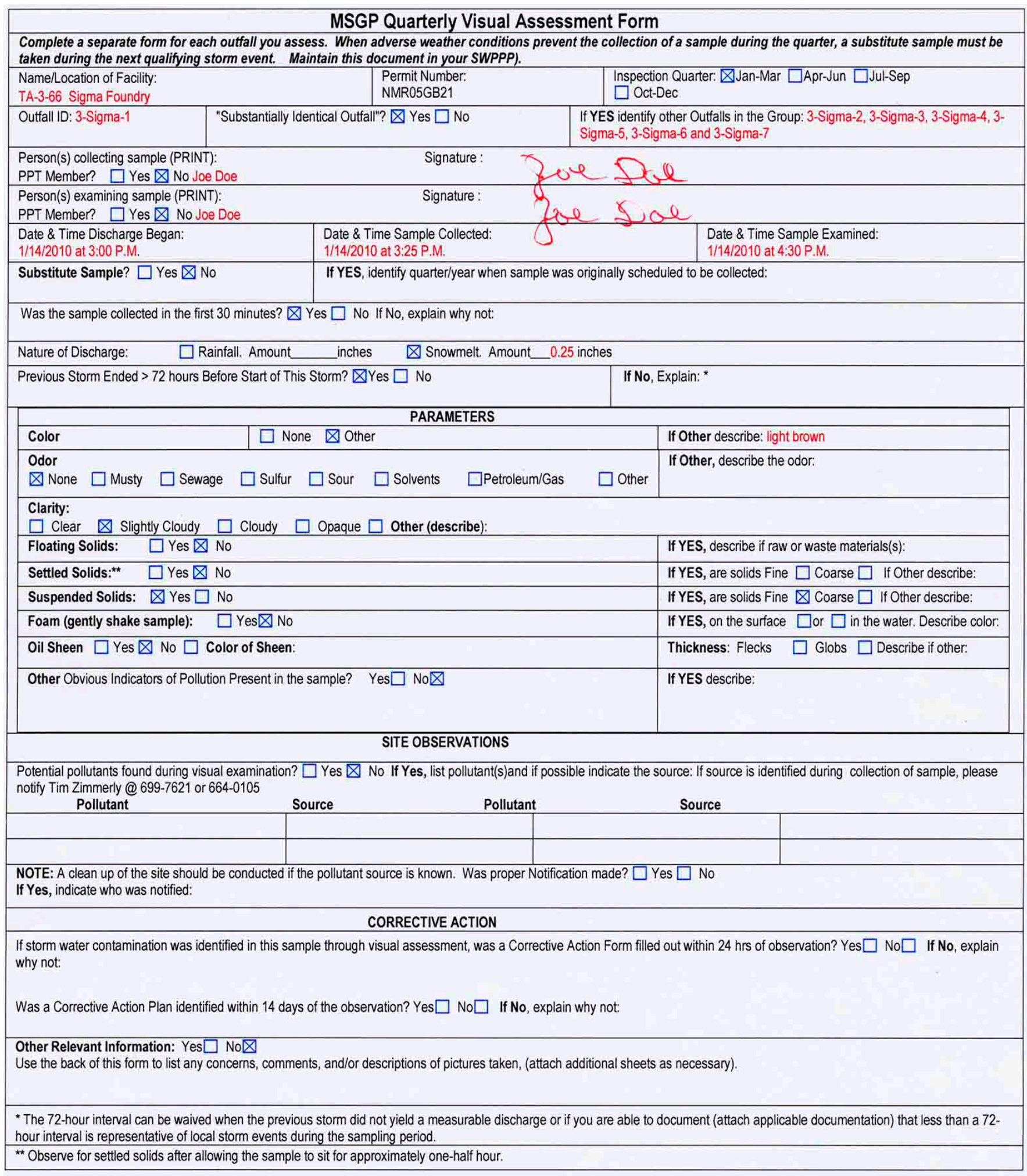




\section{Los Alamos National Laboratory \\ FACILITIES AND STORM WATER STATIONS ASSOCIATED WITH INDUSTRIAL ACTIVITY}

2008 MSGP PERMIT \#NMR05GB21

\begin{tabular}{|c|c|c|c|c|c|}
\hline LOCATION & OPERATION & Activity & Sector & STATION & DRAINAGE \\
\hline TA-3-22 & POWER PLANT & STEAM ELECTRIC POWER & $\mathrm{O}$ & $\begin{array}{c}\text { E121.9, 03-0022N, } \\
03-0022 S\end{array}$ & Sandia \\
\hline TA-3-38 & METAL SHOP & FABRICATED METALS & AA & 03-0038W & Sandia \\
\hline TA-3-39, 102 & METAL SHOP & FABRICATED METALS & AA & 03-0039E & Pajarito \\
\hline TA-3-66 & SIGMA FOUNDRY & PRIMARY METALS & $\mathrm{F}$ & E122.3 & Sandia \\
\hline TA-60 & ASPHALT BATCH PLANT & ASPHALT BATCH PLANT & $\mathrm{D}$ & E200.5 & Mortandad \\
\hline TA-54 & AREA G - South Side & TSD & $\mathrm{K}$ & 54-PAD10E, E248.5, E248 & Pajarito \\
\hline TA-54 & AREA G - North Side & TSD & $\mathrm{K}$ & E227 & Canada del Buey \\
\hline TA-54 & AREA L & TSD & $\mathrm{K}$ & E223 & Canada del Buey \\
\hline TA-54-38 & RANT & TSD & $\mathrm{K}$ & E220 & Canada del Buey \\
\hline TA-15-185 & VEHICLE MAINTENANCE SHOP & VEHICLE MAINTENANCE & $\mathrm{P}$ & E262.4 & Water \\
\hline TA-60-1 & MOTORPOOL & VEHICLE MAINTENANCE & $\mathrm{P}$ & $60-0001$ & Sandia \\
\hline TA-60 & MATERIALS RECYCLING FACILITY & RECYCLING & $\mathrm{N}$ & E122.35 & Sandia \\
\hline TA-60-250 & ROADS \& GROUNDS FACILITY & $\begin{array}{l}\text { VEHICLE MAINTENANCE \& } \\
\text { STORAGE }\end{array}$ & $\mathrm{P}$ & E123.4, 60-00RG, 60-00RGE & Sandia \\
\hline TA-3-0034 & METAL SHOP & FABRICATED METALS & $\mathrm{AA}$ & $03-0034$ & Sandia \\
\hline TA-9-28 & $\begin{array}{l}\text { HEAVY EQUIPMENT } \\
\text { MAINTENANCE OPERATIONS }\end{array}$ & $\begin{array}{l}\text { VEHICLE MAINTENANCE AND } \\
\text { STORAGE }\end{array}$ & $\mathrm{P}$ & 09-0028W & Upper Pajarito \\
\hline TA-60-2 & WAREHOUSE & WHAREHOUSE & $\mathrm{P}$ & $60-002 E$ & Sandia \\
\hline
\end{tabular}




\title{
ENV-CP-QAPP-MSGP, R5
}

Effective Date: 11/04/2013

Next Review Date: 11/04/2015

\section{Environment, Safety, Health Directorate}

\section{Environmental Protection Division - Compliance Programs Group}

\author{
Quality Assurance Project Plan
}

\section{Stormwater Multi-Sector General Permit for Industrial Activities Program}

\section{Reviewers:}

\begin{tabular}{|l|l|l|l||}
\hline $\begin{array}{l}\text { Name: } \\
\text { Melanie Lamb }\end{array}$ & $\begin{array}{l}\text { Organization: } \\
\text { ADESH-OIO, QA } \\
\text { Specialist }\end{array}$ & $\begin{array}{l}\text { Signature: } \\
\text { Signature on File }\end{array}$ & Date: \\
\hline
\end{tabular}

Derivative Classifier: $\square$ Unclassified $\square$ DUSA ENVPRO

\begin{tabular}{|l|l|l|l|}
\hline $\begin{array}{l}\text { Name: } \\
\text { Ellena Martinez }\end{array}$ & $\begin{array}{l}\text { Organization: } \\
\text { ADESH-OIO }\end{array}$ & $\begin{array}{l}\text { Signature: } \\
\text { Signature on File }\end{array}$ & Date: \\
\hline
\end{tabular}

Approval Signatures:

\begin{tabular}{||l|l|l|l||}
\hline $\begin{array}{l}\text { Subject Matter Expert: } \\
\text { Holly Wheeler }\end{array}$ & $\begin{array}{l}\text { Organization: } \\
\text { ENV-CP }\end{array}$ & $\begin{array}{l}\text { Signature: } \\
\text { Signature on File }\end{array}$ & Date: \\
\hline $\begin{array}{l}\text { Responsible Line Manager: } \\
\text { Mike Saladen }\end{array}$ & $\begin{array}{l}\text { Organization: } \\
\text { ENV-CP, Team Lead }\end{array}$ & $\begin{array}{l}\text { Signature: } \\
\text { Signature on File }\end{array}$ & Date: \\
\hline $\begin{array}{l}\text { Responsible Line Manager: } \\
\text { Anthony Grieggs }\end{array}$ & $\begin{array}{l}\text { Organization: } \\
\text { ENV-CP, Group Leader }\end{array}$ & $\begin{array}{l}\text { Signature: } \\
\text { Signature on File }\end{array}$ & Date: \\
\hline
\end{tabular}

CONTROLLED DOCUMENT

This copy is uncontrolled. The controlled copy can be found on the ENV Division Web page. 


\section{History of Revisions}

\begin{tabular}{|c|c|l|}
\hline $\begin{array}{c}\text { Document Number } \\
\text { [Include revision number, } \\
\text { beginning with Revision 0] }\end{array}$ & $\begin{array}{c}\text { Effective Date } \\
\text { [Document Control Coordinator } \\
\text { inserts effective date] }\end{array}$ & $\begin{array}{c}\text { Description of Changes } \\
\text { [List specific changes made since the previous revision] }\end{array}$ \\
\hline 0 & $06 / 03$ & New Document \\
\hline 1 & $12 / 05$ & Annual review and revision \\
\hline 2 & $07 / 07$ & $\begin{array}{l}\text { Annual review, incorporated organizational } \\
\text { restructure changes. }\end{array}$ \\
\hline 3 & $07 / 09$ & Biennial Review and Revision \\
\hline 4 & $07 / 09$ & Biennial Review and Revision \\
\hline 5 & $10 / 13$ & $\begin{array}{l}\text { Biennial Review and Revision. New format } \\
\text { implemented. }\end{array}$ \\
\hline
\end{tabular}




\section{Table of Contents}

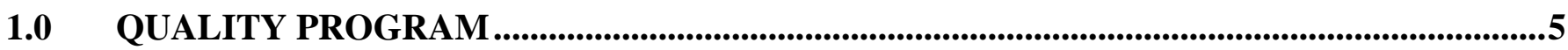

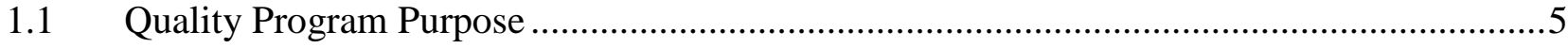

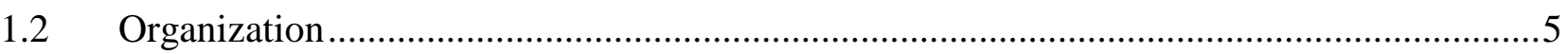

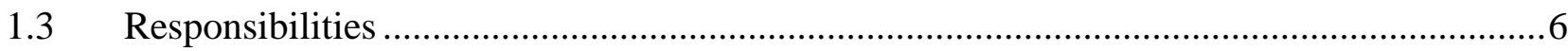

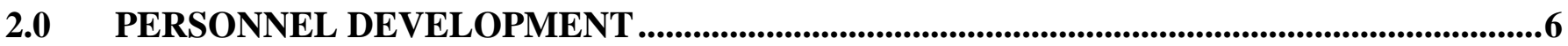

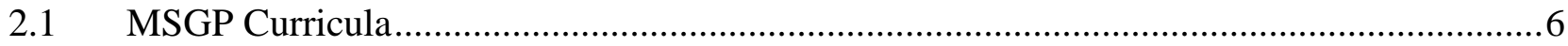

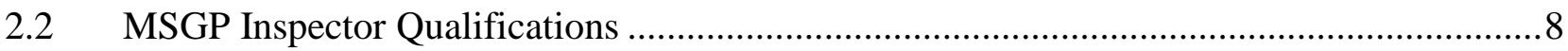

2.3 MSGP SWPPP Preparer Qualifications ................................................................... 8

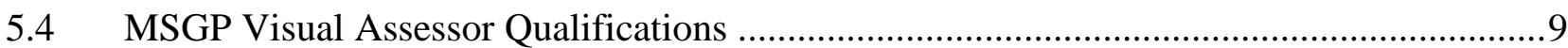

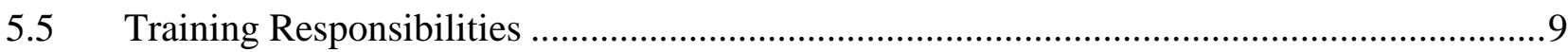

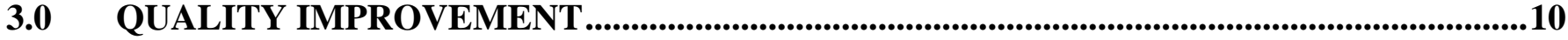

3.1 Corrective Actions within ENV-RCRA....................................................................... 10

3.3 Quality Improvement Responsibilities.................................................................... 10

4.0 DOCUMENT CONTROL/RECORDS MANAGEMENT .......................................................10

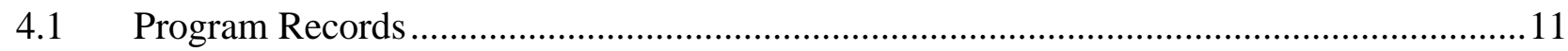

4.2 Program Records Responsibilities ............................................................................ 11

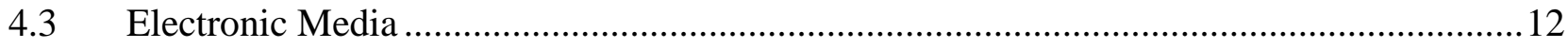

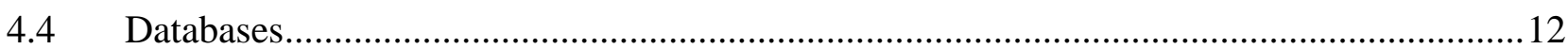

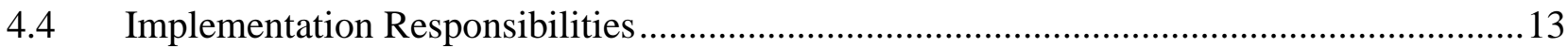

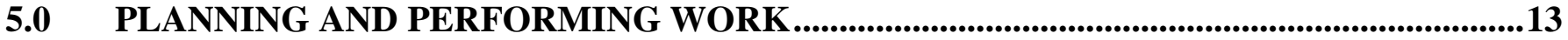

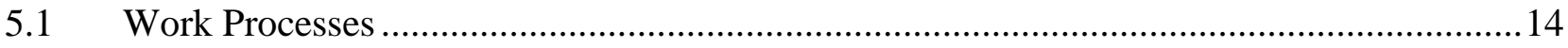

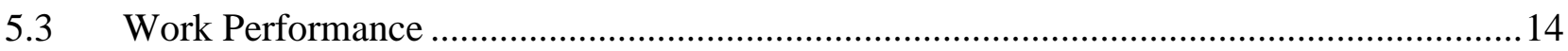

5.4 StormWater Pollution Prevention Plan ...................................................................... 14

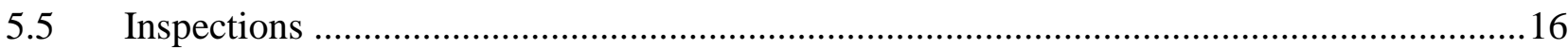

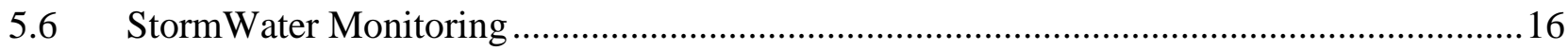

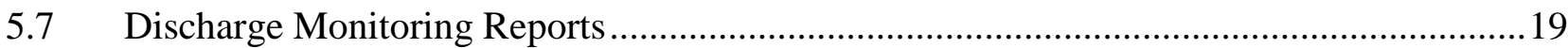

5.8 Adverse Weather Conditions and Climates with Irregular Stormwater Runoff ..............20

5.9 Reporting and Recordkeeping...............................................................................21

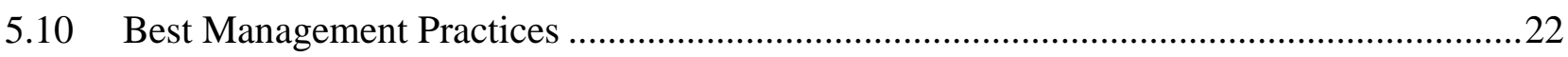

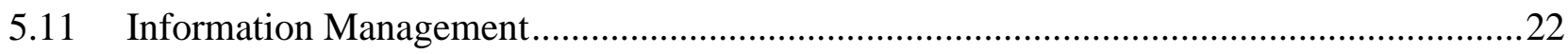

5.12 Responding to Water Quality Exceedances ...............................................................22

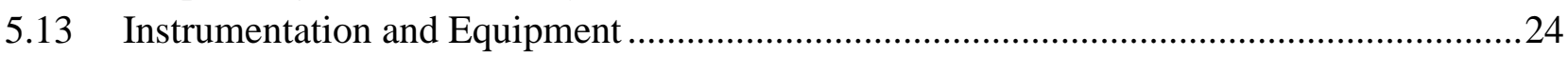

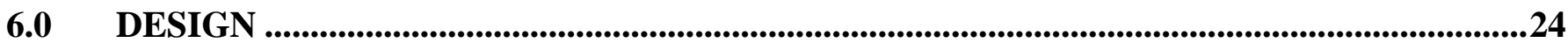

7.0 PROCUREMENT .........................................................................................................................25

8.0 INSPECTION AND ACCEPTANCE TESTING ...............................................................26

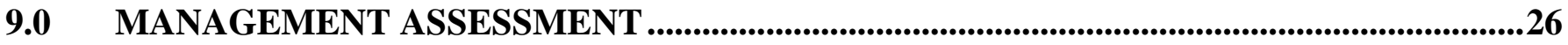

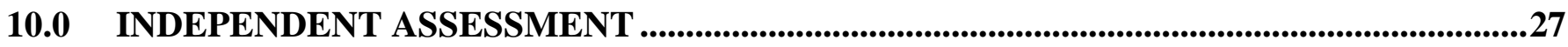

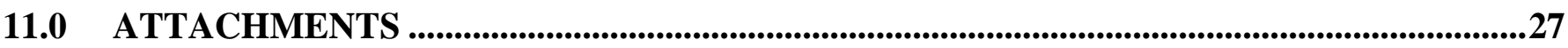




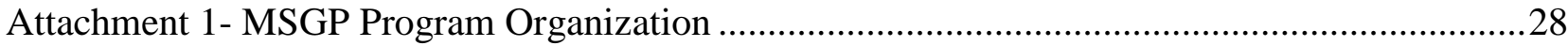

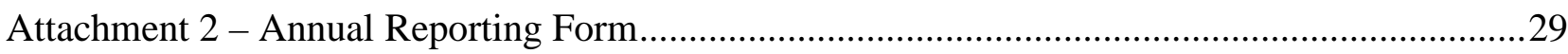

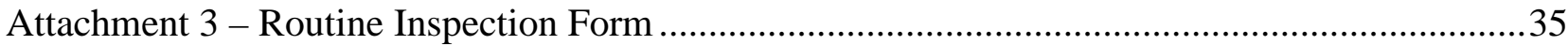

Attachment 4 -- MSGP Facilities and Storm Water Monitored Outfalls Associated with Industrial

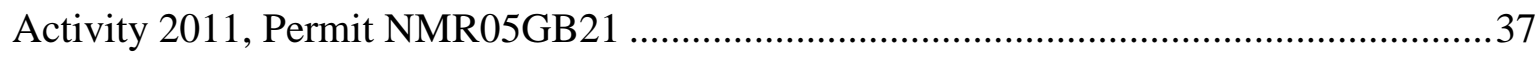

Attachment 5 - Pollutants Under Impaired Waters Monitoring .................................................38

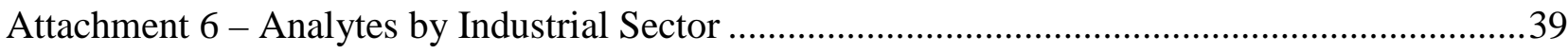

Attachment 7 - References and Guidance Documents ..........................................................40 


\subsection{QUALITY PROGRAM}

LANL will comply with the monitoring requirements as specified by the 2008 National Pollutant Discharge Elimination System (NPDES) Stormwater Multi-Sector General Permit for Industrial Activities. Compliance will be demonstrated through the successful implementation of this project plan and applicable procedures.

Los Alamos National Laboratory (the Laboratory) has established a comprehensive stormwater program for its industrial activities. Historically, the Laboratory operated under the NPDES Baseline General Permit and then under the NPDES 1995, 2000, and 2008 Multi-Sector General Permits. The Laboratory submitted its NOI for 2008 coverage in December 2008.

The 2008 MSGP was issued on September 22, 2008 and became effective on September 29, 2008. The purpose of this project plan is to ensure compliance with the following:

- 2008 NPDES Multi-Sector General Permit (MSGP) and the Clean Water Act (CWA)

- DOE Order 450.1, Environmental Protection Program, and DOE Order 5400.5, Radiation Protection of the Public and Environment, which establish environmental protection program policies, requirements, and responsibilities

The Environmental Protection, Environmental Compliance Programs (ENV-CP) Water Quality Team has been tasked with overseeing institutional stormwater compliance related activities at the Laboratory.

\subsection{Quality Program Purpose}

This Quality Assurance Project Plan (QAPP) describes the policies and requirements that ensure MSGP activities are conducted in a consistent, agreed-upon manner.

This QA Project Plan describes the policies and requirements that ensure the MSGP processes are conducted in a consistent, agreed-upon manner. Drivers for the quality plan include:

o DOE Order 414.1C, Quality Assurance

o SD330, LANL Quality Assurance Program

This QA Project Plan (QAPP), including implementing procedures, is a sub-tier document to the SD330, LANL Quality Assurance Program. The following documents provide requirements to ensure that the MSGP Program is operated in accordance with established plans and procedures:

- SD330, LANL Quality Assurance Program

- QA Project Plan for the MSGP (this document)

- Implementing procedures

\subsection{ORganization}

ENV-CP is responsible for compliance oversight of the Laboratory's MSGP coverage. The Group is organized by teams under the line management direction of the Group Leader. Teams are crossfunctional and focus on specific Laboratory water quality responsibilities, deliverables, or 
products. Teams are guided by Team Leaders who have the responsibility to assure the program is completed and properly implemented.

The Team Leader coordinates the project and reports to the ENV-CP Group Leader. The Project Lead implements program oversight, coordinates contractor efforts (if there are any), and reports to the Team Leader. A QA Specialist is assigned to work for the Team Leader to provide quality assurance assistance, advice, and review. In addition, representatives from other groups may participate and contribute to this team as subject matter experts for project activities. The project organization is shown in Attachment 1.

Applicable regulatory drivers include the following:

- Clean Water Act (CWA)

- 2008 NPDES Multi-Sector General Permit (MSGP)

- DOE Order 450.1, Environmental Protection Program

- DOE Order 5400.5, Radiation Protection of Public and Environment

- P401, Procedure to Identify, Communicate, and Implement Environmental Requirements

\subsection{RESPONSIBILITIES}

The following table lists specific responsibilities:

\begin{tabular}{|l|l|}
\hline \multicolumn{1}{|c|}{ Who } & \multicolumn{1}{c|}{ What } \\
\hline Group Leader & $\begin{array}{l}\text { Assure that qualified staff complies with regulatory } \\
\text { requirements associated with the MSGP. }\end{array}$ \\
\hline Project Lead & $\begin{array}{l}\text { Ensure that MSGP-related activities are performed in } \\
\text { accordance with the requirements specified in this plan. }\end{array}$ \\
\hline ENV-CP Staff & $\begin{array}{l}\text { Perform MSGP-related activities as assigned by the Team } \\
\text { Leader or Project Leader }\end{array}$ \\
\hline
\end{tabular}

\subsection{PERSONNEL DEVELOPMENT}

Qualified team members will be hired and trained as prescribed in ENV-DO-QP-115, Personnel Training. Minimum training requirements for ENV personnel are described in the ENV Division Qualification Standards. The LANL Human Resources Division maintains documentation of education qualification. Required MSGP qualifications and training plans are listed below.

\subsection{MSGP CURRICULA}

The MSGP Program requires personnel with the following training requirements:

\section{$\underline{\text { MSGP Inspectors }}$}

Curricula 10697 ENV-RCRA MSGP Inspector 
Item 42415 ENV-DO-QP-101 Environmental Reporting Requirements for Releases or Events Item 42547 ENV-DO-QP-111 Reporting Environmental Releases to Pueblo Governments Item 40708 ENV-DO-QP-108 Preparation of External Correspondence for Review and Approval Item 43172 ENV-DO-QP-112 Coordinating Regulatory Inspections Item 42891 ENV-DO-QP-113 Tracking Issues and Actions Item 43805 ENV-DO-QP-114 Logbook Use and Control Item 45777 ENV-DO-QP-100 General Field Safety

Curricula 131 Field Worker Training Requirements Item 43562 or 3583 or 16585 CPR/AED: LANL Workplace Item 3574 or 13264 First Aid

\section{MSGP SWPPP Preparers}

Curricula 7814 ENV-RCRA MSGP SWPPP Preparer Item 43337 ENV-CP-QAPP-MSGP Item 56593 ENV-RCRA-QP-044 Preparing Storm Water Discharge Monitoring Reports (MDMRs) for the NPDES Multi-Sector General Permit Item 40708 ENV-DO-QP-108 External Correspondence Item 43172 ENV-DO-QP-112 Coordinating Regulatory Inspections Item 42891 ENV-DO-QP-113 Tracking Issues and Actions Item 43805 ENV-DO-QP-114 Logbook Use and Control Item 45777 ENV-DO-QP-100 General Field Safety

Curricula 51 ENV-RCRA Design Engineer Item 44269, COE Review of LANL Produced Design Documents, AP-341-620 Item 44266, COE System Design Descriptions, AP-341-61 Item 44263, COE Engineering Drawings and Sketches, AP-341-608 Item 44261, COE Calculation, AP-341-605 Item 44258, COE Requirements and Criteria Document, AP-341-602 Item 44257, COE Functions \& Requirements Document, AP-341-601 Item 43658, CORE Engineering Overview Item 55428, COE Management Level Determination, AP-341-502 Item 54168, P342 Engineering Standards Item 47029, COE LANL Review of Design by External Agencies, AP-341-622 Item 43666, Engineering Design Management Item 43663, Engineering Technical Baseline Item 44225, COE Evaluation of Vendor Information, AP-341-701

\section{MSGP Visual Assessors}

Curricula 10698 ENV-RCRA MSGP Visual Assessor Item 43337 ENV-RCRA-QAPP-MSGP Item 50493 ENV-RCRA-QP-064 MSGP Storm Water Visual Assessments Item 42415 ENV-DO-QP-101 Environmental Reporting Requirements for Releases or Events Item 42547 ENV-DO-QP-111 Reporting Environmental Releases to Pueblo Governments. Item 40708 ENV-DO-QP-108 External Correspondence 
Item 43172 ENV-DO-QP-112 Coordinating Regulatory Inspections

Item 42891 ENV-DO-QP-113 Tracking Issues and Actions

Item 43805 ENV-DO-QP-114 Logbook Use and Control

Item 45777 ENV-DO-QP-100 General Field Safety

Curricula 131 Field Worker Training Requirements

Item 43562 or 3583 or 16585 CPR/AED: LANL Workplace

Item 3574 or 13264 First Aid

\subsection{MSGP INSPECTOR QUALIFICATIONS}

\section{Inspections:}

- Post high school education or experience in engineering or environmental science or a related field; or industrial site field experience involving stormwater pollution prevention.

- 2 years experience of completing MSGP inspections or 1 year MSGP inspection experience with the Certified Inspector of Sediment and Erosion Control (CISEC) certification.

- 6 months knowledge of LANL facility operations.

- Demonstrated ability, as determined by the Multi-Sector General Permit Project Lead and/or Water Quality Team Leader, to successfully and effectively evaluate and identify the following at industrial sites:

o Conditions and activities that could impact stormwater quality at the facility.

o Inadequate or ineffective BMPs.

o Required modification or maintenance of existing BMPs.

o Locations requiring new or additional BMPs.

o Potential pollutant sources associated with the facility.

o Appropriate and correct site stabilization measures.

- Demonstrated ability, as determined by the Multi-Sector General Permit Project Lead and/or Water Quality Team Leader, to evaluate the compliance status of each industrial facility and document identified issues during an inspection.

- Demonstrated ability, as determined by the Multi-Sector General Permit Project Lead and/or Water Quality Team Leader, to properly and effectively complete inspection reports, including the ability to perform the following:

o Prepare reports in a clear, concise manner, identifying site conditions and issues.

o Write legibly and describe conditions clearly and accurately.

o Use proper spelling and grammar.

o Complete the MSGP Routine Inspection Report forms accurately.

o Accurately enter findings into the Corrective Actions Report database.

- Conduct inspections in a professional manner.

- Be a member of, or contractor supporting, ENV-RCRA or ENV Division.

\subsection{MSGP SWPPP PREPARER QUALIFICATIONS}

\section{SWPPP Preparation:}

One of the 2 criteria below must be satisfied: 
- BS degree or experience in engineering, environmental science, or related field, with a background involving stormwater pollution prevention and regulatory compliance relating to MSGP sites and a 1 year minimum of LANL facility operations knowledge and 1 year experience of completing MSGP inspections; or

- Certified Professional in Erosion and Sediment Control (CPESC) or Professional Engineer (PE) with a demonstrated background in stormwater management, sediment and erosion control, and regulatory compliance.

In addition to:

- Demonstrated ability, as determined by the Multi-Sector General Permit Project Lead and/or Water Quality Team Leader, to:

o Prepare SWPPPs per LANL format and in compliance with NPDES MSGP requirements.

o Identify and specify appropriate BMPs and stabilization measures.

o Identify potential pollutant sources associated with the facility.

o Perform necessary calculations to meet regulatory requirements.

o Prepare a site map.

o Be a member of, or contractor supporting, ENV-CP or ENV Division.

\subsection{MSGP Visual AsSESSOR QUALIFICATIONS}

Quarterly Visual Assessments:

- Education or experience in engineering, environmental science, or a related field; or industrial site field experience involving stormwater pollution prevention; and

- Completed ENV-RCRA training on how to collect and evaluate visual assessment; and

- Demonstrated ability, as determined by the Multi-Sector General Permit Program Lead and/or Water Quality Team Leader, to:

o Collect quarterly visual samples at the designated outfall.

o Complete the applicable portions of the MSGP Quarterly Visual Assessment Form.

o Have working knowledge of the regulatory requirements in Section 4.2 of the MSGP.

\subsection{TRAINING RESPONSIBILITIES}

All personnel performing MSGP project-related work are required to obtain appropriate training prior to performing work governed by a procedure. Training for all project personnel will be performed and documented in accordance with ENV-DO-QP-115, Personnel Training.

The following table lists specific responsibilities regarding training requirements.

\begin{tabular}{|l|l|}
\hline \multicolumn{1}{|c|}{ Who } & \multicolumn{1}{c|}{ What } \\
\hline Group Leader & Ensure project personnel meet all Laboratory training requirements. \\
\hline Program Lead & $\begin{array}{l}\text { Establish and document job descriptions for each position within the } \\
\text { MSGP Project. } \\
\text { Ensure all project personnel have the appropriate level of education, }\end{array}$ \\
\hline
\end{tabular}


experience, and training.

\subsection{QUALITY IMPROVEMENT}

The MSGP Project subscribes to the principles of problem prevention and continuous improvement. The Project Lead is committed to evaluating improvement opportunities identified by trending and reporting.

The Project Lead provides verbal and written updates, as needed, to the Team Leader and Group Leader to keep group management apprised of the focus of the MSGP Project activities and to address any shortcomings that may be identified.

\subsection{CORRECTIVE ACTIONS WITHIN ENV-RCRA}

Corrective actions for all ENV-RCRA programs and projects are initiated, tracked, corrected, and documented according to P330-6 Nonconformance Reporting, P322-4 Laboratory Performance Feedback and Improvement Process, SD330, Los Alamos National Laboratory Quality Assurance Program, and Division/Group procedures.

\subsection{QUALITY IMPROVEMENT RESPONSIBILITIES}

The following table lists specific responsibilities for quality improvement:

\begin{tabular}{|l|l|}
\hline \multicolumn{1}{|c|}{ Who } & \multicolumn{1}{|c|}{ What } \\
\hline Project Lead & $\begin{array}{l}\text { Monitor program performance and ensure issues are corrected in a } \\
\text { timely manner. }\end{array}$ \\
\hline ENV-CP Staff & $\begin{array}{l}\text { Identify opportunities for process improvement, health and safety } \\
\text { enhancement, environmental protection, or other improvements of } \\
\text { the program’s operations. } \\
\text { Discuss the identified opportunities with the Project Lead. } \\
\text { Ensure issues are reported and corrected in a timely manner. }\end{array}$ \\
\hline
\end{tabular}

\subsection{DOCUMENT CONTROL/RECORDS MANAGEMENT}

The program lead, at least one reviewer, and the Group Leader will approve all revisions to this plan. Revisions to the plan will be provided to the QA Specialist. This plan will be reviewed and revised (if necessary) biennially.

This document will be controlled under the organization's document control system (ENV-DO-QP-106, Document Control). Controlled copies of ENV documents are located on the Internet: http://int.lanl.gov/orgs/env/rcra/qa.shtml, all other copies are uncontrolled.

Procedures will be developed as necessary and in accordance with ENV-DO-QP-105, Preparation, Review, and Approval of Procedures. 
Phone calls, email, or fax communications will be documented and controlled if the content provides direction or results in decisions.

\subsection{PROGRAM RECORDS}

The number, type, and detail of all records to be kept will provide sufficient information to allow an individual with equivalent education and training to verify or reconstruct the results. Implementing procedures specify the records, forms, logbook entries, or other information to be kept as documentation of the performance of the procedure.

Records to be kept in the ENV-CP records system include the following:

- Copy of the Multi-Sector General Permit

- Annual Site Compliance Evaluation reports

- Corrective Action Reports

- Reports and certifications required by MSGP

- Records of all data used to complete MSGP Notice of Intent

- Discharge Monitoring Reports

Records to be kept by the Deployed Environmental Professional assigned to the FOD in which the industrial facility resides includes the following:

- Copies of Stormwater Pollution Prevention Plans

- Reports and certifications required by MSGP

- Routine Inspection Forms

- Supporting analytical data reports including Visual Assessment Forms

- Corrective Action Reports

- Discharge Monitoring Reports

- Annual Site Compliance Evaluation reports

All ENV-CP records will be maintained and available (after the deadline for submittal as given in applicable procedures) for auditing in the records center at ENV-CP (ENV-DO-QP-110, Records Management). Records will be archived in compliance with Laboratory and DOE requirements for records retention, storage, and management.

\subsection{PROGRAM RECORDS RESPONSIBILITIES}

The following table lists specific responsibilities for program records management:

\begin{tabular}{|l|l|}
\hline \multicolumn{1}{|c|}{ Who } & \multicolumn{1}{|c|}{ What } \\
\hline Team Leader & $\begin{array}{l}\text { Ensure QAPP meets minimum specifications for documentation and } \\
\text { records of the SD330, Los Alamos National Laboratory Quality Assurance } \\
\text { Program }\end{array}$ \\
\hline Program Lead & $\begin{array}{l}\text { Conduct annual review of records to ensure compliance with project } \\
\text { requirements. }\end{array}$ \\
\hline
\end{tabular}




\subsection{ELECTRONic Media}

The project will utilize electronic means as necessary to maintain data and perform calculations on these data. Electronic means will not however replace paper copies. All records that must be maintained to meet the requirements of the Permit will be kept in hard copy as the official record.

\subsection{DATABASES}

Analytical data will be maintained in the LANL Water Quality Database (WQDB). Security, verification, and validation of data are maintained in accordance with LANL procedures.

Security -- ENV data will be maintained electronically in a secure manner and will be protected from loss by being maintained as part of an official dataset that is backed up at least weekly.

Verification of data -- All ENV data, either electronic or hardcopy must undergo a verification and validation process that includes the following:

\section{Verification}

- Paper deliverables match electronic data that are stored in an official dataset. Paper deliverables include:

- chain of custody for sample data

- field log, if applicable, for sample data

- data packages for analytical data

- documentation packages for supporting data (e.g., geographic information system)

- All hand-entered data have been verified by a person other than the individual performing the entry

- Electronic uploads of data (e.g., electronic data deliverables) have been spot checked (at least $10 \%$ ) to ensure the upload performed as expected

- Hard copy supporting information (e.g., data packages, chains of custody, validation reports, etc.) is evaluated for completeness, archived, and available for audit

Validation --analytical data validation is the responsibility of the EP Directorate. The process will include the following:

- Validate that sample and quality assurance/quality control data and information meet contract specifications

- Assign validation flags, as appropriate

- Identify the analytical supplier

- Identify the analytical method

Verification of calculations -- A person other than the person who generated the query will review for accuracy all compliance related calculations performed in a database through queries. This review will be documented and forwarded to the appropriate record series. 


\section{Spreadsheets:}

Backups -- All spreadsheets used to hold data and generate reports to be used in demonstrating compliance will be maintained in a secure location. The preferred location is on the Group server. Spreadsheets will be backed up at least weekly.

Verification of data -- All compliance-related data uploaded into a spreadsheet will be verified to be accurate against the original paper copy. Data that are uploaded through electronic means will undergo a $10 \%$ verification. Data that are uploaded through manual means will undergo a 100\% verification. Someone other than the data entry person must perform the $100 \%$ review. This review will be documented and forwarded to the appropriate record series.

Verification of calculations -- A person other than the person who generated the spreadsheet will review for accuracy all compliance-related calculations performed in a spreadsheet. This review will be documented and forwarded to the appropriate record series. Modifications to the function of these spreadsheets will also be verified in this manner.

Software control -- The integrity of spreadsheets will be ensured by limiting access to these spreadsheets to only trained, authorized personnel. Additionally, at least once per year, the function of the spreadsheets will be verified by hand calculations. Documentation of this review will be forwarded to the appropriate record series.

\subsection{IMPLEMENTATION RESPONSIBILITIES}

The following table lists specific responsibilities:

\begin{tabular}{|c|l|}
\hline Who & \multicolumn{1}{c|}{ What } \\
\hline Program Lead & $\begin{array}{l}\text { Regularly assess data integrity methods used by MSGP } \\
\text { personnel. }\end{array}$ \\
\hline
\end{tabular}

\subsection{PLANNING AND PERFORMING WORK}

Work conducted under this program ensures compliance with the 2008 Multi-Sector General Permit; the Clean Water Act; and DOE Orders 450.1, Environmental Protection Program, and 5400.5, Radiation Protection of the Public and Environment.

Work that contributes to achieving the quality specifications of the MSGP deliverables will be planned and documented as described in this document and implementing procedures.

Work will be performed according to applicable plans and implementing procedures. The team leader will provide first line supervision of personnel assigned to project tasks to ensure work is performed to achieve project quality specifications. Before changing a work process that affects the project quality specifications, the team leader will ensure the same level of planning and review as used in the initial project planning steps. 


\subsection{Work Processes}

All work should be regarded as a process. Each process consists of a series of actions and is planned and carried out by qualified workers using specified work processes and equipment under administrative, technical, and environmental controls established by management to achieve an end result. Workers are the best resource of contributing ideas for improving work processes and will be involved in work process design, process evaluation, and providing the feedback necessary for improvement.

All work is planned and performed using the principles of Integrated Safety Management and in compliance with P300, Integrated Work Management for Work Activities.

\subsection{WORK PERFormance}

Management should ensure that the following are clearly identified and conveyed to workers prior to beginning work:

- customer and data requirements for the work and final product;

- acceptance criteria applicable to work and final product;

- hazards associated with the work;

- technical standards applicable to work and final product; and

- safety, administrative, technical, and environmental controls to be employed during the work.

The work processes used to meet the regulatory requirements and the requirements of this plan can be divided as follows:

- Stormwater Pollution Prevention Plans (Multi-Sector General Permit Section 5.0)

- Inspections (Multi-Sector General Permit Section 4.0)

- Monitoring (Multi-Sector General Permit Section 6.0)

- Discharge Monitoring Reports (Multi-Sector General Permit Section 7.1 - Reporting Monitoring Data to EPA)

- Best Management Practices (Multi-Sector General Permit Section 2.0 -Control Measures)

— Reporting and Recordkeeping (Multi-Sector General Permit Section 7.0)

\subsection{StormWater Pollution Prevention Plan}

Stormwater Pollution Prevention Plan (SWPPP) development and implementation by the regulated industrial facility is required for MSGP compliance (refer to Section 8.0 of the 2008 MSGP for Sector-Specific Requirements for Industrial Activity and Appendix D, Sectors of Industrial Activity Covered by This Permit). The SWPPP is intended to document the selection, design, and installation of control measures. Additional documentation requirements are intended to document the implementation (including inspection, maintenance, monitoring, and corrective 
action) requirements identified in the 2008 MSGP permit. The SWPPP is a written assessment of potential sources of pollutants in stormwater runoff and control measures that will be implemented at the specific industrial facility to minimize the discharge of pollutants in runoff from the site. These control measures include site-specific Best Management Practices (BMPs), inspections, employee training, and reporting. The procedures detailed in the SWPPP must be implemented by the facility and updated as necessary, with a copy of the SWPPP kept on-site.

The SWPPP development process involves evaluating regulated industrial activities and requiring Facility Management support in implementation, improvement, and revision of the Plans.

\subsubsection{DisCHARgE MONITORING REPORTS}

The Laboratory is required to submit analytical results of stormwater monitoring and to keep the results with the facility specific SWPPP. The Laboratory must certify and submit analytical monitoring results obtained from each facility specific sampling location (i.e., the sampling station located at the monitored outfalls) associated with industrial activity on a Discharge Monitoring Report (DMR) form or use it to report any of the following:

- no discharge for all outfalls for a specific monitoring period;

- the industrial facility status has changed to inactive and unstaffed;

- the facility status has changed to active; or

- no further pollutant reductions are achievable for all outfalls and for all pollutants (see Section 6.2.1.2 of the 2008 MSGP).

\subsubsection{ANNUAL Site COMPLiAnCE EVALUATION REPORT}

The Laboratory is required to submit an annual report (Attachment 2) to the Environmental Protection Agency (EPA) that includes the findings from the comprehensive site inspection and any corrective action documentation. The documentation must include the following:

- identification of the condition triggering the need for corrective action review;

- date and description of the problem identified;

- $\quad$ summary of the corrective action taken or to be taken;

- notice of whether SWPPP modifications are required as a result of the discovery or corrective action;

- date corrective action was initiated; and

- date corrective action was completed or is expected to be completed.

The following table lists responsibilities:

\begin{tabular}{|l|l|}
\hline \multicolumn{1}{|c|}{ Who } & \multicolumn{1}{|c|}{ What } \\
\hline Project Lead & $\begin{array}{l}\text { Ensure that SWPPP requirements are performed in accordance with } \\
\text { the MSGP. }\end{array}$ \\
\hline
\end{tabular}




\begin{tabular}{|l|l|}
\hline Facility Management Support & $\begin{array}{l}\text { Implement SWPPP requirements as recommended by the Project } \\
\text { Lead. }\end{array}$ \\
\hline $\begin{array}{l}\text { ENV-CP Staff and Deployed } \\
\text { Environmental Professionals } \\
\text { (DEPs) }\end{array}$ & Assure SWPPP implementation as required by MSGP. \\
\hline DEPs & $\begin{array}{l}\text { Develop, modify, and update SWPPPs and assist facility personnel } \\
\text { with SWPPP implementation. }\end{array}$ \\
\hline
\end{tabular}

\section{$5.5 \quad$ INSPECTIONS}

The MSGP requires periodic inspection of industrial processes and maintenance of (BMPs) to assure effectiveness of control measures. The Laboratory has implemented a quarterly or monthly inspection process (depending on the industrial facility) to support this determination. A copy of the Routine Inspection Form is provided in Attachment 3.

\subsection{STORMWATER MONITORING}

Benchmark stormwater monitoring is the required mechanism for determining the effectiveness of corrective actions and meeting the requirements of the MSGP. Refer to Attachment 4, MSGP Facilities and Stormwater Monitored Outfalls Associated with Industrial Activity 2011, for a list of Laboratory sites that have monitoring requirements. Laboratory management has made an investment in time and materials, in addition to a commitment to comply with the 2008 MSGP Permit. All stormwater monitoring is conducted by ENV-CRP personnel. The MSGP Project currently has a network of 23 monitoring stations. Considerations to be used for MSGP stormwater monitoring development decisions will include MSGP requirements, new state water quality standards, Administrative Authority requests, or new permit requirements. Stormwater monitoring will be conducted as specified in the MSGP.

Effluent Limitations stormwater monitoring is required for the following type of facility of LANL:

\begin{tabular}{|l|l|l|l|l|}
\hline $\begin{array}{l}\text { Regulated } \\
\text { Activity }\end{array}$ & Parameter & $\begin{array}{l}\text { Effluent } \\
\text { Limit }\end{array}$ & $\begin{array}{l}\text { Monitoring } \\
\text { Frequency }\end{array}$ & Sample Type \\
\hline $\begin{array}{l}\text { Discharges from } \\
\text { asphalt emulsion } \\
\text { facilities }\end{array}$ & $\begin{array}{l}\text { Total Suspended } \\
\text { Solids }\end{array}$ & $\begin{array}{l}23.0 \mathrm{mg} / \mathrm{L} \\
\text { daily max. } \\
15.0 \mathrm{mg} / \mathrm{L}, \\
30-\text { day avg. }\end{array}$ & $1 /$ year & grab \\
& & $6.0-9.0$ s.u. & $1 /$ year & grab \\
\cline { 2 - 5 } & $\mathrm{pH}$ & $10.0 \mathrm{mg} / \mathrm{L}$ & $1 /$ year & grab \\
\cline { 2 - 5 } & Oil and Grease & $30-$ day avg. & & \\
\hline
\end{tabular}


This determination was made in accordance with Section 1.1.2.4 of the MSGP. The TA-60 Asphalt Batch Plant meets the criteria for effluent limitations monitoring in this section. Exceedances of the effluent limits in this table require immediate action. In addition, if follow-up monitoring after corrective actions also exceeds an effluent limit guideline, an Exceedance Report for Numeric Effluent Limits must be submitted to EPA no later than 30 days after lab results have been received and verified.

Impaired Waters stormwater monitoring is required for discharges made to an impaired water. The canyons within and surrounding Los Alamos National Laboratory are declared as Impaired Waters by the New Mexico Environment Department. The pollutants vary from canyon to canyon and are listed in Attachment 5, Pollutants Under Impaired Waters Monitoring. The pollutants may be discontinued in subsequent annual monitoring if the concentration is below background levels in stormwater or if the constituent is not detected.

Visual assessments are also required by the MSGP and are an important tool for collecting information to determine the effectiveness of controls in preventing potential contaminants from migrating off Laboratory property. Accordingly, field personnel must conduct visual assessments for stormwater collected at the monitoring stations or discharged through substantially identical outfalls associated with industrial facilities located throughout the Laboratory. Information recorded will document all observations that are required by the MSGP (see ENV-RCRA-QP-064, Multi-Sector General Permit Storm Water Visual Inspections).

The Laboratory's MSGP permit requires stormwater quality monitoring to evaluate compliance with water quality standards and evaluation against benchmarks. Parameters sampled at the monitoring stations are selected based on permit requirements and the results of the previous year.

Four stormwater samples per year are required under the 2008 MSGP, but it is not necessary to collect them in consecutive quarters if climatic conditions that prevented quarterly collection are documented (see Adverse Weather Conditions in Section 6.1.5 of the MSGP). Sample locations are listed in Attachment 4, MSGP Facilities and Stormwater Monitored Outfalls Associated with Industrial Activity 2011, and collection will be conducted in accordance with LANL and NPDES Permit requirements and the current year MSGP Sampling and Analysis Plan.

Stormwater samples are used to demonstrate compliance with water quality standards and requirements to evaluate results against benchmark parameters (Attachments 5 and 6). Any persons involved in the preparation, retrieval, and analysis must maintain positive control of samples at all times until sample disposal. ENV-RCRA personnel will follow guidance in the Associate Directorate for Environmental Programs (ADEP) document ENV-WQH-QP-029, Creating and Maintaining a Chain of Custody, as well as, ENV-RCRA-QP-047, Inspecting Storm Water Runoff Samplers and Retrieving Samples, and ENV-RCRA-QP-048, Processing MSGP Storm Water Samples. 
Chain of custody is maintained during:

\begin{tabular}{|l|l|}
\hline \multicolumn{1}{|c|}{ Activity } & \multicolumn{1}{c|}{ Responsibility } \\
\hline $\begin{array}{l}\text { Sample collection } \\
\text { and preparation }\end{array}$ & $\begin{array}{l}\text { All persons (other than analytical personnel) performing sample } \\
\text { preparation and collection will be trained to sample collection } \\
\text { procedures and must adhere to the chain of custody requirements therein. }\end{array}$ \\
\hline Analysis & $\begin{array}{l}\text { Analytical laboratories performing sample analysis will maintain } \\
\text { sufficient procedures to ensure positive control of samples as specified } \\
\text { in the existing Statement of Work. }\end{array}$ \\
\hline $\begin{array}{l}\text { Storage/ } \\
\text { disposal }\end{array}$ & $\begin{array}{l}\text { Analytical laboratories will maintain retained samples and/or sample } \\
\text { portions under chain of custody until reanalysis, or ultimate disposal. }\end{array}$ \\
\hline
\end{tabular}

The LANL Sample Management Office (SMO) will be the central point for all analytical laboratory selection, evaluations, sample submittal, and data return. The SMO will evaluate potential analytical laboratories, prepare analytical statements of work that include requirements, and arrange contracts with selected laboratories for analysis of all samples. The SMO will accept samples from field collection personnel, process the sample, ship the samples to the off-site analytical laboratories, and receive the data packages from the laboratories.

All analytical data will be received from analytical laboratories in electronic format and uploaded into a database. All received data will be checked for completeness and adherence to contract requirements. After uploading, all data will undergo verification and validation (V\&V) for evidence of laboratory contamination, improper analytical method, and other analytical issues which could potentially affect data quality.

Field data collected by sample collection personnel will be verified and validated by the SMO when field personnel deliver samples to the SMO.

If significant $\mathrm{V} \& \mathrm{~V}$ issues are identified, results will be forwarded to and discussed with the responsible project leads.

Data issues that result from procedural failures, personnel errors, or other failures to follow requirements will be documented as issues and corrected according to ENV-DO-QP-113, Tracking Issues and Actions.

The following table lists responsibilities:

\begin{tabular}{|c|l|}
\hline \multicolumn{1}{|c|}{ Who } & \multicolumn{1}{c|}{ What } \\
\hline Project Lead & $\begin{array}{l}\text { Ensure that all project monitoring requirements are performed in } \\
\text { accordance with the MSGP. } \\
\text { Review and update the MSGP Sampling and Analysis Plan annually. }\end{array}$ \\
\hline
\end{tabular}




\begin{tabular}{|c|c|}
\hline & $\begin{array}{l}\text { When complete, communicate findings to the team members for } \\
\text { implementation. Make appropriate arrangements with the SMO to accept, } \\
\text { process, and submit samples to an analytical laboratory for required } \\
\text { analyses as specified in the SAP. }\end{array}$ \\
\hline $\begin{array}{l}\text { MSGP Water } \\
\text { Quality } \\
\text { Compliance } \\
\text { Personnel }\end{array}$ & $\begin{array}{l}\text { - Implement monitoring program as required by the MSGP Project } \\
\text { Lead. } \\
\text { - Conduct stormwater sampling in accordance with the MSGP } \\
\text { Sampling and Analysis Plan and applicable procedures. } \\
\text { - Ensure procedures for sample handling and control during } \\
\text { sample preparation and retrieval are followed. }\end{array}$ \\
\hline $\begin{array}{l}\text { Sample } \\
\text { Management } \\
\text { Office }\end{array}$ & $\begin{array}{l}\text { - Develop Statements of Work (SOW) for all analytical } \\
\text { laboratories that perform analytical work for the MSGP project in } \\
\text { accordance with P840-1, Procurement Quality. } \\
\text { - Ensure analytical laboratories comply with the DOE’s SOW. } \\
\text { Conduct an annual audit of the laboratory to ensure compliance } \\
\text { with the SOW. } \\
\text { - Approve Statements of Work for analytical laboratories that are } \\
\text { contracted to analyze water samples. } \\
\text { - } \quad \text { Approve analytical laboratories that are contracted to analyze } \\
\text { - } \quad \text { Accepter samples for regulatory compliance purposes. } \\
\text { laboratory for analysis. } \\
\text { - Track progress of samples at the analytical laboratory and resolve } \\
\text { issues with sample analysis. } \\
\text { Receive data packages from the analytical laboratory and enter } \\
\text { data into the database. } \\
\text { - Provide the MSGP Project Lead with monthly invoice updates. } \\
\text { Perform V\&V of field data submitted and uploaded from forms } \\
\text { when samples are submitted to the SMO. }\end{array}$ \\
\hline $\begin{array}{l}\text { Operations } \\
\text { Integration Office } \\
\text { (OIO), Systems } \\
\text { Integration (SI) }\end{array}$ & $\begin{array}{l}\text { Perform V\&V of data packages uploaded by the SMO or send data } \\
\text { packages to a subcontractor company for independent } V \& V \text {. }\end{array}$ \\
\hline
\end{tabular}

\subsection{DISCHARgE MONITORING REPORTS}

The Laboratory is required to submit analytical results of stormwater monitoring and to keep the results with the specific SWPPP. The Laboratory must submit analytical monitoring results obtained from each monitoring station associated with industrial activity on a MSGP Discharge Monitoring Report (MDMR) form (one form must be submitted for each storm event from which, a sample was collected).

MDMRs shall be written in accordance with ENV-RCRA-QP-044, Preparing Storm Water Discharge Monitoring Reports (MDMRs) for the NPDES Multi-Sector General Permit. MDMRs shall be submitted to EPA within 30 calendar days of receiving validated 
analytical results. Refer to the DMR language under the SWPPP Section above for additional requirements.

Site analytical requirements are defined by the industrial activity in the MSGP permit. All MSGP analytes applicable to LANL are consistent with the requirements of 40 CFR Part 136, Guidelines Establishing Test Procedures for the Analysis of Pollutants.

Sample analytical requirements vary by site depending on the industrial activities performed at the site. Refer to Attachment 5 for a list of analytes by industrial sector. If an insufficient quantity of sample is available, then sample collection will be prioritized at that location for future events. Additional samples may be collected to meet permit requirements.

ENV-RCRA shall refer to the requirements of the 2008 Multi-Sector General Permit, and the most current MSGP Sampling and Analysis Plan to determine the priorities of required analyses.

The following table lists responsibilities:

\begin{tabular}{|l|r|}
\hline \multicolumn{1}{|c|}{ Who } & \multicolumn{1}{c|}{ What } \\
\hline Project Lead & $\bullet \quad \begin{array}{l}\text { Ensure implementing procedures for sample analyses are used. } \\
\text { Ensure that MDMRs are submitted to EPA and NMED in } \\
\text { accordance with the MSGP. }\end{array}$ \\
\hline $\begin{array}{l}\text { MSGP Water } \\
\text { Quality } \\
\begin{array}{l}\text { Compliance } \\
\text { Personnel }\end{array}\end{array}$ & $\begin{array}{l}\text { Assure MDMRs are completed and certified as required by the MSGP and } \\
\text { have received a full quality assurance review. }\end{array}$ \\
\hline
\end{tabular}

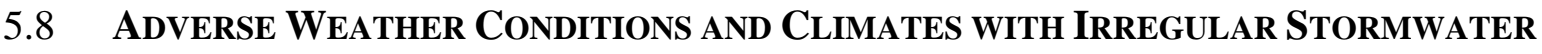 RUNOFF}

Section 4.2.3 of the 2008 MSGP allows the industrial facility to take a substitute sample during the next qualifying storm event when adverse weather conditions prevent the collection of samples during a specific quarter. Adverse weather conditions are those that are dangerous or create inaccessibility for personnel, such as local flooding, high winds, or electrical storms, or situations that otherwise make sampling impractical, such as drought or extended frozen conditions. Documentation of the rationale for no visual assessment for the quarter must be included in the facility specific SWPPP.

Since LANL is located in an area where limited rainfall occurs during parts of the year (i.e., in a semi-arid climate) and has periods of freezing conditions, LANL has identified an alternative monitoring period of four quarters as follows for each calendar year.

- April 1-May 31 
- June 1-July 31

- August 1-September 30

- October 1-November 30

The following table lists specific responsibilities.

\begin{tabular}{|c|l|}
\hline Who & \multicolumn{1}{|c|}{ What } \\
\hline Project Lead & $\begin{array}{l}\text { Ensure that the monitoring schedule is documented in } \\
\text { facility specific SWPPPs and provided to EPA on the } \\
\text { MDMRs. }\end{array}$ \\
\hline
\end{tabular}

\subsection{REPORTING AND RECORDKEEPING}

All monitoring data shall be collected in accordance with the requirements specified in the 2008 MSGP. LANL will submit monitoring results to EPA within 30 days of receiving validated laboratory results. The address for submittal of monitoring results is as follows.

\section{U.S. Environmental Protection Agency}

Office of Water, Water Permits Division

Mail Code 4203M, ATTN: MSGP Reports

1200 Pennsylvania Avenue, NW

Washington, D.C. 20460

LANL shall keep copies of the following documentation for a period of at least 3 years from the date that LANL's coverage under the MSGP expires or is terminated.

- SWPPP (including any modifications made during the term of the 2008 MSGP)

- Additional documentation requirements as identified in Section 5.4 of the MSGP

- All reports and certifications required by the MSGP

- Monitoring data

- Records of all data used to complete the NOI.

The following table lists specific responsibilities:

\begin{tabular}{|l|l|}
\hline \multicolumn{1}{|c|}{ Who } & \multicolumn{1}{c|}{ What } \\
\hline Project Lead & $\begin{array}{l}\text { Periodically audit MSGP records to ensure documentation of } \\
\text { compliance is being retained. }\end{array}$ \\
\hline $\begin{array}{l}\text { Deployed } \\
\text { Environmental } \\
\text { Professionals }\end{array}$ & $\begin{array}{l}\text { Retain records as required by the MSGP for industrial facilities } \\
\text { located in their FOD. }\end{array}$ \\
\hline
\end{tabular}




\subsection{Best Management Practices}

It is critical that the Laboratory be able to effectively inspect and maintain the Best Management Practices that have been installed at various locations. Quarterly inspections must be completed and provided to the Project Lead for inclusion into the records system. In addition, the Project Leader conducts a Comprehensive Annual Site Inspection and writes a report to document the status of BMPs and other identified corrective actions. This report is sent to EPA each year. Laboratory management has made an investment in time and materials, in addition to a commitment to minimizing the potential migration of contaminants in stormwater. Report findings are evaluated and in conjunction with facility personnel, BMPs are modified, installed, or removed as necessary.

The following table lists responsibilities.

\begin{tabular}{|l|l|}
\hline \multicolumn{1}{|c|}{ Who } & \multicolumn{1}{c|}{ What } \\
\hline Project Lead & $\begin{array}{l}\text { Assist facility personnel and Deployed Environmental Professionals with } \\
\text { implementation, inspection, and maintenance of BMPs at MSGP facilities. }\end{array}$ \\
\hline $\begin{array}{l}\text { Facility } \\
\text { Support }\end{array}$ & $\bullet \quad \begin{array}{l}\text { Coordinate with Project Lead and provide funding as needed to } \\
\text { install, inspect, maintain and implement identified BMPs. } \\
\text { Certify the corrective actions identified by the Project Lead } \\
\text { and/or facility personnel (or their representatives) for their } \\
\text { individual facilities in the Annual Report. }\end{array}$ \\
\hline
\end{tabular}

\subsection{INFORMATION MANAGEMENT}

The Water Quality Database is a database information system designed in part to support the information management (IM) needs of the Laboratory’s MSGP. MSGP support includes stormwater discharge monitoring reporting, Geographic Information System (GIS) development, and other IM activities as needed.

The following table lists responsibilities:

\begin{tabular}{|c|l|}
\hline \multicolumn{1}{|c|}{ Who } & \multicolumn{1}{c|}{ What } \\
\hline Project Lead & $\begin{array}{l}\text { Coordinate with IM support personnel to meet regulatory } \\
\text { requirements. }\end{array}$ \\
\hline
\end{tabular}

\subsection{RESPONDING TO WATER QUALITY EXCEEDANCES}

The identification of a pollutant source(s) contributing to a water quality exceedance will be addressed through the creation of a corrective action that is entered into the Corrective Acton 
Report database in accordance with ENV-DO-QP-113, Tracking Performance Feedback and Actions and ENV-RCRA-QP-022, MSGP Stormwater Corrective Actions. Federal stormwater regulations implemented under the Laboratory's MSGP (40 CFR 122, EPA Administered Permit Programs: The National Pollutant Discharge Elimination System) require that corrective action be taken if exceedances of water quality standards or MSGP numeric effluent limits are identified. Corrective actions are typically accomplished by modifying, as appropriate, existing BMPs and SWPPPs.

When a water quality exceedance occurs, the Laboratory will submit the data on the required MDMRs, investigate the occurrence, and document corrective actions.

When an exceedance of the MSGP benchmark parameters is detected, the Project Lead will assure the analytical data is reviewed, notify appropriate SWPPP owners, and recommend and track corrective actions where required.

The following steps lead to corrective actions:

\begin{tabular}{|c|l|}
\hline STEP & \\
\hline 1 & $\begin{array}{l}\text { Establish that an analytical result from a location is valid and has exceeded a } \\
\text { standard or MSGP benchmark. }\end{array}$ \\
\hline 2 & Evaluate and demonstrate that the analyte is of LANL origin, if possible. \\
\hline 3 & Determine the source and assign responsibility for the corrective action. \\
\hline 4 & Develop a corrective action plan. \\
\hline
\end{tabular}

The following table lists responsibilities:

\begin{tabular}{|c|c|}
\hline Who & What \\
\hline Project Lead & $\begin{array}{l}\text { - } \quad \text { Assure that analytical data is reviewed and accurate. } \\
\text { - } \quad \text { Notify appropriate SWPPP owners, Laboratory management, } \\
\text { and Deployed Environmental Professionals. } \\
\text { - } \quad \text { Develop a corrective action plan. } \\
\text { - } \quad \text { Track corrective actions. }\end{array}$ \\
\hline $\begin{array}{l}\text { Facility } \\
\text { Management and } \\
\text { DEP }\end{array}$ & $\begin{array}{l}\text { - Review analytical data with Project Lead and provide input into } \\
\text { a possible corrective action necessary to improve water quality } \\
\text { where needed. } \\
\text { - Evaluate and improve BMPs in accordance with site } \\
\text { conditions, industry standards, and manufacturer }\end{array}$ \\
\hline
\end{tabular}




\subsection{INSTRUMENTATION AND EQUIPMENT}

Compliance will be tracked by performing inspections of samplers and other associated equipment, inspecting BMPs, and conducting annual site compliance evaluations. Adequate records will be maintained to demonstrate the operating history of essential instrumentation and equipment.

LANL will properly operate and maintain all systems of monitoring and control and related appurtenances which are installed or used to achieve compliance with the MSGP and the SWPPP. Backup instrumentation and equipment will be timely deployed in the event of equipment failure.

Instrument calibration is essential for documenting the quality of data obtained with the instrument. All technical work that depends upon the accuracy of data will be performed using equipment for which the calibration status and limits of accuracy are known and controlled.

Field team personnel will calibrate and perform maintenance procedures on all monitoring and analytical field instruments to ensure accuracy of measurements and will maintain appropriate records of such activities. All field calibrations will be documented as prescribed by procedures or manufacturer's instructions.

The following table lists specific responsibilities.

\begin{tabular}{|c|c|}
\hline \multicolumn{1}{|c|}{ Who } & \multicolumn{1}{c|}{ What } \\
\hline Project Lead & - $\begin{array}{l}\text { Ensure data are collected and equipment is operated and } \\
\text { maintained in accordance with project requirements. }\end{array}$ \\
& $\begin{array}{l}\text { Provide equipment maintenance and calibration } \\
\text { specifications and ensure MSGP Water Quality } \\
\text { Compliance Team personnel operate and conduct field } \\
\text { activities in accordance with implementing procedures and } \\
\text { specific work orders. }\end{array}$ \\
\hline
\end{tabular}

\subsection{DESIGN}

Design activities will be conducted and reviewed in accordance with PD340, Conduct of Engineering and P341, Engineering Process Manual.

Design standards under this program include, but are not limited to temporary and permanent BMPs, corrective action measures, and stormwater monitoring support.

Design inputs will be specified and approved on a timely basis for making design decisions. Inputs will contain the level of detail required to permit the performance of design activities correctly. 
Formal design reviews, including design verifications and evaluation of design changes, will be conducted to ensure that the design input is correctly incorporated into the design output. Changes to design will undergo the same review as the original design.

Verification and validation of the adequacy of designs are conducted before relying on the performance of the design function. Verification and validation are conducted in accordance with implementing procedures.

The following table lists responsibilities.

\begin{tabular}{|l|l|}
\hline \multicolumn{1}{|c|}{ Who } & \multicolumn{1}{c|}{ What } \\
\hline Project Lead & $\begin{array}{l}\text { Provide input to the design process in accordance with } \\
\text { appropriate standards, requirements, and implementing } \\
\text { procedures. } \\
\text { Determine the qualifications required to perform a review of } \\
\text { design documents. }\end{array}$ \\
& $\begin{array}{l}\text { Identify a resource with skills, knowledge, ability, training, and } \\
\text { certifications required to complete the review of the facility } \\
\text { engineering design documents. } \\
\text { Communicate the results of the review to the requestor. }\end{array}$ \\
\hline ENV-CP Staff & $\begin{array}{l}\text { Review design documents and requests as assigned. } \\
\text { Inform the Project Lead of concerns regarding the facility engineering } \\
\text { designs. }\end{array}$ \\
\hline
\end{tabular}

\subsection{PROCUREMENT}

Items and services required for this process are commercial grade in nature and no special procurement requirements or needs are necessary. All procurements will be made in accordance with P840-1, Procurement Quality. For items and all services for which special requirements are necessary, the Project Lead and project members will identify such items or services.

The following table lists responsibilities:

\begin{tabular}{|l|l|}
\hline \multicolumn{1}{|c|}{ Who } & \multicolumn{1}{c|}{ What } \\
\hline Group Leader & Ensure all procurements are conducted in accordance with P840-1. \\
\hline Project Lead & $\begin{array}{l}\text { Recommend to Group Leader contracting items and services. } \\
\text { Develop acceptance criteria. }\end{array}$ \\
\hline ENV-CP Staff & $\begin{array}{l}\text { Identify potential suppliers of products or services necessary to complete work } \\
\text { activities that must be procured from outside ENV-RCRA. }\end{array}$ \\
\hline
\end{tabular}




\subsection{INSPECTION AND ACCEPTANCE TESTING}

Any materials or services will be inspected and/or tested prior to acceptance for use in this project in accordance with P330-8, Inspection and Test for Acceptance. Most supplies used during performance of project activities are commercial grade in nature and require no special acceptance practices or procedures.

The following table lists responsibilities:

\begin{tabular}{|l|l|}
\hline \multicolumn{1}{|c|}{ Who } & \multicolumn{1}{c|}{ What } \\
\hline Group Leader & $\begin{array}{l}\text { Ensure procedures for inspection meet SD330, Los Alamos National } \\
\text { Laboratory Quality Assurance Program requirements. }\end{array}$ \\
\hline Project Lead & Verify that all materials and services meet acceptance criteria. \\
\hline ENV-CP Staff & Follow established procedures for inspection and acceptance testing. \\
\hline
\end{tabular}

\subsection{MANAGEMENT ASSESSMENT}

The ENV-CP Group conducts internal management assessments of projects and programs in accordance with the requirements in P328-3, Management Assessment and P328-4, Management Observation and Verification. Assessments of the program are documented and filed as records.

When violations of requirements are found during a management assessment, a nonconformance report is initiated in accordance with P330-6, Nonconformance Reporting for nonconforming items.

Nonconforming services or processes are tracked and documented in accordance with P322-4, Issues and Corrective Action Management.

The following table lists responsibilities:

\begin{tabular}{|l|l|}
\hline \multicolumn{1}{|c|}{ Who } & \multicolumn{1}{|c|}{ What } \\
\hline Group Leader & $\begin{array}{l}\text { Ensure management self-assessments for the MSGP program are conducted } \\
\text { as specified in implementing procedures. }\end{array}$ \\
\hline Project Lead & Ensure program management self-assessments are conducted. \\
\hline
\end{tabular}




\subsection{INDEPENDENT ASSESSMENT}

Independent assessments are those assessments conducted by organizations external to ENV-RCRA. As required by the SD330, Los Alamos National Laboratory Quality Assurance Program, this program may be assessed by outside organizations in accordance with P328-2, Independent Assessment.

Periodically audits/assessments will be conducted, with input from the Project Lead identifying one or more areas of the project to be audited.

The following table lists responsibilities:

\begin{tabular}{|c|c|}
\hline Who & What \\
\hline Project Lead & $\begin{array}{l}\text { - } \\
\text { - } \\
\text { - } \\
\text { - } \\
\text { Revievide input to the QA Specialist as to the content of audit. } \\
\text { implement corrective actions as appropriate. }\end{array}$ \\
\hline QA Specialist & 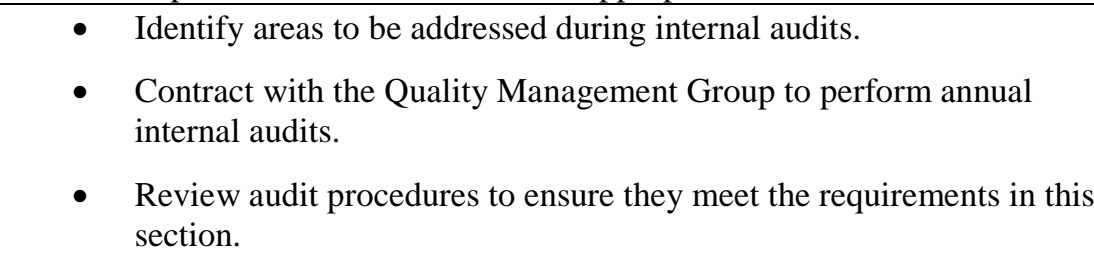 \\
\hline Team Members & $\begin{array}{l}\text { Cooperate with auditors by providing information, data, etc. } \\
\text { Implement corrective actions as directed by the Project Lead. }\end{array}$ \\
\hline
\end{tabular}

\subsection{ATTACHMENTS}

Attachment 1- MSGP Program Organization

Attachment 2 - Annual Reporting Form

Attachment 3 - Routine Inspection Form

Attachment 4 - MSGP Facilities and Storm Water Monitored Outfalls Associated with Industrial Activity 2011, Permit NMR05GB21

Attachment 5 - Pollutants under Impaired Waters Monitoring

Attachment 6 - Analytes by Industrial Sector

Attachment 7 - References and Guidance Documents 


\section{ATtaChMENT 1- MSGP PRogram ORganization}

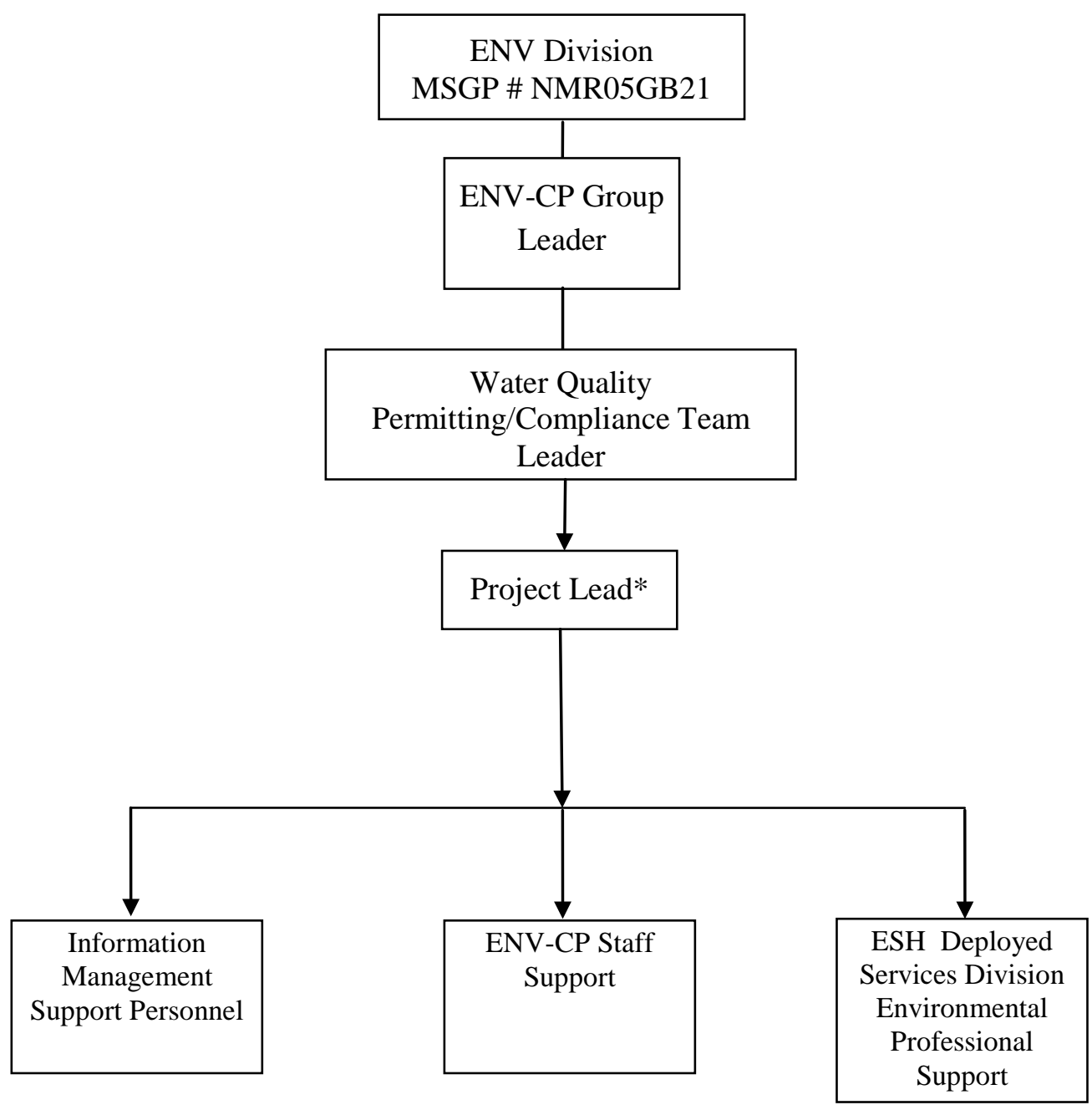

*Project Lead acts as liaison and will work directly with Team Leaders for staff assignments. 


\section{ATtachment 2 - ANNUAL Reporting Form}

NPDES Permit Tracking No.:

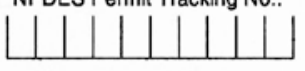

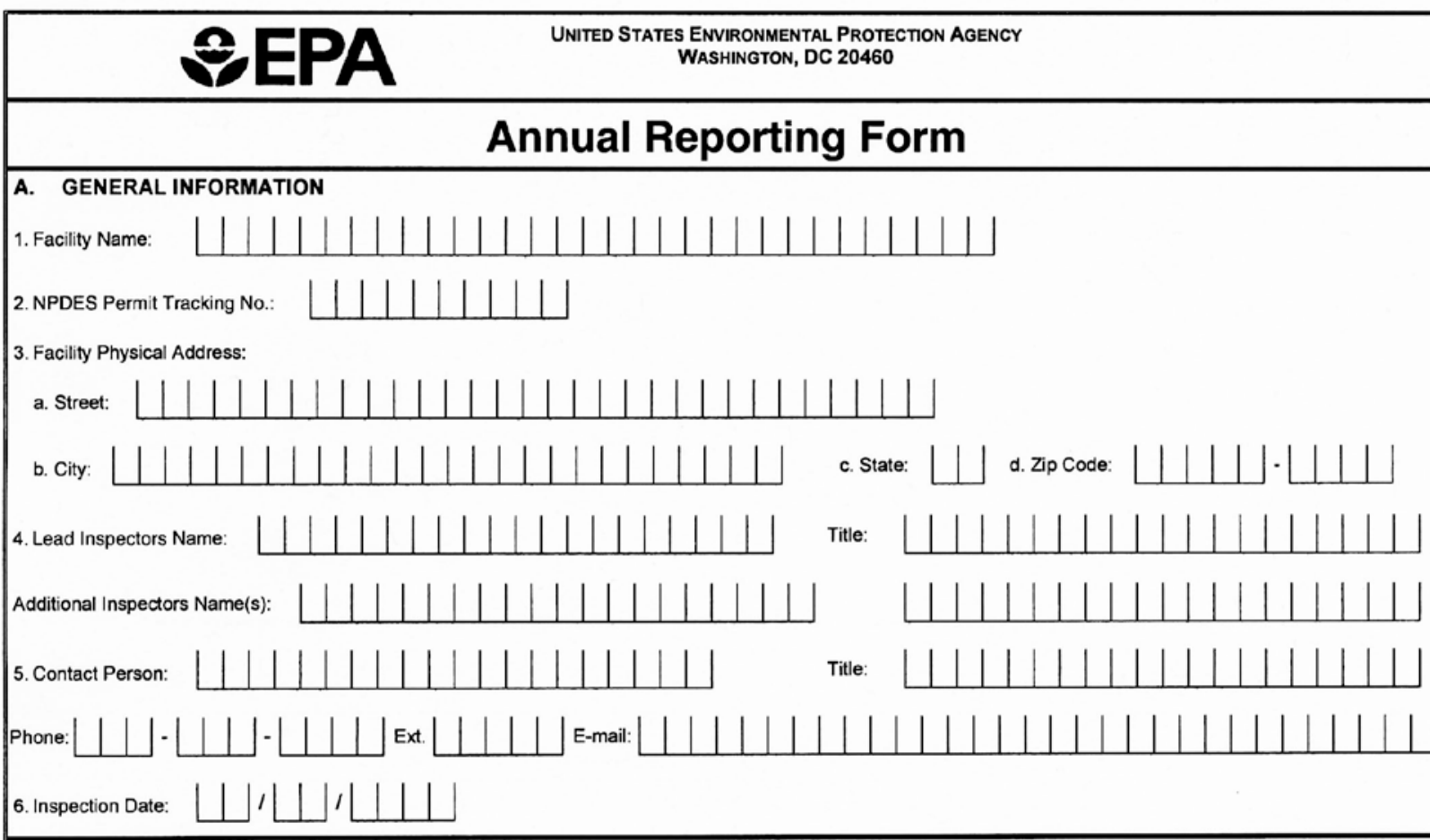

B. GENERAL INSPECTION FINDINGS

1. As part of this comprehensive site inspection, did you inspect all potential pollutant sources, including areas where industrial activity may be exposed to stormwater? $\square$ YES $\square$ NO

If NO, describe why not:

NOTE: Complete Section C of this form for each industrial activity area inspected and included in your SWPPP or as newly identified in B.2 or B.3 below where pollutants may be exposed to stormwater.

2. Did this inspection identify any stormwater or non-stormwater outfalls not previously identified in your SWPPP? $\square$ YES $\square$ NO

If YES, for each location, describe the sources of those stormwater and non-stormwater discharges and any associated control measures in place: 
NPDES Permit Tracking No.:

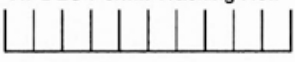

3. Did this inspection identify any sources of stormwater or non-stormwater discharges not previously identified in your SWPPP? $\square$ YES $\square$ NO

If YES, describe these sources of stormwater or non-stormwater pollutants expected to be present in these discharges, and any control measures in place:

4. Did you review stormwater monitoring data as part of this inspection to identify potential pollutant hot spots? $\square$ YES $\square$ NO $\square$ NA, no monitoring performed

If YES, summarize the findings of that review and describe any additional inspection activities resulting from this review:

5. Describe any evidence of pollutants entering the drainage system or discharging to surface waters, and the condition of and around outfalls, including flow dissipation measures to prevent scouring:

6. Have you taken or do you plan to take any corrective actions, as specified in Part 3 of the permit, since your last annual report submission (or since you received authorization to discharge under this permit if this is your first annual report), including any corrective actions identifed as a result of this annual comprehensive site inspection?

$\square$ YES $\square$ NO

If YES, how many conditions requiring review for correction action as

specified in Parts 3.1 and 3.2 were addressed by these corrective actions?

NOTE: Complete the attached Corrective Action Form (Section D) for each condition identified, including any conditions identified as a result of this comprehensive stormwater inspection. 


\section{INDUSTRIAL ACTIVITY AREA SPECIFIC FINDINGS}

Complete one block for each industrial activity area where pollutants may be exposed to stormwater. Copy this page for additional industrial activity areas. In reviewing each area, you should consider:

- Industrial materials, residue, or trash that may have or could come into contact with stormwater:

- Leaks or spills from industrial equipment, drums, tanks, and other containers:

- Oftsite tracking of industrial or waste materials from areas of no exposure to exposed areas; and

- Tracking or blowing of raw, final, or waste materials from areas of no exposure to exposed areas.

INDUSTRIAL ACTIVITY AREA

1. Brief Description:
2. Are any control measures in need of maintenance or repair?
$\square$ YES $\square$ NO
3. Have any control measures failed and require replacement?
$\square$ YES $\square$ NO
4. Are any additional/revised control measures necessary in this area?
$\square$ YES $\square$ NO

If YES to any of these three questions, provide a description of the problem: (Any necessary corrective actions should be described on the attached Corrective Action Form)

INDUSTRIAL ACTIVITY AREA

1. Brief Description:

2. Are any control measures in need of maintenance or repair? $\quad \square$ YES $\square$ NO

3. Have any control measures failed and require replacement? $\quad \square$ YES $\square$ NO

4. Are any additional/revised $c$ necessary in this area? $\quad \square$ YES $\square$ NO

If YES to any of these three questions, provide a description of the problem: (Any necessary corrective actions should be described on the attached Corrective Action Form)

INDUSTRIAL ACTIVITY AREA

Brief Description:

2. Are any control measures in need of maintenance or repair?

$\square$ YES $\square$ NO

3. Have any control measures failed and require replacement?

$\square$ YES $\square$ NO

4. Are any additional/revised BMPs necessary in this area?

$\square$ YES $\square$ NO

If YES to any of these three questions, provide a description of the problem: (Any necessary corrective actions should be described on the attached Corrective Action Form) 
INDUSTRIAL ACTIVITY AREA

1. Brief Description:

2. Are any control measures in need of maintenance or repair?

$\square$ YES $\square$ NO

3. Have any control measures failed and require replacement? $\quad \square$ YES $\square$ NO

4. Are any additional/revised BMPs necessary in this area? $\square$ YES $\square$ NO

If YES to any of these three questions, provide a description of the problem: (Any necessary corrective actions should be described on the attached Corrective Action Form)

INDUSTRIAL ACTIVITY AREA

1. Brief Description:

$\begin{array}{lll}\text { 2. Are any control measures in need of maintenance or repair? } & \square \text { YES } & \square \text { NO } \\ \text { 3. Have any control measures failed and require replacement? } & \square \text { YES } & \square \text { NO } \\ \text { 4. Are any additional/revised BMPs necessary in this area? } & \square \text { YES } & \square \text { NO }\end{array}$

If YES to any of these three questions, provide a description of the problem: (Any necessary corrective actions should be described on the attached Corrective Action Form)

INDUSTRIAL ACTIVITY AREA

1. Brief Description:

2. Are any control measures in need of maintenance or repair?

$\square$ YES $\square$ NO

3. Have any control measures failed and require replacement?

$\square$ YES $\square$ NO

4. Are any additional/revised BMPs necessary in this area?

$\square$ YES $\square$ NO

If YES to any of these three questions, provide a description of the problem: (Any necessary corrective actions should be described on the attached Corrective Action Form) 


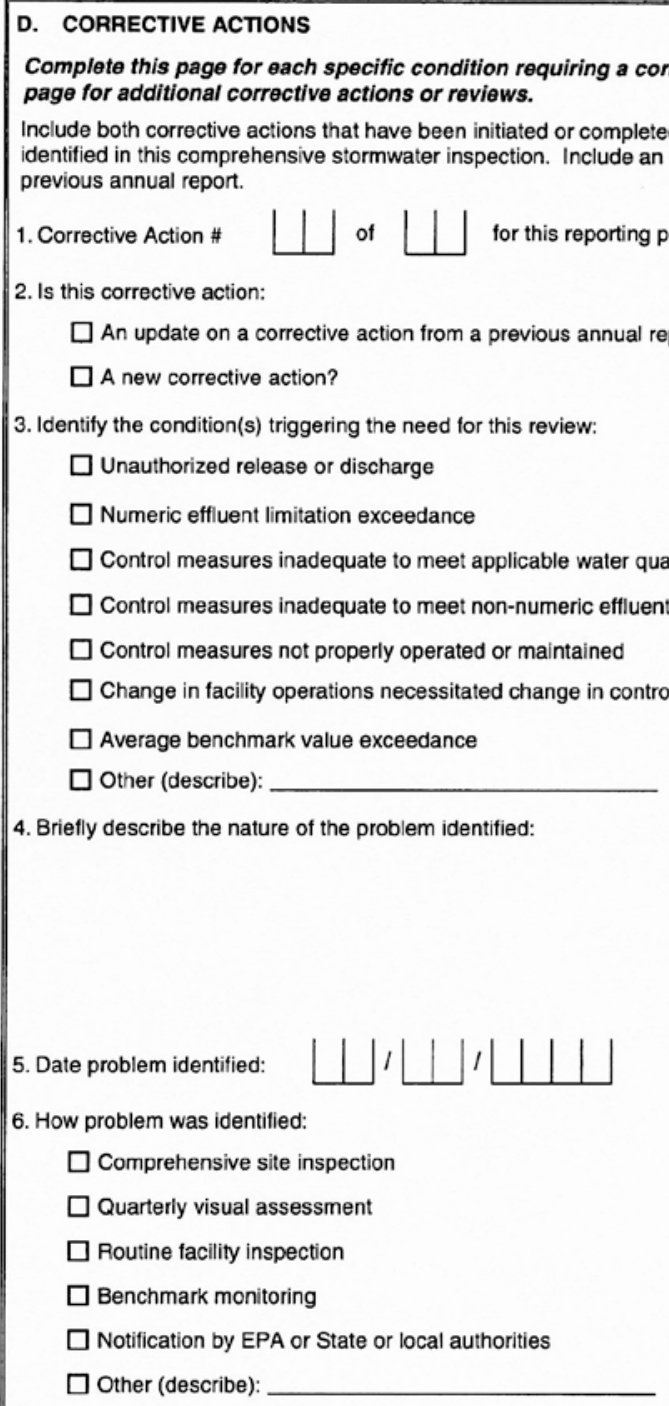

7. Description of corrective action(s) taken or to be taken to eliminate or further investigate the problem (e.g., describe modifications or repairs to control measures, analyses to be conducted, etc.) or if no modifications are needed, basis for that determination:

8. Did/will this corrective action require modification of your SWPPP? $\square$ YES $\square$ NO

9. Date corrective action initiated:

10. Date correction action completed:
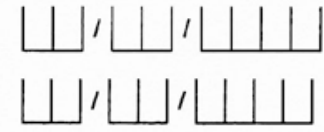

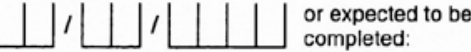

11. If corrective action not yet completed, provide the status of corrective action at the time of the comprehensive site inspection and describe any remaining steps (including timeframes associated with each step) necessary to complete corrective action: 
NPDES Permit Tracking No::

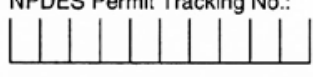

\section{E. ANNUAL REPORT CERTIFICATION}

1. Compliance Certification

Do you certify that your annual inspection has met the requirements of Part 4.2 of the permit, and that, based upon the results of this inspection, to the best of your knowledge, you are in compliance with the permit? $\square$ YES $\square$ NO

If NO, summarize why you are not in compliance with the permit:

2. Annual Report Certification

I certify under penalty of law that this document and all attachments were prepared under my direction or supervision in accordance with a system designed to assure that qualified personnel properly gathered and evaluated the information submitted. Based on my inquiry of the person or persons who manage the system, or those persons directly responsible for gathering the information, the information submitted is, to the best of my knowledge and belief, true, accurate, and complete. I am aware that there are significant penalties for submitting false information, including the possibility of fine and imprisonment for knowing violations. 


\section{ATTACHMENT 3 - ROUTINE INSPECTION FORM}

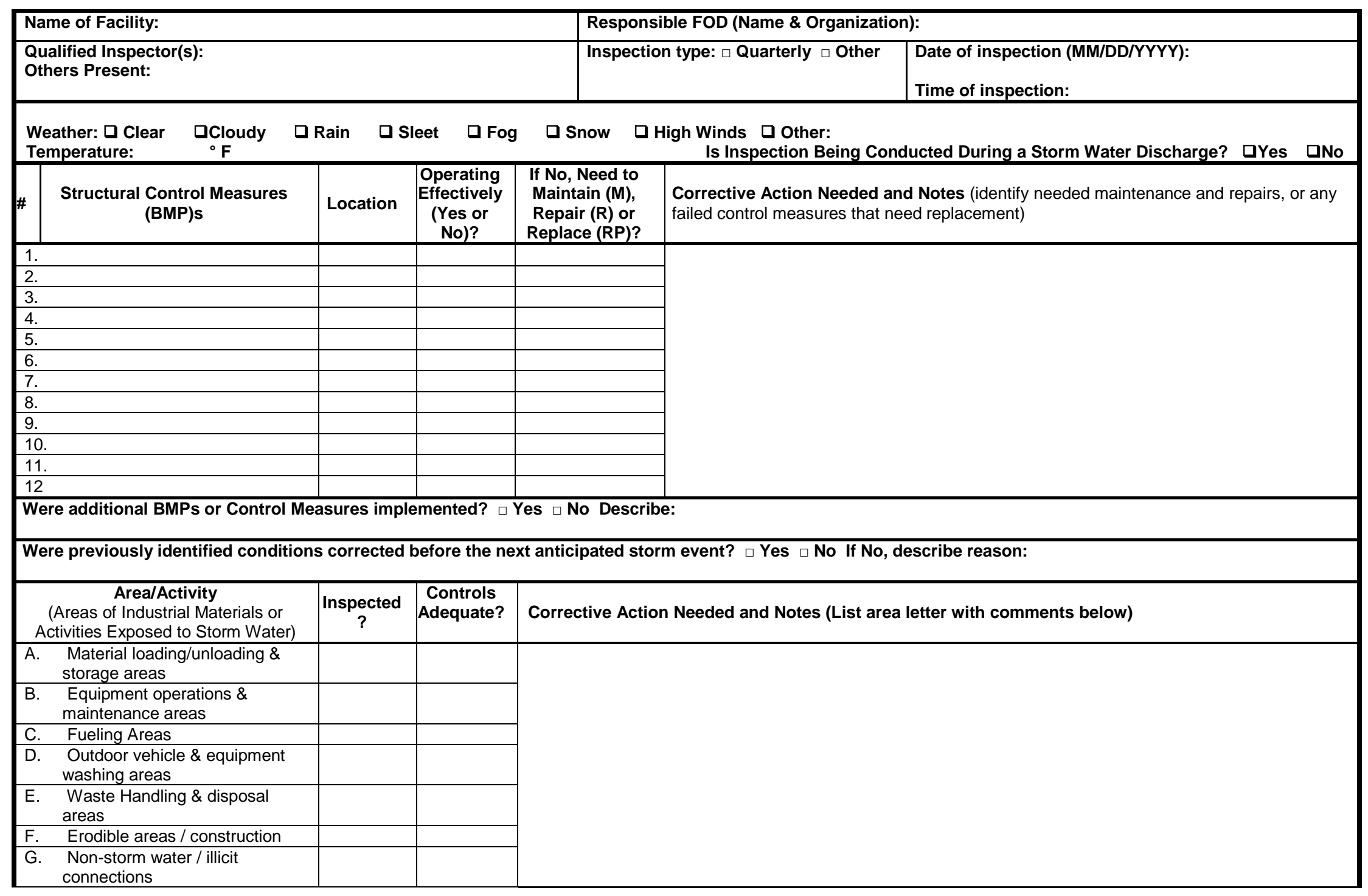




\begin{tabular}{|l|l|l|}
\hline $\mathrm{H} . \quad \begin{array}{l}\text { Salt storage piles or pile } \\
\text { containing salt }\end{array}$ & & \\
\hline $\begin{array}{l}\text { Dust generation \& vehicle } \\
\text { tracking }\end{array}$ & \\
\hline Are the SWPP Plan maintenance, schedules and procedures being implemented at the facility? $\square$ Yes $\square$ No \\
\hline Were any Corrective Actions initiated or completed? $\square$ Yes $\square$ No Describe: \\
\hline $\begin{array}{l}\text { Are there any conditions requiring Corrective Action? } \square \text { Yes } \square \text { No If Yes, List Number of Corrective Actions Required } \\
\text { (Note - You need enter a Corrective Action in the MSGP Corrective Action Report database for each listed) }\end{array}$ \\
\hline
\end{tabular}

(Note - You need enter a Corrective Action in the MSGP Corrective Action Report database for each listed) 


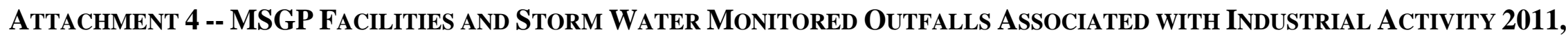
PERMIT NMR05GB21

\begin{tabular}{|c|c|c|c|c|c|c|}
\hline Location & Permitted Facility & Operation & Activity & Sector & $\begin{array}{c}\text { Monitored } \\
\text { Outfall }\end{array}$ & - Canyon \\
\hline TA-15-185 & TA-15-185 PHERMEX & $\begin{array}{l}\text { Vehicle Maintenance } \\
\text { Shop }\end{array}$ & Vehicle Maintenance & $P$ & $\begin{array}{l}\text { 15-PHRMX- } \\
1\end{array}$ & - Water \\
\hline TA-3-0034 & TA-3-0034 Metal Shop & Fabricated Metals & Fabricated Metals & AA & 3-MST-1 & - Mortandad \\
\hline TA-3-22 & TA-3-22 Power \& Steam Plant & Power Plant & Steam Electric Power & 0 & $\begin{array}{l}3-P S P-1 \\
3-P S P-5 \\
3-P S P-8\end{array}$ & $\begin{array}{ll} & \text { Sandia } \\
\text { - } & \\
\text { - } & \end{array}$ \\
\hline TA-3-38 & TA-3-38 Metals Fab Shop & Metal Shop & Fabricated Metals & AA & 3-MFS-1 & - Sandia \\
\hline TA-3-39 & TA-3-39 \& 102 Metal Shop & Metal Shop & Fabricated Metals & AA & 3-TS-1 & - $\quad$ Pajarito \\
\hline TA-3-66 & TA-3-66 Sigma Complex & Sigma Foundry & Primary Metals & $\mathrm{F}$ & 3-Sigma-6 & - Sandia \\
\hline TA-54 & TA-54 Area G & Area G - South Side & TSD & $\mathrm{K}$ & 54-G-1 & - $\quad$ Pajarito \\
\hline TA-54 & TA-54 Area G & Area G -North Side & TSD & K & $54-G-2$ & $\begin{array}{l}\text { - Canada del } \\
\text { Buey }\end{array}$ \\
\hline TA-54 & TA-54 Area G & Area G - South Side & TSD & $\mathrm{K}$ & 54-G-3 & - $\quad$ Pajarito \\
\hline TA-54 & TA-54 Area G & Area G - South Side & TSD & $\mathrm{K}$ & $54-G-4$ & - $\quad$ Pajarito \\
\hline TA-54 & TA-54 Area L & Area L & TSD & K & 54-L-1 & $\begin{array}{l}\text { - Canada del } \\
\text { Buey }\end{array}$ \\
\hline TA-54-38 & TA-54 RANT & RANT & TSD & K & 54-RANT-1 & $\begin{array}{l}\text { - Canada del } \\
\text { Buey }\end{array}$ \\
\hline TA-60 & TA-60 Asphalt Batch Plant & Asphalt Batch Plant & Asphalt Paving & $\mathrm{D}$ & $60-A B P-1$ & - Mortandad \\
\hline TA-60 & TA-60 MRF & $\begin{array}{l}\text { Materials Recycling } \\
\text { Facility }\end{array}$ & Scrap Recycling & $\mathrm{N}$ & 60-MRF-1 & - Sandia \\
\hline TA-60-250 & TA-60 Roads and Grounds & Roads \& Grounds Facility & $\begin{array}{l}\text { Vehicle Maintenance \& } \\
\text { Storage }\end{array}$ & $\begin{array}{l}P \\
P \\
P\end{array}$ & $\begin{array}{l}60-R G-1 \\
60-R G-3 \\
60-R G-8\end{array}$ & $\begin{array}{ll}\text { - } & \text { Mortandad } \\
\text { - } & \text { Sandia } \\
\text { - } & \text { Sandia }\end{array}$ \\
\hline TA-60-1 & $\begin{array}{l}\text { TA-60-1 Heavy Equipment } \\
\text { Yard }\end{array}$ & Motor pool & Vehicle Maintenance & $P$ & 60-HEY-2 & - Sandia \\
\hline TA-60-2 & TA-60-2 Warehouse & Motor pool & Vehicle Maintenance & $P$ & $60-\mathrm{WH}-1$ & - Sandia \\
\hline TA-9-28 & $\begin{array}{l}\text { TA-9-28 Heavy Equipment } \\
\text { Maintenance }\end{array}$ & Motor pool & Vehicle Maintenance & $P$ & 9-HEM-1 & - Pajarito \\
\hline
\end{tabular}




\section{ATtaChMent 5 - POLlutants Under IMPaired WATERs Monitoring}

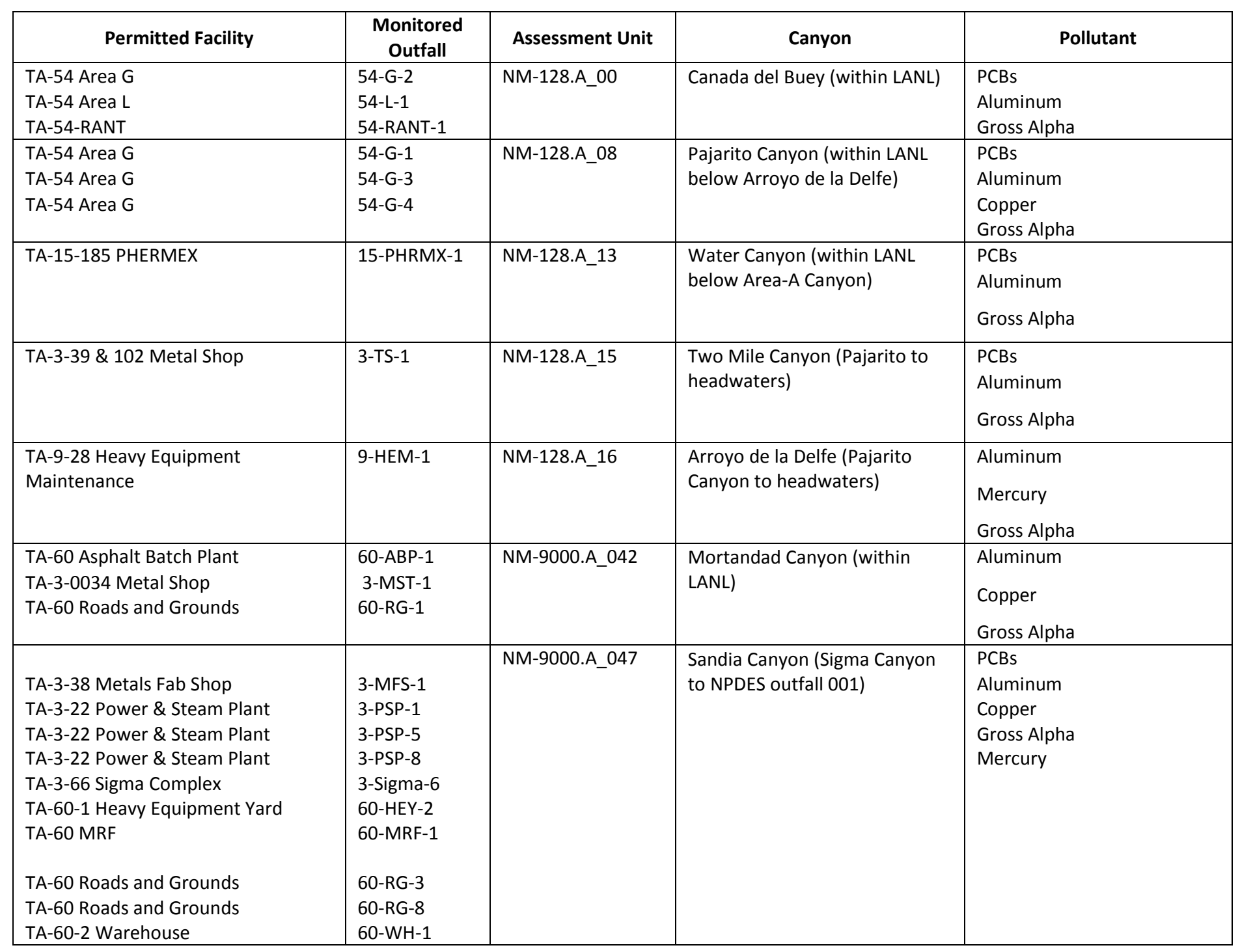




\begin{tabular}{|l|l|l|}
\hline Stormwater MSGP for Industrial Activities Program & No. ENV-CP-QAPP-MSGP, R5 & Page 39 of 40 \\
\cline { 2 - 3 } & Effective Date: $11 / 04 / 2013$ \\
\hline
\end{tabular}

\section{ATtACHMENT 6 - ANALYTES By INDUSTRIAL SECTOR}

\begin{tabular}{|c|c|c|c|c|c|}
\hline Permitted Facility & $\begin{array}{c}\text { Monitored } \\
\text { Outfall }\end{array}$ & Sector & Activity & Analyte & Monitoring Requirement \\
\hline $\begin{array}{l}\text { TA-3-0034 Metal Shop } \\
\text { TA-3-38 Metals Fab Shop } \\
\text { TA-3-39 \& } 102 \text { Metal Shop }\end{array}$ & $\begin{array}{l}\text { 3-MST-1 } \\
\text { 3-MFS-1 } \\
\text { 3-TS-1 }\end{array}$ & AA & Fabricated Metals & $\begin{array}{l}\text { Aluminum } \\
\text { Iron } \\
\text { Nitrate plus Nitrite Nitrogen } \\
\text { Zinc }\end{array}$ & $\begin{array}{l}\text { Quarterly Benchmark Monitoring } \\
\text { (QBM) } \\
\text { QBM } \\
\text { QBM } \\
\text { QBM }\end{array}$ \\
\hline TA-60 Asphalt Batch Plant & 60-ABP-1 & $\mathrm{D}$ & Asphalt Paving & $\begin{array}{l}\text { Oil and Grease } \\
\mathrm{pH} \\
\text { Total Suspended Solids }\end{array}$ & $\begin{array}{l}\text { Effluent Limitations Guidelines (ELG) } \\
\text { ELG } \\
\text { QBM and ELG }\end{array}$ \\
\hline TA-3-66 Sigma Complex & 3-Sigma-6 & $\mathrm{F}$ & Primary Metals & $\begin{array}{l}\text { Copper } \\
\text { Zinc }\end{array}$ & $\begin{array}{l}\text { QBM } \\
\text { QBM }\end{array}$ \\
\hline $\begin{array}{l}\text { TA-54 Area G } \\
\text { TA-54 Area G } \\
\text { TA-54 Area G } \\
\text { TA-54 Area G } \\
\text { TA-54 Area L } \\
\text { TA-54 RANT }\end{array}$ & $\begin{array}{l}\text { 54-G-1 } \\
54-G-2 \\
54-G-3 \\
54-G-4 \\
54-L-1 \\
54-R A N T-1\end{array}$ & K & $\begin{array}{l}\text { Treatment, Storage or } \\
\text { Disposal Facility (TSD) }\end{array}$ & $\begin{array}{l}\text { Ammonia } \\
\text { Arsenic } \\
\text { Cadmium } \\
\text { Chemical Oxygen Demand } \\
\text { Cyanide } \\
\text { Lead } \\
\text { Magnesium } \\
\text { Mercury } \\
\text { Selenium } \\
\text { Silver }\end{array}$ & $\begin{array}{l}\text { QBM } \\
\text { QBM } \\
\text { QBM } \\
\text { QBM } \\
\text { QBM } \\
\text { QBM } \\
\text { QBM } \\
\text { QBM } \\
\text { QBM } \\
\text { QBM }\end{array}$ \\
\hline TA-60 MRF & 60-MRF-1 & $\mathrm{N}$ & Scrap Recycling & $\begin{array}{l}\text { Aluminum } \\
\text { Chemical Oxygen Demand } \\
\text { Copper } \\
\text { Iron } \\
\text { Lead } \\
\text { Total Suspended Solids } \\
\text { Zinc }\end{array}$ & $\begin{array}{l}\text { QBM } \\
\text { QBM } \\
\text { QBM } \\
\text { QBM } \\
\text { QBM } \\
\text { QBM } \\
\text { QBM }\end{array}$ \\
\hline $\begin{array}{l}\text { TA-3-22 Power \& Steam } \\
\text { Plant }\end{array}$ & $\begin{array}{l}\text { 3-PSP-1 } \\
\text { 3-PSP-5 } \\
\text { 3-PSP-8 }\end{array}$ & $\mathrm{O}$ & Steam Electric Power & Iron & QBM \\
\hline
\end{tabular}




\section{ATTACHMENT 7 - REFERENCES AND GUIDANCE DOCUMENTS}

- 40 CFR 122, EPA Administered Permit Programs

- 40 CFR 136, Guidelines Establishing Test Procedures for the Analysis of Pollutants.

- Clean Water Act, Title 33 U.S.C. 1251

- DOE O 414.1C, Quality Assurance

- DOE Order 450.1, Environmental Protection Program

- DOE Order 5400.5, Radiation Protection of Public and Environment

- EPA QA/G-4, Guidance for the Data Quality Objectives Process

\section{LANL Documents:}

- P322-4, Laboratory Performance, Feedback, and Improvement

- P328-3, Management Assessments

- P328-4, Management Observation and Verification

- P330-6, Nonconformance Reporting

- P330-8, Inspection and Test for Acceptance

- P340, Conduct of Engineering

- P341, Engineering Process Manual

- P401, Procedure to Identify, Communicate, and Implement Environmental Requirements

- P407, Water Quality

- P840-1, Procurement Quality

\section{ENV Documents:}

- ENV-DO-QP-105, Preparation, Review, and Approval of Procedures

- ENV-DO-QP-106, Document Control

- ENV-DO-QP-113, Tracking Performance Feedback and Actions

- ENV-DO-QP-115, Personnel Training

- ENV-CP-QP-022, MSGP Storm Water Corrective Actions

- ENV-CP-QP-044, Preparing Storm Water Discharge Monitoring Reports (MDNRs) for NPDES MSGP

- ENV-CP-QP-047, Inspecting Storm Water Runoff Samplers and Retrieving Samples

- ENV-CP-QP-048, Processing MSGP Storm Water Samples

- ENV-CP-QP-064, Multi-Sector General Permit Storm Water Visual Inspections

- ENV-WQH-QP-029, Creating and Maintaining a Chain of Custody

- $\quad$ Surface Water Monitoring Plan, October 2001, Rev. 0.0 


\section{ENV-RCRA-QP-022.2}

Effective Date: February 28, 2013

Next Review Date: January 28, 2015

\section{Environment, Safety, Health Directorate}

\section{Environmental Protection - Water Quality and RCRA Quality Procedure}

\section{MSGP Storm Water Corrective Actions}

Reviewers:

\begin{tabular}{|c|c|c|c|}
\hline $\begin{array}{l}\text { Name: } \\
\text { Melanie Lamb }\end{array}$ & $\begin{array}{l}\text { Organization: } \\
\text { ENV-QPMO QA } \\
\text { Specialist }\end{array}$ & $\begin{array}{l}\text { Signature: } \\
\text { Signature on file }\end{array}$ & $\begin{array}{l}\text { Date: } \\
1 / 4 / 13\end{array}$ \\
\hline \multicolumn{4}{|c|}{ Derivative Classifier: $\bigotimes$ Unclassified } \\
\hline $\begin{array}{l}\text { Name: } \\
\text { Catherine Hayes }\end{array}$ & $\begin{array}{l}\text { Organization: } \\
\text { ENV-RCRA }\end{array}$ & $\begin{array}{l}\text { Signature: } \\
\text { Signature on file }\end{array}$ & $\begin{array}{l}\text { Date: } \\
2 / 8 / 13\end{array}$ \\
\hline
\end{tabular}

Approval Signatures:

\begin{tabular}{|c|c|c|c|}
\hline $\begin{array}{l}\text { Subject Matter Expert: } \\
\text { Holly Wheeler }\end{array}$ & $\begin{array}{l}\text { Organization: } \\
\text { ENV-RCRA }\end{array}$ & $\begin{array}{l}\text { Signature: } \\
\text { Signature on file }\end{array}$ & \begin{tabular}{|l} 
Date: \\
$1 / 28 / 13$
\end{tabular} \\
\hline $\begin{array}{l}\text { Responsible Line Manager: } \\
\text { Terrill Lemke }\end{array}$ & $\begin{array}{l}\text { Organization: } \\
\text { ENV-RCRA Team Lead }\end{array}$ & $\begin{array}{l}\text { Signature: } \\
\text { Signature on file }\end{array}$ & \begin{tabular}{|l} 
Date: \\
$2 / 8 / 13$
\end{tabular} \\
\hline $\begin{array}{l}\text { Responsible Line Manager: } \\
\text { Anthony Grieggs }\end{array}$ & $\begin{array}{l}\text { Organization: } \\
\text { ENV-RCRA Group Leader }\end{array}$ & $\begin{array}{l}\text { Signature: } \\
\text { Signature on file }\end{array}$ & \begin{tabular}{|l} 
Date: \\
$2 / 28 / 13$
\end{tabular} \\
\hline
\end{tabular}

\section{CONTROLLED DOCUMENT}

This copy is uncontrolled. The controlled copy can be found on the ENV Division Web page. 


\section{History of Revisions}

\begin{tabular}{|c|c|l|}
\hline $\begin{array}{c}\text { Document Number } \\
\text { [nclude revision number, } \\
\text { beginning with Revision 0] }\end{array}$ & $\begin{array}{c}\text { Effective Date } \\
\text { [Document Control Coordinator } \\
\text { inserts effective date] }\end{array}$ & $\begin{array}{c}\text { Description of Changes } \\
\text { [List specific changes made since the previous revision] }\end{array}$ \\
\hline 0 & $08 / 10$ & New Document. \\
\hline 1 & $11 / 10$ & $\begin{array}{l}\text { Incorporated ENV-RCRA-QP-062 MSGP Routine } \\
\text { Inspections into this document. }\end{array}$ \\
\hline 2 & $01 / 13$ & Biennial revision, new template implemented. \\
\hline
\end{tabular}




\section{Table of Contents}

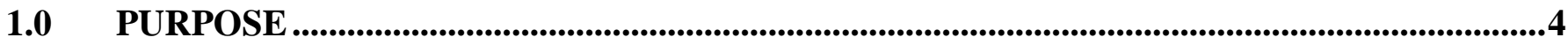

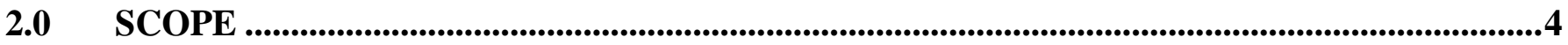

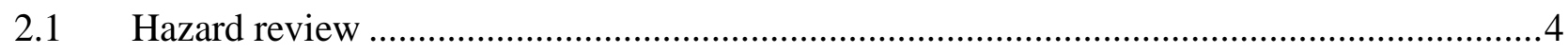

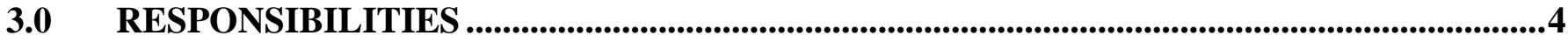

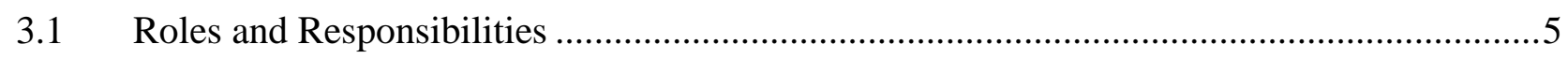

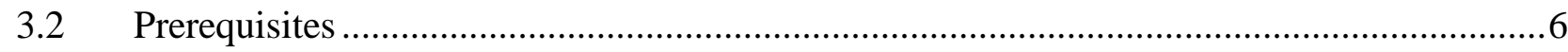

4.0 DOCUMENT CONTROL/RECORDS MANAGEMENT ......................................................7

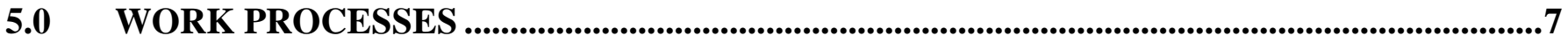

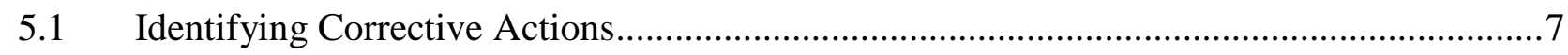

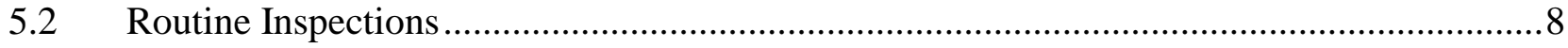

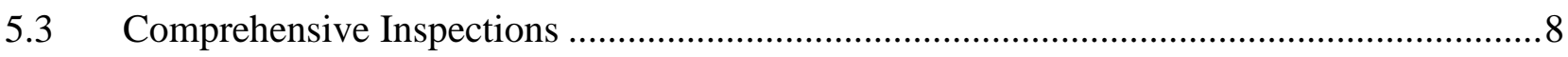

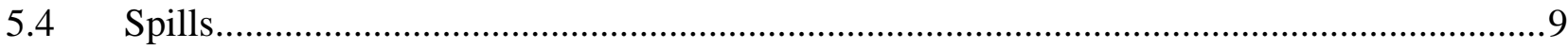

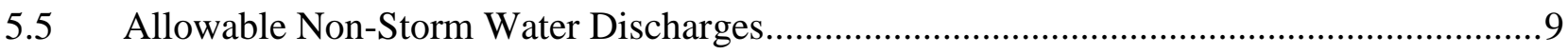

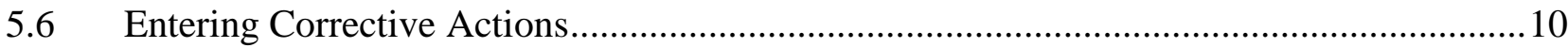

5.7 Updating Corrective Actions................................................................................. 12

$5.8 \quad$ Validating Corrective Actions............................................................................12

5.9 Institutional Performance Feedback and Improvement Tracking System $\quad$ (PFITS)........13

5.10 Notifications for New and Overdue Corrective Actions................................................14

6.0 REFERENCES ...................................................................................................................................14

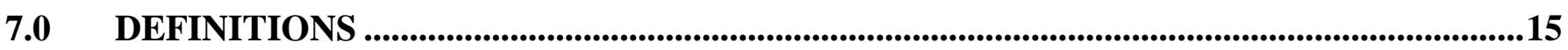

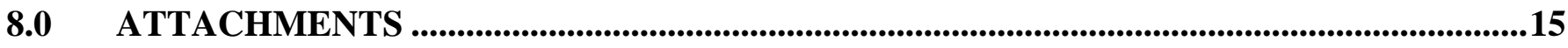

ATTACHMENT 1- Annual Reporting Form …...................................................................... 16

ATTACHMENT 2- NPDES Multi-Sector General Permit Routine Inspection Form ...................22 


\subsection{PURPOSE}

This procedure is written to provide requirements for identifying, documenting and entering corrective actions into the ENV-RCRA MSGP Corrective Action Report Findings database.

\section{$2.0 \quad$ SCOPE}

Requirements set forth in this document apply to Los Alamos National Laboratory industrial facilities covered by the National Pollutant Discharge Elimination System (NPDES) Storm Water Multi-Sector General Permit (MSGP). This "general permit" requires identification, documentation, tracking and reporting of corrective actions in accordance with sections 2.2.1, 3, 4.1.2, 4.2.2, 4.3.2, 5.0, 5.2, 5.4, 6.2.1, 6.2.1.2, 7.2 and Appendices B and I.

\subsection{HAZARD REVIEW}

The work described in this procedure is office work only and has a LOW hazard rating as documented by submittal of a completed ENV Low Hazard Verification form to the Quality Assurance Specialist.

\subsection{RESPONSIBILITIES}

The following personnel require training before implementing this procedure:

- Group and Team Leader

- ENV-RCRA MSGP Storm Water compliance personnel

- Deployed Environmental Professionals (DEPs)

- Other LANL or subcontract personnel identified as being required to conduct storm water assessments as part of their job duties.

In addition to training to this procedure, the following training is also required prior to performing this procedure:

- ENV-RCRA QAPP-MSGP Quality Assurance Project Plan for the Storm Water Multi-Sector General Permit for Industrial Activities

The training method for this procedure is "self-study" (required read). For ENV-RCRA staff, this is documented in accordance with ENV-DO-QP-115, Personnel Training. Other participating groups may require training documentation pursuant to local procedures.

Actions specified within this procedure, unless preceded with "should" or "may", are to be considered mandatory (i.e., "shall”, “will”, “must”). 


\subsection{ROLES AND RESPONSIBILITIES}

\subsubsection{ENV-RCRA MSGP STORM W ATER TEAM}

ENV-RCRA MSGP Storm Water Team members will be fully knowledgeable of the specific regulatory requirements identified in the 2008 MSGP and are responsible for ensuring compliance with these requirements and entering corrective actions. Team members will evaluate corrective actions that the DEPs enter into the ENV-RCRA MSGP Corrective Action Report Findings database and modify them as needed for quality assurance. This team will also periodically review open corrective actions and follow up with the DEPs, ES\&H Managers, or Upper Management, as deemed necessary, to ensure close out of the corrective action. The team members will notify upper management of instances of non-compliance with the permit. A team member may also be responsible for responding to the regulatory authority (EPA) regarding identified storm water issues and/or negotiate settlement of any identified issues.

\subsubsection{Deployed Environmental Professionals}

DEPs will be fully knowledgeable of the site specific Storm Water Pollution Prevention Plan (SWPPP) and corrective action requirements identified in the MSGP for the facilities they are deployed to. In addition, they shall be appropriately trained to meet the job qualifications identified in the Quality Assurance for Storm Water Multi-Sector General Permit for Industrial Activities Program (ENV-RCRA-QAPP-MSGP) and shall be familiar with the regulatory requirements identified in the 2008 MSGP. Further, they shall be familiar with facility operations so that potential pollution discharge sources can be determined and corrective actions can be identified.

The DEPs are responsible for identifying and entering corrective actions observed at their industrial facilities into the ENV-RCRA MSGP Corrective Action Report Findings database. They are also responsible for updating corrective actions in a timely manner that cannot be implemented immediately. They will work with the ES\&H Manager and ENV-RCRA storm water personnel to ensure identified corrective actions are implemented by overseeing repairs and/or improvements or instituting additional controls. If it is determined that corrective actions are necessary following an assessment, any modification to the control measures must be made before the next storm event if possible, or as soon as practicable following that storm event.

NOTE: These time intervals are not grace periods, but are schedules considered reasonable for documenting your finding(s) and for making repairs and improvements. They are included in the MSGP Permit to ensure that the conditions prompting the need for these repairs and improvements are not allowed to persist indefinitely (see Section 3.3 of the 2008 MSGP). In no instance will the corrective action remain open indefinitely. 


\subsubsection{ENV-RCRA StORM W ATER TEAm LeAdER}

The ENV-RCRA Storm Water Team Leader is responsible for compliance oversight relative to the 2008 MSGP. The Team Leader will ensure costs needed to implement the regulatory requirements identified in the 2008 MSGP are identified and environmental risks are assessed. Upper management will be notified of these costs or environmental risks, as deemed necessary. In the event there is a dispute regarding the regulatory requirements contained in the MSGP, the Team Leader will make the final determination of the required action. The Team Leader will notify upper management of instances of non-compliance with the permit.

\subsubsection{ENV-RCRA GROUP LEADER}

The ENV-RCRA Group Leader or designee is responsible for ensuring there is adequate funding to implement the regulatory requirements identified in the 2008 MSGP. The Group Leader also acts as the duly authorized signatory that certifies the reports. The Group Leader will notify upper management of instances of non-compliance with the permit or other identified environmental risk.

\subsubsection{ES\&H MANAGER}

The ES\&H manager shall identify funding for their industrial facilities to ensure compliance with the 2008 MSGP. The ES\&H Manager is also responsible for ensuring that industrial facilities are complying with the 2008 MSGP permit and notifying upper management of instances of noncompliance with the permit or other identified environmental risk.

\subsubsection{Facilities Operations Director}

The Facilities Operations Director (FOD) provides organizational leadership to ensure that all facility and programmatic activities under their authority are performed in compliance with the 2008 MSGP. The FOD is also responsible for establishing an environmental compliance envelope. It is the FOD's responsibility to maintain trained and qualified Environmental Professionals and Waste Management Coordinators on staff.

\subsubsection{COMputer Programmer}

Maintains and updates the ENV-RCRA MSGP Corrective Action Report Findings database as requested by MSGP storm water personnel.

\subsection{Prerequisites}

In addition to training to this procedure, the following training is also required prior to performing this procedure: 
- ENV-RCRA QAPP-MSGP, Quality Assurance Project Plan for the Storm water MultiSector General Permit for Industrial Activities Program

\subsection{DOCUMENT CONTROL/RECORDS MANAGEMENT}

The following records generated as a result of this procedure are to be submitted to the designated RMPOC in accordance with ENV-DO-QP-110, Records Management and filed in project files.

- MSGP Comprehensive Site Inspection Annual Report

- Completed Routine Inspection Forms

- Electronic records within the ENV-RCRA MSGP Corrective Action Report Findings database.

- Copies of automated e-mail notifications

\subsection{WORK PROCESSES}

\subsection{IdENTIFYING CoRrective ACtions}

If any of the following conditions occur, the DEP or ENV-RCRA storm water team member must review and revise the selection, design, installation, and implementation of control measures to ensure that the condition is eliminated and will not be repeated in the future:

- An unauthorized release or discharge (e.g., spill, leak, or discharge of non-storm water not authorized by the 2008 MSGP);

- You become aware, or EPA determines, that your control measures are not stringent enough for the discharge to meet applicable water quality standards;

- An inspection or evaluation of the facility by an EPA official and/or local or State entity, determines that modification to the control measures are necessary to meet the nonnumeric effluent limits in the 2008 MSGP;

- You find in the routine facility inspection, quarterly visual assessment, or comprehensive site inspection that the control measures are not being properly operated and maintained;

- Construction or a change in design, operation, or maintenance at the facility significantly changes the nature of pollutants discharged in storm water from the facility, or significantly increases the quantity of pollutants discharged; or

- The average of four quarterly sampling results exceeds an applicable benchmark. If less than four benchmark samples have been taken, but the results are such that an exceedence of the four quarter average is mathematically certain, (i.e., if the sum of quarterly sample results to date is more than four times the benchmark level) this is considered a benchmark exceedence, triggering this review;

- If effluent limitation guidelines are exceeded at the Asphalt Batch Plant (Sector D); or

- If impaired water quality standards are exceeded. 


\subsection{ROUTINE INSPECTIONS}

Routine inspections shall be conducted by the DEP (or a qualified member if the DEP is not trained and qualified) at all areas of the facility where industrial materials or activities are exposed to storm water, and of all storm water control measures used to comply with the effluent limits contained in the 2008 MSGP. Routine inspections shall be conducted at least quarterly; however, some facilities conduct monthly inspections (as specified in the facility specific SWPPP). Routine inspections shall be conducted during periods when the facility is in operation. A certified copy of completed Routine Inspection Forms shall be maintained in the facility's SWPPP.

At least once each calendar year, the routine facility inspections must be conducted during a period when a storm water discharge (either rain or snow) is occurring. The DEP(s) or storm water personnel from ENV-RCRA are responsible for identifying and entering corrective actions observed during the routine inspections into the ENV-RCRA MSGP Corrective Action Report Findings database. The database is set up to allow access for all identified DEPs associated with a particular FOD if the FOD has more than one DEP. Contact a member of the ENV-RCRA storm water team if you do not have access to this database and the FOD has assigned you responsibility for MSGP corrective actions.

NOTE: If the industrial facility is inactive and unstaffed and there are no industrial materials or activities exposed to storm water, routine inspections may not be required. A determination of whether a facility is inactive or unstaffed shall be made in coordination with storm water personnel from ENV-RCRA as there are specific documentation and certification requirements that have to be met prior to discontinuing routine inspections.

\subsection{COMPREHENSIVE INSPECTIONS}

Qualified ENV-RCRA storm water personnel will conduct one comprehensive inspection of all industrial facilities and those that meet the "no exposure" criteria subject to the 2008 MSGP before September $29^{\text {th }}$ of each year. At least one member of the facility's storm water pollution prevention team shall participate in this inspection. This is usually the DEP.

This inspection must cover all areas of the industrial facility affected by the requirements in the 2008 MSGP including the areas identified in the SWPPP as potential pollutant sources where industrial material or activities are exposed to storm water, areas where control measures are used to comply with the effluent limits, and areas where spills and leaks have occurred in the past 3 years. The inspector must include review of the monitoring data (analytical results from benchmark and impaired waters and visual assessments) collected that calendar year as part of the comprehensive inspection. Inspectors must examine the following at a minimum:

- Industrial materials, residue, or trash that may have or could come into contact with storm water;

- Leaks or spills from industrial equipment, drums, tanks, and other containers; 
- Offsite tracking of industrial or waste materials, or sediment where vehicles enter or exit the site;

- Tracking or blowing of raw, final, or waste materials from areas of no exposure to exposed areas; and

- Control measures needing replacement, maintenance, or repair.

- Storm water controls measures required by the 2008 MSGP must be observed to ensure that they are functioning correctly.

NOTE: The annual comprehensive site inspection may also be used as one of the routine inspections, as long as all components of both types of inspections are included.

ENV-RCRA will then enter all identified corrective actions into the ENV-RCRA MSGP Corrective Action Report Findings database. It is the responsibility of the DEP to update the database to reflect updates to these corrective actions.

Information compiled during the comprehensive inspection is used to complete the Annual Report. This report shall be submitted to EPA (postmarked) within 45 days of the last facility inspection completed in September of each year. For example, if the last facility was inspected (as part of the comprehensive site inspection) on September 22, the report shall be postmarked before or on November $6^{\text {th }}$. A complete certified copy of the Annual Report shall be maintained in the facility's SWPPP.

\section{$5.4 \quad$ SPILLS}

All leaks or spills shall be cleaned up immediately and entered into the ENV-RCRA MSGP Corrective Action Report Findings database. This can be done by either the DEP or an ENVRCRA MSGP storm water team member. If the spill is immediately cleaned up, and controls are put in place to prevent further leakage, the corrective action can be closed.

\subsection{Allowable Non-Storm Water Discharges}

The following are allowable non-storm water discharges authorized by the 2008 MSGP:

- Discharges from fire-fighting activities;

- Fire hydrant flushing;

- Potable water, including water line flushings;

- Uncontaminated condensate from air conditioners, coolers, and other compressors and from the outside storage of refrigerated gases or liquids;

- Irrigation drainage;

- Landscape watering provided all pesticides, herbicides, and fertilizer have been applied in accordance with the approved labeling;

- Pavement wash waters where no detergents are used and no spills or leaks of toxic or hazardous material have occurred (unless all spilled material has been removed); 
- Routine external building washdown that does not use detergents; and

- Uncontaminated ground water or spring water.

Any person authorized to conduct work at LANL can identify a potential storm water issue. If this occurs, they should contact the DEP or an ENV-RCRA MSGP storm water team member who will determine if a corrective action is needed.

\subsection{EnTering Corrective Actions}

To enter a corrective action into the ENV-RCRA MSGP Corrective Action Report Findings database, perform the following steps:

NOTE: Be clear and concise, use correct grammar and punctuation, and correct any spelling errors. This information will be used to populate a report that will be submitted to the EPA. Therefore, it is critical that all information entered into the ENV-RCRA MSGP Corrective Action Report Findings database is correct and meets these criteria.

\begin{tabular}{|c|c|}
\hline Step & Action \\
\hline 1 & $\begin{array}{l}\text { From this web page: } \\
\text { http://int.lanl.gov/environment/water/guidance/swmgp.shtml, under the } \\
\text { heading “Compliance Tools”. Click on the link "MSGP Corrective Action } \\
\text { Report Findings Database” } \\
\text { Click on "Enter New Corrective Action.” }\end{array}$ \\
\hline 2 & $\begin{array}{l}\text { Under the "Corrective Action Header" tab, enter the following: } \\
\text { - Facility Name by clicking on the "List” tab and selecting a facility. } \\
\text { - Date Problem was Identified (mm/dd/yyyy) } \\
\text { - Date of Notification to ENV-RCRA (mm/dd/yyyy) } \\
\text { - FOD Responsible for CA (Name \& Org) by clicking in the box. } \\
\text { FOD designations (for example "STO”) and the associated name } \\
\text { will come up. Just select the appropriate FOD. } \\
\text { NOTE: Contact the MSGP Project Leader at 667-1312 or } \\
\text { hbensen@lanl.gov if the FOD name or organization is incorrect, so this can } \\
\text { be corrected. } \\
\text { - Describe Specific Evaluation Location (for example "Northeast } \\
\text { corner of Building TA-3-66”) } \\
\text { Inspector Z-Number by clicking in the box, which will populate it } \\
\text { with your Z number. In most instances, the DEP should be } \\
\text { identified as the inspector. Note: If you are entering the CA and are } \\
\text { not the DEP, you will have to enter the DEP’s Z number or they will } \\
\text { not have the ability to update the corrective action. } \\
\text { Once all of the above information is entered correctly, click “Save” and go }\end{array}$ \\
\hline
\end{tabular}




\begin{tabular}{|c|c|}
\hline & $\begin{array}{l}\text { to Step 3. All boxes identified with a red asterisk are "required fields" and } \\
\text { shall be filled out. Note: The system will automatically assign a Corrective } \\
\text { Action Report ID number. }\end{array}$ \\
\hline 3 & 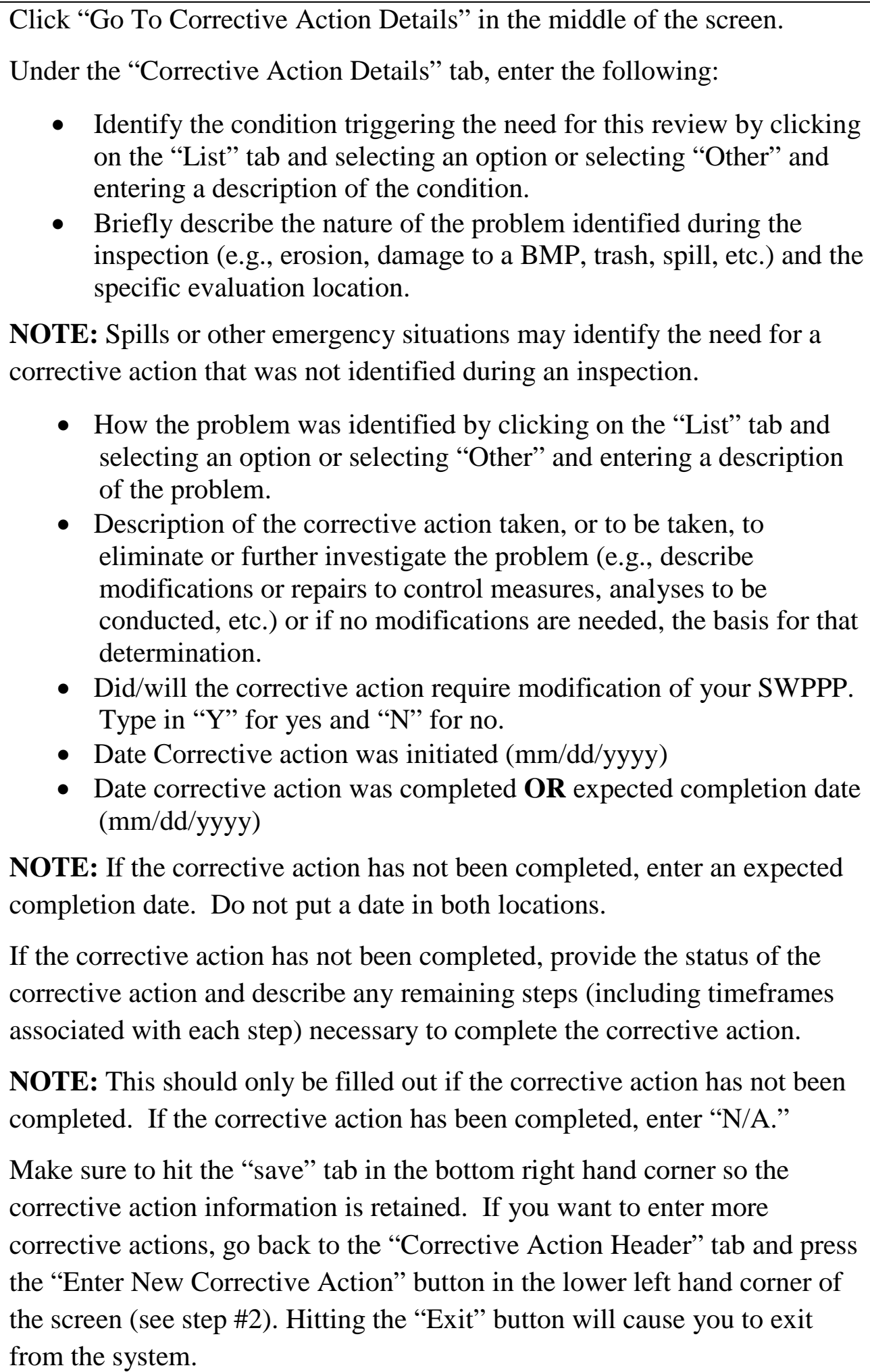 \\
\hline
\end{tabular}




\begin{tabular}{|l|l|}
\hline $\begin{array}{l}\text { All boxes identified with a red asterisk are "required fields" and shall be } \\
\text { filled out. If a date is not included or identified as an expected completion } \\
\text { date, ENV-RCRA storm water compliance personnel will enter a } \\
\text { completion date of } 30 \text { days after the corrective action was identified. }\end{array}$ \\
\hline
\end{tabular}

\subsection{Updating Corrective ACTIONS}

To update a corrective action in the ENV-RCRA MSGP Corrective Action Report Findings database, perform the following steps:

\begin{tabular}{|l|l|}
\hline Step & Action \\
\hline 1 & $\begin{array}{l}\text { From this web page: } \\
\text { http://int.lanl.gov/environment/water/guidance/swmgp.shtml, under the } \\
\text { heading “Compliance Tools”. Click on the link "MSGP Corrective Action } \\
\text { Report Findings Database” to access the database and tab down to the } \\
\text { corrective action number you want to edit. Click on "Edit.” }\end{array}$ \\
\hline 2 & $\begin{array}{l}\text { Navigate to the blank that you will be changing and input the updated } \\
\text { information. It is anticipated that most changes will occur relative to } \\
\text { updating the status of corrective actions. Save all changes to the } \\
\text { information. Remember, you should only have a date under "Date } \\
\text { corrective action completed OR the "expected to be completion," but not } \\
\text { both. }\end{array}$ \\
\hline
\end{tabular}

\subsection{Validating Corrective Actions}

ENV-RCRA storm water personnel will periodically validate the information contained in the ENV-RCRA MSGP Corrective Action Report Findings database. To validate a corrective action in the ENV-RCRA MSGP Corrective Action Report Findings database, perform the following steps:

\begin{tabular}{|l|l|}
\hline Step & Action \\
\hline 1 & $\begin{array}{l}\text { From this web page: } \\
\text { http://int.lanl.gov/environment/water/guidance/swmgp.shtml, under the }\end{array}$ \\
& $\begin{array}{l}\text { heading “Compliance Tools”. Click on the link “MSGP Corrective Action } \\
\text { Report Findings Database” to access the database. }\end{array}$ \\
\hline
\end{tabular}




\begin{tabular}{|l|l|}
\hline 2 & $\begin{array}{l}\text { Check all entered fields for a corrective action to ensure that all information } \\
\text { is clear, correct, and concise. If not, correct the information by navigating } \\
\text { to the information that needs to be changed and making the change. Save } \\
\text { all changes to the information. } \\
\text { All information shall be validated before running the final annual report. }\end{array}$ \\
\hline 3 & $\begin{array}{l}\text { For ENV-RCRA storm water personnel only, under "status" select "void" if } \\
\text { the corrective action is a repeat of a previous corrective action or if it is } \\
\text { determined not to be a corrective action. This will delete the corrective } \\
\text { action from the annual report. }\end{array}$ \\
\hline
\end{tabular}

\subsection{Institutional Performance FeEdback and Improvement Tracking System (PFITS)}

PFITS is the institutional performance and tracking system for identified issues. A corrective action that meets any of the following criteria will be entered into the PFITS system, as deemed necessary.

- Corrective action was not completed by the expected completion date entered into the database.

- No action was taken to remedy an identified issue with a control measure within 14 days of discovery or before the next storm event or as soon as practicable following that storm event (Section 3.3 of the 2008 MSGP).

- Repeat corrective actions or trends identified by ENV-RCRA MSGP storm water personnel.

- Conditions requiring immediate action, where failure to take action would result in pollutants being released to water of the state or an immediate non-compliance with the 2008 MSGP.

- Violations identified by the regulatory authority.

- Other issues as deemed necessary by MSGP storm water personnel.

Once every month, ENV-RCRA storm water personnel will evaluate a summary of open corrective actions in the ENV-RCRA MSGP Corrective Action Report Findings database and using the above criteria will determine which corrective actions, if any, should be transferred into PFITS. When the monthly notification of outstanding corrective actions is sent out, evaluate whether any of the outstanding corrective actions meet the above conditions. Send those that do to the Environmental Protection Division's Improvement Management Coordinator (IMC) so that she can enter the information into PFITS. The summary report will contain the following information, at a minimum:

- Date the corrective action was identified;

- Person that identified the corrective action; 
- A description of the nature of the problem identified and what needs to be done to address the corrective action.

- Whether the corrective action was identified internal to LANL or External to LANL.

\subsection{NOTIFICATIONS FOR NEW AND OVERdUE CORRECTIVE ACTIONS}

When a new corrective action is entered into the ENV-RCRA MSGP Corrective Action Report Findings database, the FOD, ESH\&Q Manager, Operations Manager, inspector (usually the DEP) and ENV-RCRA MSGP storm water personnel are notified automatically by e-mail (unless the corrective action is closed the same day it is entered). This will assist the FOD, ESH\& Q Managers, Operations Managers and the DEPs with keeping track of new corrective actions.

An automatic e-mail is sent the first of each month notifying the FOD, ESH\&Q Manager, Operations Manager and DEPs of all overdue corrective actions for their industrial facilities. The Environmental Protection Division Leader and ENV-RCRA Group Leader receive a web link that contains a bar graph showing corrective actions 30 to 60 days overdue, 60 to 90 days overdue, 90 days to 1 year overdue, and those greater than a year overdue. In addition, they receive a link with summary information on each corrective action overdue sorted by FOD.

\subsection{REFERENCES}

- Federal Register: Final National Pollutant Discharge Elimination System (NPDES) General Permit for Storm Water Discharges from Industrial Activities. Federal Register: September 29, 2008, Volume 73, Number 189.

- $\quad$ P300, Integrated Work Management

- P315, Conduct of Operations Manual

- PD103, Worker Safety and Health Policy

- SD100, Integrated Safety Management System Description Document with Embedded 10 CFR 851 Worker Safety and Health Program

- $\quad$ P101-18, Procedure for Pause/Stop Work

- PD410, Los Alamos National Laboratory Environmental ALARA Program

- $\quad$ 121, Radiation Protection

- ENV-DO QP-106, Document Control

- ENV-DO-QP-115, Personnel Training

- ENV-DO-QP-104, Work Safety Review

In addition to these documents, please read any site specific requirements before proceeding with work. 


\subsection{DEFINITIONS}

Best Management Practice (BMP): Schedules of activities, prohibitions of practices, maintenance procedures, and other management practices to prevent or reduce the pollution of "waters of the United States.” BMPs also include treatment requirements, operating procedures, and practices to control plant site runoff, spillage or leaks, sludge or waste disposal, or drainage from raw material storage. (40 CFR Part 122.2)

Control Measure: Any BMP or other method (including effluent limitations) used to prevent or reduce the discharge of pollutants to waters of the United States.

\section{CA: Corrective Action}

DEP: Deployed Environmental Professional

EPA: Environmental Protection Agency

FOD: Facility Operations Director

MSGP: Multi-Sector General Permit

SWPPP: Storm Water Pollution Prevention Plan

\subsection{ATTACHMENTS}

Attachment 1- Annual Reporting Form

Attachment 2- NPDES Multi-Sector General Permit Routine Inspection Form 


\section{ATTACHMENT 1- ANNUAL REPORTING FORM}

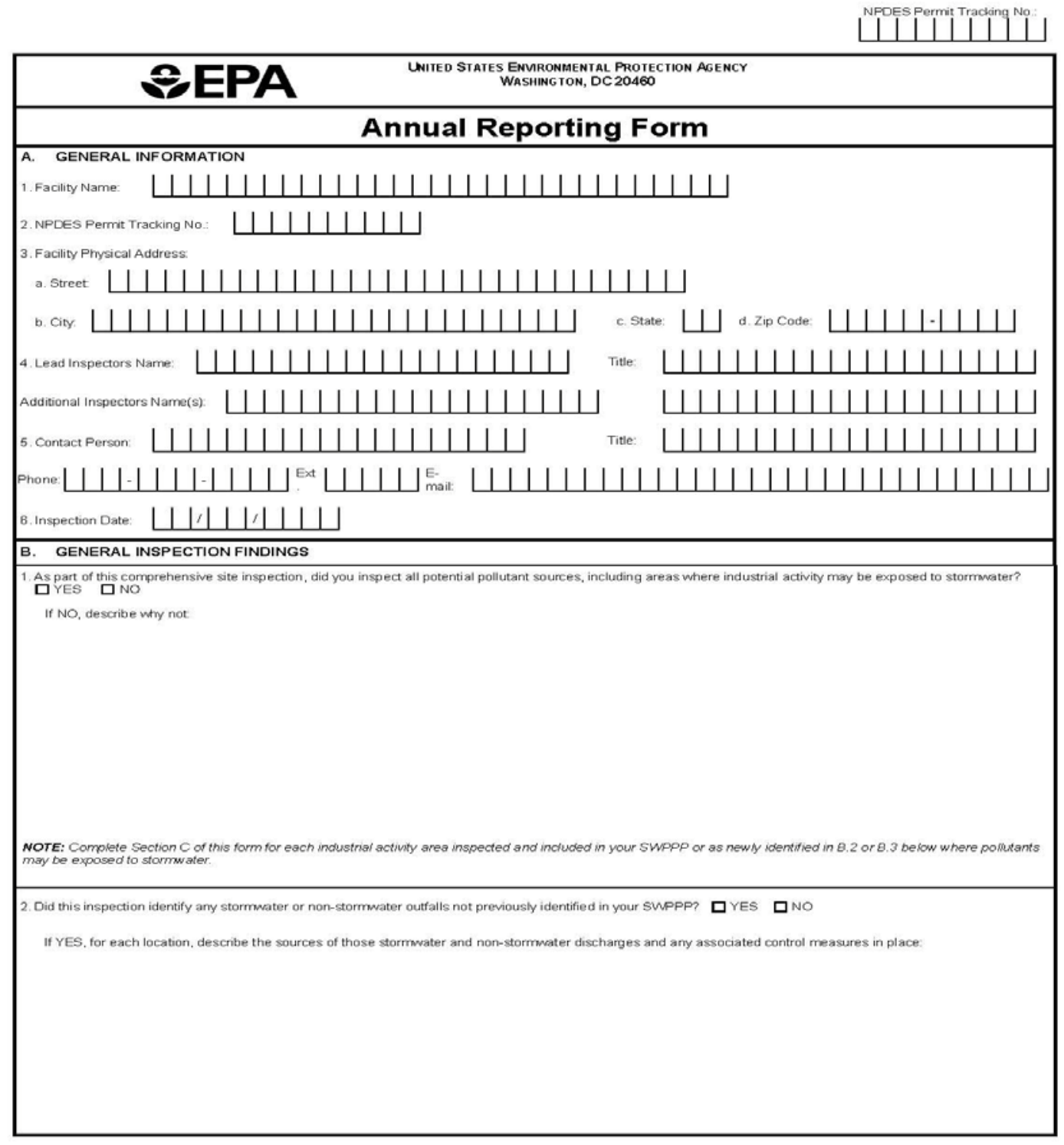


3. Did this inspection identify any sources of stormwater or non-stormwater discharges not previously identified in your SWPPP? $\square$ YES $\square$ NO

If YES, describe these sources of stormwater or non-stormwater pollutants expected to be present in these discharges, and any control measures in place:

4. Did you review stormwater monitoring data as part of this inspection to identify potential pollutant hot spots? $\square$ YES $\square$ NO $\square$ NA, no monitoring performed If YES, summarize the findings of that review and describe any additional inspection activities resulting from this review:

5. Describe any evidence of pollutants entering the drainage system or discharging to surface waters, and the condition of and around outfalls, including flow dissipation measures to prevent scouring:

6. Have you taken or do you plan to take any corrective actions, as specified in Part 3 of the permit, since your last annual report submission (or since you received authorization to discharge under this permit if this is your frst annual report), including any corrective actions identified as a result of this annual comprehensive site

inspection?
$\square$ YES $\square$ NO

If YES, how many conditions requiring review for correction action as

specified in Parts 3.1 and 3.2 were addressed by these corrective actions? 


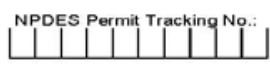

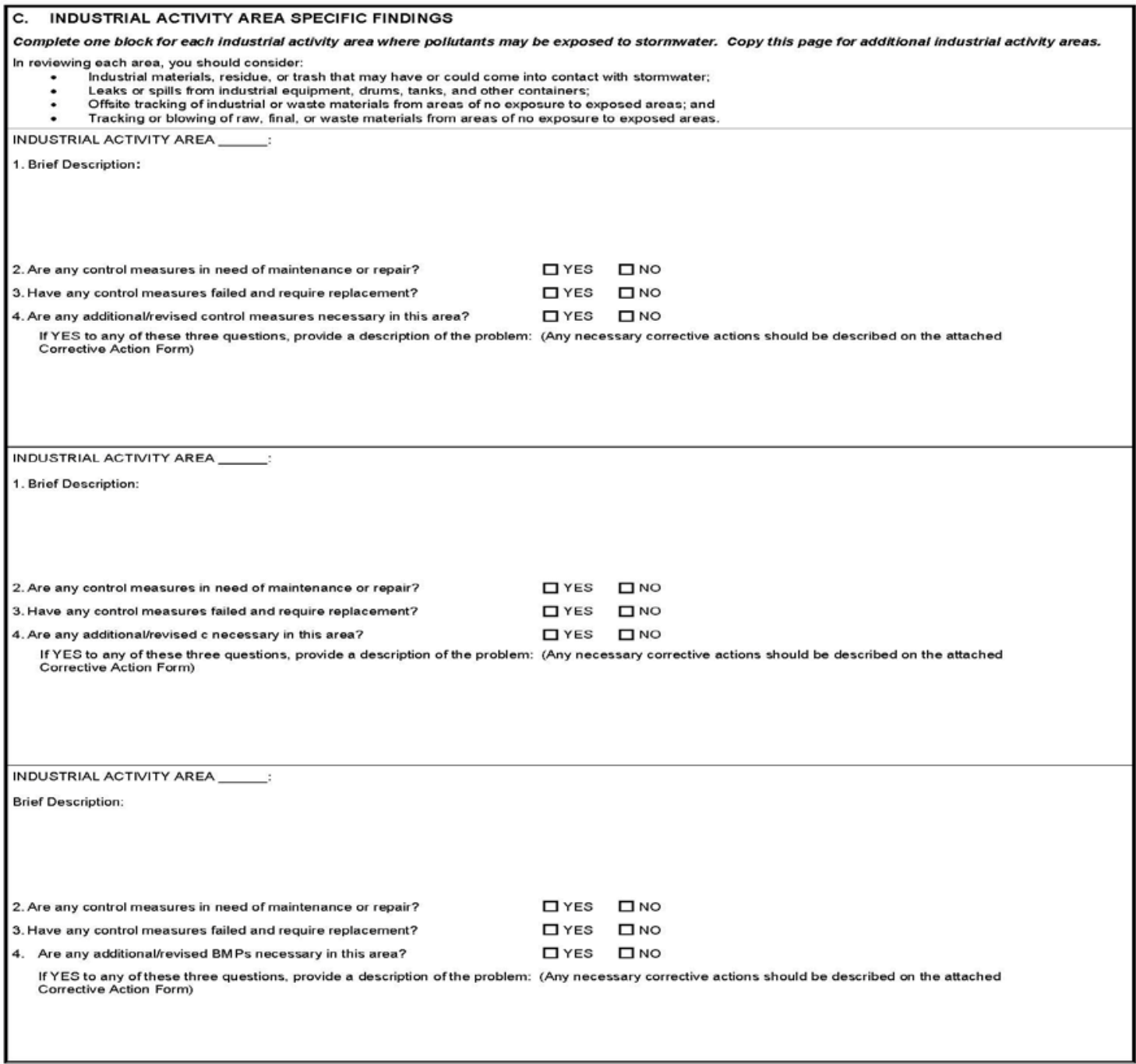




\begin{tabular}{|c|c|c|}
\hline & & NOTE: Copy this page and attach addtional pages as necessary \\
\hline \multicolumn{3}{|l|}{ INDUSTRIAL ACTIVITY AREA ___: } \\
\hline \multicolumn{3}{|l|}{ 1. Brief Description: } \\
\hline 2. Are any control measures in need of maintenance or repair? & 口YES & 口NO \\
\hline 3. Have any control measures failed and require replacement? & DYES & 口NO \\
\hline 4. Are any additional/revised BMPs necessary in this area? & DYES & 口NO \\
\hline \multicolumn{2}{|c|}{$\begin{array}{l}\text { If YES to any of these three questions, provide a description of the problem: } \\
\text { Corrective Action Form) }\end{array}$} & (Any necessary corrective actions should be described on the attached \\
\hline \multicolumn{3}{|l|}{ INDUSTRIAL ACTIVITY AREA } \\
\hline \multicolumn{3}{|l|}{ 1. Brief Description: } \\
\hline 2. Are any control measures in need of maintenance or repair? & DYES & $\square$ NO \\
\hline 3. Have any control measures failed and require replacement? & DYES & 口NO \\
\hline 4. Are any additional/revised BMPs necessary in this area? & DYES & 口NO \\
\hline \multicolumn{2}{|c|}{$\begin{array}{l}\text { If YES to any of those throe questions, provide a doscription of the problem: } \\
\text { Corrective Action Form) }\end{array}$} & : (Any nocossary corroctive actions should bo doscribed on the attached \\
\hline \multirow{2}{*}{\multicolumn{3}{|c|}{$\begin{array}{l}\text { INDUSTRIAL ACTIVITY AREA } \\
\text { 1. Brief Description: }\end{array}$}} \\
\hline & & \\
\hline 2. Are any control measures in need of maintenance or repair? & DYES & 口NO \\
\hline 3. Have any control measures failed and require replacement? & DYES & 口NO \\
\hline 4. Are any additional/revised BMPs necessary in this area? & DYES & 口NO \\
\hline \multicolumn{3}{|c|}{$\begin{array}{l}\text { If YES to any of these three questions, provide a description of the problem: (Any necessary corrective actions should be described on the attached } \\
\text { Corrective Action Form) }\end{array}$} \\
\hline
\end{tabular}




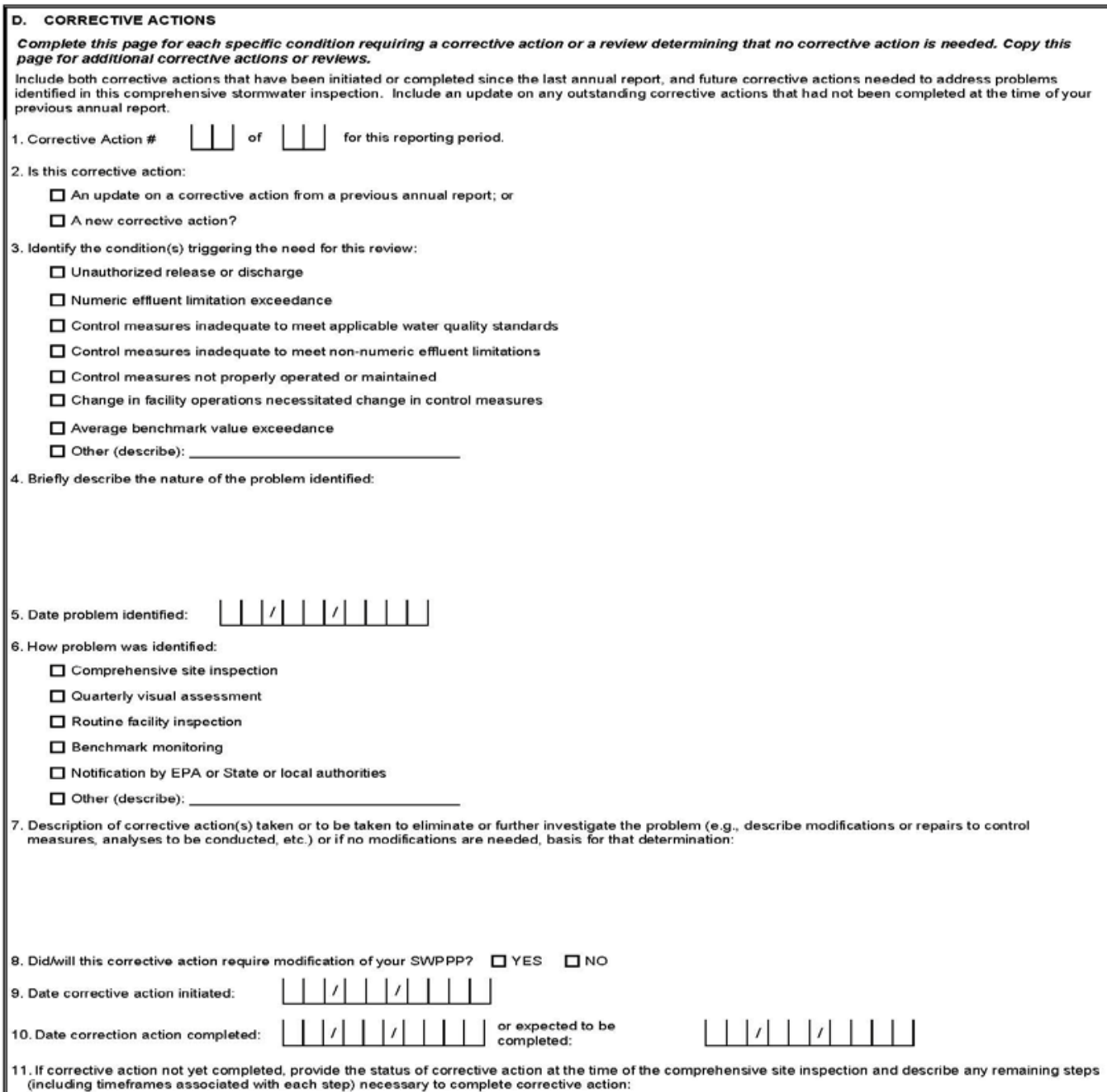




\begin{tabular}{|c|c|}
\hline \multirow{2}{*}{\multicolumn{2}{|c|}{$\begin{array}{l}\text { E. ANNUAL REPORT CERTIFICATION } \\
\text { 1. Compliance Certification } \\
\text { Do you certify that your annual inspection has met the requirements of Part } 4.2 \text { of the permit, and that, based upon the results of this inspection, to the best of } \\
\text { your knowledge, you are in compliance with the permit? } \\
\text { If NO, summarize why you are not in compliance with the permit: }\end{array}$}} \\
\hline & \\
\hline \multirow{2}{*}{\multicolumn{2}{|c|}{ 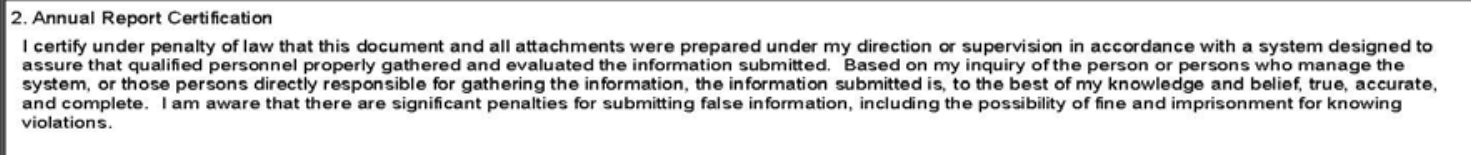 }} \\
\hline & \\
\hline \multirow{2}{*}{$\begin{array}{l}\text { Authorized Representative } \\
\text { Printed Name: } \\
\text { Signature: }\end{array}$} & 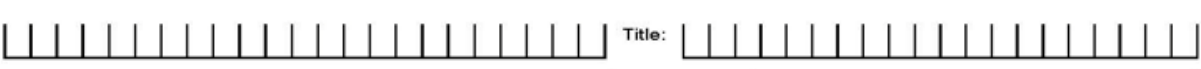 \\
\hline & $\begin{array}{ll} & \\
\end{array}$ \\
\hline
\end{tabular}




\section{ATTACHMENT 2- NPDES Multi-Sector General Permit Routine InsPection Form}

\begin{tabular}{|c|c|c|c|c|c|}
\hline \multicolumn{5}{|l|}{$\begin{array}{l}\text { Los Alamos National Laboratory } \\
\text { ENV-RCRA }\end{array}$} & \multirow[t]{2}{*}{$\begin{array}{l}\text { NPDES Multi-Sector General Permit Routine Inspection Form } \\
\text { (rev. 03/2009) Page } 1 \text { of (use additional sheets if necessary) } \\
\end{array}$} \\
\hline \multicolumn{3}{|l|}{ Name of Facility: } & \multicolumn{2}{|c|}{ Responsible FOD (Name \& Organization): } & \\
\hline \multicolumn{3}{|l|}{$\begin{array}{l}\text { Qualified Inspector(s): } \\
\text { Others Present: }\end{array}$} & \multicolumn{2}{|c|}{ Inspection type: $\square$ Quarterly $\square$ other } & $\begin{array}{l}\text { Date of inspection (MM/DD/YYYY): } \\
\text { Time of inspection: }\end{array}$ \\
\hline \multicolumn{3}{|l|}{ 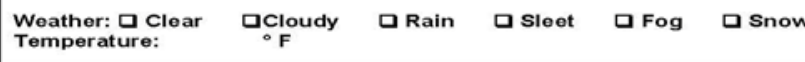 } & \multicolumn{3}{|c|}{$\begin{array}{l}\text { 口 High Winds a Other: } \\
\text { Is Inspection Being Conducted During a Storm Water Discharge? aYes aNo }\end{array}$} \\
\hline \# $\quad$ Structural Control Measures (BMP)s & Location & \begin{tabular}{|l} 
Operating \\
Ettectively \\
(Yes or No)?
\end{tabular} & $\begin{array}{l}\text { If No, Need to } \\
\text { Maintain (M), Repair } \\
\text { (R) or Replace (RP)? }\end{array}$ & $\begin{array}{l}\text { Corrective Action Needed an } \\
\text { measures that need replacem }\end{array}$ & s (identify needed maintenance and repairs, or any failed control \\
\hline \multicolumn{6}{|c|}{$\begin{array}{ll} \\
\end{array}$} \\
\hline \multicolumn{6}{|l|}{$\frac{1 .}{3 .}}$. \\
\hline \multicolumn{6}{|l|}{ 4. } \\
\hline \multicolumn{6}{|l|}{6.} \\
\hline \multicolumn{6}{|l|}{ 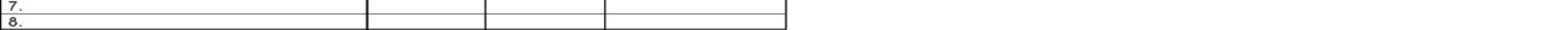 } \\
\hline \multicolumn{6}{|l|}{$\begin{array}{ll}9 . \\
10 .\end{array}$} \\
\hline \multicolumn{6}{|l|}{$\frac{10 .}{11 .}$} \\
\hline \multicolumn{6}{|c|}{ Were additional BMPs or Control Measures implemented? $\square$ Yes $\square$ No Describe: } \\
\hline \multicolumn{6}{|c|}{ Were previously identified conditions corrected before the next anticipated storm event? $\square$ Yes $\square$ No If No, describe reason: } \\
\hline 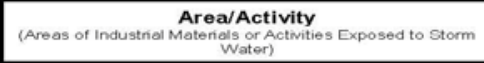 & Inspected? & $\begin{array}{l}\text { Controls } \\
\text { Adequate? }\end{array}$ & Corrective Action Neec & ed and Notes (List area letter with & nts below) \\
\hline \multicolumn{6}{|l|}{$\begin{array}{l}\text { A. Material loading/unloading \& storage } \\
\text { areas }\end{array}$} \\
\hline \multicolumn{6}{|l|}{ B. Equipment operations \& maintenance } \\
\hline \multicolumn{6}{|l|}{$\begin{array}{l}\text { C. Fueling Areas } \\
\text { D. Outdoor vehicle \& equipment washing } \\
\text { areas }\end{array}$} \\
\hline \multicolumn{6}{|l|}{$\begin{array}{l}\text { E. Waste Handling \& disposal areas } \\
\text { F. Erodible areas / construction }\end{array}$} \\
\hline \\
\hline \multicolumn{6}{|l|}{$\begin{array}{ll}\text { H. Salt storage pilios or pile containing salt } \\
\text { I. }\end{array}$} \\
\hline \multicolumn{6}{|c|}{ Are the SWPP Plan maintenance, schedules and procedures being implemented at the facility? $\square$ yes $\square$ No } \\
\hline \multicolumn{6}{|c|}{ Corrective Actions initiated or completed? $\square$ ᄀ } \\
\hline
\end{tabular}




\section{Los Alamos National Laboratory} NV-RCRA

Non-Compliance

Describe any incidents of non-compliance and/or need for corrective action observed and not described above:
NPDES Multi-Sector General Permit Inspection Form

Additional Control Measures

Describe any additional control measures needed to comply with the permit requirements

Notes

Use this space for any additional notes or observations from the inspection:

CERTIFICATION STATEMENT

"I certify under penalty of law that this document and all attachments were prepared under my direction or supervision in accordance with a system designed to assure that qualified personnel properly gathered and evaluated the information submitted. Based on my inquiry of the person or persons who manage the system, or those persons directly responsible for gathering the information, the information submitted is, to the best of my knowledge and belief, true, accurate, and complete. I am aware that there are significant penalties for submitting false information, including the possibility of fine and imprisonment for knowing violations."

\section{Print name and title:}

